\title{
Etudes sur la céramique romaine tardive d'Afrique
}

\author{
Michel Bonifay
}

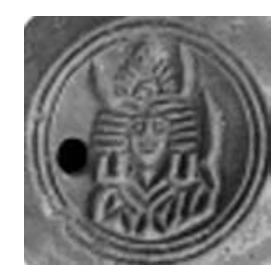

Fichier produit par l'auteur dernière version 04/12/2004 OMichel Bonifay (CCJ-CNRS) 



\section{SOMMAIRE}

Avant-propos

Introduction

Première Partie : Production 7

Vers une définition des zones d'ateliers

1- La production des amphores africaines

1.1. La recherche des provenances 9

1.2. Exemples d'ateliers $\quad 29$

1.3. Considérations techniques 41

2- La production des sigillées africaines

2.1. Les catégories de sigillées africaines

2.2. Exemples d'ateliers 53

2.3. Considérations techniques 59

3- Les autres productions

3.1. Vaisselles culinaires $\quad 67$

3.2. Vaisselles communes

3.3. Vaisselles modelées $\quad 75$

3.4. Lampes

3.5. Céramiques diverses $\quad 81$

3.6. Céramiques architecturales $\quad 84$

DEUXiÈme PARTIE : TYPOLOGIE ET CHRONOLOGIE 87

Du Nord au Sud de la Méditerranée : données comparatives

\section{1- Les amphores}

1.1. Amphores de tradition punique 89

1.2. Amphores de type romano-africain 99

1.2.1. Types précoces $\quad 99$

1.2.2. Amphores africaines classiques 105

1.2.3. Amphores africaines tardives 125

1.3. Imitations africaines de types non-africains 146

1.4. Amphores de type byzantin 151

2- La vaisselle

2.1. Les sigillées africaines 155

2.1.1. Les formes classiques : subdivisions et compléments 156

2.1.2. Les formes « locales » : reclassements 196

$\begin{array}{ll}2.1 .3 . \text { Les productions tardives } & 207\end{array}$

2.2. Les céramiques culinaires $\quad 210$

2.2.1. Céramiques culinaires africaines classiques 211

2.2.2. Céramiques culinaires africaines à diffusion régionale 231

$\begin{array}{ll}2.2 .3 \text {. Céramiques culinaires africaines tardives } & 239\end{array}$

2.3. Les céramiques communes $\quad 244$

$\begin{array}{ll}\text { 2.3.1. Bols et jattes } & 245\end{array}$

2.3.2. Mortiers et bols à listel 249

$\begin{array}{ll}2.3 .3 . \text { Bassins } & 260\end{array}$

$\begin{array}{ll}\text { 2.3.4. Couvercles } & 275\end{array}$

$\begin{array}{ll}2.3 .5 . \text { Cruches } & 278\end{array}$

2.3.6. Jarres 293

2.3.7. Braseros $[$ Kanūn] 295 
2.3.8. Formes mineures 298

2.3.9. Céramique à décor excisé 301

2.3.10. Céramique à décor peint 301

2.4. Les céramiques modelées 303

2.4.1. Céramique modelée de tradition libyco-punique 303

2.4.2. Céramique modelée culinaire à inclusions de calcite 305

3- Les lampes

3.1. Lampes moulées $\quad 312$

3.1.1. Lampes africaines de tradition italique $\quad 313$

3.1.2. Lampes de type romano-africain $\quad 329$

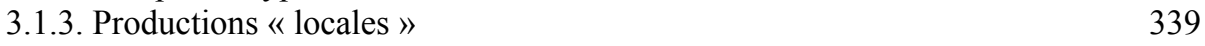

3.1.4. Lampes africaines tardives de tradition antique 343

3.1.5. Lampes en sigillée africaine $\quad 353$

3.1.6. Lampes tripolitaines $\quad 427$

3.2. Lampes tournées $\quad 427$

$\begin{array}{ll}\text { 3.2.1. Lampes dites « vandales » } & 428\end{array}$

3.2.2. Autres lampes tournées $\quad 428$

4- Céramiques diverses

4.1. Vases à décor plastique

4.2. Figurines 431

4.3. Masques $\quad 435$

4.4. Moules $\quad 435$

4.5. Autres objets $\quad 437$

5- Céramiques architecturales

5.1. Carreaux 439

$\begin{array}{ll}\text { 5.2. Tuiles } & 439\end{array}$

5.3. Tubes de voûte $\quad 442$

$\begin{array}{ll}\text { 5.4. Tuyaux } & 442\end{array}$

5.5. Autres céramiques architecturales $\quad 442$

Troisième Partie : Diffusion 443

La céramique africaine, témoin des activités économiques

1. Céramique africaine et commerce

1.1. Comptages et cartes de diffusion : étape de la recherche ou reflet du passé ? 445

1.2. La complexité des liens d'échanges : commerce intra- et inter-provincial 449

1.3. Les imitations de la céramique africaine $\quad 458$

2. Céramique africaine et production vivrière 463

3. Céramique africaine et développement économique

3.1. La céramique, témoin du « décollage » de l'économie africaine ? 477

3.2. La céramique, indice de l'hégémonie économique de l'Afrique 478

3.3. Les effets de l'invasion vandale et de la reconquête byzantine 480

3.4. La céramique africaine des derniers temps de l'époque byzantine 484

$\begin{array}{ll}\text { Conclusion } & 487\end{array}$

$\begin{array}{ll}\text { Bibliographie } & 491\end{array}$

Index typologique $\quad 519$

Planches couleur 


\section{Avant-Propos}

Ce livre a pour origine une thèse sur travaux de l'Université de Paris I, préparée sous la direction de M. Jean-Pierre Sodini et soutenue le 20 juin 2003 devant un jury composé de Mme Catherine Abadie Reynal, M. John W. Hayes et M. André Tchernia, sous la présidence de M. François Baratte.

La documentation utilisée ici a été réunie entre 1982 et 2002, tout d'abord à Marseille et en Provence, dans le cadre de mes précédentes fonctions au Service Régional de l'Archéologie, puis à partir de 1989 et surtout 1992, date de mon entrée au CNRS, en Tunisie et sur quelques sites de Méditerranée orientale. Le texte et les illustrations sont ceux du volume de synthèse, rédigé en 2003 et très légèrement amendé en 2004.

Le parcours parfois peu académique que j'ai suivi depuis trente ans m'a amené à contracter des dettes nombreuses dont il m'est agréable, aujourd'hui, d'essayer de m'acquitter.

\section{A TOULON}

Je dois tout d'abord saluer le souvenir de Marc Gérard, qui m'a donné ma première leçon de céramologie en 1972, remercier Pierre Saliceti et Jean-Pierre Brun, qui m’ont appris les rudiments de la prospection et de la fouille archéologique, témoigner mon amitié à Michel Pasqualini, mon alter ego d'alors, ainsi que ma reconnaissance à Christian Goudineau, à l'époque Directeur des Antiquités Historiques de Côte d'Azur, pour ses encouragements et sa bienveillance amicale.

\section{A Aix-en-Provence}

Je dois à l'amitié de Gaëtan Congès d'avoir pu suivre ma vocation. C'est lui, notamment, qui m'a procuré, en 1977, mon premier emploi rémunéré d'archéologue, sur le chantier de construction du « parking Pasteur », avec Danièle Foy.

Je suis infiniment reconnaissant à François Salviat, Directeur des Antiquités Historiques de Provence, de m'avoir confié en 1979 la responsabilité des fouilles de La Bourse à Marseille. Durant les cinq années que j'ai passées sur ce site prestigieux, j'ai beaucoup appris sur la conduite d'un grand chantier au contact de mon ami Marius Aubert. C'est là, également, qu'est né mon intérêt pour la céramique africaine et pour l'Antiquité tardive.

Je dois énormément à Paul-Albert Février. C'est lui qui m'a encouragé à reprendre, en 1982, mon cursus universitaire. On ne dira jamais assez combien il était tout à la fois déstabilisant et exaltant de discuter avec Paul-Albert Février. Son enseignement et son amitié m'ont beaucoup apporté.

J'ai également une pensée amicale pour Gabrielle Démians d'Archimbaud qui m'a toujours encouragé avec une grande clairvoyance et une extrême gentillesse.

\section{Au Ministère DE LA CUlture}

Je dois à la bienveillance des Conservateurs successifs, tout particulièrement Marc Gauthier, Jean Guyon et Jean-Paul Jacob, d'avoir pu maintenir une activité de recherche, malgré les lourdes tâches administratives qui incombaient au Service. Je suis reconnaissant à tous mes collègues, Gaëtan, Armelle et Mireille, Christian, Christophe, Gérard, Guy,... de l'amitié dont ils m'ont entouré. J'ai une dette particulière envers Jean Prodhomme qui m'a donné le goût de la documentation graphique.

\section{Au CNRS}

Je dois à Roger Guéry de m'avoir encouragé à lui succéder au C.N.R.S. La découverte de l'Afrique avec Pol Trousset en 1989 et en 1990, ma chance de pouvoir bénéficier de ses commentaires enthousiastes sur les paysages africains et leur histoire, ont sans doute en grande partie déterminé ce choix. Je remercie très sincèrement l'équipe d'Antiquités Africaines : Pol Trousset, Maurice Euzennat, Roger Guéry, Gilbert Hallier, Edgar Lamouroux, Jean Lenne, Sylvie Sempère, Georges Souville pour leur accueil chaleureux. J'ai tiré grand profit du dynamisme et des conseils amicaux de Véronique Blanc-Bijon. Antoine Hermary et Patrice Pomey, directeurs successifs du Centre Camille Jullian, m’ont toujours assuré de leur soutien bienveillant.

\section{EN TUNISIE}

Nejib Ben Lazreg et Ali Drine ont guidé mes premiers pas en Tunisie en 1989 et 1990, sur leurs terres de Moknine et de Zarzis, et je leur en suis pour toujours reconnaissant. Chez Latifa et Hedi Slim, j'ai retrouvé un peu du climat familial que je laissais en France : je les remercie de la confiance dont ils m'ont toujours honoré. En outre, je suis très fier du travail que Latifa et moi-même avons accompli à Nabeul de 1995 à 2002. Avec Aïcha Ben Abed, j'ai partagé plus de dix années de complicité scientifique. Le travail mené en commun sur plusieurs des sites dont elle a la responsabilité, notamment Sidi Jdidi, Pupput et Thuburbo Majus, a été véritablement passionnant et je la remercie de me permettre aujourd'hui d'en utiliser une petite partie. Je suis également reconnaissant à Habib Ben Hassen de m'avoir invité à Oudhna ; la gentillesse de Daouda Sow a été pour beaucoup dans l'agrément de mes séjours sur ce site merveilleux. Avec Taher Ghalia aussi, nous avons fait du bon travail, à Oued R'mel et sur les ateliers d'amphores de Nabeul. J'ai eu grand plaisir également à collaborer avec Mongi Ennaïfer à Kelibia, avec Nabiha Jeddi à Thaenae, avec Neila Ouertani à Hergla, avec Samir Aounallah à Sidi Khalifa. Toute ma gratitude va également à Abdelmajid Ennabli puis à Fethi Chelbi pour leur accueil au musée de Carthage, et à Mustapha Khanoussi pour son hospitalité à Gafsa. Nombreux sont les chercheurs et amis qui m'ont ainsi offert leur confiance et à qui j'espère, de mon côté, avoir rendu service.

A Lamta, j'ai été accueilli à plusieurs reprises par la mission tuniso-canadienne ; je remercie vivement Nejib Ben Lazreg, Lea Stirling, David Stone et l'ensemble de l'équipe, notamment Karen Carr, John Dore et Andrei Opait.

J'ai beaucoup apprécié d'avoir été sollicité par de nombreux étudiants tunisiens, parmi lesquels il convient de citer Faouzia Dridi, Noomene Fehri, Moufida Labayed-Ladhari, Jihen Nacef, Mongi Nasr, en soutien de leurs travaux de recherches. Ils 
retrouveront sans doute dans ce travail quelques tessons qu'ils m'ont fait identifier, quelques réflexions issues de leur documentation ; j'espère que, de leur côté, ils auront tiré quelques bénéfices de mon aide.

Enfin, ces études n'auraient pu être menées à bien en Tunisie sans l'aval des Directeurs successifs de l'Institut National du Patrimoine, Mme Riahi, MM. Daoulatli, Ben Fraj et Ben Mami, et surtout des Directeurs successifs des Etudes et de l'Inventaire, MM. Hedi Slim et Fethi Bejaoui. Rien n'aurait pu être fait sans le soutien financier du Ministère des Affaires Etrangères, ni les contributions accordées par M. Robert Ilbert, Directeur de la MMSH d'Aix-en-Provence. Je remercie également M. François Baratte pour l'appui financier dont il m'a fait bénéficier dans le cadre du GDR qu'il dirige.

\section{EN MÉDITERRANÉE ORIENTALE}

J'ai rencontré Jean-Pierre Sodini au Congrès d'Archéologie Chrétienne de Lyon, en 1986. C'est lui qui m'a poussé à travailler en Orient. Très vite devenus amis, nous nous sommes régulièrement revus pour des séminaires à Aix ou à Paris, devant des tiroirs de céramiques au Fort Saint-Jean de Marseille, à Thessalonique pour une table ronde sur la céramique des Ve-IXe s., en Tunisie sur les sites de Sidi Jdidi et de Nabeul, enfin en Albanie, dans le cadre de la mission qu'il a dirigée en 1999-2002 sur le site de Byllis. Je lui suis infiniment reconnaissant d'avoir accepté de diriger mes travaux en 2002-2003.

C'est à Beyrouth, en 1995, à l'invitation de Catherine Aubert et de Pascal Arnaud, que j'ai fait mon apprentissage de la céramique de Méditerranée orientale. Dans ce domaine que je connaissais mal, j'ai eu la chance de pouvoir bénéficier des conseils amicaux de John W. Hayes, que je remercie tout particulièrement. M. André Laronde m'a offert l'opportunité, en 1998, de travailler sur le site d'Apollonia de Cyrénaïque, puis, en 2003, sur le site de Lepcis Magna; je lui suis très reconnaissant de m'avoir fait connaître ce terrain fascinant. Enfin, j'ai pris beaucoup de plaisir à venir travailler, à plusieurs reprises, au Centre d'Etudes Alexandrines où tout est mis en œuvre pour faciliter le travail des différents spécialistes; je remercie vivement Jean-Yves Empereur et Marie-Dominique Nenna pour leur accueil.

Je voudrais aussi témoigner mon amitié à ceux et celles que j'ai eu la chance de rencontrer durant tout ce temps et qui m'ont beaucoup apporté. Il m'est impossible de les citer tous, mais je pense tout d'abord à ceux que j'ai toujours considérés comme des maîtres, notamment Claude Brenot, Noël Duval, Michel Fixot, Philippe Leveau, Bernard Liou, Louis Maurin, Jean-Paul Morel, Clementina Panella, Maurice Picon, André Tchernia, et à ceux que j'ai suivis dans leurs premiers travaux, Dominique Pieri, JeanChristophe Treglia, Stéphane Bien, Tomoo Mukai, Céline Brun... Je pense également à ceux que je côtoie avec plaisir, depuis des années, sur les mêmes terrains scientifiques, notamment Xavier Aquilué, Paul Arthur, Ariane Bourgeois, Claudio Capelli, Ylli Cerova, Lisa Fentress, Marc Griesheimer, Josep M. Gurt, Robert Lequément, Michael Mackensen, Thierry Martin (et sa merveilleuse bibliothèque...), Giovanni Murialdo, Lidia Paroli, Jean-Pierre Pelletier, Jean Piton, Claude Raynaud, Paul Reynolds, Lucien Rivet, Yves et Jacqueline Rigoir, Lucia Saguì, Lucy Vallauri, Françoise Villedieu... Je pense enfin à ceux, trop nombreux pour être tous nommés (qu'ils veuillent bien m'excuser), qui constituent aujourd'hui au Ministère de la Culture, au CNRS et à l'Université, dans les Collectivités, les Musées et à l'INRAP, la trame de l'archéologie régionale et qui, au nom de l'amitié et dans l'intérêt de la recherche, savent si bien atténuer la rigueur des procédures administratives et faire partager leur savoir. Je remercie tout particulièrement Bruno Bizot (SRA), Roger Boiron (INRAP), Marc Bouiron (INRAP), Marie-Brigitte Carre (CCJ), Georges Castellvi (Univ. de Perpignan), Lucienne Dell'Furia, Cyr Descamps (Univ. de Perpignan), Catherine Dovis (DRASSM), Lucien-François Gantès (Service Patrimoine Marseille), Antoinette Hesnard (CCJ), Monique Jannet-Vallat (Conservatrice Musée de Nice-Cimiez), Jean-Pierre Joncheray, Jérôme Kotarba (INRAP), Jean-Philippe Lagrue (Service Patrimoine de Fos-sur-Mer), Hélène Marino (Service Patrimoine Port-de-Bouc), Frédéric Marty (Musée d'Istres), Jean-Luc Massy (Chef du DRASSM), Manuel Moliner (Service Patrimoine Marseille), Florence Mocci (CCJ), Myriam Morel-Deledalle (Conservatrice Musée d'Histoire de Marseille), Luc Long (DRASSM), Núria Nin (Service Patrimoine Aix-en-Provence), Michel Pasqualini (Service Patrimoine Fréjus), Christophe Pellecuer (SRA Languedoc-Roussillon), Emmanuel Pellegrino (CEPAM), Patrick Reynaud (INRAP), Catherine Richarté (INRAP), Florence Richez (DRASSM), Corinne Rousse (Univ. de Provence), Michel Salvat (Service Patrimoine Port-Vendres), Claude Santamaria, Martine Sciallano (Conservatrice Musée d'Istres), Laurent Schneider (LAMM), Claude Sintès (Conservateur Musée de l'Arles Antique), Jean-Christophe Sourisseau (Univ. de Provence), Frédérique Verlinden (Conservatrice Musée de Gap), Karine Viatgé (Conservatrice Musée d’Antibes)...

Je sais tout ce que ce livre doit, particulièrement, aux trois chantiers tunisiens de Sidi Jdidi, Nabeul et Pupput, auxquels j'ai été associé, et je renouvelle tous mes remerciements d'une part aux responsables de ces chantiers : Aïcha Ben Abed, Latifa Slim, Michel Fixot, Marc Griesheimer, d'autre part aux membres de ces trois équipes, notamment Céline Brun, Giancarlo Filantropi, Fabio Giomblanco, Tomoo Mukai, Yumi Narasawa, Dominique Pieri, Jean Piton, Patrick Reynaud, Sylvestre Roucole, Myriam Sternberg, Jean-Christophe Treglia, sans oublier l'ensemble des ouvriers tunisiens, leur encadrement technique et plus spécialement Bechir Ayadi, à Nabeul.

Guergana Guionova et Jean-Christophe Treglia m’ont beaucoup aidé pour les travaux de reprographie. Véronique Blanc-Bijon, Sylvie Saulnier et Lucien Rivet m'ont fait bénéficier d'une relecture attentive et de leurs précieux conseils en matière éditoriale. Toute ma gratitude va également à Georges Souville qui m'a fait l'honneur de proposer cet ouvrage pour le prix Hippone de l'Académie d'Aix-en-Provence.

Enfin, je voudrais remercier Danièle pour son écoute et ses suggestions, et Cyprien, Victor et Marthe pour leur vigoureuse participation aux fouilles de Nabeul...

Aix-en-Provence, juin 2004

Maison Méditerranéenne des Sciences de l'Homme, Centre Camille Jullian (UMR 6573, Université de Provence-CNRS) 


\section{Préface}

C'est avec beaucoup de plaisir que nous constatons l'enrichissement de la bibliographie africaine par l'ouvrage de Michel Bonifay sur la céramique. Travaillant depuis plusieurs années sur les chantiers tunisiens, Michel Bonifay a su nouer au fil du temps des amitiés et des complicités avec un grand nombre de chercheurs tunisiens. J'ai moi-même eu le plaisir de le voir découvrir, trier, dessiner et classer les milliers de tessons de céramique que les fouilles de Pupput, Thuburbo Majus et Sidi Jdidi ont révélés au fur et à mesure.

J'ai toujours été reconnaissante à mon Maître Paul-Albert Février pour de multiples raisons et notamment celle de m'avoir fait rencontrer de nombreux collègues aixois devenus des amis, dont Michel Bonifay. Son apport à l'analyse et à la connaissance de la céramique africaine tardive est fondamental depuis déjà plusieurs années même s'il s'en défend modestement. Désormais son ouvrage, essentiellement basé sur le terrain, va pouvoir nous aider à mieux connaître non seulement la typologie des formes mais aussi plusieurs aspects de la vie économique à l'époque tardoantique. C'est un manuel de première nécessité que Michel Bonifay offre généreusement à tous ceux qui travaillent sur l'antiquité africaine.

Aïcha BEN ABED Directrice de Recherche Institut National du Patrimoine, Tunis 


\section{INTRODUCTION}

Depuis plus de quarante ans (Février 1963), de nombreux céramologues ont consacré tout ou partie de leur activité à identifier, classer et dater les différents objets qui composent le riche éventail des productions africaines. Peu de céramiques ont suscité une si abondante bibliographie. Je voudrais pour ma part verser au dossier une expérience concrète acquise depuis une vingtaine d'années, tout d'abord sur des sites où cette céramique fut importée en masse (Marseille), ensuite dans le principal pays où elle fut produite (l'actuelle Tunisie).

\section{Définition du sujet}

Il faut en premier lieu s'entendre sur le mot «Afrique ». Sans atteindre les excès qui font parfois ranger parmi les amphores africaines, de manière anachronique, des conteneurs produits en Egypte, « l'archéologie africaine » s'attribue traditionnellement un vaste territoire compris entre l'océan Atlantique et la frontière égyptienne (ou tout au moins l'emplacement de l'autel des Philènes dans le fond du golfe de Syrte), correspondant à peu près aux anciennes possessions coloniales des deux ou trois grandes puissances européennes ouvertes sur la Méditerranée, territoires où l'archéologie s'est développée très tôt. Bien qu'on ait récemment rappelé les fondements historiques de ce concept de «Maghreb romain » (Février 1989 et 1990), je laisserais volontairement de côté l'extrême ouest de cet occident du monde arabe, le Maroc. En effet, du point de vue de la documentation matérielle, la Maurétanie Tingitane apparaît résolument tournée vers la péninsule Ibérique (Pons Pujol 2000), ce que traduit bien, au IVe s., son rattachement au diocèse d'Espagne. Mais les aléas de mon expérience professionnelle m'ont contraint à donner au mot Afrique un sens encore plus restrictif: je ne connais pas l'Algérie et encore assez peu la Libye. L'Afrique s'entendra donc ici essentiellement du point de vue de la province romaine d'Africa Proconsularis, et plus exactement de la partie comprise dans le territoire tunisien actuel ${ }^{1}$, où j'ai eu l'occasion de travailler depuis 1989. Même à ce point réduit, ce territoire est grand lorsqu'on le mesure au nombre des faciès céramiques régionaux. Car, si hors d'Afrique la céramique africaine apparaît comme un tout, il n'en est pas de même lorsqu'on est amené à travailler sur les lieux de production, où chaque région possède son originalité.

Le terme «céramique romaine tardive» appelle également des commentaires. L'arc chronologique pris en considération correspond à celui du Late Roman Pottery de J. W. Hayes : «between the second and the seventh century A. D. » (Hayes 1972, 1). Outre le fait que le règne

\footnotetext{
1 «La parte limitate del Maghreb che rapresenta il cuore
} dell'Africa romana » (Panella 1993, 640). des Antonins marque, pour beaucoup d'historiens, une rupture dans l'histoire économique de l'Afrique (cf. notamment Carandini 1970a et Lassère 1977), c'est bien au courant du IIe s., comme le soulignait J. W. Hayes, que les céramiques africaines deviennent prépondérantes dans le bassin méditerranéen, principalement dans sa partie occidentale ; elles le resteront jusqu'à la fin du VIIe s. au moins, témoignage du long crépuscule de l'Antiquité dans ces régions. Le mot céramique, employé dans son sens premier, regroupe l'ensemble des objets de la vie quotidienne fabriqués dans ce matériau: amphores, vaisselles, lampes, petits objets et matériaux de construction, bref l'ensemble des artefacts issus de la fouille soumis, sur le terrain, à l'analyse des céramologues.

Enfin, ce travail n'a aucune prétention à l'exhaustivité. Il s'agit simplement de la synthèse d' «études » conduites au hasard des circonstances, en Tunisie et sur quelques sites consommateurs de Méditerranée occidentale et orientale (fig. 1, a-b-c).

\section{Sites étudiés}

Les sites étudiés se répartissent selon trois grandes zones géographiques.

C'est dans le Midi de la France (fig. 1b), tout d'abord, que j'ai exercé, depuis vingt-cinq ans, l'essentiel de mon activité. Le site de Marseille et en particulier le chantier de La Bourse, que j'ai dirigé de 1979 à 1984, a fourni une documentation très abondante qui constitue la base de mon apprentissage de la céramique africaine (Bonifay 1983 et 1986; Bonifay, Pieri 1995 ; Bonifay, Carre, Rigoir 1998). La création, en 1983, du groupe de travail sur la Céramique de l'Antiquité Tardive et du Haut Moyen-Age (C.A.T.H.M.A.), sous la présidence de G. Démians d'Archimbaud et de M. Picon, a donné une forte impulsion aux recherches régionales (C.A.T.H.M.A. 1986 et 1991). Les réunions de travail mensuelles qui furent régulièrement organisées autour de lots de mobiliers, généralement inédits, nous ont permis d'acquérir une bonne connaissance des céramiques africaines tardives importées sur de nombreux sites de la moitié sud de la France, de Nice à PortVendres, et dans les régions limitrophes, à Bordeaux, Lyon, Vintimille $^{2}$ et Empúries ${ }^{3}$. Enfin, les contacts entretenus de longue date avec nos collègues du Département des Recherches Archéologiques Subaquatiques et Sous-Marines, dont le siège est à Marseille, m'ont permis de côtoyer ${ }^{4}$ la plupart des amphores africaines découvertes sur le littoral français (Ben Lazreg et al. 1995, Annexe I).

Une deuxième zone géographique importante, du point de vue des sites étudiés, est la Tunisie (fig. 1c). Ma première

\footnotetext{
2 Grâce à nos collègues de l'Institut d'Etudes Ligures, notamment D. Gandolfi et G. Murialdo.

${ }^{3}$ Grâce à l'amitié du Directeur du site, X. Aquilué.

${ }^{4}$ Merci à Fl. Richez pour sa disponibilité.
} 
expérience en Tunisie a été conduite, en 1989-1990, dans le cadre du programme tuniso-français d'étude du littoral tunisien ${ }^{5}$ (Bonifay 1990). A l'occasion de ces recherches extensives sur le littoral, un certain nombre de sites de production d'amphores ont pu être également visités (Capelli 2002-2003; Capelli et al. 2001). Depuis 1991, mon activité en Tunisie s'est concentrée dans une région précise, le nord du golfe d'Hammamet, et en particulier, sur les sites de Sidi Jdidi (Aradi), Nabeul (Neapolis) et Hammamet (Pupput), où des fouilles sont menées par trois équipes tuniso-françaises ${ }^{6}$ (Ben Abed, Bonifay, Fixot 1997; Slim, Bonifay, Trousset 1999 ; Ben Abed, Griesheimer 2004). Des études plus ponctuelles ont été effectuées sur d'autres sites soit dans le cadre de missions tuniso-françaises, à Carthage (Bonifay à paraître, a), Oudhna (Barraud et al. 1998) et Rougga (Guéry, Bonifay à paraître), soit à la demande de collègues tunisiens, à Thuburbo Majus (Ben Abed, Bonifay 1998), Oued $\mathrm{R}^{\prime} \mathrm{mel}^{7}$, et El $\mathrm{Jem}^{8}$. Tout récemment encore, j'ai appris à connaître le faciès céramique d'une des villes les plus orientales de l'Afrique Proconsulaire, Lepcis Magna, dans le cadre de la Mission Archéologie Française en Libye?.

Enfin, il m'a été donné l'occasion de travailler sur quatre sites de Méditerranée orientale. Le plus à l'Est est celui de Beyrouth où je collabore, depuis 1995, à la publication des sigillées tardives des fouilles françaises du centre-ville (Bonifay 1996). En Egypte, j'ai effectué plusieurs missions à Alexandrie, à l'invitation de J.-Y. Empereur pour étudier les sigillées tardives du chantier du théâtre Diana (Bonifay 1998c) et les amphores du Sérapéum (Bonifay, Leffy 2002); d'autres projets sont en cours sur les céramiques africaines de $\operatorname{Coptos}^{10}$ et de l'oasis de Bahariya ${ }^{11}$. J'ai également une petite expérience du mobilier d'Apollonia de Cyrénaïque, à l'issue d'un séjour effectué en $1998^{12}$. Enfin, je ferai allusion dans le texte aux observations que j'ai pu réaliser sur la diffusion des céramiques africaines en Albanie, dans le cadre de la mission franco-albanaise à Byllis ${ }^{13}$.

\section{Problématiques actuelles de l'étude des céramiques africaines}

La céramique produite en Afrique romaine est sans aucun doute celle qui a été le plus longtemps et le plus largement diffusée dans le monde antique. En effet, du IIe au VIIe s., amphores, vaisselles sigillées, lampes et céramiques culinaires inondent le bassin méditerranéen et gagnent même les marches de l'Empire, du Portugal à la Crimée et de la haute-Egypte aux îles Britanniques.

Cette large diffusion explique, au moins en partie, que l'étude de la céramique africaine soit née sur des sites consommateurs. Ainsi la vaisselle sigillée africaine a été

\footnotetext{
${ }^{5}$ Dirigé par H. Slim et P. Trousset.

${ }^{6}$ Sidi Jdidi : A. Ben Abed et M. Fixot ; Nabeul : L. Slim et moimême; Pupput : A. Ben Abed et M. Griesheimer.

${ }^{7}$ Responsable du site : T. Ghalia.

${ }^{8}$ Responsable du site : H. Slim.

${ }^{9}$ Dirigée par A. Laronde.

${ }^{10}$ Etude du mobilier des fouilles S. Reinach 1910-11.

11 A l'invitation de S. Marchand, dans le cadre du projet GRAPATE

12 A l'invitation du chef de mission, A. Laronde, et en collaboration avec J. Piton et D. Pieri.

${ }^{13}$ Dirigées par Sk. Muçaj et J.-P. Sodini.
}

tout d'abord mise en évidence en Méditerranée orientale (classifications de Waagé en 1933 sur l'Agora d'Athènes et en 1948 à Antioche) puis en Italie (classification de Lamboglia en 1958 et 1963 à Vintimille). Il fallut attendre les études de J. W. Salomonson (1962, 1964 et 1968 ) et surtout la synthèse magistrale de J. W. Hayes (1972) pour que l'origine africaine de cette production soit clairement établie et que le mobilier trouvé sur les lieux de production fasse l'objet d'un début de recensement. Il en est de même pour les amphores africaines, qui ont été reconnues comme telles par A. Tchernia et $\mathrm{F}$. Zevi à partir du mobilier recueilli à Ostie et sur les côtes françaises (1969). La classification de base, due à Cl. Panella (1973), repose sur la stratigraphie des Thermes du Nageur à Ostie et la plupart des additions typologiques ultérieures, par D. Manacorda en 1977 et par S. J. Keay en 1984, sont bien révélatrices de la masse des conteneurs africains qui fut importée en Italie et en Catalogne à la fin de l'Empire. Il n'y a guère que les lampes qui aient fait l'objet de classifications dans leur pays d'origine (Deneauve 1969 ; Ennabli 1976), classifications qui, par leur succès, ont largement rayonné dans le bassin méditerranéen.

Le renouveau des études sur la céramique africaine en Afrique a coïncidé avec l'ouverture des chantiers de l'UNESCO à Carthage au milieu des années 70, animés par diverses missions étrangères. Il a été concrétisé par le colloque sur la céramique antique, tenu à Carthage en 1980 sur l'initiative d'A. Ennabli et publié en 1982 dans le premier supplément aux Cahiers $d u C E D A C$. Mais, si l'on fait le point sur les vingt années écoulées depuis ce colloque, on doit bien admettre que les avancées sur la typologie et la chronologie de la céramique africaine sont peu spectaculaires. Le seul site réellement bien documenté reste Carthage, où de nombreux contextes sont échelonnés entre la fin du IVe et la fin du VIIe s. (Hayes 1976a, 1978a et b ; Riley 1981 ; Fulford, Peacock 1984 et 1994 ; Mackensen 1991 et 1999a et b). Hors Carthage, des missions françaises, néerlandaise et allemande ont apporté des éclairages sur le matériel d'époque romaine impériale de quelques rares cités: Mactar (Bourgeois 1977, 1977-78, 1982), Bulla Regia (Bulla Regia I et II), Uzita (Van der Werff 1982a), Chemtou (Vegas 1994a). Nombreux, toutefois, sont les travaux en cours. Quelques régions sortent de l'ombre : Jerba (Fentress 2001), le Sahel et notamment Leptiminus (Dore 1992 et 2001), Haïdra (Baratte, Bejaoui, Ben Abdallah 1999), la région de Dougga (De Vos 2000) et les trois villes de Nabeul-Hammamet-Sidi Jdidi.

Dès 1963, P.-A. Février $(1964,136)$ avait bien perçu tout l'intérêt qu'il y aurait, pour l'histoire du commerce de l'Antiquité, à dessiner des cartes de diffusion des céramiques africaines. A la suite des travaux précurseurs d'Ostie (Panella 1973), l'afflux de données quantitatives sur les céramiques africaines à Carthage puis dans d'autres grandes villes de Méditerranée occidentale a amené archéologues et historiens à utiliser de manière 
intensive cette documentation pour aborder l'histoire économique de l'Afrique et du bassin méditerranéen. Cette pratique a donné lieu à une abondante littérature durant les années 80 et 90 (Fulford 1980 et 1983 ; Fentress, Perkins 1988; Panella 1983b, 1986, 1989, 1993 ; Reynolds 1995 ; Tomber 1993 ; Zanini 1996). De nos jours, la céramique est devenue le principal instrument de mesure de l'activité économique de l'Afrique antique ${ }^{14}$.

Enfin, ce n'est que récemment que l'on a commencé à se préoccuper des centres de production des céramiques africaines. Les prospections d'ateliers sont encore embryonnaires. Longtemps, nous n'avons disposé d'informations précises que sur deux ateliers de sigillée de Tunisie centrale et méridionale, dont il était en outre irritant que la production soit faiblement attestée en Méditerranée : Henchir es-Srira et Sidi Aïch (Stern 1968). Aujourd'hui encore, la base de nos connaissances repose sur des prospections conduites il y a déjà plus de quinze ans et, de surcroît, dans une région unique, le Sahel, où ont été pourtant repérés plus d'une trentaine d'ateliers d'amphores ou de sigillée (Peacock, Bejaoui, Ben Lazreg 1989 ; Peacock, Bejaoui, Ben Lazreg 1990). La seule monographie tout entière consacrée à un atelier tunisien reste celle de l'officine de sigillée d'el-Mahrine, publiée par M. Mackensen en 1993. Mais, là encore, des recherches sont en cours. L'étude de l'atelier de sigillée d'Oudhna, signalé depuis 1896 par P. Gauckler, a été reprise, cent ans après, par une mission tuniso-française (Barraud et al. 1998) et fait, en ce moment même, l'objet d'une thèse de doctorat préparée par Faouzia Dridi. D'autres étudiants tunisiens ont été dirigés vers l'étude de différents sites producteurs du nord, du centre et du sud $\mathrm{du}$ pays et on devrait disposer, à terme, d'un certain nombre de monographies sur les principaux ateliers de sigillée africaine. On doit également mentionner les recherches en cours sur l'atelier d'amphores de Leptiminus (Stone, Stirling, Ben Lazreg 1998; Stirling, Ben Lazreg 1999; Stirling 2001) et les prospections entreprises tout récemment sur le territoire de la cité de Nabeul (Ghalia, Bonifay, Capelli 2004).

On perçoit ainsi les directions successivement empruntées par la céramologie africaine durant ces vingt dernières années : typologie et chronologie, signification économique de la documentation, origine des productions. Or, malgré tout ce qui a été écrit sur le sujet, ces questions restent d'actualité et il me semble qu'elles constituent l'aiguillon des recherches présentes.

1) Désormais, l'accent est mis sur les questions de production. Si l'origine africaine, au sens large, d'une céramique est devenue facile à identifier, on ne peut plus aujourd'hui se contenter d'une telle imprécision. Il est plus que jamais nécessaire de progresser sur la

\footnotetext{
${ }^{14}$ Voir, en dernier lieu, le chapitre « économie » du colloque sur l'Afrique vandale et byzantine, in AnTard, 10, 2002, 177-196.
}

détermination des différentes régions productrices qui composent ce vaste territoire. Plusieurs voies s'offrent à la recherche, parmi lesquelles la définition des faciès locaux, le repérage des ateliers, la caractérisation pétrographique et minéralogique des argiles.

2) Le système typo-chronologique qui a régi l'étude des céramiques africaines depuis quatre décennies est en train de subir des révisions importantes. La grande affaire est désormais de confronter les typologies élaborées tout d'abord hors d'Afrique puis, en Afrique, dans la seule ville de Carthage, à la réalité du terroir africain et de ses particularismes locaux. L'examen des contextes africains oblige ainsi à modifier le découpage des catégories et à remettre en question des datations que l'on pensait acquises.

3) Il a été accordé un large crédit aux capacités de la céramique africaine à nous renseigner sur l'histoire économique des provinces africaines, voire de l'ensemble du bassin Méditerranéen. Peut-être est-on allé trop vite et trop loin dans ce domaine. Beaucoup de ces constructions historiques reposent en fait sur des bases documentaires peu fiables ou analysées avec des critères de datation qui ne sont pas homogènes entre eux. Beaucoup de certitudes sur l'origine des vaisselles ou le contenu des amphores sont en train de s'effondrer du fait des progrès réalisés dans l'origine et la datation des céramiques ou encore le contenu des amphores. La contestation des modèles bâtis dans les années 70-80 est en marche.

Production, typologie et chronologie, diffusion : ce sont donc les trois rubriques dans lesquelles je propose de classer la documentation que j'ai recueillie au cours des vingt dernières années, en France méridionale tout d'abord, en Tunisie et sur d'autres sites du bassin méditerranéen ensuite.

\section{Illustrations}

Sauf mention contraire, toutes les illustrations sont de l'auteur.

Les amphores sont aux échelles $1 / 10$ et $1 / 4$, les vaisselles à l'échelle $1 / 3$, les lampes à l'échelle $1 / 2$. Tous les exemples dont le $\mathrm{n}^{\circ} \mathrm{d}^{\prime}$ 'ordre est précédé d'un astérisque (ex. $\left.{ }^{*} 1\right)$ sont illustrés. 


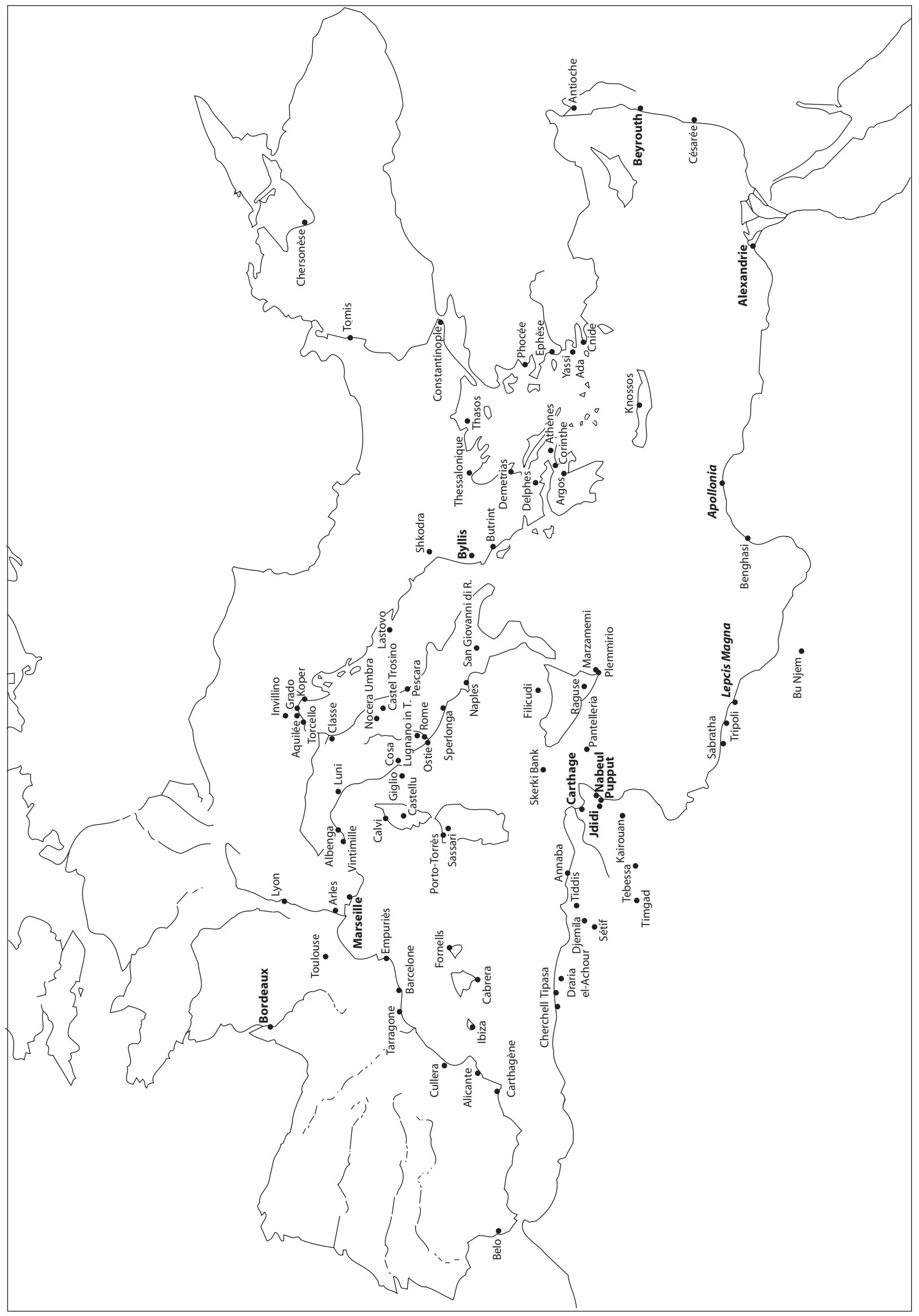

Fig. 1a. Méditerranée : carte des principaux sites étudiés (en gras) ou mentionnés. 


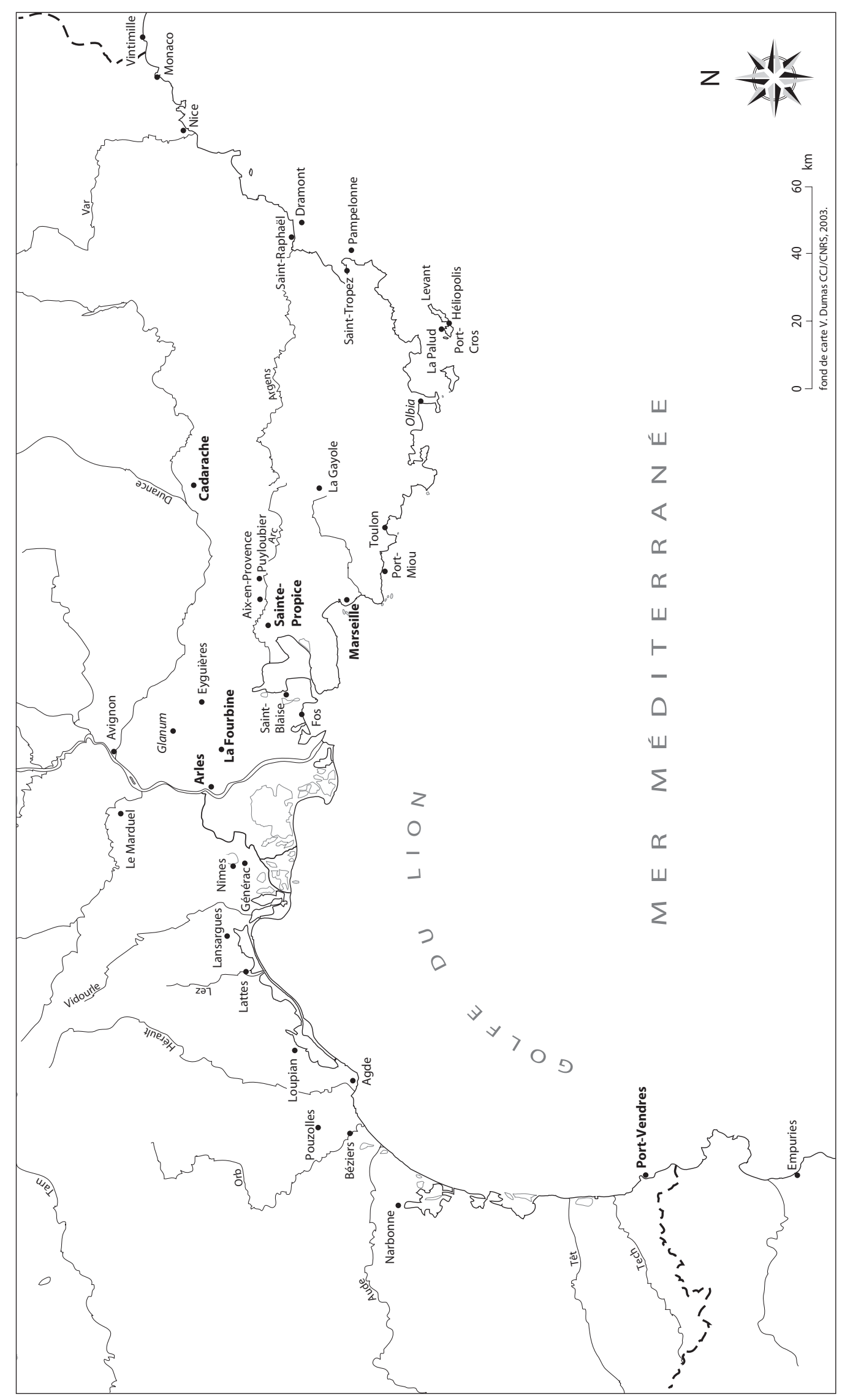

Fig. 1b. Midi de la France : carte des principaux sites étudiés (en gras) ou mentionnés. 


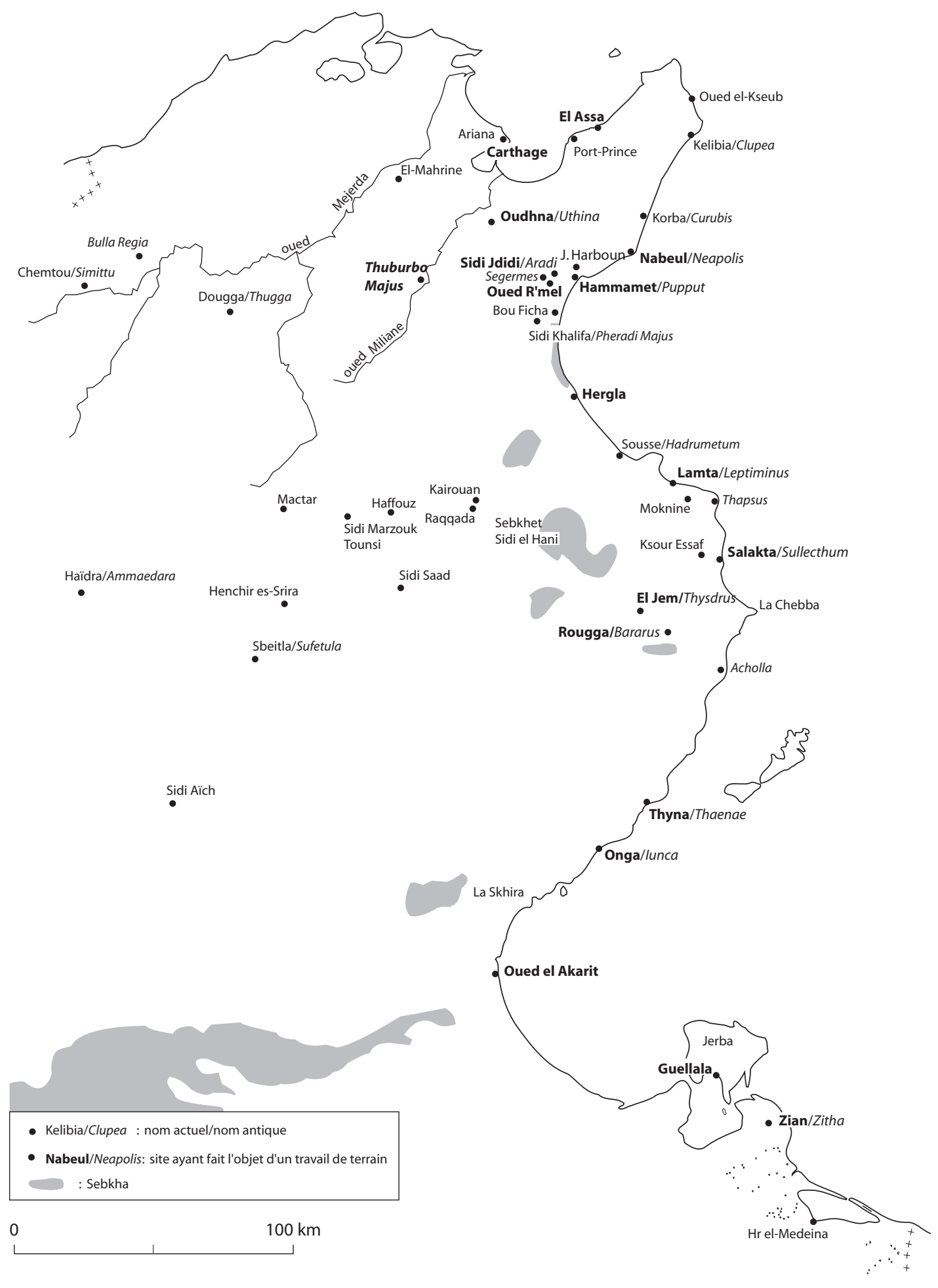

Fig. 1c. Tunisie : carte des principaux sites étudiés (en gras) ou mentionnés. 


\section{PARTIE I : Production}

\section{VERS UNE DÉFINITION DES ZONES D’ATELIERS}

Il y a quarante ans, rares étaient les céramologues qui osaient attribuer à l'Afrique des céramiques découvertes hors de ce territoire. "Contre un certain nombre d'a priori des chercheurs d'Afrique du Nord », P.-A. Février (1964, 130) réclamait «la nécessité d'un doute méthodique » sur l'origine des céramiques africaines; « seule la découverte de fours et de déchets de cuissons (...) lèvera les doutes » écrivait-il encore en 1980 (Février 1980, 172-173). Aujourd'hui, en revanche, le terme de « céramique africaine »n'apparaît plus assez précis pour caractériser les multiples productions des provinces de Zeugitane, Byzacène et Tripolitaine (Bonifay 1998d, 328).

Longtemps, n'a été connu de la céramique africaine que ce qui en avait été exporté sur les grands sites consommateurs de Méditerranée occidentale (Vintimille, Ostie) ou orientale (Athènes, Antioche). Puis, la céramique de Carthage a paru, un temps, pouvoir représenter l'ensemble de la céramique africaine. Aujourd'hui que les recherches sont mieux réparties sur le territoire africain, les productions africaines apparaissent dans toute leur complexité et il devient possible de réfléchir sur leur origine précise. J'ai moimême suivi cette évolution. Pour étudier les céramiques africaines de Marseille, j'ai tout d'abord utilisé les typologies traditionnelles établies hors d'Afrique puis tenté d'appliquer celles élaborées à Carthage. Les difficultés ressenties à ce moment-là et les questions suscitées par l'hétérogénéité des formes et des argiles, n'ont fait que s'accentuer lorsque je suis venu travailler en Tunisie. On ne dira jamais assez le caractère déroutant de la céramique d'un site un peu isolé comme celui de Sidi Jdidi pour un céramologue formé sur les rives septentrionales de la Méditerranée (Bonifay, Reynaud 2004, 229).

Il importe donc aujourd'hui de parvenir à une meilleure caractérisation géographique des productions africaines, et plusieurs pistes peuvent y conduire.

Dès la constitution du C.I.L., des noms de cités africaines ont été lus sur des timbres d'amphores. Les recherches menées conjointement sur le recensement de ces marques et leur liaison avec la typologie ont permis de localiser certaines productions sur le territoire africain (Zevi, Tchernia 1969). Ce critère d'identification est valable également pour les lampes, bien que les indications toponymiques y soit plus rares. Ici, c'est plutôt la répartition géographique des différents timbres qui joue.

De fait, la circulation des céramiques africaines sur le territoire africain n'obéit pas aux mêmes règles que le commerce extra-provincial. La carte de diffusion d'une forme de céramique peut être révélatrice, dans certaines conditions, de la proximité des centres de production. Les ramassages effectués au cours de la prospection extensive $\mathrm{du}$ littoral tunisien m'ont très vite convaincu qu'il était nécessaire de réfléchir en termes de faciès (Bonifay et al. 2002-2003). Les formes (amphores, céramiques sigillées, céramiques communes), le traitement de surface (céramiques culinaires), les décors (lampes, figurines, carreaux) sont autant de critères qui permettent d'individualiser les différents faciès africains au sein d'une production très hétérogène dans le détail.

Un des axes de recherche les plus prometteurs pour la définition de ces faciès géographiques porte sur la caractérisation archéométrique des argiles. Les observations pétrographiques réalisées sur la pâte des amphores et les analyses physico-chimiques conduites sur les sigillées permettent dès maintenant d'attribuer certaines formes à des régions ou même à des ateliers bien déterminés (Capelli et al. 2001; Capelli, Ben Lazreg, Bonifay à paraître).

Enfin, les progrès les plus substantiels que nous puissions accomplir dans notre approche des productions africaines proviennent des prospections d'ateliers. J'en ai fait l'expérience en visitant bon nombre d'ateliers d'amphores littoraux (Bonifay et al. 2002-2003 ; Ghalia, Bonifay, Capelli 2004) et en participant aux fouilles de l'atelier de sigillée d'Oudhna (Barraud et al. 1998). Ces travaux permettent également de réfléchir sur les conditions techniques de la production des céramiques africaines et sur leur originalité par rapport aux autres productions de l'Empire.

Les problèmes posés par la production des céramiques africaines sont relativement divers selon les catégories envisagées. Je proposerai donc d'examiner tour à tour les questions spécifiques posées par les amphores, puis par les céramiques sigillées et enfin par les autres catégories. 


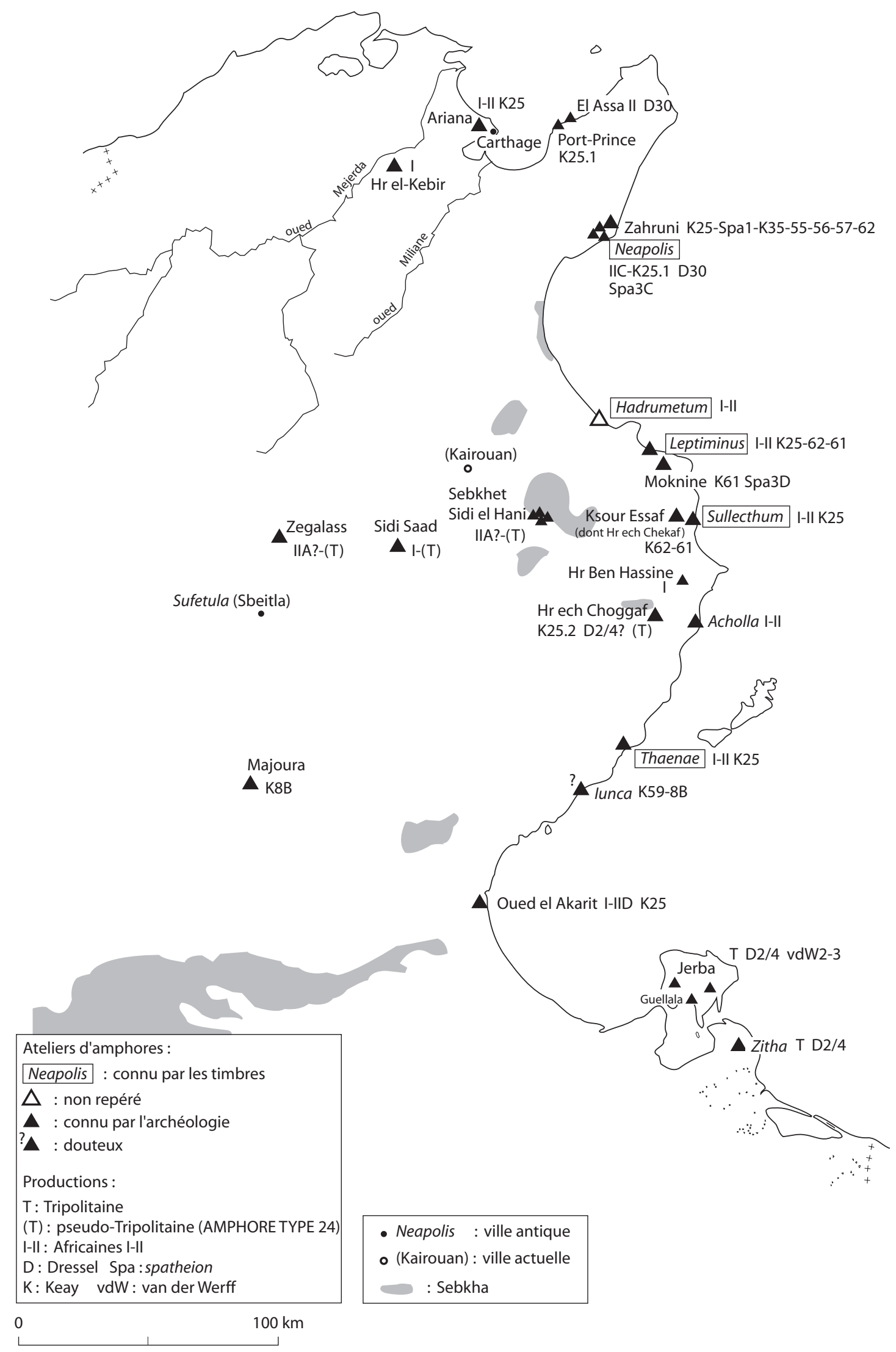

Fig. 2. Carte des principaux ateliers d'amphores connus en Tunisie. 


\section{LA PRODUCTION DES AMPHORES AFRICAINES}

Depuis l'article fondateur de Fausto Zevi et André Tchernia (Zevi, Tchernia 1969), qui a permis de mettre en relation des timbres amphoriques mentionnant des cités portuaires africaines (Hadrumetum, Leptiminus, Sullecthum) avec une série d'amphores omniprésente en Méditerranée occidentale, les progrès réalisés dans la détermination de la provenance des conteneurs africains ont été moins importants que ceux que l'on était en droit d'espérer.

Ce retard est dû au fait qu'il n'y a pas de recensement systématique des ateliers d'amphores africains. Le seul programme correspondant à cet objectif est celui conduit dans les années 80 par MM. Peacock, Bejaoui et Ben Lazreg, dans une région très limitée de l'actuel Sahel (Peacock, Bejaoui, Ben Lazreg 1989 et 1990); il est regrettable que ce programme n'ait pas pu être étendu à d'autres régions. Les autres ateliers dont la production est connue ont été repérés de manière occasionnelle dans le cadre de programmes qui ne concernaient pas directement la céramique ${ }^{15}$. Enfin, beaucoup d'ateliers d'amphores ont été découverts au cours de l'élaboration de la carte archéologique de la Tunisie (cf. Ben Baaziz 1998, 46 : « au moins une cinquantaine de centres de fabrication de la céramique antique » dans le Sahel) mais leur production n'a pas été caractérisée ${ }^{16}$. La carte (fig. 2) que nous sommes en mesure de dresser aujourd'hui est donc extrêmement lacunaire et il faut bien garder à l'esprit qu'elle ne correspond certainement pas à la réalité du passé.

Se trouvant de la sorte démunis, les archéologues du bassin méditerranéen, confrontés quotidiennement aux masses d'amphores africaines issues de leurs sites espagnols, français, italiens, ou aux objets plus rares récoltés dans sur des sites plus orientaux, ont tendance à se raccrocher aux deux seuls contextes biens connus, cités plus haut, de Carthage et du Sahel. Il s'ensuit un certain galvaudage du terme « amphore de Byzacène » appliqué à des productions qui ne proviennent pas toutes de cette région de l'Afrique ${ }^{17}$ et si l'appellation «amphore de

15 Ex. : atelier découvert fortuitement dans le quartier de l'Ariana, près de Carthage (Panella 1982, 173); ateliers découverts dans le cadre des prospections extensives du littoral tunisien (Bonifay et al. 2002-2003) et du transect récemment réalisé dans l'île de Jerba (Fentress 2001).

${ }^{16}$ Il conviendrait maintenant que des céramologues visitent ces sites et dressent le catalogue des productions. L'expérience réalisée récemment sur quelques sites de la région de Nabeul (Ghalia, Bonifay, Capelli 2004) est assez révélatrice des profits que l'on pourrait tirer d'une telle action, au demeurant fort peu mobilisatrice de moyens.

${ }^{17} \mathrm{Si}$ on peut admettre l'utilisation de ce nom pour des amphores fabriquées dans le Byzacium, avant que cette région n'acquière une autonomie administrative, en revanche, il est impropre
Tripolitaine » conserve une validité certaine, c'est parce que les formes sont, dans ce cas, assez facile à distinguer ; plus à l'Ouest, la tendance est parfois de faire une équivalence exclusive entre les « amphores maurétaniennes » et le type Dressel 30 (Laporte 197678).

Arrivé en Afrique dans ce même état de confusion, ce n'est que progressivement, en apprenant à connaître le faciès des différentes régions de Tunisie, que je me suis aperçu qu'il était possible de déterminer plus précisément l'origine de certaines productions.

\subsection{LA RECHERCHE DES PROVENANCES}

\subsubsection{Les marques d'ateliers}

\section{Les timbres : cadre général}

S'il y a des amphores pour lesquelles il n'est pas permis de douter du lieu de production, sauf dans le cas non encore avéré d'une usurpation de toponyme, ce sont bien celles portant un timbre qui mentionne le nom de leur cité d'origine. En effet, une particularité des timbres sur amphores africaines est de faire prévaloir, de manière générale, les indications toponymiques sur les données onomastiques (Manacorda, Panella 1993, 60; Panella 2001, 186) ${ }^{18}$. Dans le domaine des amphores africaines, la base de nos connaissances repose toujours sur l'inventaire réalisé par D. Manacorda dans le cadre de la publication des fouilles d'Ostie (Manacorda 1977, 190206) ${ }^{19}$.

On peut distinguer plusieurs types de timbres sur amphores africaines en fonction de leur emplacement, de leur forme et de leur contenu épigraphique (fig. 3-4).

- Les amphores tripolitaines portent des timbres avec des lettres normalement en relief, dans un cartouche, appliqués de préférence sur le bord (Manacorda 1983, 498-500, 41 attestations); les timbres sur l'anse, inhabituels sur les amphores de Proconsulaire, sont également abondants (Ibid., 23 attestations); enfin, les timbres sur le col, qui constituent la règle sur les amphores de Proconsulaire, sont minoritaires (Ibid., 19 exemples). Le $n^{\circ} \mathbf{1}$ est assez révélateur de ces pratiques, avec le même timbre répété sur le bord et sur chacune des deux anses. Quatre séries :

d'appeler « amphore de Byzacène » un vase produit à Carthage ou à Nabeul.

${ }^{18}$ Voir cependant les timbres COL BER de Beyrouth : Reynolds 1997-98, 49.

${ }^{19}$ Pour les amphores tripolitaines, voir Manacorda 1976-77. 


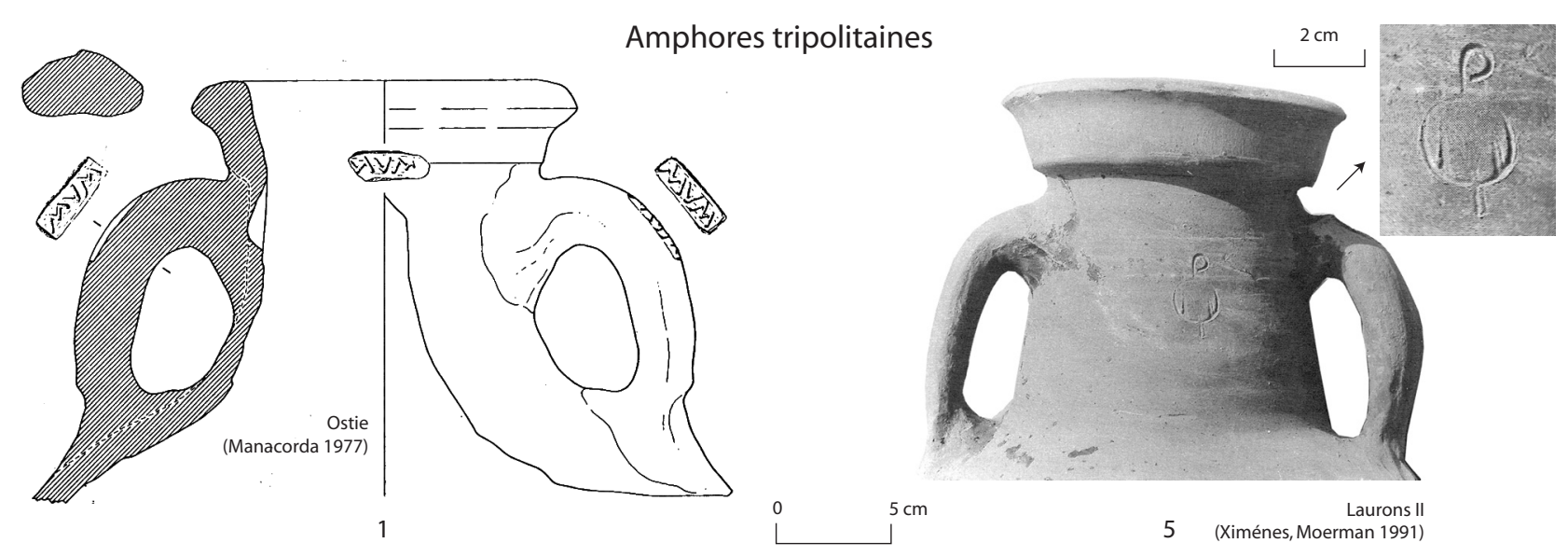

Amphores d'Afrique proconsulaire
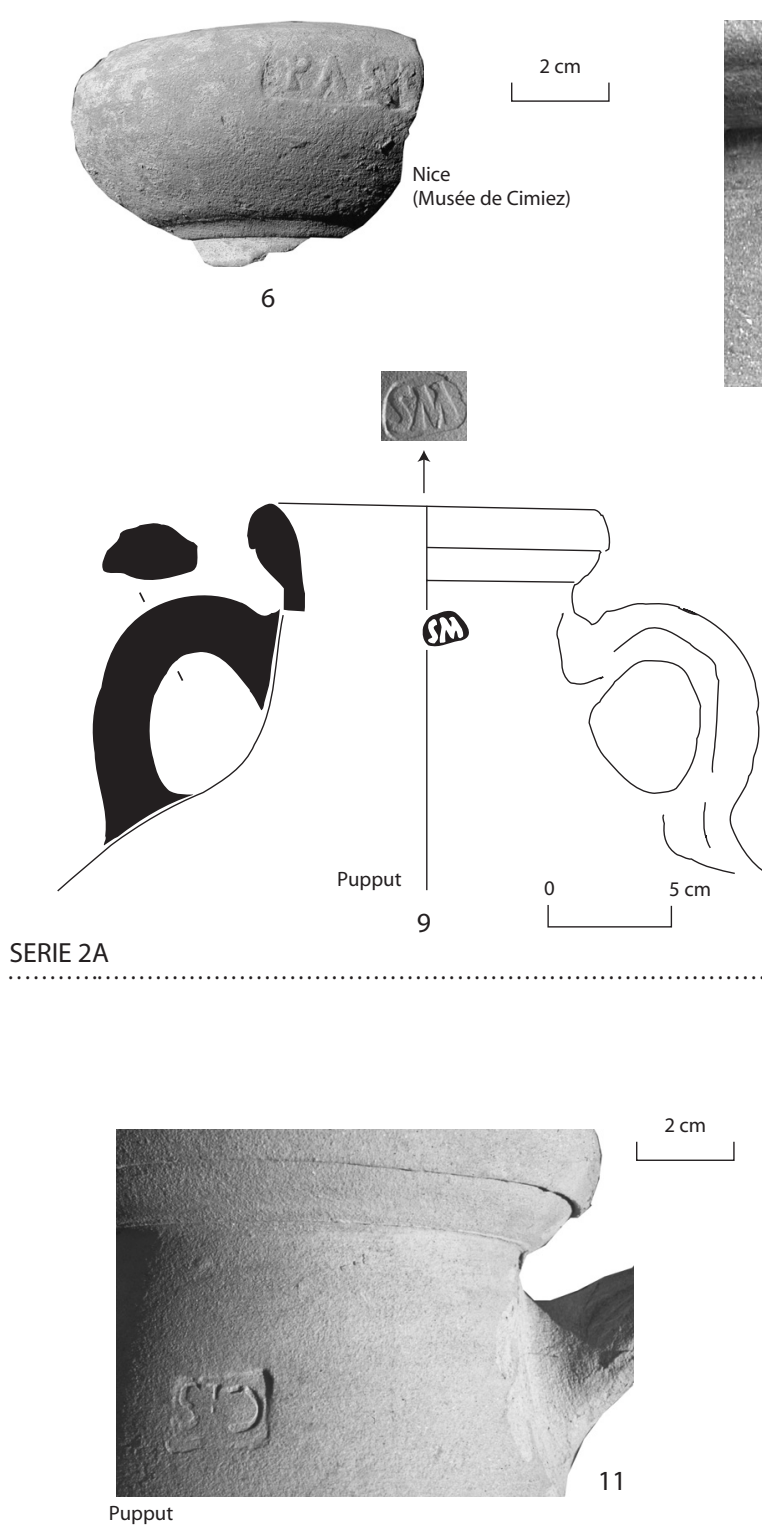

SERIE 2B
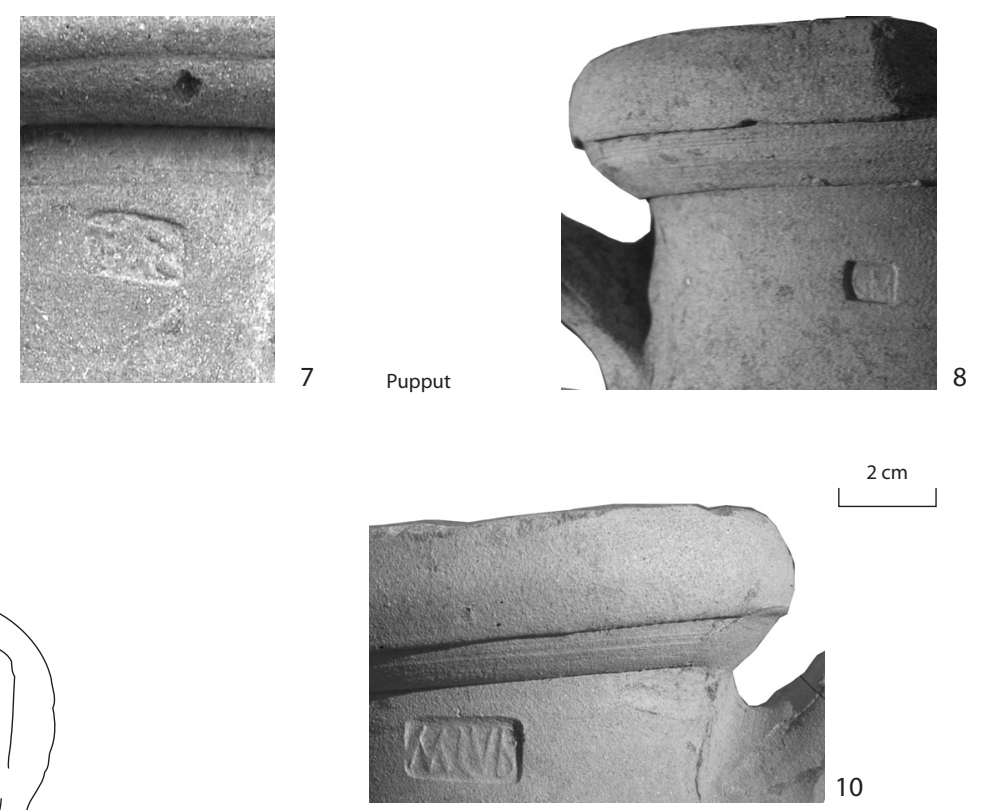

10

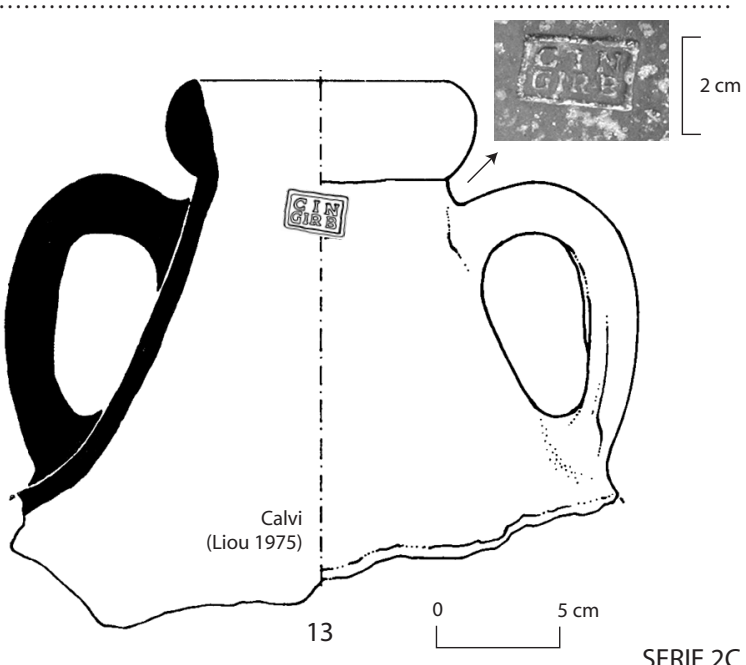

Fig. 3. Différents types de timbres sur amphores africaines. 
- [1A] De manière assez banale en Méditerranée occidentale, la majorité des timbres tripolitains sont composés de trois lettres, très probablement les initiales des tria nomina du propriétaire terrien producteur à la fois des denrées agricoles (huile) et de l'amphore destinée à les commercialiser (Manacorda 1976-77, 569).

- [1B] Mais une particularité des timbres tripolitains, qu'il convient de rappeler, tient à la mention, très fréquemment ajoutée aux initiales des tria nomina, de la dignité sénatoriale : C(larissimus) V(ir) (2) (Ibid., 570).

- [1C] De même, la terminaison en $P P$ (3) doit probablement traduire la charge exercée par le propriétaire : $P$ (raefectus) $P$ (raetorio) (Ibid. 573).

- [1D] Enfin, les timbres avec la mention $A V G$ (4) se rapportent vraisemblablement à des propriétés impériales (Ibid. 581).

Ces timbres sont attestés principalement sur le type Tripolitaine III (infra, AMPHORE TYPE 20). Le type Tripolitaine II est rarement timbré (Panella 2001, 186; voir cependant un contre-exemple de Bu Njem: infra, AMPHORE TYPE $4, \mathrm{n}^{\circ} 6$ ).

Exemples (fig. 3) :

*1 Ostie (Ostia IV, 265). Timbre MVM répété trois fois (sur le bord et sur chacune des deux anses). Pâte à strates rouges et grises, avec de nombreuses petites impuretés sableuses et une surface blanche délavée.

2 Rome (Manacorda 1976-77, Fig. A, n 3). Timbre L.S.A.CV sur le col : L. S(eptimi) A(pri) C(larissimi) V(iri).

3 Raphia (Ibid., fig. D, $\left.\mathrm{n}^{\circ} 1\right)$. Timbre CFPPP sur le col : C. F(ulvius) P(lautianus) P(raefectus) Praetorio).

4 Ostie (Zevi, Tchernia 1969, 194, fig. B). Timbre sur anse: IMPANT/AVG sur une anse: Imp(erator) Ant(oninus) Aug(ustus), probablement Caracalla (Manacorda 1976-77, 581).

Pour la plupart, les timbres sur amphores tripolitaines semblent se rattacher à l'ère sévérienne (Manacorda 1983, 492) et aux productions lepcitaines (Di Vita-Evrard 1985, 156).

Cependant, il peut exister des exceptions à ce schéma. Un curieux timbre circulaire, sur l'amphore Tripolitaine I de l'épave Laurons II (5), pourrait ainsi correspondre à une production tout à la fois pré-sévérienne (d'après la forme : infra, fig. 55a, AMPHORE TYPE 19, $\mathrm{n}^{\circ} 2$ ) et non lepcitaine (d'après la pâte : infra, p. 29).

Exemple (fig. 3)

*5 Epave Laurons II (Ximénès, Moerman 1991, fig. 7). Timbre sur le col : $M($ (?) inscrit dans un cercle, sur un $P(?)$.

- Les amphores d'Afrique proconsulaire offrent quelques rares exemples de timbres sur le bord (série 2A, $\mathrm{n}^{\circ}$ 6) et sur l'anse (série $2 \mathrm{~B}, \mathrm{n}^{\circ} \mathbf{1 2}$ ). Mais, pour leur écrasante majorité, les timbres de Proconsulaire sont appliqués sur le col, de préférence dans la partie supérieure de ce dernier. On distingue quatre séries principales :
- [2A] Une première série comprend des timbres composés de deux $(\mathbf{8}, 9)$ ou trois lettres (7) imprimées en relief dans un cartouche en creux : s'il s'agit bien encore d'initiales de tria nomina, on peut penser que le praenomen a été omis dans le premier cas. Plus rares sont les timbres composés de quatre lettres en relief (10): dans ce cas, on peut imaginer que le personnage possède deux cognomina ou bien que la quatrième lettre est déjà une indication toponymique $(?)^{20}$. Ces timbres sont principalement attestés sur des amphores Africaines II A.1, dont un bon nombre peut être attribué à la cité de Sullecthum d'après la qualité de la pâte (voir infra), et sur le bord de quelques amphores africaines II A (6), probablement de même origine. Le timbre PAS est bien attesté sur l'atelier de Salakta (Lavoie 1989, 106, s 8.5-7).

- [2B] Une deuxième série consiste dans des timbres à lettres creuses sans cartouche, ou avec un cartouche peu creusé, composés de deux ou trois lettres (11), plus rarement quatre (12). Il est possible que la présence d'un cartouche dans la série précédente soit liée à la nécessité d'imprimer plus profondément le tampon pour faire apparaître les lettres en relief, tandis que cette pratique est moins impérative dans le cas de lettres imprimées en creux (voir cependant le $\mathrm{n}^{\circ}$ 11). Cette série est bien attestée à Ostie sur des amphores africaines II A (Manacorda 1977, 191, $\left.\mathrm{n}^{\circ} 3-16\right)^{21}$. Certains de ces timbres donnent peut-être déjà une indication toponymique, par exemple le timbre SVL (pour Sullecthum ?) d'Ostie (Ibid., 1977, 191, n $\left.{ }^{\circ} 19\right)$; le développement du timbre CIS (10) en C(olonia) I(ulia) $S(\ldots)$ selon le modèle de la série suivante reste hasardeux ${ }^{22}$.

- [2C] Une troisième série comprend des timbres en creux dans un cadre, sur deux lignes. La ligne supérieure est encore composée de trois initiales, séparées par deux points: C.I.N; sur la ligne inférieure figurent d'autres initiales sans points ou bien un nom abrégé. Le $\mathrm{n}^{\circ} \mathbf{1 3}$ est représentatif de cette série attribuée par Cl. Panella $(1972,98)$ à la cité de Nabeul: C(olonia).I(ulia).N(eapolis). Ces timbres ne concernent que le type Africaine II C.

- [2D] Une quatrième série comprend des timbres de plus grande taille (au moins quatre lettres sur une seule ligne et plus généralement 7 à 12 lettres réparties sur deux lignes), en creux, sans cartouche qui abrègent, sans toutefois recourir aux initiales, des noms de personnes (15) et/ou des noms de cités (1617). Ce sont ces timbres qui ont permis à $F$. Zevi et

\footnotetext{
${ }^{20}$ Je remercie Jacques Gascou pour ces suggestions.

${ }^{21}$ En revanche, il convient de rectifier la description qui est donnée des timbres de l'épave de Monaco (Manacorda 1977, $\left.191, \mathrm{n}^{\circ} 5-6,9,12,14,16\right)$ : il s'agit de timbres à lettres en relief (série 2A) et non pas à lettres caves, d'où la présence de cartouches (observations personnelles).

22 On ne connaît pas le statut de la cité de Sullecthum (renseignement J. Gascou).
} 
Amphores d'Afrique proconsulaire

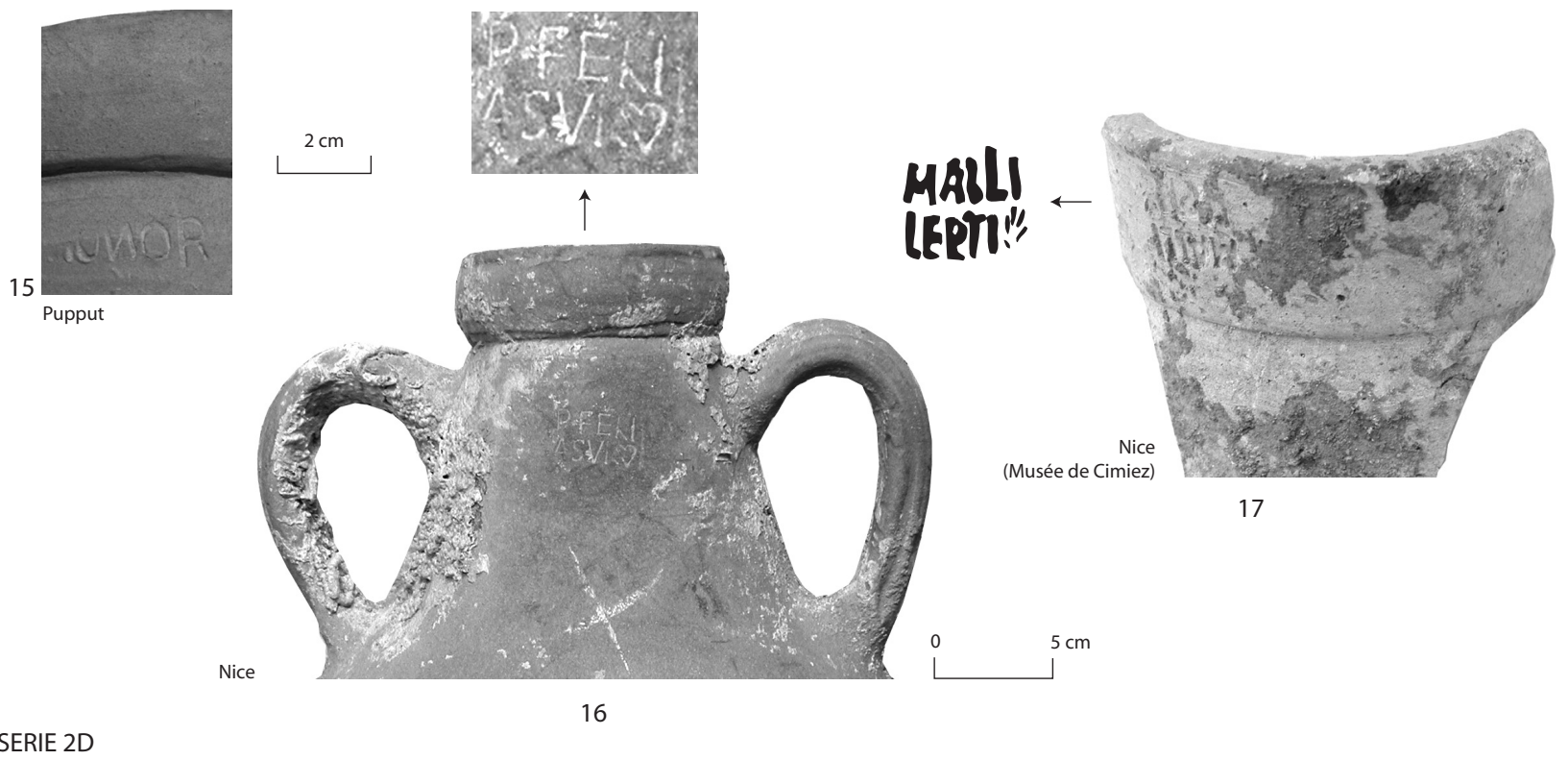

SERIE 2D

Amphores tardives

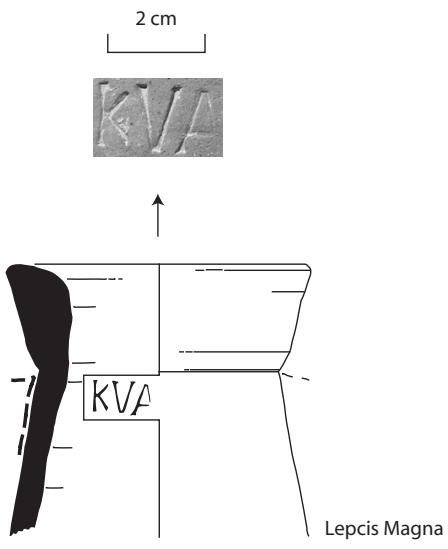

18

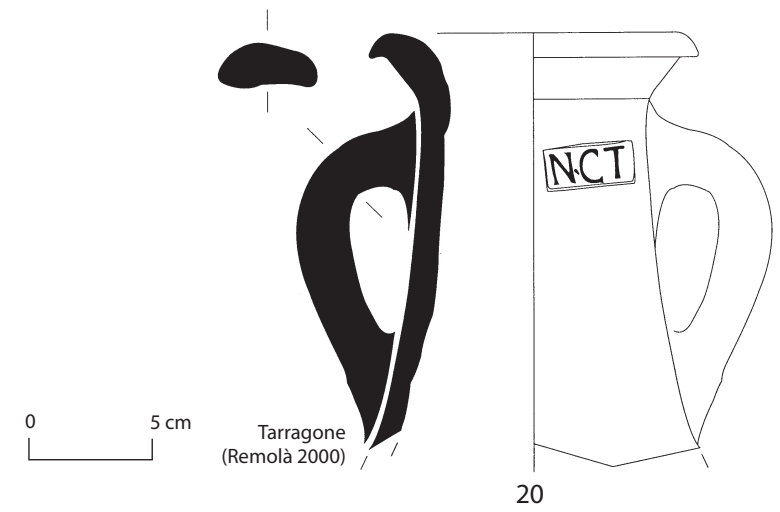

20

SERIE 3

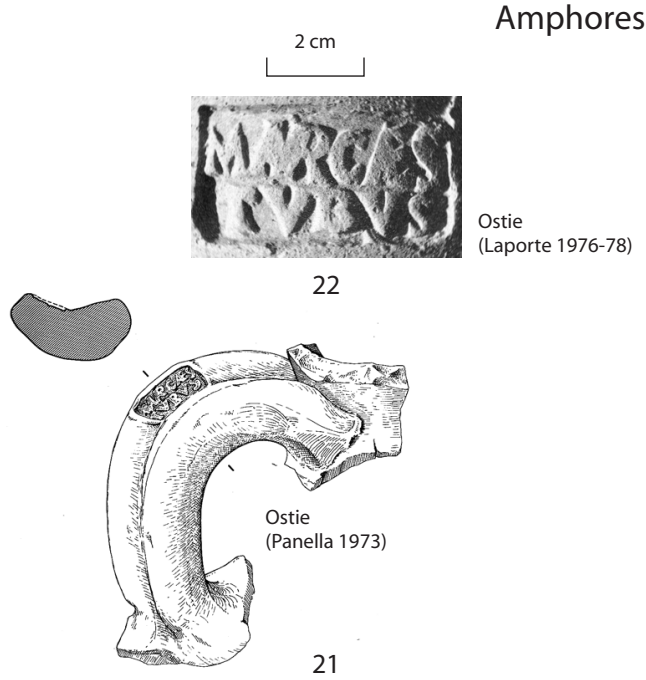

(?)

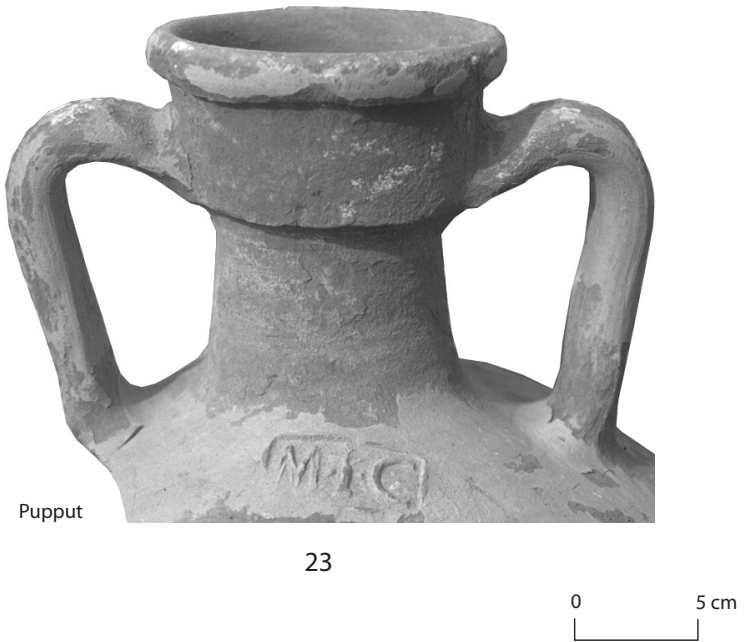

Fig. 4. Différents types de timbres sur amphores africaines. 
A. Tchernia d'identifier les deux grands types d'amphores africaines: «piccolo» (= type Africaine I B : infra, AMPHORE TYPE 21B) et « grande » (= types Africaine II B et D : infra, TYPES 23 et 26). Trois cités ont été formellement identifiées : Hadrumetum/Sousse, Leptiminus/Lamta et Sullecthum/Salakta, une quatrième restant plus douteuse : Thaenae/Thyna (Manacorda 1977, 205). Les timbres de la série 2D sont généralement appliqués au milieu du col mais on rencontre également quelques rares exemples sur le bord $(\mathbf{1 7})^{23}$

Exemples (fig. 3-4) :

SÉRIE $2 \mathrm{~A}$

*6 Nice (Musée de Cimiez, réserves). Amphore africaine I A. Timbre $P A S$, en relief dans un cartouche, sur le bord. Pâte du groupe Salakta (?).

*7 Pupput, tombe 642 (Inv. PP3436.4). Amphore Africaine II A.1. Timbre T.AZ ou PAS , en relief, dans un cartouche, sur le col. Pâte du groupe Salakta (?).

*8 Pupput, tombe 1019 (Inv. PP2889.5). Amphore Africaine II A.1. Timbre GM, en relief dans un cartouche profond, sur le col. Pâte du groupe Salakta (?).

*9 Pupput, tombe 403 (Inv. PP1585.3). Amphore Africaine II A.1. Timbre $S M$, en relief dans un cartouche, sur le col. Pâte du groupe Salakta (?).

*10 Pupput (Inv. PP1573.3). Amphore Africaine II A. Timbre $M L V B$, en relief dans un cartouche. Pâte du groupe Salakta (?).

SÉRIE 2B

*11 Pupput, tombe 403 (Inv. PP1585.4). Amphore Africaine II A. Timbre $C I S$, en creux, dans un cartouche peu profond, sur le col. Pâte du groupe Salakta (?).

12 Sibari (Sibari, fig. 538, $\mathrm{n}^{\circ} 699$ et $580, \mathrm{n}^{\circ} 22018$ ). Amphore Africaine II A.1. Timbre P.ASC, en creux, sans cartouche, sur une anse. Même nom que sur le timbre $\mathrm{n}^{\circ} \mathbf{6}(?)$.

SÉRIE 2C

*13 Calvi (Liou 1975, fig. 43). Amphore Africaine II C. Timbre C.I.N/GIRB, en creux dans un cadre, sur le col. Pâte du groupe Nabeul.

14 Golfe de Fos (Zevi, Tchernia 1969, fig. 21b; en exposition au Musée Archéologique d'Istres). Amphore Africaine II C. Timbre CIN/LCAN, en creux, dans un cadre, sur le col.

SÉRIE 2D

*15 Pupput, tombe 1610 (Inv. PP4923.1). Amphore Africaine II B. Timbre HONOR, en creux, sans cartouche, sur le col. Timbre attesté à Leptiminus (Peacock, Bejaoui, Ben Lazreg 1989, fig. 23, n² 2).

*16 Nice (DRASSM, sans $n^{\circ}$ d'inv.). Amphore Africaine II D. Timbre P.FELI/ASVL-hedera, en creux, sans cartouche, sur le col. Pâte du groupe Salakta.

*17 Nice (Musée de Cimiez, réserves). Amphore Africaine II D. Timbre MALLI ou MARI/LEPTI-palme, en creux, sans cartouche, sur le bord. Leptiminus.

\footnotetext{
${ }^{23}$ Pour un autre exemple, cf. Márquez, Molina 2001, 188, $\mathrm{n}^{\circ}$ 73 : VICTO/RINI/ASVLL sur bord d'amphore Africaine II D.
}

Ce schéma supporte bien évidemment un certain nombre d'exceptions : timbres imprimés sur l'épaulement (épave de Giannutri : Celuzza, Rendini 1991, $\mathrm{n}^{\circ}$ 107), timbres en creux dans un cadre, proches de la série $2 \mathrm{C}$, mais sur une seule ligne (Knossos: Sackett 1992, Pl. 99, $\mathrm{n}^{\circ}$ 150, également sur l'épaulement), timbres proches de la série 2A sur amphore Africaine II D (Porto Torres : Villedieu 1984, $\left.\mathrm{n}^{\circ} 264\right) \ldots$ Toutefois, cette distinction entre quatre grandes séries de timbres peut fournir des indications d'ordre non seulement géographique mais également chronologique. En effet, les timbres des séries C et D semblent bien, de manière générale, succéder à ceux des séries A et B. Sur la nécropole de Pupput, les timbres des séries $\mathrm{A}$ et $\mathrm{B}$ concernent les sépultures de la seconde moitié du IIe s. et du début du IIIe s. tandis que ceux de la série D ne semblent pas antérieurs au milieu du IIIe s. (Bonifay2004a). On peut également prendre en exemple d'une part l'épave A de Monaco, chargée d'amphores Africaines II A avec six timbres de la série A et un de la série $\mathrm{B}$, dont la datation oscille entre la fin du IIe s. et le deuxième quart du IIIe s. (Mouchot 1970), et d'autre part l'épave de Cabrera III, contenant des amphores Africaines II B et II D timbrées selon le mode D, et datées des environs de 270 (Bost et al. 1992). Les timbres de la série $\mathrm{D}$ ne semblent pas toutefois persister très audelà du IIIe s. puisqu'ils ne sont pas présents sur les amphores Keay 25.

- Les amphores tardives (amphores cylindriques de moyennes et grandes dimensions) sont rarement timbrées. Les rares timbres sur amphores Africaines III (type Keay $25=$ AMPHORES TYPES 27-29) sont composés de trois lettres en creux, sans cartouche ou dans un cartouche peu profond.

Exemples (fig. 4) :

SÉRIE 3

*18 Lepcis Magna, thermes du Levant (fouilles A. Laronde, Inv. 002.06). Amphore Africaine III A (type Keay 25.1). Timbre KVA, en creux, sans cartouche.

19 Epave pointe de la Luque B (Dovis-Vicente 2001, Pl. XXIII, $\mathrm{n}^{\circ}$ 1817). Amphore Africaine III A (type Keay 25.1 ?). Timbre $X K($ ?)S, en creux, dans un cadre (?).

*20 Tarragone (Remolà 2000, fig. 28, $\mathrm{n}^{\circ}$ 6). Amphore Africaine III B (type Keay 25.3). Timbre N.CT en creux, dans un cartouche.

Les deux amphores $\mathbf{n}^{\circ} \mathbf{1 8}$ et $\mathbf{1 9}$ portant des timbres en $K$ et $X$ pourraient également être d'origine maurétanienne (infra, p. 123).

- La documentation sur les timbres de Maurétanie Césarienne est assez hétérogène. Certes, nous sommes assez bien renseignés sur les timbres des amphores de type Dressel 30 fabriquées à Tubusuctu (Tiklat) et, plus accessoirement semble-t-il, à Saldae (Bougie). A l'imitation des modèles gaulois, les timbres sont principalement appliqués sur les anses (21, 22). Ils mentionnent à la fois l'officine (EX.O. suivi d'un nom), la cité (TVB ou TVBVS pour Tubusuctu) et même, fait unique en Afrique, la province (PROVINC MAVRETAN 


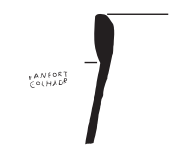

Pupput

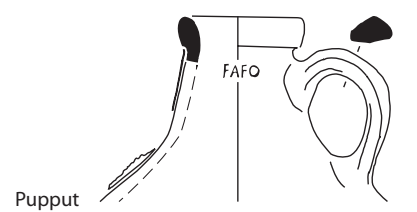

FAFO

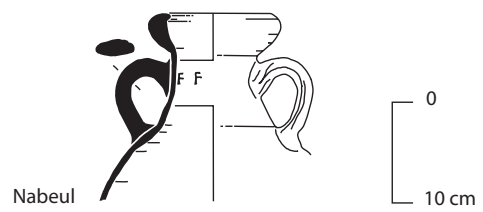

HANFOKT
COLHAOR

2
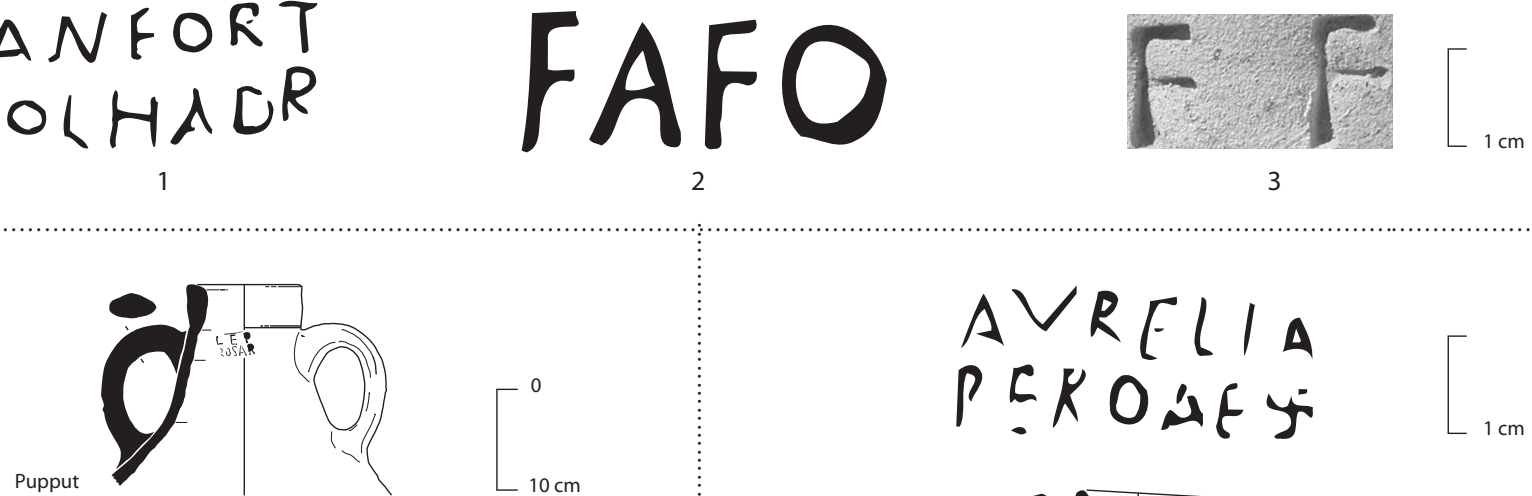

AVRELIA PEKOAF
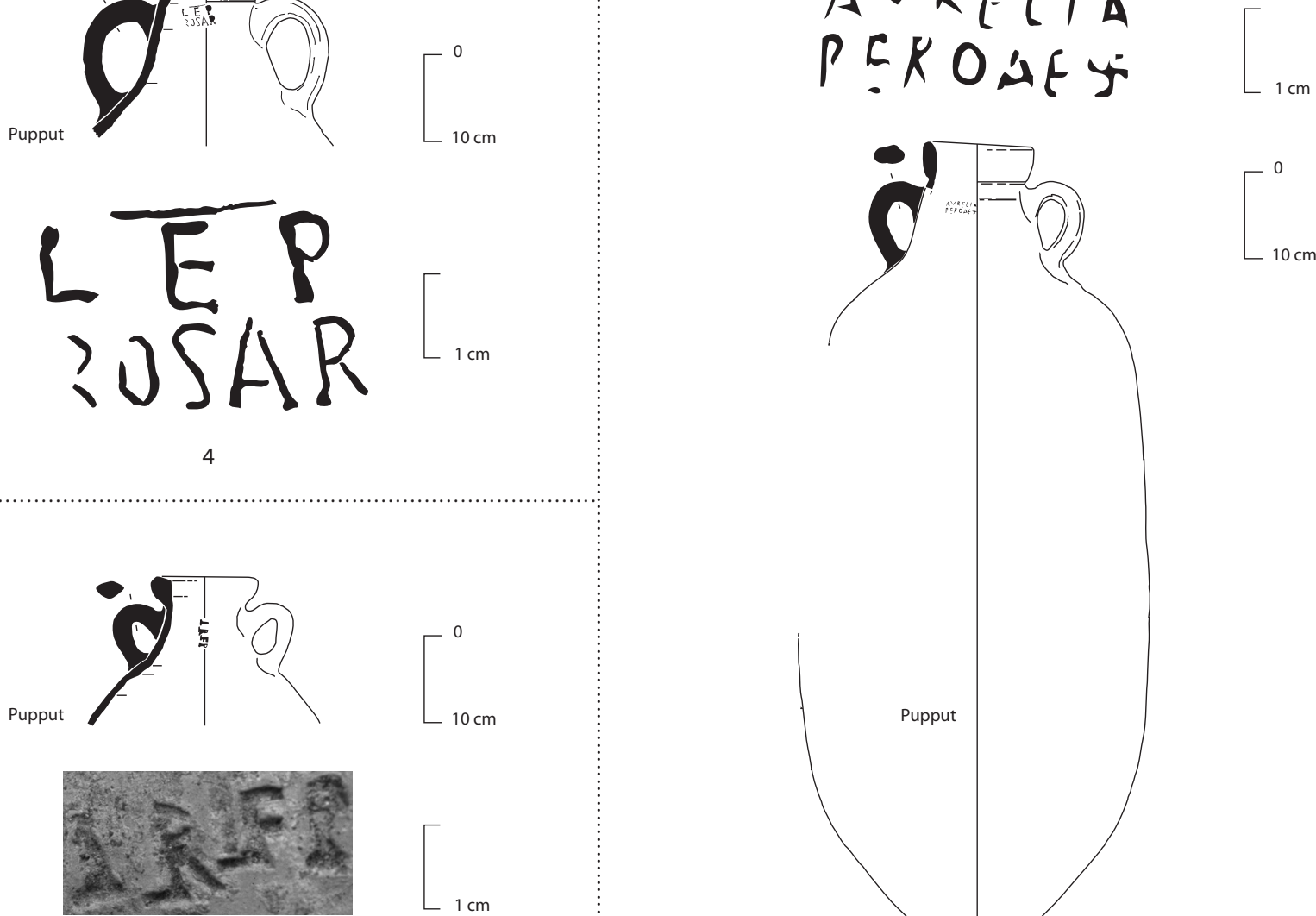

5
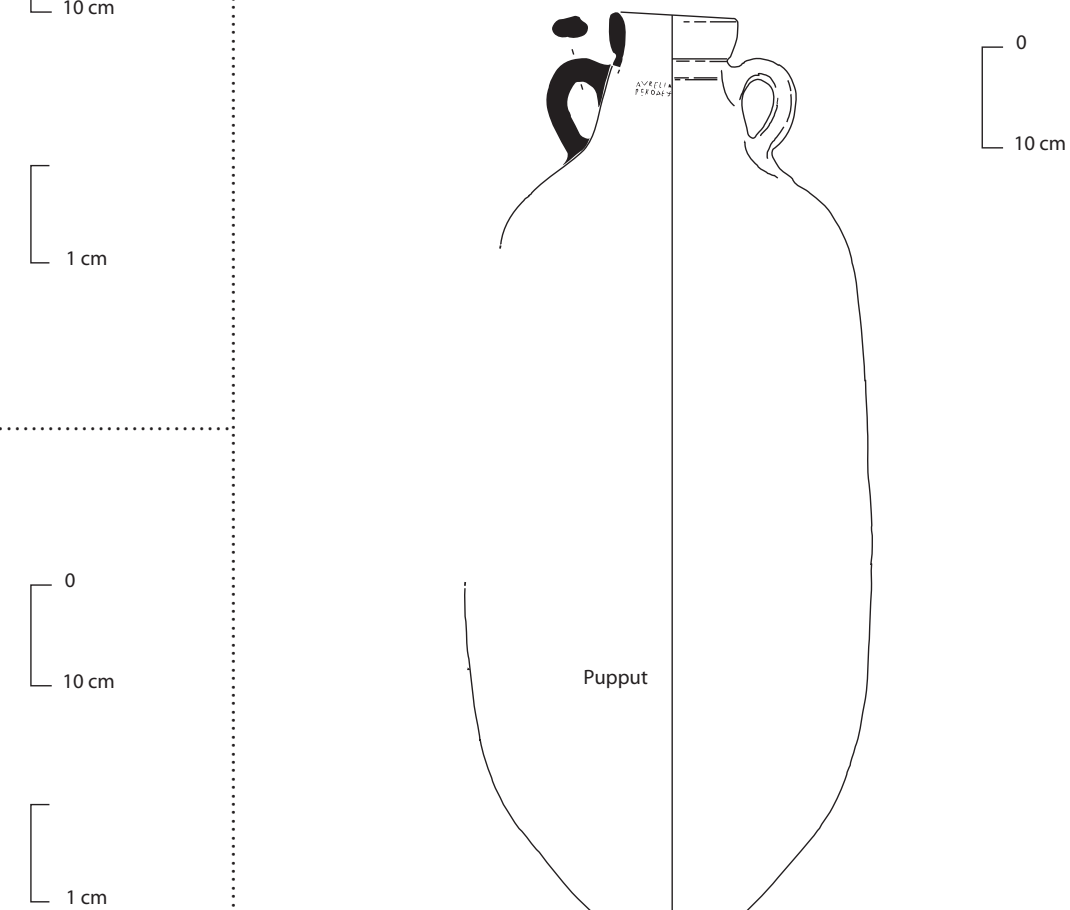

Timbres anépigraphes

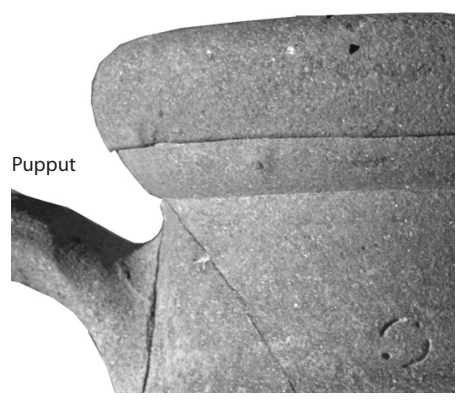

7

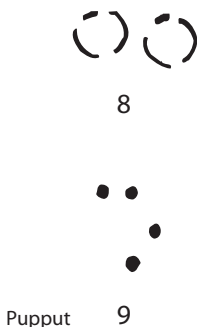

$2 \mathrm{~cm}$

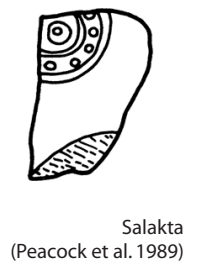

10

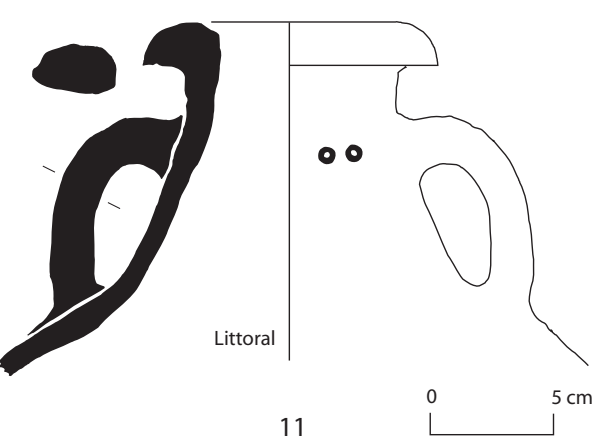

Fig. 5. Différents types de timbres sur amphores africaines. 
ou P.M.C. pour Provincia Mauretania Caesariensis). En revanche, les timbres apposés sur un type d'amphore nouvellement mis en évidence (type «station 48 de la place des Corporations »: infra, AMPHORE TYPE 30) et qu'il est vraisemblable d'attribuer à la Maurétanie Césarienne (Ben Abed, Bonifay, Griesheimer 1999), sont plus originaux par leur position, sur l'épaulement, et par leur mode d'impression (23). Il apparaît en effet que ces timbres ne sont pas appliqués directement sur la paroi du vase mais sur une petite plaque d'argile rapportée, à la manière d'un cachet de cire ${ }^{24}$ (fig. $6 \mathrm{~b}, \mathrm{n}^{\circ} 8$ ).

Exemples (fig. 4) :

Type Dressel 30

*21 Ostie (Panella 1973, 633, $\mathrm{n}^{\circ} 6$ ). Timbre MAVRCAES/TVBVS, sur anse.

*22 Ostie (Laporte 1976-78, fig. 6bis). Timbre MAVRCAES/TVBVS, sur anse.

Type « Station 48 de la place des corporations »

*23 Pupput, tombe 403 (Ben Abed, Bonifay, Griesheimer 1999, fig. 2 ; infra, AMPHORE TYPE $\left.30, \mathrm{n}^{\circ} 1\right)$. Timbrecachet $M$-palmier-C. Cf. Tabl. I et fig. $6 \mathrm{a}, \mathrm{n}^{\circ} 3$.

Ces timbres de Maurétanie Césarienne semblent essentiellement appartenir à des productions de la fin du IIe s. et de la première moitié du IIIe siècle.

\section{Les timbres : points de détail}

Au-delà de ce cadre général, il est évident que le catalogue des timbres africains ne cesse, depuis les travaux de D. Manacorda, de s'enrichir (RTAR I et II ; cf. également : corpus@ceipac.gh.ub.es). La découverte de nouveaux exemplaires de timbres déjà connus permet parfois d'en compléter la lecture: ainsi le timbre LEP/ROSAR (Leptiminus/Lamta) découvert récemment à Pupput (fig. 5, $\mathrm{n}^{\circ}$ 4) (Bonifay 2004a, fig. 11) corrige la formule d'un timbre d'Ostie (Manacorda 1977, 193, $\mathrm{n}^{\circ} 65$, lu ROSAP). D'autres timbres bien connus voient parfois augmenter le nombre de leurs variantes: par exemple, la nécropole de Pupput livre, à côté du timbre FANFORT/COLHADR (Hadrumetum/Sousse), l'un des plus fréquents de la production africaine (Manacorda 1977, 197-198, $\mathrm{n}^{\circ}$ 34) (fig. 5, $\mathrm{n}^{\circ} \mathbf{1}$ ), un timbre apparemment inédit $F A F O$ (fig. $5, \mathrm{n}^{\circ} 2$ ) qui en constitue très probablement une abréviation (voir Amar, Liou 1984, $\mathrm{n}^{\circ} 229$, pour la forme $F A N$ ) ; il est possible, enfin, que le timbre $F F$ de Nabeul signale encore le même atelier (fig. $5, \mathrm{n}^{\circ} 3$ ).

Exemples (fig. 5) :

*1 Pupput (Inv. PP1211.1). Amphore Africaine II D. Timbre FANFORT/COLHADR, en creux, sur le col.

*2 Pupput, tombe 867 (infra, AMPHORE TYPE 23, n²). Amphore africaine II B. Timbre $F A F O$, en creux, sur le col.

*3 Nabeul (infra, AMPHORE TYPE 21, $\mathrm{n}^{\circ} 6$ ). Amphore Africaine I A.2. Timbre $F F$ en creux.

*4 Pupput, tombe 1090 (Bonifay 2004a, fig. 11, $\mathrm{n}^{\circ} 20$ ). Amphore Africaine II D. Timbre LEP/ROSAR, en creux.

\footnotetext{
${ }^{24} \mathrm{Ou}$ d'un cachet de verrier.
}

En revanche, le nom d'aucune nouvelle cité n'est apparu de manière certaine sur les timbres d'amphores africaines. Bien plus, le timbre THP récemment reconnu à Thapsus (Younès 1999) pourrait même faire douter de la lecture $T H(a e n a e)$ naguère retenue pour les timbres $T H$, d'autant qu'aucun de ces timbres n'a été relevé dans les prospections des ateliers de la périphérie de Thyna; mais on pourra rétorquer qu'il en est de même des timbres $A S V L$ et $A S Y L$ à Salakta, alors que les timbres $L E P$ et $L E P M I$ sont bien attestés à Lamta (Peacock, Bejaoui, Ben Lazreg 1989, fig. 22, $n^{\circ}$ 9, fig. 23, $n^{\circ}$ 5). Un autre problème irritant est celui de la lecture des timbres TOP, dont je me demande cependant si on ne pourrait pas les attribuer (?) à la cité de Taparura (Sfax).

Ces exemples montrent que le décodage d'un nom de cité sur un timbre d'amphore est souvent malaisé. La proposition faite par $\mathrm{Cl}$. Panella de développer les initiales C.I.N en C(olonia) I(ulia) N(eapolis) aurait pu ainsi être considérée comme hasardeuse mais les prospections récemment effectuées sur quelques ateliers de la région semblent lui donner raison : il est maintenant certain que le type Africaine II C, sur lequel ces timbres apparaissent de manière exclusive, est bien produit à Nabeul, ville de Proconsulaire (Ghalia, Bonifay, Capelli 2004). De la même façon, deux timbres appliqués sur des amphores provenant de la nécropole de Pupput attirent l'attention (fig. 5) :

*5 Pupput, tombe 653 (Ben Abed, Griesheimer 2004, fig. 112, T653.3). Amphore Africaine I B; pâte marron-rouge, peu cuite; surface blanc crème, écaillée ; timbre vertical $A(V$ ligaturé ?)RFP, en creux, sans cartouche.

*6 Pupput, tombe 876 (Inv. PP2051.3). Amphore Africaine II D ; pâte beige rosé, avec de nombreuses inclusions blanches et noires; surface blanc crème, rugueuse ; timbre sur le col $A V R E L I A / P(-B$ ?)EROAE, marqué d'un swastika, en creux, sans cartouche.

La première amphore (5) présente une qualité de pâte particulière, cependant assez proche de celle des amphores du golfe d'Hammamet (infra); le profil est tout à fait conforme aux productions de Byzacène mais la position verticale du timbre est originale (autres ex. à Ostie : Ostia $I, \mathrm{n}^{\circ}$ 597, et sur l'épave de Giglio Porto : Celuzza, Rendini 1991, $\mathrm{n}^{\circ}$ 129). Pour en rester à des conjectures locales, il ne paraît pas possible de développer ces initiales en (colonia) $A(V$ ?)R(elia Commoda Pia) F(elix) P(upput) car les mentions Colonia et Commoda, importantes, n'auraient probablement pas été omises ; un développement des deux premières lettres en $A R(a d i)$, nom antique de la cité voisine de Sidi Jdidi paraît tout aussi hasardeux ${ }^{25}$. La seconde amphore (6) possède également une pâte peu commune. Mais c'est la forme générale de ce conteneur qui est la plus étrange, proche, dans l'allure générale, des conteneurs de Byzacène mais s'en distinguant cependant par des détails morphologiques, assez maladroits, du bord et des anses. Or, il se trouve que le timbre appliqué sur cette amphore

\footnotetext{
${ }^{25}$ Je remercie Jacques Gascou pour ces suggestions.
} 


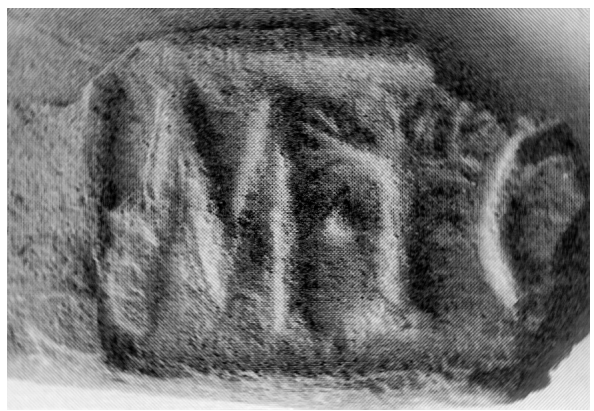

Bu Njem (Rebuffat 1997, PI. XIX, d)

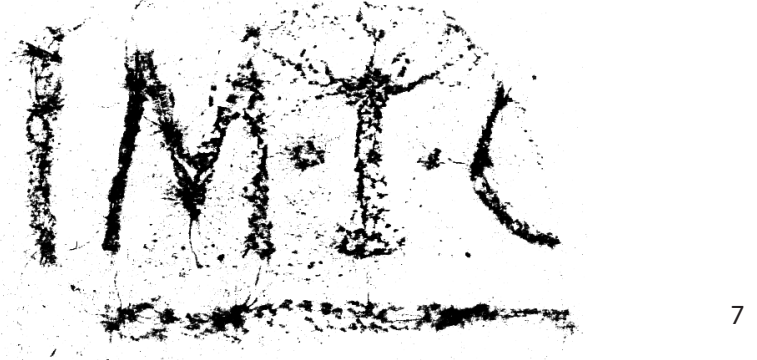

Pouzolles (Hérault) (renseignement D. Rouquette)
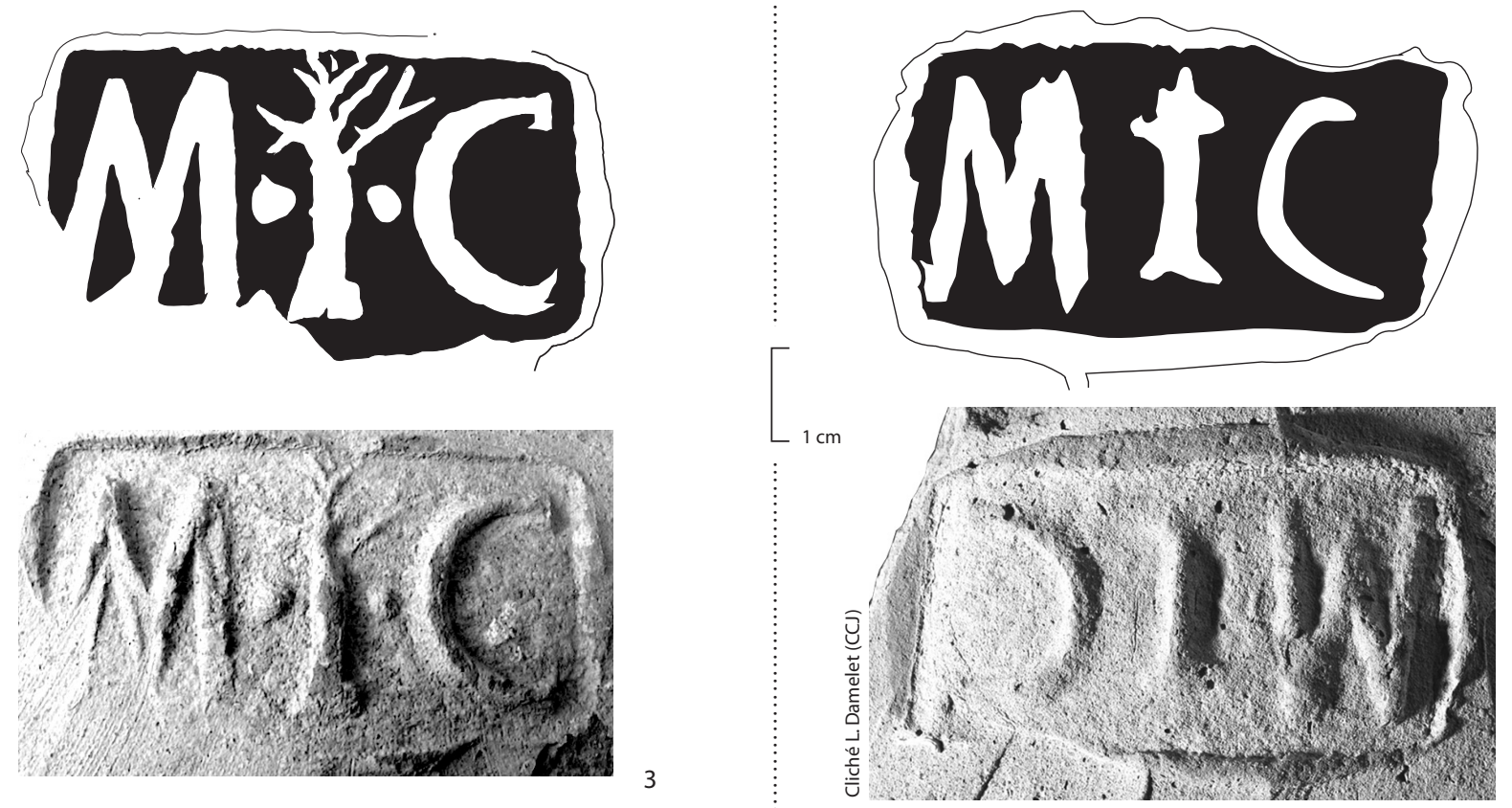

Pupput

Golfe de Fos
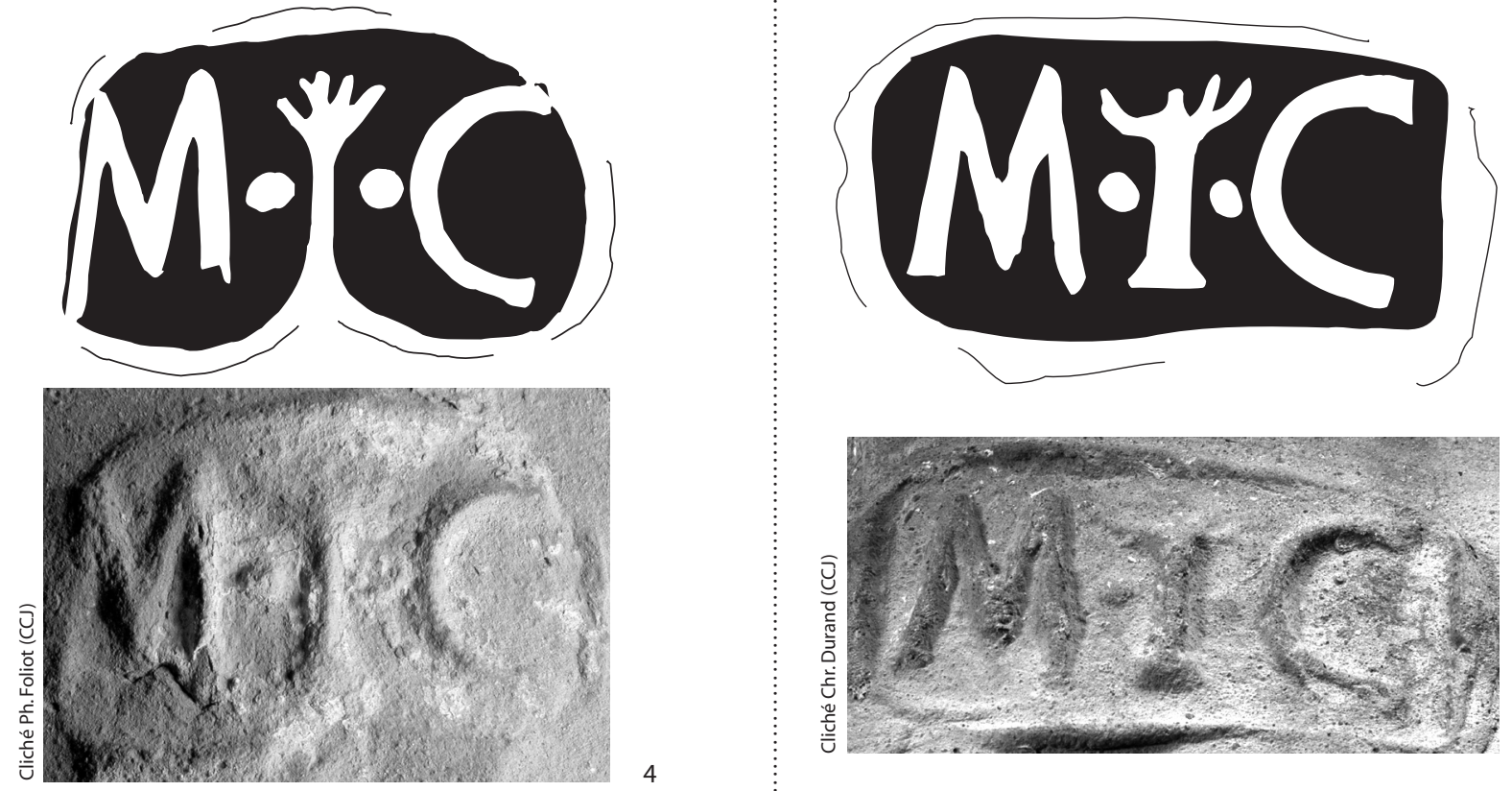

Golfe de Fos

4

Fig. 6a. Amphores du type "station 48 de la place des Corporations". Timbres $M$-palmier- $C$ (groupe 1). 


\section{$M+c$}

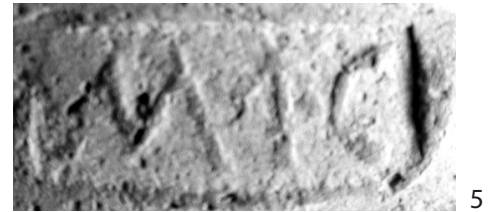

Golfe de Fos

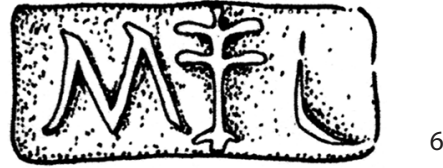

Lugnano in Teverina (Martin 1999, fig. 263, n 67)

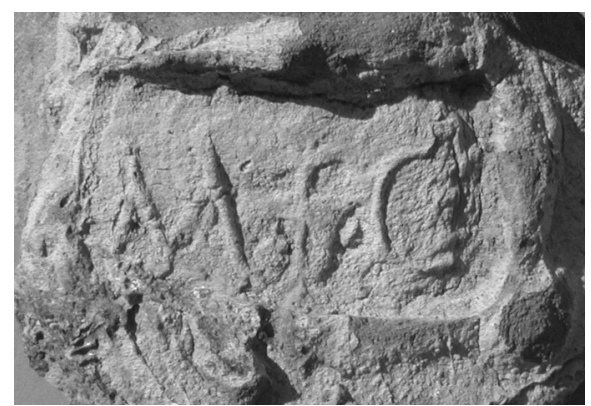

8
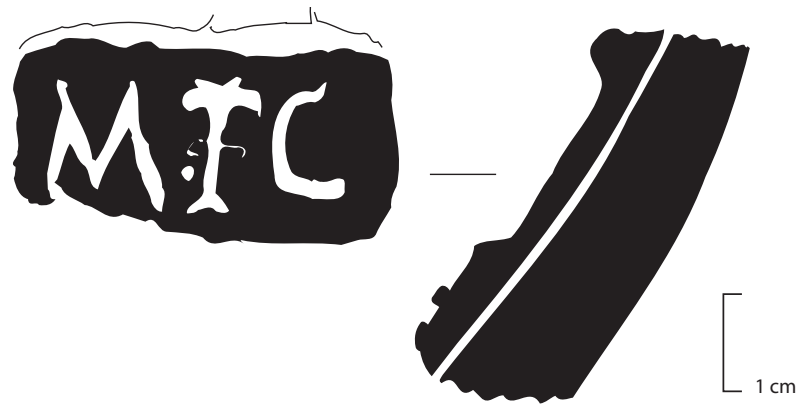

Alexandrie, chantier du Billiardo (fouille J.-Y.Empereur)

Fig. 6b. Amphores du type "station 48 de la place des Corporations". Timbres $M$-palmier- $C$. (groupe 2)

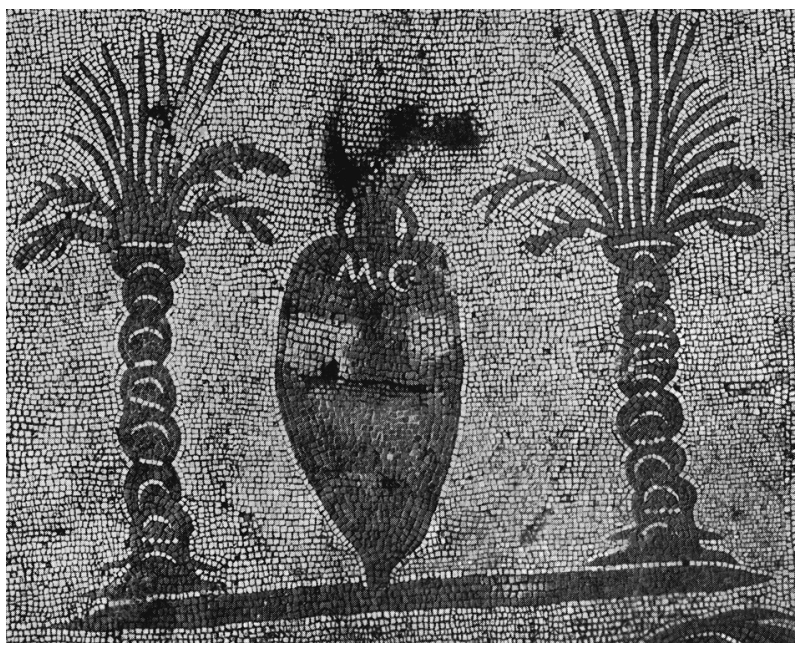

Fig. 7. Mosaïque de la station 48 de la place des Corporations à Ostie (Becatti 1961, Pl. CLXXIII) 
était connu en deux exemplaires à Rome (C.I.L. XV, $\mathrm{n}^{\circ} 3406,1$ et 2$)^{26}$ : AVRELIA/BEROE (ou BEROAE)swastika, sans qu'il ait été identifié comme africain. La parfaite similitude dans la composition des deux lignes ainsi que la présence du swastika nous convainc que la boucle inférieure du B n'a pas été imprimée sur notre exemplaire (la base du E est elle-même peu lisible). Bien que cinq villes de Méditerranée orientale, à l'instar de l'antique Beyrouth, portent le nom de Beroe $^{27}$, ce terme désigne ici plus vraisemblablement un cognomen d'origine grecque, attesté d'ailleurs en deux exemplaires sur des inscriptions funéraires de Rome $^{28}$, qu'un toponyme $^{29}$. Ainsi, cette amphore pourrait provenir du fundus d'une propriétaire terrienne nommée Aurelia $\operatorname{Bero}(a) e$, dont nous ignorons malheureusement la localisation en Afrique. Signalons toutefois que la forme générale de cette amphore n'est pas sans rappeler un exemplaire du musée de Rusguniae, en Algérie ${ }^{30}$.

\section{Timbres anépigraphes}

Parallèlement aux timbres classiques que nous venons d'examiner, D. Manacorda avait bien mentionné l'existence sur les amphores africaines de timbres anépigraphes (Manacorda 1977, 206-211 : « contrassegni »). Je voudrais simplement faire, à ce propos, les remarques suivantes :

- Les timbres anépigraphes concernent plusieurs types d'amphores africaines, du IIe s. au Ve s. : les types classiques Africaines I et II (fig. 5, $\mathrm{n}^{\circ}$ 7-9), les types Keay 25 du IVe s. (10) et quelques amphores cylindriques de grandes dimensions du Ve s. (11). En revanche, les types les plus tardifs des VIe-VIIe s. paraissent ignorer cette pratique.

- Parmi les amphores classiques, celles issues des ateliers de Salakta semblent particulièrement affectionner ce mode de timbrage (7-9).

- Même si la proportion de timbres anépigraphes est plus importante parmi les amphores Keay $25 \mathrm{du}$ IVes. (qui ne portent que très exceptionnellement des timbres inscrits), il ne paraît pas y avoir d'évolution très nette dans la forme de ces timbres. La rouelle pointée de type Manacorda J, bien attestée sur le type Africaine II A (Manacorda 1977, 209, Tabl. 3) et utilisée sur l'atelier de Salakta (10), est également présente sur les amphores Keay 25.1 de l'épave d'Héliopolis 1 au IVes. (infra, AMPHORE TYPE $27, \mathrm{n}^{\circ} 6$ ).

\footnotetext{
26 Je dois à Véronique Blanc-Bijon la découverte de ces exemplaires de comparaison.

${ }^{27}$ Paulys Realencyclopädie der classischen Altertumswissen schaft. Barbarus - Campanus. Stuttgart, 1897, pp. 303-307.

${ }^{28}$ SOLIN (H.) - Die griechischen Personnennamen in Rom. Ein Namenbuch. Berlin-New York, 1982, n 3960A : Ulpia Beroae, et 4091B : V(B)eroe.

${ }^{29} \mathrm{Je}$ remercie Jacques Gascou pour son aide.

30 Je remercie Pierre Salama de m'avoir communiqué ces clichés.
}

Exemples (fig. 5) :

*7 Pupput, tombe 615 (Inv. PP3182.1). Amphore Africaine II A.1. Timbre anépigraphe : cercle segmenté.

*8 Pupput (infra, fig. 57, $\mathrm{n}^{\circ}$ 6). Amphore Africaine II A.2. Timbre anépigraphe : double cercle segmenté.

*9 Pupput (infra, fig. $58, \mathrm{n}^{\circ}$ 8). Amphore Africaine II A.3. Timbre anépigraphe : cercle en pointillés.

*10 Salakta, atelier (Peacock, Bejaoui, Ben Lazreg 1989, fig. $\left.16, \mathrm{n}^{\circ} 6\right)$. Timbre anépigraphe : rouelle pointée de type Manacorda J.

*11 Littoral tunisien, site $\mathrm{n}^{\circ} 151$ (Oued el-Kseub) (Bonifay et al. 2002-2003, fig. 13, $\left.\mathrm{n}^{\circ} 166\right)$. Amphore Keay 35B. Timbre anépigraphe : double cercle.

\section{Nouvelles données sur le timbre M-palmier-C}

Enfin, il convient de revenir quelque peu sur le timbrecachet des amphores maurétaniennes (?) du type «station 48 de la place des Corporations ». Ce timbre, portant les lettres $M$ et $C$ disposées de part et d'autre d'un palmier, était connu depuis 1966 (Cristofani, Zevi 1966, 14 et note 21), cependant on ignorait la forme du récipient sur lequel il était appliqué jusqu'à ce que l'on en découvre, en 1999, un exemplaire quasiment complet dans la nécropole de Pupput (Ben Abed, Bonifay, Griesheimer 1999, 170 et fig. 2). Or, fait rarissime, on possède de cette amphore une représentation antique, sur la mosaïque de la station 48 de la place des Corporations à Ostie (fig. 7). Cette attribution, dont il n'est plus permis de douter, disqualifie l'identification qui avait été précédemment proposée de cette image avec le type Dressel 30 de Tubusuctu (Panella 1973, 603). Reste maintenant à déterminer le lieu qui est désigné, à la fois sur la mosaïque d'Ostie et sur l'amphore de Pupput, par l'énigmatique sigle $M C$. Si on avait pensé à l'amphore de Tubusuctu, ce n'est certes pas en raison d'une ressemblance morphologique, qui est loin d'être évidente, mais parce que les initiales de la mosaïque d'Ostie avaient été développées, dès 1913, en M(auretania) $C$ (aesariensis) et que, sur les timbres des amphores Dressel 30 de Tubusuctu, la titulature ex provinc(ia) Mauretan(ia) Caes(ariensis) est, dans un cas, abrégée P.MC. (Ben Abed, Bonifay, Griesheimer 1999, 169). Si l'on admet que le sigle $M C$ désigne bien la province de Maurétanie Césarienne (et de fait, les analyses pétrographiques démontrent, pour le moins, qu'il s'agit d'une amphore africaine: Pl. I, $\mathrm{n}^{\circ} 24$ ), on peut se demander quelle pourrait être la cité de cette province dont il ne serait pas nécessaire de préciser le nom, sinon par un idéogramme, le palmier, placé entre les deux lettres. La première idée qui vient à l'esprit est qu'il s'agit de la capitale éponyme, Césarée de Maurétanie, dont la province avait tiré son nom lors de sa création, en 42 ap. J.-C. L'évocation de la capitale provinciale ne serait pas fondée sur une éventuelle permutation des lettres $M C / C M$ mais peut-être sur la composition même du timbre : les dernières frappes de l'atelier monétaire de Iol/Césarée sous le règne du dernier roi maurétanien Ptolémée ont en effet fortement recours au thème du palmier, schématisé de la même façon que sur les timbres 
d'amphores (Ben Abed, Bonifay, Griesheimer 1999, fig. 6). Désormais, il n'est plus possible de faire du type Dressel 30 un synonyme du terme «amphore maurétanienne ».

Dans l'attente de pouvoir tester sur le terrain algérien ce jeu d'hypothèses, les attestations du timbre $M$-palmier- $C$ se multiplient en Méditerranée et permettent de compléter le tableau de Ben Abed, Bonifay, Griesheimer 1999, Annexe 1, 176 (Tabl. I).
On distingue deux groupes en fonction des dimensions du timbre :

- groupe 1 : grand timbre-cachet d'env. 32 x $60 \mathrm{~mm}$ sur amphores du type "station 48 de la place des corporations" (AMPHORE TYPE 30) ;

- groupe 2 : petit timbre-cachet d'env. 17 x $37 \mathrm{~mm}$ sur amphores de type non identifié.

\begin{tabular}{|c|c|c|c|c|c|}
\hline & Site & Type d'amphore & $\begin{array}{c}\text { Type } \\
\text { de timbre }\end{array}$ & $\begin{array}{l}\text { Dimensions et } \\
\text { place du timbre }\end{array}$ & Bibliographie \\
\hline 1 & Ostie (Inv. 14802) & Indéterminé & groupe 1 & $\begin{array}{c}? \\
\text { sur l'épaulement }\end{array}$ & Cristofani, Zevi 1966, 15 et note 21. \\
\hline$* 2$ & Bu Njem (Libye) & Indéterminé & groupe 1 & $\begin{array}{l}32 \times(>52) \mathrm{mm} \\
\text { sur l'épaulement }\end{array}$ & Rebuffat $1997,171, \mathrm{n}^{\circ} 76-87$, pl. LXIX, d. \\
\hline$* 3$ & $\begin{array}{l}\text { Pupput (Hammamet, } \\
\text { Tunisie) }\end{array}$ & $\begin{array}{c}\text { Type station } 48 \\
\text { de la place des } \\
\text { Corporations } \\
\end{array}$ & groupe 1 & $\begin{array}{c}32 \times 59 \mathrm{~mm} \\
\text { sur l'épaulement }\end{array}$ & $\begin{array}{l}\text { Ben Abed, Bonifay, Griesheimer 1999, } \\
\text { fig. } 2 .\end{array}$ \\
\hline$* 4$ & $\begin{array}{l}\text { Golfe de Fos (Port de } \\
\text { Bouc, France) }\end{array}$ & $\begin{array}{l}\text { Type station } 48 \\
\text { de la place des } \\
\text { Corporations }\end{array}$ & groupe 1 & $\begin{array}{c}32 \times 58 \mathrm{~mm} \\
\text { sur l'épaulement }\end{array}$ & $\begin{array}{l}\text { Amar, Liou 1984, 182, n 230a, pl. } 19 . \\
\text { Ben Abed, Bonifay, Griesheimer 1999, } \\
\text { fig. } 4 \text {. }\end{array}$ \\
\hline$* 5$ & $\begin{array}{l}\text { Golfe de Fos (Musée } \\
\text { archéologique d'Istres, } \\
\text { France) }\end{array}$ & Africaine II & groupe 2 & $\begin{array}{c}17 \times 37 \mathrm{~mm} \\
\text { sur l'épaulement }\end{array}$ & $\begin{array}{l}\text { Ibid., } 182, \mathrm{n}^{\circ} 230 \mathrm{~b}, \text { pl. } 19 . \\
\text { Ben Abed, Bonifay, Griesheimer 1999, } \\
\text { fig. } 5 \text {. }\end{array}$ \\
\hline$* 6$ & $\begin{array}{l}\text { Poggio Gramignano } \\
\text { (Lugnano in Teverina, } \\
\text { Italie) }\end{array}$ & Indéterminé & groupe 2 & $\begin{array}{c}16 \times 36 \mathrm{~mm} \\
\text { sur l'épaulement }\end{array}$ & Martin 1999, fig. $263, \mathrm{n}^{\circ} 67$. \\
\hline$* 7$ & $\begin{array}{l}\text { Saint-Martin (Pouzolles, } \\
\text { France) }\end{array}$ & Indéterminé & groupe 1 & $\begin{array}{l}31 \times(>51) \mathrm{mm} \\
\text { sur l'épaulement }\end{array}$ & Inédit, renseignement Daniel Rouquette. \\
\hline$* 8$ & $\begin{array}{l}\text { Alexandrie, chantier du } \\
\text { Billiardo }\end{array}$ & Indéterminé & groupe 2 & $\begin{array}{c}18 \times 36 \mathrm{~mm} \\
\text { sur l'épaulement }\end{array}$ & Inédit, fouille Jean-Yves Empereur. \\
\hline$* 9$ & $\begin{array}{l}\text { Golfe de Fos (Musée } \\
\text { archéologique d'Istres, } \\
\text { France) }\end{array}$ & Indéterminé & groupe 1 & $\begin{array}{c}32 \text { x } 58 \mathrm{~mm} \\
\text { sur l'épaulement } \\
\text { (à l'envers) } \\
\end{array}$ & Inédit. \\
\hline 10 & $\begin{array}{l}\text { Pupput (Hammamet, } \\
\text { Tunisie) }\end{array}$ & $\begin{array}{c}\text { Type station } 48 \\
\text { de la place des } \\
\text { Corporations } \\
\end{array}$ & groupe 1 & $\begin{array}{l}\text { env. } 30 \times 60 \mathrm{~mm} \\
\text { sur l'épaulement }\end{array}$ & Inédit, très érodé. \\
\hline$* 11$ & Epave Ouest-Embiez & $\begin{array}{l}\text { Type station } 48 \\
\text { de la place des } \\
\text { Corporations }\end{array}$ & groupe 1 & $\begin{array}{c}31 \times 60 \mathrm{~mm} \\
\text { sur l'épaulement }\end{array}$ & Bernard, Bonifay 2003, 169. \\
\hline
\end{tabular}

Tableau I. Timbre $M$-palmier- $C$. Les nouvelles attestations sont numérotées en gras. Cf. fig. 6a-b.

\section{Marques incisées avant cuisson}

Le timbre n'est pas la seule technique utilisée par les ateliers africains pour apposer leur marque sur les amphores qu'ils produisent. Un certain nombre de ces conteneurs portent en effet des signes divers incisés à la pointe dans la pâte encore fraîche. On peut distinguer, dans l'état actuel de la documentation, trois séries principales :

- Des amphores africaines classiques de type I et II portent des lettres tracées à main levée sur le col. Dans deux cas, il s'agit de lettres grecques : $\Pi I$ (fig. $8, \mathrm{n}^{\circ} \mathbf{1}$ ) et $\Phi$ (2). Un troisième exemple, en lettres latines, montre apparemment un $T$ ligaturé à un $E$ (3). Les amphores qui portent les marques en grec présentent des particularités morphologiques (profil massif $\mathrm{du}^{\circ} \mathbf{1}$ ) ou pétrographiques qui les distinguent des productions des grands ateliers. On pourrait ainsi supposer que ces objets sont issus d'ateliers mineurs. En revanche, le $n^{\circ} \mathbf{3}$ pourrait provenir de l'atelier de Salakta.

Exemples (fig. 8) :

*1 Pupput, tombe 863 (Inv. PP2127.3). Amphore Africaine II A. Marque incisée $\Pi I$, à la base du col. Traces de poix à l'intérieur.

*2 Pupput, tombe 427 (Inv. PP2342.7). Amphore Africaine IB. Marque incisée $\Phi$, à la base du col.

*3 Pupput 642 (Inv. PP3436.3). Amphore Africaine II A. Marque incisée TE, sur le col. Pâte du groupe Salakta.

4 Giglio Porto (Celuzza, Rendini 1991, 105, n 113). Amphore Africaine II A.3. Marque incisée lif(?), sur le col. 

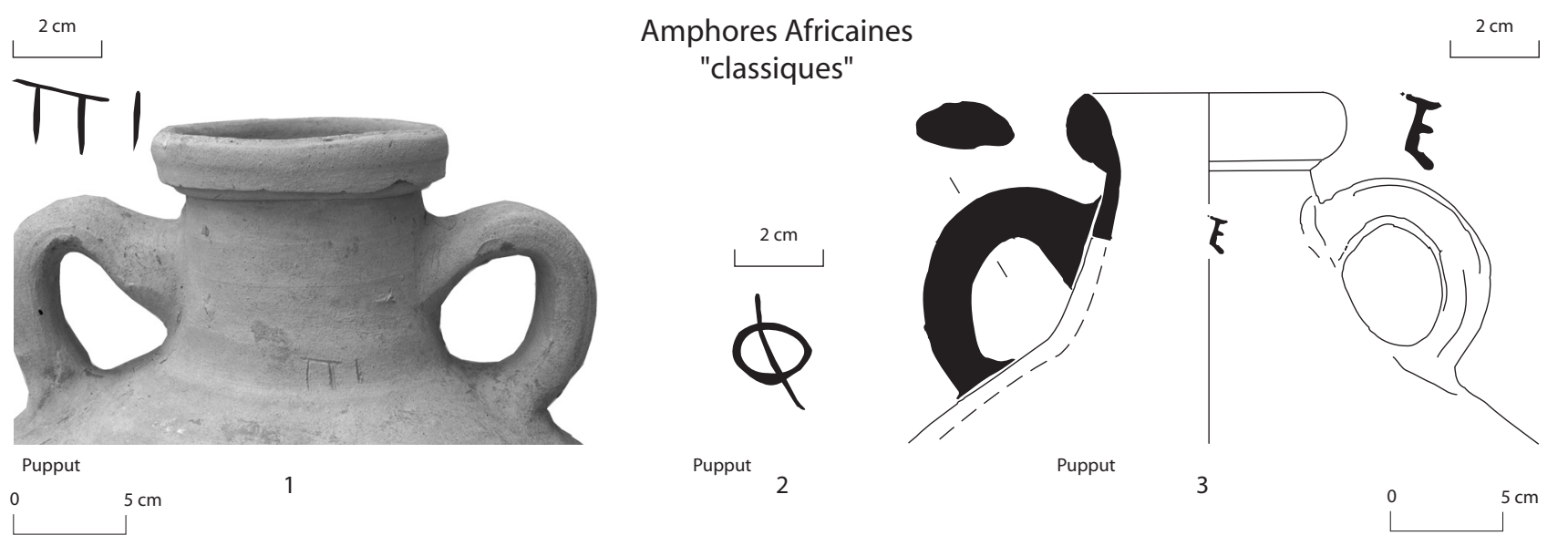

Amphores tardives de la région de Nabeul

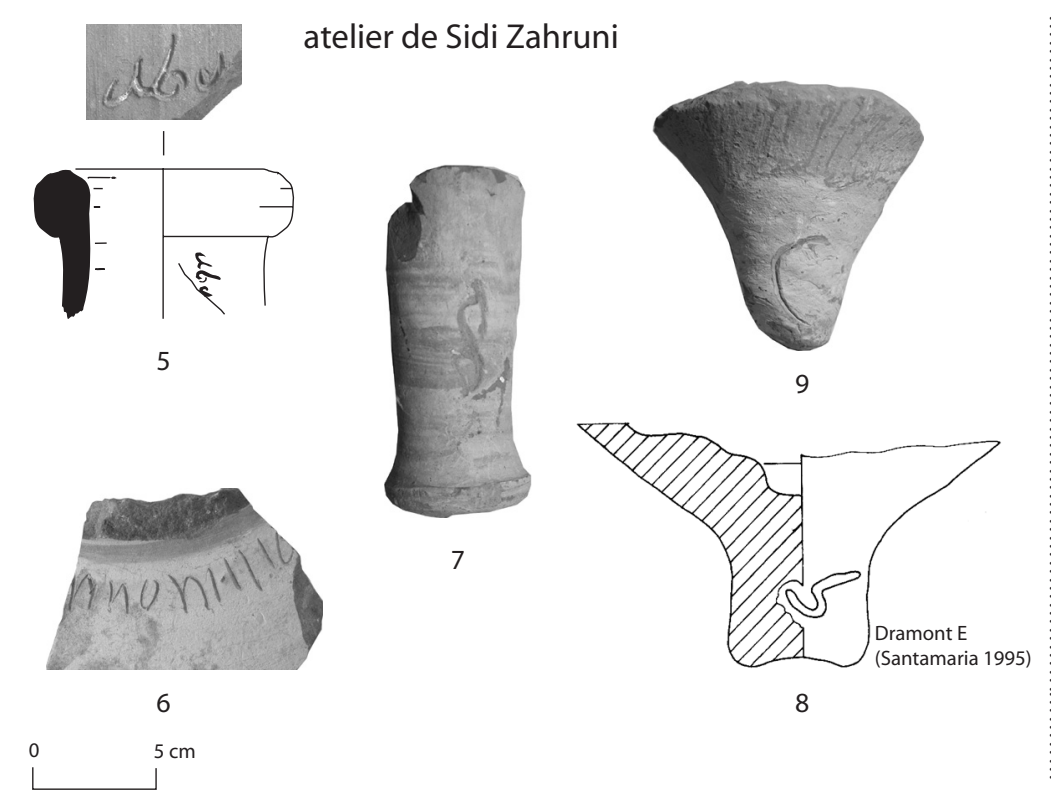

atelier proche de Sidi Zahruni (?)

Amphores de tradition punique du golfe d'Hammamet

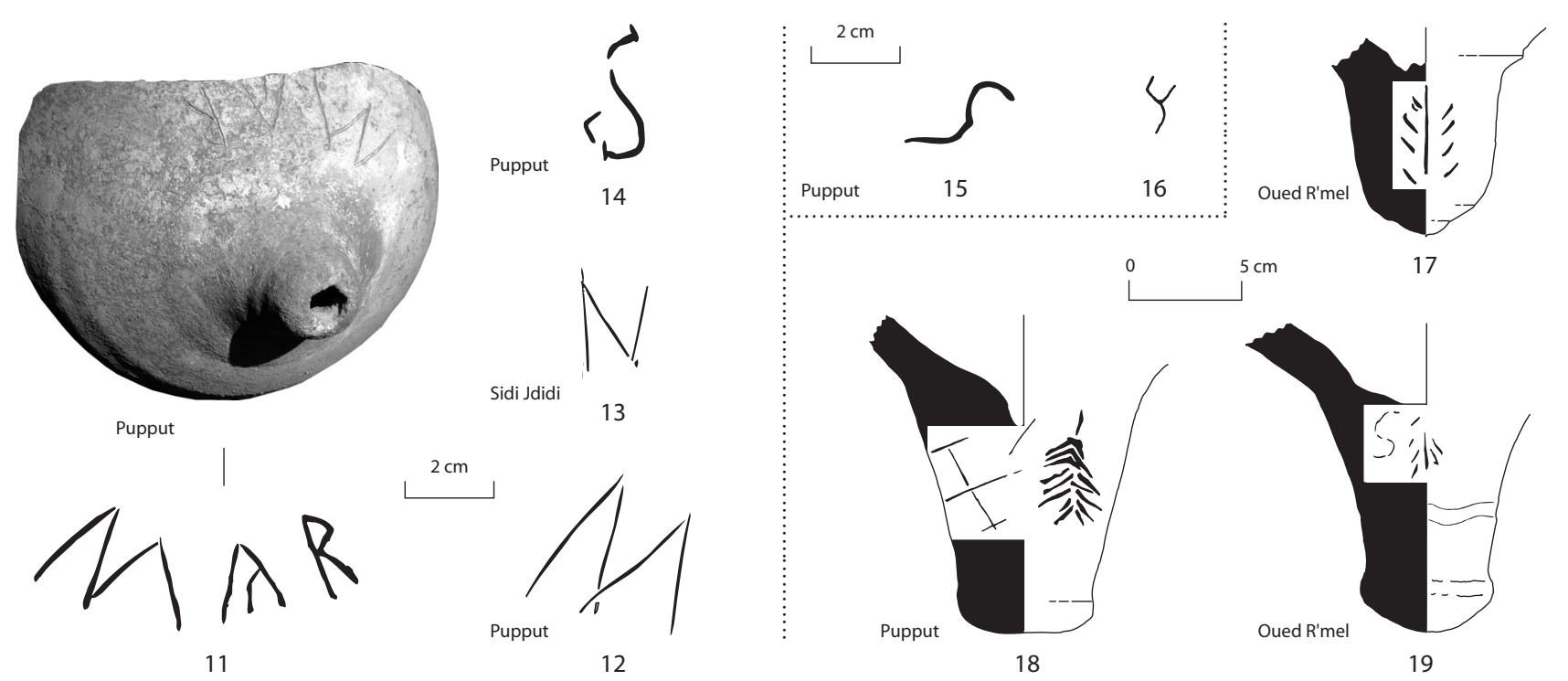

Fig. 8. Marques incisées (avant cuisson) sur amphores africaines. 
- Un groupe d'amphores tardives de type Keay 25.1, « spatheion » 1, Keay 35A et B se signale, au Ve s., par ses nombreuses marques incisées. Il semble maintenant avéré que ces objets, bien diffusés en Méditerranée occidentale, ont été produits, en partie tout au moins, dans les ateliers de la région de Nabeul, celui de Sidi Zahruni en particulier. Certaines marques, relativement rares, sont tracées sur le col : marque verticale $a b u[\ldots \mathrm{du}$ $\mathrm{n}^{\circ} 5$, ou sur le sommet de l'épaulement, au départ du col : marque ...]moni... (?) du $\mathrm{n}^{\circ} \mathbf{6}$, mais les plus fréquentes sont portées sur la pointe (7-9). Il s'agit dans ce cas de lettres ou de signes isolés dont l'épave du Dramont E à Saint-Raphaël a livré de nombreux exemplaires (Santamaria 1995, Pl. III et IV) : signes divers (barres verticales), croix, lettres latines $(A, S$ ?) et peut-être lettres néo-puniques (8). On remarque que les lettres doivent se lire pointe de l'amphore vers le haut, ce qui s'explique sans doute par le fait que les vases étaient posés sur le col pendant le séchage; de fait, le sommet du bord porte souvent des traces d'écrasement et des éraflures subies alors que la pâte était encore fraîche. Au VIe s., les amphores Keay 62 de l'épave de la Palud (Long, Volpe 1998) portent des marques chrétiennes : croix pattées, croix monogrammatiques ; elles proviennent peut-être de la même zone d'ateliers (Bonifay, Capelli, Long 2002). Exemples (fig. 8) :

*5 Atelier de Sidi Zahruni (Inv. HCZ006.9). Bord de «spatheion » 1 (?). Marque incisée : $a b u[\ldots$, verticale, sur le col.

*6 Nabeul, fouilles anciennes (sans $\mathrm{n}^{\circ}$ ). Amphore (?). Marque incisée ...]moni.. ., sur le sommet de l'épaulement.

*7 Atelier de Sidi Zahruni (sans $\mathrm{n}^{\circ}$ ). Fond de « spatheion»1. Marque incisée $: S$.

*8 Epave Dramont E, Saint-Raphaël (Santamaria 1995 Pl. III, n ${ }^{\circ} 118$ ). Fond d'amphore Keay 35A. Marque incisée : lettre néo-punique en forme de crosse : $n$ (?).

*9 Atelier de Sidi Zahruni (sans $\mathrm{n}^{\circ}$ ). Fond d'amphore Keay 35B (?). Marque incisée $\underline{C}(?)$.

*10 Epave de La Palud, Port-Cros (Long, Volpe 1998, fig. 280, $\left.\mathrm{n}^{\circ} 31\right)$. Marque incisée: croix monogrammatique flanquée d'un $b(?)$.

- Les amphores de tradition punique dites « du golfe d'Hammamet » (infra, AMPHORES TYPES 8-10) ne portent généralement pas de timbres ; elles présentent en revanche assez fréquemment des marques incisées. On distingue deux grandes séries.

- Dans la première, des lettres latines de grande taille, isolées ou groupées par deux ou trois, tracées sur la base de la panse, la lecture se faisant pointe de l'amphore vers le haut (même remarque que pour le groupe précédent) : MAR (fig. 8, $\left.\mathrm{n}^{\circ} \mathbf{1 1}\right), N, S, M(\mathbf{1 2}$ 14). Ces marques latines concernent principalement le type Hammamet 1 et, dans une moindre mesure, le type Hammamet 2.

- Dans la deuxième série, les marques sont tracées sur la pointe de l'amphore. Il s'agit tout d'abord, pour les ultimes amphores de type Hammamet 2, de lettres isolées dont certaines se rattachent peut-être à un alphabet néo-punique : $n$ (15) ou $w$ (16) (?). Ensuite, sur les amphores de type Hammamet 3, des signes divers (palmes : 17) ou chrétiens (croix : 18) sont parfois associés à des lettres $(S: 19)$.

Exemples (fig. 8) :

*11 Pupput, tombe 406 (Bonifay 2004b, fig. 14, $\mathrm{n}^{\circ} 41$ ). Amphore Hammamet $1 \mathrm{~B} / \mathrm{C}$. Marque incisée : $M A R$, à la base de la panse.

*12 Pupput, tombe 837 (Ibid., fig. 14, $\mathrm{n}^{\circ}$ 42). Amphore Hammamet 1C. Marque incisée: $M$, à la base de la panse.

*13 Pupput, tombe 1008 (Ibid., fig. 14, n 43). Amphore Hammamet 1E. Marque incisée : $N$, à la base de la panse.

*14 Sidi Jdidi, basilique 1 (Ibid., fig. 14, $\mathrm{n}^{\circ}$ 44). Amphore Hammamet 2 (?). Marque incisée : $S$, à la base de la panse.

*15 Pupput, tombe 876 (Ibid., fig. 9, $\mathrm{n}^{\circ} 20$ ). Amphore Hammamet 2D. Marque incisée : $n$ néo-punique (?) sur la pointe.

*16 Sidi Jdidi, basilique 2, destruction état II (Ibid., fig. 10, $\left.\mathrm{n}^{\circ} 26\right)$. Amphore Hammamet 2E. Marque incisée : $w$ néo-punique (?) (infra, fig. 50, $\left.\mathrm{n}^{\circ} 11\right)$.

*17 Oued R'mel (Ibid. fig. 14, n 47). Amphore Hammamet 3B ou C. Marque incisée : palme, sur la pointe.

*18 Pupput, thermes (Ibid. fig.14, $\mathrm{n}^{\circ}$ 46). Amphore Hammamet 3B ou C. Marque incisée : croix pattée et palme.

*19 Oued R'mel (Ibid., fig. 14, $\mathrm{n}^{\circ} 48$ ). Amphore Hammamet 3 B ou C. Marque incisée : $S$ et palme.

\subsubsection{L'aire de répartition des types peu diffusés}

On peut s'apercevoir, en examinant un certain nombre de contextes céramiques africains, que certaines amphores, non timbrées et pour lesquelles on ne connaît aucun atelier, sont cependant caractéristiques d'une région bien précise.

\section{Amphores de tradition punique du golfe d'Hammamet}

L'exemple le plus évident est celui de ces « amphores de tradition punique du golfe d'Hammamet (Bonifay 2004b), dont on vient d'examiner les marques incisées. Dix années de fouilles dans les cités d'Aradi/Sidi Jdidi, Pupput/Hammamet et Neapolis/Nabeul ont permis, peu à peu, de mettre en évidence ce groupe d'amphores jusqu'alors peu documenté. Ces amphores sont dites « de tradition punique » car leurs anses ne sont pas placées sur le col comme c'est le cas pour l'ensemble des amphores gréco-romaines, mais sur l'épaulement, à la manière des amphores phénico-puniques. Un classement provisoire de ces objets permet de reconnaître trois types principaux, dont la datation s'échelonne du Ier au VIIe s. (infra, AMPHORES TYPES 8-10). L'étude des pâtes (Cl. Capelli in Bonifay 2004b) tend à prouver qu'il s'agit bien, tout au long de la période, d'une même famille d'amphores (Pl. I, $\left.\mathrm{n}^{\circ} 18\right)$; d'ailleurs ces pâtes présentent de fortes analogies avec celles des céramiques communes de Sidi Jdidi 
(Bonifay, Reynaud 2004). La diffusion de ces amphores reste étroitement cantonnée dans un triangle HammametSegermes-Hergla (Bonifay 2004b, fig. 1), où il faut probablement rechercher leurs lieux de production. Elles ont été faiblement diffusées en Méditerranée : mis à part l'exemplaire complet de la Villa Adriana (infra, fig. 53, $\mathrm{n}^{\circ} 3$ ), des fragments sont signalés à Ostie, Luni, Marseille et Empúries. Il est symptomatique que ces amphores ne soient pas attestées à Carthage.

\section{Amphores Keay 34}

Les amphores Keay 34 (infra, AMPHORE TYPE 53) font également l'objet d'une assez faible diffusion en Méditerranée (infra, p. 143). La prospection du littoral tunisien a montré qu'elles étaient en revanche particulièrement fréquentes entre La Laouza et Rass Jezira (Bonifay et al. 2002-2003) et les fouilles de Rougga en ont livré deux exemplaires complets ainsi que de nombreux fragments (Guéry, Bonifay à paraître). Certes, les ateliers de Rass Botria (Acholla) ne semblent pas avoir produit ce type (Peacock, Bejaoui, Ben Lazreg 1990, 61-62) mais d'autres ateliers signalés près de Jebiniana $^{31}$ devraient être expertisés. Il reste que l'aire de diffusion assez restreinte de ces conteneurs plaide pour une production dans un triangle La Laouza-El Jem-Rass Kaboudia. La pâte de ces amphores, de couleur rouge carmin et contenant de nombreux micro-fossiles (Pl. I, $\mathrm{n}^{\circ} 8$ ), correspond à celle de la majorité des céramiques communes présentes sur le site de Rougga, donc probablement d'origine locale ou régionale.

\section{Amphores Keay 27 et 36}

D'autres aires de répartition peuvent apparaître « en négatif». Les amphores de type Keay 27 et 36 (infra, AMPHORES TYPES 35 ET 36), par exemple, sont bien attestées à Carthage (Peacock 1984b, types 44 et 54 ; Poulsen 1986, fig. 5) mais sont beaucoup plus rares sur la côte orientale de la Tunisie ${ }^{32}$. Certaines possèdent en outre un type de pâte particulier, caractérisé par une matrice «pure », c'est-à-dire sans dégraissant fin : cette pureté de la matrice, décelable seulement à la binoculaire, donne à la pâte un aspect paradoxalement plus grossier à l'œil nu car les inclusions peu nombreuses, mais d'assez grande taille, se détachent bien dans une argile d'aspect « plastique »; la couleur est généralement plus claire, tirant sur le beige ou le marron (Bonifay, Leffy 2002, 48). Cette particularité de la pâte de la plupart des amphores Keay 27 et 36, a été signalée à plusieurs reprises (notamment Keay 1984, 240 ; Bonifay 1986, 278) ; elle paraît sans équivalent dans les ateliers du littoral oriental.

\footnotetext{
${ }^{31}$ Merci à Taher Ghalia pour ce renseignement.

${ }^{32}$ Un exemplaire de type Keay 27 au musée de Lamta, a été repêché en mer au large de Mahdia; deux autres amphores lui sont peut-être associées : une variante d'Africaine II (?) et une Keay 25.1, assez proche des exemplaires de l'épave de la pointe de la Luque à Marseille.
}

Il serait donc logique, dans ces conditions, d'envisager la production des amphores Keay 27 et 36 dans une région située à l'ouest de Carthage ${ }^{33}$. Il est peut-être très significatif qu'un fragment de fond probablement de forme Keay 36, recueilli sur l'atelier d'El-Mahrine ${ }^{34}$, montre la même qualité de pâte (Pl. I, n² 23).

\section{Amphores Keay 24}

Ce même argument de diffusion me fait douter de la proposition intéressante, récemment mise en avant par J. Remolà (2000, 168-169), d'attribuer le type Keay 24 à la Tripolitaine, en raison d'une ressemblance de pâte avec des amphores Tripolitaines II. Or J. Remolà fait justement remarquer que ce type d'amphore n'a pas été signalé hors de la péninsule Ibérique et notamment à Rome où, pourtant, les amphores tripolitaines sont abondantes. Sans remettre en question l'origine africaine de ce conteneur, je me demande si son lieu de production ne devrait pas plutôt être recherché dans les régions occidentales de l'Afrique, sur le territoire de l'actuelle Algérie (Keay 1984, 184), si mal connu.

\subsubsection{Le repérage des ateliers}

Pour les types mieux diffusés, il est difficile de préciser leur origine tant que l'on ne connaît pas les ateliers. Il en est ainsi du type Keay $8 \mathrm{~B}$ dont la relative fréquence à Carthage (Peacock 1984b, type 61) aurait pu indiquer une origine septentrionale. Mais le repérage fortuit d'ateliers en Byzacène méridionale en a décidé autrement. Les premières traces, assez peu éloquentes, sont apparues sur le site de Iunca (Bonifay et al. 2002-2003) (fig. 9, g), puis un important atelier a été mis en évidence sur le site de Majoura $^{35}$ (fig. 9, f). Les deux sites sont à peu près sur le même parallèle, le premier sur la côte, le second à une centaine de $\mathrm{km}$ vers l'intérieur.

Fouillant à Nabeul une usine de salaison (Slim, Bonifay, Trousset 1999), il était impensable de ne pas tenter de caractériser la production amphorique de cette cité, dont une partie au moins avait pu contribuer à la diffusion des salsamenta. Le hasard et surtout la bienveillance de feu M. Azaïez Antit, Conservateur du Musée de Sousse et originaire de la localité de Beni Khiar, à $6 \mathrm{~km}$ au nord de Nabeul, m'ont permis de visiter dès 1997 le très grand atelier de Sidi Zahruni (fig. 11, c-d) et d'y mettre en évidence la production de types tardifs des Ve-VIe s., notamment le type Keay 35 et le type Keay 57, confirmant sur ce dernier point une intuition de Cl. Panella (Panella 1986, 259 et fig. 4). Ces deux types étant extrêmement bien diffusés en Méditerranée et même

\footnotetext{
33 Je n'ai pas une connaissance directe de cette région, hormis de son littoral.

${ }^{34}$ Dossier inédit R. Guéry.

${ }^{35}$ Découvert par M. Nasr dans le cadre de la préparation de sa thèse de doctorat.
} 

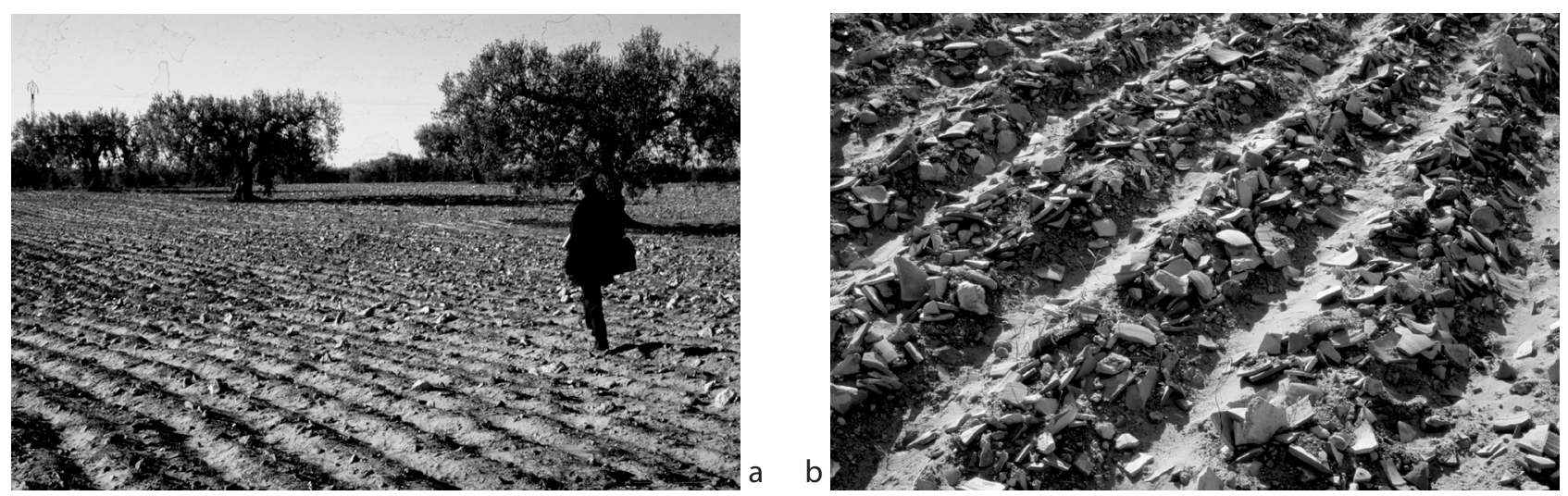

a - b : Ateliers de Zitha/Ziane (2001, sous la conduite de M. Ali Drine, INP)

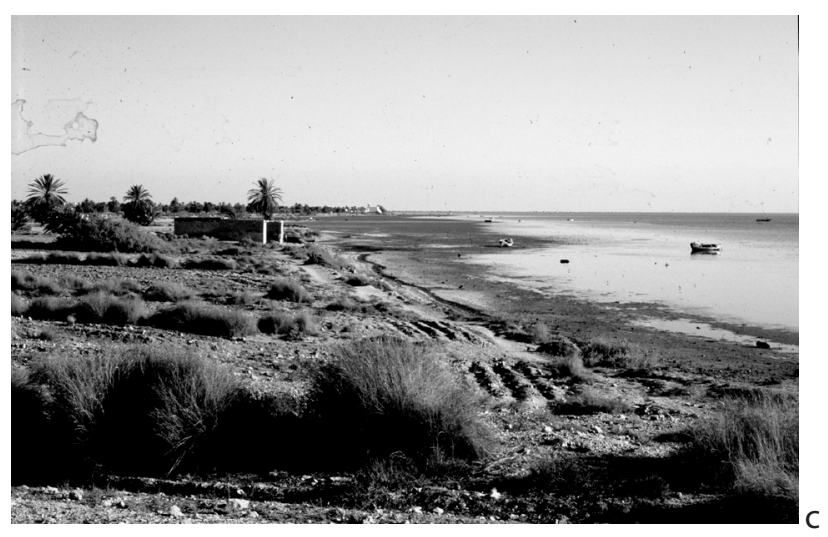

c: Atelier de Guallala (2001, sous la conduite de M. Ali Drine, INP)
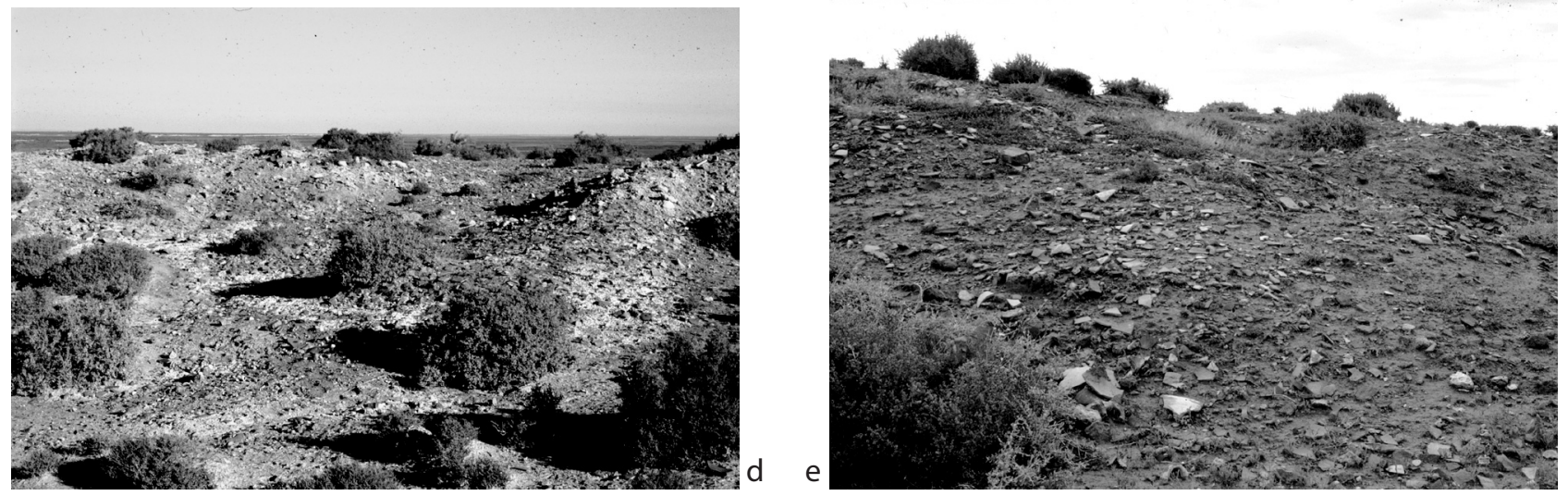

d - e : Atelier de Oued el-Akarit (1990, sous la conduite de M. Ali Drine, INP)

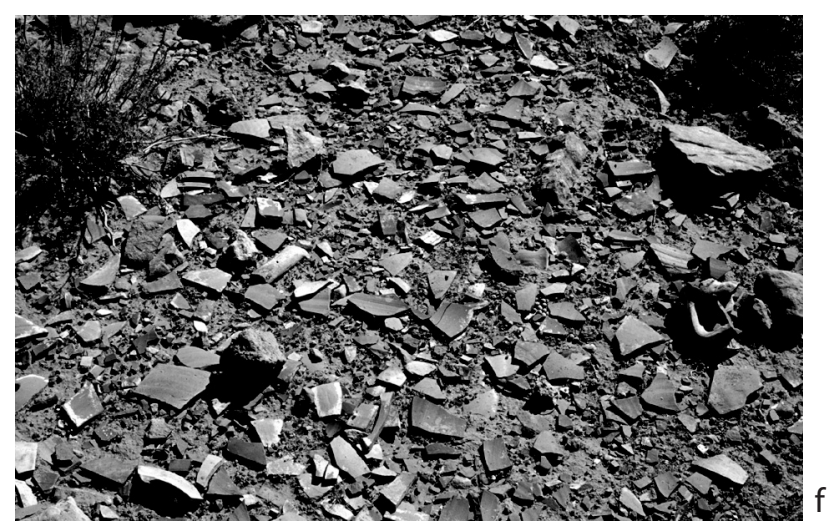

$f$ : Atelier de Majoura (2000, sous la conduite de M. Mongi Nasr)

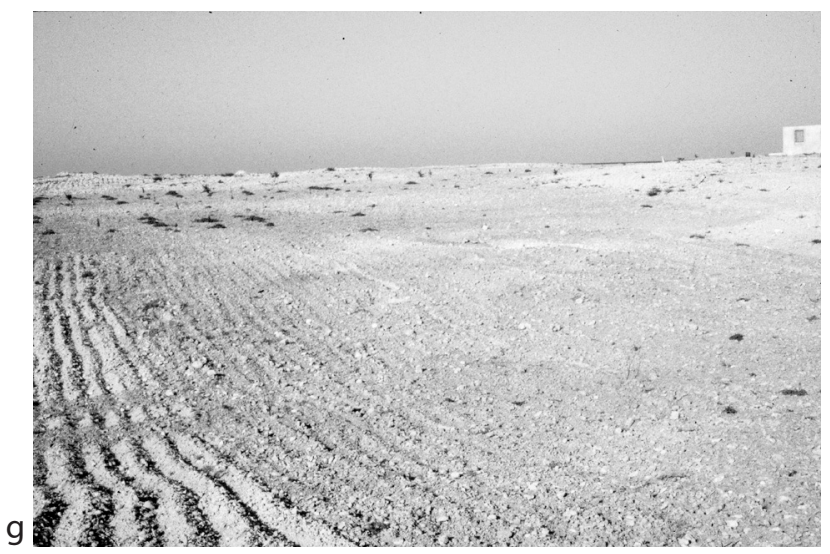

g: Ateliers (?) de lunca (1993, sous la conduite de M. Nejib Ben Lazreg)

Fig. 9. Amphores. Exemples d'ateliers (Tripolitaine et Byzacène méridionale) 

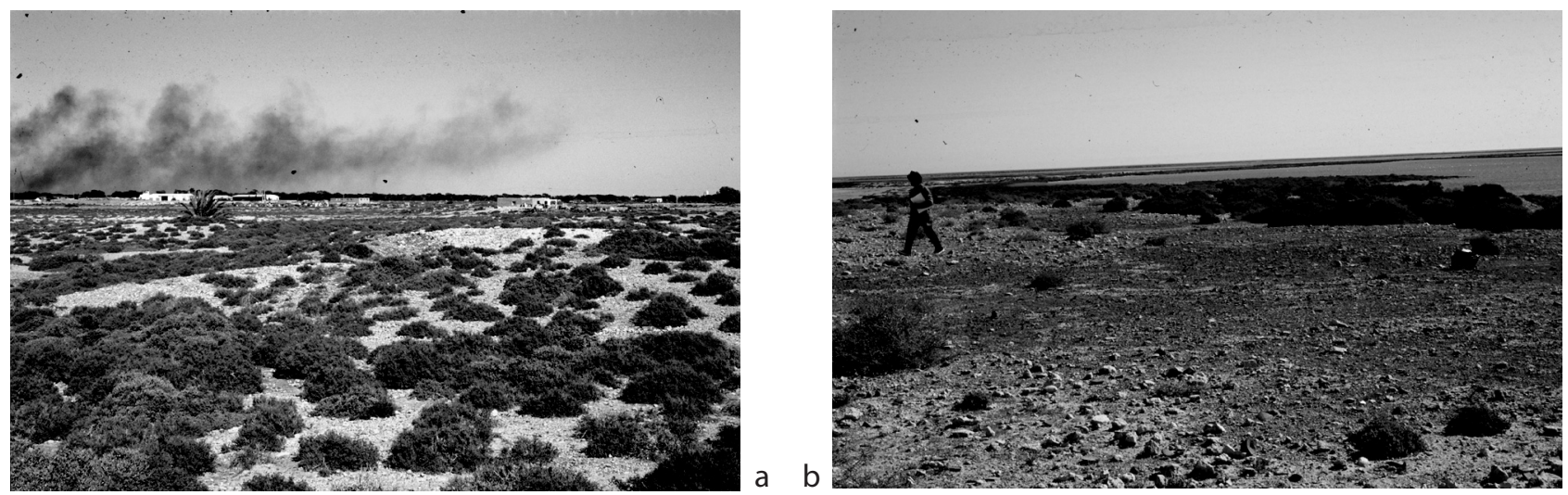

a : Ateliers de Thaenae, zone A (intra-muros) ; b : Ateliers de Thaenae, zone B (extra-muros) (2001, sous la conduite de Mme Nabiha Jeddi, INP)
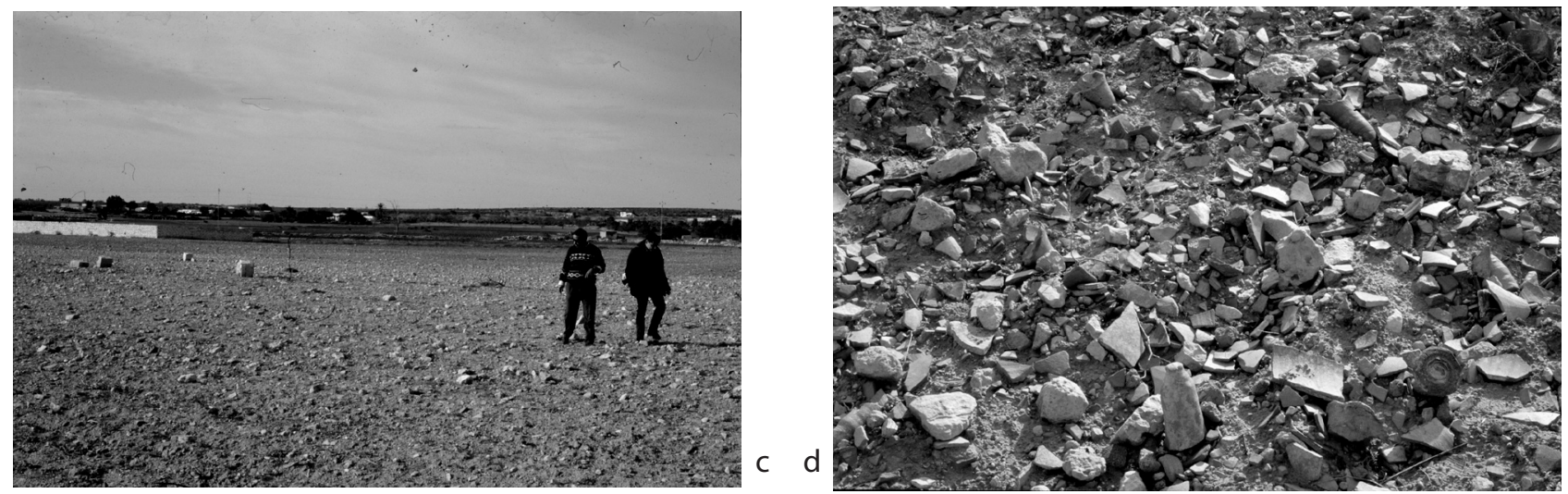

c - d : Ateliers de Salakta-catacombes (2001, sous la conduite de M. Nejib Ben Lazreg, INP)
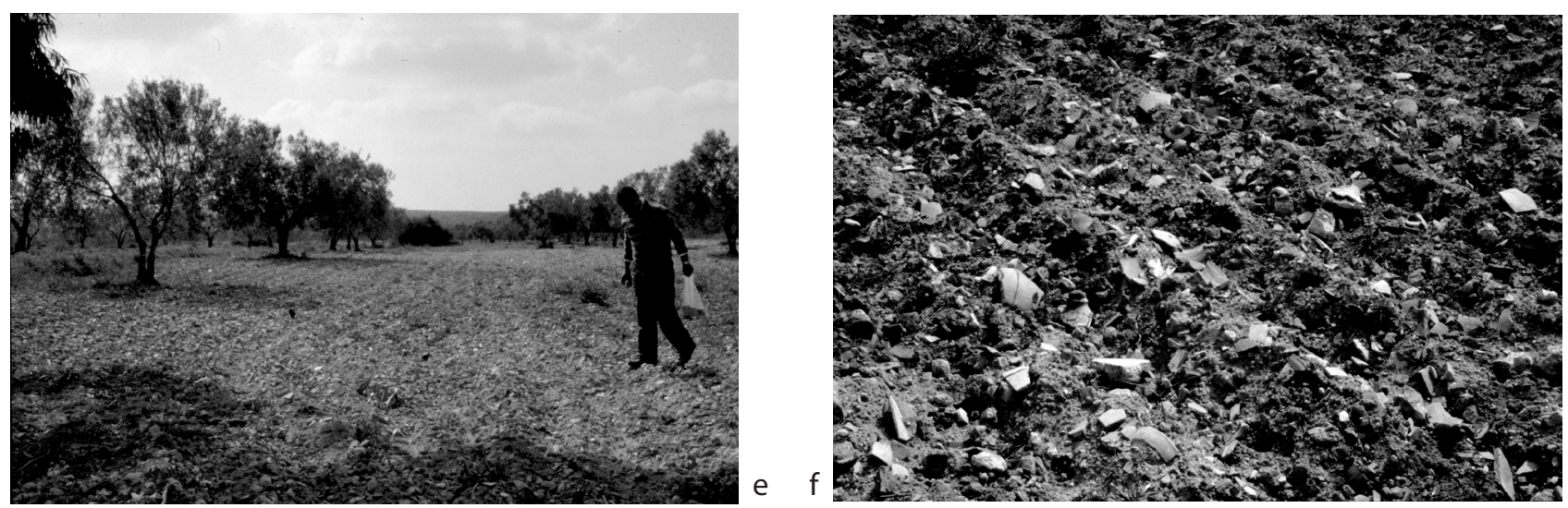

e - f : Atelier de Henchir ech-Chekaf (1993, sous la conduite de M. Nejib Ben Lazreg, INP)

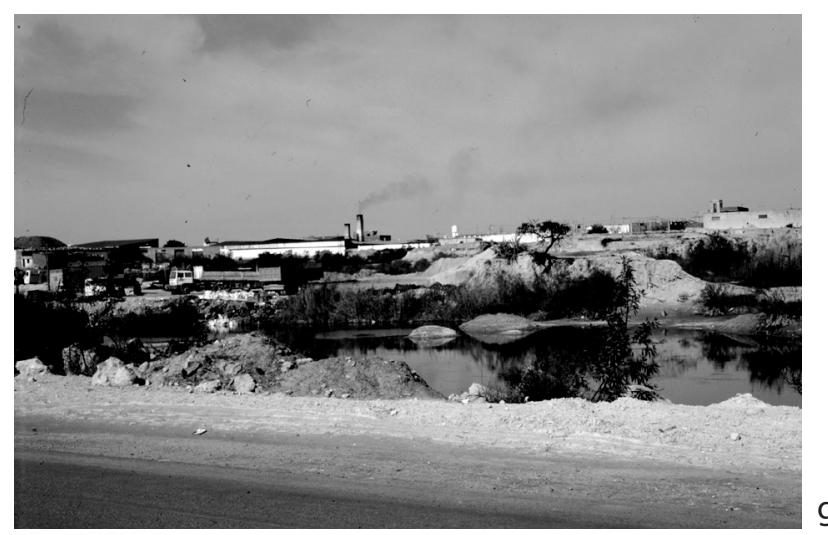

g : Moknine (sous la conduite de M. Nejib Ben Lazreg, INP). Emplacement de l'atelier (2001).

Fig. 10. Amphores. Exemples d'ateliers (littoral de la Byzacène).

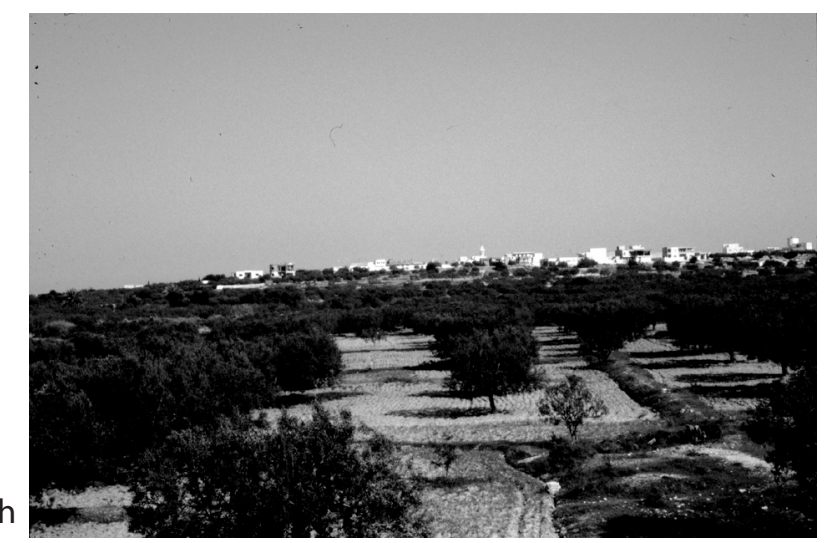

$\mathrm{h}$ : Leptiminus (sous la conduite de M. Nejib Ben Lazreg, INP). Colline de Dahar Slima (1993). 


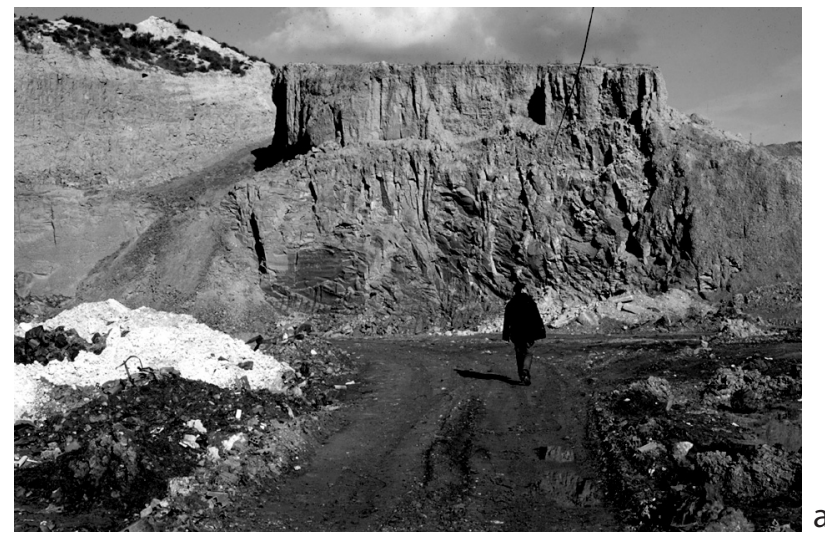

a : Nabeul-briqueterie (sous la conduite de M. Tahar Ghalia, INP). Carrière d'argile actuelle (2001).

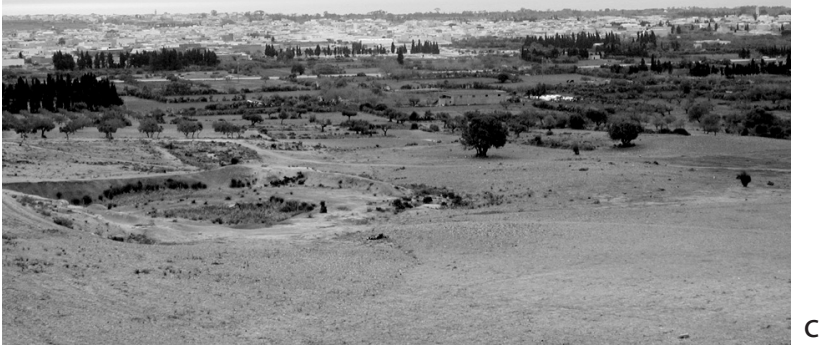

C - d : Atelier de Sidi Zahruni (2001, sous la conduite de M. Tahar Ghalia, INP)

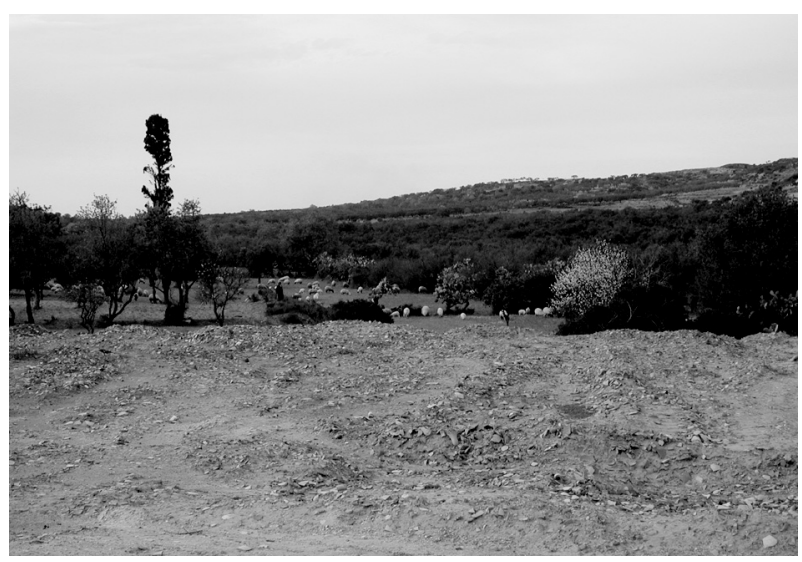

b : Nabeul-Sidi Aoun (2002, sous la conduite de M. Tahar Ghalia, INP).

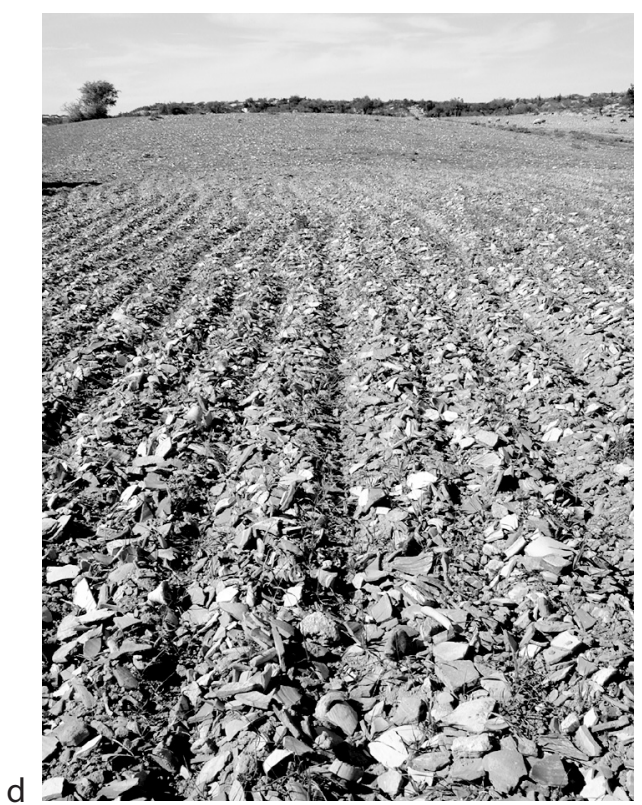

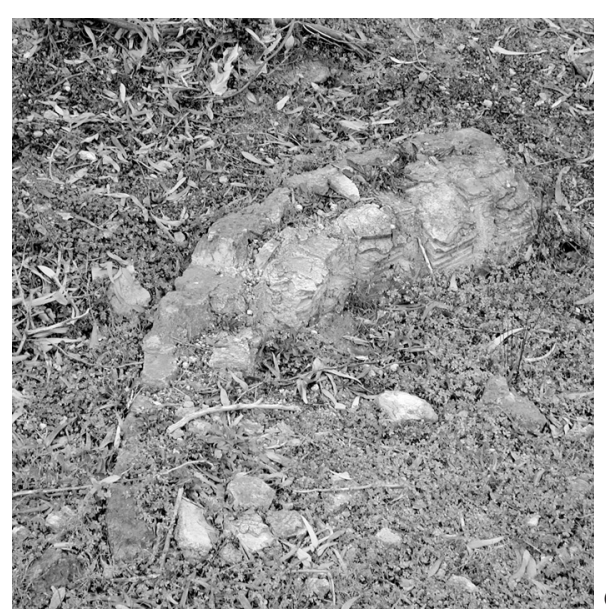

e : Nabeul-Neapolis, rue Abdul Kacem Chabbi

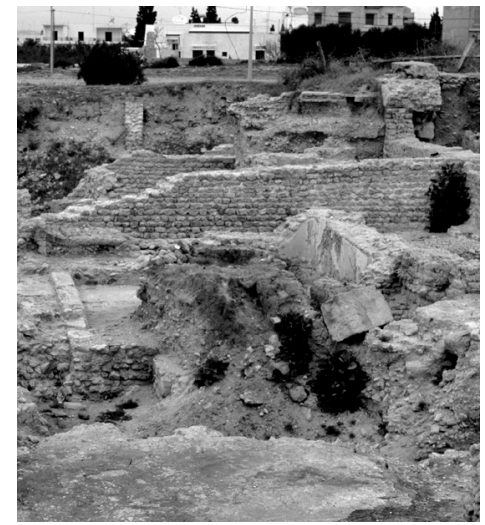

$f$ : Nabeul-thermes

(fouilles de Mme Latifa Slim)

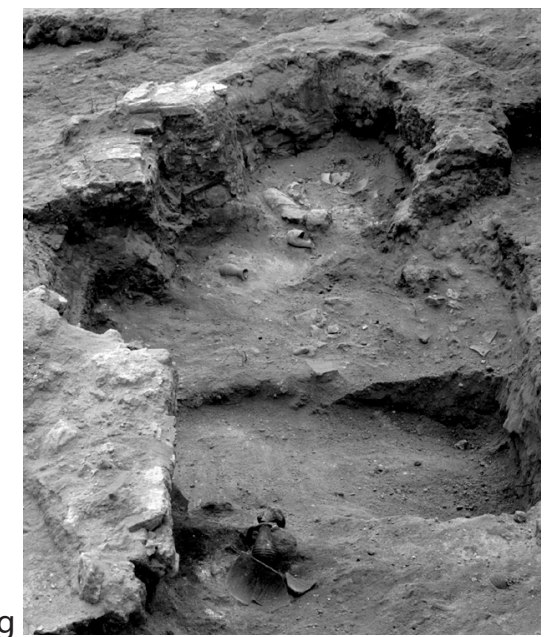

g : Nabeul-Neapolis,

îlot de la Maison des Nymphes

(2001, fouilles dirigées par Mme Latifa Slim, INP)

Fig. 11. Amphores. Exemples d'ateliers (Nabeul). 
en Tunisie (infra, fig. 254, b), seul le repérage d'un atelier pouvait permettre d'en déterminer l'origine.

Deux ateliers, l'un encore à Nabeul (Sidi Aoun, voir infra), l'autre sur la côte occidentale du cap Bon (El Assa, voir infra), ont livré les preuves de la fabrication d'amphores Dressel 30 en Tunisie septentrionale, déjà pressentie par F. Carrazé $(1976,67)$. Il est probable que ce type était également produit dans la région de Salakta (Gibbins 2001, 313 et fig. 2: amphore Dressel 30 de l'épave Plemmirio B). Le type Dressel 30 n'est donc pas synonyme des productions de Maurétanie Césarienne et il n'est plus nécessaire, désormais, d'envisager une escale algérienne pour expliquer la composition du chargement de l'épave de Trincere (Pontacolone, Incitti 1991, fig. 6, $\mathrm{n}^{\circ} 15$ et fig. $\left.7, \mathrm{n}^{\circ} 19\right)$.

Outre qu'il est difficile, pour des raisons diverses, d'entreprendre des recherches systématiques et raisonnées sur les ateliers, il reste à évoquer les écueils techniques qui peuvent surgir dans cette démarche. On vient de souligner le caractère ténu des indices de production à Iunca et, de fait, il n'est pas rare de se heurter, sur le terrain, à des problèmes de diagnostic : certains indices, zones cendreuses, tessons surcuits (recuits ?), sont peu éloquents et je préfère pour ma part m'en tenir aux preuves indiscutables (déchets de cuisson) ou aux critères énoncés par des spécialistes de la reconnaissance des ateliers (Ballet et al. 1991, 130-134). Il faut aussi se garder de tout dogmatisme : tout tesson recueilli sur un site d'atelier n'est pas forcément produit sur place. J'ai fait personnellement l'expérience de cette évidence sur la plupart des ateliers d'amphores visités en Tunisie, où il est possible, par l'expérience, de reconnaître les tessons intrusifs. Je citerai pour exemple un tesson d'amphore Keay 34 (avec sa pâte caractéristique) sur l'atelier des catacombes à Salakta, un bord d'amphore Keay 35 de Beni Khiar (?) sur l'atelier d'Henchir ech-Chekaf à Ksour Essaf, un fragment de type Africaine II C de Nabeul (?) sur les ateliers extra-muros de Thaenae. En revanche, je me suis laissé entraîner, sur ce même site, à considérer comme locales des amphores de type Ostia I, 453 (Ben Lazreg et al. 1995, 131), dont les recherches pétrographiques ultérieures ont démontré l'origine non africaine, probablement sicilienne.

\subsubsection{Les méthodes archéométriques}

Les pâtes des amphores africaines sont suffisamment grossières pour pouvoir être soumises, avant toute analyse physico-chimique lourde et coûteuse, à un examen de type pétrographique et minéralogique. Cette piste de recherche n'est pas nouvelle; elle a déjà été explorée à plusieurs reprises sur des échantillonnages toutefois restreints: matériel de sites consommateurs africains (par ex. Uzita: Van der Werff 1977-78, et Carthage : Peacock 1984a et 1994) et non africains (par ex. Rome: Schuring 1984) ou matériel de sites producteurs d'une seule région (par ex. les ateliers du Sahel : Peacock, Tomber 1991).

On sait depuis longtemps que la plupart des céramiques produites à toutes époques en Afrique du Nord (mais aussi en Palestine) sont bien caractérisables et différentiables des autres productions méditerranéennes, grâce à la présence de quartz d'origine éolienne dans la pâte (Mannoni 1972). En revanche, la pauvreté des éléments pétrographiques du dégraissant (constitué en général essentiellement de quartz, et plus ou moins de micro-fossiles et de fragments de roches calcaires) représente, encore aujourd'hui, un obstacle à la reconnaissance de l'origine précise des céramiques africaines. Cependant les recherches menées depuis 1998 par Cl. Capelli montrent qu'il est possible d'effectuer des distinctions au sein des pâtes africaines. Les principales variables pétrographiques à prendre en compte sont très subtiles: le rapport relatif des minéraux de fer ou de calcaire diffusés dans la matrice (couleur de la pâte), l'absence ou présence de fraction fine non-plastique et, dans ce dernier cas, la fréquence du quartz et des microfossiles dans cette fraction, le pourcentage, les dimensions moyennes et maximales, les degrés d'assortiment et de rotondité des composants du dégraissant (essentiellement quartz, roches calcaires, fossiles) et des vacuoles. Quelques comparaisons ponctuelles entre les distinctions pétrographiques, les classifications typologiques et les références d'ateliers actuellement disponibles devraient nous permettre de tester l'efficacité de cette méthode et de déterminer dans quels cas elles doivent être intégrées à des méthodes plus sophistiquées comme la physico-chimie (Capelli et al. 2001).

Un premier essai tenté sur quelques grands ateliers d'amphores échelonnés sur le littoral tunisien donne des résultats tout à fait encourageants. Une prospection menée en janvier 2001 sur les ateliers de Zian, de Thyna, de Salakta et de Sidi Zahruni ${ }^{36}$ a permis de constater que les pâtes relatives à chaque atelier constituaient un ensemble plutôt homogène et distinct des autres, et, dans la plupart des cas, également indépendant de la chronologie et de la typologie des produits (Capelli et al. 2001). L'atelier qui a la pâte la plus caractéristique est sans conteste celui de Salakta (Capelli, Ben Lazreg, Bonifay à paraître), pâte qui correspond à celle décrite dès 1969 par Zevi et Tchernia $(1969,181)$ comme caractéristique des amphores portant les timbres $A S Y L$ $A S V L$ : bicolore rouge et grise et constellée d'une multitude d'inclusions blanches (Pl. I, n 11-12); c'est la fabric 2.6 de Peacock (1984a). Ces inclusions sont en fait des micro-fossiles et des grains de calcaires, associés à un dégraissant de quartz moins abondant (fig. 12, a). L'observation des coupes de terrain en bordure de la route qui conduit à Salakta permet de constater que les strates d'argile sont scellées par un plancher rocheux qui

\footnotetext{
${ }^{36}$ Anciennement dénommé Chabat al-Qola.
} 

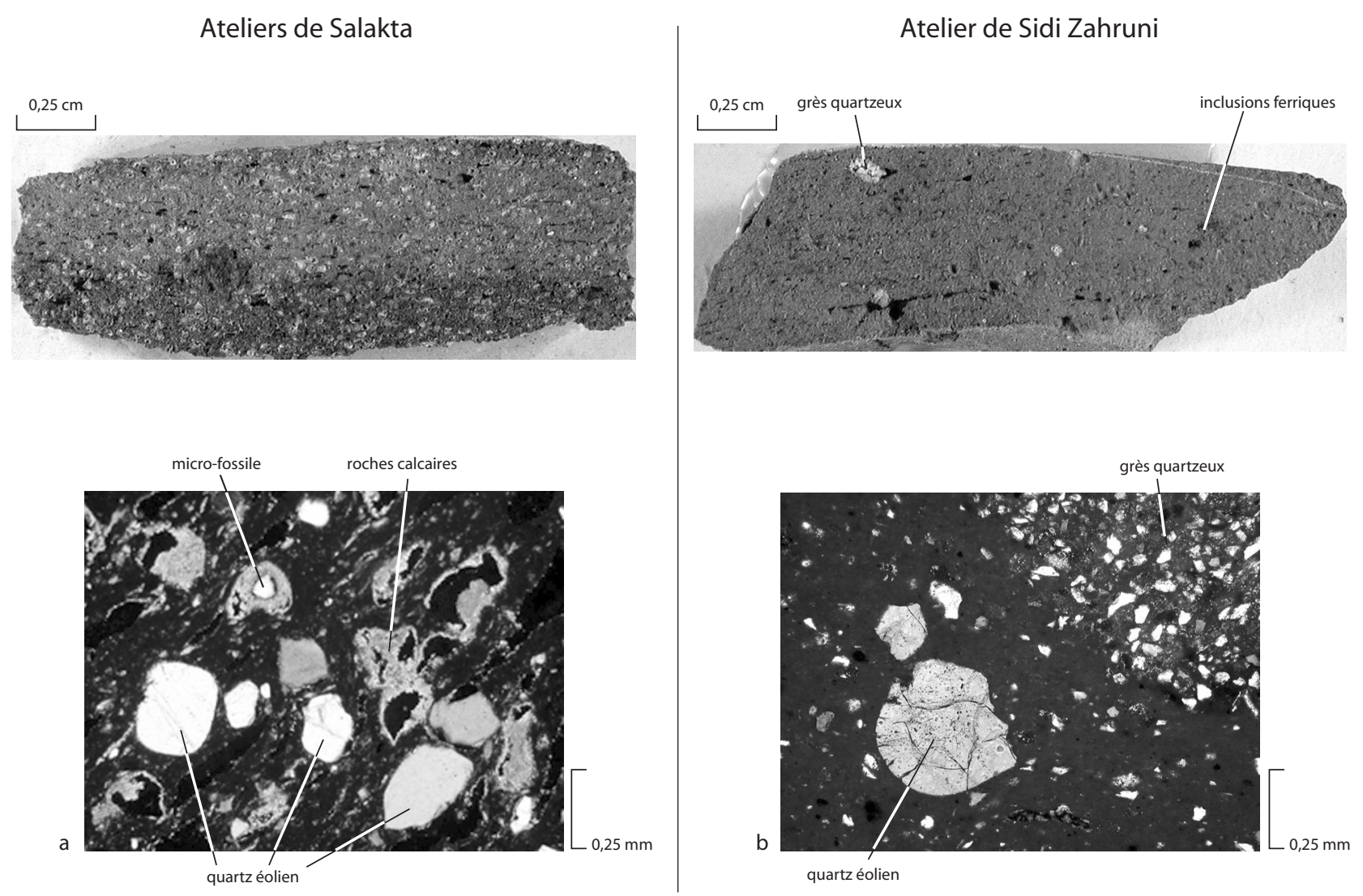

Fig. 12. Amphores. Caractérisation pétrographique des pâtes des ateliers de Salakta et de Sidi Zahruni. (micro-photographies et analyses pétrographiques d'après $\mathrm{Cl}$. Capelli) 


\section{Ateliers de Zitha/Zian}
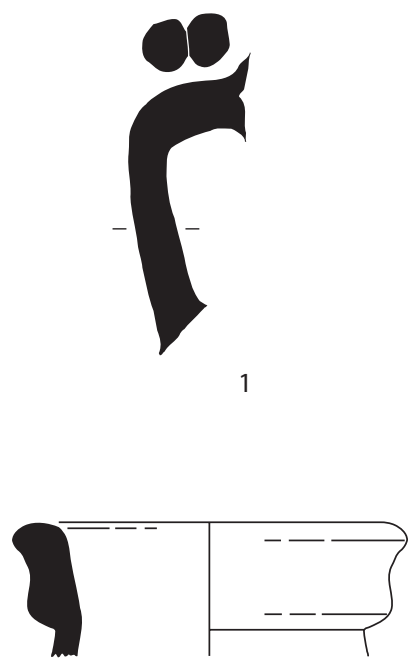

6

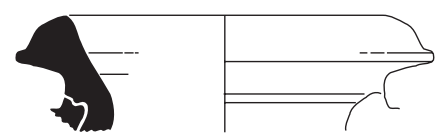

9

12

14
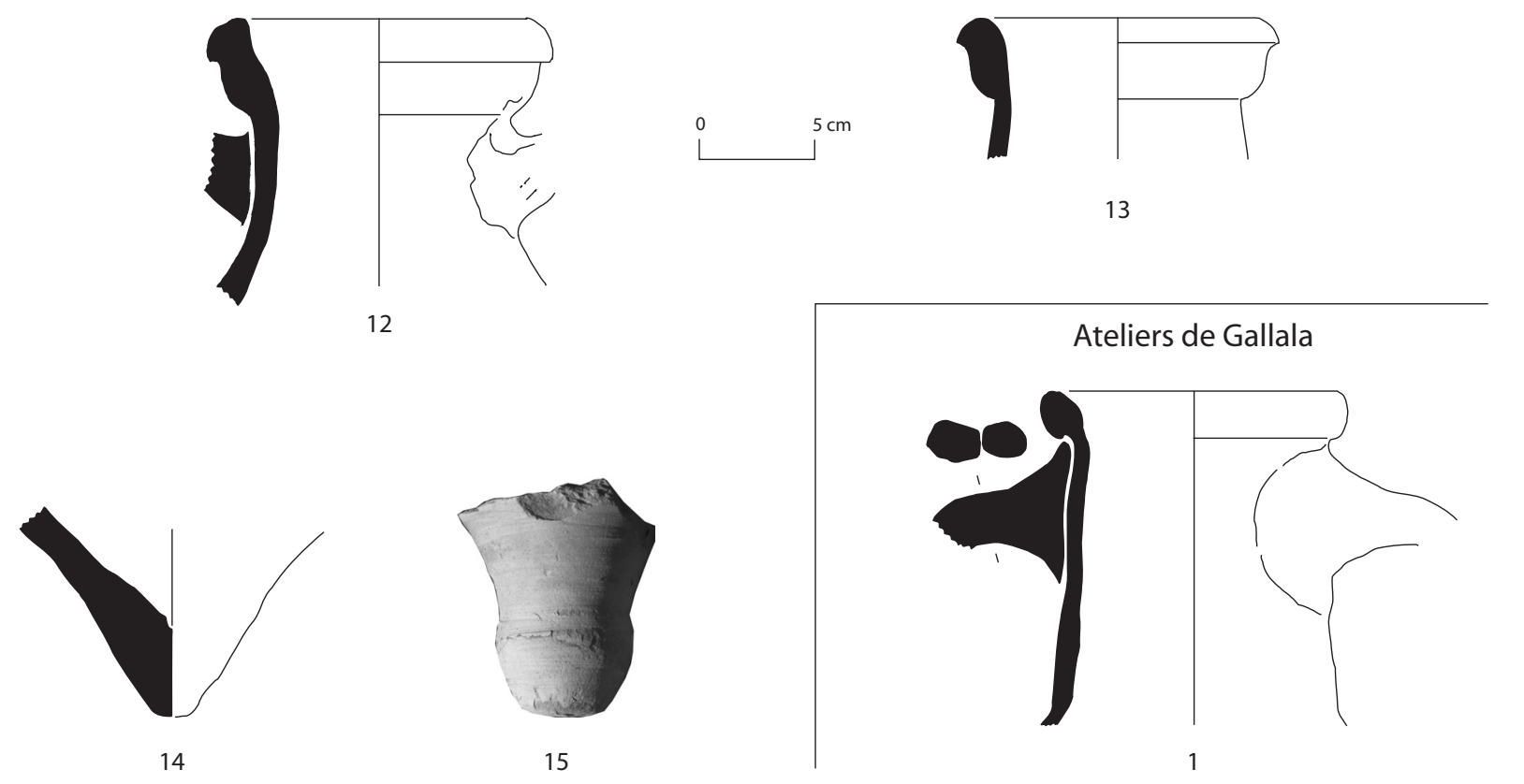
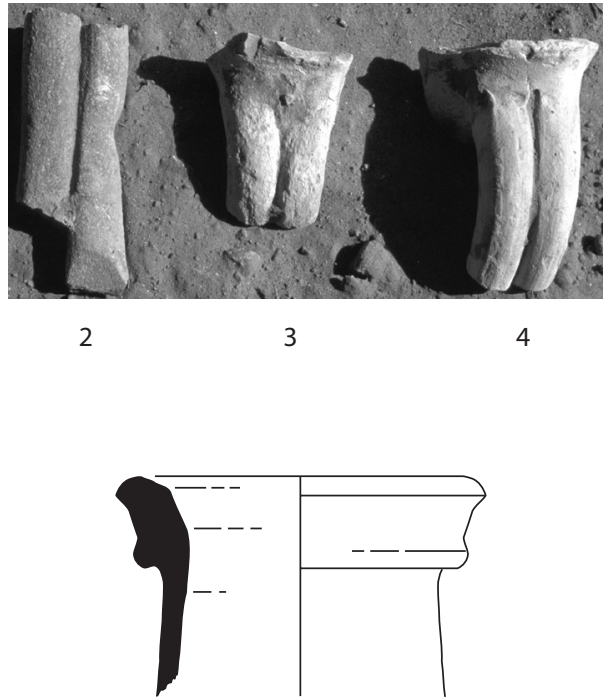

7

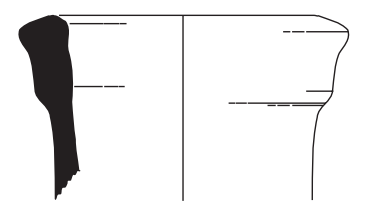

10
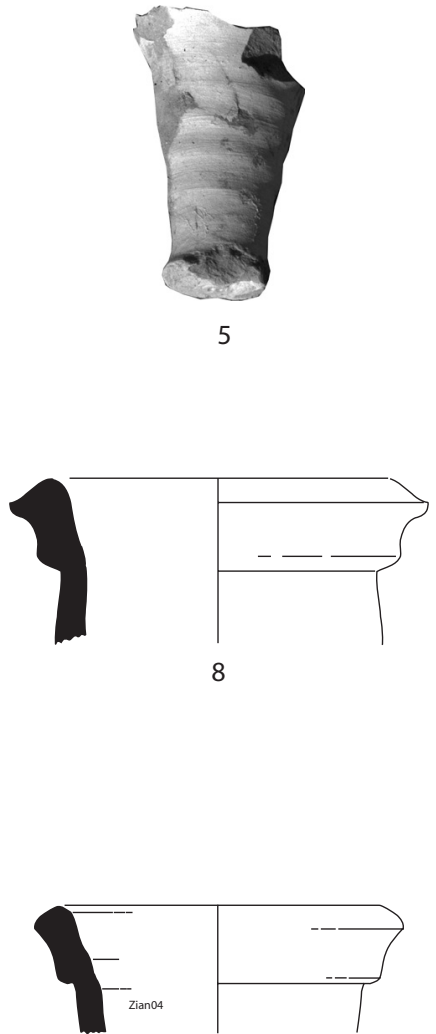

11

Fig. 13. Ateliers de Zitha/Zian et Gallala. Echantillons. 
a pu, en se désagrégeant lors du prélèvement de la terre par les potiers, se mélanger à la matrice argileuse (?).

De même, l'étude des pâtes de l'atelier de Sidi Zahruni, près de Nabeul, permet de prouver que ce sont bien les argiles locales qui ont été utilisées pour la production des amphores (Pl. I, n 20-21). En effet, les couches d'argile sont abondantes autour de l'atelier et accessibles sur la pente du jebel Chabat al-Qola ; elles sont bien adaptées à la fabrication de la céramique comme en témoigne leur utilisation actuelle par une briqueterie située à peu de distance de l'atelier antique; enfin, le grès quartzeux (fig. 12, b) qui caractérise la plupart des pâtes de l'atelier semble identique à celui qui s'intercale, comme le calcaire à Salakta, entre les strates d'argile, une pollution par cette roche des argiles lors de leur prélèvement expliquant probablement la présence de ces inclusions dans la pâte (Ghalia, Bonifay, Capelli 2004).

Ces méthodes relativement simples, associées bien entendu à une bonne détermination typologique, permettent, en retour, d'aborder le problème de l'origine des amphores africaines découvertes hors d'Afrique. Des amphores Keay 35B de Marseille (Capelli et al. 20022003) et de l'épave du Dramont E à Saint-Raphaël (Bonifay, Capelli, Long 2002 ; Ghalia, Bonifay, Capelli 2004) sont ainsi attribuables sans grand risque d'erreur, à la fois par leur typologie et par leurs caractéristiques pétrographiques, à l'atelier de Sidi Zahruni ou à un atelier voisin. Il en est de même pour les amphores Keay 25.1 provenant de l'épave d'Héliopolis 1 (île du Levant, Hyères), qui portent des timbres anépigraphes reconnus en prospection sur les ateliers de Salakta, et dont la pétrographie confirme clairement cette origine (Bonifay, Capelli, Long 2002 ; Capelli, Ben Lazreg, Bonifay à paraître). Il semble donc inutile en bien des $\operatorname{cas}^{37}$ de recourir à des méthodes plus sophistiquées pour préciser l'origine des amphores africaines les plus communes.

\subsection{EXEMPLES D'ATELIERS}

\subsubsection{Ateliers de Tripolitaine}

\section{ATELIERS DE ZITHA/ZIAN}

Les ateliers de Zitha/Zian (Drine 1999,55 et note 20$)^{38}$ s'étendent très largement dans des olivettes situées au sud-est et en contrebas de la ville antique et sont marqués par des zones cendreuses avec d'importantes jonchées de céramiques (fig. 9, a-b). D'imposants ratés de cuisson sont parfois rejetés sur les limites de parcelles. On relève

\footnotetext{
37 On pensera notamment aux recherches archéométriques effectuées sur le chargement de l'épave de Plemmirio B, clairement originaire de Salakta (Taylor, Robinson, Gibbins 1997).

${ }^{38}$ Visites du site en 1990,1993 et 2001 à l'invitation de mon ami Ali Drine, responsable du site.
}

les formes d'amphores suivantes (Bonifay et al. 20022003) :

- amphores apparentées au type Dressel 2/4 (infra, AMPHORE TYPE 57) ou Schöne-Mau XXXV, représentées par des fragments d'anses bifides, des bords à bourrelet simple, des pointes relativement effilées ;

- amphores de type Tripolitaine I (infra, AMPHORE TYPE 19) ;

- amphores de type Tripolitaine III (infra, AMPHORE TYPE 20).

Exemples (fig. 13) :

*1-4 Anses bifides d'amphores de type pseudo-Dressel 2/4.

5 Fond d'amphore de type pseudo-Dressel 2/4.

*6-8 Bords d'amphores de type Tripolitaine I.

*9-13 Bords d'amphores de type Tripolitaine III ( $\mathrm{n}^{\circ}$ 10-11 ?).

*14 Fond d'amphore de type Tripolitaine I.

*15 Fond d'amphore de type Tripolitaine III (?).

On remarque que le seul type d'amphore Tripolitaine qui ne semble pas produit sur cet atelier est le type II, en revanche très abondant dans la région de Lepcis Magna (Panella 1973, 563 ; Arthur 1982, 71). L'atelier produisait aussi des céramiques culinaires (?) et communes (infra, p. 73). De fait, les productions de l'atelier de Zitha se distinguent bien, par leur pâte orange rosé, fine et compacte (Pl. I, $\mathrm{n}^{\circ} 2-3$ ), au dégraissant peu abondant de quartz sub-anguleux et de micro-fossiles (Capelli et al. 2001), des productions de Lepcis Magna caractérisées par une pâte bicolore rouge et gris, avec de nombreuses et grosses inclusions de calcaire, comparables à celle de Salakta mais plus grossières encore $\left(\mathrm{Pl}\right.$. I, $\left.\mathrm{n}^{\circ} 1\right)$. Cet atelier semble actif durant les trois ou quatre premiers siècles ap. J.-C.

\section{ATELIERS DE GALLALA}

Les traces d'ateliers sont situées en bordure de la plage de Gallala (fig. 9, c), sur la rive sud de l'île de Jerba ${ }^{39}$. Assez ténues (Bonifay 1990, 111 ; Bonifay et al. 2002-2003), elles consistent dans l'abondance anormale de tessons, certains surcuits, d'un seul type d'amphore, apparenté au type Dressel 2/4 ou Schöne-Mau XXXV (AMPHORE TYPE 57), type local déjà signalé à Zian/Zitha. Exemple (fig. 13) :

*1 Bord d'amphore de type pseudo-Dressel 2/4 (Bonifay et al. 2002-2003, fig. 15, $\mathrm{n}^{\circ} 202$ ).

Cet atelier semble également avoir produit de la céramique culinaire (marmites apparentées au type Hayes 183, CULINAIRE TYPE 17) et commune (mortiers). Il y a une grande similitude entre la pâte de ces productions antiques des Ier-IIIe s. et celles des productions actuelles des ateliers du village de Gallala: orange sombre, relativement compacte, avec d'assez nombreux microfossiles (Pl. I, $\left.\mathrm{n}^{\circ} 4\right)$, elles se signalent en outre, comme celles de l'atelier précédent, par une présence significative de mica, inhabituelle dans les céramiques à quartz éolien (Capelli 2002-2003).

\footnotetext{
${ }^{39}$ Ateliers visités en 1990 et 2001 sous la conduite d'Ali Drine.
} 


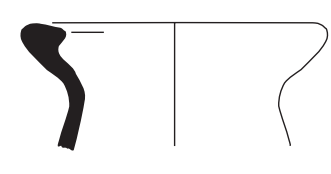

1

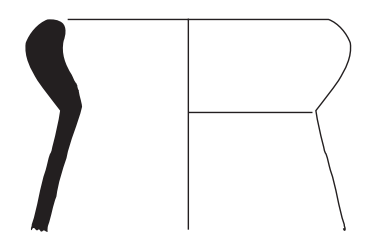

2

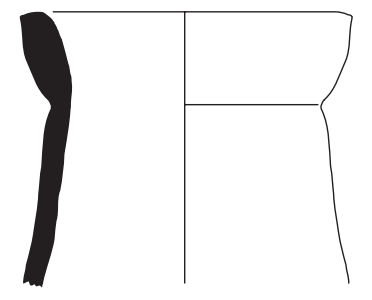

3

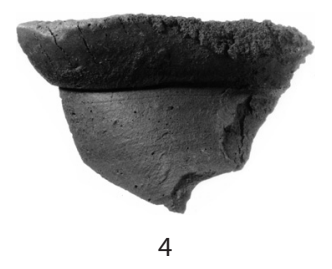

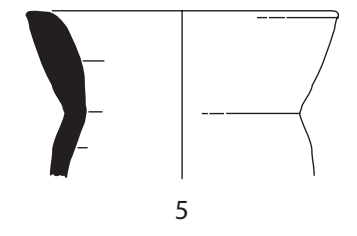

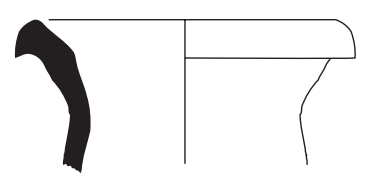

6
Atelier de Majoura

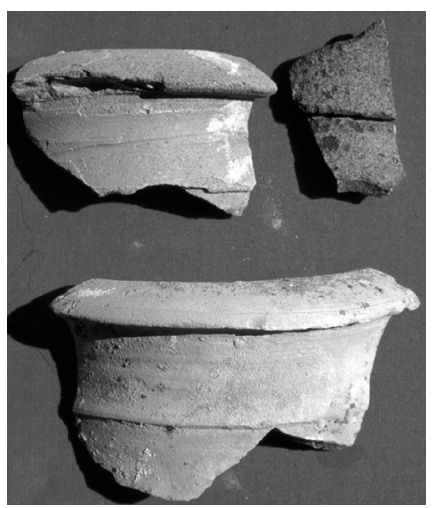

Atelier (?) de lunca
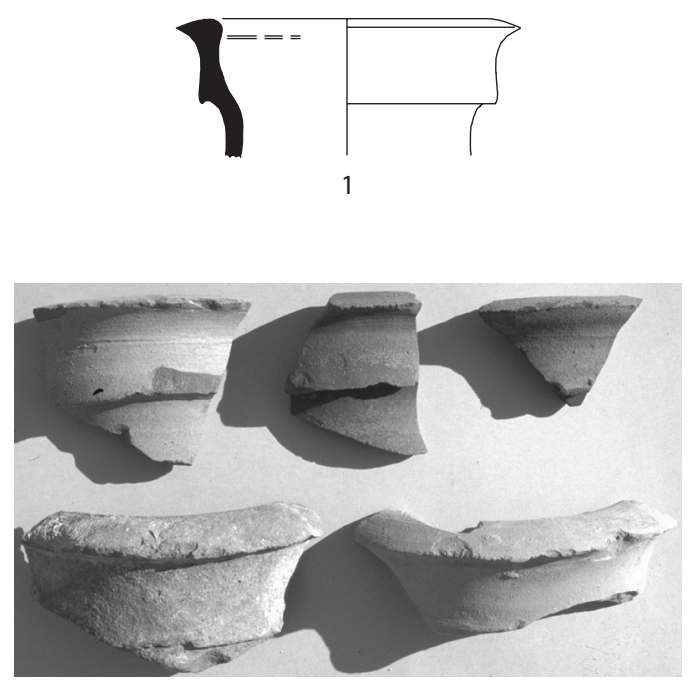

Fig. 14. Ateliers de Oued el-Akarit, Majoura et Iunca. Echantillons. 


\subsubsection{Ateliers de Byzacène}

\section{Ateliers de Byzacène méridionale}

\section{ATELIER D'OUED EL-AKARIT}

Cet atelier de taille moyenne, situé au débouché de l'Oued el-Akarit ${ }^{40}$ et à proximité d'installations de salaison d'époque romaine, est signalé par plusieurs tells formés de rebuts de cuisson de céramiques, de fragments de fours et de cendres (fig. 9, d-e). Certains de ces rebuts de cuisson sont spectaculaires (mouton: Bonifay et al. 2002-2003, fig. 17). Trois types principaux d'amphores semblent caractéristiques de cet atelier (Bonifay 1990, 111 ; Bonifay et al. 2002-2003) :

- amphores Africaines IB, variante tardive (infra, AMPHORE TYPE 21C) ;

- amphore Africaine II D (infra, AMPHORE TYPE 26)

ou, plus vraisemblablement, Keay 25.1 (TYPE 27) ;

- amphores Keay 25.2 ou 3 (?).

Exemples (fig. 14) :

*1-2 Bord d'amphore Africaine I tardive (Bonifay et al. 2002-2003, fig. 17, $\mathrm{n}^{\circ}$ 222-223).

*3-4 Bords d'amphores Africaines II D (?), dont un surcuit (Bonifay et al. 2002-2003, fig. 17, $\mathrm{n}^{\circ}$ 224-225).

*5 Bord d'amphore de type Keay 25.1 (Inv. AK001).

*6 Bord d'amphore de type Keay 25.2 ou 3 (Bonifay et al. 2002-2003, fig. $17, \mathrm{n}^{\circ} 226$ )

Cet atelier produisait aussi de la céramique culinaire et de la céramique commune (infra, p. 69 et 73). En revanche, il est probable que les sigillées E et les lampes Atlante VI découvertes sur le site ne sont pas produites sur place (ni casettes, ni moules). Mis à part un aspect très vacuolaire, la pâte ne présente pas de particularités décelables par observation macroscopique (Pl. I, $\mathrm{n}^{\circ} 5$ ). Ce centre producteur semble avoir été actif au IVe siècle.

\section{ATELIER DE MAJOURA}

Je mentionne seulement pour mémoire cet atelier qui est étudié en détail par $M$. Mongi Nasr dans sa thèse de doctorat $^{41}$. Ce site se signale au voyageur par d'imposants vestiges de thermes, non loin d'une source encore captée de nos jours. Les traces d'ateliers, plus loin en bordure de l'oued, sont très évidentes et matérialisées par d'abondantes jonchées de fragments d'amphores, avec de nombreux rebuts de cuisson (fig. 9, f). En revanche, les sigillées, pourtant abondantes sur deux monticules cendreux, ne semblent pas produites sur place (pas de casettes : infra). La production amphorique de cet atelier (fig. 14) est très homogène: il s'agit d'une variante probablement assez tardive (première moitié du VIe s. ?) du type Keay 8B (infra, AMPHORE TYPE $38, n^{\circ} 8$ ).

\section{ATELIER DE IUNCA (?)}

Nous interprétons comme des traces d'ateliers ${ }^{42}$, avec beaucoup d'incertitudes, quelques zones cendreuses et

\footnotetext{
${ }^{40}$ Visité en 1990 sous la conduite d'Ali Drine.

${ }^{41}$ Que je remercie pour m'avoir autorisé à faire état de ses travaux.

${ }^{42}$ Visite du site en 1993
}

argileuses (fig. 9, g) situées au sud-est de la basilique sud, qui livrent des tessons de typologie homogène, dont quelques-uns uns sont surcuits ${ }^{43}$. Cependant, aucun véritable déchet de cuisson n'a été mis au jour. Les amphores recueillies sont de deux types :

- type Keay 59 (infra, AMPHORE TYPE 37), amphore de la fin du IVe s. et de la première moitié du Ve s. ;

- type Keay 8B (infra, AMPHORE TYPE 38), qui constitue probablement une évolution du type précédent, dans la seconde moitié du Ve et au début du VIe siècle.

Exemple (fig. 14) :

*1 Bord d'amphore de type Keay 8B (Bonifay et al. 20022003, fig. $12, \mathrm{n}^{\circ} 156$ ).

La pâte de ces amphores est très caractéristique ( $\mathrm{Pl}$. I, $\mathrm{n}^{\circ} 6$ ) : orange rosé, compacte, avec de nombreux petits micro-fossiles; la surface extérieure est beige, douce au toucher. Cette pâte anormalement fine semble caractériser l'ensemble de la production d'amphores de types Keay 59 et $8 \mathrm{~B}$, y compris les variantes tardives issues de l'atelier de Majoura (P1. I, $\mathrm{n}^{\circ} 7$ ).

\section{ATELIERS DE THAENAE/THYNA}

La présence de traces d'ateliers d'amphores à Thaenae a été signalée dès 1973 (Panella 1982, 177). Je propose pour ma part de distinguer deux zones d'ateliers (Bonifay et al. 2002-2003) $)^{44}$ :

- La première (zone $\mathrm{A}$ ) est située à l'intérieur des remparts, dans le quart sud-est du périmètre enclos par les murs. Plusieurs petits monticules cendreux se distinguent dans une végétation assez dense d'épineux (fig. 10, a) et livrent de nombreux tessons d'amphores, avec des surcuits, et des fragments de céramiques culinaires). La production amphorique identifiée dans la zone A est uniquement constituée d'amphores Africaines I B, à bord « ad echino » (13).

- La zone d'ateliers B est située à l'extérieur des remparts, également au sud-est de l'agglomération (fig. 10, b). Le fait qu'elle occupe, vraisemblablement, l'emplacement d'une ancienne nécropole, rend plus difficile la caractérisation des productions, le grand nombre de tessons de toutes catégories opérant un «bruit de fond» assez gênant ${ }^{45}$. Les seules amphores clairement signalées par des déchets de cuisson sont du type Keay 25.1 (8-9). La production à Thaenae de cette forme (assimilée au type Ostia III, 110), en même temps que celle des types Africaine I et Africaine II, est déjà signalée par $\mathrm{Cl}$. Panella (1973, 609).

Exemples (fig. 15) :

Zone A (intra-muros) :

*1 Bord d'amphore Africaine I B (Inv. THY002).

\footnotetext{
${ }^{43}$ Je tiens à remercier mon ami Nejib Ben Lazreg qui a, le premier, attiré l'attention sur ces indices.

${ }^{44}$ Mme Nabiha Jeddi nous a très aimablement fait visiter ces ateliers en 1993 et 2001.

${ }^{45}$ D'autant que le terrain a fait l'objet de défoncements agricoles.
} 
Ateliers de Thaenae/Thyna
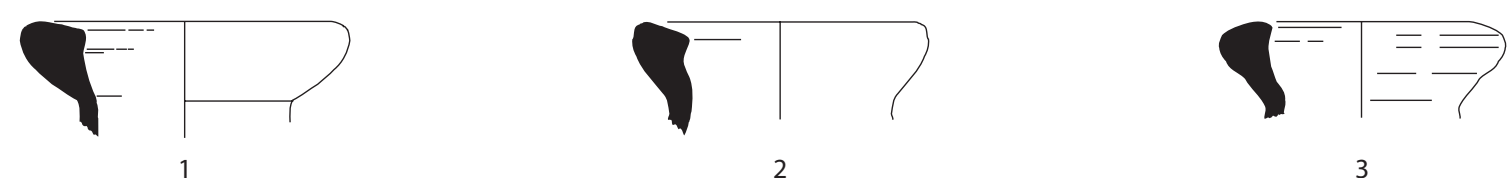

3

atelier intra-muros

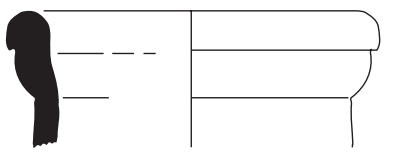

4

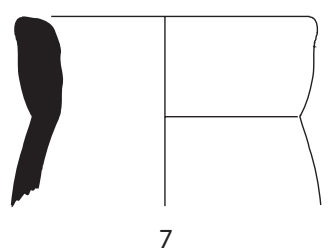

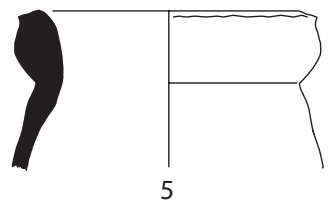

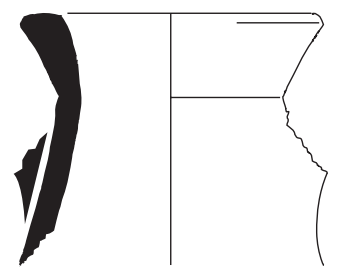

8

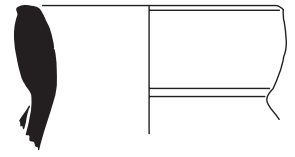

6

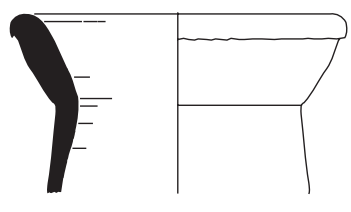

9

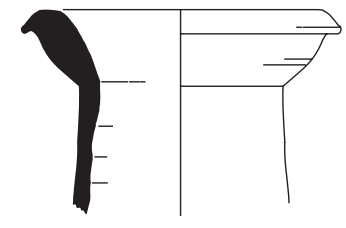

10

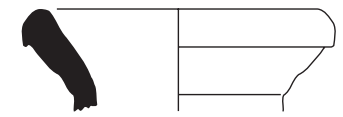

11

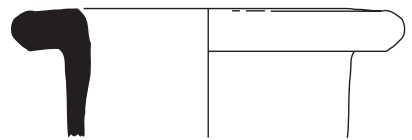

1

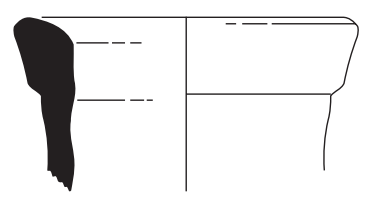

2

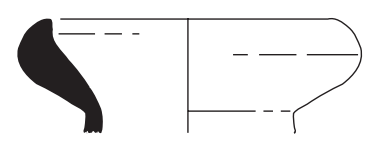

3

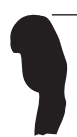

9

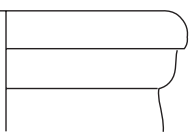

4

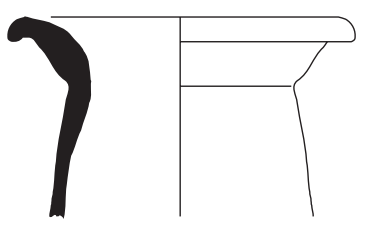

5

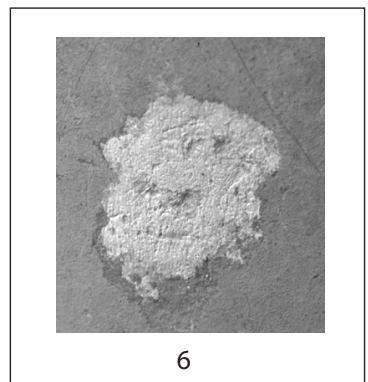

Fig. 15. Ateliers de Thaenae/Thyna et de Salakta-catacombes. Echantillons. 
*2-3 Bords d'amphores Africaines I tardives (Bonifay et al. 2002-2003, fig. 17, $\mathrm{n}^{\circ} 227-228$ ).

Zone B (extra-muros) :

*4 Bord d'amphore Africaine II A (Bonifay et al. 20022003, fig. $17, \mathrm{n}^{\circ} 229$ ).

*5 Bord d'amphore Africaine II B pseudo-tripolitaine (Ibid., $\mathrm{n}^{\circ} 234$ ).

*6-7 Bords d'amphores Africaines II D (?) (Ibid., n 230231).

*8-9 Bords d'amphores de type Keay 25.1 (Ibid., n 232 ; Inv. THY003).

*10-11 Bords d'amphores de type Keay 25.2 (?) (Ibid., $\mathrm{n}^{\circ} 233$; Inv. THY004).

Cette double zone d'ateliers peut s'expliquer si l'on prend en considération la date de construction de l'enceinte. Les remparts de Thaenae semblent avoir été bâtis dans la seconde moitié du IIIe siècle ${ }^{46}$. Dans ces conditions, il y a fort à parier que les ateliers de la zone $\mathrm{A}$, actifs à la fin du IIe s. et dans la première moitié du IIIe s., étaient situés en limite de l'agglomération du Haut-Empire, dans un quartier peu éloigné des nécropoles. En revanche, les ateliers de la zone B sont plus tardifs : ils se sont installés au IVe s. à l'extérieur des remparts. La pâte des amphores de Thaenae est généralement orange vif ou rouge sombre, couleur qui s'explique par une matrice ferrique opaque bien décelable en lame mince (Capelli 2002-2003); elle contient un dégraissant abondant mais régulier de quartz ainsi que des vacuoles peut-être liées à la dissociation, à la cuisson, de micro-fossiles ou de calcaires (Pl. I, n ${ }^{\circ}$ 9$10)$.

\section{Ateliers de Sullecthum}

Il est inutile de revenir en détail sur la description des nombreux ateliers de Salakta et de Ksour Essaf qui font sans doute partie, à l'époque antique, de la même cité de Sullecthum : on se reportera pour cela à la publication qui en a été faite par D. P. S. Peacock, F. Bejaoui et N. Ben Lazreg $(1989)^{47}$. Je me limiterai ici à quelques observations sur deux grands ateliers que j'ai eu l'occasion de pouvoir visiter ${ }^{48}$, celui du secteur des catacombes, à la périphérie de Salakta, et celui d'Henchir ech-Chekaf, à Ksour Essaf.

\section{SALAKTA-CATACOMBES}

Cet atelier s'étend assez largement autour de l'entrée des catacombes romaines de Salakta (fig. 10, c), au sud-est de la ville antique (Peacock, Bejaoui, Ben Lazreg 1989, 192194 ; Lavoie 1989). Le sol est littéralement couvert de tessons d'amphores (fig. 10, d) qui présentent deux qualités de pâtes, toutefois assez proches l'une de l'autre : - pâte A : section bicolore rouge et gris, constellée de petites inclusions blanches (calcaire et microfossiles), surface généralement grise, rugueuse (Pl. I, $\left.\mathrm{n}^{\circ} 11\right)$.

\footnotetext{
${ }^{46}$ Renseignement Nabiha Jeddi.

${ }^{47}$ Dossier repris par Jihen Nacef dans le cadre d'une thèse en préparation.

${ }^{48}$ A l'invitation de Nejib Ben Lazreg, en 1993 et 2001.
}

- pâte B : section orange saumon, petites inclusions blanches moins nombreuses ou moins visibles, surface brun orangé, rugueuse (Pl. I, $\left.\mathrm{n}^{\circ} 12\right)$.

Nous avons vu (supra, p. 26) que la pâte très particulière des amphores de Salakta permet de les reconnaître facilement hors de leur lieu d'origine (Bonifay, Capelli, Long 2002 ; Capelli, Ben Lazreg, Bonifay 2004). De fait, les nombreux exemplaires complets identifiés dans la nécropole de Pupput nous offrent l'opportunité de compléter la description de ces productions. On observe que la surface de ces conteneurs, outre le fait d'être rugueuse en raison de l'affleurement des nombreuses petites inclusions calcaires contenues dans la pâte, est souvent endommagée par l'éclatement, lors de la cuisson, de certaines de ces inclusions, probablement de plus grande taille. Or, ces cavités qui risqueraient de fragiliser le vase ou bien de nuire à sa parfaite étanchéité, ont été systématiquement réparées au plâtre ; il est probable que ces réparations (fig. $15, \mathrm{n}^{\circ} \mathbf{6}$ ) ont été pratiquées sur le lieu de production ou tout au moins avant le remplissage de l'amphore à Salakta. La production comprend de nombreux types (Bonifay et al. 2002-2003) :

- amphores Africaines I A et B (infra, AMPHORE TYPE 21);

- amphores Africaines II A con gradino (infra, AMPHORE TYPE 22) ;

- amphores Africaines III, type Keay 25.1 (infra, AMPHORE TYPE 27).

On doit ajouter à ces productions africaines classiques des IIe-IVe s., des types moins connus, peut-être plus précoces :

- amphores apparentées au type Leptiminus I (infra, AMPHORE TYPE 12) ;

- amphores Uzita Pl. 52, 10 (infra, AMPHORE TYPE 18).

On notera la découverte sur le site d'un tesson d'amphore Keay 34 qui ne provient manifestement pas des ateliers de Salakta.

Exemples (fig. 15) :

*1 Bord d'amphore apparentée au type Leptiminus I (Capelli, Ben Lazreg, Bonifay 2004, fig. 2, n 6284).

*2 Bord d'amphore de type Uzita Pl. 52, 10 (Ibid., $n^{\circ}$ 6283).

*3 Bord d'amphore Africaine I A/B (Ibid., $\mathrm{n}^{\circ}$ 5757).

*4 Bord d'amphore Africaine II A (Ibid., $\mathrm{n}^{\circ}$ 5755).

*5 Bord d'amphore de type Keay 25.1 (Bonifay et al. 2002-2003, fig. $17, n^{\circ} 239$ ).

Hors atelier :

*6 Pupput, tombe 1058 (Inv. PP2306.6). Panse d'amphore Africaine II A de Salakta réparée au plâtre.

L'homogénéité typologique et pétrographique des amphores de Salakta fait de ces dernières les productions africaines les plus faciles à identifier. Elles concernent essentiellement les quatre premiers siècles de notre ère.

\section{KSOUR ESSAF-HENCHIR ECH-CHEKAF}

Cet atelier, à la sortie du bourg de Ksour Essaf, s'étend dans les olivettes qui bordent au Sud la route C87 (km 4) menant à El Jem (fig. 10, e). La densité de l'épandage des fragments d'amphores (fig. 10, f), mêlés à de la terre 
Atelier de Henchir ech-Chekaff

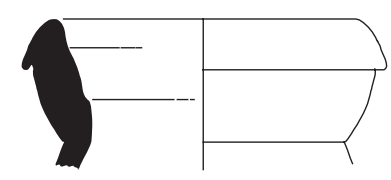

1

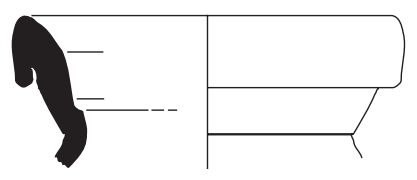

2

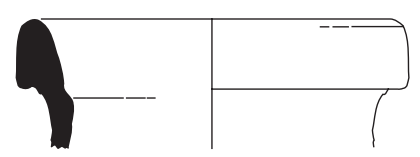

3

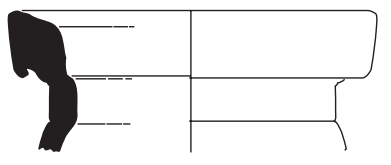

4

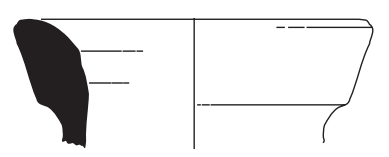

5

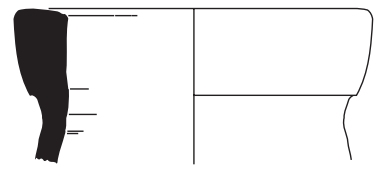

6

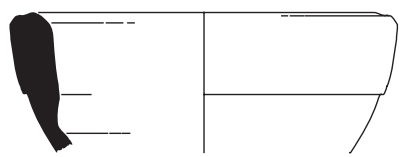

7

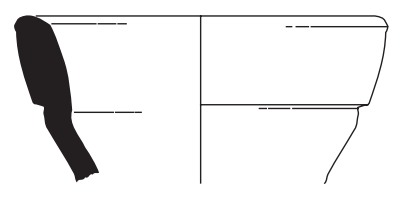

8

Atelier de Moknine
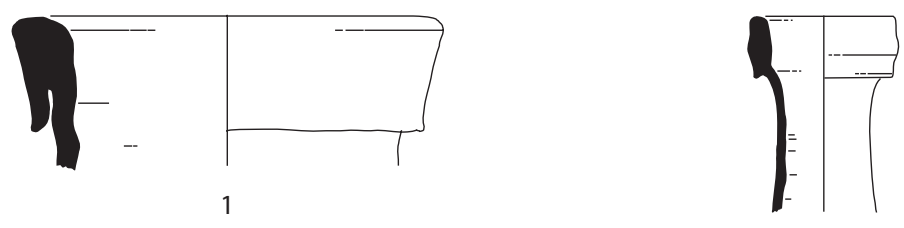

2

\section{Ateliers de Leptiminus/Lamta}

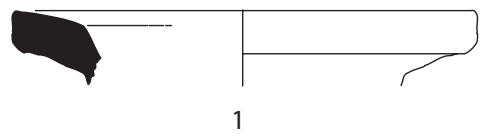

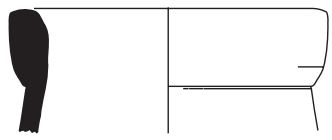

3

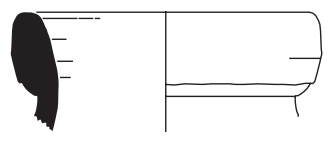

4

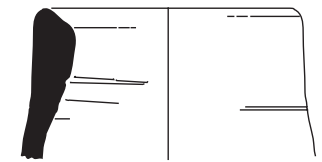

5

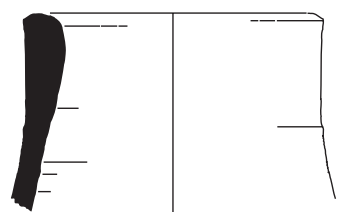

6 amphithéâtre

Dahar Slima

Fig. 16. Ateliers de Henchir ech-Chekaff (Ksour Essaf), Moknine et Leptiminus/Lamta. Echantillons. 
cendreuse, ne laisse planer aucun doute sur la présence d'un atelier (Peacock, Bejaoui, Ben Lazreg 1989, 184186). La production de cet atelier, associée à des tessons de sigillées de forme Hayes 90/105, est plus tardive (VIe - VIIe s.) que celle des ateliers de la périphérie de la ville antique de Sullecthum (Ben Lazreg et al. 1995, 129) :

- amphores Keay 62A (infra, AMPHORE TYPE 46);

- amphores Keay 61C (infra, AMPHORE TYPE 48) ;

- amphores Bonifay 1986, fig. 15, n 55 (infra, AMPHORE TYPE 47).

Cet atelier produit probablement aussi de la céramique commune: bassins à bord épaissi et à ressaut interne (COMMUNE TYPE 38 ; infra, p. 69), et peut-être des céramiques culinaires: plat à cuire à lèvre interne épaissie (CULINAIRE TYPE 38).

Exemples (fig. 16) :

*1-2 Bords d'amphores Keay 62A (Inv. HCK002 et 007).

*3 Bord d'amphore Keay 62D (?) (Inv. HCK006).

*4 Bord d'amphore Keay 62E tardif (Inv. HCK008).

*5-6 Bords d'amphores Keay 61C (Inv. HCK005 et 003).

*7-8 Bords d'amphores Bonifay 1986, fig. 15, n 55 (Inv. HCK001 et 004).

La pâte des amphores est généralement orange, parfois légèrement violacée, compacte, feuilletée, avec quelques calcaires et/ou micro-fossiles d'assez grande taille, assez espacés, identifiés comme tels par l'analyse pétrographique (Capelli 2002-2003) mais également bien visibles à l'œil nu (Pl. I, n 13$)$.

\section{Autres ateliers du Sahel}

\section{ATELIER DE MOKNINE}

Je mentionne seulement pour mémoire cet atelier sur lequel Nejib Ben Lazreg a effectué, il y a une quinzaine d'années, une fouille de sauvetage ${ }^{49}$. Il est situé à la sortie du bourg de Moknine, sur la route de Teboulba (fig. 10, g), implanté dans des terrains argileux où étaient encore visibles, en 1993, des traces de fours. La production de cet atelier paraît assez homogène :

- amphores du type Keay 61A/D (infra, AMPHORE

TYPE 49);

- « spatheia » miniatures du type D (infra, AMPHORE TYPE 33D).

Des céramiques culinaires et communes semblent également produites sur cet atelier (infra, p. 69 et 73).

Exemples (fig. 16) :

*1 Bord d'amphore Keay 61A (Bonifay 2004c, fig. 15, $\left.\mathrm{n}^{\circ} 3\right)$.

*2 Bord de «spatheion » 3D (?) (Ibid., fig. 6).

La pâte de cet atelier, actif vraisemblablement au VIIe s., est proche de celle de l'atelier précédent: brun orangé clair, parsemée de micro-fossiles de couleur blanc jaunâtre et d'assez grande taille, bien visibles à l'œil nu (Pl. I, $\left.\mathrm{n}^{\circ} 14\right)$.

\footnotetext{
49 Je remercie vivement Nejib Ben Lazreg pour m'avoir fait visiter cet atelier en 1990 et 1993.
}

\section{ATELIERS DE LEPTIMINUS}

Les ateliers de Leptiminus sont maintenant bien connus, à la suite des prospections de D. P. S. Peacock, F. Bejaoui et N. Ben Lazreg (1989) et depuis les travaux de l'équipe tuniso-canadienne dirigée par N. Ben Lazreg et Lea Stirling (Stone, Stirling, Ben Lazreg 1998 ; Stirling, Ben Lazreg 2001). Une aire de fouille ouverte sur les pentes de Dar Slima (fig. 10, h) a permis de dégager plusieurs fours (Stirling, Ben Lazreg 1999) et de caractériser leur production. La typologie des amphores couvre les trois premiers siècles de notre ère :

- amphores Leptiminus I (infra, AMPHORE TYPE 12) et II (infra, AMPHORE TYPE 5);

- amphores Africaines I (infra, AMPHORE TYPE 21) ;

- amphores Africaines II, surtout de variante D (infra, AMPHORE TYPE 26).

Une opération de sauvetage menée à l'emplacement du musée archéologique (Stirling 2001 ; Dore 2001) a révélé des productions plus tardives (VIe-VIIe s.) : - amphore Keay 62 (infra, AMPHORE TYPE 46) :

- variante $\mathrm{A}$ de Byzacène à bord courbe (Dore 2001, fig. 1.65, $\left.\mathrm{n}^{\circ} 1\right)$;

- variante E, tardive (Ibid., fig. 1.65, $\mathrm{n}^{\circ} 6$ : Keay 62 « late »).

- amphore Keay 61 (infra, AMPHORE TYPE 49) :

- variante D (Ibid., fig. 1.65, $\left.\mathrm{n}^{\circ} 13\right)$;

- variante A (Ibid., fig. 1.65, $\mathrm{n}^{\circ} 12$ et 19).

- amphore Keay 8A (?) (infra, AMPHORE TYPE 50) : un exemplaire (?) (Ibid., fig. 1.65, $\mathrm{n}^{\circ} 18$ ).

Exemples (fig. 16) :

Dar Slima (ramassages 1993) :

*1 Bord d'amphore Leptiminus I (Inv. LDS003).

*2 Bord d'AMPHORE TYPE 17 (infra) (Inv. LDS004).

*3 Bord d'amphore africaine indéterminée (Inv. LDS002).

*4 Bord d'amphore Africaine II A.3 (infra, AMPHORE TYPE 23.3) (Inv. LDS006).

*5 Bord d'amphore Africaine II D.2 (infra, AMPHORE TYPE 26.2) (Inv. LDS001).

Secteur de l'amphithéâtre (ramassages 1993) :

*6 Bord d'amphore Africaine II D.2 (infra, AMPHORE TYPE 26.2) (Inv. LAM005).

La pâte de ces amphores, de couleur marron sur les exemplaires précoces, jaune orangé sur les exemplaires plus tardifs, se distingue par son caractère extrêmement granuleux (Pl. I, $\left.\mathrm{n}^{\circ} 15-16\right)$. De fait, les analyses pétrographiques font apparaître un dégraissant plutôt abondant où le quartz fréquemment arrondi prévaut sur les calcaires et les micro-fossiles (Capelli 2002-2003).

\subsubsection{Ateliers de Zeugitane}

\section{Ateliers de Neapolis}

Les fouilles conduites dans le périmètre urbain (Slim, Bonifay, Trousset 1999) nous ont amenés à nous interroger sur les ateliers d'amphores de la cité de Nabeul. Cette enquête a été menée de manière aléatoire, en fonction des opportunités qui nous étaient offertes de visiter tel ou tel atelier. 
Atelier de Nabeul-briqueterie
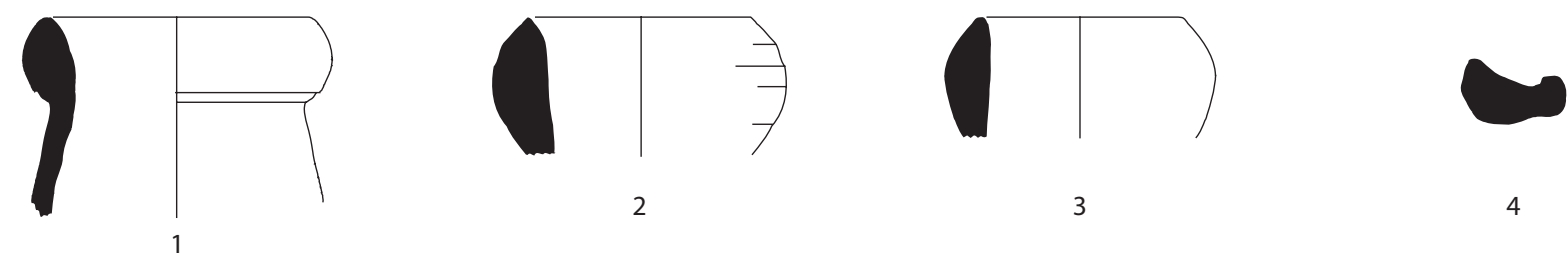

3

4

Atelier de Nabeul-Sidi Aoun

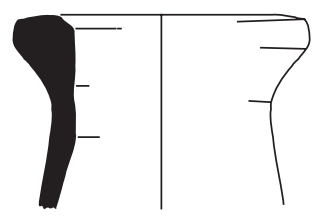

1

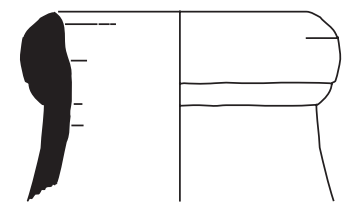

2
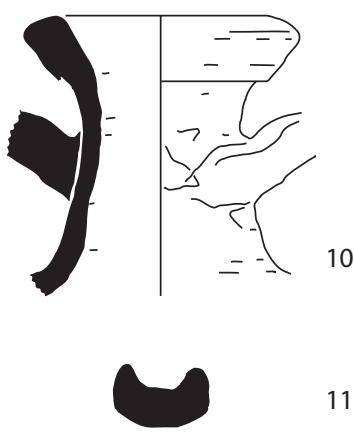

11

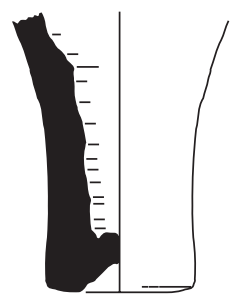

12
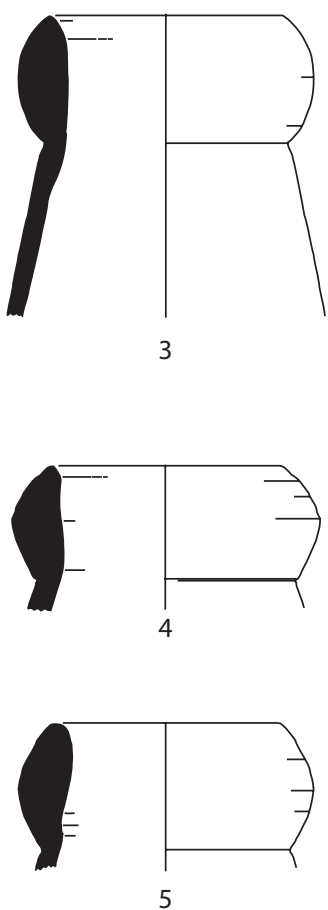

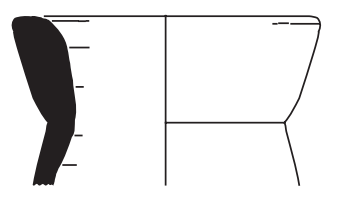

6
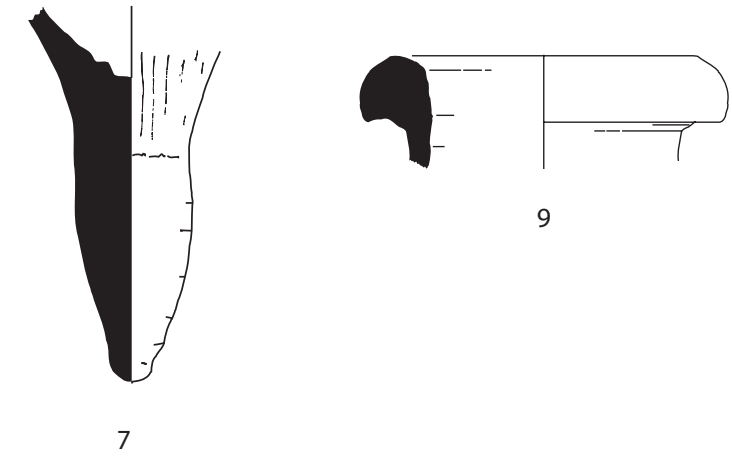

9

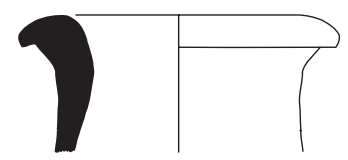

8

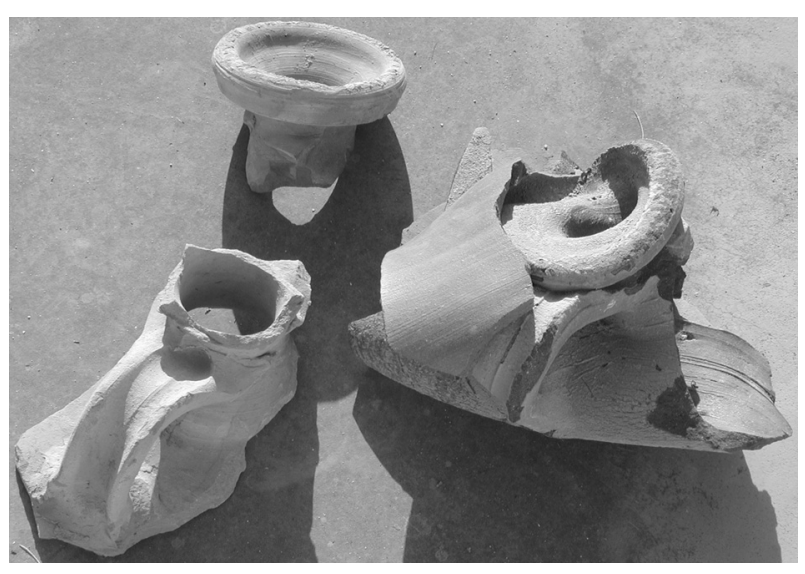

13

14

15 


\section{NABEUL-BRIQUETERIES}

Ce site inédit a été découvert en 2001. Comme son nom l'indique, ce quartier, situé à la sortie de Nabeul, sur la route de Tunis, est entièrement voué à la fabrication des céramiques, briques mais aussi poteries, depuis le déménagement à la fin des années 80 des ateliers traditionnels autrefois implantés à proximité de la gare, en centre ville (Maurières, Chambon 2002, 19). C'est aussi l'une des plus importantes carrières d'argile de Nabeul, vaste excavation à ciel ouvert (fig. 11, a) qui a entièrement dévoré les collines préexistantes dont ne subsiste plus qu'un seul témoin intact, à proximité de la caserne de la Garde Nationale. P. Lisse et A. Louis avaient déjà signalé « des traces de fours à proximité des carrières, sur la route qui va de Nabeul à Tunis » (Lisse, Louis 1956, 13). La présence d'un vestige de citerne antique bien visible depuis la route, dans la coupe de terrain des carrières, a motivé notre visite. De fait, le sommet de la colline est jonché de tessons de céramiques, vaisselles puniques à vernis noir mais surtout amphores de type Africaine II A.3 (infra, AMPHORE TYPE 22.3) (un tesson surcuit), Africaine II C (infra, AMPHORE TYPE 25.2) et Dressel 30 (infra, AMPHORE TYPE 60), faciès typique du IIIe siècle.

Exemples (fig. 17) :

*1 Bord d'amphore Africaine II A.3 (Inv. NBC002).

*2-3 Bords d'amphores Africaines II C.2 (Inv. NBC003 et 004).

*4 Anse d'amphore apparentée au type Dressel 30 (Inv. NBC005).

Bien que ces indices soient relativement minces, il est vraisemblable qu'un atelier antique d'amphores était implanté sur les contreforts collinaires qui limitent au Nord-Ouest la plaine de Nabeul. La même situation topographique se retrouve sur les autres ateliers d'amphores reconnus sur le territoire de l'ancienne cité de Neapolis.

\section{NABEUL-SIDI AOUN}

Cet atelier, situé un peu au nord-est du précédent, sur une butte à proximité du mausolée de Sidi Aoun, a été signalé pour la première fois par S. Aounallah (2001, 64, site $\left.\mathrm{n}^{\circ} 86\right)$. Un défonçage récent ${ }^{50}$ a fait remonter à la surface de très nombreux fragments de fours, de la terre cendreuse et de grandes quantités de tessons d'amphores (fig. 11, b) :

- amphores apparentées au type Africaine I (infra, AMPHORE TYPE 21C) ;

- amphores Africaines I et II A con gradino dans des variantes évoluées, probablement de la seconde moitié du IIIe s. (infra, AMPHORE TYPES $21 \mathrm{C}$ et 22.3) ;

- amphores apparentées au type Dressel 30 (infra, AMPHORE TYPE 60), en forte proportion ;

- amphores Africaines II C et tout spécialement leur variante tardive cylindrique de moyennes dimensions

\footnotetext{
${ }^{50}$ J'ai visité ce site en février 2002 avec Taher Ghalia.
}

(infra, AMPHORES TYPES 25.2 ET 3 ?) de la fin du IIIe ou du début du IVe s. ;

- amphores Keay 25.1 du début du IVe s. (infra, AMPHORE TYPE 27 précoce $\mathrm{n}^{\circ} 1$ );

- amphores Keay 25.3 de la seconde moitié du IVe s. (infra, AMPHORE TYPE 28) ;

- amphores cylindriques de grandes dimensions Keay 35A (infra, AMPHORE TYPE 40). Exemples (fig. 17) :

*1 Bord d'amphore Africaine I tardive (?) (Ghalia, Bonifay, Capelli 2004, fig. 8, $\mathrm{n}^{\circ} 36$ ).

*2 Bord d'amphore Africaine II A.3 (Ibid., $\mathrm{n}^{\circ} 37$ ).

*3-5 Bords d'amphores Africaines II C (Ibid., n 41-43).

*6-7 Bord et fond d'amphores Keay 25.1 précoces (Ibid., $\mathrm{n}^{\circ}$ 44-45).

*8 Bord d'amphore Keay 25.3 (Inv. SAO011).

*9 Bord d'amphore Keay 35A (Inv. SAO012).

*10-14 Bords, anses et fonds d'amphores apparentées au type Dressel 30 (Ghalia, Bonifay, Capelli 2004, fig. 8, $\left.\mathrm{n}^{\circ} 38-40\right)$.

*15 Surcuit ou mouton d'amphores apparentées au type Dressel 30 (Inv. SAO010).

La pâte de ces amphores est jaune orangé, assez granuleuse, avec une surface blanche assez homogène (Pl. I, $\left.\mathrm{n}^{\circ} 19\right)$. L'analyse pétrographique fait apparaître de nombreuses similitudes avec la pâte de l'atelier suivant (Ghalia, Bonifay, Capelli 2004).

\section{SIDI ZAHRUNI (BENI KHIAR)}

Implanté sur un replat au nord de la zaouia de Sidi Zahruni, le site s'étend sur une superficie de treize hectares à la base du versant méridional du relief de Chabat al-Qola (fig. 11, c) (Ghalia, Bonifay, Capelli $2004)^{51}$. L'atelier est caractérisé par des épandages très denses de céramiques (fig. 11, d) mêlés à de la terre charbonneuse où s'observent ratés de cuisson et tessons ne présentant aucune trace d'usure. L'atelier de Sidi Zahruni a essentiellement produit des amphores :

- amphores Keay 25.2 (infra, AMPHORE TYPE 29), et leurs petits modules «spatheia» de type 1 (infra, AMPHORE TYPE 31) ;

- Amphores Keay 35A (infra, AMPHORE TYPE 40) et 35B (infra, AMPHORE TYPE 41);

- Amphores Keay 55, 56, 57 (infra, AMPHORES TYPES 42-44) ;

- Amphores Keay 62 A (infra, AMPHORE TYPE 46);

- Diverses amphores africaines non répertoriées.

L'atelier de Sidi Zahruni avait également une production de céramique commune, notamment des mortiers de type CATHMA 1 (infra, COMMUNE TYPE 13) et une production marginale de céramique sigillée, bien attestée par la présence de casettes de cuisson (infra, fig. 26). Cet atelier a été principalement actif aux Ve-VIIe siècles. Exemples (fig. 18)

*1-6 Bords et fonds d'amphores Keay 25.2 et «spatheion $1 »$ (Ghalia, Bonifay, Capelli 2004, fig. 3, n० 1-6).

*7-8 Bord et fond d'amphores Keay 35A (Ibid., n 7-8).

\footnotetext{
51 J'ai visité cet atelier pour première fois en 1997 avec l'autorisation de M. Hedi Slim, guidé par M. Khmaïs Chtioui, puis en 2001 et 2002 en compagnie de M. Taher Ghalia.
} 
Atelier de Nabeul-Sidi Zahruni
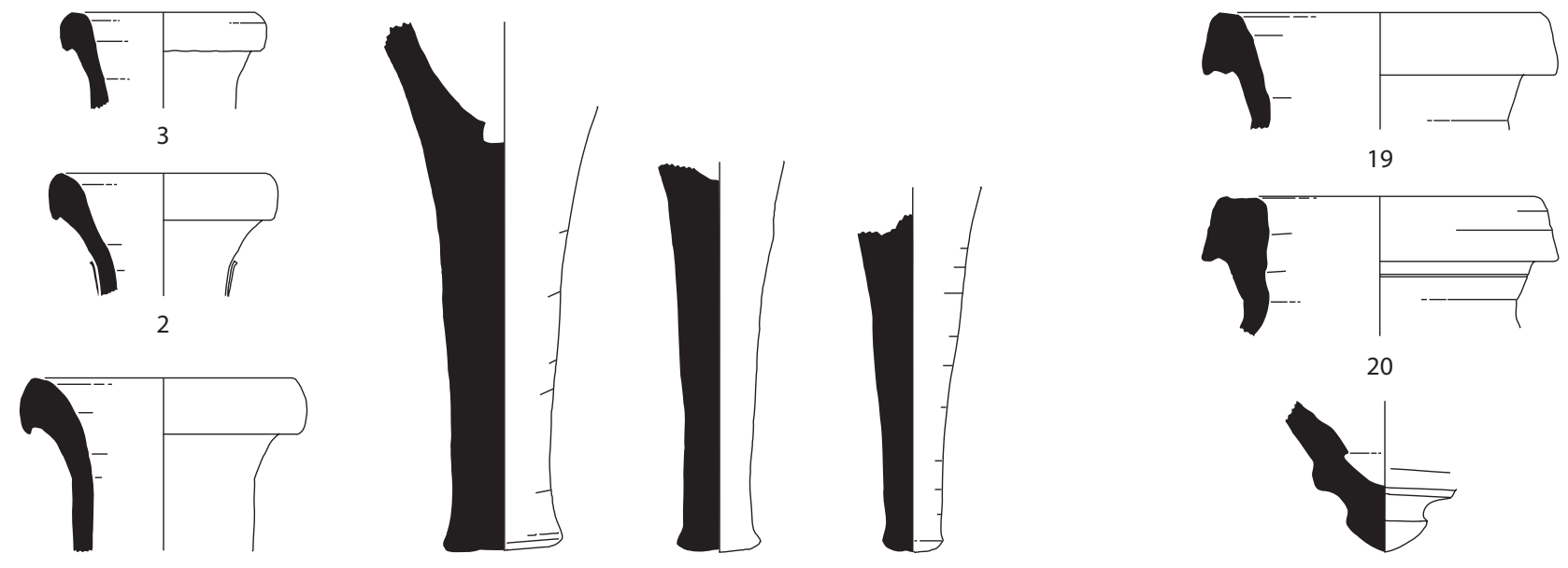

4

5

6

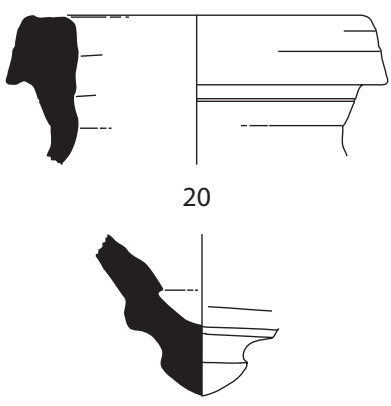

21
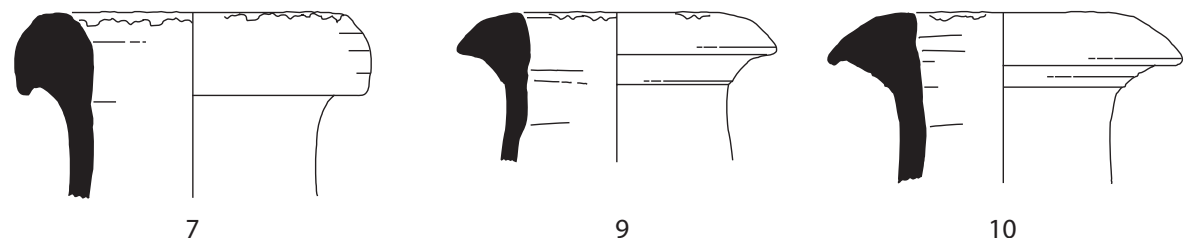

10
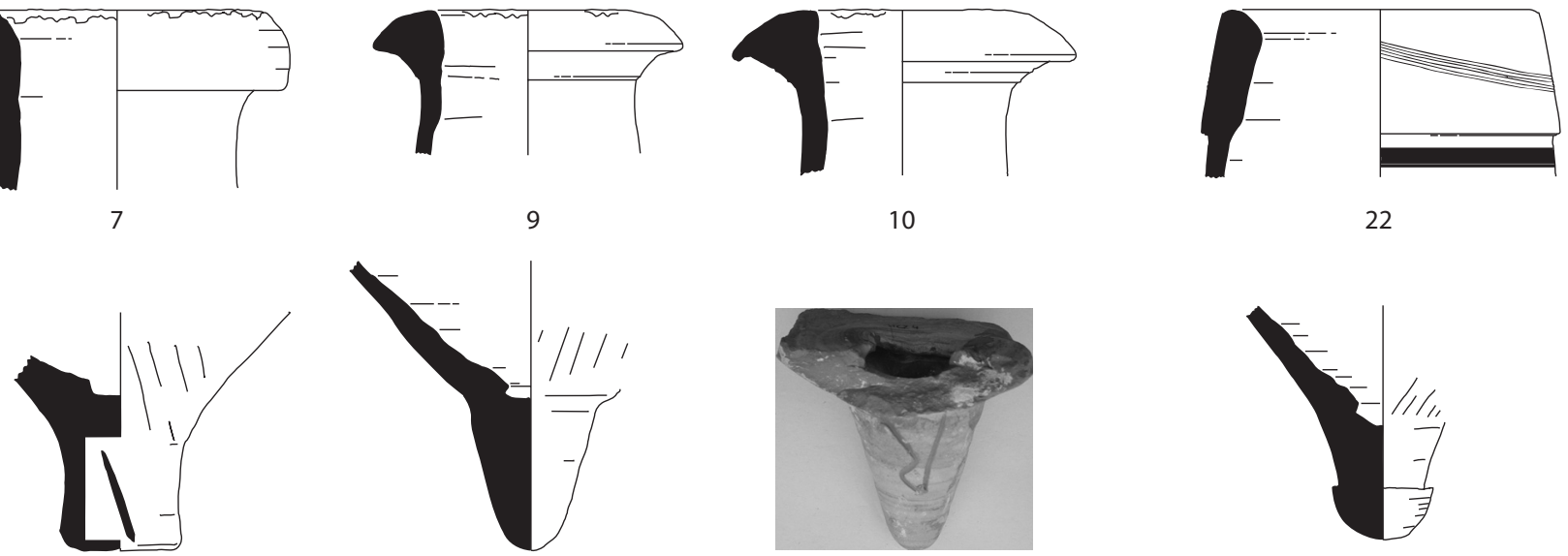

8

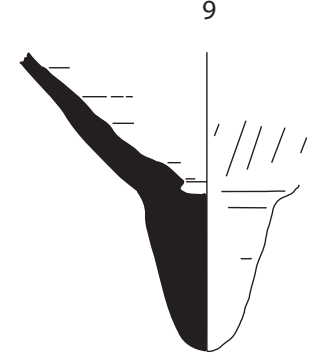

11

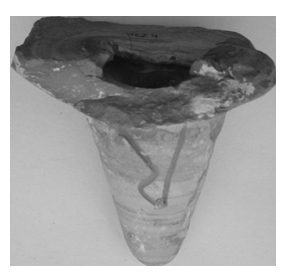

12

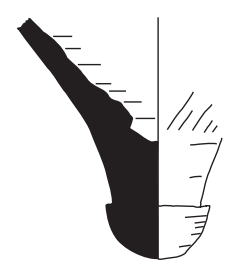

23

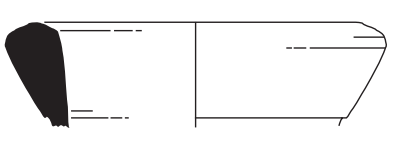

24

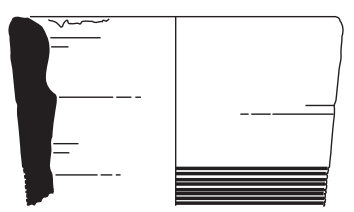

13

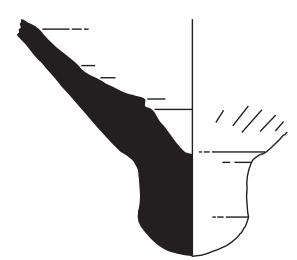

14

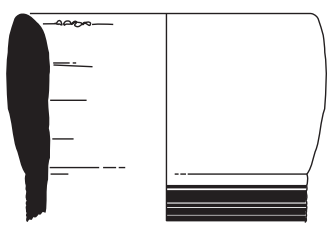

15

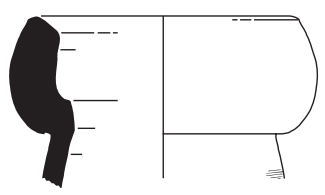

16

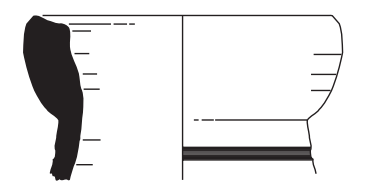

17

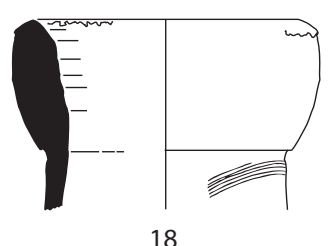

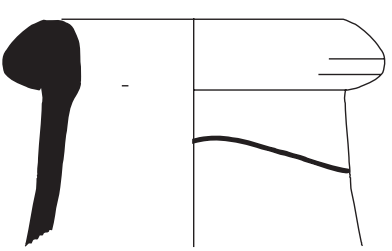

25

Fig. 18. Ateliers de Nabeul-Sidi Zahruni. Echantillons. 
*9-12 Bords et fonds d'amphores Keay 35B (Ibid. $\mathrm{n}^{\circ}$ 9-12).

*13-14 Bord et fond d'amphores Keay 55 (Ibid., fig. 4, $\mathrm{n}^{\circ}$ 1314).

*15 Bord d'amphore Keay 56 (Ibid., $\left.\mathrm{n}^{\circ} 15\right)$.

*16-18 Bords d'amphores Keay 57 (Ibid., n 16-18).

*19-21 Bords et fond d'amphores Keay 62A (Ibid., n 19-21).

*22 Bord d'amphore indéterminée (Ibid., $\mathrm{n}^{\circ} 22$ ).

*23 Fond «en bouchon de champagne», peut-être d'amphore « con orlo a fascia » (infra, AMPHORE TYPE 52) (Ibid., $\mathrm{n}^{\circ} 24$ ).

*24 Bord d'amphore Keay 61 variante (infra, AMPHORE TYPE 49) (Ibid., n 23).

*25 Bord d'amphore type Sidi Jdidi 1 (?) (infra, AMPHORE TYPE 54) (Ibid., n² 25).

La pâte de ces amphores est orange à rouge brique, avec quelques inclusions blanches ou jaunes, parfois des stries de la même couleur et de rares inclusions anguleuses rouge-violet $\left(\mathrm{Pl}\right.$. I, $\mathrm{n}^{\circ}$ 20-21). On a déjà mentionné la présence, apparue en lame mince, d'inclusions ferriques et surtout de minéraux de grès quartzeux qui semblent caractéristiques de l'argile de cet atelier (fig. 12, b). La surface extérieure présente un éclaircissement blanc jaunâtre, parfois nuancé d'orange ou de brun-violet en correspondance avec certains coups d'estèque verticaux ; l'intérieur est orange, souvent zébré de bandes plus ou moins blanches parallèles au tournage (Ghalia, Bonifay, Capelli 2004, fig. 6).

\section{NEAPOLIS-VILLE}

Contrairement à ce qui avait été affirmé à l'issue des prospections du littoral (Bonifay et al. 2002-2003), les indices de production de céramique ne manquent pas à l'intérieur même du périmètre urbain de Neapolis :

\section{- Fours en bordure de la voie ferrée}

Les terrains vagues situés au nord-ouest du site protégé de Neapolis, entre la rue Assan Hosni Abdlwhab et la voie ferrée Hammamet-Nabeul sont réputés receler des vestiges de fours; de fait, on y voit affleurer quelques blocs d'argile cuite ainsi que de nombreux tessons d'amphores (qui, eux, ne prouvent rien, en raison de la proximité de l'habitat). Des fours antiques ont été signalés par le passé dans le talus de la voie ferrée qui longe le site antique (Lisse, Louis 1956, 13, note 2); on ignore tout de leur production.

\section{Chabbi}

- Fours en bordure de la rue Abdul Kacem

Les vestiges de deux fours ont été mis au jour à l'intérieur du périmètre protégé, lors de la construction de la clôture le long de la rue Abdul Kacem Chabbi. Ces fours sont en partie enfouis et cachés par la végétation mais paraissent bien construits avec des briques disposées en lits réguliers; des départs d'arceaux sans doute destinés à soutenir une sole, sont visibles (fig. 11, e). On ignore quelle fut la production de ces fours: le type de construction pourrait peut-être mieux convenir à un four pour la production de vaisselle ${ }^{52}$.

\section{- Fours dans les thermes}

Signalons pour mémoire la découverte par Mme Latifa Slim, au cours des fouilles de sauvetage qu'elle a menées, hors du périmètre protégé, à l'emplacement d'un établissement thermal, de plusieurs fours à céramiques. L'un d'eux a été conservé in situ (fig. 11, f). Un grand nombre de fragments de «spatheia» de type 3C a été découvert à proximité de ces fours.

\section{- Four dans l'îlot de la maison des Nymphes}

Les dégagements opérés en 2000-2001 par Mme Latifa Slim dans la partie sud-ouest de l'îlot de la Maison des Nymphes ont permis de mettre au jour trois fours à chaux et un four de potier (Slim, Bonifay, Piton 2002, 3 et fig. 3). Ces installations artisanales se superposent aux ruines d'un habitat qui commence à se désorganiser au courant de l'époque vandale (tombes); le matériel recueilli dans le comblement des fours ne paraît pas antérieur au VIIe siècle. La production principale des potiers était la céramique commune (infra, fig. 37), mais de très nombreux fragments de «spatheia » de type $3 \mathrm{C}$, dont un rebut de cuisson (1) ont été également recueillis à proximité.

Exemples (fig. 19) :

*1 Surcuit ou mouton de «spatheion» 3C (?) (Slim, Bonifay, Piton 2002, fig. 6 ; Bonifay 2004c, fig. 6).

*2 Bord de «spatheion » 3C (Nabeul, usine de salaison, Inv. 1428.12).

*3 Bord de «spatheion » 3C sans anses (?) (îlot de la maison des Nymphes, fouilles anciennes, sans $\mathrm{n}^{\circ}$ ).

*4-5 Fonds de «spatheia» 3C (îlot de la maison des Nymphes, fouilles anciennes, sans $\mathrm{n}^{\circ}$ ).

*6-7 Bords de «spatheia» 3D, variante (?) (îlot de la maison des Nymphes, fouilles anciennes, sans $\mathrm{n}^{\circ}$ ).

*8-9 Fonds de «spatheia » 3D (?) (îlot de la maison des Nymphes, fouilles anciennes, sans $\mathrm{n}^{\circ}$ ).

Les pâtes observables sur les céramiques communes et les «spatheia» de type 3C produits dans les ateliers urbains de Neapolis ont la particularité d'être blanches (Pl. I, n 22). Cette généralisation des pâtes très claires, qui annonce manifestement une situation typique de l'époque islamique, peut s'expliquer de différentes façons (utilisation d'une argile plus calcaire, changement des techniques de cuisson, combiné ou pas avec l'emploi d'eau saumâtre $)^{53}$ et rappelle les modifications apparues concomitamment dans la production des sigillées (infra).

\section{Ateliers du cap Bon}

ATELIER DE EL-ASSA

Les preuves de la présence d'un atelier de céramique sur le site d'el-Assa, sur la face occidentale du cap Bon, sont assez ténues : à l'extrémité nord du site, un épandage de

\footnotetext{
52 Cependant, de nombreux fragments de «spatheia» de type $3 \mathrm{C}$ ont été trouvés alentour.

${ }^{53}$ Interprétation due à $\mathrm{Cl}$. Capelli.
} 
Production - Amphores

Atelier de Nabeul-ville

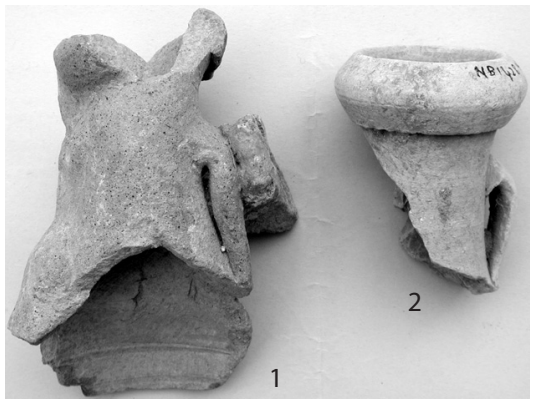

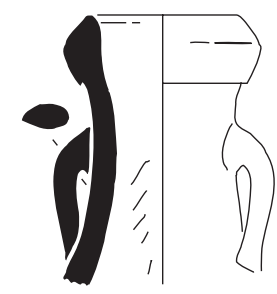

2

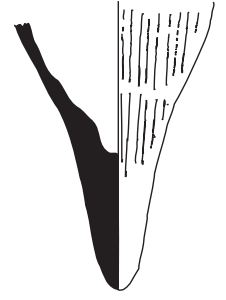

5

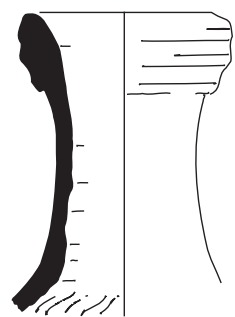

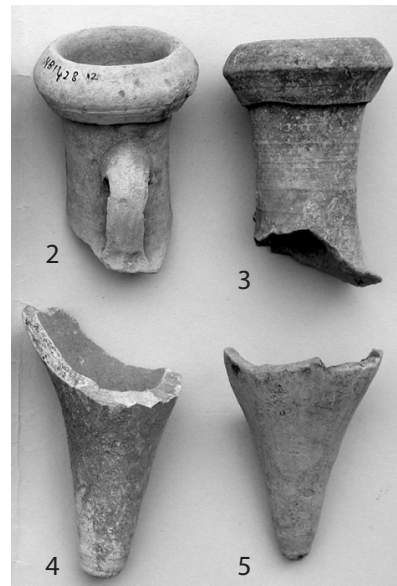
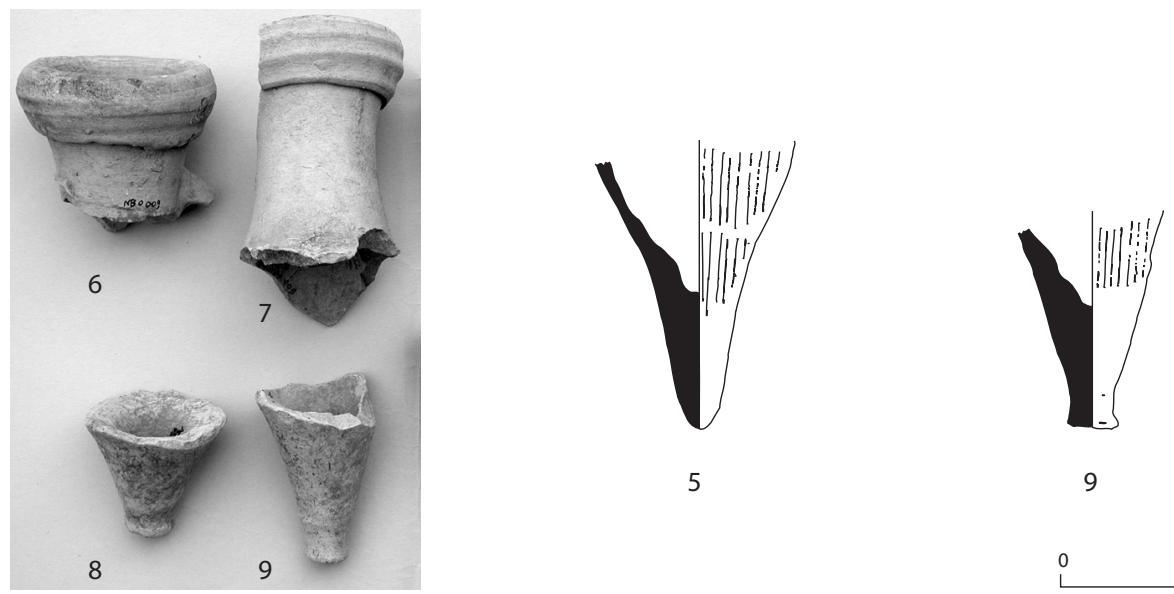

9 $5 \mathrm{~cm}$
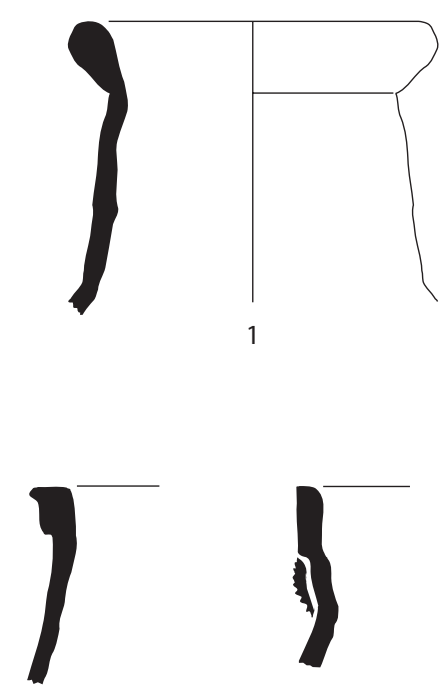

4

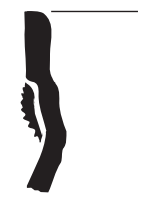

5

Atelier d'el-Assa
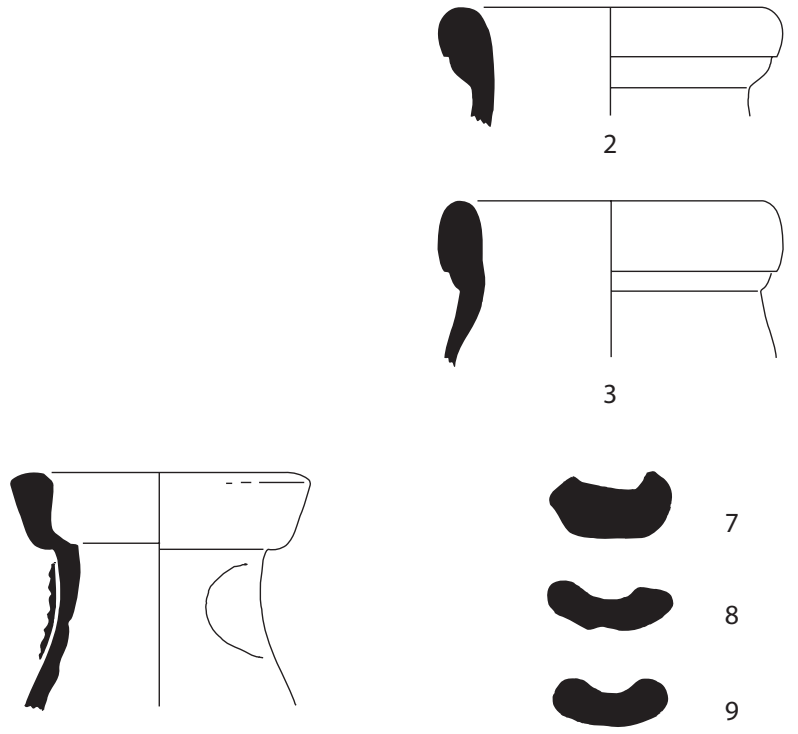

6

Fg. 19. Ateliers de Nabeul-ville et d'el-Assa. Echantillons. 
tessons d'amphores dans un terrain cendreux, à proximité de mottes d'argile mal cuite (Bonifay et al. 2002-2003). Le faciès de la production est comparable à celui de l'atelier de Sidi Aoun: amphores Africaines II A con gradino et amphores apparentées au type Dressel 30.

Exemples (fig. 19) :

*1-3 Bords d'amphores Africaines II A (Bonifay et al. 2002-2003, fig. 17, $\mathrm{n}^{\circ} 240-242$ ).

*4 Bord d'amphore indéterminée (Ibid., $\mathrm{n}^{\circ} 243$ ).

*5-9 Bords et anses d'amphores apparentées au type Dressel 30 (Ibid., $\mathrm{n}^{\circ} 244-248$ ).

\section{ATELIER DE PORT-PRINCE}

Ce site n'avait révélé aucune trace d'atelier lors des prospections du littoral en 1990. La poursuite de l'érosion marine depuis dix ans a mis en évidence à la fois des traces d'usines de salaison sur la plage et fait apparaître, légèrement en contre-haut, le tracé d'un four à amphores $^{54}$. Des tessons d'amphores Africaines II D ou Keay 25.1, avec une pâte orange assez grossière, contenant de nombreux grains de quartz, peuvent appartenir la production de ce four. Il s'agit probablement d'un petit atelier peut-être lié à la production locale de salsamenta.

\subsection{CONSIDÉRATIONS TECHNIQUES}

\section{Les matières premières}

Malgré la pauvreté de ce recensement, un certain nombre de constantes apparaissent dans la localisation des ateliers. On constate tout d'abord qu'il y a trois catégories d'ateliers : ruraux, péri-urbains et urbains, et que ces différences de localisation correspondent souvent à des différences de datation. On essaiera plus loin (infra, p. 482) de proposer une interprétation pour le déplacement des ateliers au cours du temps, phénomène qui n'est pas spécifique à la production des amphores. Mais, la production des amphores étant véritablement une production de masse et aussi de première nécessité pour l'économie d'une cité, elle mobilise une grande quantité de matières premières et de combustible ; ces facteurs, en même temps que les effets inévitables de leur mise en œuvre, conditionnent bien évidemment la localisation des ateliers.

Constater, ainsi, que les ateliers de Nabeul se sont installés sur les gisements d'argiles les plus abondants et les plus faciles d'accès peut sembler une banalité mais c'est sans doute ce qui a conditionné, durant les quatre premiers siècles de notre ère, leur implantation assez loin de l'agglomération antique, sur les contreforts de collines distantes de près de trois $\mathrm{km}$ du littoral : les analyses pétrographiques confirment que ces ateliers ont utilisé l'argile locale (Ghalia, Bonifay, Capelli 2004). Ce cas de figure n'exclut peut-être pas d'autres situations plus

\footnotetext{
${ }^{54}$ J'ai visité ce site en 2001 sous la conduite de Taher Ghalia.
}

proches de celles que connaissent les ateliers traditionnels actuels qui importent leurs argiles de carrières situées à plusieurs kilomètres, comme c'est le cas à Gallala (fig. 20, a). Ainsi, lorsque les potiers se sont installés plus près des agglomérations, comme à Thaenae, Salakta et Leptiminus, on constate qu'ils se sont généralement groupés au sud-ouest des zones habitées. N'y a-t-il pas là aussi une volonté de prévention des nuisances, la direction des vents dominants, peut-être de la brise marine, rendant nécessaire cette localisation pour les atténuer?

Le combustible, sans doute composé comme aujourd'hui de grignons d'olives (fig. 20, d et f) (Stirling, Ben Lazreg 2001, 228; Lisse, Louis 1956) et de broussailles (Maurières, Chambon 2002, 29), est plus facilement transportable mais qu'en est-il de l'eau?

\section{L'utilisation de l'eau salée}

On sait (Peacock 1984c ; Sherriff, McCammon, Stirling 2002) que la surface blanche de la plupart des amphores africaines de l'Antiquité et des poteries tunisiennes actuelles (fig. 20, g) est due à l'utilisation d'eau salée pour le délayage de l'argile (fig. 20, b). Si j'emploie le terme « eau salée» et non « eau de mer», c'est précisément parce que certains ateliers de potiers actuels (Nabeul) ajoutent volontairement du sel à l'eau douce dont ils disposent ${ }^{55}$, tandis que d'autres ateliers (Jerba) préfèrent aller s'approvisionner à la mer avec des citernes tractées ou des charrettes. Cette constatation réalisée récemment $^{56}$ en observant le travail de trois grands centres potiers tunisiens, Nabeul, Moknine et Gallala (Jerba), doit nous interroger quant à l'approvisionnement en eau salée d'ateliers fort éloignés du littoral, comme celui de Sidi Aoun à Nabeul ou de Henchir ech-Chekaf à Ksour Essaf, qui ont pourtant produit des amphores avec une belle surface blanche. Doit-on penser, dans le deuxième cas, que les puits pouvaient donner une eau saumâtre ? Dans le premier cas, doit-on envisager que du sel, peut-être récolté dans les sebkhret et les lagunes du littoral (et dont on faisait déjà un grand usage dans les fabriques de salaison de poisson) était transporté jusqu'aux contreforts des collines de Nabeul, où se trouvaient les gisements d'argile et les ateliers?

Si l'éclaircissement de la surface des amphores africaines est ainsi un effet volontairement recherché, comme c'est

\footnotetext{
55 A Nabeul, le sel est parfois ajouté directement à l'argile préalablement au malaxage (Lisse, Louis 1956). A Jerba, "pendant le concassage, le chamelier qui a amené l'argile s'occupe du transport de l'eau nécessaire au trempage (...). Veut-il obtenir de la poterie blanche, et c'est le cas le plus fréquent, il se sert de l'eau de mer. Préfère-t-il des poteries rouges (...), il emploie l'eau du puits ou de la citerne » (Combès, Louis 1967, 40). «Dans certains ateliers, l'eau du puits est naturellement salée (Ibid., note 8).

${ }^{56}$ Documentation ethnographique rassemblée en janvier 2001, en collaboration avec Cl. Capelli.
} 


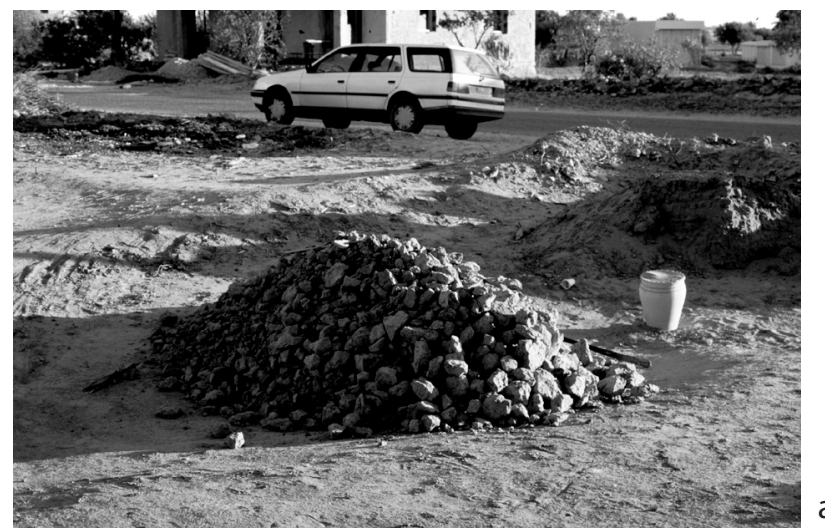

a : Mottes d'argiles venant de la carrière (Gallala, 2001)

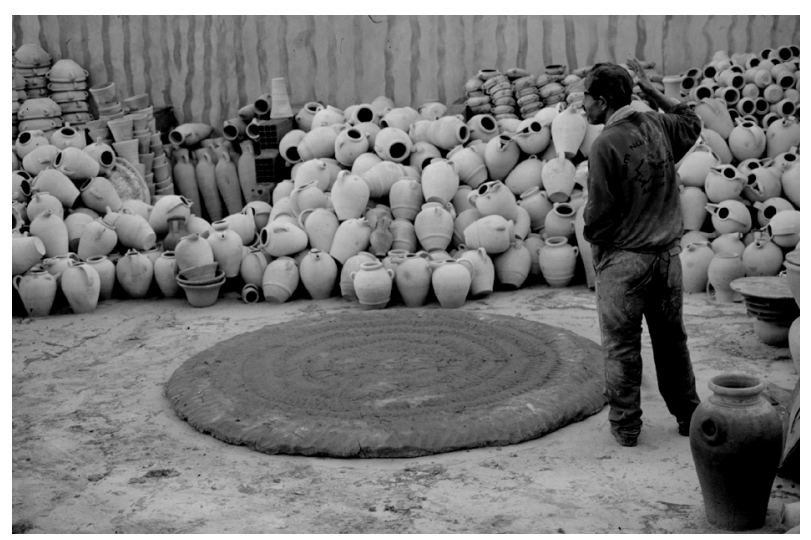

c:Marchage de l'argile (Moknine, 2001)

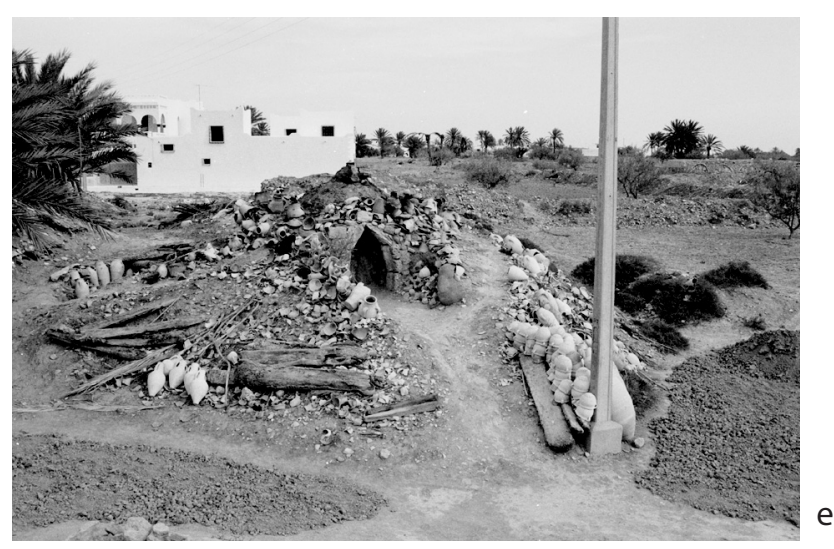

e : Four (Gallala, 1995)

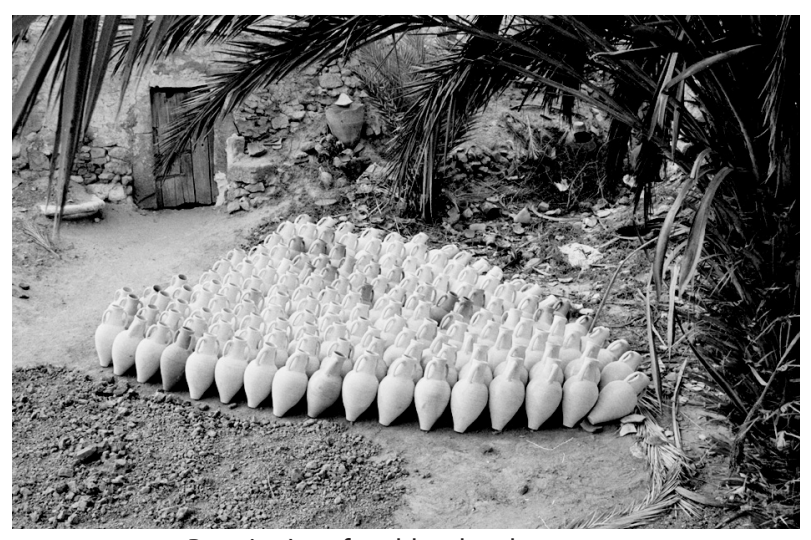

$\mathrm{g}$ : Poteries à surface blanche obtenues par délayage de l'argile à l'eau salée (Gallala, 1995)

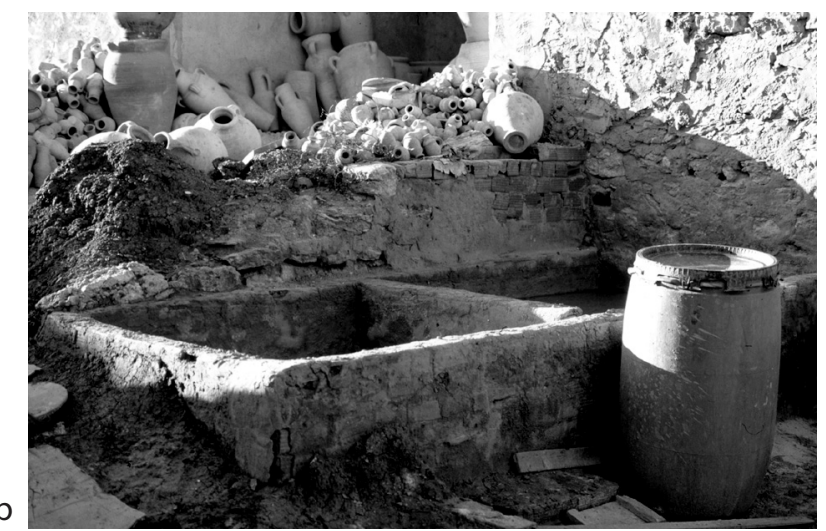

b : Délayage de l'argile à l'eau salée (Moknine, 2001)

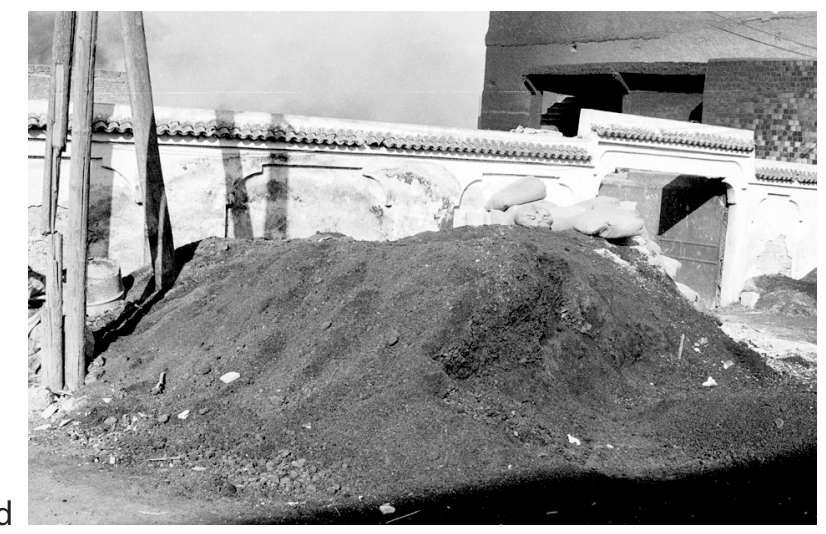

d : Réserve de combustible, grignons (Fès, 1999)

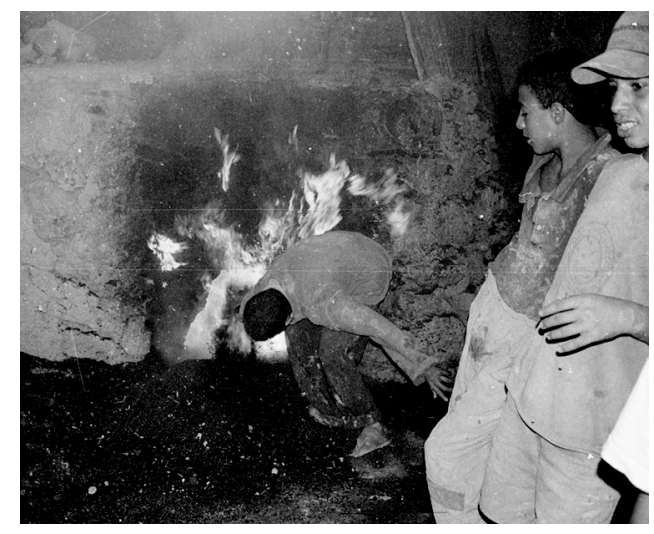

f: Feu de grignons (Fès, 1999)

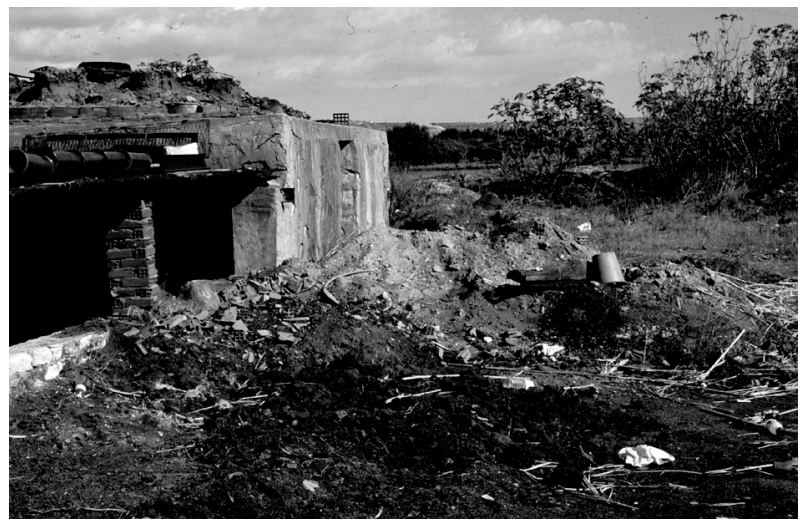

$\mathrm{h}:$ Cendrier et dépotoir à côté du four (Nabeul, 2001)

Fig. 20. Aspects du travail des potiers traditionnels au Maghreb. 


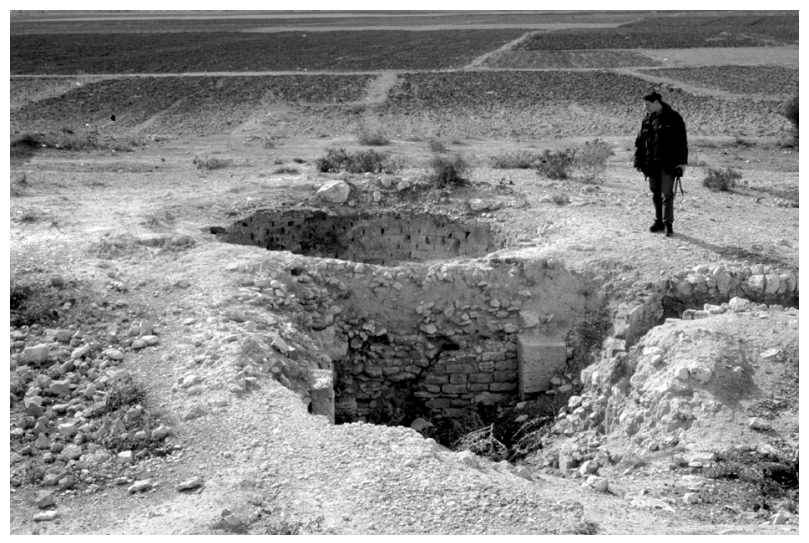

a : Atelier de Maklouba (2001)

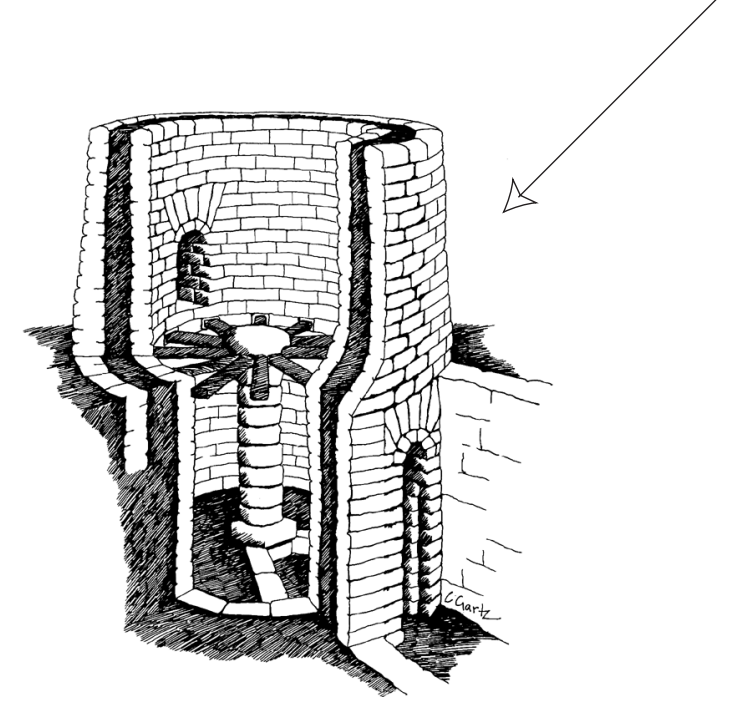

C : Atelier de Leptiminus (Stirling, Ben Lazreg 2001, fig. 3.3)

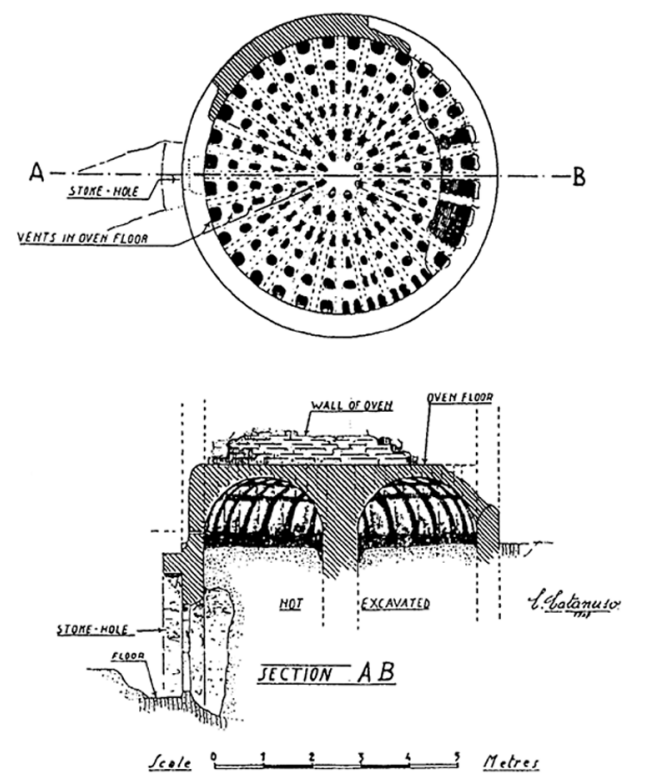

e : Atelier de Aïn Scerciara, Libye (Goodchild 1951, fig. 6)

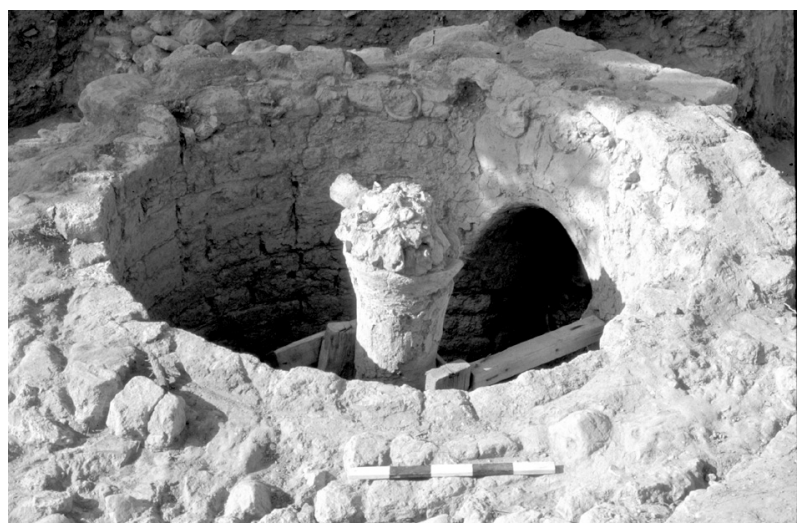

b : Atelier de Leptiminus (1998, fouilles L. Stirling - N. Ben Lazreg)

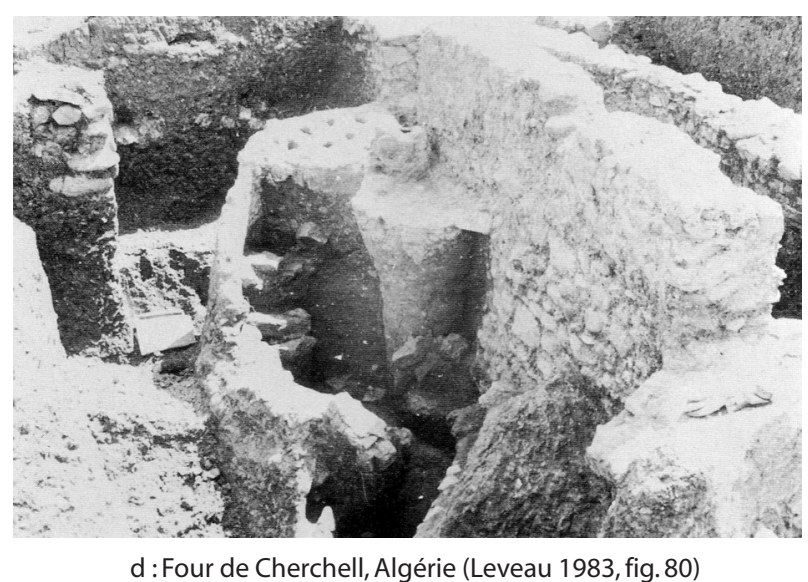

d: Four de Cherchell, Algérie (Leveau 1983, fig. 80)

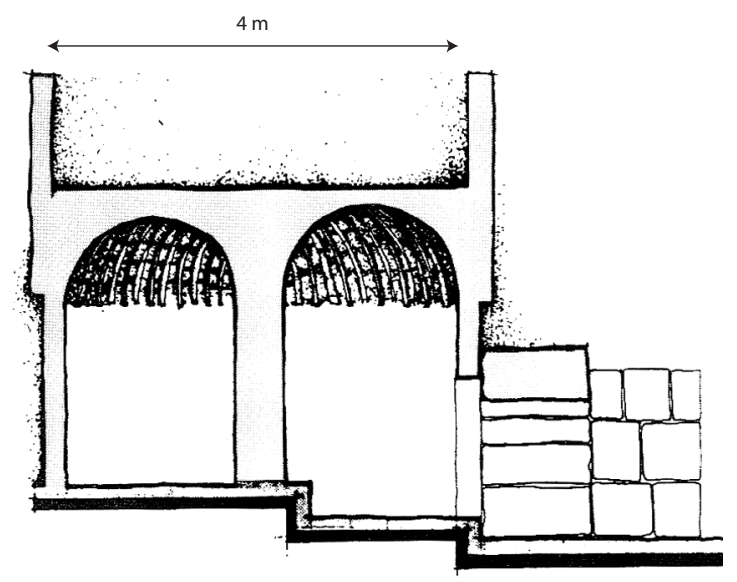

$\mathrm{f}$ : Atelier de Hai al-Andalus, Tripoli, Libye (Faraj Shakshuki, Shebani 1998, fig.2)

Fig. 21. Exemples de fours d'amphores. 
le cas pour les poteries «chawat» actuelles, on doit alors se poser la question de son utilité. Dans le cas des poteries actuelles, on nous dit que la surface blanche augmente la porosité du vase, généralement une cruche, dont attend qu'elle garde l'eau bien au frais. Mais dans le cas d'une amphore, une porosité excessive me paraît constituer plutôt un inconvénient, qu'il s'agisse d'une amphore à huile ou d'une amphore à garum ou à vin qu'il est nécessaire de poisser.

\section{Le façonnage}

On reste assez mal renseigné sur les techniques mises en œuvre pour le façonnage de vases d'aussi grande taille avec des parois proportionnellement aussi minces, que sont les amphores africaines. La configuration du tour, notamment, nous échappe encore complètement. Tout au plus peut-on noter un certain nombre de détails :

- La fabrication du corps des amphores cylindriques avec plusieurs cylindres tournés séparément puis raboutés les uns aux autres (Schuring 1984, 153155), paraît prouvée par les traces de collage bien visibles sur la panse et l'épaulement des nombreuses amphores Africaines I et II complètes découvertes dans la nécropole de Pupput.

- La pointe des amphores Africaines II paraît également tournée à part puis collée sur le fond, comme le montrent beaucoup d'exemplaires privés de pointe après usage (amphores réutilisées dans la nécropole de Pupput). En revanche, la longue quille cylindrique des amphores Keay 25.2 et des «spatheia» paraît solidaire du corps du vase (contra: Schuring 1984, 153) car elle casse généralement à mi-hauteur.

- Malgré tout le soin apporté à leur apposition sur le col, les anses des types classiques restent très fragiles, comme en témoigne le nombre d'exemplaires retrouvés avec une anse manquante (infra, fig. 59-60). La célèbre trace de doigt imprimée à l'intérieur du col de la plupart des amphores tripolitaines montre que les potiers ont tenu compte de ce problème; à ce titre, l'exemple fourni par le col d'une amphore Africaine II D de Port-Vendres, dont l'attache supérieure de l'anse est munie d'un tenon qui traverse complètement la paroi $\mathrm{du}$ col (fig. 62a, $\mathrm{n}^{\circ} 11$ ), apporte une solution radicale, bien que rarement mise en œuvre, à ce problème de solidité de l'attache des anses...

- Le modelé du bord est généralement obtenu par évasement de l'embouchure du vase puis repliement de la lèvre sur elle-même (Schuring 1984, fig. 2) : c'est notamment les cas des amphores Africaines I (Ibid., fig. 6). Toutefois le bord en $\mathrm{S}$ de certaines amphores Tripolitaines paraît obtenu par ajout de pâte (Ibid., fig. 4). Des études ethnographiques, conduites sur les ateliers actuels d'amphores à Ballâs en Egypte, montrent cependant qu'il ne faut peut-être pas, du point de vue typologique, trop s'attacher aux différences minimes dans le profil du bord: ces dernières traduisent souvent le tour de main propre à chaque potier (Nicholson, Patterson 1992, fig. 2.6).

\section{Les fours}

Les fours à amphores africains, pour ce qu'on en connaît, sont généralement de grande taille et leur sole soutenue par un pilier central. C'est le cas des fours de Maklouba (fig. 21, a) (Peacock, Bejaoui, Ben Lazreg 1989, 194-195 et fig. 19), de Leptiminus (Stirling, Ben Lazreg 1999) (fig. 21, b-c) mais également de ceux de Tripolitaine (Faraj Shakshuki, Shebani 1998,280-281, fig. 1-2) (fig. 21, f) et de Maurétanie Césarienne (Leveau 1983, 155) (fig. 21, d). On distingue toutefois deux variantes dans l'architecture de ces fours, selon le dispositif utilisé pour bâtir la sole. Dans les fours de Byzacène (Leptiminus : fig. 21, b-c) mais également de Maurétanie Césarienne (fig. 21, d), la sole est soutenue par des barres horizontales qui rayonnent à partir du pilier central. Dans les fours de Tripolitaine (fig. 21, e-f) la sole est supportée par une voûte en anneau qui prend appui sur le pilier central.

\section{La taille et la spécialisation des ateliers}

La taille des ateliers d'amphores africaines peut être extrêmement variable, depuis la petite unité de production de Port-Prince $^{57}$ jusqu'aux vastes groupements d'ateliers péri-urbains de Salakta ou ruraux de Sidi Zahruni. Cette atomisation de la production explique qu'une même forme d'amphore a pu être produite en plusieurs lieux différents et apparaître avec des qualités de pâtes très dissemblables (exemples de l'amphore Africaine II A con gradino et du type Keay 62).

On observe par ailleurs que ces ateliers se limitent rarement à la production des seules amphores. Cette production principale est très souvent associée à une production de céramiques communes (Zitha, Oued elAkarit, Sidi Aoun, Sidi Zahruni) et/ou de céramiques culinaires (Oued el-Akarit, Thaenae, Leptiminus). L'association des amphores à une production de céramique sigillée est plus rare (Sidi Zahruni).

\footnotetext{
${ }^{57}$ La place manque sur ce site encaissé dans une petite baie pour $\mathrm{y}$ voir un atelier important.
} 


\section{LA PRODUCTION DES CÉRAMIQUES SIGILLÉES AFRICAINES}

Pour toute une génération de céramologues, à laquelle j'appartiens, l'origine africaine des sigillées claires A, C et D n'est pas toujours allée de soi. A mes débuts en archéologie, en 1972, année de parution du LRP de John W. Hayes, les archéologues du Midi de la France étaient encore assujettis à l'école de Nino Lamboglia qui, jusqu'à sa mort en 1977, a douté de l'origine africaine de son type A (Lamboglia 1974). Les certitudes naissantes du début des années 80, concomitantes à la parution de l'Atlante delle forme ceramiche (Atlante $I)^{58}$, étaient ébranlées par des découvertes troublantes, comme celle des pseudo-imitations de sigillées africaines du port de Classe (Maioli 1983 et 1989) ${ }^{59}$. Toutefois, il fallut attendre les analyses physico-chimiques effectuées par Maurice Picon en $1986^{60}$, puis les études stylistiques de Michael Mackensen (Mackensen 1993, 445) et, tout récemment archéométriques (Mackensen, Schneider 2002), pour que les sigillées pseudo-ravennates soient enfin rendues à leurs ateliers africains et, plus précisément, pour une part, à un atelier de la région de Nabeul $^{61}$.

De fait, jusqu'en 1985 (Mackensen 1985), les deux seuls ateliers de sigillée africaine ayant fait l'objet d'une étude céramologique, ceux de Sidi Aïch et Henchir es-Srira (Stern 1968), n'étaient pas d'un grand secours pour les archéologues de Méditerranée car leurs productions n'ont pas été beaucoup exportées outre-mer: elles appartiennent au faciès continental de la céramique africaine, inconnu -ou presque- hors d'Afrique. C'est la publication de l'atelier d'El Mahrine (Mackensen 1985 et 1993) puis celle des ateliers du centre de la Tunisie (Peacock, Bejaoui, Ben Lazreg 1990) qui ont marqué un nouveau départ dans la caractérisation des ateliers de sigillée africaine. Ces études, auxquelles s'ajoutent actuellement d'autres, confiées à plusieurs étudiants

\footnotetext{
${ }^{58}$ Voir cependant les précautions encore utilisées, en 1983, dans Bonifay 1983, 305 et 345 , note 16 .

59 L'aspect des tessons exposés à Ravenne en 1983 était cependant équivoque: déchets de fours ou simples tessons brûlés?

${ }^{60}$ Non publiées ; cf. Brun 2001, échantillons ACD 74 à 76.

${ }^{61}$ On comparera le spectre des poinçons relevés sur les sigillées pseudo-ravennates, réuni par Mackensen 1993, fig. 122 (p. 445 : « dieses Stempelspektrum ist nun nicht für El Mahrine, sondern für ein zweites, noch nicht identifiziertes nordtünesisches Töpfereizentrum charakteristisch ») avec celui des sigillées de l'épave du Dramont E, près de Saint-Raphaël (Santamaria 1995, Pl. XIII-XV ; sur la provenance de l'épave du Dramont E, voir Bonifay, Capelli, Long 2002). La forme Hayes 50B-n ${ }^{\circ}$ 61, avec sa décoration très simple de rouelles dentelées, illustrée dans Maioli 1986, fig. 3, est attestée sur l'atelier de Sidi Zahruni (Ghalia, Bonifay, Capelli 2004, fig. 5, n² 29-30).
}

tunisiens en thèse ${ }^{62}$, permettent non plus seulement de réfléchir en termes de provenance africaine lato sensu mais également de préciser l'origine régionale de ces sigillées.

\subsection{LA VALIDITÉ DES GRANDES CATÉGORIES DE SIGILLÉE AFRICAINE}

On regroupe sous le terme de sigillée africaine une multitude de productions d'aspect très varié. Le problème est que les prospections d'ateliers de sigillées africaines, pourtant bien plus avancées que pour les amphores (Mackensen 1993, 21-24), sont loin d'être exhaustives. On en est encore réduit à appliquer les vieilles classifications de productions de Waagé (1948: Late Roman Wares $A$ et $B$ ) et de Lamboglia (1958 et 1963 : sigillata chiara A, C et D), revues par Carandini (Atlante I). Or, ces classifications recouvrent à la fois des distinctions géographiques (la catégorie Lamboglia D provient du nord et la $\mathrm{C}$ du centre de la Tunisie) et chronologiques (la A précède la $\mathrm{D}$ ). Dès 1972, J. W. Hayes avait proposé de parler de «North, Central and South Tunisian [groups] » (Hayes 1972, 299), à l'image de ce qui est fait pour la sigillée gauloise, mais cette proposition se heurte aujourd'hui encore à un certain nombre de difficultés.

Rappelons tout d'abord les hypothèses traditionnelles de localisation des ateliers de sigillée africaine et voyons ensuite de quelle manière certaines se trouvent aujourd'hui remises en question.

\section{La question de la sigillée africaine $A$}

Bien qu'aucune trace de production de sigillée africaine A n'ait été à ce jour reconnue en Afrique, l'origine de cette céramique ne fait plus de doute: les études pétrographiques, l'aspect du vernis ou encore la filiation punique de certaines formes la rattachent à l'Afrique. Cependant la localisation des ateliers pose toujours problème.

\section{- Nord ou centre de la Tunisie ?}

L'hypothèse traditionnelle veut que la catégorie A soit originaire du nord de la Tunisie et, plus précisément, de la région de Carthage (Hayes 1972, 298; Hayes 1980a, 518). Les arguments en faveur de cette hypothèse ont été largement développés par A. Carandini qui croyait pouvoir déceler une filiation entre les catégories A et D

\footnotetext{
${ }^{62}$ Faouzia Dridi pour Oudhna ; Moufida Labayed-Lahdari pour Henchir es-Srira; Mongi Nasr pour Sidi Aïch; pour Sidi Khalifa, voir Ben Moussa 2001.
} 


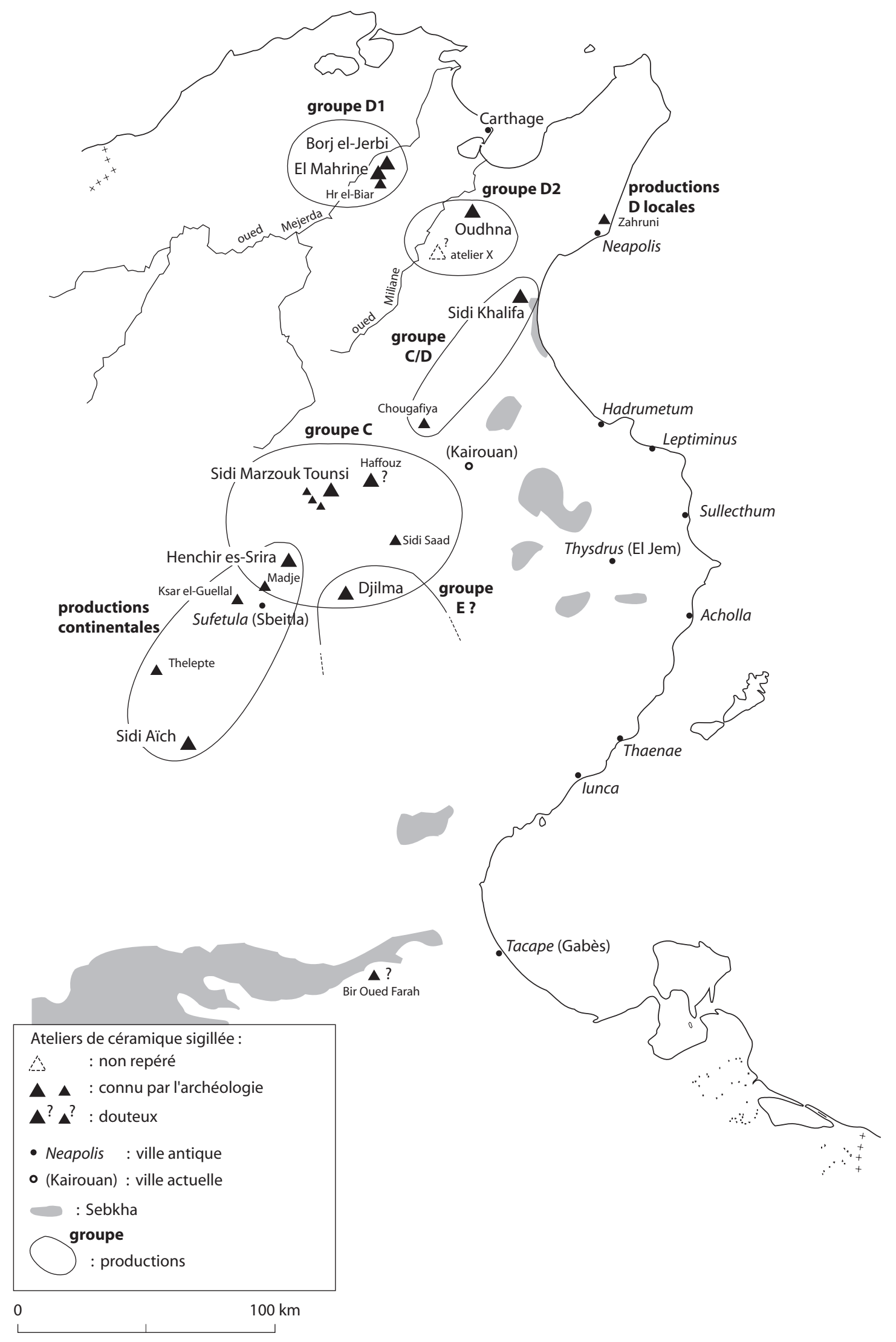

Fig. 22. Carte des principaux ateliers de céramique sigillée connus en Tunisie. 


\begin{tabular}{|c|c|c|c|c|}
\hline zones d'ateliers & Waagé 1948 & $\begin{array}{c}\text { Lamboglia } \\
1958-60\end{array}$ & Hayes 1972 & $\begin{array}{c}\text { Carandini } \\
\text { (1981) }\end{array}$ \\
\hline Nord de la Tunisie (?) & $\begin{array}{c}\text { Late Roman B ware } \\
\text { (early) }\end{array}$ & sigillata chiara $\mathrm{A}$ & $\begin{array}{l}\text { formes } 1 \text { à } 11, \\
13 \text { à } 27\end{array}$ & $\begin{array}{c}\text { sigillata africana } \\
\text { A1-2 }\end{array}$ \\
\hline Nord de la Tunisie & $\begin{array}{c}\text { Late Roman B ware } \\
\text { (middle-late) }\end{array}$ & sigillata chiara $\mathrm{D}$ & formes 12,58 à 111 & $\begin{array}{c}\text { sigillata africana } \\
\text { D1-2 }\end{array}$ \\
\hline Centre de la Tunisie (?) & - & - & formes $28-33$ & $\begin{array}{c}\text { sigillata africana } \\
A / D\end{array}$ \\
\hline Centre de la Tunisie & Late Roman A ware & sigillata chiara $\mathrm{C}$ & $\begin{array}{c}\text { formes } 40 \text { à } 58,71 \text { à } \\
74,82 \text { à } 85,89\end{array}$ & $\begin{array}{c}\text { sigillata africana } \\
\text { C1-5 }\end{array}$ \\
\hline Centre-sud de la Tunisie (?) & - & - & $\begin{array}{c}\text { formes } 60,62,68 \\
70,77,92\end{array}$ & $\begin{array}{c}\text { sigillata africana } \\
E\end{array}$ \\
\hline Phocée & Late Roman C ware & - & $\begin{array}{c}\text { Phocean Red Slip } \\
\text { ware }\end{array}$ & $\begin{array}{c}\text { ceramica } \\
\text { microasisatica }\end{array}$ \\
\hline Chypre & Late Roman $D$ ware & - & $\begin{array}{c}\text { Cypriot Red Slip } \\
\text { ware }\end{array}$ & $\begin{array}{c}\text { ceramica } \\
\text { cipriota }\end{array}$ \\
\hline Gaule du Sud & - & $\begin{array}{c}\text { sigillata chiara B } \\
\text { e lucente }\end{array}$ & - & ceramica narbonese \\
\hline
\end{tabular}

Tableau II. Hypothèses traditionnelles de localisation des ateliers de sigillée africaine.

(Carandini 1970a, 114 ; Atlante I, 19 ; voir également Tortorella 1987, 282). Or Michael Mackensen (1993) a pu prouver qu'il n'y avait, sur les trois importants ateliers de sigillée africaine $\mathrm{D}$ qu'il a prospectés dans la région de Tebourba, aucune trace d'une production antérieure de sigillée A2; le lien avec la catégorie D1 ne peut donc, dans l'état actuel des recherches, être établi (désormais : Pavolini, Tortorella 1997, 267).

Notre collègue tunisien Moncef Ben Moussa $(2000,54)$ a récemment proposé de rechercher les plus anciens ateliers de sigillée africaine dans la moyenne vallée de la Mejerda, entre Bulla Regia et Chemtou ou bien autour de Dougga et Uchi Majus, sans toutefois en apporter de preuves archéologiques. Il fait cependant remarquer, à la suite de J. W. Hayes (1980, 518), que les traces ont pu en être recouvertes par les dépôts fluviatiles du grand fleuve tunisien (Ben Moussa 2000, 54).

Enfin, la présence de variantes locales apparentées à la sigillée africaine A (Hayes 1972, 298) sur la nécropole de Raqqada, près de Kairouan (Salomonson 1968, 97-108 : formes A3-4, 12b, 17, 21, 23, 27) a également fait envisager qu'une production de sigillée africaine $\mathrm{A}$ ait pu exister dans le centre de la Tunisie (Pröttel 1996, 25 et note 3$)^{63}$. De fait, certaines formes anciennes de cette catégorie possèdent une pâte très fine, proche de celle qui sera plus tard caractéristique de la catégorie C. J'ai remarqué cette particularité sur les formes Hayes 2/3A qui constituent peut-être tout simplement la variante centro-tunisienne de la coupe à marli courbe Hayes 3 (infra, SIGILLÉE TYPE 1). Elle s'observe également sur des fragments de bols Hayes 8A de Pupput (Ben Abed,

\footnotetext{
${ }^{63}$ Je suis tout à fait d'accord avec les observations de Philipp Pröttel sur l'approvisionnement de la ville de Sétif en sigillées d'origine centro-tunisienne.
}

Griesheimer 2004, fig. 46, $\mathrm{n}^{\circ} 2.4$ ) et de Rougga (Guéry, Bonifay à paraître, $\mathrm{n}^{\circ} 31$ ), alors que d'autres exemplaires de la même forme ont, en revanche, une pâte tout à fait conforme aux descriptions de Lamboglia et un vernis granuleux («peau d'orange »); sur les exemplaires les plus anciens, ce dernier couvre incomplètement l'intérieur du vase laissant brute toute la partie située sous la carène (Ben Abed, Griesheimer 2004, fig. 84, $\mathrm{n}^{\circ}$ 2). On comparera les macro-photographies des pâtes de deux vases Hayes 8A, l'un avec une pâte fine proche des sigillées africaines $\mathrm{C}\left(\mathrm{Pl}\right.$. II, $\mathrm{n}^{\circ}$ 6), provenant de Rougga, l'autre avec une pâte granuleuse plus conforme à la norme des sigillées africaines $\mathrm{A}\left(\mathrm{Pl}\right.$. II, $\left.\mathrm{n}^{\circ} 7\right)$, découvert à Marseille.

\section{- Oudhna ?}

L'aspect granuleux de la pâte et du vernis qui la couvre, pourrait bien être une caractéristique des productions de sigillée africaine A du nord de la Tunisie, surtout si l'on compare ces productions avec celles provenant des ateliers du VIe s. à Oudhna, classées dans la catégorie D2. Il est parfois difficile de faire la différence entre les tessons si l'on fait abstraction de deux éléments: la forme, bien sûr, et le fait que les productions en D2 ne soient pas vernies à l'extérieur. De fait, les meilleurs céramologues se sont laissés prendre à ce piège par le passé : J. W. Hayes lui-même avait classé parmi les formes anciennes (donc celles que nous classons dans la catégorie A) un petit bol (forme 12) qu'il a, à la suite des fouilles de Carthage (Hayes 1980a, 486-487), replacé dans les séries tardives (catégorie D2 selon la terminologie de Carandini : Atlante I, 78). Lucien Rivet, en 1980, avait attribué à la sigillée africaine A un fond de bol Hayes 99, dont il faisait cependant remarquer la « couverte [seulement] interne » (Guild, Guyon, Rivet 1980, 150 et fig. 34, $\left.\mathrm{n}^{\circ} 3090\right)$. 
Dans ces conditions, on pourrait se demander si l'atelier d'Oudhna qui fut si productif durant les VIe-VIIe s. (Barraud et al. 1998), ne fut pas également, quelques siècles plus tôt, à l'origine d'une partie au moins des productions classées dans la catégorie A. De fait, au sein du matériel d'Oudhna qu'il m'a été donné d'étudier pour le compte de l'I.N.P. ${ }^{64}$, j'ai pu constater une abondance toute particulière, dans des contextes du début du IIIe s., de sigillées africaines A à décor d'applique de formes Hayes 24, 35 et 38 (infra, SIGILLÉE TYPES 18-23); ces productions sont tout à fait similaires à celles du VIe $\mathrm{s}$. issues des ateliers d'Oudhna. Toutefois, il ne faut pas en conclure trop vite que toutes les sigillées africaines A à décor d'applique seraient issues d'un même atelier et, $a$ fortiori, de celui d'Oudhna: les nombreuses patères de forme Atlante XVII, 17 découvertes à Pupput (Bonifay 2004a, fig. 16 ; infra, SIGILLÉE TYPES 14-15) n'ont pas toutes exactement la même pâte ni la même qualité de vernis.

\section{- La piste algérienne?}

Dans cette question de l'origine de la sigillée africaine A, on doit encore tenir compte de l'abondante diffusion de cette céramique en Algérie. Cette observation se vérifie dans les contextes du IIe $\mathrm{s}$. et de la première moitié du IIIe s., par exemple à Tipasa (Lancel 1970, fig. 75) et à Sétif (Guéry 1985a), mais également dans les contextes plus tardifs, probablement de la fin du IIIe s. et de la première moitié du IVe siècle. Le cas de la nécropole de Draria el-Achour (Camps 1955) est particulièrement symptomatique, avec la présence de bols apparentés à la forme Hayes 15 en association avec des plats en sigillée africaine D de formes Hayes 59 et $61 \mathrm{~A}$. Tout autant que la présence de formes précoces, celle de formes tardives (groupe A2) (infra, fig. 85) peut être significative de la proximité des lieux de production. Cette diffusion préférentiellement occidentale de la sigillée africaine A recoupe en partie celle des céramiques culinaires qui ont été assimilées à cette production, notamment les formes Hayes 23A et B.

La question de l'origine géographique des premières sigillées africaines est toujours restée énigmatique mais les recherches actuelles sur le terrain africain montrent une situation encore plus complexe qu'elle ne pouvait le paraître sur d'autres rivages. La même constatation peut être faite pour d'autres catégories.

\section{Les productions de Zeugitane : la sigillée africaine « $\mathbf{D} »$}

On pourrait dire, paraphrasant Maurois, qu' « il en est de la sigillée africaine D comme des auberges espagnoles : on y trouve ce qu'on y apporte ». De fait, il n'y a pas de

\footnotetext{
${ }^{64}$ Fouilles de la façade orientale du Capitole, dirigée par M. Habib Ben Hassen. Etude du matériel conduite en 1999, inédite.
}

catégorie plus hétérogène au sein de la famille des sigillées africaines.

\section{- Les classifications traditionnelles : difficultés d'application}

A la sigillata chiara $\mathrm{D}$ de Lamboglia ${ }^{65}$, qui correspond à la «Late B » ware de Waagé (1948) et qui est devenue la catégorie D1-phase 1 chez Carandini (Atlante I, 78), sont venues s'ajouter d'autres sous-catégories sous la plume de Hayes, notamment celle, «more or less identical in appearance with that of the earliest African products » (Hayes 1972, 292, 3ème paragraphe), qui caractérise les productions d'Oudhna (catégorie D2-phase 2 de Carandini : Atlante I, 78). Le contraste entre la grossièreté de la pâte et l'aspect lustré du vernis, très épais pour masquer les irrégularités de la surface, est une caractéristique qui se retrouve sur les autres produits classés en D2 (-phase 1 selon Carandini : Atlante I, 78 ; Hayes 1972, 291, 4ème paragraphe).

Ne parvenant pas à appliquer la terminologie proposée par Carandini, j'avais tenté de constituer à Marseille mes propres groupes de pâtes (Bonifay 1983, 305-306). Le groupe 1 et le groupe 2 correspondaient grosso modo aux distinctions D1(-phase 1) et D2(-phases 1 et 2 regroupées). Le groupe D3 était constitué de tessons de vases Hayes 90, 91D, 101, 105 et 109A (?), présentant une pâte granuleuse et vacuolaire couverte d'un vernis assez particulier, orange ou rose, souvent tacheté de points plus sombres, mince au point de devenir parfois inexistant et procurant à la surface un aspect nettement granuleux. Enfin, le groupe D4 était caractérisé par une pâte beige, poreuse et assez tendre, et un vernis rose orangé terne, écaillé et savonneux au toucher (formes Hayes 98, 99C et 109). La publication de nouveaux contextes en 1998 (Bonifay et al. 1998, 363) m'avait amené à adopter également une description de pâte (D5) faite par P. Reynolds (1987, 15, type 1a) : pâte sableuse et tendre, engobe rouge-marron, mat et peu adhérent, typique à Marseille comme à Alicante, des formes Hayes 87B et C.

La confrontation avec la situation africaine m'a convaincu que les classifications de pâtes traditionnelles n'étaient plus adaptées au développement actuel de la recherche. En effet, ces distinctions, pour la plupart élaborées hors d'Afrique, ne parviennent pas à traduire la complexité des groupes de pâtes d'un matériel local à l'écart des grands courants commerciaux maritimes.

\section{- Recensement des ateliers et diffusion des productions}

Il faut bien admettre que nos connaissances sur les ateliers de la vaste catégorie D sont peu étendues. On

\footnotetext{
${ }^{65}$ On dit habituellement aux étudiants que cette production rappelle l'aspect de nos pots de fleurs actuels.
} 
distingue, dans l'état actuel des recherches, trois grands ateliers ou zones d'ateliers (fig. 22) :

- La première est située dans la basse vallée de la Mejerda, à proximité de la ville de Thuburbo Minus. M. Mackensen (1993) y a reconnu, dans les années 80-90, trois ateliers importants : El-Mahrine, Henchir el-Biar et Borj el-Jerbi, qui ont produit des sigillées africaines de catégorie D1 (Pl. II, $\left.\mathrm{n}^{\circ} 11\right)$.

- Le deuxième grand atelier, connu depuis la fin du XIXe s. et revisité en 1995-1997 (Barraud et al. 1998), est celui d'Oudhna, implanté dans la basse vallée de l'Oued Miliane. Ses productions se rattachent au groupe D2-phase 2 de Carandini (Pl. II, $n^{\circ}$ 9-10).

- Enfin, l'atelier de Sidi Khalifa s'étend en périphérie de la ville de Pheradi Majus, dans le golfe d'Hammamet (voir désormais : Ben Moussa 2001). Sa production ( $\mathrm{Pl}$. II, $\mathrm{n}^{\circ} 8$ ) est habituellement classée dans la catégorie D2 (en dernier lieu: Mackensen, Schneider 2002, 123) mais, à mon sens, elle s'en distingue nettement et se rapproche, par certains côtés, des productions de Tunisie centrale (voir les observations de Hayes sur sa forme 88 : Hayes 1972, 136 et 292$)^{66}$. Je proposerais volontiers de créer une nouvelle catégorie « $\mathrm{C} / \mathrm{D}$ » à laquelle pourrait également se attacher le petit atelier de Chougafiya, qui a produit la forme Hayes 88 (Peacock, Bejaoui, Ben Lazreg 1990, fig. 4, n²2-23).

Il est aujourd'hui possible d'ajouter à ces trois grands centres producteurs reconnus sur le terrain, un quatrième atelier de sigillée africaine D que M. Mackensen a pu récemment mettre en évidence sur des bases stylistiques (Mackensen 1998a) mais qui n'a pas encore été localisé.

- Ce quatrième atelier, dénommé tout simplement « large D2 pottery» par M. Mackensen et G. Schneider $(2002,128)$ (Pl. II, $\left.\mathrm{n}^{\circ} 13\right)$ mais que je proposerais de désigner ci-après sous le terme d' " atelier X », a produit les grands plats Hayes 103104 à décor de style $\mathrm{E}(\mathrm{ii})$, particulièrement abondants à Carthage. Sa localisation est pressentie dans la région de El-Fahs, Zaghouan et Oudhna (Ibid.).

Mais cette liste de grands ateliers dont la production est parfaitement lisible, y compris sur les sites non africains, ne suffit pas à cerner la complexité de la production de ce qu'il est convenu d'appeler la sigillée africaine D. Les particularités de l'approvisionnement en sigillée africaine d'une petite ville du nord de la Byzacène comme Aradi/Sidi Jdidi, sont bien révélatrices de ce phénomène : du Ve au VIIe s., l'essentiel des sigillées susceptibles d'être classées dans la catégorie D se répartissent en deux groupes (Bonifay, Reynaud 2004, 233). Le premier (SG1), minoritaire, est homogène et peut, du point de vue morphologique (Hayes 88 majoritaire) tout autant que

\footnotetext{
${ }^{66}$ « fine grained ware with well-smoothed surfaces », « possibly from he same workshops as Forms 82-85».
}

pétrographique $^{67}$, être rapporté avec quelque vraisemblance au grand atelier voisin (une vingtaine de $\mathrm{km}$ ) de Sidi Khalifa. Le deuxième (SG2), majoritaire, regroupe des pâtes dont la composition n'est pas très stable et le répertoire de formes composé d'adaptations locales de formes classiques (types Sidi Jdidi 1, 2, 3, variantes de plats Hayes 67 et 68). Des prospections sur le terroir de la cité d'Aradi ou des cités voisines permettraient probablement de repérer le ou les atelier(s) qui ont produit ces vaisselles de qualité inférieure et de diffusion principalement locale.

Le cas de Nabeul illustre également bien cette proposition : grande ville ouverte sur l'extérieur, elle a un approvisionnement en sigillée africaine bien plus varié que celui de la petite bourgade de Sidi Jdidi. Pourtant, aux côtés de productions bien identifiables, originaires de El-Mahrine (Hayes 66: Slim, Bonifay, Trousset 1999, 161 et fig. 30), d'Oudhna (nombreuses formes Hayes 99 bien caractéristiques), de Sidi Khalifa (Hayes 88), sans parler des importations plus lointaines de sigillée africaine $\mathrm{C}$, on remarque une bonne représentation de produits moins classiques, avec une pâte plus grossière (Pl. II, $\left.\mathrm{n}^{\circ} 14\right)$ et un répertoire de formes particulier (Hayes 50B variante, formes apparentées au type Fulford 27). Or, l'atelier qui a fourni ces vaisselles vient d'être repéré sur le territoire même de la cité de Nabeul, à Sidi Zahruni (Ghalia, Bonifay, Capelli 2004, fig. 5).

L'exemple de Carthage s'inscrit dans la même logique. La grande métropole est principalement alimentée par trois ateliers de sigillée africaine D : El-Mahrine (Mackensen 1993, 651 ; Bonifay à paraître, a), Oudhna (Barraud et al. 1998, 165) et l' " atelier X», caractérisé par les décors de style E(ii), qui n'a pas été repéré à ce jour (Mackensen 1998a, 36-37). Les deux premiers ateliers ne sont pas très éloignés de la ville (situés respectivement à 45 et $30 \mathrm{~km}$ de Carthage) et il en est probablement de même du troisième. En revanche, celui de Sidi Khalifa, plus distant, paraît peu représenté à Carthage (Fulford 1984a, 63, à propos de la forme Hayes 88).

Les conditions du progrès de nos connaissances sur les sigillées africaines D passent donc tout autant par la poursuite $\mathrm{du}$ recensement des ateliers que par la caractérisation du faciès céramique de chacune des cités africaines: la distribution des différents groupes de sigillée africaine D sur le territoire africain peut être révélatrice de leur origine. Citons deux derniers exemples. Les plats Hayes 88 si abondants sur le rivage de la sebkhra Sidi Khalifa sont issus de l'atelier du même nom situé à quelques kilomètres en arrière de la côte (infra, fig. 254, c). Peut-être les grands plats Hayes 90 et une partie au moins des assiettes Hayes 105, abondantes à Leptiminus (Dore 1992, 154), à Rougga (Guéry, Bonifay à paraître, $\mathrm{n}^{\circ} 52-61, \mathrm{n}^{\circ} 71-76$ et $\left.78-81\right)$ et, d'une manière

\footnotetext{
${ }^{67}$ Observations à la binoculaire par Claudio Capelli.
} 
générale sur le littoral compris entre Sfax et Salakta (Bonifay et al. 2002-2003), sont-ils originaires de Byzacène centrale (Bonifay 1998d, 332) ?

\section{- Méthodes archéométriques}

Contrairement à celle des amphores (supra, p. 26), la pâte des sigillées africaines, même de la catégorie $\mathrm{D}$, la plus grossière, est trop épurée pour pouvoir être circonscrite par une simple analyse pétrographique (Mackensen, Schneider 2002, 135). Cette méthode peut constituer une approche complémentaire ou, au contraire, un aboutissement pour vérifier et rendre plus abordables des résultats obtenus par des méthodes plus sophistiquées, mais le détour par les analyses physico-chimiques reste actuellement indispensable.

Maurice Picon avait effectué en 1985-86, dans le cadre des activités du groupe CATHMA, un certain nombre d'analyses de sigillées africaines D issues de sites provençaux (Saint-Julien-lès-Martigues, Saint-Blaise , La Gayolle, Marseille: Saint-Victor et chantier de La Bourse). Ces travaux avaient révélé la grande hétérogénéité de composition de cette catégorie. Récemment, ce dossier a été rouvert dans le cadre de la préparation de deux diplômes universitaires : une thèse sur l'atelier d'Oudhna (infra, note 73), dans le prolongement des travaux de la mission tuniso-française sur ce site (Barraud et al. 1998), et un Diplôme d'Etudes Supérieures Spécialisées sur l'étude pétrographique et l'analyse chimique des sigillées africaines du chantier de l'Alcazar à Marseille (Brun 2001). L'analyse d'échantillons de l'atelier d'Oudhna ${ }^{68}$ est venue ainsi s'ajouter aux références d'atelier de Sidi Khalifa déjà disponibles dans la banque de données du laboratoire d'Archéométrie de Lyon et ont permis de mettre en perspective l'ensemble des échantillons de sigillée africaine précédemment analysés. Les travaux sur les échantillons d'Oudhna ont été menés en concertation avec le laboratoire de M. Gerwulf Schneider à Berlin qui étudiait de son côté la caractérisation des ateliers d'ElMahrine, Henchir el-Biar et Borj el-Jerbi et du groupe dit « large D2 pottery » (Mackensen, Schneider 2002).

Ces travaux récents suscitent un certain nombre de remarques.

- Il est remarquable que les trois ateliers voisins d'ElMahrine, Henchir el-Biar et Borj el-Jerbi, qu'il est impossible de reconnaître par une simple observation macroscopique, puissent se distinguer aussi aisément par l'analyse physicochimique (Mackensen, Schneider 2002, 137-139). En revanche, il y a peu de différences entre ces trois ateliers, d'une part, et l'atelier d'Oudhna, d'autre part, hormis une proportion de sodium plus élevée à Oudhna, due peut-être à l'utilisation d'eau saumâtre pour la préparation des argiles dans cet atelier (Ibid., 140).

- Les analyses effectuées par G. Schneider tout comme celles conduites par C. Brun font apparaître deux groupes de

\footnotetext{
${ }^{68}$ Fournis par M. Habib Ben Hassen, responsable du site.
}

pâtes dans l'atelier d'Oudhna. Cette distinction se lit en filigrane dans la première publication (Mackensen, Schneider 20002, fig. 13 et Tabl. 5), les échantillons Ou 2, 9, 10-15 correspondant au groupe $\mathrm{A}$ de Céline Brun, et les échantillons 1, 3-9 à son groupe B (Brun 2001, 25, Tabl. 2). Les deux groupes se distinguent par les proportions d'alumine et de titane, plus élevées dans le groupe A que dans le groupe B, et de silice, plus élevée dans le groupe $\mathrm{B}$ que dans le groupe $\mathrm{A}$.

- Le groupe dit « large D2 pottery » paraît plus hétérogène. Cela tient probablement à la nature de l'échantillonnage : il ne s'agit pas de prélèvements d'atelier(s) puisque l'emplacement de ce(s) dernier(s) n'est pas connu mais de tessons recueillis sur des sites consommateurs et regroupés en fonction de critères stylistiques. Or, le dendrogramme publié à la fig. 13 (Mackensen, Schneider 2002, 136) fait nettement apparaître deux sous-ensembles, qui sont également assez distincts du point de vue typologique. Le premier ensemble (échantillons D2.12 à 21) est constitué de tessons de formes Hayes 103-104 et de décors de style E(ii) ; ils proviennent tous de Carthage. Ce groupe homogène correspond à celui initialement et très pertinemment défini par M. Mackensen comme "group D2 » (Mackensen 1998a). Le second ensemble est plus hétérogène dans sa composition chimique, ses caractères typologiques et la provenance des fragments (Lorenzberg, Moosberg et Classe) : ce sont les échantillons D2.1 à D2.11, dont trois sont même exclus de la moyenne (échantilllons D2.3, 6, 7 : cf. tabl. 5). Le $\mathrm{n}^{\circ} \mathrm{D} 2.6$ est proche de la forme Hayes $61 \mathrm{~B} 3$, à profil en « $\mathrm{S}$ » (infra, SIGILLÉE TYPE 38), attestée sur l'atelier de Sidi Khalifa, et, de fait, sa composition est compatible avec certains échantillons marginaux de cet atelier (Brun 2001, 27, Tabl. 3). Deux autres échantillons ( ${ }^{\circ}$ D2.1 et D2.4), plus proches encore de la composition chimique relevée sur l'atelier de Sidi Khalifa, présentent des décors connus sur cet atelier (Ben Moussa 2001, styles $\mathrm{I} / 2.2$ et $\mathrm{I} / 3.4$ ). Enfin, le décor et la composition des $\mathrm{n}^{\circ} \mathrm{D} 2.6$ et D2.7 semblent désigner encore d'autres ateliers. Ce groupe ne semble donc réellement fonctionner que pour le premier sous-ensemble caractérisé par le style décoratif E(ii).

\section{Les productions de Byzacène centrale : les sigillées africaines « $A / D »$ et « $C$ »}

Les prospections du littoral ont montré que les tessons de la catégorie A/D étaient groupés sur des sites au sud de La Chebba (Bonifay et al. 2002-2003). Cette répartition confirme la localisation proposée pour les ateliers (Atlante I, 53), le principal d'entre eux ayant été identifié à Henchir el-Gellal-Djilma, à environ $150 \mathrm{~km}$ à l'ouest de La Chebba (Peacock, Bejaoui, Ben Lazreg 1990, fig. 1 ; Pröttel 1996, 20).

La localisation des ateliers de sigillée africaine $\mathrm{C}$ ne pose plus, et depuis longtemps (Hayes 1972, 297-298), de problème majeur. Un atelier important, à Sidi Marzouk Tounsi (Peacock, Bejaoui, Ben Lazreg 1990, 66-74), semble avoir produit l'essentiel des formes, non seulement celles, les plus tardives, de la catégorie C5, mais également celles du IIIe s. (Mackensen, Schneider 2002, 131). Les productions à relief d'applique et les plats rectangulaires sont bien attestés sur l'atelier de Haffouz (Guéry, Slim 1998). Tout récemment M. Ben Moussa a identifié trois autres ateliers: Henchir Bloul, Henchir Tebraria et Henchir el-Kouky, apparemment 
d'importance mineure, dans la même région (Ben Moussa 2001, 328-330).

Une difficulté peut surgir du fait que certaines formes de la catégorie $\mathrm{C}$ ont été imitées sur des ateliers d'autres régions. Il en est ainsi de la forme Hayes 84 en sigillée C5 dont on retrouve des dérivés sur l'atelier de Sidi Zahruni (infra, p. 57) et surtout sur l'atelier de Sidi Khalifa. Ici, la confusion avec les ateliers du centre de la Tunisie est facile ${ }^{69}$ car certaines productions de Sidi Khalifa ont une texture très fine (supra : groupe C/D).

La question qui se pose actuellement concerne plutôt la fin de la production des ateliers de cette région. M. Mackensen a bien montré que l'atelier de Sidi Marzouk Tounsi pouvait être encore actif au début (Mackensen 1998b, 370) et même au milieu du VIe s. (Mackensen 2003) et qu'il produisait des formes Hayes $89 \mathrm{~B}$ ou 90A. Il est clair maintenant que la forme Hayes 90B est également produite dans la région. Son abondance à Rougga, mentionnée dans les lignes qui précèdent, et sa présence sur l'atelier de Haffouz, sans qu'il soit toutefois possible d'assurer que cette forme était réellement produite sur place ${ }^{70}$, laisse entrevoir une poursuite de la fabrication de sigillée africaine en Byzacène centrale peut-être plus longue qu'on ne le pensait. Le problème de la forme Hayes 105 est plus compliqué : cette forme est très abondante partout en Tunisie ; elle a été largement exportée en Méditerranée. Mais, d'un autre côté, on ne peut nier la filiation existant entre la forme Hayes 90 et certaines variantes de la forme Hayes 105. La pâte des exemplaires de Rougga est assez grossière par rapport aux productions classiques de Byzacène centrale, mais, dans ce cas, il faut se demander s'il ne s'agirait pas d'une pâte de sigillée africaine C, non épurée.

Les productions du sud tunisien : les sigillées africaines « $\mathrm{C} / \mathrm{E} »$ et $« \mathrm{E} »$

Il faut tout d'abord affirmer que toutes les formes Hayes 68 n'appartiennent pas à la catégorie E. Les ateliers de Sidi Aïch et de Henchir es-Srira ont produit des formes comparables (Stern 1968, forme VII) et le matériel de Sidi Jdidi en fournit d'autres exemples dans

\footnotetext{
${ }^{69}$ C'est probablement les cas d'une bonne part des assiettes Hayes 84 identifiées dans la prospection de la vallée de Segermes (Lund 1995, 514-515) : 47 exemplaires pour seulement 3 tessons de la forme 82 et aucun de la forme 85 . L'exemplaire illustré fig. 11 est peut-être une production de Sidi Khalifa.

${ }^{70}$ J'ai visité ce site en 1999, sous la conduite de Moufida Labayed-Ladhari, dans le cadre de la préparation de sa thèse de doctorat. J'y ai vu quelques vestiges de fours de céramiques communes mais aucune trace de l'atelier de sigillée qui aurait produit les grands plats rectangulaires publiés par R. Guéry et L. Slim. Selon M. Labayed-Ladhari, les fragments de plats Hayes 90B proviennent d'une autre zone du site qui a livré des témoins de production de sigillée africaine $\mathrm{C}$.
}

un groupe de pâte local (Bonifay, Reynaud 2004, $\left.\mathrm{n}^{\circ} 6 \mathrm{~B} .2,9.2,12.5\right)$. Les productions classiques $^{71}$ de sigillée africaine E présentent une pâte marron orangé ( $\mathrm{Pl}$. II, $\mathrm{n}^{\circ}$ 1) qui se distingue très bien, à la binoculaire, par la présence de nombreux micro-fossiles, plus ou moins bien signalés par une auréole blanc-jaune; il y a très peu de quartz dans cette fraction fine ainsi que dans le dégraissant; le vernis est marron-rouge, satiné, très adhérent, et porte parfois sous le fond, comme le signale J. W. Hayes, des traces de végétaux (palmes ?).

Exemples (fig. 23) :

$* 1 \quad$ Sigillée africaine E. Littoral tunisien, site $\mathrm{n}^{\circ} 39$ (Oued el-Akarit) (Bonifay et al. 2002-2003, fig. 16, $\mathrm{n}^{\circ} 219$ ).

*2 Production continentale. Atelier de Henchir es-Srira (Inv. HSR016, collection R. Guéry, Centre Camille Jullian, Aix-en-Provence).

*3 Production continentale. Atelier de Sidi Aïch (Inv. SAI015, collection R. Guéry, Centre Camille Jullian, Aix-en-Provence).

*4 Production locale du nord du golfe d'Hammamet. Sidi Jdidi, basilique 1 (Bonifay, Reynaud 2004, $\mathrm{n}^{\circ}$ 9.2).

*5 Production indéterminée. Marseille, chantier de La Bourse (Bonifay 1983, fig. 19, $\mathrm{n}^{\circ}$ 14). Pâte orange clair, engobe beige orangé, mat, granuleux.

La diffusion des productions attribuables à la sigillée africaine $\mathrm{E}$ est bien concentrée dans le sud tunisien (infra, fig. 254, c), principalement dans le golfe de Gabès, comme le signalait J. W. Hayes (1972, 298). Aucune des propositions de localisation d'atelier pour cette catégorie ne me paraît entièrement satisfaisante. Les variantes de plats Hayes 68 produites sur l'atelier de Henchir elGellal-Djilma, me paraissent assez éloignées des modèles classiques (cf. Bonifay et al. 2002-2003, fig. 7, $\mathrm{n}^{\circ}$ 59-61). Les ateliers de sigillée africaine $\mathrm{E}$ restent encore à découvrir.

\section{Les productions continentales}

Deux des ateliers les plus anciennement connus en Tunisie, situés dans le sud-ouest de la Byzacène, ont pour particularité d'avoir diffusé leurs produits à une échelle non pas méditerranéenne comme les grands ateliers des groupes A, C et D, mais continentale. Certains de ces produits sont attestés sur la côte sud-est (infra, fig. 254, c) mais leur présence est particulièrement évidente sur les sites de l'intérieur d'Afrique proconsulaire et de Numidie. A la suite de S. Tortorella, on peut distinguer :

- des ateliers rattachés aux productions de Tunisie centrale, comme celui d'Henchir es-Srira qui pourrait être considéré par sa qualité de pâte (Pl. II, $\mathrm{n}^{\circ} 3$ ) et

\footnotetext{
71 Tessons de référence : 1) fragment de forme Hayes 68 provenant du site $n^{\circ} 37$ des prospections du littoral tunisien, Henchir Chouggaf, dans le golfe de Gabès (Bonifay et al. 20022003, fig. $\left.191, \mathrm{n}^{\circ} 58\right)$; 2) fragment de fond à décor de double guillochis provenant des fouilles tuniso-françaises de Rougga (Guéry, Bonifay à paraître, fig. $2, \mathrm{n}^{\circ} 41$ ). La pâte et le vernis de ces deux tessons sont identiques.
} 

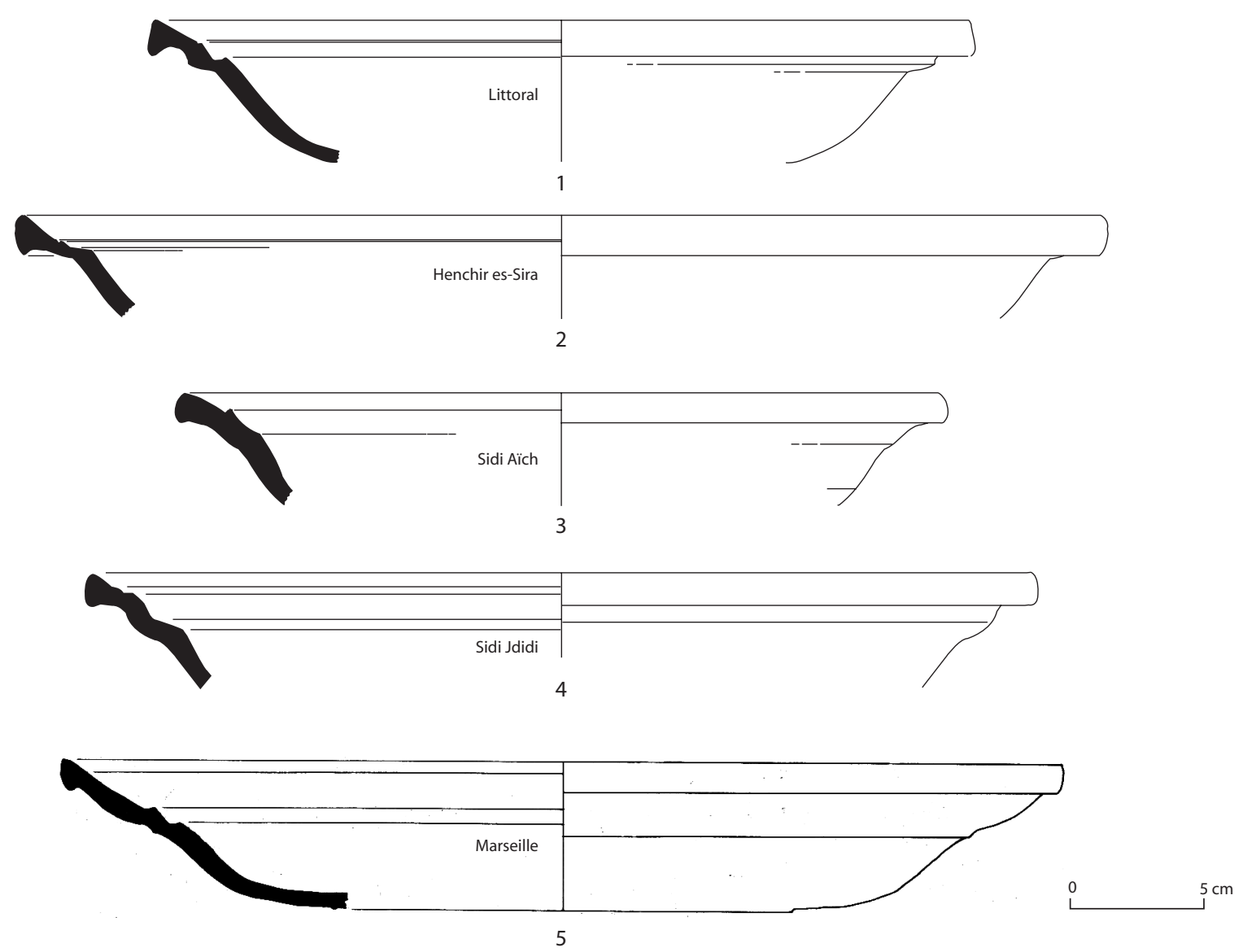

Fig. 23. Variantes de la forme Hayes 68. 
son répertoire de formes, comme une sigillée africaine $\mathrm{C}$ à diffusion continentale ;

- des ateliers de Tunisie méridionale et occidentale, comme celui de Sidi Aïch (Pl. II, n 2) qui paraît influencé par les sigillées africaines E (Stern 1968 ; Nasr 1992) ou encore celui de Thélepte, mis en évidence par M. Nasr (1995). Des ateliers très méridionaux sont signalés, comme celui de Bir Oued Farah (Trousset 1974, 53 : site $\mathrm{n}^{\circ} 26$, Oued Nakhla) mais on ignore tout du détail de leur production.

D'autres ateliers, mis en évidence dans la partie orientale et centrale de l'Algérie, notamment à Tiddis (Berthier 2000, 84-132), ne semblent avoir qu'une diffusion locale. Enfin, un important atelier de sigillée tripolitaine vient d'être récemment révélé non loin de Lepcis Magna (Felici, Pentiricci 2002).

\subsection{EXEMPLES D'ATELIERS}

Parmi les différents sites de production de céramique sigillée africaine qui ont été publiés ou que j'ai eu la l'occasion de pouvoir visiter, il est possible de distinguer les ateliers urbains des ateliers ruraux. J'insisterai sur les quelques sites dont je possède une connaissance concrète, même si elle reste, dans la plupart des cas, très superficielle.

\subsubsection{Ateliers urbains ou péri-urbains}

\section{ATELIER D'OUDHNA}

Oudhna est l'un des ateliers de sigillée africaine les plus anciennement connus $^{72}$ : en 1896 , en dégageant deux des salles des thermes des Laberii, dont le frigidarium pavé de la célèbre mosaïque d'Orphée, P. Gauckler avait mis au jour une épaisse couche de cendres contenant céramiques, outils, moules, et témoignant de la présence d'un important atelier de céramique (Gauckler 1896, 215, note 1). Quelque peu oublié pendant une cinquantaine d'années, cet atelier a suscité d'abondants commentaires (bibliographie dans Mackensen 1993, 27-30) dans la seconde moitié du XXes., quand on a commencé à s'interroger sur l'origine des sigillées africaines D. Mais, il y a peu encore, l'essentiel de nos connaissances sur son organisation et ses productions reposait sur les trois publications de Gauckler (1896, 1897 et $C M A)$ et les observations typologiques de J. W. Hayes (1972, 229 sq, 296). P.-A. Février avait même émis, dès 1964, un doute méthodique sur l'existence d'un atelier à l'intérieur des thermes des Laberii, doute encore repris par M. Mackensen (1993, 27-32) : s'il était bien clair qu'un important atelier de sigillée avait existé à Oudhna entre la fin du Ve s. et le milieu du VIe s. (Hayes 1972, 298), les preuves que son activité se soit exercée l'intérieur des

\footnotetext{
${ }^{72}$ Le plus ancien est celui de Sidi Aïch, par Cagnat, en 1888 (Mackensen 1993, 38). Je remercie Mongi Nasr d'avoir attiré mon attention sur l'antériorité de la découverte de cet atelier.
}

thermes désaffectés demeuraient très minces; il pouvait s'agir simplement d'un dépotoir ou d'un remblai transporté de plus loin (Barraud et al. 1998, 139).

Les travaux de la mission tuniso-française (1994-1996) ${ }^{73}$ ont renouvelé nos connaissances (Barraud et al. 1998). Ils ont permis d'une part de confirmer la présence d'un atelier de sigillée à l'intérieur des thermes des Laberii et de localiser une nouvelle zone d'ateliers dans la périphérie nord-est du site, d'autre part de mieux caractériser les productions de l'atelier.

\section{- Oudhna : l'atelier des thermes des Laberii}

La recherche des indices de production de céramique dans un contexte thermal n'est pas toujours aisée: le fonctionnement d'un établissement de bains produit inévitablement des couches de cendres et rien ne ressemble plus à un four qu'un praefurnium... Un examen attentif des structures a cependant permis d'identifier en 1995 (fig. 24, b) l'emplacement d'un four de potiers (four $\mathrm{n}^{\circ} 1$ ), encastré dans une étuve semi-circulaire accolée à la pièce $C$, et les vestiges de deux autres (fours $n^{\circ} 2$ et 3 ) situés dans la pièce adjacente B (fig. 24, a) (Barraud et al. 1998, fig. 2) ; un quatrième four, très arasé, a été mis au jour en 1997 dans la partie occidentale de la pièce C. Le four $n^{\circ} 1$ a été fouillé en $1996^{74}$ (fig. 24, c) et a révélé un comblement assez homogène du VIIe s. (Ibid., 159-160 et fig. 17). Mais une coupe stratigraphique effectuée en 1997 dans la pièce $\mathrm{A}$, au contact de ses fondations, a permis de démontrer que sa construction remonte au VIe siècle.

Si la durée de fonctionnement de l'atelier a pu être allongée (VIIe s.) par rapport aux estimations précédentes (milieu du VIe s.), on peut se demander à quel moment il a pris place dans l'établissement thermal. Or, au sein du matériel recueilli lors les dégagements de $1990-91^{75}$, il est facile d'opérer une distinction entre le mobilier des VIeVIIe s. issu de l'atelier et un contexte assez homogène de la fin du IVe s. ou du début du Ve s. qui comporte une assez nombreuse série de fragments de bassins, fortement concrétionnés, ainsi qu'un lot de lampes en céramique commune beige, de type Deneauve VIII/sous-type 4 tardif et Deneauve XI B à côtes de melon (LAMPES TYPES 32 et 33), également concrétionnées, qui appartiennent vraisemblablement, en raison de l'utilité évidente de ces objets dans ce type d'établissement, à la phase terminale

\footnotetext{
${ }^{73}$ Cette mission, associant l'INP de Tunis, l'Agence pour la Mise en Valeur du Patrimoine et de Promotion Culturelle (AMVPPC), le Ministère français de la Culture et de la Communication, et le laboratoire Ausonius (Maison de l'Archéologie, Bordeaux), était dirigée par M. Habib Ben Hassen et MM. Dany Barraud puis Jean-Luc Massy (19971999). Je remercie M. Habib Ben Hassen de m'avoir invité à participer aux campagnes 1995-1999. ; le dossier a été repris en 1997 par Mme Faouzia Dridi, dans le cadre de la préparation d'une thèse de doctorat sous la direction de M. Louis Maurin.

${ }^{74}$ Soit exactement 100 ans après la découverte de l'atelier par P. Gauckler

${ }^{75}$ Fouilles dirigées par Mme Ben Mansour.
} 


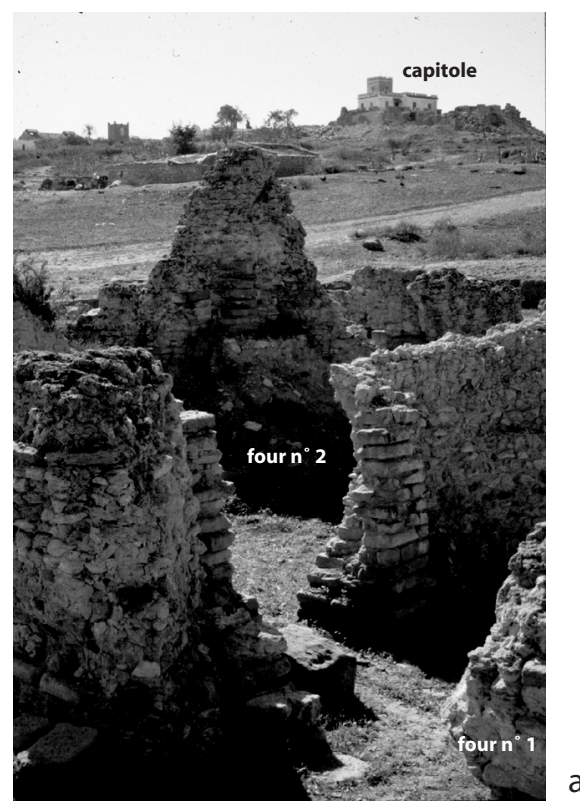

a : Pièce B des thermes des Laberii (1996)

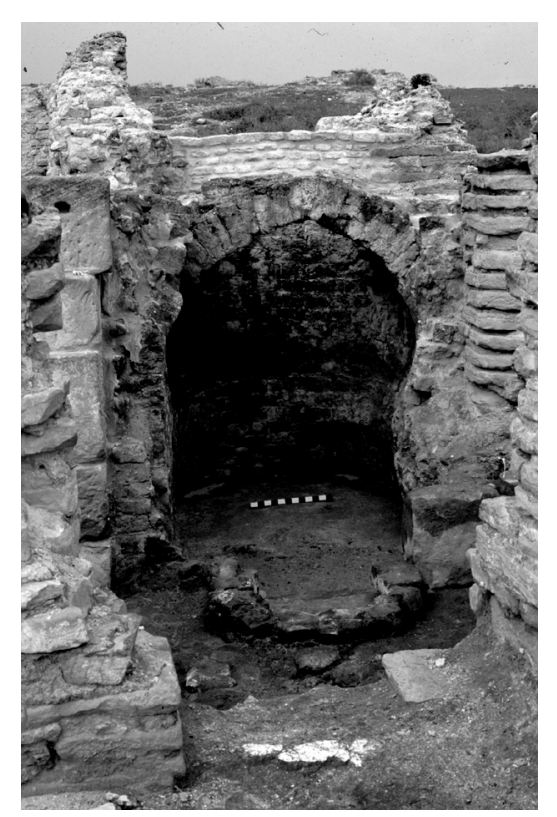

c : Le four $n^{\circ} 1$ en cours de fouille (1996) $a \quad b$

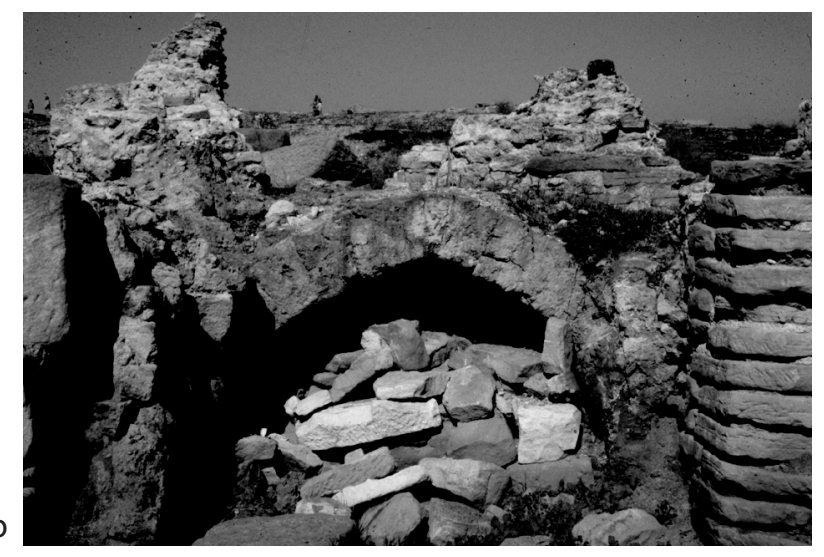

b : Le four $\mathrm{n}^{\circ} 1$ lors de sa découverte (1995)

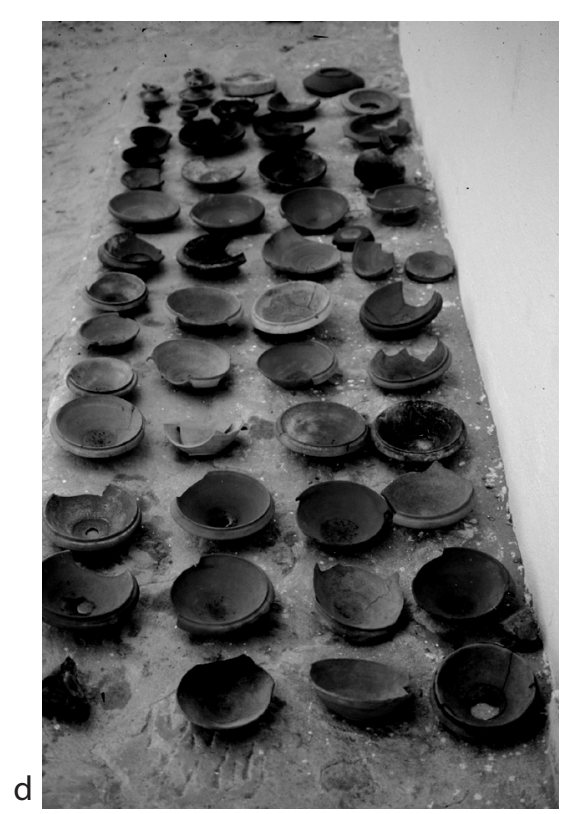

d : Production de l'atelier des thermes des Laberii (mobilier des dégagements 1990-91)

Fig. 24. Oudhna. Atelier des Thermes des Laberii. 
d'utilisation des thermes. On peut donc envisager une désaffectation des thermes des Laberii au début du Ve s., suivi peut-être d'un abandon durant la majeure partie de l'époque vandale, puis une prise de possession des lieux par les potiers dans les dernières années du Ve s. ou, plus vraisemblablement, au début du VIe siècle.

\section{- Oudhna : la zone périphérique d'ateliers}

Les prospections effectuées en 1994 et 1995 au nord-est de la ville ont révélé une deuxième zone d'ateliers. Sur au moins trois ou quatre hectares, on distingue nettement de nombreux fours arasés (une quinzaine au minimum) et d'impressionnants épandages de céramiques : fragments de casettes et de sigillées. C'est dans ce secteur qu'a également été découvert un polissoir (fig. 29, $\mathrm{n}^{\circ} 2$ ) (Barraud et al. 1998, 161 et fig. 18, $\mathrm{n}^{\circ} 34$ ). L'un des fours (four $\mathrm{n}^{\circ} 4$ ) a été sondé et a livré un comblement du milieu du VIe s. (Ibid., 157-159 et fig. 16).

Le développement de quartiers artisanaux aux VIe et VIIe s. semble être un phénomène assez général à Oudhna, puisque des fragments de casettes pour la cuisson des céramiques se rencontrent en plusieurs points $\mathrm{du}$ centre-ville et même dans les niveaux de démolition du capitole.

\section{- La production des ateliers d'Oudhna}

La production de cet atelier (fig. 24, d) compte maintenant plus d'une vingtaine de formes ouvertes (dont près de la moitié inédites) et une dizaine de formes fermées :

- toute la série des formes Hayes 95-98;

- toutes les variantes de bols Hayes 99A-C, y compris la variante très tardive dénommée de manière peu adéquate 80B/99 (infra, SIGILLÉE TYPE $55 \mathrm{~A}-\mathrm{D})$; une attention particulière est apportée à la classification des différentes variantes de cette forme-phare de l'atelier produite du début du VIe s. à la fin du VIIe s. ;

- les bols à listel Hayes 91B (grand et petit modèles : (infra, SIGILLÉE TYPES 50-51) et 91C (infra, SIGILLÉE TYPE 52) ;

- une série de cruches, caractérisées par un vernis rouge carmin ou jaunâtre lustré (infra, SIGILLÉE TYPES 61-64).

Le catalogue des poinçons utilisés pour la décoration des formes ouvertes de sigillée a également été complété. Ces poinçons sont autant de marques de fabrique qui permettent de suivre sans risque d'erreur la diffusion des produits d'Oudhna. Le dépouillement en cours de la bibliographie indique une répartition assez uniforme dans le bassin méditerranéen : Égypte, Levant, Grèce, Italie, Midi de la France, Espagne.

Par ailleurs, la découverte, dans les thermes des Laberii et le comblement des niveaux inférieurs du capitole (Bonifay, Dridi, Jacquest à paraître), de sigillées africaines datables de la fin du IVe s. ou du début du Ves. mais dont l'aspect rappelle étroitement celui des productions d'Uthina, pose le problème de la phase initiale de la production de ces ateliers. Ces céramiques, qui appartiennent sans doute à la phase d'abandon des thermes, sont bien antérieures à la réutilisation de ces derniers par les potiers vers l'extrême fin du Ve s. ou le début du VIe siècle. Peuvent-elles toutefois avoir été produites à Uthina? Pour tenter de répondre à cette question, des échantillons de pâte de ces vases du IVe s. ont été analysés par fluorescence $\mathrm{X}$ au laboratoire "Archéométrie et archéologie » (CNRS, Maison de l'Orient Méditerranéen, Lyon) et comparés aux productions des ateliers plus tardifs (Brun 2001). Ces analyses permettent d'envisager que certaines de ces formes anciennes sont originaires d'Oudhna et confirment que cet atelier était déjà actif dans la seconde moitié du IVe siècle.

La technique de la sigillée (vernis argileux semi-grésé) était aussi appliquée à la fabrication de lampes du type Atlante X (infra, LAMPE TYPE 65, groupe D2) (Barraud et al. $1998,152-154$ et fig. $13, \mathrm{n}^{\circ} 12$ et 13 ), de figurines (Ibid., 154-156, et fig. 14) et même de tuiles (Ibid., 156157 et fig. 15).

Les ateliers d'Oudhna produisaient également, de manière plus accessoire, des céramiques culinaires : bouilloires (infra, CULINAIRE TYPES 33-34), marmites basses (peut-être de la catégorie $L R C W 6$ : Hayes 1978b), casseroles à manche plat (infra, CULINAIRE TYPE 35), et des céramiques communes, notamment des mortiers Carthage Class 1 (infra, CULINAIRE TYPE 11) et des lampes tournées Atlante XVI A et B (infra, LAMPE TYPE 83).

\section{ATELIER DE SIDI KHALIFA}

L'atelier de Sidi Khalifa (Pheradi Majus) est connu de longue date (Mackensen 1993, 32, avec bibliographie). Une thèse vient de lui être consacrée (Ben Moussa $2001)^{76}$.

La situation semble assez proche de celle d'Oudhna, puisqu'il s'agit d'un atelier principalement tardif, à la fois péri-urbain et urbain. Une vaste zone d'épandage de céramiques (fig. 25, a), avec des traces de fours arasés, s'étend dans la partie sud-ouest du site, en bordure du tracé actuel de l'oued, non loin de l'amphithéâtre ; le sol y est jonché de casettes et de tessons de vaisselles sigillées (fig. 25, b), notamment de forme Hayes 88 . Cependant, un four vient également d'être partiellement dégagé plus près du centre-ville (Ben Moussa 2001, 198). La production de céramique sigillée comprend plusieurs types:

- la forme Hayes 61B (infra, SIGILLÉE TYPE 38B3, $\left.\mathrm{n}^{\circ} 31\right)$;

- des assiettes Hayes 86, variante Lamboglia 60 (infra, SIGILlÉE TYPE 73, $\mathrm{n}^{\circ} 2$; cf. Ben Abed, Bonifay 1998, 233, note 4, et fig. 1, $\mathrm{n}^{\circ} 1$ );

- la forme Hayes 87A (infra, SIGILLÉE TYPE 45), mais peut-être pas sa variante à décor lustré ;

\footnotetext{
${ }^{76}$ J'ai eu l'occasion de visiter à deux reprises cet atelier (en 1997 et en 2001), à l'invitation de M. Samir Aounallah que je tiens à remercier ici.
} 

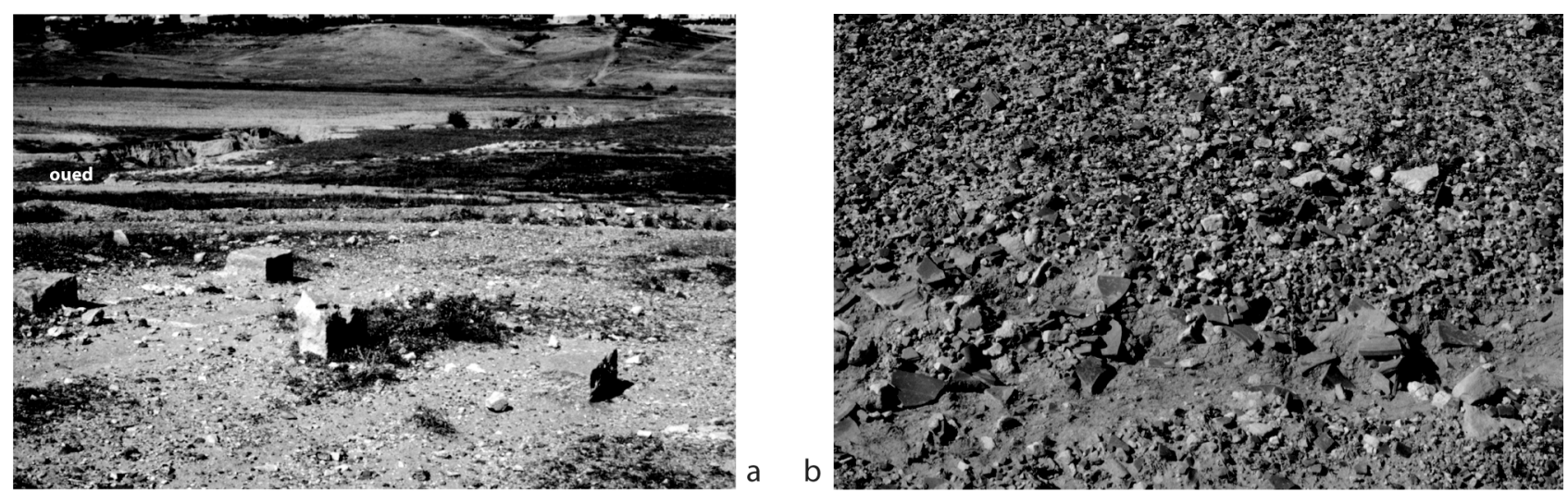

a-b : Ateliers de Sidi Khalifa (1998, sous la conduite de S. Aounallah, INP)

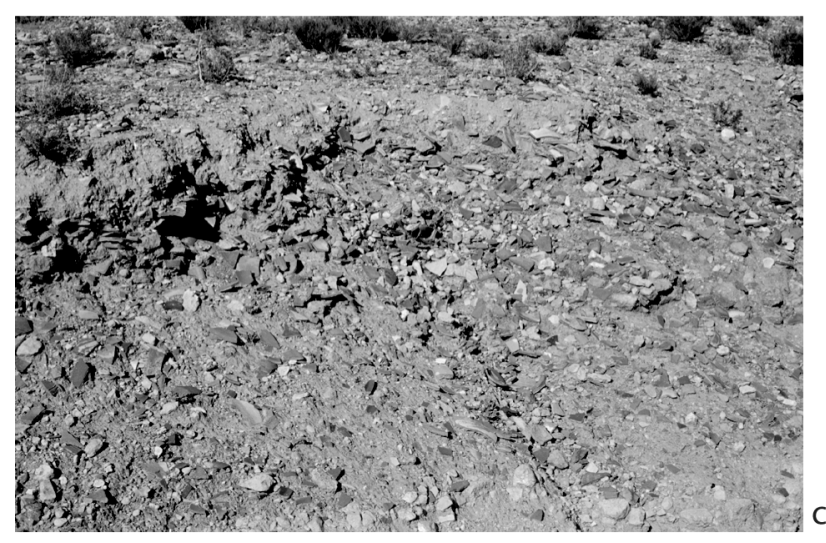

c: Ateliers de Sidi Aïch (2000, sous la conduite de M. Nasr)

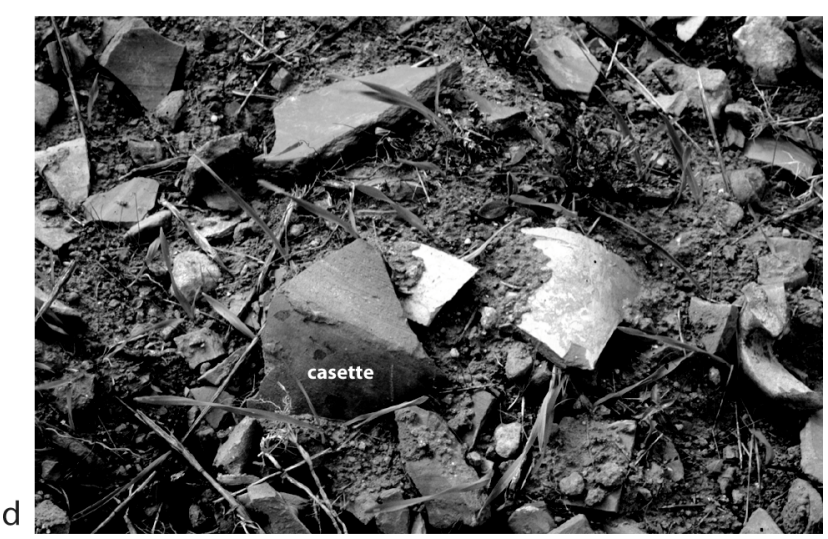

d : Ateliers de Sidi Zahruni (2001, sous la conduite de T. Ghalia, INP)

Fig. 25. Autres ateliers de sigillée africaine.

- la forme-phare de l'atelier de Sidi Khalifa est, sans contexte, le plat Hayes 88 (infra, SIGILLÉE TYPE 46) qui comprend de multiples variantes (Lund 1995, fig. 11-12 ; Ben Moussa 2001, P1. XLIV-XLV) ${ }^{77}$; - des variantes locales du bol à listel Hayes 91 (infra, SIGILLÉE TYPE 78, $\mathrm{n}^{\circ}$ 2) ;

- une variante locale du plat Hayes 103A (infra, SIGILLÉE TYPE 79) ;

- des formes non répertoriées (infra, SIGILLÉE TYPES 80-83 ; cf. également Ben Moussa 2001, Pl. XLVILIII).

Il n'est pas impossible que cet atelier ait également produit des céramiques culinaires, peut-être des marmites du type Sidi Jdidi $3^{78}$. A. Carandini $(1968,45)$ signale y avoir découvert des ratés de cuisson de couvercles Hayes 182. Aucune trace, en revanche, d'une production de lampes.

\section{ATELIER DE Sidi AÏCH}

Le phénomène des ateliers urbains d'époque tardive n'est pas limité à la Tunisie septentrionale. Je citerai simplement pour mémoire l'atelier de Sidi Aïch, qui fait

\footnotetext{
${ }^{77}$ Le nombre de variantes distingué dans ces deux publications me parait toutefois un peu excessif.

${ }^{78}$ Nombreux fragments sur le site, dont un de grande taille dont la cuisson paraissait incomplète.
}

partie du sujet de thèse de M. Mongi $\mathrm{Nasr}^{79}$. La configuration des traces d'atelier est la même qu'à Oudhna et à Sidi Khalifa : elles sont concentrées de manière périphérique dans le secteur sud-ouest du site, non loin des mausolées; d'autres traces paraissent s'avancer plus dans le centre-ville. Les dépotoirs d'ateliers forment plusieurs tells assez spectaculaires livrant une grande quantité de tessons de céramique sigillée (fig. 25, c) et surtout de fragments de casettes; on distingue l'emplacement d'un four arasé.

Ces observations conduisent à se demander si beaucoup de cités ne possédaient pas, en fait, de petits ateliers de sigillée, dont la production de faible qualité était réservée à une consommation essentiellement locale. On pensera ici aux productions « apparentées à la sigillée » mises en évidence à Rougga (infra, SIGILLÉE TYPE 84) (Guéry, Bonifay à paraître, $n^{\circ}$ 87-94) mais aussi à la Dougga ware (De Vos, Polla, Gliozzo 2004) ou encore aux productions de l'atelier de Thélepte (Nasr 1995). On ne manquera pas de mettre en parallèle l'abondance des sigillées de facture locale à Sidi Jdidi (Bonifay, Reynaud 2004, 233, groupe SG2) et la découverte dans la fouille de l'îlot contigu aux basiliques nord d'un pugillum de potier (fig. $29, \mathrm{n}^{\circ} 1$ ). Toujours en milieu urbain, on notera

\footnotetext{
${ }^{79}$ Je remercie mon ami Mongi Nasr de m'avoir invité, en juillet 2000 , à visiter cet atelier.
} 
la présence difficilement explicable de fragments de casettes pour la cuisson des sigillées, découverts de manière erratique dans la fouille de l'usine de salaison de Nabeul (Slim, Bonifay, Trousset 1999, 163 et note 31).

\subsubsection{Ateliers ruraux}

Toutefois, la plupart des grands ateliers à diffusion méditerranéenne repérés à ce jour sont des ateliers ruraux, probablement liés à des domaines agricoles : par exemple El-Mahrine (Mackensen 1993, 479-486) et Sidi Marzouk Tounsi (Peacock, Bejaoui, Ben Lazreg 1990, 74). Malheureusement, ils ne sont connus qu'en prospection et on ne sait pas comment s'organisait réellement la production de céramique par rapport aux autres productions, artisanales et surtout agricoles, de la villa. Je ne connais concrètement qu'un seul atelier rural de céramique sigillée :

\section{UN ATELIER MINEUR : SIDI ZAHRUNI (BENI KHIAR)}

Les sigillées n'occupent qu'une place marginale dans l'atelier de Sidi Zahruni (supra, p. 37), essentiellement tourné vers la production des amphores (Ghalia, Bonifay, Capelli 2004). Dans un premier temps des prospections, il a été envisagé que les casettes recueillies sur le site avaient été fabriquées, mais non utilisées sur place. Mais très vite, il a fallu se rendre à l'évidence que ces casettes portaient des traces d'utilisation et que, groupées dans un secteur du site, elles étaient mêlées à des tessons de sigillées (fig. 25, d), certains étant en outre surcuits.

La production de cet atelier se caractérise tout d'abord par une pâte plus grossière que celle de la plupart des sigillées africaines (pâte comparable à celles des amphores produites sur l'atelier) (Pl. II, $\mathrm{n}^{\circ} 14$ ), avec un vernis orange sombre, mat, granuleux. Les formes ne correspondent pas non plus aux standards des sigillées africaines :

- forme Hayes 50B-n ${ }^{\circ} 61$ (infra, SIGILLÉE TYPE 65) (1-2) ;

- forme apparentée à Hayes 53B (infra, SIGILLÉE TYPE 66) (3) ;

- formes apparentées aux plats Hayes 58 et $61 \mathrm{~B}$ (infra, SIGILLÉE TYPE 67) (4);

- forme apparentée à la coupe Hayes 84 en sigillée C5 (type Fulford 27 : infra, SIGILLÉE TYPE 75) (5-6).

Les décors, très caractéristiques, sont constitués de rouelles très simples disposées en couronne (2).

Exemples (fig. 26) :

*1-2 Bord et fond de plat Hayes 50B $\mathrm{n}^{\circ} 61$, décor de rouelles (Ghalia, Bonifay, Capelli 2004, fig. 5, $\mathrm{n}^{\circ} 29$ 30).

*3 Bord d'assiette Hayes 53B, variante Sperlonga 3 (Ibid., $\mathrm{n}^{\circ} 32$ ).

*4 Bord de plat Hayes 61B, variante (Ibid., $\left.\mathrm{n}^{\circ} 31\right)$.

*5 Bord d'assiettes Fulford 27 (Ibid., n 33-34).

Ces productions, accessoires par rapport à la production d'amphores de l'atelier, ont cependant une diffusion à la fois locale et méditerranéenne (infra, p. 201).

\section{Atelier de Nabeul-Sidi Zahruni}

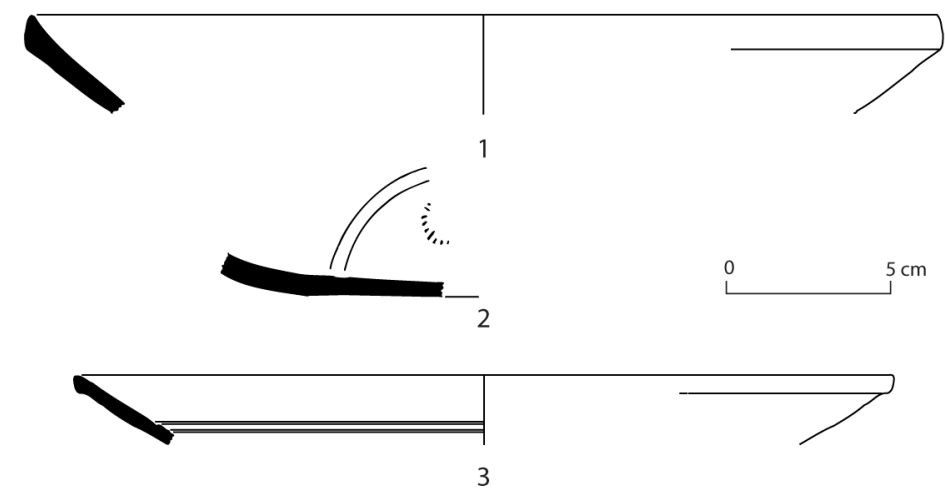

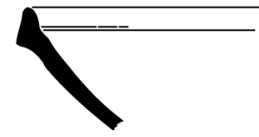

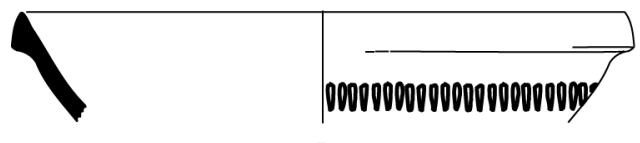

5

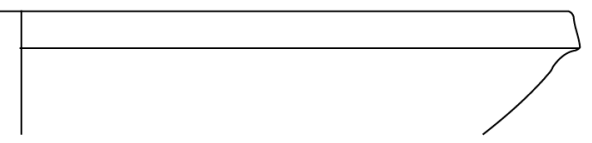

4
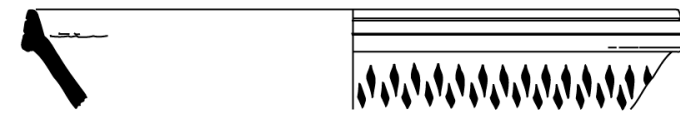

6

Fig. 26. Céramique sigillée africaine. Productions de l'atelier de Sidi Zahruni. 


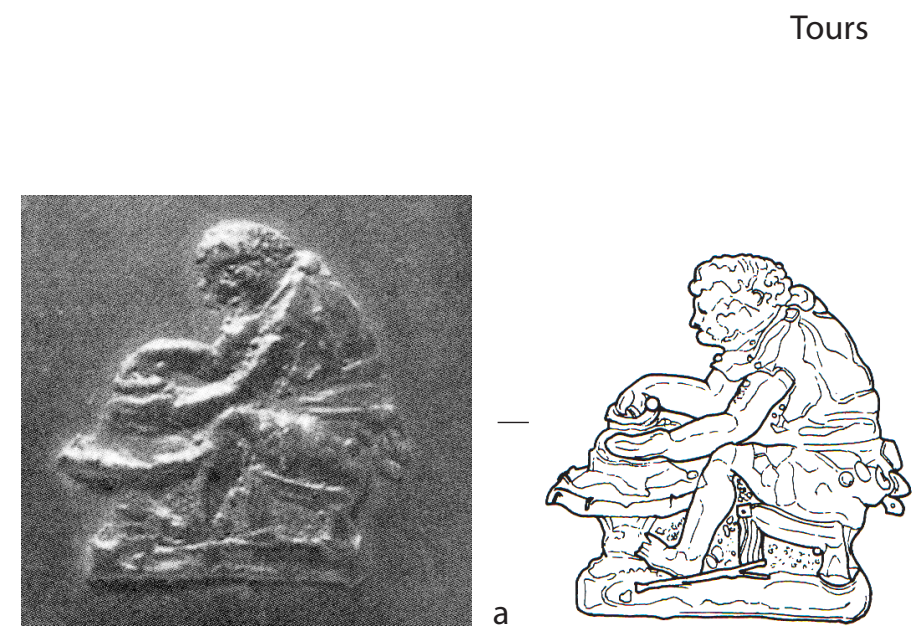

a : Représentation sur un vase en céramique sigillée $C 1$ d'un potier africain utilisant un tour à main ou à bâton (Mackensen 1993, fig. 12)

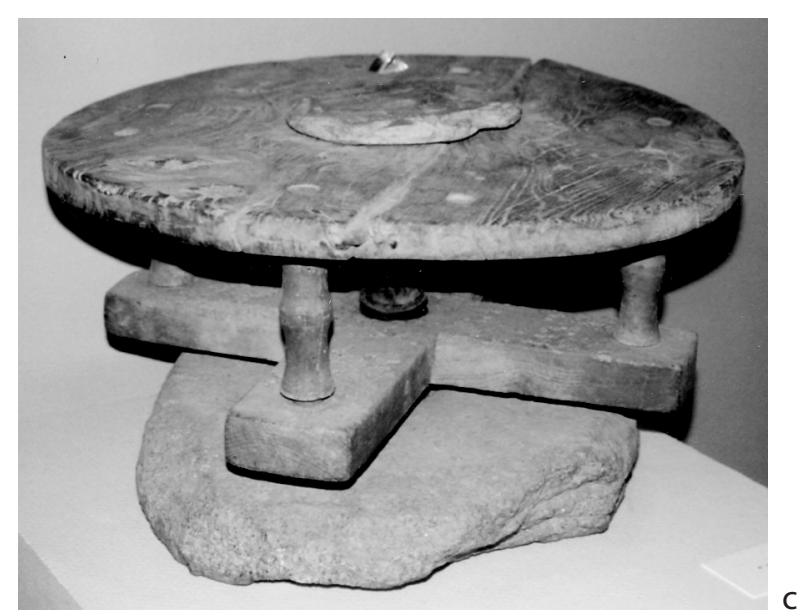

c: Tour à main du Portugal, début XXe s. (Musée de Barcelos) Le socle est en pierre.

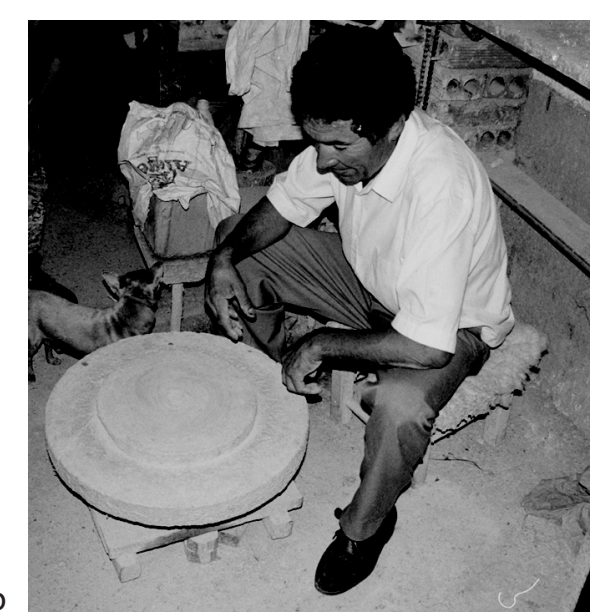

b : Potier galicien (Agapatos, Espagne) devant son tour à main (1996)

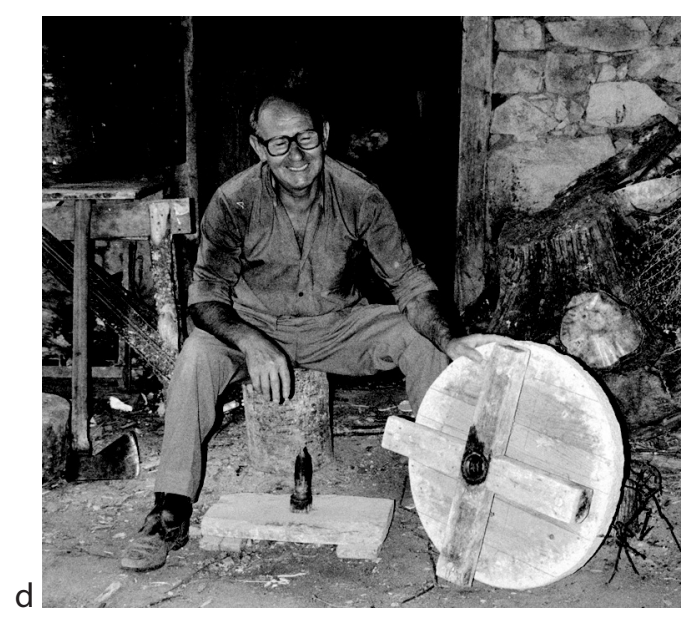

$d$ : Potier galicien (Agapatos, Espagne)

montrant le fonctionnement de son tour à main (1996). Le socle en bois est muni d'un axe en buis, enduit de graisse.

Fig. 27. Façonnage des sigillées africaines : tour antique et comparaisons actuelles. 


\subsection{CONSIDÉRATIONS TECHNIQUES}

\section{Le façonnage}

J. W. Hayes avait longuement insisté sur l'utilisation du moule pour la fabrication des sigillées africaines, beaucoup de formes élancées, aux parois minces et au bord effilé ne pouvant être obtenues, selon lui, par simple tournage (Hayes 1972, 292-295). Il remarquait cependant l'absence de toute référence explicite à des découvertes de moules pour l'estampage des formes de vaisselle sur les sites d'ateliers (Ibid., 293). J. M. Schuring (1988, 3435) a apporté, quant à elle, des arguments techniques qui semblent démontrer que certaines formes (notamment Hayes 50) ont effectivement été tournées dans des moules.

De fait, l'iconographie, même peu abondante, nous renseigne plutôt sur l'usage du tour. Il est même symptomatique que la représentation la plus évidente d'un tour de potier (Mackensen 1993, fig. 12) (fig. 27, a) apparaisse sur une des poteries les plus difficiles à obtenir avec cet instrument: une sigillée $\mathrm{C} 1$ de forme Salomonson 1/Hayes 171, aux parois très fines. De plus il s'agit d'un tour à main ou d'un tour à bâton dont on pourrait penser qu'ils sont généralement plus rudimentaires, en tout cas moins rapides que le tour à pied, plus largement répandu de nos jours. En fait, le tour à main est un tour tout aussi rapide que le tour à pied. J'ai eu moi-même la surprise de le constater en regardant travailler les potiers de Galice qui utilisent encore ce type de tour (fig. 27, b). Ce tour, constitué de deux parties séparables : un plateau circulaire solidaire d'un croisillon et un socle en pierre ou en bois sur lequel est fixé l'axe, présente en outre l'avantage d'être extrêmement mobile (fig. 27, c-d).

Je n'ai pas remarqué, dans le matériel de l'atelier d'Oudhna, d'objet en plâtre ou en céramique, qui puisse faire réellement penser à un moule. Tout au plus, quelques fragments de grandes vasques, au demeurant peu nombreux (fig. 28, a), peuvent-ils être interprétés comme des gabarits de tournage ${ }^{80}$ ou des rondeaux, à l'image de ceux couramment utilisés de nos jours dans les ateliers traditionnels de Jerba. En revanche, suivant en cela les avis de J. W. Hayes et de J. M. Schuring, il semble bien, à l'observation, que certains vases en sigillée n'ont pas été tournés mais moulés. A mon sens, il en est ainsi des patères en sigillée africaine $\mathrm{A}$ de type Atlante XVII, 17, dont la partie inférieure est obtenue par estampage comme le montrent les traces rayonnantes visibles sur la face extérieure (et non pas concentriques comme ce devrait être le cas avec l'usage du tour); le bord en virgule et le petit pied annulaire pouvaient être, en revanche, ajoutés sur le tour (Bonifay 2004a, 39) (fig. 28, b).

\footnotetext{
${ }^{80}$ Ou tout au moins des « accessoires de tournage », comme celui publié par Mackensen 1993, 69 et fig. 14, $\mathrm{n}^{\circ} 1$.
}

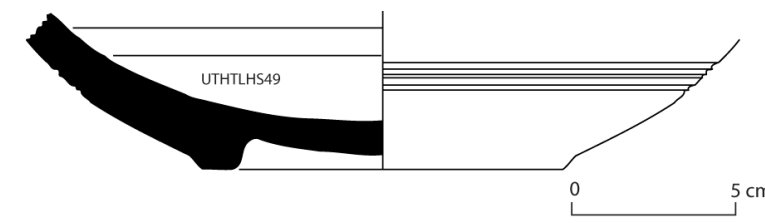

a : Oudhna, atelier des thermes des Laberii. Gabarit de tournage (?).

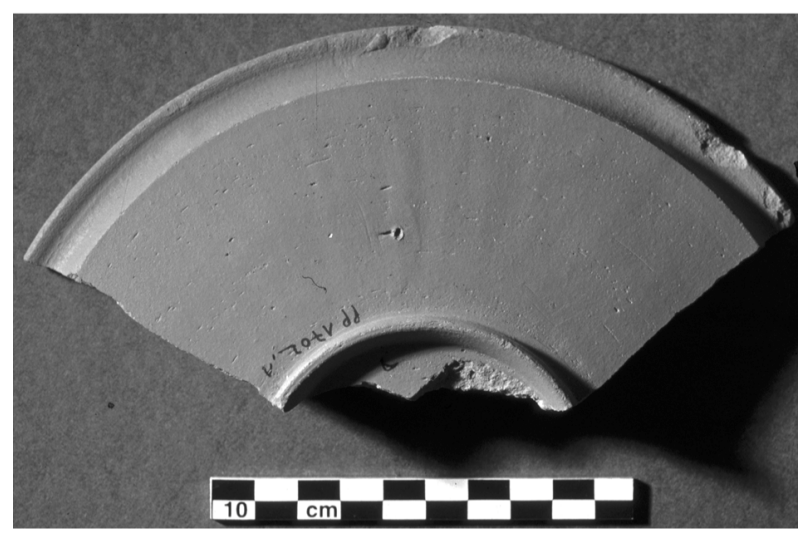

$b$ : Sigillée africaine $A$.

Traces de moulage sur la partie inférieure d'une patère Atlante XVII, 17 (SIGILLÉE TYPE 14).

Fig. 28. Façonnage des sigillées africaines : gabarit (?) et moules

\section{Le polissage}

Un des outils les plus fréquemment retrouvés sur les ateliers de sigillée africaine est le polissoir (Mackensen 1998c). Plusieurs types sont connus (fig. 29) :

- Le type le plus simple et le plus répandu (El Mahrine: Mackensen 1993, 74-83) est celui du «pugillum », qui a la forme générale d'un galet, avec des profils différents symétriques/dissymétriques et pouvant comporter deux grandes faces concaves ou une face concave et l'autre convexe ${ }^{81}$.

Exemple (fig. 29) :

*1 Sidi Jdidi, basilique 3 (Inv. JD5088.1). Pugillum de type Salomonson 1 à deux grandes faces concaves (Salomonson 1982). Marque incisée : SAPE( ?)I.

- Un autre type de polissoir, bien connu à El Mahrine (Mackensen 1993, fig. 15, $\mathrm{n}^{\circ} 1-2$ ) est en forme de champignon, la face utile étant légèrement convexe et l'autre face munie d'un manche court et plein : Exemple (fig. 29) :

*2 Oudhna, zone périphérique d'ateliers (Barraud et al. 1998, fig. 18, $\mathrm{n}^{\circ}$ 34). Marque incisée : Vitalis.

- Egalement en forme de champignon, ce polissoir, déjà attesté sur l'atelier de Tiddis en Algérie (Mackensen 1993, fig. 17, $\mathrm{n}^{\circ} 1$ et 2 ) et peut-être sur l'atelier d'El Mahrine en Tunisie (Ibid., fig. 15, $\mathrm{n}^{\circ} 3$ ), est entièrement creux et muni d'une sorte de douille dans laquelle on peut introduire un manche (en bois ?) :

\footnotetext{
81 Typologie élaborée par Salomonson (1982) et reprise par Mackensen 1993, 74-80.
} 

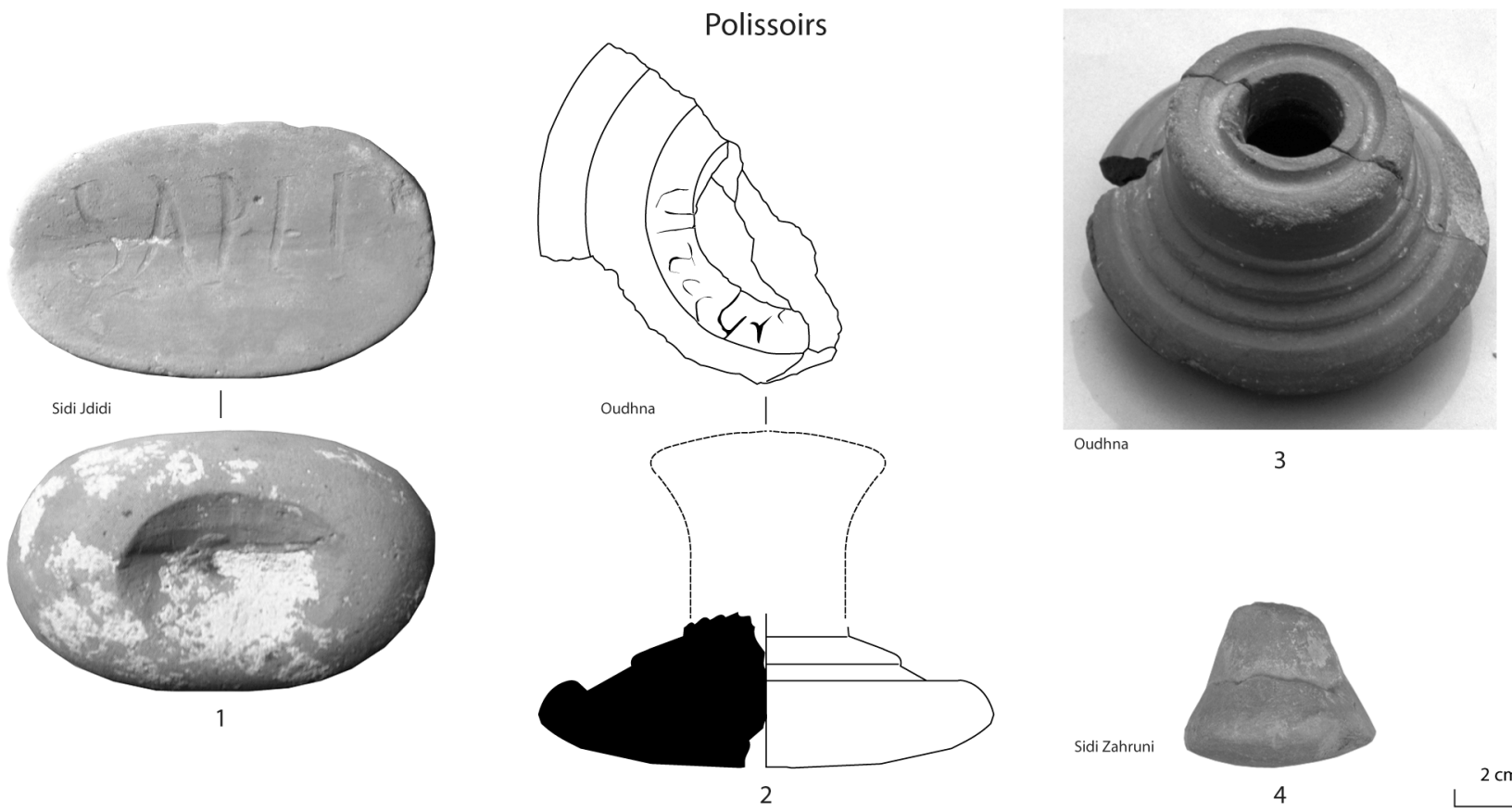

3

Fig. 29. Céramiques sigillées africaines. Exemples de polissoirs.

Exemple (fig. 29) :

*3 Oudhna, thermes des Laberii (sans $n^{\circ}$ d'inv.).

- Certains polissoirs, enfin, sont de toute petite taille (Mackensen 1993, fig. 17, $\left.\mathrm{n}^{\circ} 4\right)$ :

Exemple (fig. 29) :

*4 Atelier de Sidi Zahruni (sans n d'inv.).

Comme beaucoup d'outils d'artisans, ces polissoirs portent des inscriptions avec les noms des potiers (1-2). La fonction exacte de ces objets a fait l'objet de discussions (Mackensen 1993, 80-83) mais l'hypothèse la plus vraisemblable est qu'il s'agisse de polissoirs utilisés sur les poteries après la phase de séchage, alors qu'elles avaient déjà acquis la texture dite « du cuir » $(\text { Ibid., } 83)^{82}$. Le fait que les pugilla reprennent, de manière artificielle, la forme générale d'un galet, objet encore utilisé de nos jours pour le polissage des céramiques modelées traditionnelles (Fayolle 1992, 138), va dans le sens de cette hypothèse.

Le polissage revêt parfois un caractère très rudimentaire, notamment sur certaines productions de Byzacène méridionale apparentées à la sigillée (infra, SIGILLÉE TYPE 84 ; Bonifay et al. 2002-2003, fig. 10, $\mathrm{n}^{\circ} 120$ et 259). Dans ce cas, le polissage a eu lieu après l'engobage de la pièce ou directement sur l'argile brute dans les cas majoritaires où les vases ne sont pas engobés, avec un objet (un chiffon ?) qui a retenu certaines particules lourdes et provoqué de très caractéristiques rayures.

\footnotetext{
${ }^{82}$ M. Mackensen a remarqué des traces de frottement sur les faces convexes des pugilla qui ne pourraient pas se comprendre si ces derniers avaient été utilisés sur l'argile fraîche, lors du tournage.
}

\section{L'enfournement : les casettes de cuisson}

La casette de cuisson («Brennhilfsmittel»: Mackensen 1993, 88 ; « saggar»: Peacock, Bejaoui, Ben Lazreg 1990, 68) est l'objet qui, en Afrique, signale un atelier de sigillée. En effet, cet outil de cuisson figure, systématiquement et en grande quantité, sur tous les ateliers reconnus en Tunisie (El Mahrine ${ }^{83}$ : Mackensen 1993, fig. 24 ; Sidi Marzouk Tounsi, Henchir es-Srira, Henchir el-Gellal Djilma : Peacock, Bejaoui, Ben Lazreg 1990, fig. $7, \mathrm{n}^{\circ} 1$, fig. 12 , a, b, c ; fig. 14, a-p) ; sa présence est la condition nécessaire pour l'identification d'un atelier de sigillée africaine (fig. 25,d).

Exemples (fig. 30) :

*1 Atelier de Sidi Zahruni (cf. Ghalia, Bonifay, Capelli 2004 , fig. $\left.5, \mathrm{n}^{\circ} 35\right)$. D. $26,5 \mathrm{~cm}$.

2 Atelier d'El-Mahrine (Mackensen 1993, fig. 24, nº 6). Traces de lutage à l'argile au sommet d'une casette.

*3 Atelier de Sidi Marzouk Tounsi (Peacock, Bejaoui, Ben Lazreg 1990, fig. 7, $\mathrm{n}^{\circ}$ 1). D. 22,5 cm.

*4 Atelier d'Oudhna (Barraud et al. 1998, fig. 19). D. 24 $\mathrm{cm}$.

*5 Atelier d'El-Mahrine (Mackensen 1993, fig. 101, $\mathrm{n}^{\circ}$ 5). D. $40 \mathrm{~cm}$.

*6 Atelier d'Oudhna (Barraud et al. 1998, fig. 20, n 39). D. $24 \mathrm{~cm}$. Marque incisée sur le rebord.

*7 Atelier d'El-Mahrine (Mackensen 1993, fig. 24, n 7). Décor de style A(ii/iii) imprimé à l'extérieur.

*8 Atelier d'Oudhna (Barraud et al. 1998, fig. 20, n³7). Décor de style E(i) imprimé à l’intérieur.

\footnotetext{
${ }^{83}$ Je me demande si les « jarres spécialement fabriquées pour un usage funéraire » de la nécropole d'El-Mahrine (Slim 1969-70, fig. 2) ne seraient pas, finalement, des casettes de haute taille provenant de l'atelier proche.
} 
En effet, les casettes de cuisson jouent, en Afrique, le rôle inverse des tuyères utilisées dans les ateliers du Sud de la Gaule $^{84}$ pour canaliser flammes et fumées (fig. 32, a). Ici ce sont les vases à cuire qui sont protégés par des récipients cylindriques emboîtés les uns dans les autres (fig. 32, b), selon une méthode qui sera employée à grande échelle dans les ateliers de faïence de l'époque moderne (d'Alembert et Diderot, Pl. VIII et IX ; Rosen 1995, 49-50). Peut-être faut-il chercher l'origine de ce procédé de cuisson au Proche-Orient, puisque les faïences égyptiennes sont produites selon la même technique (Nenna, Seif el-Din 2000, 26 et fig. 3).

La découverte à Oudhna de profils complets de casettes et d'assiettes Hayes 99B dans le comblement homogène, au milieu du VIe s., du four $n^{\circ} 4$, m'a incité à réfléchir ${ }^{85}$ sur la façon dont les vases étaient empilés dans les casettes et sur la disposition de ces dernières dans le laboratoire du four (Barraud et al. 1998, 162-165). Un dessin (fig. 31, ad) résume les quatre hypothèses envisageables ; l'hypothèse « $\mathrm{c}$ » paraît la seule vraisemblable ${ }^{86}$. Il apparaît ainsi que les casettes doivent être regardées tête en bas par rapport au sens dans lequel elles sont généralement illustrées (Barraud et al. 1998, la fig. 19 est à retourner; idem pour les casettes publiées dans Mackensen 1993 et Peacock, Bejaoui, Ben Lazreg 1990). Ce sont des boîtes cylindriques dont le fond aurait été largement découpé. Cette ouverture est sans doute destinée à passer la main et soutenir l'empilement des vases, encore fragiles, lors du chargement de la casette (12 ou 13 bols Hayes 99B tiennent dans une casette du four $\mathrm{n}^{\circ} 4$ ). Etant donné que le fond est nettement convexe, les vases doivent être disposés dans leur sens normal, ouverture vers le haut. Les casettes sont ensuite transportées pleines dans le four. La vue en plan du four avec son chargement de casettes (fig. $31, \mathrm{f}$ ) est purement théorique et on pourrait plutôt imaginer une disposition similaire à celle adoptée actuellement dans les ateliers de Moknine $^{87}$ : en colimaçon en partant des parois du four, en veillant bien toutefois à laisser libres les orifices de la sole. Les casettes sont superposées les unes sur les autres, soigneusement lutées entre elles avec de l'argile. Les casettes supérieures sont probablement fermées par des couvercles dont on a, semble-t-il, identifié des fragments à Oudhna. Les ateliers actuels de faïence à Fès (Maroc), qui utilisent des casettes assez proches de celles d'Oudhna, montrent toutefois un autre mode d'empilement, les casettes étant posées inversées l'une sur l'autre, de manière à former une boîte (fig. 31, e) ; ce

\footnotetext{
${ }^{84}$ La casette signalée par A. Vernhet (1981, fig. 9, $n^{\circ}$ 6) sur l'atelier de La Graufesenque me parait douteuse.

85 J'ai bénéficié des conseils et de l'expérience de Jacques Thiriot et Lucy Vallauri, mes collègues et amis du Laboratoire d'Archéologie Médiévale Méditerranéenne.

${ }^{86} \mathrm{M}$. Maurice Picon, qui a été consulté sur cette question, penche également pour cette hypothèse.

${ }^{87}$ Enquête ethnographique de janvier 2001.
}

type d'empilement n'est possible qu'avec des casettes dont le fond est plat, comme celles de Fès.

En prenant pour modèle le seul four de sigillée fouillé en Tunisie, le four $n^{\circ} 1$ d'Oudhna, et en suivant l'hypothèse $\mathrm{c}$ d'empilement, il semble que l'on puisse disposer une trentaine de casettes à la surface du laboratoire, et si l'on admet que la hauteur d'un four est au moins égale à son diamètre, ce sont six à huit étages de casettes qui peuvent prendre place dans ce four de 1,70 à $1,90 \mathrm{~m}$ de haut. A raison d'au moins 12 vases par casette et de 180 casettes par four, on peut estimer de manière tout à fait théorique que le chargement du four $n^{\circ} 1$ permettait de cuire entre 2160 et 2880 bols Hayes $99^{88}$. Ce modèle théorique d' " encastage » décrit à Oudhna (Barraud et al. 1998) devrait pouvoir être appliqué, à quelques détails près, à l'ensemble des ateliers de sigillée africaine (fig. 32, b).

M. Mackensen a remarqué 1'absence à El-Mahrine des accessoires de cuisson fréquents sur les ateliers de sigillée gauloise $^{89}$ (Mackensen 1993, 92) à l'exception toutefois de quelques séparateurs très simples (Ibid., fig. 42-43). $\mathrm{Si}$, à Oudhna, même ces supports semblent absents, c'est peut-être en raison de la morphologie des vases produits sur cet atelier, dotés sur le fond d'un solide ressaut qui facilite l'empilement dans les casettes et joue lui-même le rôle de séparateur (Barraud et al. 1998, 165). Le diamètre des casettes varie d'un site à l'autre en fonction de la taille des vases les plus souvent fabriqués. A Oudhna, les casettes ont une taille standard (D. 22-24 cm) adaptée à la plupart des formes (Hayes 91B tardive, Hayes 95-99) tandis que celles de Sidi Khalifa, de plus grand diamètre, correspondent aux grands plats Hayes 61B, 87A, 88, 103.

Les casettes sont donc un élément essentiel du fonctionnement des ateliers de sigillée africaine. On est d'autant plus surpris du résultat des analyses pétrographiques et physico-chimiques effectuées sur un certain nombre d'échantillons de ces objets. Il apparaît ainsi que la pâte des casettes de l'atelier de Sidi Zahruni est assez différente de celle des autres productions de l'atelier (Ghalia, Bonifay, Capelli 2004) et qu'il en est de même pour les casettes de l'atelier d'Oudhna qui ont été analysées (Brun 2001) ${ }^{90}$. Ces différences posent le problème de l'origine des casettes de ces deux ateliers, qui ont été soit fabriquées sur place avec une argile locale différente ou une argile importée, soit fabriquées sur un

\footnotetext{
${ }^{88}$ Evaluation cohérente avec celles concernant les fours de sigillée gauloise: Th. Martin (in : Bémont, Jacob 1986, 69) estime à 800 ou 1000 le nombre de pièces de céramiques pouvant être cuites dans un four circulaire de la première moitié du Ier s. et à 4000 dans un grand four rectangulaire de l'époque flavienne.

${ }^{89}$ Cf. Vernhet 1981.

${ }^{90}$ L'expertise pétrographique effectuée par Claudio Capelli, antérieurement à l'analyse physico-chimique, avait donné les mêmes résultats.
} 
Production - Sigillées

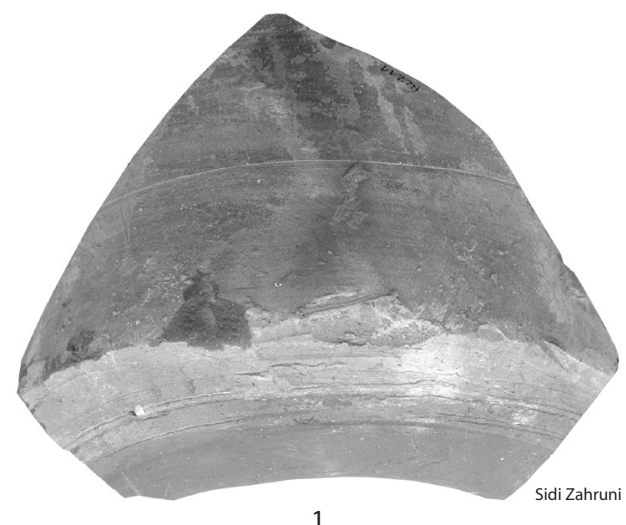

Casettes

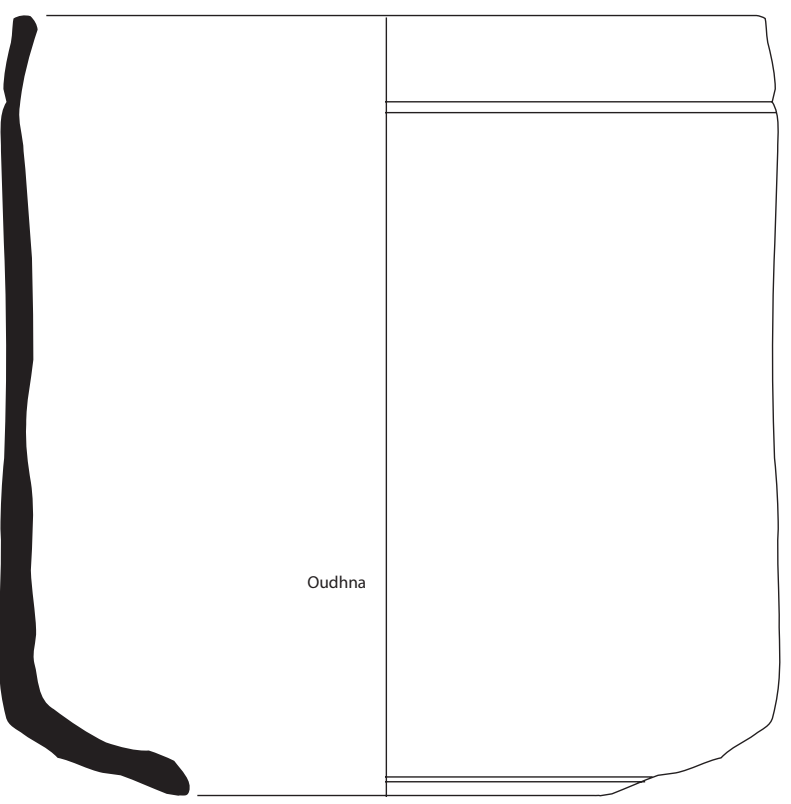

3

4

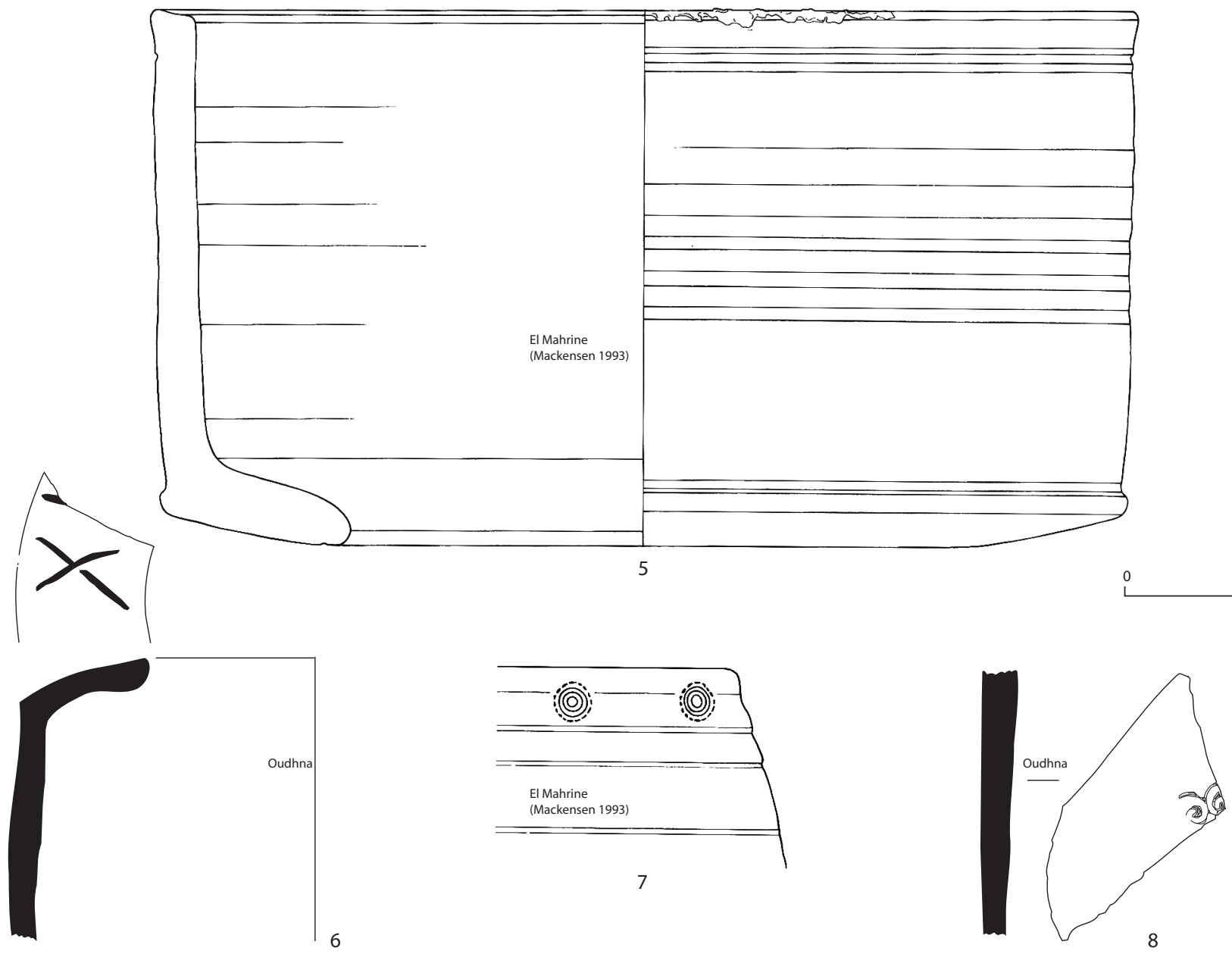

Fig. 30. Exemples de casettes pour la cuisson des céramiques sigillées africaines.

62 


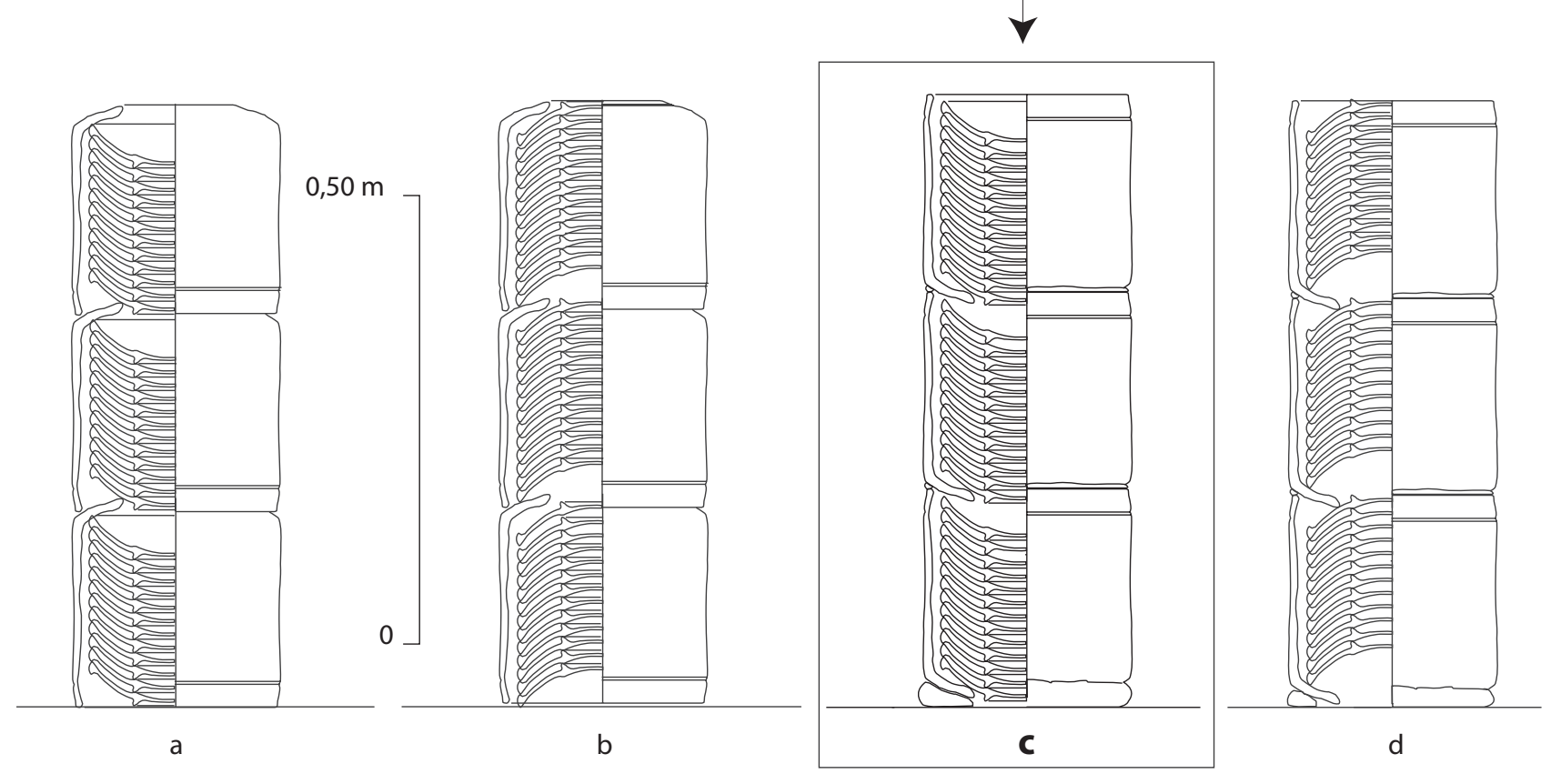

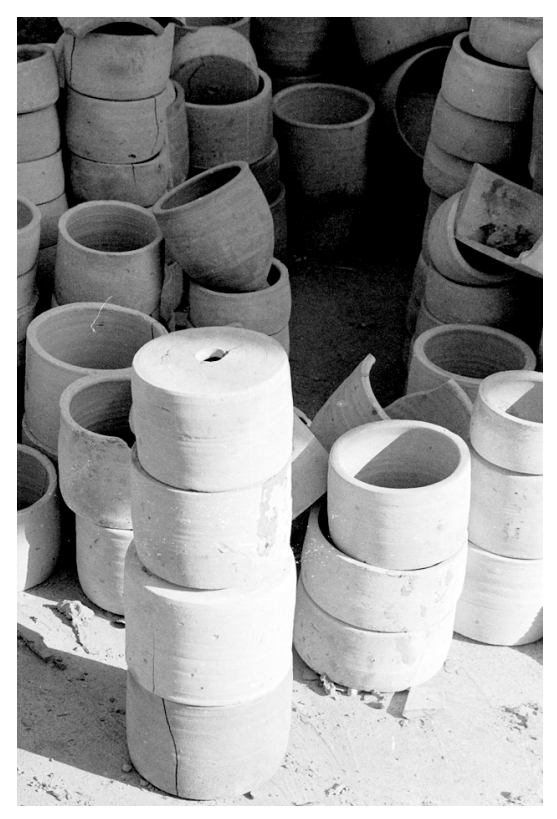

e

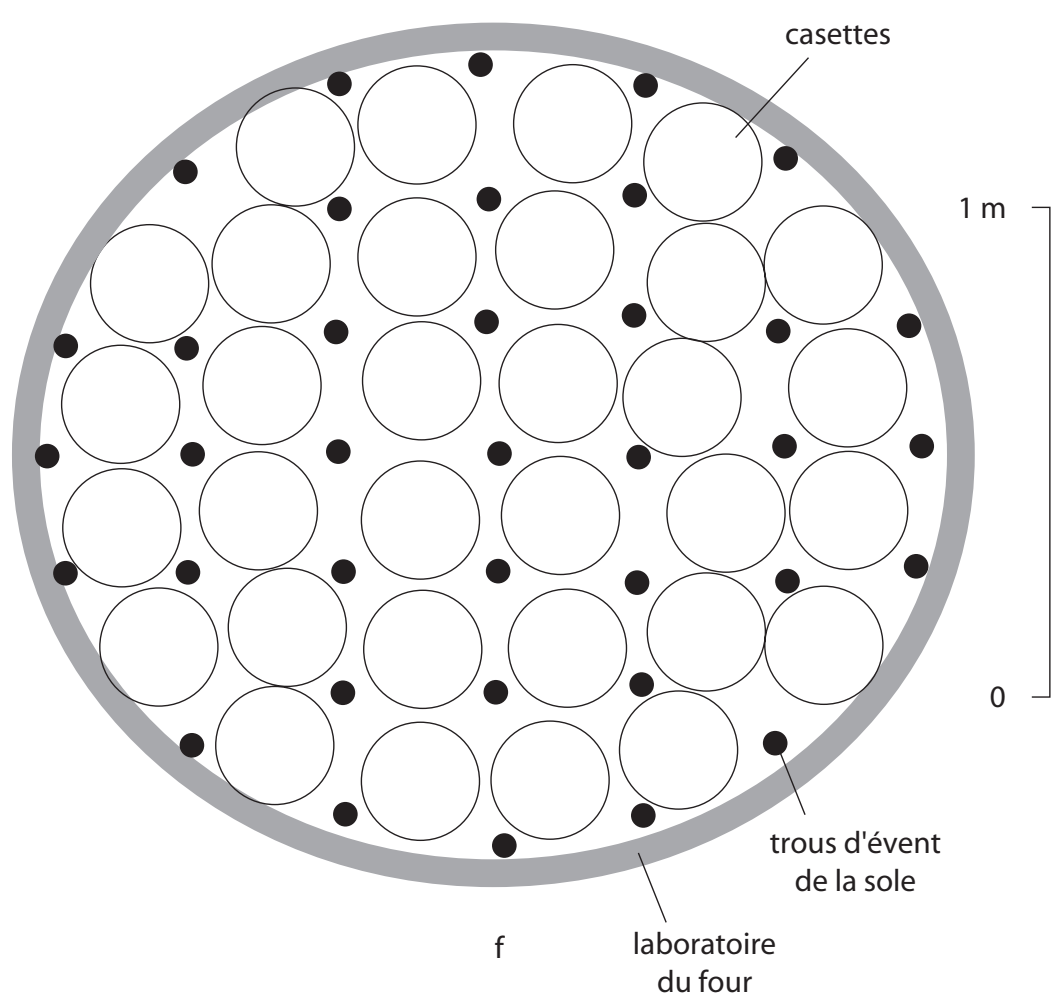

Fig. 31. Hypothèses de reconstitution des procédés d'encastage.

a-d : Propositions pour l'empilement des vases dans les casettes : la proposition c est la plus vraisemblable.

e : Solution adoptée actuellement dans un atelier de faïences de Fès (1999)

$\mathrm{f}$ : Proposition pour une vue en plan d'un four avec son chargement de casettes. 


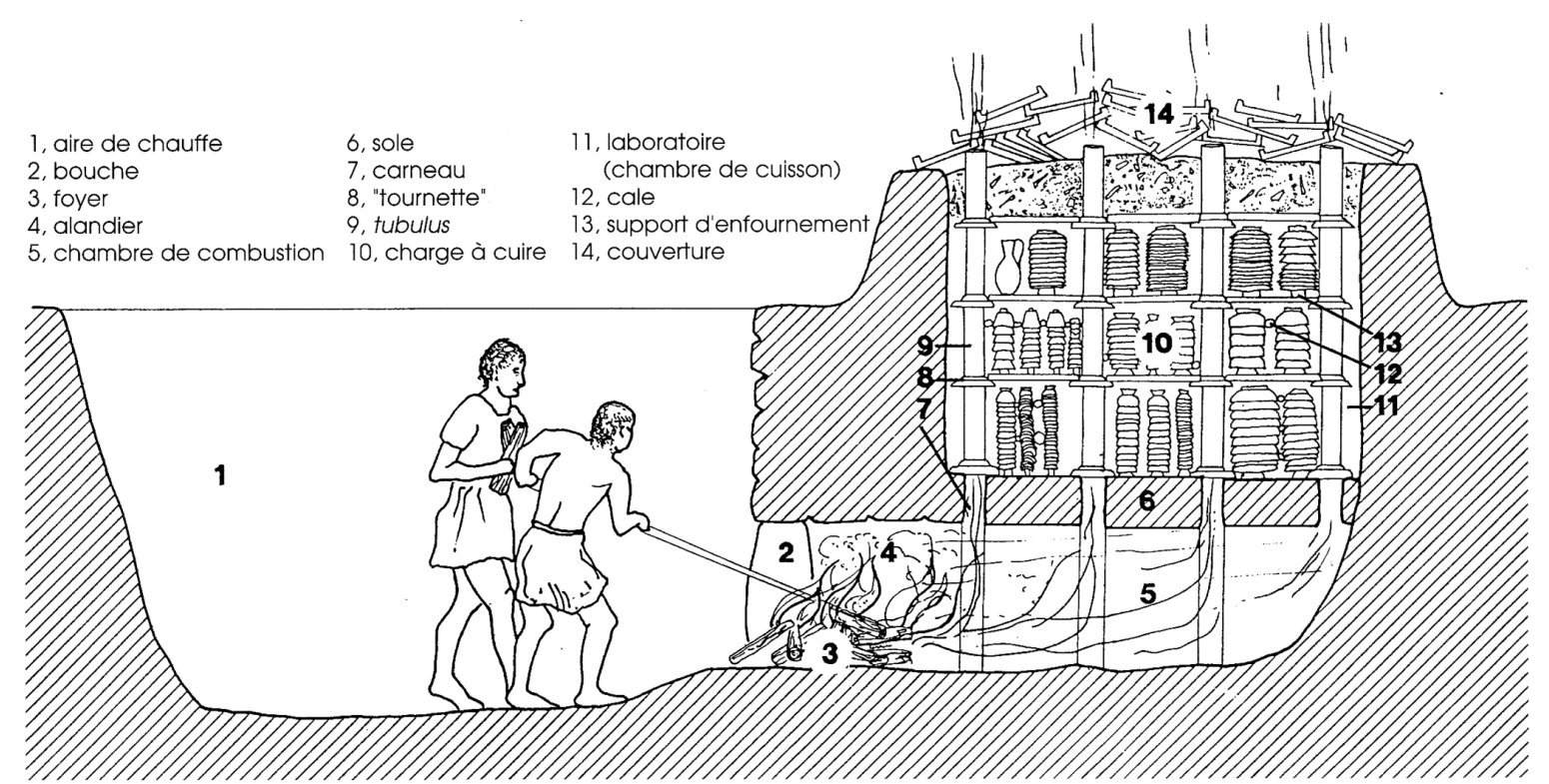

a : Céramique sigillée gauloise, coupe schématique d'un four de Montans (Martin 1996, fig. 29)

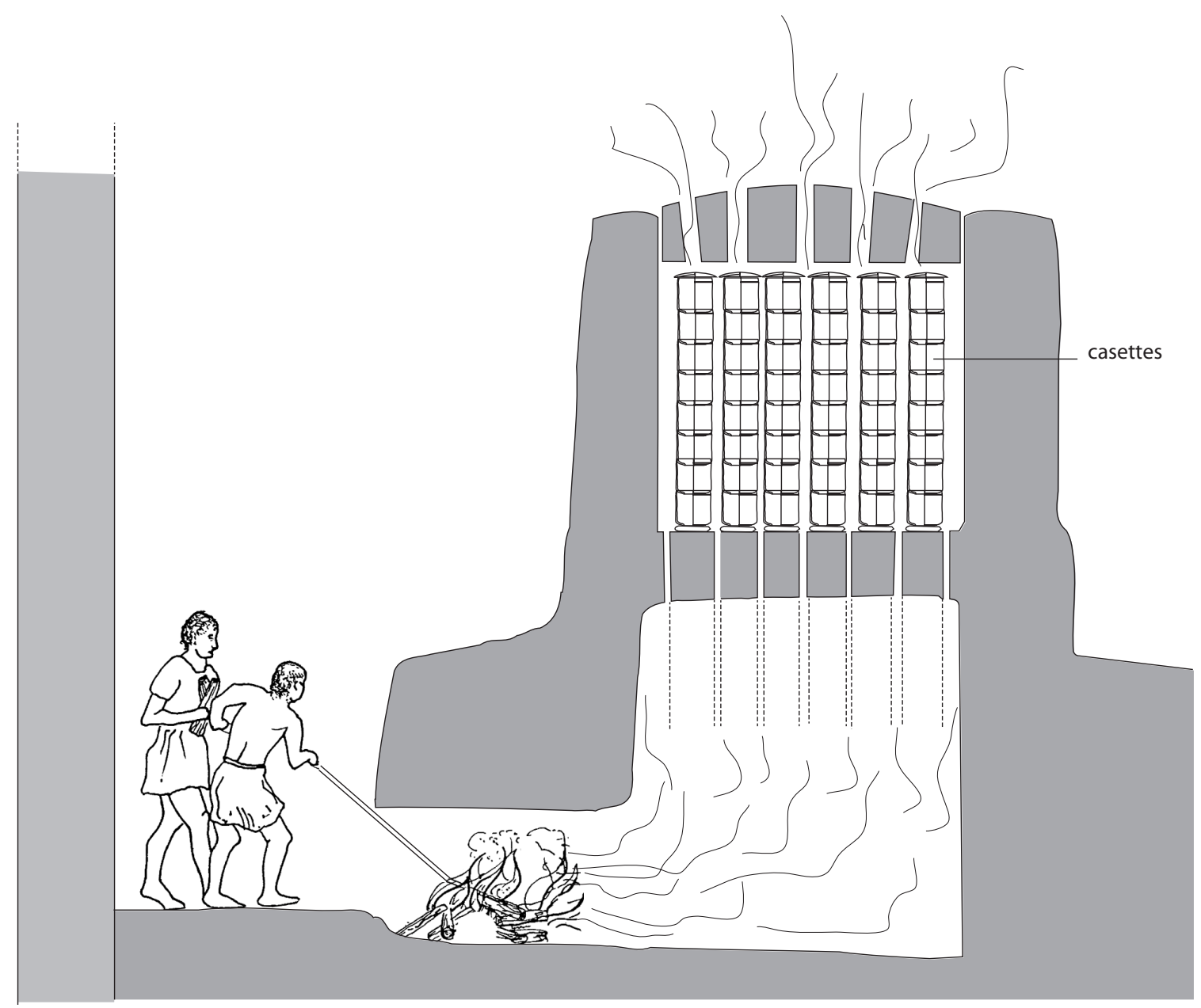

b : Céramique sigillée africaine, coupe théorique inspirée de l'atelier des thermes des Laberii à Oudhna.

Fig. 32. Hypothèses de restitution du fonctionnement des fours à sigillées. 
autre atelier et importées. Etant donné que la pâte des casettes nécessite une particulière résistance à la chaleur, on peut se demander si la production des casettes n'est pas liée à la production de céramiques culinaires, précisément absentes à Sidi Zahruni et peu abondantes à Oudhna. Dans ce dernier cas, la situation est encore troublée par le fait qu'une casette découverte dans les thermes des Laberii porte l'empreinte d'un poinçon de sigillée bien attesté sur cet atelier (fig. $30, \mathrm{n}^{\circ} 8$ )... Ce problème est d'autant plus déconcertant ${ }^{91}$ que sur d'autres ateliers, par exemple Sidi Khalifa (Brun 2001), la pâte des casettes s'intègre parfaitement à celle des autres productions.

A l'époque byzantine tardive (ou au début de l'époque omeyyade, des céramiques sigillées de la région de Nabeul-Hammamet présentent un aspect tout à fait particulier : pâte blanche, engobe incomplètement grésé de couleur marron ou noirâtre (Pl. II, ${ }^{\circ} 20$ et fig. 111), alors que les formes ne changent pas fondamentalement (Hayes 105, 109, 99C ? ; infra, SIGILlÉE TYPE 95). Ces vases sont le témoin d'un changement technologique radical: la cuisson de ces «dérivées de sigillées africaines » n'est plus maîtrisée et, très certainement, l'utilisation des casettes abandonnée (Bonifay 2002, 183).

\section{Les fours}

Les fours d'Oudhna (Barraud et al. 1998, 140-146) et celui de Sidi Khalifa (Ben Moussa 2001) semblent construits sur le même modèle : une chambre de chauffe circulaire, de modestes dimensions, dotée d'arceaux pour le support de la sole. Ils se distinguent bien des fours à amphores plus grands et munis d'un pilier central (supra, p. 44). Selon J. W. Salomonson (1971, fig. 8), un four de potier à voûte permanente est représenté sur le relief d'applique d'une assiette Hayes 53 en sigillée C3 (représentation similaire : Atlante I, Pl. LXXXVI, $\mathrm{n}^{\circ} 12$, motif $\mathrm{n}^{\circ} 120$ ).

91 Quoique cette situation soit parfaitement connue sur les ateliers de faïence modernes (renseignement L. Vallauri). 


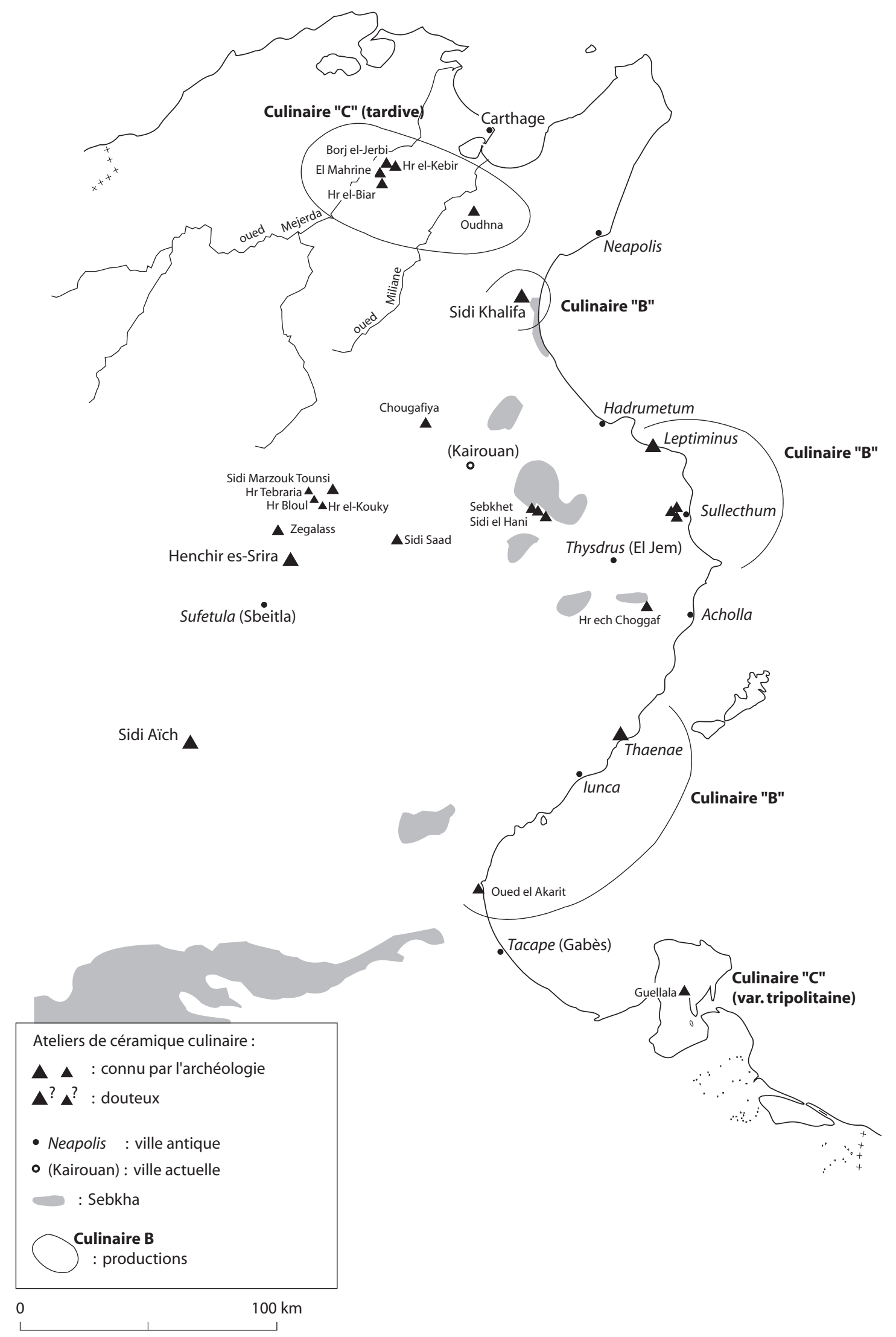

Fig. 33. Carte des principaux ateliers de céramique culinaire connus en Tunisie. 


\section{LES AUTRES PRODUCTIONS}

\subsection{VAISSELLES CULINAIRES}

\section{Provenances}

On distingue de manière traditionnelle (Atlante I, 209210) trois grandes catégories de céramiques culinaires africaines :

A) La céramique culinaire apparentée à la sigillée africaine $\mathbf{A}$, représentée par les formes Hayes 23A et B, et peut-être une partie des plats Hayes 181, notamment leurs variantes tardives (Ostia $\mathrm{IV}$, fig. 1/Hayes 26 type Carthage), considérée comme originaire du nord de la Tunisie, probablement de la région de Carthage.

B) La céramique culinaire africaine «polita a strisce » (A. Carandini in Ostia I, 31, 46) ou « with burnished slip on one face only » (Hayes 1972, 200), représentée par les formes Hayes 181 (toutes les variantes), 182, 184 et 185, qui aurait été produite en Byzacène.

C) La céramique culinaire « a patina cenerognola e ad orlo annerito » (A. Carandini in Ostia I, $86 \mathrm{sq}$ ) ou «Black Top ware» (Hayes 1976a, 87), représentée par les formes Hayes 191-198, qui serait principalement une production du nord de la Tunisie, mais également (forme Hayes 183) de certains ateliers du centre-ouest et du centre-sud-ouest de la Byzacène, ou encore de Tripolitaine.

Les prospections du littoral tunisien confirment ces hypothèses de provenances. Les formes Hayes 23 (catégorie A), mis à part quelques tessons isolés entre Jerba et la frontière libyenne, sont groupées sur les sites de la côte nord, entre le cap Bon et la frontière algérienne $^{92}$; elles sont rares également à Uzita (Van der Werff 1982a, 72), sur la nécropole de Pupput (Bonifay 2004a) ainsi qu'à Nabeul (inédit) ${ }^{93}$; en revanche, elles sont fréquentes à Carthage (Hayes 1976a, 85) et en Algérie (Guéry 1985a, Pl. XXXI : type Hayes 23 A principalement). La seule anomalie dans ce tableau consiste dans la présence probable de cette forme sur l'atelier de Thaenae (fig. 34, $\mathrm{n}^{\circ} 5$ ). J'ai interprété, peutêtre à tort, comme des variantes tardives de la forme Hayes 23, des marmites à bord interne épaissi et engobées à l'intérieur d'un vernis qui dessine de larges coulures à l'extérieur (infra, CULINAIRE TYPE 38). Ces objets sont regroupés sur le littoral de Byzacène

\footnotetext{
92 Cf. les notices céramologiques du catalogue des sites in: PASKOFF (R.), OUESLATI (A.), SLIM (H.), TROUSSET (P.) dir. - Le littoral de la Tunisie, Etude géoarchéologique et historique. Paris, CNRS, sous presse (Etudes d'Antiquités Africaines).

${ }^{93}$ A peine $1 \%$ de l'ensemble de la vaisselle culinaire inventoriée au cours des fouilles du quartier des fabriques de salaison.
}

méridionale entre Sfax et Sousse : sites de Jezira (Bonifay et al. 2002-2003, fig. 18, $\mathrm{n}^{\circ} 258$ ), Rougga (Guéry, Bonifay à paraître, $\left.\mathrm{n}^{\circ} 169-173\right)$, ateliers de Rass Aïed, d'Henchir ech-Chekaf à Ksour Essaf et de Moknine (observations personnelles).

Les formes 181-182 et 184 sont omniprésentes en Byzacène (catégorie $B$ ) et, de manière générale, sur tout le littoral oriental de la Tunisie : ainsi, elles sont tout aussi bien attestées à Pupput (Bonifay 2004a, fig. 17) qu'à Nabeul (inédit) ${ }^{94}$. Il est curieux, alors que ces productions de Byzacène sont rares à Carthage (tout comme la sigillée africaine C), de trouver aux IVe-Ve s. un plat qui semble dériver de la forme Hayes 181, généralement noté «Hayes 26 variant» dans les publications anglo-saxones. Il est probable qu'il s'agit là d'une production de la région de Carthage (infra, CULINAIRE TYPE 3C).

La catégorie $\mathrm{C}$ est moins facile à cerner. Les formes classiques, la marmite Hayes 197 et son couvercle Hayes 196 , ont probablement une origine septentrionale puisque leur diffusion correspond à peu près à celle des plats Hayes 23 ; ces deux types de vases à feu ont d'ailleurs en commun un traitement spécifique du fond, avec des microsillons (catégorie C/A). Il convient peut-être de sortir de cette catégorie les marmites Hayes 183, variantes de grande taille et non engobée des formes Hayes 184, et probablement originaires de Tunisie centrale (catégorie $\mathrm{C} / \mathrm{B}$ ), et aussi les nombreuses productions locales mises en évidence dans plusieurs régions d'Afrique.

En effet, aux côtés des grandes classes de céramiques culinaires largement exportées dans le bassin méditerranéen, il faut compter aujourd'hui avec les productions locales qui constituent l'essentiel du faciès de la céramique culinaire de certaines régions. L'exemple le plus évident est celui des céramiques culinaires du nord du golfe d'Hammamet (infra, CULINAIRES TYPES 20-30) dont la typologie a été élaborée à Sidi Jdidi et à Pupput (Bonifay, Reynaud 2004, fig. 141-143 ; Bonifay 2004a, fig. 18-19). De cette typologie, il faut peut-être sortir les marmites Sidi Jdidi 4 (infra, CULINAIRE TYPE 31), plutôt caractéristiques du Cap Bon.

\footnotetext{
94 Environ 25\% de l'ensemble de la vaisselle culinaire inventoriée au cours des fouilles du quartier des fabriques de salaison.
} 


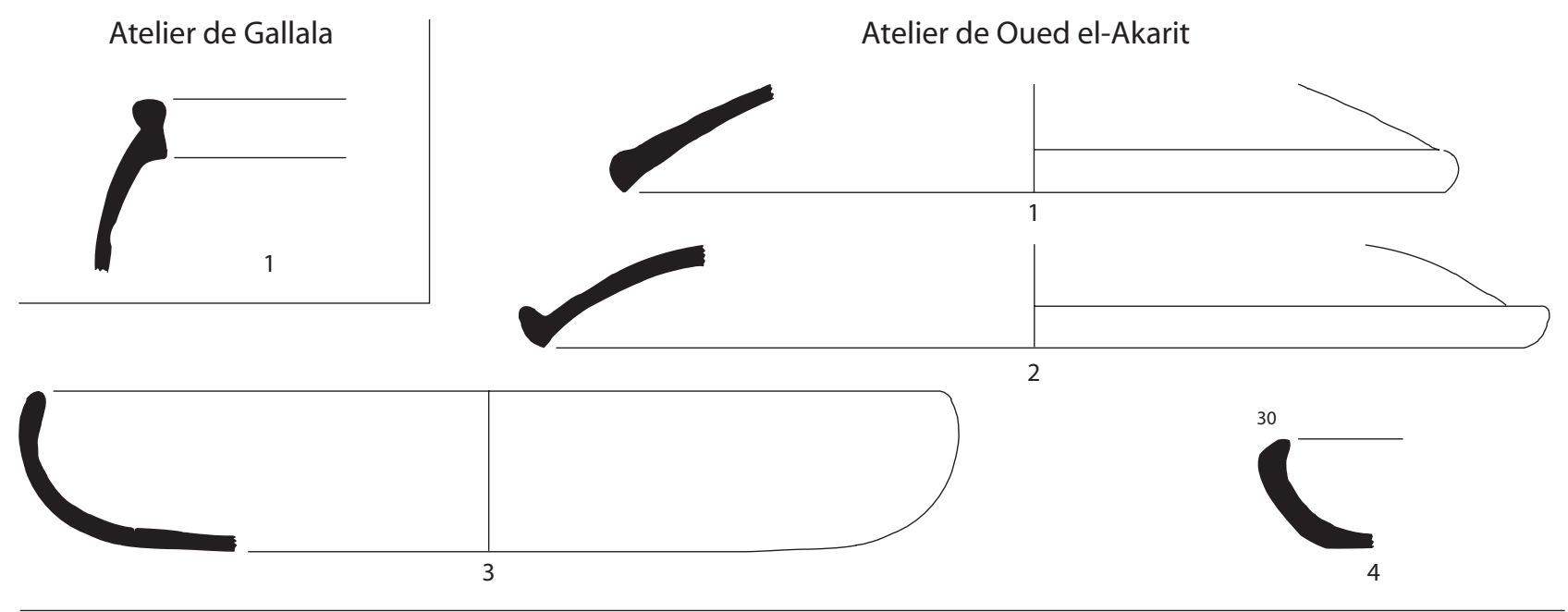

Atelier de Thaenae/Thyna
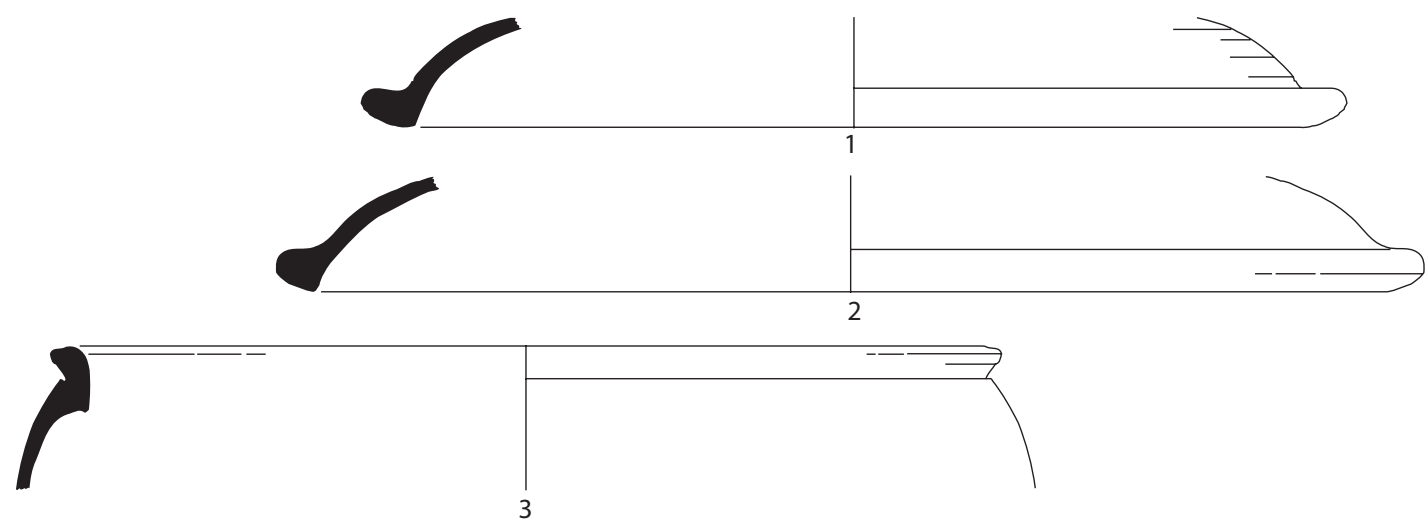

3
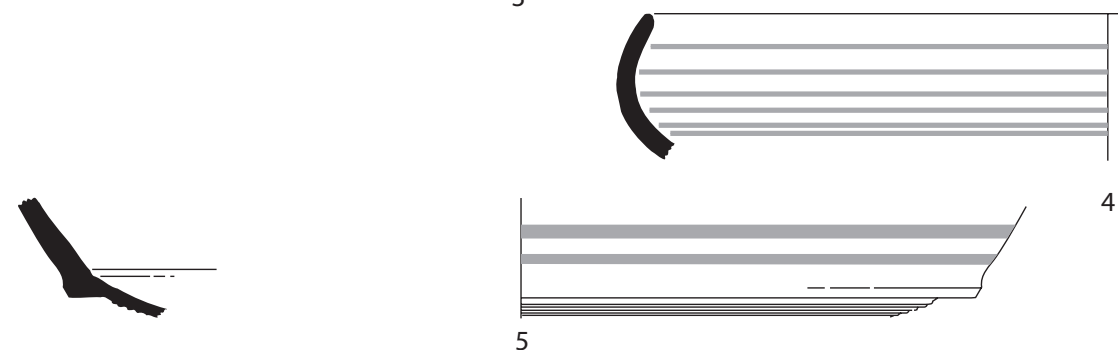

4

Atelier de Leptiminus/Lamta
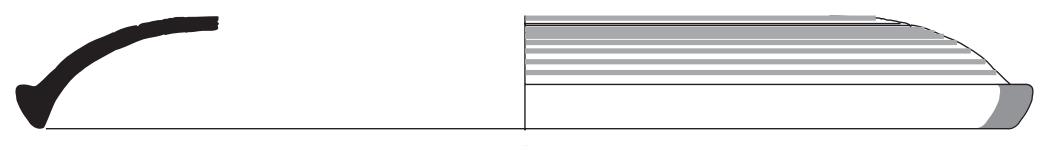

1
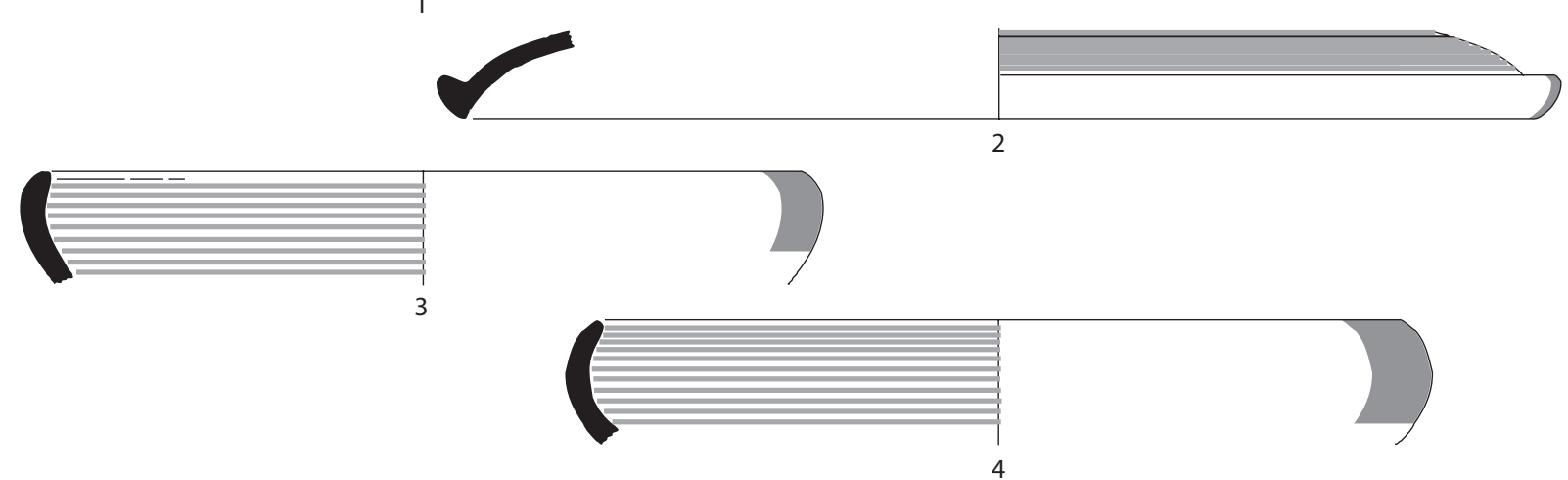

Fig. 34. Céramiques culinaires. Ateliers de Gallala, Oued el-Akarit, Thaenae/Thyna et Leptiminus/Lamta. Echantillons. 

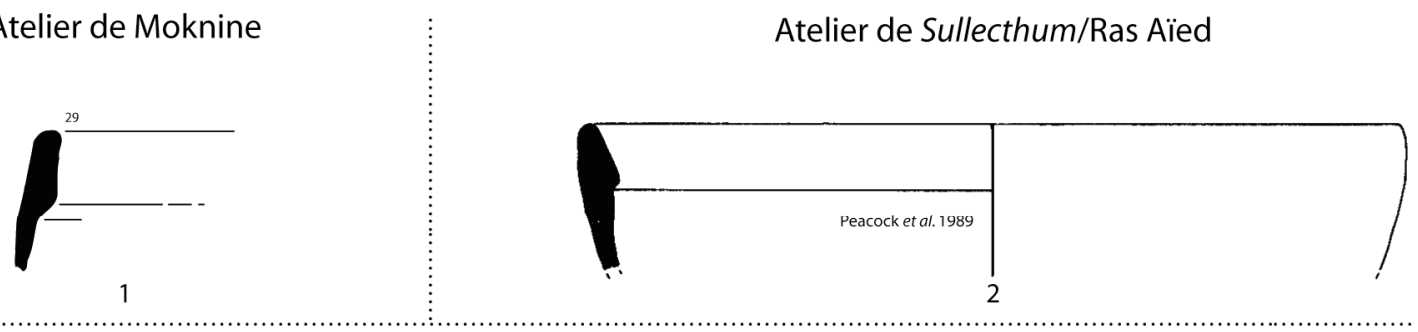

Atelier de Henchir ech-Chekaf
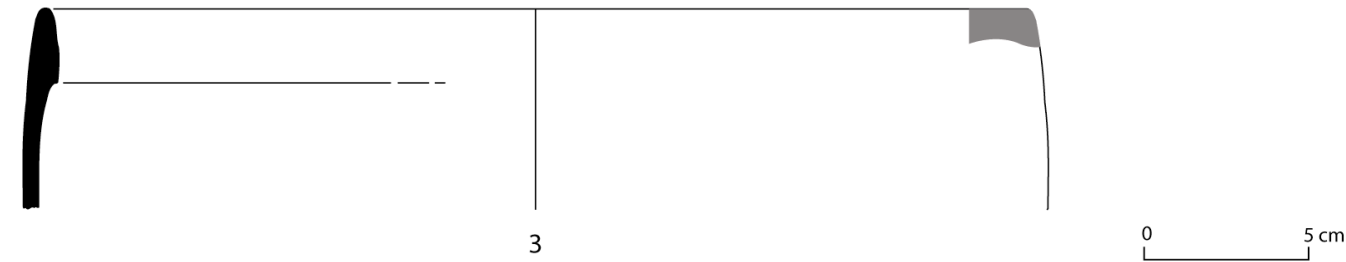

Fig. 35. Céramique culinaire tardive. Ateliers de Moknine, Ras Aïed et Henchir ech-Chekaf.

\section{Ateliers}

La production des céramiques culinaires paraît le plus souvent associée à celle des amphores. Cette situation est bien illustrée en Tripolitaine par les ateliers de Zitha/Zian (?) et de Gallala (Bonifay et al. 2002-2003) qui produisaient une variante locale de marmites Hayes 183. Des ateliers d'Oued el-Akarit (Ibid.) et de Thaenae (supra, p. 31), en Byzacène, sortaient des plats Hayes 181 et des couvercles Hayes 182. Enfin, il apparaît que la production de céramique culinaire de Leptiminus était particulièrement importante: Hayes 181, 182 et 184. Notons au passage que la fabrication de vaisselle sigillée dans cette ville est peu probable compte tenu de l'absence de casettes ; les productions de Leptiminus parfois notées comme «Red Slip ware» (Mattingly et al. 2000, 79 : « common ARS forms 181-182»), correspondent en fait à la céramique culinaire « with burnished slip on one face only » (Hayes 1972, 200).

\section{Exemples (fig. 34) :}

Atelier de Gallala :

*1 Culinaire C, marmite Hayes 183, variante tripolitaine (infra, CULINAIRE TYPE 17) (Bonifay et al. 2002-2003, fig. $\left.15, \mathrm{n}^{\circ} 205\right)$.

Atelier d'Oued el-Akarit

*1 Culinaire C, couvercle proche de Hayes 196 (Bonifay et al. 2002-2003, fig. 16, $\mathrm{n}^{\circ} 206$ ).

*2 Culinaire B(?), couvercle Hayes 182, variante C (infra, CULINAIRE TYPE 6C) (Ibid., $\mathrm{n}^{\circ} 208$ ).

*3 Idem, plat Hayes 181, variante D (infra, CulinAIRE TYPE 5D) (Ibid., $\mathrm{n}^{\circ}$ 209).

*4 Idem, plat Hayes 181, variante B (Ibid., n² 210)

Ateliers de Thaenae (ramassages 1993)

*1-2 Culinaire B(?), couvercles Hayes 182, variante D (infra, CULINAIRE TYPE 6D) (Inv. THY005-6).

*3 Culinaire C, marmite Hayes 183 (infra, CULINAIRE TYPE 15) (Inv. THY007).

*4 Culinaire A (?), plat Hayes 181 (Inv. THY008).

*5 Idem, fond de plat Hayes 23 (?) (Inv. THY009).

Ateliers de Leptiminus (ramassages 1993)

*1 Culinaire B, couvercle Hayes 182, variante B (infra, CULINAIRE TYPE 6B) (INV. LAM001).

*2 Idem, couvercle Hayes 182, variante C (Inv. LAM002).

*3 Idem, plat Hayes 181, variante B (infra, CULINAIRE TYPE 5B) (INV. LAM003).

*4 Idem, plat Hayes 181, variante C (Inv. LAM005).

On retrouve la même situation sur les ateliers d'amphores d'époque tardive, notamment ceux, dans la région du Sahel qui ont produit les plats à cuire à bord interne épaissi (infra, CULINAIRE TYPE 38) :

Exemples (fig. 35) :

Atelier de Moknine (ramassages 1993)

*1 Culinaire tardive, plat à cuire TYPE 38 (sans n d'inv.).

Atelier de Sullecthum/Ras Aïed

*2 Culinaire tardive, plat à cuire TYPE 38 (Peacock, Bejaoui, Ben Lazreg 1989, fig. 9, $n^{\circ} 7$ ).

Atelier de Henchir ech-Chekaf (ramassages 1993)

*3 Culinaire tardive, plat à cuire TYPE 38 (sans nº d'inv.).

Si certains ateliers d'amphores semblent ne pas avoir produit de céramiques culinaires (exemple: Sidi Zahruni), en revanche, la plupart des ateliers de sigillée ont un petit répertoire de vases à feu. M. Mackensen a bien montré que la production de céramiques culinaires à El-Mahrine était minoritaire (Mackensen 1993, 436). Il en est de même à Oudhna où, de plus, les formes produites sont très particulières: quelques marmites (probablement la catégorie $L R C W$ 6: Hayes 1978b, 


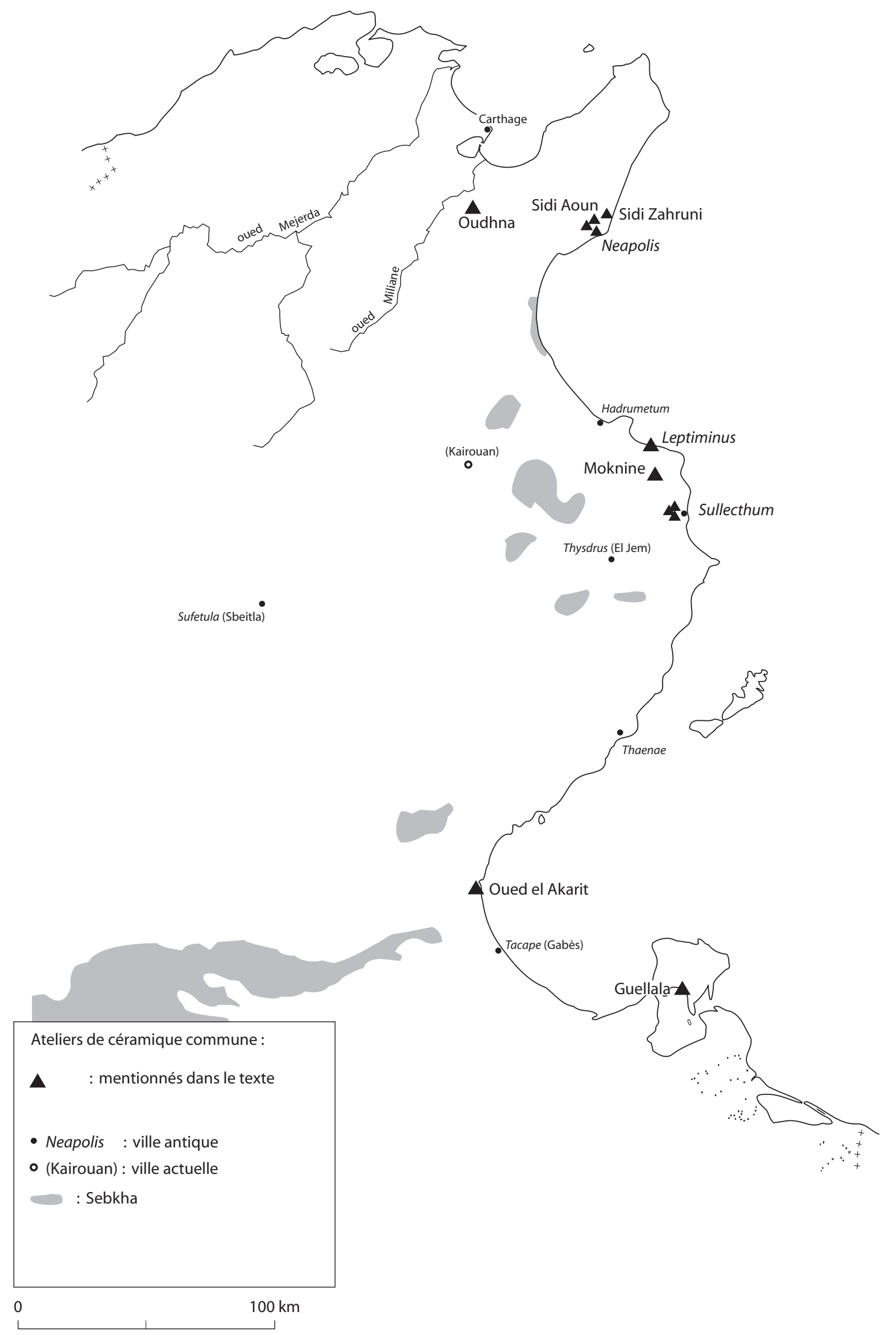

Fig. 36. Carte des ateliers de céramique commune cités dans le texte. 
fig. 9, $\mathrm{n}^{\circ}$ 15-16) mais surtout des bouilloires et des casseroles à manche plat (infra, CULINAIRE TYPE 35). L'atelier de Sidi Khalifa semble avoir produit les casseroles Sidi Jdidi 3 (?) et 9 (infra, CULINAIRE TYPES 25 et $\left.35-n^{\circ} 4\right)$.

Dans ce domaine encore, il est indispensable de faire l'inventaire des centres de productions et de découvrir dans quels types d'ateliers, associée à la production des amphores ou à celle de la sigillée, ou encore issue d'ateliers propres, la production de céramique culinaire a $\mathrm{pu}$ être suffisamment importante pour expliquer la diffusion massive dont elle a fait l'objet dans tout le bassin méditerranéen.

\section{Aspects techniques}

Les céramiques culinaires africaines doivent probablement une bonne part de leur succès à leurs grandes qualités de résistance thermique (Schuring 1988, 44 ; Picon 1998 ; Ikäheimo 2001).

A la différence des sigillées, les céramiques culinaires, même lorsqu'elles sont partiellement engobées, ne sont pas, sauf exception (?) ${ }^{95}$, cuites dans des casettes. C'est précisément cet empilement sans protection dans le four qui a produit les colorations habituellement dénommées « orlo annerito » et «patina cenerognola », caractéristiques de ces productions. Cette explication technique, désormais bien connue (Hayes 1972, 205 ; Mackensen 1993, 436; Aguarod 1991, fig. XIII ; voir cependant Pröttel 1996, 11), se vérifie sur toutes les formes de cette production. Il en est ainsi, à Oudhna, des bouilloires dont la surface extérieure est entièrement grise ou des casseroles dont le bord et la tranche du manche plat sont seuls noircis (infra, CULINAIRE TYPE 35).

D'autres détails morphologiques peuvent peut-être trouver une justification fonctionnelle. Ainsi, les fines cannelures (microsillons) sous le fond, caractéristiques des formes Hayes 23 et 197, ont été parfois expliquées par leur capacité à absorber le choc thermique (Schuring 1988, 44). Ne peuvent-elles pas également trouver une justification dans la manière dont les africains portaient leurs vases au feu? En effet, la céramique commune fournit de nombreux témoins d'un ustensile très commun dans les cuisines africaines : le brasero (infra, COMMUNE TYPE 66). Or, ce brasero ressemble en fait beaucoup aux actuels kanūn[s] tunisiens : une vasque de plus ou moins grand diamètre, dans laquelle les braises étaient entretenues, et un bord muni de trois ergots sur lesquels était posé le plat ou la marmite. La restitution proposée à Lepcis Magna d'une marmite Hayes 183 posée sur un «kanūn » (Pentiricci et al. 1998, fig. 11) laisse penser qu'un fond strié pouvait stabiliser l'assise du vase à feu sur les ergots (infra, fig. 165); le ressaut caractéristique

\footnotetext{
${ }^{95}$ Cas de grands plats Hayes 181 ne présentant pas le classique « orlo annerito », découverts à Nabeul (inédit).
}

de transition entre le fond et la paroi sur les plats Hayes 23 pourrait trouver la même explication.

\subsection{VAISSELLES COMMUNES}

\section{Provenances}

Le faciès des céramiques communes à Carthage est relativement bien connu, sur le plan à la fois des formes (Fulford 1984b et 1994) et de la pétrographie (Peacock 1984a). Ces classifications sont utiles à l'étude des contextes carthaginois; il faut toutefois se garder de vouloir les appliquer à l'ensemble de la Tunisie. Les particularismes régionaux sont très affirmés comme le montrent quelques exemples.

Ainsi, les productions du littoral de la Byzacène centrale (Bonifay et al. 2002-2003) se caractérisent par des pâtes orange sombre ou rouge carmin, granuleuses, avec des micro-fossiles abondants et du quartz dans la matrice et de plus rares inclusions de quartz éolien, de taille moyenne-fine, classé (P1. III, $\left.\mathrm{n}^{\circ} 11\right)(\mathrm{Cl}$. Capelli in Guéry, Bonifay à paraître). Pour l'Antiquité tardive, trois formes semblent spécifiques de cette région :

- Des plats apparentés à la forme Hayes 103 de sigillée africaine (infra, SIGILLÉE TYPE 84); on peut considérer qu'il s'agit là d'une production intermédiaire entre la vaisselle fine et la vaisselle commune (Bonifay et al. 2002-2003, fig. 10, $\mathrm{n}^{\circ} 118$ 120, 259 ; Guéry, Bonifay à paraître, $n^{\circ}$ 112-146).

- Des bassins à bord épaissi et ressaut interne (infra, COMMUNE TYPE 38) (Bonifay et al. 2002-2003, fig. 11, $\mathrm{n}^{\circ} 121-125$; Guéry, Bonifay à paraître, $\mathrm{n}^{\circ} 222-248$ ).

- De petites cruches mono-ansées à long col (infra, COMMUNE TYPE 63) (Guéry, Bonifay à paraître, $\left.\mathrm{n}^{\circ} 292-295\right)$.

Le faciès du nord du golfe d'Hammamet commence à être bien cerné, grâce aux fouilles de Sidi Jdidi (Bonifay, Reynaud 2004, fig. 144-146) et de Pupput (Bonifay 2004a fig. 20-22). On peut retenir, comme étant caractéristiques de cette région, les formes suivantes :

- La cruche Pupput 1, grand vase pansu à col tubulaire et à une seule anse, attachée directement sur le bord (infra, COMMUNE TYPE 47) (Bonifay 2004a, fig. 20, $\mathrm{n}^{\circ} 74$ ), des IIe-IIe siècles.

- Le bassin Sidi Jdidi 1, ovale, caractérisé par un bord grossièrement triangulaire (infra, COMMUNE TYPE 23) (Bonifay, Reynaud 2004, fig. 145), daté du Ve siècle.

- Le mortier Sidi Jdidi groupe 2, aux parois épaisses, avec un listel pendant et une lèvre haute (infra, COMMUNE TYPE 15) (Bonifay, Reynaud 2004, fig. 144), contemporain du précédent.

Les pâtes se rattachent à un vaste groupe local caractérisé par une matrice de couleur variable (orange, jaune, brune), compacte, et un dégraissant de quartz sub- 
Ateliers de la région du Sahel

Sullecthum/Ras Aïed

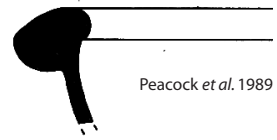

1
Leptiminus

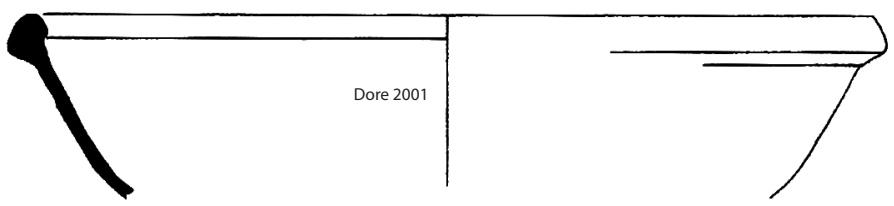

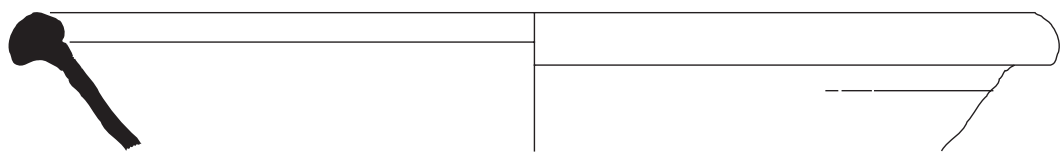

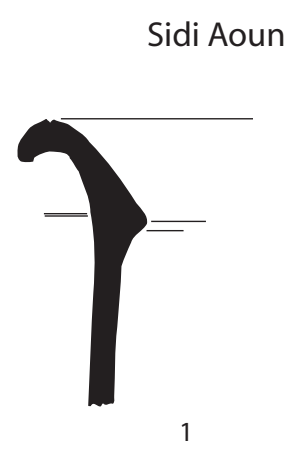

Sidi Aoun

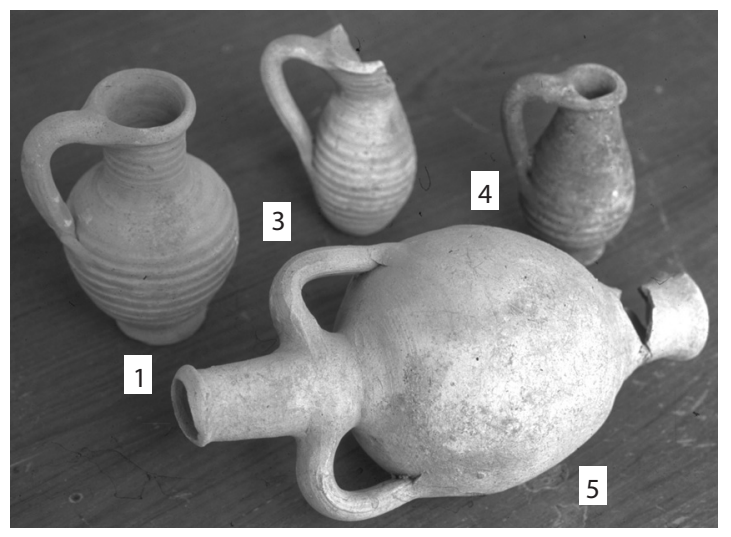

Sidi Zahruni
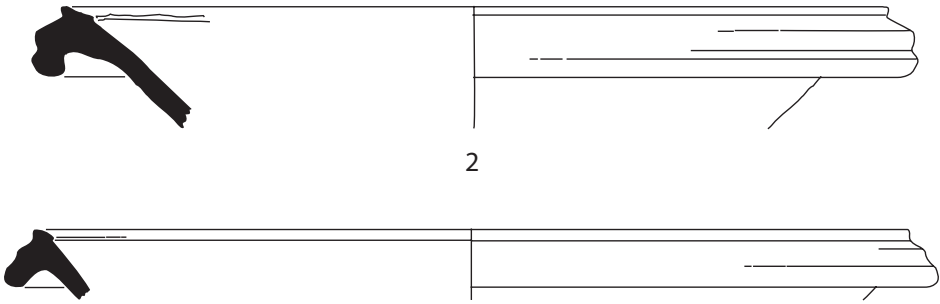

Atelier urbain tardif de Neapolis

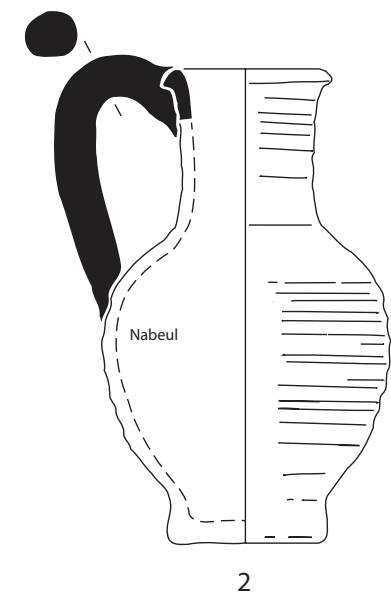

Fig. 37. Céramique commune. Ateliers de la région du Sahel et de Nabeul. 
anguleux à arrondi (éolien), classé, de taille moyenne-fine à moyenne (Pl. III, $\left.\mathrm{n}^{\circ} 10\right)$.

Toutes ces formes sont rares ou absentes à Carthage. Parallèlement, la pâte la plus fréquente dans la métropole, la «Cream sandy ware » (P1. III, n 6) (Peacock 1984a, 17 : fabric 2.5), ne semble attestée ni en Byzacène, ni dans la région d'Hammamet. On pourrait sans doute multiplier ces exemples qui devraient permettre, peu à peu, de déterminer les provenances des céramiques communes.

\section{Ateliers}

Je ne connais pas d'atelier africain voué spécifiquement à la production des céramiques communes: il s'agit toujours, semble-t-il, d'une production complémentaire, que la production principale soit consacrée aux amphores ou à la sigillée. Quelques exemples, parmi ces ateliers, permettent, au passage, de localiser quelques productions. Ainsi, des ateliers côtiers du Sud tunisien, Zitha/Zian, Gallala et Oued el-Akarit, ont en commun dans leur répertoire morphologique une variante de mortier à marli courbe portant des incrustations de grains de basalte sur le fond (infra, COMMUNE TYPE 9). Les bassins à bord épaissi et ressaut interne sont présents sur trois ateliers du Sahel : Sullecthum/Ras Aïed, Leptiminus et Moknine. Les ateliers de la région de Nabeul produisent des bassins dérivés du type Uzita 2 (infra, COMMUNE TYPE 22) et des mortiers de type Fulford 22-23 (infra, COMMUNE TYPE 13), tandis que les ateliers d'Oudhna sont à l'origine d'une part sans doute importante des mortiers Carthage Class 1 (infra, COMMUNE TYPE 11).

Exemples (fig. 37) :

Atelier de Gallala

1 Fond de mortier TYPE 9 (?) (Bonifay et al. 20022003 , fig. $\left.15, \mathrm{n}^{\circ} 205\right)$.

Atelier d'Oued el-Akarit

2 Mortier TYPE 9 (Ibid., fig. 16, n 212-213) (infra, fig. $\left.138, n^{\circ} 3-4\right)$

Atelier de Sullecthum/Ras Aïed

*1 Bassin TYPE 38 (Peacock, Bejaoui, Ben Lazreg 1989, fig. $\left.9, \mathrm{n}^{\circ} 18\right)$.

Atelier de Leptiminus

*2 Bassin TYPE 38 (Dore 2001, fig. 1.70, $\mathrm{n}^{\circ} 114$ ).

Atelier de Moknine

*3 Bassin TYPE 38 (sans n d'inv.).

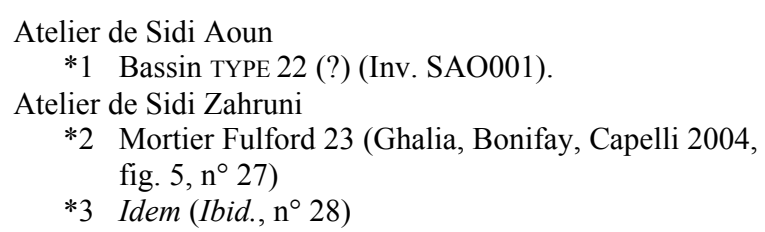

Atelier d'Oudhna

1 Mortier Carthage Class 2 B (Barraud et al. 1998, fig. $\left.12, \mathrm{n}^{\circ} 11\right)$.
Toutefois, les ateliers urbains de Neapolis pourraient constituer une exception à ce modèle ou peut-être, en raison de leur date très tardive (VIIe s. avancé), un modèle différent. En effet, bien qu'un rebut de cuisson de « spatheion » 3C ait été découvert à proximité, l'essentiel de la production mise en évidence dans le quartier de la Maison des Nymphes (Slim, Bonifay, Piton 2002, 180) concerne la céramique commune. Une citerne du quartier paraît entièrement comblée (observation personnelle) de petites cruches mono-ansées du même type que celle trouvée dans le four, probablement des rebuts de cuisson. Exemples (fig. 37) :

*1 Four. Petite cruche cannelée (infra, COMMUNE TYPE 60, fig. 162, $n^{\circ}$ 6) (Inv. NB3034.1).

*2 Citerne. Petite cruche cannelée du même type que la précédente.

*3 Four. Petite cruche (Inv. NB3034.0).

*4 Four. Petite cruche piriforme (infra, COMMUne TYPE 52) (infra, fig. 159a, $n^{\circ} 9$ ).

*5 Four, Cruche bi-ansée (infra, COMMUNE TYPE 49) (fig. 157, $\mathrm{n}^{\circ} 10$ ).

\section{Aspects techniques}

On a pu observer à plusieurs reprises (Sidi Jdidi : Bonifay, Reynaud 2004, 253 ; Rougga : Guéry, Bonifay à paraître) que, dans une même région, les pâtes de céramiques communes ne différaient pas fondamentalement des pâtes d'amphores. Le traitement de surface est également très similaire (surface blanche). L'ensemble de ces éléments fait qu'il est souvent difficile de distinguer les fragments de panses de bassins ou de cruches et les fragments de panses d'amphores.

A l'époque byzantine tardive, on constate, tout au moins dans la région de Nabeul-Hammamet, une généralisation de la pâte blanchâtre aussi bien au sein des céramiques communes que des amphores (supra; Bonifay 2002, 186).

\section{Un cas particulier : la céramique à décor peint}

Il y a certainement plusieurs catégories de céramiques à décor peint à l'époque romaine en Afrique. Des cruches peintes sont mentionnées au IIIe s. dans la nécropole de Raqqada (Salomonson 1968, fig. 45, 46 et 48) et je ne sais pas à quelle catégorie rattacher le tesson recueilli lors des prospections du littoral tunisien (Bonifay et al. 20022003, fig. 11, $\mathrm{n}^{\circ} 134$ ), encore qu'un décor assez proche soit attesté à Carthage (Mackensen 1999a, fig. 3, n² 2-4). La production la plus homogène a cependant été identifiée dans cette ville (Hayes 1976a, 89; Fulford 1984b, 225-228) : il s'agit de bols, pots, jattes et cruches, décorés de motifs essentiellement géométriques ou végétaux, plus rarement animaliers peints en brun-rouge ou en noir sur la surface beige (infra, fig. 169).

D. P. S. Peacock ne semblait pas émettre de doutes sur l'origine africaine de cette céramique (Peacock 1984a, 16 , fabric 2.4) et J. W. Hayes a supposé qu'elle pouvait 


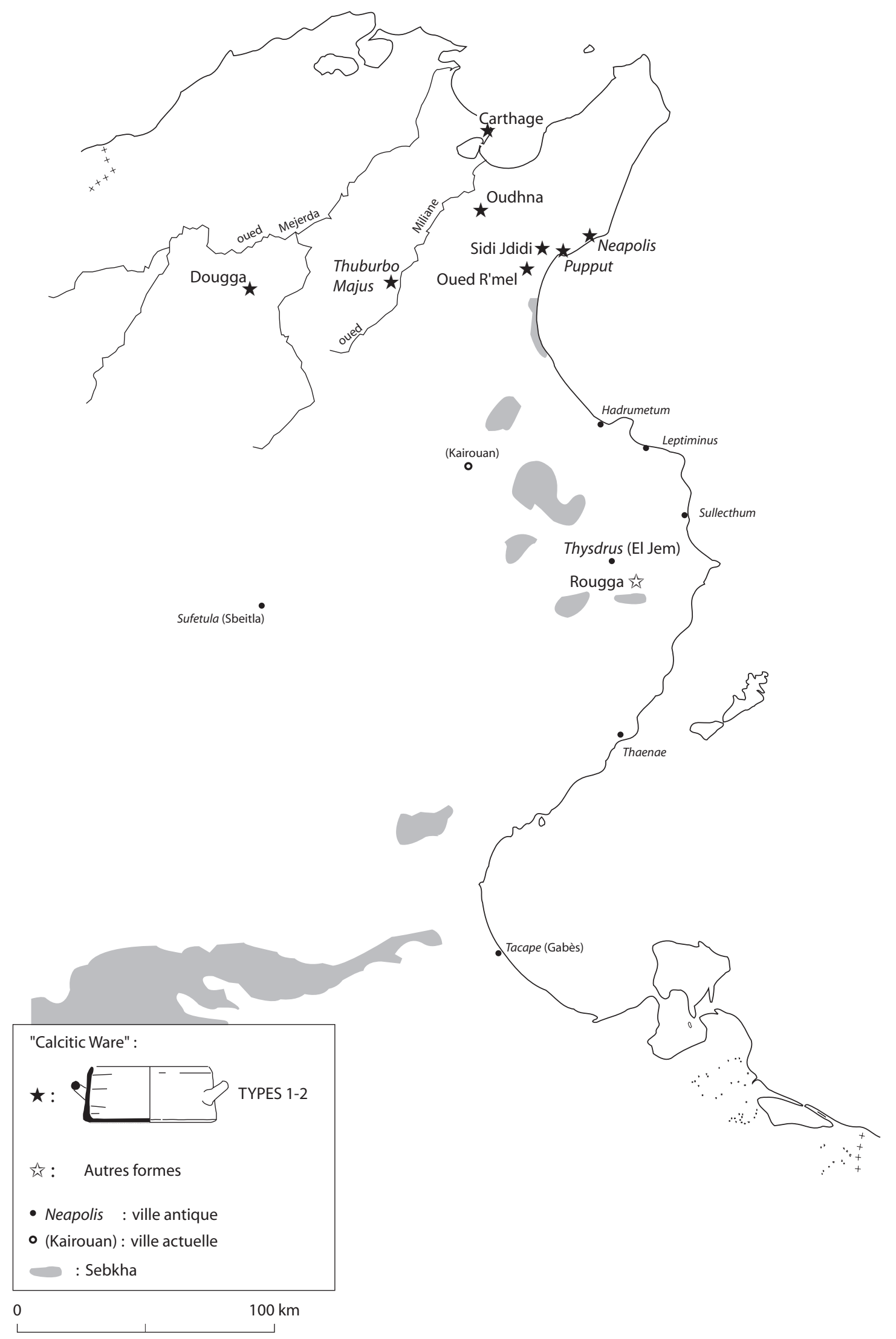

Fig. 38. Carte de diffusion de la céramique modelée C ("calcitic ware"). 
avoir été fabriquée, au moins en partie, dans la région de Thuburbo Majus (Hayes 1976a, 89). De fait, cette céramique présente une pâte marron relativement fine, avec de petites inclusions blanches et rouges (Pl. III, $\mathrm{n}^{\circ} 12$ ), qui ne sont pas sans rappeler celles des pâtes des céramiques communes de cette ville (Pl. III, $\left.n^{\circ} 9\right)$.

\subsection{VAISSELLES MODELÉES}

\section{Provenances}

Parmi les assez nombreuses céramiques modelées présentes dans les contextes africains, il est possible de distinguer au moins deux grandes catégories d'origine locale :

- La «céramique modelée à engobe lustré » $($ Bourgeois 1977) $=$ Rood handgevormd aardewerk (Van der Werff 1982a) : Cette vaisselle de table issue de la tradition libyco-punique est surtout caractéristique de la Byzacène (Morel 1998). J. H. Van der Werff distingue deux groupes dans cette production selon le traitement de la surface, que je propose de classer de la façon suivante :

- groupe A (= Van der Werff 1982a, deuxième groupe, «vases à surface rouge polie » = Sidi Jdidi, groupe B): vases enduits d'un engobe rouge vif, épais, soigneusement poli.

- groupe B (= Van der Werff 1982a, premier groupe, "vases à surface grossièrement lissée » $=$ Sidi Jdidi, groupe C) : surface de couleur variable, grise, beige et/ou jaune orangé, parfois sommairement lissée, parfois polie.

- La céramique modelée à inclusions de calcite (groupe C) = «Calcitic ware» (Peacock 1984a, fabric 1.3) = Late Roman Cooking Ware 5 (Hayes 1976a). Cette céramique culinaire (marmites, plats et couvercles) à base couverte de grains de calcite : «grits » (Hayes 1976a, 97; Id. 1978b, 78) est répandue, du IVe au VIIe s., dans toute la Tunisie septentrionale, mais il en existe peut-être des variantes en Tunisie centrale et méridionale.

Les catégories $\mathrm{A}$ et $\mathrm{B}$, bien connues dès l'époque punique (Morel 1998), sont considérées comme des productions domestiques, réalisées par une main d'œuvre non spécialisée (Van der Werff 1984, 128 ; Morel 1998, 129), probablement féminine, à l'image des céramiques modelées produites actuellement dans plusieurs régions d'Afrique du Nord (Fayolle 1992, 23).

Je crois qu'il faut adopter la même opinion sur la catégorie $\mathrm{C}$, caractéristique de l'Antiquité tardive. En effet, les pâtes des exemplaires de «Calcitic ware » de Carthage (Bonifay à paraître, a), de Thuburbo Majus (Ben Abed, Bonifay 1998, 236 ; Capelli 1998, 252-253), de Nabeul (inédit) et de Sidi Jdidi (Bonifay, Reynaud 2004, 250) ont des points communs mais ne sont jamais exactement semblables. Aussi, plutôt que de rechercher une origine unique à cette céramique (comme le propose Ciotola 2000, 40), il est, à mon sens, plus vraisemblable de considérer cette dernière comme un vaste groupe technique, fabriqué en de multiples points du territoire africain, avec les argiles locales auxquelles une main d'œuvre également non spécialisée (?), mais expérimentée, aurait tout simplement pris le soin d'ajouter de la calcite. Le répertoire de formes est très homogène au nord (Bonifay, Reynaud 2004, fig. 148 ; même faciès à Dougga : Ciotola 2000, Pl. I, n 5-6). La Tunisie centrale semble adopter d'autres formes (?) (Rougga: Guéry, Bonifay à paraître, $\mathrm{n}^{\circ}$ 306-309) (fig. 38).

\section{Aspects techniques}

La céramique modelée de catégorie A dont les caractéristiques ont été décrites à plusieurs reprises (Bourgeois 1977, 186-187 ; Van der Werff 1984, 127128) est d'un assez bas niveau technique. La terre n'est pas très bien travaillée, peu homogène, la cuisson peu soignée (couleur variable sur un même vase). Le dégraissant, peu abondant, mêlé aux impuretés de l'argile originelle, est constitué de quartz éolien et plus rarement de calcaire (Pl. III, $\left.\mathrm{n}^{\circ} 13\right)$.

Les pâtes de la catégorie $\mathrm{C}$ présentent un certain nombre de caractéristiques communes :

- la matrice est de couleur claire, en général beige plus ou moins grisâtre, avec parfois un épiderme rougeâtre (Pl. III, $\left.\mathrm{n}^{\circ} 14\right)$.

- Le dégraissant, plus ou moins abondant, est principalement constitué de calcite translucide, parfois altérée (couleur rousse), très anguleuse (veines broyées) et sûrement ajoutée intentionnellement, de taille moyenne à grossière, parfois très grossière, avec dans certains cas des calcaires arrondis et parfois aussi des inclusions de quartz éolien. Dans certaines régions (Thuburbo Majus : Capelli 1998, 252), on note la présence abondante de coquilles broyées qui tendent à remplacer la calcite.

- La surface intérieure des couvercles et le dessous $\mathrm{du}$ fond des marmites et des plats sont systématiquement couverts de grains de calcite.

La calcite broyée ajoutée à la pâte et disposée sous le fond des vases à feu ${ }^{96}$ est sans doute destinée à protéger cette vaisselle culinaire contre les chocs thermiques. Il ne semble pas (?) que le tour, même sous une forme rudimentaire, ait été utilisé pour la fabrication de ces poteries, sauf peut-être pour leurs variantes du centre de la Tunisie.

On ignore tout des structures utilisées pour la cuisson des vases de chacune de ces deux catégories. J. H. Van der Werff $(1984,128)$ suppose des cuissons en fosse pour la

\footnotetext{
${ }^{96}$ Des productions de céramiques modelées culinaires (grands plats) de la région de Moknine présentent encore de nos jours cette particularité.
} 


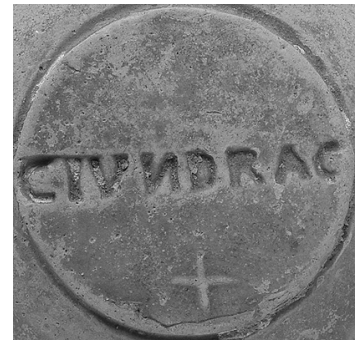

PP379401

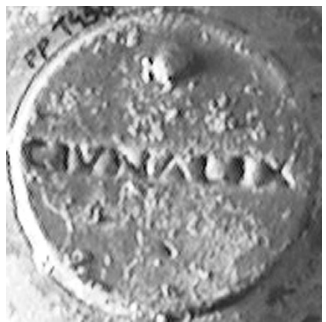

PP146101 2

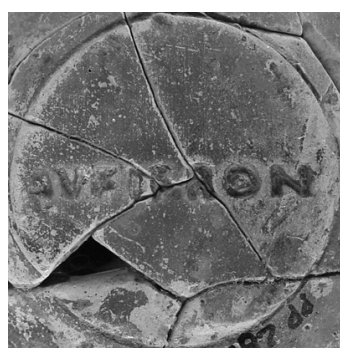

PP283102

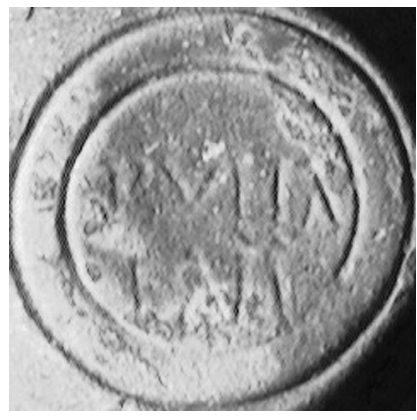

PP166702

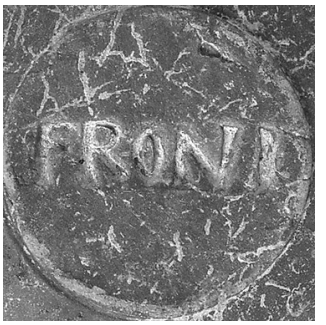

PP228511 4

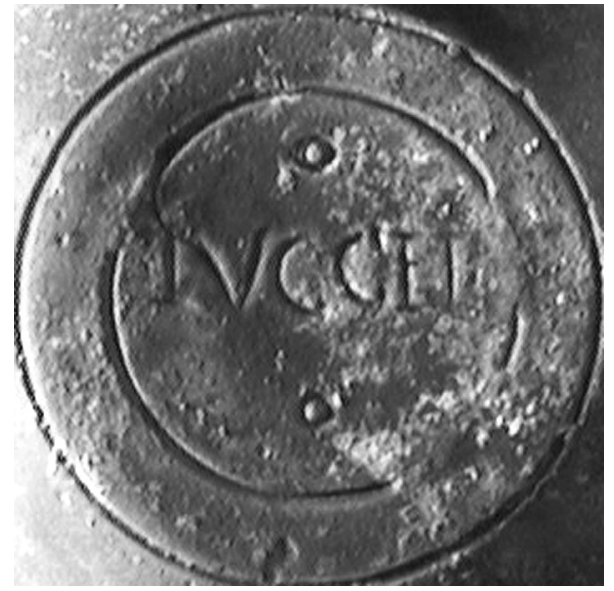

PP134502

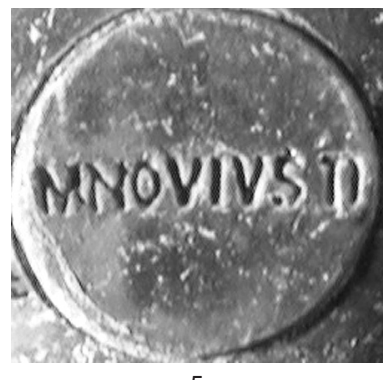

PP144501

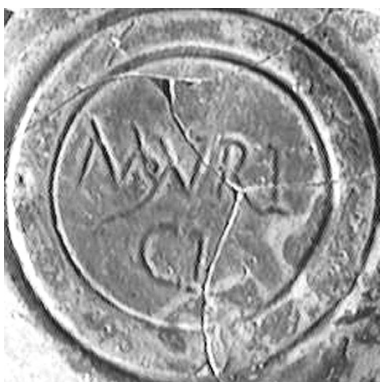

$\begin{array}{ll}\text { PP335301 } & 8\end{array}$

Fig. 39. Marques sur lampes de la nécropole de Pupput. 
catégorie A. On pourrait tout aussi bien penser à l'utilisation de fours domestiques du type tabuna. Ceuxci, jouant le rôle de grandes casettes, auraient pu favoriser l'obtention de la couleur rouge relativement uniforme qui caractérise de la surface extérieure de ces poteries.

\subsection{LAMPES}

\section{Provenances}

On reste assez mal renseigné sur la production des lampes africaines, mis à part celles, les plus tardives, fabriquées par les grands ateliers de vaisselle sigillée. Un certain nombre de critères sont cependant susceptibles de nous aider à préciser l'origine de ces objets.

\section{- Les marques de fabrique}

Beaucoup de lampes africaines du IIe s. et, dans une moindre mesure, du IIIe s. portent des timbres ou des marques incisées. Ceux qui mentionnent les lieux mêmes de fabrication sont rares :

- EX OFFICINA .CV.S. AB AQVAS REGIAS, sur lampes Deneauve VIII : Aquas Regias/Haffouz (?) (Carton 1916, 86) ;

- EX ISTATIONE BARARITANA FAVSTINI : Bararus/Rougga (Salomonson 1968, 87).

La répartition géographique des autres marques, qui ne mentionnent que le nom du fabriquant (fig. 39), peut-elle donner des indications sur la localisation des ateliers ?
Sur la nécropole de Raqqada, les timbres les plus nombreux sont ceux de CIVNDRAC (15 exemplaires), $M$ NOVI IVSTI (et variantes : 15 exemplaires) et CIVNALEX (10 exemplaires); les marques PVLLAENI et LVCCEI sont faiblement représentées (4 exemplaires de chaque).

De même, en observant les lampes de la nécropole de Pupput (Bonifay 2004a), on s'aperçoit que l'essentiel des signatures est composé d'une part des timbres CIVNDRAC et CIVNALEX (respectivement 38 et 35 exemplaires) (fig. 39, $\mathrm{n}^{\circ} 1-2$ ), d'autre part des timbres AVFIFRON et FRONI (15 et 26 exemplaires) (fig. 39, $\mathrm{n}^{\circ} 3$-4). On relève sept attestations du timbre $M$ NOVI IVST (fig. 39, $\mathrm{n}^{\circ} 5$ ), cinq de la marque LVCCEI (fig. 39, $\left.\mathrm{n}^{\circ} 7\right)$ ou $M A V R I C I\left(\mathrm{n}^{\circ} 8\right)$ et seulement trois de la marque PVLLAENI (fig. 39, $\mathrm{n}^{\circ}$ 6).

La situation est encore différente à Carthage (Deneauve 1969, 87-93) : Les timbres CIVNDRAC et CIVNALEX, ne totalisent à eux deux que 11 exemplaires; $A V F F R O N$ n'est représenté que par un seul timbre, $M$ NOVI IVSTI sept, tandis que les marques PVLLAENI se révèlent plus nombreuses (15 exemplaires). Le timbre africain (?) le mieux représenté à Carthage est $C L O$ SVC (32 attestations), tandis qu'il ne compte que deux exemplaires à Pupput.

Le tableau suivant est établi à partir des trois volumes du Catalogue du Musée Alaoui (CMA, CMA Suppl., CMA Suppl. 2), pour les mêmes marques :

\begin{tabular}{|l|l|l|l|l|l|l|l|l|r|}
\hline & $\begin{array}{l}\text { Bulla } \\
\text { Regia }\end{array}$ & Carthage & Pupput & $\begin{array}{l}\text { El } \\
\text { Aouja }\end{array}$ & Sousse & Lamta & Sullecthum & Thysdrus & Total \\
\hline CLO SVC & 9 & 11 & & & & 1 & & 4 & 25 \\
\hline CIVNDRAC & & 1 & 7 & 2 & & 1 & 1 & 19 & 31 \\
\hline CIVNALEX & 2 & & 4 & & & & & 21 & 27 \\
\hline AVFI FRON & & 1 & 4 & & & & & 1 & 6 \\
\hline FRONI & & & 2 & & & & & & 25 \\
\hline M NOVI IVSTI & 1 & 3 & 2 & 5 & 6 & 4 & & 3 & 46 \\
\hline PVLLAENI & 13 & 2 & & 1 & 1 & & & 3 & 20 \\
\hline LVCCEI & 5 & & & 3 & & & & 76 & 168 \\
\hline Total & 31 & 19 & 19 & 11 & 7 & 6 & 1 & & 76 \\
\hline
\end{tabular}

Tableau III. Répartition géographique de quelques marques sur lampes africaines selon le $C M A$.

On peut estimer que ce tableau possède une certaine fiabilité puisqu'on retrouve à Pupput les tendances précédemment observées dans la proportion des différentes marques, et à Carthage la prééminence des timbres CLO SVC. Il est remarquable aussi que cette répartition corresponde aux minces indices de provenance dont nous disposons : des déchets de cuisson portant la signature M NOVI IVSTI ont été découverts à Sousse et, de fait, il s'agit du timbre le mieux représenté à El Jem (25 exemplaires: un tiers du total des marques); la famille des Pullaeni possédait des terres à Uchi Majus et, de fait, cette marque est la mieux attestée à Bulla Regia (un tiers du total des marques). Les marques CIVNDRAC et CIVNALEX, rares dans le nord et à Carthage, sont en revanche fréquentes en Byzacène, de Pupput à Thysdrus. Les timbres AVFI FRON et FRONI sont rares partout sauf à Pupput mais, comme un autre exemplaire provient de Missua/Sidi Daoud (CMA Suppl., $\mathrm{n}^{\circ}$ 959), une origine dans les environs du cap Bon serait plausible. En marge de ce tableau, on peut noter que les attestations de la marque $S A B B A T I C V S$, qui apparaît parfois dans une version supposée bilingue (latin/néo-punique) (Bonifay 2004b, note 51), semblent groupées en Tunisie centrale 


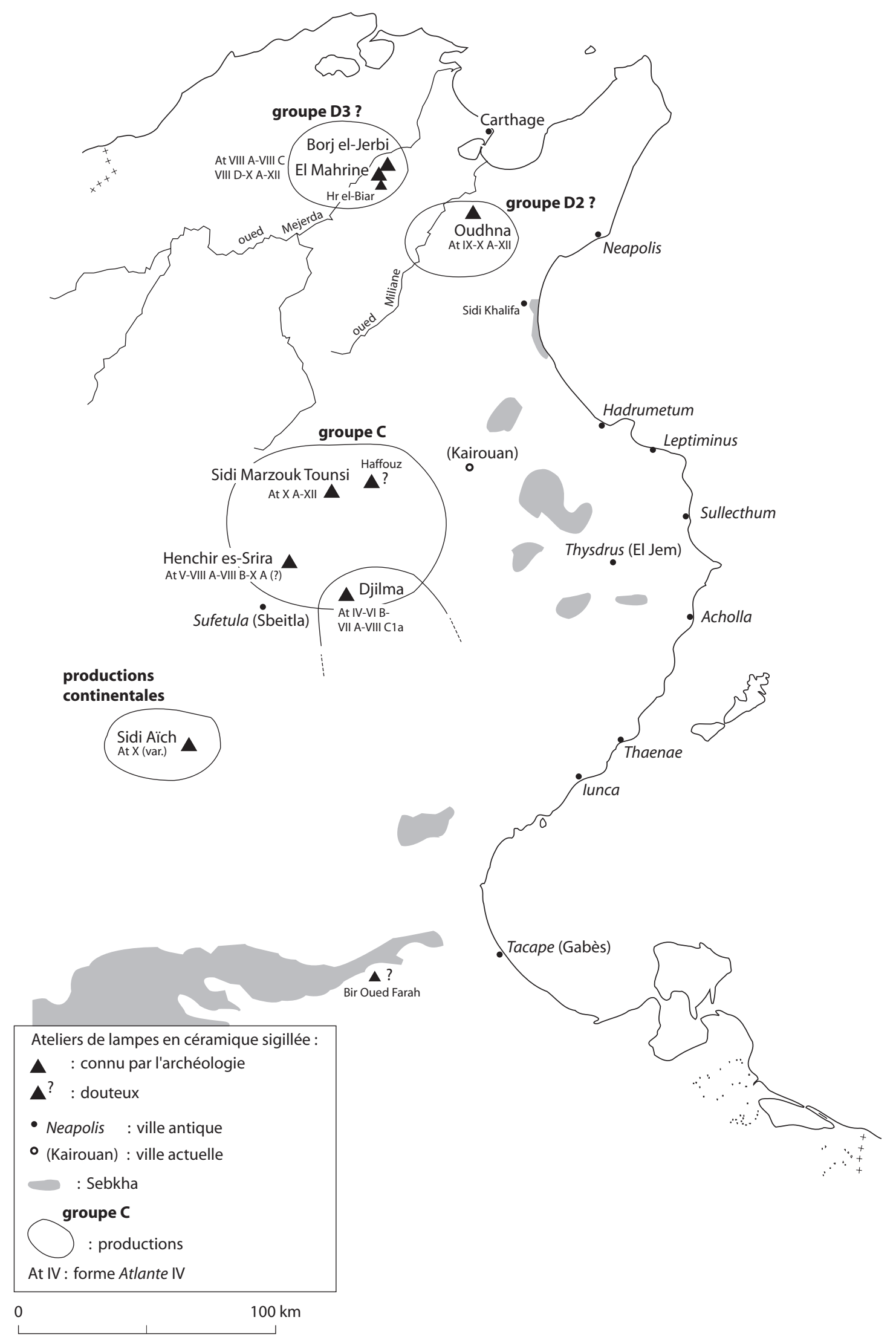

Fig. 40. Carte des principaux ateliers de lampes en céramique sigillée connus en Tunisie. 


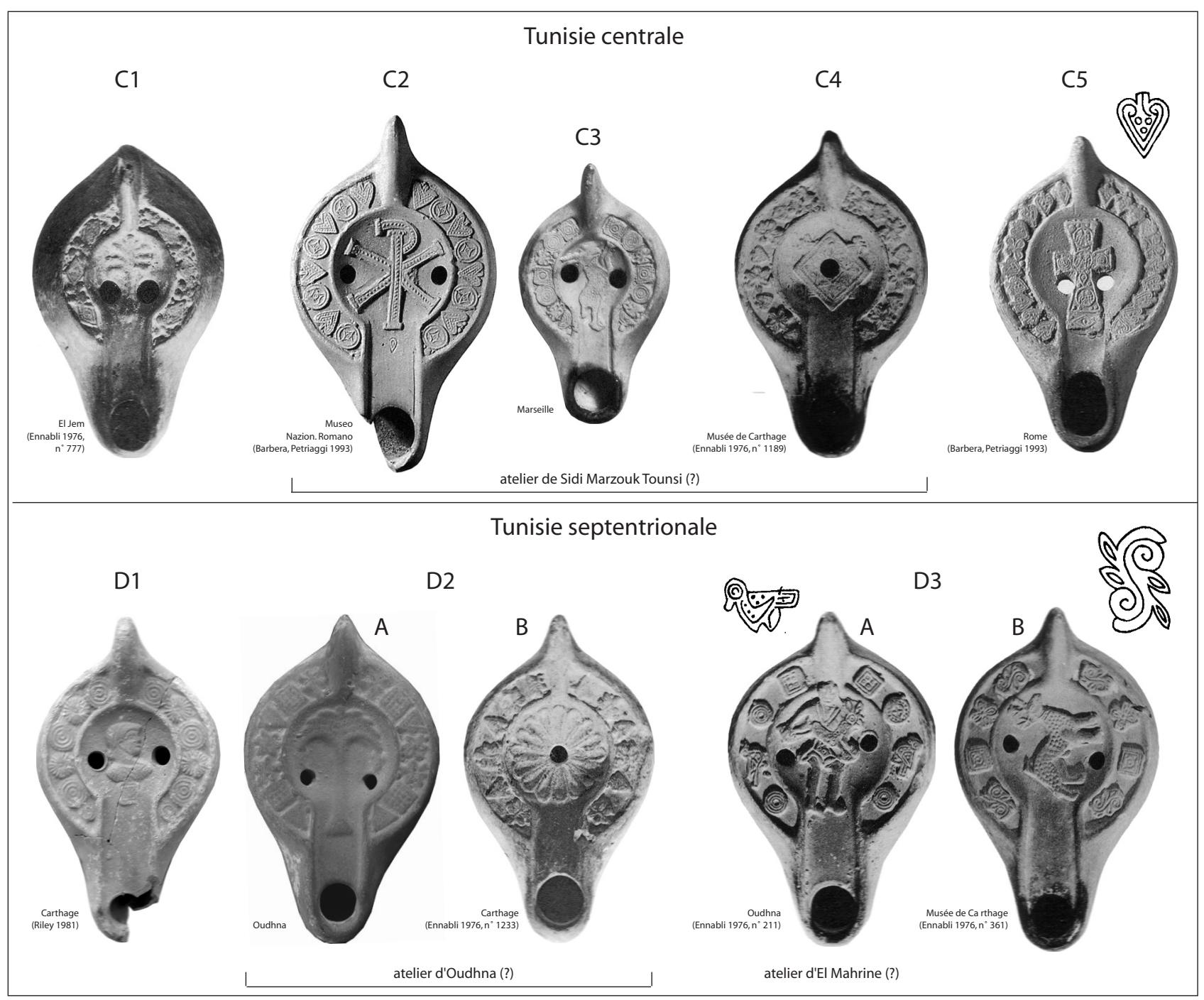

Fig. 41. Groupes de décors sur lampes en sigillée africaine Atlante X. 
(notamment Thysdrus; à Leptiminus: Hayes 2001, fig. 2.102, c).

Il faut cependant rester prudent car tous les timbres CLO $S V C$ ne sont pas africains ; c'est, à l'origine, un atelier italien, même si un déchet de cuisson avec cette signature est signalé en Tunisie (Bussière 2000, 143). Le même problème se pose avec CIVNDRAC: des exemplaires anciens de Pupput ne semblent pas africains en raison de leur pâte micacée (Bonifay 2004a, 33). La situation est encore compliquée par la pratique bien connue du surmoulage: des productions locales timbrées CCLOSVC, dont la facture se distingue de celles des produits italiques et tunisiens, sont signalées en Algérie (Bussière 2000, 146).

\section{- Les formes et les décors}

Les formes et les décors peuvent également révéler des particularités régionales.

On observe tout d'abord un net cloisonnement entre les deux sous-types principaux de lampes Deneauve VII (infra, LAMPES TYPES 4 ET 5). Cette distinction, assez évidente sur le plan de la forme, est en outre confirmée par la répartition des marques: un premier groupe (CIVNDRAC, CIVNALEX, MNOVISTI, etc.), attesté sur le sous-type 1, renvoie plutôt à des ateliers de Byzacène, tandis que le second (LVCCEI, MAVRICI, PVLLANEI, etc.), présent sur le sous-type 2 , se réfère à des ateliers nord-occidentaux.

Cette observation est, ensuite, particulièrement évidente lorsque l'on compare les faciès respectifs des nécropoles de Pupput et de Raqqada. Les types « locaux » identifiés dans cette dernière nécropole (Ennabli 13, 14, 15 et 16 : infra, LAMPES TYPES 20-23) sont complètement absents à Pupput. De même, le type Deneauve VIII/sous-type 3 (infra, LAMPE TYPE 12) bien attesté en Tunisie septentrionale et à Pupput, n'est représenté que par un seul exemplaire à Raqqada. Alors que le type Deneauve X de production probablement septentrionale, tout au moins pour les exemplaires marqués PVLLAENI (infra, LAMPE TYPE 15), est bien attesté à Pupput, il est remplacé à Raqqada par une variante locale de moindre qualité (type Ennabli 16 : infra, LAMPE TYPE 23). Mais il faut toutefois noter que ces différenciations régionales n'interviennent réellement qu'à partir du deuxième quart $\mathrm{du}$ IIIe s. (Pavolini in Atlante I, 188 ; infra, p. 314 : période 5).

Il en est de même des premières lampes en sigillée africaine. Alors que quelques lampes de type Atlante I ont été découvertes à Nabeul (infra, LAMPE TYPE 37, $\mathrm{n}^{\circ} 2$ ) (fig. 199), les prospections du littoral tunisien permettent de confirmer la diffusion essentiellement méridionale du type Atlante VI (infra, LAMPE TYPE 40), notamment celles ornées d'un lion bondissant à gauche, décor qui semble relativement répandu (Bonifay et al. 2002-2003, fig. 9, $\mathrm{n}^{\circ}$ 92-93). Ces lampes sont attestées sur l'atelier de Djilma (Peacock, Bejaoui, Ben Lazreg 1990, fig. 14, r). Les lampes Atlante VIII semblent produites à la fois au centre et au nord de la Tunisie sauf celles de la variante B qui sont caractéristiques du centre et, plus spécifiquement, de l'atelier de Henchir es-Srira (Mackensen 1993, 162).

Certes, la pâte permet généralement de reconnaître, au sein des lampes en sigillée de type Atlante X, les productions du centre (sigillée africaine C) et celles du nord de la Tunisie (sigillée africaine D). Mais on peut atteindre le même but en examinant les décors : c'est le sens de la distinction établie par J. W. Hayes (1972, 311) entre son type II A (Tunisie centrale) et son type II B (Tunisie septentrionale) (Hayes 1980b, 66 ; Bailey 1988, 182 ; Mackensen 1993, 163-64). Enfin, dans certains cas, il est possible, à mon sens, de préciser encore la provenance des lampes en sigillée africaine Atlante $\mathrm{X}$ (fig. 40 et 41) :

LAMPES ATLANTE X/HAYES II A DE TUNISIE CENTRALE Les lampes Atlante X « classiques » produites en Tunisie centrale (Hayes 1972, 311: «decoration neat and sharp ») sont assez facilement identifiables à leur forme élégante et à leur décor soigné, composé sur le bandeau de motifs géométriques bien imprimés, souvent serrés les uns contre les autres (infra, LAMPES TYPES 54-55, groupes $\mathrm{C} 2$ et $\mathrm{C} 3$ ). Ces lampes, caractéristiques du Ve s., sont bien attestées sur l'atelier de Sidi Marzouk Tounsi (Peacock, Bejaoui, Ben Lazreg 1990, fig. 9). Mais l'examen des lampes Atlante X conservées dans les grands musées tunisiens (Ennabli 1976) ou européens (Hoff 1986; Bailey 1988; Barbera, Petriaggi 1993 ; Trost, Hellmann 1996) et découvertes sur des sites de Byzacène, permet de reconnaître d'autres productions probablement originaires de Tunisie centrale (infra; groupes C1, C4, C5). Il en est notamment ainsi de lampes tardives portant sur le disque un décor caractéristique des VIe et VIIe s. (grande croix gemmée) et sur le bandeau une frise essentiellement constituée de feuilles cordiformes de petite taille, serrées les unes contre les autres et encore assez finement dessinées (infra, LAMPE TYPE 57, GROUPE C5). Ces lampes sont bien attestées sur les sites côtiers de Byzacène (Bonifay et al. 2002-2003, fig. $9, \mathrm{n}^{\circ} 100$, et fig. 202, $\mathrm{n}^{\circ} 256$ ) et à Rougga (Guéry, Bonifay à paraître, $\mathrm{n}^{\circ} 368$ ). Il n'est pas impossible que cette production soit encore vivace dans un VIIe s. avancé si l'on en juge par quelques exemplaires de lampes à décor estompé dont les motifs présentent des affinités avec ceux des ateliers de Tunisie centrale (infra, LAMPE TYPE 69, $\mathrm{n}^{\circ}$ 1-4).

\section{LAMPES ATLANTE X/HAYES II A DE TUNISIE SEPTENTRIONALE}

On attribue généralement aux ateliers de Tunisie septentrionale des lampes Atlante X avec une forme plus lourde et une décoration moins soignée (Hayes 1972, 311 : «with rather blurred decoration »). En fait, plus que 
la mauvaise impression de ces décors, c'est leur disposition et la nature des motifs utilisés qui sont significatives. Il est ainsi facile de distinguer, au sein du catalogue rassemblé par A. Ennabli (1976), trois groupes principaux (infra, groupes D1, D2 et D3). Le premier (D1) correspond au groupe «rosette and geometric» identifié à Carthage par S. V. Chapman, S. M. Davies et D. P. S. Peacock (1984, 234), en raison du décor du bandeau, composé essentiellement de rosettes G2 et de carrés A12 : alors qu'il est bien représenté sur plusieurs sites de la ville, on ignore tout de son lieu exact de production (infra, LAMPE TYPE 64). Le deuxième groupe (D2) se distingue par des décors proches dans le détail de ceux des ateliers de Tunisie centrale mais moins bien imprimés et surtout disposés de manière plus lâche, avec une fréquence particulière de fers de lance N1, pointe vers l'extérieur et de losanges à volutes R2, placés perpendiculairement par rapport au bandeau (infra, LAMPE TYPE 65). Certaines de ces lampes sont présentes en plusieurs exemplaires identiques au sein du matériel de l'atelier des thermes des Laberii à Oudhna (Ennabli $1976,17)$ et il me paraît probable qu'il s'agit d'une des productions de cet atelier. Enfin, le troisième groupe (D3) se caractérise par un bandeau décoré de motifs en fort relief, très espacés car seulement au nombre quatre ou cinq de chaque côté, et se compose de deux séries principales, la première (A) se reconnaissant à l'emploi assez fréquent de l'oiseau U5, et l'autre (B) affectionnant les rinceaux O1 (infra, LAMPE TYPE 66). La série A du groupe D3 semble bien correspondre aux productions de l'atelier d'El-Mahrine (Mackensen 1993, fig. 31).

\section{Ateliers (fig. 40)}

Pour la période du IIe au IVe s., on ne dispose guère, comme témoins d'ateliers, que des ratés de cuisson de lampes timbrées $M$ NOVI IVSTI découverts à Sousse (BCTH, 1941-42, $282 s q)$ et des moules en plâtre provenant de Carthage (Deneauve 1969, 226 et Pl. CIV$\mathrm{CV})$.

Jean Deneauve avait tout d'abord associé ces moules au dépôt de lampes découvert par Delattre à Bordj Djedid (Delattre 1913, 185), avant de remettre en cause cette hypothèse (Deneauve 1986a, 157 et note 69). Il serait plus probable à mon sens que ces moules proviennent de l'atelier (?) découvert en 1945 à proximité du sanctuaire de Tanit (Picard 1943-45, 476). Leur décoration correspond en effet à celle des lampes découvertes à proximité du four: «toutes présentent les mêmes caractères: queue pleine, trou d'alimentation unique, marli souvent chargé d'un grènetis ou réservoir à côtes » (Ibid., 362). De plus, M. Mackensen (1993, 148 et note 132) pense avoir retrouvé dans les $n^{\circ} 1119$ (Diane chevauchant un cerf, cf. Picard 1943-45, 417) et $1120 \mathrm{du}$ catalogue de Deneauve (1969, P1. CI) des lampes provenant de cette fouille (Ben Abed, Bonifay 1998, 243 et note 57 ).
La documentation est plus abondante pour les lampes en sigillée de type Atlante VIII et X, produits par la plupart des grands ateliers de céramique sigillée: Oudhna (Barraud et al. 1998, 152-154), El-Mahrine (Mackensen 1993, 95-165), Sidi Marzouk Tounsi (Peacock, Bejaoui, Ben Lazreg 1990, fig. 9), Henchir es-Srira (Ibid., fig. 12), Sidi Aïch (Nasr 1992). Rappelons que l'élément déterminant pour l'identification de ces ateliers de lampes africaines est la découverte de moules en plâtre. On doit toutefois se contenter d'un très petit nombre de décors de référence et de moules provenant d'ateliers dûment repérés.

\section{Aspects techniques}

L'utilisation de moules en plâtre (fig. 42, $\mathrm{n}^{\circ} 1$-4) dont H. Vertet (1983, 40-41) souligne les avantages (simplicité d'utilisation) et les inconvénients (usure rapide), semble être une particularité des officines tunisiennes (Deneauve 1969, 226) et de certaines officines algériennes (Bussière 2000, Pl. 155-156). Toutefois, un moule découvert à Timgad, pour des lampes de type Loeschcke IV (Bussière 2000, 273, n ${ }^{\circ} 680 \mathrm{Pl}$. 46), est en céramique. Un moule de Rougga est également en céramique mais il s'agit d'un objet extrêmement tardif (Guéry 1985b, fig. 4c) (fig. 42, $\left.n^{\circ} 5\right)$.

D'autres particularités techniques ont une signification chronologique. Le surmoulage, tout d'abord, tend à devenir, à la fin de l'Antiquité, le mode normal de production des lampes. Ainsi, les lampes Atlante X de la seconde moitié du VIe et du VIIe s., ont des décors de moins en moins lisibles (fig. 42, $\left.\mathrm{n}^{\circ} 4\right)$ (infra, LAMPE TYPE 69). Lorsque les lampes sont le produit d'un moule original, la décoration de ce dernier n'est plus obtenue par l'empreinte dans le plâtre d'un archétype (Mackensen 1993, 101-105) mais par l'incision directe des motifs sur le moule. Ce phénomène est bien visible à la fois sur des lampes de tradition antique en céramique commune au Ve s. (Ben Abed, Bonifay 1998, 241 et fig. 28) et sur des lampes en sigillée du VIIe s. avancé (infra, LAMPE TYPE 70). Le décor du moule de Rougga est une bonne illustration de cette technique (fig. 42, $n^{\circ} 5$ ); la même observation peut être faite à propos des moules de Tiddis (Berthier 2000, 128-129). Il semble qu'il faille en déduire qu'à cette époque, les moules de lampes africaines sont en céramique.

\subsection{CÉRAMIQUES DIVERSES}

\section{Les figurines}

L'Afrique produit un grand nombre de figurines en terre cuite, la plupart étant obtenues par moulage (infra, FIGURINES TYPES 2-4). Les principaux lieux de découverte de ces objets sont les nécropoles, qui apportent cependant quelques informations sur le faciès respectif des différentes régions de l'Afrique. 

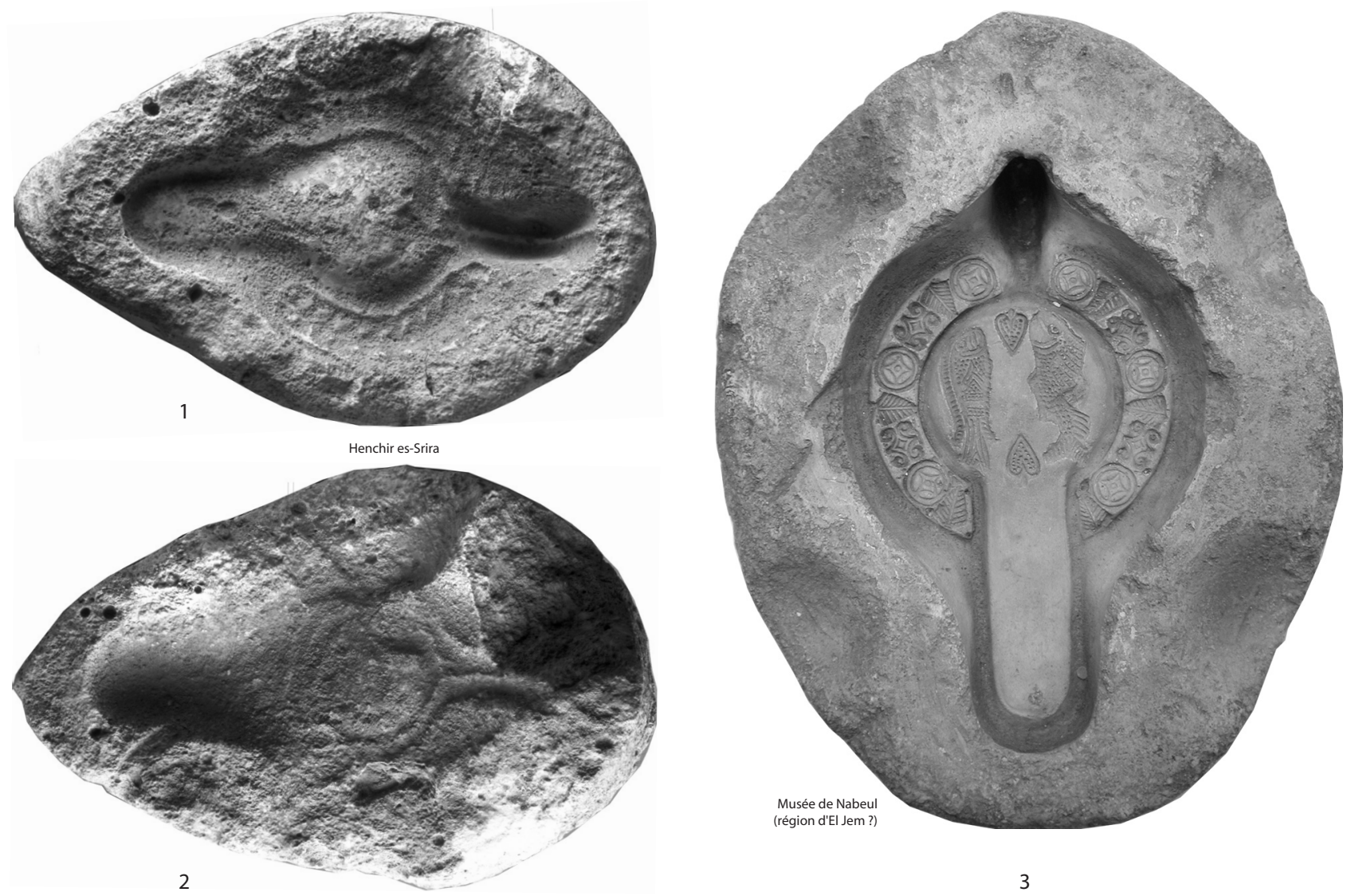

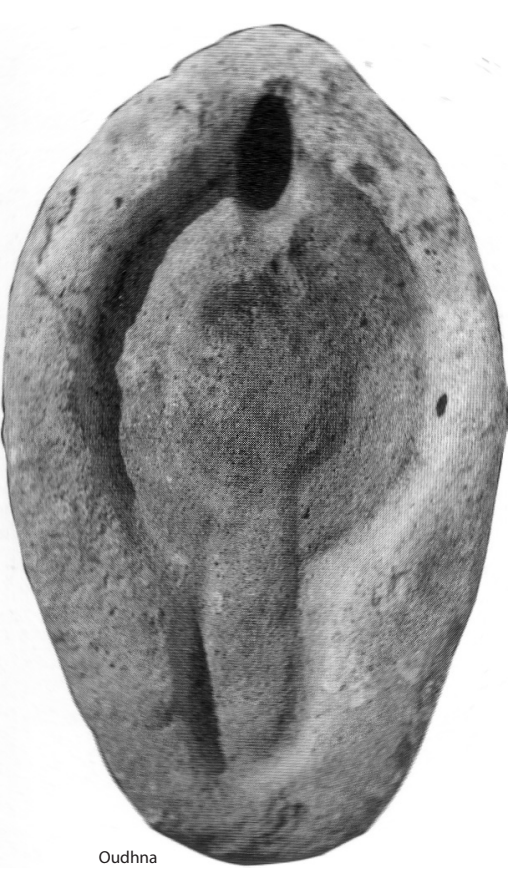

4

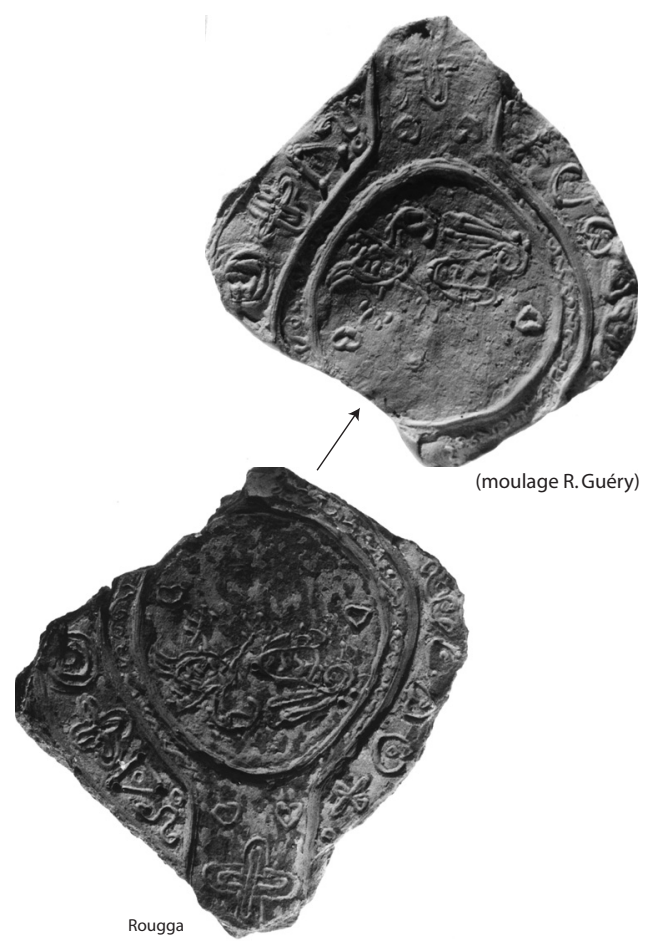

Fig. 42. Moules de lampes en sigillée africaine ( $n^{\circ} 1-4$ : en plâtre ; $n^{\circ} 5$ : en céramique) 
Ainsi, il est connu que les nécropoles de Sousse ont livré une grande quantité de figurines de Vénus (CMA, 134137). Un faciès comparable s'observe à El Jem (Slim 1985, 81). La nécropole de Pupput (Ben Abed, Griesheimer 2004) livre quant à elle un bon nombre de figurines de TYPE 2 représentant des déesses-mères, situation locale qu'il faut peut-être mettre en relation avec la proximité du sanctuaire de Tanit à Thinissut. Provenant de ce sanctuaire, on connaît en effet une statue en terre cuite presque grandeur nature représentant une déessemère assise dans un fauteuil en osier et allaitant un enfant (Merlin 1910, Pl. IV).

On sait peu de chose sur les ateliers de coroplathes d'époque romaine en Afrique. Des figurines de qualité supérieure (infra, FIGURINE TYPE 3) paraissent liées aux ateliers de lampes; certaines portent en outre des marques incisées (infra, p. 433). Un atelier de figurines de TYPE 2 est signalé à Hergla dans un contexte funéraire $^{97}$ : des déchets de cuisson de figurines de Vénus ${ }^{98}$, ont été découverts dans une tombe spoliée, à proximité d'un four détruit. On ne sait pas si cette production est antérieure à la nécropole ou bien au contraire contemporaine de celle-ci.

Pour l'époque tardive, la documentation la plus récente concerne l'atelier d'Oudhna, où une production de figurines bivalves (infra, FIGURINE TYPE 4) a été mise en évidence dans l'atelier de sigillée des thermes des Laberii (Barraud et al. 1998, 154-156 et fig. 14). Ces figurines, connues à Carthage (Delattre 1907, 39 et 41), représentent des déesses-mères proches de celles de Pupput, et des déesses de la fertilité comparables à celles des contextes coptes d'Alexandrie et d'Abou-Mina (Ibid., 156) ; dans le premier cas, une identification à la Vierge serait probable en raison de la date tardive de ces objets (voir également l'exemplaire de Cherchell: Gauckler $1895,78)$. L'aspect fini de ces figurines est tout à fait semblable à celui des lampes en céramique sigillée (vernis rouge orangé). La présence d'un moule en plâtre prouve que le mode de fabrication était identique (fig. 43).

\footnotetext{
${ }^{97}$ Fouilles de la nécropole nord d'Hergla dirigée par Mme Neila Ouertani en août 1997. Je tiens à remercier Mme Ouertani pour ces renseignements.

98 J'ai proposé à Mme Ouertani cette identification à partir de moutons très déformés où sont collées, les unes aux autres, plusieurs figurines; on reconnaît bien sur l'un d'eux $(15 \mathrm{~cm} \mathrm{x}$ $6 \mathrm{~cm}$ ), les jambes de la première figurine, puis, derrière celles de la deuxième, puis un bras et la tête diadémée de la troisième, etc., ainsi que les cadres rectangulaires (édicule ?) de chacune des figurines.
}

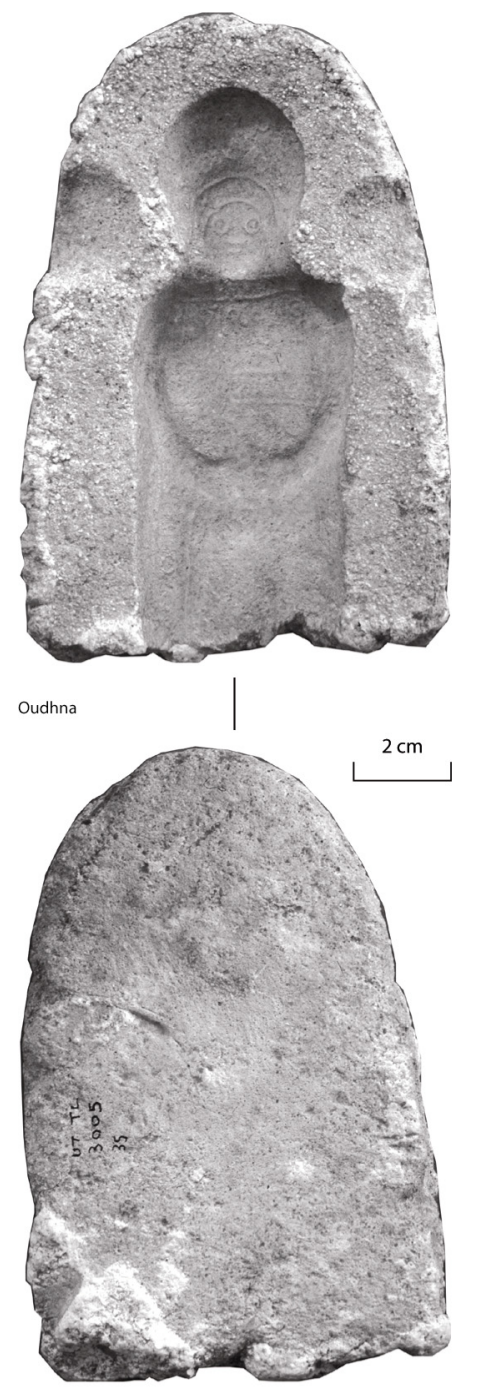

Fig. 43. Moules de figurines (plâtre).

\section{La question des moules bivalves}

Dès 1972, J. W. Salomonson (1972, 99 et note 48) avait mis en évidence en Tunisie une série de moules bivalves en céramique, bien datés du premier tiers du IIIe s., portant, imprimées en négatif, des scènes de spectacle : courses de char, bestiaires et athlètes. Il proposait que ces moules aient été destinés à la production d'objets en matière périssable puisque aucun positif, en quelque matière que ce soit, n'a jamais été retrouvé. L'hypothèse la plus vraisemblable (Deneauve 1986b, 139 ; Rebourg 1987, 219) est qu'ils aient servi à mouler non pas de véritables pains (selon l'hypothèse de Pasqui 1906), car il faudrait alors que ces moules portent les traces de cuisson répétées, mais peut-être des pâtisseries non cuites dont on trouve des mentions dans la littérature (Pétrone, Satiricon, 40 et 60). 


\section{"Moules bivalves" non africains (?)}

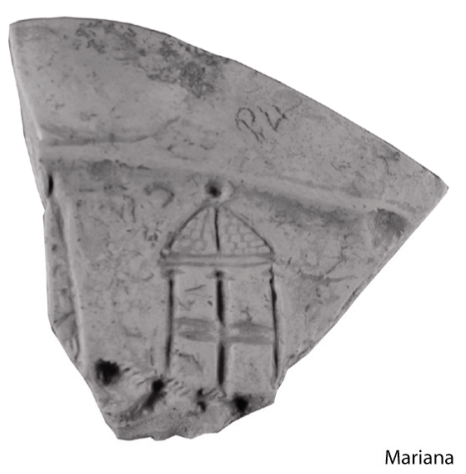

1

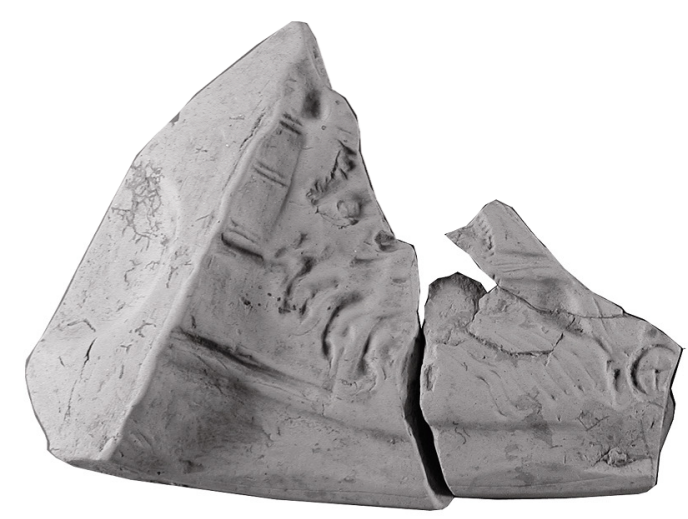

2

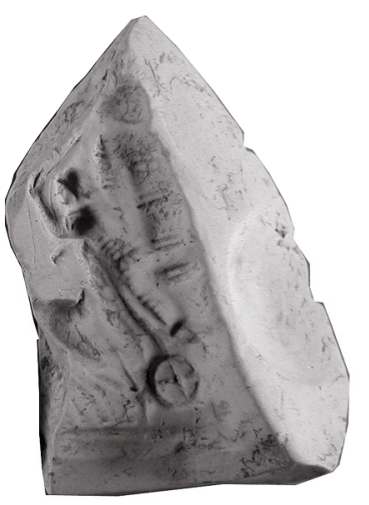

Moule contemporain

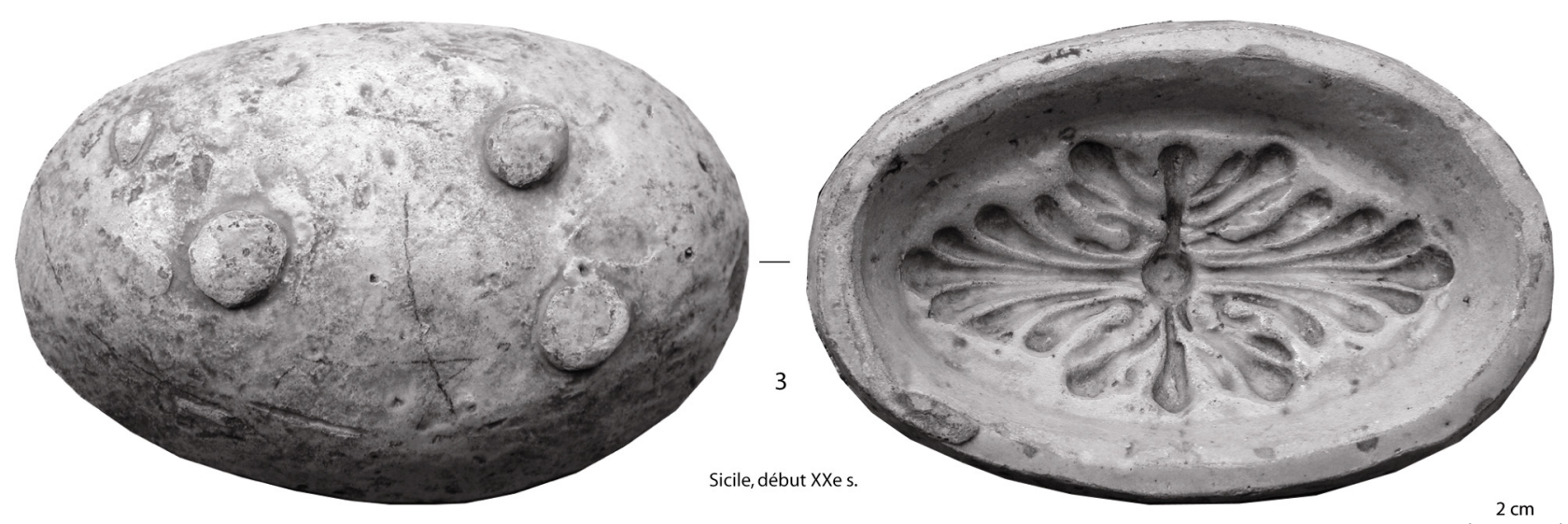

Fig. 44. "Moules bivalves" en céramique et comparaisons actuelles.

Je me demande si on ne doit pas rapprocher ces moules antiques d'objets actuels fabriqués en Sicile (fig. 44, $n^{\circ} 3$ ) qui servent effectivement à préparer des pâtes de coing («cotognata ») et des pâtes de moût de raisin $(« \operatorname{mostard} a »)^{99}$. Ils diffèrent des exemplaires antiques par le fait qu'ils ne comportent qu'une seule valve, posée sur trois petits pieds.

Les moules bivalves sont extrêmement répandus dans les contextes africains, à la fois au nord (Nabeul) et au centre de la Tunisie (El Jem). Des fragments recueillis à Nabeul sont même d'une qualité proche de celle de la sigillée (infra, MOULE TYPE $2, \mathrm{n}^{\circ} 8$ ). Il ne faut cependant pas en conclure hâtivement que tous les moules bivalves à scènes de spectacle sont africains: les fragments provenant de Mariana (Corse) ont une pâte beige finement micacée qui a bien peu de chance d'être africaine (fig. 44, $\mathrm{n}^{\circ}$ 1-2) (fouille G. Moracchini-Mazel ;

\footnotetext{
${ }^{99}$ Je tiens ces renseignements de mon ami Fabio Giomblanco, de Syracuse.
}

cf. Bonifay in Foy, Nenna 2001, 178, notice $\mathrm{n}^{\circ} 285$ ). Il en est probablement de même des moules d'Ostie, d'après la description qui en est donnée par Floriani-Squarciapino (1954, 83, note 2). Toutefois, un moule avec un décor de course de chars, très comparable à ceux d'Ostie, provient d'une épave d'Alghero qui transportait également un chargement d'amphores africaines (D'Oriano 1989, 508509, Pl. I).

\subsection{CÉRAMIQUES ARCHITECTURALES}

\section{Tuiles}

Il a été constaté à plusieurs reprises que l'approvisionnement en briques et en tuiles des chantiers de construction africains est resté longtemps, tout au moins au début de l'Empire, tributaire des importations italiques : «L'image qui se dégage est donc celle d'une région où les productions locales ne suffisent pas à satisfaire les besoins en matériaux de terre cuite » 
(Thébert 2000, 354) ; « un pays expert en céramique, utilisant cependant peu de briques mais en important» (Ibid., 355).

Le cas de Pupput est tout à fait symptomatique : au IIe s., la plupart des tuiles utilisées dans l'architecture des tombes sont d'importation italique (fig. $\left.45, \mathrm{n}^{\circ} 1\right)^{100}$. A cette époque, les productions locales, minoritaires, imitent directement les tegulae italiques dans le module et le profil des rebords, sans doute afin de pouvoir combiner, lors de leur mise en œuvre, ces matériaux d'origine différente (infra, fig. 248).

La construction des grands édifices rend cependant nécessaire la production de matériaux de construction dans les grandes villes africaines. Ainsi, à Oudhna, deux fragments d'antéfixes recueillis dans le comblement du troisième sous-sol du capitole méritent l'attention (Bonifay, Dridi, Jacquest à paraître, $n^{\circ}$ 56-57) : le premier correspond à la face décorative et montre un beau visage de Junon (?) ; le second provient de la partie arrière courbe et porte une marque de fabrique tracée avant cuisson sur trois lignes (fig. $45, \mathrm{n}^{\circ} 2$ ) :

$$
\begin{aligned}
& \text { EXOFIC[---] } \\
& \text { NA } \cdot \text { MARTI } \\
& {[\text { V]SVTINENSI }}
\end{aligned}
$$

Cette marque témoigne de l'existence à Uthina, à l'époque impériale ${ }^{101}$, d'une officine de céramiques architecturales qui a peut-être fourni une partie du décor du capitole $^{102}$; on peut se demander si cet atelier produisait d'autres objets en céramique, des poteries par exemple (supra, p. 47).

Enfin, les tuiles deviennent peut-être plus nombreuses à l'époque tardive. D'assez nombreux fragments de tegulae ont été mis au jour dans les contextes VIe-VIIe s. de l'établissement rural d'Oued R'mel, tandis que l'atelier de sigillée d'Oudhna produit, au VIe s., des tuiles et des chenaux (?) enduits d'un vernis comparable à celui des sigillées (Barraud et al. 1998, 156-157 et fig. 15). Il est remarquable que ces tuiles de qualité, probablement destinées à la couverture d'édifices privilégiés, notamment les basiliques chrétiennes (Stevens, Kalinovski, Van der Leest 1998, 379 : 80\% des tegulae du site), aient été exportées dans d'autres régions du bassin méditerranéen (attestations à Marseille : Bonifay $1998 d, 333$ et note 20). L'Afrique, à cette époque, est passée du statut d'importateur de tuiles à celui d'exportateur.

\footnotetext{
${ }^{100}$ Pâte beige contenant de nombreuses inclusions volcaniques. Expertise $\mathrm{Cl}$. Capelli qui pense à une origine du Latium.

${ }^{101}$ Cf. l'étude détaillée de cette inscription par M. Habib Ben Hassen, à paraître dans le prochain volume des publications de la mission tuniso-française à Oudhna.

${ }^{102} \mathrm{Un}$ autre fragment d'antéfixe, en forme de palmette, provenant des fouilles de la façade est du capitole, est d'importation italique (inclusions volcaniques).
}

On a tenté (Tomber 1987, 169 ; voir également Zucca 1987, 665) d'expliquer la forte proportion à Carthage de tuiles importées d'Italie par la nécessité de lester la cale vide des navires revenant d'Ostie. Mais cette hypothèse a été, à juste titre, contestée (Thébert 2000, 355). Il est plus vraisemblable de considérer qu'il y a, en Afrique, au début de la période romaine, une sorte de résistance culturelle contre le toit de tuiles. Le toit-terrasse, lui, est africain comme le montrent, pour l'époque punique, les fouilles de Kerkouane (Fantar 1984 ; Zucca 1987, 664) et, pour l'époque romaine, un certain nombre d'indices, par exemple, les écoulements d'eau de pluie dans des tuyaux insérés dans les murs (Slim, Bonifay, Trousset 1999, 168 et note 46) ou encore le fait que les sites archéologiques soient rarement signalés en prospection par la présence de tuiles comme c'est, en revanche, le cas dans le Midi de la France.

\section{Tegula d'importation italique}

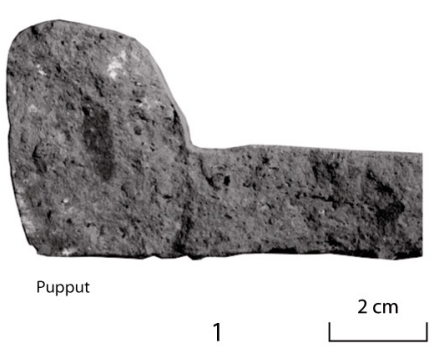

Antéfixe de fabrication uthinaise

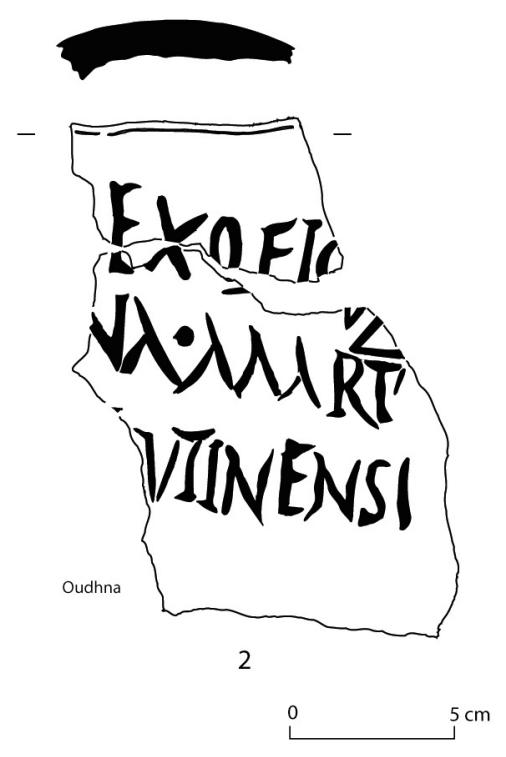

Fig. 45. Tuiles et antéfixes.

\section{Autres matériaux de couverture}

S'il est une céramique architecturale typiquement africaine, c'est bien le tube de voûte (Olivier, Storz 
1983 ; Wilson 1992). Probablement utilisé dans la construction des toitures en terrasse, il est, à la différence des tuiles, omniprésent sur les sites africains reconnus en prospection. L'établissement de typologies régionales semble un peu prématuré, mêmes si les tubes de voûtes $\mathrm{du}$ centre de la Tunisie peuvent sembler, en règle générale, plus courts que leurs homologues du nord du pays (infra, fig. 249). On ne sait rien de leurs lieux de production qui devaient cependant être liés à la fabrication d'autres céramiques tournées, amphores et/ou céramiques communes.

Le tuyau est un autre matériau de construction très commun en Afrique, probablement associé aux toitures en terrasse et aux problèmes d'alimentation en eau. Le schéma classique est que l'eau de pluie était canalisée dans ces tuyaux, souvent maçonnés dans les murs, pour rejoindre la citerne de la maison. Ces objets ont souvent posé des problèmes d'identification, pouvant être facilement confondus avec des fragments de cruches (Bonifay, Reynaud 2004, $\mathrm{n}^{\circ} 28.18$; voir également Hayes 1978b, 80 et fig. 25, $\left.n^{\circ} 71\right)$.

\section{Céramiques décoratives}

Les carreaux « chrétiens » décorés en relief constituent également une spécificité africaine ${ }^{103}$, et plus précisément tunisienne ${ }^{104}$. Ces carreaux étaient utilisés principalement dans l'architecture des basiliques chrétiennes, soit pour la décoration de plafonds à caissons, soit sur les murs. Plusieurs groupes régionaux ont été délimités par N. Ben Lazreg (1991), qui oppose une production standardisée, de bonne qualité, dans la région de Carthage à une pluralité de centres de fabrication, au rendu plus irrégulier, en Byzacène. Une production présumée a été localisée à Aouine es-Soltane, dans un atelier d'amphores de la rive sud de la sebkhra Sidi el-Hani, près d'El Jem (Peacock, Bejaoui, Ben Lazreg 1990, 64).

De fait, les fragments de carreaux qui ont été retrouvés dans une fosse tardive (comblée au VIIe s.) des fouilles $\mathrm{du}$ quartier des fabriques de salaison à Nabeul (inédit) renvoient au groupe le plus septentrional de la Byzacène, celui reconnu à Bou Ficha. On y retrouve le carreau avec deux personnages assis sur un trône (infra, fig. 247), interprété comme une double représentation de la Vierge à l'Enfant (Duval 1995, 290, n ${ }^{\circ} 1$ ). Ces images ne sont pas sans rappeler également les déesses-mères des figurines de Pupput et du sanctuaire voisin de Thinissut ainsi que l'ambiguïté des figurines d'Oudhna (supra, p. 83). Bien qu'on ne puisse exclure totalement la proximité d'un lieu de culte qui n'aurait pas été reconnu, on peut se demander, avec N. Duval (1994, 290), si ce type de décor n'était pas aussi utilisé dans les édifices profanes. L'iconographie des autres carreaux issus du

\footnotetext{
${ }^{103}$ Rares exemples en Andalousie et en Macédoine exyougoslave.

${ }^{104}$ Rares exemples en Algérie.
}

même contexte : rosaces, panthères affrontées dans une rosace, scène de chasse $(?)^{105}$, ne renvoie pas directement à une thématique chrétienne.

\footnotetext{
${ }^{105}$ Motif inédit.
} 


\title{
PARTIE II : TYPOLOGIE ET CHRONOLOGIE
}

\author{
DU NORD AU SUD DE LA MÉDITERRANÉE : DONNÉES COMPARATIVES
}

Une des particularités de la céramique africaine est que sa typologie et son cadre chronologique ont été établis hors d'Afrique, sur des sites consommateurs souvent très éloignés des sites producteurs (supra, p. 2). Il est évident, comme l'écrivait Paul-Albert Février en 1964, qu'il est aujourd'hui plus que jamais «nécessaire, sur les sites africains, de tenter de fixer une chronologie précise, non point en projetant les conclusions imparfaites déjà élaborées au nord de la Méditerranée, mais en dégageant du contexte africain, et même de chaque site, des faits assurés » (Février 1964, 135).

J'ai tout d'abord cherché à appliquer en Afrique, comme tous les céramologues qui ne sont pas natifs de cette terre, des typologies et des chronologies que j'avais apprises sur d'autres rivages. En effet, le cadre chronologique que je me suis peu à peu fixé, en manipulant depuis plus de vingt ans d'assez grandes quantités de mobilier africain, puise ses fondations dans la stratigraphie de Marseille (Bonifay 1983 et 1986 ; Bonifay et al. 1998).

Ensuite, en venant en 1989 travailler en Tunisie, j'ai découvert que la céramique africaine n'était pas un tout, comme le laissent souvent penser les publications européennes, mais une juxtaposition de petits faciès locaux assez différents les uns des autres. De ce point de vue, mon premier contact avec l'Afrique fut extrêmement enrichissant puisqu'il s'est agi d'enregistrer et d'étudier le matériel d'une prospection très extensive, sur les $1600 \mathrm{~km}$ de côtes de la Tunisie (Bonifay 1990). Dès ce moment-là, des faciès typo-chronologiques ont commencé à se dessiner, que j'ai pu approfondir à la faveur de l'étude de mobiliers de fouilles. A la différence de beaucoup de céramologues occidentaux qui ont travaillé en Tunisie, je n'ai du faciès de Carthage qu'une mince expérience (Bonifay à paraître, a). En revanche, je connais bien, à la faveur des fouilles tuniso-françaises qui y ont été menées depuis 1991, le faciès de trois cités limitrophes situées à la frontière de la Zeugitane et de la Byzacène : Nabeul, Pupput et Sidi Jdidi, qui présente à la fois des points communs et des particularités. Le panorama céramique de Nabeul est celui d'une grande ville, assez ouverte sur l'extérieur, comme l'est également Kelibia, plus au Nord, d'après ce que j'ai pu en voir ${ }^{106}$. Déjà tourné vers la Byzacène, le faciès de Pupput est relativement proche de celui d'Hergla ${ }^{107}$, les

\footnotetext{
${ }^{106}$ Fouilles J.-M. Lassère et H. Slim, étude par J. Piton.

${ }^{107}$ Fouilles N. Ouertani, étude par M. Pasqualini et J. Piton.
}

activités portuaires drainant un commerce principalement intra-africain. Enfin, la céramique de Sidi Jdidi traduit l'isolement de cette petite bourgade de l'intérieur qui paraît vivre en quasi-autarcie. D'autres villes de Tunisie me sont connues par les activités ponctuelles que j'y ai menées : Oudhna, Thuburbo Majus, El Jem, Rougga. Enfin, des expertises pour des collègues tunisiens ou l'encadrement de travaux universitaires m'ont permis d'entrevoir le mobilier de la partie tunisienne de la Tripolitaine $^{108}$ et de la zone continentale de l'Afrique proconsulaire $^{109}$. En revanche, j'ai peu travaillé dans le nord-ouest et ne connais le matériel de Dougga et de Chemtou, souvent assez différent de celui de Carthage ou de la côte orientale, que par les publications, peu nombreuses, dont il a fait l'objet.

Je vais donc, dans cette deuxième partie, passer en revue les principales catégories de céramiques en insistant sur les quelques séries dont il est possible de cerner l'évolution. Certes, l'accroissement considérable de la documentation, aussi bien en Afrique que sur tout le pourtour méditerranéen, justifierait de repenser entièrement la façon de classer les différentes catégories de céramiques africaines. Mais je n'ai pas souhaité remanier de fond en comble les systèmes de classifications existants, souvent bien ancrés dans la pratique céramologique. J'ai plutôt tenté de faire entrer les données nouvelles dans le cadre existant, quitte à opérer quelques retouches dans le découpage des catégories ou à les disposer d'une autre manière.

Ce travail, fondé sur le matériel issu de quelques sites archéologiques choisis sur les deux rives de la Méditerranée, ne prétend pas à l'exhaustivité. J'ai cherché à utiliser en priorité une documentation de première main et à la situer dans la perspective des classifications existantes. Ce n'est donc pas une nouvelle typologie globale de la céramique africaine. La nomenclature proposée en filigrane pour chaque grande catégorie de mobilier, notée en petites capitales (AMPHORE TYPE 1, SIGILLÉE TYPE 33, etc.) n'est pas une classification mais un simple index destiné à faciliter la liaison entre le texte et les figures.

Nota : dans les catalogues, les $\mathrm{n}^{\circ}$ précédés d'un astérisque renvoient à une illustration.

\footnotetext{
${ }^{108}$ Collections du Musée de Zarzis : A. Drine.

${ }^{109}$ Par ex. le site de Sidi Aïch : thèse en cours de M. Nasr.
} 


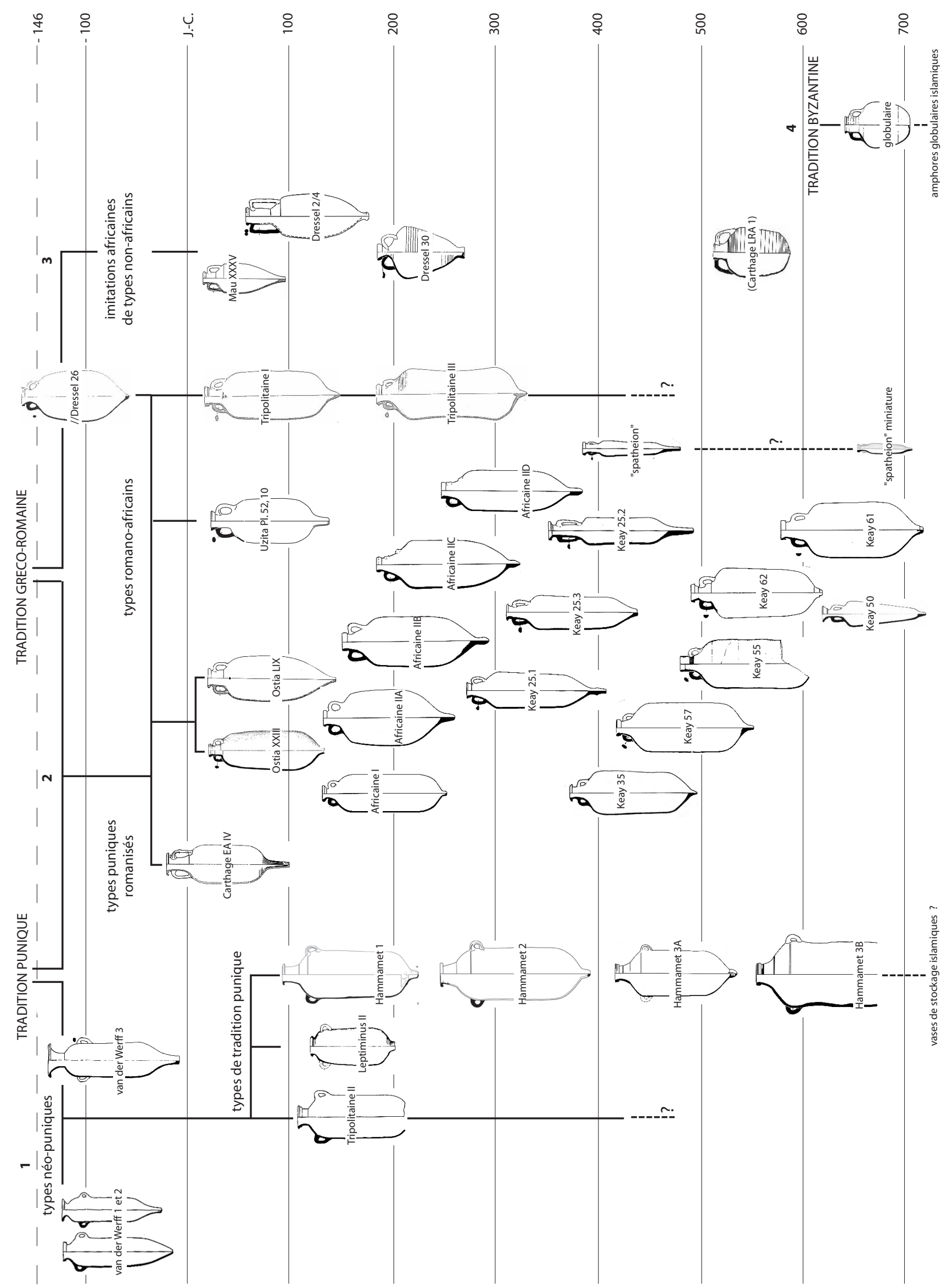

Fig. 46. Proposition de schéma évolutif des amphores africaines d'époque romaine. 


\section{LES AMPHORES}

Les nouvelles données sur la typologie, la chronologie et le contenu des amphores africaines collectées, depuis une vingtaine d'années, au hasard des études qui m'ont été confiées, m'incitent à proposer un nouveau schéma évolutif (Bonifay 2004c), sans doute aussi imparfait que les précédents, mais qui correspond peut-être mieux à l'état actuel de nos connaissances (fig. 46).

La production d'amphores en Afrique, à partir de la conquête romaine, paraît se scinder en quatre lignées typologiques :

1) La première reste entièrement fidèle au modèle punique dans ses trois caractères essentiels : a) la pâte orange à surface extérieure blanche, b) le corps cylindrique, c) les anses placées sur l'épaulement, dans la tradition des amphores phéniciennes.

2) La deuxième, la plus importante, tout en conservant la ligne cylindrique des amphores puniques, va adopter le principal caractère morphologique des amphores grécoromaines : les anses placées sur le col.

3) Une troisième filière, commune à toutes les régions de l'Empire et sporadique durant toute la période, consiste à imiter des types non-africains.

4) Enfin, une quatrième génération naît à la fin de la période byzantine et va probablement se poursuivre après la conquête arabe : les amphores à corps globulaire.

\subsection{AMPHORES DE TRADITION PUNIQUE}

Ce terme a été inventé par Fernand Benoit (1962) et repris avec succès par J. H. Van der Werff (1977-78) pour caractériser des amphores fabriquées en Afrique après la chute de Carthage mais dont «le type obéit incontestablement à une tradition punique par l'emplacement des anses et la forme générale » (Benoit 1962, 327).

\section{Principaux types d'amphores de tradition punique}

Longtemps, cette appellation ne s'est appliquée qu'aux trois types précoces définis par Van der Werff (1977-78). Je propose de l'étendre à l'ensemble des amphores africaines d'époque romaine qui répondent à la définition de F. Benoit cité plus haut, c'est-à-dire aux amphores Tripolitaines II, au type Leptiminus II récemment identifié par A. Opait (2000) et à d'autres types, moins bien documentés, de Tunisie occidentale et d'Algérie.

\section{— Types néo-puniques (fig. 47)}

\section{AMPHORES TYPES 1-3}

Il conviendrait peut-être, de ce fait, de renommer « amphores néo-puniques » (Peacock 1994, 42) ${ }^{110}$ ou

\footnotetext{
110 « Neo-Punic amphorae of the form Van der Werff 1-3, Keay $8-9 »$.
}

« amphores tardo-puniques » (Martin-Kilcher 1999, 414) les trois types d'amphores identifiés par Van der Werff, dont on sait maintenant qu'ils sont déjà produits à l'époque punique (Ben Younès 1998, 67-68 ; déjà : Van der Werff 1977-78, 178-180) et que leur diffusion ne paraît pas dépasser le Ier s. av. J.-C. (retractatio de J. Van der Werff, 1982b). Le type 1 (= Cintas $312=$ type A de Martin-Kilcher 1999) paraît typique des productions du nord de la Tunisie ${ }^{111}$, tandis que les types 2 et 3 (= type B de Martin-Kilcher 1999) sont plutôt, mais pas exclusivement (Martin-Kilcher 1999, 414), originaires de Byzacène et de Tripolitaine : des ateliers viennent d'être découverts à Jerba (Fentress 2001). Leur contenu est supposé être du garum pour le type 1 (Martin-Kilcher 1999,420 ) et du vin pour les types 2 et 3 (Fentress 2001, 263).

Exemples (fig. 47) :

TYPE 1

*1 Van der Werff 1977-78, fig. 4, n 1.

TYPE 2

Variante A (type Van der Werff 2)

*1 Van der Werff 1977-78, fig. 4, $n^{\circ} 2$.

Variante B (type Schöne-Mau XL)

*2 Pompéi (Panella 2001, fig. 19, $\mathrm{n}^{\circ}$ 143).

TYPE 3

*1 Van der Werff 1977-78, fig. 4, nº 3.

Il semble que le type Schöne-Mau XL puisse être considéré comme une évolution au Ier s. ap. J.-C. du type Van der Werff 2 (Panella 2001, 207).

\section{- Amphore Tripolitaine II (fig. 47-48)}

\section{AMPHORE TYPE 4}

Comme cela a été suggéré, peut-être de manière un peu excessive, pour l'ensemble des amphores tripolitaines impériales (Riley 1979, 138), le type Tripolitaine II semble issu du type Van der Werff 3. On retrouve sur ces amphores cylindriques, surmontées d'un col court, la même façon de profiler le bord, triangulaire et évasé, avec un gradin très accentué qui dérive vraisemblablement de la «houppe» plus ou moins prononcée (Van der Werff 1977-78, 184, notamment fig. 12, $\mathrm{n}^{\circ} 7$ ) des bords de l'amphore néo-punique ( $\mathrm{Cf}$. Keay 1989, fig. 9, $\left.\mathrm{n}^{\circ} 129-142\right)$; comme sur cette dernière, le fond est conique, creux ou plein (Panella 1973, 564).

Exemples :
Variante A, précoce (fig. 47)
*1 La Longarina (Ostie) (Hesnard 1980, fig. 4)
Variante B, classique
2 Misurata, Ier s. (Panella 1973, 628, $\mathrm{n}^{\circ} 21$ ).
3 Lm4 farm (Barker et al. 1996, fig. 9.11).
*4 Pupput, tombe 277 (Inv. PP5658.1). Pâte du type de

${ }^{111}$ Rappelons toutefois que le seul atelier avéré de ce type est situé à Kouass, sur la côte atlantique du Maroc (Ponsich 196970). 
Typologie - Amphores
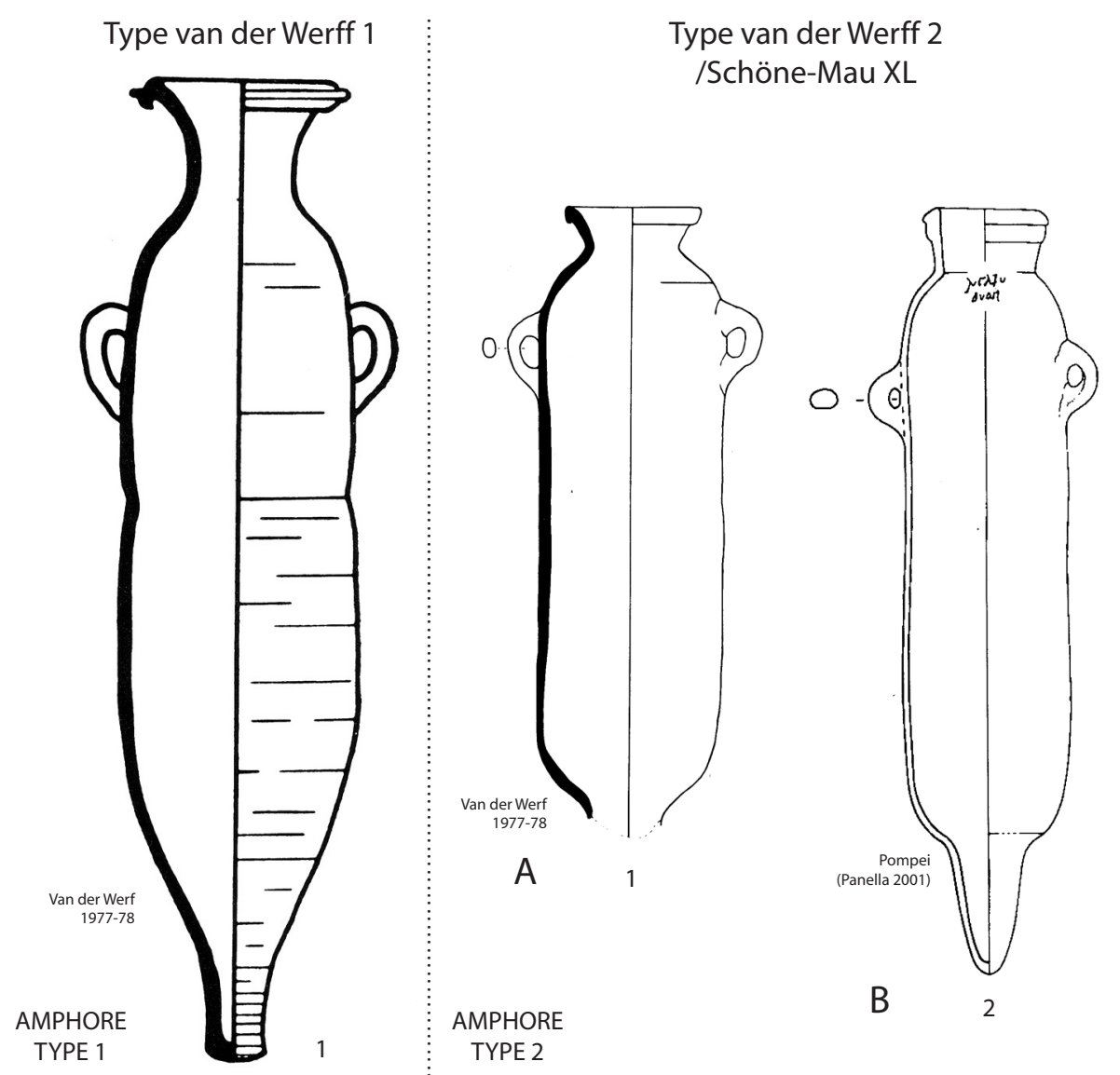

Type van der Werff 3
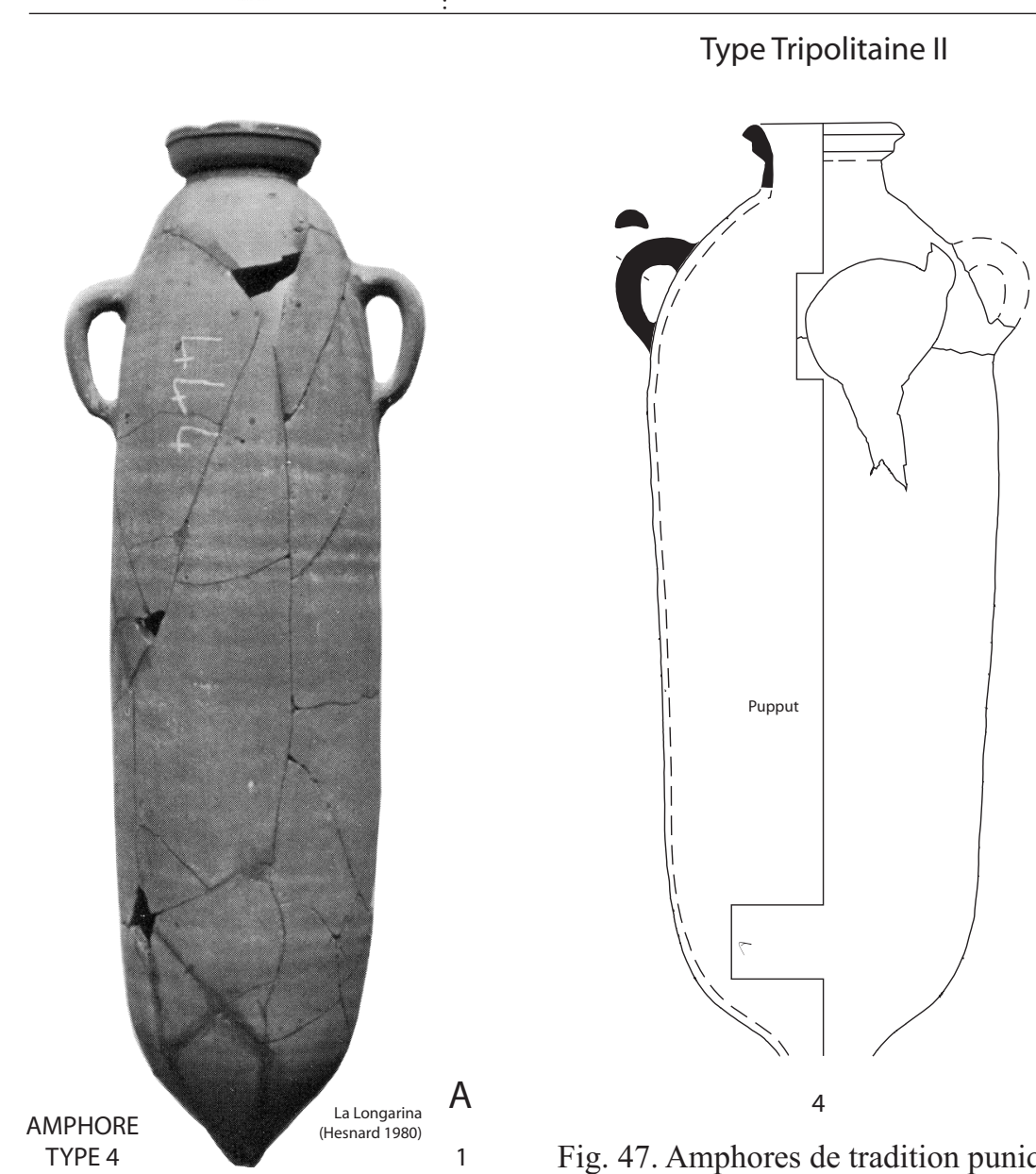

Fig. 47. Amphores de tradition punique.

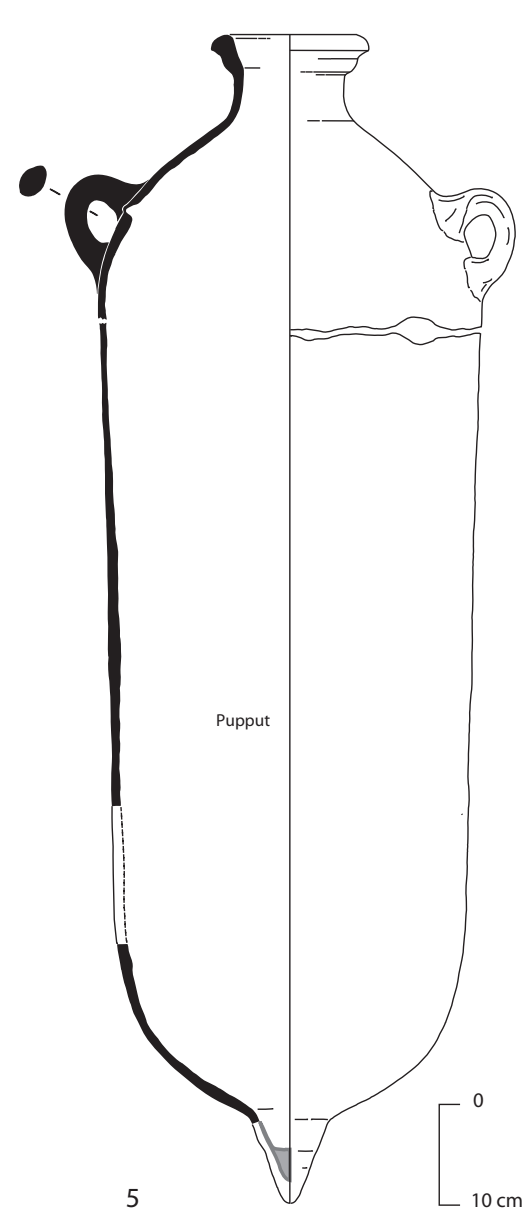



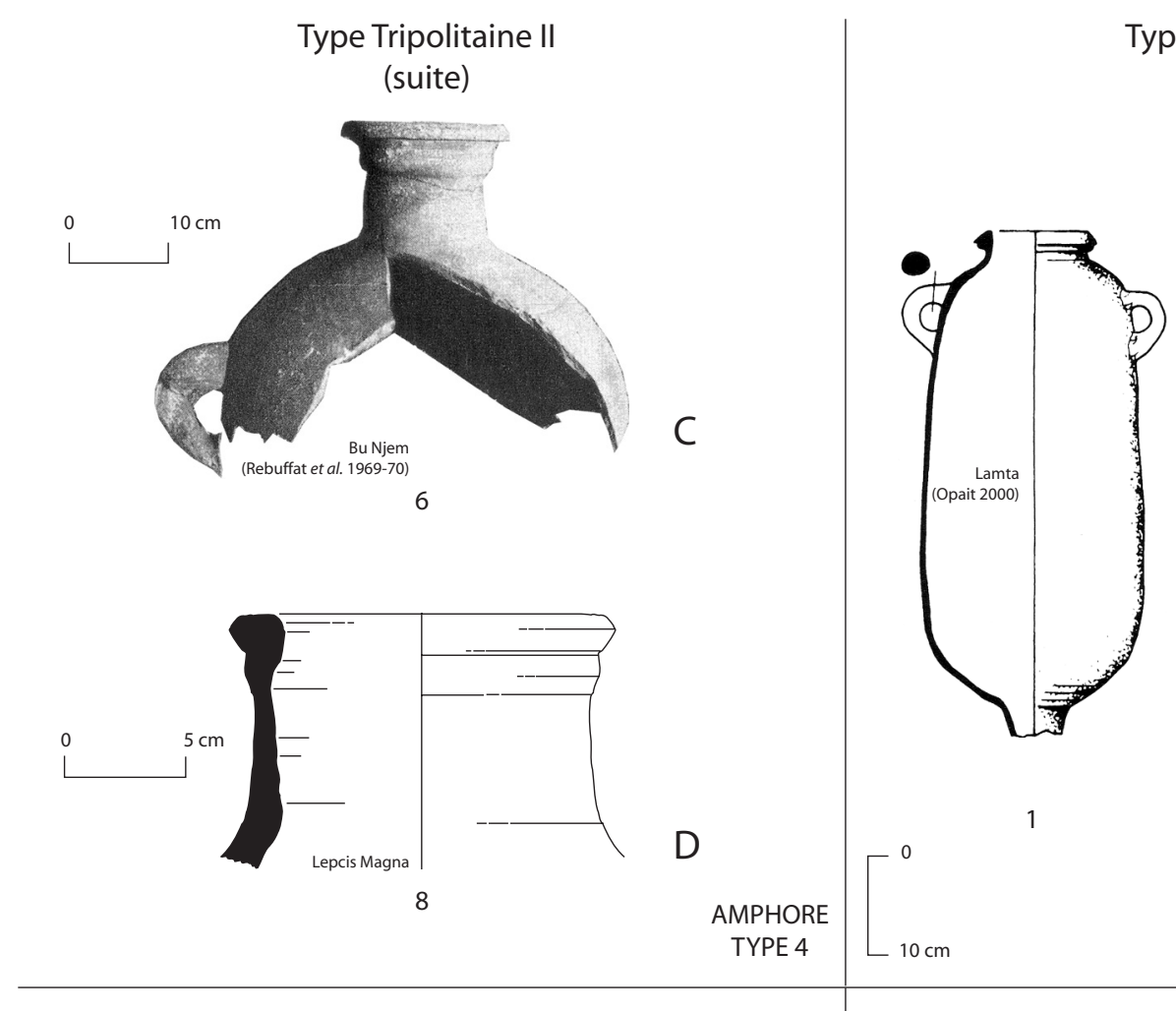

Type Leptiminus II
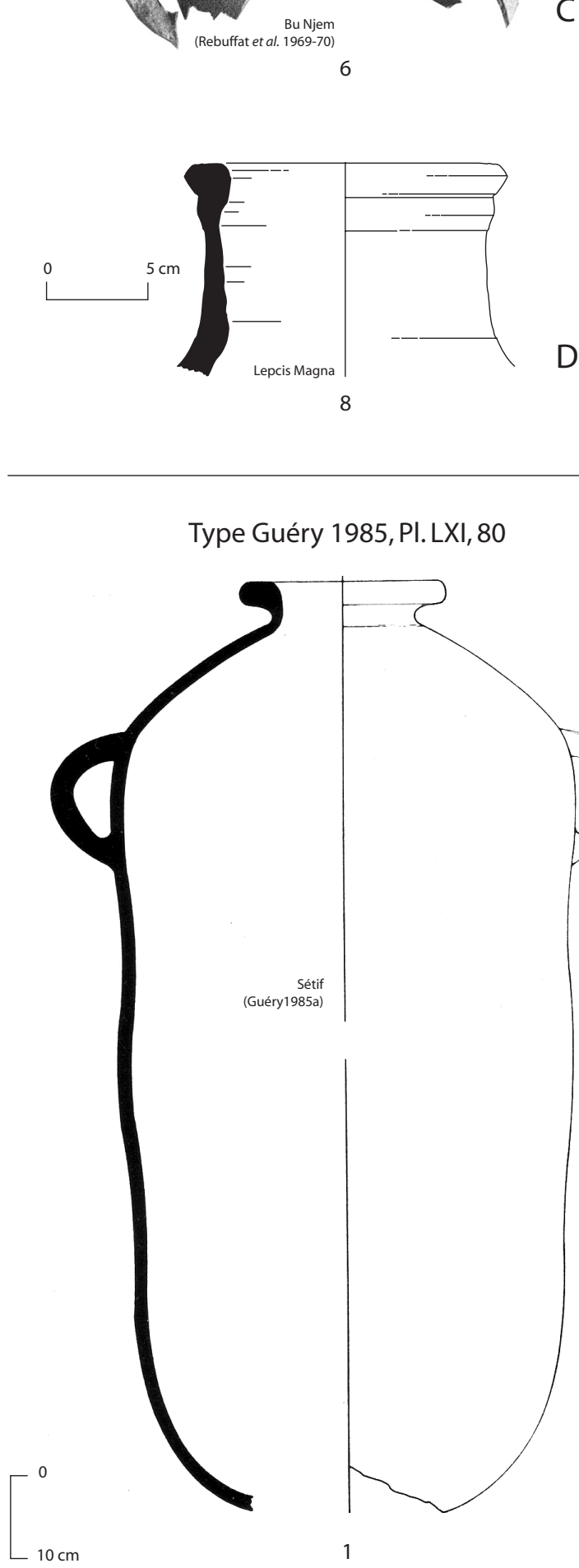

Type Guéry 1985, PI. LXI, 80

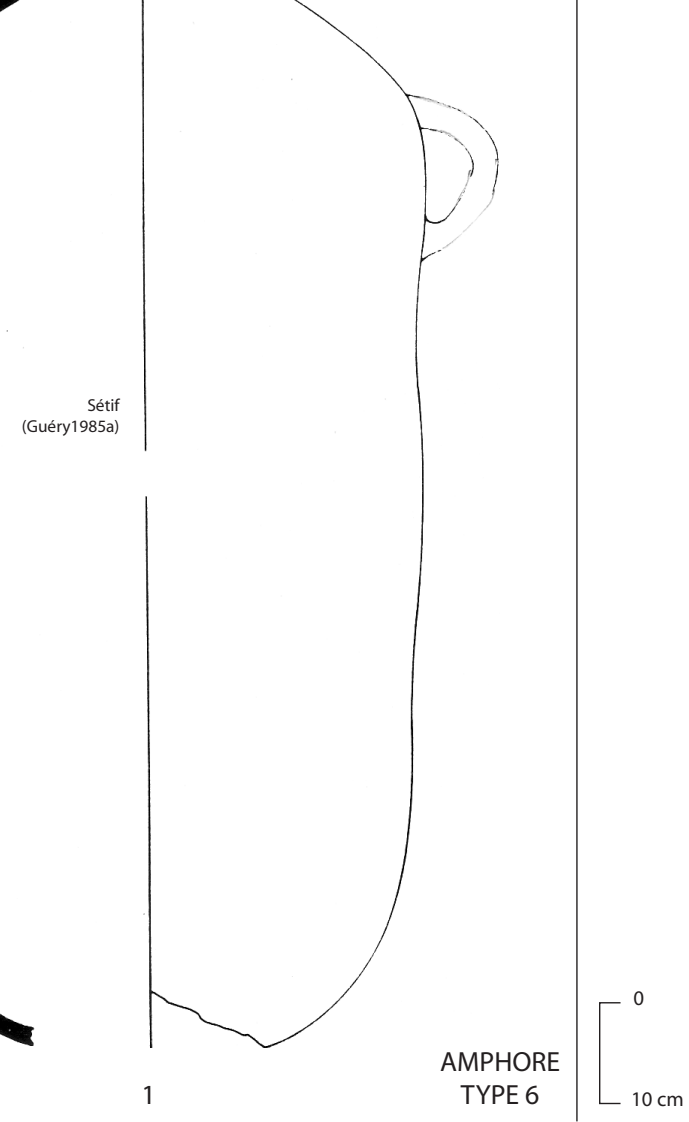

Fig. 48. Amphores de tradition punique.
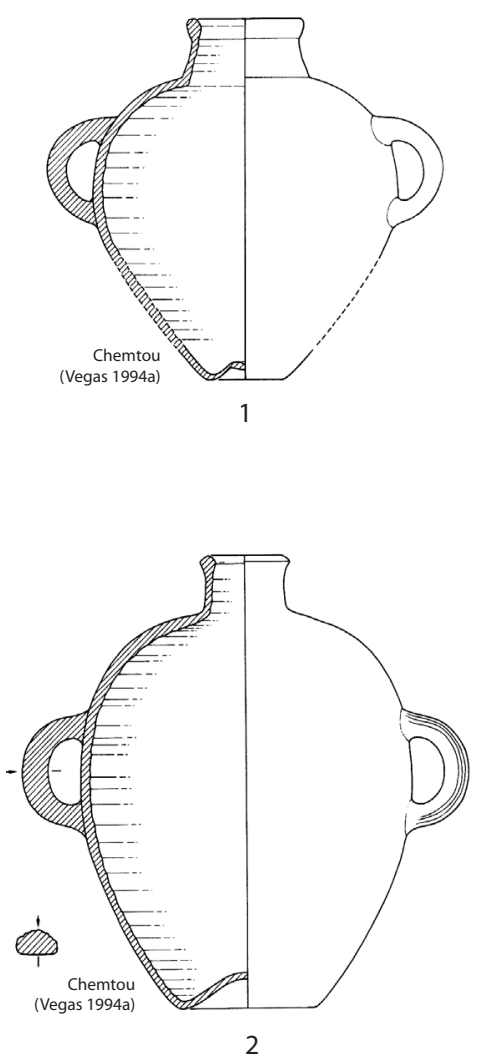

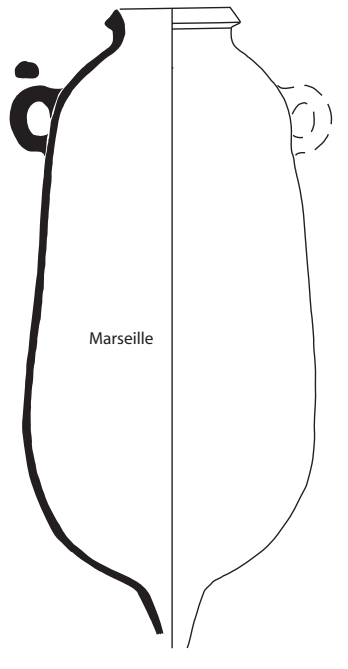

2 
Lepcis Magna (supra, Pl. I, $\left.\mathrm{n}^{\circ} 1\right)$. Dessin C. Brun.

*5 Pupput (Inv. PP6606.1). Pâte fine. Enduite de poix ou de bitume (infra, fig. 262, $n^{\circ} 5$ ). Dessin C. Brun.

Variante C, évoluée (fig. 48)

*6 Bu Njem (Rebuffat 1969-70, Pl. XXXVII, c). Timbre $P B A V$ sur l'anse.

Variante D, tardive (fig. 48)

*7 Lepcis Magna, Thermes du Levant (fouilles A. Laronde, Inv. 136.1). Contexte c. 365.

Autre variante

8 Lepcis Magna, Théâtre (Mandruzzato 1992, fig. 192, C55). Bord en bandeau, panse cannelée.

Ces amphores, identifiées pour la première fois à Ostie (Panella 1972, 78-81 ; Panella 1973, 562-564), proviennent, sur ce site, de niveaux datés de la fin du Ier s. jusqu'au milieu du IIIe s., avec un indice de fréquence élevé sous les Antonins. En Tripolitaine, elles sont attestées dès la première moitié du Ier s. et jusqu'à la fin du IVe s. (Panella 1973, 563; Keay 1989, 43). L'évolution morphologique de la forme durant ces trois siècles reste encore imprécise (Cf. cependant Panella 1973, 564). L'exemplaire de La Longarina (1), daté du début du Ier s., est à l'évidence une forme de transition avec le type néo-punique Van der Werff 3 (supra, TYPE 3). Les deux amphores de Pupput (4-5) à col court proviennent de contextes de la fin du IIe siècle. Les exemplaires du IIIe paraissent se distinguer par un col plus allongé (6) et ceux du IVes. par un bord atrophié (7). L'évolution semble aller vers des conteneurs de très grandes dimensions avec un bord simple en bandeau et une panse cannelée (8), attestés dans des contextes du Ve s. (Mandruzzato 1992, 186).

Les données sur le contenu de cette amphore sont contradictoires. Alors qu'un exemplaire complet a été découvert, en place, dans un pressoir à huile de l'arrière pays de Lepcis Magna (Barker et al. 1996, 279-280 et fig. 9.11), un autre, fragmentaire, recueilli dans le comblement du port antique de Toulon, s'est révélé poissé (Leguilloux 1988b, 158) ${ }^{112}$. L'amphore entière de Pupput (5) semble enduite de bitume (?). L'ouverture circulaire sur le $n^{\circ} \mathbf{4}$ peut avoir été pratiquée pour prélever un contenu semi-solide (salaisons de poissons ?) (infra, p. 468).

\section{— Type Leptiminus II (fig. 48)}

\section{AMPHORE TYPE 5}

L'amphore de tradition punique qui vient d'être mise en évidence (Opait 2000) au sein des productions des fours de Leptiminus/Lamta (Stirling, Ben Lazreg 2001, fig. 3.14) trouve peut-être son origine dans le type Van der Werff 2 dont «le centre de gravité de l'aire de diffusion se situe en Byzacène » (Van der Werff 1977-78, 179). Sa forme présente de fortes analogies avec celle de l'amphore néo-punique : le bord à section grossièrement triangulaire, arrondi au sommet et mouluré à la base, la quasi-absence de col, le fond tubulaire (?) creux ; le corps

\footnotetext{
${ }^{112}$ Un autre exemplaire de la variante B, poissé, à Fos-sur-Mer (dépôt municipal, resp. J.-Ph. Lagrue).
}

de l'amphore impériale est toutefois beaucoup plus large, c'est pourquoi je pense que les exemplaires Opait 2000, $\mathrm{n}^{\circ}$ 25-27 appartiennent plus vraisemblablement au type Mau XL (supra, AMPHORE TYPE 2B).

Exemples (fig. 48) :

*1 Lamta (Tunisie) (Opait 2000, fig. 2, $\mathrm{n}^{\circ} 24$ ).

*2 Marseille, chantier de La Bourse (Inv. B261), pâte beige orangé, intérieur poissé.

A. Opait date la production de son type II entre la fin du Ier s. et le milieu du IIIe s. (Opait 2000, 442). L'exemplaire de Marseille $^{113}$ (2) provient d'un contexte de la fin du IIe s. ou du début du IIIe siècle.

Le poissage de l'amphore de Marseille paraît confirmer l'hypothèse du garum avancée par A. Opait (2000, 442).

\section{- Autres types (fig. 48)}

\section{AMPHORE TYPE 6}

Même si on reste mal renseigné sur ce territoire, il est probable que les productions d'amphores de Maurétanie Césarienne n'échappent pas au conservatisme morphologique, observé partout ailleurs en Afrique. On en voudra pour témoin cette amphore cylindrique, à bord replié à l'horizontale, quasiment privée de col et munie de deux anses arrondies sur l'épaulement, découverte dans une tombe du IIe s. à Sétif (n 1 : Guéry 1985a, 360, Pl. LXI, $\left.\mathrm{n}^{\circ} 80\right)^{114}$.

\section{AMPHORE TYPE 7}

Je ne sais pas s'il faut interpréter comme des amphores ou (plus vraisemblablement ?) comme des cruches à eau, les vases globulaires de plus petite taille (H. 370 et $460 \mathrm{~mm}$ ) à anses sur l'épaulement, long col cylindrique et fond ombiliqué, fréquents dans les régions intérieures de l'Afrique Proconsulaire et en Maurétanie Césarienne ( ${ }^{\circ}$ 1-2 : Vegas 1994a, 168 et fig. 179, $n^{\circ} 397-398$, avec bibliographie pour Mactar et Tiddis). Un exemple de Haïdra (Jacquest 1998, H2F) paraît associé à un couvercle en forme de cloche (Ibid., H1G) qui trouve comparaison avec ceux des amphores puniques (Cintas 1950, P1. XVIII, $\mathrm{n}^{\circ} 231$; cf. aussi les amphores $L R A 5 / 6$ de Jalame : Johnson 1988 fig. 7/55-7/56).

\section{Les amphores de tradition punique du golfe d'Hammamet}

Le développement des recherches dans la région de Sidi Jdidi et Pupput a permis de mettre en évidence un nouveau groupe d'amphores de tradition punique jusqu'ici peu documenté et dont la diffusion paraît concentrée dans le golfe d'Hammamet (Bonifay 2004b). Trois types principaux s'échelonnent du IIe s. au VIIe s. :

\footnotetext{
113 Comblement du bassin d'eau douce. Cette amphore sera étudiée par G. Rossi dans la publication collective du mobilier, dirigée par M. B. Carre.

${ }^{114}$ Roger Guéry pensait pouvoir déceler sur cette amphore des caractères tardifs mais il affirme par ailleurs que la tombe appartient à la phase Ic de la nécropole. J'ai préféré m'en tenir à la position stratigraphique.
} 


\section{— Type Hammamet 1 (fig. 49)}

\section{AMPHORE TYPE 8}

Amphore (1,05 $\mathrm{m}$ de haut, 0,36 $\mathrm{m}$ de diamètre) caractérisée par un bord déversé (à collerette) et mouluré, un long col, une panse cylindrique portant deux petites anses nervurées ( 2 ou 3 nervures), et un fond à petite pointe cylindro-conique, creuse. Quatre variantes :

- variante 1A: bord en collerette, lèvre presque horizontale, à double replat en « $\mathrm{S} »$, effilée à son extrémité ;

- variante 1B: bord déversé, horizontal, à lèvre pendante épaissie et discrètement bifide à son extrémité ;

- variante $1 \mathrm{C}$ : bord court, horizontal ou légèrement tombant, au sommet faiblement concave, lèvre moulurée bifide, section triangulaire du raccord entre le bord et le col ;

- variante $1 \mathrm{D}$ : bord à section en crochet, au sommet légèrement concave, lèvre très épaissie, tombante.

Exemples (fig. 49) :

Variante A

*1 Pupput, tombe 406 (Bonifay 2004b, fig. 4, n 1).

Variante B

*2 Pupput, tombe 1308 (Ibid., fig. 4, $\mathrm{n}^{\circ}$ 2).

Variante C

*3 Pupput, tombe 1008 (Ibid., fig. 5, n 4). Marque incisée illisible.

4 Pupput, tombe 406 (Ibid., fig. 5, $\mathrm{n}^{\circ} 3$ ).

5 Pupput, tombe 615 (Ibid., fig. 2, $\mathrm{n}^{\circ}$ 5).

6 Pupput, tombe 837 (Ibid., fig. 14, $\mathrm{n}^{\circ}$ 42). Marque incisée $M$ à la base de la panse.

Variante D

*7 Pupput, tombe 1145 (Ibid., fig. 6, n 6).

Variante E (grand module ou type $1 / 2$ )

*8 Pupput, tombe 394 (Ibid., fig. 7, $\mathrm{n}^{\circ}$ 7).

9 Pupput, tombe 1008 (Ibid., fig. 7, $\mathrm{n}^{\circ} 8$ ).

Ce type d'amphore, fréquemment rencontré en prospections de surface sur les sites côtiers du golfe d'Hammamet (Bonifay et al. 2002-2003, fig. 15, $\mathrm{n}^{\circ} 195$ 198), est désormais connu en stratigraphie à Nabeul et surtout dans la nécropole de Pupput (Bonifay 2004b). C'est sur ce dernier site qu'ont été publiés les premiers exemplaires de ces amphores (Cassaigne 1914, fig. 12, $15,72)$.

Datation proposée : IIe s. - début du IIIe s.

\section{— Type Hammamet 2 (fig. 50)}

\section{AMPHORE TYPE 9}

Amphore cylindrique (jusqu'à 1,20 m de haut et $0,45 \mathrm{~m}$ de diamètre), caractérisée par un bord à lèvre courte et massive repliée horizontalement vers l'extérieur, un col tronconique, des anses plates marquées longitudinalement par une profonde rainure, un fond conique creux ou plein. Ce type comporte plusieurs variantes qui ont été déterminées sur le site de Sidi Jdidi (Bonifay, Reynaud 2004, fig. 150) :

- variante A : bord à section en crochet, au sommet légèrement convexe, lèvre assez longue (transition avec le type 1 ?), effilée, et recourbée sur la face inférieure du bord;

- variante B : bord horizontal proéminent, le repliement de la lèvre est complet de façon à former un épaississement arrondi à l'extrémité du bord ;

- variante $\mathrm{C}$ : bord torique, incliné vers l'intérieur, lèvre courte arrondie (à section quasiment circulaire) ;

- variante D : bord anguleux incliné vers l'intérieur, lèvre «pincée » tendant à s'épaissir et à devenir verticale à son extrémité ;

- variante E : bord massif incliné vers l'intérieur, lèvre à section carrée (transition avec le type 3 ?), pendante sur quelques exemplaires de transition avec la variante $\mathrm{D}$, face extérieure parfois discrètement cannelée.

Il existe également des petits modules.

Exemples (fig. 50) :

Variante A

*1 Pupput, tombe 1058 (Bonifay 2004b, fig. 8, $\mathrm{n}^{\circ} 11$ ).

2 Sidi Jdidi, basilique 1, état B1A (Bonifay, Reynaud 2004, $\left.n^{\circ} 12.38\right)$.

Variante B

*3 Pupput, tombe 203 (Bonifay 2004b, fig. 8, $\mathrm{n}^{\circ} 14$ ).

4 Sidi Jdidi, basilique 1, état B2A (Bonifay, Reynaud 2004, $n^{\circ}$ 18.48).

Variante $\mathrm{C}$

*5 Pupput, tombe 876 (Bonifay 2004b, fig. 9, $\mathrm{n}^{\circ} 17$ ).

6 Sidi Jdidi, basilique 1, état B1A (Bonifay, Reynaud 2004, $n^{\circ} 12.39$ ).

Variante D

*7 Pupput, tombe 876 (Bonifay 2004b, fig. 9, n²0).

8 Sidi Jdidi, basilique 1, état C1 (Bonifay, Reynaud 2004, $n^{\circ} 14.12$ ).

Variante E

*9 Sidi Jdidi, basilique 2, destruction état II (Bonifay 2004b, fig. $\left.10, \mathrm{n}^{\circ} 25\right)$.

*10 Sidi Jdidi, basilique 1, état B1A (Bonifay, Reynaud 2004, $\mathrm{n}^{\circ}$ 12.40).

*11 Sidi Jdidi, basilique 2, destruction état II (Bonifay $2004 \mathrm{~b}$, fig. $\left.10, \mathrm{n}^{\circ} 26\right)$. Marque incisée $: w$ néopunique (?).

Ce type connaît une longue évolution, du IIIe au Ve s., encore difficile à cerner dans le détail (Bonifay 2004b). Une amphore de type $\mathrm{B}$ est associée à une amphore Africaine III A (= type Keay 25.1), dans une tombe de Jebel Harboun à la fin du IIIe s. s. - début du IVe s. (Ben Abed et al. 2000, 3-4, fig. 7, $\mathrm{n}^{\circ} 2$ ).

Datation proposée :

- Variantes A-D - milieu du IIIe - IVe s. (variante D jusqu'au Ve s.)

- Variante E - Ve s.

\section{— Type Hammamet 3 (fig. 51)}

\section{AMPHORE TYPE 10}

Amphore cylindrique (hauteur indéterminée mais probablement équivalente ou supérieure à celle du type précédent, diamètre : $0,50 \mathrm{~m}$ ) caractérisée par un bord en bandeau, le plus souvent cannelé sur sa face extérieure, des anses massives à section ovale ou « en haricot» 
Typologie - Amphores

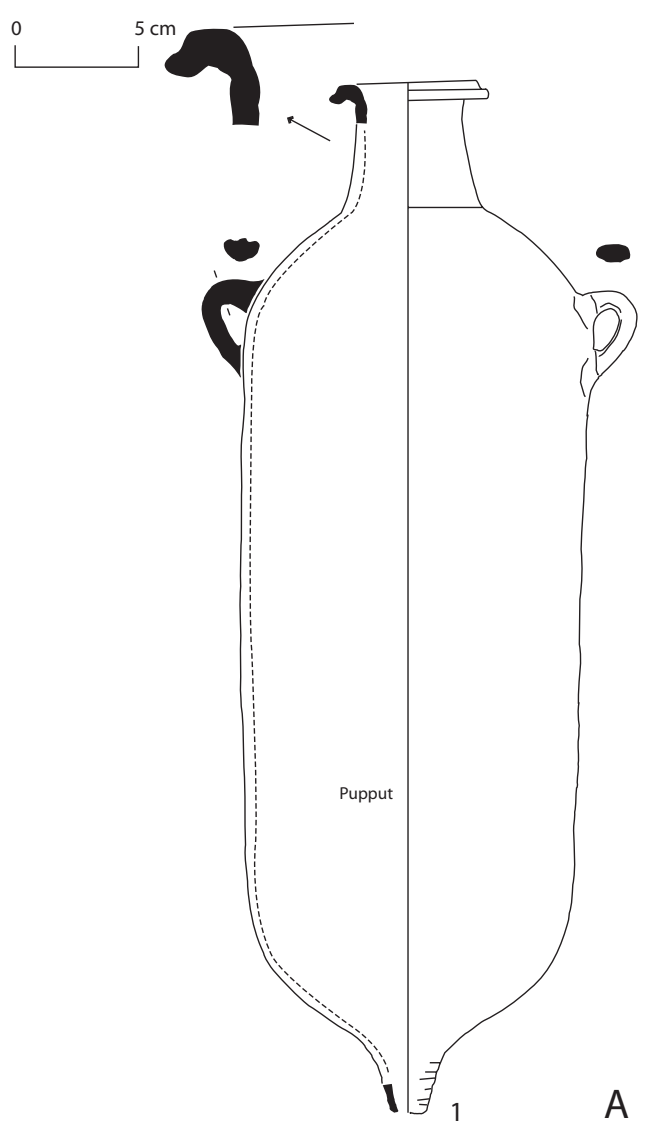

Type

Hammamet 1

$A$

B
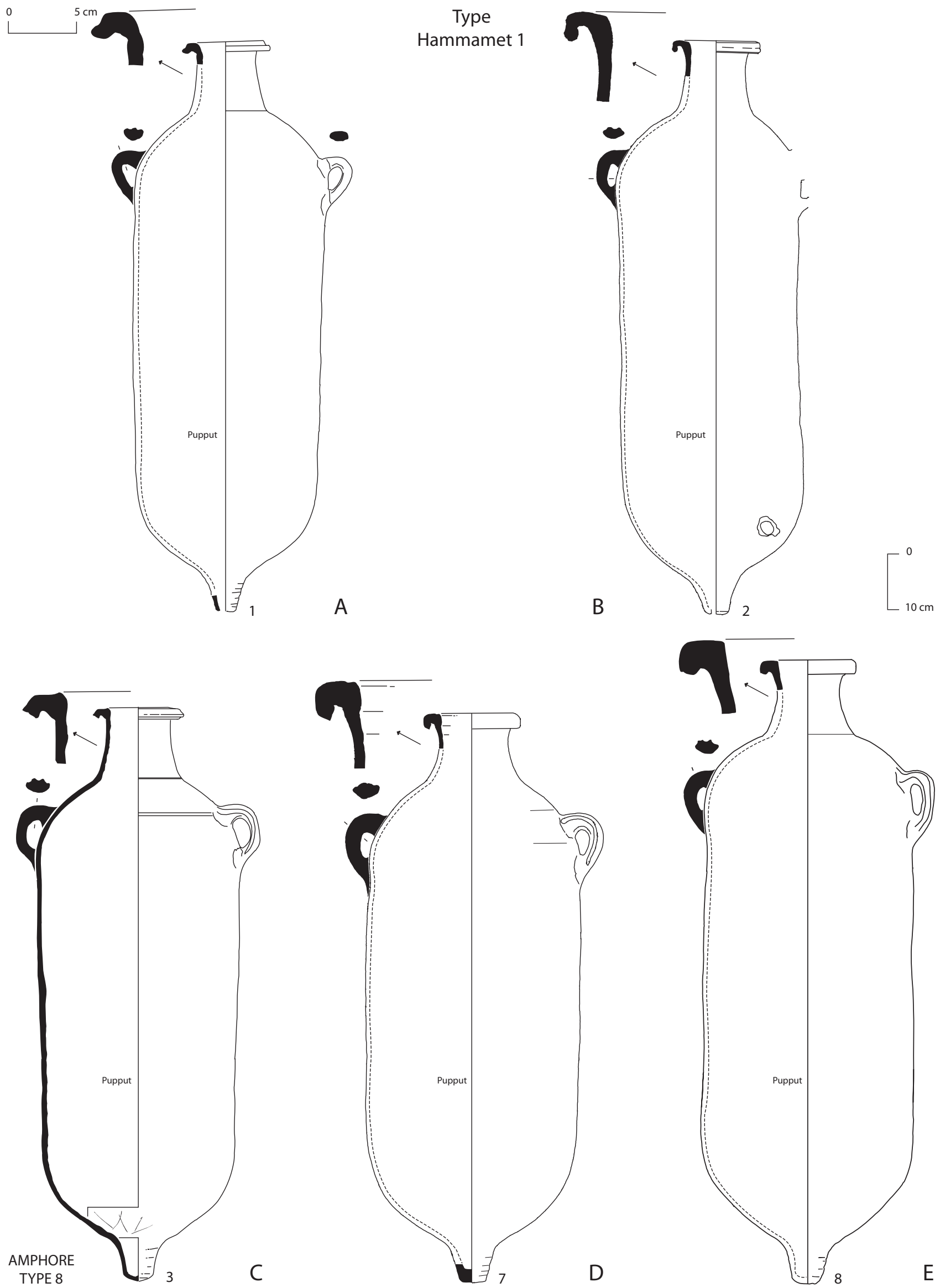

Fig. 49. Amphores de tradition punique. 
Typologie - Amphores

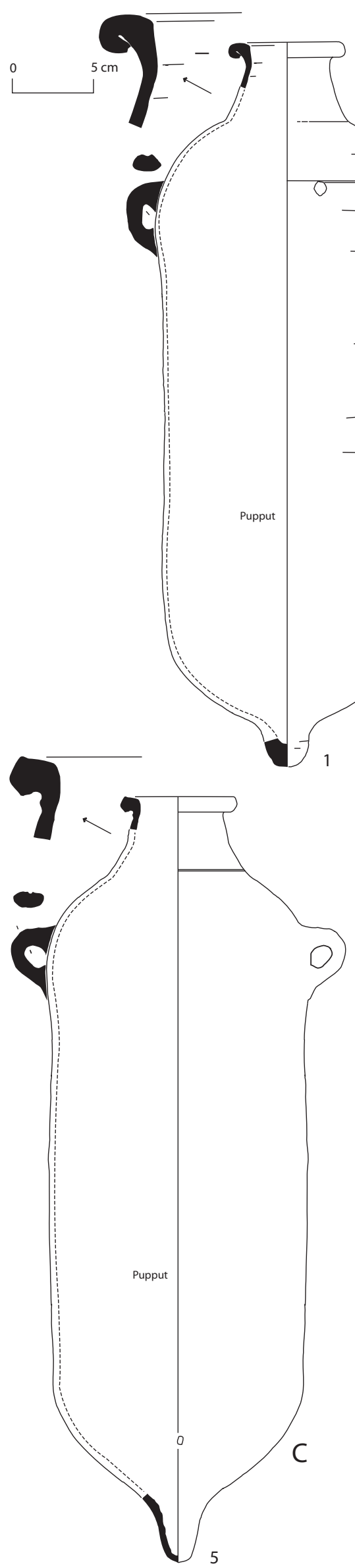

Type

Hammamet 2
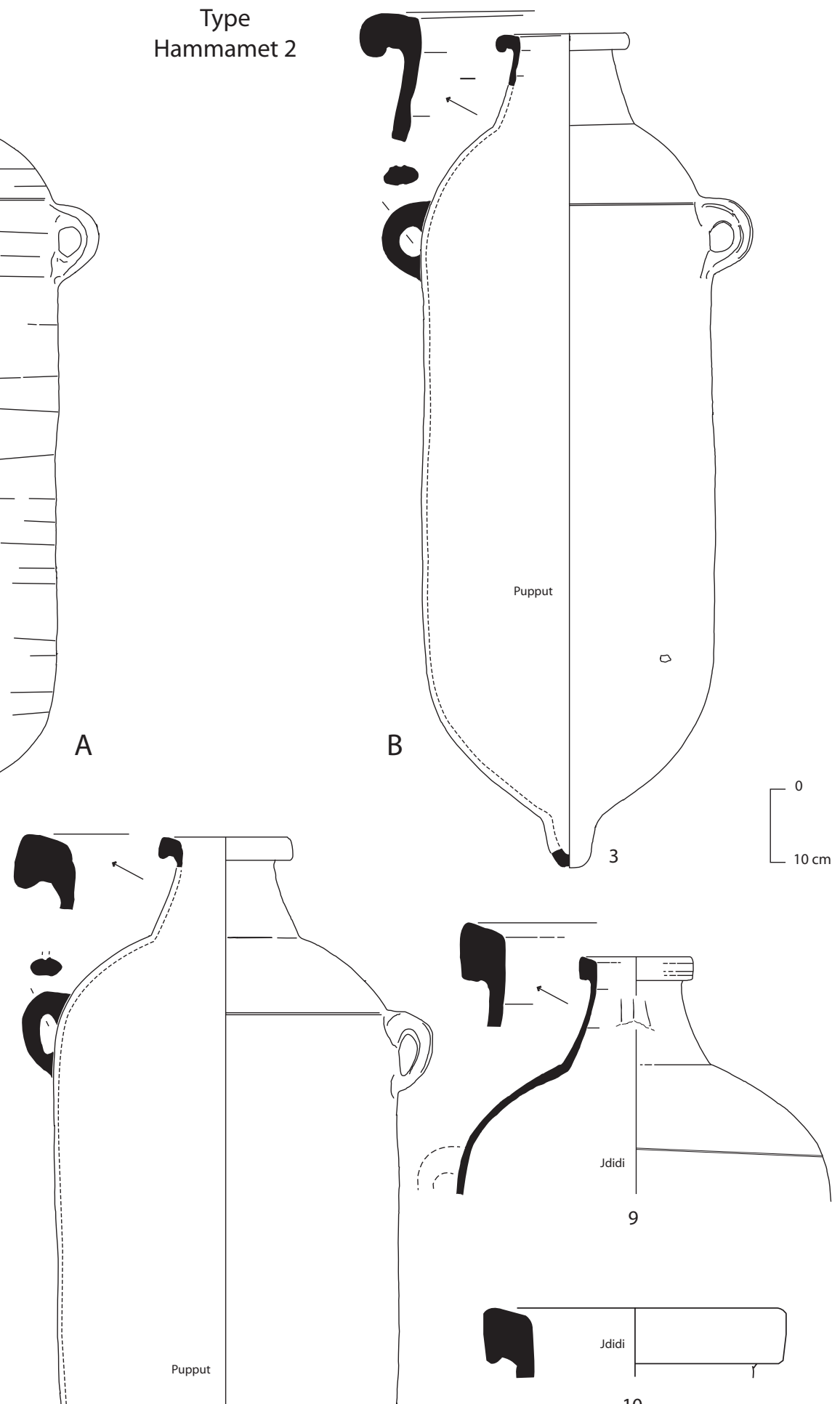

10

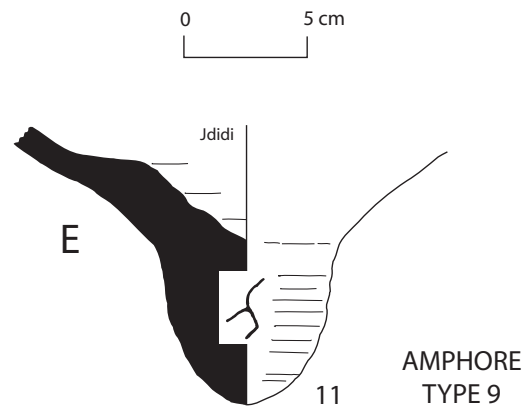

Fig. 50. Amphores de tradition punique. 
Typologie - Amphores

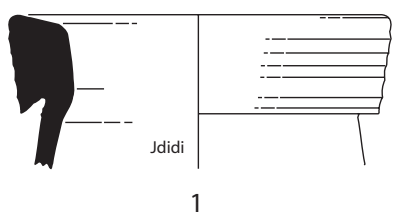

Type Hammamet 3

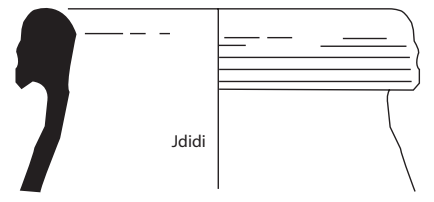

4
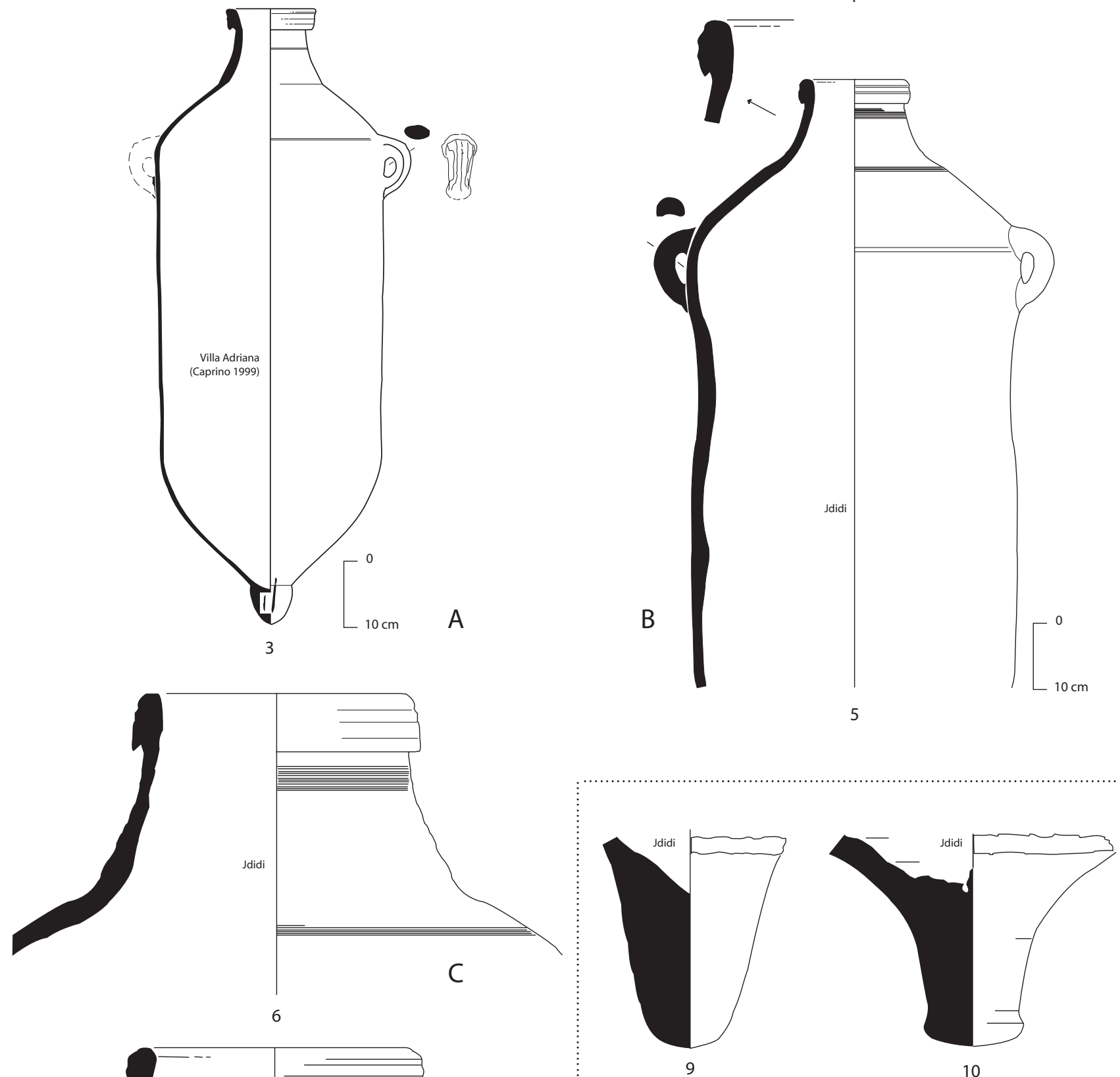

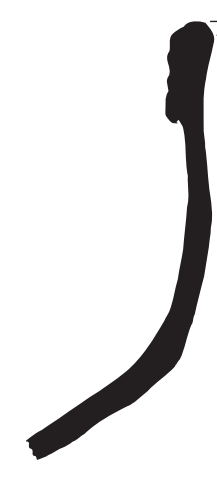

AMPHORE TYPE 10

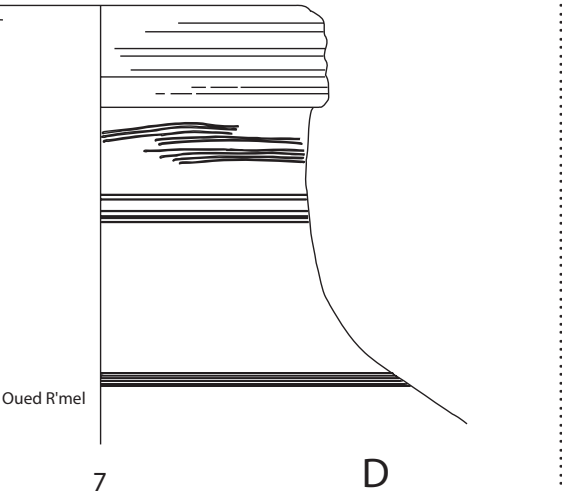

Fig. 51. Amphores de tradition punique.

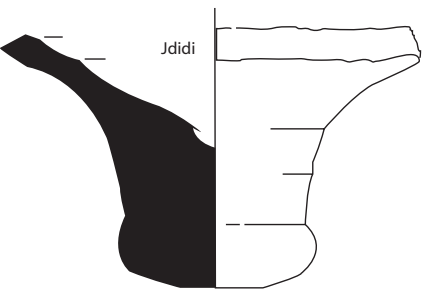

11 
(disparition de la nervure longitudinale) et trois variantes de fonds : conique plein, cylindrique allongé légèrement renflé à la base, cylindrique court et très renflé à la base. Le col porte fréquemment (variantes B-D) un décor peigné (lignes horizontales ou ondulées) sous le bord ou à la transition avec la panse. On distingue quatre variantes de bords :

- Variante A : bord à section quadrangulaire formant un bandeau cannelé à l'extérieur (transition avec le type $2 \mathrm{E}$ ?), parfois assez large, lèvre tombante à angle vif, anses massives parcourues à l'extérieur de petites cannelures longitudinales ;

- Variante B : bord en bandeau arrondi au sommet, lisse ou cannelé à l'extérieur, anses massives à section en haricot ;

- Variante C : profil comparable mais plus haut et aminci ;

- Variante D : bord légèrement rentrant, en bandeau mince et haut, cannelé sur sa face extérieure.

Exemples (fig. 51) :

Variante A

*1 Sidi Jdidi, basilique 2, destruction état II (Bonifay 2004b, fig. 11, $\left.\mathrm{n}^{\circ} 27\right)$.

2 Littoral tunisien, sebkhra Sidi Khalifa, site 127bis (Bonifay et al. 2002-2003, fig. 15, $\mathrm{n}^{\circ} 198$ ).

*3 Tivoli (Italie), Villa Adriana (Panella in: Caprino 1999, 44)

Variante B

*4 Sidi Jdidi, basilique 1, état C2A (Bonifay, Reynaud 2004, $\left.n^{\circ} 26.13\right)$.

*5 Sidi Jdidi, basilique 1, état C2A (Ibid., n²4.19).

Variante C

*6 Sidi Jdidi, basilique 1, état C2A (Bonifay, Reynaud 2004, $\left.n^{\circ} 24.15\right)$.

Variante D

*7 Oued R'mel (Bonifay 2004b, fig. 13, $\mathrm{n}^{\circ} 38$ ).

8 Sidi Jdidi, basilique 1, état C2B (Bonifay, Reynaud 2004, $n^{\circ} 31.11$ ).

Variante indéterminée (fonds)

*9 Sidi Jdidi, basilique 1, état C2B (Bonifay, Reynaud 2004, $\left.n^{\circ} 24.16\right)$.

*10 Sidi Jdidi, basilique 1, état C2A (Ibid., $\mathrm{n}^{\circ} 24.18$ ).

*11 Sidi Jdidi, basilique 1, état C2A (Ibid., n 24.17).

Le type 3 est caractéristique des VIe-VIIe siècles. La forme du bord rappelle d'ailleurs celle des amphores africaines classiques de cette période, les types Keay 6162 (Panella in : Caprino 1999, 44), ressemblance encore accentuée par la présence d'un fréquent décor peigné sur le col et sur l'épaulement. La variante A est la plus précoce, elle apparaît dans les niveaux de destruction de l'état II du groupe épiscopal de Sidi Jdidi (niveaux du dernier quart du Ve s.) (1), et c'est aussi celle qui semble avoir le plus voyagé, comme en témoigne l'exemplaire complet de la villa Adriana (3). Les variantes B-C sont, à Sidi Jdidi, les variantes classiques de l'état C2A de la basilique 1 (4-6), daté de la seconde moitié du VIe s. ou du début du VIIe s. (Bonifay, Reynaud 2004). Enfin, la variante $\mathrm{D}$ qui, à Sidi Jdidi figure seulement dans l'état C2B du VIIe s. (8), est fréquente sur le site de l'Oued R'mel (7), dans des contextes de la seconde moitié du VIIe siècle.
Datation proposée :

- Variante A - fin du Ve s.- première moitié du VIe s.

- Variantes B et C - milieu du VIe- début du VIIe s.

- Variante D - VIIe s.

Les amphores de tradition punique du golfe d'Hammamet portent assez fréquemment des marques tracées à la pointe avant cuisson (supra, p. 21) :

- sur le type 1, des inscriptions en lettres latines sont tracées sur la base de la panse ;

- sur le type 2, les marques, plus courtes (lettres isolées, certaines peut-être en alphabet néo-punique, signes divers) migrent progressivement sur la pointe de l'amphore ;

- sur le type 3, des lettres isolées, toujours placées sur la pointe sont parfois associées à des signes chrétiens (croix).

Aux Ve-VIIe s. la lettre $\mathrm{S}$, parfois associée à une palme et/ou à une croix, est la marque la mieux attestée.

Ces amphores ne sont pas seulement des conteneurs de transport mais également, tout au moins pour les exemplaires les plus tardifs, de très grande taille, des vases de stockage et de transformation des produits agricoles. On pensera notamment au processus de la vinification comme peuvent l'indiquer les couvercles percés de trous auxquels ces amphores sont souvent associées dans les celliers (infra, p. 278). Un certain nombre d'exemplaires poissés semblent confirmer la piste du vin (Bonifay 2004b, 224-225), plus vraisemblable que celle du garum, puisque ces amphores sont abondantes en contexte rural non littoral.

Cette typologie, toute récente (Bonifay 2004b), est encore susceptible d'évoluer, au gré des nouvelles découvertes. Déjà, il convient de mentionner une variante tardive qui rappelle le type Hammamet 3 mais avec des anses sur le col (Ben Abed, Bonifay, Fixot 1997, fig. 11, $\left.\mathrm{n}^{\circ} 60\right)$. D'autre part, les exemplaires les plus anciens sont datés du IIe s. mais il est fort probable qu'il existe des variantes $\mathrm{du}$ Ier s., non encore reconnues: Cassaigne publie une amphore provenant d'une tombe du Ier s. avec un bord en collerette plus large que celle de notre type 1: «la collerette en est plate et très large » (Cassaigne 1914, 22, fig. 12 et 13). On peut en effet se demander si l'amphore découverte dans un contexte du Ier s. au Castro Pretorio à Rome et classée par H. Dressel sous le $n^{\circ} 18$ ne devrait pas, finalement, être rattachée aux amphores de tradition punique du golfe d'Hammamet. Dans ce cas, si les types Tripolitaine II et Leptiminus II sont issus des amphores néo-puniques Van der Werff 3 et 2, ne devrait-on pas imaginer, en poursuivant le raisonnement de S. MartinKilcher (1999, fig. 7), que le type Hammamet 1 dérive de l'amphore néo-punique Van der Werff 1 ? Mais, alors que les amphores de tradition punique de la région de Carthage cessent d'être fabriquées au milieu du Ier s. (Martin-Kilcher 1999, 418), il est remarquable que celles du golfe d'Hammamet traversent toute l'époque romaine jusqu'aux périodes vandale et byzantine. 


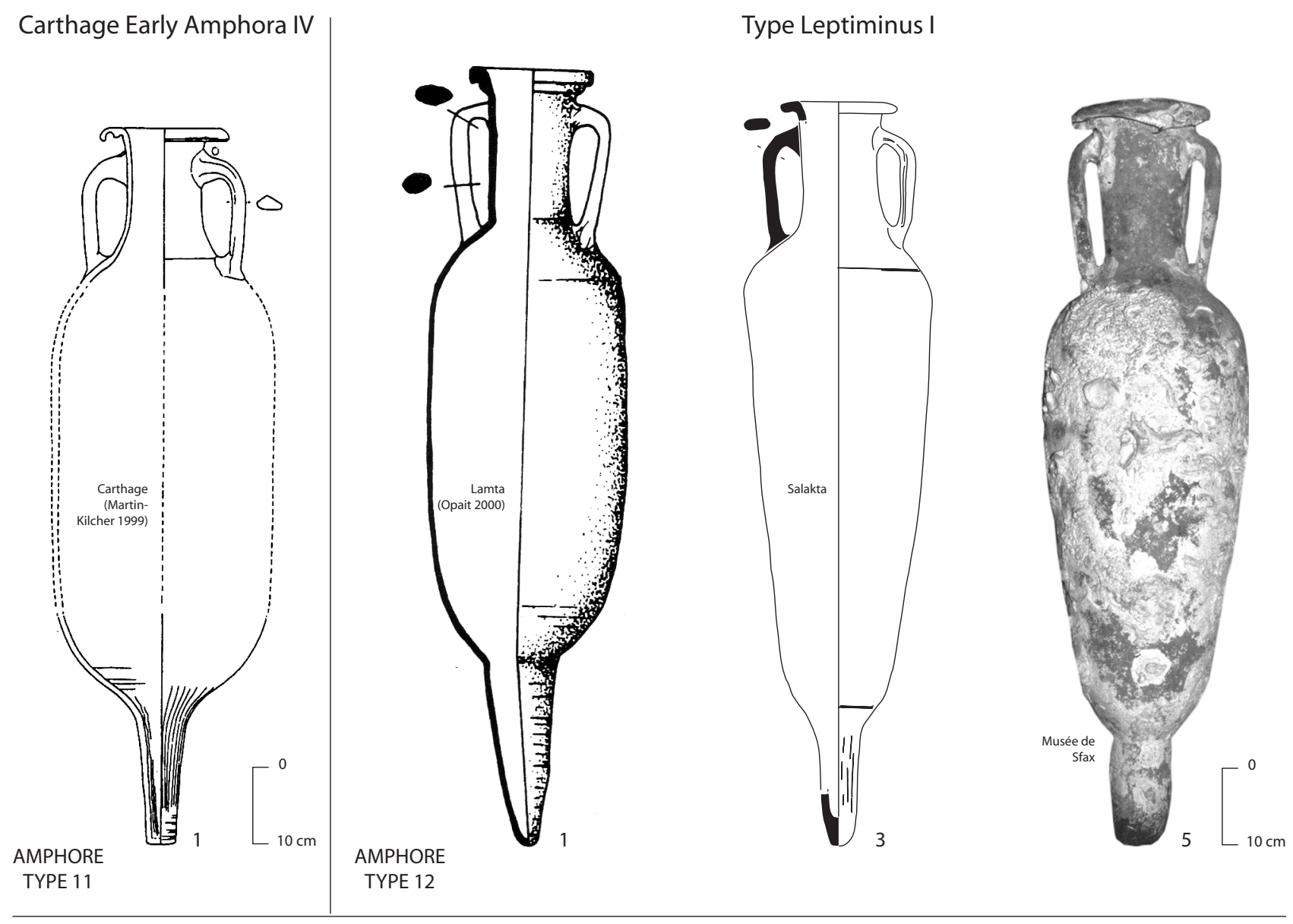

Type Dressel 26

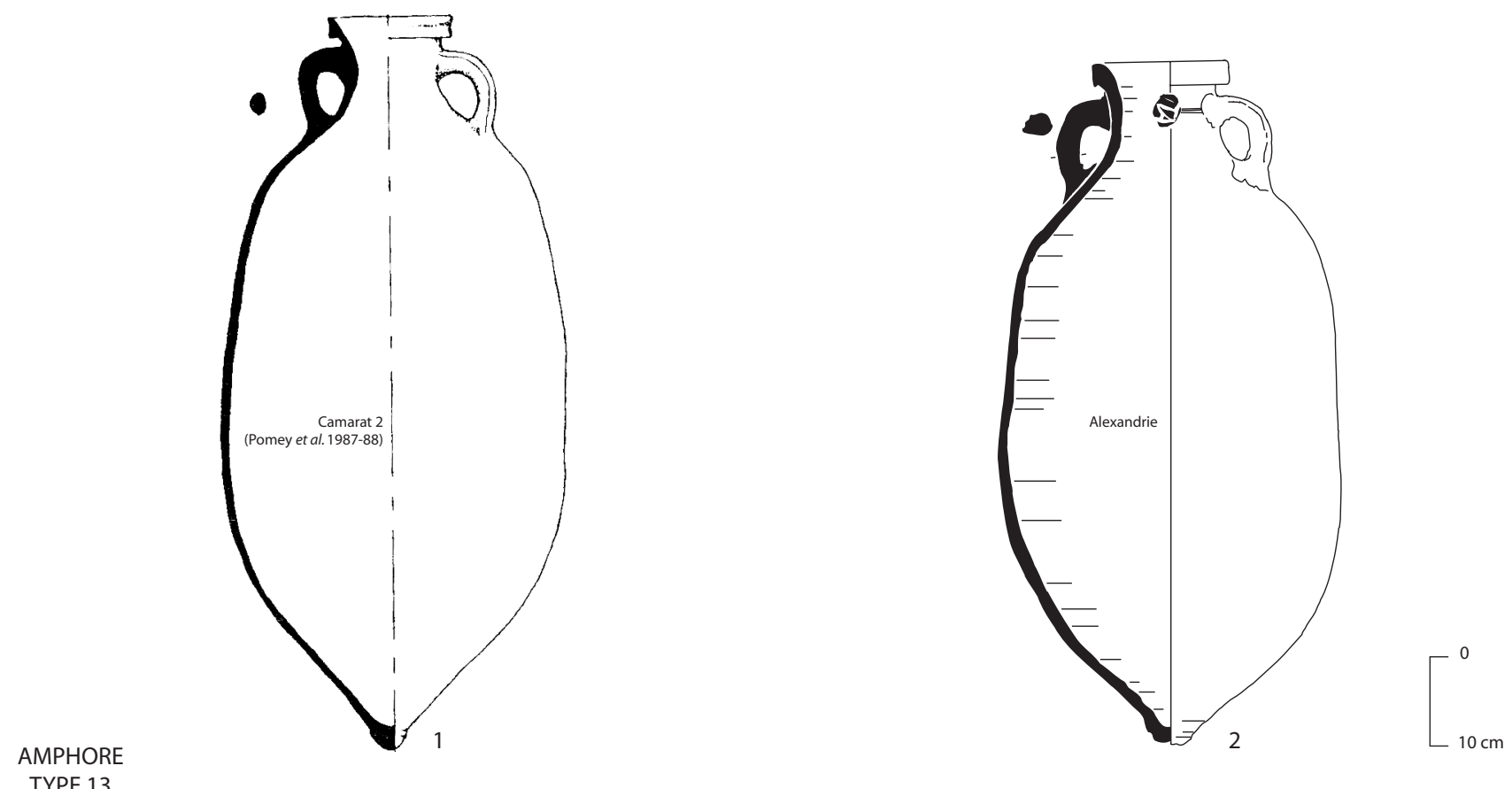

Fig. 52. Types puniques romanisés. 


\subsection{AMPHORES DE TYPE ROMANO-AFRICAIN}

Parallèlement à la poursuite de la fabrication d'amphores dont la forme est directement issue de la tradition punique, une deuxième branche de la production africaine prend naissance, qui adopte le modèle gréco-romain des anses placées sur le col. En laissant de côté, pour l'instant, les imitations de types non-africains (infra, TYPES 56-62), on peut distinguer plusieurs étapes dans le développement d'un répertoire proprement africain d'amphores gréco-romaines.

\subsubsection{Types précoces}

Je n'insisterai pas sur les premières manifestations de la production d'amphores romano-africaines, par manque de données personnelles. Je me contenterai seulement d'en mentionner les types les plus fréquents, en distinguant deux groupes :

- les types puniques romanisés,

- les types précurseurs des types africains classiques.

\section{Types puniques romanisés ?}

\section{- Type Carthage Early Amphora IV (fig. 52)}

\section{AMPHORE TYPE 11}

S. Martin-Kilcher a bien montré comment on percevait, à Carthage, au courant de la première moitié du Ier s. ap. J.C., une «romanisation » des types puniques par déplacement des anses de l'épaulement vers le col (Martin-Kilcher 1999, 418) ${ }^{115}$. C'est l'apparition, vers le milieu du Ier s., du type Carthage Early Amphora IV (J. Riley in Hayes 1976a, 110 et fig. 19, $\left.\mathrm{n}^{\circ} 11\right)=$ Spätpunische Amphore A 9 (Martin-Kilcher 1999, fig. 7). Les attestations de cette amphore sont nombreuses au milieu du Ier s. (Vegas 1994b, fig. 7, $\mathrm{n}^{\circ}$ 87-88; Ortisi 1999, fig. 20, n 379) mais le fragment publié par Riley provient encore d'un contexte de la fin du Ier s. (J. Riley in Hayes 1976a, 110). Enfin, l'exemplaire de l'épave Saint-Gervais 3 est daté du milieu du IIe s. (Liou, Gassend 1990, fig. 72 ; Martin-Kilcher 1999, 419 et fig. 7, A 10).

Selon S. Martin-Kilcher $(1999,420)$ le type Carthage EA IV était destiné au transport des salaisons de poissons; l'exemplaire de l'épave Saint-Gervais 3 est poissé (observation personnelle).

Ce type est attesté à Oudhna (observations personnelles) et à Nabeul (Cf. Slim, Bonifay, Trousset 1999, période 3) mais ni à Pupput, ni à Sidi Jdidi, probablement en raison de la présence des amphores de tradition punique du golfe d'Hammamet. En effet, les types Carthage EA IV et Hammamet 1 peuvent être considérés comme deux filiations divergentes de l'amphore néo-punique de Tunisie septentrionale Van der Werff 1. Le premier

\footnotetext{
115 « Eine gewisse Romanisierung der punischen Form ».
}

semble mieux diffusé outre-mer ${ }^{116}$ que le second, peutêtre en raison de la prééminence du port de Carthage sur ceux des cités du golfe d'Hammamet (?). Ce type n'est pas sans présenter des analogies avec un autre modèle précoce d'amphore romano-africaine, le type Leptiminus I, produit en Byzacène.

Exemples (fig. 52) :

*1 Carthage (Martin-Kilcher 1999, fig. 7, A9).

2 Nabeul, fabrique de salaisons, période 3 (Inv. 1423.6).

\section{- Type Leptiminus 1 (fig. 52)}

\section{AMPHORE TYPE 12}

A. Opait $(2000,439-441)$ a identifié le premier ce type d'amphore produit dans les fours de Lamta (Stirling, Ben Lazreg 2001). Il s'agit, selon lui, d'une imitation du type Dressel $14^{117}$. Il est vrai que l'allure générale de ce conteneur rappelle d'assez près les amphores hispaniques, par ailleurs relativement bien diffusées en Tunisie (Bonifay 2004a), mais elle est également proche de celle des amphores post-puniques Carthage $E A$ IV. On pourrait ainsi penser qu'il s'agit d'une version locale de ce type plutôt (ou les deux à la fois) qu'une imitation d'un type non africain. Le bord plat et proéminent, parfois souligné d'une mouluration sur sa face inférieure, fort éloigné du supposé modèle hispanique, me semble aller dans le sens de cette nouvelle hypothèse.

Le deuxième point à souligner est que le type Leptiminus I n'est pas uniquement produit à Leptiminus. Un exemplaire découvert fortuitement à Salakta et conservé au musée de cette ville (Bonifay et al. 20022003, fig. 20, $\mathrm{n}^{\circ} 288$ ) présente une pâte typique de Sullecthum, identification confirmée par la présence de rebuts de cuisson de cette forme dans la zone d'ateliers des Catacombes (supra, fig. 15, $\mathrm{n}^{\circ} 1$; Capelli, Ben Lazreg, Bonifay à paraître, fig. $2, \mathrm{n}^{\circ}$ 6284), auxquels il faut rattacher l'ensemble des fragments identifiés comme « Keay LIX » par Peacock, Bejaoui, Ben Lazreg 1989 sur plusieurs ateliers périphériques (Bir Abbad: fig. 11, $\mathrm{n}^{\circ} 9$; El Mokaïda : fig. 12, $\mathrm{n}^{\circ} 7,10,16$; El Hri 1 : fig. $13, \mathrm{n}^{\circ} 10$; El Hri 2 : fig. $14, \mathrm{n}^{\circ} 9$ et 11 ) ou dans le secteur même des catacombes (Ibid., fig. 17, $\mathrm{n}^{\circ} 11$, et fig. $\left.18, \mathrm{n}^{\circ} 9\right)$.

Exemples (fig. 52) :

*1 Leptiminus (Opait 2000, fig. 1, $\mathrm{n}^{\circ}$ 6).

2 El Jem (Bonifay et al. 2002-2003, fig. 20, n² 289). Contenait des restes de poissons.

*3 Salakta (Bonifay et al. 2002-2003, fig. 20, $\mathrm{n}^{\circ} 288$ ). Variante tardive (?).

4 Salakta (Capelli, Ben Lazreg, Bonifay à paraître, fig. 2, $\mathrm{n}^{\circ}$ 6284).

*5 Musée de Sfax, concrétionnée: découverte sousmarine (en exposition).

116 Exemplaire de l'épave Saint-Gervais 3 ; tessons à Arles (renseignement J.-Chr. Treglia) et à Olbia de Provence (observations personnelles); un col à Fos-sur-Mer (dépôt municipal, resp. J.-Ph. Lagrue).

${ }^{117} \mathrm{~J}$ 'ai moi-même retenu tout d'abord cette hypothèse (Bonifay et al. 2002-2003). 


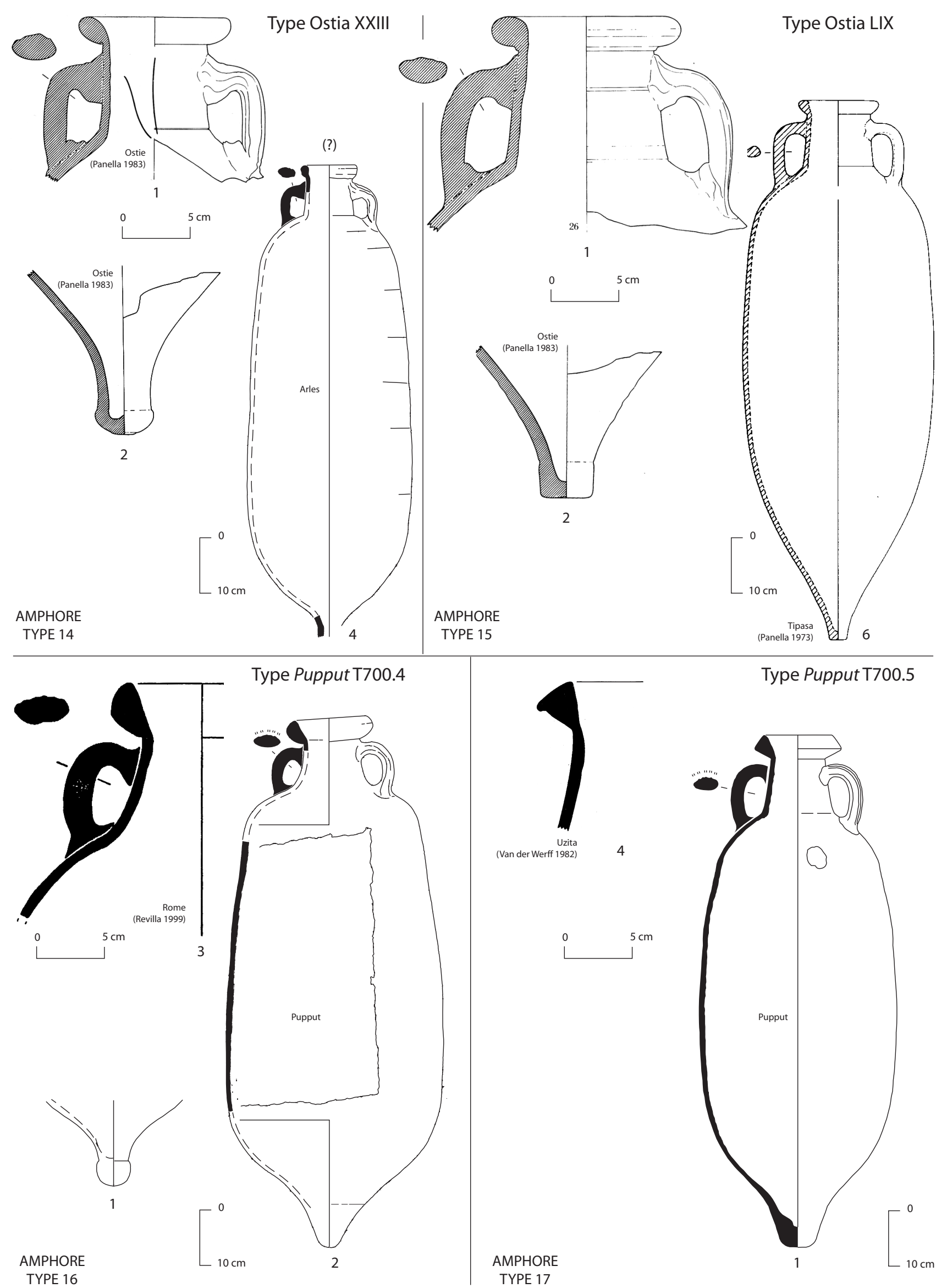

Fig. 53. Types africains précoces. 
Même si l'hypothèse d'une imitation des amphores hispaniques Dressel 14 n'est plus très sûre, celle, également avancé par A. Opait, concernant le contenu de l'amphore Leptiminus I, est toujours valable: il est pratiquement certain que cette amphore transportait des salaisons de poissons, comme le prouvent les restes ichtyologiques découverts dans le fond $n^{\circ} 2$ (Bonifay et al. 2002-2003) $)^{118}$.

La datation de ces amphores reste imprécise. A. Opait propose, comme pour son type II, une fourchette comprise entre la fin du Ier s. et le milieu du IIIe s. (Opait $2000,441)$. De fait, il est probable que la variante à corps fuselé (2-3), hors stratigraphie mais provenant d'un contexte général des IIIe-IVe s., soit plus tardive que le type classique pansu (1). On manque de données stratigraphiques.

\section{- Type Dressel 26 (fig. 52)}

\section{AMPHORE TYPE 13}

Il faut rattacher, pour mémoire (Raynaud, Bonifay 1993, 21), à ce phénomène de romanisation des types puniques, une amphore dont l'origine est restée longtemps controversée, le type Dressel 26. Le bord de cette amphore rappelle celui de la forme néo-punique Van der Werff 3 et on a supposé qu'il pouvait s'agir d'un précurseur du type Tripolitaine I. Il faudrait alors convenir d'une date haute pour la migration des anses sur le col, puisque cette amphore est bien attestée dans les contextes de la fin du IIe s. av. J.-C. (Py, Adroher Auroux, Sanchez 2001, 253-257; Pascual, Ribera 2002, 311). On a récemment proposé que cette amphore puisse avoir été produite en Sicile (Wilson 1999, 534). Cependant, un exemplaire complet que j'ai pu examiner à Alexandrie (2) présente incontestablement une pâte africaine. On pourrait peut-être imaginer que ce type ait été produit à la fois en Sicile et en Afrique ; on retrouvera ce problème de possible production parallèle entre la Sicile et l'Afrique avec le type Agora M254 (infra, p. 148).

Exemples (fig. 52) :

*1 Epave Camarat 2 (Saint-Tropez) (Pomey et al. 198788, fig. 40, d ; Sciallano, Sibella 1991).

*2 Alexandrie, nécropole de Gabbari (Inv. GAB98 60052.2). Timbre ATI (?) sur le col. Dessin R. Leffy.

\section{Types précurseurs des types africains classiques}

Un certain nombre d'autres types se détachent, semble-til, plus nettement des modèles puniques et annoncent véritablement les types africains classiques mieux connus.

\footnotetext{
${ }^{118}$ Il s'agit malheureusement d'écailles, à l'exclusion de tout ossement, ce qui rend difficile une détermination précise des espèces (expertise Myriam Sternberg, CNRS-CCJ).
}

\section{- Types Ostia XXIII et Ostia LIX (fig. 53)}

\section{AMPHORES TYPES 14 ET 15}

Je ne m'attarderai pas sur ces deux types solidement ancrés dans la bibliographie (Panella 1973, 571-574; $1982,171-173 ; 2001,209$, et Pl. 20, n 149) mais que je n'ai, personnellement, que très rarement rencontrés sur le terrain. Ces amphores ne m'ont pas paru être très fréquentes en Tunisie ; elles sont rares dans la nécropole de Pupput, pourtant utilisée dès le début du IIe siècle. On notera que la plupart des comparaisons avancées pour ces types par $\mathrm{Cl}$. Panella ont été choisies en Algérie (Panella 1973, 571-574).

Toutefois, je ne suis pas convaincu par l'exemplaire de comparaison choisi à Tipasa pour le type Ostia XXIII (cf. Panella 1982, fig. 2): il me paraît devoir être plus vraisemblablement attribué au type Africaine I. En revanche, l'exemplaire recueilli dans les eaux du Rhône à Arles (4) possède un fond à longue pointe cylindrique renflée à la base comparable à celui signalé par Cl. Panella à Ostie (2). Un exemplaire du musée de Carthage (3) possède le même type de fond, également attesté sur certains exemplaires du TYPE 16 (voir infra, $n^{\circ}$ 1). L'exemplaire $n^{\circ} 5$ provient d'un contexte de la fin $\mathrm{du}$ Ier siècle.

Exemples (fig. 53) :

Type Ostia XXIII [TYPE 14]

*1 Ostie (Panella 1983, fig. 34).

*2 Idem (Ibid., fig. 37).

3 Carthage (Musée de Carthage, salle des amphores, $\mathrm{n}^{\circ} 40$ ).

*4 Arles, fouilles du Rhône (Cf. Long 1994, fig. 28.2).

5 Arles, fouilles du Rhône ${ }^{119}$.

Les amphores Ostia LIX, illustrées par de nombreux exemples à Pompéi (Panella 1982, 172 et note 7) ${ }^{120}$ (4), sont mieux connues. En Tunisie, on peut signaler l'exemplaire du Musée de Carthage (5) et celui du dépôt d'El Jem (7); le fond est tronconique, creux, aplati à la base (2). Les ateliers de la périphérie de Salakta semblent livrer (?) quelques tessons de ce type (Peacock, Bejaoui, Ben Lazreg 1989, fig. 11, $\left.\mathrm{n}^{\circ} 2-3\right)$. L'exemplaire $\mathrm{n}^{\circ} \mathbf{3}$ provient d'un contexte de la fin du Ier siècle.

Exemples (fig. 53) :

Type Ostia LIX [TYPE 15]

*1 Ostie (Panella 1983, fig. 26).

*2 Idem (Ibid., fig. 36).

3 Fréjus, Plate-Forme (Béraud, Gébara, Pasqualini 1992, fig. 14).

4 Pompéi (Panella 1977, Pl. LXVII, n 33).

5 Carthage (Musée de Carthage, salle des amphores, $\left.\mathrm{n}^{\circ} 39\right)$

*6 Tipasa (Panella 1973, 632, $\mathrm{n}^{\circ} 49$ ).

7 El Jem (Nacef 2001, fig. 43 et photo 14).

\footnotetext{
119 Je remercie mon ami Jean Piton de m'avoir invité à examiner ce matériel.

${ }^{120}$ Plusieurs exemplaires exposés dans les magasins du forum et au Musée de Boscoreale.
} 
Typologie - Amphores

Type Uzita PI. 52, 10
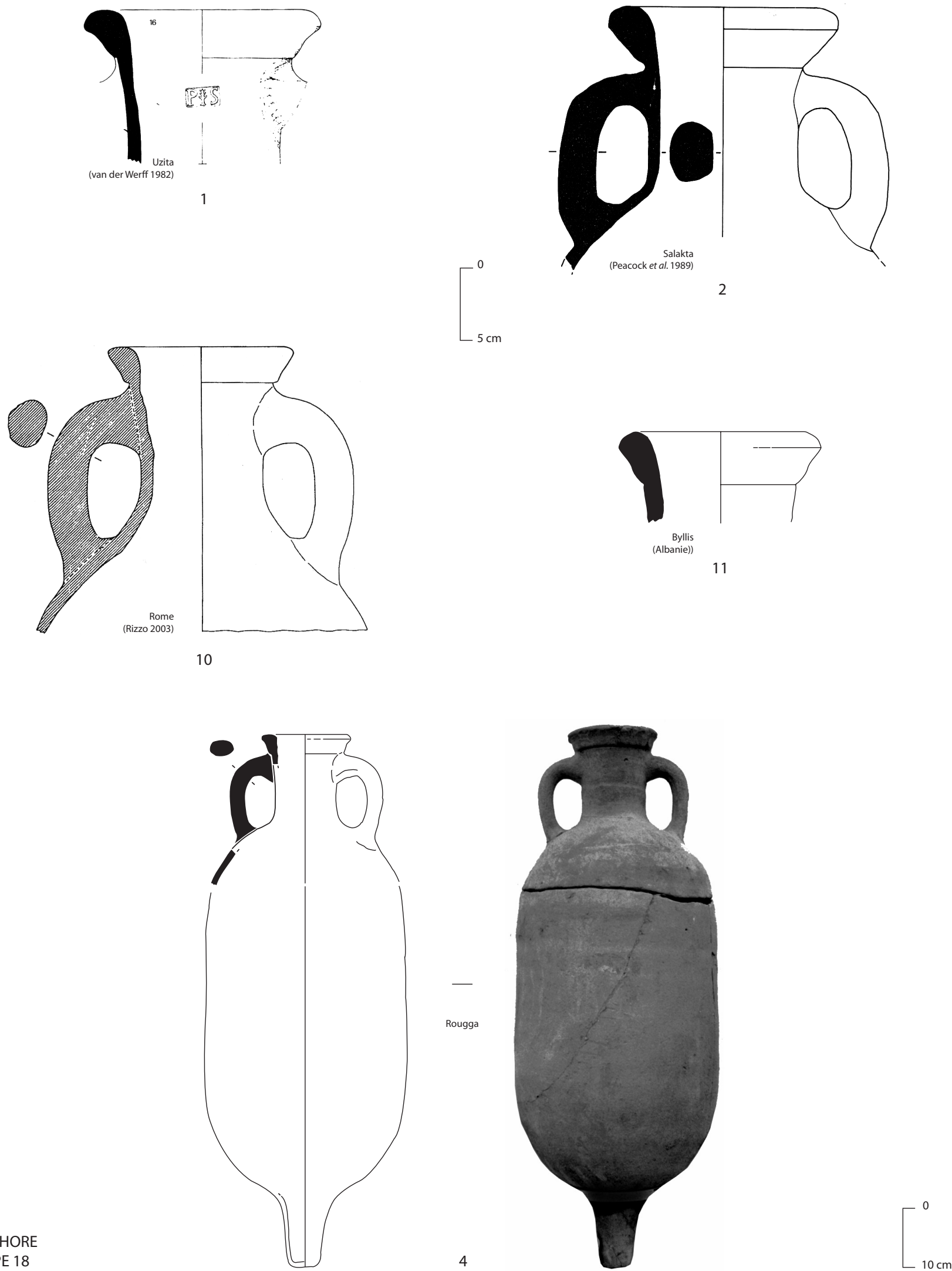

Fig. 54. Amphores africaines précoces. 


\section{- Autres types : Pupput T700.4 et 5 (fig. 53)}

\section{AMPHORES TYPES 16 ET 17}

Deux types nouveaux, associés dans une tombe du milieu du IIe s. de la nécropole de Pupput (Bonifay 2004a, fig. 9, $\mathrm{n}^{\circ}$ 10-11), paraissent également constituer des types précurseurs des amphores romano-africaines de Byzacène.

- Le premier, Pupput T700.4 (TYPE 16), rappelle le type Africaine I A par le profil du bord, avec une face extérieure fortement convexe, mais le reste de la forme montre qu'il s'agit d'une tout autre amphore, avec un corps très pansu, encore élargi à la base et terminé par un bouton conique proéminent (2) ou une pointe renflée à la base (1).

- Le second, Pupput T700.5 (TYPE 17), présente un bord massif à section triangulaire, très caractéristique, un col tronconique assez haut, et un corps pansu terminé par une pointe courte et massive, à base aplatie.

Dans les deux cas, les anses sont larges, plates et striées longitudinalement sur la face extérieure. Ces caractères semblent se retrouver sur certaines productions des fours de Leptiminus ${ }^{121}$.

Exemples (fig. 53) :

TYPE 16

*1 Pupput, tombe 700, amphore $\mathrm{n}^{\circ} 4$ (Bonifay 2004a, fig. $\left.9, \mathrm{n}^{\circ} 10\right)$.

*2 Pupput, tombe 1302 (Inv. PP2989.1).

*3 Rome, Monte Testaccio (Revilla 1999, fig. 81, $\mathrm{n}^{\circ}$ 90/1129).

TYPE 17

*1 Pupput, tombe 700, amphore $\mathrm{n}^{\circ} 5$ (Bonifay 2004a, fig. $\left.9, \mathrm{n}^{\circ} 11\right)$.

2-*4 Uzita (Van der Werff 1982a, Pl. 50, n²-4).

Le TYPE 16 est attesté au milieu du IIe s. sur le Monte Testaccio (3), date en accord avec celle de la tombe 700 de Pupput. Les deux types ne sont pas précisément datés à Lamta; ils sont situés, comme beaucoup d'autres productions de cet atelier, entre la fin du Ier et le milieu du IIIe siècle. Les trois fragments du TYPE 17, auquel J.H. Van der Werff avait attribué l'appellation d'amphore Africaine III (Van der Werff 1982a, 185 et Pl. $\left.50, \mathrm{n}^{\circ} 2-4\right)$, proviennent d'un comblement du puits de la première moitié du IIIe s., et sont peut-être résiduels dans ce contexte.

Datation proposée : IIe s.

\section{- Type Uzita Pl. 52, 10 (fig. 54)}

\section{AMPHORE TYPE 18}

J. H. Van der Werff (1982, 185 et Pl. 52, $\left.\mathrm{n}^{\circ} 10\right)$ avait identifié à Uzita un curieux type d'amphore à bord en doucine, qu'il avait attribué à une production africaine. Cette origine trouve confirmation dans la présence de rebuts de cuisson de cette forme sur plusieurs ateliers de

\footnotetext{
${ }^{121}$ Je remercie Andrei Opait de m'avoir communiqué en 2000 une première version du manuscrit qu'il prépare pour un prochain volume des publications de Leptiminus.
}

la région de Salakta, en particulier Bir Abbad (Peacock, Bejaoui, Ben Lazreg 1989, 189 et fig. 11, $\mathrm{n}^{\circ}$ 1, 4, 6 ?), El Hri 1 (Ibid., fig. 13, $\mathrm{n}^{\circ} 26$ ) et Salakta même (Ibid., fig. $17, \mathrm{n}^{\circ} 1$ et 2 ).

Le site de Rougga a, le premier, livré une forme complète de ce conteneur (4). On retrouve le même bord caractéristique «en doucine», le col cylindrique légèrement évasé vers le haut et les anses à section ronde déjà visibles sur l'exemplaire d'Uzita; le corps est cylindrique, pansu, court et terminé, comme l'avaient proposé Peacock, Bejaoui, Ben Lazreg 1989 (189 et fig. $11, \mathrm{n}^{\circ} 6$ ) par une pointe allongée, cylindrique et creuse.

Exemples (fig. 54) :

*1 Uzita (Van der Werff 1982a, Pl. 52, n 10). Timbre $P$ palme-S.

*2 Salakta, ateliers (Peacock, Bejaoui, Ben Lazreg 1989, fig. $17, \mathrm{n}^{\circ} 2$ ).

3 Salakta-Catacombes, ateliers (Capelli, Ben Lazreg, Bonifay à paraître, fig. $2, \mathrm{n}^{\circ} 6283$ ).

*4 Rougga (Guéry, Bonifay à paraître, n 341 ; photographie dans Guéry 1985b, fig. 4, e). H. $92 \mathrm{~cm}$; D. $35 \mathrm{~cm}$.

5 Dépôt d'El Jem (Nacef 2001, fig. 91 et photo 44).

6 Musée de Sfax (en exposition). H. $87 \mathrm{~cm}$; D. $\max$ $33 \mathrm{~cm}$.

7 Salakta, récupération en mer (Bonifay et al. 20022003, fig. $\left.19, \mathrm{n}^{\circ} 274\right)$.

8 Hergla, fouilles anciennes (Inv. HG.000.69).

9 Carthage (Tomber 1986, fig. 8, $\mathrm{n}^{\circ} 236$; en exposition au Musée Paléochrétien).

*10 Rome (Rizzo 2003, Pl. XXXVIII, n 198).

*11 Byllis (Albanie) (fouilles Sk. Muçaj et J.-P. Sodini, Inv. BYL.B232.1).

Cette amphore a été interprétée de deux manières. Peacock, Bejaoui, Ben Lazreg $(1989,188)$ y ont vu une possible imitation d'amphore hispanique à garum de type Dressel 7-11 et R. Guéry a proposé, en raison de la mouluration du bord, une comparaison avec les amphores tripolitaines (Guéry 1985b, 404). Même s'il est difficile de se laisser convaincre totalement par l'une ou l'autre de ces deux hypothèses, il reste que la forme de cette amphore est assez originale dans un contexte africain, ne serait-ce qu'en raison de ses anses massives à section ronde.

L'hypothèse d'un contenu à base de salsamenta reste en revanche plausible : l'exemplaire 7 est poissé ${ }^{122}$.

Le contexte stratigraphique de l'exemplaire de Rougga (4) est totalement aberrant : cette amphore a été réutilisée comme sarcophage dans une nécropole post-byzantine datant des «environs du VIIIe s. » (Guéry 1985b, 407). Toutes les autres attestations tunisiennes, aucune n'étant cependant très précise, rangent cette amphore aux côtés des productions classiques. Le col d'Uzita (1) et le fragment de Byllis (11), peut-être résiduels, sont associés à du matériel de la première moitié du IIIe siècle. L'indication chronologique la plus précise est donnée par l'exemplaire de Rome (10), issu d'un contexte d'époque

\footnotetext{
${ }^{122}$ Un autre fragment poissé dans le port de Toulon (fouilles M. Pasqualini).
} 
Typologie - Amphores

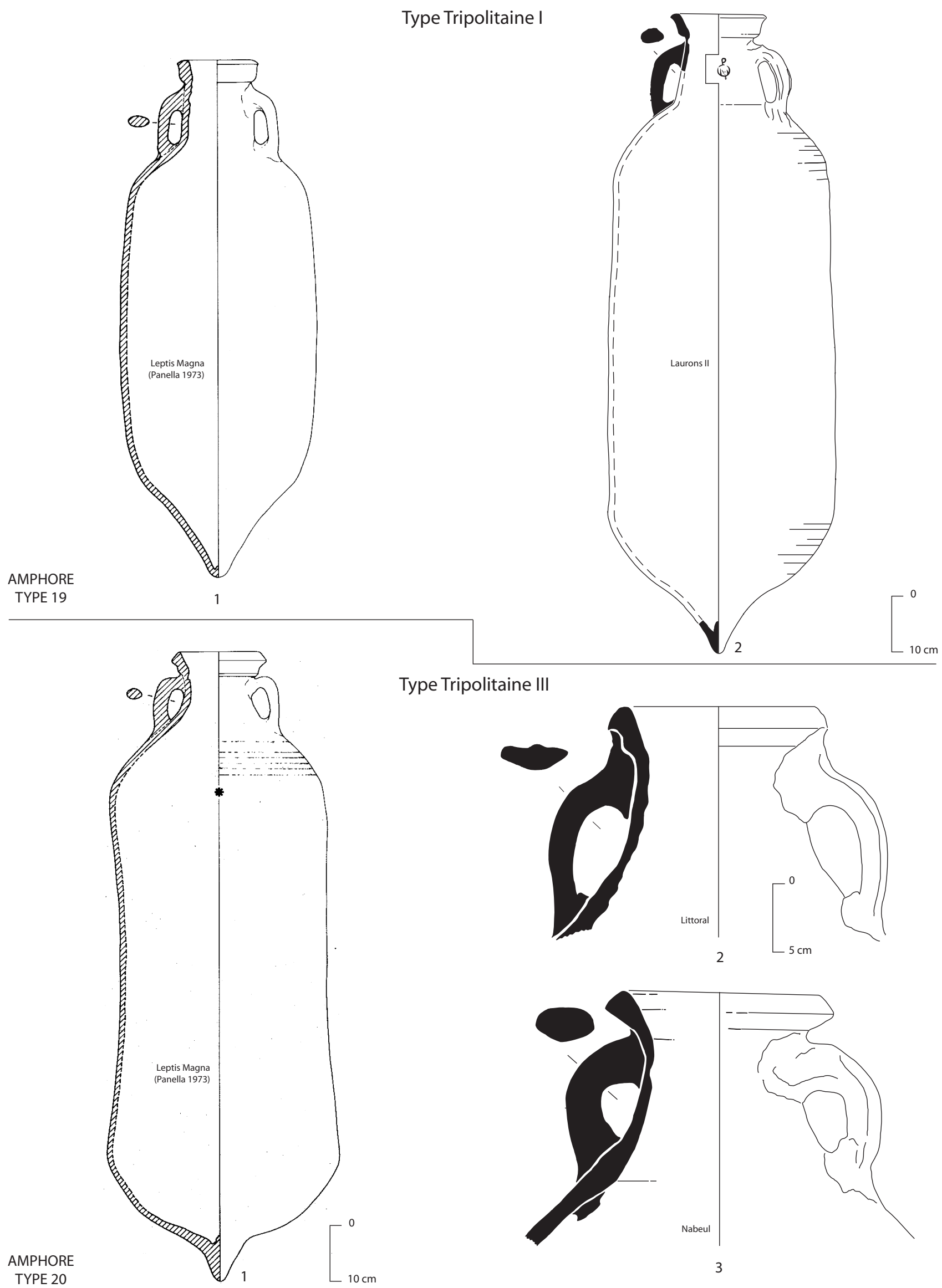

Fig. 55a. Amphores africaines classiques (productions tripolitaines). 
flavienne. Un autre tesson d'Uzita, dont l'identification est cependant douteuse (Van der Werff 1977-78, fig. 7, $\mathrm{n}^{\circ} 25-181$ ), provient également de remblais d'époque flavienne.

Datation proposée : fin Ier - IIe s. ; résiduel au IIIe s. (?).

\subsubsection{Amphores africaines classiques}

Afin de tenter de dresser un tableau le plus complet possible des productions d'amphores impériales en Afrique, pour y insérer les quelques données dont je dispose, j'ai conservé la distinction traditionnelle entre les amphores «tripolitaines» et les amphores « africaines ». Cette distinction qui ne correspond à aucune réalité administrative jusqu'au début du IVes., répond en revanche à une tradition d'études solidement établie (Panella 1973, 574) et au demeurant assez commode. Je mentionne enfin, pour mémoire, la production d'amphores de type africain récemment mise en évidence dans la province voisine de Maurétanie Césarienne.

\section{Amphores « tripolitaines »}

\section{- Tripolitaines I et III (fig. 55)}

\section{AMPHORES TYPES 19 ET 20}

Les amphores tripolitaines impériales de type romanoafricain, peut-être dérivées d'amphores républicaines assimilables, pour partie, au type Dressel 26, s'articulent en deux formes principales I et III (Panella 1973, 560-562 et 564-571), dont la distinction n'est pas toujours aisée à partir d'un petit fragment de bord :

- Type I (TYPE 19) : bord massif à double gradin, peu évasé, col cylindrique ou très légèrement tronconique formant un angle à la jonction avec la panse ;

- Type III (TYPE 20) : bord moins massif, à double gradin, plus haut et plus évasé, col tronconique qui s'unit à la panse suivant une ligne continue. Exemples (fig. 55)

Type I (fig. 55a)

*1 Lepcis Magna (Panella 1973, 628, $\left.\mathrm{n}^{\circ} 22\right)$.

*2 Epave Laurons II (DRASSM, Marseille ; cf. Ximénès, Moerman 1991, fig. 7, et Sciallano, Sibella 1991 [photographies]). Pâte fine.

Type III (fig. 55a)

*1 Lepcis Magna (Panella 1973, 629, $\left.\mathrm{n}^{\circ} 24\right)$.

*2 Littoral tunisien, site $\mathrm{n}^{\circ} 1$ (Henchir el-Medeina) (Bonifay et al. 2002-2003, fig. 12, $\mathrm{n}^{\circ}$ 147). Pâte fine.

*3 Nabeul, fabrique de salaison, pièce XLIV (Inv. NB1878.14). Pâte fine.

Type III, variantes tardives (fig. 55b)

*4 Lepcis Magna, thermes du Levant (fouilles A. Laronde, Inv. 010.9). Pâte fine.

*5 Lepcis Magna, thermes du Levant (fouilles A. Laronde, Inv. 015.1). Pâte bicolore rouge et gris, à inclusions blanches.

*6 Ostia IV, 118.
Type Tripolitaine III, variantes tardives

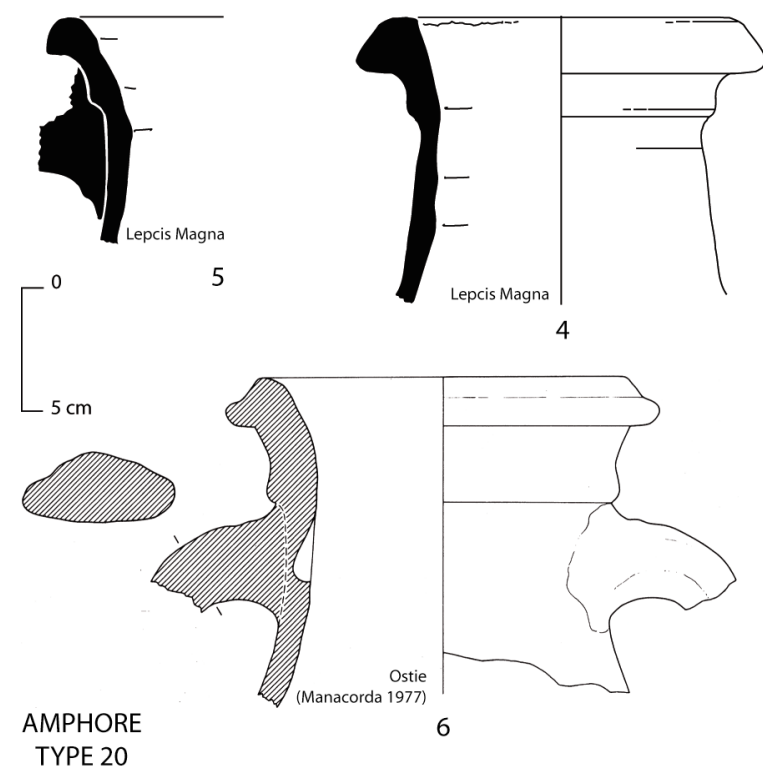

Fig. 55b. Amphores africaines classiques (productions tripolitaines, variantes tardives)

Le type I est probablement produit de l'époque augustéenne jusqu'au milieu du IIes. (pour des exemplaires du milieu du Ier s. à Lepcis Magna, voir Reynolds 1997, fig. 4, $\mathrm{n}^{\circ}$ 33-34), avec une phase d'exportation intense (données d'Ostie) à la fin du Ier s. et au début du IIe s. (Panella 1973, 562). Le type III succède au type I dans la seconde moitié du IIe s. et constitue l'amphore tripolitaine typique du IIIe siècle. Ainsi, malgré quelques controverses sur la datation de ce gisement (Ximénès, Moerman 1991), l'exemplaire de l'épave Laurons II appartient encore au type I (2) et date vraisemblablement du IIe s. (association avec une lampe Deneauve VII/sous-type 1). La production se poursuit au IVe s. (Panella 2001 211), avec une variante caractérisée par une hypertrophie de la mouluration supérieure du bord (profil « en casquette ») (type III, variante tardive). Cette variante domine dans les contextes des décennies centrales du IVe s., notamment à Ostie (6) et Lepcis Magna (4-5) ${ }^{123}$.

La mise en évidence d'une production importante de ces amphores dans la partie aujourd'hui tunisienne de la Tripolitaine, notamment sur l'atelier de Zitha/Zian (supra, fig. 13), permet d'attribuer à cette région une partie des types I et III qui, au lieu de présenter une pâte bicolore rouge et grise avec de nombreuses inclusions blanches (Peacock 1984a, 18: fabric 2.8, «Coarser Tripolitanian ware ») typique de la région de Tripoli (Panella 1973, 564 : fours de Gargaresh) et de Lepcis Magna (Arthur 1982) (infra, Pl. I, nº 1), sont fabriqués

\footnotetext{
${ }^{123}$ Même observation à Arles (matériel en cours d'étude par J. Piton) et à Aquilée (matériel en cours d'étude par C. Rousse). Ces variantes semblent toutefois déjà présentes dans des contextes datés du premier tiers du IIIes. sur le Monte Testaccio (ex. : Revilla 2001, fig. 89, $n^{\circ}$ 92/775).
} 
Type Africaine I

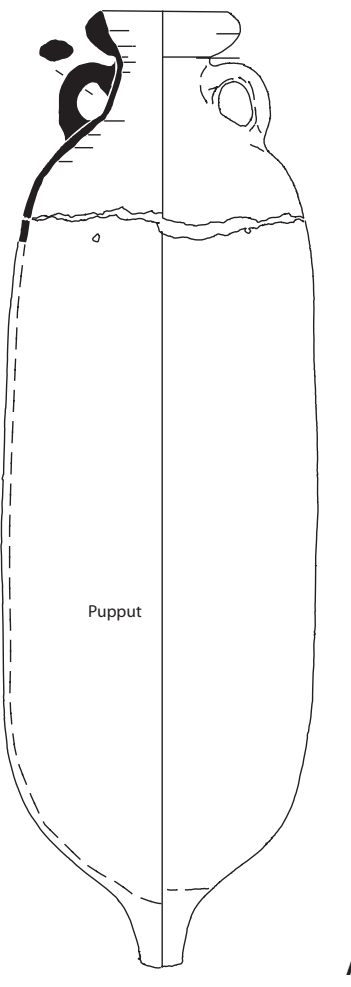

A
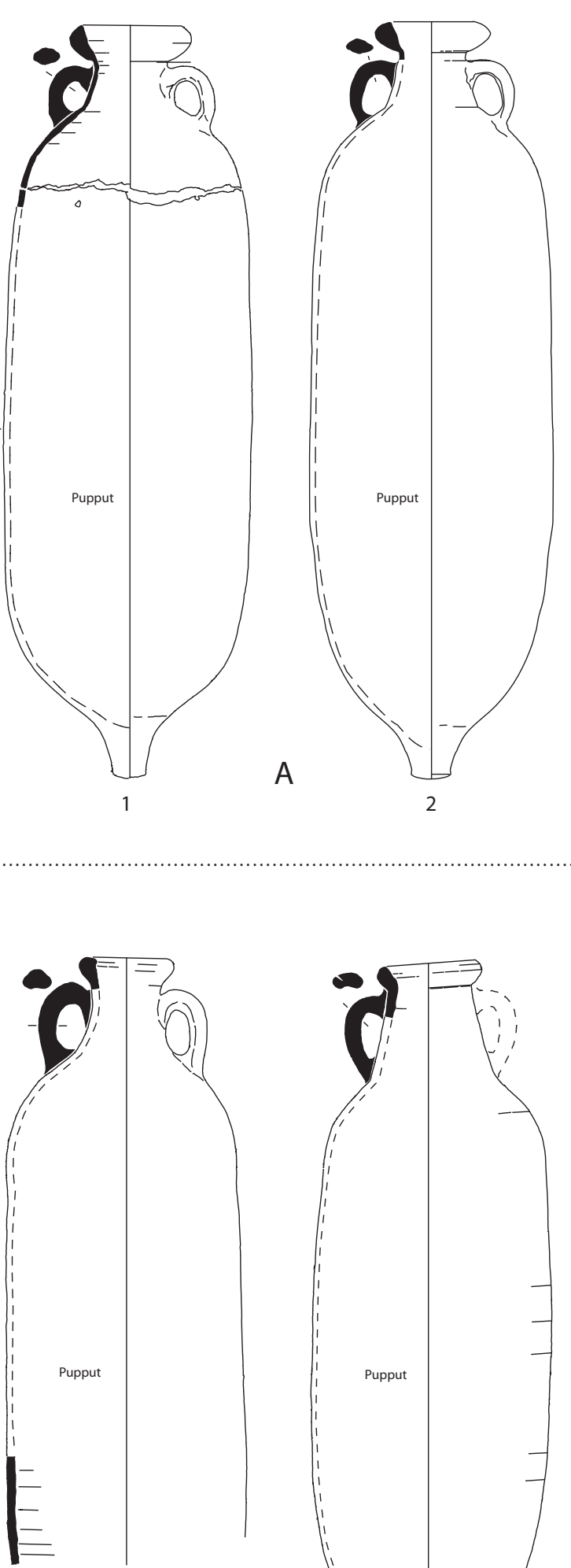

9

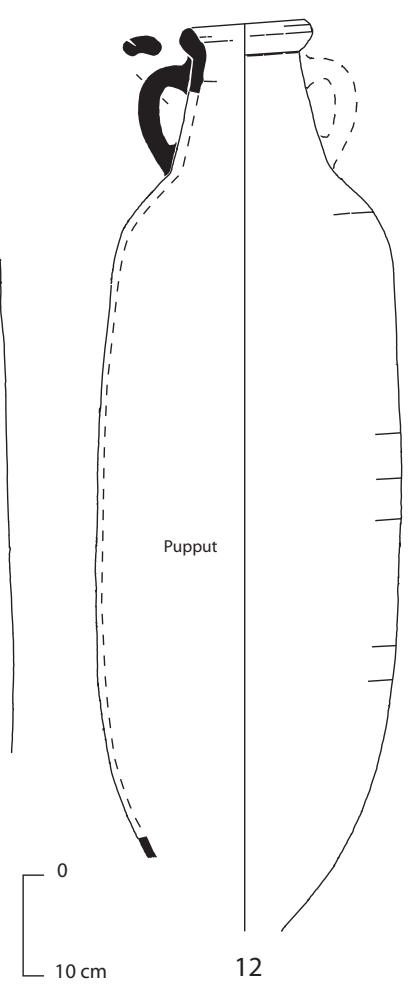

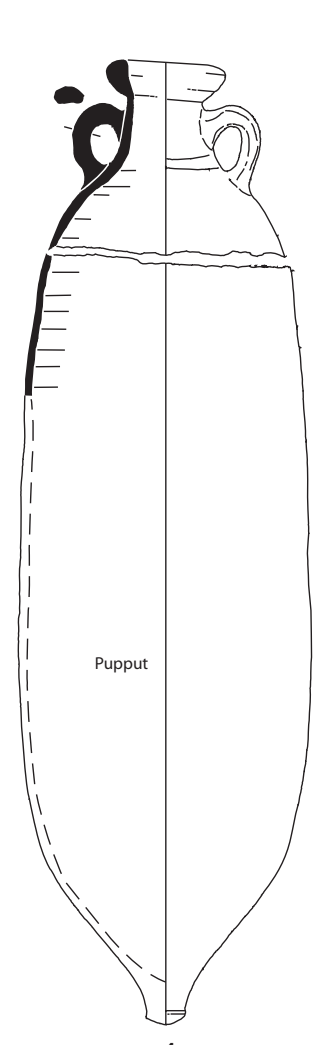

4
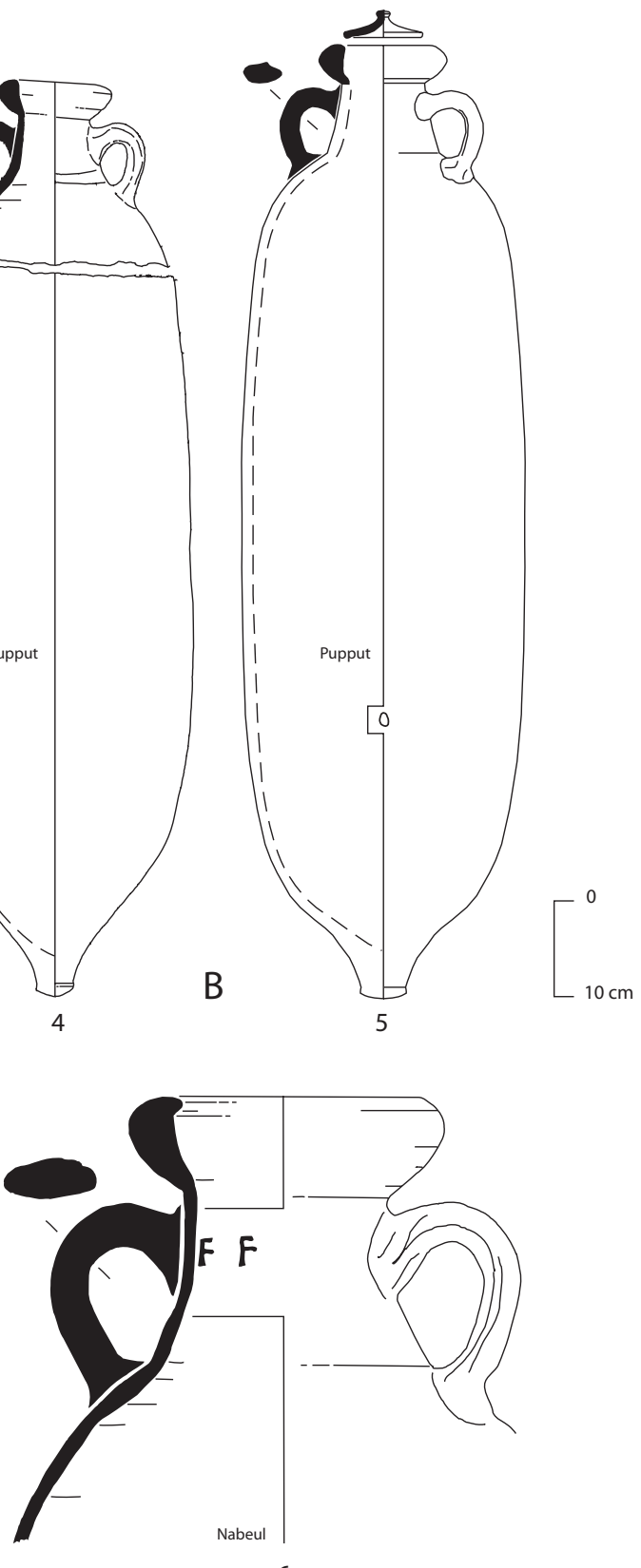
$5 \mathrm{~cm}$

C

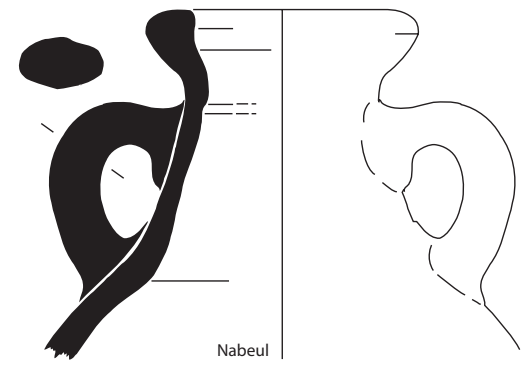

Fig. 56. Amphores africaines classiques. 
avec une argile orange rosé, fine et compacte $\left(\mathrm{Pl} . \mathrm{I}, \mathrm{n}^{\circ} 2\right)$. C'est à cette catégorie de pâte que se rattachent non seulement les fragments de Tripolitaine I (Bonifay et al. 2002-2003, fig. 12, $\mathrm{n}^{\circ}$ 146) et de Tripolitaine III recueillis à l'extrême sud du littoral tunisien (type III, $n^{\circ} 2$ ) mais également l'amphore de l'épave des Laurons II (type I, $\mathrm{n}^{\circ}$ 2) et enfin le col de type Tripolitaine III découvert à Nabeul (type III, $\mathrm{n}^{\circ} \mathbf{3}$ ), dans un contexte de la fin IIIe s. ou du début du IVe siècle.

Ces amphores, en général non poissées, étaient vraisemblablement destinées au transport de l'huile (infra, Tabl. IV).

\section{Amphores « africaines »}

La typologie élaborée à Ostie (Panella 1972 et 1973) à la suite des premiers classements de F. Zevi et A. Tchernia (1969) est encore opérante. Reprise en 1984 sous une numérotation différente par S. Keay (types 3 à 7), la nomenclature d'Ostie reste généralement la plus citée. Cependant, l'une des difficultés majeures de cette typologie vient du fait qu'elle repose presque uniquement sur la morphologie des bords.

\section{- Amphores Africaines I (fig. 56)}

\section{AMPHORE TYPE 21}

Les amphores Africaines I sont des conteneurs de dimensions modestes (H. : 96-99 cm, D. : 30-33 cm), d'où leur première appellation de «tipo Africano piccolo » (Zevi, Tchernia 1969, 174), et, de manière générale, parfaitement cylindriques. La typologie établie par Cl. Panella (1973, 575-579) sur la base de la documentation d'Ostie, fait apparaître trois variantes principales, selon le profil du bord :

- Africaine A (= Ostia III, 262 ; Ostia IV, 432-433) : bord « avec une face externe fortement convexe et une face interne plate » (Keay 1984, 100);

- Africaine B (=Ostia I, 526-529) : bord « articolato ad echino » (Panella 1982, 173), «avec une face interne profondément concave accompagnée d'une face externe extrêmement convexe » (Keay 1984, 100-101);

Nota : le profil extérieur du bord me paraît être un bon critère de différenciation: l'arc de cercle est grossièrement symétrique sur la variante $\mathrm{A}$, avec parfois une imperceptible arête à mi-hauteur, dissymétrique, aplati sur le haut, sur la variante B ;

- Variante « tardive » ou C (= Ostia IV, 169) : « bord simplifié et légèrement proéminent » (Panella 1982, 173).

Exemples (fig. 56) :

Variante A

*1 Pupput, tombe 1213 (Inv. 2678.1).

*2 Pupput, tombe 402, amphore $n^{\circ} 3$ (Bonifay 2004a, fig. $\left.10, \mathrm{n}^{\circ} 12\right)$.

Variante $\mathrm{A} / \mathrm{B}$ ?

3 Pupput, tombe 402, amphore $\mathrm{n}^{\circ} 2$ (Ibid., fig. 10, $\left.\mathrm{n}^{\circ} 13\right)$.
Variante B

*4 Pupput, tombe 1313 (Inv. 3046.1).

*5 Pupput, tombe 425, amphore $\mathrm{n}^{\circ} 3$ (Inv. PP2342.3).

*6 Nabeul, bassin XLIX (Inv. NB 1850.sans $\mathrm{n}^{\circ}$ ). Timbre $F F$ sur le col (supra, fig. 5, $\mathrm{n}^{\circ} 3$ ).

7 Pupput, tombe 653, amphore $\mathrm{n}^{\circ} 3$ (Ben Abed, Griesheimer 2004, fig. 112, T653.3).

Variantes tardives

*8 Nabeul, pièce XLIV (Inv. NB 1878.15).

*9 Pupput, tombe 1207 (Inv. PP2686.1).

10-11 Oued el-Akarit, atelier (supra, fig. 14, $\mathrm{n}^{\circ}$ 1-2).

*12 Pupput, tombe 1058 (Inv. PP2306.2).

Il semble, même si ces deux variantes sont associées dans l'épave d'Ognina (Manacorda 1977, 157), que la diffusion du type $\mathrm{I} A$ à Ostie précède légèrement, dans le courant du IIe s., celle du type I B (Panella 1982, 174); les conteneurs du type Ostia IV, 169, paraissent appartenir à la phase la plus tardive (fin du IVe - début du Ve s.) de la production de ces amphores (Ibid.).

La documentation utilisée ici, émanant en majorité de la nécropole de Pupput, conforte, dans ses grandes lignes, ce schéma d'évolution. Si l'on exclut des amphores qui ont seulement en commun avec le type Africaine I le profil de leur embouchure (supra: TYPE 16), les premiers exemplaires de la variante A apparaissent dans le courant de la seconde moitié du IIe s. et conservent une certaine tendance à un élargissement de la panse vers le bas (1) (cf. également Peacock, Bejaoui, Ben Lazreg 1989, fig. 15; Sciallano, Sibella 1991, golfe de Fos: «cas limite d'appartenance à ce type »). Ils sont parfois associés, dans la même tombe, à des exemplaires de la variante B (3). Mais seule la variante B subsiste dans les tombes les plus tardives (première moitié ou milieu du IIIe s. ?) (4-5), et dans la seconde moitié IIIe s. à Nabeul (6). Un type très abâtardi (12) est associé à des amphores Africaines III dans une tombe du IVe siècle. Je n'ai pas d'élément sur la poursuite d'une production des amphores Africaines I au début du Ves.; les formes tardives qui leur ont été rattachées par S. Keay (1984, type 3 « similis ») sont en fait de tout autres amphores (infra: TYPE 34).

Il paraît bien assuré que ces amphores, qui ne sont en général jamais poissées, étaient destinés au transport de l'huile (infra, p. 471).

Datation proposée:

Variantes A et B - fin du IIe s. - début du IIIe s., variante B jusqu'au milieu du IIIe s.

Variantes tardives — seconde moitié du IIIe s. IVe s.

\section{- Amphores Africaines II}

Les amphores Africaines II sont des conteneurs de dimensions plus importantes (« tipo Africano grande » de Zevi, Tchernia 1969) mais également plus hétérogènes. La hauteur peut ainsi varier de 95 à $120 \mathrm{~cm}$ env. (avec une majorité d'exemplaires compris entre 100 et $110 \mathrm{~cm}$ ) et le diamètre de 28 à $45 \mathrm{~cm}$. L'articulation en quatre grands sous-types A, B, C et D, proposée par Cl. Panella permet d'ordonner l'essentiel des exemplaires connus. 
Typologie - Amphores

Type Africaine II A

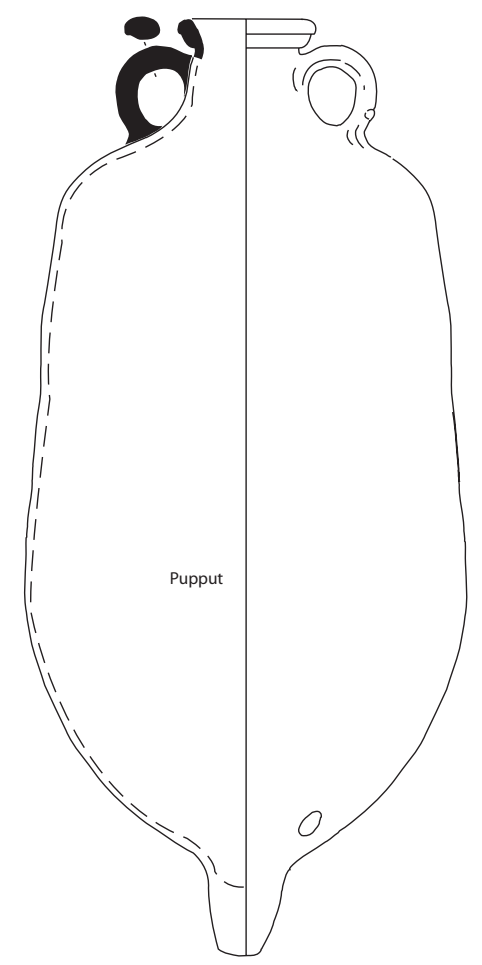

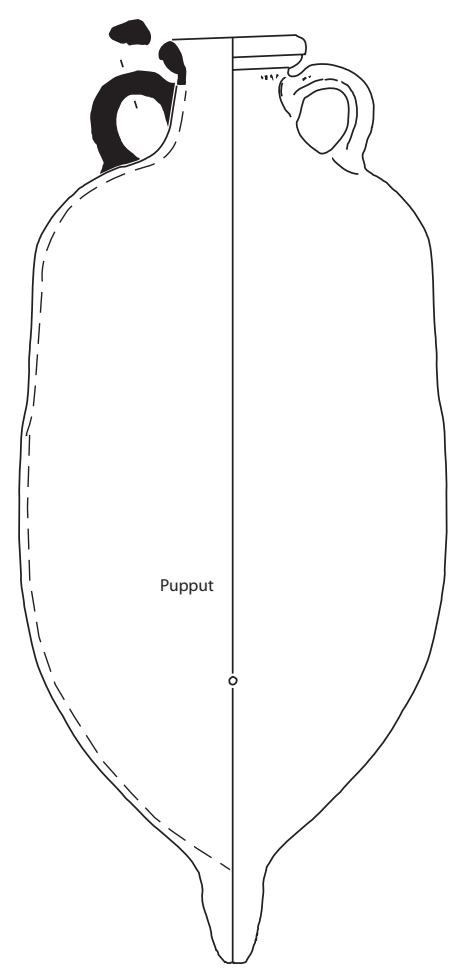

A1

3
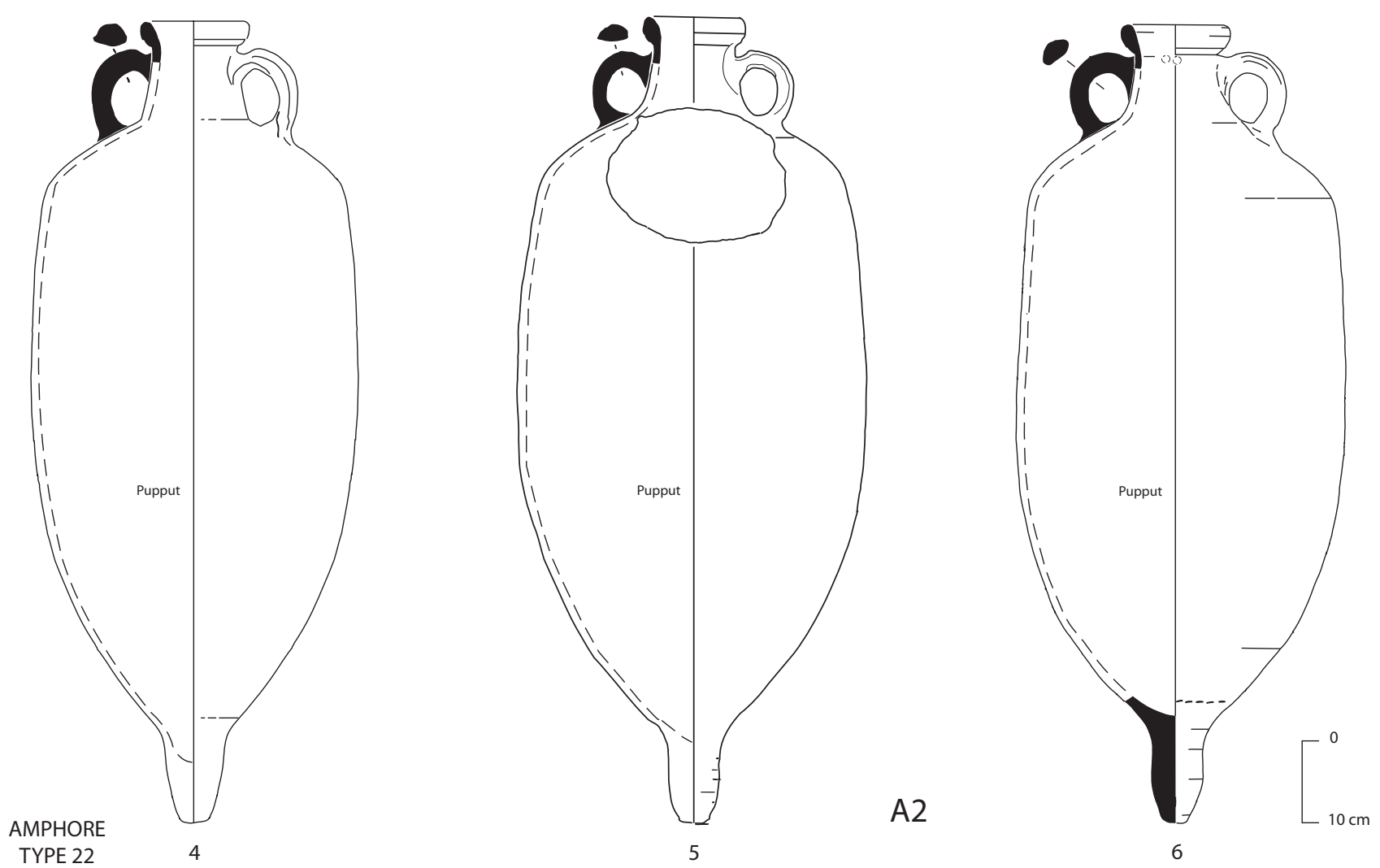

Fig. 57. Amphores africaines classiques. 
Typologie - Amphores

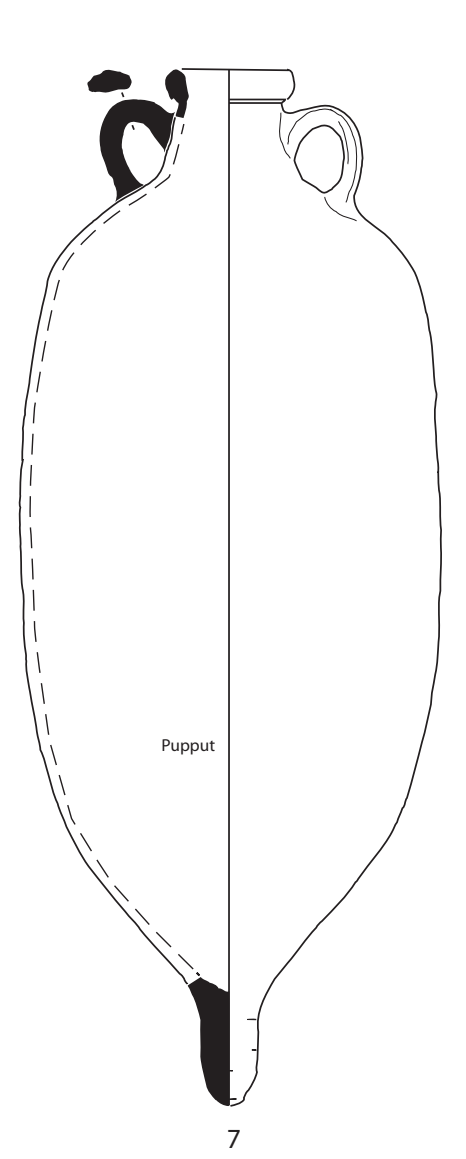

Type Africaine II A

A3
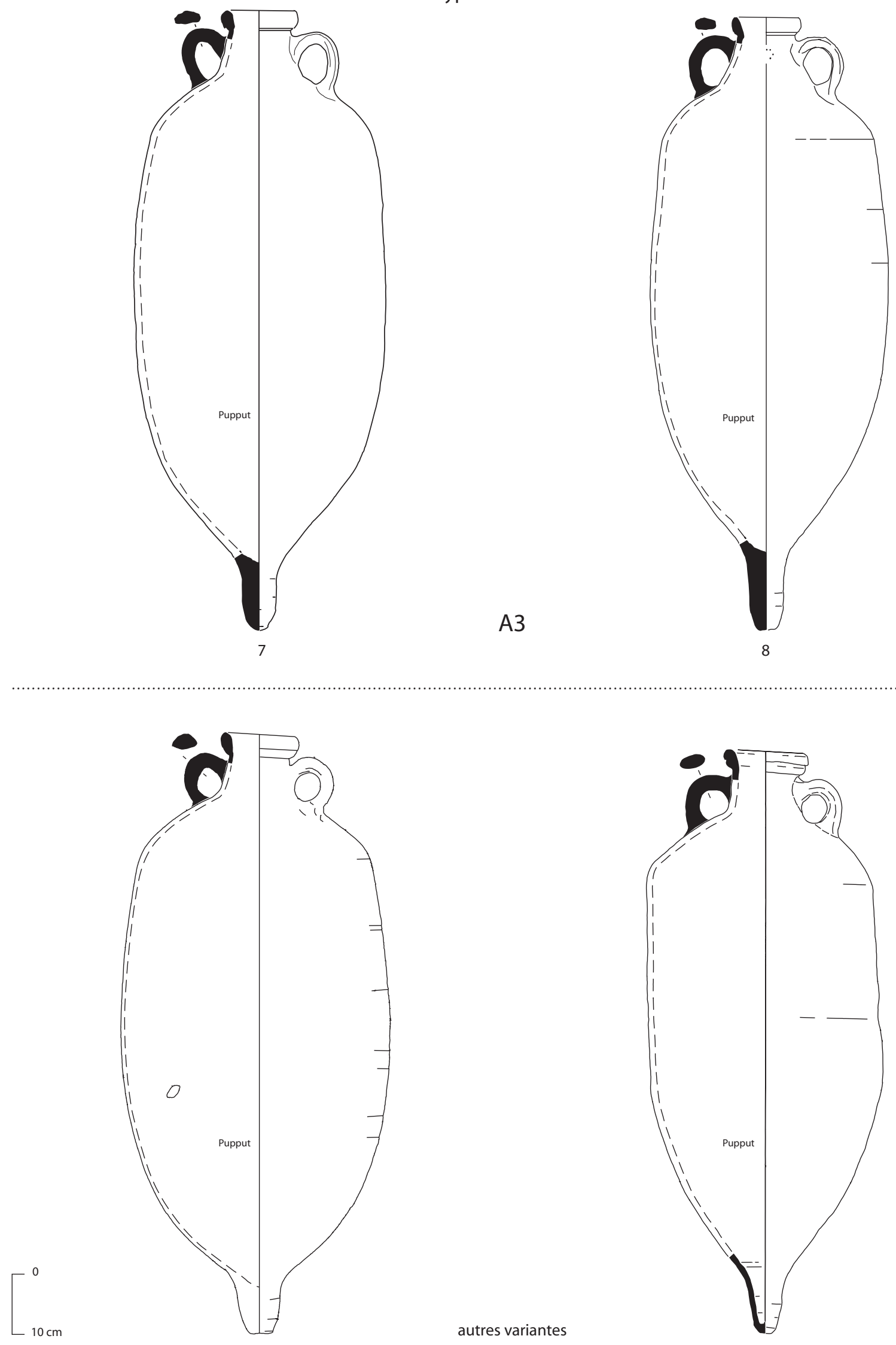

10

autres variantes

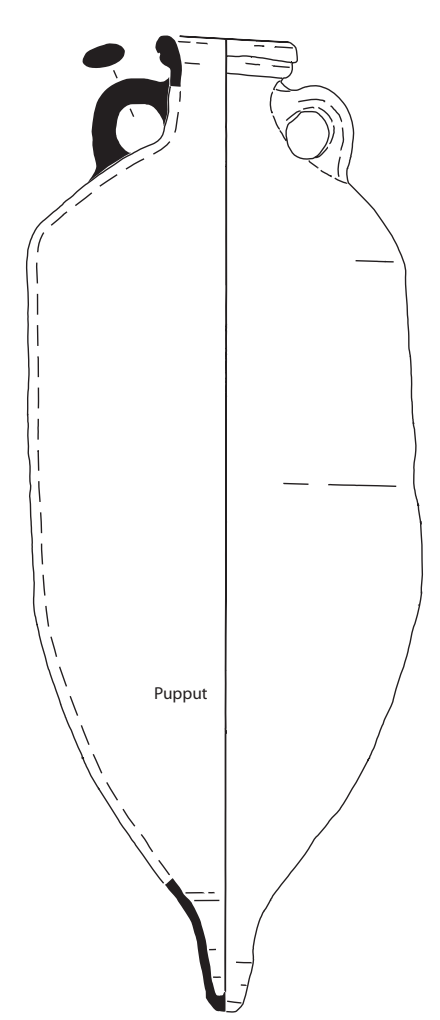

11

Fig. 58. Amphores africaines classiques. 
Typologie - Amphores

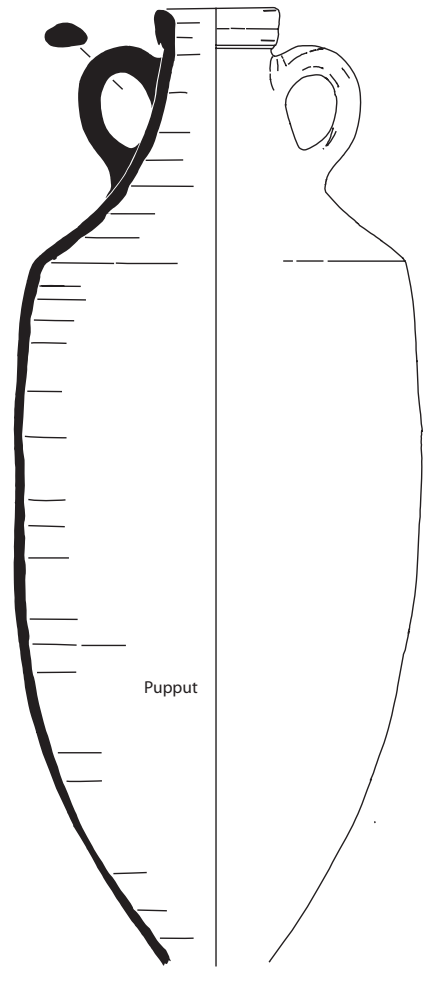

Type Africaine II B
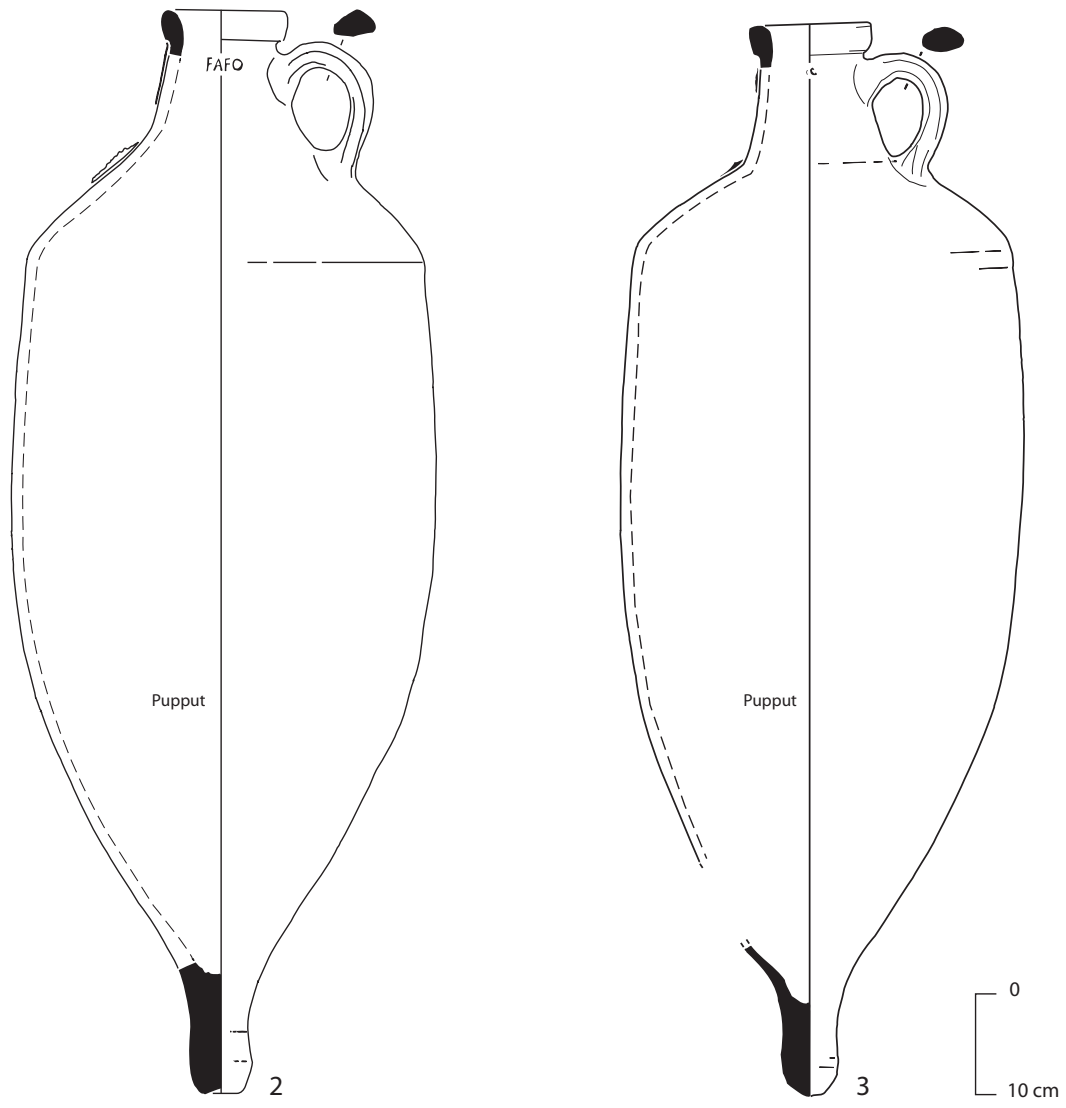

Type Africaine II B "pseudo-tripolitaine"
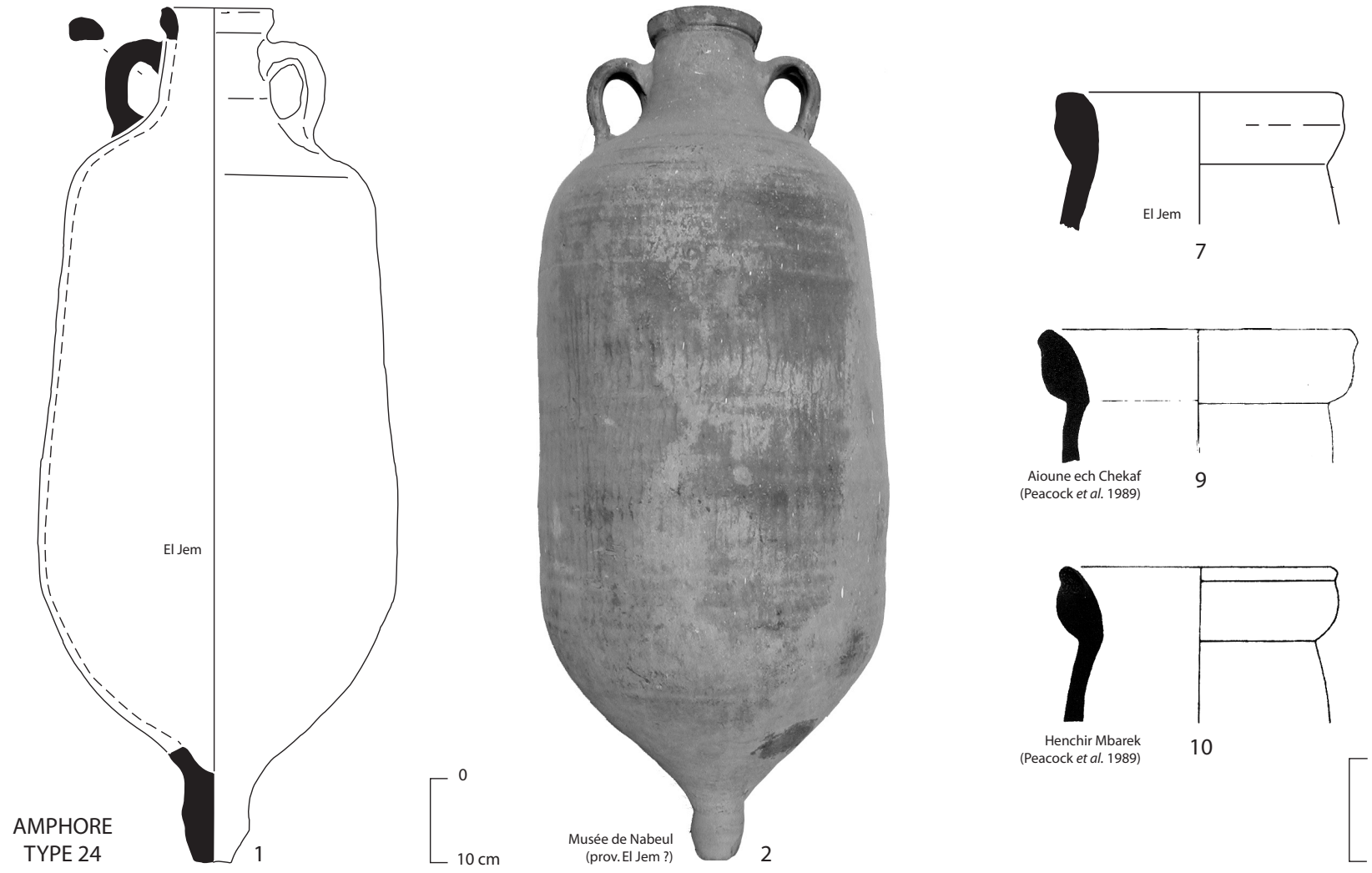

Fig. 59. Amphores africaines classiques.

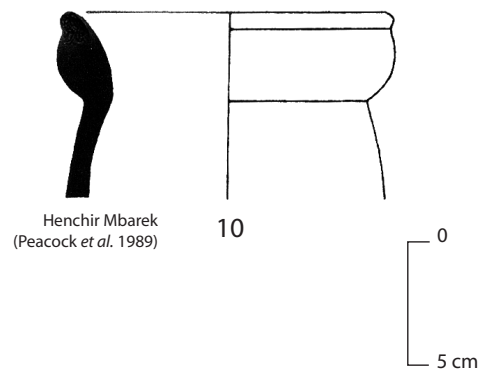




\section{— Africaine II A (fig. 57-58)}

\section{AMPHORE TYPE 22}

Le type Africaine II A se définit par un «bord épaissi et arrondi à l'extérieur avec un profil en amande » (Panella 1973, 581), un «col tronconique» muni d'«anses en ruban avec profil en oreille », caractère commun à toutes les amphores Africaines II (Panella 1982, 175), « une panse plus basse mais en proportion plus ample» (Panella 1973, 584) que celle des autres amphores du type II, et une pointe pleine tronconique à extrémité arrondie «privée du renflement qui caractérise les autres conteneurs publiés par Zevi et Tchernia » (Ibid.).

J'émets personnellement un doute sur la nécessité de maintenir la distinction introduite par D. Manacorda (1977, 160) entre les bords «senza gradino» et ceux « con gradino ». Le col Ostia I, 523, choisi pour illustrer la première variante laisse voir un léger gradin à la jonction entre le bord et le col, marqué en pointillés sur le dessin. De même, les exemples choisis par S. J. Keay pour illustrer son type IV (= Africana II A «senza gradino $\gg)$ ne me paraissent pas appartenir au type Africaine II A (Keay 1984, fig. 19, n 4-7, fig. 20, n 1-3, fig. 42, $\mathrm{n}^{\circ} 5-6$ ) mais, plus vraisemblablement, à des amphores cylindriques de grandes dimensions, comme l'indique d'ailleurs la date tardive de leurs contextes de découverte (Ibid., 111-114). Le bord des amphores habituellement classées dans le type Africaine II A présente presque systématiquement cette particularité technique, plus ou moins évidente, d'un «gradin » en léger retrait par rapport au sommet de la lève.

Le type II A apparaît en fait assez hétérogène lorsqu'on considère non plus des fragments de bords mais des exemplaires complets. La documentation de Pupput permet ainsi de distinguer trois variantes :

- La variante A1, de petite taille (H. : 96-98 cm, comme les amphores Africaines I), présente un profil piriforme, avec une panse qui s'élargit vers le bas et un col très court.

- La variante A2, plus grande $(\mathrm{H} .: 100 \mathrm{~cm})$ et de forme plus élancée, possède également un col plus étiré.

- La variante A3, de grande taille $(104 \mathrm{~cm})$, toujours caractérisée par un bord «en amande » (ou «en olive », selon l'expression de Rebuffat 1997, 165), marqué par un léger gradin à la jonction avec le col, présente en revanche un corps comparable à celui des Africaines II B.

Exemples (fig. 57-58) :

Variante A1

*1 Pupput, tombe 402, amphore $\mathrm{n}^{\circ} 5$ (Bonifay 2004a, fig. 10, $\left.\mathrm{n}^{\circ} 14\right)$.

2 Pupput, tombe 642, amphore $\mathrm{n}^{\circ} 1$ (Ibid., fig 59, 642.2).

*3 Pupput, tombe 1007, amphore ${ }^{\circ} 1$ (Inv PP1685.1). Variante A2

*4 Pupput, tombe 642, amphore $\mathrm{n}^{\circ} 2$ (Bonifay 2004a, fig. $\left.10, \mathrm{n}^{\circ} 15\right)$.

*5 Pupput, tombe 1043 (Inv. PP1824.5).

*6 Pupput, tombe 615 (Inv. PP1382.1).
Variante A3

*7 Pupput, tombe 867 (Inv. PP1888.3).

*8 Pupput, tombe 867, amphore $\mathrm{n}^{\circ} 4$ (Bonifay 2004a, fig. $\left.10, \mathrm{n}^{\circ} 16\right)$.

Autres variantes

9 Nabeul, fabrique de salaisons, période 4 (Bonifay et al. 2002-2003, fig. 20, $\mathrm{n}^{\circ} 287$; Slim, Bonifay, Trousset 1999, fig. 28).

*10 Pupput, tombe 615 (Inv. PP3182.3).

*11 Pupput (Inv. PP5330.3).

Cet essai d'affinement de la typologie ne permet pas de classer tous les exemplaires rencontrés, comme le prouve l'existence de nombreuses variantes intermédiaires (1011 et Ben Abed, Griesheimer 2004, fig. 103, T642.2 et 4). En revanche, il montre la nécessité de raisonner non plus seulement sur des fragments de bords mais également, dans la mesure du possible, sur des exemplaires complets. Ces trois variantes semblent plus ou moins se succéder dans le temps. La variante A1 qui, d'après la qualité de sa pâte, pourrait être originaire de Salakta, ne semble pas apparaître avant la fin du IIe s. (tombe 642). Elle est associée à la variante A2 dans la tombe 402, de la fin du IIe s. ou du premier quart du IIIe s. (lampe marquée Pullaeni). Les exemplaires de la variante A3, associés dans la tombe 867 à des amphores Africaines II B, sont plus tardifs, du milieu ou de la seconde moitié du IIIe s. (Bonifay 2004a). Cette chronologie recoupe celle proposée par Cl. Panella $(1977,584)$ sur la base du matériel d'Ostie. En revanche, je ne pense pas qu'il soit possible, comme le propose D. Manacorda (1977, 161), d'envisager la poursuite de la production du type II A au IVe s. : je ne dispose en tout cas d'aucune donnée en ce sens.

Il semble assuré aujourd'hui que les amphores Africaines II A, dont beaucoup d'exemplaires sont poissés, n'étaient pas destinées à la commercialisation de l'huile (infra, Tabl. IV).

Datation proposée :

Variante A1 et A2 - fin du IIe s. - première moitié du IIIe s.

Variante A3 - milieu ou seconde moitié du IIIe s.

\section{— Africaine II B (fig. 59)}

\section{AMPHORE TYPE 23}

Le type B (Panella 1973, 585-586) est, parmi les quatre groupes créés à Ostie, celui qui est le moins clairement défini (Manacorda 1977, 162). De fait, la ressemblance entre les deux fragments d'Ostie choisis pour le caractériser (Ostia I, 521 et 522) n'est pas évidente et les deux auteurs ont éprouvé des difficultés à réunir des comparaisons qui demeurent, dans l'ensemble, peu convaincantes (Panella 1973, 582 ; Manacorda 1977, 163). En raison de son manque d'homogénéité, ce type a eu tendance à devenir le «fourre-tout» de la classification des amphores africaines classiques, où sont rangés les exemplaires qui ne peuvent être classés dans les trois autres types A, C et D, mieux caractérisés.

J'avais pour ma part fini par douter de l'existence de ce type et envisagé de classer parmi les variantes tardives du 
Typologie - Amphores

Type Africaine II C

C 1
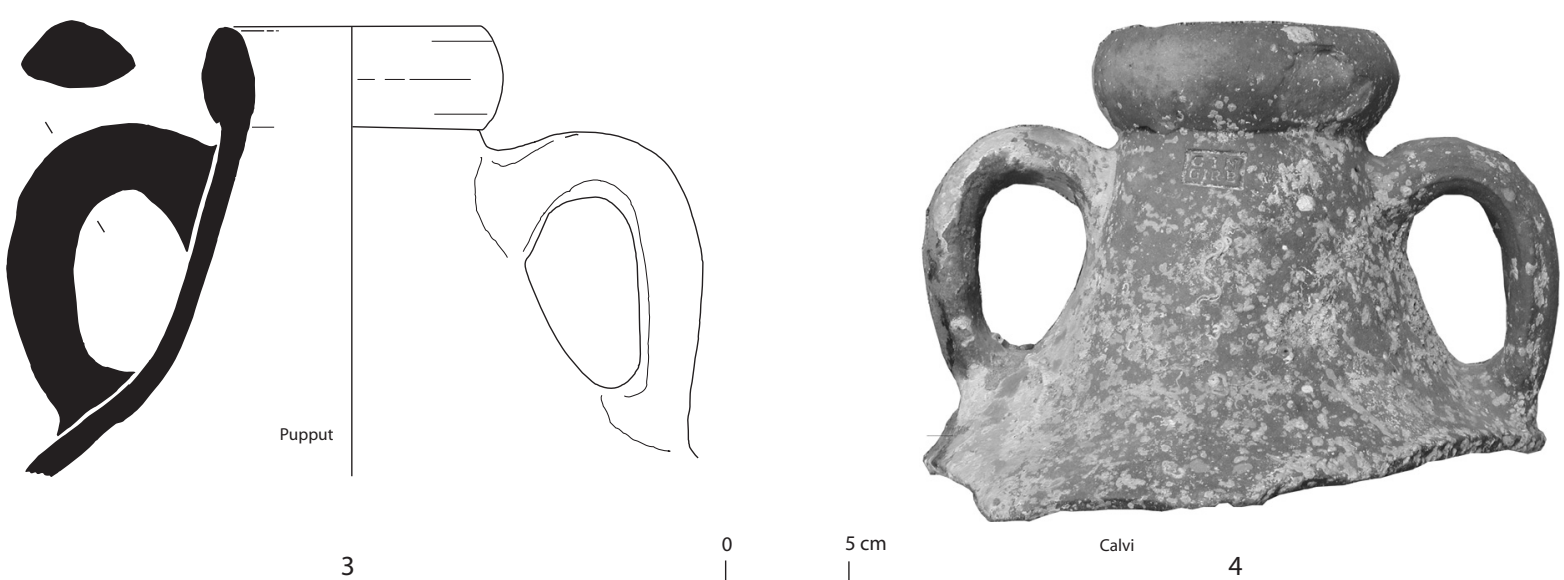

3

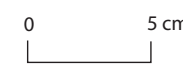

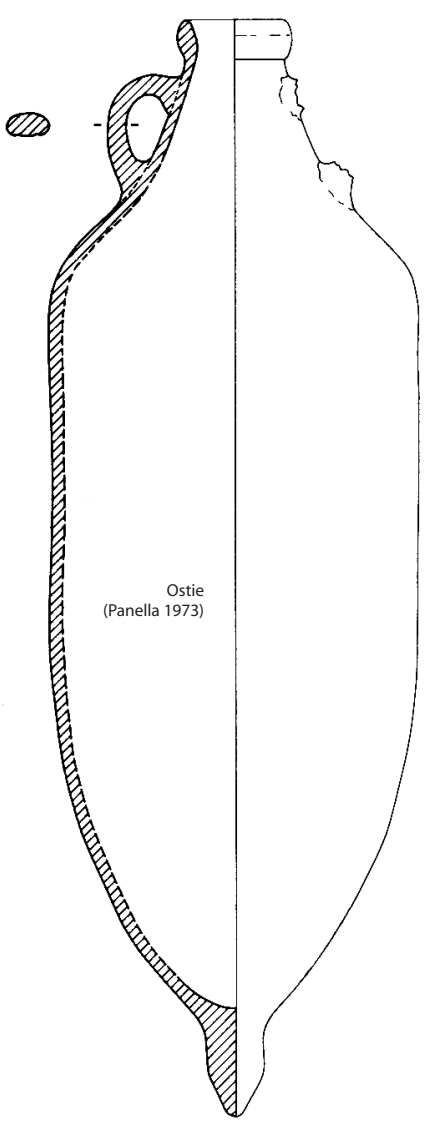

1

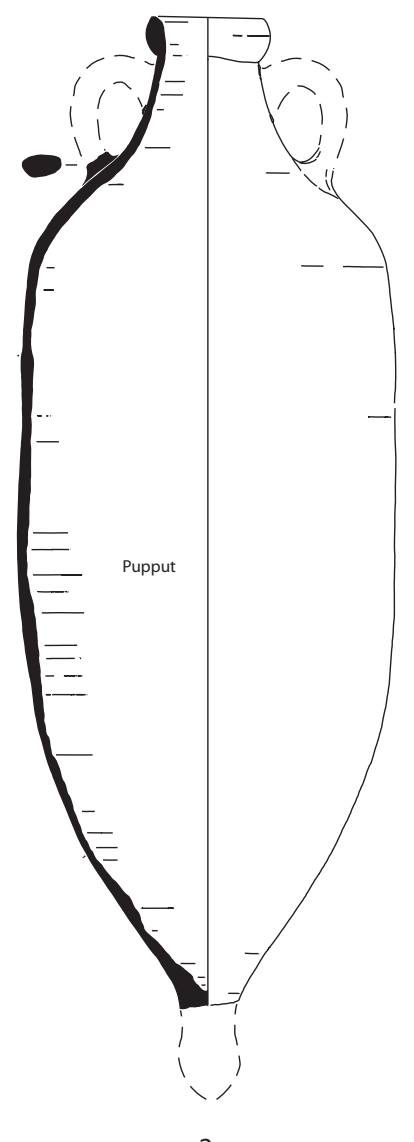

2

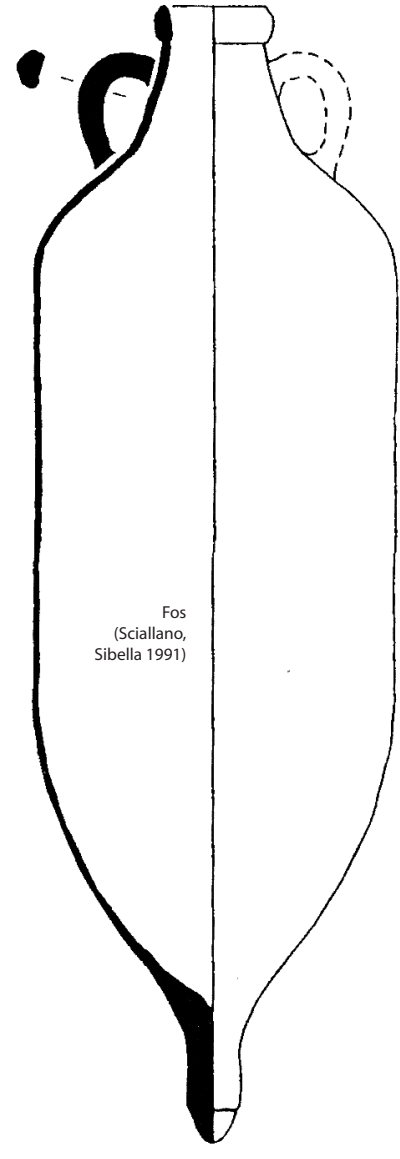

5

Fig. 60. Amphores africaines classiques. 
C 2

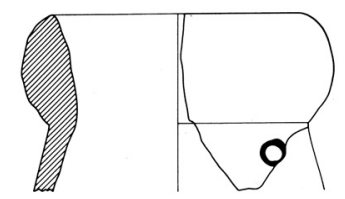

12
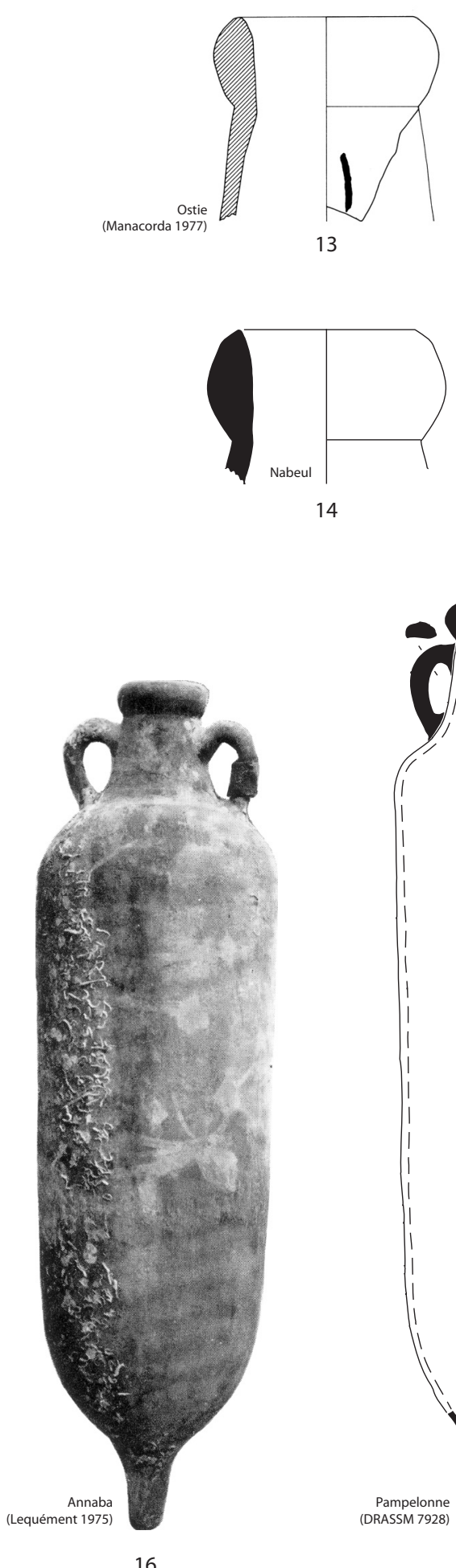

16
Type Africaine II C

C 3
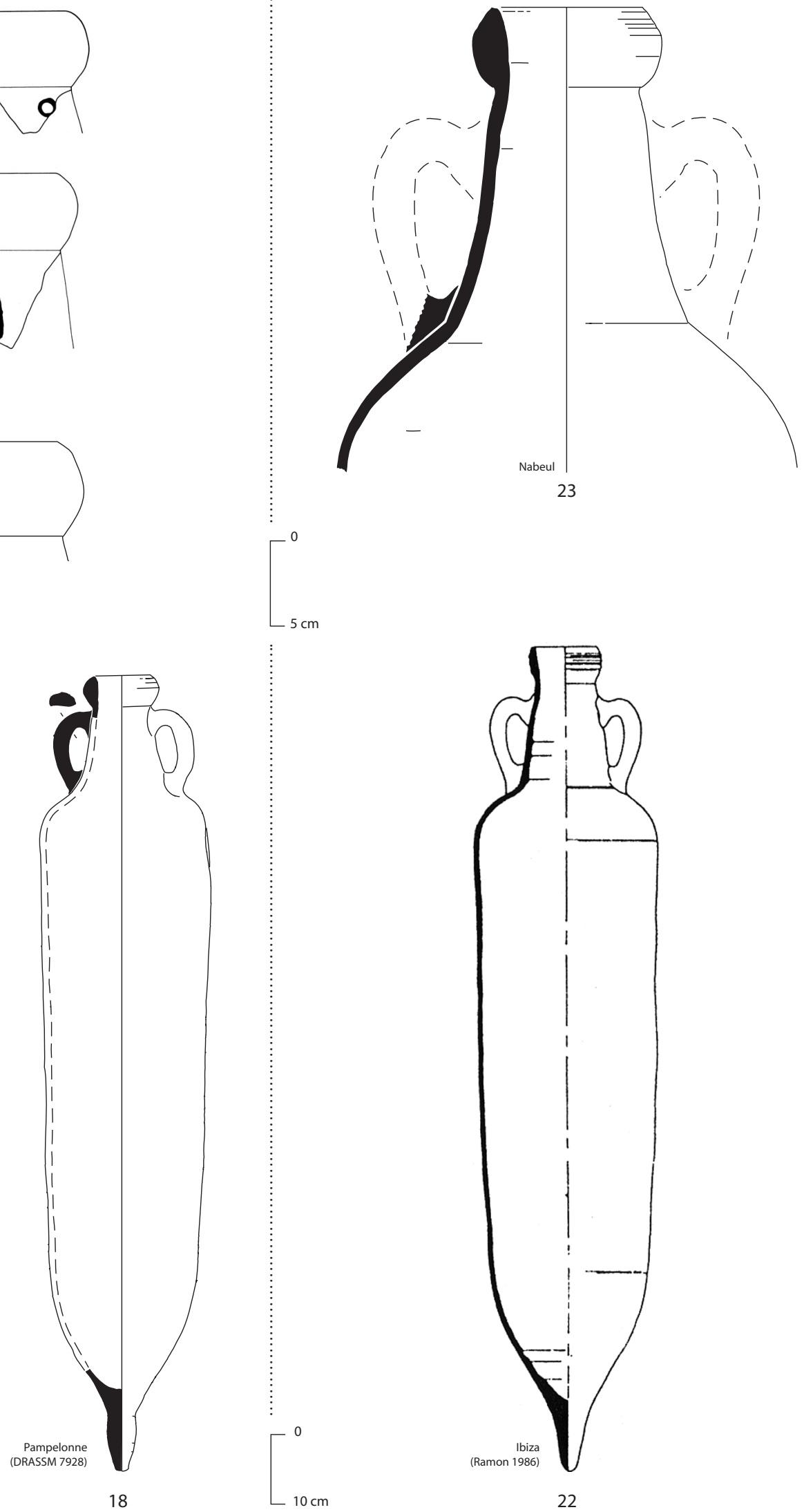

Fig. 61. Amphores africaines classiques. 
type II A les exemplaires attribués par Cl. Panella au type II B « con gradino », avant de m'apercevoir, en classant l'abondante documentation de Pupput, que le type II B est une réalité, même s'il reste peu abondant. Cette amphore de grande taille (110 cm env.) possède un long col tronconique terminé par un bord en bandeau grossièrement quadrangulaire, de $3 \mathrm{~cm}$ de haut; le corps, large au niveau de l'épaulement (D. : $40 \mathrm{~cm}$ ), va en s'effilant vers la base munie d'une pointe pleine, légèrement renflée à la base.

Exemples (fig. 59) :

*1 Pupput (Inv. PP4924.4).

*2 Pupput, tombe 867, amphore $\mathrm{n}^{\circ} 1$ (Bonifay 2004a, fig. 11, $\left.\mathrm{n}^{\circ} 18\right)$. Timbre $F A F O$.

*3 Pupput, tombe 867, amphore $\mathrm{n}^{\circ} 2$ (Inv. PP1888.2).

4 Pupput, tombe 1639, amphore $\mathrm{n}^{\circ} 3$ (Ibid., fig. 11, $\left.\mathrm{n}^{\circ} 17\right)$.

Ces amphores ne semblent pas antérieures au IIIe s. (tombe 867, avec une lampe Deneauve X). On ne dispose d'aucune information sur leur contenu.

Datation proposée : IIIe s.

\section{- Africaine II B, variante «pseudo-tripolitaine» (fig. 59)}

\section{AMPHORE TYPE 24}

La seule amphore issue d'un contexte catalan attribuée par Keay au type Africaine II B (= Keay V bis) est caractérisée par un bord en bandeau à profil externe en « $\mathrm{S}$ », un col cylindrique très légèrement tronconique, un corps pansu élargi à la base, terminé par une pointe courte et renflée. Elle trouve une comparaison directe avec un exemplaire du dépôt d'El Jem (1). De fait, ce type de bord est particulièrement bien attesté sur plusieurs ateliers situés sur la rive sud de la sebkhra Sidi el-Hani, à une quarantaine de $\mathrm{km}$ au nord-ouest d'El Jem (Peacock, Bejaoui, Ben Lazreg 1990, 63-64 et fig. 3, nº 1 et 8). Nous avons vraisemblablement affaire à un type cohérent.

Exemples (fig. 59) :

*1 Dépôt d'El Jem (Bonifay et al. 2002-2003, fig. 13, $\left.\mathrm{n}^{\circ} 162\right)$.

*2 Musée de Nabeul, proviendrait d'El Jem (?) (Inv. NBM.A03).

3 Tarragone (Keay 1984, fig. 19, n 3).

4 Pola, amphithéâtre (Manacorda 1977, fig. 554).

5 Musée de Sfax (en exposition). H. $97 \mathrm{~cm}$; D. max. 40 $\mathrm{cm}$.

6 Musée de Sfax (Zevi, Tchernia 1969, fig. 13, c). H. cons. $101 \mathrm{~cm}$; D. $\max 45 \mathrm{~cm}$.

*7 El Jem, maison d'Africa (fouilles H. Slim, Inv. EJMA.000.031).

8 Littoral tunisien, site $\mathrm{n}^{\circ} 1$ (Henchir el-Medeina, au sud de la Bahiret el-Biban) (Bonifay et al. 20022003, fig. 13, $\mathrm{n}^{\circ} 161$ ).

*9 Aioune ech-Chekaf, atelier (Peacock, Bejaoui, Ben Lazreg 1990, fig. 3, n 1).

*10 Henchir Mbarek, atelier (Ibid., fig. 3, n 8).

Cette variante d'Africaine II $B$ à bord en « $S$ » a été rapprochée du type Tripolitaine III par Peacock, Bejaoui, Ben Lazreg $(1990,82)$ qui identifient aussi une série de bords de type «pseudo-tripolitain » dans la région d'Acholla. J'ai choisi de conserver cette appellation (Bonifay et al. 2002-2003) pour individualiser ces amphores produites dans l'arrière pays sahélien et faiblement exportées outre-mer. Cette amphore est vraisemblablement contemporaine des autres amphores Africaines II.

Etant donné la localisation des ateliers, on aurait tendance à imaginer un contenu oléicole ou vinicole.

Datation proposée : IIIe s. (?)

- Africaine II C (fig. 60-61)

\section{AMPHORE TYPE 25}

Cl. Panella (1973, 586) définit cette amphore comme étant « caractérisée par un bord haut à profil convexe, un col tronconique, des anses en ruban épaissi tout à fait semblables à celles des types II A et II B, (...) une panse cylindrique dont le diamètre diminue légèrement vers le bas, et une pointe pleine, de grande taille ». Manacorda (1977, 165) suggère l'existence de deux variantes qu'il est aujourd'hui possible de mieux caractériser et de compléter par une troisième :

- Variante 1: lèvre peu haute $(\mathrm{H} .: 4 \mathrm{~cm})$ à face extérieure très convexe et lisse (D. du bord: 12,5 $\mathrm{cm}$ ), col tronconique, anses en oreilles, panse large (D. $38 \mathrm{~cm}$ ). Hauteur : $110-115 \mathrm{~cm}$.

- Variante 2 : lèvre haute $(\mathrm{H} .: 4,5$ à $5 \mathrm{~cm})$ à face extérieure peu convexe et parfois légèrement cannelée (D. du bord : 12 ou 11,2 cm), col plus long et plus cylindrique, panse plus fuselée (D. $26-28 \mathrm{~cm}$ ). Hauteur : $110-120 \mathrm{~cm}$.

- Variante 3: lèvre très haute $(5-6 \mathrm{~cm})$ à face extérieure cannelée (D. du bord: $11 \mathrm{~cm})$, col très allongé (H. 14 à $15 \mathrm{~cm}$ ), anses en poignées attachées sur le col, panse fuselée et longue (H. $120 \mathrm{~cm})$.

Exemples (fig. 60-61) :

Variante 1

*1 Ostia III, 131 (archétype de la classification: Panella 1973, 629, n 28 ; Zevi, Tchernia, 1969, fig. 4 et 13, a). H. $110 \mathrm{~cm}$; D. $37 \mathrm{~cm}$.

*2 Pupput (Inv. PP4923.3).

*3 Pupput (Bonifay 2004a, fig. 11, $\mathrm{n}^{\circ}$ 19)

*4 Calvi (Corse), timbre C.I.N/GIR.B (supra, fig. $3, \mathrm{n}^{\circ} 13$ ; cf. Liou 1975, fig. 43).

*5 Golfe de Fos (Sciallano, Sibella 1991 ; Zevi, Tchernia 1969, fig. 21, b). Timbre C.I.N./LCAN. H. $115 \mathrm{~cm}$; D. $\max .38,5 \mathrm{~cm}$.

6 Planier VII (Zevi, Tcherna 1969, fig. 18, c). «Argile rouge brique ». H. 113,4 cm ; D. $\max .34,2 \mathrm{~cm}$.

7 Ratino (Bonifaccio, Corse) (Zevi, Tchernia 1969, fig. $25, \mathrm{c}$ ). « Argile rouge brique avec marge extérieure plus sombre ». H. $114 \mathrm{~cm}$; D. $35 \mathrm{~cm}$.

8 Cabrera III (Mayet in Bost et al., 1992, fig. 16, $n^{\circ} 6$ ). H. $119 \mathrm{~cm}$; D. $38 \mathrm{~cm}$.

9 Musée de Salakta (en exposition). Titulus pictus rouge sur le col : A. H. $112 \mathrm{~cm}$; D. $\max .37 \mathrm{~cm}$.

10-11 Nabeul, Sidi Aoun, atelier (supra, fig. 17, $\mathrm{n}^{\circ} 4-5$ )

Variante 2

*12-13 Ostia IV, 125-126.

*14 Nabeul, bassin XLVI (Inv. NB1455D). 
15 Nabeul-briqueteries, atelier (supra, fig. 17 haut, $\mathrm{n}^{\circ} 3$ ).

*16 Annaba (Lequément 1975, fig. 1). H. 107 mm.

17 Athènes, destruction de 267 (?) (Grace 1961, fig. 37).

*18 Epave de Pampelonne (Saint-Tropez, Var) (DRASSM, Inv. 7928 ; cf. Lequément 1976, fig. 3, b).

19 Marseille, découverte sous-marine (Zevi, Tchernia 1969, fig. 18,d).

Variante 3

20 Ostia IV, 127.

21 Musée de Barcelone (Espagne) (Manacorda 1977, fig. 555). H. $129 \mathrm{~cm}$; D. max. $31 \mathrm{~cm}$. Cf. Ostia IV, 127.

*22 Ibiza (Espagne) (Ramon 1986, fig. 16, n 5). H. 122 $\mathrm{cm}$; D. max. $27 \mathrm{~cm}$.

*23 Nabeul, fabrique de salaison, période 4C, pièce XLIV (Inv. NB1878.12).

24 Sidi Aoun, atelier (supra, fig. 17 bas, $\mathrm{n}^{\circ}$ 3).

On possède de solides présomptions sur l'origine de cette amphore. Tout d'abord, comme l'avait remarqué D. Manacorda $(1977,164)$ : « très constante, l'argile de ces conteneurs » est « de couleur rouge vif ou orange, plutôt compacte et souvent à surface blanche »; la pâte caractéristique de l'atelier de Salakta n'est pas attestée sur ce type d'amphore. D'autre part, Manacorda (1977, 165) relève que les seuls timbres reconnus sur ce type d'amphore se rattachent à la série C.I.N., que Cl. Panella $(1973,588)$ propose de lire (C)olonia (I)ulia (N)eapolis. Manquent en revanche les timbres attribués à Hadrumète, Leptiminus $^{124}$ et Salakta. Enfin, le type II C est celui qui est le mieux attesté dans les zones d'ateliers de la périphérie de Nabeul que nous avons eu l'occasion de visiter (supra, p. 35).

Plusieurs indices plaident en faveur des salsamenta pour le contenu des amphores Africaines II C (infra, p. 472). Les exemplaires de Planier VII, de Pampelonne, d'Annaba sont poissés. Ceux d'Annaba portaient en outre, enroulées à l'une des anses, des étiquettes en plomb mentionnant une officina que R. Lequément (1975, 678-679) propose d'interpréter comme une fabrique de salaisons de poissons.

Cette forme dérive probablement de la forme II A con gradino (supra, atelier de Sidi Aoun, fig. 17, $\mathrm{n}^{\circ} 2$ ). Les données d'Ostie semblent indiquer que la période de diffusion maximale de cette amphore se situe dans la seconde moitié du IIIe $\mathrm{s}$. et au IVe siècle. La variante 1 paraît seule attestée dans la seconde moitié du IIIe s. (2, 8 ; contra : 17) tandis qu'elle coexiste avec la variante 2 au début du IVe s. (épave de Pampelonne: Lequément 1976, fig. 3, b-c). Cette dernière variante se rattache déjà à la série des amphores cylindriques de moyennes dimensions (Africaines III); elle peut également annoncer certains types du Ve s. dont le bord présente la même face convexe, parcourue de légères cannelures (type Keay 57).

Datation proposée :

Variante $\mathrm{C} 1$ - milieu du IIIe s. - début du IVe s. ;

${ }^{124}$ Une amphore découverte en Israël et portant un timbre $L E P M I / B S C D$ a été attribuée naguère au type 2C. Cette attribution est aujourd'hui contestée par D. Manacorda (1977).
Variante $\mathrm{C} 2$ - pas avant la fin du IIIe s. - première moitié du IVe s. (?) ;

Variante C3 - IVe s. (?).

\section{— Africaine II D (fig. 62)}

\section{AMPHORE TYPE 26}

Le type Africaine II D « est caractérisé par un bord à face plane, parfois légèrement proéminent, et non distinct du col si ce n'est par un léger sillon de séparation » (Manacorda 1977, 166). Il correspond à l'essentiel des amphores choisies par Zevi et Tchernia (1969, fig. 1 à 3) pour illustrer leur type «Africano grande». D. Manacorda (Ibid., 166-167) proposait, de manière préliminaire, la distinction entre quatre variantes :

- a) Ostia IV, Fig. 128 : «bord à face pas très haute, parfois à peine proéminente, et distinct du col par un sillon peu profond, cependant bien marqué ») ;

- b) Ostia IV, Fig 129-130: se distingue du type précédent " par un col extrêmement tronconique »;

- c) Ostia IV, Fig 131 : «se distingue par la hauteur notable de la face du bord qui apparaît distincte, par un léger sillon, d'un col légèrement tronconique » (le sommet de la lèvre est légèrement biseauté, celle-ci étant également légèrement déversée vers l'extérieur) ;

- d) Ostia IV, Fig 132-133 : «bord à face très haute mais non distincte ou à peine différenciée d'un col presque parfaitement cylindrique ».

J'ai personnellement éprouvé des difficultés à appliquer cette typologie et je préfère m'en tenir à la distinction de deux variantes principales :

- La variante D1 correspond à la variante (a) de Manacorda, avec un bord en bandeau plus haut $(4 \mathrm{~cm})$ et plus mince $(1,5 \mathrm{~cm})$ que celui des amphores Africaines II B.

- La variante D2 correspond aux variantes (b) et (d) de Manacorda, avec un bord qui peut être légèrement épaissi à l'intérieur (variante b) mais dont la face extérieure ne se distingue pas de la ligne du col, sinon par un très léger sillon.

J'ai des doutes sur l'appartenance de la variante (c) au type Africaine II : ces bords au diamètre resserré, me sembleraient plutôt provenir d'un type de transition (15) entre les amphores Africaines II D1 et les amphores Keay 25.1 .

Exemples (fig. 62a et 62b) :

Variante 1

*1 Epave Planier VII (DRASSM, Inv. C410 ; cf. Zevi, Tchernia 1969, fig. $17, \mathrm{c}-\mathrm{d})$. H. $117,5 \mathrm{~cm}$; D. $33,5 \mathrm{~cm}$.

2 Pupput (Inv. PP1211.1).

Timbre FANFORT/COLHADR. (supra, fig. 5, $\mathrm{n}^{\circ} 1$ ). Comparable à Villedieu 1984, fig. 255.

3 Pupput, tombe 1090 (Bonifay 2004a, fig. 11, n 20). Timbre LEP/ROSAR (supra, fig. 5, $\mathrm{n}^{\circ} 4$ ).

*4 Pomègues (DRASSM, cf. Liou 1975, fig. 12). timbre ASVL/CAEL.

5 Epave Cabrera III (Bost et al. 1992, fig. 35, n 1). Timbre TER(palme)TI /ASY(palme) $L L$.

*6 Port-Vendres, anse Gerbal (Inv. PV1.A19). 
Typologie - Amphores

D 1
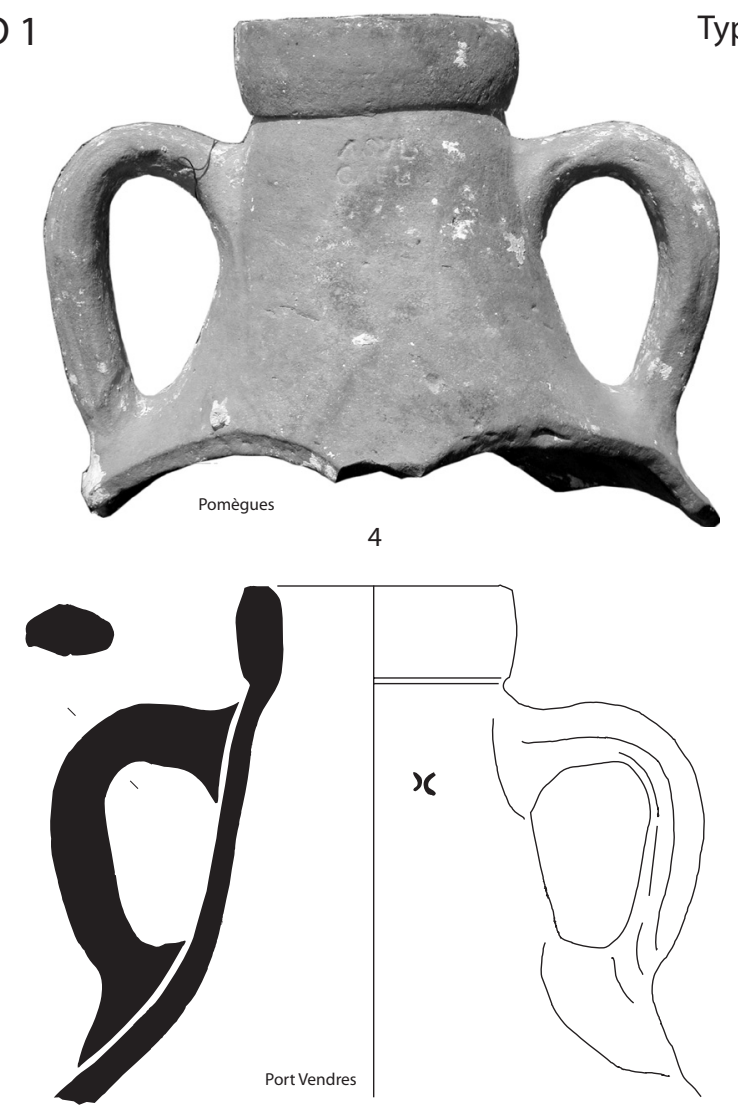

6

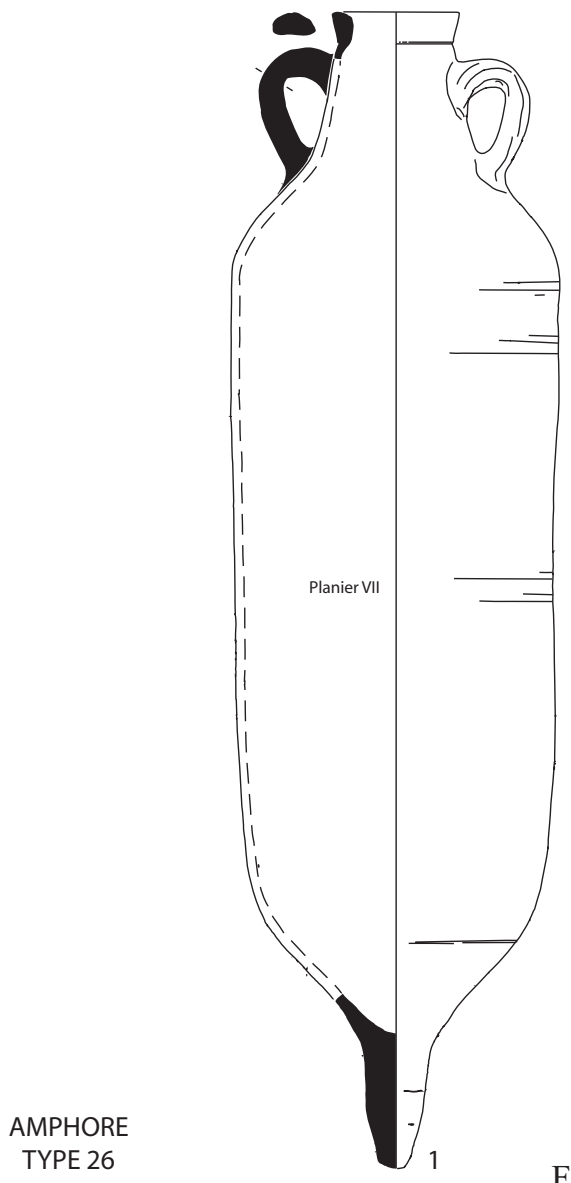

Fig. 62a. Amphores africaines classsiques.

Type Africaine II D
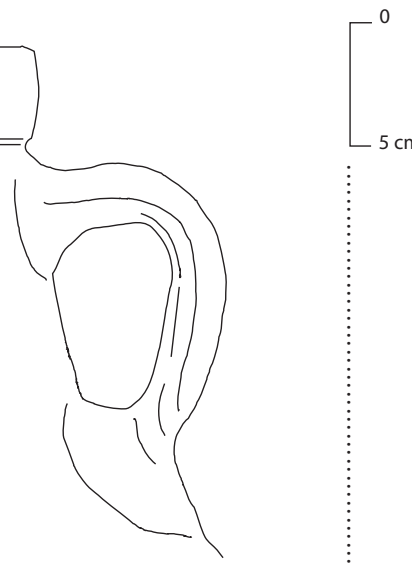

D 2
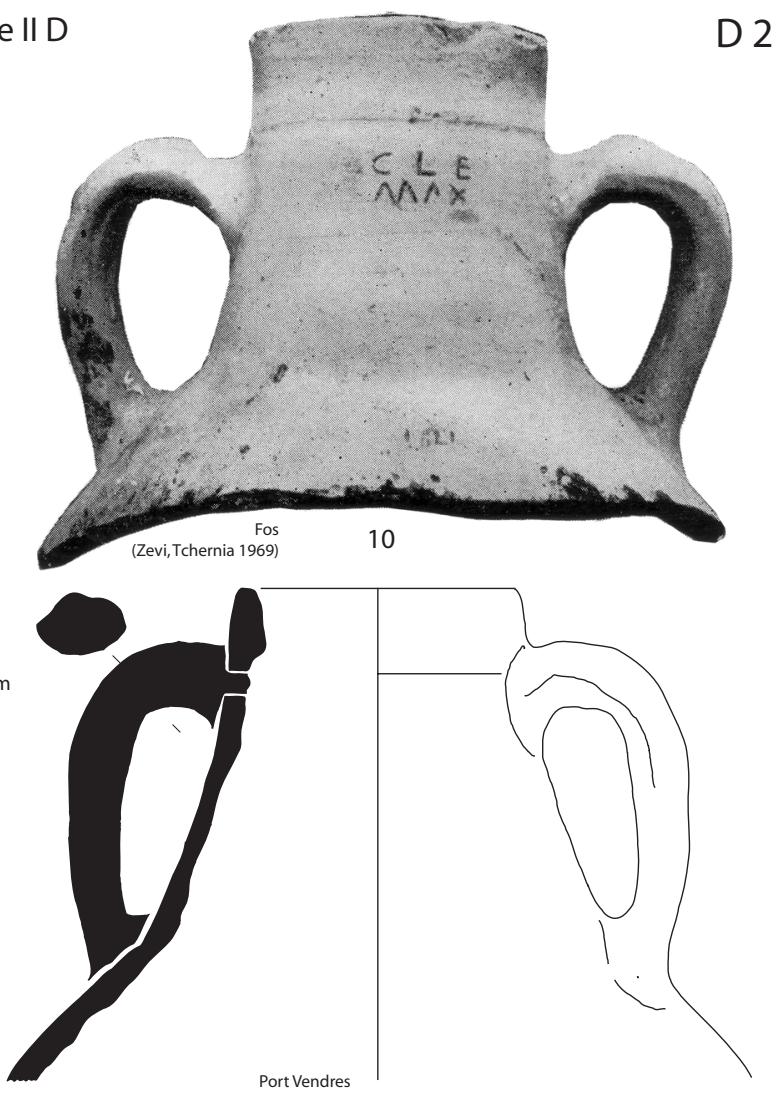

11

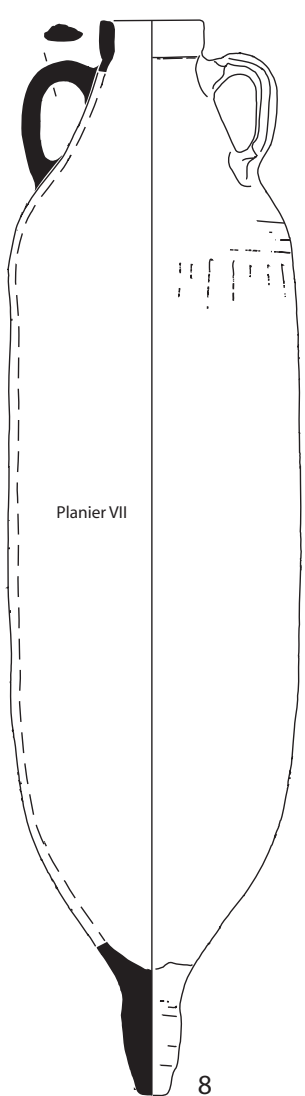

8 
7 Leptiminus, atelier (Peacock, Bejaoui, Ben Lazreg 1989, fig. 22, $\mathrm{n}^{\circ} 3$ ).

Variante 2

*8 Epave de Planier VII (DRASSM, Inv. C430 ; cf. Zevi, Tchernia 1969, fig. 17). H. $109 \mathrm{~cm}$; D. $29,5 \mathrm{~cm}$.

9 Porto Torres (Villedieu 1984, fig. 257). Timbre COLHADR/HERCE[-]I[

*10 Fos, timbre CLE/MAX (Zevi, Tchernia 1969, fig. 20)

*11 Port-Vendres, anse Gerbal (Inv. PV1.A78). Bord intérieur fortement épaissi. Attache supérieure de l'anse en tenon.

12 Epave pointe de la Luque B (Inv. PL1960). Poissée (infra, fig. 262, $\mathrm{n}^{\circ} 4$ ). Production algérienne?

13 Barcelone (Keay 1984, fig. 20, $\mathrm{n}^{\circ} 4$ ).

14 Leptiminus, atelier (Peacock, Bejaoui, Ben Lazreg 1989, fig. 22, n 9 ).

Variante de transition avec le type Africaine III

*15 Ostia IV, 131.

*16 Arles, fouilles du Jardin d'Hiver (Musée de l'Arles Antique, Inv. JHI75.00.7285).

«On a la nette impression, qu'au sein du groupe des amphores (Africaines II), ces conteneurs à face plane sont les derniers à être produits et exportés » (Manacorda 1977, 168). De fait, les données d'Athènes (milieu IIIe s. : Robinson 1959, 69, K116) et d'Ostie (seconde moitié du IIIe s. : Manacorda 1977, 168) sont confirmées par celles de Pupput (2 et 3) ainsi que par le chargement de l'épave Cabrera III (5). Cependant, l'affirmation de Manacorda (Ibid.) selon laquelle « la documentation est beaucoup plus abondante pour le IVe s. » me paraît moins évidente. La présence de ce type sur l'épave de Planier VII ne renvoie pas à une date très avancée dans le IVe s. et les fragments récupérés sur l'épave de la pointe de la Luque (12), peut-être plus tardive, ne sont pas nombreux. La plupart des amphores recueillies sur les épaves du IVe s. en Provence sont du type Africaine III (infra, p. 467). C'est pourquoi reste très étonnante la forte proportion du type Africaine II D2 dans les entrepôts de Turris Libysonis après 425 (Villedieu 1984, 183). En revanche, on sait maintenant que les fragments d'amphores découverts dans un contexte de la fin du Ve début du VIe s. au Castellum du Nador (Manacorda 1989, fig. 42, $\left.\mathrm{n}^{\circ} 227-229\right)$ sont en fait des types plus tardifs Keay 56 et 57 (infra, TYPES 42-43).

Des analyses de contenu effectuées sur des tessons du type II D ont donné des résultats contradictoires: présence de traces d'huile pour les unes (Passi et al. 1981) et absence pour les autres (Panella 1982, 176 et note 5 : rapport inédit d'A. Tchernia et F. Formenti). Mais, beaucoup d'exemplaires étant poissés (infra, Tabl. IV), on est en droit de se demander si le titulus pictus relevé sur un exemplaire d'Ostie (Zevi, Tchernia 1969, 187) n'a pas été apposé pour prévenir les utilisateurs d'une exception au contenu habituel de cette amphore (?) ${ }^{125}$.

Datation proposée : milieu du IIIe s. - premier tiers du IVe s. + (?)

\section{transition avec Africaine III}
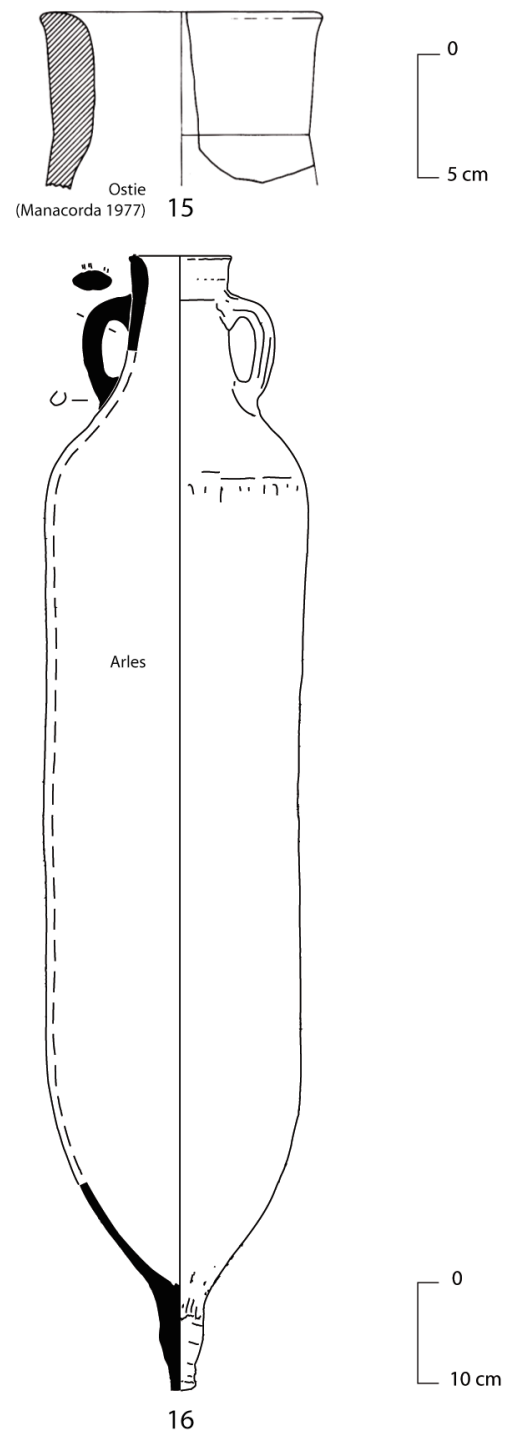

Fig. 62b. Amphores africaines classiques.

En conclusion, les amphores Africaines II forment un groupe peut-être moins hétérogène qu'il n'y paraît. On peut se demander si les divisions que nous opérons entre les quatre types principaux A, B, C, D et d'autres variantes moins diffusées, ne correspondent pas tout d'abord à une diversité d'origines et ensuite seulement à une évolution chronologique. Ainsi, nous avons vu que le type II A «con gradino » semble, au départ, avoir été produit sur les ateliers de Salakta. Le type B, peu homogène, a été produit à Hadrumète et probablement aussi sur des ateliers mineurs, notamment une variante à bord sinueux fréquente à $\mathrm{El}$ Jem. Le type $\mathrm{C}$ est une production de Nabeul tandis que le type D est une formephare des ateliers de Leptiminus (mais aussi d'Hadrumète). A ces origines différentes se mêlent évidemment des questions de chronologie et aussi

\footnotetext{
${ }^{125}$ Cette hypothèse m'a été suggérée par A. Tchernia.
} 
Typologie - Amphores

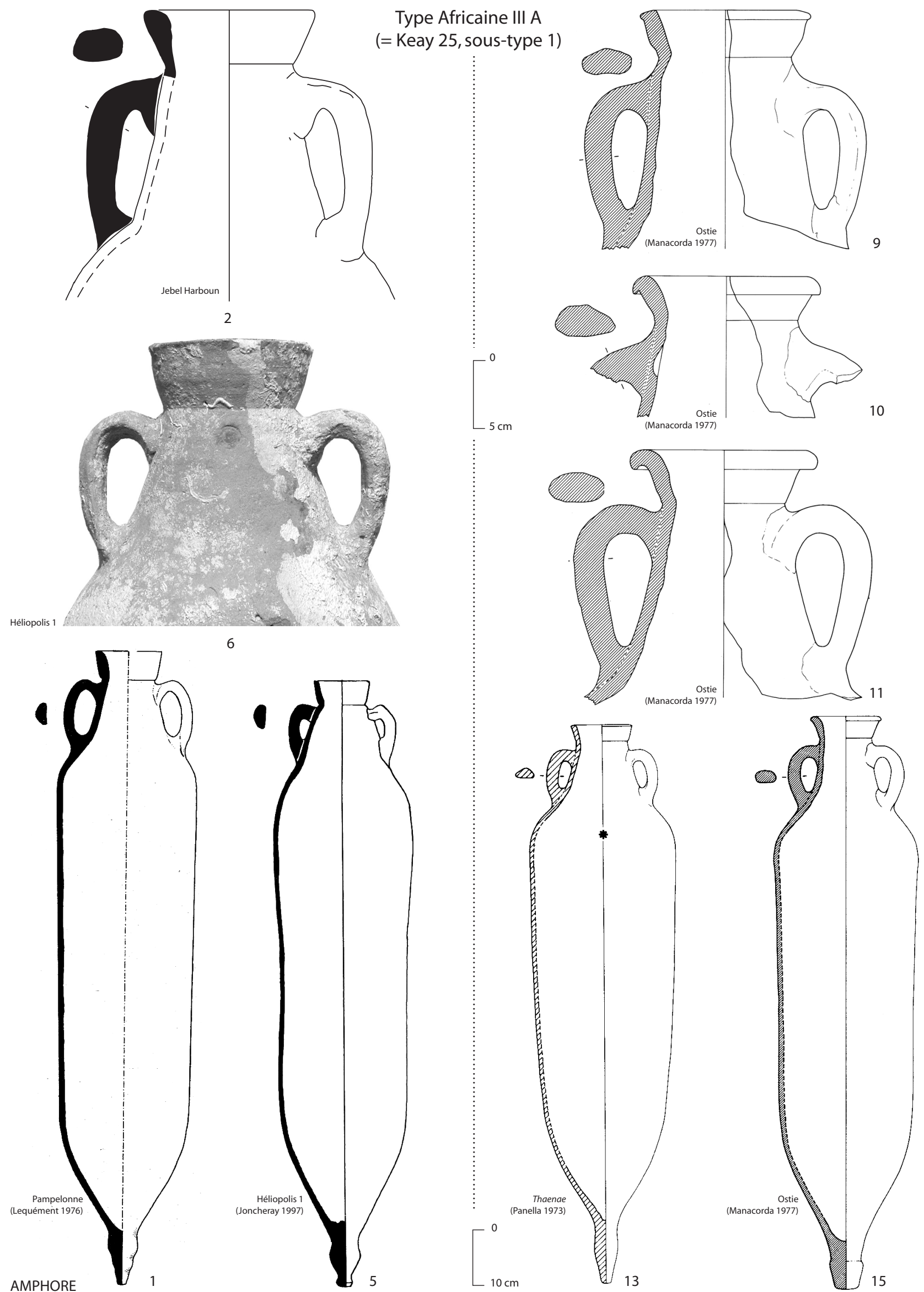

Fig. 63. Amphores africaines cylindriques de moyennes dimensions. 
d'influences morphologiques mutuelles qui compliquent encore notre compréhension de ce groupe d'amphores.

\section{- Amphores Africaines III}

Je propose de nommer «Amphores Africaines III » la série d'amphores de moyennes dimensions (H. : entre 100 et $110 \mathrm{~cm}$ env. ; D. : entre 25 et $28 \mathrm{~cm}$ en moyenne) qui prend la suite des amphores Africaines II.

Les amphores cylindriques de moyennes dimensions, mises en évidence pour la première fois par D. Manacorda (1977, 171-185 : « contenitori cilindrici della tarda età imperiale »), ont été classées sous le $n^{\circ} 25$ dans la typologie de Keay $(1984,184-212)$ qui distingue pas moins de vingt-neuf variantes (25 A à $25 \mathrm{Z4}$ ). Depuis 1984, la plupart des céramologues ont tenté d'appliquer cette classification très morcelée, sans tenir compte du fait que S. J. Keay regroupe ses variantes en sept soustypes et que les trois premiers suffisent à rassembler l'essentiel de sa documentation (variantes A à V).

C'est pourquoi, alors même que d'autres regroupements ont été par ailleurs proposés (Freed 1995), j’ai préféré pour ma part (Raynaud, Bonifay 1993 ; Bonifay, Pieri 1995, 95 ; Ben Lazreg et al. 1995, 126) m'en tenir aux trois grandes subdivisions de Keay, qui peuvent être mises en parallèle avec les classifications d'Ostie (Manacorda 1977, 171-179) et permettent de classer l'essentiel des amphores Africaines III.

\section{— Africaine III A (fig. 63)}

\section{AMPHORE TYPE 27}

La variante A (= Keay 25, sous-type $\mathbf{1}=$ variantes A-C) correspond aux variantes Ostia IV, 138-141, Ostia IV, 142-144 et Ostia IV, 146 (Manacorda 1977, 258, n 18, $19,21 ?)$.

Le bord est constitué d'un bandeau (H. : $4 \mathrm{~cm})$ presque vertical sur la variante Ostia IV, 138-141, plus évasé (jusqu'à $30^{\circ}$ ) sur les deux autres variantes d'Ostie, et son sommet est toujours marqué d'un léger gradin à l'extérieur (profil «a becco »). Le col est tronconique (H. : $15 \mathrm{~cm}$ de l'épaulement à la base du bord). Le corps est fuselé vers le bas et terminé par une pointe à renflement médian, très caractéristique. Les variantes précoces de Nabeul peuvent correspondre à la série $\mathrm{A} 1 \mathrm{du}$ type Keay 25 identifiée par J. Freed (1995, fig. 1, n 1 ; voir également Freed 1990, fig. 2).

Exemples (fig. 63) :

Variantes précoces

Ateliers de Nabeul (?)

*1 Epave de Pampelonne (Lequément 1976, fig. 4).

*2 Jebel Harboun (Ben Abed et al. 2000, fig. 7, n 1).

3 Nabeul, fabrique de salaisons, bassin XLVI (NB1455.1).

4 Nabeul, Sidi Aoun, atelier (supra, fig. 17, $\mathrm{n}^{\circ} 6$ ).

Ateliers de Salakta (?)

*5 Epave d'Heliopolis 1 (île du Levant, Hyères, France) (Joncheray 1997, 148, n 1).
*6 Idem (Inv. H1.9265). Timbre anépigraphe.

7 Salakta, ateliers, timbre anépigraphe (Peacock, Bejaoui, Ben Lazreg 1989, fig. 17, $\mathrm{n}^{\circ} 6$ ).

8 Oued el-Akarit, atelier (supra, fig. 14, $\mathrm{n}^{\circ} 5$ ).

Variantes classiques

*9 Ostia IV, 138.

*10 Ostia IV, 143.

*11 Ostia IV, 146.

12 Carthage (Panella 1982, fig. 20).

*13 Thaenae (Panella 1973, 630, $\mathrm{n}^{\circ} 31$ ).

14 Musée de Carthage (Freed 1995, fig. 1, n² 2).

*15 Ostie (Manacorda 1977, 116, n 5).

16 Leptiminus, ateliers (Peacock, Bejaoui, Ben Lazreg 1989, fig. 23, $\left.\mathrm{n}^{\circ} 7\right)$.

17 Salakta, ateliers (Peacock, Bejaoui, Ben Lazreg 1989, fig. $\left.18, n^{\circ} 3\right)$.

18 Thaenae, ateliers, zone B (supra, fig. 15, $\mathrm{n}^{\circ} 8$ ).

— Africaine III B (fig. 64)

\section{AMPHORE TYPE 28}

La variante B (= Keay 25, sous-type 3 = variantes K-V) correspond aux variantes Ostia IV, 149-153 et Ostia IV, 154-156 (Manacorda 1977, 258, nº 20 et 23).

Le bord est simplement épaissi et recourbé vers l'extérieur (parfois avec un profil « a becco ») : comme le souligne D. Manacorda $(1977,177)$, «l'embouchure n'a pas la forme en entonnoir qui caractérise la variante $\mathrm{A} »$. Le col est toujours tronconique mais plus allongé $(H$. : $20 \mathrm{~cm}$ de l'épaulement à la base du bord) que sur la variante $\mathrm{A}$. Le corps est relativement cylindrique et terminé par une pointe massive sans renflement médian. Exemples (fig. 64) :

*1 Ostia IV, 150.

*2 Ostia IV, 154.

*3 Ostie (Manacorda 1977, 116, $\mathrm{n}^{\circ} 2$ ).

*4 Pupput, tombe 495 (Bonifay 2004a, fig. 11, $\mathrm{n}^{\circ} 21$ ).

*5 Ostie (Manacorda 1977, 116, $\mathrm{n}^{\circ} 2$ ).

*6 Musée d'Antibes (Inv. 017). H. 111,5 cm ; D. 26,5 cm.

7 Carthage (Panella 1982, fig. 21).

*8 Nabeul, fabrique de salaisons, bassin XXXI (Inv. NB1186.82).

*9 Idem (Inv. NB1186.87).

*10 Littoral tunisien, site $\mathrm{n}^{\circ} 1$ (Henchir el-Medeina) (Bonifay et al. 2002-2003, fig. 13, $\mathrm{n}^{\circ} 165$ ).

\section{— Africaine III C (fig. 65)}

\section{AMPHORE TYPE 29}

La variante C (= Keay 25, sous-type $2=$ variantes E-I $)^{126}$ correspond à la variante Ostia IV, 147. (Manacorda 1977, 258, n²2).

A première vue, lorsqu'on ne dispose que d'un petit fragment, le bord de la variante $\mathrm{C}$ se distingue difficilement de celui de la variante A. Le bandeau est cependant beaucoup plus long $(4,5$ à $5 \mathrm{~cm})$ et il est surtout beaucoup plus évasé (jusqu'à $45^{\circ}$ ), formant une véritable collerette. L'examen des autres parties de la

\footnotetext{
${ }^{126}$ Je laisse volontairement de côté la variante $\mathrm{D}$, classée par Keay dans le sous-type 2, mais plus caractéristique, à mon sens, du sous-type 1 .
} 
Typologie - Amphores

Type Africaine III B

(= Keay 25 , sous-type 3 )
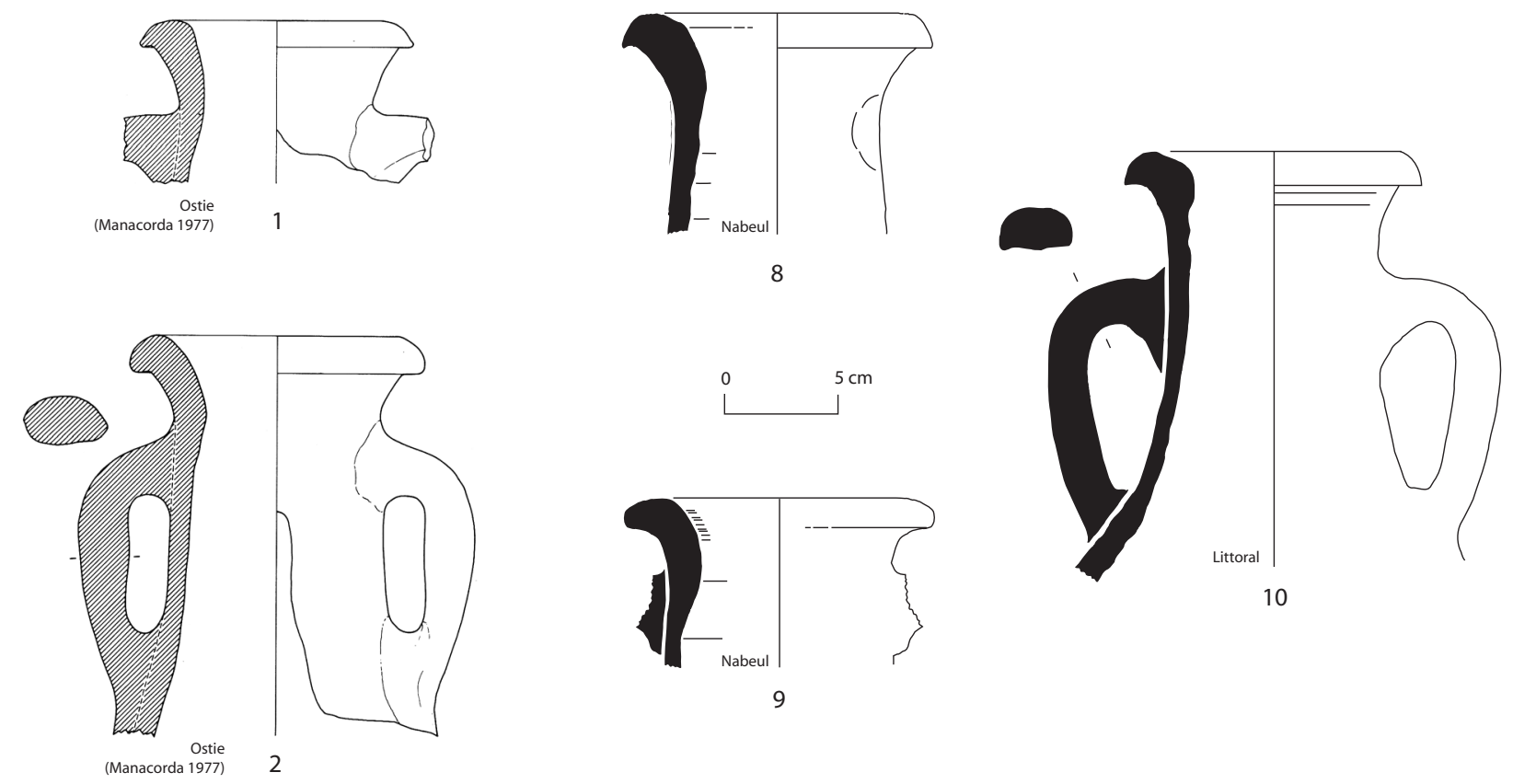

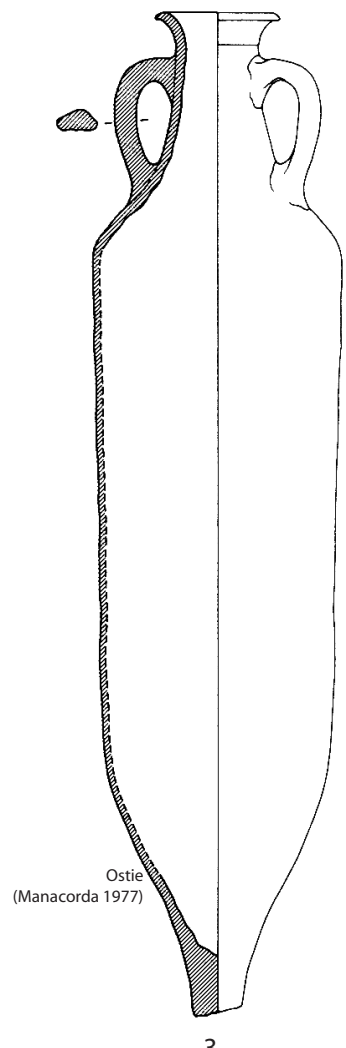

3

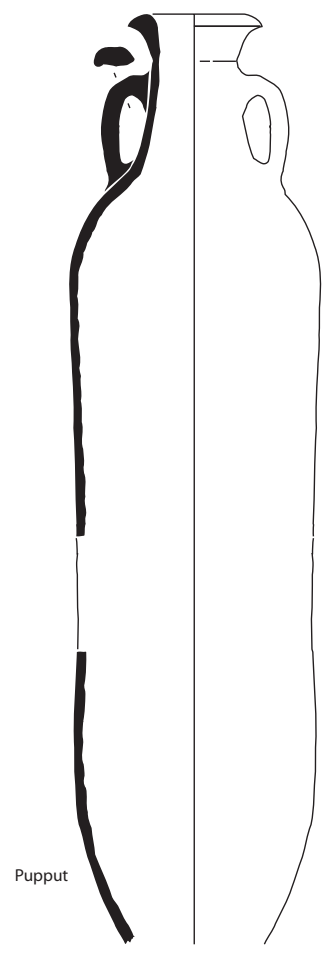

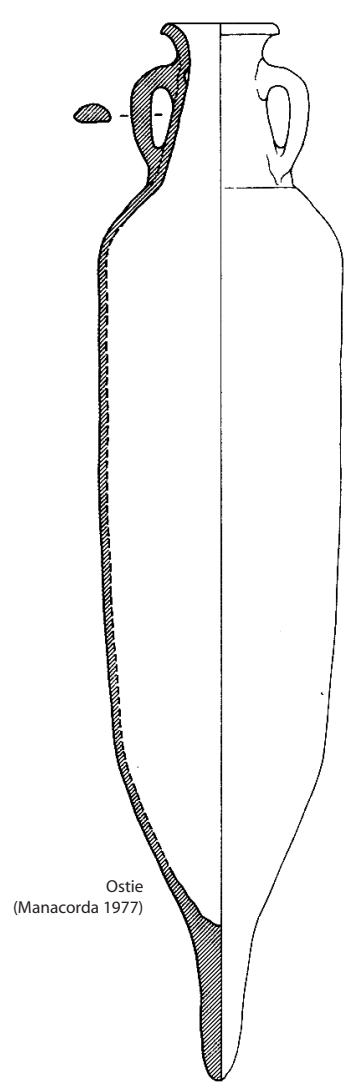

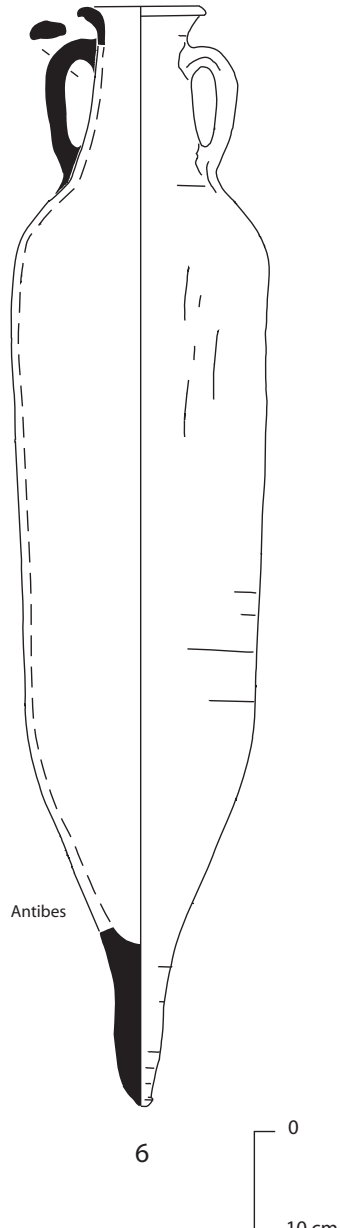

Fig. 64. Amphores africaines cylindriques de moyennes dimensions. 


$$
\begin{aligned}
& j=y \\
& \{1\}
\end{aligned}
$$


forme montre qu'il s'agit d'une tout autre amphore. En particulier, le col, quasiment cylindrique, est très allongé (H. : 22 à $25 \mathrm{~cm}$ de l'épaulement à la base du bord). Le corps, parfaitement cylindrique et étroit (D. : 20 à $25 \mathrm{~cm}$ ) est terminé par une longue pointe cylindrique $(\mathrm{H} . \mathrm{:} 18$ à $25 \mathrm{~cm}$; D. max. : $6 \mathrm{~cm}$ ) aplatie à la base.

Exemples (fig. 65) :

*1 Ostia IV, 147.

2 Tarragone (Remolà 2000, fig. 28, $\mathrm{n}^{\circ} 8$ ).

*3 Carthage (Freed 1995, fig. 1, $\mathrm{n}^{\circ} 3$ ).

*4 Musée de Nabeul (Inv. NBM A01).H. 965 mm.

*5 Giannutri (Celuzza, Rendini 1991, fig. 79).

*6 Dramont E (Joncheray 1975a, 106, $\mathrm{n}^{\circ}$ 2).

7 Carthage (Panella 1982, fig. 20).

*8 Dramont F (Joncheray 1975b, 106, $\mathrm{n}^{\circ} 1$ ).

*9 Marseille-Bourse, période 1 (Bonifay 1986 fig. 5, $\mathrm{n}^{\circ}$ 9).

10 Beni Khiar, Sidi Zahruni, atelier (supra, fig. 18, $\mathrm{n}^{\circ} 4$ ). Fond.

Cette typologie des amphores cylindriques de moyennes dimensions recoupe le schéma évolutif simplifié proposé par Cl. Panella $(1982,177)$ : «Le bord, par rapport au type Africaine II D, tend [sur la variante A] à s'évaser vers l'extérieur (selon divers angles formés avec le col) et [sur la variante $C$ ] à se replier sur lui-même, tout en restant distinct du col («orlo a corolla con labro a becco » : Ostia IV, 139-149) ou [sur la variante B] à se recourber, le bord allant en s'épaississant (Ostia IV, 150156) et perdant la distinction avec le col ». Mais elle ne permet pas de classer tous les exemplaires (se reporter aux fig. 23 et 24 de Keay 1984), laissant notamment de côté des amphores qui présentent des caractéristiques générales proches des amphore Africaines III mais qui ont été prudemment classées comme des variantes tardives du type Africaine II (types IIC3 et IID1 variante). Enfin, on peut se demander si la variante $\mathrm{C}$ doit réellement être rattachée à cette série ou bien déjà classée parmi les amphores plus tardives affiliées aux « spatheia » (infra, p. 125).

Ces distinctions typologiques ont une double signification chronologique et géographique. Du point de vue chronologique, il semble que l'on ne puisse pas faire remonter trop haut la date d'apparition de ces conteneurs. Leur absence sur l'épave Cabrera III (Bost et al. 1992), qui n'est pas antérieure à 265 , est probablement très significative. Les variantes précoces (TYPE 27, 1, 2, 5, 6), que ce soit les exemplaires produits en Byzacène méridionale (TYPE 27, 5-8) ou ceux fabriqués en Zeugitane (TYPE 27, 1-4), apparaissent dans des contextes de la fin du IIIe s. ou du début du IVe siècle. Je n'ai pas de nouveaux éléments sur la datation du type III A (Byzacène) mais, en revanche, la variante III B (région de Nabeul ?) est bien attestée dans la seconde moitié du IVe s. à Nabeul (TYPE 28, 8-9), ce qui confirme les hypothèses précédentes sur une datation générale au IVe s. (Panella 1982, 178). En Languedoc, les variantes A et B sont associées dans des contextes datés du IVe s. par des sigillées luisantes (Raynaud 1984, fig. 10, $\mathrm{n}^{\circ} 178$, 179,181 et fig. $\left.10, \mathrm{n}^{\circ} 182-183\right)$; elles sont encore bien présentes vers 400 à Arles (Piton 1998, fig. 4-5). Enfin, le type III C, originaire de la région de Nabeul (TYPE 29, 4, 6, 10) et de Byzacène (Henchir ech-Choggaf: Peacock, Bejaoui, Ben Lazreg 1990, 62, fig. 2, $n^{\circ} 12$ ) est la seule amphore cylindrique de moyenne dimension qui subsiste jusqu'au milieu du Ve siècle; elle est bien attestée à Arles au premier quart du Ves. (Congès, Leguilloux 1991, fig. 7, n 24, 26), à Rome (Whitehouse et al. 1982, fig. 10, $\mathrm{n}^{\circ} 131-132$ ) et à Tarragone (Remolà, Abello 1989, fig. 132, n 8.14) au deuxième quart du Ve s. ; les contextes du milieu du Ve s. à Marseille (TYPE 29, 9) n'en comptent que peu d'exemplaires (Bonifay, Pieri 1995, 95). Ce sont des amphores poissées, peut-être vinaires (infra, Tabl. IV).

Datation proposée :

Type III A, variantes précoces — fin du IIIe - début du IVe s.

Types III A et B - IVe s.

Type III C - fin du IVe s. (?) - première moitié du Ves.

\section{Amphores de Maurétanie Césarienne}

On sait maintenant que la province de Maurétanie Césarienne n'a pas produit seulement, comme on l'a cru longtemps, des imitations d'amphores gauloises, du type Dressel 30, mais qu'elle est aussi à l'origine de types cylindriques dans la tradition des autres productions africaines.

\section{- Type «station 48 de la place des Corporations » (fig. 66)}

\section{AMPHORE TYPE 30}

Si le timbre $M$-palmier- $C$, désignant avec vraisemblance la province de Mauretania Caesariensis et peut-être plus précisément la cité de Caesarea Mauretaniae (Ben Abed, Bonifay, Griesheimer 1999, 173-175) était connu de longue date (Cristofani, Zevi 1966), on ignorait encore il y a deux ans sur quel type d'amphore il était appliqué. La nécropole de Pupput a fourni trois exemplaires de cette amphore (1-3), qui ont permis de l'identifier à celle qui est représentée sur la mosaïque de la station 48 de la place des Corporations d'Ostie (supra, fig. 7).

Il s'agit d'un conteneur de grande taille (H. conservée : $92 \mathrm{~cm}$ ), avec un corps pansu (D. : $42 \mathrm{~cm}$ ), un épaulement marqué par une légère carène, un col court et étroit, et une embouchure constituée d'un cylindre rapporté de 6$7 \mathrm{~cm}$ de haut, terminé par une lèvre arrondie ; les anses en oreilles, de section ovale avec une simple nervure médiane, sont attachées à la jonction de l'embouchure et du col et reposent sur l'épaulement. La pointe, allongée, est dotée d'un renflement médian (3).

Exemples (fig. 66) :

*1 Pupput, tombe 403 (supra, fig. 4, n 23 ; Ben Abed, Bonifay, Griesheimer 1999, fig. 2).

Timbre $M$-palmier- $C$.

*2 Pupput, tombe 462 (Ibid., fig. 3 ; Ben Abed, Griesheimer 2004, fig. 103, T642.1). Non timbré. 
3 Pupput, tombe 919 (Inv. PP6036.4). Timbre $M$ palmier- $C$, usé.

4 Golfe de Fos, récupération en mer (Ben Abed, Bonifay, Griesheimer 1999, fig. 4).

Timbre $M$-palmier- $C$.

5 Epave Ouest-Embiez (Bernard, Bonifay 2003, 169). Timbre $M$-palmier- $C$.

6 Baelo Claudia-Tarifa, Espagne (Bernal Casasola 1997a, Pl. CXXXII, n² 273).

7 Ostia IV, 168 (Manacorda 1977, Pl. XXVI).

Le contexte de découverte des $n^{\circ} \mathbf{1}, \mathbf{2}$ et $\mathbf{3}$ indique une fourchette chronologique comprise entre la fin du IIe s. et le milieu du IIIe s., datation en accord avec celle des mosaïques de la place des Corporation (Ben Abed, Bonifay, Griesheimer 1999, 172 ; voir cependant la note 22). L'exemplaire d'Ostie (7), avec les anses courtes et attachées très près du bord, pourrait être plus tardif.

Le poissage du $n^{\circ} 4$ indique un contenu aqueux : vin ou salaisons de poissons.

Datation proposée: IIe s. - milieu du IIIe s., variantes tardives seconde moitié du IIIe s. (?).

Type "station 48 de la place des Corporations"
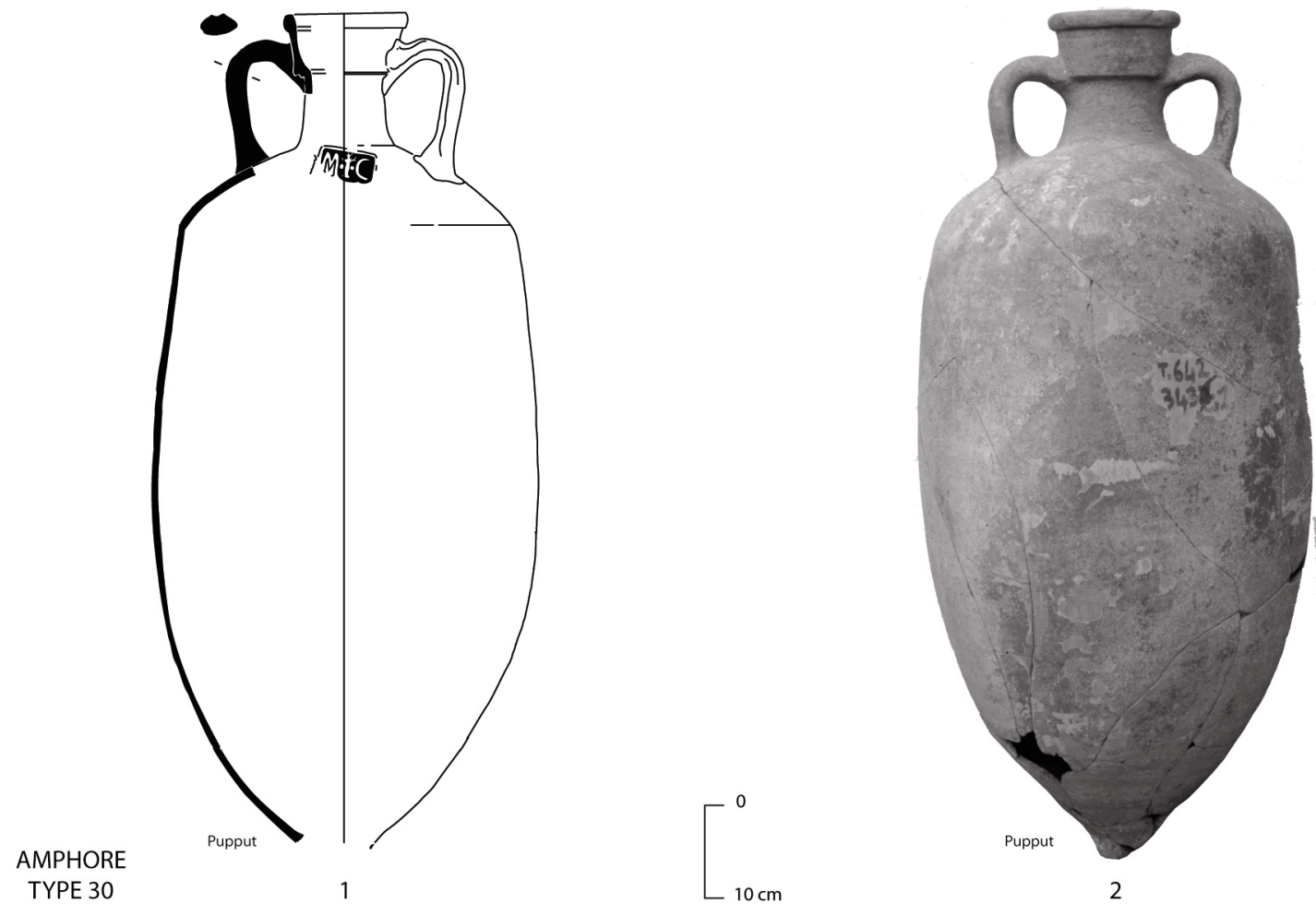

Fig. 66. Amphores cylindriques de Maurétanie Césarienne (?).

\section{- Variantes maurétaniennes d'amphores Africaines II}

Le même timbre (deuxième groupe : supra) a été mis en évidence sur une amphore apparentée au type Africaine II, découverte dans le golfe de Fos (Ben Abed, Bonifay, Griesheimer 1999, fig. 5); toutefois, l'emplacement du timbre, sur l'épaulement et non sur le col, est conforme à la pratique observée sur le type précédent. On peut donc imaginer qu'il s'agit d'un type imité par les potiers de Maurétanie Césarienne, sans doute en vue de la commercialisation d'un produit qui était le contenu habituel du modèle: là encore, ce n'est pas l'huile qui semble devoir être retenue mais plutôt les salaisons de poissons.

Exemple :

1 Golfe de Fos, récupération en mer (Ben Abed, Bonifay, Griesheimer 1999, fig. 5).

\section{- Variantes maurétaniennes d'amphores Africaines III (?)}

Il y a fort à parier que toutes les amphores Africaines III retrouvées en Méditerranée occidentale ne sont pas originaires de Tunisie. Je me demande notamment si les amphores de l'épave pointe de la Luque B, qui comprend aussi un chargement important de lampes des ateliers de la région de Tipasa-Cherchell (Bussière 2000, 148), ne seraient pas également originaires du littoral occidental de la Maurétanie Césarienne.

Exemples:

1 Epave pointe de la Luque B (Dovis-Vicente 2001, Pl. XVIII, $\left.\mathrm{n}^{\circ} 1736\right)(?)$.

2 Idem (Ibid., Pl. XXVIII, n 2080) (?).

3 Tipasa (Bouchenaki 1972, fig. 275) (?). 
Typologie - Amphores

"Spatheion" type 1
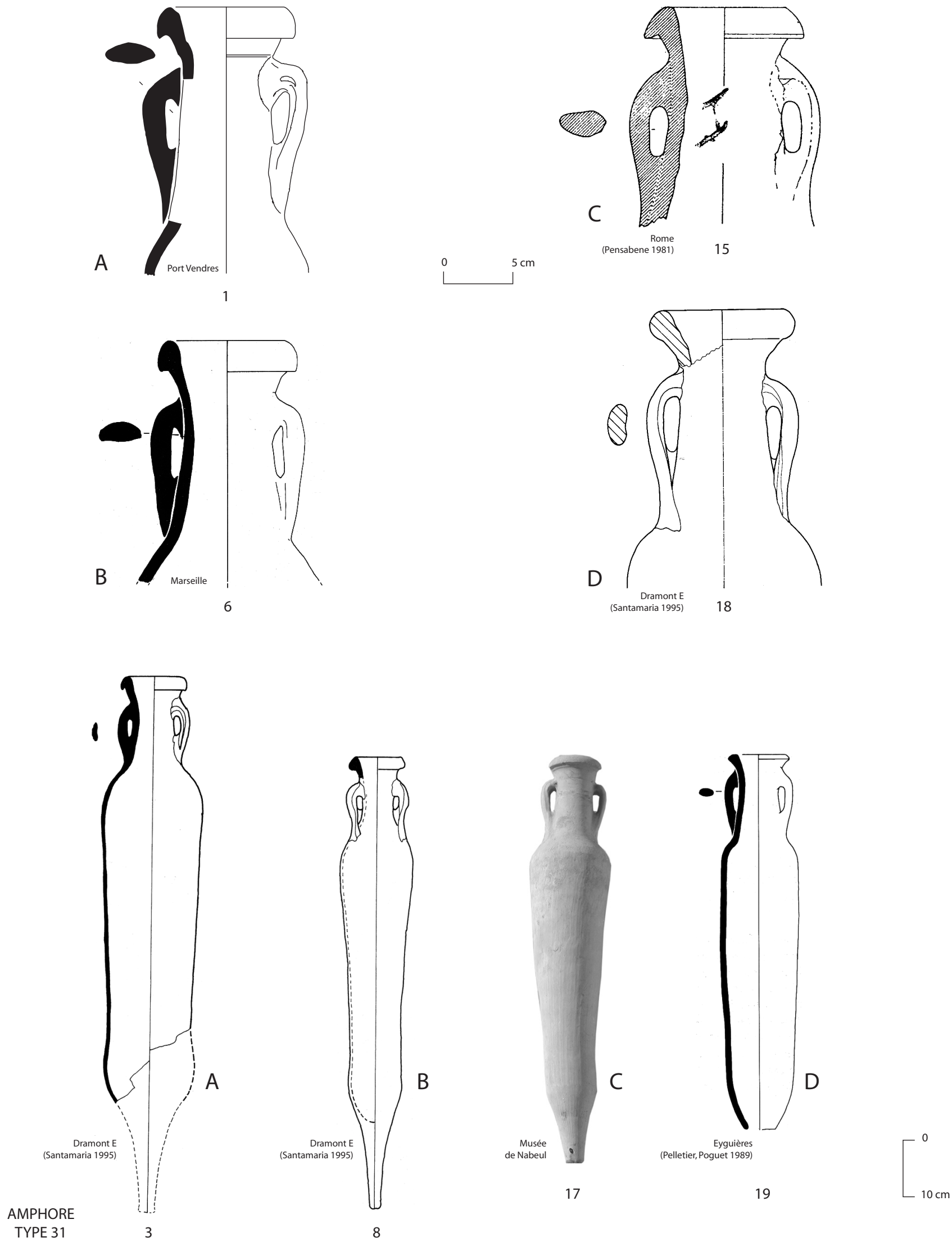

Fig. 67. Amphores africaines cylindriques de petites dimensions, dites "spatheia" 
La même question se pose à propos des amphores «africaines » cylindriques de moyennes dimensions provenant du comblement de la citerne du Sérapéum d'Alexandrie (Bonifay, Leffy 2002, 48-50), pour lesquelles il est difficile de trouver des comparaisons en Tunisie. Mais peut-être s'agit-il plutôt d'une imitation locale (infra, p. 459)?

La céramique africaine produite en Tunisie et dans une moindre mesure celle produite dans la partie libyenne de la Tripolitaine étant de mieux en mieux connues, il devient évident qu'un nombre important d'amphores provient d'Algérie, pays pour lequel, malheureusement, nous manquons actuellement d'informations (Bonifay à paraître, c).

\subsubsection{Amphores africaines tardives}

Les amphores africaines de l'Antiquité tardive, à partir du Ves., subissent une double tendance, inverse, dans la miniaturisation et le gigantisme des formes.

\section{Africaines cylindriques de petites dimensions}

Il s'agit du type Keay 26, dit « spatheion ».

La catégorie dite des «spatheia» pose à la fois un problème de vocabulaire et de définition. Pour ce qui concerne le vocabulaire, il paraît maintenant assuré que cette appellation retenue par Virginia Grace (1961, fig. 67) à partir d'un terme figurant sur des papyri égyptiens des IIe-IVe s. a été usurpée par les amphores africaines. Ce terme, comme l'a démontré Donald Bailey dans la publication du mobilier d'El-Ashmunein (Bailey 1998, 121), se rapporte plus vraisemblablement aux amphores bitronconiques égyptiennes, ce qui est particulièrement évident sur une figurine du musée d'Alexandrie (Bonifay, Leffy 1998, 48, note 42 ; Bonifay 2004c, fig. 4a). Il reste que cette appellation est bien pratique et qu'il faut continuer à l'utiliser, mais peut-être désormais avec des guillemets.

Pour la définition, on peut se demander si elle correspond bien à une catégorie autonome ou bien s'il ne s'agit pas plutôt, tout au moins à l'origine, de petits modules d'amphores Africaines III C (= type Keay 25.2), comme le montre, là encore, la cargaison du Dramont $\mathrm{E}$ (Joncheray 1975a, Pl. II). Cl. Panella, à propos de l'atelier d'el-Ariana, près de Carthage, mentionne que les deux types sont produits concomitamment (Panella 1982, 179). Nous pouvons faire la même remarque pour l'atelier de Sidi Zahruni, près de Nabeul, d'où semble originaire une majorité des amphores Africaines III $\mathrm{C}$ et des «spatheia » trouvés à Rome, Marseille ou Tarragone (Ghalia, Bonifay, Capelli 2004). La confusion vient peutêtre du fait que l'on désigne également sous ce nom de « spatheion " de très petites amphores $(\mathrm{H} .40-45 \mathrm{~cm}, \mathrm{D}$. $8 \mathrm{~cm}$ ) caractéristiques du VIIe s. : on peut se demander s'il y a une réelle filiation entre ces grands «spatheia» $\mathrm{du}$ Ve s. et les «spatheia» miniatures du VIIe s. (fig. 46). En effet, autant ces deux catégories connaissent une diffusion importante en Occident et en Orient, autant il est difficile de déceler des formes de transition.

Au risque de simplifier à l'excès, je proposerais de distinguer trois générations de «spatheia » :

\section{— « spatheion » 1 (fig. 67)}

\section{AMPHORE TYPE 31}

Sont généralement rangées parmi les «spatheia» de grande taille des amphores dont la hauteur varie entre 77 et $92 \mathrm{~cm}$, pour un diamètre de 13 à $18 \mathrm{~cm}$. Le bord peut former une collerette évasée comme sur le type Africaine III $\mathrm{C}$ mais plus fréquemment un simple bourrelet à lèvre légèrement tombante.

On peut dresser une liste non exhaustive des variantes les plus communes :

- Variante A : bord à collerette évasée comme sur le type Africaine III C, fréquent sur les exemplaires de grande taille;

- Variante B : bord à simple bourrelet à lèvre légèrement tombante ;

- Variante $\mathrm{C}$ : bord triangulaire à lèvre tombante ;

- Variante D : bord simplement épaissi, évasé.

Exemples (fig. 67) :

Variante A

*1 Port-Vendres, anse Gerbal (Inv. A46).

2 Arles, quartier de l'Esplanade (Congès, Leguilloux 1991, fig. $\left.7, \mathrm{n}^{\circ} 28\right)$.

*3 Dramont E (Santamaria 1995, Pl. VII).

Variante B

4 -*6 Marseille-Bourse (Bonifay 1986, fig. 4, $\mathrm{n}^{\circ}$ 2, 4, 6).

7 Classe (Maioli, Stoppioni 1989b, 573, $\mathrm{n}^{\circ} 12$ ).

*8 Dramont E (Santamaria 1995, Pl. VII, SPA 02/81).

9 Tarragone (Remolà 2000, fig. 31, n 3).

10 Musée de Sousse, récupération en mer (en exposition). H. conservée : $82 \mathrm{~cm}$.

11-13 Beni Khiar, atelier (supra, fig. 18, $\mathrm{n}^{\circ} 1-3$ ).

Variante $\mathrm{C}$

14 Marseille-Bourse (Bonifay 1986, fig. 4, n7).

*15 Rome (Pensabene 1981, fig. 8, ${ }^{\circ} 7$ ).

16 Dramont E (Santamaria 1995, Pl. VI, n 1$)$.

*17 Musée de Nabeul (Inv. NBM.A04).

Variante D

*18 Dramont E (Santamaria 1995, Pl. VI, n ${ }^{2}$ ).

*19 Eyguières (Pelletier, Poguet 1989, fig. 2, $\mathrm{n}^{\circ} 4$ et fig. 3).

Les attestations s'échelonnent du premier quart (2) au milieu du Ve s. (4-6, 14).

Datation proposée : première moitié et milieu du Ve s.

— « spatheion » 2 (fig. 68)

\section{AMPHORE TYPE 32}

Deux variantes :

- Variante A : Quelques amphores fuselées de petites dimensions (autour de $85 \mathrm{~cm}$ de hauteur pour seulement $13 \mathrm{~cm}$ de diamètre) apparaissent dans des contextes de la seconde moitié du Ves. ou de la 
Typologie - Amphores

"Spatheion" type 2
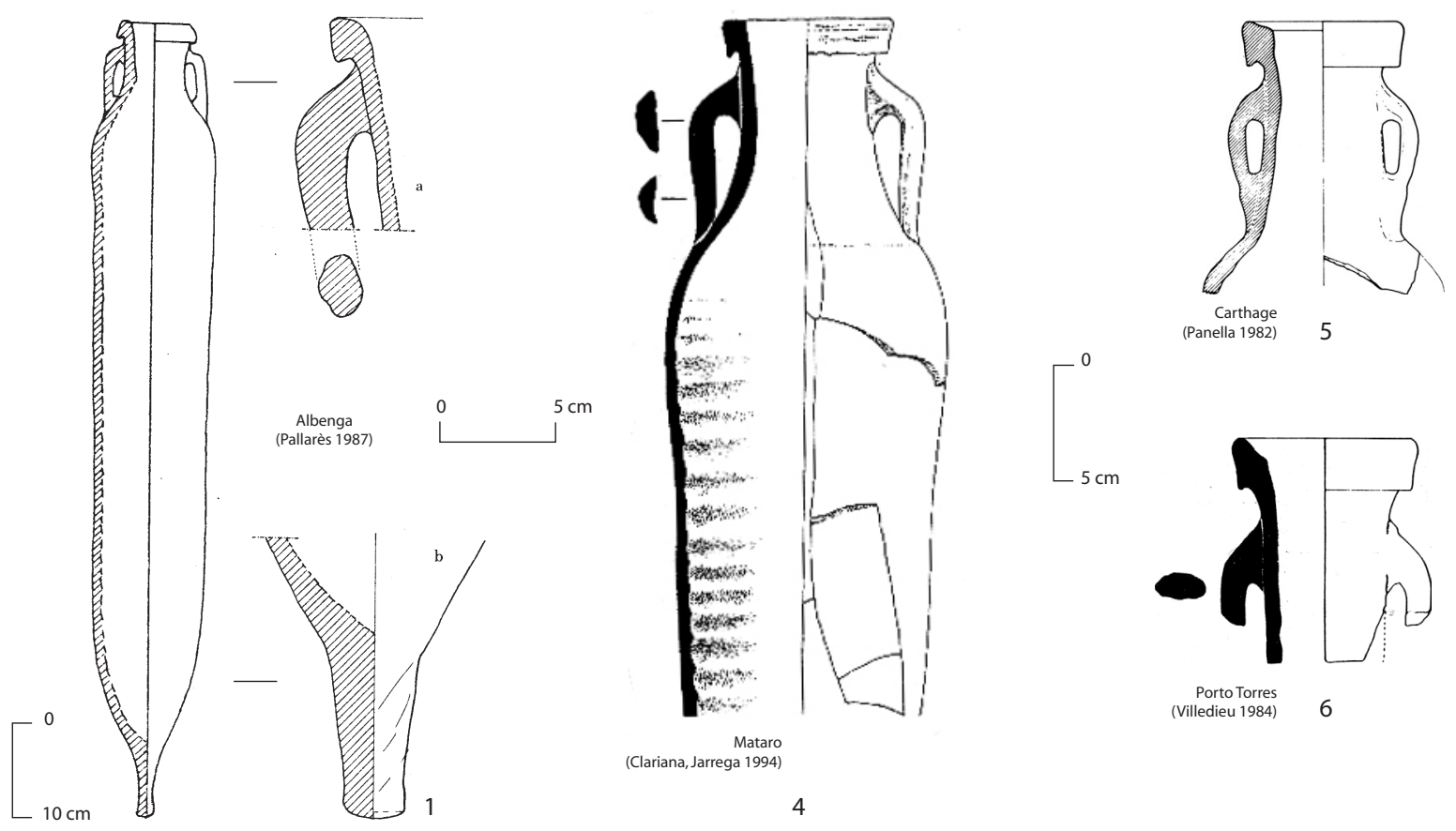

$\begin{array}{ll}\text { Porto Torres } & \\ \text { Villedieu 1984) } & 6\end{array}$

(Clariana

4

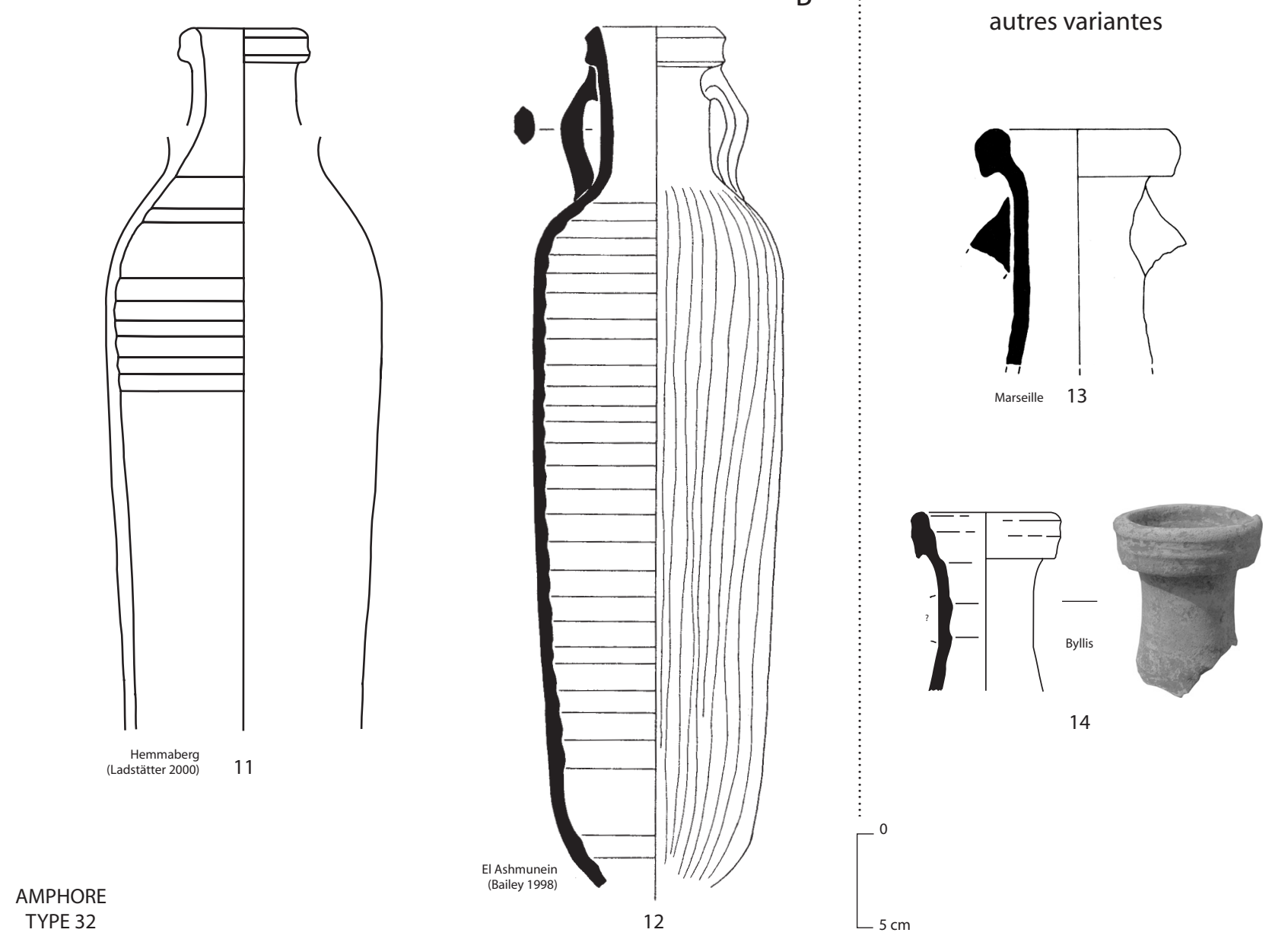

Fig. 68. Amphores africaines cylindriques de petites dimensions, dites "spatheia" 
première moitié du VIe siècle. Le bord prend une section nettement quadrangulaire que l'on ne lui connaissait pas dans les contextes plus anciens ; il en est ainsi des «spatheia » de la coupole du baptistère d'Albenga, datables de la seconde moitié du Ve s. (1: pour la datation, cf. Murialdo 1995, 435), et de ceux de Shkodra (8-10). Un exemplaire de Mataro (4) est associé à une amphore cylindrique de grande dimension Keay 62A et un autre de San Giovanni di Ruoti à une sigillée D Hayes 99 (Freed in Small, Buck 1994, fig. 83, $\mathrm{n}^{\circ} 121$ ).

- Variante B : D'autres « spatheia », plus trapus (H. env. 50-55 cm, D. $15 \mathrm{~cm})$, découverts au Hemmaberg (11) ou à El-Ashmunein (12), datés vraisemblablement plus avant dans le VIe s., annoncent peut-être les véritables «spatheia» miniatures.

Exemples (fig. 68) :

Variante A

*1-2 Albenga, coupole du baptistère (Pallarès 1987, fig. 2223). H. $860 \mathrm{~mm}$; D. $130 \mathrm{~mm}$.

3 Musée de Sienne (Manacorda 1977, Pl. LXXVII, $\mathrm{n}^{\circ}$ 573). H. env. $850 \mathrm{~mm}$; D. $135 \mathrm{~mm}$.

*4 Mataro (Clariana, Jarrega 1994, fig. 20, n 1 ).

*5 Carthage (Panella 1982, fig. 22).

*6 Porto-Torres (Villedieu 1984, n 284).

7 Toulouse (Catalo, Foy, Llech 1998, fig. 5, $\mathrm{n}^{\circ} 1$ ).

8-10 Shkodra (Hoxha 1992, Pl. VIII, n² 2-4).

Variante B

*11 Hemmaberg (Ladstätter 2000, Pl. 29).

*12 El-Ashmunein (Bailey 1998, Pl. 76).

Autres variantes

*13 Marseille, puits du Bon-Jésus (Bonifay, Pieri 1995, fig. 1, n $\left.{ }^{\circ} 4\right)$.

*14 Byllis (Albanie) (fouilles Sk. Mucaj, Inv. BYL94 IX.VII.Sh1.279).

Le $\mathrm{n}^{\circ} \mathbf{1 3}$, issu d'un contexte du troisième quart du Ve s. (?), paraît constituer une variante de transition entre le type 1 et le type 2 . La variante B est attestée dans les décennies centrales du VIe s. (Ladstätter 2003, 838). Enfin, le $\mathrm{n}^{\circ} \mathbf{1 4}$, daté de la fin du VIe s., annonce les «spatheia» du type 3. L'évolution dans le VIe s. n'est pas claire (Bonifay et al. 1998, 372).

Datation proposée :

Variante A - seconde moitié du Ve s.

Variante B - VIe s.

— « spatheion » 3 (fig. 69)

\section{AMPHORE TYPE 33}

Les « spatheia miniatures » (H. 40-44 cm ; D. 8-9 ou 12$13 \mathrm{~cm})$ comportent de nombreuses variantes. Les principales sont les suivantes :

\section{-Variante A}

Diamètre « large » $(12-13 \mathrm{~cm})$, bord quadrangulaire à deux nervures, avec l'attache supérieure des anses collée immédiatement sous la lèvre ; peut-être dans la suite de la série $2 \mathrm{~B}$.

Exemples (fig. 69) :

*1 Saint-Jean de Garguier (Féraud 1987, 182, n 1).
Dessin C. Richarté.

*2 Udine (Villa 1998, fig. 4).

2 Vranje (Knific 1979, fig. 159).

4 Kellia (Egloff 1977, P1. 58, n 3).

5 Musée de Carthage (en exposition, Inv. R6 $4^{\circ} 6$ ).

Variante tardive :

6 Epave Saint-Gervais 2 (Jézégou 1998, fig. 306, nº 7).

\section{- Variante B}

Bord effilé, déversé, à deux gradins.

Exemples (fig. 69) :

Avec anses :

*1 Yassi Ada (Bass, van Doorninck 1982, fig. 8.18).

2 Castel Trosino (Baldassare 1967, $\mathrm{n}^{\circ} 48$ ).

3 Murighiol (Opait 1997-98, $\mathrm{n}^{\circ} 42$ et 43).

4 Rome (Saguì 1998, fig. 7, D. $13 \mathrm{~cm}$ ).

Sans anses :

*5 Yassi Ada (Bass, van Doorninck 1982, fig. 8.18).

\section{- Variante C}

Bord en demi-lune.

Exemples (fig. 69) :

Avec anses :

*1 Saint-Etienne de Candau (Gagnière 1965, fig. 26).

2 Carthage (Peacock 1984b, fig. 42, $\mathrm{n}^{\circ} 103$ ).

3 Castel Trosino (Baldassare 1967, $\mathrm{n}^{\circ} 50$ ).

Sans anses :

*4 Murighiol (Opait 1997-98, $\mathrm{n}^{\circ}$ 44).

5 Ibligo-Invillino (Mackensen 1987, fig. 43, n 14).

*6-7 Nabeul (Inv. NB0001.9-10).

8 Raguse (Fallico 1967, fig. 12).

Exemplaire tardif :

9 Nabeul, fabrique de salaison, période 6 (Bonifay 2002, fig. $\left.6, n^{\circ} 44\right)$.

\section{- Variante D}

Bord à large bandeau vertical et mouluré, sans anses.

Exemples (fig. 69):

*1 San Giusto (Biffino et al. 1998, fig. 320).

*2 Sant'Antonino di Perti (Murialdo 2001, Pl. 14, n 152).

3 Ibligo-Invillino (Fingerlin et al. 1968, fig. 11, n 1 et $3)$.

4 Moknine, atelier (supra, fig. 16, $\mathrm{n}^{\circ} 2$; Bonifay 2004c, fig. 6).

Les éléments de datation sont encore trop peu nombreux pour permettre de nettes distinctions chronologiques. La variante A semble la plus ancienne : elle est présente dans la couche d'incendie datée du début du VIIe s. à Caričin Grad (Mackensen 1992, 251, note 79, fig. 3,3) et dans les contextes de la fin du VIe et du début du VIIe s. au Hemmaberg (Ladstätter 2003, fig. 6, n 3); c'est également la variante que l'on rencontre sporadiquement dans les contextes du faciès D de Marseille (Bonifay et al. 1998). Des exemplaires de plus petite taille semblent subsister dans la seconde moitié du VIIe s. (6). La variante B est présente sur l'épave de Yassi Ada $(\mathbf{1}, \mathbf{5})$ avec un terminus post quem vers 625 , mais mais elle est encore associée à la variante $\mathrm{C}$ dans les niveaux de la fin du VIIe s. à la Crypta Balbi (4). Les exemplaires de la variante $\mathrm{C}$ à Nabeul sont également de la fin du VIIe s. (6-7); l'un d'eux pourrait même être post byzantin (9). 


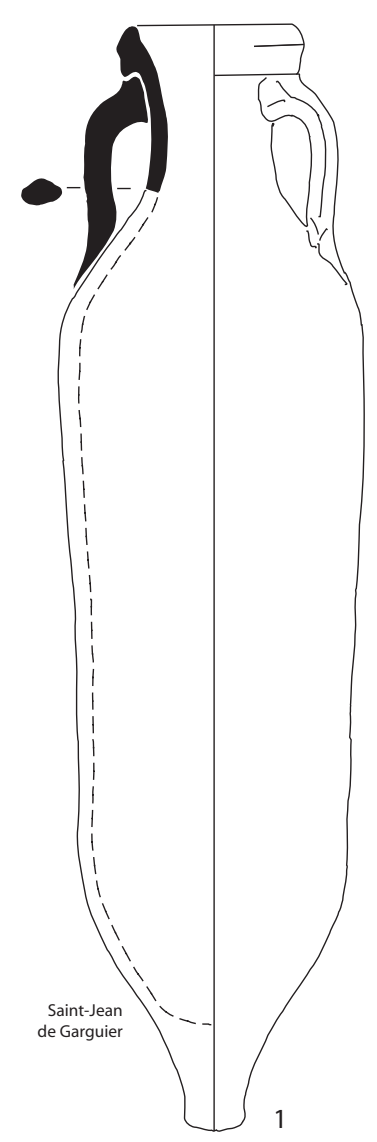

A

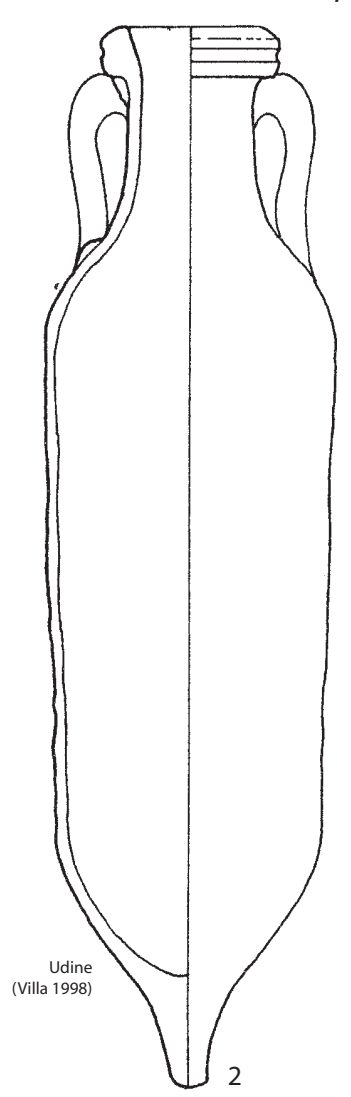

C

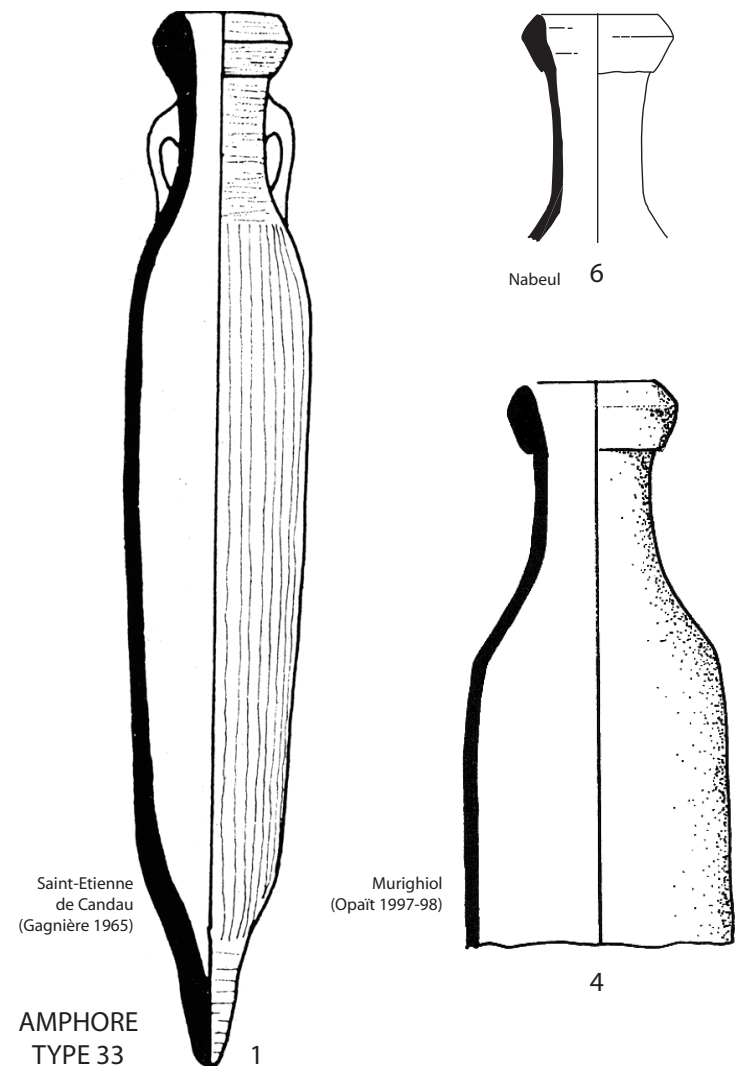

"Spatheion" type 3

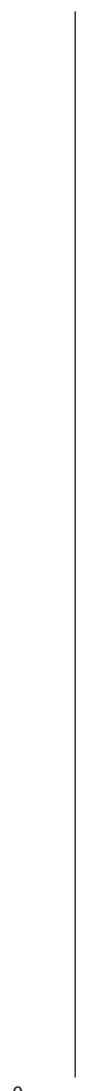

0

$5 \mathrm{~cm}$
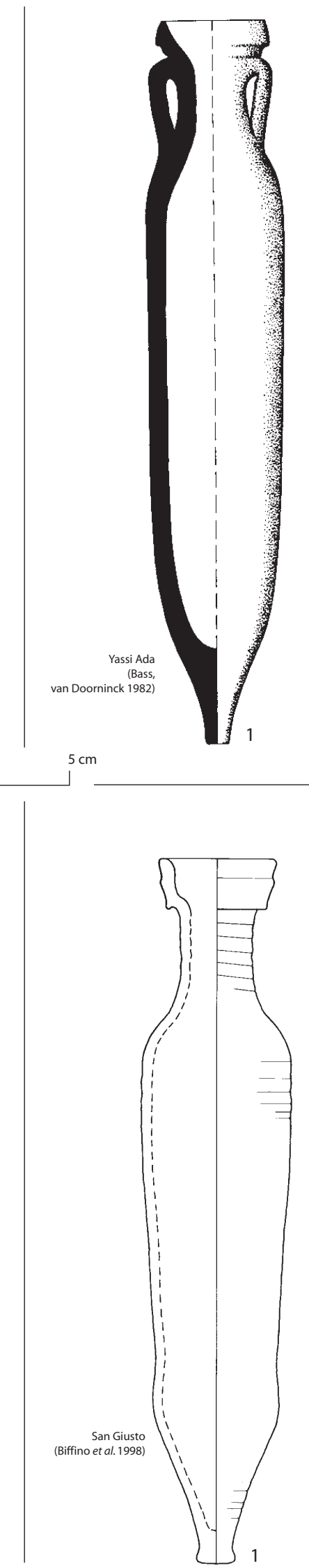

B

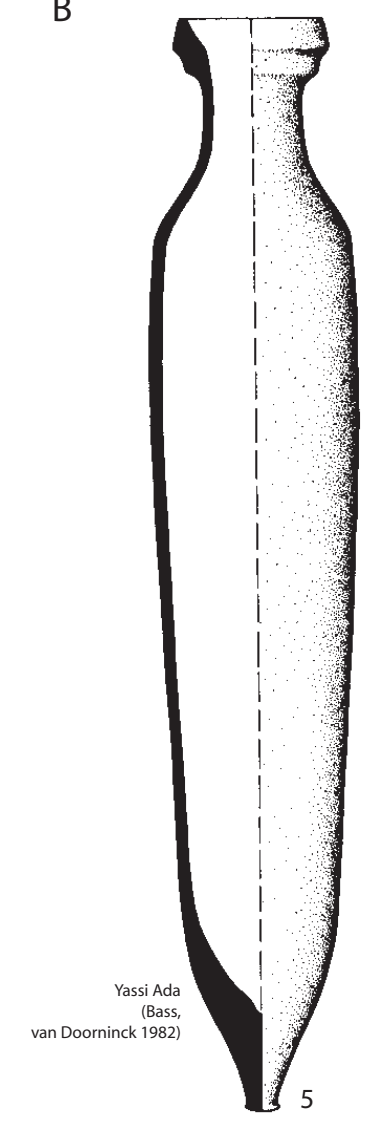

D

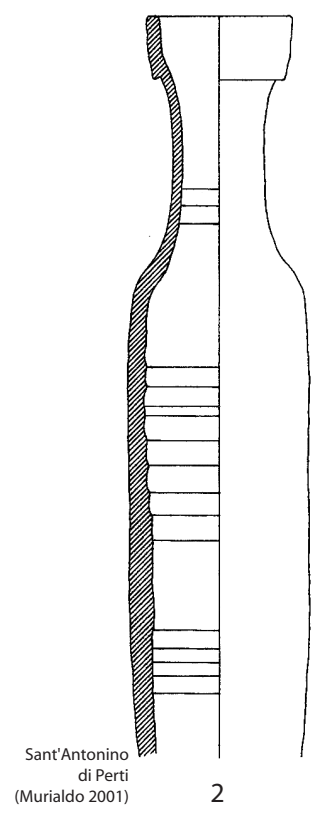

Fig. 69. Amphores africaines cylindriques de petites dimensions, dites "spatheia". 
Peut-être l'absence de ces amphores dans le cimetière de Nocera Umbra et, en revanche, leur présence dans celui de Castel Trosino (3), réputé plus tardif, est-elle significative. Les exemplaires connus de la variante D sont datés du VIIe s. (1-3).

Nous avons énormément progressé ces dernières années dans la mesure où il apparaît désormais évident que la plupart des «spatheia » miniatures diffusés dans toute la Méditerranée, pour certains desquels on suspectait une origine orientale (Mackensen 1992, 250) sont bien africains, même lorsqu'ils n'ont pas d'anses (bien que cette caractéristique soit à accueillir avec prudence : j'ai vu des anses se détacher de «spatheia» du type C sans laisser de traces d'arrachement), et même lorsque leur pâte est blanche (cf. déjà : Arthur 1989, 82, note 1). La pâte claire de ces exemplaires tardifs n'est pas un argument pour une origine non africaine. Les analyses pétrographiques de Claudio Capelli sur le matériel de la Crypta Balbi et de Sant'Antonino di Perti l'avaient bien montré (Capelli in Saguì 1998, 331 ; Capelli 2001), mais les données de terrain le confirment aujourd'hui pleinement. Un atelier situé à Nabeul, à l'intérieur même de la ville, dans des quartiers qui se ruinent progressivement dès la seconde moitié du Ves. pour laisser place à des activités artisanales, chaufourniers et potiers, produisait, comme le montrent les déchets de cuisson (supra, fig. 19, $\mathrm{n}^{\circ} 1$; Bonifay 2004c, fig. 6a) la variante $\mathrm{C}$ des «spatheia» de petite taille. Un atelier de Moknine, fouillé il y a quelques années par Nejib Ben Lazreg (supra, p. 35), produisait peut-être la variante D (4).

On ignore quel était précisément le contenu des « spatheia» et s'il fut identique au Ve et au VIIe siècle. Ce qui est certain, c'est qu'il faut exclure l'huile car ces conteneurs sont toujours poissés (lorsqu'il est possible de réaliser cette observation). Des noyaux d'olives retrouvés dans certains «spatheia» du Dramont E font pencher plutôt pour une production agricole que pour le garum, bien que des restes de poissons aient été découverts dans un fragment de Tarragone (Morales Muñiz 1989). L'hypothèse la plus vraisemblable, compte tenu de l'ample diffusion de ces amphores, est qu'il s'agisse d'amphores principalement vinaires (infra, Tabl. IV).

\section{Datation proposée :}

Variante A - fin du VIe s. - première moitié du VIIe s. ; exemplaires tardifs seconde moitié du VIIe s.

Variante B et D - VIIe s.

Variante $\mathrm{C}$ - seconde moitié du VIIe s. $(+)$

\section{Africaines cylindriques de grandes dimensions}

Ces amphores constituent un ensemble très hétérogène. Il est impossible de les passer toutes en revue, mais je voudrais simplement proposer quelques regroupements typologiques en vue de préciser la chronologie et l'origine de celles que j'ai eu l'occasion d'étudier.

\section{- type Keay 3B similis/Keay 39 (fig. 70)}

\section{AMPHORE TYPE 34}

Il semble que S. J. Keay ait hésité sur le classement de ces amphores, les rattachant d'une part au type Africaine I en raison de la forme du bord, et les rapprochant aussi de son type 39. Il s'agit incontestablement d'une amphore de grandes dimensions (H. : $100 \mathrm{~cm}$; D. : $43 \mathrm{~cm}$ ) comme le montre l'exemplaire complet découvert par la mission japonaise à Tarquinia (3).

- Variante A : type Keay 3B similis

- Variante B : type Keay 39

Exemples (fig. 70) :

Variante A

1 Tarragone (Remolà, Abello 1989, fig. 131).

*2 Tarragone (Keay 1984, fig. 39, n 4).

*3 Tarquinia (Aoyagi 1994, fig. 21).

4 Le Marduel, Saint-Bonnet-du-Gard (Py, Raynaud 1982, fig. 26, n²6).

5-8 Port-Vendres, épave de l'anse Gerbal (Inv. PV1 A1-2, 5-6).

9 Hergla, fouilles anciennes (Inv. HS 60).

Variante B

10 Tarragone (Keay 1984, fig. 107, $\mathrm{n}^{\circ} 2$ ).

*11 Port-Vendres, épave de l'anse Gerbal (Inv. PV1 A11).

Variante indéterminée

*12 Port-Vendres, épave de l'anse Gerbal (Inv. PV1 A14). Fond.

Les $\mathrm{n}^{\circ} \mathbf{3}$ et $\mathbf{4}$ proviennent de contextes de la première moitié du Ve siècle. C'est bien la datation qui ressort des contextes où ces amphores, Keay 3B « similis » et Keay 39 sont fréquentes : à Tarragone $(\mathbf{1 - 2}, \mathbf{1 0})$ et à PortVendres (5-8, 11-12). Leur diffusion essentiellement occidentale (cette amphore est rare à Marseille et en Italie, mis à part l'exemplaire de Tarquinia), ainsi que l'aspect particulier de leur pâte, à matrice argileuse très pure, me fait pencher pour une origine africaine (?) assez occidentale: l'extrémité ouest de la Zeugitane, la Numidie ou la Sitifienne. Mais il ne s'agit, bien évidemment que d'une intuition. L'absence de poix sur le matériel sous-marin de Port-Vendres peut indiquer qu'il s'agit d'un conteneur à huile (?).

Datation proposée : fin IVe s. - première moitié Ve s.

- type Keay 27 et Keay 36 (fig. 70-71)

AMPHORES TYPES 35 ET 36

Ces deux amphores doivent être associées (Keay 1984, 240 ; contra : Remolà 2000, 130 , note 215 ) en raison de caractères morphologiques communs (anses immédiatement sous le bord) et de leur qualité de pâte, souvent 
Types Keay 3B "similis"/Keay 39
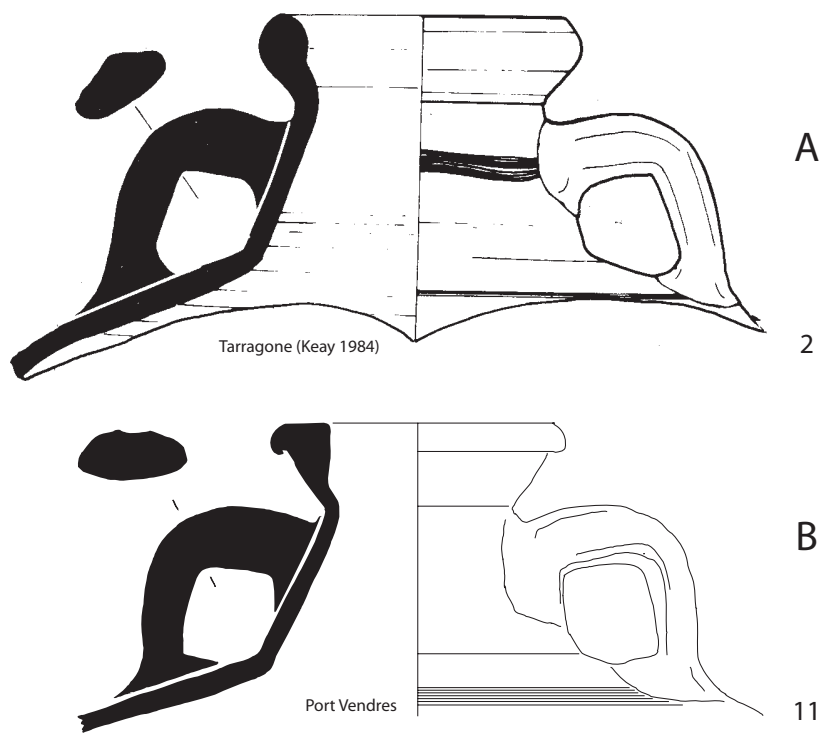

$B$

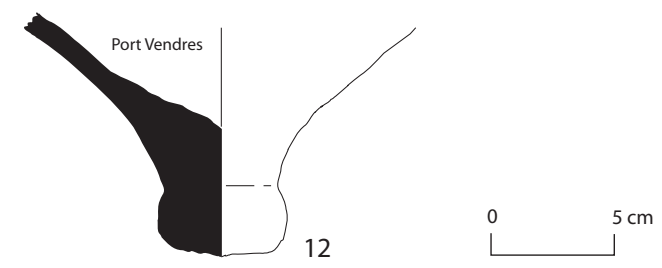

AMPHORE

12

$5 \mathrm{~cm}$

Type Keay 27
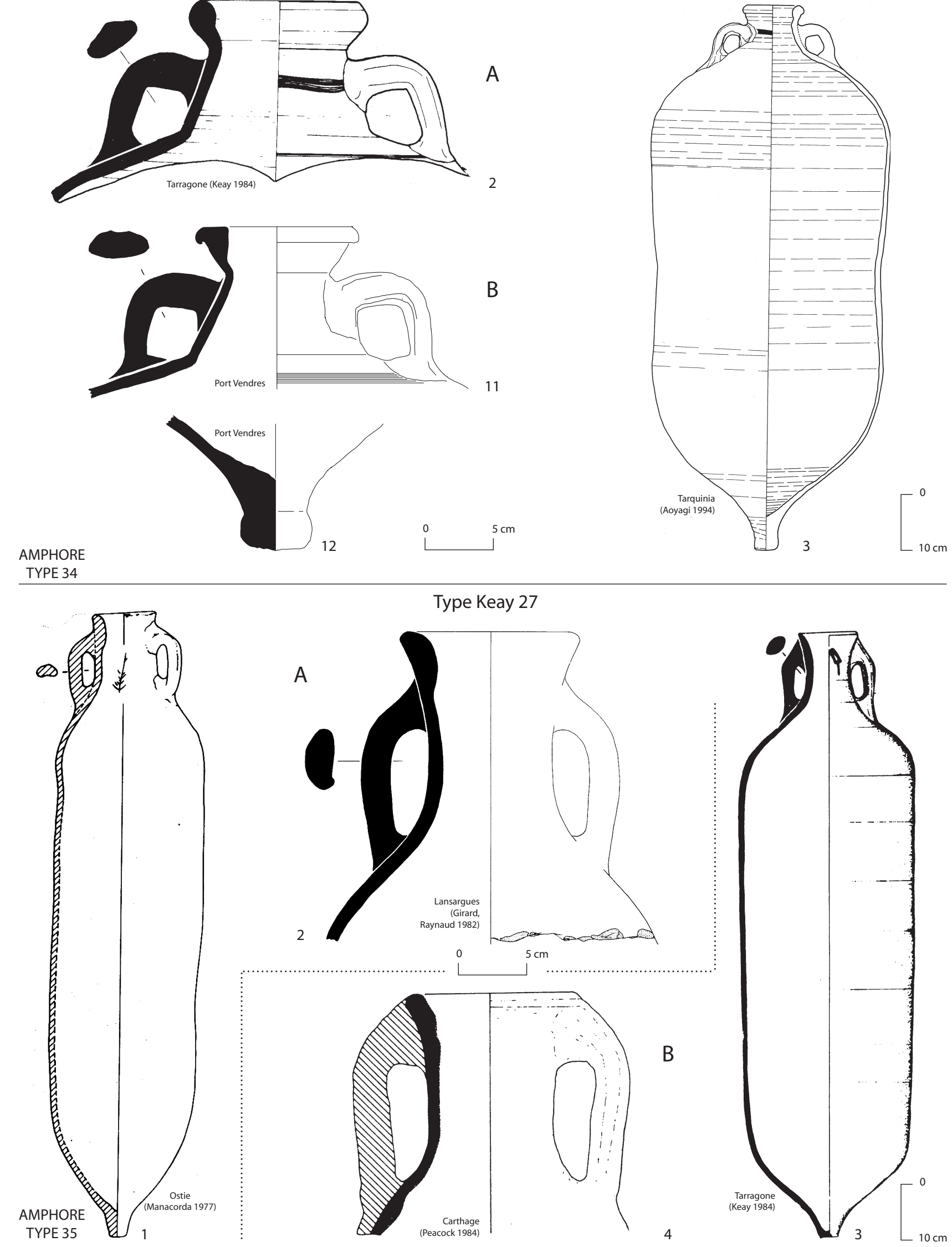

Fig. 70. Amphores africaines cylindriques de grandes dimensions. 
Typologie - Amphores
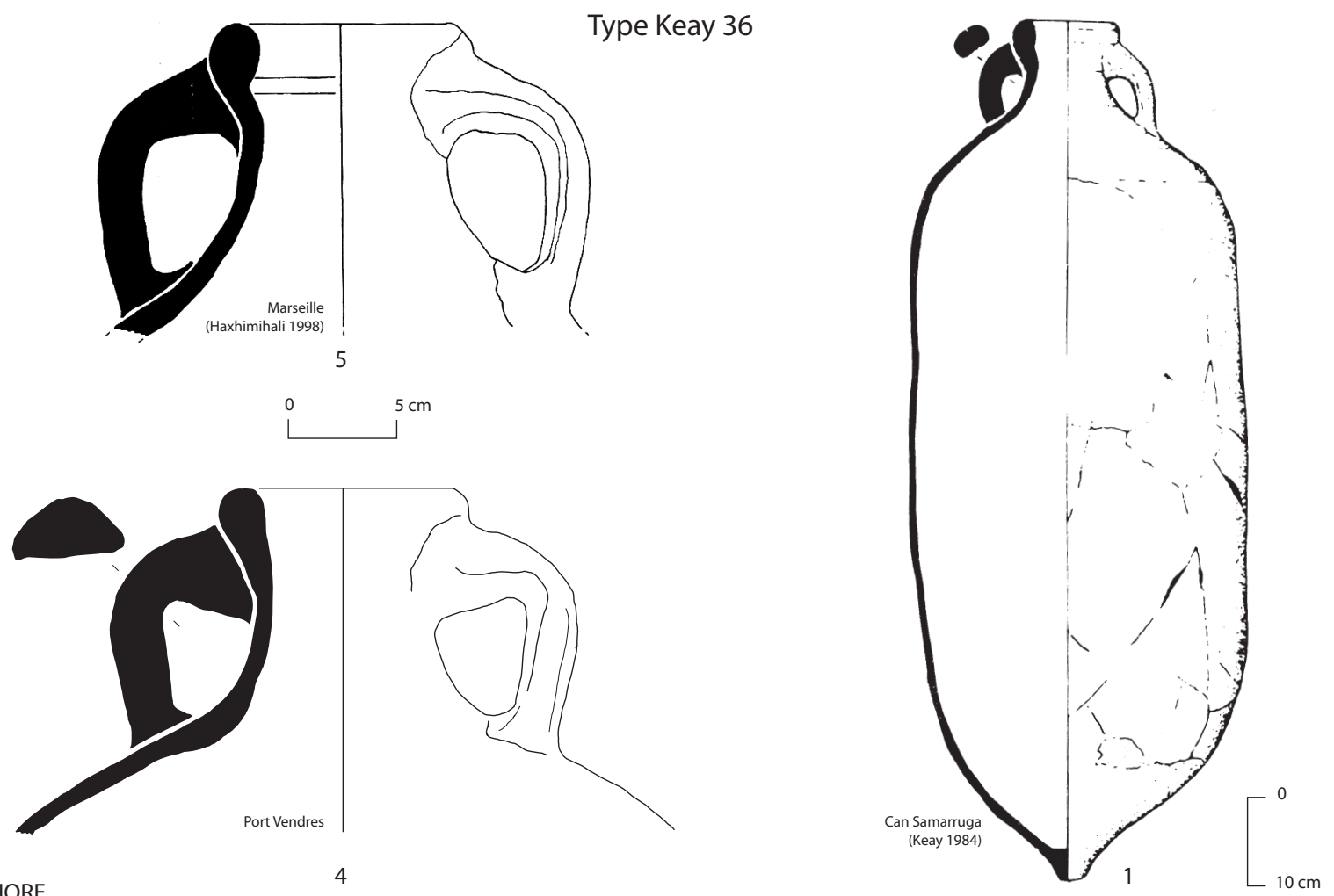

Type Keay 59

Type Keay 8B
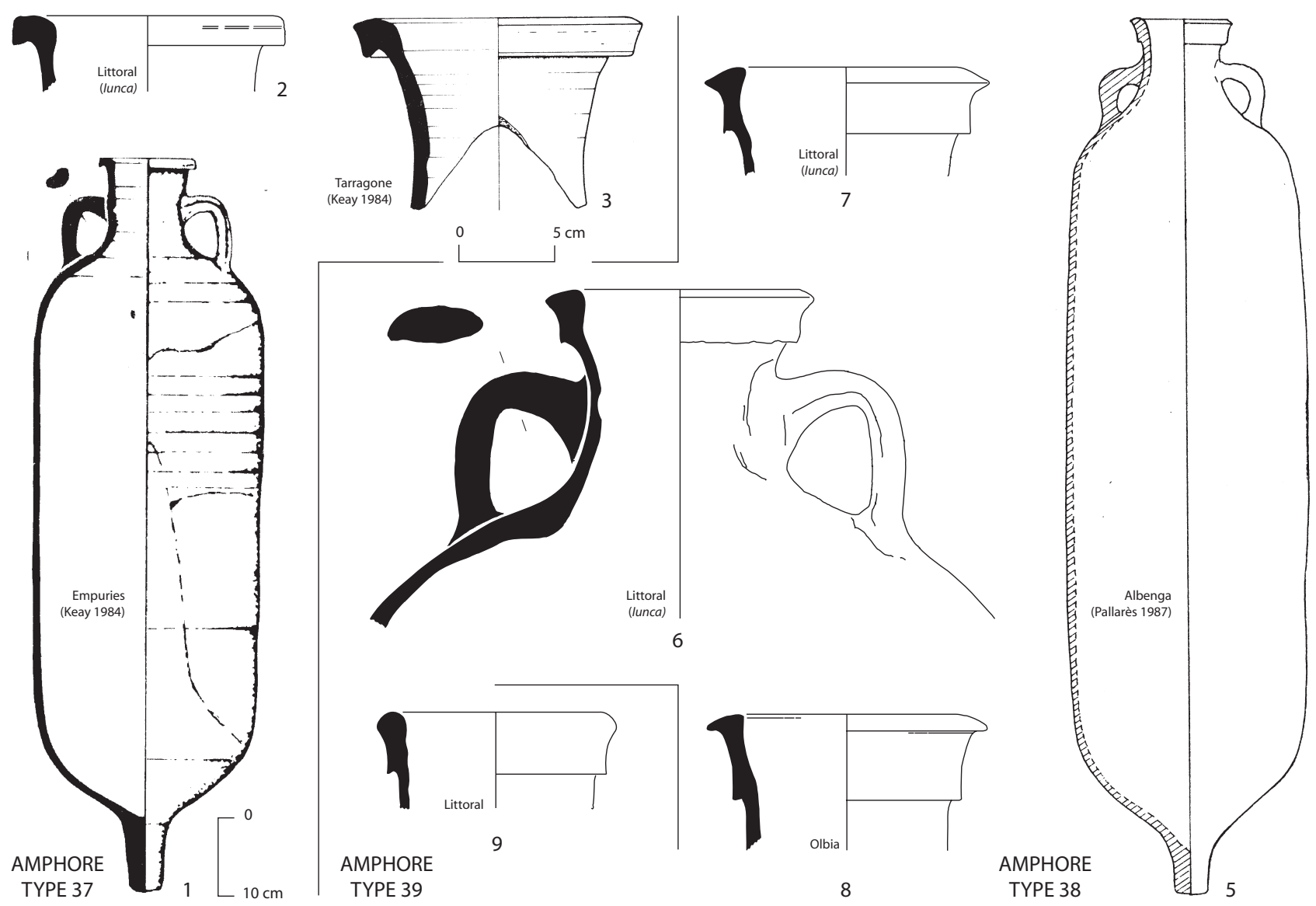

Fig. 71. Amphores africaines cylindriques de grandes dimensions. 
(mais pas toujours) à matrice argileuse pure, en tout cas bien différente des pâtes que l'on rencontre sur la côte orientale de la Tunisie.

- Type Keay 27 (AMPHORE TYPE 35): amphore cylindrique très allongée $(\mathrm{H}$. : 110 ou $120 \mathrm{~cm}$; D. : $30 / 32 \mathrm{~cm})$, terminée par une courte pointe aplatie ; long col cylindrique sans lèvre, anses en poignées. Deux variantes :

- Variante A : bord droit ou évasé à renflement interne, anses basses.

- Variante B : bord évasé, anses hautes.

- Type Keay 36 (AMPHORE TYPE 36): amphore cylindrique plus pansue (H. : 100 ou 110 ? cm ; D. : $38 / 40 \mathrm{~cm})$, terminée par une courte pointe aplatie ; col plus court, évasé, bord en bourrelet; anses massives.

\section{Exemples:}

Type Keay 27 (fig. 70)

Variante A

*1 Ostie (Manacorda 1977, 116).

*2 Lansargues (Girard, Raynaud 1982, fig. 5, n³2).

Variante B

*3 Tarragone (Keay 1984, fig. 26, $n^{\circ} 3$ ).

*4 Carthage (Peacock 1984b, fig. 39).

5-6 Marseille-Bourse (Bonifay 1986, fig. 6, $\mathrm{n}^{\circ}$ 17-18).

Type Keay 36 (fig. 71)

*1 Can Samarruga (Keay 1984, fig. 29, n 3).

2 Arles, quartier de l'Esplanade (Congès, Leguilloux 1991, fig. $7, \mathrm{n}^{\circ} 29$ ).

3 Marseille, chantier de La Bourse (Bonifay 1986, fig. 6, $\left.\mathrm{n}^{\circ} 15\right)$.

*4 Port-Vendres, anse Gerbal (Inv. PV1A52).

*5 Marseille, chantier de La Bourse (Haxhimihali 1998, fig. 134, $\mathrm{n}^{\circ} 223$ ).

6 Alexandrie, chantier du théâtre Diana (Bonifay, Leffy 2002 , fig. $\left.6, n^{\circ} 54\right)$

Là encore, à mon avis, l'origine de ces amphores est à rechercher soit dans l'intérieur des terres, soit sur la côte, mais alors à l'ouest de Carthage (supra, p. 22). Bien que des exemplaires de type Keay 36 aient été découverts à Alexandrie (6) et même en Nubie (à Firka : Kirwan 1939, Pl. XXII, $\left.\mathrm{n}^{\circ} 1 \mathrm{a}\right)$, elles sont plus largement diffusées en Méditerranée occidentale, principalement durant les deux premiers tiers du Ve siècle. Une variante précoce du type 27 (variante A : Raynaud, Bonifay 1993, 18), avec les anses placées plus bas sur le col (1), est déjà présente au IVe s. à Ostie (1) et à Lansargues (2), tandis que la variante $\mathrm{B}$ est caractéristique des décennies centrales du Ve s. (4). Le type Keay 36 est encore présent dans la seconde moitié du Ves. (5) (Bonifay et al. 1998, 372). On hésite sur la nature du contenu, certains exemplaires étant poissés, d'autres non (infra, Tabl. IV).

Datation proposée :

Type Keay 27A - seconde moitié du IVe s.

Type Keay 27B - première moitié du Ve s.

Type Keay 36 - Ve s.

\section{- type Keay 59 et Keay 8B (fig. 71)}

AMPHORES TYPES 37 - 38 - 39

Il convient aussi d'associer ces deux types en raison de la morphologie du bord, creusé d'une gorge sur la face extérieure, des anses, plates et coudées, du fond, cylindrique et plein. Il s'agit en fait des deux états principaux de l'évolution d'un même type, apparenté aux amphores tripolitaines (?) (Bonifay 2004c), mais j'ai eu l'occasion de voir en Tunisie et à Marseille de nombreuses variantes intermédiaires ou plus tardives. La pâte est très caractéristique, rose, compacte, très fine (Pl. I, $\mathrm{n}^{\circ} 6-7$; elle comporte un grand nombre de microfossiles dans le dégraissant (observation due à Cl. Capelli) ; la surface extérieure est généralement beige.

\section{Exemples (fig. 71):}

Type Keay 59 [TYPE 37] :

*1 Empúries(Keay 1984, fig. 34, n 6).

*2 Iunca (Bonifay et al. 2002-2003, fig. 12, $\mathrm{n}^{\circ} 158$ ).

*3 Tarragone (Keay 1984, fig. 130, $\mathrm{n}^{\circ} 2$ ).

4 Arles (Congès, Leguilloux 1991, fig. 7, n 30).

Type Keay 8B [TYPE 38] :

*5 Albenga (Pallarès 1987, fig. 17).

*6-*7 Iunca (Bonifay et al. 2002-2003, fig. 12, n 154-155).

*8 Olbia de Provence (Inv. 97.1055.1295-6).

Autres variantes [TYPE 39] :

*9 Littoral tunisien, site 73 (Henchir el-Flouss) (Bonifay et al. 2002-2003, fig. 12, $\left.\mathrm{n}^{\circ} 157\right)$.

10 Marseille, puits du cap Titol (Pieri 1998c, fig. 220, $\left.\mathrm{n}^{\circ} 70\right)$.

Ces amphores, très abondantes à Carthage (dans un contexte de la fin du Ve ou du début du VIe s. récemment fouillé par Mlle Jihen Nacef au pied des absides de Beulé, inédit ; voir également Peacock 1984b, fig. 41, n 90-91), bien diffusées en Méditerranée occidentale, quoique toujours en petite quantité (par exemple à Marseille : Pieri 1998b, fig. 198, $\mathrm{n}^{\circ}$ 280-282; à Nîmes: Manniez 1993, fig. 147, $\mathrm{n}^{\circ} 83$ ), sont relativement bien attestées par rapport aux autres types africains en Méditerranée orientale (par ex. à Apollonia de Cyrénaïque, Mission Archéologique Française, inédit; à Alexandrie : Bonifay, Leffy 2002, fig. 6, $\mathrm{n}^{\circ}$ 51-53; à El Ashmunein : Bailey 1998, Pl. 76, T8, interprété comme africaine I; à Istanbul : Hayes 1992, fig. 22, $\mathrm{n}^{\circ} 1$; en Roumanie : Opait 1997-98, n 17 à 26, 27?). Elles sont originaires, semble$\mathrm{t}$-il, du sud de la Byzacène: des traces ateliers sont soupçonnées aux abords de la ville de Iunca (supra, p. 31 ) et incontestables sur le site rural de Majoura à l'est de Gafsa (variante comparable au $\mathrm{n}^{\circ} 7$ : supra fig. 14). La localisation des ateliers et l'absence de poix pourraient indiquer que ces amphores transportaient de l'huile.

Datation proposée :

Type Keay 59 - fin IVe - première moitié Ve s.

Type Keay $8 \mathrm{~B}$ - seconde moitié du Ve s. - premier tiers du VIe s.

Autres variantes - VIe s. 
Type Keay 35A

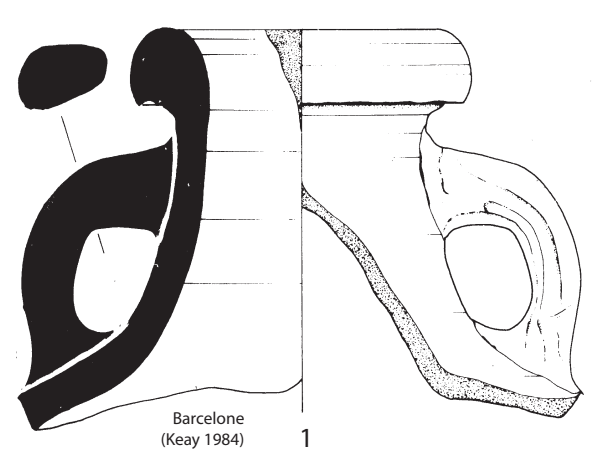

Type Keay 35B / 85

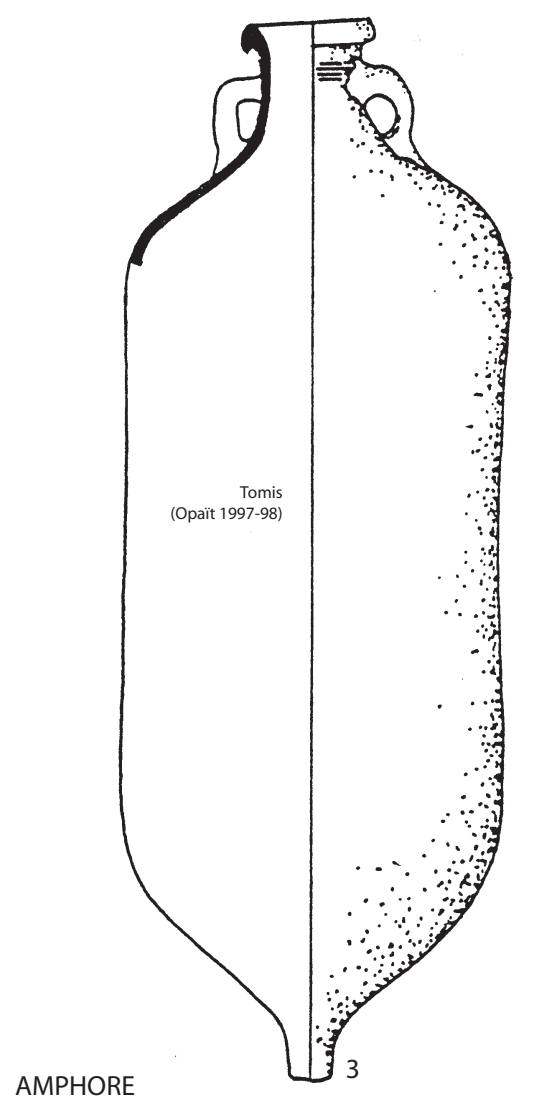

TYPE 40

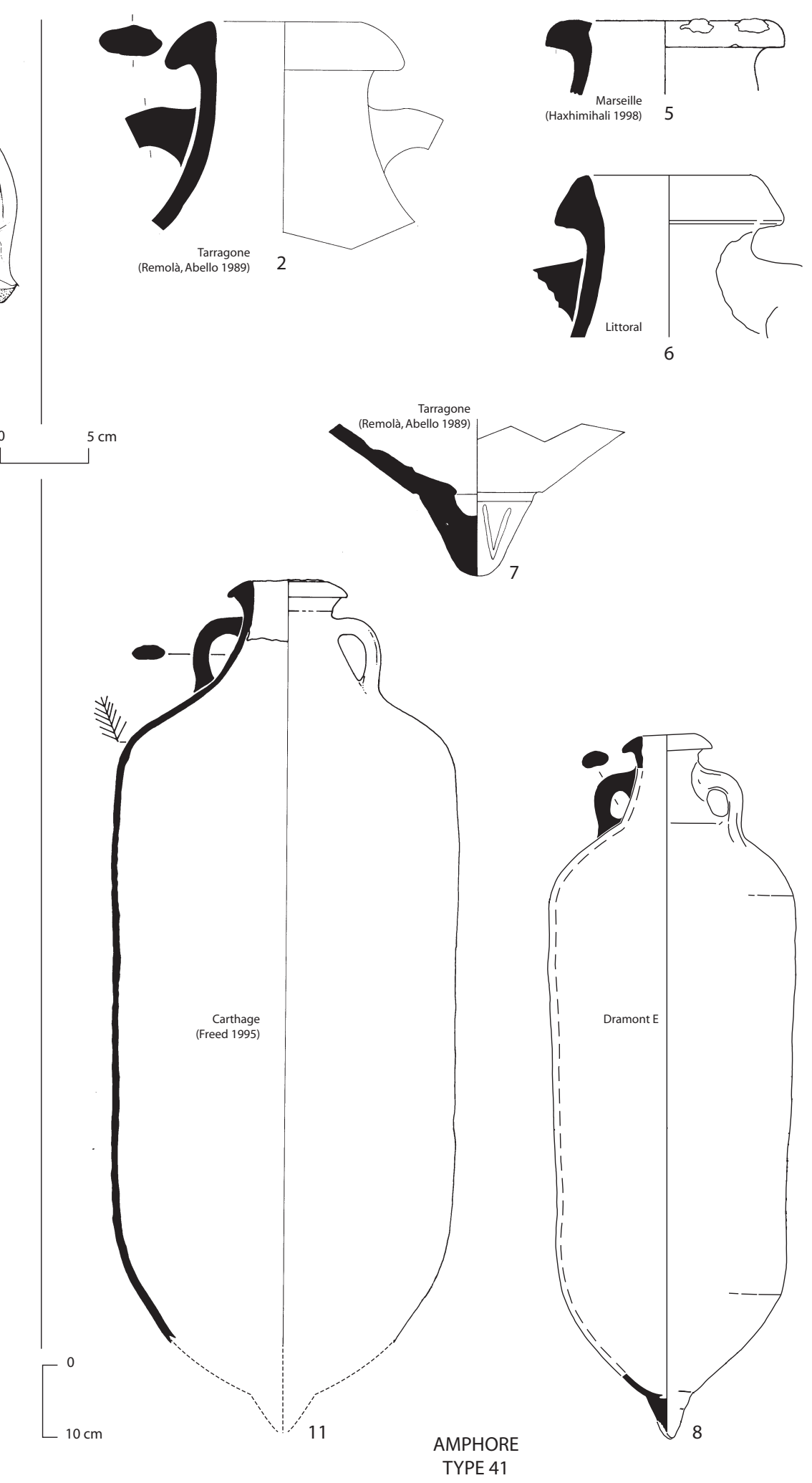

Fig. 72a. Amphores africaines cylindriques de grandes dimensions. 
- types Keay 35A et B (fig. 72a et b)

\section{AMPHORES TYPES 40 ET 41}

Si S. J. Keay a eu raison d'associer ces deux types, ce sont néanmoins deux amphores distinctes par la taille et par plusieurs détails morphologiques :

- Le type Keay 35A (AMPHORE TYPE 40) correspond à une amphore de taille apparemment constante $(\mathrm{H}$. : $108 \mathrm{~cm}$; D. : $38 \mathrm{~cm}$ ) avec un bord très épaissi, arrondi au sommet et sur la face extérieure et creusé d'une gorge sur la face inférieure. Le col est tronconique à la base, plus cylindrique au sommet. Le corps, parfaitement cylindrique, est terminé par une courte pointe pleine, cylindrique.

- Le type Keay 35B (AMPHORE TYPE 41) existe en, au moins, deux tailles différentes : un petit modèle $(H$. $99 \mathrm{~cm} ;$ D. : $34 \mathrm{~cm})$ et un grand modèle (H. : 120 $\mathrm{cm}$; D. : $48 \mathrm{~cm})$. Le bord présente une section « en forme de bec», très étiré vers l'extérieur ; il comporte plusieurs variantes. Le col est comparable à celui du type $\mathrm{A}$, de même que la panse; en revanche, la pointe courte, également pleine, n'est pas cylindrique mais conique (un contre-exemple au Musée d'Aquilée : Cipriano, Carre, 1987, fig. 25).

Exemples :

Type Keay 35A (fig. 72a)

*1 Barcelone (Keay 1994, fig. 98, $\mathrm{n}^{\circ} 4$ ).

*2 Epave Dramont E (Santamaria 1995, Pl. III).

*3 Tomis (Opait 1997-98, Pl. 13).

4 Beni Khiar, Sidi Zahruni, atelier (supra, fig. 18, n 7).

Type Keay 35B (fig. 72a)

Variante précoce (?)

1 Agde (Manacorda 1977, Pl. LXXVI, n 569).

Petit modèle

*2 Tarragone (Remolà, Abello 1989, fig. 134).

3 Marseille, chantier de La Bourse (Bonifay 1986, fig. 5, $\left.\mathrm{n}^{\circ} 11\right)$.

4 Littoral tunisien, site $\mathrm{n}^{\circ} 151$ (Oued el-Kseub, près de Kelibia) (Bonifay et al. 2002-2003, fig. 13, $\mathrm{n}^{\circ} 166$ ).

*5 Marseille, chantier de La Bourse (Haxhimihali 1999, fig. 133).

*6 Littoral tunisien, site ${ }^{\circ} 147$ (Henchir Lebna, près de Kelibia) (Bonifay et al. 2002-2003, fig. 13, n 167).

*7 Tarragone (Remolà, Abello 1989, fig. 138).

*8 Epave Dramont E (cf. Santamaria 1995, Pl. I).

9-10 Beni Khiar, Sidi Zahruni, atelier (supra, fig. 18, $\mathrm{n}^{\circ}$ 9$10)$.

Grand modèle

*11 Carthage (Freed 1995, fig. 2).

12 Hergla, fouilles anciennes (Inv. HG.000.27).

13 Arles (Musée de l'Arles Antique, fonds ancien).

14 Marseille, chantier de La Bourse (Bonifay 1986, fig. 5, $\left.\mathrm{n}^{\circ} 12\right)$.

Autre variante (?) (fig. 72b)

15 La Skhira (Fendri 1961, Pl. XXXIII, 2).

16 Musée de Zarzis (en exposition).

*17 Dépôt d'El Jem (Inv. EJ.5).

18 Marseille (L'Hour et al. 1985, 105, n 455). H. 99 cm.

\section{amphores apparentées \\ au type Keay 35B}
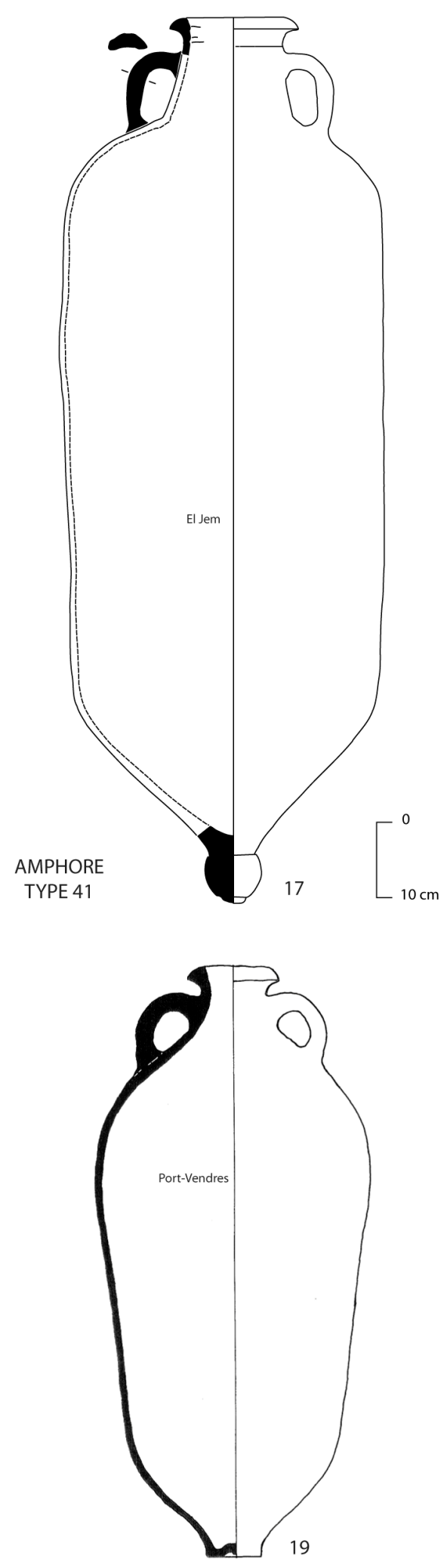

Fig. 72b. Amphores africaines apparentées au type Keay 35B. 
Variante (?) à fond plat (fig. 72b)

*19 Epave Redoute Béar, Port-Vendres ( Inv. 00-295). H. $80,5 \mathrm{~cm}$. Dessin C. Descamps.

20 Epave Isis, Skerki Bank, détroit de Sicile (Freed 1994, fig. 58 , a). H. $49,5 \mathrm{~cm}$.

Ce sont les amphores africaines parmi les plus fréquentes en Méditerranée occidentale durant les deux premiers tiers du Ve siècle. Il y a probablement une évolution typologique à saisir dans le bord des amphores Keay $35 \mathrm{~B}$ dont les plus récentes, celles de la seconde moitié du Ve s. (Bonifay et al. 1998, 372) présentent un bord très aplati (5) alors que le bord classique (2) est nettement tombant (cf. les exemplaires du Dramont E : Santamaria 1995) ; un bord triangulaire à face externe plane, classé comme type 85 par Keay, doit également être rattaché à la même série (6). Le bord des exemplaires de grande taille est souligné par une moulure (11-14). L'exemplaire d'Agde (1) qui combine un bord typique du type Keay 35B et un corps d'amphore Africaine III est peut-être un exemplaire précoce (fin du IVe s. ?). La constante présence de bavures de pâte, aplaties, au sommet du bord s'explique peut-être par le fait que ces amphores étaient mises à sécher sur le col ; c'était sans doute le moment choisi pour graver dans l'argile encore crue, les nombreuses marques visibles sur les fonds (Keay 35A, 2 et Keay 35B, 7) (supra, p. 21).

On connaît maintenant l'atelier qui a produit tout ou partie de ces amphores : c'est l'atelier de Sidi Zahruni, sur le territoire de la cité de Nabeul. On se reportera à Ghalia, Bonifay, Capelli 2004 pour la description des pâtes et leur traitement de surface, très caractéristiques. Certaines variantes d'amphores Keay 35B (15-18), qui se distinguent par leur pâte plus rugueuse et par certains détails morphologiques (fond à renflement), sont probablement produites sur d'autres ateliers, peut-être situés en Byzacène. Il existe également de curieux exemplaires à fond plat (19-20).

Le contenu des amphores Keay 35 A et B semble radicalement différent (infra, Tabl. IV). Un bon observatoire est donné par l'épave du Dramont E où tous les exemplaires de la variante B sont poissés et aucun de la variante A (Santamaria 1995). Cette dernière était donc peut-être une amphore à huile et la seconde plutôt affectée au transport des salsamenta car elle est fréquente sur les sites de salaisons de poissons repérés sur la côte est du cap Bon entre Nabeul et Kelibia (Bonifay et al. 2002-2003). De même, il faut sans doute attribuer au type Keay $35 \mathrm{~B}$ et peut-être à l'atelier de Sidi Zahruni, une amphore fragmentaire retrouvée à Aguilas (Espagne) contenant des arêtes de poissons (Pareja 1972).

Datation proposée : Ve s.

\section{- types Keay 57-56-55 (fig. 73)}

\section{AMPHORES TYPES 42-43-44}

Ces trois types peuvent être regroupés en fonction de caractères morphologiques communs, dont la présence constante d'un décor peigné sur le col :
- Type Keay 57 (AMPHORE TYPE 42) : La taille de cette amphore correspond parfaitement à celle du type Keay 35A (H. : $108 \mathrm{~cm}$; D. : 38). Le bord assez haut (H. : 4 à 4,8 cm) a une face extérieure fortement convexe, sorte de réminiscence du type néapolitain Africaine II C.

- Type Keay 56 (AMPHORE TYPE 43) : Amphore plus élancée (H. : $112 \mathrm{~cm}$; D. : $35 \mathrm{~cm})$. Le bord est plus haut $($ H. : 5 à $6 \mathrm{~cm})$ et sa convexité extérieure moins prononcée.

- Type Keay 55 (AMPHORE TYPE 44) : Amphore de même taille que la précédente. Bord rectiligne à l'extérieur et marqué d'un ressaut (support du bouchon ?) à l'intérieur. Il faut souligner que le fond qui apparaît sur le dessin de Keay pour son type 55 (Keay 1984, fig. 31, $\mathrm{n}^{\circ} 2$ ), résultat d'une restauration intempestive d'époque contemporaine, n'est pas le véritable fond de cette amphore (ce que spécifiait bien Simon Keay dans son texte); il pourrait bien s'agir d'un fond de type Keay 59 ou 8B. Le fond des amphores Keay 55 est court, muni d'un bouton arrondi (Keay 55, $\mathrm{n}^{\circ} \mathbf{6}$ ). Cette précision est importante car ce dessin trompeur est systématiquement reproduit dans les publications.

Exemples (fig. 73) :

Type Keay 57 :

*1 Barcelone (Keay 1984, fig. 128, n 5).

*2 Tarragone (Remolà 2000, fig. 44).

3 Littoral tunisien, site 165 (Mraïssa, face occidentale du cap Bon) (Bonifay et al. 2002-2003, fig. 13, $\mathrm{n}^{\circ} 173$ ).

*4 Farfa (Gilkes et al. 1999, fig. 4).

*5 Fos (Sciallano, Sibella 1991).

6 Carthage, Musée Paléochrétien (en exposition).

7-8 Hergla, fouilles anciennes (Inv. HG.000.5 et 28).

9-11 Beni Khiar, Sidi Zahruni, atelier (supra, fig. 18, $\mathrm{n}^{\circ} 16-$ 18).

Type Keay 56

*1 Barcelone (Keay 1984, fig. 128, n 1).

*2 Barcelone (Ibid., fig. 127, $\mathrm{n}^{\circ} 4$ ).

3 Beni Khiar, Sidi Zahruni, atelier (supra, fig. 18, $\mathrm{n}^{\circ} 15$ ).

*4 Tarragone (Keay 1984, fig. 127, $\mathrm{n}^{\circ}$ 6).

*5 Fornells (Palol 1982, fig. 23).

Type Keay 55

*1 Epave La Palud (Long, Volpe 1998, fig. 276, $\mathrm{n}^{\circ}$ 14).

*2 Epave La Palud (Ibid., fig. 274, $\mathrm{n}^{\circ} 5$ ).

3 Nabeul, fabrique de salaisons, citerne de la pièce XXXIX (Inv. NB 1396.4).

4 Oudhna, est capitole (fouilles H. Ben Hassen, Inv. UTH7.000.33).

*5 Tomis (Roumanie) (Opait 1997-98, Pl. 8).

*6 Epave La Palud (Long, Volpe 1998, fig. 292).

7-8 Beni Khiar, Sidi Zahruni, atelier (supra, fig. 18, $\mathrm{n}^{\circ} 13-$ 14).

Ces trois types ont été produits sur l'atelier de Beni Khiar-Sidi Zahruni. C'est dire l'importance de cet atelier de la cité de Nabeul, qui a produit beaucoup des types les mieux diffusés en Méditerranée. Ces amphores se 
Type Keay 57

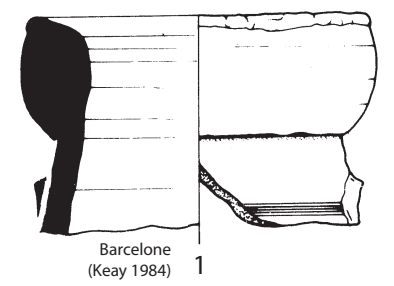

(B)

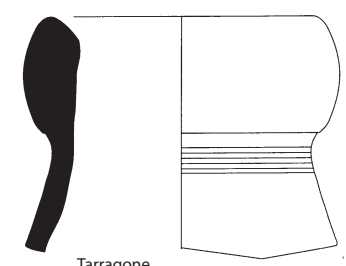

Tarragone
(Remolà 2000)

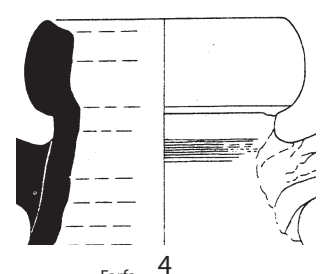

Farfa 4

(Gilkes et al. 19999)

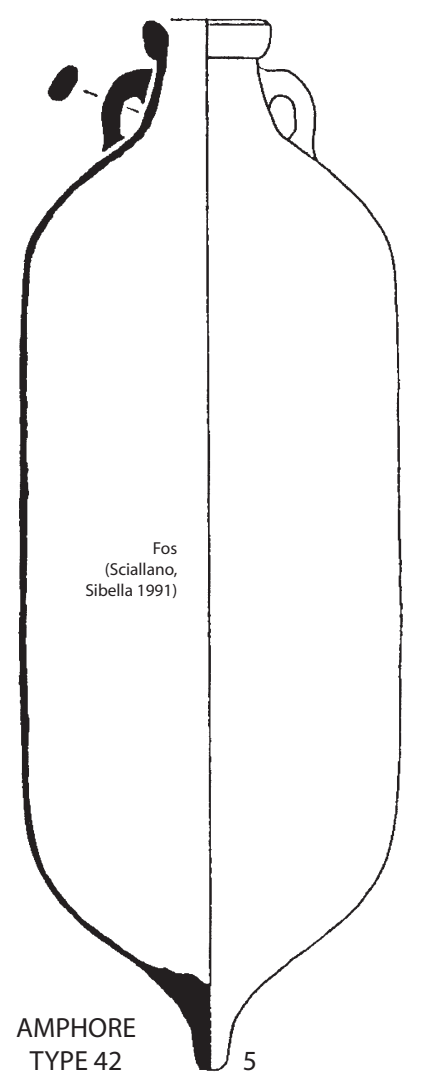

Type Keay 56

(C)

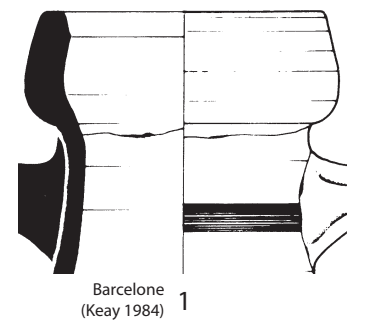

(B)

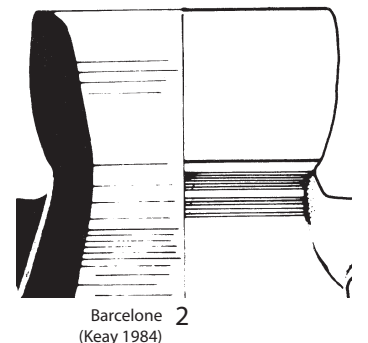

(A)

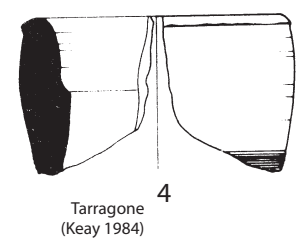

Type Keay 55

(B)

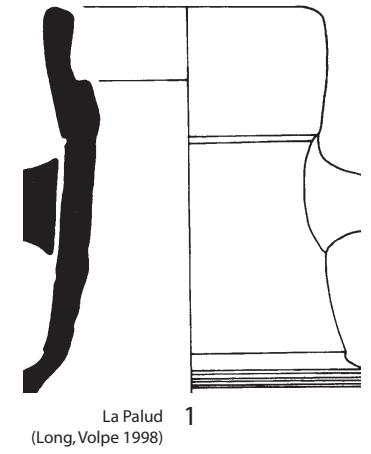

(A)

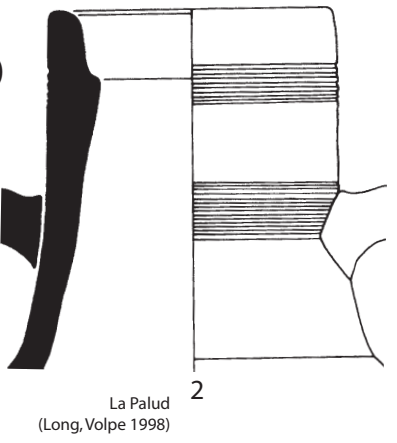

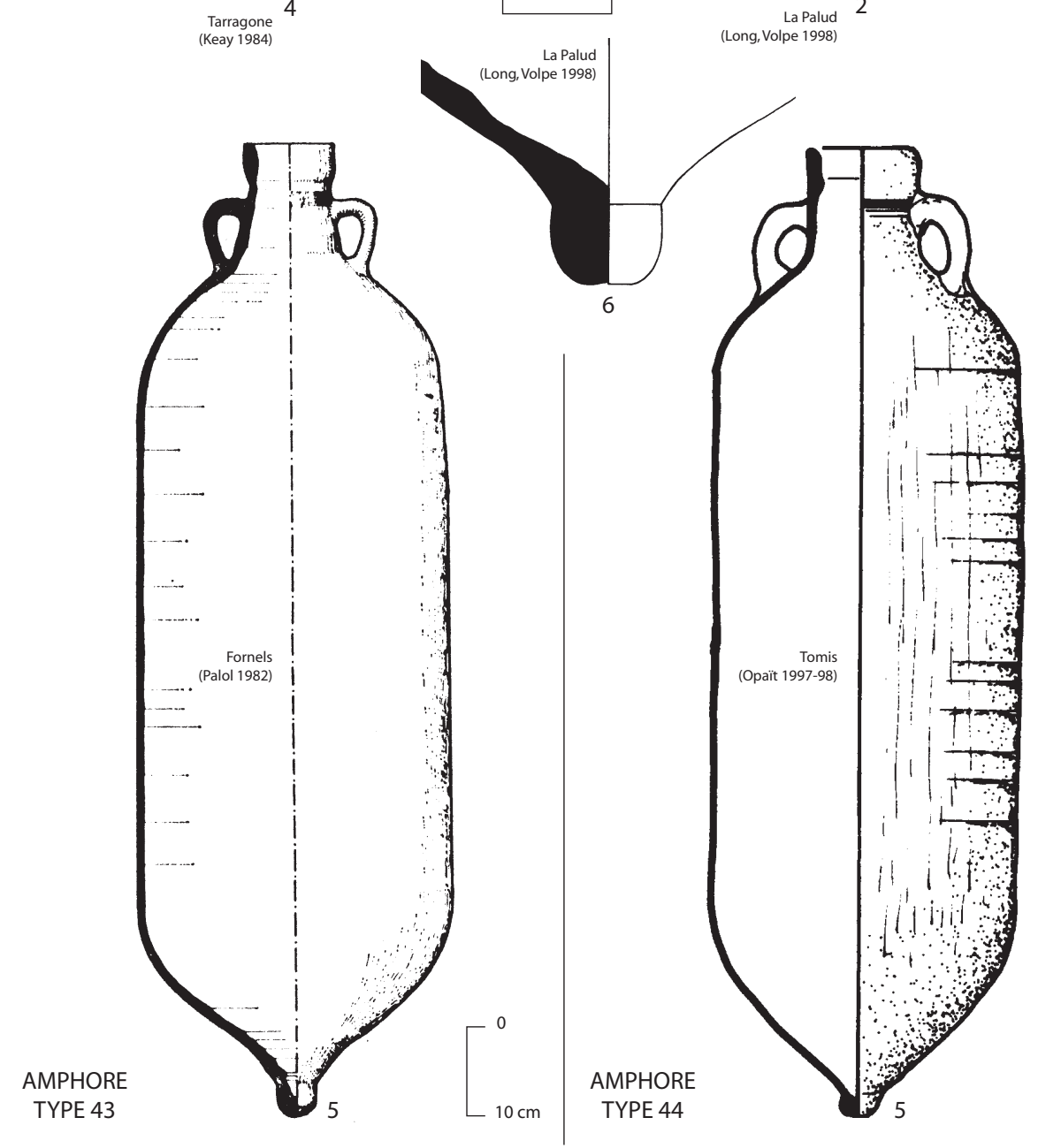

Fig. 73. Amphores africaines cylindriques de grandes dimensions. 
rencontrent dans les contextes du dernier tiers du Ve s. (Bonifay et al. 1998, 372) et de la première moitié du VIe s. (voir, notamment, à Tarragone : Remolà 1993, fig. $110, \mathrm{n}^{\circ} 10-12$, contexte fin Ve s. - début VIe s.). Le type 57, qui a encore l'allure générale des conteneurs Keay 35, puis le type 56 (tous deux associés à Albenga au type Keay 35A : Pallarès 1987) semblent apparaître avant le type 55 (associé à La Palud au type Keay 62A : Long et Volpe 1998). Le fragment Keay 55, n 3 (Nabeul), provient d'un contexte de la fin du Ve ou du début du VIe siècle.

On hésite sur le contenu des amphores Keay 55. J'ai eu l'occasion d'observer plusieurs exemplaires poissés mais aucun de ceux de l'épave de la Palud ne l'est (Long, Volpe 1998, 340). Alors ? Mauvaise conservation de la poix sur les amphores africaines de l'épave de la Palud ou bien possibilité de deux contenus différents pour un même type d'amphore?

Datation proposée :

Type Keay 57 - seconde moitié du Ve s.

Type Keay 56 - fin du Ve - début du VIe s. (+ ?)

Type Keay 55 - fin du Ve (?) - première moitié du VIe s. $(+?)$

\section{- types Keay 62Q (ou Albenga 11-12) et Keay 62R} (fig. 74)

\section{AMPHORE TYPE 45}

Nous avons souhaité, dans une publication récente (Bonifay, Pieri 1995, 102), sortir la variante Q de la série des amphores Keay 62, avec lesquelles elle a peu de caractères en commun. En effet, il s'agit d'une amphore plus haute et plus élancée (H. : $112 \mathrm{~cm}$; D. : 34-36 cm), avec un col cylindrique et étroit alors que celui des Keay 62 est tronconique et large ; le fond est également très différent (5) des fonds à renflement annulaire caractéristiques du type Keay 62 (pour une bonne illustration des différences entre les deux types, cf. Pelletier, Poguet 2000, fig. $41, \mathrm{n}^{\circ} 4$ et 5).

On ne connaît pas l'origine de ces amphores, peut-être peu éloignée de Nabeul (en raison de leur présence sur l'épave de la Palud, associée aux amphores Keay 55). La variante $\mathrm{R}$ du type 62 de Keay semble devoir être rattachée à la même série $(\mathbf{8})$.

- Variante A : type Keay $62 \mathrm{Q}=$ Albenga 11-12 ;

- Variante B : type Keay 62R.

Exemples (fig. 74) :

Variante A

*1 Albenga (Pallarès 1987, fig. 18).

*2 Tomis (Opait 1997-98, Pl. 2).

*3, *5 Marseille (Bonifay, Pieri 1995, fig. 3, n² 22 et 21).

4 Empúries (Keay 1984, fig. 33, n 7).

6 Littoral tunisien, site $\mathrm{n}^{\circ} 70$ (El Aouabed, côte au nord de Sfax) (Bonifay et al. 2002-2003, fig. 13, $\mathrm{n}^{\circ} 175$ ).

7 Littoral tunisien, site $n^{\circ} 78$ (La Louza II, même zone) (Ibid., $\mathrm{n}^{\circ}$ 176).

Variante B

*8 Empúries(Keay 1984, fig. 156, $\mathrm{n}^{\circ} 1$ ).

*9 Carthage (Freed 1995, fig. 2, n 4).
Dans les stratigraphies marseillaises, l'apparition du type Keay $62 \mathrm{Q}=$ Albenga $11-12$ précède celle du type Keay 62 (Bonifay et al. 1998, 372 ; Bonifay 2004c). Les deux types sont ensuite associés durant le premier tiers du VIe s. (par exemple sur l'épave de La Palud: Long, Volpe 1998).

Datation proposée: dernier tiers du Ves. - première moitié du VIe s. (?).

\section{- type Keay 62 (fig. 74)}

\section{AMPHORE TYPE 46}

Je ne reviendrai pas sur la présentation de ce type très répandu en Méditerranée occidentale, plus rare en Méditerranée orientale (cependant : deux exemplaires en Roumanie : Opait 1997-98, n $^{\circ} 11$ et 12 ; un fragment à Chersonèse : Sazanov 1991, fig. 13, $n^{\circ} 6$ ), sauf pour dire que la détermination des vingt-deux variantes distinguées par Keay demeure toujours assez aléatoire, d'autant qu'on ne dispose que de peu d'exemplaires complets. On a déjà vu que les variantes $Q$ et $R$ pouvaient plutôt constituer un type séparé, il en serait probablement de même pour les variantes $\mathrm{L}$ et $\mathrm{V}$. Ces variations typologiques sont tout d'abord le reflet d'une multiplicité d'ateliers. Les prospections de M. Peacock, Bejaoui et Ben Lazreg (1989) avaient bien montré d'une part que le Sahel était l'une des sources principales de ces amphores et d'autre part qu'il n'y avait pas qu'un seul atelier les produisant, bien que celui d'Henchir ech-Chekaf, à Ksour Essaf soit, sans doute, l'un des plus important. On sait maintenant que l'atelier de Chabat al Qola - Zahruni à Beni Khiar a également produit des amphores Keay 62, même s'il ne semble pas s'agir d'une production abondante, qui rompt quelque peu avec la tradition typologique des ateliers néapolitains, comme si ces ateliers avaient voulu imiter un type originaire plutôt de Byzacène. De fait, le profil des exemplaires de Nabeul est plus lourd et plus rectiligne (1 et $\mathbf{3 - 4}$ ) que celui des exemplaires sahéliens, nettement convexe à l'extérieur (5-7), et pourrait, avec un peu d'expérience, se distinguer facilement. On hésite sur l'origine précise de la variante $\mathrm{D}$, à ressaut interne $(\mathbf{8})$.

Exemples (fig. 74) :

Variante A (Zeugitane ?)

*1 Epave La Palud (Long et Volpe 1998, fig. 280).

*2 Filicudi Porto (Albore Livadie 1984, fig. 104).

3-4 Beni Khiar, Sidi Zahruni, atelier (supra, fig. 18, n 1920).

Variante A (Byzacène ?)

*5 Barcelone (Keay 1984, fig. 33, n 5). Classé par l'auteur dans sa variante $\mathrm{D}$ mais voir le dessin agrandi de la fig. 18.

6 Littoral tunisien, site $\mathrm{n}^{\circ} 78$ (La Louza II, côte nord de Sfax) (Bonifay et al. 2002-2003, fig. 14, $\mathrm{n}^{\circ}$ 178).

*7 Henchir ech-Chekaf, atelier (Peacock, Bejaoui, Ben Lazreg 1989, fig. 7, $\mathrm{n}^{\circ} 2$ ).

Variante D

*8 Tarragone (Keay 1984, fig. 146, $\mathrm{n}^{\circ} 3$ ).

Variante tardive (E ?)

9 Littoral tunisien, site $\mathrm{n}^{\circ} 94$ (Salakta sud) (Bonifay et al. 2002-2003, fig. $\left.14, \mathrm{n}^{\circ} 180\right)$. 
Types Keay "62Q" = Albenga 11-12 et Keay "62R"
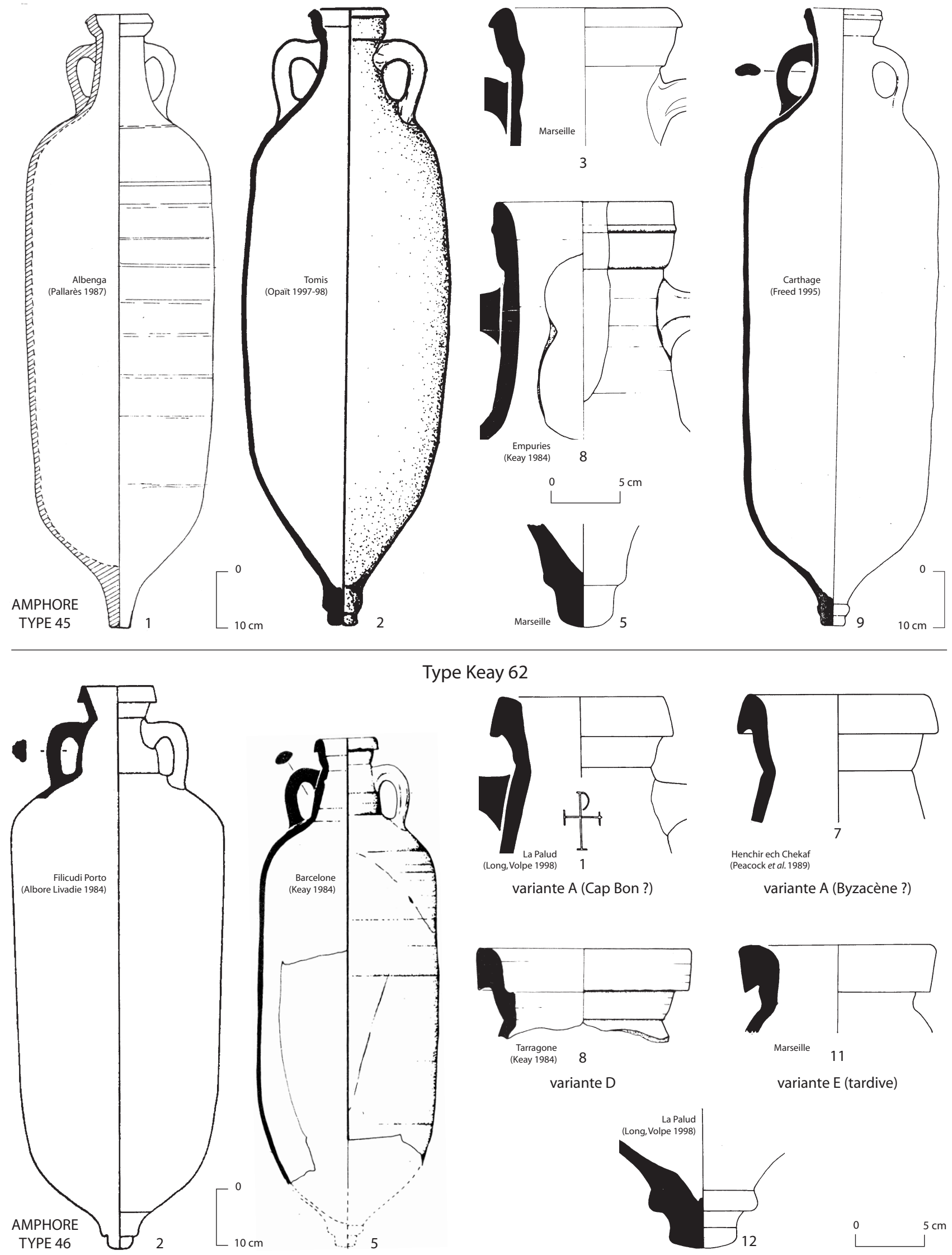

Fig. 74. Amphores africaines cylindriques de grandes dimensions. 
Type Keay 62 var. (Bonifay 1986, fig. 12.55)
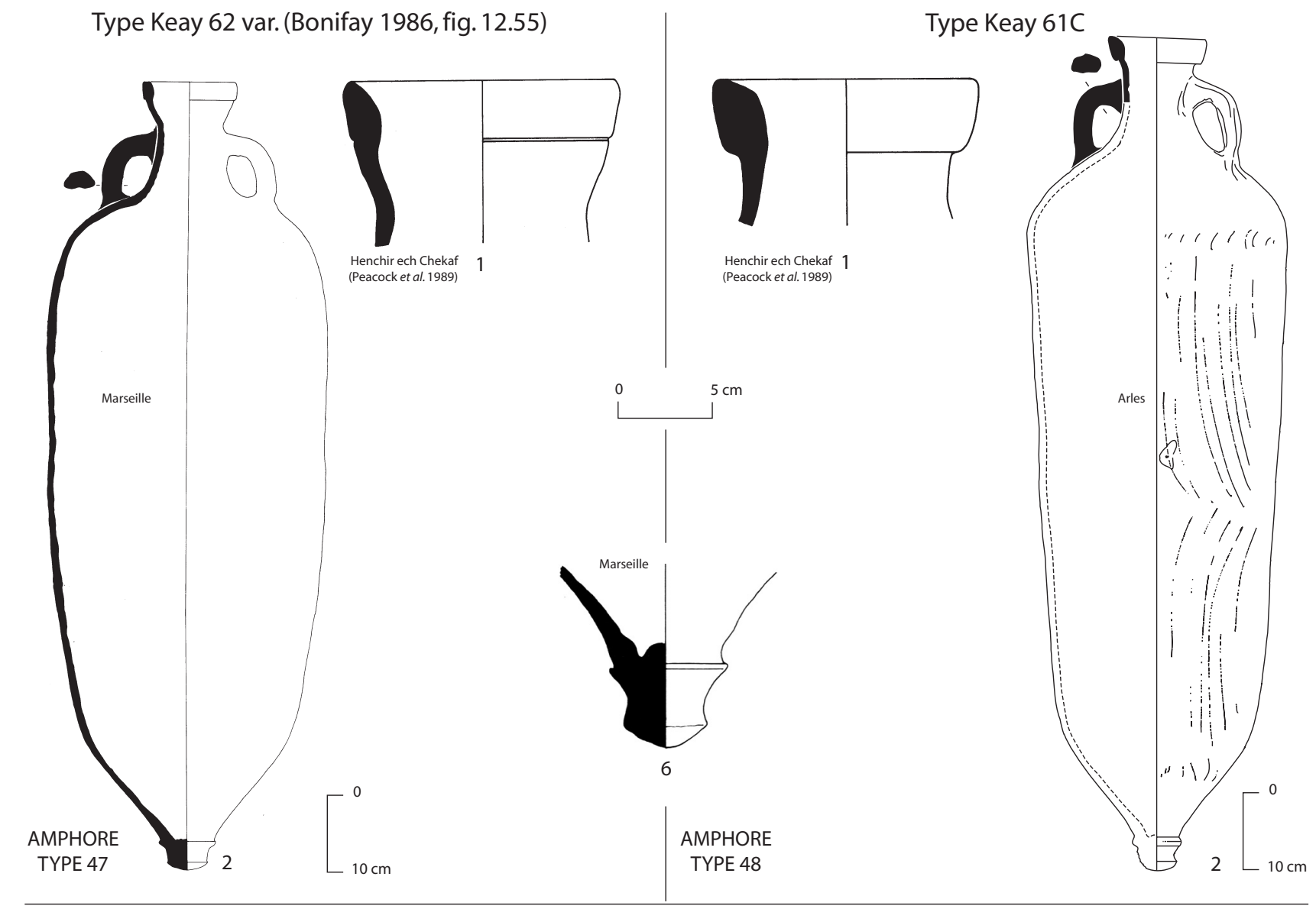

Type Keay $61 C$

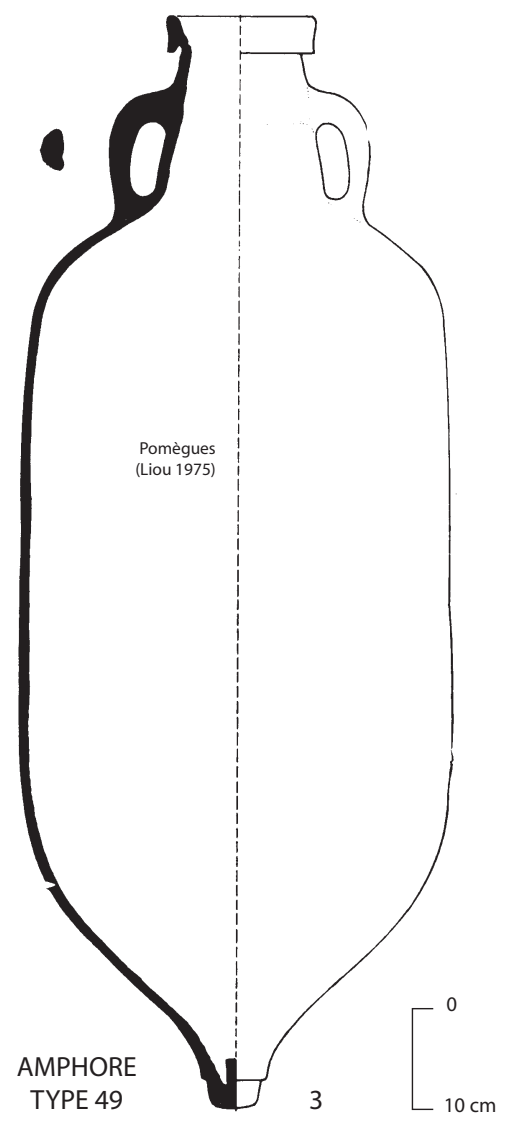

Type Keay 61
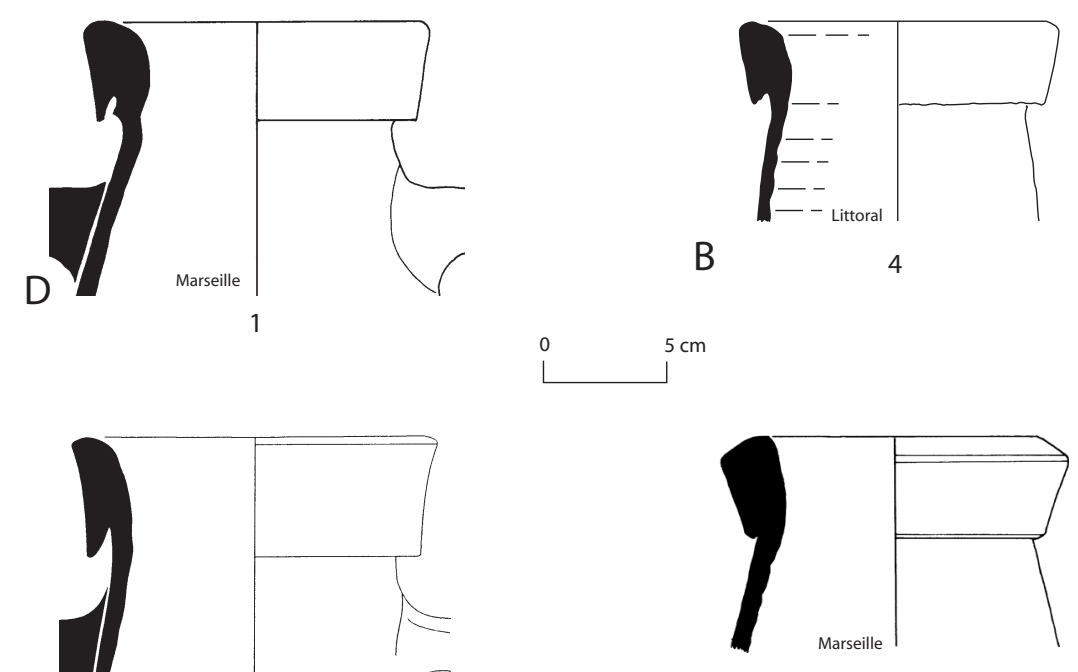

A

Marseille
(Bien 2004)

10

8

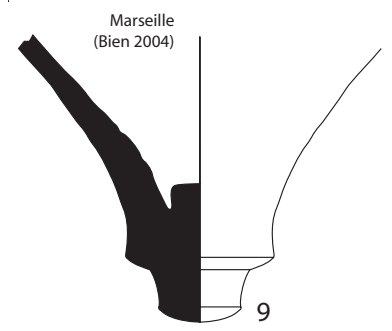

Fig. 75. Amphores africaines cylindriques de grandes dimensions. 
10 Marseille, chantier de La Bourse (Bonifay 1986, fig. $11, n^{\circ} 49$ ).

*11 Idem (Pieri 1998a, fig. 91, n 104).

Divers

*12 Epave La Palud, fond (Long, Volpe 1998, fig. 293).

Ces distinctions typologiques ont également une valeur chronologique et là, je m'en tiendrais à la distinction apparue sur les fouilles de Marseille entre les types classiques de la première moitié du VIe s. (essentiellement la variante A) et ceux de la fin du VIe s. ou du début du VIIe s. (proche de la variante E) (11): cette variante tardive est caractérisée par un bord à section quadrangulaire surmontant immédiatement l'étranglement du col (voir les exemplaires de Slovénie associés à des sigillées D Hayes $104 \mathrm{C}$ et 105A : Vidrih Perko 1995, fig. 3, $\mathrm{n}^{\circ} 2-6$; ceux de Norique sont associés à des sigillées africaines Hayes 109A : Ladstätter 2003, fig. $6, \mathrm{n}^{\circ} 2$ ) ; d'après sa diffusion en Tunisie, elle pourrait être originaire de Byzacène (9). Il existe de nombreux types intermédiaires que je suis, pour ma part, incapable de distinguer clairement. Il s'agit donc d'une amphore du VIe s., qui, dans les stratigraphies, apparaît généralement en concomitance avec les sigillées africaines Hayes 99 (Nieto Prieto 1993, fig. 42-43); l'amphore Keay 62, naguère considérée comme le type vandale par excellence (Freed 1995), constitue le chargement principal de l'épave de la Palud à Port Cros que les poids monétaires de la balance de bord datent au plus tôt du deuxième quart du VIe s. (Bonifay 1998d, 328). Beaucoup d'exemplaires sont poissés (Filicudi Porto: Albore Livadie 1984, 96 ; Carthage : Opait 1998a, 25-26).

Datation proposée :

Variante $\mathrm{A}$ - première moitié du VIe $\mathrm{s}$.

Variante E - fin du VIe s. - début du VIIe s.

- types Keay 62 variante Bonifay 1986, fig. 12.55 et Keay 61C (fig. 75)

\section{AMPHORES TYPES 47 ET 48}

Il convient d'associer ces deux types d'amphores qui sont proches du point de vue de la morphologie du bord et de l'aspect de leur pâte, généralement de couleur brun orangé, parfois violacée, avec une surface extérieure jaune vif, lorsqu'elle est bien conservée. La forme du fond est particulière, presque « en diabolo ».

- Type Keay 62, variante Bonifay 1986, fig. 12.55 (AMPHORE TYPE 47): amphore cylindrique pansue (H. : $105 \mathrm{~cm}$; D. : 35-36 cm) ; fond en diabolo ; col resserré puis évasé en entonnoir hémisphérique, lèvre en amande, à renflement interne; anses à profil surbaissé ;

- Type Keay 61C (AMPHORE TYPE 48) : amphore de forme plus élancée que la précédente $(2)$; fond en diabolo ; col tronconique sans étranglement à bord en amande ; anses à profil surbaissé.

Exemples (fig. 75) :

Type Keay 62 variante

*1 Henchir ech-Chekaf, atelier (Peacock, Bejaoui, Ben
Lazreg 1989, fig. 8, $\mathrm{n}^{\circ}$ 9).

*2 Marseille (Bonifay 1986, fig. 12, $\mathrm{n}^{\circ} 55$ ).

3 Littoral tunisien, site $\mathrm{n}^{\circ} 85$ (Jezira, près d'Acholla) (Bonifay et al. 2002-2003, fig. 18, $\mathrm{n}^{\circ} 266$ ).

4 Littoral tunisien, site $\mathrm{n}^{\circ} 99$ (Douira, au nord de Salakta) (Bonifay et al. 2002-2003, fig. 14, $\mathrm{n}^{\circ} 183$ ).

Type Keay 61C

*1 Henchir ech-Chekaf, atelier (Peacock, Bejaoui, Ben Lazreg 1989, fig. 7, $\mathrm{n}^{\circ} 4$ ).

*2 Arles (Musée de l'Arles Antique, fonds ancien).

3 Punta de l'Illa de Cullera (García, Rosselló 1992, fig. $\left.2, \mathrm{n}^{\circ} 10\right)$.

4 Littoral tunisien, site $\mathrm{n}^{\circ} 99$ (Douira, au nord de Salakta) (Bonifay et al. 2002-2003, fig. 14, $\mathrm{n}^{\circ} 182$ ).

5 Salakta, récupération en mer (Bonifay et al. 20022003, fig. $19, n^{\circ} 275$ ).

Forme de fond commune aux deux types

*6 Marseille, chantier de La Bourse (Bonifay 1986, fig. $15, \mathrm{n}^{\circ} 72$ ).

Ce sont des amphores fréquentes à la fin du VIe s. et dans la première moitié du VIIe s., probablement originaires de l'atelier de Henchir ech-Chekaf à Ksour Essaf, par comparaison avec les exemplaires que j'ai pu prélever sur cet atelier (TYPE 47, $\mathrm{n}^{\circ} 1$; TYPE 48, $\mathrm{n}^{\circ}$ 1) (supra, p. 3335). Le TYPE $47, n^{\circ} 3$ provient d'un contexte d'habitat de la fin du VIe - VIIe siècle. Des traces de poix sont visibles sur certains exemplaires (TYPE $47, \mathrm{n}^{\circ} 2$ ) ; le TYPE $48, \mathrm{n}^{\circ} 5$, récupéré en mer, n'est pas poissé.

Datation proposée : fin du VIe s. - première moitié du VIIe s. $(+)$

- type Keay 61 (fig. 75)

\section{AMPHORE TYPE 49}

Il y a peut-être une filiation entre les derniers exemplaires d'amphores Keay 62 et les premiers exemplaires d'amphores Keay 61 (variante D : 1). L'évolution du type Keay 61 semble en effet consister dans un amincissement et une augmentation de la hauteur du bandeau caractéristique de son bord (variante A : 6-9). Il est également facile de distinguer le fond des Keay 61 par rapport à celui des Keay 62, les premiers étant généralement munis d'un pivot axial qui dépasse à l'intérieur (9), caractère qui ne se remarque pas sur les Keay 62 (cf. fig. 74, $\mathrm{n}^{\circ}$ 12) (ainsi, à Bordeaux, Berthault 1999 : le fond $n^{\circ} 4$ de la fig. 17 serait du type Keay 61 et non 62 , ce qui en ferait l'un des témoins les plus tardifs des arrivages africains dans cette ville). La variante B semble constituer un développement séparé (4-5). Enfin, une autre variante tardive a été identifiée à Marseille et sa production localisée à Beni Khiar - Sidi Zahruni (10-12). Exemples (fig. 75) :

Variante $\mathrm{D}$, précoce (?)

*1 Marseille (Bonifay, Pieri 1995, fig. 5, $\mathrm{n}^{\circ} 36$ ).

2 Littoral tunisien, site $n^{\circ} 76$ (Sidi Mezara nord, côte nord de Sfax) (Bonifay et al. 2002-2003, fig. 14, $\left.\mathrm{n}^{\circ} 184\right)$.

*3 Pomègues, récupération en mer (Liou 1975, fig. 13). 
Variante B, précoce (?)

*4 Littoral tunisien, site $\mathrm{n}^{\circ} 99$ (Douira, au nord de Salakta) (Bonifay et al. 2002-2003, fig. 14, $\mathrm{n}^{\circ} 185$ ).

5 Carthagène (Ramallo, Ruiz, Berrocal 1996, fig. 19, $\mathrm{n}^{\circ} 253$ ).

Variante classique A

6 Moknine, atelier (supra, fig. 16, $\mathrm{n}^{\circ} 1$ )

7 Marseille, chantier de La Bourse (Bonifay 1986, fig. $15, \mathrm{n}^{\circ} 70$ ).

*8-*9 Marseille, chantier de l'Alcazar (Bien 2004, fig. 6, $\mathrm{n}^{\circ} 2$ et 1).

Variante tardive (?)

*10 Marseille, chantier de La Bourse (Bonifay 1986, fig. $\left.15, \mathrm{n}^{\circ} 71\right)$.

11 Nabeul, fabrique de salaisons, période 6 (Inv. NB1389.11).

12 Beni Khiar, Sidi Zahruni, atelier (supra, fig. 18, ${ }^{\circ} 24$ ).

Nota : La variante $\mathrm{C}$ a été sortie de la catégorie (voir forme précédente).

C'est une amphore typique du VIIe s., dont l'origine semble bien devoir être recherchée dans le Sahel tunisien. L'atelier de Moknine, fouillé par Nejib Ben Lazreg et dont nous avons déjà parlé (supra, p. 35 et 127), produisait ce type d'amphore (6), tout comme, vraisemblablement aussi, l'atelier de Leptiminus (Dore 2001, fig. 1.65, $\mathrm{n}^{\circ} 10-17,19$ ?). En revanche, la variante $\mathrm{n}^{\circ}$ 10-12 est originaire de Zeugitane; elle est tardive, comme tend à le prouver sa présence, à Roses, associée au type Keay 8A (Nolla, Casas 1997, fig. 2).

Datation proposée :

Variantes D et B - fin du VIe -première moitié du VIIe s.

Variante A - milieu et seconde moitié du VIIe s. (autre variante tardive : idem).

\section{- type Keay 8A (fig. 76)}

\section{AMPHORE TYPE 50}

Giovanni Murialdo (1988), le premier, a proposé d'attribuer à ce type défini par S. J. Keay à partir de trois fragments de bords (Keay 1984, fig. 47), une amphore fréquente dans les niveaux les plus tardifs du castrum de Sant'Antonino di Perti. Un exemplaire presque complet à Pieve del Finale (1) montre qu'elle se rattache à la série des amphores cylindriques de grandes dimensions, dont elle pourrait constituer l'évolution ultime (Murialdo 2001, 267). Le fond à renflement annulaire et à pivot axial interne se distingue de celui des amphores Keay 61 par un profil plus pointu (8).

Exemples (fig. 76) :

*1 Pieve del Finale (Murialdo 1988, fig. 7.6).

*2 Sant'Antonino di Perti (Murialdo 2001, Pl. 10).

3 Ile de Port-Cros (Hyères, France), anse de la Palud, découverte isolée (fouille L. Long et G. Volpe).

4 Sidi Jdidi (Ben Abed, Bonifay, Fixot 1997, fig. 11, $\mathrm{n}^{\circ}$ 64).

5 Marseille, place Jules-Verne (Bonifay, Pieri 1995, fig. $\left.5, n^{\circ} 39\right)$.

6 Marseille, nécropole du Pharo, tombe 41 (fouille C. Richarté, 1995).

7 Golfe de Fos (épave Saint-Gervais 2 ?), musée d'Istres (en exposition).
*8 Epave Saint-Gervais 2 (Fos, France) (Jézégou 1998, fig. 305).

9 Tarragone (Macias, Remolà 2000, fig. 3, n 4).

Ces amphores apparaissent régulièrement dans les contextes du VIIe s. avancé (1-2, 4-5, 6, 8-9). En Tunisie, elles semblent plutôt attestées sur les sites septentrionaux (4) (Pupput et Nabeul : plusieurs fragments des deux types), qui pourraient encore, à cette date, être sous contrôle byzantin (?) (voir cependant un fragment à Leptiminus: Dore 2001, fig. 1.65, $\mathrm{n}^{\circ} 18$ ). Il est remarquable que le type Keay $8 \mathrm{~A}$ soit exporté jusqu'en mer Egée (Chios : Boardman 1989, Pl. 24, n² 231). Les exemplaires trouvés en mer sont parfois poissés (8 : Jézégou 1998, 346, mais douteux selon l'auteur; 7 : observations personnelles); le $\mathrm{n}^{\circ} \mathbf{3}$ ne l'est pas.

Datation proposée : seconde moitié du VIIe s. $(+)$.

\section{Autres séries}

\section{- type Keay 50 et « orlo a fascia » (fig. 76)}

\section{AMPHORES TYPES 51 ET 52}

Il est actuellement difficile d'y voir clair dans les séries les plus tardives d'amphores africaines cylindriques. Les exemplaires complets manquent pour interpréter de nombreux fragments de bords et de fonds découverts dans des contextes du VIIes. avancé et les rapprochements avec la typologie de Keay restent hasardeux. Ainsi, des bords caractérisés par un bandeau large, mince et très évasé, ont été attribués au type Keay 50 par G. Murialdo (1995, 443) (TYPE 51, 2-3). Une autre amphore, le type «con orlo a fascia» présent en une dizaine d'exemplaires à la Crypta Balbi (Saguì 1998, 315 et fig. 8.1) (TYPE 52, 2), se distingue des amphores Keay 50 par un long col parfaitement cylindrique (Ibid., note 34 ). Nous peinons à trouver un exemplaire complet $\mathrm{du}$ type Keay 50, à moins qu'il ne faille considérer comme tel une amphore de l'épave de Lastovo en Croatie (Radič 1993, fig. 9, 2ème amphore en partant de la gauche, associée à des « spatheia » de type 3D) (TYPE 51, 1), dont le fond pointu pourrait, de fait, rappeler celui d'un exemplaire de Sant'Antonino di Perti (Murialdo 2001, Pl. 11, $\mathrm{n}^{\circ}$ 72). En revanche, nous disposons plus sûrement d'un exemplaire complet d'amphore « con orlo a fascia », également découvert en Croatie, à Koper (Cunja 1991, 44, n 22) (TYPE 52, 1). Cette amphore, peut-être également présente sur l'épave de Lastovo (Radič 1993, fig. 9, 1ère amphore à gauche ?), est intéressante à plus d'un titre car elle permet d'interpréter un type de fond en « bouchon de Champagne » (TYPE 52, 5) fréquent, à l'état de fragments, dans les contextes du VIIe s. avancé (par ex. : Jézégou 1998, fig. 305, n 5-6). Le même fond figure sur un exemplaire de Lamta (TYPE $52,8)$ qui présente un bord «a fascia» moins haut, comparable à des fragments de Marseille (7). Les deux premières amphores (TYPE 51, 1 et TYPE 52, 1), dotées d'un corps en fuseau (D. au niveau de l'épaulement : 25 $\mathrm{cm})$, évoquent les amphores cylindriques de moyennes dimensions dont elles pourraient constituer, en quelque 


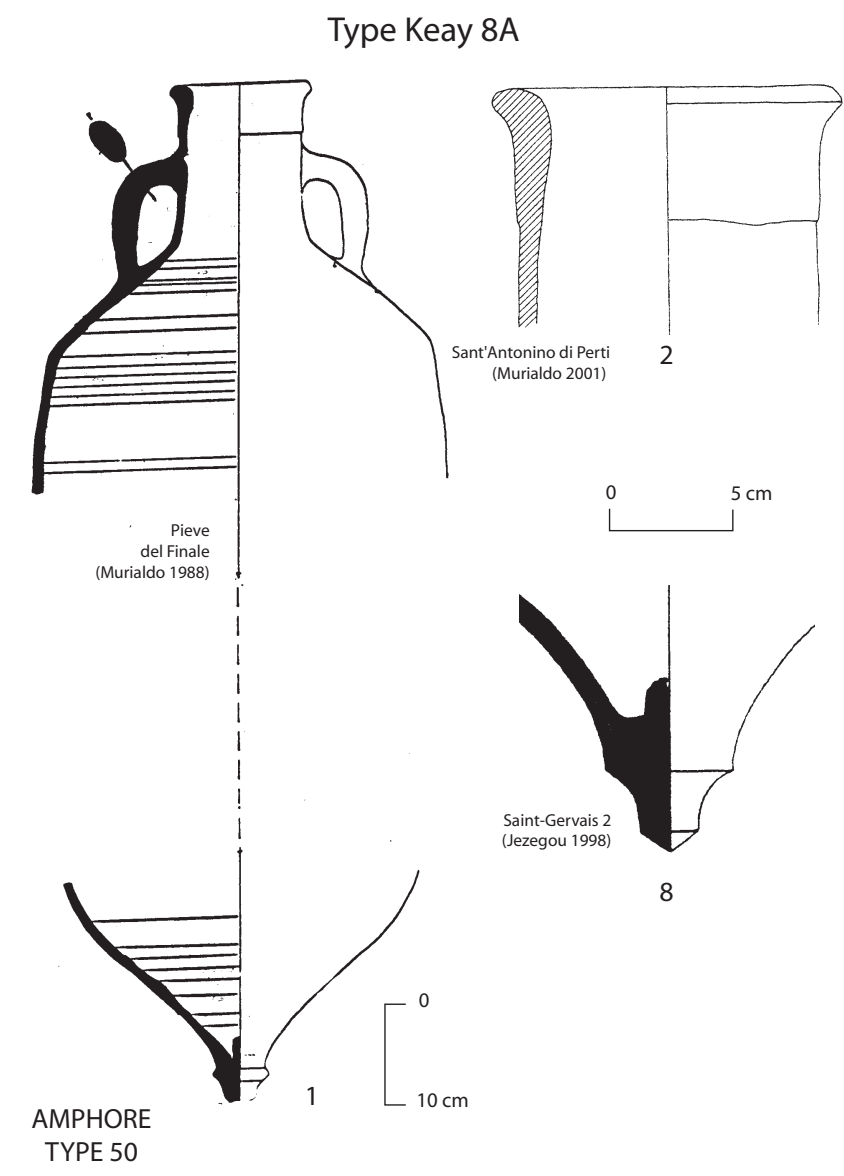

Type Keay 50
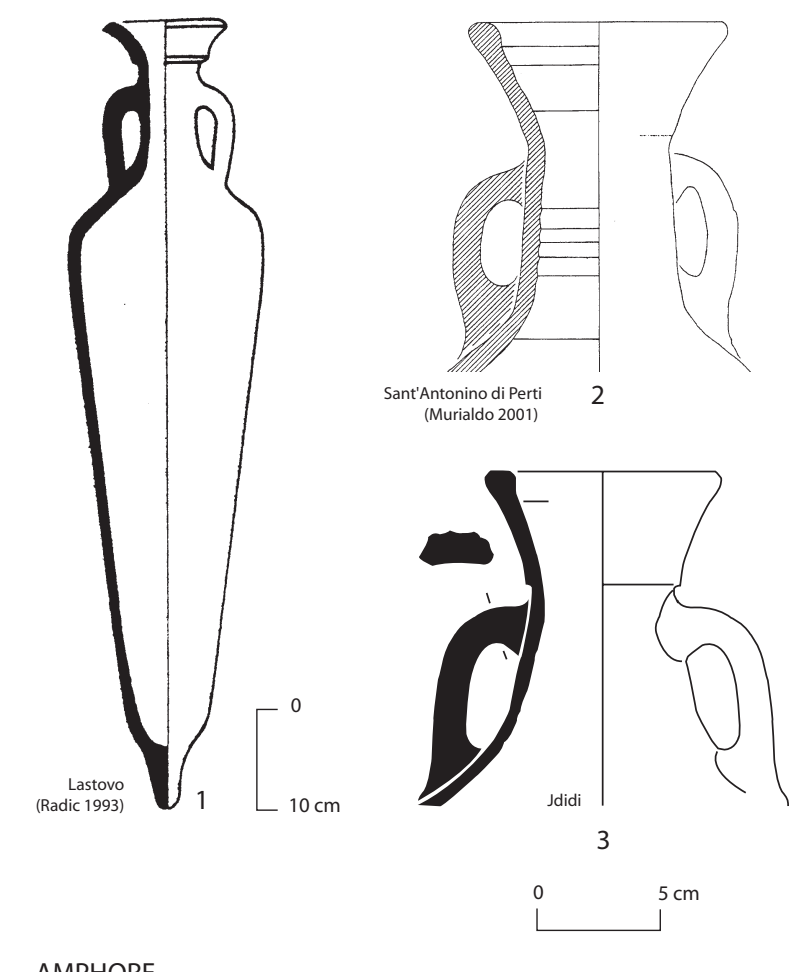

HORE

TYPE 51

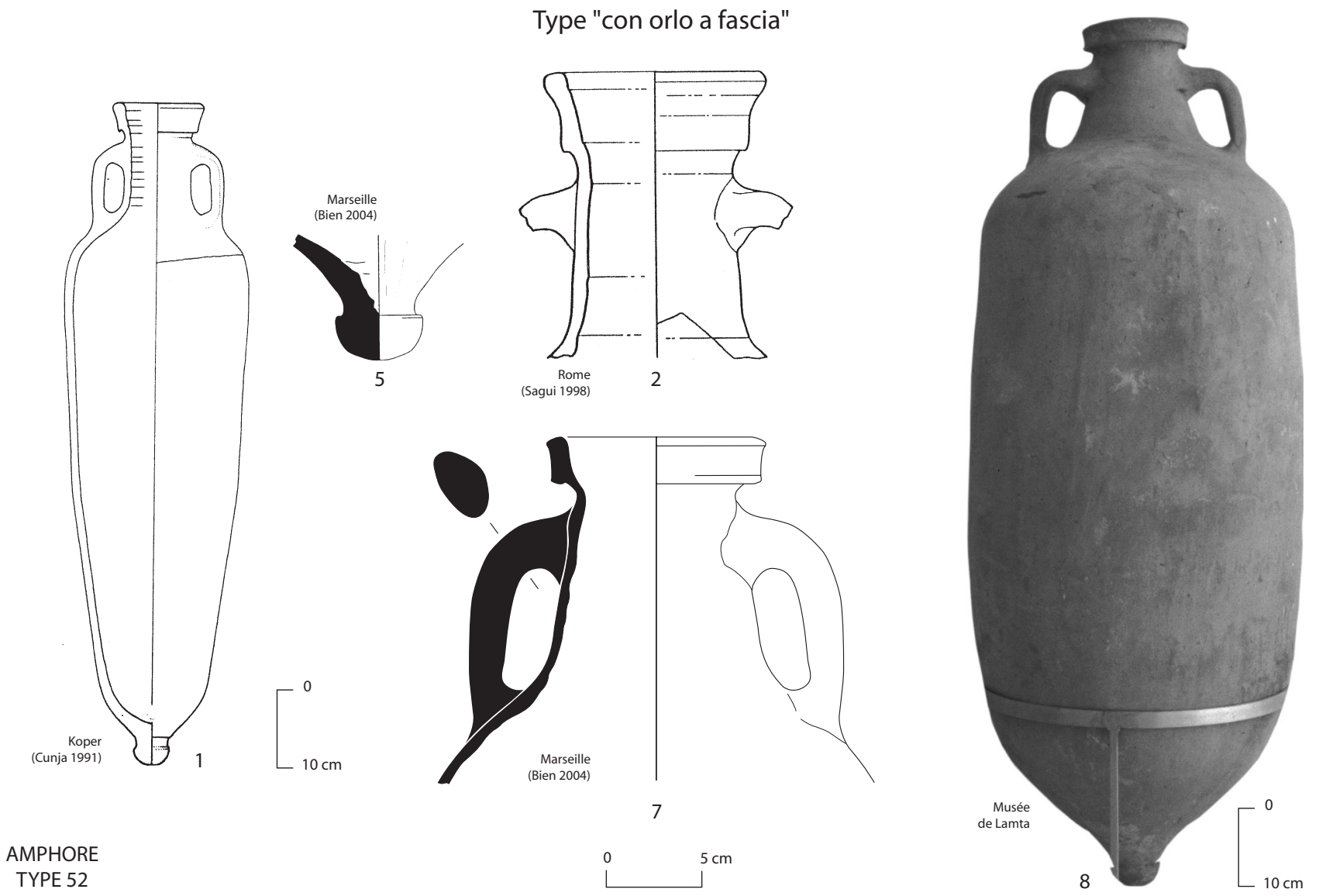

Fig. 76. Amphores africaines cylindriques de grandes dimensions et autres séries. 
sorte, une résurgence tardive (Murialdo 2001, 271), mais on peut également, au vu de la troisième (TYPE $52, \mathbf{8}$ ), les considérer comme de petits modules d'amphores Keay 61 et $8 \mathrm{~A}$.

Exemples (fig. 76) :

Type Keay 50 (AMPHORE TYPE 51)

*1 Epave de Lastovo (Radič 1993, fig. 9).

*2 Sant'Antonino di Perti (Murialdo 2001, Pl. 11).

*3 Sidi Jdidi (Ben Abed, Bonifay, Fixot 1997, fig. 11, $\left.\mathrm{n}^{\circ} 65\right)$.

Amphore « con orlo a fascia » (AMPHORE TYPE 52)

*1 Koper (Cunja 1991, 44, n 22 ).

*2 Rome, Crypta Balbi (Saguì 1998, 1998, fig. 8).

3 Nabeul, fabrique de salaisons, période 6 (Inv. NB1428.15).

4 Pupput, thermes du Centre (fouilles A. Ben Abed, Inv. PPC.101.5). Fond.

*5 Marseille, chantier de l'Alcazar (Bien 2004, fig. 2, $\left.\mathrm{n}^{\circ} 11\right)$. Fond.

6 Tarragone (Macias, Remolà 2000, fig. 3, n 3).

Variante (?)

*7 Marseille, chantier de l'Alcazar (Bien 2004, fig. 7, $\left.\mathrm{n}^{\circ} 10\right)$.

*8 Musée de Lamta (en exposition).

9 Sidi Jdidi, basilique 1, état C2B (Bonifay, Reynaud 2004, $n^{\circ} 33.3$ ).

Datation proposée : seconde moitié du VIIe s. $(+)$.

- type Keay 34 (fig. 77)

\section{AMPHORE TYPE 53}

Ce type d'amphore (Keay 1984, fig. $98, \mathrm{n}^{\circ} 1$; le $\mathrm{n}^{\circ} 2$ n'appartient peut-être pas au même type) est passé un peu inaperçu car il est représenté en petit nombre sur les marchés de Méditerranée occidentale. Nous en connaissons maintenant deux exemplaires complets provenant des fouilles tuniso-françaises effectuées entre 1971 et 1974 sur le site de Rougga/Bararus, près d'El Jem (1 et 4). De fait, cette amphore est très fréquente sur le littoral tunisien entre la Chebba et Salakta et il y a fort à parier que les ateliers doivent se situer dans l'arrière pays d'Acholla (supra, p. 22). La pâte est assez caractéristique, rouge carmin, avec de nombreuses cavités jaunes de micro-fossiles (Pl. I, $\left.\mathrm{n}^{\circ} 8\right)$; c'est également la pâte de la plupart des céramiques communes de Rougga (observations pétrographiques par $\mathrm{Cl}$. Capelli). La trace de doigt à l'intérieur du col, au niveau de l'attache supérieure de l'anse, rappelle une particularité bien connue des amphores tripolitaines. On peut distinguer deux variantes :

- A : bord en bandeau large et vertical, col parfaitement cylindrique ;

- $\mathrm{B}$ : bord triangulaire à lèvre pendante détachée, col plus évasé, certains exemplaires portent un décor peigné.

Exemples (fig. 77) :

Variante A

*1 Rougga (Guéry, Bonifay à paraître, $\mathrm{n}^{\circ} 340$ ).

*2 Littoral tunisien, site $\mathrm{n}^{\circ} 75$ (Sidi Mezara sud, au sud d'Acholla) (Bonifay et al. 2002-2003, fig. 14, $\left.\mathrm{n}^{\circ} 187\right)$.
*3 Apollonia de Cyrénaïque (fouilles A. Laronde, Inv. 89TS Surf 450).

Variante B

*4 Rougga (Guéry, Bonifay à paraitre, fig. 14 et 15 , $\left.\mathrm{n}^{\circ} 341\right)$.

*5 Littoral tunisien, site $\mathrm{n}^{\circ} 78$ (La Louza, au sud d'Acholla) (Bonifay et al. 2002-2003, fig. 14, $\mathrm{n}^{\circ} 188$ ).

6 Marseille, chantier de l'Alcazar (Bien 2001, $\mathrm{n}^{\circ} 201$ ).

7 Sant'Antonino di Perti (Murialdo 2001, Pl. 9, n 40).

Autre variante

*8 Rougga (Guéry, Bonifay à paraître, $n^{\circ} 328$ ).

Fonds

*9 Littoral tunisien, site $\mathrm{n}^{\circ} 84$ (Marsa Mellouleche, au nord d'Acholla) (Bonifay et al. 2002-2003, fig. 14, $\left.\mathrm{n}^{\circ} 189\right)$.

*10 Rougga (Guéry, Bonifay à paraître, $n^{\circ} 334$ ).

Les deux variantes sont associées à Rougga, où elles ont été datées de la première moitié du VIe siècle. Mais je me demande si cette datation n'est pas trop haute car beaucoup de fragments sont liés, en prospection, à des sigillées africaines du VIIe s. (Bonifay et al. 2002-2003, fig. 18, $\left.n^{\circ} 269-270\right)$; le type est également présent dans le même horizon chronologique à Sant'Antonino (7), sur le site de Giarranauti en Sicile (Basile 1996, fig. 8) ainsi qu'à Marseille (6). Une inscription peinte sur un exemplaire découvert en Roumanie pourrait indiquer (?) ${ }^{127}$ que ce conteneur était « utilisé spécialement pour le vin » (Opait 1997-98, 58, n³2).

Datation proposée : VIe s. - VIIe s.

\section{- types tardifs à diffusion limitée}

\section{— type Sidi Jdidi 1 (fig. 78)}

AMPHORE TYPE 54

Il s'agit d'une amphore de très grande taille (H. : 124 $\mathrm{cm}$; D. max. : $56 \mathrm{~cm}$ ), caractérisée par un bord à section ronde, très proéminent, parfois souligné à l'intérieur d'une légère gorge. Le col est court et tronconique, le corps très pansu et terminé par une courte pointe renflée à la base. Un décor peigné (lignes ondées et rectilignes) court au niveau de chacune des deux attaches d'anses.

Exemples (fig. 78) :

*1 Sidi Jdidi (Bonifay, Reynaud 2004, $\mathrm{n}^{\circ} 29.1$ ).

*2 Nabeul, fabrique de salaisons, période 6 (Inv. NB1428.27).

3 Beni Khiar, Sidi Zahruni, atelier (supra, fig. 18, $n^{\circ} 25$ ). Variante (?)

*4 Carthage (Peacock 1984b, fig. 39, n 63).

L'atelier de Chabat al Qola - Zahruni produit, au VIIe s. (d'après la position stratigraphique des $n^{\circ} \mathbf{1}$ et 2 ), ce type bien diffusé en Tunisie septentrionale (fragments à Pupput) mais rare en Méditerranée occidentale (Keay 1984, type 64 (?), 352, et fig. 164, n² 2, 3 et 5 seulement). Le $\mathrm{n}^{\circ} \mathbf{2}$ est associé à la forme Hayes $109 \mathrm{~B}$ de sigillée africaine. Le $\mathrm{n}^{\circ} \mathbf{4}$, avec un bord moins proéminent,

\footnotetext{
${ }^{127}$ Une autre inscription, sur un col conservé au Musée Copte $\mathrm{du}$ Caire, donne une indication complètement contraire, en mentionnant l'huile (renseignement et étude en cours Jean-Luc Fournet).
} 
Typologie - Amphores

A

2
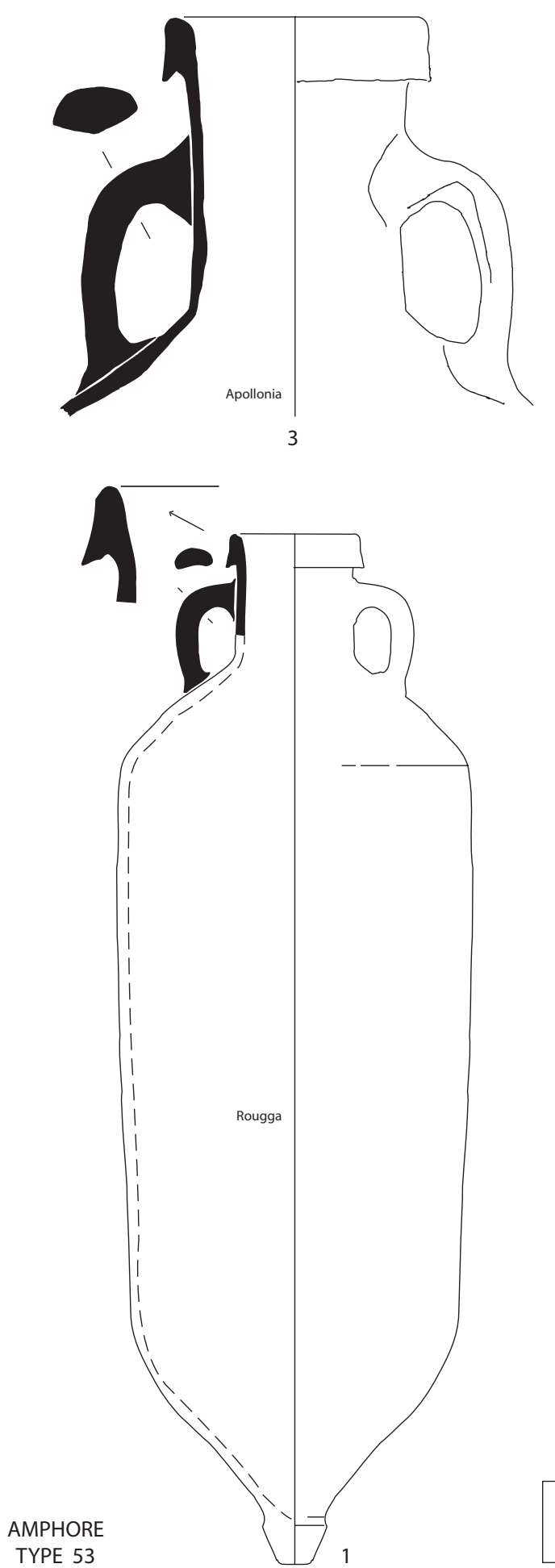

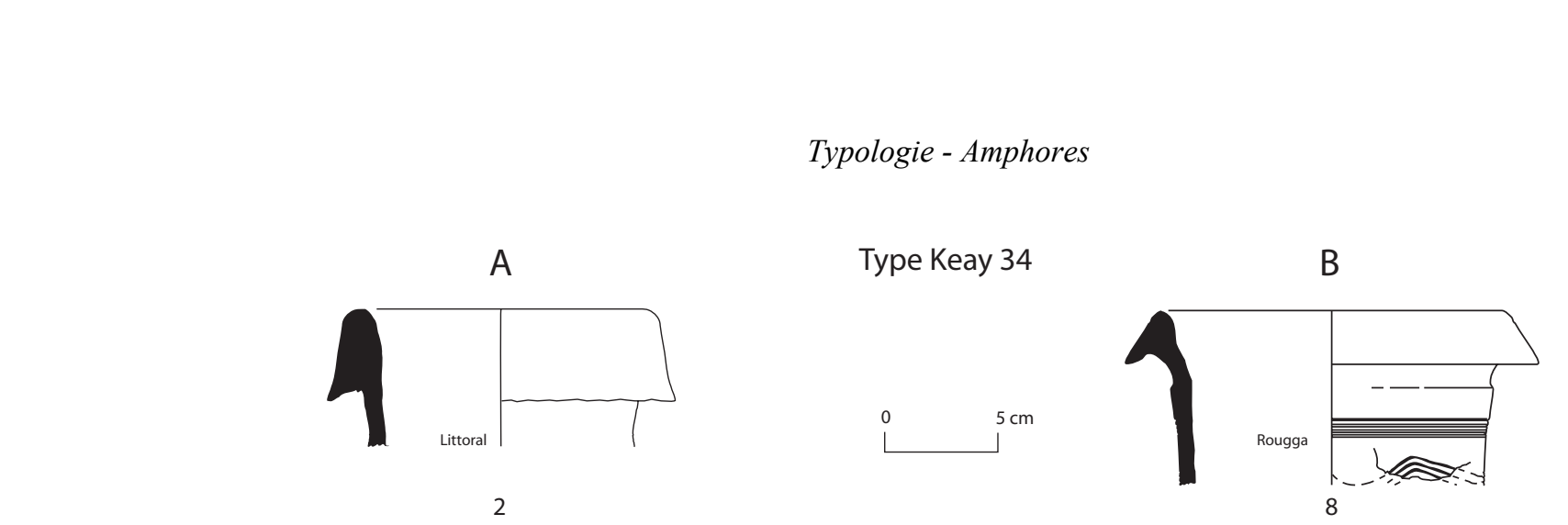

Type Keay 34
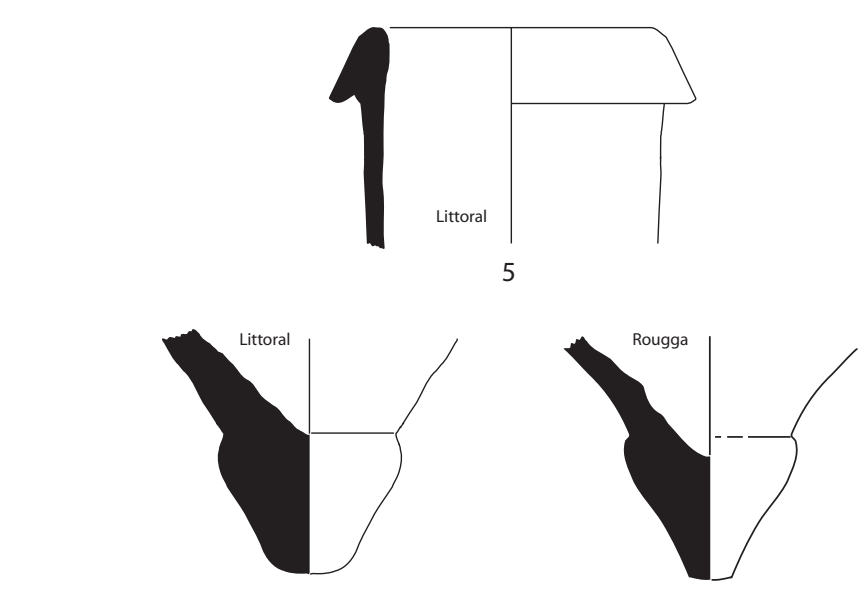

10

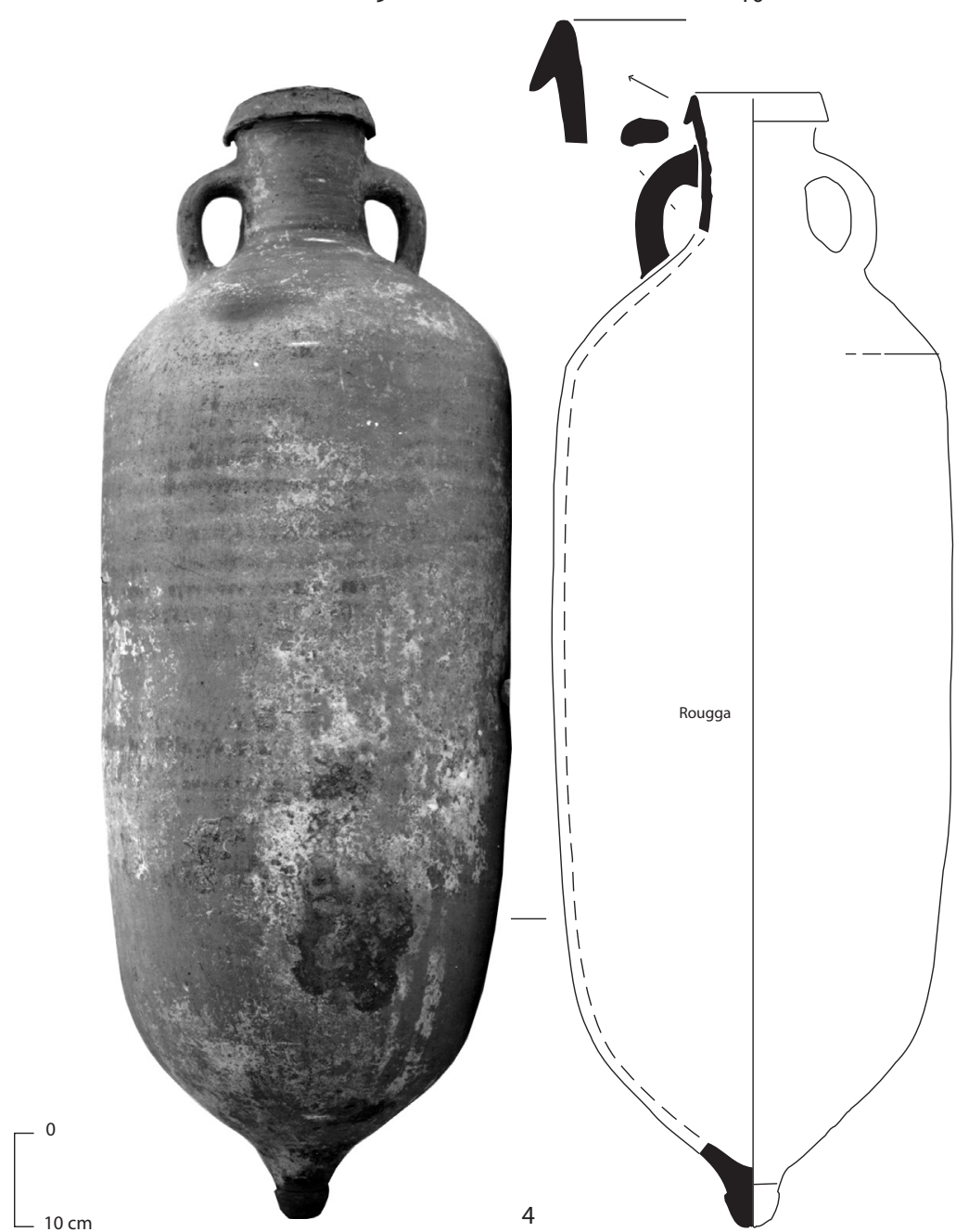

$-10 \mathrm{~cm}$

B 8
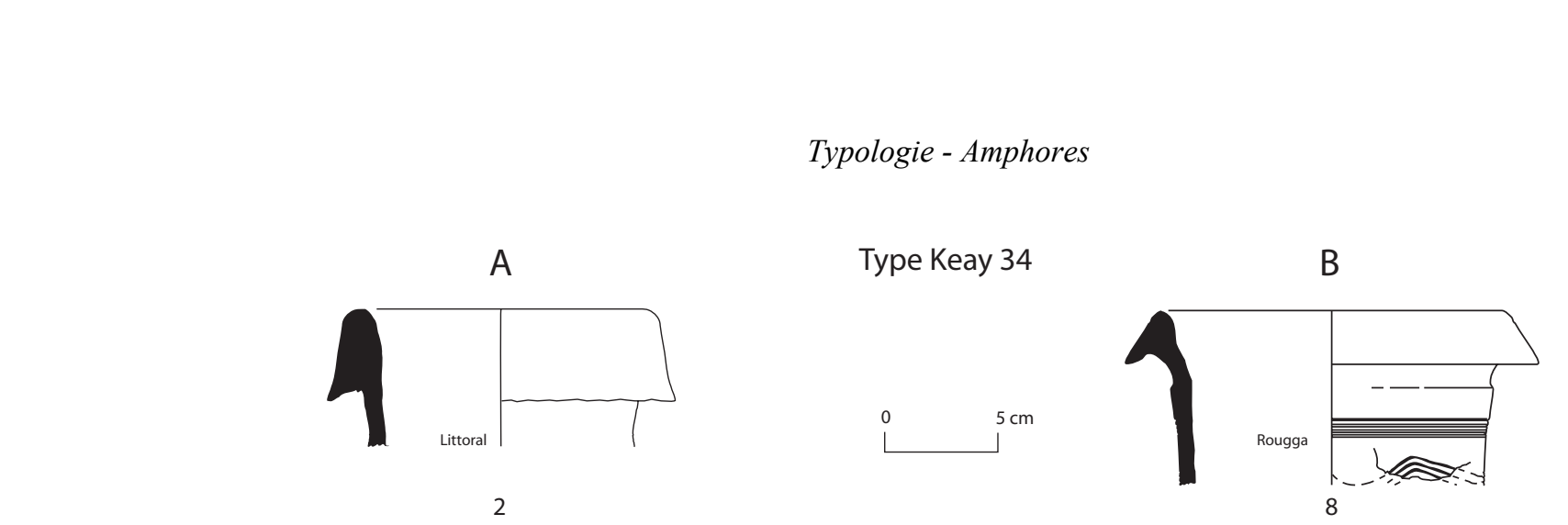

Fig. 77. Amphores africaines cylindriques de grandes dimensions. 


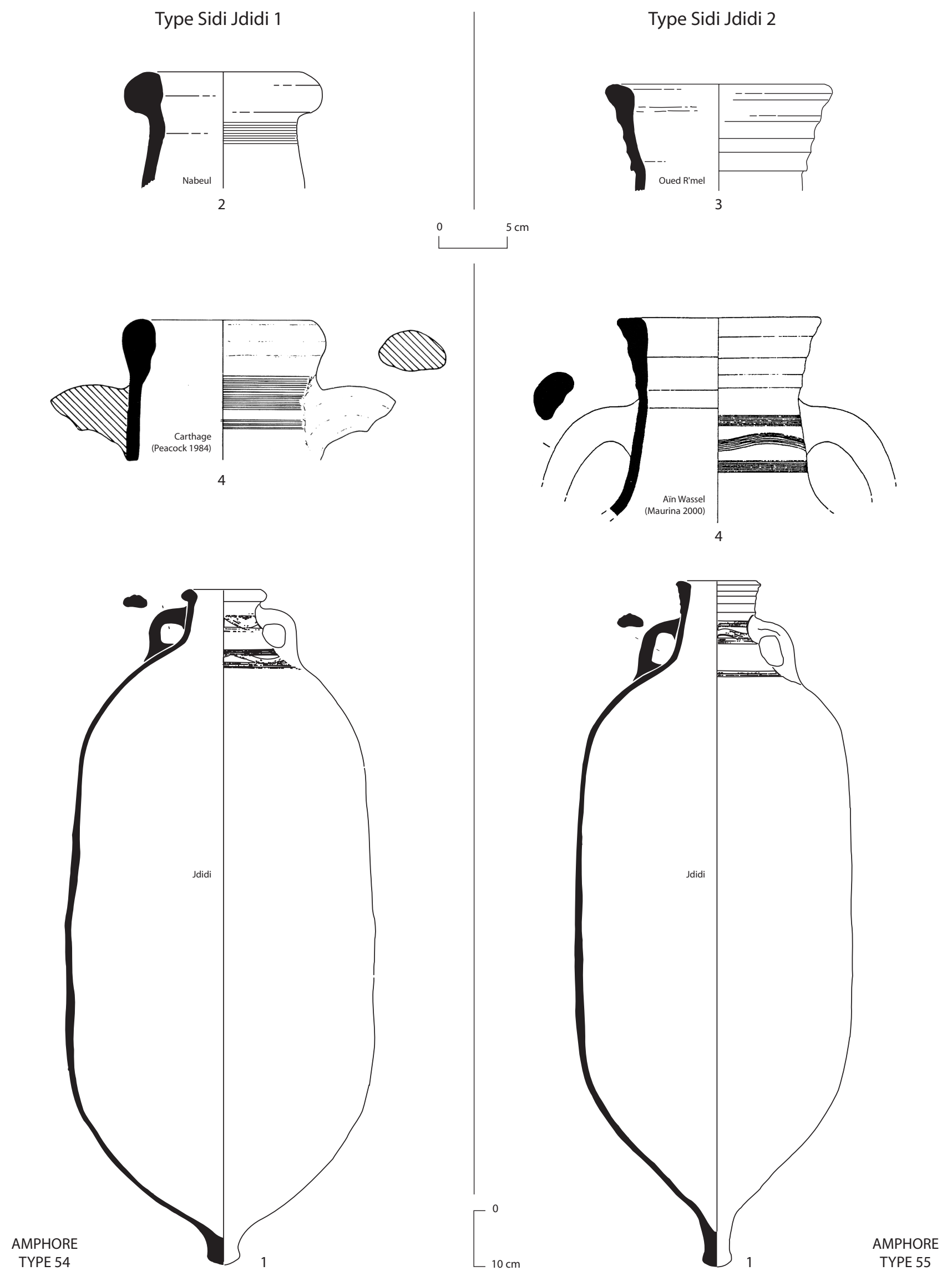

Fig. 78. Amphores africaines cylindriques de grandes dimensions (types à diffusion continentale). 
provient de contextes de la fin du Ve s. (Peacock 1984b, 133).

Datation proposée: VIIe s., variantes précoces au VIe s. (?).

\section{— type Sidi Jdidi 2 (fig. 78)}

\section{AMPHORE TYPE 55}

Cette amphore cylindrique de grandes dimensions est fréquente dans les contextes du VIIe $\mathrm{s}$. de la région de Nabeul/Hammamet/Sidi Jdidi (Bonifay, Reynaud 2004, type Sidi Jdidi 2). De grande taille (H. : $126 \mathrm{~cm}$; D. max. : $49 \mathrm{~cm})$, elle est caractérisée par un bord en large et mince bandeau cannelé (H. : $5 \mathrm{~cm}$ en moyenne). Le col est tronconique, relativement allongé ; un décor court au niveau de chacune des deux attaches d'anses. En dépit de certaines analogies, elle se distingue clairement des types Keay 61 et $8 \mathrm{~A}$ par la forme du fond, cylindrique, sans renflement annulaire.

Exemples (fig. 78) :

*1 Sidi Jdidi (Bonifay, Reynaud 2004, $\mathrm{n}^{\circ}$ 29.2).

2 Pupput, thermes du Centre (fouilles A. Ben Abed, Inv. PPC182.10).

*3 Oued R'mel (fouilles T. Ghalia, Inv. OR4004.1).

*4 Aïn Wassel (Maurina 2000, Pl. VI, n 1).

Cette amphore apparaît régulièrement dans les niveaux les plus tardifs (VIIe s. avancé) des villes de Sidi Jdidi (1: trouvée en association avec le type Sidi Jdidi 1), Pupput (2) et Nabeul (inédit), ainsi que dans les niveaux d'abandon de l'établissement rural de l'Oued R'mel (3). Cette amphore est également présente, avec la même datation, dans l'intérieur des terres, à Dougga (4).

Datation proposée : VIIe s.

\subsection{IMITATIONS AFRICAINES DE TYPES NON-AFRICAINS}

Très tôt et parallèlement au développement d'un répertoire de formes gréco-romain propre à l'Afrique, cette région a imité des types créés dans d'autres régions. Ce phénomène n'est pas spécifique à l'Afrique et il revêt dans cette province un caractère limité.

\section{Imitations d'amphores italiques}

Le type d'amphore vinaire à anses bifides, inventé dans l'île de Cos (Freed 2000), est celui qui a été le plus amplement copié dans l'Empire romain. L'Afrique n'échappe pas à cette tendance générale.

\section{- type Dressel 2/4 ou Schöne-Mau XXXV variante (fig. 79)}

\section{AMPHORES TYPES 56-57-58}

Le site de Gallala, sur la rive sud de l'île de Jerba, et les ateliers péri-urbains de Zitha/Zian, près de Zarzis, ont livré les témoins peu discutables de la production d'un type d'amphores à anses bifides (supra, fig. 13). La même production a été mise en évidence sur des ateliers situés plus à l'intérieur de l'île de Jerba (Fentress 2001, 261-264). On ne sait précisément à quelle typologie rattacher ces objets. Il semble y avoir plusieurs types d'amphores africaines à anses bifides :

- Le type Dressel 2/4 : il semble que des amphores très proches de ce type ont été produites en Afrique. Les exemplaires de Chamakh (1) et de Pupput (2) ont des tailles (H. : 83 et $95 \mathrm{~cm}$; D. max. : 27 et 34 $\mathrm{cm}$ ) et un profil conformes à ceux des exemplaires italiques. Leur datation varie entre le début du Ier s. (1) et le milieu du IIe s. (2).

- Type pseudo-Dressel 2-4 : on a produit également dans la partie tunisienne de la Tripolitaine des amphores apparentées au type Dressel 2/4 mais qui s'en distinguent par des dimensions moindres $(\mathrm{H}$. inférieure à $80 \mathrm{~cm}$ ) et un profil très mou, en manière d' « évocation de Dressel 2/4 ».

- Type Schöne-Mau XXXV: le type Schöne-Mau XXXV, dont on connaît des ateliers en Libye (Panella 1973, 481), est attesté en Tunisie, mais je n'ai pas découvert de preuves sûres de sa production dans la région de Zarzis-Jerba.

Exemples (fig. 79) :

Type Dressel 2/4 [TYPE 56]

*1 Chamakh, Musée de Zarzis (Bonifay et al. 2002-2003, fig. $15, \mathrm{n}^{\circ} 203$ ).

*2 Pupput, tombe 1308 (Bonifay 2004a, fig. 9, $\mathrm{n}^{\circ}$ 9).

Type pseudo-Dressel 2/4 [TYPE 57]

*1 Musée de Zarzis (en exposition).

*2 Jerba, atelier (Fentress 2001, fig. 6, $\mathrm{n}^{\circ}$ 6).

*3 Gallala, atelier (Bonifay et al. 2002-2003, fig. 15, $\mathrm{n}^{\circ}$ 202).

4 Pupput (Ben Abed, Griesheimer 2004, fig. 130, $\mathrm{n}^{\circ} 11.2$ ?).

Type Schöne-Mau XXXV [TYPE 58]

*1 Pompéi (Panella 1973, 632, $\mathrm{n}^{\circ} 42$ ).

*2 Pupput (Bonifay 2004a, fig. 9, $\mathrm{n}^{\circ} 8$ ).

— type pseudo-Dressel 1 (fig. 79)

\section{AMPHORE TYPE 59}

A. Opait a proposé d'identifier parmi les productions des fours de Lamta une imitation d'amphores de type Dressel 1 (Opait 1998b). Outre le fait que la datation proposée (IIe s. - milieu IIIe s.) paraît un peu tardive, même pour une imitation, je me demande si on ne pourrait pas également y voir, quitte à trouver une comparaison hors d'Afrique, une imitation des amphores d'Adriatique Dressel 6a, mieux diffusées en Tunisie (Ex. : Bonifay et al. 2002-2003, fig. $12, \mathrm{n}^{\circ} 142$ ).

\section{— Problème du type Agora M254}

Le type Agora M254 (= Ostia II, 522 et Ostia III, 464 pour la variante ancienne; = Ostia I, 453-454 pour la variante plus tardive) a été longtemps considéré, en raison de son abondance dans les dépôts de fouille de Lepcis Magna (Panella 1973, 471; Manacorda 1977, 232), comme une production de Tripolitaine (Ex.: Galliou 1990), d'où, parfois, son appellation de «petite 
Type Dressel 2/4

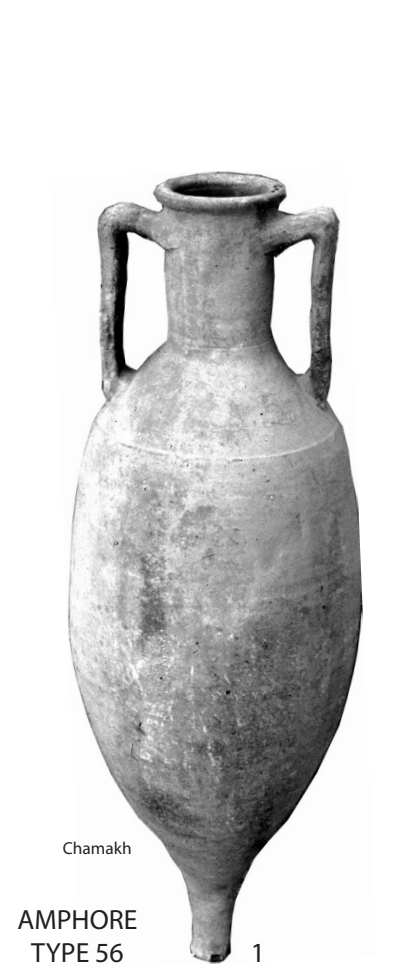

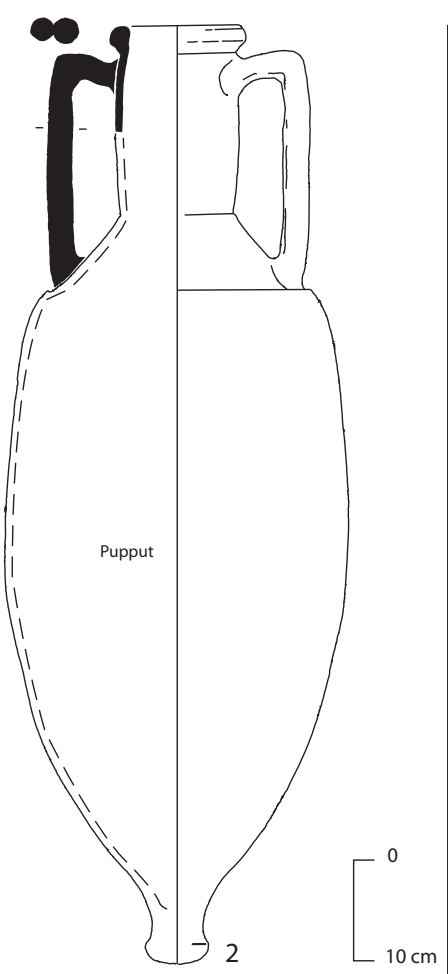

Type Schöne-Mau XXXV
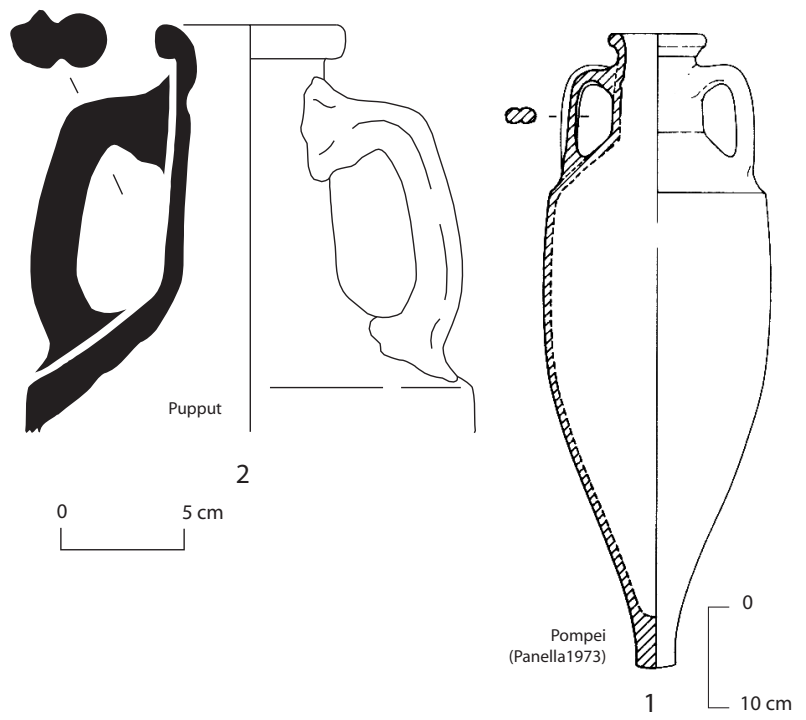

AMPHORE

TYPE 58

Type pseudo-Dressel 2/4

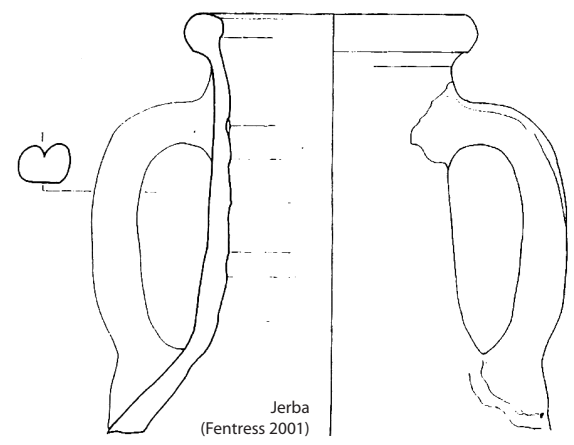

(Fentress 2001)
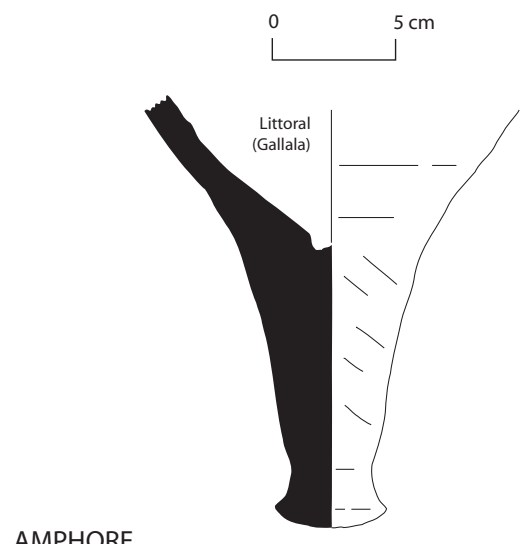

AMPHORE TYPE 57

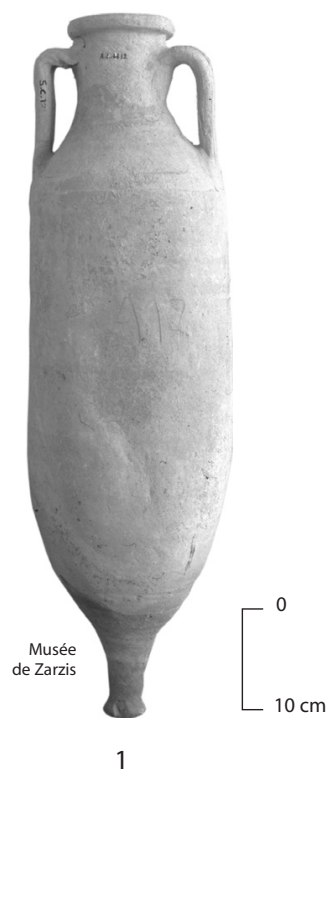

3
Type pseudo-Dressel 1

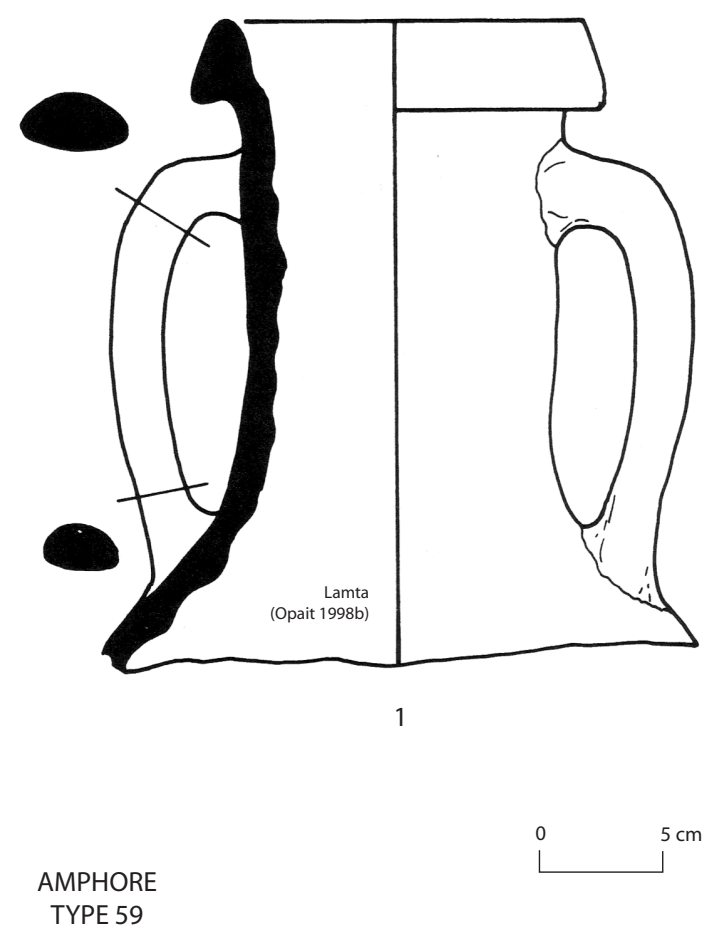

Fig. 79. Imitations africaines de types italiques. 
tripolitaine » (voir également Villedieu 1984, 180). A cet argument, et bien que la pâte ne soit pas semblable à celles de Tripolitaine orientale (Panella 1973, 471), s'ajoutait également le fait que la variante ancienne de ces amphores est représentée sur une mosaïque de Dougga (Yacoub 1996, fig. 100).

Mais l'hypothèse qui a cours actuellement est plutôt que ces amphores sont d'origine sicilienne (Wilson 1990, 264 et fig. 224 ; Freed, Wilson, 1999, 268 ; Wilson 2000, 361-363 et fig. 20). De fait, la mention d'une production de ce type à Thaenae (Ben Lazreg et al. 1995, 131) doit être désormais abandonnée, au vu du résultat des analyses pétrographiques de $\mathrm{Cl}$. Capelli (inédit). De même, l'exemplaire de Pupput (Bonifay 2004a, fig. 8, $\mathrm{n}^{\circ} 4$ ) est très probablement italique. La présence de cette amphore sur la mosaïque de Dougga ne fait pas grande difficulté dans la mesure où l'on a peut-être voulu évoquer un cru importé, donc de prix, de la même manière que les amphores vinaires orientales de type Kapitän I ou II sont représentées sur des lampes africaines de type Deneauve VII/sous-type 1 (infra, fig. 178, $\mathrm{n}^{\circ} 11$ ).

Pourtant les nombreux exemplaires dans le dépôt d'El Jem ne laissent pas d'interroger (fig. 80) et on pourrait se demander avec J. W. Hayes, qui souligne la difficulté à distinguer les pâtes de Naxos et les pâtes africaines (Hayes in Wilson 2000, 364-365), s'il n'y aurait pas une production d'amphores de typologie similaire dans les deux provinces (voir en particulier le curieux exemplaire « a » de la fig. 80).

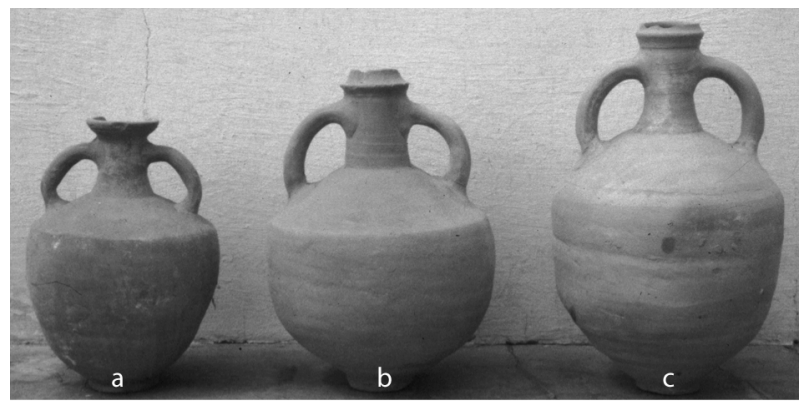

Fig. 80. Amphores italiques (?) Agora M254 (dépôt de fouille d'El Jem).

\section{Imitations du type gaulois}

\section{— type Dressel 30 (fig. 81-82)}

\section{AMPHORE TYPE 60}

Depuis la mise en évidence, sur des bases tout d'abord épigraphiques (supra, p. 15) puis archéologiques (Laporte 1976-78), d'une production d'amphores assimilables au type Dressel 30 (1) sur le territoire de la cité de Tubusuctu (actuelle Tiklat, en Algérie), on a eu tendance à faire de manière trop systématique une équivalence entre cette typologie et l'origine des conteneurs : c'est ainsi qu'est née l'appellation «amphores de Maurétanie
Césarienne » pour désigner l'ensemble des amphores africaines qui imitent, de près (1) ou de loin (2), les amphores gauloises à fond plat (Panella 1973, 600-605 ; Manacorda 1977, 149-151).

Dans ces conditions, la révélation que des amphores apparentées au type Dressel 30 aient pu être également produites en Tunisie, revêt un intérêt particulier. Cette observation a été faite pour la première fois sur un site d'atelier peu évident, El-Assa, situé sur la côte nord-ouest du cap Bon (Ben Lazreg et al. 1995, 131 et fig. 12, n 89) (11-15), puis elle a été confirmée de manière irréfutable sur un atelier de la périphérie de Nabeul, Sidi Aoun (supra, p. 37 ; Ghalia, Bonifay, Capelli 2004) (810). En fait, l'extrême variété morphologique et pétrographique des amphores attribuables au type Dressel 30 oblige désormais à admettre une grande diversité de provenance, au sein de l'aire africaine.

Exemples (fig. 81-82) :

Production de Maurétanie Césarienne (?) (fig. 81) : variante Keay $1 \mathrm{~A}$

*1 Annaba/Bougie, forme recomposée (Panella 1973, $\left.630, \mathrm{n}^{\circ} 33\right)$. variante Keay $1 \mathrm{~B}$

*2 Epave Saintes-Maries-de-la-Mer 19 (Long 2002, fig. 36, c).

Production de Proconsulaire (Salakta ?) (fig. 81) :

*3 Epave Plemmirio B (Gibbins 2001, fig. 2). Pâte identique aux amphores Africaines I et II A de la cargaison.

Production de Proconsulaire (cap Bon) (fig. 81) :

*4 Ostia I, 536 (cf. Panella 1973, 602). Timbre $C A S$ en creux, dans un cadre. Pâte rouge vif, surface blanc crème. Origine hypothétique.

*5 Nabeul, fabrique de salaison, bassin XVII (Inv. NB1055.3).

*6 Nabeul, fabrique de salaison, bassin XLVI (sans $\mathrm{n}^{\circ}$ d'inv.).

*7 Nabeul, fabrique de salaison, bassin XXXI (Inv. NB1186.74).

8-10 Nabeul, Sidi Aoun, atelier (supra, fig. 17, $\mathrm{n}^{\circ}$ 10-12).

11-15 El Assa, atelier (supra, fig. 19, El Assa, $n^{\circ}$ 5-9).

Production indéterminée (fig. 82) :

*16 Pupput, tombe 680 (Inv. PP3769.1). Pas de quartz éolien : non africain?

*17 Pupput, tombe 2376 (Inv. PP7404.2). Marque incisée : L, sur le col. Pâte beige, surface verdâtre. Traces de poix à l'intérieur. Présence de quartz éolien.

*18 Pupput, tombe 2376 (Inv. PP7404.3). Marque incisée : $\mathrm{L}$, sur le col. Présence de quartz éolien.

J'ai peu d'informations nouvelles sur les productions de Maurétanie Césarienne (1-2) ; le type Keay IB est bien attesté dans les contextes du milieu du IVe s. à Arles ${ }^{128}$. En revanche, on distingue assez nettement une ébauche d'évolution au sein des exemplaires néapolitains : ceux $\mathrm{du}$ deuxième quart ou milieu du IIIe $\mathrm{s}$. (5), auxquels se rattache peut-être un exemplaire d'Ostie avec un timbre $C A S$ (4), ceux de la fin du IIIe s. ou du début du IVe s. (6) et ceux de la seconde moitié du IVes. (7). L'atelier de Salakta semble également avoir produit des amphores de type Dressel 30 (3), d'après les analyses de pâtes qui ont

\footnotetext{
${ }^{128}$ Etude et renseignement J. Piton.
} 
Type Dressel 30

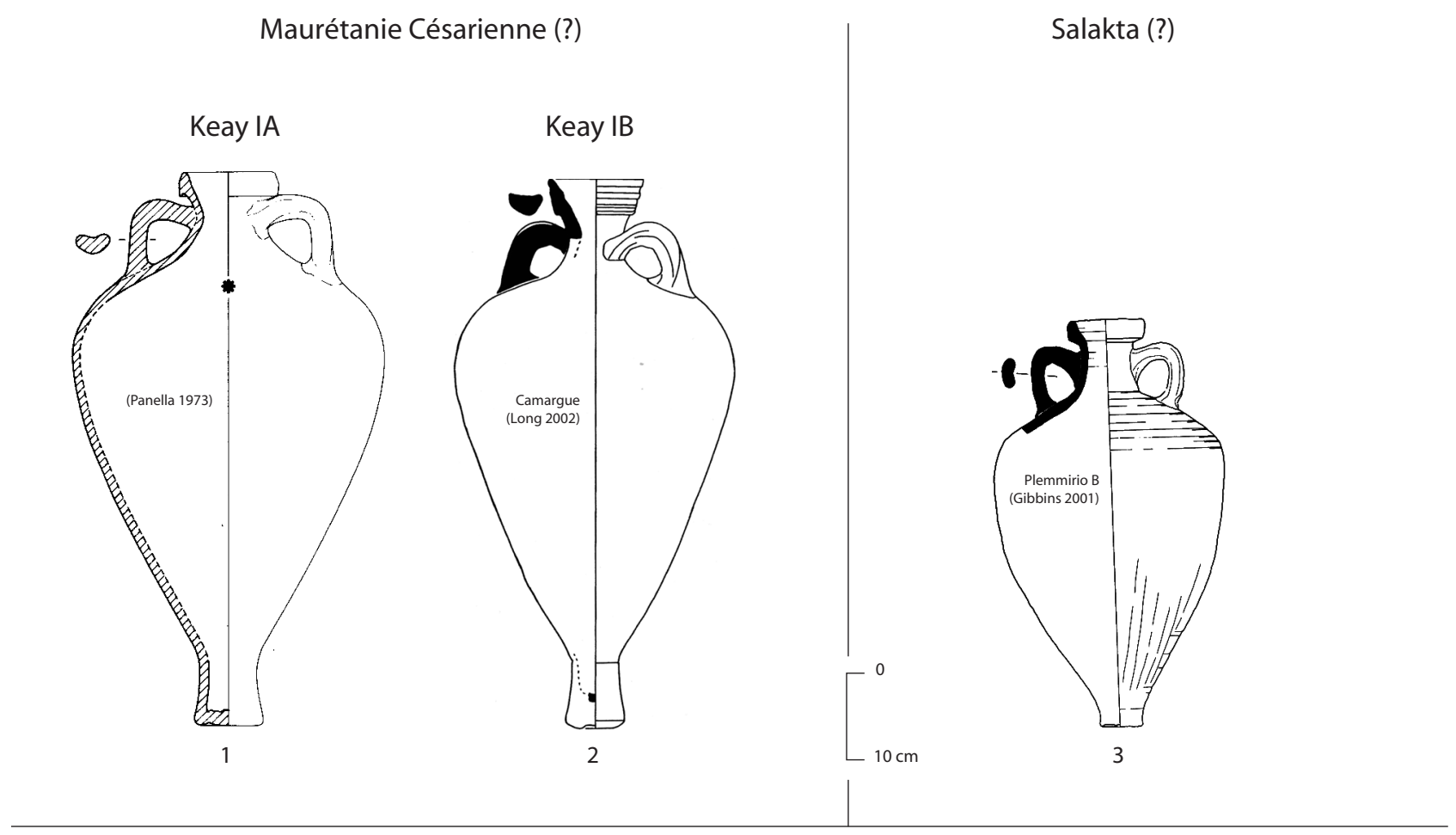

Cap Bon (?)
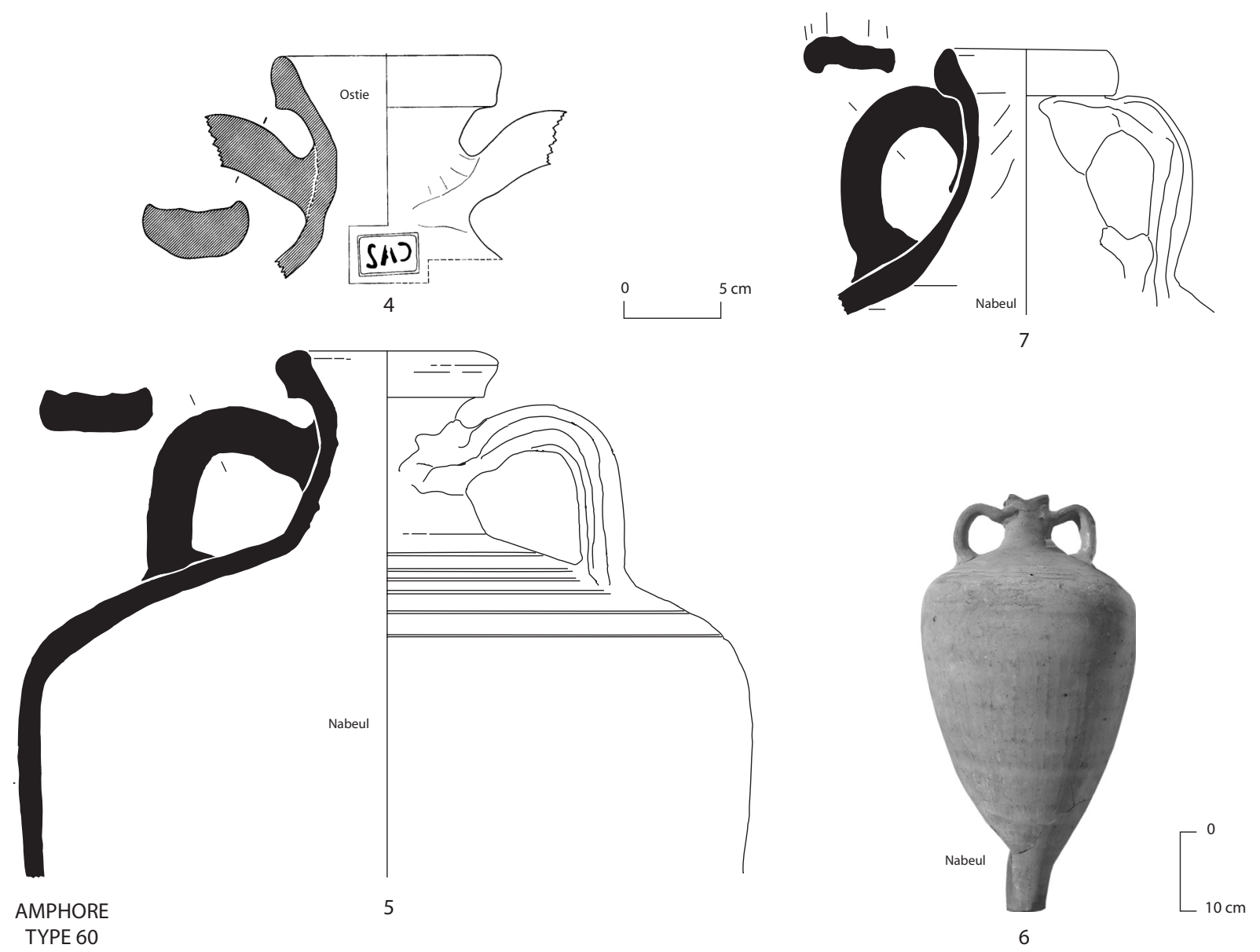

Fig. 81. Imitations africaines du type gaulois. 
Typologie - Amphores

Type Dressel 30 (?)

origine inconnue

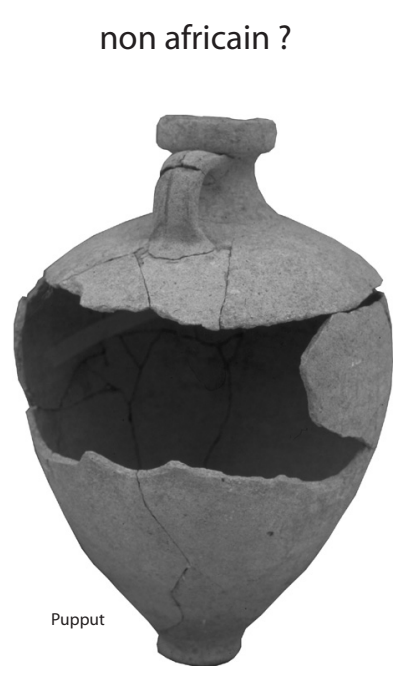

16

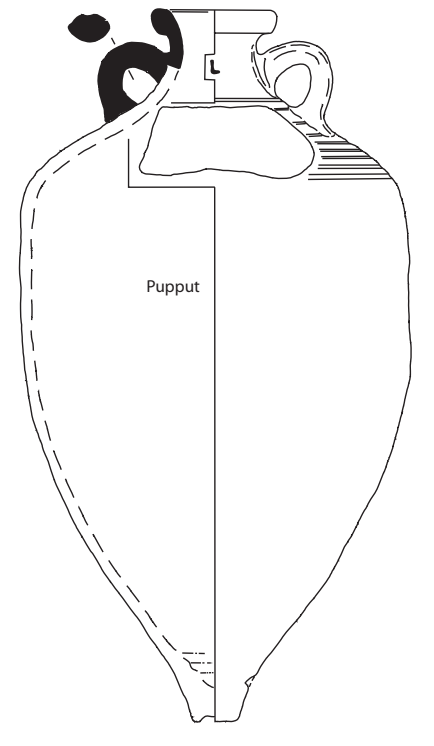

17
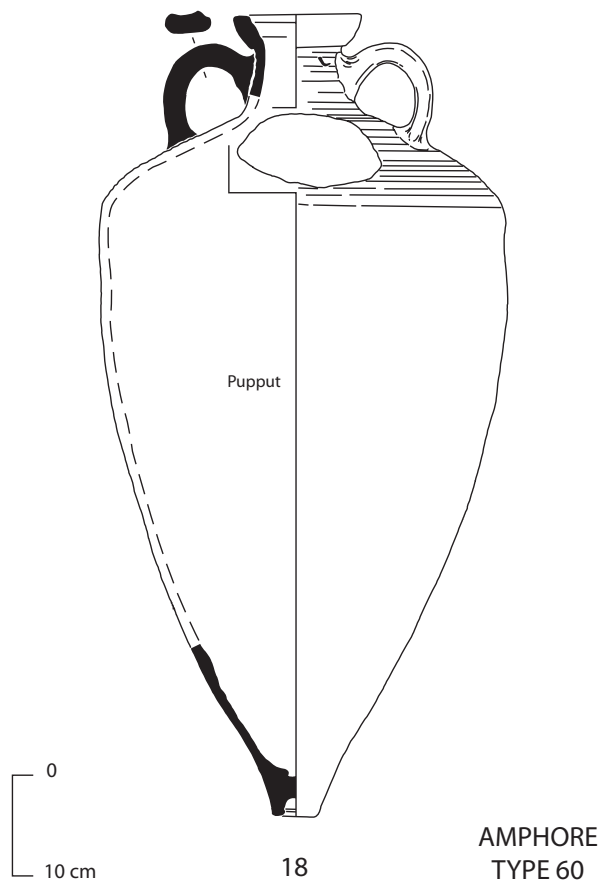

Type Ostia IV, 172 (?)

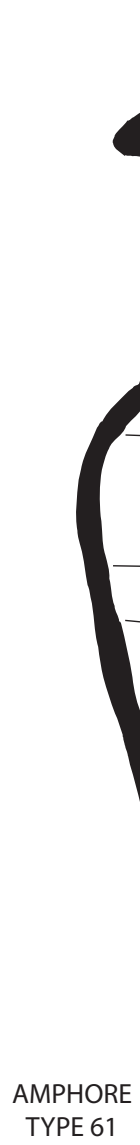

Type Ostia IV, 263

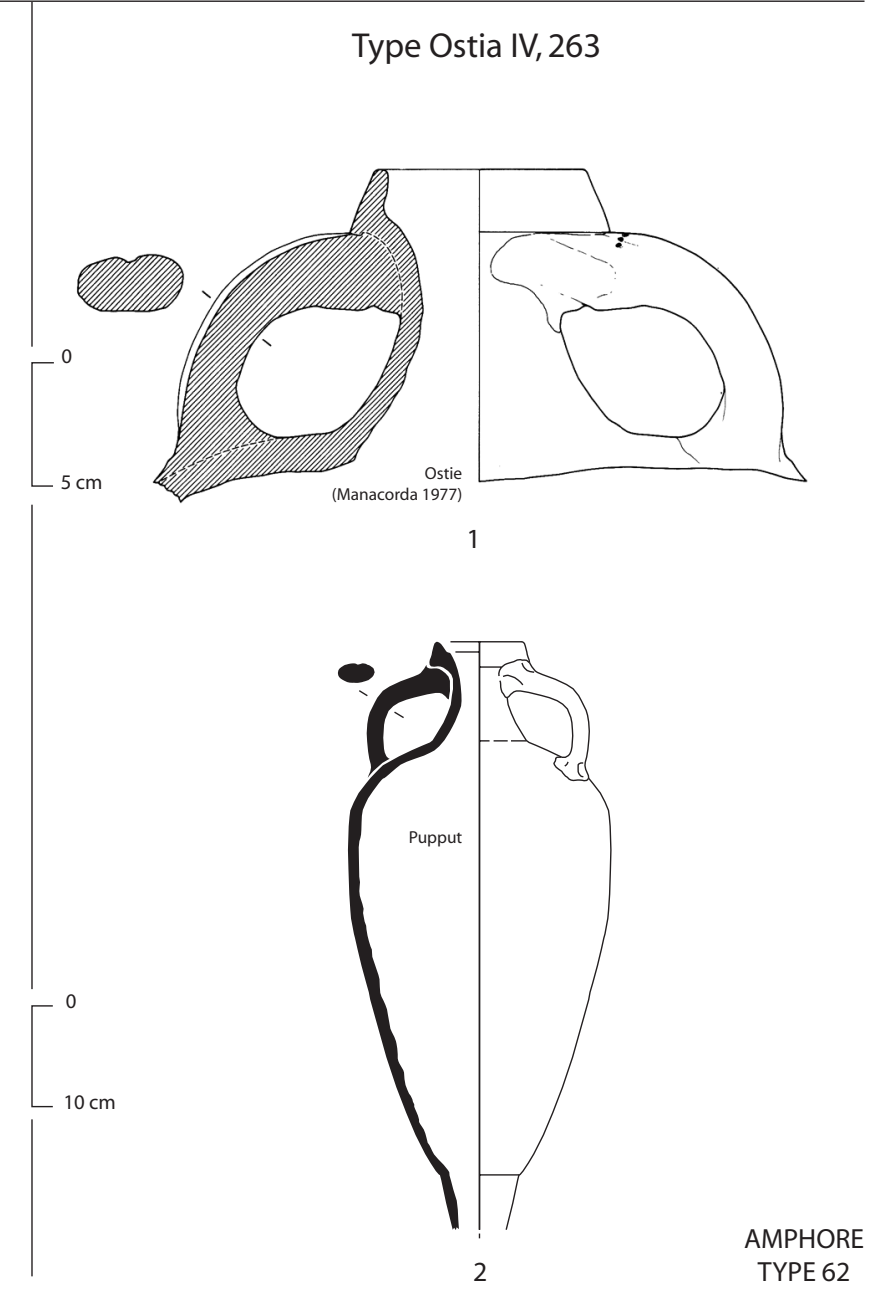

Fig. 82. Imitations africaines de types gaulois ou hispaniques. 
été faites sur l'exemplaire de l'épave de Plemmirio B, datée de la fin du IIe s. ou du début du IIIe s. (Gibbins 2001, 313). Enfin, j'ignore l'origine précise d'une petite amphore, proche du type Dressel 30 mais probablement non-africaine (?) ${ }^{129}$, représentée en plusieurs exemplaires dans les tombes de la première moitié du IIIe $\mathrm{s}$. de la nécropole de Pupput (16). Deux autres exemplaires, plus sûrement africains, provenant d'une même tombe, ont une forme un peu particulière, avec un épaulement cannelé et un fond très pointu (17-18).

S'agissant d'une imitation d'amphore gauloise, il semble assez évident que cette amphore était destinée à la commercialisation du vin africain local (contra : Laporte 1976-78; cf. l'intervention de J. Desanges sur les amphores Dressel 30 de Meroë in Ben Lazreg et al. 1995, 141-142, discussions). Le $\mathrm{n}^{\circ} \mathbf{2}$ est poissé (Long 2002, 57). Toutefois, les larges ouvertures pratiquées sur l'épaulement des $\mathrm{n}^{\circ} \mathbf{1 7}$ et $\mathbf{1 8}$ pourraient aller à l'encontre de cette hypothèse (infra, p. 468).

Deux autres formes se distinguent assez nettement de la série précédente :

\section{— type Ostia IV, 172 (?) (fig. 82)}

\section{AMPHORE TYPE 61}

Amphore de petite taille, à corps piriforme, avec un col très resserré et un bord à lèvre haute, à face extérieure concave et légèrement cannelée, formant un bourrelet proéminent à la jonction avec le col. Les anses, à section en « $\mathrm{S} »$, s'attachent au sommet du col et sur l'épaulement.

Exemple (fig. 82) :

*1 Pupput, enclos 55 (Inv. PP1756.1). Pâte orange, surface beige.

Cette amphore ne doit pas être confondue avec le type Keay IB ; elle pourrait plutôt se rattacher au type Ostia IV, 172 (Manacorda 1977, Pl. XXVII et fig. 522 ?). La datation de cet exemplaire ainsi que d'autres fragments provenant d'Aquilée ${ }^{130}$ est cohérente avec celle des niveaux d'abandon du mausolée 55 de la nécropole de Pupput : le IVe siècle.

\section{— type Ostia IV, 263 (fig. 82)}

\section{AMPHORE TYPE 62}

Amphore de petite taille à corps piriforme, avec un col très resserré et un bord en baïonnette, à lèvre triangulaire légèrement rentrante. Les anses, en ruban, parcourues d'un profond sillon médian, s'attachent immédiatement sous le bord et reposent sur la face plane de l'épaulement. Le fond est tubulaire, creux.

\footnotetext{
${ }^{129}$ Pas de quartz éolien dans la pâte.

130 Fouilles du port fluvial dirigées par M.-B. Carre et C. Zaccaria; étude du matériel et renseignement Corinne Rousse.
}

Exemples (fig. 82) :

*1 Ostia IV, 263 (Manacorda 1977, Pl. XXXVII).

*2 Pupput, enclos 31 (Bonifay 2004a, fig. 8, $\mathrm{n}^{\circ}$ 5). Pâte orange clair, avec inclusions de quartz éolien.

Cette forme est assez proche du type hispanique Almagro $51 \mathrm{C}$, avec lequel elle a été dans un premier temps confondue (Bonifay 2004a, 22, voir cependant la note 9), et dont elle constitue peut-être une imitation(?). La présence de quartz éolien dans la pâte ${ }^{131}$ nous incite à la rattacher au type africain Ostia IV, 263 (Manacorda 1977, 152-153), dont la datation au IVe s. correspond à celle de l'exemplaire de Pupput. Ce type est également attesté à Aquilée ${ }^{132}$ et à Lepcis Magna ${ }^{133}$ dans les mêmes horizons chronologiques. Une variante avec un bord plus détaché des anses, comparable à un exemplaire de Brescia (Bruno 2002, 301, $\mathrm{n}^{\circ} 57$ et 62 ?), apparaît en plusieurs exemplaires à Nabeul, dans des contextes de la seconde moitié du IIIe s. et du début du IVe s. (inédit). Aucune indication de contenu.

\section{Imitations d'amphores hispaniques}

A. Opait a émis l'hypothèse que son type Leptiminus I puisse être une imitation d'amphore hispanique Dressel 14. Nous avons vu (supra, TYPE 12) que cette forme pouvait être également interprétée comme une variante locale du type punique romanisé Carthage Early Amphora IV. Personnellement, j'hésite à trancher, de même que pour l'origine de la curieuse forme Uzita P1. 52, 10 (supra, TYPE 18) qui ressemble, de loin, à une amphore hispanique Dressel 7-11. Ces deux séries d'amphores hispaniques, tout comme la forme Almagro 51c précédemment évoquée à propos du type Ostia IV, 263 (TYPE 62), sont destinées au transport des salaisons de poissons.

\section{Imitation des types orientaux}

Il semble que les potiers africains ont réalisé, aux $\mathrm{Ve}$ ou VIe s., des imitations du type cilicien (ou chypriote) $L R A 1$, si l'on en croit un exemplaire exposé dans la salle des amphores du Musée de Carthage et une découverte inédite de Naples ${ }^{134}$.

\subsection{AMPHORES DE TYPE BYZANTIN}

Les amphores africaines à corps globulaire, mises en évidence pour la première fois par Giovanni Murialdo (Sant'Antonino 1988, 362-364), ont été généralement toutes rapportées au « type Castrum Perti » ou « anfore a fondo umbonato » (voir désormais Murialdo 2001, 289291). Mais les fouilles récentes menées sur d'autres sites de Méditerranée septentrionale (Rome) et en Tunisie

\footnotetext{
${ }^{131}$ Observations Cl. Capelli.

132 Voir note 123 .

${ }^{133}$ Prospections sous-marines, sous la direction d'A. Laronde.

${ }^{134}$ Renseignement Michel Pasqualini.
} 


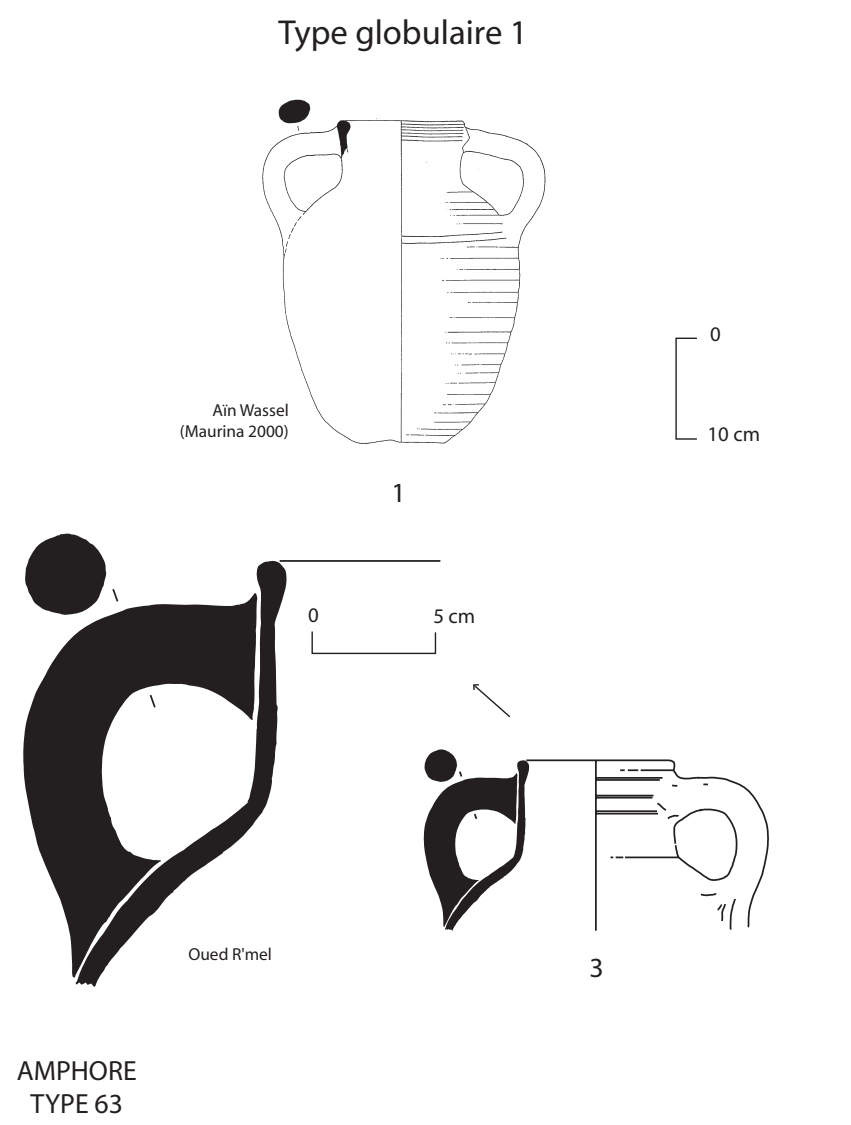

TYPE 63

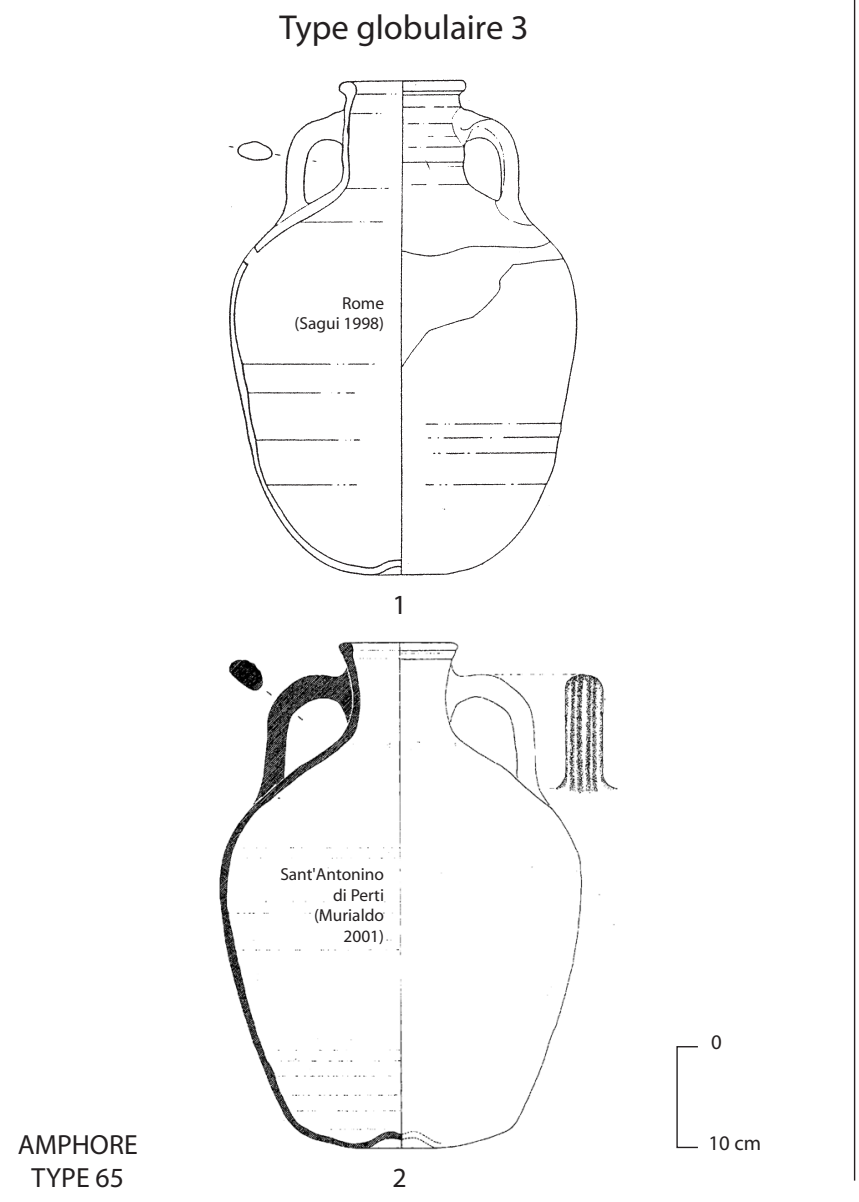

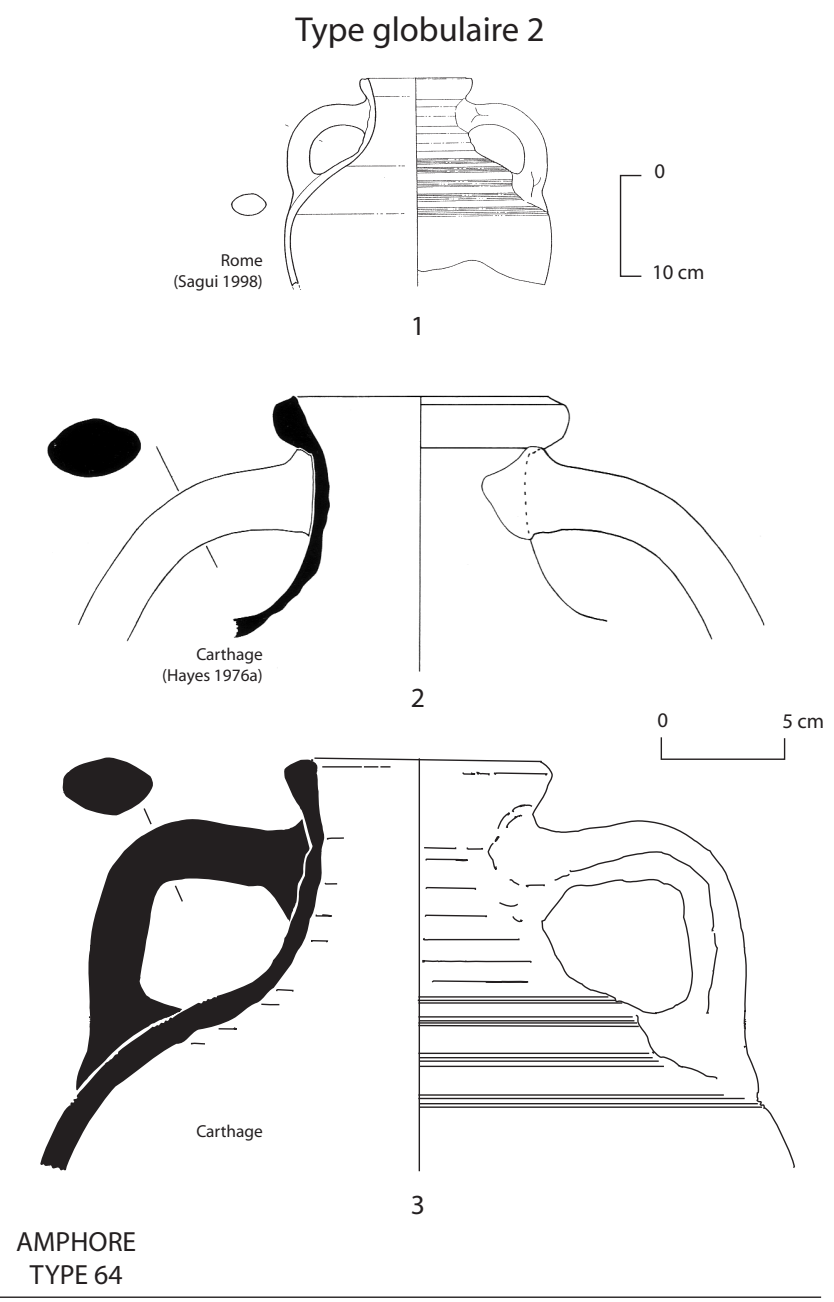

Type globulaire 4
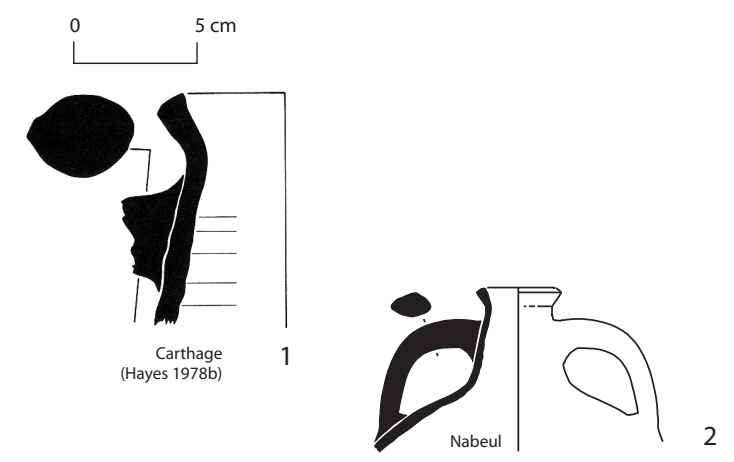

AMPHORE

TYPE 66

Fig. 83. Amphores africaines de type byzantin. 
(Nabeul, Dougga) permettent aujourd'hui d'entrevoir une plus grande diversité typologique. En fait, cette série d'amphores semble conjuguer deux paramètres typologiques : d'une part l'influence, déjà signalée à plusieurs reprises (Keay 1998, 148-149; Saguì 1998, 315), du modèle oriental d'amphores sphériques (LRA 1 tout autant que $L R A 2$ ), d'autre part la tradition punicoromaine des aiguières africaines, à une ou deux anses, généralement dotées d'un fond ombiliqué (voir par exemple Van der Werff 1982a, fig. 9, $\mathrm{n}^{\circ} 2 \mathrm{a}$; Fulford 1984b, fig. 83, $\mathrm{n}^{\circ}$ 55) (infra, COMMUNE TYPES 45-47). D'où, à mon sens, une difficulté : en contexte africain, et surtout en présence d'un simple fragment de fond, il est parfois difficile de décider si l'on a affaire à une amphore de transport ou à une cruche (je considère maintenant comme douteux le fragment de Sidi Jdidi : Ben Abed, Bonifay, Fixot 1997, fig. 11, $\mathrm{n}^{\circ}$ 66).

Dans l'état actuel de nos connaissances, il est possible de distinguer quatre types principaux :

- type globulaire 1 (fig. 83)

\section{AMPHORE TYPE 63}

Type Aïn Wassel (Maurina 2000, Pl. VII) : avec une hauteur inférieure à celle des «spatheia » du type 3 (33 $\mathrm{cm}$ ), une large embouchure (D. $13 \mathrm{~cm}$ ) par rapport au faible diamètre de la panse (D. max. $24 \mathrm{~cm}$ ), des anses massives à section ronde et un fond ombiliqué, ce vase est plus proche d'une cruche que d'une amphore de transport; un doute subsiste sur sa fonction. Exemples (fig. 83) :

*1 Aïn Wassel (Maurina 2000, Pl. VII).

2 Sidi Jdidi, basilique 2 (Inv. JD2170.01).

*3 Oued R'mel (fouilles T. Ghalia, Inv. OR1601.1).

Il est attesté non seulement dans la région de Dougga (1) mais également dans le golfe d'Hammamet (2-3), dans des contextes du VIIe siècle.

\section{- type globulaire 2 (fig. 83)}

\section{AMPHORE TYPE 64}

Type Carthage F11-12 (Hayes 1976a, 120 et fig. 21) : ce vase de forme sphéroïde est surtout caractérisé par un bord à tendance bifide et la présence occasionnelle (?) d'un décor peigné sur l'épaulement, trahissant peut-être l'influence des amphores LRA 2; les anses sont de section ovale ou ronde et, bien qu'aucun exemplaire complet ne soit connu, le fond est supposé être bombé.

Exemples (fig. 83) :

*1 Rome, Crypta Balbi (Saguì 1998, fig. 8, n 3).

*2 Carthage (Hayes 1976a, fig. 21).

*3 Carthage, maison de la Rotonde (fouille J.-P. Darmon, Inv. 180.118).

Ce type est bien attesté à Carthage (2-3 ; ce dernier provient des fouilles de J.-P. Darmon dans la « maison de la rotonde ") ainsi qu'à Rome (1) et à Barcelone (Remolà 2000, 168 et fig. 46, $\mathrm{n}^{\circ} 3$ ) dans des contextes du VIIe $\mathrm{s}$. avancé.

\section{- type globulaire 3 (fig. 83)}

\section{AMPHORE TYPE 65}

Type Castrum Perti (Murialdo 2001, type 47, P1. 18, $\mathrm{n}^{\circ}$ 216-220) : il s'agit de conteneurs plus volumineux $(\mathrm{H}$. env. $50 \mathrm{~cm}$ ), cylindro-sphériques plutôt que proprement globulaires (en cela, ils se rapprochent des variantes les plus tardives d'amphores $L R A 1$ ), à anses coudées et fond ombiliqué.

Exemples (fig. 83) :

*1 Rome, Crypta Balbi (Saguì 1998, fig. 8, $\mathrm{n}^{\circ} 4$ ).

*2 Sant'Antonino di Perti (Murialdo 2001, Pl. 18, n²16).

Ce type domine à Sant'Antonino di Perti (2) et à Rome (1) dans les contextes de la seconde moitié du VIIe s. (Murialdo 2001, 290-291 ; Saguì 1998, 31) mais, curieusement, n'a pas été jusqu'à présent signalé de manière certaine en Afrique.

\section{- type globulaire 4 (fig. 83)}

\section{AMPHORE TYPE 66}

Type Benghazi LRA 13 (Riley 1979, 231): je propose d'utiliser cette référence typologique pour caractériser une amphore dont la forme évoque les variantes les plus tardives du type $L R A 2$, et qui semble produite en plusieurs points du bassin méditerranéen.

Exemples (fig. 83) :

*1 Carthage (Hayes 1978b, fig. 9, $\mathrm{n}^{\circ} 25$ ).

*2-3 Nabeul (Bonifay 2002, fig. 8, $n^{\circ} 8, n^{\circ} 50-51$ ).

Ce type est attesté dans les niveaux byzantins tardifs de Carthage (1) ou immédiatement post-byzantins (?) de Nabeul (2-3). 

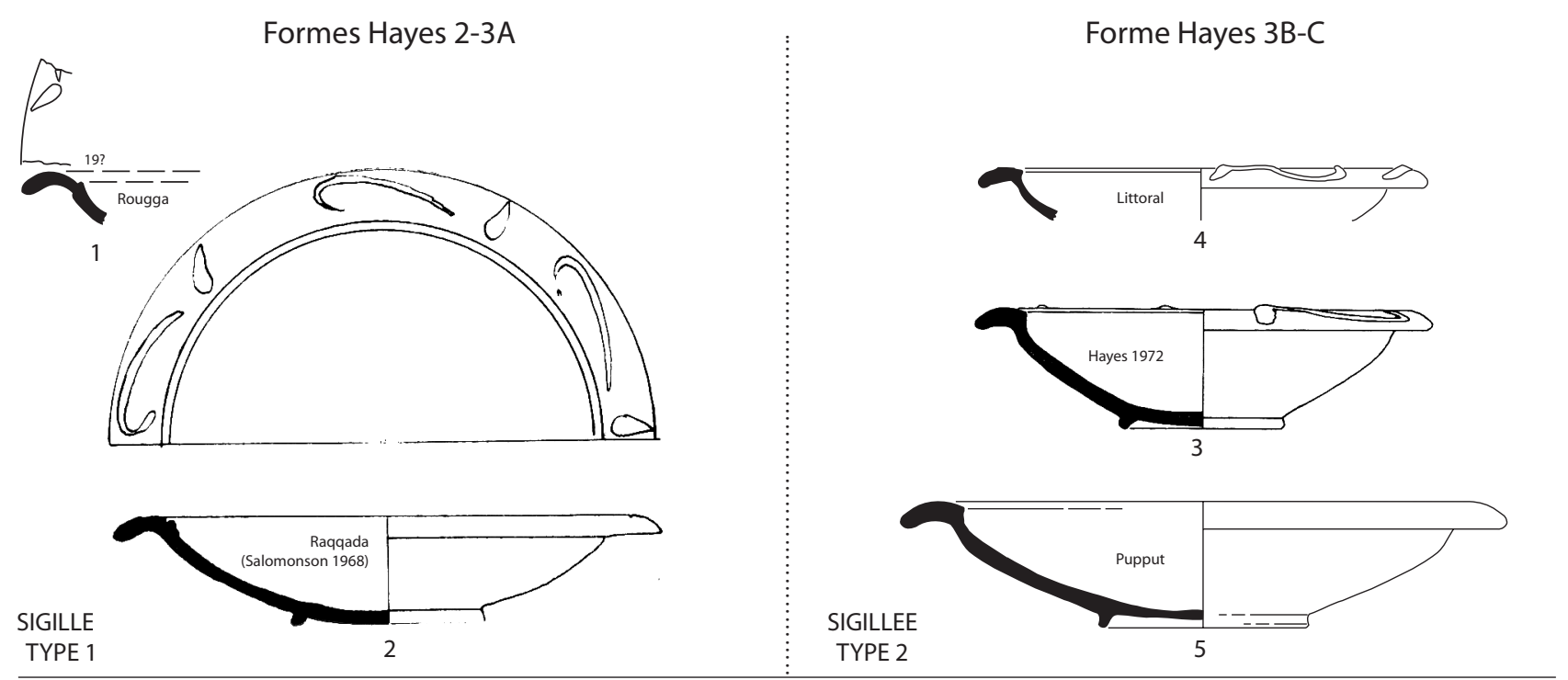

Forme Hayes 8
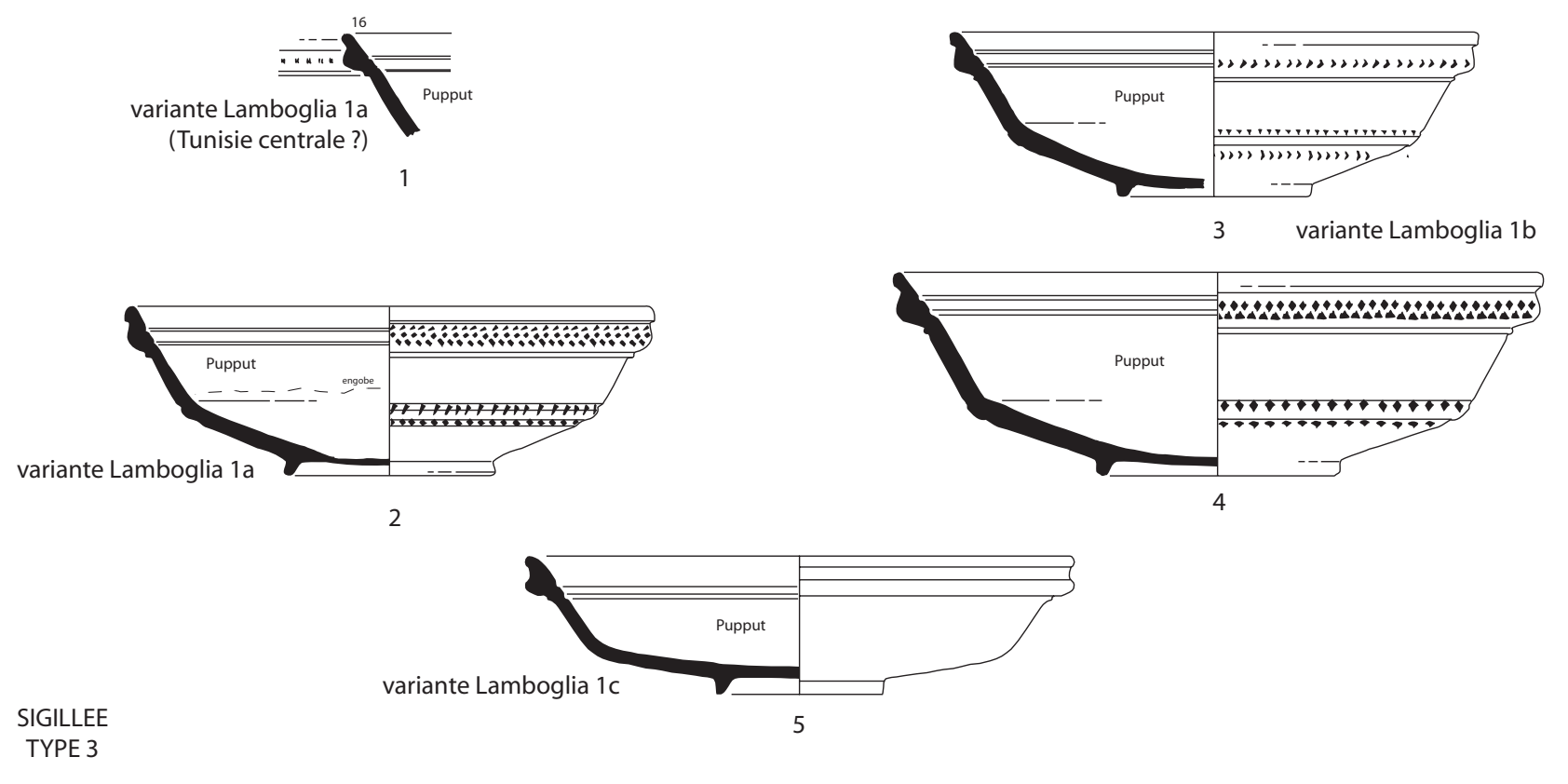

Forme Hayes 10

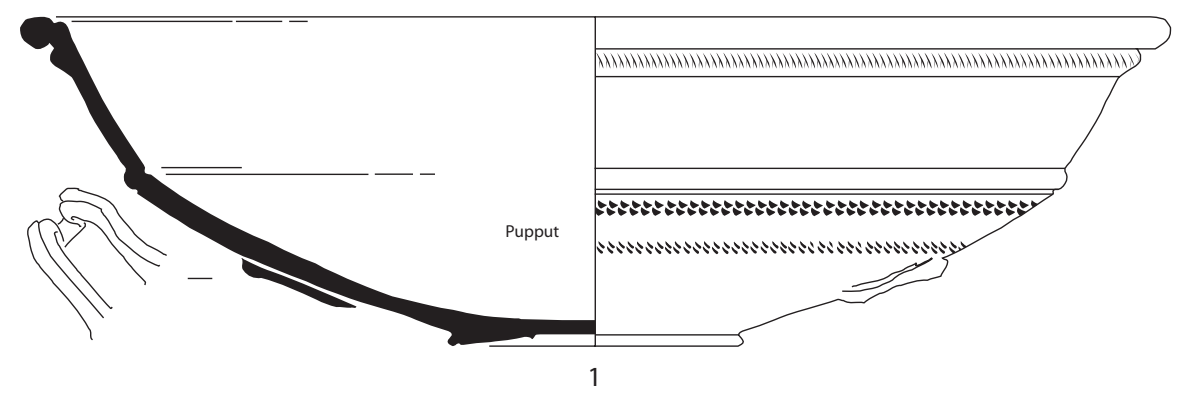

Fig. 84. Vaisselle sigillée africaine A. 


\section{LA VAISSELLE}

La vaisselle retrouvée sur les chantiers africains peut se répartir en quatre grandes catégories :

- les céramiques sigillées,

- les céramiques culinaires,

- les céramiques communes,

- les céramiques modelées.

La sigillée africaine représente l'essentiel des céramiques fines produites en Afrique du IIe au VIIe siècles. Sans revenir sur les céramiques à vernis noir puniques, dont cependant on ne cerne pas encore très bien la fin de la production (Morel 1982, 55), ni sur l'erreur d'attribution qui a fait considérer comme africaine une céramique campanienne du Ier s. ap. J.-C., la pseudo «tripolitanian sigillata » (Soricelli 1987), il suffit de rappeler que l'Afrique des deux premiers tiers du Ier s. importe une grande quantité de céramique fine, d'origine italique (Guéry 1987, 150 ; Id. 1992 et 1994), gauloise (Guéry 1982 ; Bourgeois 1986) et, dans une moindre proportion, hispanique (Th. Martin in Bonifay et al. 2002-2003) et orientale (Hayes 1976a, 77). Elle importe aussi de la céramique à parois fines (Ibid., 78), catégorie que pourtant, mais peut-être un peu plus tard, elle produit également. On pensera ici aux exemplaires de Pupput (Bonifay 2004a, fig. 16, $\mathrm{n}^{\circ}$ 55) et de Sétif (Guéry 1985a, 343 et Pl. XXVI). Une autre catégorie apparaît de manière assez peu abondante : la céramique à glaçure plombifère. Il convient, bien sûr, de distinguer ici les productions de haute époque, bien attestées à El Jem, où on a cru pouvoir déceler les traces d'une production (Slim $1985,81)$ mais également présentes, quoique de manière discrète, à Pupput (Bonifay 2004a, 41 : un bol à décor de pomme de pin dans une tombe de la première moitié du IIIe s.), et les productions de l'époque byzantine. Ces dernières sont attestées à Carthage par quelques tessons de « Constantinople Glazed White ware » et de probables imitations locales (Hayes 1978b, 93). La première catégorie de vaisselle examinée sera donc la céramique sigillée africaine.

Je regroupe dans la catégorie des céramiques culinaires (= ceramica da cucina $=$ Cooking wares $)$ toute la céramique africaine tournée destinée à aller au feu, qu'elle soit ou non partiellement couverte d'un engobe. En cela, je suis pleinement la tradition d'étude italienne (Atlante I, 208), préférable, à mon sens, à une conception anglo-saxonne (par exemple : Fulford, Peacock 1984 et 1994 ; Dore 1989) qui regroupe les céramiques culinaires avec les autres céramiques communes. En effet, la céramique culinaire africaine produite au tour présente une réelle originalité et des qualités techniques qui ont favorisé son exportation lointaine et massive (Ikäheimo 2003, 127); la standardisation de son répertoire de formes a en outre suscité une abondante littérature.
Les céramiques communes (= ceramica comuna = Domestic wares) sont définies comme des «céramiques ordinaires sans vernis grésé et généralement sans décor, à pâte parfois grossière " (Bats 1996, 481). Elles ne sont pas destinées à porter les aliments au feu, fonction assumée par la catégorie précédente, mais parfois à recevoir le feu lui-même (braseros) et, le plus souvent, à réaliser certaines préparations culinaires (mortiers), à suppléer les céramiques sigillées sur la table (bols, cruches, céramique peinte), à conserver certaines denrées (jarres) et à tenir, dans les actes de la vie quotidienne, la place qui est, de nos jours, celle des ustensiles en matière plastique (bassins multi-usages).

Enfin, j’ai préféré réserver une catégorie spécifique à la céramique modelée, plutôt que de noyer ces produits dans une catégorie fonctionnelle (en les associant par exemples aux autres céramiques culinaires), alors même que la plupart de ces objets (mais pas tous), sont effectivement destinés à la cuisson.

\subsection{LES SIGILLÉES AFRICAINES}

$\mathrm{Au}$ sein de toutes les sigillées méditerranéennes, la sigillée africaine occupe une place dominante en raison du caractère massif de sa production et de sa diffusion (dont témoigne le nombre de pages qui lui est consacré à la fois dans Hayes 1972 et dans l'Atlante I). C'est, durant la période qui nous occupe, du IIe au VIIe s., une céramique vraiment universelle. Il s'ensuit qu'un grand nombre de références s'ajoutent, se recoupent et sont susceptibles de fournir, pour tous les sites du bassin méditerranéen, une échelle chronologique commune. Or, il faut bien admettre que le plus grand désordre règne actuellement non seulement dans la classification des pâtes (supra, p. 45-53) mais également dans la typologie et la chronologie de cette céramique (Bonifay et al. 1998, 361).

On est tout d'abord frappé par le foisonnement des références typologiques. Le manque de coordination des recherches a conduit à multiplier les classements (Waagé 1948 ; Lamboglia 1958 et 1963 ; Salomonson 1968 ; Hayes 1972; Fulford 1986a; Mackensen 1993). A l'inverse, le désir d'attribuer le moindre tesson à une forme dûment répertoriée fait parfois ranger sous une même étiquette des choses différentes : il n'y a qu'à songer à la confusion qui entoure la classification des plats Hayes 61B (Bonifay 1998a) ou des mortiers Hayes 91. D'autre part, la chronologie de cette céramique devient labyrinthique. Il y a une sorte de non-dit sur le flou de la datation des sigillées africaines : on les suppose bien connues, on les utilise pour dater d'autres 
céramiques ou pour appréhender l'évolution des courants commerciaux (Fentress, Perkins 1988 ; Reynolds 1995 ; Lund 1995 ; Zanini 1998 ; Fentress et al. 2004), mais, dans le détail, les variations chronologiques sont considérables: il suffit de prendre l'exemple de la datation de la forme Hayes 99. Il est inutile de discuter ici les datations de Lamboglia (1958 et 1963), périmées pour tout ce qui ne concerne pas sa catégorie A, ou celles de Waagé (1948) qui ont servi de base au système présenté par Hayes (1972). En revanche, il convient de réhabiliter ce dernier, tout au moins dans ses grandes lignes: en effet, comme l'a très bien démontré M. Mackensen, (1993, 385-396), les propositions de refonte drastique de ce système, basées sur des ensembles de mobilier dont l'homogénéité ou les critères de datations sont parfois critiquables, ne sont pas convaincantes (Bonifay et al. 1998, 362). Même P.-A. Février, après avoir longtemps critiqué la typologie de J. W. Hayes auquel il reprochait de n'avoir « connu l'Afrique et l'Occident qu'à travers les musées et très rarement les fouilles » (Février 1976, 7), finissait par reconnaître que «le système a une cohérence » (Février 1992, 248).

Au risque d'ajouter encore à la confusion générale, je présente ci-après les quelques nouvelles données typologiques et chronologiques que j'ai pu réunir sur les deux rives de la Méditerranée, en me proposant de suivre un peu la démarche de retouches appliquée par J. W. Hayes dans son Supplement (Hayes 1980a). Je souhaiterais tout d'abord montrer que la typologie de Hayes reste toujours opérante pour l'essentiel des formes rencontrées, au prix peut-être de quelques subdivisions et compléments. Ensuite, il faut mettre en évidence l'existence de typologies locales, correspondant à des productions peu diffusées hors d'Afrique. Enfin, les nouveautés les plus importantes concernent la phase la plus tardive de la fabrication, mais là le travail n'est pas suffisamment abouti pour permettre une refonte complète de la typologie.

\subsubsection{Les formes classiques: subdivisions et compléments}

\section{Catégorie A}

\section{— l'origine des formes Hayes 2 et 3a (fig. 84)}

\section{SIGILLÉE TYPES 1 ET 2}

Je souhaiterais attirer l'attention sur le fait que ces deux formes, caractérisées par la présence d'une cannelure à la jonction du marli et de la panse et dont un tesson a été trouvé à Rougga (1), présentent habituellement une pâte plus fine que la plupart des sigillées africaines A. On rapprochera cette qualité de pâte de celle des exemplaires anciens de la forme Hayes 8 (P1. II, $\mathrm{n}^{\circ} 6$ ), dont un fragment provient également de Rougga (Guéry, Bonifay à paraître, $\left.\mathrm{n}^{\circ} 31\right)$. Cette qualité de pâte, comme cela a été mentionné plus haut (supra, p. 47), rappelle celle de la production $\mathrm{C}$.
Etant donné que cette variante des formes Hayes 2-3 correspond à celle présente sur la nécropole de Raqqada, classée par J. W. Salomonson sous son type A1, et que plusieurs exemplaires proviennent également du centre de la Tunisie (Hayes 1972, forme $2: \mathrm{n}^{\circ} 5-11$ ?, 12 ; forme $3 \mathrm{~A}: \mathrm{n}^{\circ} 4,12-15$ ?), je me demande s'il ne s'agit pas là d'une variante locale, propre à la Byzacène, plutôt que d'une variante précoce, comme cela est généralement supposé (Hayes 1972, 21 et 25 ; Atlante I, 24) ${ }^{135}$. Exemples (fig. 84) :

Formes Hayes 2-3A (TYPE 1 : Byzacène ?) :

*1 Rougga, couche 19 (Guéry, Bonifay à paraître, $n^{\circ} 30$ ).

*2 Raqqada (Salomonson 1968, fig. 14, A1).

Forme Hayes 3B-C (TYPE 2) :

*3 Hayes 1972, forme 3B, $\mathrm{n}^{\circ} 28$

*4 Littoral tunisien, site 16 (El Qantara, Jerba) (Bonifay et al. 2002-2003, fig. $\left.5, \mathrm{n}^{\circ} 25\right)$.

*5 Pupput (Ben Abed, Griesheimer 2004, fig. 46, n².1).

\section{— la datation de la forme Hayes 8 (fig. 84)}

\section{SIGILLÉE TYPE 3}

L'examen du mobilier des tombes de Pupput a mis en évidence un problème de chronologie qui concerne une des formes de sigillée africaine les plus fréquentes dans la nécropole, la forme Hayes 8A. En effet, mis à part quelques exemplaires dont le caractère précoce paraît bien affirmé (variante Lamboglia 1a à lèvre déversée ou à lobe du bord arrondi : 1-2), la plupart des autres vases, toujours de bonne facture, mais qui se rapportent à la variante Lamboglia $1 b$, à lobe du bord plus anguleux (34), sont à placer dans la seconde moitié du IIe siècle ${ }^{136}$. Les exemplaires de la variante Hayes 8B (= Lamboglia 1c) proviennent des niveaux de circulation de la nécropole, au IIIe s. (5).

Exemples (fig. 84) :

*1 Pupput, zone ouverte sud, phase 2 (Ben Abed, Griesheimer 2004, fig. 46, $\mathrm{n}^{\circ} 2.4$ ).

*2 Idem (Ibid., fig. 44, $\mathrm{n}^{\circ} 2.3$ ).

*3 Pupput, tombe 134 (Ibid., fig. 80, T134.2).

*4 Pupput, tombe 603 (Ibid., fig. 65, T603.2).

*5 Pupput (Bonifay 2004b, fig. 15, $\mathrm{n}^{\circ} 44$ ).

On est donc ici dans le cas de figure rare où il faut peutêtre préférer la datation proposée par Lamboglia (1958, 263), à celle de Hayes $(1972,35)$ qui ne fait pas dépasser le milieu du IIe $\mathrm{s}$. à son type $8 \mathrm{~A}$ et la fin du siècle à son type $8 \mathrm{~B}$.

\section{— forme Hayes 10 à anses plaquées (fig. 84)}

\section{SIGILLÉE TYPE 4}

Une attention particulière doit être portée à une variante de la forme Hayes 10 qui vient s'ajouter à celles reconnues par A. Carandini (1976). Deux exemplaires de Pupput (1-2), de grande taille (D. : $35 \mathrm{~cm}$ ), sont munis de

135 D'autant que Salomonson $(1968,99)$ signale que les deux variantes (avec ou sans sillon à la jonction du bord et de la paroi) « semblent être plus ou moins contemporaines (fin du Ier et première moitié du IIe $\mathrm{s}$.) ».

${ }^{136}$ Lampe avec marque incisée LVCCEI dans la tombe 134. 
deux petites anses plaquées sur la partie inférieure de la panse. Cette forme rappelle une variante de la forme Hayes 11, voisine de la forme 10, provenant de Carthage (Fulford, Timby 1994, fig. 1.7, $\mathrm{n}^{\circ} 2$ ) et qui porte les mêmes anses plates sur la partie inférieure de la panse. Ce dernier objet provient d'un contexte de la fin du Ier s. ou $\mathrm{du}$ début du IIe s. (Ibid., 79) tandis que les deux exemplaires de Pupput ne sont pas antérieurs au milieu du IIe s. (Bonifay 2004a, 39 et note 67).

Exemples (fig. 84) :

*1 Pupput (Bonifay 2004a, fig. 15, $\mathrm{n}^{\circ} 43$ ).

2 Pupput, tombe 1037 (Inv. PP5184.6).

\section{- formes Hayes 14/17 et 31 : les sigillées africaines « $\mathrm{A} »$ tardives (fig. 85)}

\section{SIGILLÉES TYPES 5-11}

Ces formes, dont la classification est difficile à saisir dans le détail, semblent produites pendant une longue période. Les variantes les plus anciennes (forme Hayes 14A-B, 16 et 17) sont présentes dans les niveaux de circulation de la nécropole de Pupput au IIIe s. (6 : Bonifay 2004a, 39). Si, plus tard, on en perd trace en Byzacène (voir cependant l'exemplaire hors stratigraphie d'El Jem (4), ce n'est peut-être pas seulement par manque de données stratigraphiques mais peut-être aussi en raison de leur faible diffusion dans cette région. En effet, les sites de la façade orientale de la Tunisie sur lesquels j'ai eu l'occasion de travailler semblent alimentés à partir de la seconde moitié du IIIes. par les ateliers de Tunisie centrale (catégorie C) puis, au IVe s., par des ateliers locaux (catégorie D). En revanche, des formes tardives de la catégorie A sont signalées sur un certain nombre de sites de Méditerranée occidentale dans la seconde moitié du IIIe s. et, probablement, encore au IVe siècle.

\section{Exemples (fig. 85) :}

Forme Hayes 14 A [TYPE 5]

*1 Marseille, chantier de La Bourse, épave (Lang 1998, fig. 54, $\left.n^{\circ} 24\right)$.

2 Vintimille (Lamboglia 1958, 265, forme 3a). Variantes

*3 Oudhna, est capitole (fouilles H. Ben Hassen, Inv. UTH7.000.1).

*4 El Jem, maison d'Africa (fouilles H. Slim, Inv. EJMA.000.036).

Forme Hayes 16 [TYPE 6]

*5 Pupput (Inv. PP1803.2).

Forme Hayes 14 B [TYPE 7]

*6 Pupput (Bonifay 2004a, fig. 15, $\mathrm{n}^{\circ} 45$ ).

Forme Hayes 15 [TYPE 8] Variante précoce (Hayes 14/15)

*7 Epave Cabrera III (Fr. Mayet in Bost et al. 1992, fig. $\left.45, \mathrm{n}^{\circ} 1-4\right)$. Parois relativement minces, sommet $\mathrm{du}$ bord arrondi.

8 Puyloubier, villa romaine de Richeaume (fouilles Fl. Mocci ; Inv. RICHI/02.4129.3306).

\author{
Variante classique \\ *9 Vintimille (Lamboglia 1958, 265, forme 3b1). Bord en \\ biseau. \\ Variante tardive \\ 10 Carthage (Fulford 1984a, fig. 71, forme 7.1). \\ *11 Carthage (Fulford, Timby 1994, 21 et fig. 1.8, $\mathrm{n}^{\circ} 58$ ). \\ Bord presque bifide. \\ 12 Carthage (Tomber 1988, 446 et fig. 1, $\mathrm{n}^{\circ}$ 5) \\ *13 Draria el-Achour (d'après Camps 1955, fig. 6, n 1). \\ 14 Puyloubier, villa romaine de Richeaume (fouilles Fl. \\ Mocci; Inv. RICHI/02.11003.3054). Rainure sur le \\ sommet du bord.
}

Forme Hayes 14 C [TYPE 9]

*15 Vintimille (Lamboglia 1958, 265, forme 3c).

Forme Hayes 17 [TYPE 10]

16 Malte (Hayes 1972, fig. 6, forme 18.5).

*17 Epave Cabrera III (Mayet in Bost et al. 1992, fig. 45, $\mathrm{n}^{\circ} 5$ ).

Variante

*18 Pupput (Inv. PP2125.1). Décor de guillochis.

Forme Hayes 31 [TYPE 11]

*19 Oudhna, est capitole (fouilles H. Ben Hassen, Inv. UTH7.000.28).

La typologie proposée par J. W. Hayes (1972) à la suite de Lamboglia (1958) permet de classer l'essentiel des exemplaires. On remarque toutefois des variantes particulières de la forme Hayes 14A, caractérisées par une carène très prononcée et une paroi supérieure rectiligne (proche de l'exemplaire Hayes 1972, fig. 6, forme 14.4), provenant d'Oudhna et d'El Jem (3-4); leur datation n'est pas certaine (IIIe s. ?). L'interprétation de la forme Lamboglia $3 b 2$ (15) comme une évolution tardive (variante C) de la forme Hayes 14 ne me paraît pas très convaincante. Avec son bord effilé, cette variante pourrait tout aussi bien être rapprochée des formes Hayes 17 et 31 .

En revanche, la parenté entre la forme 14A-B et la forme 15 ne paraît pas faire de doute. La transition pourrait être assurée par des exemplaires au bord chanfreiné mais arrondi sur le sommet et aux parois relativement minces (7-8), ou par des exemplaires encore proches de la forme Hayes 14B mais aux parois très épaisses (Musoleu, Corse: Marchesi 2000, fig. 6, $\mathrm{n}^{\circ} 7$ ). Les variantes classiques de la forme Hayes 15 (9-14) sont caractérisées par un bord nettement en biseau, parfois parcouru d'une rainure sommitale ou à tendance bifide. Les parois sont épaisses. Le vernis de mauvaise qualité ne recouvre souvent que l'intérieur du vase; la distinction avec une céramique culinaire ou commune devient difficile. L'exemplaire choisi à Vintimille (9) pour illustrer la forme Lamboglia 3b1 (= Hayes 15) a été trouvé en association avec une monnaie du milieu du IIIe s. et deux vases de sigillée luisante (Lamboglia 1958, 265 et note 2) qui peuvent, à mon sens, faire encore avancer la datation dans la seconde moitié du IIIe s. ou au IVe siècle. Bien que rare à Carthage (Fulford 1984a, 191), la 
Forme Hayes $14 \mathrm{~A}$
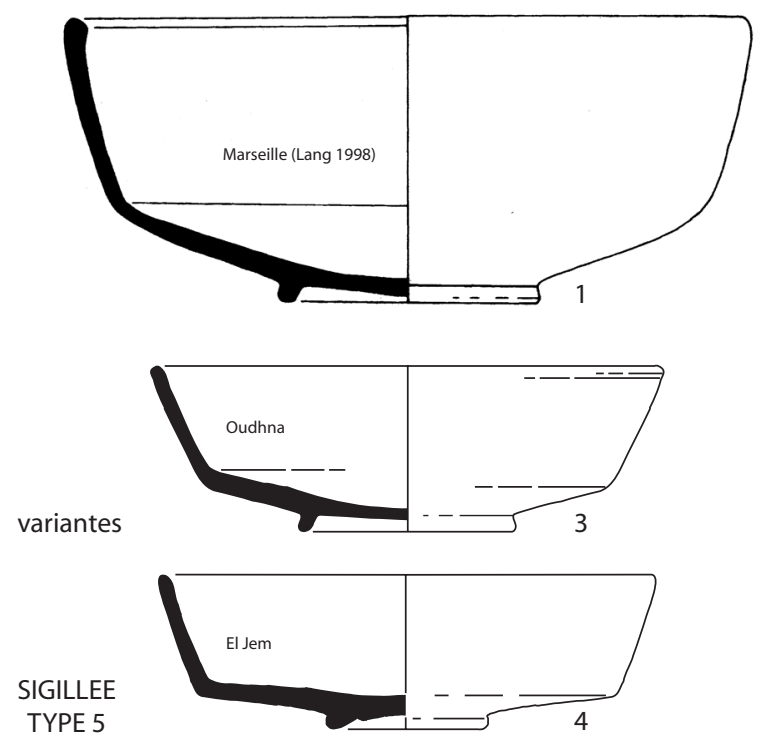

Forme Hayes 16

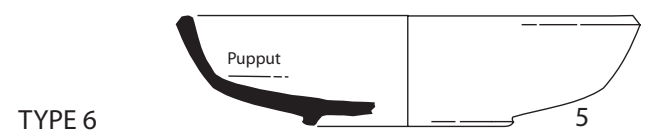

Forme Hayes 14 B

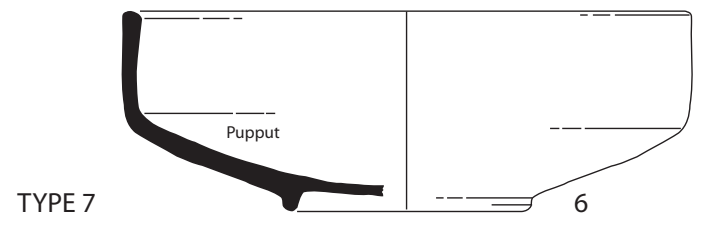

Forme Hayes $14 \mathrm{C}$

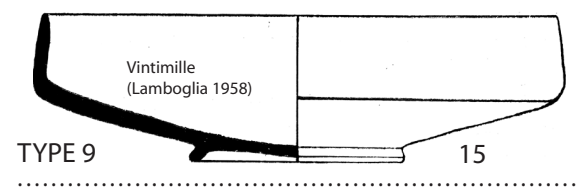

TYPE 10
Forme Hayes 15
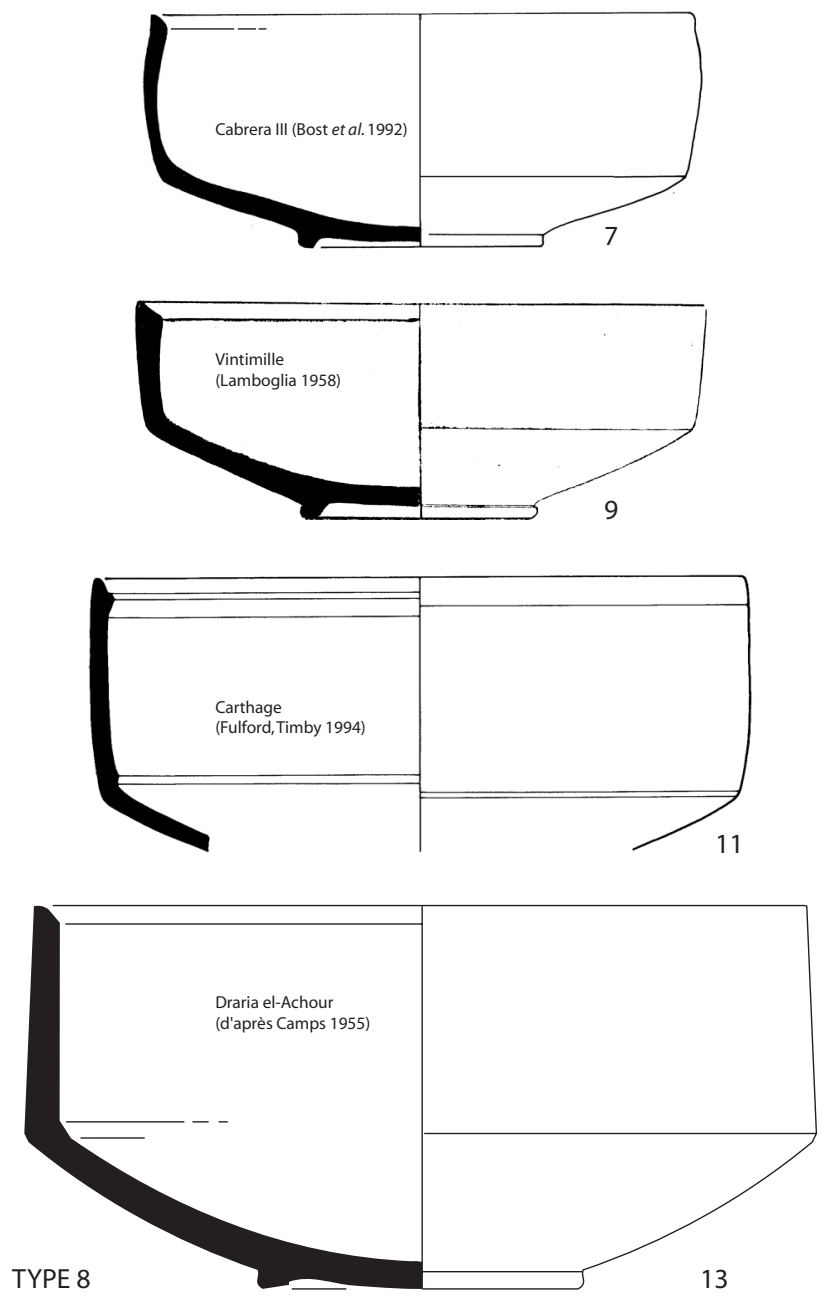

Forme Hayes 17

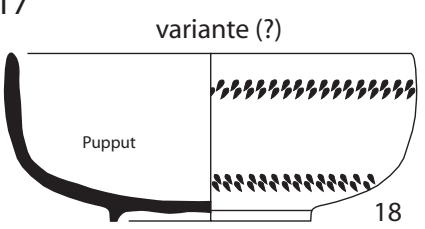

17

Forme Hayes 31

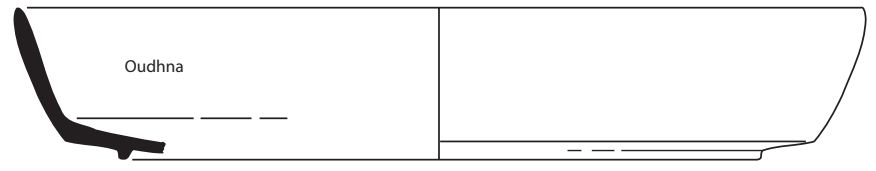

TYPE 11

19

Forme Hayes 26

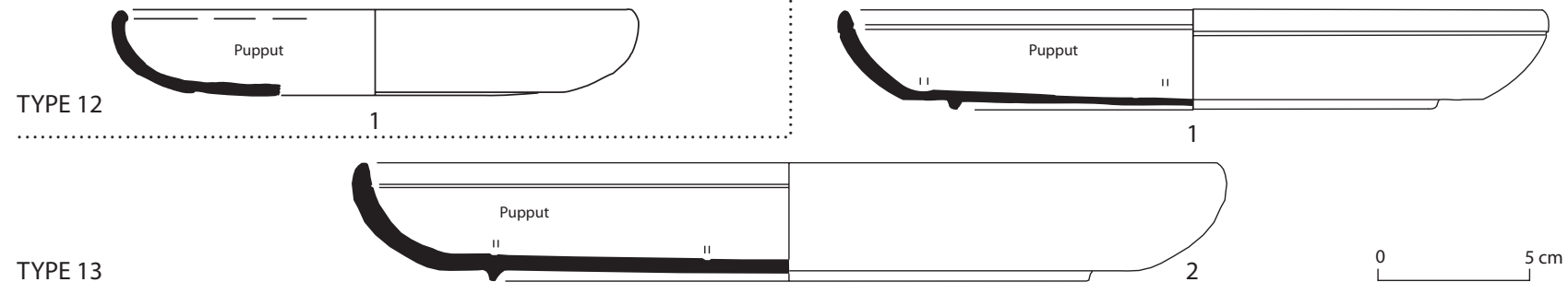

Fig. 85. Vaisselle sigillée africaine A. 
forme Hayes 15 y est attestée dans des contextes du IVe s. (Ibid., fig. 71, forme 7.1 ; Fulford, Timby 1994, 21 et fig. 1.8, $\mathrm{n}^{\circ} 58$; Tomber 1988, 446 et fig. $1, \mathrm{n}^{\circ} 5$ ). Enfin, les exemplaires de la nécropole de Draria elAchour en Algérie (13) sont associés à des sigillées de catégorie D du IVe s. (Camps 1955).

Il est donc nécessaire d'envisager une production plus longue qu'initialement prévue des formes tardives de sigillée africaine A (principalement Hayes 15), en sachant toutefois que ces productions peuvent s'apparenter de plus en plus aux céramiques culinaires (extérieur noirci de certains exemplaires de Carthage) et qu'elles émanent, étant donné leur diffusion, d'ateliers africains probablement très occidentaux (voir supra, p. 48). Cet étirement de la production pourrait également expliquer la présence de ces formes, à titre résiduel, dans les contextes de dépotoirs, par ailleurs homogènes, du port de Marseille (Bonifay 1983, fig. 19, $\mathrm{n}^{\circ} 24$ et fig. 22, $\left.n^{\circ} 33\right)$.

\section{Datation proposée :}

Forme $14 \mathrm{~A}$ et 16 (et, pour mémoire, forme Hayes 18) - fin du IIe s. - début du IIIe s.

Forme Hayes $14 \mathrm{~B}$ - IIIe s. (première moitié ?)

Forme Hayes 15 :

variantes précoces - seconde moitié du IIIe s.

variantes classiques - IVe s.

Formes Hayes 14C, 17, 31 — IIIe s.

\section{— formes Hayes 26/27 (fig. 85)}

\section{SIGILLÉES TYPES 12-13}

La nécropole de Pupput nous renseigne sur la chronologie de la forme Hayes 27. Sur la vingtaine d'exemplaires complets retrouvés, un seul provient d'une tombe, en association avec une lampe marquée PVLLAENI qui ne paraît pas pouvoir être antérieure à la fin du IIe s. (tombe 402) ; tous les autres ont été recueillis en surface, dans les niveaux de fréquentation de la nécropole au IIIe s. (1-2). Cette datation est conforme à celle proposée à Ostie (Atlante $I, 54) ; 1$ 'exemplaire $\mathrm{n}^{\circ} \mathbf{3}$ est bien daté du milieu du IIIe siècle. Il est confirmé que la variante apode Hayes 26 est rare (Hayes 1972, 49). Exemples (fig. 85) :

$$
\begin{aligned}
& \text { Forme Hayes } 26 \text { (TYPE 12) } \\
& \text { *1 Pupput (Inv. PP1272.1). }
\end{aligned}
$$

Forme Hayes 27 (TYPE 13)

*1 Pupput (Inv. PP1272.1).

*2 Pupput (Inv. PP1306.2).

3 Ibiza (Gonzalez Villaescusa 1990, fig. 8, nº03).

— patères (fig. 86)

\section{SIGILLÉES TYPES 14-18}

La forme de sigillée africaine A la plus abondante dans le contexte funéraire de la nécropole de Pupput est une patère très plate [TYPE 14] que l'on dirait conçue pour tenir dans la paume de la main et peut-être servir aux libations (?). Près de 500 fragments et 36 exemplaires complets ont été mis au jour, alors que cette forme était jusqu'alors connue en fort peu d'exemplaires et, accessoirement, classée sous deux types différents (Atlante LXXII, 2 et XVII, 17) selon qu'elle était ou non décorée de reliefs d'applique. Une autre forme de patère [TYPE 15] (apparemment non répertoriée) porte les mêmes décors d'applique, d'autres encore [TYPES 16-18], mais sans décor (Salomonson A3 et A17), sont signalées sur la nécropole de Raqqada.

- TYPE 14 (= Atlante XVII, 17 et LXXII, 2) : petite assiette plate (H. : $2-3 \mathrm{~cm} ;$ D. : $20-25 \mathrm{~cm})$, à bord en virgule parfois souligné d'une cannelure au sommet, parois rectilignes probablement obtenues par estampage (supra, fig. 28, b) et petit pied annulaire.

- variante A : sans décor;

- variante B : avec un cercle de guillochis sur le fond ;

- variante C : avec un cercle de guillochis sur le fond et des décors d'applique sur les parois ;

- variante D : avec un cercle de guillochis sur le fond et des décors d'applique sur le bord.

- TYPE 15 (nouvelle forme?) : petite assiette plate (H. : $2 \mathrm{~cm}$; D. : $20-25 \mathrm{~cm}$ ), petit bord épaissi, à face supérieure aplatie et face inférieure pendante, parois rectilignes à décors d'applique et petit fond annulaire.

- TYPE 16 (= Salomonson A3) : petite assiette (H. : $1,6 \mathrm{~cm}$; D. : $17,5 \mathrm{~cm})$ «à bord chanfreiné à l'intérieur », " pied bas annulaire », « deux sillons concentriques sur le fond $»$.

- TYPE 17 (= Salomonson A17) : petite assiette (H. : $1,8 \mathrm{~cm}$; D. : $18,5 \mathrm{~cm}$ ) «à petit bord chanfreiné ", fond plat aux parois épaisses, pied annulaire.

- TYPE 18 : pour mémoire, exemplaire en catégorie C (forme Atlante LXXIII, 2).

Exemples (fig. 86) :

TYPE 14

Variante A

*1 Pupput (Bonifay 2004a, fig. 16, $\mathrm{n}^{\circ}$ 50). Variante B

*2 Pupput (Ibid., fig. 16, $\mathrm{n}^{\circ}$ 51). Variante C

*3 Pupput (Ibid., fig. 16, $\mathrm{n}^{\circ}$ 52). Variante D

*4 Pupput (Inv. PP540503). Dessin C. Brun. TYPE 15

*1 Pupput (Ibid., fig. 16, $\left.{ }^{\circ} 54\right)$.

*2 Oudhna, est capitole (fouilles H. Ben Hassen, UTH7.000.17).

TYPE 16

*1 Raqqada (Salomonson 1968, fig. 21, A17).

TYPE 17

*1 Raqqada (Ibid., fig. 14, A3).

TYPE 18

1 Raqqada (Ibid., Tabl. II, XXVIIIbis).

Ces objets ont probablement une fonction essentiellement funéraire (nécropoles de Pupput et Raqqada) ou liturgique (capitole d'Oudhna), qui explique sans doute qu'elles n'ont pas beaucoup circulé hors 
Forme Atlante XVII, 17 = LXXII, 2
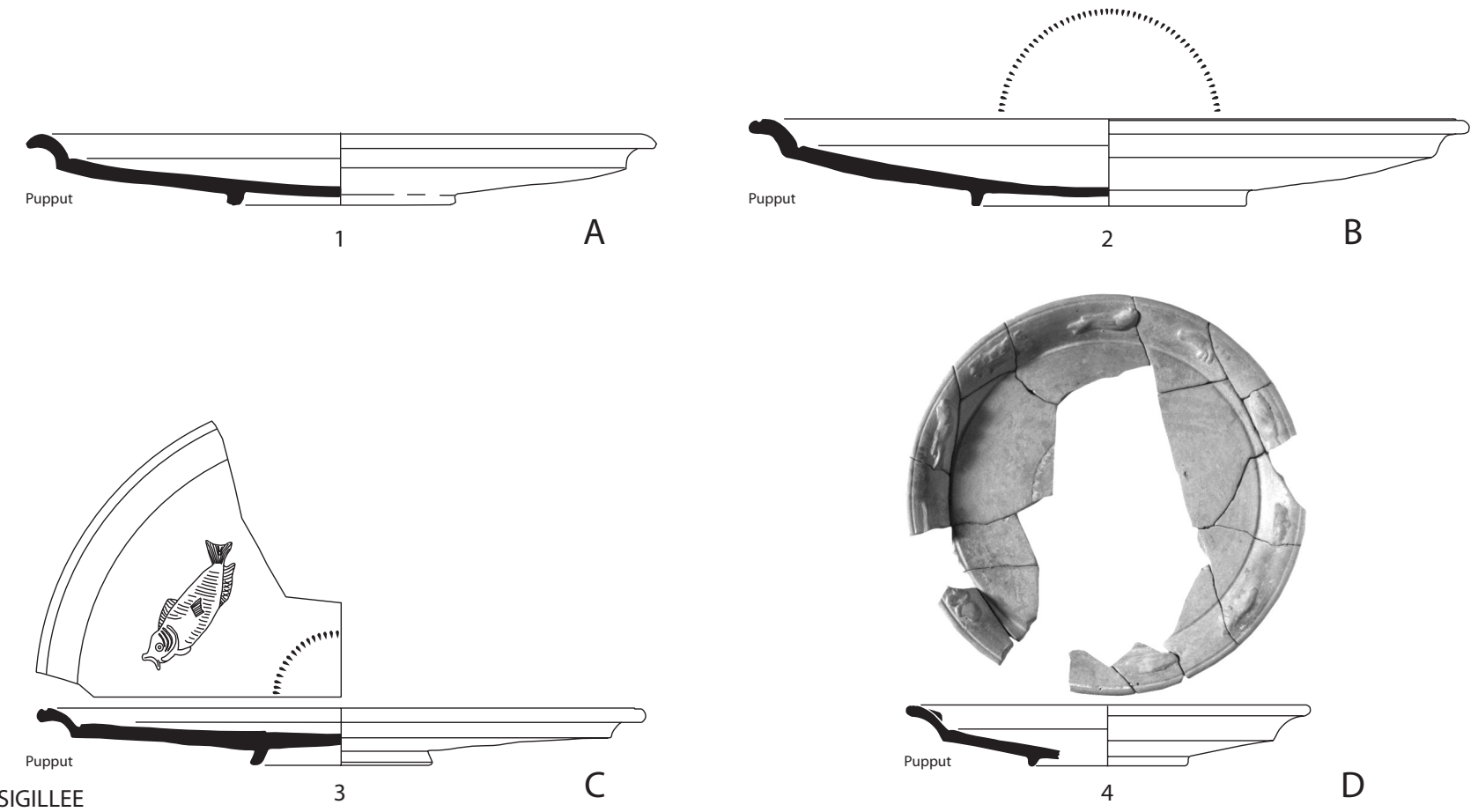

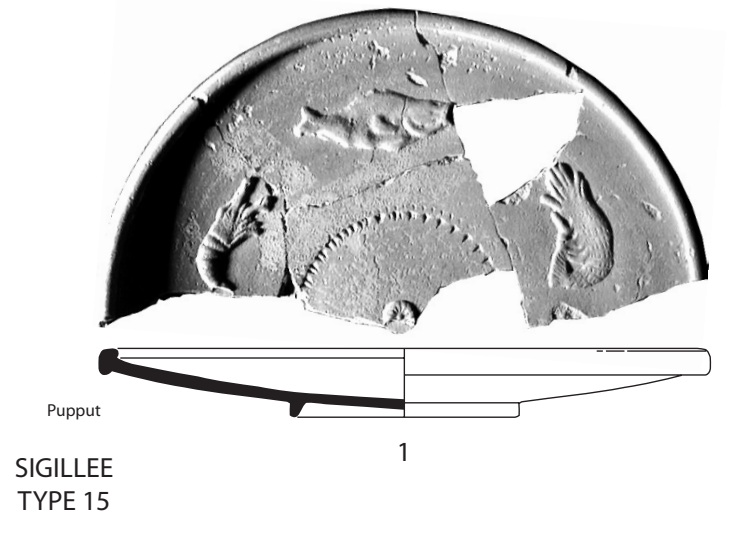

Forme Salomonson A17

SIGILLEE

TYPE 16

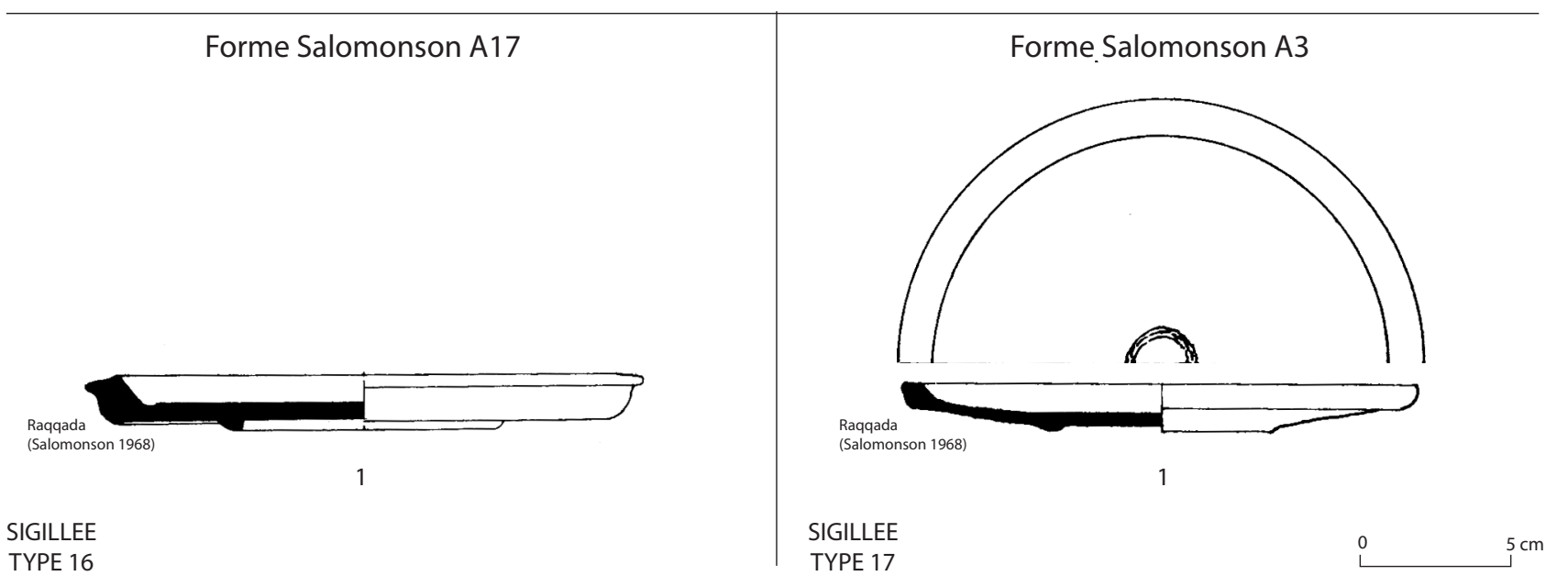

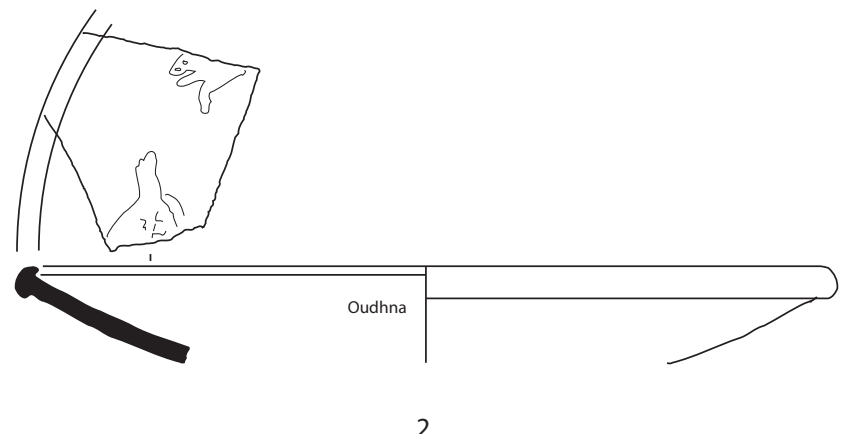

Forme Salomonson A3

SIGILLEE

TYPE 17

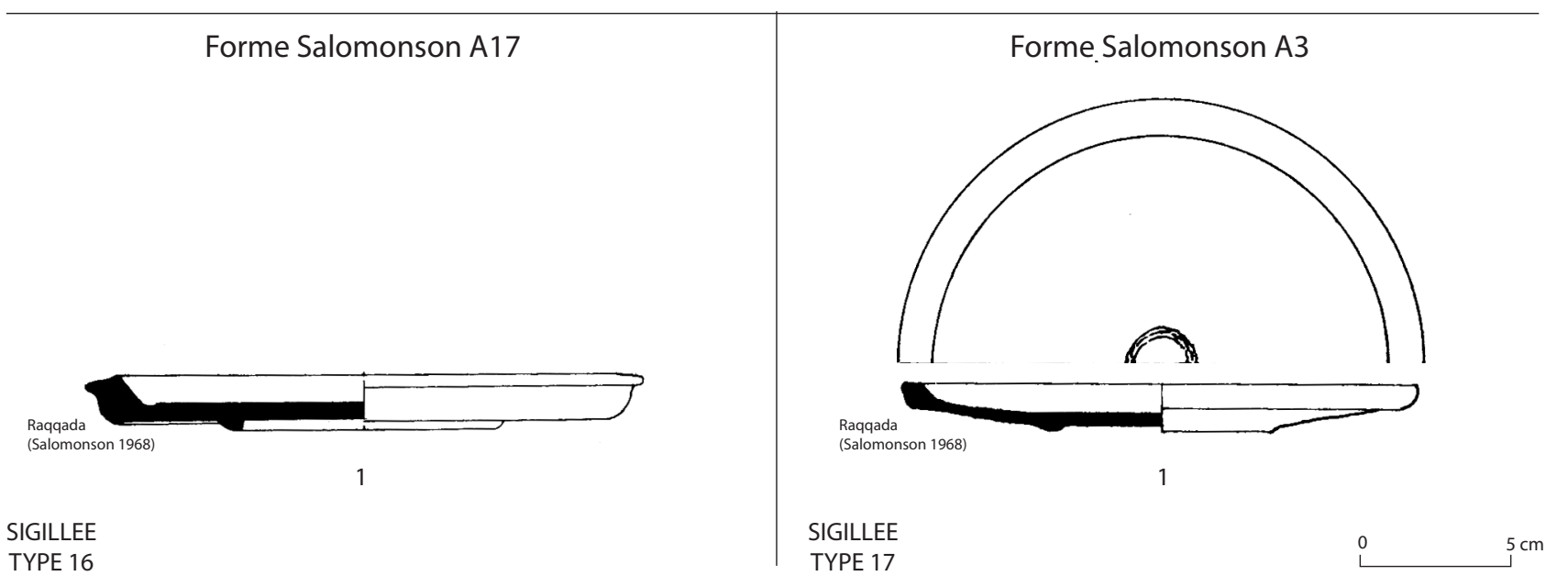

D

Fig. 86. Vaisselle sigillée africaine A. Patères. 


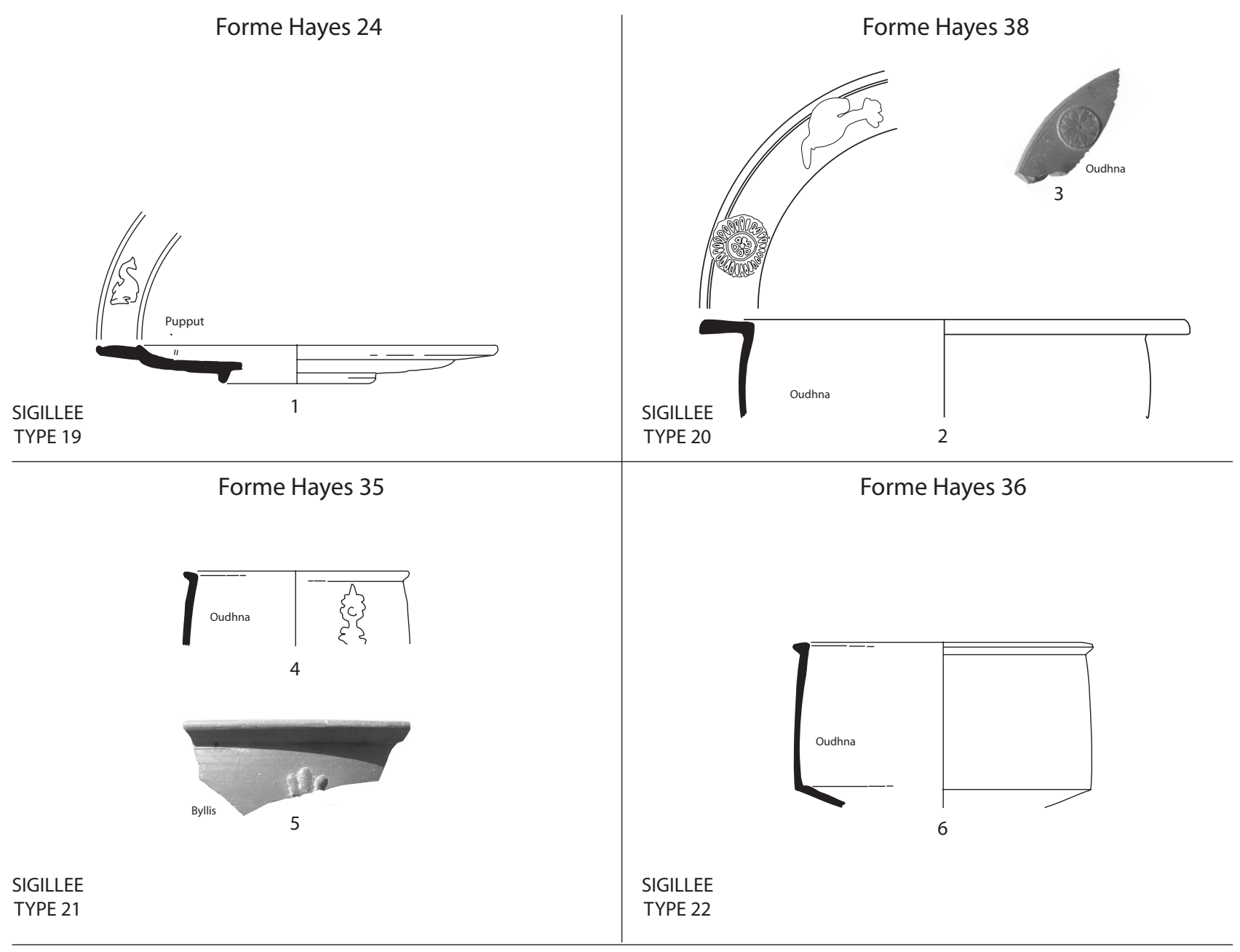

Forme Ostia III, 156

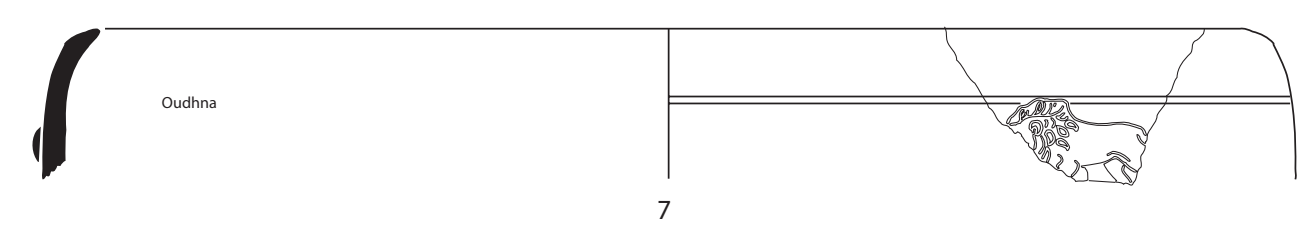

SIGILLEE

TYPE 23

\section{Divers}

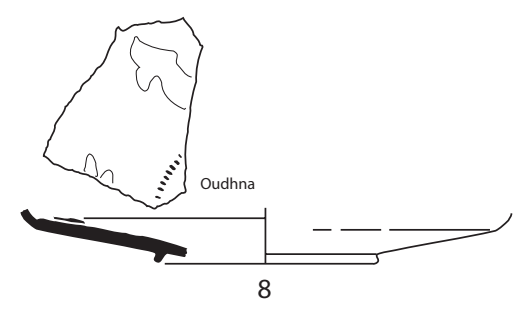

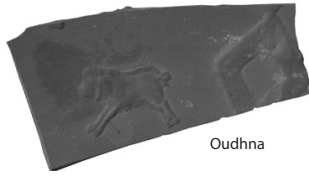

9

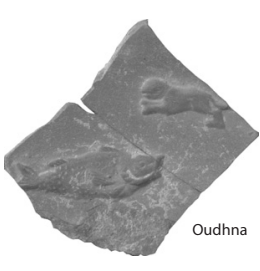

10

Fig. 87. Vaisselle sigillée africaine A à décor d'applique. 
$\mathrm{d}^{\prime}$ Afrique ${ }^{137}$ et qu'elles sont peu mises en évidence dans les grandes classifications. Il est difficile d'appréhender la chronologie relative des trois variantes de la patère TYPE 14 dans la mesure où tous les exemplaires proviennent des niveaux de circulation de la nécropole (ce qui est logique s'il s'agit de vases à libations). Peutêtre la présence d'un décor d'applique est-elle un indice pour une date tardive (début IIIe s. ?), si l'on se base sur la chronologie généralement admise pour les sigillées africaines A à décor d'applique (Atlante I, 144-145). On peut supposer que les patères TYPES 14-15 sont les contreparties des patères TYPES 16-17 de Tunisie centrale, dont une autre variante est publiée à Uzita dans un contexte de la première moitié du IIIe $\mathrm{s}$. (Van der Werff 1982a, Pl. 41, n 20). Une patère en sigillée africaine $C$ à décor d'applique [TYPE 18] est également signalée par J. H. Salomonson.

Chronologie proposée :

Nord de la Tunisie

Patères TYPE 14 A-B - IIe s.

Patères TYPES $14 \mathrm{C}$-D et 15 - première moitié du IIIe s. (?)

Centre de la Tunisie

Patère TYPE 16 - fin Ier - première moitié IIe $\mathrm{s}$.

Patère TYPE 17 - IIe s. (Salomonson 1968)

Patère TYPE 18 - IIIe s. (Atlante I, 148)

\section{— groupe A à relief d'applique (fig. 87)}

\section{SIGILLÉES TYPES 19-23}

Plus encore que sur la nécropole de Pupput, j'ai été frappé de l'abondance à Oudhna des productions de sigillée africaine A à décor d'applique (supra, p. 48). Le répertoire des formes représentées est relativement large. Exemples (fig. 87) :

Patère TYPE 15 : pour mémoire (fig. 86).

Type Hayes 24 [TYPE 19]

*1 Pupput, niveaux de circulation de la nécropole, décor de dauphins (Bonifay 2004a, fig. 16, $\mathrm{n}^{\circ}$ 53).

Type Hayes 38 [TYPE 20]

*2 Oudhna, est capitole (fouilles H. Ben Hassen, Inv. UTH7.000.18).

*3 Idem (Inv. UTH7.000.19).

Type Hayes 35 [type 21]

*4 Oudhna, capitole (Inv. UTH1.002.1).

*5 Byllis (Albanie) (sans $n^{\circ}$ d'inv.).

Type Hayes 36 [type 22]

*6 Oudhna, est capitole (Inv. UTH7.000.16).

Type Ostia III, 156 (=Ostia I, 25 ?) [type 23]

*7 Oudhna, est capitole (Inv. UTH7.000.22).

Divers fonds

*8 Oudhna, capitole (Inv. UTH1.003.3).

*9 Oudhna, est capitole (Inv. UTH7.000.66).

*10 Idem (Inv. UTH7.000.67).

Toutes ces formes sont bien connues, sauf, peut-être, celle du $n^{\circ} 7$ que j'ai rapprochée hypothétiquement d'un tesson d'Ostie. L'exemplaire d'Oudhna est cependant de bien plus grande taille, probablement le plus grand vase

137 Un exemplaire à Antibes, cave Biénès, renseignement Annelise Marsolat. connu de sigillée africaine A à relief d'applique (voir également Ben Abed 2003, Pl. 22). Je ne sais pas non plus à quelles formes rattacher les fonds $n^{\circ} \mathbf{8}$ à 10 : le premier est peut-être une patère (?), le second peut-être un fond Hayes 24 de grande taille, bien que les décors sur la paroi n'aient jamais été signalés sur cette forme. Je ne dispose d'aucun élément de datation pour ces objets.

\section{Catégorie A/D}

Je n'ai pas de compléments à apporter à la typologie de cette catégorie, hormis sur deux points de détail :

— forme Sperlonga 39 (fig. 88)

\section{SIGILLÉE TYPE 24}

Une assiette à bord découpé (4 ou 6 pans), classée en catégorie D à Sperlonga (Saguì 1980, 500 et fig. 39a-b) et à Carthage (Atlante I, 92, Pl. XL, 5) est attestée en catégorie A/D sur un site littoral de Tunisie centrale (1). Hors contexte.

Exemple (fig. 88) :

*1 Littoral tunisien, site 88, Sidi Abdallah (Bonifay et al. 2002-2003, fig. $\left.5, \mathrm{n}^{\circ} 27\right)$.

\section{— forme Hayes 32 (fig. 88)}

\section{SIGILLÉE TYPE 25}

La nécropole de Pupput livre quelques exemplaires de variantes jusqu'à présent non signalées de cette forme, dans des contextes de la première moitié du IIIe s. (1). Exemple :

*1 Pupput (Bonifay 2004a, fig. 15, $\mathrm{n}^{\circ} 47$ ).

\section{Catégorie C}

\section{- bols à listel apparentés à la forme Salomonson C9}

\section{— forme Salomonson C9 (fig. 88)}

J. W. Salomonson $(1968,117)$ avait identifié à Raqqada une forme de bol à listel dans une catégorie de pâte qui « s'approche de celle des vases de transition A-C plutôt que de celle de la sigillée $\mathrm{C}$ proprement dite » et à laquelle il avait néanmoins attribué le $n^{\circ} \mathrm{C} 9$ (1).

Exemple (fig. 88) :

*1 Raqqada, forme Salomonson C9 (Salomonson 1968, fig. 29).

Quelques objets découverts à El Jem et dans sa région semblent dériver de cette forme.

\section{— bols à listel à décor imprimé (fig. 88)}

\section{SIGILLÉE TYPE 26}

Un fragment de bol à listel dont le profil rappelle la forme Salomonson C9, provient de la maison d'Africa, à El Jem (1). Il présente cependant la particularité de porter un décor imprimé de palmette(s ?) disposée(s ?) en biais sur 
Forme Sperlonga 39

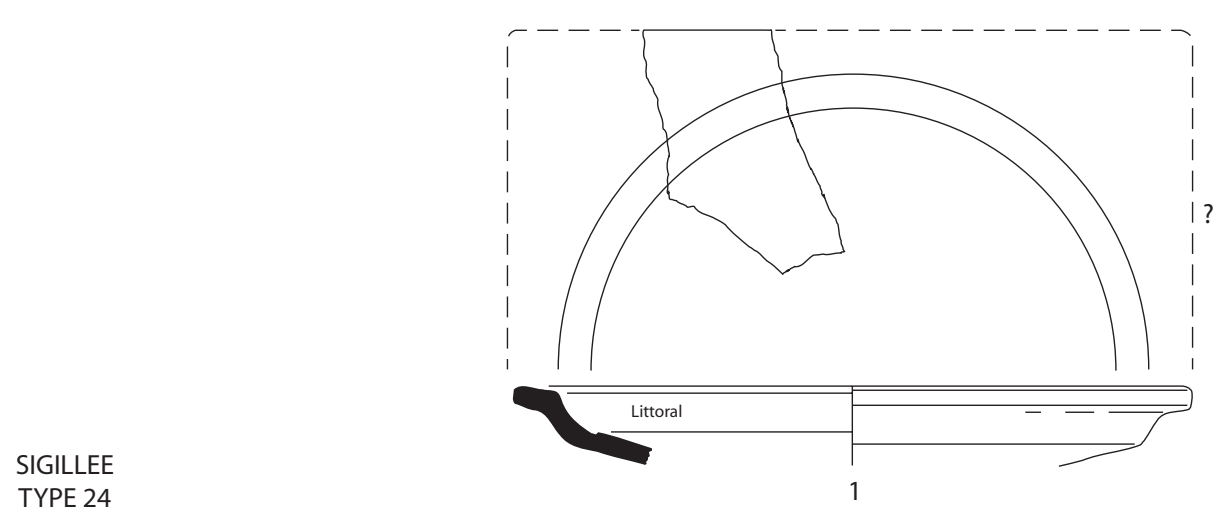

Forme Hayes 32 variante
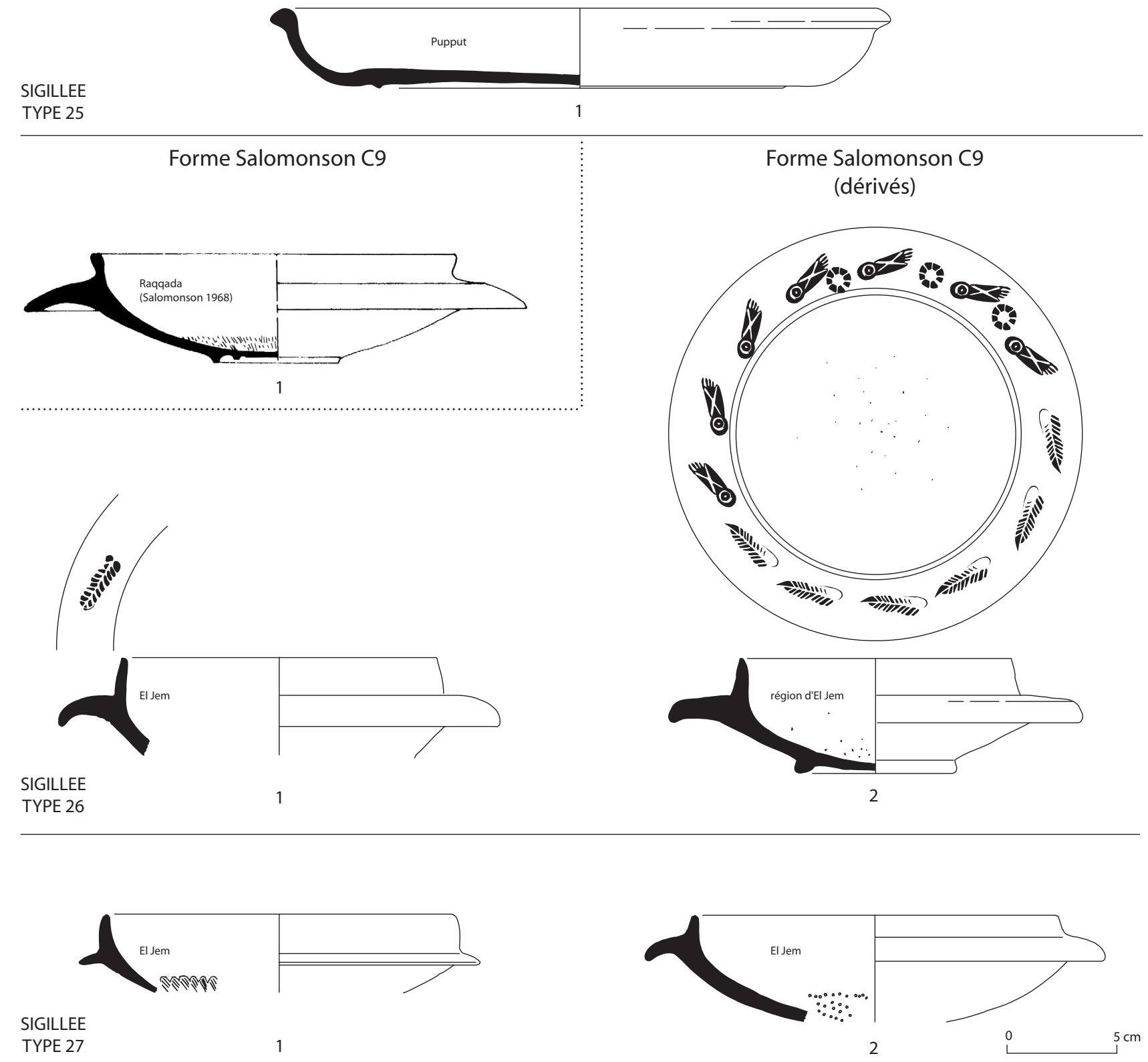

Fig. 88. Vaisselles sigillées africaines A/D et C. 
Formes Hayes 82-84-85
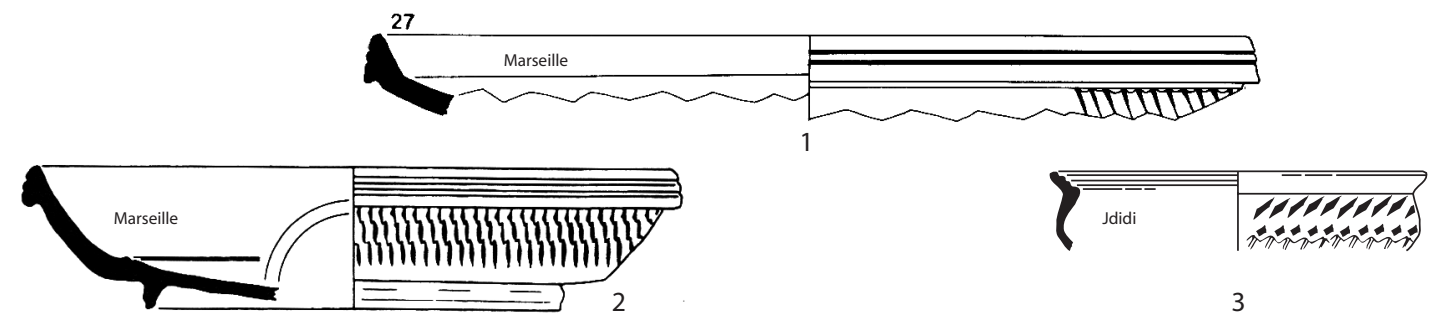

3

Formes Hayes 83
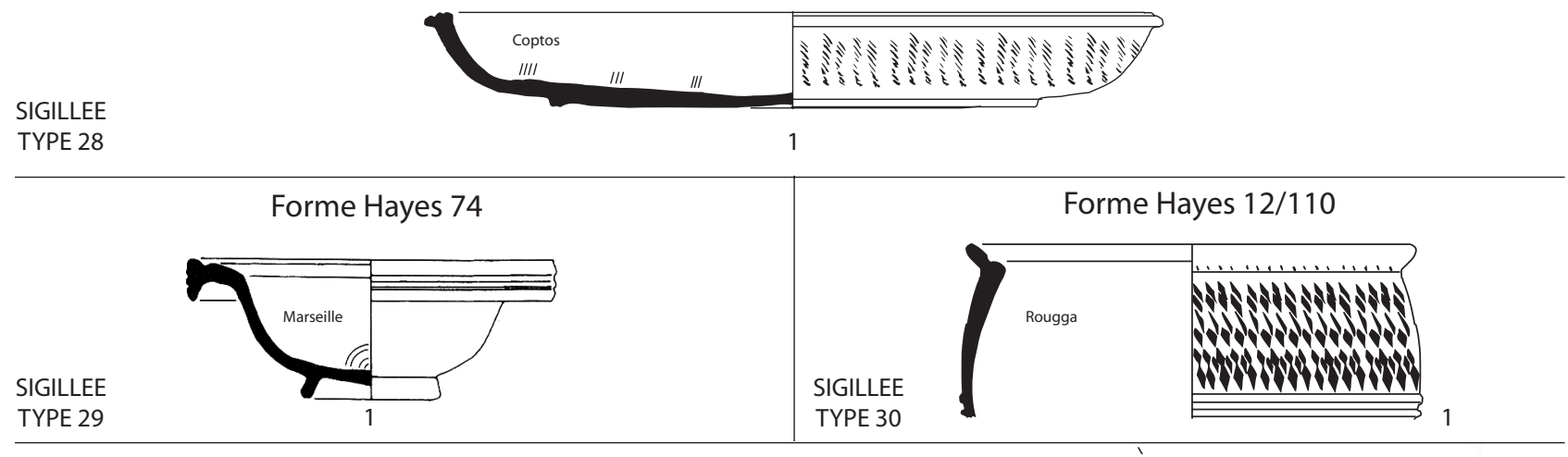

Forme Gourvest E3
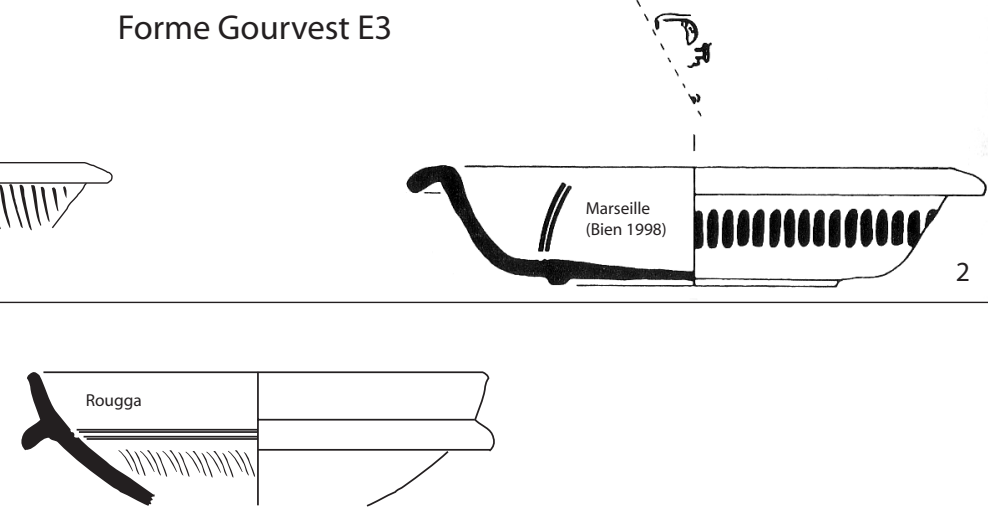

Forme Hayes 90A

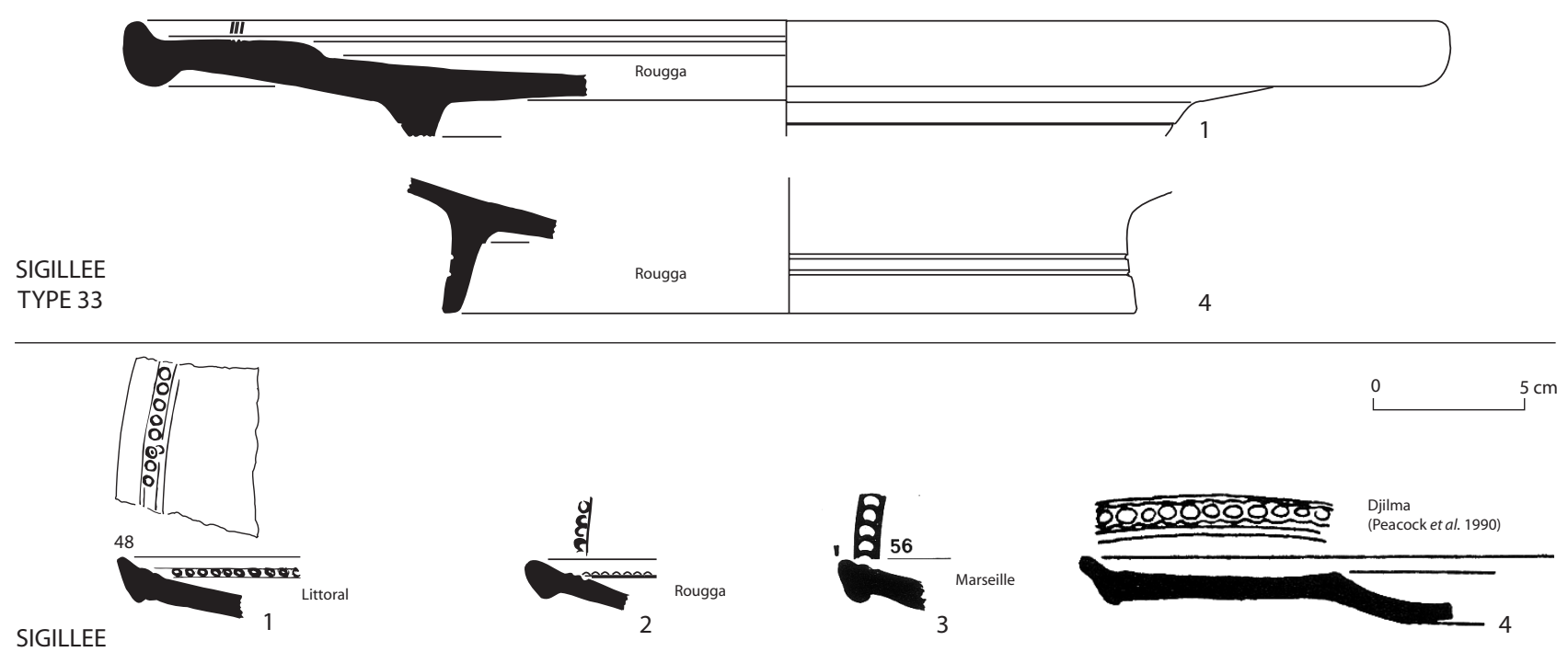

Fig. 89. Vaisselle sigillée africaine C5 et apparentée. 
le listel. Cet objet peut être comparé à un vase complet (3) conservé dans une collection privée ${ }^{138}$, qui présente également un décor imprimé sur le listel, composé de six palmettes et de sept «plantae pedis» dont quatre alternent avec trois rouelles; l'intérieur du fond est parsemé de petits grains de basalte.

Exemples (fig. 88) :

*1 El Jem, Maison d'Africa (fouilles H. Slim, Inv. EJMA.000.18). Vernis orange intérieur et extérieur.

*2 Région d'El Jem (collection M. Cornet, Jouques). Pâte brune et vernis écaillé à l'intérieur et à l'extérieur. Douteux :

3 Sousse (Carton 1900, Pl. XVIII). Mortier avec décor de "plantae pedis» sur le listel, mais en céramique commune?

Les décors imprimés sont attestés sur sigillée africaine A/D (Atlante XXIV, 7) et sur sigillée africaine C (Atlante XXVII, 3-4) dès le IIIe s. ; dans les deux cas, l'emplacement est le même : sur le marli. Mais les motifs en "plantae pedis» du $\mathrm{n}^{\circ} \mathbf{2}$ rappellent plutôt ceux imprimés sur la paroi de formes anciennes de sigillée africaine A : Atlante $\mathrm{n}^{\circ}$ 104-105 (Atlante I, 127 et Pl. XVIIa, 43-44). Ces comparaisons ne font qu'accentuer notre incertitude quant à l'origine de ces productions dont l'aspect, comme le signalait Salomonson, n'est pas vraiment conforme à celui de la $\mathrm{C}$. Des décors similaires sont attestés sur céramique commune (3 ; voir également Dore 1992, 151, n 77).

Les deux bols à listel identifiés par Salomonson (forme C9) sont hors contexte, mais leur datation estimée aux trois premiers quarts du IIIe siècle. Le tesson d'El Jem est également hors stratigraphie, mais dans un contexte général des III - IVe siècles.

Datation proposée : IIIe s.

\section{— bols à listel à décor guilloché ou incisé (fig. 88)}

\section{SIGILLÉE TYPE 27}

Deux fragments de vases à listel provenant de la Maison d'Africa à El Jem, ont en commun un profil surbaissé et une lèvre haute et verticale, dans la tradition de la forme Salomonson C9 :

Exemples (fig. 88) :

*1 El Jem, Maison d'Africa, pièce 23 (fouilles H. Slim, Inv. EJMA.2300.3). Catégorie C 3-4, vernis à l'intérieur et à l'extérieur. Décor guilloché sur le fond.

*2 Idem (Inv. EJMA.2300.6). Pâte plus grossière, vernis à l'intérieur seulement. Décor de petits points en creux.

Ces deux formes, issues d'un contexte du IVes. (associées à une forme Hayes 58A), sont peut-être les précurseurs des variantes les plus anciennes de la forme Hayes 91 en sigillée africaine D (Atlante XLVIII, 11) (infra, TYPE 48).

\footnotetext{
${ }^{138}$ Collection de M. Marcel Cornet, à Jouques (France), dont la famille, autrefois établie en Tunisie, possédait des terres dans la région d'Agareb, à l'ouest de Sfax. Je tiens à saluer la mémoire de M. Cornet, aujourd'hui décédé, et à le remercier de m'avoir proposé d'examiner sa petite collection.
}

\section{- groupe C5 (fig. 89)}

Le groupe C5, considéré comme l'ultime production des ateliers de Tunisie centrale (Atlante I, 59), caractéristique du faciès $\mathrm{B}$ (seconde moitié du Ve s. - début du VIe s.) de Marseille (Bonifay et al. 1998, 356), comporte un répertoire de formes plus étendu que celui de la seule « triade », bien connue, des formes Hayes 82-84-85 (Bonifay et al. 1998, 362).

Exemples (fig. 89) :

*1 Marseille, chantier de La Bourse (Bonifay 1983, fig. $\left.19, n^{\circ} 30\right)$. Forme Hayes 82.

*2 Marseille, puits de la rue du Bon-Jésus (Bonifay 1998b, fig. 171, n 3). Forme Hayes 84.

*3 Sidi Jdidi, basilique 2, destruction état II (Inv. JD2144.02). Forme Hayes 85.

\section{— forme Hayes 83 (fig. 89)}

\section{SIGILLÉE TYPE 28}

Etant donné la relative rareté de cette forme (Atlante I, 68), je crois utile de mentionner sa présence à Coptos, en Egypte, pays d'où provenaient déjà les deux exemples catalogués par Hayes $(1972,131)$ :

1 Coptos (Egypte), Musée des Beaux-Arts de Lyon (fouilles A. Reinach, 1910-11, Inv. 2667 ; cf. Bonifay 2000b).

La décoration de cet exemplaire, utilisant les motifs Hayes 28 et 110 (variante), indique une date assez précoce (milieu du Ve s. ?) qui confirme les hypothèses de J. W. Hayes sur la chronologie de cette forme.

\section{— forme Hayes 74 (fig. 89)}

\section{SIGILLÉE TYPE 29}

Il convient d'ajouter au répertoire de la catégorie C5 le petit bol à marli Hayes 74, habituellement classé en catégorie $\mathrm{C} 3 / \mathrm{C} 4$ (Atlante I, 73).

Exemple (fig. 89) :

*1 Marseille, puits de la rue du Bon-Jésus (Bonifay 1998b, fig. 171, $n^{\circ} 1-2$ )

Cette forme est attestée sur l'atelier de Sidi Marzouk Tounsi (Peacock, Bejaoui, Ben Lazreg 1990, fig. 7, n 6). Le décor de double cannelure sur la lèvre pendante du marli rappelle celui des formes 82-84 auxquelles elle est souvent associée dans les contextes de la seconde moitié du Ve s., notamment à Athènes (Hayes 1972, 124), Benghazi (Kenrick 1985, 423), Carthage (Fulford 1984a, 55) et Marseille (Bonifay et al. 1998, 362).

\section{— forme Hayes 12/110 (fig. 89)}

\section{SIGILLÉE TYPE 30}

Il existe une variante en C5 de la forme Hayes 12/110 (Atlante I, 114).

Exemples (fig. 89) :

1 Carthage (Hayes 1978b, fig. 21, n 43).

*2 Rougga, couche 13 (Guéry, Bonifay à paraître, $n^{\circ} 51$ ). Cette forme est associée, à Rougga, aux formes 84 et 85 . 


\section{— forme Gourvest E3 (fig. 89)}

\section{SIGILLÉE TYPE 31}

Une autre forme doit être rattachée à cette production : il s'agit d'une petite assiette creuse à marli recourbé, pied bas, décorée de guillochis sur la paroi extérieure. Un exemplaire de Marseille (2) porte un poinçon de style D sur le fond. La pâte et l'engobe sont ceux des formes Hayes 82-85.

Exemples (fig. 89) :

*1 Littoral tunisien, site $\mathrm{n}^{\circ} 55$ (Henchir Leich, au nord de Iunca) (Bonifay et al. 2002-2003, fig. 5, $\mathrm{n}^{\circ} 30$ ).

*2 Marseille, Parc des Phocéens (Bien 1998, fig. 238, $\left.\mathrm{n}^{\circ} 3\right)$.

3 Marseille, chantier de La Bourse (Bonifay 1983, fig. 22, $n^{\circ} 42$ ).

Cette forme a été classée en 1958 par Jacques Gourvest dans la forme 3 de sa catégorie $\mathrm{E}$, équivalent de la catégorie C5 de Carandini (Gourvest 1998, 40 et fig. 260262 ; cf. Bonifay, Carre, Rigoir 1998, sommaire). Je propose de conserver cette appellation en souvenir du pionnier de la céramologie de l'après-guerre que fut J. Gourvest, auquel J. W. Hayes a d'ailleurs rendu hommage récemment (Hayes 2003, 527).

On rencontre sporadiquement cette forme à Marseille ( $\mathrm{n}^{\circ}$ 2-3 ; Bonifay 1983, fig. 22, $\mathrm{n}^{\circ} 41-42$ et fig. 24, $\mathrm{n}^{\circ} 81$ ), à Belo (Bourgeois, Mayet 1991, Pl. CIV, n 425-426), à Naples (Soricelli 1994, fig. 64, n 34-35), à Mactar (Bourgeois 1982, fig. 4, n 178-179) et peut-être (?) sur l'atelier de Sidi Marzouk Tounsi (Peacock, Bejaoui, Ben Lazreg 1990, fig. 7, n 14). Elle semble appartenir à une phase tardive de la production $\mathrm{C} 5$.

- bols à listel Peacock, Bejaoui, Ben Lazreg 1990, fig. 7, 12 (fig. 89)

\section{SIGILLÉE TYPE 32}

Il convient de mentionner encore deux vases de Rougga (Guéry, Bonifay à paraître, $\mathrm{n}^{\circ}$ 63-64) qui constituent, avec la présence d'une double cannelure interne, une variante de la forme Hayes 91A. La pâte est orange, dure, très fine; le vernis orangé ne couvre que l'intérieur du vase et déborde sur le listel.

Exemples (fig. 89) :

*1 Rougga, couche 12 (Guéry, Bonifay à paraître, $n^{\circ} 63$ ).

2 Sidi Marzouk Tounsi, atelier (Peacock, Bejaoui, Ben Lazreg 1990, fig. 7, n 12).

Cette forme peut être rattachée aux productions de Tunisie centrale, probablement de la catégorie C5, comme le prouve sa présence parmi les rebuts de cuisson de l'atelier de Sidi Marzouk Tounsi (2). Le contexte stratigraphique de Rougga (1) indique le milieu ou la seconde moitié du VIe siècle.

\section{— forme Hayes 90A (fig. 89)}

\section{SigILLÉE TYPE 33}

Comme cela avait été déjà avancé par J. W. Hayes (1972, 139) la variante A de la forme 90 est produite en catégorie C5 (Atlante I, 97). Je crois utile d'illustrer un peu plus qu'elle ne l'était, cette forme bien attestée à Rougga.

Exemples (fig. 89) :

*1 Rougga, couche 12 (Guéry, Bonifay à paraître, $n^{\circ} 60$ ).

2 Rougga, couche 12 (Ibid., $\mathrm{n}^{\circ} 53$ ).

3 Rougga, couche 10 (Ibid., n 59). Résiduel (?).

*4 Rougga, couche 10 (Ibid., $\mathrm{n}^{\circ}$ 61). Résiduel (?).

L'absence de cette forme dans la couche 13 de Rougga, d'où proviennent l'essentiel des formes classiques de C5 indique peut-être que nous sommes dans une phase ultérieure de la production tardive des ateliers du centre de la Tunisie (un hypothétique groupe « C6»?), probablement dans les décennies centrales du VIe s. (voir également la forme précédente).

\section{- groupe indéterminé (fig. 89)}

\section{SIGILLÉE TYPE 34}

Un certain nombre de tessons appartenant probablement à une variante de la forme Hayes 76 sont caractérisés par une pâte fine, très dure, et un vernis orangé clair, satiné. Le sommet de la lèvre est décoré d'une suite d'impressions circulaires contiguës produisant un motif perlé.

Exemples (fig. 89) :

*1 Littoral tunisien, site $\mathrm{n}^{\circ} 71$ (Henchir el-Majdoul, côte nord de Sfax) (Bonifay et al. 2002-2003, fig. 6, $\mathrm{n}^{\circ} 42$ ).

*2 Rougga, couche 10 (Guéry, Bonifay à paraître, $n^{\circ} 44$ ). Résiduel (?).

*3 Marseille, chantier de La Bourse (Bonifay 1983, fig. $26, \mathrm{n}^{\circ} 142$ ).

*4 Djilma - Henchir el-Guellal, atelier (Peacock, Bejaoui, Ben Lazreg 1990, fig. 13, n 19).

Cette forme apparaît à Rougga et à Marseille dans des contextes du VIe s. et postérieurs; cette datation paraît difficile à admette du point de vue stylistique et dans la mesure où l'atelier de Djilma - Henchir el-Guellal où elle a pu être, au moins en partie, produite (4), ne paraît plus actif après la fin du Ve s. (Peacock, Bejaoui, Ben Lazreg 1990, 79). J'hésite également sur la catégorie à laquelle rattacher cette forme: $\mathrm{C}, \mathrm{E}, \mathrm{C} / \mathrm{E}$ ? Une autre variante de la forme Hayes 76, provenant d'un site littoral au nord de Salakta (Bonifay et al. 2002-2003, fig. 7, $\mathrm{n}^{\circ} 61$ ), plus proche de l'aspect de la catégorie E, est également attestée sur l'atelier de Djilma - Henchir el-Guellal (Peacock, Bejaoui, Ben Lazreg 1990, fig. 13, n²3).

\section{Catégorie D}

\section{— forme Hayes 58, variante Lamboglia 52B (fig. 92)}

\section{SigILLÉE TYPE 35}

Je souhaiterais attirer l'attention sur une forme de grand plat aux parois relativement épaisses, avec un petit bord légèrement replié à l'horizontale et un petit pied annulaire, qui a été classée, depuis Lamboglia (1963, 197 , forme 52B), dans la série des plats à marli court Hayes 58 (Atlante I, 82; contra: Hayes 1972, 447). Ce rattachement peut se révéler commode, surtout dans le cas de petits fragments, à condition de bien souligner que 
ce plat n'a probablement rien à voir avec le prototype de la forme Hayes 58 (Gandolfi 1981, 107: forme Vintimiglia 1).

En effet, l'exemplaire complet de cette forme Hayes 58, variante Lamboglia 52B, découvert à Sainte-Propice (1) provient d'un contexte du deuxième quart ou du milieu $\mathrm{du}$ VIe s., datation fort éloignée de celle des autres variantes de la forme Hayes 58 (IVe s.).

Exemple (fig. 92) :

*1 Sainte Propice (Velaux, France) (Boixadera et al. 1987, fig. 9, nº 7).

\section{— forme Hayes « 59 C » (fig. 92)}

\section{SigILLÉE TYPE 36}

On pourrait peut-être envisager de créer ce néologisme pour désigner une variante de la forme Hayes 59 caractérisée par un bord à marli redressé et au sommet mouluré «en escalier». Curieusement, c'est cette variante de diamètre réduit et proportionnellement plus profonde qui avait été choisie par Lamboglia comme prototype de sa forme 51 (Lamboglia 1963, 194-195) alors qu'il s'agit vraisemblablement d'une variante tardive, bien attestée dans la première moitié du Ve s., par exemple à Narbonne (Sabrié 1991, fig. 3, n 31), à Tarragone (Aquilué 1989, fig. 39), à Garlate (2) ou encore à Carthage (1). Le fond du n ${ }^{\circ} \mathbf{3}$ est muni d'un petit pied.

Exemples (fig. 92) :

*1 Carthage, Byrsa (Bonifay à paraître $\mathrm{a}, \mathrm{n}^{\circ} 1$ ).

2 Garlate, tombe 6 (Nobile 1992, $\mathrm{n}^{\circ} 22.10$ ).

3 Maroc (Jodin, Ponsich 1960, fig. 6).

\section{— formes Hayes 61A/B, 61B et « 61C »}

La forme Hayes 61 mérite qu'on s'y attarde. C'est l'une des formes de sigillée africaine dont l'évolution et la datation restent les plus controversées. On a déjà noté les difficultés de classement entre les deux variantes de la forme 61 et la forme $87 \mathrm{~A}$ (Hayes $61 \mathrm{~A}=$ Lamboglia 54 ; Lamboglia $53=$ Hayes $61 \mathrm{~B}+87 \mathrm{~A}$ ) (Bourgeois, Mayet 1991, 296 et 301; Mackensen 1993, 321 ; CavaillèsLlopis, Vallauri 1994, 96). On a récemment proposé d'attribuer la fabrication de la forme $61 \mathrm{~A}$ aux ateliers de la vallée de la Mejerda (production D1) (Mackensen 1993, 321) et celle de la forme 61B à la production D2 (principalement atelier de Sidi Khalifa ?) (Mackensen 1993, 32-33 ; contra : Reynolds 1995, 10). On a surtout beaucoup discuté la date d'apparition de la forme Hayes 61B : initialement placée autour de 400-420 par Hayes $(1972,106)$, elle a été reculée à la fin du IVe s. par le même auteur (Hayes 1980a, 515) sur la base de données aujourd'hui remises en question (Mackensen 1993, 386) ; $M$. Mackensen envisage toutefois une longue coexistence des deux formes $61 \mathrm{~A}$ et $61 \mathrm{~B}$ dès la seconde moitié du IVe s. (Ibid., 402); plus récemment, P. Reynolds a proposé de repousser l'apparition de la forme $61 \mathrm{~B}$ vers 420 (Reynolds 1995, 10). La date d'extinction est tout aussi incertaine: suggérée vers le milieu du Ves. par
Hayes, elle est aujourd'hui reportée jusqu'au troisième quart, voire même à la fin du Ve s. par Fulford (1984a, 49). En fait, la question de la datation de la forme Hayes 61B n'a pas réellement de sens tant, dans l'état actuel des recherches, les formes de vases rangées sous cette appellation sont diverses: le nombre de variantes rattachées à la forme Hayes 61B est tel que l'on finit par appeler d'un même nom une multitude de profils très différents (Bonifay 1998a, 71-72).

Dans l'attente d'une refonte de la classification de la forme 61, qui devient aujourd'hui d'une "nécessité pressante» (Mackensen 1993, 321 et note 294), je propose, provisoirement, de distinguer les formes et variantes suivantes :

\section{- Hayes 61 A/B (fig. 90)}

\section{SiGILLÉE TYPE 37}

J. W. Hayes avait créé cette appellation pour désigner des exemplaires qui lui paraissaient faire la transition entre les deux grands types A et B. Il distinguait au sein de ce groupe « transitional » (Hayes 1972, 105) deux variantes (ici variantes 2 et 3 ), auxquelles on peut maintenant ajouter celle (variante $n^{\circ} 1$ ) identifiée par Mackensen $(1993,592)$ et celle (variante 4) déjà connue à Antioche (Waagé 1948, Pl. IX, 831 k ; Atlante I, XXXIV, 3) :

- Variante A/B 1 (= El Mahrine 4.3): plat peu profond à bord légèrement rentrant, sans lèvre pendante à l'extérieur (ce qui le distingue du type Hayes 61B, variante 1) mais avec cannelure interne. - Variante A/B 2 (= El-Mahrine 4.4 = Waagé 831 u) : plat à bord plus haut, presque vertical ou très peu rentrant, sans cannelure interne.

- Variante A/B 3 (= Hayes 61 «transitional», $\left.\mathrm{n}^{\circ} 26\right)$ : plat large et profond, à parois épaisses et bord atrophié peu rentrant; non décoré, production peu soignée.

- Variante A/B 4 (= Waagé $831 \mathrm{k}$ ) : plat large et peu profond, bord en amande recourbé vers l'intérieur, marqué d'un ressaut à l'extérieur.

- Hayes 61 B (fig. 90-91)

\section{SIGILLÉE TYPE 38}

J. W. Hayes distinguait deux variantes principales : d'une part une variante classique (ici variante 2) évoluant vers un fond plus étroit et une panse plus longue et plus évasée; d'autre part «a fairly distinct sub-type » (ici variante 1), caractérisée par un bord haut, à face extérieure verticale. J'avais pour ma part proposé en 1998 d'ajouter deux autres variantes (Bonifay 1998a, 72, variantes 3 et 4) mais il est aujourd'hui nécessaire de refondre un peu cette ébauche de classification interne :

- Variante B 1 (= Hayes 61B, ${ }^{\circ}{ }^{29}$ ) : forme Hayes $61 \mathrm{~B}$, plat assez large et peu profond, bord haut, vertical, souligné à l'extérieur par un ressaut marqué et à l'intérieur par une cannelure. Peut-être une continuation de la variante A/B4. 
Forme Hayes 61A/B
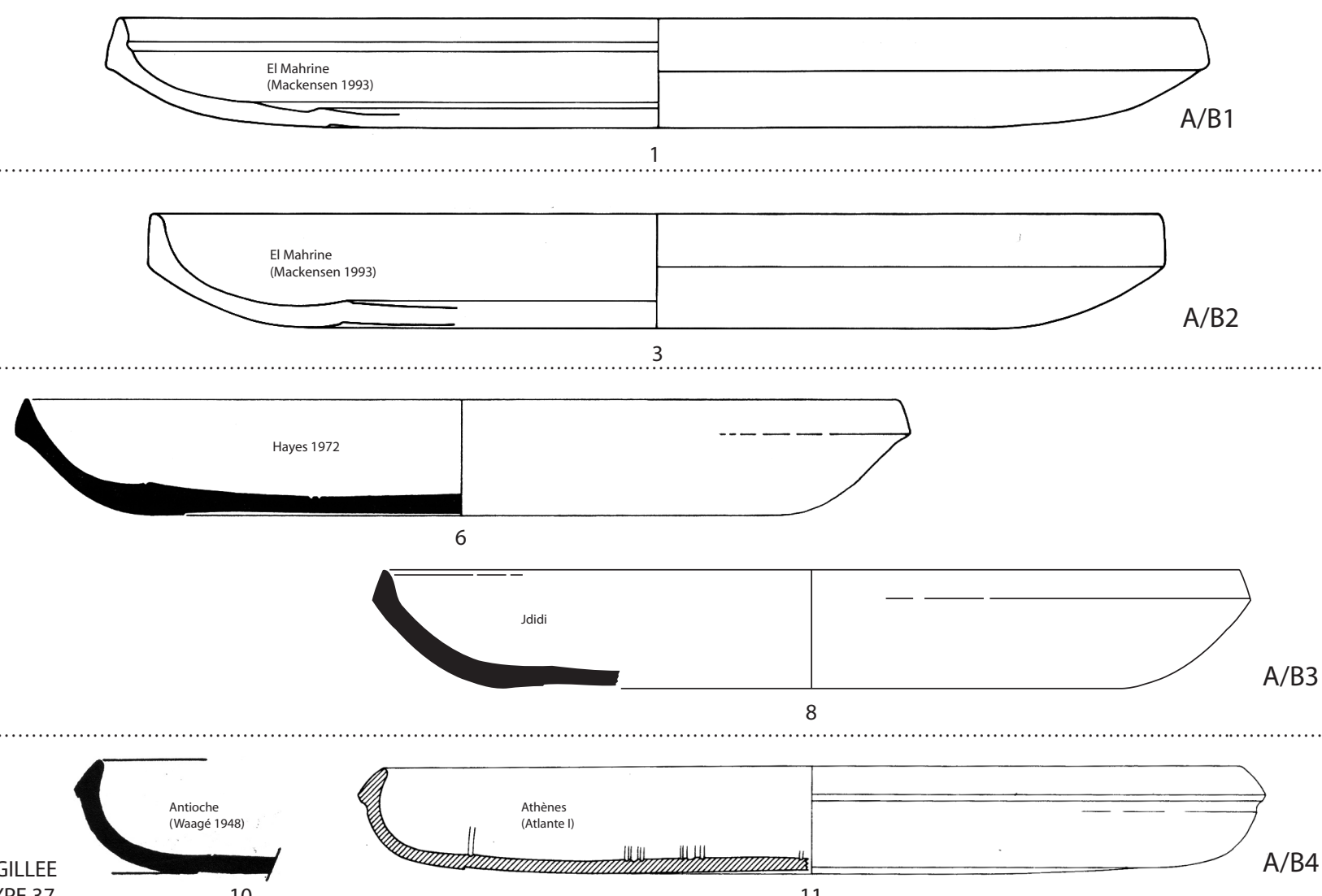

Forme Hayes 61 B

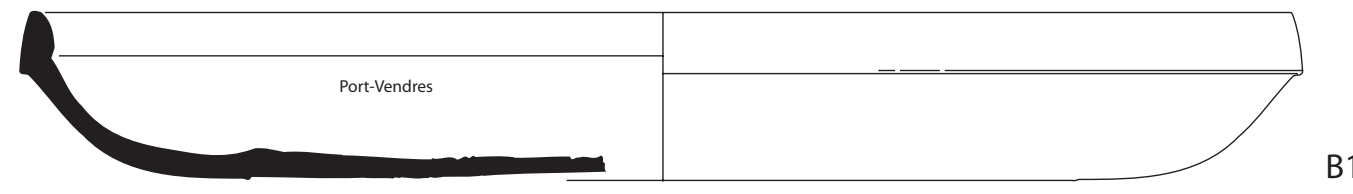

17
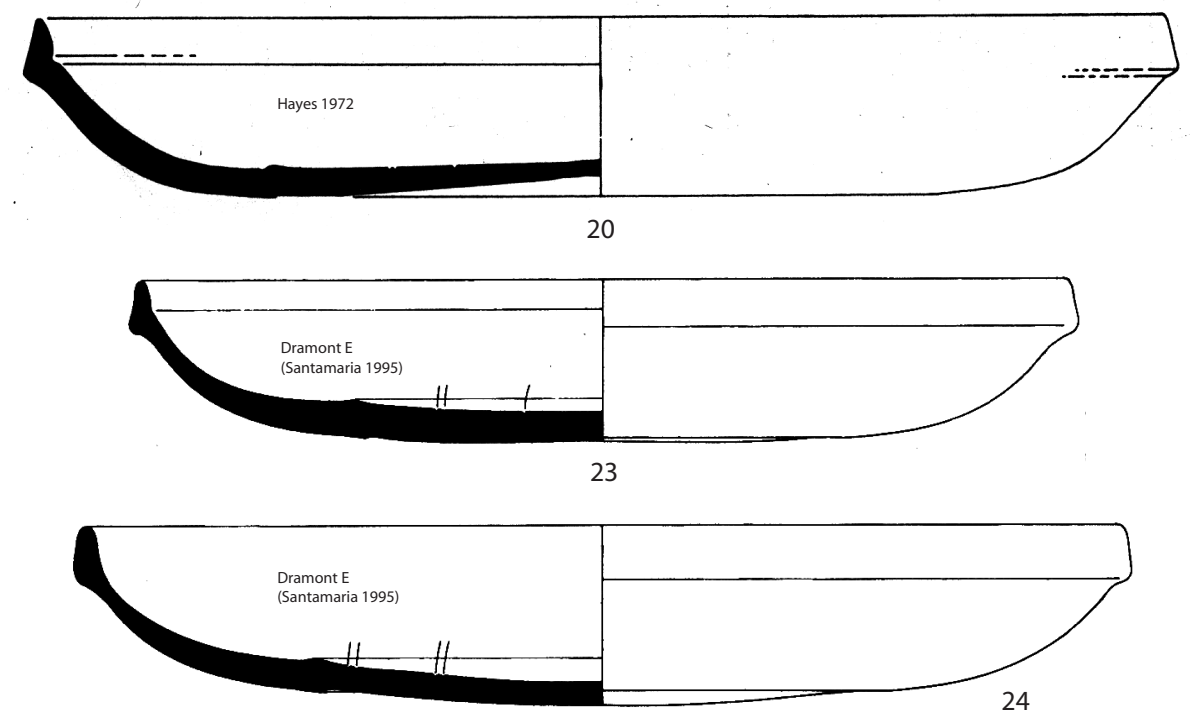

B2 variante

Fig. 90. Vaisselle sigillée africaine D. 


\section{Forme Hayes 61 B}
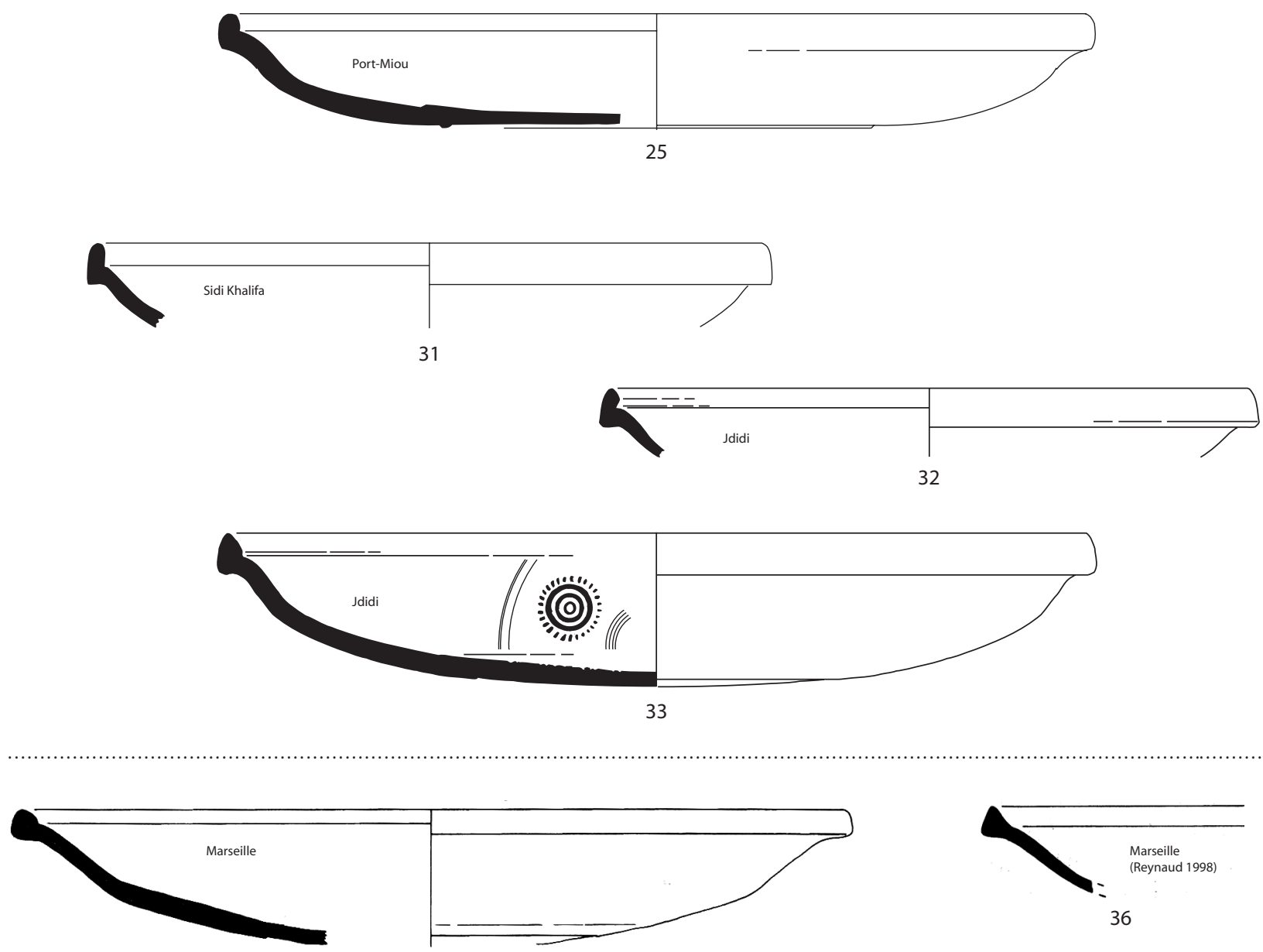

Forme Hayes $61 \mathrm{C}$
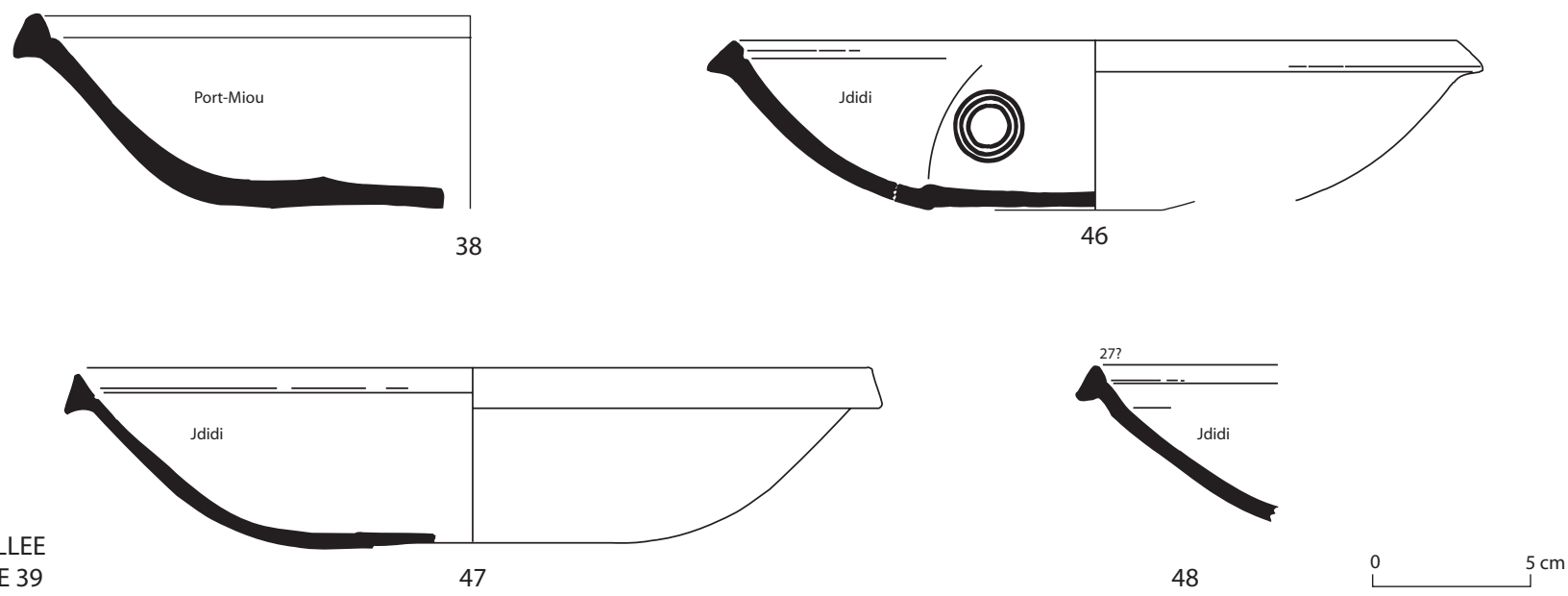

Fig. 91. Vaisselle sigillée africaine D. 
- Variante B 2 (= Hayes 61B, $\left.\mathrm{n}^{\circ} 30\right)$ : forme Hayes 61B classique, plat assez profond, bord rentrant, de section triangulaire à sommet effilé et face intérieure convexe, ressaut extérieur peu marqué.

- Variante B 3 (=Fulford 1B) : forme Hayes 61B à bord épaissi débordant largement à l'extérieur, paroi à profil en « $\mathrm{S} »$.

- Variante B 3 tardive : comme la précédente, mais avec le bord atrophié, les parois très évasées et le fond bombé.

La variante 4 (Bonifay 1998a, 72 et fig. 2, n 1-4) devient la nouvelle forme $61 \mathrm{C}$.

\section{- Hayes 61 C (fig. 91)}

\section{SIGILLÉE TYPE 39}

Ce type n'était inconnu ni de J. W. Hayes (il s'agit probablement du $\mathrm{n}^{\circ} 36$, « triangular rim », non illustré : Hayes 1972, 106), ni de M. Mackensen (1993, 321 et note 294), et il avait été repéré par plusieurs céramologues (Deneauve 1972; Freed 1983 ; Kenrick 1985), mais on doit à J. Lund $(1995,500)$ d'avoir osé lui attribuer une nouvelle lettre dans la nomenclature de Hayes, sur la base d'une référence empruntée à I. Dvoržak Schrunk (1989) ${ }^{139}$.

La forme « 61C » est caractérisée par un bord massif à section triangulaire, pointant plus ou moins fortement vers l'extérieur et souligné par une cannelure à l'intérieur. Le décor sur le fond est assez régulièrement composé (39, 41, 46 ; voir également à Naples : Soricelli 1994, fig. 65, $\mathrm{n}^{\circ} 43$, fig. $72, \mathrm{n}^{\circ} 120$ ) de cercles concentriques Hayes 25, 27, 28 disposés selon le style A(iii). La pâte est généralement de couleur orange clair ou saumon, parfois à cœur beige, d'aspect grumeleux (Pl. II, $\left.\mathrm{n}^{\circ} 12\right)$; le vernis, à l'intérieur, est souvent rouge mat (Bonifay, Reynaud 2004 : groupe SG2 ; voir également Brun 2001).

Exemples :

\section{Hayes 61 A/B [TYPE 37] (fig. 90) \\ Variante $\mathrm{A} / \mathrm{B} 1$}

*1 El Mahrine, atelier (Mackensen 1993, Pl. 53, n 9). Variante A/B 2

2 Antioche (Waagé 1948, Pl. VIII, 831 u).

*3 El Mahrine, atelier (Mackensen 1993, Pl. 54, n 1).

4 Hrušica (Slovénie) (Pröttel 1996, Pl. 15, n 12).

5 Tarragone (Aquilué 1989, Fig. 42, n 1.68). Variante avec rainure sur la face extérieure du bord. Variante A/B 3

*6 Musée de Londres, sans provenance (Hayes 1972, forme $\left.61, \mathrm{n}^{\circ} 26\right)$.

7 Marseille (Cœur-Mezzoud 1998, fig. 101, $\mathrm{n}^{\circ} 4$ ).

*8 Sidi Jdidi, basilique 2, destruction état II (Inv. JD2204.1). Bord atrophié.

9 Jebel Harboun, tombe isolée (Ben Abed et al. 2000, fig. $8, n^{\circ} 3$ ). Bord atrophié.

139 Référence au demeurant erronée : la forme Hayes 61 à laquelle I. Dvoržak Schrunk attribue la lettre C correspond en fait à la variante B3 (Dvoržak Schrunk 1989, Pl. 13, n 167169).
Variante A/B 4

*10 Antioche (Waagé 1948, Pl. IX, 831 k).

*11 Athènes (Atlante I, Pl. 34, $\mathrm{n}^{\circ} 3$ ).

12 Arles, chantier de l'Esplanade (Bonifay 1998a, fig. 1, $\left.\mathrm{n}^{\circ} 1\right)$.

13 Carthage (Tomber 1988, fig. 3, $\mathrm{n}^{\circ} 31$ ).

14 Vallée de Segermes (Lund 1995, fig. 6, ARS 61B).

Hayes 61 B [type 38] (fig. 90-91)

Variante B 1

15 Mayence, Römische Germanische Zentral Muzeum, sans provenance (Hayes 1972, forme 61, $\mathrm{n}^{\circ} 29$ ).

16 Tominčeva jama (Slovénie) (Pröttel 1996, P1. 28, n 1 ).

*17 Port-Vendres, Redoute Béar (Inv. 95-6/8, 98-2/4, 991283, 00-181). Dessin M. Salvat ${ }^{140}$.

18 Port-Miou (Deneauve 1972, Pl. III, $\mathrm{n}^{\circ} \mathrm{C}$ 839).

19 Tarragone (Aquilué 1989, fig. 42, $\mathrm{n}^{\circ} 1.23,1.28,1.30$, 1.32).

Variante B 2

*20 Musée du Vatican, sans provenance (Hayes 1972, forme $61, \mathrm{n}^{\circ} 30$ ).

22 Narbonne, basilique du Clos de la Lombarde (Sabrié 1991, fig. 3, $\left.n^{\circ} 35\right)$.

*23 Epave Dramont E (Santamaria 1995, Pl. X, n 06/81). Variante B2 simplifiée

*24 Epave Dramont E (Santamaria 1995, Pl. X, n 20/81).

Variante B 3

*25 Epave de Port Miou (Cassis, France) (Bonifay 1998a, fig. $1, \mathrm{n}^{\circ}$ 5). Dessin C. Dovis.

26 Marseille, chantier de La Bourse (Bonifay 1983, fig. 19, $\left.\mathrm{n}^{\circ} 12\right)$.

27 Sperlonga (Saguì 1979, fig. 3 ; Saguì 1980, n 31 ).

28 Classe (Maioli 1983, $\mathrm{n}^{\circ}$ 4.77).

29 Carthage (Fulford 1984a, fig. 11, $\mathrm{n}^{\circ} 1.2$ ).

30 Nador (Manacorda 1989, fig. 29, $\mathrm{n}^{\circ} 34$ ).

*31 Sidi Khalifa, atelier (Bonifay et al. 2002-2003, fig. 6, $\left.\mathrm{n}^{\circ} 41\right)$.

*32 Sidi Jdidi, basilique 2, destruction état II (Inv. JD2200.8).

*33 Idem (Inv. JD2243.1). Décor : infra, fig. 101, n 4. Variante B 3 tardive

*34 Marseille, puits de la rue du Bon-Jésus (Bonifay 1998b, fig. 171, $\mathrm{n}^{\circ}$ 9).

35 Sperlonga (Saguì 1980, $\mathrm{n}^{\circ} 30$ ).

*36 Marseille, puits du cap Titol (Reynaud 1998, fig. 213, $\left.\mathrm{n}^{\circ} 1\right)$.

37 Classe (Maioli 1983, $\mathrm{n}^{\circ}$ 4.76).

Hayes 61 C [TYPE 39] (fig. 91)

*38 Epave de Port Miou (Cassis, France) (Bonifay 1998a, fig. $2, \mathrm{n}^{\circ} 1$; cf. Deneauve 1972, Pl. II, $\mathrm{n}^{\circ} \mathrm{C} 870$ ). Dessin C. Dovis.

39 Marseille, chantier de La Bourse (Cour-Mezzoud 1998, fig. 103, $\mathrm{n}^{\circ}$ 19).

40 Saint-Blaise (Cavaillès-Llopis, Vallauri 1994, fig. 59, $\left.\mathrm{n}^{\circ} 122\right)$.

41 Sperlonga (Saguì 1980, $n^{\circ} 29$ ).

42 San Giovanni di Ruoti (Freed 1983, fig. 4, n P 1360, P 3108).

43 Classe (Maioli 1983, $\left.\mathrm{n}^{\circ} 4.74\right)$.

44 Benghazi (Kenrick 1985, $\mathrm{n}^{\circ}$ 638.2).

45 Sidi Jdidi, basilique 1 (Ben Abed, Bonifay, Fixot 1997,

\footnotetext{
${ }^{140}$ Je remercie MM. G. Castellvi, C. Descamps et M. Salvat de m'avoir autorisé à faire état de cette découverte.
} 
fig. $2, n^{\circ} 3$; Bonifay, Reynaud 2004, $n^{\circ} 12.2$ ).

*46 Sidi Jdidi, îlot basilique 2, destruction état II (Inv. JD2243.3).

*47 Idem (Inv. JD2200.1).

*48 Idem (Inv. JD2252.11).

Cette classification est très imparfaite dans la mesure où elle cherche à ordonner en chronologie relative des objets distincts surtout par leur origine. S'il est certain que les variantes $\mathrm{A} / \mathrm{B} 1$ et $\mathrm{A} / \mathrm{B} 2$ ont été fabriquées à El Mahrine, que des ateliers de la région de Sidi Jdidi ont produit certaines des variantes $\mathrm{A} / \mathrm{B} 3$ et $\mathrm{C}$, que celui de Sidi Khalifa est la source d'une grande partie des exemplaires de la variante $\mathrm{B} 3$, on ignore tout de l'origine de la majorité des innombrables exemplaires de forme Hayes 61 qui passent entre nos mains sur les chantiers africains et de Méditerranée occidentale.

Du point de vue chronologique, on manque de données pour réfléchir sur une base strictement africaine, sauf au début et à la fin de la séquence. Ainsi, M. Mackensen date ses variantes $4.3(\mathrm{~A} / \mathrm{B} 1)$ et $4.4(\mathrm{~A} / \mathrm{B} 2)$ du début du Ve s. (Mackensen 1993, 403). De fait, la forme 61B classique ne semble pas attestée au tout début du Ve s., dans les stratigraphies du nord de la Méditerranée. Sur le chantier de l'Esplanade à Arles, seule la variante A/B4 est présente au premier quart du Ves. (Bonifay et al. 1998, 416, Tabl. CIII). A Narbonne, vers 425 (Ibid.), les variantes $\mathrm{A} / \mathrm{B} 3$ et $\mathrm{A} / \mathrm{B} 4$ sont associées à la forme B1 (Sabrié 1991, fig. 3, respectivement $n^{\circ} 37,36$ et 35). Sur l'épave du Dramont E (Santamaria 1995), au deuxième quart du Ves. (Bonifay et al. 1998, 416, Tabl. CIII), abonde la forme B2 tandis qu'au même moment (Ibid.) à Tarragone (Aquilué 1989), c'est la forme B1, probablement contemporaine, qui est plus fréquente. La variante B3 va dominer dans la plupart des contextes du milieu et de la seconde moitié du Ve s., notamment à Marseille (Bonifay et al. 1998, 416, Tabl. CIII) avec des évolutions tardives vers la fin du siècle (à Ibiza, association de la forme Hayes 61B3 avec les formes Hayes 12/102 et 99A : Ramon, Cau 1997). Mais dès le milieu du Ves. (épave de Port Miou: Bonifay et al. 1998, 416, Tabl. CIII), apparaît également la variante C qui va évoluer avec un bord de plus en plus étiré et donc de plus en plus éloigné de la forme 61, jusque dans les dernières années du Ves. comme le prouve son abondance dans les niveaux des années 480 à Sidi Jdidi ; dans ces contextes, subsistent encore des exemplaires relativement peu soignés de la variante A/B3.

\section{Datation proposée :}

Variante A/B1 et A/B2 - début Ve s. (-milieu Ve ?) Variante A/B3 - première moitié du Ves., exemplaires tardifs jusque vers 480

Variante A/B4 - premier tiers du Ve s.

Variante B1 et B2 - première moitié du Ve s.

Variante B3 - milieu du Ve s., exemplaires tardifs fin du Ves.

Variante $\mathrm{C}$ - milieu-seconde moitié du Ve s.

\section{— forme Hayes 62/64, variante Fulford 6 (fig. 92)}

\section{SIGILLÉE TYPE 40}

Une variante de la forme Hayes 62 ou 64, caractérisée par un bord bifide, bien attestée à Carthage (Fulford 1984a, 53 , et fig. 13 , forme 6), apparaît régulièrement dans les contextes de la fin du IVe s. et du début du Ve s., comme à Narbonne (1), où elle est associée à une variante ancienne de bol à listel Hayes 91 (variante Atlante XLVIII, 11) ou à Thuburbo Majus (2). Le décor de style A(ii) de l'exemplaire de Narbonne ${ }^{141}$ rattache cette forme aux productions de Tunisie septentrionale, bien que la facture en soit particulièrement soignée.

Exemples (fig. 92) :

*1 Narbonne, clos de la Lombarde (Sabrié 1991, fig. 14, $\left.\mathrm{n}^{\circ} 235\right)$.

2 Thuburbo Majus, édifice aux Asclepeia (Ben Abed, Bonifay 1998, fig. 2, $\left.\mathrm{n}^{\circ} 19\right)$.

3 Ostie (Ostia III, 113).

\section{— forme Hayes 67 (fig. 92)}

\section{SigILLÉE TYPE 41}

La forme Hayes 67 est l'une des plus abondamment représentée sur les sites de Méditerranée occidentale. En Afrique, elle est surtout présente dans la partie nord de la Tunisie; par exemple, elle n'apparaît pas au sein du matériel de Rougga (Guéry, Bonifay à paraître). L'atelier septentrional d'El Mahrine était sans doute l'un des centres majeurs de production de cette forme (Mackensen 1993) mais très probablement pas le seul, ce qui induit ici encore une grande diversité de variantes au sein desquelles il est difficile de se retrouver (Hayes 1972, 115).

J'ai, pour ma part, pris l'habitude de répartir très grossièrement ce matériel en trois variantes principales, en prenant comme critère de distinction le profil du bord :

- Variante A : bord de la même épaisseur que les parois, ou peu épaissi, marli extérieur court et subhorizontal (= El Mahrine 9.4, $\mathrm{n}^{\circ} 5$ ?).

- Variante B : bord classique, à lèvre triangulaire dégagée par une ou deux cannelure(s) sommitale(s), marli extérieur plus long et courbe (= El Mahrine 9.1 et 9.3).

- Variante $\mathrm{C}$ : bord à lèvre pendante arrondie, avec ou sans cannelure sommitale, marli extérieur long et courbe (= El Mahrine 9.2 et 9.5).

Exemples (fig. 92) :

Variante A

*1 Oudhna, capitole (Inv. UTH1.001.76 ; Bonifay, Dridi, Jacquest à paraître, $\left.\mathrm{n}^{\circ} 8\right)$.

*2 Carthage, Cirque (Tomber 1988, fig. 3, n 34).

Variante intermédiaire A/B

3 Thuburbo Majus, édifice aux Asclepeia (Ben Abed, Bonifay 1998, fig. 2, $n^{\circ} 18$ ).

Variante B

4 Carthage, Byrsa (Bonifay à paraître, a, nº 4).

\footnotetext{
${ }^{141}$ Décor constitué de cercles concentriques (poinçon Hayes 27) alternant avec des palmettes (Sabrié 1991,120).
} 
Forme Lamboglia 52B

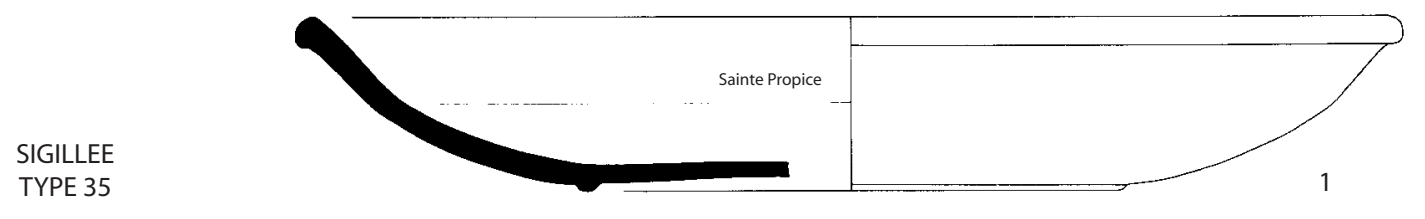

Forme Hayes 59 variante
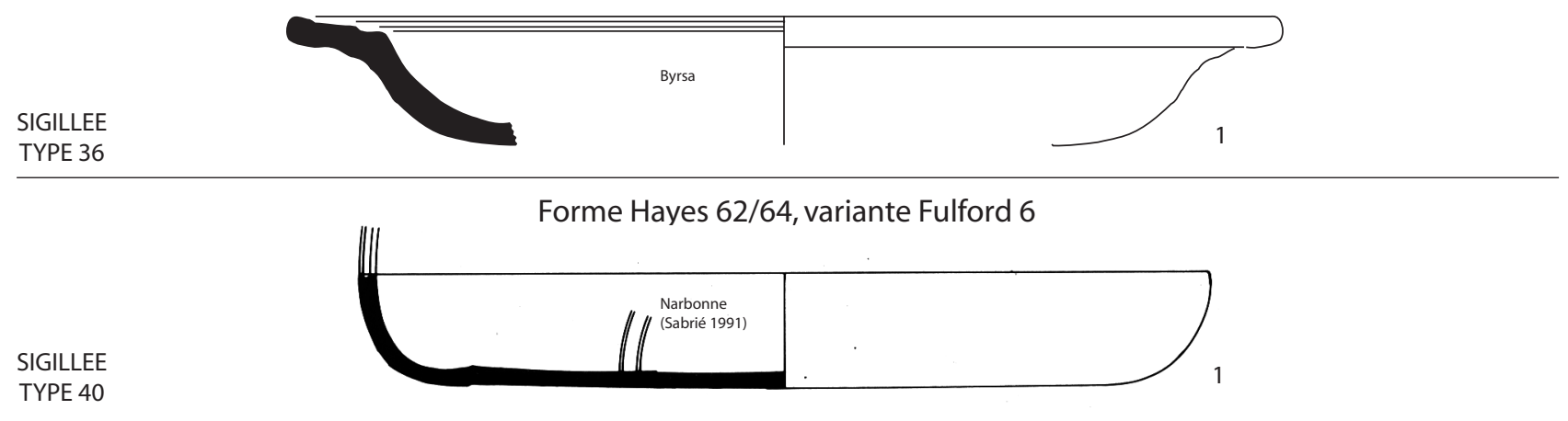

Forme Hayes 67
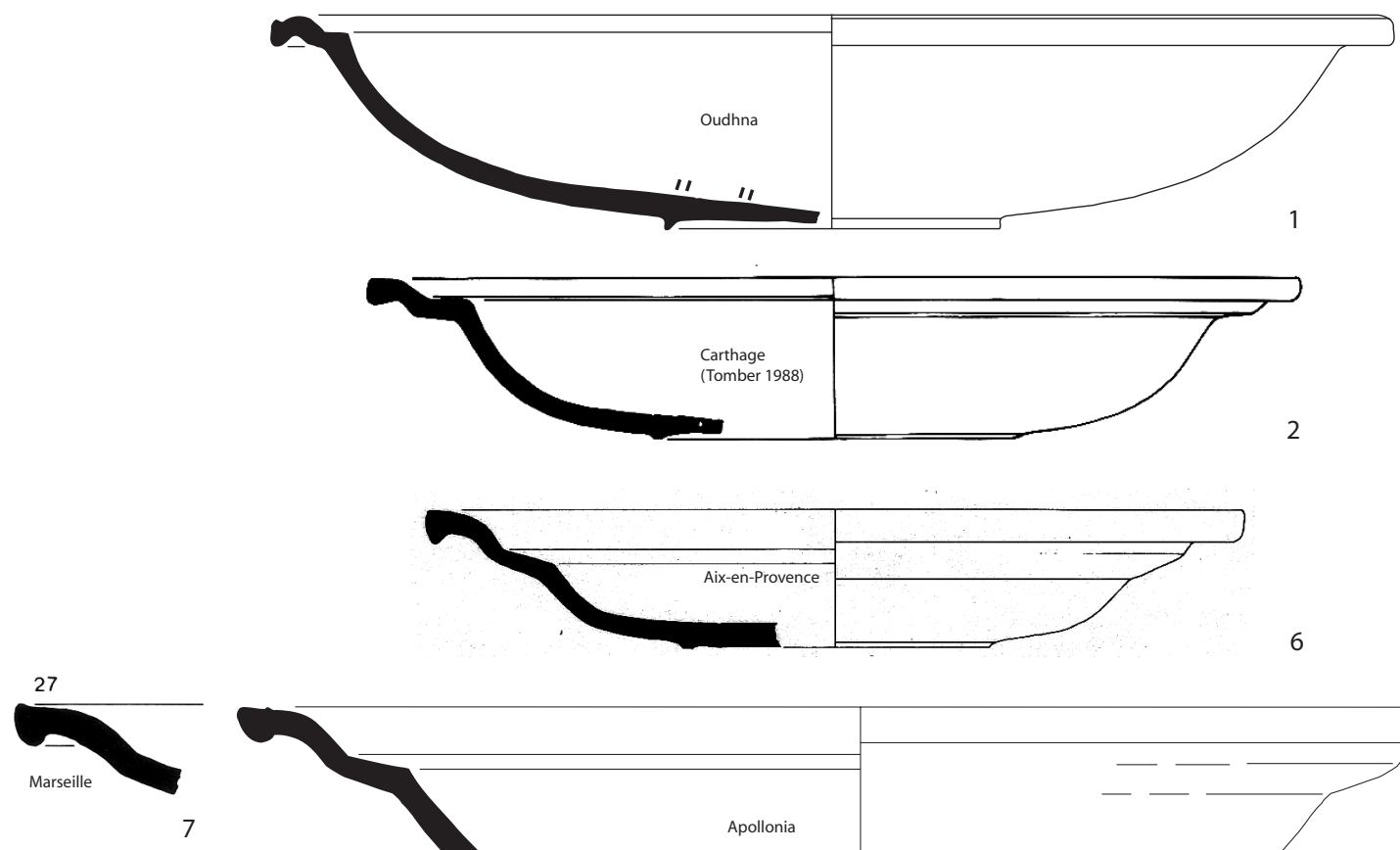

SIGILLEE

TYPE 41

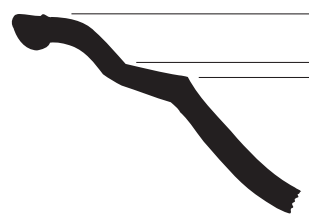

Forme Hayes 79

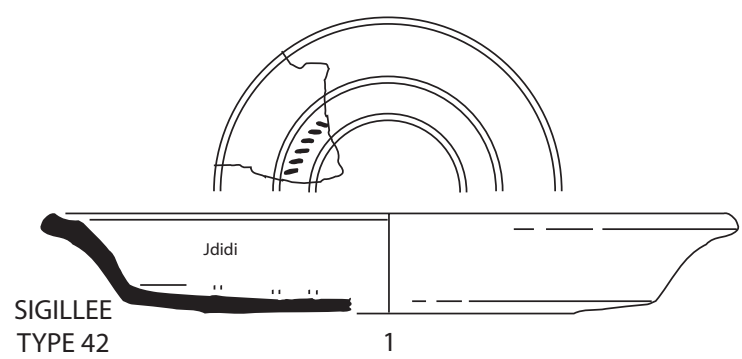

A

6

B

C

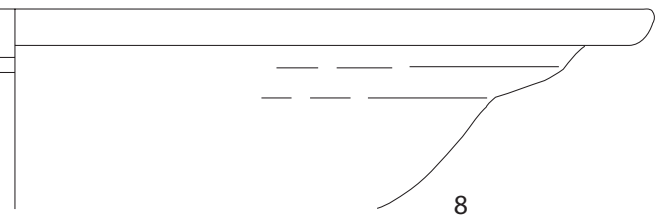

Apollonia
Forme Hayes $81 \mathrm{~A}$ variante

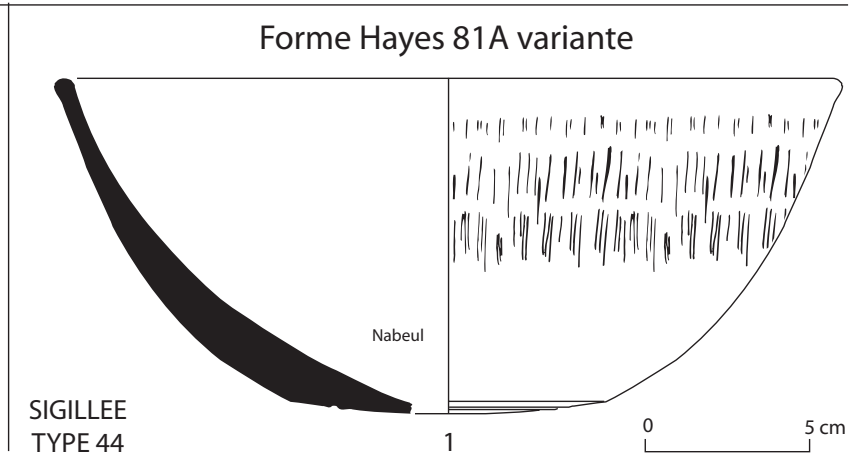

Fig. 92. Vaisselle sigillée africaine D. 
5 Sidi Jdidi, basilique 1 (Bonifay, Reynaud 2004, $\mathrm{n}^{\circ}$ 9.1).

*6 Aix-en-Provence (C.A.T.H.M.A. 1986, fig. 6, nº 4).

Variante C

*7 Marseille, chantier de La Bourse (Bonifay 1983, fig. 19, $\left.\mathrm{n}^{\circ} 13\right)$.

*8 Apollonia de Cyrénaïque, chenal portuaire, phase 2 (Fouille A. Laronde, Inv. AP93.CHE.C3.1152).

Les exemplaires précoces peu standardisés (1) de cette forme, regroupés un peu artificiellement au sein d'une "variante A », sont attestés dans la seconde moitié du IVe à Oudhna (1) et à Carthage (2); un exemplaire de Césarée de Palestine (Tomber 1999, fig. $1, \mathrm{n}^{\circ} 8$ ) est bien daté des environs de 400 . La variante $\mathrm{B}$ peut apparaître à la fin du IVes. ou au début du Ves. (3) et semble caractéristique des contextes de la première moitié du Ve s. (4, 5 et 6). Pour des comparaisons en Méditerranée septentrionale, on se reportera également aux contextes de Narbonne (Sabrié 1991, fig. 4, n 41-42 ; V. Belbenoit in Ginouvez 1996-97, fig. 44, $\mathrm{n}^{\circ} 6$ ). La variante $C$ ne paraît pas antérieure au milieu du Ves. (7) et perdure dans la seconde moitié du siècle $(\mathbf{8})$. On remarquera toutefois que les variantes $\mathrm{B}$ et $\mathrm{C}$ sont associées dans une casette à El Mahrine (Mackensen 1993, fig. 101). Néanmoins, J. W. Hayes avait attiré l'attention sur les exemplaires les plus tardifs munis d'un « heavy roll at rim », comme l'exemplaire $\mathrm{n}^{\circ} \mathbf{8}$ (voir également à Marseille: Reynaud 1998, fig. 213, $\mathrm{n}^{\circ} 3$ ). Tous les exemplaires publiés à Saint-Blaise, dans des contextes non antérieurs au milieu du Ve s., sont de la variante $\mathrm{C}$ (Cavaillès-Llopis, Vallauri 1994, fig. 46, n 16-19).

\section{— forme Hayes 79 (fig. 92)}

\section{SIGILLÉE TYPE 42}

L'assiette Hayes 79, assez peu documentée en Méditerranée occidentale, est bien attestée à Sidi Jdidi (1), dans un groupe de pâte homogène (Bonifay, Reynaud 2004: groupe SG5), peu éloigné du groupe A/D; le décor guilloché sur le fond paraît constant. La stratigraphie de Sidi Jdidi précise un peu les datations proposées par J. W. Hayes (1972, 127 ; Atlante I, 90) : cette forme est caractéristique des contextes de l'état $\mathrm{C} 1$ (seconde moitié du Ve s.).

Exemples (fig. 92) :

*1 Sidi Jdidi, basilique 1, état C1 (Bonifay, Reynaud 2004, $\left.n^{\circ} 14.1\right)$.

2 Vintimille (Gandolfi 1981, fig. 23).

\section{— formes Hayes 80 A/B et 81 B (fig. 92)}

\section{SIGILLÉES TYPES 43-44}

Les formes Hayes 80 [TYPE 43] et 81 [TYPE 44] sont des formes voisines. Leur fonctionnalité qui procède, à l'évidence, de la simplicité de leur profil, est sans doute à l'origine de l'émergence de nombreuses variantes locales (infra, SIGILLÉE TYPE 72). Il reste que ces deux formes classiques, largement exportées en Méditerranée occidentale, n'ont pas en Afrique, la même diffusion, ni donc, probablement, la même origine. Il est clair que la forme Hayes 80 est typique des contextes de Carthage (par exemple, à Byrsa : Bonifay à paraître, a, $n^{\circ}$ 6-12), ce qui peut s'expliquer par le fait qu'elle est produite, au moins en partie, sur l'atelier d'El Mahrine (Mackensen 1993, formes 11 et 12). En revanche, la forme Hayes 81, rare à Carthage (Fulford 1984a, 57: « no example of rouletted version $\gg)$, est bien attestée sur les sites de la façade orientale du cap Bon, avec notamment, à Nabeul, une variante de grande taille jusqu'ici non signalée (1). Bien que la plupart des exemples catalogués par J. W. Hayes proviennent de la région de Beja, on pourrait également proposer, compte tenu du fait que cette forme est bien diffusée sur les côtes septentrionales de la Méditerranée, une production dans l'est de la Zeugitane. Je n'ai pas de modification à apporter à la datation proposée pour ces deux formes : milieu - seconde moitié du Ve s. (Hayes 1972, 128 ; Mackensen 1993, 406). Exemple (fig. 92) :

*1 Nabeul, fouilles anciennes (Inv. NB0084.2).

— forme Hayes 87 A (fig. 93)

\section{SIGILLÉE TYPE 45}

La forme Hayes 87 A pose les mêmes problèmes de classification que la forme Hayes 61B (Reynolds 1995, 11). De ce point de vue, la distinction faite sur le site de Saint-Blaise de deux variantes dans la forme Hayes 87A me paraît intéressante (Cavaillès-Llopis, Vallauri 1994, 96 et fig. 49 ; voir également Gourvest 1998, fig. 17, $\mathrm{n}^{\circ} 174$ et 151 ; Bonifay et al. 1998,364$)^{142}$ :

- Variante A1 (= Hayes 87A, $\mathrm{n}^{\circ} 1=$ Saint-Blaise type 2) : caractérisée par « une lèvre triangulaire et haute, un pied annulaire épais et triangulaire » (Cavaillès-Llopis, Vallauri 1994, 96), elle porte une décoration lustrée de bandes concentriques et de motifs géométriques floraux ou chrétiens ${ }^{143}$; la pâte est du groupe D2.

- Variante A2 (= Hayes 87B, $\mathrm{n}^{\circ} 2$ = Saint-Blaise type 1): se distingue par « une lèvre arrondie et courte et un pied atrophié et bas " ainsi que par une décoration de style $\mathrm{E}(\mathrm{i})^{144}$; pâte sableuse et tendre, vernis rouge-marron, mat et peu adhérent.

Exemples (fig. 93) :

Variante A1

*1 Saint-Blaise (Cavaillès-Llopis, Vallauri 1994, fig. 49, $\mathrm{n}^{\circ} 50$ ).

Variante A2

*2 Idem (Cavaillès-Llopis, Vallauri 1994, fig. 49, n48).

Il a été suggéré (Atlante I, 94), en fonction du style décoratif, que l'atelier d'Oudhna ait pu produire une

\footnotetext{
${ }^{142}$ La numérotation des deux variantes, inversée dans CavaillèsLlopis, Vallauri 1994, est ici conforme à celle de Hayes 1972.

143 "Burnished patterns », cf. Aquilué 1992. Les décors lustrés sont toujours sur les variantes $\mathrm{A}$ et $\mathrm{C}$.

${ }^{144}$ Palmette type Hayes 118 à Saint-Blaise, croix et oiseau type Hayes 309 sur l'exemplaire de Corinthe.
} 
Forme Hayes 87A

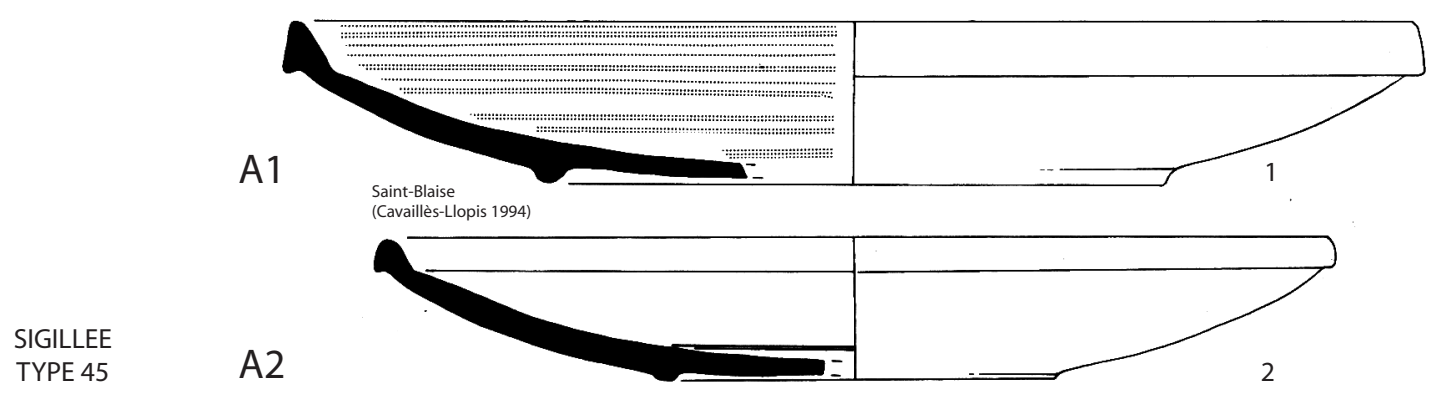

TYPE 45

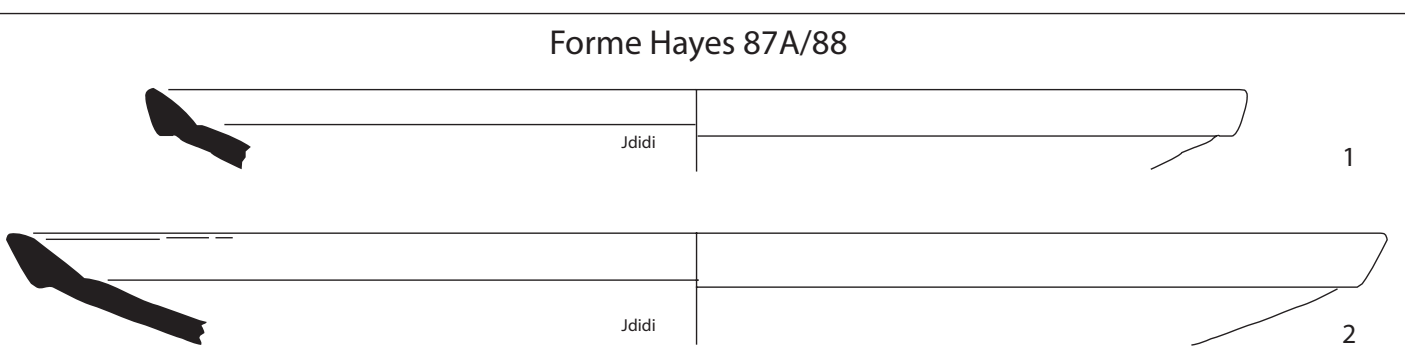

Forme Hayes 88
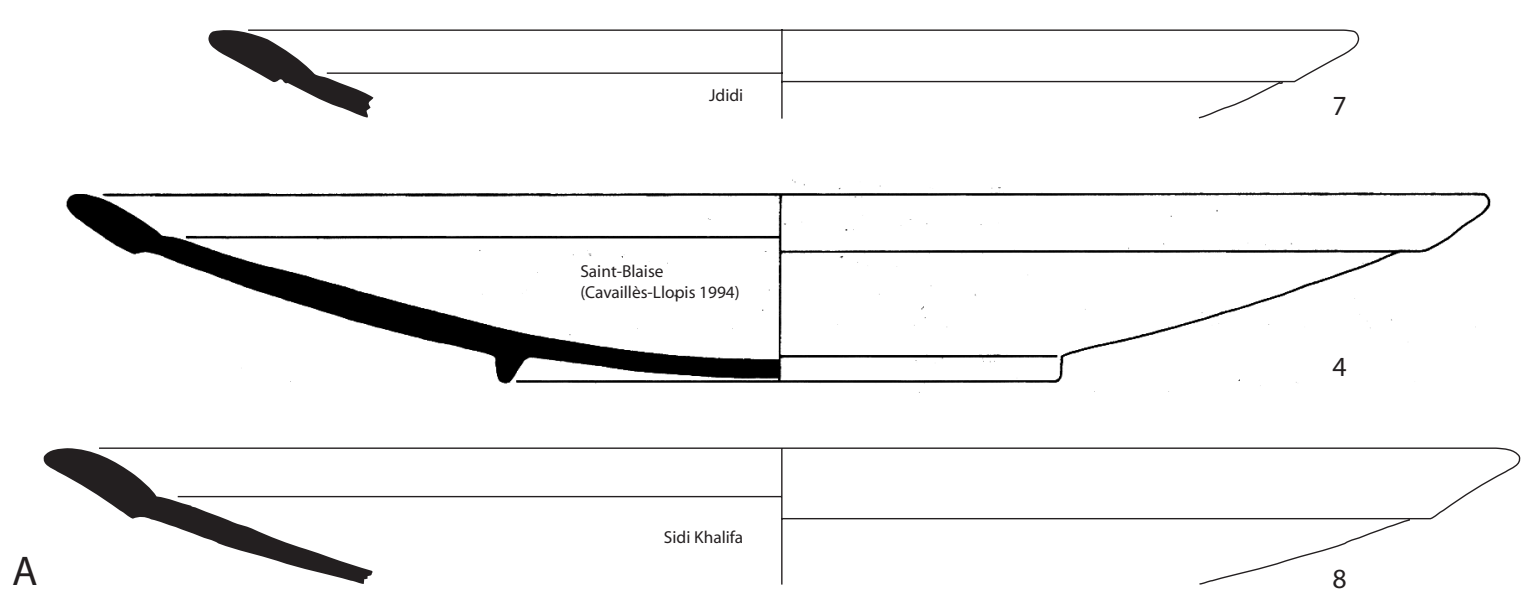

A
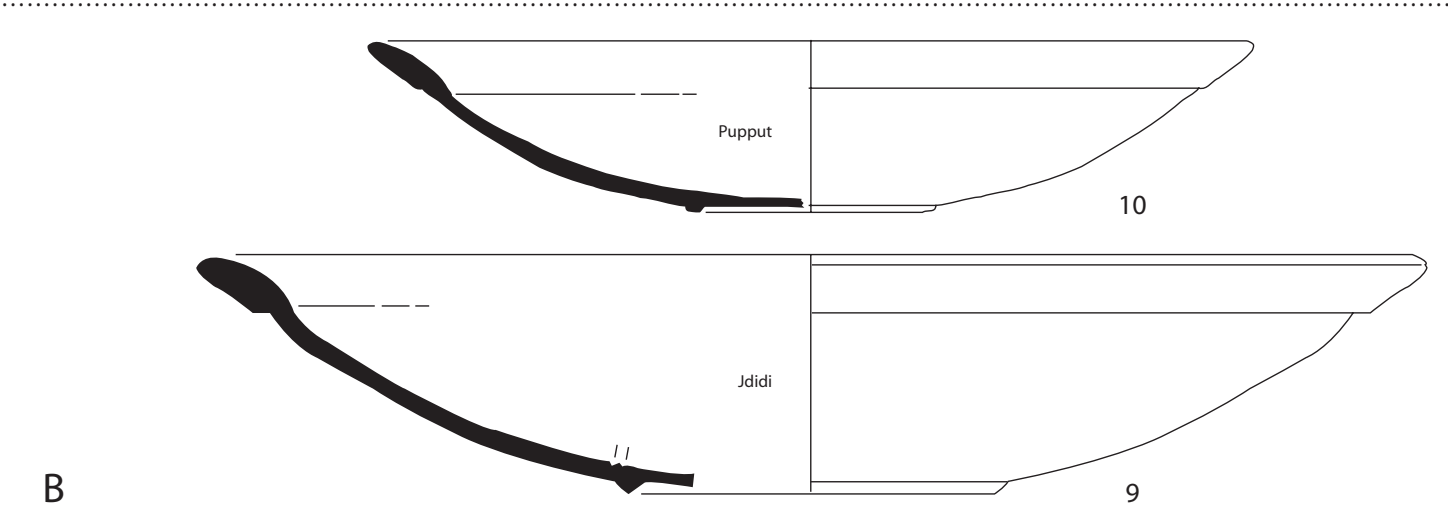

C
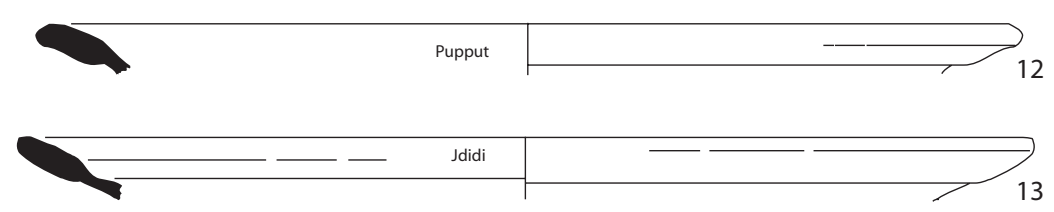

Fig. 93. Vaisselle sigillée africaine D. 
partie au moins des exemplaires de la variante A2 ; mais leur pâte ne semble pas correspondre à celle des productions de l'atelier. On ne connaît pas non plus l'origine des produits à décor lustré de la variante A1 et ce serait trop schématiser que de les attribuer (Pavolini, Tortorella 1997, 267) au seul atelier de Sidi Khalifa. En effet, je n'ai pas remarqué une fréquence particulière de la forme Hayes 87 dans la zone de l'atelier de Sidi Khalifa que j'ai visitée, où les trois formes les plus répétitives sont Hayes $61 \mathrm{~B}, 88$ et 103 . De même, si l'on considère que les prospections de la vallée de Segermes (Lund 1995) constituent un bon observatoire des productions de l'atelier de Sidi Khalifa, en raison de la proximité de celui-ci, on note, au sein des sigillée africaines, une sur-représentation des formes Hayes 61B (81 ex.), Hayes 88 (71 ex.) et 103 (217 ex.) alors que les différentes variantes de la forme 87 ne dépassent pas 25 exemplaires. Le faciès est le même sur les sites du littoral de la sebkhra Sidi Khalifa que nous avons explorés (Bonifay et al. 2002-2003) (145. $^{\text {. }}$

Ces deux variantes sont contemporaines des productions de sigillée C5 (Bonifay et al. 1998, 364 et 417, Tabl. CIII). Plutôt que de voir dans la forme 87A une dérivation de la forme 61B, je me demande s'il ne s'agit pas plutôt d'une variante septentrionale de la forme de Tunisie centrale Hayes 82. Toutefois, un exemplaire de la variante $\mathrm{A}$ à décor lustré est également signalé à Jerba (Fontana 2000, fig. 2, $\mathrm{n}^{\circ}$ 4).

Par ailleurs, P. Reynolds (1995, 11) a émis l'hypothèse qu'une partie des formes Hayes $87 \mathrm{~B}$ et $\mathrm{C}$, celles avec une pâte du groupe D5 (supra, p. 48), soit d'origine algérienne. De fait, ces formes sont très abondantes à Alicante (Reynolds 1987, n 11-76) alors qu'on n'y relève qu'un seul fragment de forme Hayes 88 (Ibid., $\mathrm{n}^{\circ} 78$ ), typique de l'atelier de Sidi Khalifa.

\section{— forme Hayes 88 (fig. 93)}

\section{SIGILLÉE TYPE 46}

La forme Hayes 88 est véritablement la forme-phare de l'atelier de Sidi Khalifa (supra, p. 56). Les productions de cet atelier ont parfois une pâte fine et un vernis orange satiné qui peut les faire confondre avec les catégories C5 ou C4 (Hayes 1972, 136 ; Atlante I, 93). Les tentatives de J. Lund (1995, 516) puis de M. Ben Moussa (2001) de reconstituer la chronologie relative des différentes variantes de la forme Hayes 88 se sont révélées difficiles, en raison du caractère fragmenté et hors contexte du matériel dont ils disposaient. C'est pourquoi, je crois utile de présenter ici les quelques éléments d'évolution typologique qui m'ont été fournis par les stratigraphies de Sidi Jdidi et Pupput, sites fort peu éloignés $(15 \mathrm{~km}) \mathrm{de}$

\footnotetext{
${ }^{145}$ Les quelques décors «à spatule » recensés par Moncef Ben Moussa dans ses prospections à Pheradi Majus appartiennent à la génération tardive (infra, groupe 2: VIIe s.) de ce style décoratif, non à celle caractéristique de la forme Hayes 87A1 (infra, groupe 1) : Ben Moussa 2001, Pl. CXVI.
}

l'atelier de Sidi Khalifa. Je propose de distinguer, provisoirement, les variantes suivantes :

- Variante précoce 87A/88 (= Hayes 87, $\mathrm{n}^{\circ} 4=$ Atlante XL, 9): cette variante de la forme $87 \mathrm{~A} 1$, avec un bord très évasé, assez allongé, est considérée depuis longtemps (Hayes 1972, 136 ; Atlante I, 93) comme un type intermédiaire entre la forme 87 et la forme 88 .

- Variante 88 A (= Hayes 88, $\left.\mathrm{n}^{\circ} 2\right)$ : variante classique; le bord est assez allongé, à extrémité généralement effilée, faiblement convexe à l'intérieur, plat à l'extérieur; les parois, dans le prolongement $\mathrm{du}$ bord, sont rectilignes ou très légèrement convexes; le fond est muni d'un pied triangulaire, relativement haut.

- Variante 88 B : le bord est allongé, oblique, très convexe à l'intérieur, légèrement concave à l'extérieur; la panse, nettement convexe, forme parfois un « $\mathrm{S}$ » à la jonction avec le bord; le fond, plus étroit (?), est muni d'un petit pied bas, triangulaire.

- Variante $88 \mathrm{C}$ : variante tardive, à bord atrophié.

Deux groupes se distinguent en fonction du diamètre : un groupe autour de $40 \mathrm{~cm}$ et un autre autour de $30 \mathrm{~cm}$ : les exemplaires tardifs de la variante $\mathrm{C}$ sont plutôt du deuxième groupe.

Exemples (fig. 93) :

Variante précoce (forme 87A/88) :

*1 Sidi Jdidi, basilique 1, état B1B (Bonifay, Reynaud 2004, $n^{\circ} 16.2$ ).

*2 Sidi Jdidi, îlot basilique 2, destruction état II (Inv. JD2325.5). Dessin T. Mukai.

3 Pupput, thermes du centre (fouilles A. Ben Abed, Inv. PPC.111.0).

Variante A

*4 Saint-Blaise, « maison du fondeur » (Cavaillès-Llopis, Vallauri 1994, fig. 60, $\mathrm{n}^{\circ}$ 137).

5 Epave de La Palud (Hyères, France) (Long, Volpe 1998, fig. 302, $\mathrm{n}^{\circ}$ 90).

6 Sidi Jdidi, basilique 1, état B2A (Bonifay, Reynaud 2004, $n^{\circ} 18.3$ ).

*7 Sidi Jdidi, basilique 2, destruction état II (Inv. JD2205.1).

*8 Sidi Khalifa, atelier (Bonifay et al. 2002-2003, fig. 6, $\left.\mathrm{n}^{\circ} 45\right)$.

Variante B

*9 Sidi Jdidi, basilique 1, état C2A (Ben Abed, Bonifay, Fixot 1997, fig. 2, $\mathrm{n}^{\circ} 8$; Bonifay, Reynaud 2004, $\left.\mathrm{n}^{\circ} 19.1\right)$.

*10 Pupput, thermes du centre, pièce XXVII (fouilles A. Ben Abed ; sans $n^{\circ} \mathrm{d}^{\prime}$ inv.).

11 Marseille, chantier de La Bourse (Bonifay 1983, fig. 24, $\left.\mathrm{n}^{\circ} 109\right)$.

Variante C

*12 Pupput, thermes du centre (fouilles A. Ben Abed, Inv. PPC.156.6).

*13 Sidi Jdidi, basilique 1, état C2B (Bonifay, Reynaud 2004, $\left.n^{\circ} 24.1\right)$.

14 Vallée de Segermes (Lund 1995, fig. 12, ARS 88, variant 2).

La variante précoce apparaît régulièrement dans les contextes de la fin du Ve s. ou du début du VIe s. (1-2). 
Forme Hayes 90B

B1
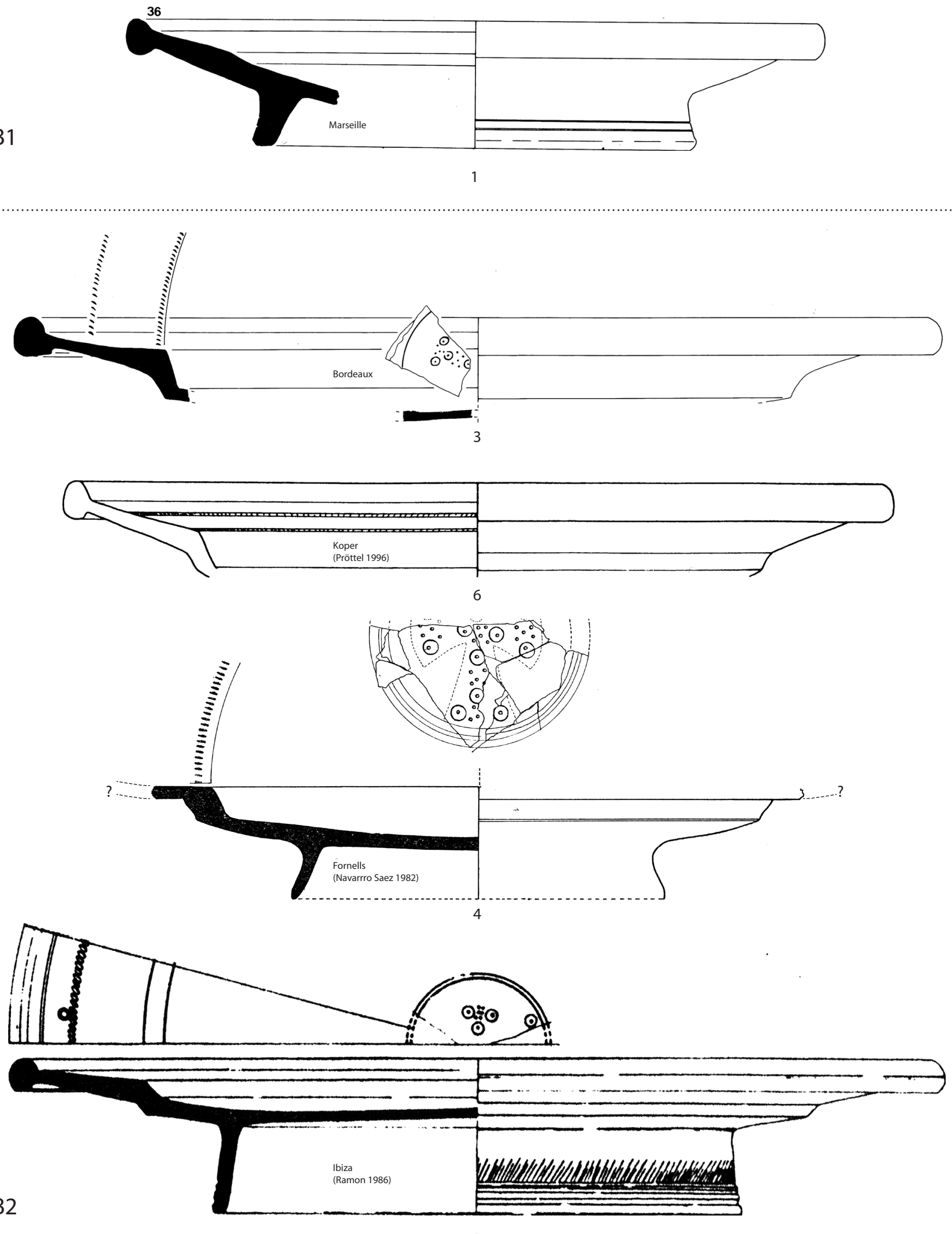

SIGILLEE

TYPE 47

Fig. 94. Vaisselle sigillée africaine D. 
Un exemplaire de Tarragone, avec un bord encore assez relevé, date de la fin du Ves. (Aquilué 1993, fig. 95, $\left.\mathrm{n}^{\circ} 51\right)$. Un consensus semble actuellement s'établir pour dater l'apparition des premiers exemplaires de la forme Hayes 88 (variante A) vers la fin du premier quart du VIe s. (Fulford 1984a, 63 ; Lund 1995, 516) et non au début du siècle comme le proposait J. W. Hayes (1972, 136). De fait, les $n^{\circ} 4$ et 5 proviennent bien de contextes du deuxième quart du VIe $\mathrm{s}$. (Bonifay et al. 1998, 417, Tabl. CIII). Il est plus difficile de situer chronologiquement la variante B. Le $\mathrm{n}^{\circ} \mathbf{9}$ ne semble pas antérieur au milieu du VIe s. (Bonifay, Reynaud 2004), datation qui semble également convenir au tesson marseillais (11) (Bonifay et al. 1998, 418, Tabl. CIII, contexte $\left.n^{\circ} 29\right)$; le $n^{\circ} \mathbf{1 0}$ est associé à des éléments de la seconde moitié du VIe s. (amphore Hammamet 3B). Enfin, la variante $\mathrm{C}$ est caractéristique des niveaux de la fin du VIe s. (12) ou du début du VIIe s. $(\mathbf{1 3})^{146}$.

Datation proposée :

Variante précoce (Hayes 87A/88) — fin du Ve début du VIe s.

Variante $\mathrm{A}$ - deuxième quart - milieu du VIe s.

Variante B - milieu - seconde moitié du VIe s.

Variante C - fin du VIe - début du VIIe s.

\section{— forme Hayes 90B (fig. 94)}

\section{SIGILLÉE TYPE 47}

Alors que la variante A de la forme Hayes 90 est très probablement une production de Tunisie centrale (C tardive : supra, TYPE 33), la variante B, plus grossière comme le signalait Hayes (Hayes 1972, 139: «fabric coarse »), devrait plutôt appartenir à la catégorie D (Atlante I, 97). Mais il faut bien admettre que cette forme n'est pas très répandue dans le nord de la Tunisie, moins, en tout cas, qu'en Tunisie centrale (Bonifay et al. 20022003) d'où elle pourrait bien, finalement, être également originaire, pour partie tout au moins (variante B1); un exemplaire est signalé en Tripolitaine (Marsa el-Brega : Preece 2000, fig. 11, $\mathrm{n}^{\circ}$ 9). J. W. Hayes illustrait deux exemples qui constituent en fait les deux variantes principales de cette forme :

- Variante B1 (= Hayes 90B, $\mathrm{n}^{\circ} 2$ ) : bord très épaissi, arrondi sur le sommet, légèrement aplati sur la face inférieure, paroi rectiligne marqué d'un escalier à l'intérieur, pied haut et massif, décoré de guillochis ou de cannelures.

- Variante B2 (= Hayes 90B, $\mathrm{n}^{\circ} 4$ ) : bord comparable au précédent, mais face inférieure dans certain cas plus large et nettement aplatie, paroi formant un escalier important, à l'intérieur et à l'extérieur; le marli supérieur est décoré d'une double ligne de guillochis; pied haut. Décor de style «F $\mathrm{F}$ (infra, p. 193).

Exemples (fig. 94) : Variante B1

\footnotetext{
${ }^{146}$ Associé à un bord de sigillée africaine de type Sidi Jdidi 8 (infra, SIGILLÉE TYPE 83).
}

*1 Marseille, chantier de La Bourse (Bonifay 1983, fig. 29, $\mathrm{n}^{\circ} 186$ ).

Variante de transition avec Hayes 105 :

2 Bordeaux, chantier de la place Camille-Jullian (Bonifay à paraître, b, fig. $2, \mathrm{n}^{\circ} 10$ ).

Variante B2

*3 Bordeaux, chantier de la place Camille-Jullian (Bonifay à paraître, b, fig. 2, $n^{\circ} 5-6$ ).

*4 Majorque, basilique de Fornells (Navarro Saez 1982, fig. 40).

*5 Ibiza (Ramon 1986, fig. 14, $\mathrm{n}^{\circ} 16$ ).

*6 Koper (Croatie) (Pröttel 1996, Pl. 29, n 5).

7 Carthage (Riley 1981, fig. 5, $\mathrm{n}^{\circ} 4-5$ ).

8 Carthage (Fulford, Timby 1994, fig. 1.8, n 53 ?) ${ }^{147}$.

Confirmant les hypothèses de J. W. Hayes (1972, 140), on voit, d'après les exemples ci-dessus, que les deux variantes de cette forme sont bien attestées dans la seconde moitié du VIe s. et au début du VIIe s. (Bonifay à paraître, b). Il est clair également, encore en accord avec Hayes, que la variante 1 constitue un précurseur de la forme Hayes 105 (2).

\section{— forme Hayes 91}

La forme Hayes 91 est l'une de celles qui ont fait couler le plus d'encre. Il faut en effet rappeler la polémique née dans les années 1970 à propos de la datation tardive proposée par J. W. Hayes $(1972,144)$ des plus anciennes versions de bols à listel en sigillée africaine et de son refus de déceler dans cette forme une influence de la sigillée gauloise Drag. 38 (Février 1976,68$)^{148}$. Je pense que la retractatio de Hayes (1977 et 1980) concernant ce dernier point n'était pas justifiée : les bols à listel sont connus en Tunisie depuis les premiers siècles de l'Empire, tout d'abord en céramique commune (infra, COMMUNE TYPE 8) puis en sigillée africaine C (supra, SIGILLÉES TYPES 26-27); pour le premier point, tout le malentendu vient d'une question de nomenclature typologique.

En effet, les datations proposées par Hayes pour ses quatre variantes sont toujours valables, au prix seulement d'un vieillissement de la date d'apparition des variantes A et B, peut-être vers les années 400/420 au lieu de 450 (Mackensen 1993, 431) ; ce changement est donc moins important que celui auquel il s'était résigné en 1977. En revanche, P.-A. Février avait raison lorsqu'il affirmait la présence en Afrique de bols à listel en sigillée dans la seconde moitié du IVes. : il s'agit d'une part des séries locales qu'il avait lui-même classées à Sétif (infra, p. 203), d'autre part de sigillées africaines D proprement dites mais avec une forme différente de celles cataloguées par J. W. Hayes.

En restant pour le moment dans la catégorie D, je souhaiterais simplement illustrer une variante précoce et

\footnotetext{
${ }^{147}$ Identifié comme Hayes 76.

${ }^{148}$ Forme jamais signalée, à ma connaissance, en Tunisie.
} 
Forme Hayes 91

variante précoce

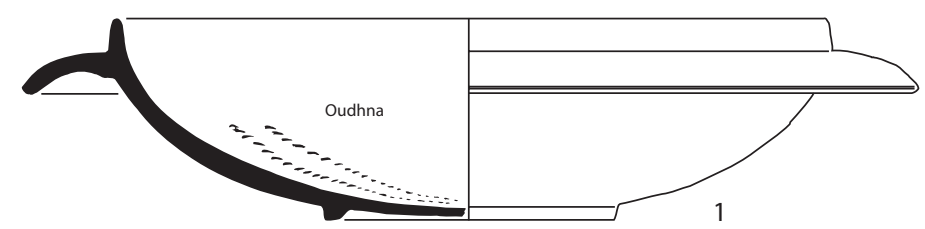

SIGILLEE

TYPE 48

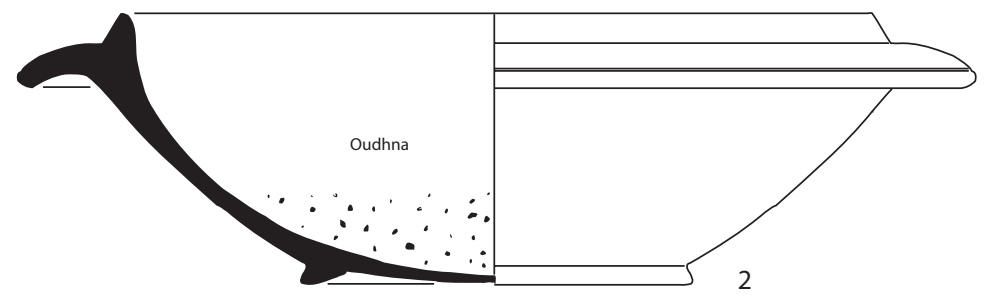

Forme Hayes $91 \mathrm{~A}$

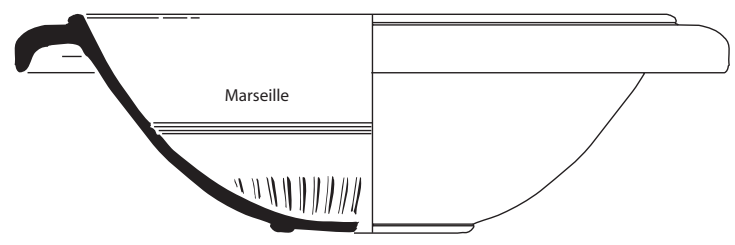

TYPE 49

1

Forme Hayes 91 B

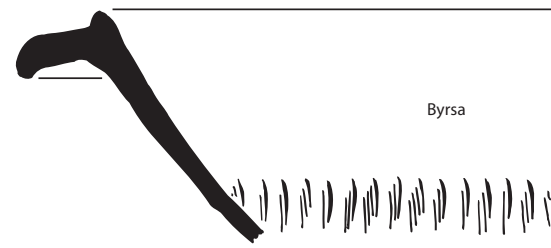

TYPE 50

1

Forme Hayes 91 B tardive
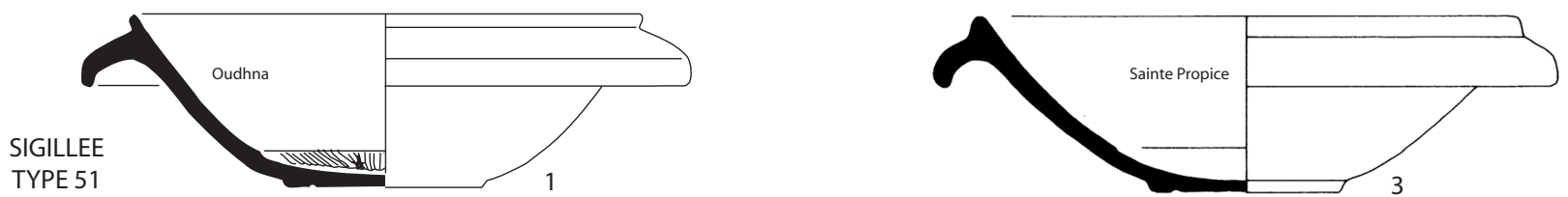

Forme Hayes $91 \mathrm{C}$

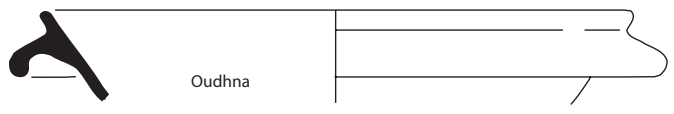

TYPE 52

1

Forme Hayes 91, variante Atlante XLIX, 10

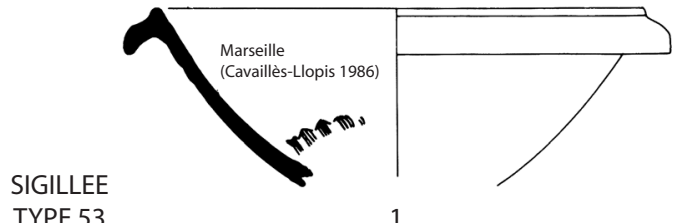

TYPE 53
Forme Hayes $91 \mathrm{D}$

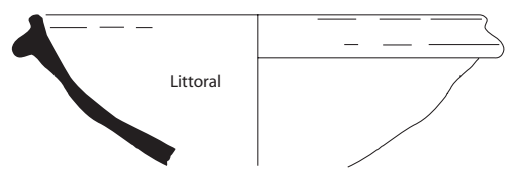

TYPE 54

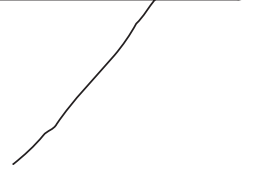

Fig. 95. Vaisselle sigillée africaine D. 
deux autres plus tardives qui ont parfois suscité des difficultés d'interprétation.

\section{(fig. 95) \\ - Hayes 91, variante précoce (Atlante XLVIII, 11)}

\section{SIGILLÉE TYPE 48}

Cette variante précoce, déjà décrite (Atlante I, 105) est caractérisée par un bord haut et effilé (qui l'a parfois fait confondre avec la variante 91C), un listel long et courbe, parfois marqué d'une cannelure à son extrémité, une panse hémisphérique très évasée posée sur un petit pied triangulaire ou trapézoïdal (comme sur la variante A). Le fond est décoré de guillochis, allongés et fins, ou bien de grains de basalte. Ce dernier détail relie directement cette variante précoce aux mortiers en céramique commune et aux variantes anciennes de bols à listel de Tunisie centrale (supra, SIGILLÉE TYPE 27).

Exemples (fig. 95) :

*1 Oudhna, capitole (Inv. UTH1.001.116 ; Bonifay, Dridi, Jacquest à paraître, $\left.\mathrm{n}^{\circ} 10\right)$.

*2 Idem (Inv. UTH1.001.117; Ibid., n¹1). Grains de basalte sur le fond.

La datation proposée dans l'Atlante I correspond bien aux données des deux exemplaires d'Oudhna issus d'un contexte homogène de la seconde moitié du IVe siècle.

- Hayes 91 A (fig. 95)

\section{SIGILLÉE TYPE 49}

Pour mémoire.

Exemple :

*1 Marseille, chantier de La Bourse (Inv. MB2871.1).

Datation proposée : première moitié du Ve s.

- Hayes 91 B (fig. 95)

\section{SIGILLÉE TYPE 50} \\ Pour mémoire. \\ Exemple : \\ *1 Carthage, Byrsa (Bonifay à paraître, a, $\mathrm{n}^{\circ} 16$ ). \\ Datation proposée : décennies centrales du Ve s.
}

\section{- Hayes 91 B, variante tardive (fig. 95)}

\section{SigILLÉE TYPE 51}

Une autre série de bols à listel a pu être confondue, en raison de leur taille cette fois, avec ceux de la forme 91C, alors qu'il s'agit de variantes de petit diamètre de la forme $91 \mathrm{~B}$. Le profil général est comparable : le bord, à section fréquemment triangulaire dépasse à peine du listel ; ce dernier devient plus court et sub-horizontal, ou encore long mais tombant ou parfois arrondi ; la panse est évasée et le fond plat comme celui de la variante C. Le décor de guillochis n'est pas toujours présent (3) ; il est généralement sommaire (1-2). La caractéristique principale de ces objets est leur petit diamètre $(16-20 \mathrm{~cm}$ environ), encore comparable à celui de la variante C. Il est clair que les exemplaires d'Oudhna (1) subissent la contamination morphologique des mortiers en céramique commune Carthage Class 1 (listel tombant, fond plat avec léger pied dégagé par une simple rainure.

Exemples (fig. 95) :

*1 Oudhna, atelier des Thermes des Laberii (Barraud et al. 1998, fig. 9, $\mathrm{n}^{\circ}$ 6).

2 Sainte Propice (Velaux, France) (Boixadera et al. 1987, fig. $\left.9, \mathrm{n}^{\circ} 15\right)$.

*3 Idem (Ibid., $\left.\mathrm{n}^{\circ} 16\right)$.

4 Sidi Jdidi, basilique 1, état B1B (Bonifay, Reynaud 2004, n 16.1).

Certes, il existe bien des exemplaires de la forme Hayes $91 \mathrm{~B}$ de taille réduite au milieu du Ve s. (Bonifay à paraître, $\left.\mathrm{a}, \mathrm{n}^{\circ} 13-14\right)$ et dans la seconde moitié du siècle (Bonifay 1998b, fig. 171, $\mathrm{n}^{\circ}$ 6) (voir également Hayes 1972 , forme $91, \mathrm{n}^{\circ} 8-10$ ) mais ces objets restent très proches du standard de la forme (Hayes 1972, forme 91, $\mathrm{n}^{\circ} 3$ ). Les exemplaires un peu abâtardis catalogués cidessus appartiennent, eux, à des contextes de l'extrême fin du Ve s. ou de la première moitié du VIe s. (2-4). D'autres exemples peuvent être choisis à Saint-Blaise, provenant d'un contexte du deuxième quart du VIe s. (Cavaillès-Llopis, Vallauri 1994, fig. 60, n 139).

\section{- Hayes 91 C (fig. 95)}

\section{SIGILLÉE TYPE 52}

Pour mémoire.

Exemple :

*1 Oudhna, zone périphérique d'ateliers (Barraud et al. 1998, fig. 16, $\mathrm{n}^{\circ} 21$ ).

Datation proposée : décennies centrales du VIe s.

\section{- Hayes 91, variante Atlante XLIX, 10 (fig. 95)}

\section{SigiLlÉE TYPE 53}

Une variante identifiée à Sperlonga (Saguì 1980, fig. 64), se rapproche des mortiers en céramique commune Carthage Class $1 \mathrm{~B} / \mathrm{C}$, avec le bord noyé dans un listel tombant, épaissi et légèrement anguleux.

Exemples (fig. 95) :

*1 Marseille, chantier de La Bourse (Cavaillès-Llopis 1986, fig. 24, $\mathrm{n}^{\circ} 181$ ).

2 Pupput, thermes du centre (fouilles A. Ben Abed, Inv. PPC.156.8).

3 Alicante (Reynolds 1987, 35, $\mathrm{n}^{\circ} 171$ ).

Cette variante est typique des contextes de la fin du VIe s. et du début du VIIe s. (1 : Bonifay et al. 1998, 418, Tabl. CIII : contexte 7); deux tessons figurent dans le dépotoir d'atelier des thermes des Laberii à Oudhna. Le $\mathrm{n}^{\circ} \mathbf{2}$ est associé à la forme $88, \mathrm{n}^{\circ} 12$ (supra, p. 175).

\section{- Hayes 91 D (fig. 95)}

Pour mémoire.

\section{SIGILLÉE TYPE 54}

Exemple :

*1 Littoral tunisien (site $\mathrm{n}^{\circ} 50$, Dzirat el-Laboua) (Bonifay et al. 2002-2003, fig. 6, $\mathrm{n}^{\circ}$ 47).

Datation proposée : VIIe s.

Ces modestes compléments à la complexe typologie de la forme Hayes 91 ne permettent bien évidemment pas 
Typologie - Sigillées

Forme Hayes $99 \mathrm{~A}$
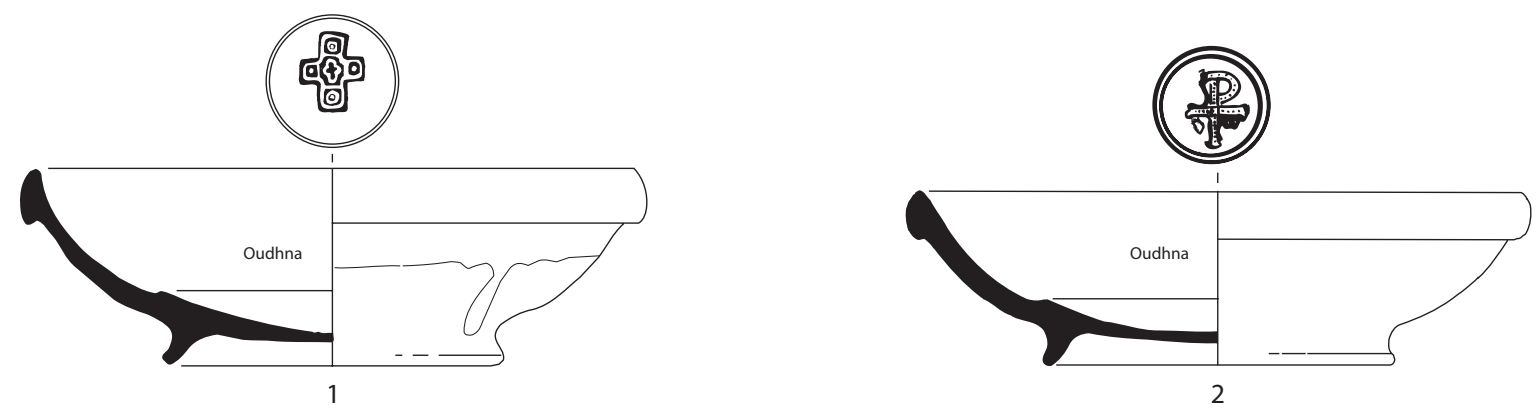

Forme Hayes 99 B
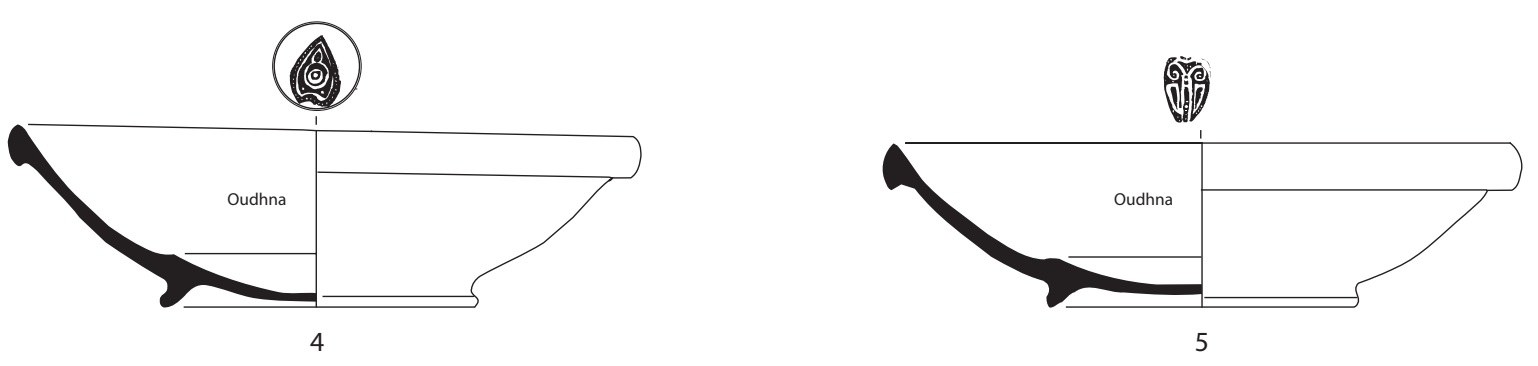

Forme Hayes $99 \mathrm{C}$
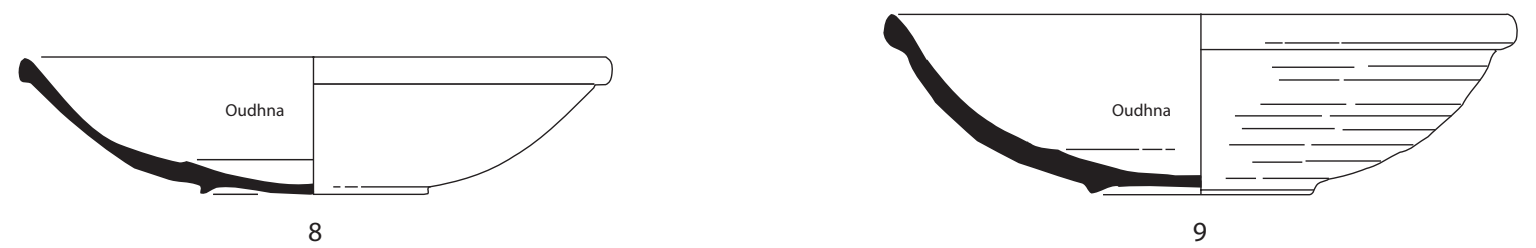

Forme Hayes $99 \mathrm{D}$

(= variante Hayes $80 \mathrm{~B} / 99$ )

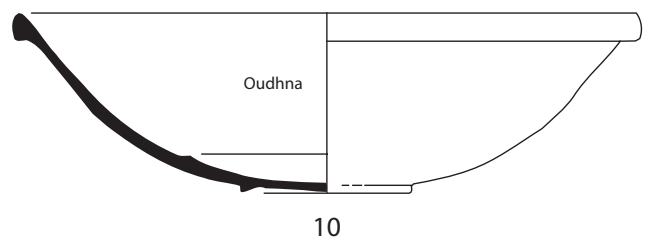

Fig. 96. Vaisselle sigillée africaine D. 
d'identifier tous les bols à listel, d'autant que nombre d'entre eux se rapportent à des productions locales qui ont peu voyagé et qu'il est préférable de traiter séparément des grandes séries (infra, SIGILLÉE TYPE 78).

— forme Hayes 99 (fig. 96)

\section{SIGILLÉE TYPE 55}

Bien qu'également produite sur d'autres ateliers (Mackensen 1993 : type El Mahrine 29), la forme Hayes 99 est la forme-phare de l'atelier d'Oudhna (Barraud et al. 1998, 148). On retrouve sur cet atelier les trois principales variantes identifiées par J. W. Hayes (1972, 152) ainsi que de nombreuses variantes intermédiaires et d'autres formes dérivées (Barraud et al. 1998, fig. 8, n 45 et fig. $17, \mathrm{n}^{\circ}$ 29-30). Sans revenir sur leur description, bien connue, je crois utile, avant de discuter leur datation, d'illustrer quelques-unes de ces variantes.

Exemples (fig. 96) :

Variante A

*1 Oudhna, atelier des thermes des Laberii (Barraud et al. 1998, fig. $\left.8, \mathrm{n}^{\circ} 1\right)$.

*2 Idem (Antiquarium d'Oudhna, Inv. MU.6).

3 Marseille, chantier de La Bourse (Bonifay 1983, fig. 22, $\left.n^{\circ} 65\right)$.

Variante B

*4 Oudhna, atelier des thermes des Laberii (Barraud et al. 1998, fig. 8, n 2).

*5 Idem, zone périphérique d'ateliers, four $\mathrm{n}^{\circ} 4$ (Ibid., fig. $\left.16, n^{\circ} 23\right)$.

6 Marseille, chantier de La Bourse (Cavaillès-Llopis 1986, fig. $\left.27, \mathrm{n}^{\circ} 290\right)$.

7 Byllis (Albanie), basilique C (Inv. C006.12).

Variante $\mathrm{C}$

*8 Oudhna, atelier des thermes des Laberii (Barraud et al. 1998, fig. $8, \mathrm{n}^{\circ} 3$ ).

*9 Oudhna, atelier des thermes des Laberii, four $\mathrm{n}^{\circ} 1$ (Inv. UTH4.1001.8). Parois épaisses, extérieur facetté.

Variante D (= variante « 80B/99»)

*10 Oudhna, atelier des thermes des Laberii, four $\mathrm{n}^{\circ} 1$ (Barraud et al. 1998, fig. 17, $\mathrm{n}^{\circ} 26$ ).

11 Marseille, chantier de La Bourse (Inv. EIV.6).

La forme Hayes 99 est sans doute l'une de celles dont la datation a été la plus controversée. Située initialement (Hayes 1972, 155) au début du VIe s., soit un peu après les autres formes de la série (Hayes 95-98) ${ }^{149}$, l'apparition de cette forme a été avancée au troisième quart du Ve s. sur la base des fouilles de Conimbriga (Conimbriga IV, 305 ; Hayes 1980a, 516), voire même au deuxième quart (Aquilué 1989, 139) ou au début du Ves. (Tortorella 1986, 306). Cependant, ces données sont aujourd'hui remises en question (Mackensen 1993, 386-391) et la forme Hayes 99 est à nouveau considérée comme caractéristique du VIe s., avec une apparition, au plus tôt, dans les vingt dernières années du Ve s. (Ibid., 417). A l'opposé, il ne semble plus possible de limiter la

\footnotetext{
${ }^{149} \mathrm{~J}$. W. Hayes remarquait en effet que le poinçon de la croix monogrammatique pointée (Hayes 289 B), présent sur les formes Hayes 96-97, n'était pas attesté, en revanche, sur la forme Hayes 99.
}

production de la variante $\mathrm{C}$ aux vingt premières années du VIIe s. (Hayes 1972, 155) : en effet, elle est régulièrement présente dans les contextes du VIIes. avancé, en association avec les dernières formes de la production de sigillée africaine, par exemple à Istanbul (Hayes 1992, fig. 40, n 44-45), à Sant'Antonino di Perti (Murialo 2001, Pl. 21-22) et à Rome (Saguì et al. 1997, fig. 1). On est donc tenté de dire que l'histoire de la forme Hayes 99 se confond avec celle de l'atelier d'Oudhna, de la fin du Ve s. jusqu'à une date encore indéterminée du VIIe s. (Barraud et al. 1998, 148).

Ainsi, il est clair maintenant que la forme Hayes 99A apparaît en même temps que les autres formes de la série, puisque le poinçon Hayes $289 \mathrm{~B}$, également attesté sur sigillée africaine $\mathrm{C} 5$, se trouve bien sur cette forme (2). Cette datation (fin du Ve s. - premier quart du VIe s.) pourrait correspondre à celle du tesson de Marseille (3) (peut-être résiduel dans un contexte légèrement plus tardif: Bonifay et al. 1998, 417, Tabl. CIII, contexte $\left.n^{\circ} 28\right)$. La variante $B$ est caractéristique des décennies centrales du VIe s. (5) (Barraud et al. 1998, 157-159: comblement du four $\left.\mathrm{n}^{\circ} 4\right)$; on se reportera également aux exemples de Marseille (Bonifay 1983, fig. 24, n $96-97$ et 99-100 ; Bonifay et al. 1998, 418, Tabl. CIII, contexte $\left.n^{\circ} 29\right)$. Toutefois cette variante $B$ est toujours présente à la fin du VIe et probablement au début du VIIe s. comme le prouvent des exemples de Marseille (6) (Ibid., contexte $\mathrm{n}^{\circ} 8$ ), de Byllis (7) et surtout de Carthage (Riley 1981, 102 et fig. $\left.5, \mathrm{n}^{\circ} 10,12,13\right)$. Enfin, la variante $\mathrm{C}$, dont l'apparition est contemporaine des dernières variantes $\mathrm{B}$ (Ibid., $\mathrm{n}^{\circ} 11$ ), est principalement attestée au VIIe siècle.

Quant à la variante «80B/99» (10), à mon sens mal nommée, elle constitue réellement l'une des évolutions les plus tardives (variante D) de la forme, bien représentée dans les contextes de la seconde moitié du VIIe s. (Saguì 1998, fig. 3, n 3 ); le $n^{\circ} 11$ est associé à une forme Pelletier A6 en céramique commune grise provençale, de même chronologie.

Datation proposée :

Variante A - fin du Ve s. - milieu du VIe s.

Variante B - deuxième quart du VIe - début du VIIe s.

Variante C - fin du VIe - VIIe s.

Variante $\mathrm{D}$ « 80B/99» : seconde moitié du VIIe s.

\section{— forme Hayes 104 (fig. 97)}

\section{SigILLÉE TYPE 56}

Tout comme la précédente, la forme Hayes 104 est plutôt caractéristique du nord de la Tunisie, ainsi que le montre son absence sur le site de Rougga (Guéry, Bonifay à paraître). J. W. Hayes avait bien signalé l'existence de deux productions parallèles représentées par ses variantes $\mathrm{A} / \mathrm{B}$ d'une part, $\mathrm{C}$ d'autre part. Il semble, contrairement à ce qui a pu être affirmé, que cette forme a été produite non seulement en D2 (Atlante I, 94-95) mais également en D1 (Mackensen 1993). M. Mackensen a également identifié une variante tardive de la forme 104 A (forme El Mahrine 34) qui a une diffusion non négligeable. 
Typologie - Sigillées

Forme Hayes 104
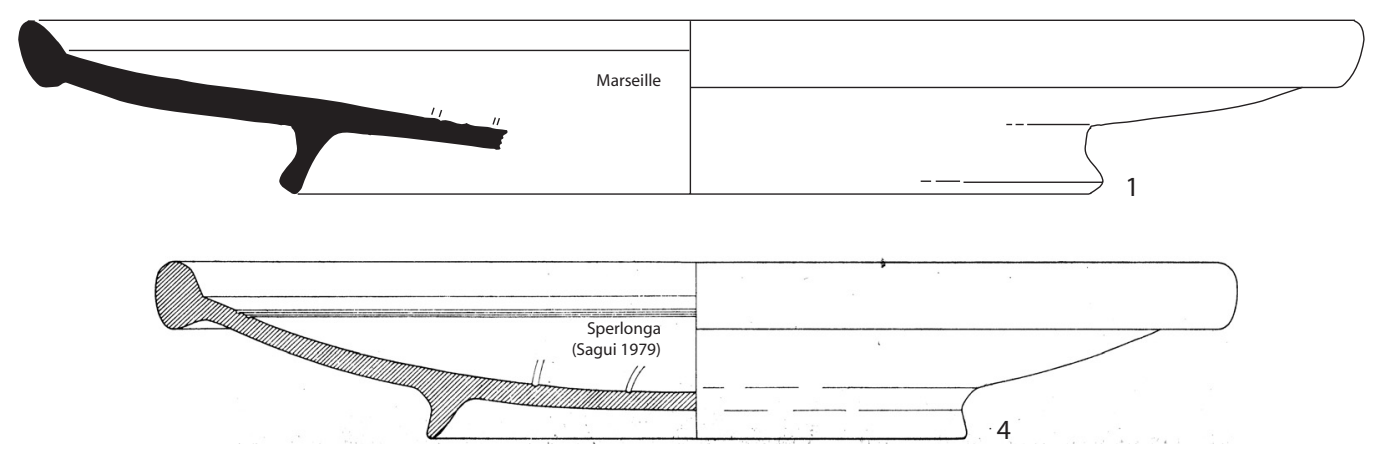

A1

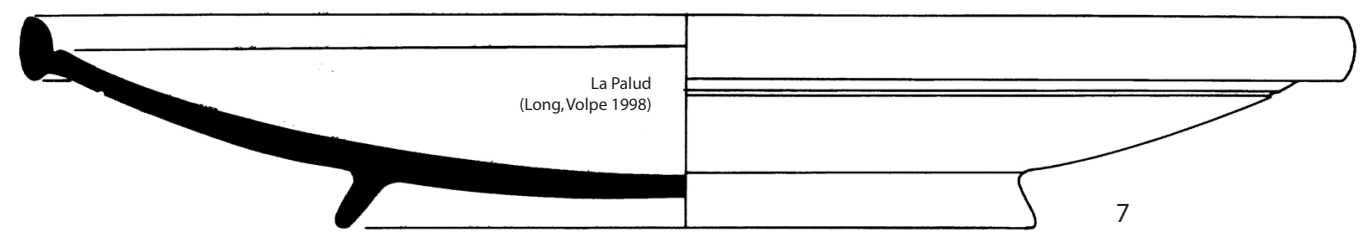

A2
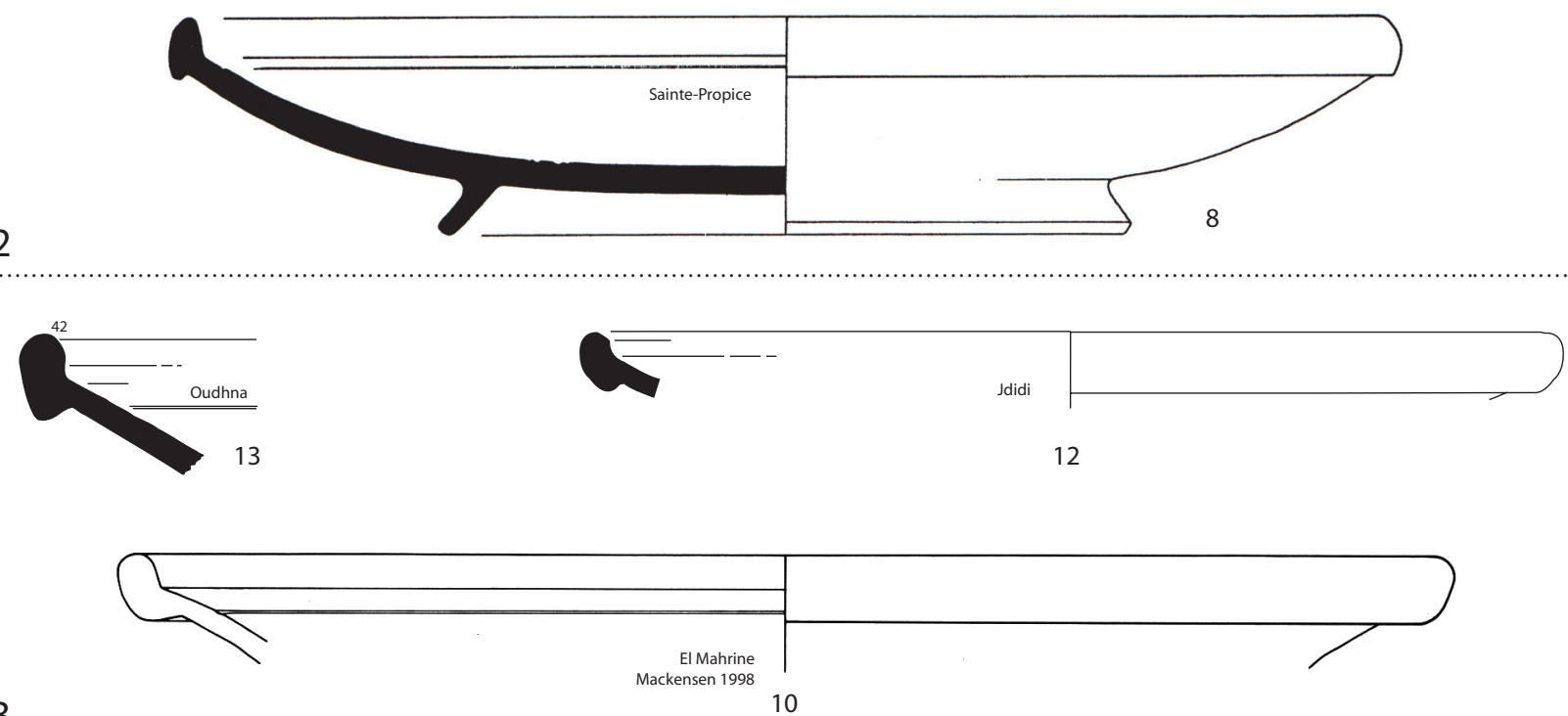

A3
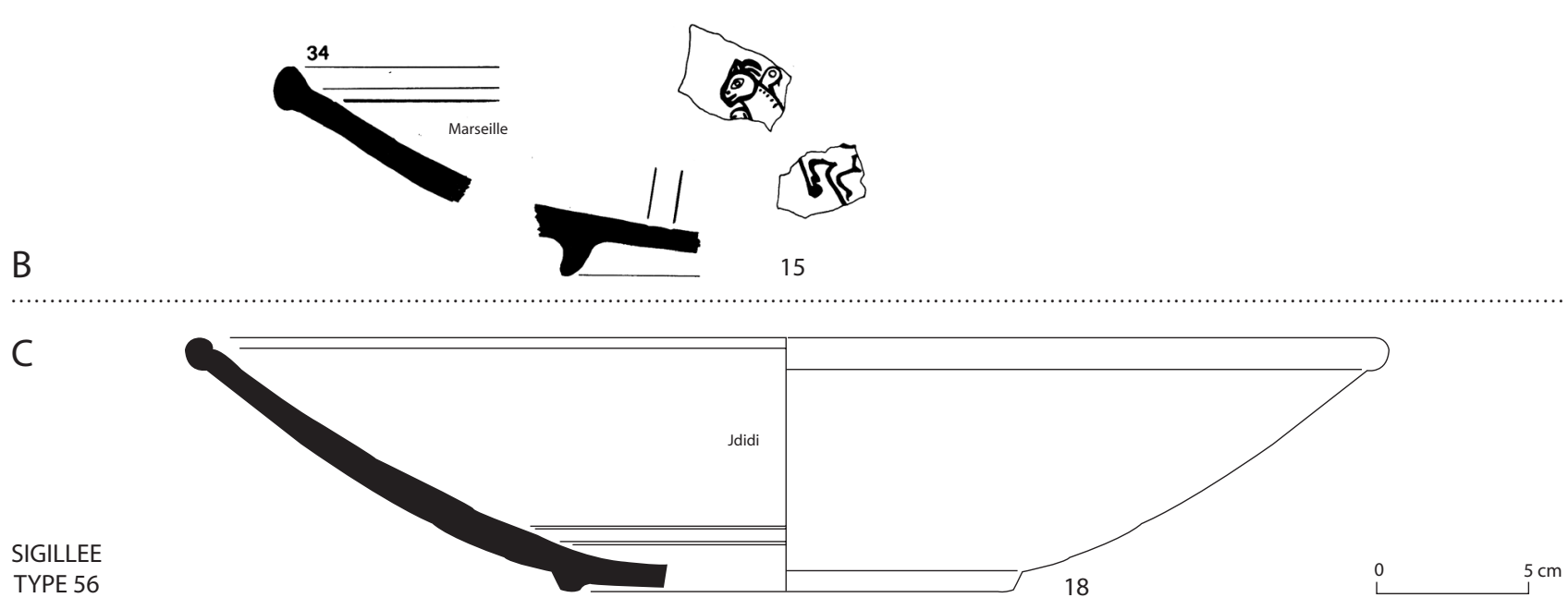

Fig. 97. Vaisselle sigillée africaine D. 
M. Mackensen a enfin proposé de vieillir la date d'apparition de cette forme de plus d'un demi-siècle (vers 460) par rapport à ce que proposait J. W. Hayes (vers 530). Sa démonstration repose sur des bases essentiellement stylistiques, par la constatation que certains exemplaires portent une décoration de style El Mahrine II ou Hayes A(iii)/E(i) alors que les exemplaires de la variante A catalogués par J. W. Hayes sont généralement ornés de motifs du style $\mathrm{E}(\mathrm{ii})$. Je me demande, pour ma part, s'il ne serait pas utile de créer une variante désignant ces exemplaires précoces. Le schéma évolutif pourrait se présenter ainsi :

- Variante A1 (précoce $=$ Waagé 803 ) : le bord est un peu différent de celui de la variante classique A. Il est soit très arrondi (4), soit, plus fréquemment très allongé, évasé (obliquant vers l'extérieur) (1); la forme générale est moins profonde encore que celle de la variante $\mathrm{A} 2$, en raison de parois assez rectilignes, courtes. Le fond, large (D. fond égal ou supérieur à la moitié du D. du bord), est muni d'un pied très haut (plus haut que celui de la variante $\mathrm{A} 2$ ). Souvent deux cannelures à l'intérieur, près du bord, au lieu d'une seule $(\mathbf{2}, \mathbf{4})$. Décors de style A(iii)/E(i).

- Variante A2 (classique = Hayes 104 A, n 2-3 = Waagé 804a)

- Variante A3 (tardive = El Mahrine 34 = Waagé 805a?)

- Variantes B et C : inchangé.

Exemples (fig. 97) :

Variante A1

*1 Marseille, chantier de La Bourse (Inv. P681). Décor de style A(iii)/E(i), fragmentaire.

2 Marseille, chantier de La Bourse (Treglia 1998, fig. $\left.149, \mathrm{n}^{\circ} 26\right)$.

3 La Gayole (C.A.T.H.M.A. 1986, fig. 6, n 12).

*4 Sperlonga (Saguì 1979, fig. 7).

Variante A1/2 ?

5 Athènes (Hayes $104 \mathrm{~A}, \mathrm{n}^{\circ}$ 13).

Variante A2

6 Sperlonga (Saguì 1979, fig. 8).

*7 Epave de la Palud (Hyères, France) (Long, Volpe 1998, fig. 302, $\mathrm{n}^{\circ}$ 91).

*8 Ste-Propice (Boixadera et al. 1987, fig. 10, $\mathrm{n}^{\circ} 24$ ).

Variante A3

9-*10 El Mahrine, atelier (Mackensen 1993, Pl. 70, n 3-4).

11 Carthage (Hayes 1978b, fig. 12, $n^{\circ}$ XXIV, 17).

*12 Sidi Jdidi, basilique 1, état C2A (Ben Abed, Bonifay, Fixot 1997, fig. 3, n 17 ; Bonifay, Reynaud 2004, $\left.\mathrm{n}^{\circ} 22.1\right)$.

*13 Oudhna, capitole (fouilles H. Ben Hassen, Inv. UTH1.003.2). D. : $42 \mathrm{~cm}$.

14 Alicante, (Reynolds 1987, 79, $\mathrm{n}^{\circ}$ 677).

Variante B

*15 Marseille, chantier de La Bourse (Bonifay 1983, fig. $24, n^{\circ} 118-119$ et 113-114 ?).

16 Ibiza (Ramon 1986, fig. 14, n 13 ).

Variante C

17 Marseille, chantier de La Bourse (Bonifay 1983, fig. $24, n^{\circ} 112$ ).

*18 Sidi Jdidi, basilique 1, état C2B (Ben Abed, Bonifay, Fixot 1997, fig. 3, $\mathrm{n}^{\circ} 19$; Bonifay, Reynaud 2004, $\left.\mathrm{n}^{\circ} 26.6\right)$
Certes, ces distinctions typologiques peuvent correspondre à des différences d'ateliers : M. Mackensen (1998b) a bien mis en évidence, en négatif, l'existence d'un atelier non encore reconnu (supra, p. 49 : atelier « $\mathrm{X} »)$ qui a produit l'essentiel des décors du style E(ii), donc l'essentiel des plats Hayes 104A, forme pourtant également produite à El Mahrine. Cependant, la datation avancée par M. Mackensen pour les exemplaires précoces que je propose maintenant de réunir dans une variante A1, semble se confirmer à Marseille. Le $\mathrm{n}^{\circ} \mathbf{2}$ est issu d'un contexte de la fin du Ves. (Treglia 1998, 177 : période $2 \mathrm{~A}$ ), datation qui peut également convenir à l'exemplaire de la Gayole (3) ${ }^{150}$. La variante A2, conformément aux propositions de J. W. Hayes, est caractéristique des contextes du deuxième quart et des décennies centrales du VIe s. (7-8). En accord avec les hypothèses de M. Mackensen (1993, 350), l'apparition de la variante A3 peut être située vers la fin du VIe s. ou le début du VIIe s. (12); en revanche, je ne sais pas si le fragment de Carthage (11), trouvé dans un contexte de la fin du VIIe s., doit être considéré ou non comme résiduel. Je n'ai pas beaucoup de données sur la datation de la variante B : l'exemplaire de Marseille (15) provient d'un contexte du milieu ou du troisième quart du VIe s. (Bonifay et al. 1998, 357, faciès C3). Enfin, les éléments dont je dispose pour la chronologie de la variante $\mathrm{C}$ sont tout à fait conformes aux propositions de J. W. Hayes : seconde moitié du VIe s. et début du VIIe s. (18).

Datation proposée :

Variante A1 - fin du Ve - premier tiers du VIe s.

Variante A2 - deuxième quart - milieu du VIe s.

Variante A3 - fin du VIe - milieu du VIIe s.

Variante B - milieu - seconde moitié du VIe s.

Variante $\mathrm{C}$ - milieu du VIe - milieu du VIIe s.

\section{— forme Hayes 105 (fig. 98)}

\section{SIGILLÉE TYPE 57}

J. W. Hayes n'avait pas souhaité créer de variantes distinctes à l'intérieur du vaste groupe, assez hétérogène, constitué par la forme 105 mais il avait tenté d'ordonner en chronologie relative les différents exemplaires de son catalogue. De fait, il distinguait trois groupes d'objets :

- Variante A (= Hayes $105, \mathrm{n}^{\circ} 2$ à 7 ) : bord à section grossièrement quadrangulaire, parfois plus haut que large, dont les faces supérieure et inférieure, planes, dépassent nettement de la paroi ; la face extérieure peut être plus ou moins arrondie. Les parois sont généralement courtes et rectilignes, souvent épaisses. Le fond, large, est muni d'un pied relativement haut, parfois parcouru d'une ou deux cannelures.

- Variante B (= Hayes 105, n 8 à 14) : bord à section plus arrondie, aplatie sur le dessus; la face supérieure du bord, parfois concave, est dans le prolongement de la paroi tandis que la face inférieure est en demi-cercle; les parois sont plus courbes et

150 Associé à un plat en sigillée africaine C5 Hayes 82 (C.A.T.H.M.A. 1986, fig. 6, n 11 ). 
Typologie - Sigillées

Forme Hayes 105
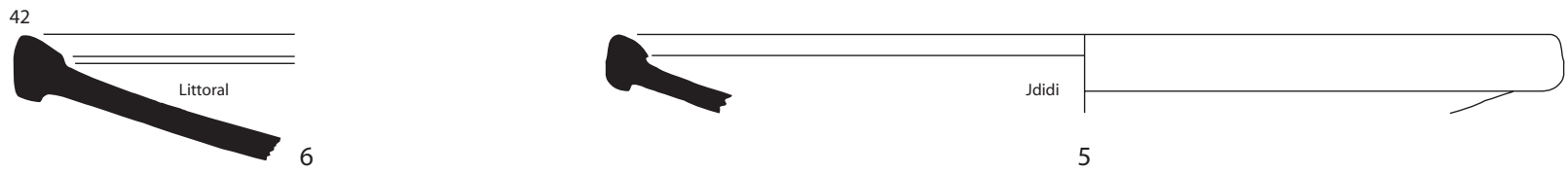

5
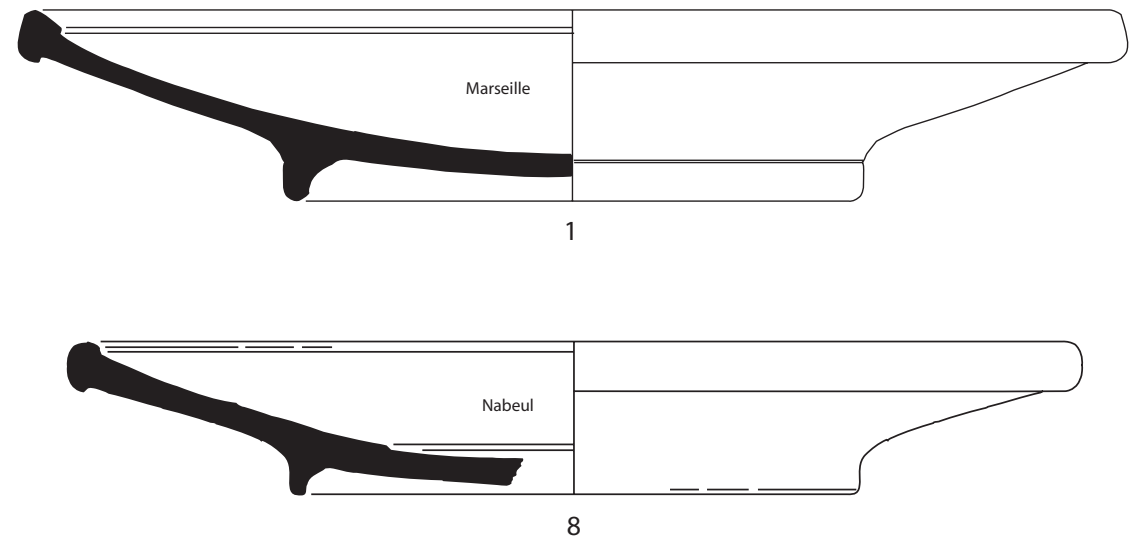

A

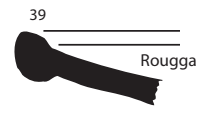

11

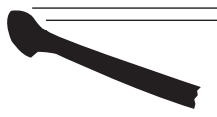

10

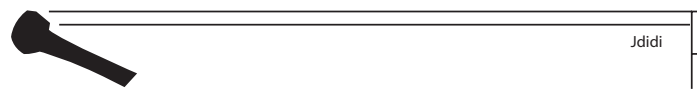

12

15

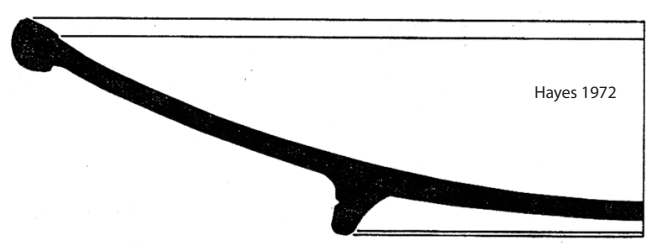

B

16

C

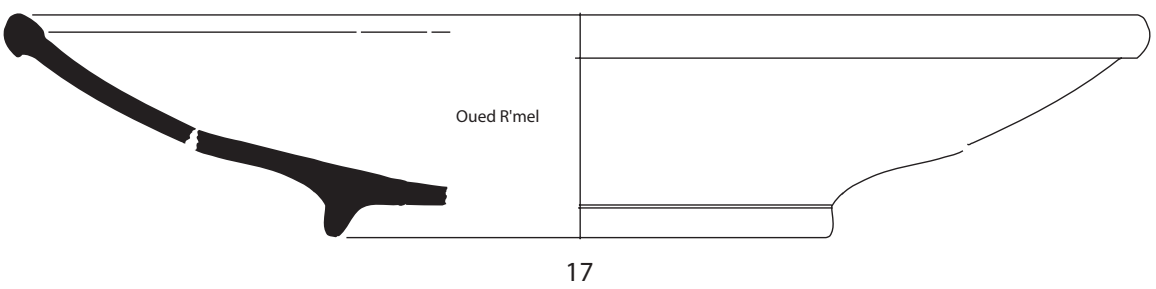

SIGILLEE

TYPE 57

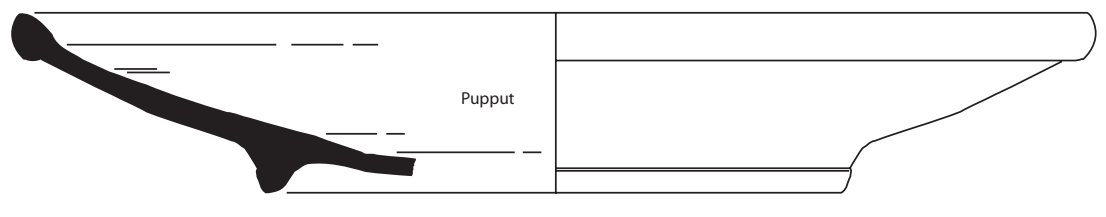

18

0

Fig. 98. Vaisselle sigillée africaine D. 
plus minces. Le fond, proportionnellement plus étroit, est muni d'un pied plus bas qui ne peut porter, le cas échéant, qu'une seule cannelure.

- Variante C (?) (= Hayes 105, n 15-17) : bord à section ovale, plus haut que large, à face supérieure proéminente, parois courbes procurant plus de profondeur à la forme.

Exemples (fig. 98) :

Variante A

*1 Marseille, chantier de La Bourse (Inv. MB2483.1).

2 Idem (Bonifay 1983, fig. 29, $\mathrm{n}^{\circ} 179$ ).

3 Idem (Ibid., $\left.\mathrm{n}^{\circ} 180\right)$.

4 Idem (Ibid., $\mathrm{n}^{\circ} 181$ ).

*5 Sidi Jdidi, basilique 1, état C2B (Bonifay, Reynaud 2004, $\left.n^{\circ} 31.3\right)$.

*6 Littoral tunisien, site $\mathrm{n}^{\circ} 71$ (Henchir el-Majdoul, côte nord de Sfax) (Bonifay et al. 2002-2003, fig. 6, $\left.\mathrm{n}^{\circ} 50\right)$.

7 Idem, site $\mathrm{n}^{\circ} 85$ (Jezira, au nord d'Acholla) (Ibid., fig. $18, n^{\circ} 249$ ).

Forme apparentée à la variante (A ?).

*8 Nabeul, fouilles anciennes (Inv. 0001.5).

Variante B

*9 Sidi Jdidi, basilique 1, état C2B (Ben Abed, Bonifay, Fixot 1997, fig. 9, $\mathrm{n}^{\circ} 45$; Bonifay, Reynaud 2004, $\mathrm{n}^{\circ}$ 32.2).

*10 Pupput, thermes du centre (fouilles A. Ben Abed, Inv. PPC182.1).

*11 Rougga, couche 9 (Guéry, Bonifay à paraître, fig. 3, $\left.\mathrm{n}^{\circ} 72\right)$.

*12 Idem, couche 12 (Ibid., $\mathrm{n}^{\circ} 75$ ).

13 Idem (Ibid., $\left.\mathrm{n}^{\circ} 76\right)$.

14 Littoral tunisien, site $\mathrm{n}^{\circ} 85$ (Jezira, au nord d'Acholla) (Bonifay et al. 2002-2003, fig. 18, $\mathrm{n}^{\circ} 250$ ).

*15 Sidi Jdidi, basilique 1, état C2B (Bonifay, Reynaud 2004, n 31.4).

*16 Hayes 1972, forme 105, $n^{\circ} 8$.

Variante C

*17 Oued R'mel (fouilles T. Ghalia, Inv. OR0802.1). Bord et fond du même objet (?).

*18 Pupput, thermes du centre (Bonifay 2002, fig. 1, $\mathrm{n}^{\circ} 4$ ).

J. W. Hayes précisait que la présence ou non de cannelures sur le pied ne semblait pas avoir d'incidences chronologiques (Hayes 1972, 167). En revanche, ce détail pourrait revêtir une signification pour l'origine des productions. En effet, la variante à pied haut décoré de deux cannelures (Hayes 105, $\mathrm{n}^{\circ} 2$ ) semble caractéristique du centre de la Tunisie. Elle est présente sur 1'atelier d'amphores d'Henchir ech-Chekaf à Ksour Essaf (observation personnelle) ainsi qu'à Marseille (Bonifay 1983, fig. 26, $\mathrm{n}^{\circ} 150$ ) avec, dans les deux cas, les mêmes associations de formes d'amphores (Keay 62 variante et 61C). Ce serait un nouvel argument en faveur de l'hypothèse de Hayes selon laquelle la forme 105 est issue de la forme 90.

Les datations proposées par Hayes (1972, 169) sont confirmées par les contextes que j'ai pu étudier. La variante 1 , datée vers 600 à Corinthe et au premier quart $\mathrm{du}$ VIIe s. à Antioche, est présente à Marseille (1-4), dans les contextes 2 et 3 du faciès D (Bonifay et al. 1998, 418, Tabl. CIII), ainsi qu'à Chersonèse, en association avec des monnaies de Maurice-Tibère (Romancuk, Sazanov
1991, P1. 22, n 218-220). La variante 2, attestée à Apollonia de Cyrénaïque vers 640 et sur l'épave de Yassi Ada, est caractéristique du faciès de Rougga (11-13), en liaison peut-être avec le trésor monétaire de 647 (Guéry, Morrisson, Slim 1982 ; Guéry 1985b). Enfin, la variante C, associée à des monnaies de 660 à Chios, apparaît, bien que moins facile à cerner, dans les niveaux les plus tardifs de Pupput (18) ${ }^{151}$. Les comparaisons hors d'Afrique vont dans le même sens : variante B à Istanbul (Hayes 1992, fig. 40, $\mathrm{n}^{\circ} 30.40$ ) et à Rome (Saguì 1998, fig. 3, $\mathrm{n}^{\circ} 6$ ), variante C à Sant'Antonino di Perti (Murialdo 20001, Pl. 24, $\mathrm{n}^{\circ}$ 81-86). Les variantes les plus récentes se caractérisent également par une qualité de fabrication très appauvrie (infra, SIGILLÉE TYPE 88).

Datation proposée :

Variante A - fin VIe s. - première moitié du VIIe s.

Variante B - décennies centrales du VIIe s.

Variante $\mathrm{C}$ - seconde moitié du VIIe s.

\section{— formes Hayes 98/108 (fig. 99)}

Assez peu diffusé en Méditerranée (Hayes 1972, 171 ; Atlante I, 113), le petit bol Hayes 108 est extrêmement fréquent en Tunisie mais il est parfois difficile à distinguer de variantes plus anciennes, également bien répandues, appartenant à la forme 98 . Je propose de modifier très légèrement la classification :

\section{SIGILLÉE TYPE 58}

- Hayes 98 : bord à court marli plat ou légèrement tombant, panse en arc de cercle évasé, ressaut sur le fond à la jonction avec la panse ${ }^{152}$, fond large muni d'un pied haut. Deux tailles : $18-19 \mathrm{~cm}$ et $12-14 \mathrm{~cm}$.

- Variante 98 A (Hayes 1972, 151) : exemplaires de grande taille.

- Variante 98 B (= Hayes 98B, n² 2 = Hayes 94 B ?) : exemplaires de petite taille. Un décor de style E(i) est attesté mais pas de manière systématique. Je propose de ne conserver dans cette variante que le premier des deux exemplaires catalogués par Hayes.

- Variante $98 \mathrm{C}\left(=\right.$ Hayes $\left.98 \mathrm{~B}, \mathrm{n}^{\circ} 3\right)$ : cette variante de très petite taille (D. : $11,5 \mathrm{~cm})$ est caractérisée par la présence d'une série de cannelures à l'intérieur de la panse, au-dessus du ressaut. Aspect peu soigné.

\section{SIGILLÉE TYPE 59}

- Hayes 108 : bord plus épais, parfois légèrement effilé, panse coudée (inflexion verticale du tiers supérieur de la panse), pas de ressaut à l'intérieur du fond, fond moins large. Généralement de petite taille : D. : 14-16 cm.

- Variante : certains exemplaires sont posés sur un pied très haut.

\footnotetext{
${ }^{151}$ Associé à la forme Hayes 99D (Hayes 80B/99).

152 J. W. Hayes a été trompé par le dessin inexact de Lamboglia: l'exemplaire de Saint-Blaise comporte bien un ressaut sur le fond, à la jonction avec la panse : voir désormais Cavaillès-Llopis, Vallauri 1994, fig. 60, n 140-141.
} 

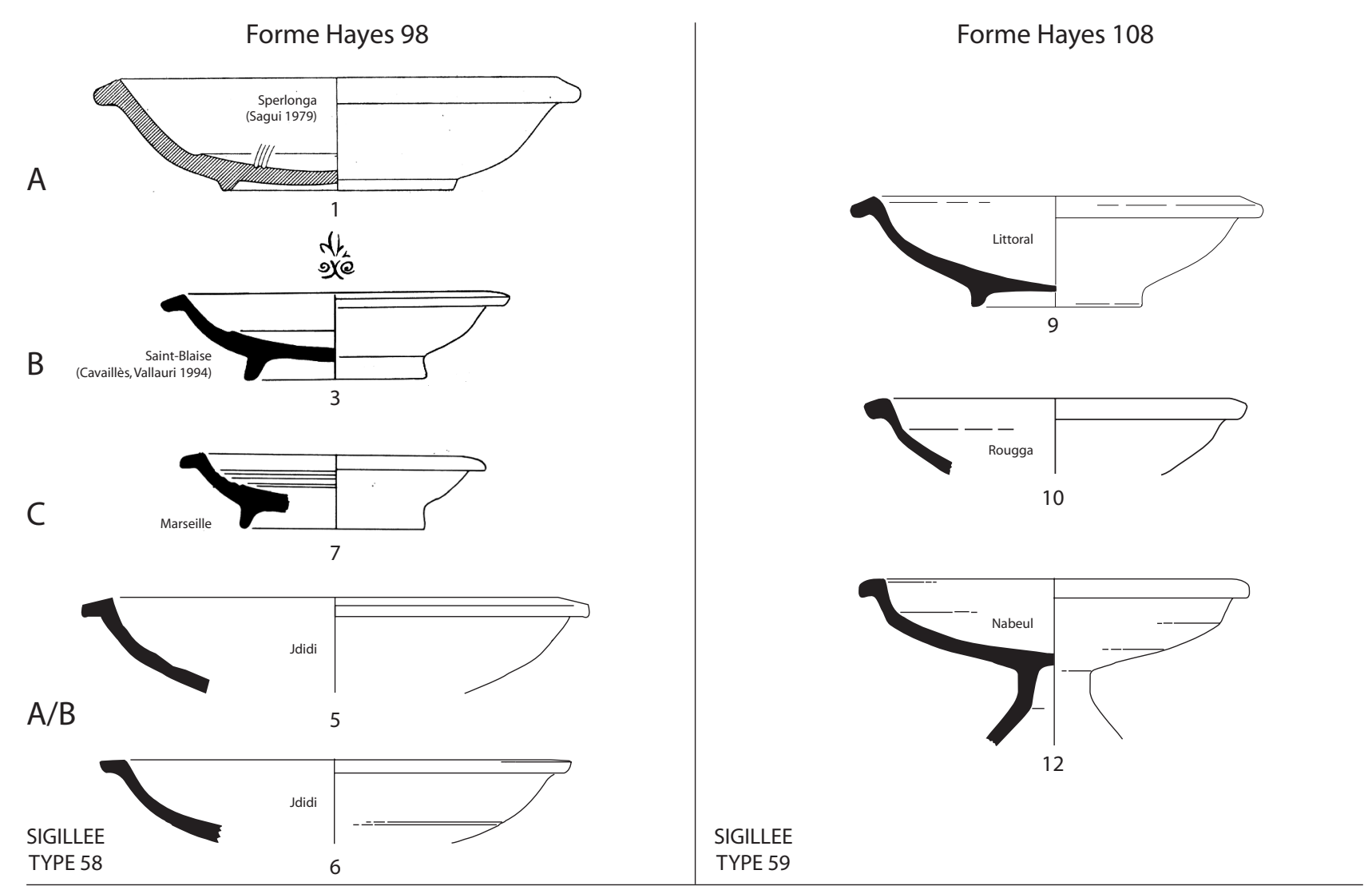

Forme Hayes 109

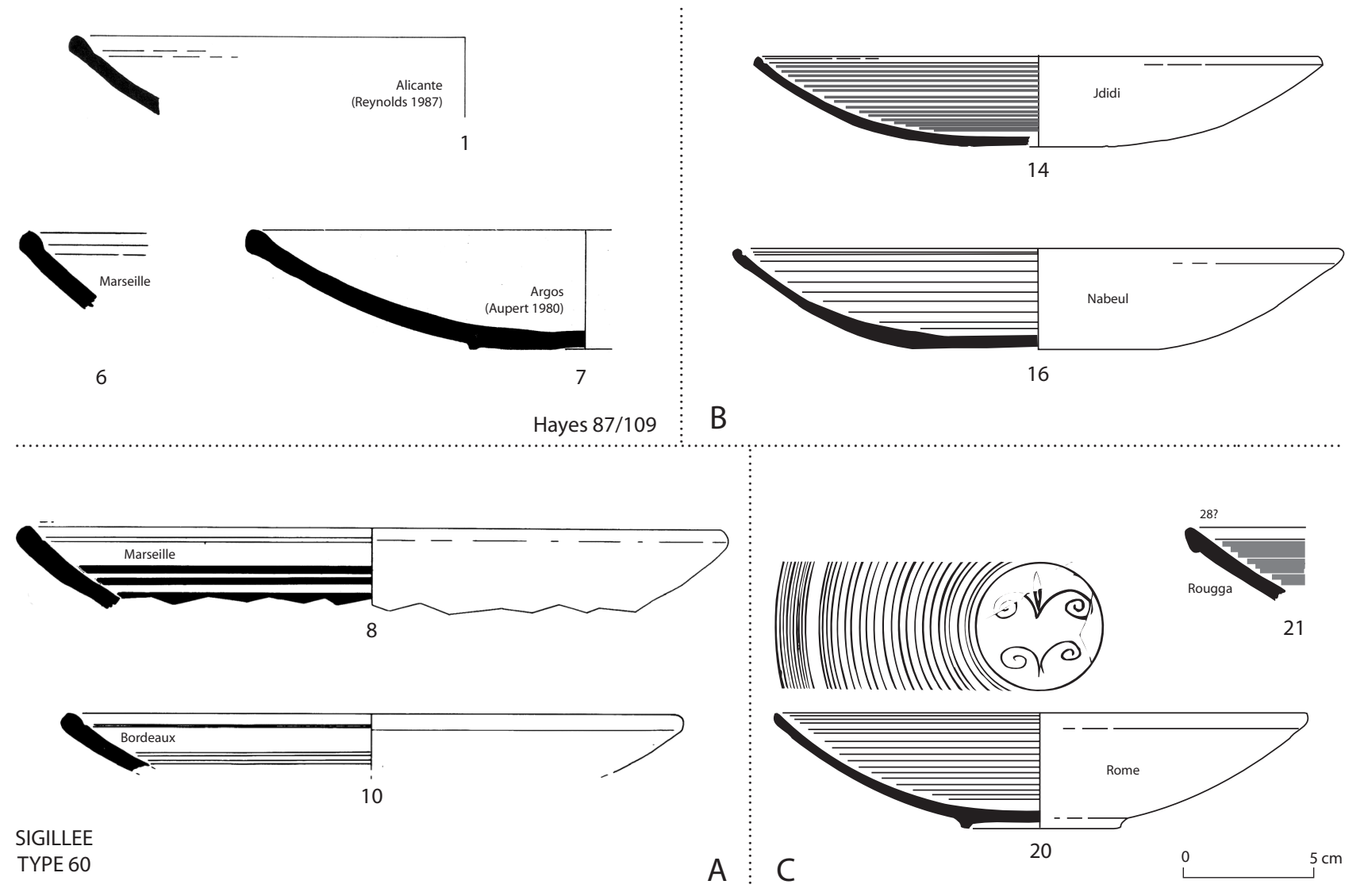

Fig. 99. Vaisselle sigillée africaine D. 
Exemples (fig. 99) :

Type Hayes 98 [TYPE 58] Variante $98 \mathrm{~A}$

1 Carthage (Hayes 1972, forme 98, $\mathrm{n}^{\circ} 1$ ).

*2 Sperlonga (Saguì 1979, fig. 5). Sur le fond: décor du style $\mathrm{E}(\mathrm{i})$, animal à droite. Variante 98 B

*3 Saint-Blaise, maison du fondeur (Cavaillès-Llopis, Vallauri 1994, fig. 60, $\mathrm{n}^{\circ} 140$ ). D. : 13,6 cm. Décor de style E(i), poinçon Hayes 118: atelier d'Oudhna (?).

4 Sainte-Propice (Boixadera et al. 1987, fig. 10, ${ }^{\circ} 17$ ). D. : $12,3 \mathrm{~cm}$. Sans décor. Variante indéterminée (A/B)

*5 Sidi Jdidi, basilique 1, état C2A (Bonifay, Reynaud 2004, $\left.\mathrm{n}^{\circ} 24.2\right)$. D. : $19 \mathrm{~cm}$.

*6 Sidi Jdidi, basilique 2 (Inv. JD2242.2). Deux cannelures sur l'extérieur de la panse. Variante $98 \mathrm{C}$

*7 Marseille, chantier de La Bourse (Bonifay 1983, fig. 29, $\left.\mathrm{n}^{\circ} 153\right)$. D. : $11,5 \mathrm{~cm}$. Pâte brune, vernis rose écaillé.

8 Idem (Cavaillès-Llopis 1986, fig. 27, n 291).

Type Hayes 108 [TYPE 59]

*9 Littoral tunisien, site $\mathrm{n}^{\circ} 85$ (Jezira, au nord d'Acholla) (Bonifay et al. 2002-2003, fig. 18, $\mathrm{n}^{\circ} 251$ ).

*10 Rougga, couche 10 (Guéry, Bonifay à paraître, $n^{\circ} 83$ ).

11 Epave Saint-Gervais 2 (Fos, France) (Jézégou 1998, fig. $\left.308, n^{\circ} 10\right)$. Variante

*12 Nabeul (Inv. NB2001.1). Pied haut et étroit.

Les variantes A et $\mathrm{B}$ de la forme Hayes 98, distinctes seulement par leur taille (Hayes 1972, 151) appartiennent à la même série que les formes Hayes 95-97 et 99 et sont probablement en grande partie issues de l'atelier d'Oudhna, comme le prouve le décor du $\mathrm{n}^{\circ} \mathbf{3}$. Les exemplaires tardifs du milieu du VIe s. ne sont pas décorés (4). A la fin du VIe s. et au début du VIIe s., une variante $\mathrm{C}$ est fréquente sur les rivages nord de la Méditerranée (7-8); en Tunisie, dans le golfe d'Hammamet, la variante A/B paraît subsister, peut-être en évoluant vers la forme 108. Cette dernière n'est réellement bien attestée que dans les niveaux du VIIe s. (9-10) avec parfois des variantes assez singulières (12) dans la seconde moitié du siècle. Le $\mathrm{n}^{\circ} \mathbf{1 1}$ est associé à une forme 109B.

Datation proposée :

Forme 98 A/B - fin du Ve s. - milieu du VIe s., exemplaires tardifs jusqu'à la fin du VIe s.

Variante $98 \mathrm{C}$ - fin du VIe- début du VIIe s.

Forme 108 - VIIe s.

\section{— forme Hayes 109 (fig. 99)}

\section{SIGILLÉE TYPE 60}

J'avais proposé, en fonction des données stratigraphiques de Marseille, de distinguer deux variantes au sein de la forme Hayes 109 (Bonifay 1998a, 77-79). Une troisième semble apparaître dans la bibliographie.

- Variante précoce Hayes 87C/109 : plat assez lourd semblant dériver de la forme Hayes 87C (Aupert 1980, 417).
- Variante A (= Waagé $805 \mathrm{x}=$ Hayes $109, \mathrm{n}^{\circ} 2$ ?) : bord à extrémité arrondie, parois épaisses (6-9 mm), sans décor ou avec un décor lustré en larges bandes.

- Variante B (= Hayes 109, $\left.\mathrm{n}^{\circ} 1\right)$ : bord à extrémité parfois un peu aplatie, parois minces (3-5 mm), décor lustré de fines bandes concentriques. Forme générale plus plate que celle de la variante $\mathrm{A}$.

- Variante $\mathrm{C}$ : bord à section triangulaire aplatie, fond muni d'un petit pied.

Exemples (fig. 99) :

Variante précoce (forme 87C/109)

*1-4 Alicante (Reynolds 1987, 23, nombreux exemples : $\left.n^{\circ} 40,42,43,44\right)$.

5 Avignon, imprimerie Aubanel (C.R. réunion CATHMA du 18 juin 1993, fig. 10, $n^{\circ} 1$ ).

*6 Marseille, chantier de La Bourse (Bonifay 1983, fig. $\left.29, n^{\circ} 174\right)$.

*7 Argos (Aupert 1980, fig. 35, $\mathrm{n}^{\circ} 119$ ).

Variante A

*8 Marseille, chantier de La Bourse (Bonifay 1983, fig. 29, $\left.n^{\circ} 27\right)$.

9 Saint-Blaise (Cavaillès-Llopis, Vallauri 1994, fig. 58, $\left.\mathrm{n}^{\circ} 114\right)$.

*10 Bordeaux, chantier de la place Camille-Jullian (Bonifay à paraître, b, fig. 2, $\mathrm{n}^{\circ} 15$ ).

11 Olbia de Provence, fouilles anciennes (Bonifay 1998a, fig. $\left.3, n^{\circ} 5\right)$.

12 Beyrouth, site Bey002 (Bonifay 1996, 89, $\mathrm{n}^{\circ} 4$ ). Variante A/B (?).

Variante A/B

13 Marseille, place Villeneuve-Bargemon (Bien 2003, fig. $\left.4, \mathrm{n}^{\circ} 16\right)$.

Variante B

*14 Sidi Jdidi, (Ben Abed, Bonifay, Fixot 1997, fig. 9, $\mathrm{n}^{\circ} 49$; Bonifay, Reynaud 2004, $\left.\mathrm{n}^{\circ} 32.4\right)$.

15 Idem, (Ben Abed, Bonifay, Fixot 1997, fig. 9, n 48 ; Bonifay, Reynaud 2004, ${ }^{\circ}$ 34.1).

*16 Nabeul, fabrique de salaison, période 6 (Bonifay 2002, fig. $\left.2, \mathrm{n}^{\circ} 15\right)$.

17 Marseille, chantier de la place Jules-Verne (Bonifay 1998a, fig. 3, nº 6).

Variante C

18 Carthage (Hayes 1978b, fig. 21, $\mathrm{n}^{\circ}$ B66).

19 Alexandrie (Rodziewicz 1984, Pl. 34, n 116).

*20 Rome, Crypta Balbi (Saguì 1995, fig. 3, n² 2).

*21 Rougga, couche 10 (Guéry, Bonifay à paraître, n 86). Les exemplaires les plus anciens semblent former transition avec la forme $87 \mathrm{C}$. Le $\mathrm{n}^{\circ} \mathbf{1}$ doit pouvoir être daté de la seconde moitié du VIe s., de même que l'exemplaire d'Argos (7) morphologiquement assez proche. Le $\mathrm{n}^{\circ} \mathbf{6}$, déjà plus évolué, est associé à des exemplaires de la variante A dans des contextes de la fin du VIe et du début du VIIe s. (Bonifay et al. 1998, 418, Tabl. CIII : contextes $n^{\circ} 8$ et 2 ), datation qui paraît convenir également aux $n^{\circ} 9$ et $\mathbf{1 0}$. La variante B est la variante classique de la forme 109 pour laquelle Hayes $(1980,517)$ suggérait de revenir à la datation initialement proposée par Waagé à Antioche : après 610-620. Mais les découvertes récentes montrent que cette variante est surtout fréquente au milieu et dans la seconde moitié du siècle à Marseille (13), à Istanbul (Hayes 1992, fig. 40, $\mathrm{n}^{\circ}$ 42-43), à Sant'Antonino di Perti (Murialdo 2001, 


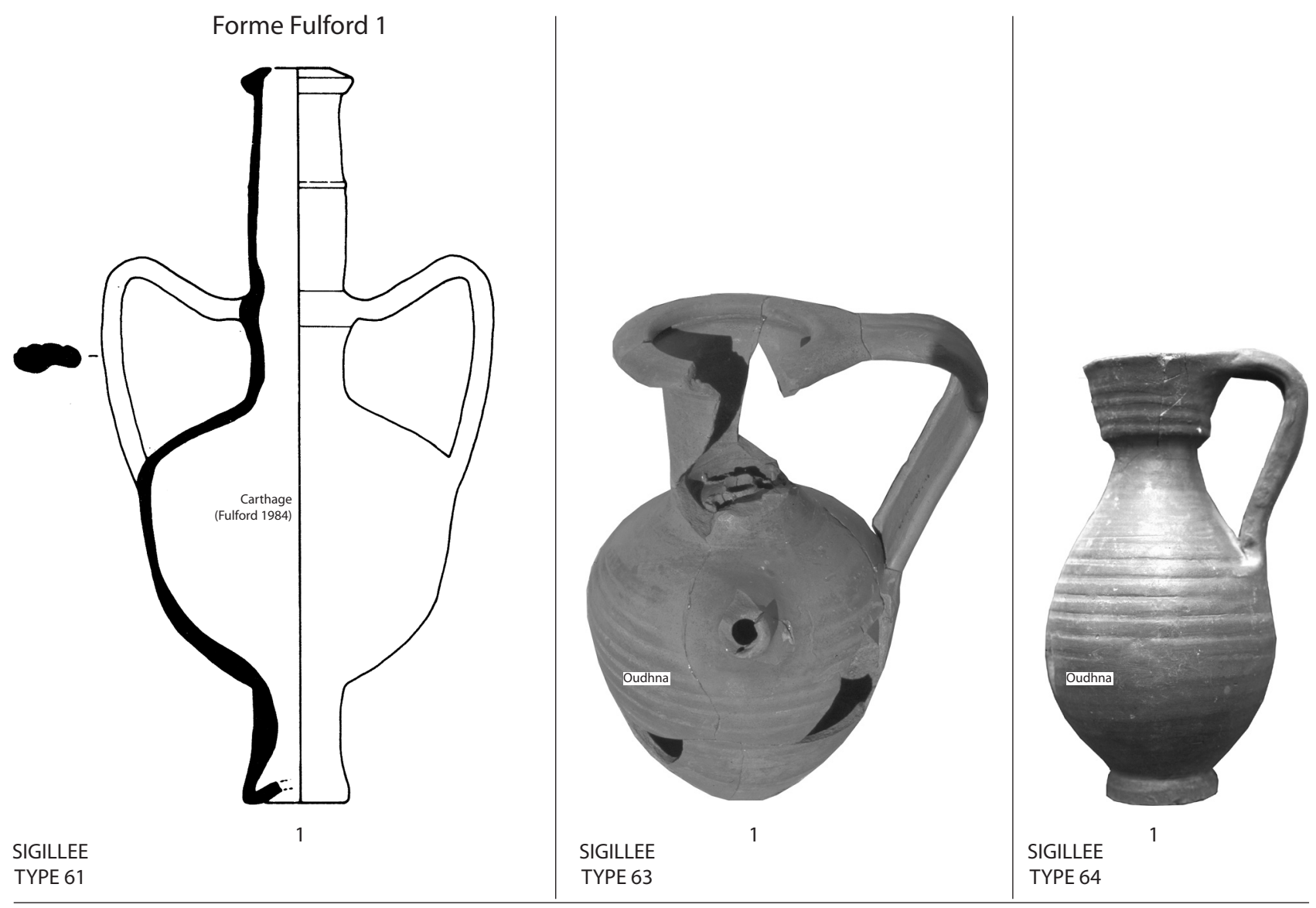

Forme Fulford 2

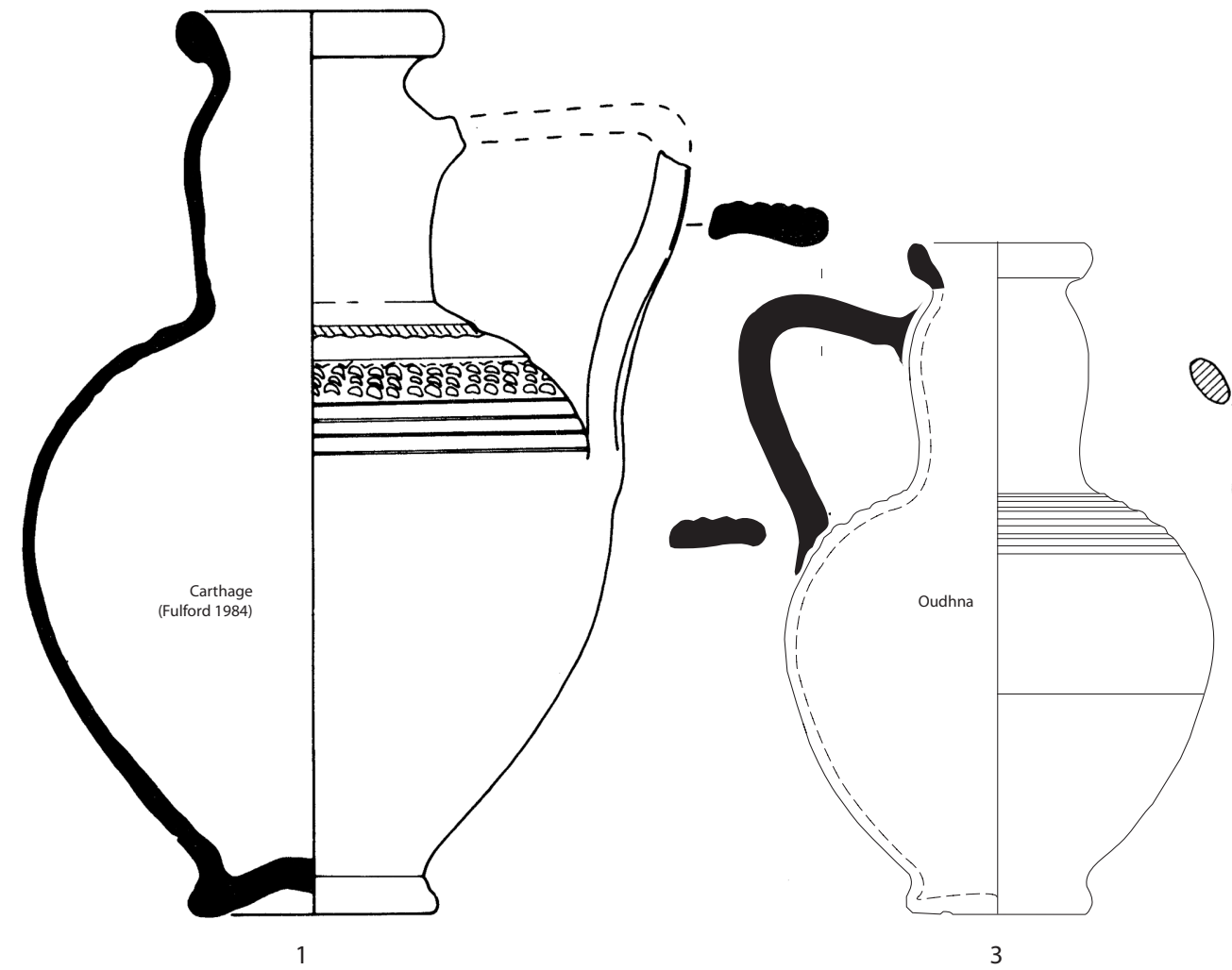

SIGILLEE

TYPE 62

Fig. 100. Vaisselle sigillée africaine D.

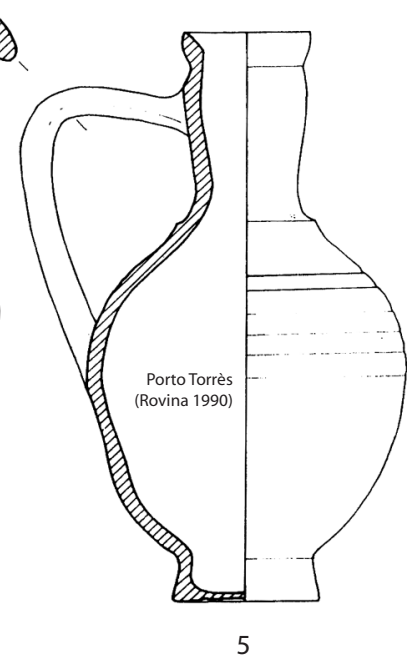


Pl. 25, n 93-98), à Rome (Saguì 1998, fig. 3, n 7-8) et à Carthage (Hayes 1978b, fig. 8, $\mathrm{n}^{\circ} 1$, et fig. 12, $\mathrm{n}^{\circ} 11-12$ ). De fait, les exemplaires de Sidi Jdidi (14-15) proviennent de contextes associés à une monnaie de Constantin IV et ceux de Nabeul (16) et de Marseille (17) ne sont pas antérieurs à la fin du VIIe s. (Bonifay 2002, 183 ; Bonifay 1998a, 77). Un autre exemplaire est présent sur l'épave de Saint-Gervais 2 en association avec des amphores africaines Keay $8 \mathrm{~A}$ et «spatheion » de type 3 (Jézégou 1998, fig. $\left.308, n^{\circ} 11\right)$. Il n'est pas impossible que les exemplaires les plus tardifs, à parois très fines et de qualité très fruste soient à rattacher à l'époque postbyzantine (infra, SIGILLÉE TYPE 93). La variante C est également attestée à Rome à la fin du VIIe s. (20).

Datation proposée :

Forme $87 \mathrm{C} / 109$ - dernier tiers du VIe s.

Variante 109 A - fin VIe - milieu du VIIe s.

Variante 109 B - milieu - seconde moitié du VIIe s., exemplaires tardifs début du VIIIe s. ?

Variante $109 \mathrm{C}$ — seconde moitié du VIIe s. (?)

— cruches (fig. 100)

L'un des apports typologiques importants des fouilles de Carthage consiste dans la mise en évidence d'un riche répertoire de «formes fermées » attribuables à la production D (Fulford 1984a, 84-87). La reprise des recherches sur l'atelier d'Oudhna a montré que cet atelier, à la différence de celui d'El Mahrine, avait produit beaucoup de ces formes (Barraud et al. 1998, fig. 10, $\mathrm{n}^{\circ} 10$, et fig. $17, \mathrm{n}^{\circ} 32$ ). Il en est ainsi notamment des grandes cruches à long col et deux anses Fulford 1 [TYPE 61] (Fulford 1984a, fig. 25; Hayes 1976a, fig. 3, $\left.\mathrm{n}^{\circ} 39\right)^{153}$ et des cruches mono-ansées à décor cannelé et/ou guilloché Fulford 2 [TYPE 62] (Ibid.; Riley 1981, fig. $3, \mathrm{n}^{\circ} 50$ ). On retrouve également sur les produits d'Oudhna les particularités techniques signalées par les fouilleurs de Carthage, le vernis rouge presque carmin, un peu écaillé, fréquent sur la forme Fulford 1 et le vernis brun-jaune caractéristique des cruches Fulford 2. Bien d'autres formes fermées ont été relevées sur l'atelier d'Oudhna $^{154}$, en particulier une cruche à bord en baïonnette, à bec tubulaire et anse latérale [TYPE 63], qui rappelle les biberons en céramique commune de la haute époque romaine (infra, COMMUNE TYPE 53) et une cruche piriforme à col en entonnoir [TYPE 64]. Cette dernière forme en rappelle une autre, en céramique commune, également produite à Oudhna et exportée en Catalogne (Aquilué 1994, fig. 1, 586a). D'après les stratigraphies de Carthage, l'ensemble de ces objets couvre la fin du Ve s. et le VIe s.; un certain nombre de fragments sont présents à Marseille, au milieu du VIe s. (Bonifay 1983, fig. $\left.24, \mathrm{n}^{\circ} 115-117\right)$.

\footnotetext{
${ }^{153}$ Une collection importante de ces cruches a été récemment mise au jour, par Mlle Jihen Nacef, dans la fouille des absides de Beulé à Carthage (contexte du début VIe s.).

${ }^{154} \mathrm{La}$ typologie précise sera livrée dans la thèse, en préparation, de Mme Faouzia Dridi.
}

Exemples (fig. 100) :

Forme Fulford 1 [SIGILLÉE TYPE 61]

*1 Carthage (Fulford 1984a, fig. 25, $\mathrm{n}^{\circ} 1.3$ ).

2 Carthage (Hayes 1976a, fig. 3, n 39 ).

Forme Fulford 2 [SIGILLÉE TYPE 62]

*1 Carthage (Fulford 1984a, fig. 25).

2 Carthage (Riley 1981, fig. 3, $\mathrm{n}^{\circ}$ 50).

*3 Oudhna (Barraud et al. 1998, fig. 10, n 10).

Variante de petites dimensions

4 Musée de Cagliari (Boninu 1971-72, fig. 43 ; Atlante Pl. XXI, 4).

*5 Porto Torrès (Rovina 1990, fig. 9, 2). H. $17 \mathrm{~cm}$.

SIGILLÉE TYPE 63

1 Oudhna (sans $n^{\circ}$ d'inv.).

SIGILLÉE TYPE 64

1 Oudhna (sans $n^{\circ} d^{\prime}$ inv.).

\section{Catégorie E}

Je n'ai pas beaucoup de documentation sur la sigillée africaine $\mathrm{E}$, mis à part les tessons hors contexte des prospections du littoral qui confirment, s'il en était besoin, que la diffusion de la catégorie $\mathrm{E}$ intéresse principalement le sud de la Tunisie (infra, fig. 254, c). Toutefois, il faut compter avec la localisation relativement centrale, à Djilma-Henchir Guellal (à $25 \mathrm{~km}$ à l'est de Sbeitla), du seul atelier important ayant probablement produit, parallèlement à la catégorie C1C4, ce type de sigillée (Peacock, Bejaoui, Ben Lazreg 1990, 76-81 ; Pröttel 1996, 20-21 et note 51); on avait initialement supposé que les ateliers se situaient entre Gabès et Sfax (Hayes 1972, 298 ; Atlante I, 119). Il faudrait cependant vérifier que la pâte des produits de Djilma correspond bien au standard de la production E, puisqu'il est maintenant avéré que la forme Hayes 68, forme-phare de la catégorie $\mathrm{E}$, a été également produite (imitée ?) dans d'autres régions (supra, fig. 23). Ainsi, les fragments recueillis à Sidi Jdidi ne présentent pas la pâte typique de cette production (Bonifay, Reynaud 2004, $\mathrm{n}^{\circ} 6 \mathrm{~B} .2,9.2$, et 12.5$)$; on ignore leur origine : il pourrait s'agir d'imitations locales (supra, p. 51 et fig. $23, \mathrm{n}^{\circ} 4$ ).

\section{Décors}

La décoration à relief d'applique de la sigillée africaine A a déjà été mentionnée (supra, SIGILLÉES TYPES 19-23). La question des plats rectangulaires à décor moulé est volontairement laissée de côté ; on se reportera en dernier lieu à Guéry, Slim 1998. N'ayant pas de documentation de première main sur celle de la catégorie $C$, l'essentiel des informations concerne la décoration imprimée et lustrée de la catégorie D. 
Typologie - Sigillées
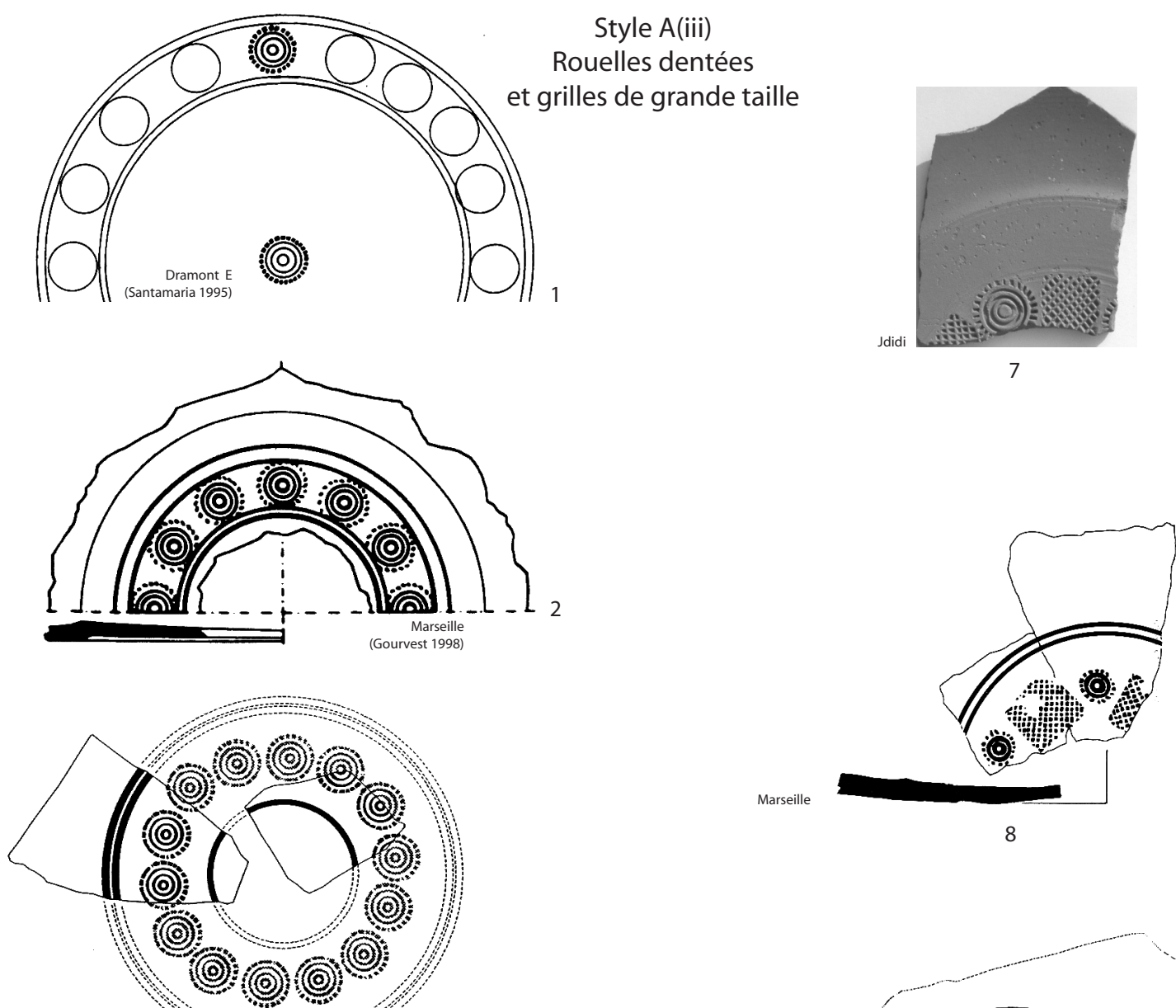

8

Saint-Blaise
(Rivet 2001)

3

3

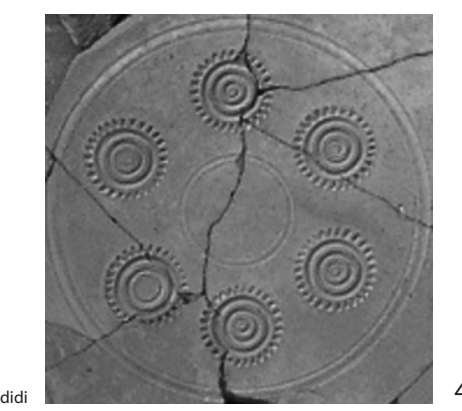

Style A(iii)

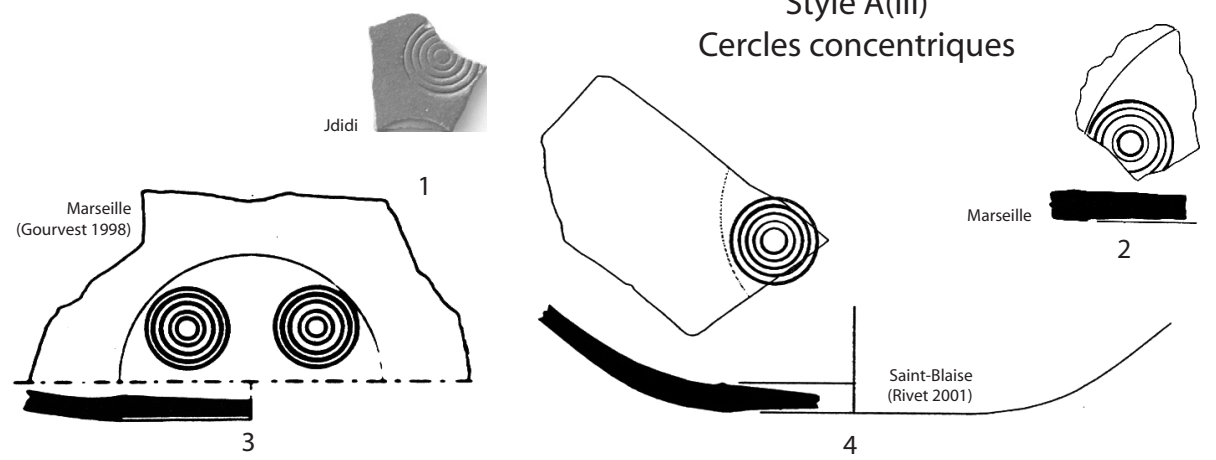

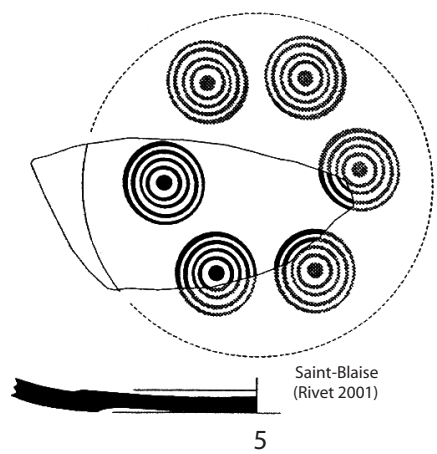

Fig. 101. Vaisselle sigillée africaine D. Décors imprimés. 

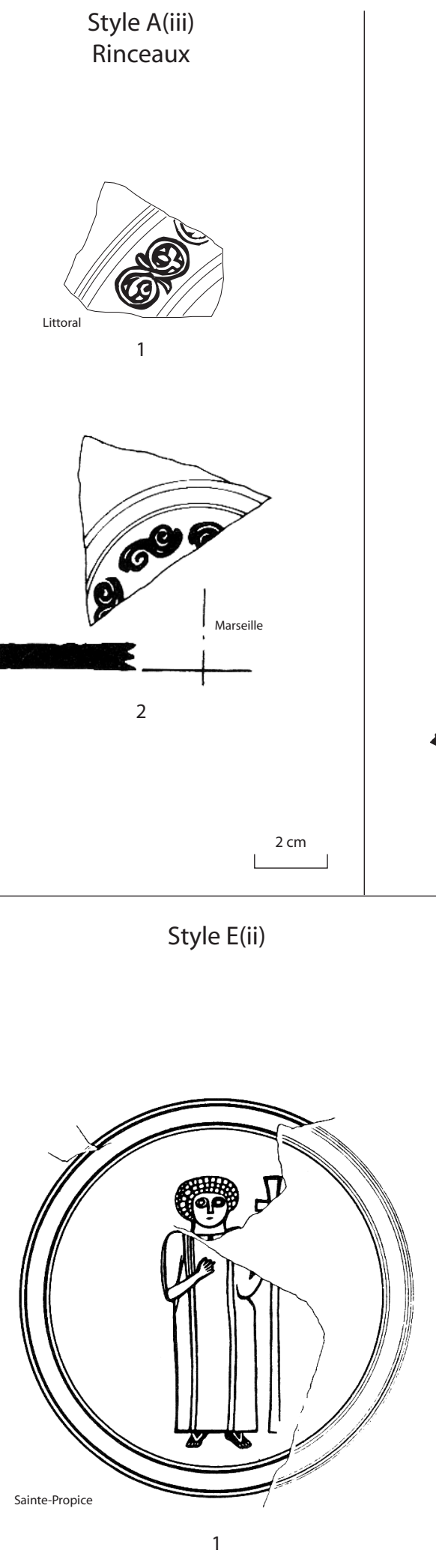

0

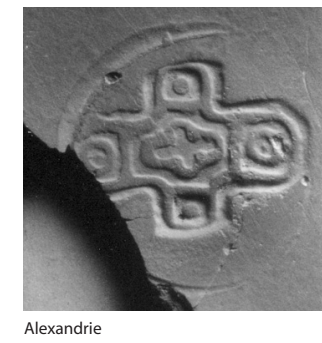

3
Styles $A(i i i) / E(i)$ et $E(i)$
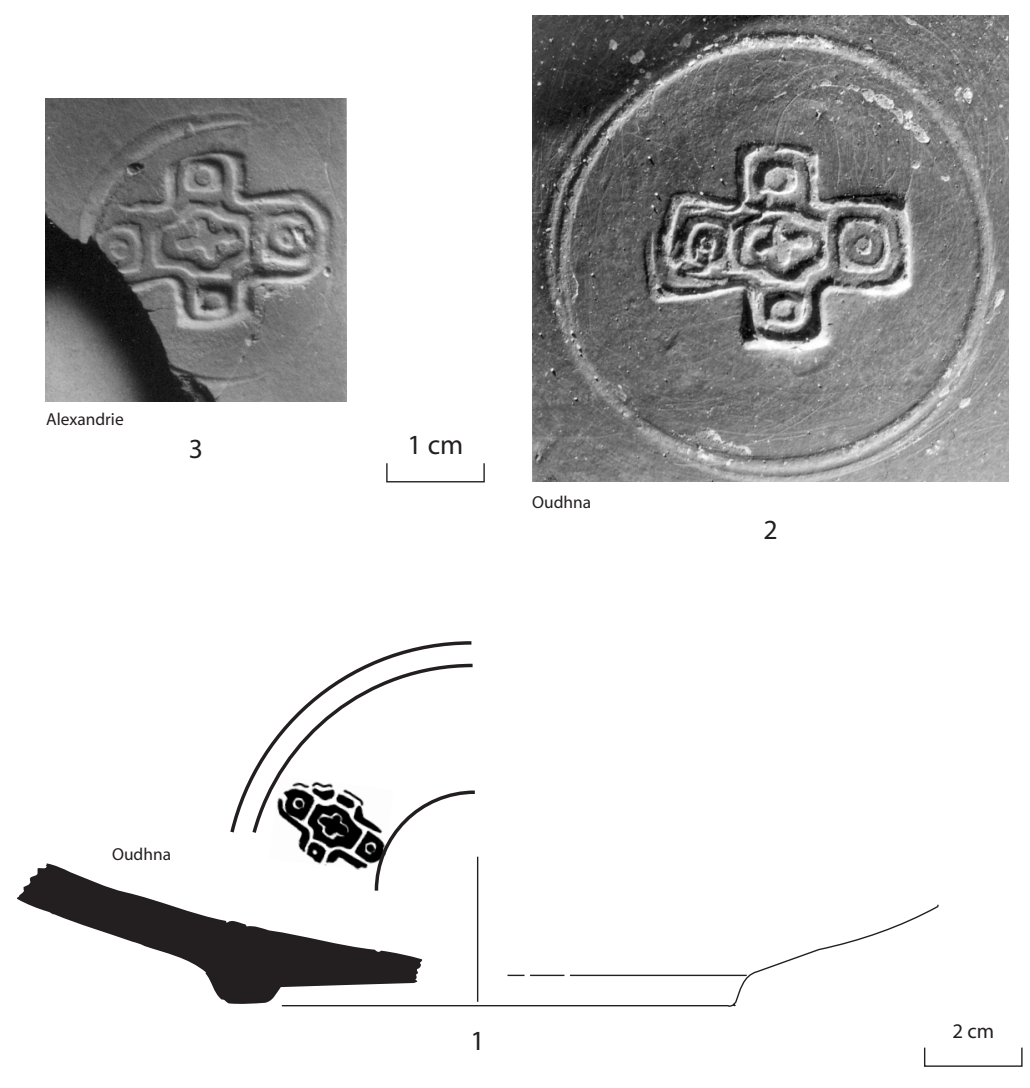

Style "F"
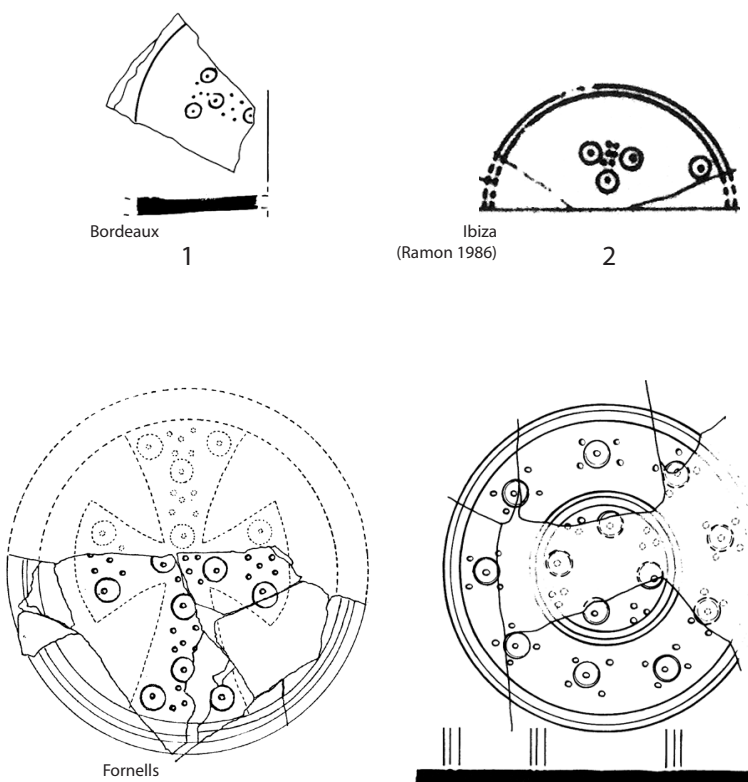

Fornells
(Navarro Saez 1982)

3

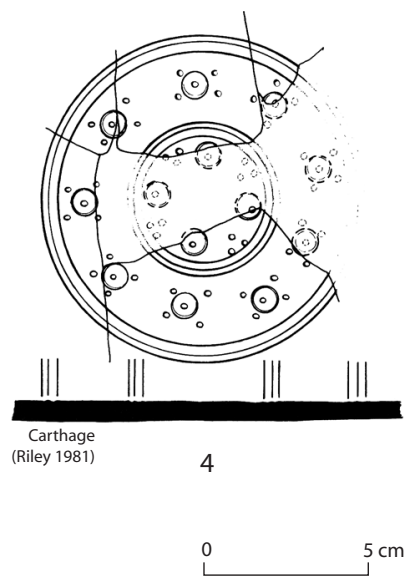

Fig. 102. Vaisselle sigillée africaine D. Décors imprimés. 


\section{— décors imprimés}

Le matériel de Sidi Jdidi et de l'atelier d'Oudhna apporte quelques compléments aux styles décoratifs recensés par J. W. Hayes.

- Style A(iii) (fig. 101-102)

- Rouelles dentées et grilles de grande taille

Un riche contexte de la seconde moitié du Ve s. en cours de fouille dans les dépendances du groupe épiscopal (basiliques 2 et 3 ) de la cité d'Aradi/Sidi Jdidi fournit un ensemble intéressant de décors du style A(iii). Cette documentation permet de localiser dans cette région des confins de la Byzacène et de la Zeugitane, le ou les ateliers qui ont utilisé des poinçons de grande taille, rouelles dentées, grilles, palmettes courtes et ovales, disposés en couronne, dont on a un abondant témoignage à Marseille et sur des épaves du littoral français.

Il est possible que l'atelier de Sidi Khalifa soit à l'origine d'une partie au moins de ces décors (5-6, 10-11).

Exemples (fig. 101) :

Rouelles seules

*1 Epave Dramont E (Santamaria 1995, 92, n 71). Sur Hayes 61B.

*2 Marseille (Gourvest 1998, fig. 22, n²28). Douze rouelles en couronne.

*3 Saint-Blaise (Rivet 2001, fig. 14, $\mathrm{n}^{\circ}$ 59). Quatorze rouelles en couronne.

*4 Sidi Jdidi, basilique 2, destruction état II (Inv. JD2315.21). Sur Hayes 61B (supra, fig. 91, n 33). Six rouelles en couronne.

5-6 Atelier de Sidi Khalifa (Ben Moussa 2001, Pl. LXXVIII, $n^{\circ} 2-3$ ).

Alternance de rouelles et de grilles

*7 Sidi Jdidi, basilique 2, destruction état II (Inv. 2360.12).

*8 Marseille, chantier de La Bourse (Bonifay 1983, fig. $\left.19, \mathrm{n}^{\circ} 16\right)$.

*9 Saint-Blaise (Rivet 2001, fig. 13, $\mathrm{n}^{\circ}$ 5-75). Six rouelles et six grilles en alternance.

10-11 Atelier de Sidi Khalifa (Ben Moussa 2001, P1. LXXVI, $\left.n^{\circ} 1-2\right)$.

\section{- Cercles concentriques}

Un autre atelier de la région de Sidi Jdidi a produit, dans une qualité de pâte particulière (supra, SIGILLÉE TYPE 39), la majeure partie des exemplaires de la forme Hayes 61C présents sur le site. Or ces plats apparaissent systématiquement (?) décorés selon le style A(iii) avec la répétition d'un unique poinçon de cercles concentriques. Beaucoup d'exemplaires de cette forme découverts sur les rives nord de la Méditerranée portent cette décoration. Cette répétition d'un motif unique semble être une caractéristique des décors de style A(iii) de la seconde moitié du Ve siècle.

Exemples (fig. 101):

*1 Sidi Jdidi, basilique 2, destruction état II (Inv. JD2357.25). Probablement plat Hayes 61C.

*2 Marseille, chantier de La Bourse (Bonifay 1983, fig. $\left.19, \mathrm{n}^{\circ} 15\right)$.

*3 Marseille (Gourvest 1998, fig. 21, n²02).
*4 Saint-Blaise (Rivet 2001, fig. 15, $\mathrm{n}^{\circ} 45$ ).

*5 Saint-Blaise (Rivet 2001, fig. 15, $\mathrm{n}^{\circ} 44$ ).

\section{- Rinceaux}

En revanche, il faut sans doute rechercher une origine septentrionale pour les décors de rinceaux bien attestés à Carthage (Fulford 1984a, fig. 29, n 97, 102), sur le littoral septentrional (1) ainsi qu'en Algérie (Guéry 1970a, fig. 84). Des décors assez similaires se trouvent représentés sur les lampes du groupe D3 (infra, LAMPE TYPE 66, variante B).

Exemples (fig. 102) :

*1 Littoral tunisien (site ${ }^{\circ} 165$, Mraïssa) (Bonifay et al. 2002-2003, fig. $\left.8, \mathrm{n}^{\circ} 78\right)$.

*2 Marseille, puits du Bon Jésus (Bonifay 1998b, fig. 171, $\left.\mathrm{n}^{\circ} 13\right)$.

\section{- Styles A(iii)/E(i) et E(i) (fig. 102)}

Le catalogue des poinçons de l'atelier d'Oudhna ébauché par P. Gauckler (1897) a été considérablement augmenté depuis la reprise des recherches sur l'atelier en 1995. Ces poinçons appartiennent essentiellement au style E(i), qui est le style d'Oudhna par excellence, traditionnellement daté de la fin du Ve s. et de la première moitié du VIe s. (Hayes 1972, 221-222). Mais ce style décoratif, certes majoritaire à Oudhna, n'est peut-être pas le seul à avoir été employé sur cet atelier. Si les tessons décorés avec des poinçons de style E(ii), découverts dans le dégagement des Grands Thermes, n'ont probablement pas été fabriqués à Oudhna (Mackensen 1998a), les prospections dans la zone périphérique d'ateliers, en revanche, ont livré quelques fragments portant un décor de style A(iii) ou A(iii)/E(i) (Barraud et al. 1998, 149). La production d'un tel décor à Oudhna n'est pas étonnante dans la mesure où Gauckler reproduisait déjà quelques palmettes (cf. Mackensen 1993, fig. 4, $\mathrm{n}^{\circ}$ 1-3) peu en accord avec le style E(i). Par ailleurs, il y a maintenant de fortes présomptions pour anticiper le début de l'atelier de sigillée d'Oudhna dans la seconde moitié du IVe s., si ce n'est même plus tôt encore (supra, p. 4748). Enfin, le style E(i), un seul poinçon imprimé au centre du vase, correspond à une nécessité pratique, celle d'orner des formes de petite taille, dont le diamètre utile du fond dépasse rarement $8-10 \mathrm{~cm}$. En revanche, sur les rares formes de plus grande taille, notamment une forme Hayes 103 variante (Barraud et al. 1998, fig. 16, $\mathrm{n}^{\circ} 24$ ), les potiers ont eu la place de disposer selon le style A(iii) les poinçons qu'ils utilisaient au même moment pour les décors de style E(i).

Exemples (fig. 102) :

Style A(iii)/E(i)

*1 Oudhna, zone périphérique d'ateliers (Inv. UTH.ZA.HS.07). 
Style E(i)

*2 Oudhna, thermes des Laberii (Barraud et al. 1998, fig. $\left.11, \mathrm{n}^{\circ} 2\right)$.

*3 Alexandrie, chantier du théâtre Diana (Bonifay 1998c, fig. $\left.2, \mathrm{n}^{\circ} 1\right)$.

Le décor présent sur les formes Hayes 99 apporte quelques précisons sur l'évolution du style E(i) :

- Sur la variante A, on relève des poinçons d'assez grande taille dessinant des motifs qui ont une signification claire, essentiellement des oiseaux et des croix (Barraud et al. 1998, fig. 11, n 1-4). Ces poinçons sont toujours imprimés au centre d'un ou deux cercles tracés en léger creux sur le fond du vase. J. W. Hayes avait déjà relevé que certains décors étaient en relation avec le style $\mathrm{D}$ utilisé sur la sigillée africaine C5 de la seconde moitié du Ves., notamment le poinçon Hayes 297 (croix monogrammatique inversée) et, désormais (supra, p. 181), le poinçon 289B (croix monogrammatique pointée), qui n'était jusqu'à présent attesté que sur les formes Hayes 96-97.

- La variante B porte un certain nombre de nouvelles empreintes, de signification plus obscure : il semble s'agir pour beaucoup (Barraud et al. 1998, fig. 11, $n^{\circ}$ 5-6) de reproductions de bijoux. Ces nouveaux poinçons et ceux déjà attestés sur la variante $\mathrm{A}$ sont imprimés avec beaucoup moins de soin et sont rarement entourés d'une cannelure.

- Enfin, la variante C n'est jamais décorée.

- Style E(ii) (fig. 102)

Pour mémoire.

Exemple :

*1 Sainte Propice (Boixadera et al. 1987, fig. 10, n²4).

- Style « F » (fig. 102)

Le plat Hayes 90B de Bordeaux (1) porte un décor original que je propose de nommer provisoirement « style $\mathrm{F} »$ : des points et des cercles pointés, imprimés de façon très rudimentaire, dessinent un motif cruciforme tout à fait comparable à ceux observés sur d'autres exemplaires de la même forme à Ibiza (2) et à Majorque (3). Il semblerait que ce type de décor soit donc caractéristique de cette forme de grande taille (D. du fond : $30 \mathrm{~cm}$ ) et de date tardive (supra, SIGILLÉE TYPE 47). Un tesson de Carthage, décoré selon la même technique, apparaît dans un contexte de la fin du VIe s. ou du début du VIIe s. (4). Exemples (fig. 102):

*1 Bordeaux, place Camille-Jullian (Bonifay à paraître, b, fig. $2, \mathrm{n}^{\circ} 6$; supra, fig. $94, \mathrm{n}^{\circ} 3$ ).

*2 Ibiza (Ramon 1986, fig. 14, $\mathrm{n}^{\circ} 16$; supra, fig. 94, $\left.\mathrm{n}^{\circ} 5\right)$.

*3 Minorque, basilique de Fornells (Navarro Saez 1982, fig. 40 ; supra, fig. $\left.94, \mathrm{n}^{\circ} 4\right)$.

*4 Carthage (Riley 1981, fig. 6, n³2).

\section{— décors lustrés (fig. 103-104)}

Ce type de décoration « est obtenu par un lustrage du dessin à l'ébauchoir, la spatule de l'outil étant probablement enduite d'un vernis qui fait ressortir le décor en brillant sur le fond mat» (Gourvest 1998, 37). Signalé pour la première fois, il y a plus de cinquante ans, sur le site de Saint-Blaise (Rolland 1951, 182 ; voir désormais Cavaillès-Llopis, Vallauri 1994, 108), il est également bien attesté en Catalogne où il a même fait l'objet d'une étude spécifique (Aquilué 1992) et en Espagne du Sud (Reynolds 1987, fig. 56). En revanche, les contours de sa diffusion en Tunisie, relativement faible, n'apparaissent pas avec une grande clarté.

Il semble qu'il faille distinguer deux générations au sein des décors lustrés sur sigillée africaine :

- Groupe 1: sur formes Hayes 87A1 (supra, p. 173) et $87 \mathrm{C}$. On peut distinguer une évolution parallèle à celles des décors imprimés :

1 A : le décor se développe en couronne (festons, lignes brisées, motifs végétaux) autour de la partie centrale du fond réservée (espace d'environ 8-9 cm de D.).

$1 \mathrm{~B}$ : le décor quitte la périphérie du fond pour venir se placer au centre, et dessiner sur la partie réservée des motifs végétaux ou chrétiens (chrismes, croix).

$1 \mathrm{C}$ ? : certains fragments présentent des bribes d'inscriptions linéaires ou de pseudoinscriptions (?).

- Groupe 2: sur formes Hayes 106, 107, 109 et d'autres formes tardives non encore cataloguées (infra, TYPES 85-93). Ce décor peut être soit très simple: bandes espacées sur la paroi, petit motif floral au centre, ou au contraire tout à fait exubérant, combinant motifs floraux et motifs chrétiens.

2 A : décor simplifié, composé de bandes lustrées espacées sur la paroi, parfois terminées par une spirale sur le fond (Waagé 1948, fig. 28, $\left.\mathrm{n}^{\circ} 15\right)$.

$2 \mathrm{~B}$ : décor floral au centre du fond, composé d'une tige verticale portant deux ou trois ramifications symétriques recourbées en spirale. $2 \mathrm{C}$ : décor complexe, associant un motif floral ou chrétien au centre du fond et une ou deux frises florales périphériques.

Exemples (fig. 103-104) :

Groupe $1 \mathrm{~A}$

1 Marseille, Vieux Quartiers (Gourvest 1998, fig. 23, $\mathrm{n}^{\circ}$ 247).

*2 Idem (Ibid., $\left.\mathrm{n}^{\circ} 248\right)$.

3 Saint-Blaise (Rivet 2001, fig. 20, $\mathrm{n}^{\circ} 143$ ).

*4 Idem (Rivet 2001, fig. 20, $\mathrm{n}^{\circ}$ 144).

*5 Port-Vendres (Martin 1977, fig. 4, n 1 ; Aquilué 1992, fig. $\left.8, n^{\circ} 5\right)$. 
Typologie - Sigillées
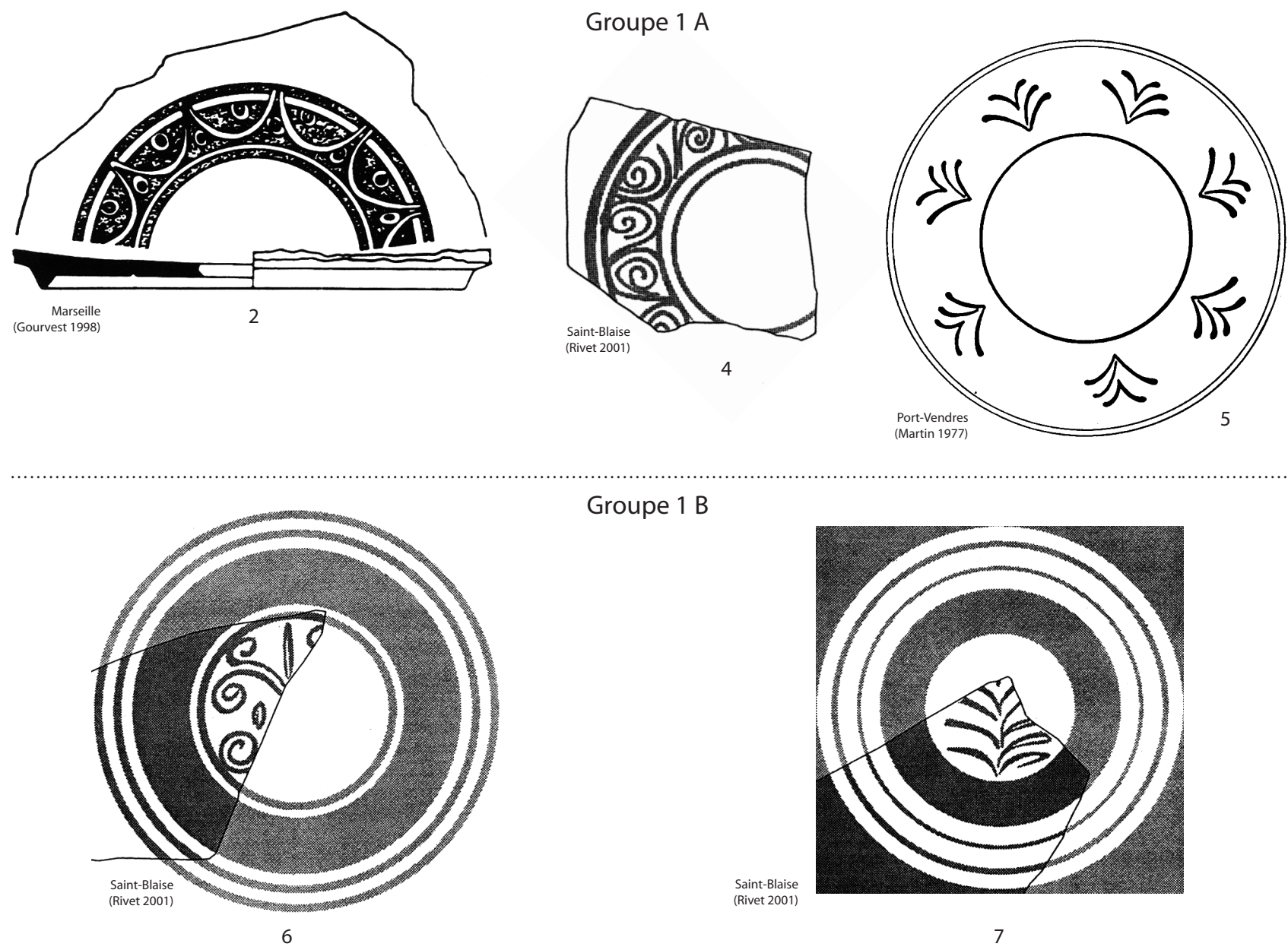

Groupe 1 B
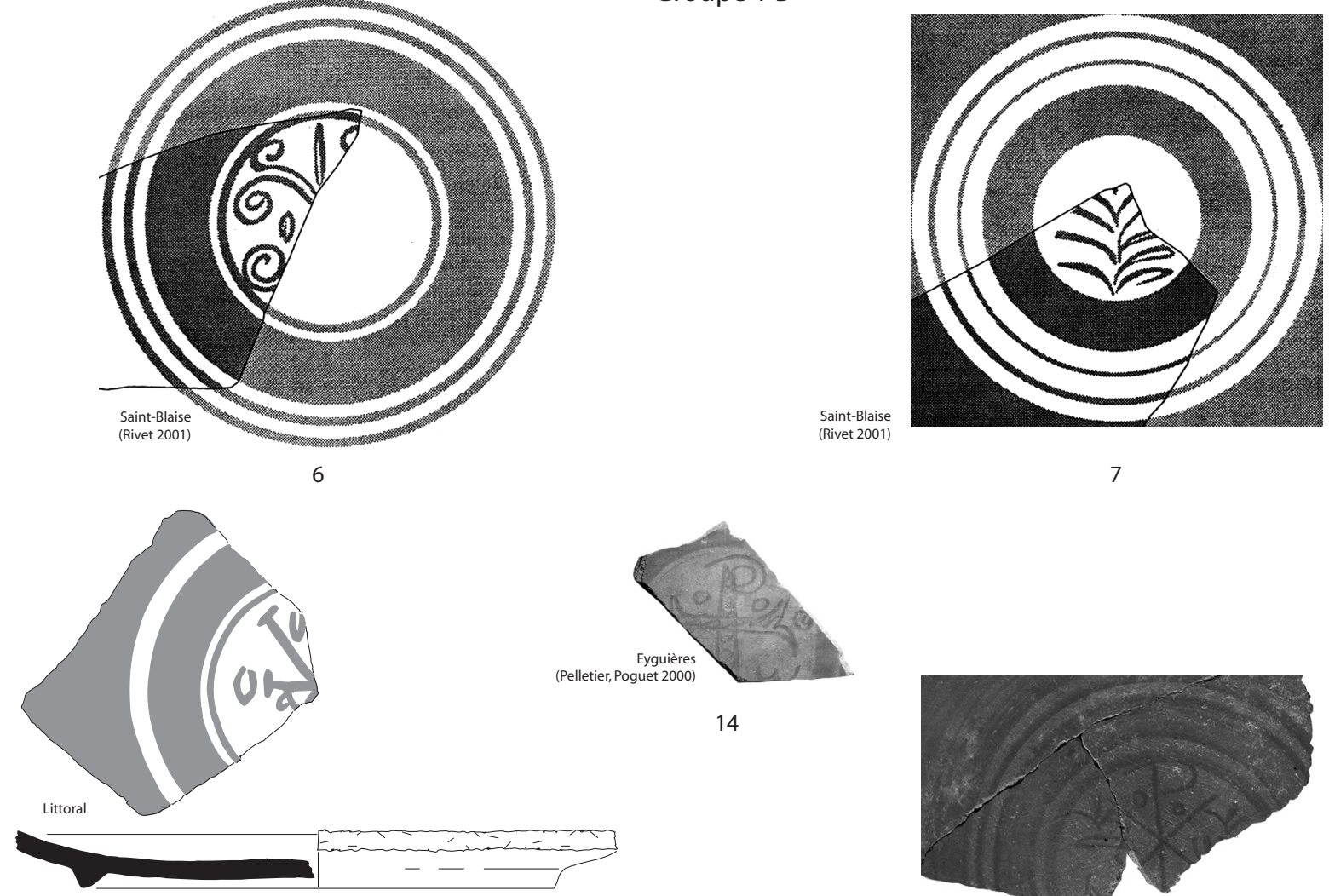

14

11

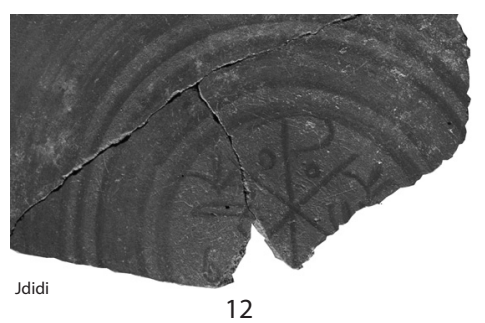

Groupe $1 \mathrm{C}$
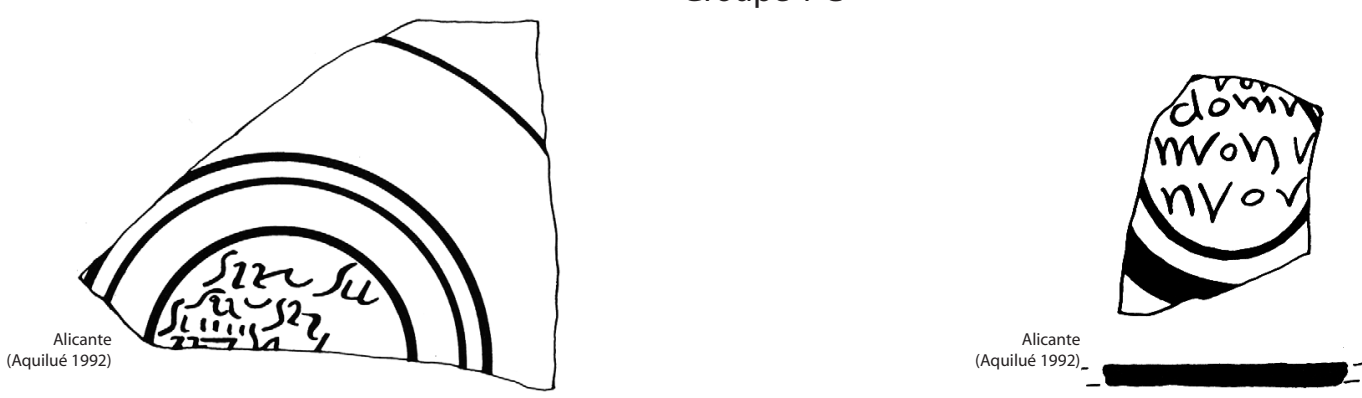

15

16

Fig. 103. Vaisselle sigillée africaine D. Décors lustrés. 


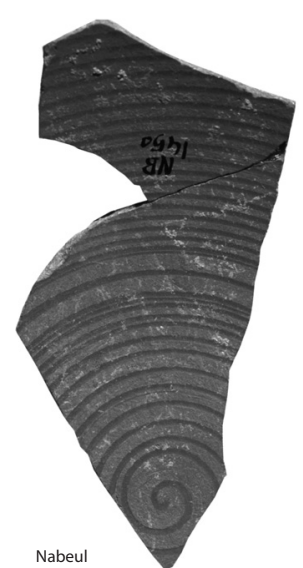

20 $2 \mathrm{~cm}$
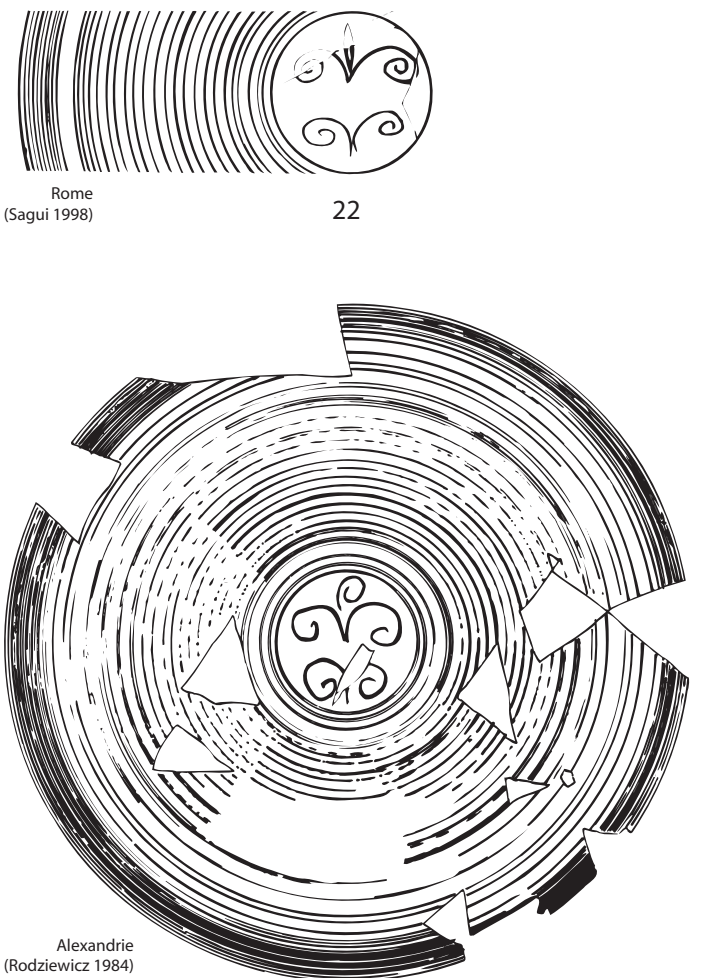

23 $5 \mathrm{~cm}$

Groupe 2 C

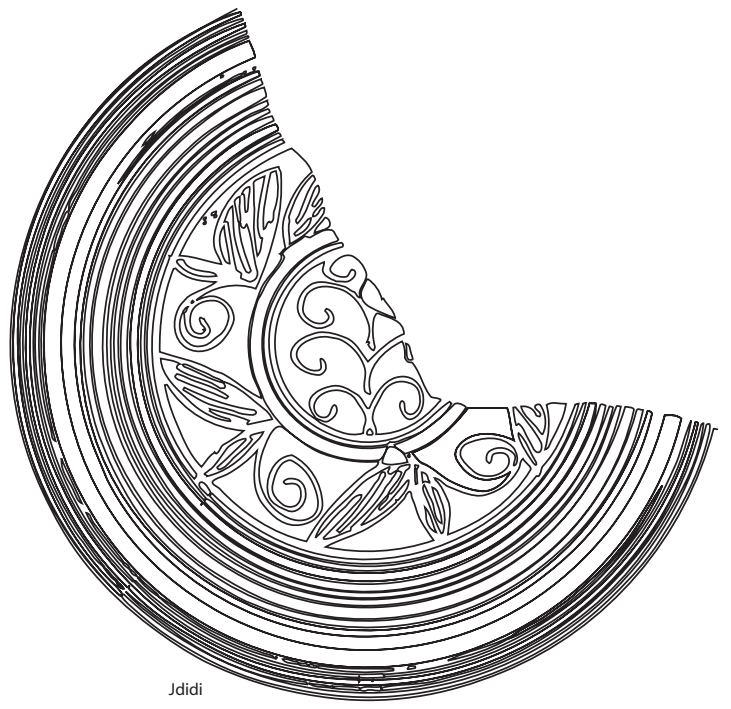

25

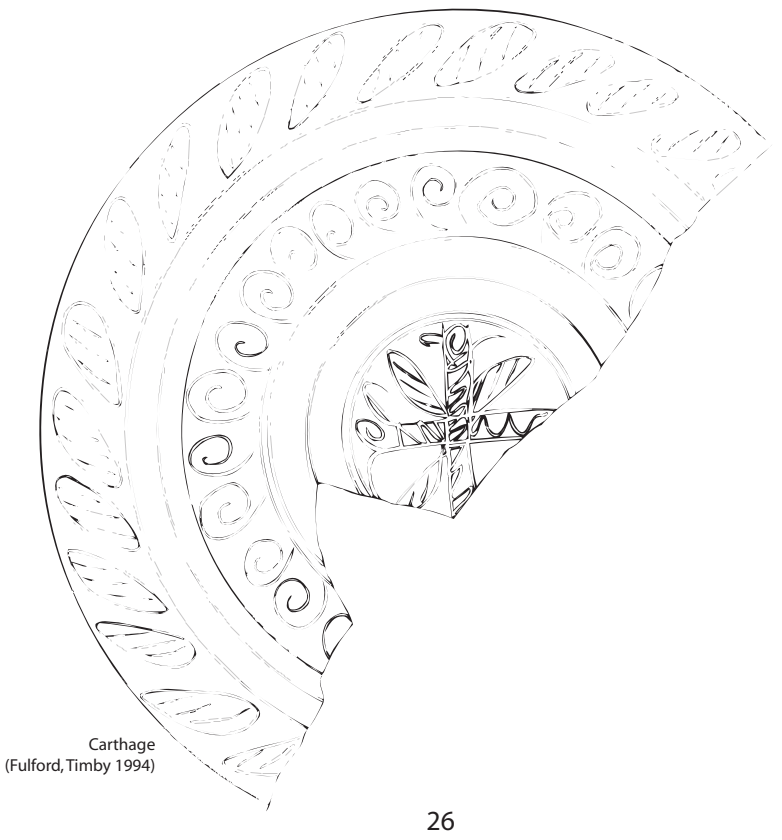

26

Fig. 104. Vaisselle sigillée africaine D. Décors lustrés. 
Groupe 1 B

Décors végétaux

*6 Saint-Blaise (Rivet 2001, fig. 20, $\mathrm{n}^{\circ}$ 141). Forme Hayes 87 A1.

*7 Idem (Rivet 2001, fig. 20, $\mathrm{n}^{\circ}$ 142).

8 Benalúa (Aquilué 1992, fig. 4, n²2). Forme Hayes 87 A1. Décors chrétiens

9-10 Saint-Blaise (Cavaillès-Llopis, Vallauri 1994, fig. 63, $\mathrm{n}^{\circ}$ 23-24). Chrisme.

*11 Littoral tunisien, site $\mathrm{n}^{\circ} 70$ (El Aouabed, côte nord de Sfax) (Bonifay et al. 2002-2003, fig. 6 et 8, $\mathrm{n}^{\circ} 52$ ). Chrisme.

*12 Sidi Jdidi (Inv. JD2112.1). Chrisme.

13 Saint-Blaise (Cavaillès-Lopis, Vallauri 1994, fig. 63, $\mathrm{n}^{\circ}$ 27). Croix.

*14 Eyguières (Pelletier, Poguet 2000, fig. 37). Croix monogrammatique.

Groupe $1 \mathrm{C}$

*15 Alicante (Aquilué 1992, fig. 5, n 31).

*16 Idem (Aquilué 1992, fig. 5, n 33).

17 Nabeul, fabrique de salaison (Inv. NB1492.16).

18 Belo (Bourgeois, Mayet 1991, Pl. CXIII, nº 586).

Groupe 2 A

19 Sidi Jdidi, basilique 1, état C2B (Ben Abed, Bonifay, Fixot 1997, fig. 9, $\mathrm{n}^{\circ} 49$; Bonifay, Reynaud 2004, $\mathrm{n}^{\circ}$ 32.4). Sur forme Hayes 109B.

*20 Nabeul, fabrique de salaison, période 6 (Inv. NB1450.2). Sur forme Hayes 109 (?).

Groupe 2 B

21 Sainte-Propice (Boixadera et al. 1987, fig. 10, n 27). Forme indéterminée. Précoce (?)

*22 Rome, Crypta Balbi (Saguì 1998, fig. 3, n 9). Sur forme 109 variante $\mathrm{C}$.

*23 Alexandrie (Rodziewicz 1984, fig. 14, $n^{\circ} 116$ ). Sur forme 109 , variante $\mathrm{C}$.

24 Nabeul, fabrique de salaison, période 6 (Bonifay 2002, fig. $\left.2, n^{\circ} 17\right)$. Forme indéterminée.

Groupe $2 \mathrm{C}$

*25 Sidi Jdidi, basilique 1, état C2B (Ben Abed, Bonifay, Fixot 1997, fig. 9, n 47 ; Bonifay, Reynaud 2004, $\mathrm{n}^{\circ} 32.3$ ). Sur forme Hayes 107, variante (infra, type $\left.92, n^{\circ} 1\right)$.

*26 Carthage, port circulaire (Fulford, Timby 1994, fig. 1.9, $\left.\mathrm{n}^{\circ} 61\right)$. Sur forme Hayes 106.

27 Nabeul, fabrique de salaison (Bonifay 2002, fig. 2, $\left.\mathrm{n}^{\circ} 18\right)$.

Indéterminé

28 Rougga, couche 12 (Guéry, Bonifay à paraître, $n^{\circ} 62$ ). Sur forme Hayes 90 (?).

La diffusion du groupe 1 est très clairsemée en Tunisie : rare à Carthage (Fulford 1984a), il est attesté en faible quantité sur quelques sites du littoral : Nabeul (17), Sidi Jdidi (12), El Aouabed (11), Jerba (Fontana 2000, fig. 2, $\left.\mathrm{n}^{\circ} 4\right)$. La diffusion des formes-vecteurs de ce décor (Hayes 87A1 et 87C) fait apparaître deux groupes : le premier dans le cap Bon et le nord du golfe d'Hammamet, le second dans le golfe de Gabès au sud du rass Jezira. Il n'est pas impossible qu'il y ait eu une production de formes Hayes 87 dans cette partie méridionale de la Tunisie (Bonifay et al. 2002-2003). En revanche, si la production de la forme Hayes 87A1 est attestée, quoique de manière discrète, sur l'atelier de Sidi Khalifa (supra, SIGILLÉE TYPE 45), les décors lustrés, peu nombreux, recensés sur cet atelier (Ben Moussa 2001, Pl. CXVI) appartiennent au groupe 2. De fait, ce groupe 2 est relativement bien diffusé à Sidi Jdidi $(\mathbf{1 9}, \mathbf{2 5})$, Pupput et Nabeul $(\mathbf{2 0}, \mathbf{2 4}, \mathbf{2 7})$ et il est moins rare à Carthage que le groupe 1 .

Le groupe $1 \mathrm{~A}$ est caractéristique des contextes de la seconde moitié du Ve s. (Aquilué 1993, fig. 95, n 56, et fig. 97, $\mathrm{n}^{\circ} 78$ ) tandis que le groupe $1 \mathrm{~B}$ apparaît principalement dans les contextes du milieu du VIe s. (910). Le groupe 2 peut être présent, avec quelques exemplaires de la variante $B(\mathbf{2 1})$, dès le milieu du VIe s., mais il est surtout caractéristique du VIIe s. (19-20) et probablement encore de la fin du siècle $(\mathbf{2 2}, \mathbf{2 4}, \mathbf{2 5})$.

La disparition des décors imprimés est un fait marquant de l'histoire des sigillées africaines, alors que les autres productions initialement inspirées de cette céramique (Egyptian Red Slip ware A, Jerash Bowls) montrent une débauche de décors, notamment peints, au point que certaines formes, non décorées en Afrique, le sont en Orient (exemple: Hayes 105). Les décors lustrés du groupe 2, qui sont seuls à subsister au VIIe s., constituent ainsi la contrepartie africaine des décors «libres» orientaux.

\section{Datation proposée :}

Groupe 1A - seconde moitié Ve s. - début VIe s.

Groupes $1 \mathrm{~B}$ et $1 \mathrm{C}-\mathrm{VIe}$ s.

Groupe 2 - VIIe s., variantes précoces seconde moitié du VIe s. (?).

\subsubsection{Les formes « locales » : reclassements}

J. W. Hayes $(1972,300)$ avait distingué, à côté des grandes productions de sigillée africaines du nord, du centre et du sud (catégorie E ?) de la Tunisie (Ibid., 298299) bien diffusées dans le bassin méditerranéen, d'autres productions pour la plupart «similaires en qualité et en apparence aux séries principales » mais qui témoignaient d'une diffusion purement locale (Atlante I, 137: «produzioni per uso regionale »). Je propose aujourd'hui d'élargir cette catégorie aux produits suivants :

1) Cette catégorie concernait traditionnellement des productions que l'on pourrait qualifier de «continentales" aussi bien pour la localisation de leurs ateliers que pour l'essentiel de leur diffusion, dans lesquelles on a de longue date (Ibid.) regroupé :

a) la Tripolitanian Red Slip ware (Hayes 1972, 304-309),

b) les ateliers de Sidi Aïch et Henchir es-Srira (Stern 1968)

c) les "productions algériennes » classées à Sétif (Février 1963 et 1965).

2) Mais il est aujourd'hui possible de distinguer en Tunisie, depuis que les recherches céramologiques n'ont plus seulement Carthage comme terrain 
d'étude, d'autres productions à diffusion essentiellement locale mais qui ont parfois aussi, accessoirement, une diffusion méditerranéenne. Il s'agit généralement d'imitations ou d'interprétations locales, par des ateliers de premier rang (Exemple : Sidi Khalifa) ou plus obscurs (Exemple: Sidi Zahruni), de «formes standard» qui sont habituellement l'apanage d'autres régions productives.

3) Enfin, un certain nombre de productions locales de faible qualité technique, occupent une place intermédiaire avec les productions de céramique commune.

\section{Les productions continentales}

Je mentionne seulement pour mémoire ces productions sur lesquelles j'ai personnellement peu travaillé et qui font en outre l'objet, pour deux d'entre elles (ateliers de Sidi Aïch et Henchir es-Srira) de thèses en cours de préparation $^{155}$. La difficulté majeure de l'étude de ces deux ateliers est leur faible diffusion méditerranéenne et l'absence de stratigraphies urbaines dans les régions de production, qui entravent les tentatives de datations des différentes formes. N'oublions pas, en effet, que c'est grâce aux stratigraphies de Carthage et de nombreux sites du bassin méditerranéen que les produits d'El Mahrine et d'Oudhna ont pu être datés. La méthode la plus fréquemment utilisée (Stern 1968 ; Guéry 1986), un peu aléatoire, a consisté à rapprocher les formes pourtant assez originales de ces deux ateliers des formes standard des productions du nord et du centre de la Tunisie (Atlante I, 138-140).

Quelques données sont cependant disponibles en Algérie, notamment à Tébessa (Lequément 1968) et surtout à Sétif (Février 1963 et 1965 ; Guéry 1970b). En effet, ces produits ont peut-être eu une diffusion plus grande qu'on ne le pense, irriguant non seulement de nombreux sites de l'actuelle Algérie intérieure (Février 1963, fig. 7 et 8) mais également une partie de la côte tripolitaine septentrionale (infra, fig. 254, c). Les formes les mieux représentées dans ce dernier secteur, dont l'origine ne peut être précisée (Sidi Aïch et autres), sont les plats Stern I, XXIX, XXXV, X et surtout IV (Ibid. fig. 7, $\mathrm{n}^{\circ}$ 65-72).

Notons enfin que les productions plus spécifiquement algériennes (Février 1965, fig. 32, à vernis métallescent) ne paraissent pas très bien diffusées sur le littoral tunisien (Bonifay et al. 2002-2003).

\footnotetext{
${ }^{155}$ M. Mongi Nasr prépare une thèse sur les ateliers de sigillée africaine du sud-ouest de la Byzacène avec comme site principal, celui de Sidi Aïch. Mme Moufida Labayed-Ladhari prépare une thèse sur l'atelier de Henchir es-Srira.
}

\section{Les variantes locales de formes standard}

Les rapprochements avec les formes standard des grands ateliers sont en revanche évidents pour toute une série de productions marginales du nord et du centre de la Tunisie.

\section{- forme Hayes 50B, $\mathrm{n}^{\circ} 61$ (« Late Variant ») (fig. 105)}

\section{SIGILLÉE TYPE 65}

Coupe «à lèvre plus ou moins biseautée, parois rectilignes ou évasées, décor de rouelles frustes »; "pâte granuleuse, feuilletée, bien cuite, engobe fin ou inexistant, mat, brun rouge » (Cavaillès-Llopis, Vallauri 1994, 94). Décoration assez caractéristique de rouelles très simples. Qualité assez peu soignée : la face inférieure du fond présente des bavures de pâte qui n'ont pas été effacées après le tournage (identifiées comme traces de végétaux par Reynolds 1995, 7). Deux tailles (D. : $18 \mathrm{~cm}$ et D. : $29 \mathrm{~cm})$.

Exemples (fig. 105) :

*1 Marseille, chantier de La Bourse (Cavaillès-Llopis, Vallauri 1994, fig. 47).

*2 Saint-Blaise (Ibid., fig. 47, $\mathrm{n}^{\circ} 29$ ).

*3 Epave Dramont E (Santamaria 1995, fig. 117).

*4 Elda (Espagne) (Reynolds 1993, Pl. 132, n 1695 ; Reynolds 1995, fig. 8).

5-7 Naples (Soricelli 1994, fig. 71, $\mathrm{n}^{\circ}$ 104-105 et fig. 72, $\left.\mathrm{n}^{\circ} 117\right)$.

8 Nabeul, fabrique de salaisons (Inv. NB1377.10).

9 Beni Khiar, Sidi Zahruni, atelier (supra, fig. 26, $\mathrm{n}^{\circ} 1$ 2).

Les prospections de Sidi Zahruni (supra, p. 57) ont révélé que cette forme était produite dans cet atelier (9), sans en exclure d'autres dans la région de Nabeul. Elle est relativement bien diffusée en Méditerranée occidentale, dans des contextes de la première moitié du Ve s. (1-4). Datation proposée : première moitié du Ve s.

\section{- forme Hayes 53B, variante Sperlonga 33 (fig. 105)}

\section{SigILLÉE TYPE 66}

Cette version plus évasée, aux parois plus épaisses, de la forme Hayes 53 de la catégorie C3 (Atlante I, 67), a été identifiée pour la première fois à Sperlonga (Saguì 1980, 498) et rattachée à la production D. La qualité de la pâte et du vernis est comparable à celle de la forme précédente; on observe les mêmes irrégularités sous le fond. D. : 19,5 cm. Décoration de guillochis ou de rouelles très simples.

Exemples (fig. 105) :

*1 Sperlonga (Saguì 1980, fig. 33). Guillochis.

*2 Tarragone (Aquilué 1989, fig. 40, $\mathrm{n}^{\circ} 1.11$ ).

*3 Epave Dramont E (Santamaria 1995, fig. 116).

4-5 San Giovanni di Ruoti (Freed in Small, Buck 1994, fig. 82, $\left.\mathrm{n}^{\circ} 100-101\right)$.

6 Beni Khiar, Sidi Zahruni, atelier (supra, fig. 26, $\mathrm{n}^{\circ} 3$ ).

Forme également produite sur l'atelier de Sidi Zahruni ou un atelier voisin de la région de Nabeul, contemporaine de la forme précédente (2-3).

Datation proposée : première moitié du Ves. 
Forme Hayes $50 \mathrm{~B}, \mathrm{n}^{\circ} 61$
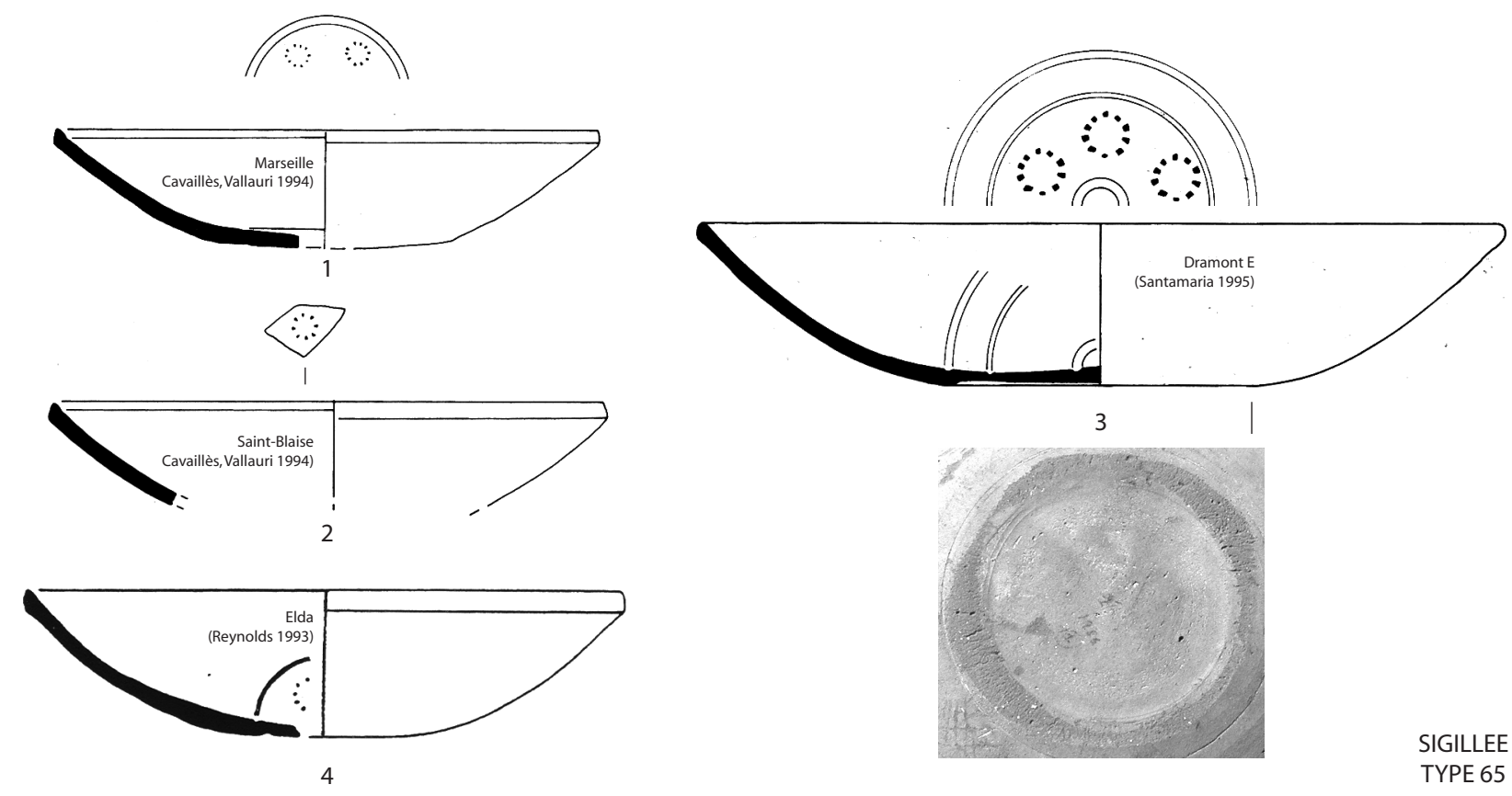

Forme Hayes 53 B, variante Sperlonga 3
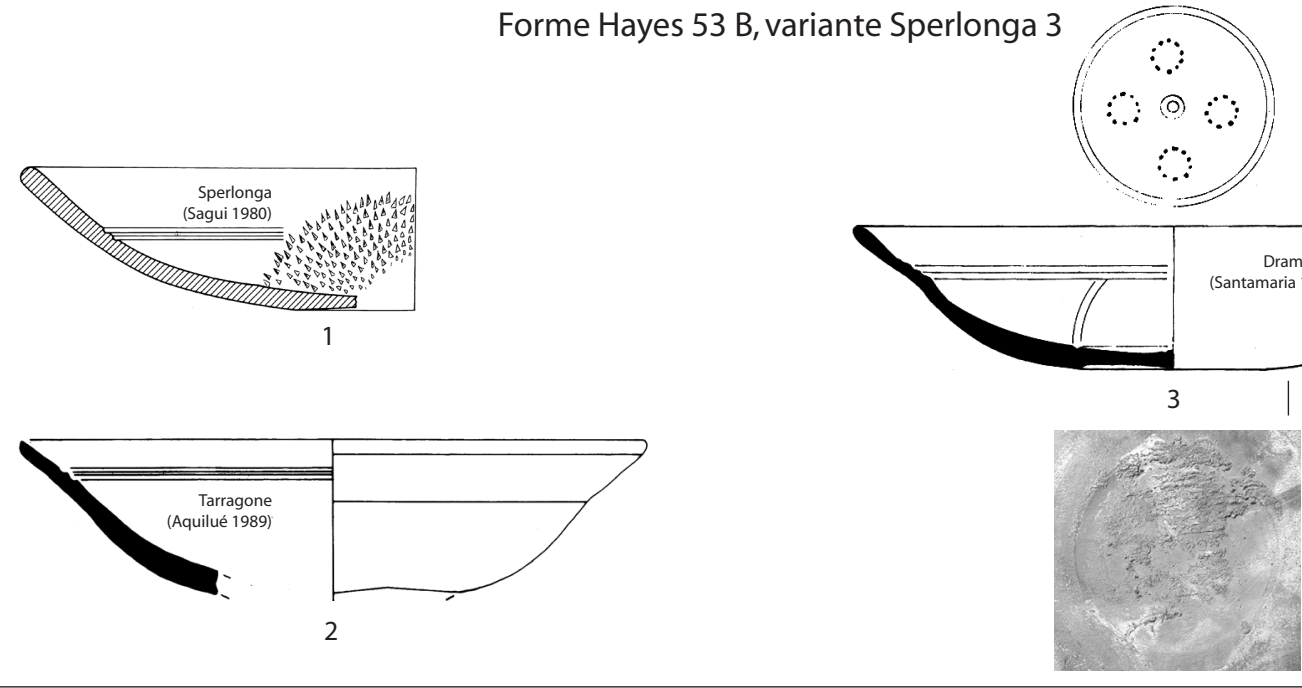

Forme Hayes 61 , variantes tripolitaines et sitifiennes
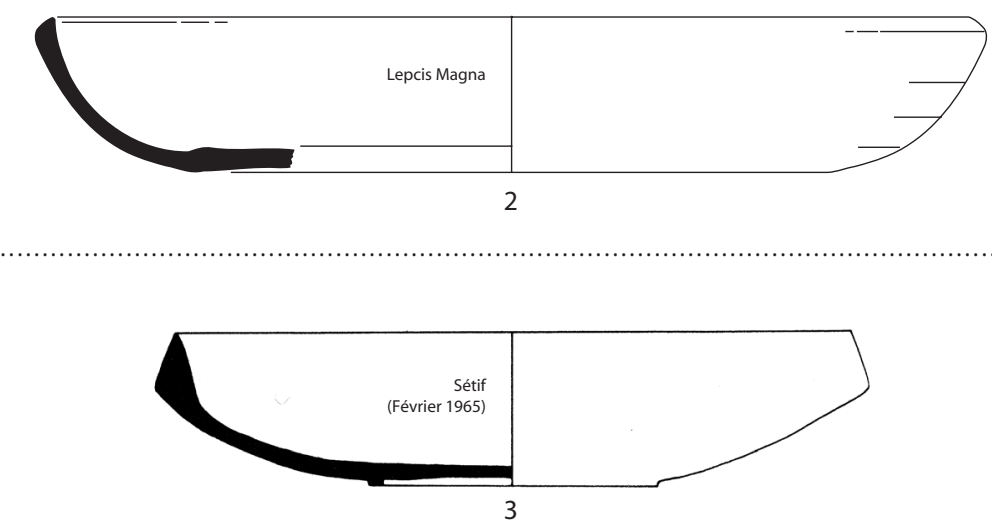

Fig. 105. Vaisselle sigillée africaine D. Variantes locales. 


\section{- formes dérivées de la forme Hayes 61}

La forme Hayes 61, dont la typologie très complexe témoigne de la multiplicité des lieux de production (supra, SIGILLÉES TYPES 37-39), comporte également un certain nombre d'imitations ou d' « évocations » réalisées par des ateliers mineurs ou situés hors des grands courants commerciaux maritimes.

\section{- Hayes 61, variante Sidi Zahruni}

\section{SIGILLÉE TYPE 67}

Profil gracile évoquant la forme Hayes 61B1, fabrication peu soignée comparable à celle des deux formes précédentes (Hayes 50B, $\mathrm{n}^{\circ} 61$ et Hayes $53 \mathrm{~B} /$ Sperlonga 33) ou à celle de la forme Fulford 27 (infra, SIGILLÉE TYPE 75). Attesté sur l'atelier de Beni Khiar - Sidi Zahruni (supra, fig. 26, $\mathrm{n}^{\circ} 4$; Ghalia, Bonifay, Capelli 2004, fig. 5, n 31). Première moitié du Ve s. (?).

\section{- Hayes 61, variante Rougga}

\section{SIGILLÉE TYPE 68}

Quelques vases découverts à Rougga, avec une pâte rouge assez fine et un engobe jaune orangé mince ou inexistant, proviennent probablement d'ateliers locaux (Guéry, Bonifay à paraître : " céramique apparentée à la sigillée africaine, groupe $1 »)$. Les formes évoquent les formes Hayes $61 \mathrm{~B}$ et $61 \mathrm{C}$ et portent un décor de fines bandes lustrées à l'intérieur (Ibid., n 87-90). Première attestation en couche 13 : seconde moitié du Ve siècle.

\section{- Hayes 61, variantes tripolitaines et sitifiennes (fig. 105)}

Mentionnons pour mémoire que des interprétations de la forme Hayes 61 se retrouvent dans la forme Hayes 3 de la Tripolitanian Red Slip ware et dans les formes Février 1963, fig. 8 et Février 1965, fig. 32 des «productions algériennes ».

Exemples (fig. 105) :

Productions tripolitaines

1 British Museum (Hayes 1972, fig. 60, forme 3).

*2 Lepcis Magna, thermes du Levant (fouilles A. Laronde, Inv. LEP099.2). Contexte milieu IVe s.

3 Littoral tunisien, site ${ }^{\circ} 12$ (Henchir el-Abid) (Bonifay et al. 2002-2003, fig. 7, $\mathrm{n}^{\circ} 73$ ).

Productions sitifiennes (?)

*3 Sétif (Février 1965, fig. 32, nº 10).

4 Sétif (Ibid., fig. 32, n 7).

- variante de la forme Hayes 62 = type Sidi Jdidi 1 (fig. 106)

\section{SIGILLÉE TYPE 69}

Assiette à bord arrondi, panse oblique et carénée, fond plat muni d'un petit pied. Pâte du groupe local SG2 (Bonifay, Reynaud 2004). Sans décor.

Exemples (fig. 106) :

*1 Sidi Jdidi, basilique 1(Bonifay, Reynaud 2004, fig. 138, forme 1).

2 Idem, basilique 2, destruction état II (Inv. JD2206.2).

3 Oued R'mel (fouilles T. Ghalia, Inv. OR0204.1).

Cette forme est bien attestée sur le territoire des cités d'Aradi/Sidi Jdidi (1-2) et de Segermes ( ${ }^{\circ} 3$; Lund 1995, fig. 8, «Hayes 63 variant Lamboglia Forma $9 \mathrm{~A} » ?)$.

Datation proposée: Ves., le $\mathrm{n}^{\circ} \mathbf{2}$ au profil plus bas et plus évasé provient d'un contexte de la seconde moitié du siècle.

- variante de la forme Hayes 60, n³/Hayes 66 (fig. 106)

\section{SIGILLÉE TYPE 70}

Grand plat à marli courbe et à lèvre pendante dégagée par une ou deux cannelures sommitales, fond plat ou légèrement concave sur sa face inférieure. Décor de double bande de guillochis (« double rouletted band ») ou de cannelures ; pas de décor imprimé (?).

Exemples (fig. 106) :

*1 Sidi Jdidi, basilique 2, destruction état II (Inv. JD 2195.1).

*2 Idem (Inv. JD2258.52).

3 Idem (Inv. JD2198.1).

Cette forme évoque la forme Hayes $60, \mathrm{n}^{\circ} 3$ ou Hayes 66 en sigillée africaine E, y compris dans le décor de double guillochis. Cependant, sa fréquence sur le site de Sidi Jdidi et l'aspect médiocre de son type de fabrication font obstacle à l'hypothèse d'une importation de Tunisie centro-méridionale. La pâte se rattache au groupe local SG 2, comme la forme précédente. Tous les exemplaires proviennent de contextes de la seconde moitié du Ve siècle.

\section{- variante de la forme Hayes 68}

Pour mémoire. La forme Hayes 68 est bien attestée sur le site de Sidi Jdidi avec une pâte qui se rattache au groupe local SG 2. Voir supra, p. 51 et fig. $23, \mathrm{n}^{\circ} 4$.

- variantes de la forme Hayes 76 = type Sidi Jdidi 3 (fig. 106)

\section{SIGILLÉE TYPE 71}

Grand plat à large marli incliné muni d'une lèvre tombante, ressaut plus (variante A) ou moins (variante B) prononcé à la jonction avec la panse, panse carénée, fond plat muni d'un petit pied. Décor guilloché, pas de décor imprimé (?). Pâte du groupe local SG 2 (Bonifay, Reynaud 2004).

- Variante A : ressaut à la jonction du marli et de la panse ;

- Variante B : sans ressaut à la jonction du marli et de la panse.

Exemples (fig. 106) :

Variante A

*1 Sidi Jdidi, basilique 1, état C1 (Bonifay, Reynaud 2004, $n^{\circ} 13.3$ ). 
Forme Hayes 62, variante Sidi Jdidi 1

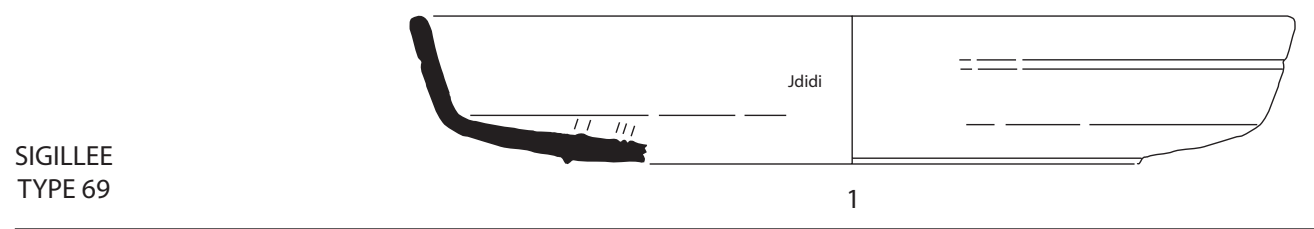

Forme Hayes $60, n^{\circ} 3$ / Hayes 66, variantes

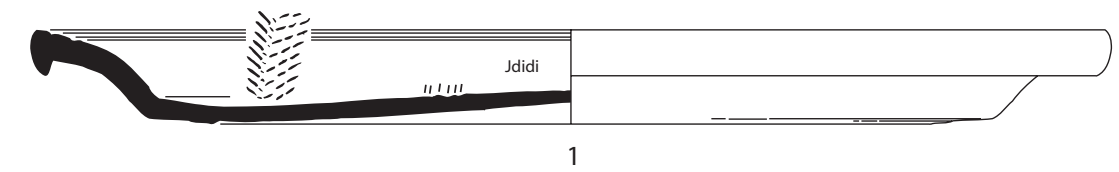

A

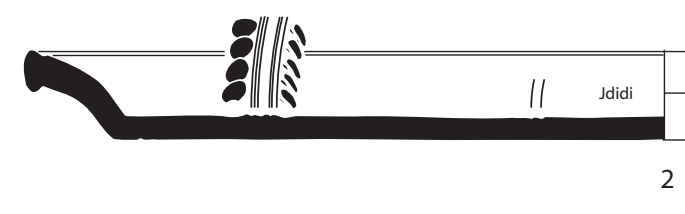

Forme Hayes 76, variante Sidi Jdidi 3

B
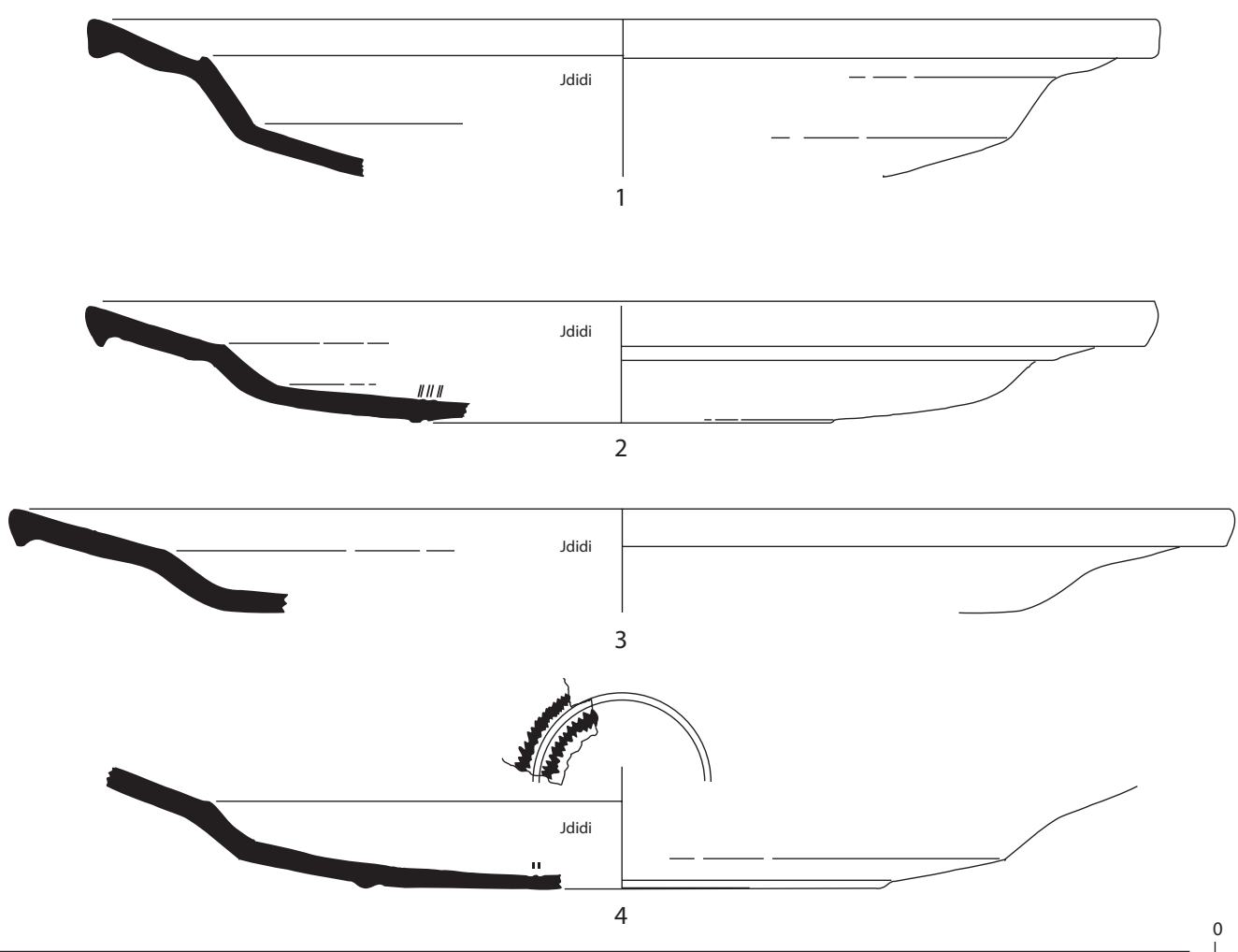

Forme Hayes 80/81, variante Sidi Jdidi 2

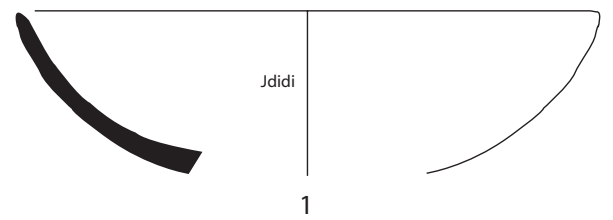

SIGILLEE TYPE 72

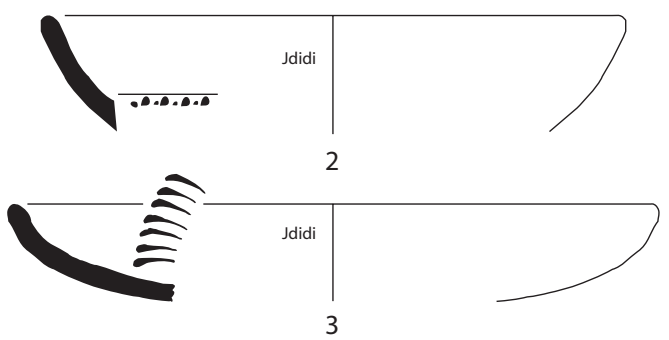

Fig. 106. Vaisselle sigillée africaine D. Variantes locales. 
Variante B

*2 Idem (Ibid. $\mathrm{n}^{\circ}$ 13.4). Décor de guillochis

*3 Idem, basilique 2, destruction état II (Inv. JD2243.4).

*4 Idem (Inv. JD2198.5).

Des variantes comparables de la forme Hayes 76 ont déjà été rencontrées sur plusieurs ateliers de Tunisie centrale et centro-méridionale, comme ceux de Sidi Marzouk Tounsi (Peacock, Bejaoui, Ben Lazreg 1990, fig. 7, $\mathrm{n}^{\circ}$ 26), Ksar el-Guellal (Ibid. fig. 10, $\mathrm{n}^{\circ} 22$ ) et surtout Djilma - Henchir el-Guellal (Ibid., fig. 13, $\mathrm{n}^{\circ}$ 21-22). C'est probablement d'ateliers de cette région que proviennent les exemplaires de Rougga (Guéry, Bonifay à paraître, $\mathrm{n}^{\circ} 45$ et 46-47 ?). La même forme est attestée sur l'atelier de Sidi Khalifa (Ben Moussa 2001, forme 21) mais la pâte des exemplaires de Sidi Jdidi correspond plutôt à un autre groupe local. Tous les tessons proviennent de contextes de la seconde moitié du Ve siècle.

\section{- variantes des formes Hayes 80/81 = type Sidi Jdidi 2} (fig. 106)

\section{SIGILLÉE TYPE 72}

Bol ou petite coupe hémisphérique (les $n^{\circ} \mathbf{1}$ et $\mathbf{2}$ sont véritablement des demi-sphères), à bord arrondi ou légèrement effilé, parfois guilloché à l'intérieur. Pâte du groupe local SG2 (Bonifay, Reynaud 2004).

Exemples (fig. 106).

*1 Sidi Jdidi, basilique 1, état A2 (Ben Abed, Bonifay, Fixot 1997, fig. 2, $\mathrm{n}^{\circ} 2$; Bonifay, Reynaud 2004, $\left.\mathrm{n}^{\circ} 9.3\right)$.

*2 Idem (Ibid., $\mathrm{n}^{\circ}$ 9.4).

*3 Idem, état C1 (Ibid., $\mathrm{n}^{\circ}$ 13.2).

4 Idem, basilique 2, destruction état II (Inv. JD2324.15).

Cette forme constitue probablement, aux côtés des formes Hayes 80 et 81 , une troisième variante, mais à diffusion apparemment plus restreinte, des bols hémisphériques en sigillée africaine $\mathrm{D}$ courants au Ve siècle. C'est la chronologie retenue pour ce type à Sidi Jdidi : les $\mathrm{n}^{\circ} \mathbf{1 - 2}$ sont datés de la première moitié du Ves.; d'autres exemplaires, plus évasés (3-4), proviennent de contextes du milieu ou de la seconde moitié du Ve siècle.

\section{- Les formes dérivées des types Hayes 84/86}

La forme Hayes 84, la plus commune du répertoire de la catégorie $\mathrm{C} 5$, a inspiré un grand nombre de productions en Afrique et hors d'Afrique. En Afrique, tout d'abord, on peut relever :

\section{— forme Hayes 86, $\mathbf{n}^{\circ} 1$ (fig. 107)}

\section{SIGILLÉE TYPE 73}

L'atelier de Sidi Khalifa produisait cette forme Hayes 86, sans guillochis, dont le prototype provenant d'Arles a été publié par Lamboglia $(1963,205)$. De toutes les formes apparentées à la forme Hayes 84 , celle-là est la plus semblable au modèle. En outre, j’ai déjà signalé les risques de confusion avec les productions du centre de la
Tunisie du fait de la texture extrêmement fine de certains produits de cet atelier (supra, p. 49).

Exemples (fig. 107) :

*1 Arles (Lamboglia 1963, 205).

*2 Sidi Khalifa, atelier (Bonifay et al. 2002-2003, fig. 5, $\mathrm{n}^{\circ} 33$ ).

3 Vallée de Segermes (Lund 1995, fig. 11). Classée comme Hayes 84.

*4 Sidi Jdidi, basilique 2, destruction état II (Inv. JD2087.2).

5 Thuburbo Majus, édifice aux Asclepeia (Ben Abed, Bonifay 1998 ; fig. 1, $\mathrm{n}^{\circ} 1$ ).

6 Tarragone, «Antigua Audiència » (Aquilué 1993, fig. $\left.96, n^{\circ} 63\right)$.

\section{— forme Hayes 86, $n^{\circ} 2$ (fig. 107)}

\section{SIGILLÉE TYPE 74}

Il semble que l'on puisse rattacher à cette variante de la forme Hayes 86 des exemplaires en catégorie D2, à engobe épais et lustré à l'intérieur, dont l'aspect n'est peut-être pas éloigné de celui des productions d'Oudhna (?).

Exemples (fig. 107) :

1 Carthage (Fulford 1984a, fig. 15, forme 37.3).

*2 Marseille, chantier de La Bourse (Inv. P.148.1, cité dans Février, Leyge 1986, 42, n 42). D. $21 \mathrm{~cm}$. Décor imprimé fragmentaire de style E(i) : croix ?

3 Idem (Bonifay 1983, fig. 22, $\mathrm{n}^{\circ}$ 49).

4 Saint-Blaise (Cavaillès-Llopis, Vallauri 1994, fig. 54, $\mathrm{n}^{\circ} 85$ ). Variante sans cannelures sur le sommet $\mathrm{du}$ bord.

*5 El Monastil (Reynolds 1993, Pl. 133, n 1712).

— forme Fulford 27 (fig. 107)

\section{SIGILLÉE TYPE 75}

Cette forme avait déjà été signalée par Lamboglia (1963, 206) comme une « imitation » de sa forme 60 , fréquente à Vintimille (Lamboglia 1950, 128, $\mathrm{n}^{\circ} 3$, et $144, \mathrm{n}^{\circ} 47$; Gandolfi 1981, 109, forme 60 C). Le profil général publié à Carthage (Fulford 1984a, fig. 14, forme 27) est assez proche de celui de la forme Hayes 84, bien que l'on ait en général fait l'économie des cannelures sur le bord et que les guillochis sur la panse soient moins soignés. La pâte, en revanche, est grossière, avec un vernis mat, granuleux au toucher. Cette forme est produite, au moins en partie, sur l'atelier de Beni Khiar - Sidi Zahruni (supra, p. 57 ; Ghalia, Bonifay, Capelli 2004).

Exemples (fig. 107) :

*1 Nabeul, fouilles anciennes (Inv. NB.0001.1).

2 Beni Khiar, Sidi Zahruni, atelier (supra, fig. 26, $\mathrm{n}^{\circ} 5$ ).

3 Idem (supra, fig. 26, $\mathrm{n}^{\circ} 6$ ).

4 Kelibia, maison de l'Ecole de Pêche (Inv. 90.218).

*5 Littoral tunisien, site $\mathrm{n}^{\circ} 78$ (La Louza, côte nord de Sfax) (Bonifay et al. 2002-2003, fig. 5, $\mathrm{n}^{\circ} 31$ ).

*6 Idem, site $\mathrm{n}^{\circ} 55$ (Henchir Leich) (Ibid., fig. 5, $\mathrm{n}^{\circ} 32$ ).

*7 Tarragone, «Antigua Audiència» (Aquilué 1993, fig. 98, $n^{\circ} 86$ ).

*8 La Albufera (Reynolds 1993, Pl. 86, n 53).

9 Marseille, chantier de La Bourse (Cavaillès-Llopis 1986, fig. $\left.26, n^{\circ} 254\right)$. 
Forme Hayes $86, \mathrm{n}^{\circ} 1$
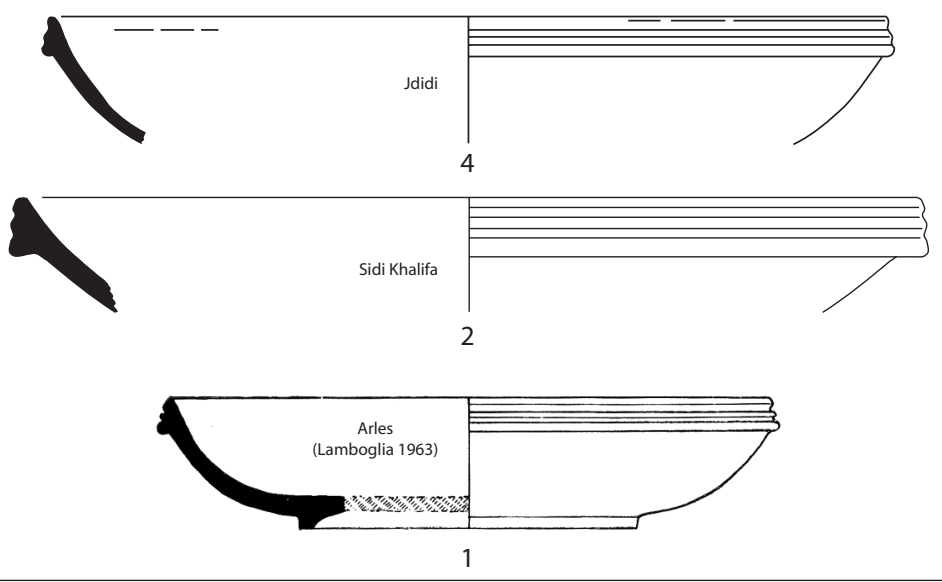

Forme Hayes $86, \mathrm{n}^{\circ} 2$
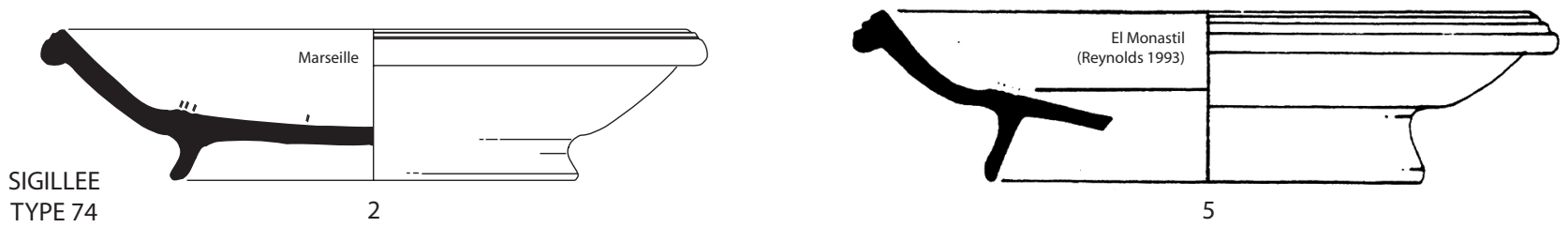

Type Fulford 27
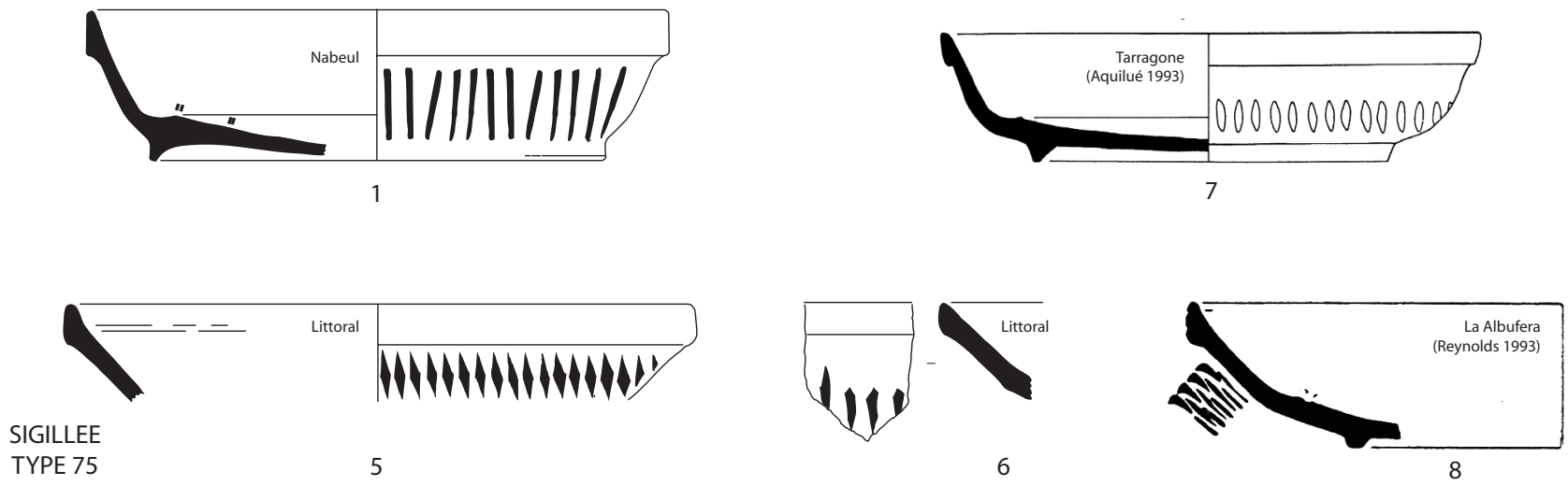

Type Fulford 39-40
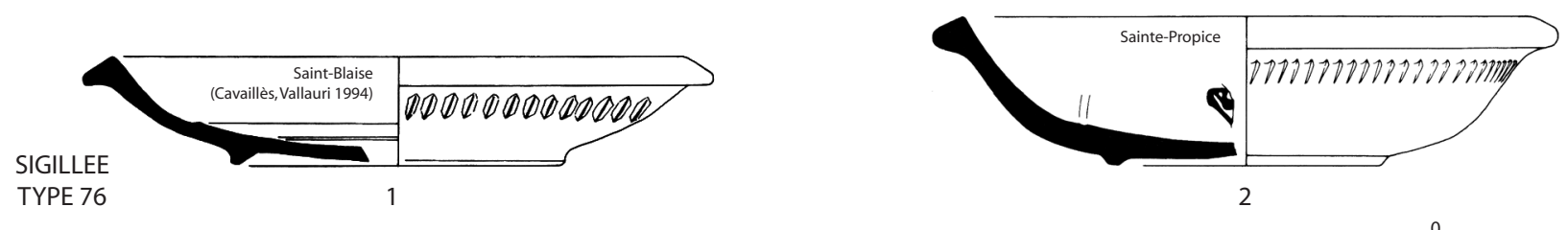
$5 \mathrm{~cm}$

Dérivés Hayes 82/87A (?)

SIGILLEE TYPE 77

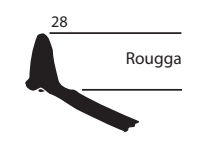

2

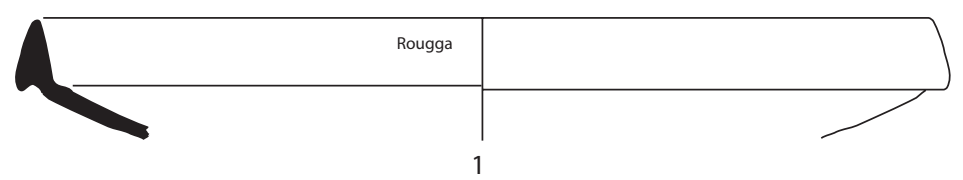

Fig. 107. Vaisselle sigillée africaine D. Variantes locales. 
10 Saint-Blaise (Cavaillès-Llopis, Vallauri 1994, fig. 59, $\left.\mathrm{n}^{\circ} 126\right)$.

— formes Fulford 39-40 (fig. 107)

\section{SIGILLÉE TYPE 76}

On peut encore rattacher aux dérivées de la forme Hayes 84, les formes Fulford 39-40 qui, au contraire de la forme 38 , ne portent plus de cannelures sur le sommet du bord, triangulaire et sub-horizontal. La parenté avec la forme Hayes 84 est toutefois rappelée par le profil général et le décor de guillochis sur l'extérieur de la panse.

Exemples (fig. 107) :

*1 Saint-Blaise (Cavaillès-Llopis, Vallauri 1994, fig. 54, $\mathrm{n}^{\circ}$ 79). Décor de style E(i) (?) imprimé sur le fond.

*2 Sainte-Propice (Boixadera et al. 1987, fig. 9, nº 6). Décor imprimé sur le fond.

Il importe donc de bien distinguer ces diverses productions apparentées à la forme Hayes 84, même si ces distinctions à caractère géographique ne semblent pas avoir d'incidences majeures du point de vue chronologique. En effet, toutes les variantes locales de la forme Hayes 84 qui ont pu être situées en stratigraphie sur les deux rives de la Méditerranée datent de la seconde moitié du Ves. ou du début du VIe s. et sont donc contemporaines des productions de Tunisie centrale. D'autres variantes apparaissent peut-être à Rougga à la même époque (Guéry, Bonifay à paraître, $\left.\mathrm{n}^{\circ} 107\right)$. Seules les formes Fulford 39-40, morphologiquement plus éloignées du modèle, paraissent également plus tardives : milieu du VIe siècle.

Rappelons enfin que la forme de sigillée africaine Hayes 84 est l'une de celles qui a été le plus abondamment imitée hors d'Afrique (infra, p. 460), par d'autres sigillées méditerranéennes, que ce soit la sigillée chypriote tardive, forme Hayes 2, la sigillée égyptienne A (Assouan), formes Gempeler T218 et T220, ou la sigillée égyptienne B, forme Rodziewicz K18.

\section{- les formes dérivées des types Hayes 82/87 (fig. 107)}

\section{SIGILLÉE TYPE 77}

On peut se demander s'il n'y a pas le même transfert morphologique entre les formes Hayes 82 et $87 \mathrm{~A}$. Je ne sais pas exactement à laquelle de ces deux formes rattacher un type de plat à bord triangulaire vertical et lèvre tombante, produit dans une catégorie apparentée à la céramique sigillée, identifiée à Rougga (Guéry, Bonifay à paraître: groupe 2). La pâte rouge brique contient de nombreux micro-fossiles (argile proche de celle des amphores Keay 34 : supra, AMPHORE TYPE 53) et porte un vernis couleur lie-de-vin, épais, mat, ne couvrant que l'intérieur du vase.

Exemples (fig. 107) :

*1 Rougga, couche 12 (Guéry, Bonifay à paraitre, $\mathrm{n}^{\circ} 101$.

*2 Idem, couche 13 (Ibid., n 95).
Cette forme est attestée au plus tôt dans les contextes de la seconde moitié du Ve s. (2). Des formes comparables sont signalées sur l'atelier de Leptiminus (Dore 2001, fig. 1.64, $\mathrm{n}^{\circ} 22$ : «regional 82/87») et sur celui de Thélepte (renseignement M. Nasr).

\section{- formes apparentées à Hayes 91}

\section{— forme Hayes 91, variante Sidi Khalifa (fig. 108)}

\section{SIGILLÉE TYPE 78}

Il est difficile de classer avec la nomenclature de Hayes un type de bol à listel trouvé dans le nord du golfe d'Hammamet, caractérisé par un bord haut au sommet arrondi, un listel court tombant, et des parois épaisses. Cette variante de la forme Hayes 91 est probablement originaire de l'atelier de Sidi Khalifa.

Exemples (fig. 108) :

*1 Sidi Jdidi, basilique 1, état B2A (Bonifay, Reynaud 2004, $n^{\circ} 18.5$ ).

*2 Sidi Khalifa, atelier (Inv. SK002).

3 Hergla, fouilles anciennes (Inv. HS 93).

4 Vallée de Segermes (Lund 1995, fig. 12, «ARS 91 D large variant $»)$.

La forme Hayes 91-variante Sidi Khalifa ne paraît pas attestée à Sidi Jdidi au deuxième quart du Ve s. ; elle est absente des niveaux de la seconde moitié du Ve siècle. Datation proposée : première moitié du VIe s. (?).

\section{— autres variantes locales de bols à listel (fig. 108)}

La forme précédente vient s'ajouter aux nombreuses variantes locales de bols à listel en sigillée africaine, qu'il importe de bien distinguer des séries classiques, que ce soit la forme Hayes 92 en catégorie E (1), la forme Stern XXXV produite dans le sud-ouest de la Byzacène (2) ou encore les séries algériennes (3).

Exemples (fig. 108) :

Forme Hayes 92 (catégorie E)

*1 Littoral tunisien (site $\mathrm{n}^{\circ} 37$, Henchir Chouggaf) (Bonifay et al. 2002-2003, fig. 7, ${ }^{\circ}$ 63).

Forme Stern XXXV (atelier de Sidi Aïch ?)

*2 Littoral tunisien (site $\mathrm{n}^{\circ} 31$, Laflala) (Bonifay et al. 2002-2003, fig. $\left.7, \mathrm{n}^{\circ} 66\right)$.

Forme Février 1963, fig. 5 (Algérie)

*3 Sétif (Février 1965, fig. 32, $\mathrm{n}^{\circ} 1$ ).

\section{- forme Hayes 103, variante Sidi Khalifa (fig. 108)}

\section{SIGILLÉE TYPE 79}

Egalement bien attestée sur les sites du nord du golfe d'Hammamet, cette variante du plat Hayes 103 est caractérisée par un bord à section triangulaire, chanfreiné sur sa face extérieure, et des parois minces, très rectilignes; on ignore l'aspect du fond. La qualité de la pâte fait supposer une fabrication sur l'atelier de Sidi Khalifa, ce que les ramassages de surface confirment pleinement. Exemples (fig. 108) :

1 Sidi Jdidi, basilique 1, état C2A (Bonifay, Reynaud 2004, $\mathrm{n}^{\circ} 26.2$ ). 
Forme Hayes 91, variante Sidi Khalifa

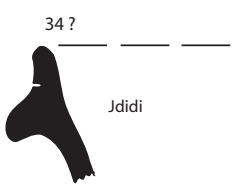

1

TYPE 78

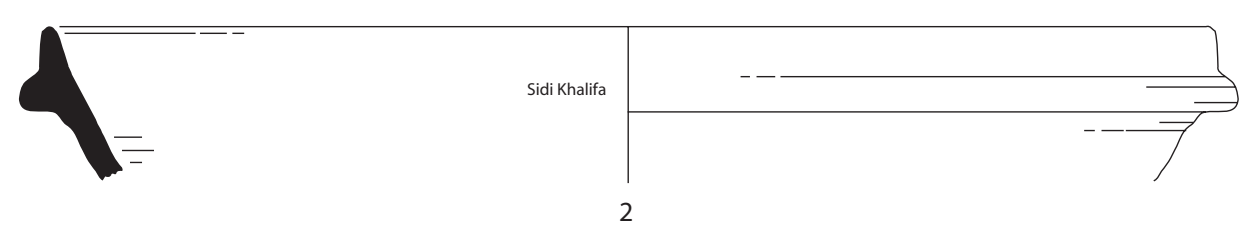

Autres variantes locales de bols à listel
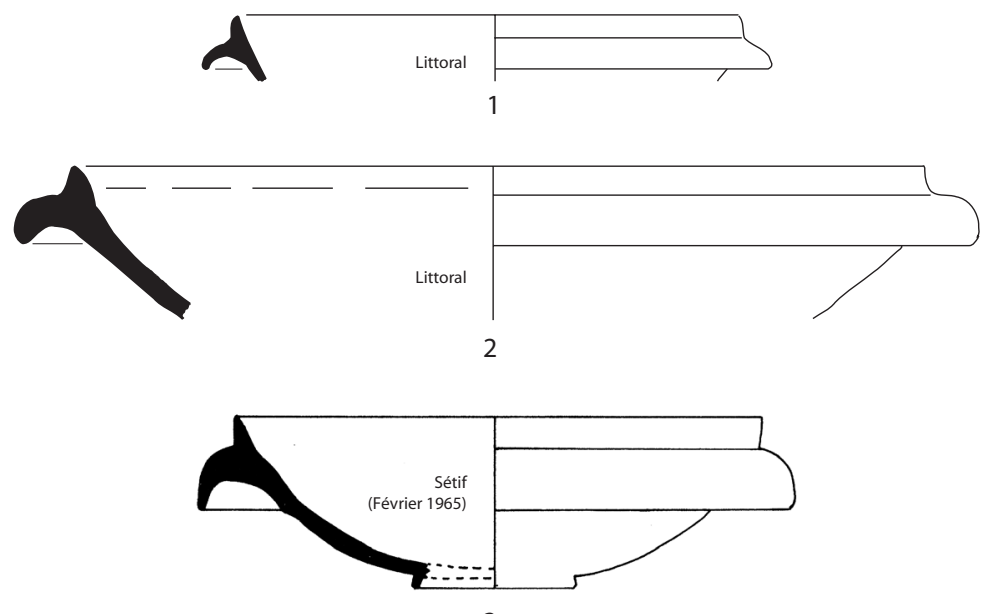

3

Forme Hayes 103, variante Sidi Khalifa

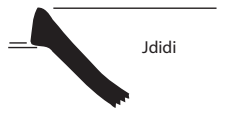

2
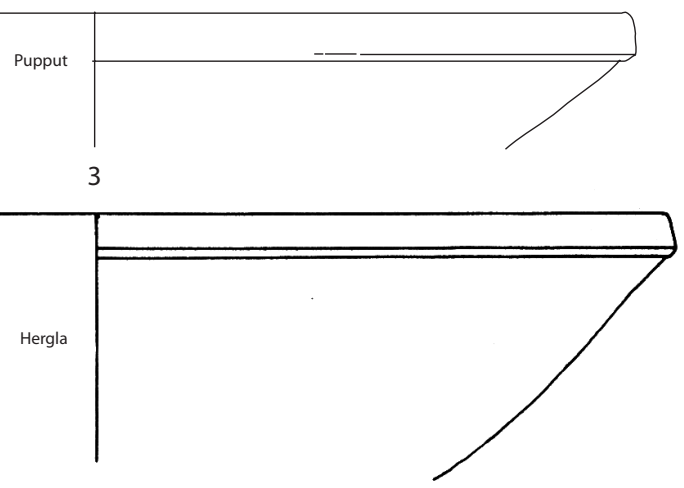

4

Forme Hayes 104, variante Sidi Khalifa

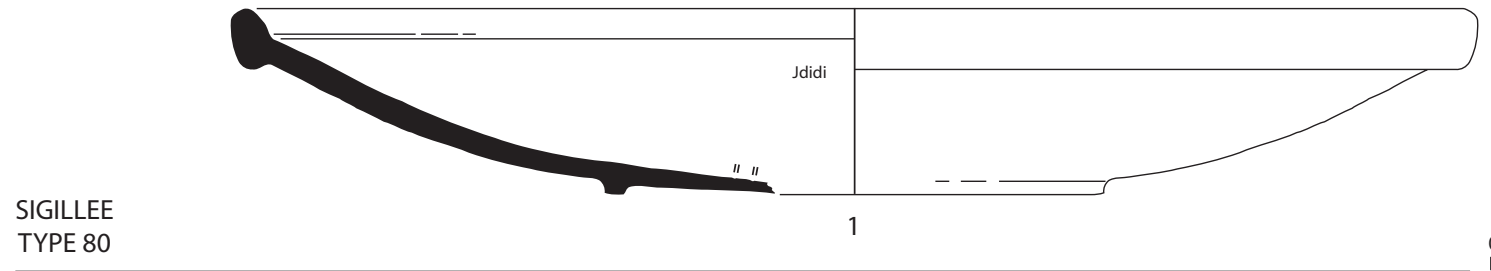
$\stackrel{5}{5} \mathrm{~cm}$

Type Sidi Jdidi 4 (forme Hayes 88/109 ?)

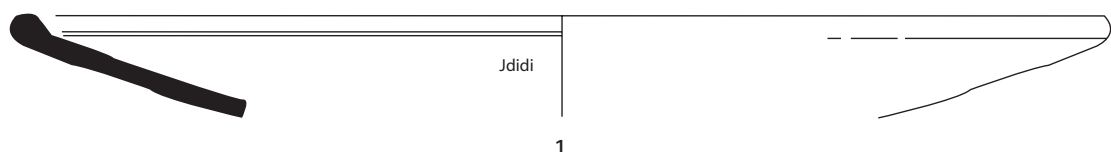

Fig. 108. Vaisselle sigillée africaine D. Variantes locales. 
*2 Idem (Ibid. $\left.\mathrm{n}^{\circ} 28.1\right)$.

*3 Pupput, thermes du centre (fouilles A. Ben Abed, Inv. PPC139.2).

*4 Hergla, fouilles anciennes (Inv. HG.000.94). Dessin M. Pasqualini.

5 Sidi Khalifa, atelier (sans $\mathrm{n}^{\circ}$ d'inv.).

6 Tarragone, "Antigua Audiència » (Aquilué 1993, fig. 96, $\left.n^{\circ} 73\right)$.

La forme Hayes 103-variante Sidi Khalifa se distingue assez facilement des séries classiques par son chanfrein très caractéristique sous le bord. Les exemplaires de Sidi Jdidi et de Pupput (1-3) sont issus de contextes du VIe s. mais il n'est pas impossible que la forme apparaisse dès la fin du Ve s. (6). Un autre fragment découvert à Fos est hors contexte (Jézégou 1998, fig. 313, n²6).

\section{— forme Hayes 104, variante Sidi Khalifa (fig. 108)}

\section{SIGILLÉE TYPE 80}

Variante locale de la forme Hayes 104, caractérisée par un bord fortement proéminent, des parois très évasées, un pied bas; pas de cannelure interne sous le bord, deux cannelures sur le fond.

Exemple (fig. 108) :

1 Sidi Jdidi, basilique 2, état III (Inv. JD2242.1). Dessin T. Mukai.

Datation proposée : VIe s., atelier de Sidi Khalifa (?)

\section{- autres formes}

\section{— forme Sidi Jdidi 4 (Hayes 88/109 ?) (fig. 108)}

\section{SIGILLÉE TYPE 81}

Grand plat à lèvre épaissie à l'intérieur, marquée par une cannelure comme sur la forme Hayes 88, et à parois rectilignes comme sur la forme Hayes 109.

Exemple (fig. 108) :

*1 Sidi Jdidi, basilique 1, état C2A (Bonifay, Reynaud $2004, n^{\circ} 25.3$ et fig. 138 , forme 4 ).

2 Marseille, chantier de l'Alcazar (Bien 2001, n 1556).

3 Marseille, place Villeneuve-Bargemon (Bien 2003, fig. $\left.3, n^{\circ} 8\right)$.

4 Marseille, tunnel de la Major (renseignement S. Bien). Datation proposée : fin du VIe s. - VIIe s. (?), atelier de Sidi Khalifa (?).

\section{— forme Sidi Jdidi 7 (fig. 109)}

\section{SIGILLÉE TYPE 82}

Assiette creuse évoquant la forme El Mahrine 18.5., caractérisée par un bord tombant à section triangulaire étirée, une panse en arc de cercle, un fond à ressaut interne muni d'un pied bas. D. : $24-25 \mathrm{~cm}$.

Exemples (fig. 109) :

*1 Sidi Jdidi, basilique 1, état C2A (Bonifay, Reynaud 2004, $\left.\mathrm{n}^{\circ} 25.1\right)$.

*2 Idem (Ibid., $\mathrm{n}^{\circ}$ 25.2).

Datation proposée : seconde moitié du VIe ou début du VIIe s. ( ?), peut-être atelier de Sidi Khalifa (Ben Moussa 2001 , forme 44 ?)

\section{— forme Sidi Jdidi 8 (fig. 109)}

\section{SIGILLÉE TYPE 83}

Grand plat évoquant la forme Hayes 90/105, caractérisé par un bord épaissi et étiré, creusé d'une gorge sommitale, et formant un léger escalier interne à la jonction avec la panse. Les parois sont faiblement arquées et le fond muni d'un pied haut. Double cannelures sur le fond, pouvant encadrer une bande de guillochis.

Exemples (fig. 109) :

*1 Sidi Jdidi, basilique 2, état IV (Inv. JD2170.7).

*2 Hergla, fouilles anciennes (Inv. HG.000.96). Dessin M. Pasqualini.

3 Carthage (Kalinovski 1993, 168-169, n 5).

Datation proposée: VIIe s., l'exemplaire $\mathrm{n}^{\circ} \mathbf{2}$, avec un pied moins haut et un décor guilloché, pourrait être plus précoce (VIe s.). Probablement atelier de Sidi Khalifa (Ben Moussa 2001, formes 67/68 ?).

\section{Les productions intermédiaires avec la céramique commune}

Quelques productions très peu soignées mais utilisant des techniques et des formes encore empruntées aux productions de sigillée africaine, semblent faire une transition avec la céramique commune. Je citerai deux exemples :

\section{— « Rougga groupe 3 » (Hayes 103 ?) (fig. 109)}

\section{SiGILLÉE TYPE 84}

Ce groupe de céramique apparenté à la sigillée africaine a été mis en évidence à Rougga (Guéry, Bonifay à paraître) et il est bien diffusé sur le littoral de la Byzacène méridionale (Bonifay et al. 2002-2003, 235). La pâte est rouge brique, avec de nombreux micro-fossiles, comme celle du groupe 2 de Rougga et des amphores africaines Keay 34 (supra, AMPHORE TYPE 53), mais c'est la finition des surfaces qui est particulièrement caractéristique. Il n'est pas certain qu'il y ait toujours application d'un engobe ; les irrégularités de la surface, à l'intérieur du vase, semblent parfois avoir été simplement effacées ou atténuées au moyen d'un chiffon humide dont on voit les traces, ou plutôt celles des minuscules particules minérales entraînées par ce dernier. L'extérieur du vase n'a subi aucune finition particulière, sauf le bord qui est engobé et/ou lustré de la même manière que l'intérieur du vase et prend souvent une teinte sombre à la manière des production de céramiques culinaires « ad orlo annerito »; ce détail montre que ces vases étaient cuits sans l'utilisation de casettes. On ne connaît qu'une forme : un vase creux de grand diamètre, à bord en amande, rappelant la forme Hayes 103.

Exemples (fig. 109) :

*1 Rougga, couche 10 (Guéry, Bonifay à paraître, $\left.\mathrm{n}^{\circ} 146\right)$.

2 Idem, couche 13 (Ibid., n ${ }^{\circ} 126$ ).

*3 Littoral tunisien (Bonifay et al. 2002-2003, fig. 10, $\left.\mathrm{n}^{\circ} 118\right)$. 
Type Sidi Jdidi 7
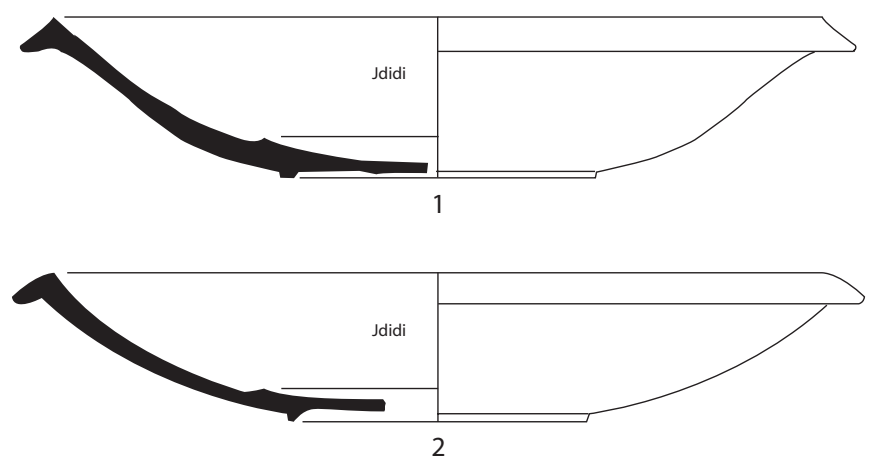

Type Sidi Jdidi 8
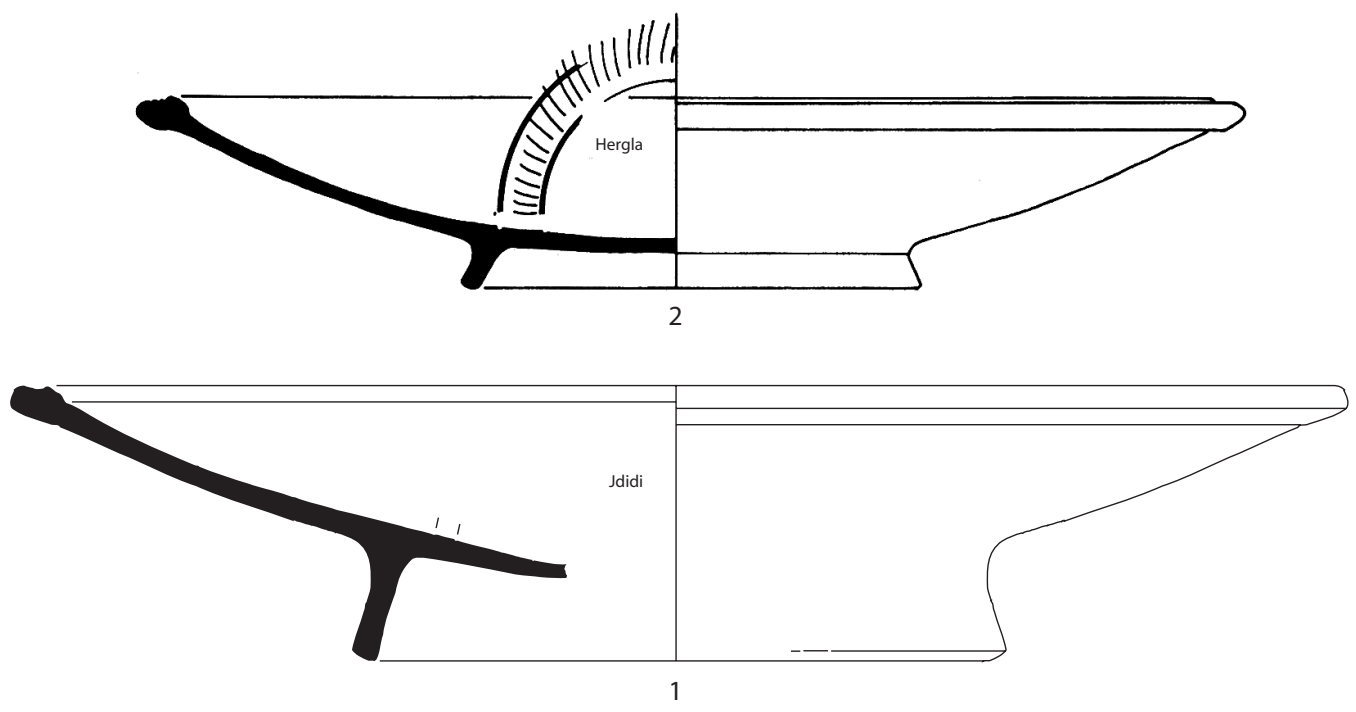

Rougga groupe 3
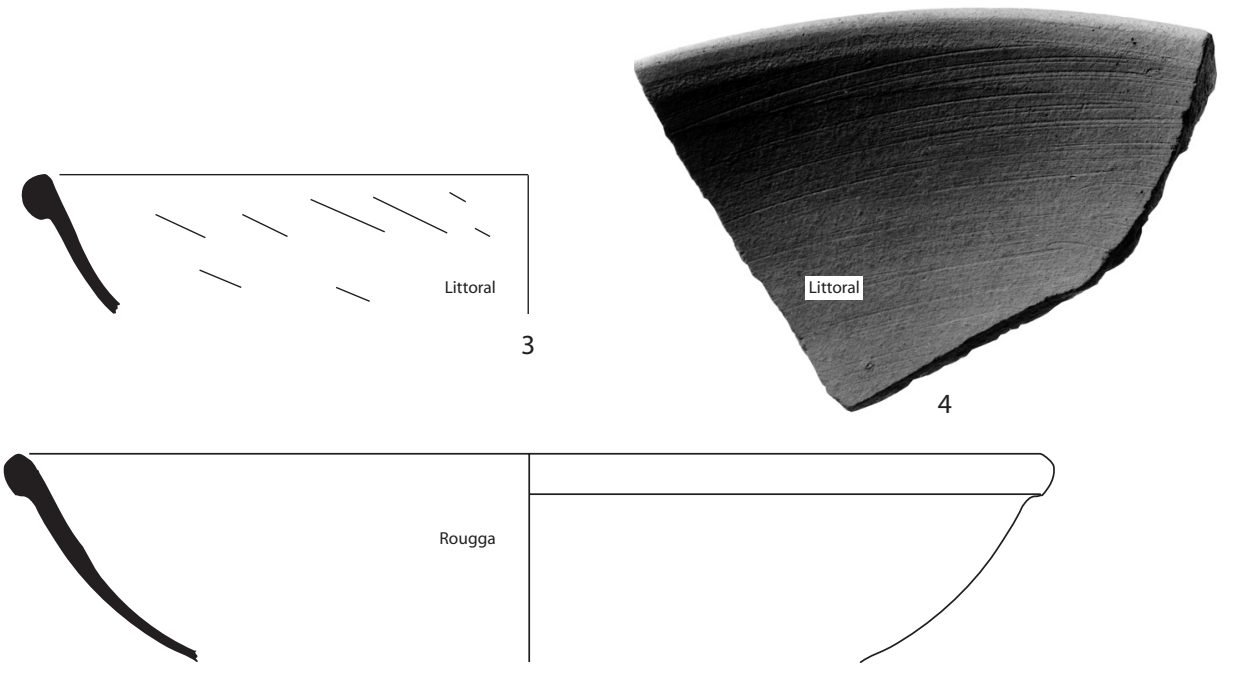
$5 \mathrm{~cm}$

Fig. 109. Vaisselle sigillée africaine D. Variantes locales. 
*4 Idem (site $\mathrm{n}^{\circ} 85$, rass Jezira) (Ibid., fig. 10 et 18 , $\mathrm{n}^{\circ}$ 259). Cliché Ph. Foliot (CCJ).

Les plus anciennes attestations de cette forme à Rougga datent de la seconde moitié du Ve s. (2). Mais il semble qu'elle soit encore très fréquente au VIIe s. $(\mathbf{1}, \mathbf{4})$. La production de cette forme est attestée à Leptiminus (Dore 2001, fig. 1.64, $\mathrm{n}^{\circ} 39$ : « local »).

\section{— « Dougga Ware »}

Pour mémoire, mentionnons la mise en évidence, dans le territoire de la cité de Dougga, d'une production apparentée à la sigillée africaine, avec un répertoire de formes particulier (De Vos, Polla, Gliozzo 2004) et des décors guillochés. Je n'en connais qu'un tesson à Oued R'mel, douteux.

\subsubsection{Les productions tardives}

Les fouilles entreprises depuis une dizaine d'années ${ }^{156}$ dans trois villes antiques situées au nord du golfe d'Hammamet, sur la frontière des provinces de Zeugitane (Neapolis/Nabeul) et de Byzacène (Aradi/Sidi Jdidi et Pupput/Hammamet) ont permis d'étudier en détail le faciès céramique des ultimes niveaux d'occupation antique de ces agglomérations (Slim, Bonifay, Piton 2002 ; Bonifay 2002).

Dans quelle fourchette chronologique convient-il de placer ces niveaux d'abandon et/ou d'occupation précaire? Les éléments de datation extérieurs à la céramique sont rares. Un triens de Constantin IV découvert à Sidi Jdidi, bien qu'il ne soit pas directement associé aux céramiques, indique que l'occupation s'y poursuit jusque dans le dernier tiers du VIIe siècle. Les verreries trouvées à Sidi Jdidi et surtout à Nabeul se rattachent, tant du point de vue de la morphologie que de la matière, à des productions connues ailleurs en Méditerranée à la fin du VIIe ou au début du VIIIe siècle. La comparaison avec les ensembles de céramiques publiés à Carthage (Hayes 1976a et 1978b) pointe vers la même date et, plus récemment, le contexte de la Crypta Balbi a démontré que sigillées et amphores africaines étaient encore exportées à Rome à l'extrême fin du VIIe s. (Saguì 1998). En somme, la limite haute de la fourchette chronologique peut être située sans grand risque d'erreur dans le dernier tiers du VIIe s. mais on hésite encore sur la limite basse. L'exemple de la Syrie (Sodini, Villeneuve 1992), conquise par les arabes plus d'un demi-siècle avant l'Afrique, devrait nous inciter à la prudence : ici comme là, sans doute, la céramique des premiers temps de l'occupation arabe était-elle fort peu différente de celle des derniers temps de la période byzantine. N'est-ce pas faire une erreur d'interprétation que de persister dans les datations précoces (pré- islamiques) que nous proposons traditionnellement? Il est difficile de trancher: à Nabeul, quelques indices plaident en faveur d'une date clairement post-byzantine mais, pour l'instant, nous manquons de preuves.

La sigillée africaine demeure très abondante dans ces niveaux, mais, moins homogène qu'aux époques antérieures, elle offre trois qualités de pâte.

\section{— catégorie D3 (fig. 110)}

On peut rattacher schématiquement à cette catégorie inventée pour les besoins du traitement du mobilier de Marseille (Bonifay 1983, 306 ; Bonifay et al. 1998, 363 et note 173), un certain nombre de fragments qui relèvent encore des classifications traditionnelles. Le vernis est plus mince, plus terne, mais les formes sont parfaitement identifiables. La plus fréquente est la forme Hayes 105, dans sa variante B (supra, SIGILLÉE TYPE 57) mais on rencontre également une bonne proportion de bols Hayes 108 (supra, SIGILLÉE TYPE 59).

D'autres formes, dans la même qualité de pâte, n'avaient pas été répertoriées par Hayes. Il en est ainsi d'un plat dérivé de la forme Hayes 105 mais avec un bord plus étiré, parcouru de cannelures sur le sommet: la forme Atlante XLI, 3-4 [SIGILLÉE TYPE 85].

Exemple (fig. 110) :

*1 Sidi Jdidi, basilique 1, état C2B (Ben Abed, Bonifay, Fixot 1997, fig. 9, $\mathrm{n}^{\circ} 46$; Bonifay, Reynaud 2004, $\mathrm{n}^{\circ} 31.5$ )

Il est possible que les exemplaires de Carthage (Atlante I, 93 ; Hayes 1978b, fig. 12, 4-5) soient originaires de l'atelier d'El Mahrine (Mackensen 1993, forme 43), où cette forme est datée prudemment de la fin du VIe s. et de la première moitié du VIIe s. Cependant l'exemplaire publié par Hayes provient d'un contexte de la seconde moitié du VIIe s. (Hayes 1978b, 50, deposit XXIV); d'autres exemplaires de Carthage sont datés du troisième quart du VIIe s. (Mackensen 1999b, fig. 2, n 8-9).

\section{— catégorie D4 à décor lustré (fig. 110)}

La plus grande part du matériel est d'assez mauvaise qualité, avec une pâte marron et un vernis rouge carmin écaillé. Ce type de fabrication a pu être observé ailleurs, notamment à Marseille (Bonifay 1983, 306 ; Bonifay et al. 1998,363 et note 173 : type D4), dès la fin du VIe s. (?), et à Rougga, au milieu du VIIe s. (Guéry, Bonifay à paraître). Les formes sont de typologie plus incertaine et, d'une manière générale, les variantes non répertoriées tendent à se multiplier :

\footnotetext{
Variantes tardives de la forme Hayes 99 C [SIGILLÉE TYPE 86] (fig. 110)

*1 Sidi Jdidi, basilique 1, état C2B (Bonifay, Reynaud 2004, $\mathrm{n}^{\circ} 30.1$ ).

*2 Nabeul, fabrique de salaison (Inv. NB1438.3).
}

\footnotetext{
${ }^{156}$ Missions tuniso-françaises associant des chercheurs de l'INP de Tunis et des équipes de la MMSH d'Aix-en-Provence.
} 
Forme Atlante XLI, 3-4

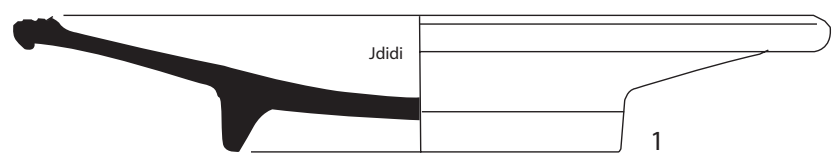

Forme Hayes 99, variantes tardives

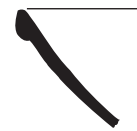

1

TYPE 86

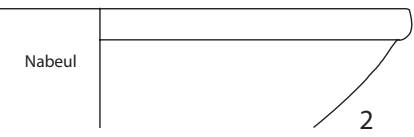

Jdidi

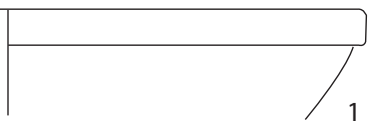

Forme Hayes 101, variante tardive

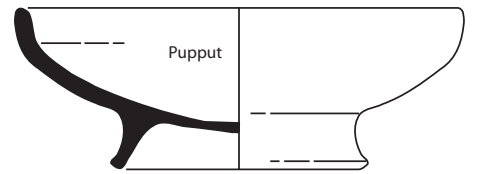

1

TYPE 87

Forme Hayes 105 , variante tardive

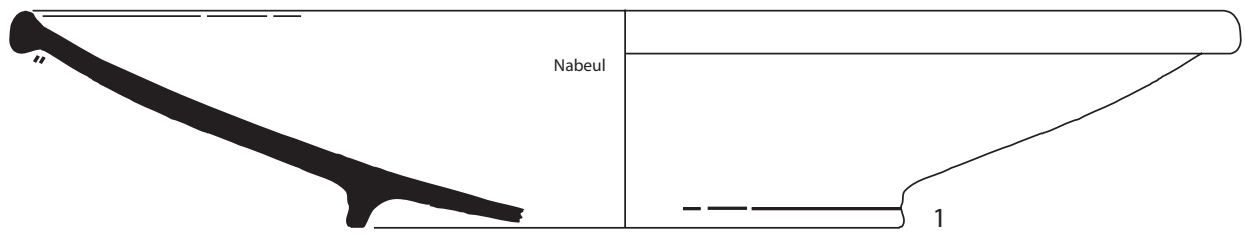

TYPE 88

Forme Atlante $\mathrm{XLI}$, 3-4, variantes tardives

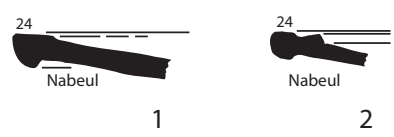

TYPE 89

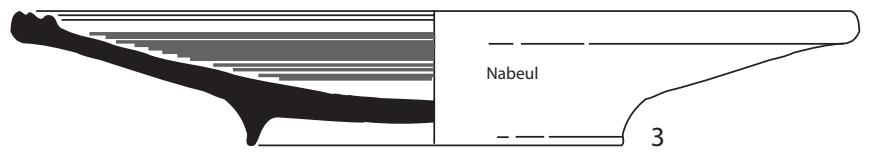

Type Sidi Jdidi 8, variante tardive

Forme Hayes 106, variante tardive TYPE 90

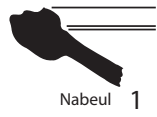
Nabeul 1

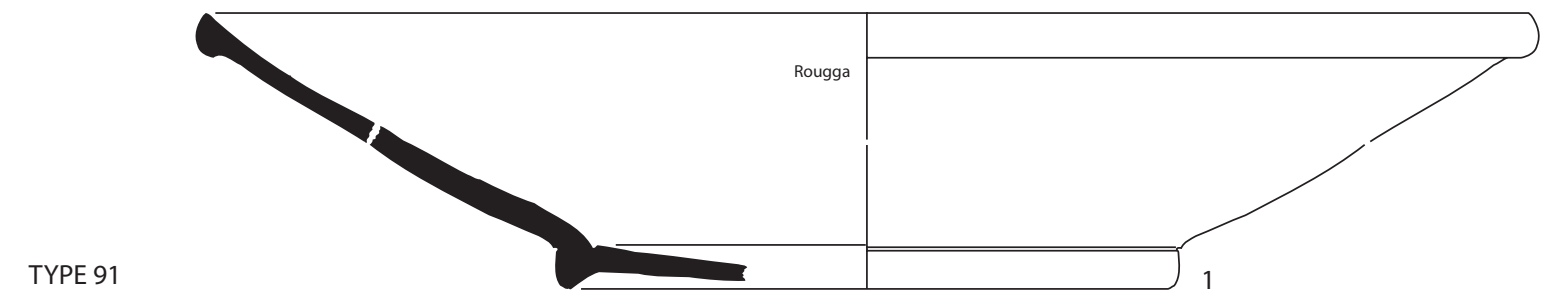

Forme Hayes 107, variantes tardives
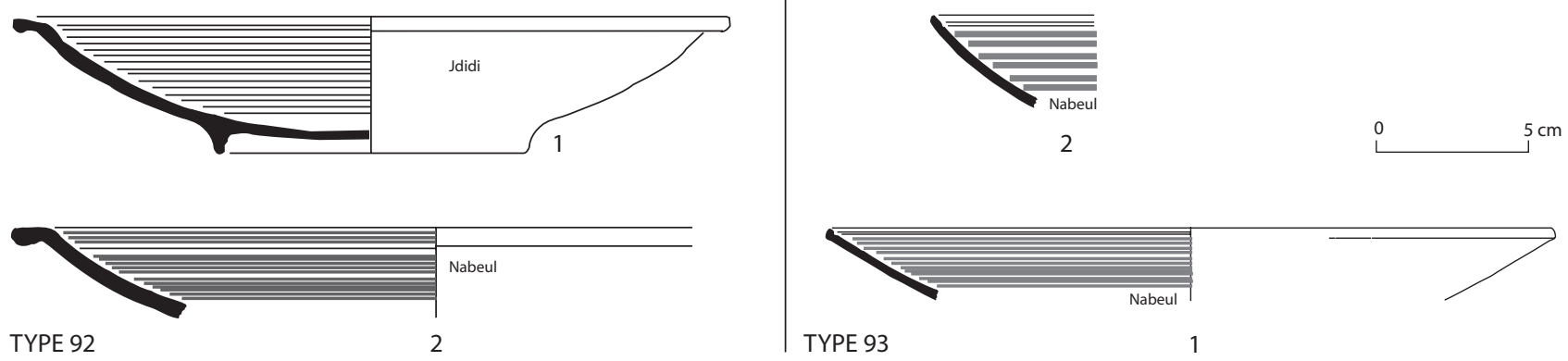

Fig. 110. Vaisselle sigillée africaine D. Productions tardives. 


\section{Typologie - Sigillées}

Formes dérivées de Hayes 91 (?)
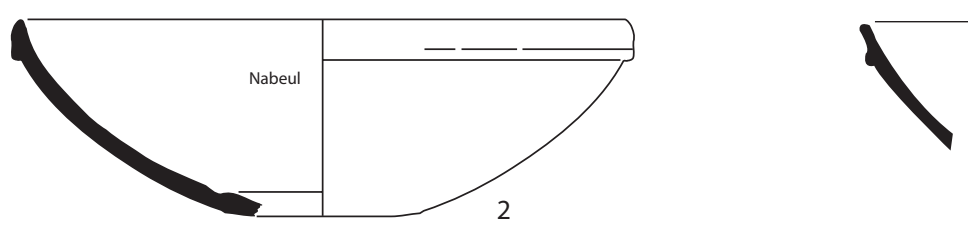

Jdid

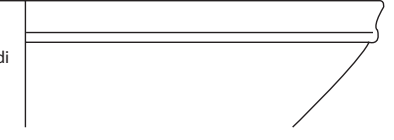

1

0

$5 \mathrm{~cm}$

Catégorie D4 tardive
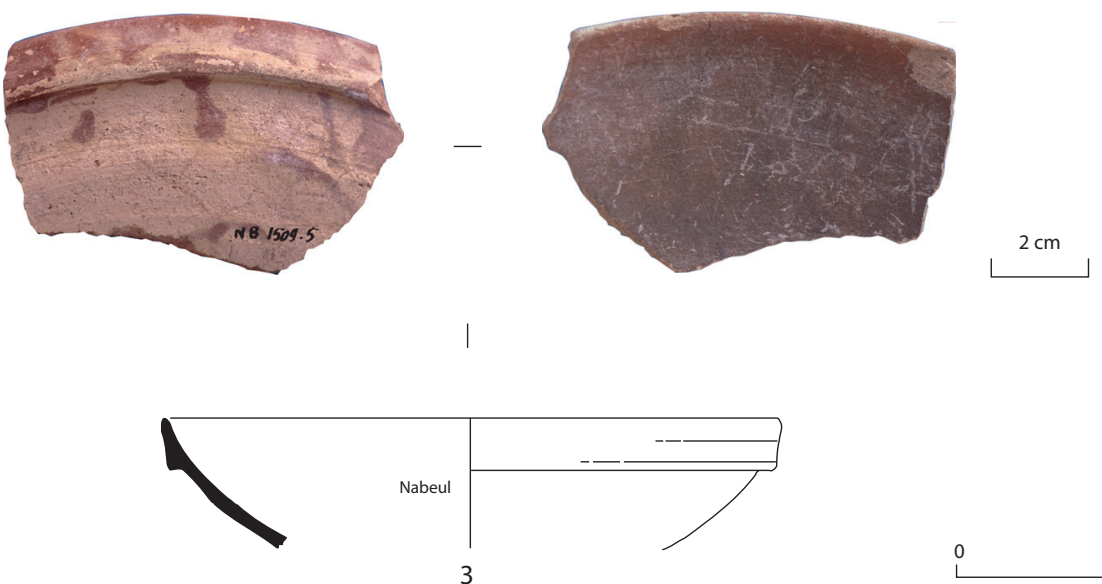
$5 \mathrm{~cm}$

"Dérivée de sigillée" brune à pâte blanche
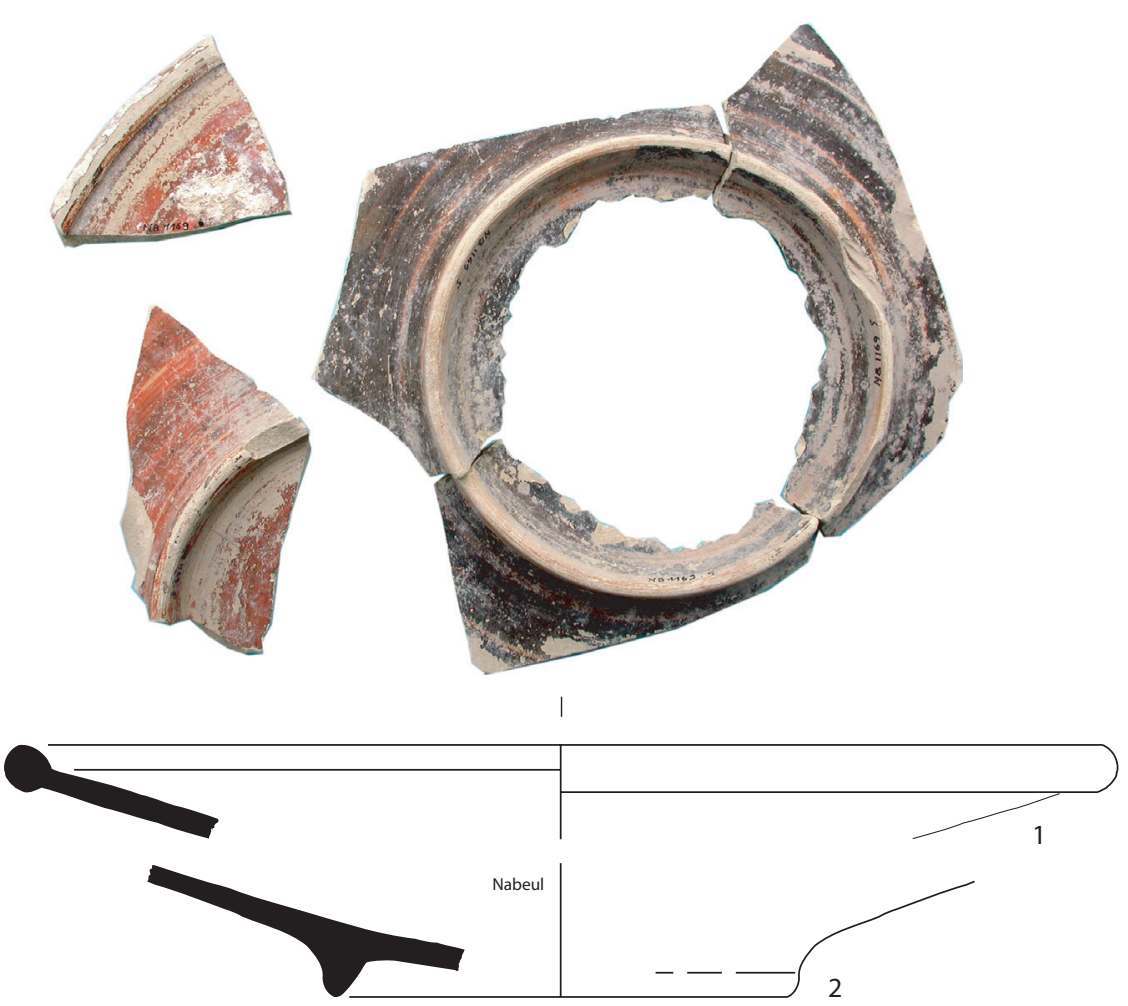

0

Fig. 111. Vaisselle sigillée africaine D. Productions tardives. 
Variante tardive de la forme Hayes 101 (?) [SIGILLÉE TYPE 87] (fig. 110)

*1 Pupput, thermes du centre (Bonifay 2002, fig. 1, $\left.\mathrm{n}^{\circ} 12\right)$.

Forme Hayes 105, variante C [SIGILLÉE TYPE 88] (fig. 110)

1 Pupput, thermes du centre (supra, SIGILlÉE TYPE 57, $\left.\mathrm{n}^{\circ} 18\right)$.

Autre variante tardive de la forme Hayes 105

*2 Nabeul, fabrique de salaison, période 6 (Bonifay 2002, fig. $\left.1, \mathrm{n}^{\circ} 5\right)$.

Variantes de la forme Atlante XLI, 3-4 [SIGILLÉE

TYPE 89] (fig. 110)

*1 Nabeul, fabrique de salaison, période 6 (Bonifay 2002, fig. $\left.1, n^{\circ} 9\right)$.

*2 Idem (Ibid., $\left.\mathrm{n}^{\circ} 10\right)$.

*3 Idem (Ibid., $\mathrm{n}^{\circ} 11$ ).

4 Idem (Ibid., fig. 2, $\left.\mathrm{n}^{\circ} 18\right)$.

Variante tardive de la forme Sidi Jdidi 8

[SIGILLÉE TYPE 90] (fig. 110)

*1 Nabeul, fabrique de salaison, période 6 (Bonifay 2002, fig. $\left.1, \mathrm{n}^{\circ} 8\right)$.

Forme Hayes 106, variante [SIGILLÉE TYPE 91] (fig. 110)

*1 Rougga, couche 10 (Guéry, Bonifay à paraître, $\mathrm{n}^{\circ} 85$ ).

\section{Variantes tardives de la forme Hayes $\mathbf{1 0 7}$}

[SIGILLÉE TYPE 92] (fig. 110)

caractérisées par un marli atrophié, parfois souligné par un sillon intérieur sur la paroi.

*1 Sidi Jdidi, basilique 1, état C2B (Ben Abed, Bonifay, Fixot 1997, fig. 9, $\mathrm{n}^{\circ} 47$; Bonifay, Reynaud 2004, $\left.\mathrm{n}^{\circ} 32.3\right)$. Pour le décor, voir fig. $104, \mathrm{n}^{\circ} 25$.

*2 Nabeul, fabrique de salaison (Bonifay 2002, fig. 2, $\left.n^{\circ} 14\right)$.

\section{Variantes tardives de la forme Hayes 109 B \\ [SIGILLÉE TYPE 93] (fig. 110) \\ caractérisées par des parois extrêmement minces. \\ *1 Nabeul, fabrique de salaison (Inv. NB1425.3). \\ *2 Idem (Inv. NB1428.4).}

\section{Forme Hayes 1978b, B62-63 (dérivée de}

Hayes 91 ?) [SIGILLÉE TYPE 94] (fig. 111)

*1 Sidi Jdidi, basilique 1, état C2B (Bonifay, Reynaud $2004, n^{\circ} 30.2$ ).

*2 Nabeul, fabrique de salaison (Bonifay 2002, fig. 1, $\left.\mathrm{n}^{\circ} 7\right)$.

Beaucoup de ces vases portent un décor lustré du groupe 2 (supra, fig. 104). Le VIIe s. semble constituer un moment fort pour la réalisation de ces décors (supra, p. 196, groupe 2).

L'aspect très particulier de ces ultimes productions de sigillée africaine pourrait peut-être permettre d'élucider une partie du mystère de la pseudo - « Egyptian Red Slip ware C » (Hayes 1972, 399-401), qui correspond peut- être aux exemplaires les plus tardifs de la production africaine (Bonifay 1998c, 145, note 21) (infra, p. 461).

\section{— catégorie D4 tardive (fig. 111)}

Un certain nombre de vases de la catégorie D4, notamment dans les formes Hayes $99 \mathrm{C}$ variante, Hayes 1978b, B62-63, et Hayes 109 B, voient encore leur qualité se dégrader, avec un engobe de plus en plus mince et une cuisson sans casette provoquant l'apparition de bandes jaunes ou grises sur l'extérieur du bord.

Exemple (fig. 111):

TYPE 94 (suite)

*3 Nabeul, fabrique de salaison (Inv. NB1509.5).

Datation proposée : fin du VIIe s. - début du VIIIe s. (?)

— «dérivée de sigillée » brune à pâte blanche (fig. 111)

\section{SIGILLÉE TYPE 95}

Enfin, une troisième catégorie de céramique fine apparentée à la sigillée africaine, a été mise en évidence à Nabeul : la pâte complètement blanche, fine, assez tendre, est couverte d'un engobe très peu grésé, de couleur marron ou noirâtre, écaillé. Une forme unique reproduit, de manière assez simplifiée, le type Hayes 105 :

Exemples (fig. 111) :

*1 Nabeul, fabrique de salaison (Bonifay 2002, fig. 2, $\left.\mathrm{n}^{\circ} 21\right)$

*2 Idem.

3 Sidi Jdidi, basilique 3 (Inv. JD 5008).

Ces vases se font le témoin d'un changement technologique radical: à cette époque, peut-être déjà post-byzantine, la cuisson de ces « dérivées de sigillées africaines » n'est plus maîtrisée et, très certainement, l'utilisation des casettes abandonnée. Le passage à la pâte blanche rappelle un phénomène observé sur la céramique commune (supra, p. 73) et annonce peut-être les productions de céramique fine d'époque islamique.

Datation proposée : fin du VIIe s. - début du VIIIe s. (?)

\subsection{LES CÉRAMIQUES CULINAIRES}

L'essentiel de nos connaissances sur la céramique culinaire africaine d'époque romaine repose sur la synthèse que lui a consacré $\mathrm{S}$. Tortorella en 1981 (Atlante $I, 208-211$ ), avec les compléments apportés par les publications de Carthage (Hayes 1976a; Fulford 1984b). C'est dire que nous avons une vision très italienne $(\text { Ostie })^{157}$ et très carthaginoise de cette catégorie de vaisselle, alors que la réalité sur le terrain africain est beaucoup plus complexe, comme le montrent le matériel d'Uzita (Van der Werff 1982) de Sidi Jdidi (Bonifay, Reynaud 2004) et de Pupput (Bonifay 2004a). Cette situation conduit à réunir parfois sous la même

\footnotetext{
157 Voir également Ikäheimo 2003 (Rome) et Aguarod 1991 (Catalogne)
} 
appellation, «casseruole a patina cenerognola », des productions d'origine sans doute très différente, comme la forme Hayes 193 et la marmite Ostia I, 267 (= Sidi Jdidi 3), ou alors à dissocier des productions semblables, par exemple au sein des formes Lamboglia $9 \mathrm{~A}^{158}$ et Hayes 181. Toutefois, la nouvelle documentation, encore trop lacunaire, ne permettant pas un remaniement complet du système, j'ai choisi un plan comparable à celui utilisé pour les vaisselles sigillées. J'essaie tout d'abord d'apporter un certain nombre de compléments à la typologie et à la chronologie des trois grandes classes de céramique culinaire définies par S. Tortorella. Ensuite, afin d'illustrer la complexité de la situation africaine, je donne un exemple de typologie locale, celle élaborée pour le nord du golfe d'Hammamet. Enfin, j'énumère quelques acquis récents sur les productions les plus tardives.

\subsubsection{Céramiques culinaires africaines classiques}

Pour distinguer les trois catégories de vaisselle culinaire africaine énumérées par S. Tortorella, j'ai trouvé commode de conserver les lettres (supra, p. 67) qu'il avait placées au début de chacun des trois paragraphes de sa description (Atlante I, 208).

\section{Culinaire A : céramique culinaire apparentée à la sigillée africaine $A$}

Le fait que cette vaisselle culinaire porte un vernis interne comparable à celui de la sigillée africaine $\mathrm{A}$, explique qu'elle ait souvent été classée parmi la vaisselle fine (Lamboglia 1958 et Hayes 1972). Cette catégorie comporte principalement les deux formes, bien connues, Hayes $23 \mathrm{~A}$ et $\mathrm{B}$, auxquelles s'ajoutent de manière plus aléatoire la forme Hayes 193 et peut-être une partie des formes Hayes 181.

\section{- Hayes 23 A et Hayes 23 B (fig. 112)}

\section{Culinaire (A) TYPE 1}

Pour la description de cette forme, voir Hayes 1972, 4547.

Exemples (fig. 112) :

Forme Hayes 23 A

*1 Pupput (Inv. PP1235.20).

Forme Hayes 23 B

*2 Nabeul, fabrique de salaison, bassin XLVI (Inv. NB1506.c).

*3 Idem (Inv. NB1500.a).

*4 Oudhna, capitole (Inv. UTH1.001.61 ; Bonifay, Dridi, Jacquest à paraître, $\left.\mathrm{n}^{\circ} 16\right)$.

J'ai assez peu rencontré ces deux formes sur la côte orientale de la Tunisie. La forme Hayes 23 A est attestée dès l'époque flavienne (Atlante I, 217 ; Aquilué 1985, 211) ${ }^{159}$ mais je l'ai surtout remarquée dans des contextes

\footnotetext{
158 L'exemplaire de Tarragone, choisi par Lamboglia pour illustrer son type 9A est tardif.

${ }^{159}$ Dès l'époque de Claude, selon Aguarod 1991, 269.
}

du IIe s. (1). La forme Hayes 23 B apparaît un peu plus tard, dans la première moitié du IIe s. (Atlante I, 217 ; Aquilué 1985,212$)^{160}$. Le $\mathrm{n}^{\circ} \mathbf{2}$ provient d'un contexte du deuxième quart ou du milieu du IIIe s., tandis que le $n^{\circ} \mathbf{3}$ date de la fin du IIIe s. ou du début du IVe s. : l'évolution la plus facile à appréhender (Atlante I, Pl. CVI, $\mathrm{n}^{\circ} 10$ et 11) consiste dans l'augmentation progressive de la hauteur de la lèvre interne. A la fin du IVe s. (4), les parois deviennent également plus épaisses et le ressaut à la jonction de la panse et du fond, plus proéminent; les micro-sillons sous le fond tendent à disparaître.

\section{- Hayes 193 (fig. 112)}

\section{CULinAire (A) TYPE 2}

On a proposé récemment (Aquilué 1994) d'ajouter à la catégorie $A$ une troisième forme qui possède généralement un engobe intérieur proche de celui des deux formes précédentes. Je n'en ai personnellement rencontré qu'un seul exemplaire.

Exemple (fig. 112) :

*1 Oudhna, capitole (Inv. UTH1.001.44 ; Bonifay, Dridi, Jacquest à paraître, $n^{\circ} 22$ ).

Cet exemplaire provient du même contexte de la fin du IVe s. d'où est issu le plat Hayes $23, \mathrm{n}^{\circ} 4$. Cette forme est généralement datée du IIIe s. (Atlante I, 222) ; il s'agit ici d'une variante tardive, caractérisée par une carène aiguë et très proéminente.

\section{— Hayes 181 (fig. 112)}

\section{Culinaire (A) TYPE 3}

S. Tortorella (Atlante I, 215) propose de rattacher également à cette catégorie une partie des plats Hayes 181 , forme normalement produite dans la catégorie $\mathrm{B}$, à vernis lustré, des céramiques culinaires (Hayes 1972, 200). La variante en catégorie A (forme Atlante CVI, 4) se distingue par son vernis «peau d'orange » comparable à celui de la sigillée africaine $\mathrm{A}$ et par un profil généralement plus gracile. Tortorella classe encore dans cette catégorie le plat de type Ostia IV, 1, qui représente, selon lui, « la phase finale » de cette production (Atlante $I, 215)$. Cette solution me paraît préférable à celle proposée par J. W. Hayes $(1976,85)$, qui a été le premier à avoir individualisé cette forme tardive, mais qui y voit un successeur de sa forme 26 en sigillée africaine $\mathrm{A} 2^{161}$. En effet, la grande difficulté vient du fait que la forme Hayes 181 et ses variantes tardives existent à la fois dans la catégorie $\mathrm{A}$ et dans la catégorie $\mathrm{B}$ des céramiques culinaires $^{162}$. Ne détenant pas une grande documentation

\footnotetext{
${ }^{160}$ Dès l'époque flavienne, selon Aguarod 1991, 267.

${ }^{161}$ Une solution consensuelle consisterait à adjoindre les deux $\mathrm{n}^{\circ}$ de formes (Hayes 26/181) pour distinguer ces plats tardifs des autres exemplaires plus classiques (Ikäheimo 2003).

${ }^{162}$ Par exemple, les deux exemplaires de forme Hayes 181 associés dans le matériel du secteur de l'épave sur le chantier de La Bourse à Marseille appartiennent chacun à une production différente : $\mathrm{n}^{\circ} 49$ en production $\mathrm{B}, \mathrm{n}^{\circ} 50$ en production $\mathrm{A}$ : Del Vais 1998a, 78-79.
} 
Forme Hayes 23
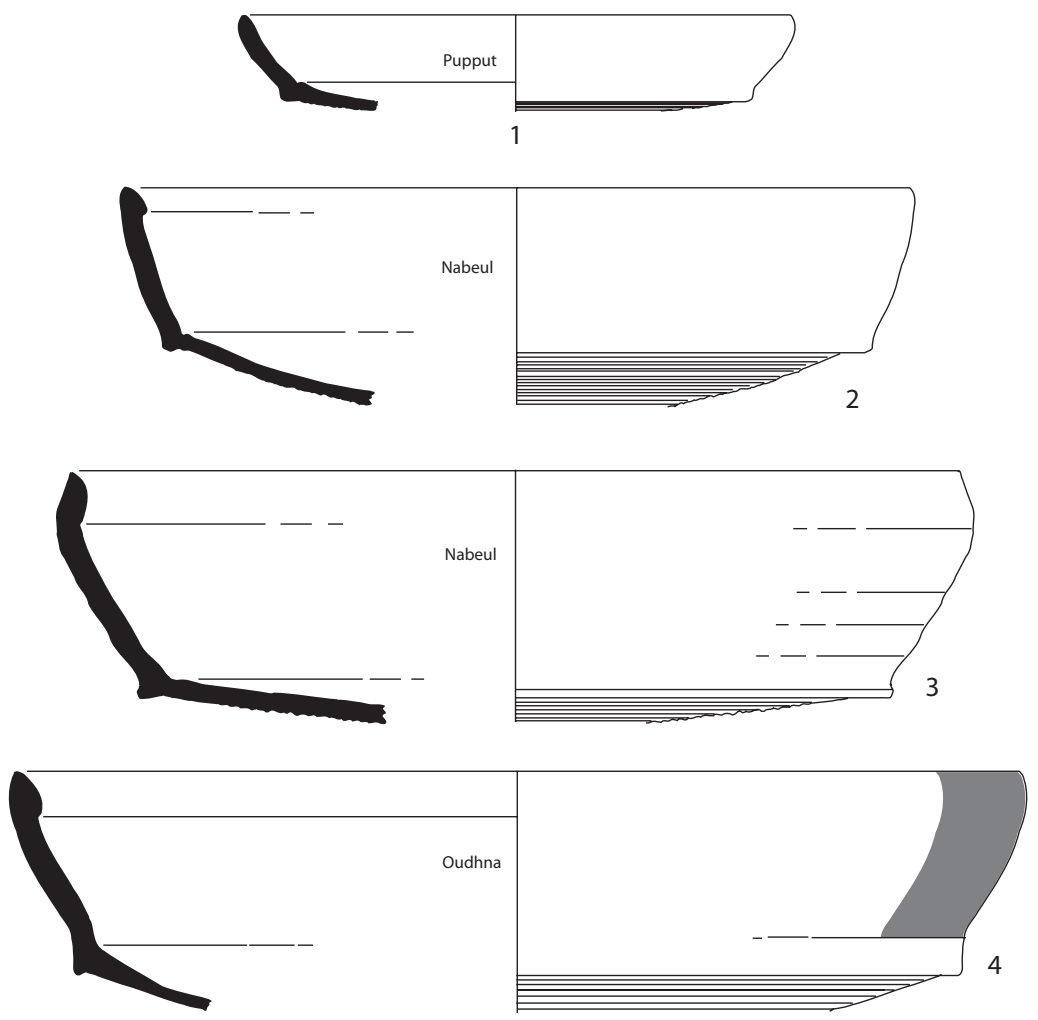

Forme Hayes 193
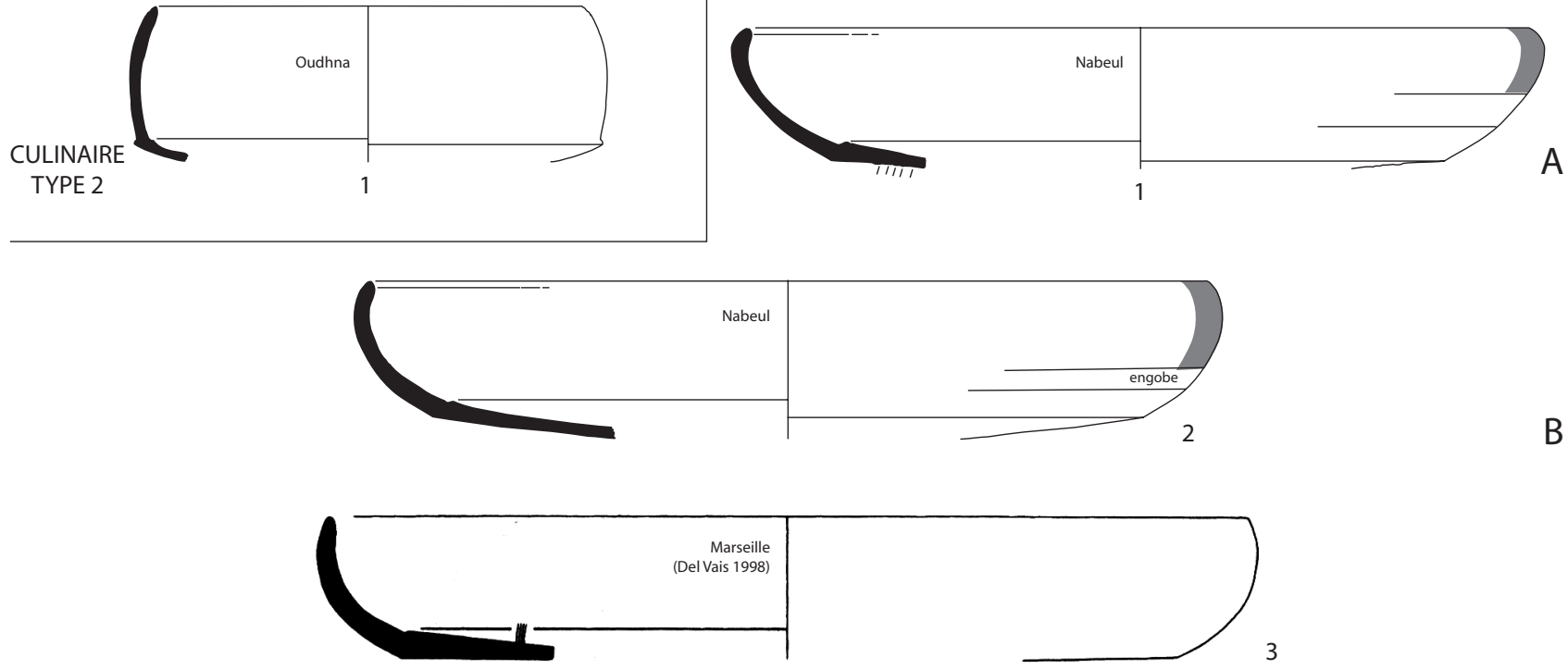

Forme Hayes 181
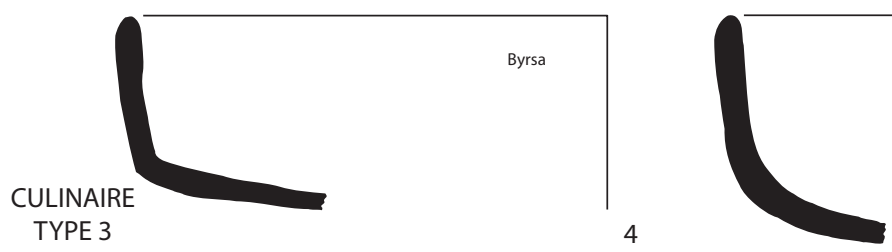

3

Fig. 112. Vaisselle culinaire africaine. Catégorie A. 
sur la production septentrionale de cette forme, je préfère distinguer sommairement les trois variantes suivantes :

- Variante A, précoce : un exemplaire découvert à Nabeul montre quelques similitudes avec la forme Hayes 23A, comme le bord épaissi et légèrement rentrant ou le fond convexe parcouru de petites cannelures plates évoquant les micro-sillons.

- Variante B, normale : cf. Atlante I, 215, diffère des exemplaires de Byzacène par l'absence de décor lustré et une panse plus verticale, parfois carénée à la jonction avec le fond.

- Variante C, tardive (= Ostia IV, $1=$ Hayes 26 variant $=$ Fulford 1984b, Coarse ware Dish 6) : plat aux parois hautes, plus ou moins verticales, à base plus ou moins carénée et fond plat parfois en léger talon; l'intérieur porte un engobe mince et mat, l'extérieur est noirci.

Exemples (fig. 112) :

Variante A

*1 Nabeul, fabrique de salaison, état 4 (Inv. NB1863.3). Variante B

*2 Nabeul, fabrique de salaison, pièce LIX, état 4 (Inv. NB1789.6).

*3 Marseille, chantier de La Bourse (Del Vais 1998a, fig. $\left.57, \mathrm{n}^{\circ} 50\right)$.

Variante C

*4 Carthage, Byrsa (Bonifay à paraître, a, $n^{\circ} 27$ ).

*5 Idem (Ibid., $\left.\mathrm{n}^{\circ} 28\right)$.

Le $\mathrm{n}^{\circ} \mathbf{1}$, provenant d'un contexte du début du IIe s., fait envisager une possible connexion entre la forme Hayes 23A et les tout premiers exemplaires de la forme Hayes 181. Cette forme aurait pu ainsi trouver, au moins en partie, son origine dans le répertoire de formes des céramiques culinaires du nord de la Tunisie avant de connaître un développement considérable en Byzacène. Les exemplaires de la variante $\mathrm{B}$ sont présents à Nabeul (2) et à Marseille (3) dans des contexte de la fin du IIe s. ou du début du IIIe siècle. Alors qu'elle est extrêmement abondante à Chemtou (Vegas 1994a, 155 et fig. 162, $\left.\mathrm{n}^{\circ} 130-132\right)$, la variante $\mathrm{B}$ n'est, semble-t-il, pas très fréquente à Carthage (Hayes 1976a, 88) ; un des rares exemples publiés est apparemment résiduel dans un contexte de la fin du IVes. (Fulford, Timby 1994, fig. 1.8, $\left.\mathrm{n}^{\circ} 37\right)$. En revanche, la variante tardive (4-5) est extrêmement fréquente dans cette ville, principalement à la fin du IVe s. et au Ve s. (Hayes 1976a, fig. 14, B24; Id. 1978a, fig. 1, XVII.15-16 ; Mackensen 1991, fig. 18, $\mathrm{n}^{\circ} 13-15$; Neuru 1980, Pl. IV, $\mathrm{n}^{\circ} 19$; Tomber 1988, fig. $\left.1, \mathrm{n}^{\circ} 8-13\right)$.

Datation proposée :

Variante A - début du IIe s.

Variante B - fin du IIe s. - milieu du IVe s. (?)

Variante $\mathrm{C}$ - fin du IVe s. - milieu du Ve s.

\section{Catégorie $B$ : céramique culinaire de Byzacène à vernis lustré}

Cette catégorie, définie par A. Carandini (Ostia I, 32), caractérisée par son vernis interne lustré (Atlante I, 209 : « ceramica polita a strisce »; Hayes 1972, 200 : « vessels with burnished on one face only »; Van der Werff 1982a, 77 : «Gepolijst Byzaceens aardewerk»), a été produite sur divers ateliers de Byzacène (supra, p. 67). Elle comprend trois formes principales: Hayes 181, 182 et 184.

- Hayes 181, $\mathbf{n}^{\circ} 1$ (fig. 114)

\section{Culinaire (B) TYPE 4}

Je n'ai rencontré que deux exemplaires de la forme Hayes 181, $\mathrm{n}^{\circ} 1$, généralement considérée comme précoce (Hayes 1972, 200 ; Atlante I, 215).

Exemples (fig. 114) :

*1 Pupput, tombe 268 (Bonifay 2004a, fig. 17, $\mathrm{n}^{\circ}$ 56).

2 Pupput, tombe 1075 (Inv. 3017.1).

*3 Uzita (Van der Werff 1982a, fig. 4, n 1).

Tous deux proviennent de contextes du IIe s. avancé ${ }^{163}$. Ces données confirment les observations de J. H. Van der Werff à Uzita, où cette forme couvre en fait tout le IIe s. (Van der Werff 1982a, 81 et note 220).

— Hayes 181 (fig. 113-114)

\section{Culinaire (B) TYPE 5}

Cette forme bien connue (Hayes 1972, 200-201; Atlante $I, 215)$, très répandue en Tunisie, comporte un grand nombre de variantes. L'abondante documentation réunie sur cette forme à Nabeul et à Pupput m'a incité à proposer l'ébauche d'une typologie interne :

- Variante A : bord légèrement épaissi et effilé, avec un effet rentrant produit par une inflexion de la paroi, longue et peu arquée, dans le quart supérieur de celle-ci ; fond convexe, de diamètre moyen, marqué par un double ressaut intérieur/extérieur.

- Variante B (= Hayes 181, $\left.n^{\circ} 13\right)$ : bord légèrement épaissi, effilé et nettement rentrant par l'effet d'une inflexion de la paroi, elle-même assez courte, dans le tiers supérieur de celle-ci; fond plat, plus large, marqué par un simple ressaut intérieur.

- Variante C (= Hayes 181, $\mathrm{n}^{\circ} 2$ et 12 ) : bord non épaissi à extrémité arrondie, paroi en arc de cercle presque parfait (Hayes 1972, 200 : « quarter round profile $»)$, fond plat, large, ressaut intérieur à la jonction avec la panse. Des variantes tardives ont des parois épaisses dont l'inflexion est plus marquée dans la moitié inférieure.

- Variante D : bord non épaissi à extrémité arrondie ou effilée, paroi haute et verticale par l'effet d'une inflexion dans le tiers inférieur de celle-ci, fond plat large ; le ressaut interne tend à disparaître.

Exemples (fig. 114) :

Variante A (inflexion dans le quart supérieur de la paroi)

*1 Pupput, zone ouverte sud, période 1 (Ben Abed, Griesheimer 2004, fig. 46, $\mathrm{n}^{\circ} 1.4$ ).

*2 Idem, période 2 (Ibid., $\mathrm{n}^{\circ} 2.7$ ).

*3 Pupput, tombe 442 (Bonifay 2004a, fig. 17, $\mathrm{n}^{\circ}$ 58).

${ }^{163}$ Tombe 268 avec une série de lampes marquées FRONI et tombe 1075 avec un couvercle Hayes 196, variante Ostia III, 332. 
Variante B (inflexion dans le tiers supérieur de la paroi)

*4 El Jem (fouilles H. Slim, Inv. EJMA.2300.008).

*5 Nabeul, fabrique de salaison, bassin XVII (Inv. NB1056.1).

Variante $\mathrm{C}$ (arc de cercle presque parfait)

6 Pupput (Bonifay 2004a, fig. 17, $\mathrm{n}^{\circ}$ 59).

7 Nabeul, fabrique de salaison, bassin XLVI (Inv. NB1519.a).

*8 Nabeul, fabrique de salaison, bassin XVII (Inv. NB1052.2).

*9 Nabeul, fabrique de salaison, bassin XLIX (Inv. NB1850.1).

Variante $\mathrm{C}$, exemplaires tardifs

10 Nabeul, fabrique de salaison, bassin XLVI (Inv. NB1500.b).

A

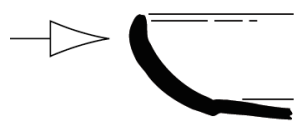

B

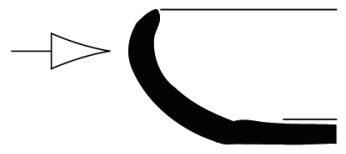

Hayes $181, n^{\circ} 13$
*11 Nabeul, fabrique de salaison, pièce XLIV (Inv. NB1878.142).

*12 Idem (Inv. NB1878.140).

Variante D (inflexion dans le tiers inférieur de la paroi)

*13 Nabeul, fabrique de salaison, bassin XXXI (Inv. NB1186.27).

14 Littoral tunisien, site $\mathrm{n}^{\circ} 55$ (Henchir Leich, au nord de Iunca) (Bonifay et al. 2002-2003, fig. 10, $\mathrm{n}^{\circ} 107$ ).

*15 Pupput, enclos 56 (Bonifay 2004a, fig. 17, $\mathrm{n}^{\circ} 61$ ) IVe s.

*16 Nabeul, fabrique de salaison, espace XXII (Inv. NB1146.5).

Fig. 113. Vaisselle culinaire africaine. Catégorie B. Schéma évolutif de la forme Hayes 181.

Cette succession d'exemplaires bien positionnés en stratigraphie permet de dégager plusieurs critères d'évolution (fig. 113) :

a) L'emplacement du point d'inflexion qui donne à la paroi sa courbure, paraît constituer le critère le plus important : placé très haut sur la variante précoce $\mathrm{A}$ (peut-être comme sur la forme Hayes 23 A : supra, CULINAIRE TYPE 1), il descend progressivement (variante B) pour atteindre une situation moyenne sur la variante classique dont les parois sont alors en arc de cercle $(\mathrm{C})$, et descendre encore sur la variante tardive $\mathrm{D}$ dont les parois deviennent, de fait, verticales.

b) Un bord de la même épaisseur que les parois est la règle sur la variante classique $(\mathrm{C})$; un léger épaississement de la lèvre est caractéristique des variantes $\mathrm{A}$ et $\mathrm{B}$; le bord tend en revanche à s'effiler sur les exemplaires les plus tardifs (D).

c) La hauteur de la paroi ne semble pas être un critère absolu (cf. Hayes 181, $\mathrm{n}^{\circ} 2$ et $\mathrm{n}^{\circ} 12$ ) même si, globalement, elle augmente dans le dernier stade de l'évolution.

d) Le fond tend à s'élargir, en même temps que les parois se redressent. Le «faux pied» (Salomonson 1968, 125) présent sur la variante A disparaît ensuite. En revanche la gorge qui, à l'intérieur, cerne le fond en légère saillie (Ibid.), est présente durant toute l'évolution sauf sur les exemplaires les plus tardifs de la variante $\mathrm{D}$.

Je ne suis pas sûr que ce schéma évolutif puisse être appliqué à d'autres régions de Byzacène (notamment El Jem), ni, malgré quelques similitudes, à la forme Hayes 181 de la catégorie A (supra, CULINAIRE TYPE 3).
La variante A est présente, seule, dans la première moitié du IIe s. à Pupput (1-3); une apparition dès la fin du Ier $\mathrm{s}$. ne serait peut-être pas à exclure (Bonifay 2004a, 42). Les éléments de datation concernant la variante $B$ sont les mêmes que ceux avancés par Hayes (1972, 201, $\mathrm{n}^{\circ} 13$ ), la première moitié du IIIe $\mathrm{s}$. (5). La variante $\mathrm{C}$, assez variable dans le détail, domine tous les contextes de la fin du IIe s. et du IIIe s. (7-9) ${ }^{164}$. Des exemplaires tardifs peuvent être datés de la fin du IIIe s. ou du début du IVe s. (10-12) ${ }^{165}$. Enfin, la variante D, en parallèle avec la variante Ostia IV, 1 de la production A, est caractéristique des contextes de la seconde moitié du IVe s. $(\mathbf{1 3})^{166}$ et de la première moitié du Ve s. $(\mathbf{1 6})^{167}$. Datation proposée :

Variante $\mathrm{A}$ - fin Ier (?) - première moitié du IIe s.

Variante $\mathrm{B}$ - première moitié du IIIe $\mathrm{s}$. (?)

Variante C - fin IIe s. - IIIe s. (début du IVe s. ?)

Variante $\mathrm{D}$ - seconde moitié du IVe s. - première moitié du Ves.

\footnotetext{
${ }^{164}$ Comblement des bassins de salaison au milieu du IIIe siècle. ${ }^{165}$ Comblement supérieur du bassin XLVI et de la pièce XLIV, associé à des amphores Africaines IC et IIC1 et 2, des sigillées africaines $\mathrm{C}$ Hayes 48, 50A et $\mathrm{B}$ et des lampes Africaines $6 \mathrm{~A}$ et $6 \mathrm{D}$.

${ }^{166}$ Comblement du bassin XXXI, associé à des amphores Africaines III B, des sigillées africaines D Hayes 57, 58, 59, $61 \mathrm{~A}$, des lampes Africaines 10 et 11 et en sigillée africaine Atlante 8B.

${ }^{167}$ Comblement de la cour à péristyle XXII, associé à des amphores Africaines III C, Keay 35B, des sigillées africaines Hayes 61B, 64 et 91B, des lampes en sigillée africaine Atlante $8 \mathrm{~A}$ et $8 \mathrm{C}$.
} 
Forme Hayes $181, \mathrm{n}^{\circ} 1$

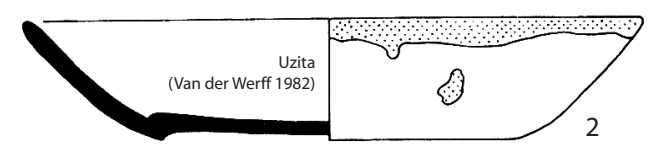

Forme Hayes 181
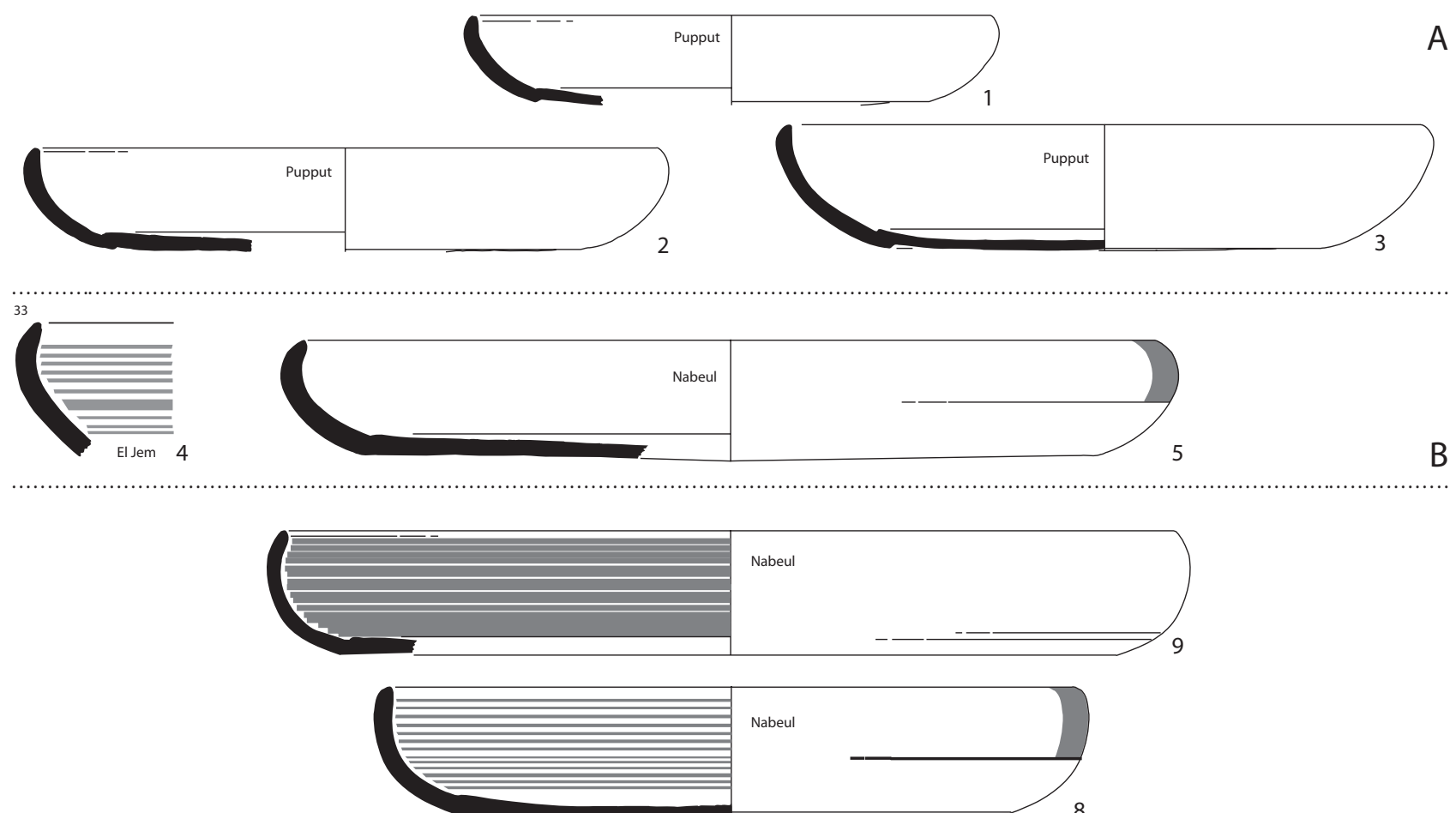

Nabeul
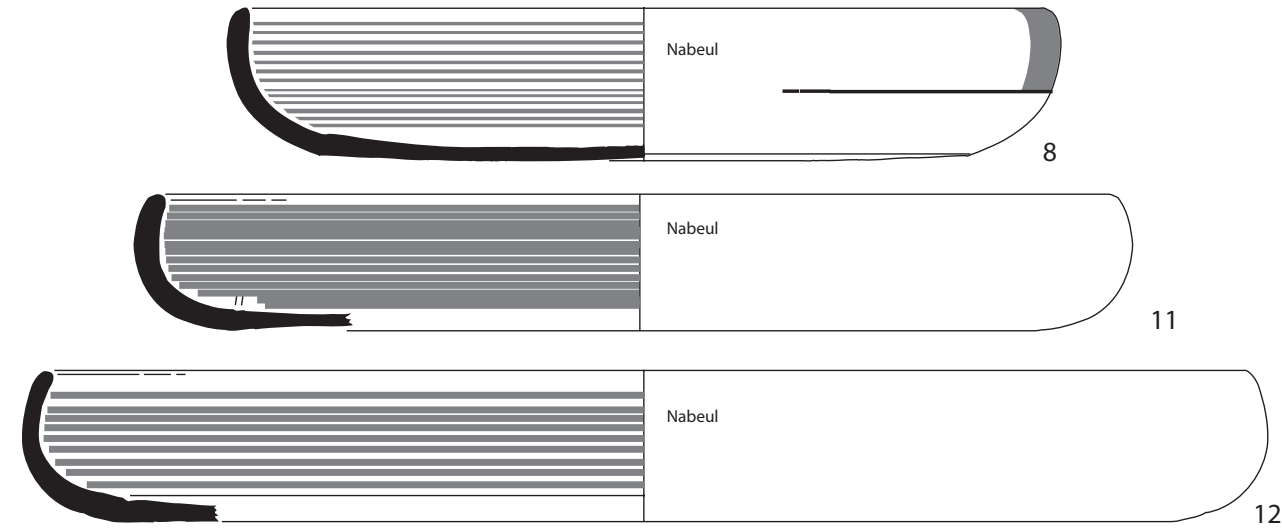

C
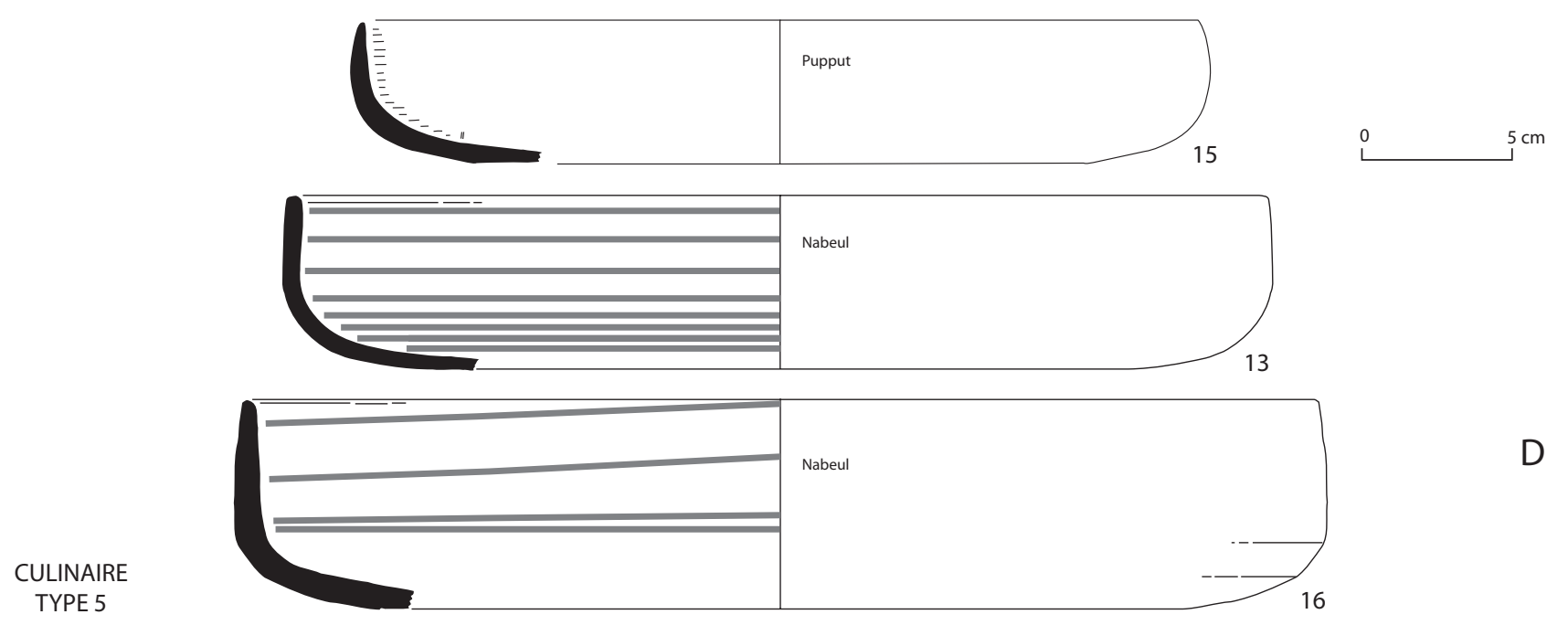

Fig. 114. Vaisselle culinaire africaine. Catégorie B. 
Typologie - Culinaires

Forme Hayes 182
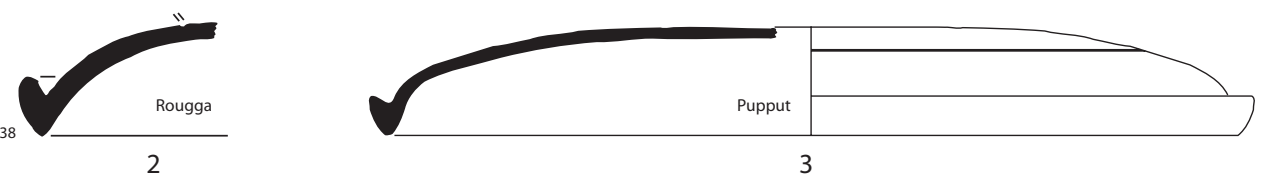

A
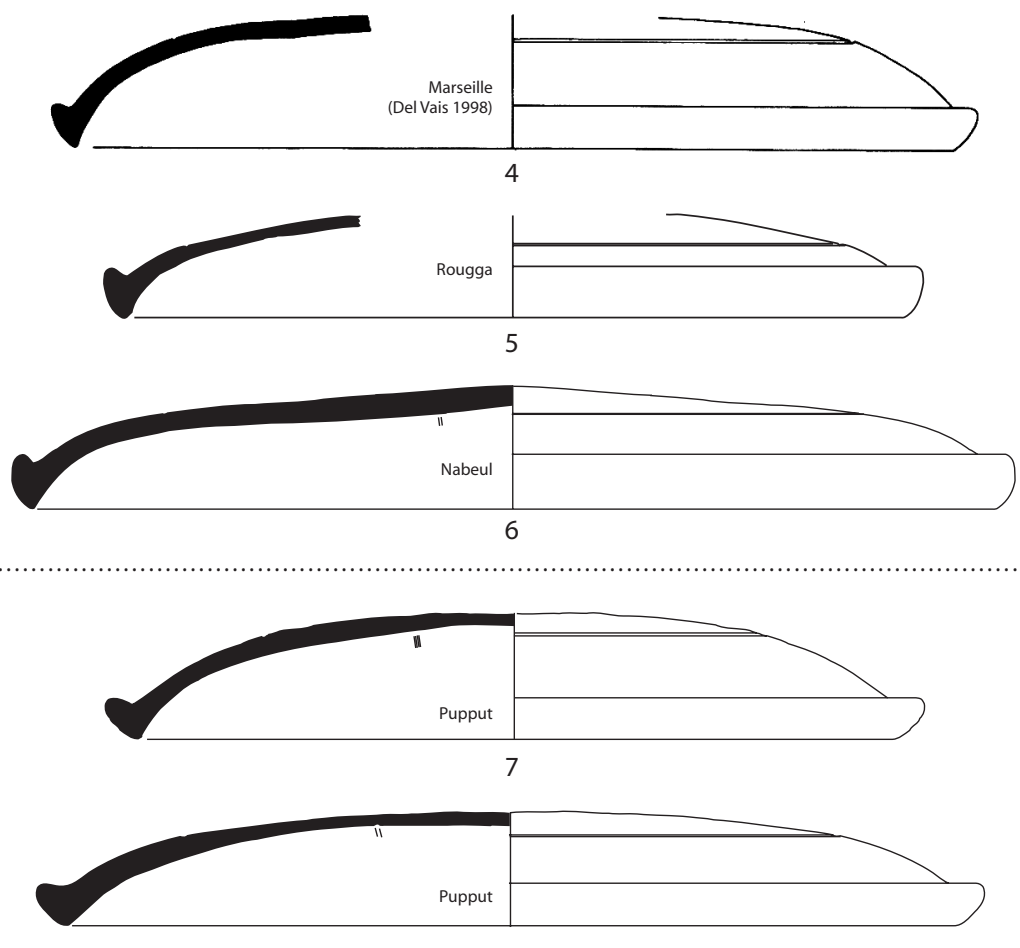

C
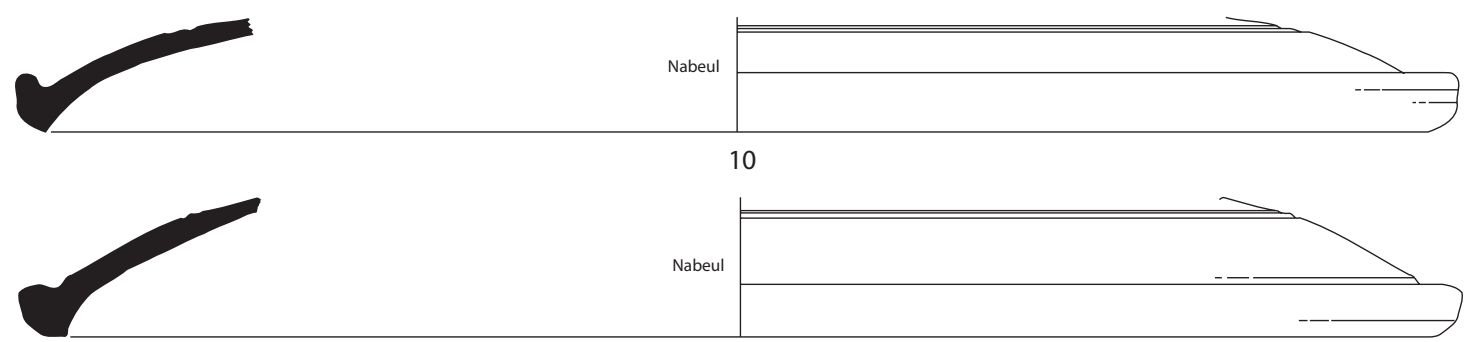

11

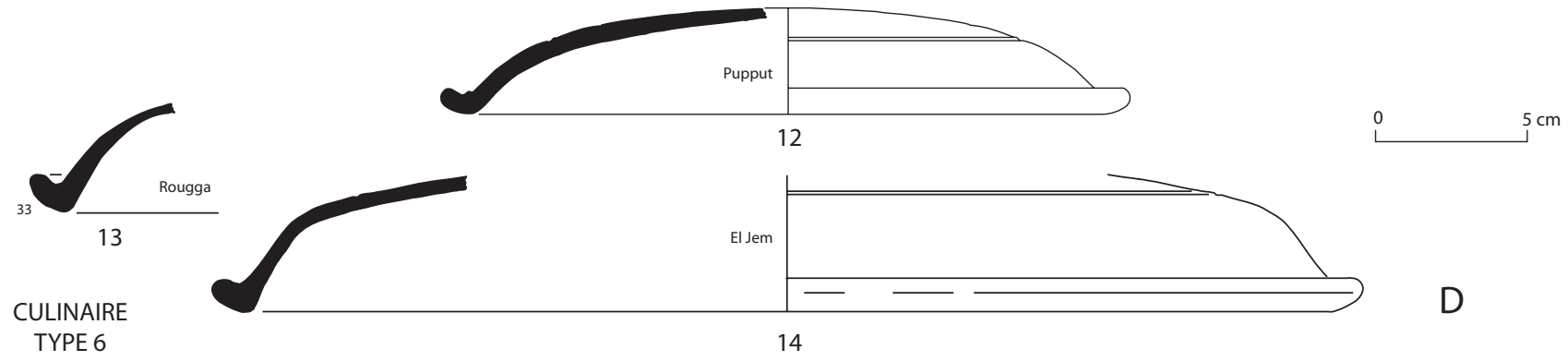

Fig. 115. Vaisselle culinaire africaine. Catégorie B. 


\section{— Hayes 182 (fig. 115)}

\section{CULINAIRE (B) TYPE 6}

Bien que probablement destiné à accompagner la forme précédente, le couvercle Hayes 182 est moins bien documenté que le plat Hayes 181. L'état fragmentaire des découvertes, qui tient probablement à la minceur des parois $\mathrm{du}$ fond apode, ne facilite pas le classement typologique. Une autre difficulté vient du fait que cette forme est également produite en culinaire $\mathrm{C}$ (forme Hayes 195). Pour les productions à vernis lustré, j'ai procédé à un classement sommaire des exemplaires à ma disposition:

Exemples (fig. 115) :

Variante A

*1 Pupput, tombe 1308 (Bonifay 2004a, fig. 17, $\mathrm{n}^{\circ}$ 57).

*2 Rougga (Guéry, Bonifay à paraitre, $\mathrm{n}^{\circ} 181$ ).

*3 Pupput (Inv. PP1767.1).

Variante B

*4 Marseille, chantier de La Bourse (Del Vais 1998a, fig. $\left.60, n^{\circ} 67\right)$.

*5 Rougga (Guéry, Bonifay à paraître, $\mathrm{n}^{\circ} 180$ ).

*6 Nabeul, bassin XVII (Inv. NB1055.20).

Variante C

*7 Pupput, tombe 137 (Ben Abed, Griesheimer 2004, fig. 59, $\left.\mathrm{n}^{\circ} \mathrm{T} 137.3\right)$.

*8 Pupput (Bonifay 2004a, fig. 17, $\mathrm{n}^{\circ}$ 60).

9 Marseille, chantier de La Bourse (Del Vais 1998a, fig. $\left.60, \mathrm{n}^{\circ} 66\right)$.

Variantes de grande taille

*10 Nabeul, fabrique de salaison, pièce XLIV (Inv. NB1878.151).

*11 Nabeul, pièce XLIV (Inv. NB1878.148).

Variante D

*12 Pupput, (Inv. PP1808.14).

*13 Rougga (Guéry, Bonifay à paraître, $\mathrm{n}^{\circ} 184$ ).

*14 El Jem, maison d'Africa (fouilles H. Slim, Inv. EJMA.2300.019).

Cette liste d'objets fait apparaître deux éléments d'évolution :

a) Le bord est délié, avec une lèvre très pendante (cf. type Ostia I, 262), sur les exemplaires anciens (1-3). Il devient plus triangulaire (4-6) ou aplati (7-8), puis arrondi (12-14) sur les exemplaires tardifs.

b) La paroi est fortement coudée (Hayes 1972, 201 : " domed shape ») sur les exemplaires anciens (1-3, 4), puis en arc de cercle aplati sur les exemplaires plus tardifs (7-8). Toutefois, la première configuration est associée au bord aplati et arrondi sur certains exemplaires tardifs de Byzacène méridionale (13-14).

Nota: un bord jaune au lieu d'être noirci est une constante des culinaires B d'El Jem.

Il est peut-être significatif que les plats Hayes 181A de Pupput ne soient pas associés aux couvercles Hayes 182 dans les phases les plus anciennes de la nécropole, au début du IIe s. (Ben Abed, Griesheimer 2004, 100). En effet, la chronologie de ces couvercles paraît principalement liée à celle des variantes $\mathrm{B}$ et $\mathrm{C}$ du plat Hayes 181 : la majeure partie des exemples de Pupput et de Nabeul date du milieu (1) ou de la seconde moitié du
IIe s. (7) et de la première moitié du IIIe s. $(6,8)$. La variante $\mathrm{D}$ est déjà connue au milieu du IIIe s. (Gonzalez Villaescusa 1990, fig. 23) mais des variantes tardives semblent subsister au IVe s. $(\mathbf{1 2}, \mathbf{1 4})^{168}$. Dans la région d'Hammamet-Nabeul, ils côtoient d'assez nombreux exemplaires de la forme Hayes 195 (= Hayes 182 non vernie, en culinaire $C$ ) ; le $n^{\circ} \mathbf{1 1}$, en culinaire $B$, issu d'un contexte du début du IVe s., s'apparente à cette dernière forme.

Datation proposée :

Variante A - milieu du IIe s.

Variante B - fin du IIe - IIIe s.

Variante C - fin du IIe (?) - IIIe s.

Variante D - IVe s.

\section{— Hayes 184 (fig. 116-117)}

\section{CULINAIRE (B) TYPE 7}

Cette forme, apparemment peu exportée (Hayes 1972, 203 ; Atlante I, 224), est en revanche très fréquente en Tunisie, tout au moins sur les sites de Byzacène. Il s'agit de marmites (du «type tajine » selon Salomonson 1970, 64, ou «tadjine », à l'algérienne, selon Guéry 1985a, 353) généralement de petite taille, peut-être prévues pour un usage individuel (?), qui présentent la particularité de porter un beau vernis lustré sur la paroi extérieure, tandis que la surface intérieure est restée brute. Des traces de feu sous le fond, avec parfois des portions de vernis éclatées, ne laissent cependant planer aucun doute sur l'usage de ces petits vases. Deux tailles ont été principalement identifiées à Pupput :

a) D. : env. $15-16 \mathrm{~cm}$; H. : env. 6-6,5 cm ;

b) D. : env. $18-19 \mathrm{~cm}$; H. : 7-8 cm.

Les exemplaires plus petits sont rares. Ceux de plus grande taille sont bien attestés sur les sites d'habitat, par exemple à El Jem (11).

La documentation concernant la forme Hayes 184, très abondante sur la nécropole de Pupput (Bonifay 2004a), étant encore en cours de traitement, je ne suis pas en mesure de présenter autre chose qu'un classement préliminaire.

Variante A : bord à section grossièrement triangulaire, oblique et légèrement concave à l'extérieur, arrondi et convexe à l'intérieur; la transition avec la panse est marquée par une gorge étroite à l'intérieur, une arête vive à l'extérieur.

Variante B (= Sabratha 58): bord à section également triangulaire plus arrondi à l'extérieur et concave à l'intérieur; la transition avec la panse est marquée par un fort ressaut à l'intérieur, une arête vive à l'extérieur.

Variante C (= Sabratha 59): bord à section grossièrement quadrangulaire, oblique et plat à l'extérieur, plat ou légèrement concave à l'intérieur ;

${ }^{168}$ Le $\mathrm{n}^{\circ} 12$ est associé à une variante ancienne de plat Hayes $61 \mathrm{~A}$ en sigillée africaine $\mathrm{D} ;$ le $\mathrm{n}^{\circ} 14$ est associé à un plat Hayes 58 . 
Typologie - Culinaires

Forme Hayes 184
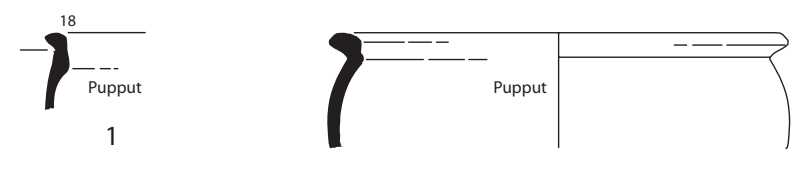

2
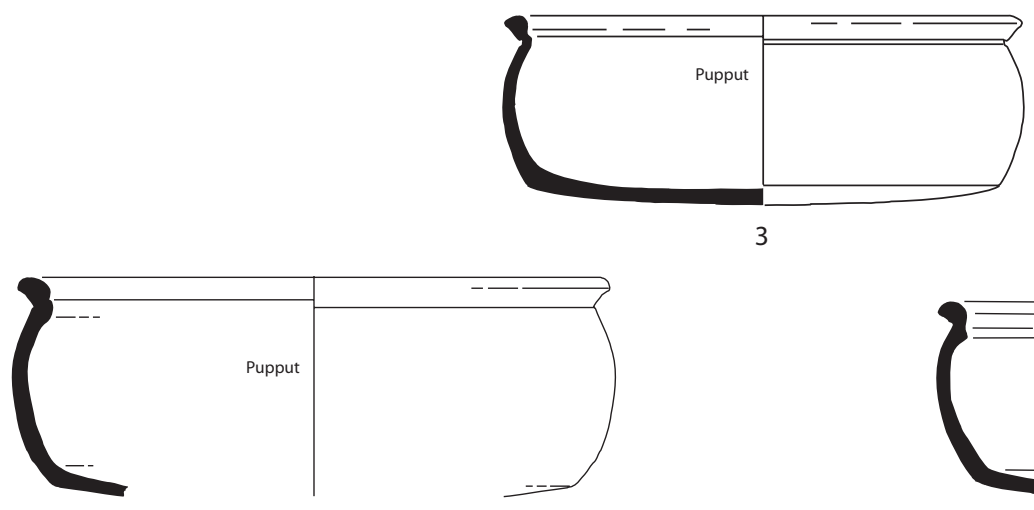

4

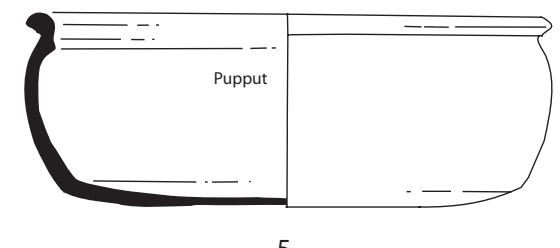

A
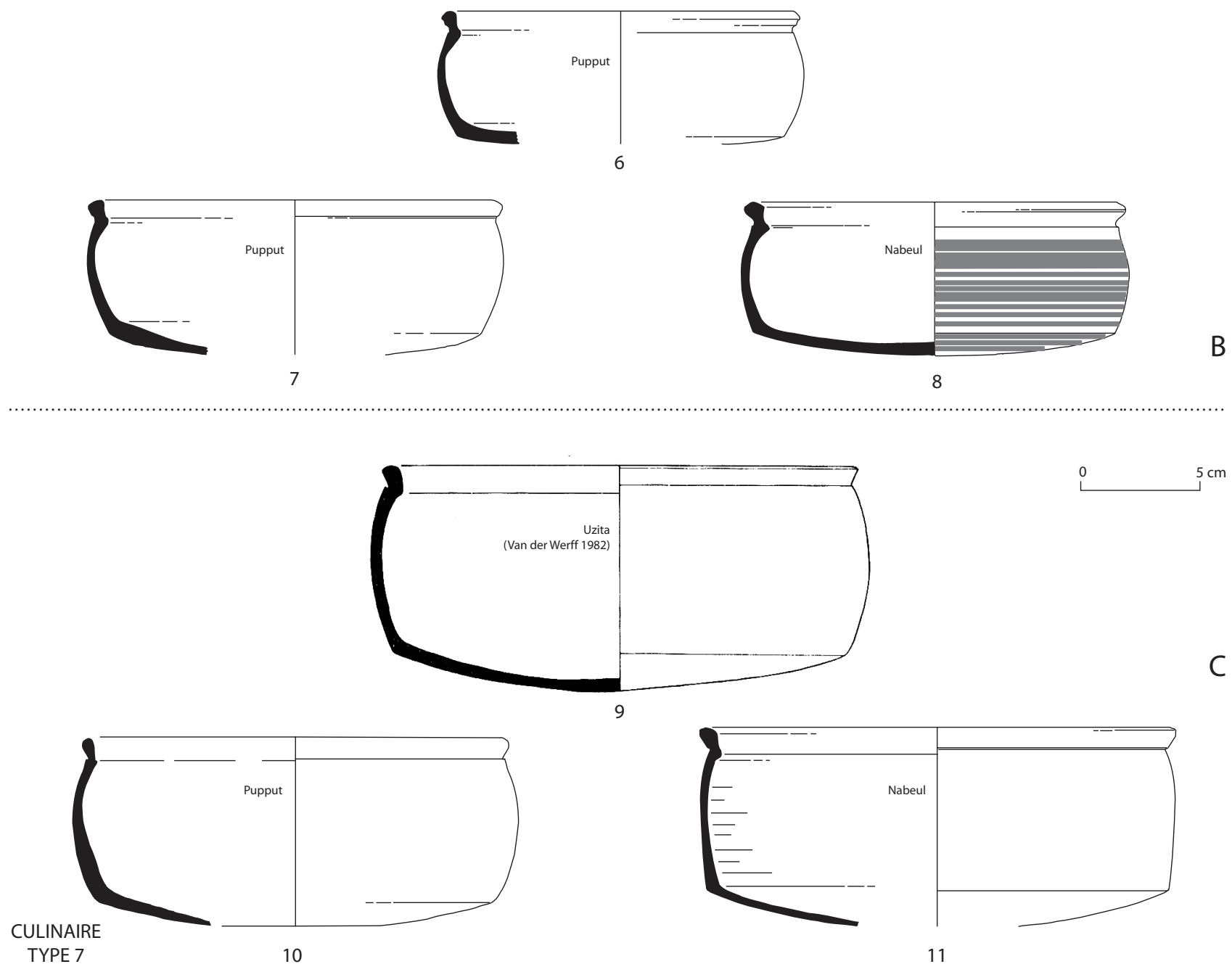
$5 \mathrm{~cm}$

Fig. 116. Vaisselle culinaire africaine. Catégorie B. 
diamètre généralement plus grand que sur les variantes A et B.

Variantes tardives : tendance à un épaississement des parois, parfois associée à une forme plus évasée ; bord empâté simplement déversé.

Exemples (fig. 116-117) :

Variante A, précoce (?)

*1 Pupput (Ben Abed, Griesheimer 2004, fig. 46, $\left.\mathrm{n}^{\circ} 1.10\right)$.

*2 Pupput (Ibid., fig. 46, $\mathrm{n}^{\circ} 2.9$ ).

Variante A

*3 Pupput, tombe 22 (Bonifay 2004a, fig. 17, $\mathrm{n}^{\circ} 63$ ).

*4 Pupput, tombe 196 (Ben Abed, Griesheimer 2004, fig. 84, $\left.\mathrm{n}^{\circ} \mathrm{T} 196.5\right)$.

*5 Pupput (Bonifay 2004a, fig. 17, $\mathrm{n}^{\circ}$ 64).

Variante B

*6 Pupput (Ben Abed, Griesheimer 2004, fig. 131, $\left.\mathrm{n}^{\circ} 11.21\right)$.

*7 Pupput (Ben Abed, Griesheimer 2004, fig. 84, $\left.\mathrm{n}^{\circ} \mathrm{T} 196.4\right)$.

*8 Nabeul, bassin XVII (Inv. NB1055.9).

Variante C

*9 Uzita (Van der Werff 1982a, fig. 4, n 10).

*10 Pupput (Inv. PP1809.8).

*11 Nabeul, fabrique de salaison, bassin XLIX (Inv. NB1850.0)

Variantes tardives (fig. 119)

*12 Pupput, enclos 30 (Inv. PP1090.34). Dessin P. Reynaud.

*13 Pupput (Bonifay 2004a, fig. 17, $\mathrm{n}^{\circ}$ 65).

*14 El Jem, maison d'Africa (fouilles H. Slim, Inv. EJMA.2300.010).

Cette forme est déjà présente dans les premières phases de la nécropole de Pupput, au début du IIe s. (Ben Abed, Griesheimer 2004 : phase 2), mais il semble difficile de faire ressortir les caractéristiques de ces variantes précoces. Tout au plus le bord triangulaire du $\mathrm{n}^{\circ} \mathbf{2}$ est-il peut-être plus fortement projeté vers l'extérieur que sur les variantes plus tardives, et les parois plus nettement rentrantes par comparaison avec le léger évasement des exemplaires plus récents. J. Dore, à Sabratha, avait eu les mêmes difficultés avec ses formes 58-62 (= Hayes $183 / 184$, sans distinction), auxquelles il ne parvenait pas à trouver d'antécédents avant le milieu du IIe s. (Dore $1989,102)^{169}$. On pourrait toutefois proposer (fig. 119) que le passage du tronc commun Hayes 191/198 à la forme Hayes 183/184 puisse être matérialisé par le type $E R C W$ 2B identifié par J. W. Hayes (1976a, fig. 15, C9) à Carthage mais dont il pressentait l'origine non locale ${ }^{170}$ et qui est, de fait, attesté à Sidi Jdidi (Bonifay, Reynaud $2004, n^{\circ} 2.5$ ) et à Nabeul (inédit) à la fin du Ier siècle.

Quoi qu'il en soit, les formes classiques de la forme Hayes 184 découvertes à Pupput correspondent en majorité au profil des formes Sabratha 58 et 59 (= formes Uzita 5 et 10), caractérisées par un bord triangulaire ou quadrangulaire, légèrement déversé ; à l'extérieur, le bord est séparé du haut de la panse par un ressaut anguleux très

\footnotetext{
169 «It is somewhat more difficult to find a convicing antecedent for types 58-62».

170 «a Central Tunisian source is probable ».
}

marqué ; à l'intérieur, il est creusé, sur la forme Sabratha 58, d'une gorge qui tend à disparaître sur la forme Sabratha 59. Ces deux variantes classiques sont associées dans des contextes de la fin du IIe s. et de la première moitié du IIIe s. à Pupput (6-7, 10) ainsi qu'à Nabeul (8), mais, peut-être, comme l'a fait observer J. H. Van der Werff (1982a, fig. 4), la variante Sabratha 59 se poursuit plus tardivement $\left(\mathrm{n}^{\circ} 11\right.$ : milieu ou seconde moitié du IIIe s.). Enfin, quelques variantes tardives se distinguent par la simplification du bord et un épaississement des parois (12-14).

Datation proposée :

Variante A - IIe s.

Variante B - fin du IIe s. - milieu du IIIe s.

Variante $\mathrm{C}$ - IIIe s.

Variantes tardives - seconde moitié IIIe s. - IVe s.

\section{Culinaire (B) TYPE 8}

On observe, sur plusieurs sites du nord de la Byzacène et du sud de la Zeugitane, une continuité ou une résurgence (?) de la forme Hayes 184 au Ve siècle. Ces petits vases (D. : 18-22 cm en moyenne) ont un profil général tout à fait comparable à celui des marmites Hayes 184, mais s'en distinguent par des parois très épaisses et un bord triangulaire déversé, très anguleux; le fond est parfois muni d'un léger pied. Mais surtout, le vernis, qui recouvre seulement l'extérieur du vase, a une qualité comparable à celui des sigillées africaines D.

Exemples (fig. 117) :

*1 Sidi Jdidi, basilique 2, destruction état II (Inv. JD2166.3). D. : $18 \mathrm{~cm}$.

*2 Oudhna, est capitole (fouilles H. Ben Hassen, Inv. UTH7.000.69). D. $20,5 \mathrm{~cm}$.

3 Pupput, thermes du Centre (fouilles A. Ben Abed, Inv. PPC230.5).

*4 Sidi Jdidi, basilique 2, destruction état II (Inv. JD2279.17). Variante de petite taille, D. : 17,5 cm, H. : 4,6 cm. Dessin T. Mukai.

*5 Idem (Inv. JD2332.16). Variante de grande taille, avec pied, D. : $24 \mathrm{~cm}$, H. : 8,4 cm. Dessin T. Mukai.

Cette forme, très fréquente à Sidi Jdidi et dans la vallée de Segermes (Lund 1995, fig. 19, «Stern 1968 Forms XLa et $b$ » ?) est peut-être produite sur l'atelier de Sidi Khalifa (Ben Moussa 2001, formes 102-105). Elle apparaît régulièrement dans les contextes de la seconde moitié du Ve s. $(\mathbf{1}, \mathbf{4 - 5})$.

Enfin, uniquement pour mémoire, mentionnons la présence à Lepcis Magna d'une production de marmites dérivées des types Hayes 184, qui se distingue des autres productions tripolitaines par un traitement très soigné des surfaces extérieures, non vernissées, avec une belle teinte rouge uniforme et parcourues de cannelures très régulières ; ces objets, dont la pâte est proche de celle des sigillées tripolitaines, a été produite sur les mêmes ateliers, comme le prouvent les prospections de l'oued Tharghlat (Felici, Pentiricci 2002, 1896, fig. 12, n 25-26). Exemple (fig. 117b) :

*1 Lepcis Magna, thermes du Levant (fouilles A. Laronde, Inv. LEP078.9). Contexte milieu du IVe s. 
Forme Hayes 184

variantes tardives

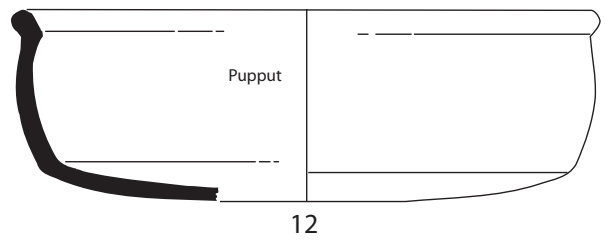

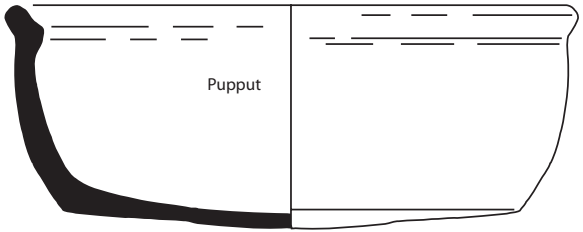

13

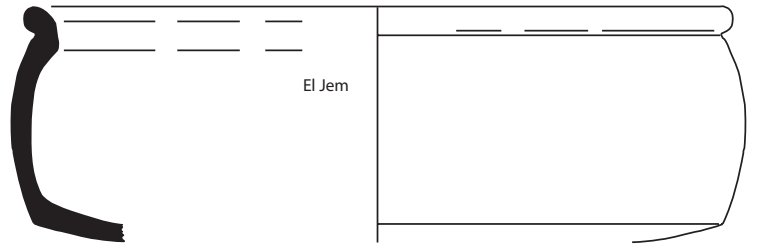

14

CULINAIRE

TYPE 7
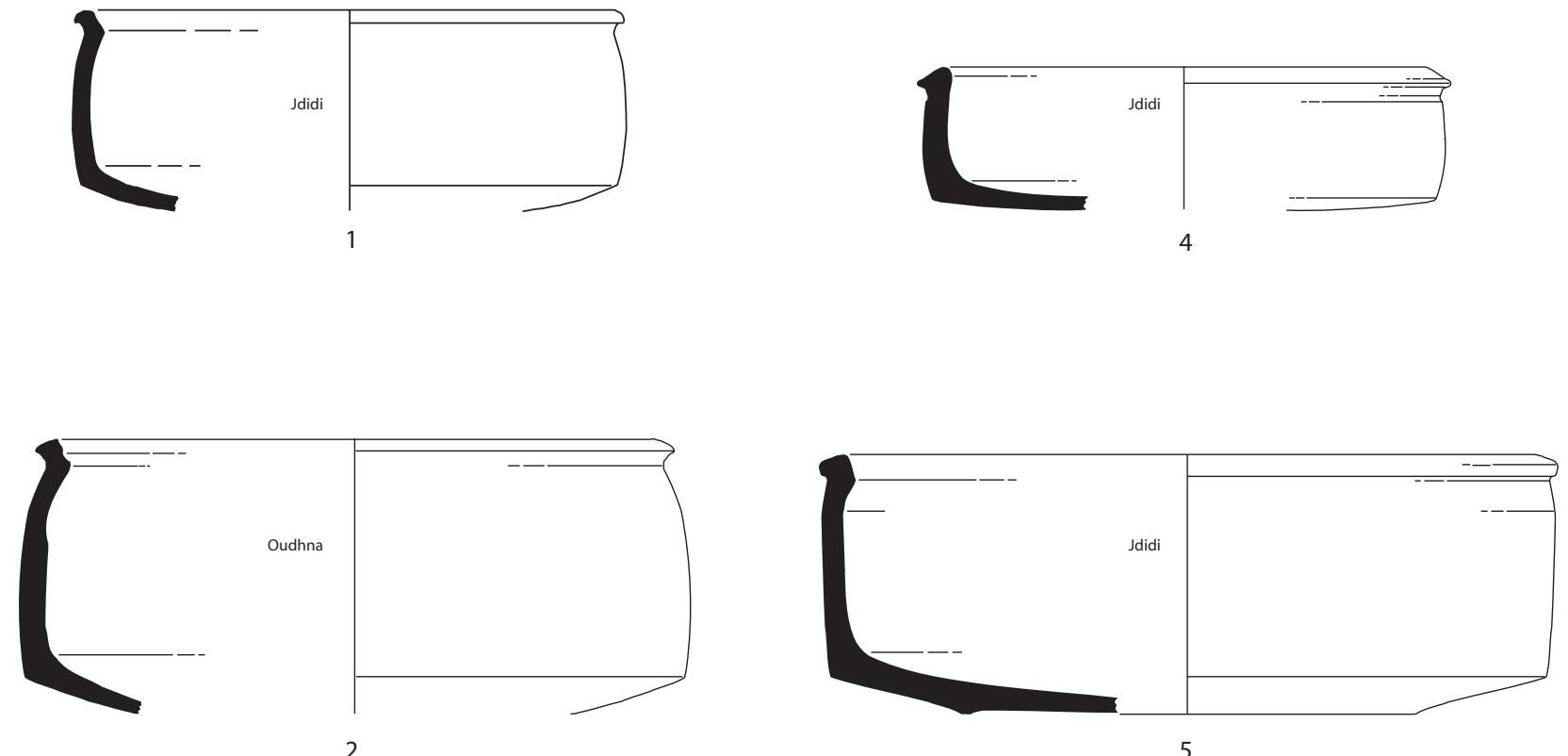

CULINAIRE L $5 \mathrm{~cm}$

Fig. 117a. Vaisselle culinaire africaine. Catégorie B. 
Dérivée de la forme Hayes 184

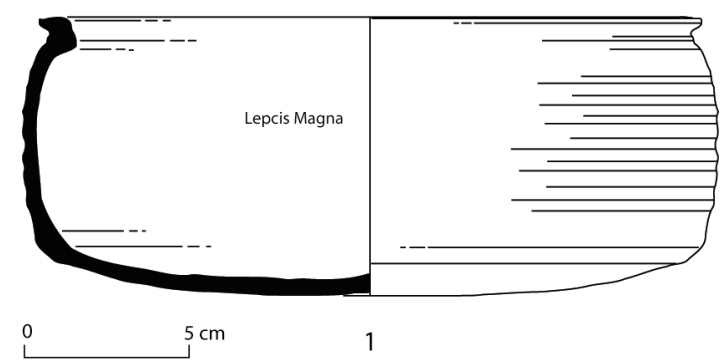

Fig. 117b. Vaisselle culinaire africaine. Productions de Tripolitaine.

— Hayes 185 (fig. 118)

\section{CULINAIRE (B) TYPE 9}

Ce couvercle est défini (Hayes 1972, 204) comme étant celui de la casserole Hayes 184 mais il peut présenter bien d'autres profils que les deux illustrés par J. W. Hayes (1972). Deux grandes variantes se succèdent à Uzita (A-B); les fouilles de Pupput et de Nabeul livrent plus fréquemment une troisième variante $(C)$; enfin le prototype de la classification de Hayes pourrait plutôt correspondre à une variante tardive (D). Cette liste n'est sans doute pas exhaustive.

- Variante A (= forme Uzita 7) : bord à petite lèvre épaissie et arrondie, paroi courbe, fond à pied annulaire $(?)^{171}$.

- Variante B (= forme Hayes $185, \mathrm{n}^{\circ} 3=$ forme Uzita 11): bord à lèvre triangulaire pendante, parois coniques, fond à pied annulaire.

- Variante C (= type Ostia I, 18 ?) : bord de la même épaisseur que la paroi, arrondi ou légèrement biseauté, panse très légèrement courbe, fond en talon, plat et étroit. Cette variante paraît avoir subi l'influence de la forme Hayes 196.

- Variante D (= forme Hayes 185, $\mathrm{n}^{\circ} 1$ ) : bord épaissi et arrondi, paroi courbe cannelée à l'intérieur, fond en bouton.

Exemples (fig. 118) :

Variante proche de Hayes 22

*1 Pupput, tombe 708 (Inv. PP1441.1).

Variante A

*2 Uzita (Van der Werff 1982a, fig. 4, n 7).

*3 Pupput, zone ouverte sud, phase 1 (Ben Abed, Griesheimer 2004, fig. 46, $\mathrm{n}^{\circ} 1.8$ ).

Variante B

*4 Uzita (Van der Werff 1982a, fig. 4, n 11).

5 Pupput (Inv. PP1074.1).

*6 Rougga (Guéry, Bonifay à paraître, $n^{\circ} 175$ ).

Variante C

*7 Pupput, enclos 30 (Inv. PP1090.10).

*8 Nabeul, fabrique de salaison, bassin XVII (Inv.

\footnotetext{
${ }^{171}$ Notons que la restitution d'un fond en anneau sur la forme Uzita 8 est hypothétique (Van der Werff 1982a, fig. 4); par ailleurs, la forme correspondante (forme 5) en "Rood Byzaceens gebruiksaardewerk » présente un fond en bouton (Ibid., fig. 6).
}

NB1052.13).

*9 Idem (Inv. NB1055.22).

Variante D

*10 Hayes $185, \mathrm{n}^{\circ} 1$.

*11 El Jem, maison d'Africa (fouilles H. Slim, Inv. EJMA.2300.023).

En accord avec la chronologie proposée par J. H. Van der Werff $(1982,84)$, la variante A paraît ancienne : elle figure à Pupput (3) dans un lot de matériel de l'extrême fin du Ier s. ou du début du IIe siècle. Les exemplaires de la variante B (5) et de la variante C (7-9) proviennent de contextes compris entre la fin du IIe s. et le milieu du IIIe s. à Pupput et à Nabeul. Enfin la variante D est attestée dans un contexte du IVe s. à El Jem (11).

\section{— Autres formes (fig. 118)}

Un certain nombre d'autres formes ouvertes, dont la typologie reste assez mal connue, sont signalées dans cette catégorie de céramique culinaire.

Exemples (fig. 118) :

*1 Uzita (Van der Werff 1982a, fig. 4, $\mathrm{n}^{\circ}$ 2).

*2 Pupput, tombe 643 (Ben Abed, Griesheimer 2004, fig. $\left.106, n^{\circ} \mathrm{T} 643.4\right)^{172}$.

3 Nabeul, bassin XLVI (Inv. NB1506.0).

*4 Uzita (Van der Werff 1982a, fig. 4, n³).

Catégorie $\mathrm{C}$ : céramique culinaire «à bord noirci » et « à patine cendreuse »

Cette catégorie se définit par une technique de façonnage et de cuisson: les vases ne sont pas vernissés, parfois simplement polis à l'extérieur et/ou à l'intérieur (« politura a bande »: Atlante $I, 208$ ) et cuits à feu libre. C'est cette technique de cuisson qui produit les surfaces externes des marmites «a patina cenerognola» et les couvercles « ad orlo annerito » (supra, p. 71).

La difficulté vient du fait que cette technique est utilisée en plusieurs points du territoire africain. Elle n'est pas spécifique d'une région, à la différence de la culinaire $\mathrm{A}$, affiliée à la sigillée africaine A (nord de la Tunisie ?), et de la culinaire $B$, caractéristique de la Byzacène. Toutefois, le répertoire des formes et la diffusion des céramiques culinaires $\mathrm{C}$ permettent de distinguer deux groupes principaux qui se rattachent aux deux précédents :

- culinaire C/A : production non vernie du nord de la Tunisie, affiliée à la culinaire $\mathrm{A}$;

- culinaire $\mathrm{C} / \mathrm{B}$ : production non vernie de la Byzacène, affiliée à la culinaire $\mathrm{B}$.

Un certain nombre de formes de la catégorie $\mathrm{C}$ ne peuvent être attribuées avec certitude à l'une de ces deux régions, objets au sein desquels il est cependant possible d'identifier quelques produits de Tripolitaine.

\footnotetext{
${ }^{172}$ Classé à tort en sigillée A/D.
} 
Forme Hayes 185

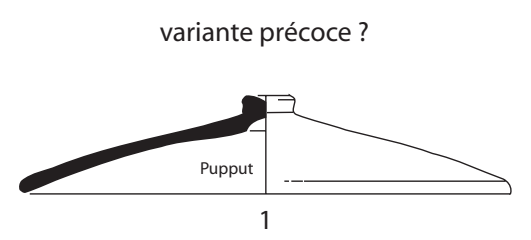

19?

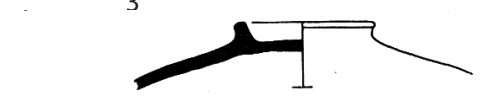

(Van der Werff 1982)
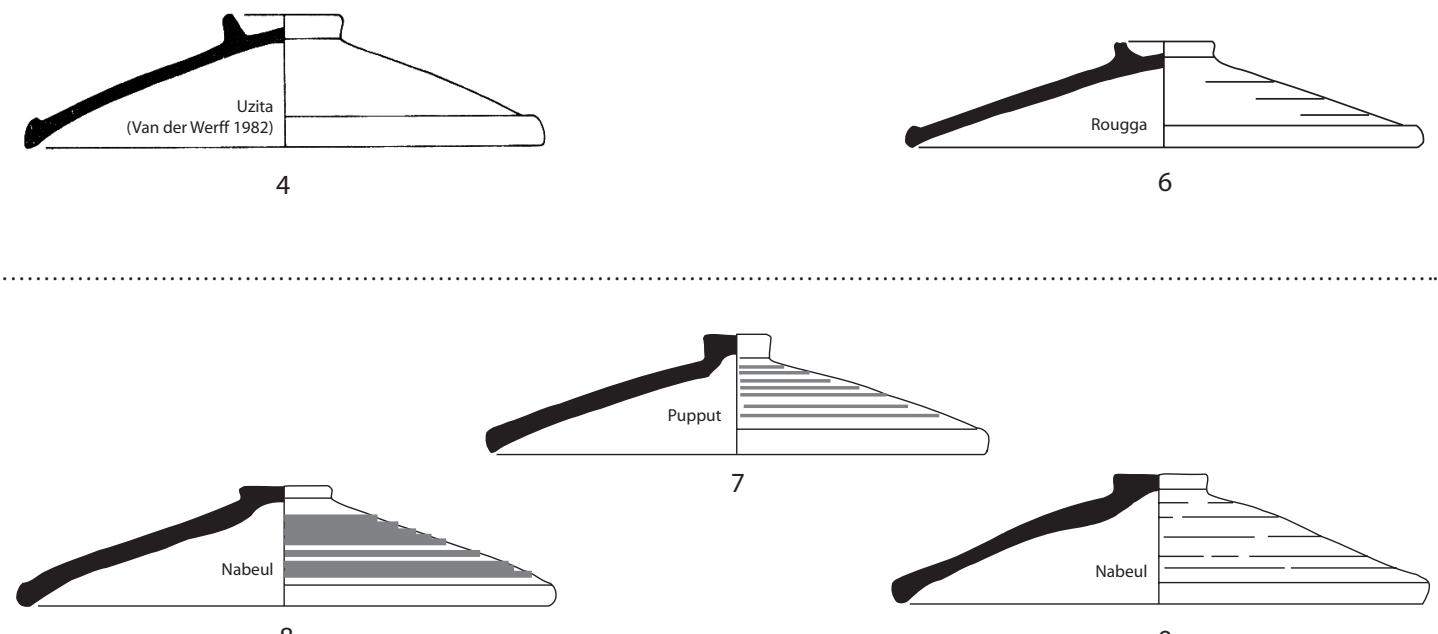

8

9
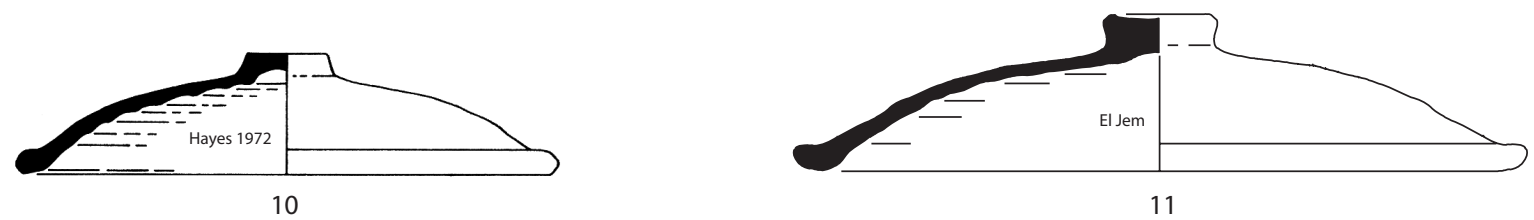

Autres formes
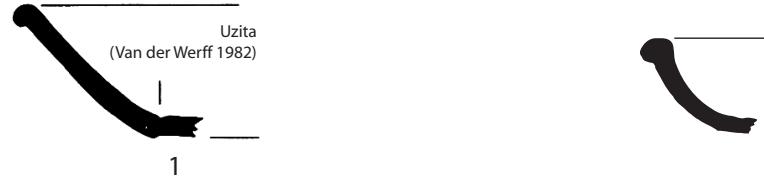

Pupput

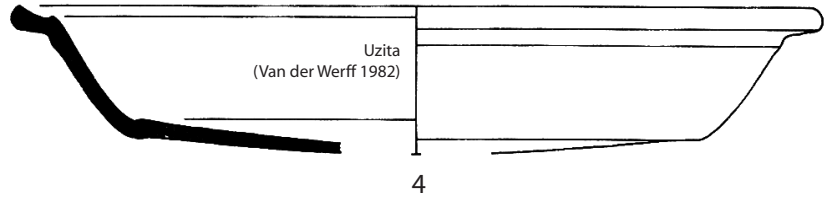

Fig. 118. Vaisselle culinaire africaine. Catégorie B. 


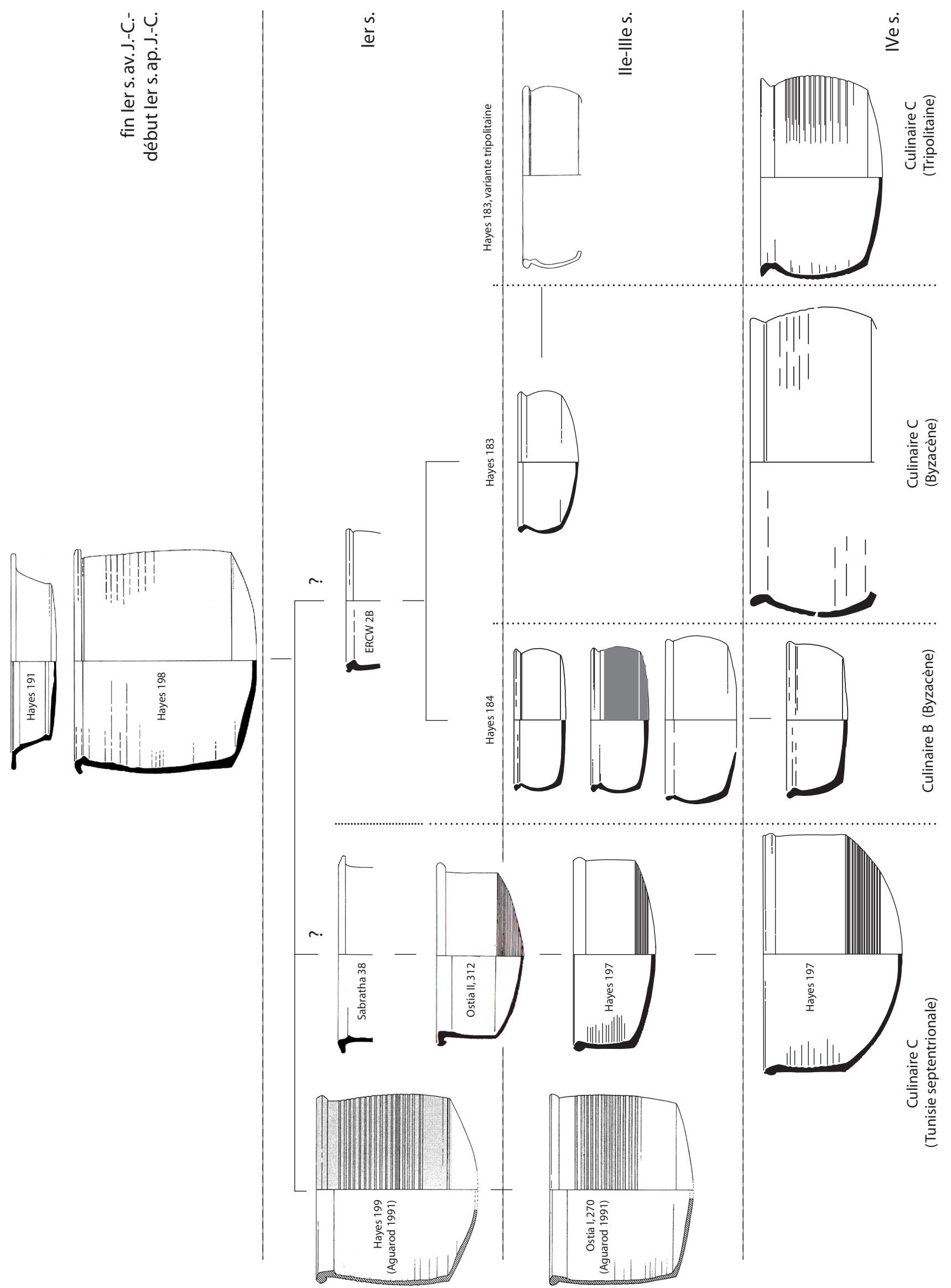

Fig. 119. Vaisselle culinaire africaine. Proposition de schéma évolutif. 
Typologie - Culinaires

Forme Hayes 197
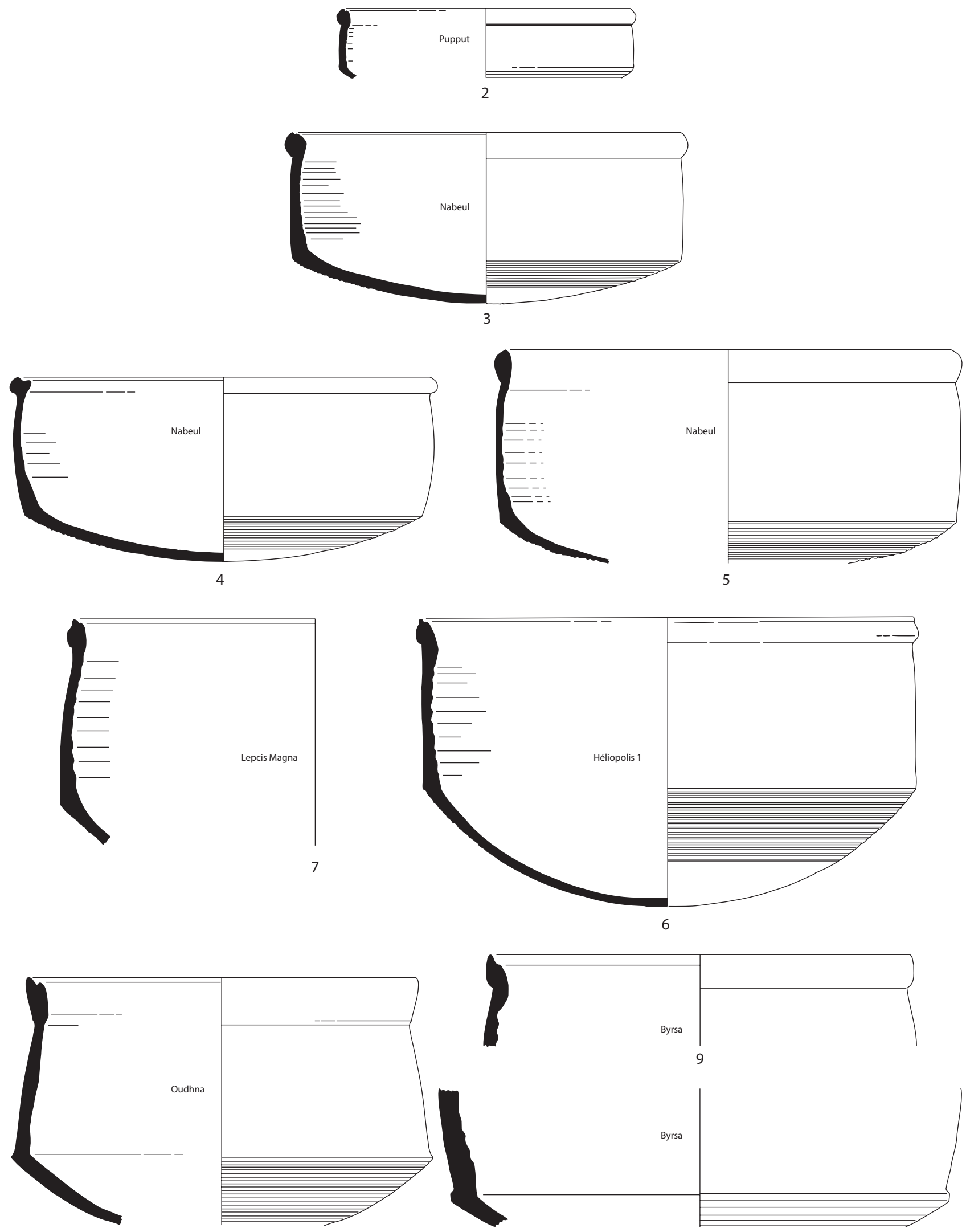

CULINAIRE
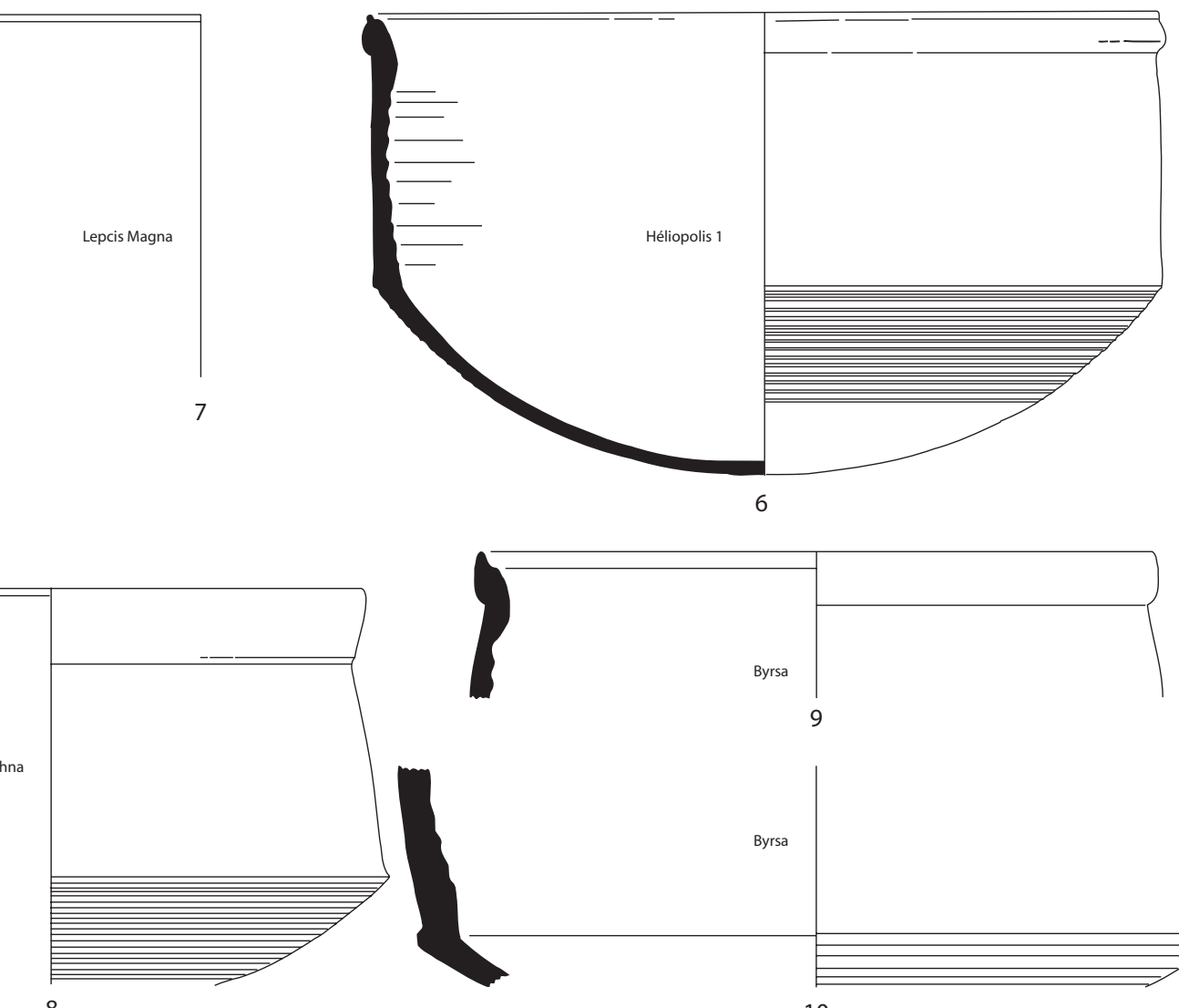

8

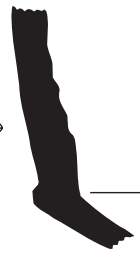

TYPE 10

Fig. 120. Vaisselle culinaire africaine. Catégorie C. 


\section{- Céramique culinaire C/A (nord de la Tunisie)}

Comme cela a déjà été signalé à plusieurs reprises (Hayes 1972, 205 ; Dore 1989, 102 ; Fulford 1994, 53), cette production est directement issue des céramiques culinaires d'époque punique ou néo-punique (fig. 119). Ainsi, la forme Hayes 191, forme néo-punique dérivant d'un type punique (Byrsa II, fig. 23, $\mathrm{n}^{\circ} 47$ ), va côtoyer, au Ier s. ap. J.-C., la forme Hayes 198 puis, par l'intermédiaire des formes Sabratha 37-40 (Dore 1989, 118 ; Sabratha 40 = Ostia II, 312, cf. Aquilué 1994, fig. $6, \mathrm{n}^{\circ} 4$ ), donner la forme Hayes 197 au courant du IIe siècle. La forme Hayes 194, du Ier s. ap. J-C. dérive également de modèles gréco-puniques, quant à la forme Ostia II, 306 elle est le témoignage d'une influence de productions attestées en Italie dès l'époque républicaine (Atlante I, 216).

La céramique culinaire $\mathrm{C}$ du nord de la Tunisie (« Black Top ware » des anglo-saxons: Hayes 1976a, 87) est directement reliée à la culinaire $\mathrm{A}$ par les contours de sa diffusion en Tunisie, essentiellement Carthage et le littoral à l'ouest de cette ville (supra, p. 67) et par certains détails morphologiques, comme les micro-sillons gravés sous le fond des formes Hayes 23 et 197. Cette production comprend deux formes principales, bien connues : la marmite Hayes 197 et son couvercle Hayes 196, mais il convient peut-être d'ajouter d'autres objets dont la spécificité régionale est moins affirmée.

\section{— Hayes 197 (fig. 120)}

\section{CULINAIRE (C/A) TYPE 10}

Je n'ai pas de données susceptibles de modifier fondamentalement la typologie et la chronologie de cette forme, assez peu diffusée au sud de Nabeul. Tout au plus faut-il mentionner la présence sur ce site d'une variante à bord en amande, sans rainure sommitale (5). Une autre variante, tardive, d'Oudhna paraît influencée, dans le détail de sa morphologie (bord très bifide) (8), par les productions locales du cap Bon (infra, CULINAIRE TYPE 31). En revanche, les variantes tardives de Carthage (910) ne diffèrent guère de celles déjà publiées dans cette ville.

Exemples (fig. 120) :

Variante précoce (?)

1 Pupput, tombe 601 (Inv. PP3619.2).

*2 Pupput (Ben Abed, Griesheimer 2004, fig. 131, $\left.\mathrm{n}^{\circ} 11.25\right)$

Forme classique

*3 Nabeul, bassin XVII (Inv. NB1055.5).

Variantes de la forme classique

*4 Nabeul, bassin XVII (Inv. NB1055.8).

*5 Nabeul, bassin XLVI (Inv. NB1506.a).

Variantes tardives

*6 Epave Héliopolis 1 (DRASSM, Inv. 40 ; cf. Joncheray 1998, 156).

*7 Lepcis Magna, thermes du Levant (fouilles A. Laronde, Inv. LEP05.025).

*8 Oudhna, capitole (Inv. UTH1.001.58 ; Bonifay, Dridi,
Jacquest à paraître, $\mathrm{n}^{\circ}$ 25). Cf. aussi infra, CULINAIRE TYPE 31 .

*9_*10 Carthage, Byrsa (Bonifay à paraître, a, n 33-34).

L'essentiel des attestations de la forme Hayes 197 à Pupput et à Nabeul concerne la fin du IIe s. (2) et le IIIe s. (3-4). Le $\mathrm{n}^{\circ} \mathbf{5}$, sans rainure sommitale, est issu d'un contexte de la fin du IIIe s. ou du début du IVe siècle. Les exemplaires de l'épave Héliopolis I (6) et de Lepcis Magna (7) illustrent bien la forme habituelle du IVe s., à lèvre haute et moulurée et à fond bombé. La variante assez particulière d'Oudhna est datée de la fin du IVes. (8). Enfin, les exemplaires de Carthage (9-10) trouvent dans cette ville de nombreuses comparaisons pour la fin du IVe s. et la première moitié du Ve s. (Hayes 1978a, fig. $1, \mathrm{n}^{\circ} 23-25$; Tomber 1988, fig. $12, \mathrm{n}^{\circ} 250$ et 256 ?; Mackensen 1991, fig. $18, \mathrm{n}^{\circ} 17$ ? et 20 ).

\section{- Hayes 196 (fig. 121)}

\section{Culinaire (C/A) TYPE 11}

Ce couvercle (ou assiette/couvercle) est réputé s'adapter tout autant au plat Hayes 23 qu'à la marmite Hayes 197 (Hayes 1972, 208) : à Pupput, le total des couvercles Hayes 196 correspond à peu près à celui des deux formes de vases à feu. Les deux variantes définies par Hayes sont présentes (A et B : avec et sans pied). L'évolution maintes fois mentionnée (Atlante I, 212 ; Fulford 1994, 66), consistant dans un épaississement progressif du bord, semble se vérifier.

Exemples (fig. 121):

Forme précoce (?)

*1 Nabeul, fabrique de salaison, période 3 (Inv. NB1325.2).

2 Sidi Jdidi, basilique 1, état A0 (Bonifay, Reynaud 2004, $n^{\circ} 2.1$ ).

Forme classique, variante A

3 Pupput, tombe 937 (Bonifay 2004a, fig. 18, $n^{\circ}$ 66).

*4 Nabeul, bassin XLVI (Inv. NB1506.b).

*5 Nabeul, bassin XVII (Inv. NB1052.1).

Forme classique, variante B (= Ostia III, 332)

*6 Marseille, chantier de La Bourse (Del Vais 1998a, fig. $\left.60, n^{\circ} 58\right)$.

*7 Nabeul, bassin XVII (Inv. NB1052.11).

Variantes tardives (= Ostia IV, 60-61 = Tomber Black Top Lid B)

*8 Héliopolis 1 (DRASSM, Inv. 41 ; cf. Joncheray 1998, $154, \mathrm{n}^{\circ} 3$ et Dovis-Vicente 2001, Pl. VIII, $\mathrm{n}^{\circ} 2$ ).

9 Byrsa, première moitié Ve $\mathrm{s}$. (Bonifay à paraître, a, $\mathrm{n}^{\circ} 24$ ?).

Je n'ai pas beaucoup d'informations sur les variantes précoces de ce couvercle, mis à part un exemplaire (1) découvert en position sur une marmite Hayes 194, dans un contexte du Ier s. (Slim, Bonifay, Trousset 1999, fig. 12), et deux autres, fragmentaires, issus d'un contexte de la fin du Ier s. à Sidi Jdidi (2). Ces objets ne sont toutefois pas très éloignés du type Ostia II, 302, supposé précéder (Atlante I, 212) les variantes classiques de la forme Hayes 196. Si l'on s'en tient aux datations d'Ostie (Ibid.), il serait préférable d'inverser les lettres des deux variantes de Hayes, la seconde (B), caractéristique du IIe s., précédant la première $(\mathrm{A})$, attestée seulement à 
Forme Hayes 196
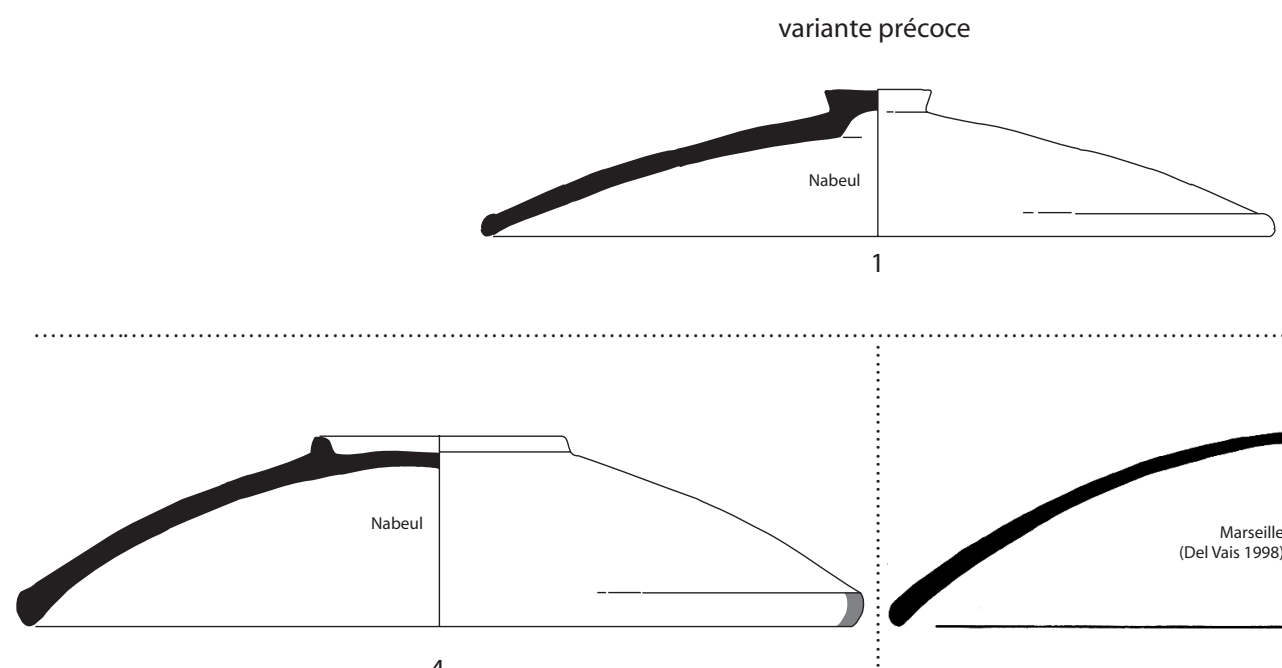

4

A
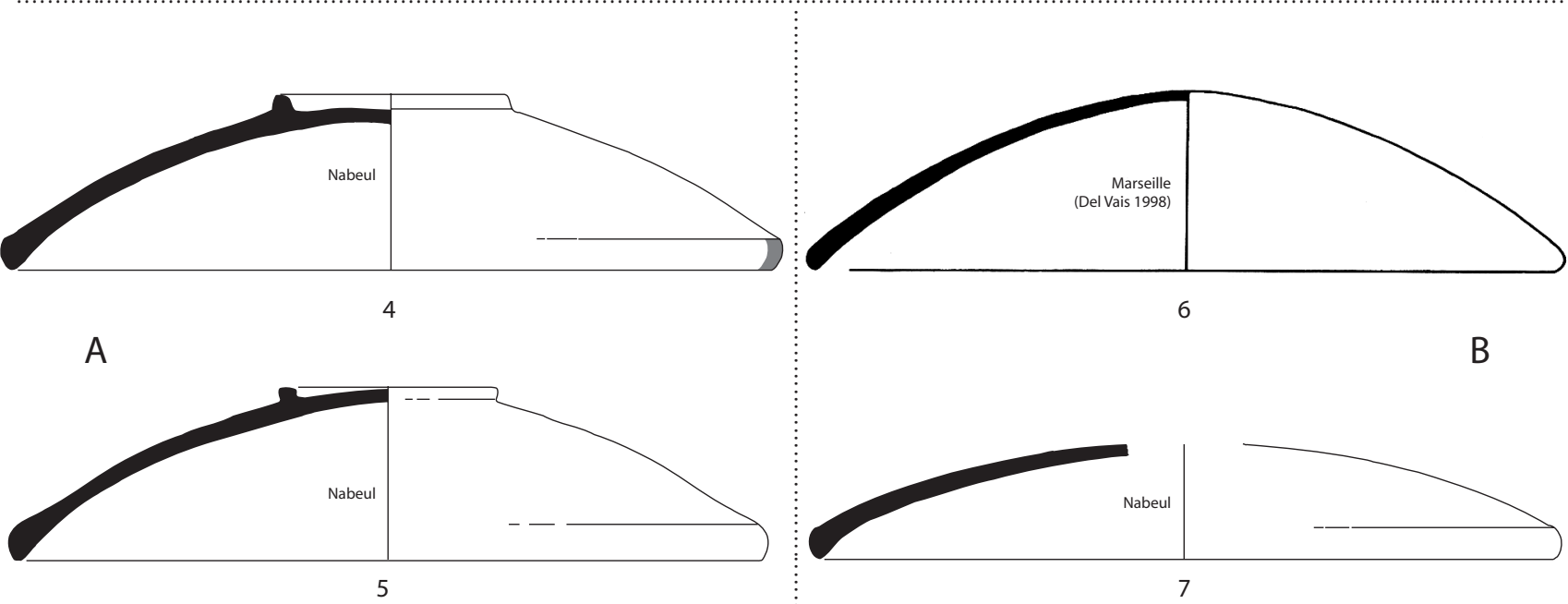

variante tardive

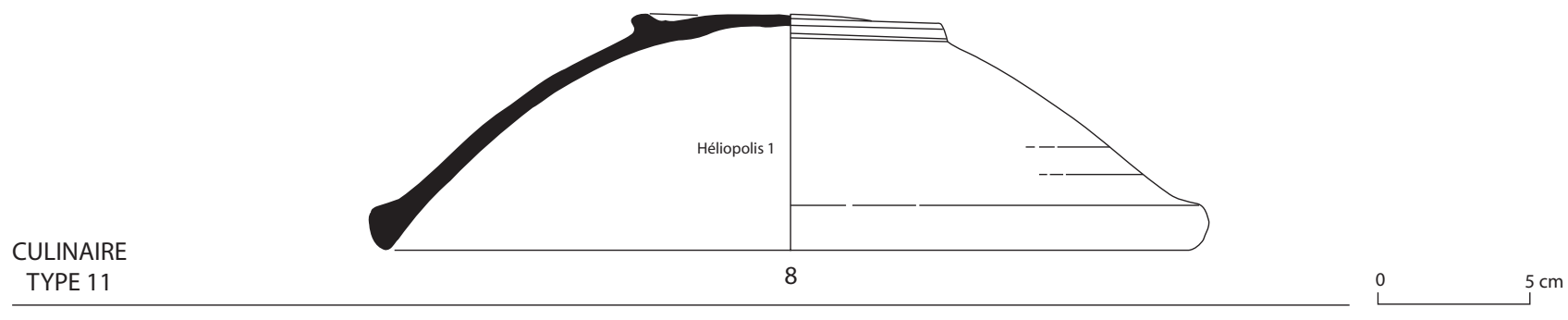

Forme Hayes 195

variante tardive

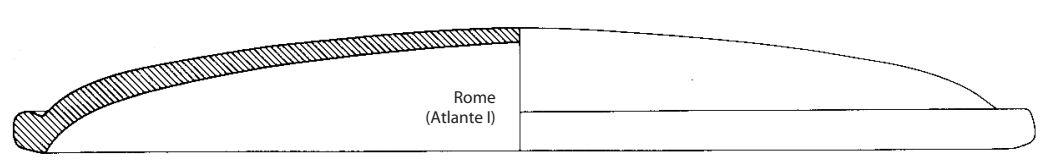

CULINAIRE TYPE 12

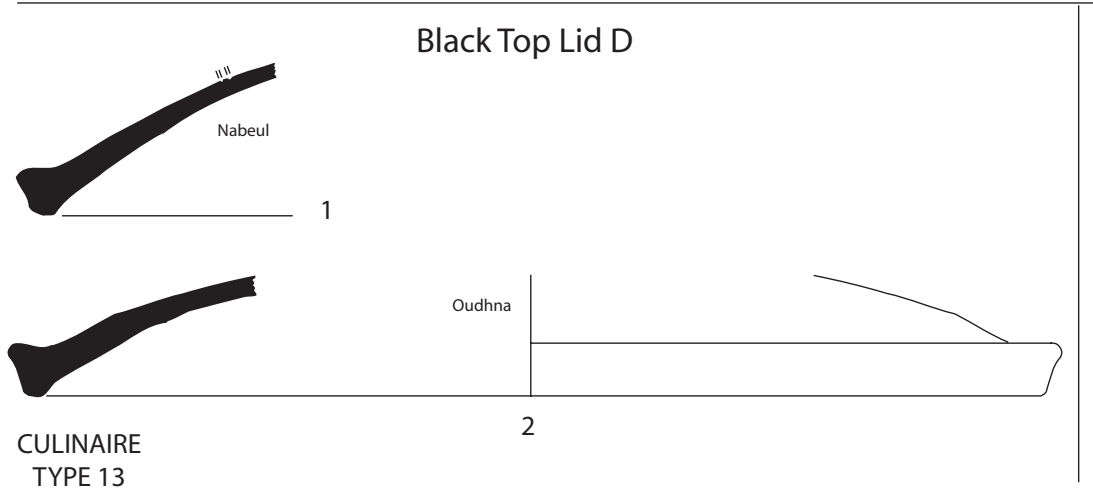

Late Roman Cooking pot 1

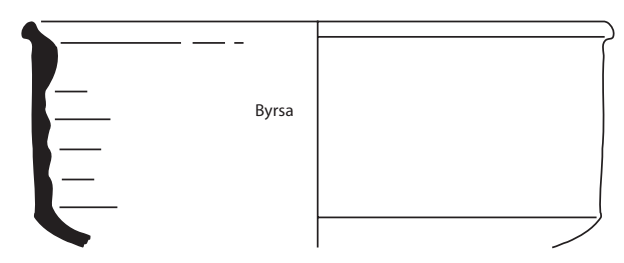

CULINAIRE

TYPE 14

Fig. 121. Vaisselle culinaire africaine. Catégorie C. 
partir de l'époque sévérienne. On observe toutefois que les deux variantes sont associées dans le même contexte du milieu du IIIe s. à Nabeul (5 et 7 ) et à Ibiza (Gonzalez Villaescusa 1990, fig. 19), tandis que la variante A pourrait déjà être présente dans la seconde moitié du IIe $\mathrm{s}$. à Pupput (3). Les variantes à bord épaissi sont bien datées du IVes. et du début du Ves. (Atlante I, 212), datation confirmée par les $n^{\circ} \mathbf{8}$ et $\mathbf{9}$, ce dernier pouvant même être un peu plus récent.

\section{— Hayes 195 (fig. 121) \\ - Variante classique}

On manque de données sur la production de cette forme dans le nord de la Tunisie. Quelques exemplaires sont signalés dans les rares contextes de la fin du IIe-début du IIIe s. de Carthage (Fulford 1994, 64: «few examples »); quelques tessons issus de contextes plus tardifs peuvent être résiduels (Tomber 1988, fig. 13, $\mathrm{n}^{\circ}$ 278-280 et fig. 14, $\mathrm{n}^{\circ}$ 281-282: Black Top Lid C; Bonifay à paraître, $\mathrm{a}, \mathrm{n}^{\circ} 23$ ). On notera toutefois que des marmites Hayes 197 et des couvercles Hayes 195 sont associés sur l'épave de Camarina (Parker 1976, fig. 7 et 8), également chargée de marbre de Chemtou.

\section{- Variante tardive}

= Hayes 195 late (Hayes 1976a)= Ostia I, 264 (Atlante I, Pl. CV, $7-8)=$ Dish $/$ Lid $10($ Fulford 1984b) $=$ Black Top Lid B (Tomber 1988)

\section{Culinaire (C/A) TYPE 12}

$\mathrm{Au}$ vu de la bibliographie et de la documentation que j'ai pu examiner directement, il me semble que la version septentrionale de cette forme, en culinaire $\mathrm{C} / \mathrm{A}$, concerne principalement ses variantes les plus tardives, de la fin du IVe s. et de la première moitié du Ve siècle. La ressemblance avec la forme Hayes 182, dont la forme Hayes 195 constitue la contrepartie non vernissée, est toute relative, le bord est complètement replié sur luimême; en revanche, subsiste parfois la (double) cannelure à mi-panse, caractéristique de la forme plus ancienne.

Exemple (fig. 121) :

*1 Rome (Atlante I, Pl. CV, $\mathrm{n}^{\circ} 8$ ).

2 Carthage, Byrsa (Bonifay à paraître, a, n² 25).

- Black Top Lid D (Tomber 1988)

= Hayes 1976a, fig. 14, B26 = Dish/Lid 12 (Fulford 1984b, fig. $72, \mathrm{n}^{\circ} 12.1$ et 2 )

\section{CUlinaire (C/A) TYPE 13}

Ce couvercle est traditionnellement interprété comme une dérivation de la forme Hayes 196 (Hayes 1976a, 92; Fulford 1984b, 191-193 ; Tomber 1988, 488 et fig. 14, $\mathrm{n}^{\circ}$ 283-285). Cependant, je propose plutôt de le rattacher aux variantes tardives de la forme Hayes 195, en raison de la forme du bord triangulaire à lèvre pendante, de la forme très arrondie de ses parois et surtout de la présence d'une double cannelure extérieure à mi-panse (déjà signalée par Tomber $(1988,488)$. La plupart de ces objets sont en catégorie $\mathrm{C}$, à pâte orange et à bord noirci. Mais certains exemplaires d'Oudhna, portant un engobe rouge extérieur avec parfois des bandes lustrées, se rattachent encore plus directement à la tradition de la forme Hayes 182.

Exemples (fig. 121) :

*1 Nabeul, fabrique de salaison, période 5B (Inv. NB1145.27). Dessin M. Labayed-Ladhari.

*2 Oudhna, thermes des Laberii (Inv. UTH.TL., sans $\mathrm{n}^{\circ}$ ). Cette forme est très fréquente sur l'atelier d'Oudhna, où elle a pu être produite. Les datations sont homogènes : fin du IVe s. - début du Ve s. à Carthage, première moitié du Ve s. à Nabeul (1).

- Hayes 183, variante tardive (fig. 121)
$=$ Late Roman Cooking pot 1

CULINAIRE (C/A) TYPE 14

Un certain nombre de casseroles issues de contextes de la fin du IVe s. et de la première moitié du Ve s. semblent apparentées à la forme Hayes 183 (Hayes 1978a, fig. 1, $\mathrm{n}^{\circ} 28$; Tomber 1988, fig. 14, $\mathrm{n}^{\circ}$ 287-295 : Late Roman Cooking pot 1). Je ne connais pas, en culinaire C/A, d'exemples plus anciens de cette forme, normalement produite en catégorie $\mathrm{C} / \mathrm{B}$.

Exemple :

*1 Carthage, Byrsa (Bonifay à paraître, a, n 36).

\section{- Céramique culinaire C/B (Byzacène)}

Deux des formes de la céramique culinaire $\mathrm{B}$ à vernis lustré, les couvercles Hayes 182 et les casseroles Hayes 184, sont également produites en Byzacène, en catégorie C sans vernis : il s'agit des couvercles Hayes 195 et des casseroles Hayes 183.

\section{— Hayes 195}

Comme le notait Hayes $(1972,208)$, la variante non vernissée de la forme Hayes 182 est assez rare. A Pupput, quasiment tous les fragments de couvercles de cette forme peuvent être rattachés à la production $\mathrm{B}$, à vernis lustré : il s'agit donc de formes 182 et non 195. On aurait pu penser que ce traitement plus fruste était réservé aux exemplaires de grande taille. En effet, le diamètre des couvercles Hayes 182 varie entre 22 et $33 \mathrm{~cm}$ (Ibid., 201), tandis que le seul exemplaire complet de forme 195 catalogué par Hayes mesure $35 \mathrm{~cm}$; mais plusieurs exemplaires d'El Jem avec un diamètre de $44 \mathrm{~cm}$ sont vernissés (fouilles de la maison d'Africa).

— Hayes 183 (fig. 122)

\section{Culinaire (C/B) TYPE 15}

Les casseroles Hayes 183 se distinguent des casseroles Hayes 184 non seulement par l'absence de vernis mais aussi par une taille généralement plus grande (Hayes 
Forme Hayes 183
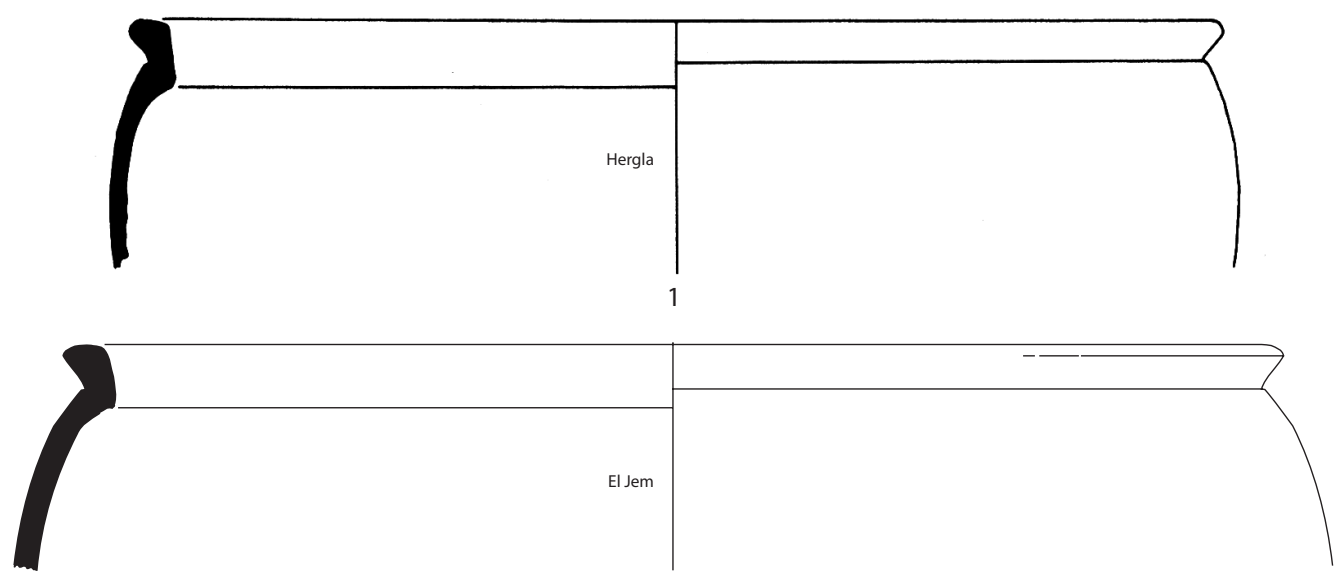

2

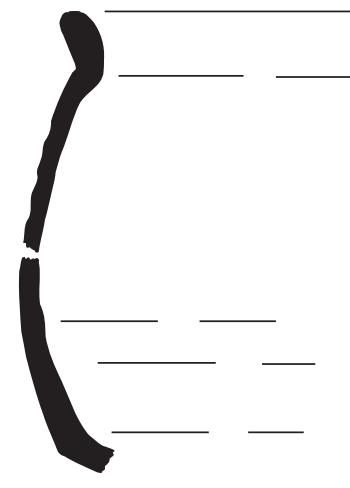

CULINAIRE

TYPE 15

Forme Hayes 185, variante
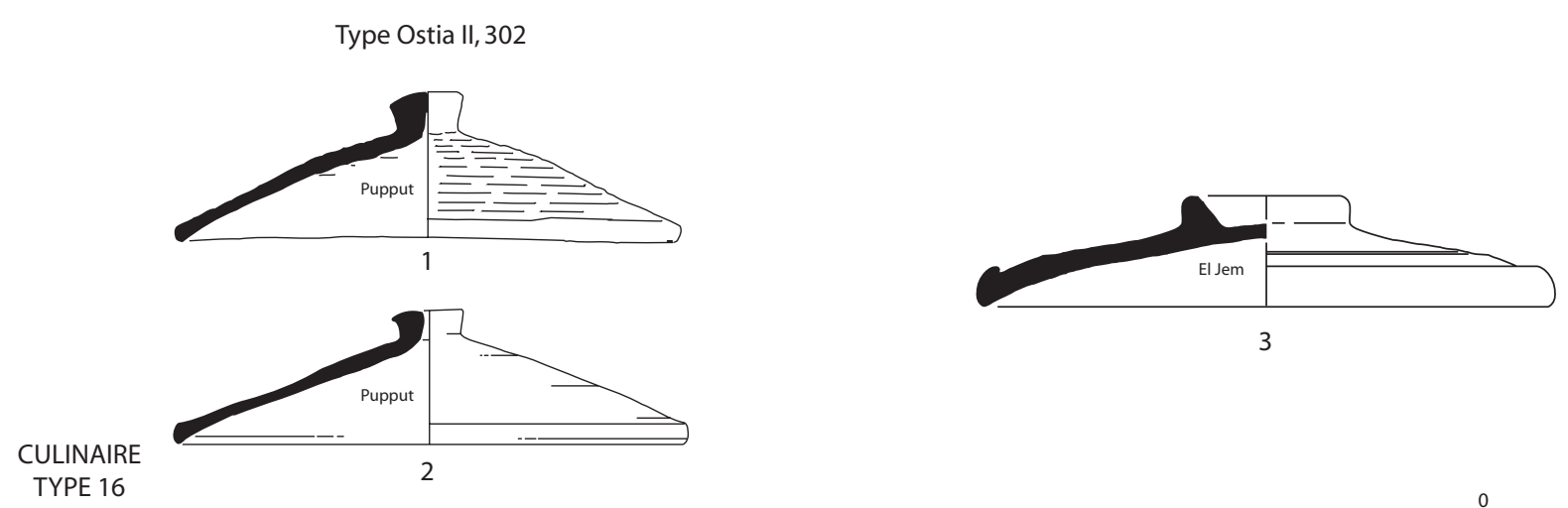

Forme Hayes 183, variante tripolitaine

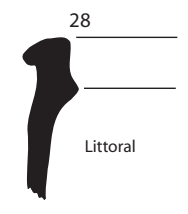

1

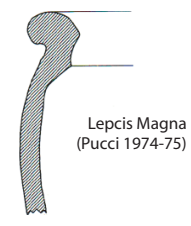

3

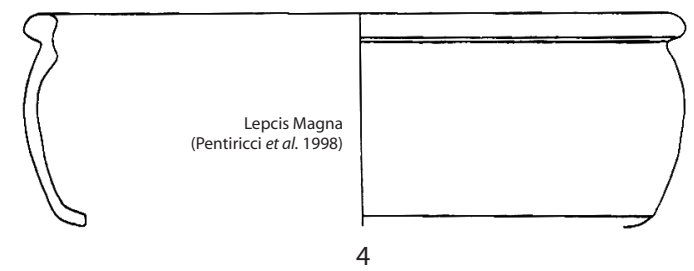

Fig. 122a. Vaisselle culinaire africaine. Catégorie C. 
1972, 203). Cette observation est particulièrement évidente sur le matériel d'Uzita (Van der Werff 1982a, fig. 6). Les exemplaires de petite taille semblent plus rares ; ils ont un fond plus bombé que celui de la forme Hayes $184\left(\mathrm{n}^{\circ} 4\right.$; voir aussi Del Vais 1998a, fig. 58, $\left.\mathrm{n}^{\circ} 56\right)$.

Exemples (fig. 122) :

Variante classique

*1 Hergla, fouilles anciennes (Inv. HG.000.125). Dessin M. Pasqualini.

*2 El Jem, maison d'Africa (fouilles H. Slim, Inv. EJMA.2311.3)

*3 Idem (Inv. EJMA.2300.003)

Variante de petite taille (forme Hayes 183/184)

*4 Pupput (Bonifay 2004a, fig. 17, $\mathrm{n}^{\circ}$ 62)

On retrouve les deux variantes de bords observées sur la production vernissée (supra, CULINAIRE TYPE 7B ET C). La variante Sabratha 59 est la plus fréquente dans le matériel présenté ci-dessus, dont la chronologie est toutefois relativement tardive : seconde moitié du IIIe s. ou IVe s. (2 et 3). Le seul exemplaire de la variante 58 , de plus petite taille, date de la fin du IIe s. ou de la première moitié du IIIe s. (4).

- Hayes 185, variante (fig. 122)

\section{Culinaire (C/B) TYPE 16}

Cette forme, dans sa variante non vernissée, est aussi le couvercle de la casserole Hayes 183. On remarque surtout des exemplaires de petite taille, proches du type Ostia II, 302 (1-2) ou du type Uzita 13 (Rood Byzaceens gebruiksaardewerk) (3).

Exemples (fig. 122) :

*1 Pupput, tombe 418 (Inv. PP2948.5).

*2 Pupput, tombe 937 (Inv. PP3250.6).

*3 El Jem (fouilles H. Slim, Inv. EJMA.000.002).

\section{- Autres céramiques culinaires $\mathbf{C}$}

- Hayes 183, variantes de Byzacène méridionale (?) et de Tripolitaine (fig. 122)

\section{Culinaire (C) TYPe 17}

Les régions les plus méridionales de la Tunisie produisent un type de marmite Hayes 183 caractérisé par un bord massif, vertical, simplement marqué par un épaississement sommital et une profonde gorge interne.

Exemples (fig. 122) :

*1 Littoral tunisien, site $\mathrm{n}^{\circ} 55$ (Henchir Leich, au nord de Iunca) (Bonifay et al. 2002-2003, fig. 10, $\mathrm{n}^{\circ} 109$ ).

2 Jerba, atelier de Guallala (supra, fig. 37, $\mathrm{n}^{\circ} 1$ ).

*3 Lepcis Magna (Pucci 1974-75, fig. 60).

*4 Lepcis Magna (Pentiricci et al., fig. 1, $\mathrm{n}^{\circ} 1.3$ ).

5 Sidi as-Sid (Arthur 1982, fig. 7, $\mathrm{n}^{\circ} 18$ ).

Cette forme est assez répandue sur les sites de Tripolitaine (Sabratha: Dore 1989, 128 et fig. 34, forme 61 ; Lepcis Magna : 3-4) au IIIe siècle.

\section{— Hayes 183, variante tardive de Tripolitaine}

Pour mémoire. Production tripolitaine à pâte grossière, voisine de celle des amphores, et à surface extérieure grise.

Exemple (fig. 122b) :

*1 Lepcis Magna, thermes du Levant (fouille A. Laronde, Inv. LEP078.11). Timbre en relief, sous le fond: $E(?) M B$.

Cet exemplaire présente la particularité, unique à ce jour sur le territoire africain (?), de porter une marque de fabrique imprimée sous le fond ; il provient d'un contexte du IVe siècle.

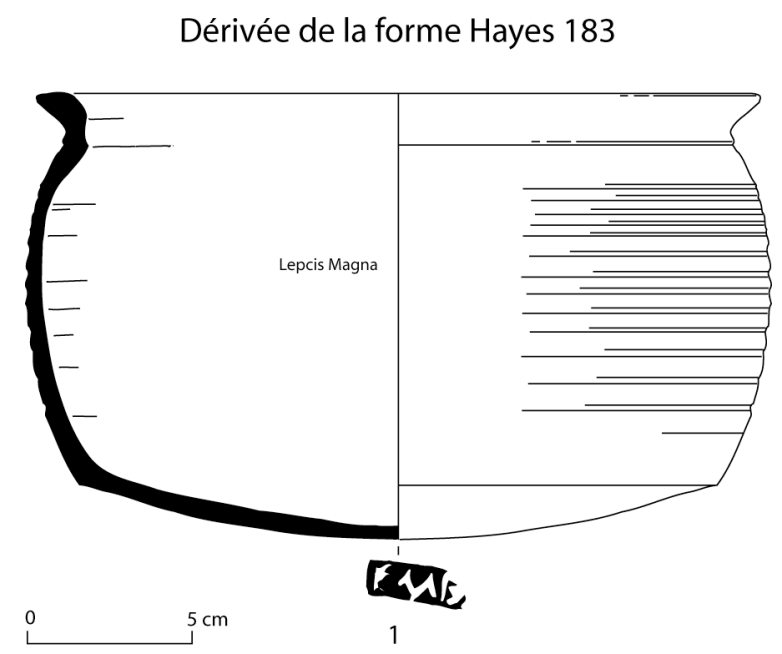

Fig. 122b. Vaisselle culinaire africaine. Productions de Tripolitaine.

- Bouilloires (fig. 123)

\section{Culinaire (C) TYPE 18}

Des fragments de vases à liquide à bec trilobé, avec une pâte apparentée à la céramique culinaire de type $\mathrm{C}$, sont attestés en petite quantité dans les contextes des IIe IVe s. à Pupput et Nabeul. Il s'agit vraisemblablement de bouilloires, forme connue en d'autres lieux à l'époque romaine (Batigne, Desbat 1996) et qui connaîtra un plus grand développement en Afrique aux époques vandale et byzantine (infra, CULINAIRE TYPES 33-34). Ces objets assez fragiles nous parviennent souvent dans un état très fragmentaire mais une forme est cependant bien connue et semble avoir eu une certaine diffusion outre-mer (Gonzalez Villaescusa 1993), la forme Uzita 48, 1 : vase à liquide à panse basse, carénée et fond bombé, long col tronconique, bec trilobé, munie d'une anse nervurée.

Exemples (fig. 123) :

1 Uzita, puits (Van der Werff 1982a, Pl. 48, nº 1).

*2 Villa romaine de Tolegassos (Catalogne) (Casas, Nolla 1986-89, fig. 10, $\mathrm{n}^{\circ} 3$ ).

3 Arles (Inv. IRPA 1332.1).

4 Sabratha (Dore 1989, fig. 67, forme 380). Variante ?

Variante tardive

*5 Sidi Jdidi, basilique 2, destruction état II (Inv. JD2200.2). Surface beige, rugueuse, fond noirci. 


\section{Bouilloires}
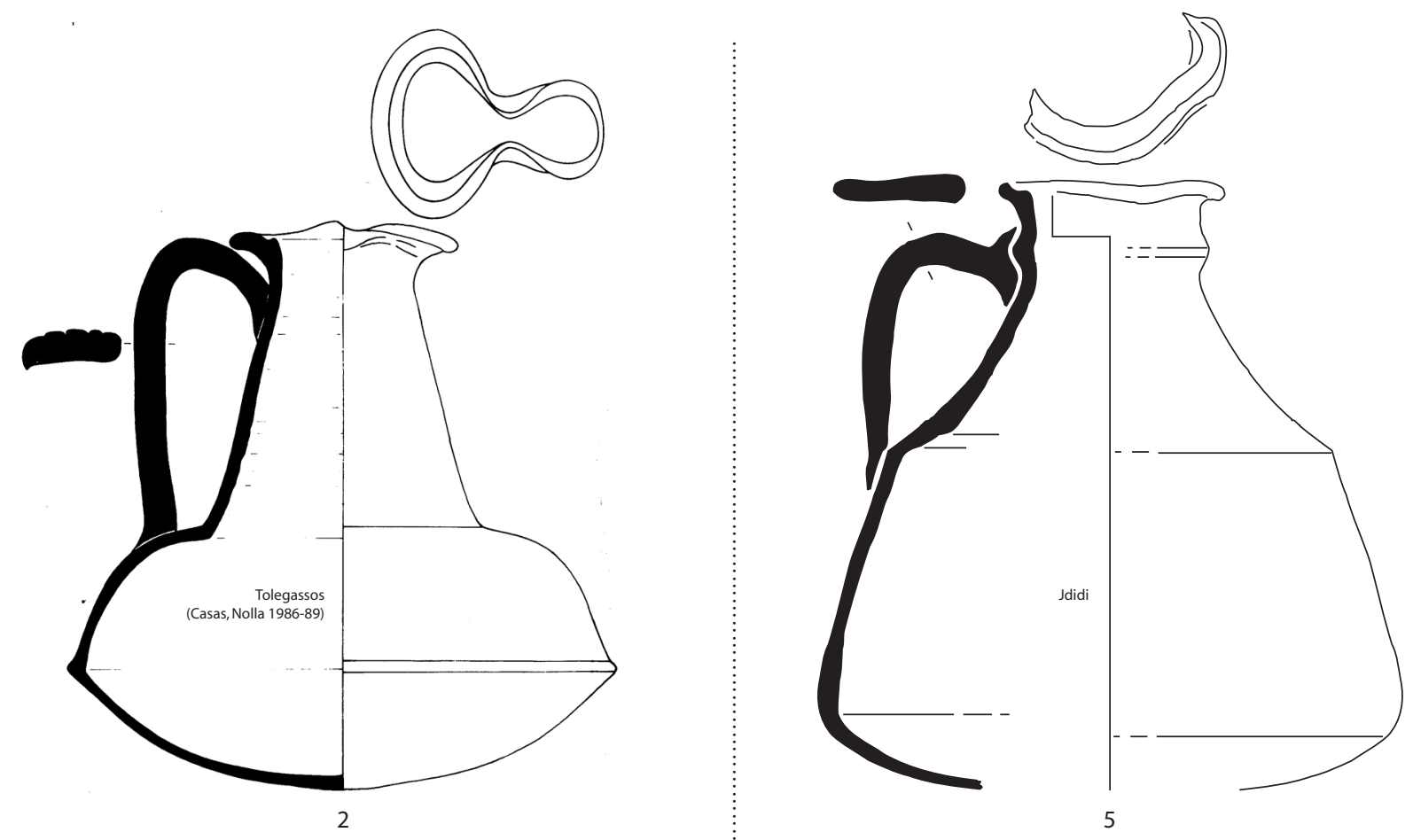

CULINAIRE

Plat Fulford 1

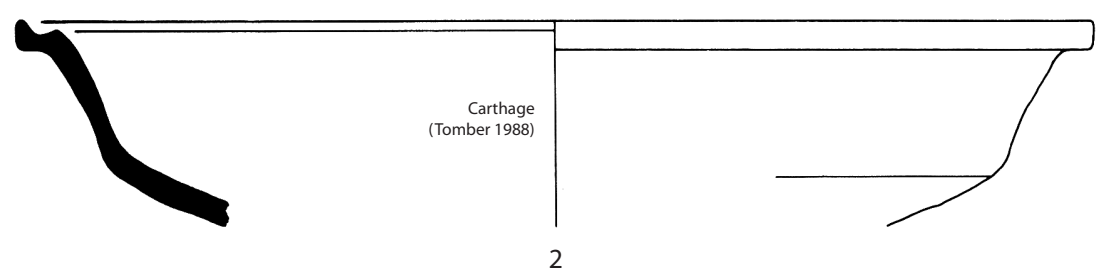

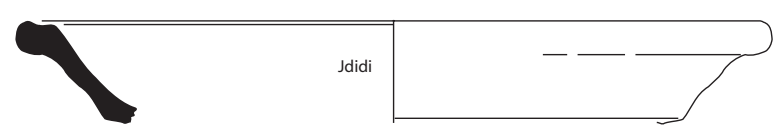

4

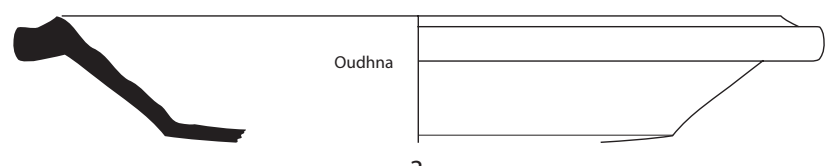

3

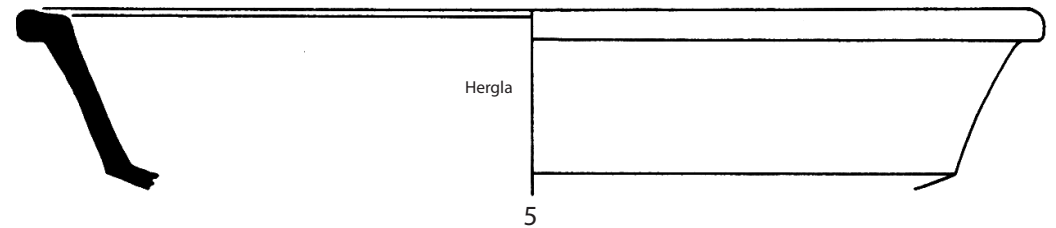

CULINAIRE

TYPE 19

Fig. 123. Vaisselle culinaire africaine. Catégorie C. Byzacène. 
Cette forme, dont une variante (1-3) paraît spécifique de la Byzacène (bien attestée à Leptiminus : Dore 1992, 153, $\mathrm{n}^{\circ} 89$ et observations personnelles), est généralement rencontrée dans les contextes du IIIe s., datation confirmée par les exemplaires de $\mathrm{Nabeul}^{173}$ et d'Ibiza (Gonzalez Villaescusa 1990, fig. 27, $\mathrm{n}^{\circ}$ 77-78). L'exemplaire de Sidi Jdidi, daté de la seconde moitié du Ves., constitue peut-être une évolution tardive de la même forme.

\section{- Plats Fulford $1=$ LR Cooking Pot 2 (Tomber 1988)} (fig. 123)

\section{Culinaire (C) TYPe 19}

Trouvant peut-être son origine dans quelques exemplaires précoces du Ier s. (Dore 1989, 112, forme 22) ou du IIe s. (Riley 1979, fig. 101, D465), ce plat à feu à fond convexe, parois évasées et petit marli concave est connu au IIIe s. en Byzacène, en production B (forme Uzita 3 : supra, fig. 118) et en production C (forme Uzita 43, 17). Des variantes tardives sont attestées à la fin du IVe s. et au début du Ve s. à Carthage (Fulford Dish/Lid $1=$ Tomber Cooking Pot 2) et encore dans la seconde moitié du Ve s. à Sidi Jdidi (4). On peut également se demander s'il n'y a pas une filiation entre la forme produite en culinaire vernissée de type B et la forme Hayes 79 en sigillée africaine D.

Exemples (fig. 123) :

1 Carthage (Fulford 1984b, fig. 71, $\mathrm{n}^{\circ} 1.1$ ).

*2 Carthage, cirque (Tomber 1988, fig. 14, 297).

*3 Oudhna, capitole (Inv. UTH1.001.49 ; Bonifay, Dridi, Jacquest à paraître, $\left.n^{\circ} 23\right)$. Dessin $H$. Jacquest.

*4 Sidi Jdidi, basilique , état B2A (Bonifay, Reynaud 2004, n 18.18). Résiduel dans le contexte 18.

*5 Hergla, fouilles anciennes (Inv. HG.000.119). Dessin M. Pasqualini.

\subsubsection{Céramiques culinaires africaines à diffusion régionale}

Les fouilles menées depuis une dizaine d'années sur le site de Sidi Jdidi ont permis de montrer que l'essentiel de la céramique culinaire de cette petite ville à $15 \mathrm{~km}$ en retrait de la côte échappe aux classifications traditionnelles de la céramique culinaire africaine et se caractérise par une pâte particulière et un répertoire de formes spécifique. Ces productions se retrouvent également à Pupput, grande ville voisine du littoral, mais en proportion moindre ${ }^{174}$ car elles côtoient les céramiques culinaires africaines classiques. A Nabeul, la situation est encore différente car la ville reçoit une grande quantité de céramiques culinaires des catégories $\mathrm{C} / \mathrm{A}$ et $\mathrm{C} / \mathrm{B}$, une petite quantité de productions locales du golfe d'Hammamet mais aussi quelques céramiques culinaires apparemment produites dans le cap Bon. Cette situation

\footnotetext{
${ }^{173}$ Comblement du bassin XLVI, milieu IIIe s. (NB1519).

${ }^{174}$ La céramique culinaire régionale du golfe d'Hammamet représente plus d'un tiers des céramiques culinaires de la nécropole de Pupput : Bonifay 2004a, 44.
}

très morcelée, très complexe, doit probablement se retrouver dans d'autres régions de Tunisie, notamment celles situées plus à l'intérieur des terres.

\section{Productions locales du golfe d'Hammamet}

La céramique culinaire régionale du golfe d'Hammamet se caractérise par une pâte généralement orange vif mais aussi très souvent brun violacé, parfois bicolore, d'aspect un peu brillant, avec de nombreuses inclusions de quartz, parfois de grande taille, et quelques inclusions rouille; la surface est généralement grise ou marron à l'extérieur, orange ou beige à l'intérieur; cette production n'est habituellement pas engobée. La typologie établie à Sidi Jdidi (Bonifay, Reynaud 2004, 239-243) est complétée à Pupput par quelques nouvelles formes (Bonifay 2004a, 44-48). On remarque que les nouveaux types attestés à Pupput trouvent des comparaisons en Byzacène plus méridionale (notamment à Uzita), tandis que ceux identifiés à Sidi Jdidi ne semblent pas être diffusés ni très au Sud (ils sont attestés à Hergla mais pas à El Jem), ni au nord (ils sont, semble-t-il, absents de Carthage). L'ensemble de ces objets connaît une très faible diffusion en Méditerranée, ce qui explique qu'ils n'ont pas ou peu été pris en compte par les grandes classifications.

\section{- formes apparentées au faciès général de Byzacène}

\section{— Marmites ou casseroles}

$$
\text { - marmite type Pupput } 1 \text { (fig. 124) }
$$

\section{Culinaire (C) TYPE 20}

Marmite globulaire à bord plat déversé, épaissi à son extrémité, légèrement concave au sommet. Exemples (fig. 124):

*1 Pupput, tombe 411 (Bonifay 2004a, fig. 18, $\mathrm{n}^{\circ} 68$ ).

2-3 Idem, tombe 447 (Inv. PP2366.10-11).

4 Idem, tombe 1097 (Inv. PP2553.1).

Variante engobée

*5 Pupput, tombe 418 (Inv. PP2948.7). Engobe marronrouge à l'extérieur.

Cette forme, qui trouve également des parallèles à Uzita (Van der Werff 1982a, Pl. 51, n 5 ), apparaît régulièrement dans les contextes du IIe siècle. Notamment, le $\mathrm{n}^{\circ} \mathbf{4}$ était associé à deux lampes de type Deneauve VII/1 timbrées CIVNDRAC.

- marmite type Pupput 2 (fig. 124)

\section{CULinAire (C) TYPE 21}

Marmite globulaire à bord en bandeau vertical. Cette forme en céramique tournée est peut-être influencée par les marmites modelées de Pantelleria de type Sabratha 291-292 (Bonifay 2004a, fig. 23, n 93-94). Exemples (fig. 124) :

*1 Pupput, tombe 1061 (Bonifay 2004a, fig. 18, n 69).

2-3 Pupput, tombe 937 (Inv. PP3250.20-21). 
Marmite type Pupput 1
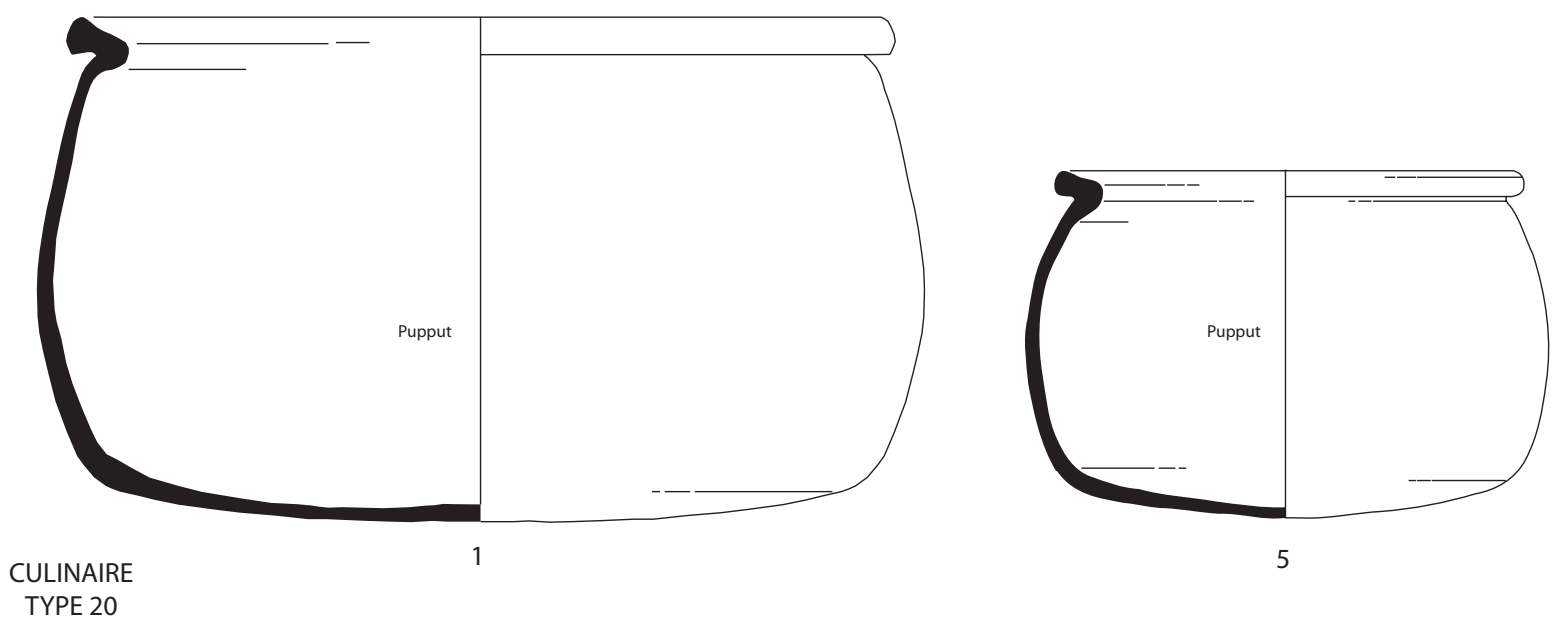

Marmite type Pupput 2

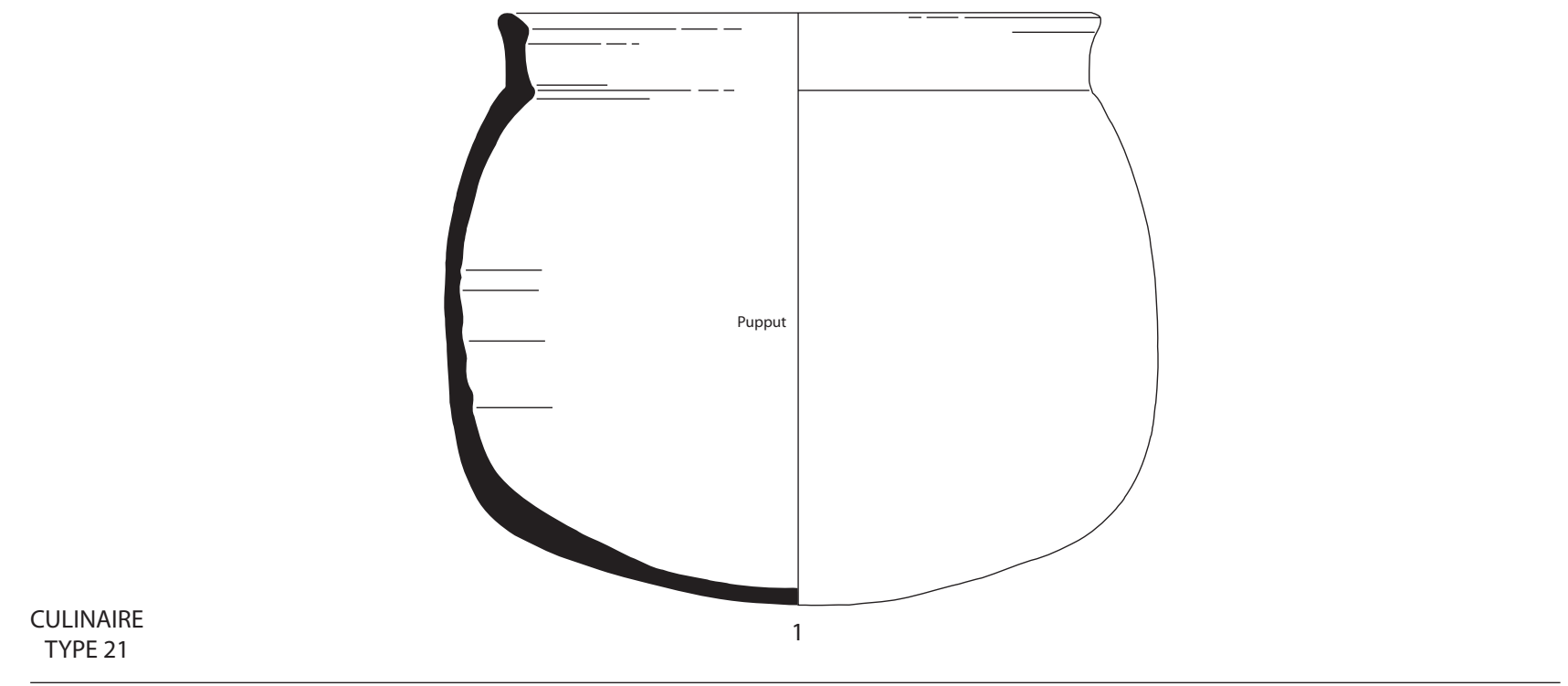

Couvercle type Pupput 1
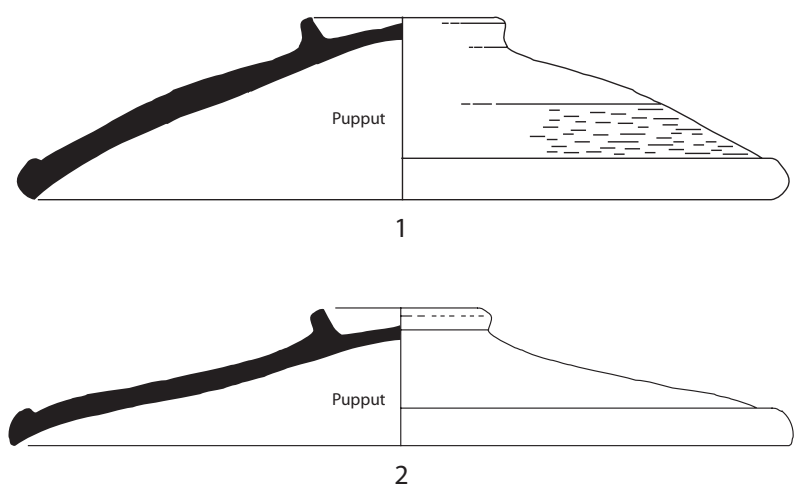

Fig. 124. Vaisselle culinaire africaine. Catégorie C. Golfe d'Hammamet. 
Marmite type Sidi Jdidi 1

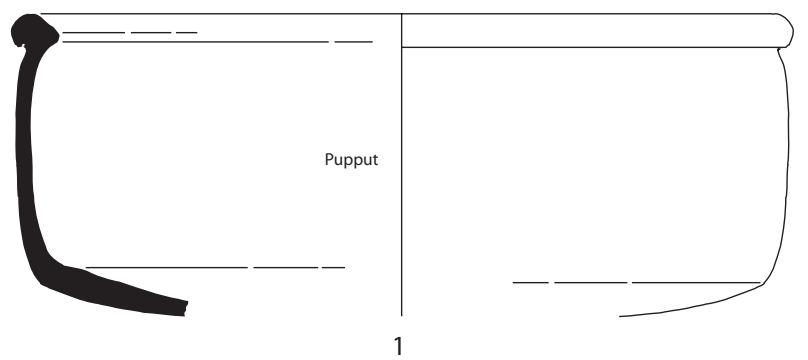

Marmite type Sidi Jdidi 2

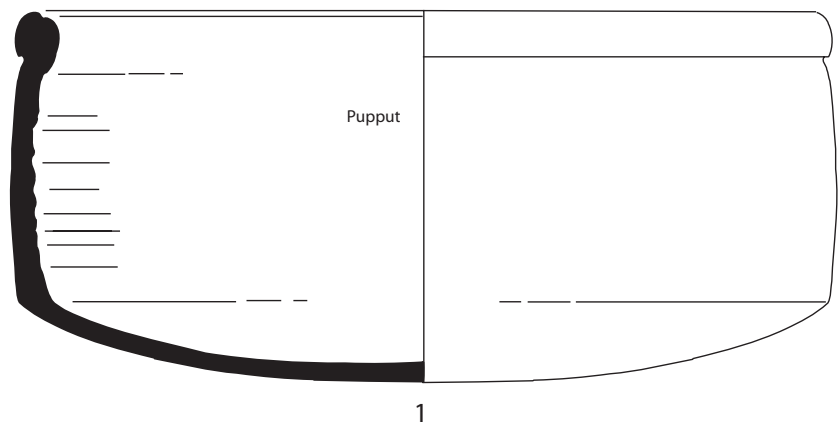

Marmite type Sidi Jdidi 3
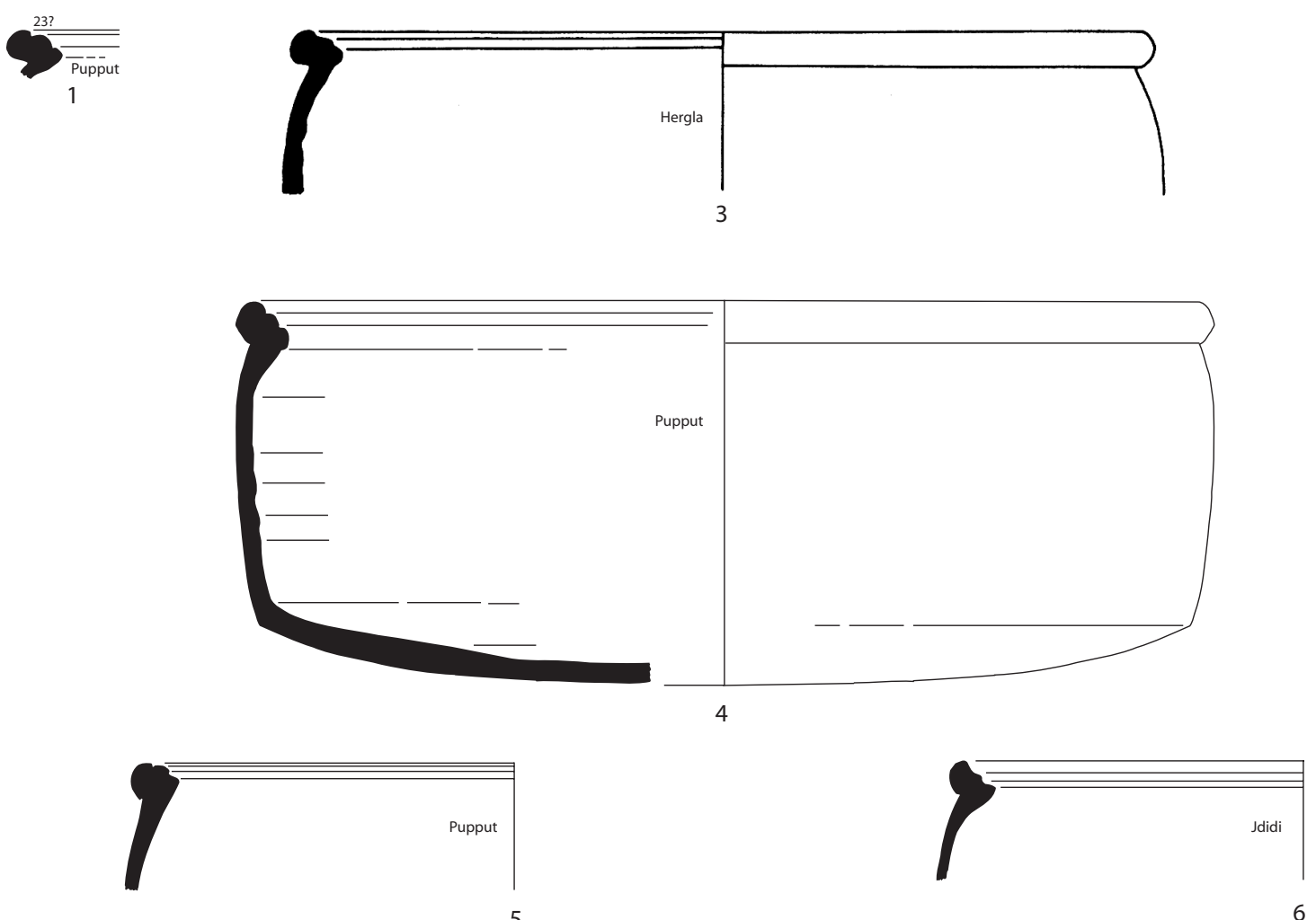

Fig. 125. Vaisselle culinaire africaine. Catégorie C. Golfe d'Hammamet. 
Les seuls exemplaires bien datés (2-3) proviennent d'une tombe du IIe siècle ${ }^{175}$.

\section{- Couvercles}

- couvercle type Pupput 1 (fig. 124)

\section{Culinaire (C) TYPE 22}

Couvercle de forme conique très aplatie aux parois rectilignes terminées par une lèvre en amande et munie d'un pied annulaire. Cet objet, qui ne comporte aucune trace de façonnage à l'intérieur a dû être tourné sur une forme en motte (?). Ce couvercle accompagne principalement les marmites de type Pupput 1 (cf. $\mathrm{n}^{\circ} \mathbf{2}$ ).

D. : 22-23 en moyenne.

Exemples (fig. 124) :

*1 Pupput, tombe 411 (Inv. PP1951.17).

*2 Pupput, (Bonifay 2004a, fig. 18, $\mathrm{n}^{\circ}$ 67).

Petit modèle

3 Pupput, tombe 411 (Inv. PP1951.15). D. $19 \mathrm{~cm}$.

Ce type n'est pas original. Il s'apparente à la forme la plus courante des couvercles de céramique culinaire en Byzacène : forme Hayes 185, $\mathrm{n}^{\circ} 3$, (supra, CULINAIRE TYPE 16, $\mathrm{n}^{\circ} 3$ ) ou forme Uzita 13 (Rood Byzaceens gebruiksaardewerk). Ces couvercles apparaissent à Pupput dans les tombes du IIe au IIIe s. sans qu'il soit possible, à l'heure actuelle, de discerner une nette évolution. Tout au plus peut-on comparer le profil arrondi $\mathrm{du} \mathrm{n}^{\circ} \mathbf{1}$, issu d'une tombe du IIe $\mathrm{s}$. et celui très aplati du $\mathrm{n}^{\circ} \mathbf{2}$, provenant des niveaux de fréquentation de la nécropole (IIIe s.).

\section{- formes plus spécifiquement locales (?)}

\section{— Marmites ou casseroles}

\section{- marmite type Sidi Jdidi 1 (fig. 125)}

\section{Culinaire (C) TYPe 23}

Marmite à bord épaissi recourbé vers l'extérieur, parois verticales et fond convexe. Allure générale proche de la forme Hayes 183.

Exemples (fig. 125) :

*1 Pupput (Bonifay 2004a, fig. 19, $\mathrm{n}^{\circ} 70$ ).

2 Pupput, tombe 1104 (Inv. 3091.4).

Une forme assez proche est connue à Chemtou au IIIe s. (Vegas 1994a, 158 et fig. 163, $\mathrm{n}^{\circ} 145$ ). Les exemplaires de Pupput sont issus de contextes de la fin du IIe s. ${ }^{176}$ (2) ou de la première moitié du IIIe s. ${ }^{177}(\mathbf{1})$.

\section{- marmite type Sidi Jdidi 2 (fig. 125)}

\section{CULinAIRE (C) TYPE 24}

Marmite à bord épaissi recourbé vers l'extérieur et marqué d'une cannelure sur son sommet, parois verticales

\footnotetext{
${ }^{175}$ Tombe 937 associée à des lampes africaines Deneauve VII/1 avec des timbres CIVNALEXI, AVFIFRON et FRONI.

${ }^{176}$ Tombe 1104 , avec une lampe Deneauve VII/1 fruste.

${ }^{177}$ Niveaux de circulation de la nécropole.
}

et fond convexe. Peut-être une imitation de la forme Hayes 197 de la catégorie C/A, mais sans les microsillons sous le fond.

Exemples (fig. 125) :

*1 Pupput (Bonifay 2004a, fig. 19, $\mathrm{n}^{\circ} 71$ ).

Un seul exemplaire complet, en surface de la nécropole : première moitié du IIIe s. (?).

\section{- marmite type Sidi Jdidi 3 (fig. 125)}

\section{Culinaire (C) TYPE 25}

Marmite à bord épaissi recourbé vers l'extérieur et marqué de deux cannelures sur son sommet, qui lui donnent un aspect nettement trifide; les parois sont verticales et le fond convexe.

Exemples (fig. 125) :

*1 Pupput, zone ouverte sud, période 2 (Ben Abed, Griesheimer 2004, fig. 46, $\mathrm{n}^{\circ} 2.11$ ).

2 Jebel Harboun (Ben Abed et al. 2000, fig. 8, $\mathrm{n}^{\circ} 5$ ).

*3 Hergla, fouilles anciennes (Inv. HG.000.122). Dessin M. Pasqualini.

*4 Pupput (Bonifay 2004a, fig. 19, $\mathrm{n}^{\circ}$ 72).

*5 Pupput, zone ouverte sud, période 11 (Ben Abed, Griesheimer 2004, fig. 131, $\left.\mathrm{n}^{\circ} 11.24\right)$.

*6 Sidi Jdidi, état B1A (Bonifay, Reynaud 2004, $\mathrm{n}^{\circ}$ 12.15).

On distingue assez bien une évolution entre les exemplaires anciens à lèvre étirée et aplatie de la première moitié du IIe s. (1), jusqu'aux exemplaires tardifs à lèvre compacte du milieu du IIIe s. (5-6); le n ${ }^{\circ} 4$ représente sans doute un stade intermédiaire de cette évolution. Il est possible que cette forme soit produite, au moins en partie, à Pheradi Majus/Sidi Khalifa (supra, p. 56). Forme diffusée à Ostie dans la première moitié du IIIe s. (Ostia I, 267).

\section{- marmite type Sidi Jdidi 5 (fig. 126)}

\section{Culinaire (C) TYPE 26}

Marmite à bord quadrangulaire et parois légèrement rentrantes; fond probablement convexe. La section quadrangulaire du bord est obtenue par repliement de la lèvre sur elle-même (2). Pas de forme complète.

Exemples (fig. 126) :

*1 Sidi Jdidi, basilique 3, phase de construction (Inv. JD506913).

*2-*3 Idem, basilique 1, état B1A (Bonifay, Reynaud 2004, $\mathrm{n}^{\circ} 12.10$ et 12$)$.

4 Idem (Ibid., n 12.13).

5 Nabeul, fabrique de salaison, période 5B (Inv. NB 1166.57). Semblable au $n^{\circ} 4$.

6 Sidi Jdidi, basilique 2, destruction état II (Inv. JD2087.12).

Le plus ancien exemplaire bien daté provient d'un contexte de la fin du IVes. (1) ; celui qui est attesté au milieu du IIIe s. à Sidi Jdidi (Bonifay, Reynaud 2004, $n^{\circ} 3.8$ ) est peut-être intrusif dans la mesure où cette forme est complètement absente de la nécropole de 
Marmite type Sidi Jdidi 5
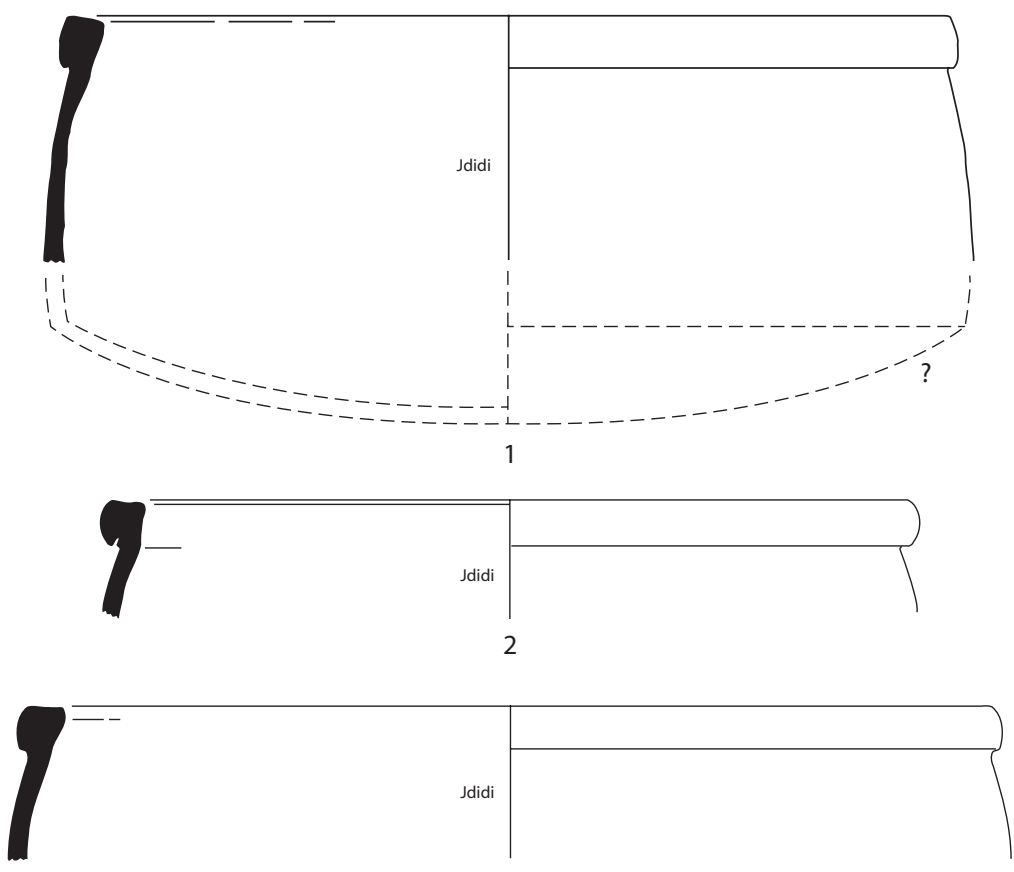

Marmite type Sidi Jdidi 6
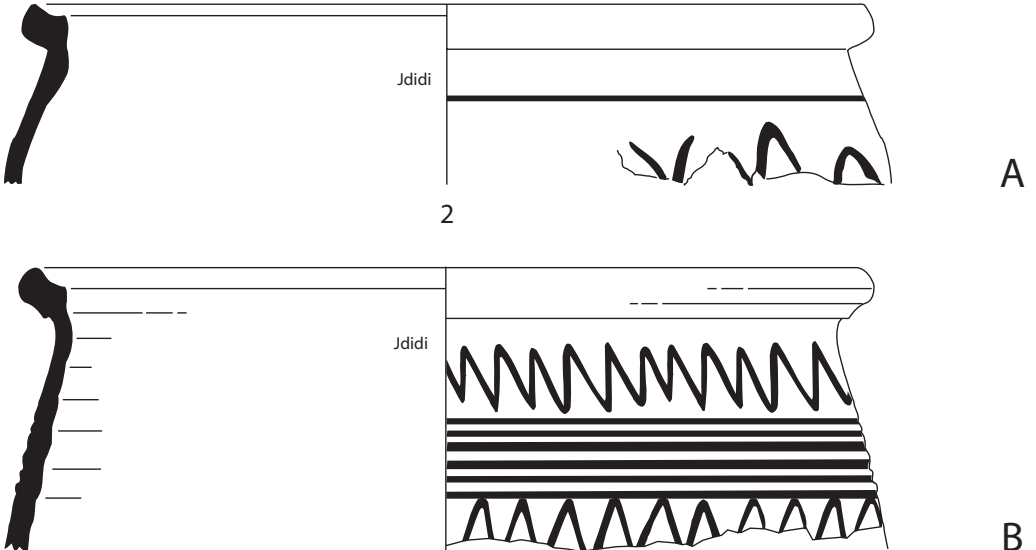

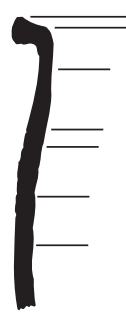

CULINAIRE TYPE 27

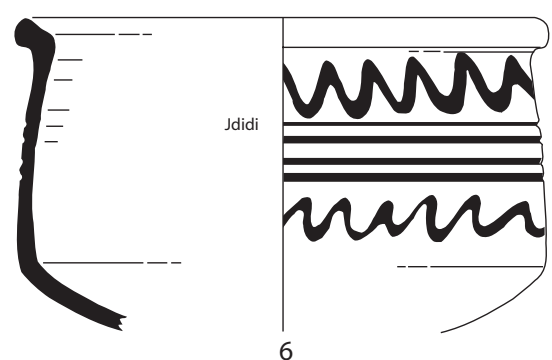

C

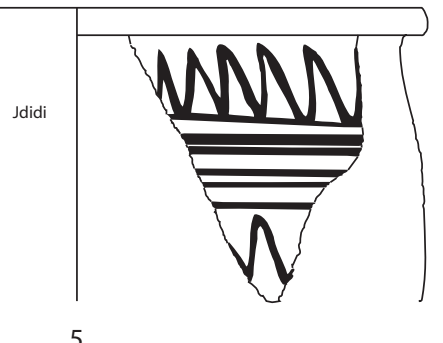

$\stackrel{0}{\llcorner}$ $5 \mathrm{~cm}$

Fig. 126. Vaisselle culinaire africaine. Catégorie C. Golfe d'Hammamet. 
Marmite type Sidi Jdidi 7
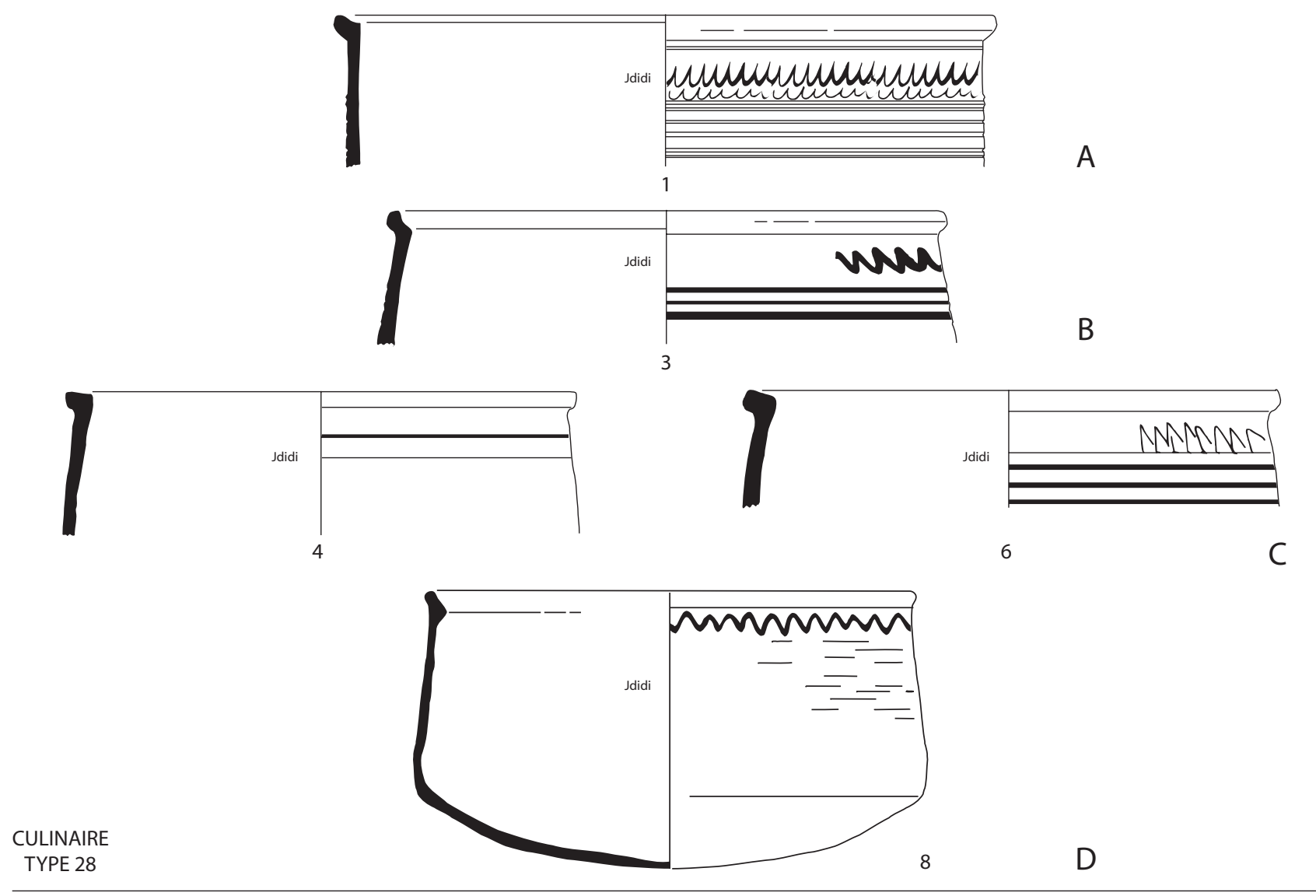

Marmite type Sidi Jdidi 8

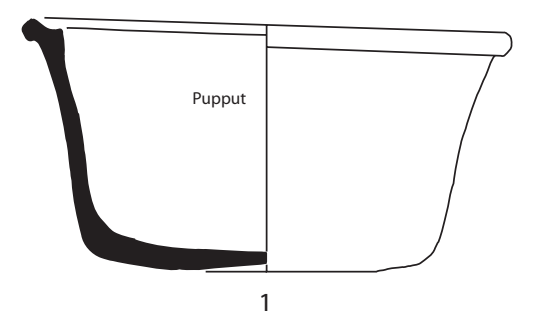

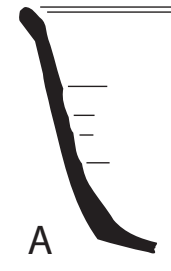

CULINAIRE TYPE 29

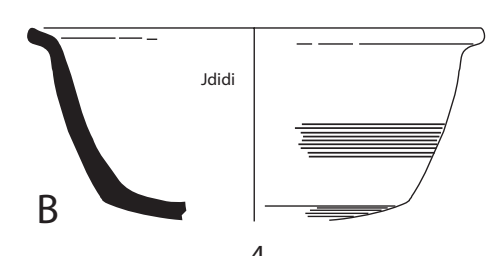

4

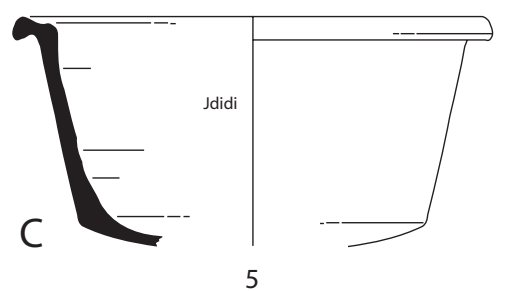

Couvercle Sidi Jdidi 1

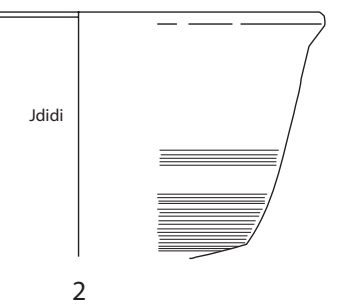

2

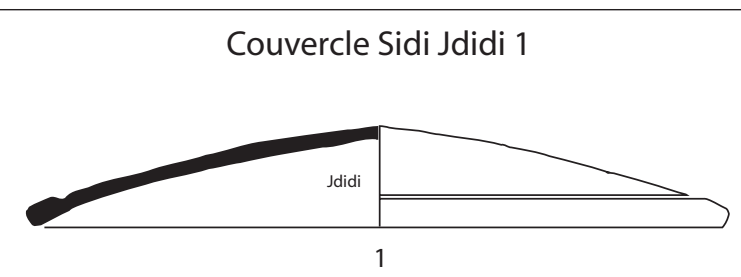

0 $5 \mathrm{~cm}$

Fig. 127. Vaisselle culinaire africaine. Catégorie C. Golfe d'Hammamet. 
Pupput. D'autres exemples sont datés de la première moitié (2-5) et de la seconde moitié du Ve s. (6).

- marmite type Sidi Jdidi 6 (fig. 126)

\section{Culinaire (C) TYPe 27}

Marmite à bord rentrant, petite lèvre déversée au sommet creusé d'une gorge, paroi courbe décoré de deux lignes ondées séparées par un groupe de cannelures. Vague analogie avec la forme Ostia I, 268 (?). Trois variantes connues, dans l'état actuel de la documentation :

- variante A : bord très épaissi, à section grossièrement quadrangulaire, parois courbes et rentrantes ;

- variante B : bord plus étiré, avec une arête vive sur la face inférieure, à la jonction avec la panse ;

- variante $\mathrm{C}$ : bord court, aminci.

Exemples (fig. 126):

Variante A

1 Sidi Jdidi, basilique 1, état A2 (Bonifay, Reynaud 2004, $\mathrm{n}^{\circ}$ 11.2).

*2 Idem, état B2A (Ibid., $\mathrm{n}^{\circ} 18.22$ ). Résiduel dans le contexte 18 .

Variante B

*3 Sidi Jdidi, basilique 2, destruction état II (Inv. JD 2300.9). Dessin T. Mukai.

4 Idem (Inv. JD2087.14).

Variante $\mathrm{C}$

*5 Sidi Jdidi, basilique 2, destruction état II (Inv. JD 2087.11).

*6 Idem (Inv. JD2326.20). Dessin T. Mukai.

Le plus ancien exemple de la variante A est attesté dans un contexte du premier tiers du Ve s. (1). Les deux autres variantes sont présentes dans des contextes de la seconde moitié du Ve $\mathrm{s}$. (3-6) : la variante $\mathrm{B}$, très fragmentaire dans ces niveaux, pourrait dater plutôt du milieu du siècle.

\section{- marmite type Sidi Jdidi 7 (fig. 127)}

\section{Culinaire (C) TYPE 28}

Casserole (?) aux parois rectilignes. Peut-être une simple variante de la forme précédente. Décor ondé et/ou de cannelures. Quatre variantes, dans l'état actuel de la documentation :

- variante A: petite lèvre courte redressée, grossièrement triangulaire, et au sommet légèrement concave ;

- variante B: petite lèvre courte redressée en virgule ;

- variante $\mathrm{C}$ : petite lèvre courte quadrangulaire et massive ;

- variante $\mathrm{D}$ : lèvre atrophiée à renflement interne. Exemples (fig. 127) :

Variante A

*1 Sidi Jdidi, basilique 1, état A1 (Bonifay, Reynaud 2004, $n^{\circ} 3.12$ ).

2 Marseille, chantier de l'Alcazar (Bien 2001, $\mathrm{n}^{\circ} 48$ ).

Variante B

*3 Sidi Jdidi, basilique 1, état A2 (Bonifay, Reynaud 2004, $n^{\circ}$ 9.8)
Variante C

*4 Sidi Jdidi, basilique 1, état A2 (Ibid., $\mathrm{n}^{\circ}$ 9.7).

5 Idem, état B2A (Ibid., $\mathrm{n}^{\circ}$ 18.21). Résiduel dans le contexte 18.

*6 Idem, état B2A (Ibid., $\mathrm{n}^{\circ}$ 18.20). Résiduel dans le contexte 18 .

Variante D

7 Nabeul, fabrique de salaison, période 5B (Inv. NB 1166.34). Semblable au n ${ }^{\circ} 8$.

*8 Sidi Jdidi, basilique 2, destruction état II (Inv. JD 2258.23). Dessin P. Reynaud.

La variante $\mathrm{A}$ semble déjà présente au milieu du IIIe s. (1), à moins qu'il ne s'agisse d'une intrusion. Les variantes $\mathrm{B}(\mathbf{3})$ et $\mathrm{C}(\mathbf{4})$ sont bien attestées au premier quart du Ve s. (?) tandis que la variante D, qui apparaît avant le milieu du Ve s. (7) est encore présente à la fin du siècle $(\mathbf{8})$.

\section{- marmite type Sidi Jdidi 8 (fig. 127)}

\section{Culinaire (C) TYPE 29}

Petite casserole (?) à parois légèrement évasées et fond bombé ; extérieur légèrement strié par endroits. Trois variantes dans l'état actuel de la documentation :

- variante $A$ : lèvre très légèrement déversée ou simplement dégagée par une gorge peu prononcée ;

- variante B : lèvre nettement déversée ;

- variante $\mathrm{C}$ : lèvre pincée sub-horizontale.

Exemples (fig. 127) :

Variante précoce?

*1 Pupput (Inv. PP1122.6)

Variante A

*2 Sidi Jdidi, basilique 1, état C1 (Bonifay, Reynaud 2004, $\left.n^{\circ} 13.5\right)$.

3 Idem (Ibid., $\left.\mathrm{n}^{\circ} 13.6\right)$.

Variante B

*4 Sidi Jdidi, basilique 1, état B1B (Bonifay, Reynaud 2004, $\left.n^{\circ} 17.1\right)$.

Variante C

*5 Sidi Jdidi, basilique 2, destruction état II (Inv. JD2258.23).

Mis à part le $\mathrm{n}^{\circ} \mathbf{1}$, qui peut-être daté de la seconde moitié $\mathrm{du}$ IIIe s. ou du IVe s. (?), les trois variantes semblent s'échelonner ou se côtoyer au Ve s., principalement dans la seconde moitié du siècle.

\section{- Couvercles}

D'assez nombreux fragments de couvercles, tous très fragmentaires, sont associés à ces vases à feu. Une seule forme est complète :

- couvercle type Sidi Jdidi 1 (fig. 127)

\section{CULINAIRE (C) TYPE 30}

Couvercle aux parois coniques très aplaties, bord non épaissi dégagé par une gorge.

Exemple (fig. 127) :

*1 Sidi Jdidi, basilique 2, destruction état II (Inv. JD2258.32). Dessin P. Reynaud. 
Marmite type Sidi Jdidi 4
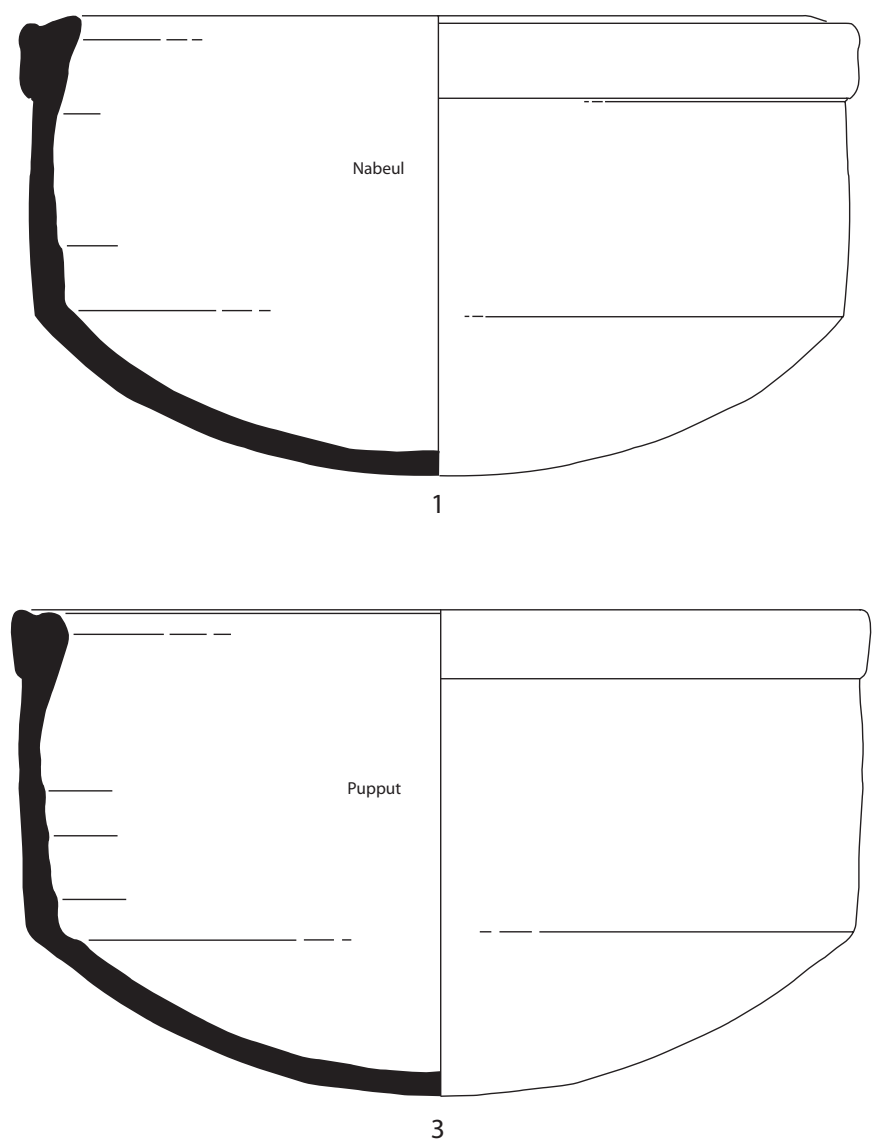

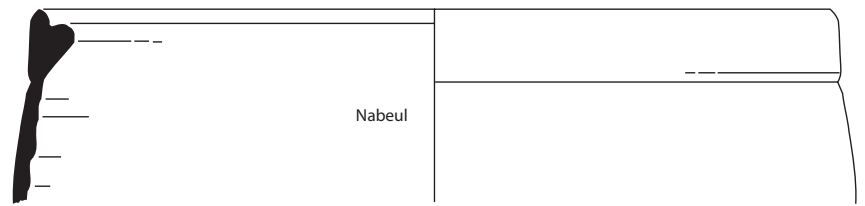

4

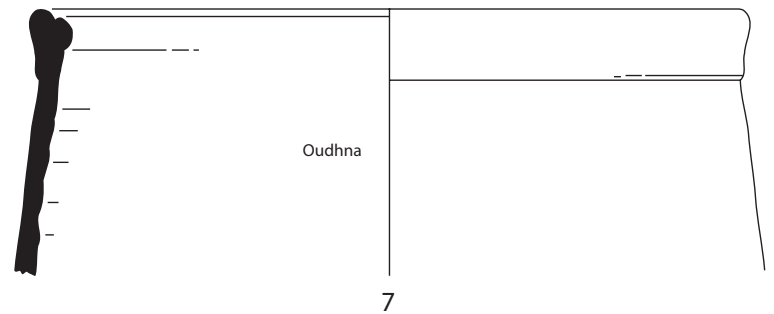

CULINAIRE

TYPE 31

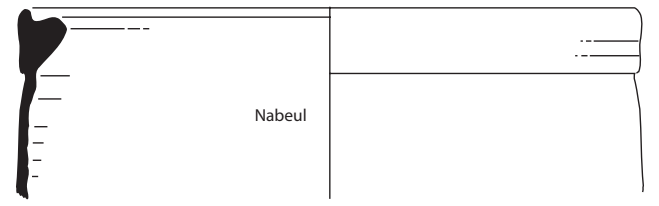

5

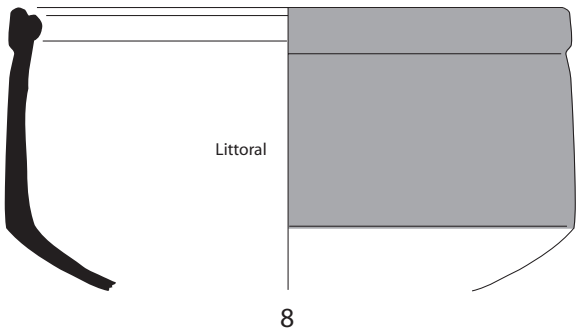

8

Fig. 128. Vaisselle culinaire africaine. Catégorie C. Cap Bon. 
Ce couvercle était associé à la marmite de type Sidi Jdidi $7 \mathrm{D}, \mathrm{n}^{\circ} 8$, dans un contexte de la seconde moitié du Ve siècle.

\section{Production locale du cap Bon (?)}

Le type Sidi Jdidi 4 doit être isolé de la série qui précède car, bien qu'attesté en petite quantité à Sidi Jdidi, Pupput et dans le terroir de Segermes (Lund 1995, 557 et fig. 24), il est surtout fréquent à Nabeul et dans le cap Bon. La pâte est assez proche de celle des productions du golfe d'Hammamet avec cependant un dégraissant plus abondant de quartz arrondi et une cuisson plus poussée donnant généralement une teinte brun orangé.

- marmite Sidi Jdidi 4 (fig. 128)

\section{CULINAIRE (C) TYPE 31}

Marmite à bord en bandeau à sommet bifide, parois verticales et fond fortement bombé. Peut-être à rapprocher de la forme Ostia I, $278(\text { ? })^{178}$.

Exemples (fig. 128) :

*1 Nabeul, fabrique de salaison, bassin XLVI (Inv. NB 1519.1).

2 Pupput, tombe 1227 (Inv. PP6913.1).

*3 Pupput (Bonifay 2004a, fig. 19, $\mathrm{n}^{\circ} 73$ ).

*4 Nabeul, fabrique de salaison, bassin XLVI (Inv. NB 1500.2)

*5 Idem, pièce XLIV (Inv. NB1878.166).

6 Idem (Inv. NB1878.65).

Variante?

*7 Oudhna, est capitole (fouilles H. Ben Hassen, Inv. UTH7.000.55).

*8 Littoral tunisien, site $n^{\circ} 145$ (Henchir Lebna, façade orientale du cap Bon) (Bonifay et al. 2002-2003, fig. $10, \mathrm{n}^{\circ} 108$ ).

Les exemplaires de Nabeul permettent d'identifier quelques éléments d'évolution: il semble, sur les exemplaires anciens de la première moitié ou du milieu du IIIe s., que la lèvre intérieure du bord bifide soit plus haute que la lèvre extérieure (1-2). Cette tendance semble s'inverser sur les variantes plus récentes de la fin du IIIe s. (4). Certains exemplaires du début du IVe s. (5-6) se distinguent en outre par une lèvre intérieure épaissie et proéminente. Il n'est pas impossible que les $n^{\circ} \mathbf{7 - 8}$, à bord atrophié, représentent une évolution encore plus tardive (voir également supra: forme Hayes $197=$ CULINAIRE TYPE 10 , variante $\mathrm{n}^{\circ} 8$ ).

Cette forme semble avoir connu une certaine diffusion en Méditerranée occidentale: outre l'exemplaire d'Ostie, elle est attestée à Rome (Ikäheimo 2003, Pl. 13, n 67), en Catalogne (Aguarod 1991, fig. 83, $n^{\circ} 3-4$ ) et dans le Midi de la France, notamment à Arles ${ }^{179}$, Saint-Jean-deGarguier et Antibes (observations personnelles). Il s'agit principalement de variantes tardives.
Bien d'autres productions locales de céramiques culinaires tournées doivent exister sur le territoire africain, notamment en Byzacène du sud-ouest, sur lesquelles je n'ai, personnellement, pas d'informations.

\subsubsection{Céramiques culinaires africaines tardives}

Grâce à l'abondance des niveaux tardifs étudiés dans cette ville, la céramique culinaire des Ve - VIIe s. a été bien classée et étudiée à Carthage. Mais cette classification est difficilement applicable au reste de la Tunisie. J'ai déjà signalé un certain nombre d'évolutions tardives des catégories classiques de la céramique culinaire africaine de Zeugitane et de Byzacène (supra, CULINAIRE TYPES $3,4,8,10,13,14,18,19)$ et des productions locales du golfe d'Hammamet et du cap Bon (supra, CULINAIRE TYPES 26-31). D'autres objets, de conception plus novatrice, caractérisent les ultimes productions de céramique culinaire tournée en Tunisie. Je souhaiterais attirer l'attention sur quelques-uns d'entre eux, certains déjà connus, d'autres plus insolites.

- Marmites globulaires à anses (fig. 129)

$=L R C W 1$, forme $\mathrm{C} 24=$ Fulford Casserole $19=$ CATHMA type A3

\section{CULINAIRE TYPE 32}

Une des formes les plus novatrices de la céramique culinaire africaine de l'Antiquité tardive est une marmite globulaire à panse cannelée avec un bord épaissi déversé et creusé d'une gorge interne; deux anses s'attachent directement sur la lèvre et viennent s'appuyer à mipanse ; le fond est probablement ombiliqué.

Exemples (fig. 129) :

1 Carthage (Hayes 1976a, fig. 15, C24).

2 Carthage (Fulford 1984b, 185 et fig. 69, Casserole 19).

3 Marseille, chantier de La Bourse (Bonifay 1986, fig. $\left.16, n^{\circ} 78\right)$.

*4 Tarragone (Aquilué 1989, fig. 91, $\mathrm{n}^{\circ}$ 5.47).

5 Carthage (Dietz, Trolle 1979, 103, $\mathrm{n}^{\circ} 12$ ).

*6 Marseille, chantier de la Major (Etude S. Bien, inédit). Variante précoce (?).

7-*8 Marseille (Cœur-Mezzoud 1998, fig. 129, n 197-198). Variantes tardives (?).

Ce pot à cuire a été remarqué pour la première fois par J. W. Hayes (1) qui l'a rattaché à sa catégorie $L R C W 1$; il n'a pu toutefois en reconnaître le profil, en raison du caractère très fragmentaire de sa documentation. La forme en tant que telle a été identifiée simultanément en plusieurs points de Méditerranée occidentale : à Carthage tout d'abord (2), puis en Catalogne (4) et en France méditerranéenne (3 ; C.A.T.H.M.A. 1991, 30-32 et fig. 7, type A3). C'est donc une forme très différente de celles qui ont fait le succès de la céramique culinaire africaine mais qui voyage tout autant, ou presque.

\footnotetext{
${ }^{178}$ L'orientation du dessin est différente.

${ }^{179}$ Renseignement J. Piton.
} 
Fulford Casserole 19 = type CATHMA A3
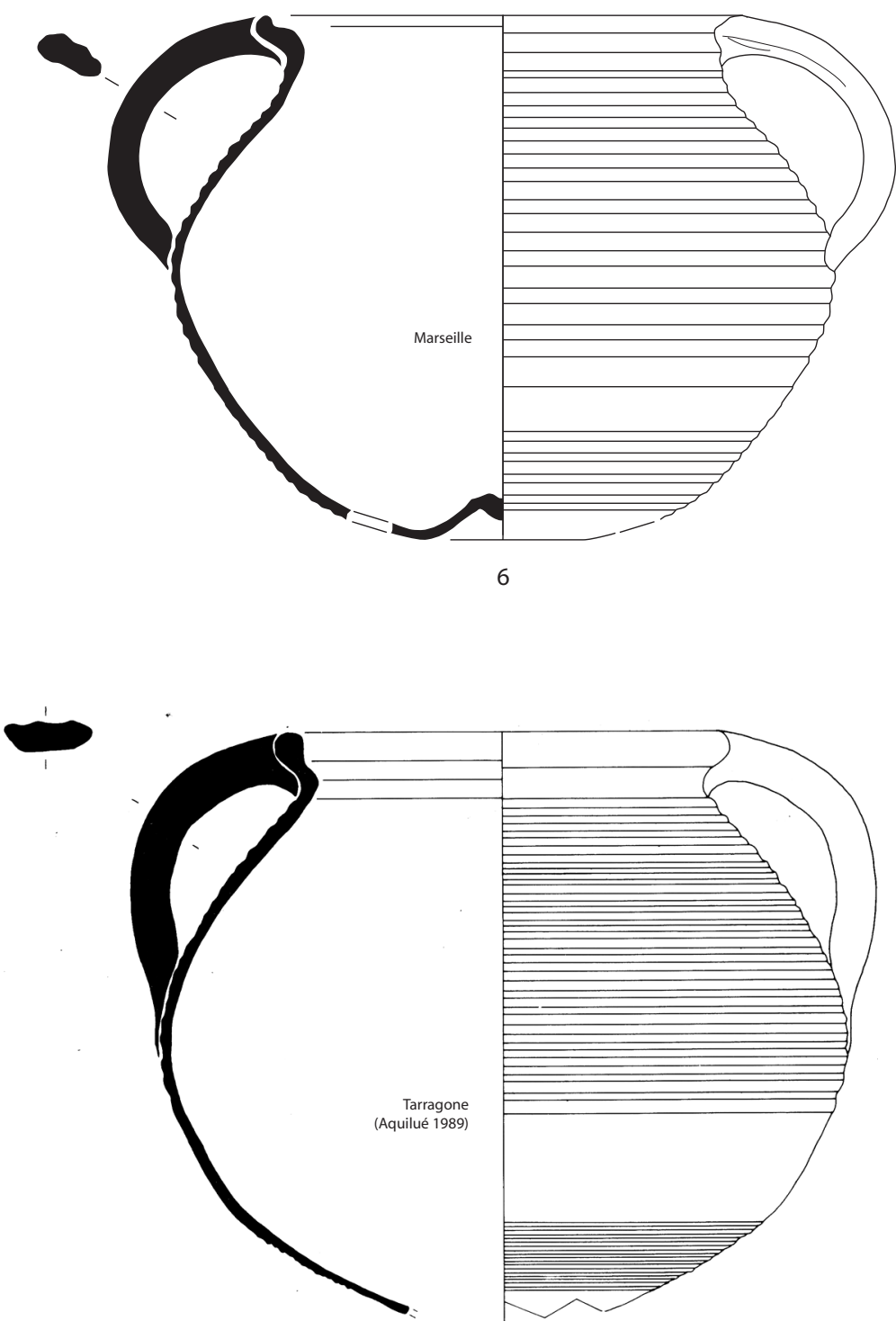

4

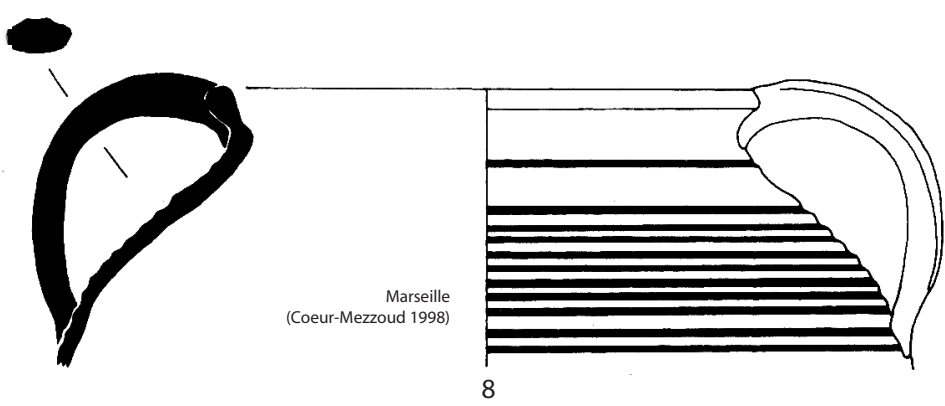

Fig. 129. Vaisselle culinaire africaine. Productions tardives. 
Bouilloires

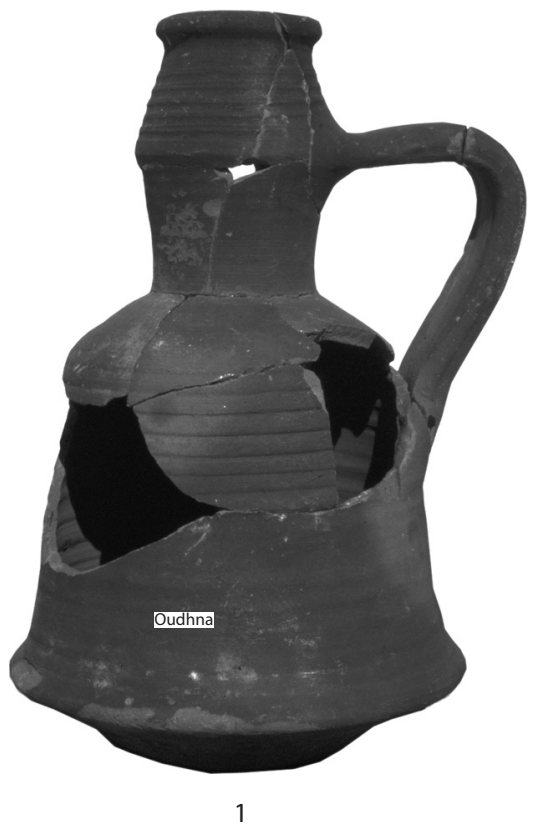

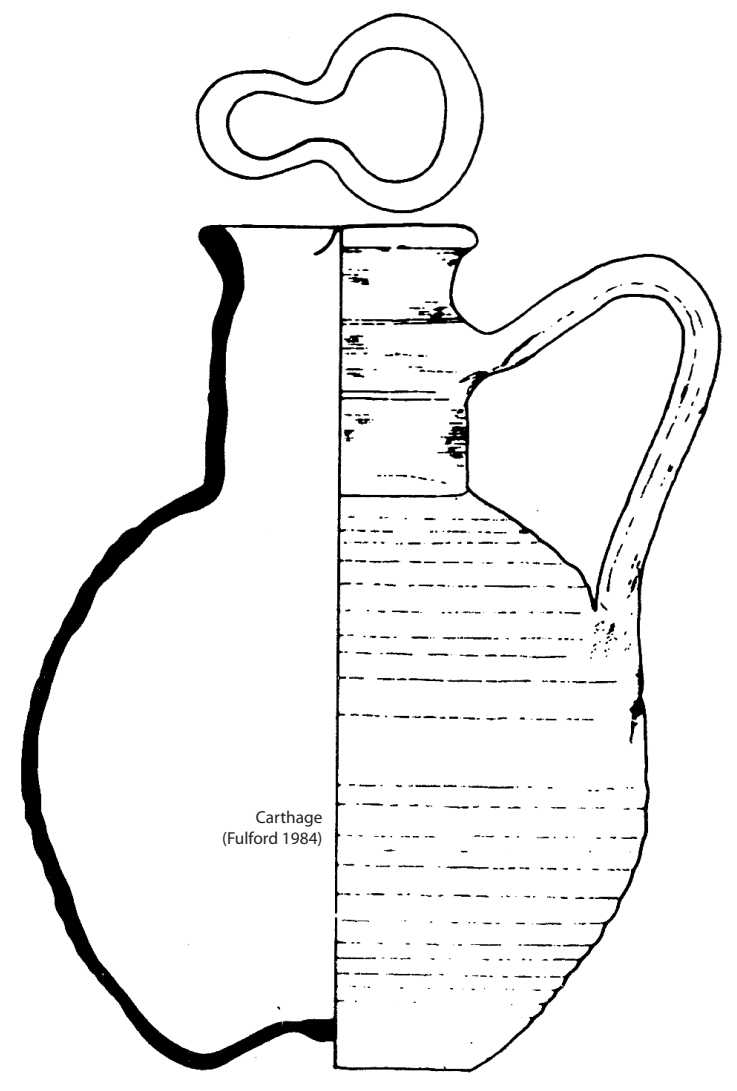

1

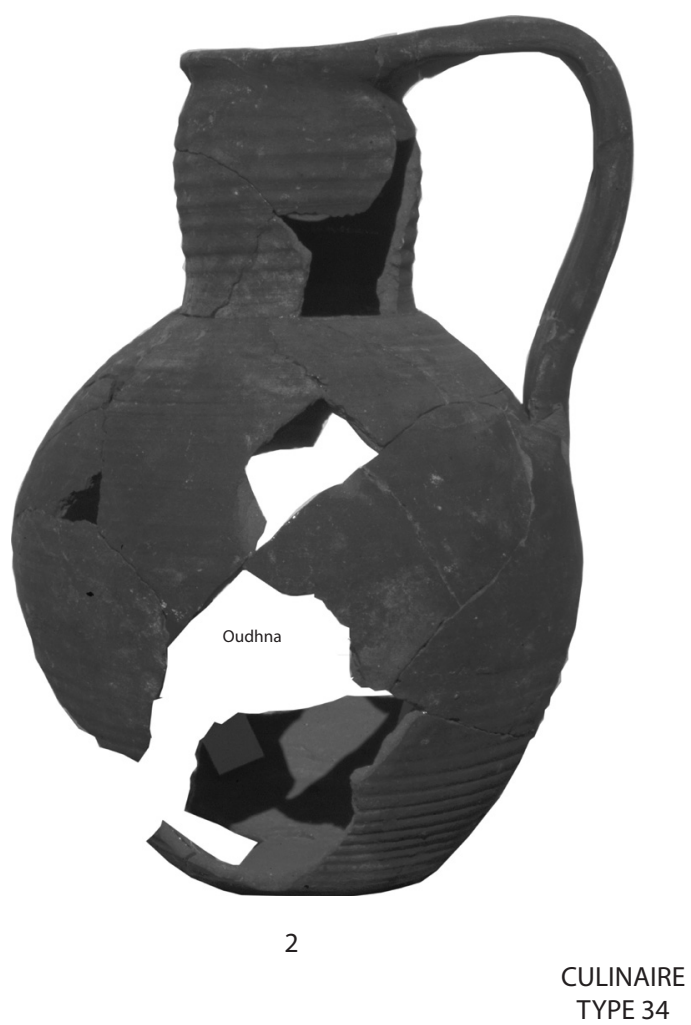

TYPE 34

Fig. 130. Vaisselle culinaire africaine. Productions tardives. 
Sa relative fréquence à Carthage et sur d'autres sites septentrionaux ${ }^{180}$ indique probablement une production $\mathrm{du}$ nord de la Tunisie ${ }^{181}$. Une évolution est peut-être décelable entre les premiers exemplaires apparaissant à la fin du IVe s., à lèvre sub-horizontale (6), et les ultimes (?) variantes à bord effilé (7-8) de la fin du Ve s., la plus grande diffusion étant atteinte avec la forme classique (15) dans les décennies centrales du Ve s. (C.A.T.H.M.A. 1991, 32).

Datation proposée : Ve s.

- Bouilloires (fig. 130)

\section{CULINAIRE TYPES 33 ET 34}

J'ai déjà mentionné l'évolution tardive, au Ve s., des bouilloires de Byzacène, bien connues depuis les IIeIIIe s. (supra, CULINAIRE TYPE 18). Mais ici il s'agit ici de toutes nouvelles formes, produites sur l'atelier d'Oudhna (Barraud et al. 1998, 152), que je ne mentionnerai que pour mémoire dans l'attente de la typologie précise qui en sera prochainement présentée ${ }^{182}$. Parmi les exemplaires déjà publiés, on distingue grossièrement deux types :

- TYPE 33 : corps piriforme cintré, col cylindrique renflé terminé par une petite lèvre arrondie, une anse plate adhérant à mi-col pour venir reposer sur l'épaulement ; le fond est ombiliqué (1).

- TYPE 34 : corps plus globulaire, col cylindrique, renflé ou non, anse s'attachant soit sur le col (1), soit directement sur le bord (2) ; fond ombiliqué.

Exemples (fig. 130) :

Type 33

*1 Oudhna, thermes des Laberii (sans $n^{\circ}$ d'inv.).

Type 34

*1 Carthage (Fulford 1984b, fig. 81, $\mathrm{n}^{\circ} 27$ ).

*2 Oudhna, thermes des Laberii (sans $\mathrm{n}^{\circ}$ d'inv.).

Un exemplaire du TYPE 33 a été publié à Carthage dans un contexte du Ve s. (Poulsen 1986, fig. 6) ; un autre est signalé à Majorque (Orfila 1989, fig. 7) avec une date similaire. Le TYPE 34 est attesté dans la seconde moitié du Ve s. et au VIe s. non seulement à Carthage (Neuru 1980, Pl. VI, $\mathrm{n}^{\circ} 30$; Fulford 1984b, fig. 81, $\mathrm{n}^{\circ} 27: \mathrm{n}^{\circ} \mathbf{1}$; Riley 1981, fig. 8, $\mathrm{n}^{\circ} 69$ ?) mais également à Ibiza (Ramon 1986, fig. 15, $\mathrm{n}^{\circ}$ 12). Cependant, contrairement aux hypothèses de R. Gonzalez Villaescusa (1993), il ne faut pas voir dans ces bouilloires une évolution du type Uzita 48,1 de Byzacène. Il s'agit de productions tardives de Tunisie septentrionale et s'il faut chercher une influence, c'est peut-être plutôt du côté de la céramique byzantine (?).

\footnotetext{
${ }^{180}$ Le seul fragment recueilli au cours des prospections du littoral tunisien provient du site d'Oum en Noual, à l'est de Tabarka. Quelques fragments à Nabeul.

181 Cette forme est toutefois bien attestée à Thapsus: je remercie mon ami Nejib Ben Lazreg de m'avoir invité à examiner, en 1998, le matériel de ses fouilles.

${ }^{182}$ Cf. note 154 .
}

Un autre objet, découvert à Marseille dans un contexte postérieur à $534-548^{183}$, pourrait bien correspondre à une bouilloire, sur le même modèle typologique que les précédentes (C.A.T.H.M.A. 1991, 33 et fig. 12, type A12).

\section{— Casseroles (fig. 131)}

\section{CULINAIRE TYPE 35}

- Avec manche: Une forme assez insolite, mise en évidence à Carthage (Hayes 1978b, fig. 9, 17) ne peut être interprétée que comme l'équivalent de nos casseroles actuelles. Il s'agit d'un bol au fond convexe, aux parois évasées terminées par un bord triangulaire étiré, au sommet parfois concave, et muni d'une anse attachée directement sur le bord ; cette anse est plate et coupée en double biseau à son extrémité.

Exemples (fig. 131) :

1 Carthage (Hayes 1978b, fig. 9, $\left.\mathrm{n}^{\circ} 17\right)$. D. 15, $5 \mathrm{~cm}$.

*2 Oudhna, thermes des Laberii (sans $n^{\circ}$ d'inv.).

*3 Idem (Inv. UT.TL.000.364). D. : 19, 5 cm. Surface orange, bord noirci.

Cette forme est particulièrement fréquente sur l'atelier d'Oudhna (2-3) où elle est associée, avec la même pâte, à des formes de marmites attribuées par J. W. Hayes (1978b, fig. 9, $\left.\mathrm{n}^{\circ} 15-16\right)$ à sa catégorie $L R C W 6$. A Carthage, elle est attestée dans des contextes du VIIe s. (1).

- Sans manche (?) : Une forme voisine est présente sur le site Sidi Jdidi mais, jusqu'à présent, sans trace d'anse : il s'agit, là encore, d'une casserole à parois évasées et lèvre horizontale au sommet légèrement concave (type Sidi Jdidi 9 : Bonifay, Reynaud 2004, fig. 143).

Exemple (fig. 131) :

*4 Sidi Jdidi, basilique 1, état C2B (Ben Abed, Bonifay, Fixot 1997, fig. 4, $\mathrm{n}^{\circ} 21$; Bonifay, Reynaud 2004, $\mathrm{n}^{\circ} 26.8$ ). D. $22,5 \mathrm{~cm}$. Surface orange, bord noirci.

Le $n^{\circ} \mathbf{4}$ est daté de la fin du VIe s. ou du début du VIIe s. mais il y a peut-être des exemplaires plus anciens, dès le Ve s. (Bonifay, Reynaud 2004, $\mathrm{n}^{\circ}$ 12.19). Il est possible que cette forme, bien attestée dans la vallée de Segermes (Lund 1995, fig. 25, formes 32-34 ?, 36 ?) ait été produite sur l'atelier de Sidi Khalifa (Ben Moussa 2001, forme 94 ?).

\section{— Couvercles type Fulford 1984 Lid 3 (fig. 131)}

\section{CULINAIRE TYPE 36}

Couvercle conique terminé par un bouton aplati ; bord à lèvre triangulaire. Peut-être le couvercle des casseroles du TYPE 35. Exemples (fig. 131):

1 Carthage (Fulford 1984b, fig. 75, $\mathrm{n}^{\circ} 3.1$ )

*2 Oudhna, thermes des Laberii (sans $\mathrm{n}^{\circ}$ d'inv.).

Les exemplaires de Carthage (1) sont datés du Ve s. et de la première moitié du VIe s. (Fulford 1984b, 197) ; ceux d'Oudhna (2) paraissent associés à du mobilier du VIe siècle.

\footnotetext{
${ }^{183}$ En association avec une monnaie de Théodebert Ier.
} 
Forme Hayes 1978b, fig. 9.17 / type Sidi Jdidi 9
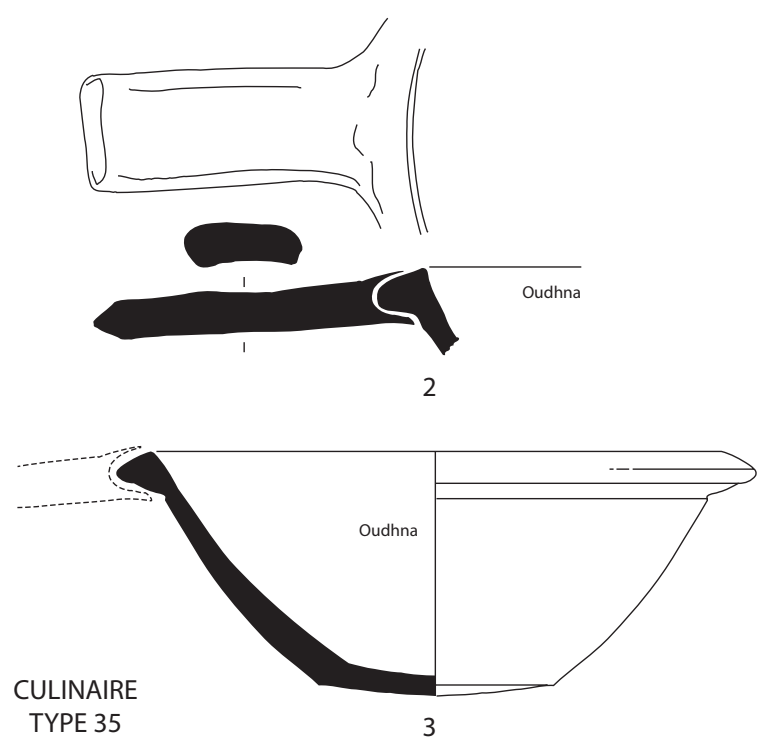

Fulford Lid 3
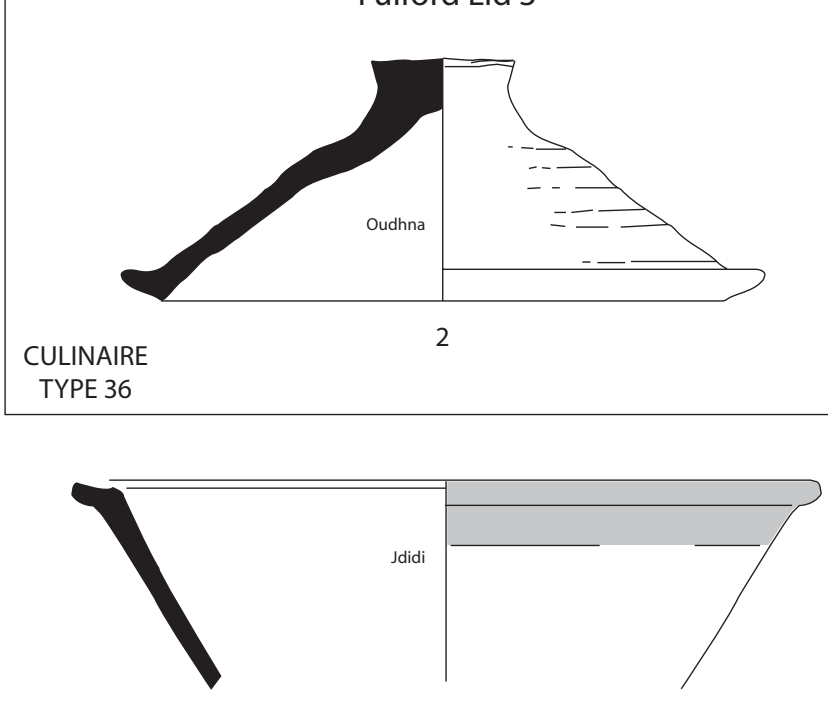

Plats à cuire (golfe d'Hammamet)
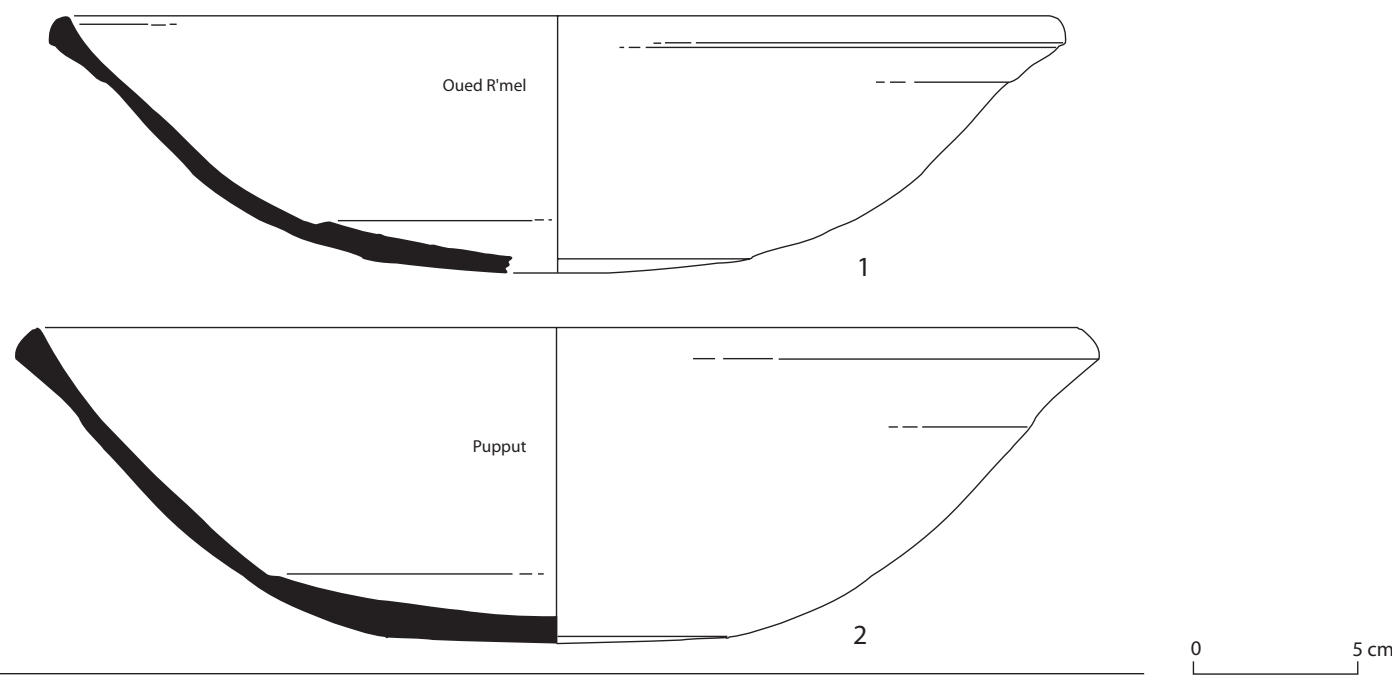

Plats à cuire (Byzacène méridionale)
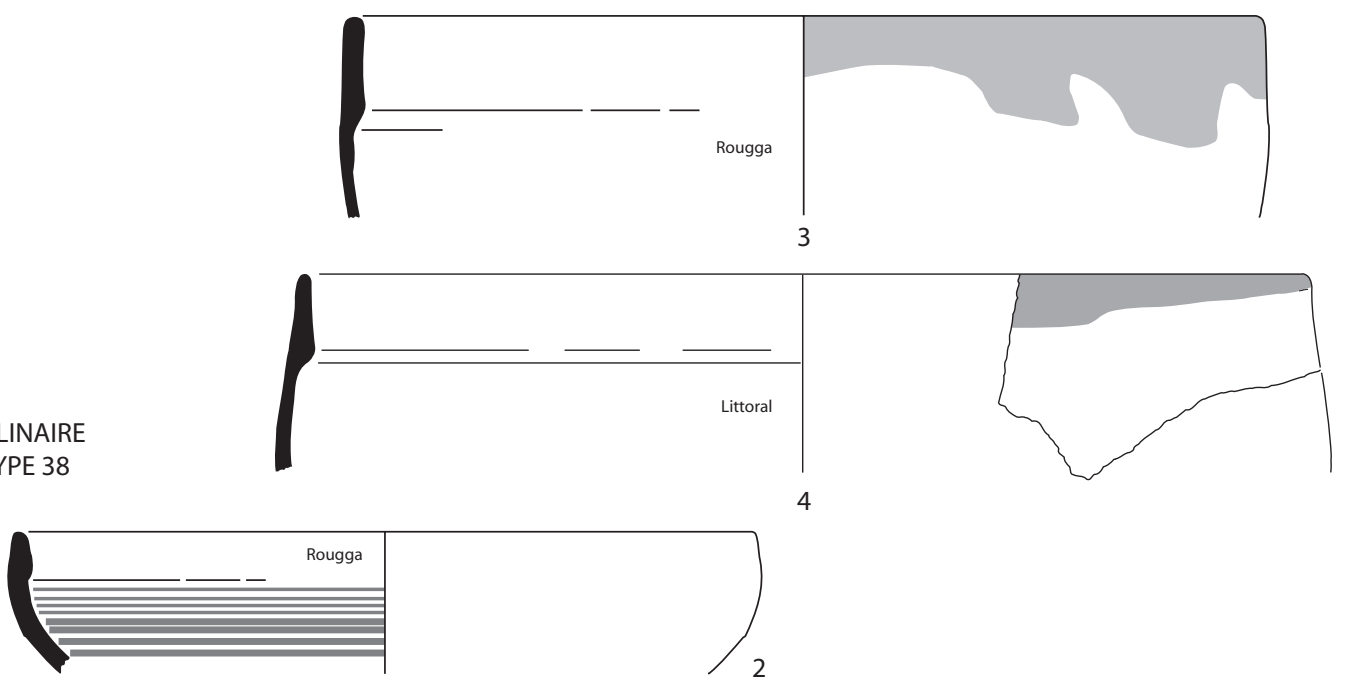

4

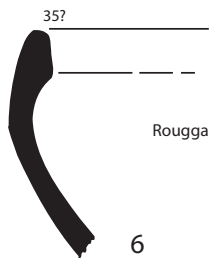

Fig. 131. Vaisselle culinaire africaine. Productions tardives. 


\section{— Plats à cuire du golfe d'Hammamet (fig. 131)}

\section{CULINAIRE TYPE 37}

Les niveaux les plus tardifs des sites du nord du golfe d'Hammamet livrent une forme unique de plat à feu, de grande taille (D. : $30-33 \mathrm{~cm}$ ), avec un profil hémisphérique aplati et un bord épaissi légèrement biseauté, blanc ou gris à l'extérieur. Il semble bien s'agir d'un plat et non d'un couvercle, car l'intérieur est soigneusement poli et peut-être, dans certains cas, enduit d'un engobe rouge mat, mince. Le fond est convexe, marqué d'un ressaut à l'intérieur. Cette forme ne rappelle aucune des productions antérieures, sauf peut-être des variantes tardives de plats Hayes 103 produits à Sidi Khalifa (Ben Moussa 2001, forme 50).

Exemples (fig. 131).

*1 Oued R'mel (fouilles T. Ghalia, Inv. OR1809.5).

*2 Pupput, thermes du centre (fouilles A. Ben Abed, Inv. PPC230.4).

Dans les deux cas ( $\mathbf{1}$ et $\mathbf{2}$ ), la datation n'est pas antérieure au milieu du VIIe siècle.

\section{— Plats à cuire de Byzacène méridionale (fig. 131)}

\section{CULINAIRE TYPE 38}

Un type particulier de plat à feu est fréquent sur les sites tardifs du littoral tunisien entre Sousse et Sfax (Bonifay et al. 2002-2003, fig. 10, $\left.\mathrm{n}^{\circ} 112-117\right)$, ainsi qu'à Rougga (Guéry, Bonifay à paraître, $\mathrm{n}^{\circ} 169-173$ ). La forme complète nous échappe ; il s'agit probablement d'un vase assez profond, d'assez grand diamètre (D. : 26-27 en moyenne, mais il existe des exemplaires jusqu'à $34 \mathrm{~cm}$ ) avec un bord renflé à l'intérieur sur une hauteur assez importante (H. : jusqu'à $3 \mathrm{~cm}$ ); le vernis rouge-brun, mat, qui couvre l'intérieur du vase dessine de larges coulures, parfois noircies, à l'extérieur. La relation morphologique qui a été faite avec la forme Hayes 23 (Bonifay et al. 2002-2003) est probablement à rejeter ; la région de production des deux formes est différente et certains exemplaires de Rougga ( $\mathbf{1}$ et $\mathbf{2}$ ), avec un bord renflé moins prononcé mais aussi un décor intérieur de bandes lustrées, laissent plutôt entrevoir une liaison avec la forme Hayes 181 (?).

Exemples (fig. 131):

Variantes précoces (?)

1 Rougga, couche 13 (Guéry, Bonifay à paraître, $\left.\mathrm{n}^{\circ} 166\right)$.

*2 Idem, couche 10 (Ibid., $\mathrm{n}^{\circ} 167$ ).

Variante classique

*3 Rougga, couche 13 (Ibid., $\mathrm{n}^{\circ} 173$ ).

*4 Littoral tunisien, site $\mathrm{n}^{\circ} 78$ (La Louza, côte nord de Sfax) (Bonifay et al. 2002-2003, fig. 10, $\mathrm{n}^{\circ} 112$ ).

5 Idem, site $\mathrm{n}^{\circ} 84$ (Marsa Mellouleche) (Ibid., fig.10, $\left.\mathrm{n}^{\circ} 117\right)$.

Variante tardive (?)

*6 Rougga, couche 8 (Guéry, Bonifay à paraître, $\mathrm{n}^{\circ} 168$ ). Plusieurs arguments plaident en faveur d'une date très tardive. La forme est présente sur le site homogène de Jezira, en association avec du matériel de la fin du VIeVIIe s. (Bonifay et al. 2002-2003) et sur plusieurs sites d'ateliers tardifs (VIe-VIIe s.) de la région de Salakta et de Leptiminus: Henchir ech-Chekaf, Rass el-Aïed, Moknine (supra, p. 69). Les attestations les plus anciennes sont présentes à Rougga, dans la couche 13 (fin $\mathrm{du}$ Ve s.). A titre d'hypothèse, le $\mathrm{n}^{\circ} \mathbf{6}$, recueilli sur le même site mais dans une couche post-byzantine, est considéré comme une évolution tardive.

Ces exemples montrent le caractère novateur de la céramique culinaire africaine à partir du Ve siècle. Pour Carthage, J. W. Hayes avait déjà démontré que de nouvelles productions ( $L R C W 1,4$ et 6) succédaient progressivement, entre le Ve et le VIIes., aux productions traditionnelles; certaines de ces nouvelles formes semblent ouvertes aux influences orientales. Plus au sud, quelques rares formes tournées subsistent (plats à feu de grande taille) mais, d'une manière plus générale, il semble que les céramiques culinaires tournées soient peu à peu, au courant du VIe s., remplacées par la céramique modelée du groupe C (infra, MODELÉE C TYPES 1-5).

\subsection{LES CÉRAMIQUES COMMUNES}

Cette catégorie prolifique est sans doute celle qui pose, actuellement, les plus gros problèmes de classification. Il importe, là encore, de ne pas se laisser aveugler par les typologies élaborées à Carthage. Même s'il existe souvent des similitudes entre les formes de différentes régions de l'Africa, cette typologie ne peut pas être transposée telle quelle en Byzacène, en Tripolitaine, et surtout dans les terroirs qui sont situés très à l'intérieur des terres.

Il en est de même de la classification des pâtes proposée par D. Peacock (1984a), souvent appliquée à l'ensemble de la céramique africaine, alors qu'elle n'est réellement valable que pour Carthage même. Les études menées par $\mathrm{Cl}$. Capelli sur plusieurs faciès homogènes du sud de la Zeugitane (Thuburbo Majus: Capelli 1998) et de Byzacène (Littoral tunisien: Capelli 2002-2003; Sidi Jdidi : Bonifay, Reynaud 2004 ; Rougga : Guéry, Bonifay à paraître) montrent que la pâte des céramiques communes (comme celle des amphores) de chaque région, voire même de chaque cité, possède ses particularités. Des différences infimes perceptibles à l'intérieur du faciès d'une ville (Carthage) s'estompent lorsqu'on prend en considération plusieurs sites différents, tandis qu'en contrepartie, la situation apparaît toujours de plus en plus complexe ${ }^{184}$.

Loin de moi l'idée de vouloir proposer une typologie de la céramique commune africaine du IIe au VIIe siècle. Mon objectif ci-après est seulement de regrouper et de classer sommairement un certain nombre de données recueillies de manière éparse sur les quelques sites où j'ai

184 Ainsi, il apparaît désormais difficile de conserver l'appellation « pâte de type Carthage/Nabeul ». 
travaillé, et de les situer par rapport aux typologies plus générales précédemment élaborées.

\subsubsection{Bols et jattes}

\section{- Bols}

Cette catégorie comprend, au IIe s., deux formes essentielles.

\section{- Bols simples à bord épaissi (forme Uzita 1) (fig. 132)}

\section{COMMUNE TYPE 1}

Il s'agit d'une forme très simple, avec une paroi hémisphérique dans sa partie supérieure, plus conique vers le bas; le bord, probablement replié sur lui-même, dessine une lèvre de section arrondie, légèrement pendante à l'extérieur; fond à talon faiblement concave, avec un petit pied dégagé par une rainure. Une discrète gorge peut souligner la rupture de courbe sur la partie supérieure de la panse (2-3).

Exemples (fig. 132) :

1 Uzita (Van der Werff 1982a, fig. 7, forme 1b).

*2 Raqqada, tombe B 20 (Ennabli, Mahjoubi, Salomonson 1973, Pl. XXVII).

*3 Sidi Jdidi, basilique 2, état 0 (Inv. JD2185.8).

*4 Oudhna, capitole (fouilles H. Ben Hassen, Inv. UTH1.1002.11).

Variante tardive (?)

*5 Oued el-Akarit, atelier (Bonifay et al. 2002-2003, fig. 16, $\mathrm{n}^{\circ}$ 217). Bord bifide.

Cette forme, connue à Carthage au Ier s. (Hayes 1976a, fig. 17, D1 : Late Roman Buff ware, Bowl type 1 ? ; Ortisi 1999, fig. 12, n 253-259), est bien attestée à Uzita au IIe $\mathrm{s}$. et dans la première moitié du IIIe s. (Van der Werff 1982a, 142). Les $n^{\circ} \mathbf{2}$ et $\mathbf{4}$ se situent aux deux extrémités de cette fourchette chronologique: première moitié du IIe $\mathrm{s}$. à Raqqada $(\mathbf{2})^{185}$ et première moitié du IIIe $\mathrm{s}$. à Oudhna (4); le $n^{\circ} \mathbf{3}$ est également associé à du mobilier du IIe siècle ${ }^{186}$. Le $\mathrm{n}^{\circ} 5$, avec un bord bifide, paraît en revanche plus tardif : il provient d'un contexte de la fin $\mathrm{du}$ IIIe s. ou du IVe s.; une autre variante de bord, triangulaire, signalée par un fragment dans le comblement du puits à Uzita (Van der Werff 1982a, Pl. 44, $\left.\mathrm{n}^{\circ} 14\right)$, est présente sur l'atelier de Dahar Slima à Leptiminus (Peacock, Bejaoui, Ben Lazreg 1989, fig. 22, $\left.\mathrm{n}^{\circ} 27-28\right)$.

\section{— Bols à profil en « $\mathrm{S}$ » (forme Uzita 2) (fig. 132)}

\section{COMMUNE TYPE 2}

Bol dont la paroi est composée d'une partie supérieure concave, terminée par un bord à lèvre pendante plus ou moins repliée sur elle-même, et d'une partie inférieure convexe.

\footnotetext{
${ }^{185}$ Sigillée africaine A, Hayes 4B, variante, et lampe Pupput Deneauve VII/1.

${ }^{186}$ Sigillée africaine A Hayes 4, 7A, 6.
}

Exemples (fig. 132) :

*1 Uzita (Van der Werff 1982a, fig. 7, forme 2).

*2 Pupput, tombe 268 (Inv. PP2285.1).

*3 Pupput, tombe 387 (Inv. PP 6477.2).

4 Utique (Soren 1978, Pl. 5, forme 2).

Cette forme, issue d'un modèle gréco-romain amplement diffusé en Méditerranée (Riley 1979, 329-330), est bien connue en Afrique, dès l'époque flavienne, notamment à Utique (4), à Carthage (Hayes 1976a, 100-102 et fig. 17, D2-8: Early Roman Buff ware, Basins types 1 à 4 ; Fulford 1984b, 174 et fig. 64, forme 21 ; Fulford 1994, fig. 56 et fig. 4.2, forme 19 ; Ortisi 1999, fig. 12, n $263-$ 265, fig. 13, $\mathrm{n}^{\circ}$ 266-274), à Leptiminus (Dore 1992, 145 , $\mathrm{n}^{\circ}$ 40-41), à Sabratha (Dore 1989, 191-197 et fig. 52, formes 213-219). Elle est principalement attestée au IIe s. (Van der Werff 1982a, 142). Les exemplaires de Pupput (2-3) proviennent de tombes de la seconde moitié du IIe s. ${ }^{187}$. Il n'est pas impossible que dérivent de cette forme de grands vases à paroi bipartite concave/convexe, issus de contextes de la fin du IIIe-IVe s. (Bonifay et al. 2002-2003, fig. 16, n 214-216).

\section{- Jattes}

J'attribue de manière un peu arbitraire l'appellation de « jatte » (lat. gabata) à des vases hémisphériques de plus grande taille que les précédents.

\section{— Jattes à bord trifide (fig. 133)}

\section{COMMUNE TYPE 3}

Grand vase hémisphérique à bord horizontal creusé de deux cannelures sur le sommet. Décor incisé (2) ou rapporté (1).

Exemples (fig. 133) :

*1 Uzita, puits (Van der Werff 1982a, Pl. 50, n 7).

*2 Pupput (Inv. PP1803.4).

*3 Sidi Jdidi, basilique 2, destruction état II (Inv JD 2349.5).

4 Idem (Inv. JD2364.6).

Les exemples de Sidi Jdidi, datés du Ve s. (3-4), semblent dériver d'une forme connue à Uzita et à Pupput au IIIe s. (1-2).

\section{— Jattes hémisphériques à anses horizontales plaquées (fig. 133)}

\section{COMMUNE TYPE 4}

Grand vase hémisphérique à bord trifide ou bifide. Anses horizontales plaquées sous le bord.

Exemples (fig. 133) :

*1 Chemtou (Vegas 1994a, fig. 168, n 237).

*2 Pupput (Bonifay 2004a, fig. 22, $\mathrm{n}^{\circ}$ 91).

3 Pupput, tombe 387 (Inv. PP6477.1).

Les exemplaires de Chemtou et de Pupput sont datés du IIIe siècle. Il existe des variantes sans anses.

\footnotetext{
187 Associé à des lampes de type Deneauve VII/1 timbrées FRONI.
} 
Bol Uzita 1
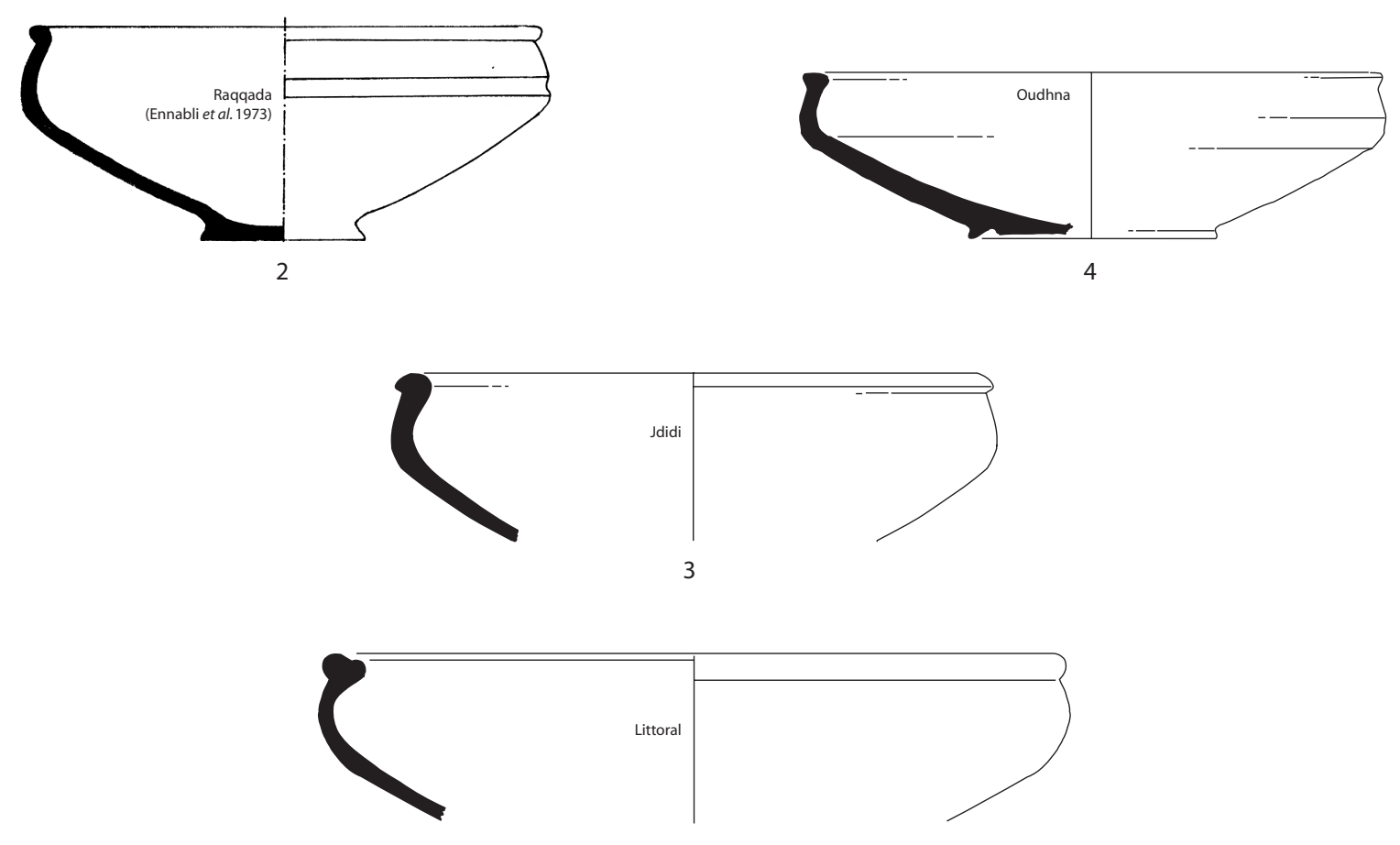

Bol Uzita 2
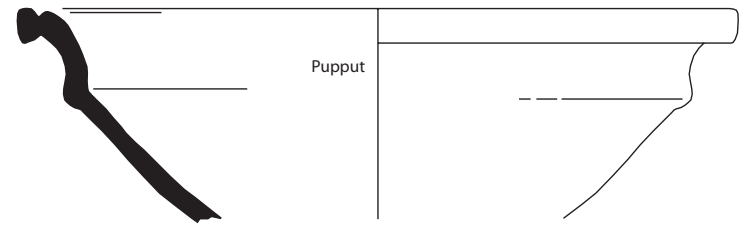
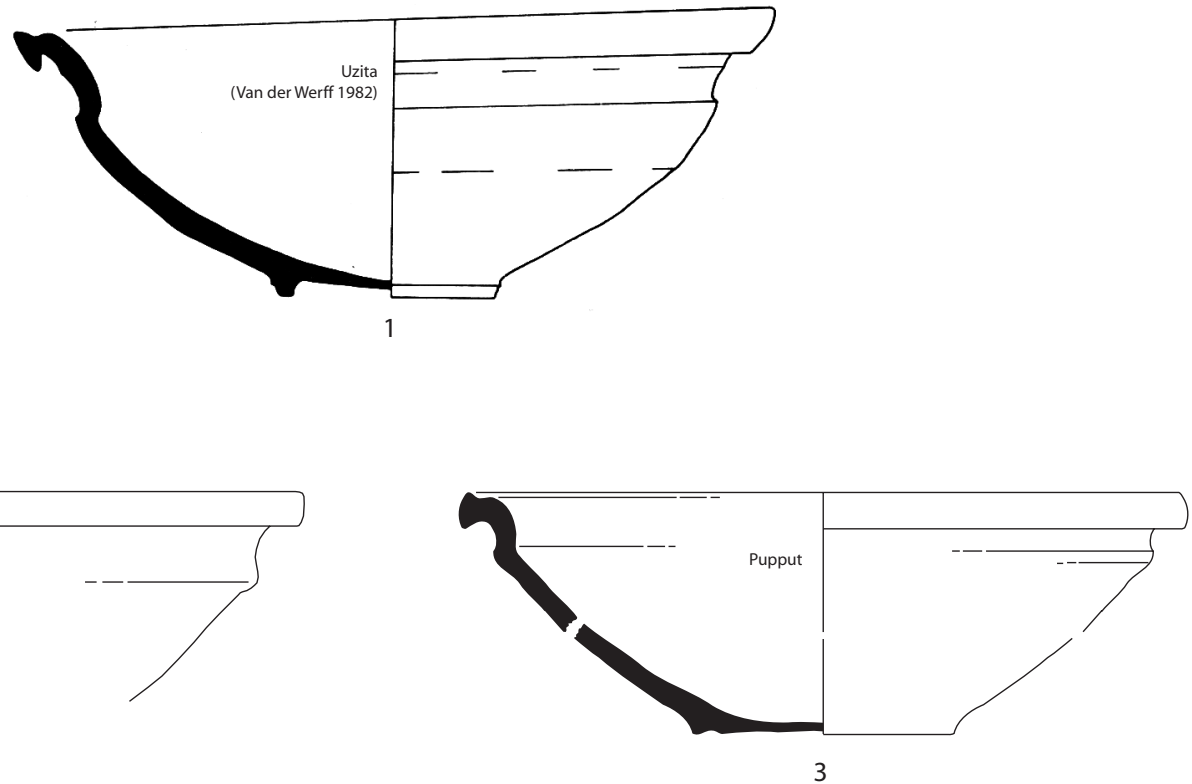

Fig. 132. Vaisselle commune africaine. Bols. 
Jattes à bord trifide

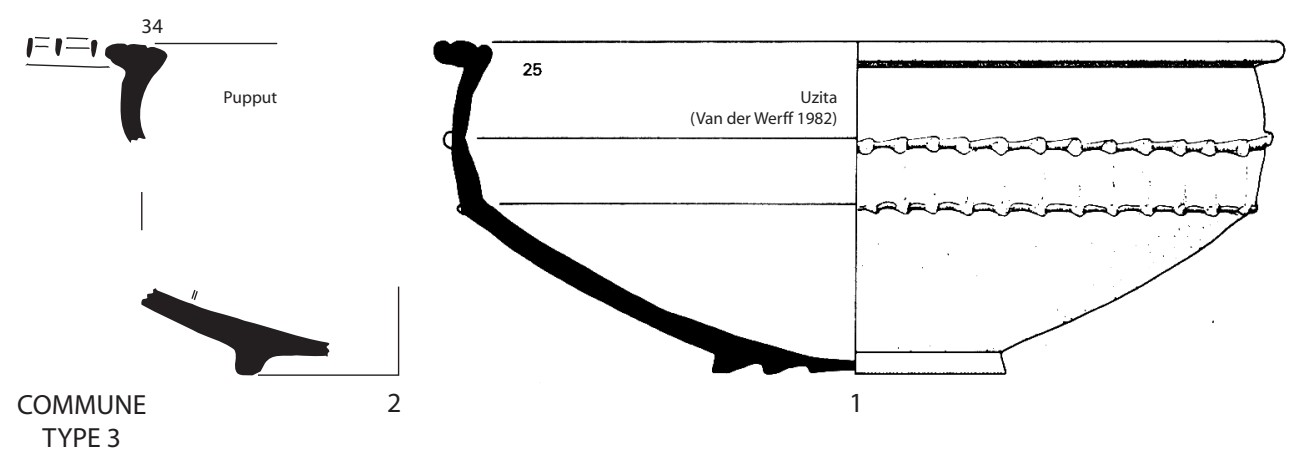

Jattes à anses horizontales plaquées

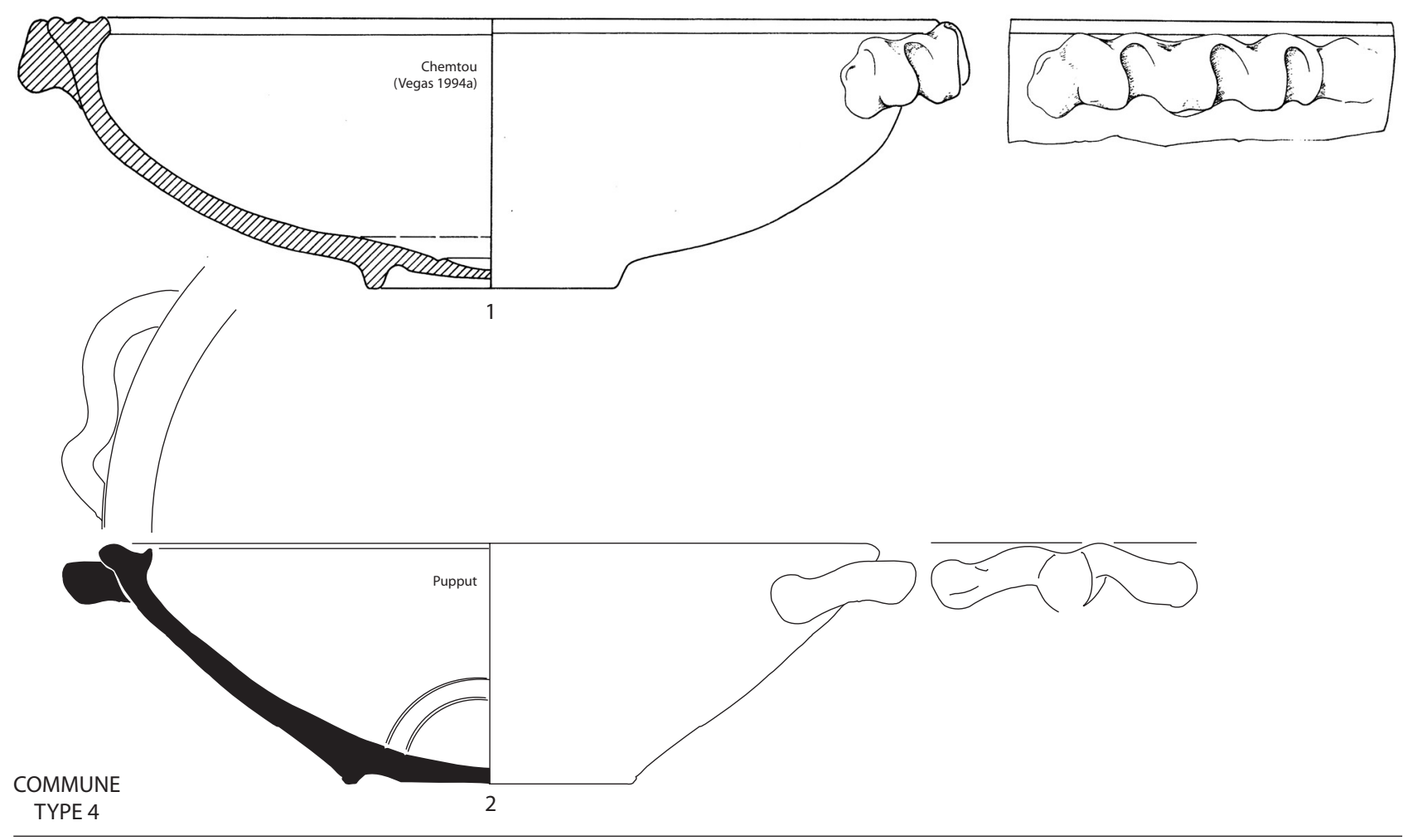

Jattes à anses en panier

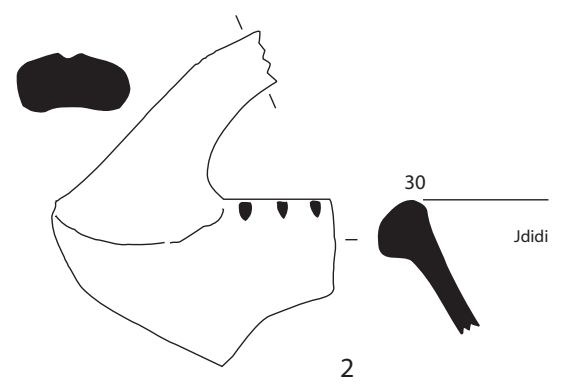

Fig. 133. Vaisselle commune africaine. Jattes. 


\section{Typologie - Communes}

Bol à marli courbe 1
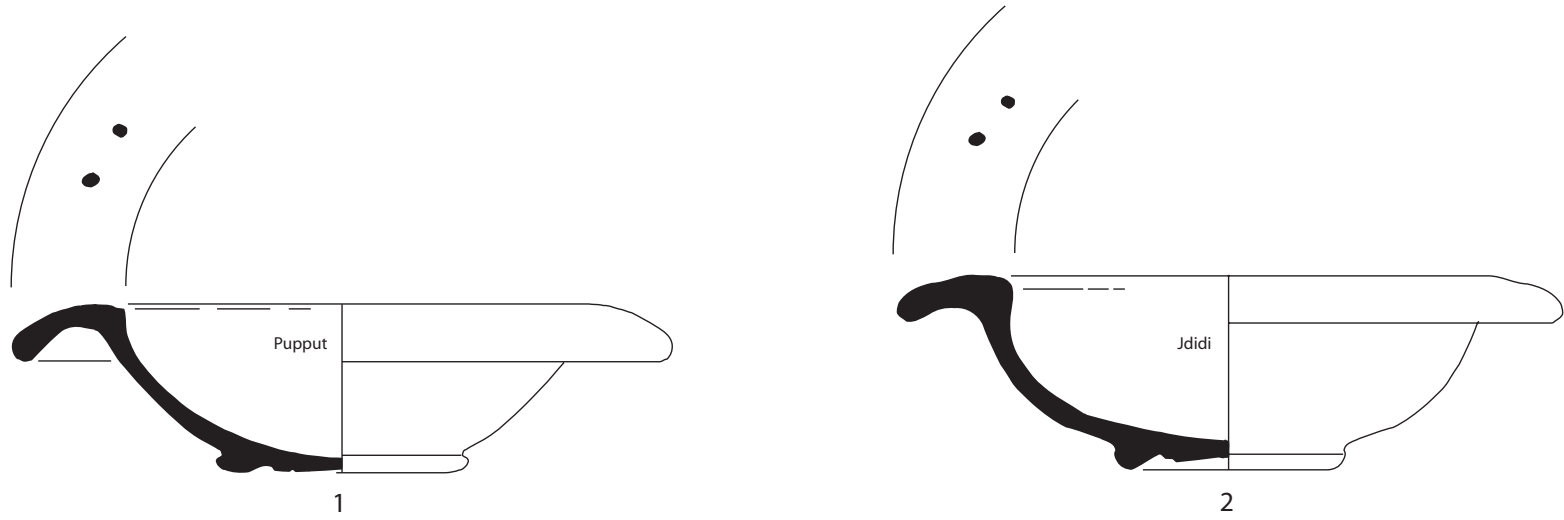

Bol à marli courbe 2

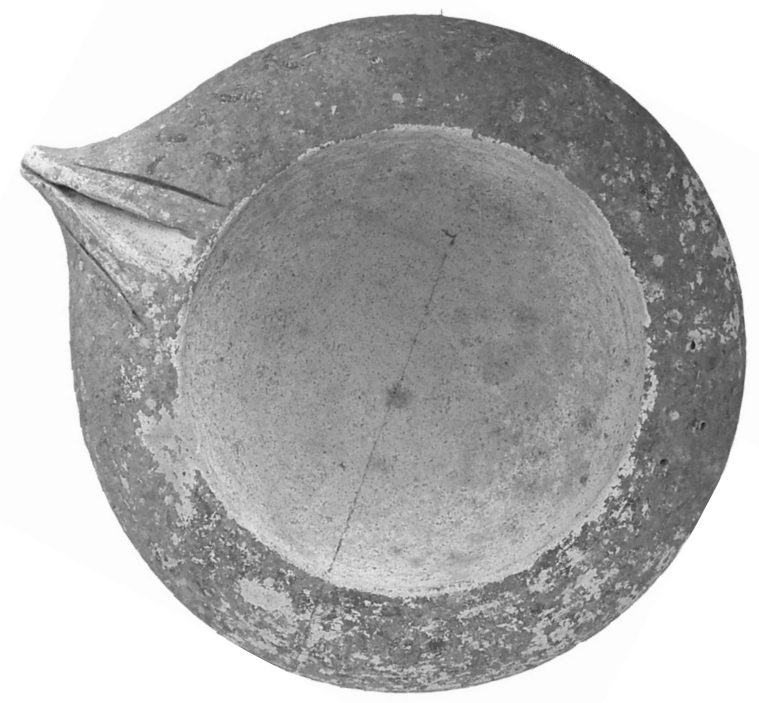

(3)
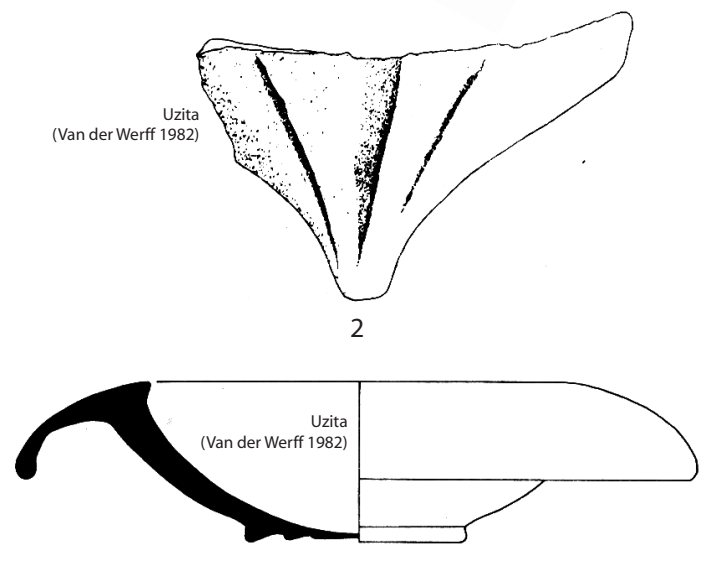

COMMUNE

TYPE 7

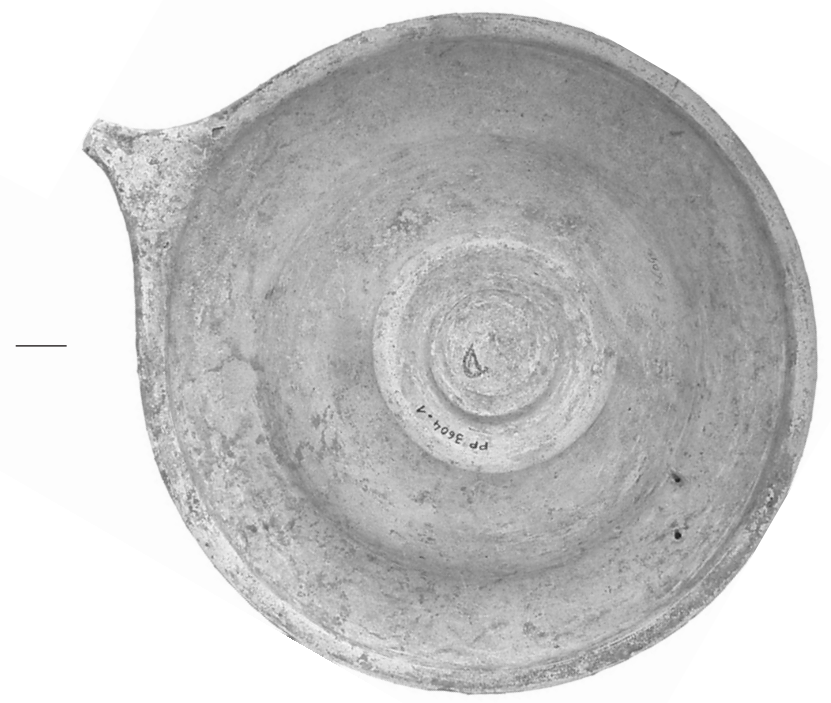

(3)

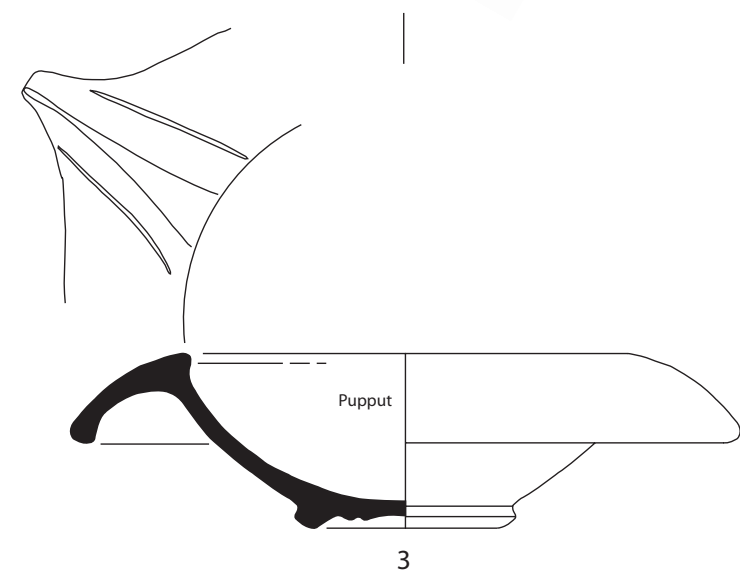

$5 \mathrm{~cm}$

Fig. 134. Vaisselle commune africaine. Bols à marli courbe. 


\section{— Jattes à anses en panier (fig. 133)}

\section{COMMUNE TYPE 5}

Grand vase dont la forme complète n'est pas connue, à bord en bourrelet épaissi, muni d'anses en panier à la verticale du bord. Peut-être à comparer avec le bassin de type Sidi Jdidi 1 (COMMUNE TYPE 23)?

Exemples (fig. 133) :

*1 Sidi Jdidi, basilique 2, destruction état II (Inv. JD2187.5).

2 Idem (Inv. JD2200.33).

Les exemples de Sidi Jdidi sont datés du Ve siècle.

\section{- Bols ou jattes à marli courbe}

— bols à marli courbe 1 (fig. 134)

\section{COMMUNE TYPE 6}

Je souhaite attirer ici l'attention sur un type d'objet que son type de fabrication rend remarquable : la pâte beige orangé est relativement grossière mais la surface est couverte d'un engobe argileux très lisse de couleur blanche. La forme générale évoque la coupe Hayes 3 en sigillée africaine $\mathrm{A}$, avec un marli courbe qui présente la particularité d'être toujours percé avant cuisson de deux trous de suspension.

Exemples (fig. 134) :

*1 Pupput (Bonifay 2004a, fig. 22, $\mathrm{n}^{\circ} 88$ ).

*2 Sidi Jdidi, basilique 1, état B1B (Bonifay, Reynaud 2004, ${ }^{\circ}$ 16.4). Résiduel dans le contexte 16 .

Ces bols sont présents dans des contextes de la seconde moitié du IIe s. (1) et de la première moitié du IIIe s. (2?).

\section{- bols à marli courbe 2 ou pelvis (forme Uzita 5) (fig. 134)}

\section{COMMUNE TYPE 7}

Cette forme ressemble beaucoup à la précédente, avec le même type de fabrication, mais le marli est ici plus long, très tombant et, en un point, étiré et pincé de façon à constituer un bec verseur, rainuré sur le sommet.

Exemples (fig. 134) :

*1 Uzita (Van der Werff 1982a, fig. 7, forme 5).

*2 Idem (Ibid., Pl. 44, $\mathrm{n}^{\circ} 10$ ).

*3 Pupput, tombe 645 (Bonifay 2004a, fig. 22, n 89).

4 Oudhna, capitole (fouilles H. Ben Hassen, Inv. UTH1.1002.13).

Forme datée de la première moitié du IIIe s. à Uzita (1-2). Cette chronologie semble confirmée par l'exemplaire de Pupput (3), qui provient d'une tombe de la fin du IIe s. ou de la première moitié du IIIe $s^{188}{ }^{18}$, et par celui d'Oudhna (4), également issu d'un contexte de la première moitié IIIe s. (?).

\footnotetext{
${ }^{188}$ Associé à une lampe de type Deneauve VII/2.
}

\subsubsection{Mortiers et bols à listel}

Dès le Ier s. ap. J.-C, comme le montre la stratigraphie d'Uzita (Van der Werff 1982a, 143-144, formes 4a-c), le bol à listel en céramique commune fait partie intégrante de la vaisselle africaine ${ }^{189}$. C'est probablement lui, sans aucun emprunt à un modèle étranger (Hayes 1977, 280), qui va donner naissance, dans la seconde moitié du IVe s., aux premières variantes de la forme Hayes 91, en sigillée africaine. En céramique commune, cette forme va également connaître un formidable développement durant l'Antiquité tardive. Ces objets ne comportant pas tous des inclusions abrasives sur le fond, il est difficile de savoir s'ils ont toujours une fonction de mortier (cf. Treglia 2002). Le regroupement proposé ci-après n'est donc pas d'ordre fonctionnel mais tout simplement morphologique.

- les bols à listel des IIe-IIIe s. (fig. 135)

\section{COMMUNE TYPE 8}

$=$ Uzita forme 4

J. H. Van der Werff a distingué, à Uzita, trois variantes (a-c) de sa forme 4, qui s'échelonnent entre la fin du Ier s. et le milieu du IIIe siècle. Les données que j'ai pu recueillir confirment cette classification. Il est peut-être utile d'ajouter une variante D pour des exemplaires qui ont un listel plus court et une lèvre plus haute (légèrement rentrante) que ceux de la variante $\mathrm{C}$.

Exemples (fig. 135) :

Variante A

*1 Uzita (Van der Werff 1982a, fig. 7, forme 4a).

*2 El Jem, maison d'Africa (fouilles H. Slim, Inv. EJMA. 2324.4).

Variante B

*3 Uzita (Van der Werff 1982a, fig. 7, forme 4b).

4 Oudhna, capitole (fouilles H. Ben Hassen, Inv. UTH1.1002.12).

*5 Oudhna, est capitole (Inv. UTH7.000.41).

Variante $\mathrm{C}$

*6 Uzita (Van der Werff 1982a, fig. 7, forme 4c).

7 Oudhna, est capitole (Inv. UTH7.000.63).

*8 Hergla, fouilles anciennes (Inv. HG.000.103). Dessin M. Pasqualini.

*9 El Jem, maison d'Africa (Inv. EJMA.000.024)..

Variante D

*10 Uzita, puits (Van der Werff 1982a, Pl. 44, n 6).

*11 Pupput (Bonifay 2004a, fig. 22, $\mathrm{n}^{\circ}$ 90).

*12 Raqqada, tombe A9 (Ennabli, Mahjoubi, Salomonson 1973, Pl. VII).

Ces exemples introduisent de nouvelles données dans la chronologie proposée par J. H. Van der Werff. Le tesson d'El Jem (2) a été trouvé dans un contexte de la seconde moitié du IIe s.; c'est également à cette date que les exemplaires d'Uzita, attestés dès la fin du Ier s., sont les plus nombreux. La datation du fragment $n^{\circ} 4$ à Oudhna, au début du IIIe $\mathrm{s}$. au plus tôt, est légèrement plus tardive que celle obtenue à Uzita pour la variante $\mathrm{B}$, étroitement associée à la première (variante $\mathrm{A}$ ) dans la stratigraphie

${ }^{189}$ Pour un exemple du milieu du Ier s., voir Martin-Kilcher 1999, fig. $17, \mathrm{n}^{\circ} 79$. 


\section{Typologie - Communes}

Bols à listel Uzita 4
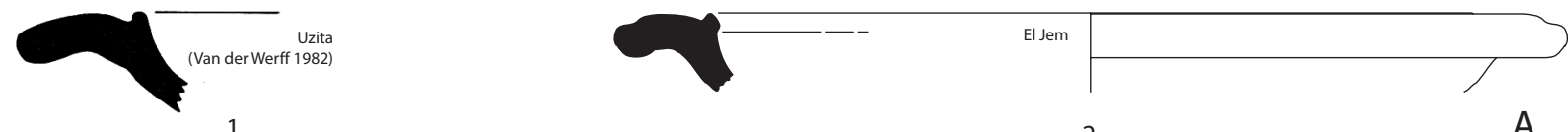

1
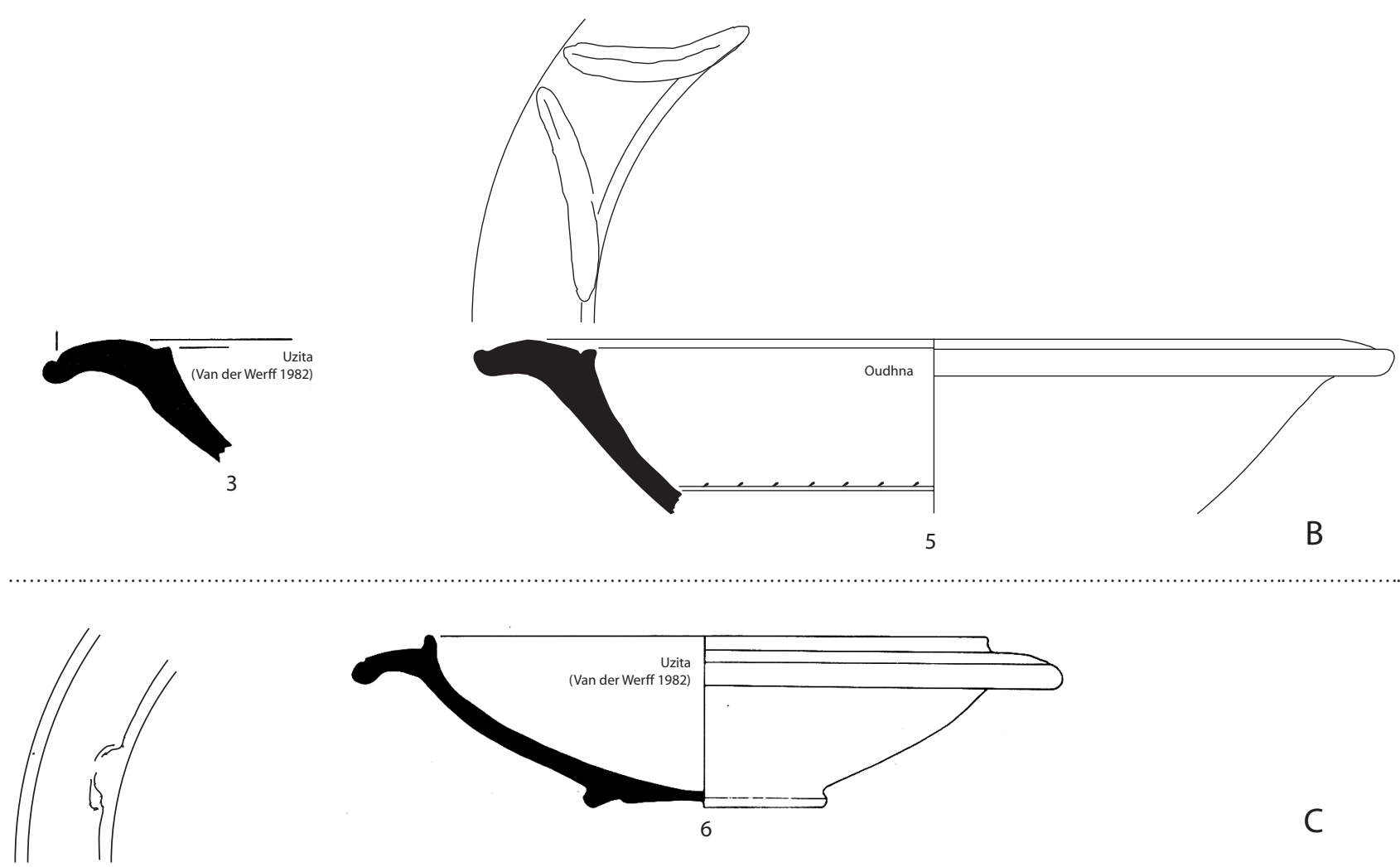

C
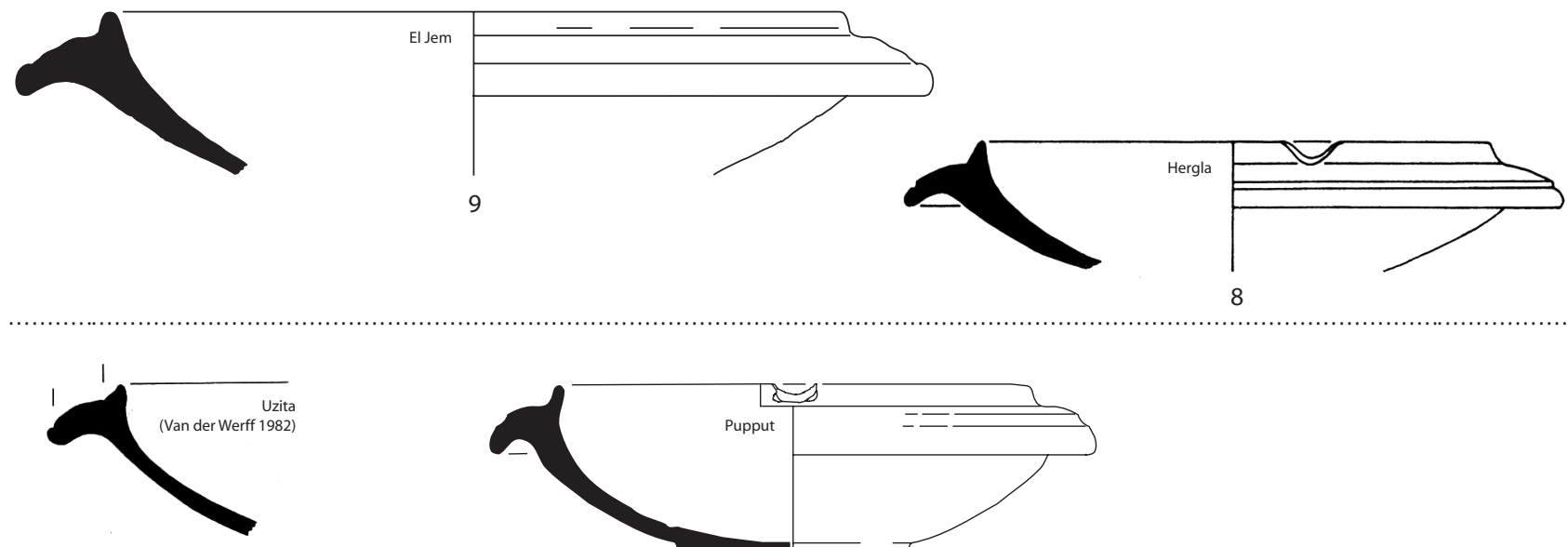

10

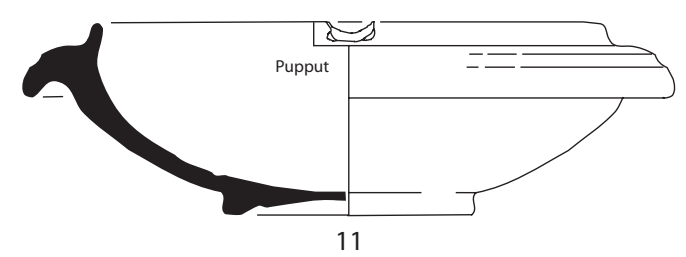

D

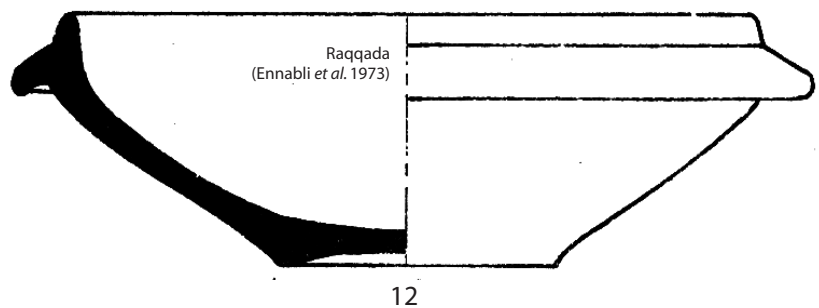

Fig. 135. Vaisselle commune africaine. Bols à listel. 
Mortiers

(Byzacène)
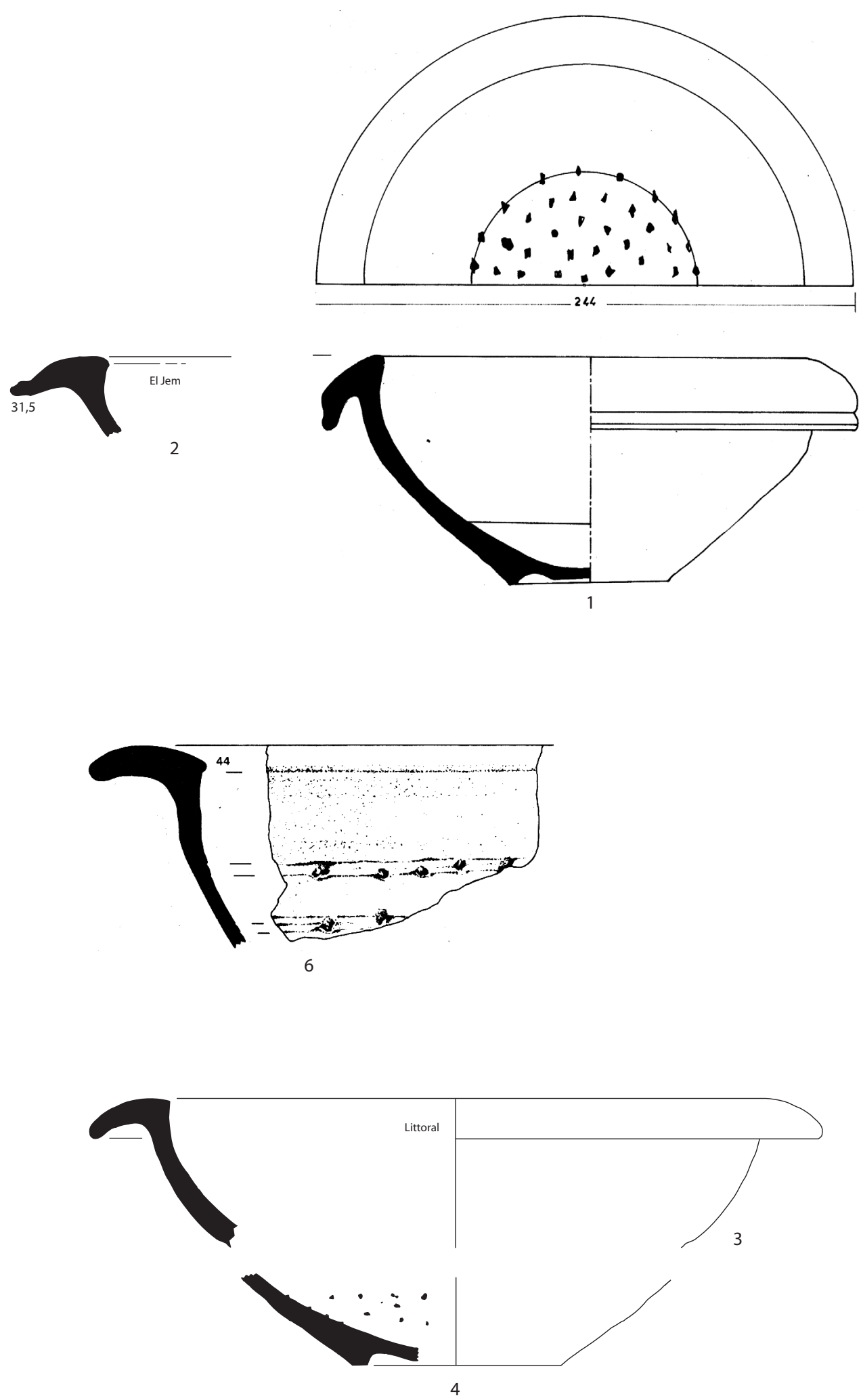

Fig. 136. Vaisselle commune africaine. Mortiers. 
de cette ville. Enfin, si les comparaisons ajoutées à la variante $\mathrm{C}$ ne sont pas précisément datées, en revanche, les exemplaires de la variante $\mathrm{D}$ ne paraissent pas antérieurs au IIIe s. et plus vraisemblablement au milieu du siècle (10).

\section{- variantes de Byzacène méridionale et de Tripolitaine (fig. 136)}

\section{COMMUNE TYPE 9}

Parallèlement au développement de la forme précédente dans le nord de la Byzacène et peut-être jusqu'à Chemtou (Vegas 1994a, fig. 165, $\mathrm{n}^{\circ} 180-181$ ), une autre forme paraît plutôt caractéristique des contextes de Byzacène méridionale et de Tripolitaine. Il s'agit d'un bol à marli convexe, aux parois courbes, assez profond; le fond, muni d'un petit pied dégagé par évidement, est parsemé, à l'intérieur, de grains de basalte.

Exemples (fig. 136) :

*1 Raqqada, tombe B47 (Ennabli, Mahjoubi, Salomonson 1973, Pl. XLV).

*2 El Jem, maison d'Africa (fouilles H. Slim, Inv. EJMA. 000.25).

*3-*4 Oued el-Akarit, atelier (Bonifay et al. 2002-2003, fig. $\left.16, n^{\circ} 212-213\right)$.

5 Zitha/Zian, atelier (sans $\mathrm{n}^{\circ} \mathrm{d}^{\prime} \mathrm{inv}$.).

*6 Uzita (Van der Werff 1982a, Pl. 51, n 9).

Les deux seuls exemplaires pour lesquels nous disposons d'informations chronologiques, apparaissent relativement tardifs : seconde moitié du IIIe s. à Raqqada (1), fin du IIIe s. ou IVe s. sur l'atelier d'Oued el-Akarit (3-4). Il est probable que les ateliers de Leptiminus aient également produit cette forme (Dore 1992, 151, $\mathrm{n}^{\circ} 74$ ).

\section{- principaux types de l'Antiquité tardive}

Sans filiation apparente avec les bols à listels de forme Uzita 4 qui vont plutôt donner naissance aux premiers exemplaires de la forme Hayes 91 en sigillée africaine D, les mortiers en céramique commune deviennent une forme extrêmement répandue, avec des variantes très diverses, durant l'Antiquité tardive.

\section{— mortiers à listel cannelé (fig. 137)}

\section{COMMUNE TYPE 10}

Grand bol hémisphérique ; bord à listel plus ou moins courbe, au sommet cannelé, dépassant en hauteur la lèvre, très atrophiée; fond muni d'un petit pied dégagé par évidement; grains de basalte à l'intérieur.

Exemples (fig. 137) :

Variantes précoces

1 Nabeul, fabrique de salaison, pièce XLIV (Inv. NB 1878.77).

*2 Idem (Inv. NB1878.76).

Variante classique

*3 Nabeul, fabrique de salaison, bassin XXXI (Inv. NB 1186.64).

*4 Sidi Jdidi, basilique 3, construction (Inv. JD 5069.7).

*5 Arles, chantier de l'I.R.P.A. (Inv. 610.893). Dessin J. Bremond.
Cette forme est présente dès le début du IVe s . (2), avec un listel relativement rectiligne et parfois légèrement tombant. Elle dérive peut-être de bols à marli à section crénelée attestés à la fin du IIe s. (1). Mais la grande période de production de ces mortiers à listel courbe cannelé est la seconde moitié (3) et la fin du IVe s. (4-5). On note que les grains de basalte sont parfois disposés de manière régulière et décorative sur les exemplaires de la fin du IVe siècle.

- mortiers de type Carthage Class 1 (fig. 138)

$=$ Fulford 1984 Mortaria 1-3 = CATHMA A10

\section{COMMUNE TYPE 11}

Cette catégorie de bols à listel, identifiée et décrite à Carthage (Hayes 1976a, 88-89; 1978b, 68-69), bien diffusée en Méditerranée occidentale (C.A.T.H.M.A. 1991, 33), a été produite, au moins en partie, sur l'atelier d'Oudhna (Barraud et al. 1998, 149-152, fig. 12, fig. 16, $\mathrm{n}^{\circ} 25$ et fig. $17, \mathrm{n}^{\circ} 33$ ). Sans revenir sur la typologie de cette forme, qui sera bientôt exposée en détail ${ }^{190}$, je souhaiterais simplement illustrer les deux variantes rencontrées dans l'atelier des thermes des Laberii et souligner l'existence de deux tailles différentes dans la variante $\mathrm{C}$, caractérisée par un listel atrophié.

Exemples (fig. 138) :

Variante A

*1 Carthage, Byrsa (Bonifay à paraître, $\mathrm{a}, \mathrm{n}^{\circ} 37$ ).

Variante B

*2 Oudhna, thermes des Laberii (Barraud et al. 1998, fig. $\left.12, \mathrm{n}^{\circ} 11\right)$.

Variante $\mathrm{C}$

*3 Oudhna, thermes des Laberii, four $\mathrm{n}^{\circ} 1$ (Ibid., 17, $\mathrm{n}^{\circ} 33$ ). Grand modèle, D. $27 \mathrm{~cm}$.

*4 Oudhna, thermes des Laberii (Inv. UTH.TL.2003.17). Petit modèle, D. $13,2 \mathrm{~cm}$.

Mentionnons pour mémoire que la variante A est présente à Carthage dès le deuxième quart du Ve $s$. (1). La variante $\mathrm{B}$ (2) est bien attestée dans le comblement du four $\mathrm{n}^{\circ} 4$ de la zone périphérique d'ateliers d'Oudhna, dans un contexte du milieu du VIe s. (Barraud et al. 1998, 157 et fig. $\left.16, \mathrm{n}^{\circ} 25\right)$. La variante $\mathrm{C}$ (3 et 4 ), associée à la forme Hayes 99D (= 80B/99) dans le comblement du four $\mathrm{n}^{\circ} 1$, correspond aux ultimes traces d'activité de l'atelier des thermes des Laberii, probablement à la fin du VIIe siècle. En effet, la même association de formes se rencontre à Rome dans le contexte de la Crypta Balbi daté des dernières années du VIIe s. (Saguì 1998, fig. 4, $\left.\mathrm{n}^{\circ} 4-5\right)$.

\section{- mortiers de type Carthage Class 2 (fig. 138) \\ = Fulford 1984 Flanged Bowls 14-15}

COMMUNE TYPE 12

Cette deuxième catégorie de bols à listel a été, comme la première, identifiée à Carthage (Hayes 1976a, 88-89) mais on n'en connaît pas l'origine précise. De fait, cette forme paraît mieux diffusée en Tunisie que la précédente

\footnotetext{
${ }^{190}$ Cf. note 154.
} 
Mortiers à listel cannelé
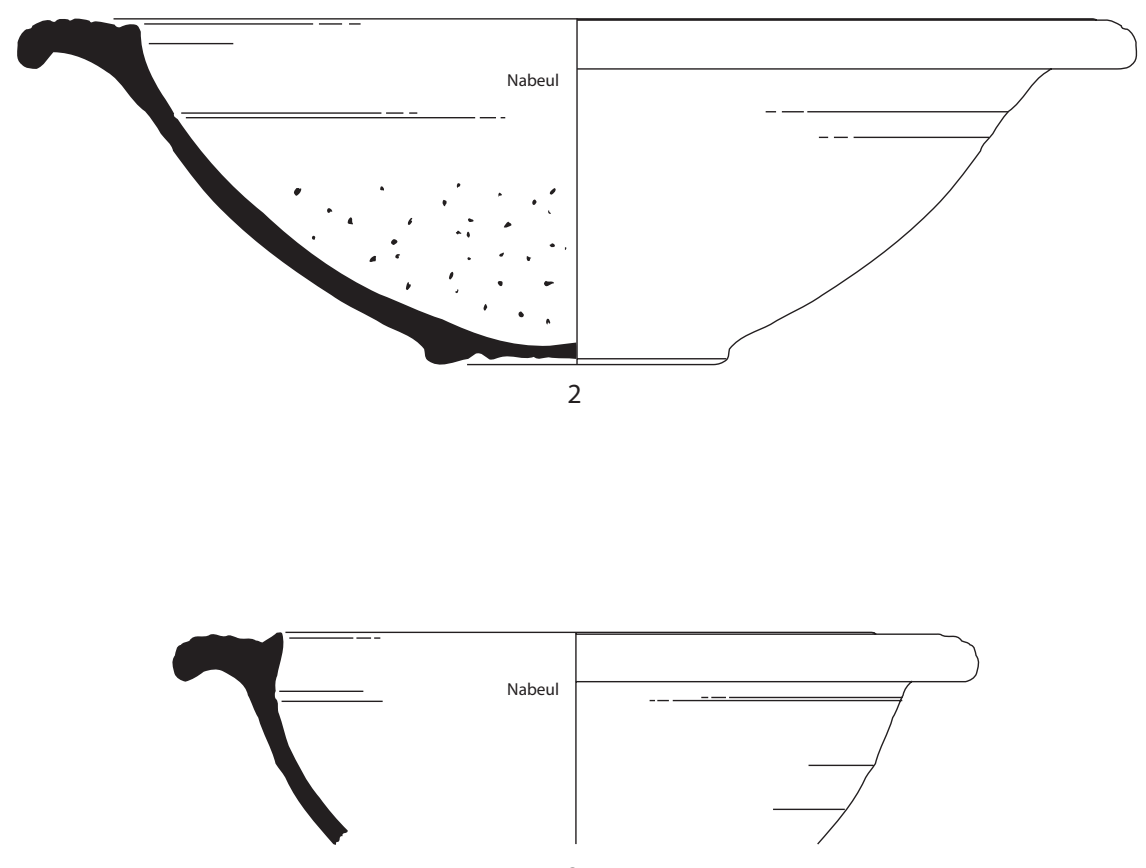

3
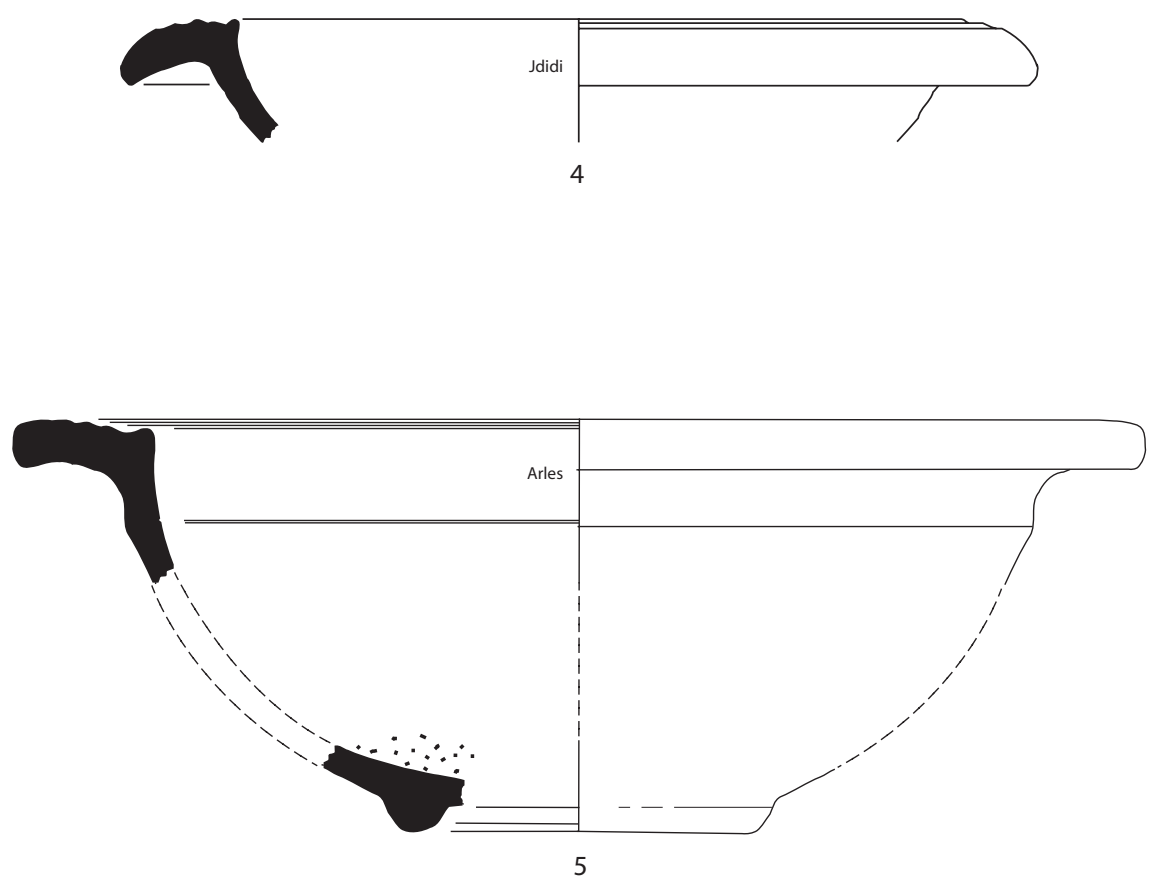

Fig. 137. Vaisselle commune africaine. Bols à listel tardifs. 
Type Carthage Class 1
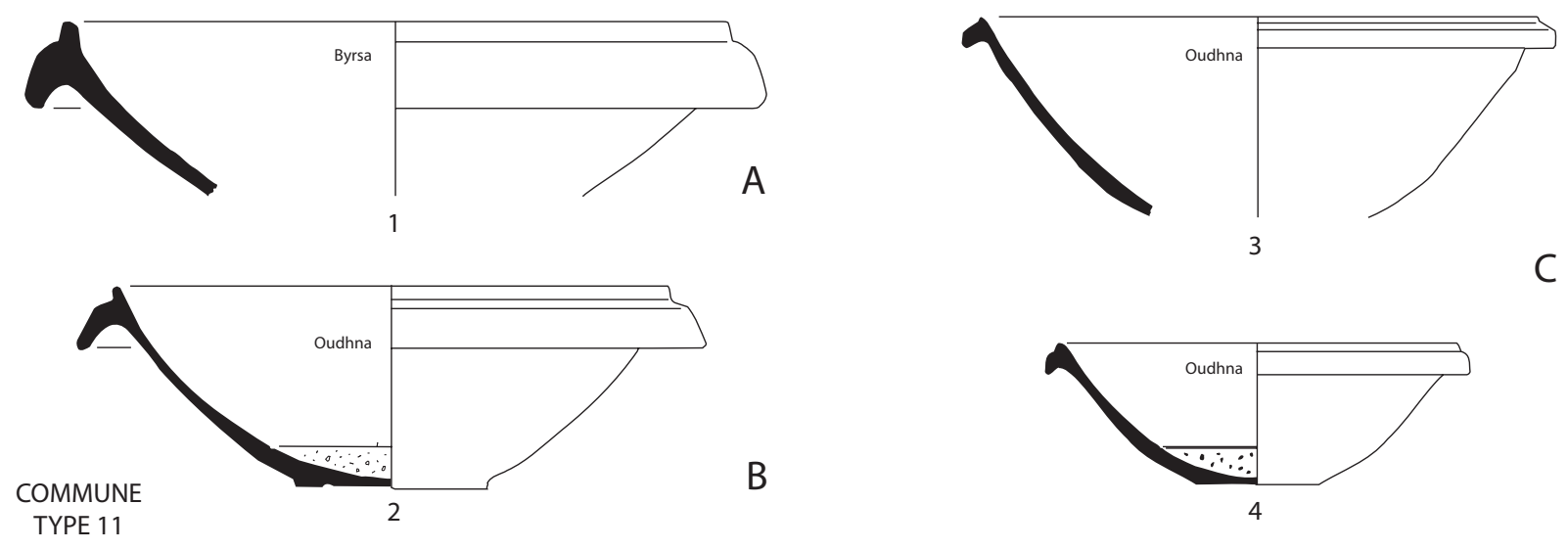

B

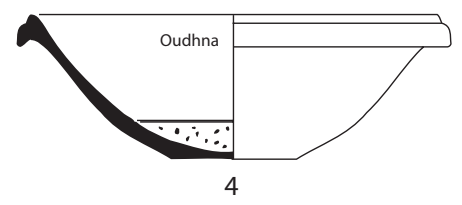

Type Carthage Class 2
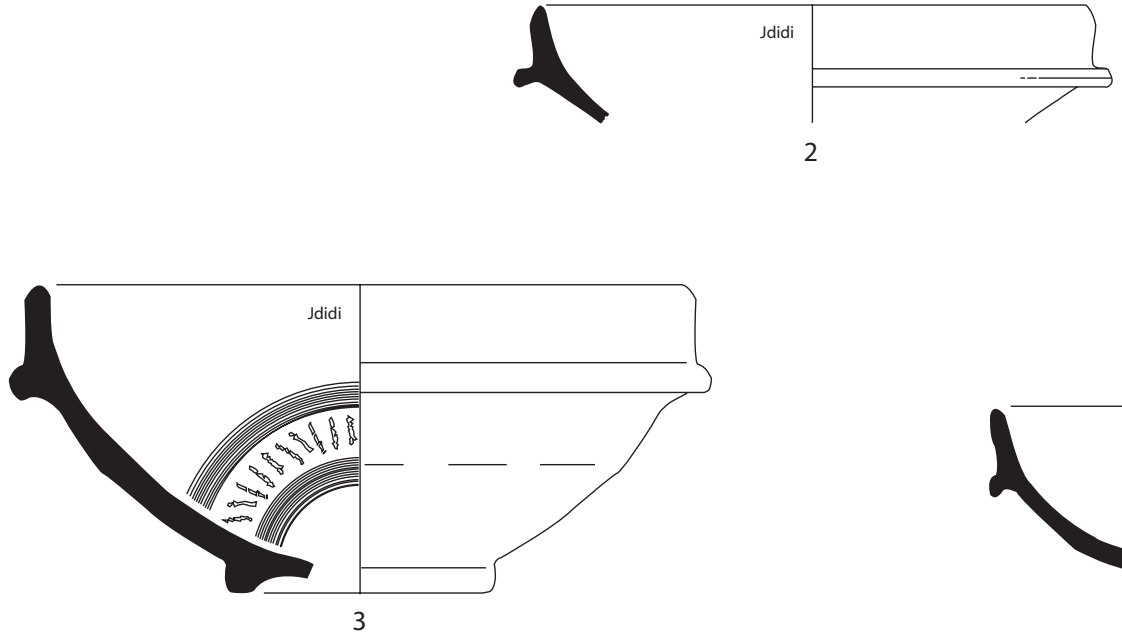

2

A
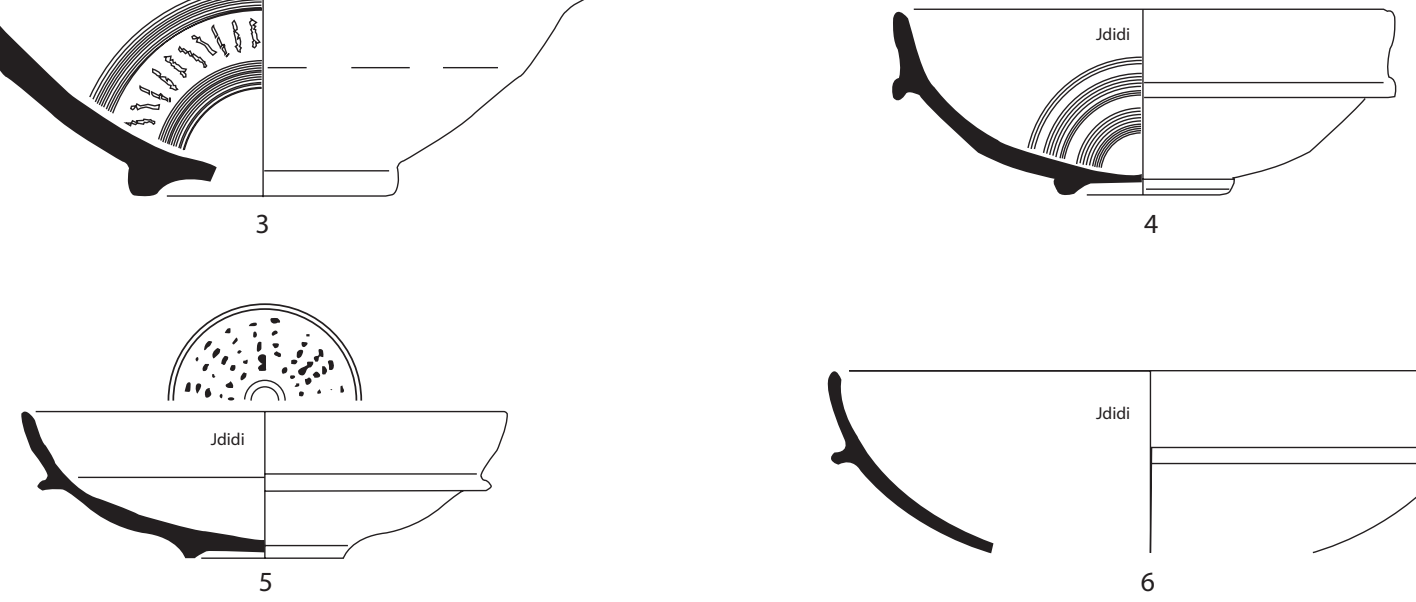

B
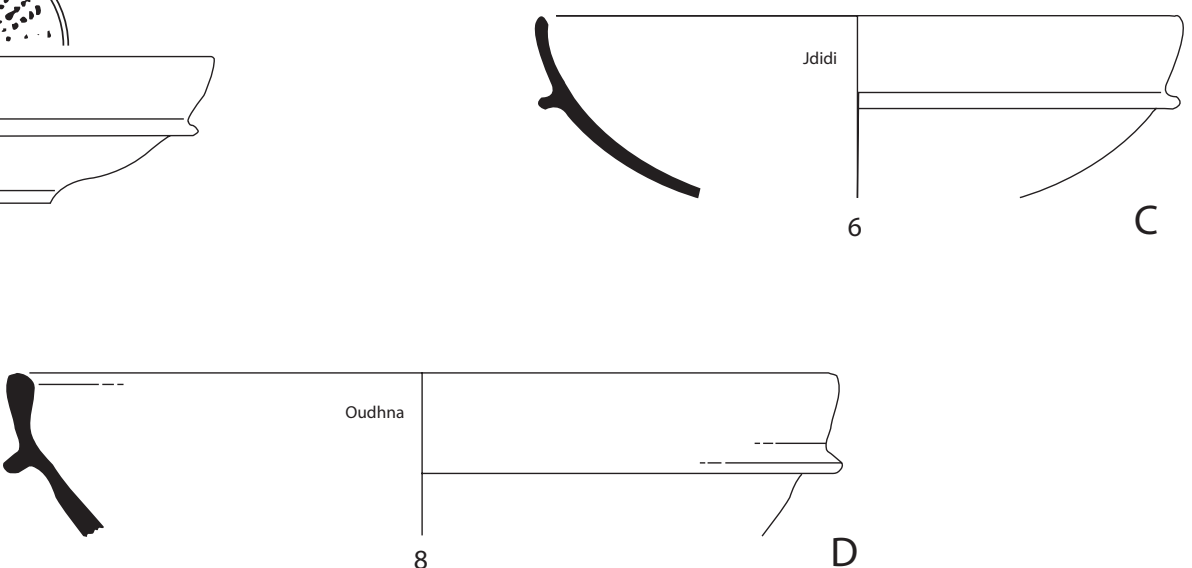

Fig. 138. Vaisselle commune africaine. Bols à listel tardifs. 
et pourrait avoir été produite en plusieurs lieux différents. La documentation de Sidi Jdidi permet d'entrevoir des éléments d'évolution (Bonifay, Reynaud 2004, fig. 144) qui complètent ceux déjà mis en évidence à Carthage (Hayes 1978b, 68-69); trois variantes ont pu être distinguées :

- Variante A (= Hayes 1976a, fig. 14, B30 ; Fulford 1984b, fig. $77, \mathrm{n}^{\circ} 14.3$ ) : panse épaissie au niveau du listel, lèvre effilée légèrement courbe vers l'intérieur ; décor peigné.

- Variante B (= Fulford 1984b, fig. 77, n 14.4 et 15.3) : bord relativement rectiligne et vertical au dessus d'un listel atrophié ; parois épaisses ; fond muni d'un pied massif, assez haut; décors peignés complexes.

- Variante C (= Fulford 1984b, fig. 77, $\mathrm{n}^{\circ}$ 14.1) : forme plus évasée avec des parois plus minces; le bord épouse parfaitement la courbure de la panse ; le listel est plus détaché, mince, et placé plus bas; le fond est porté par un petit pied à peine marqué ; décor peigné simplifié

- Variante D (= Hayes 1978b, XXI.9, XXII.3, XXV.20) : forme de grand diamètre, bord au sommet renflé, petit listel tombant, décor de cercles concentriques incisés.

Exemples (fig. 138) :

Variante A

1 Carthage (Hayes 1976a, fig. 14, B30).

*2 Sidi Jdidi, basilique 2 (Inv. JD2089.1).

Variante B

*3 Sidi Jdidi, basilique 1, état C2A (Bonifay, Reynaud $\left.2004, n^{\circ} 23.1\right)$.

*4 Idem (Ibid., $\mathrm{n}^{\circ}$ 24.6).

Variante C

*5 Idem (Ibid., $\mathrm{n}^{\circ} 26.9$ ).

*6 Idem, état C2B (Ibid., n 34.1).

Variante D

7 Carthage (Hayes 1978b, fig. 14, $\mathrm{n}^{\circ}$ XXV.20).

*8 Oudhna, est capitole (fouilles H. Ben Hassen, Inv. UTH7.000.52).

9 Oued R'mel (fouilles T. Ghalia, Inv. OR1413.3).

Autres variantes

10 Rougga, couche 10 (Guéry, Bonifay à paraître, $\mathrm{n}^{\circ} 213$ ).

11 Littoral tunisien, site $\mathrm{n}^{\circ} 85$ (Jezira) (Bonifay et al. 2002-2003, fig. $18, \mathrm{n}^{\circ} 262$ ).

Les variantes les plus anciennes apparaissent à Carthage dans le deuxième quart du VIe s. (Fulford 1984b, 202). A Sidi Jdidi, les premiers exemplaires de la variante A sont attestés dans des contextes de la fin du Ve s. ${ }^{191}$ mais il n'est pas impossible qu'ils soient alors intrusifs ; d'autres fragments sont associés à du matériel du deuxième quart du VIe s. (2) ${ }^{192}$. Les exemplaires un peu massifs de la variante B figurent dans les niveaux de la seconde moitié ou de la fin du VIe s. (3 et 4) (voir également Riley 1981, fig. $4, \mathrm{n}^{\circ} \mathrm{XXVIII.19)}$ tandis que ceux, plus fins, de la variante $\mathrm{C}$ ne paraissent pas antérieurs au VIIe s. (5 et 6). J'ai regroupé dans une variante $\mathrm{D}$ les exemplaires de la

\footnotetext{
${ }^{191}$ Associés à des sigillées africaines Hayes $61 \mathrm{C}$.

${ }^{192}$ Sigillée africaine Hayes 88A.
}

fin du VIIe s. présentés par J. W. Hayes (1978b, fig. 8, $\mathrm{n}^{\circ}$ XXI.9-10, fig. 10, $\mathrm{n}^{\circ}$ XXII.3) (7) qui, outre leur décor simplifié de cannelures en spirale, sont caractérisés par un bord à extrémité renflée; un tesson de comparaison découvert à Oudhna $(\mathbf{8})$ est hors stratigraphie mais celui de Oued R'mel provient vraisemblablement d'un contexte de la seconde moitié du VIIe s. (9). Enfin, les $\mathrm{n}^{\circ} \mathbf{1 0}$ et 11 illustrent des variantes de cette forme peutêtre produites en Byzacène méridionale.

\section{- mortiers de la région de Nabeul (fig. 139) = Fulford 1984 Bowls 22-23 = CATHMA type A1}

\section{COMMUNE TYPE 13}

L'origine néapolitaine de ces mortiers identifiés à la fois à Carthage (Fulford 1984b, 173-174) et en Méditerranée nord-occidentale (C.A.T.H.M.A. 1991, 30 et fig. 4), avait déjà été pressentie (Bonifay et al. 1998, 371; Slim, Bonifay, Trousset 1999, 332, note 17) mais elle est désormais assurée depuis les dernières prospections menées sur l'atelier de Sidi Zahruni (Ghalia, Bonifay, Capelli 2004 ; supra, p. 73). On peut désormais distinguer quatre variantes :

Variante A (précoce ?): listel mouluré, lèvre haute aplatie au sommet.

Variante B (= Fulford 23.1): listel mouluré, lèvre basse marquée par une arête vive à l'intérieur.

Variante C (= Fulford 22): listel rectiligne, à extrémité renflée $(\mathrm{C} 1)$ ou non $(\mathrm{C} 2)$.

Variante D (= Fulford 23.2) (tardive) : bord triangulaire et massif, listel légèrement mouluré, vase plus profond (?).

Exemples (fig. 139) :

Variante A

*1 Hergla, fouilles anciennes (Inv. HG.000.104). Dessin M. Pasqualini.

2 Narbonne (Raynaud 1991, fig. 3, n²).

3 Sabratha (Dore 1989, fig. 59, $\mathrm{n}^{\circ} 280$ ).

Variante B

4-5 Beni Khiar, Sidi Zahruni, atelier (supra, fig. 37, $\mathrm{n}^{\circ} 2-$ $3)$.

6 Narbonne (Raynaud 1991, fig. 3, n 4).

*7 Sidi Jdidi, basilique 2 (Inv. JD2346.25). Dessin Y. Narasawa.

Variante C

*8 Saint-Blaise (C.A.T.H.M.A. 1991, fig. 4).

*9 Nabeul, fouilles anciennes (sans $n^{\circ}$ d'inv.).

10 Marseille, chantier de La Bourse (Bonifay 1986, fig. $\left.16, \mathrm{n}^{\circ} 77\right)$. D. $23,2 \mathrm{~cm}$.

*11 Narbonne (Raynaud 1991, fig. 3, $\mathrm{n}^{\circ}$ 5).

Variante D (tardive)

*12 Sidi Jdidi, basilique 2, destruction état II (Inv. JD 2193.1). D. : $20,5 \mathrm{~cm}$.

*13 Nabeul, fabrique de salaison, période 5 (Inv. NB 1385.47).

14 Idem (Inv. NB1385.50).

Les exemplaires avec une lèvre très haute (1) (variante $A$ ) sont peut-être précoces comme l'indique le fragment de Narbonne (2) dans un contexte du premier quart du Ve s. (voir toutefois un exemplaire identique dans un contexte VIe s. à Sabratha: $\mathrm{n}^{\circ} \mathbf{3}$ ). Je ne dispose pas de données 
Type Fulford Bowl 22-23 = CATHMA A1

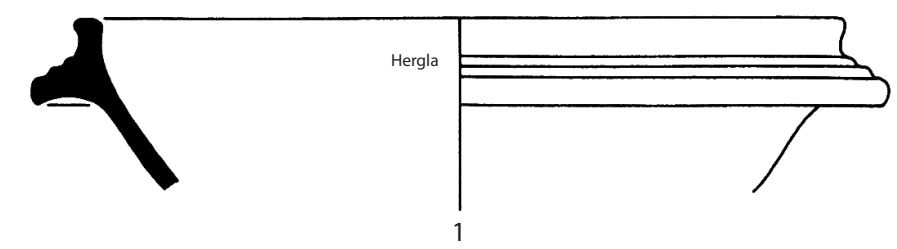

A
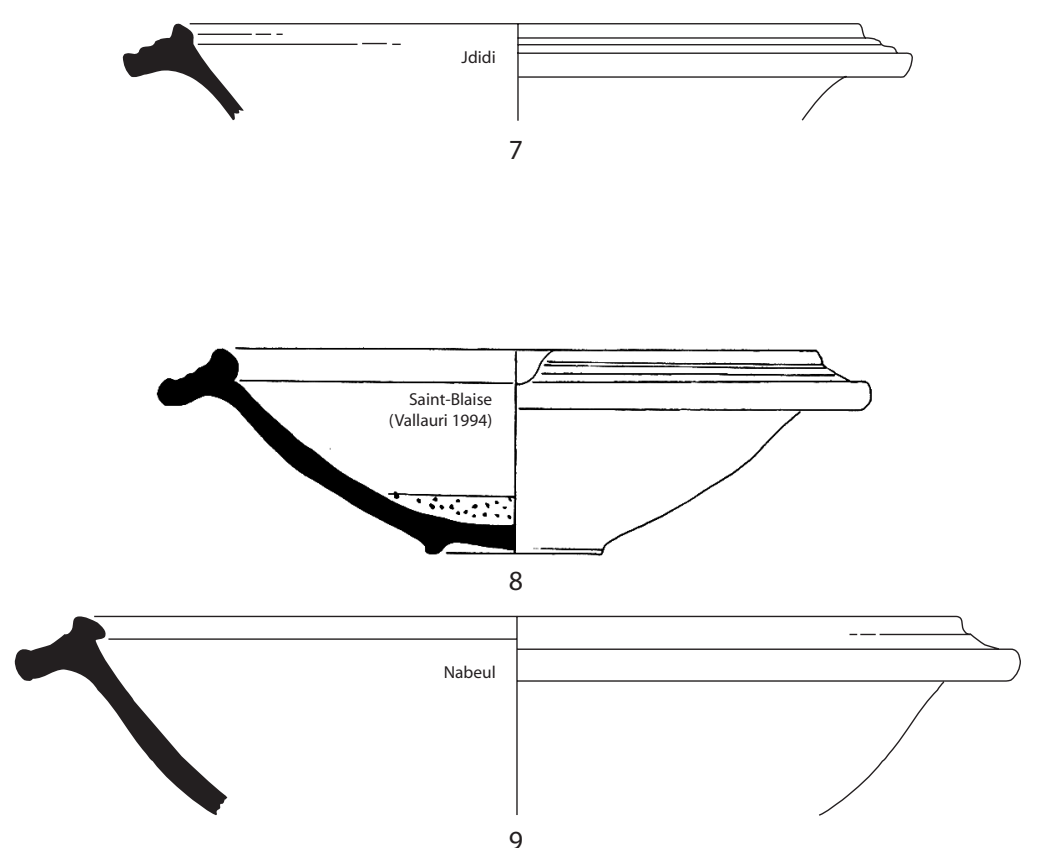

C

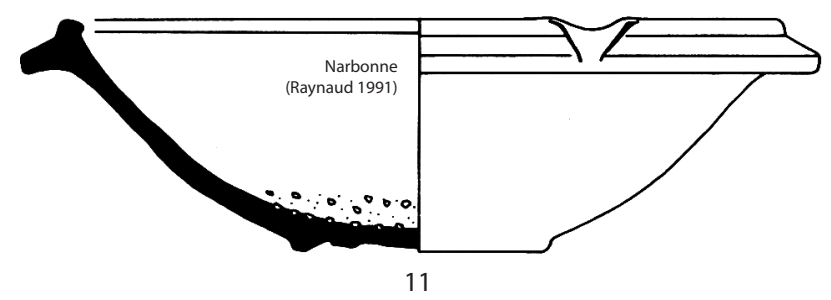

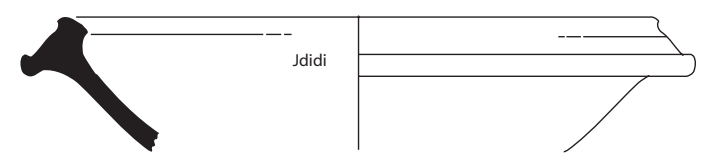

12

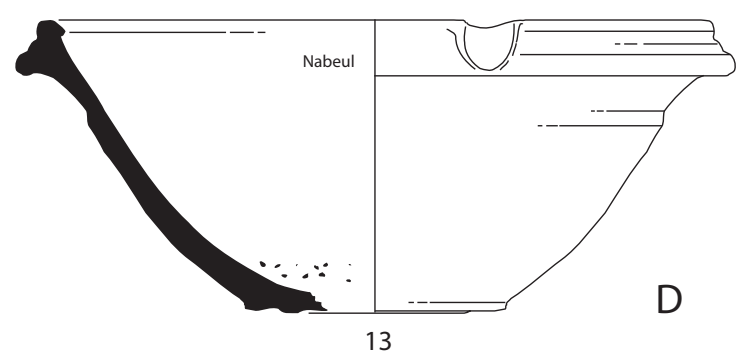

D

Fig. 139. Vaisselle commune africaine. Bols à listel tardifs. Région de Nabeul. 


\section{Typologie - Communes}

Type Sidi Jdidi 1
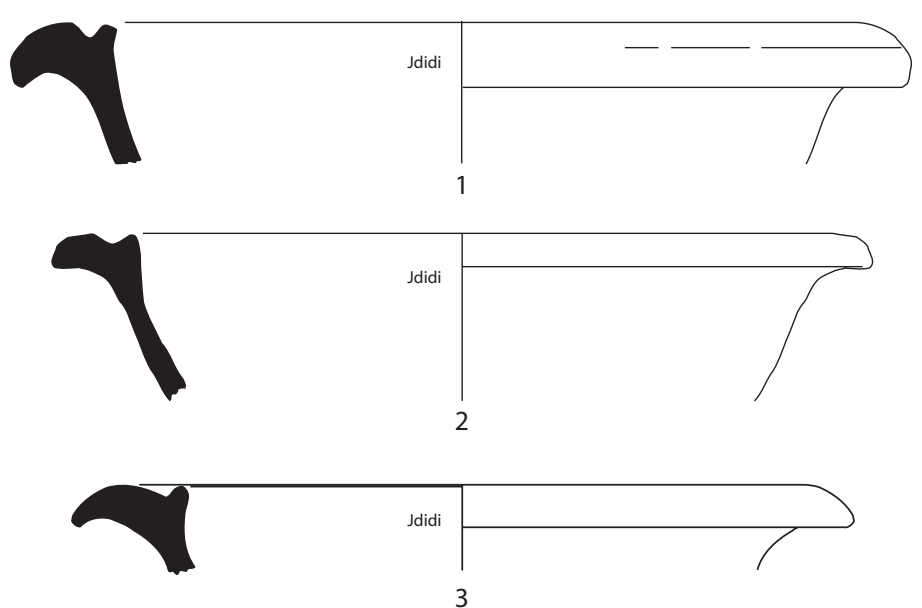

Type Sidi Jdidi 2
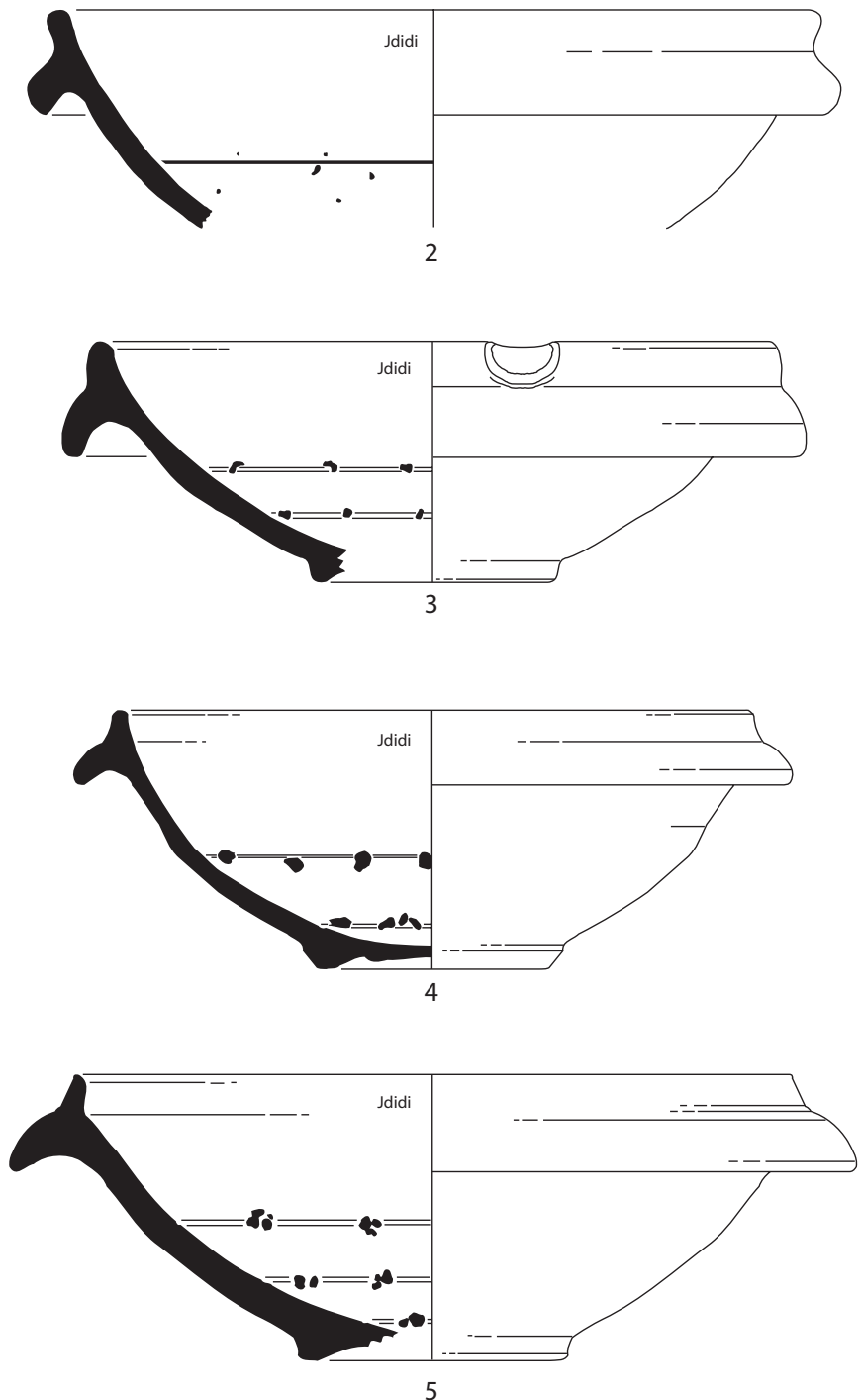

Fig. 140. Vaisselle commune africaine. Bols à listel tardifs. Golfe d'Hammamet. 
très précises sur la datation de la variante $B$ (le $n^{\circ} 7$ pourrait être résiduel dans un contexte de la seconde moitié du Ve s.) mais elle est probablement contemporaine de la variante $\mathrm{C}$ (simple différence d'atelier?). Celle-ci est bien attestée dans la première moitié et au milieu du Ve $\mathrm{s}$. (10-11); sa diffusion suit celle des amphores Keay 35B, produites dans le même secteur d'ateliers. L'information la plus nouvelle consiste dans l'identification d'une variante tardive $\mathrm{D}$, caractéristique des contextes de la seconde moitié du Ves. (12), voire même du premier tiers du VIe s. (13-14) ${ }^{193}$.

Ces mortiers, bien diffusés dans toute la Méditerranée occidentale, sont particulièrement fréquents en Catalogne (Macias 1999, Pl. 38 et Pl. 39).

Datation proposée :

Variante A - premier quart du Ve s.

Variantes B et $\mathrm{C}$ - première moitié-milieu du Ve s.

Variante D - seconde moitié Ve s. +

\section{— mortiers du nord du golfe d'Hammamet}

Deux types de mortiers font l'originalité de Sidi Jdidi, et relèvent du groupe de pâte dominant sur ce site (Bonifay, Reynaud 2004 : groupe CM 1). Ils sont également bien attestés sur les sites de la vallée de Segermes (Poulsen 2000, fig. $118, \mathrm{n}^{\circ}$ 09.11).

\section{- mortiers de type Sidi Jdidi 1 (fig. 140)}

\section{COMMUNE TYPE 14}

Vases probablement hémisphériques à bord légèrement rentrant muni d'un listel très courbe et relevé au même niveau ou plus haut que le sommet de la lèvre intérieure. Exemples (fig. 140) :

*1 Sidi Jdidi, basilique 1, état A2 (Bonifay, Reynaud 2004, $n^{\circ}$ 6A.2)

*2 Idem (Ibid., n 9.11).

*3 Sidi Jdidi, basilique 3, phase de construction (Inv. JD 5049.32).

Ce type est caractéristique des contextes de la fin du IVe s. (3) et du premier tiers du Ve s. (1-2).

- mortiers de type Sidi Jdidi 2 (fig. 140)

\section{COMMUNE TYPE 15}

Vases hémisphériques, lèvre haute, listel court, rectiligne ou légèrement en crochet, tombant ; fond muni d'un petit pied dégagé par évidement; intérieur décoré avec des grains de basalte, tantôt régulièrement alignés sur deux cannelures assez espacées l'une de l'autre, tantôt disposés en désordre et délimités par une seule (?) cannelure. Ce dernier détail ainsi que l'allure générale du vase rappellent, d'assez loin cependant, les bols à listel Carthage Class 1.

Exemples (fig. 140)

1 Sidi Jdidi, basilique 1, état A2 (Bonifay, Reynaud

\footnotetext{
${ }^{193}$ Nabeul, fabrique de salaisons. Couche de destruction de la pièce XXXIX, associée à des sigillées africaines Hayes 87A/B et des amphores Keay 55A.
}

2004, $\left.n^{\circ} 8.1\right)$

*2 Sidi Jdidi, basilique 1, état C1 (Ibid., $\mathrm{n}^{\circ} 13.9$ ).

*3 Sidi Jdidi, basilique 2, destruction état II (Inv. JD2320.1). Dessin Y. Narasawa.

*4 Idem (Inv. JD2313.42). Dessin T. Mukai.

*5 Idem (Inv. JD2313.3). Dessin T. Mukai.

Ce type est caractéristique des décennies centrales et de la seconde moitié du Ve s. (2-5).

\section{— mortiers de Byzacène centrale et méridionale}

Il faut signaler ici que le répertoire des formes de bols à listel est différent sur les sites de Byzacène méridionale et de Tripolitaine. Aucune étude précise n'en a encore été faite mais on peut se référer aux exemples recueillis lors de la prospection du littoral tunisien (Bonifay et al. 20022003, fig. $11, \mathrm{n}^{\circ} 128$ à 133).

\section{— types byzantins tardifs}

Nombreux sont les bols à listel d'époque byzantine tardive qui ne peuvent être rapportés à aucun des deux types classés à Carthage. On observe cependant sur ces objets les deux tendances générales de l'évolution déjà observée par Hayes, que sont la miniaturisation progressive des vases, comme sur le type Carthage Class 1c, et la simplification du décor en simples lignes concentriques ou en spirale, comme sur le type Carthage Class 2 D (supra, COMMUNE TYPE 12).

Les niveaux byzantins les plus tardifs de Sidi Jdidi (seconde moitié du VIIe s.) et de Rougga (milieu VIIe s.) livrent des bols de très petite taille (D. : 10-15 cm), à listel atrophié. Tous ces objets sont très fragmentaires (Sidi Jdidi : Bonifay, Reynaud 2004, fig. 144 ; Rougga : Guéry, Bonifay à paraître, $\mathrm{n}^{\circ} 211$ et 212). Des exemplaires complets découverts à Pupput et à Nabeul permettent cependant de signaler deux types récurrents dans le nord du golfe d'Hammamet :

\section{- type byzantin tardif à décor imprimé (fig. 141)}

\section{COMMUNE TYPE 16}

Petit bol hémisphérique à listel atrophié, fond plat creusé d'une rainure, décoré à l'intérieur de motifs imprimés cantonnés par deux cannelures. D. : $15 \mathrm{~cm}$.

Exemples (fig. 141) :

*1 Pupput, thermes du Centre (Bonifay 2002, fig. 4, $\left.\mathrm{n}^{\circ} 27\right)$.

*2 Idem (Inv. PPC257.1). Dessin T. Mukai.

Les deux exemplaires proviennent de contextes de la seconde moitié du VIIe siècle ${ }^{194}$.

\section{- type byzantin tardif à décor peint (fig. 141)}

\section{COMMUNE TYPE 17}

Petit bol hémisphérique, à bord en bandeau large $(\mathrm{H}$. : $1,5 \mathrm{~cm})$, parfois concave, souligné par un listel atrophié ;

\footnotetext{
${ }^{194}$ Associé à des sigillées africaines Hayes 105 C.
} 
Type byzantin tardif à décor imprimé

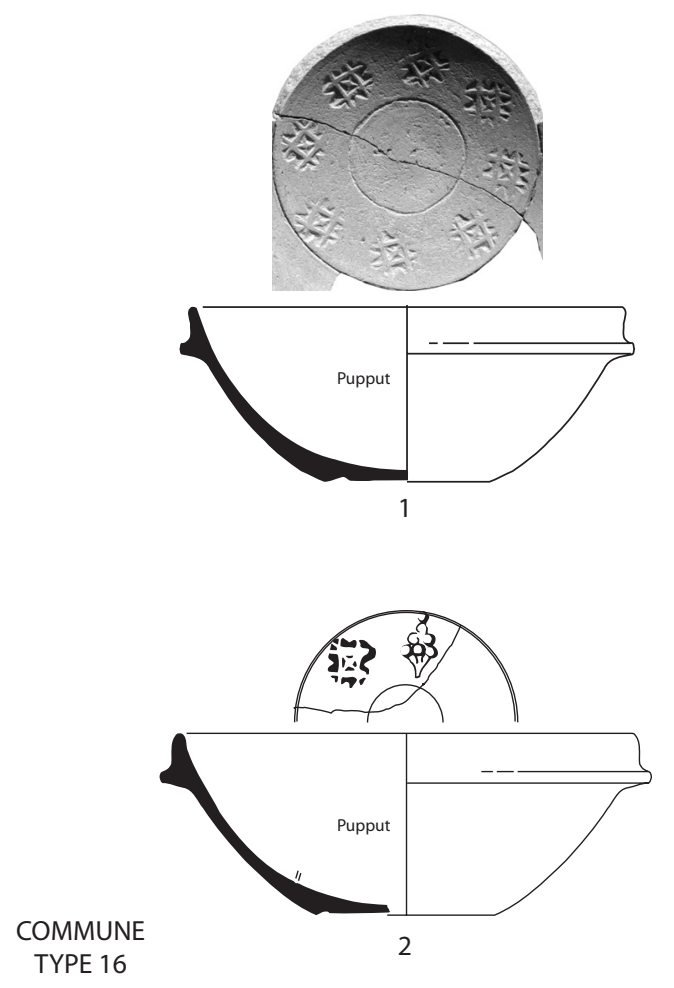

Type byzantin tardif à décor peint
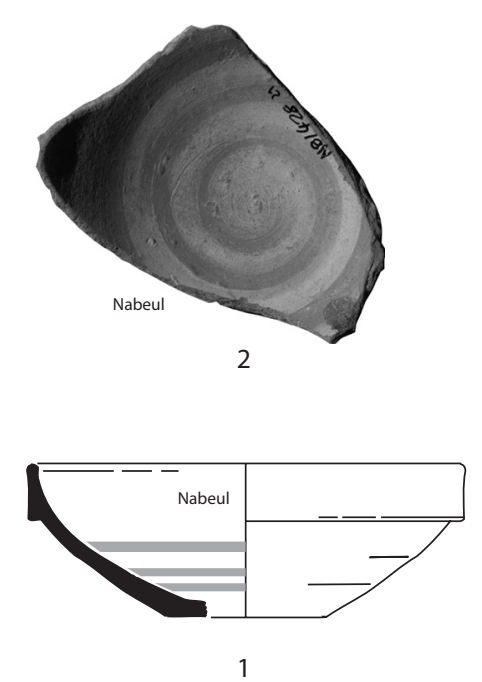

COMMUNE TYPE 17

Autres types byzantins tardifs
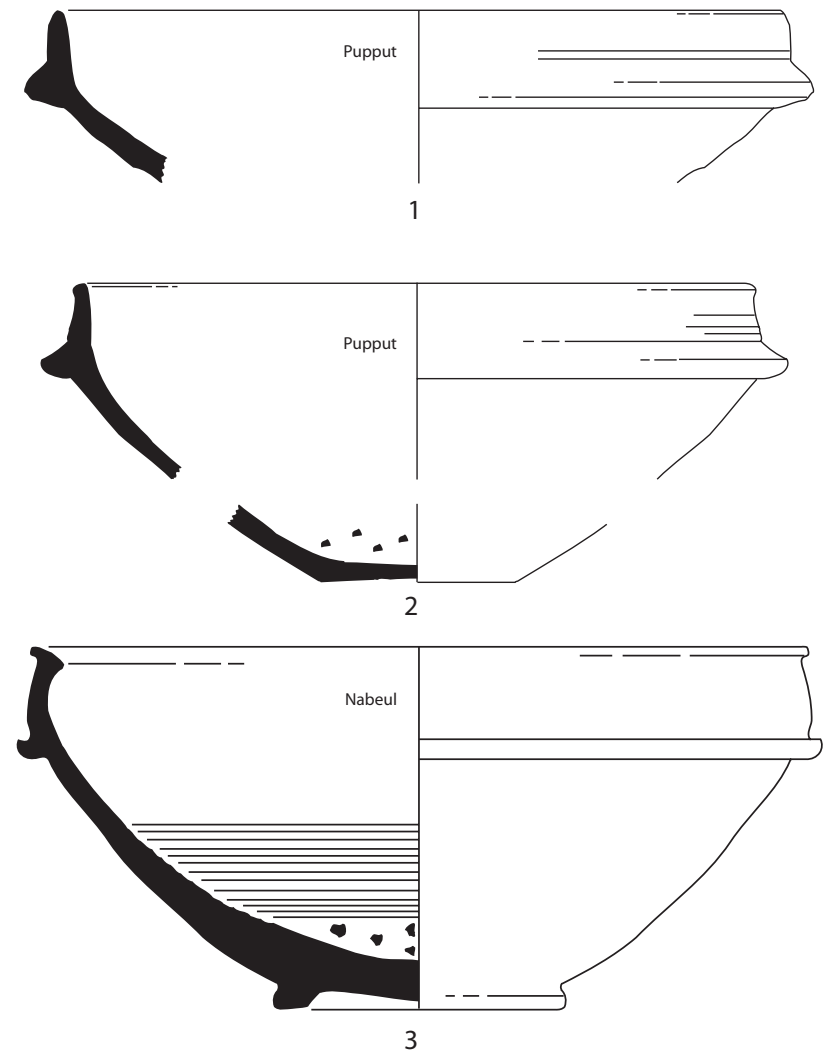

Fig. 141. Vaisselle commune africaine. Bols à listel. Epoque byzantine tardive. 
fond plat. A l'intérieur, la moitié inférieure du vase est décorée de bandes blanches ou rouges en spirale.

Exemples (fig. 141) :

*1 Nabeul, fabrique de salaison, période 6 (Bonifay 2002, fig. $\left.4, \mathrm{n}^{\circ} 28\right)$. Décor de bandes blanches. D. $13,5 \mathrm{~cm}$.

*2 Idem (Inv. NB1428.21). Fond, décor de bandes blanches.

3 Oued R'mel (fouilles T. Ghalia, Inv. OR0718.2). Décor de bandes rouges.

*4 Idem (Inv. OR0803.2). Décor de bandes rouges. D. 16 $\mathrm{cm}$.

Les exemplaires $n^{\circ} \mathbf{3}$ et $\mathbf{4}$, à décor de bandes rouges, proviennent de contextes de la seconde moitié du VIIe siècle $^{195}$. Les $n^{\circ} \mathbf{1}$ et $\mathbf{2}$, à bandes blanches, pourraient être encore plus tardifs ${ }^{196}$. Un exemplaire de Carthage, de plus grande taille (D. : $20 \mathrm{~cm}$ ), avec un décor de bandes blanches ondulées, appartient probablement aux mêmes horizons chronologiques (Fulford 1994, 68 et fig. 4.11, $\mathrm{n}^{\circ}$ 9) $)^{197}$.

\section{- autres types byzantins tardifs (fig. 141)}

\section{COMMUNE TYPE 18}

La tendance à la miniaturisation des bols à listel n'est cependant pas une règle absolue. Des vases de grande taille subsistent, dont la fonction de mortier ne fait guère de doutes, en raison de la présence de grains de basalte sur le fond. Toutefois ces inclusions sont parfois associées à une décoration de cercles concentriques (3). Exemples (fig. 141) :

*1 Pupput, thermes du Centre (fouilles A. Ben Abed, Inv. PPC137.14). D. $23 \mathrm{~cm}$

*2 Idem (Abside XXVII, sans n ${ }^{\circ}$ 'inv.). D. $24 \mathrm{~cm}$.

*3 Nabeul, fabrique de salaison, période 6 (Bonifay 2002, fig. $\left.4, \mathrm{n}^{\circ} 29\right)$. D. $24,5 \mathrm{~cm}$.

4 Nabeul, coupe stratigraphique Decumanus (Inv. NB 2000.44).

Ces objets sont datés de la fin du VIIe s. (1-2) et peut-être du début du siècle suivant (3).

\subsubsection{Bassins}

Il est d'usage (Van der Werff 1982a, 147) de regrouper sous l'appellation «bassins» (lat. baccus) des « récipients portatifs creux, de forme généralement ronde ou ovale », " servant à divers usages domestiques ou industriels ${ }^{198}$. Du point de vue de la diversité de leurs fonctions, ces bassins sont un peu l'équivalent de nos bassines en plastique actuelles. Certes, on a signalé récemment leur utilité spécifique en tant que pots de chambre (Pasqualini 2002). Cependant, les seules traces

\footnotetext{
${ }^{195}$ Associés à des amphores Keay 50, Sidi Jdidi 2 et Hammamet $3 \mathrm{D}$.

${ }^{196}$ Associés à des sigillées africaines D4 à décor lustré et à des dérivées de sigillées à pâte blanche.

${ }^{197}$ La datation proposée - fin du VIe s.- me paraît trop haute en raison de la présence, dans le même contexte, de sigillées africaines Hayes 99D $(=80 \mathrm{~B} / 99)$ et 105 (Fulford 1994, 68 et 93 : phase 6.33-a).

${ }^{198}$ Petit Robert, Ed. 1993, p. 201.
}

évidentes consistent, au sein du matériel que j'ai pu examiner, dans des restes importants de chaux qui attestent leur utilisation comme auge pour gâcher le mortier. Par exemple, à Sidi Jdidi, le bassin 18.30 (infra, TYPE $34, n^{\circ} 2$ ), pratiquement complet et couvert de chaux, est probablement contemporain de la reconstruction de la basilique 1 au deuxième quart du VIe siècle. Un autre exemple est signalé à Dougga (De Vos, Polla, Gliozzo 2004).

Les bassins, peu diversifiés dans la céramique commune africaine des IIe-IIIe s., vont connaître, tout comme les mortiers, un développement considérable à partir du IVes. et durant toute l'Antiquité tardive. La multiplication des formes et des variantes rend extrêmement difficile toute tentative de classification précise; c'est à titre purement provisoire que je propose de réorganiser les typologies partielles, élaborées sur différents chantiers, de la façon suivante.

\section{- les formes de tradition punique (fig. 142)}

\section{COMMUNE TYPE 19}

Je propose de rattacher à l'évolution d'un type punique bien connu de bassin largement ouvert (Lancel 1987, type 131), une forme assez bien représentée dans le nord du golfe d'Hammamet et caractérisée par un bord à lèvre pendante qui tend à se replier complètement sur sa face inférieure.

Exemples (fig. 142) :

1 Jebel Harboun (Ben Abed et al. 2000, fig. 8, $\mathrm{n}^{\circ} 8$ ).

*2 Nabeul, fabrique de salaison, pièce XLIV (Inv. NB 1878.93). Dessin C. Brun.

*3 Idem (Inv. NB1878.92). Dessin C. Brun.

*4 Sidi Jdidi, basilique 2, destruction état II (Inv. JD 2103.3)

Les deux seuls exemplaires bien datés (2-3) proviennent d'un contexte de la fin du IIIe ou du début du IVe siècle. Le $\mathrm{n}^{\circ} \mathbf{1}$, plus proche du supposé modèle punique, est probablement plus ancien. Le $n^{\circ} \mathbf{4}$ est peut-être résiduel (?) dans son contexte de la seconde moitié du Ve siècle.

\section{- les formes des IIe-IVe s.}

Les bassins en céramique commune africaine des IIeIVes. peuvent se répartir en deux formes essentielles, définies à Uzita (Van der Werff 1982a, 147-149, formes Uzita 1 et 2). J. H. Van der Werff signalait également deux autres fragments. Le premier (Ibid., P1. 40, $\mathrm{n}^{\circ} 22$ ) appartient à un type ancien de bassin à ergots, connu à Carthage au milieu du Ier s. (Martin-Kilcher 1999, n 409 et fig. 16, $\mathrm{n}^{\circ}$ 70-71). Le deuxième (Van der Werff 1982a, Pl. 45, 3), en revanche, est illustré par de nombreux exemples à la fin du IIIe s. et au IVe s. et doit pouvoir être érigé en forme 3. 


\section{Typologie - Communes}

Bassins de tradition punique
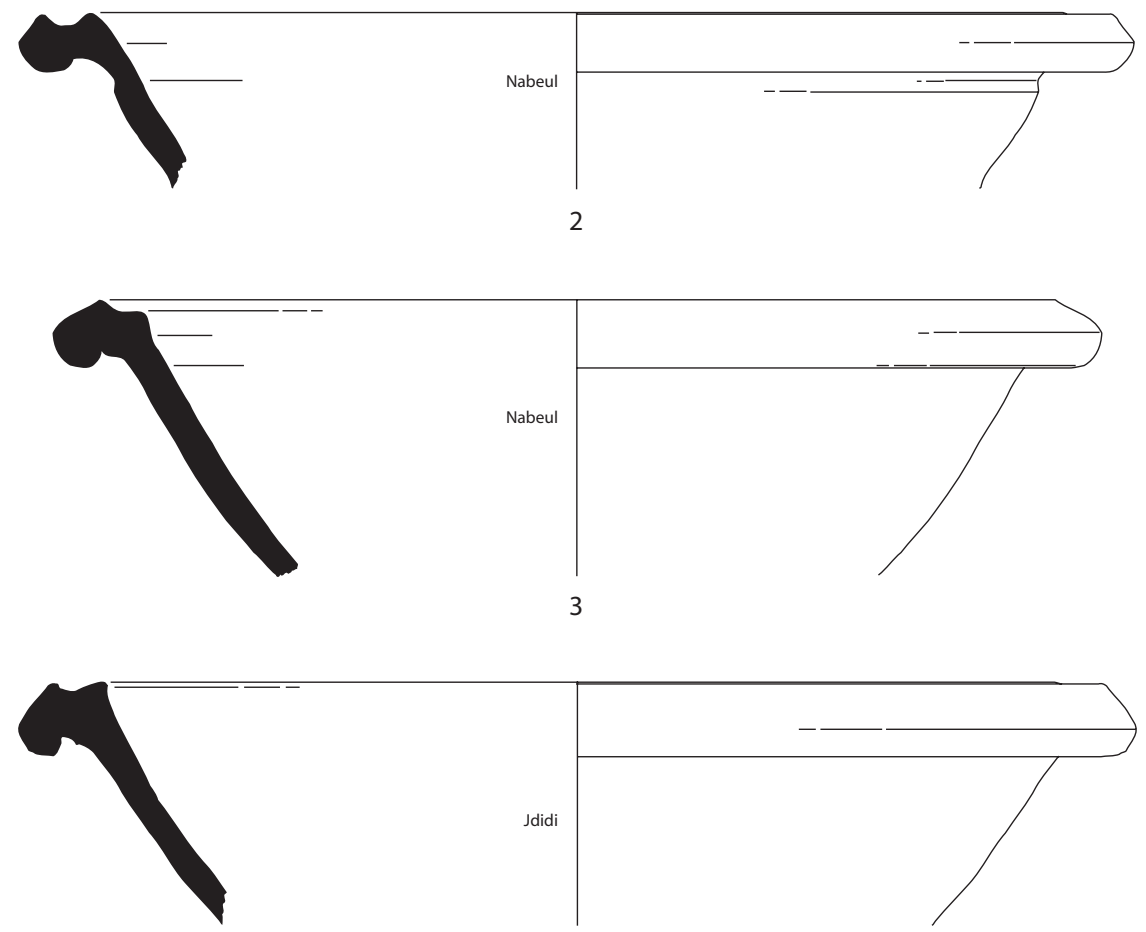

4

Bassin Uzita 1
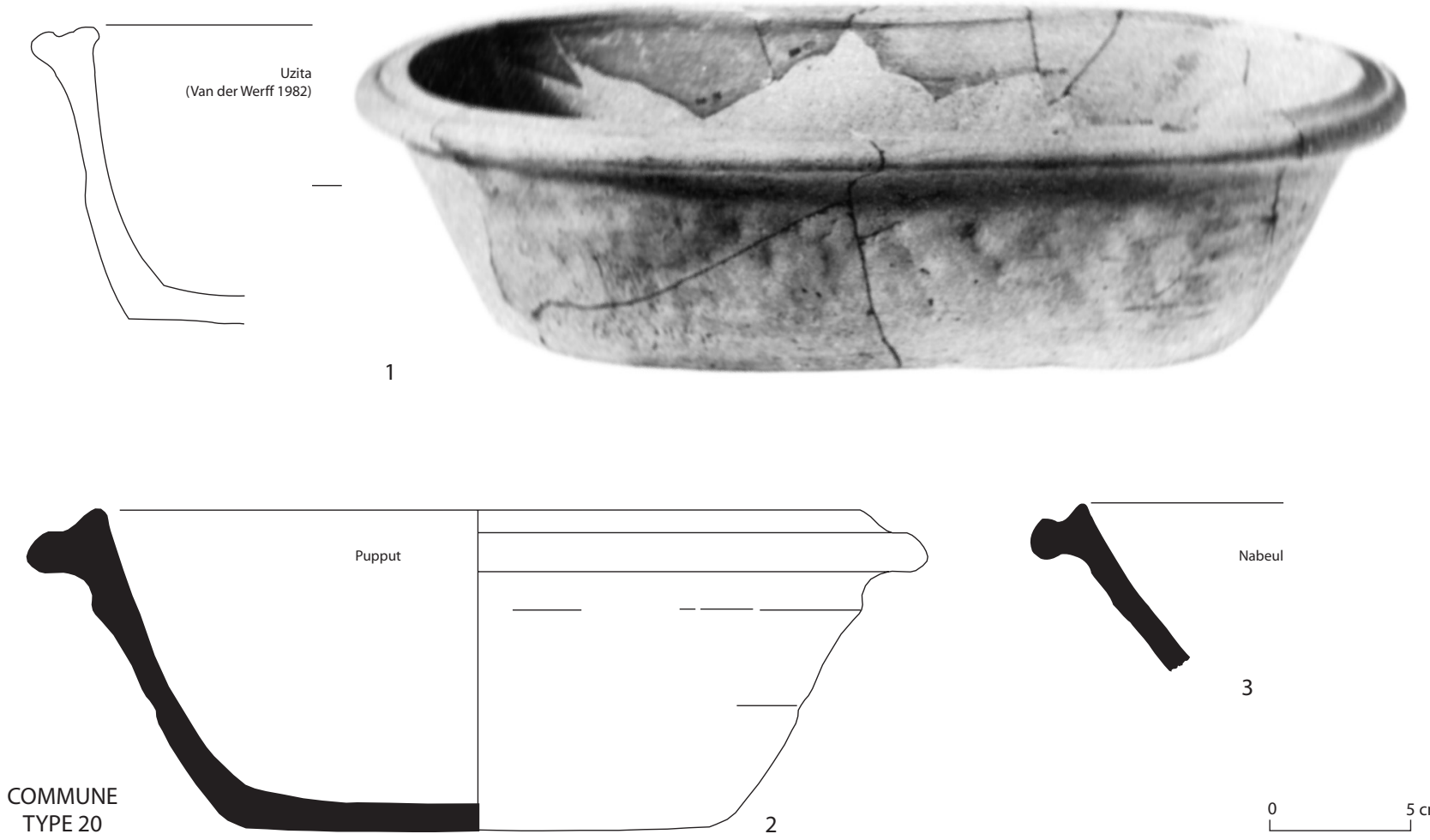

Fig. 142. Vaisselle commune africaine. Bassins. 


$$
\begin{aligned}
& \sum T^{Y} \\
& \text { 7) } \\
& 7
\end{aligned}
$$




\section{— bassins Uzita 1 (fig. 142)}

\section{COMMUNE TYPE 20}

Vase oblong et peu profond (H. : 10 - $12 \mathrm{~cm} ; 1$. : 24 - 32 $\mathrm{cm}$; L. : $36-45 \mathrm{~cm}$ ), fabriqué par découpe d'un vase tourné et raccordement des deux parties avec des plaques d'argile modelées (Van der Werff 1982a, 147). Le bord est triangulaire, au sommet concave.

Exemples (fig. 142) :

*1 Uzita (Van der Werff 1982a, P1. 68).

*2 Pupput, tombe 1082 (Inv. PP2514.1).

*3 Nabeul, fabrique de salaison, bassin XVII (Inv. NB1055.15).

4 Sidi Jdidi, basilique 1, état A1 (Bonifay, Reynaud 2004, $\mathrm{n}^{\circ} 3.15$ ).

Les exemples de Pupput et de Nabeul confirment la datation généralement admise pour cette forme, aux IIe IIIe siècles.

\section{— bassins Uzita 2 (fig. 143)}

\section{COMMUNE TYPE 21}

Vase rond ou ovale, profond (H. estimée : $20-25 \mathrm{~cm}$ ). Bord à large marli rectiligne sur les variantes anciennes puis arrondi sur les variantes tardives. Panse tronconique et rectiligne ou très faiblement galbée. Fond plat. A la suite des observations de J. H. Van der Werff, je propose, dans l'état actuel de la documentation réunie, de distinguer schématiquement cinq variantes :

- Variante A (=Uzita, Pl. 45, $\left.\mathrm{n}^{\circ} 4\right)$ : bord oblique rectiligne, presque parfaitement plat sur le dessus, légèrement mouluré sur sa face inférieure, parfois faiblement épaissi à son extrémité ; arête vive à la jonction avec la panse.

- Variante $\mathrm{B}\left(=U z i t a, \mathrm{Pl} .45, \mathrm{n}^{\circ} 5\right)$ : bord oblique très légèrement convexe, terminé par une lèvre triangulaire pendante; ressaut interne marqué à la jonction avec la panse.

- Variante $\mathrm{C}\left(=\right.$ Uzita, $\left.\mathrm{Pl} .45, \mathrm{n}^{\circ} 6\right)$ : bord oblique très légèrement convexe, épaissi et parfois marqué d'une cannelure à son extrémité.

Exemples (fig. 143) :

Variante A

*1 Uzita (Van der Werff 1982a, Pl. 45, n 4).

*2 Hergla, fouilles anciennes (Inv. HG.000.127). Dessin M. Pasqualini.

*3 Oudhna, est capitole (fouilles H. Ben Hassen, Inv. UTH7.1002.14).

4 Nabeul, fabrique de salaison, bassin XVII (Inv. NB 1053.9)

Variante B

*5 Uzita (Van der Werff 1982a, Pl. 45, n 5).

*6 El Jem, maison d'Africa (fouilles H. Slim, Inv. EJMA. 2316.029).

Variante $\mathrm{C}$

*7 Uzita (Van der Werff 1982a, Pl. 45, nº 6).

*8-9 Nabeul, fabrique de salaison, bassin XVII (Inv. NB 1052.6 et 1055.0).

La variante A est bien attestée au IIe s. et dans la première moitié du IIIe s. $(\mathbf{1}, \mathbf{4})$. Les variantes B et C pourraient être contemporaines (5-6 et 7-9), tout au moins dans la première moitié et au milieu du IIIe s., mais, par rapport à la variante précédente, elles ne paraissent guère diffusées hors de Byzacène méridionale. La fabrication de cette forme est attestée à Salakta (Lavoie 1989, Pl. II, C2, Pl. III, C11, P1. V, E3).

Un certain nombre de bassins, trouvés dans des contextes du début (10) à la fin du IVe s. (12), voire même encore au Ves. (11 ?) paraissent dériver de ce type : dans tous les cas, ils sont caractérisés par une panse rectiligne ou faiblement galbée, sans resserrement sous le bord, luimême relativement court et peu incliné, à extrémité arrondie.

Exemples (fig. 143) :

Variantes tardives (?)

*10 Nabeul, fabrique de salaison, pièce XLIV (Inv. NB 1878.74).

*11 Oudhna, thermes des Laberii (Inv. UTH.TL, sans $n^{\circ}$ ). Deux cannelures à mi-bord. Une onde incisée au sommet de la panse. Ovale (?).

*12 Oudhna, capitole (Inv. UTH1.1001.23 ; Bonifay, Dridi, Jacquest à paraître, $\mathrm{n}^{\circ} 35$ ). Rond, D. : $32 \mathrm{~cm}$.

— bassin Uzita Pl. 45, n³ (fig. 144)

\section{COMMUNE TYPE 22}

Je propose de nommer «forme Uzita 3 » un type de bassin dont J. H. Van der Werff n'avait illustré qu'un seul fragment mais qui lui paraissait différent des précédents (Van der Werff 1982a, Pl. 45, n 3). Ces différences résident en deux points : a) le bord est très convexe, au lieu d'être plat; b) les parois sont très galbées, au lieu d'être rectilignes. Ces deux caractéristiques donnent à ce bassin un profil suffisamment divergent des précédents pour justifier la création d'un autre type. On peut cependant, dans l'état actuel de la documentation, distinguer deux variantes :

- Variante A (=Uzita, Pl. 45, $\left.\mathrm{n}^{\circ} 3\right)$ : bord oblique convexe, marqué d'une cannelure à son extrémité ; arête vive à la jonction avec la panse.

- Variante B (= Fulford 1984b, Jar 4 = Tomber 1988

$L R$ Basin 3): bord presque vertical, très convexe, épaissi et arrondi à son extrémité, marqué d'une ou deux cannelures, plus rarement sans cannelure; renflement et arête plus ou moins prononcés à la jonction avec la panse.

Exemples (fig. 144) :

Variante A

1 Uzita (Van der Werff, Pl. 45, $\mathrm{n}^{\circ}$ ) Orientation du dessin à restituer en fonction de l'exemplaire d'Hergla (?).

*2 Hergla, fouilles anciennes (Inv. HG.000.126). Dessin M. Pasqualini.

Variante B

*3 Carthage (Fulford 1984b, fig. 73, $\mathrm{n}^{\circ} 4.2$ ).

*4 El Jem, maison d'Africa (fouilles H. Slim, Inv. EJMA. 2316.030).

*5 Nabeul, fabrique de salaison, pièce XLIV (Inv. NB 1878.95). Dessin C. Brun.

*6 Carthage, Byrsa (Bonifay à paraître, a, n 38).

7 Oudhna, est capitole (fouilles H. Ben Hassen, Inv. 


\section{Typologie - Communes}

"Bassins Uzita 3"
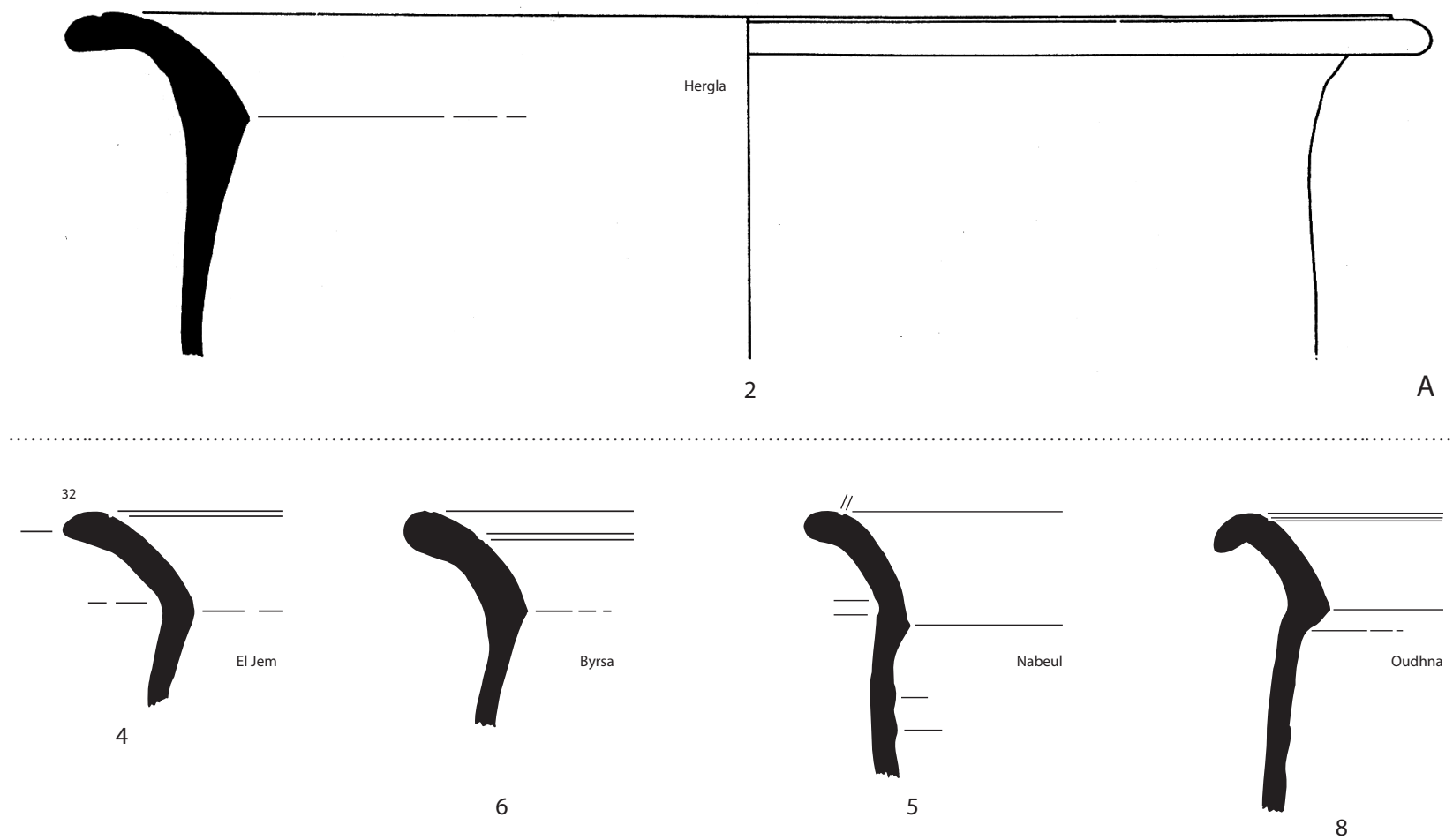

6

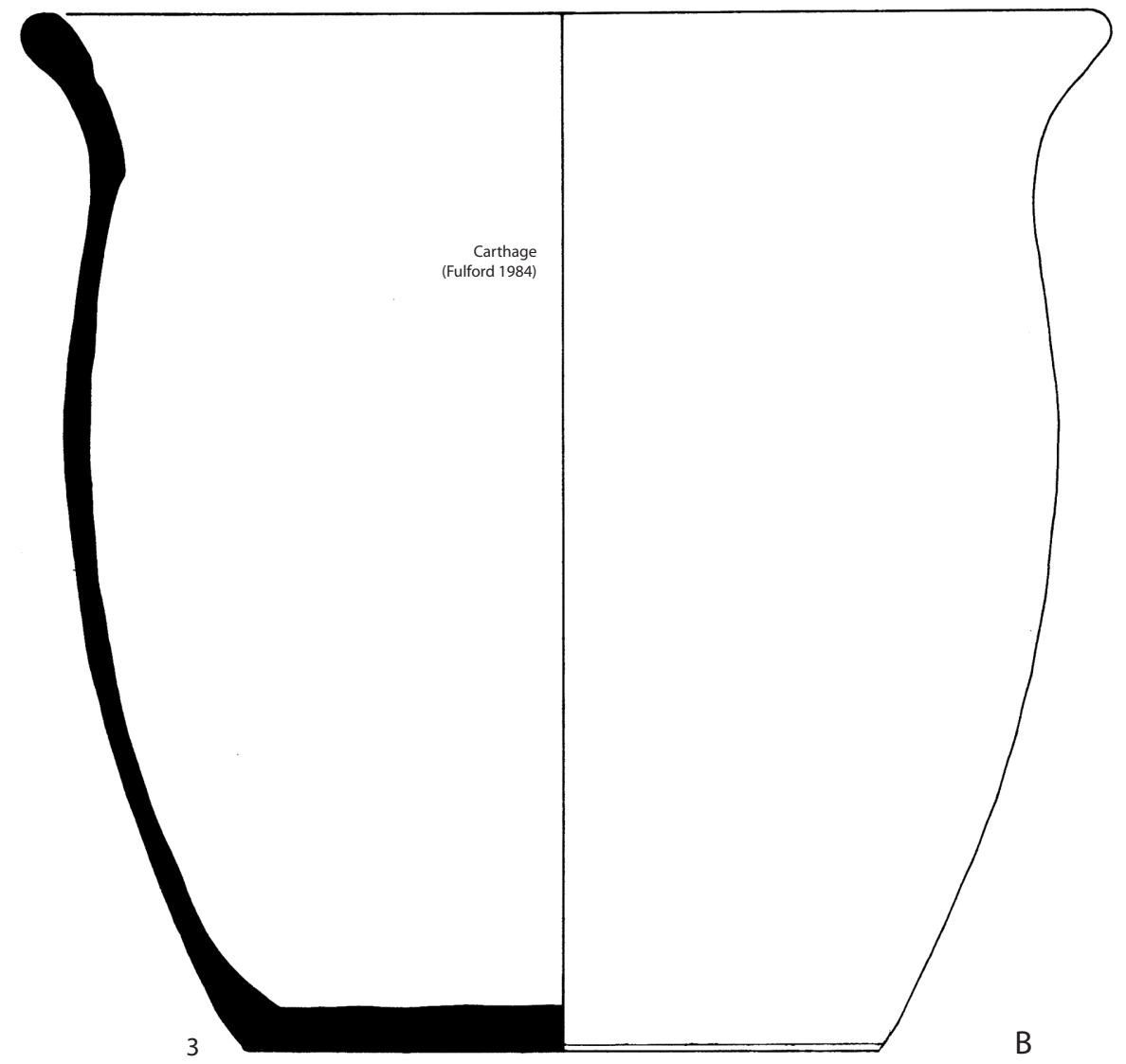

Fig. 144. Vaisselle commune africaine. Bassins. 
UTH7.000.39). D. : $31 \mathrm{~cm}(?)$.

*8 Idem (Inv. UTH7.000.51). Variante à lèvre pendante. D. : $38 \mathrm{~cm}(?)$.

La variante A semble apparaître dès le milieu du IIIe $\mathrm{s}$. (Van der Werff 1982a, 150). Lui succède la variante B à la fin du IIIe s. ou au début du IVe s. (5) et probablement durant tout le IVe s. (6 ?). La fabrication de cette forme est attestée à Leptiminus (Dore 1992, 149, n $^{\circ} 60$; Id. 2001, fig. 1.66, $\left.\mathrm{n}^{\circ} 18\right)$.

\section{- principaux types de l'Antiquité tardive}

- bassins dérivés du type Uzita 1 (fig. 145)

= Fulford 1984 Bowl 17 = Fulford 1994 Bowl 26 = type Sidi Jdidi 1

\section{COMMUNE TYPE 23}

Bassin oblong à parois évasées, parfois discrètement cannelées à l'extérieur; bord massif de section grossièrement triangulaire, à extrémité arrondie et sommet légèrement concave; les exemplaires les plus tardifs ont une lèvre aiguë et pendante. Ce type de bassin, qui est connu à Carthage (Fulford 1984b, 173 et fig. 63, forme 17 ; Fulford 1994, 56 et fig. 4.2, forme 26), paraît dériver de la forme Uzita 1, surtout lorsque l'on considère sa variante Uzita $\mathrm{Pl} .45, \mathrm{n}^{\circ} 2$. La stratigraphie de Sidi Jdidi permet d'ordonner les différents exemplaires de la façon suivante :

Exemples (fig. 145) :

*1 Oudhna, capitole (fouille H. Ben Hassen, Inv. UTH1.1003.1).

*2 Sidi Jdidi, basilique 2, état 0 (Inv. JD2185.7). Bord arrondi, paroi extérieure cannelée. Dessin P. Reynaud.

3 Sidi Jdidi, basilique 5, phase de construction (Inv. JD 5049.37). Bord arrondi.

*4 Sidi Jdidi, basilique 1, état A2 (Bonifay, Reynaud 2004, $\mathrm{n}^{\circ}$ 7.4). Bord arrondi, paroi extérieure cannelée.

5 Idem (Ibid., $\mathrm{n}^{\circ}$ 7.3). Bord anguleux, paroi extérieure cannelée.

6 Idem (Ibid., $\mathrm{n}^{\circ}$ 9.12). Bord anguleux.

*7 Sidi Jdidi, basilique 2, destruction état II (Inv. JD2210.1). Bord anguleux à lèvre pendante, paroi extérieure non cannelée.

*8 Idem (Inv. JD2264.21). Bord anguleux à lèvre pendante, paroi extérieure cannelée.

*9 Idem (Inv. JD2277.9). Bord anguleux à lèvre pendante. Dessin Y. Narasawa.

L'évolution de cette forme va d'exemplaires aux parois évasées, le plus souvent cannelées, avec un bord aux extrémités arrondies, à des exemplaires aux parois plus verticales, rarement cannelées, avec un bord anguleux à lèvre pendante. La liste ci-dessus montre que ce schéma n'est certes pas absolu (cf. $\mathrm{n}^{\circ} \mathbf{5}$ et 8). Les variantes qui sont les plus proches de l'exemplaire Pl. 45, $\mathrm{n}^{\circ} 2$ d'Uzita sont bien attestées au IVe s. (?) (2) et jusqu'à la fin du siècle (3); les exemplaires de Carthage sont également datés du IVes. (Fulford 1994, 56). Les contextes de la première moitié et du milieu du Ves. livrent des exemplaires plus évolués (4-6). Enfin, la phase finale de l'évolution prend place dans la seconde moitié du Ve s. (7-9).

\section{— bassins dérivés du type Uzita 2 (fig. 146)}

COMMUNE TYPE 24 À 28

Les niveaux tardifs de Sidi Jdidi livrent une grande quantité de fragments de bassins qui paraissent tous dérivés du type Uzita 2 mais au sein desquels il paraît prématuré de vouloir opérer un classement rigide. Je signale ici quelques-uns des types provisoirement identifiables :

- TYPE 24 : bord oblique, relativement rectiligne, à extrémité épaissie et arrondie, au sommet creusé d'une gorge; arête vive et renflement interne à la jonction avec la panse.

- TYPE 25 : bord oblique épais, à extrémité effilée et légèrement pendante, marqué d'une cannelure au sommet; arête vive ou ressaut interne à la jonction avec la panse.

- TYPE 26 : bord oblique atrophié, épais et court, à extrémité arrondie et sommet marqué d'une cannelure ; arête vive ou ressaut interne à la jonction avec la panse.

- TYPE 27 : bord déversé presque à l'horizontale, à section légèrement sinueuse (variante $A$ ) ou en amande (variante B), au sommet marqué d'une cannelure; paroi cannelée à l'extérieur, parfois décorée d'une onde incisée ou d'impressions ovales ; la cannelure et le renflement interne tendent à disparaître sur les variantes tardives. Ce type pourrait tout aussi bien dériver du type Uzita 3 (?).

- TYPE 28 : bord à section en «T $»$. Parenté avec le type Uzita 2 discutable.

Exemples (fig. 146) :

Type 24

*1 Sidi Jdidi, basilique 2, destruction état II (Inv. JD 2198.18).

TYPE 25

*1 Sidi Jdidi, basilique 1, état A2 (Bonifay, Reynaud 2004, $\left.n^{\circ} 11.4\right)$.

*2 Sidi Jdidi, basilique 2, destruction état II (Inv. JD 2200.32).

TYPE 26

*1 Sidi Jdidi, basilique 1, état A2 (Bonifay, Reynaud 2004, $\left.n^{\circ} 10.4\right)$.

*2 Idem, état B1A (Ibid., $\mathrm{n}^{\circ} 13.13$ ).

3 Sidi Jdidi, basilique 2, destruction état II (Inv. JD 2275.18).

TYPE 27

Variante A

1 Sidi Jdidi, basilique 2, destruction état II (Inv. JD 2194.25). Décor ondé.

*2 Sidi Jdidi, basilique 1, état C1 (Bonifay, Reynaud 2004, $\mathrm{n}^{\circ}$ 15.4). Décor d'impressions ovales.

*3 Sidi Jdidi, basilique 2, destruction état II (Inv. JD 


\section{Typologie - Communes}

Type Sidi Jdidi 1
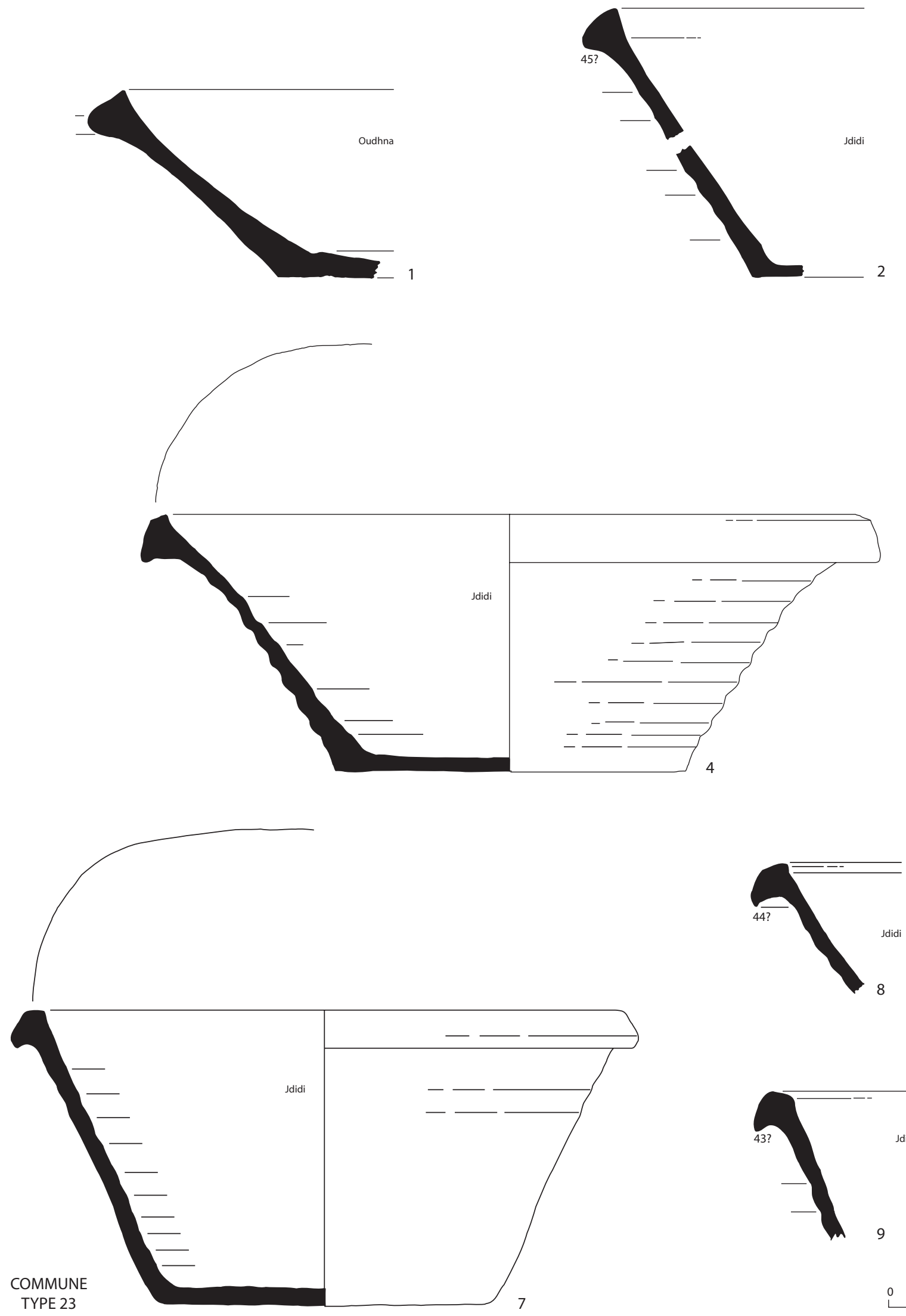

Fig. 145. Vaisselle commune africaine. Bassins dérivés du type Uzita 1. 
2313.20). Décor ondé incisé à l'extérieur. Dessin Y. Narasawa.

*4 Idem (Inv. JD2217.7). Décor d'impressions ovales. Variante B

*5 Sidi Jdidi, basilique 1, état A2 (Bonifay, Reynaud 2004, $n^{\circ}$ 9.13).

*6 Idem, état B1A (Ibid. $\mathrm{n}^{\circ}$ 12.22).

Type 28

*1 Sidi Jdidi, basilique 1, état A2 (Bonifay, Reynaud 2004, $n^{\circ}$ 6A.3).

*2 Idem, basilique 2, destruction état II (Inv. JD2275.16). Dessin T. Mukai.

Le TYPE 24 (1) peut être assimilé aux ultimes variantes du bassin Uzita 2 proprement dit, par exemple le $n^{\circ} 12$ (COMMUNE TYPE 21), daté de la fin du IVe s. à Oudhna. Le TYPE 25 apparaît à Sidi Jdidi dès le premier tiers du Ves. (1) mais des exemplaires avec un puissant renflement interne (2) peuvent encore survivre dans la seconde moitié du siècle. Il en est de même pour le TYPE 26, bien attesté du début (1) à la fin du Ve s. (3), avec une évolution vers un bord de plus en plus épaissi. La variante A du TYPE 27 n'est attestée que dans les décennies centrales (2) et la seconde moitié du Ve s. (1, 3-4) tandis que la variante $B$, déjà présente dans la première moitié du Ves. (5) donnera des variantes tardives simplifiées encore au VIe s. (6 ?). Le TYPE 28 est présent tout au long du Ve s. (1-2).

Cette liste établie sur la base du matériel d'un seul site ne rend certainement pas compte de la diversité morphologique des bassins africains tardifs en céramique commune, issus de la forme Uzita 2. Les trois fragments publiés à Thuburbo Majus suffisent à illustrer cette complexité (Ben Abed, Bonifay 1998, fig. 2, n 21-23).

\section{- bassins dérivés du type Uzita 3 : type Carthage $L R$ Basin 1 (fig. 147) \\ $=$ Fulford 1984 Jar 2}

\section{COMMUNE TYPE 29}

Le type LR Basin 1 (Hayes 1976a, 102 et fig. 9, $\mathrm{n}^{\circ}$ XIV 39 et 40 ) paraît directement issu des bassins Uzita 3. Il s'agit d'un grand vase à la paroi très galbée, avec un fond ombiliqué muni d'un pied. Le bord peut se présenter sous deux variantes assez peu dissemblables :

- Variante A : bord déversé très convexe, lèvre à extrémité épaissie, étirée, au sommet creusé d'une gorge.

- variante $\mathrm{B}$ : bord déversé très convexe, lèvre trapue à extrémité très épaissie, cannelure au sommet.

Exemples (fig. 147):

Variante A

*1 Carthage (Tomber 1988, fig. 8, $\mathrm{n}^{\circ}$ 195).

*2 Carthage, Byrsa (Bonifay à paraître, $a, n^{\circ} 41$ ).

Variante B

3 Carthage (Hayes 1976a, fig. 9, $\mathrm{n}^{\circ}$ XIV. 40).

*4 Carthage (Tomber 1988, fig. 8, $\mathrm{n}^{\circ}$ 196).

*5 Carthage, Byrsa (Bonifay à paraître, $\left.a, n^{\circ} 44\right)$.
Ces deux variantes sont communes dans les contextes de la fin du IVe $\mathrm{s}$. et de la première moitié du Ves. à Carthage.

- bassins de type Carthage LR Basin 2 (fig. 147)

$=$ Fulford 1984 Handled Bowls 2-3 et 6

\section{COMMUNE TYPE 30}

Le second type de bassin défini par Hayes (1976a, 102 et fig. $1, \mathrm{n}^{\circ}$ III.4) est construit sur un modèle très différent. Il s'agit de vases tronconiques, probablement munis de deux (?) anse (s), avec un bord rentrant, au sommet plat et mouluré (généralement à quatre nervures), incliné vers l'extérieur ou l'intérieur ; on ignore la forme du fond.

Exemples (fig. 147) :

*1 Carthage, Byrsa (Bonifay à paraître, a, $n^{\circ} 48$ ).

*2 Idem (Ibid., n 49).

3 Sidi Jdidi, basilique 1, état B2A (Bonifay, Reynaud 2004, $\left.n^{\circ} 18.28\right)$. Résiduel dans le contexte 18 (?).

*4 Carthage (Fulford 1984b, fig. 66, 3.3).

Variantes tardives (?)

5 Carthage (Neuru 1980, Pl. V, nº 42).

6 Thuburbo Majus, édifice aux Asclepeia (Ben Abed, Bonifay 1998, fig. 1, n 7).

Je n'ai pas beaucoup de données nouvelles sur cette forme. Elle paraît peu représentée hors de Carthage (un fragment à Sidi Jdidi). Les exemplaires que j'ai étudiés à Carthage sont du deuxième quart du Ve $s$. (1-2). L'inclinaison du bord vers l'intérieur du vase est peutêtre un indice pour une date avancée dans le Ve s. (4-5). Un exemplaire tardif (?), au bord atrophié, à Thuburbo Majus (6).

\section{— bassins à marli}

Les fouilles de Carthage et de Sidi Jdidi ont permis de classer un certain nombre d'autres formes de bassins de la fin du IVe et du Ve s., que je signale rapidement :

\section{- type Carthage LR Basin 4 (fig. 148)}

$=$ type Sidi Jdidi 2

\section{COMMUNE TYPE 31}

Type défini par R. Tomber $(1988,476)$ à partir d'un seul fragment de bord (Ibid., fig. 9, $\mathrm{n}^{\circ}$ 209), assez fréquent à Sidi Jdidi (Bonifay, Reynaud 2004, fig. 145, forme 2). Bassin ovale (D. : $33-42 \mathrm{~cm})$, peu profond (H. : $14 \mathrm{~cm})$; bord à marli sub-horizontal, légèrement incliné vers l'intérieur du vase, épaissi à son extrémité et au sommet concave; fond plat.

Exemples (fig. 148):

*1 Sidi Jdidi, basilique 1, état A2 (Bonifay, Reynaud 2004, $n^{\circ}$ 9.14).

*2 Idem, basilique 2, destruction état II (Inv. JD2364.2). Dessin Y. Narasawa.

Type attesté du début (1) à la fin du Ve s. (2). 


\section{Typologie - Communes}

Bassins dérivés du type Uzita 2
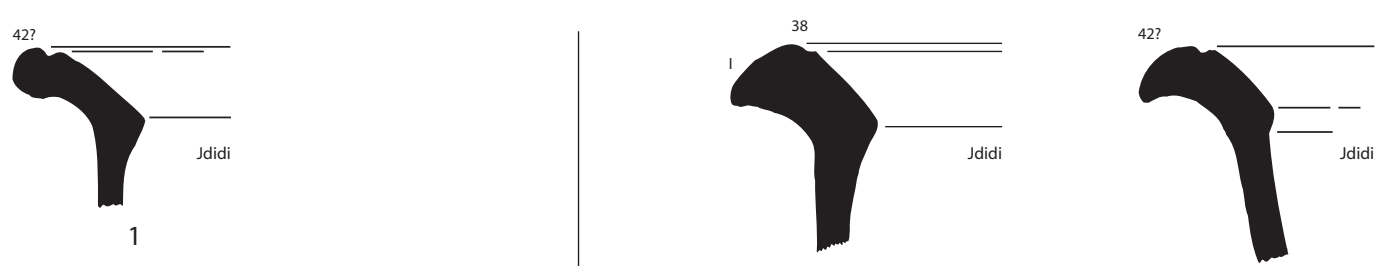

2
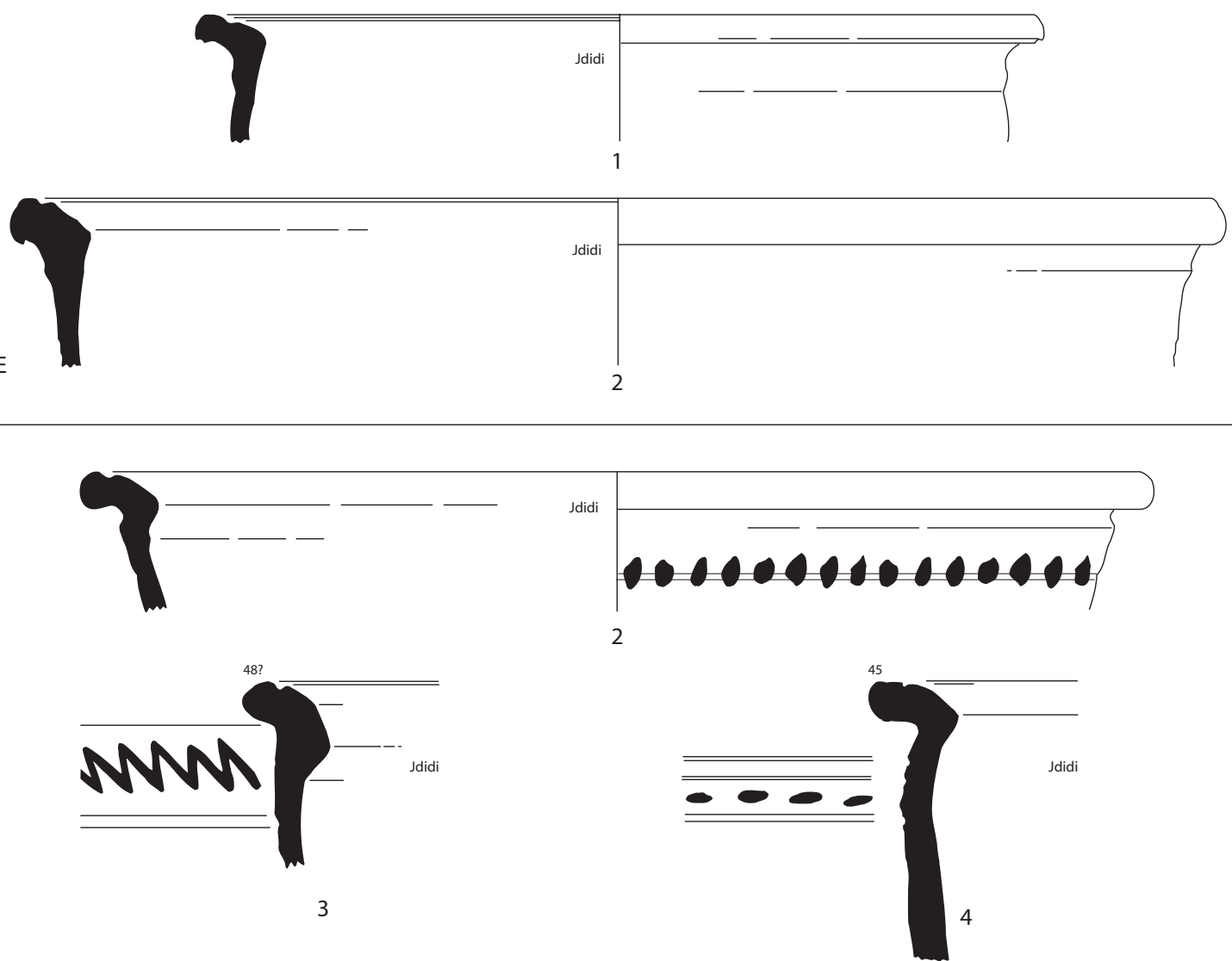

3
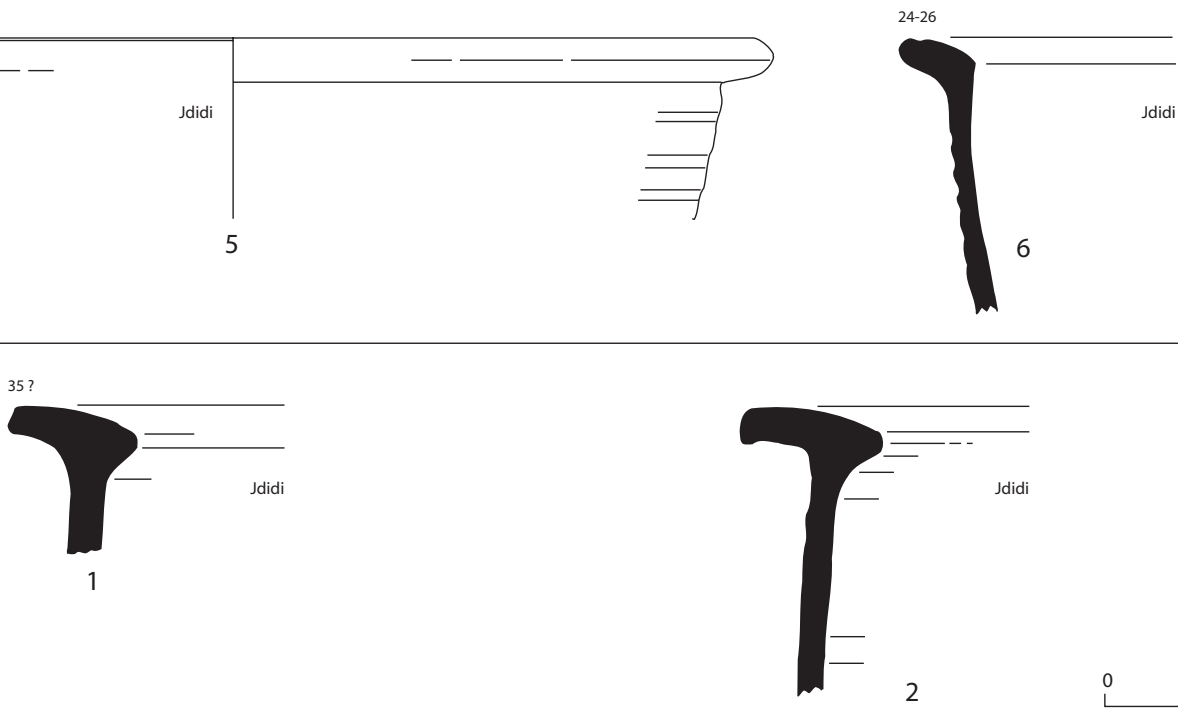

0 $5 \mathrm{~cm}$

Fig. 146. Vaisselle commune africaine. Bassins dérivés du type Uzita 2. 
Type Carthage Late Roman Basin 1

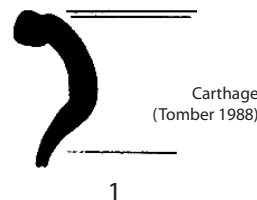

1

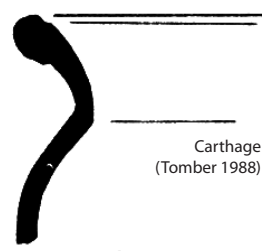

4

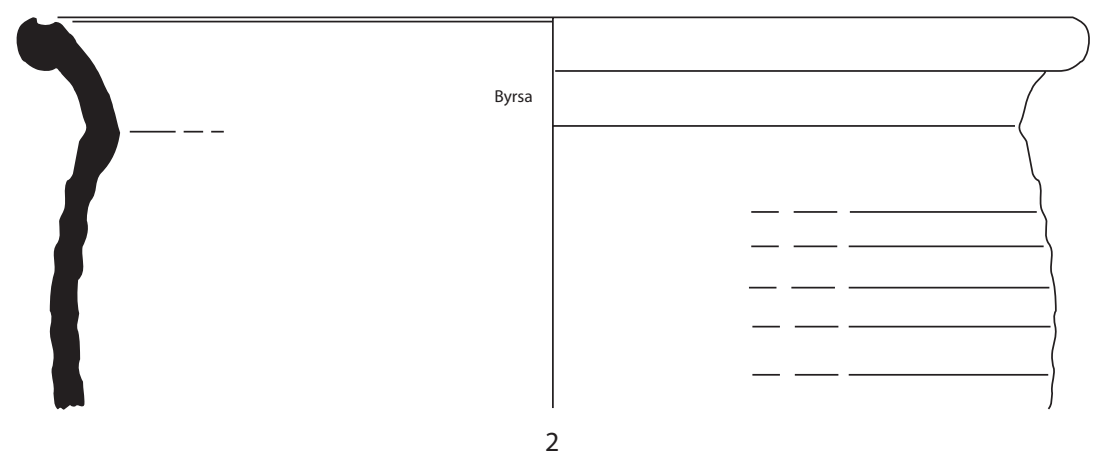

A

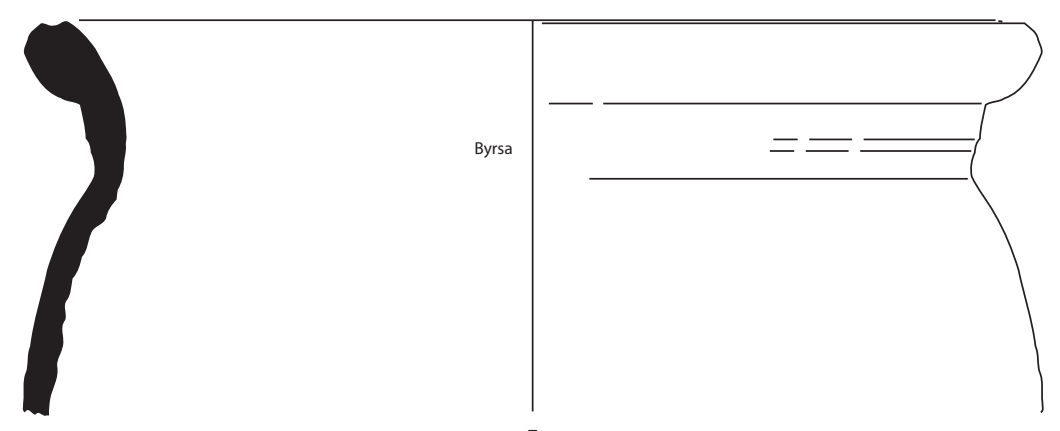

5

Type Carthage Late Roman Basin 2

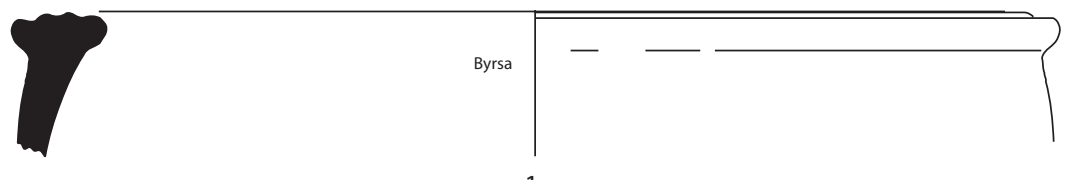

1

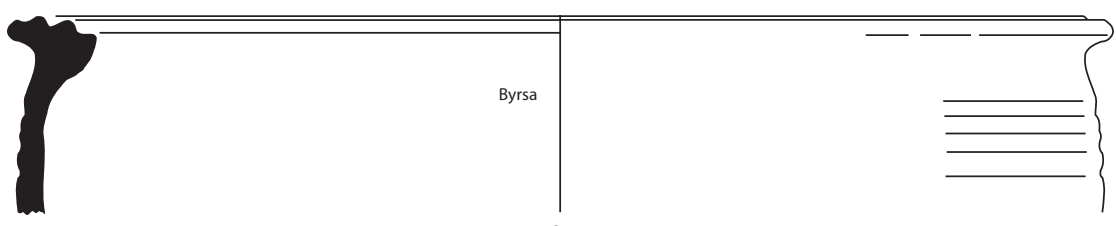

2

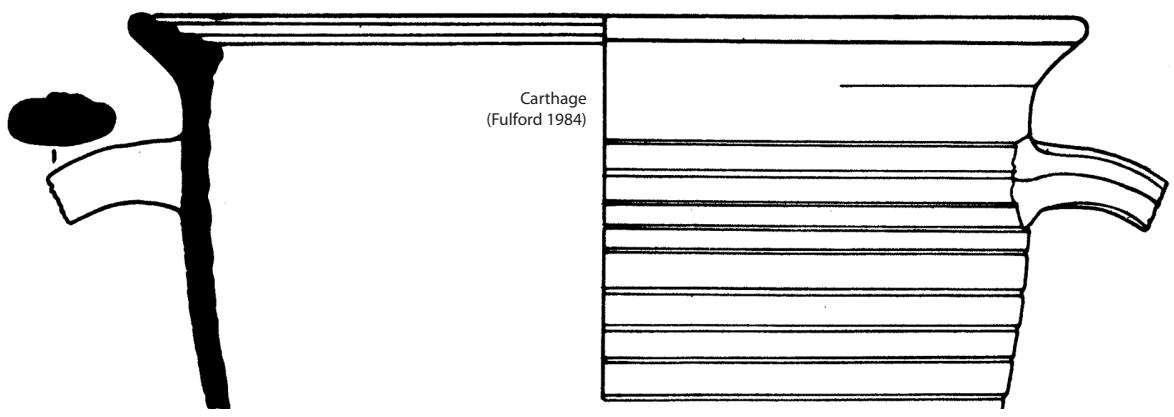

Fig. 147. Vaisselle commune africaine. Bassins dérivés du type Uzita 3 et autres bassins tardifs. 


\section{Typologie - Communes}

Type Carthage Late Roman Basin 4

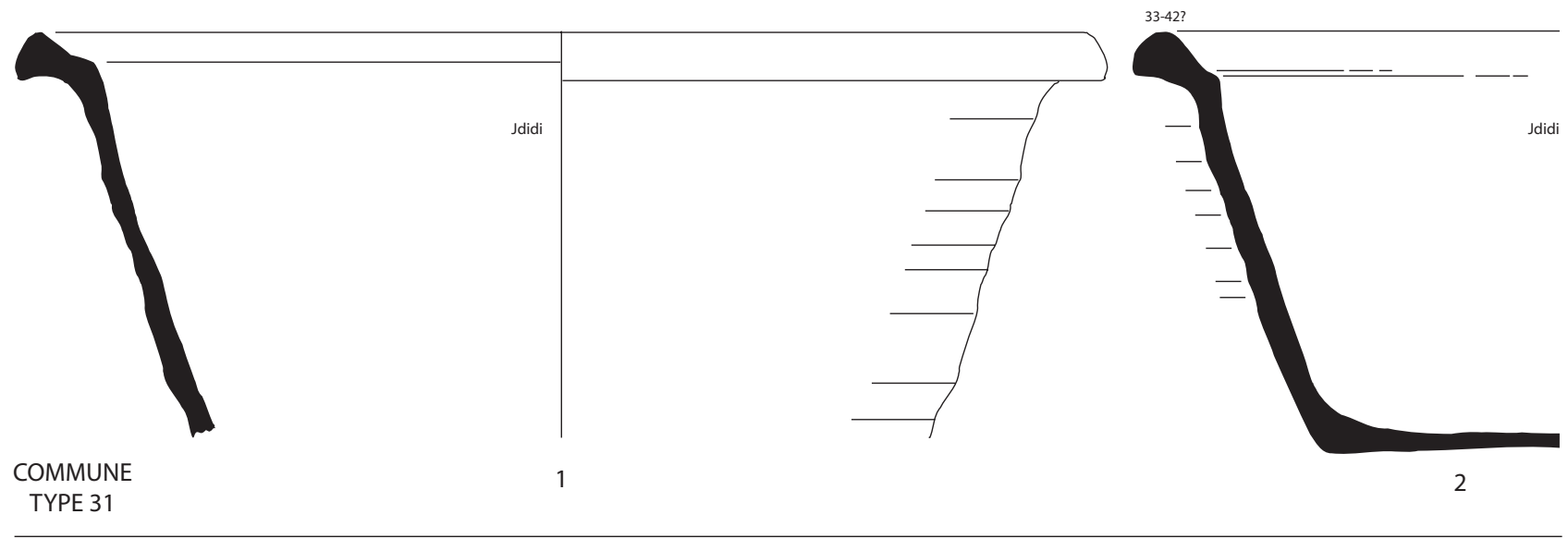

Type Carthage Late Roman Basin 6
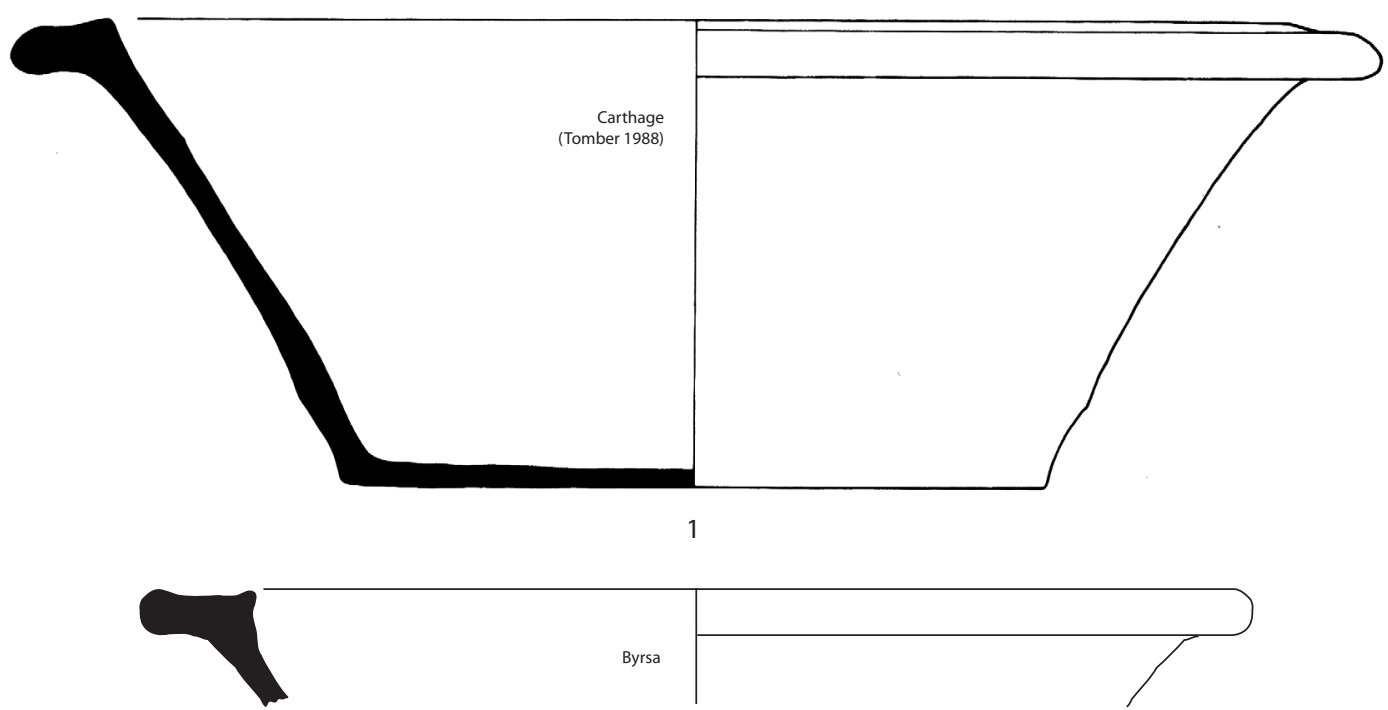

2

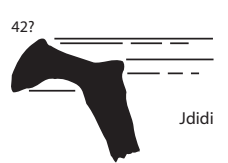

4

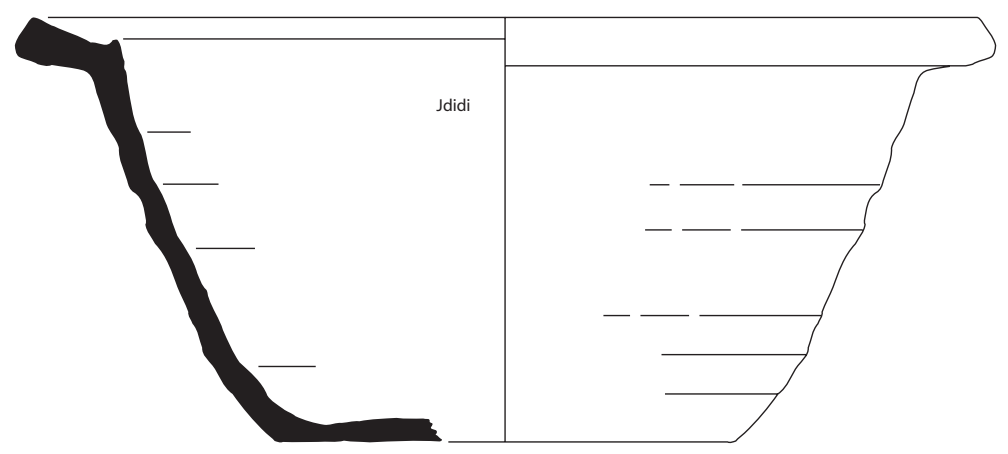

3

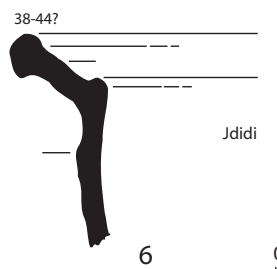

COMMUNE

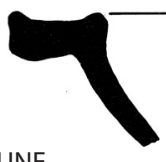

TYPE 32

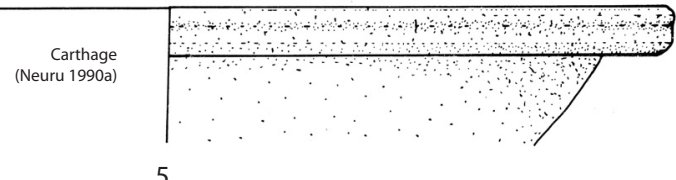

Fig. 148. Vaisselle commune africaine. Bassins à marli. 
Type Carthage Late Roman Basin 5
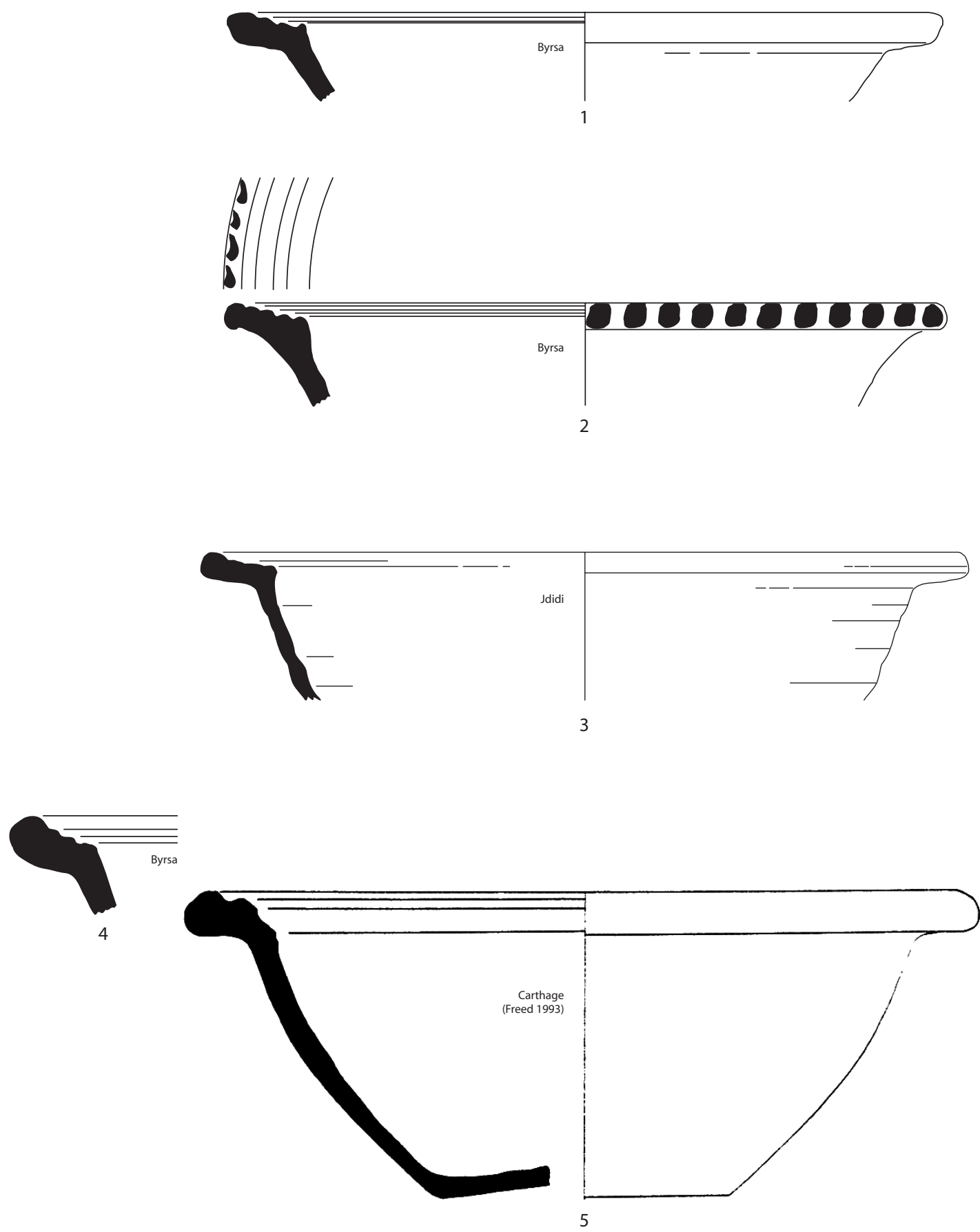

Fig. 149. Vaisselle commune africaine. Bassins à marli. 
- type Sidi Jdidi 3 (fig. 148)

= Tomber 1988 LR Basin 6 (?)

COMMUNE TYPE 32

Type voisin du précédent $(\mathrm{H} . \mathrm{s} 13 \mathrm{~cm})$, probablement ovale. Bord à marli sub-horizontal, épaissi à son extrémité, sommet légèrement concave marqué d'une arête vive à la jonction avec la panse.

Exemples (fig. 148) :

*1 Carthage, Cirque (Tomber 1988, fig. 9, $\mathrm{n}^{\circ} 215$ ).

*2 Carthage, Byrsa (Bonifay à paraître, $\mathrm{a}, \mathrm{n}^{\circ} 51$ ).

*3 Sidi Jdidi, basilique 1, état A2 (Bonifay, Reynaud 2004, $\mathrm{n}^{\circ}$ 13.10).

*4 Idem, basilique 2, destruction état II (JD2193.9).

*5 Carthage (Neuru 1990a, 37, n²6).

Variante (?)

*6 Sidi Jdidi, basilique 2, destruction état II (JD2189.7).

A titre d'hypothèse, je propose de retracer l'évolution de cette forme de la façon suivante. Les plus anciens exemplaires connus, datés de la fin du IVe s. ou du début du Ve s., sont ceux publiés par R. Tomber (1988, 476 et fig. $\left.9, \mathrm{n}^{\circ} 214-215\right)$, avec un marli légèrement tombant et une arête interne peu marquée (1). Le $\mathrm{n}^{\circ} \mathbf{2}$ constitue peutêtre, au deuxième quart du Ve s., une évolution du type précédent, avec un marli horizontal et une arête bien marquée. Les exemplaires de Sidi Jdidi (3-4, 6 ?) avec une incertitude venant du fait qu'il s'agit vraisemblablement d'ateliers différents, non carthaginois ${ }^{199}$, illustrent les variantes du milieu et de la seconde moitié du Ve siècle. Le $\mathrm{n}^{\circ} \mathbf{5}$ est l'aboutissement de cette évolution à Carthage, dans la première moitié ${ }^{200}$ du VIe $s$. (voir également Mackensen 1999a, fig. 4, $\mathrm{n}^{\circ} 1-3$ ).

- type Carthage LR Basin 5 (fig. 149)

= Fulford 1984 Bowl 3 (sauf 3.4) et 5

\section{COMMUNE TYPE 33}

Type défini par R. Tomber (1988, 476 et fig. 9, $\mathrm{n}^{\circ} 210-$ 213). Forme générale comparable aux précédentes $(H$. : $14 \mathrm{~cm}$ ), mais ronde plutôt qu'ovale (?). Bord à marli subhorizontal au sommet mouluré (trois ou quatre nervures, plus rarement cinq) et à extrémité épaissie, parfois décorée d'impressions circulaires («faux-godrons »). Exemples (fig. 149) :

*1 Carthage, Byrsa (Bonifay à paraître, $\mathrm{a}, \mathrm{n}^{\circ} 53$ ).

*2 Idem (Ibid., $\mathrm{n}^{\circ} 55$ ). Décor d'impressions ovales sur l'extrémité du marli.

*3 Sidi Jdidi, basilique 2, destruction état II (Inv. JD2363.13). Mouluration faiblement marquée.

*4 Carthage, Byrsa (Bonifay à paraître, a, n 56). Exemplaire de grande taille.

*5 Carthage (Freed 1993, 82 et fig. 84, n 31). Idem.

\footnotetext{
${ }^{199}$ Cependant, ces variantes sont attestées à Oudhna, dans le matériel correspondant à l'occupation finale des thermes des Laberii, vers la fin du IVe s. ou le début du Ve siècle.

${ }^{200} \mathrm{Au}$ vu du matériel associé, le niveau publié par L. Neuru me paraît dater plutôt du premier tiers du VIe s., donc de l'époque immédiatement pré-byzantine.
}

Type attesté à la fin du IVe s. (Mackensen 1991, fig. 19, $\mathrm{n}^{\circ}$ 28-29) et au Ve s. (1-2); l'exemplaire $\mathrm{n}^{\circ} \mathbf{4}$, de grande taille, avec un bord épaissi et recourbé vers le haut trouve des comparaisons au Ves. (5; Hayes 1978a, fig. 2, $\left.\mathrm{n}^{\circ} 43\right)$. L'exemplaire de Sidi Jdidi (3), dans un contexte de la seconde moitié du Ve s., très proche aussi du type $L R$ Basin 6, montre que toutes ces formes de bassins du Ve s. forment un ensemble assez homogène.

\section{— bassins à bord simple}

A partir du VIe s., la tendance est à la simplification des bords (cf. Fulford 1984b, fig. 74, forme 5).

\section{- bassins à bord en amande (fig. 150)}

\section{COMMUNE TYPE 34}

Quelques bassins peuvent être interprétés comme les successeurs de la variante B des bassins tardifs dérivés du type Uzita 2 (TYPE 27B). Bord en amande presque horizontal, parois épaisses.

Exemples (fig. 150):

*1 Sidi Jdidi, basilique 1, état B1B (Bonifay, Reynaud 2004, $\left.n^{\circ} 16.3\right)$.

*2 Idem, état B2A (Ibid., $\left.\mathrm{n}^{\circ} 18.30\right)$. Traces importantes de mortier à l'intérieur.

Ces bassins sont attestés dans la première moitié (1) et au milieu du VIe s. (2).

\section{- bassins à bord triangulaire (fig. 150)}

\section{COMMUNE TYPE 35}

Bassin ovale (?), peut-être une évolution du type précédent. Bord grossièrement triangulaire, légèrement oblique, à extrémité arrondie ou plate, face intérieure en angle droit; parois tronconiques $(\mathrm{H} .: 17 \mathrm{~cm})$; fond concave.

Exemples (fig. 150) :

*1 Thuburbo Majus, édifice aux Asclepeia (Ben Abed, Bonifay 1998, fig. 1, $\mathrm{n}^{\circ} 12$ ).

*2 Sidi Jdidi, basilique 1, état C2A (Bonifay, Reynaud $\left.2004, n^{\circ} 26.10\right)$.

Variante tardive (?)

*3 Sidi Jdidi, basilique 2, état III (Inv. JD2153.1). Dessin P. Reynaud.

Ces bassins sont attestés au milieu (1) et dans la seconde moitié du VIe s. (2). Le $\mathrm{n}^{\circ} \mathbf{3}$ provient d'un contexte du VIIe s. (cf. Hayes 1978 b, fig. 13, $n^{\circ} 40$ ).

\section{- bassins à bord en bourrelet épaissi (fig. 151)}

\section{COMMUNE TYPE 36}

Bord en bourrelet arrondi, plus ou moins massif; parois tronconiques légèrement galbées ; fond concave (?) (5). Eventuellement, décor peigné (4).

Exemples (fig. 151) :

*1 Nabeul, fabrique de salaison, période 6 (Inv. NB1428.25).

2 Nabeul (Inv. NB1491.0).

*3 Carthage (Hayes 1978b, fig. 13, XXIV.40).

*4 Carthage (Ibid., fig. 13, XXIV.39). 


\section{Typologie - Communes}

Bassins à bord en amande
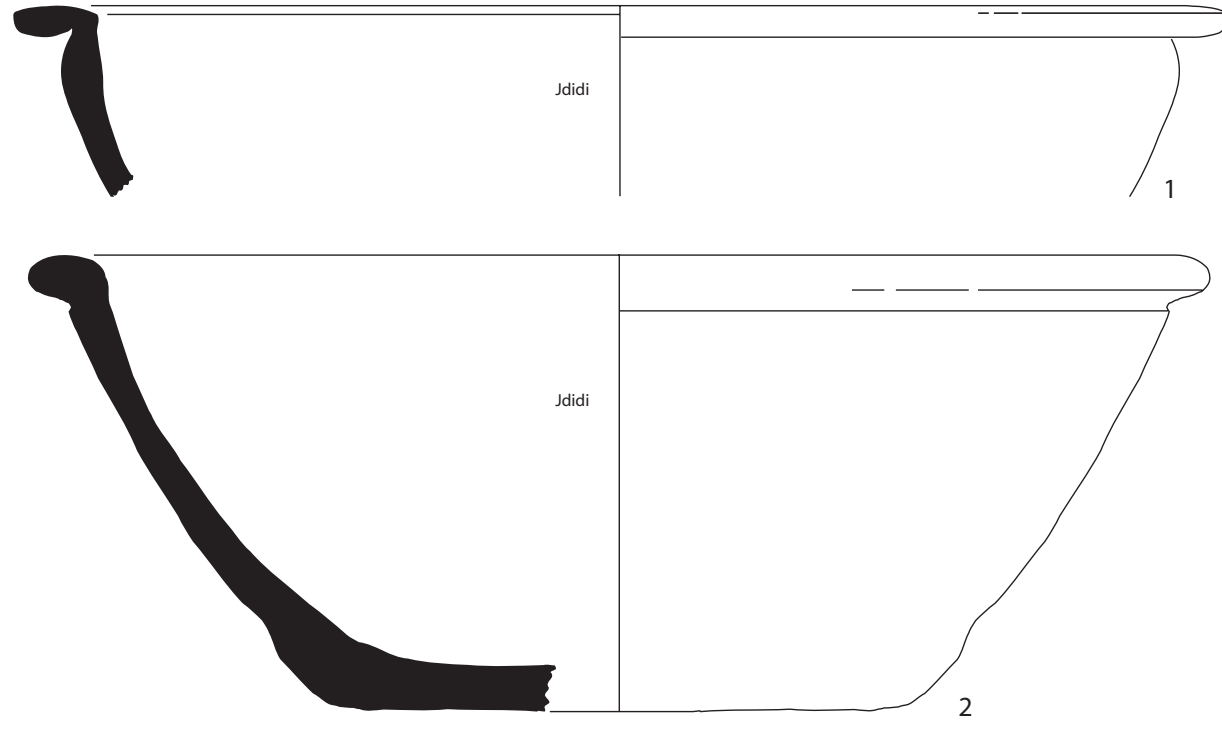

Bassins à bord triangulaire

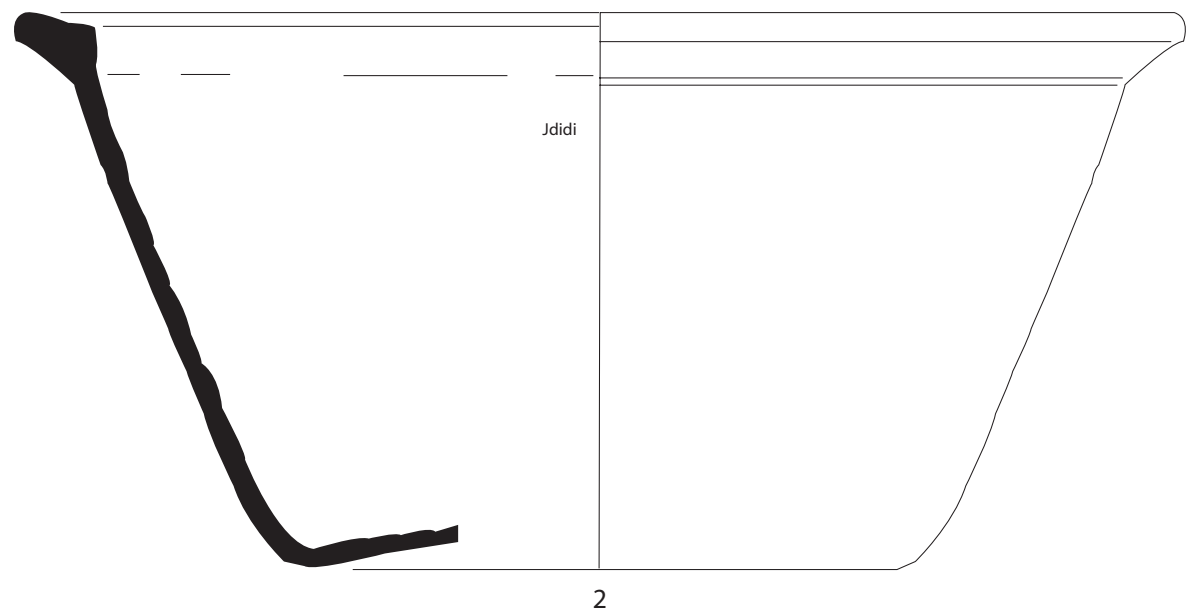

$44-46$

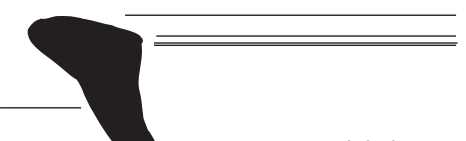

1
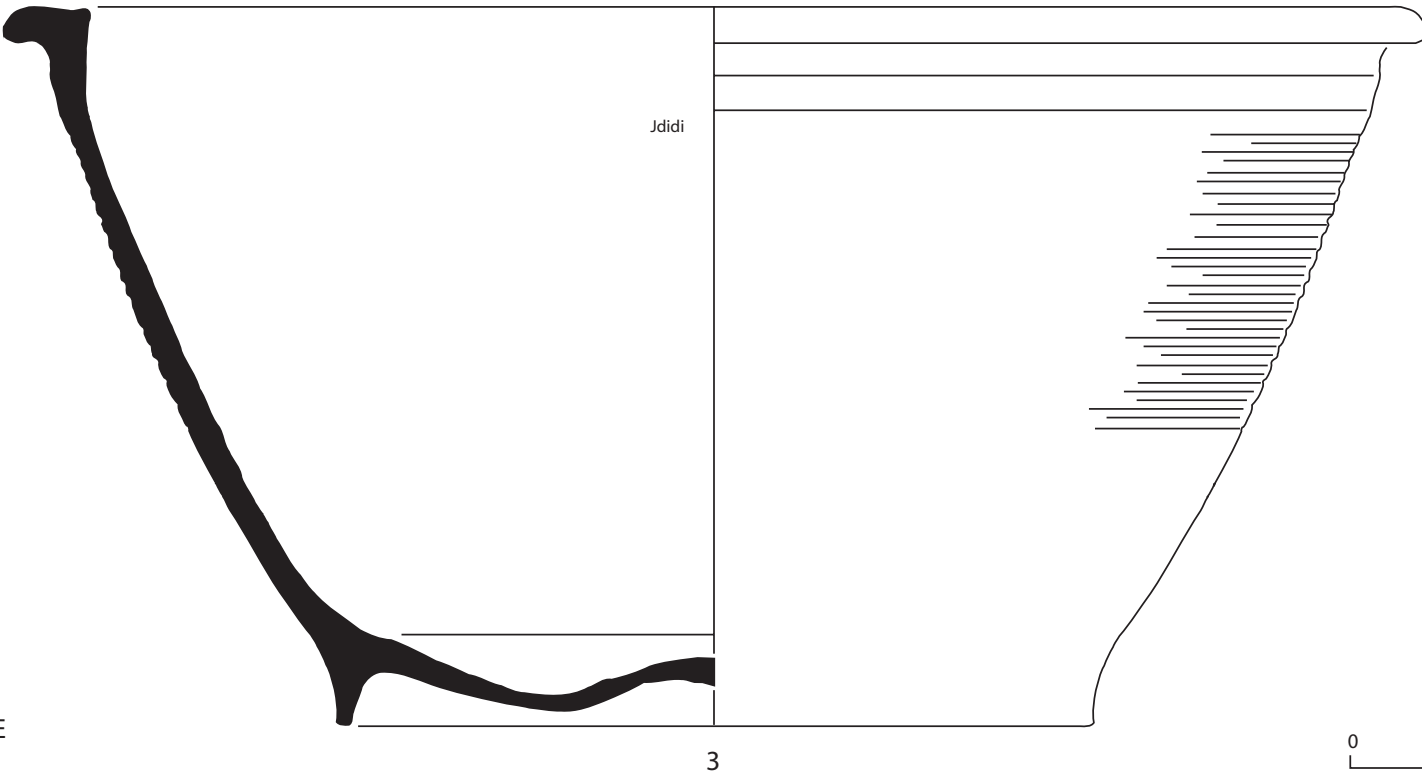

Fig. 150. Vaisselle commune africaine. Bassins à bord simple. 
Bassins à bord en bourrelet épaissi
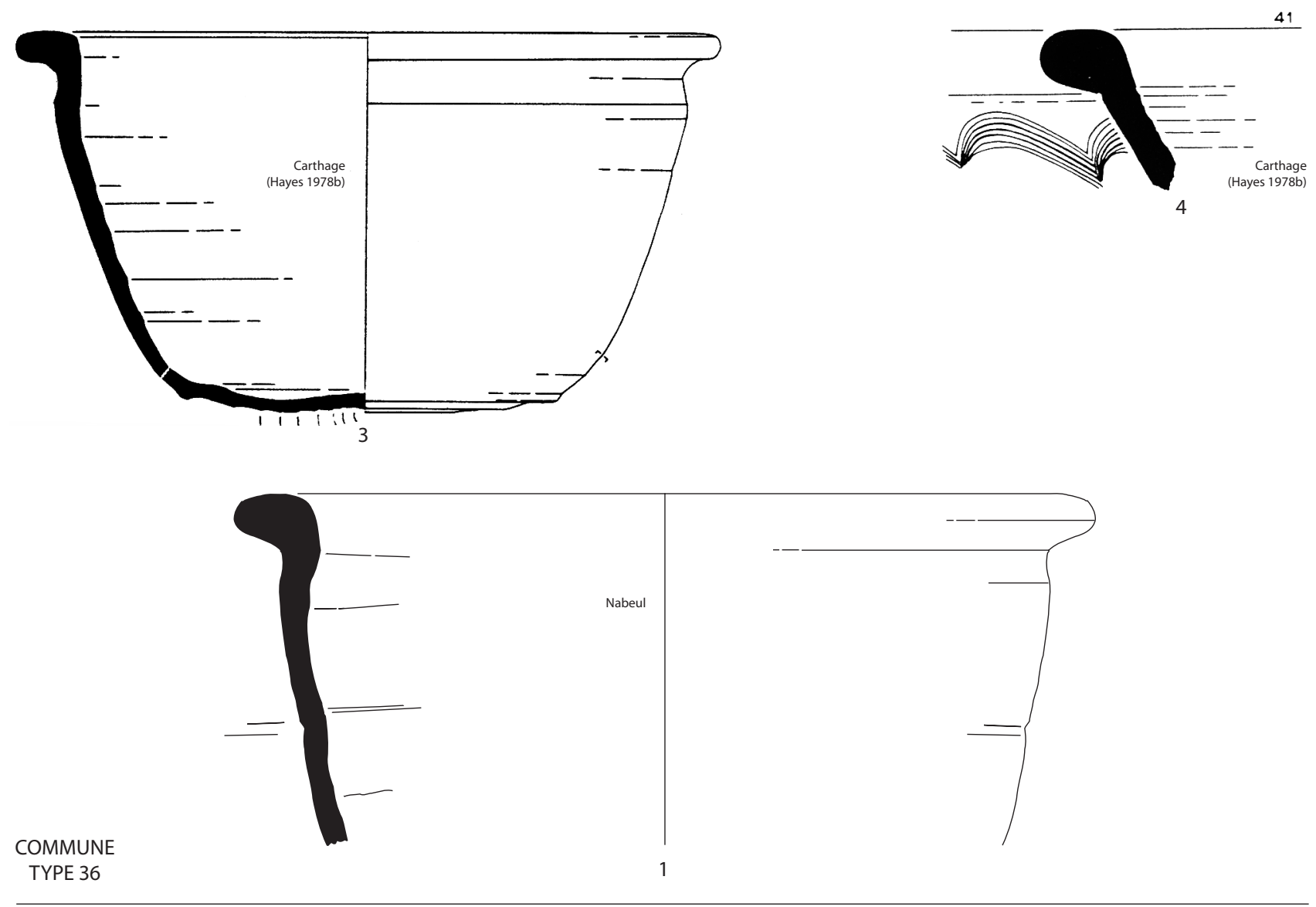

Bassins à bord déversé

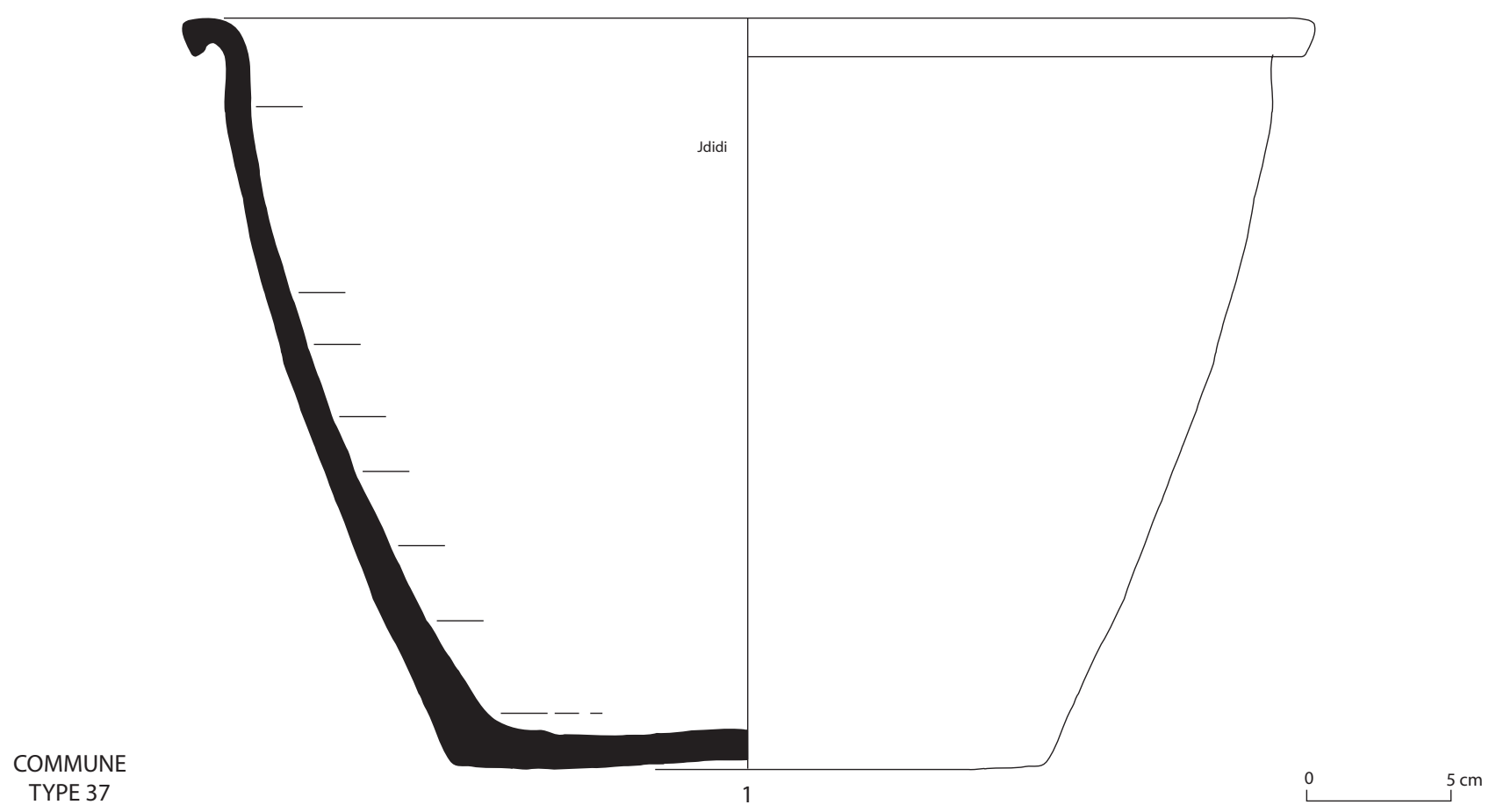

Fig. 151. Vaisselle commune africaine. Bassins à bord simple. 
5 Carthage (Ibid., fig. 16, XXV.55).

6 Carthage (Fulford 1984b, fig. 74, 5.4).

Forme caractéristique du VIIe s. avancé (1, 3-5).

- bassins à bord déversé (fig. 151)

\section{COMMUNE TYPE 37}

Bord court simplement déversé, à extrémité épaissie. Eventuellement, décor peigné (Hayes 1978b, fig. 16, XXV.56).

Exemple (fig. 151) :

*1 Sidi Jdidi, basilique 1, état C2B (Bonifay, Reynaud 2004, n³4.9).

Le $\mathrm{n}^{\circ} \mathbf{1}$ est issu d'un contexte byzantin tardif ou postbyzantin.

\section{- bassins tardifs de Byzacène centrale et méridionale} (fig. 152)

La typologie qui vient d'être exposée risque de ne pas être complètement opérante en Byzacène centrale et méridionale. En effet, mis à part quelques variantes locales, plus ou moins reconnaissables, des types dérivés de la forme Uzita 3 (Guéry, Bonifay à paraître, ${ }^{\circ} 265$ ) et peut-être des types tardifs à lèvre en bourrelet épaissi (Ibid., $\mathrm{n}^{\circ} 266$ ), la principale originalité de cette région réside dans une forme très répandue sur la partie centrale du littoral de la Byzacène, à Rougga (Ibid., $\mathrm{n}^{\circ}$ 222-248) et sur trois sites d'atelier de la région du Sahel: Salakta/Rass el-Aïed, Moknine et Leptiminus (supra, fig. 37).

\section{COMMUNE TYPE 38}

$\mathrm{Ne}$ disposant actuellement d'aucun exemplaire complet, on ignore la configuration exacte de ce bassin : il semble toutefois s'agir d'un vase plus ou moins hémisphérique, peut-être posé sur un pied haut (?) (Bonifay et al. 20022003, fig. 11, $\mathrm{n}^{\circ}$ 124-125). Cependant, cette forme est facilement identifiable au moindre fragment de bord: épaissi, grossièrement quadrangulaire ou parfois triangulaire, il est marqué d'un ressaut interne à la jonction avec la panse, un peu à la manière des formes de sigillée africaine D Hayes 105.

Exemples (fig. 152) :

*1 Rougga, couche 11 (Bonifay et al. 2002-2003, fig. 11, $\mathrm{n}^{\circ} 124$; Guéry, Bonifay à paraître, $\mathrm{n}^{\circ} 222$ ).

*2 Idem, couche 13 (Bonifay et al. 2002-2003, fig. 11, $\mathrm{n}^{\circ} 125$; Guéry, Bonifay à paraître, $\mathrm{n}^{\circ} 250$ ). Fond, peut-être de la même forme (?).

*3 Rougga, couche 10 (Ibid., $\mathrm{n}^{\circ} 224$ ).

*4 Idem, couche 12 (Ibid., fig. 8, $\mathrm{n}^{\circ}$ 232).

*5 Littoral tunisien, site $\mathrm{n}^{\circ} 84$ (Marsa Mellouleche) (Bonifay et al. 2002-2003, fig. 11, $\mathrm{n}^{\circ} 123$ ).

Cette forme est caractéristique des contextes de la seconde moitié du VIe s. (4) et du VIIe s. (3).

\subsubsection{Couvercles}

- couvercles de grands vases (fig. 152)

\section{COMMUNE TYPES 39-40}

Ces couvercles, de taille moyenne à grande (D. : 18-34 $\mathrm{cm})$, étaient sans doute destinés à couvrir de grands vases en céramique commune: jattes, bassins, mais probablement aussi, de manière occasionnelle, des marmites $^{201}$. De fait, leur typologie présente des analogies avec celle des couvercles en céramique culinaire B (supra, CULINAIRE TYPE 9). Deux variantes apparaissent de manière répétitive :

TYPE 39 (apparenté à la forme Hayes 185 B ?) : bord en amande, très allongé. Particulièrement fréquente en Byzacène méridionale et en Tripolitaine (type Sabratha 104).

TYPE 40 (apparentée à la forme Hayes 185 C ?) : bord chanfreiné. Région de Nabeul-Pupput.

Exemples (fig. 152)

TYPE 39

*1-2 El Jem, maison d'Africa (fouilles H. Slim, Inv. EJMA.2300.032 et 031).

*3 Idem (Inv. EJMA.000.017).

4 Rougga, couche 10 (Guéry, Bonifay à paraître, $\left.\mathrm{n}^{\circ} 283\right)$.

5 Lepcis Magna, thermes du Levant (fouilles A. Laronde, Inv. LEP005.22).

TYPE 40

*1 Pupput, tombe 308 ouest (Inv. PP1229.2).

Les exemplaires du TYPE 39 recueillis à El Jem et à Lepcis Magna proviennent de contextes des IIIe- IVes. $(\mathbf{1 - 2}, \mathbf{5})$. Le couvercle de Pupput (TYPE 40, $\left.\mathrm{n}^{\circ} \mathbf{1}\right)$ est issu d'une tombe de la fin du IIe $\mathrm{s}$. ou de la première moitié du IIIe siècle.

\section{- couvercles de cruches et d'amphores}

Les contextes africains des IIe - VIIe s. livrent un grand nombre de couvercles destinés à couvrir des vases à liquide (infra, fig. 154, COMMUNE TYPE 45, $\mathrm{n}^{\circ} 3$ ) ou à boucher des amphores (supra, fig. 56, AMPHORE TYPE 21, $\left.\mathrm{n}^{\circ} 5\right)$.

— opercules de cruches ou d'amphores, type Uzita 1-3 (fig. 152)

$=$ Carthage ERBW Lid 1 (Hayes 1976a) = Fulford 1984 Lid $9=$ Fulford 1994 Lid 29

\section{COMMUNE TYPE 41}

Petit opercule (D. : 6-10 cm) de forme conique aplatie, bord replié à l'intérieur, pointe sommitale généralement percée. J. H. Van der Werff a distingué trois formes différentes, renommées ci-après variantes $\mathrm{A}, \mathrm{B}, \mathrm{C}$.

Variante $\mathrm{A}$ : bord triangulaire, à lèvre tombante à l'intérieur.

Variante B : bord non épaissi, en large collerette plate.

\footnotetext{
${ }^{201}$ Observation faite sur la nécropole de Pupput.
} 
Bassins à bord épaissi à ressaut interne
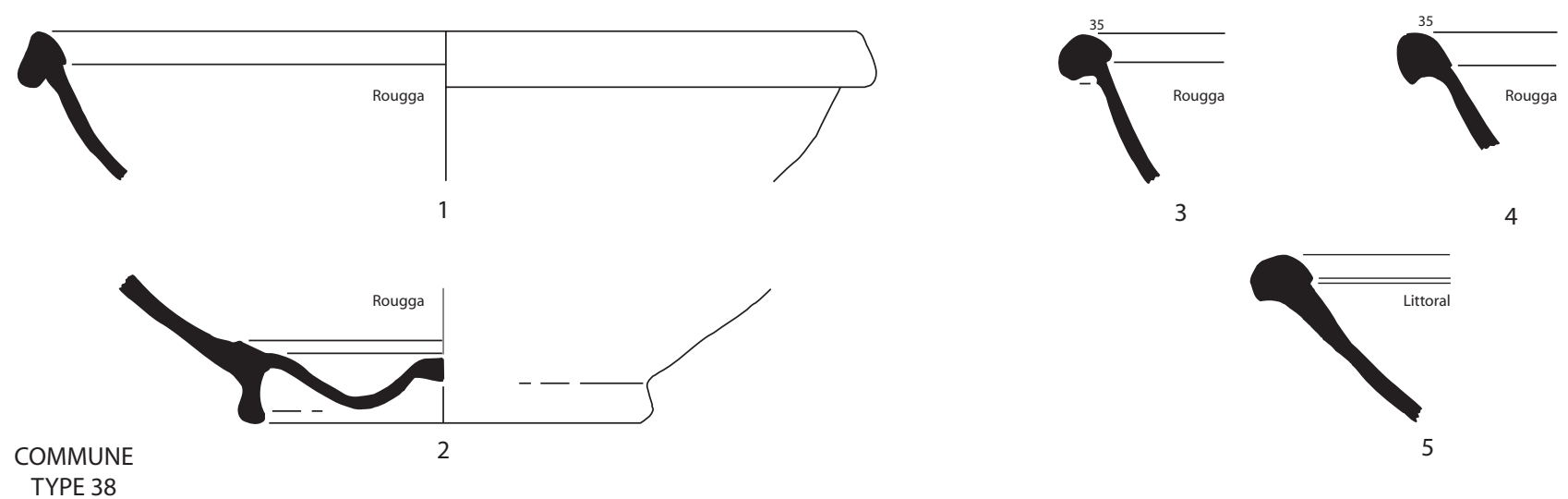

3

4

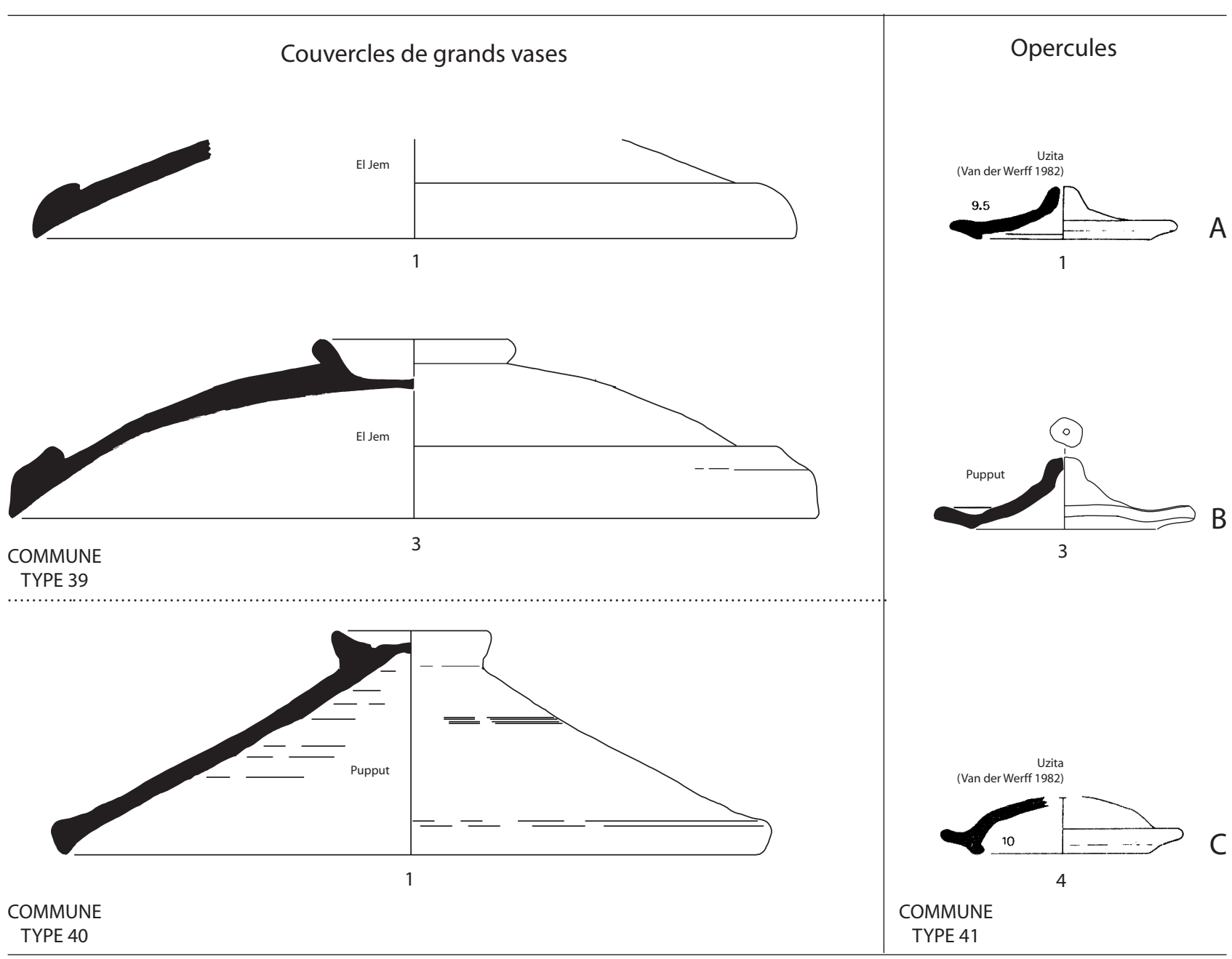

Patères-couvercles
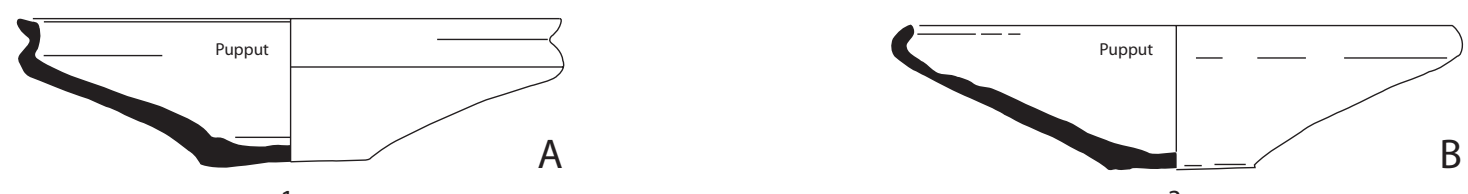

COMMUNE

A

TYPE 42

Fig. 152. Vaisselle commune africaine. Bassins. Couvercles. 


\section{Typologie - Communes}
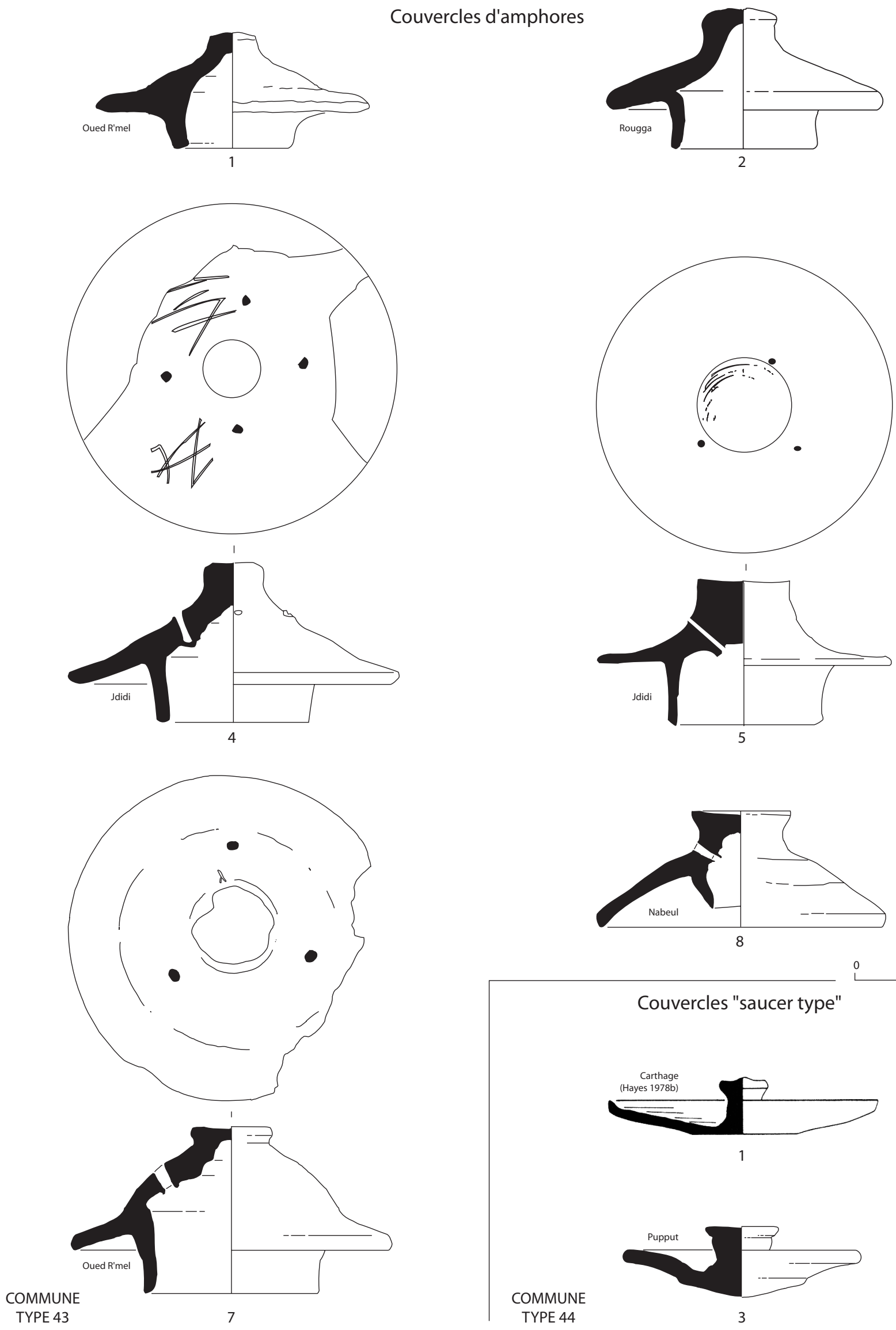

0

Couvercles "saucer type"

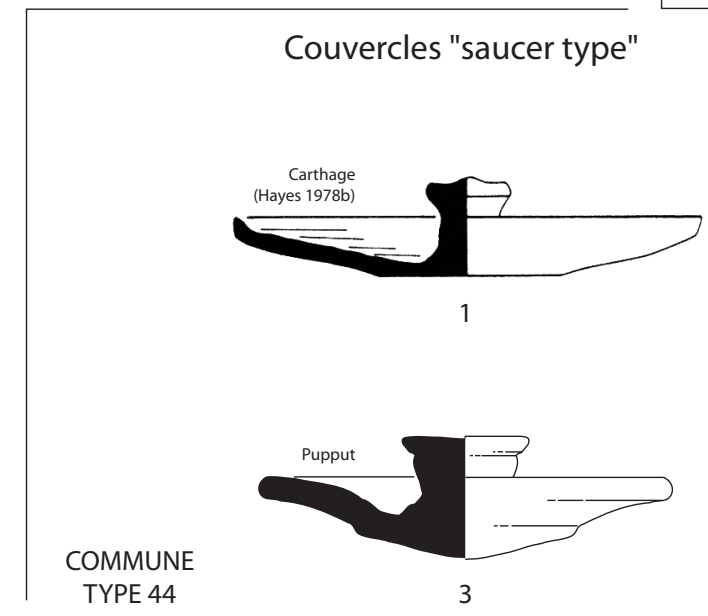

Fig. 153. Vaisselle commune africaine. Couvercles. 
Variante $\mathrm{C}$ : forme plus arrondie, bord en listel audessus d'une lèvre verticale.

Exemples (fig. 152) :

Variante A

*1 Uzita (Van der Werff 1982a, Pl. 35, n² 26 : forme 1).

Variante B

2 Uzita (Ibid., P1. 35, $\mathrm{n}^{\circ} 25$ : forme 2).

*3 Pupput, tombe 1686 (Inv. PP5545.2).

Variante C

*4 Uzita (Van der Werff 1982a, Pl. 16, n 23 : forme 3).

Les trois variantes sont bien attestées au IIe s. (Van der Werff 1982a, 190). La variante A, déjà connue à l'époque punique (Lancel 1987, type 911a1) est présente à Carthage au Ier s. (Hayes 1976a, 102; Ortisi 1999, fig. 14, $n^{\circ} 290-312$ ). Le $n^{\circ} 4$ provient d'une tombe de la première moitié ou du milieu du IIe siècle ${ }^{202}$.

— patères-couvercles (fig. 152)

\section{COMMUNE TYPE 42}

Deux types de patères en céramique commune, abondantes sur la nécropole de Pupput, interprétées comme des patères à libation (Bonifay 2004a, 52), ont pu également servir de couvercles pour les vases à liquide. La forme générale est identique : parois coniques aplaties, fond plat avec traces de découpe au fil, facture peu soignée ; la distinction des deux types se fait par le bord :

Variante A : bord déversé souligné par une carène très prononcée à la jonction avec la panse.

Variante $\mathrm{B}$ : bord recourbé très rentrant. Exemples (fig. 152) :

Variante A

*1 Pupput, tombe 1454 (Bonifay 2004a, fig. 22, n 86). Type 1.

2 Pupput, tombe 411 (Inv. PP1951.1).

Variante B

*3 Pupput (Ibid., fig. 22, $\mathrm{n}^{\circ} 87$ ). Type 2.

4 Pupput (Inv. 1454.9).

J. H. Van der Werff suggère qu'au-delà du IIe s., les petits opercules Uzita 1-3 disparaissent et que les cruches sont désormais couvertes avec d'autres pièces de vaisselles (assiettes). De fait, les patères-couvercles apparaissent dans des tombes de la fin du IIe s. ou du début du IIIe s. (1) $)^{203}$ ou dans les niveaux de circulation du milieu du IIIe s. (3).

\section{— couvercles d'amphores (fig. 153)}

\section{COMMUNE TYPE 43}

Les couvercles d'amphores sont connus dès la haute époque punique, avec des formes en cloche adaptées au col proéminent des amphores de type Cintas 276/280 (nombreux exemples à Carthage : Byrsa II, fig. 341, 354, $382,399,411,454)$, mais ceux dont il est question ici dérivent d'une autre forme punique (Lancel 1987, type 913a1), conique, assez proche de celle des opercules dont

\footnotetext{
${ }^{202}$ Associé à des lampes de type Deneauve VII/1 timbrées CIVNDRAC.

${ }^{203}$ Associés à des lampes de type Deneauve VII/2.
}

il vient d'être question plus haut (supra, COMMUNE TYPE 41C).

Ces couvercles, dont le détail de la forme peut être assez variable, ont tous en commun une base tubulaire étroite (D. : 6-10 cm) destinée à être insérée dans l'embouchure de l'amphore, surmontée d'une collerette aplatie plus ou moins large (D. : 10-18 cm) pouvant, selon la position du couvercle, couvrir soit partiellement, soit complètement l'ouverture du vase (infra, fig. 265); le sommet du couvercle est généralement conique, terminé par un petit bouton cylindrique (D. : $2-5 \mathrm{~cm}$ ) mais il peut être simplement arrondi. Ces couvercles sont souvent, mais ce n'est pas systématique ${ }^{204}$, percés avant cuisson de trois, quatre, cinq ou sept trous d'aération.

Exemples (fig. 153) :

*1 Oued R'mel (Bonifay 2004b, fig. 16, n 52).

*2 Rougga, couche 9 (Guéry, Bonifay à paraître, $\left.\mathrm{n}^{\circ} 335\right)$.

3 Sidi Jdidi, basilique 2, destruction état II (Inv. JD 2363.3).

*4 Sidi Jdidi, basilique 1, état C2A (Bonifay, Reynaud 2004, $n^{\circ} 23.3$ ).

*5 Sidi Jdidi, basilique 1, état C2A (Ibid., n² 24.14).

6 Idem (Ibid., $\mathrm{n}^{\circ}$ 23.2). Variante.

*7 Oued R'mel (Bonifay 2004b, fig. 16, n 51).

*8 Nabeul (Inv. NB3000.1). Variante.

Ces couvercles, qui n'ont pas été signalés à Carthage, sont très fréquents dans le nord du golfe d'Hammamet et à Rougga. Ils apparaissent régulièrement dans des contextes de l'Antiquité tardive, dès la seconde moitié du Ves. (3) et principalement dans la seconde moitié du VIe s. (4-6) et au VIIe s. $(\mathbf{1 , 7 , 8 )}$.

\section{— Couvercles « saucer type » (fig. 153)}

\section{COMMUNE TYPE 44}

Le couvercle en forme de petite coupe, muni d'un pivot central, est typique des contextes byzantins tardifs. A Carthage (Hayes 1978b, fig. 9, $\mathrm{n}^{\circ} 23$; fig. 17, $\mathrm{n}^{\circ} 87$ ) comme à Pupput (3), il apparaît dans les niveaux du milieu ou de la seconde moitié du VIIe siècle. Produite en Afrique, il s'agit clairement d'une forme d'inspiration orientale.

Exemples (fig. 153) :

*1 Carthage (Hayes 1978b, fig. 17, $\mathrm{n}^{\circ} 87$ ).

2 Idem (Ibid., fig. 9, $\mathrm{n}^{\circ} 23$ ).

*3 Pupput, thermes du centre (fouille A. Ben Abed, Inv. PPC181).

4 Leptiminus (Dore 2001, fig. 1.70, $\mathrm{n}^{\circ} 116$ ).

\subsubsection{Cruches}

Les formes fermées constituent un ensemble très hétérogène qui mériterait une étude détaillée. J'ai choisi d'illustrer un certain nombre de types principaux,

\footnotetext{
204 Sur certains exemplaires (ex. : 4), les trous ne sont pas complètement percés, peut-être pour laisser le choix à l'utilisateur de les ouvrir ou non.
} 


\section{Typologie - Communes}

\section{Cruche type Pupput 2}
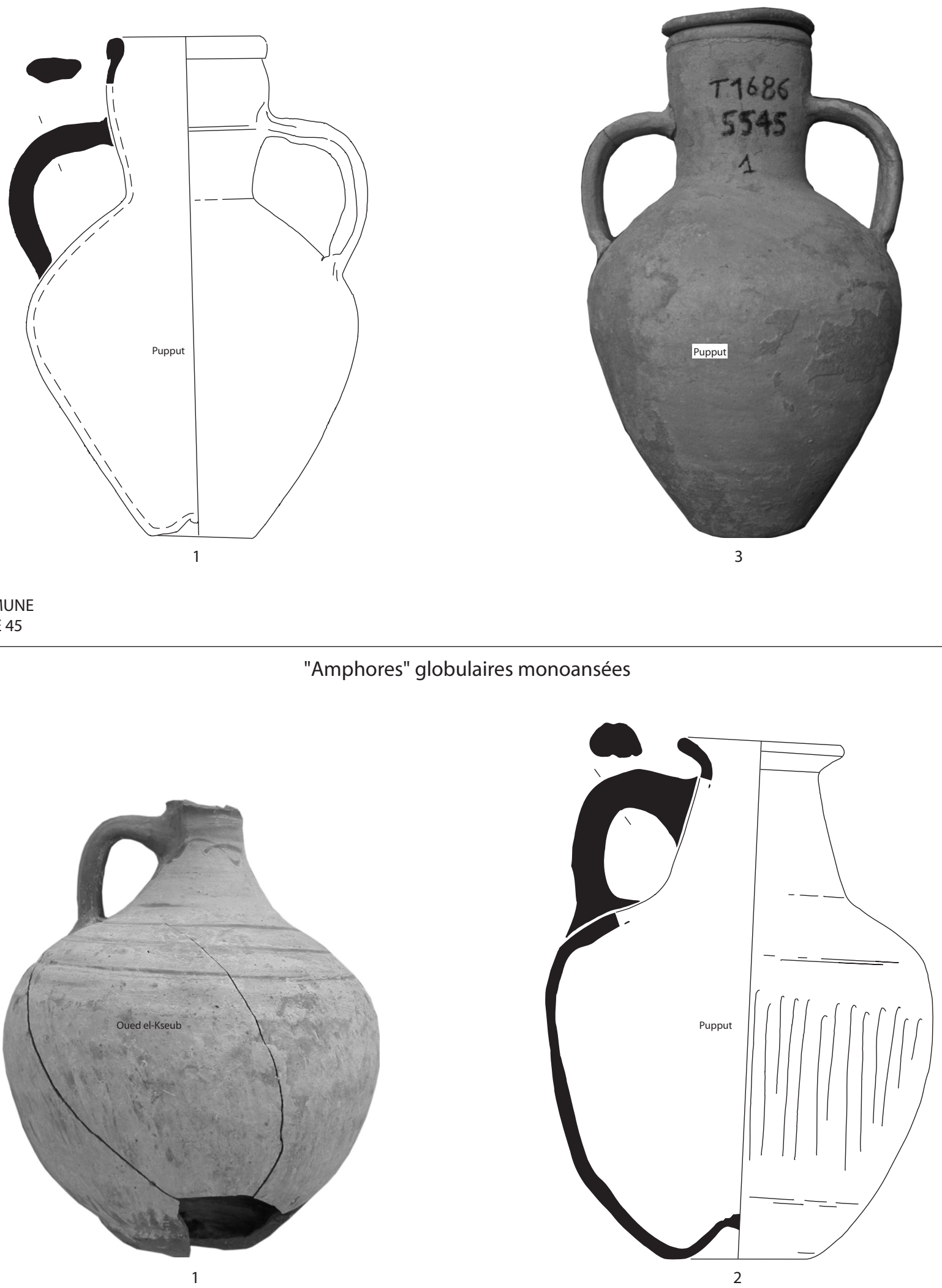

COMMUNE

Fig. 154. Vaisselle commune africaine. Cruches de transport. 


$$
\dot{\rho} \bar{i}
$$




\section{Typologie - Communes}

Cruche type Pupput 1

(variantes tardives)
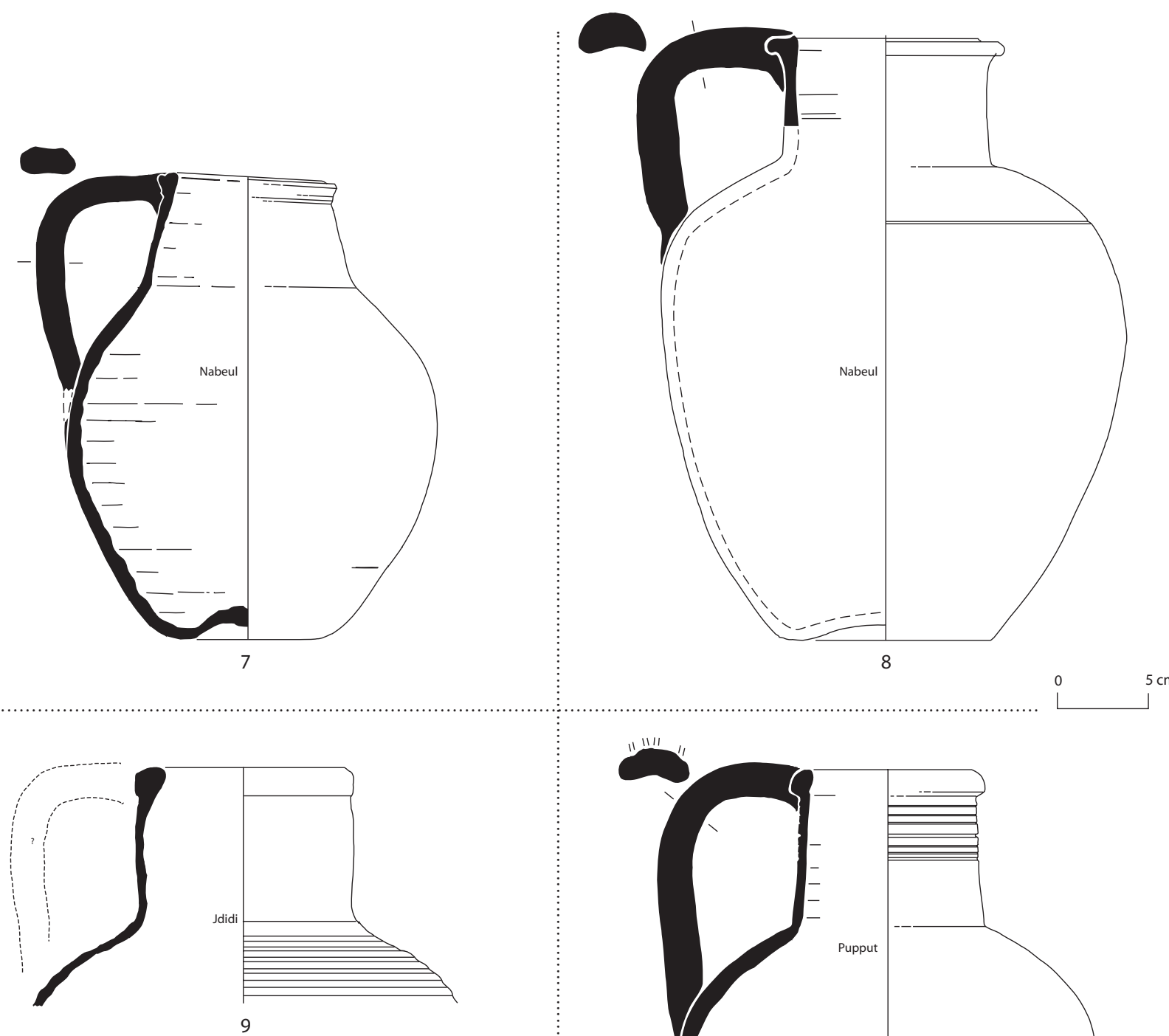

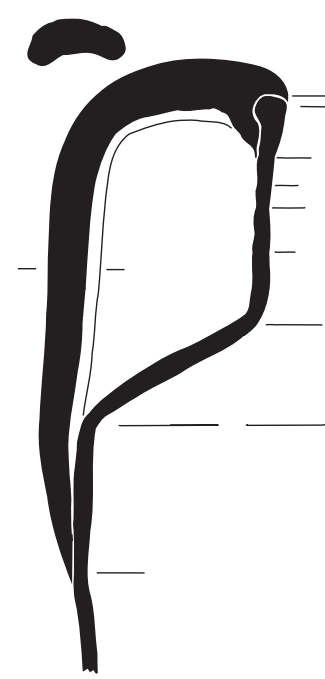

COMMUNE

TYPE 47
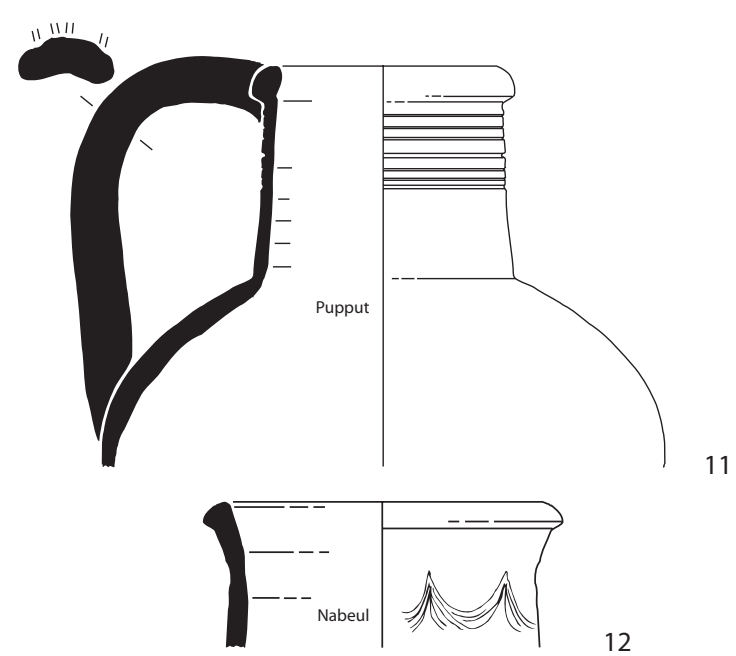

12

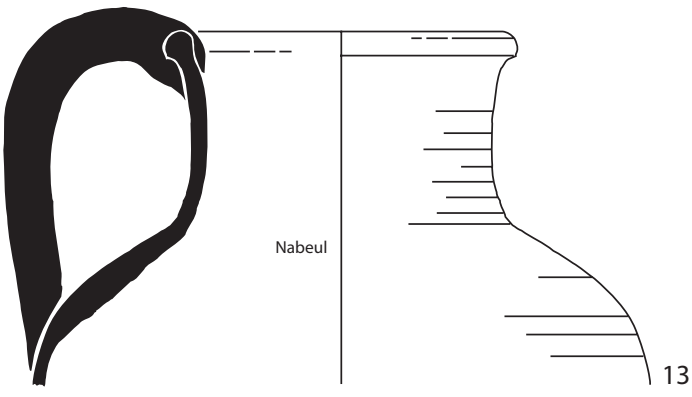

Nabeul

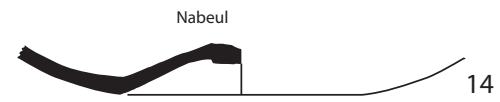

Fig. 156. Vaisselle commune africaine. Cruches de transport (golfe d'Hammamet). 
sélectionnés en fonction de leur caractère répétitif dans les contextes que j'ai pu examiner.

\section{- cruches « de transport»}

Je propose de créer cette catégorie pour désigner les vases à liquide de grande taille, probablement destinés au transport de l'eau.

- cruches dérivées du type Cintas 337-338 (fig. 154)

$=$ Uzita fig. $9, \mathrm{n}^{\circ}$ 2a-c $=$ type Pupput 2

\section{COMMUNE TYPE 45}

Connu dès l'époque punique (Cintas 1950, types 337338 ; Carton 1909, Pl. I, n 2 ; Dore 1989, fig. 69, forme 397), ce type présente un long col cylindrique ou légèrement renflé, une panse grossièrement biconique et un fond ombiliqué à bouton; les anses sont attachées à mi-col (emplacement marqué d'une cannelure) et reposent sur le sommet de la panse.

Exemples (fig. 154) :

*1 Pupput, zone ouverte sud, tombe 601 (Ben Abed, Griesheimer 2004, fig. 65, T601.1).

2 Uzita (Van der Werff 1982a, fig. 9, $\mathrm{n}^{\circ} 2 \mathrm{c}$ ).

*3 Pupput, tombe 1686 (Inv. 5545.1).

4 Leptiminus (Dore 1992, 153, ${ }^{\circ} 81$ ).

Le TYPE 45 est bien attesté sur la nécropole de Pupput au IIe s. $(\mathbf{1}, \mathbf{3})$. Un type comparable est attesté à Uzita (2) à la même époque.

\section{— « amphores » globulaires à anses sur l'épaulement}

\section{[AMPHORE TYPE 7]}

On pourrait également rattacher aux cruches de transport de tradition punique des vases globulaires, à anses sur l'épaulement, classés parmi les amphores (supra, AMPHORE TYPE 7, $\mathrm{n}^{\circ} 1$ : Vegas 1994a, fig. 179, $\mathrm{n}^{\circ}$ 397). De manière assez évocatrice, Renault $(1908,44)$ réunit sur la même figure ce vase avec une cruche mono-ansée de TYPE 47, pour illustrer les objets recueillis dans les niveaux romains du Kef. On note également leur présence dans le puits de la maison de Vénus à Mactar (Bourgeois 1985, fig. $4, \mathrm{n}^{\circ} 60$ ).

\section{— « amphores » globulaires mono-ansées (fig. 154)}

\section{COMMUNE TYPE 46}

Ce barbarisme désigne des vases pansus, à col étroit et fond ombiliqué, véritables amphores globulaires avant la date (supra, AMPHORES TYPES 63-66), mais munis d'une seule anse.

Exemples (fig. 154) .

*1 Oued el-Kseub (fouilles T. Ghalia ; sans $\mathrm{n}^{\circ}$ ).

*2 Pupput, thermes du Centre (fouilles A. Ben Abed, Inv. PPC230.1).

Le $\mathrm{n}^{\circ} \mathbf{1}$, issu d'un contexte du Ve s., est probablement originaire, d'après l'aspect de la pâte, de l'atelier de Sidi Zahruni à Beni Khiar. Le $\mathrm{n}^{\circ} \mathbf{3}$ est plus tardif, probablement du VIIe siècle.

\section{- cruches mono-ansées du nord du golfe d'Hammamet (fig. 155-156) \\ = type Pupput 1}

\section{COMMUNE TYPE 47}

Il s'agit d'un grand vase à panse globulaire prolongée par un col cylindrique; le bord est en bandeau, à sommet bifide; une anse en ruban prend attache directement sur le bord et vient reposer sur l'épaulement ; fond ombiliqué à bouton (variante $\mathrm{A}$ ). Les dimensions moyennes sont constantes: H. 38-39 cm; D. 27-28 cm (exception: $\mathrm{n}^{\circ} 4$ ). On distingue une variante $\mathrm{B}$ caractérisée par un col tronconique, d'une longueur démesurée par rapport à la panse, et un bord en bandeau massif, parcouru d'une cannelure sur sa face extérieure. Un certain nombre de variantes tardives, plus hétérogènes, ne sont pas encore classées.

Exemples (fig. 155-156) :

Variante A

*1 Pupput (Inv. PP1374.24). Dessin D. Pieri.

*2 Pupput (Bonifay 2004a, fig. 20, $\mathrm{n}^{\circ} 74$ ).

3 Fos-sur-Mer, anse Saint-Gervais (Marty 2002, fig. 3, $\left.\mathrm{n}^{\circ} 14\right)$.

*4 Pupput, surface enclos 31 (Inv. PP3333.11). Petit modèle : H. $32,5 \mathrm{~cm}$; D. $22 \mathrm{~cm}$.

Variante B

*5 Pupput, surface nécropole (sans $\mathrm{n}^{\circ}$ ).

*6 Pupput, surface mausolée 4 (Inv. PP1140.29).

Variantes tardives (fig. 156)

*7 Nabeul, usine de salaison, pièce XLIV (Inv. NB1878. 120). Dessin T. Mukai.

*8 Nabeul, usine de salaison, bassin XXXI (Inv. NB 1186.3).

*9 Sidi Jdidi, basilique 1, état A2 (Bonifay, Reynaud 2004, $n^{\circ}$ 7.6).

*10 Sidi Jdidi, basilique 2, destruction état II (Inv. JD 2315.1). Dessin T. Mukai.

*11 Pupput, thermes du Centre (fouilles A. Ben Abed; sans $n^{\circ}$ d'inv.).

*12 Nabeul, fabrique de salaison, état 6 (Bonifay 2002, fig. $\left.4, \mathrm{n}^{\circ} 31\right)$.

*13 Idem (Ibid., $\mathrm{n}^{\circ} 30$ ).

*14 Idem, fond ( $\left.\mathrm{n}^{\circ} 32\right)$.

Cette forme est omniprésente dans la nécropole de Pupput. La variante A, classique, est caractéristique du IIe $\mathrm{s}$. et de la première moitié du IIIe s. (1-2, 4); la variante B ne paraît pas antérieure au milieu du IIIe s. (56). Les cruches mono-ansées se retrouvent jusqu'à la fin de l'Antiquité, avec une évolution morphologique continue, malgré quelques petits particularismes locaux : à Nabeul au début (7) puis à la fin du IVe s. (8), à Sidi Jdidi au début (9) et dans la seconde moitié du Ve s. (10), à Pupput au VIe s. (11), à Nabeul encore à la fin du VIIe s. (12-14).

Cette forme ne semble pas exclusivement diffusée dans le nord du golfe d'Hammamet (un exemple à Haïdra : Jacquest 1998, H52 ; au Kef : Renault 1908, 44).

\section{- cruches de table}

Il est impossible de passer en revue toutes les formes de cruches de table en céramique commune africaine. La 

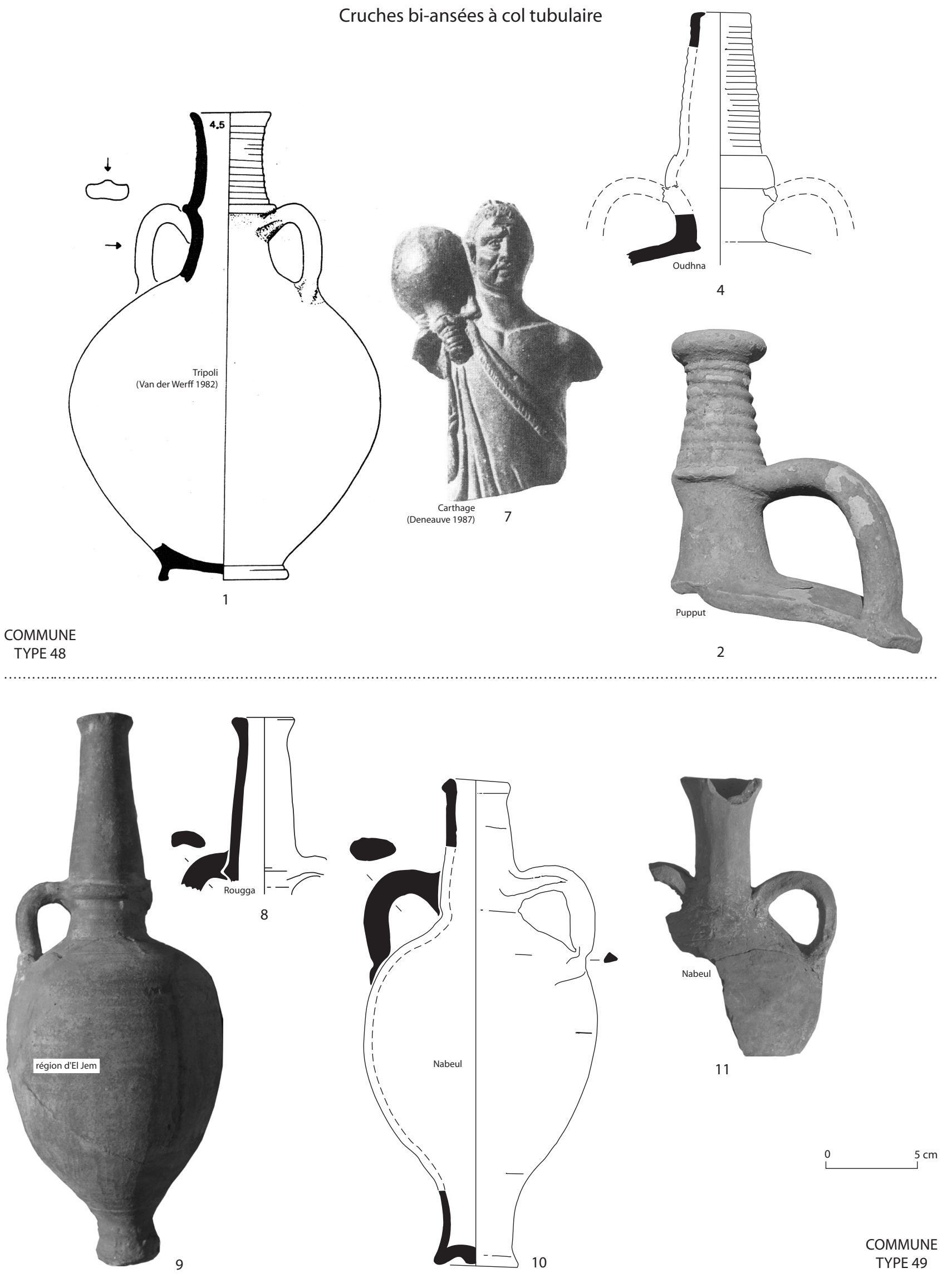

Fig. 157. Vaisselle commune africaine. Cruches. 


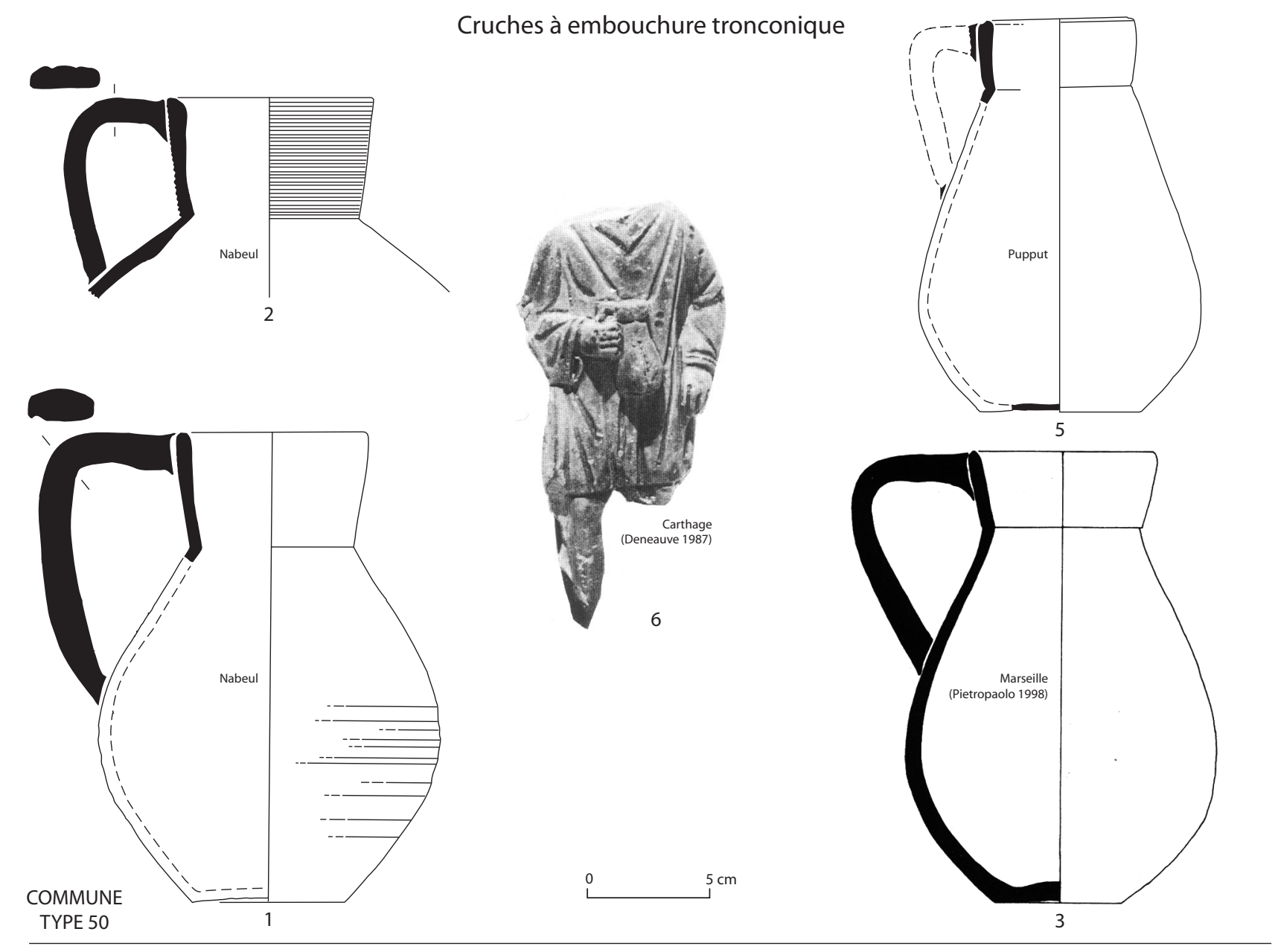

Cruches biconiques à bord en bandeau
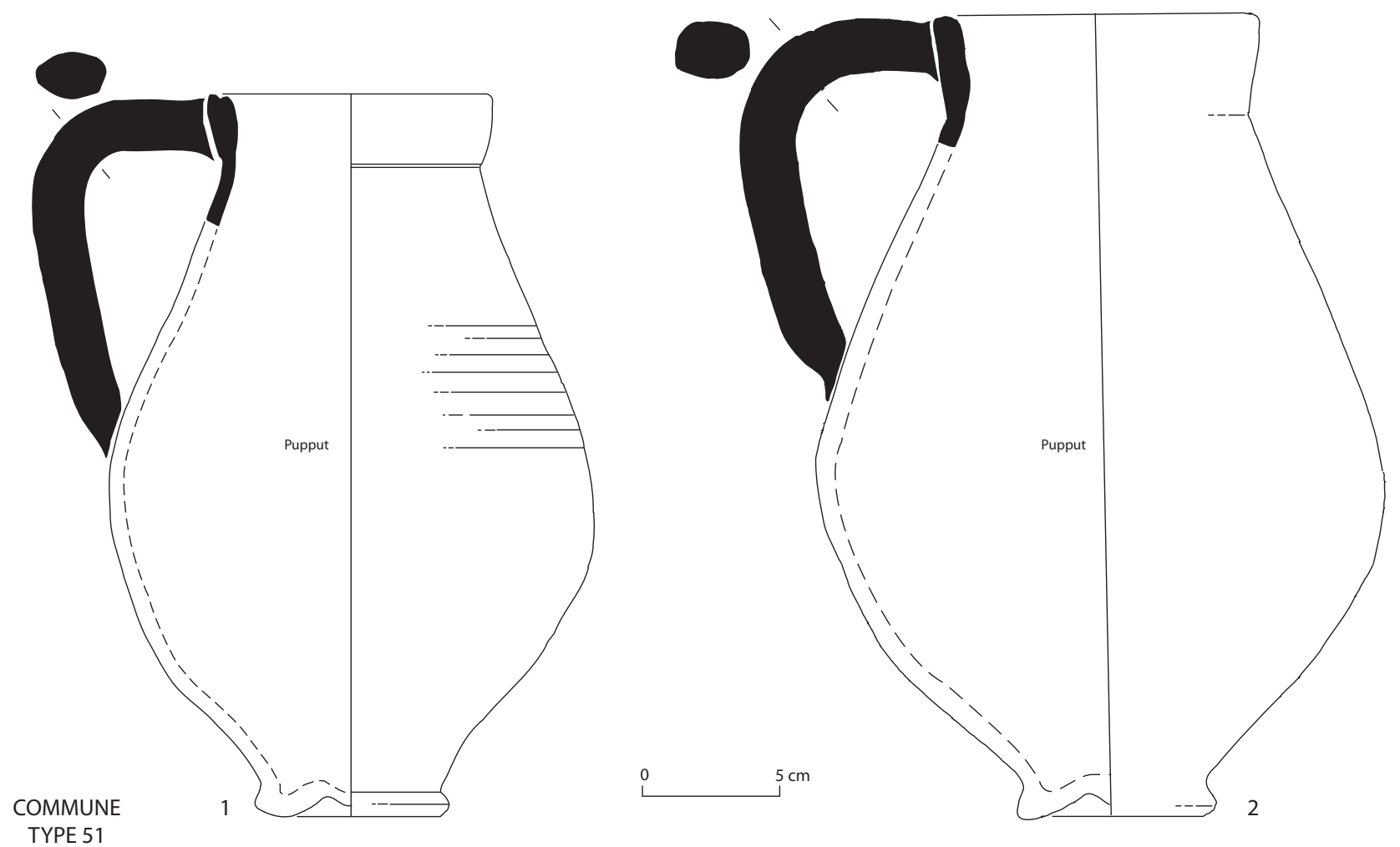

Fig. 158. Vaisselle commune africaine. Cruches de table. 
série publiée à Raqqada par J. H. Salomonson est assez révélatrice de cette diversité morphologique. Je me contenterai de signaler quelques-uns des types les plus fréquents que j'ai pu rencontrer, principalement dans le nord du golfe d'Hammamet, mais également en Byzacène méridionale. Il est remarquable que beaucoup de ces formes subsistent, en se transformant, jusqu'à la fin de l'Antiquité.

\section{— cruches bi-ansées à col tubulaire (fig. 157)}

\section{COMMUNE TYPES 48-49}

On peut distinguer deux grands types de cruches à col tubulaire :

TYPE 48 (= Uzita fig. 9, 5 = Fulford 1984b Closed Form 52): Cette forme, également produite en sigillée africaine C1 (forme Hayes 173) et en verre (Rütti 1991, forme AR 176 = Isings 129), est bien connue (1) : corps globulaire porté par un petit pied annulaire, long col cylindrique renflé au niveau de l'attache des anses et terminé par un tube cannelé. Le $\mathrm{n}^{\circ} 4$ montre bien le mode de fabrication de cette cruche, en plusieurs parties.

TYPE 49 : Le col tubulaire est plus allongé et n'est pas cannelé. La panse, plus ovoïde, est terminée par un fond étroit.

Exemples (fig. 157) :

TYPE 48

*1 Tripoli, Rijksmuseum van Oudheden, Leiden (Van der Werff 1982a, fig. $9, \mathrm{n}^{\circ} 5$ ).

*2 Pupput, enclos 17 (Inv. PP3345.1).

3 Marseille, chantier de La Bourse (Pietropaolo 1998, fig. 61, $\left.n^{\circ} 69\right)$.

*4 Oudhna, thermes des Laberii ( sans $^{\circ}{ }^{\circ}$.

5 Nabeul, fabrique de salaison, bassin XXIX (Inv. NB 1187.0)

Représentation antique de la forme

*7 Musée de Carthage, figurine de triclinarius (Deneauve 1987, fig. 20, $\operatorname{Tr} 2$ ).

TYPE 49

*8 Rougga, couche 13 (Guéry, Bonifay à paraître, $\left.\mathrm{n}^{\circ} 291\right)$.

*9 Région d'El Jem (collection M. Cornet, Jouques). Variante tardive

*10 Nabeul, quartier de la maison des Nymphes (fouilles L. Slim, Inv. NB3034.1)

*11 Nabeul, idem (Inv. NB3004.1).

Les variantes anciennes du TYPE 48, à la fin du IIe s. ou dans la première moitié du IIIe s., semblent se distinguer par un col tubulaire à extrémité évasée (1) ou terminé par une lèvre épaissie (2-3). Cette forme est surtout bien attestée au IIIe s. (Van der Werff 1982a, Pl. 48, 3-4) mais elle demeure fréquente à la fin du IVes. (4) (pour un exemplaire complet à Carthage, cf. Renault 1913, fig. 67). A partir du Ves. (5), le col ne semble plus cannelé. De fait, il n'est pas impossible que le TYPE 49, bien diffusée en Byzacène (8-9) et dans la partie occidentale de l'Africa (un exemple à Haïdra : Jacquest 1998, H80) soit exclusivement tardif: une forme comparable est produite en céramique sigillée africaine D, probablement sur l'atelier d'Oudhna au VIe s. (Fulford 1984a, Closed Form 1 ; supra, SIGILLÉE TYPE 61). Le n ${ }^{\circ} 8$ provient d'un contexte vandale tardif. Enfin, les $\mathrm{n}^{\circ} \mathbf{1 0}$ et 11 montrent la longue durée de vie de cette forme, puisqu'ils sont issus de contextes byzantins tardifs ou post-byzantin (11).

Le TYPE 48 est représenté sur une figurine de triclinarius (FIGURINE TYPE 3) provenant de Carthage (voir les observations de J. Deneauve, 1987, 217 fig. 4 et 5), datée du IIIe s. (7), qui laisse penser que ces vases étaient destinés au service du vin.

\section{— cruches piriformes à embouchure tronconique (fig. 158) \\ $=$ Vegas 43.3}

\section{COMMUNE TYPE 50}

Il s'agit d'une autre forme bien connue de la céramique commune africaine (Pavolini 2000, 125-127, avec bibliographie).

Exemples (fig. 158) :

*1 Nabeul, fabrique de salaison, bassin XVII (Inv. NB1055.6).

*2 Idem (Inv. NB1053.11). Variante : col strié.

*3 Marseille, chantier de La Bourse (Pietropaolo 1998, fig. 61, $\mathrm{n}^{\circ} 74$ ).

4 Raqqada, tombe B47 (Ennabli, Mahjoubi, Salomonson 1973, Pl. XLV).

*5 Pupput (Bonifay 2004a, fig. 21, $\mathrm{n}^{\circ}$ 78).

Représentation antique de la forme

*6 Musée de Carthage, figurine de triclinarius (Deneauve 1987, fig. 20, Tr 1)

Il semble que l'on puisse distinguer des exemplaires avec un bord haut et évasé (1-3), bien attestés dans la première moitié du IIIe s., et d'autres avec un bord plus ramassé et vertical, caractéristiques de la fin du IIIe s. (4) et du IVes. (5). Le profil général du vase, initialement biconique (3 ; voir également Pavolini 2000, n 46 et 49), tend à devenir nettement piriforme, avec un diamètre maximum de la panse située très près du fond $(5$; voir également Pavolini 2000, $\mathrm{n}^{\circ} 47$ et 48). Ce type de vase est représenté, comme le précédent, sur une figurine de triclinarius (Cf. Deneauve 1987, 216 et fig. 3) (6).

\section{— cruches biconiques à bord en bandeau (fig. 158)}

\section{COMMUNE TYPE 51}

Grandes cruches (H. 25-30 cm) de forme grossièrement biconique, munies d'un fond concave à bouton (D. $7,5 \mathrm{~cm}$ ) et d'un bord en bandeau (H. env. $3 \mathrm{~cm}$ ) à sommet parfois bifide (1). Une anse coudée, de section ronde, prend naissance directement sur le bandeau et repose sur la partie la plus large de la panse.

Exemples (fig. 158) :

*1 Pupput, tombe 1023 (Inv. PP1731.2).

*2 Pupput, tombe 1167 (Ben Abed, Griesheimer 2004, fig. 91, T1167.2).

3 Musée de Carthage (en exposition). Inscription peinte en rouge : SELAVA. 


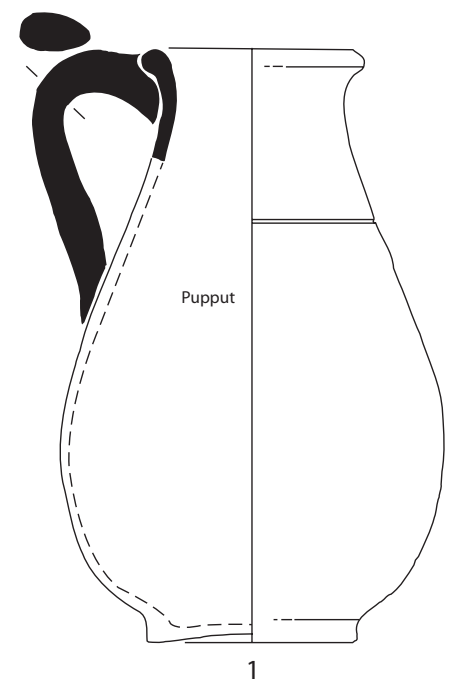

Cruches piriformes à bord arrondi

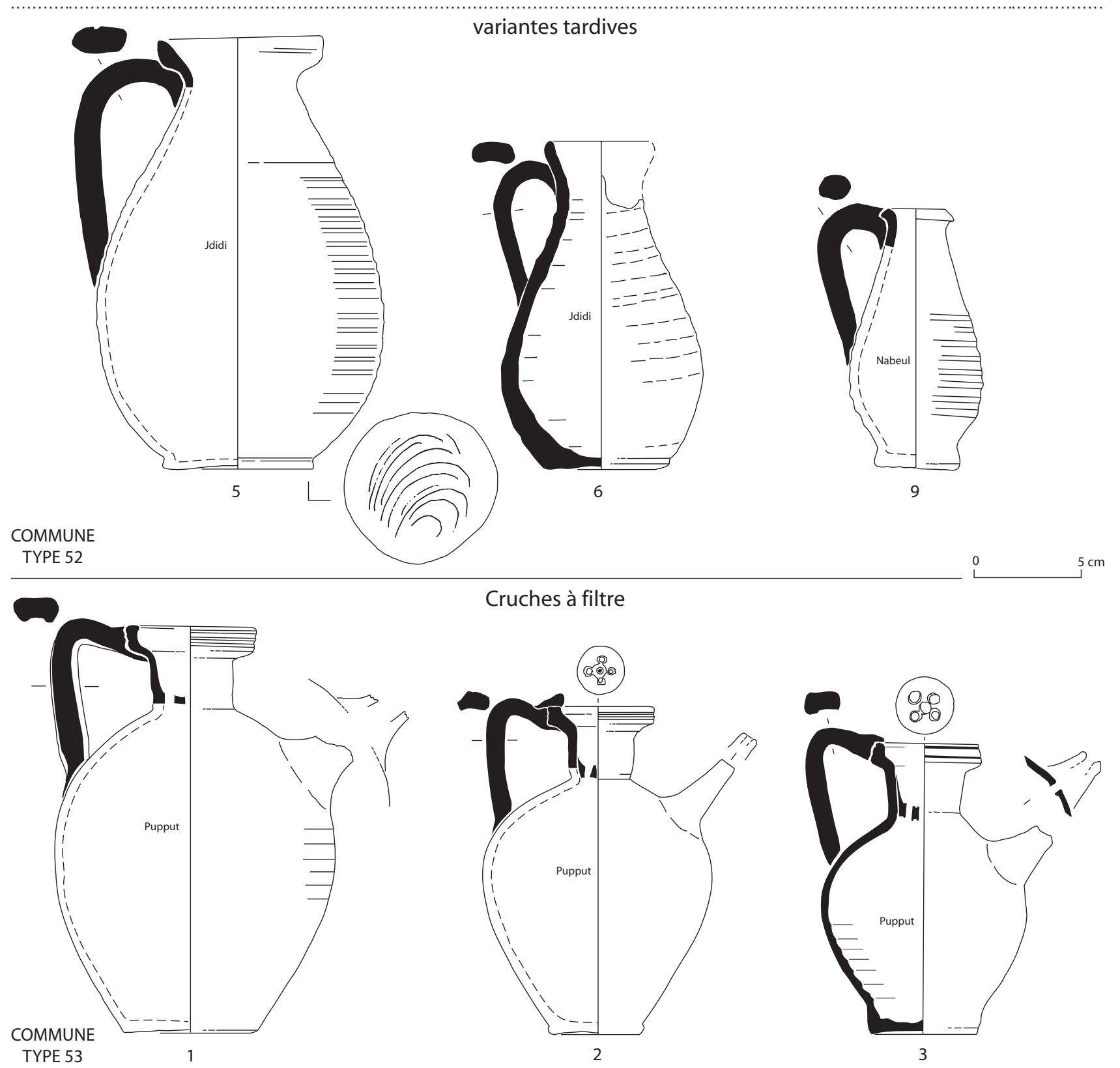

Fig. 159a. Vaisselle commune africaine. Cruches. 
Le $\mathrm{n}^{\circ} \mathbf{1}$, associé à un bord d'amphore Hammamet $1 \mathrm{E}$ (AMPHORE TYPE 8), pourrait être de la seconde moitié du IIe s.; le $\mathrm{n}^{\circ} \mathbf{2}$ est probablement plus tardif (première moitié du IIIe s.).

— cruches piriformes à bord arrondi (fig. 159a)

= Guéry 1985 type XXX

\section{COMMUNE TYPE 52}

Cette forme, largement répandue dans le monde méditerranéen (Vegas 1973, type 44.4), est également abondamment produite en Afrique. Panse très nettement piriforme ; bord simplement épaissi et arrondi ; une anse, attachée sous le bord, rejoint un point marqué par une cannelure situé sous le tiers supérieur de la panse ; fond plat, à talon, avec traces de découpe au fil. Facture d'ensemble peu soignée.

Quatre tailles différentes : H. $18 \mathrm{~cm}$, H. $15 \mathrm{~cm}$, H. 13,5 $\mathrm{cm}$, H. $11 \mathrm{~cm}$.

Exemples (fig. 159a) :

*1 Pupput, tombe 867 (Inv. PP1954.1). H. $18 \mathrm{~cm}$.

*2 Pupput, enclos 25 (Inv. PP1252.2). H. 14,7 cm.

*3 Pupput, enclos 39 (Bonifay 2004a, fig. 21, $\mathrm{n}^{\circ} 76$ ). H. $13,3 \mathrm{~cm}$.

*4 Pupput, mausolée 9 (Inv. PP1122.7). H. $11 \mathrm{~cm}$.

Variantes tardives

*5 Sidi Jdidi, basilique 3, destruction (Inv. JD5029.1).

*6 Sidi Jdidi, basilique 2 (JD2277.50). Dessin Y. Narasawa.

7 Oudhna, thermes des Laberii, four $\mathrm{n}^{\circ} 1$ (Inv. UTH.TL.1001.0)

8 Sidi Jdidi, basilique 1, état C2B (Bonifay, Reynaud 2004, n 34.6). Décor peigné.

*9 Nabeul, quartier de la maison des Nymphes (fouilles L. Slim, Inv. NB3034.3).

Les exemplaires classiques (1-4) sont bien datés du IIe s. et de la première moitié du IIIe siècle. Mais je souhaiterais insister ici sur les variantes tardives du Ve s. (5), du VIe s. (6) et du VIIe s. (7-8); le $n^{\circ}$ 9, qui pourrait déjà être post-byzantin, témoigne de la longévité de cette forme.

\section{— cruches à filtre (fig. 159a)}

\section{COMMUNE TYPE 53}

Les vases à liquide munis d'un filtre et d'un bec verseur tubulaire sur le haut de la panse sont parfois interprétés comme des biberons ou des tire-lait (Rouquet, Loridant 2000 et 2003). Bien que souvent de taille différente, ils sont tous du même type : panse globulaire sur un fond plat à talon, petit col cylindrique muni d'un filtre rapporté, percé de cinq ou six trous, et bord en baïonnette cannelé sur sa face extérieure, sur lequel vient s'attacher une anse rubanée coudée. Il convient toutefois de signaler que cette anse est placée dans l'axe du bec verseur tubulaire et non perpendiculairement à ce dernier comme il se doit, en principe, sur un guttus (exemplaires avec anse perpendiculaire: Guéry 1985a, Pl. XLVI, type XXXV).
Exemples (fig. 159a) :

*1 Pupput, tombe 1203 (Inv. PP2589.1).

*2 Pupput, tombe 1730 (Inv. PP6103.2).

*3 Pupput, nécropole (Bonifay 2004a, fig. 21, n 80).

4 Nabeul, fabrique de salaison, bassin XVII (Inv. NB 1055.18).

Forme bien attestée dans la première moitié du IIIe s. (14) et assez largement diffusée en Méditerranée : Ostie (Pavolini 2000, fig. 63, $\mathrm{n}^{\circ}$ 136), Alicante (Reynolds 1993, Pl. 86, n 21).

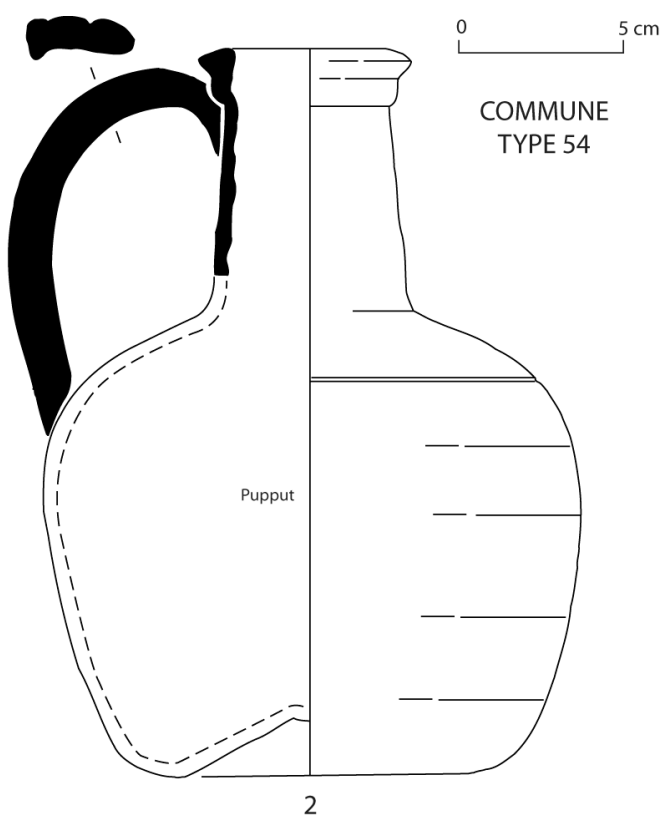

Fig. 159b. Vaisselle commune africaine. Cruches.

\section{— cruches trapues à col tubulaire (fig. 159b)}

\section{COMMUNE TYPE 54}

Cruche à corps trapu (diamètre légèrement supérieur à la hauteur) munie d'un col tubulaire terminé par un bord en bandeau cannelé ou mouluré ; une anse à deux nervures s'attache sous le bord et repose sur l'inflexion supérieure de la panse. Fond concave ombiliqué.

Exemples (fig. 159b) :

1 Pupput, hors contexte (sans $\mathrm{n}^{\circ} \mathrm{d}^{\prime} \mathrm{inv}$.).

*2 Pupput, tombe 402 (Inv. PP1667.4).

L'exemplaire $\mathrm{n}^{\circ} \mathbf{1}$ provient d'une tombe de la fin du IIe $\mathrm{s}$. ou du premier tiers du IIIe siècle ${ }^{205}$.

\section{— cruches piriformes à col tubulaire (fig. 159c)}

\section{COMMUNE TYPE 55}

Cruche à panse piriforme aplatie, munie d'un col tubulaire terminé par un bord en bandeau mouluré ; une anse à section ovale s'attache au sommet du col et repose à mi-panse. Fond concave ombiliqué.

Exemples (fig. 159c) :

*1 Pupput, hors contexte (sans $\mathrm{n}^{\circ} \mathrm{d}$ 'inv.).

2 Epave pointe de la Luque B (Dovis-Vicente 2001,

\footnotetext{
205 Associée à des lampes du type Deneauve VII/sous-type 2 (LAMPE TYPE 5).
} 
Pl. $\left.X, n^{\circ} 2\right)$

3 Epave Dramont E (Santamaria 1995, n 58). Décor incisé.

Le $n^{\circ} \mathbf{1}$ n'est pas daté mais pourrait provenir d'un contexte du IIIe siècle. Les deux autres exemples, qui semblent dériver du premier, sont datés du IVe s. (2) et du Ve s. (3).

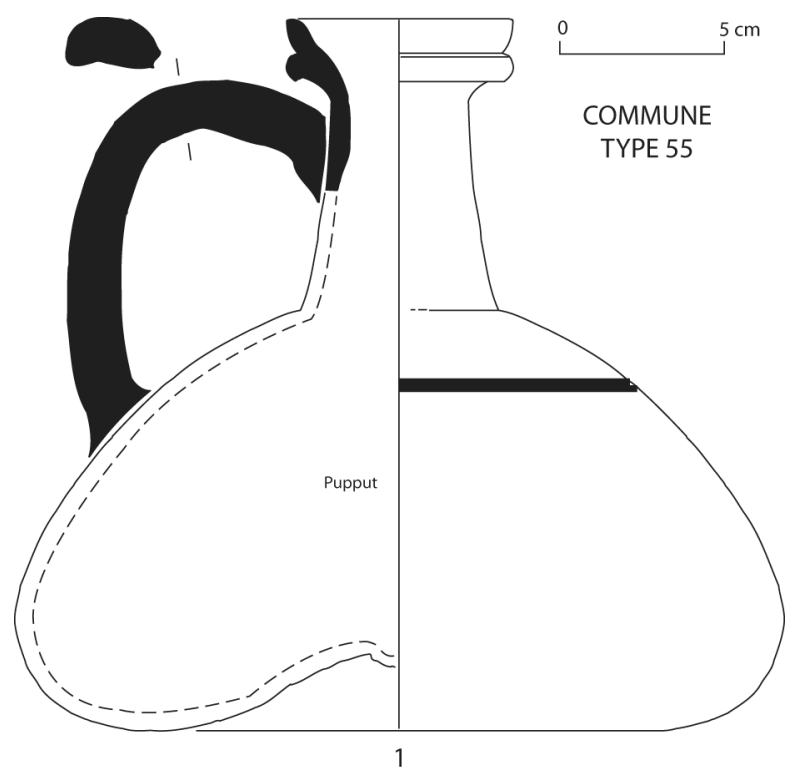

Fig. 159c. Vaisselle commune africaine. Cruches.

\section{- cruches ou gobelets tronconiques type Uzita fig. 5,} $\mathbf{n}^{\circ} 3$ (fig. 160)

\section{COMMUNE TYPE 56}

Petite cruche (ou gobelet?) de forme grossièrement tronconique (H. 14-15 cm; D. env. 9-10 cm), sans encolure, largement ouverte (D. 7-7,5 cm), avec un petit bord en amande au sommet bifide. La base de la panse est carénée pour rejoindre un fond à talon étroit (D. env. $5 \mathrm{~cm}$ ). Une anse en arc de cercle, de section ronde, nervurée sur les tranches, prend naissance sur le bord et vient reposer à mi-panse. Cannelure au niveau de l'attache inférieure de l'anse. Pâte orange et surface blanche très soignée.

Exemples (fig. 159) :

1-2 Uzita (Van der Werff 1982a, fig. 5, n $3 a$ et 3b). H. du $\mathrm{n}^{\circ} 1: 10 \mathrm{~cm}$.

*3 Pupput, enclos 36 (Inv. PP1366.1).

*4 Pupput, tombe 376 (Inv. PP6151.1).

5 Utique (Soren 1978, Pl. 12, UP172c).

Le $\mathrm{n}^{\circ} \mathbf{1}$ provient d'un niveau daté du dernier quart du IIe s. ; les exemplaires de Pupput (3-4) sont de la première moitié du IIIe siècle.

\section{— amphorette à profil lancéolé (fig. 160)}

\section{COMMUNE TYPE 57}

Petite amphorette au profil lancéolé, à panse généralement cannelée, terminée par un bord en entonnoir; les deux anses en oreilles s'attachent au sommet de l'épaulement; le fond plat, en léger talon, porte des traces de découpe au fil.

Exemples (fig. 160) :

*1 Pupput (Bonifay 2004a, fig. 21, $\mathrm{n}^{\circ} 75$ ).

*2 Pupput, tombe 927 (Inv. PP612901).

3 Nabeul, fabrique de salaison, bassin XVII (Inv. NB 1053.7).

4 Fos-sur-Mer (Marty 2002, fig. 8, $\mathrm{n}^{\circ}$ 36).

Forme bien attestée au IIe s. (1). Il semble que les exemplaires de la première moitié du IIIe s. aient les anses plus près du bord et un fond en galette débordante (2-3).

\section{- flacons}

Les deux formes qui suivent, de très petite taille, ont probablement un usage spécifique, peut-être commercial pour la première, sans doute funéraire pour la seconde.

— flacons mono-ansés à corps tubulaire (fig. 160)

$=$ Soren 1978 form 15

\section{COMMUNE TYPE 58}

Ces petits récipients sont omniprésents en Afrique, dès l'époque punique (Cintas 1950, Pl. VIII, n 106 ; Ben Younès 1988, Pl. IX, TB/5.6). Ils sont abondants sur la nécropole d'El Jem (Slim 1984, P1. I, III-IV, VI-VII). On pourrait supposer qu'ils aient transporté une denrée de prix, peut-être du garum (?).

Exemples (fig. 160):

*1 Pupput, (Bonifay 2004a, fig. 21, $\mathrm{n}^{\circ}$ 82).

*2 Nabeul, fabrique de salaison, bassin XVII (Inv. NB 1055.16).

*3 Nabeul, fabrique de salaison, bassin XXXI (Inv. NB1186.66).

*4 Epave du Dramont E, deuxième quart Ve s. (Santamaria 1995, fig. 60).

*5 Carthage (Dietz, Trolle 1979, 87, $\mathrm{n}^{\circ}$ 2).

Ces cinq exemples permettent de suivre l'évolution typologique de ces petits flacons : fin du IIe s. (1), milieu du IIIe s. (2), fin du IVes. (3), deuxième quart du Ve s. (4), seconde moitié du Ves. (5 ?). Ces récipients ont pu être encore fabriqués à l'époque byzantine (Pavolini 2000, 228).

\section{— flacons anthropomorphes (fig. 160)}

\section{COMMUNE TYPE 59}

Cette forme est abondante sur la nécropole de Pupput : il s'agit d'un petit vase de forme grossièrement anthropoïde (H. : $15 \mathrm{~cm}$ env.), avec un petit col cylindrique terminé par un bord trilobé ; la plupart de ces flacons portent un décor en relief fait de deux pastilles d'argile collées sur la partie supérieure de la panse, destinées à évoquer une poitrine féminine. Ce caractère féminin se rapporte peutêtre à la déesse Astarté, comme sur les figurines puniques tournées qui ne se distinguent de nos objets que par le fait qu'elles ne sont pas munies d'une embouchure sommitale (Ferron, Aubet 1974). De fait, ces petits vases anthropomorphes existent aussi à l'époque préromaine, 

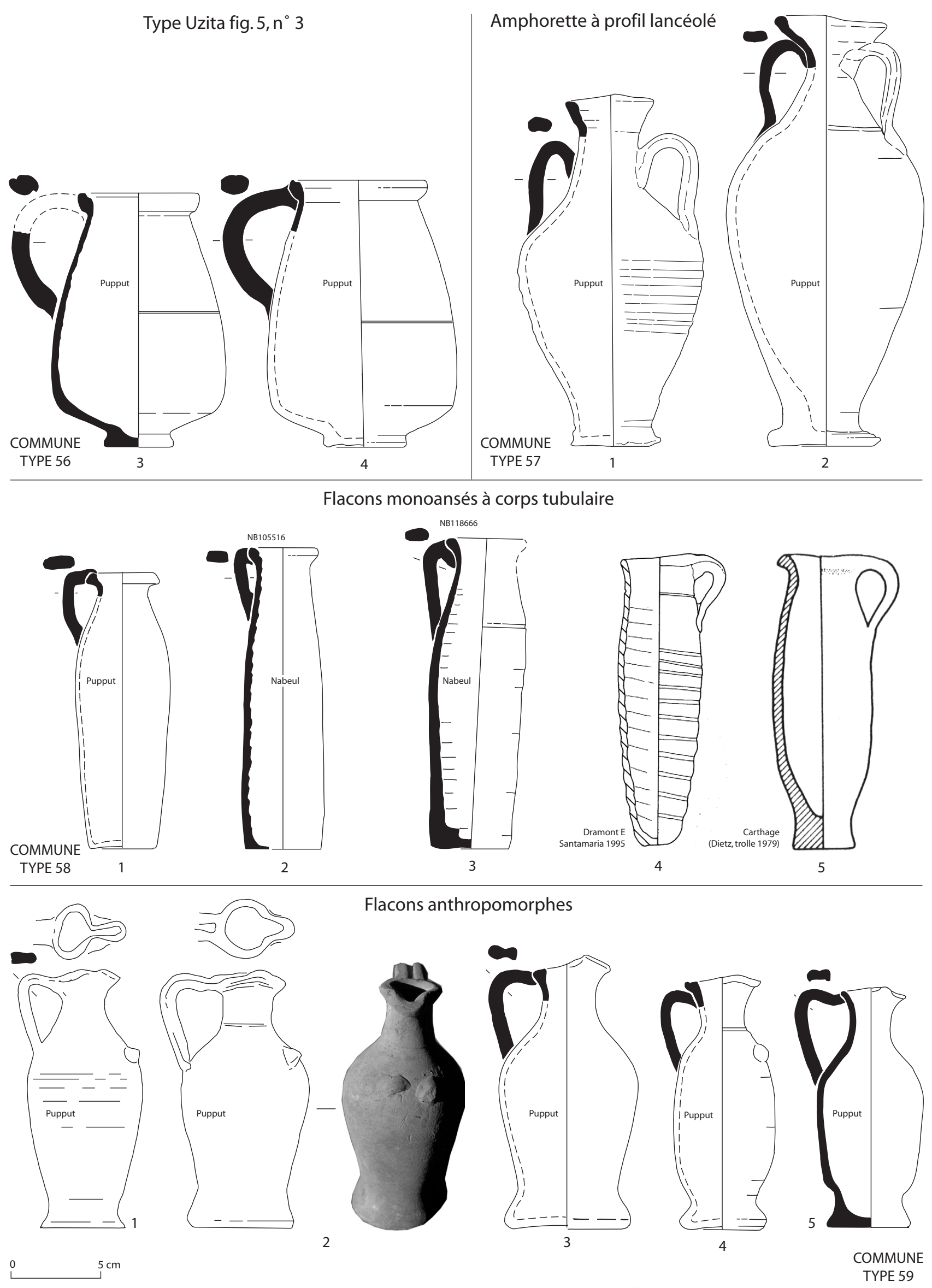

Fig. 160. Vaisselle commune africaine. Cruches et flacons. 
notamment sur deux sites à l'Ouest de Carthage (Cintas 1950, Pl. LVIII, n²0-23, avec bibliographie), et il paraît clair que les flacons de Pupput sont bien de tradition punique.

Exemples (fig. 160) :

*1 Pupput, tombe 120 (Inv. 1129.2).

*2 Pupput (Bonifay 2004a, fig. 21, $\mathrm{n}^{\circ} 81$ ).

*3 Pupput, tombe 443 (Inv. 1454.13).

*4 Pupput, tombe 411 (Inv. 1951.11).

*5 Pupput, tombe 463 (Inv. 1499.4).

Forme attestée au IIe s. et dans le premier tiers du IIIe s. Il est difficile de cerner une évolution. Les exemplaires massifs se rencontrent durant tout le IIe s. : le $n^{\circ} \mathbf{3}$ est de la première moitié du siècle; les $n^{\circ} \mathbf{1}$ et $\mathbf{2}$ ne sont pas antérieurs au dernier quart. Les exemplaires étroits à long col (5) et base resserrée (4-5) paraissent plus précoces.

\section{- types tardifs}

Alors que beaucoup de cruches de l'Antiquité tardive ne sont que l'évolution de types plus anciens, certaines semblent apparaître seulement au Ve siècle. Je prendrai quelques exemples, notamment à Carthage, dans le nord du golfe d'Hammamet et en Byzacène méridionale.

- type Carthage Late Roman Jug 1 (fig. 161)

$=$ Fulford 1984b, Closed form 10

COMMUNE TYPE 60

Petite cruche globulaire à large encolure cannelée, et à bec pincé.

Type Carthage Late Roman Jug 1

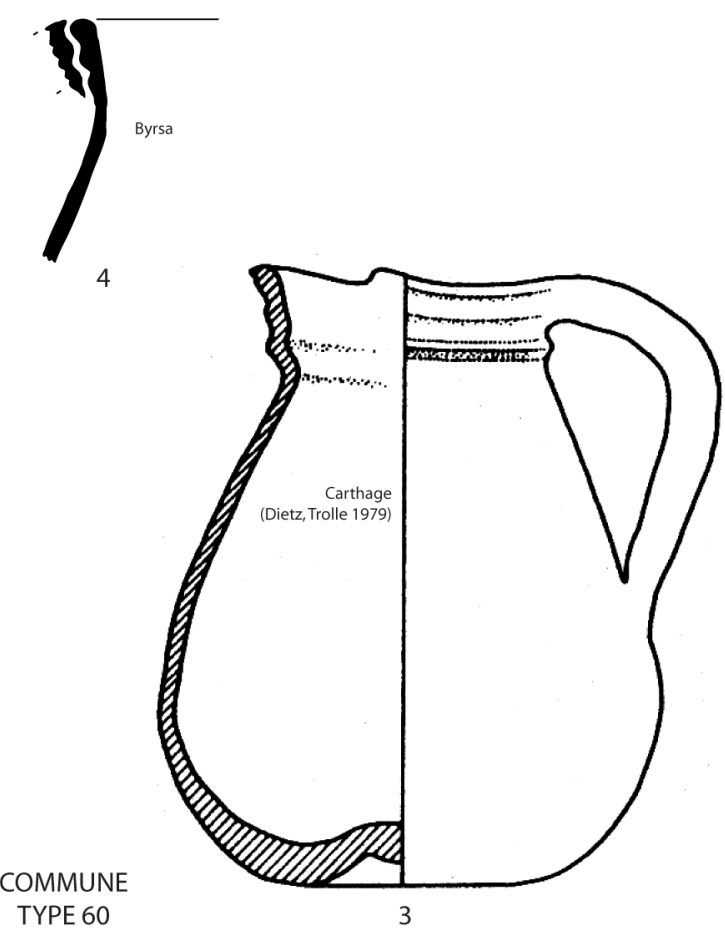

Exemples (fig. 161) :

1 Carthage (Tomber 1988, fig. 7, $\mathrm{n}^{\circ} 163-164$ ).

2 Carthage (Fulford 1984b, fig. 79, forme 10).

*3 Carthage (Dietz, Trolle 1979, 103, $\mathrm{n}^{\circ} 1$ ).

*4 Carthage, Byrsa (Bonifay à paraître, a, n 63-64).

5 Carthage (Dietz, Trolle 1979, 87, $n^{\circ} 3$ ).

6 Oudhna, thermes des Laberii, atelier (Inv. UTH.TL. 3002.69).

Forme attestée dès la fin du IVes. (1) mais principalement au Ve (3-4) et dans la première moitié du VIe siècle (5-6). Peut-être produite à Oudhna (6).

- type CATHMA A6 (fig. 161)

$=$ Fulford 1984b, Closed form 6

\section{COMMUNE TYPE 61}

Cruches à panse globulaire et long col cylindrique légèrement cannelé, caractérisées par une anse torsadée qui prend naissance directement sur le bord et vient reposer sur l'épaulement. Fond ombiliqué ou plat. Tailles diverses.

Exemples (fig. 161) :

1 Carthage (Fulford 1984b, fig. 79, forme 6).

*2 Epave Dramont E (Santamaria 1995, fig. 52).

3 Saint-Blaise (C.A.T.H.M.A. 1991, fig. 8, type A6 ; Vallauri 1994, fig. 68, $\mathrm{n}^{\circ} 13$ ).

Forme bien attestée au Ves. (2) et dans la première moitié du VIe s. (3). L'intérieur poissé des exemplaires du Dramont E laisse penser que ces objets ont pu voyager pour leur contenu (vin ?). Probablement une production de la région de Nabeul.

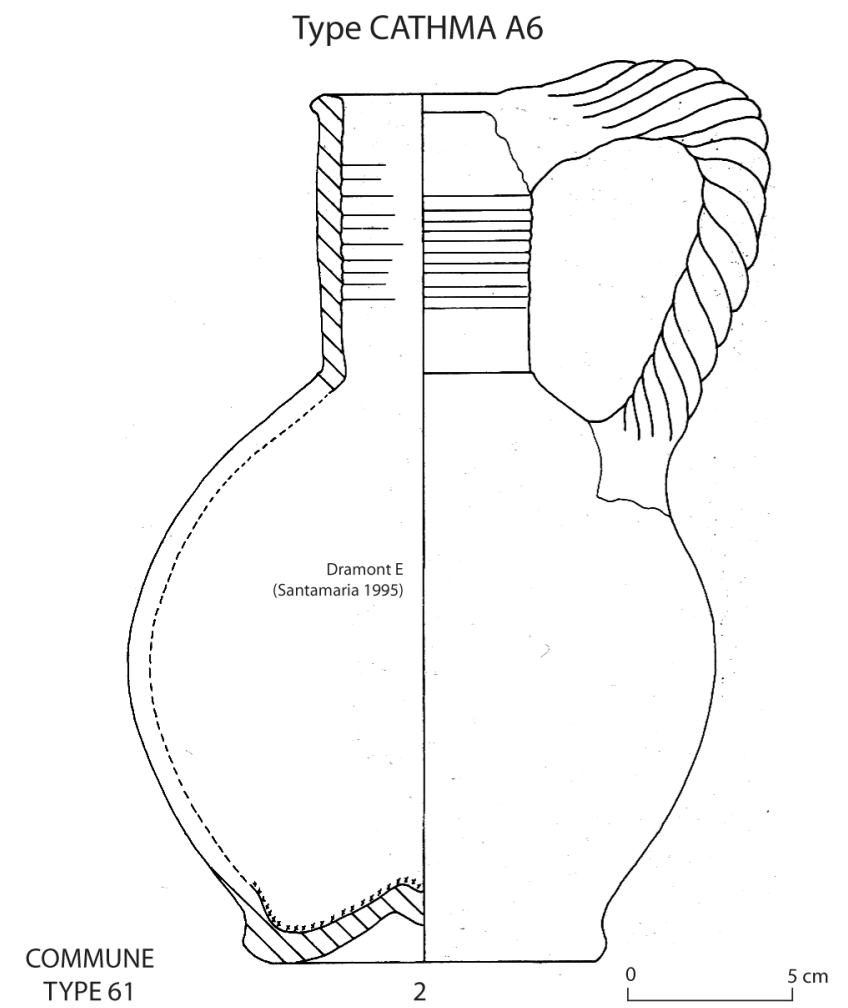

Fig. 161. Vaisselle commune africaine. Cruches, types tardifs. 
Petites cruches cannelées
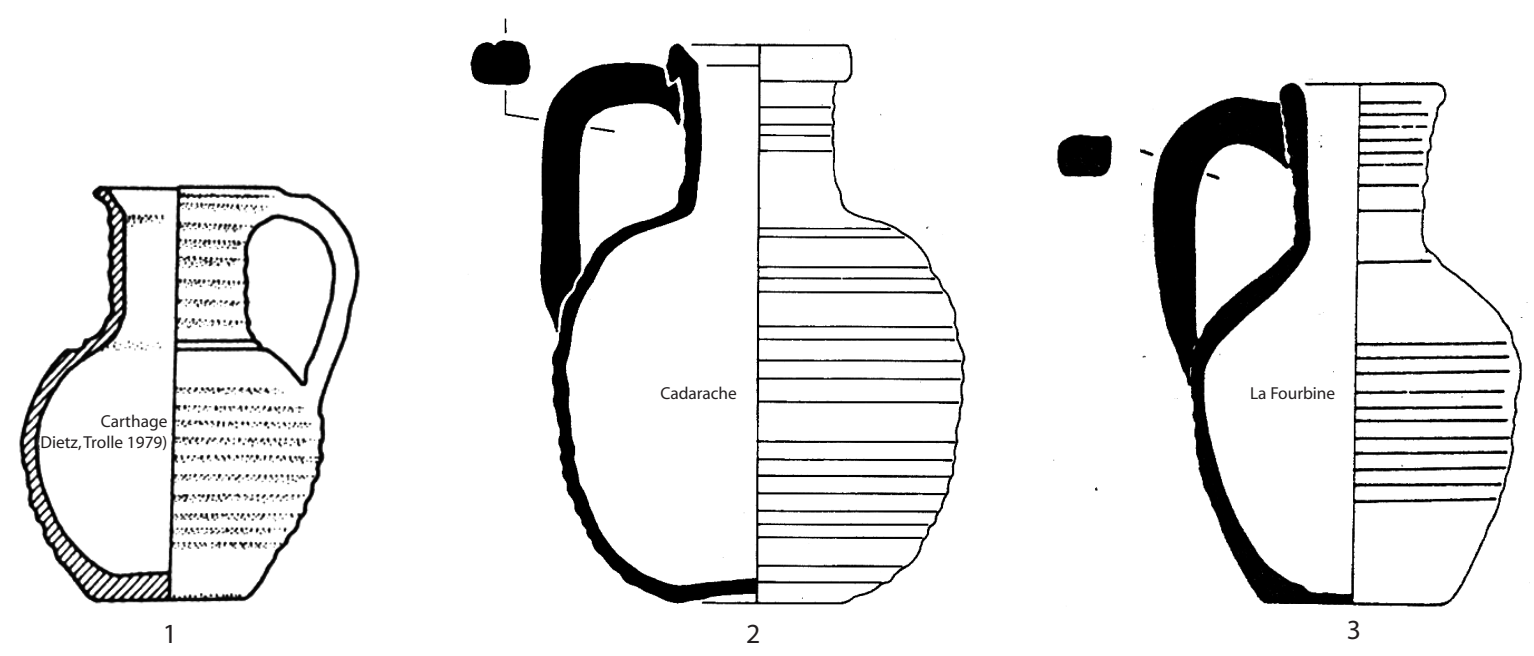

Productions de la région de Nabeul (?)
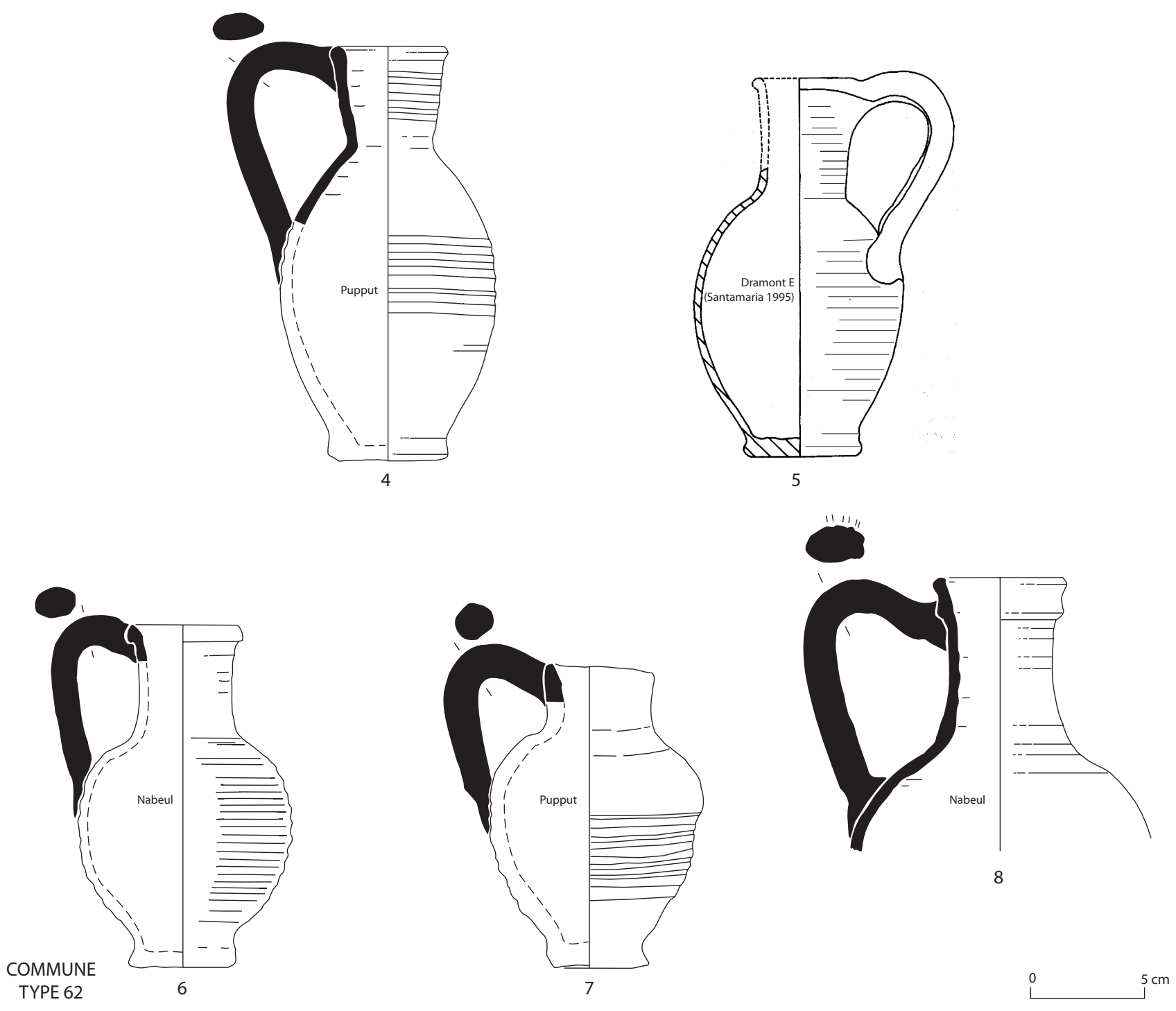

Fig. 162. Vaisselle commune africaine. Cruches, types tardifs. 
Type "Trésor de Rougga"
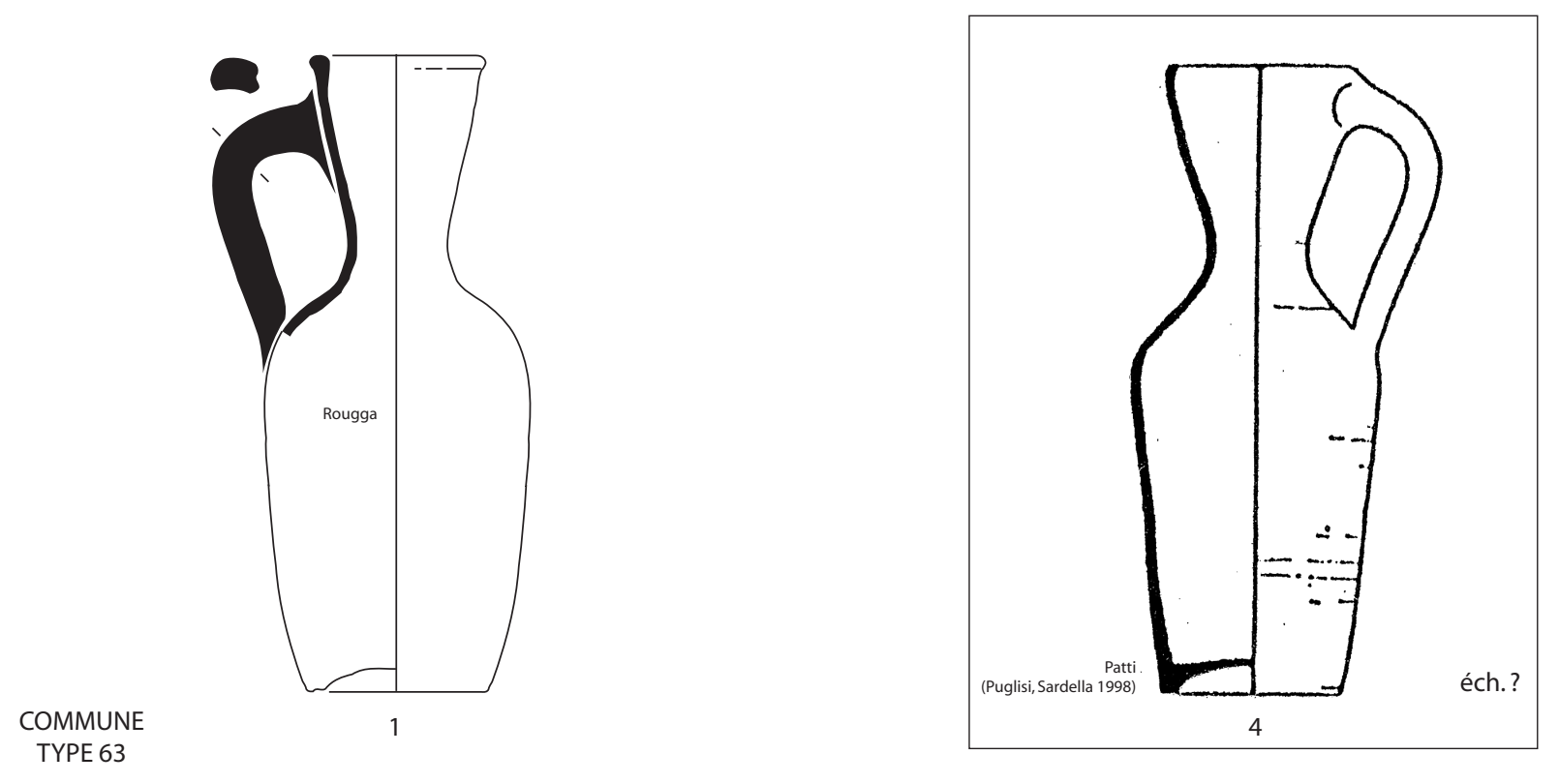

Type CATHMA A24
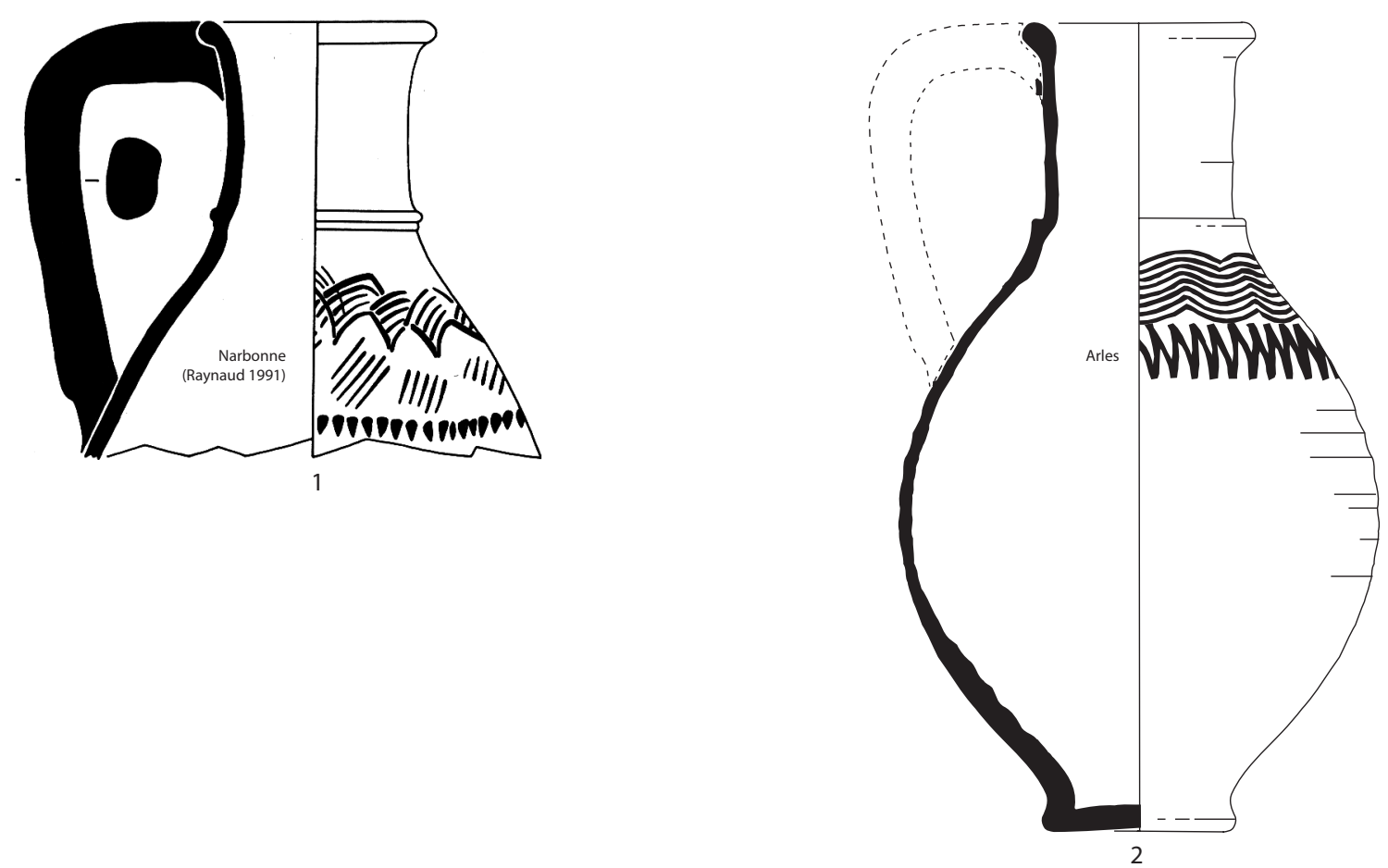

$\stackrel{0}{L}$ $5 \mathrm{~cm}$

Fig. 163. Vaisselle commune africaine. Cruches, types tardifs. 
- Petites cruches cannelées (fig. 162)

$=$ Fulford 1984b, Closed form 4 et 18

\section{COMMUNE TYPE 62}

Plusieurs types de petites cruches cannelées ont été mis en évidence dans les niveaux tardifs de Carthage (Fulford 1984b, fig. 79, Closed forms 4 et 18) et de quelques sites de Méditerranée occidentale (2-3 ; C.A.T.H.M.A. 1991, fig. 6, type A2 ; voir également, à Alicante : Reynolds 1993, Pl. 86, n $^{\circ} 20$ ). Les ateliers urbains de Nabeul (supra, p. 73) ont également livré les indices d'une production de céramiques communes à pâte blanche, byzantine tardive, composée en grande partie de ces petites cruches cannelées.

Bien que différentes dans le détail, elles ont toutes en commun leur petite taille $(\mathrm{H} .: 12-18 \mathrm{~cm})$, un corps globulaire finement cannelé, un col cylindrique terminé par un petit bord faiblement épaissi ou triangulaire, une anse coudée de section quadrangulaire, prenant naissance sur ou immédiatement sous le bord, un fond plat ou légèrement concave. Il n'est pas impossible, à mon sens, que ces vases aient eu une fonction commerciale, pour le transport de quelque denrée de prix, vin fin ou autre, d'autant que beaucoup sont poissés et que l'un d'eux (3) porte une marque à la peinture rouge sous le fond, fait curieux pour une simple cruche, qui rappelle plutôt les tituli picti sur amphores (?).

Exemples (fig. 162) :

*1 Carthage (Dietz, Trolle 1979, 103, $\mathrm{n}^{\circ}$ 7).

*2 Nécropole de Cadarache, Saint-Paul-les-Durance (Pouyé et al. 1994, 1, fig. 6, t 14).

*3 Grotte de la Fourbine, Saint-Martin-de-Crau (Congès et al. 1983, fig. $\left.4, \mathrm{n}^{\circ} 4\right)$.

*4 Pupput, tombe 1515 (Inv. PP4460.1).

*5 Epave Dramont E (Santamaria 1995, fig. 56).

*6 Nabeul, atelier urbain (fouilles L. Slim, Inv. NB 3034.1). Cf. supra, fig. 37, $\mathrm{n}^{\circ} 1$.

*7 Pupput, thermes du Centre (fouilles A. Ben Abed, Inv. PPC230.3).

*8 Nabeul, atelier urbain (fouilles L. Slim; sans $\mathrm{n}^{\circ}$ d'inv.). Variante.

Ces petites cruches cannelées paraissent couvrir une assez longue période de production, de la fin du IVe s. jusqu'à la fin du VIIe s. au moins. Les différences morphologiques entre les $n^{\circ} \mathbf{1}, \mathbf{2}$ et $\mathbf{3}$, alors qu'ils sont à peu près contemporains dans la première moitié du Ve s., révèlent probablement des différences d'ateliers. En revanche, il y a de fortes chances que les $n^{\circ} \mathbf{4}$ à 8 aient une origine commune, à l'échelle d'une micro-région, HammametNabeul; rappelons que le chargement homogène de l'épave du Dramont E (5) provient en grande partie de l'atelier de Sidi Zahruni à Beni Khiar (supra, p. 37). Dans ce cas, il faut bien constater que l'évolution entre les exemplaires du Ve s. (4-5) et ceux du VIIe s. (6) n'est pas très sensible; elle est plus évidente sur le $n^{\circ} \mathbf{8}$, qui provient de niveaux très tardifs, peut-être déjà postbyzantins.
— type du « trésor de Rougga » (fig. 163)

= Guéry 1982, fig. 6

\section{COMMUNE TYPE 63}

S'il est un type de cruche précisément daté, c'est bien celui qui, à Rougga, contenait le fameux trésor de 268 pièces d'or byzantines, dont la plus récente date de 647 (Guéry, Morrisson, Slim 1982) Cette cruche est composée d'une panse cylindrique pour la moitié de la hauteur du vase, surmontée par un col en tronc de cône renversé pour l'autre moitié; le bord est faiblement épaissi à l'intérieur; une anse coudée, à section en haricot, prend naissance sous le bord et vient s'appuyer sur l'épaulement; le fond est légèrement concave. Les trois exemplaires de ce type de cruche recueillis sur le site ont la même pâte brun-rouge clair, assez fine, propre à plusieurs formes de céramiques communes de Rougga. Exemples (fig. 163) :

*1 Rougga, couche 10 (Guéry, Bonifay à paraître, $\left.\mathrm{n}^{\circ} 294\right)$.

2 Idem, couche 13 (Ibid., ${ }^{\circ} 292$ ).

3 Idem (Ibid., n $\left.{ }^{\circ} 293\right)$.

*4 Patti (Sicile) (Puglisi, Sardella 1998, fig. 2).

La datation fournie par le contenu du $\mathrm{n}^{\circ} \mathbf{1}$, deuxième quart ou milieu du VIIes., paraît contredite par la position stratigraphique des $\mathrm{n}^{\circ} \mathbf{2}$ et $\mathbf{3}$, déjà dans des contextes de la fin du Ve siècle. L'exemplaire $\mathrm{n}^{\circ} \mathbf{4}$, exporté en Sicile, confirme plutôt la première des deux datations.

\section{— type CATHMA A24 (fig. 163)}

\section{COMMUNE TYPE 64}

Grande cruche (H. 26-27 cm) ovoïde, col parfaitement cylindrique marqué d'un ressaut à la jonction avec la panse. Une anse coudée, attachée directement sur le bord. Décor peigné sur l'épaulement.

Exemples (fig. 163) :

*1 Narbonne (C.A.T.H.M.A. 1991, fig. 14, type A24 ; Raynaud 1991, fig. 2, $n^{\circ}$ 5).

*2 Arles, chantier de l'I.R.P.A. (Inv. 608.220). Dessin J. Bremond.

3 Ostie (Pavolini 2000, fig. 35).

4 Marseille, puits de la rue du Bon Jésus (Reynaud 1998, fig. $\left.189, \mathrm{n}^{\circ} 219\right)$.

Les exemplaires $\mathrm{n}^{\circ} \mathbf{1}$ et $\mathbf{2}$ proviennent de contextes du premier tiers du Ve siècle. Je ne connais pas d'exemple en Afrique. Cette cruche ne paraît pas originaire de la côte orientale de la Tunisie.

\subsubsection{Jarres (fig. 164)}

\section{COMMUNE TYPE 65}

Des fragments de grandes jarres apparaissent sporadiquement dans les contextes africains. Elles ont en commun un bord déversé (D. : 20-30 cm env.) et un corps très pansu. Certains exemplaires complets $(3)^{206}$ montrent la présence d'anses et d'un fond à pied annulaire mais il est difficile d'affirmer que ces caractéristiques sont

\footnotetext{
${ }^{206}$ Un autre, plus fragmentaire, provient de Pupput.
} 


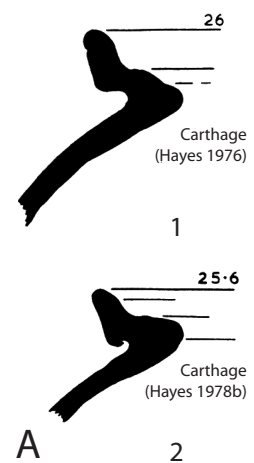

Jarres
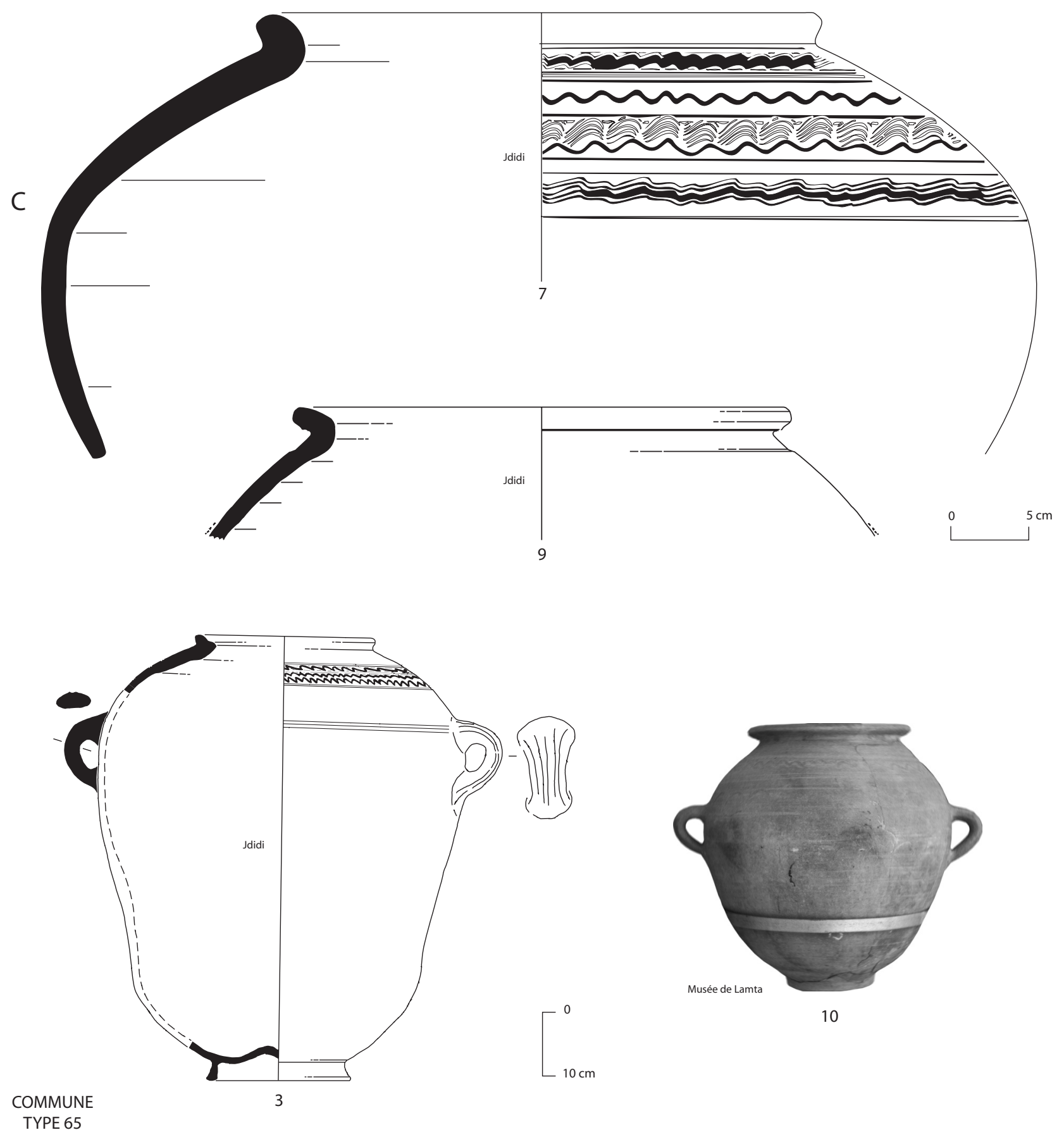

Fig. 164. Vaisselle commune africaine. Jarres. 
constantes. Dans l'état actuel de la documentation, il est possible de distinguer trois variantes :

- Variante A : bord déversé muni d'une face verticale et d'un fort ressaut interne, lui donnant un aspect « en baïonnette ».

- Variante B : bord simple déversé muni d'un fort ressaut interne, lui donnant un aspect bifide.

- Variante C: bord simple déversé, sans ressaut interne.

Exemples (fig. 164) :

Variante A

*1 Carthage (Hayes 1976a, fig. 18, $n^{\circ}$ XIII.25).

*2 Idem (Hayes 1978b, fig. 4, n XVIII.36).

Variante B

*3 Sidi Jdidi, îlot basilique 2, destruction état II (Inv. JD 2373.1). Décor ondé

*4 Sidi Jdidi, basilique 1, état C2A (Ben Abed, Bonifay, Fixot 1997, fig. 4, $n^{\circ} 26$; Bonifay, Reynaud 2004, $\mathrm{n}^{\circ}$ 26.12). Décor ondé.

5 Benghazi (Riley 1979, fig. 132, $\mathrm{n}^{\circ} 1040$ ).

Variante C

6 Sidi Jdidi, basilique 1, état C2B (Bonifay, Reynaud 2004, n³1.9)

*7 Idem (Ben Abed, Bonifay, Fixot 1997, fig. 10, n 58 ; Bonifay, Reynaud 2004, n 31.10). Décor ondé.

8 Sidi Jdidi, basilique 2, état III (Inv. JD2037.1).

*9 Sidi Jdidi, basilique 1, état C2B (Bonifay, Reynaud 2004, n 34.8). Départ d'anse.

*10 Musée de Lamta (en exposition). Décor ondé.

Autres variantes

11 Rougga, couche 13 (Guéry, Bonifay à paraître, $\mathrm{n}^{\circ} 264$ ).

Ces objets semblent connus dès le Ier s. à Carthage (variante $\mathrm{A}: \mathbf{1}$ et 2) mais ils paraissent surtout abondants aux VIe-VIIe siècles. La variante $B$ est plutôt caractéristique des contextes de la fin du Ve . (3) et du VIe s. (4). La variante C est fréquente au VIIe s. (6-9 $)^{207}$ et sans doute encore à l'époque islamique (Hayes 1978b, 60 et fig. XXV.62-63). D'autres types de jarres sont présents en Byzacène méridionale (11).

\subsubsection{Braseros $[k a n u ̄ n]$}

Alors que dans beaucoup d'autres régions du bassin méditerranéen, le brasero est un objet attesté essentiellement à l'époque préromaine (Riley 1979, 303), il se rencontre en Afrique, de manière abondante, tout au long de l'Empire, puis aux époques vandale et byzantine. De fait, le brasero (arabe dialectal : «kanūn ») constitue encore de nos jours un élément important de la culture matérielle traditionnelle des populations d'Afrique du Nord, notamment pour la préparation du thé, comme en témoigne sa fabrication aussi bien domestique, en céramique modelée, qu'artisanale, dans les grands centres potiers de Nabeul et de Jerba.

\footnotetext{
${ }^{207}$ Quelques fragments, peut-être intrusifs, ont cependant été recueillis à Sidi Jdidi, dans les contextes de la seconde moitié du Ve s. de la basilique 2 .
}

La fonction de ces objets était vraisemblablement plus étendue dans l'Antiquité : au regard du grand nombre de fragments retrouvés, on peut supposer que dans beaucoup de maisons africaines, il n'y avait peut-être pas d'autre endroit pour faire chauffer les aliments que ces fourneaux portatifs en céramique. Cette utilisation ne fait guère de doute, comme en témoigne la découverte, in situ dans la nécropole de Sousse, d'un kanūn supportant une marmite (Carton 1909, 30 ; Carton 1916, 62 ; cf. également la restitution proposée par Pentiricci et al. 1998, fig. 11). Mais une distinction doit être faite entre les kanūn[s] en céramique modelée et ceux en céramique tournée. Les premiers (infra, fig. 170) ont été rencontrés en abondance en Byzacène méridionale, notamment à Uzita (Van der Werff 1982a, 151-153 et fig. 8), et en Tripolitaine (Pentiricci et al. 1998, fig. 10), tandis que les exemplaires tournés paraissent plus abondants dans le nord de la Tunisie. Il sera question ici des braseros en céramique commune tournée, qui peuvent se répartir en deux grands types.

\section{- type 1 : braseros à ergots (fig. 165-166a)}

\section{COMMUNE TYPE 66}

Ces vases, souvent de grande taille (D. : 30-40 cm), ont en commun un bord rentrant épaissi, parfois souligné à l'extérieur d'une gorge ou de cannelures, des parois obliques et rectilignes, un fond plat. Ils sont munis de trois ergots régulièrement espacés qui convergent vers le centre du vase (pour supporter les vases de cuisson) et débordent parfois vers l'extérieur (pour former des tenons de préhension); un trou, généralement de fort diamètre (D. : $2 \mathrm{~cm}$ ) est percé avant cuisson, dans la paroi du vase, sous chacun de ces trois ergots (pour la ventilation des braises). Certains de ces vases portent des traces de combustion à l'intérieur.

Exemples (fig. 165-166a) :

*1 Nabeul, fabrique de salaison, bassin XVII (NB1055.4 ; Bonifay, Reynaud 2004, fig. 147).

*2 Pupput, enclos 64 (Inv. PP3107.1).

*3 Sidi Jdidi, basilique 1, état B2A (Bonifay, Reynaud 2004, n 18.35). Résiduel dans le contexte 18 (?).

*4 Oudhna, capitole (fouilles H. Ben Hassen, Inv. UTH1.1002.019).

*5 Hergla, fouilles anciennes (Inv. HG.000.1). Dessin M. Pasqualini.

*6 Carthage (Fulford 1994, fig. 4.2).

Variantes tardives (?) (fig. 166)

*7 Sidi Jdidi, basilique 1, état B1A (Bonifay, Reynaud 2004, $n^{\circ}$ 12.24).

*8 Sidi Jdidi, basilique 2, destruction état II (Inv. JD 2343.7). Dessin Y. Narasawa.

*9 Pupput, thermes du Centre (fouilles A. Ben Abed, Inv. PPC.243).

Autre variante

*10 Nabeul, maison de la couronne agonistique (fouilles L. Slim ; sans $\mathrm{n}^{\circ}$ ).

La mise en évidence de cette catégorie abondante de braseros en céramique tournée permet peut-être d'expliquer un certain nombre de fragments de Carthage, avec des bords rentrants et des trous sur la paroi (Fulford 


\section{Typologie - Communes}

Braseros à ergots
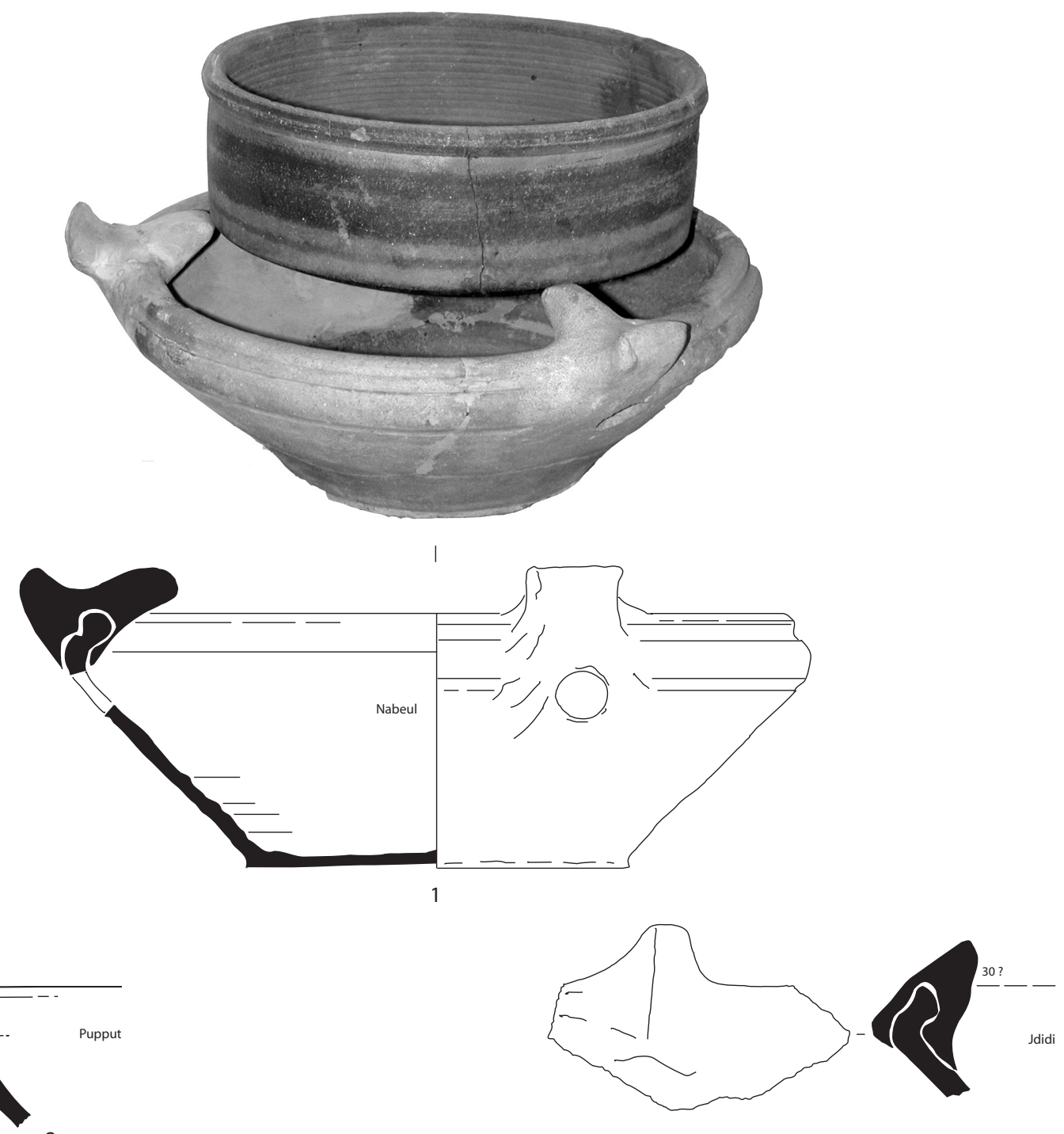

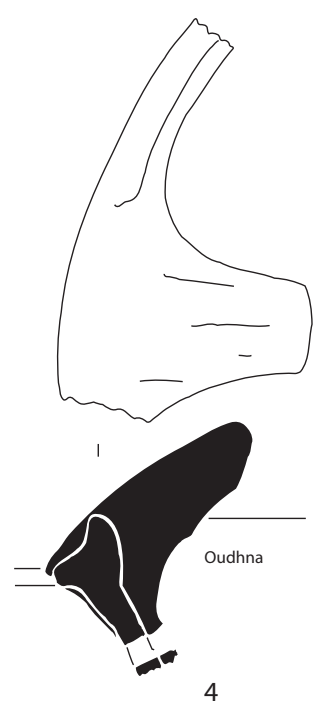

COMMUNE

TYPE 66

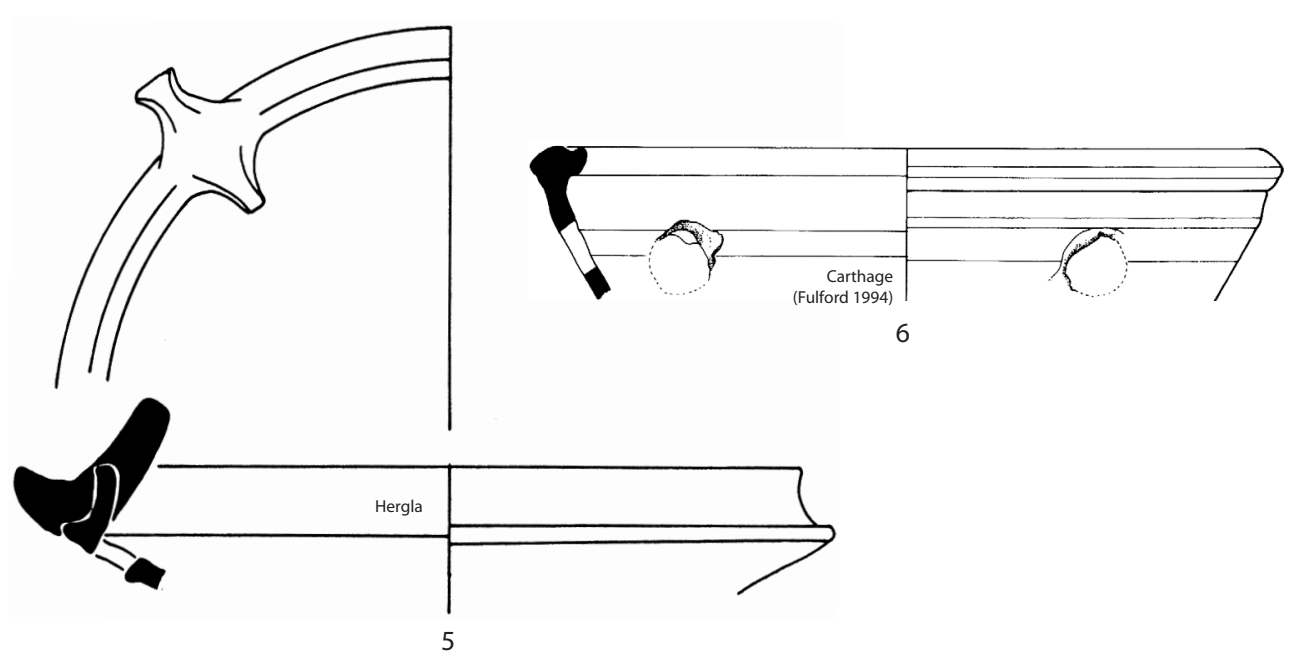

$\stackrel{0}{L}$ $5 \mathrm{~cm}$

Fig. 165. Vaisselle commune africaine. Braseros. 


\section{Typologie - Communes}

Braseros à ergots
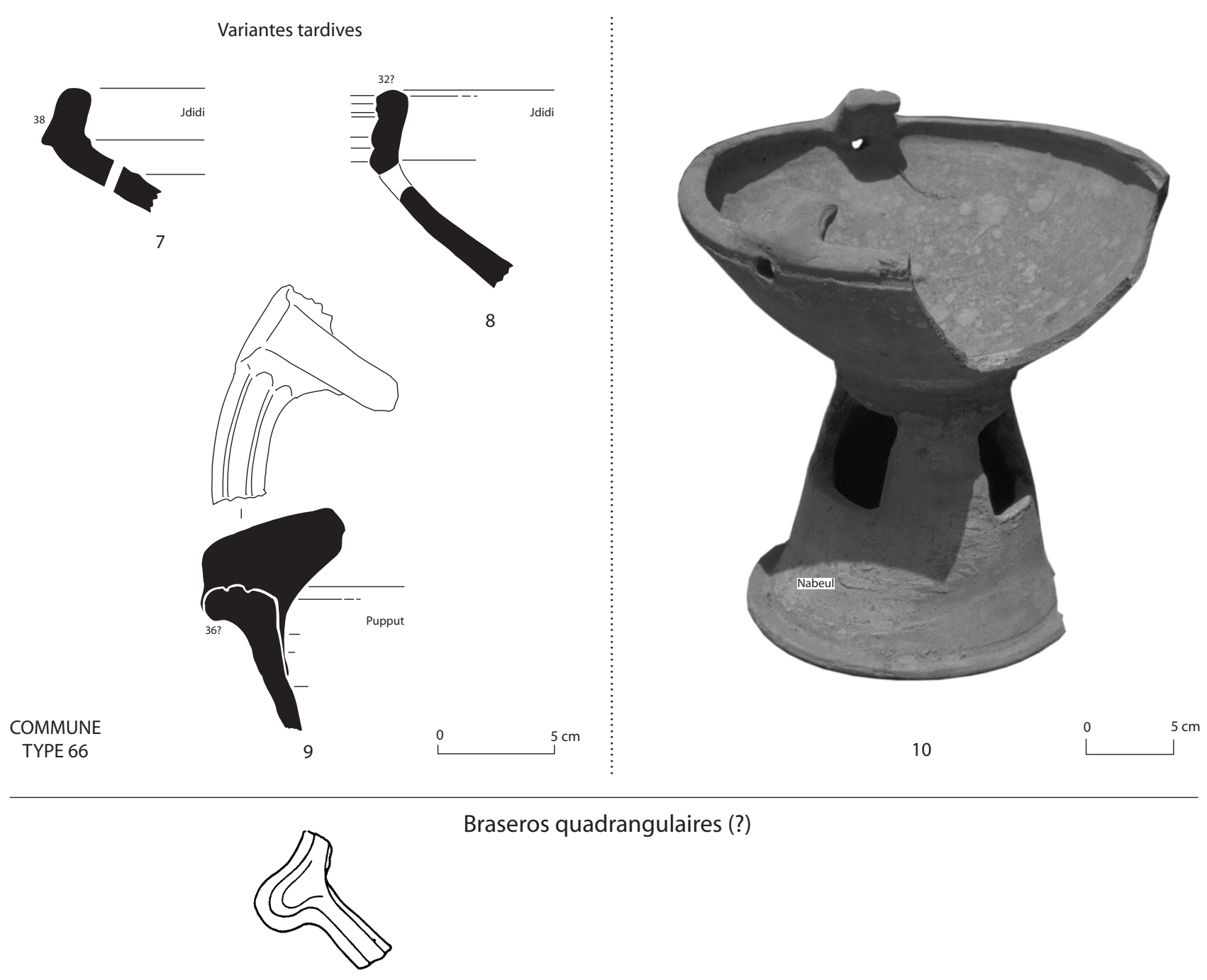

Braseros quadrangulaires (?)
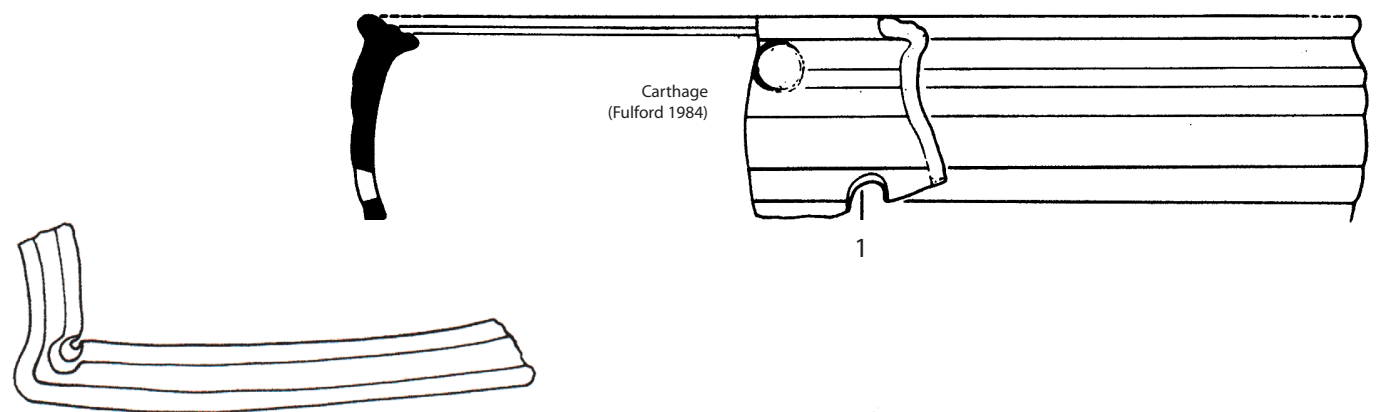

1
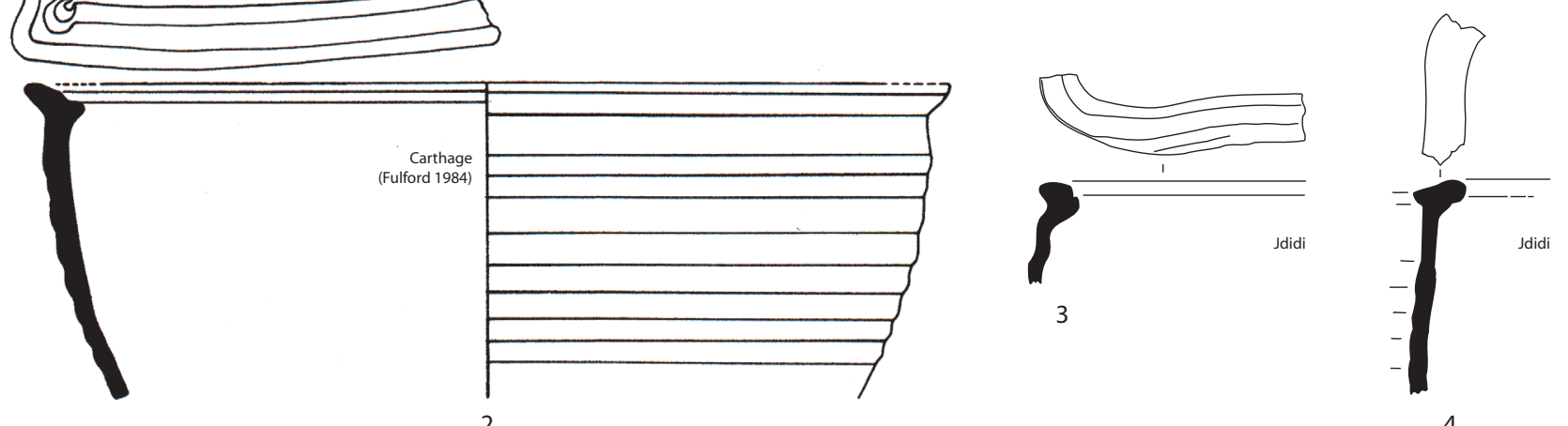

COMMUNE TYPE 67

Fig. 166a. Vaisselle commune africaine. Braseros.

$\stackrel{0}{L}$ $5 \mathrm{~cm}$ 
1984b, fig. 65, Bowls 35-36, fig. 66, Handled Bowls 4 ; Fulford 1994, fig. 4.2, Bowl $22: \mathrm{n}^{\circ}$ 6).

Beaucoup de ces objets proviennent de contextes du IIIe s. (1-2, probablement aussi 3-6). Des variantes plus tardives, peut-être du Ve s. (7-8), ont un bord en bandeau presque vertical, parfois mouluré. Le $\mathrm{n}^{\circ} \mathbf{9}$, avec un bord horizontal à trois nervures pourrait être encore plus tardif. Il est probable qu'il existait une grande variété de braseros à ergots, certains de très haute taille, munis de socles tronconiques $(\mathbf{1 0})$.

\section{- type 2 : braseros quadrangulaires (?) (fig. 166a)}

\section{COMMUNE TYPE 67}

Une forme de céramique commune très particulière a été identifiée à Carthage, dont on ne dispose malheureusement d'aucun profil complet (Fulford 1984b, 179 et fig. 66, Handled Bowls 7-8). Il s'agit d'un bassin tourné (cannelures sur la panse extérieure) transformé en bassin quadrangulaire par pincement du bord en quatre (?) points. Le bord, à section en « $\mathrm{T} »$ marqué de trois nervures, est assez proche de celui des Late Roman Basins 2 (supra, COMMUNE TYPE 30); on suppose que cette forme était également munie d'anses. Mais surtout, plusieurs fragments sont percés avant cuisson de trous d'assez grande taille (D. : $2 \mathrm{~cm}$ ), sous le bord et généralement aux angles.

Braseros quadrangulaires: exemple de comparaison contemporain

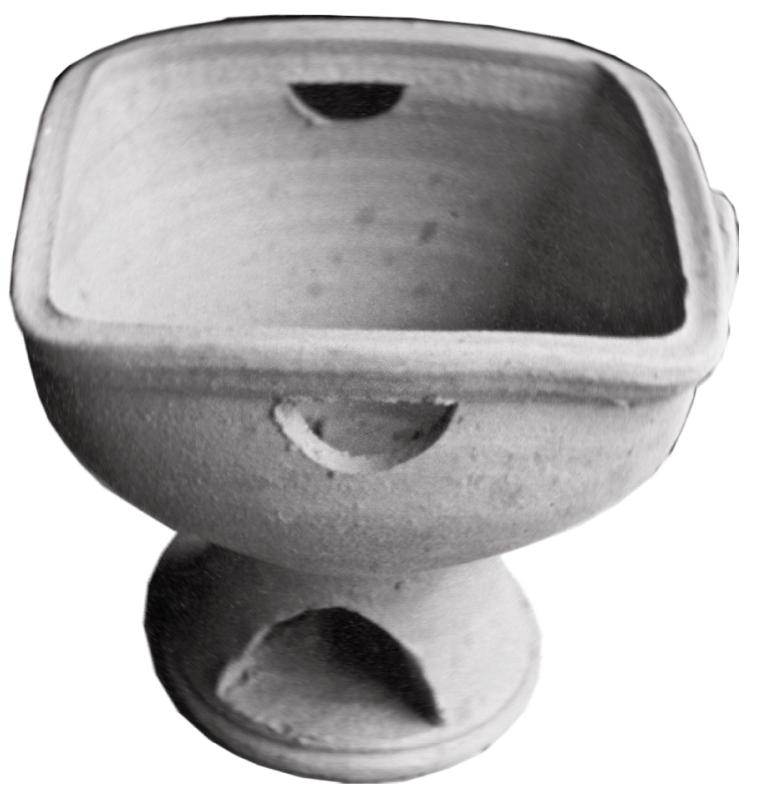

Fig. 166b. "Réchaud à braises".

Ouest de la France, XIXe s. (Pillet 1982)

Je me demande s'il n'y a pas lieu d'identifier cette forme comme un brasero. J. Riley avait eu cette intuition, sans toutefois la justifier, à partir d'un très petit tesson (Riley
1981, 94 et fig. 3, XXVII.45) ${ }^{208}$, mais j'ai pu moi-même observer, provenant de Carthage ${ }^{209}$, un fragment de bord rectiligne qui porte une curieuse trace de combustion arrondie, prouvant qu'un objet circulaire très chaud a été posé sur l'embouchure quadrangulaire du vase. La forme quadrangulaire du brasero de type 2 remplirait ainsi la même fonction que les ergots du brasero de type 1 : supporter une marmite tout en permettant le tirage des braises. Cette hypothèse demande évidemment à être vérifiée, mais des exemples sont connus dans la céramique contemporaine de l'ouest de la France (Pillet 1982, 123) (fig. 166b).

Exemples (fig. 166a) :

*1 Carthage (Fulford 1984b, fig. 66, $\mathrm{n}^{\circ} 7.3$ ).

*2 Idem (Ibid., $\mathrm{n}^{\circ} 7.2$ ).

*3 Sidi Jdidi, basilique 1, état B1A (Bonifay, Reynaud 2004, $n^{\circ} 12.23$ ).

*4 Sidi Jdidi, basilique 2, destruction état II (Inv. JD 2200.46).

5 Idem (Inv. JD2297.13).

6 Oued R'mel (fouilles T. Ghalia, Inv. OR1506.3).

Les stratigraphies de Carthage suggèrent une datation du début du Ve s. au milieu du VIe s. (Fulford 1984b, 179) mais cette forme est peut-être encore attestée à la fin du VIIe s. (?) (Hayes 1978b, fig. 13, XXIV.43). Les données réunies dans le nord du golfe d'Hammamet confirment cette datation : Ve s. pour les $n^{\circ} \mathbf{3 - 5}$, VIe ou VIIe s. pour le $\mathrm{n}^{\circ} \mathbf{6}$.

\subsubsection{Formes mineures}

Un certain nombre de formes d'importance mineure sont fabriquées en céramique commune. J'en donne ci-après une liste non exhaustive.

- baratte (fig. 167)

\section{COMMUNE TYPE 68}

Tonnelet (axe du tournage à l'horizontale) muni d'un col vertical décoré de festons à l'embouchure. Cet objet peut être interprété comme une baratte ou comme un vase pour la préparation du lait caillé (arabe : «leban »). Exemple (fig. 167) :

*1 Nabeul, usine de salaison, période 6 (Inv. NB1428.16) Datation proposée: fin du VIIes. ou début du VIIIe s. (?).

\section{- biberons (fig. 167)}

\section{COMMUNE TYPE 69}

Je ne reviens pas sur les cruches à filtre (supra, COMMUNE TYPE 53) qui ont pu avoir une fonction de biberon. Je voudrais seulement mentionner ici l'existence, en céramique commune comme en sigillée africaine (type Hayes 123), de vases du type guttus, tournés puis déformés pour leur donner la forme d'un

\footnotetext{
208 " this rim could belong to a vertical ? brazier».

${ }^{209}$ Fouille aux abords des absides de Beulé, dirigée par J. Nacef que je remercie de m'avoir invité à examiner son matériel.
} 


\section{Typologie - Communes}

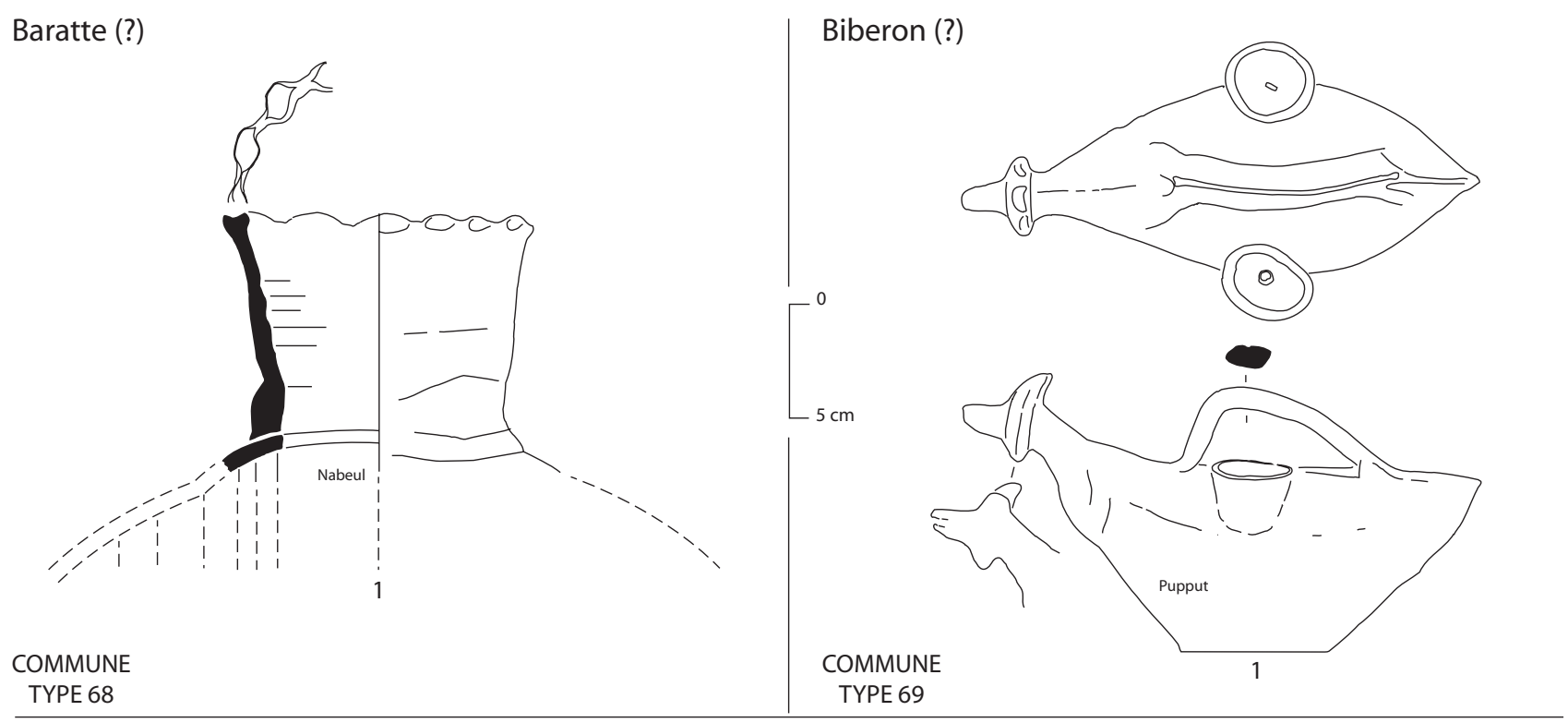

Brûle-parfums
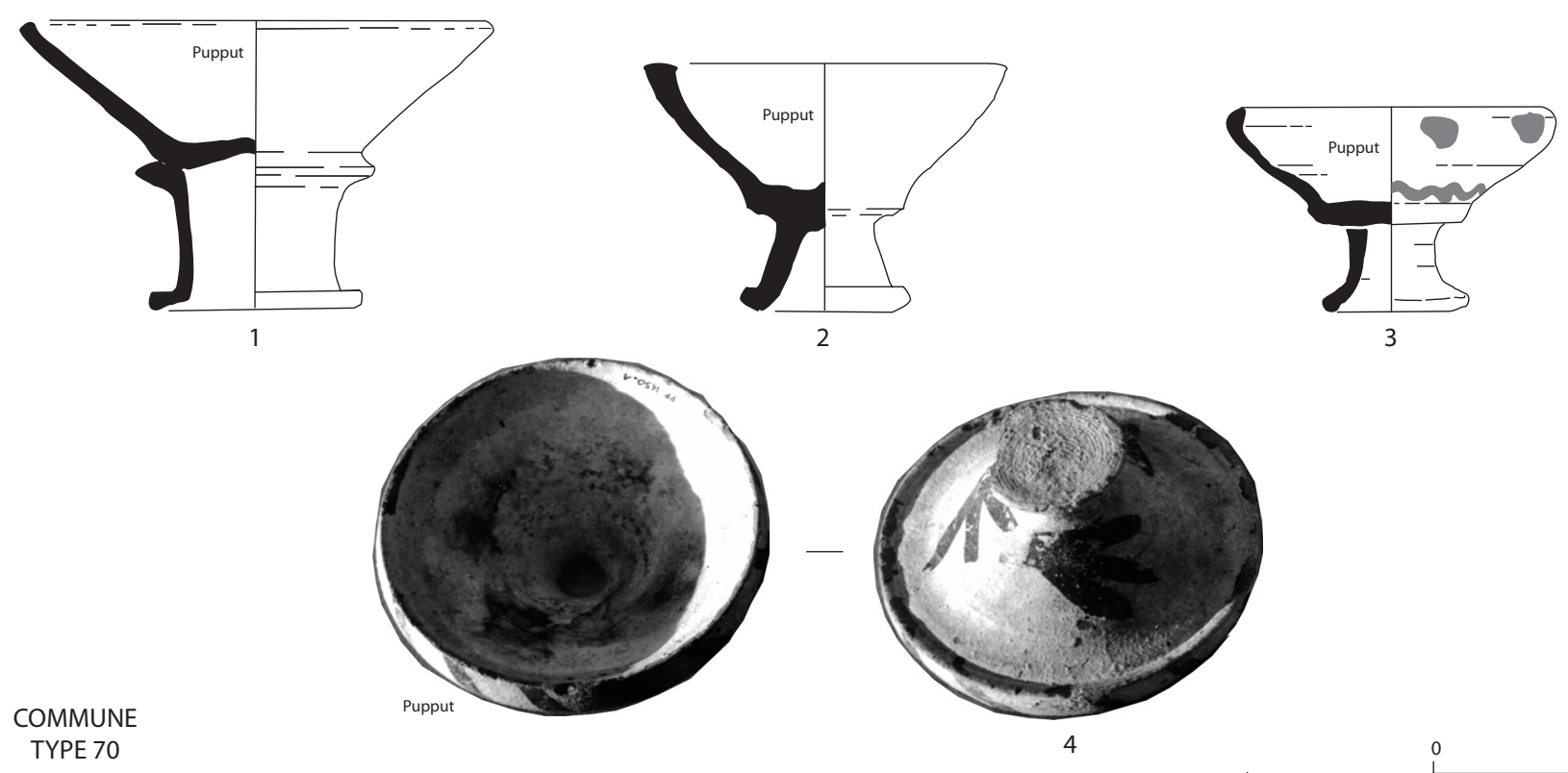

Ecope (?)

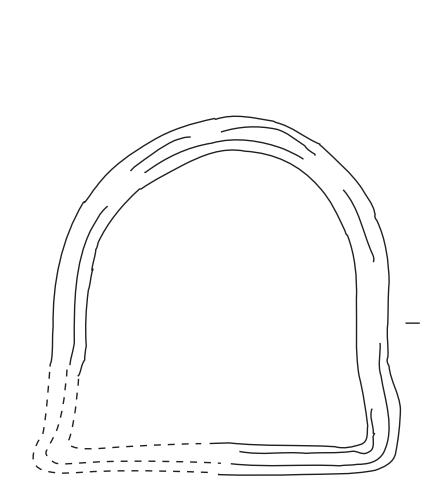

COMMUNE

TYPE 71

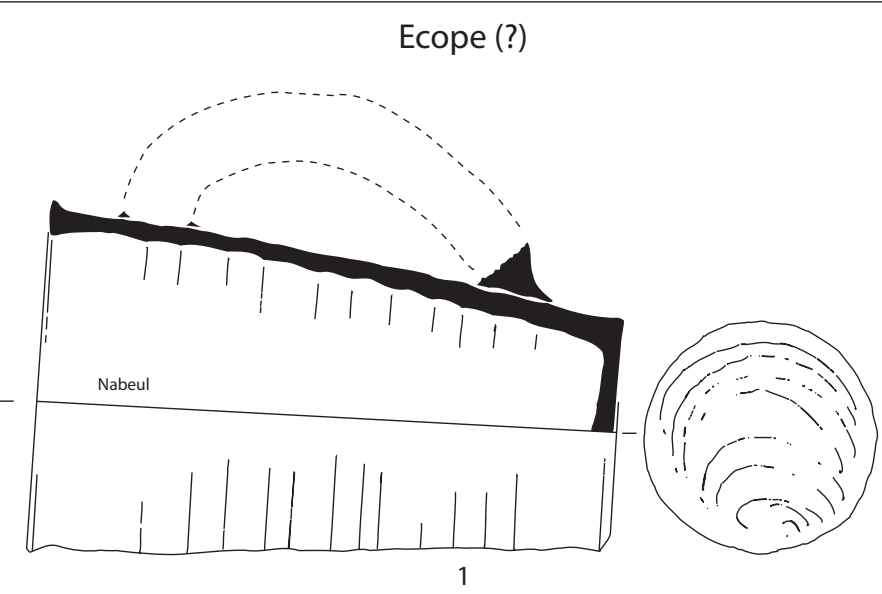

Fig. 167. Vaisselle commune africaine. Formes mineures.

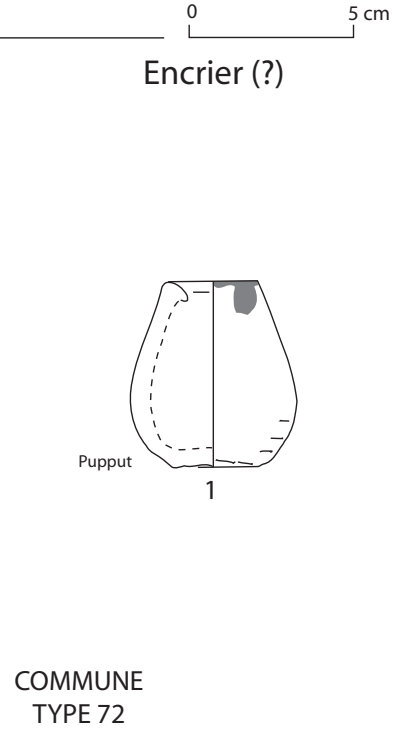




\section{Typologie - Communes}

Tirelires
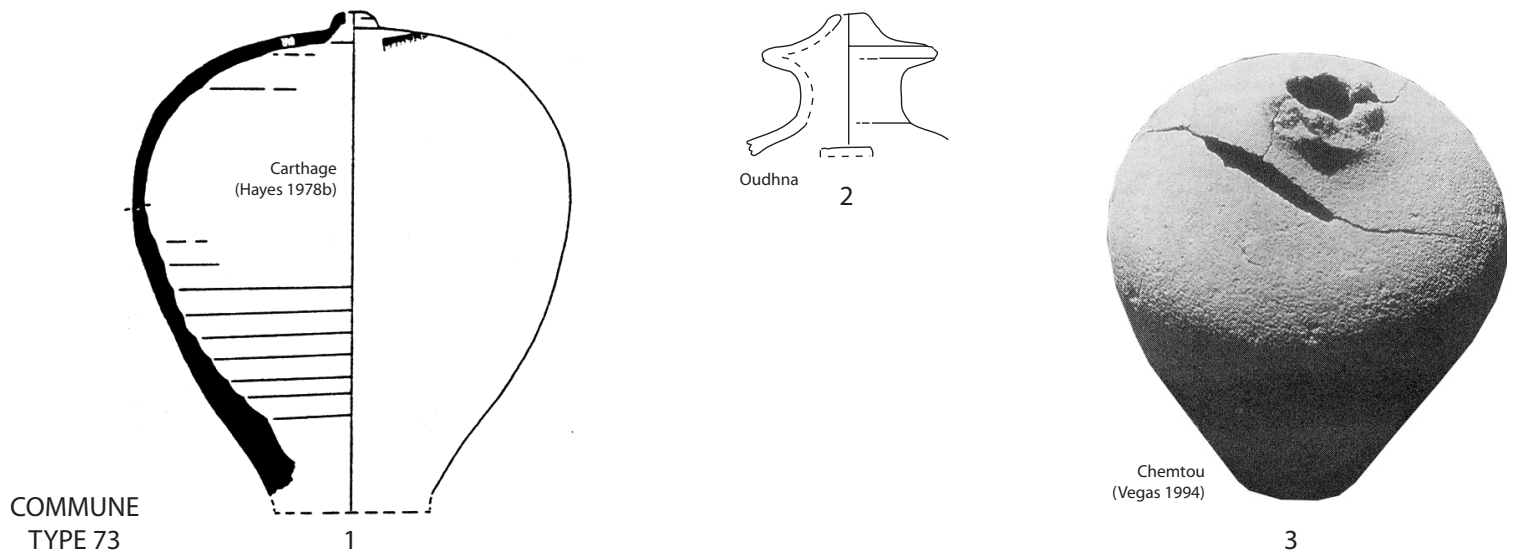

TYPE 73

Vases miniatures
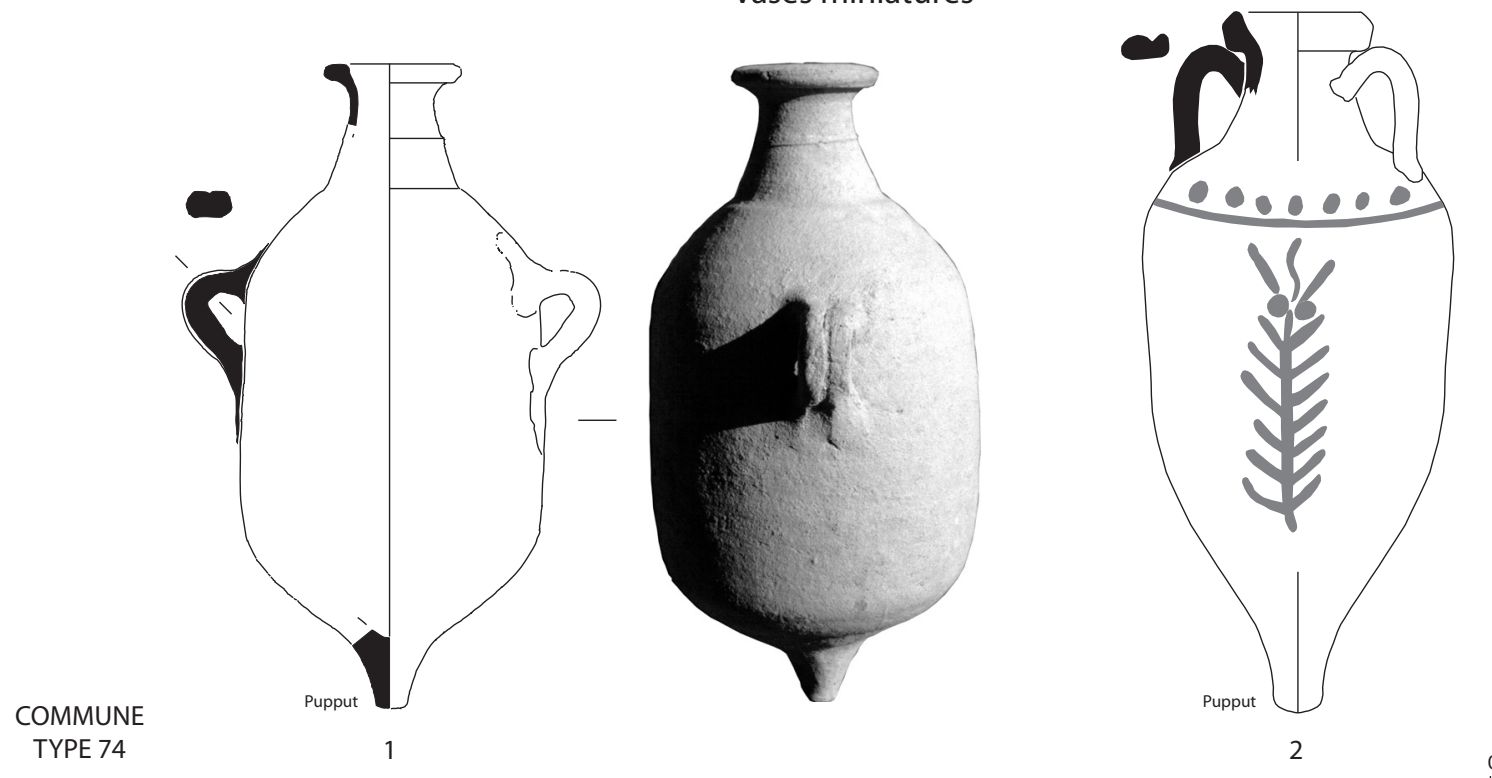

0 $5 \mathrm{~cm}$

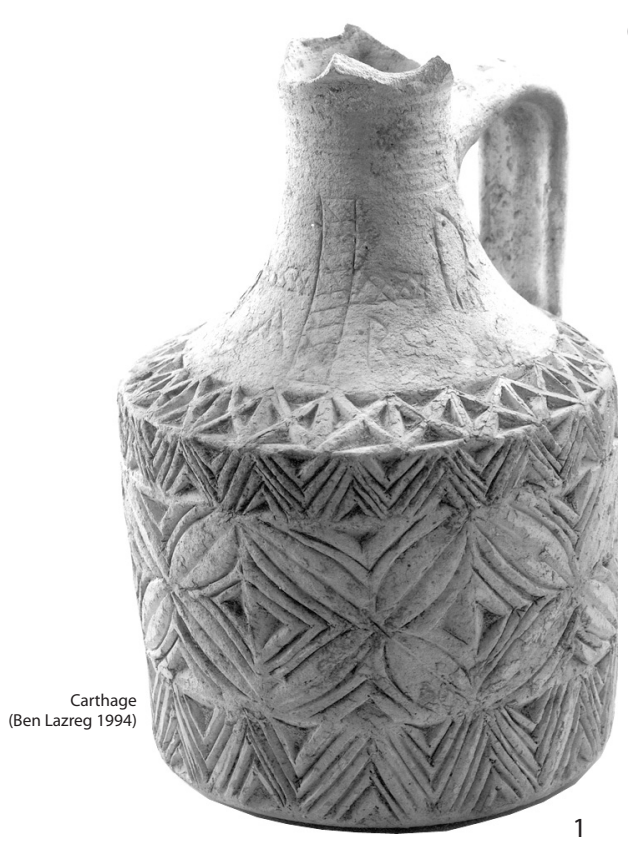

Céramique à décor excisé

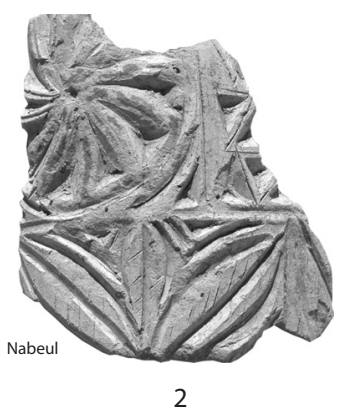

Fig. 168. Vaisselle commune africaine. Formes mineures (suite). Céramique à décor excisé. 
oiseau. Par comparaison avec des objets du même type, d'époque punique, la fonction de biberon ne semble guère faire de doute.

Exemple (fig. 167) :

*1 Pupput, nécropole (Inv. PP1357.1).

Datation poposée : IIe s. (?)

\section{- brûle-parfums (fig. 167)}

\section{COMMUNE TYPE 70}

Ce type d'objet, fréquent dans les nécropoles, est bien représenté à Pupput (26 exemplaires complets). On observe que ces vases sont fabriqués en deux parties : la coupe et le fond tubulaire sont tournés séparément. Certains portent des décors peints en noir ou en rouge. Exemples (fig. 167) :

*1 Pupput, tombe 814 (Bonifay 2004a, fig. 22, n 83).

*2 Idem, tombe 768 (Ibid., $\mathrm{n}^{\circ} 84$ ).

*3 Idem, tombe 350 (Ibid., $\mathrm{n}^{\circ}$ 85). Décor peint en rouge.

*4 Idem, tombe 493 (Inv. 1450.7). Décor peint en rouge.

Le $n^{\circ} 1$ est issu d'une tombe du IIe s., le $n^{\circ} 2$ d'une tombe de la première moitié du IIIe s., et le $n^{\circ} \mathbf{3}$ d'une tombe du IVe siècle (Bonifay 2004a, 52). Une variante sans pied et avec un bord à lèvre tombante (4) provient également d'une tombe du IVe siècle.

• écopes (?) (fig. 167)

\section{COMMUNE TYPE 71}

Cette forme nouvelle a été mise en évidence dans les fouilles de la fabrique de salaison de Nabeul. Il s'agit d'un gobelet cylindrique (H. : $18 \mathrm{~cm}$ env. ; D. : $10 \mathrm{~cm}$ env.) dont une face a été aplatie et l'autre munie d'une anse suffisamment grande pour qu'on puisse la saisir à pleine main. Cet objet semble pouvoir être interprété comme une écope, dont il a pu être fait usage soit sur une embarcation, soit dans le cadre de la production des salsamenta (nettoyage des bassins?). On pourrait également considérer qu'il s'agit d'une mesure à liquide. Exemple (fig. 167) :

*1 Nabeul, fabrique de salaison, état 4 (NB1784.43). Dessin C. Brun.

Datation proposée : IIIe s. (?).

\section{- encriers (fig. 167)}

\section{COMMUNE TYPE 72}

Cette forme est beaucoup plus simple que celle connue en sigillée africaine (Hayes 124).

Exemple (fig. 167) :

*1 Pupput, tombe 612 (Inv. 3271.1). Traces de pigment rouge sur le bord. D. : $5 \mathrm{~cm}$; H. : $5,7 \mathrm{~cm}$. Dessin T. Mukai.

Datation proposée : Ile s. (?).

- tirelires (fig. 168)

\section{COMMUNE TYPE 73}

Vases piriformes, galbés dans leur partie haute et complètement fermés, mis à part un minuscule trou dans l'axe du tournage et une fente horizontale au sommet de la paroi. Certains de ces objets se terminent par une préhension en forme de bobine $\left(\mathrm{n}^{\circ} \mathbf{2}\right.$; Hayes 1976a, fig. 1, III.5 ?). Les rares exemples connus proviennent de niveaux tardifs (sauf 3 ?).

Exemples (fig. 168) :

*1 Carthage (Hayes 1978b, fig. 25, D72). Datation incertaine.

*2 Oudhna, thermes des Laberii $\left(\operatorname{sans~}^{\circ}\right.$ ).

*3 Chemtou (Vegas 1994a, Pl. 123, d). Sans échelle.

\section{- vases d'horticulture (?)}

Ces vases ont été mis en évidence un peu partout dans le monde romain mais pas encore, à ma connaissance, en Afrique. Ceux qui avaient pu être interprétés comme tels à Carthage (Barat, Morize 1999, fig. 28-29) sont plus probablement des braseros (supra, COMMUNE TYPE 66).

\section{- vases miniatures (fig. 168)}

\section{COMMUNE TYPE 74}

Je mentionne pour mémoire l'existence de céramiques qui reproduisent en miniature des formes réelles, soit comme jouet (?), soit pour un usage votif. Ce dernier aspect est bien illustré sur la nécropole de Pupput par deux modèles réduits d'amphores.

Exemples (fig. 168) :

*1 Pupput, mausolée 1 (Bonifay 2004a, fig. 15, n 49). Modèle réduit d'amphore Hammamet 2 (AMPHORE TYPE 9).

*2 Pupput, tombe 419 (Inv. PP2356.1). Décor peint. Datation proposée : IIIe siècle.

\subsubsection{Céramique à décor excisé (fig. 168)}

Cette catégorie de céramique se caractérise par un décor géométrique excisé. Plusieurs formes ont été recensées (Pinard 1952) dont la plus commune est une cruche mono-ansée, avec un corps cylindrique sur lequel se développe le décor (1).

Exemples (fig. 168) :

*1 Carthage, basilique de Bir Ftouha (Ben Lazreg 1994, $\left.n^{\circ} 47\right)$.

*2 Nabeul, fouilles anciennes (sans $n^{\circ}$ ).

Datation proposée : VIIe s.

\subsubsection{Céramique à décor peint (fig.169)}

Cette catégorie de céramique a été identifiée à Carthage (Hayes 1976a, 89; Fulford 1984b, 225-228). Elle présente une pâte marron relativement fine (supra, p. 75 ; $\mathrm{Pl}$. III, $\mathrm{n}^{\circ} 12$ ). Des motifs essentiellement géométriques ou végétaux, plus rarement animaliers, sont peints en brun-rouge ou en noir sur la surface beige. L'origine africaine de cette céramique est vraisemblable (Peacock 1984a, 16); elle paraît plus abondante dans la région de Thuburbo Majus, où elle pourrait être produite, au moins en partie (Hayes 1976a, 89), qu'à Carthage même. 


\section{Typologie - Communes}

Céramique à décor peint
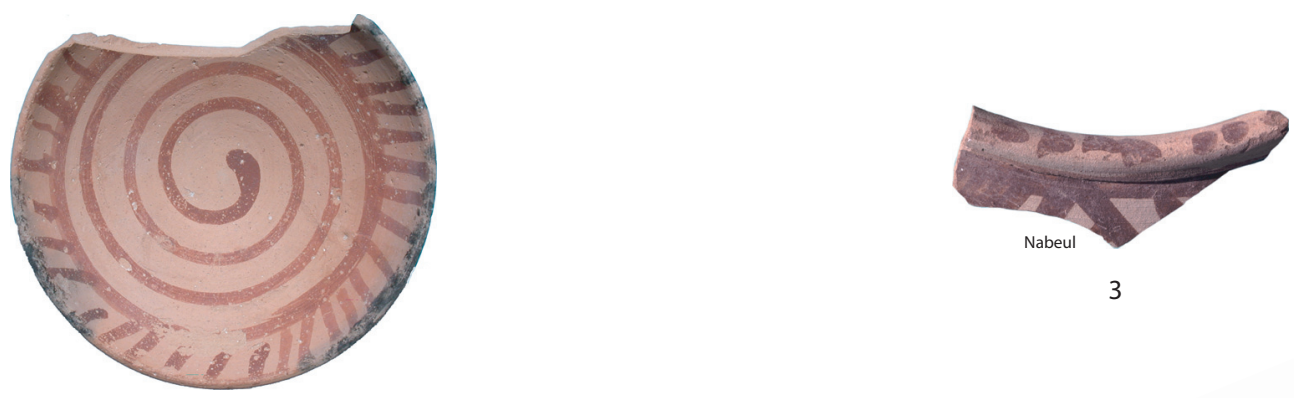

3
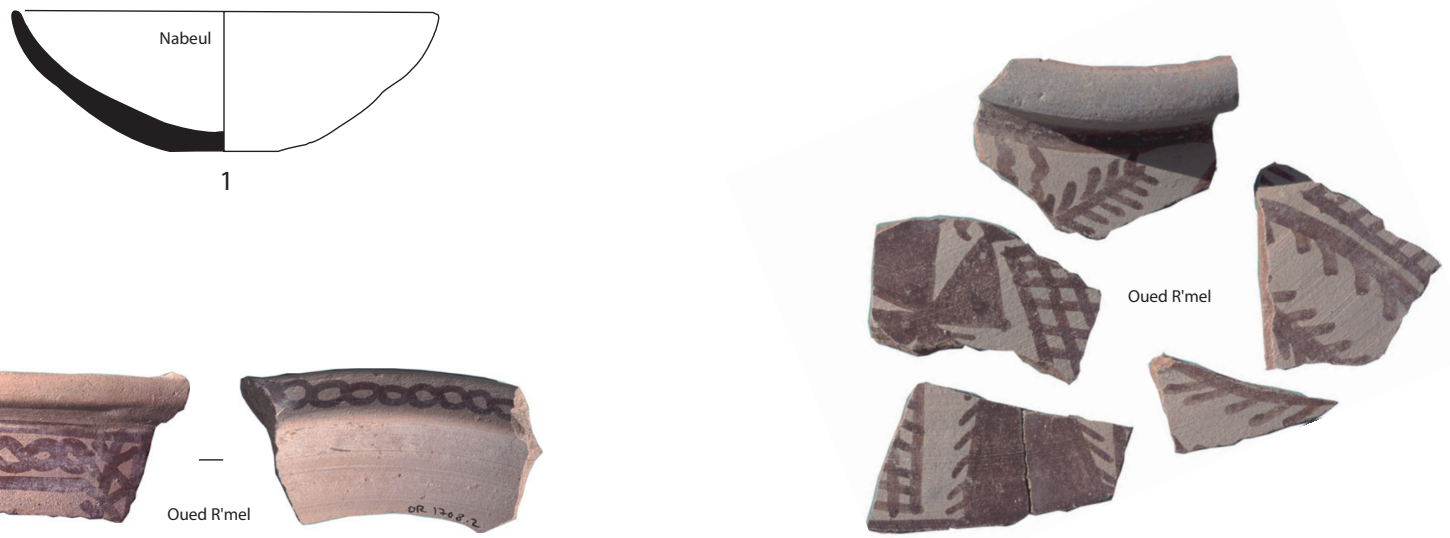

4

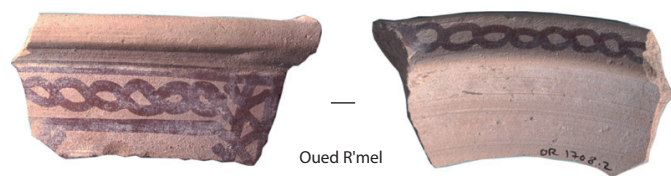

2

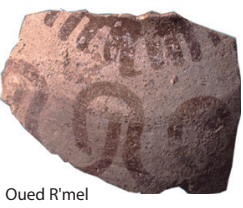

9

6

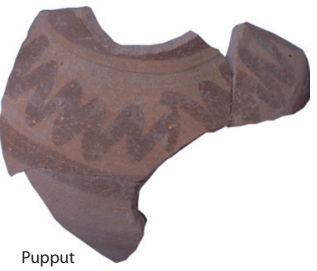

10

Fig. 169. Vaisselle commune africaine. Céramique à décor peint. 
Le répertoire morphologique, essentiellement constitué de formes fermées (Fulford 1984b, 225), n'est pas connu dans le détail. On distingue, dans l'état actuel de la documentation, les formes suivantes :

- Bols : les fouilles de Nabeul permettent de mettre en évidence une forme de bol hémisphérique, jusqu'à présent rarement signalée à Carthage (cf. cependant Kalinovski 1993, 173-174, $\mathrm{n}^{\circ} 33$ ), avec un décor interne de festons et de spirale (1).

- Jattes (= Fulford 1984b, forme 1) : vases de grande taille (D. $45 \mathrm{~cm}$ ) dotés d'anses en panier directement attachées sur le bord à marli, et portant une décoration interne et externe (2).

- Pots : un pot à bord déversé et anses en panier, mais dont on ne possède aucune forme complète, a été identifié à Nabeul et Oued R'mel; décoration externe (3-4).

- Cruches : le vase exposé au Musée de Carthage (5) est l'un des rares exemplaire complets connus à ce jour mais les tessons publiés par M. G. Fulford (Fulford 1984b, « formes » 3 à 14) laissent apparaître une assez large variété typologique, avec, notamment de nombreuses variantes de petites taille (« flagons »).

Exemples (fig. 169) :

Bol :

*1 Nabeul, fouilles anciennes (Inv. NB0084.1).

Jatte :

*2 Oued R'mel (fouilles T. Ghalia, Inv. OR1708.2).

Pot :

*3 Nabeul, fouilles anciennes (sans $n^{\circ}$ d'inv.).

*4 Oued R'mel (fouilles T. Ghalia, Inv. OR1703.1). Cruches :

5 Musée de Carthage (en exposition).

*6 Sidi Jdidi, basilique 2, destruction état II (Inv. JD2296.5).

*7 Oudhna, thermes des Laberii (sans n d'inv.).

8 Littoral tunisien, site 35 (Oued Zerkine, golfe de Gabès) (Bonifay et al. 2002-2003, fig. 11, n 134)

Variantes de petite taille

*9 Oued R'mel (fouilles T. Ghalia, Inv. OR44065).

*10 Pupput, thermes du centre (fouilles A. Ben Abed; sans $\mathrm{n}^{\circ}$ d'inv.).

A Carthage, cette céramique apparaît généralement dans les niveaux de la fin du Ve s. et du VIe s. (Hayes 1976a, 89; Fulford 1984b, 228), datation applicable au tesson de Sidi Jdidi (6). Toutefois, les fragments recueillis à Nabeul $(\mathbf{1}, \mathbf{3})$, Pupput $(\mathbf{1 0})$ et Oued R'mel $(\mathbf{2}, \mathbf{4}, \mathbf{9})$ dans des contextes du VIIe s. me paraissent trop nombreux pour être considérés comme résiduels.

\subsection{CÉRAMIQUe MODELÉE}

L'Afrique importe, durant l'époque romaine et surtout à la fin de l'Antiquité, un certain nombre de céramiques modelées (Hayes 1976a, ERCW 4, LRCW 2 et 3; Peacock 1984a, fabrics 1.1, 1.2, 1.6, 1.7-10) en provenance principalement des îles de Méditerranée centrale. L'île de Pantelleria, que l'on pourrait tout aussi bien considérer comme partie intégrante du territoire africain, fournit notamment une grande quantité de plats à cuire et de marmites (Bonifay 2004a, 54 et fig. 23) dont on peut suivre l'évolution, sur les sites côtiers africains, du IIe au Ves. (Pupput: Ibid.; Nabeul, Hergla: observations personnelles; Leptiminus : Dore 1992, 144 ; Sabratha: Dore 1989, 216-230, fabric a). Mais il sera question ici des productions de céramiques modelées plus proprement africaines, que l'on peut répartir en deux catégories principales.

\subsubsection{Céramique modelée de tradition libyco-punique (groupes A-B) (fig. 170)}

On a souligné à plusieurs reprises l'origine libyque de cette céramique particulièrement bien attestée dans les nécropoles du Sahel aux IIIe-IIe s. av. J.-C. (Morel 1998). Le problème qui se pose à nous est de savoir quelle est la limite chronologique basse applicable à cette production. J. H. Van der Werff (1984) développe une théorie selon laquelle le développement de la production de céramique culinaire tournée au début du Ier s. ap. J.-C. aurait porté un coup fatal aux débouchés de la céramique modelée sahélienne en milieu urbain. Toutefois, on pourrait également penser que cette céramique domestique n'a jamais cessé d'être produite, si l'on considère notamment qu'une partie, au moins, des braseros d'Uzita sont produits dans cette céramique (Van der Werff 1982a, 152).

\section{- Vaisselles de table et marmites}

Les données que j'ai pu recueillir ne se laissent pas facilement interpréter. Certes, les tessons de Rougga sont tous situés dans l'une des couches les plus profondes de la stratigraphie, probablement préromaine, et la céramique modelée A (supra, p. 75) est quasiment absente du mobilier des IIe-IIIe s. de la nécropole de Pupput. Cependant, la bourgade rurale d'Aradi/Sidi Jdidi montre une situation plus nuancée. Cette production y est peu abondante dans les niveaux de l'Antiquité tardive mais on observe que les rares fragments du groupe $\mathrm{A}$, à engobe rouge lustré, peut-être résiduels, ont été recueillis dans les niveaux du Ves. (2-3, 5), tandis que les fragments du groupe B (supra, p. 75) sont plutôt concentrés dans les niveaux de la seconde moitié du VIe s. et du VIIe s. (7-8). Ce faciès pourrait laisser penser que la céramique modelée de tradition libyco-punique continue à être produite, à l'échelle domestique, dans une partie de la société, tout au long de la période romaine, mais on ne peut toutefois pas exclure que l'ensemble de ces tessons soit résiduel. En tout état de cause, il semble que le groupe $\mathrm{A}$, à engobe rouge lustré, qui constituait « une particularité sahélienne» (Morel 1998, 129), ait peu à peu disparu pour ne laisser subsister que le groupe $\mathrm{B}$, plus fruste, à la fin de l'Antiquité, puis à l'époque islamique. 
Céramique modelée du groupe $\mathrm{A}$

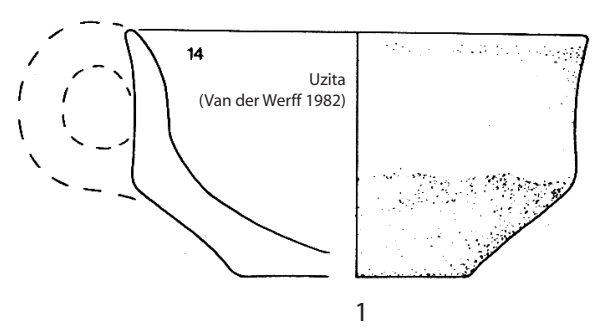

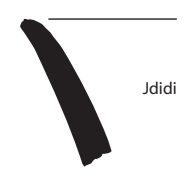

3

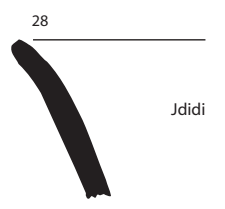

4

0 $\mathrm{cm}$

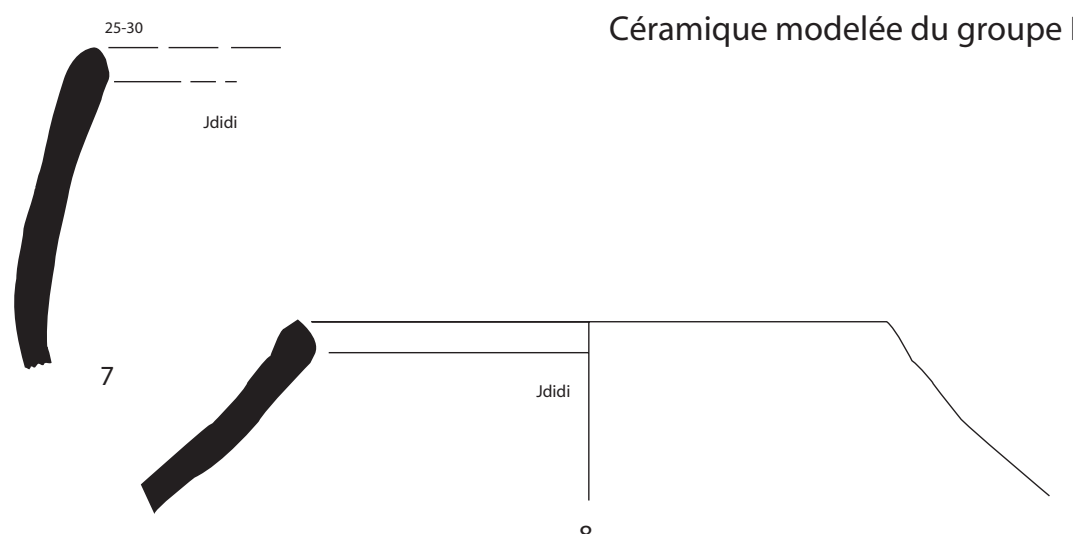

8
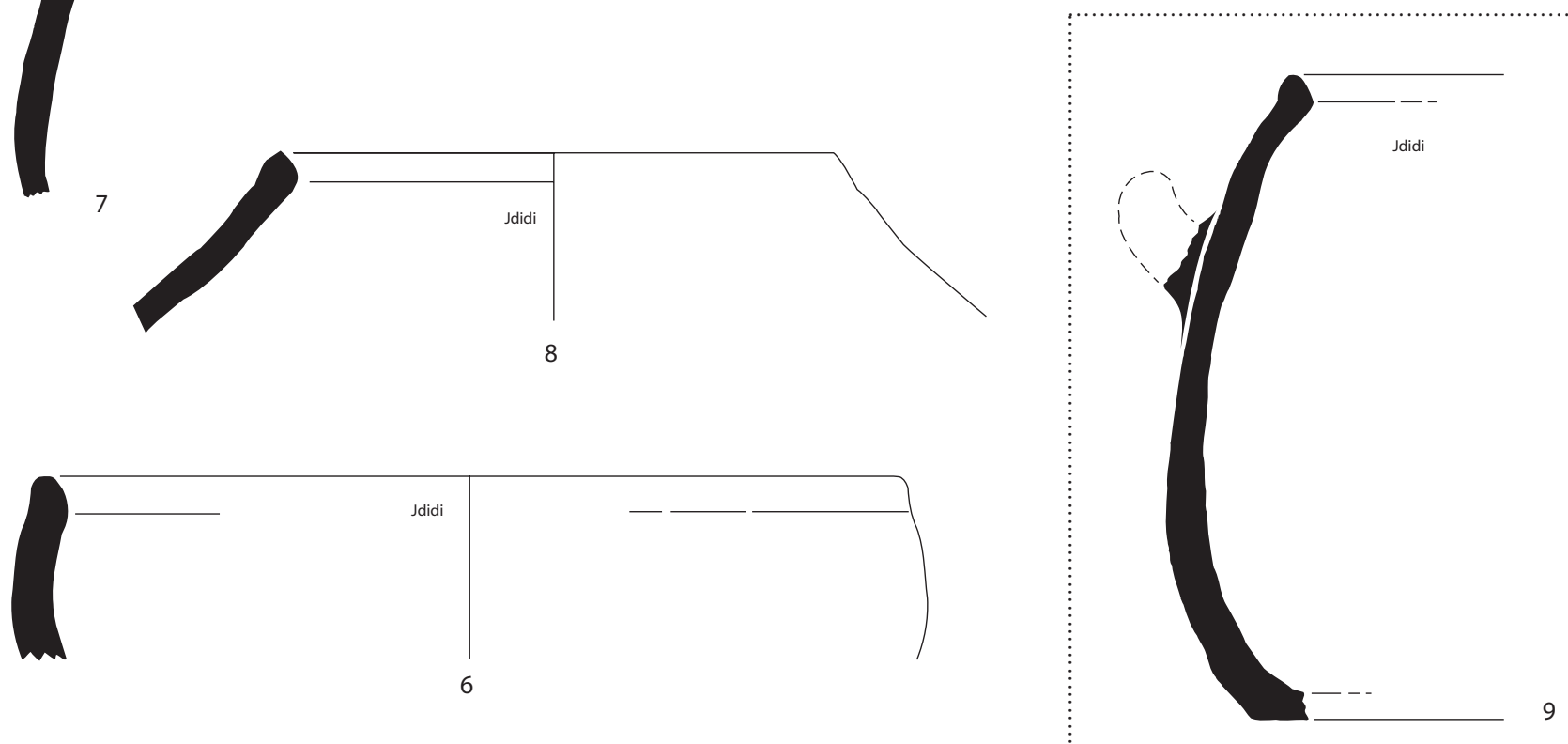

Céramique modelée du groupe $B$ braseros
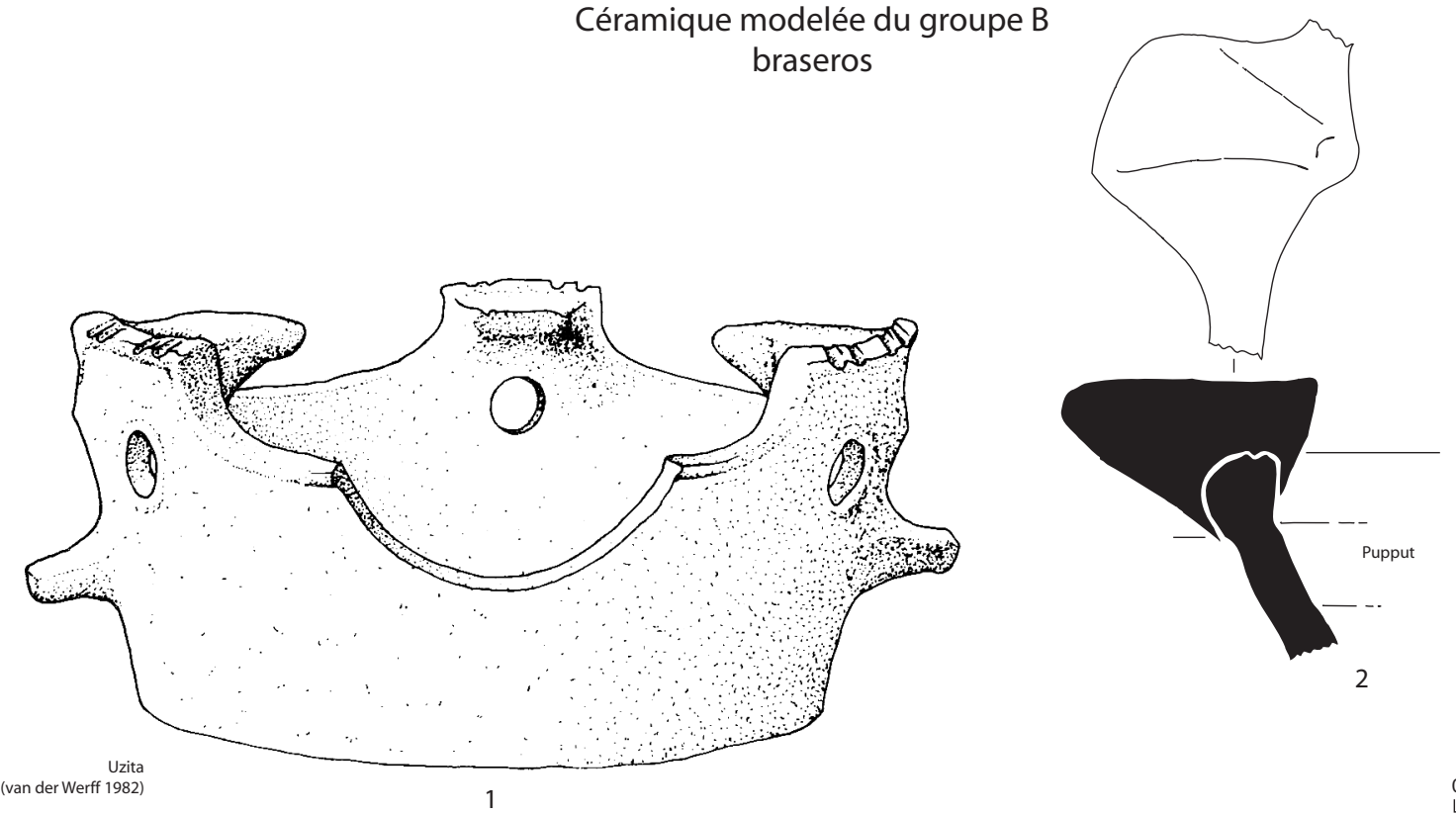

Fig. 170. Vaisselle commune africaine. Céramique modelée (groupes A et B). 
Exemples (fig. 170) :

Groupe A Bols

*1 Uzita (Van der Werff 1984, fig. 1, n 8).

2 Sidi Jdidi, basilique 1, état B1A (Bonifay, Reynaud 2004, $n^{\circ}$ 12.34). Résiduel ?

*3 Idem, état C1 (Ibid., $\mathrm{n}^{\circ}$ 14.7). Résiduel ?

*4 Idem, état C2A (Ibid., $\mathrm{n}^{\circ}$ 28.10). Résiduel? Cruche (?)

5 Idem, état B1A (Bonifay, Reynaud 2004, $\mathrm{n}^{\circ}$ 12.35). Cruche? Résiduel?

Groupe B

*6 Sidi Jdidi, état C1 (Bonifay, Reynaud 2004, $n^{\circ}$ 14.7).

*7 Idem, état C2A (Ibid. $\mathrm{n}^{\circ} 25.6$ ).

*8 Idem, état C2B (Ibid., $\mathrm{n}^{\circ} 28.11$ ).

Variante, époque islamique (?)

*9 Sidi Jdidi, basilique 2 (en surface).

Comme l'avait déjà remarqué J. H. Van der Werff, les formes du groupe A sont plutôt de petits bols biconiques (1-4), bien que les formes fermées ne soient pas complètement absentes (5), et celles du groupe B des vases de plus grande taille, peut-être des marmites (6-8). Le $\mathrm{n}^{\circ} \mathbf{9}$, probablement d'époque islamique, est clairement dans la filiation des vases du groupe B.

\section{- Braseros}

Alors que le nord du golfe d'Hammamet et la ville de Carthage semblent, à partir du IIe s. au moins, utiliser de préférence (mais pas exclusivement: 2) des braseros en céramique commune tournée (supra, COMMUNE TYPE 66), les régions du Sahel et de Tripolitaine restent fidèles aux braseros en céramique modelée du groupe $B$. Je ne dispose pas d'une documentation très abondante sur ce type d'objets, faiblement attesté à Pupput.

Exemples (fig. 170) :

*1 Uzita (Van der Werff 1984, fig. 8, n 1 ).

*2 Pupput (Inv. PP3096.1).

3-4 Lepcis Magna, thermes du Levant (fouilles A. Laronde, Inv. LEP002.18 et 004.21). Contexte du IVe s.

Ces braseros sont datés des IIe-IVe siècles.

\subsubsection{Céramique modelée culinaire à inclusions de calcite (groupe C : « Calcitic ware »)}

On a pris l'habitude de réunir sous l'appellation Late Roman Cooking Ware 5 (Hayes 1976a, 97) deux séries de vases non tournés dont la typologie et la composition géologique sont cependant assez différentes (supra, p. 75). La série originale comprend des marmites globulaires à bord rentrant (Hayes 1976a, fig. 15, C5052 ; Fulford 1984b, fig. 58, Hand-made ware 18) ; elles sont datées de la seconde moitié du VIe s. et du VIIe s. et leur argile correspond au groupe 1.4 de Peacock (Fulford, Peacock 1984a, 11 : «Fossiliferous limestone ware »). Mais on préfère désormais utiliser l'appellation $L R C W 5$ (Neuru 1986, 75 ; Tomber 1988, 482) pour désigner une sous-série plus précoce (elle est présente dès le Ve s.) évoquée par Hayes (1976a, 97 et fig. 4, VII.65), comprenant des marmites à bord vertical et des couvercles dont le dessous est systématiquement couvert de grains de calcite (Cf. Hayes 1978b, 78 et fig. 24 : " Grit-studded lids »); l'argile qui contient également de grosses inclusions anguleuses de calcite appartient au groupe 1.3 de Peacock (Peacock 1984a, 11 : «Calcitic ware »; Fulford 1984b, fig. 57, Hand-made wares 13-17). Il n'est pas certain, comme on l'a proposé (Neuru 1986, 75), que la première série soit une évolution tardive de la seconde. En effet, dans la région d'Hammamet (Ben Abed, Bonifay, Fixot 1997, 18-19 et fig. 5), les céramiques de la seconde série sont particulièrement abondantes du Ve au VIIe s. tandis que celles de la première série sont absentes; l'évolution morphologique au sein de la seconde série consiste dans une augmentation de la hauteur de la paroi (qui demeure cependant verticale) et dans le remplacement des anses en tenon (Ve s.) (infra, TYPE 2A) par des anses horizontales en anneau (VIe et VIIe s.) (infra, TYPE 2B). Il serait donc plus vraisemblable d'attribuer une origine diverse à ces deux productions.

La typologie ci-après emprunte des exemples disséminés sur le territoire de la Tunisie du Nord. Cet exercice peut paraître un peu périlleux, mais les comparaisons entre le matériel de Carthage, de Thuburbo Majus, de Nabeul, de Pupput et même de Dougga (ici seulement d'après la bibliographie) paraissent assez concluantes.

- Couvercles (fig. 171)

= forme Sidi Jdidi 1

\section{MODELÉE C TYPE 1}

Couvercle en cône aplati, généralement (?) muni d'une anse en anneau au sommet. Face inférieure couverte de grains de calcite. Quatre variantes :

A : bord simple, de la même épaisseur que la paroi ou très légèrement épaissi ;

$\mathrm{B}$ : bord épaissi avec une arête vive au sommet ;

$\mathrm{C}$ : bord en amande, modérément à très épaissi ;

$\mathrm{D}$ : bord redressé à la verticale, légère gorge sur la face extérieure.

Exemples (fig. 171) :

Variante A

*1 Sidi Jdidi, basilique 3, phase de construction (Inv. JD5069.25).

*2 Carthage, Cirque (Tomber 1988, fig. 16, $\mathrm{n}^{\circ} 325$ ).

3 Sidi Jdidi, basilique 2, destruction état II (Inv. JD2087.6).

Variante B

*4 Sidi Jdidi, basilique 1, état C1 (Bonifay, Reynaud 2004, $n^{\circ} 13.21$ ).

*5 Idem, basilique 2, destruction état II (Inv. JD2187.20/2200.27).

Variante C

*6 Sidi Jdidi, basilique 1, état C2A (Bonifay, Reynaud $\left.2004, \mathrm{n}^{\circ} 20.2\right)$.

*7-8 Idem (Ibid., $\mathrm{n}^{\circ}$ 24.9-10).

9 Sidi Jdidi, basilique 1, état C2B (Ibid., nº 28.8).

*10 Idem (Ibid., $\left.\mathrm{n}^{\circ} 28.9\right)$. 
Typologie - Modelées

Couvercles Sidi Jdidi 1

A
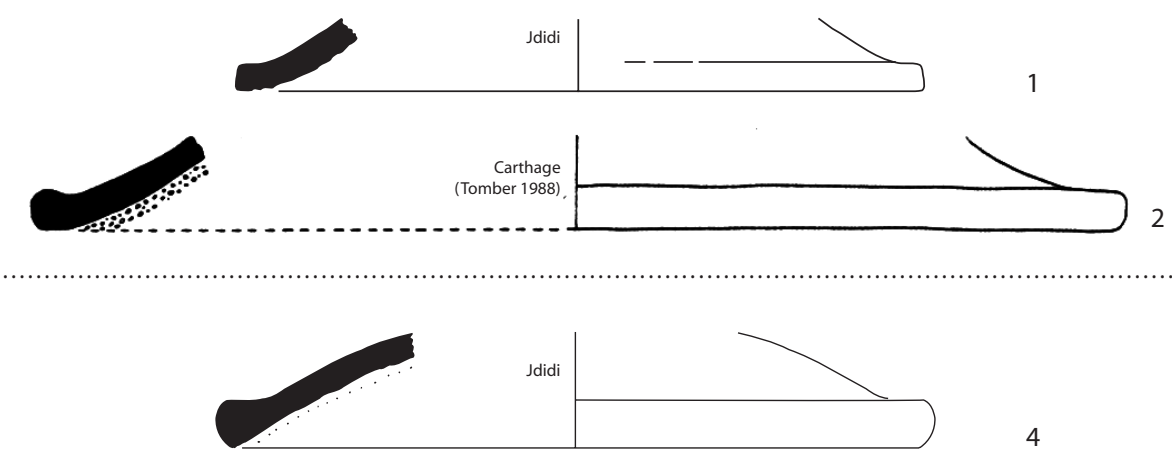

4

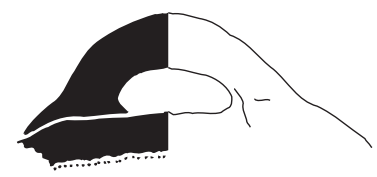

B
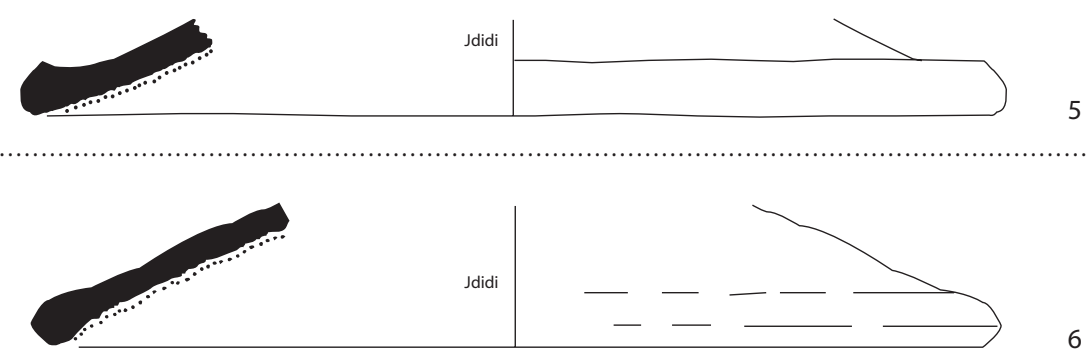

6
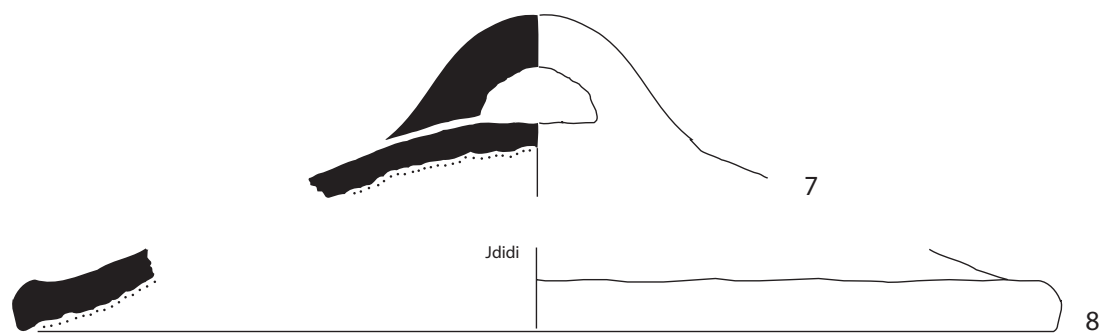

C

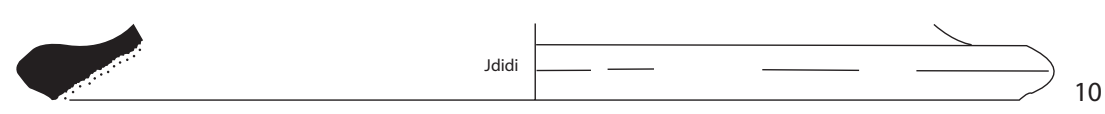

D
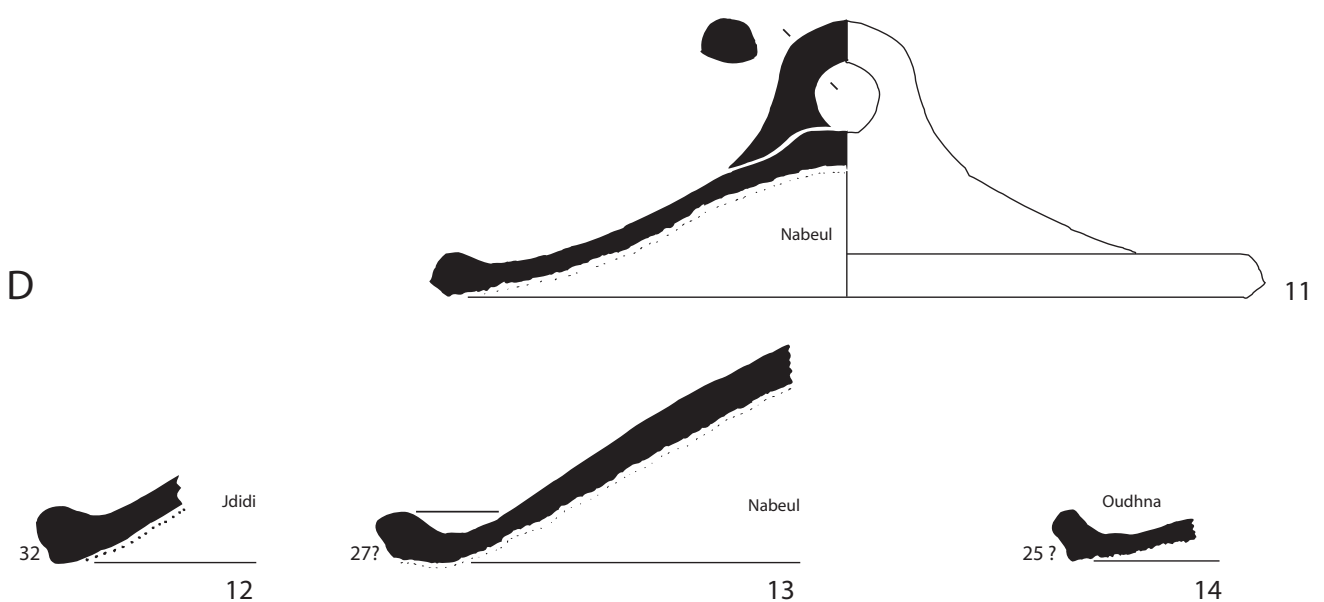

MODELÉE C

TYPE 1

Fig. 171. Vaisselle commune africaine. Céramique modelée du groupe C (Calcitic ware). 
Forme Sidi Jdidi 2 (marmites)

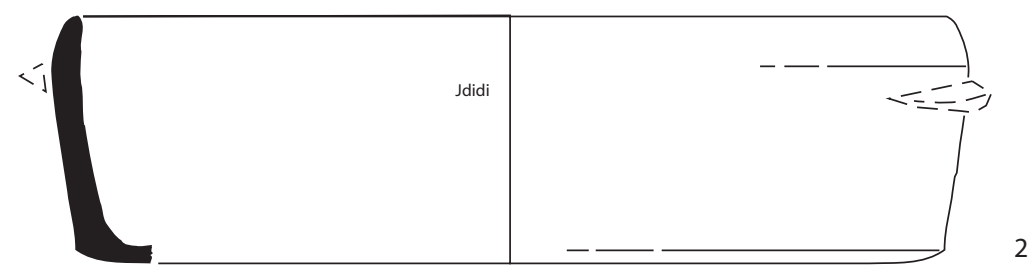

A

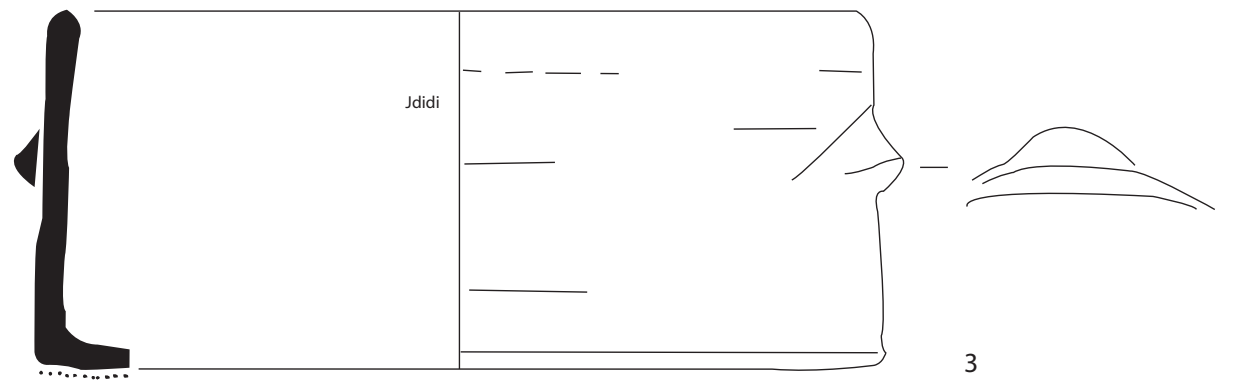

B
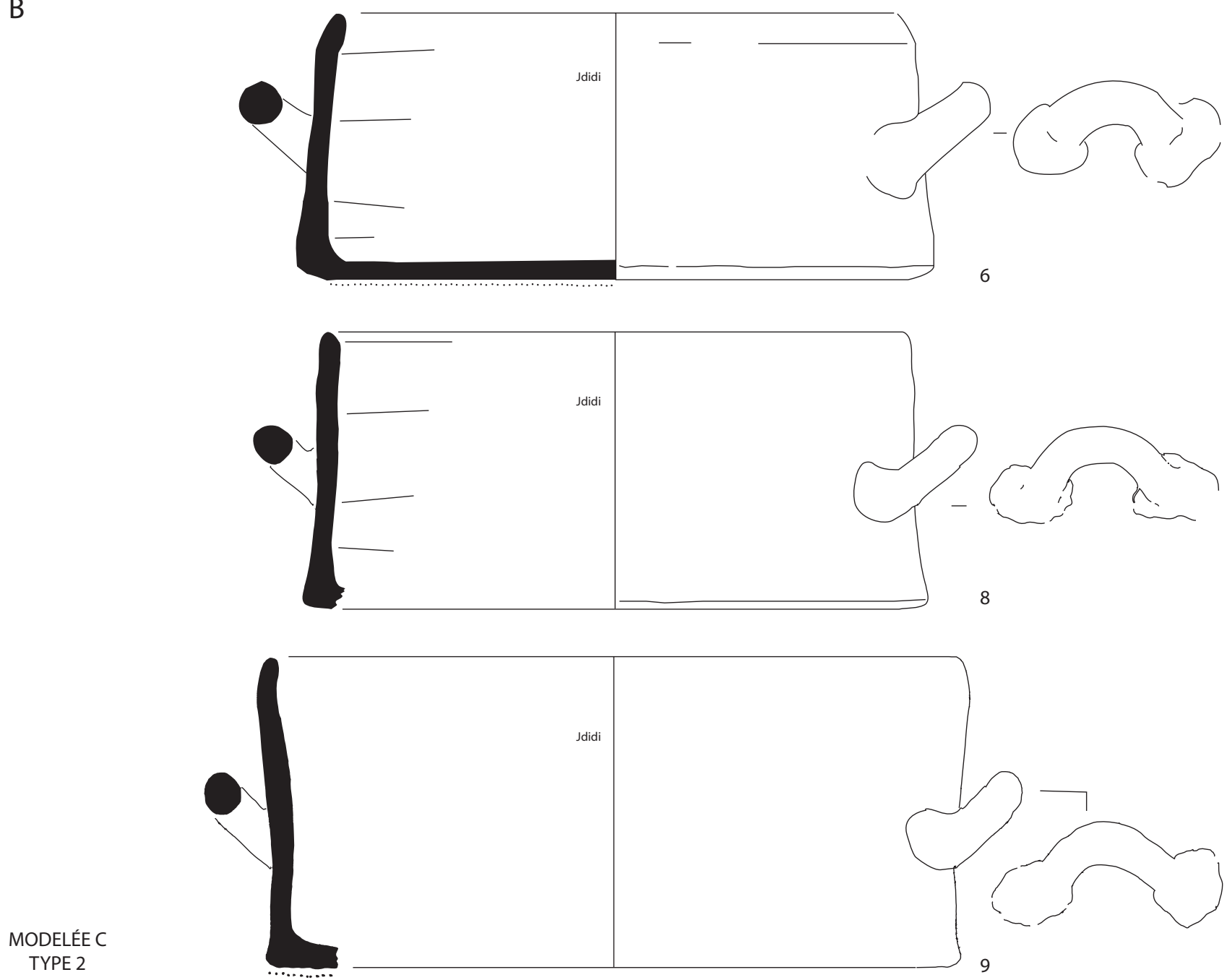

Fig. 172. Vaisselle commune africaine. Céramique modelée du groupe C (Calcitic ware). 
Forme Sidi Jdidi 2 (plats)
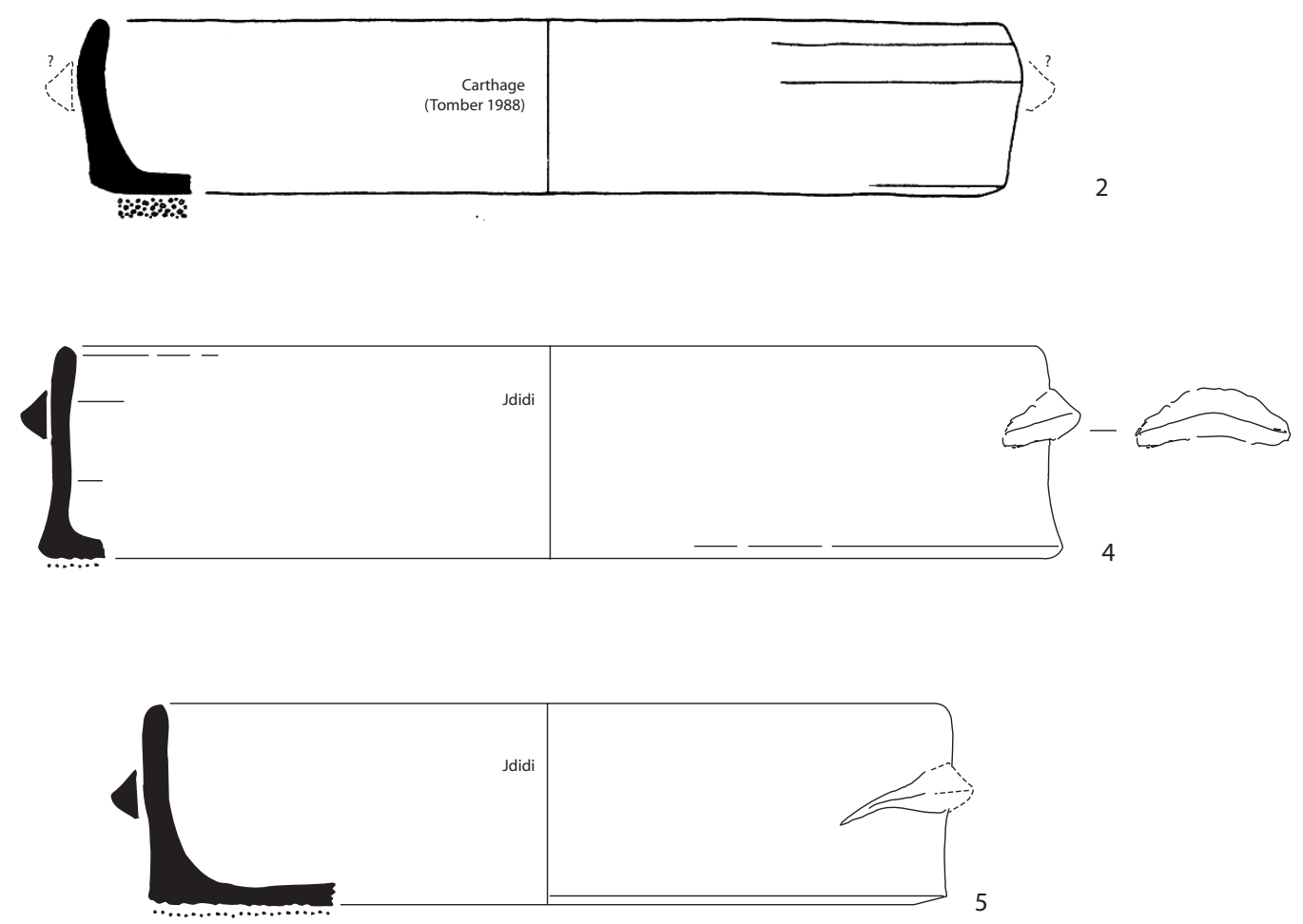

A

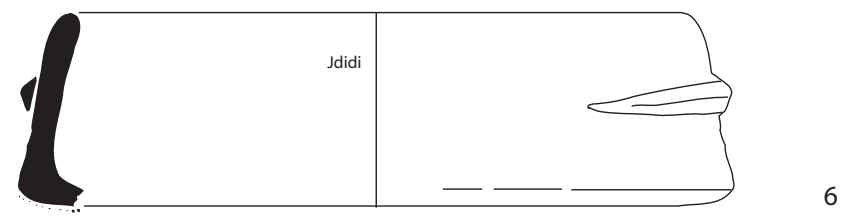

6

B
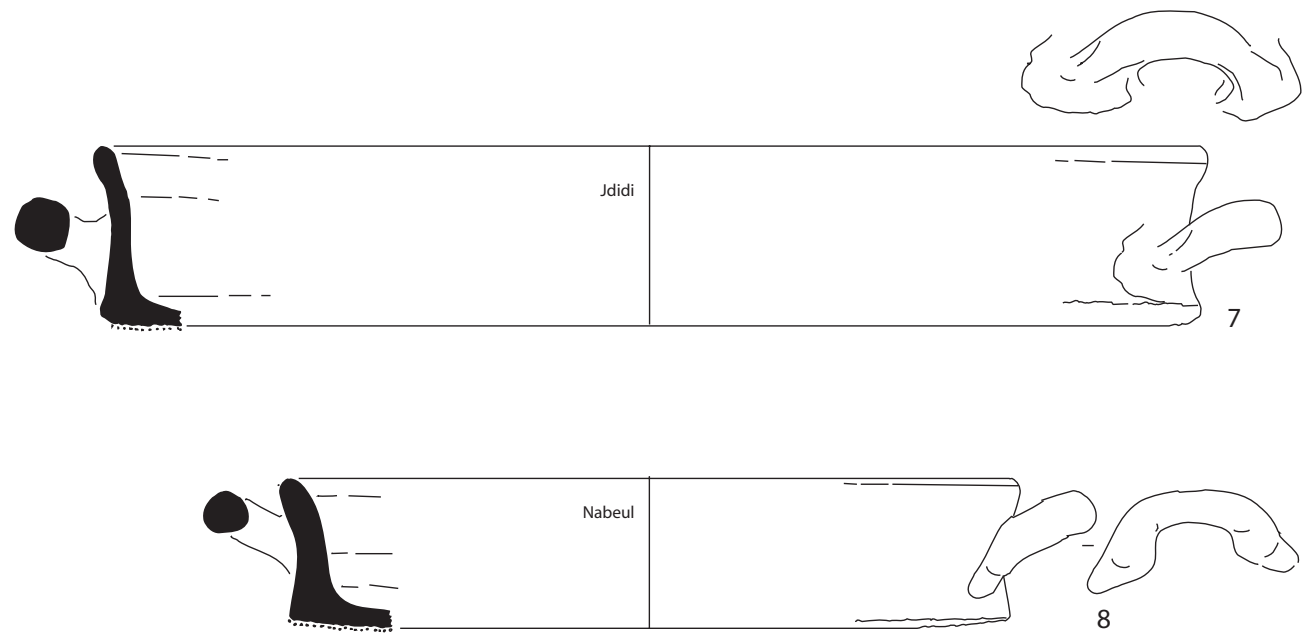

MODELÉE C

TYPE 3

Fig. 173. Vaisselle commune africaine. Céramique modelée du groupe C (Calcitic ware). 
Variante D

*11 Pupput, thermes du Centre (Bonifay 2002, fig. 5, $\left.\mathrm{n}^{\circ} 35\right)$.

*12 Sidi Jdidi, basilique 1, état C2B (Bonifay, Reynaud 2004, n³4.4).

*13 Nabeul, période 6 (Bonifay 2002, fig. 5, n 36).

*14 Oudhna, est capitole (Inv. UTH7.000.48).

*15 Idem (Inv. UTH7.000.49).

16 Dougga, (De Vos 2000, fig. 98, à droite).

La variante A est caractéristique des contextes de la fin du IVes. et du début du Ve s. (1-2); elle peut encore subsister au Ve s., un peu épaissie. La variante avec un bord en virgule (B) est bien attestée dans les niveaux de la seconde moitié du Ve s. (4-5). La variante $C$ constitue la forme classique de la seconde moitié du VIe (6-8) et de la première moitié du VIIe s. (9-10); l'évolution se fait dans le sens d'un épaississement progressif du bord. Enfin, une ultime variante D, avec un bord plus ou moins redressé (11-16), se trouve régulièrement dans les contextes les plus tardifs (byzantins et/ou post-byzantins), jusqu'à la fin du VIIe s. au moins.

- Marmites cylindriques (fig. 172)

= forme Sidi Jdidi 2

\section{MODElÉE C TYPE 2}

Il s'agit de vases cylindriques dont le diamètre (D. : 24$30 \mathrm{~cm}$ ) n'est pas supérieur à deux fois ou deux fois et demi la hauteur des parois (H. : 10-15 cm env.). Le fond est généralement plat et sa face inférieure couverte de grains de calcite. La forme des appendices de préhension, significative, permet de distinguer deux variantes principales :

- Variante 2A: marmites cylindriques, munies d'anses en tenon;

- Variante 2B: marmites cylindriques à anses en anneau horizontales, bord légèrement rentrant ;

- 2B1 : paroi de la même hauteur que sur le type $2 \mathrm{~A}$

- 2B2 : paroi plus haute, l'anse en anneau est dans la moitié inférieure de la panse. Exemples (fig. 172) :

Variante 2A

1 Carthage, Cirque (Tomber 1988, fig. 16, $\mathrm{n}^{\circ} 329$ ). Classé par l'auteur en $L R C W 8$.

*2 Sidi Jdidi, basilique 3, phase de construction (Inv. JD 5049.26).

*3 Sidi Jdidi, basilique 1, état C1 (Bonifay, Reynaud 2004, n 13.18).

4 Carthage, Cirque (Tomber 1988, fig. 30, $\mathrm{n}^{\circ} 530$ ), contexte vandale.

5 Sidi Jdidi, basilique 2, destruction état II (Inv. JD 2276.30).

Variante 2B

*6 Sidi Jdidi, basilique 1, état C2A (Bonifay, Reynaud 2004, $\left.n^{\circ} 24.12\right)$.

7 Idem (Ibid., $\mathrm{n}^{\circ}$ 26.11). Variante à fond bombé (?).

*8 Idem, état C2B (Ibid., $\mathrm{n}^{\circ} 33.2$ ).

*9 Sidi Jdidi, basilique 2, état III (Inv. JD2149.03 : Bonifay, Reynaud 2004, fig. 148).

10 Carthage (Mackensen 1999b, fig. 6, $\mathrm{n}^{\circ} 7$ ).
La variante A est caractéristique de la fin du IVe s. et du Ve siècle. Les exemplaires avec une paroi courbe, un bord rentrant, et les tenons placés dans la partie supérieure de la panse sont les plus anciens (1-2); ceux avec une paroi et un bord verticaux, et des tenons situés à mi-panse doivent plutôt être placés dans la seconde moitié du Ves. (3-5). La variante B se rencontre principalement au VIe $\mathrm{s}$. et dans la première moitié $\mathrm{du}$ VIIe siècle. On ne sait pas réellement quand placer son apparition. Quelques fragments dans les contextes de la fin $\mathrm{du}$ Ve s. sont peut-être intrusifs (Bonifay, Reynaud 2004, $\mathrm{n}^{\circ} 13.20$ ) et on ne dispose pas de données sûres pour la première moitié du VIe siècle. En revanche, cette variante $B$ est particulièrement bien attestée dans la seconde moitié du VIe s. (6), avec parfois quelques particularités morphologiques (fond bombé du $\mathrm{n}^{\circ} 7$ ). Les exemplaires du VIIe s. ont tendance à avoir une paroi plus haute (8) et des anses placées dans la partie inférieure du vase, parfois juste au-dessus du fond (9-10).

\section{- Plats à cuire cylindriques (fig. 173)}

\section{MODELÉE C TYPE 3}

Cette forme est comparable à la précédente mais avec un autre rapport de dimensions. Le diamètre (D. : 24-30 cm env.) représente au moins quatre à cinq fois la hauteur du vase $(\mathrm{H}$. : : 6-7 cm). Deux variantes :

- Variante A: vase parfaitement cylindrique, fond plat, anses en tenon ;

- Variante B : vase de faible hauteur (H. : 4-5 cm), avec une paroi nettement recourbée vers l'extérieur, fond plat ou légèrement convexe, anses en anneau horizontales.

Exemples (fig. 173) :

Variante A

1 Nabeul, fabriques de salaison, comblement du bassin XXXI (Inv. NB1186.52).

*2 Carthage (Tomber 1988, fig. 16, $\left.n^{\circ} 324\right)$, contexte fin IVe-début Ve s.

3 Sidi Jdidi, basilique 2, état I (Inv. JD2289.24).

*4 Sidi Jdidi, basilique 1, état C1 (Bonifay, Reynaud 2004, $\mathrm{n}^{\circ}$ 14.5).

*5 Sidi Jdidi, basilique 1, état C1 (Bonifay, Reynaud 2004, n 13.19).

*6 Sidi Jdidi, basilique 2, destruction état II (Inv. JD2200.29).

Variante B

*7 Sidi Jdidi, basilique II, état II (Inv. JD2195.06).

*8 Nabeul, fabrique de salaison, période 5B (Inv. NB1492.30).

Les premiers exemplaires de la forme $3 \mathrm{~A}$, tout comme ceux de la forme $2 \mathrm{~A}$, ont une paroi légèrement courbée vers l'intérieur (1) ou un bord faiblement rentrant (2); leurs tenons de préhension sont placés dans la partie supérieure de la paroi (3). Ils sont datés de la fin du IVe s. et du début du Ve siècle. Dans la seconde moitié du Ve s. la variante A présente une paroi parfaitement rectiligne, verticale (5) ou un peu oblique vers l'intérieur (6); les tenons sont plus fréquemment situés à mi-panse (5-6). La variante $B$ peut apparaître dès la fin du Ves. (7). Plus 
Forme Sidi Jdidi 3 (marmites)

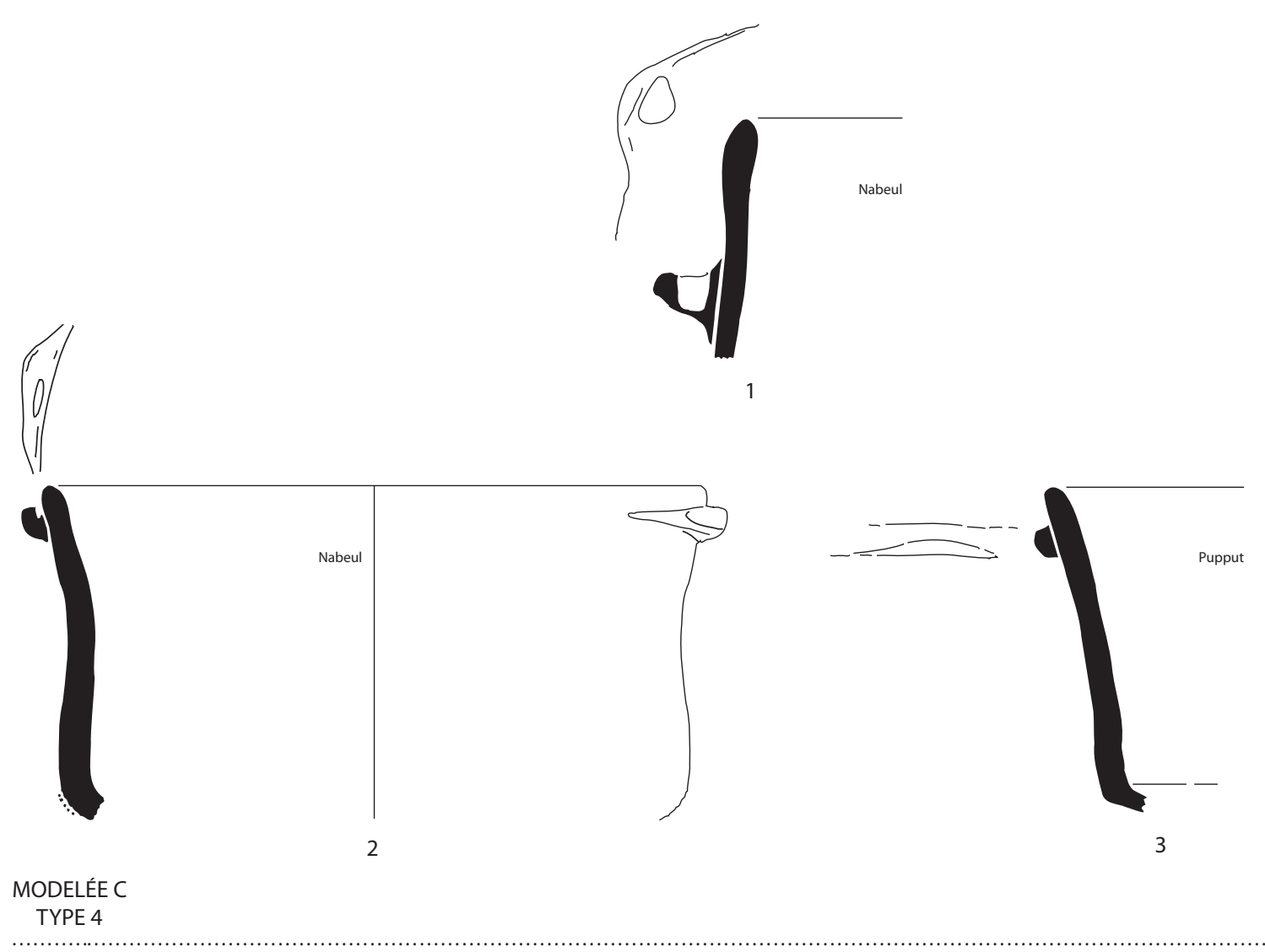

Forme Sidi Jdidi 3 (plats)

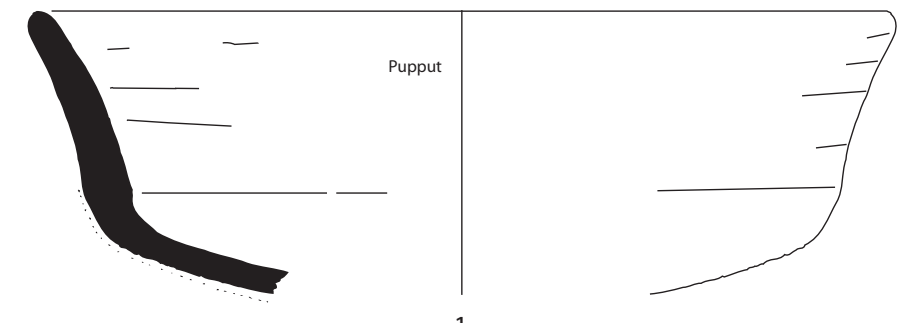

MODELÉE C

TYPE 5

Types de Byzacène méridionale

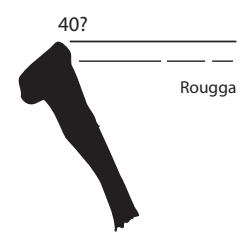

2

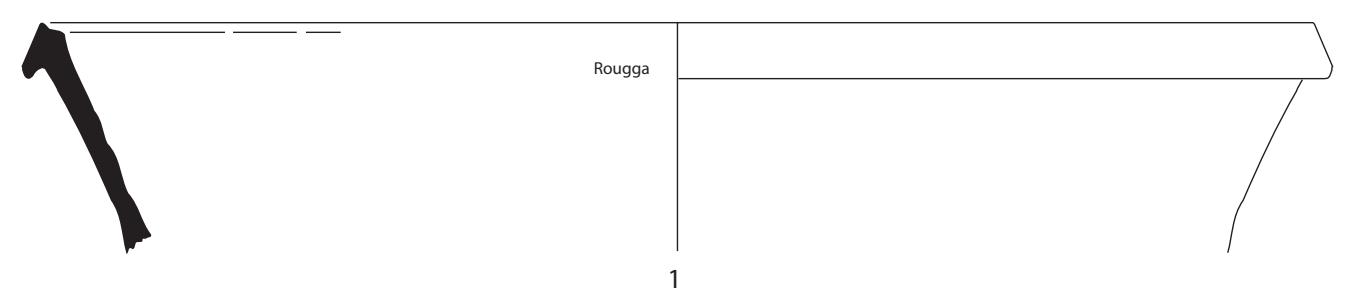

MODELÉE C

TYPE 6

Fig. 174. Vaisselle commune africaine. Céramique modelée du groupe C (Calcitic ware). 
rare que la précédente, elle n'est pas, pour l'instant, attestée au-delà de la première moitié du VIe s. (8).

- Marmites et plats à profil sinueux et fond bombé (fig. 174)

= Fulford 1984 Hand-made Ware 30 = forme Sidi Jdidi 3

\section{MODELÉE C TYPES 4-5}

Je ne sais pas s'il faut considérer cette forme comme une simple évolution des précédentes (1) ou bien s'il s'agit, comme le suggère Peacock (1984, 13, fabric 1.8), d'une tout autre production. La pâte des exemplaires que j'ai eu en main est, certes, un peu différente d'aspect (inclusions de calcite plus clairsemées) mais elle me semble néanmoins se rattacher au groupe de la «Calcitic ware» (voir également les observations de Fulford 1984b, 166).

Deux types :

- TYPE 4: marmites hautes, à profil légèrement sinueux, anse en tenon à demi percé sous le bord ;

- TYPE 5: plats profonds à parois évasées, sans anses (?).

Exemples (fig. 174) :

TYPE 4

*1 Nabeul, fouilles anciennes (Inv. NB0001.7). Variante précoce (?).

*2 Nabeul, fabrique de salaison, période 6 (Bonifay 2002, fig. $\left.5, \mathrm{n}^{\circ} 37\right)$.

*3 Pupput, thermes du Centre (fouilles A. Ben Abed, Ibid., fig. $\left.5, \mathrm{n}^{\circ} 38\right)$.

4 Sidi Jdidi, basilique 1, état C2B (Bonifay, Reynaud 2004, $n^{\circ} 34.5$ ).

5 Carthage (Fulford 1984b, fig. 59, n 30). Fabric 1.8.

6 Carthage (Mackensen 1999b, fig. 6, n 8 ).

TYPE 5

*1 Pupput, thermes du Centre (Bonifay 2002, fig. 5, $\left.\mathrm{n}^{\circ} 39\right)$.

$2 \operatorname{Idem}\left(\operatorname{sans} \mathrm{n}^{\circ}\right)$.

Ces deux types apparaissent dans les niveaux byzantins tardifs ou post-byzantins (seconde moitié du VIIe s. début du VIIIe s. ?) où ils sont associés aux couvercles de forme $1 \mathrm{D}$. L'exemplaire $\mathrm{n}^{\circ} \mathbf{1}$, muni une anse plus large, plus basse et presque complètement ouverte, pourrait être une variante de transition avec la forme $2 \mathrm{~B}$ (?). Les types $2 \mathrm{~B}$ (variante tardive ?) et 4 sont associés à une sigillée Hayes 109B dans un contexte de Carthage que M. Mackensen (1999b, fig. 6, $n^{\circ} 7-8$ ) propose de dater de la première moitié du VIIe $\mathrm{s}$. mais qui pourrait plus vraisemblablement, à mon sens, être situé dans la seconde moitié du siècle.

- Variantes locales de céramique modelée à inclusions de calcite (fig. 174)

\section{MODELÉE C TYPE 6}

Un type local de céramique modelée à inclusions de calcite est présent à Rougga, dans les niveaux postbyzantins de la seconde moitié du VIIe s. et du VIIIe s. (couches 7 et 8 ). Il s'agit de plats à cuire de grande taille (D. : 38-40 cm), avec un bord de section triangulaire, à lèvre pendante, et des parois rectilignes et obliques. Par comparaison avec des exemplaires plus tardifs, peut-être d'époque aghlabide $(?)^{210}$, on peut estimer que le fond portait également des grains de calcite sur sa face inférieure.

Exemples (fig. 174) :

*1 Rougga, couche 8 (Guéry, Bonifay à paraître, $\mathrm{n}^{\circ}$ 309)

*2 Idem, couche 7 (Ibid., n 306)

D'autres variantes locales de ces céramiques culinaires avec adjonction de calcite doivent exister ailleurs, par exemple à Mactar (Bourgeois, Gautier 1975-76, 122 « groupe 1 ») ou à Sidi Aïch, près de Gafsa (observation personnelle).

\footnotetext{
${ }^{210}$ Matériel en cours d'étude par L. Vallauri.
} 


\section{LES LAMPES}

Les typologies de lampes africaines sont foisonnantes (Ponsich 1961; Salomonson 1968; Deneauve 1969; Ennabli 1970-73; Hayes 1972; Joly 1974; Ennabli 1976 ; Pavolini in Atlante I; Bailey 1988 ; Mackensen 1993 ; Barbera, Petriaggi 1993 ; Bussière 2000, etc.), mais aucune ne permet, à elle seule, de rendre compte du détail des formes présentes sur chaque site africain. C'est pourquoi les céramologues ont souvent pris le parti de confectionner des typologies propres à leur chantier, qui n'ont pas vocation générale mais permettent, à l'image de ce qui a été réalisé sur la nécropole de Raqqada (Ennabli 1970-73), de mieux caractériser le faciès du site. C'est ce que j'ai tenté de faire avec le matériel de la nécropole de Pupput en choisissant un classement en numérotation continue, sans suivre de manière stricte la succession chronologique des types, ni me référer à une quelconque articulation morphologique (Bonifay 2004a, 30-37 et fig. 12-14).

Il faut cependant admettre que deux, parmi ces classifications, sans doute en raison de leur simplicité, sont tout particulièrement utilisées : celle de Deneauve (1969) pour les lampes romaines classiques et celle de Pavolini (Atlante I) pour les lampes en sigillée africaine. J'ai donc essayé, pour la présentation qui suit, d'intégrer à ces deux typologies désormais classiques les nouvelles données obtenues sur les quelques sites où j'ai travaillé.

Il y a lieu, tout d'abord, de distinguer entre les lampes moulées et les lampes tournées.

\subsection{LAMPES MOULÉES}

Comme le fait remarquer J. Deneauve $(1969$, 79), la plupart des typologies sont basées sur la forme du bec. En réaction contre cette démarche, le bec est parfois abandonné au profit d'un autre critère principal, tout aussi exclusif des autres. Ainsi, J. Bussière $(2000,105)$ refuse, à juste titre, de dissocier " d'après la forme du bec » des lampes par ailleurs identiques sur le plan du schéma décoratif, mais, en optant pour un pur «classement par décors de bandeau », il en revient à associer des lampes très différentes du point de vue de leur forme générale (Ibid., types D X 1 et 2). C'est, pour ma part, à cette forme générale que je me suis attaché, un peu dans la suite de la démarche de J. H. Salomonson (1968, 83-88). J'ai essayé d'associer plusieurs éléments pour confectionner mes groupements typologiques: la forme $\mathrm{du}$ bec, $\mathrm{du}$ fond et l'anse, les dimensions et le décor. Le fond, en particulier, est un élément important qui est souvent sous-exploité : en effet, la face supérieure de la lampe est toujours photographiée et/ou dessinée mais on connaît plus rarement l'aspect de la face inférieure. De même, toutes les dimensions ne sont généralement pas données : le diamètre ou la longueur-largeur presque systématiquement, la hauteur du réservoir moins souvent, très rarement le diamètre du fond. Enfin, s'agissant d'un des domaines les plus difficiles de la typologie des céramiques africaines, en raison des effets conjugués de la diffusion massive des grands ateliers, de la multiplication des imitations locales et du surmoulage successif des mêmes types sur de longues périodes, il faut rester très prudent dans les identifications. Il est peut-être préférable, à mon sens, d'en rester à quelques types homogènes principaux (fig. 175a et b), peu nombreux, qui permettent de classer une majorité d'exemplaires (mais pas tous), plutôt que de vouloir bâtir une typologie plus générale, plus ouverte, mais souvent aussi trop théorique.

C. Pavolini (Atlante I, 186-188) a distingué plusieurs périodes dans le développement des lampes africaines moulées :

- Période 1: Jusqu'à l'époque augustéenne, l'Afrique produit des lampes puniques en coupelle et importe des lampes grecques et hellénistiques.

- Période 2 : Du début du Ier s. et jusqu'à Domitien, parallèlement à une production locale assez réduite (type Deneauve V E à Carthage), l'Afrique importe en masse des lampes italiques (Deneauve I à VIIA et VIIIA).

- Période 3 : A l'époque flavienne et durant le règne de Trajan, les importations d'ateliers italiques (timbres COPPIRES) commencent à être devancées par les productions de leurs succursales (?) locales (timbres CCLOSVC, GABINIA, LMVNADIEC).

- Période 4 : Du règne d'Hadrien jusqu' à la fin du premier quart du IIIe s., les productions des officines africaines se substituent aux importations italiques :

- A) un premier groupe comprend des lampes à bec rond proches des modèles italiques (timbres AVFIFRON, CIVNALEX, CIVNDRAC, M NOVI IVSTI) ;

- B) un deuxième groupe se distingue par des marques non plus imprimées mais incisées (marques AGRI, LVCCEI, MAVRICI, PVLLAENI) et une typologie renouvelée: nouvelles variantes de lampes à bec rond (Deneauve VII B), lampes à bec cordiforme (Deneauve VIIIB-C), lampes à bec triangulaire (Deneauve X).

- Période 5 : A partir du deuxième quart du IIIe s., on assiste à un double processus :

- A) le remplacement des grands ateliers par une multitude de petites officines locales dont la production est de faible niveau technique (en 
Tunisie centrale: types Raqqada 13-16; à Carthage : types Deneauve XI A-C) ;

- B) le début de la production des lampes en sigillée (Tunisie centrale : types Atlante I-VII).

Ce schéma évolutif reste valable dans ses grandes lignes (Bussière 2000, 141-148).

\subsubsection{Lampes africaines de tradition italique}

Il est possible qu'une partie déjà des lampes à volutes de type Deneauve V A soit de production africaine (Hayes 1980, 63-64 et Pl. 32, $\mathrm{n}^{\circ} 270$ ) mais je n'ai pas d'informations de première main sur ce type de la seconde moitié du Ier siècle. A partir du IIe s., les « imitations » de lampes italiques se font plus nombreuses.

\section{- types précoces}

— lampes à « oreilles » (fig. 176)

$=$ Deneauve $\mathrm{V} \mathrm{G}$

\section{LAMPE TYPE 1}

Lampes d'assez petite taille, au réservoir circulaire (D. $68 \mathrm{~mm}$ ) muni de deux oreilles (ou ailettes) latérales. Disque sans décor, souligné par un sillon et relié au bec par un étroit canal. Bec assez proéminent, à extrémité arrondie, et cantonné de deux trait obliques en relief, peut-être les vestiges de volutes dégénérées. Fond plat (D. : 37-38 mm) dégagé par un sillon.

Exemples (fig. 176) :

*1 Pupput, tombe 447 (Bonifay 2004a, fig. 12, $\mathrm{n}^{\circ} 22$ ). 1./L. $8 / 9,1 \mathrm{~cm}$.

2 Idem (Inv. PP2366.3).

3 Carthage (Deneauve 1969, $\mathrm{n}^{\circ}$ 642). Timbre $L M V$ ADIEC.

Les deux seuls exemplaires de Pupput proviennent d'une tombe de la première moitié du IIe s. (1-2) ${ }^{211}$ un exemplaire très proche de Carthage (3) est timbré $L M V$ $A D I E C$, officine réputée active entre 90 et 140 (Bussière 2000, 225).

Datation proposée : fin du Ier - première moitié du IIe s.

— lampes à « volutes dégénérées 》 (fig. 176)

$=$ Bussière C V 2 = Bailey $\mathrm{K}$

\section{LAMPE TYPE 2}

Lampes de taille moyenne, allongées (1. : 63-65 mm ; L. : 107-108; H. du réservoir : 24-26 mm). Disque ovale, souligné par un sillon, relié au bec par un canal étroit. Bec à extrémité arrondie, cantonné de deux traits obliques. Fond en « larme » pointue, dégagé par un sillon. J. Bussière $(2000,82)$ distingue nettement son type C V 2 du type Deneauve V F (= type Bussière C V 1), très peu diffusé et dont l'origine africaine est douteuse (Ibid., 82).

211 Associées à une lampe Deneauve VII/sous-type 1, des marmites de type Pupput 1, des flacons de type «Astarté » ancien.
Exemples (fig. 176) :

1ère série (selon Bussière 2000), bandeau non décoré

1 Pupput, tombe 755 (Inv. 2375.3). Engobe marron à reflets bruns. Sans décor. Sur le fond : un ove. 1./L. $6,3 / 10,8 \mathrm{~cm}$

*2 Pupput, tombe 439 (Inv. 2378.3). Identique à la précédente. 1./L. 6,3/10,8 cm.

3 Pupput (Inv. 1374.6). Engobe lie-de-vin, épais, luisant. Sans décor. Sur le fond : un ove.

4 Tipasa (Bussière 2000, P1. 45, n 729). Timbre CTESO.

5 Sétif, nécropole orientale (Guéry 1985a, Pl. XVII, $\left.\mathrm{n}^{\circ} 125 \mathrm{c}\right) .1 . / \mathrm{L} .6,3 / 10,6 \mathrm{~cm}$.

5ème série (selon Bussière 2000), bandeau décoré de globules

6 Pupput, tombe 604 (Ben Abed, Griesheimer 2004, fig. 76, T604.1). Une palme incisée sur le fond.

*7 Pupput, tombe 208 (Inv. 2877.1). Engobe brun à reflets métalliques. Sur le fond, marque incisée: OMISE (lecture anse en bas). 1.: $63 \mathrm{~mm}$; L.: $112 \mathrm{~mm}$; H. : $25 \mathrm{~mm}$.

8 Pupput (Inv. 1351.1). Engobe lie-de-vin écaillé.

Le $\mathrm{n}^{\circ} \mathbf{1}$, qui appartient à la première série (bandeau non décoré) du type Bussière $\mathrm{C} \mathrm{V} \mathrm{2,} \mathrm{provient} \mathrm{d'une} \mathrm{tombe} \mathrm{du}$ milieu du IIe s. ${ }^{212}$, date en accord avec celle proposée pour le $\mathrm{n}^{\circ} \mathbf{4}$ (Bussière 2000, 83 : avant 180 ?). Le $\mathrm{n}^{\circ} \mathbf{6}$, de la cinquième série (à bandeau décoré de globules), pourrait être plus tardif, de la seconde moitié ou de la fin du IIe s. (Ben Abed, Griesheimer 2004, 125).

Datation proposée : IIe s. - début du IIIe s.

- lampes à globules et à bec long (fig. 176)

$=$ Bussière C V 3/C VI = Ennabli 9 (n 356)

LAMPE TYPE 3

Il convient de rassembler les lampes des types Bussière $\mathrm{C}$ $\mathrm{V} 3$ et C VI, dont ni le disque, ni le fond ne présentent plus la forme ovale ou en «larme» caractéristiques du type C V (= Bailey K). En revanche une lampe de Pupput conserve un caractère mixte (1), c'est-à-dire avec à la fois un bandeau circulaire fermé et un fond en forme de « larme ».

Exemples (fig. 176) :

Variante précoce (?)

*1 Pupput, tombe 643 (Ben Abed, Griesheimer 2004, fig. 106, T643.3). Trace d'engobe gris-noir très écaillé. Sur le bandeau: trois rangées de globules. Sur le fond : marque incisée en grec (?), illisible. 1.66 mm; L. 105 mm ; H. 29 mm.

Variantes courantes

*2 Pupput, tombe 207 (Inv. 2915.1). Engobe brun orangé usé. Sur le bandeau : trois rangs de globules. Sur le fond: timbre en creux CIVNDRAC (?), très empâté. $1.76 \mathrm{~mm}$; L. $32 \mathrm{~mm}$; D. du fond $41 \mathrm{~mm}$.

*3 Pupput (Inv. 1847.1). Traces d'engobe brun-noir. Sur le fond : timbre CCORN[.. 1. $64 \mathrm{~mm}$; L. $120 \mathrm{~mm}$; H. $27 \mathrm{~mm}$; D. du fond $32 \mathrm{~mm}$.

Variantes avec canal

*4 Pupput, tombe 1145 (Inv. 2720.1). Traces d'engobe brun orangé. Sur le fond : marque incisée $C M E V P O$.

\footnotetext{
${ }^{212}$ Associé à deux lampes Deneauve VII/1 timbrées AVFFRON et MNOVIVSI.
} 
Typologie - Lampes

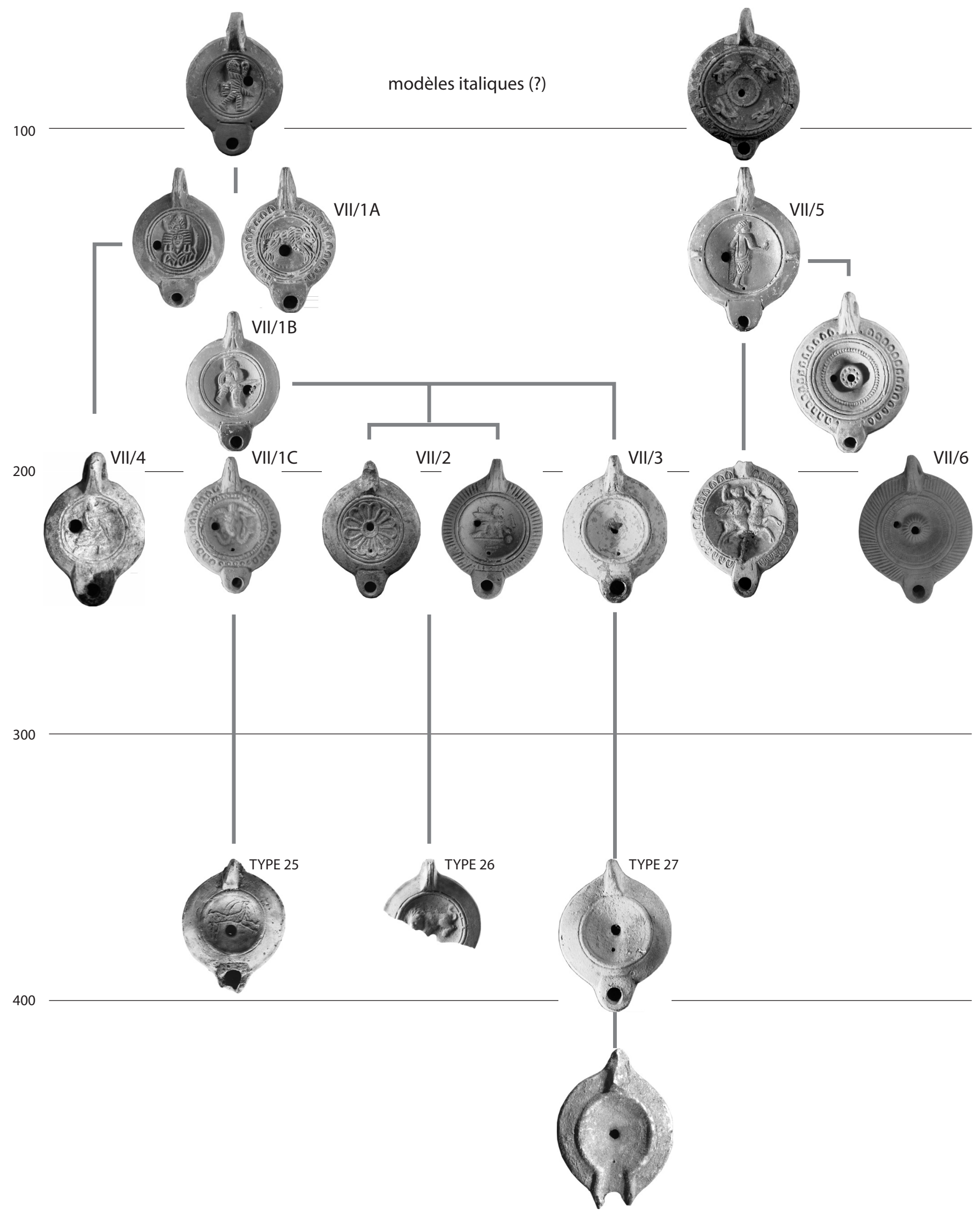

Fig. 175a. Lampes africaines. Proposition de schéma évolutif. Type Deneauve VII. 

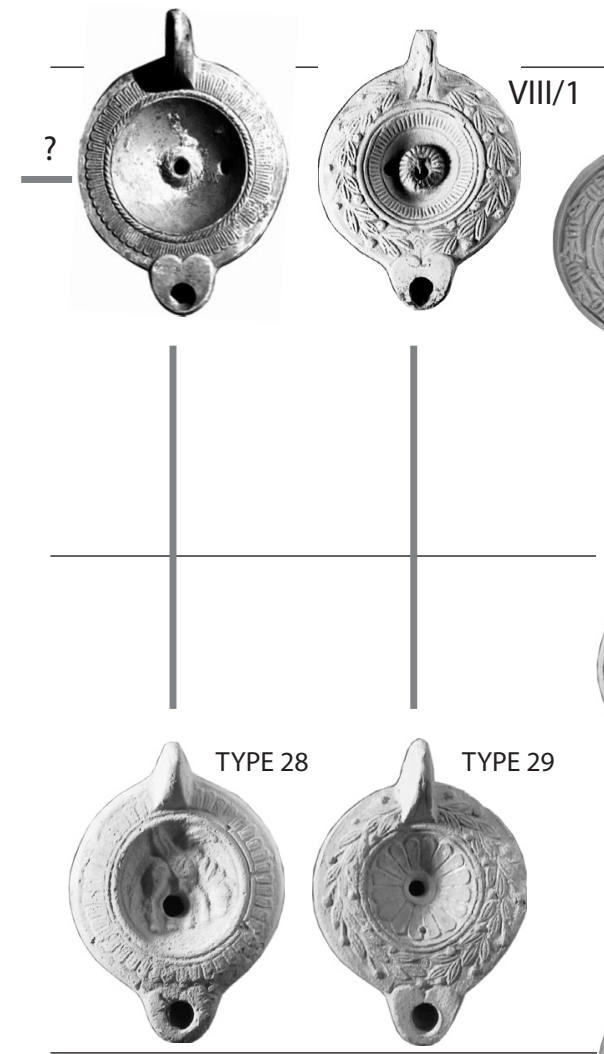

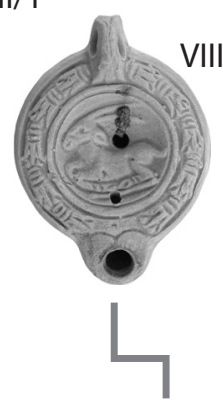

$\mathrm{VIII} / 2$
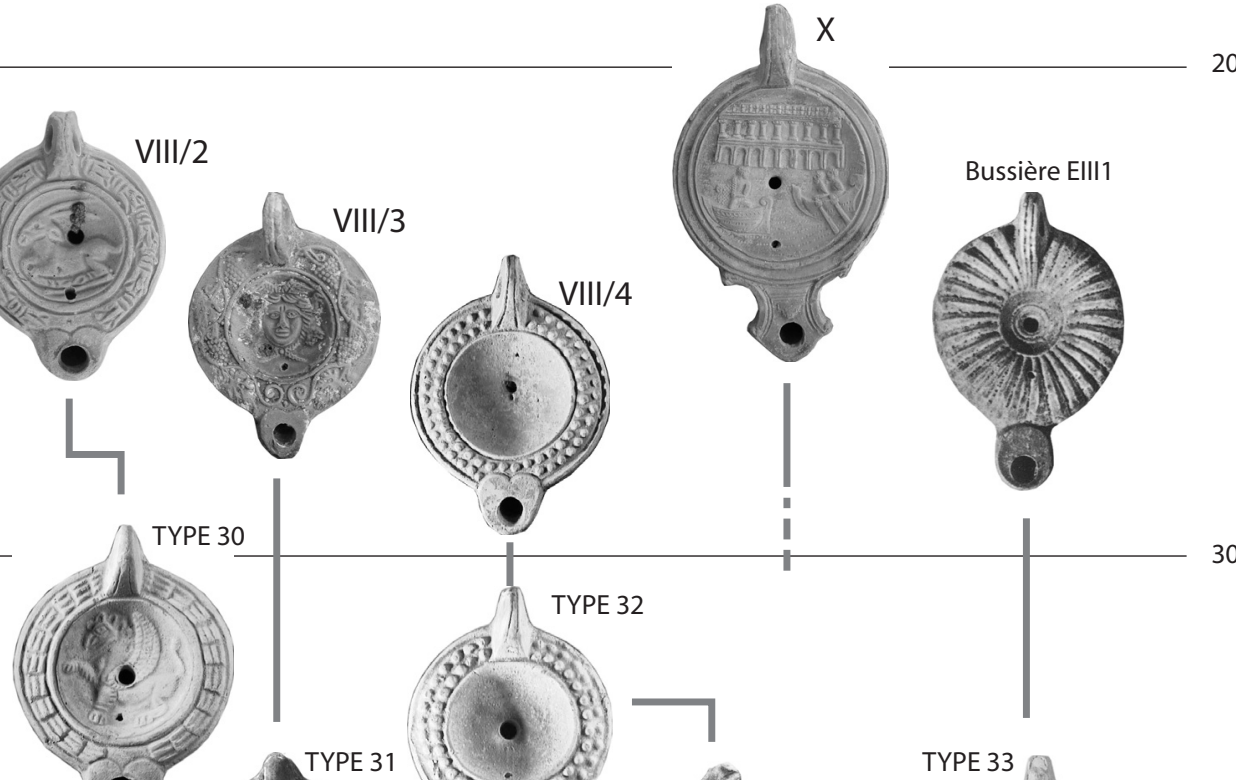

200
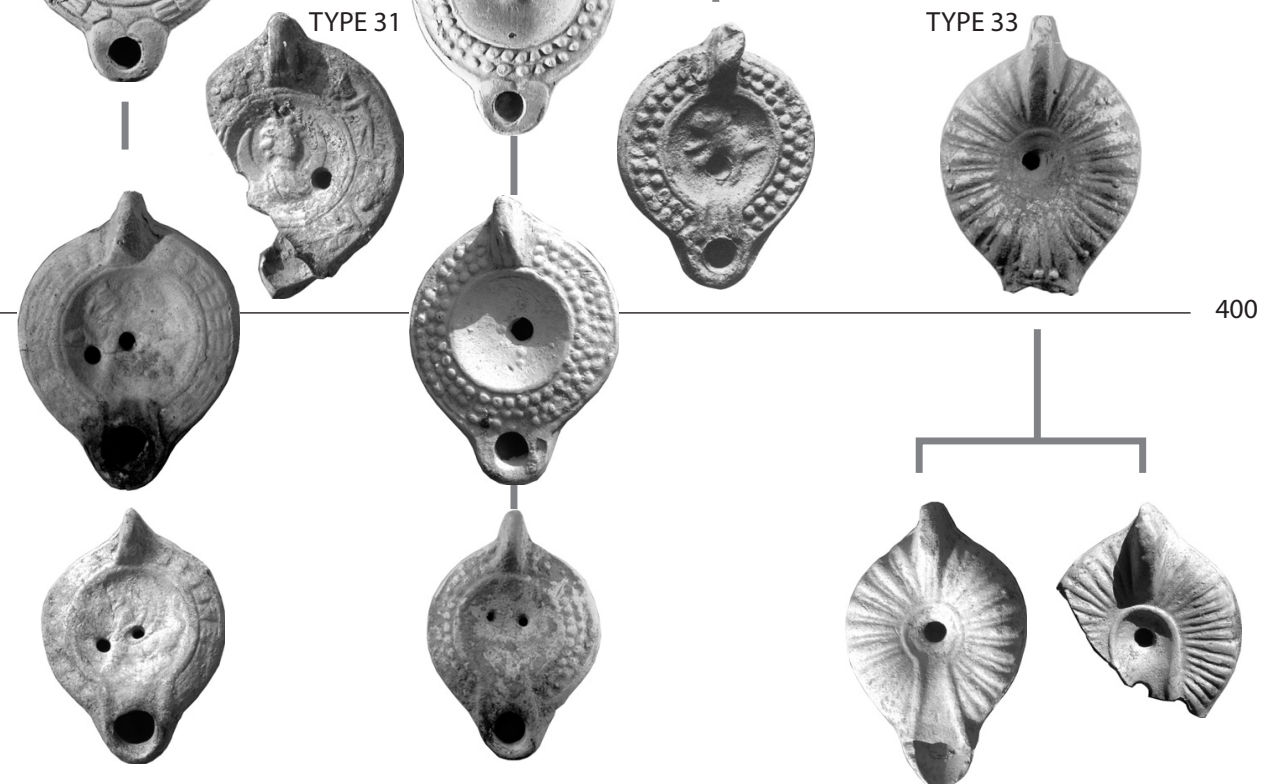

Fig. 175b. Lampes africaines. Proposition de schéma évolutif. Types Deneauve VIII et X. 
Typologie - Lampes
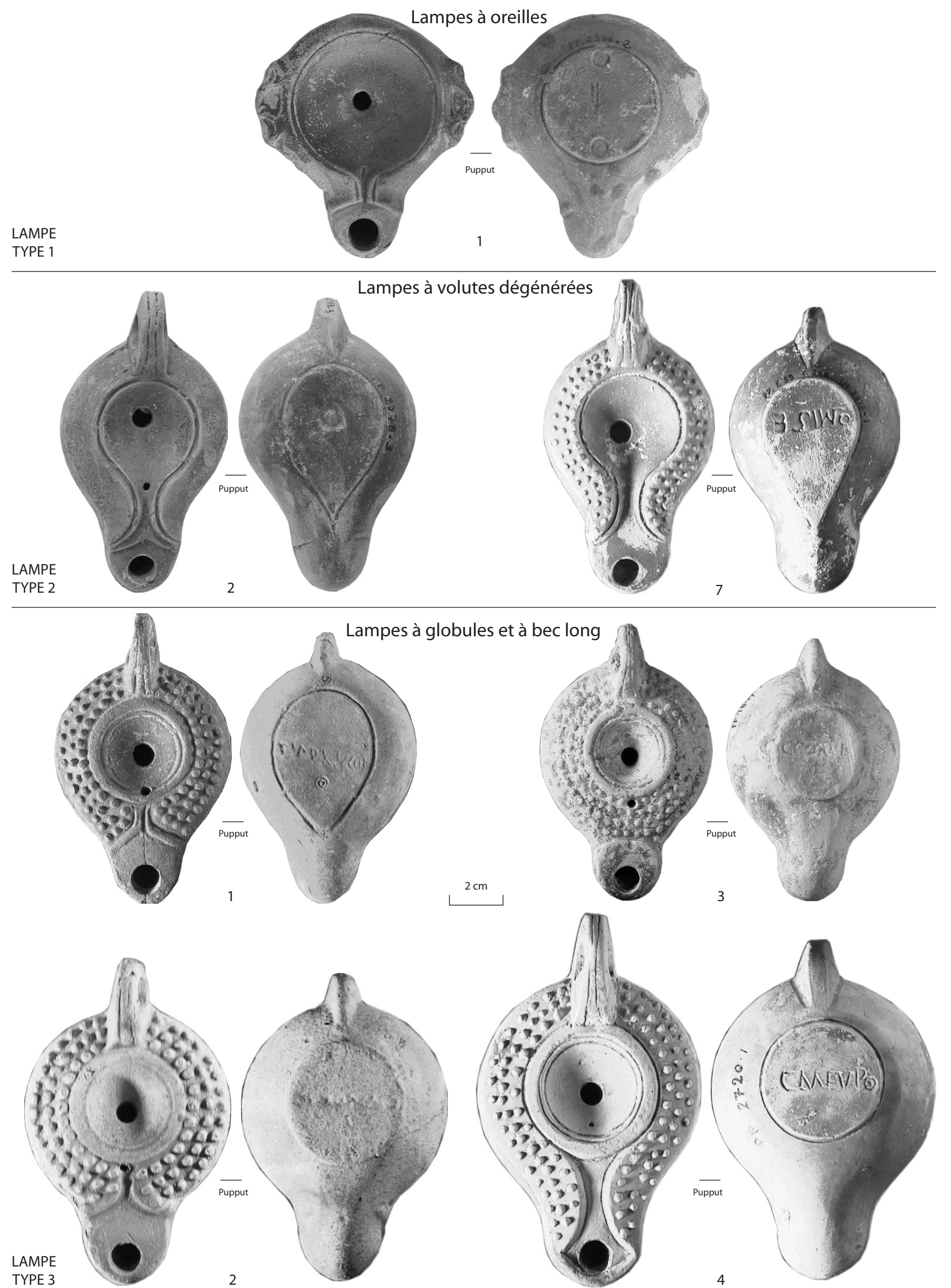

Fig. 176. Lampes africaines de tradition italique. 
1. $83 \mathrm{~mm}$; L. $132 \mathrm{~mm}$; H. $32 \mathrm{~mm}$; D. du fond : 41 $\mathrm{mm}$.

5 Carthage (Deneauve 1969, $\mathrm{n}^{\circ} 1033$ ). Canal du type Firmalampen. $1.75 \mathrm{~mm}$; L. $114 \mathrm{~mm}$; H. $27 \mathrm{~mm}$.

Le $n^{\circ} \mathbf{1}$, associé à des lampes de type Deneauve VII-soustype 1 déjà évoluées (timbres empâtés), n'est vraisemblablement pas antérieur à la seconde moitié du IIe s., date qui conviendrait également au $n^{\circ} \mathbf{2}$, au timbre également empâté, et au $\mathrm{n}^{\circ} \mathbf{3}$, dont la signature, peut-être d'origine tripolitaine (Bailey 1988, 96-97) est attestée entre 150 et 180 (Bussière 2000, 219).

\section{- Type Deneauve VII : lampes dites « à bec rond »}

J'ai regroupé sous cette appellation traditionnelle, « Deneauve VII », des lampes assez diverses qui ont en commun un bec rond à base plate ou parfois directement attaché sur le disque (plus rarement un bec cordiforme), un bandeau incliné vers l'extérieur, le plus souvent lisse mais parfois aussi décoré en creux, un disque décoré en relief, un fond plat dégagé par un ou deux sillons, la plupart du temps signé d'un timbre ou d'une marque incisée, et une anse forée dont la tranche est décorée de deux sillons.

L'observation concernant le décor du bandeau, au demeurant fort minoritaire sur ce type, est importante : il s'agit bien d'un décor en creux, et non en relief comme sur le type Deneauve VIII. J. Bussière signale que « l'ornementation la plus prisée, à toutes les époques, (est) une suite d'oves ». Sans doute est-ce parce que cette décoration, pour l'artisan, est facultative $\mathrm{e}^{213}$.

Je propose de distinguer six sous-types.

— type Deneauve VII/sous-type 1 (fig. 177-179)

$=$ Salomonson type f 1-2 = Ennabli 11-1ère série et 2ème série, groupes 1 et $2=$ Bussière D II $1=$ type Pupput 1

\section{LAMPE TYPE 4}

Lampe de petite taille (D. : 70-76 mm ; H. du réservoir : 25-30 $\mathrm{mm}$ ), à bec rond séparé du réservoir par une incision cantonnée de deux points en ceux. Le fond est toujours plat, dégagé par un sillon. On peut distinguer, sur la base de la documentation de Pupput, trois variantes principales :

- Variante A (= Salomonson f 1): Le bandeau est généralement lisse, plus rarement décoré d'oves, et le disque décoré de motifs répétitifs: cornes

\footnotetext{
${ }^{213}$ On peut se demander, en effet, si les oves, avant d'apparaître en relief dans le moule, n'ont pas été tout d'abord imprimés directement sur le bandeau après démoulage, les bavures de pâte étant alors effacées d'un coup d'estèque (voir ci-dessous, soustype $1, n^{\circ} 8$ ). Le même poinçon pouvait être ensuite utilisé sur le fond, pour agrémenter le timbre, au-dessus ou au-dessous de celui-ci: ce procédé semble même assez fréquent sur les exemplaires du sous-type 1 (voir ci-dessous, $\mathrm{n}^{\circ} \mathbf{8}, 9$ ?, 20, 21 ?). Le mode de fabrication du $n^{\circ} 9$ est plus incertain, peut-être s'agit-il d'un surmoulage (?).
}

d'abondance croisées, canthare, corybante au tympanon, croissant de lune sur un globe, déesse Africa, dauphin au gouvernail, buste féminin de face, homme débouchant une amphore, scène érotique sur un lit, pour les plus fréquents. La plupart de ces décors sont traités selon la technique de «l'incision profonde » (Salomonson 1968, 85). Le fond, plus ou moins large (en moy. 33-34 mm), porte toujours un timbre, bien imprimé : CIVNDRAC, CIVNALEX, AVFFRON, MNOVIVSTI sont les plus fréquents.

- Variante B (Salomonson f 2): Peut-être obtenue par surmoulage d'exemplaires de la variante A, elle se distingue de cette dernière par un décor et des timbres plus empâtés. Certaines marques ne sont plus lisibles, de sorte qu'il est parfois difficile de distinguer entre CIVNDRAC et CIVNALEX; le timbre $A V F F R O N$ tend à être remplacé par un timbre FRONI plus grand, assez fruste, profondément imprimé sur un fond souvent de très petit diamètre (24 mm). Les décors sur le bandeau comprennent des impressions d'oves et de cercles ocellés. Le décor du disque devient plus varié : à côté de dégénérescences de motifs présents sur la variante $\mathrm{A}$, on rencontre des décors originaux: Vénus, gladiateurs, amours, et d'autres typiques du sous-type 2 : une rosace ou deux palmes. Les disques non décorés sont fréquents.

- Variante C : Quelques exemplaires semblent encore se rattacher à la variante 1 par leurs dimensions, la forme du bec et du fond, mais s'en distinguent par un bandeau qui semble presque systématiquement décoré (oves, cercles ocellés), un décor du disque plus chargé, et un fond de grand diamètre (40-40 $\mathrm{mm})$. Les marques ne sont plus imprimées mais incisées : LVCCEI.

- Variante fruste : Certains exemplaires non décorés se caractérisent par le peu de soin apporté à leur fabrication : réservoir bosselé, sillons périphériques du disque peu marqués ou absents, fond indistinct avec des bavures d'argile, engobe irrégulier, pas de marque.

- Variante à bec cordiforme: Quelques lampes ont une forme générale tout à compatible avec la définition du sous-type 1 mais s'en distinguent par un bec cordiforme.

Exemples:

Variante précoce, non africaine (?) (fig. 177)

*1 Pupput, tombe 313 (Inv. PP1270.1). Pâte micacée, engobe orange écaillé. Sur le disque : corybante (?) au tympanon (Bussière 2000, 171), à droite. Sur le fond: timbre en relief dans un cartouche à queues d'aronde : CIVNDRACO.

Variante A (fig. 177)

Bandeau lisse

*2 Pupput, enclos 8 (Inv. PP1157.4). Engobe brun. Sur le disque : deux cornes d'abondance croisées. Sur le fond : timbre en creux CIVNDRAC. D. $74 \mathrm{~mm}$; H. 27 $\mathrm{mm}$; D. du fond $33 \mathrm{~mm}$.

*3 Pupput, tombe 149 (Bonifay 2004a, fig. 12, n 24). Traces d'engobe brun. Sur le disque : deux cornes d'abondance croisées. Sur le fond: timbre en creux 
Typologie - Lampes
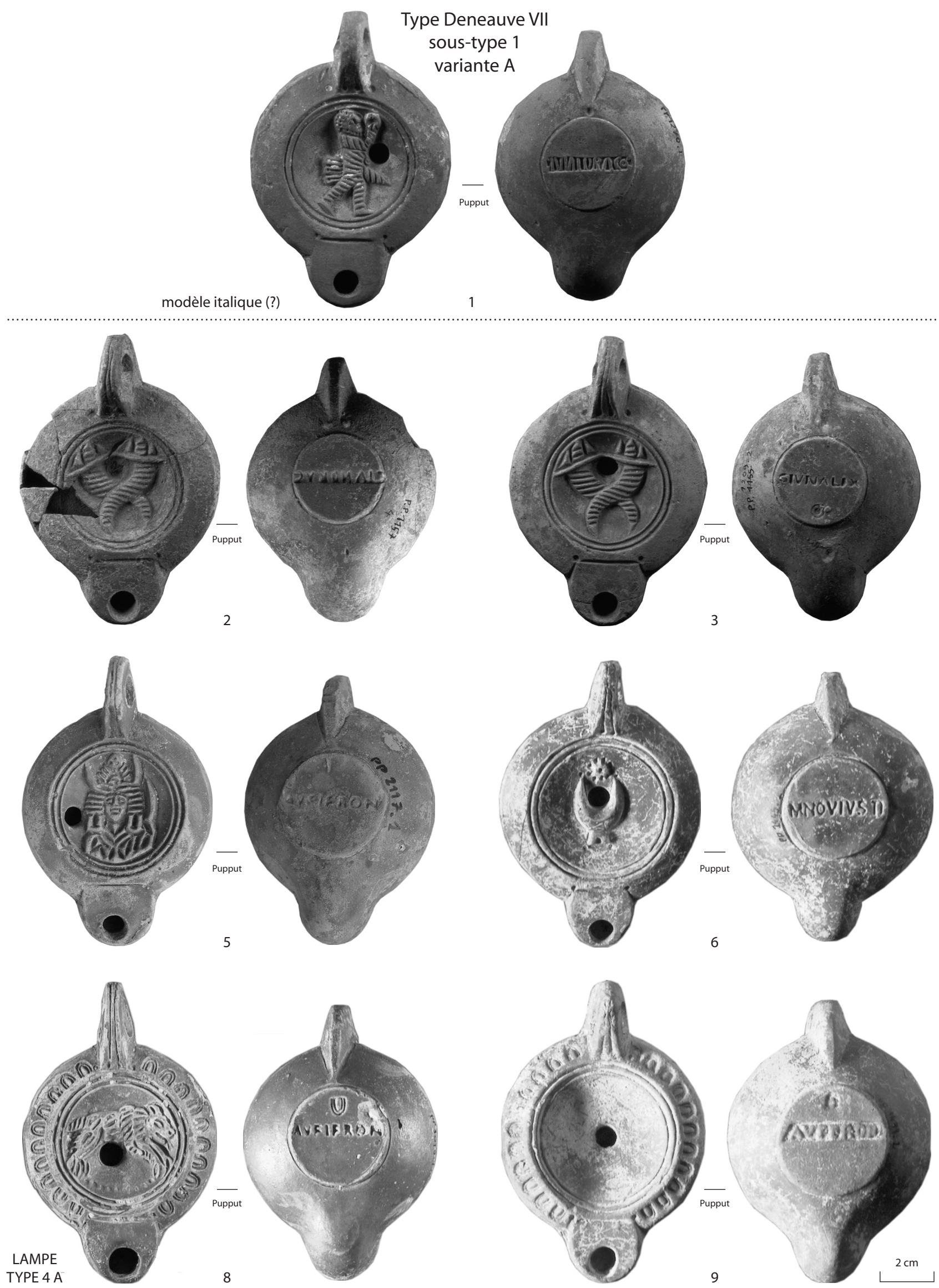

Fig. 177. Lampes africaines "à bec rond" (type Deneauve VII). 
Typologie - Lampes
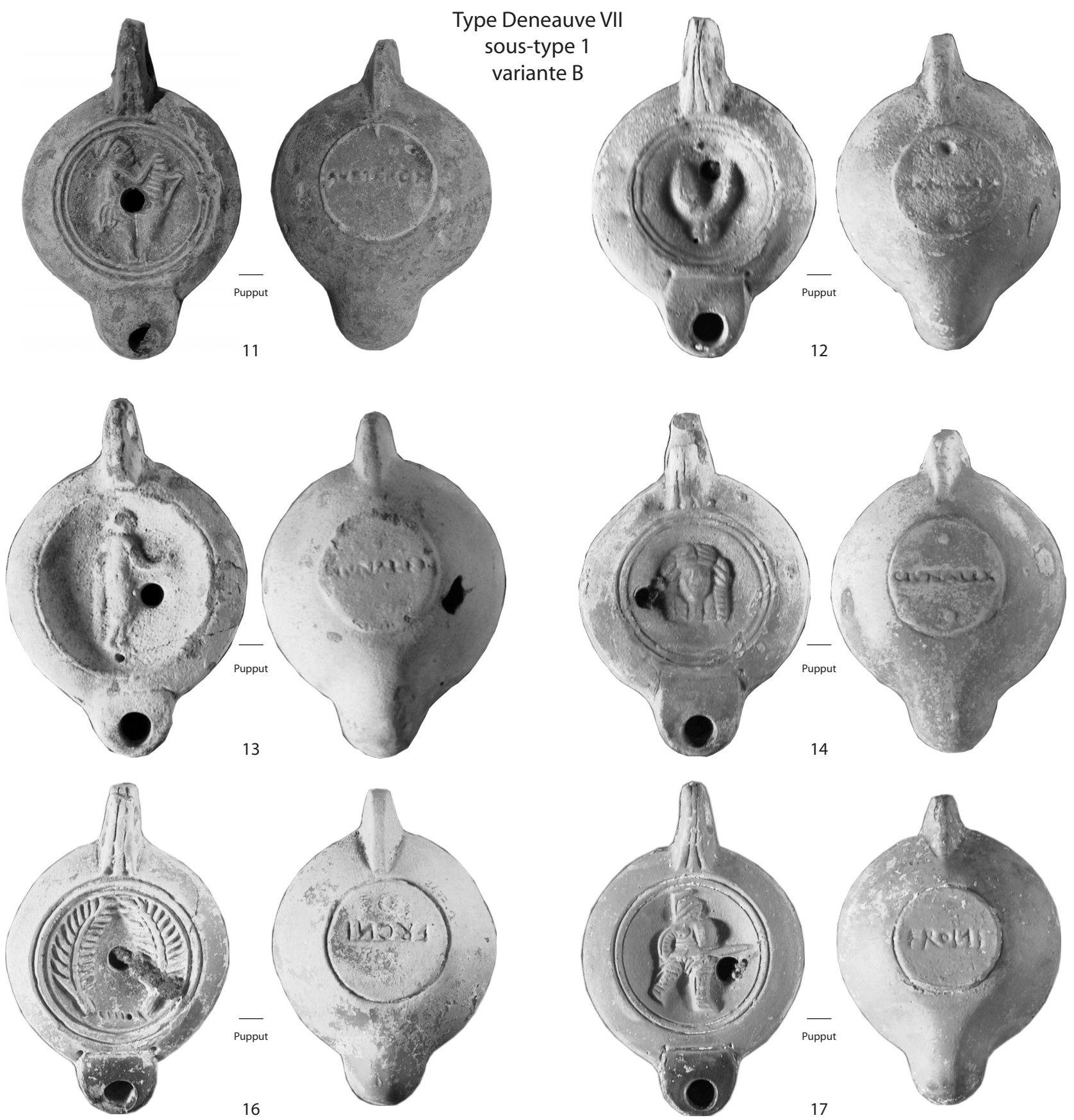

Lwowe

TYPE 4 B

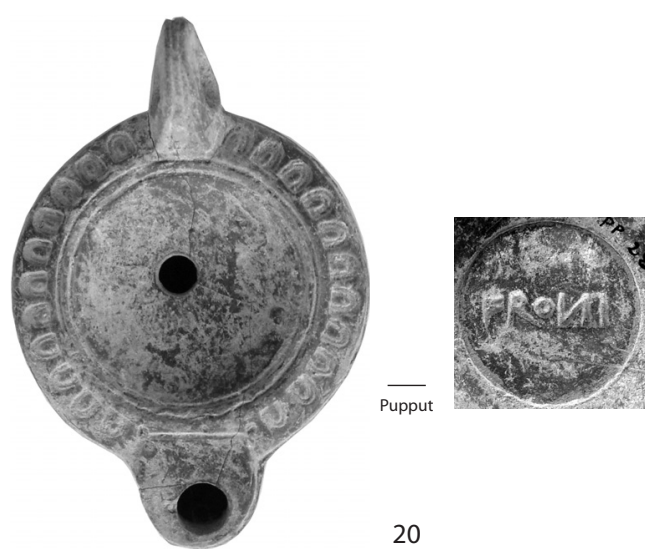

Fig. 178. Lampes africaines "à bec rond" (type Deneauve VII). 
Typologie - Lampes

Type Deneauve VII sous-type 1

Variante C
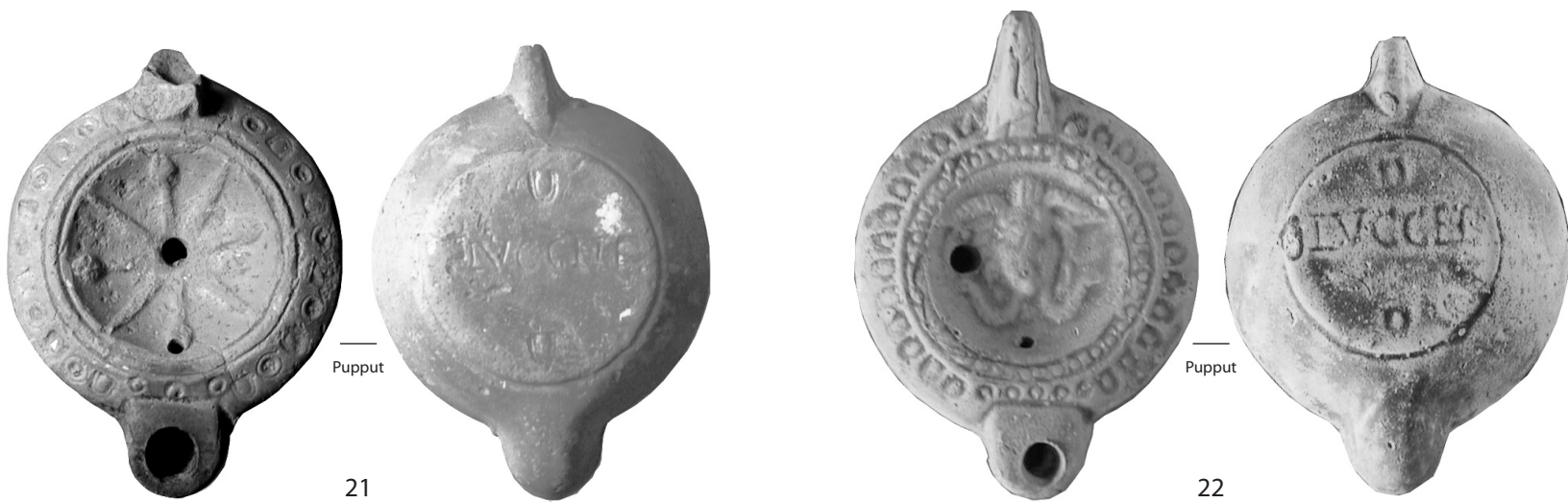

Variante fruste
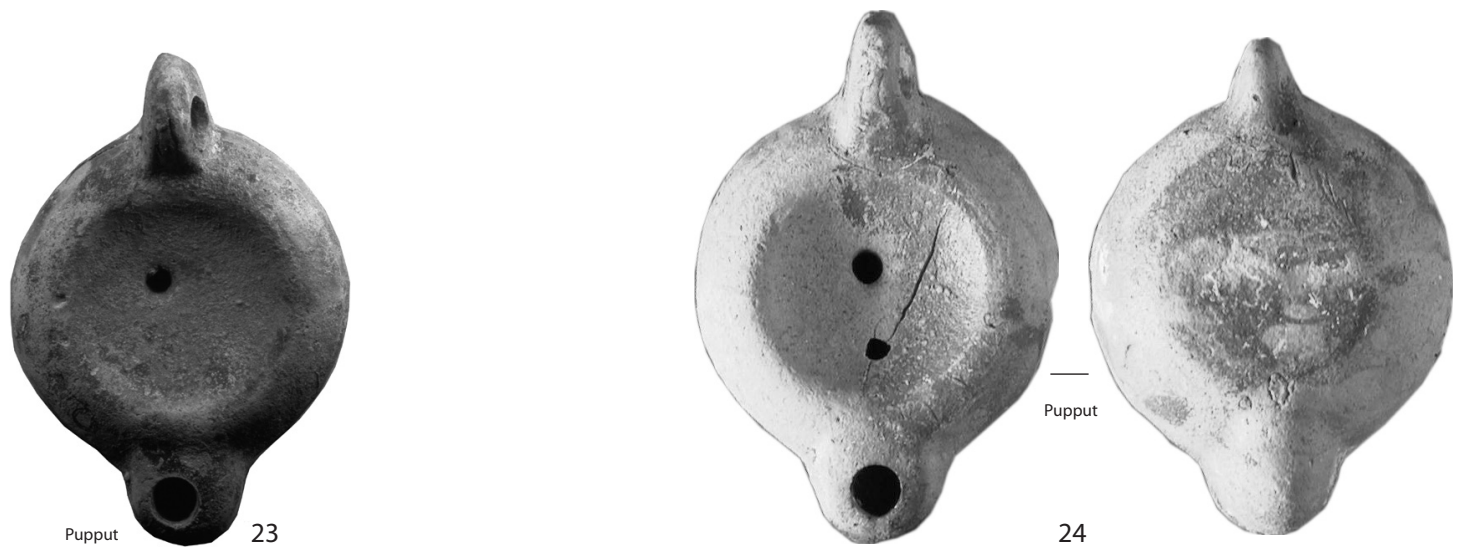

Variante à bec cordiforme

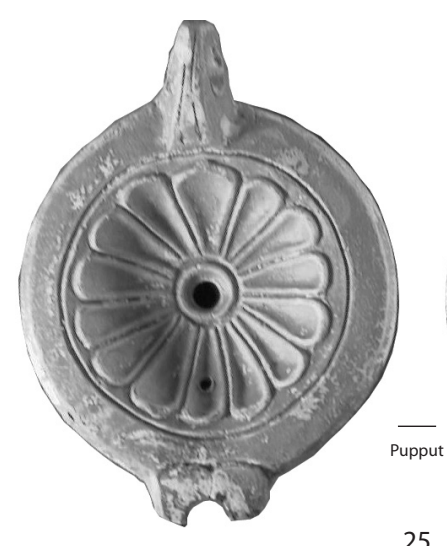

25

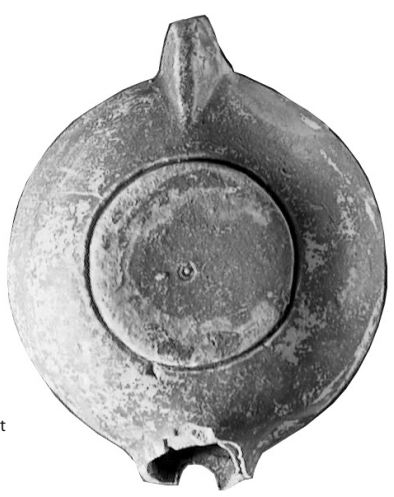

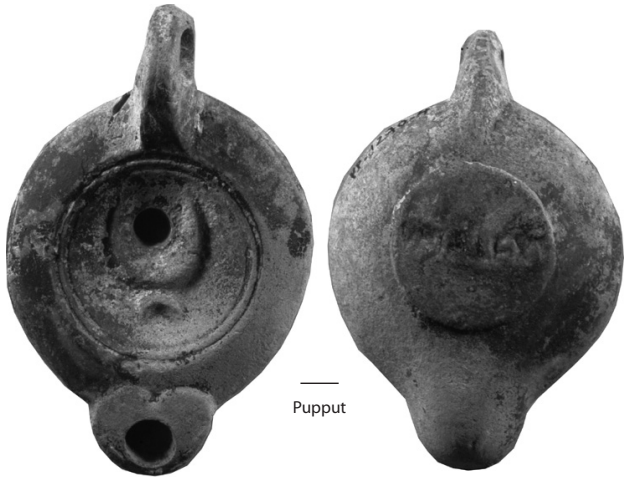

26

LAMPE

TYPE $4 \mathrm{C}$ et variantes

Fig. 179. Lampes africaines "à bec rond" (type Deneauve VII). 
CIVNALEX. D. $73 \mathrm{~mm}$; H. $28 \mathrm{~mm}$; D. du fond 32 mm.

4 Pupput, tombe 138 (Ben Abed, Griesheimer 2004, fig. 84, T138.1). Engobe brun orangé écaillé. Sur le disque : croissant de lune sur un globe. Sur le fond : timbre en creux CIVNALEX. D. : $73 \mathrm{~mm}$; H. 26 $\mathrm{mm}$; D. du fond : $33 \mathrm{~mm}$.

*5 Pupput (Bonifay 2004a, fig. 12, $\mathrm{n}^{\circ} 25$ ). Engobe orangé à brun. Sur le disque : déesse Africa. Sur le fond : timbre en creux AVFIFRON. D. : $70 \mathrm{~mm}$; H. : $25 \mathrm{~mm}$; D. du fond : $33 \mathrm{~mm}$.

*6 Pupput (Inv. PP1445.1). Engobe noir. Sur le disque : croissant de lune sur un globe. Sur le fond : timbre en creux MNOVIVSTI. D. $74 \mathrm{~mm}$; H. $26 \mathrm{~mm}$; D. du fond $36 \mathrm{~mm}$.

7 Pupput, tombe 940 (Inv. PP3371.1). Traces d'engobe brun-gris. Disque non décoré. Sur le fond : timbre en creux L MVN PHILE, en bas, croix en relief dans un cercle. D. $65 \mathrm{~mm}$; H. $24 \mathrm{~mm}$; D. du fond $37 \mathrm{~mm}$. Bandeau décoré

*8 Pupput, tombe 1307 (Inv. PP3019.1). Engobe brun à reflets métalliques. Sur le bandeau: oves en creux. Sur le disque : ours ou chien courant à droite. Sur le fond, timbre AVFIFRON surmonté d'un ove. D. $71 \mathrm{~mm}$; H. : $25 \mathrm{~mm}$; D. du fond : $34 \mathrm{~mm}$.

*9 Pupput, tombe 463 (Inv. PP1499.2). Engobe brun clair. Sur le bandeau: oves en creux. Disque non décoré. Sur le fond : timbre $A V F F R O N$ en relief dans cartouche quadrangulaire, un ove au-dessus. D. $75 \mathrm{~mm}$; H. $26 \mathrm{~mm}$; D. du fond $35 \mathrm{~mm}$.

10 Musée d'Oran (Bussière 2000, Pl. 83, n 3043). Sur le bandeau : oves en creux. Sur le disque : Corybante à droite $\left(\mathrm{cf} . \mathrm{n}^{\circ} 1\right)$. Sur le fond : timbre CIVNDRAC. D. $66 \mathrm{~mm}$; H. $23 \mathrm{~mm}$.

Variante B (fig. 178)

Bandeau lisse

*11 Pupput, tombe 408 (Bonifay 2004a, fig. 12, n 26). Traces d'engobe brun. Sur le disque: homme débouchant une amphore, empâté. Sur le fond: timbre en creux AVFIFRON, empâté. D. $70 \mathrm{~mm}$; H. : $40 \mathrm{~mm}$; D. du fond : $34 \mathrm{~mm}$.

*12 Pupput, tombe 137 (Ben Abed, Griesheimer 2004, fig. 59, T137.2). Engobe brun à reflets métalliques. Sur le disque : croissant sur un globe, empâté. Sur le fond : timbre très empâté, peut-être CIVNALEX. D. : $72 \mathrm{~mm}$; H. : $28 \mathrm{~mm}$; D. du fond : $33 \mathrm{~mm}$.

*13 Pupput, tombe 643 (Ben Abed, Griesheimer 2004, fig. 106, T643.1). Surface usée, beige verdâtre. Sur le disque: Vénus, empâtée. Sur le fond: timbre en creux, CIVNALEX (?), empâté. D. $78 \mathrm{~mm} ; \mathrm{H}$. $32 \mathrm{~mm}$; D. du fond $34 \mathrm{~mm}$.

*14 Pupput, tombe 603 (Ben Abed, Griesheimer, fig. 65, T603.1). Engobe brun foncé écaillé. Sur le disque : buste féminin, empâté. Sur le fond : timbre en creux CIVNALEX, très empâté. D. 74 mm; H. 29 mm ; D. $\mathrm{du}$ fond $34 \mathrm{~mm}$.

15 Pupput, tombe 135 (Ben Abed, Griesheimer 2004, fig. 51, T135.2). Engobe brun sombre à reflets métalliques. Sur le disque : deux palmes. sur le fond : timbre en creux CIVN[..., empâté. D. $72 \mathrm{~mm} ; \mathrm{H}$. $30 \mathrm{~mm}$; D. du fond : $33 \mathrm{~mm}$.

*16 Pupput, tombe 427 (Inv. 2471.1). Engobe orange écaillé. Sur le disque : deux palmes. Sur le fond, timbre FRONI au-dessus d'un cercle imprimé, lecture anse en bas. D. : $71 \mathrm{~mm}$; H. : $25 \mathrm{~mm}$; D. du fond:
$24 \mathrm{~mm}$.

*17 Pupput, tombe 499 (Inv. 3021.1). Engobe orange. Sur le disque : mirmillon à droite. Sur le fond, timbre FRONI. D. : $71 \mathrm{~mm}$; H. : $24 \mathrm{~mm}$; D. du fond: $30 \mathrm{~mm}$.

18 Pupput (Inv. 3351.1). Engobe lie de vin à reflets métalliques. Sur le disque : canthare. Sur le fond: timbre en creux FRONI. D. : $73 \mathrm{~mm}$; H. : $24 \mathrm{~mm}$; D. du fond : $34 \mathrm{~mm}$.

Bandeau décoré

19 Pupput, tombe 643 (Ben Abed, Griesheimer 2004, fig. 106, T643.2). Trace d'engobe gris-noir très écaillé. Sur le bandeau: cercles ocellés. Sur le disque : tête de Gorgone (?). Sur le fond : timbre très empâté, illisible, encadré de cercles ocellés.

*20 Pupput, tombe 268 (Bonifay 2004a, fig. 12, n 27). Engobe orangé à brun. Sur le bandeau : oves. Disque non décoré. Sur le fond : timbre $F R O N I$. D. : $73 \mathrm{~mm}$; H. : $26 \mathrm{~mm}$; D. du fond : $32 \mathrm{~mm}$.

Variante C (fig. 179)

*21 Pupput, tombe 672 (Ben Abed, Griesheimer 2004, fig. 51, T672.1). Engobe lie-de-vin écaillé. Sur le bandeau: cercles ocellés et oves. Sur le disque: étoile à huit branches dont quatre terminées par des pommes de pin. Sur le fond : marque incisée $L V C C E I$ entre quatre oves disposés en croix. D. $72 \mathrm{~mm}$; H. $30 \mathrm{~mm}$; D. du fond $45 \mathrm{~mm}$.

*22 Pupput, tombe 134 (Ben Abed, Griesheimer 2004, fig. 80, T134.1). Trace d'engobe brun foncé très écaillé. Sur le bandeau : oves. Sur le disque : tête de Gorgone (?). Sur le fond: marque incisée LVCCEI, un ove au-dessus et au-dessous. D. : $75 \mathrm{~mm}$; H. : $25 \mathrm{~mm}$; D. du fond : $43 \mathrm{~mm}$.

Variante fruste (fig. 179)

*23 Pupput, tombe 1102 (Inv. PP3094.1). Engobe brun à reflets métalliques écaillé. Disque sans décor. Fond sans sillon, peu soigné. D. $74 \mathrm{~mm}$; H. $28 \mathrm{~mm}$; D. du fond $40 \mathrm{~mm}$ (?).

*24 Pupput, tombe 931 (Inv. 3597.1). Engobe brun peu écaillé. D. $72 \mathrm{~mm}$; H. $27 \mathrm{~mm}$; D. du fond $42 \mathrm{~mm}$.

Variante à bec cordiforme (fig. 179)

*25 Pupput, tombe 135 (Ben Abed, Griesheimer 2004, fig. 51, T135.1). Engobe orange-brun clair à reflets métalliques. Sur le disque : rosace. Sur le fond : une petite rouelle (deux cercles concentriques). D. $78 \mathrm{~mm}$; H. : $28 \mathrm{~mm}$; D. du fond : $38 \mathrm{~mm}$.

*26 Pupput (Inv. PP1270.4). Sur le disque : croissant. Sur le fond: timbre VNALEX, empâté. D. $63 \mathrm{~mm}$; H. $24 \mathrm{~mm}$; D. du fond $33 \mathrm{~mm}$.

En mettant de côté les productions italiques, bien connues depuis la seconde moitié du Ier s., auxquels appartiennent peut-être quelques exemplaires à pâte micacée, timbrés CIVNDRACO en relief (1), la lampe de type Deneauve VII-sous-type 1 constitue, en Afrique, la forme « standard » (Bussière 2000, 96) du IIe siècle.

Il est difficile de déterminer une limite chronologique franche entre les variantes $\mathrm{A}$ et $\mathrm{B}$. On remarque cependant que la variante $\mathrm{B}$, souvent associée dans les tombes avec des lampes du sous-type 2, est plutôt caractéristique de la seconde moitié, voire même de la fin du IIe s. (Bonifay 2004a, 33). Il en est de même pour la variante $\mathrm{C}$, qui porte des marques incisées $L V C C E I$. Les exemplaires avec le bandeau décoré, rares, semblent 
sortir de la même officine tout au long du IIe s. : AVFIFRON sur la variante A et FRONI sur la variante B. Datation proposée :

Variante A : première moitié - milieu du IIe s.

Variante B : seconde moitié du IIe s.

Variante $\mathrm{C}$ : fin du IIe - premier quart du IIIe s.

- type Deneauve VII/sous-type 2 (fig. 180-181)

$=$ Salomonson $\mathrm{f} 3=$ Ennabli 11 , 3ème série $=$ Bussière D II 1 = type Pupput 2

\section{LAMPE TYPE 5}

Il est assez facile de distinguer le sous-type 2. La forme est comparable à celle du sous-type 1 mais présente souvent (mais pas toujours) un profil plus trapu (diamètre identique: $70-75 \mathrm{~mm}$, pour une hauteur de réservoir légèrement plus importante : 30-32 $\mathrm{mm}$ ). La décoration $\mathrm{du}$ disque n'est jamais traitée selon la technique de l'incision profonde : sont particulièrement fréquentes les rosaces ou deux palmes encadrant le trou de remplissage. Le bandeau est parfois décoré de stries ou d'oves. Le fond, plus large (D. : 38-42 mm env.) est délimité par deux sillons concentriques et n'est jamais timbré. Il porte assez fréquemment des marques incisées, notamment: AVGENDI, LVCCEI, MAVRICI. La pâte paraît de moins bonne qualité (engobe fin écaillé).

Exemples:

Bandeau lisse (fig. 180)

*1 Pupput (Bonifay 2004a, fig. 13, $\mathrm{n}^{\circ} 28$ ). Traces d'engobe lie de vin. Sur le disque: rosace. D. : $75 \mathrm{~mm}$; H. : $31 \mathrm{~mm}$; D. du fond : $38 \mathrm{~mm}$.

*2 Pupput, tombe 137 (Ben Abed, Griesheimer 2004, fig. 59, T137.1). Trace d'engobe brun-gris. Sur le disque: rosace. Sur le fond: marque incisée MAVRI/CI. D. : $71 \mathrm{~mm}$; H. : $25 \mathrm{~mm}$; D. du fond : 38 $\mathrm{mm}$.

*3 Pupput, tombe 120 (Inv. PP1129.3). Traces d'engobe lie-de-vin. Sur le disque : deux palmes. D. $74 \mathrm{~mm}$; H. $30 \mathrm{~mm}$; D. du fond : $42 \mathrm{~mm}$.

*4 Pupput, tombe 1160 (Ben Abed, Griesheimer 2004, fig. 123, T1160.1). Traces d'engobe gris. Sans décor. Sur le fond: marque incisée $A V G E N D I$. D. $73 \mathrm{~mm}$; H. $26 \mathrm{~mm}$; D. du fond $40 \mathrm{~mm}$.

Bandeau décoré (fig. 180)

*5 Pupput, tombe 1054 (Bonifay 2004a, fig. 13, n²9). Traces d'engobe brun. Sur le bandeau : stries. Sur le disque : sphinx à droite. D. : $77 \mathrm{~mm}$; H. : 29 mm ; D. $\mathrm{du}$ fond : $40 \mathrm{~mm}$.

*6 Pupput, tombe 402 (Inv. PP1667.2). Engobe brun écaillé. Sur le bandeau: stries; disque sans décor. Sous le fond: marque incisée PVLLA/ENI. D. $72 \mathrm{~mm}$; H. $27 \mathrm{~mm}$; D. du fond $41 \mathrm{~mm}$.

7 Pupput, tombe 863 (Inv. PP2135.2). Sur le bandeau : oves. Sur le disque : félin courant à gauche. Sur le fond : marque incisée AGRI. D. $75 \mathrm{~mm}$; H. $27 \mathrm{~mm}$; D. du fond $39 \mathrm{~mm}$.

*8 Pupput, tombe 1454 (Inv. PP4097.9). Traces d'engobe noir. Sur le bandeau : oves en creux. Sur le disque : Léda et le cygne. D. $77 \mathrm{~mm}$; H. $42 \mathrm{~mm}$; D. du fond $38 \mathrm{~mm}$.

Variante de grande taille (fig. 181)

*9 Pupput (Inv. PP1345.2). Engobe lie-de-vin écaillé.
Sur le bandeau : oves en creux. Sur le disque : deux ichtyopanthères à droite. Sur le fond : marque incisée LVCCEI. D. $98 \mathrm{~mm}$; H. $35 \mathrm{~mm}$; D. du fond $59 \mathrm{~mm}$.

Variante à bec cordiforme (fig. 181)

*10 Pupput (Inv. PP1374.1). Traces d'engobe orangé. Sur le disque : gazelle bondissant à droite. Sur le fond : marque incisée $M A R C O$ (?), au-dessus de 5 points en quinconce. D. $77 \mathrm{~mm}$; H. $27 \mathrm{~mm}$; D. du fond $52 \mathrm{~mm}$.

11 Carthage, British Museum (Bailey 1988, Q 1707). Même décor que la précédente. D. $78 \mathrm{~mm}$.

12 Pupput, tombe 402 (Inv. PP1546.1). Engobe orangé écaillé. Sans décor. D. $79 \mathrm{~mm}$; H. $27 \mathrm{~mm}$; D. du fond $36 \mathrm{~mm}$.

Ce type est assez fréquent en surface, dans les niveaux de circulation de la nécropole, et apparaît régulièrement dans les tombes de la seconde moitié du IIe s. et du début du IIIe s. (par ex. : tombe 402) ${ }^{214}$. Les marques incisées, qui font référence à des ateliers différents de ceux du soustype 1 (supra, p. 80), confirment cette datation.

Datation proposée: seconde moitié du IIe s. - premier tiers du IIIe siècle.

\section{— type Deneauve VII/sous-type 3 (fig. 181) \\ = type Pupput 3}

\section{LAMPE TYPE 6}

Le sous-type 3 se distingue des autres lampes à bec rond par son diamètre important (env. $80-85 \mathrm{~mm}$, pour une hauteur de réservoir peu éloignée de celle des exemplaires du sous-type 2: env. $35 \mathrm{~mm}$ ) et par l'absence de tout décor. Malgré la raideur générale de leur ligne, ces objets conservent une assez bonne qualité de production: disque souligné par deux sillons, anse forée, pâte fine engobée. Fond plat, assez large (D. : $50 \mathrm{~mm}$ env.), dégagé par un sillon; des marques sont tracées à la pointe : PVLLAENORVM, MAVRICI.

Exemples (fig. 181):

*1 Pupput, tombe 695 (Bonifay 2004a, fig. 13, $\mathrm{n}^{\circ} 30$ ). Pâte beige. Sur le fond, marque incisée: PVLLAENORV. D. : $82 \mathrm{~mm}$; D. du fond $50 \mathrm{~mm}$.

*2 Pupput, tombe 1312 (Inv. PP3042.1). Traces d'engobe brun. Sur le fond, marque incisée: (M ?)AVR(I ?)CI. D. : $79 \mathrm{~mm}$; H. : $35 \mathrm{~mm}$; D. du fond $47 \mathrm{~mm}$.

3 Pupput, tombe 445 (Inv. PP2471.2). Traces d'engobe marron. D. $85 \mathrm{~mm}$; H. $34 \mathrm{~mm}$; D. du fond $52 \mathrm{~mm}$.

Ces lampes apparaissent dans des tombes de la fin du IIe s. et de la première moitié du IIIe s. (par exemple : tombe 1312$)^{215}$. Les marques incisées confirment cette datation.

\section{- type Deneauve VII/sous-type 4 (fig. 181) \\ $=$ Bussière D VI = type Pupput 4}

\section{LAMPE TYPE 7}

Lampes de forme comparable à celle des sous-types 1 et 2 mais caractérisées par un bec massif qui prend

\footnotetext{
214 Associée à une assiette en sigillée africaine A Hayes 27.

215 Associée à un balsamaire en verre de type « chandelier ».
} 
Typologie - Lampes

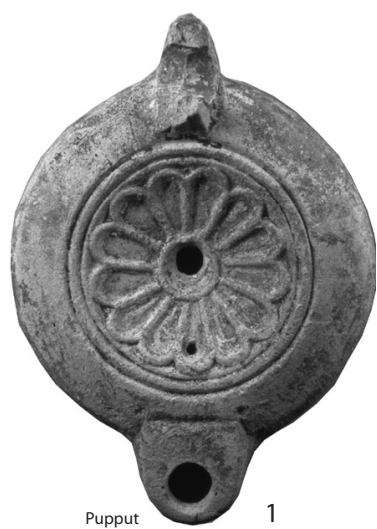

Type Deneauve VII

sous-type 2
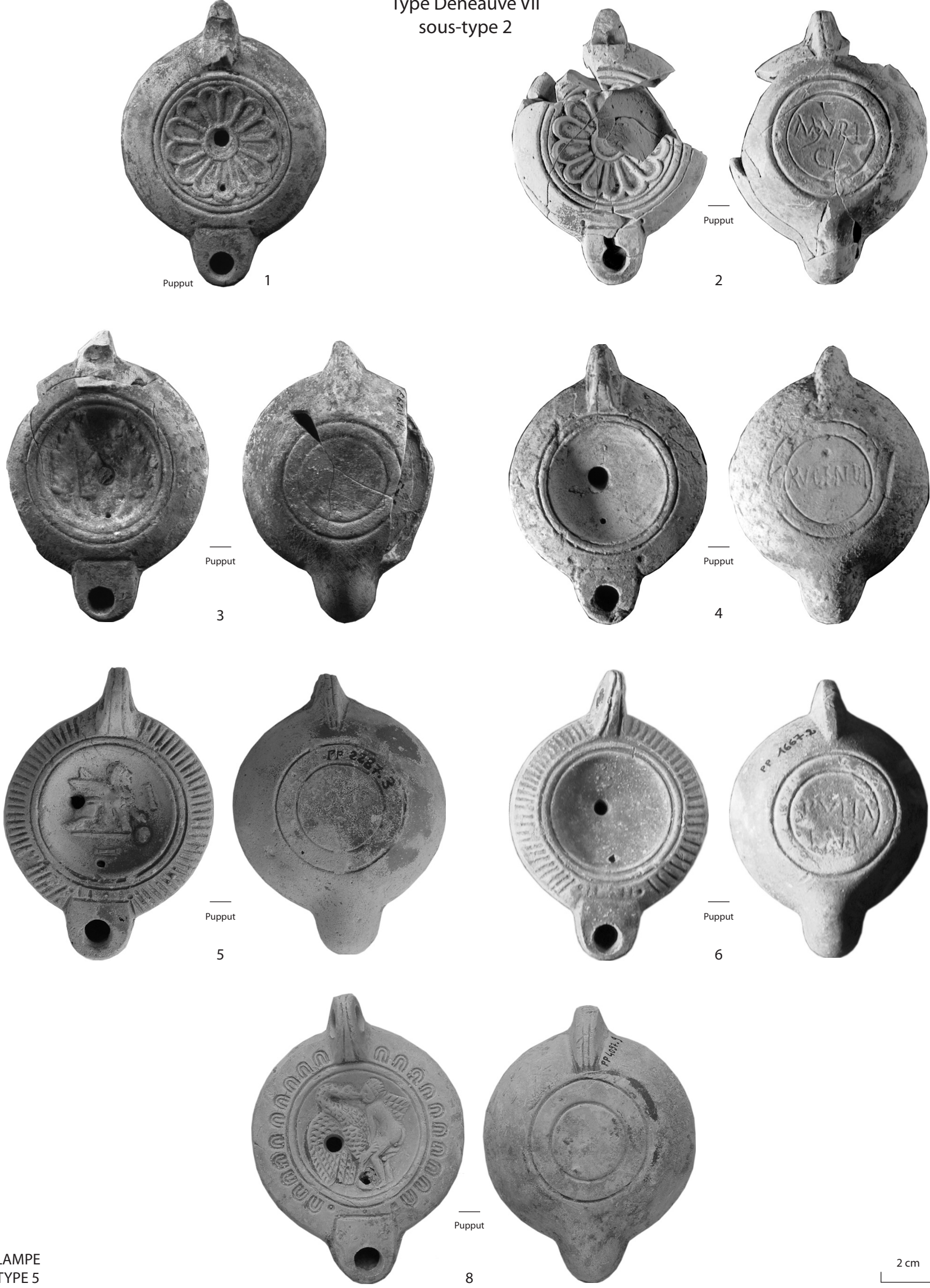

Fig. 180. Lampes africaines "à bec rond" (type Deneauve VII). 
Typologie - Lampes

Type Deneauve VII sous-type 2

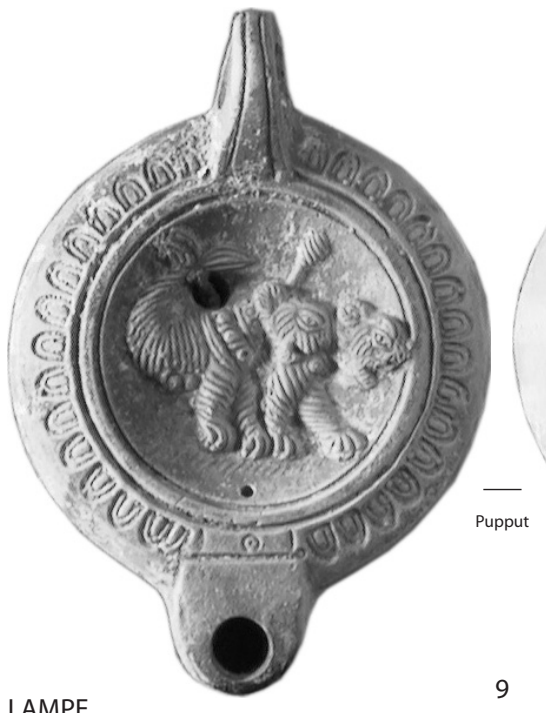
variantes
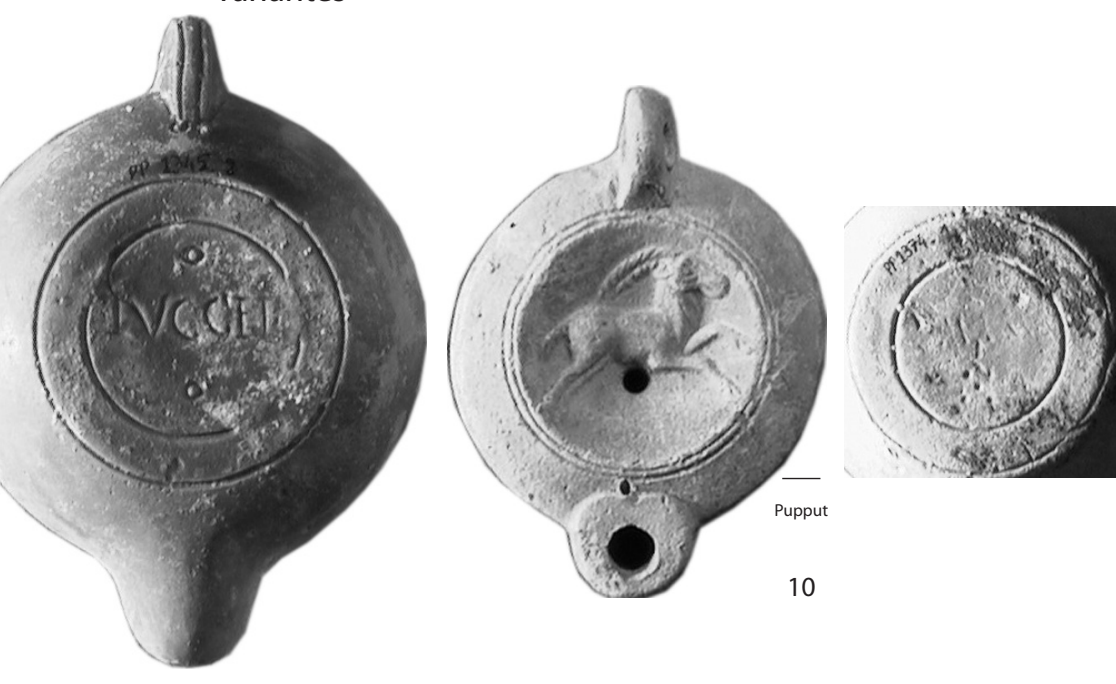

Type Deneauve VII sous-type 3
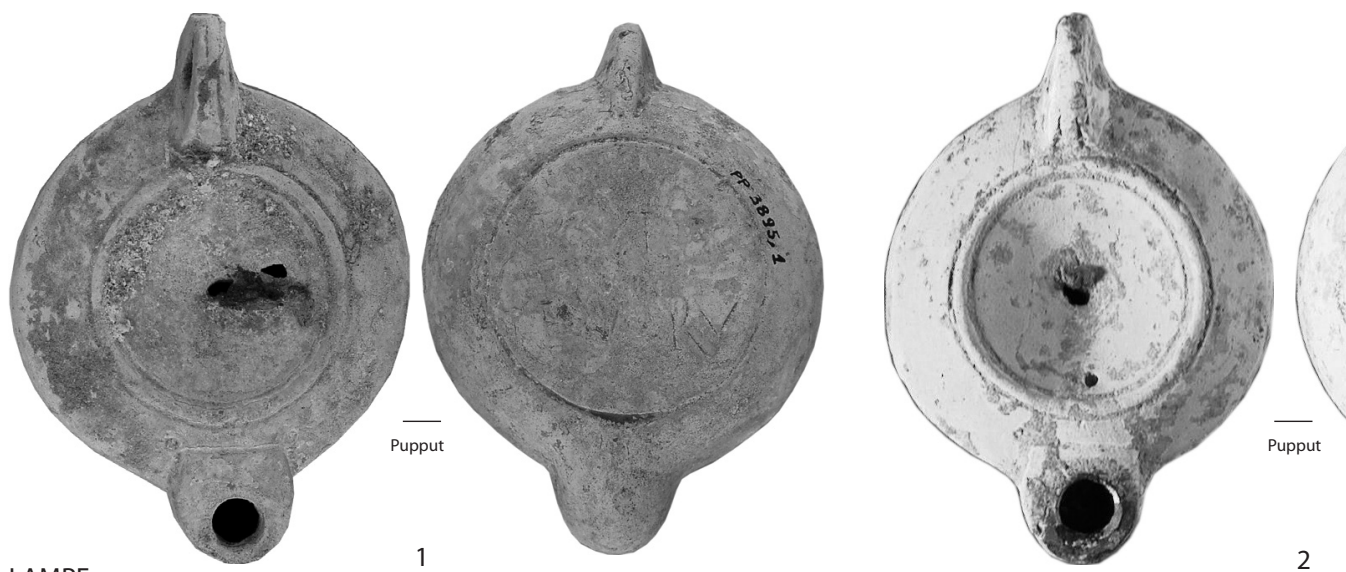

Type Deneauve VII sous-type 4
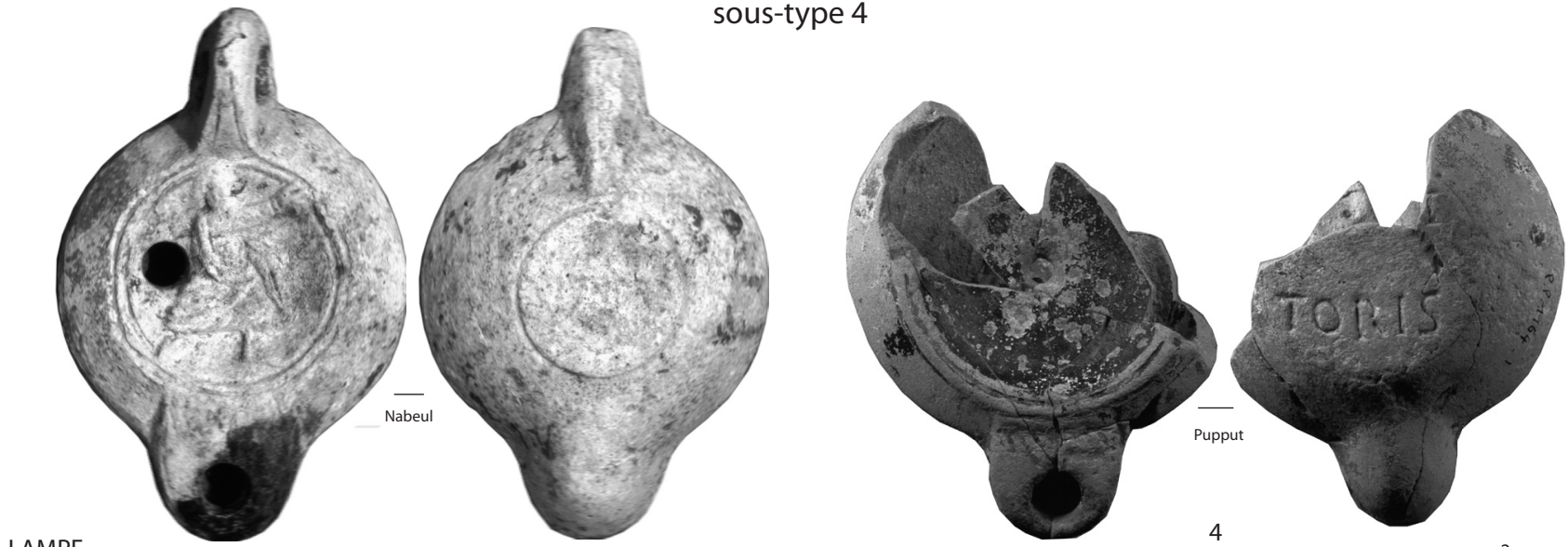

LAMPE
TYPE 7

Fig. 181. Lampes africaines "à bec rond" (type Deneauve VII). 
naissance directement sur le disque. Des hachures marquent parfois le départ du bec.

Exemples (fig. 181) :

*1 Nabeul, fabrique de salaison, bassin III (Slim, Bonifay, Trousset 1999, fig. 27) Traces d'engobe rouge. Sur le disque : acteur de théâtre (?). Sur le fond, timbre : C.IVNDRA (?), empâté. D. : $76 \mathrm{~mm}$; H. : $46 \mathrm{~mm}$.

2 Carthage (Deneauve 1969, $\mathrm{n}^{\circ} 732$ ). Sur le disque : pégase ou griffon à gauche. Sur le fond: timbre CIVNDRA. D. $74 \mathrm{~mm} ;$ H. $27 \mathrm{~mm}$.

3 Bu Njem (Rebuffat 1987, 89, n 1-2). Sans décor. Sur le fond, timbre CIVNDRAC.

*4 Pupput, tombe 172 (Inv. PP1164.1). Engobe brun luisant. Disque non décoré. Sur le fond, marque incisée : ]I/TORIS. D. du fond $50 \mathrm{~mm}$.

Ce sous-type de lampe à bec rond, assez rarement signalé en Tunisie, est plus fréquent dans l'Est algérien (Bussière 2000,101 ) et en Tripolitaine (Joly 1974, $\mathrm{n}^{\circ}$ 481-523). L'exemplaire de Nabeul est issu d'un contexte du deuxième quart ou du milieu du IIIe siècle.

\section{— type Deneauve VII/sous-type 5 (lampes « galettes ») (fig. 182-183) \\ $=($ Deneauve VII C $)=$ Bussière D III/D V/D X 1 \\ $=$ type Pupput 5}

\section{LAMPE TYPE 8}

Sous cette appellation empruntée à J. Bussière $(2000,99)$, je propose de regrouper des lampes d'assez grande taille, larges et plates (D. : $80 \mathrm{~mm}$ en moyenne; H. : 26$32 \mathrm{~mm}$ ). Je souscris parfaitement à la proposition de J. Bussière $(2000,99)$ de rassembler au sein d'un même type les exemplaires munis de tenons sur le bandeau (type Deneauve VII C) et ceux qui n'en ont pas. Mais je pense qu'il est nécessaire de faire le même regroupement avec les exemplaires dont le bandeau est décoré d'oves, avec tenons (type D V) ou sans tenons (D X 1). Ces deux derniers types me paraissent constituer une évolution du premier.

Exemples:

Variante précoce (non africaine ?) (fig. 182)

*1 Pupput, tombe 313 (Inv. PP1270.5). Engobe brun noirâtre, usé. Tenons sur le bandeau. Sur le disque : gladiateur à gauche d'un autel sur lequel est posé un casque. Sur le fond : timbre en creux MNAELVCI. D. $84 \mathrm{~mm}$; H. $26 \mathrm{~mm}$; D. du fond $50 \mathrm{~mm}$.

*2 Pupput, tombe 313 (Inv. PP1270.6). Engobe brun noirâtre, usé. Sur le bandeau : oves. Sur le disque : 2 chiens alternés avec 2 lièvres disposés en cercle. Sur le fond: timbre en creux BICAGAT. D. $85 \mathrm{~mm} ; \mathrm{H}$. $29 \mathrm{~mm}$; D. du fond $53 \mathrm{~mm}$.

Variante classique (fig. 182)

Tenons sur le bandeau

3 Pupput, tombe 713 (Inv. PP2393.1). Engobe orangé à marron. Sur le disque : un cercle en relief. Sur le fond: timbre en creux CIVNALEX. D. $88 \mathrm{~mm}$; H. $29 \mathrm{~mm}$; D. du fond $41 \mathrm{~mm}$.

4 Pupput, tombe 836 (Inv. PP1592.1). Engobe lie-devin, épais, écaillé. Sur le disque : cercle en relief et rinceau de lierre. Sur le fond: timbre en creux OMISE. D. $90 \mathrm{~mm}$; H. $29 \mathrm{~mm}$; D. du fond $41 \mathrm{~mm}$.
*5 Pupput, tombe 1317 (Bonifay 2004a, fig. 12, $\mathrm{n}^{\circ} 23$ ). Engobe orange granuleux. Sur le bandeau: deux tenons latéraux. Sur le disque: Vénus à droite accoudée à une colonne torsadée, tenant un miroir de la main droite (cf. LAMPE TYPE $4 \mathrm{~B}, \mathrm{n}^{\circ} 13$ ). Sur le fond, timbre en creux CIVNALEX. D. $87 \mathrm{~mm}$; H. $28 \mathrm{~mm}$; D. du fond $39 \mathrm{~mm}$.

*6 Pupput (Inv. PP1769.1). Engobe lie-de-vin. Sur le disque : Ulysse enchaîné sur son bateau. Sur le fond : timbre CIVNALEX. D. $89 \mathrm{~mm}$; H. $29 \mathrm{~mm}$; D. du fond $42 \mathrm{~mm}$.

Bandeau décoré (fig. 182-183)

*7 Pupput (Inv. PP1375.1). Sur le bandeau : oves en creux. Disque non décoré. Sur le fond: timbre AVFFRON en relief dans un cartouche. D. $94 \mathrm{~mm}$; H. $29 \mathrm{~mm}$; D. du fond $47 \mathrm{~mm}$.

*8 Pupput, tombe 462 (Inv. PP1492.1). Engobe orange vif, écaillé. Sur le bandeau: oves. Sur le disque : Chimère. Sur le fond: timbre $A$ (tête en bas) $A$ ( ?)AFFRON. D. $89 \mathrm{~mm}$; H. $30 \mathrm{~mm}$; D. du fond $42 \mathrm{~mm}$.

*9 Pupput, tombe 968 (Inv. 3081.2). Engobe brun-gris. Sur le bandeau: oves. Sur le disque : cercle radié, ombilic central marqué de points. Sur le fond : timbre en creux MNOVIVS TI, empâté. D. $90 \mathrm{~mm}$; H. $33 \mathrm{~mm}$; D. du fond $46 \mathrm{~mm}$.

Variante tardive (fig. 183)

*10 Pupput, tombe 811 (Inv. PP2099.1). Traces d'engobe brun. Sur le bandeau: oves. Sur le disque : cercle radié, ombilic central marqué de points. Sur le fond : marque incisée CHELIAN. D. 89 mm ; H. 32 mm ; D. $\mathrm{du}$ fond $42 \mathrm{~mm}$.

*11 Pupput, tombe 1165 (Ben Abed, Griesheimer 2004, fig. 80, T1165.1). Engobe brun-gris à reflets métalliques, écaillé. Sur le bandeau: oves. Sur le disque : Diane chevauchant un cerf, à droite. Sur le fond: marque incisée LVCCEI. D. : $82 \mathrm{~mm}$; H. : $28 \mathrm{~mm}$; D. du fond : $44 \mathrm{~mm}$.

Sur les exemplaires les plus anciens, dans les ensembles de la première moitié ou du milieu du IIe s. (par exemple : tombe 1103$)^{216}$, le bandeau porte des tenons à la manière des Firmalampen (caractère retenu par J. Deneauve pour distinguer son type VII C). Certains, comme l'exemplaire découvert dans la tombe $313^{217}$, timbré MNAELVCI, sont probablement italiques (Bailey 1980, 99 : fin flavien-Hadrien) mais les autres, timbrés CIVNDRAC, CIVNALEX, OMISE, AVFFRON, sont africains. Sur les exemplaires plus tardifs, de la seconde moitié du IIe s., le bandeau est décoré d'oves et le bec prend naissance directement sur le disque (8-11). Les exemplaires de la fin du IIe s. et du début du IIIe s. se distinguent par des marques non plus timbrées mais incisées (10-11).

\footnotetext{
${ }^{216}$ Exemplaire comparable au $\mathrm{n}^{\circ} 3$ associé à six lampes du soustype 1 timbrée $C I V N D R A C$ ou CIVNDRACO.

${ }^{217}$ Associé à 11 monnaies de l'extrême fin du Ier siècle.
} 


\section{Typologie - Lampes}

Type Deneauve VII

sous-type 5
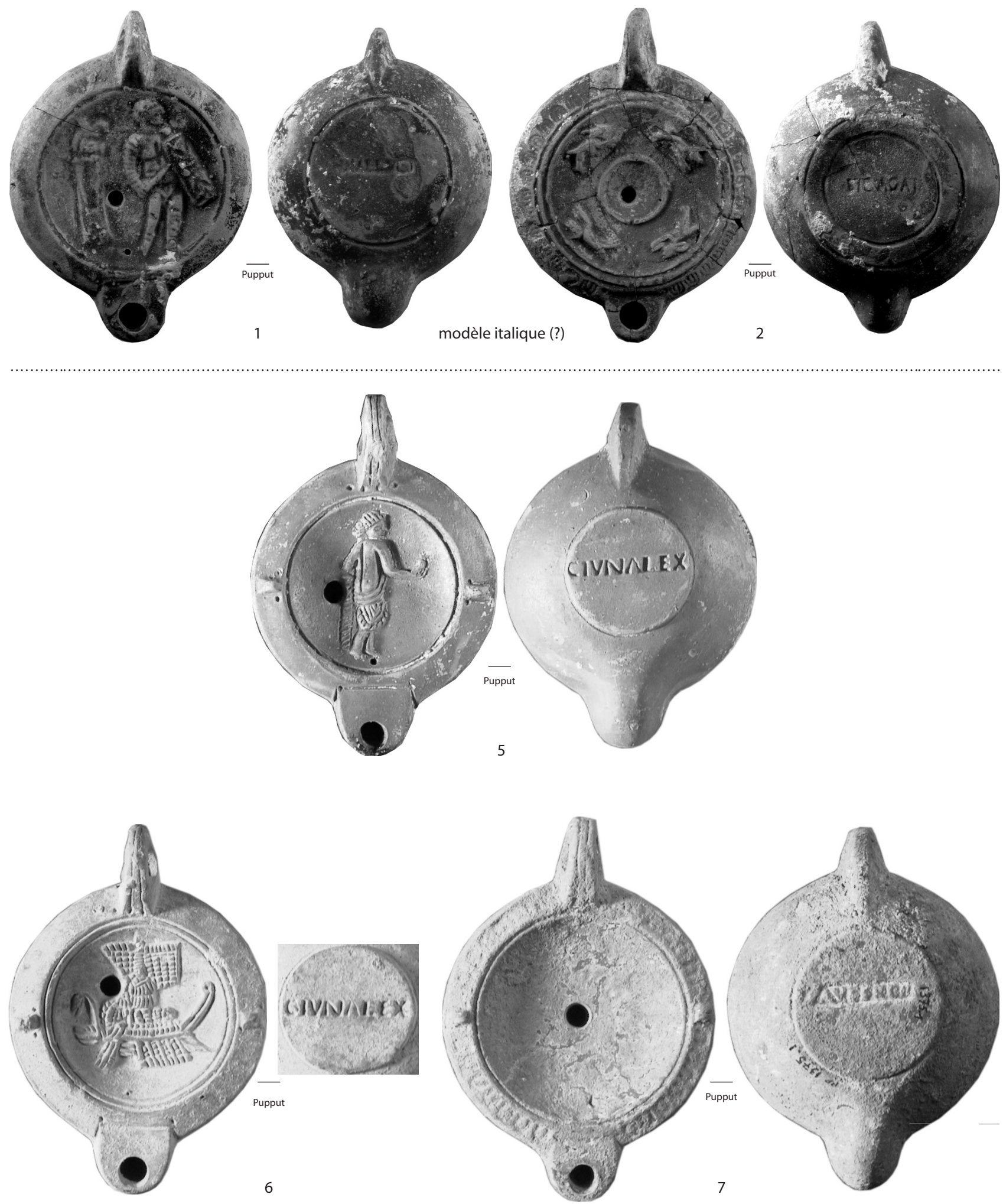

Fig. 182. Lampes africaines "à bec rond" (type Deneauve VII). 
Typologie - Lampes

Type Deneauve VII sous-type 5
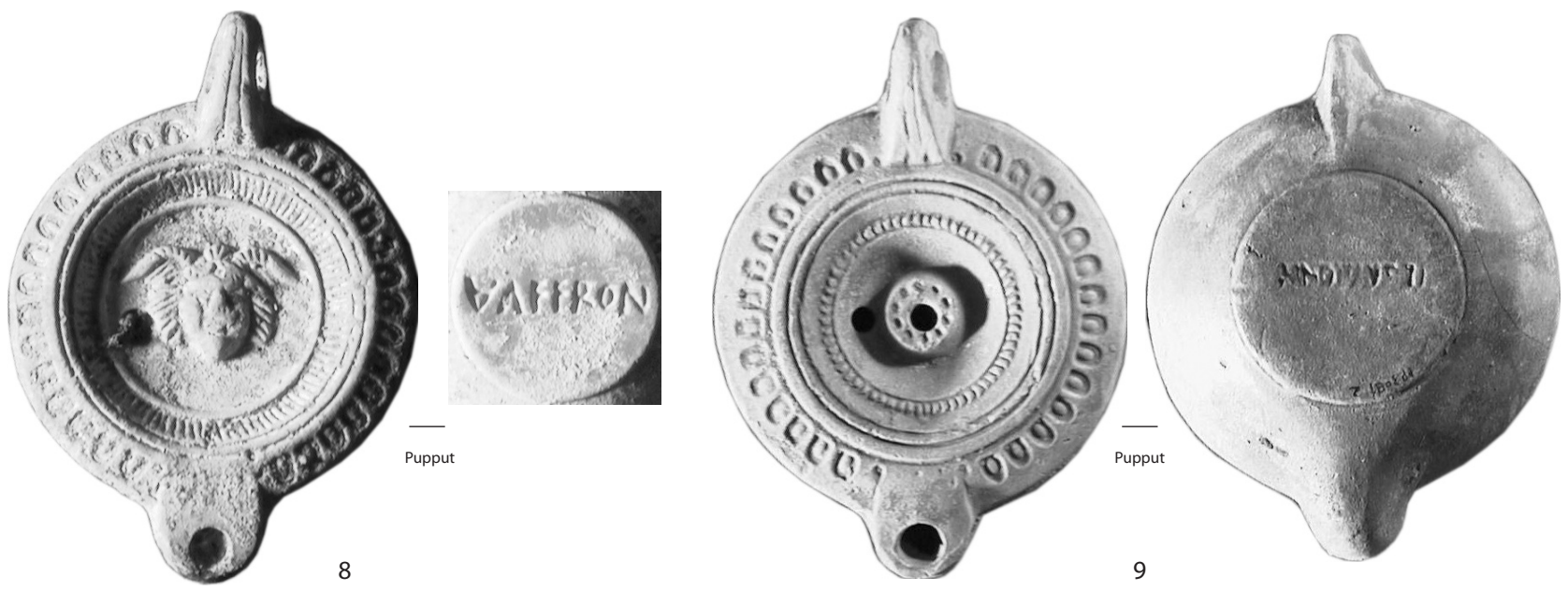

variante tardive
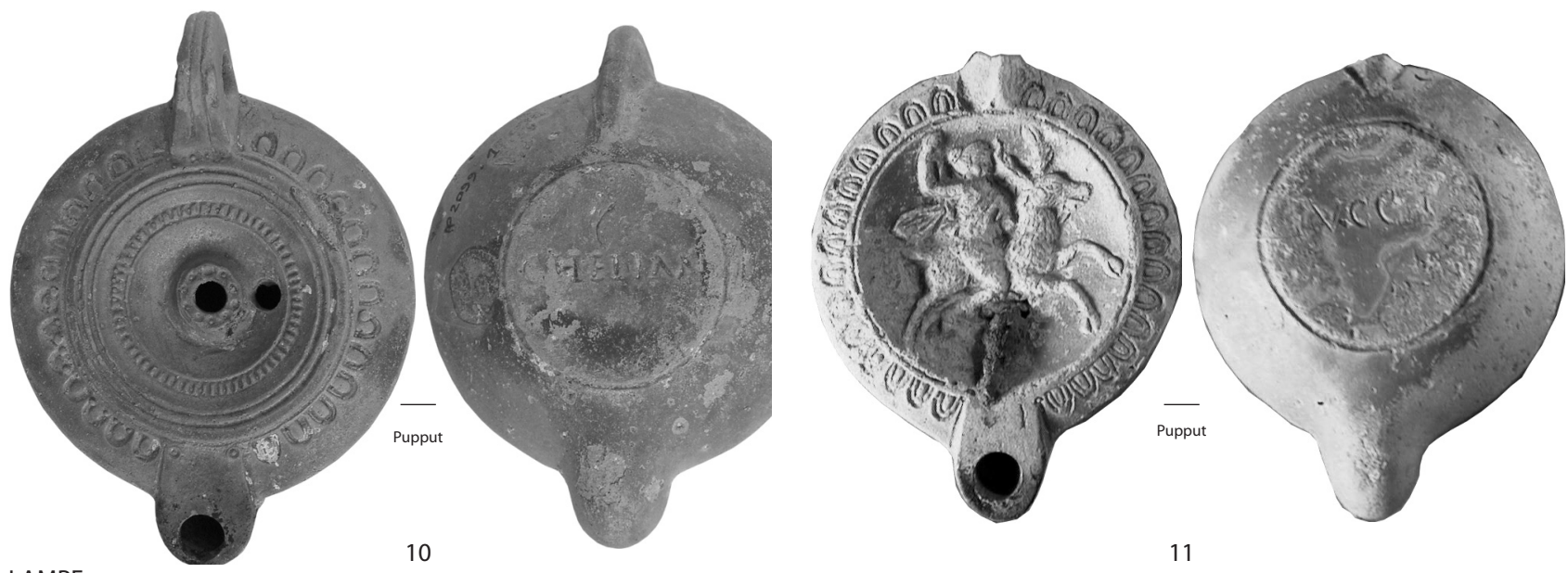

11

TYPE 8

Type Deneauve VII

sous-type 6

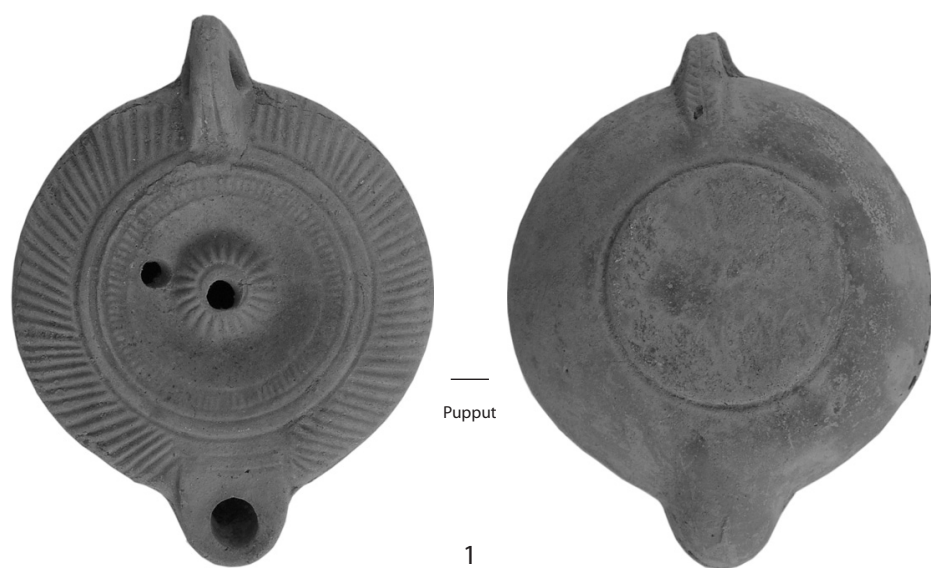

Fig. 183. Lampes africaines "à bec rond" (type Deneauve VII). 
Typologie - Lampes

Type Deneauve VIII

sous-type 1
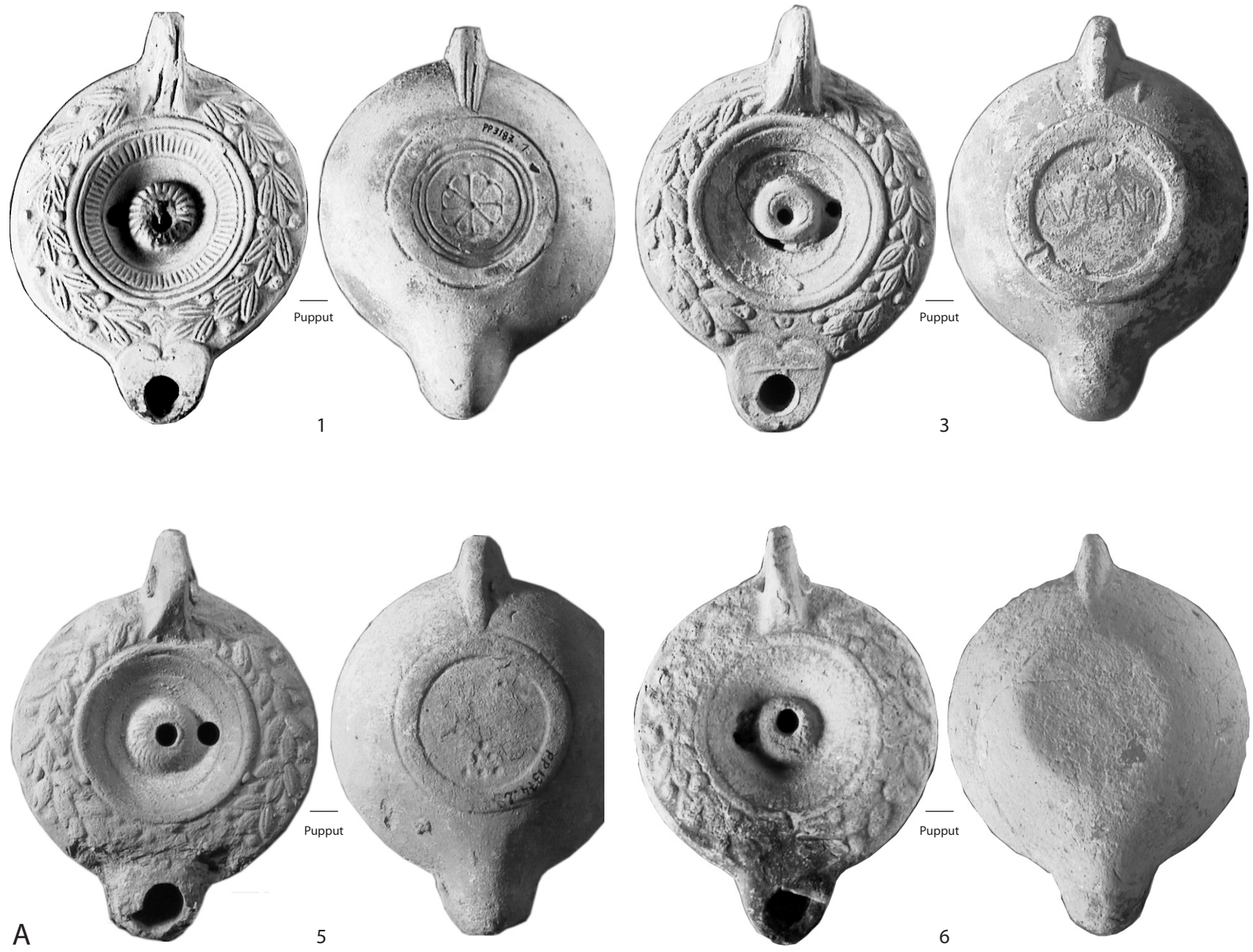

variante à bec rond
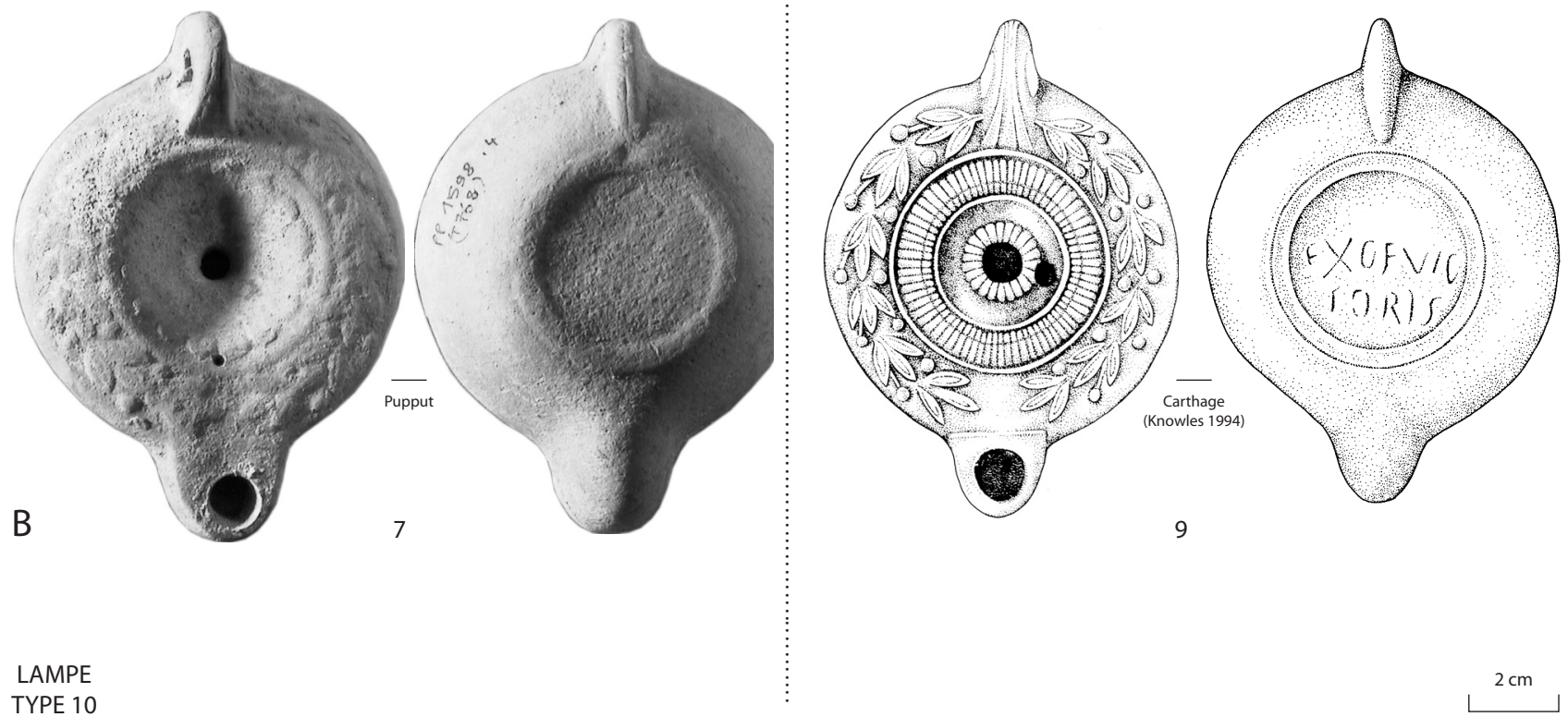

Fig. 184. Lampes africaines "à bec cordiforme" (type Deneauve VIII). 
— type Deneauve VII/sous-type 6 (fig. 183)

$=$ Bussière D X 2

\section{LAMPE TYPE 9}

Cette lampe reproduit la forme standard du type Deneauve VII avec des dimensions encore supérieures à celles du sous-type 3, voisines en fait de celles des lampes de type Deneauve VIII. Comme sur ces dernières, le bandeau est toujours décoré, dans le cas présent de stries obliques en creux. En revanche, le bec est rond et le fond plat, dégagé par un sillon, comme sur les lampes du sous-type 1. L'ombilic central n'est pas un argument de classement puisqu'il apparaît aussi bien sur les lampes de type VII-5 que sur les lampes de type VIII. Pour ces raisons, j'ai préféré conserver cette lampe au sein du type Deneauve VII.

Exemples (fig. 183) :

*1 Pupput, tombe 890 (Inv. PP2096.2). Traces d'engobe rouge orangé. Sur le disque : cercle radié et ombilic central strié. Sur le fond : marque incisée illisible. D. $86 \mathrm{~mm}$; H. $30 \mathrm{~mm}$; D. du fond $49 \mathrm{~mm}$.

2 Musée d'Oran (Bussière 2000, Pl. 90, n 3258). Comparable à la précédente. D. $83 \mathrm{~mm}$; H. $30 \mathrm{~mm}$.

Ce type ne constitue pas un groupe important. La plupart des exemplaires catalogués par $\mathrm{J}$. Bussière doivent en fait être rattachés au sous-type 2, en raison de leurs faibles dimensions (D. $75 \mathrm{~mm}$ env.) et de leur fond marqué de deux sillons. L'exemplaire $\mathrm{n}^{\circ} \mathbf{1}$, provient d'une tombe $\mathrm{du}$ milieu ou de la seconde moitié du IIIe siècle ${ }^{218}$.

\subsubsection{Lampes de type romano-africain}

\section{- Type Deneauve VIII : lampes dites « à bec cordiforme »}

Le regroupement typologique qui suit, pour lequel j'ai conservé l'appellation traditionnelle « Deneauve VIII », correspond en fait plus à celui effectué par J. Bussière sous son type D X. En effet, il s'agit de lampes généralement de grande taille (D. 80-90, mais il existe de petits modèles du sous-type 3 ), avec un bec habituellement cordiforme (mais quelquefois rond à base plate ou arrondie), un bandeau qui porte presque toujours un décor en relief (rameaux d'olivier, couronne de laurier, pampres de vigne, globules, plus rarement festons), un fond annulaire décoré de cercles concentriques, plus rarement signé d'une marque incisée, et une anse forée. Mais, à la différence de J. Bussière, j'ai toutefois exclu les lampes à bandeau décoré en creux, de plus petite taille (D. $75 \mathrm{~m}$ en moyenne), avec un bec rond (plus rarement cordiforme), et un fond plat dégagé par un ou deux sillons (types Deneauve VII/sous-types 1 et 2) ainsi que les lampes «galettes » (sous-type 5) et le soustype 6 ci-dessus. Les lampes à bec cordiforme avec un bandeau décoré de stries parallèles en creux (Deneauve $1969, \mathrm{n}^{\circ}$ 920-926) ou de festons en relief (en creux sur le

\footnotetext{
218 Associé à une lampe Deneauve VIII/sous-type 4 et une amphore Africaine II C.
}

type Deneauve VII) (Deneauve 1969, n 928-931) pourraient être considérées comme des formes de transition.

— type Deneauve VIII/sous-type 1 (fig. 184)

$=$ Salomonson g $1=$ Ennabli 12 , 1ère et 2ème séries $=$ Bussière D X $4 \mathrm{a}=$ type Pupput 6A

\section{LAMPE TYPE 10}

Le décor de cette lampe est invariablement composé de rameaux d'olivier ${ }^{219}$ sur le bandeau et de motifs géométriques circulaires sur le disque, selon deux variantes :

- Variante A : disque décoré d'un cercle en relief ou d'une bande circulaire hachurée et d'un ombilic central strié ou non, perforé ou non.

- Variante B : disque décoré d'une rosace.

Exemples (fig. 184) :

Variante A

*1 Pupput, tombe 615 (Bonifay 2004a, fig. 13, n 31). Traces d'engobe brun. Sur le fond rosace à huit pétales. D. $82 \mathrm{~mm}$; H. $29 \mathrm{~mm}$; D. du fond $43 \mathrm{~mm}$.

2 Pupput, tombe 615 (Inv. 3182.6). Engobe brun violacé à reflets métalliques. Sur le fond, marque incisée: $A V G E N D I$ au-dessus d'un cercle imprimé. D. $87 \mathrm{~mm}$; H. $31 \mathrm{~mm}$; D ; du fond $46 \mathrm{~mm}$.

*3 Pupput (Inv. PP1573.2). Traces d'engobe noir. Sur le fond: marque incisée $A V G E N D I$. D. $83 \mathrm{~mm}$; H. $30 \mathrm{~mm}$; D. du fond $47 \mathrm{~mm}$.

4 Nabeul, fabrique de salaison, bassin III (Slim, Bonifay, Trousset 1999, fig. 27). Traces d'engobe brun. D. 89 ; H. $32 \mathrm{~mm}$; D. du fond $47 \mathrm{~mm}$.

*5 Pupput (Inv. PP1374.2). Pas de trace d'engobe. D. $85 \mathrm{~mm}$; H. $34 \mathrm{~mm}$; D. du fond $44 \mathrm{~mm}$.

*6 Pupput, tombe 196 (Ben Abed, Griesheimer 2004, fig. 84, T196.1). Traces d'engobe orange vif. Décor empâté. D. $85 \mathrm{~mm}$; H. $34 \mathrm{~mm}$; D. du fond $38 \mathrm{~mm}$.

Variante B

*7 Pupput (Inv. PP1598.4). Traces d'engobe orangé. D. $86 \mathrm{~mm}$; H. $32 \mathrm{~mm}$; D. du fond $44 \mathrm{~mm}$.

8 Nabeul, fabriques de salaison, pièce XLIV (Inv. NB1878.34). Surmoulage (?) avec des décors très peu distincts, une surface granuleuse et parsemée de petites bavures d'argile, et une pâte comparable à celle du type mineur du cap Bon (infra, LAMPE TYPE 24).

Variante à bec rond

*9 Carthage, port circulaire (Knowles 1994, fig. 2.3, $\mathrm{n}^{\circ}$ 64). Sur le fond: EXOFVIC/TORIS. D. $78 \mathrm{~mm}$; H. $28 \mathrm{~mm}$.

10 Tipasa, nécropole de la porte de Césarée (Bussière 2000, Pl. 92, $\mathrm{n}^{\circ}$ 3322). Sur le fond: EXOFVIC/TORIS. D. $84 \mathrm{~mm}$; H. $31 \mathrm{~mm}$.

A Pupput, les plus anciennes de ces lampes apparaissent dans une tombe de la fin du IIe s. ou du début du IIIe s. (tombe 615$)^{220}$, mais le type dure certainement tout au long du IIIe s. puisque on en retrouve une variante

\footnotetext{
${ }^{219}$ Sur la question de savoir s'il s'agit de rameaux d'olivier, de myrte ou de laurier, voir Bussière 2000, 109, note 86 .

${ }^{220}$ Avec une couverture d'amphores Africaines II A con gradino et Hammamet $1 \mathrm{C}$.
} 
Type Deneauve VIII

sous-type 2
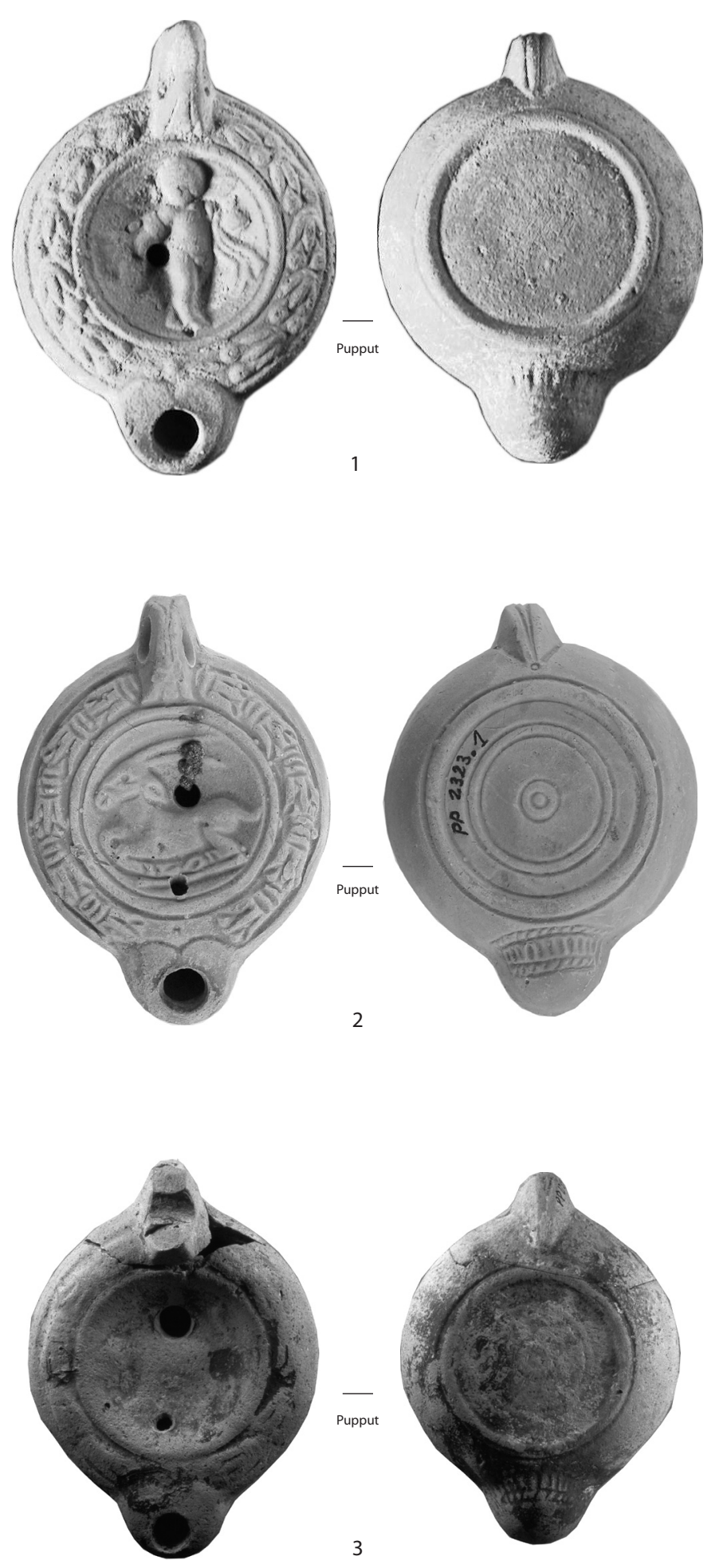

Fig. 185. Lampes africaines "à bec cordiforme" (type Deneauve VIII). 
abâtardie dans les contextes du IVe s. (infra, LAMPE TYPE 29). La présence d'un bec rond limité par un trait, à la place du bec cordiforme n'est pas forcément un critère chronologique mais peut-être une particularité locale de certaines lampes marquées EXOFVICTORIS, probablement produites à Tipasa ou à Cherchell (Bussière 2000, 147).

Des lampes peu nombreuses, absentes de la documentation de Pupput mais attestées dans la bibliographie, ont une décoration de bandeau assez proche (avec parfois de longues tiges reliant les baies rondes aux feuilles ou pas de baies du tout) mais se distinguent par un disque à décor figuré : Mars conduisant un char tiré par des loups (Deneauve 1969, $\mathrm{n}^{\circ}$ 937), Méléagre chassant le sanglier de Calydon (Bussière 2000, Pl. 92, $\mathrm{n}^{\circ}$ 3382), scène érotique (Ben Lazreg 2000, 69, $\mathrm{n}^{\circ} 28$ ). Ces lampes ne doivent pas être attribuées au sous-type 1, d'autant que certaines (les deux premières des trois précédemment citées) portent une décoration hachurée sous le bec, à la manière des lampes du sous-type 2 . On doit probablement ranger dans cette série les lampes Deneauve VIII avec un bandeau décoré de festons en relief (ex. Deneauve 1969, n 928-929) dont le dessous du bec est également décoré.

- type Deneauve VIII/sous-type 2 (fig. 185)

$=$ Salomonson g $2=$ Ennabli 12, 3ème série

$=$ Bussière D X 4b = type Pupput 6B

\section{LAMPE TYPE 11}

Le sous-type 2, de plus petite taille que le précédent (D. $80 \mathrm{~mm}$ en moyenne), se distingue par la présence systématique, sur le bandeau, d'une guirlande de laurier nouée (?). Le décor sur le disque est plus varié que sur le sous-type 1 , avec une fréquence toute particulière de représentations animales. Le dessous du bec est généralement décoré d'une bande hachurée entre deux cordons et le fond de plusieurs cercles concentriques en relief.

Exemples (fig. 185) :

*1 Pupput, tombe 897 (Inv. PP3338.1). Traces d'engobe orange. Sur le disque : amour à droite (Deneauve 1969, $\mathrm{n}^{\circ}$ 952). Sous le bec: bande hachurée et cordon. D. : $83 \mathrm{~mm}$; H. : $30 \mathrm{~mm}$; D. du fond : $57 \mathrm{~mm}$.

*2 Pupput, tombe 906 (Bonifay 2004a, fig. 13, n 32). Traces d'engobe marron orangé. Sur le disque: gazelle couchée à gauche. Sous le bec: bande hachurée encadrée de deux cordons. Sous le fond: cercles concentriques. D. : $80 \mathrm{~mm}$; H. : $31 \mathrm{~mm}$; D. $\mathrm{du}$ fond : $52 \mathrm{~mm}$.

*3 Pupput, tombe 318 (Inv. PP1213.1). Traces d'engobe brun. Sur le disque : félin à gauche. Sous le bec : hachures. Sur le fond cercles concentriques. D. $76 \mathrm{~mm}$; H. $29 \mathrm{~mm}$; D. du fond $50 \mathrm{~mm}$.

4 Pupput, tombe 332 (Inv. PP3826.1). Traces d'engobe brun. Sur le disque : coq à droite. Sous le bec : bande hachurée encadrée de deux cordons. Sur le fond: cercles concentriques. D. $77 \mathrm{~mm}$.

Les données de Pupput ne permettent pas, actuellement, de préciser la datation de ce type, traditionnellement placé au deuxième quart ou au milieu du IIIe s. (Bussière 2000, 110).

\section{- type Deneauve VIII/sous-type 3 (fig. 186) \\ $=$ Bussière D X 5 = type Pupput $6 \mathrm{C}$}

\section{LAMPE TYPE 12}

Ces lampes, qui ont en commun un bandeau décoré de pampres de vigne, forment un ensemble assez hétérogène dans le détail. J. Bussière $(2000,110)$ distingue six séries selon la disposition des grappes et des feuilles sur la partie du bandeau comprise entre l'anse et le bec. La documentation de Pupput, associée à celle de Carthage (Deneauve 1969), fait apparaître, en fonction du décor, de la forme du bec et de quelques marques, trois variantes homogènes :

- Variante A: Lampe de petite taille (D. : 75$78 \mathrm{~mm}$ ). Le décor du bandeau est disposé, selon le rythme grappes-feuilles-grappes-feuilles, en deux rinceaux continus terminés par deux volutes affrontées au-dessus du bec cordiforme (un point en relief sous les volutes). Le dessous du bec est décoré. Cercles concentriques en creux sous le fond. Marque C HEL sur un exemplaire de Carthage (2).

- Variante B : Lampe de grande taille (D. 95-99 mm). Le décor du bandeau est disposé, selon le rythme grappe-feuille-grappe-feuille, avec des motifs discontinus mais pressés les uns contre les autres. Le disque donne la même impression de remplissage maximum de l'espace décoratif. L'aspect cordiforme du bec est accentué par deux ébauches de volutes dégageant une tige verticale. Le dessous du bec n'est pas décoré. Le fond est annulaire, souligné par deux cannelures concentriques. Marques STERCEI sur des exemplaires de Pupput (3) et de Carthage (4).

- Variante C: Lampes de petite taille (D. $80 \mathrm{~mm}$ à $65 \mathrm{~mm}$ ). Le décor du bandeau est disposé, selon le rythme feuille-grappe-feuille-grappe, en éléments légèrement espacés. Deux points ocellés en creux, au-dessus du bec à base arrondie. Décor du disque généralement composé de deux amours, l'un soutenant l'autre, ivre, qui porte une grappe de raisin. Dessous du bec non décoré. Fond annulaire délimité par deux cannelures, entre lesquelles le motif pseudo-épigraphique $O V O$ (?) est répété trois fois, et souligné par un cercle.

Exemples (fig. 186):

Variante A

*1 Pupput, tombe 449 (Bonifay 2004a, fig. 13, n 33). Traces d'engobe beige à brun. Sur le disque : tête de Méduse (?). Sous le bec: hachures en creux et festons en relief. Sous le fond : cercles concentriques en creux. D. : $78 \mathrm{~mm}$; H. : $28 \mathrm{~mm}$; D. du fond : $44 \mathrm{~mm}$.

2 Carthage (Deneauve 1969, $\mathrm{n}^{\circ}$ 981). Engobe rouge. Sur le disque : Sérapis et Isis à droite. Sous le fond : marque incisée C HEL. D. $75 \mathrm{~mm}$; H. $28 \mathrm{~mm}$.

Variante B

*3 Pupput, tombe 285 (Inv. PP4000.1). Traces d'engobe brun. Sur le disque : Europe sur un taureau, à gauche. 


\section{Typologie - Lampes}

Type Deneauve VIII sous-type 3

A
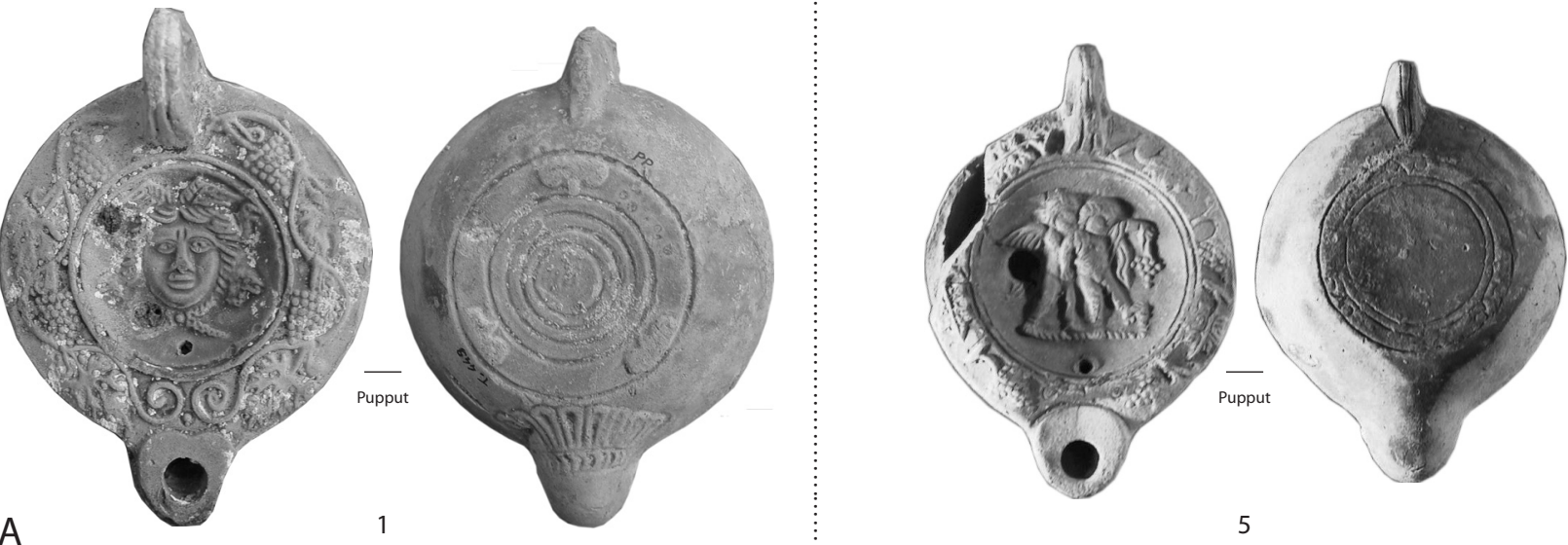

C
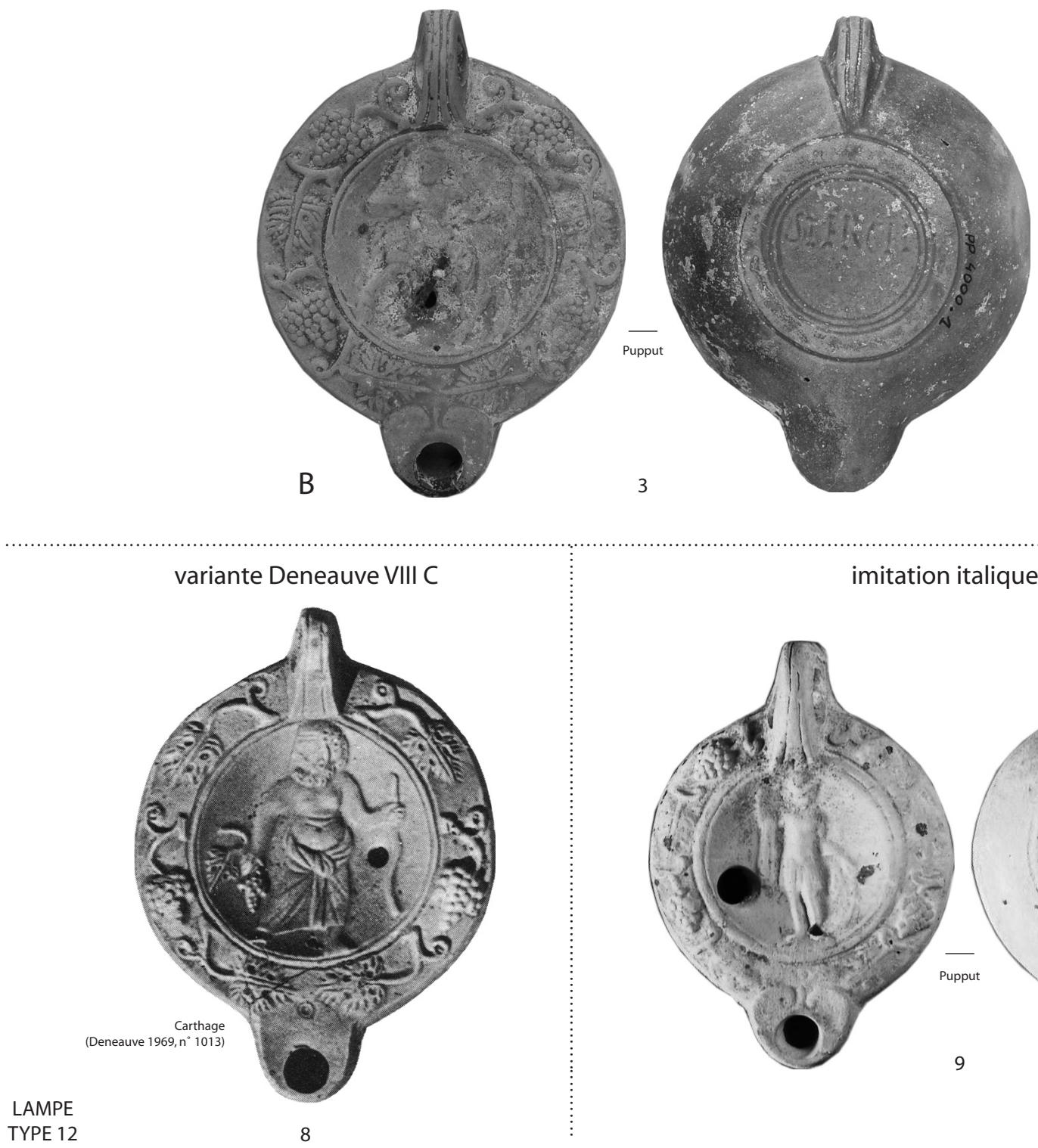

imitation italique (?)

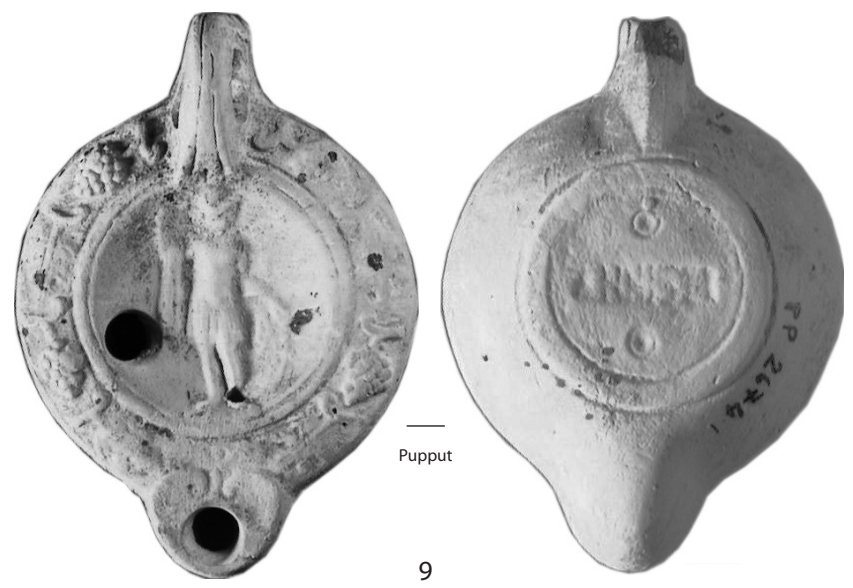

Fig. 186. Lampes africaines "à bec cordiforme" (type Deneauve VIII). 
Type Deneauve VIII sous-type 4
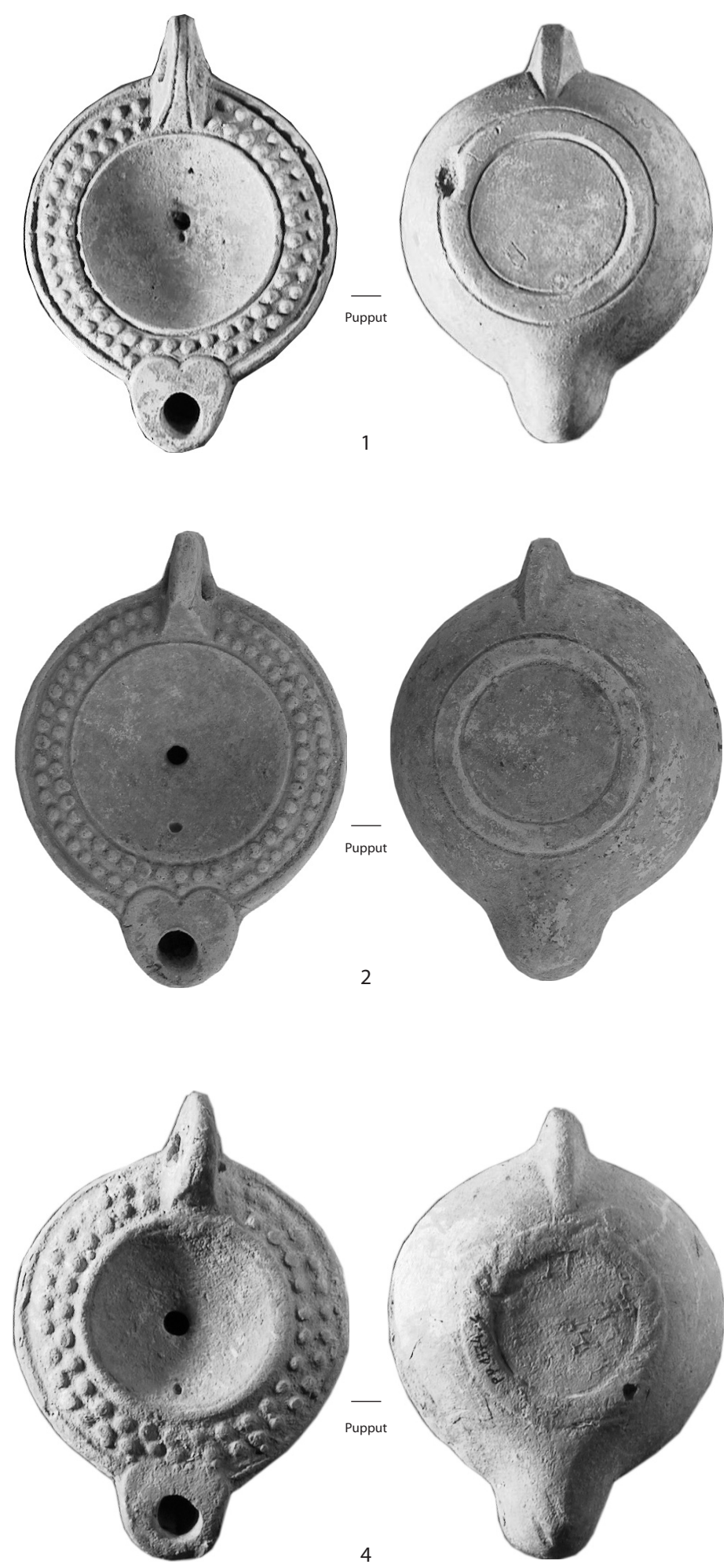

Fig. 187. Lampes africaines "à bec cordiforme" (type Deneauve VIII). 
Sous le fond : marque incisée STERCEI. D. $99 \mathrm{~mm}$; D. du fond $52 \mathrm{~mm}$.

4 Carthage (Deneauve 1969, $\mathrm{n}^{\circ}$ 973). Engobe jaunerouge. Sur le disque : CEdipe devant le Sphinx. Sur le fond: marque incisée STERCEI. D. $95 \mathrm{~mm}$; H. $34 \mathrm{~mm}$.

Variante $\mathrm{C}$

*5 Pupput, tombe 944 (Inv. 3441.1). Engobe brunorange écaillé. Bec rond à base arrondie. Sur le disque : deux amours. D. : $64 \mathrm{~mm}$; H. : $26 \mathrm{~mm}$; D. $\mathrm{du}$ fond : $41 \mathrm{~mm}$.

6 Carthage (Deneauve 1969, $\mathrm{n}^{\circ}$ 906). D. $81 \mathrm{~mm}$.

7 Musée de Skikda (ex-Philippeville) (Bussière 2000, Pl. 97, $\mathrm{n}^{\circ}$ 3721). D. $78 \mathrm{~mm} ; \mathrm{H} ; 2,8 \mathrm{~mm}$.

Cette typologie interne est loin d'être exhaustive. Un quatrième groupe avait été identifié par J. Deneauve (1969, 206-207: type VIII C) (8) : non représenté à Pupput, il apparaît de manière très homogène à Carthage, caractérisé par des motifs feuilles-grappes-feuilles de grande taille régulièrement espacés sur le bandeau et un décor central de grande qualité graphique (Silène, satyres, bacchantes...) ; le bec, à extrémité arrondie, n'est pas délimité par rapport au bandeau; certaines de ces lampes sont marquées EX OFFI POMPEI PONTIANI. Exemple (fig. 186) :

*8 Carthage, Bordj Djedid (Deneauve 1969, n 1013). " Terre brun très pâle, engobe rouge ». Sur le disque : Silène. D. $96 \mathrm{~mm}$.

Bien représentées en Tunisie septentrionale, ces lampes semblent plus rares en Tunisie centrale (un seul exemplaire à Raqqada). Elles ont été reproduites par de nombreux ateliers locaux (cf. les exemplaires algériens : Bussière 2000, 360-362) et imitées en Italie (Ceci 2001, fig. 1a : imitation de la variante B).

Exemple (fig. 186) :

*9 Pupput (Inv. 2674.1). Engobe brun orangé écaillé. Sur le disque : Mars (?). Sur le fond, marque incisée : $\operatorname{ANNISE}(R)$ ? entre deux cercles imprimés. D. : $82 \mathrm{~mm}$; H. : $27 \mathrm{~mm}$; D. du fond : $48 \mathrm{~mm}$. Imitation italique, atelier d'Annius Serapiodorus à Ostie (?) : Ceci 2003, fig. $1, \mathrm{n}^{\circ} 4$.

Les données de Pupput ne permettent pas, actuellement, de préciser la datation de ce type traditionnellement placé au deuxième quart-milieu du IIIe $\mathrm{s}$. et peut-être encore produit jusqu'à la fin du siècle (Bussière 2000, 111). Voir la variante tardive non engobée (infra, LAMPE TYPE 31 ).

\section{- type Deneauve VIII/sous-type 4 (fig. 187)}

$=$ Ennabli 12, 4ème série $=$ Bussière D X 6

$=$ type Pupput $6 \mathrm{D}$

\section{LAMPE TYPE 13}

Ces lampes se caractérisent par un bandeau décoré de deux ou parfois trois rangées de globules et un disque sans décor. Le bec est cordiforme, le fond annulaire et l'anse généralement forée.

Exemples (fig. 187) :

*1 Pupput, tombe 628 (Bonifay 2004a, fig. 14, n 34).
Engobe brun écaillé. D. $81 \mathrm{~mm}$; H. $30 \mathrm{~mm}$; D. du fond $51 \mathrm{~mm}$.

*2 Pupput, tombe 890 (Inv. PP2096.1). Traces d'engobe rouge orangé. D. $86 \mathrm{~mm}$; H. $30 \mathrm{~mm}$; D. du fond $49 \mathrm{~mm}$.

3 Pupput (Inv. PP2531.1). Pâte légèrement micacée, engobe orange écaillé. Sur le fond marque incisée : VICTOR. D. $84 \mathrm{~mm}$; H. $35 \mathrm{~mm}$; D. du fond $47 \mathrm{~mm}$.

*4 Pupput (Inv. PP1374.4). Pâte beige orangé, traces d'engobe orangé. D. $87 \mathrm{~mm}$; H. $32 \mathrm{~mm}$; D. du fond $48 \mathrm{~mm}$.

La datation de ce type est assez controversée. Une datation trop haute, dans la seconde moitié du IIe s., doit être accueillie avec prudence. Beaucoup de lampes citées en comparaison appartiennent en fait à d'autres catégories (Bussière 2000, 111 : le $\mathrm{n}^{\circ} 3568$ me paraît être plutôt une variante tardive du type Bussière C VI). Les quelques exemplaires trouvés dans des tombes ne sont pas antérieurs au IIIe s., par exemple à Vintimille ${ }^{221}$. A Pupput, l'exemplaire $\mathrm{n}^{\circ} \mathbf{2}$ provient d'une tombe de la seconde moitié du IIIe siècle.

Une série avec un seul rang de perles souligné par des festons semble caractéristique des productions de Tripolitaine (Joly 1974, n 678-701; Bailey 1994, $\mathrm{n}^{\circ}$ 246-248; Rebuffat $1987, \mathrm{n}^{\circ} 5$ et 6 : « rang de perles cernées d'un méandre ») (Ben Abed, Bonifay 1998, 242 et note 48 ; infra, LAMPE TYPE 19).

Datation proposée : seconde moitié du IIIe s.

\section{- lampes à bec triangulaire}

La forme de ces lampes, tout à fait originale par rapport aux modèles italiques contemporains, les a fait qualifier par J. Deneauve de véritablement «africaines ». Généralement de grande taille, elles se composent d'un réservoir circulaire (D. 80-90 mm en moyenne) auquel est attaché un long bec à extrémité triangulaire décoré de volutes (L. max. des lampes : 100-150 mm). J. Deneauve distingue deux types principaux, aujourd'hui complétés d'un troisième par J. Bussière.

- type Deneauve X/sous-type 1 (fig. 188)
= Deneauve X B = Bussière E I 3

\section{LAMPE TYPE 14}

Ces lampes sont encore très proches de celles du type Deneauve VIII, avec un bandeau décoré soit en creux (variante A), soit en relief (variantes B et C) ; les volutes du bec sont ornées d'un motif baroque évoquant des ailes d'oiseau. Quatre variantes, en fonction de la décoration du bandeau :

221 LAMBOGLIA (N.) - La stratigrafia del theatro di Albintimilium. RELig, XVI, 1950, p. 196, fig. 23 : la tombe 160 , initialement datée de la seconde moitié du IIe s. par une monnaie de Marc Aurèle, a été rajeunie d'un siècle lorsque l'auteur s'est aperçu, en faisant son classement des sigillées claires, qu'elle était accompagnée d'un vase en sigillée luisante (forme 28) qui ne pouvait être antérieur au milieu du IIIes. (Lamboglia 1963, 176 et note 1). 
- Variante A : bandeau non décoré, anse en ruban.

- Variante B : bandeau décoré de strigiles, anse en ruban (?).

- Variante C : bandeau décoré de rameaux d'olivier (cf. lampe africaine Deneauve VIII/1), anse en anneau.

- Variante D : bandeau décoré de pampres de vigne (cf. lampe africaine Deneauve VIII/3) ; anse en ruban décorée de stries parallèles.

Lampes citées pour mémoire, pas de documentation nouvelle.

Exemples (fig. 188) :

Variante A

1 Uzita (Van der Werff 1982a, Pl. 64).

Variante B

*2 Carthage (Deneauve 1969, $\mathrm{n}^{\circ}$ 1061). Timbre $M$ NOV IVSTI. D. $85 \mathrm{~mm}$; H. $36 \mathrm{~mm}$.
Variante C

*3 Carthage (Deneauve 1969, $\mathrm{n}^{\circ}$ 1060). D. $92 \mathrm{~mm}$; H. $35 \mathrm{~mm}$.

Variante D

*4 Carthage (Deneauve 1969, $\mathrm{n}^{\circ}$ 1063). D. $96 \mathrm{~mm}$; H. $39 \mathrm{~mm}$.

Variante à décor plastique

5 Carthage, Bordj Djedid (Deneauve 1969, $\mathrm{n}^{\circ} 1066$ ). Lion couché dressant la tête surmontant le disque. D. $120 \mathrm{~mm}$.

La variante A pourrait être la plus ancienne (fin du IIe s. ?), avec son décor de strigiles et son timbre $M N O V$ IVSTI (Bussière 2000, 115-116); mais l'anse en ruban se rapproche de celle de la variante $C$. Les variantes $B$ et $C$ sont probablement plus tardives (fin du IIe s. - début du IIIe s. ?), peut-être contemporaines des types suivants.

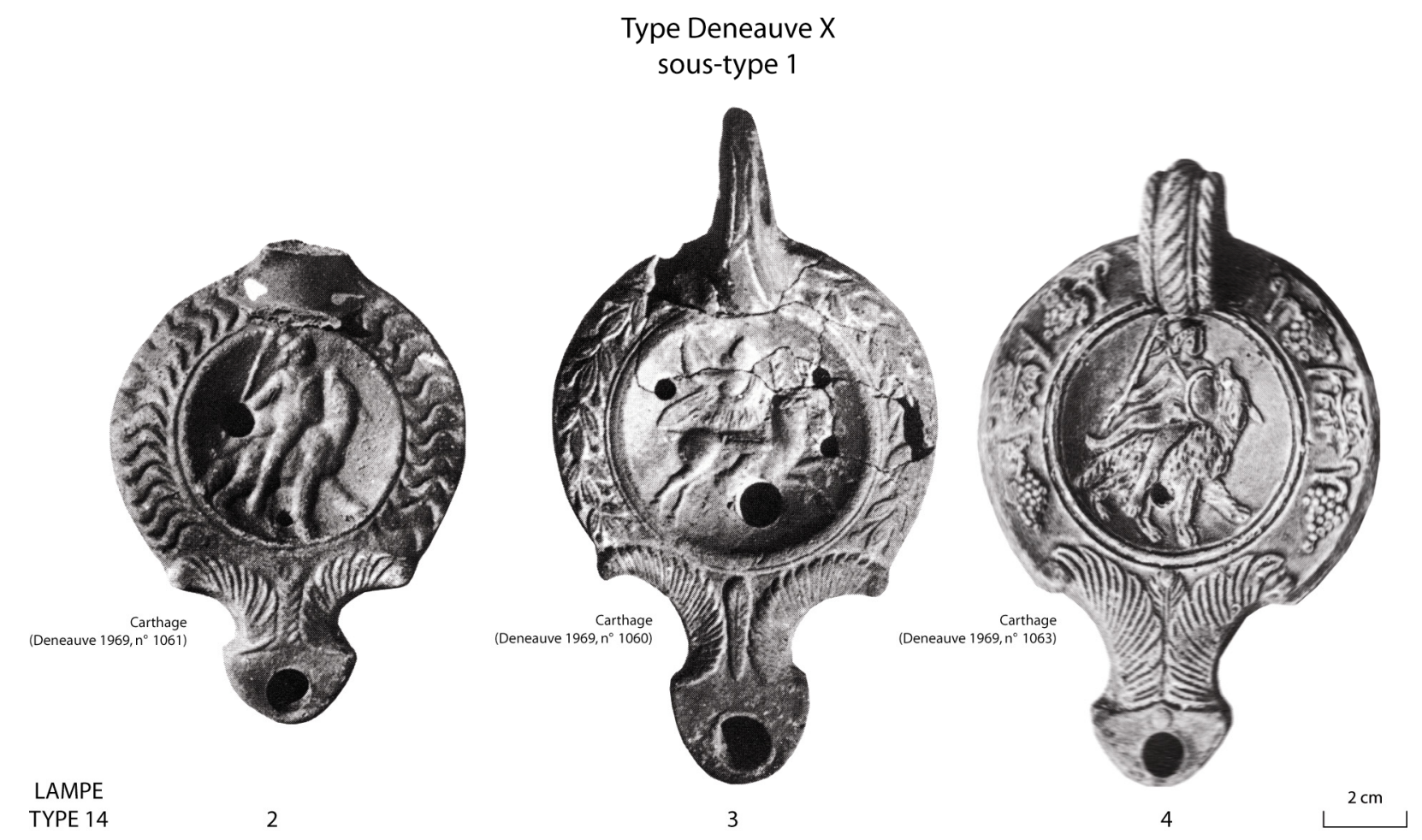

Fig. 188. Lampes africaines "à bec triangulaire" (type Deneauve X).

- type Deneauve X/sous-type 2 (fig. 189-190)

$=$ Deneauve $\mathrm{X} \mathrm{A}=$ Bussière $\mathrm{E}$ I 1

\section{LAMPE TYPE 15}

Je propose, sur la base de la documentation de Pupput et surtout de celle rassemblée par J. Deneauve à Carthage (Deneauve 1986a), de distinguer les variantes suivantes :

- Variante A (= Deneauve 1986a, groupe 1) : Lampe de petite taille (D. : $65-70 \mathrm{~cm}$; H. du réservoir : 25 $30 \mathrm{~mm}$ ). Bandeau mouluré. Bec triangulaire court cantonné de deux demi-lunes sans volutes. Fond mouluré. Sur le disque : deux masques de théâtre dans un rectangle.

- Variante B (= Deneauve 1986a, groupe 2) : Lampe de grande taille (D. $85-92 \mathrm{~mm}$ ). Bandeau étroit séparé du disque par deux sillons. Bec triangulaire cantonné de deux demi-lunes très rapprochées; volutes atrophiées; cœur ou larme au départ du bec. Fond à trois anneaux. Sur le disque : nature morte. - Variante C: Lampe de grande taille (D. $85 \mathrm{~mm}$ env. ; H. 35 mm env.). Bandeau mouluré. Bec étroit cantonné de deux volutes. Fond en anneau. Sur le disque : motif mythologique.

- Variante D (= Deneauve 1986a, groupe 4) : Lampe de taille comparable à la précédente. Bandeau mouluré. Bec large, cantonné par des volutes en fort relief, avec « représentation d'un phare à plusieurs gradins, son sommet dirigé vers l'orifice de la mèche » (Deneauve 1986a, 146). Fond mouluré. Sur le disque : scènes portuaires et autres édifices. 
Typologie - Lampes

Type Deneauve X

sous-type 2

A
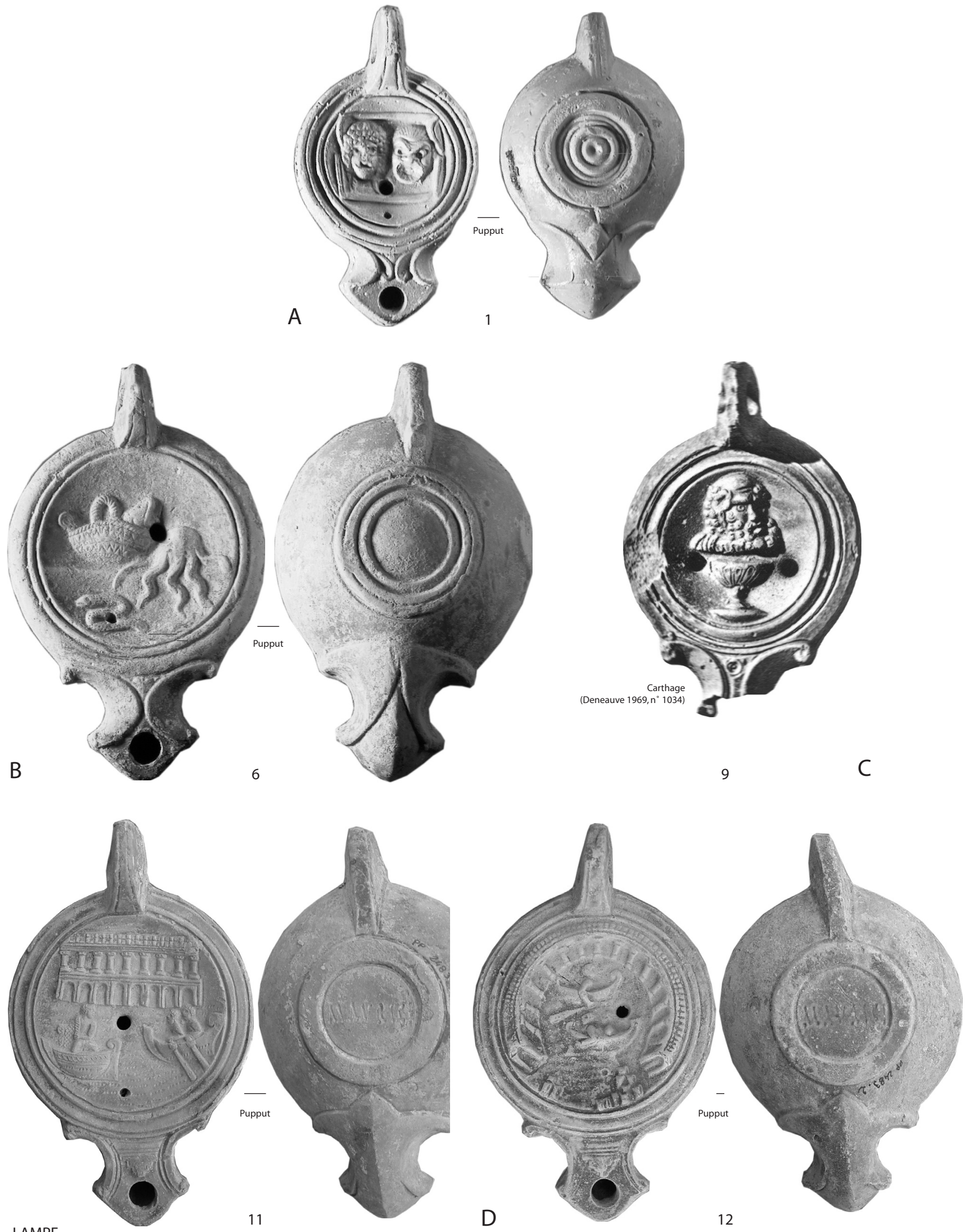

TYPE 15

Fig. 189. Lampes africaines "à bec triangulaire" (type Deneauve X). 
- Variante E (= Deneauve 1986a, groupe 5) : Lampe de taille comparable à la précédente. Bandeau mouluré. Bec cantonné par deux volutes, à extrémité aplatie. Fond en anneau. Sur le disque : scènes de banquets.

- Variante F (= Deneauve 1986a, groupe 3) : Lampes de grande taille (D. $92 \mathrm{~mm}$ ). Bandeau lisse. Bec étroit et proéminent, cantonné de deux volutes simplifiées. Sur le disque : scènes mythologiques.

- Variante G (= Deneauve 1986a, groupe 6) : Lampe de très grande taille (D. 90-95 mm; H. $34 \mathrm{~mm}$ ). Bandeau décoré de feuilles d'acanthes. Bec triangulaire assez court, cantonné de deux quarts de lune. Fond mouluré (ou en anneau : $\mathrm{n}^{\circ} 1050$ ). Sur le disque : scène de jeux ou de théâtre.

- Variante H: Bandeau décoré de festons. Bec triangulaire cantonné de deux volutes en fort relief; pelte au centre, au départ du bec. Fond en anneau. Sur le disque : bestiaires.

Exemples :

Variante A (fig. 189)

*1 Pupput, tombe 1096 (Inv. 2574.1). Surface saumon à reflets métalliques. Sur le disque : deux masques de théâtre dans un rectangle. Sur le fond: cercles concentriques. Sur la paroi droite marque en relief (incisée dans le moule) LVCCEI. D. $66 \mathrm{~mm} ; \mathrm{H}$. $27 \mathrm{~mm}$; D. du fond $37 \mathrm{~mm}$.

2 Carthage (Deneauve 1969, $\mathrm{n}^{\circ}$ 1035).

3 Bulla Regia, Musée du Bardo (CMA, Pl. XXXVI, $\left.\mathrm{n}^{\circ} 344\right)$.

4 British Museum (Bailey 1988, Q 1716).

5 Bu Njem (Rebuffat 1987, 89, $\mathrm{n}^{\circ} 10$ ).

Variante B (fig. 189)

*6 Pupput, tombe 867 (Inv. 1954.2). Traces d'engobe brun. Sur le disque : panier contenant poisson, poulpe et murène. D. $92 \mathrm{~mm}$; H. $33 \mathrm{~mm}$; D. du fond $48 \mathrm{~mm}$.

7 Carthage (Deneauve 1969, $\mathrm{n}^{\circ}$ 1040). Sur le disque : fruits. D. $86 \mathrm{~mm}$; H. $36 \mathrm{~mm}$.

8 Idem (Ibid., $\mathrm{n}^{\circ}$ 1041). Sur le disque: légumes et pains. D. 89 ; H. $33 \mathrm{~mm}$.

Variante C (fig. 189)

*9 Carthage (Deneauve 1969, $\mathrm{n}^{\circ}$ 1034). Sur le disque : tête de Silène au-dessus d'une coupe. D. : $85 \mathrm{~mm}$; H. : $35 \mathrm{~mm}$.

10 Idem (Ibid., $\mathrm{n}^{\circ}$ 1037). Sur le disque: Méléagre chassant le sanglier de Calydon. D. : $86 \mathrm{~mm}$; H. : $32 \mathrm{~mm}$.

Variante D (fig. 189)

*11 Pupput, tombe 446 (Bonifay 2004a, fig. 14, n 35). Traces d'engobe brun. Sur le disque : architecture portuaire. Sur le fond : marque incisée MAVRICI. D. $88 \mathrm{~mm}$; H. $32 \mathrm{~mm}$; D. du fond $47 \mathrm{~mm}$.

*12 Pupput, tombe 446 (Inv. 2483.2). Traces d'engobe brun. Sur le disque : architecture portuaire. Sur le fond: marque incisée MAVRICI. D. $87 \mathrm{~mm}$; H. $30 \mathrm{~mm}$; D. du fond $45 \mathrm{~mm}$.

13 Carthage (Deneauve 1969, $\left.n^{\circ} 1044\right)$. Décor identique à la précédente. D. $85 \mathrm{~mm} ;$ H. $28 \mathrm{~mm}$.

14 Idem (Ibid. , $\mathrm{n}^{\circ}$ 1045). Sur le disque : architecture portuaire et pêcheurs. D. $88 \mathrm{~mm}$; H. $32 \mathrm{~mm}$.

15 British Museum (Bailey 1988, Q 1715). Sur le fond : marque incisée $A V G E N D I$. D. $86 \mathrm{~mm}$.
Variante E (fig. 190)

16 Carthage (Bailey 1988, Q 1717). D. : $87 \mathrm{~mm}$.

*17 Carthage (Deneauve 1986a, fig. 15). Sur le disque : scène de banquet (?). Sur le fond: marque incisée VENVSII.

Variante F (fig. 190)

*18 Carthage (Deneauve 1969, $\mathrm{n}^{\circ}$ 1042. Sur le disque : Europe à droite. Sur le fond: marque incisée PVLLAENII. D. $93 \mathrm{~mm}$.

Variante G (fig. 190)

*19 Carthage (Deneauve 1969, $\mathrm{n}^{\circ} 1050$ ). Sur le disque : acteur. D. $94 \mathrm{~mm}$; H. $34 \mathrm{~mm}$.

20 Idem (Ibid., $\mathrm{n}^{\circ}$ 1052). D. $90 \mathrm{~mm}$.

21 British Museum (Bailey 1988, Q 1718). D. $95 \mathrm{~mm}$

22 Littoral tunisien, site $\mathrm{n}^{\circ} 38$ (Henchir er-Rekrama) (Bonifay et al. 2002-2003, fig. 9, $\mathrm{n}^{\circ} 83$ ). D. $94 \mathrm{~mm}$.

Variante H (fig. 190) Variante courante

23 Carthage (Deneauve 1969, $\mathrm{n}^{\circ} 1053$ ). Sur le disque : bestiaire. D. $85 \mathrm{~mm}$; H. $28 \mathrm{~mm}$.

*24 Idem (Ibid., $\mathrm{n}^{\circ}$ 1055). D. 84 mm ; H. 24 mm.

25 Carthage, port circulaire (Knowles 1994, fig. 2.3, $\mathrm{n}^{\circ}$ 94). D. $85 \mathrm{~mm}$; H. $24 \mathrm{~mm}$.

Variante de grande taille

26 Carthage (Deneauve 1969, $\mathrm{n}^{\circ}$ 1056). D. $94 \mathrm{~mm}$; H. $32 \mathrm{~mm}$.

La datation traditionnelle de ce type entre 175 et 250 (Bailey 1988, 189) est confirmée par la marque incisée du $\mathrm{n}^{\circ} \mathbf{1}$. Le $\mathrm{n}^{\circ} \mathbf{6}$ provient d'une tombe du milieu ou de la seconde moitié du IIIe siècle ${ }^{222}$. Un curieux exemplaire de la variante $G$, muni d'un pied tubulaire haut de $25 \mathrm{~cm}$, est issu d'un contexte de la fin du IIIe s., dans la villa de Vilauba, près de Gérone (Castanyer, Tremoleda 1999, 283-284, fig. 174).

- type Deneauve X/sous-type 3 (fig. 190)

$=$ Deneauve X A, $\mathrm{n}^{\circ} 1059=$ Bussière E I 2

\section{LAMPE TYPE 16}

J. Bussière $(2000,115)$ a proposé de créer une nouvelle variante de la forme Deneauve $\mathrm{X}$, en rapprochant les exemplaires 1059 et 1103 de J. Deneauve (1969, Pl. XCVI). Chacun des deux correspond à une variante différente :

- Variante A (groupe 2 de Bussière): lampe « coquille», en forme de vasque à cannelures concaves sur le dessus et convexes au-dessous, avec un bec court et large.

- Variante B (groupe 1 de Bussière): lampe « oursin », pouvant évoquer (?) la structure rayonnée de la carapace de l'animal une fois dépouillée de ses spicules.

Lampes citées pour mémoire, pas de documentation nouvelle.

Exemples (fig. 190) :

Variante A

*1 Carthage (Deneauve 1969, $\mathrm{n}^{\circ} 1103$ ). D. $95 \mathrm{~mm}$; H. $35 \mathrm{~mm}$.

2 Marseille, chantier de La Bourse (Del Vais 1998b, fig. $\left.55, \mathrm{n}^{\circ} 33\right)$.

\footnotetext{
${ }^{222}$ Associée à des amphores Africaines II B.
} 
Typologie - Lampes

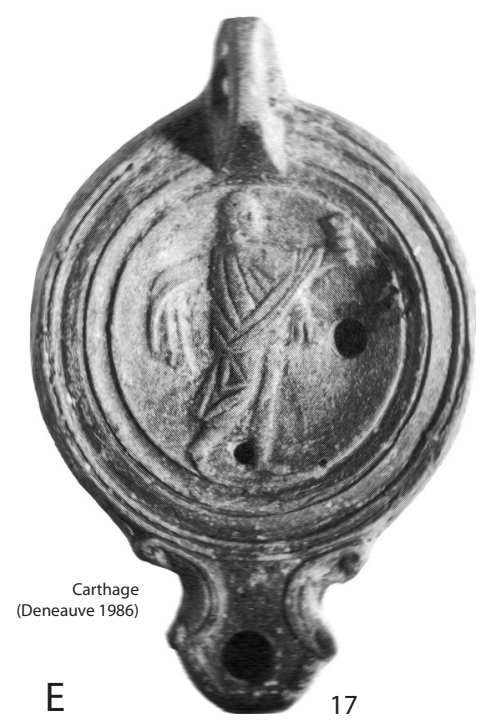

Type Deneauve X sous-type 2
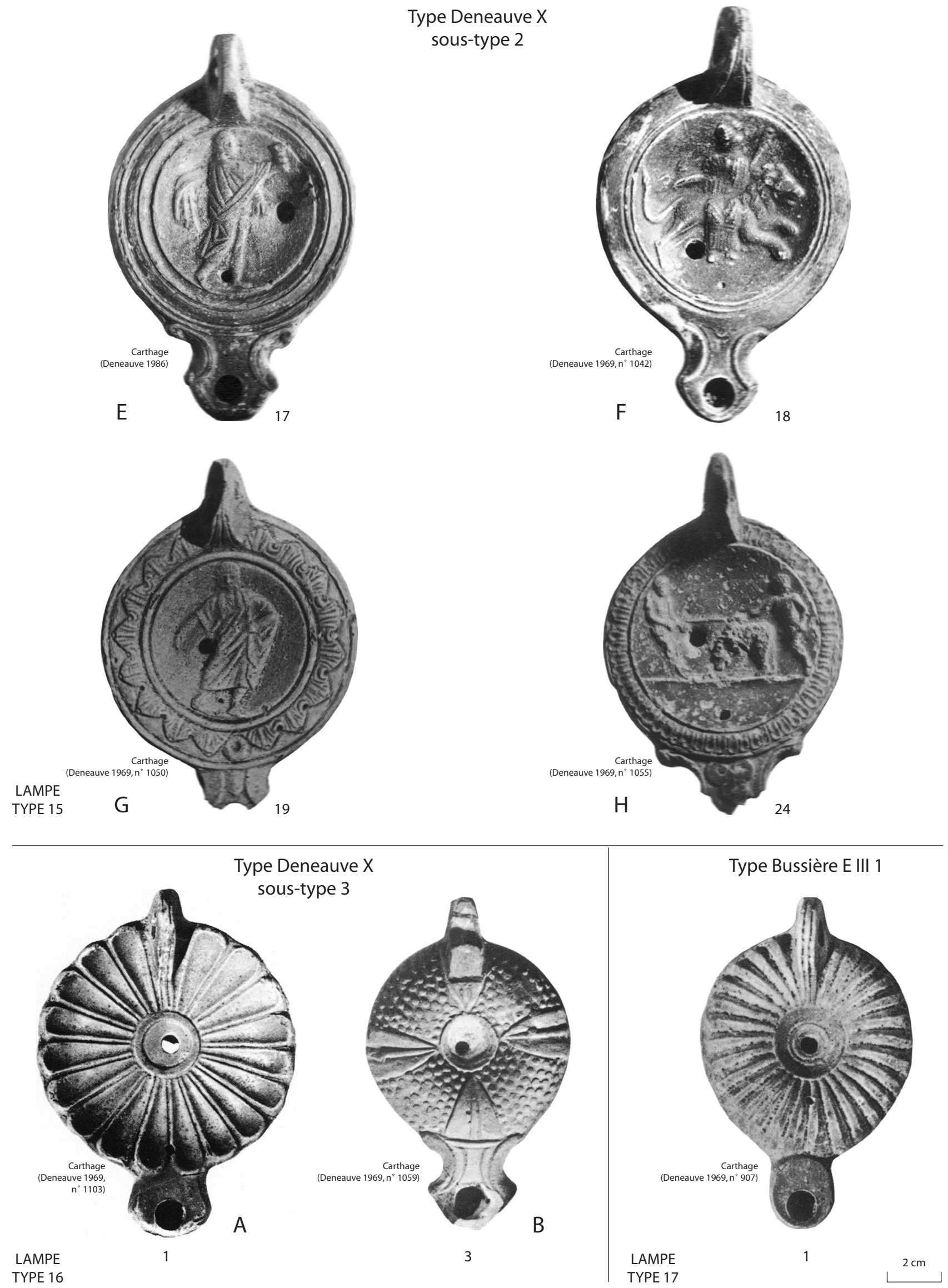

Fig. 190. Lampes africaines "à bec triangulaire" (type Deneauve X). 
Variante B

*3 Carthage (Deneauve 1969, $\mathrm{n}^{\circ} 1059$ ). D. $75 \mathrm{~mm}$; H. $33 \mathrm{~mm}$.

4 Carthage (?), British Museum (Bailey 1988, Q 1719). D. $80 \mathrm{~mm}$.

Ces deux lampes sont traditionnellement placées dans le dernier quart du IIe $\mathrm{s}$. et la première moitié du IIIe $\mathrm{s}$. (Bussière 2000, 115). L'exemplaire de Marseille (2) s'inscrit dans la même fourchette chronologique.

- lampes à côtes de melon (fig. 190)

= Bussière E III 1

\section{LAMPE TYPE 17}

La forme générale de cette lampe n'est pas très éloignée de celle des deux précédentes. Le réservoir circulaire est fortement galbé sur le dessus et décoré de côtes rayonnantes en relief, parfois alternées avec des nervures plus fines (Bussière 2000, 119). Le bec, très proéminent, est ovale, fermé du côté du réservoir par un trait semicirculaire. Le fond est dégagé par un sillon. L'anse est généralement forée.

Exemples (fig. 190) :

*1 Carthage (Deneauve 1969, $\mathrm{n}^{\circ}$ 907). Engobe grisrouge foncé. Sur le fond: marque incisée $L V C C E$ MAVRICI. D. $78 \mathrm{~mm}$; H. $35 \mathrm{~mm}$.

2 El Jem, maison d'Africa (fouille H. Slim ; sans $\mathrm{n}^{\circ}$ ). Je ne connais aucun exemple de ces lampes, au demeurant relativement rares en Tunisie, découvert en stratigraphie. La marque du $\mathrm{n}^{\circ} \mathbf{1}$ semble indiquer une datation assez haute : fin du IIe $\mathrm{s}$. ou première moitié du IIIe s. (Bussière 2000, 119-120). Les exemples de Chemtou (Vegas 1994a, 228 et fig. 184, n 464-467) sont attribués à la fin du IIIe s., mais ils pourraient tout aussi bien ressortir du type tardif en céramique commune (infra, LAMPE TYPE 33). En revanche, un exemplaire à deux longs becs à volutes opposés, et signé PVLLAENI, provient d'un contexte de la fin du IIIe s. sur la villa de Vilauba, près de Gérone (Castanyer, Tremoleda 1999, fig. 177).

\subsubsection{Productions locales}

Aux côtés des types majeurs qui viennent d'être énumérés, souvent porteurs de timbres ou de marques incisées dûment répertoriés et probablement issus de grands ateliers, existent de nombreuses productions locales. Ces lampes sont de deux catégories :

- les unes, obtenues par surmoulage, copient très étroitement les types majeurs ;

- les autres développent un répertoire morphologique plus original.

Les lampes de la première catégorie sont parfois difficilement repérables mais il est probable, par exemple, qu'une grande partie des lampes à bec rond de type Deneauve VII/sous-type 1 des musées d'Algérie soit issue d'ateliers locaux imitant les modèles italiques (Bussière 2000, 98) ou d'Afrique Proconsulaire. Il en est de même des lampes de type Deneauve X (Ibid., 114, voir notamment les $\left.n^{\circ} 3650-3660,3663,3665\right)$.

Les lampes de la seconde catégorie se rencontrent dans plusieurs régions d'Afrique. Aux types mineurs de Maurétanie Césarienne, de Tripolitaine et de Byzacène méridionale, bien connus par la bibliographie, je crois pouvoir ajouter une production locale peut-être originaire du cap Bon.

\section{— types mineurs de Maurétanie Césarienne}

Je citerai pour mémoire un type local particulièrement original mis en évidence par R. Guéry (1985) et J. Bussière (2000).

- « lampes-sabots » de Sétif (fig. 191)

= Guéry type local $\mathrm{A}=$ Bussière C VIII

\section{LAMPE TYPE 18}

« La forme générale, ovoïde et très massive, rappelle celle d'un sabot : la queue, toujours forée, fait corps avec la bordure sur laquelle elle s'appuie verticalement» (Guéry 1985a, 335). «Le bourrelet périphérique qui entoure d'un seul tenant la cuvette et le canal, de même que deux protubérances carrées sur le bandeau sont des traits qui évoquent les Firmalampen à canal Loeschcke X. La pâte épaisse, peu dure, exceptionnellement engobée, se reconnaît aisément malgré des variations de teintes allant du blanchâtre au jaune pâle et à l'ocre rose. Ces lampes sont agrémentées d'un décor très fruste, exécuté à main levée après démoulage et avant cuisson » (Bussière 2000, 86).

Exemples (fig. 191):

*1 Sétif, nécropole orientale (Guéry 1985a, Pl. XIX, $\left.\mathrm{n}^{\circ} 161 \mathrm{~b}\right) .1 .66 \mathrm{~mm}$; L. $101 \mathrm{~mm}$.

2 Idem (Ibid., Pl. XXI, n 122a). 1.65 mm; L. 98 mm. Type probablement originaire de la région de Sétif et daté du IIe $\mathrm{s}$. et de la première moitié du IIIe s. (Bussière 2000, 86).

D'autres types locaux sont signalés par J. Bussière (2000, 116-119, types E I 4 et E II), moins homogènes.

\section{— types mineurs de Tripolitaine (fig. 191)}

\section{LAMPE TYPE 19}

Le catalogue du musée de Sabratha (Joly 1974) fait apparaître des variantes locales des types de Tunisie centrale et septentrionale. Il en est notamment ainsi pour deux séries particulières de lampes à globules :

- Variante A : bandeau décoré d'un « rang de perles cernées d'un méandre » (Rebuffat 1987, 88).

- Variante B : bandeau décoré d'une «triple rangée de grosses perles » (Ibid.)

Exemples (fig. 191):

Variante A

*1 Sabratha (Joly 1974, $\mathrm{n}^{\circ}$ 682). Sur le disque : Diane chasseresse à gauche. Sur le fond: marque incisée ANI/ANE. 

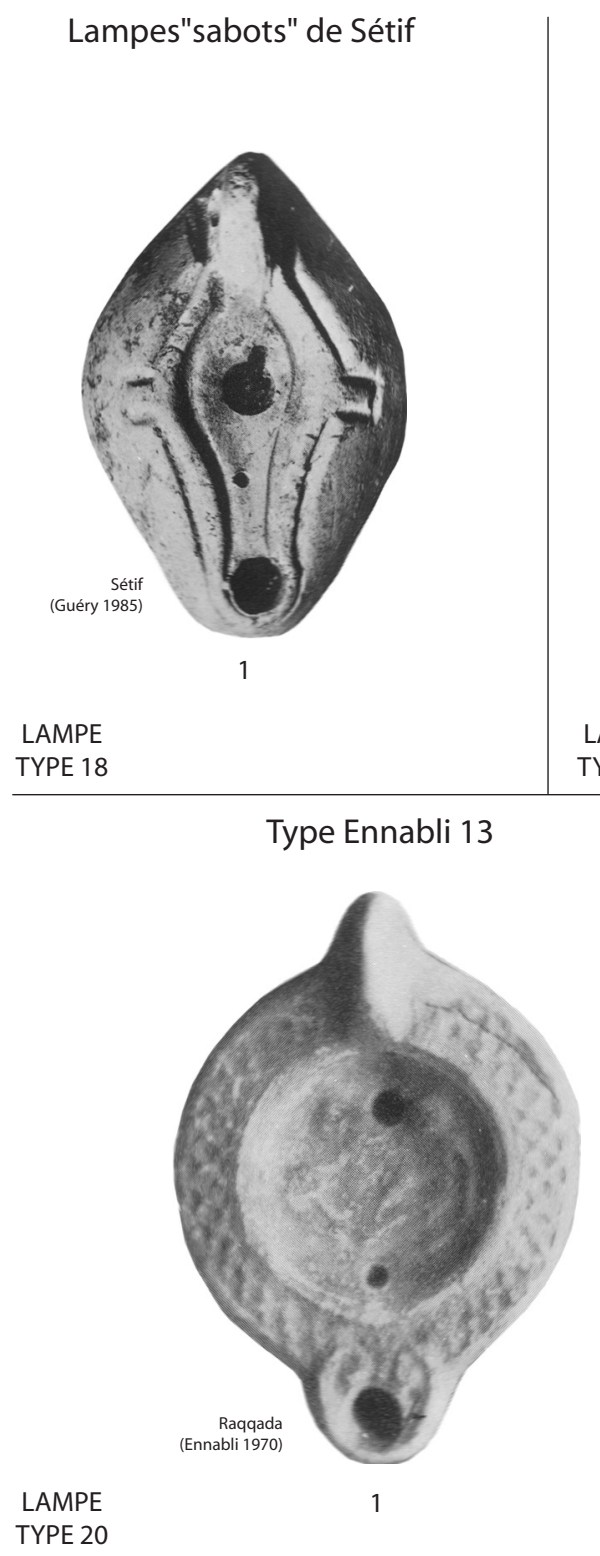

Variante tripolitaine du type Deneauve VIII/sous-type 4

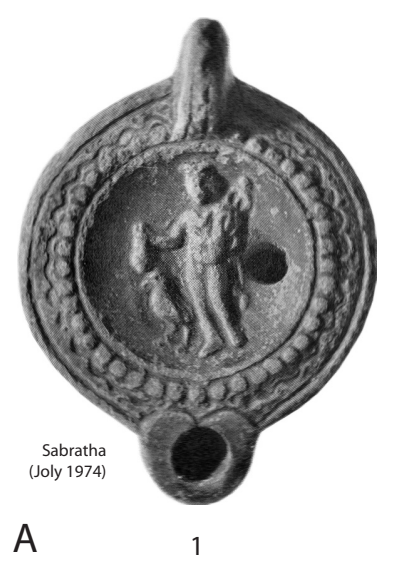

LAMPE

TYPE 19

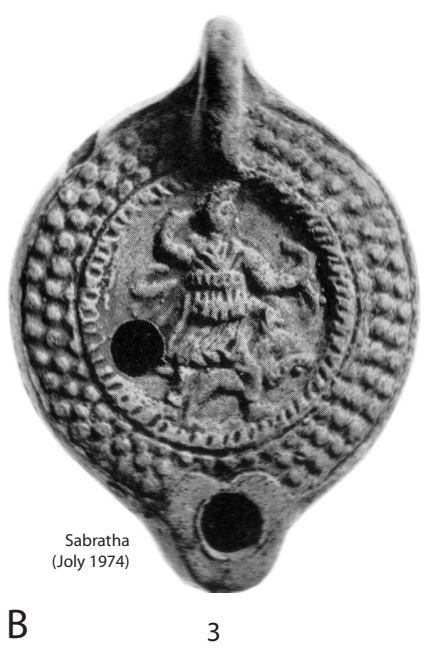

Type Ennabli 14

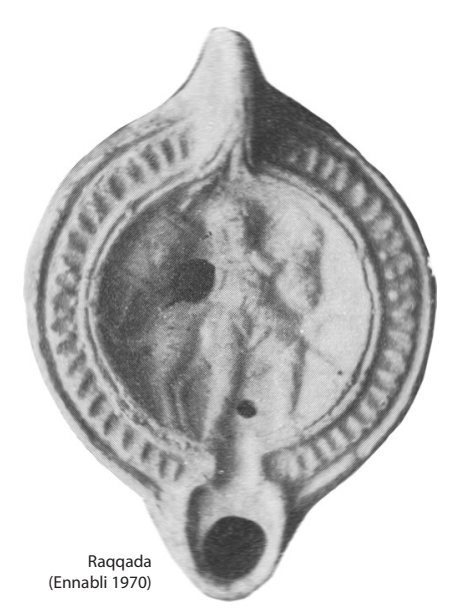

LAMPE TYPE 21

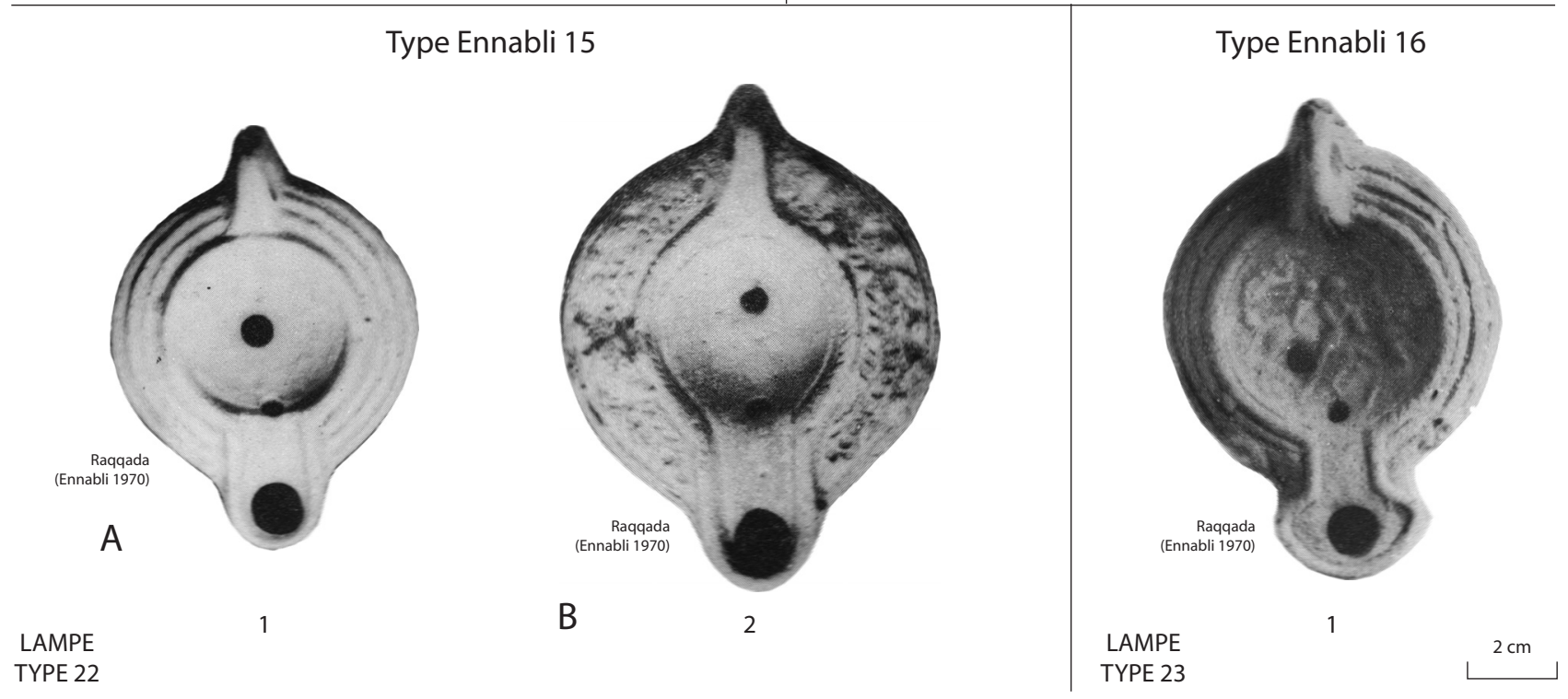

Fig. 191. Lampes africaines. Productions locales. 
$2 \mathrm{Bu}$ Njem (Rebuffat 1987, 89, $\mathrm{n}^{\circ}$ 6). Sur le disque : Diane chasseresse à gauche (?).

Variante B

*3 Sabratha (Joly 1974, $\mathrm{n}^{\circ}$ 638). Sur le disque: Diane chasseresse à droite.

4 Bu Njem (Rebuffat et al. 1969-70, Pl. XVIII, n 81-3). Sans décor.

Ces deux variantes se distinguent nettement des types plus septentrionaux dont le bandeau ne porte généralement qu'un double rang de globules et dont le disque n'est jamais décoré (supra, LAMPE TYPE 13).

\section{— types mineurs de Byzacène méridionale}

A. Ennabli avait mis en évidence à Raqqada l'existence de produits locaux « qui ne s'intègrent dans aucune des classifications connues ». Rappelons pour mémoire les quatre types identifiés.

\section{- type Ennabli 13 (fig. 191)}

\section{LAMPE TYPE 20}

Lampe proche du type Deneauve VIII ; bec «entouré d'un bourrelet dont les extrémités s'enroulent en petites spirales »; bandeau décoré par « des motifs géométriques (stries, quadrillages, postes) qui ne sont pas habituels aux modèles précédents »; le décor du disque peu net en raison de « surmoulages intensifs »; anse « tantôt percée, tantôt pleine, quelquefois portant seulement un début de forage » (Ennabli 1970-73, 106-107).

Exemple (fig. 191) :

*1 Raqqada (Ennabli 1970-73, Pl. XXVI, n² 28).

\section{- type Ennabli 14 (fig. 191)}

\section{LAMPE TYPE 21}

Lampe proche du type précédent. Cependant, « un gros bourrelet contourne la totalité du bec et rejoint après un décrochement perpendiculaire, le bourrelet de la moulure qui s'ouvre à ce niveau, en créant un petit canal »; bandeau à décors "géométriques simples (stries, denticules, oves ou globules) » (Ennabli 1970-73, 107). Exemple (fig. 191) :

*1 Raqqada (Ennabli 1970-73, Pl. XXVII, n² 292).

- type Ennabli 15 (fig. 191)

$=$ Salomonson $\mathrm{h}$

\section{LAMPE TYPE 22}

« Sa caractéristique la plus évidente est un large canal reliant le bec à la cuvette grâce à un bourrelet bien net qui circonscrit entièrement et sans interruption les éléments constitutifs de la lampe : bec-canal-cuvette ». « La lampe devient oblongue; c'est surtout cette tendance à l'allongement qui différencie les lampes de cette série des autres » (Ennabli 1970-73, 107-108). Deux variantes principales :

- Variante A (Salomonson h1) : bandeau décoré de trois sillons.
- Variante B (Salomonson h2) : bandeau décoré de motifs divers en creux (stries, points, chevrons) ou en relief (guirlande nouée, rameaux d'olivier, globules).

Exemples (fig. 191) :

Variante A

*1 Raqqada (Ennabli 1970-73, Pl. XXIX, n² 299).

Variante B

*2 Idem (Ibid., Pl. XXX, n 350 ).

- type Ennabli 16 (fig. 191)

\section{LAMPE TYPE 23}

Lampes à canal qui «se caractérisent par un bec proéminent, plutôt demi-circulaire que triangulaire, nettement détaché du corps de la lampe » (Ennabli 197073, 109), avec des esquisses de volutes sur certains exemplaires. Ces lampes me paraissent inspirées des lampes de type Deneauve X (LAMPE TYPE 15 D). Exemple (fig. 191) :

*1 Raqqada (Ennabli 1970-73, Pl. XXXI, n 405).

Les indications chronologiques fournies par la nécropole de Raqqada sont très restreintes (Ennabli 1970-73, 109). Le type Ennabli 15 est présent dans une tombe du milieu ou du troisième quart du IIIe $\mathrm{s}$. (Ennabli, Mahjoubi, Salomonson 1973, Pl. XIX, tombe B11 bis), associé à une cruche en sigillée $\mathrm{C}$ à décor d'applique Salomonson VIII/Hayes 172. En fonction de considérations stylistiques, l'ensemble de ces lampes est placé au milieu ou dans la seconde moitié du IIIe s. (Salomonson 1968, 87).

- type mineur de la région du cap Bon (?) (fig. 192)

$=$ Hayes $1980 \mathrm{~b}, \mathrm{n}^{\circ} 280$

\section{LAMPE TYPE 24}

Les fouilles de Pupput et de Nabeul ont permis de mettre en évidence plusieurs exemplaires de ces lampes qui se caractérisent par la même pâte beige assez dure, couverte très irrégulièrement, en coulures, par un engobe roux orangé, transparent, comme délavé. Il s'agit d'une lampe de large diamètre (D. $88 \mathrm{~mm}$ ), assez aplatie (H. $33 \mathrm{~mm})$, aux parois fortement carénées; le bandeau est large, légèrement convexe, décoré de plusieurs (entre trois et sept) rangs de petits globules, assez irréguliers, dont la disposition n'est pas sans évoquer le décor des lampes tripolitaines (infra, LAMPE TYPE 82); le disque non décoré est percé d'un orifice de remplissage central et d'un petit trou d'évent près du bec; le bec, à extrémité arrondie, est très proéminent ; le fond est plat, sans relief. Il semble que la forme des $\mathrm{n}^{\circ} \mathbf{3}$ et $\mathbf{4}$ ait été surmoulée sur des lampes de TYPE $10 \mathrm{~B}^{223}$.

Exemples (fig. 192) :

*1 Pupput (Inv. PP1598.1). Sur le bandeau : cinq à huit rangs de petits globules. D. $88 \mathrm{~mm}$; H. $32 \mathrm{~mm}$; D. $\mathrm{du}$ fond $45 \mathrm{~mm}$.

\footnotetext{
${ }^{223}$ On distingue les traces très effacées du décor de rosace sur le disque.
} 
Variante Cap Bon du type Deneauve VIII/sous-type 4
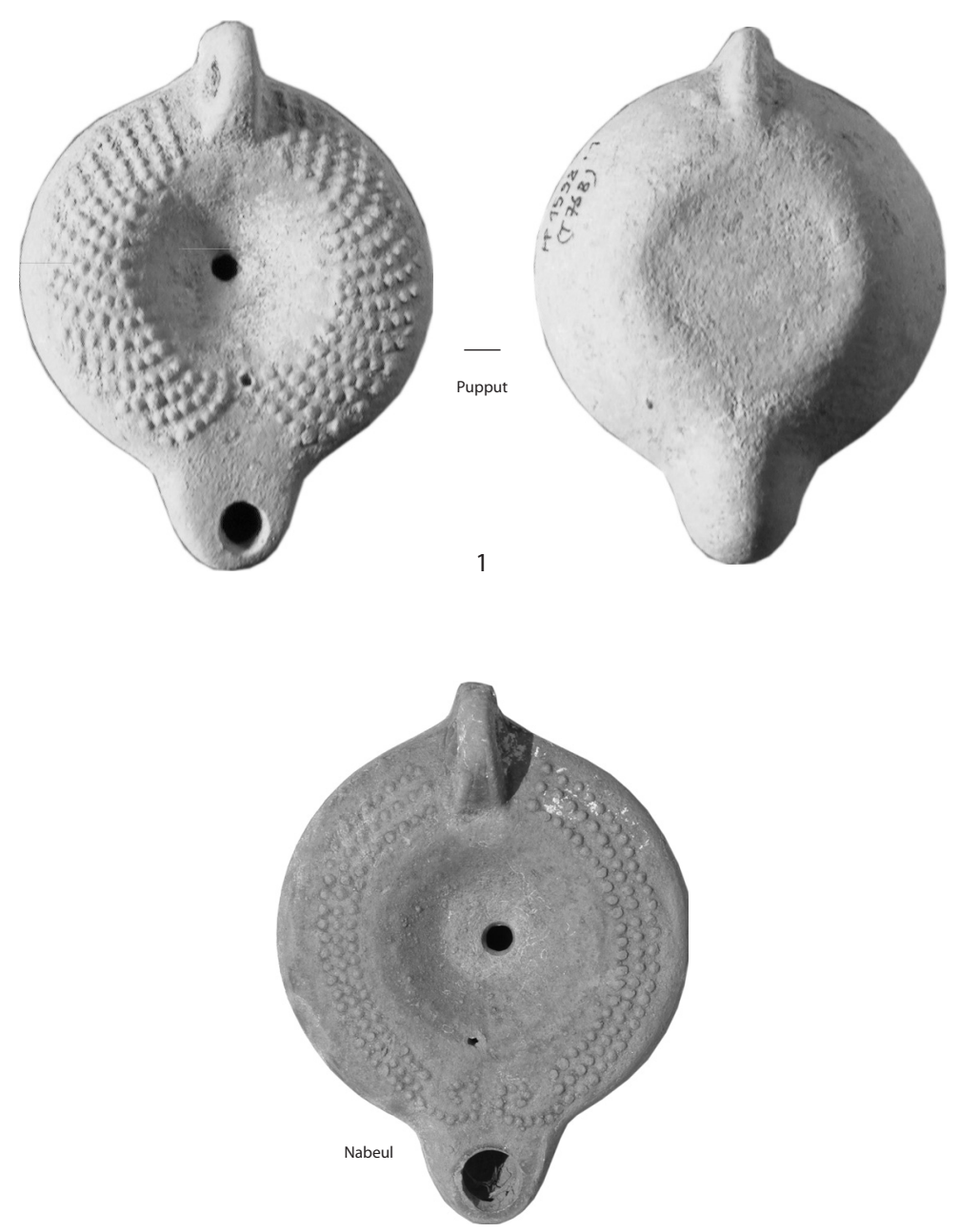

3
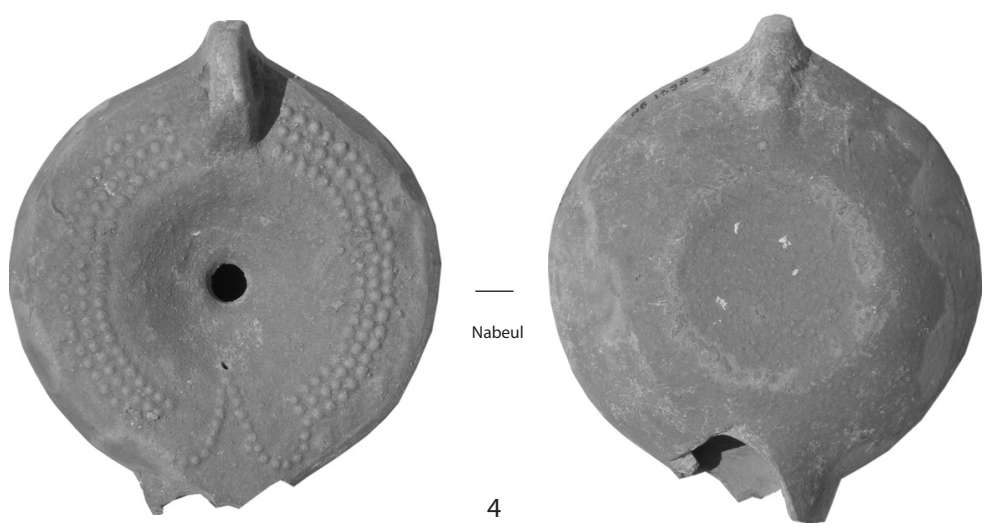

Fig. 192. Lampes africaines. Productions locales. 
2 Carthage (Hayes 1980b, Pl. 33, n²80). Sur le bandeau : quatre à cinq rangs de petits globules. D. $88 \mathrm{~mm}$; H. $33 \mathrm{~mm}$.

*3 Nabeul, fabrique de salaison, pièce XLIV (Inv. NB1398.2). Sur le bandeau: trois rangs de petits globules se terminant en volutes au-dessus du bec.

*4 Idem (Inv. NB1878.42). Sur le bandeau : trois rangs de petits globules se terminant en accolade au-dessus du bec.

Les exemplaires $\mathbf{1}$ et $\mathbf{2}$, avec plus de trois rangs de globules paraissent les plus anciens. Il y a peu de probabilités pour que l'exemplaire de Pupput (1) dépasse la seconde moitié du IIIe siècle. En revanche, les exemplaires $\mathbf{3}$ et $\mathbf{4}$ proviennent d'un contexte qui n'est probablement pas antérieur au début du IVe siècle.

\section{— autres types mineurs}

D'autres types mineurs sont décelables dans le nord-ouest de la Tunisie, notamment à Chemtou. Certains des types présents sur ce site (Simitthus II, Pl. 52) renvoient aux lampes «d'art indigène» décrites par Carton (1915). Mais il est, en bien des cas, difficile de distinguer ces productions locales des lampes tardives en céramique commune de tradition antique, caractéristiques des IVe Ve siècles.

\subsubsection{Lampes africaines tardives de tradition antique}

En effet, il paraît aujourd'hui bien établi que la typologie des lampes de tradition antique produites en Afrique ne subit pas de modifications fondamentales, parallèlement au développement des lampes en céramique sigillée et, notamment, à l'apparition des lampes dites chrétiennes à la fin du IVes. : les fouilles de Carthage ont démontré que les lampes en céramique commune dérivées des types Deneauve VII et VIII sont encore majoritaires dans les contextes de la seconde moitié du IVe s. et de la première moitié du Ves. (Hayes 1976a, 121; Anselmino 1982, 160-161 ; Rossiter 1988 ; Mackensen 1993, 146).

Les caractères distinctifs des lampes africaines tardives de tradition antique sont bien connus (Hayes 1980b, 63 ; Bailey 1988, 81 ; Ben Abed, Bonifay 1998, 240-242) :

- facture devenant de plus en plus grossière avec disparition progressive de l'engobe ;

- anses non forées, parfois maladroitement collées au lieu d'être moulées avec le reste de la lampe ;

- marques peu profondément incisées ou absentes ; - décors empâtés parce que surmoulés sur des lampes plus anciennes ou stylisés parce que simplement incisés à main levée dans le moule.

On peut, dans l'état actuel de la documentation archéologique, distinguer plusieurs types.

\section{- lampes dérivées du type Deneauve VII \\ $=$ Rossiter group 2}

Les exemples de lampes africaines tardives de tradition antique dérivées du type Deneauve VII sont nombreux et variés, notamment à Carthage. On peut distinguer trois sous-types particulièrement répétitifs.

\section{- dérivés du type Deneauve VII/sous-type 1 (fig. 193)}

\section{LAMPE TYPE 25}

Les dimensions de cette lampe sont plus proches de celles du sous-type 2 (1) ou du sous-type 3 (2) mais la composition décorative est celle du sous-type 1. Le bandeau est lisse et le disque décoré d'un motif simple. Le fond (D. $50 \mathrm{~mm}$ ) est dégagé par un sillon. L'anse n'est pas forée.

Exemples (fig. 193) :

*1 Oudhna, capitole (Inv. UTH1.001.157 ; Bonifay, Dridi, Jacquest à paraître, $\mathrm{n}^{\circ} 49$ ). Sur le disque : animal à droite. D. $72 \mathrm{~mm}$.

*2 Thuburbo Majus, édifice aux Asclepeia (Ben Abed, Bonifay 1998, fig. 3, $\mathrm{n}^{\circ} 28$ ). Sur le disque : bouquetin sautant à droite tracé à la pointe dans le moule. Sur le fond: marque incisée illisible. D. $80 \mathrm{~mm}$; H. $32 \mathrm{~mm}$; D. du fond : $50 \mathrm{~mm}$.

Les deux exemplaires sont issus de contextes de la fin du IVe ou du début du Ve siècle.

\section{- dérivés du type Deneauve VII/sous-type 2 (fig. 193)}

\section{LAMPE TYPE 26}

Lampes légèrement plus grandes (D. $80 \mathrm{~mm}$ en moyenne) que le modèle du Haut-Empire (D. $75 \mathrm{~mm}$ en moyenne). La composition du décor demeure cependant identique : bandeau lisse ou décoré en creux, disque généralement orné d'un motif simple (celui de la rosace reste fréquent). Le fond, où apparaissent parfois encore quelques marques incisées, est toujours délimité par deux sillons concentriques. L'anse n'est jamais forée.

Exemples (fig. 193) :

*1 Thuburbo Majus, édifice aux Asclepeia (Ben Abed, Bonifay 1998, fig. 3, n²4). Sur le disque lion à gauche. Sur le fond: marque incisée PVLL/AEN. D. $80 \mathrm{~mm}$; H. $29 \mathrm{~mm}$; D. du fond $44 \mathrm{~mm}$.

*2 Idem (Ibid., $\left.\mathrm{n}^{\circ} 25\right)$. Décor du disque identique à celui de la précédente. D. $81 \mathrm{~mm}$.

*3 Oudhna, capitole (Inv. UTH1.001.153 ; Bonifay, Dridi, Jacquest à paraître, $\mathrm{n}^{\circ} 50$ ). Sur le bandeau : hastes et cercles pointés alternés. Sur le disque : rosace. D. $70 \mathrm{~mm}$.

4 Carthage, Cirque (Rossiter 1988, Pl. 1, n 4). Sur le bandeau : cercles pointés. Sur le disque : rosace. Sur le fond : marque incisée [PVLLA]ENI.

5 Idem (Ibid., $\mathrm{n}^{\circ}$ 3). Sur le bandeau: cercles pointés. Sur le disque: sphinx à gauche (supra: type Deneauve VII/sous-type 2, $\mathrm{n}^{\circ}$ 5). Sur le fond: marque incisée PVLLAENI.

Les exemplaires cités ci-dessus proviennent tous de contextes de la fin du IVe ou du début du Ve siècle. 


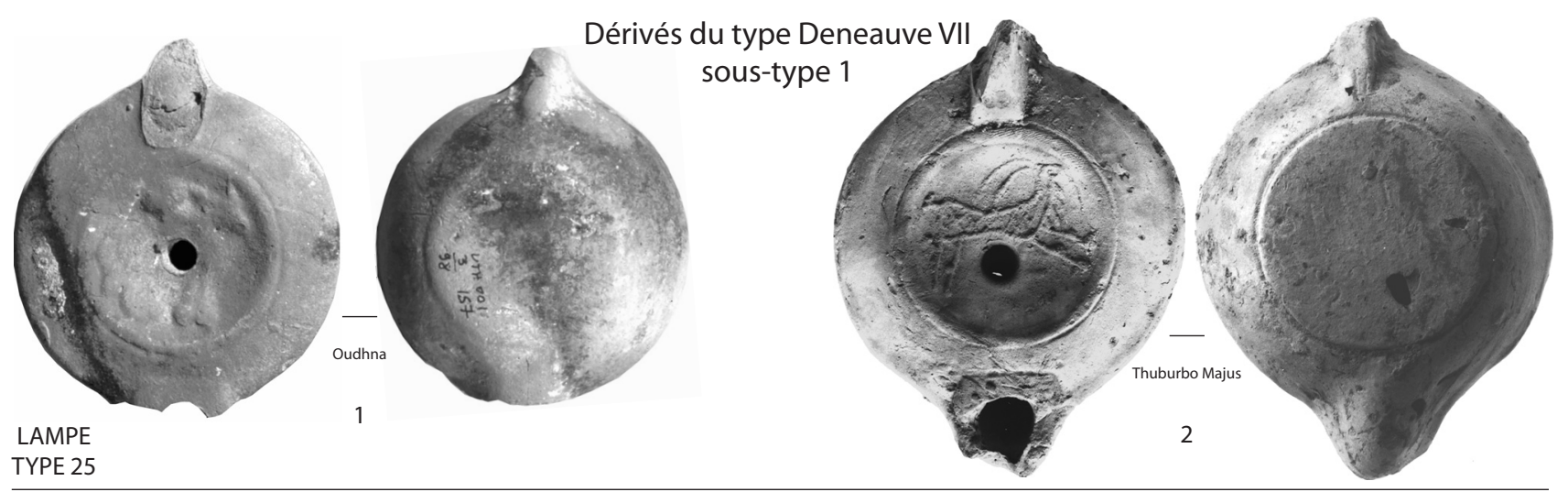

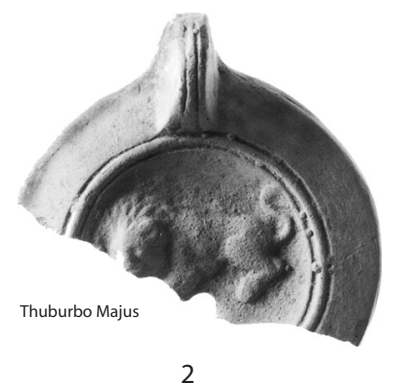

LAMPE

TYPE 26
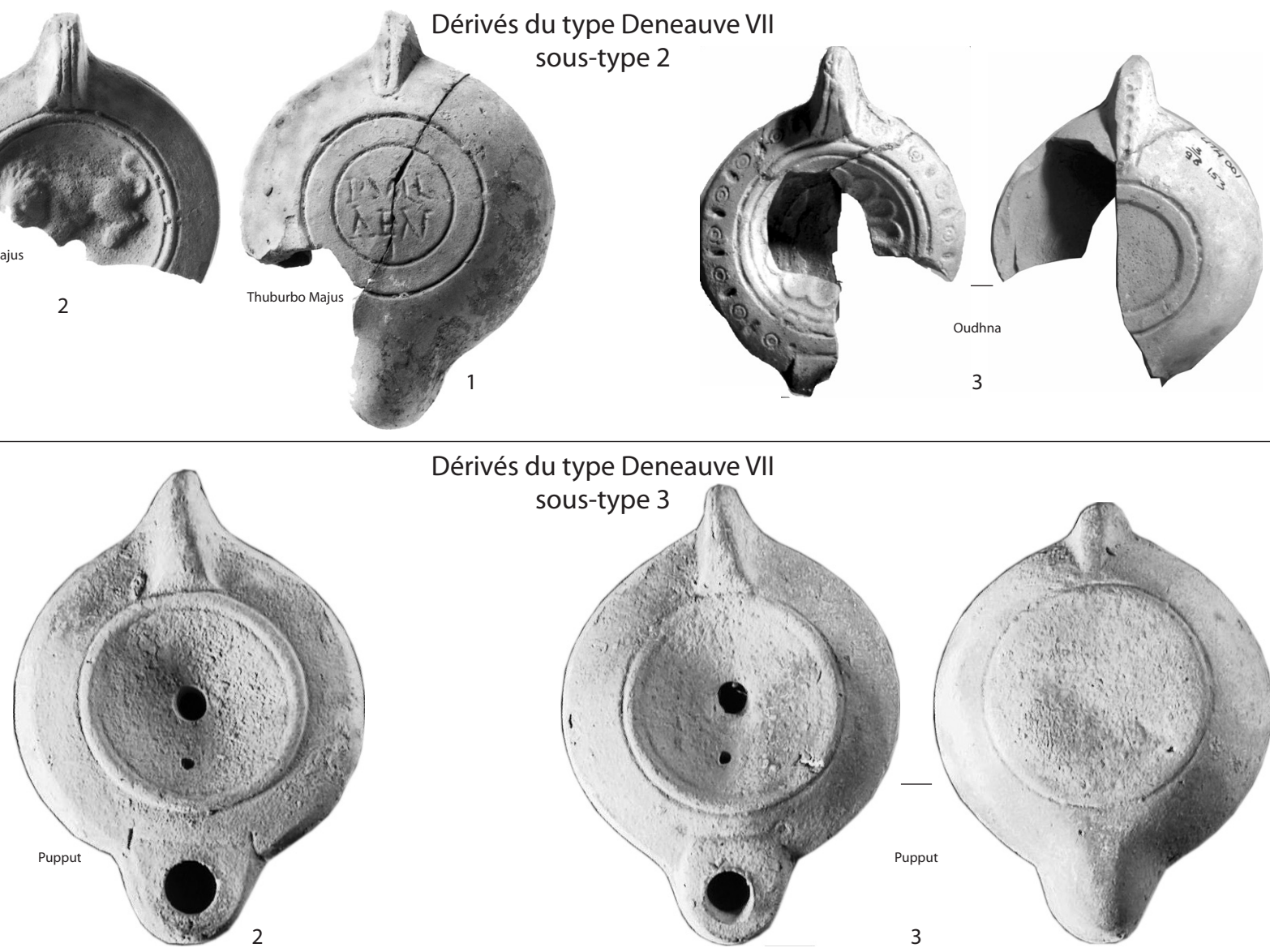

Dérivés du type Deneauve VII
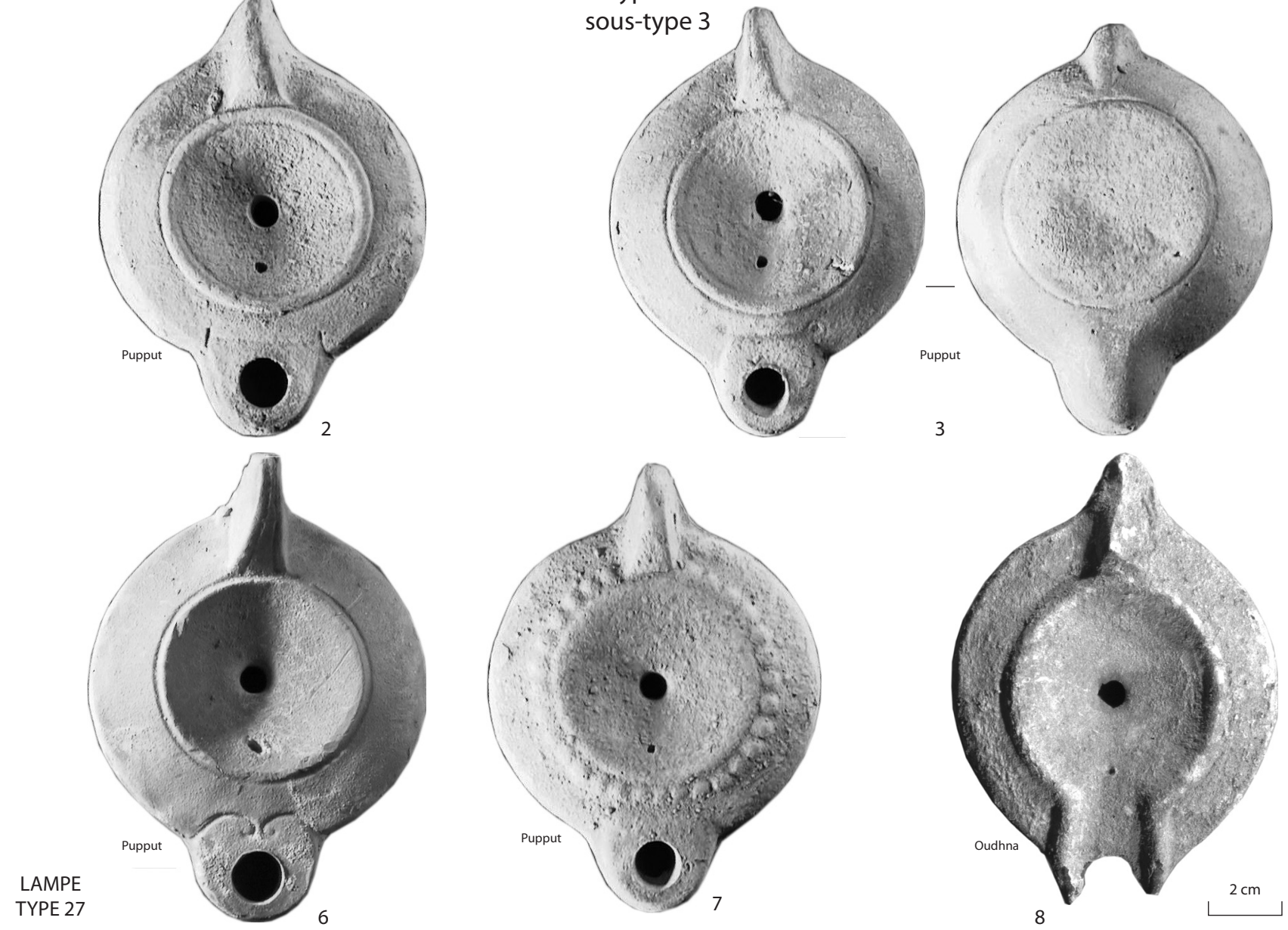

Fig. 193. Lampes africaines tardives de tradition antique. 


\section{Dérivés du type \\ Deneauve VIII à décor de festons}
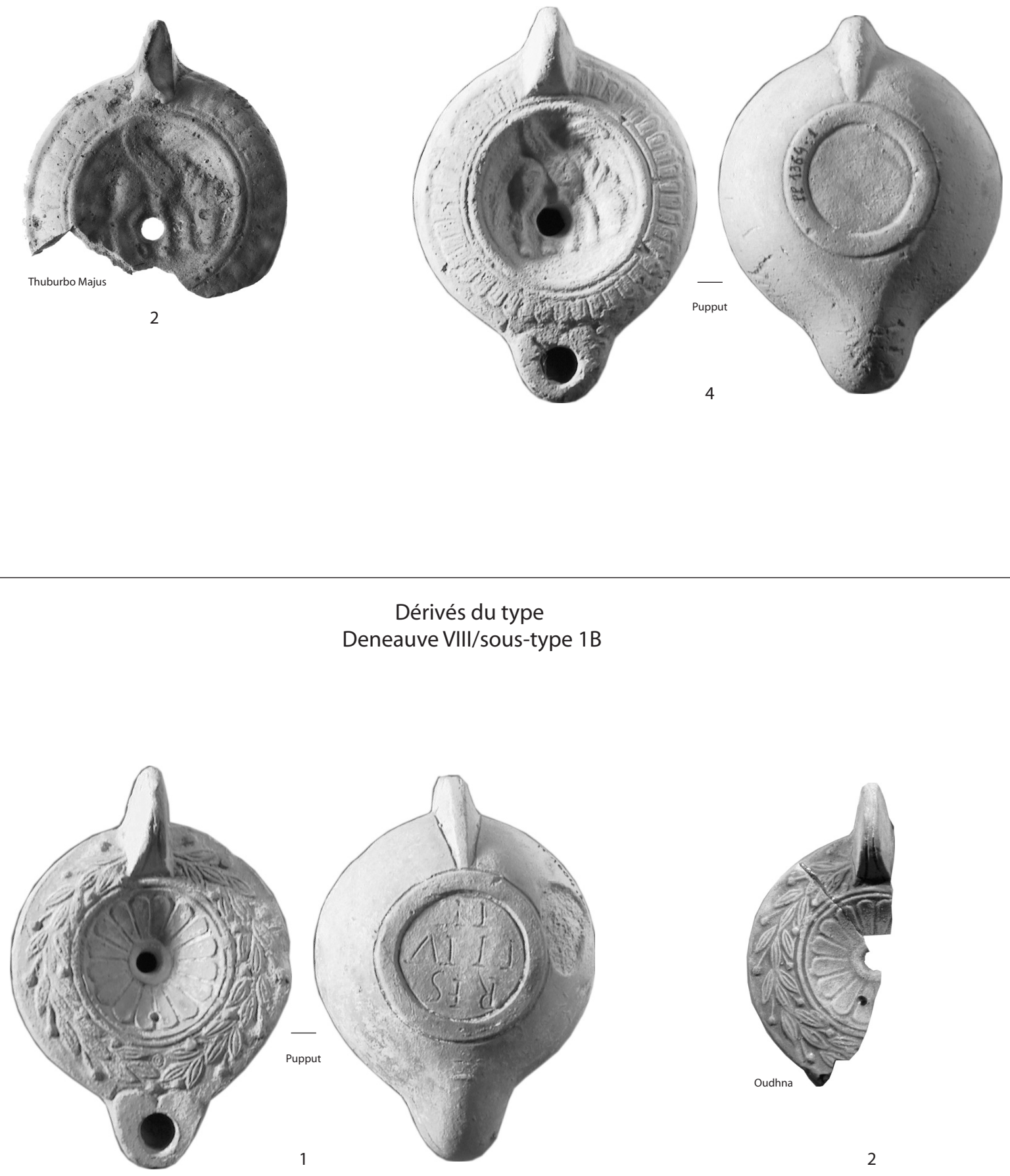

2

Fig. 194. Lampes africaines tardives de tradition antique. 
Dérivés du type

Deneauve VIII/sous-type 2
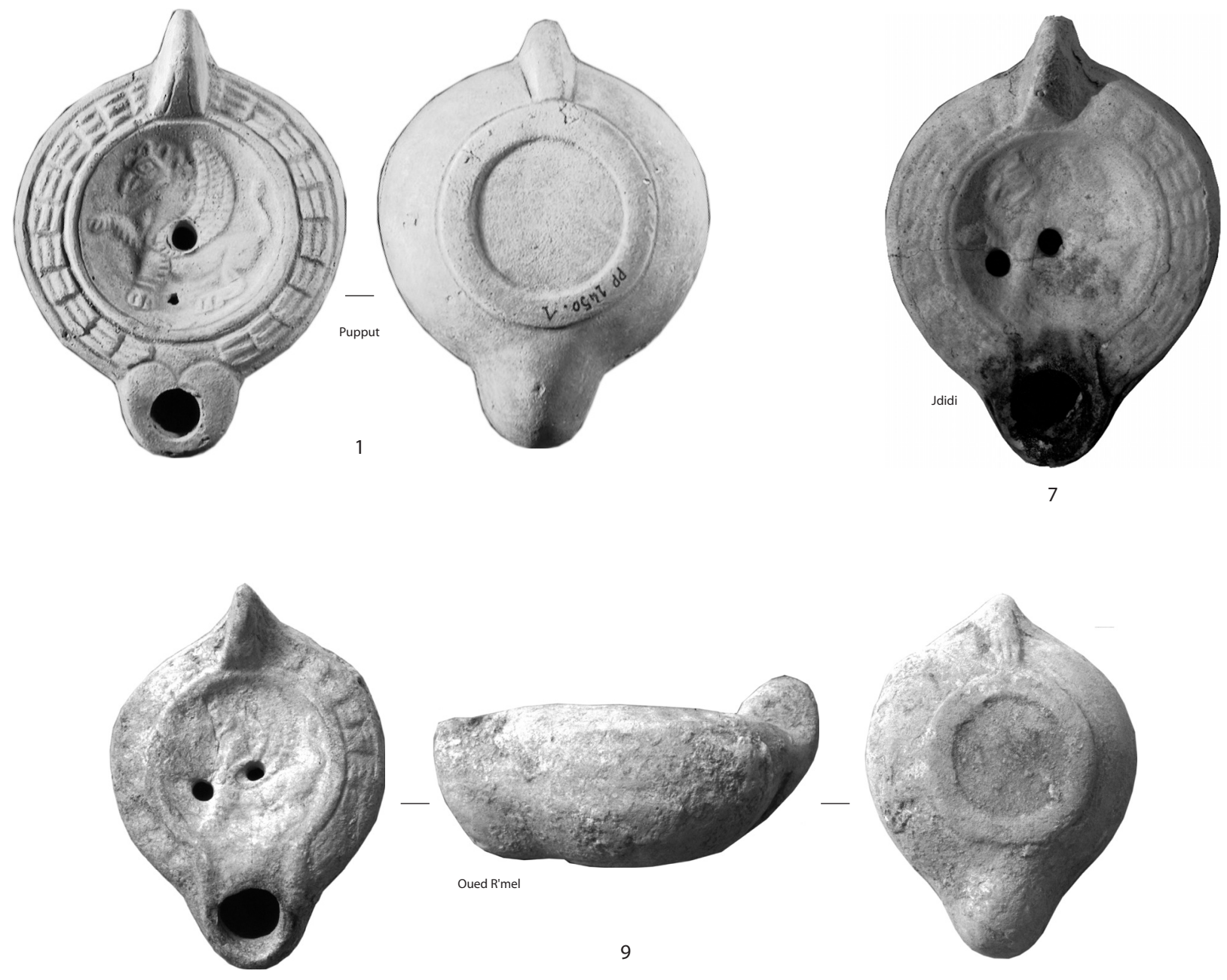

Dérivés du type

Deneauve VIII/sous-type 3

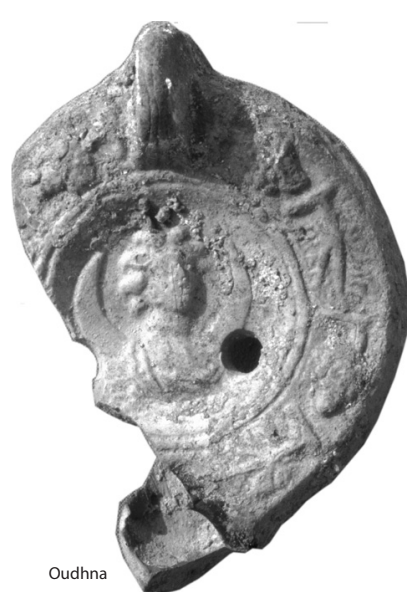

TYPE 31

Fig. 195. Lampes africaines tardives de tradition antique. 
- dérivés du type Deneauve VII/sous-type 3 (fig. 193)

$=$ Deneauve 1969, $\mathrm{n}^{\circ} 859$

\section{LAMPE TYPE 27}

Les dimensions des exemplaires tardifs ne varient pas par rapport à celles des exemplaires anciens (D. $85 \mathrm{~mm} ; \mathrm{H}$. $35 \mathrm{~mm}$; D. du fond $50 \mathrm{~mm}$, en moyenne). Les deux cannelures qui entourent le disque, dégagent un bourrelet en fort relief ; l'anse n'est jamais forée.

Exemples (fig. 193) :

1 Pupput (Bonifay 2004a, fig. 14, $\mathrm{n}^{\circ}$ 36). Pâte beige. Sur le fond: marque incisée ]VT[ (?), effacée. D. $89 \mathrm{~mm}$; H. $38 \mathrm{~mm}$; D. du fond $47 \mathrm{~mm}$.

*2 Pupput, tombe 350 (Inv. 3334.1).

*3 Pupput, tombe 350 (Inv. 3334.3). Traces d'engobe brun-gris. D. $85 \mathrm{~mm}$; H. : $37 \mathrm{~mm}$; D. du fond : $51 \mathrm{~mm}$.

4 Pupput, mausolée 5 (Ben Abed, Bonifay 1998, fig. 7, a). Deux trous de remplissage.

5 Carthage, Cirque (Rossiter 1988, Pl. 1, n 9).

Variante

*6 Pupput (Inv. PP1374.9). Volutes incisées au départ du bec. D. $90 \mathrm{~mm}$.

*7 Pupput, tombe 350 (Inv. 3334.5). Traces d'engobe brun granuleux. Bandeau décoré d'un rang de globules. D. : $90 \mathrm{~mm}$; H. : $38 \mathrm{~mm}$; D. du fond: $52 \mathrm{~mm}$.

Variante avec canal

*8 Oudhna, thermes des Laberii (sans ${ }^{\circ}$ ). D. $88 \mathrm{~mm}$.

Les exemplaires de Pupput (1-4) proviennent de tombes du IVe siècle. Les exemplaires de Carthage (5) sont plutôt de la fin du IVes. ou du début du Ves. (voir également Hayes 1976a, 70, e). Le $n^{\circ}$ 8, à canal, pourrait être du début du Ve siècle.

\section{- lampes dérivées du type Deneauve VIII \\ $=$ Rossiter groups 3 - 4 - 5}

La plupart des lampes du IIIe s. classées sous le type Deneauve VIII perdurent sous une forme abâtardie aux IVe-Ve siècles.

\section{- dérivés du type Deneauve VIII à décor de festons (fig. 194)}

\section{LAMPE TYPE 28}

Lampe de taille moyenne (D. $80-85 \mathrm{~mm}$ ). Bec généralement cordiforme. Festons en relief sur le bandeau et pégase à droite, tête baissée, sur le bandeau. Fond annulaire.

Exemples (fig. 194) :

1 Carthage, collection Louis (Ponsich 1960, Pl. III, $\left.\mathrm{n}^{\circ} 41\right)$.

*2 Thuburbo Majus, édifice aux Asclepeia (Ben Abed, Bonifay 1998, fig. 3, $\mathrm{n}^{\circ}$ 26). Pâte beige orangé. D. $82 \mathrm{~mm}$.

3 Idem (Ibid., $\left.\mathrm{n}^{\circ} 27\right)$.

*4 Pupput (PP1364.1). Pâte beige rosé. D 84 mm; H. $34 \mathrm{~mm}$; D. du fond $43 \mathrm{~mm}$.

5 Carthage (Deneauve 1969, Pl. XXXV, n 935). Sur le fond: marque incisée EX OF GARGILI. D. $78 \mathrm{~mm}$; H. $36 \mathrm{~mm}$
6 Idem (Ibid., $\mathrm{n}^{\circ}$ 1110). Sous le fond : marque incisée NVNDINI. D. $61 \mathrm{~mm}$; H. $30 \mathrm{~mm}$.

7 Carthage, Cirque (Rossiter 1988, Pl. 2, $\mathrm{n}^{\circ} 18$ ).

8 Nabeul, fabrique de salaison, état 5B (NB 1145.71).

Très peu d'exemples sont datés. Le $\mathrm{n}^{\circ} \mathbf{4}$ pourrait provenir d'une occupation tardive de la nécropole de Pupput au IVe s. (?). Les $\mathrm{n}^{\circ} \mathbf{2 - 3}$ et $\mathbf{7}$ sont issus de contextes de la fin du IVe ou du début du Ve siècle. Le $n^{\circ} \mathbf{8}$ est associé à du matériel du deuxième quart du Ve $\mathrm{s}$. (lampes en sigillée Atlante VIII A et VIII B). Le classement adopté ci-dessus tient compte à la fois de la lisibilité des décors et de la taille (décroissante) de l'objet.

\section{- dérivés du type Deneauve VIII/sous-type 1 (fig. 194)}

\section{LAMPE TYPE 29}

Les exemples de surmoulages du type Deneauve VII/sous-type 1 (bandeau décoré de rameaux d'olivier) sont bien attestés durant tout le IVe s. (Hayes 1976a, 70, b ; Rossiter 1988, Pl. 1, n 13 et Pl. 2, n 14). Il semble toutefois que seule subsiste la variante $\mathrm{B}$, au disque décoré d'une rosace.

Exemples (fig. 196) :

*1 Pupput, enclos 31 (Inv. PP1604.2). D. $87 \mathrm{~mm}$; H. $32 \mathrm{~mm}$; D. du fond $50 \mathrm{~mm}$. Marque incisée RES/TITV/TI sur le fond.

*2 Oudhna, capitole (Inv. UTH1.001.150 ; Bonifay, Dridi, Jacquest à paraître, $\left.\mathrm{n}^{\circ} 51\right)$.

3 Arles (Robin Petitot 2000, $\mathrm{n}^{\circ}$ 351). Marque incisée AVGENDI sur le fond.

Les deux exemples tunisiens proviennent de contextes du IVe siècle.

- dérivés du type Deneauve VIII/sous-type 2 (fig. 195)

\section{LAMPE TYPE 30}

Les exemples de surmoulages directs du type Deneauve VII/sous-type 2 (bandeau décoré d'une guirlande nouée) ne manquent pas (Rossiter 1988, Pl. 1, n 10-12). Mais je voudrais insister ici sur un type original, bien individualisé par une guirlande nouée sommairement stylisée par trois traits parallèles répétés en frise et au disque orné d'un griffon à gauche, patte droite levée. Le fond est annulaire; l'anse n'est jamais forée. Deux variantes :

- Variante A : à bec cordiforme, sans canal.

- Variante B : avec canal.

Exemples (fig. 195) :

Variante A

*1 Pupput, tombe 493 (Inv. PP1450.1). Pâte blanchâtre, traces d'engobe orangé. D. $90 \mathrm{~mm}$; H. $34 \mathrm{~mm}$; D. $\mathrm{du}$ fond $54 \mathrm{~mm}$.

2 Pupput, fouilles anciennes (Ben Abed, Bonifay 1998, fig. 7, b). D. $86 \mathrm{~mm}$.

3 Thuburnuc (Carton 1915, 141, $\mathrm{n}^{\circ} 21$ ).

4 Musée d'Alger (Bussière 2000, Pl. 101, n 3636). D. $85 \mathrm{~mm}$; H. $33 \mathrm{~mm}$.

Variante B

5 Carthage, collection Louis (Ponsich 1960, Pl. V, $\mathrm{n}^{\circ}$ 45). D. $90 \mathrm{~mm}$; H. $30 \mathrm{~mm}$.

6 Oudhna, thermes des Laberii (sans $n^{\circ}$ d'inv.). 
Typologie - Lampes

Dérivés du type

Deneauve VIII/sous-type 4
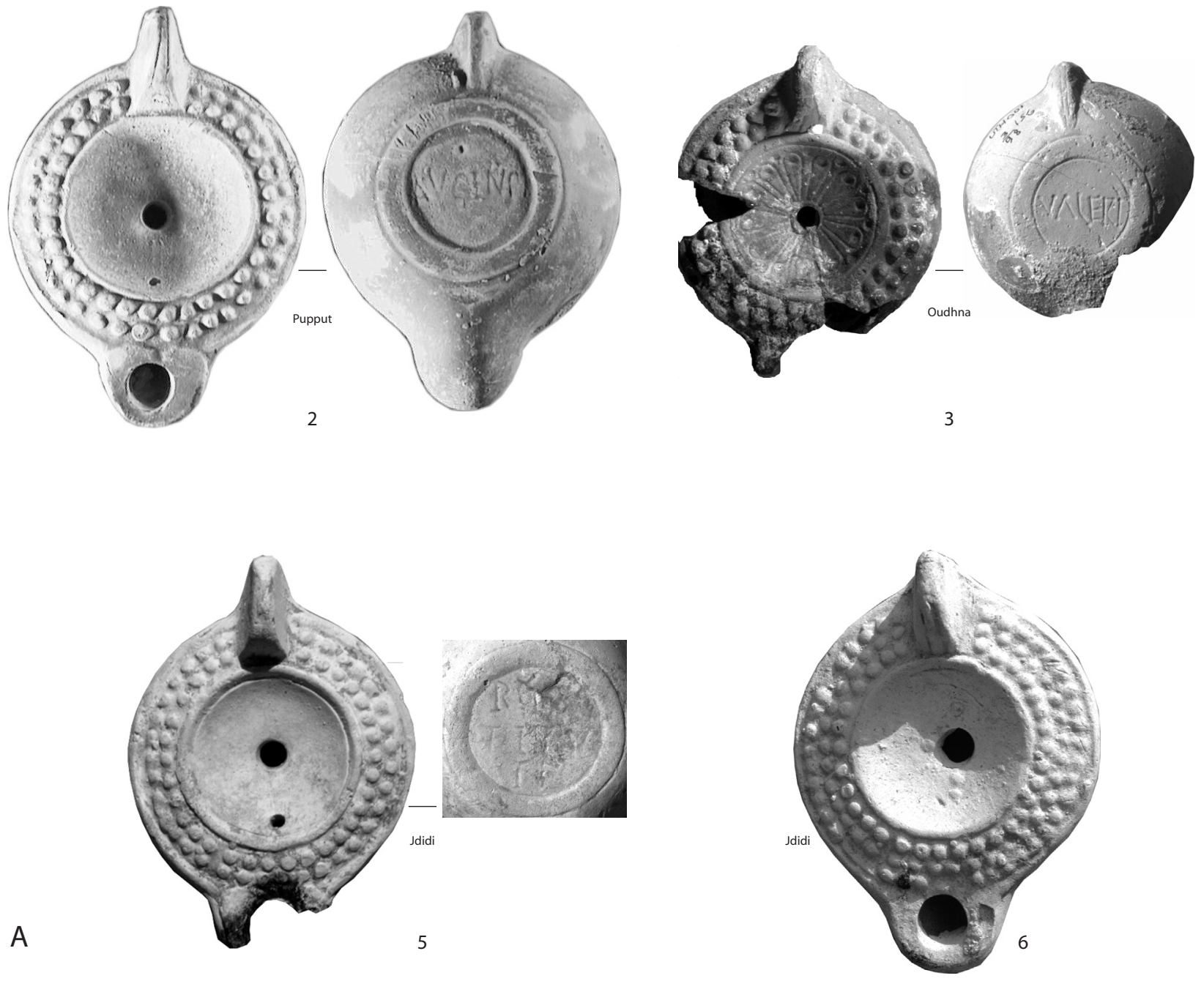

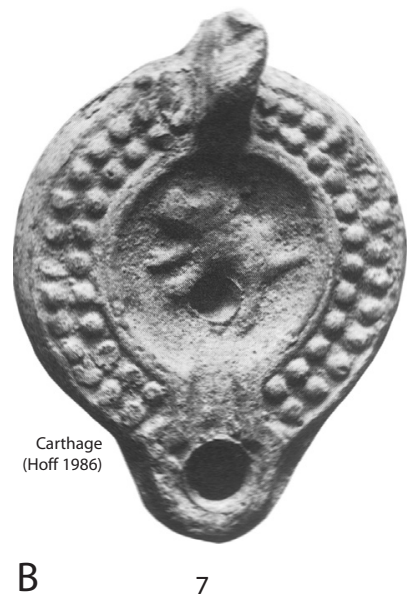

LAMPE

TYPE 32
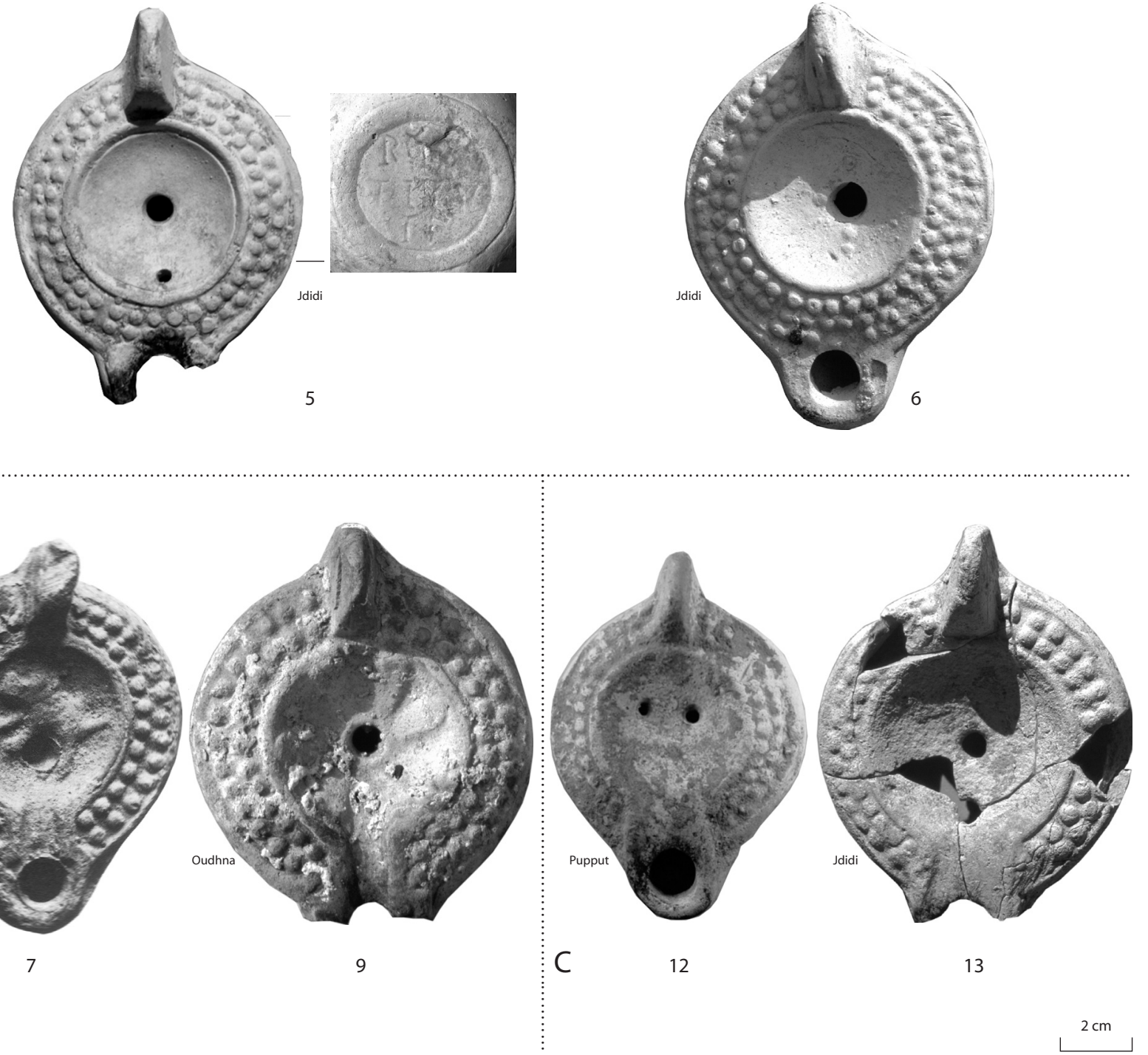

Fig. 196. Lampes africaines tardives de tradition antique. 
*7 Sidi Jdidi, basilique 2, état III (Ben Abed, Bonifay 1998, fig. 7, c). D. $84 \mathrm{~mm}$; H. $48 \mathrm{~mm}$; D. du fond $49 \mathrm{~mm}$.

8 Sidi Jdidi, basilique 3, phase d'abandon (Inv. JD5045.8). D. $87 \mathrm{~mm}$; H. $32 \mathrm{~mm}$; D. du fond $52 \mathrm{~mm}$.

*9 Oued R'mel (fouille T. Ghalia ; sans n ${ }^{\circ}$ ). D. $75 \mathrm{~mm}$; H. $44 \mathrm{~mm}$.

Cette lampe semble connaître une assez longue durée de production. Les exemplaires les plus anciens de la variante $\mathrm{A}$, probablement des décennies centrales du IVe s. (1), conservent une assez bonne qualité de pâte, avec la persistance d'un engobe, et des décors bien lisibles. Les exemplaires $\mathrm{n}^{\circ} \mathbf{2}$ à $\mathbf{4}$ ne sont pas datés, mais on rencontre déjà la variante $\mathrm{B}$ dans un contexte du début du Ve s. à Oudhna (6) et peut-être aussi au deuxième quart du Ves. à Nabeul (bec non conservé). Cette variante à canal est toujours bien attestée dans les contextes de la seconde moitié du Ve s ; à Sidi Jdidi (78). L'exemplaire d'Oued R'mel, très grossier, pourrait être encore plus tardif (9).

\section{- dérivés du type Deneauve VIII/sous-type 3 (fig. 195)}

\section{LAMPE TYPE 31}

Un exemple de surmoulage de lampe à bandeau décoré de pampres, en céramique commune, mérite d'être signalé, car il complète la série des dérivées tardives de lampes de tradition antique. Cet objet provient d'un contexte de la fin du IVe siècle.

Exemple (fig. 195) :

*1 Oudhna, thermes des Laberii (sans $\mathrm{n}^{\circ} \mathrm{d}$ 'inv.). D. $92 \mathrm{~mm}$. Sans engobe. Anse forée.

- dérivés du type Deneauve VIII/sous-type 4 (fig. 196)

$=$ Warzenlampen $=$ Rossiter groups 4 et 5

\section{LAMPE TYPE 32}

Les lampes à globules connaissent un développement important à partir du IVe siècle. Au sein de cette catégorie foisonnante, on peut distinguer trois variantes principales :

- Variante A : sans canal, avec un bec cordiforme ; disque rarement décoré.

- Variante B : avec canal étroit s'élargissant autour $\mathrm{du}$ bec, qui rappelle celui des Firmalampen; le disque porte assez régulièrement un décor en relief.

- Variante $\mathrm{C}$ : avec canal large à extrémité arrondie, comparable à celui des lampes en sigillée Atlante VIII.

Exemples (fig. 196) :

Variante A

1 Pupput, tombe 635 (Bonifay 2004a, fig. 14, $\mathrm{n}^{\circ} 37$ ). Trace d'engobe gris-noir. D. $90 \mathrm{~mm}$; H. $33 \mathrm{~mm}$; D. $\mathrm{du}$ fond $54 \mathrm{~mm}$.

*2 Idem (Inv. PP3335.4). Engobe brun à reflets métalliques. Sous le fond: marque incisée $\operatorname{AVGEN(D).~D.~} 83 \mathrm{~mm}$; H. $31 \mathrm{~mm}$; D. du fond $47 \mathrm{~mm}$.

*3 Oudhna, capitole (Inv. UTH1.001.156 ; Bonifay, Dridi, Jacquest à paraître, $\left.\mathrm{n}^{\circ} 54\right)$. Sur le disque : rosace en creux. Sous le fond: marque incisée VALERI. D. $76 \mathrm{~mm}$.

4 Carthage, Cirque (Rossiter 1988, Pl. 2, n 23). Sur le disque : rosace en relief.

*5 Sidi Jdidi, basilique 2, état II (Ben Abed, Bonifay 1998, fig. 7, d). Pâte blanche. Sous le fond : marque incisée RESTITVTI. D. $85 \mathrm{~mm}$; H. $37 \mathrm{~mm}$; D. du fond $51 \mathrm{~mm}$.

*6 Idem (Bonifay à paraître, c, fig. 3). Trois rangs de globules. D. $85 \mathrm{~mm}$; H. $36 \mathrm{~mm}$; D. du fond $47 \mathrm{~mm}$.

Variante B

*7 Carthage (Hoff $1986,91, \mathrm{n}^{\circ}$ 5). Sur le disque : animal à gauche.

8 Carthage, Cirque (Rossiter 1988, Pl. 3, n 30). Sur le disque : rosace en relief.

*9 Oudhna, thermes des Laberii (Inv. UTH.TL.000.12). Décor proche du $\mathrm{n}^{\circ} 8$. D. $94 \mathrm{~mm}$.

10 Carthage, quartier Magon (Mackensen 1991, fig. 19, $\mathrm{n}^{\circ} 36$ ). Sur le disque : palmes.

11 Oudhna, thermes des Laberii (sans $n^{\circ} \mathrm{d}^{\prime}$ inv.). Disque non décoré.

Variante C

*12 Pupput, fouilles anciennes (Ben Abed, Bonifay 1998, fig. 7, f). D. $76 \mathrm{~mm}$.

*13 Sidi Jdidi, basilique 2, destruction état II (Inv. JD2268.1). D. $87 \mathrm{~mm}$.

14 Nabeul, fouilles anciennes (sans $n^{\circ}$ d'inv.).

Il y a une parfaite continuité entre les exemplaires attribuables au type Deneauve VIII/sous-type 4 et ceux que l'on peut considérer, de manière un peu artificielle, comme en étant dérivés. Les critères de distinctions de la variante A sont assez subjectifs : anse non forée, absence d'engobe, globules plus gros. A ce titre, les exemplaires $\mathrm{n}^{\circ}$ 1-2 provenant de tombes du IVes. à Pupput constituent plutôt des variantes de transition (voir également supra, fig. 187: LAMPE TYPE 13, $\mathrm{n}^{\circ} 4$ ). Beaucoup d'exemplaires de la fin du IVes. et du début du Ves. (3 et 4) portent un décor sur le disque, ce qui n'était jamais le cas des exemplaires du IIIe s. (hormis en Tripolitaine). Enfin, le $n^{\circ} \mathbf{5}$, pourtant bien daté du Ve s., conserve une marque incisée sous le fond. La variante B est principalement attestée à Carthage $(\mathbf{7 - 8}, \mathbf{1 0})$ et à Oudhna $(\mathbf{9}, \mathbf{1 1})$, à la fin du IVe s. et au début du Ve s.; le canal, dont la ressemblance avec celui des Firmalampen est purement formelle, revêt incontestablement un caractère tardif. Enfin, les exemplaires de la variante $\mathrm{C}$ apparaissent dans des contextes du Ve s. avancé à Pupput (12) et à Sidi Jdidi (13).

Les lampes de la variante A sont exportées (Arles : Robin Petitot 2000, $n^{\circ} 348$; Mandelieu : Fixot 1990, fig. 109 ; Lyon : Ayala 1998, fig. 29, $\left.\mathrm{n}^{\circ} 120\right)$.

\section{— lampes Deneauve XI B (fig. 197)}

$=$ Melonenlampen $=$ Rossiter group 6

\section{LAMPE TYPE 33}

Ces lampes dérivent du type Deneauve 1969, nº 907 (supra, LAMPE TYPE 17). Elles s'en distinguent par une forme plus allongée : le réservoir devient ovale et il se fond avec l'anse et le bec, eux mêmes moins proéminents. L'anse n'est généralement pas forée. La 


\section{Typologie - Lampes}

Type Deneauve XI B

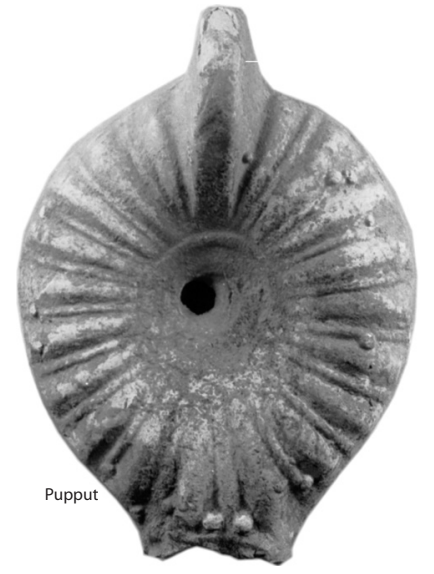

A

1

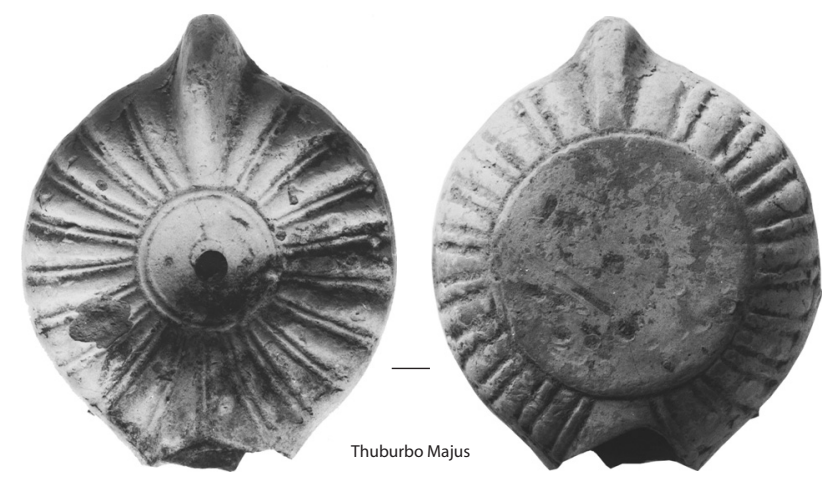

3

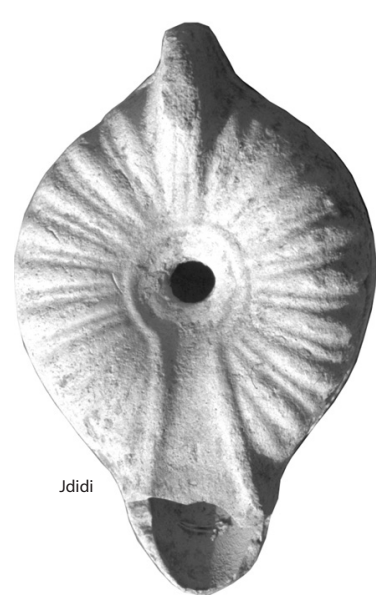

B

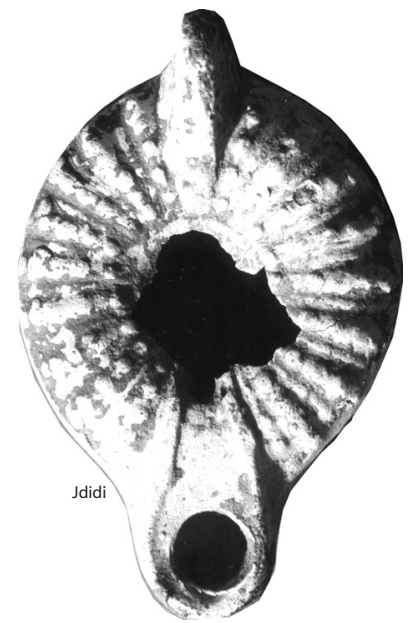

8

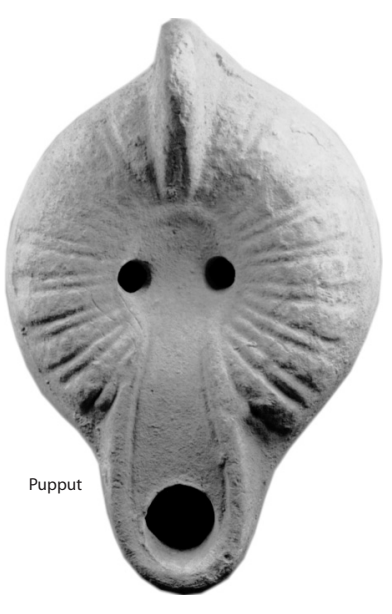

9

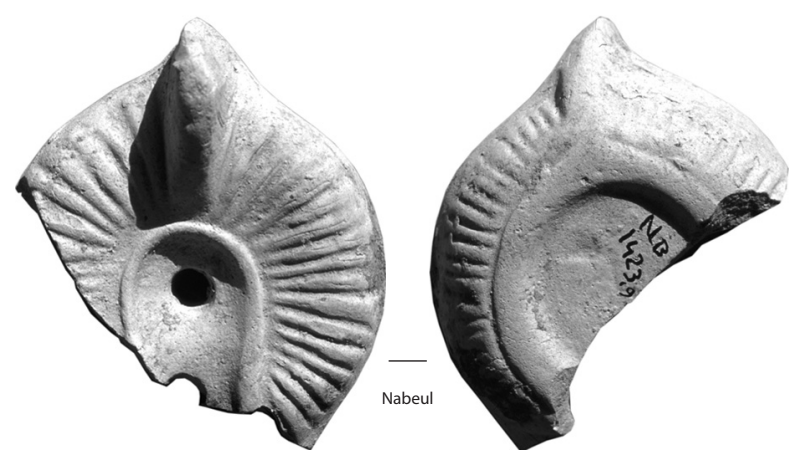

10

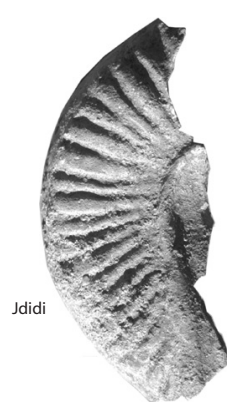

12

Fig. 197. Lampes africaines tardives de tradition antique. 
pâte, plus grossière, n'est pas engobée. On peut distinguer trois variantes :

- Variante A : sans canal.

- Variante B : avec canal, plus ou moins resserré au départ du disque, à extrémité arrondie; les côtes portent parfois une décoration de globules.

- Variante C : canal large et rectiligne, souligné par un fort bourrelet, côtes étroites séparées par des incisions profondes.

Exemples (fig. 197) :

Variante A

*1 Pupput, fouilles anciennes (Ben Abed, Bonifay 1998, fig. 7, g). D. $82 \mathrm{~mm}$.

2 Pupput (Inv. 1062.1). D. $84 \mathrm{~mm}$; H. $34 \mathrm{~mm}$; D. du fond $58 \mathrm{~mm}$.

*3 Thuburbo Majus, édifice aux Asclepeia (Ben Abed, Bonifay 1998, fig. 5, n 35). D. $80 \mathrm{~mm}$; H. $37 \mathrm{~mm}$.

4 Carthage, Cirque (Rossiter 1988, Pl. 3, n 38).

Variante B

5 Pupput, fouilles anciennes (Ben Abed, Bonifay 1998, fig. $7, \mathrm{~h})$. Côtes à grènetis. D. $75 \mathrm{~mm}$.

6 Nabeul, fabrique de salaison, état 5B (Inv. NB 1145.73). Côtes à grènetis.

*7 Sidi Jdidi, basilique 3, phase d'abandon (Inv. JD 5045.6). Côtes simples. D. $72 \mathrm{~mm}$.

*8 Idem (Inv. JD5020.2). Côtes à grènetis. D. $78 \mathrm{~mm}$.

*9 Pupput, fouilles anciennes (Ben Abed, Bonifay 1998, fig. 7, i). Côtes à grènetis peu prononcés. D. $78 \mathrm{~mm}$. Variante $\mathrm{C}$

*10 Nabeul, fabrique de salaison, pièce XXXIX (Inv. NB 1423.9). D. $88 \mathrm{~mm}(?)$; H. $35 \mathrm{~mm}$.

11 Oudhna, thermes des Laberii (sans $n^{\circ}$ d'inv.).

*12 Sidi Jdidi, basilique 2, destruction état II (Inv. JD 2251.21).

La variante A reste encore proche, morphologiquement (1), des exemplaires du IIIe siècle. Elle apparaît dans les contextes du IVe s. à Pupput et à la fin du IVe s. ou au début du Ve s. à Thuburbo Majus (3) et à Carthage (4). La variante B est plus caractéristique du Ve siècle. Les exemplaires avec un canal très resserré au départ du réservoir sont probablement les plus anciens (5). La plupart des autres exemples se placent dans le deuxième quart (6) ou la seconde moitié du Ve s. (7-8). Le ${ }^{\circ}$ 9, avec un canal large et deux orifices de remplissage paraît typologiquement évolué. Enfin, une troisième variante (C) (10-12) pourrait être encore plus tardive : elle est associée à Nabeul (10) à du matériel de la fin du Ve s. ou du début du VIe siècle.

\section{— lampes à pâte claire d'Algérie}

Pour mémoire, je rappelle les deux types principaux de lampes en céramique commune spécifiques du territoire algérien, mis en évidence par J. Bussière (2000, 120126).

- lampes à canal courbe (type Bussière E IV) (fig. 198)

\section{LAMPE TYPE 34}

Ces lampes «sont caractérisées par un canal aux bords courbes qui fait plus ou moins communiquer leur médaillon circulaire ou ovale, au trou de mèche. La forme générale de l'objet est ovoïde » (Bussière 2000, 120). J. Bussière distingue une production de Numidie et de Maurétanie Sitifienne, assez fruste, à diffusion essentiellement locale, et une production de Maurétanie Césarienne probablement originaire de Tipasa, avec un atelier principal dirigé par un coroplathe nommé Assenes, d'après les inscriptions en relief qui figurent sur le bandeau de certaines de ces lampes, par exemple LVCERNAS COLLATAS DE OFICINA ASSENIS ou EMITE LVCERNAS COLATAS AB ASSE. Cette deuxième production connaît une petite diffusion en Méditerranée occidentale.

Exemples (fig. 198) :

Groupe 2 (Bussière 2000)

*1 Musée de Carthage (Deneauve 1969, $\mathrm{n}^{\circ}$ 1137). Pâte brun clair, surface blanche. Sur le bandeau: inscription en relief $A B$ ASSENE LVCE/RNAS VENALES. D. $77 \mathrm{~mm} ; \mathrm{H} ; 33 \mathrm{~mm}$.

2 Carthage (Hayes 1976a, Pl. 27, n III.7). Pâte beige fine, surface blanc crème. Sur le bandeau: entrelacs en relief. D. $76 \mathrm{~mm}$; H. $41 \mathrm{~mm}$.

Ces lampes sont traditionnellement datées des IVe-Ve s. ; le $\mathrm{n}^{\circ} \mathbf{2}$ provient d'un contexte de la fin du IVe siècle.

\section{- lampes de type Bussière E V (fig. 198)}

\section{LAMPE TYPE 35}

Ces lampes forment un groupe relativement hétérogène. Trois groupes principaux ont été distingués par J. Bussière $(2000,124)$ «qui montrent bien le passage d'une lampe au corps rond ou légèrement ovoïde et à bec court» (groupe 1), dans la tradition antique des types Deneauve VII et VIII, «à une lampe à médaillon circulaire et bec long à canal droit» (groupes 2 et 3 ), influencée par les types Atlante VIII et X des productions en sigillée africaine. Certaines des lampes du groupe 1 portent des marques incisées: VICTORIS, EXOF/VICTO/RIN, DEOFIC/INA CECILI, parfois inscrites de manière circulaire, sous le fond; probablement originaires de Tipasa, elles sont diffusées, mais assez faiblement, en Méditerranée occidentale.

Exemples (fig. 198) :

Groupe 1

*1 Musée de Carthage (Deneauve 1969, n 1111). Pâte brune très pâle. D. $75 \mathrm{~mm}$; H. $25 \mathrm{~mm}$.

2 Marseille, épave pointe de la Luque B (Liou 1973, fig. 16 ; Bussière 2000, Pl. 162, n 7588 ). D. $75 \mathrm{~mm}$; H. $37 \mathrm{~mm}$.

Production attestée du IVe s. au VIe s. (Bussière 2000, 126). Le $n^{\circ} 2$ provient d'un contexte du IVe siècle.

\section{— lampes à becs multiples (fig. 198)}

\section{LAMPE TYPE 36}

Mentionnons rapidement l'existence de lampes circulaires à becs multiples, en céramique commune, en forme de couronne évidée. Cette forme est connue en Algérie (type Bussière $\mathrm{E} V$ 7) mais deux exemples 
Type Bussière E IV

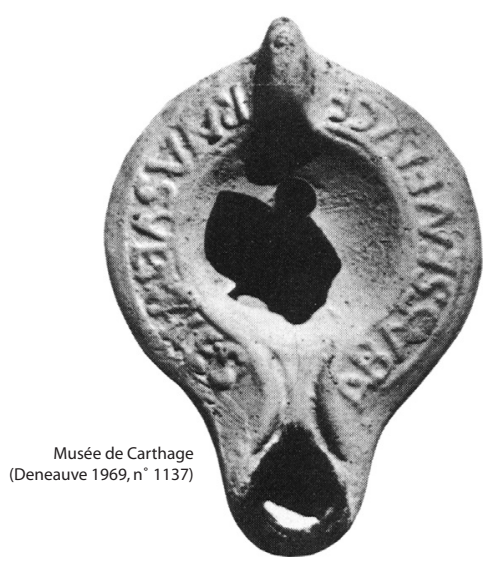

1
Type Bussière E V

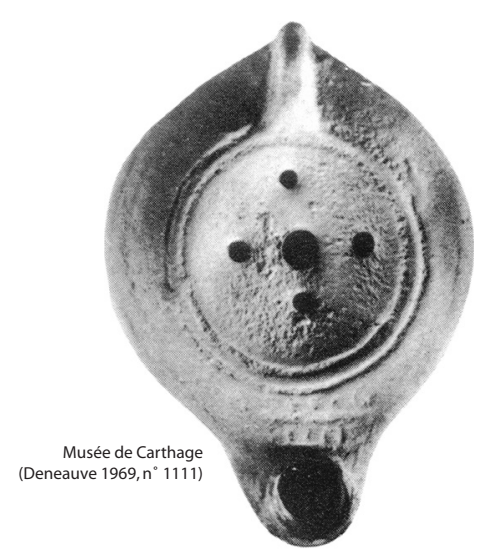

1

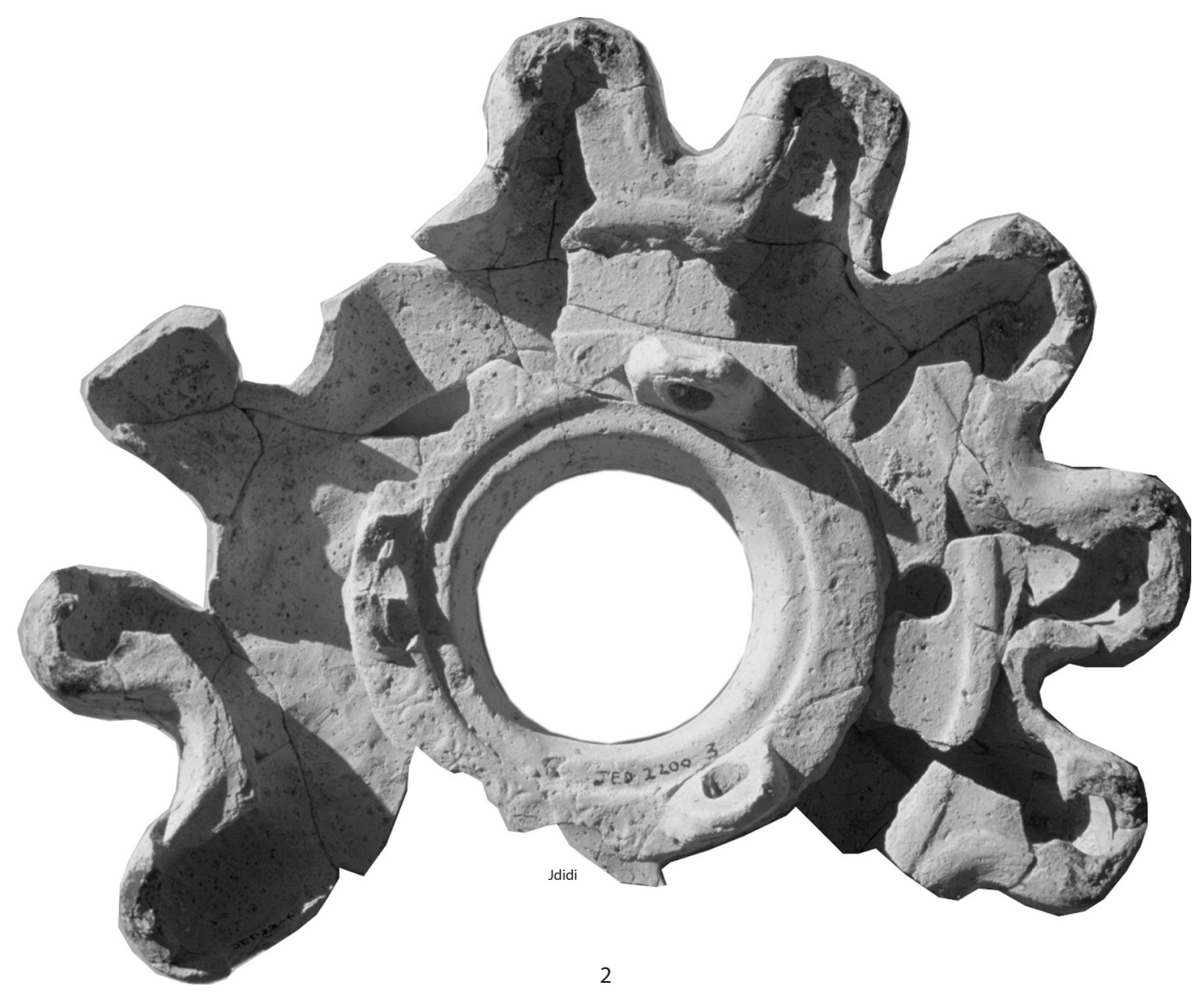

Fig. 198. Lampes africaines tardives de tradition antique. 
proviennent également de basiliques chrétiennes du nord de la Tunisie.

Exemples (fig. 198) :

1 Kelibia (Cintas, Duval 1958, Pl. XII, d-e). D. $290 \mathrm{~mm}$.

*2 Sidi Jdidi, basilique 2, destruction état II (Inv. JD2200.3). D. $280 \mathrm{~mm}$ env.

La lampe de Sidi Jdidi provient d'un contexte de la seconde moitié du Ve s. (2).

\subsubsection{Lampes en sigillée}

Les études sur les lampes en céramique sigillée africaine bénéficient depuis maintenant plus de vingt ans de la typologie élaborée par L. Anselmino et C. Pavolini (Atlante I, 184-207). Certes, le volume et la complexité de la documentation, en perpétuel accroissement, ont conduit M. Mackensen (1993, 95-165) à proposer quelques modifications de détail pour insérer les types nouveaux découverts sur l'atelier d'El Mahrine, et C. Pavolini à transformer sa classification en un système plus ouvert (Barbera, Petriaggi 1993). Cependant, même s'il est parfois plus commode de revenir aux distinctions schématiques établies par J. W. Hayes (1972, 310-314), l'architecture d'ensemble de cette typologie ne paraît pas devoir être remise en question (Pavolini, Tortorella 1997).

Le seul point sur lequel il est possible d'améliorer cette classification concerne les décors. Ces derniers, en effet, n'ont pas souvent été utilisés alors qu'ils peuvent apporter des indications très précieuses sur la région de production (supra, p. 80).

Je vais donc suive cette typologie, dans son dernier état (selon les « séries » définies par Barbera, Petriaggi 1993), en mentionnant les points sur lesquels la documentation que j'ai pu examiner apporte des informations nouvelles.

Formes précoces: productions de Byzacène méridionale ?

Les trois premières séries de lampes en sigillée africaine sont probablement des productions de Tunisie centrale et méridionale, et leur diffusion reste, somme toute, relativement restreinte.

\section{- Série 1}

Les « lampes à réservoir circulaire sans canal » à vernis rouge ne se distinguent pas ou se distinguent peu, morphologiquement, des lampes africaines à pâte claire engobée, contemporaines. Je ne dispose d'informations que sur le type I.

\section{- forme Atlante I (fig. 199)}

\section{LAMPE TYPE 37}

La forme Atlante I est la variante en céramique sigillée du type Deneauve VIII/sous-type 2.
Exemples (fig. 199) :

*1 Isola Sacra (Atlante I, Pl. CLV, 2).

*2 Nabeul, fabrique de salaisons, bassin XVII (Inv. NB1053.4).

3 Idem (Inv. NB1053.24).

Les deux exemples de Nabeul (2-3) proviennent d'un contexte du deuxième quart ou du milieu du IIIe s., date parfaitement en accord avec celle des productions en céramique à pâte claire engobée connues pour le même type de lampe (supra TYPE 11). Ce sont, à ma connaissance, les attestations les plus septentrionales enregistrées pour ce type en Tunisie.

\section{- Série 2}

Les « lampes à réservoir circulaire et à canal court ou peu allongé » sont plus caractéristiques de la production naissante de lampes en sigillée africaine. Je passe rapidement sur les types Atlante IV et V, avant de m'attarder un peu plus sur le type VI, en raison d'une documentation plus abondante.

- forme Atlante IV (fig. 199)

\section{LAMPE TYPE 38}

Ce type est dit «d'El-Aouja », en raison de son abondance dans la nécropole du même nom. C'est le parallèle en sigillée africaine des lampes locales de type Ennabli 15 (supra, TYPE 22) : le disque est circulaire, limité par des sillons larges et profonds (variante A) ou plus rarement par une palme étroite en relief (variante B), et relié au bec par un canal plus ou moins allongé. Fond en anneau saillant, anse pleine.

Exemples (fig. 199) :

Variante A

*1 El Jem, maison d'Africa (sans $\mathrm{n}^{\circ}$ d'inv.). Sur le disque : Dionysos (?). D. : $81 \mathrm{~cm}$.

Variante B

*2 Littoral tunisien, site $n^{\circ} 42$ (En Nadour) (Bonifay et al. 2002-2003, fig. $9, \mathrm{n}^{\circ} 86$ ).

*3 Institut Archéologique d'Utrecht (Atlante I, Pl. CLV, 9).

Les deux premiers exemples sont hors stratigraphie. Le $\mathrm{n}^{\circ} 1$ provient néanmoins d'un contexte général de la seconde moitié du IIIe et de la première moitié du IVe s., date en accord avec celle initialement proposée par Salomonson $(1968,88)$.

\section{- forme Atlante V (fig. 199)}

\section{LAMPE TYPE 39}

Lampe à réservoir circulaire, bec à canal allongé, bandeau décoré d'une couronne végétale en relief, fond annulaire, anse forée. Ce type, dit « de Navigius » en raison de la présence d'une marque incisée $E X$ OFI/CINA/NAVIGI sur l'unique exemplaire publié (Salomonson 1969, fig. 134), est très peu documenté. D'où l'intérêt du fragment recueilli sur un site du golfe de Gabès : 
Typologie - Lampes

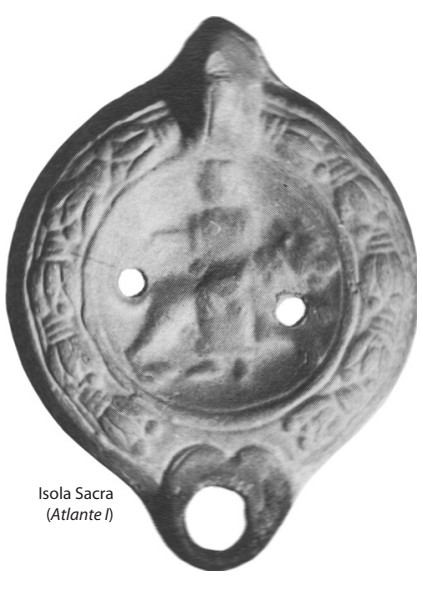

Type Atlante I
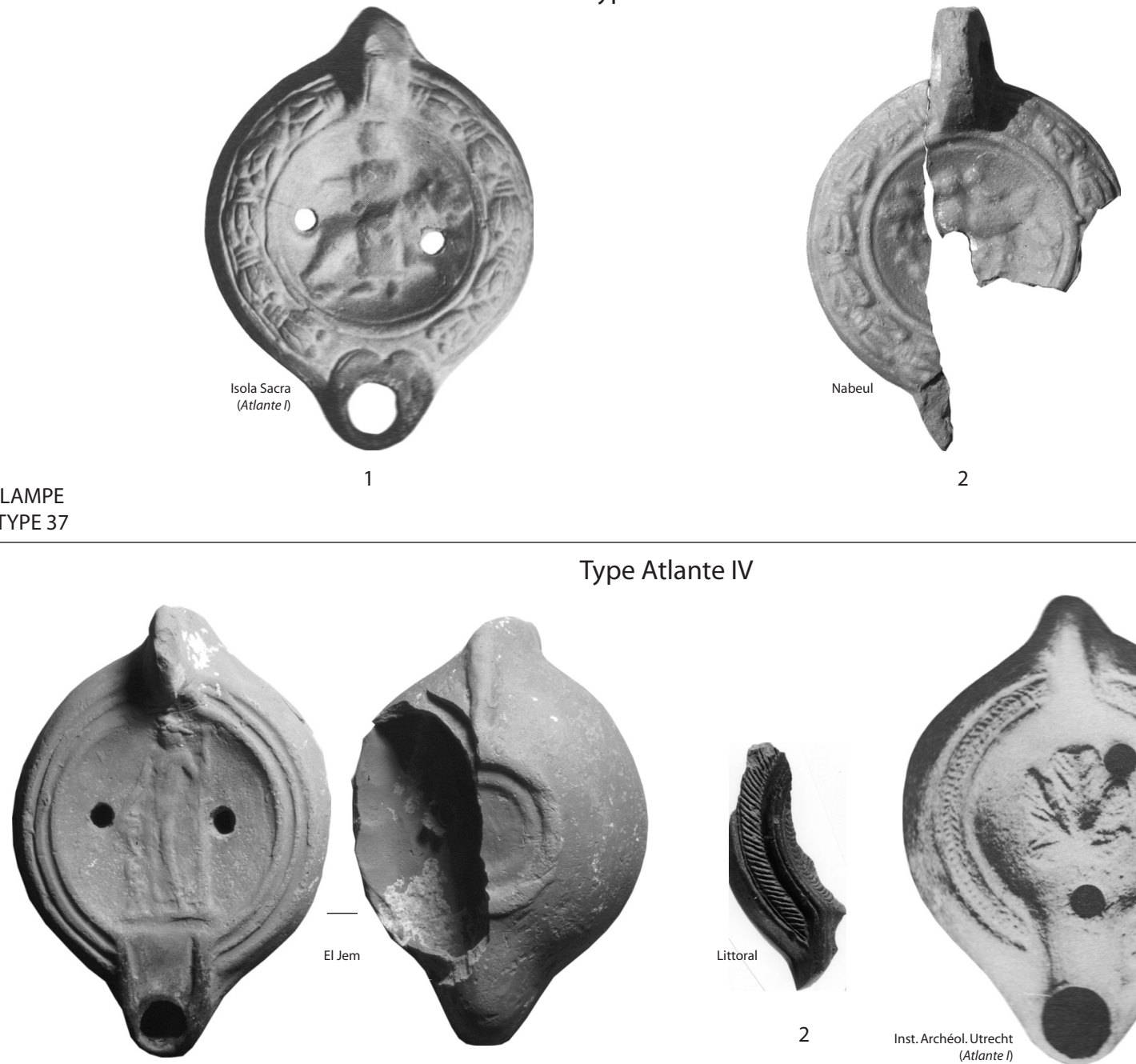

1
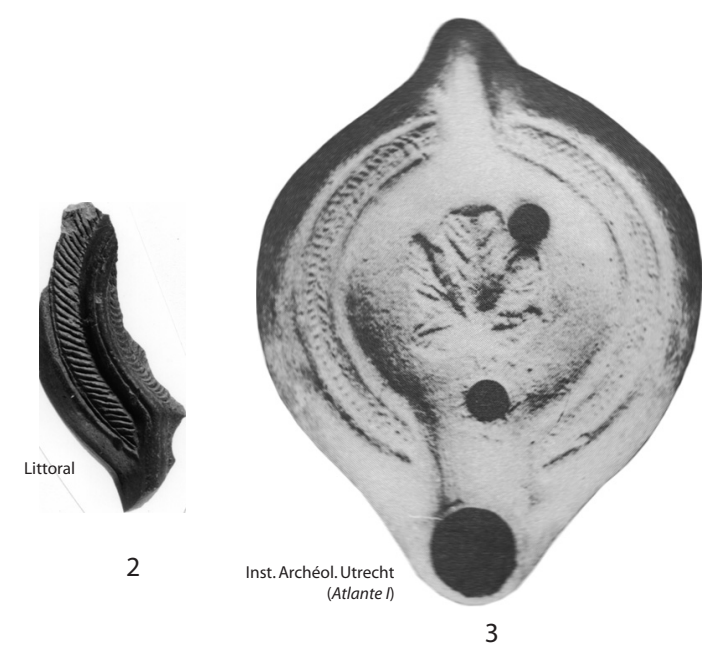

LAMPE

TYPE 38

Type Atlante V

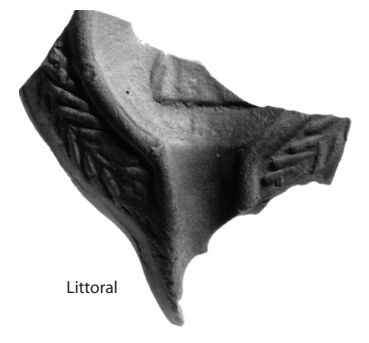

2

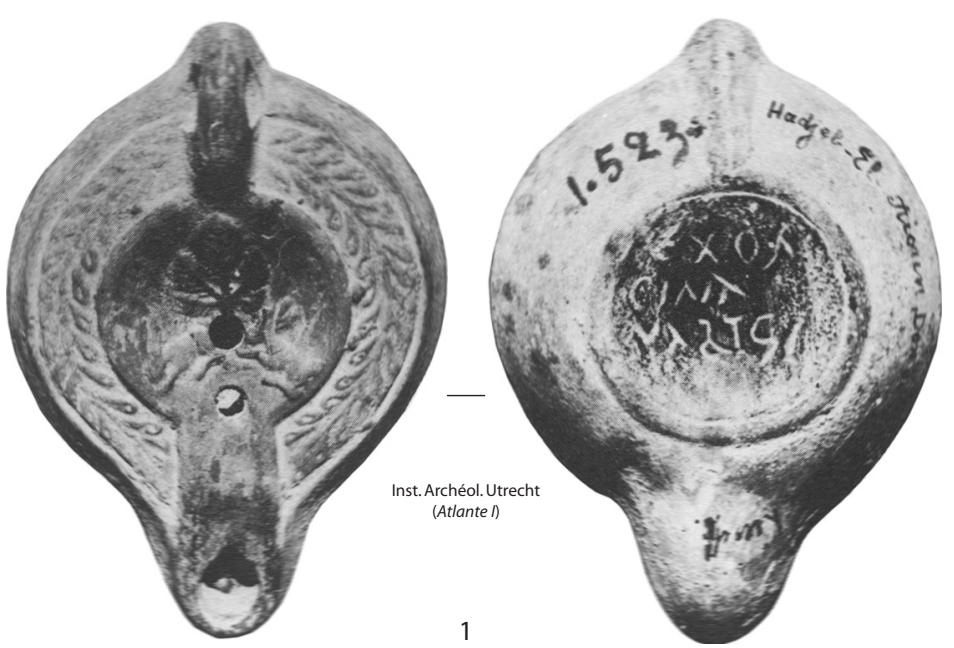

Fig. 199. Lampes en sigillée africaine (Tunisie centrale). 


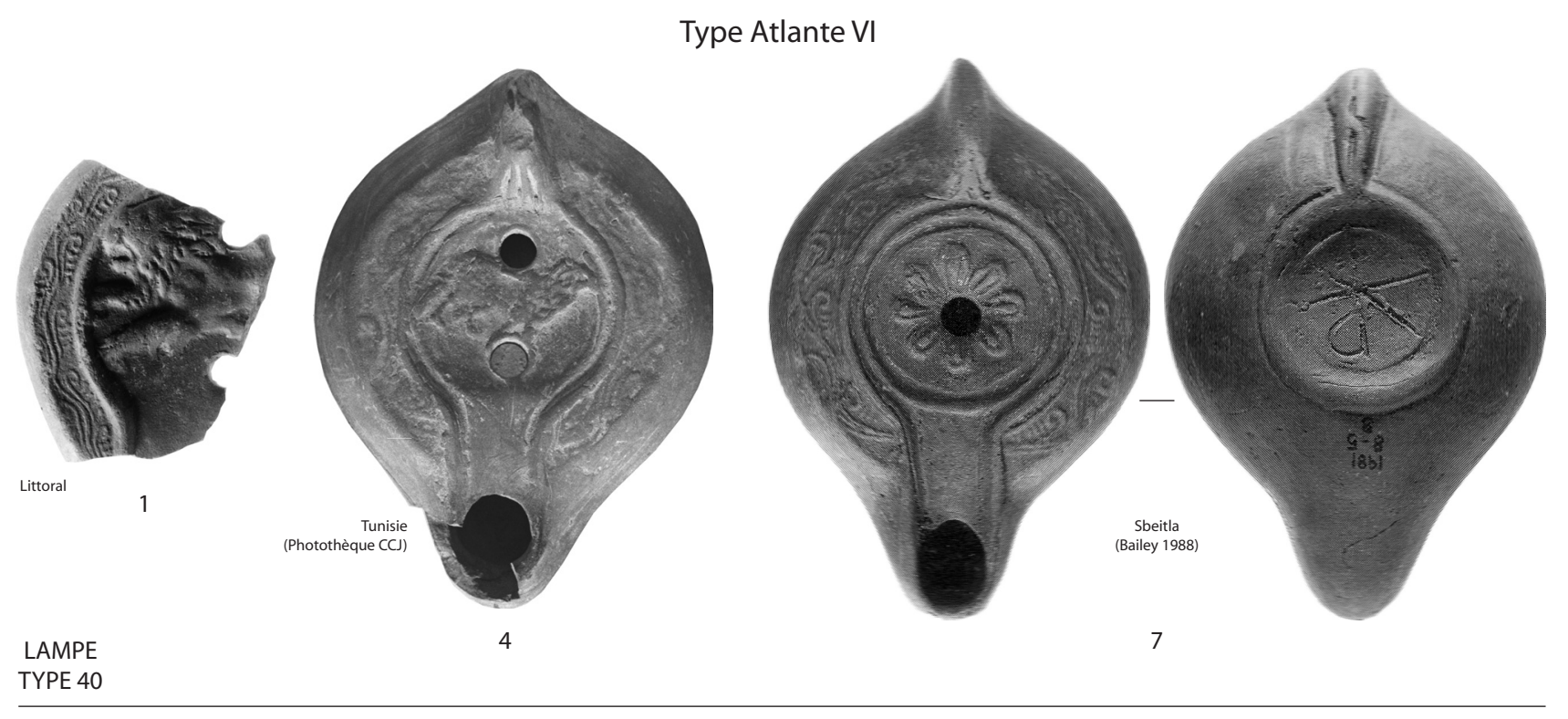

Lampes apparentées au type Atlante VI

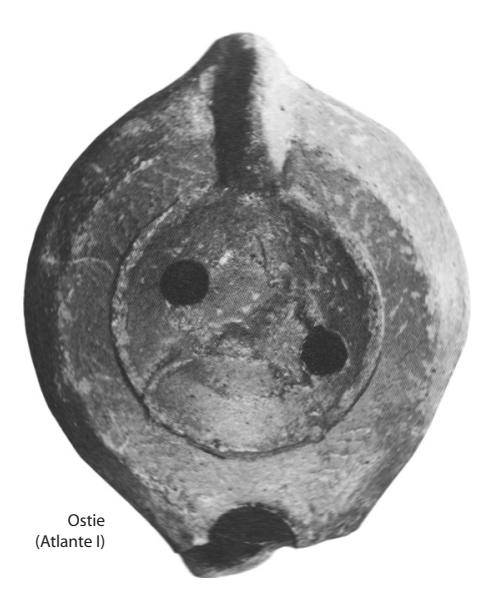

1

3
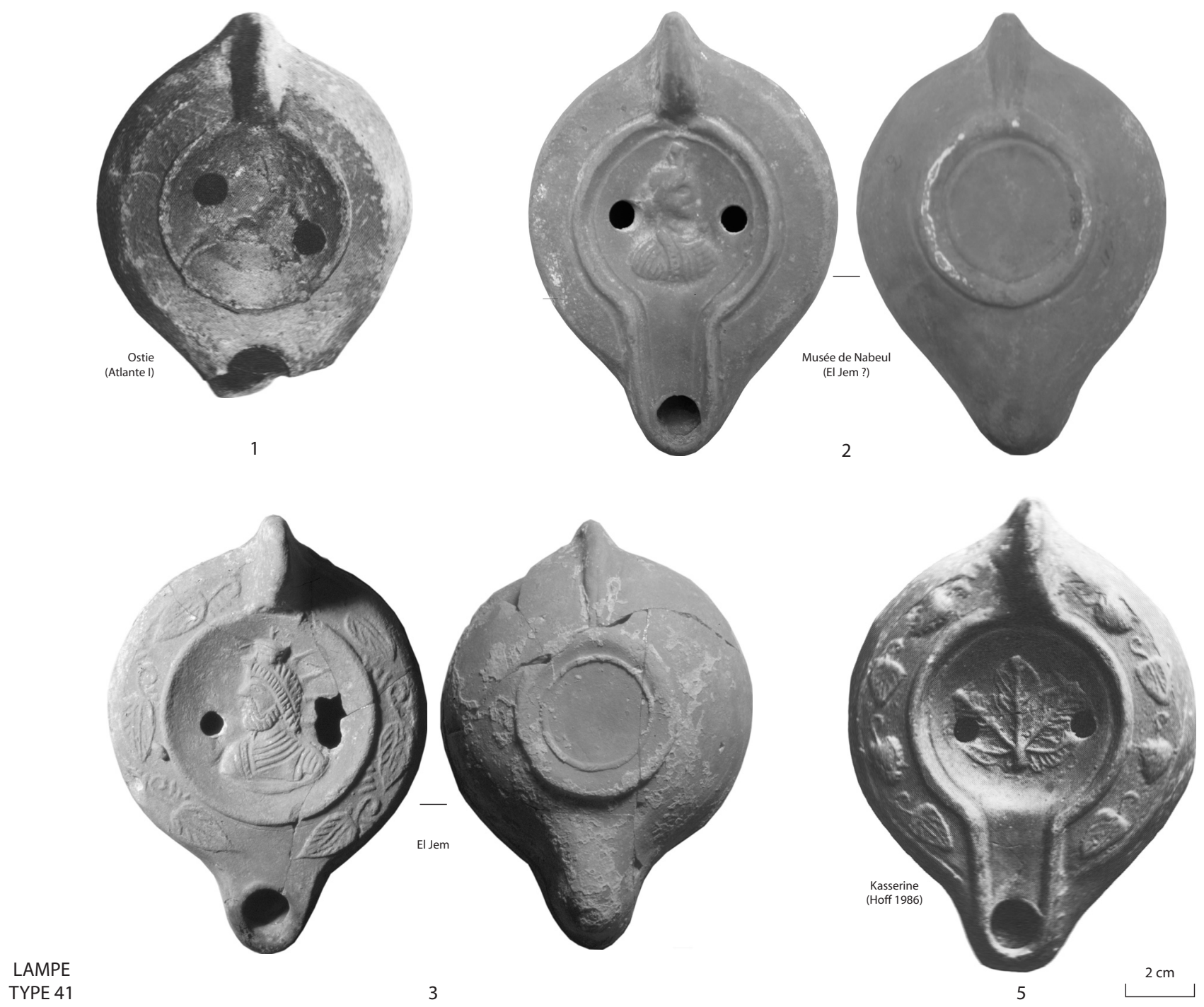

Fig. 200. Lampes en sigillée africaine (Tunisie centrale). 


\section{Typologie - Lampes}

Type Atlante VII

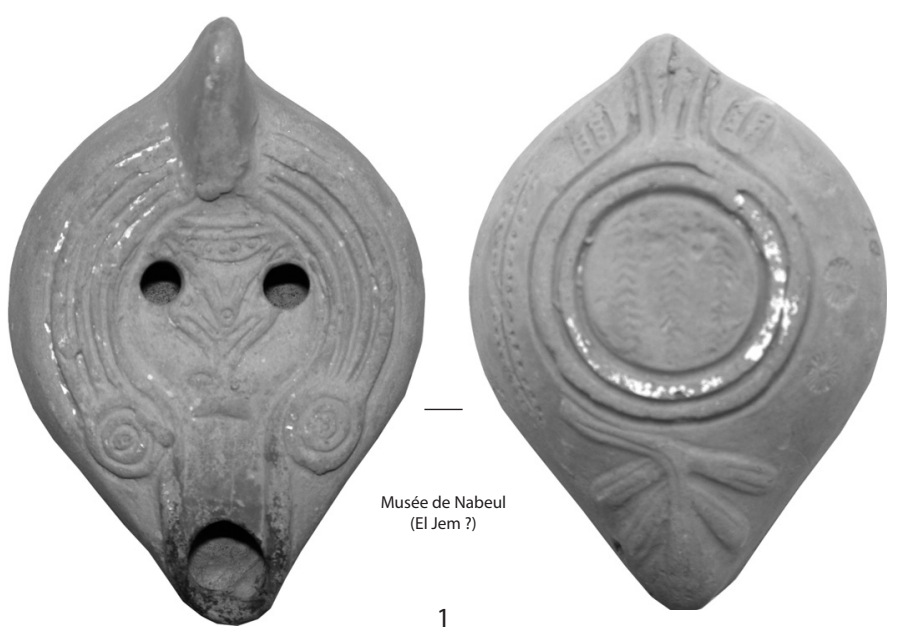

Type Atlante VIII B
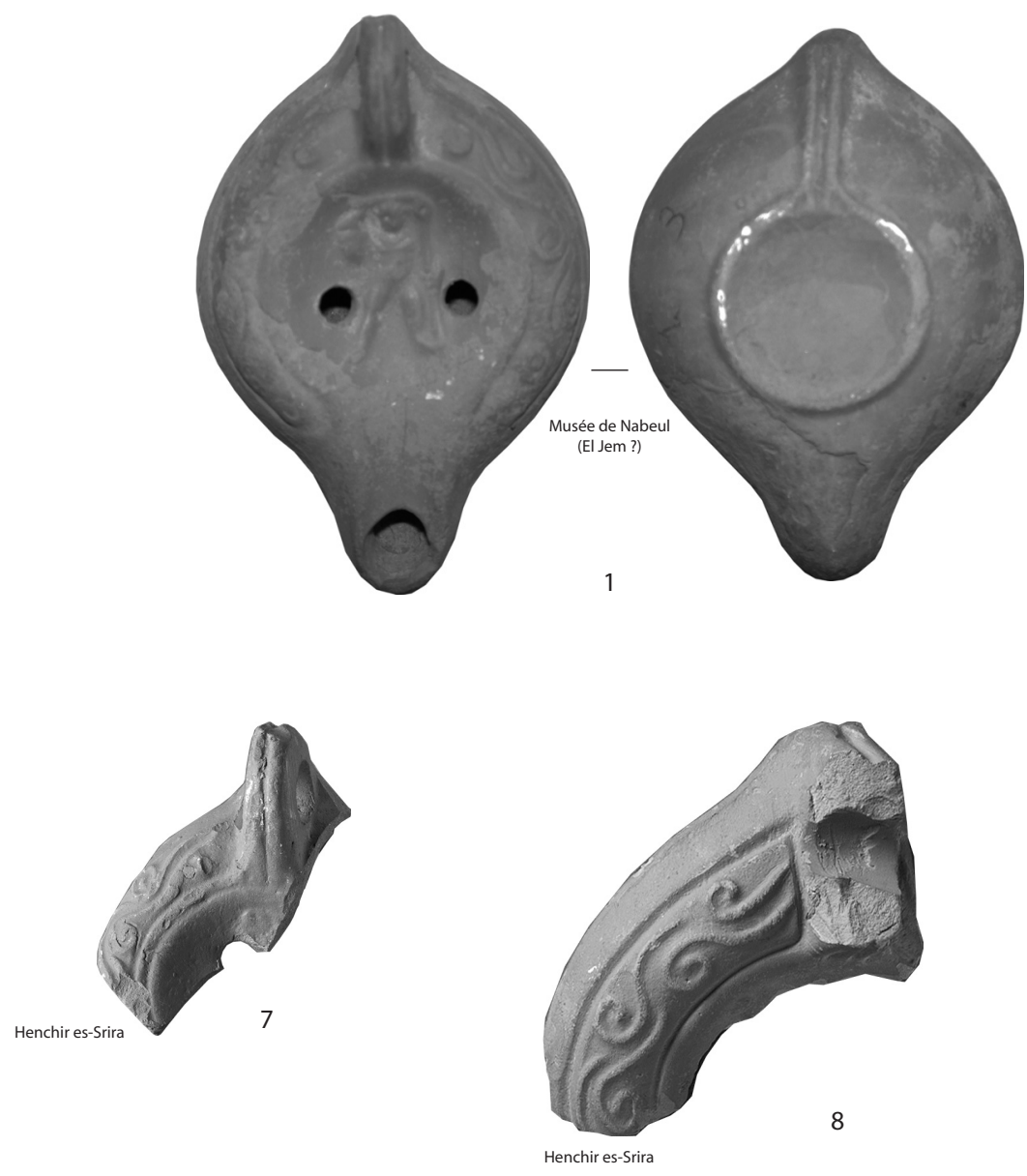

Fig. 201. Lampes en sigillée africaine (Tunisie centrale). 
Exemples (fig. 199) :

*1 Institut Archéologique d'Utrecht (Atlante I, Pl. CLVI, $1)$.

*2 Littoral tunisien, site $n^{\circ} 42$ (En Nadour) (Bonifay et al. 2002-2003, fig. $9, \mathrm{n}^{\circ} 96$ ).

Les présomptions sur une production du type Atlante $\mathrm{V}$ sur l'atelier d'Henchir es-Srira (Salomonson 1969, 93) n'ont pas été confirmées par les prospections plus récentes (Peacock, Bejaoui, Ben Lazreg 1990) et la datation proposée (fin du IIIe s. -premier quart du IVe s.) repose uniquement sur des bases stylistiques (Salomonson 1969, 93).

\section{- forme Atlante VI (fig. 200)}

\section{LAMPE TYPE 40}

Ce type, jusqu'à présent assez peu documenté, se définit par son réservoir circulaire à bandeau plat ou légèrement incliné vers l'extérieur, décoré de rinceaux en faible relief, et relié au bec par un canal allongé. Ce canal peut être complètement ouvert (variante A) ou bien fermé par un cercle en léger relief qui entre dans la composition du décor du disque (variante B). Fond annulaire. Anse pleine.

Exemples (fig. 200) :

Variante A

*1 Littoral tunisien, site $\mathrm{n}^{\circ} 29$ (Henchir Chelaki) (Bonifay et al. 2002-2003, fig. 9, $\mathrm{n}^{\circ}$ 92). Sur le bandeau : rinceau en faible relief. Sur le disque : lion bondissant à gauche.

2 Idem, site $\mathrm{n}^{\circ} 1$ (Henchir el-Medeina) (Bonifay et al. 2002-2003, fig. $9, \mathrm{n}^{\circ}$ 93). Décor comparable au $n^{\circ}$ précédent.

3 La Skhira (Fendri 1961, Pl. XXXVI, n 4). Sur le disque : mouton à droite.

*4 Tunisie (photothèque du Centre Camille Jullian, négatif $n^{\circ} 74231$ ). Décor identique au $n^{\circ}$ précédent. D. $88 \mathrm{~mm}$.

Variante B

5 Littoral tunisien, site $\mathrm{n}^{\circ} 39$ (Oued el-Akarit) (Bonifay et al. 2002-2003, fig. 16, $\left.\mathrm{n}^{\circ} 220\right)$. Sur le bandeau : rinceau en faible relief. Sur le disque: rosace (?) limitée par un cercle (?).

6 Djilma/Henchir el-Guellal, atelier (Peacock, Bejaoui, Ben Lazreg 1990, fig. 14, r). Décor comparable au précédent.

*7 Sbeitla, British Museum (Bailey 1988, n Q1733). Décor comparable au précédent (?). Sous le fond: chrisme incisé avant cuisson. D. $85 \mathrm{~mm}$.

8 Museo Nazionale Romano (Barbera, Petriaggi 1993, 17-18, n 189449). Décor comparable au précédent. D. $95 \mathrm{~mm}$.

9 Ovilava/Wels (Autriche) (Ladstätter 1998, fig. 4). Décor comparable au précédent.

Les données stratigraphiques manquent, une fois de plus, pour cerner la datation de ce type. L'Atlante est muet à ce sujet et D. Bailey propose le IVe s. pour son exemplaire $\mathrm{du}$ British Museum. Cette chronologie pourrait bien correspondre au contexte de découverte du $n^{\circ} 5$. L'atelier de Djilma/Henchir el-Guella, qui semble avoir produit ce type de lampe (6), aurait fonctionné du début du IVe s. jusque vers 450-470 (Peacock, Bejaoui, Ben Lazreg
1990, 79). Particulièrement intéressante est la diffusion de ce type de Tunisie méridionale sur le limes de Norique (9).

De fait, je me demande si cette lampe ne constitue pas l'évolution d'une série propre à la Byzacène méridionale, représentée par le type suivant.

\section{LAMPE TYPE 41}

La forme générale est assez caractéristique : le bandeau est de faible largeur alors que les parois latérales sont hautes, galbées, avec un profil légèrement rentrant, ce qui procure un aspect chanfreiné au pourtour du réservoir, bien visible sur les photographies verticales. Cette particularité, qui ne se rencontre généralement pas sur les autres formes précoces de lampes en sigillée africaine, permet de dresser une ébauche de typologie :

Exemples (fig. 200) :

Sans canal, bandeau lisse

*1 Ostie (Atlante I, Pl. CLV, $\left.{ }^{\circ} 4\right)$.

Avec canal, bandeau lisse

*2 Musée de Nabeul, provenant d'El Jem (?) (Inv. NBML10). Vernis orange-brun, rugueux. Sur le disque : buste à droite. D. $89 \mathrm{~mm}$; H. $33 \mathrm{~mm}$.

Sans canal, bandeau décoré de feuilles en relief

*3 Dépôt d'El Jem (sans $n^{\circ}$ d'inv.). Pâte orange clair, engobe orange. Sur le bandeau: feuilles. Sur le disque : buste de Sérapis. D. $92 \mathrm{~mm}$.

4 Littoral tunisien, site $\mathrm{n}^{\circ} 35$ (Oued Zerkine) (Bonifay et al. 2002-2003, fig. $9, \mathrm{n}^{\circ}$ 90).

Avec canal, bandeau décoré de pampres schématisés

*5 Kasserine, Musée du Louvre (Hoff 1986, 95, nº 19). Sur le bandeau : pampres schématisés en fort relief. Sur le disque : feuille de figuier (?) nervurée. Sur le fond: marque incisée illisible. D. $100 \mathrm{~mm}$; H. $40 \mathrm{~mm}$.

6 Littoral tunisien, site $\mathrm{n}^{\circ} 12$ (Henchir el-Abid) (Bonifay et al. 2002-2003, fig. 9, $\mathrm{n}^{\circ} 88$ ).

Les connexions sont nombreuses avec d'autres types de lampes. Le $\mathrm{n}^{\circ} \mathbf{1}$, qui n'est probablement pas postérieur au IIIe s. (?), a été classé par C. Pavolini dans le type Atlante II. Le décor du bandeau des $n^{\circ} \mathbf{3}$ et $\mathbf{4}$ rappelle ou annonce les rinceaux du type Atlante VI, tandis que la forme générale de la lampe se rattache au type Deneauve VIII. Le décor du bandeau des $\mathrm{n}^{\circ} \mathbf{5}$ et $\mathbf{6}$ dérive de celui des lampes Deneauve VIII/sous-type 3 mais la forme générale est celle du type Atlante VI. Il est difficile, dans l'état actuel des recherches sur la Tunisie méridionale, d'en dire plus sur la chronologie et sur la production de ces lampes qui semblent toutefois précéder et annoncer le type Atlante VI.

\section{- Série 3}

- forme Atlante VII (fig. 201)

\section{LAMPE TYPE 42}

La documentation concernant cette forme essentiellement diffusée en Tunisie centrale et méridionale est toujours aussi faible. 
Exemples (fig. 201) :

*1 Musée de Nabeul, provenant d'El Jem (?) (Inv. NBML07). D. $84 \mathrm{~mm}$

2 Tarfaoui, vallée de Chaal (prospections géomorphologiques de M. N. Fehri, 2002).

Le $n^{\circ} 2$ a été recueilli sur un site tardif, en association avec un fond de plat en céramique sigillée de l'atelier de Sidi Aïch.

\section{Formes classiques, dites « lampes chrétiennes »}

Ces lampes sont produites par les grands ateliers de sigillée africaine $\mathrm{C}$, en Byzacène, et $\mathrm{D}$ en Zeugitane. La distinction typologique essentielle a été réalisée par Hayes (1972, 310-311) :

- Type I (=Atlante VIII et IX, séries 4 et 5) : lampes ovoïdes, avec un disque légèrement concave relié au bec, peu distinct du corps de la lampe, par un canal assez court; le bandeau est étroit, convexe ou plus rarement plat, l'anse verticale, pleine ou forée, parcourue d'une cannelure qui se prolonge sur l'arrière de la lampe et, en se dédoublant sur le fond, délimite ce dernier. Assez fréquentes marques incisées : lettre isolée ou signe anépigraphe.

- Type II (=Atlante X et XI, séries 6 et 7) : lampes à réservoir circulaire prolongé par un long bec très proéminent; le disque, très légèrement concave, est relié au bec par un canal large et rectiligne ; bandeau plat et large; anse, pleine, triangulaire, placée obliquement sur le bandeau ; fond annulaire relié au dos de l'anse. Rares marques incisées comparables à celles du type I.

Mais, dans le détail, le schéma évolutif de cette typologie est d'une rare complexité. J'ai cherché pour ma part à ordonner les exemples, souvent très fragmentaires, dont je disposais, en prenant en considération non seulement la morphologie de la lampe mais également son décor. Je ne propose pas de nouvelle classification mais un aménagement de celles qui existent déjà, en essayant avant tout de préciser les zones de production et la chronologie (fig. 202a et b).

\section{- série 4 (type Atlante VIII)}

On sait maintenant que ces lampes ne sont pas uniquement originaires de Tunisie centrale comme on a pu le penser naguère (Hayes 1976a, 121), mais qu'elles sont produites à la fois en Byzacène et en Zeugitane (Mackensen 1993, 161). Il me paraît primordial, d'un point de vue typologique et chronologique, de chercher à distinguer ces deux productions. M. Mackensen (Ibid.) a pu démontrer que l'origine des types VIII B et VIII D de la classification de Pavolini pouvait être localisée de manière probablement exclusive, respectivement en Byzacène et en Zeugitane. En revanche, même si certains caractères, comme l'anse forée, sont plutôt spécifiques d'une région (la Byzacène), la grande masse des lampes de type VIII A et $\mathrm{C}$ demeure difficile à classer.

\section{— productions de Tunisie centrale}

- type Atlante VIII B (fig. 201)

\section{LAMPE TYPE 43}

Ce type est caractérisé par son bandeau convexe décoré de rinceaux en relief.

Exemples (fig. 201) :

*1 Musée de Nabeul, provenant d'El Jem (?) (Inv. NBM.L06). Sigillée C. Vernis orange clair, écaillé. Sur le bandeau : rinceaux. Sur le disque : amour à la vigne. Anse forée. D. $83 \mathrm{~mm}$; H. $37 \mathrm{~mm}$.

2 Musée d'Alexandrie (en exposition). Décor identique à celui du $\mathrm{n}^{\circ}$ précédent.

3 Nabeul, fabrique de salaison, bassin XXXI (Inv. NB1186.9-10). Sigillée C. Anse forée.

4 Idem, état 5B (Inv. NB1145.78). Sigillée C. Anse pleine.

5 Idem, bassin XXIX (Inv. NB1187). Surmoulage (?). Anse pleine.

6 Henchir es-Srira, atelier (Peacock, Bejaoui, Ben Lazreg 1990, fig. 12, m)

*7 Idem (collection R. Guéry, Centre Camille Jullian, Inv. HS.06). Sigillée C. Anse forée.

*8 Idem (Inv. HS.03).

Il est clair depuis longtemps (en dernier lieu : Mackensen 1993, 161) que ce type est originaire de Tunisie centrale, principalement de l'atelier de Henchir es-Srira, où plusieurs moules en plâtre, portant ce motif, ont été recueillis (Peacock, Bejaoui, Ben Lazreg 1990, fig. 12, e ; supra, fig. $\left.45, \mathrm{n}^{\circ} 1-2\right)$. Les exemplaires à anse forée sont les plus anciens; ils apparaissent à Nabeul dans des contextes de la seconde moitié ou de la fin du IVe s. (3). Ceux avec l'anse pleine sont plus tardifs: on les rencontre, sur le même site, dans les niveaux de la première moitié du Ve s. (4-5).

\section{— productions communes à la Tunisie centrale et septentrionale}

Les types VIII A et VIII C ont pu être produits aussi bien en Byzacène qu'en Zeugitane. La pâte des exemplaires originaires de Tunisie centrale, comparable à la catégorie $\mathrm{C}$ de la céramique sigillée africaine, est assez facilement identifiable mais cet aspect n'est pas systématiquement abordé dans les descriptions. Les marques ou les signes incisés sous le fond ne sont pas d'un grand secours. Un signe en forme d'ancre (?) paraît caractéristique de l'atelier de Henchir es-Srira (Peacock, Bejaoui, Ben Lazreg 1990, fig. 12, f) mais on le retrouve sur une lampe Atlante VIII D/IX qui parait bien de facture septentrionale (Bailey 1988, Q 1735). Une marque en forme de palme, parfois associée à un motif en « $\mathrm{S}$ » horizontal en bordure de la circonférence du fond, apparaît à la fois sur une lampe probablement originaire de Byzacène en raison de son anse forée (Hoff 1986, 98, $\mathrm{n}^{\circ} 29$ ) et sur les productions d'El Mahrine (Mackensen 1993, fig. 32, $\mathrm{n}^{\circ} 1$ et 9). Il convient donc d'être prudent dans l'utilisation de ces divers critères de différenciation. 


\section{- bandeau convexe, disque à rosace centrale (types Atlante VIII A1c, VIII A2b) (fig. 203)}

\section{LAMPE TYPE 44}

Ces lampes ne possèdent qu'un orifice de remplissage central autour duquel le décor, géométrique, est organisé de manière rayonnante. Le motif le plus fréquent est une rosace mais on rencontre également des peltes ou des stries.

Exemples (fig. 203) :

Variante A (=Type VIII A1c : palmes sur le bandeau)

*1 Sicile, Museo Nazionale Romano (Barbera, Petriaggi 1993, n 30). Anse forée. D. $72 \mathrm{~mm}$.

*2 Musée de Nabeul, provenant d'El Jem (Inv. NBM.L01). Sigillée C. Vernis orange clair, écaillé. Sur le bandeau : palme double. Sur le disque : rosace. Anse non forée. D. $73 \mathrm{~mm}$; H. $30 \mathrm{~mm}$.

3 Ostie (Atlante I, Pl. CLVII, $\mathrm{n}^{\circ}$ 2).

4 Sbeitla, Musée du Louvre (Hoff 1986, 99, n 37). Anse non forée. D. $75 \mathrm{~mm}$; H. $33 \mathrm{~mm}$.

5-6 Henchir es-Srira, atelier (Peacock, Bejaoui, Ben Lazreg 1990, fig. 12, j et q)

7 Beisan (Jordanie), Royal Ontario Museum (Hayes 1980b, Pl. 34, n 281). D. $73 \mathrm{~mm}$.

Variante B (=Type VIII A2b : incisions obliques sur le bandeau)

*8 Sbeitla, Musée du Louvre (Hoff 1986, 98, n 33). D. $77 \mathrm{~mm}$; H. $38 \mathrm{~mm}$

9 Ostie (Atlante I, Pl. CLVII, $\left.\mathrm{n}^{\circ} 4\right)$

10 El Mahrine, atelier (Mackensen 1993, fig. 33, $\mathrm{n}^{\circ} 1$ ).

Ce type extrêmement fréquent, dont on a des preuves de production aussi bien en Byzacène (5-6) qu'en Zeugitane (10), semble néanmoins plus caractéristique de la première des deux régions. Cette identification d'origine est sûre pour les exemplaires $n^{\circ} \mathbf{1}$ et $\mathbf{8}$, dont l'anse est percée, et pour le $\mathrm{n}^{\circ} \mathbf{2}$, à anse pleine, dont j'ai pu observer la pâte. Elle est très probable encore pour le $\mathrm{n}^{\circ} \mathbf{4}$, en raison de son lieu de découverte, et pour l'exemplaire de Jordanie (7), d'après J. W. Hayes. Il est remarquable que le type VIII A1c ne soit pas attesté sur l'atelier d'El Mahrine (Mackensen 1993, 113) mais J. W. Hayes $(1980 \mathrm{~b}, 66)$ signale cependant un exemplaire de Carthage probablement de production septentrionale. La production du type VIII A2b à El Mahrine est sûre, avec en outre une variante à décor centré non plus géométrique mais figuré (Mackensen 1993, fig. 32, n 9). Il m'est apparu utile de privilégier ici le schéma décoratif centré du disque, car ce motif est bien connu sur les lampes africaines durant toute l'époque romaine, et en particulier sur les lampes en sigillée africaine de type Atlante VI. Ce décor centré est connu également sur les types Atlante VIII C1 et 2 (infra, LAMPE TYPE 46).

Il est très probable que les exemplaires de types VIII A1c et VIII A2b à anse forée soient anciens, peut-être de la seconde moitié ou de la fin du IVe siècle. On ne dispose d'aucune indication stratigraphique pour les exemplaires à anse pleine, qui persistent vraisemblablement durant la première moitié du Ve siècle.

\section{- bandeau convexe, disque à décor libre (types Atlante VIII A1a-b, VIII A2a) (fig. 203)}

\section{LAMPE TYPE 45}

Le décor du disque, libre, consiste le plus souvent (mais pas toujours: $\mathrm{n}^{\circ}$ 2) dans des représentations animales dont la lecture se fait généralement bec en bas ou anse à droite.

Exemples (fig. 203) :

Variante A (=Type VIII A1a-b : palmes sur le bandeau)

*1 Musée de Nabeul, provenant d'El Jem (?) (Inv. NBM.L04). Vernis orange rosé, usé. Sur le disque : ours à gauche. Anse forée. D. $85 \mathrm{~mm} ;$ H. $36 \mathrm{~mm}$.

*2 Ostie (Barbera, Petriaggi 1993, 33, $\mathrm{n}^{\circ} 12$ ). Bandeau cantonné de deux points au départ du bec. Sur le disque : buste féminin (?) à droite. Anse pleine. D. $77 \mathrm{~mm}$.

3-6 Henchir es-Srira, atelier (Peacock, Bejaoui, Ben Lazreg 1990, fig. 12, g, i, 1, n).

7 El Mahrine, atelier (Mackensen 1993, fig. 32, n 1). Anse pleine. D. $78 \mathrm{~mm}$.

Variante B (=Type VIII A2a: incisions obliques sur le bandeau)

*8 El Jem, British Museum (Bailey 1988, Q 1748). Sur le bandeau: les incisions obliques délimitent des bandes lisses alternant avec des bandes striées. Sur le disque: chien courant à droite. Anse forée. D. $85 \mathrm{~mm}$.

*9 Musée de Nabeul, provenant d'El Jem (?) (Inv. NBM.L02). Sigillée C. Vernis orange clair écaillé. Sur le disque : bouquetin à droite. Anse pleine. D. $73 \mathrm{~mm}$; H. $31 \mathrm{~mm}$

10 Carthage (Trost, Hellmann 1996, Pl. II, nº 8). Sur le disque : chien courant, dans l'axe de la lampe. Anse pleine. D. $79 \mathrm{~mm}$.

11 El Mahrine, atelier (Mackensen 1993, fig. 32, $\mathrm{n}^{\circ} 7$ ). Anse pleine. D. $82 \mathrm{~mm}$.

La production de ces lampes est attestée sur les ateliers de Henchir es-Srira (3-6) et d'El Mahrine (7 et 11). Les exemplaires à anse forée sont probablement originaires de Tunisie centrale ( $\mathbf{1}$ et $\mathbf{8}$ ) mais une anse pleine n'est pas incompatible avec une telle origine (9). Les exemplaires de facture moins soignée $(\mathbf{2}$ ?, 10) sont plus probablement produits dans le nord de la Tunisie ${ }^{224}$.

La datation de ces lampes, pourtant très répandues, reste toujours un peu problématique. Le type VIII Ala-b (palmes) apparaît à Carthage à la fin du IVes. (Mackensen 1993, 147) et le type VIII A2 (incisions) peut-être pas avant le début du siècle suivant (Ibid., 148). Dans la seconde moitié ou à la fin du Ve s., ne subsistent plus, à côté du type Atlante $\mathrm{X}$, que des lampes à bandeau plat de type VIII C ou D (Neuru 1980, Pl. II ; Riley 1981, deposit XXVII, P1. 2 et 3 ). La chronologie de la variante « carthaginoise » des lampes à bandeau convexe s'insère ainsi dans une fourchette comprise entre 380 et 460 . Le début de la production (en Byzacène ?) reste traditionnellement placé au milieu du IVe s. (Mackensen 1993, 147 ; Pavolini, Tortorella 1997, 255) mais on manque toujours de stratigraphies en Tunisie centrale

\footnotetext{
${ }^{224}$ Les deux points cantonnant le bandeau du $\mathrm{n}^{\circ} \mathbf{2}$ rappellent les productions du groupe D1 (infra, LAMPE TYPE 64).
} 


\section{Typologie - Lampes}

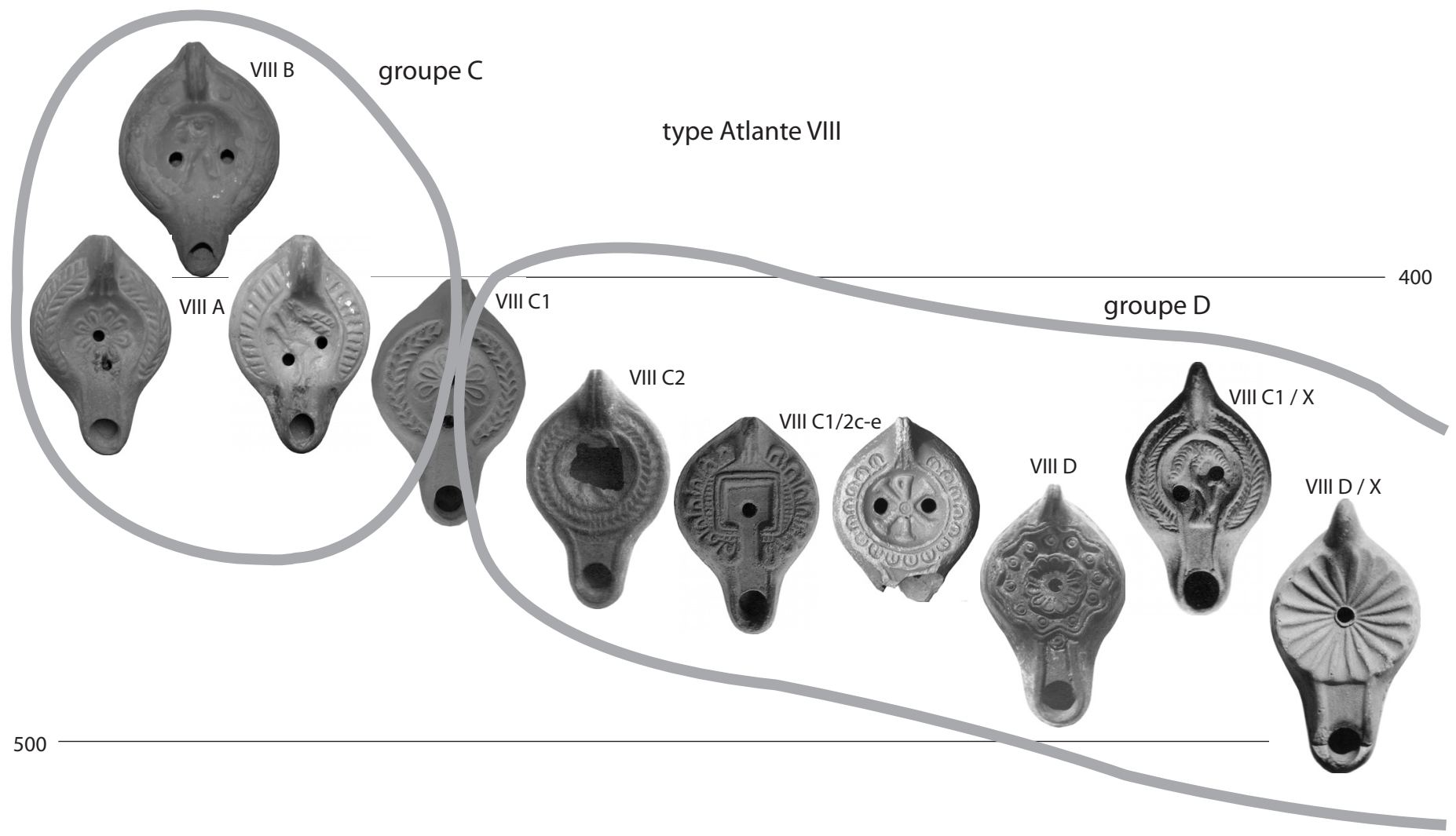

600

Fig. 202a. Lampes tardives en sigillée africaine. Proposition de schéma évolutif. Type Atlante VIII. 


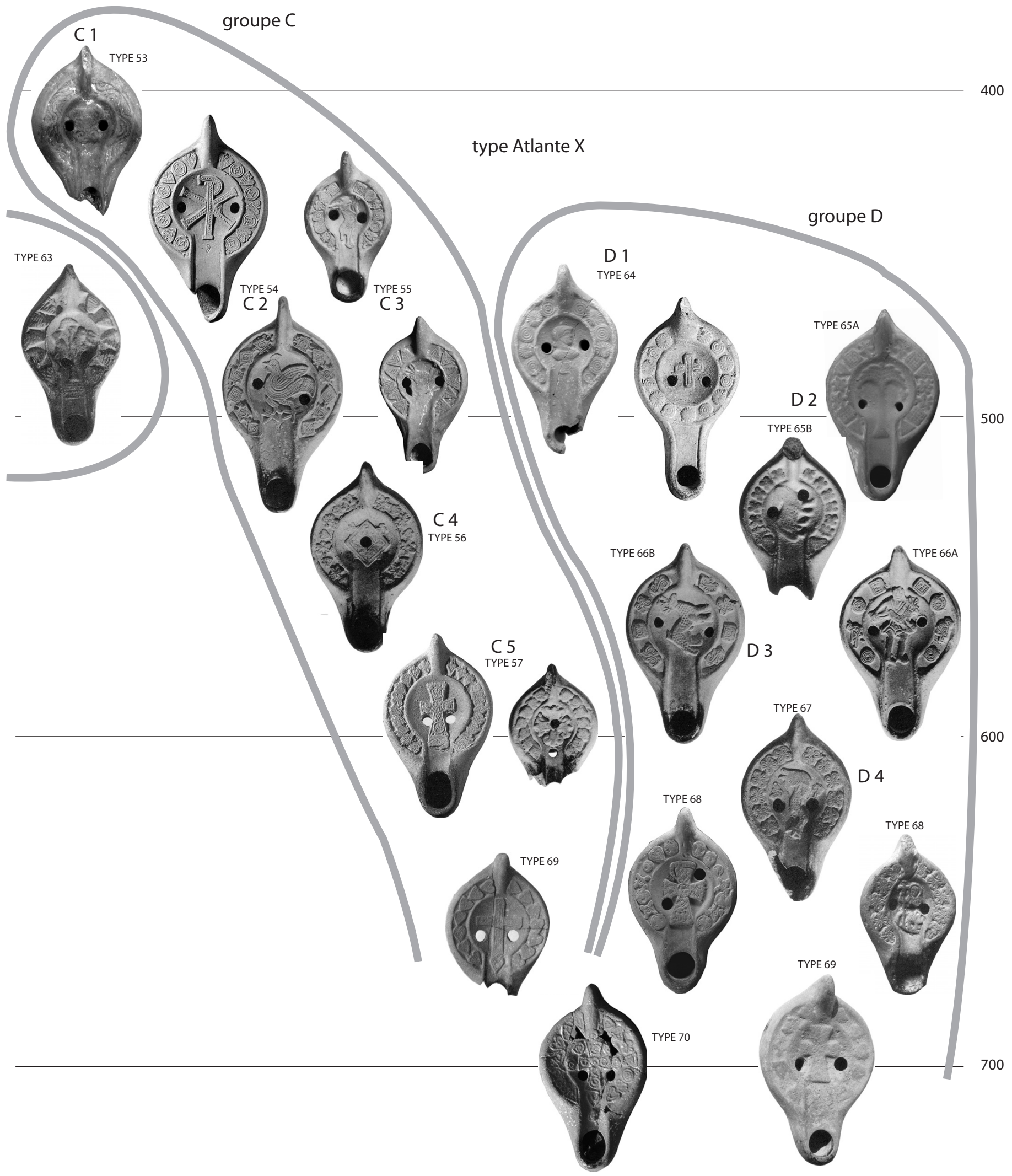

Fig. 202b. Lampes tardives en sigillée africaine. Proposition de schéma évolutif. Type Atlante X. 
Type Atlante VIII A1c/A2b
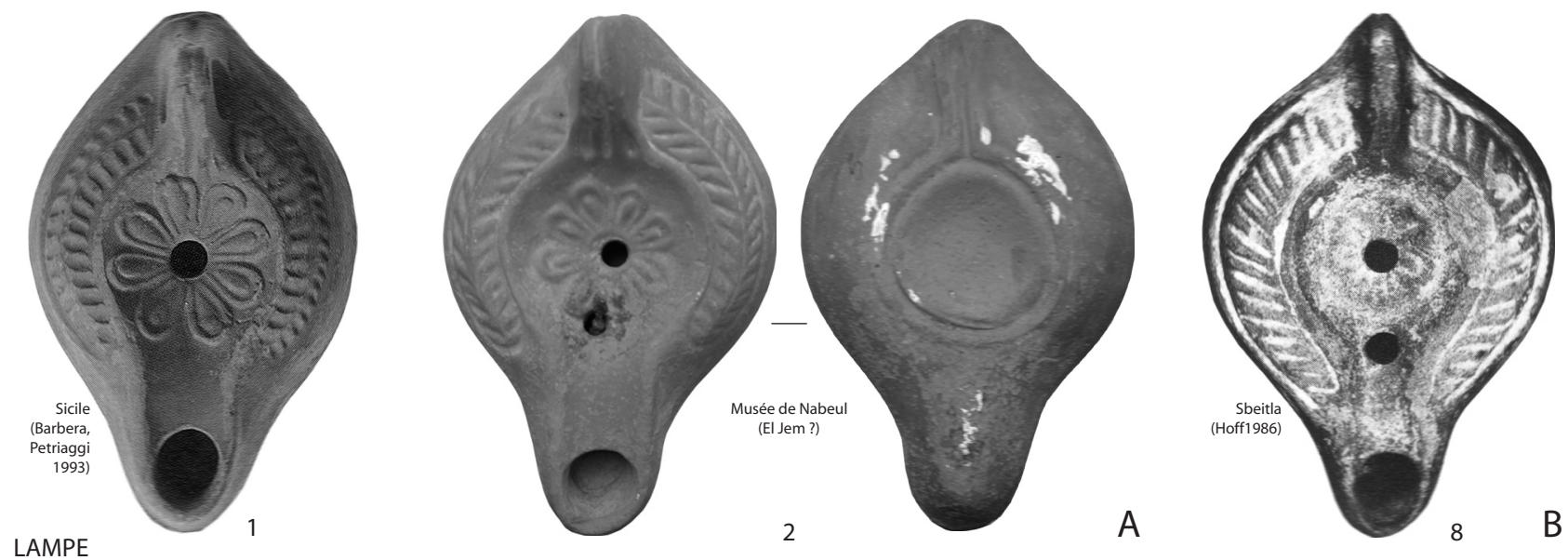

TYPE 44

Type Atlante VIII A1a-b/A2a
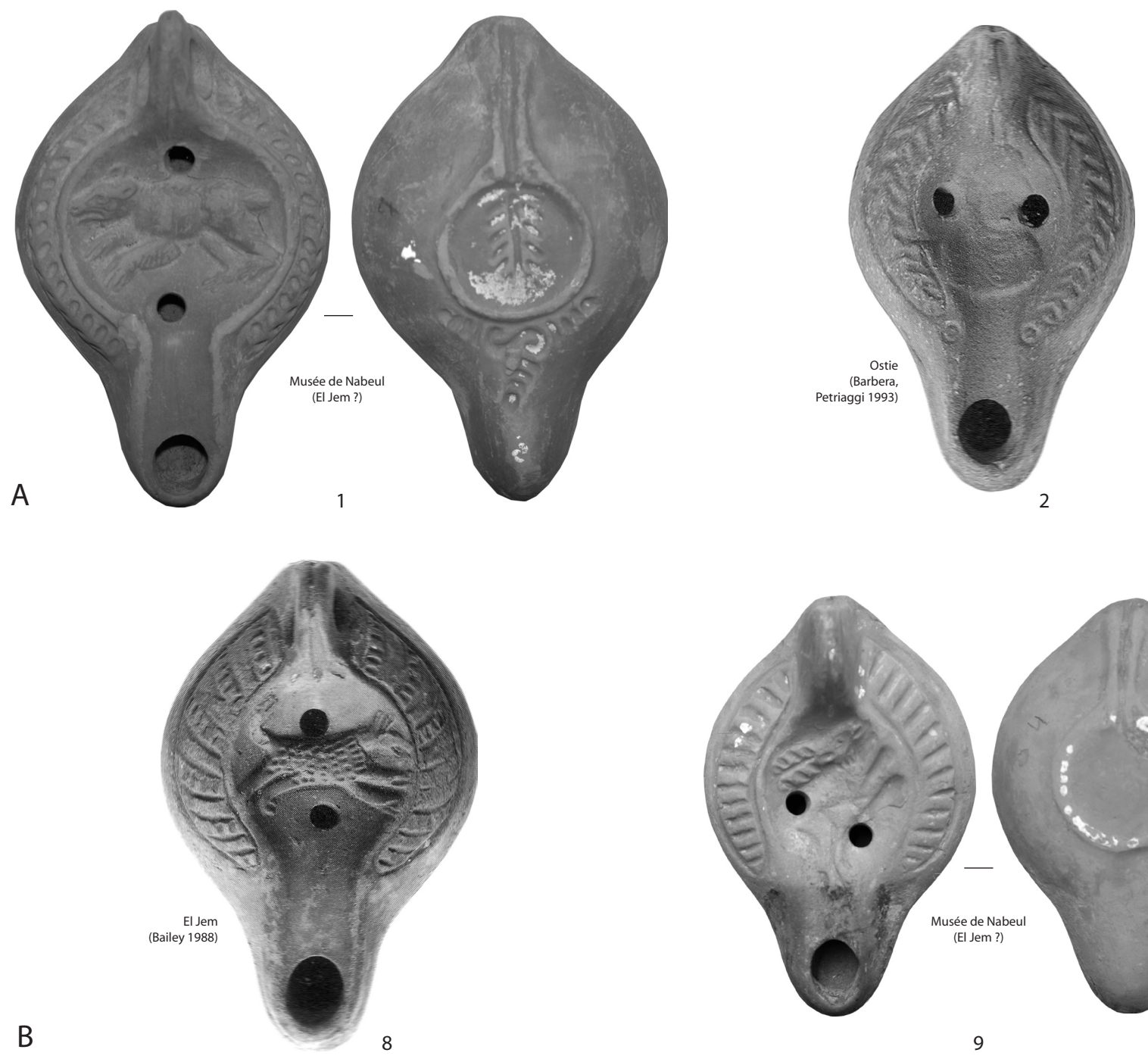

LAMPE

TYPE 45

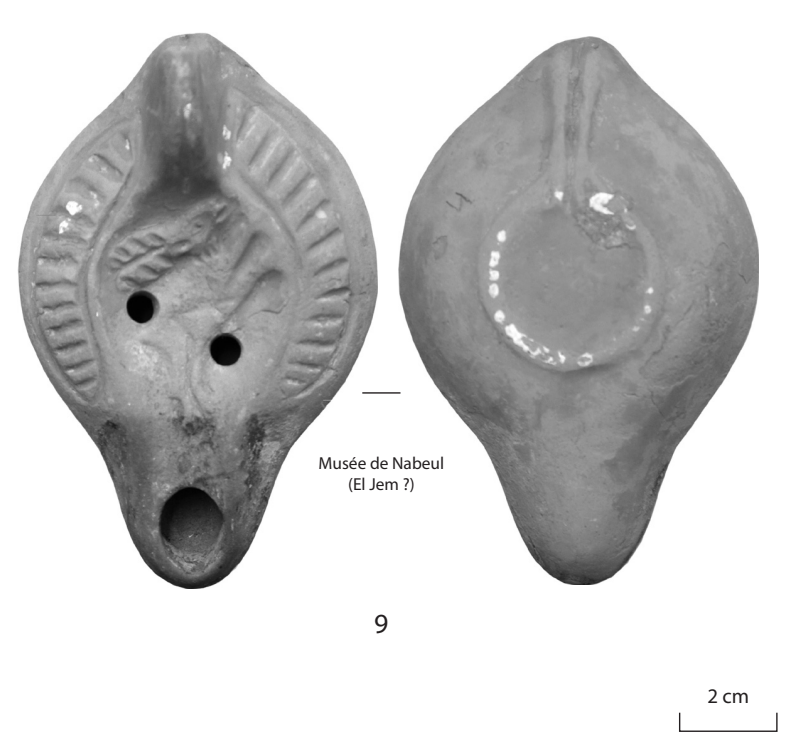

Fig. 203. Lampes en sigillée africaine (Tunisie centrale et septentrionale). 


\section{Typologie - Lampes}

Type Atlante VIII C1a-b

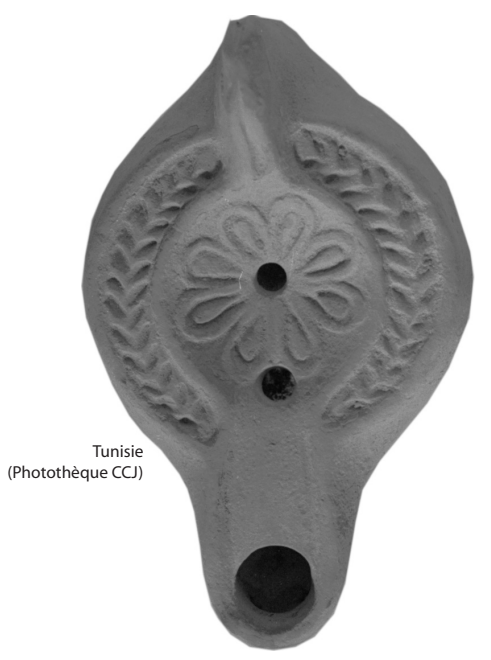

1

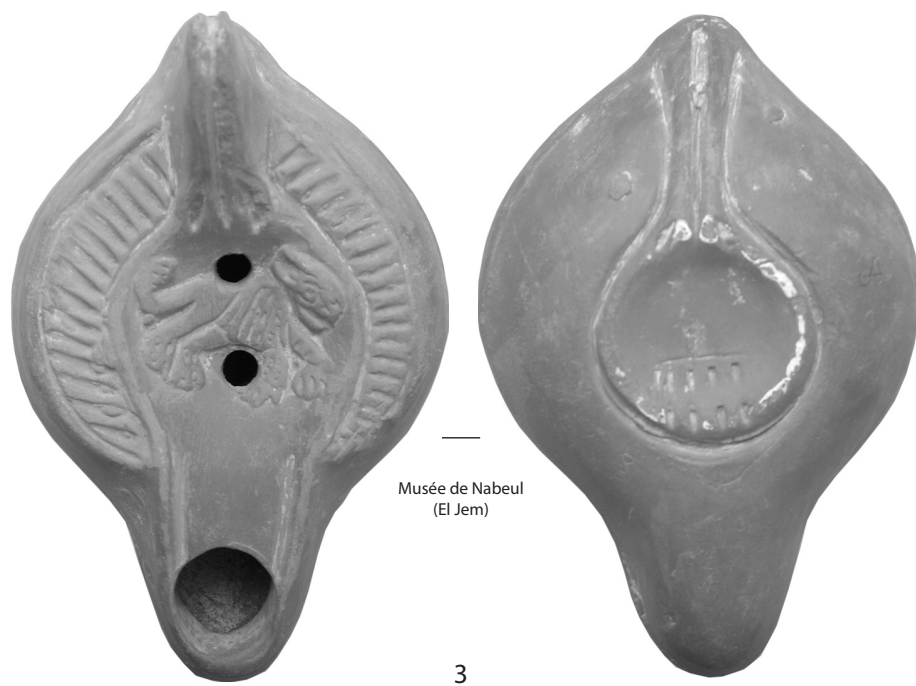

3
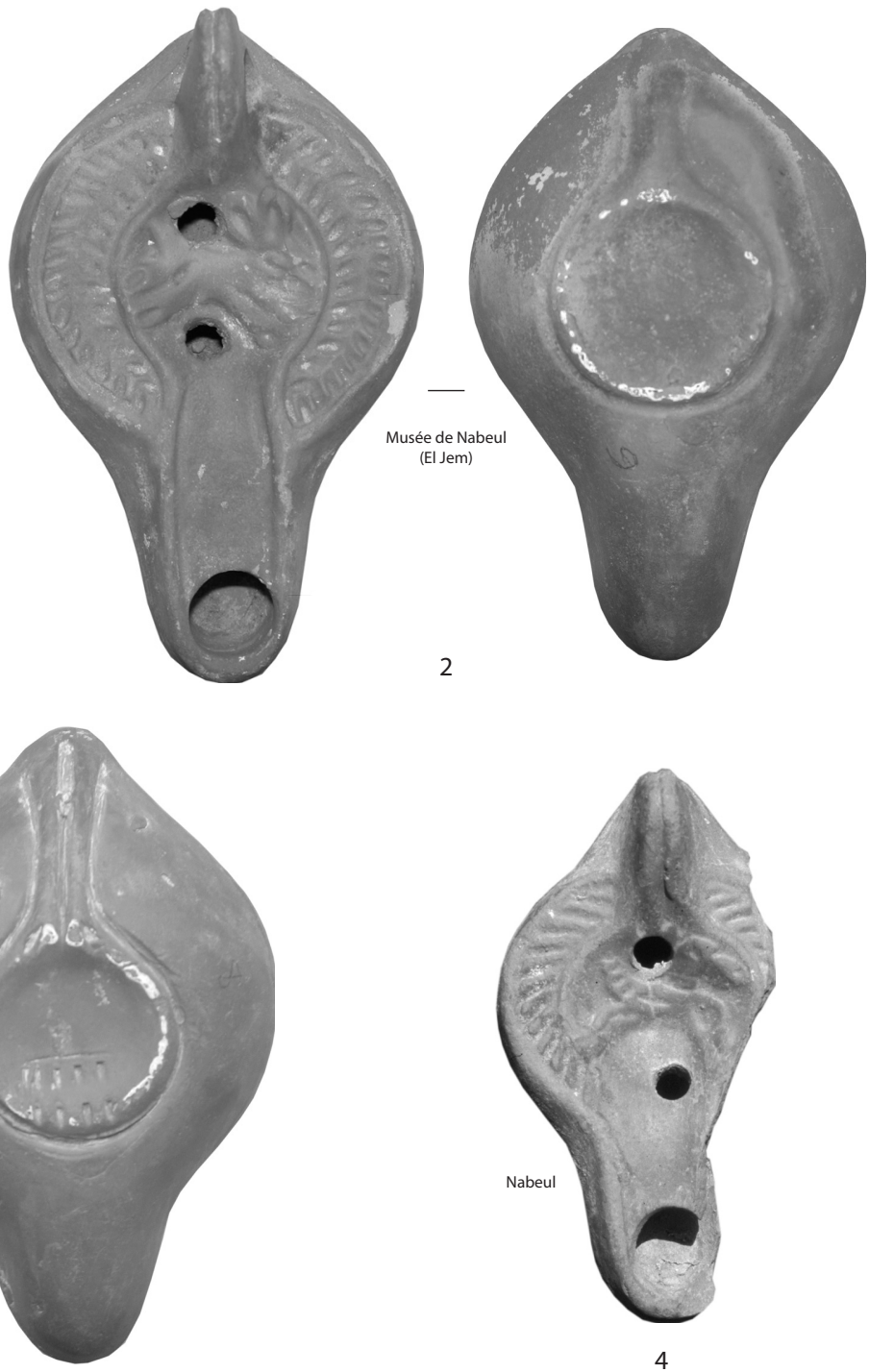

LAMPE

TYPE 46

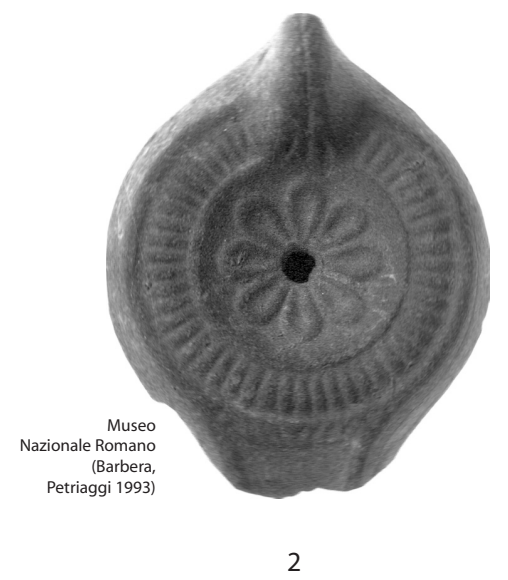

LAMPE

TYPE 47

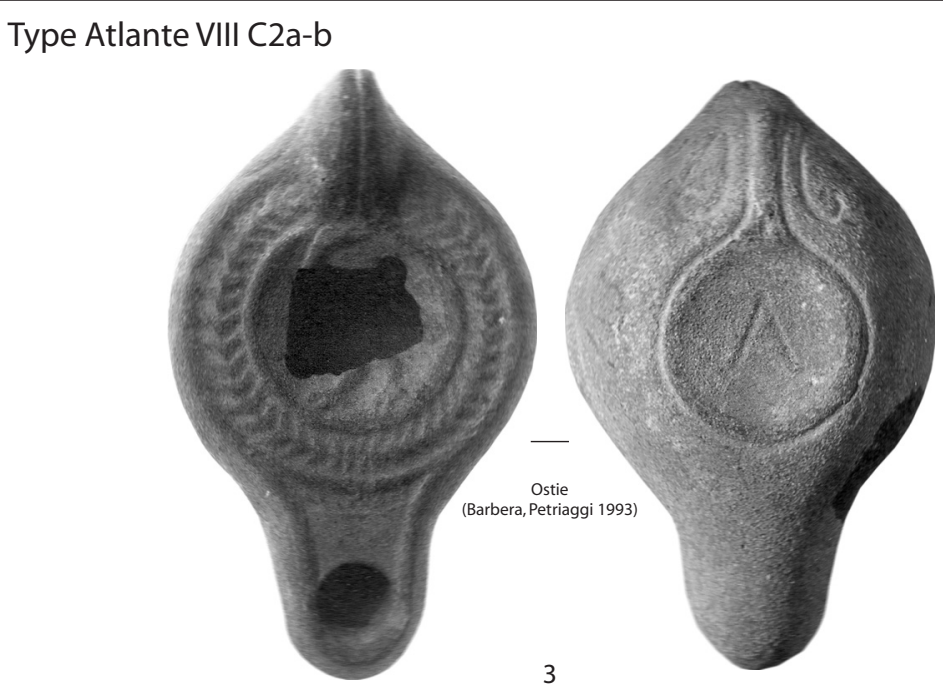

Fig. 204. Lampes en sigillée africaine (Tunisie centrale et septentrionale). 
pour le prouver. De fait, une datation aussi haute paraît poser problème si l'on considère que d'autres types de lampes en sigillée africaine, parfois considérés comme les précurseurs des lampes Atlante VIII, sont eux aussi datés du milieu du IVe s. (ex. le type Atlante VII). A Nabeul, le seul type sûrement attesté à la fin du IVe s. est le type VIII B, tandis que les types VIII A1 et A2 sont plutôt caractéristiques de la première moitié du Ve siècle, comme sur tant d'autres sites de Méditerranée occidentale (par ex. à Narbonne : Sabrié 1991, fig. 10-11).

\section{- bandeau plat (type Atlante VIII C1a-b) (fig. 204)}

\section{LAMPE TYPE 46}

Lampe de forme ovoïde dont le bandeau est plat comme sur le type Atlante X ; ce bandeau peut être décoré de palmes ou d'incisions obliques, parfois aussi de triangles incisés (Hayes 1980b, Pl. 34, $\mathrm{n}^{\circ} 286$ ).

Exemples (fig. 204) :

Disque à rosace centrale (type VIII C1b)

*1 Tunisie (photothèque du Centre Camille Jullian, négatif $\left.\mathrm{n}^{\circ} 74291\right)$. D. $80 \mathrm{~mm}$.

Disque à décor libre (type VIII C1a)

*2 Musée de Nabeul, provenant d'El Jem (?) (Inv. NBM.L05). Sigillée C. Vernis orange flammé, mat. Sur le bandeau : palme. Sur le disque : lièvre à droite. Anse forée. D. $84 \mathrm{~mm}$; H. $35 \mathrm{~mm}$.

*3 Musée de Nabeul, provenant d'El Jem (?) (Inv. NBM.L09). Sigillée C. Vernis orange clair. Sur le bandeau : incisions obliques. Sur le disque : lion à droite. Sur le fond: marque incisée pseudoépigraphique (?) de deux lignes de quatre ou cinq points. Anse pleine. D. $89 \mathrm{~mm}$; H. $38 \mathrm{~mm}$.

*4 Nabeul, fabrique de salaison, état 5B (Inv. NB1145.75). Sigillée C (?). Vernis orange clair. Sur le bandeau : stries obliques. Sur le disque : pégase (?) à droite. Anse pleine.

5-6 El Mahrine, atelier (Mackensen 1993, fig. 34, $\mathrm{n}^{\circ}$ 67).

Le type VIII C1b, à décor géométrique centré (rosace), paraît beaucoup moins fréquent que sur les types VIII A1 et $\mathrm{A} 2$; l'origine du $\mathrm{n}^{\circ} \mathbf{1}$ (Byzacène, Zeugitane ?) n'est pas déterminée. En revanche, les $n^{\circ} 2$ à 4 paraissent clairement provenir d'ateliers de Tunisie centrale. Ce pourrait être le cas, également, des nombreux exemples trouvés sur l'épave de Port Miou (Deneauve 1972, Pl. XXII). Mais le type est aussi produit sur l'atelier d'El Mahrine (5-6).

Je ne suis pas tout à fait convaincu par les exemples que fournit M. Mackensen pour placer l'apparition du type VIII C1-1 (palmes sur le bandeau) dans le dernier quart du IVes., en concomitance avec le type VIII B (Mackensen 1993, 146-147) à Carthage: il s'agit de petits fragments (Mackensen 1991, fig. 19, $\mathrm{n}^{\circ}$ 38) dont un, en outre, est en céramique commune (Ibid., fig. 18, $\mathrm{n}^{\circ} 7$ ). Certes, le $\mathrm{n}^{\circ} \mathbf{2}$ ci-dessus, hors stratigraphie mais avec une anse forée, pourrait indiquer une date relativement haute. Mais le $n^{\circ} \mathbf{4}$ est, lui, bien situé dans un contexte du deuxième quart du Ve siècle. Cette datation pourrait convenir à l'essentiel des lampes de type VIII C1 à bandeau décoré d'incisions obliques, comme celles de l'épave de Port Miou, dont il convient encore de repousser un peu la datation par rapport aux corrections déjà proposées par J. W. Hayes (Bonifay et al. 1998, 416, Tabl. CIII).

- disque fermé (type Atlante VIII C2a-b) (fig. 204)

\section{LAMPE TYPE 47}

Le disque est complètement ceinturé par un bandeau plat, décoré de manière classique par des palmes ou des incisions parallèles.

Exemples (fig. 204) :

Disque à rosace centrale (type VIII C2b)

1 Carthage (Chapman, Davies, Peacock 1984, Pl. 4, $\left.\mathrm{n}^{\circ} 11\right)$. Sur le bandeau: palmes. Anse pleine. D. $80 \mathrm{~mm}$.

*2 Museo Nazionale Romano (Barbera, Petriaggi 1993, $\mathrm{n}^{\circ}$ 89). Sur le bandeau incisions parallèles; Anse pleine. D. $78 \mathrm{~mm}$.

Disque à décor libre (type VIII C2a)

*3 Ostie (Barbera, Petriaggi 1993, 109, n 85). Sur le bandeau : palmes. Sur le disque : autruche à gauche. D. $75 \mathrm{~mm}$.

Un doute subsiste sur le lieu de production du type VIII C2a-b. Certes, ce type n'est pas attesté sur l'atelier d'El Mahrine et les lampes de type Atlante X D1, dont le disque est pareillement ceinturé d'une frise continue, sont principalement originaires du centre de la Tunisie. Toutefois l'allure générale de ces lampes se rapproche beaucoup de celle des types VIII C2c-d dont la production sur l'atelier d'El Mahrine est sûre. En outre, un certain nombre d'exemplaires (Barbera, Petriaggi $1993, \mathrm{n}^{\circ} 86,89$, portent sous le fond une marque incisée A attestée sur une lampe du type VIII C1d (infra, LAMPE TYPE 48, $\mathrm{n}^{\circ} 8$ ). Une origine septentrionale semble donc plus probable ${ }^{225}$. Les éléments de datation autre que stylistiques sont peu nombreux: le $\mathrm{n}^{\circ} \mathbf{1}$ ne paraît pas antérieur à 400-425 (Chapman, Davies, Peacock 1984, 239).

\section{— productions de Tunisie septentrionale}

Comme le fait remarquer M. Mackensen (1993, 162), de la même façon que le type VIII B est caractéristique des ateliers du centre de la Tunisie, le type VIII D apparaît, lui, spécifique des ateliers septentrionaux.

Mais la séparation entre ce type et quelques-unes des subdivisions du type VIII C n'est pas complètement étanche. Le rattachement au type $\mathrm{C} 1$ des lampes de type VIII C1d-e n'est pas très convaincant. De même, la distinction radicale entre les lampes à médaillon quadrangulaire de type VIII C1d et VIII D6 ne tombe pas sous le sens. C. Pavolini, qui a bien souligné les difficultés de classement des lampes en sigillée africaine

225 Un exemplaire de Glanum, analysé par des méthodes physico-chimiques, se distingue nettement du groupe de lampes attribué à la Tunisie centrale : Bémont 2002, 237-238, 240 et Pl. $39, n^{\circ} 470$. 


\section{Typologie - Lampes}

Type Atlante VIII C1c-d-e
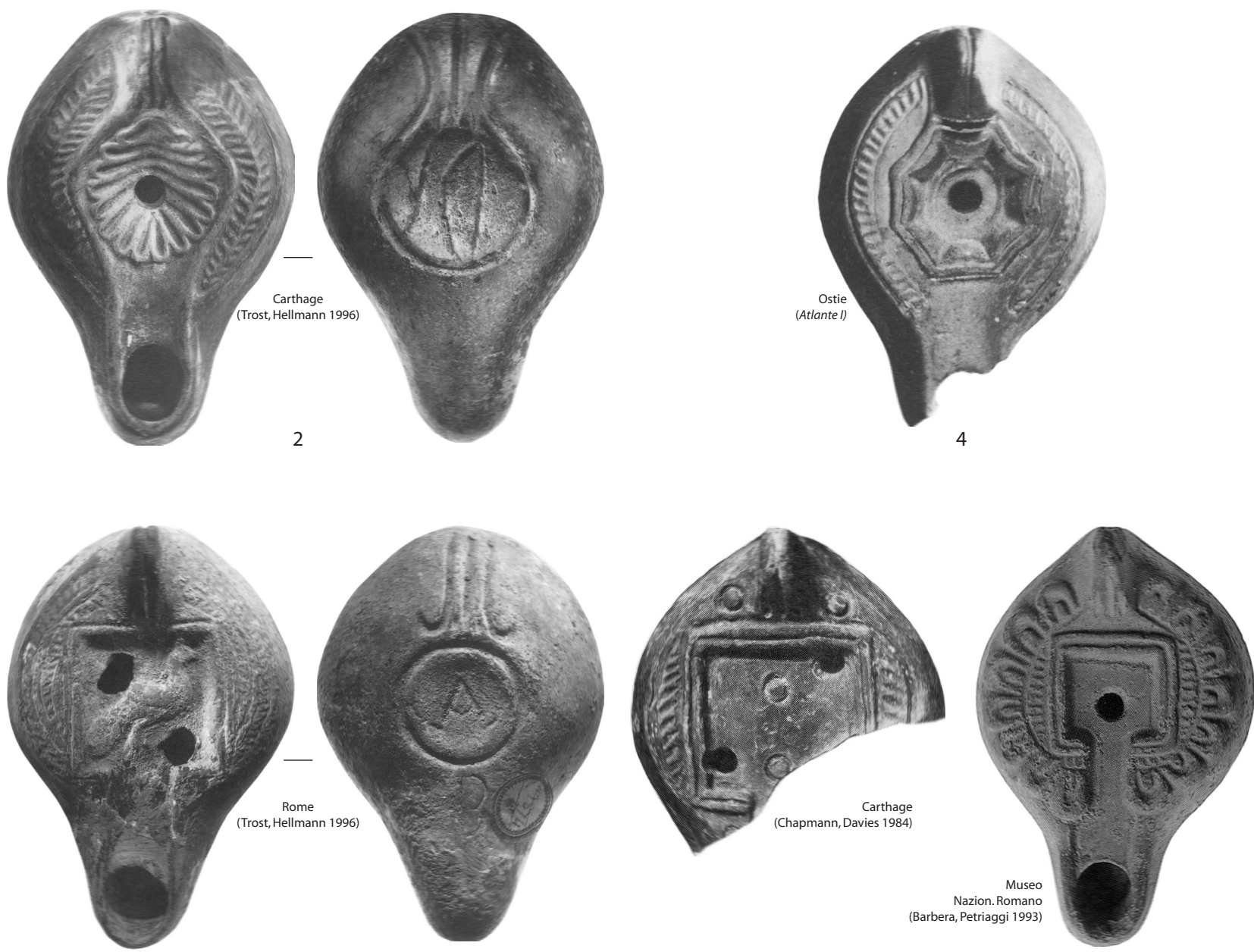

13

Type Atlante VIII C2c-d

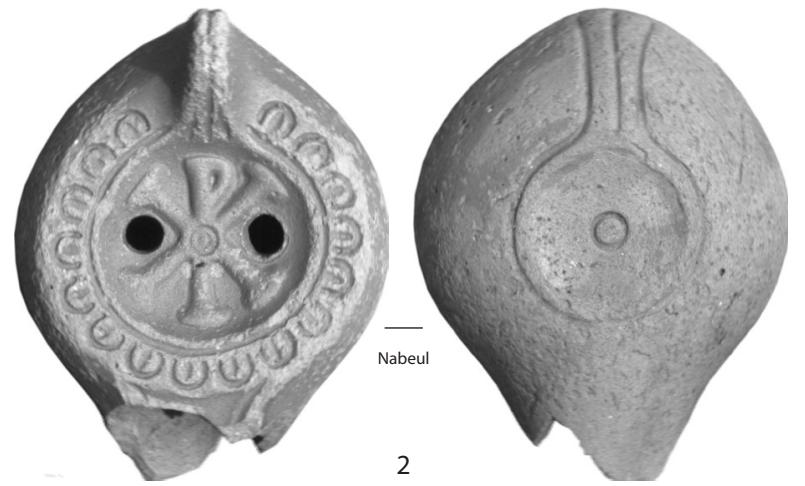

LAMPE

TYPE 49

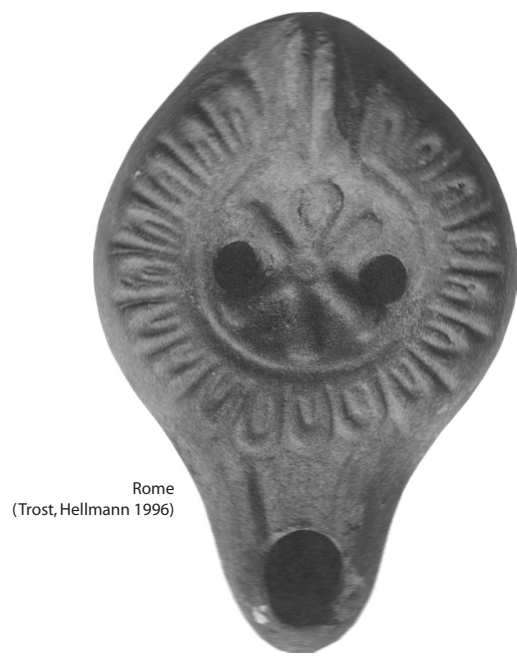

3
$2 \mathrm{~cm}$

Fig. 205. Lampes en sigillée africaine (Tunisie septentrionale). 
de type Hayes I (Pavolini, Tortorella 1997, 250) ${ }^{226}$, s'était déjà résolu, en 1982, à supprimer le type VIII C1e et à le faire passer dans le type VIII D4a (Ibid., 252).

A mon sens, il faut bien distinguer d'une part les séries VIII A1, A2, VIII C1a-b et, peut-être VIII C2a-b, qui sont des lampes issues d'une tradition artisanale centrotunisienne étendue, dans un second temps, au nord de la Tunisie, et d'autre part les séries VIII C1d-e, C2c-d et VIII D qui sont de réelles innovations typologiques des ateliers septentrionaux. La caractéristique de ces types nouveaux consiste dans la disparition progressive du bandeau, tout d'abord atrophié (type VIII C1d-e) puis intégré à la composition centrale du décor du disque (type VIII C2c-d) et enfin inexistant (VIII D).

\section{- lampes à bandeau atrophié : type VIII C1c-d-e (fig. 205)}

\section{LAMPE TYPE 48}

Par leur allure générale et le caractère envahissant du décor de leur médaillon central, ces lampes annoncent le type VIII D. On retrouve dans l'ornementation du disque de ces lampes chacun des éléments décoratifs qui sont à la base de la typologie interne des lampes du type VIII D. Mais la présence d'un reliquat de bandeau plat, plus ou moins atrophié, les a fait rattacher au type VIII C. Il s'agit vraisemblablement de formes de transition.

Exemples (fig. 205) :

Coquille au centre du disque (type VIII C1c)

1 Carthage, Royal Ontario Museum (Hayes 1980b, $\mathrm{n}^{\circ}$ 282). D. $77 \mathrm{~mm}:$ H. $27 \mathrm{~mm}$.

*2 Carthage, Bibliothèque Nationale de France (Trost, Hellmann 1996, P1. VI, n 34).

Rosace au centre du disque

3 Carthage, Bibliothèque Nationale de France (Trost, Hellmann 1996, Pl. V, n²9).

Octogone ou motif curviligne au centre du disque (type

VIII C1e,2)

*4 Ostie (Atlante I, Pl. CLVIII, 1).

5 Marseille, chantier de La Bourse (Bonifay 1983, fig. 31, $\mathrm{n}^{\circ}$ 198). Surmoulage? Bandeau étroit d'incisions parallèles.

6 El Mahrine, atelier (Mackensen 1993, fig. 27, $\mathrm{n}^{\circ} 2$ ). Décor comparable au précédent.

7 Carthage, locus des sept moines de Gafsa (Ennabli 2000, fig. X, 1). Décor comparable au précédent.

Médaillon quadrangulaire (type VIII C1d)

Grand médaillon carré, bandeau atrophié décoré de palmes

*8 Rome (?), Bibliothèque Nationale de France (Trost, Hellmann 1996, Pl. II, $\mathrm{n}^{\circ}$ 12). Bandeau étroit de palmes. Sur le médaillon: paon à droite. Sous le fond : marque incisée : A. D. $77 \mathrm{~mm}$.

Grand médaillon carré, bandeau atrophié décoré de stries en relief

*9 Carthage (Chapman, Davies, Peacock 1984, Pl. 5, $\left.\mathrm{n}^{\circ} 1\right)$. Replat autour du médaillon décoré de stries en faible relief.

\footnotetext{
${ }^{226}$ « il classico banco di prova per chiunque voglia misurarsi sul terreno della classificazione delle lucerne in TSA ».
}

10 Carthage, Byrsa (Deneauve 1974, fig. 12, $\mathrm{n}^{\circ} 27$ ).

11 El Mahrine, atelier (Mackensen 1993, fig. 27, $\mathrm{n}^{\circ} 4$ ). Décor du bandeau comparable aux précédents. Petit médaillon carré entouré d'oves

12 Carthage (Chapman, Davies, Peacock 1984, Pl. 5, $\left.\mathrm{n}^{\circ} 3\right)$. D. $75 \mathrm{~mm}$. Replat autour du médaillon décoré d'oves.

*13 Museo Nazionale Romano (Barbera, Petriaggi 1993, $\left.106, \mathrm{n}^{\circ} 82\right)$.

14 Oudhna, thermes des Laberii (sans $n^{\circ}$ ). Identique au $\mathrm{n}^{\circ}$ précédent.

15 Arles, chantier de l'I.R.P.A. (en exposition, Musée de l'Arles Antique).

On manque réellement d'arguments, autres que stylistiques, pour fixer sérieusement la chronologie de ces lampes. Le $\mathrm{n}^{\circ} \mathbf{5}$, qui est probablement une imitation locale marseillaise du type VIII Cle, provient d'un contexte du deuxième quart ou du milieu du Ve siècle ; mais il ne faut peut-être plus retenir la datation très haute proposée naguère (Raynaud 1982, 348 : milieu du IVe s.) pour les imitations du type VIII C1d produites par l'atelier de Générac, près de Nîmes (infra, fig. 259). Les exemplaires de Carthage (9-10 et 12) sont datés de la seconde moitié du Ve siècle.

\section{- lampes à bandeau intégré au disque : type VIII C2c- d (fig. 207)}

\section{LAMPE TYPE 49}

Les éléments géométriques répétitifs qui devraient « normalement» orner le bandeau sont ici complètement intégrés à la composition centrale du décor du disque, que ce soit les oves délimitant le médaillon dans lequel est inséré le chrisme ${ }^{227}$ du type VIII C2c, ou bien les stries en faible relief qui entourent discrètement une coquille constituant l'élément décoratif essentiel du type VIII $\mathrm{C} 2 \mathrm{~d}$.

Exemples (fig. 205) :

Chrisme (type VIII C2c)

1 Lorenzberg bei Epfach (Pohl 1962, Pl. 31, n 19).

*2 Nabeul, fabrique de salaison, état 5B (sans $n^{\circ}$ d'inv.). D. $76 \mathrm{~mm}$.

*3 Rome (?), Bibliothèque Nationale de France (Trost, Hellmann 1996, Pl. III, n 16). D. $86 \mathrm{~mm} ; \mathrm{H}$. $36 \mathrm{~mm}$.

4 El Mahrine, atelier (Mackensen 1993, fig. 25, $\mathrm{n}^{\circ}$ 3)

Coquille (type VIII C2d)

5 Ostie (Barbera, Petriaggi 1993, 115, $\mathrm{n}^{\circ}$ 91)

6 El Mahrine, atelier (Mackensen 1993, fig. 28, n 1). D. $71 \mathrm{~mm}$.

Ces deux types ont été produits par l'atelier d'El Mahrine (4 et 6). Nous avons quelques éléments de datation pour le type VIII C2c. Le $\mathrm{n}^{\circ} \mathbf{2}$ est issu d'un contexte du deuxième quart du Ves., datation en accord celle proposée par M. Mackensen pour l'exemplaire du Lorenzberg (en dernier lieu Mackensen 1998d, 134), bien

\footnotetext{
${ }^{227}$ Par exemple ce motif de chrisme dans un médaillon d'oves constitue le décor du disque d'une lampe de type VIII Cla avec palmes sur le bandeau à Tominceva Jama (Slovénie) : Pröttel 1996, Pl. 70, $\mathrm{n}^{\circ}$ 1. La couronne d'oves et le chrisme sont, dans ce cas, indissociables.
} 
Typologie - Lampes

Type Atlante VIII D

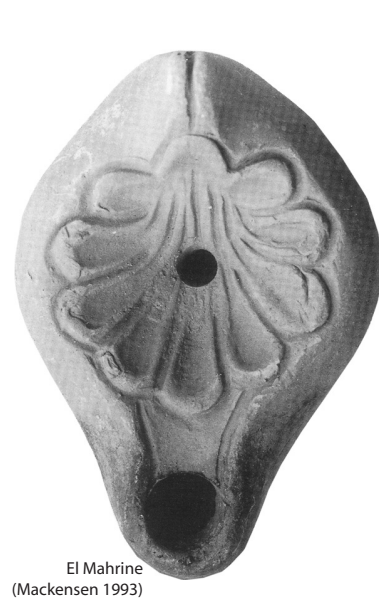

D1

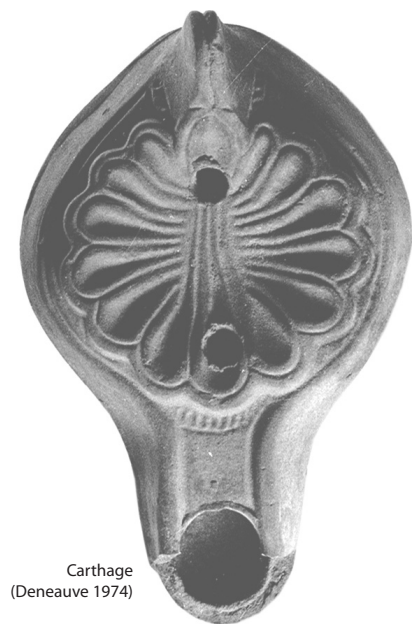

3

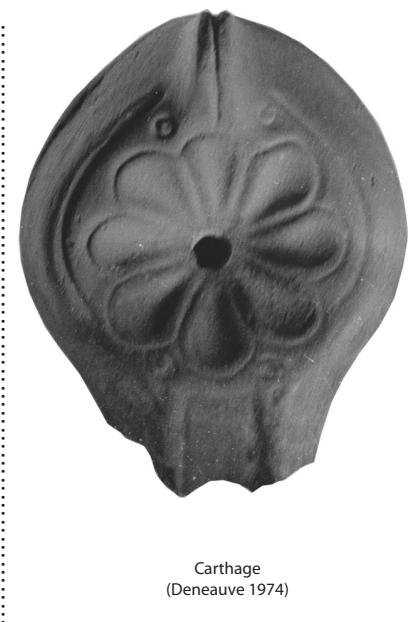

D2

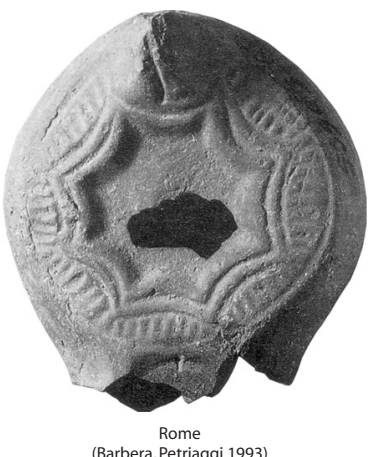

11

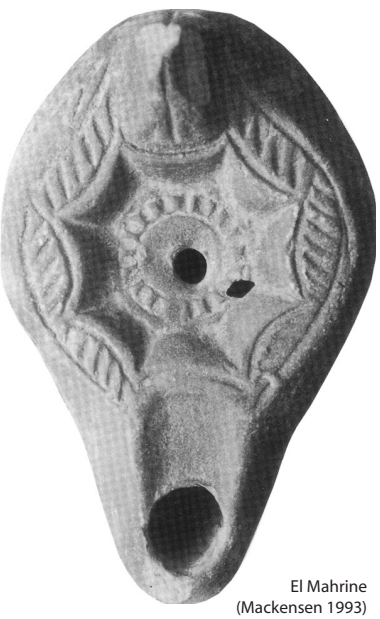

D4

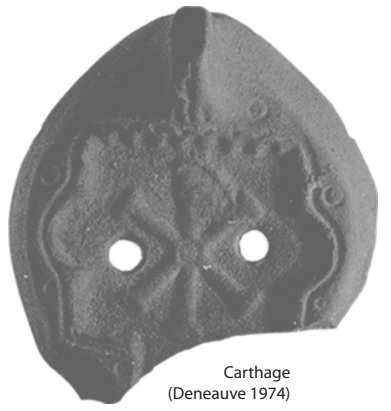

D6

17

LAMPE

TYPE 50

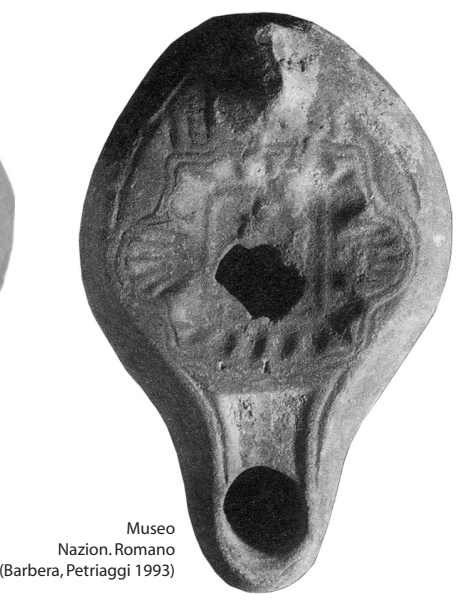

18

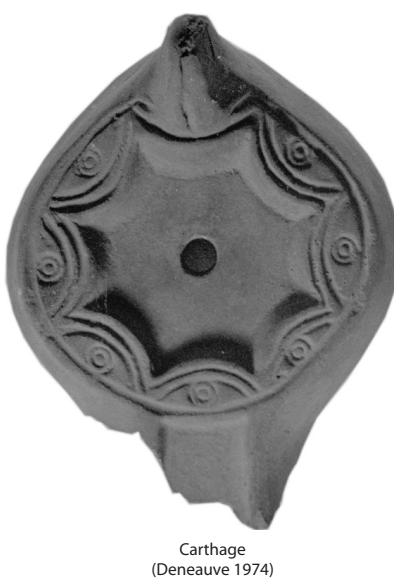

13
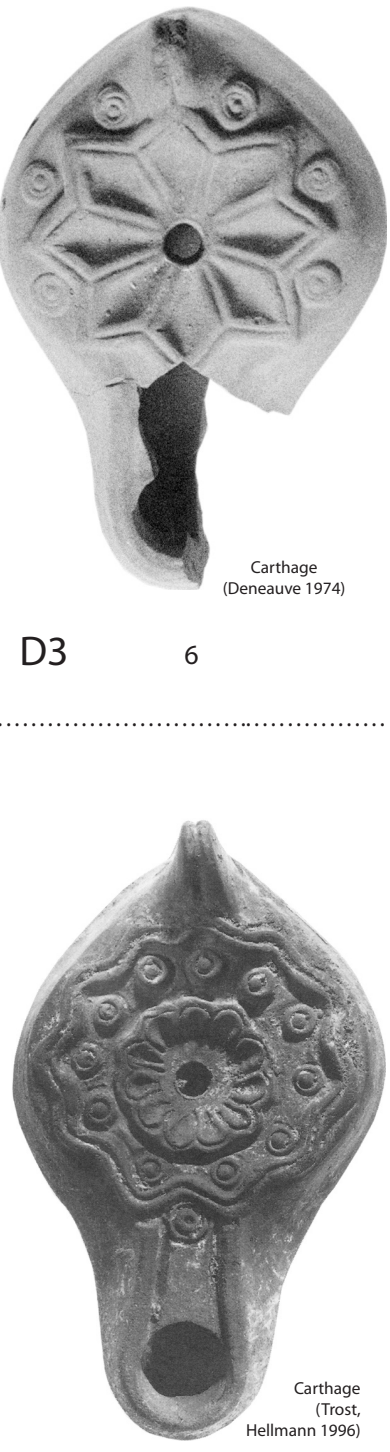

D5 16

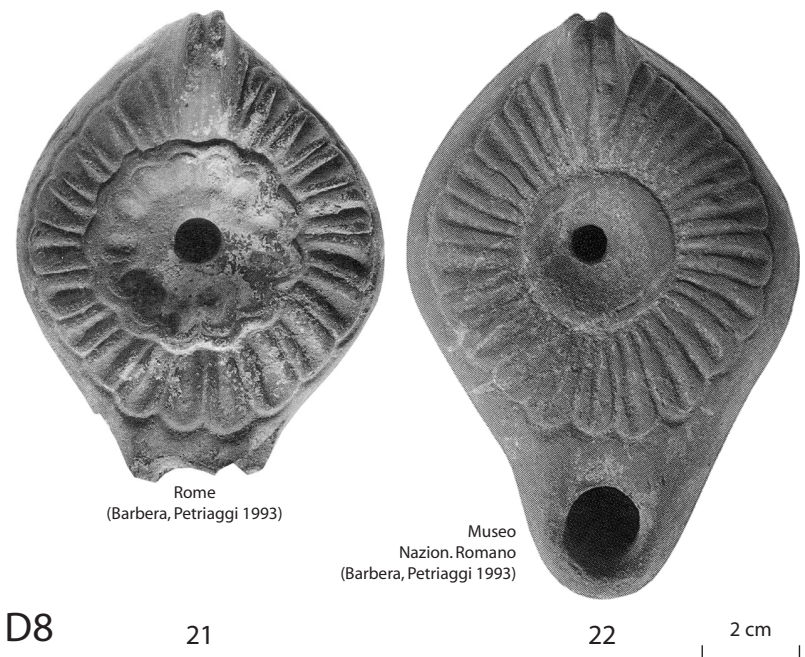

Fig. 206. Lampes en sigillée africaine (Tunisie septentrionale). 
que ce dernier paraisse stylistiquement un peu plus archaïque (1). L'exemplaire de Rome (3) semble en revanche le plus évolué des trois avec un chrisme rétrograde (?) au rendu très empâté et des oves qui envahissent toute la surface du disque. Je ne connais pas d'élément de datation extérieur pour le type VIII C2d.

- lampes sans bandeau : type VIII D (fig. 206)

\section{LAMPE TYPE 50}

Sur ces lampes, la bipartition du décor, bandeau d'une part, disque d'autre part, commune à toutes les lampes de l'Antiquité, a disparu. La face supérieure de la lampe est entièrement occupée par un décor géométrique tracé à grands traits et généralement centré autour de l'orifice de remplissage. Je reprends ci-après la typologie de C. Pavolini (Atlante I) complétée par M. Mackensen (1993), en cherchant à l'illustrer principalement par des exemples africains et en proposant quelques ajustements de détails :

- Variante D1 : médaillon en forme de coquille.

- Variante D2 : médaillon en forme de rosace.

- Variante D3 : médaillon en forme d'étoile.

- Variante D4 : médaillon octogonal entouré d'incisions obliques ou de cercles pointés. Je propose de distinguer :

- D4a : variante précoce (?), la disposition des incisions obliques rappelle encore un bandeau atrophié comme sur le type VIII C1e ;

- D4b : variante évoluée, les incisions obliques dessinent un cercle complet dans lequel le médaillon octogonal est inséré, selon le schéma du type D4c ;

- D4c: variante D4 classique, même disposition que $\mathrm{D} 4 \mathrm{~b}$ mais avec un décor de cercles pointés.

- Variante D5 : médaillon à tracé curviligne.

- Variante D6 : médaillon quadrangulaire à canal ouvert (a) ou fermé (b).

- Variante D8 : médaillon à godrons (Mackensen 1993, 122).

Nota: la variante D7 n'est représentée que par un seul exemplaire, provenant de Rome (Atlante I, 196, P1. XCVIII, 8).

Exemples (fig. 206) :

Variante D1

*1 El Mahrine, atelier (Mackensen 1993, fig. 28, n² 2). Un orifice de remplissage au centre de la lampe. D. $74 \mathrm{~mm}$.

2 Oudhna, thermes des Laberii (sans $\mathrm{n}^{\circ}$ d'inv.). Deux orifices de remplissage dans l'axe de la lampe.

*3 Carthage, Byrsa (Deneauve 1974, fig. 14, n 43). Comparable au ${ }^{\circ}$ précédent. D. $80 \mathrm{~mm}$.

Variante D2

*4 Carthage, Byrsa (Deneauve 1974, fig. 14, n 43). D. $78 \mathrm{~mm}$.

5 Carthage (Riley 1981, Pl. 1, $\mathrm{n}^{\circ} 13$ ). Bec très proéminent : variante de transition avec le type $\mathrm{X}$ (?). D. $75 \mathrm{~mm}$.

Variante D3

*6 Carthage, Byrsa (Deneauve 1974, fig. 14, n 41). D. $78 \mathrm{~mm}$.

7 Carthage (Neuru 1980, Pl. 2, L2). D. $71 \mathrm{~mm}$.
8 El Mahrine, atelier (Mackensen 1993, fig. 30, $\mathrm{n}^{\circ}$ 2).

Variante D4

Variante D4a

*9 El Mahrine, atelier (Mackensen 1993, fig. 27, n 6). D. $76 \mathrm{~mm}$.

10 Museo Nazionale Romano (Barbera, Petriaggi 1993, 126, $\left.\mathrm{n}^{\circ} 101\right)$. D. $76 \mathrm{~mm}$.

Variante D4b

*11 Rome, Museo Nazionale Romano (Barbera, Petriaggi 1993, 126, n ${ }^{\circ}$ 102). D. $74 \mathrm{~mm}$.

12 Carthage (Chapman, Davies, Peacock 1984, Pl. 4, $\left.\mathrm{n}^{\circ} 15\right)$. Comparable au ${ }^{\circ}$ précédent.

Variante D4c

*13 Carthage, Byrsa (Deneauve 1974, fig. 14, $\mathrm{n}^{\circ} 40$ ). D. $80 \mathrm{~mm}$.

14 Carthage (Chapman, Davies, Peacock 1984, Pl. 4, $\left.n^{\circ} 14\right)$. Comparable au ${ }^{\circ}$ précédent.

Variante D5

15 Carthage, Byrsa (Deneauve 1974, fig. 14, $\mathrm{n}^{\circ} 45$ ).

*16 Carthage, Bibliothèque Nationale de France (Trost, Hellmann 1996, Pl. V, n 31). D. 76 mm ; H. 36 mm. Variante D6

Variante D6a

*17 Carthage, Byrsa (Deneauve 1974, fig. 11, $\mathrm{n}^{\circ} 26$ ). D. $74 \mathrm{~mm}$.

Variante D6b

*18 Museo Nazionale Romano (Barbera, Petriaggi 1993, 131, $\mathrm{n}^{\circ}$ 105). D. $76 \mathrm{~mm}$.

19 Carthage, Byrsa (Bonifay à paraître, a, n 20).

20 El Mahrine, atelier (Mackensen 1993, fig. 30, $\mathrm{n}^{\circ} 3$ ).

Variante D8

*21 Rome (Barbera, Petriaggi 1993, 128, n 103 bis). D. $75 \mathrm{~mm}$.

*22 Museo Nazionale Romano (Barbera, Petriaggi 1993, $\left.329, \mathrm{n}^{\circ} 287\right)$. D. $80 \mathrm{~mm}$.

23 El Mahrine, atelier (Mackensen 1993, fig. 30, $n^{\circ}$ 5). D. $71 \mathrm{~mm}$.

24 El Mahrine, atelier (Mackensen 1993, fig. 30, $\mathrm{n}^{\circ} 4$ ).

Le type VIII D1 est produit sur l'atelier d'El Mahrine (1) et peut-être aussi d'Oudhna (2-3). Les exemplaires d'Oudhna se distinguent de ceux d'El Mahrine par une coquille plus grande qui occupe tout le dessus de la lampe, un bec plus long légèrement élargi à son extrémité et la présence de deux orifices de remplissage dans l'axe de la lampe au lieu d'un placé au centre. La plupart des autres types sont attestés sur l'atelier d'El Mahrine (8, 9, 20, 23-24).

Ces lampes se rencontrent principalement dans des contextes de la seconde moitié du Ve s. et du début du VIe s. $(4,5,6,7,12,14,15,17)$. La position stratigraphique du $\mathrm{n}^{\circ} \mathbf{1 9}$ pourrait indiquer une date un peu plus précoce pour la variante D6 : deuxième quart du Ve s., chronologie confirmée par sa présence dans le contexte du Clos de la Lombarde à Narbonne (Sabrié 1991, fig. 10, $\mathrm{n}^{\circ} 189$ ), en association avec des lampes du type VIII C1e. Par ailleurs, il convient à mon sens de ne pas se laisser abuser par la ressemblance qui peut émaner de photographies prises à la verticale, entre les lampes en sigillée Atlante VIII D8 et les lampes en céramique commune Deneauve IX B (LAMPE TYPE 33). Les godrons allongés du type Atlante VIII D8 n'ont rien à voir avec les côtes de melon du type Deneauve IX qui, en outre, se 
Type Atlante VIII B / IX

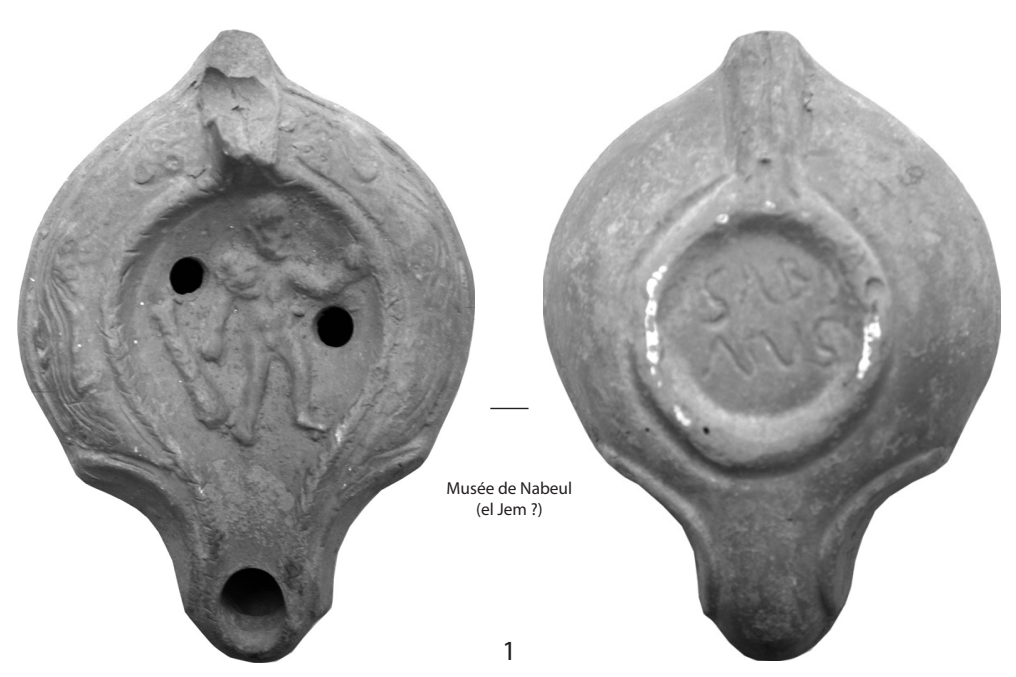

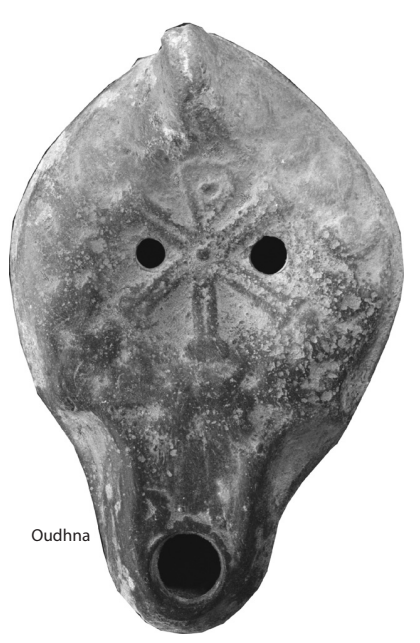

1

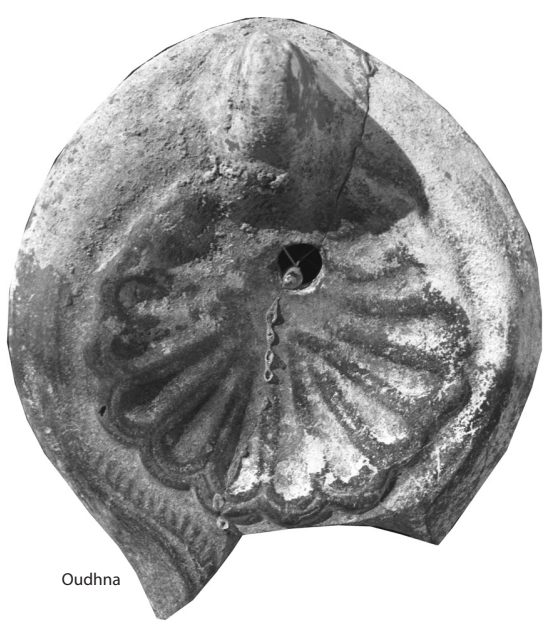

2

Fig. 207. Lampes en sigillée africaine (Tunisie centrale et septentrionale). 
prolongent sur la face inférieure de la lampe, ce qui n'est pas le cas sur la lampe en sigillée ${ }^{228}$. La forme générale des lampes Deneauve IX B est circulaire (surtout celles de la variante A, sans canal) tandis que la lampe Atlante VIII D8 est ovoïde. Enfin, si le canal commun à toutes les lampes du type Atlante VIII paraît absent sur l'exemplaire d'El Mahrine (23), c'est parce que la décoration de godrons, très large, empiète sur son emplacement. Ces arguments stylistiques ne me paraissent pas suffisamment solides pour étayer la date haute, dans la seconde moitié du IVe s., proposée par M. Mackensen (1993, 150 ; voir également Pavolini, Tortorella 1997, 254) pour le type Atlante VIII D8.

\section{- série 5 (type Atlante IX)}

Les lampes du type Atlante IX ne se distinguent de celles $\mathrm{du}$ type VIII que par des dimensions légèrement plus importantes et par les deux protubérances à la jonction du réservoir et $\mathrm{du}$ bec, qui sont probablement des réminiscences de volutes, cet élément récurrent du décor des lampes antiques. Les lampes de type Atlante IX sont donc étroitement liées à celles du type VIII, mais surtout, d'après la typologie qui en est présentée dans l'Atlante, à la phase la plus tardive, «carthaginoise » de cette production. En effet, les parallèles suivants peuvent être établis, de manière approximative, entre les deux typologies :

- type IX A1 = type VIII C1a

- type IX A2 = type VIII C1b

- type IX A3 = type VIII C1d

- type IX B = type VIII C2c

- type IX C = type VIII D1

Cependant, alors que les difficultés de classement des lampes du type VIII s'expliquent en partie par la pléthore de documentation, celles rencontrées pour les lampes de type IX procèdent peut-être du manque d'effectifs. Quelques nouveaux exemplaires permettent ainsi d'une part de démontrer que ce type n'est pas exclusivement produit par les ateliers du nord de la Tunisie, d'autre part de préciser encore l'origine de certains types septentrionaux.

\section{- production de Tunisie centrale (type VIII B/IX)} (fig. 207)

\section{LAMPE TYPE 51}

Une variante de grande taille de la forme VIII B possède les deux volutes atrophiées caractéristiques de la forme Atlante IX. On ne possède aucun élément de datation pour cet exemplaire.

Exemple (fig. 207) :

*1 Musée de Nabeul, provenant d'El Jem (?) (Inv.

\footnotetext{
${ }^{228}$ Ce qui n'exclut pas que des lampes à côtes de melon puissent avoir été produites en céramique sigillée : un fragment à Lepcis Magna, thermes du Levant (fouilles A. Laronde, Inv. LEP139.3).
}

NBM.L12). Sigillée C. Vernis beige orangé. Sur le bandeau : rinceaux. Sur le disque : Hercule à droite. Sur le fond: marque incisée $S A B I / N V S$. Anse forée. D. $93 \mathrm{~mm}$; H. $45 \mathrm{~mm}$.

\section{- productions de Tunisie septentrionale (type IX B et} C) (fig. 207)

\section{LAMPE TYPE 52}

Les variantes B et C de la forme Atlante IX apparaissent en plusieurs exemplaires dans le mobilier issu du dégagement des thermes de Laberii à Oudhna. Ce matériel hors stratigraphie peut appartenir soit à la dernière phase de l'utilisation de l'établissement thermal à la fin du IVe s. ou au début du Ve s., soit à la première phase de l'atelier de céramique dans le dernier tiers du Ve siècle. Etant donné que le matériel en liaison avec l'abandon des thermes est généralement recouvert d'une épaisse gangue de calcite, et que toutes les lampes qui présentent cette particularité sont des productions en céramique commune de tradition antique, faciès habituel pour la région de Carthage au début du Ves., je pencherais plutôt pour la seconde hypothèse. Il est donc probable que les types Atlante IX B et $\mathrm{C}$ ont été produits dans les ateliers d'Oudhna.

Exemples (fig. 207) :

*1 Oudhna, thermes des Laberii, musée du Bardo (Inv. CMA 615). Sur le bandeau: fleurs de lotus. Sur le disque : chrisme. D. $80 \mathrm{~mm}$.

*2 Oudhna, thermes des Laberii (sans $n^{\circ}$ d'inv.). Sur le disque : coquille. D. $108 \mathrm{~mm}$.

Même si le $\mathrm{n}^{\circ} \mathbf{2}$ ne possède pas les deux protubérances caractéristiques du type IX, il se rattache à ce type par son allure générale et ses dimensions (on pourrait également considérer qu'il s'agit d'un grand modèle du type VIII D). En revanche, je n'ai relevé à Oudhna aucune trace de la variante du type IX B avec un chrisme entouré d'oves (Barbera, Petriaggi 1993,139-140, n 110111).

\section{- séries 6 et 7 (types Atlante X et XI)}

Les lampes de type Atlante X et XI posent un double problème d'origine et de chronologie. Ce sont les deux types de lampes africaines pour lesquels la documentation est, de loin, la plus importante (plus de 1200 exemplaires sont publiés dans le seul catalogue d'Ennabli 1976). Face à cette masse de données, la typologie proposée par L. Anselmino et C. Pavolini (Atlante I, 200-204) permet, certes, d'ordonner commodément la plupart des exemplaires. Elle n'est cependant pas entièrement satisfaisante car les subdivisions proposées, qui ne tiennent pas compte du détail des décors, permettent difficilement de distinguer une origine et une chronologie. Ainsi, l'organisation du décor du disque autour d'un orifice central (X A2), ou son insertion dans un cercle $(\mathrm{X} A 1 \mathrm{~b})$, la présence ou non d'un réflecteur $(\mathrm{X}$ A1c), la fermeture du canal par un bandeau continu (X D), la présence de deux protubérances de part et d'autre du bec (XI), ne semblent pas constituer, seuls, des critères 
de distinction déterminants. A l'opposé de cette démarche, la tentative de classement proposée par S. V. Chapman, S. M. Davies et D. P. S. Peacock (1984), basée principalement sur le style décoratif, est sans doute plus proche de la réalité. Mais, comme le précisent ces auteurs, ce classement très lacunaire n'a pas d'autre utilité que de présenter de manière commode la documentation d'un seul site ${ }^{229}$.

Du point de vue de l'origine des productions, il est utile de revenir à la distinction établie par J. W. Hayes (1972, 311) entre son type II A et son type II B. On sait depuis longtemps que cette distinction est plus géographique que chronologique (Hayes 1980b, 66; Bailey 1988, 182 ; Mackensen 1993, 163-64). Il est donc envisageable, en théorie, de distinguer les produits de Tunisie centrale (type Hayes II A) caractérisés par une pâte fine et un vernis orange clair satiné, et une décoration très soignée, avec des motifs bien dessinés et de petite taille, des produits de Tunisie septentrionale (type Hayes II B), avec une pâte plus grossière et un vernis mat rouge brique, des décors de plus grande taille d'aspect souvent empâté. Mais, dans la pratique, ces critères ne sont pas toujours faciles à utiliser. Le second problème, d'ordre chronologique, se heurte à la remarquable longévité de la forme Atlante X qui atteint presque, sur près de trois siècles, celle des formes les plus tenaces de l'Antiquité, tels les types Deneauve VII et VIII. Comme les inventaires de musées offrent de nombreuses lampes entières mais sans contexte chronologique, et que les fouilles stratigraphiques livrent le plus souvent de petits fragments difficilement identifiables et pas toujours bien décrits, il demeure malaisé d'établir une typo-chronologie qui tienne compte à la fois de la forme, des décors et du type de fabrication.

Le classement qui est proposé ci-après tente pourtant de concilier ces différentes approches, avec, en filigrane, l'évolution perçue à Marseille (Bonifay et al. 1998, 366) qui, dans ses grandes lignes, s'est révélée applicable en Afrique. Le grand nombre d'exemples empruntés aux principaux catalogues existants (Ennabli 1976; Hayes 1980 ; Hoff 1986; Bailey 1988; Barbera, Petriaggi 1993 ; Trost, Hellmann 1996) se justifie par la nécessité de tester la cohérence des nouveaux groupes que je propose de constituer.

\section{— productions du centre de la Tunisie}

L'attribution de ces lampes aux ateliers de Byzacène repose sur les critères formels énumérés plus haut, et sur la connaissance pratique de ces objets. Des points d'ancrage objectifs sont en outre fournis par les fragments publiés comme provenant de l'atelier de Sidi Marzouk Tounsi (Peacock, Bejaoui, Ben Lazreg 1990) et

\footnotetext{
229 « The classification should be seen as a convenient means of presenting a mass of data than a rigid scheme » (Chapman, Davies, Peacock 1984, 233).
}

par le lieu de découverte (« région d'El Jem) de certains objets de musées. Il est à noter qu'une part importante de la documentation retenue n'a pas été découverte en Afrique car les fouilles dans le centre de la Tunisie restent peu développées, tandis que les importations de ces lampes à Carthage apparaissent paradoxalement moins volumineuses que celles enregistrées dans les grands ports de Méditerranée occidentale (Rome, Marseille). Je propose de distinguer cinq groupes.

\section{- type Atlante X A, groupe C1 (fig. 208)}

\section{LAMPE TYPE 53}

Lampes ovoïdes, souvent hautes (H. $>35 \mathrm{~mm}$ ), avec des parois très galbées et rentrantes ne laissant au bandeau, faiblement incliné vers l'intérieur, et au disque qu'un périmètre restreint. Le bec n'est pas nettement détaché du corps de la lampe. Il s'agit peut-être d'une variante de transition avec le type Atlante VIII, ou encore de la production spécifique d'un atelier et/ou d'un coroplathe. Le décor très particulier du bandeau du $n^{\circ} 2$ se retrouve sur deux lampes Atlante XI du catalogue d'A. Ennabli (1976, $\mathrm{n}^{\circ} 912$ et 1256$)$ qui proviennent manifestement, avant décoration, du même archétype ; la première des deux porte également un chrisme nervuré identique à celui du $\mathrm{n}^{\circ} \mathbf{8}$ (infra, LAMPE TYPE $58, \mathrm{n}^{\circ} 2$ ). Une autre, au musée de Nabeul, présente à la fois le palmier du $\mathrm{n}^{\circ} \mathbf{1}$ et le bandeau du $\mathrm{n}^{\circ} 2$ (infra, LAMPE TYPE 58, $\mathrm{n}^{\circ} 1$ ). L'ensemble de ces lampes est de facture peu soignée. En revanche, le rythme décoratif du bandeau du $n^{\circ} \mathbf{1}$ est attesté sur des lampes également de type Atlante XI mais de bonne facture (Bailey 1988, Q1822 ; Ben Lazreg 2000, $\left.71, \mathrm{n}^{\circ} 39\right)$.

Exemples (fig. 208) :

Variante A (taille standard)

*1 Région d'El Jem (Ennabli 1976, n $777 ; C M A$, 2594). Sur le bandeau : $3+4$ quadrifoliés I3 (?), $3+$ 3 losanges C2. Sur le disque : palmier. D. $83 \mathrm{~mm}$; H. $42 \mathrm{~mm}$.

*2 Nabeul, fabrique de salaison, période 5B (sans $\mathrm{n}^{\circ}$ d'inv.). Sur le bandeau : sinusoïde. Sur le disque : calice $^{230}$. D. $82 \mathrm{~mm}$.

3 Oudhna (Ennabli 1976, $\mathrm{n}^{\circ}$ 916). Sur le disque : élément architectural avec chrisme. D. $82 \mathrm{~mm}$ env.; H. $38 \mathrm{~mm}$.

Variante B (petit format)

4 Sousse (Hoff 1986, $\mathrm{n}^{\circ} 120$ ). Sur le bandeau : rinceaux alternant avec des quadrifoliés I4/5. Sur le disque : rosace. D. $60 \mathrm{~mm}$; H. $30 \mathrm{~mm}$.

5 Timgad (Ibid., $\mathrm{n}^{\circ}$ 126). Sur le bandeau : cordiformes M8 alternant avec des palmettes P3. Sur le disque : carreau cantonné de triangles D4. D. $60 \mathrm{~mm}$; H. $30 \mathrm{~mm}$.

6 Idem (Ibid., $\mathrm{n}^{\circ} 119$ ). Sur le bandeau: carrés A4/6 alternant avec des losanges à volutes. Sur le disque : palmier. D. $60 \mathrm{~mm}$; H. $20 \mathrm{~mm}$.

*7 Cnide, British Museum (Bailey 1988, Q1751). Sur le bandeau : tresse. Sur le disque : lion dans l'axe de la

\footnotetext{
${ }^{230}$ Ce décor est connu sur la vaisselle sigillée D2 de l'atelier d'Oudhna : poinçon Hayes 274.
} 
Type Atlante X, groupe $\mathrm{C} 1$
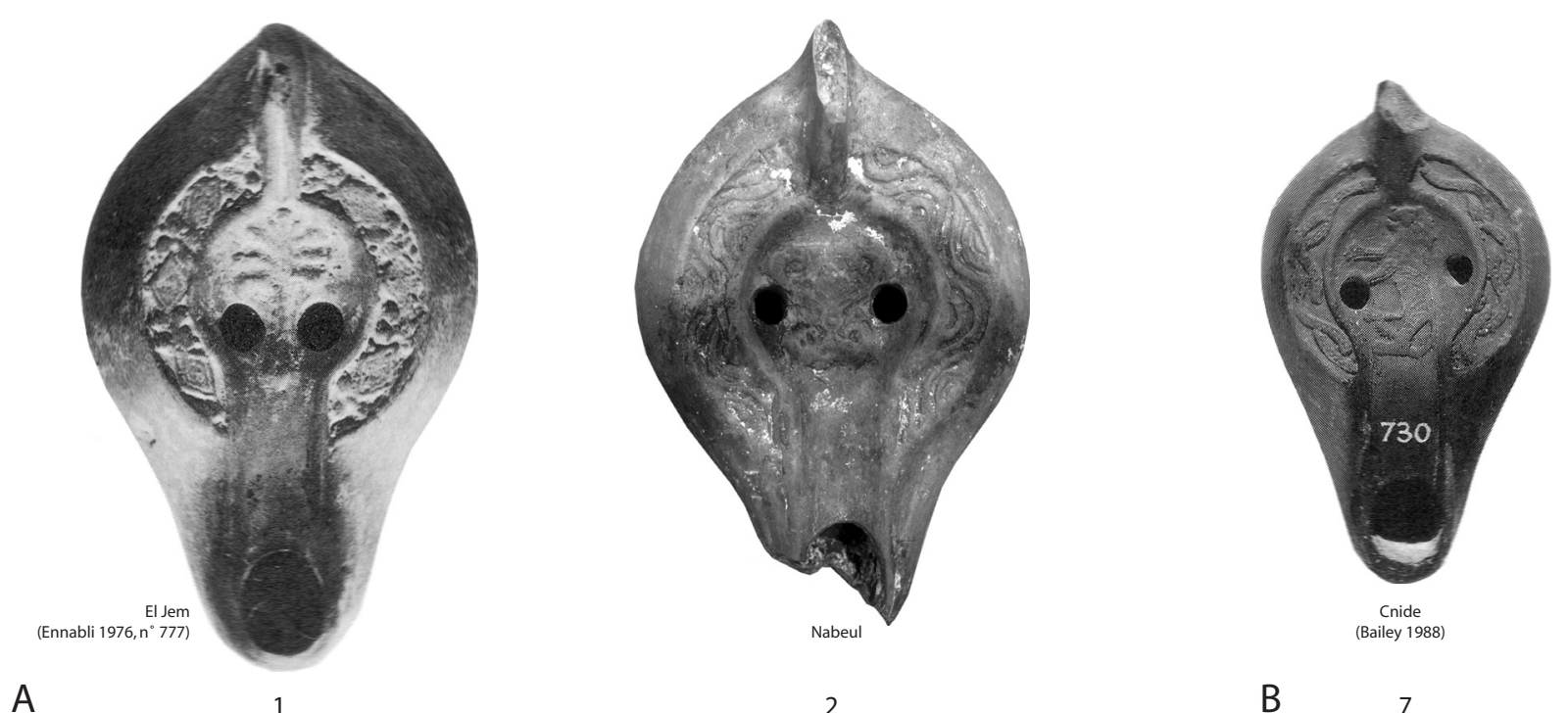

A 1 2

B 7 groupe C2

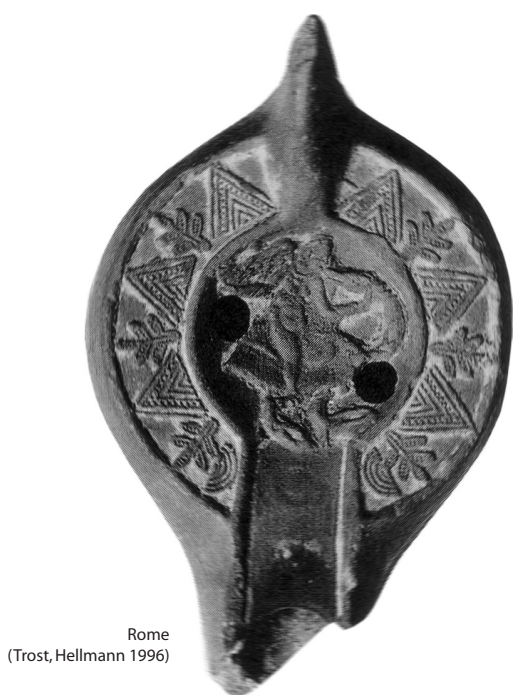

A

LAMPE

TYPE 54

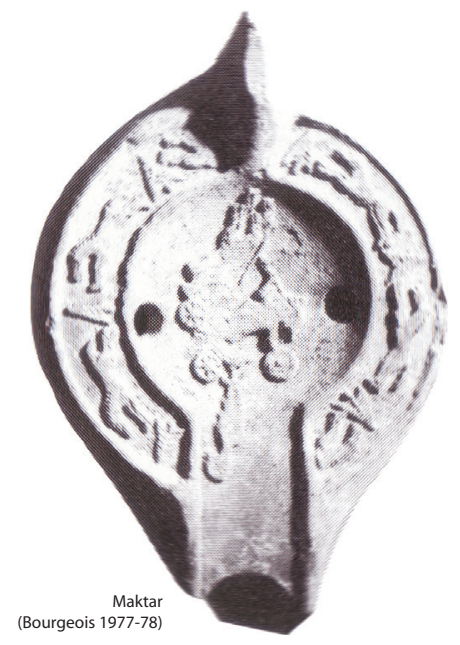

4

Fig. 208. Lampes en sigillée africaine (Tunisie centrale). 
lampe. D. $60 \mathrm{~mm}$.

8 Museo Nazionale Romano (Barbera, Petriaggi 1993, 200, $\left.\mathrm{n}^{\circ} 160\right)$. Sur le bandeau : $8+8$ cercles. Sur le disque : chrisme rétrograde nervuré. D. $62 \mathrm{~mm}$.

Le $\mathrm{n}^{\circ} \mathbf{2}$ provient d'un contexte du deuxième quart du Ve s., associé à des lampes Atlante VIII B, VIII Cla et VIII C2c, à l'exclusion de toute autre lampe Atlante X. Stratigraphiquement et stylistiquement, $\mathrm{j}$ 'aurais tendance à considérer ce groupe comme appartenant à une phase précoce de la production des lampes Atlante XA de Tunisie centrale.

- type Atlante X A, groupe C2 (fig. 208 à 213)

\section{LAMPE TYPE 54}

C'est le type classique des lampes Atlante X de Tunisie centrale. Le réservoir à bandeau plat est circulaire, avec des parois galbées, parfois très légèrement rentrantes, et le bec est allongé, bien distinct de ce dernier. Le diamètre standard est à peu près constant : $80-85 \mathrm{~mm}$, avec quelques exemplaires légèrement plus petits : 75-78 $\mathrm{mm}$; les exemplaires de grand format ${ }^{231}$ sont rares.

Les motifs le plus souvent utilisés sur le bandeau sont : les carrés A10, A11, les losanges C4, les chevrons D1-5, les cercles E2, les disques F6, F7, les rosettes G2 (Barbera-Petriaggi 3), les oves K2 et L5, les cordiformes M8, les quadrifoliés I3, les pampres Barbera-Petriaggi 114 , les palmettes P3, les tresses Barbera-Petriaggi 48 et 49, les losanges à volutes R2 (Barbera-Petriaggi 21) et les rameaux $\mathrm{S} 1$. Une phase probablement plus tardive de décoration voit apparaître les étoiles H3, les cartouches Trost-Hellmann La1 et les premiers cordiformes M7. Certains décors particuliers semblent également de deuxième génération: les bustes des apôtres ou les impressions monétaires de Théodose II. Le choix des motifs ornant le bandeau est fait avec le plus grand soin. Ainsi, on remarque que les pampres Barbera-Petriaggi 114 sont toujours associés à un décor sur le disque ayant un rapport avec la vigne: grappe de raisin de Canaan (16), veilleur de la vigne (19), canthare avec vigne et amours vendangeurs $\left(\mathrm{n}^{\circ} 55\right.$; Ennabli 1976, $\left.\mathrm{n}^{\circ} 844\right)$, amour vendangeur (Ennabli 1976, $\left.\mathrm{n}^{\circ} 168\right)^{232}$. Les cercles F2 et F3 contenant une croix ou un chrisme sont associés, sur le disque, à des scènes bibliques ou chrétiennes (1113). Sous le fond, on remarque souvent la présence de deux cercles concentriques incisés, à l'exclusion, semble$\mathrm{t}$-il, de toute marque.

Plusieurs variantes peuvent être distinguées en fonction du décor du disque; par souci d'uniformité, je suis l'ordre de présentation choisi par A. Ennabli (1976), déjà repris par V. Hoff (1986) et par C. Trost et M.-C. Hellmann (1996) :

- Variante A : Scènes mythologiques

Peu nombreuses (Léda et le cygne (1), Orphée jouant de la lyre (2-3), Achille et Hector (4).

- Variante B : Scènes bibliques et chrétiennes

\footnotetext{
${ }^{231}$ Ex. : Ennabli 1976, n 958.

${ }^{232}$ Cette lampe n'est pas très éloignée du type Atlante VI.
}

Plusieurs thèmes sont illustrés (liste non exhaustive), qui correspondent généralement à des ornementations de bandeau spécifiques :

- Adam et Eve (5); sur le bandeau : quadrifoliés I3 alternant avec des chevrons D2 $(8 \times 2$ motifs) ;

- les hébreux dans la fournaise (6); sur le bandeau: palmettes P4, cercles E2, losanges à volutes R2, quadrifoliés I3, chevrons D2 (7 x 2 motifs) ;

- un saint (7); sur le bandeau: chevrons D2, rameaux $\mathrm{S} 1$ (7,5 x 2 motifs);

- sacrifice d'Abraham (11); sur le bandeau: disques F3 alternant avec des disques F2 (7 x 2 motifs);

- le Christ foulant aux pieds le serpent (13); sur le bandeau: disques F3 alternant avec des disques F2 ;

- les trois Hébreux rapportant la grappe de Canaan (16) ; sur le bandeau : pampres BarberaPetriaggi 114 ;

- le veilleur de la vigne ${ }^{233}$ (19); sur le bandeau : pampres Barbera-Petriaggi 114.

- Variante C : Personnages

On distingue :

a) les bustes : généralement de profil (27) ou de trois-quarts, parfois dans un médaillon circulaire (30) ;

b) les personnages en pied: peu nombreux, ils comprennent essentiellement: 1) des amours ailés, 2) des femmes drapées dans diverses attitudes (sur un siège, tenant un miroir, debout bras tendu) (32), 3) un curieux personnage (féminin ?) vêtu d'un pagne, parfois interprété comme un orant mais qui semble plutôt exécuter une danse (33).

- Variante D : Animaux

Lions (35), cervidés (37), dromadaire (40), chevaux, brebis, oiseaux (44-46), poissons (48), généralement disposés dans l'axe de la lampe, le plus souvent tête vers l'anse; certains d'entre eux (cervidés, brebis, oiseaux, poissons) peuvent évidemment avoir une connotation chrétienne.

- Végétaux : on distingue essentiellement :

a) des palmiers, avec parfois deux régimes de dattes symétriques (52);

b) des arbres feuillus (53) ou lancéolés ;

c) une feuille nervurée, probablement de vigne, occupant toute la surface du disque (54).

- Variante E : Vases

Deux variantes :

a) vases seuls : il s'agit de canthares de grande taille, munis d'anses ${ }^{234}$;

\footnotetext{
${ }^{233}$ A propos de cette scène, voir en dernier lieu Foy 1998.

${ }^{234}$ Dans un cas au moins, le vase est fabriqué avec des motifs de décoration de bandeaux (demi-chevron pour la base, ove L5 pour la panse, demi-esses Q1 pour les anses et Q2 pour l'encolure). Ex. : Hoff 1986, n 115 et Bailey 1988, Q1790.
} 

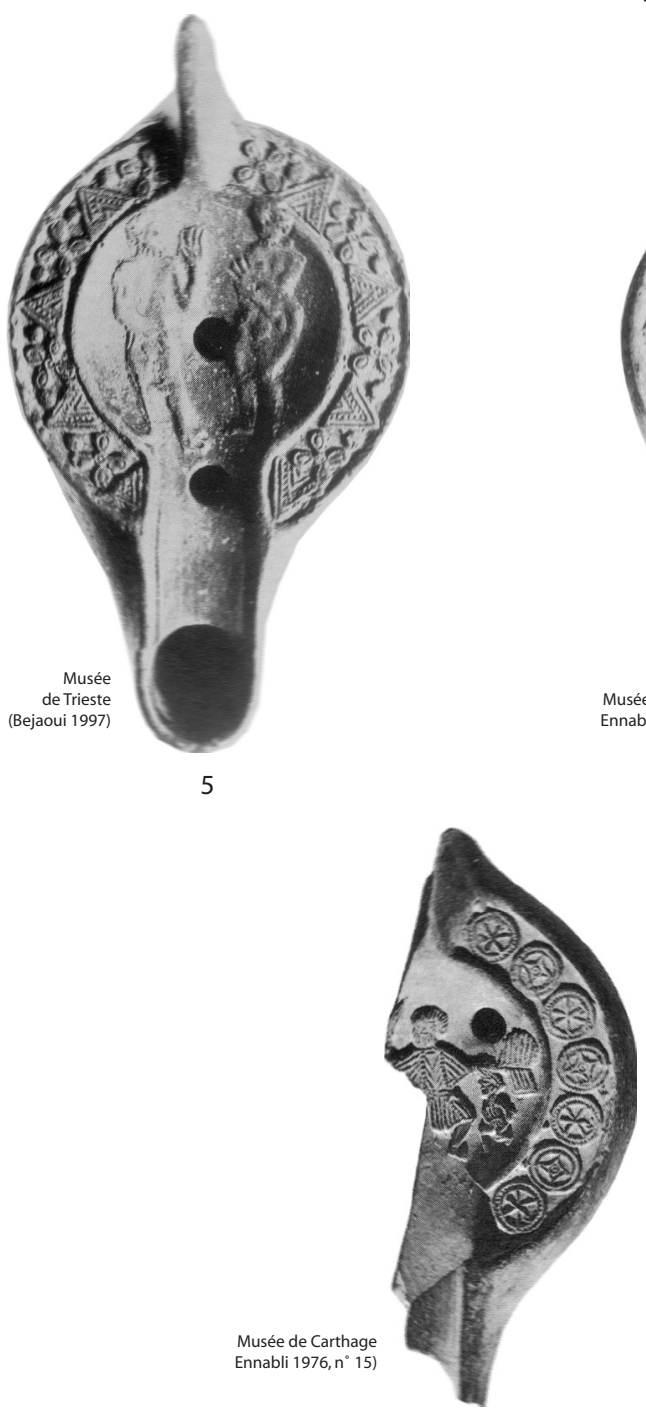

11

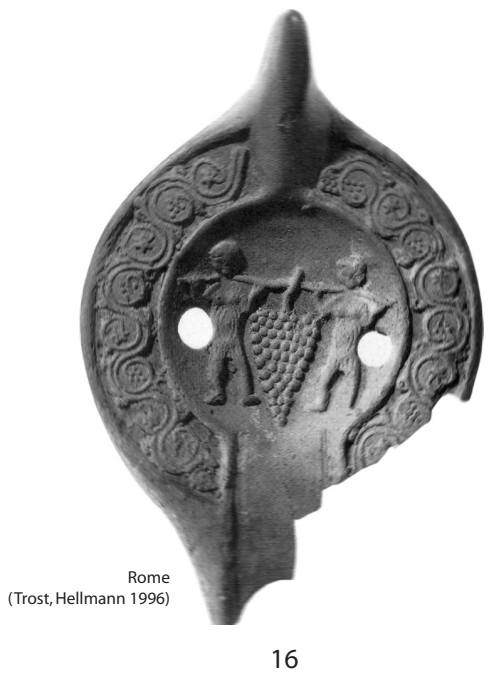

16

Type Atlante X, groupe C2
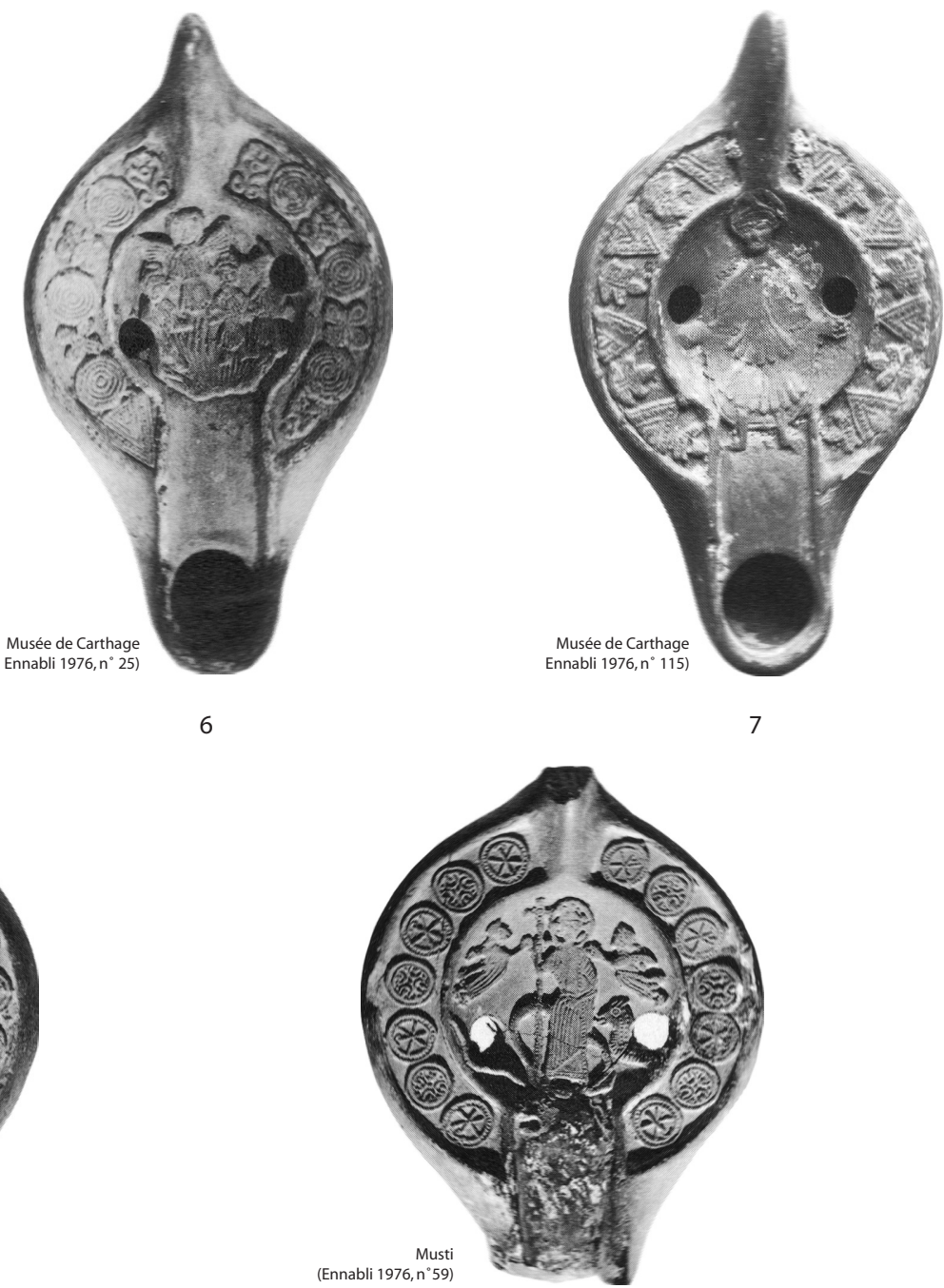

13

B

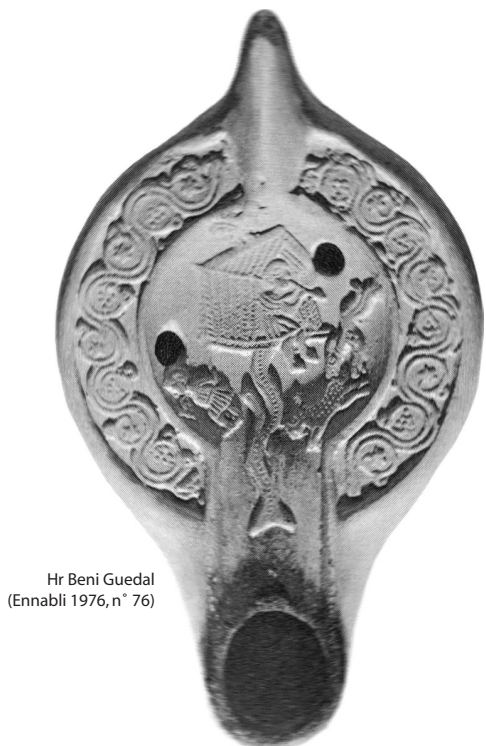

19

Fig. 209. Lampes en sigillée africaine (Tunisie centrale). 
b) vases avec rinceaux de vignes : du vase, plus petit et/ou disposé plus bas sur le disque (engagé dans le canal), sortent des pampres pouvant être habités d'oiseaux et/ou d'amours vendangeurs ; fréquent sur les lampes du groupe $\mathrm{C} 2$, ce décor trouve de nombreux parallèles dans l'art de la mosaïque (55) ;

c) vases surmontés d'animaux: vase surmonté d'un cerf $^{235}$ ou d'oiseaux ${ }^{236}$.

- Variante F : Chrismes

Le chrisme est le premier emblème chrétien attesté dans ce groupe de production. Il est généralement perlé, le plus souvent simple $(\mathbf{5 6}, \mathbf{6 0})$, plus rarement patté (64). Certains, de petite taille, sont insérés dans un médaillon perlé ou palmé (66). Les chrismes rétrogrades sont peut-être d'une deuxième génération (67). Le chrisme gemmé est probablement encore plus tardif (68).

- Variante G : Croix monogrammatiques ${ }^{237}$

Alors que les croix monogrammatiques perlées paraissent peu nombreuses (celles du type BarberaPetriaggi 210D semblent réservées à l'ornementation $\mathrm{du}$ groupe $\mathrm{C} 3$ ), la première série de croix monogrammatiques (non représentée chez Barbera, Petriaggi 1993), présente de manière notable sur le groupe $\mathrm{C} 2$, semble construite sur le modèle du chrisme gemmé (70); elles sont relativement élancées, avec la haste du rhô plus longue que la barre horizontale de la croix et disposée devant celleci. Les croix uniquement décorées de cercles, avec l'alpha et l'oméga (c), constituent une série à part (Barbera, Petriaggi 210C), peut-être directement issue du répertoire décoratif des sigillées africaines C5 (72). Les croix de type Barbera-Petriaggi 210B/1, toujours latines mais plus larges, sont décorées de cercles, de losanges et de cercles pointés (75). Enfin, la plus tardive dans le groupe est sans doute la variante Barbera-Petriaggi 210A, dont la haste du rhô ne se distingue plus de la barre horizontale de la croix (77), décorée de pampres, de carrés et de petites croix grecques (type Barbera-Petriaggi 210A), avec une fréquence toute particulière du type $210 \mathrm{~A} / 2$ (80).

- Variante H : Décors géométriques

Ils sont de trois sortes :

a) un carreau ( $25 \times 25 \mathrm{~mm}$ en moyenne), portant un décor perlé et linéaire, parfois végétal, généralement posé sur une base, plus rarement sur la pointe et le plus souvent cantonné de

\footnotetext{
${ }^{235}$ Exemple : Ennabli 1976, n 400.

${ }^{236}$ Exemples : Ibid., ${ }^{\circ} 808$; Mackensen 1998d, n 157.

237 J'ai repris partiellement la typologie de Barbera, Petriaggi 1993, en éliminant les motifs qui ne me paraissaient pas ressortir de la production de Tunisie centrale, en distinguant au sein des types $210 \mathrm{~A}$ et $210 \mathrm{~B}$ des variantes (notées $/ 1$ et $/ 2$ dans l'ordre de la disposition sur la planche 18 de cet ouvrage) et en les ordonnant selon ce que je pense être leur chronologie relative.
}

motifs empruntés à la décoration des bandeaux (chevrons, demi-étoiles, cordiformes, demilosanges à volutes, rameaux...) (83) ;

b) un décor rayonnant, disposé le plus souvent (mais pas toujours, autour d'un orifice de remplissage central, composé de motifs empruntés encore au décor des bandeaux mais peut-être aussi (en raison de leur grande taille) à celui de la vaisselle sigillée C5 (87).

c) un décor vertical, soigneusement dessiné, de rinceaux et de volutes, interprété comme un iota (89).

Exemples (fig. 208 à 213) :

A) Scènes mythologiques (fig. 208)

*1 Rome (?) (Trost, Hellmann 1996, n 41). Sur le bandeau : chevrons D2, rameaux S1, demi-cercles E2 ( $6,5 \times 2$ motifs). Sur le disque : Léda et le cygne. D. $87 \mathrm{~mm}$; H. $36 \mathrm{~mm}$.

2 Musée de Carthage (Ennabli 1976, n 157). Sur le bandeau : motifs en « $\mathrm{S}$ » Q1 formant une tresse. Sur le disque : Orphée (?) jouant de la lyre. Réflecteur. D. $83 \mathrm{~mm}$; H. $45 \mathrm{~mm}$

3 Littoral tunisien, site $\mathrm{n}^{\circ} 37$ (Henchir Chouggaf) (Bonifay et al. 2002-2003, fig. 9, $\mathrm{n}^{\circ}$ 97). Décor identique au $\mathrm{n}^{\circ}$ précédent, sans réflecteur.

*4 Mactar (Bourgeois 1977-78, $\mathrm{n}^{\circ} 1$ ). Sur le bandeau : chevaux et palmes pédonculées. Sur le disque: Achille et Hector. D. $85 \mathrm{~mm}$.

B) Scènes bibliques ou chrétiennes (fig. 209) Adam et Eve

*5 Musée de Trieste (Bejaoui 1997, fig. 53). D. $82 \mathrm{~mm}$. Les Hébreux dans la fournaise

*6 Musée de Carthage (Ennabli 1976, $\mathrm{n}^{\circ}$ 25). D. $79 \mathrm{~mm}$; H. $35 \mathrm{~mm}$.

Saint, de face

*7 Musée de Carthage (Ennabli 1976, $\mathrm{n}^{\circ} 115$ ). D. $84 \mathrm{~mm}$; H. $36 \mathrm{~mm}$.

8 Bibliothèque Nationale de France (Hoff 1986, $\mathrm{n}^{\circ} 57$ ). D. $80 \mathrm{~mm}$; H. $33 \mathrm{~mm}$.

9 Rome (Atlante I, Pl. CLX, n 3).

10 British Museum (Bailey 1988, Q1794). Moule en plâtre.

Le sacrifice d'Abraham.

*11 Musée de Carthage (Ennabli 1976, n 15).

12 Littoral tunisien, site $\mathrm{n}^{\circ} 70$ (El Aouabed) (Bonifay et al. 2002-2003, fig. $9, \mathrm{n}^{\circ}$ 99).

Le Christ foulant aux pieds le serpent

*13 Musti (Ennabli 1976, $\mathrm{n}^{\circ}$ 59).

14 Timgad (Hoff 1986, n 48). D. $80 \mathrm{~mm}$; H. $30 \mathrm{~mm}$.

15 Rome (Barbera, Petriaggi 1993, 175, $\mathrm{n}^{\circ} 133$ ). D. $83 \mathrm{~mm}$.

Les trois Hébreux rapportant la grappe de Canaan.

*16 Rome (?) (Trost, Hellmann 1996, n 44). D. 82 mm.

17 Museo Nazionale Romano (Barbera, Petriaggi 1993, $\left.196, n^{\circ} 156\right)$.

18 Mactar (Bourgeois 1977-78, $n^{\circ} 4$ ).

Le veilleur de la vigne.

*19 Henchir Beni Guedal (Ennabli 1976, n 76). D. $87 \mathrm{~mm}$; H. $32 \mathrm{~mm}$.

20 Sidi Marzouk Tounsi, atelier (Peacock, Bejaoui, Ben Lazreg 1990, fig. 9, O). 
Typologie - Lampes

Type Atlante X, groupe C2
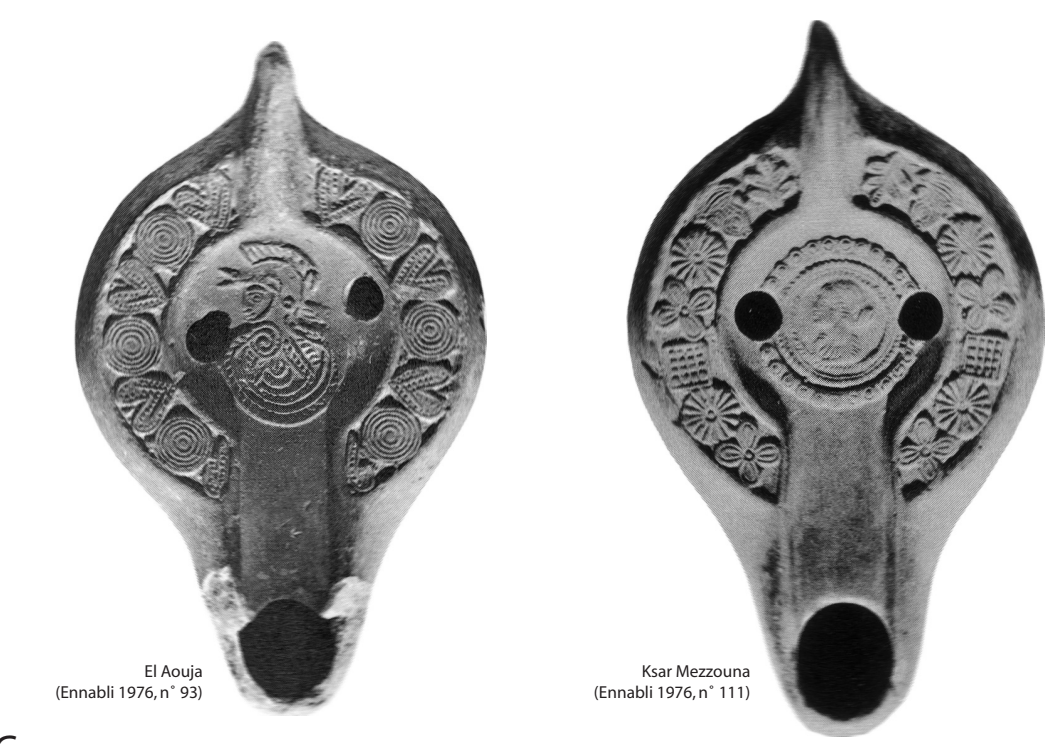

C

27
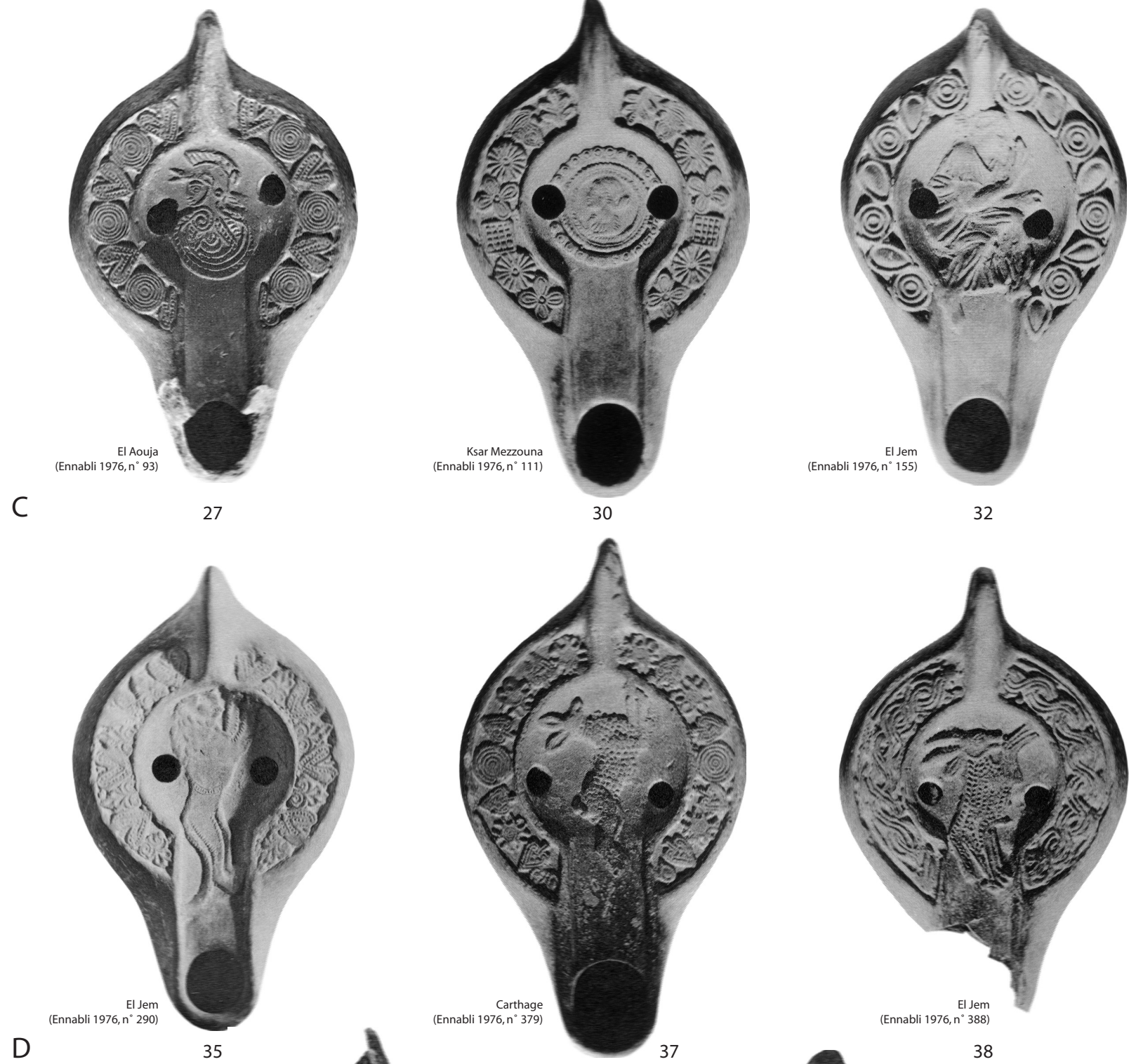

32
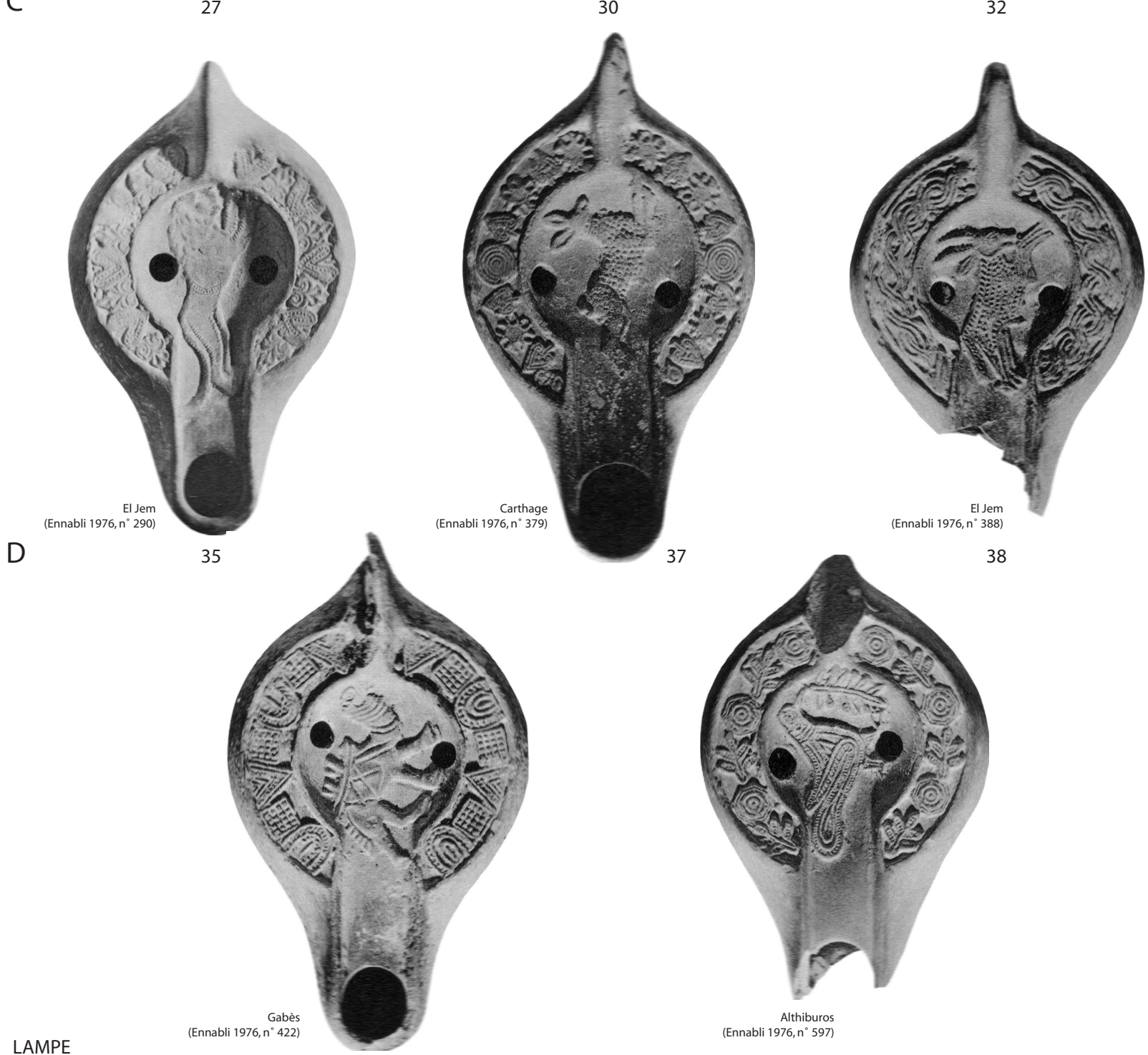

TYPE 54

40

44

Fig. 210. Lampes en sigillée africaine (Tunisie centrale). 
21-24 Carthage (Ibid., $\mathrm{n}^{\circ}$ 77-79). D. 83-85 mm; H. 34$35 \mathrm{~mm}$.

25 Rome (Trost, Hellmann 1996, $\mathrm{n}^{\circ}$ 45). D. $82 \mathrm{~mm}$; H. $36 \mathrm{~mm}$.

26 Museo Nazionale Romano (Barbera, Petriaggi 1993, $\left.207, \mathrm{n}^{\circ} 168\right)$. D. $87 \mathrm{~mm}$.

C) Personnages (fig. 210) Bustes

*27 El Aouja (Ennabli 1976, $\mathrm{n}^{\circ}$ 93). Sur le bandeau : cordiformes M8 et cercles E2 (6,5 x 2 motifs). Sur le disque: buste d'homme casqué. D. $84 \mathrm{~mm}$; H. $33 \mathrm{~mm}$.

28 British Museum (Bailey 1988, Q1803). Sur le bandeau : chevrons D2, cercles D3, quadrifoliés I4 (7 x 2 motifs). Sur le disque : buste féminin (?). D. $82 \mathrm{~mm}$.

29 El Jem (Ennabli 1976, n 106) ${ }^{238}$. Sur le bandeau : disques F6 et cordiformes M8 (7,5 x 2 motifs). Sur le disque : buste de femme nue. D. $82 \mathrm{~mm}$; H. $39 \mathrm{~mm}$.

*30 Région de Ksar Mezzouna (Ennabli 1976, n 111). Sur le bandeau: rameaux $\mathrm{S} 1$, cratères $\mathrm{O} 3$, disques G2, quadrifoliés I3, carrés A9 (7 x 2 motifs). Sur le disque : buste de l'impératrice Fausta, à gauche, dans un médaillon circulaire. D. $85 \mathrm{~mm}$; H. $36 \mathrm{~mm}$.

Personnages en pied

31 El Jem (Bailey 1988, Q1801). Moule en plâtre. Sur le bandeau : rosettes proches de G2 et cordiformes M8 $(6,5 \times 2$ motifs). Sur le disque : amour ailé tenant une torche.

*32 El Jem (Ennabli 1976, $\left.\mathrm{n}^{\circ} 155\right)$. Sur le bandeau: cercles E5 et oves K2 ( 8 et 7 motifs). Sur le disque: femme drapée accroupie et tenant un miroir. D. $83 \mathrm{~mm}$; H. $34 \mathrm{~mm}$.

33 Bibliothèque Nationale de France (Hoff 1986, $\left.\mathrm{n}^{\circ} 59\right)^{239}$. Sur le bandeau : disques E2, cordiformes M8, triangles D2 (7 x 2 motifs). Sur le disque: personnage vêtu d'un pagne. D. $80 \mathrm{~mm}$; H. $40 \mathrm{~mm}$.

D) Animaux (fig. 210-211) Lion

34 Musée de Nabeul, provenant d'El Jem (?) (Inv. L13). Sur le bandeau : chevrons D1, disques ( 9 × 2 motifs). Sur le disque: lion assis à droite. D. $84 \mathrm{~mm}$; H. $37 \mathrm{~mm}$.

*35 Région d'El Jem (Ennabli 1976, n²90). Sur le bandeau: cordiformes M8, palmettes P3. Sur le disque : lion courant dans l'axe de la lampe, pattes à droite. D. $82 \mathrm{~mm}$; H. 34.

36 Bibliothèque Nationale de France (Trost, Hellmann 1996, $\left.\mathrm{n}^{\circ} 71\right)$. Sur le bandeau: carrés A10, quadrifoliés I3, disques rayonnants, palmettes. Sur le disque : lion couchée ${ }^{240}$ dans l'axe de la lampe, pattes à droite. D. $85 \mathrm{~mm}$; H. $34 \mathrm{~mm}$.

Biche

*37 Carthage (Ennabli 1976, n 379). Sur le bandeau : étoiles H3, cordiformes M7, disques E1. Sur le

\footnotetext{
${ }^{238}$ Identique à Trost, Hellmann 1996, $\mathrm{n}^{\circ} 63$ et à Bourgeois 1977-78, nº 8 .

${ }^{239}$ Décor du disque identique : Trost, Hellmann 1996, n 51.

${ }^{240}$ Un moule de Sidi Marzouk Tounsi montre le même décor sur le disque mais avec la tête du lion vers le bec et une décoration de bandeau différente: Peacock, Bejaoui, Ben Lazreg 1990, fig. 9, d.
}

disque : biche dans l'axe de la lampe. D. $83 \mathrm{~mm}$; H. $37 \mathrm{~mm}$. Exemplaire tardif (?).

Bouquetin

*38 El Jem (Ennabli 1976, $\mathrm{n}^{\circ}$ 388). Sur le bandeau: entrelacs. Sur le disque : bouquetin courant dans l'axe de la lampe. D. $84 \mathrm{~mm}$; H. $38 \mathrm{~mm}$.

Bélier

39 Carthage (Ennabli 1976, $\left.\mathrm{n}^{\circ} 440\right)$. Sur le bandeau : quadrifoliés I5, oves L5 (7,5 motifs). Sur le disque : bélier à droite, devant lui une feuille de vigne. D. $86 \mathrm{~mm}$; H. $32 \mathrm{~mm}$.

Dromadaire

*40 Région de Gabès (Ennabli 1976, n 422). Sur le bandeau chevrons D2, oves L5. Sur le disque: dromadaire dans l'axe de la lampe. D. $86 \mathrm{~mm}$; H. $37 \mathrm{~mm}$.

41 Coll. privée (Mackensen 1998d, 136, n 155). Sur le bandeau: bustes des apôtres. sur le disque: dromadaire identique au $\mathrm{n}^{\circ}$ précédent. D. $84 \mathrm{~mm}$. Cheval

42 Musée du Louvre (Hoff 1986, n 96). Sur le bandeau : quadrifoliés I4, cercles E2. Sur le disque : cheval galopant dans l'axe de la lampe, swastika sur la croupe. D. $75 \mathrm{~mm}$; H. $32 \mathrm{~mm}$.

Chien

43 Rome (Barbera, Petriaggi 1993, 170, n 127). Sur le bandeau: palmettes proches de P3, chevrons D2, palmes $\mathrm{N} 2$ ( 8 × 2 motifs). Sur le disque: chien courant, dans l'axe de la lampe. D. $82 \mathrm{~mm}$. Colombe

*44 Althiburos (Ennabli 1976, $\mathrm{n}^{\circ}$ 597). Sur le bandeau : octogones $\mathrm{B} 2$ et rameaux S1 $(6 \times 2$ motifs $)$. D. $82 \mathrm{~mm}$; H. $36 \mathrm{~mm}$. Coq

*45 El Jem (Ennabli 1976, $\mathrm{n}^{\circ}$ 623). Sur le bandeau: chevrons D4, disque E2 (7 x 2 motifs). D. $83 \mathrm{~mm}$; H. $35 \mathrm{~mm}$.

*46 Musée de Carthage (Ennabli 1976, n 626). Sur le bandeau: cartouches et carreaux (6 62 motifs). Exemplaire tardif (?).

47 Sidi Jdidi, basilique 1, état C1 (Bonifay, Reynaud 2004, $\mathrm{n}^{\circ}$ 13.22). Décor identique au précédent. Poisson

*48 El Jem (Ennabli 1976, $\mathrm{n}^{\circ}$ 687). Sur le bandeau: carreaux A9, rameaux S1 (7 x 2 motifs). D. $85 \mathrm{~mm}$; H. $36 \mathrm{~mm}$.

49 Région d'El Jem (Ennabli 1976, n 757). Sur le bandeau : disques F6, oves L2 (6 x 2 motifs). D. : $79 \mathrm{~mm}$; H. $31 \mathrm{~mm}$.

50 Museo Nazionale Romano (Barbera, Petriaggi, 258, $\left.\mathrm{n}^{\circ} 219\right)^{241}$. Sur le bandeau : disques F5, palmes N2, losanges à volutes R2 ( $8 \times 2$ motifs). Sur le disque : deux poissons affrontés et deux cordiformes. D. $85 \mathrm{~mm}$.

51 Musée de Nabeul, provenant d'El Jem (Inv. NBM.L16). Moule en plâtre. Décor identique au précédent (supra, fig. $42, \mathrm{n}^{\circ} 3$ ).

E) Végétaux (fig. 211)

Palmier

*52 Musée de Carthage (Ennabli 1976, $\mathrm{n}^{\circ}$ 762). Sur le bandeau : $2+2$ rameaux S2, $1+1$ Carreaux A9, $1+$ 1 chevrons D6, $1+1$ rosace $\mathrm{J} 1,1+1$ carreaux A9, 1

\footnotetext{
${ }^{241}$ Décor identique : Trost, Hellmann 1996, nº 103.
} 

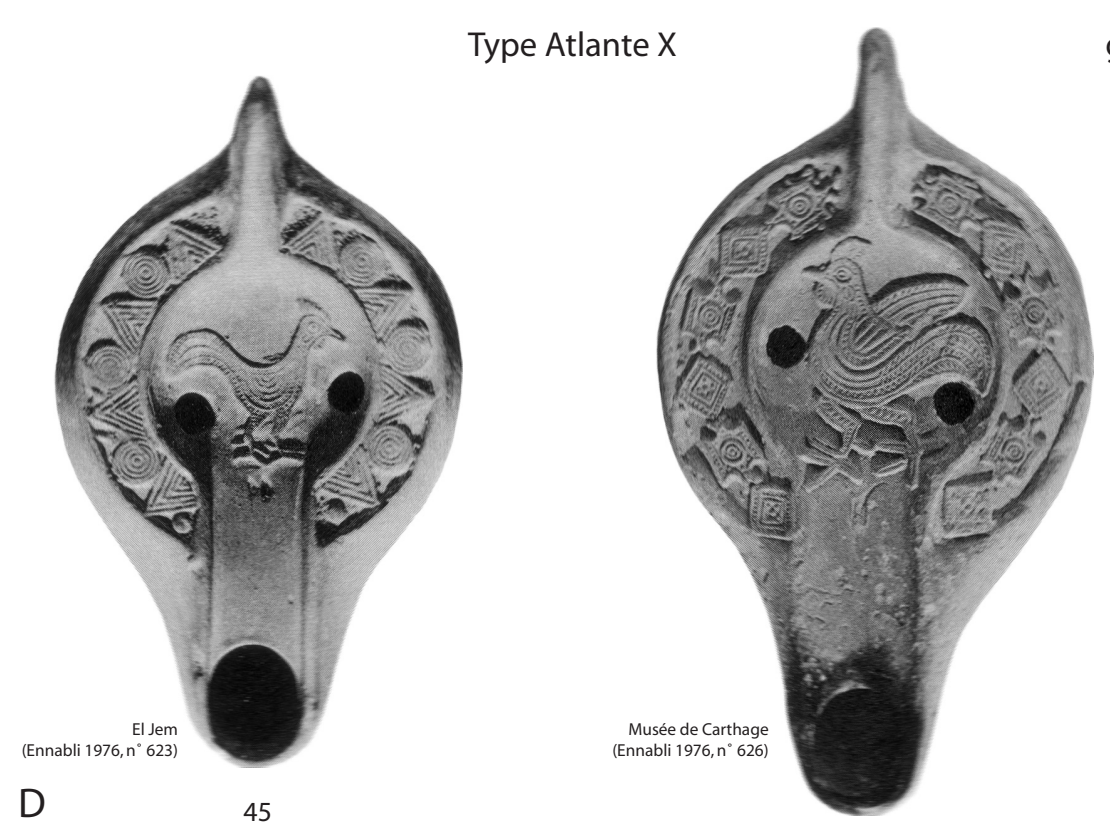

groupe C2
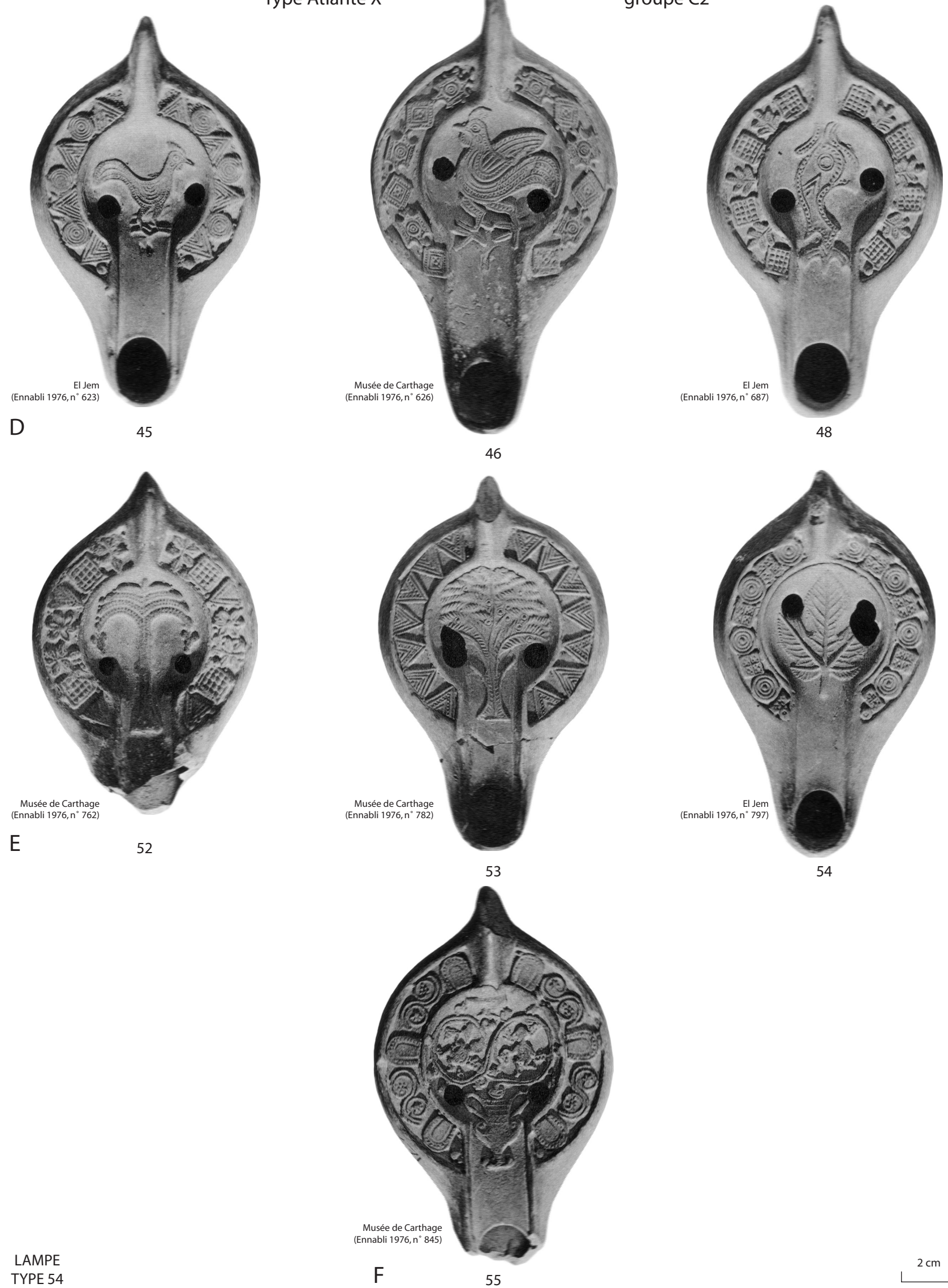

TYPE 54

55

Fig. 211. Lampes en sigillée africaine (Tunisie centrale). 
Type Atlante X, groupe C2

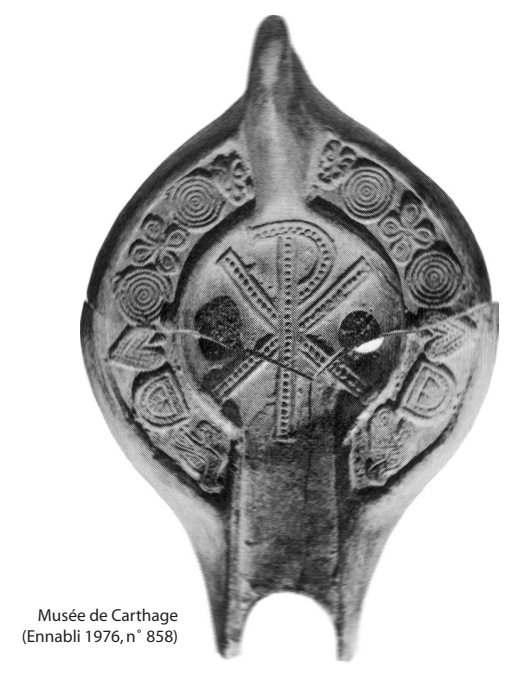

57

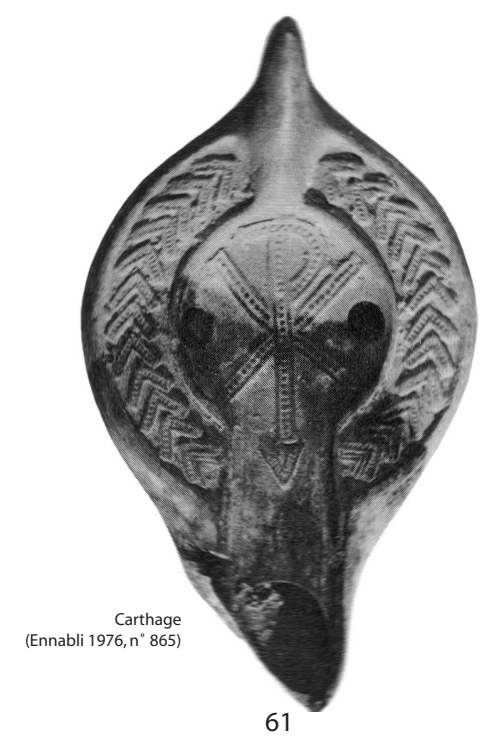

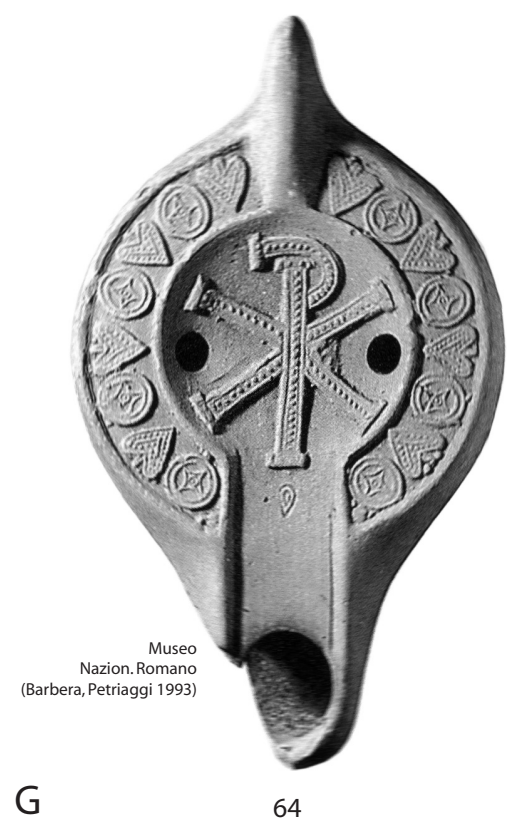

G 64

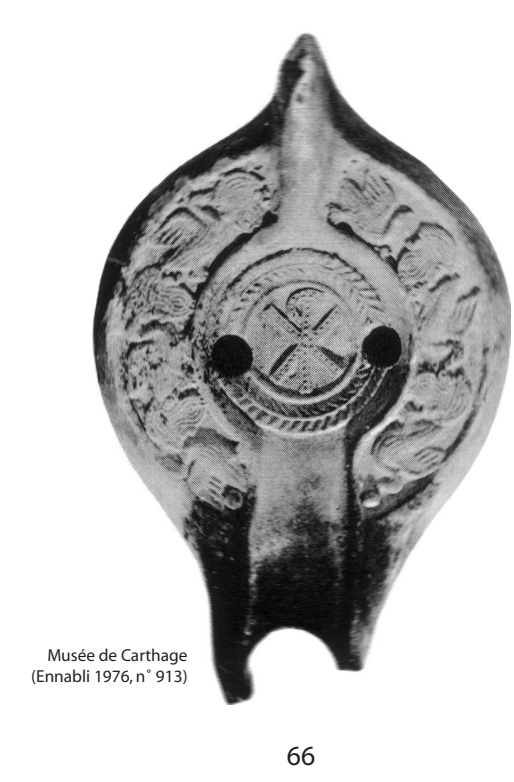

66

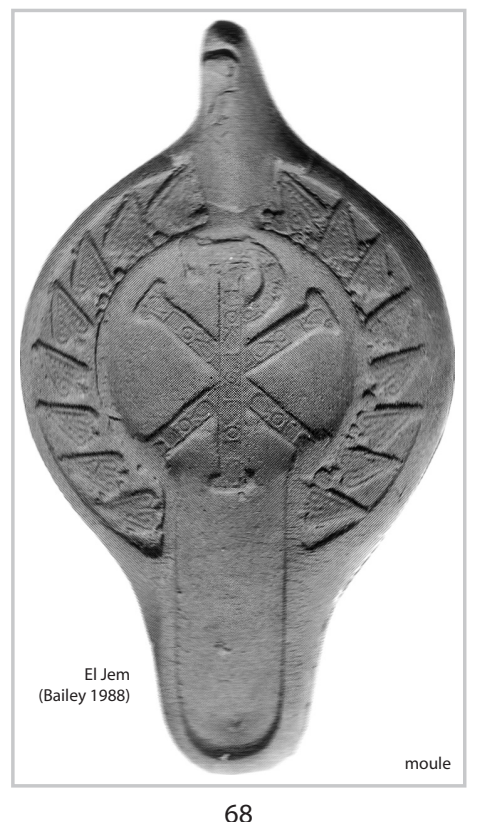

68

Fig. 212. Lampes en sigillée africaine (Tunisie centrale). 
+1 chevrons D6. D. $81 \mathrm{~mm}$; H. $33 \mathrm{~mm}$.

Arbre feuillu

*53 Musée de Carthage (Ennabli 1976, $\mathrm{n}^{\circ}$ 782). Sur le bandeau : $4+4$ chevrons D2, $3+3$ chevrons D4. D. $83 \mathrm{~mm}$; H. $35 \mathrm{~mm}$.

Feuille de vigne

*54 Région d'El Jem ( Ennabli 1976, n 797). Sur le bandeau: disques E4 et carreaux A11(7 x 2 motifs). D. $78 \mathrm{~mm}$; H. $31 \mathrm{~mm}$.

F) Vases (fig. 211)

*55 Musée de Carthage (Ennabli 1976, $\mathrm{n}^{\circ}$ 845). Sur le bandeau : oves L5 et pampres ( 5 x 2 motifs). Sur le disque: vase d'où sort une vigne avec un amour vendangeur. D. $86 \mathrm{~mm}$; H. $34 \mathrm{~mm}$.

56 Malte (Bailey 1988, Q1789). Sur le disque : cercle E1 et quadrifoliés I4 (6,5 motifs). Sur le disque : grand canthare. D. $86 \mathrm{~mm}$.

G) Chrismes (fig. 212)

Chrisme perlé simple

*57 Carthage (Ennabli 1976, $\mathrm{n}^{\circ}$ 858). Sur le bandeau : palmettes P3, cercles E1, quadrifoliés I4, cordiformes M8, oves L6, oiseaux U6 ( 7 x 2 motifs). Sur le disque : chrisme perlé. D. $85 \mathrm{~mm}$; H. $35 \mathrm{~mm}$.

58 Museo Nazionale Romano (Barbera, Petriaggi 1993, 197, $\mathrm{n}^{\circ}$ 157). Sur le bandeau : cercles E1 et palmettes P3 (8 x 2 motifs). Sur le disque : chrisme perlé comparable à celui du $\mathrm{n}^{\circ}$ précédent. D. $85 \mathrm{~mm}$.

59 Sidi Marzouk Tounsi, atelier (Peacock, Bejaoui, Ben Lazreg 1990, fig. 9, k). Décor identique au $\mathrm{n}^{\circ}$ précédent.

60 Idem (Landes, Ben Hassen 2001, 165, $\mathrm{n}^{\circ} 21$ ). Moule en plâtre. Sur le bandeau de la lampe : losanges à volutes, disques F5, oiseau (?) (7 x 2 motifs). Sur le disque: chrisme perlé comparable à celui des $n^{\circ}$ précédent.

*61 Carthage (Ennabli 1976, $\mathrm{n}^{\circ}$ 865). Sur le bandeau : 12 +12 chevrons D10. Sur le disque : chrisme perlé identique à celui des $\mathrm{n}^{\circ}$ précédent. D. $81 \mathrm{~mm} ; \mathrm{H}$. $35 \mathrm{~mm}$.

62 Rome (Hoff 1986, n 100). Sur le bandeau: douze bustes d'apôtres. Sur le disque: chrisme perlé rétrograde (?). D. $70 \mathrm{~mm} ; \mathrm{H} .30 \mathrm{~mm}$.

63 Carthage (Bejaoui 1997, 140, $\mathrm{n}^{\circ}$ 76). Décor similaire. D. $75 \mathrm{~mm}$.

Chrisme perlé à branches pattées

*64 Museo Nazionale Romano (Barbera, Petriaggi 1993, 199, $\mathrm{n}^{\circ} 159$ ). Sur le bandeau: cordiformes M8 et disques F5 ( 8 x 2 motifs). Sur le disque: chrisme perlé à branches pattées. D. $89 \mathrm{~mm}$.

65 British Museum (Bailey 1988, Q1753). Moule en plâtre. Sur le bandeau de la lampe : fers de lance et oves. Sur le disque: chrisme perlé aux branches pattées, cercle à l'intersection des branches, rétrograde.

Chrisme perlé dans un médaillon

*66 Musée de Carthage (Ennabli 1976, n ${ }^{\circ}$ 913). Sur le bandeau : cygnes proches de W5 et cratères O3 ( 5 x 2 motifs). Sur le disque : chrisme perlé rétrograde dans un médaillon palmé. D. $85 \mathrm{~mm}$; H. $34 \mathrm{~mm}$.

67 El Jem (Ennabli 1976, n 915). Sur le bandeau: étoiles $\mathrm{H} 3$ et losanges $\mathrm{C} 3$ ( 6 x 2 motifs). Chrisme perlé rétrograde dans un médaillon perlé. D. $84 \mathrm{~mm}$; H. $36 \mathrm{~mm}$.
Chrisme gemmé

*68 El Jem (Bailey 1988, Q1760). Moule en plâtre (positif moderne). Sur le bandeau : $8+8$ cordiformes M10. Sur le disque: chrisme gemmé à branches pattées.

69 Carthage (Ennabli 1976, $\mathrm{n}^{\circ} 883$ ). Décor identique au $\mathrm{n}^{\circ}$ précédent, mais surmoulé : production septentrionale du groupe D2 (?) (infra, fig. 214, LAMPE TYPE $\left.65, \mathrm{n}^{\circ} 29\right)$ D. $80 \mathrm{~mm}$; H. $35 \mathrm{~mm}$.

H) Croix monogrammatiques gemmées (fig. 213)

Croix monogrammatique dessinée sur le modèle du chrisme gemmé

*70 El Jem (Bailey 1988, Q1767) ${ }^{242}$. Sur le bandeau : carrés proches A7 (type Barbera-Petriaggi 24), disques F3, chevrons D10 ( 9 x 2 motifs). D. $82 \mathrm{~mm}$.

71 Sidi Marzouk Tounsi, atelier (Peacock, Bejaoui, Ben Lazreg 1990, fig. 9, h). décor identique au $\mathrm{n}^{\circ}$ précédent.

Croix monogrammatique rétrograde type BarberaPetriaggi 210C

*72 Museo Nazionale Romano (Barbera, Petriaggi 1993, 201, $\mathrm{n}^{\circ}$ 161). Sur le bandeau: $4+4$ impressions d'une monnaie de Théodose II. Sur le disque : deux oiseaux placés symétriquement sous la croix monogrammatique de type Barbera-Petriaggi 210C/1. D. $84 \mathrm{~mm}$.

73 Carthage (Ennabli 1976, n 1044). Sur le bandeau : étoiles H3 et octogones B2 ( 7 × 2 motifs). Sur le disque : croix monogrammatique de type BarberaPetriaggi 210C/1. D. $81 \mathrm{~mm}$; H. $36 \mathrm{~mm}$.

Croix monogrammatique type Barbera-Petriaggi 210B

74 Rome (?) (Trost, Hellmann 1996, $\left.\mathrm{n}^{\circ} 117\right)^{243}$. sur le bandeau : carrés A4, triangles D2 et cercles E2 $(8 \times 2$ motifs). Sur le disque : croix monogrammatique type Barbera-Petriaggi 210B/1. D. $84 \mathrm{~mm}$; H. $34 \mathrm{~mm}$.

*75 Musée de Carthage (Ennabli 1976, n 952) ${ }^{244}$. Sur le bandeau: $4+4$ impressions d'une monnaie de Théodose II. Sur le disque : croix monogrammatique type Barbera-Petriaggi 210B/1. D. $84 \mathrm{~mm}$; H. $34 \mathrm{~mm}$.

76 Rome (Barbera, Petriaggi 1993, 178, n 136). Sur le bandeau: $10+10$ oves K2. Sur le disque : croix monogrammatique type Barbera-Petriaggi 210B/2. D. $84 \mathrm{~mm}$.

Croix monogrammatique type Barbera-Petriaggi 210A

*77 Musée de Carthage (Ennabli 1976, $\left.\mathrm{n}^{\circ} 951\right)^{245}$. Sur le bandeau: $6+6$ oves proches de L5 (BarberaPetriaggi 41A). Sur le disque: croix monogrammatique type Barbera-Petriaggi 210A/1. D. $84 \mathrm{~mm}$; H. $34 \mathrm{~mm}$.

78 El Jem (Bailey 1988, Q1763) ${ }^{246}$. Sur le bandeau : $7+$ 7 chevrons D10 pointe vers le bec. Sur le disque : croix monogrammatique type Barbera-Petriaggi 210A/2. D. $84 \mathrm{~mm}$.

\footnotetext{
${ }^{242}$ Moule portant un décor identique : Mackensen 1980, Pl. 20.

${ }^{243}$ Décor identique : Barbera, Petriaggi 1993, 307, $\mathrm{n}^{\circ} 265$.

${ }^{244}$ Décor identique sur une lampe provenant d'El Jem : Bailey 1988, Q1766 (D. $77 \mathrm{~mm}$ ).

${ }^{245}$ Décor identique : Barbera, Petriaggi 1993, 236, n 198.

${ }^{246}$ Lampes identiques : Barbera, Petriaggi 1993, 195, $\mathrm{n}^{\circ} 155$; Mackensen 1998d, 137, $\mathrm{n}^{\circ} 158$.
} 
Typologie - Lampes

Type Atlante X, groupe C2

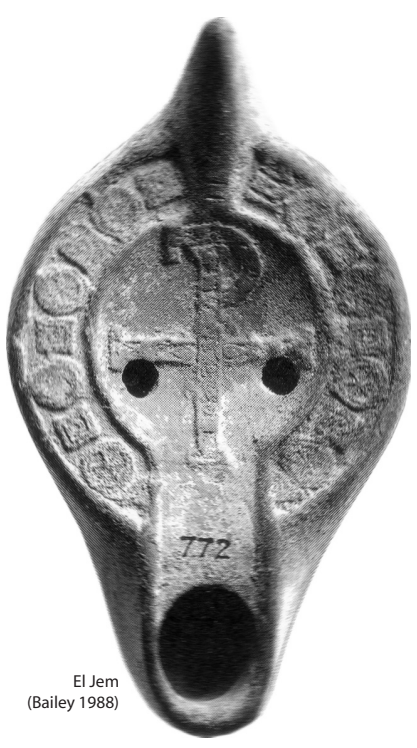

70

$\mathrm{H}$

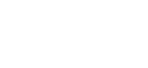
Musée de Carthage
(Ennabli 1976, n 951)

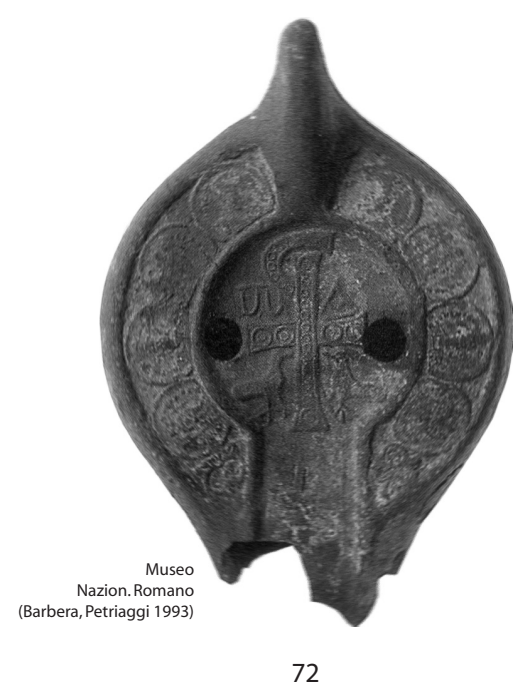

72

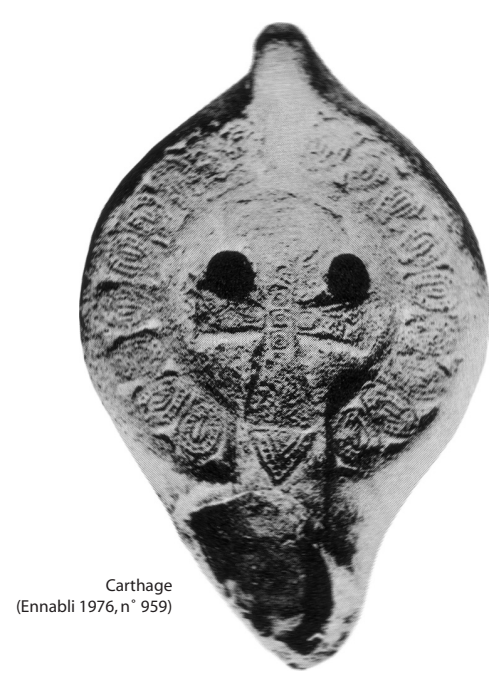

75

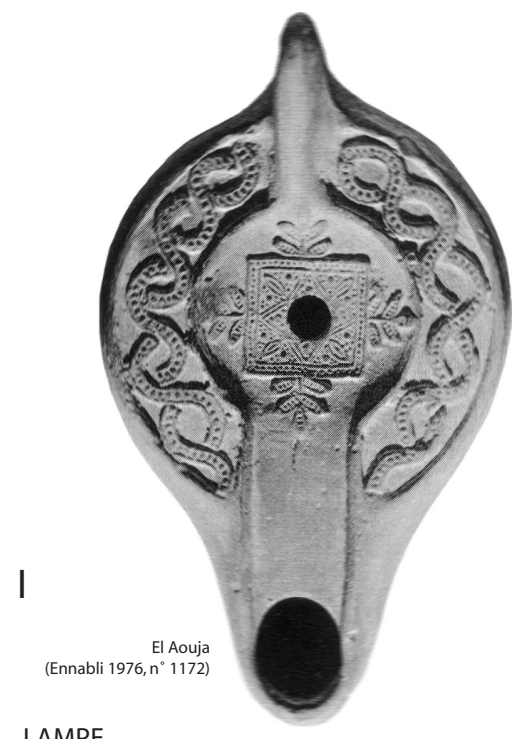

LAMPE

TYPE 54
77

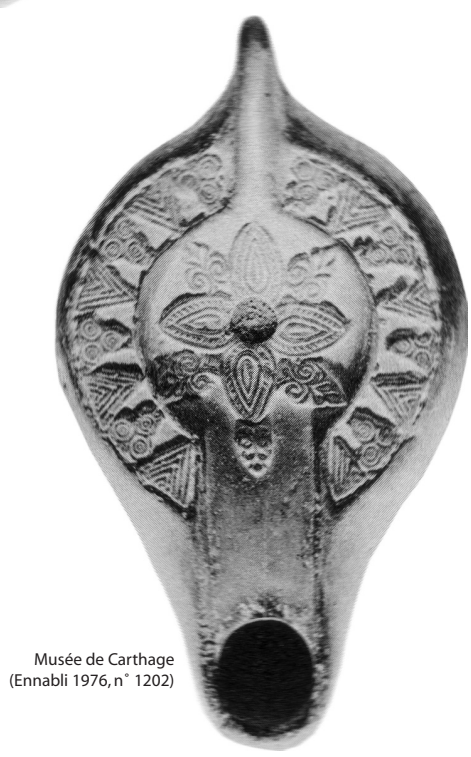

87
[80]

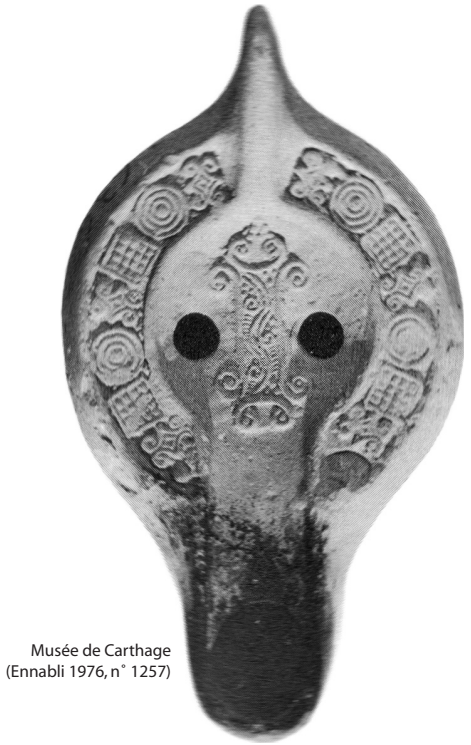

89
$2 \mathrm{~cm}$

Fig. 213. Lampes en sigillée africaine (Tunisie centrale). 
79 Idem (Ibid., Q1762) ${ }^{247}$. Moule en plâtre: décor identique au $\mathrm{n}^{\circ}$ précédent.

[*80] Carthage (Ennabli 1976, $\mathrm{n}^{\circ}$ 959). Sur le bandeau : $9+$ 9 oves proches de L5. Sur le disque: croix monogrammatique type Barbera-Petriaggi 210A/2. D. $83 \mathrm{~mm}$; H. $34 \mathrm{~mm}$. Surmoulage local ? ${ }^{248}$

Autres croix monogrammatiques

81 Carthage (Ennabli 1976, $\mathrm{n}^{\circ}$ 1025). Sur le bandeau: quadrifoliés I5 et oves type Barbera-Petriaggi 1993 41A. Sur le disque: croix monogrammatique rétrograde. D. $81 \mathrm{~mm}$; H. $34 \mathrm{~mm}$.

82 Carthage, Musée Paléochrétien (en exposition). Décor identique au $n^{\circ}$ précédent.

I) Décors géométriques (fig. 213) Carreaux

*83 El Aouja (Ennabli 1976, $\mathrm{n}^{\circ} 1172$ ). Sur le bandeau : 6 +6 «S» Q1, en tresse. Sur le disque : carré. D. $84 \mathrm{~mm}$; H. $35 \mathrm{~mm}$.

84 Carthage (Hoff 1986, $\left.\mathrm{n}^{\circ} 125\right)^{249}$. Sur le bandeau : $4+$ 4 rosaces $\mathrm{J} 2,4+4$ cordiformes M9. D. $80 \mathrm{~mm}$; H. $30 \mathrm{~mm}$.

85 Sidi Marzouk Tounsi, atelier (Peacock, Bejaoui, Ben Lazreg 1990, fig. 9, n)

86 Marseille, chantier de La Bourse (Bonifay 1983, fig. 31, $\mathrm{n}^{\circ}$ 199). Sur le bandeau : $3+3$ végétaux $\mathrm{S} 2,3$ +3 disques F6.

Motifs rayonnants

*87 Musée de Carthage (Ennabli 1976, $\mathrm{n}^{\circ}$ 1202). Sur le bandeau : $4+4$ fleurons E7, $4+3,5$ chevrons D4. D. $84 \mathrm{~mm}$; H. $38 \mathrm{~mm}$.

88 Sidi Marzouk Tounsi, atelier (Peacock, Bejaoui, Ben Lazreg 1990, fig. 9, b). Moule en plâtre. Iota

*89 Musée de Carthage (Ennabli 1976, n 1257). Sur le bandeau : losanges à volutes R2, cercles E5, carrés A9 (7 x 2 motifs). D. $82 \mathrm{~mm}$; H. $35 \mathrm{~mm}$.

Les exemplaires avec un profil galbé légèrement outrepassé (transition avec le groupe C1 ?) sont probablement les plus anciens $\left(\mathrm{n}^{\circ} \mathbf{2 7}, 29\right.$ ?, 30, 33, 35, 36, 45, 49, 53, 54?, 86); les motifs du bandeau sont généralement de grande taille et serrés les uns contre les autres. Le $\mathrm{n}^{\circ} \mathbf{8 6}$ provient d'un contexte du deuxième quart ou du milieu du Ve siècle. Il est clair que la variante $\mathrm{B}$, à scènes bibliques ou chrétiennes, ne fait pas partie de cette première série. Des exemplaires de grande taille, avec un nombre réduit de motifs sur le bandeau (six au lieu des sept ou huit habituels), disposés de manière relativement désordonnée (pointes des carrés sur les bords du bandeau) et non repris après le démoulage (petites bulles d'argile provoquées par le moule en plâtre $)^{250}$, sont probablement tardifs (46-47). Comme il y a le même nombre de motifs sur le bandeau de ces

\footnotetext{
${ }^{247}$ Moule identique : Mackensen 1998d, 137, n 159.

${ }^{248}$ Une lampe identique a été choisie par J. W. Hayes (1972, Pl. XXI, a) pour illustrer son type II B.

${ }^{249}$ Même modèle: Bailey 1988, Q1786; Ennabli 1976, $\mathrm{n}^{\circ} 1189$

${ }^{250}$ Les mêmes imperfections sont visibles sur une lampe de l'atelier de Sidi Marzouk Tounsi: Peacock, Bejaoui, Ben Lazreg 1990, fig. 9, i.
}

exemplaires tardifs de grande taille que sur les exemplaires probablement contemporains du groupe $\mathrm{C} 3$, de petite taille, ces motifs sont plus espacés. Le $n^{\circ} 47$ est associé à une lampe de type Atlante X A1 du groupe D2 (Bonifay, Reynaud 2004, $\mathrm{n}^{\circ}$ 13.23). Les exemplaires ornés d'un chrisme précèdent sans doute ceux ornés d'une croix monogrammatique; ces derniers n'apparaissent peut-être pas avant la fin du Ves. (Barbera, Petriaggi 1993, 375-376) et durent sans doute encore dans la première moitié du VIe siècle. La datation des lampes tardives du groupe C2 reste difficile car elles ne sont exportées en grande quantité ni à Carthage (où les groupe D1 et D2 sont déjà prépondérants), ni en Méditerranée occidentale (où les lampes du groupe C3 sont majoritaires). De plus, les stratigraphies urbaines restent rares dans la région de production.

- lampes Atlante X A, groupe C3 (fig. 214)

\section{LAMPE TYPE 55}

Lampes de petite taille (D. env. 64-66 mm ; H. env. 25$28 \mathrm{~mm}$ ). Le nombre de variantes paraît moins important que dans le groupe $\mathrm{C} 2$.

Les décors de bandeaux sont identiques à ceux du groupe $\mathrm{C} 2$ mais on remarque une fréquence particulière de chevrons D1, d'étoiles H3, de triangles Trost-Hellmann $\mathrm{Jb} 5$, et surtout de palmettes $\mathrm{P} 3$ et de losanges à volutes $\mathrm{R} 2^{251}$. Le choix dans le décor du disque est limité par la faible surface de ce dernier. Cependant, mises à part les scènes mythologiques et bibliques, probablement de trop grande taille, on retrouve dans le groupe C3 la plupart des variantes décoratives du groupe $\mathrm{C} 2$, avec seulement quelques particularités :

- En raison de la petite taille des lampes, les bustes sont particulièrement fréquents (voir notamment le $\mathrm{n}^{\circ} 2$ ), tandis que les personnages de grande taille sont absents.

- Les animaux de petite taille sont également privilégiés, en particulier un bouquetin (6), un lièvre (10), un coq (13) qui semblent avoir eu une grande faveur. Le poisson des $n^{\circ} \mathbf{1 4 - 1 5}$, associé à un autre sur les lampes du groupe C2 (groupe C2, $n^{\circ} 50-51$ ), est ici utilisé seul.

- Un chrisme de petite taille, non pas perlé mais hachuré, semble affecté de préférence à ce groupe de lampes (21). Les croix monogrammatiques sont rares, on en relève un seul type, à décor perlé (type Barbera-Petriaggi 210D) (24).

Exemples (fig. 214) :

Personnages

Bustes

*1 Rome (?) (Trost, Hellmann 1996, n 62). Sur le bandeau: palmettes $\mathrm{P} 3$ et losanges à volutes R2. Sur le disque: buste d'homme casqué à gauche (cf. groupe $\left.\mathrm{C} 2, \mathrm{n}^{\circ} 27\right)$. D. $66 \mathrm{~mm}$; H. $28 \mathrm{~mm}$.

\footnotetext{
${ }^{251}$ Voir par exemple : Barbera, Petriaggi 1993, 181, n 140.
} 
Typologie - Lampes
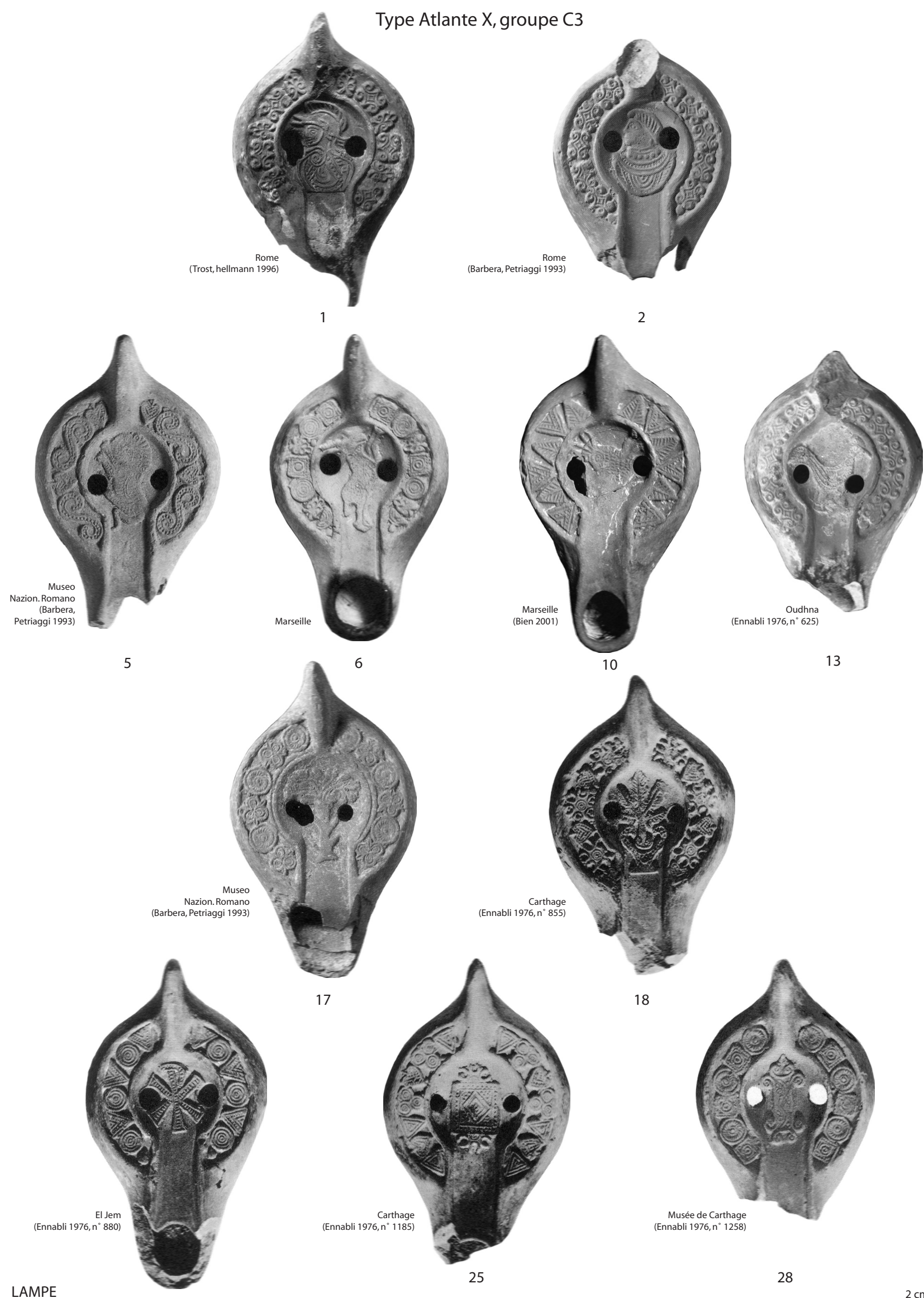
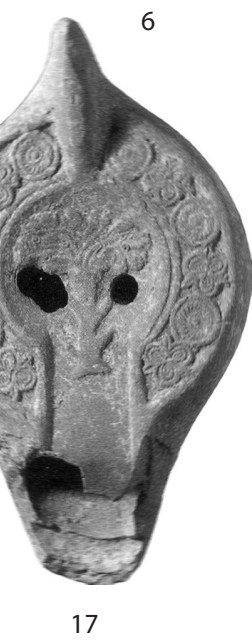

17

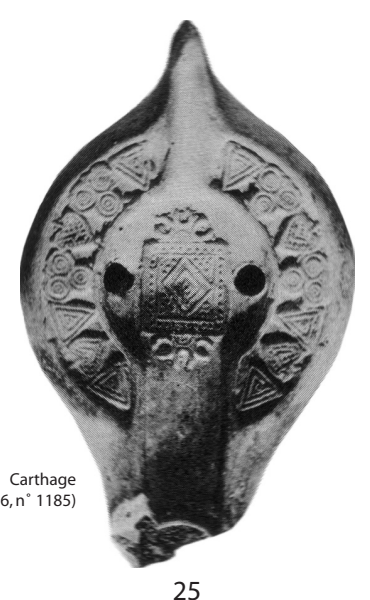

25

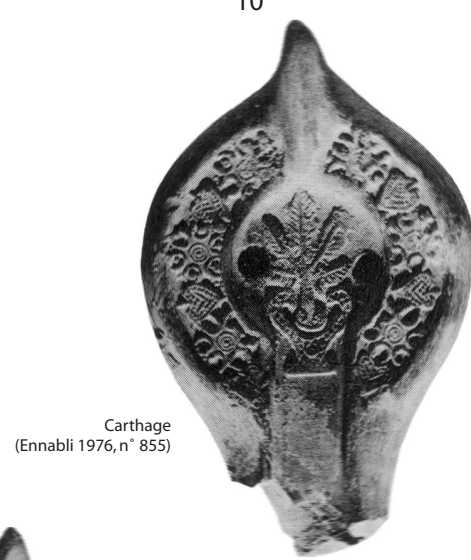

18

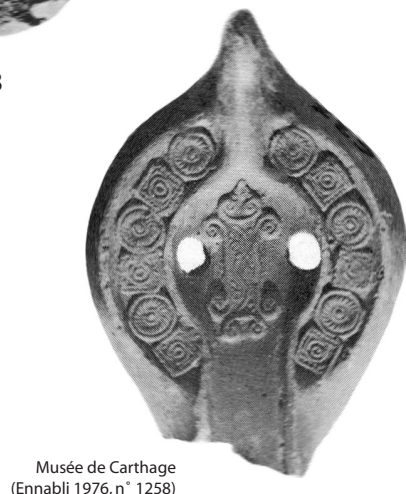

28

TYPE 55

21

Fig. 214. Lampes en sigillée africaine (Tunisie centrale). 
*2 Rome (Barbera, Petriaggi 1993, 262, $\left.\mathrm{n}^{\circ} 223\right)^{252}$. Sur le bandeau: $5+5$ losanges à volutes $\mathrm{R} 2$. Sur le disque : buste féminin (?) à gauche (cf. groupe $\mathrm{C} 2$, $\left.\mathrm{n}^{\circ} 27\right)$. D. $65 \mathrm{~mm}$.

3 El Jem (Bailey 1988, Q1804). Moule en plâtre. Décor identique au $\mathrm{n}^{\circ}$ précédent.

Personnages en pied

4 Rome (?) (Trost, Hellmann 1996, n 49). Sur le bandeau : cordiformes M8 et triangles ( 7 x 2 motifs). Sur le disque: amour ailé tenant une torche. D. $68 \mathrm{~mm}$; H. $30 \mathrm{~mm}$.

\section{Animaux \\ Lion}

*5 Museo Nazionale Romano (Barbera, Petriaggi 1993, 246, $\mathrm{n}^{\circ}$ 207bis). Sur le bandeau : cordiformes M8 et esses Q2 (4 x 2 motifs). Sur le disque : lion couché. D. $68 \mathrm{~mm}$.

Bouquetin

*6 Marseille, chantier de La Bourse (Février, Leyge $\left.1986, n^{\circ} 48 / f\right)^{253}$. Sur le bandeau : carrés proches de A4, cercles E2, palmettes P3 (6,5 x 2 motifs). D. $65 \mathrm{~mm}$.

Lièvre

7 Thamuda (Ponsich 1961, $\mathrm{n}^{\circ}$ 369). Sur le bandeau: chevrons D1 et triangles Trost-Hellmann Jb5, têtebêche ( $6 \times 2$ motifs). Sur le disque : lièvre dans l'axe de la lampe, tête en arrière. D. $63 \mathrm{~mm}$; H. $28 \mathrm{~mm}$.

8 Arles (Inv. FAN91.00.2200).

9 Eyguières (in Terres Naufragées, Aix-en-Provence 1998, p. 106).

*10 Marseille, chantier de l'Alcazar (Bien 2001, n 38). Variante tardive (?) à bec long.

11 Montagnac (Mauné, Feugère 1999, fig. 7, nº 1, et fig. 8). Idem.

Coq

12 Carthage (Ennabli 1976, $\left.\mathrm{n}^{\circ} 624\right)^{254}$. Sur le bandeau : disque E4, carreaux A4 (6 x 2 motifs). Sur le disque : Coq à droite. D. $64 \mathrm{~mm}$; H. $33 \mathrm{~mm}$.

*13 Oudhna (cf. Ennabli 1976, nº 625 ; CMA 2514). Sur le bandeau: losanges à volutes R2 (5 x 2 motifs). Disque identique au $\mathrm{n}^{\circ}$ précédent. D. $65 \mathrm{~mm} ; \mathrm{H}$. $26 \mathrm{~mm}$.

Poisson

14 Rome (?), Bibliothèque Nationale de France (Trost, Hellmann 1996, $\left.\mathrm{n}^{\circ} 101\right)^{255}$. Sur le bandeau : cercles E2, rameaux S2 (6 x 2 motifs). Sur le disque : poisson (cf. groupe C2, n ${ }^{\circ} 47$ ). D. $66 \mathrm{~mm}$; H. $27 \mathrm{~mm}$.

15 Idem (Ibid., $\left.\mathrm{n}^{\circ} 102\right)^{256}$. Sur le bandeau : chevrons D1 et disques F6. Disque identique au $\mathrm{n}^{\circ}$ précédent. D. $65 \mathrm{~mm}$; H.28 mm

\footnotetext{
252 Deux autres lampes identiques au Museo Nazionale Romano : Barbera, Petriaggi 1993, 231, n 192-193.

${ }^{253}$ Lampe identique : Trost, Hellmann 1996, ${ }^{\circ} 78$.

${ }^{254}$ Même modèle à la Bibliothèque Nationale de France (Trost, Hellmann 1996, $\mathrm{n}^{\circ}$ 97) et au British Museum, provenant d'Ephèse (Bailey 1988, Q1838).

${ }^{255}$ Lampe identique : Barbera, Petriaggi 1993, 244, ${ }^{\circ} 206$.

${ }^{256}$ Décor identique : Barbera, Petriaggi 1993, 248, nº 209.
}

Végétaux

Palmier

16 Carthage (Ennabli 1976, $\left.\mathrm{n}^{\circ} 771\right)$. Sur le bandeau: disques E6 et quadrifoliés I4 ( 8 × 2 motifs). Sur le disque : palmier. D. $65 \mathrm{~mm}$; H. $28 \mathrm{~mm}$. Arbre feuillu

*17 Museo Nazionale Romano (Barbera, Petriaggi 1993, 222, $\left.\mathrm{n}^{\circ} 183\right)$. Sur le bandeau : disques F6, trifoliés (6 x 2 motifs). D. $68 \mathrm{~mm}$.

Vases

*18 Carthage (Ennabli 1976, n 855) $)^{257}$. Sur le bandeau : étoiles $\mathrm{H} 2$ et cordiformes M9. Sur le disque : vase surmonté d'une feuille de vigne. D. $68 \mathrm{~mm}$; $\mathrm{H}$. $28 \mathrm{~mm}$.

19 Carthage (Chapman, Davies, Peacock 1984, Pl. 1, $\mathrm{n}^{\circ} 7$ ). Décor identique au $\mathrm{n}^{\circ}$ précédent.

Chrisme

20 British Museum (Bailey 1988, Q1755). Sur le bandeau: cercles E2, losanges $\mathrm{C} 1$, étoiles $\mathrm{H} 3$, disques F6. Sur le disque : chrisme hachuré, simple. D. $68 \mathrm{~mm}$

*21 El Jem (Ennabli 1976, $\mathrm{n}^{\circ} 880$ ). Sur le bandeau: cercles E2 et chevrons D2 (6 x 2 motifs). Sur le disque : chrisme hachuré, patté. D. $66 \mathrm{~mm}$; H. $27 \mathrm{~mm}$. Variante tardive (?) à bec long.

22 Rome (Barbera, Petriaggi 1993, 263, n 224). Sur le bandeau : cercles E2 et palmettes P3. Sur le disque : motif identique au $\mathrm{n}^{\circ}$ précédent. D. $67 \mathrm{~mm}$.

23 Marseille, puits de la rue du Bon-Jésus (Bonifay 1998b, fig. 172, n 19). Sur le disque: losanges à volutes R2 et quadrifoliés I4. Sur le disque : motif identique au $\mathrm{n}^{\circ}$ précédent.

Croix monogrammatique

24 Museo Nazionale Romano (Barbera, Petriaggi 1993, 166, $\left.\mathrm{n}^{\circ} 123\right)$. Sur le bandeau : carrés proches de A6 et triangles D5 (?) ( 7 × 2 motifs). Sur le disque : croix monogrammatique perlée type Barbera-Petriaggi 210D. D. $68 \mathrm{~mm}$.

Décors géométriques Carreaux

*25 Carthage (Ennabli 1976, $\mathrm{n}^{\circ} 1185$ ). Sur le bandeau : triangles D8, cercles E7, cordiformes M9 $(7 \times 2$ motifs). Sur le disque: losange inscrit dans un carreau à cadre perlé, cantonné de deux demi étoiles H3. D. $68 \mathrm{~mm}$.

26 Carthage (Chapman, Davies, Peacock 1984, Pl. 1, $\left.n^{\circ} 4\right)$. Décor identique au précédent.

Motifs rayonnants

27 Museo Nazionale Romano (Barbera, Petriaggi 1993, $\left.283, \mathrm{n}^{\circ} 243\right)^{258}$. Sur le bandeau : triangles D8 et quadrifoliés I4 (7, 5 x 2 motifs). Sur le disque: triangles D8 et petits cercles disposés en rosace autour de l'orifice central de remplissage. D. $61 \mathrm{~mm}$.

${ }^{257}$ Lampe identique, provenant de Rome : Barbera, Petriaggi $1993, n^{\circ} 142$.

${ }^{258}$ Lampe identique, provenant d'Egypte : Bailey 1988, Q1788. 
Type Atlante X, groupe C4

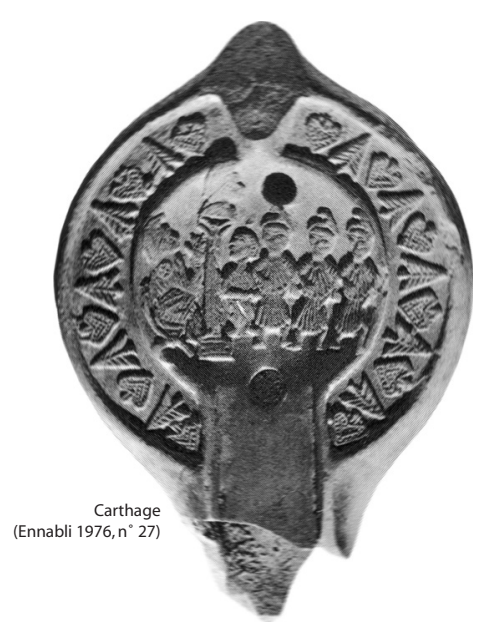

1

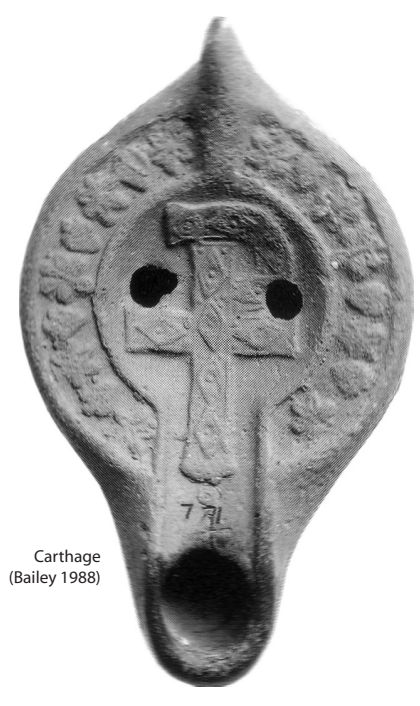

19

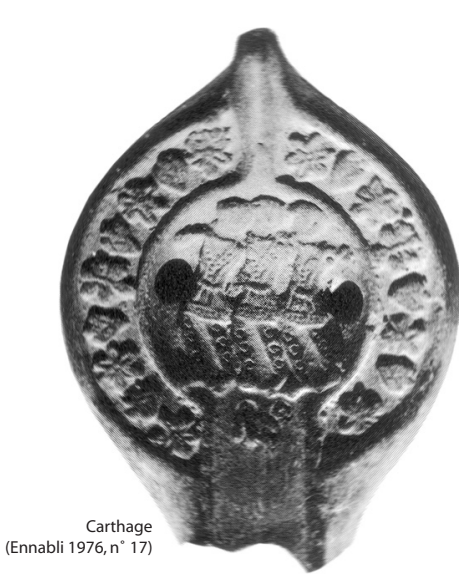

4

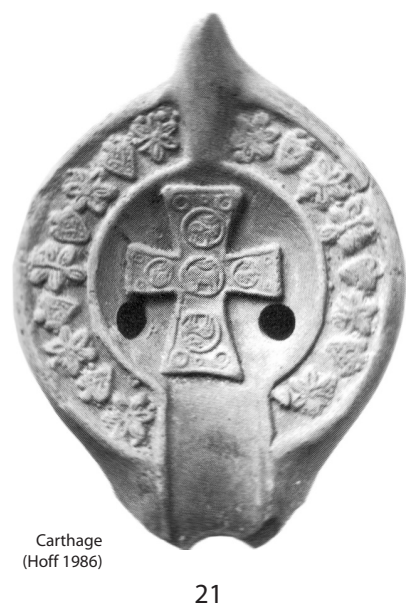

21

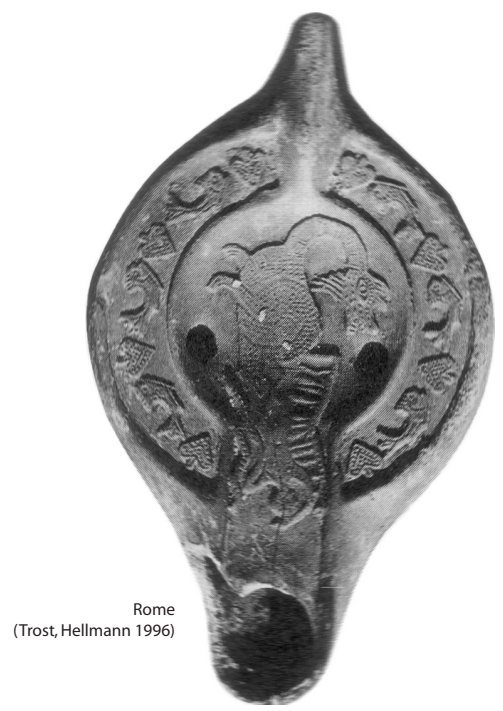

15

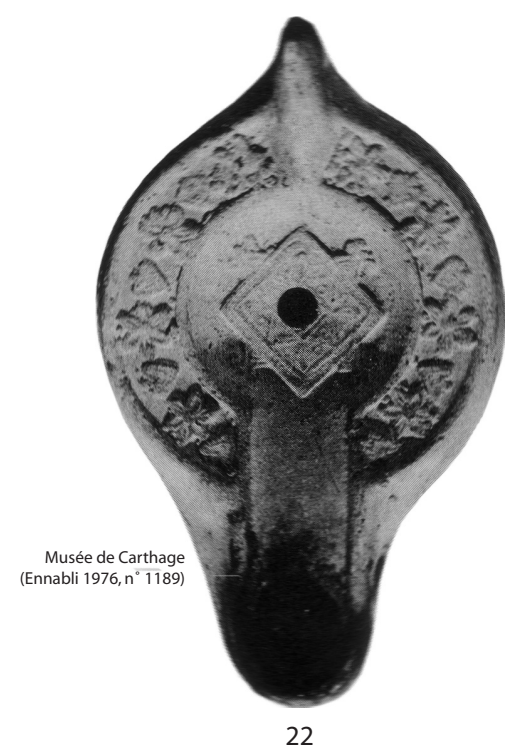

Fig. 215. Lampes en sigillée africaine (Tunisie centrale). 
Iota

*28 Musée de Carthage (Ennabli 1976, n 1258) ${ }^{259}$. Sur le bandeau : disques F6 et carrés proches de A4. Sur le disque: motif en forme de Iota ( $\mathrm{cf}$. groupe $\mathrm{C} 2$, $\left.\mathrm{n}^{\circ} 89\right)$. D. $65 \mathrm{~mm}$.

Variantes indéterminées

29-35 Marseille, chantier de La Bourse (Bonifay 1983, fig. $31, n^{\circ} 200-204$, et fig. $32, n^{\circ} 205-206$ ).

Le groupe C3 est typique des contextes de la seconde moitié du Ve s. $(\mathbf{1 9}, \mathbf{2 3}, \mathbf{2 6}, \mathbf{2 9 - 3 5})$; certains exemplaires peuvent durer dans la première moitié du VIe s. (10-11). Il est largement exporté en Méditerranée occidentale (peut-être à la faveur de sa petite taille) comme l'attestent, notamment, les découvertes de Marseille et la collection du Museo Nazionale Romano.

\section{- type Atlante X A, groupe C4 (fig. 215)}

\section{LAMPE TYPE 56}

J'ai réuni dans ce groupe des lampes avec un bandeau décoré de motifs de petite taille, plutôt espacés. Les motifs les plus fréquemment utilisés sont les rameaux S2, les rosaces $\mathrm{J} 2$, les cordiformes $\mathrm{M} 9$, les fers de lance $\mathrm{N} 1$, les dauphins V3, avec, souvent, l'alternance de deux motifs.

Le décor du disque est assez peu varié :

- Variante A : Scènes bibliques

- Nabuchodonosor et les trois Hébreux (1); sur le bandeau: motifs cordiformes M6 alternant avec des fers de lance N1;

- Les trois Hébreux dans la fournaise (4); sur le bandeau : rosaces J1 alternant avec des motifs cordiformes M9, rameaux S2. L'abondance de ce type à Carthage pourrait plaider pour une origine septentrionale, hypothèse de Bailey. Première moitié du VIe s. (?).

- Jonas et la baleine (15); sur le bandeau : motifs cordiformes M9 alternant avec des dauphins V3.

- Variante B : Croix monogrammatiques

Dans ce groupe ne subsistent plus que les croix monogrammatiques les plus tardives du groupe $\mathrm{C} 2$ (type Barbera-Petriaggi 210A/2). Je propose également d'associer à ce groupe une variante non rétrograde de la croix monogrammatique de type Barbera-Petriaggi 210E (19) qui, dans sa version (normale) rétrograde, connaîtra une grande faveur au sein du groupe C5. L'origine centro-tunisienne des $n^{\circ} \mathbf{1 8 - 1 9}$ reste très hypothétique mais la version non rétrograde (et de très grande taille) de la croix de type Barbera-Petriaggi $210 \mathrm{E}$ est attestée sur une lampe de type Atlante XII certainement produite en Byzacène (Mackensen 1998d, $\mathrm{n}^{\circ} 160$; infra, fig. $\left.238, \mathrm{n}^{\circ} 2\right)$.

\footnotetext{
259 Modèle identique : Barbera, Petriaggi 1993, 174, $\mathrm{n}^{\circ}$ 132, $266, \mathrm{n}^{\circ} 227$.
}

\section{- Variante C : Croix pattées}

La croix pattée Barbera-Petriaggi 212, qui est surtout caractéristique du groupe $\mathrm{C} 5$, apparaît ici avec un décor de bandeau typique du groupe C4 (21).

- Variante D : Motifs géométriques

C'est également le décor du bandeau qui m'a incité à rattacher au groupe $\mathrm{C} 4$, de manière hypothétique, quelques lampes portant un décor géométrique tout à fait comparable à ceux du groupe C2 (22), par ailleurs attestées sur l'atelier de Sidi Marzouk Tounsi (23).

Exemples (fig. 215) :

A) Scènes bibliques ou chrétiennes

Nabuchodonosor et les trois Hébreux

*1-2 Carthage (Ennabli 1976, $\mathrm{n}^{\circ} 27$ et 28). D. $85 \mathrm{~mm}$; H. $35 \mathrm{~mm}$.

3 El Jem (Bailey 1988, Q1795). Moule en plâtre.

Les trois Hébreux dans la fournaise

*4 Carthage (Ennabli 1976, $\mathrm{n}^{\circ}$ 17). D. $79 \mathrm{~mm}$; H. $33 \mathrm{~mm}$.

5-11 Idem (Ibid., $\mathrm{n}^{\circ}$ 18-24). D. 78-81; H. 30-36 mm.

12-13 Carthage, British Museum (Bailey 1988, Q1796-1797). D. $78-81 \mathrm{~mm}$.

Jonas et la baleine

14 Rome (Atlante I, Pl. CLX, $\mathrm{n}^{\circ} 2 \mathrm{a}$ ).

*15 Rome (?) (Trost, Hellmann 1996, n 42). D. 83 mm ; H. $34 \mathrm{~mm}$.

16 British Museum (Bailey 1988, Q1798). D. $84 \mathrm{~mm}$.

B) Croix monogrammatique Croix type Barbera-Petriaggi 210A/2

17 Tharros (Bailey 1988, Q1764). Sur le bandeau: cercles E2, pampres, cratères. Sur le disque : croix monogrammatique.

Croix type Barbera-Petriaggi 210E non rétrograde

18 Carthage (Ennabli 1976, $\mathrm{n}^{\circ}$ 963). Sur le bandeau : rameaux S2, rosaces J2, fers de lance N1. D. $81 \mathrm{~mm}$; H. $33 \mathrm{~mm}$.

*19 Carthage (Bailey 1988, Q1765). Sur le bandeau: rosaces J1 et cordiformes M7 (?). D. $80 \mathrm{~mm}$.

20 Carthage (Chapman, Davies, Peacock 1984, Pl.2, $\mathrm{n}^{\circ} 6$ ). Surmoulage local (?).

C) Croix pattée type Barbera-Petriaggi 212

*21 Carthage (Hoff 1986, $\mathrm{n}^{\circ} 109$ ). Sur le bandeau : rosaces J1, cordiformes M9, rameau S2 $(9 \times 2$ motifs). Sur le disque: croix pattée à quatre médaillons à l'agneau. D. $80 \mathrm{~mm}$; H. $30 \mathrm{~mm}$.

D) Motifs géométriques

*22 Musée de Carthage (Ennabli 1976, $\left.{ }^{\circ} 1189\right)^{260}$. Sur le bandeau: rosaces $\mathrm{J} 2$ et cordiformes M9 $(8 \times 2$ motifs). Sur le disque: étoile à quatre branches inscrite dans un carreau sur la pointe cantonné de quatre demi-losanges à volutes R2. D. $83 \mathrm{~mm}$; H. $33 \mathrm{~mm}$.

23 Sidi Marzouk Tounsi, atelier (Peacock, Bejaoui, Ben Lazreg 1990, fig. 9, n). Décor identique au précédent.

\footnotetext{
260 Lampes identiques provenant de Carthage: Hoff 1986,
} n 125 ; Bailey 1988, Q1786. 


\section{Typologie - Lampes}

Type Atlante X A, groupe C5
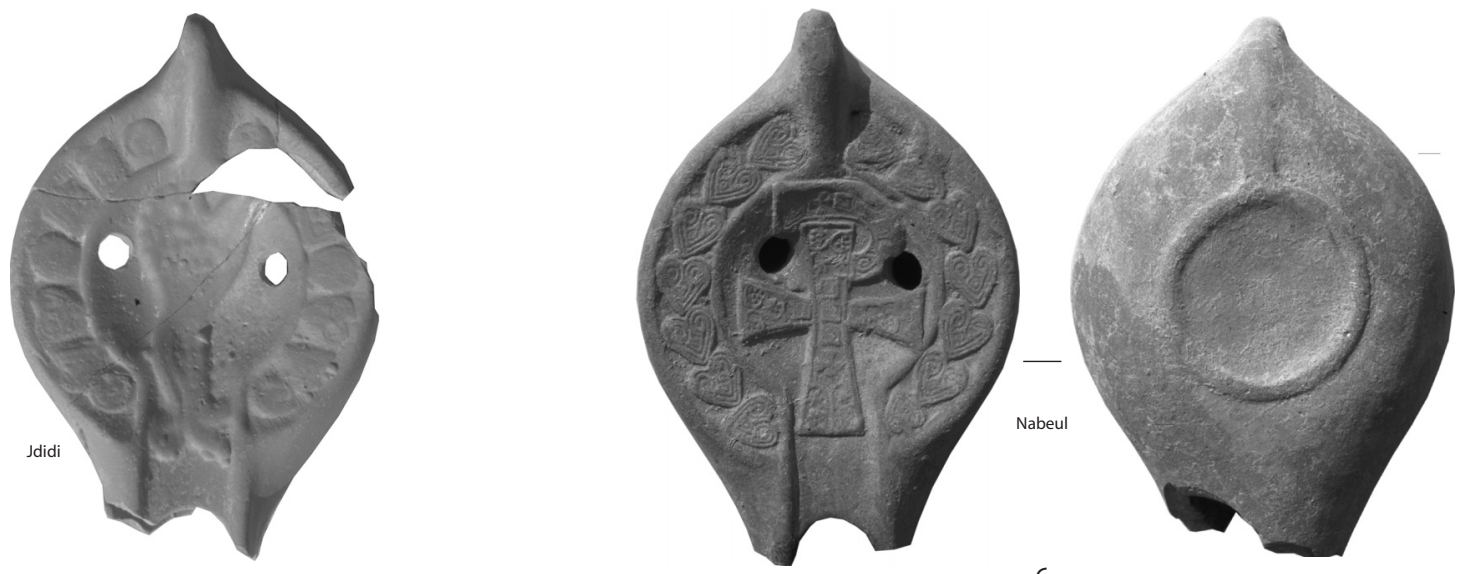

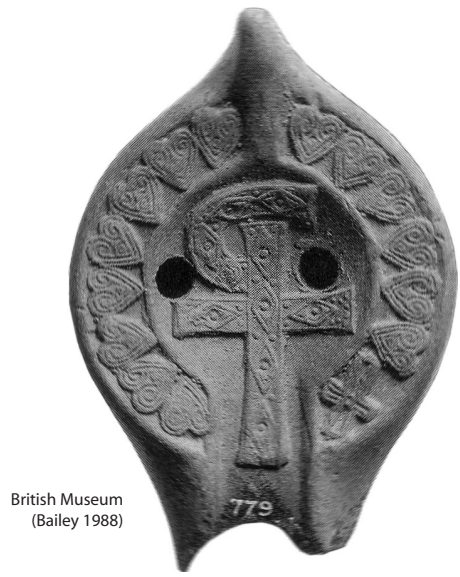

10

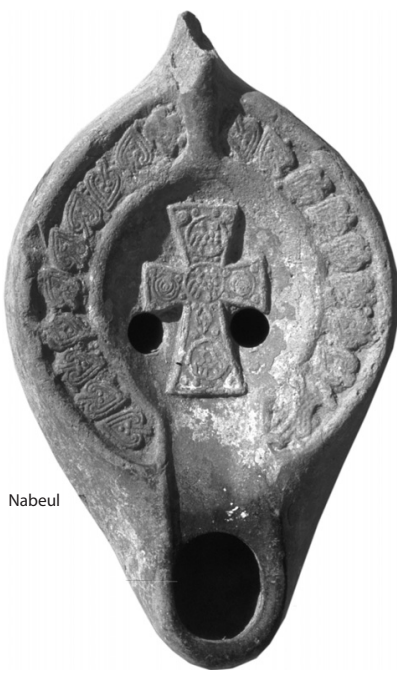

16

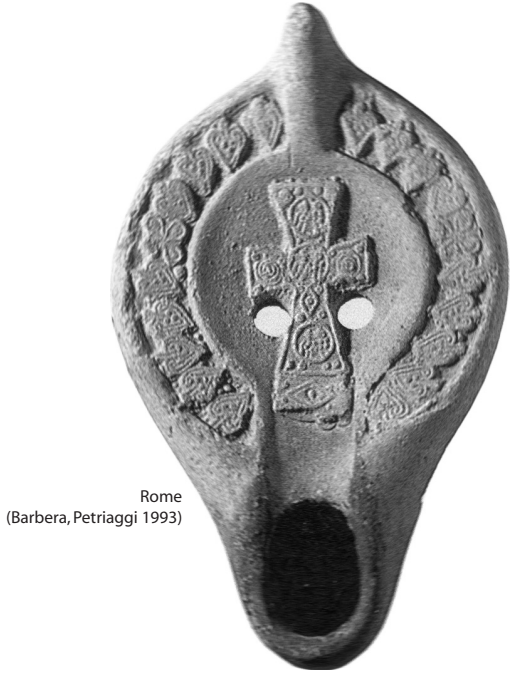

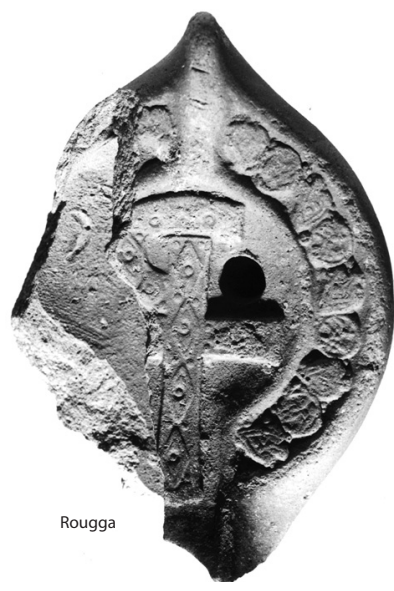

13
Ennable de Carthage

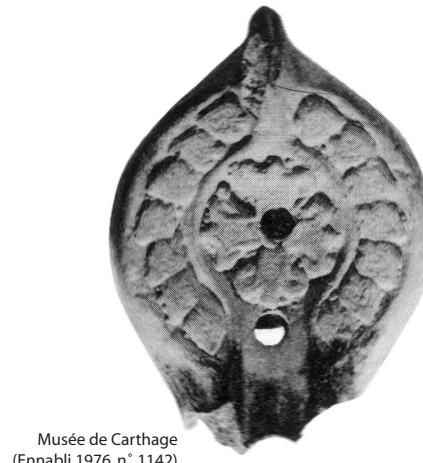

20

Fig. 216. Lampes en sigillée africaine (Tunisie centrale). 
Je ne possède pas de données autres que stylistiques pour situer chronologiquement ce groupe. Le $n^{\circ} \mathbf{2 0}$ dont l'origine centro-méridionale n'est toutefois pas assurée, est attribué au VIe s. (décennies centrales ?), date qui pourrait sans doute convenir à l'ensemble de ces lampes.

- type Atlante X A, groupe C5 (fig. 216)

\section{LAMPE TYPE 57}

La qualité des lampes du groupe C5 est extrêmement dégradée par rapport à celle des groupes C2-C3. La pâte orange clair est moins fine, l'engobe peu épais a parfois complètement disparu. Le décor du bandeau utilise presque exclusivement les motifs cordiformes M5 et surtout M7, généralement nombreux dans ce dernier cas $(10+10)$ et serrés les uns contre les autres. Le disque porte presque invariablement un décor cruciforme :

- Variante A : décor non cruciforme ;

- Variante B : croix monogrammatique BarberaPetriaggi $210 \mathrm{~A}$ et Barbera-Petriaggi $210 \mathrm{E}$ (rétrograde);

- Variante C : croix pattée de type Barbera-Petriaggi 212 ;

- Variante D : croix fleuronnée (petit format).

Exemples (fig. 216) :

A) Décors non cruciformes

*1 Sidi Jdidi, basilique 2 (Inv. 2152.3). Sur le bandeau : cordiformes Ennabli M7, carrés et cercles non identifiés. Sur le disque : lion courant, dans l'axe de la lampe. D. $78 \mathrm{~mm}$.

2 Marseille (Moliner 1998, fig. 225, $\mathrm{n}^{\circ}$ 11). Sur le bandeau : $10+10$ cordiformes M7. Sur le disque : décor identique au précédent. D. $75 \mathrm{~mm}$.

3 Vérone, Musée du Théâtre Romain (Graziani Abbiani 1969, $\mathrm{n}^{\circ}$ 558). Décor identique au $\mathrm{n}^{\circ}$ précédent. Sous le fond: croix en relief. D. $78 \mathrm{~mm}$; H. $33 \mathrm{~mm}$.

4 Musée de Sabratha (Joly 1974, n 1194). Sur le bandeau : $10+10$ cordiformes M7. Sur le disque : colombe dans l'axe de la lampe et cordiforme M5 (?). D. $78 \mathrm{~mm}$.

B) Croix monogrammatiques

Croix monogrammatique Barbera-Petriaggi 210A

5 Carthage (Ennabli 1976, $\mathrm{n}^{\circ}$ 955). Sur le bandeau : $6+$ 5 cordiformes M5 +1 cordiforme M7. D. $79 \mathrm{~mm} ; \mathrm{H}$. $37 \mathrm{~mm}$. Exemplaire précoce dans la série?

*6 Nabeul (sans $\mathrm{n}^{\circ} \mathrm{d}^{\prime}$ inv.). Sur le bandeau: $7+7$ cordiformes M5. D. $76 \mathrm{~mm}$.

7 Sabratha (Joly 1974, n 1079). Décor comparable au précédent. D. $80 \mathrm{~mm}$.

8 Bibliothèque Nationale de France (Trost, Hellmann 1996, $\left.\mathrm{n}^{\circ} 118\right)$. Sur le bandeau : $10+10$ cordiformes M7. Décor empâté. D. $83 \mathrm{~mm}$; H. $40 \mathrm{~mm}$.

9 Idem (Ibid., $\mathrm{n}^{\circ}$ 129). Sur le bandeau: $7+7$ cordiformes M5. Sur le disque : la boucle de la croix monogrammatique a été enlevée pour transformer cette dernière en simple croix pattée. D. $83 \mathrm{~mm}$; H. $36 \mathrm{~mm}$. Exemplaire tardif dans la série?
Croix monogrammatique de type Barbera-Petriaggi 210E (rétrograde)

Exemplaire précoce (?)

*10 British Museum (Bailey 1988, Q1771). Sur le bandeau : motifs cordiformes Ennabli M5. D. $79 \mathrm{~mm}$. Exemplaires évolués

*11 Calymna (Bailey 1988, Q1772). Sur le bandeau : $1+$ 1 canthares, $7+7$ motifs cordiformes Ennabli M7, 1 +1 cercles concentriques. D. $79 \mathrm{~mm}$.

12 Museo Nazionale Romano (Barbera, Petriaggi 1993, 204, $\mathrm{n}^{\circ}$ 164). Décor identique au $\mathrm{n}^{\circ}$ précédent. D. $82 \mathrm{~mm}$.

*13 Rougga, couche 10 (Guéry, Bonifay à paraître, $\mathrm{n}^{\circ} 368$ ). Décor comparable à celui du $\mathrm{n}^{\circ}$ précédent.

14 Sabratha (Joly 1974, $\mathrm{n}^{\circ}$ 1065). Décor comparable au précédent. D. $78 \mathrm{~mm}$.

15 Jlidia, vallée de Chaal (prospections géomorphologiques de M. N. Fehri, 2002).

C) Croix pattées

*16 Nabeul, quartier de la maison des Nymphes (fouilles L. Slim, Inv. NB3018.1). Sur le bandeau : motifs cordiformes Ennabli M7. D. $80 \mathrm{~mm}$.

17 Littoral tunisien, site $\mathrm{n}^{\circ} 78$ (La Louza) (Bonifay et al. 2002-2003, fig. $9, n^{\circ} 100$ ). Décor identique à celui du $\mathrm{n}^{\circ}$ précédent.

18 Littoral tunisien, site $\mathrm{n}^{\circ} 85$ (Jezira) (Bonifay et al. 2002-2003, fig. $18, \mathrm{n}^{\circ} 256$ ). Décor identique à celui du $\mathrm{n}^{\circ}$ précédent (?)

*19 Rome, Museo Nazionale Romano (Barbera, Petriaggi 1993, 176-177, $\mathrm{n}^{\circ} 135$ ). Sur le bandeau: motifs cordiformes M7. D. $81 \mathrm{~mm}$.

D) Croix fleuronnées (petit format)

*20 Musée de Carthage (Ennabli 1976, $\mathrm{n}^{\circ}$ 1142). Sur le bandeau : $7+7$ cordiformes M7 « entassés ». Sur le disque : «croix fleuronnée percée en son centre par l'orifice d'alimentation ». D. $66 \mathrm{~mm}$; H. $31 \mathrm{~mm}$.

21 Carthage (Trost, Hellmann 1996, $\mathrm{n}^{\circ} 134$ ). Décor identique au $\mathrm{n}^{\circ}$ précédent. D. $65 \mathrm{~mm}$; H. $30 \mathrm{~mm}$.

22 Marseille, chantier de La Bourse (Bonifay 1983, fig. 32, $\left.\mathrm{n}^{\circ} 208\right)$. Décor identique aux $\mathrm{n}^{\circ}$ précédents.

23 Rome (Barbera, Petriaggi 1993, 174, n 131). D. $61 \mathrm{~mm}$.

Variantes indéterminées

24 Marseille, chantier de La Bourse (Bonifay 1983, fig. $\left.32, n^{\circ} 210\right)$.

L'examen des lampes du groupe C5 découvertes dans la partie centro-méridionale du littoral $(15,17,18)$ et à Rougga (13), alors qu'elles sont plutôt rares à Carthage, montre que la production des lampes de Byzacène ne se limite pas au Ves. et au début du VIe siècle. Bien au contraire, cette production est encore vivace aux VIeVIIe $\mathrm{s}$. avec des types à peine modifiés par rapport aux modèles classiques. Les premiers exemplaires ne semblent pas antérieurs au milieu du VIe s. (24) mais les attestations les plus nombreuses couvrent la fin du VIe s. et le VIIe s. $(\mathbf{1 - 2}, \mathbf{1 3}, \mathbf{1 8})$. 


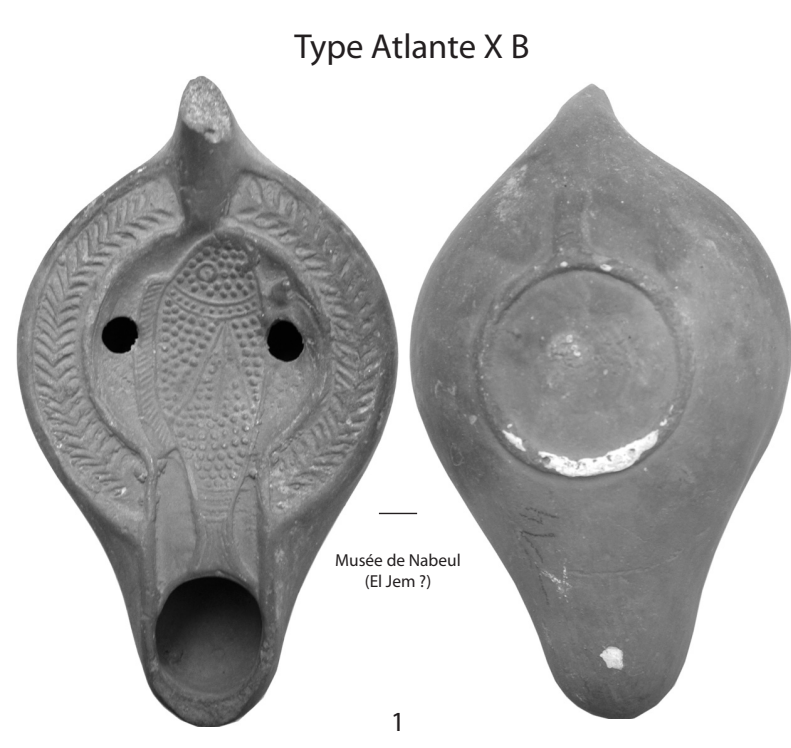

LAMPE

TYPE 58

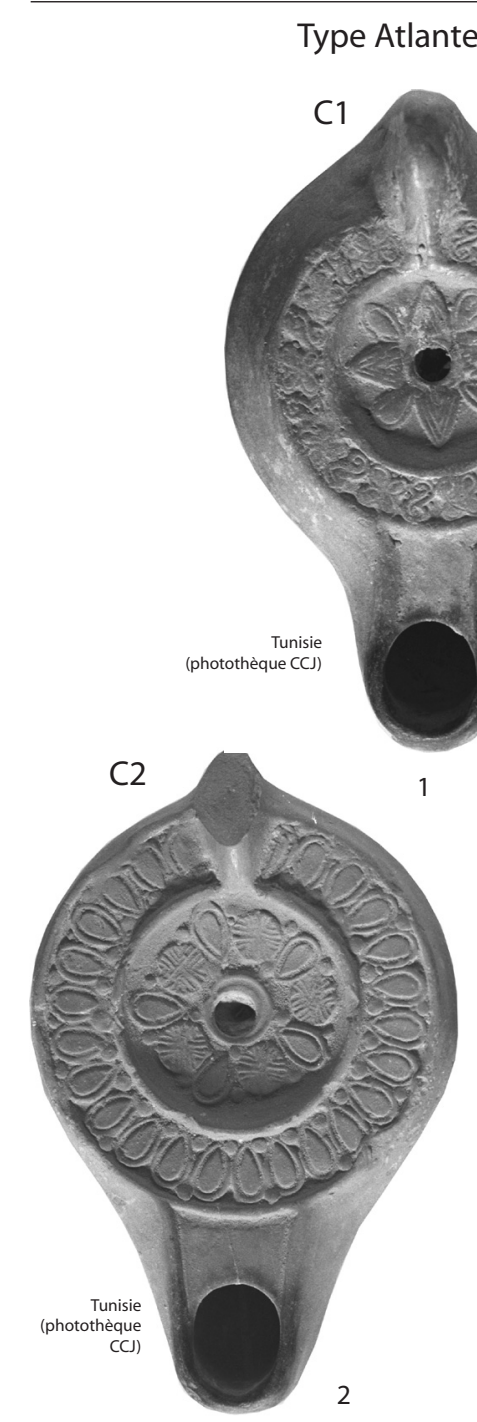

LAMPE

TYPE 59

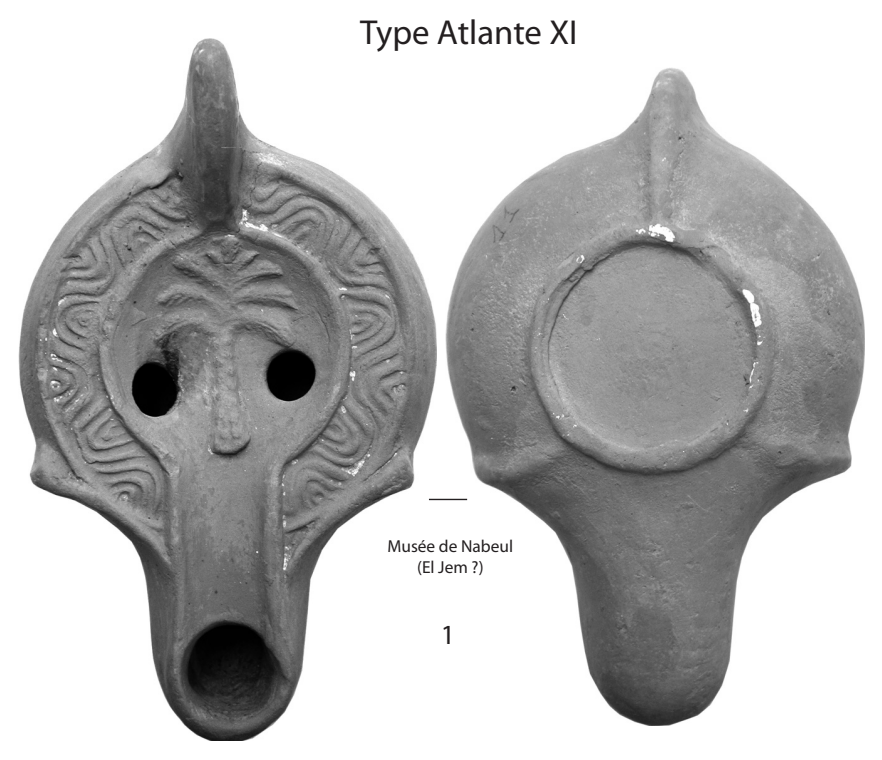

Type Atlante XI
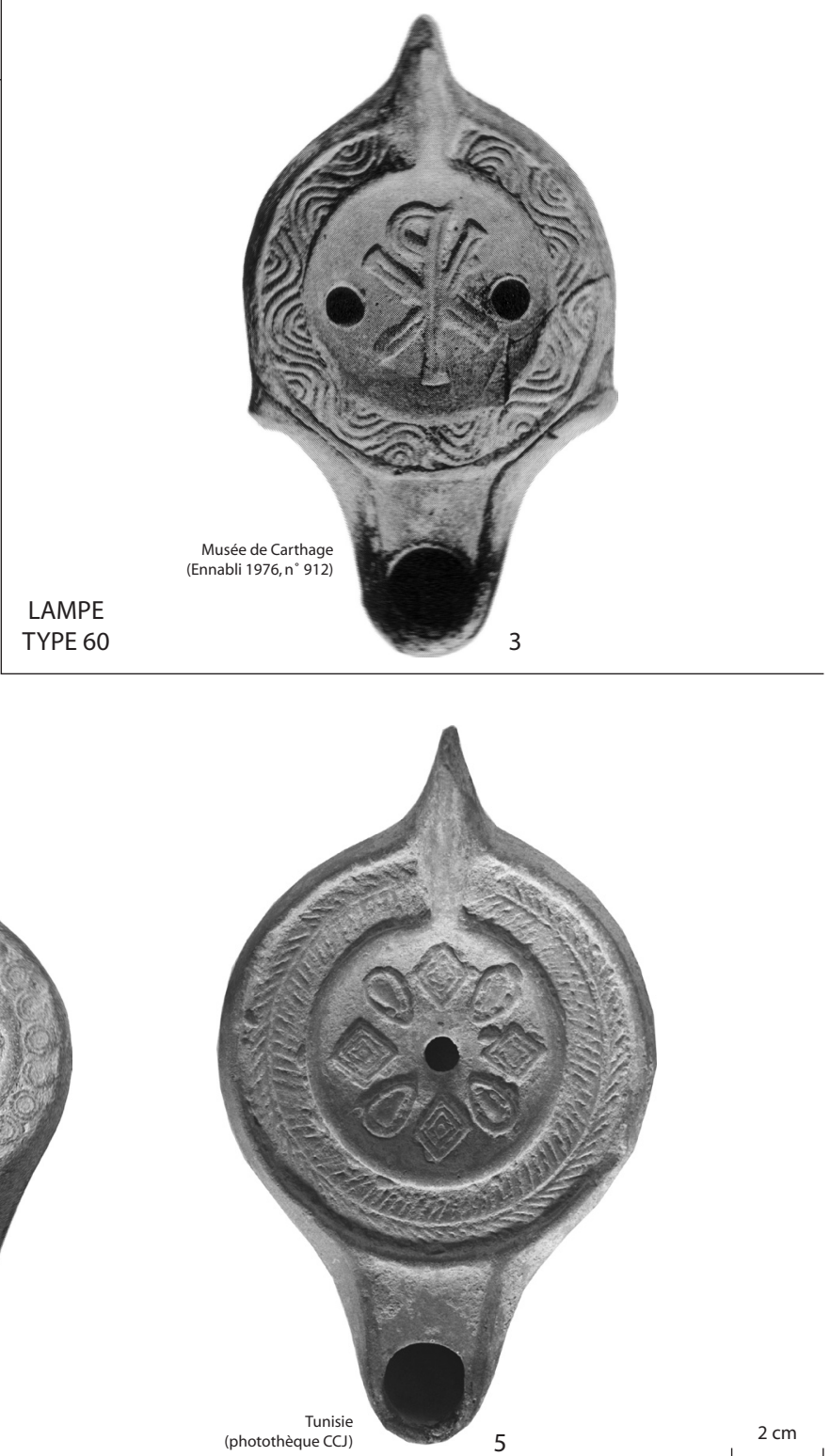

$2 \mathrm{~cm}$

Fig. 217. Lampes en sigillée africaine (Tunisie centrale). 


\section{- type Atlante X B (bandeau décoré d'une palme)} (fig. 217)

\section{LAMPE TYPE 58}

Ces lampes sont caractérisées par un bandeau portant un décor de palmes incisées. Beaucoup d'exemplaires initialement classés dans cette forme (Atlante I, 203 : Ennabli 1976, $\left.\mathrm{n}^{\circ} 513,630,778,786,923\right)^{261}$ me paraissent en fait ressortir de variantes intermédiaires entre les formes VIII C1 et X (infra, LAMPE TYPE 61) ; ils sont très probablement fabriqués en Tunisie septentrionale, de même, peut-être, que la variante Atlante X B au disque décoré d'une rosace (Ennabli $\left.1976, \mathrm{n}^{\circ} 1226,1230,1240,1243\right)$. Finalement, les lampes Atlante X B sûrement produites en Tunisie centrale (4) semblent se réduire à un modèle principal, de très belle qualité, décoré sur le disque d'un grand poisson disposé dans le sens bec-anse. On ne dispose d'aucune donnée stratigraphique pour dater cette lampe qui se rattache toutefois au groupe $\mathrm{C} 2$ de la seconde moitié du Ve s. et du début du VIe siècle.

Exemples (fig. 217) :

*1 Musée de Nabeul, provenant d'El Jem (?) (Inv. L15). D. $78 \mathrm{~mm}$; H. $35 \mathrm{~mm}$.

2 Musée de Carthage (Ennabli 1976, n 744). D. $80 \mathrm{~mm}$; H. $31 \mathrm{~mm}$.

3 Sbeitla (Ibid., n $\left.{ }^{\circ} 745\right)$. D. $83 \mathrm{~mm}$; H. $32 \mathrm{~mm}$.

4 Sidi Marzouk Tounsi, atelier (Peacock, Bejaoui, Ben Lazreg 1990, fig. 9, a). Moule en plâtre. Décor identique aux $n^{\circ}$ précédents.

5 Musée d'Alexandrie (en exposition).

D'autres lampes de type Atlante X B produites en Tunisie centrale, mais dont l'ensemble du décor linéaire est directement incisé dans le moule, se rattachent aux productions byzantines tardives (infra, LAMPE TYPE 70C).

\section{- type Atlante X D (fig. 217)}

\section{LAMPE TYPE 59}

Les lampes de type X D, à canal fermé, représentent une faible part du total des lampes Atlante X (Atlante I, 203 : seulement dix exemplaires recensés). Celles produites en Tunisie centrale se rattachent parfaitement aux groupes $\mathrm{C} 1, \mathrm{C} 2$ et $\mathrm{C} 3$, dont elles constituent une simple variante. Exemples (fig. 217):

Groupe C1

*1 Tunisie (photothèque CCCJ, négatif $\mathrm{n}^{\circ}$ 74229). $86 \mathrm{~mm}$.

Groupe $\mathrm{C} 2$

*2 Tunisie (photothèque CCCJ, négatif $n^{\circ} 74314$ ). D. $87 \mathrm{~mm}$.

Groupe C3

*3 Rome (Barbera, Petriaggi 1993, 293, n² 253) ${ }^{262}$. Sur le disque : 19 cercles E6 (?). Sur le disque, décor géométrique: carré sur la pointe, cantonné de chevrons D10. D. $64 \mathrm{~mm}$.

4 Museo Nazionale Romano (Ibid., 291, n 251). Sur le

\footnotetext{
${ }^{261}$ En outre, le bandeau du $n^{\circ} 865$ est décoré de chevrons D10.

${ }^{262}$ Décors identiques: Barbera, Petriaggi 1993, 294, $\mathrm{n}^{\circ} 254$; Atlante I, Pl. CLXI, ${ }^{\circ} 1$, provenant d'Ostie.
}

bandeau : palmettes $\mathrm{P} 3$, oves L4, losanges à volutes R2 (12 motifs). Sur le disque : Iota (cf. groupe C3, $\left.\mathrm{n}^{\circ} 28\right)$. D. $64 \mathrm{~mm}$.

Variante Atlante X B/D

*5 Tunisie (photothèque CCCJ, négatif $\mathrm{n}^{\circ}$ 74216). D. $95 \mathrm{~mm}$.

- type Atlante XI (fig. 217)

\section{LAMPE TYPE 60}

Les lampes de type Atlante XI, ne constituent qu'une simple variante du type $\mathrm{X}$ dont elles se distinguent seulement par deux protubérances de part et d'autre du bec, peut-être des vestiges de volutes comme sur le type Atlante IX. Ce type est mal documenté (Atlante I, 203 : seulement une vingtaine d'exemplaires). Ces lampes, dont on connaît une variante à canal ouvert (A) et une autre à canal fermé (B) (Atlante I, 203), se rattachent aisément aux groupes $\mathrm{C} 1$ et $\mathrm{C} 2$; il n'y a apparemment pas d'exemplaires de petite taille du groupe C3.

Exemples (fig. 217) :

Apparentés au groupe $\mathrm{C} 1$ Variante A

*1 Musée de Nabeul, provenant d'El Jem (?) (Inv. NBM.L14). Sur le bandeau: sinusoïdes. Sur le disque : palmier. D. $85 \mathrm{~mm}$; H. $41 \mathrm{~mm}$.

2 Coll. privée (Herrmann, van den Hoek 2002, $n^{\circ} 47$ ). Décor du bandeau comparable au ${ }^{\circ}$ précédent. Sur le disque : personnage tenant une couronne. D. $75 \mathrm{~mm}$. Variante B

*3 Musée de Carthage (Ennabli 1976, n 912). Sur le bandeau : décor comparable aux $n^{\circ}$ précédents. Sur le disque : chrisme nervuré. D. $80 \mathrm{~mm}$; H. $39 \mathrm{~mm}$.

4 Idem (Ibid., $\mathrm{n}^{\circ}$ 1256). Décor du bandeau identique aux $\mathrm{n}^{\circ}$ précédents. Sur le disque: tombeau de Lazare (?) (Bejaoui 1997, fig. 41b). D. $87 \mathrm{~mm}$; H. $37 \mathrm{~mm}$.

Groupe C2

5 Museo Nazionale Romano (Barbera, Petriaggi 1993, 298, $\mathrm{n}^{\circ} 256$ ). Sur le bandeau : chevrons D2 emboîtés (évoquant un peu le schéma décoratif des $\mathrm{n}^{\circ} 1-4$ ). Sur le disque : décor géométrique de carrés. D. $86 \mathrm{~mm}$. Variante A.

\section{— productions de Tunisie septentrionale}

Il est clair que la production des lampes Atlante X débute en Tunisie septentrionale alors qu'elle est déjà établie depuis plusieurs années (ou décennies) en Tunisie centrale. Ainsi, les premiers exemplaires sont soit des lampes hybrides, intermédiaires avec les types Atlante VIII C1 et D caractéristiques de Tunisie septentrionale (TYPES 61-62-63), soit des imitations serviles des types Atlante X de Byzacène (TYPES 64-65). Dans un second temps, les lampes Atlante X du nord de la Tunisie vont développer des styles particuliers, clairement dissociables des productions du centre du pays (TYPE 66). Au sein de ces objets, j'ai tenté de départager les productions des deux grands ateliers connus en Zeugitane : Oudhna et El Mahrine. Cette démarche peut paraître réductrice, tout autant que téméraire, dans la mesure où ces deux ateliers n'épuisent pas toutes les variétés de productions de 
sigillée africaine de Tunisie septentrionale (Mackensen 1998a). Bien d'autres ateliers ont dû exister, qui n'ont pas encore été archéologiquement reconnus; on remarque toutefois que l'atelier de Sidi Khalifa ne semble pas, dans l'état actuel de nos connaissances, avoir produit de lampes en sigillée ${ }^{263}$. Parallèlement, d'autres groupes apparaissent clairement au sein du matériel de Carthage dont l'origine n'a pu être localisée ${ }^{264}$.

\section{- lampes hybrides Atlante VIII/X}

\section{- type Atlante VIII (C1)/X (fig. 218)}

\section{LAMPE TYPE 61}

Je propose de classer parmi les lampes hybrides de type Atlante VIII/X un certain nombre d'exemplaires de forme ovoïde, caractérisés par un bandeau plat décoré de palmes ou d'incisions obliques ${ }^{265}$ comme sur le type Atlante VIII $\mathrm{C} 1$, et associés à une anse et un fond de type Atlante X. Toutefois, l'hypothèse de l'origine nord-tunisienne de ces objets est extrêmement fragile. Elle pourrait, en effet, être contredite par le lieu d'acquisition du $n^{\circ} \mathbf{3}$ et par le décor du disque des $n^{\circ} \mathbf{1}$ et $\mathbf{2}$, qui paraît inspiré du décor végétal de certaines lampes Atlante $\mathrm{X}$ précoces de Tunisie centrale (Ennabli 1976, $\mathrm{n}^{\circ}$ 782). De même, la description de la pâte des exemplaires de Carthage évoque plutôt la production de sigillée africaine $\mathrm{C}$. Exemples (fig. 218) :

*1 Musée de Carthage (Ennabli 1976, n 778). Sur le bandeau: palmes. Sur le disque: palmier (?). D. $75 \mathrm{~mm}$; H. $36 \mathrm{~mm}$.

*2 Idem (Ibid., $\mathrm{n}^{\circ} 779$ ). Sur le disque : palmier (?). D. $86 \mathrm{~mm}$; H. $30 \mathrm{~mm}$.

*3 El Jem (Bailey 1988, Q1752). D. $82 \mathrm{~mm}$.

Aucune donnée stratigraphique.

Datation proposée: deuxième quart ou milieu du Ve s. (?).

\section{- type Atlante VIII (D)/X (fig. 218)}

\section{LAMPE TYPE 62}

Les lampes qui ont été regroupées ici ont toutes les caractéristiques décoratives des types Atlante VIII D1-3 de Tunisie septentrionale. En revanche, leur forme générale et certains détails (anse, fond) les rattachent au type Atlante X.

Exemples (fig. 218) :

Variante VIII D1/X

*1 Carthage (Chapman, Davies, Peacock 1984, Pl. 4, $\left.\mathrm{n}^{\circ} 10\right)$.

Variante VIII D2/X

2 Carthage (Riley 1981, Pl. 3, n²3).

${ }^{263} \mathrm{La}$ rareté des lampes en sigillée sur le site de Sidi Jdidi (Bonifay, Reynaud 2004) pourrait être un argument en faveur de cette hypothèse.

${ }^{264}$ Il en est de même de certaines lampes de la collection africaine du musée de Faverges (Chrzanovski et al. 1998-99, notamment $\left.\mathrm{n}^{\circ} 18,20,22\right)$.

${ }^{265}$ Caractère qui les a fait parfois rattacher au type Atlante X B (Atlante I, 203).
*3 Idem (Ibid., P1. 1, n 14).

Variante VIII D3/X

4 Carthage (Chapman, Davies, Peacock 1984, Pl. 4, $\left.n^{\circ} 13\right)$.

*5 Carthage (Ennabli 1976, $\mathrm{n}^{\circ}$ 1247).

6 Fos (Rivet 2003, n ${ }^{\circ} 558$ ).

La datation de ces lampes (1-4) recoupe celle des types Atlante VIII D : seconde moitié du Ve s. (supra, LAMPE TYPE 50).

\section{- type Atlante X précoce (fig. 218)}

\section{LAMPE TYPE 63}

Lampes ovoïdes avec un bandeau plat décoré de très gros motifs en fort relief, assez maladroitement exécutés, bien attestées à Carthage.

Exemples (fig. 218):

*1 Musée de Carthage (Ennabli 1976, n 781). Sur le bandeau: triangles striés disposés pointe vers le centre de la lampe. Sur le disque: arbre stylisé comme sur les lampes Atlante VIII C1/X. Deux points et un double galon au départ du bec. D. $73 \mathrm{~mm}$; H. $40 \mathrm{~mm}$.

*2 Idem (Ibid., $\mathrm{n}^{\circ} 760$ ). Sur le bandeau : $5+5$ cercles concentriques en fort relief. Sur le disque: deux poissons sous deux arcs. Deux points et un double galon au départ du bec. D. $75 \mathrm{~mm}$; H. $40 \mathrm{~mm}$.

3 Carthage (Riley 1981, Pl. 1, n 16, deposit XXVII). Sur le bandeau : alternance de triangles comme ceux du $\mathrm{n}^{\circ} 1$ et de cercles comme ceux du $\mathrm{n}^{\circ} 2$. Sur le disque : architecture comme sur le $n^{\circ} 2$. Deux points au départ du bec. D. $74 \mathrm{~mm}$.

Le $\mathrm{n}^{\circ} 3$ provient d'un contexte de la seconde moitié du Ve s., comme les lampes précédentes.

- lampes Atlante X, groupe D1 (fig. 219-220)

$=$ forme Chapman-Davies-Peacock $1 \mathrm{~B}$

\section{LAMPE TYPE 64}

Ce groupe a été nommé " rosette and geometric " par S. V. Chapman, S. M. Davies et D. P. S. Peacock (1984, 234), en raison du décor du bandeau, composé essentiellement de rosettes G2 et de carrés A12, associés de manière plus accessoire à des cercles et à quelques cordiformes et chevrons. Par l'observation d'une connexion décorative entre les croix figurant sur le disque des $n^{\circ} 1138$ (16) et 1140 (3) du catalogue d'A. Ennabli, je pense qu'il est possible de rattacher à ce groupe une série de lampes dont le bandeau est décoré exclusivement d'oiseaux U8. En fonction de la forme et du décor de ces lampes, on peut distinguer trois variantes :

- Variante A : lampe au réservoir ovoïde avec un bec très allongé élargi à son extrémité ; disque ovalisé, parfois limité par un galon incisé; deux points en creux au départ du bec, à l'extérieur du bandeau. Cette variante est très proche des lampes hybrides de TYPE 63.

- Variante B : forme Atlante X classique ; bandeaux décoré de cinq ou six motifs (principalement rosettes G2 et carrés A12), parfois cantonnés de deux cercles E6 aux extrémités. Bustes fréquents sur le disque (4- 


\section{Typologie - Lampes}

Type Atlante VIII C1 / X
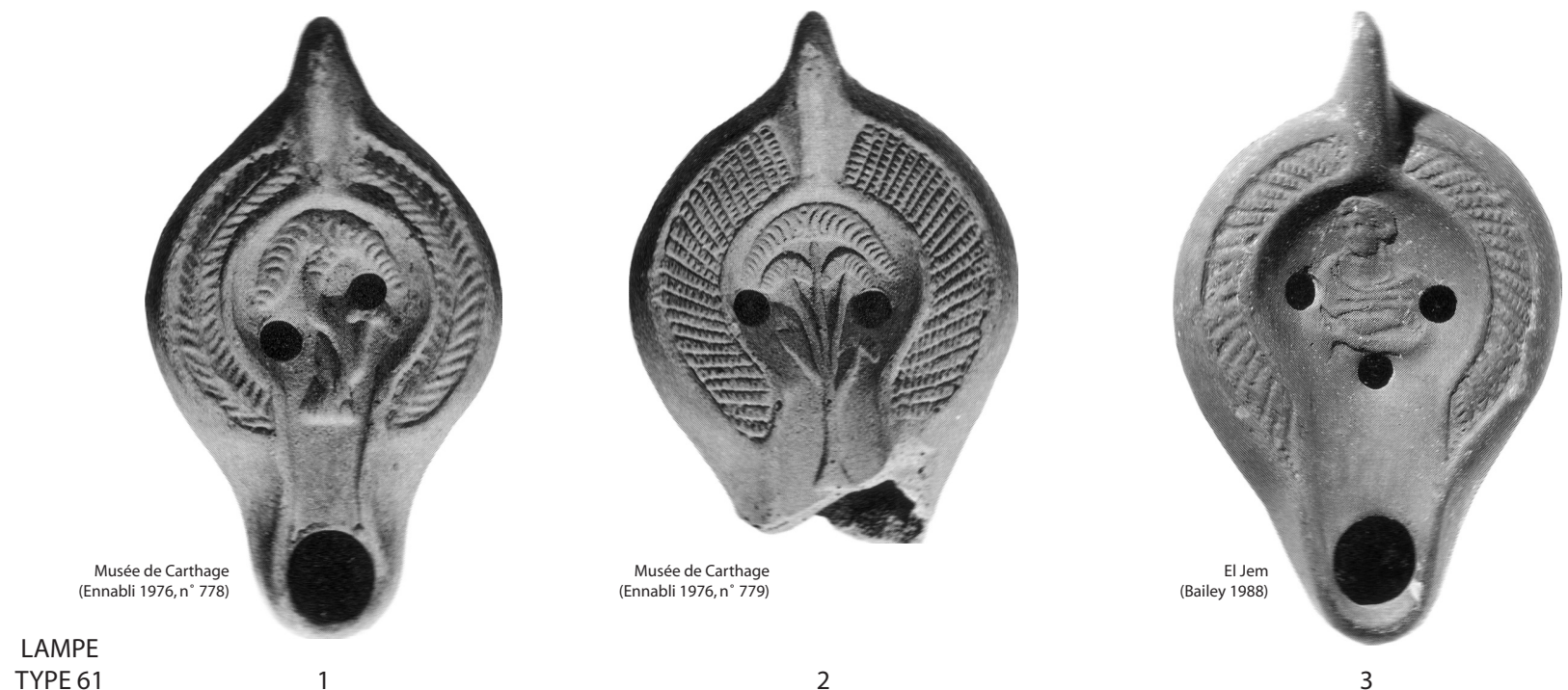

TYPE 61

2

3

Type Atlante VIII D / X
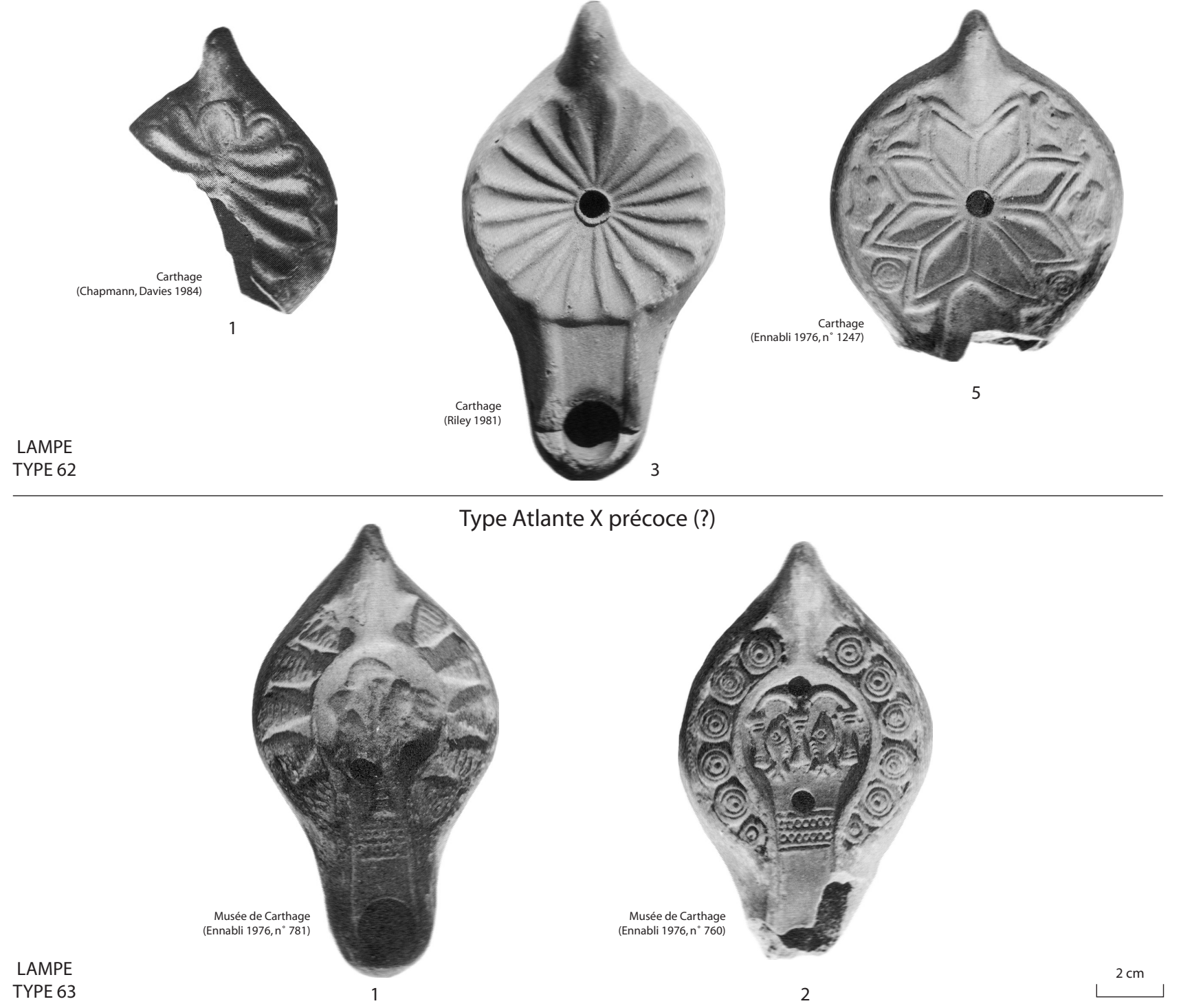

Fig. 218. Lampes en sigillée africaine (Tunisie septentrionale ?). 
Type Atlante X, groupe D1
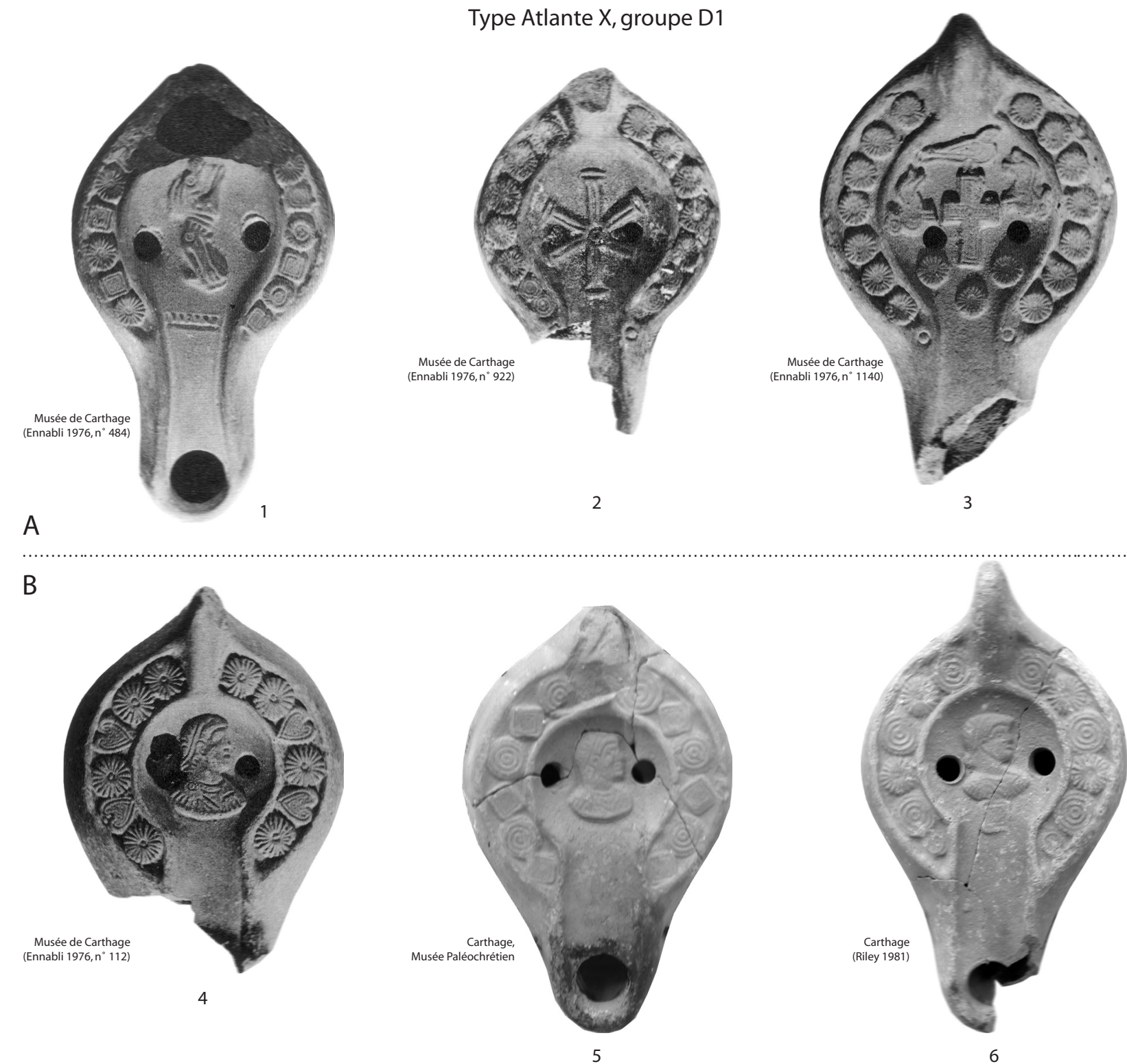

3
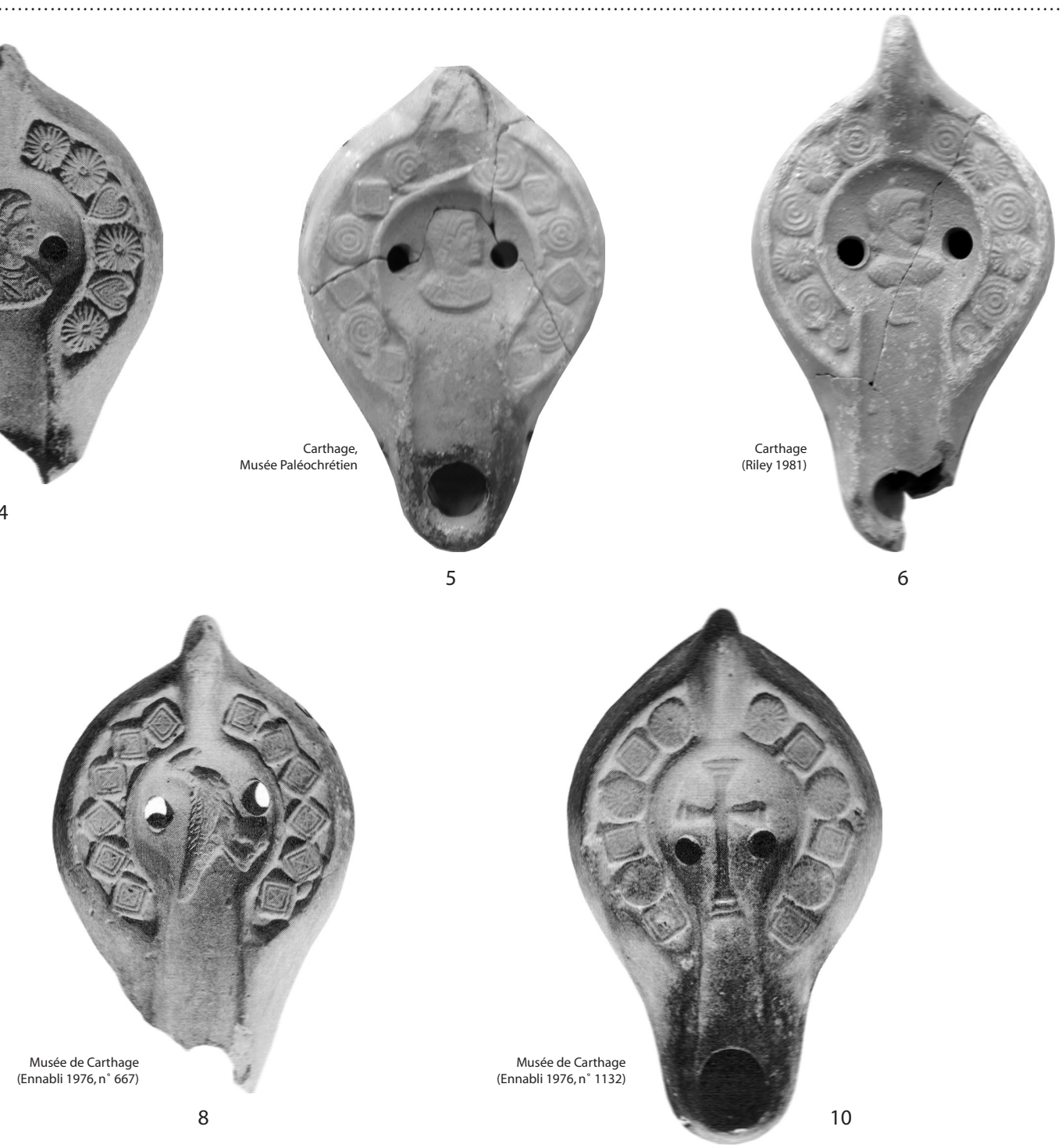

Lwere

TYPE 64

Fig. 219. Lampes en sigillée africaine (Tunisie septentrionale ?). 
Type Atlante X, groupe D1

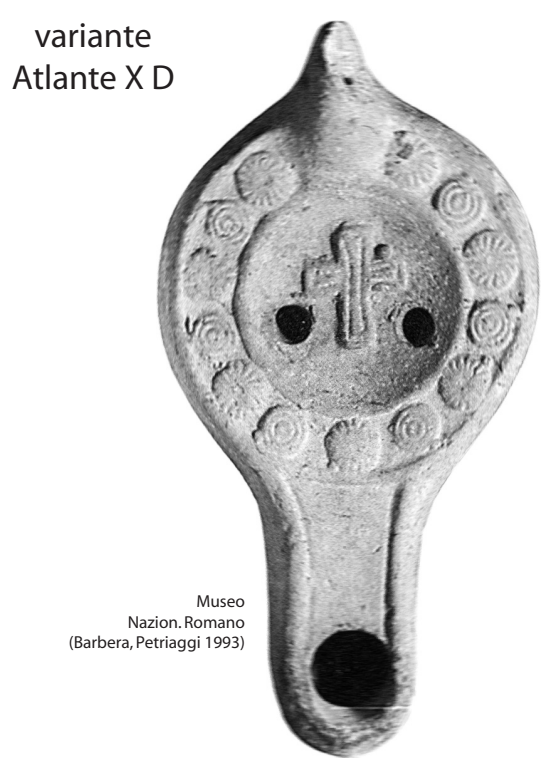

11

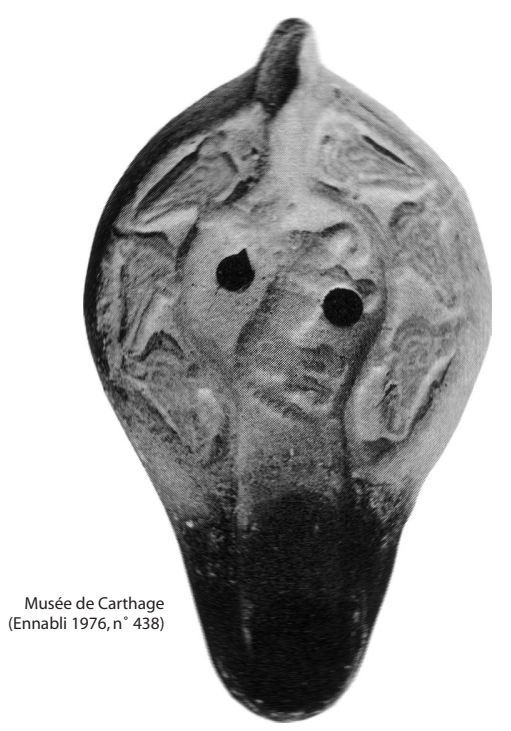

13

\section{C}

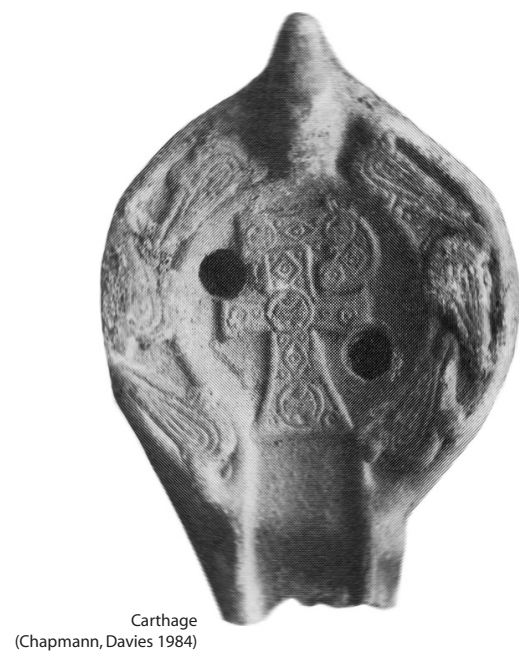

15

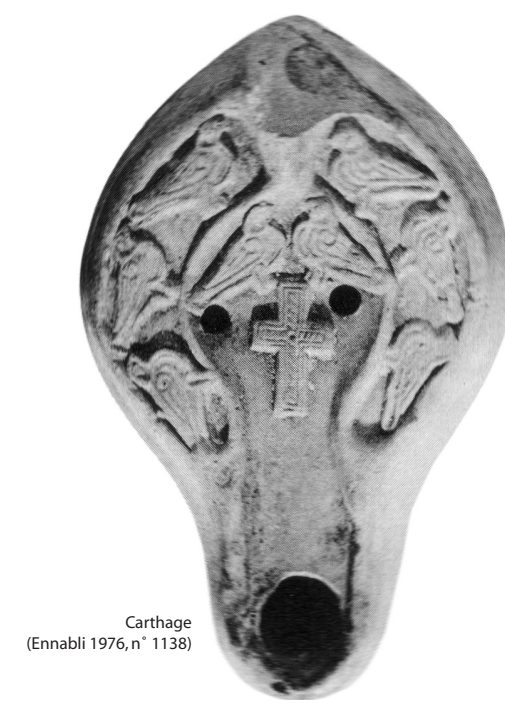

16

Fig. 220. Lampes en sigillée africaine (Tunise septentrionale ?). 
6). Cette variante compte également des exemplaires de la forme Atlante X D, avec un bec très allongé (11).

- Variante C : forme Atlante X, assez allongée. Décor du bandeau principalement constitué d'oiseaux U8.

Nota: les deux points qui cantonnent le bandeau au départ du bec (variantes A et B) s'observent également sur une lampe du type Atlante VIIIAla-b (supra, LAMPE TYPE $45, \mathrm{n}^{\circ}$ 2) dont le disque est décoré d'un buste féminin. Il y a peut-être là un argument en faveur d'une origine commune (même zone d'ateliers ?).

Exemples (fig. 219-220) :

Variante A (fig. 219)

*1 Musée de Carthage (Ennabli 1976, n 484). Sur le bandeau : rosettes G2 et carrés A12 ( 7 × 2 motifs ?). Sur le disque : chien courant, dans l'axe de la lampe. D. $78 \mathrm{~mm}$; H. $32 \mathrm{~mm}$.

*2 Idem (Ibid., $\mathrm{n}^{\circ}$ 922). Sur le bandeau : rosettes G2 et cercles E6 (7 x 2 motifs) ; deux points au départ du bec. Sur le disque : chrisme sans boucle. D. $73 \mathrm{~mm}$; H. $39 \mathrm{~mm}$.

*3 Idem (Ibid., $\mathrm{n}^{\circ}$ 1140). Sur le bandeau : $7+7$ rosettes G2. deux points au départ du bec. Sur le disque : croix cantonnée d'un oiseau U8 et de deux moutons W6. D. $88 \mathrm{~mm}$.

Variante B (fig. 219)

Style « Rosettes and Geometric » classique

*4 Musée de Carthage (Ennabli 1976, n 112). Sur le bandeau : rosettes $\mathrm{G} 2$ et cordiformes (6 x 2 motifs). Sur le disque : buste à droite. D. $83 \mathrm{~mm}$; H. $37 \mathrm{~mm}$.

*5 Carthage, Musée Paléochrétien (en exposition). Sur le bandeau: cercles E2 (?) et carrés A12 (6 x 2 motifs). Sur le disque : buste identique au précédent.

*6 Carthage (Riley 1981, Pl. 2, n 17, deposit XXVII). Sur le bandeau : rosettes G2 et cercles proches de E2 ( 5 x 2 motifs). Sur le disque : buste à droite sur un support carré. D. $79 \mathrm{~mm}$.

7 Carthage (Riley 1981, Pl. 2, n 18 , deposit XXVII). Sur le bandeau : cercles proches de E2 et carrés A12 sur la pointe (6 $\mathrm{x} 2$ motifs). Sur le disque : colombe à gauche. D. $72 \mathrm{~mm}$.

*8 Musée de Carthage (Ennabli 1976, n 667). Sur le bandeau: $6+6$ carrés A12 sur la pointe. Sur le disque : colombe dans l'axe de la lampe. D. $79 \mathrm{~mm}$.

9 Carthage (Chapman, Davies, Peacock 1984, $\mathrm{n}^{\circ} 19$ ). Sur le bandeau : carrés A12 et rosettes G2 $(6 \times 2$ motifs). Sur le disque : chrisme.

*10 Musée de Carthage (Ennabli 1976, $\mathrm{n}^{\circ}$ 1132). $3+3$ rosettes G2 et $3+3$ carrés A12 alternés. Sur le disque : croix pattée. D. $82 \mathrm{~mm}$.

Variante Atlante X D (fig. 220)

*11 Museo Nazionale Romano (Barbera, Petriaggi 1993, 290, $\mathrm{n}^{\circ} 250$ ). Sur le bandeau: 7 rosettes $\mathrm{G} 2+6$ cercles E6. Sur le disque : croix. Bec très allongé comme sur la variante A. D. $78 \mathrm{~mm}$.

12 Carthage (Chapman, Davies, Peacock 1984, n 16). Sur le bandeau : carrés A12 et rosettes G2. Sur le disque : chien comme sur le $\mathrm{n}^{\circ} 1$.

Variante C (fig. 220)

*13 Musée de Carthage (Ennabli 1976, n 438). Sur le disque : cheval, dans l'axe de la lampe. D. $83 \mathrm{~mm}$; H. $38 \mathrm{~mm}$.

*14 Carthage (Ennabli 1976, $\mathrm{n}^{\circ}$ 918). Sur le disque : chrisme sans boucle. Deux points au départ du bec.
D. $81 \mathrm{~mm}$; H. $35 \mathrm{~mm}$.

*15 Carthage (Chapman, Davies, Peacock 1984, Pl. 2, $\left.\mathrm{n}^{\circ} 17\right)$. Sur le disque: croix monogrammatique gemmée et pattée.

*16 Carthage (Ennabli 1976, $\mathrm{n}^{\circ}$ 1138). Sur le disque : croix surmontée de deux oiseaux. Un point au départ du bec. D. $88 \mathrm{~mm}$; H. $36 \mathrm{~mm}$.

Les arguments permettant d'attribuer ce groupe aux productions de Tunisie septentrionale sont certes peu nombreux. La description de la pâte de certains exemplaires $(4,8)$ renverrait plutôt à la production de sigillée africaine C. Le style des poinçons est directement issu du répertoire de Tunisie centrale mais leur disposition est anormalement sobre ; les exemplaires les plus tardifs ont par ailleurs des connexions décoratives avec le groupe D3 (colombes U8 de la variante C, croix monogrammatique du $\mathrm{n}^{\circ} \mathbf{1 5}$ ). La forme de la variante A semble bien issue du type Atlante VIII D (voir par exemple Ennabli 1976, n 483). L'ensemble du groupe est bien attesté à Carthage alors qu'un seul exemplaire apparaît à Mactar (Bourgeois 1977-78, Pl. XI, n 49 ?).

La série principale de lampes Atlante X du groupe D1 est bien située en stratigraphie : à Carthage, le style « Rosette and Geometric » apparaît régulièrement dans les contextes de la seconde moitié du Ve s. et du début du VIe s. (6-7). Du point de vue stylistique, les exemplaires de la variante A paraissent plus précoces (milieu ou troisième quart du Ve $\mathrm{s}$. ?). Enfin, on ne dispose d'aucune donnée pour les bandeaux à décor d'oiseaux qui peuvent peut-être se placer plus avant dans le VIe siècle (15). Datation proposée :

Variante A - décennies centrales du Ve s. (?)

Variante B - seconde moitié du Ve s.

- lampes Atlante X, groupe D2 (fig. 221-223)

= formes Chapman-Davies-Peacock 1 F-J

\section{LAMPE TYPE 65}

Il semble qu'une partie des productions du nord de la Tunisie consiste purement et simplement dans le surmoulage ou la copie de modèles de Tunisie centrale. On reconnaît un certain nombre de ces lampes dans le catalogue d'A. Ennabli en fonction des descriptions d'argile et du rendu empâté des décors. Quelques-unes apparaissent également en plusieurs exemplaires au sein du matériel recueilli par P. Gauckler dans le dégagement des thermes des Laberii à Oudhna, ce qui peut donner une indication sur leur lieu de production.

On peut distinguer deux variantes au sein de ce groupe : - Variante A : copies de lampes du groupe C2 (motifs du bandeau de grande taille: carrés A5-6, A9-10, chevrons D2, disque F5, cordiformes M6, etc., régulièrement disposés) et du groupe $\mathrm{C} 4$ (motifs du bandeau de plus petite taille: quadrifoliés I4-5, rosettes $\mathrm{J} 1$, fers de lance $\mathrm{N} 1$, losanges à volutes $\mathrm{R} 2$, rameaux $\mathrm{S} 1$, moins soignés). Le décor du disque copie également les thèmes en faveur sur les lampes 
Type Atlante X, groupe D2 variante $A$

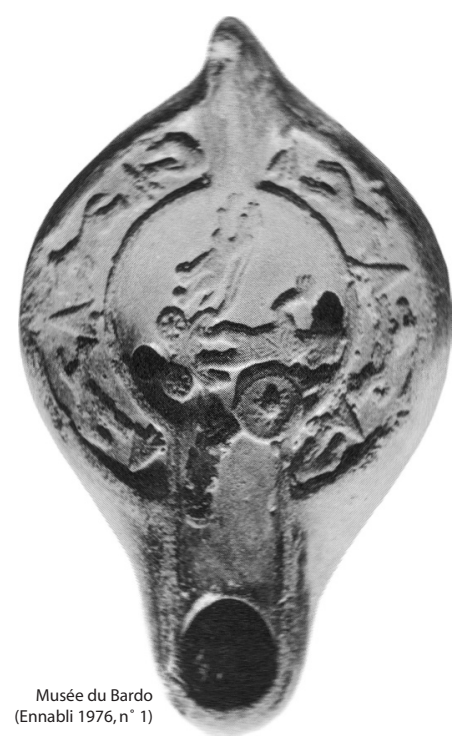

6

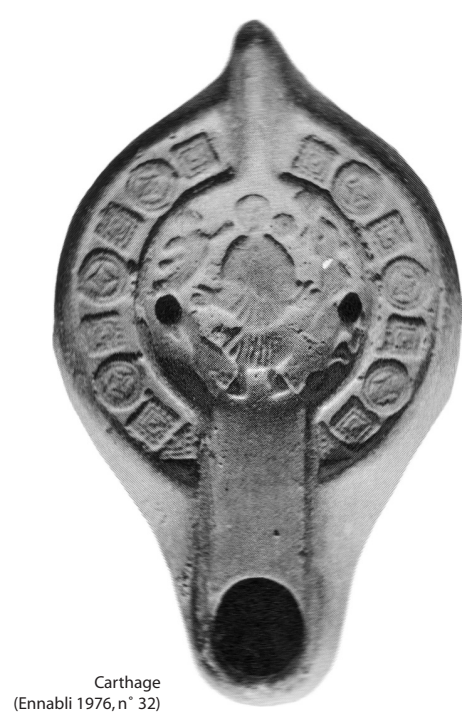

9

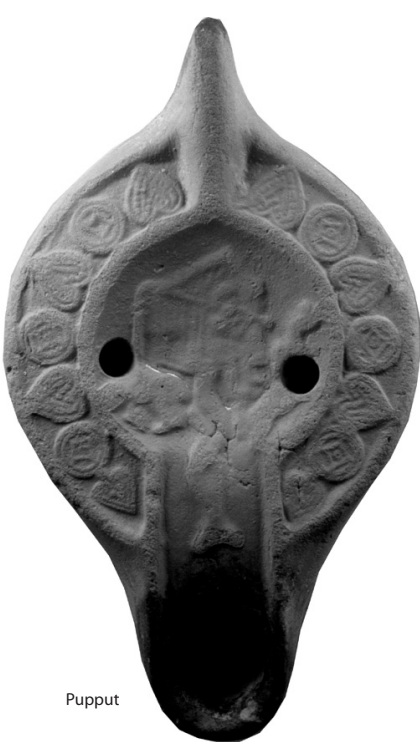

21

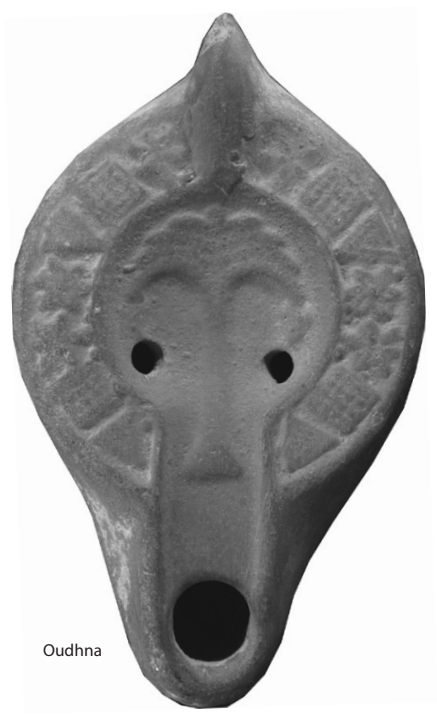

23

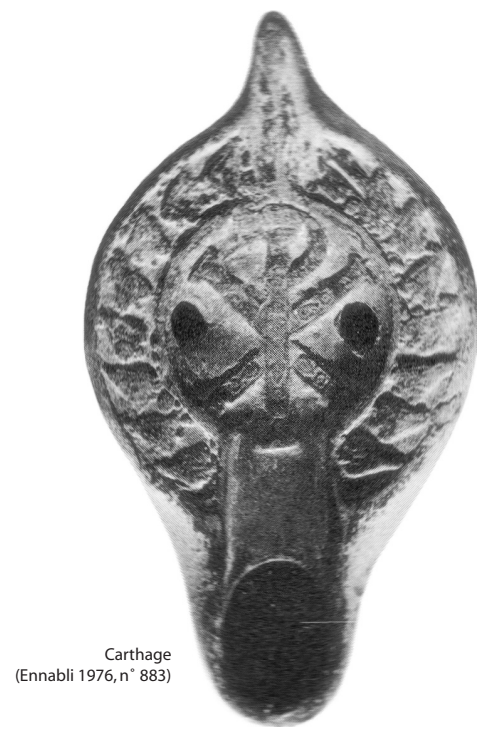

29

Fig. 221. Lampes en sigillée africaine (Tunisie septentrionale). 
de Tunisie centrale: scènes mythologiques ou bibliques, palmier.

- Variante B : style plus original (?), probablement influencé à la fois par le groupe $\mathrm{C} 4$ et par le groupe D3, avec généralement 5 ou 6 motifs seulement, relativement espacés: quadrifoliés $\mathrm{I} 5$, rosettes $\mathrm{J} 1$, cordiformes M6, rameaux S1. Deux motifs sont particulièrement fréquents: les fers de lance N1, pointe vers l'extérieur (parfois seuls, disposés obliquement), et les losanges à volutes R2, placés perpendiculairement par rapport au bandeau. Le décor du disque, généralement moins soigné, souvent assez empâté, emprunte ses sujets aux groupes C2-4 (motifs cruciformes, décors géométriques rayonnants) et au groupe D3 (personnages en pied) ou revient à des thèmes classiques des lampes de Tunisie septentrionale (rosaces).

En parallèle avec le groupe $\mathrm{C} 3$, on note quelques exemplaires de petit format (D. env. $65 \mathrm{~mm}$ ) dans chacune des deux variantes.

Exemples (fig. 221 à 223) :

Variante A (fig. 221)

Scènes mythologiques

Achille et Hector ; sur le bandeau : chevaux (?) W1 et fers de lances $\mathrm{N}^{266}$ :

1 Carthage (Hoff 1986, $\mathrm{n}^{\circ} 43$ ). D. $80 \mathrm{~mm}$; H. $30 \mathrm{~mm}$.

2-4 Carthage (Hoff 1986, $\left.\mathrm{n}^{\circ} 41-42,44\right)$. D. $80 \mathrm{~mm}$; H. $30 \mathrm{~mm}$.

5 Carthage (Trost, Hellmann 1996, $\mathrm{n}^{\circ}$ 40). D. $81 \mathrm{~mm}$; H. $34 \mathrm{~mm}$.

*6 Musée du Bardo (Ennabli 1976, n 1). D. 86 mm; H. $35 \mathrm{~mm}$.

7-8 Oudhna, thermes des Laberii (sans n ${ }^{\circ}$ d'inv.).

Scènes bibliques et chrétiennes

Daniel entre les lions; sur le bandeau : carreaux A5 ou A6 et disques F5 :

*9 Carthage (Ennabli 1976, $\mathrm{n}^{\circ}$ 32). D. $83 \mathrm{~mm}$; H. $31 \mathrm{~mm}$.

10-16 Idem (Ibid., $\mathrm{n}^{\circ} 33,36-42$ ). 80-85 mm ; H. 31-33 mm.

17 Carthage (Hoff 1986, $\mathrm{n}^{\circ}$ 45). D. $90 \mathrm{~mm}$; H. $30 \mathrm{~mm}$.

18 Oudhna, thermes des Laberii (Ennabli 1976, $\left.\mathrm{n}^{\circ} 34\right)$. D. 83-81 mm; H. $34 \mathrm{~mm}$.

19 Idem (Ibid., n 35). D. 81 mm; H. 34 mm.

Le veilleur de la vigne; sur le bandeau: $3=3$ cordiformes M6, $3+3$ disque F5, $1+1$ cordiformes M7 ; cordiforme M7 au départ du bec ${ }^{267}$ :

20 Carthage (Ennabli 1976, $\mathrm{n}^{\circ}$ 81). D. $83 \mathrm{~mm}$; H. $37 \mathrm{~mm}$.

*21 Pupput (Bonifay 2004a, fig. 14, $\mathrm{n}^{\circ} 39$ ). D. $86 \mathrm{~mm} ; \mathrm{H}$. $36 \mathrm{~mm}$.

22 El Azam (Egypte), British Museum (Bailey 1988, Q1799). D. $84 \mathrm{~mm}$

\footnotetext{
${ }^{266}$ Pour le modèle centro-tunisien, voir Bourgeois 1977-78, $\mathrm{n}^{\circ} 1$ (supra, groupe C2, TYPE 54, $\mathrm{n}^{\circ} 4$ ).

${ }^{267}$ Les exemplaires de Tunisie centrale ont généralement un bandeau décoré de pampres (supra, groupe C2, TYPE 54, $\mathrm{n}^{\circ} 19$ ).
}

Végétaux

Palmier $^{268}$ (= forme Chapman-Davies-Peacock 1J) :

*23 Oudhna, thermes des Laberii (Barraud et al. 1998, fig. 13, $\left.\mathrm{n}^{\circ} 12\right)$. Surmoulage de la lampe Atlante $\mathrm{X}$ A1, groupe C2, n ${ }^{\circ}$ 52. D. $84 \mathrm{~mm}$; H. $36 \mathrm{~mm}$.

24 Carthage (Hoff 1986, $\mathrm{n}^{\circ} 118$ ). D. $80 \mathrm{~mm}$; H. $30 \mathrm{~mm}$.

25 Carthage (Chapman, Davies, Peacock 1984, Pl. 2, $\left.\mathrm{n}^{\circ} 11\right)$.

Motifs cruciformes

Chrisme perlé269 (= forme Chapman-Davies-Peacock $1 \mathrm{H})$ :

26 Carthage (Ennabli 1976, n 870 ${ }^{270}$. « Rouge à pâte rugueuse ». Sur le bandeau: quadrifoliés I6 et disques E2 (9 x 2 motifs). Sur le disque : chrisme perlé patté. D. $83 \mathrm{~mm}$; H. $35 \mathrm{~mm}$.

27 Carthage (Chapman, Davies, Peacock 1984, Pl. 2, $\left.\mathrm{n}^{\circ} 10\right)$. Décor identique au ${ }^{\circ}$ précédent.

28 Carthage (Hayes 1976a, Pl. 27, n VII.73). Décor identique aux $\mathrm{n}^{\circ}$ précédents.

Chrisme gemmé ${ }^{271}$ :

*29 Carthage (Ennabli 1976, n 883). Pâte « jaune-gris ». Sur le bandeau : fers de lance disposés obliquement. Sur le disque: chrisme gemmé. D. $80 \mathrm{~mm}$; H. $35 \mathrm{~mm}$.

Variante B (fig. 222)

Scènes bibliques et chrétiennes

Les trois Hébreux rapportent la grappe de Canaan; sur le bandeau : disques et carreaux, fer de lance $\mathrm{N}^{272}$ :

*30 Carthage (Ennabli 1976, $\mathrm{n}^{\circ}$ 46). D. $85 \mathrm{~mm}$; H. $33 \mathrm{~mm}$.

Personnages (fig. 222)

Buste :

*31 Oudhna, thermes des Laberii (cf. Ennabli 1976, $\left.\mathrm{n}^{\circ} 99 ; C M A, 515\right)$. Sur le bandeau : fers de lance N1 (6 $\times 2$ motifs). Sur le disque : buste d'homme de face, tenant une coupe (?). D. $83 \mathrm{~mm}$; H. $35 \mathrm{~mm}$.

Personnage en pied

*32 Carthage (Ennabli 1976, $\mathrm{n}^{\circ}$ 121). Sur le bandeau : $5+$ 5 rameaux S1. Sur le disque: personnage bras tendus, courant à gauche ${ }^{273}$. D. $82 \mathrm{~mm} ;$ H. $35 \mathrm{~mm}$.

33 Idem (Ibid., $\mathrm{n}^{\circ} 212$ ). Sur le bandeau: disques E2, chevrons D2, fers de lance N1, cordiformes M6 (5x 2 motifs). Sur le disque: personnage tenant un faon (?). D. $79 \mathrm{~mm}$; H. $31 \mathrm{~mm}$.

\footnotetext{
${ }^{268}$ Pour le modèle centro-tunisien, voir Ennabli 1976, $\mathrm{n}^{\circ} 762$ (supra, groupe C2, TYPE 54, $\mathrm{n}^{\circ} 52$ ).

${ }^{269}$ Pour le modèle centro-tunisien de cette lampe, avec le même décor de bandeau, voir, par exemple: Trost, Hellmann 1996, $\mathrm{n}^{\circ} 115$ ("pâte rouge rosé, fine et légère ; engobe de même ton $\gg)$.

${ }^{270}$ Décor identique dans la même qualité de pâte (?) : Ennabli 1976, $\mathrm{n}^{\circ} 871,872,875,876$ (Carthage); Hayes 1980b, n 290 (Carthage) ; Hoff 1986, n 101-103 (Carthage); Bailey 1988, Q1761(Carthage); Trost, Hellmann 1996, nº 115.

${ }^{271}$ Pour l'origine centro-tunisienne de ce décor, voir le moule provenant d'El Jem : Bailey 1988, Q1760 (supra, groupe C2, TYPE 54, $\mathrm{n}^{\circ} 68$ ).

${ }^{272}$ En Tunisie centrale, ce décor de disque est généralement associé à un bandeau décoré de pampres (supra, groupe $\mathrm{C} 2$, TYPE $\left.54, n^{\circ} 16\right)$.

${ }^{273}$ Même personnage sur la lampe Atlante XII d'Oudhna (infra, TYPE $81, n^{\circ} 1$ ).
} 


\section{Typologie - Lampes}

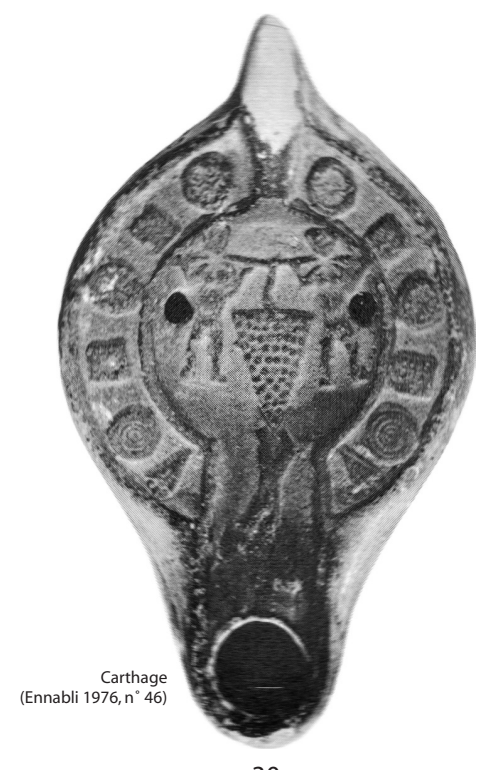

30

Type Atlante X, groupe D2 variante $B$
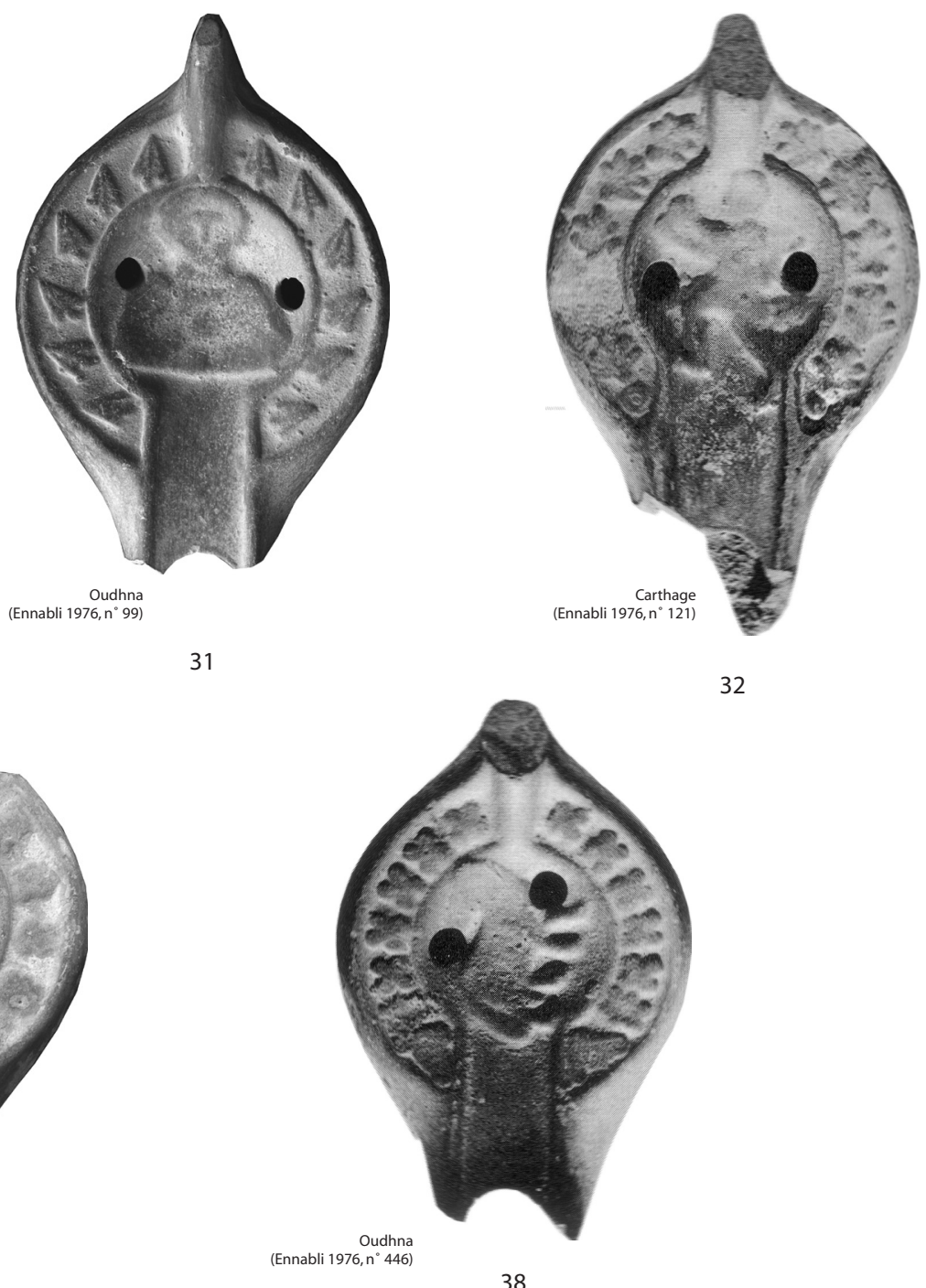

32

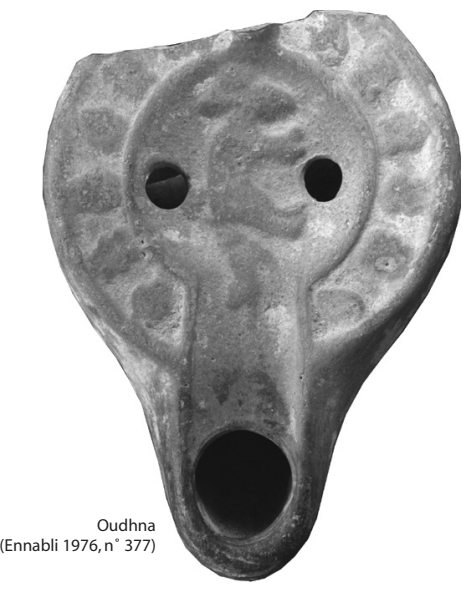

34
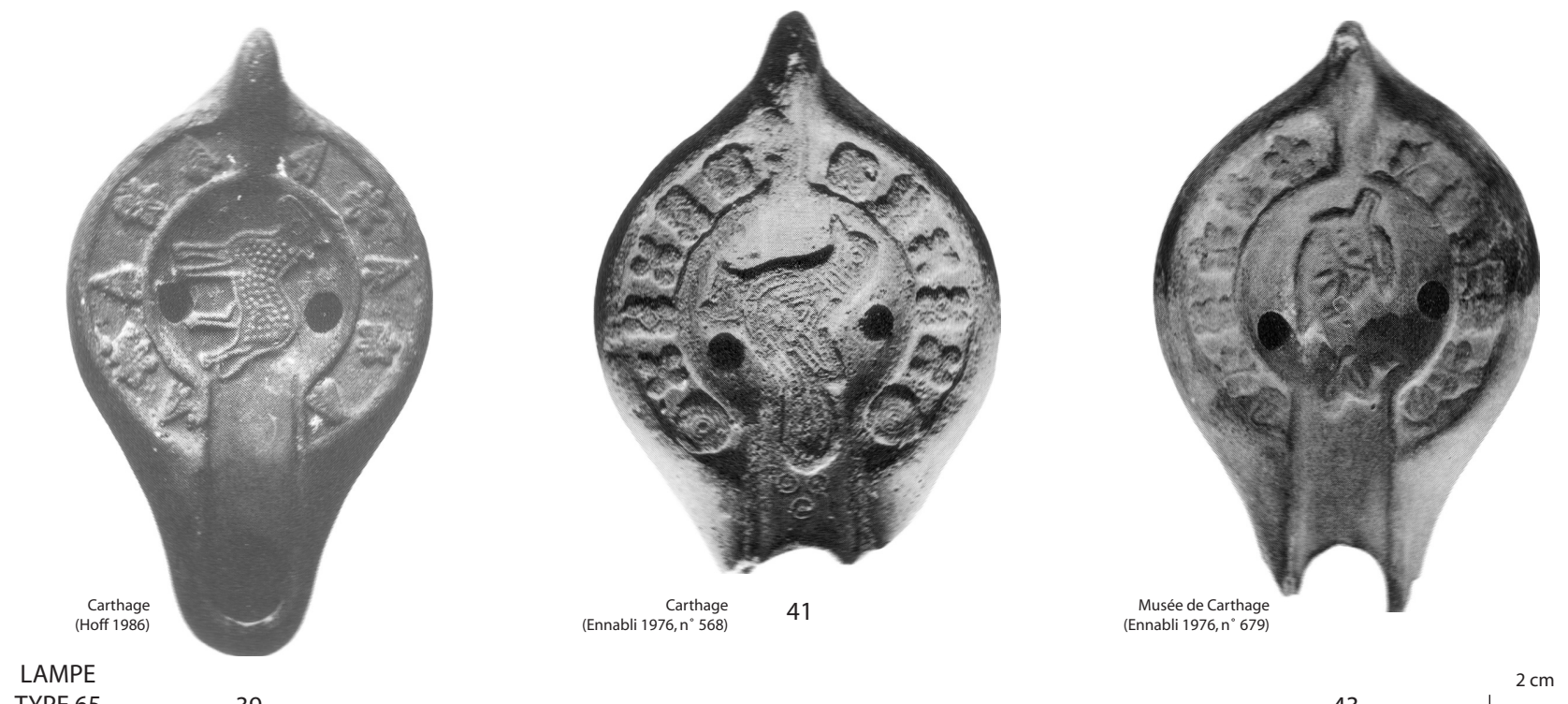

TYPE 65

39

Fig. 222. Lampes en sigillée africaine (Tunisie septentrionale). 


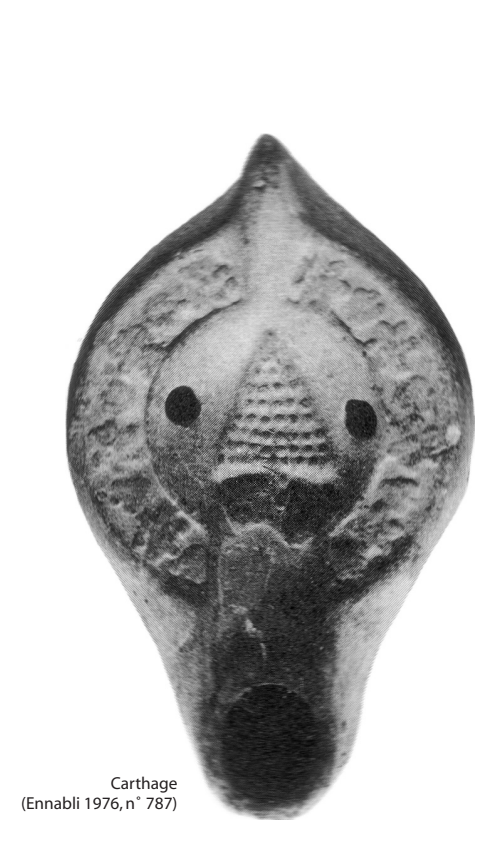

44

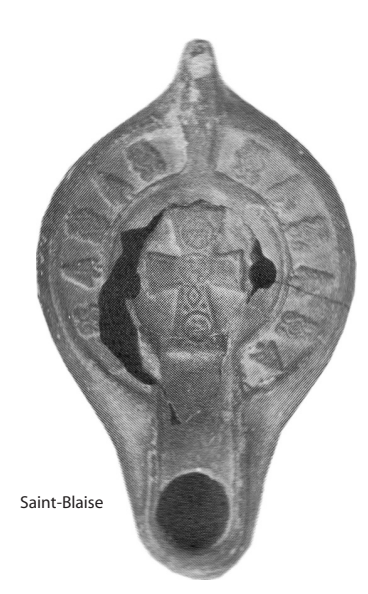

50

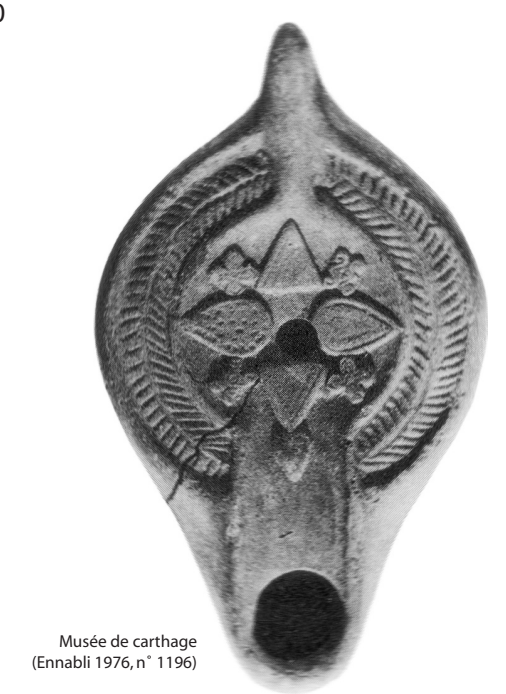

55

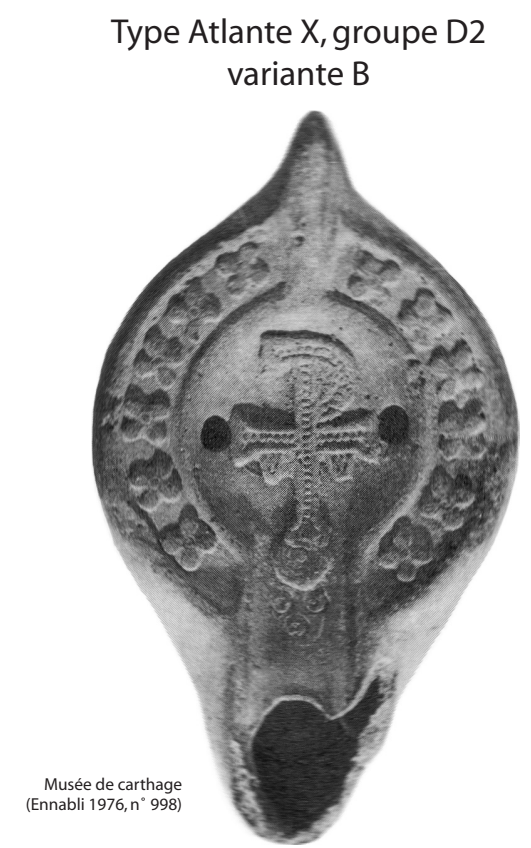

47

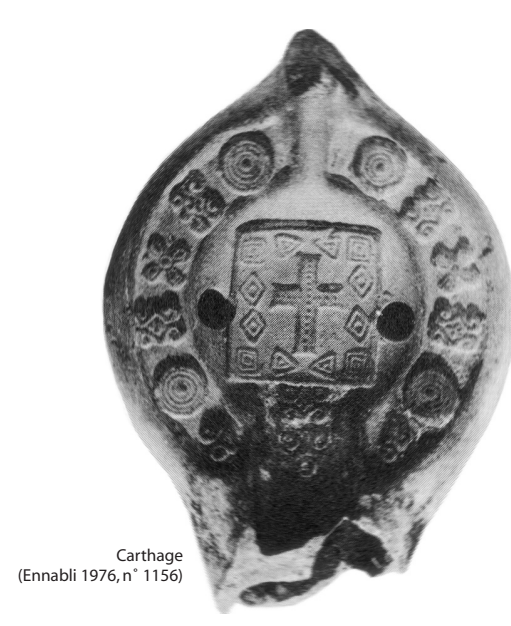

51

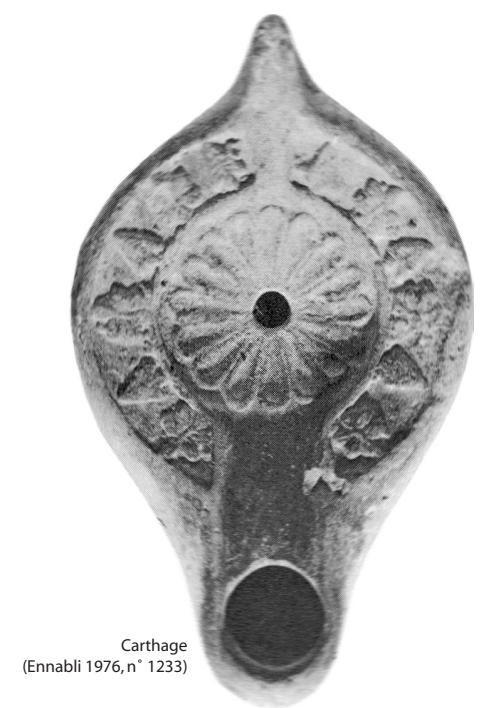

56

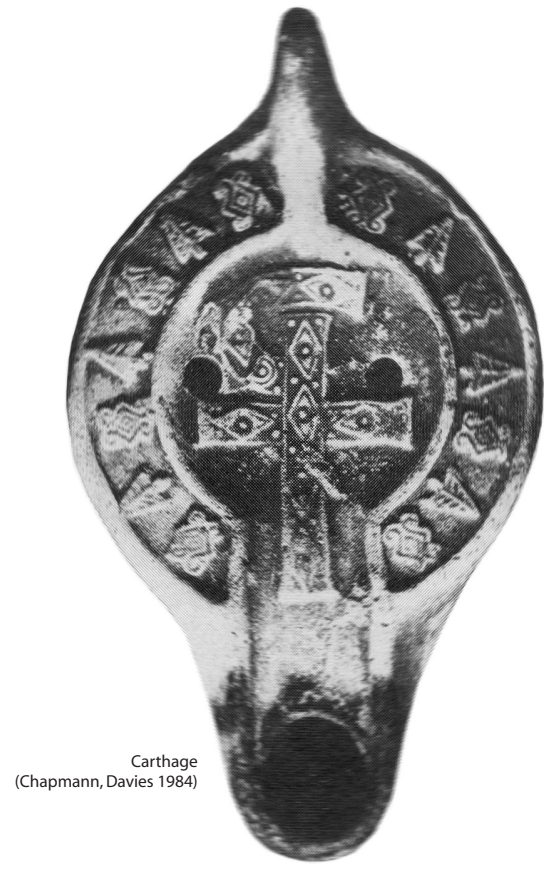

49

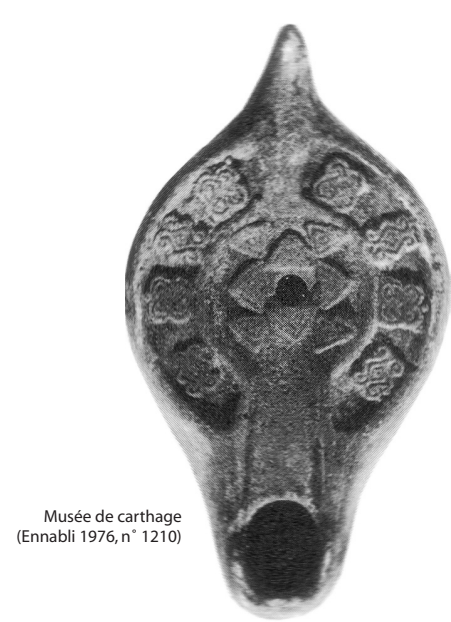

54

Fig. 223. Lampes en sigillée africaine (Tunisie septentrionale). 
Animaux (fig. 222)

Cervidés :

*34 Oudhna (cf. Ennabli 1976, n 377 ; CMA, 578). Sur le bandeau : cordiformes M6, losanges à volutes R2, oves K1 (6 x 2 motifs). Sur le disque : cerf broutant, dans l'axe de la lampe, derrière lui, lièvre (?). D. $85 \mathrm{~mm}$; H. $35 \mathrm{~mm}$.

35 Musée de Carthage (Ennabli 1976, n 378). Sur le bandeau : losanges à volutes R2, quadrifolés (5 et 6 motifs). Sur le disque : cerf comme le $\mathrm{n}^{\circ}$ précédent, sans le lièvre. D. $68 \mathrm{~mm}$; H. $30 \mathrm{~mm}$. Petit format.

Cheval :

36 Carthage (Ennabli 1976, $\mathrm{n}^{\circ}$ 423). Sur le bandeau : disques E1 et fers de lance N1 (6 x 2 motifs). Sur le disque : cheval dans l'axe de la lampe, portant deux swastikas sur la croupe et sur l'épaulement. D. $86 \mathrm{~mm}$; H. $39 \mathrm{~mm}$.

37 Rome (Barbera, Petriaggi 1993, 168, n 125). Sur le bandeau : rosettes $\mathrm{J} 1$ (?) et fers de lance N1 (7 x 2 motifs). Sur le disque: cheval comme le $\mathrm{n}^{\circ}$ précédent. Décors très empâtés. D. $81 \mathrm{~mm}$. Bélier :

*38 Oudhna, thermes des Laberii (Ennabli 1976, $\mathrm{n}^{\circ} 446$ ). Sur le bandeau: $5+5$ quadrifoliés I5 (?), $1+1$ losanges à volutes, $1+1$ colombes (?). D $79 \mathrm{~mm} ; \mathrm{H}$. $33 \mathrm{~mm}$.

Agneau :

*39 Carthage (Hoff 1986, $\mathrm{n}^{\circ} 77$ ). Sur le bandeau : fers de lance N1 et rosettes J1 ( 5 × 2 motifs). Sur le disque : agneau dans l'axe de la lampe. D. $80 \mathrm{~mm}$; H. $30 \mathrm{~mm}$.

40 Idem (Ennabli 1976, $\mathrm{n}^{\circ}$ 467). Décor identique au $\mathrm{n}^{\circ}$ précédent mais très empâté. D. $84 \mathrm{~mm} ; \mathrm{H}$. $37 \mathrm{~mm}$.

Oiseau :

*41 Carthage (Ennabli 1976, $\mathrm{n}^{\circ}$ 568). Sur le bandeau : quadrifoliés I5 (?), losanges à volutes R2, quadrifoliés I3, disque E2 (6 x 2 motifs). Sur le disque: colombe ${ }^{274}$, dans l'axe de la lampe. D. $88 \mathrm{~mm}$; H. $34 \mathrm{~mm}$.

42 Carthage (Chapman, Davies, Peacock 1984, Pl. 2, $\left.\mathrm{n}^{\circ} 14\right)$. Décor identique au $\mathrm{n}^{\circ}$ précédent. Poissons :

*43 Musée de Carthage (Ennabli 1976, n 679). Sur le bandeau: rameaux S2, losanges à volutes R2, cordiformes M7 (6 x 2 motifs). Sur le disque : dauphin dans l'axe de la lampe. D. $84 \mathrm{~mm}$; H. $33 \mathrm{~mm}$.

Végétaux (fig. 223)

*44 Carthage (Ennabli 1976, $\mathrm{n}^{\circ}$ 787). Sur le bandeau : rameaux S2, cordiformes M9 et fers de lance N1 $(8 x$ 2 motifs). Sur le disque : grappe de raisin ou conifère. D. $83 \mathrm{~mm}$; H. $36 \mathrm{~mm}$.

45 Carthage (Chapman, Davies, Peacock 1984, Pl. 2, $\left.\mathrm{n}^{\circ} 4\right)$. Décor identique au $\mathrm{n}^{\circ}$ précédent.

46 Carthage (Ennabli 1976, $\mathrm{n}^{\circ} 793$ ). Sur le bandeau : losanges à volutes R2, quadrifoliés II6 et I2 $(6 \times 2$ motifs). Disque comparable aux $\mathrm{n}^{\circ}$ précédents. D. $69 \mathrm{~mm}$; H. $32 \mathrm{~mm}$. Petit format.

\footnotetext{
${ }^{274}$ Surmoulage de la colombe du groupe C2, TYPE 54, $\mathrm{n}^{\circ} 44$ (Ennabli 1976, n 597 ; Bourgeois 1977-78, $n^{\circ} 25$ ).
}

Motifs cruciformes (fig. 223)

Croix monogrammatique perlée (= forme ChapmanDavies-Peacock 1G) :

*47 Musée de Carthage (Ennabli 1976, n 998). Sur le bandeau: $6+6$ quadrifoliés I4-5. Sur le disque: croix monogrammatique perlée, avec alpha et oméga sous la branche horizontale, posée sur un demi-cercle E2. D. $87 \mathrm{~mm}$; H. $35 \mathrm{~mm}$

48 Carthage (Chapman, Davies, Peacock 1984, Pl. 2, $\mathrm{n}^{\circ} 8$ ). Décor identique au $\mathrm{n}^{\circ}$ précédent.

Croix monogrammatique gemmée ${ }^{275}$ :

*49 Carthage (Chapman, Davies, Peacock 1984, Pl. 2, $\left.\mathrm{n}^{\circ} 12\right)$. Sur le bandeau : losanges à volutes $\mathrm{R} 2$ et fers de lance N1 ( 7 x 2 motifs). Sur le disque : croix monogrammatique (rétrograde) Barbera-Petriaggi 210E. D. $96 \mathrm{~mm}$.

Croix pattée :

*50 Saint-Blaise (Février, Leyge 1986, $\mathrm{n}^{\circ}$ 402). Sur le bandeau : losanges à volutes R2 et fers de lance N1 (6 x 2 motifs). Sur le disque : croix pattée BarberaPetriaggi 212. D. $65 \mathrm{~mm}$.

Croix dans un carreau :

*51 Carthage (Ennabli 1976, $\mathrm{n}^{\circ} 1156$ ). Sur le bandeau : disques E2, losanges à volutes R2, quadrifoliés I3 (5, $5 \times 2$ motifs). D. $84 \mathrm{~mm}$; H. $33 \mathrm{~mm}$.

52 Oudhna, est capitole (fouilles H. Ben Hassen, Inv. UTH7.000.6). Décor identique au $\mathrm{n}^{\circ}$ précédent, empâté.

Motifs géométriques (fig. 223)

Motifs rayonnants ${ }^{276}$ :

53 Carthage (Ennabli 1976, n 1193). Sur le bandeau : disque E2, losanges à volutes R2, quadrifoliés I5 (6x 2 motifs). Sur le disque : chevrons D3 et oves K1 disposés autour de l'orifice de remplissage. D. $83 \mathrm{~mm}$; H. $34 \mathrm{~mm}$.

*54 Musée de Carthage (Ennabli 1976, n 1210). Sur le bandeau : carreaux tressés $\mathrm{O} 4$ et losanges à volutes R2 (4 x 2 motifs). Sur le disque : chevrons disposés autour de l'orifice de remplissage. D. $66 \mathrm{~mm}$; H. $27 \mathrm{~mm}$. Petit format. Type Atlante X B :

*55 Musée de Carthage (Ennabli 1976, n 1196). Sur le bandeau : palmes incisées. Sur le disque : chevrons D4 et oves K2, alternant avec des quadrifoliés I5 et des losanges à volutes R2, disposés autour de l'orifice de remplissage. D. $80 \mathrm{~mm}$; H. $39 \mathrm{~mm}$.

Rosace :

*56 Carthage (Ennabli 1976, $\mathrm{n}^{\circ}$ 1233). sur le bandeau : 3 +3 fers de lance N1, $3=3$ rameaux S2. Sur le disque : rosace. D. $82 \mathrm{~mm}$; H. $32 \mathrm{~mm}$.

57 Oudhna, thermes des Laberii (sans $\mathrm{n}^{\circ}$ d'inv.).

58-60 Carthage (Hoff 1986, $\left.\mathrm{n}^{\circ} 121-123\right)$. D. 79-80 ; H. 33$40 \mathrm{~mm}$.

On ne sait pas de quelle manière se produit le transfert stylistique entre les ateliers de Tunisie centrale (notamment Sidi Marzouk Tounsi) et certain(s) atelier(s) de Tunisie septentrionale (probablement Oudhna, mais peut-être aussi d'autres, car la production n'est pas

\footnotetext{
${ }^{275}$ Modèle de Tunisie centrale (supra : groupe C4 et C5).

276 Pour l'origine centro-tunisienne de ce décor, voir supra (groupe C2, TYPE $54, n^{\circ} 87$ ).
} 
parfaitement homogène): surmoulages de lampes, transport ou achat de moules et/ou de poinçons, déplacement d'artisans coroplathes ? Mais le fait est que des lampes sûrement produites en sigillée africaine $\mathrm{C}$ le sont aussi en sigillée africaine $\mathrm{D}$, avec toutefois un rendu des décors de moins bonne qualité. C'est la définition même du type II B de J. W. Hayes (1972, 311), dont l'illustration (Ibid., Pl. XXI, a, lampe de droite) renvoie à une lampe du groupe D2, elle-même surmoulage d'une lampe du groupe C2 (supra, LAMPE TYPE 54, $\mathrm{n}^{\circ} 77$ ), et non à une lampe du groupe D3.

Les rares exemplaires de la variante $\mathrm{A}$ recueillis en stratigraphie $(\mathbf{2 5}, \mathbf{2 7})$ indiquent le début du VIe s.; le $\mathrm{n}^{\circ} \mathbf{2 8}$ provient d'un contexte contenant une majorité de céramiques de la fin du Ve et de la première moitié du VIe s. (Hayes 1976a, 54). Cette date correspond à une phase tardive des productions de lampes du groupe C2 ainsi que de la vaisselle en sigillée africaine de catégorie $\mathrm{C} 5$, mais à la phase la plus évidente de la production de sigillée D2 à Oudhna. La variante $\mathrm{B}(\mathbf{4 2}, \mathbf{4 5}, \mathbf{4 8}, \mathbf{4 9})$ est plutôt caractéristique des décennies centrales du VIe s., probablement pas avant 530 (Chapman, Davies, Peacock 1984, 235-236). Un exemplaire très proche $\mathrm{du} \mathrm{n}^{\circ} \mathbf{5 6}$ provient d'un contexte du deuxième quart du VIe $\mathrm{s}$. à Carthage (Neuru 1990a, 37, n 32).

\section{Datation proposée :}

Variante A - fin du Ve - début du VIe s.

Variante B - décennies centrales du VIe s.

\section{- lampes Atlante X, groupe D3 (fig. 224 à 227)}

$=$ forme Chapman-Davies-Peacock $1 \mathrm{~L}$

\section{LAMPE TYPE 66}

Lampe de taille standard (D. $86 \mathrm{~mm}$ en moyenne) avec quelques exemplaires plus grands (D. $89 \mathrm{~mm}$ ) et rares exemplaires plus petits (D. $81 \mathrm{~mm}$ ). Le décor du bandeau est assez caractéristique : les motifs au nombre de quatre ou cinq de chaque côté, sont en fort relief, parfois empâtés, très espacés et disposés de manière souvent peu régulière, quelquefois dissymétrique. Les associations de motifs laissent entrevoir deux variantes :

- Variante A: les éléments principaux de la décoration du bandeau sont les cordiformes M2 et M5, les carrés A4 et $\mathrm{A} 5$, le carré à faces concaves B1, le cercle E1 (?), le quadrifolié I2 et l'oiseau U5, particulièrement reconnaissable. On trouve également d'autres motifs plus accessoires : le carré $\mathrm{A} 2$, le disque $\mathrm{F} 4$, les rosettes $\mathrm{J} 1$ et $\mathrm{J} 2$, les rinceaux O2 et Q3, une palmette proche de P2 (cf. Mackensen 1993, fig. $31, \mathrm{n}^{\circ} 6$, motif du bas), l'oiseau U8, le dauphin V1, le poisson V2. Appartiennent probablement à la même variante : la croix $\mathrm{T} 2$, le mouton dans un cercle W3.

- Variante B : le motif-directeur de la décoration des bandeau est ici le rinceau $\mathrm{O} 1$ qui est associé à un petit nombre d'autres motifs : le carré A6, le losange C5, un cercle proche de E2 (mais plus petit), le cordiforme M4, une variante plus petite et pointue de cordiforme M2, un chevron proche de D10, un quadrifolié proche de I2, une variante large de losange à volutes $\mathrm{R} 2$, deux dauphins (à droite et à gauche) proches de V1, le lapin W4 (?), l'agneau (?) W6.

Les cloisons entre ces deux variantes de décor de bandeau ne sont toutefois pas complètement étanches (cf. Ennabli $\left.1976, \mathrm{n}^{\circ} 147,628,761,1219 / 1221\right)$. Il semble également y avoir une connexion décorative avec les lampes du groupe $\mathrm{D} 1$, variante $\mathrm{C}$, au bandeau entièrement décoré de colombes U8 (supra, LAMPE TYPE 64).

Les sujets représentés sur les disques sont variés. Quelques exemplaires s'inspirent encore des décors des lampes de Tunisie centrale : scènes bibliques des $n^{\circ} \mathbf{1}, \mathbf{3 1}$, 32, buste imité de celui de Fausta (4), amour ailé tenant un flambeau (5). Mais d'autres motifs sont plus originaux: des personnages masculins apparaissent en nombre, dans diverses attitudes, portant des armes (épée, épieu) $(6,39-40)$ ou des animaux (faon, lièvres) (7-8). On relève toujours beaucoup d'animaux, souvent traités de manière naïve (voir les poissons des $n^{\circ} \mathbf{1 8 - 1 9}$ et 51), avec une utilisation fréquente des grènetis pour évoquer les poils, les plumes, les écailles. La biche du no $384 \mathrm{du}$ catalogue d'A. Ennabli (non illustrée ici) est la copie inversée de celle du $\mathrm{n}^{\circ} 37$ du groupe C2 (supra, LAMPE TYPE 54, fig. 210). Les motifs cruciformes ne sont pas, comme dans le groupe D2, directement issus du répertoire des lampes de Tunisie centrale. Mais les influences sont perceptibles: l'ornementation interne (gemmes, agneau dans un cercle) des croix monogrammatiques des $n^{\circ} \mathbf{2 3}$ et $\mathbf{5 3}$ ressemble beaucoup à celle des croix pattées Barbera-Petriaggi 212 (supra, groupe C2, LAMPE TYPE 54, $\left.\mathrm{n}^{\circ} 77,80\right)$. La croix monogrammatique à décor de losange du $\mathrm{n}^{\circ} \mathbf{2 5}$ répond à la croix Barbera-Petriaggi 210E. Enfin, le décor stylisé de pampres et la croix grecque centrale de la croix pattée du $\mathrm{n}^{\circ} \mathbf{2 6}$ est sans doute inspirée de la croix Barbera-Petriaggi 210A1. Les décors géométriques sont très peu variés (27, 56).

C'est sur ce type de lampes Atlante X que les marques incisées sous le fond sont les moins rares : des lettres isolées, en particulier le $\mathrm{B}(\mathbf{1 7}, \mathbf{3 9}, \mathbf{4 9}, \mathbf{5 0})$ et des rouelles le plus souvent disposées en grappe.

Ces lampes sont très nombreuses à Carthage (Chapman, Davies, Peacock 1984, 236, forme $1 \mathrm{~L})^{277}$ et leur fabrication dans un ou plusieurs ateliers de Tunisie septentrionale ne fait pas de doute. Peut-on préciser encore leur origine ? Un lien avec le style E(i) d'Oudhna a été suggéré (Chapman, Davies, Peacock 1984, 236). Cependant, le $\mathrm{n}^{\circ} \mathbf{7}$ découvert dans les thermes des Laberii ne me convainc pas pour placer à Oudhna tout ou partie de la production du groupe D3 : cet atelier semble plutôt avoir produit des lampes du groupe D2 (encore que l'un

\footnotetext{
277 « This class is the most common on the whole site ».
} 
Typologie - Lampes

Type Atlante X, groupe D3 variante $A$
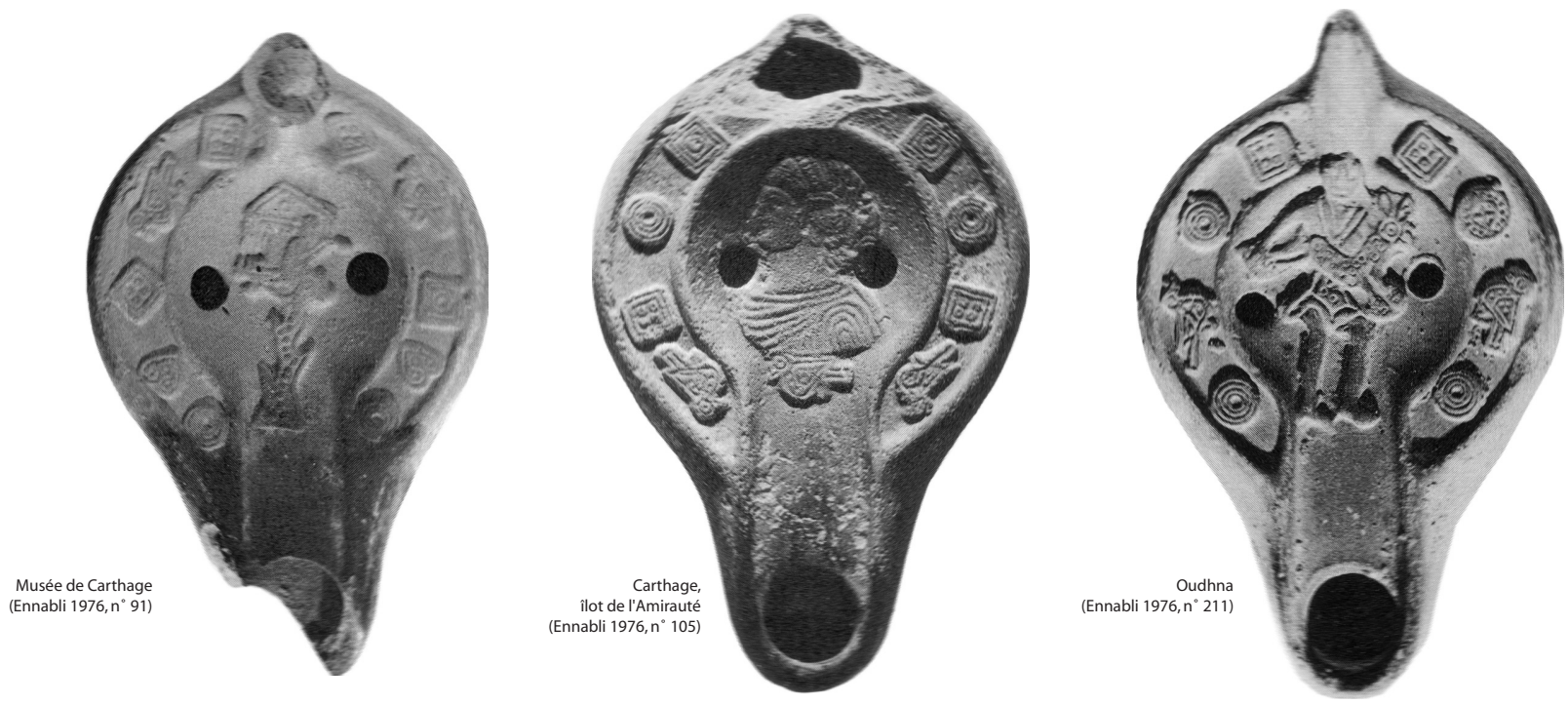

7
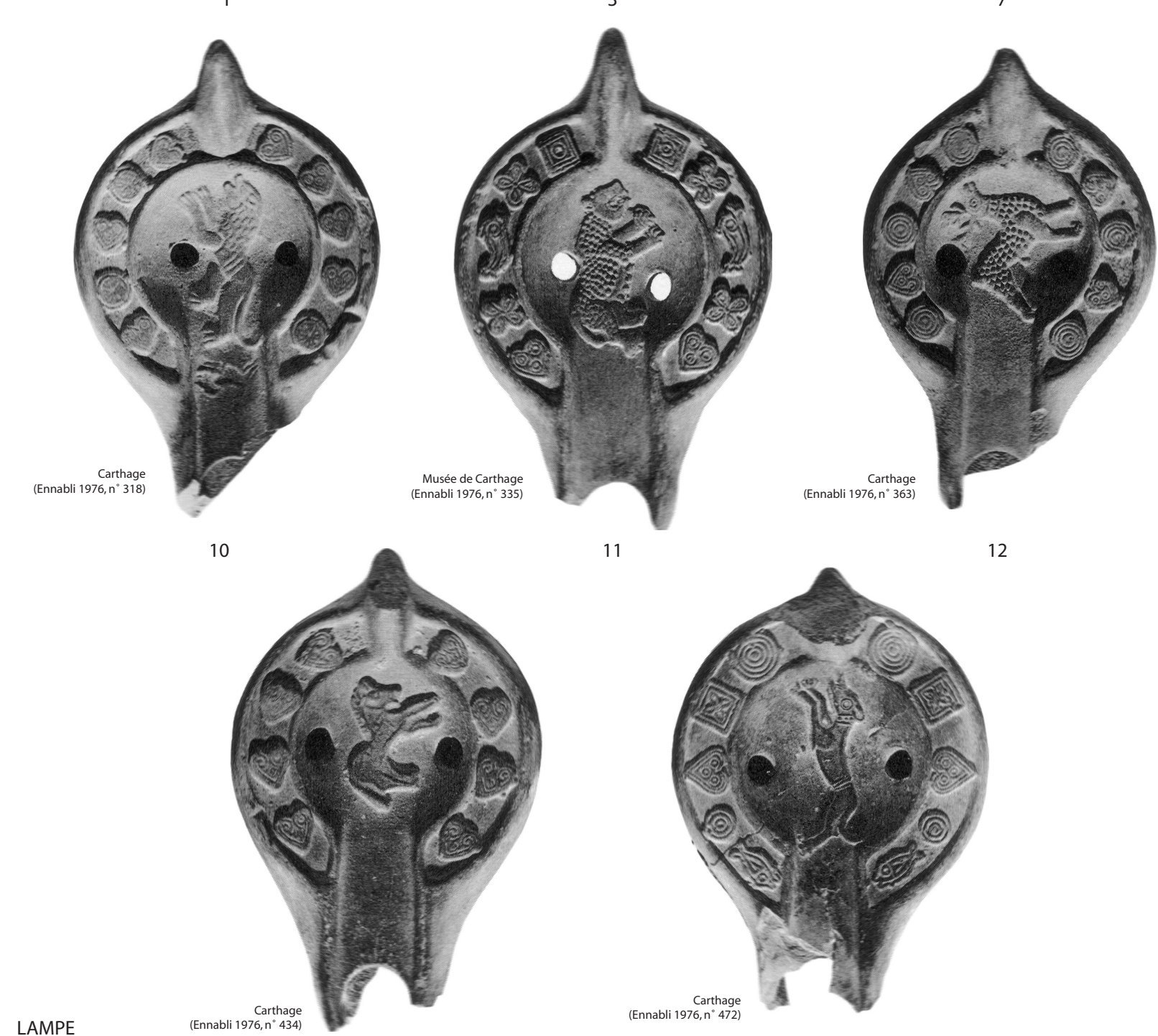

11

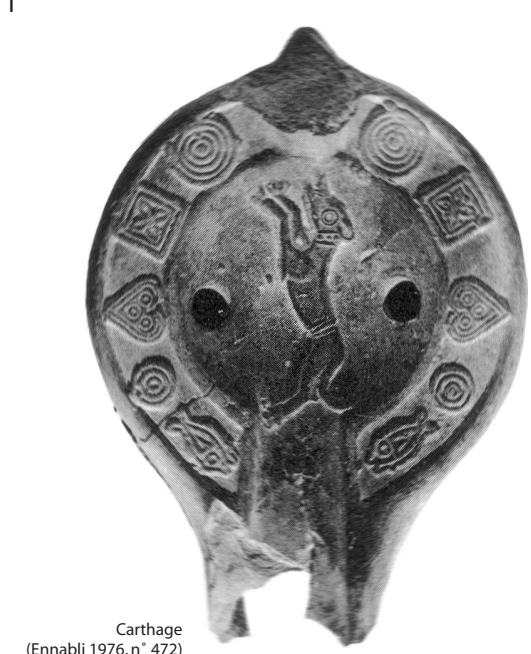

12

Fig. 224. Lampes en sigillée africaine (Tunisie septentrionale). 
Typologie - Lampes

Type Atlante X, groupe D3

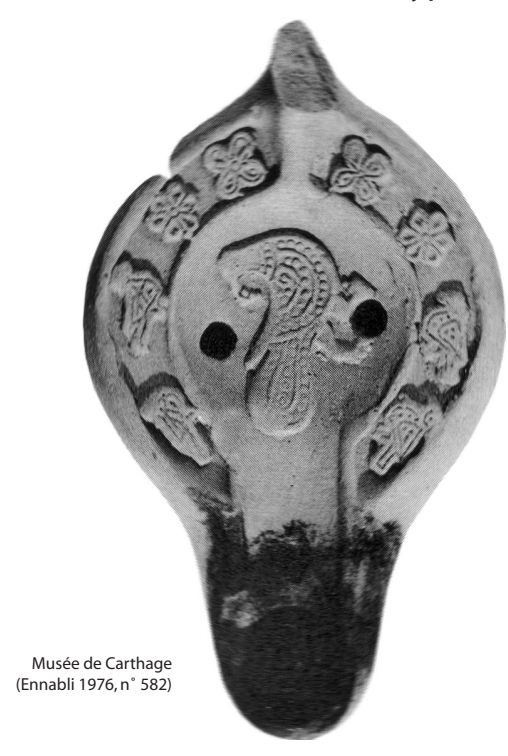

variante $A$

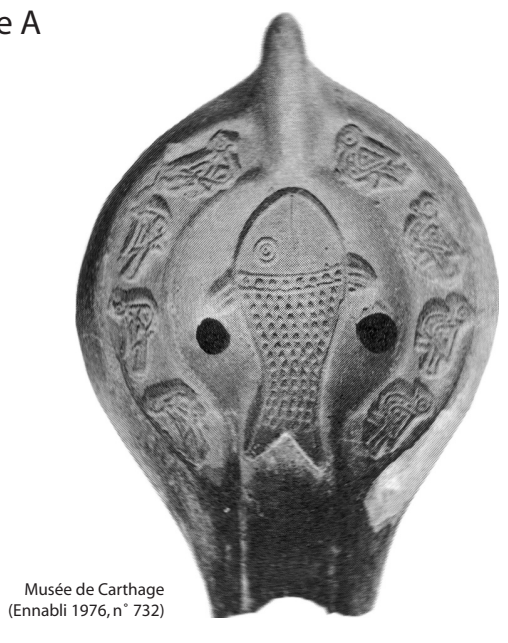

18

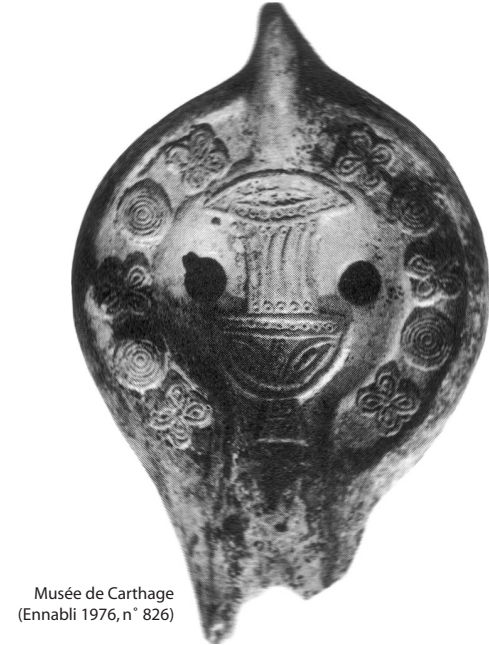

21

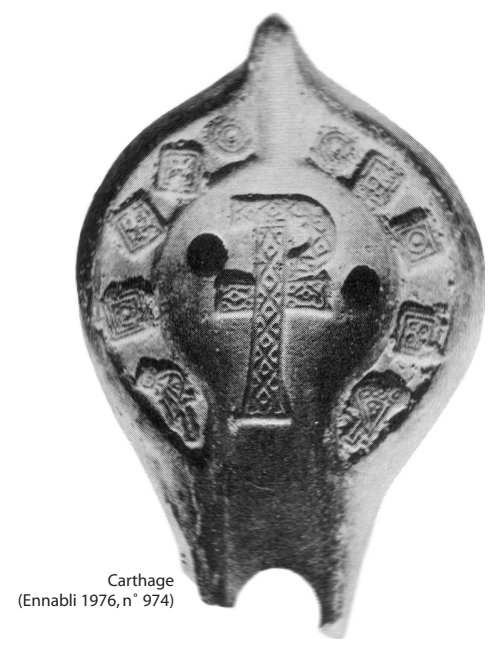

LAMPE

TYPE 66

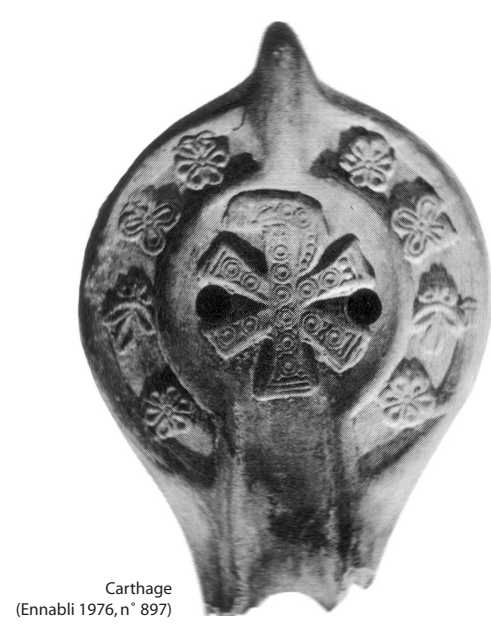

22

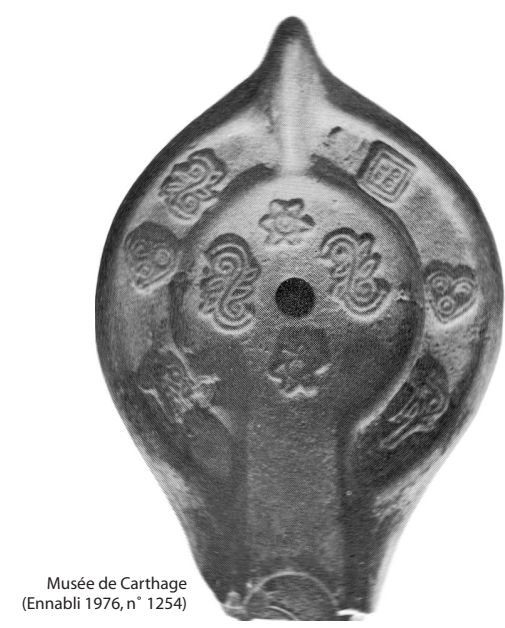

27

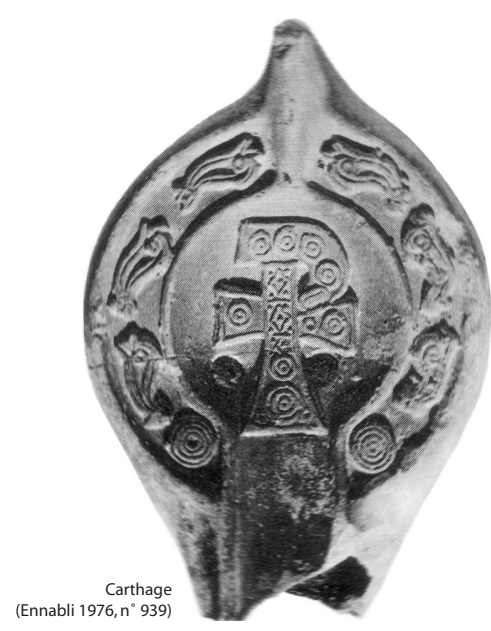

24

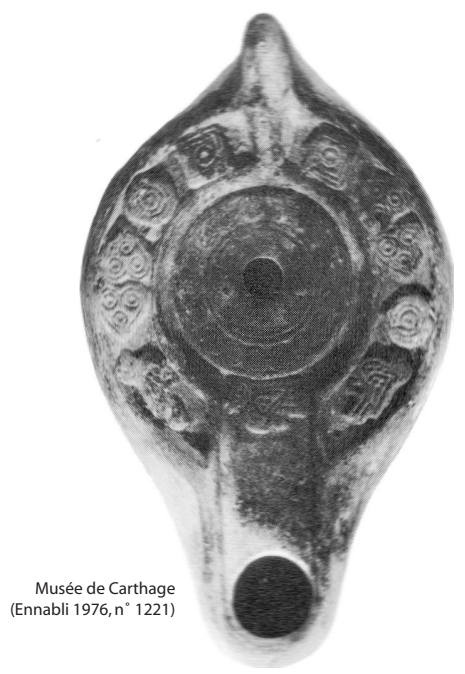

28

Fig. 225. Lampes en sigillée africaine (Tunisie septentrionale). 
ne soit pas forcément exclusif de l'autre). De fait, certains décors attestés sur les bandeaux du groupe D3 sont proches plutôt de ceux reconnus par M. Mackensen à El Mahrine (Mackensen 1993, fig. 31). Si les rares lampes de type Atlante X qui ont été trouvées sur cet atelier ont effectivement été produites sur place (comme semblent le prouver les analyses physico-chimiques: Mackensen, Schneider 2002), alors il est très probable que de nombreuses lampes du groupe D3, notamment celles de la variante A, proviennent d'El Mahrine ou d'ateliers situés dans la même zone géographique. Cette provenance est très vraisemblable pour les $\mathrm{n}^{\circ} 129,336$, 507, 582, 886, 897 du catalogue d'A. Ennabli.

L'idéal serait ici encore de reclasser entièrement les lampes publiées des différentes collections de musées. Je me contenterai ici de citer des exemples des types les plus communs et les plus représentatifs du groupe 3 .

\section{Exemples (fig. 224 à 227) :}

\section{Variante A (fig. 224-225)}

Scènes bibliques et chrétiennes (fig. 224) Le veilleur de la vigne :

*1 Musée de Carthage (Ennabli 1976, n 91). Sur le bandeau : carrés A4 et A5, oiseaux U5, cordiformes $\mathrm{M} 1 / 5$, disques E4 (5 x 2 motifs). D. $84 \mathrm{~mm} ; \mathrm{H}$. $37 \mathrm{~mm}$.

Jonas :

2 Musée de Carthage (Ennabli 1976, n 53). Sur le bandeau : $3+3$ dauphins V1. Sur le disque : décor comparable à celui du groupe $\mathrm{C} 4, \operatorname{TYPE} 56, \mathrm{n}^{\circ} 15$. D. $82 \mathrm{~mm}$; H. $36 \mathrm{~mm}$.

Personnages (fig. 224-225)

Buste :

*3 Carthage, îlot de l'Amirauté (Ennabli 1976, n 105). Sur le bandeau : carrés A4 et A5, cercles E1, oiseaux U5 (4 x 2 motifs). D. $91 \mathrm{~mm}$; H. $37 \mathrm{~mm}$.

4 Musée de Carthage (Ennabli 1976, n 113). Sur le bandeau: dauphins V1, chevrons D4, oiseaux U1, poissons V2 (4 × 2 motifs). Sur le disque : buste de femme (impératrice Fausta ?) à droite. D. $78 \mathrm{~mm}$; H. $36 \mathrm{~mm}$.

Personnage en pied :

5 Carthage (Ennabli 1976, $\left.\mathrm{n}^{\circ} 151\right)$. Sur le bandeau: disques F4, colombes U8, cercles E1 (4 x 2 motifs). Sur le disque : amour ailé tenant un flambeau, dans l'axe de la lampe. D. $87 \mathrm{~mm}$; H. $33 \mathrm{~mm}$.

6 Idem (Ibid., $\mathrm{n}^{\circ}$ 169). Sur le bandeau : quadrifoliés I2, cercles E1, cordiforme M1/5 (3 x 2 motifs). Sur le disque : homme dégainant son épée. D. $86 \mathrm{~mm}$; H. $32 \mathrm{~mm}$.

*7 Oudhna, thermes des Laberii (Ennabli 1976, $\mathrm{n}^{\circ} 211$ ). sur le bandeau : carrés A5, disques F1, E1, oiseau U5. Sur le disque: homme portant un faon. D. $89 \mathrm{~mm}$; H. $33 \mathrm{~mm}$.

8 Carthage (Chapman, Davies, Peacock 1984, Pl. 3, $\left.\mathrm{n}^{\circ} 4\right)$. Sur le bandeau : cordiformes et croix T2 (?). Sur le disque : motif identique au précédent.

9 Carthage (Hayes 1976a, Pl. 27, n VII.75). Sur le bandeau : carrés A4 et A5, cercle E3 (?), cordiforme
M2. Sur le disque : homme à droite portant quelque chose sur son épaule.

Animaux (fig. 225)

Lion:

*10 Carthage (Ennabli 1976, $\mathrm{n}^{\circ}$ 318). Sur le bandeau: cordiformes M2 et disques F4 (5 x 2 motifs). D. $87 \mathrm{~mm}$; H. $30 \mathrm{~mm}$

Ours :

*11 Musée de Carthage (Ennabli 1976, n 335). Sur le bandeau: carrés A4, quadrifoliés I2, dauphins proches de V1, cordiformes M2 (5 x 2 motifs). D. $90 \mathrm{~mm}$.

Cerf :

*12 Carthage (Ennabli 1976, n 363). Sur le bandeau : cercles E1 et cordiformes M1/5 (5 x 2 motifs). D. $83 \mathrm{~mm}$; H. $32 \mathrm{~mm}$.

Cheval :

*13 Carthage (Ennabli 1976, n 434). Sur le bandeau : cordiformes M5 (4 x 2 motifs). D. $88 \mathrm{~mm}$; H. $31 \mathrm{~mm}$.

Chien :

*14 Carthage (Ennabli 1976, $\mathrm{n}^{\circ}$ 472). Sur le bandeau: cercles E2, carrés A1, cordiformes M2, cercles E6, poissons V2. D. $90 \mathrm{~mm}$; H. $33 \mathrm{~mm}$.

Oiseau :

15 Carthage (Ennabli 1976, $\mathrm{n}^{\circ} 565$ ). Sur le bandeau : dauphins V1, cordiformes M5, carrés A5 et A6 $(4 \times 2$ motifs). Sur le disque: colombe dans l'axe de la lampe. D. $85 \mathrm{~mm}$; H. $35 \mathrm{~mm}$.

*16 Musée de Carthage (Ennabli 1976, n 582). Sur le bandeau: quadrifoliés $\mathrm{I} 3$, rosaces $\mathrm{J}$, oiseaux dont U5. Sur le disque : colombe. D. $86 \mathrm{~mm}$; H. $37 \mathrm{~mm}$.

17 Carthage (Bailey 1988, Q1823). Sur le bandeau : cordiformes M2, carrés A5, losanges $\mathrm{C} 1$, oiseau (U4 ?). Sur le disque : deux colombes U8. Sous le fond : marque incisée « $B »$. D. $86 \mathrm{~mm}$.

Poisson :

*18 Musée de Carthage (Ennabli 1976, n 732). Sur le bandeau : oiseaux dont U5 (4 x 2 motifs). D. 86 ; H. $32 \mathrm{~mm}$.

19 Carthage (Ennabli 1976, $\left.\mathrm{n}^{\circ} 724\right)$. Sur le bandeau: carrés A5, B1, cordiformes M2 et M5, cercle E2, oiseau U5 (4 x 2 motifs). D. $86 \mathrm{~mm}$; H. 33mm.

20 Musée de Carthage (Ennabli 1976, $\mathrm{n}^{\circ}$ 688). Sur le bandeau: palmettes proche de P2, quadrifoliés I3, rosaces J2, cercles E2, cordiformes M5 $(5 \times 2$ motifs). Sur le disque: dauphin. D. $89 \mathrm{~mm}$; H. $36 \mathrm{~mm}$.

Vases (fig. 225)

*21 Musée de Carthage (Ennabli 1976, n 826). Sur le bandeau : quadrifoliés I2 et cercles E2 ( 5 x 2 motifs). Sur le disque: vase sans anses. D. $85 \mathrm{~mm}$; H. $32 \mathrm{~mm}$.

Motifs cruciformes (fig. 225)

Chrisme :

*22 Musée de Carthage (Ennabli 1976, n 897). Sur le bandeau: rosettes J2, quadrifoliés I2, palmettes proches de P2 (4 x 2 motifs). Sur le disque : chrisme gemmé patté. D. $84 \mathrm{~mm}$; H. $33 \mathrm{~mm}$.

Croix monogrammatiques gemmées :

23 Carthage (Ennabli 1976, $\mathrm{n}^{\circ}$ 935). Sur le bandeau : 
disques F4, cordiformes M5, disques E4 $(6 \times 2$ motifs). Sur le disque: croix monogrammatique comme celle du n ${ }^{\circ} 40$. D. $96 \mathrm{~mm}$; H. $35 \mathrm{~mm}$.

*24 Idem (Ibid., n ${ }^{\circ}$ 939). Sur le bandeau : dauphins V1 et cercles E5 (?). Sur le disque: croix monogrammatique pattée à branche horizontale dissymétrique. D. $83 \mathrm{~mm}$; H. $38 \mathrm{~mm}$.

*25 Idem (Ibid., $\mathrm{n}^{\circ}$ 974). Sur le bandeau: cercles E4, carrés A5, carrés A4, oiseaux U5 (5 x 2 motifs). Sur le disque: croix monogrammatique gemmée. D. $83 \mathrm{~mm}$; H. $35 \mathrm{~mm}$.

Croix pattée :

26 Musée de Carthage (Ennabli 1976, n 1110). Sur le bandeau : $6+6$ cordiformes M5. Sur le disque : croix pattée avec pampres stylisés et croix grecque au centre, cantonnée de deux colombes. D. $121 \mathrm{~mm}$; H. $43 \mathrm{~mm}$.

Décors géométriques (fig. 225)

Motifs rayonnants :

*27 Musée de Carthage (Ennabli 1976, n 1254). Sur le bandeau : rinceaux $\mathrm{O} 1$ rétrogrades, cordiformes $\mathrm{M} 2$, oiseau U4, carré A5 (3 x 2 motifs). Sur le disque : 2 rinceaux $\mathrm{O} 2$ et 2 étoiles autour de l'orifice de remplissage. D. $83 \mathrm{~mm}$; H. $27 \mathrm{~mm}$.

Rosace :

*28 Musée de Carthage (Ennabli 1976, n 1221). Sur le bandeau: carrés A4, cercle E5, cordiformes M2, oiseaux U5 (5 x 2 motifs). Sur le disque : rosace dans un cercle limité par des rouelles. D. $76 \mathrm{~mm}$.

Décor indéterminé

29 El Mahrine, atelier (Mackensen 1993, fig. 31, nº 6). Sur le bandeau : rosette J1, carré A5, palmette proche de P2.

30 Idem (Ibid., $\mathrm{n}^{\circ} 7$ ). Sur le bandeau : cercle E2 (?), quadrifolié I2, oiseau U5.

Variante B (fig. 226-227)

Scènes bibliques et chrétiennes (fig. 226)

Les explorateurs de Canaan. Sur le bandeau: $2+2$ disques E2, $1+1$ carreaux A6, $2+2$ croix T1 :

31 Carthage (Ennabli 1976, $\mathrm{n}^{\circ}$ 50). Sur le bandeau : disque E2, carrés A6, croix T1 (5 x 2 motifs). D. $81 \mathrm{~mm}$; H. $34 \mathrm{~mm}$.

Le veilleur de la vigne. Sur le bandeau : décors variés :

*32 Carthage (Ennabli 1976, $\mathrm{n}^{\circ} 85$ ). Sur le bandeau : carrés A6, cordiformes M4 (5 x 2 motifs). D. $87 \mathrm{~mm}$; H. $32 \mathrm{~mm}$

33-38 Idem (Ibid., $\left.\mathrm{n}^{\circ} 84, \mathrm{n}^{\circ} 86-91\right)$. D. 80-88 mm; H. 31$38 \mathrm{~mm}$.

Personnages en pied (fig. 226)

*39 Carthage (Hoff 1986, $\mathrm{n}^{\circ}$ 62). Sur le bandeau: rinceaux O1, quadrifoliés E2, cercles E2 (4 x 2 motifs). Sur le disque : homme dégainant son épée. Sous le fond: marque incisée « $B$ ». D. $80 \mathrm{~mm}$; H. $30 \mathrm{~mm}$.

40 Carthage (Hoff 1986, $n^{\circ}$ 63). Sur le disque : rinceaux O1 et cordiformes M5 (3 x 2 motifs). Sur le disque : homme tenant un épieu, à droite. D. $80 \mathrm{~mm}$; H. $40 \mathrm{~mm}$.
Animaux (fig. 226)

Lion :

*41 Carthage (Trost, Hellmann 1996, $\left.\mathrm{n}^{\circ} 67\right)^{278}$. Sur le bandeau: rinceaux $\mathrm{O} 1$, dauphins proches de V1, quadrifoliés $\mathrm{I} 2$ ( $4 \times 2$ motifs). Sur le disque : lion dans l'axe de la lampe, tête en arrière. Sous le fond : marque incisée « $B »$. D. $86 \mathrm{~mm}$; H. $33 \mathrm{~mm}$.

42 Carthage (Hoff 1986, $\left.\mathrm{n}^{\circ} 90\right)^{279}$. Sur le bandeau : carrés A6 et rinceaux $\mathrm{O} 1$ ( 4 x 2 motifs). Sur le disque: lion dans l'axe de la lampe, pâte gauche levée. D. $80 \mathrm{~mm}$; H. $30 \mathrm{~mm}$. Ours :

*43 Musée de Carthage (Ennabli 1976, n 336). Sur le bandeau: carrés A3 et A6, rosace J2, cordiformes M4 (4 x 2 motifs). D. $85 \mathrm{~mm}$; H. $33 \mathrm{~mm}$.

Cerf :

*44 Musée de Carthage (Ennabli 1976, n 361). Sur le bandeau: rinceaux $\mathrm{O} 1$ et quadrifoliés E2 $4 \times 2$ motifs). D. $88 \mathrm{~mm}$; H. $35 \mathrm{~mm}$.

45 Carthage (Ennabli 1976, $\left.\mathrm{n}^{\circ} 365\right)^{280}$. Sur le bandeau : rinceaux $\mathrm{O} 1$ et quadrifoliés E2 4 x 2 motifs). D. $81 \mathrm{~mm}$; H. $36 \mathrm{~mm}$.

46 Carthage (Chapman, Davies, Peacock 1984, Pl. 3, $\mathrm{n}^{\circ} 8$ ). Sur le bandeau : quadrifoliés E2, rinceaux O1, rosettes J2 (5 × 2 motifs).

Cheval :

*47 Musée de Carthage (Ennabli 1976, n 435). Sur le bandeau : carrés A6, rinceaux O1, cordiformes M4, quadrifoliés I3. D. $89 \mathrm{~mm}$.

Chien :

*48 Carthage (Ennabli 1976, $\mathrm{n}^{\circ}$ 475). Sur le bandeau : quadrifoliés I2, cercles E2, rinceaux O1 (4 x 2 motifs). Sur le disque : lévrier dans l'axe de la lampe. D. $88 \mathrm{~mm}$; H. $33 \mathrm{~mm}$.

49 Carthage (Hoff 1986, $\mathrm{n}^{\circ}$ 98). Sur le bandeau: quadrifoliés $\mathrm{I} 2$ et rinceaux $\mathrm{O} 1$ ( 4 × 2 motifs). Sur le disque : lévrier dans l'axe de la lampe. Sous le fond : marque incisée « $B$ ». D. $80 \mathrm{~mm} ; \mathrm{H} .30 \mathrm{~mm}$.

Oiseau :

*50 Carthage (Ennabli 1976, $\mathrm{n}^{\circ} 590$ ). Sur le bandeau : rinceaux $\mathrm{O} 1$ et quadrifoliés $\mathrm{I} 2$ (4 x 2 motifs). sur le bandeau : colombe dans l'axe de la lampe. Sous le fond : marque incisée « $B »$. D. $89 \mathrm{~mm}$; H. $33 \mathrm{~mm}$.

Poisson :

*51 Musée de Carthage (Ennabli 1976, n 681). Sur le bandeau: rinceaux O1, disques, quadrifoliés I3, cordiformes. Sur le disque : dauphin, dans l'axe de la lampe. D. $85 \mathrm{~mm}$; H. $32 \mathrm{~mm}$.

Vases (fig. 227)

*52 Musée de Carthage (Ennabli 1976, n 815). Sur le bandeau : rinceaux O1, dauphins V1 (4 x 2 motifs). Sur le disque : grand canthare. D. $90 \mathrm{~mm}$; H. $37 \mathrm{~mm}$.

Motifs cruciformes (fig. 227)

Croix monogrammatique gemmée :

*53 Carthage (Ennabli 1976, $\mathrm{n}^{\circ}$ 925). Sur le bandeau : rinceaux $\mathrm{O} 1$ ( 4 × 2 motifs). Sur le disque : croix

278 Lampe identique au Musée de Carthage: Ennabli 1976, $\mathrm{n}^{\circ} 285$.

${ }^{279}$ Lampe identique au Musée de Carthage: Ennabli 1976, $\mathrm{n}^{\circ} 277$.

${ }^{280}$ Même modèle à la Bibliothèque Nationale de France, provenant de Carthage : Hoff 1986, ${ }^{\circ} 72$. 


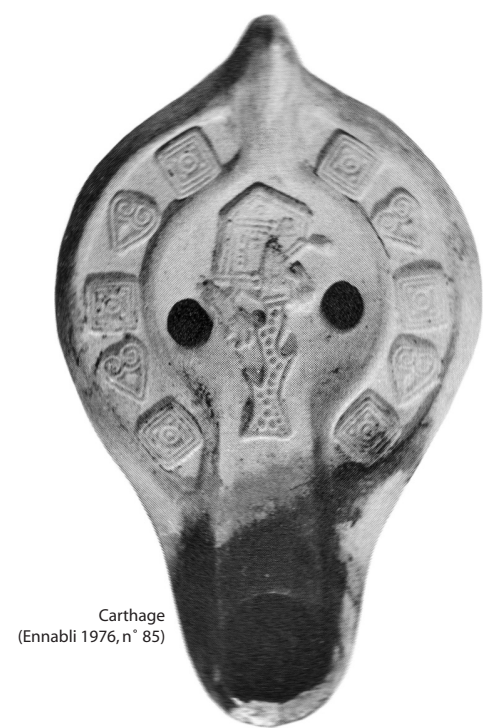

32

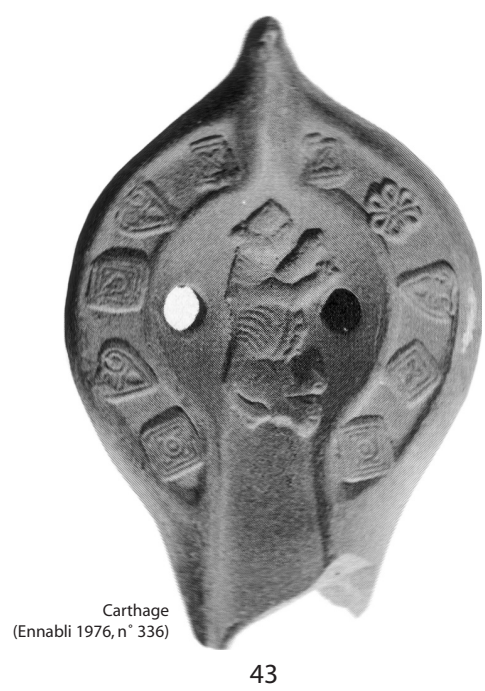

43

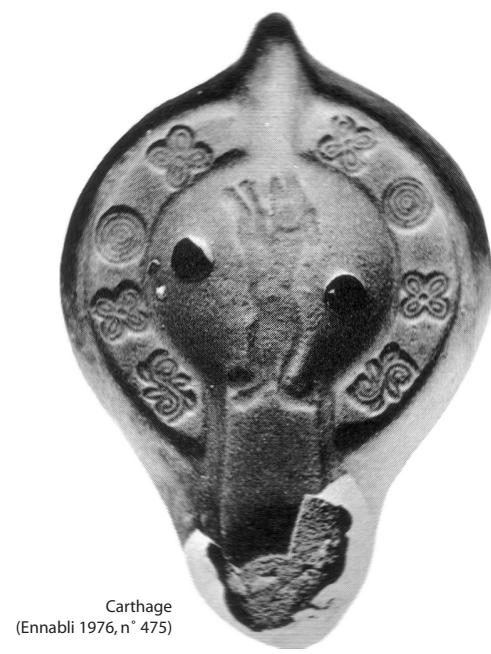

LAMPE

TYPE 66

48
Type Atlante X, groupe D3

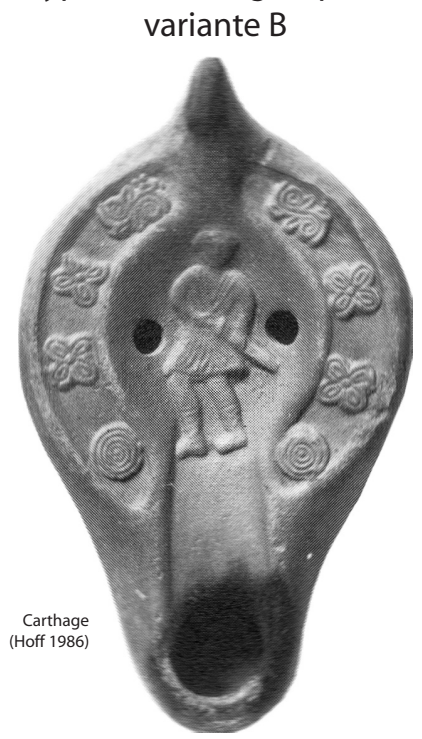

39
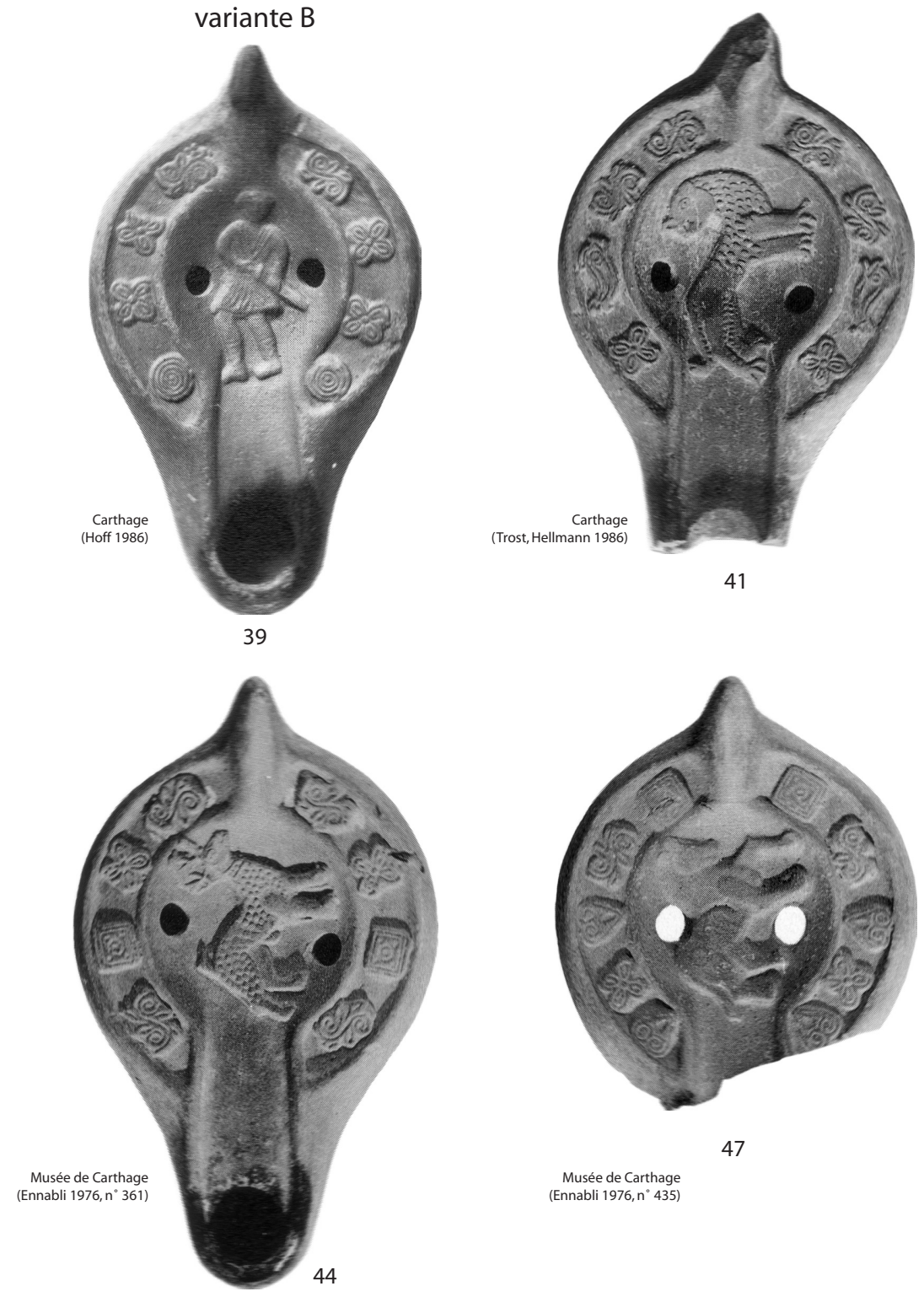

41

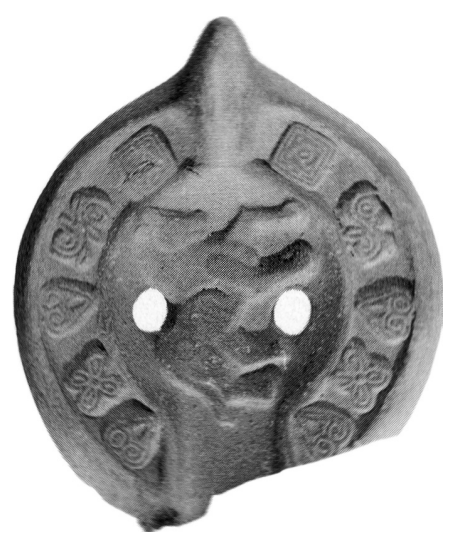

47

Musée de Carthage

(Ennabli 1976, n' 435)

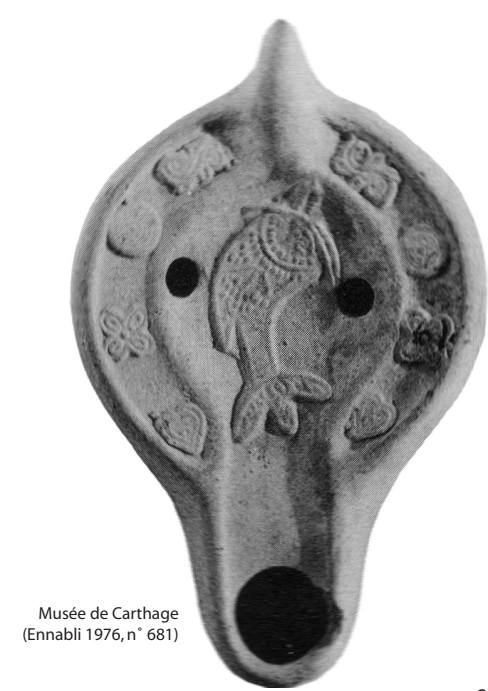

51
$2 \mathrm{~cm}$

50

Fig. 226. Lampes en sigillée africaine (Tunisie septentrionale). 
Type Atlante X, groupe D3

variante $B$

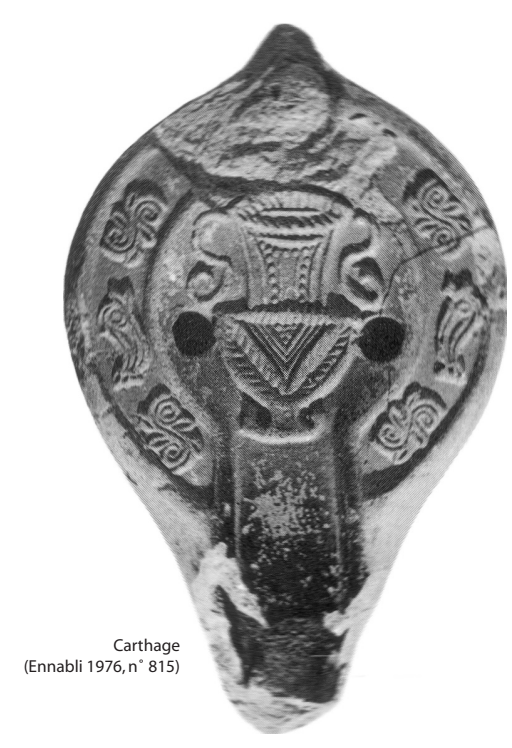

52

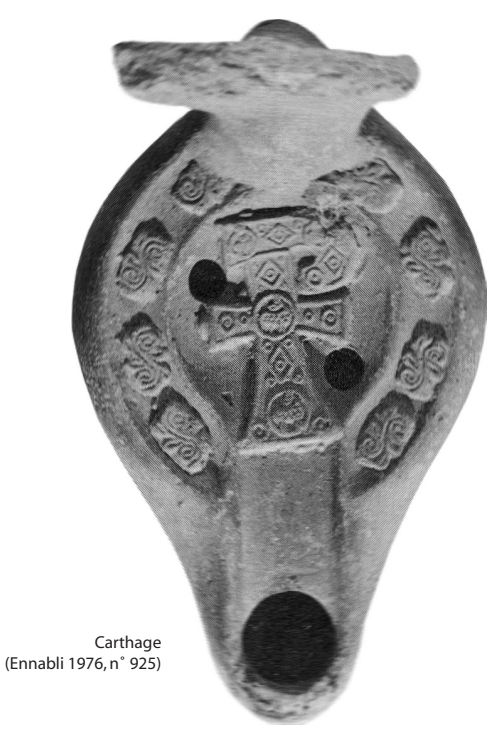

53

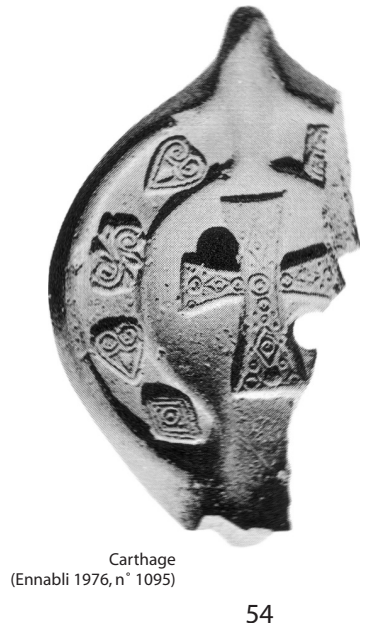

54

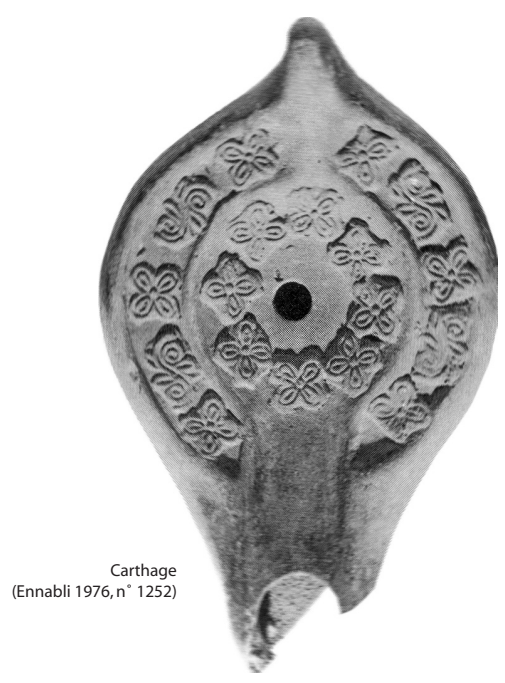

56

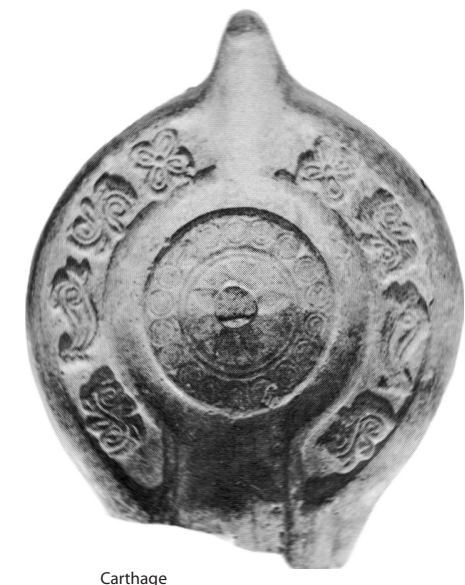

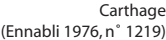

Fig. 227. Lampes en sigillée africaine (Tunisie septentrionale). 
monogrammatique comme celle du $\mathrm{n}^{\circ} \mathbf{2 3}$. Réflecteur. D. $84 \mathrm{~mm}$; H. $37 \mathrm{~mm}$.

Croix pattée :

*54 Carthage (Ennabli 1976, $\mathrm{n}^{\circ}$ 1095). Sur le bandeau : cordiformes M4, rinceaux O1, losanges C5 (4 x 2 motifs). Sur le disque : croix pattée gemmée.

55 Carthage (Chapman, Davies, Peacock 1984, Pl. 3, $\mathrm{n}^{\circ}$ 7). Sur le bandeau : quadrifoliés I3 et rinceaux O1. Disque comme le $\mathrm{n}^{\circ}$ précédent.

Décors géométriques (fig. 227)

Motifs rayonnants :

*56 Carthage (Ennabli 1976, $\mathrm{n}^{\circ}$ 1252). Sur le bandeau : quadrifoliés $\mathrm{I} 3$ et rinceaux O1 (5 x 2 motifs). Sur le disque : huit quadrifoliés I3 autour de l'orifice de remplissage. D. $81 \mathrm{~mm}$; H. $30 \mathrm{~mm}$.

Rosace :

*57 Carthage (Ennabli 1976, $\mathrm{n}^{\circ}$ 1219). Sur le bandeau : quadrifoliés I3, rinceaux O1, dauphins V1. Sur le disque : rosace dans un cercle limité par des rouelles. D. $89 \mathrm{~mm}$; H. $35 \mathrm{~mm}$.

Décor indéterminé

58 Sidi Jdidi, basilique 2, destruction état II (Inv. JD2353.20/2362.23).

59 Marseille, chantier de La Bourse (Bonifay 1983, fig. $\left.32, n^{\circ} 211\right)$. Sur le bandeau : cordiformes.

Les fragments de Sidi Jdidi (58) proviennent d'un contexte de la fin du Ve s. et ceux de Carthage $(\mathbf{8}, \mathbf{9}, \mathbf{4 6}$, 55) sont datés de la première moitié du VIe siècle. Les contextes carthaginois du milieu du VIe s. livrent des lampes appartenant majoritairement au groupe D3 (Rossiter 1993, 179, n 9, 23-27; Mackensen 1999a, fig. $\left.2, n^{\circ} 24\right)$. Il est remarquable que les contextes de la seconde moitié du Ves. dans cette ville ne livrent, en matière de lampes Atlante $\mathrm{X}$, que des exemplaires des groupes C2 et D1 et, peut-être, du groupe D2. Une lampe de Saint-Blaise (Février, Leyge 1986, n 403 ; CavaillèsLlopis, Vallauri 1994, fig. 61) a été trouvée en association avec du matériel du deuxième quart du VIe $s$. mais les autres fragments du même site (Ibid., fig. 64, $\left.\mathrm{n}^{\circ} 5-7,11\right)$ sont probablement résiduels dans des contextes de la fin du VIe siècle. Un fragment de Marseille (59) provient d'un contexte du deuxième tiers du VIe siècle.

Datation proposée: fin du Ve s. - troisième quart du VIe s.

On remarque que ces produits n'apparaissent pratiquement pas au sein de la collection du Museo Nazionale Romano (Barbera, Petriaggi 1993: n 190, $\mathrm{n}^{\circ} 229$ )

- lampes Atlante X, groupe D4 (fig. 228)

$=$ forme Chapman-Davies-Peacock $1 \mathrm{M}$

\section{LAMPE TYPE 67}

Lampes massives et allongées, avec un médaillon souvent ovalisé (type Atlante X C). L'élément principal de décoration $\mathrm{du}$ bandeau est ici le quadrifolié I1 («quatrefoil-without-centre »: Chapman, Davies, Peacock 1984, 237), répété quatre ou cinq fois et parfois associé, de manière accessoire, à des disques F9 (Ennabli $1976, n^{\circ} 508$ et 527), à des cercles concentriques ou des cordiformes M5 (?) (Ibid., $\mathrm{n}^{\circ} 651$ ), à des oiseaux U3 $\left(n^{\circ} 62,1043,1255\right)$.

\section{Exemples (fig. 228) :}

Scène chrétienne

Christ tenant la croix et foulant aux pieds le serpent ; sur le bandeau : $4+4$ quadrifoliés I1, $1+1$ oiseaux U3 :

*1 Carthage (Ennabli 1976, $\mathrm{n}^{\circ}$ 62). D. $71 \mathrm{~mm} ;$ H. $34 \mathrm{~mm}$.

2-3 Idem (Ibid., ${ }^{\circ}$ 63-64). D. 70-73 mm; H. 32-36 mm.

4 Musée du Louvre (Hoff 1986, n 49). D. 70 mm; H. $30 \mathrm{~mm}$.

Animaux : Lion:

*5 Carthage (Bailey 1988, Q1813). Sur le bandeau : $6+$ 6 quadrifoliés I1, 1 oiseau , 1 dauphin. Sur le disque : lion assis. D. $77 \mathrm{~mm}$.

6 Carthage (Ennabli 1976, $\left.\mathrm{n}^{\circ} 261\right)$. Sur le bandeau: quadrifoliés I1 et cordiformes M5. Disque comme le $\mathrm{n}^{\circ}$ précédent. D. $83 \mathrm{~mm} ;$ H. $35 \mathrm{~mm}$.

*7 Idem (Ibid., $\mathrm{n}^{\circ}$ 271). Sur le bandeau : quadrifoliés I3. Sur le disque : lion courant, dans l'axe de la lampe. D. $78 \mathrm{~mm}$; H. $34 \mathrm{~mm}$.

Sanglier :

*8 Musée de Carthage (Ennabli 1976, n 345). Sur le bandeau : $6+6$ quadrifoliés E1 et $1+1$ oiseaux U3. Sur le disque : sanglier, dans l'axe de la lampe. D. $80 \mathrm{~mm}$; H. $35 \mathrm{~mm}$.

Oiseau :

9 Carthage (Ennabli 1976, $\mathrm{n}^{\circ}$ 527). Sur le bandeau : $5+$ 4 quadrifoliés E1 et 1 disque F9. Sur le disque : colombe, dans l'axe de la lampe. D. $86 \mathrm{~mm}$; H. $39 \mathrm{~mm}$.

*10 Musée du Bardo (Ennabli 1976, n 542). Sur le bandeau: quadrifoliés I1. Sur le disque: paon (?) dans l'axe de la lampe. D. $84 \mathrm{~mm}$; H. $40 \mathrm{~mm}$. Poisson :

*11 Musée de Carthage (Ennabli 1976, n ${ }^{\circ} 700$ ). Sur le bandeau: $6+6$ quadrifoliés E1. Sur le disque : dauphin dans l'axe de la lampe. D. $81 \mathrm{~mm} ; \mathrm{H}$. $33 \mathrm{~mm}$.

Motifs cruciformes

Croix monogrammatique :

*12 Carthage (Chapman, Davies, Peacock 1984, Pl. 3, $\left.\mathrm{n}^{\circ} 10\right)$. Sur le bandeau: $6+6$ quadrifoliés E1, 2 cercles E6 (?). Croix monogrammatique gemmée rétrograde (infra, LAMPE TYPE 68, $\mathrm{n}^{\circ} 6$ : motif identique). D. $94 \mathrm{~mm}$.

Croix pattée :

*13 Musée de Carthage (Ennabli 1976, n 1084). Sur le bandeau : $5+3$ quadrifoliés E1, 1 cordiforme M5, 1 disque F9 (6 x 2 motifs). Sur le disque : croix pattée gemmée cantonnée d'oiseaux U3. D. $76 \mathrm{~mm}$; H. $35 \mathrm{~mm}$.

Décor indéterminé :

14 Marseille, chantier de La Bourse (Bonifay 1983, fig. $\left.32, n^{\circ} 212\right)$. Sur le bandeau : quadrifoliés E1. 
Typologie - Lampes

Type Atlante X, groupe D4

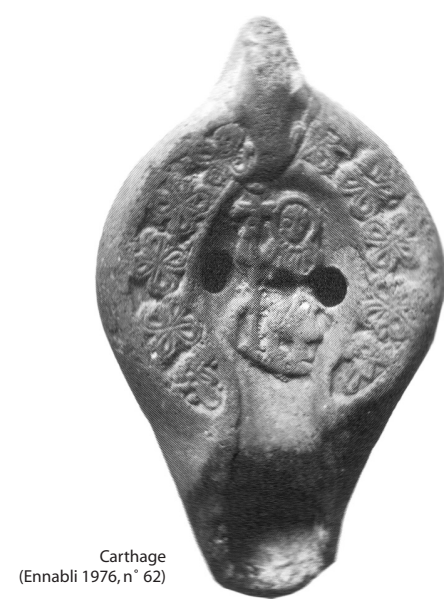

1

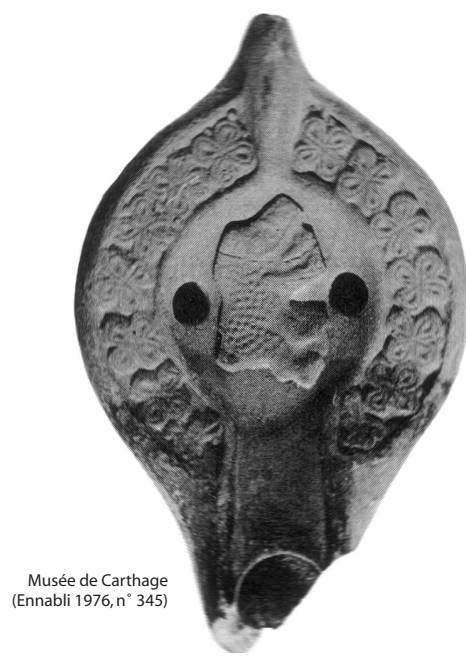

8
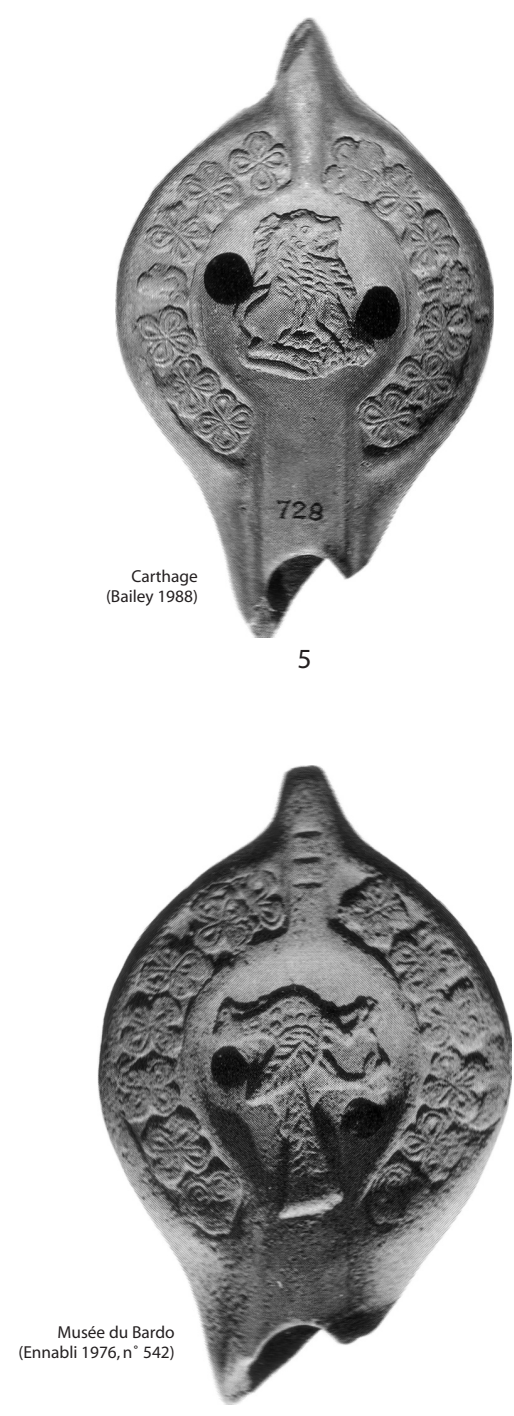
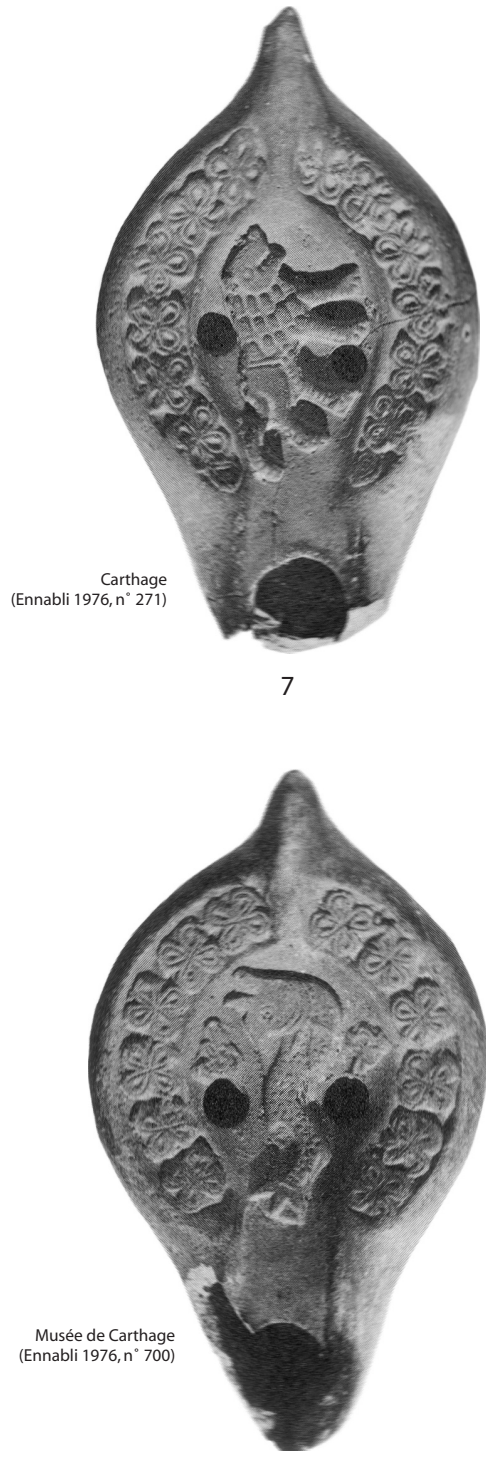

11

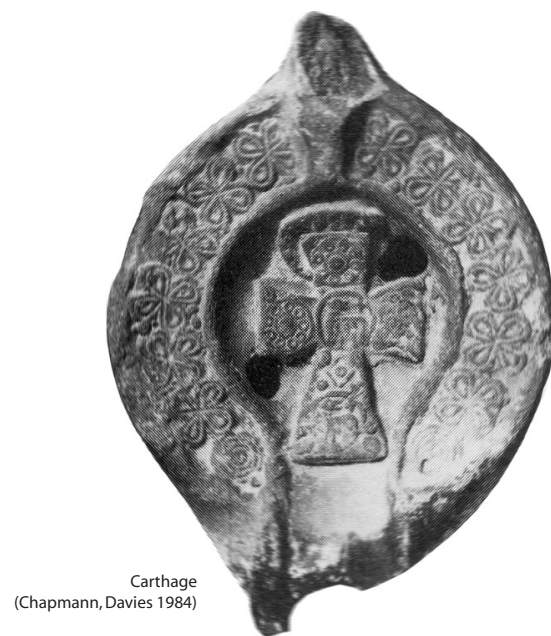

12

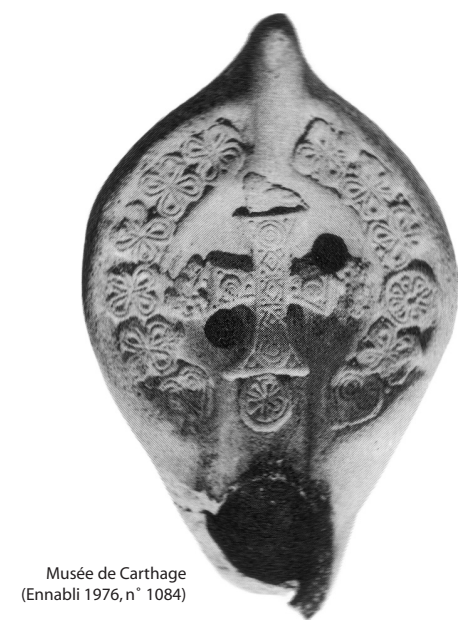

13

Fig. 228. Lampes en sigillée africaine (Tunisie septentrionale). 
Il est probable que certaines de ces lampes ont été produites sur l'atelier d'Oudhna (12 ?) (infra, LAMPE TYPE $68, \mathrm{n}^{\circ} 6$, décor du disque); mais on remarque également sur le $\mathrm{n}^{\circ} \mathbf{8}$, une connexion décorative avec le groupe D3 (Ennabli 1976, n 344 et 345). Les données chronologiques de Carthage (12) et de Marseille (14) concordent pour situer ce groupe à la fin du VIe s. et dans la première moitié du VIIe siècle. Le $\mathrm{n}^{\circ} \mathbf{5}$, de bonne facture (attribué à la forme Hayes II A par D. Bailey), pourrait être plus précoce.

\section{— productions tardives}

Les productions les plus tardives de lampes en sigillée africaine peuvent présenter diverses particularités :

- des décors à contours saillants, se chevauchant parfois,

- des décors estompés,

- des décors linéaires.

Ces caractères qui distinguent les lampes tardives ne sont pas exclusifs les uns des autres; ils ne constituent pas non plus des règles absolues. Ils se joignent à d'autres particularités, comme la dégradation de la pâte et du vernis (qualité proche de la sigillée D4) et une tendance à des formes plus ovoïdes, avec un bec relevé. Il est, dans cette phase de la production, difficile de distinguer les origines des différents types qui commencent tout juste, dans l'état des recherches, à se détacher.

\section{- décors à contours saillants et/ou se chevauchant (fig. 229)}

\section{LAMPE TYPE 68}

Sur un certain nombre de lampes, les décors du bandeau et du médaillon portent, autour de chaque motif, une bordure irrégulière en relief évoquant les contours d'une image qui aurait été découpée à grands coups de ciseaux. Cette particularité se rencontre déjà sur quelques lampes de bonne facture, généralement de production D3 (ex. : Trost, Hellmann 1996, $\mathrm{n}^{\circ} 110$ ), mais également, dans un cas, sur un moule du groupe C2 ou C4 (Bailey 1988, Q1824); elle est toutefois plus fréquente sur les lampes du groupe D4 (ex. : Trost, Hellmann 1996, n 76,148 ). Ces objets indiquent selon toute vraisemblance (Ibid., 4243) que les décors d'applique n'ont pas été ébarbés lors de la confection de l'archétype qui a servi à la fabrication du moule en plâtre. Mais on ne peut pas non plus exclure, pour certains exemplaires tardifs, que les poinçons aient été directement imprimés dans un moule en argile. Cette dernière hypothèse pourrait en particulier s'appliquer aux exemplaires sur lesquels les motifs du bandeau se chevauchent (4) et à ceux dont le décor présente un relief très anguleux $(\mathbf{2}, \mathbf{5})$.

Exemples (fig. 229) :

Variante précoce (?)

*1 Musée de Carthage (Ennabli 1976, n 147). Sur le disque : cordiformes M4, rinceaux O1 et Q3. Sur le disque : «guerriers combattant (?) ». D. $82 \mathrm{~mm}$; H. $34 \mathrm{~mm}$.

Scènes chrétiennes

*2 Carthage (Ennabli 1976, n 69). Sur le bandeau : disques F9, cordiformes M4, quadrifoliés K5, croix T1 (5 x 2 motifs). Sur le disque : le Christ foulant aux pieds le serpent. D. $84 \mathrm{~mm}$; H. $34 \mathrm{~mm}$.

3 Carthage (Riley 1981, Pl. 4, n 40). Sur le bandeau : quadrifoliés, oiseaux. Disque comme le $\mathrm{n}^{\circ}$ précédent (?).

*4 Musée de Carthage (Ennabli 1976, n 73). Sur le bandeau : disques à l'agneau $\mathrm{W} 3$, oiseaux U1 et U2, losanges $\mathrm{C} 5$, masques (6 2 motifs). Sur le disque : archange (?). D. $78 \mathrm{~mm}$; H. $36 \mathrm{~mm}$.

*5 Carthage (Ennabli 1976, $\mathrm{n}^{\circ} 82$ ). Sur le bandeau : $6+$ 6 disques à l'agneau W3. Sur le disque : le veilleur de la vigne. D. $81 \mathrm{~mm}$; H. $36 \mathrm{~mm}$.

*6 Oudhna (Barraud et al. 1998, fig. 13, n 13). Sur le bandeau: disques à l'agneau W3, cordiforme M5, masque humain, quadrifoliés K5 (?) (7 x 2 motifs). D. $80 \mathrm{~mm}$; H. $36 \mathrm{~mm}$.

Sans décor

*7 Carthage (Ennabli 1976, $\mathrm{n}^{\circ}$ 1265). Sur le bandeau : $5+$ 5 quadrifoliés I1. D. $80 \mathrm{~mm}$; H. $38 \mathrm{~mm}$.

Décor indéterminé

8 Marseille, chantier de La Bourse (Bonifay 1983, fig. $\left.32, \mathrm{n}^{\circ} 215\right)$. Sur le bandeau: oiseau, masque, disque à l'agneau $\mathrm{W} 3$.

Les exemples ci-dessus montrent bien qu'il s'agit principalement de productions du nord de la Tunisie (décors des groupes D3 et D4). Les rares éléments en stratigraphie proviennent de contextes de la fin du VIe s. et du début du VIIe siècle (8).

- décors estompés (fig. 230)

\section{LAMPE TYPE 69}

Des séries de lampes assez nombreuses, qui conservent par ailleurs une forme classique, ont un décor partiellement ou complètement estompé ; ce dernier n'est parfois plus signalé que par une légère ondulation de la surface du bandeau. Cette particularité est probablement due à des surmoulages répétés et/ou à l'utilisation de moules usés (9). On peut toutefois encore distinguer les lampes se rattachant aux groupes $\mathrm{C} 4$ ou $\mathrm{C} 5$, probablement produites en Tunisie centrale, dont le décor reste toujours relativement lisible (1-2, 3-5). Certains exemplaires sont également de type centro-tunisien (cordiformes serrés entre eux ou imbriqués avec des chevrons, sur le bandeau) (6-8) mais paraissent plutôt produits dans le nord de la Tunisie, du fait de leur bonne diffusion dans la région de Carthage. Enfin, les productions classiques des ateliers septentrionaux subissent également des surmoulages intensifs (groupes D2 : 10-11 et D3-4 : 12-19)

Exemples (fig. 230) :

Groupe $\mathrm{C} 4$ ou $\mathrm{C} 5$, productions de Tunisie centrale (?)

$* 1$ Littoral tunisien, site $\mathrm{n}^{\circ} 85$ (Jezira) (Bonifay et al. 2002-2003, fig. $18, \mathrm{n}^{\circ} 253$. Sur le disque: croix monogrammatique type Barbera-Petriaggi 210E (?). 
Type Atlante X tardif,

décors à contours saillants
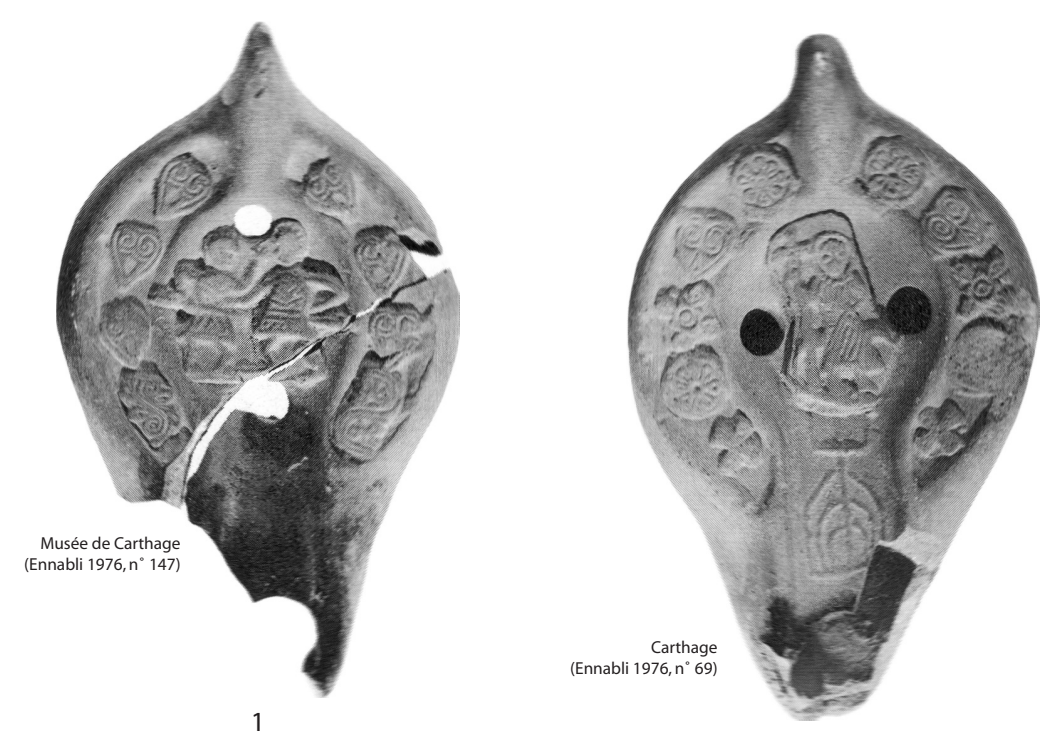

2

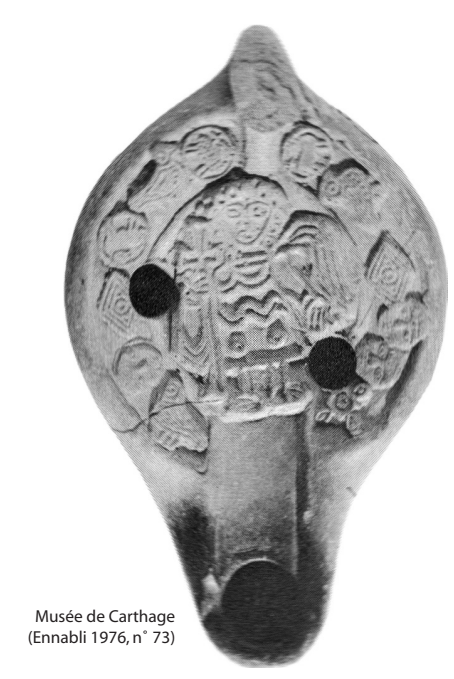

4

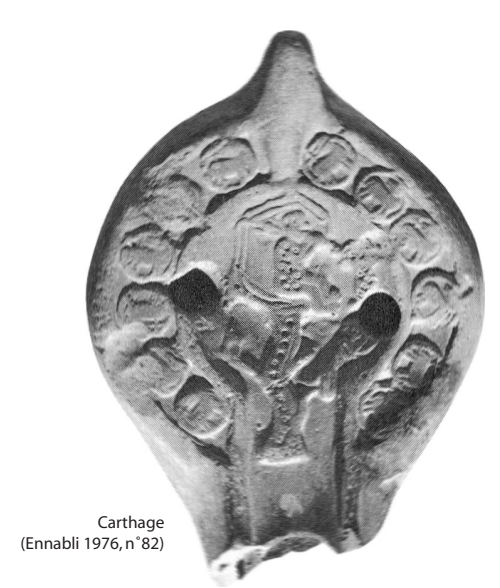

5

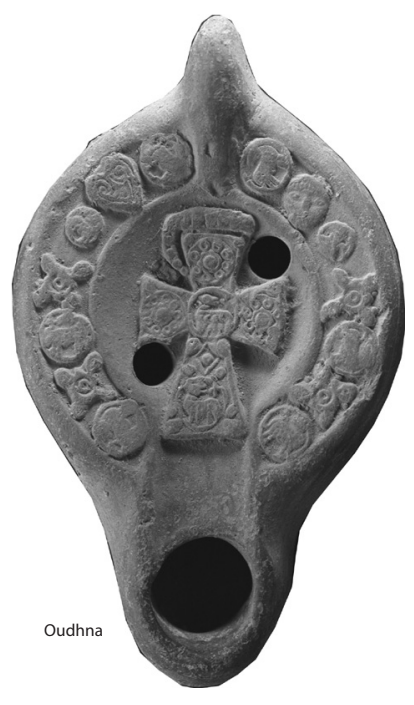

6

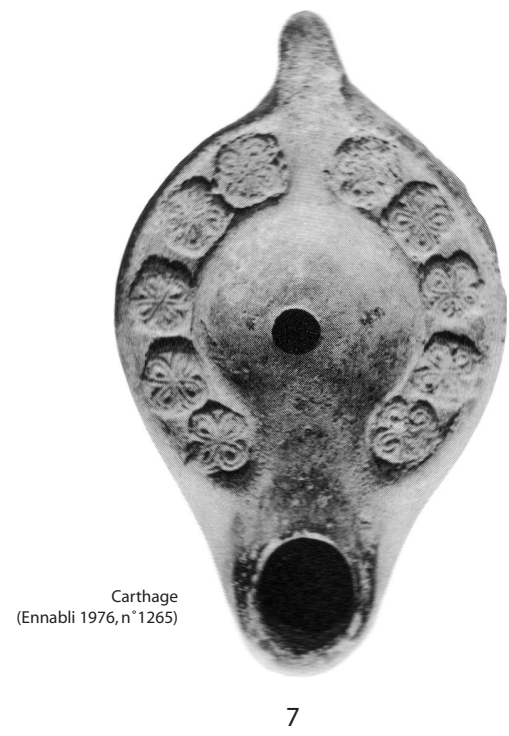

Fig. 229. Lampes en sigillée africaine, productions tardives. 


\section{Typologie - Lampes}
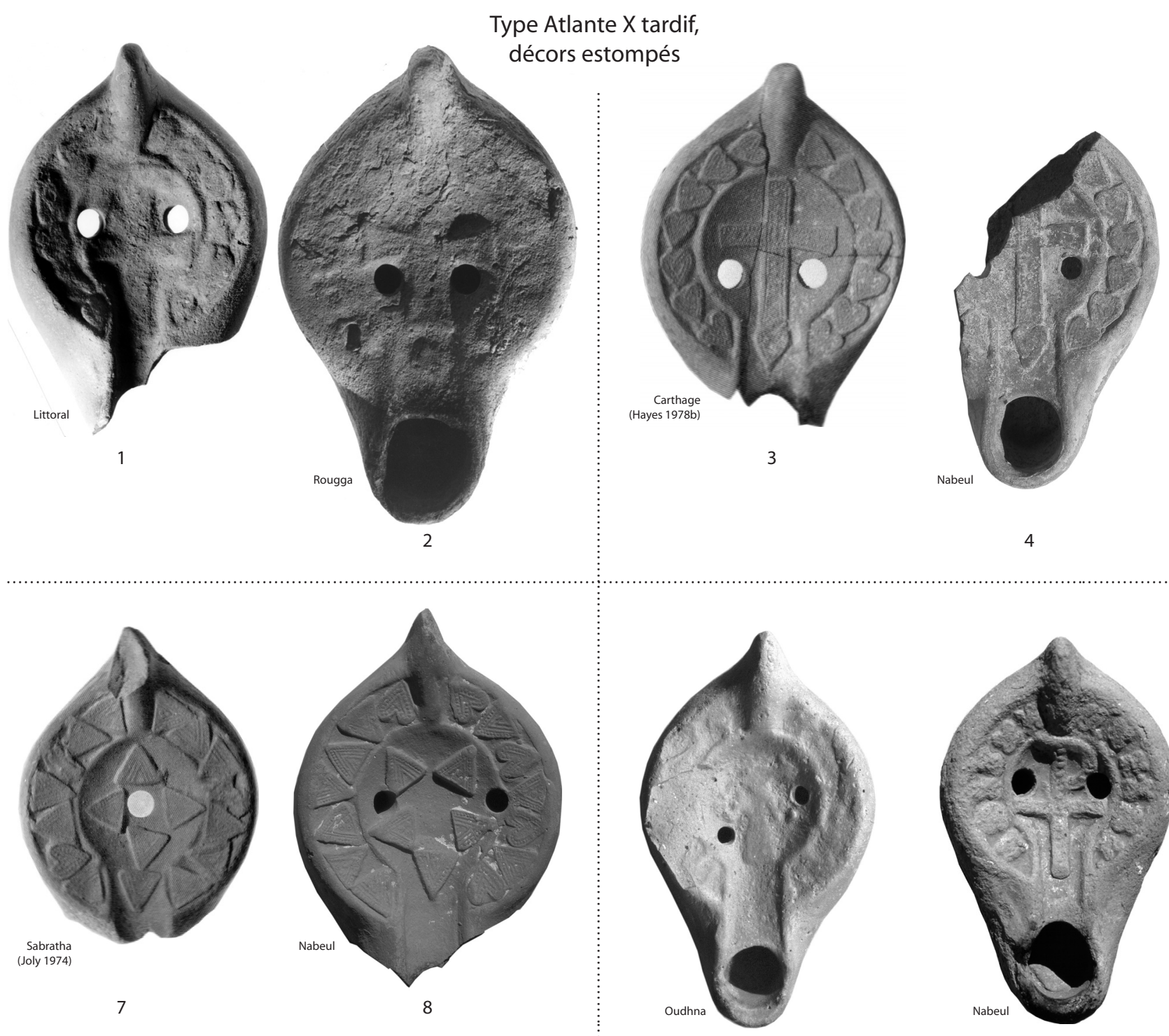

10

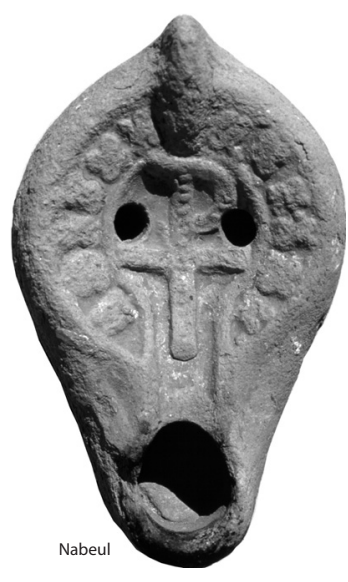

11
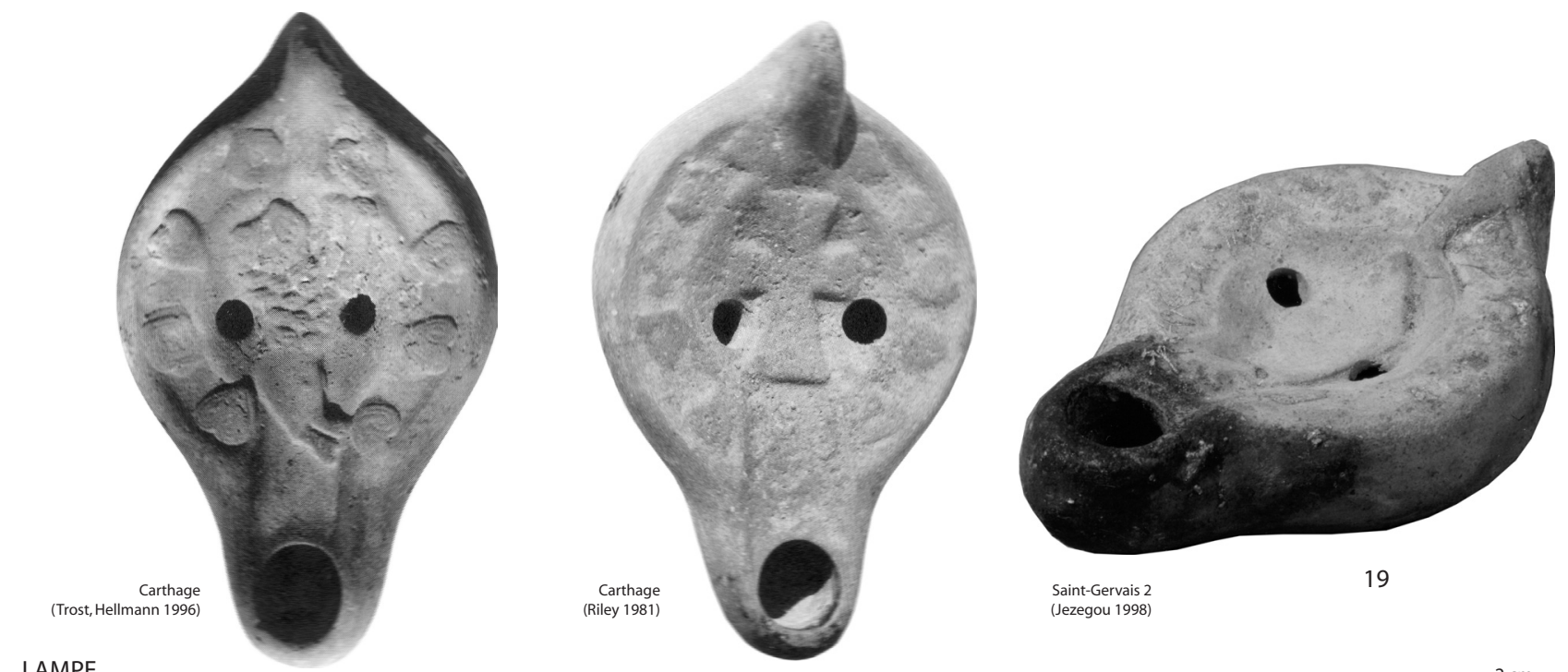

TYPE 69

12

15

$2 \mathrm{~cm}$

Fig. 230. Lampes en sigillée africaine, productions tardives. 
D. $76 \mathrm{~mm}$.

*2 Rougga, couche 10 (Guéry, Bonifay à paraître, $\mathrm{n}^{\circ} 373$ ). Sur le disque : croix pattée (?). D. $85 \mathrm{~mm}$.

Groupe C5, productions de Tunisie centrale ou imitations septentrionales (?)

Croix latine posée sur un cordiforme

*3 Carthage (Hayes 1978b, G35). Sur le bandeau : $7+7$ cordiformes M8 (?). Sur le disque: grande croix latine sur un cordiforme. D. $77 \mathrm{~mm}$.

*4 Nabeul, fouilles anciennes (sans $\mathrm{n}^{\circ}$ d'inv.). Décor identique.

5 Torcello (Italie) (Leciejwicz, Tabaczińska, Tabacziński 1977, fig. 57). Décor identique. Croix en relief sous le fond. D. env. $80 \mathrm{~mm}$.

Variante

6 Rome, Crypta Balbi (Pavolini 1998, fig. 3). Croix Barbera Petriaggi 210A.

Décor géométrique à motifs rayonnants

*7 Musée de Sabratha (Joly 1974, $\mathrm{n}^{\circ}$ 1133). Sur le bandeau: chevrons D2 et cordiformes M8 (?) imbriqués. Sur le disque: cinq chevrons D2. D. $70 \mathrm{~mm}$.

*8 Nabeul, fabrique de salaison, période 6 (Inv. NB1428.55). Décor analogue à celui du ${ }^{\circ}$ précédent. D. $78 \mathrm{~mm}$.

Groupe D2

9 Oudhna, thermes des Laberii (supra, fig. 42, $\mathrm{n}^{\circ} 4$; Barraud et al. 1998, fig. 18, n 35). Moule en plâtre.

*10 Oudhna, capitole (fouilles H. Ben Hassen, Inv. UTH1.002.181). Sur le disque : oiseau, dans l'axe de la lampe. Surmoulage de la lampe Ennabli 1976, $\mathrm{n}^{\circ} 532$. D. $69 \mathrm{~mm}$.

*11 Nabeul, fabrique de salaison, période 6 (Bonifay 2002 , fig. $3, n^{\circ} 23$ ). Schéma décoratif proche de celui $\mathrm{du}$ groupe $\mathrm{D} 2$ mais forme particulière, à bec très relevé. Pâte brune, engobe rouge carmin écaillé. D. $67 \mathrm{~mm}$; H. $34 \mathrm{~mm}$.

Groupes D3 et D4

*12 Carthage (Trost, Hellmann 1996, n 66). Décors empâtés. Sur le bandeau: carrés A5 et A6 (?), cordiformes M5 (?) (4 x 2 motifs). Sur le disque: lion courant, dans l'axe de la lampe. D. $84 \mathrm{~mm}$; H. $34 \mathrm{~mm}$.

13 Carthage (Riley 1981, Pl. 4, n XXVIII.13). Sur le bandeau : quadrifoliés I1 estompés.

14 Carthage (Riley 1981, Pl. 40, n XXIX.38). Sur le disque : croix monogrammatique. D. $86 \mathrm{~mm}$.

*15 Idem (Ibid., $\mathrm{n}^{\circ}$ XXIX.37). Sur le disque : croix pattée. D. $81 \mathrm{~mm}$.

16-17 Marseille, chantier de La Bourse (Bonifay 1983, fig. $32, n^{\circ} 214$ et 216 ).

18 Saint-Blaise (Cavaillès-Llopis, Vallauri 1994, fig. 65, $\left.\mathrm{n}^{\circ} 14\right)$.

*19 Epave Saint-Gervais 2 (Fos-sur-Mer, France) (Jézégou 1998, fig. 308, $\mathrm{n}^{\circ}$ 12).

Les exemplaires positionnés en stratigraphie sont proportionnellement ici plus nombreux car ces lampes sont trop peu esthétiques pour avoir attiré la convoitise des musées. Tous indiquent une production à la fin du VIe s. et au VIIe siècle. Cette datation convient bien aux exemplaires de Carthage (12-15) et au contexte général de découverte du $n^{\circ} \mathbf{1}$. Le $n^{\circ} \mathbf{2}$ provient d'une couche de la première moitié du VIIe siècle. Les données provenant de sites non africains confirment cette datation tardive (16-18). Le $n^{\circ} 5$ ne paraît pas antérieur au milieu du VIIe s. et les $n^{\circ} 6,11$ et 19 pourraient atteindre la fin du siècle. A Rome, le contexte de la Crypta Balbi daté de la fin $\mathrm{du}$ VIIe s. livre plusieurs exemplaires dérivés du groupe C5 (Crypta Balbi, ${ }^{\circ}$ II.3.68, 71, 74, 79) et du groupe D4 (Ibid., n II.3.69-70, 76). L'exemplaire de la maison forte de Sant-Peyre au Bouquet (Gard) n'est peutêtre pas antérieur au VIIIe s. (Provost et al. 1999, 260 et fig. 241).

\section{• décors linéaires (fig. 231-232)}

\section{LAMPE TYPE 70}

De nouveaux types, peu standardisés, présentent la particularité d'avoir une décoration non plus effectuée avec des poinçons-matrices appliqués sur un archétype servant à la confection du moule en plâtre, mais directement incisée à la pointe sèche dans le moule. Ce moule se doit alors d'être en argile, comme celui de Rougga (supra, fig. 42, n 5) (Guéry 1985b, 404 et fig. 4, c). Le décor du bandeau et du disque prennent une allure à la fois linéaire et naïve (Ibid.) déjà signalée sur une lampe en céramique commune de TYPE $25\left(\mathrm{n}^{\circ} 2\right)$ (supra, fig. 193). Mais il est remarquable qu'une technique employée en d'autres temps et en d'autres lieux, pour imiter sommairement les lampes africaines (infra, p. 461) soit adoptée par les ateliers proprement africains ; parfois, au demeurant, la technique reste mixte (4). Peut-être ne faut-il pas voir dans cette mutation qu'un simple appauvrissement technologique mais également l'influence des autres productions méditerranéennes, lampes syropalestiniennes et surtout siciliennes. La technique du décor linéaire semble se propager à la fois dans les ateliers du centre et du nord de la Tunisie. La pâte de certaines de ces lampes s'éloigne de la qualité de la céramique sigillée pour se rapprocher parfois de celle de la céramique commune (infra, LAMPE TYPE 71).

Malgré l'état encore embryonnaire de la documentation, il semble possible de distinguer trois grandes variantes :

- Variante A : lampes dérivées du type Atlante X A, avec un décor incisé dans le moule reproduisant sur le bandeau les traditionnels motifs géométriques de carrés, triangles, disques, quadrifoliés.

- Variante B : même forme que la précédente mais avec une inscription sur le bandeau, en caractères grecs et néo-puniques (selon Hoff 1986), incisée dans le moule.

- Variante C: dérivées du type Atlante X B, ces lampes comportent un bandeau décoré d'une palme. Ce décor, ainsi que celui du disque, est gravé dans le moule $(\mathbf{1 4})$ ou directement sur la lampe $(\mathbf{1 3}, \mathbf{1 5})$.

Exemples (fig. 231-232) :

Variante A (fig. 231)

Production du nord de la Tunisie (?)

*1 Musée de Sabratha (Joly 1974, n 1187). Sur le bandeau: quadrifoliés et cercles. Sur le disque: chien (?) et lièvre côte à côte, dans l'axe de la lampe. D. $78 \mathrm{~mm}$. 
Type Atlante $\mathrm{X}$ tardif, décors linéaires
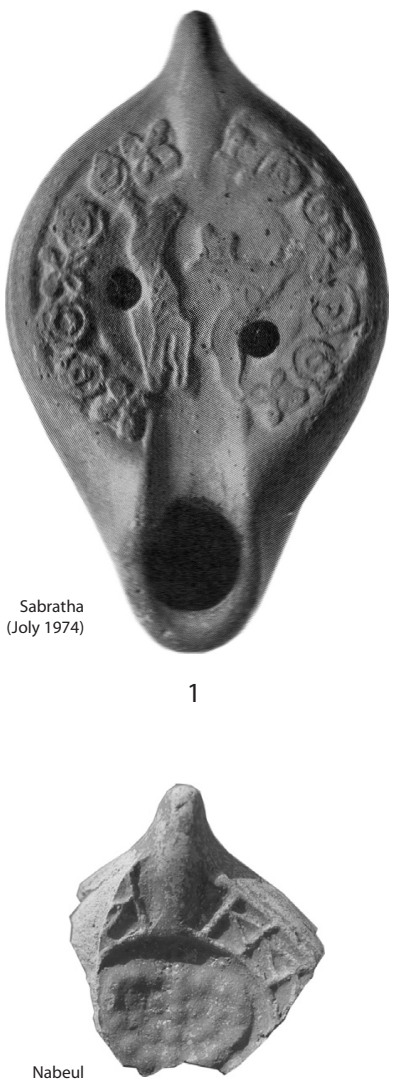

4

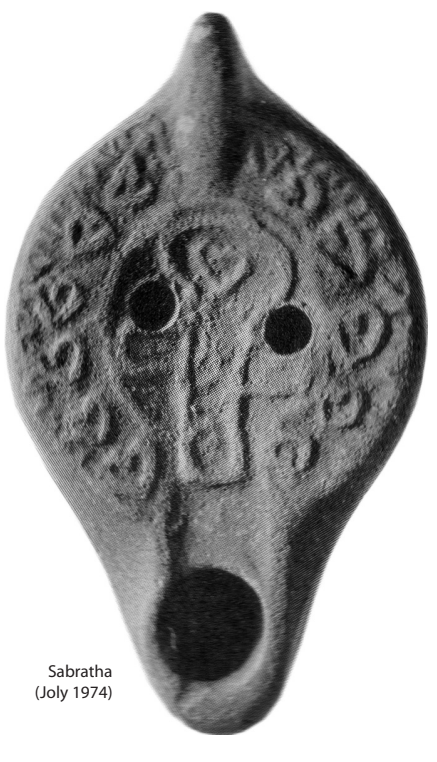

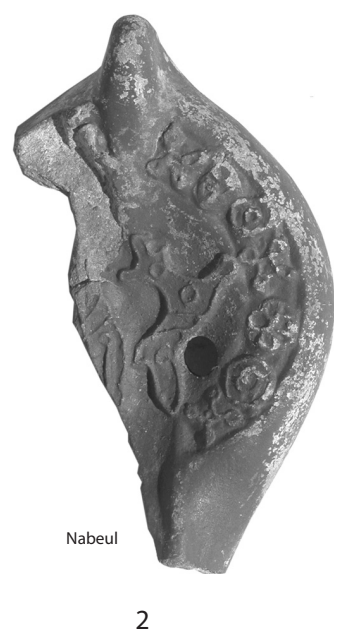

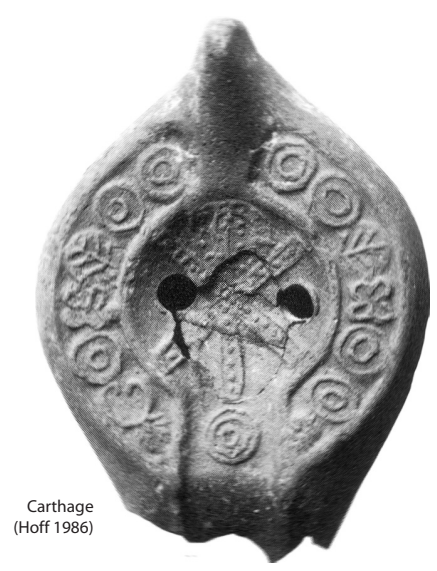

5

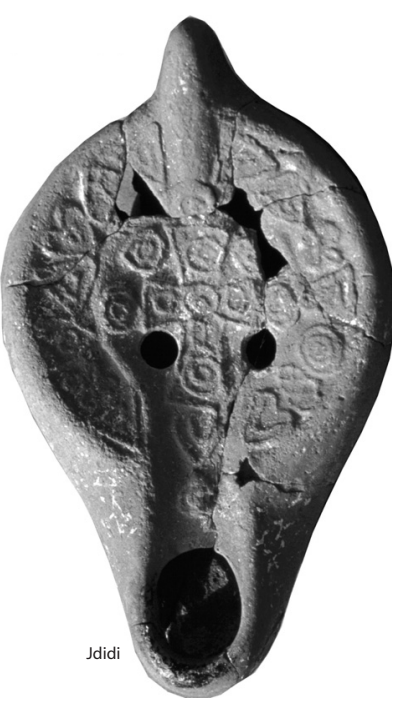

8

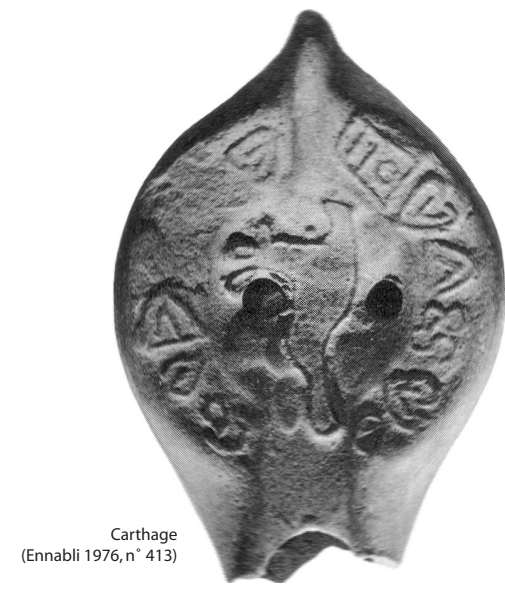

3
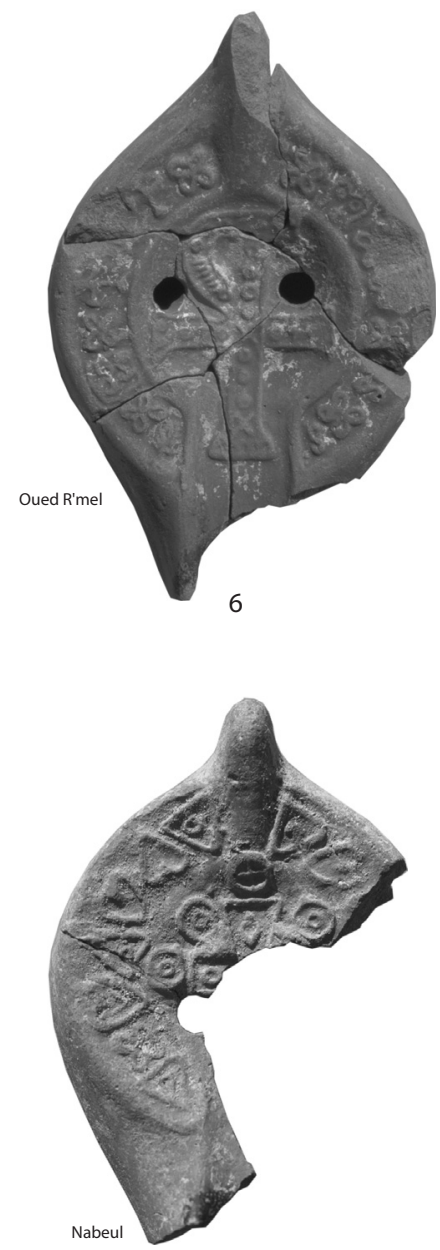

10

A 
*2 Nabeul, fouilles anciennes (sans $\left.\mathrm{n}^{\circ}\right)$. Décoration comparable à celle du $\mathrm{n}^{\circ}$ précédent.

*3 Carthage (Ennabli 1976, $\mathrm{n}^{\circ}$ 413). Sur le bandeau : cordiformes et chevrons. Sur le disque: lièvre courant. D. $80 \mathrm{~mm}$.

*4 Nabeul (sans $n^{\circ}$ d'inv.). Sur le bandeau: guirlande stylisée (?). Sur le disque : chandelier à sept branches obtenu au poinçon-matrice.

*5 Carthage (Hoff 1986, $\mathrm{n}^{\circ}$ 104). Sur le bandeau : cercles, palmes, quadrifoliés, cordiforme ?). Sur le disque : chrisme perlé sur un cercle. D. $80 \mathrm{~mm}$; H. $30 \mathrm{~mm}$.

*6 Oued R'mel (fouilles T. Ghalia, Inv. 2417.2). Sur le bandeau: quadrifoliés. Sur le disque: croix monogrammatique rétrograde.

*7 Musée de Sabratha (Joly 1974, $\mathrm{n}^{\circ}$ 1248). Sur le bandeau : $6+6$ cordiformes. Sur le disque : croix monogrammatique. D. $86 \mathrm{~mm}$.

*8 Sidi Jdidi, basilique 1, état C2B (Bonifay 2002, fig. $3, n^{\circ} 22$ ). Sur le bandeau: cordiformes. Sur le disque: croix pattée gemmée, imitant le type Barbera-Petriaggi 212, cantonnée de rouelles. D. $78 \mathrm{~mm}$.

9 Sidi Jdidi, basilique 1, état C2B (Bonifay, Reynaud 2004, $\left.\mathrm{n}^{\circ} 32.7\right)$. Identique au $\mathrm{n}^{\circ}$ précédent.

*10 Nabeul, fabrique de salaison, période 6 (Inv. NB1536.11). Décoration comparable à celle des deux $\mathrm{n}^{\circ}$ précédents.

Variante B (fig. 232)

*11 Carthage (Hoff 1986, $\mathrm{n}^{\circ}$ 137). Sur le bandeau: inscription en caractères grecs et néo-puniques (?).
Sur le disque: poisson dans l'axe de la lampe. D. $80 \mathrm{~mm}$; H. $40 \mathrm{~mm}$

*12 Nabeul, fouilles anciennes (sans $n^{\circ}$ ). Sur le bandeau : inscription analogue à celle du $\mathrm{n}^{\circ}$ précédent ou pseudo-inscription (?). Sur le disque : croix cantonnée de rouelles, comparable à celles des $n^{\circ} 8$ 10.

Variante C (fig. 232)

*13 Rougga, couche 11 (Guéry, Bonifay à paraître, $\mathrm{n}^{\circ}$ 374). Sur le disque : chrisme.

*14 Rougga, couche 10 (Guéry, Bonifay à paraître, $\mathrm{n}^{\circ} 375$ ). Sur le disque : rosace.

*15 Olbia de Provence, fouilles anciennes (sans $n^{\circ}$ d'inv.). Sur le disque : décor rayonnant sommairement incisé à même la lampe.

Les lampes de la variante A apparaissent généralement dans les niveaux d'époque byzantine tardive ou du début de l'époque islamique. Les exemplaires de Sidi Jdidi et Nabeul (8-10) sont issus des contextes les plus tardifs des deux sites, probablement pas antérieurs à la fin du VIIe siècle. La même datation vaut pour l'exemplaire de la Crypta Balbi à Rome (Crypta Balbi, n ${ }^{\circ}$ II.3.72). Les exemplaires de la variante $C$ trouvés en stratigraphie à Rougga (13-14) paraissent plus anciens : fin du VIe s. et première moitié du VIIe siècle. Pas d'éléments de datation pour la variante $\mathrm{B}$ à bandeau inscrit (11-12).

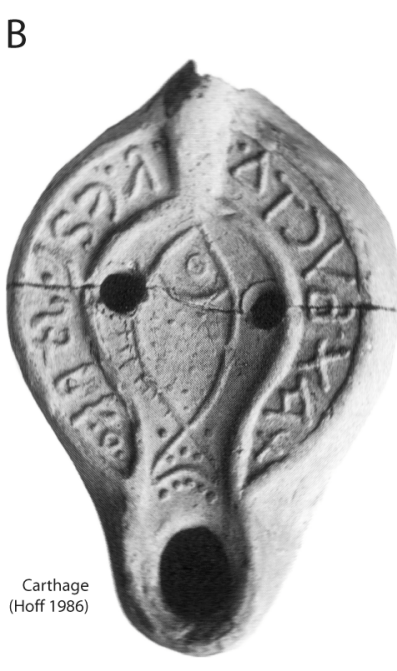

11

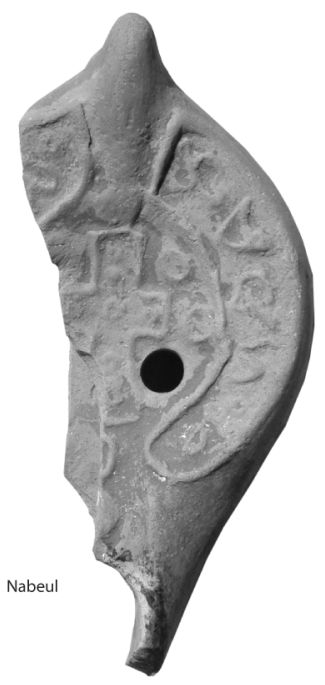

12

\section{Type Atlante X tardif,}

\section{décors linéaires}

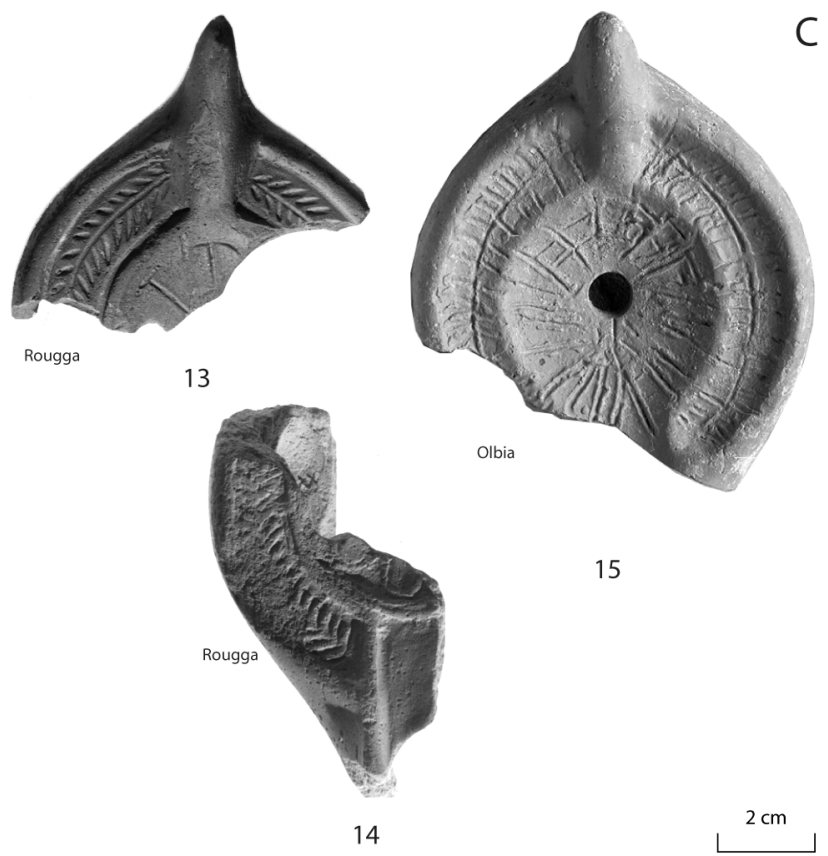

Fig. 232. Lampes en sigillée africaine, productions tardives. 
Copies en céramique commune de lampes en sigillée type Atlante $X$
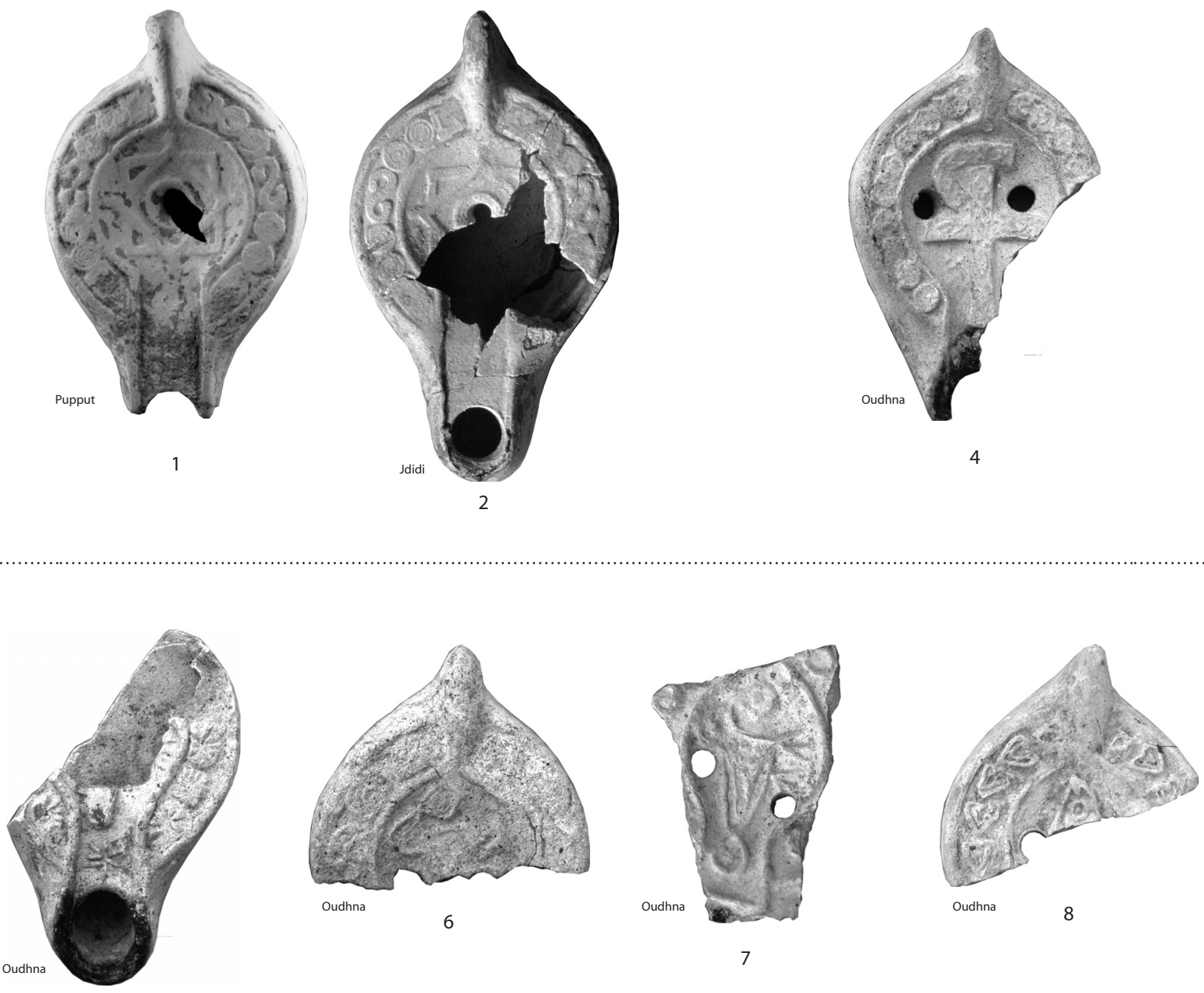

5

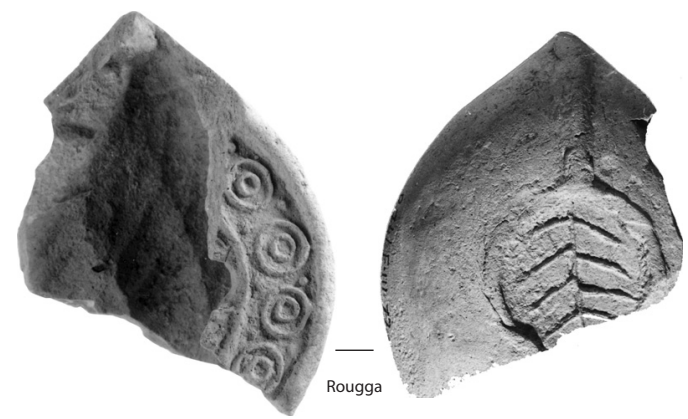

9

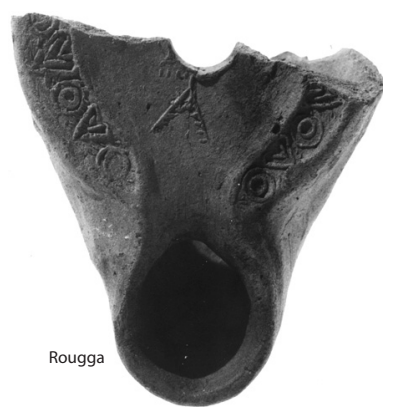

10

Fig. 233. Lampes en sigillée africaine : copies en céramique commune. 
- copies des types Atlante VIII, IX et $\mathrm{X}$ en céramique commune (fig. 233)

\section{LAMPE TYPE 71}

Les lampes en sigillée de forme Atlante X ont fait l'objet d'imitations en céramique commune africaine. Ce phénomène concerne principalement le début et la fin de la production de ces lampes.

Exemples (fig. 233) :

Surmoulages de lampes du groupe $\mathrm{C} 2$

*1 Pupput, fouilles anciennes (Ben Abed, Bonifay 1998, fig. 8). Surmoulage de lampe Atlante $\mathrm{X}$ du groupe C2.

*2 Sidi Jdidi, basilique 3, niveau d'abandon (Inv. JD5067.1). Exemplaire identique au précédent.

3 Nabeul, fabrique de salaison, période 5B (Inv. NB1146.87). Surmoulage d'une lampe Atlante XI du groupe $\mathrm{C} 2$.

Surmoulages de lampes du groupe C5

*4 Oudhna, est capitole (fouilles H. Ben Hassen, Inv. UTH7.10). Décoration inspirée des lampes Atlante X du groupe C5 : $9+9$ cordiformes et cercles sur le bandeau, croix monogrammatique (rétrograde) Barbera-Petriaggi 210E sur le disque. D. $69 \mathrm{~mm}$.

Productions tardives à décor linéaire Tunisie septentrionale

*5 Oudhna, est capitole (fouilles H. Ben Hassen, Inv. UTH7.12). Décoration linéaire (?) : rosettes et carrés sur le bandeau, croix (?) sur le disque.

*6 Idem (Inv. UTH7.11). Décoration linéaire : oves (?) sur le bandeau, colombe sur le disque.

*7 Oudhna, capitole (sans $\mathrm{n}^{\circ}$ d'inv.). Décoration linéaire : cercles (?) sur le bandeau, colombe sur le disque.

*8 Idem (sans $\mathrm{n}^{\circ}$ d'inv.). Décoration linéaire : cordiformes sur le bandeau, poisson dans l'axe de la lampe sur le disque.

Tunisie centrale

*9 Rougga, couche 6 (Guéry, Bonifay à paraître, $\mathrm{n}^{\circ} 381$ ). Sur le bandeau : cercles. Sur le fond : grande palme en relief.

*10 Rougga, couche 7 (Guéry, Bonifay à paraître, $\left.\mathrm{n}^{\circ} 383\right)$. Sur le bandeau : cercles et chevrons.

11 Rougga, couche 7 (supra, fig. 42, $\mathrm{n}^{\circ} 5$; Guéry 1985b, fig. 4, c ; Guéry, Bonifay à paraître, n 384). Moule en céramique. Sur le bandeau : quadrifoliés, triangle, cercles. Sur le disque : faucon poursuivant un lièvre.

12 Sbeitla, basilique IV (Duval 1971, fig. 432). Sur le bandeau : oves (?). Sur le disque : rosace.

Les trois premiers exemplaires sont purement et simplement des surmoulages en céramique commune de lampes du centre de la Tunisie, effectués à un moment, le deuxième tiers du Ve s. (2-3), où les officines de Tunisie septentrionale n'ont pas encore entrepris une production de masse du type Atlante X. Les cinq autres (4-8) datent plutôt de la fin de la production de ces lampes, à une époque (seconde moitié du VIIe s. ?) où l'atelier d'Oudhna produit encore des surmoulages de lampes de Tunisie centrale du groupe $\mathrm{C} 5$ et où, dans beaucoup d'ateliers, se fait le passage à la technique de décoration linéaire. Les fragments de Rougga (9-10) accompagnées d'un moule en céramique (11), proviennent de couches certainement post-byzantines, datées du VIIIe s. par le fouilleur (Guéry 1984, 96). Le décor de palme en relief du $n^{\circ} 9$ n'est pas sans rappeler les marques au revers des lampes siciliotes de la fin du VIIes. (Baccheli, Pasqualucci 1998, fig. 3, $n^{\circ}$ 2b).

\section{— lampes à deux becs}

Les lampes à deux becs comportent deux modèles :

- des lampes à becs opposés ;

- des lampes à becs divergents.

\section{- lampes à becs opposés (fig. 234)}

Les lampes à becs opposés sont bien attestées dans la production de lampes africaines classiques (Deneauve 1969, Pl. XCVIII).

\section{(= Atlante X D2)}

\section{LAMPE TYPE 72}

L'exemplaire choisi par C. Pavolini (Atlante I, Pl. CI, $\mathrm{n}^{\circ} 4$ ) pour illustrer son type $X \mathrm{D} 2$, provenant du British Museum (Bailey 1988, Q1836), est l'un des rares exemples connus. Il comporte un bandeau circulaire fermé décoré de cercles E2 et de quadrifoliés I3, caractéristiques du groupe $\mathrm{C} 2$. La forme générale rappelle une curieuse lampe de Kairouan (Ennabli 1976, n 663) qui possède le même type de bec à extrémité quadrangulaire.

Deux lampes à becs opposés (= Atlante X A1e), de dimensions comparables (D. env. $120 \mathrm{~mm}$ ), peuvent être rattachées au groupe D3 A et D1, en fonction du décor du bandeau composés dans un cas de colombes U8 et dans 1'autre de cercles E2 et de carrés A2 ( 2 et 4 , Ennabli $1976, n^{\circ} 887$ et 894$)$. Le décor de chrisme comparable sur les deux objets indique peut-être une date relativement précoce dans la production : fin du Ve ou début du VIe siècle.

Un moule de lampe à becs opposés est également signalé à Oudhna (3).

Exemples (fig. 234) :

Groupe $\mathrm{C} 2$

*1 British Museum (Bailey 1988, Q1836). D. 98 mm.

Groupe D1

*2 Musée de Carthage (Ennabli 1976, n 887). Sur le bandeau : colombes, extrémités cantonnées de deux points. Sur le disque : chrisme gemmé. D. $120 \mathrm{~mm}$. Groupe D2 (?)

3 Oudhna $\left(C M A, \mathrm{n}^{\circ} 397\right)$. Moule en plâtre.

Groupe D3

*4 Musée de Carthage (Ennabli 1976, n 894). Sur le bandeau: dauphins V2, carrés A2 A et cercles E2. Sur le disque : chrisme gemmé. D. $117 \mathrm{~mm}$.

\section{- lampes à becs divergents}

Les lampes à becs divergents sont connues depuis la plus haute Antiquité. La plupart des lampes puniques tournées comportent deux becs (Deneauve 1969, 21), de même 
Type Atlante $\mathrm{X}$ à deux becs opposés

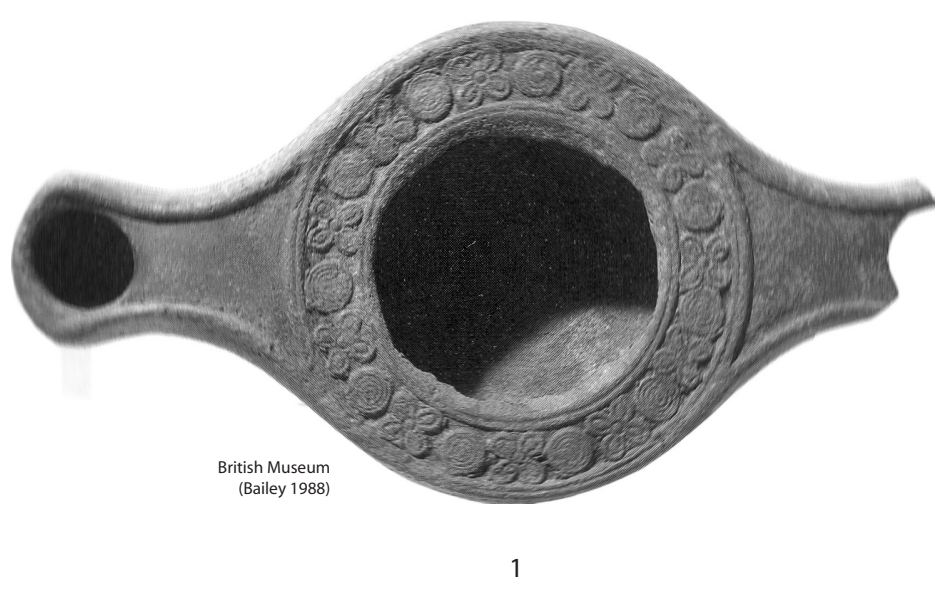

groupe C2

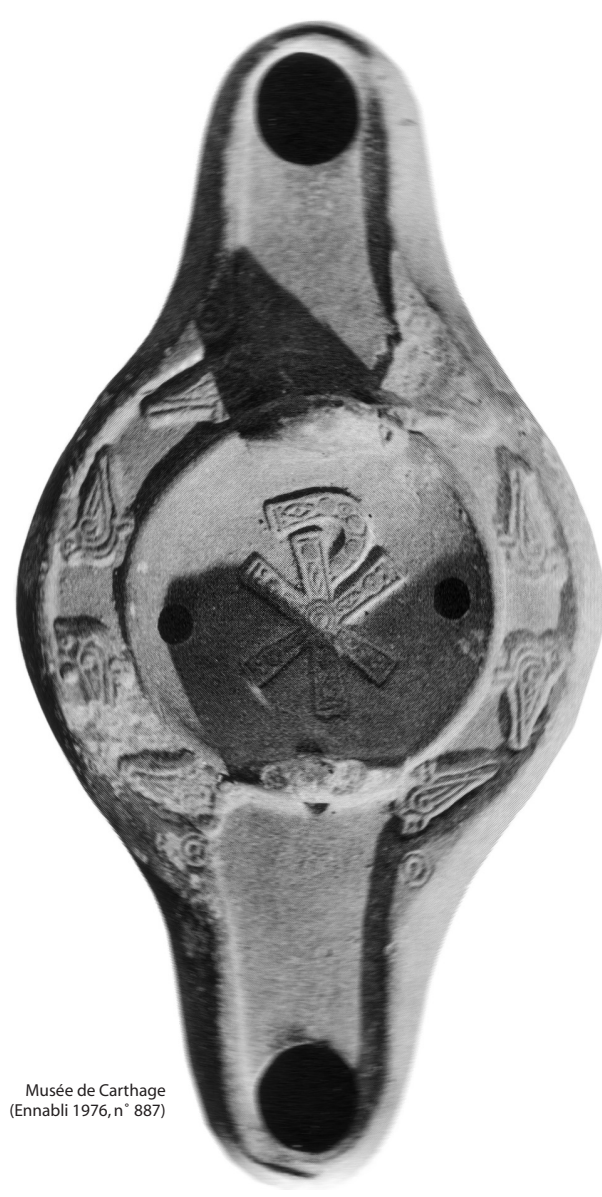

2

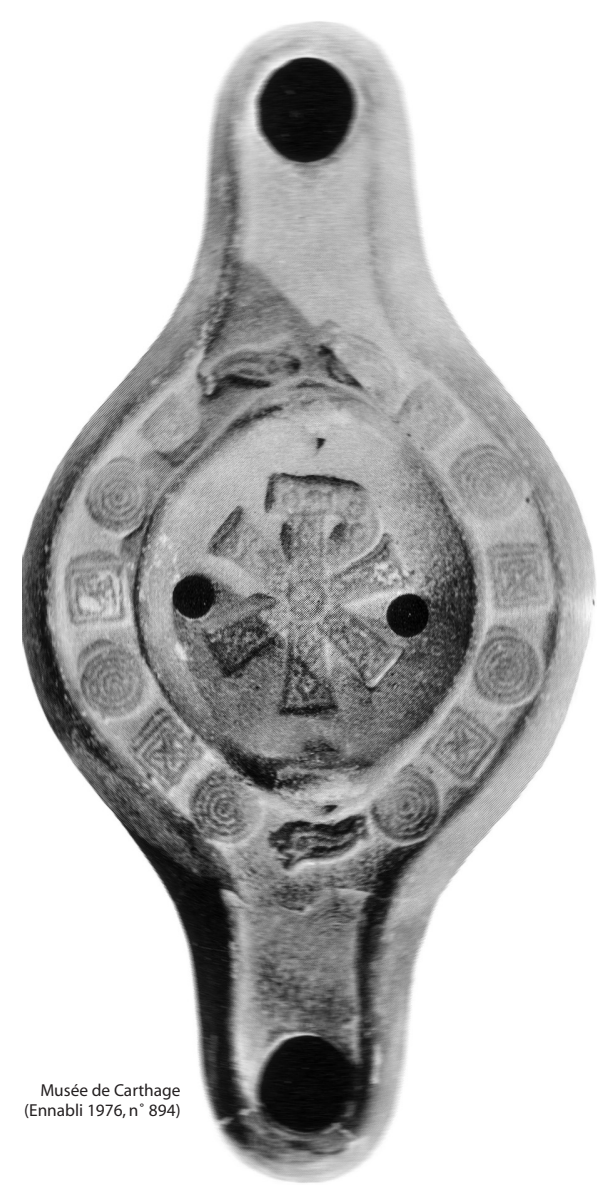

groupe D3

LAMPE

TYPE 72

Fig. 234. Lampes en sigillée africaine. 


\section{Typologie - Lampes}

Type Atlante $\mathrm{X}$ à deux ou trois becs divergents

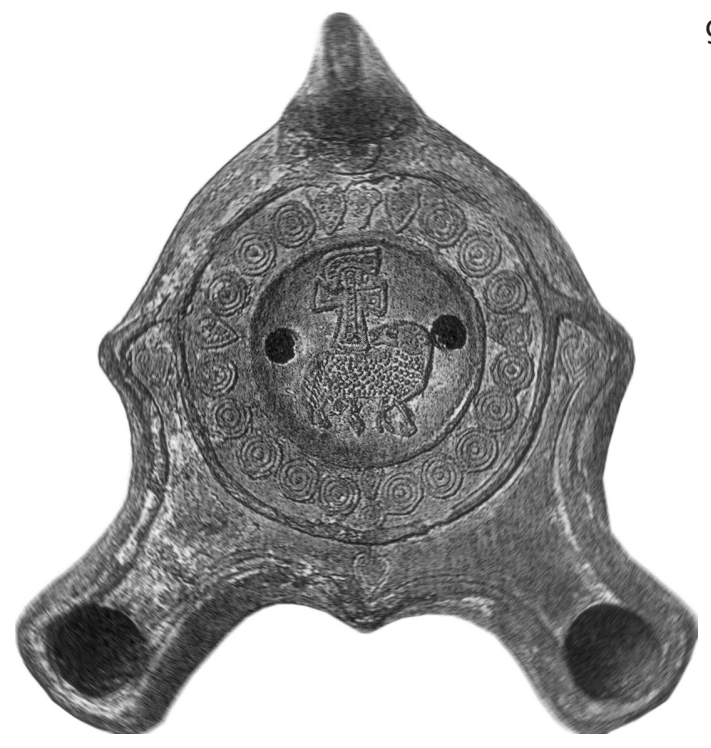

Munich, coll. priv. groupe C2

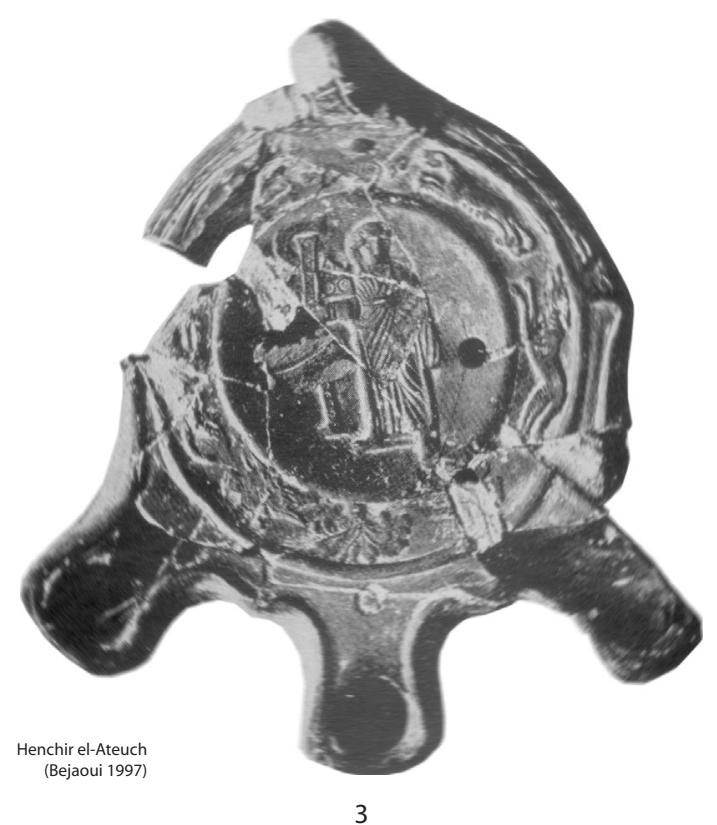

groupe D2

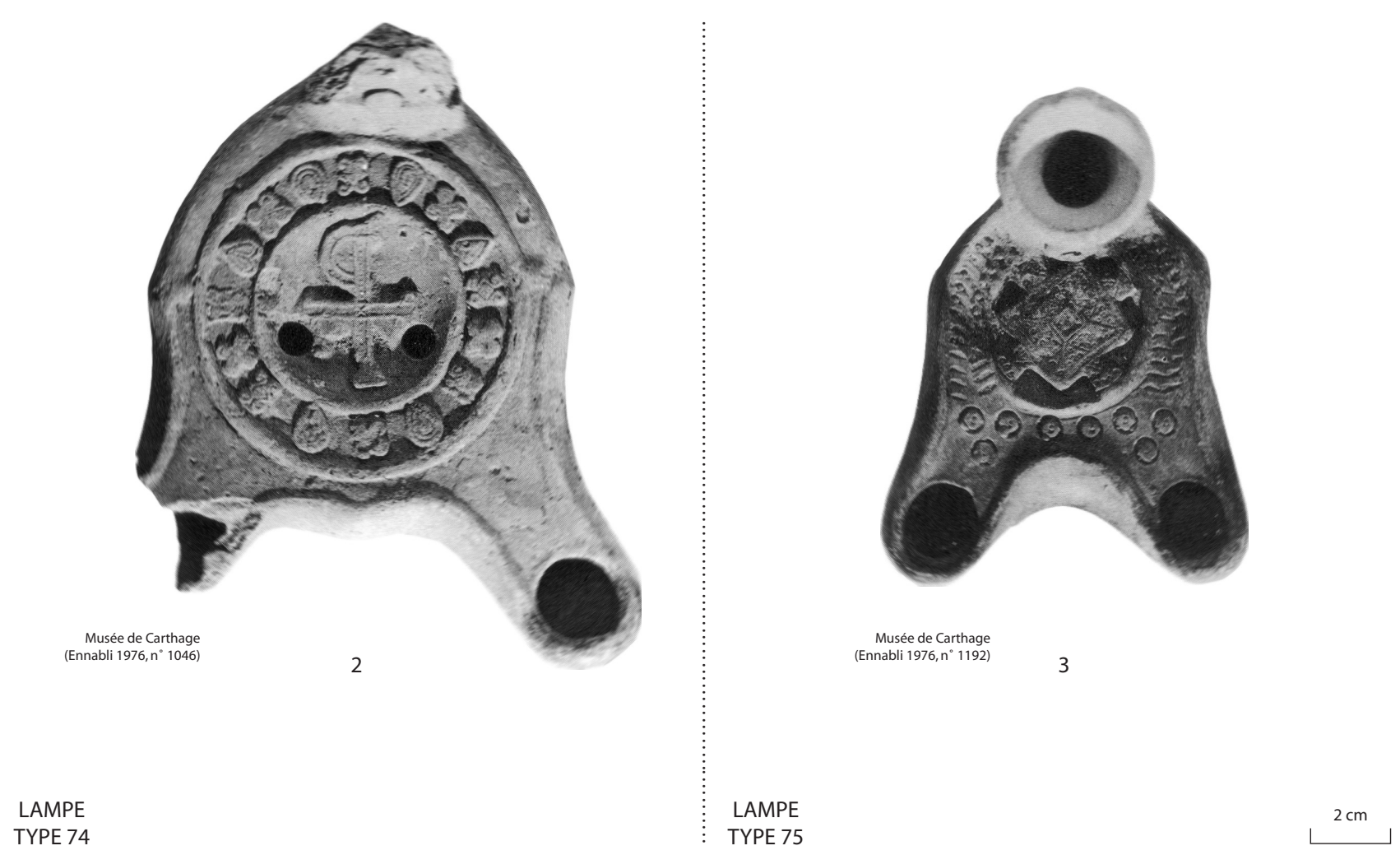

Fig. 235. Lampes en sigillée africaine. 
qu'un certain nombre de lampes italiques moulées (Ibid., type V B).

$$
\text { - groupe C2 (fig. 235) }
$$

\section{LAMPE TYPE 73}

Lampes de grand diamètre (env. $115 \mathrm{~mm}$ ), à becs très divergents et proéminents, à bandeau circulaire fermé, à protubérances latérales plus ou moins marquées. Les becs à extrémité quadrangulaire (comme sur le $\mathrm{n}^{\circ} 1 \mathrm{du}$ type précédent) paraissent fréquents $(\mathbf{1}, \mathbf{3})$. L'origine centrotunisienne de ce type de lampe à becs divergents est prouvée par le décor du $\mathrm{n}^{\circ} \mathbf{3}$, avec un christ connu sur les décors d'applique de sigillée africaine $\mathrm{C}$ (Atlante I, Pl. LXXXVIII, $\mathrm{n}^{\circ}$ 9, poinçon $\mathrm{n}^{\circ} 162$ ). La décoration de cet exemplaire muni de trois becs, avec une procession d'animaux sur le bandeau, est également proche de celle des lampes en couronne à six ou douze becs (type Atlante XII : infra, LAMPE TYPE 80).

Exemples (fig. 235) :

*1 Munich, collection privée (Mackensen 2001, $\mathrm{n}^{\circ}$ II 16.1). Sur le bandeau : cercles A2 et cordiformes. Sur le disque: agneau surmonté d'une croix monogrammatique rétrograde. D. $113 \mathrm{~mm}$.

2 Munich, collection privée (Mackensen 2001, n II. 16.2). Sur le bandeau: cercles A2, palmes et fleurons. Sur le disque: grande croix monogrammatique. D. $119 \mathrm{~mm}$.

*3 Henchir el-Ateuch (Algérie) (Bejaoui 1997, 128 et fig. 67). Sur le bandeau : chien, lion, feuillages. Sur le disque : le Christ serrant la croix. Variante à trois becs.

Datation stylistique par comparaison avec celle des lampes du groupe C2 : Ve s.

- groupe D2 (fig. 235)

LAMPE TYPE 74

Lampes de grand diamètre (D. $105 \mathrm{~mm}$ ), de forme similaire à celle du type précédent, munies d'un réflecteur (= type Atlante XI B1). La composition des motifs dans le bandeau circulaire continu est celle de la variante B du groupe D2: losanges à volutes placés de manière perpendiculaire et quadrifoliés I5, alternant avec d'autres motifs. Le décor du disque du $\mathrm{n}^{\circ} 2$ est particulièrement intéressant: la croix monogrammatique de type Hayes $289 \mathrm{~b}$ renforce l'hypothèse d'une fabrication de ce groupe de lampes sur l'atelier d'Oudhna (infra, fig. 268).

Exemples (fig. 235) :

1 Musée de Carthage (Ennabli 1976, n 851). Sur le bandeau : losanges à volutes $\mathrm{R} 2$ et triangles à volutes. Sur le disque : vase. D. $105 \mathrm{~mm}$; H. $37 \mathrm{~mm}$.

*2 Idem (Ibid., $\mathrm{n}^{\circ}$ 1046). Sur le bandeau: losanges à volutes R2, oves K3, quadrifoliés I3. Sur le disque : croix monogrammatique Hayes 289b. D. $104 \mathrm{~mm}$; H. $38 \mathrm{~mm}$.

Les éléments de datation sont stylistiques: la croix monogrammatique Hayes $289 \mathrm{~b}$ indique la fin du Ve s. et le début du VIe s., date plus précoce que celle proposée pour la variante B du groupe D2, caractéristique des décennies centrales du VIe siècle (supra, p. 401).

\section{LAMPE TYPE 75}

Lampe de petit diamètre (D. $70 \mathrm{~mm}$ en moyenne), avec des becs peu divergents, caractérisée par une poignée de préhension en entonnoir, servant d'orifice de remplissage. Le disque circulaire est fermé par un cercle en relief, les deux canaux et le bandeau ne formant qu'un seul espace, sommairement décoré de palmes incisées (comme sur le type Atlante X B) ou d'impressions circulaires.

Exemples (fig. 235):

1 Musée de Carthage (Ennabli 1976, n ${ }^{\circ}$ 558). Sur le disque : colombe. D. $70 \mathrm{~mm}$; H. $30 \mathrm{~mm}$.

2 Idem (Ibid., $\mathrm{n}^{\circ}$ 997). Sur le disque: croix monogrammatique perlée. D. $71 \mathrm{~mm}$; H. $33 \mathrm{~mm}$.

*3 Idem (Ibid., n 1192). Sur le disque : carreau sur la pointe, cantonné de demi-losanges à volutes. D. $70 \mathrm{~mm}$; H. $35 \mathrm{~mm}$.

Les poinçons utilisés pour le décor des disques de ces trois lampes semble se rattacher au groupe D2, encore fortement inspiré de la décoration des lampes du centre de la Tunisie. Pas d'argument chronologique autre que stylististique.

Datation proposée : fin du Ve s. - début du VIe s. (?)

- groupe D3 (fig. 236-237)

Les lampes à bec divergent du groupe D3 comprennent trois catégories d'objets qui semblent pouvoir se répartir au sein des deux grandes variantes (D3A et D3B) déjà définies sur la base du décor.

\section{LAMPE TYPE 76}

\section{(= Atlante XI B1)}

Lampe de grand diamètre (D. $130 \mathrm{~mm}$ ), bandeau circulaire fermé placé au plus près de la circonférence de la lampe, réflecteur (?). Les rinceaux Q3 du $\mathrm{n}^{\circ} \mathbf{1}$ et le sanglier du $\mathrm{n}^{\circ} \mathbf{2}$, présent sur une lampe portant un oiseau U5 sur le bandeau (Ennabli 1976, n 352), permettent de rattacher ce type au groupe D3 A.

Exemples (fig. 236) :

*1 Musée de Carthage (Ennabli 1976, n 1085). Sur le bandeau : oiseaux, losanges à volutes R3, rinceaux Q3. Sur le disque: croix gemmée cantonnée d'oiseaux et posée sur un rinceau Q3. D. $130 \mathrm{~mm}$; H. $45 \mathrm{~mm}$.

2 Idem (Ibid., $\mathrm{n}^{\circ}$ 354). Sur le bandeau: cordiformes M2, carré A4, disque E2, oiseau U1. Sur le disque : sanglier et chien (?).

La croix gemmée du $n^{\circ} \mathbf{1}$ indique une date dans le VIe s.

\section{LAMPE TYPE 77}

(= Atlante XI A1b, X A1d, X B1b)

Lampes de grand diamètre (D. 115-120 mm), avec deux becs peu écartés rejoints par un modelé en accolade très prononcé, pouvant être ou non renforcé par deux protubérances latérales, et munies d'un réflecteur. Le bandeau est limité par un fort bourrelet.

- Variante A (= Atlante XI A1b) : disque circulaire concave fermé par deux cannelures à la jonction des canaux, protubérances latérales. 
Typologie - Lampes

Type Atlante $\mathrm{X}$ à becs divergents

groupe D3
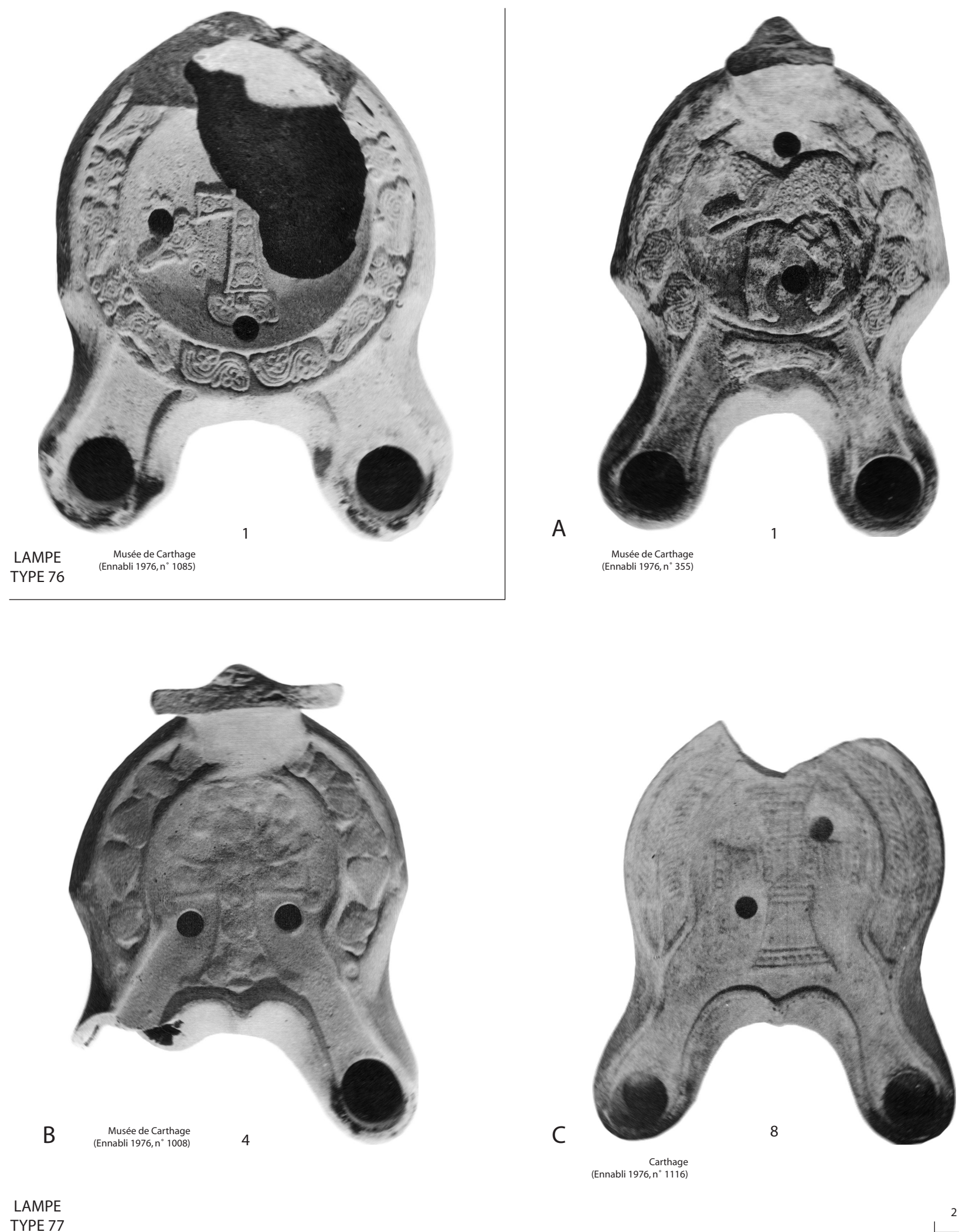

Fig. 236. Lampes en sigillée africaine. 
- Variante B (= Atlante X A1d) : disque plat ouvert sur les deux canaux, avec ou sans protubérances latérales.

- Variante C (= Atlante X $\mathrm{B} 1 \mathrm{~b})$ : forme identique à celle la variante $\mathrm{B}$, bandeau décoré de palmes incisées, apparemment sans protubérances latérales.

Les rinceaux Q3 des $\mathrm{n}^{\circ} \mathbf{1}$ et $\mathbf{2}$, les carrés A3 et les colombes $\mathrm{U} 8 \mathrm{du} \mathrm{n}^{\circ} \mathbf{3}$, permettent de rattacher ce type aux groupes D3 A ou D1. Un fragment découvert à El Mahrine, qui semble provenir d'une lampe du même type (5), pourrait être un argument pour la localisation du ou des atelier(s). On ne peut toutefois exclure que les $n^{\circ}$ 6-9, de facture assez fine, soient plutôt d'origine centrotunisienne.

Exemples (fig. 236) :

Variante A

*1 Musée de Carthage (Ennabli 1976, n 355). Sur le bandeau : $5+5$ rinceaux Q3. Sur le disque : cerf (?) et deux chiens. A la jonction des deux canaux : chien (?) à gauche. D. $116 \mathrm{~mm}$; H. $41 \mathrm{~mm}$.

2 Idem (Ibid., $\mathrm{n}^{\circ} 827$ ).

3 Carthage (Ennabli 1976, $\mathrm{n}^{\circ}$ 1070). Sur le bandeau: colombes U8 et rinceaux Q3. Sur le disque : croix gemmée Barbera-Petriaggi 212 cantonnée de deux oiseaux U8. D. $115 \mathrm{~mm}$; H. $40 \mathrm{~mm}$.

Variante B

*4 Musée de Carthage (Ennabli 1976, n 1008). Sur le bandeau : cordiformes et rinceaux, estompés. Sur le disque: croix monogrammatique, estompée. D. $115 \mathrm{~mm}$; H. $44 \mathrm{~mm}$.

5 El Mahrine, atelier (Mackensen 1993, fig. 31, $\mathrm{n}^{\circ} 11$ ). Fragment de la jonction entre les deux canaux, avec base d'une croix à décor de losanges.

6 Carthage (Ennabli 1976, $\mathrm{n}^{\circ}$ 1114). Sur le bandeau : quadrifoliés $\mathrm{I} 3$ et disques. Sur le bandeau: grande croix pattée gemmée. D. $120 \mathrm{~mm}$; H. $37 \mathrm{~mm}$.

7 Musée de Sabratha (Joly 1974, ${ }^{\circ}$ 1247). Sur le bandeau : cercles E2 (?) et carrés A3 (5 x 2 motifs). Disque identique à celui du $\mathrm{n}^{\circ}$ précédent.

Variante $\mathrm{C}$

*8 Carthage (Ennabli 1976, $\mathrm{n}^{\circ} 1116$ ). Sur le disque : grande croix. D. $119 \mathrm{~mm}$; H. $39 \mathrm{~mm}$.

9 Musée de Carthage (Ennabli 1976, $\mathrm{n}^{\circ}$ 1117). Sur eldisque : croix comparable à celle du $\mathrm{n}^{\circ}$ précédent mais avec une boucle. D. $116 \mathrm{~mm}$; H. $42 \mathrm{~mm}$.

Les arguments de datations sont stylistiques. La croix Barbera-Petriaggi 212 du n $^{\circ} \mathbf{3}$ et les grandes croix pattées des $\mathrm{n}^{\circ}$ 6-9 semblent indiquer les décennies centrales du VIe siècle.

\section{LAMPE TYPE 78}

Lampes de petit diamètre (D. 80-85 mm en moyenne), avec des becs peu divergents, un modelé général assez flou et caractérisées par une poignée de préhension en entonnoir, servant d'orifice de remplissage. Sur certains exemplaires, un contour anguleux du réservoir rappelle les protubérances latérales du type Atlante XI.

- Variante A : disque circulaire concave fermé par un bourrelet (comme sur le TYPE 77A).

- Variante B : disque plat ouvert sur les deux canaux (comme sur le TYPE 77B).
- Variante $\mathrm{C}$ : forme identique à celle la variante $\mathrm{B}$, bandeau décoré de palmes incisées (comme sur le TYPE 77C).

Les rinceaux $\mathrm{O} 1$ des $\mathrm{n}^{\circ} \mathbf{2}, \mathbf{3}$ et $\mathbf{5}$, les cordiformes M4 du $\mathrm{n}^{\circ} \mathbf{5}$, la croix du $\mathrm{n}^{\circ} \mathbf{6}$ rattachent ce type au groupe D3 B. Exemples (fig. 237) :

Variante A

1 Musée de Carthage (Ennabli 1976, $\mathrm{n}^{\circ}$ 571). Sur le bandeau: $2+2$ quadrifoliés I3. Sur le disque: colombe dans l'axe de la lampe. D. $78 \mathrm{~mm}$; H. $34 \mathrm{~mm}$.

*2 Idem (Ibid., $\mathrm{n}^{\circ}$ 587). Sur le bandeau: quadrifoliés I3 (?) et rinceaux O1 ( $2 \times 2$ motifs). Sur le disque : colombe dans l'axe de la lampe. D. $85 \mathrm{~mm}$; H. $39 \mathrm{~mm}$.

3 Carthage (Ennabli 1976, n 761). Sur le disque: cordiformes M5 et rinceaux O1. Sur le disque: poisson dans l'axe de la lampe. D. $83 \mathrm{~mm}$; H. $42 \mathrm{~mm}$.

Variante B

4 Musée de Carthage (Ennabli 1976, n 686). Sur le bandeau: quadrifoliés $\mathrm{I} 3$ et rinceaux $\mathrm{O} 1(2 \times 2$ motifs). Sur le disque: dauphin. D. $83 \mathrm{~mm}$; H. $35 \mathrm{~mm}$.

5 Idem (Ibid., $\mathrm{n}^{\circ}$ 930). Sur le bandeau: $3+3$ cordiformes M4. Sur le disque: croix monogrammatique. D. $80 \mathrm{~mm}$; H. $38 \mathrm{~mm}$.

*6 Idem (Ibid., n ${ }^{\circ}$ 1097). Sur le bandeau: $3+3$ (?) cordiformes M5. Sur le disque : croix pattée gemmée. D. $83 \mathrm{~mm}$; H. $41 \mathrm{~mm}$.

7 Idem (Ibid., $\mathrm{n}^{\circ} 461$ ). Sur le bandeau: disques très estompés. Sur le disque : agneau (?), estompé. D. $98 \mathrm{~mm}$; H. $38 \mathrm{~mm}$.

Variante C

*8 Musée de Carthage (Ennabli 1976, n 743). Sur le disque : poisson, estompé. D. $88 \mathrm{~mm}$; H. $42 \mathrm{~mm}$.

En considérant les croix gemmées des $n^{\circ} \mathbf{5}$ et $\mathbf{6}$ et l'aspect très estompé du décor du $\mathrm{n}^{\circ} 7$, ce type paraît couvrir tout le VIe siècle.

\section{— lampes à becs multiples}

Mis à part un type rare comportant quatre becs disposés en croix (Bailey 1988, Q1836bis) et un modèle original imitant la forme d'un bateau dont les dix rames sont autant de becs (en dernier lieu: Ben Lazreg 2000, 73, $n^{\circ} 47$ ), les lampes à becs multiples en sigillée africaines sont généralement des lampes en couronne, de six à douze becs. On peut distinguer les lampes en couronne évidée et les lampes en couronne pleine.

- lampes en couronne évidée (fig. 237)

\section{LAMPE TYPE 79}

Ces lampes qui se rattachent au répertoire classique des lampes africaines classiques (Bussière 2000, Pl. 147 ; Joly $1974, \mathrm{n}^{\circ} 162$ ) et des lampes africaines tardives en céramique commune (supra, LAMPE TYPE 36), sont faiblement documentées ${ }^{281}$.

281 Un troisième exemplaire est signalé par M. Mackensen (1998, 139 : bibliographie). 
Type Atlante $\mathrm{X}$ à becs divergents

groupe D3
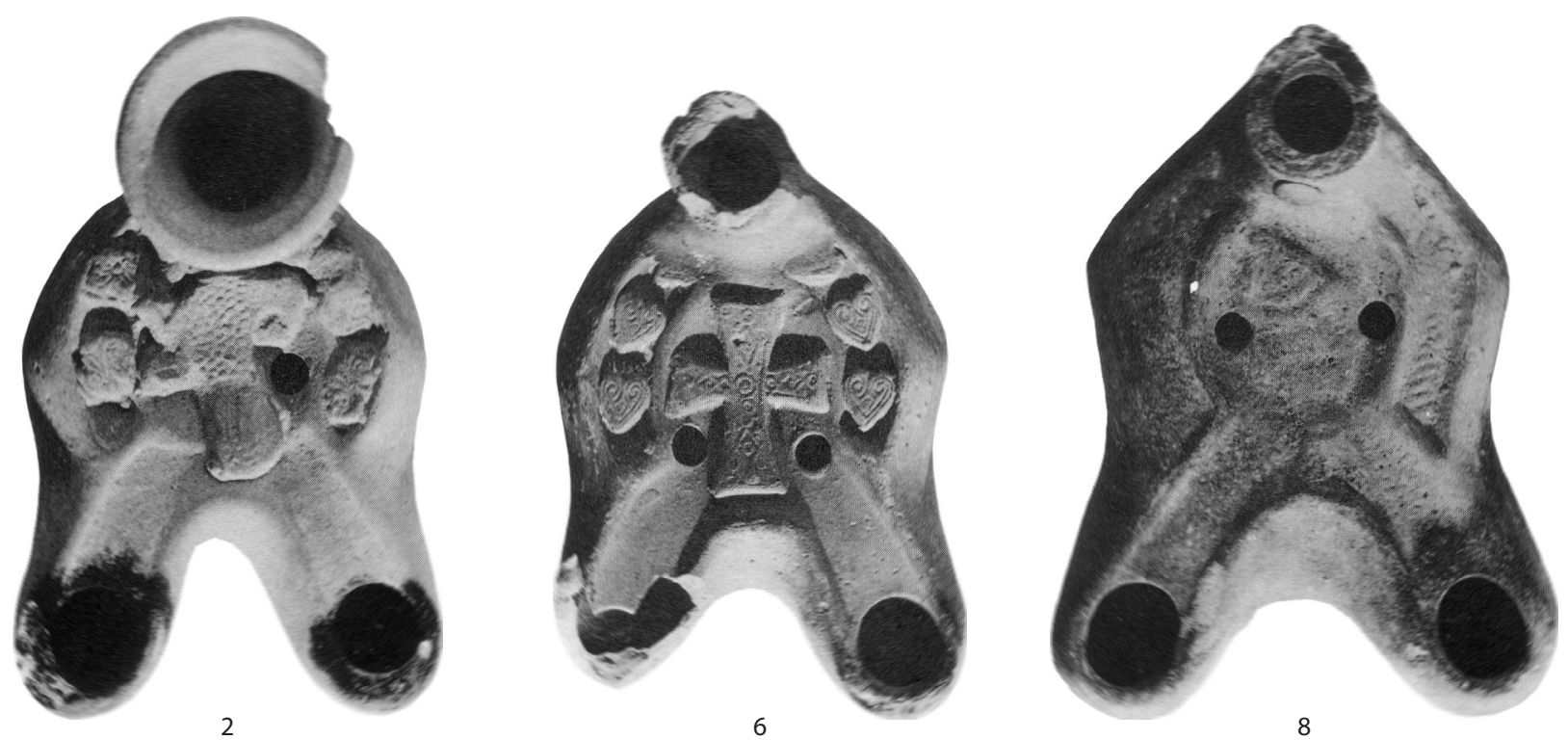

Musée de Carthage
(Ennabli 1976, n` 587)

Musée de Carthage
Ennabli 1976, nं 1097)

Musée de Carthage
(Ennabli 1976, $n^{\circ} 743$ )

8

A

C

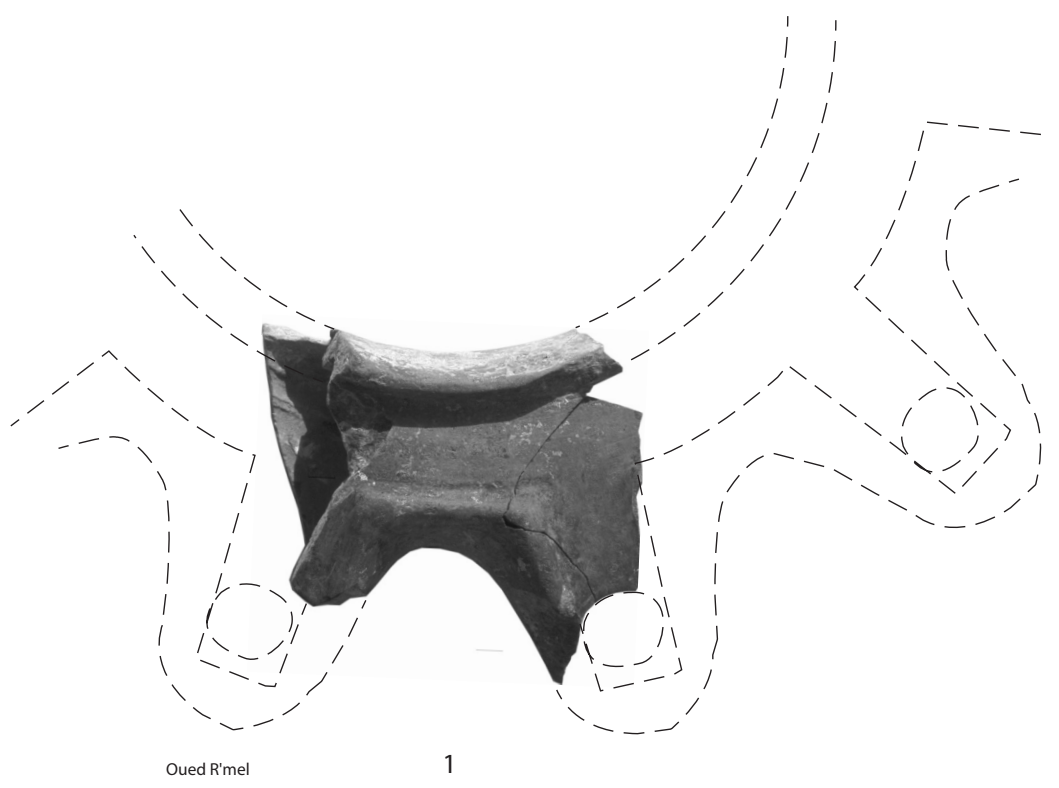

Fig. 237. Lampes en sigillée africaine. 


\section{Typologie - Lampes}

Type Atlante XII
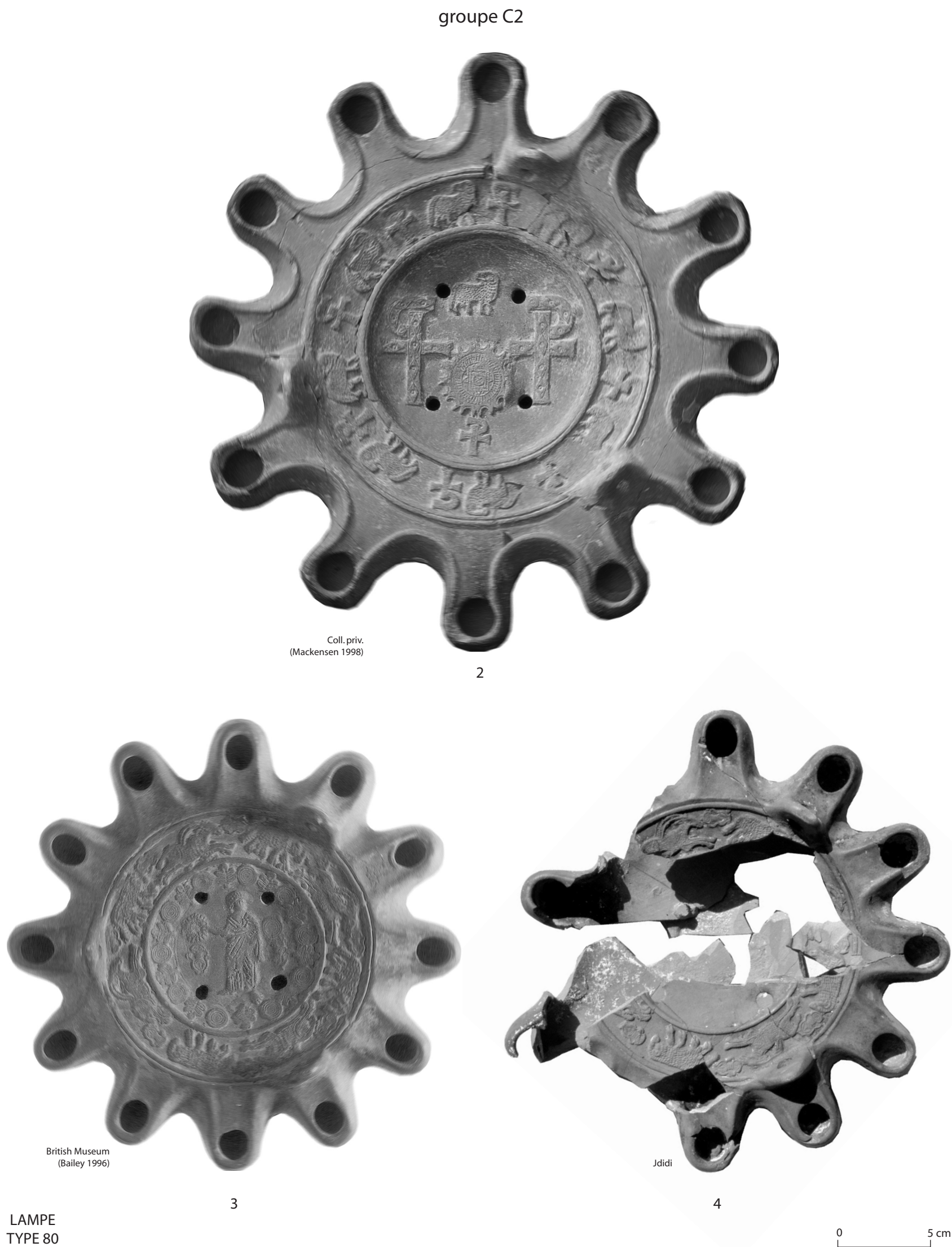

Fig. 238. Lampes en sigillée africaine (Tunisie centrale). 


\section{Typologie - Lampes}

Type Atlante XII

\section{groupe D2}
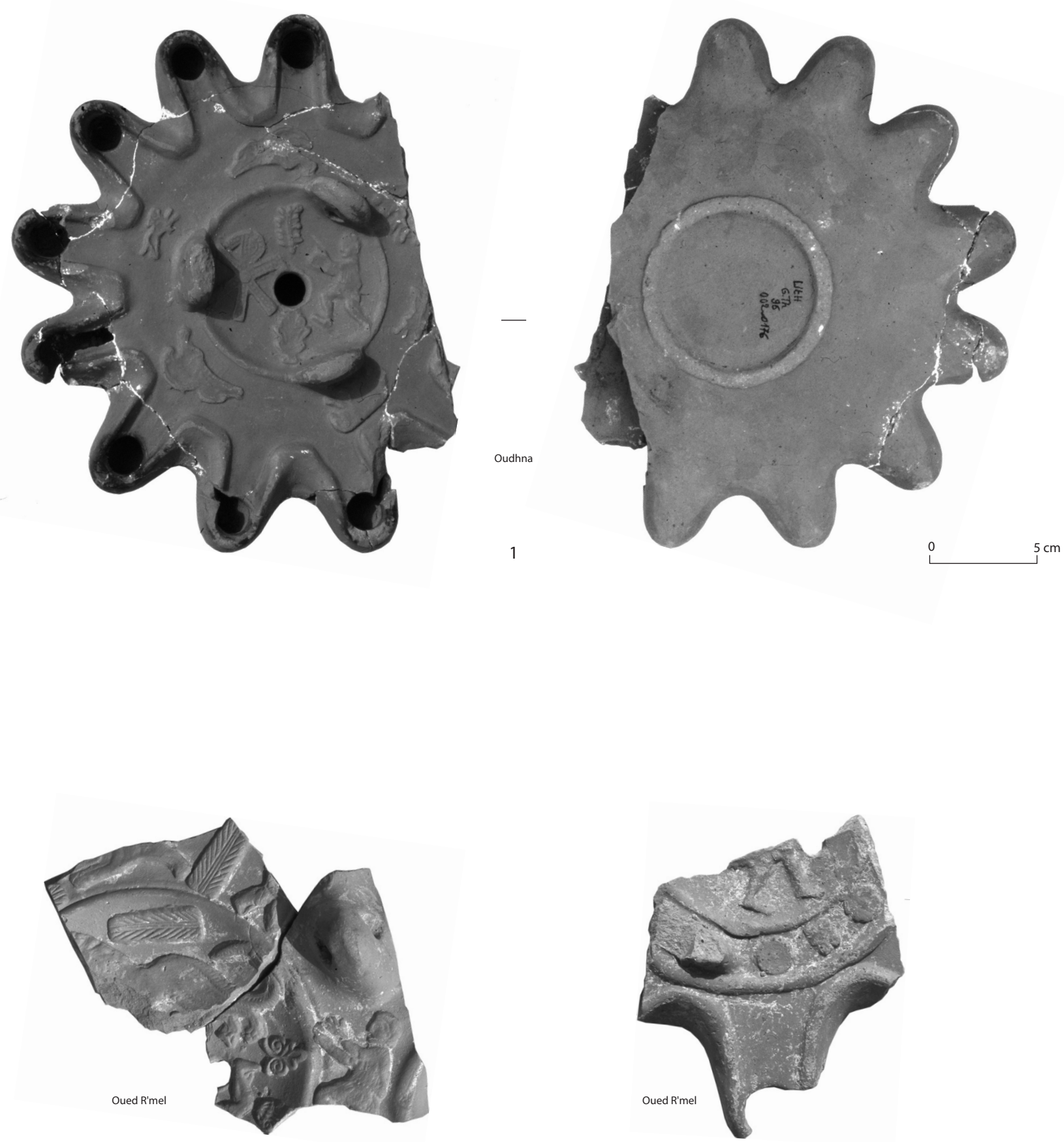

2

3

$2 \mathrm{~cm}$

Fig. 239. Lampes en sigillée africaine (Tunisie septentrionale). 
Lampes tripolitaines

type Atlante XIII
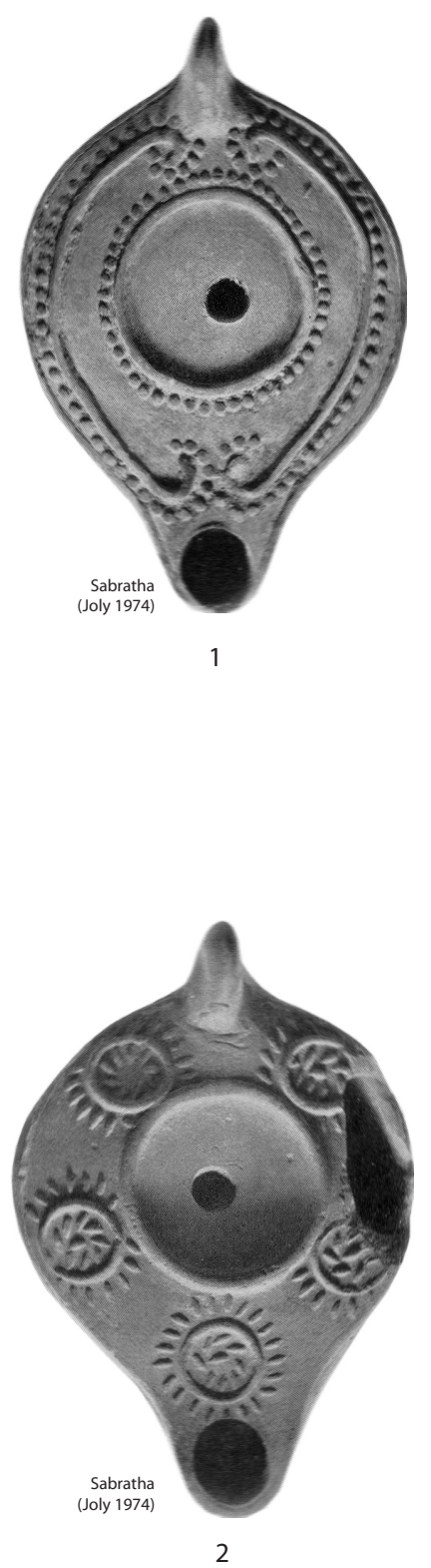

type Atlante XV
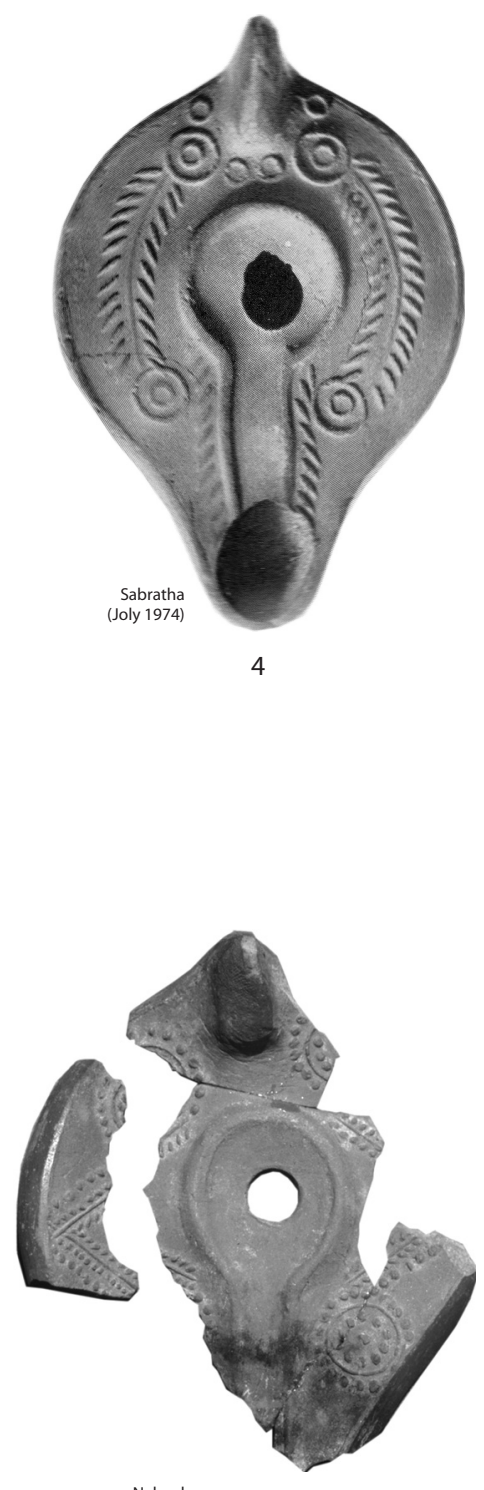

5

Fig. 240. Lampes en sigillée africaine (Tripolitaine). 
Exemples (fig. 237) :

*1 Oued R'mel (fouilles T. Ghalia, Inv. OR1700.2).

2 Rome, mitreum de la Crypta Balbi (Saguì, Coletti 2004, fig. 9). Chrisme et inscription ZACON incisés.

L'exemplaire $\mathrm{n}^{\circ} \mathbf{2}$ provient d'une destruction du milieu $\mathrm{du}$ Ve siècle.

\section{- lampes en couronne pleine (fig. 238-239) = Atlante XII}

On peut distinguer, au sein de ce type décrit par L. Anselmino et C. Pavolini (Atlante I, 204), des variantes propres à chaque groupe de production.

\section{- Groupe C2}

\section{LAMPE TYPE 80}

Lampe de taille variable ( 8 ou 12 becs), avec un bandeau circulaire fermé, limité par deux bourrelets bifides. Trois tenons de préhension forés. Quatre orifices de remplissage. Il s'agit sans aucun doute d'une production de Tunisie centrale, au regard du style des décors et de la qualité de la pâte (groupes $\mathrm{C} 2 / \mathrm{C} 4$ ).

Exemples (fig. 238) :

1 Musée de Constantine (Atlante I, Pl. CLXI, $\mathrm{n}^{\circ} 4$ ). Sur le bandeau : rinceau. Sur le disque : lion.

*2 Coll. privée (Mackensen 1998d, n 160). Sur le bandeau : 8 moutons tête à gauche, alternant avec 8 croix monogrammatiques type Barbera-Petriaggi 210A2. Sur le disque : même mouton, une croix du même type, deux croix Barbera-Petriaggi 210E et un motif géométrique. D. $324 \mathrm{~mm}$.

*3 British Museum (Bailey 1996, Q1835bis). Sur le bandeau: bouquetin (Cf. Trost, Hellmann 1996, $\mathrm{n}^{\circ} 79$ ) et béliers séparés par des vases. Sur le disque : femme tenant une couronne, cantonnée de deux cratères et entourée par une frise circulaire de cercles concentriques et de rameaux. D. $248 \mathrm{~mm}$.

*4 Sidi Jdidi, basilique 2, destruction état II (Inv. JD2189.19). Sur le bandeau : bouquetin (Cf. Trost, Hellmann 1996, n 79 ) et béliers séparés par des vases. D. $275 \mathrm{~mm}$.

L'association des croix monogrammatiques BarberaPetriaggi $210 \mathrm{~A} 2$ et $210 \mathrm{E}$ indique une date entre la fin du Ve s. et la première moitié du VIe siècle.

\section{- Groupe D2}

\section{LAMPE TYPE 81}

Lampe dont les seuls exemplaires connus sont de grande taille (12 becs). Le disque circulaire étroit (D $84 \mathrm{~mm}$ ) est fermé par un cercle en relief sur lequel viennent s'attacher les trois tenons de préhension forés. Les canaux conduisant aux becs et le bandeau ne forment qu'un seul espace, décoré de manière très aérée. L'ensemble de la forme évoque les lampes de TYPE 75 ; cette ressemblance est particulièrement troublante entre le TYPE $75, n^{\circ} 3$ et la variante précoce $n^{\circ} \mathbf{4}$ ci-dessous (même traitement de la palme incisée). Le personnage sur le disque du $\mathrm{n}^{\circ} \mathbf{1}$ et sur le bandeau du $\mathrm{n}^{\circ} \mathbf{2}$, de même que le bélier sur le bandeau, se retrouvent sur des lampes du groupe D2 (supra, TYPE
$65, n^{\circ} 32$; Ennabli 1976, $\mathrm{n}^{\circ} 448$ et 450 ); il est possible que ce type soit originaire de l'atelier d'Oudhna.

Exemples (fig. 239) :

Groupe D2, variante A

*1 Oudhna, Grands Thermes (fouilles H. Ben Hassen, Inv. UTH2.176). Sur le bandeau: deux groupes composés d'un bouquetin et d'un bélier (surmoulage des décors du TYPE 80, ${ }^{\circ} 3-4$ ), séparés par un petit animal indéterminé. Sur le disque: Chrisme perlé, palme, personnage courant à gauche (Cf. Ennabli $\left.1976, n^{\circ} 121\right)$, vase ; orifice de remplissage central.

*2 Oued R'mel (fouilles T. Ghalia, Inv. OR1800). Sur le bandeau, notamment: personnage courant à gauche comme sur le $\mathrm{n}^{\circ} 1$. Sur le disque : lion à gauche.

Groupe D2, variante B

*3 Oued R'mel (Inv. 0R2504). Sur le bandeau, notamment: losange à volutes R2 placé perpendiculairement.

Variante précoce (?)

4 Kelibia (Cintas, Duval 1958, Pl. XII, a-c). Sur le bandeau: décor incisé (palme circulaire, cercles pointé, un chrisme). Sur le disque : chrisme incisé.

Les décors utilisés pour le $\mathrm{n}^{\circ} \mathbf{1}$ viennent directement du répertoire des productions de Tunisie centrale: une datation dans la première moitié du VIe s. semble probable. Le $\mathrm{n}^{\circ} \mathbf{4}$ pourrait plutôt dater du Ve siècle.

\section{- Groupe D3}

D'autres types doivent probablement exister dans le nord de la Tunisie (groupe D3), qui ne sont pas encore clairement identifiés. Un seul petit fragment a été recueilli sur l'atelier d'El Mahrine.

Exemple :

1 El Mahrine (Mackensen 1993, fig. 31, $\mathrm{n}^{\circ}$ 12).

\subsubsection{Lampes tripolitaines (fig. 240)}

\section{LAME TYPE 82}

J'ai peu d'informations nouvelles sur les lampes tripolitaines, sauf à mentionner la présence de fragments du type Atlante XV à Nabeul, dans un contexte du deuxième quart du Ve s. (5).

Exemples (fig. 240) :

Type Atlante XIII (= Hayes I)

*1 Sabratha (Joly 1974, $\mathrm{n}^{\circ}$ 972). D. $82 \mathrm{~mm}$.

*2 Sabratha (Joly 1974, $\mathrm{n}^{\circ}$ 969). D. $79 \mathrm{~mm}$.

3 Littoral tunisien (site $n^{\circ} 4$, Henchir Daoui) (Bonifay et al. 2002-2003, fig. 9, $\mathrm{n}^{\circ} 102$ ). Proche de Joly 1974 , $\mathrm{n}^{\circ}$ 916-937.

Type Atlante XV (= Hayes II)

*4 Sabratha (Joly 1974, $\left.\mathrm{n}^{\circ} 1005\right)$. D. $84 \mathrm{~mm}$.

*5 Nabeul, fabrique de salaisons, période 5B (Inv. NB 1145.69-70). Décor de chevrons et de cercles perlés.

\subsection{LAMPES TOURNÉES}

Les lampes tournées refont leur apparition dans le répertoire des potiers africains plus de six cents ans après avoir été abandonnées. J. Bussière recense cinq formes différentes (types EVI 1 à 5). Trois seulement sont 


\section{Typologie - Lampes}

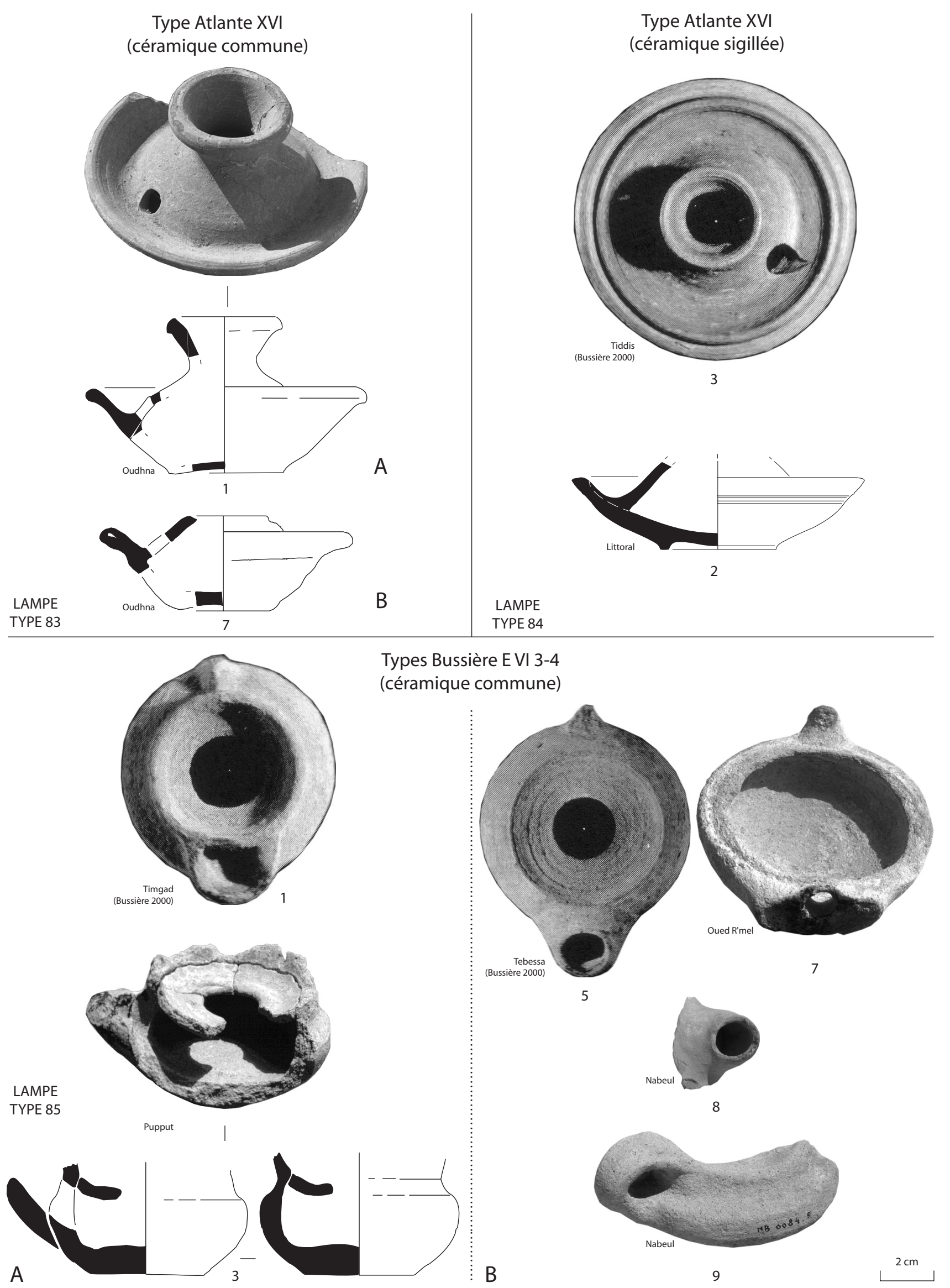

Fig. 241. Lampes tournées. 
présentes dans le matériel tunisien que j'ai eu l'occasion d'examiner, qui peuvent être réparties en deux grandes catégories.

\subsubsection{Lampes dites « vandales » (fig. 241)}

\section{$=$ Atlante XVI $=$ Bussière E VI 2}

Les lampes à corps bi-tronconique, traditionnellement dénommées «vandales » à la suite de Delattre (1889; Cardaillac 1890, 321 ; Carton 1916, 102-103) ont été intégrées par L. Anselmino et C. Pavolini à leur classification des lampes en sigillée africaine (Atlante I, 205-206), en raison de la présence de quelques exemplaires produits dans cette qualité de pâte. Il n'en reste pas moins que la plupart des lampes dites "vandales" sont en céramique commune. Un atelier important est connu à Oudhna (Barraud et al. 1998, 154) mais ce n'est probablement pas le seul. Il n'est pas impossible que ces objets soient issus d'un modèle de lampe tournée largement répandu dans la région syropalestinienne dès le IIIe s. (Orssaud, Sodini 1997).

\section{LAMPE TYPE 83}

Lampes tournées bi-tronconiques en céramique commune beige. A la suite de L. Anselmino et C. Pavolini (Atlante I, 206) ${ }^{282}$, on peut distinguer deux variantes :

- Variante A (= Atlante XVI A) : l'orifice de remplissage est muni d'un goulot cylindrique ou évasé.

- Variante B (= Atlante XVI B): large orifice de remplissage sans goulot; parfois deux trous de mèche.

Exemples (fig. 241) :

Variante A

*1 Oudhna, thermes des Laberii (Barraud et al. 1998, fig. 13, $\mathrm{n}^{\circ}$ 14). D. $102 \mathrm{~mm}$; H. $58 \mathrm{~mm}$.

2 Carthage (Trost, Hellmann 1996, $\mathrm{n}^{\circ}$ 180). D. $108 \mathrm{~mm}$; H. $53 \mathrm{~mm}$.

3 Djemila (Bussière 2000, $\mathrm{n}^{\circ}$ 6759). D. env. 75 mm; H. env. $35 \mathrm{~mm}$.

4 Tipasa (Bussière 2000, $\mathrm{n}^{\circ}$ 6778). D. env. $90 \mathrm{~mm}$; H. env. $62 \mathrm{~mm}$.

5 Carthage (Hayes 1976a, fig. 4, VII.75).

6 Carthage (Hayes 1978b, fig. 10, XXII.6)

Variante B

*7 Oudhna, thermes des Laberii (Barraud et al. 1998, fig. $\left.13, \mathrm{n}^{\circ} 15\right)$. D. $93 \mathrm{~mm} ;$ H. $36 \mathrm{~mm}$.

8 Musée d'Alger (Bussière 2000, $\mathrm{n}^{\circ}$ 6770). D. env. $95 \mathrm{~mm}$; H. $80 \mathrm{~mm}$.

Variante indéterminée, avec anse

9 Nabeul, fouilles anciennes $\left(\operatorname{sans} \mathrm{n}^{\circ}\right)$.

Variante indéterminée

10-12 Carthage (Hayes 1978b, fig. 2bis, VII.1003-105).

La datation de ces lampes n'est pas très bien assurée. Il est probable que le qualificatif « vandale» qui leur est

\footnotetext{
282 « Bien que cette distinction, établie à partir d'un nombre très réduit d'exemplaires connus, résiste en fait assez mal au classement des 358 exemplaires algériens pour lesquels on constate toutes sortes de variations dans l'étranglement du dôme supérieur » : Bussière 2000, 126.
}

traditionnellement attribué ne corresponde, en fait, à aucune réalité. La plupart des exemplaires trouvés en stratigraphie proviennent de contextes byzantins : ainsi, les $\mathrm{n}^{\circ} 5$ et 10-12 viennent d'un contexte du milieu du VIe s., le $n^{\circ} 6$ d'un niveau du VIIe siècle. En revanche, les contextes de la seconde moitié du Ves. en sont généralement dépourvus ${ }^{283}$. Il est possible que ces lampes survivent durant les premiers temps de l'époque islamique.

Datation proposée : VIe-VIIe s. +

\section{LAMPE TYPE 84}

Lampes tournées bi-tronconiques, comparables aux précédentes, en céramique sigillée africaine. Cette version fine des lampes Atlante XVI est relativement rare $^{284}$. A Tiddis, un atelier produisait ce type de lampes (Berthier 2000) «dans une terre sigillée de couleur brun clair » propre à ce site (Bussière 2000, 400).

Exemples (fig. 241) :

1 Carthage (Atlante I, Pl. CLXII, $\mathrm{n}^{\circ} 3 \mathrm{a}-\mathrm{c}$ ).

*2 Littoral tunisien, site $\mathrm{n}^{\circ} 40$ (Henchir Adame) (Bonifay et al. 2002-2003, fig. 9, $\mathrm{n}^{\circ}$ 101). D. $106 \mathrm{~mm}$.

Atelier de Tiddis

*3 Tiddis, atelier (Bussière 2000, $\mathrm{n}^{\circ}$ 6548). D. env. $90 \mathrm{~mm}$; H. env. $60 \mathrm{~mm}$.

4 Idem (Ibid., $\mathrm{n}^{\circ}$ 6549). Avec « son support en forme de manchon cylindrique » (D. $98 \mathrm{~mm} ;$ H. $100 \mathrm{~mm}$ ).

5 Idem (Ibid., $\mathrm{n}^{\circ}$ 7447). «Raté de cuisson trouvé près d'un four ».

Datation probablement comparable à celle du type précédent.

\subsubsection{Autres lampes tournées (fig. 241)}

D'autres lampes tournées, jusqu'à présent exclusivement signalées en Algérie (Bussière 2000, 127), sont également présentes en Tunisie ${ }^{285}$. Je souhaiterais insister principalement sur les types Bussière E VI 3-4, qu'il paraît possible de regrouper.

\section{LAMPE TYPE 85}

Lampe hémisphérique à bassin ventru, de diamètre moyen (D. env. $75 \mathrm{~mm}$ ), dotée d'un cuvette sommitale plus ou moins accentuée et d'une petite anse conique ; la base est plate et épaisse. Céramique commune beige ou blanchâtre ${ }^{286}$. Deux variantes :

- Variante A : cuvette sommitale entourée d'un col assez développé ; bec constitué d'un demi-cercle de pâte rapporté sur la paroi de la lampe préalablement forée.

283 «Only one example was found securely in layers of the Vandal period »: Chapman, Davies, Peacock 1984, 240.

${ }^{284} \mathrm{~J}$. Bussière signale cependant huit exemplaires en sigillée au Musée d'Hippone (Bussière 2000, 400).

$285 \mathrm{~J}$. Bussière fait toutefois allusion à la découverte, par un fouilleur clandestin, de lampes du type E VI 5 dans la région de Sbeitla (?).

${ }^{286}$ J. Bussière $(2000,401)$ signale trois exemplaires de son type EVI en sigillée africaine ( $\left.n^{\circ} 7051-7053\right)$ : cette attribution paraît douteuse au vu de la photographie du $n^{\circ} 7051$. 
- Variante B : cuvette sommitale en faible relief; bec tubulaire court rapporté sur la paroi de la lampe préalablement forée.

Exemples (fig. 241) :

Variante A

*1 Timgad (Bussière 2000, n 6907). D. 75 mm; H. $35 \mathrm{~mm}$.

2 Tébessa (Bussière 2000, $\mathrm{n}^{\circ} 6921$ ).

*3 Pupput, thermes du Centre (Bonifay 2002, fig. 3, $\left.\mathrm{n}^{\circ} 25\right)$. D. $75 \mathrm{~mm}$.

4 Nabeul, fouilles anciennes (sans $n^{\circ}$ ).

Variante B

*5 Région de Tébessa (Bussière 2000, $\mathrm{n}^{\circ}$ 7074). D. $77 \mathrm{~mm}$; H. $33 \mathrm{~mm}$.

6 Cherchell (Bussière 2000, n 7099). D. 74 mm; H. $34 \mathrm{~mm}$.

*7 Oued R'mel (fouilles T. Ghalia, Inv. OR0803.1).

*8 Nabeul, fouilles anciennes $\left(\operatorname{sans~}^{\circ}{ }^{\circ}\right.$ ). Fragment de bec. Variante indéterminée

*9 Nabeul, fouilles anciennes (sans $n^{\circ}$ ). Anse en oreille.

$\mathrm{J}$. Bussière estime que ces lampes sont contemporaines de son type E VI 2. L'exemplaire de Pupput (3) provient d'un contexte de la fin du VIIe siècle. Le fait que ce type soit absent de tous les contextes VIe - VIIe s. de Sidi Jdidi est peut-être un argument pour une date très tardive (?).

Datation proposée : VIe (?) - VIIe s. + 


\section{CERAMIQUES DIVERSES}

Je souhaiterais aborder brièvement ici les céramiques marginales que sont les vases à décor plastique, les figurines, les masques et les moules.

\subsection{VASES À DÉCOR PLASTIQUE}

Les potiers africains ont produit un grand nombre de vases à décor plastique, certains tournés, d'autres moulés (Atlante I, 176-183). Je signalerai simplement trois catégories d'objets que j'ai moi-même rencontrés.

- ampullae oleariae (fig. 242)

\section{DÉCORS PLASTIQUES TYPE 1}

A. Carandini avait mis en évidence, dès $1970 \mathrm{~b}$, ces petits vases destinés selon lui à contenir des huiles parfumées. De fait, c'est bien ce type de récipient biconique, plutôt à mon sens en céramique qu'en métal, qui est figuré aux côtés d'un pugiliste sur des moules bivalves africains découverts à Fréjus (Janon 1978, fig. 3) et à Carthage (Janon 1984, fig. 1).

Ces petits vases sont obtenus par moulage, à la façon des lampes à huile. Les timbres qui figurent parfois sous le fond : LVCCEIVS, PVLLAENI, renvoient d'ailleurs à des officines de lampes, de même que la forme des anses, typique des luminaires (Salomonson 1972, fig. 22). Quatre variantes peuvent être distinguées, en fonction du détail de la forme et du décor (Carandini 1970b, fig. 9, 12, 16, 38). Les deux exemplaires d'El Jem (type Carandini 1970b, fig. 12) sont probablement d'origine locale. L'inventaire dressé par Carandini fait apparaître que les décors de poursuites d'animaux (2) sont fréquents en Tunisie centrale.

Nota : On connaît également quelques lampes de même forme (Ben Lazreg 1994, $\mathrm{n}^{\circ} 27$ ).

Exemples (fig. 242) :

*1 El Jem, maison d'Africa $\left(\right.$ sans n $\left.^{\circ}\right)$. Motifs végétaux.

*2 El Jem, maison d'Africa (sans $\mathrm{n}^{\circ}$ ). Poursuite d'animaux.

*3 Carthage (Carandini 1970b, fig. 12; Atlante I, Pl. XCIII, 2).

Datation proposée : IIe-IIIe s. (?).

\section{- vases en forme de grenade (fig. 242)}

\section{DÉCORS PLASTIQUES TYPE 2}

En 1969, A. Carandini découvrait au Musée de Carthage une forme inédite de sigillée africaine A: une pyxis reproduisant la forme d'une grenade (1). La représentation de ce fruit typiquement africain était un argument fort (Carandini 1969) pour l'origine de cette céramique, à l'époque encore controversée. Une forme similaire, qui n'est cependant plus une pyxis mais un petit récipient ouvert par la queue du fruit qu'il est censé représenter, a été attribué à la sigillée africaine $\mathrm{C}$ (forme Atlante CXXXIV, 6).

Les fouilles de la nécropole de Pupput on livré un objet comparable à cette dernière forme. Il ne s'agit plus cependant de sigillée africaine mais d'une production proche de la céramique à parois fines africaine (cf. Bonifay $2004 \mathrm{a}$, fig. $16, \mathrm{n}^{\circ} 55$ ). Ce vase a été tourné puis retravaillé par impressions et modelage.

Exemples (fig. 242) :

*1 Musée de Carthage (Carandini 1969, fig. 1). Sigillée africaine A.

*2 Pupput (Inv. PP3092.2). Pâte beige, surface brun-gris. Datation proposée : IIe s.

- céramique dite de Navigius (fig. 242)

\section{DÉCORS PLASTIQUES TYPE 3}

Les collections du musée de Nabeul recèlent deux vases moulés en céramique dite de «Navigius», production apparentée à la sigillée africaine $\mathrm{C}$ des ateliers de Tunisie centrale, et peut-être spécifique de celui d'Henchir esSrira (Atlante I, 176). Ces deux vases proviendraient de la région d'El Jem, confirmation de la diffusion essentiellement locale de ces objets.

Tous deux appartiennent au type Salomonson 1969, fig. 128, représentant des visages féminins. Il sont toutefois d'un modèle apparemment non répertorié en 1981 (cf. Atlante I). Ces vases ne portent aucune marque. Exemples (fig. 242) :

*1 Musée de Nabeul, provenant d'El Jem (?) (Inv. NBM.V11).

*2 Idem (Inv. NBM.V12).

Ces vases sont généralement datés de la fin du IIe s. et du premier quart du IIIe s. (Salomonson 1969).

\subsection{FIGURINES}

Il faut tout d'abord distinguer entre :

A) Des figurines obtenues à la fois par moulage puis par modelage de l'argile, dont chacune constitue presque une œuvre originale.

B) Des figurines bivalves obtenues par moulage, susceptibles donc de constituer des séries. Ces productions sont elles-mêmes de trois sortes :

-1) Des productions de qualité courante, en céramique commune, dans la tradition des figurines puniques, portant parfois des traces de peinture.

- 2) Des productions de qualité supérieure, tout à fait comparable à celle des lampes africaines, finement moulées et recouvertes d'un engobe; ces objets peuvent également être signés.

- 3) Des productions en sigillée africaine, comparables aux lampes issues des mêmes ateliers. 


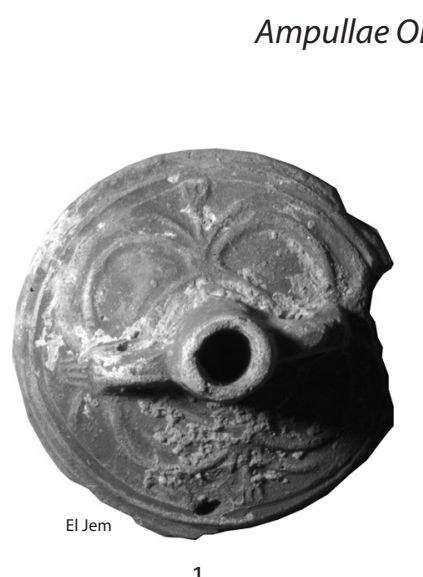

1

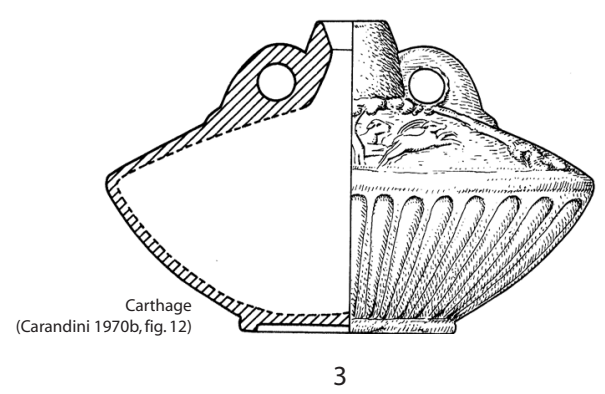

DECORS PLASTIQUES TYPE 1
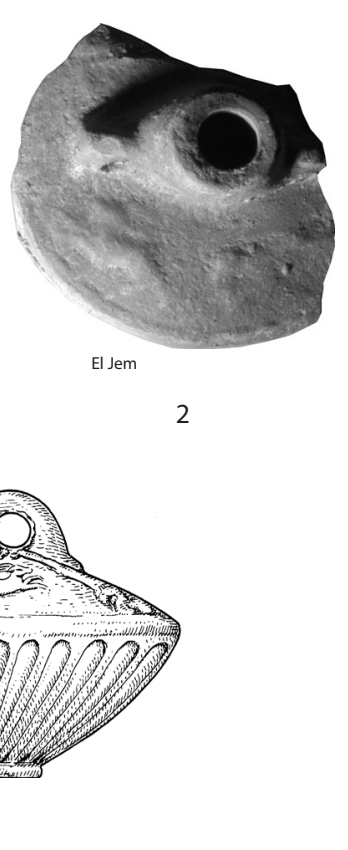

$2 \mathrm{~cm}$

Céramique dite de Navigius
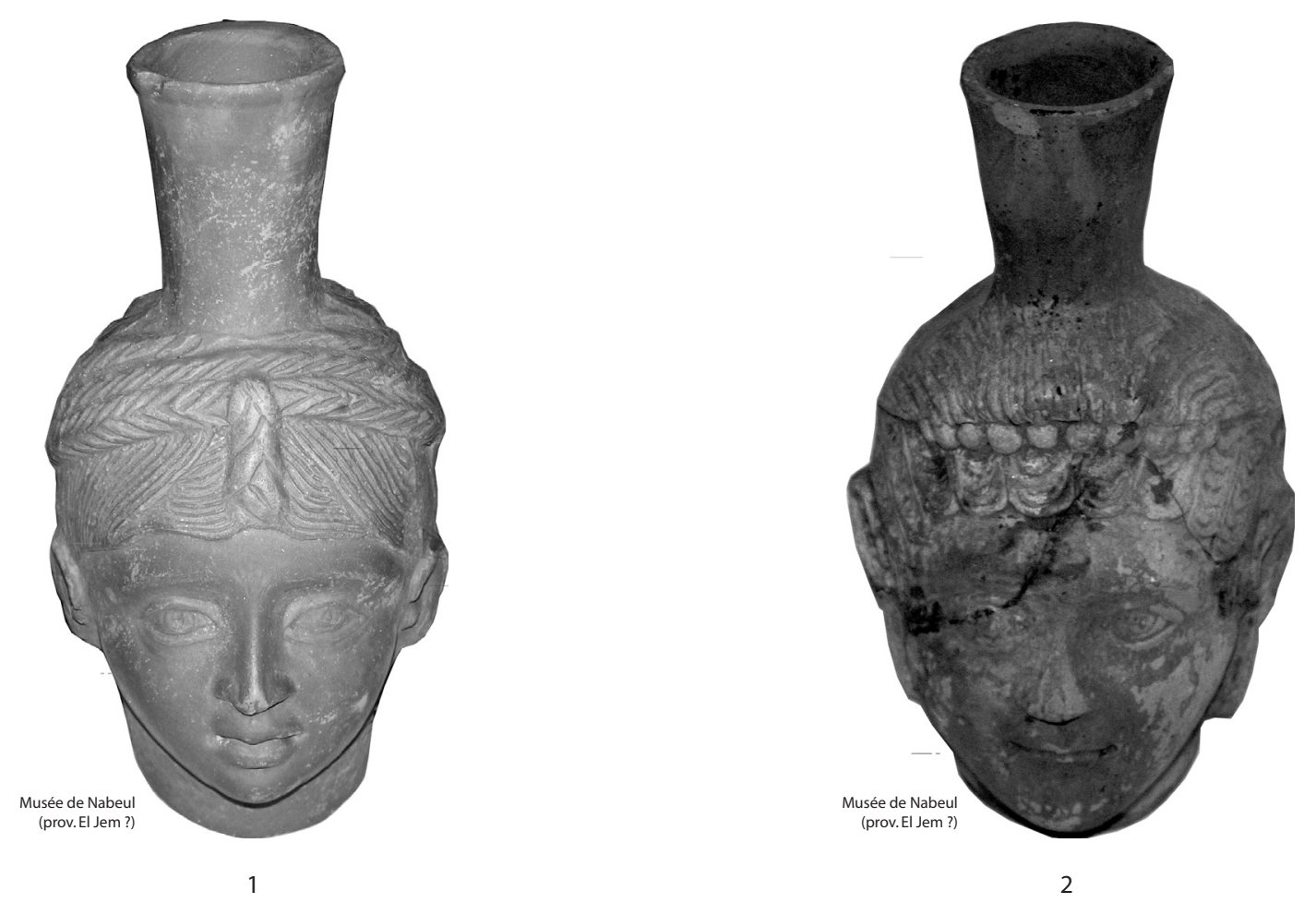

DECORS PLASTIQUES

TYPE 3
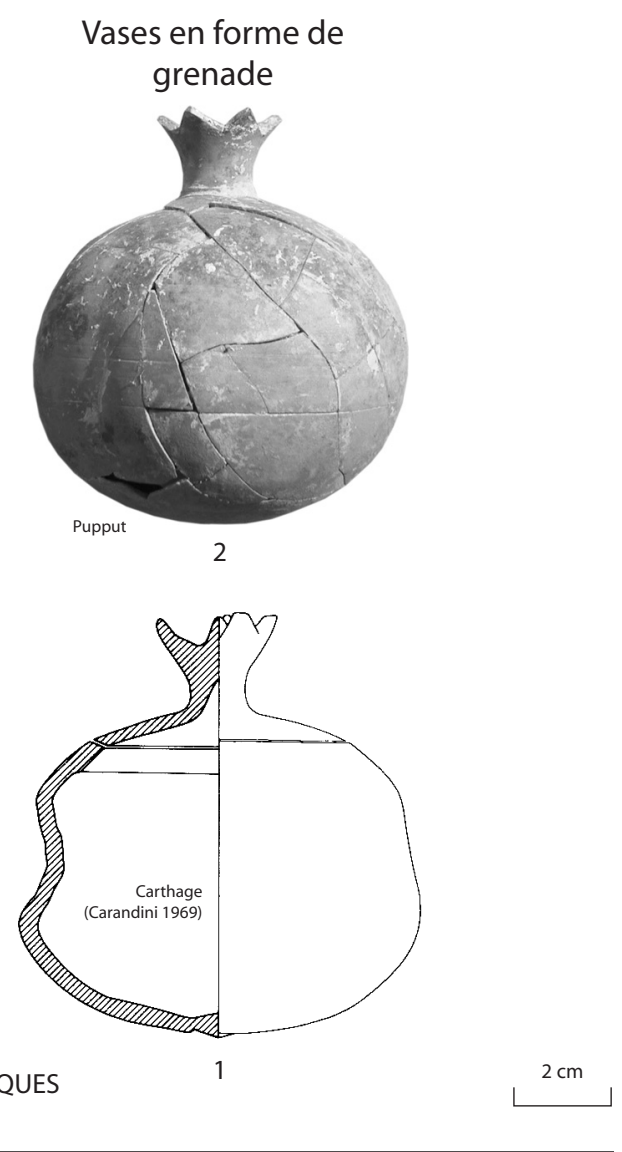

DECORS PLASTIQUES
TYPE 2

$2 \mathrm{~cm}$

\section{Céramique dite de Navigius}




\section{- figurines moulées et modelées (fig. 243)}

\section{FIGURINES TYPE 1}

Ces objets constituent des modèles réduits de la statuaire romano-africaine en céramique, bien attestée, par exemple, sur le sanctuaire de Thinissut à Bir Bou Regba (Merlin 1910). Je ne m'attarderai pas sur ces objets, dont la nécropole de Pupput a cependant livré plusieurs très beaux exemples (inédits).

Exemple (fig. 243) :

*1 Pupput (Inv. PP1573.00). Déesse-mère. Le corps de la divinité est moulé, ainsi que l'enfant qu'elle porte sur son genou gauche, en deux pièces. En revanche, le bras droit et le fauteuil sont modelés. H. $170 \mathrm{~mm}$.

Les exemplaires de Pupput proviennent de tombes de la seconde moitié du IIe siècle.

\section{- figurines moulées}

— figurines en céramique commune (fig. 243)

\section{FIGURINES TYPE 2}

L'argile peu épurée utilisée pour ces figurines, de couleur orange ou jaunâtre, n'a permis qu'un moulage assez grossier, les détails étant soulignés par des méthodes picturales. Le dos des figurines présente souvent une large ouverture circulaire, habituellement qualifiée de « trou d'évent» (Deneauve 1964-65, 124 ; Deneauve 1987, 199), probablement destinée à faciliter le séchage. Un grand nombre de ces figurines a été découvert, notamment dans les nécropoles d'Hadrumète (CMA 131136 ; CMA Suppl., 163-167) qu'il est hors de mon propos de rassembler ici ; je ne prendrais que quelques exemples choisis dans le mobilier de la nécropole de Pupput.

Exemples (fig. 243) :

Déesses-mères

*1 Pupput, tombe 1313 (Inv. 3045.1). Pâte beige orangé. H. $190 \mathrm{~mm}$.

Vénus

*2 Pupput, tombe 239 (Inv. T239.1). Pâte jaunâtre. H. $225 \mathrm{~mm}$.

Ces figurines se rencontrent dans des tombes de la seconde moitié du IIe $\mathrm{s}$. et de la première moitié du IIIe siècle.

\section{— figurines à pâte fine engobée (fig. 243)}

\section{FIGURINES TYPE 3}

J. Deneauve $(1987,199)$ a bien décrit ce groupe de figurines, dont la "surface a été couverte d'un engobe semblable à celui utilisé pour les lampes ». Il distingue deux qualités de pâtes : l'une, majoritaire, est rouge foncé et très dure, avec un engobe brun-rouge ou jaune-rouge résistant; l'autre est plus claire, moins dure, avec un engobe écaillé. Je prendrai comme seul exemple le groupe bien connu de Vénus aux trois Eros (Deneauve 1964-65, 124 ; Deneauve 1987, 25), dont un troisième exemplaire vient d'être mis au jour sur la nécropole de Pupput.
Exemple (fig. 243) :

*1 Pupput, tombe 822 (Inv. PP2010.1). Engobe lie-devin satiné. Marque incisée sur le socle : LVCRETI. $\mathrm{H}$. $200 \mathrm{~mm}$.

La même catégorie de pâte fournit également des figurines-lampes et des figurines-flacons (Deneauve 1987).

\section{— figurines en céramique sigillée (fig. 243)}

Un certain nombre de figurines sont produites dans une qualité de pâte identique à celle des lampes en sigillée africaine, avec des moules en plâtre tout à fait comparables à ceux habituellement utilisés pour ces dernières (supra, fig. 43). Cette production semble déjà attestée dans les ateliers du centre de la Tunisie mais elle est particulièrement évidente sur l'atelier d'Oudhna au VIe siècle.

\section{- productions de Tunisie centrale}

On est assez mal renseigné sur la production de figurines en sigillée africaine C. D'où l'intérêt du fragment recueilli lors de la prospection du littoral tunisien :

Exemple (fig. 243) :

1 Littoral tunisien, site $\mathrm{n}^{\circ} 37$ (Henchir Chouggaf) (Bonifay et al. 2002-2003, fig. 9, $\mathrm{n}^{\circ} 103$ ). Pâte orange fine, vernis orange satiné. Oiseau (?).

\section{- productions de Tunisie septentrionale}

L'atelier d'Oudhna a produit d'assez nombreuses figurines en sigillée africaine D2 (Barraud et al. 1998, 154-156), dont la classification précise reste à élaborer (supra, note 73). Deux types principaux apparaissent cependant :

- Type 1 : femmes enceintes, debout; certaines sont vêtues de longues tuniques ornées de motifs circulaires, d'autres ont la poitrine dénudée ; toutes ont les mains posées sur le ventre.

- Type 2: femmes assises dans un fauteuil en osier (?), allaitant un enfant posé sur leurs genoux. Il y a de nombreuses variantes dans la forme de la coiffure et l'habillement; certaines ont une coiffure très haute et portent un collier torsadé.

Exemples (fig. 243) :

Type 1

*1 Oudhna, thermes des Laberii (Barraud et al. 1998, fig. 14, $\left.\mathrm{n}^{\circ} 16, \mathrm{a}-\mathrm{b}\right)$. Femme enceinte vêtue d'une longue tunique.

2 Idem (Ibid. , n 17). Femme enceinte poitrine dénudée.

3 Oudhna, thermes des Laberii (CMA, $\mathrm{n}^{\circ}$ 80). Idem.

Type 2

*4 Oudhna, thermes des Laberii (Barraud et al. 1998, fig. 14, $\left.\mathrm{n}^{\circ} 18, \mathrm{a}-\mathrm{b}\right)$. Femme assise allaitant un enfant.

On a déjà évoqué l'interprétation de ces figurines (supra, p. 83). Les femmes enceintes debout sont peut-être des représentations de déesses de la fécondité, connues dès l'époque punique (Ferjaoui 1993, 78-79, Pl. X, n 2, 
Figurines moulées-modelées
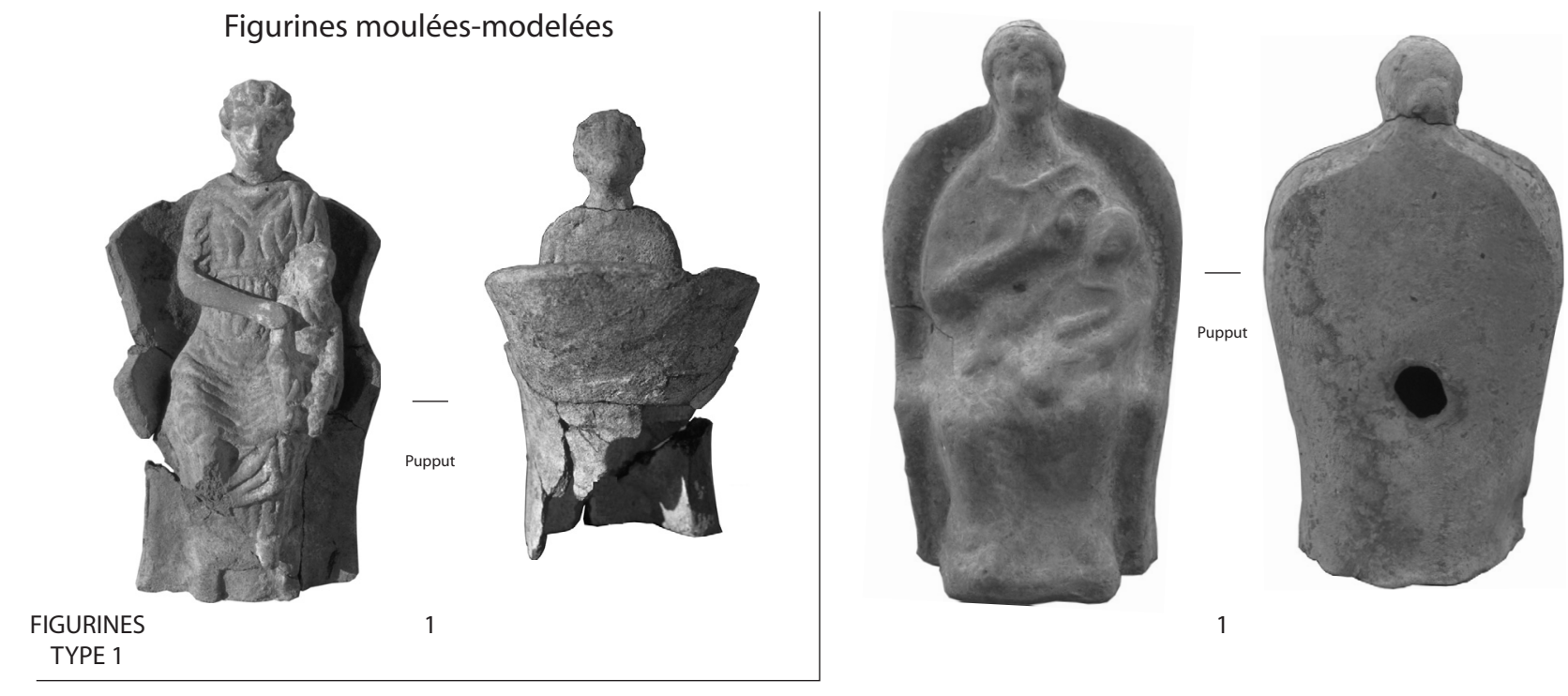

Figurines moulées

(céramique commune peinte)
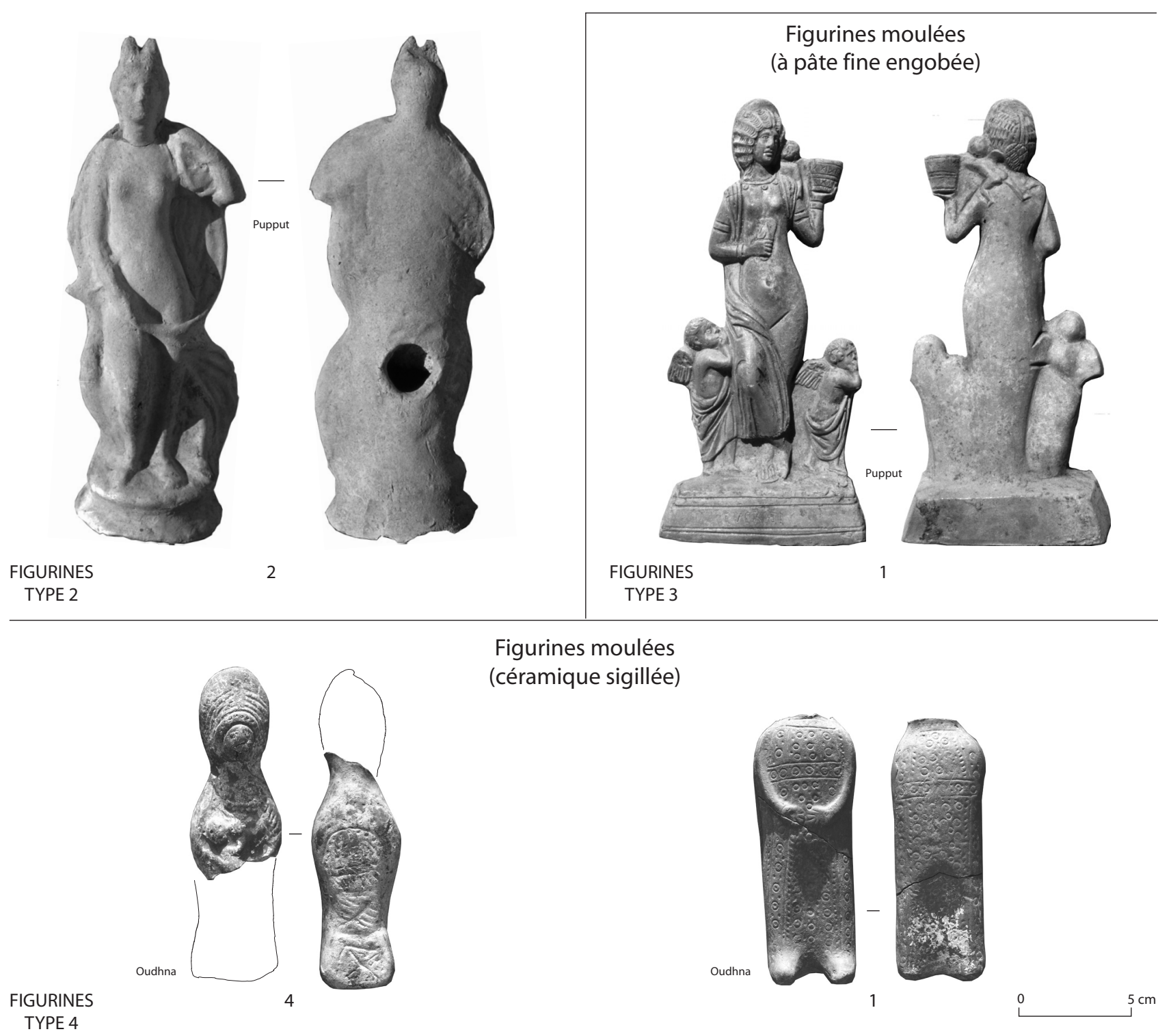

Figurines moulées (céramique sigillée)

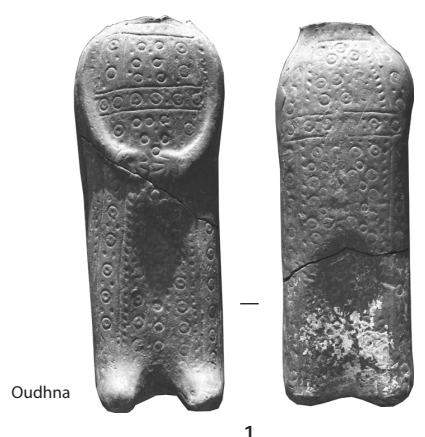

1 $5 \mathrm{~cm}$

Fig. 243. Figurines. 
Pl. XI), et les femmes assises à l'enfant rappellent les figurines de déesses-mères mentionnées plus haut. Examinant deux exemplaires de Carthage, le Père Delattre (1907, 39 et 41) a hésité, pour leur interprétation, entre la Vierge portant Jésus et Isis allaitant Horus ; dans le catalogue du musée Lavigerie, il avait opté pour la deuxième hypothèse (Delattre 1889,45 et $\mathrm{Pl}$. II, $\mathrm{n}^{\circ} 5$ ). Mais la datation de ces objets, aujourd'hui bien établie, contemporaine des formes Hayes 99 B de sigillée africaine, renvoie plus vraisemblablement à une représentation chrétienne.

\subsection{Masques}

Les nécropoles de l'Afrique romaine livrent fréquemment des masques funéraires en céramique, suivant une tradition bien ancrée dans la civilisation punique (voir, en dernier lieu, Schindler 2001). On distingue deux grands types de masques :

- Type 1: masques de grande qualité plastique, de style hellénistique, à pâte fine, rehaussée de couleurs.

- Type 2 : masques en céramique commune, de style punique.

Tous paraissent munis de trois trous de fixation : deux au niveau des oreilles, un au-dessus du front.

Exemples (fig. 244) :

Type 1

1 Leptiminus (Schindler 2001, Pl. couleur U-W).

2 Pupput, tombe 1087 (Ben Abed, Griesheimer 2001, fig. 11).

Type 2

*3 Pupput (Inv. PP1002.9).

Les masques de Pupput sont issus de contextes des IIe IIIe siècles.

\section{Masques}

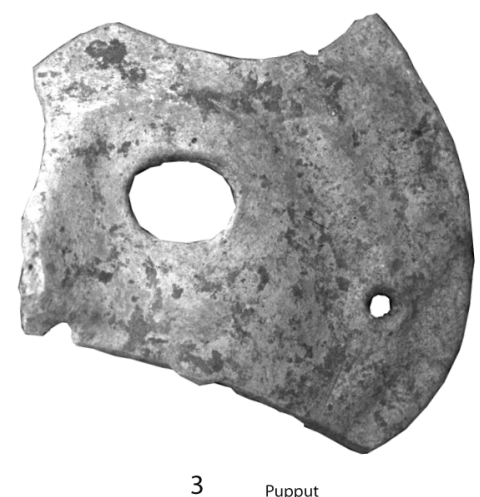

MASQUE

TYPE 2

0 $5 \mathrm{~cm}$

Fig. 244. Céramiques diverses : masques.

\section{Moules}

\section{- moules bivalves}

Sur la base de la plus grande collection publiée de moules bivalves, issue des fouilles d'Ostie, dont cependant l'origine africaine n'est pas prouvée, et des fragments sûrement africains recueillis sur la fouille tunisonéerlandaise d'Uzita, J. W. Salomonson (1972) a proposé de distinguer deux grands types de moules bivalves :

- Type 1, Rundplastische Figuren: ces moules reproduisent un seul sujet ou une seule scène groupant plusieurs sujets, l'une des valves correspondant à la vue de face, l'autre à la vue de dos. Le creux du moule correspond très exactement aux contours du sujet représenté. Comme le remarque J. Deneauve $(1986 \mathrm{~b}, 141)$ : «à cette catégorie appartiennent d'assez nombreuses représentations d'animaux traités isolément ou dans des combats les opposants entre eux ou à des venatores ».

- Type 2, Reliefbilder : ces moules sont destinés à la reproduction de mottes de forme géométrique dont les deux côtés sont ornés de reliefs identiques ou différents. Malgré leur état souvent très fragmentaire et leur dispersion sur un vaste territoire, les moules du type 2 découverts en Afrique font, à mon sens, apparaître au moins trois variantes différentes, selon la forme de la motte : semi-lenticulaire (variante A), quadrangulaire (variante $\mathrm{B}$ ) ou conique (variante $\mathrm{C}$ ). L'exemple le mieux documenté de la variante A est celui du moule de Fréjus (Janon 1978 et 1984), très probablement d'origine africaine, dont chacune des faces est ornée d'un motif différent : une scène de pugilistes et une scène de lutteurs. La valve des pugilistes trouve une comparaison directe avec deux fragments conservés au musée de Carthage (Janon 1984, fig. 1 et 2 ; Deneauve 1986b, fig. 2); la valve des lutteurs est assez proche d'un fragment de Nabeul (4) qui porte en outre une inscription similaire sur la face extérieure. Les rares exemples de moules de la variante $B$ portent des représentations de courses de chars (5 et $\mathbf{6}$; voir également à Ostie: Floriani-Squarciapino 1954, Pl. XIX, $\left.n^{\circ} 1 \mathrm{a}\right)$.

Les deux types de moules peuvent porter des inscriptions incisées avant cuisson, soit sur la face extérieure, soit sur la face intérieure :

- Sur la face extérieure :

- des inscriptions indiquent le sujet qui est représenté sur le moule: (ELEFA)NTVS LEO sur un moule d'Ostie, VENATIO LEONVM sur un moule de Lepcis Magna (Floriani-

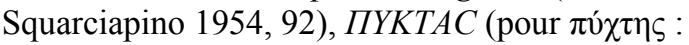

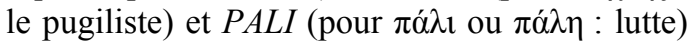
sur des moules de Fréjus (Janon 1978, 256) et de Nabeul (4); 


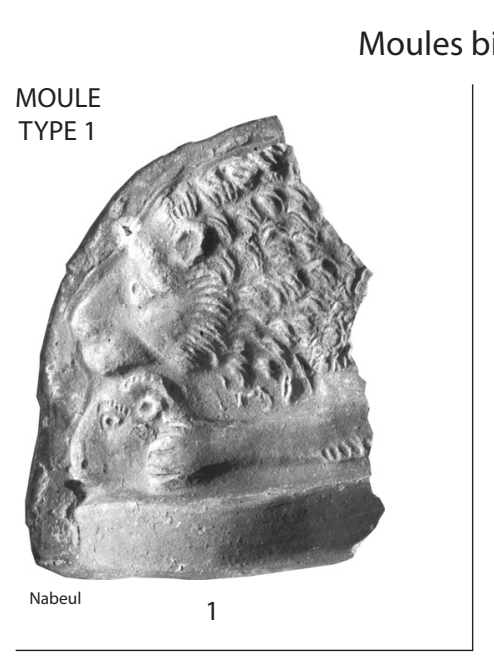

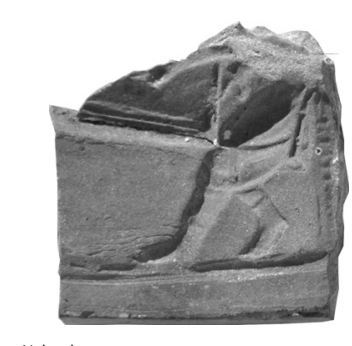

3

Nabeul
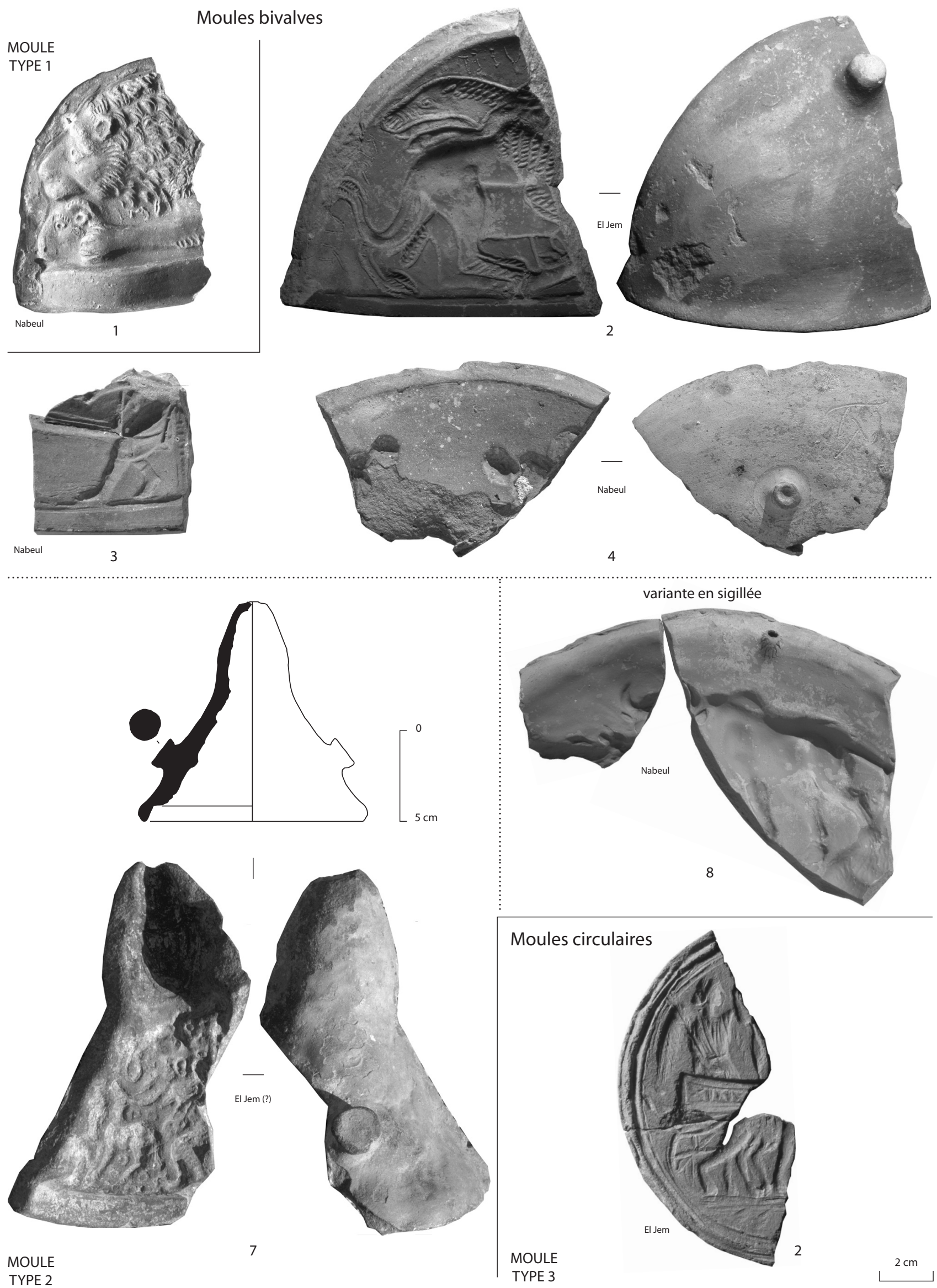

Fig. 245. Moules. 
- d'autres sont des marques de fabrique : $[O] F$ LVCCEIORVM et MAVRICI sur des moules d'Uzita (Salomonson 1972, 103).

- Sur la face intérieure, des inscriptions rétrogrades en creux sont destinées à être lues en relief sur l'objet tiré du moule. Je ne connais qu'un seul exemple en Afrique, d'interprétation incertaine : ]LVI ET REGVLI, sur un moule d'El Jem (2).

Exemples (fig. 245) :

Type 1 :

*1 Nabeul, fabrique de salaisons (Inv. NB1029.3). Lion assaillant un bélier (?).

Type 2:

Variante A

*2 El Jem, Maison d'Africa (sans $\mathrm{n}^{\circ}$ d'inv.). Lion attaquant un onagre (?). Inscription rétrograde dans le moule : ]LVI ET REGVLI. Proche d'un exemplaire de Sabratha: Joly 1992, fig. 12.

*3 Nabeul, fouilles anciennes (sans $\mathrm{n}^{\circ} \mathrm{d}$ 'inv.). Venatio (?).

*4 Nabeul, fouilles anciennes (sans $\mathrm{n}^{\circ}$ d'inv.). Pugilistes (?). Marque incisée sur l'extérieur du moule, en cursive : Pal[ (?)

Variante B

5 Timgad (Salomonson 1972, fig. 17). Course de chars.

6 Volubilis (Chergui, Ichkhakh, Limane 2000, fig. 2-3). Course de chars.

Variante $\mathrm{C}$

*7 Région d'El Jem (?) (collection M. Cornet, Jouques). Poursuite d'animaux (?).

Variante en céramique sigillée (?)

*8 Nabeul, fouilles anciennes (sans $\mathrm{n}^{\circ}$ ). Taureau.

La datation de ces moules bivalves renvoie régulièrement à la fin du IIe $\mathrm{s}$. et à la première moitié du IIIe $\mathrm{s}$. (Salomonson 1972, 113 ; Janon 1978, 253 ; Janon 1984, 352). Le $n^{\circ} 2$ provient d'un contexte du IIIe ou du IVe siècle.

\section{- moules circulaires}

J. W. Salomonson signalait également une deuxième catégorie de moules, plats et de forme circulaire, proches d'exemples connus en Pannonie (Salomonson 1972, 113, fig. 30).

Exemples (fig. 245) :

1 Carthage (Salomonson 1972, fig. 30). Saisons, inscription : TEMPORA.

*2 El Jem, Maison d'Africa (fouilles H. Slim, Inv. EJMA7503.1). Victoire ailée sur un char.

La datation de ces moules ne paraît pas être différente de celle des moules bivalves. Le $n^{\circ} 2$ provient d'un contexte du IIIe siècle.

\subsection{Autres objets}

- pesons de filets (fig. 246)

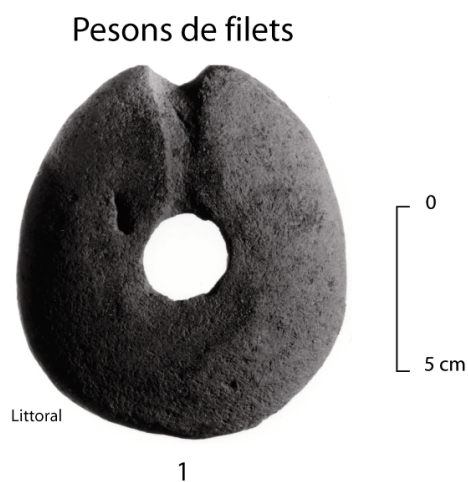

Fig. 246. Objets divers.

Les sites côtiers livrent un grand nombre de pesons de filets de pêche.

Exemples :

*1-3 Littoral tunisien (Bonifay et al. 2002-2003, fig. 20, $\left.n^{\circ} 283-285\right)$. 


\section{Carreaux à décor en relief}

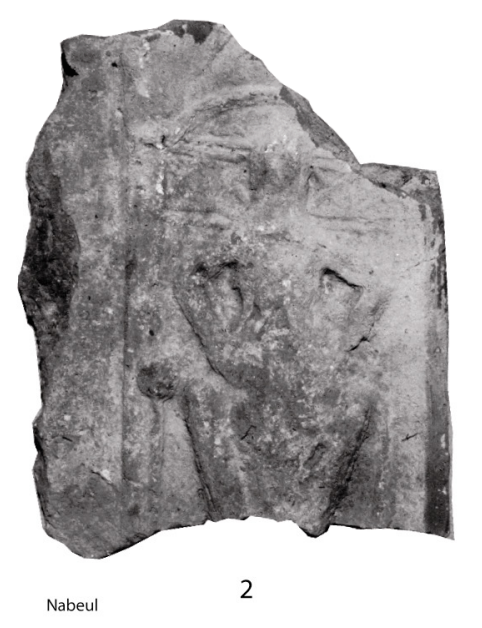

CARREAU

TYPE 3

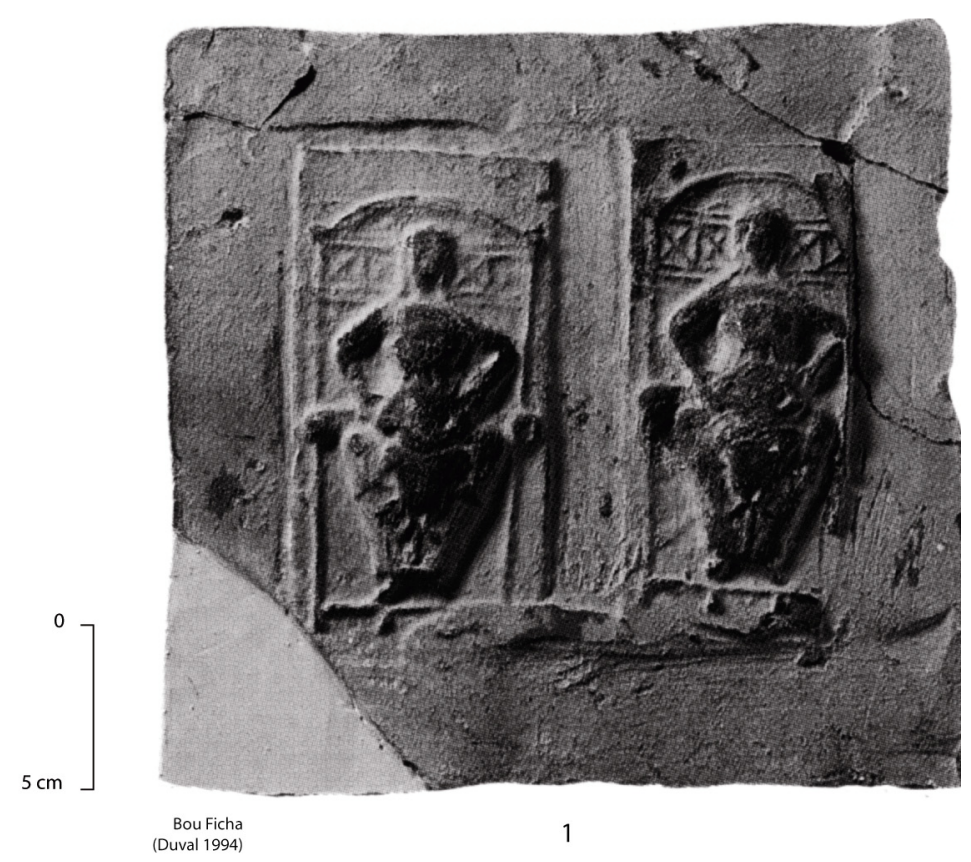

Bou Ficha
(Duval 1994)

Fig. 247. Céramiques architecturales : carreaux. 


\section{CERAMIQUES ARCHITECTURALES}

La céramique architecturale romaine d'Afrique est une documentation encore largement sous-exploitée. Je mentionne rapidement ici quelques objets parmi les plus courants.

\subsection{CarreauX}

Les carreaux à décor en relief étaient destinés à l'ornementation du plafond charpenté des basiliques chrétiennes ou de certains édifices profanes, ou encore pouvaient être utilisés en décoration murale. N. Ben Lazreg (1991) distingue trois types principaux de carreaux :

- Type 1 : carreaux à réglettes,

$1 \mathrm{~A}$ : deux réglettes courtes à l'aplomb de deux bords opposés du carreau; les marges d'appui sur les solives du plafond sont perpendiculaires aux réglettes ;

1B : deux réglettes longues en retrait de deux bords opposés du carreau; les marges d'appui sur les solives du plafond sont parallèles aux réglettes. Ces carreaux de forme rectangulaire sont rares et leur diffusion limitée à la région d'El Jem.

- Type 2 : carreaux à colonnes. Les colonnes jouent le rôle des réglettes du type $1 \mathrm{~A}$ mais une découverte de Hajeb el-Aioun prouve que ces carreaux ont pu être également utilisés en décoration murale. Ils sont caractéristiques de la région de Kairouan.

- Type 3 : carreaux à cadre simple, dotés de quatre marges autour d'un cadre circulaire ou quadrangulaire dans lequel s'inscrit le décor.

Des fragments de carreaux recueillis à Nabeul dans un contexte profane (?) appartiennent à ce dernier type. Le décor des deux déesses-mères assises dans des fauteuils en osier (ou représentations de la Vierge) est caractéristique du groupe décoratif de Bou Ficha. Exemples(fig. 247) :

*1 Bou Ficha (Duval 1994, 290, n 1).

*2 Nabeul, fabrique de salaisons (Inv. NB1428.23).

Datation proposée : VIe - VIIe s. (?).

\subsection{TUILES}

L'exemple de Pupput montre que les plus anciennes tegulae africaines sont faites à l'imitation des tuiles italiques, dont elles reprennent très exactement les dimensions. Elles s'en distinguent cependant par la pâte, comparable à celle des amphores ou des céramiques communes africaines, et par quelques détails morphologiques :

- absence d'encoches d'emboîtement sur la face inférieure ;
- plus longue échancrure des rebords sur la face supérieure, probablement pour pallier l'absence des encoches d'emboîtement ;

- cambrure du profil transversal de la tuile ;

- face inférieure parcourue de profondes cannelures longitudinales.

Exemples (fig. 248) :

Tegula italique importée

*1 Pupput (Inv. 3340.1). L. $470 \mathrm{~mm}$; 1. $400 \mathrm{~mm}$; ép. $22 \mathrm{~mm}$. Pâte beige avec inclusions noires volcaniques (supra, fig. $48, \mathrm{n}^{\circ} 1$ ).

Tegula africaine

*2 Pupput (sans $\mathrm{n}^{\circ}$ d'inv.). L. $470 \mathrm{~mm}$; 1. $400 \mathrm{~mm}$; ép. $22 \mathrm{~mm}$. Pâte orange.

Quelques fragments recueillis sur des sites assez voisins (Oued R'mel, Nabeul, Oudhna) permettent d'entrevoir quelques critères d'évolution de la forme des tegulae africaines. Les tuiles munies d'un rebord haut et arrondi au sommet (3-4) paraissent appartenir à une production ancienne. Les bords plus frêles (5) ou massifs avec un sommet plat (6) proviennent de contextes de l'Antiquité tardive ; à cette époque, la partie centrale de la tuile perd en épaisseur et les cannelures sur la face inférieure semblent disparaître (les tuiles de la basilique IV de Sbeitla sont en revanche cannelées sur la face supérieure : Duval 1971, fig. 387).

Exemples (fig. 248) :

*3 Oued R'mel, sanctuaire (Inv. 0502).

*4 Oued R'mel, établissement agricole (Inv. 1905.4).

*5 Oued R'mel, établissement agricole (Inv. 0800).

*6 Nabeul, quartier de la maison des Nymphes (Inv. 3017).

On est mal renseigné sur la morphologie des tuiles en sigillée produites aux VIe s. et VIIe s. (?) sur l'atelier d'Oudhna. Le type de bord se rapproche des exemplaires tardifs de tuiles communes. Des imbrices et peut-être des chéneaux sont produits dans la même technique céramique.

Exemples (fig. 248) :

Imbrex

7 Carthage (Hayes 1978b, 74 et fig. 22, $\mathrm{n}^{\circ} 101$ ) Tegula

*8 Oudhna, thermes des Laberii (Barraud et al. 1998, fig. $\left.15, \mathrm{n}^{\circ} 19\right)$. Chéneau (?)

9 Oudhna, thermes des Laberii (Barraud et al. 1998, fig. $\left.15, \mathrm{n}^{\circ} 20\right)$. 
Imitations africaines de tuiles italiques

Importation italique
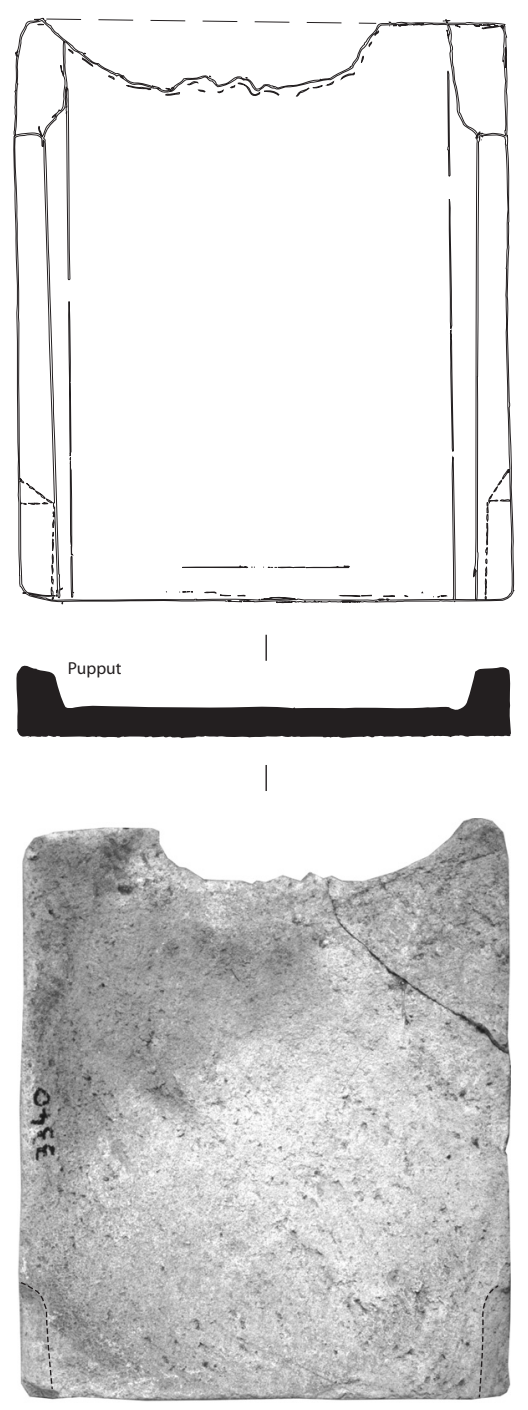

1
Production africaine

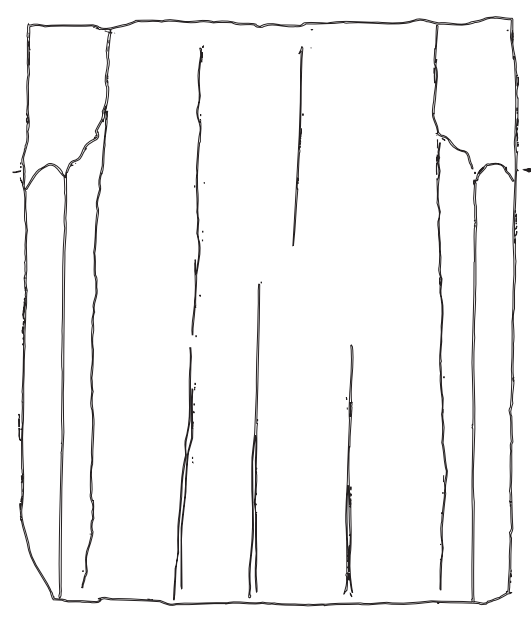

Pupput
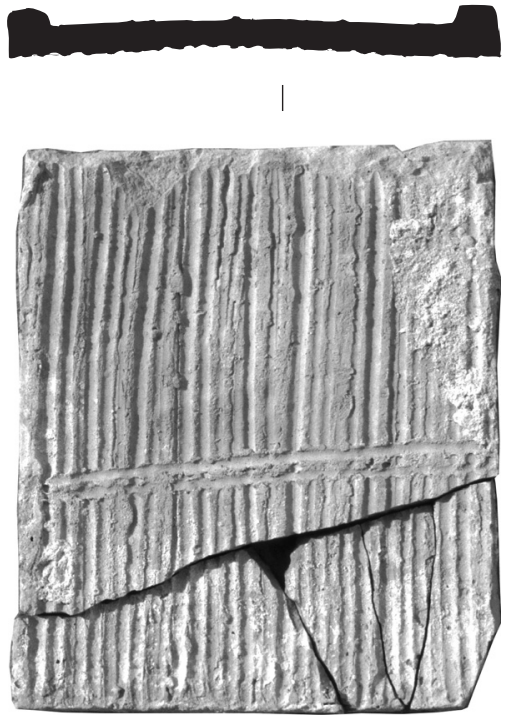

2

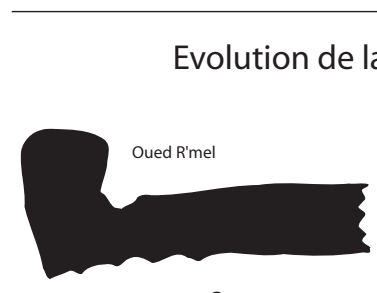

3

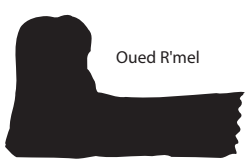

4

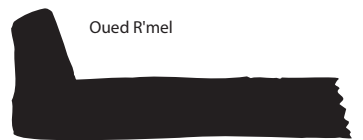

5

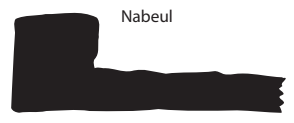

6
Tuiles en céramique sigillée
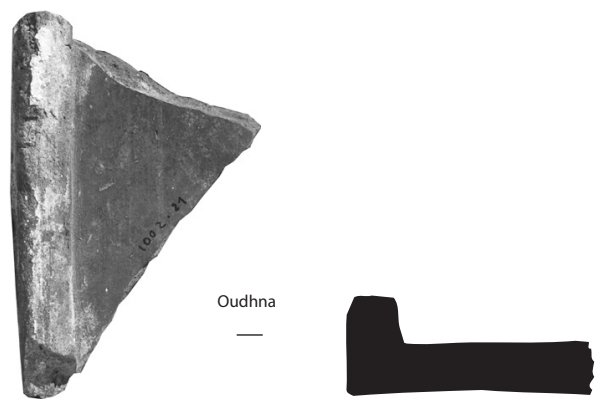

8

0 $5 \mathrm{~cm}$

Fig. 248. Céramiques architecturales : tuiles. 
Tubes de voûte

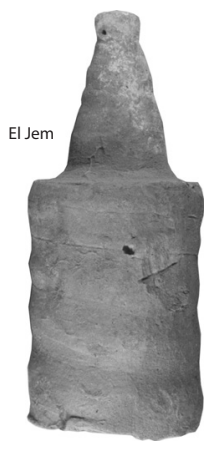

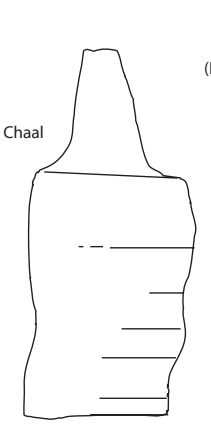

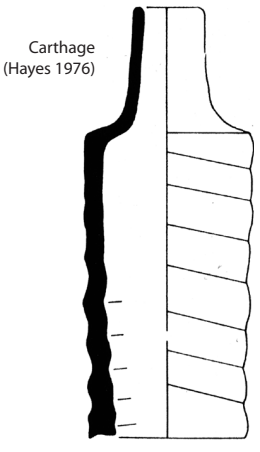

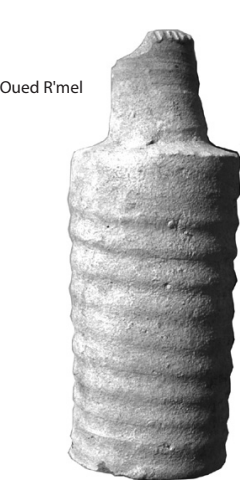

4

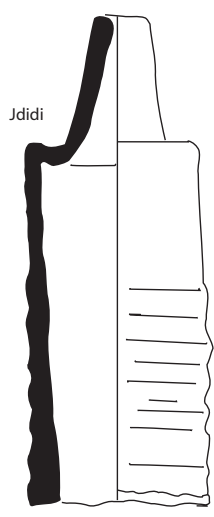

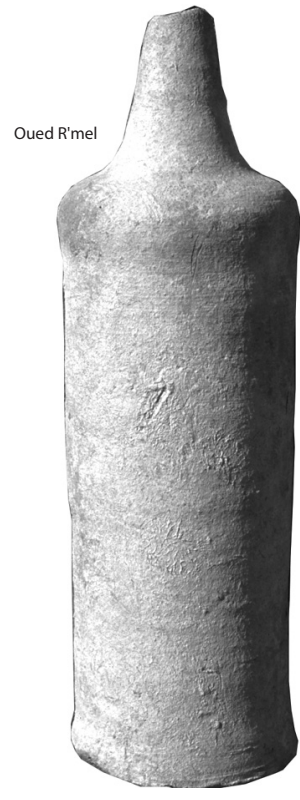

6

Tuyaux

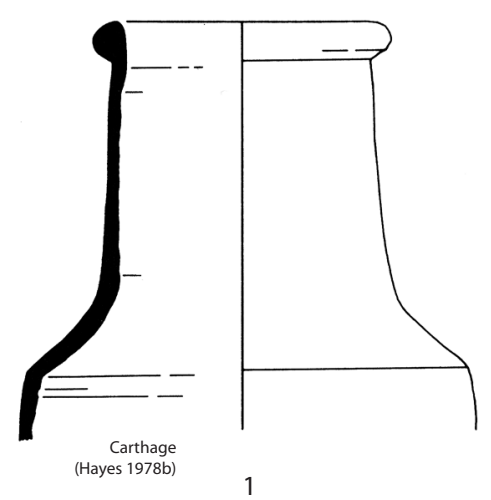

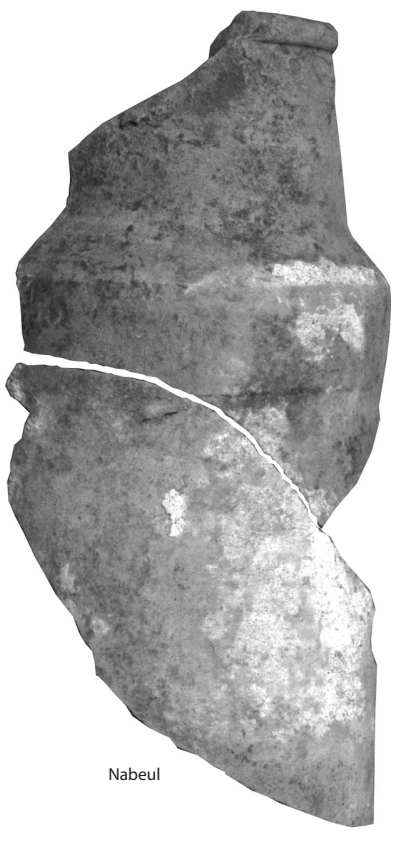

2

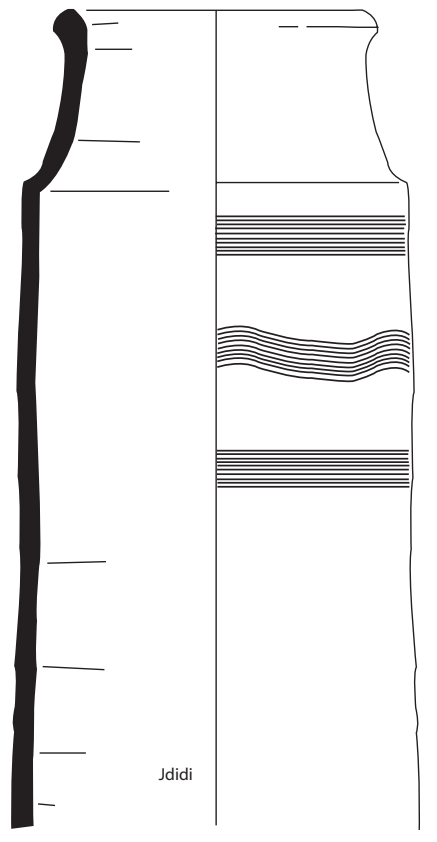

3

0 $5 \mathrm{~cm}$

Fig. 249. Céramiques architecturales. 


\subsection{TUBES DE VOÛTE}

Omniprésents sur tous les sites d'habitat, les tubes de voûte peuvent varier dans le détail de leur taille et de leur forme (Olivier, Storz 1983, Wilson 1992). Ainsi, les tubes de petite taille (H. $12 \mathrm{~cm}$; D. $4,5 \mathrm{~cm}$ ) avec une pointe très allongée paraissent typiques de la Byzacène (?) (1-2). Les tubes d'env. 13-15 cm de haut et env. $5 \mathrm{~cm}$ de diamètre sont très fréquents en Zeugitane (3-5). Il existe également des tubes de voûtes de grande taille (H. 22,5 cm; D. 7,5 cm), plus rares (6).

Exemples (fig. 249) :

*1 El Jem, maison d'Africa (sans n ${ }^{\circ}$ d'inv.).

*2 Chaal (Graïba, région de Mahrès) (prospections géomorphologiques de M. N. Fehri, 2001).

*3 Carthage (Hayes 1976a, fig. 2, V.10).

*4 Oued R'mel (fouilles T. Ghalia, Inv. OR4009.1).

*5 Sidi Jdidi, basilique 3 (sans $n^{\circ}$ d'inv.)

*6 Oued R'mel (sans n d'inv.).

On reste assez mal renseigné sur la datation des différents types de tubes de voûtes. A Sbeitla, N. Duval a pu déceler une évolution entre les types anciens, à cylindre court et pointe allongée, et ceux utilisés dans les basiliques, avec un cylindre plus long et une pointe plus courte (Duval 1971, 88). Le $\mathrm{n}^{\circ} \mathbf{1}$ date du IIIe $\mathrm{s}$. (pièce 23 de la maison d'Africa) et le $\mathrm{n}^{\circ} \mathbf{3}$ a été découvert dans un contexte antérieur au IVe siècle. J. W. Hayes $(1978,79)$ signale que les tubes de voûte, à Carthage, sont moins nombreux dans les contextes tardifs (Hayes 1978b, 79).

\subsection{TUYAUX}

Présents en grand nombre de fragments sur tous les sites d'habitats, les tuyaux d'évacuation des eaux de toiture sont des tubes en céramique de $14-18 \mathrm{~cm}$ de diamètre ; un exemplaire presque complet découvert sur le site d'Oued el-Kseub mesure plus d'un mètre de longueur (voir également celui de Sbeitla: Duval 1971, fig. 133). Ils sont munis d'une embouchure resserrée pour pouvoir être emboîtés les uns dans les autres. Il est parfois difficile de distinguer les fragments de tuyaux de ceux d'amphores ou de cruches (1) (voir Ortisi 1999, fig. 18, $\mathrm{n}^{\circ} 355$ ). Certains portent un décor peigné (3).

Exemples (fig. 249) :

*1 Carthage (Hayes 1978b, fig. 25, D71).

*2 Nabeul (sans $n^{\circ}$ d'inv.).

*3 Sidi Jdidi, basilique 1, état C2B (Bonifay, Reynaud 2004, $\left.\mathrm{n}^{\circ} 28.18\right)$.

\subsection{AUTRES CÉRAMIQUES ARCHITECTURALES}

Sans chercher à dresser une liste exhaustive des céramiques architecturales rencontrées sur les chantiers africains, je souhaiterais insister sur un objet original, assez fréquent en Tunisie, destiné à la confection des parois de briques murales permettant la circulation de l'air chaud dans les établissements thermaux. Ce séparateur de briques de thermes combine en un seul objet la tige métallique et le tube en céramique (Bouet 1999, 67 : « bobines ») associés dans d'autres régions de l'Empire pour le même usage. L'Espagne, notamment, paraît avoir également produit des matériaux similaires (Torrecilla Aznar 1999, fig. 1).

Exemples (fig. 250) :

*1 Oued R'mel (sans n d'inv.).

*2 Musée de Lamta (en exposition; cf. J. Richerson in Leptiminus II, fig. 5.19).

\section{Séparateurs de briques de thermes}
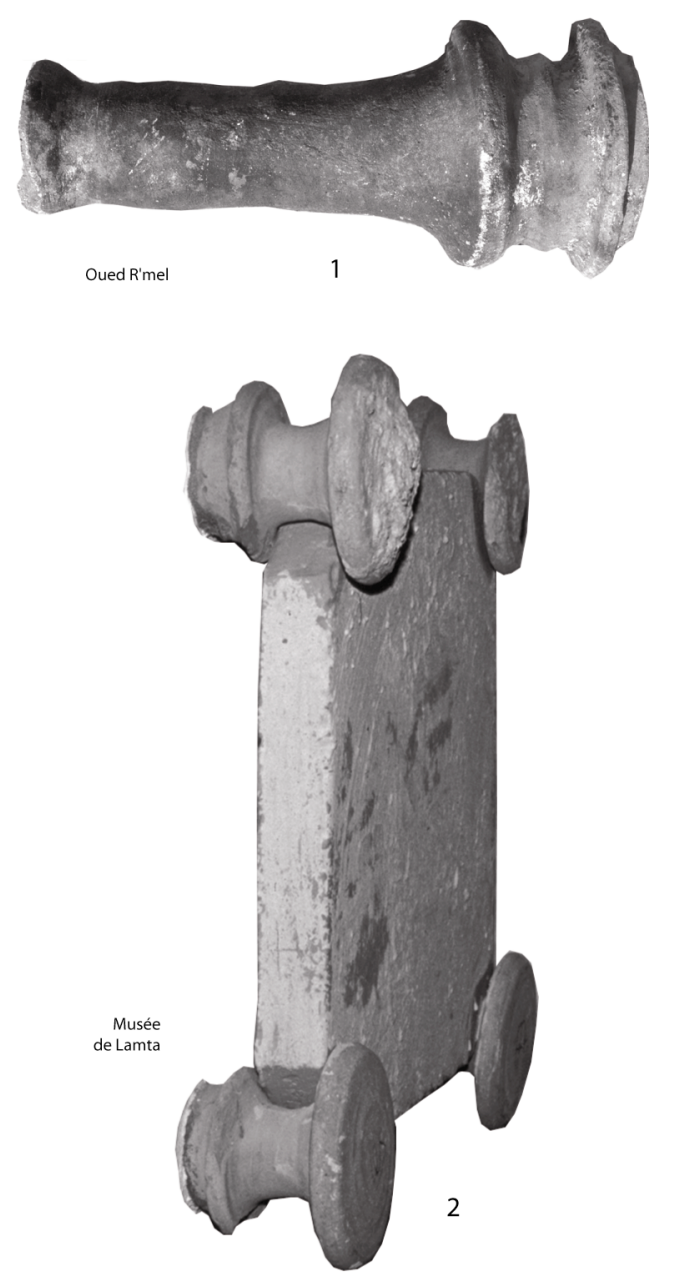

Fig. 250. Céramiques architecturales. 


\section{PARTIE III : DIfFUSION}

\section{LA CÉRAMIQUE AFRICAINE, TÉMOIN DES ACTIVITÉS ÉCONOMIQUES}

Depuis trente ans, il a été fait un usage intensif - excessif diront certains - de la céramique africaine comme indice des activités économiques en Afrique et dans l'ensemble du bassin méditerranéen. Les études sur les fluctuations de l'économie africaine, envisagées du strict point de vue de la diffusion des vaisselles sigillées ou des amphores produites dans cette région, ne se comptent plus (cf. notamment : Carandini 1970a et 1983 ; Fulford 1980 et 1983 ; Fentress, Perkins 1988 ; Panella 1989 et 1993 ; Panella, Saguì 2001 ; Reynolds 1995 ; Tomber 1993 ; Zanini 1996).

De fait, l'attention, au cours de ces années, s'est tout d'abord portée sur la commercialisation. On a souligné que les sigillées africaines, malgré leur importance mineure dans l'ensemble de l'économie africaine, portaient le témoignage concret d'un «monde (...) de production, de commerce et de consommation, largement invisible dans les sources écrites » (Fentress, Perkins 1988). A cette documentation qui ne faisait naguère l'objet que de catalogues érudits, ont été appliquées les méthodes statistiques les plus pointues; les cartes de diffusion périodisées se sont multipliées. Ces méthodes ont cependant essuyé de justes critiques ${ }^{287}$, car comment se fier aux conclusions historiques tirées de ces statistiques alors que l'origine précise des productions reste floue dans beaucoup de cas, que l'identification des catégories peut varier d'un chercheur à un autre, que les datations subissent des révisions considérables, portant parfois sur plus d'un demi-siècle (ex. : Keay 62, Hayes 99) ?

On s'est également interrogé sur la nature des denrées de première nécessité (agricoles ou autres) que les amphores pouvaient transporter et les céramiques sigillées accompagner. Dans les deux cas, une production a été particulièrement mise en avant: l'huile. Il est apparu évident dès 1969 (Zevi, Tchernia) que l'essentiel des amphores africaines étaient destinées au transport de l'huile et que la commercialisation des sigillées africaines ne pouvait que suivre le développement de l'oléiculture

\footnotetext{
${ }^{287}$ Cf. P. Gros in Opus, II, 1983, p. 76 : "La tendance actuelle qui consiste, sous prétexte de rigueur méthodologique et de positivisme scientifique, à tirer des conclusions historiques de graphiques ou de schémas de répartition, dont on sait par ailleurs qu'ils sont lourdement lacunaires ou approximatifs, me paraît procéder d'un leurre ».
}

en Afrique Proconsulaire, bien attesté par les textes (Carandini 1970a). Cette thèse, fondée sur des arguments convaincants développés notamment par les écoles italienne (cf. notamment : Carandini 1983 ; Panella 1989 et 1993) et anglo-saxonne (Mattingly 1988a et b; Hitchner 1993), s'est trouvée peu à peu contestée par l'évidence surprenante que beaucoup d'amphores africaines n'étaient pas dévolues au transport de l'huile mais à celui d'autres denrées, le garum et probablement aussi le vin. Que reste-t-il aujourd'hui des certitudes des années 70 ?

Enfin, et pour en revenir aux territoires africains, notre perception du développement économique de cette région et de la façon dont la céramique peut éventuellement en rendre compte est gênée par la rareté des fouilles sur les lieux de productions de denrées nobles: huile, vin, blé, salsamenta. La fouille de la fabrique de salaisons de Nabeul met en relief les problèmes de datation des installations et d'identification des conteneurs utilisés pour la commercialisation des produits (Slim, Bonifay, Trousset 1999). La rareté des informations sur les sites ruraux n'en est que plus flagrante : les données apportées par les prospections de surface sont très imprécises, tant du point de vue de la chronologie des sites que de la nature des productions. Un pressoir à huile laissera des traces plus facilement identifiables sans fouille qu'un pressoir à vin (Brun 2003) et le blé pourra passer complètement inaperçu. Cette lacune dans les recherches sur le monde rural explique aussi l'indigence de nos connaissances sur la façon dont les ateliers d'amphores et de sigillées étaient ou non intégrés aux unités de production de biens de première nécessité.

J'ai hésité sur la manière d'aborder ces questions. Il eut été logique de partir à nouveau du terrain africain, des lieux de production, et de terminer par les témoignages les plus lointains, la diffusion. Mais c'était partir de l'inconnu (ou du moins bien connu) vers le mieux connu. Il m'a semblé finalement plus aisé de commencer par la question la plus facile, celle de la diffusion en Méditerranée, puis d'aborder le problème de la nature des productions vivrières transportées à l'intérieur ou à côté de ces vases et enfin de m'interroger sur la façon dont la céramique, finalement, nous renseigne, bien ou mal, sur le développement de l'économie africaine. 


\section{CÉRAMIQUE AFRICAINE ET COMMERCE}

La diffusion des céramiques africaines a suscité une abondante littérature qu'il est hors de mon propos de commenter ici, surtout après les récentes synthèses de P. Reynolds (1995) pour la Méditerranée occidentale et de J.-P. Sodini (2000) pour la Méditerranée orientale. Je souhaiterais seulement aborder, de manière ponctuelle, un certain nombre de questions qui m'ont été dictées par la composition des lots de matériels que j'ai eu l'occasion d'étudier.

\subsection{COMPTAGES ET CARTES DE RÉPARTITION : ÉTAPES DE LA RECHERCHE OU REFLET DU PASSÉ ?}

\section{Remarques préliminaires}

Il est d'usage, dans la littérature archéologique actuelle, de procéder à des études quantitatives de céramiques d'où l'on cherche à tirer des conclusions d'ordre économique, culturel, voire même démographique. La céramique africaine a été particulièrement mise à contribution (Fentress, Perkins 1988; Zanini 1996). Sans prétendre remettre en question le bien fondé de cette démarche ${ }^{288}$, il importe de relever un certain nombre de difficultés (Bonifay 1983, 295-296). La plus grande prudence s'impose en effet lorsqu'on désire comparer des statistiques faites sur des sites différents, ceci pour quatre raisons principales.

\section{- Difficultés d'application des typologies}

L'attribution d'un fragment de céramique à un type dûment répertorié dans les classifications est un acte subjectif : il dépend de l'avancement de la recherche, de l'état de conservation du fragment, de la formation et de la perspicacité du céramologue. Les difficultés d'application des classements sont particulièrement flagrantes dans le domaine des amphores. En effet, la plupart des typologies de céramiques sont des typologies de bords. Ce travers peut ne pas avoir de graves conséquences lorsque le vase est petit (céramiques sigillées). En revanche, dans le cas des amphores, la seule prise en considération de la section du bord peut être à l'origine de réels contresens. Les cas où des fragments de bords ont été attribués à la forme Keay 25 alors qu'il s'agissait de tout autres amphores et surtout pas d'amphores cylindriques de moyennes dimensions, ne se comptent plus. Il en est de même pour des Keay 25 soustype 2 (Ve s.) interprétées comme des Keay 62 (VIe s.), des Africaines II C (IIIe s.) devenues des Keay 56 (fin

\footnotetext{
${ }^{288}$ Encore que je reste, à titre personnel, extrêmement perplexe sur l'interprétation chronologique et démographique des comptages de céramiques récoltées en surface (Bonifay et al. 2002-2003)
}

Ve s.), etc. En fait, le désir de donner un numéro de forme à chaque tesson pousse parfois les céramologues à des excès d'interprétation et quand on constate $a$ posteriori les erreurs commises par chacun d'entre nous, on frémit à l'idée que des chronologies entières de sites reposent sur des inventaires de tessons qu'aucun dessin ne permet de vérifier. Pour ma part, je reste attaché aux publications de contextes ${ }^{289}$, illustrées par de nombreux dessins, même lorsque les objets se ressemblent.

\section{- Imprécision et subjectivité des datations}

L'intérêt est de pouvoir comparer des lots de matériel contemporains. Or, en Méditerranée occidentale, la datation des niveaux romains tardifs repose principalement sur la céramique sigillée africaine dont les problèmes de chronologie sont trop souvent occultés. Un certain nombre d'écoles se sont créées qui n'appliquent pas réellement les mêmes «systèmes chronologiques"). On peut aisément constater que les céramologues italiens ont, sauf exception (Saguì 1998), l'habitude de dater « haut» (Tortorella 1986, 1995, 1998) par rapport aux céramologues allemands (Mackensen 1993), anglosaxons (Hayes 1972) ou français (Bonifay 1998a). Il est donc très important de connaître en détail les bases de la datation $\mathrm{du}$ contexte archéologique (stratigraphie, monnaies, répertoire de formes des différentes catégories de céramiques, avec une illustration abondante) afin de pouvoir éventuellement les critiquer.

\section{- Diversité des contextes archéologiques}

Pour ne pas risquer de comparer ce qui n'est pas comparable, il est souvent utile de pouvoir se reporter au terrain d'où est issu le matériel : un dépotoir n'aura pas la même composition qu'un remblai, un sol d'habitat n'aura pas le même faciès qu'un comblement de citerne. D'autre part, il faut rappeler que l'échantillonnage sur lequel nous travaillons est souvent extrêmement réduit: P. Reynolds (1995) a montré qu'il était bien rare de pouvoir disposer de séquences chronologiques longues.

\section{• Hétérogénéité des méthodes de comptages}

Une certaine anarchie règne actuellement dans les méthodes de comptage de céramiques. Les expériences menées depuis trente ans en la matière sont parfois assez différentes les unes des autres (Riley 1979; Fulford, Peacock 1984 ; C.A.T.H.M.A. 1986, 32 ; Bonifay 1986, 302-304 ; C.A.T.H.M.A. 1990 ; Arcelin, Truffreau-Libre 1998) :

\footnotetext{
${ }^{289}$ A l'image de ce que J. W. Hayes réalise depuis trente ans tout autour du bassin méditerranéen.
} 
- A) les comptages bruts de tessons: le RBHS (rim/base/handle/sherd) ou TT (Total des Tessons) ; - B) les comptages d'éléments significatifs : le RBH (rim/base/handle) ou BFA (bord/fond/anse).

- C) les conversions en nombre de vases par application d'un coefficient de fragmentation ou d'une péréquation entre les comptages de chacun des éléments significatifs (NMI: nombre minimum d'individus);

- D) les anglo-saxons utilisent parfois une méthode plus complexe où, pour chaque tesson de bord, est calculé le pourcentage conservé de la circonférence totale du vase (EVEs: Estimated Vessel Equivalents) ;

- E) la pesée du total des tessons ou des éléments significatifs, principalement utilisée par les anglosaxons.
R. Tomber (1993) a testé la compatibilité des différentes méthodes et préconise la plus simple de toutes, le comptage du total des tessons (A). Une comparaison entre les données de Marseille calculées en TT, BFA et NMI suggère la même conclusion (Bonifay 1986, 97 et 303).

Au-delà de ces observations à caractère général, qui sont des lieux communs pour la plupart des archéologues (mais peut-être moins pour les historiens susceptibles d'utiliser nos données), je souhaiterais insister sur deux aspects de l'interprétation économique ou historique des données céramologiques.
Amphores africaines

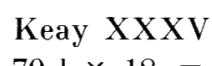

$701 \times 18=12601$
Amphores orientales

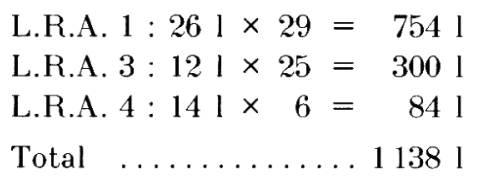

Total ...........1138 I

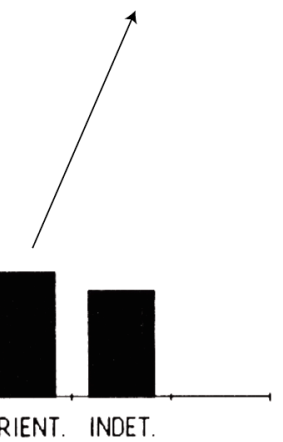

Fig. 251. Comptages de tessons et capacité des amphores : l'exemple de Marseille (deuxième quart - milieu du Ve s.).

\section{Comptages de tessons et capacité des amphores}

Les comptages de céramiques effectués sur les contextes de l'Antiquité tardive à Marseille avaient démontré l'essor des importations d'amphores orientales au deuxième quart ou au milieu du Ve s., au détriment, semblait-il, des amphores africaines (Bonifay 1986; Bonifay, Congès, Leguilloux 1989). Le contexte $n^{\circ} 1 \mathrm{du}$ chantier de La Bourse (Bonifay et al. 1998, 416, Tabl. CIII) comprend ainsi $44 \%$ de fragments d'amphores orientales contre seulement $20 \%$ d'amphores africaines. Mais peut-être ne doit-on pas surestimer le volume réel de ces échanges. Si l'on convertit ces comptages bruts en nombre d'exemplaires pour chacune des deux zones géographiques exportatrices (64 amphores orientales pour seulement 18 amphores africaines) et si l'on prend en considération la capacité de ces conteneurs (entre 6 et 26 litres pour les amphores orientales, et près de 70 litres pour les amphores africaines), on obtient pour la Méditerranée orientale un maximum de 1138 litres et pour l'Afrique un chiffre moyen de 1260 litres (fig. 251). Les quantités réelles de produits importés s'équilibrent (Bonifay, Villedieu 1989, 39).

En fait, les amphores africaines sont peut-être moins nombreuses au Ve s. qu'au IVes. mais elles sont plus volumineuses. Le fléchissement progressif des proportions d'amphores africaines durant la première moitié du Ve s. traduit simplement l'arrivée d'amphores orientales toujours plus nombreuses mais ne signifie pas forcément que la quantité de produits importés d'Afrique décline. Une expérience comparable tentée sur les amphores du dépotoir de la fin du VIIe s. à la Crypta Balbi de Rome permet d'aboutir aux mêmes conclusions, c'est-à-dire à une équivalence en volume des denrées orientales et africaines (Panella, Saguì 2001, 802, fig. 3). 
On a tenté d'apporter les mêmes correctifs aux comptages de vaisselles africaines (Hawthorne 2000), en considérant que le nombre de tessons diminue au moment où les formes de sigillée africaine deviennent plus grandes. Cette démonstration ne me convainc pas entièrement dans la mesure où elle applique une méthode que je trouve très théorique, celle de la répartition des différentes formes par tranche de cinq ans ("vessels per year »). Mais il y a certainement là aussi du vrai.

\section{Cartes de diffusion et réalité historique}

\section{- Cartes de diffusion et progrès de la recherche}

On ne dira jamais assez que les cartes de répartition « marquent souvent une étape de la recherche plus qu'une réalité du passé » (P.-A. Février). Comparons, par exemple, les cartes de diffusion des ultimes formes de sigillées africaines (Hayes 105-106) publiées par J. W. Hayes $\left(1972,463\right.$, carte $\left.\mathrm{n}^{\circ} 30\right)$ puis par S. Tortorella $\left(1986,219\right.$, carte $\left.n^{\circ} 8\right)$. On s'aperçoit que S. Tortorella complète la vision de J. W. Hayes, basée sur les sites orientaux, par sa connaissance de la péninsule Italique et les résultats des travaux menés en Provence au début des années 80 . Mais cette deuxième carte est encore bien loin de la réalité, puisqu'il serait aujourd'hui possible (fig. 252) de griser toute la côte hispanique méditerranéenne (Jarrega Dominguez 1991; Reynolds 1993 et 1995), de porter plusieurs points au Maroc et de dessiner une flèche jusqu'à Bordeaux, tout en sachant que cette vision actuelle est probablement vouée à être modifiée.

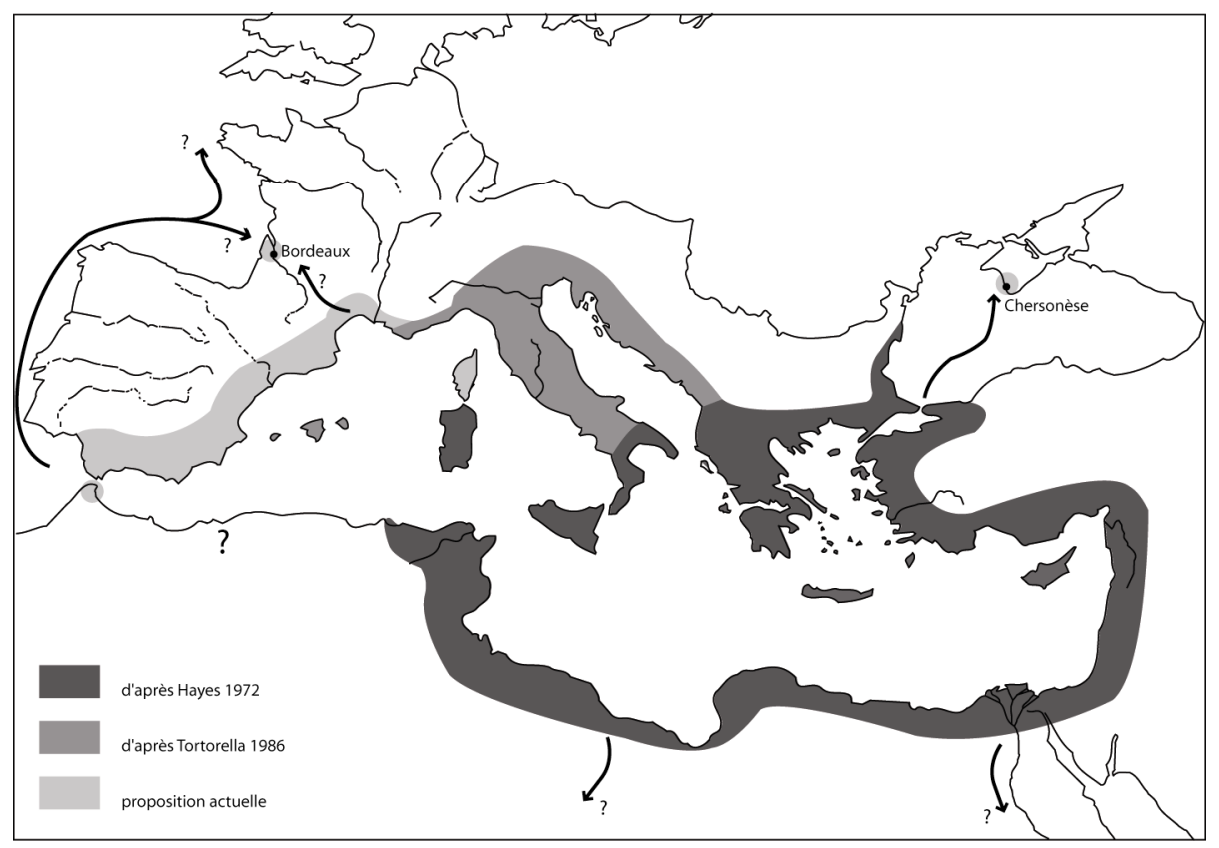

Fig. 252. Evolution des cartes de diffusion des sigillées africaines.

L'exemple des formes Hayes 105-106.

\section{- Cartes de diffusion et géographie politique}

Plus récemment, on a tenté de mettre en relation la diffusion des formes tardives de sigillées africaines avec la géographie politique de la fin du VIe et du VIIe s. et notamment avec la perte progressive par Byzance des territoires qu'elle avait reconquis, sous Justinien, en Espagne et en Italie.

- en Espagne

En raison de la reconquête par les Wisigoths, vers 630, du littoral andalou passé au milieu du VIe s. sous domination byzantine, la plupart des niveaux tardifs de Carthagène, comportant de nombreuses importations africaines, ont été prudemment situés dans le premier quart du VIIe s.
(Ramallo, Ruiz, Berrocal. 1996). Cette interprétation chronologique supposait une stricte relation entre la diffusion des céramiques de l'Afrique byzantine et les possessions de Byzance sur le littoral hispanique au sud de Valence. Or, des découvertes récentes (Macias et Remolà 2000) montrent que des productions orientales et africaines arrivent encore à Barcelone à la fin du VIIe s., alors même que cette ville est intégrée au royaume wisigothique sans interruption depuis 418 .

Dans ces conditions, le pointage des attestations de sigillées africaines tardives sur le littoral hispanique peut se libérer de tout a priori historique. On observe que cette répartition ne tient absolument pas compte des frontières politiques de la seconde moitié du VIe s. et du premier quart du VIIe siècle. La carte que je propose (fig. 253, a), 


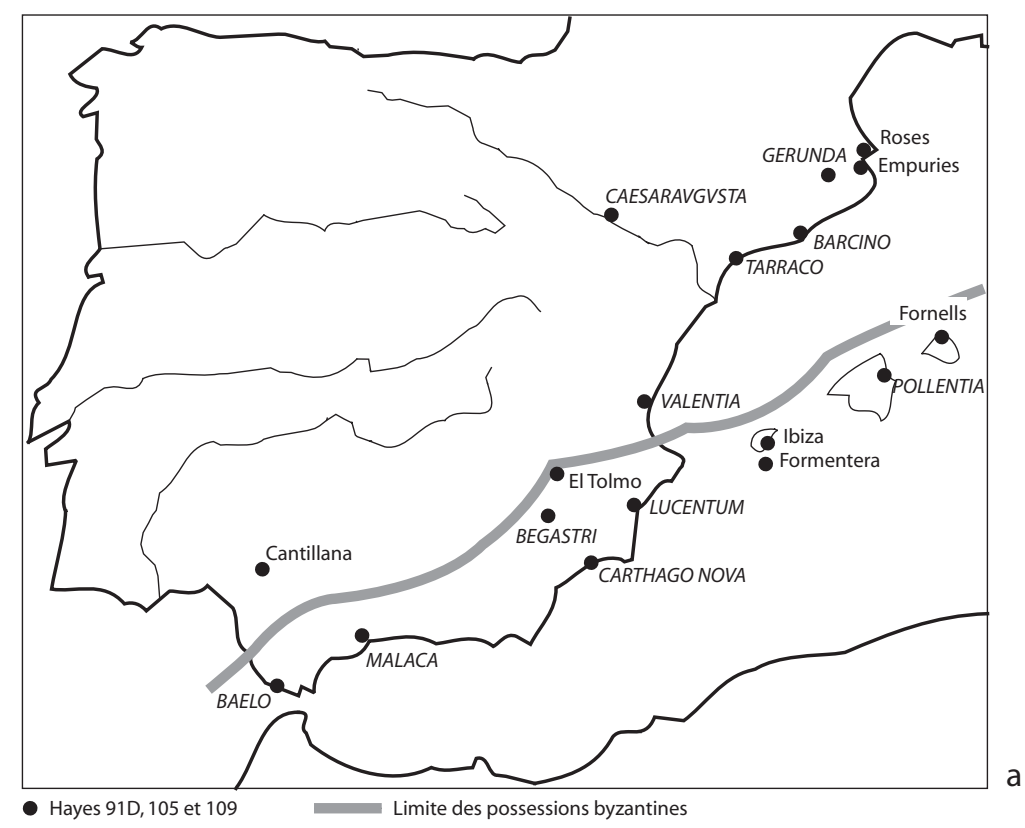

(fond de carte d'après Gutiérrez Lloret 1998, diffusion des formes d'après Jarrega Dominguez 1991)

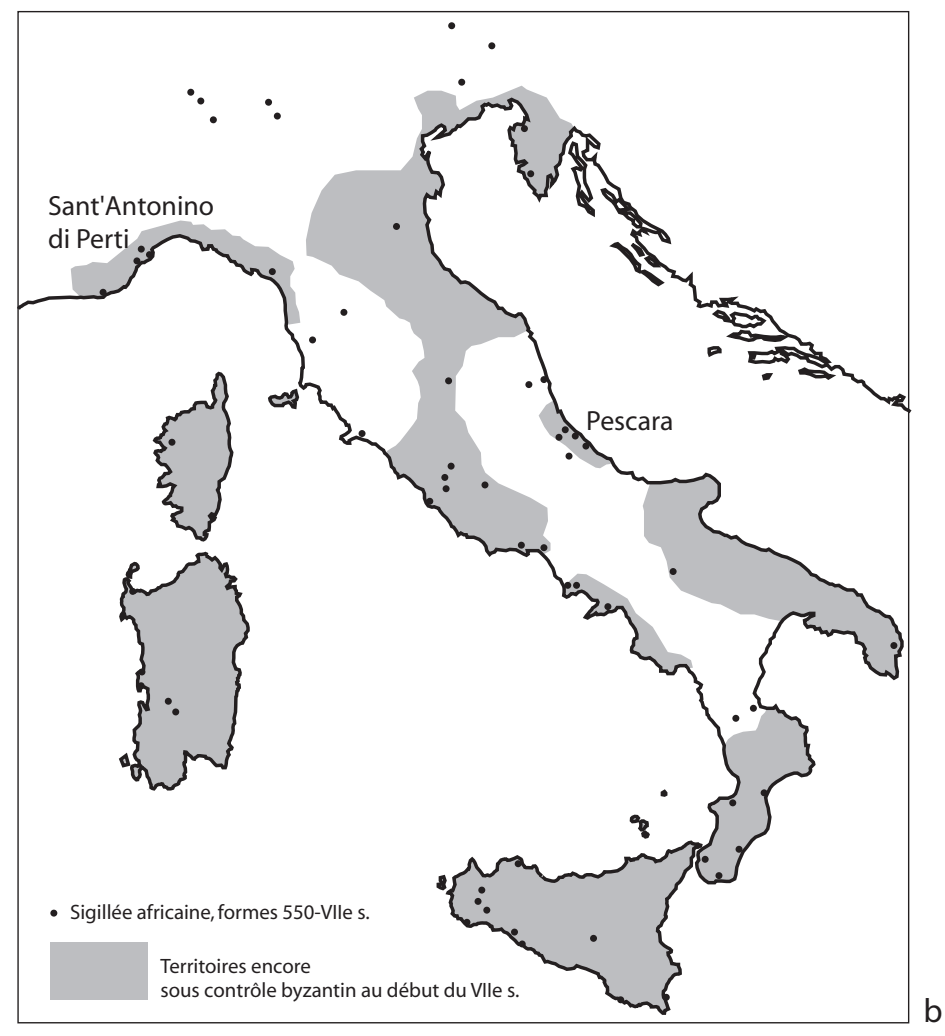

(d'après Zanini 1998)

Fig. 253. Mise en relation de la diffusion des formes tardives de sigillée africaine et de la géographie politique de la fin du VIe s. et de la première moitié du VIIe s. 
réalisée à partir des travaux de $\mathrm{S}$. Gutiérrez (1998 fig. 2) et de R. Jarrega Dominguez (1991) montre bien, selon l'expression de S. Gutiérrez, que «le commerce et les relations politiques peuvent suivre des voies différentes » (Gutiérrez Lloret 1998, 557 et note 43).

- en Italie

La carte dressée pour l'Italie par E. Zanini (1998, p 322, carte 99) (fig. 253, b), qui met en relation directe la diffusion des formes tardives de sigillée africaine et la géographie de la domination byzantine dans la péninsule à la fin du VIe s. et au début du VIIe s., n'est pas sans poser d'intéressants problèmes de lecture des documents archéologiques. Je prendrai seulement deux exemples (Bonifay à paraître, c).

a) Les points de découverte signalés dans l'enclave de Pescara me paraissent très controversés. Le matériel issu du centre historique de cette ville (Staffa 1991, 313-330) et dont une partie est attribuée "proprio alle fasi della riconquista bizantina » (Ibid. 330), ne me paraît pas, d'après la documentation graphique présentée, dépasser les premières décennies du VIe siècle. L'essentiel du matériel peut être daté de la seconde moitié du Ve s. : sigillée africaine D Hayes 61B3 (Ibid., fig. 55, 2), sigillée africaine C5 Hayes 85 (Ibid., fig. 55, 4), mortier en céramique commune type Fulford 22-23 (Ibid., fig. 55,1$)$, etc. J'ai quelques doutes également sur la datation proposée par A. Staffa pour le comblement de la citerne de Crecchio (Staffa, Pellegrini 1993) : ce contexte, qui livre une étonnante collection de céramiques peintes supposées d'influence copte (Staffa 1998, Pl. couleur I et II), est attribué à la fin du VIe s.-début du VIIe siècle. Je ne sais pas s'il faut remettre en question l'homogénéité de ce comblement mais, en tout état de cause, le répertoire des sigillées africaines, comportant une forte représentation de la catégorie $\mathrm{C} 5$ (forme Hayes 84) et de la « variante Pescara fig. 55, 2 » (Hayes 61B 3), me paraît plutôt renvoyer à la fin du Ve s. ou au début du VIe s., donc à une période antérieure à l'arrivée des Byzantins (Bonifay 2000c).

b) En raison de la conquête par les Lombards, en 644, des derniers territoires restés sous domination byzantine en Ligurie, l'occupation du site de Sant'Antonino di Perti (fig. 257, b), remarquablement fouillé et publié par G. Murialdo, a tout d'abord été restreinte à la première moitié du VIIe s. (avant 646) : l'abondance des produits africains, sigillées et amphores, ne pouvait qu'être liée à la présence byzantine (Sant'Antonino 1988 et 1992). Mais, dans son article sur les amphores, africaines de Ligurie (Murialdo 1995) puis dans la monographie définitive qu'il vient de faire paraître (Mannoni, Murialdo 2001), Giovanni Murialdo est revenu sur cette idée et conçoit que ce site fortifié ait pu recevoir des importations africaines jusqu'à la fin du VIIe s. au moins. Cette nouvelle interprétation est cohérente avec les données similaires obtenues à Marseille et dans les fouilles de la Crypta Balbi à Rome. D'autres contextes de Ligurie mériteraient sans doute les mêmes révisions (Biagini-Piera, Torre 1998 ; Lavagna 1996 et 1998).

Ainsi, deux des zones pointées sur la carte de la fig. 253, b sont sujettes à discussion, l'une parce que le mobilier pris en considération pourrait se révéler antérieur à la conquête byzantine, l'autre parce qu'il pourrait être postérieur à la perte des territoires. Ces observations montrent bien les difficultés de l'utilisation de la documentation céramique sur une carte géopolitique.

Enfin, les cartes de diffusion réalisées à l'échelle de la Méditerranée risquent également de donner une image un peu réductrice du commerce de la céramique africaine. Elles ne rendent pas compte de la complexité des liens d'échanges attestés par la céramique africaine et en particulier de l'importance du commerce intra-provincial.

\subsection{LA COMPLEXITÉ DES LIENS D'ÉCHANGES : COMMERCE INTRA- ET INTER-PROVINCIAL}

\subsubsection{Le commerce intra-provincial}

\section{Réalité du commerce intra-provincial}

La vision pan-méditerranéenne de la céramique africaine qui a été la nôtre depuis trente ans, due au fait que l'essentiel de nos connaissances sur ce matériel a été acquis hors d'Afrique ou, en Afrique, dans la seule ville de Carthage, nous a fait quelque peu oublier que ces objets avaient été avant tout produits pour les Africains, pour leur approvisionnement en denrées de première nécessité, pour leur table, pour leur éclairage. Je prendrai trois exemples (fig. 254) :

a) Beaucoup de céramiques africaines, parce qu'elles n'ont pas une diffusion méditerranéenne, ont été souvent qualifiées de céramiques « à distribution locale » (Hayes 1972, 300) ou « régionale » (Atlante I, 137) : c'est le cas de l'atelier de sigillée de Sidi Aïch. On sait (Ibid., 138) que cet atelier a diffusé ses produits dans l'est de la Tripolitaine, dans la partie occidentale de la Byzacène (Kasserine: Neuru 1987, fig. 2, $\mathrm{n}^{\circ} 15$, fig. 3, $\mathrm{n}^{\circ}$ 31-32; Althiburos: Ennaïfer 1976, Pl. CXCVI, $\left.\mathrm{n}^{\circ} 35\right)$ et en Numidie. D'autre part, les prospections du littoral tunisien ont permis d'attester leur présence, en nombre non négligeable, dans le golfe de Gabès (Bonifay et al. 2002-2003, fig. 21) (fig. 254, c). On s'aperçoit ainsi que la distribution de cet atelier, au IVe et au Ve s., concerne plusieurs provinces mais qu'il s'agit d'une distribution essentiellement continentale, dans les limites du diocèse d'Afrique.

b) L'étude des amphores de la nécropole de Pupput montre que la majorité de ces conteneurs est d'origine non locale, même si elle reste africaine (Bonifay 2004a, 28-30). En effet, un tiers seulement se rattache aux amphores de tradition punique du golfe d'Hammamet produites à Pupput même ou sur le territoire de quelques cités voisines. Les autres amphores sont de types Africaine I et II et proviennent, d'après l'aspect de la pâte et/ou les timbres, de cités plus ou moins lointaines: Nabeul, Hadrumetum, Leptiminus, Salakta; un exemplaire vient même de la région de Lepcis Magna (type Tripolitaine II). Cet exemple montre à l'évidence 

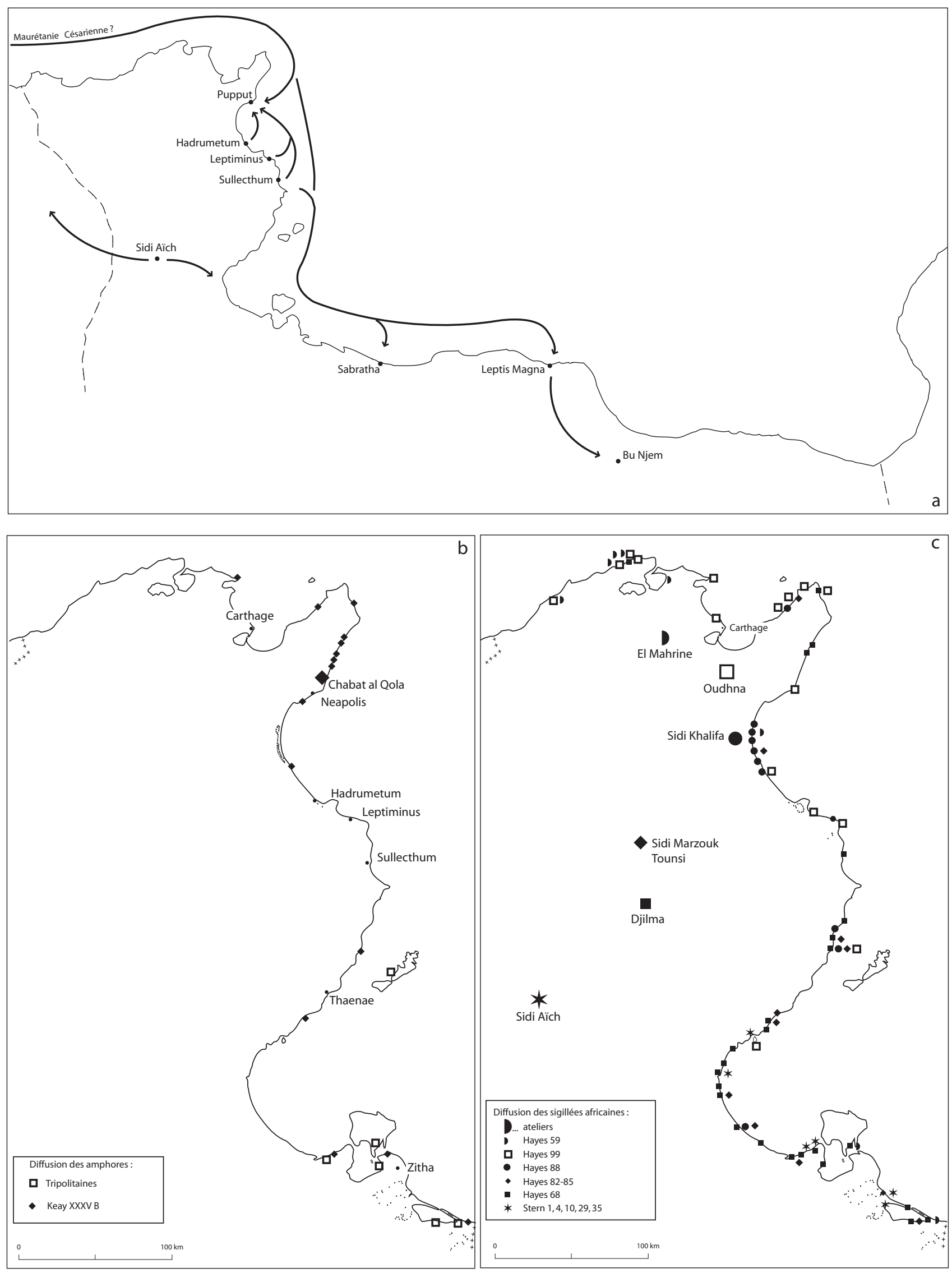

Fig. 254. Commerce intra-provincial. a : exemples de Sidi Aïch, Pupput et Bu Njem, $\mathrm{b}$ : diffusion des amphores, $\mathrm{c}$ : diffusion des sigillées, sur le littoral tunisien. 
que les amphores qui alimentaient régulièrement Rome et les autres grandes villes de l'Empire, faisaient également l'objet d'un commerce en Afrique même.

c) Pour l'essentiel, les céramiques retrouvées sur le camp $\mathrm{de} \mathrm{Bu}$ Njem sont africaines, mais elles ne sont pas forcément toutes d'origine locale. Ainsi, les amphores (Rebuffat 1997) témoignent d'un approvisionnement en huile effectué en Tripolitaine même, mais les arrivages de salsamenta et de vin (?) proviennent sans doute de régions africaines plus lointaines, la Byzacène (type Africaine II $)^{290}$, et peut-être d'une province voisine, la Maurétanie Césarienne (type «Station 48 de la place des Corporations »). Il est plus curieux de constater l'arrivée d'amphores Africaines I de Byzacène, peu nombreuses au demeurant, dans une ville, Sabratha (Keay 1989, fig. 13, 226), dont l'arrière-pays produit de l'huile (Arthur 1982, fig. 1).

Ces trois exemples prouvent l'importance du commerce africain intra-provincial peu documenté par les textes (voir cependant le tarif de Zaraï: Darmon 1964). Le gigantisme de la province d'Afrique Proconsulaire avant la réforme administrative de Dioclétien donne à ce commerce tous les caractères d'un commerce à grande échelle, avec utilisation de moyens de transports diversifiés : les routes (diffusion des sigillées de Sidi Aïch), le cabotage (amphores de Pupput) ou les deux à la fois (amphores de Bu Njem) (fig. 254, a). Ces contraintes géographiques, la diversité des produits transportés et, il faut bien le dire, la faiblesse de la documentation archéologique disponible à ce jour donnent une image assez contrastée de ce commerce intra-provincial. Les traces archéologiques en sont dispersées tout au long de la période romaine et jusqu'à l'époque byzantine, sans que cette documentation, encore peu abondante, ne permette pour le moment de percevoir d'évolution dans la nature des produits transportés, la direction ou l'intensité des flux commerciaux.

\section{Différences entre amphores et vaisselles}

Les amphores et les denrées qu'elles transportent (huile, salsamenta, vin) circulent bien. Les prospections du littoral tunisien ont mis en évidence l'ample diffusion sur la côte africaine, au Ve s., des amphores Keay 35B probablement originaires de la région de Nabeul (Bonifay et al. 2002-2003, fig. 22) (fig. 254, b). A la même époque, les amphores Keay 8B, vraisemblablement produites en Byzacène méridionale, sont fréquentes à Carthage (Peacock 1984b, fig. 41, n 90-91 ; observations personnelles), aussi bien que dans l'ouest de la Byzacène (Neuru 1990b, fig. 16, j-1, o ?). Les timbres et la pétrographie des amphores Africaines I et II permettent de suivre leur grande diffusion au IIIe s.: amphores

\footnotetext{
${ }^{290}$ Je ne suis pas convaincu par l'hypothèse de R. Rebuffat qui propose de voir dans les amphores Africaines II de Bu Njem des imitations locales d'amphores de Byzacène.
}

d'Hadrumetum à Pupput (Bonifay 2004a, 28) et à Nabeul (supra, p. 15), amphores de Nabeul à Thaenae (supra, p. 31), amphores de Salakta très abondantes à Pupput (Bonifay 2004a, 30 et note 31 ).

La vaisselle semble circuler avec moins de facilité sur le territoire africain (fig. 254, c). L'approvisionnement de la petite ville d'Aradi (Sidi Jdidi) en sigillée africaine aux Ve-VIe s. dépend principalement de deux sources : d'une part, un grand atelier proche (une vingtaine de $\mathrm{km}$ ), Sidi Khalifa, dont une partie au moins de la production est destinée au commerce à longue distance, d'autre part, un ou plusieurs ateliers mineurs dont les formes sont des variantes locales du répertoire classique, très ponctuellement exportées sur une grande échelle. D'autres groupes pétrographiques correspondent probablement à des ateliers plus éloignés (rareté de la catégorie $\mathrm{C}$ ); les ateliers très lointains (catégorie E) ne sont pas représentés. C'est également le cas de Carthage. La métropole, bien alimentée aux Ve et VIe s. par les ateliers d'El Mahrine et d'Oudhna situés dans un rayon de $40 \mathrm{~km}$, reste relativement imperméable aux importations d'autres régions d'Afrique : les sigillées D de Sidi Khalifa et des sigillées $\mathrm{C}$ sont peu abondantes. Si certaines sigillées de Sidi Zahruni parviennent à Carthage au Ve s., c'est parce que la production est couplée avec celle des amphores (infra, p. 57) qui sont, elles, bien attestées (types Keay 35, 55). Ainsi, les catégories de sigillées africaines apparaissent paradoxalement plus variées à Marseille qu'à Carthage.

\section{Productions à vocation continentale et productions à vocation méditerranéenne}

Toutes les amphores africaines ne circulent pas en Afrique avec la même fluidité. Les amphores de tradition punique du golfe d'Hammamet n'ont pas été signalées à Carthage et elles sont rares en Byzacène méridionale (Monastir est actuellement le point le plus au sud). Leur pénétration à l'intérieur des terres reste toutefois à préciser : quelques tessons, peu nombreux, apparaissent à Oudhna (observations personnelles). En revanche, on rencontre à Dougga une amphore tardive qui est peut-être également originaire du golfe d'Hammamet et qui semble n'avoir pas ou peu été diffusée en Méditerranée (supra, AMPHORE TYPE 55). Ainsi, plus que pour le marché local, un certain nombre d'ateliers paraissent avoir produit pour les zones non méditerranéennes du territoire africain.

\section{Villes côtières et villes de l'intérieur}

La diffusion des produits africains en Afrique fait apparaître une distinction importante entre les villes côtières et les villes de l'intérieur. Or, de ce point de vue, «l'intérieur » est atteint très rapidement, dès que l'on s'éloigne d'une quinzaine de $\mathrm{km}$ des côtes. On peut aisément faire la différence entre le faciès céramique de Pupput et celui d'Aradi/Sidi Jdidi. Le premier reste largement ouvert au commerce, non seulement africain 
mais également méditerranéen, même aux époques tardives, tandis que le second traduit un approvisionnement essentiellement local. On a déjà examiné le cas de la vaisselle sigillée mais celui des amphores est particulièrement révélateur : dans ce petit bourg agricole, la plupart sont des amphores de tradition punique du golfe d'Hammamet, d'origine locale (Bonifay, Reynaud 2004, 315). De même, l'analyse du mobilier céramique de la petite ville d'Uzita, située à moins de $10 \mathrm{~km}$ de la côte, a montré combien elle était refermée sur elle-même (Van der Werff 1982a, 220) : un seul timbre sur amphore africaine mentionne la cité de Leptiminus, distante de $12 \mathrm{~km}$, et les importations africaines les plus lointaines semblent provenir de Salakta.

En revanche, les faciès céramiques des villes du littoral comprennent de nombreuses importations africaines. Cette observation, évidente pour les grandes villes comme Thapsus, qui reçoit d'assez nombreuses sigillées d'Oudhna et des mortiers Fulford 22-23 (supra, COMMUNE TYPE 13) de la région de Nabeul (observations personnelles), s'impose aussi pour les petites agglomérations, comme Horrea Caelia/Hergla, qui livrent des amphores de Nabeul.

La remarque précédente vaut également lorsque les villes de l'intérieur sont de grandes villes. El Jem reçoit ainsi des produits très diversifiés (fouilles de la maison d'Africa) mais cette diversité se traduit plus sur le plan méditerranéen, avec quelques importations italiques, lusitaniennes, orientales, signe peut-être de l'aisance de certains habitants, que sur le plan africain où l'essentiel du matériel, amphore et vaisselle, reste local (sigillée africaine $\mathrm{C}$ ).

La faculté de se ravitailler en denrées de toutes sortes au sein même de l'Afrique Proconsulaire, explique sans doute, aux IIe et IIIe s., la relative faiblesse des importations de céramiques et d'amphores non africaines. En effet, ces dernières se résument, sur la nécropole de Pupput, à quelques exemplaires d'amphores vinaires gauloises et italiques, quelques amphores hispaniques à huile et surtout à garum, et quelques rares amphores orientales (Bonifay 2004a, 22-24). Ces dernières sont plus fréquentes à Nabeul et à El Jem (observations personnelles), avec un nombre non négligeable de conteneurs vinaires Kapitän II, amphore qui est peut-être représentée sur un disque de lampe africaine de type Deneauve VII/sous-type 1 (supra, fig. 178, $\mathrm{n}^{\circ} 11$ ). Ce sont les amphores vinaires qui présentent la plus grande variété d'origines, à l'instar de ce qui a été observé à Carthage (Martin-Kilcher 1998).

\subsubsection{Le commerce inter-provincial}

\section{Rareté des importations de vaisselles en Afrique}

De manière générale, il y a peu d'importations de vaisselle en Tunisie, à partir de la fin du Ier s., moment où les ateliers africains prennent en main la production de vaisselle fine. Le cas a été déjà signalé à Carthage, qui est pourtant la métropole de l'Afrique: les fouilles de l'avenue Bourguiba ne comptent que trois fragments de sigillée phocéenne tardive (Late Roman $C$ ware) et un tesson de Dérivées-des-Sigillées Paléochrétiennes (DS.P.) des ateliers de Marseille. Dans ce contexte, la découverte d'un tesson de sigillée orientale B à Pupput ${ }^{291}$ et de fragments de bols à reliefs corinthiens à Nabeul (inédit) revêt un caractère purement anecdotique.

En revanche, les prospections du littoral tunisien ont mis en évidence, de manière assez surprenante, l'importation en quantités non négligeables de sigillées claires luisantes de production rhodanienne au Ve s. (Bonifay 1990, 110 ; Bonifay et al. 2002-2003, fig. 4, n 19-23) ; les analyses physico-chimiques ont confirmé l'origine savoyarde de ces céramiques : Portout ou sa région (M. Picon, Ibid., fig. 24). Ces importations, principalement concentrées sur les sites du nord du golfe de Gabès, signalent des arrivages en provenance directe du port maritime situé au débouché de la vallée du Rhône: Arles. Cependant, Marseille ne se trouve pas complètement en reste: le tesson de bol Rigoir 18 à décor d'arceaux publié à Carthage (Fulford 1984b, fig. 88, $\mathrm{n}^{\circ}$ 64) et surtout le fragment de plat Rigoir 1 très récemment découvert ${ }^{292}$ dans le petit bourg rural d'Aradi/Sidi Jdidi sont les signaux, faibles au demeurant, de l'arrivée de marchandises en provenance du grand port du sud de la Gaule au moment de l'annexion de la Provence par le royaume wisigothique (477). L'importation inattendue de Dérivées-de-Sigillées Paléochrétiennes Provençales dans cette petite ville des confins de la Zeugitane et de la Byzacène reflète cependant les contacts directs entretenus, aux Ve et VIe s., entre le nord du golfe d'Hammamet et la Provence.

\section{Contacts directs entre les ports de la côte orientale de l'Afrique et la Provence}

En effet, les contacts directs de certains ports d'Afrique avec la Provence sont prouvés par la composition des cargaisons de quelques épaves du littoral français (Bonifay, Capelli, Long 2002).

L'épave du Dramont E, à Saint-Raphaël, remarquablement publiée par Cl. Santamaria (1995), a livré une cargaison très homogène d'amphores issues des ateliers de la région de Nabeul. Le chargement

\footnotetext{
${ }^{291}$ Fouille des thermes du centre, US 111 (A. Ben Abed avec le concours de F. Giomblanco).

${ }^{292}$ Documentation T. Mukai, inédit.
} 
complémentaire de céramique sigillée comprend quelques formes des mêmes ateliers ainsi que la production d'un centre important, encore non identifié, mais dont le style décoratif se rapproche de celui de Sidi Khalifa (supra, p. 192). Il y a donc tout lieu de penser que ce navire, de taille modeste, est venu directement de Nabeul sombrer au large du cap Dramont. Cet événement s'est produit dans le deuxième quart du Ve siècle.

L'épave de la Palud (Long, Volpe 1998) présente un faciès comparable. Les amphores Keay 55 et 62A, qui composent l'essentiel de la cargaison, proviennent, d'après leurs caractères typologiques et pétrographiques, d'ateliers de la région de Nabeul. La vaisselle de bord comprend des sigillées africaines issues d'ateliers proches : Oudhna (Hayes 99B) et Sidi Khalifa (Hayes 88). La cargaison complémentaire d'amphores orientales $L R A 1,2,4$ et 5 n'est pas un obstacle à une origine néapolitaine, dans la mesure où ces amphores sont bien attestées à Nabeul (observations personnelles). On aurait ainsi tendance à restituer le même itinéraire pour ce bateau que pour le précédent. Se dirigeant probablement vers Marseille, il a pu cependant s'en rapprocher un peu plus avant de s'échouer sur les récifs qui barrent l'entrée de l'anse de la Palud sur l'île de Port-Cros. Ce naufrage est survenu, semble-t-il, un siècle après celui du Dramont E.

L'épave de Pampelonne (Lequément 1976), au large de Saint-Tropez, est plus ancienne : fin du IIIe s. ou début du IVes., mais son origine peut tout aussi bien être déterminée. L'association d'amphores Keay 25.1 et d'Africaines II C qui compose l'essentiel de la cargaison se retrouve sur l'atelier de Sidi Aoun à Nabeul. Les analyses pétrographiques confirment cette origine.

Enfin, la dernière épave examinée, Héliopolis 1 (Joncheray 1997), contemporaine de la précédente, a coulé au large de l'île du Levant. Elle livre, à l'évidence, un lot d'amphores entièrement chargé à Salakta, homogénéité confirmée par la typologie, les timbres, bien qu'anépigraphes, et la pétrographie.

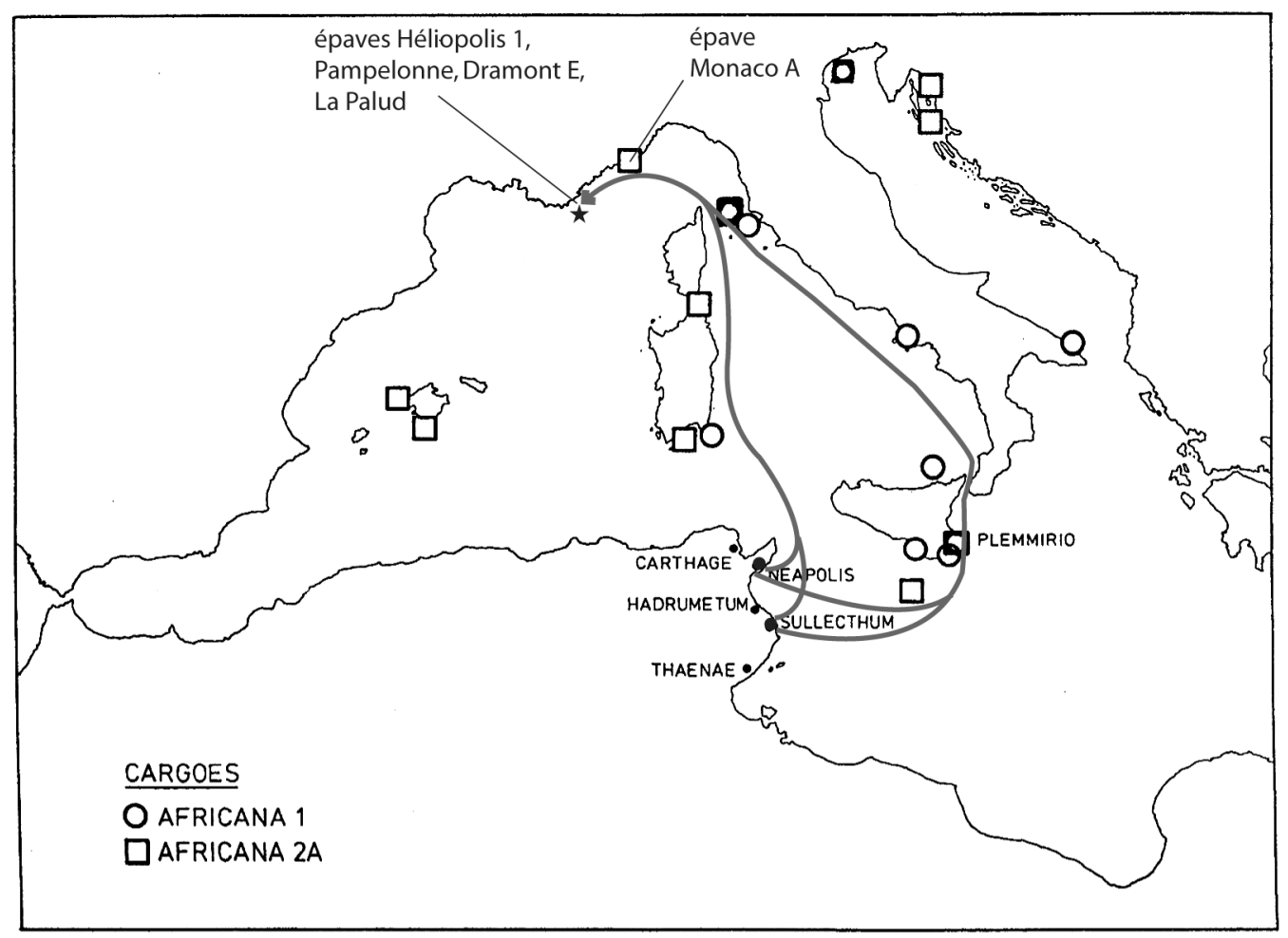

Fond de carte d'après Gibbins 2001, avec situation de cinq épaves du littoral français et propositions d'itinéraires.

Fig. 255. Contacts directs entre les ports de la côte orientale de la Tunisie et la Provence : l'exemple des épaves Héliopolis 1, Pampelonne, Dramont E, La Palud et Monaco A.

Ces quatre épaves sont des navires d'assez modestes dimensions ( $15 \mathrm{~m}$ env.) qui peuvent correspondre tout aussi bien à des caboteurs qu'à de petits bateaux de ligne. L'homogénéité des cargaisons nous a cependant incité à opter pour la deuxième solution. Il est en effet difficile de concevoir que les amphores à 100\% néapolitaines de l'épave du Dramont $\mathrm{E}$ aient été chargées à Carthage ou dans un port redistributeur d'Italie (Ostie) ou d'Espagne. On remarque également que ces vaisseaux ont tous sombré dans un périmètre assez restreint, entre SaintRaphaël et les îles d'Hyères. Leur itinéraire se laisse assez bien imaginer : le départ sous beau temps des ports 
de Salakta ou de Nabeul, la remontée des côtes orientales de la Sardaigne et de la Corse, puis la rencontre du mauvais temps à l'arrivée sur les côtes provençales (fig. 255) 293 $^{2}$. Le naufrage s'est alors produit au passage d'un des caps du Dramont ou de Saint-Tropez, ou bien au cours de la recherche d'un abri temporaire dans les îles d'Hyères.

Il est probable qu'une poursuite de l'enquête permettrait de compléter la liste des bateaux venus en ligne directe des côtes d'Afrique jusqu'en Provence. Je pense notamment à l'épave A de Monaco, remarquablement publiée par D. Mouchot (1970) et dont le mobilier a été récemment retrouvé ${ }^{294}$. Le chargement est principalement constitué d'amphores Africaines II A con gradino dont la pétrographie et les timbres de la série 2A permettent de déduire l'origine : vraisemblablement Salakta. L'une de ces amphores porte même un graffito de phare à étages (Ibid., P1. IX, 4-5) qui rappelle celui choisi pour emblème par les naviculaires de Sullecthum sur leur mosaïque de la place des Corporations à Ostie.

\section{Autres exemples de contacts directs entre l'Afrique et les provinces}

Deux cités apparaissent ainsi de manière récurrente dans les épaves à cargaison africaine homogène du littoral français : Sullecthum et Neapolis. Certes, les productions de Salakta sont peut-être plus facilement identifiables que les autres, peut-être aussi les travaux de repérage d'ateliers sont-ils particulièrement avancés à Nabeul ? Mais on pourrait en dire autant de Leptiminus, sans pour cela identifier clairement des chargements complets en provenance de cette ville. Il reste que le dynamisme économique de ces deux cités portuaires est attesté de longue date, pour Salakta par la mosaïque de la place des Corporations déjà mentionnée, pour Nabeul par deux inscriptions du début du Ve s. dont les dédicants sont des naviculaires (Lepelley 1981, 153).

De fait, on trouve la trace des productions de Salakta sur bon nombre de sites de Méditerranée occidentale et orientale, sans pour autant savoir de quelle manière ces objets ont transité. Il en est ainsi, notamment, des nombreux fragments d'amphores Africaines I et II de Salakta découverts à Alexandrie (observations personnelles). La situation est peut-être plus claire dans certaines régions moins bien irriguées par la céramique africaine, comme par exemple la côte occidentale de la province de Macédoine, dans l'actuelle Albanie. Le site de Byllis, dans l'arrière-pays de Vlorë (Bonifay, Cerova 2002), livre (hors stratigraphie) de nombreux fragments de sigillées africaines A/D et C (Hayes 31, 32, 33 ; Hayes 45 et 50 ) qui suggèrent l'existence de relations directes entre la Byzacène et les côtes adriatiques de la province

\footnotetext{
293 Je remercie Patrice Pomey pour ses suggestions.

294 Je remercie Monique Jannet-Vallat, Conservatrice du Musée de Nice-Cimiez, pour m'avoir donné accès à ce matériel.
}

de Macédoine au IIIe siècle. Ces contacts sont confirmés par la présence d'un fragment d'amphore originaire de Salakta, de type Uzita P1. 52, 10 (supra, fig. 54, $\mathrm{n}^{\circ} 11$, AMPHORE TYPE 18), dont la diffusion est habituellement assez restreinte.

Comme à Marseille, les produits de Nabeul sont présents en abondance à Tarragone tout au long du Ve siècle. Le contexte de la «Antiga Audiència », daté de la fin du Ve s., associe les productions des ateliers de la zone de Sidi Zahruni : amphores Keay 55 et 57 (Remolà 1993, fig. 110, $\mathrm{n}^{\circ} 20-21$ ) et sigillées locales (Aquilué 1993, fig. 98, $n^{\circ} 86-87$ ), et celles de l'atelier de Sidi Khalifa : sigillées Hayes 86 et 103 variante (Ibid., fig. 96, n 62-64 et $\mathrm{n}^{\circ} 73$ ) tandis que les productions contemporaines des ateliers de Tunisie centrale sont complètement absentes. La composition de ce matériel laisse donc entrevoir des voyages depuis un port du nord du golfe d'Hammamet (Nabeul ?) soit directement vers Tarragone, soit via Marseille puisque la céramique DS.P. est également bien représentée dans ce contexte ${ }^{295}$.

En conséquence, il ne semble pas y avoir, sur le fond, de modifications considérables entre la situation du IIIe s. et celle du Ve siècle. Des contacts directs sont bien établis entre des ports d'Afrique et d'autres ports de Méditerranée occidentale et orientale. Je ne prendrai pas parti sur le statut juridique de ces relations commerciales : système annonaire aux IIIe-IVe s., dont il a été souligné que la ville de Rome n'était pas la seule bénéficiaire mais également les provinces (Février 1990, 97), ou commerce «normal» aux Ve-VIe s. (Sodini 2000, 196)?

\section{Particularités de la diffusion des céramiques africaines en Egypte}

Une autre preuve de la complexité de l'organisation des circuits commerciaux est fournie par l'absence des produits de Sidi Khalifa en Egypte (pas de forme Hayes 61B ni Hayes 88) et par l'abondance, en revanche, des sigillées de Tunisie centrale de catégorie C5 (Bonifay 1998c). En effet, à la fin du IVe s., rompant avec une simple diffusion côtière (Hayes 1972, 462-463, cartes), la vaisselle africaine pénètre réellement en Egypte et, durant les Ve et VIe s., trois ateliers vont se partager le marché (Bonifay 2000b: exemple de Coptos) (fig. 256). Le centre d'El Mahrine, au Ve s., semble fournir l'essentiel des grands plats en sigillée D1 (surtout Hayes 67) décorés du style A, celui d'Oudhna, au VIe s., la série des bols Hayes 95-99 en sigillée D2 décorés du style E(i) et celui de Sidi Marzouk Tounsi, dans la seconde moitié du Ve s., les services guillochés Hayes 82-84 en sigillée C5. Alors que la diffusion des deux premiers ateliers, situés en Tunisie septentrionale, ne souffre guère de lacunes dans le pourtour du bassin méditerranéen, celle du troisième,

\footnotetext{
295 Rappelons qu'à cette époque Tarragone et Marseille appartiennent toutes deux au royaume wisigothique.
} 


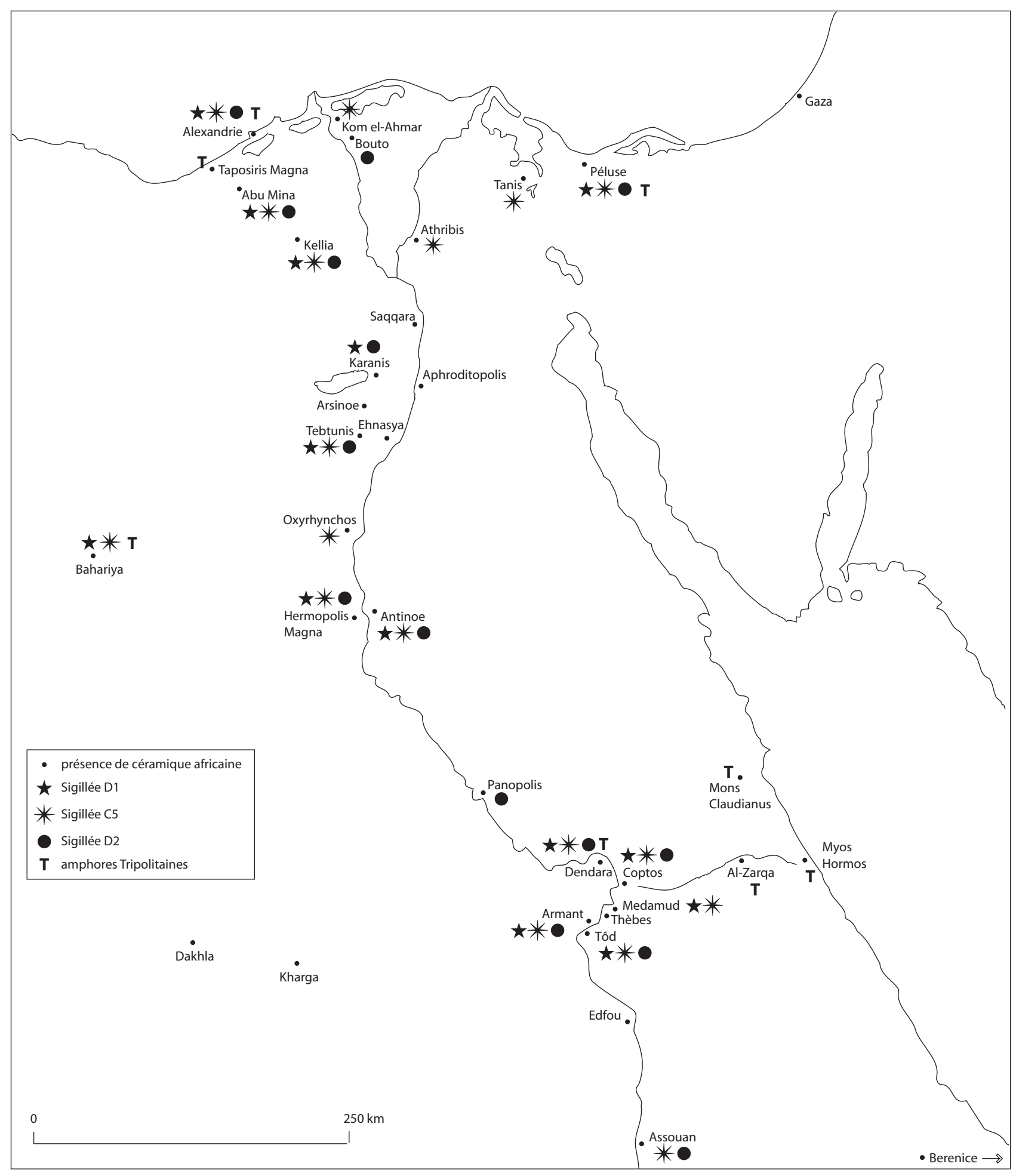

Fig. 256. Eléments sur la diffusion des céramiques africaines en Egypte. 
situé en Tunisie centrale, est plus inégale. L'engouement tout particulier de l'Egypte pour ces objets est d'autant plus remarquable; J. W. Hayes $(1972,421)$ avait déjà noté que, sur les sites égyptiens, "the fine ware types Forms 82-84 make up a large proportion of the known pieces $»$. On peut se demander s'ils n'ont pas, en raison de leur qualité assez exceptionnelle, voyagé pour leur valeur propre, et s'ils n'ont pas emprunté des voies différentes de celles utilisées par les autres ateliers, à savoir des pistes caravanières (Bonifay 2000b) ?

De fait, les transports terrestres sont bien attestés par l'approvisionnement des forts de la route Coptos-Myos Hormos (Brun 1994 : amphores africaines à Al-Zarqa) ou des carrières du Mons Claudianus (Tomber 1996, 44 : les amphores Africaines I et Tripolitaines I-III constituent la plus grande part des importations), même si un cabotage le long du rivage de la mer Rouge n'est pas à exclure (Tomber 1998, fig. 6-7, n 77 : amphore Africaine II D à Berenice). On peut s'interroger de la même manière sur le chemin suivi par les amphores africaines importées du Ier au IIIe s. dans les oasis de Bahariya, dans le désert occidental (Bonifay à paraître, d). Doit-on envisager un transport mixte, par mer puis par route (avec ou non un intermède fluvial) ou bien un simple transport terrestre ? La forte homogénéité typologique des amphores africaines importées à Bahariya durant le Haut-Empire pourrait nous inciter, contre toute vraisemblance (?), à pencher pour la seconde hypothèse. En effet, alors que les amphores africaines des IVe-VIIe s. sont originaires du nord de la Tunisie, celles des trois premiers siècles de notre ère proviennent des régions les plus méridionales de 1'Africa Proconsularis (Tripolitaines I et II, amphores africaines précoces).

En revanche, les comptages effectués sur le mobilier du chantier du théâtre Diana confirment que le faciès d'Alexandrie est tout à fait méditerranéen et que la ville, $\mathrm{du}$ point de vue de son approvisionnement en vaisselle fine, tourne résolument le dos à l'Egypte. Du IVe au VIe s., les sigillées africaines font part égale avec les productions égyptiennes et chypriotes (Bonifay 1998c, 141-142). On trouve encore à Alexandrie les formes les plus tardives du répertoire des sigillées africaines (Rodziewicz 1984 : Hayes 109 à décor lustré).

\section{Particularités de la diffusion des céramiques africaines en Méditerranée orientale}

L'observation du faciès des amphores africaines en Egypte est d'autant plus intéressante qu'on a souligné à plusieurs reprises la part paradoxalement minime de ces amphores en Méditerranée orientale, alors que les sigillées de même provenance sont largement répandues (Abadie-Reynal 1989, 147 ; Sodini 2000, 191). De fait, la présence d'amphores africaines classiques reste assez anecdotique à Beyrouth (Reynolds 1997-98, fig. 203), en Crète (Rendini 1997, Pl. CXLV, a) ou à Argos et Athènes (Abadie-Reynal 1989, 145), et, pour l'Antiquité tardive, seuls les « spatheia » ont une certaine diffusion, du Ve au VIIe s. («spatheion» de type 1 à Paphos: Megaw 1972, 328, B ; à Gortyne, types 1 et 3 : Rendini 1988, 273, $\mathrm{n}^{\circ}$ 277, fig. 217 et 225 ; Portale, Romeo 2001, Pl. LVIII, e-g). Une exception notable est constituée par les régions du Pont-Euxin, avec en premier lieu le matériel de Constantinople, comprenant des amphores Keay 8B, 62 et 61 (Sodini 2000, 191). Le « spatheion »-type 1 de Iatrus en Roumanie (Conrad 1999 fig. 1, III.3) provient probablement de l'atelier de Nabeul car il présente, bien décelable sur le dessin, le traitement de surface caractéristique de l'atelier de Sidi Zahruni. La côte roumaine livre également un faciès amphorique africain qui n'est pas très différent, toutes proportions gardées, de celui de Méditerranée occidentale (Opait 1997-98), avec les types Keay 59/8B, 35, 55, 62. Un fragment d'amphore Keay 62 a même été relevé à Chersonèse (Sazanov 1991 Pl. 13, $\left.n^{\circ} 6\right)$. Dans ce panorama, des amphores modérément attestées en Occident apparaissent de manière récurrente : le type Keay $8 \mathrm{~B}$ est présent non seulement en mer Noire (outre la Roumanie, voir, pour la Bulgarie : Poulter 1998, fig. 9.53, $\mathrm{n}^{\circ}$ 1076-79) mais également à Apollonia de Cyrénaïque (Mission archéologique française, observations personnelles), à Alexandrie (Bonifay, Leffy 2002, fig. 6, n 51-53), aux Kellia (renseignement Fr. Bonnet), à Tebtynis (type précoce Keay 59: renseignement D. Foy), à El Ashmunein (?) (Bailey 1998, Pl. 76, T8); le type Keay 34 est encore attesté à Apollonia (observation personnelle), au Caire (renseignement J.-L. Fournet) et en Roumanie (Opait 1997-98, Pl. 13, n 32). Ces types proviennent sans doute directement de ports de Byzacène méridionale ou de Tripolitaine (sur l'origine de ces deux types, voir supra, AMPHORES TYPES 37-38 ET 53).

En revanche, viennent sans doute de Carthage les céramiques d'El Mahrine et d'Oudhna abondantes en Orient (Egypte, Levant, Antioche). Les attestations de l'atelier d'El Mahrine ont été relevées par M. Mackensen (1993, 651-661) mais celles d'Oudhna sont passées souvent inaperçues. Des décors caractéristiques prouvent cependant leur présence non seulement à Alexandrie (Bonifay 1998 c, fig. 2, 1 et 2), à Beyrouth (inédit) et bien sûr à Antioche (Waagé 1948, fig. 29, n 16-20, fig. 30, n 1-3), mais également en Crète (Dello Preite 1997 fig. 11, b-c, fig. 12, a-b, Pl. XV). Par rapport à Alexandrie, le pourcentage global des sigillées africaines au sein de l'ensemble des sigillées tardives recueillies à Beyrouth reste modeste $(15 \%)$ face aux productions chypriotes ou phocéennes, mais, dans cette ville comme à Antioche ou en Grèce, les vaisselles africaines présentent, à la fin du IVe s., une situation de quasi-monopole (Bonifay 1996).

\section{Le poids des différentes régions africaines}

La diffusion des amphores montre que chaque zone productive a, toutefois, des débouchés préférentiels. On a signalé la fréquence des amphores tripolitaines en Egypte, la proportion remarquable des types Keay 59 et 
8B en Orient. On pourrait tout aussi bien relever que la plupart des amphores Keay 3B similis ont été découvertes dans la partie la plus occidentale du bassin méditerranéen, notamment en Espagne ; une telle distribution plaide en faveur d'une production dans une région occidentale de l'Afrique. Pour la même raison, je ne crois pas à l'origine tripolitaine du type Keay 24 récemment proposée par A. Remolà (2000, 168-169) : la plupart de ces amphores ont été découvertes en Espagne et aucune, à ma connaissance, en Italie (supra, p. 22) ; l'hypothèse d'une production en Algérie, avancée par Keay (1984, 184), paraît plus vraisemblable.

Il faut insister une fois de plus sur le poids de la Byzacène. Cette prééminence est particulièrement nette dans le domaine des lampes tardives en sigillée. La plupart des lampes en sigillée africaine trouvées à Marseille sont du groupe C. De même, les lampes Atlante $\mathrm{X}$ du groupe $\mathrm{D}$ n'apparaissent pratiquement pas au sein du matériel du Museo Nazionale Romano (Barbera, Petriaggi $\left.1993: n^{\circ} 190, n^{\circ} 229\right)$. Les villes d'Italie et de Provence restent alimentées, de manière principale et tardivement encore, par les ateliers de Byzacène. Il faut peut-être attendre la seconde moitié du VIIe s. pour que la situation change au profit des ateliers de Tunisie septentrionale. En revanche, on remarque la bonne proportion des lampes $\mathrm{du}$ groupe $\mathrm{D}$ en Espagne méridionale et à Ibiza (Ramon $1986 \mathrm{Pl}$. VII, $\mathrm{n}^{\circ} 3,5$ ) où l'essentiel de la sigillée africaine des Ve-VIIe s. provient également d'ateliers septentrionaux (Ibid., fig. 14).

Certaines régions sont bien représentées partout par leurs produits, indice, peut-être, de leur prééminence commerciale : c'est le cas de Salakta et de Nabeul. D'autres, en revanche, paraissent moins importants : les amphores de tradition punique et la céramique culinaire $\mathrm{du}$ golfe d'Hammamet sont faiblement diffusées (voir cependant la cruche de type Pupput 1 découverte à Fossur-Mer : supra, COMMUNE TYPE 47, $\mathrm{n}^{\circ} 3$ ).

\section{Fluctuation des courants commerciaux durant l'Antiquité tardive}

Les contextes étudiés à Marseille permettent de déceler un certain nombre de modifications dans le faciès des céramiques africaines au cours des Ve-VIIe siècle.

\section{- La seconde moitié du Ve siècle}

Les sigillées africaines de la seconde moitié du Ve s. présentent trois particularités (Bonifay 1998b). Tout d'abord, ces céramiques apparaissent en faible proportion au sein de la vaisselle en usage à Marseille à cette époque; c'est la proportion la plus faible enregistrée dans cette ville entre le deuxième quart du Ve $\mathrm{s}$. et le milieu du VIIe siècle. Ensuite, la majorité des produits ne paraît pas originaire des ateliers de la région de Carthage : ils proviennent plutôt d'ateliers situés en Byzacène, soit dans la région de Kairouan (type C5), soit dans la région de Pheradi Maius (formes Hayes 61B). Enfin, dans ce dernier cas, le répertoire des formes ne paraît pas en notable évolution par rapport à celui de la première moitié du Ve siècle. Réduction relative des importations, approvisionnement auprès de nouveaux centres producteurs, stagnation du répertoire de formes : telles pourraient être les caractéristiques du faciès des sigillées africaines importées à Marseille à l'époque du royaume vandale de Carthage. Du point de vue des amphores, le type Keay 8B, originaire de Byzacène méridionale, constitue un bon « fossile-directeur ». Enfin, les lampes sont quasiment toutes du groupe $\mathrm{C} 3$ (de petite taille).

\section{- Deuxième quart ou milieu du VIe siècle}

Les sigillées africaines importées en Provence dans le deuxième quart ou au milieu du VIe s. traduisent un déplacement géographique des ateliers les plus dynamiques. Ceux de Byzacène disparaissent du marché pour laisser place à un atelier émergeant, celui d'Oudhna, qui fournit l'essentiel des bols Hayes 95-99 et 91C. D'autres ateliers connus diffusent toujours leur production: grands plats Hayes 88 de Sidi Khalifa, D'autres, non encore localisés (atelier «X», supra, p. 49) fournissent les grands plats Hayes 104 à décor E(ii). Les amphores semblent majoritairement originaires de Zeugitane : ateliers de Nabeul.

\section{- Fin du VIe s. - première moitié du VIIe s.}

Il semble que l'essentiel des formes Hayes 90 et 105 importées en Provence provient d'ateliers situés en Byzacène (supra, p. 49). Elles côtoient ainsi les amphores Keay 62 tardives et Keay $61 \mathrm{C}$ des ateliers de la région de Salakta, ainsi que les lampes du groupe $\mathrm{C} 5$.

\section{- Seconde moitié du VIIe siècle}

Les rares contextes de la seconde moitié du VIIe s. montrent un faciès plutôt septentrional, avec les variantes tardives de la forme Hayes 109, bien attestée à Carthage, les amphores Keay 50 et $8 \mathrm{~A}$ connues dans l'arrière-pays d'Hammamet, les « spatheia » $3 \mathrm{C}$ produits à Nabeul, etc.

On a donc l'impression, en examinant la céramique africaine de Marseille, d'assister très schématiquement à un jeu de balancier entre la région de Carthage et la Byzacène, l'une ou l'autre de ces deux régions devenant tour à tour dominante au sein des échanges.

\section{Importation de masse des céramiques africaines en Provence}

Les importations africaines atteignent également l'ouest et le nord de la Gaule (Hanoune 1996). On trouve à Bordeaux aux VIe-VIIe s., toutes proportions gardées, les mêmes objets qu'à Marseille : sigillées africaines Hayes 99, 90B, 105, 109A (Bonifay à paraître, b), amphores Keay 62 et 61 (Berthault 1999). Ces découvertes, qui paraissent toutefois ne pas avoir, à une époque si tardive, de parallèles au Portugal (?), jalonnent peut-être une route maritime qui conduisait jusqu'en Grande-Bretagne. Mais on ne peut pas exclure totalement un transit de ces vaisselles africaines par l'intérieur des terres, depuis les côtes septentrionales de la Méditerranée. En effet, le faciès très particulier des importations méditerranéennes tardives en Grande-Bretagne (Thomas 1981), avec une 
forte majorité de sigillées phocéennes et d'amphores égéennes, est plutôt le signe de contacts directs avec l'Orient méditerranéen, peut-être liés au commerce de l'étain (Fulford 1989 ; Wooding 1996).

Echappant de moins en moins souvent à la sagacité des archéologues, même peu familiers du mobilier méditerranéen, les productions africaines surgissent maintenant un peu partout. Particulièrement intéressantes sont les lampes africaines tardives signalées dans la région de Rouen, dont une provient des fouilles du groupe épiscopal (Bonifay 2000a, 38, note 2) et date de la seconde moitié du VIe s. (supra, LAMPES TYPE 57 : groupe C5). Toutefois, les quantités toujours faibles (Bordeaux), voire très faibles (Gaule interne) de tessons suggèrent que ces objets n'avaient peut-être pas le même statut qu'en Gaule méditerranéenne : F. Berthault (Amiel, Berthault 1996, 257) a suggéré, à propos du matériel de la villa de Séviac, que seules les élites pouvaient s'offrir le luxe des produits (huile, garum ?) transportés dans les grandes amphores cylindriques du VIe s. (type Keay 62).

En Provence, en revanche, les importations de céramiques africaines sont des importations massives. Ce processus qui est parfaitement dans l'ordre des choses durant la pleine époque romaine apparaissait, il y a peu, comme plus difficile à concevoir pour les époques très tardives. Cependant, les vaisselles et les amphores africaines des Ve-VIIe s. ne se rencontrent pas seulement dans les grandes villes du littoral. On relève leur présence sur les habitats ruraux (Sainte-Propice : Boixadera et al. 1987), parfois fort éloignés des côtes (ex. : un fragment de mortier Fulford 22-23 à Fontaine de Vaucluse : Borgard 1984, fig. III, $\mathrm{n}^{\circ} 20$ ), dans les nécropoles (Cadarache : Pouyé et al. 1994,), dans les grottes (La Fourbine : Congès et al. 1983 ; Sainte-Victoire : un bol Hayes 91B, inédit) ; l'un des rares exemplaires complets de «spatheion» 3C découvert en Gaule provient d'une tombe de Saint-Etienne-de-Candau (supra, AMPHORE TYPE 33C, $\mathrm{n}^{\circ} 1$; Gagnière 1965, fig. 26). Des tuiles en sigillée africaine sont même importées à Marseille, probablement pour couvrir la cathédrale (Barraud et al. 1998, 156-157 et note 72).

\subsection{LES IMITATIONS DE LA CÉRAMIQUE AFRICAINE}

Avec la céramique africaine, ce ne sont pas seulement des objets qui se déplacent, mais également des modèles. L'imitation de la céramique africaine est un phénomène de grande ampleur, bien que cette production ne soit pas la seule à avoir fait l'objet de copies au cours de l'Antiquité.
Il est nécessaire tout d'abord de distinguer entre les imitations d'amphores et les imitations de vaisselles ou d'autres objets céramiques.

\section{Imitation des amphores africaines}

L'imitation d'un modèle d'amphore suppose que l'on cherche à commercialiser un contenu comparable à celui qui a fait le succès du modèle. Ainsi, la qualité d'un cru suscite souvent l'imitation de l'amphore qui lui sert habituellement de conteneur: le cas des amphores Dressel 2/4 ou des amphores Gauloises le prouve. De fait, chercher des exemples d'imitation d'amphores africaines ne tombe pas sous le sens. On a cru un temps que les « spatheia » miniatures (supra, AMPHORE TYPE 33) à pâte blanchâtre, a fortiori ceux ne possédant pas d'anses, pouvaient être des imitations orientales des modèles africains plus anciens. Il apparaît maintenant, sans exclure la possibilité de contrefaçons ponctuelles dans telle ou telle région de Méditerranée, y compris en Calabre ou en Sicile (Hayes 1992, 67), que l'essentiel de ces petits conteneurs est bien d'origine africaine (supra, p. 129). De même, les «spatheia » de type 1 que l'on a cru un temps fabriqués à Classe (Maioli, Stoppioni 1989, $\left.571, n^{\circ} 8-9\right)$ sont probablement, tout comme la sigillée trouvée sur le même site (supra, p. 50), des productions africaines.

Je relève toutefois, au sein du matériel que j'ai eu l'occasion d'étudier, deux possibilités d'imitations d'amphores africaines.

\section{- Amphore Keay 25.3 à pâte micacée}

Une amphore découverte à Pupput (1), dans un contexte $\mathrm{du}$ début du Ve s., a une forme très voisine du type Africaine IIIB (Keay 25.3) mais dans une pâte de couleur noisette, très micacée, qui a bien peu de chances d'être africaine. La surface extérieure n'étant qu'imparfaitement éclaircie à la cuisson, les potiers ont poussé la contrefaçon jusqu'à, semble-t-il, enduire l'amphore d'un engobe blanchâtre peu adhérent, aujourd'hui très largement écaillé. D'autres exemplaires sont connus sur une épave du détroit de Sicile (2-3).

Exemple (fig. 257) :

*1 Pupput (Inv. PP4455.1). H. $94 \mathrm{~cm}$.

*2-3 Epave Isis, Skerki Bank (Freed 1994, fig. 23, n 7-8). H. $93 \mathrm{~cm}$.

Ces imitations contribuent à suggérer que le type Keay 25.3 est bien un conteneur à vin. Je ne sais pas à quelle région rattacher cette imitation, qu'il est étrange de rencontrer en Afrique même.

Datation proposée : première moitié du Ve s. 

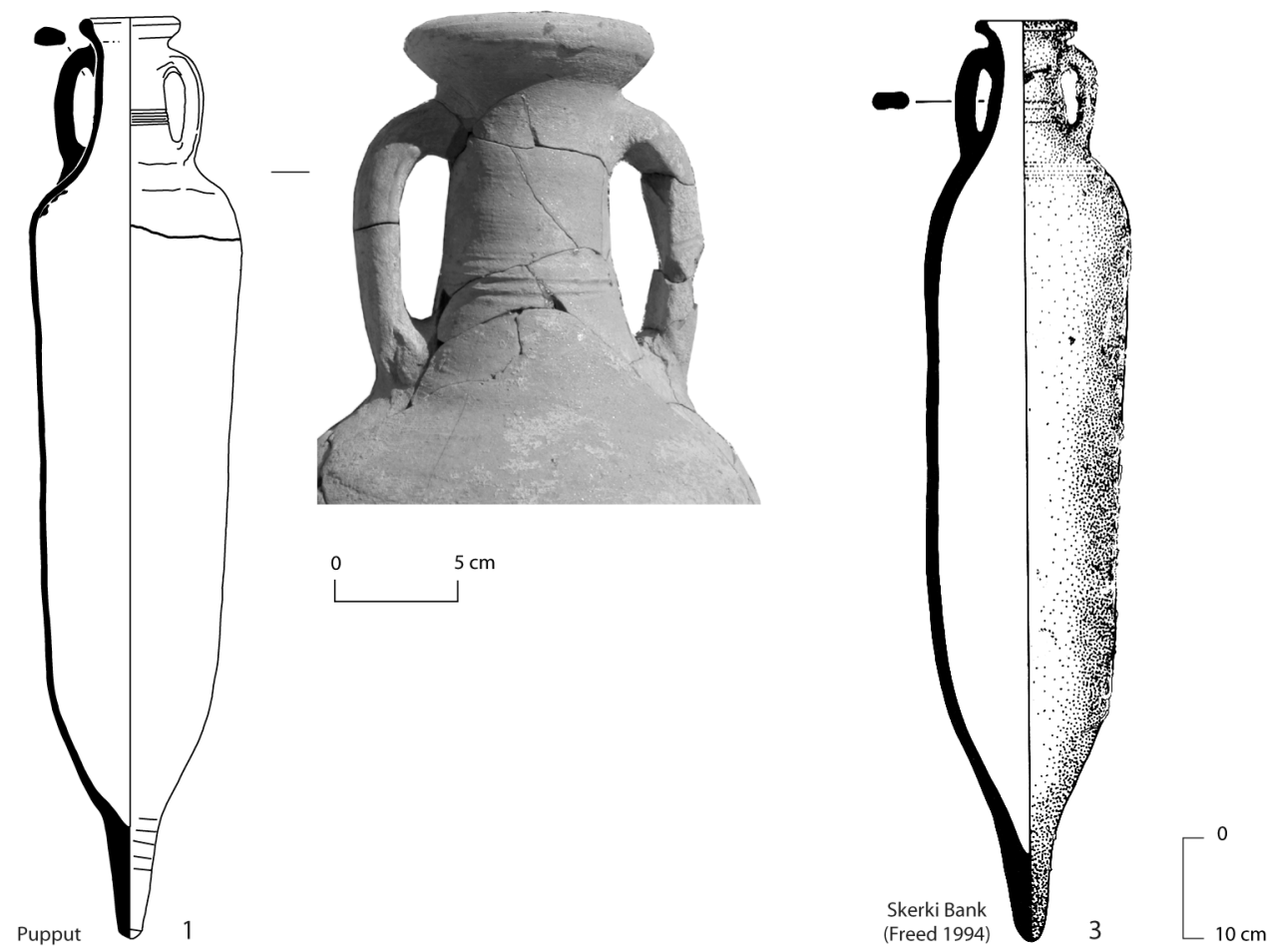

Fig. 257. Imitations d'amphores africaines.

\section{— Imitations d'amphores africaines en Egypte?}

S. Marchand (à paraître, fig. 30-33) pense avoir mis en évidence, dans l'oasis de Bahariya, une production imitant les amphores africaines. Une telle hypothèse n'est pas réellement surprenante. Les conteneurs cylindriques découverts en Haute-Egypte ou en Nubie, et parfois pris pour des amphores africaines sur la foi des dessins, sont sans doute en majorité d'origine égyptienne : parmi les amphores cylindriques de Ballana représentées sur la Pl. III de la publication de W. B. Emery et L. P. Kirwan (1938), seul le $n^{\circ} 5$, fragmentaire de surcroît, pourrait être africain (type Keay 62Q = Albenga 11-12 ?) ; les autres $\left(\mathrm{n}^{\circ} 1\right.$ à $3,4 \mathrm{a}$ et $\left.4 \mathrm{~b}\right)$ sont probablement égyptiens. Un exemplaire complet provenant du monastère d'Epiphanius à Thèbes évoque d'assez près les formes africaines, avec la même surface blanchâtre («dull drab») et un peignage vertical pouvant imiter les « steccature » des amphores africaines (Winlock, Crum 1926, P1. XXX, photographie de droite).

Je me demande si je n'ai pas trop hâtivement attribué à l'Afrique les amphores cylindriques de moyenne dimension de la citerne du Sarapéion à Alexandrie (Bonifay, Leffy 2002, fig. 4 et 5). La pétrographie semblait certes confirmer cette attribution mais la difficulté de trouver des comparaisons typologiques a fini par ébranler mes hypothèses. On pourrait évidemment penser à une production africaine marginale ou à une production d'une province voisine, peut-être plus occidentale, encore mal connue (Algérie ?), mais il ne faut sans doute pas exclure complètement une production égyptienne en pâte non nilotique, imitant les formes africaines.

\section{Imitation des vaisselles sigillées africaines}

Ce qui peut apparaître comme un poncif des études sur les céramiques romaines tardives de l'Antiquité est une réalité dont il faut tenir compte: l'influence de la vaisselle africaine sur les autres productions du bassin méditerranéen est considérable, surtout à partir du IVe siècle. On ne peut pas comprendre le développement des sigillées phocéennes et chypriotes tardives (Late Roman $C$ et $D$ wares), ni l'émergence des sigillées grises du Sud de la Gaule (Dérivées-des-Sigillées Paléochrétiennes: DS.P.) (Bonifay, Vallauri 2002) et de la région de Thessalonique (Macedonian T.S. Grise), sans considérer l'extraordinaire diffusion des produits africains à décors imprimés et l'ascendant qu'ont dû avoir ces modèles, parfaitement intégrés dans la culture matérielle des populations méditerranéennes, sur les traditions céramiques locales (Sodini 2000, 187, parle du « prestige des vaisselles africaines »). Mais il s'agit dès lors de bien distinguer au sein de ces diverses productions celles qui subissent une simple influence technologique ou artistique, parfois mêlée à d'autres traditions culturelles, et celles qui traduisent une véritable intention d'imitation.

\section{- Céramiques influencées par la sigillée africaine}

Dans le premier groupe, il convient de classer les deux grandes productions de Méditerranée orientale, sigillées phocéenne et chypriote, qui sont les descendantes d'une longue tradition artisanale et qui n'adoptent que très ponctuellement des caractères empruntés aux sigillées 
africaines, principalement dans le domaine des décors. Dès 1972, J. W. Hayes avait signalé avec objectivité la similarité dans le choix et la disposition des motifs imprimés de la sigillée phocéenne (Hayes 1972, 346). Plus troublante est la correspondance morphologique entre la forme 2 de la sigillée chypriote tardive et la forme 84 de la sigillée africaine C5: il s'agit là clairement, selon Hayes (Ibid., 375), d'une influence directe des productions africaines de la seconde moitié du Ve s. qui ont, en Afrique même, suscité tant d'imitations locales (supra, SIGILLÉE TYPES 73-76). On s'étonnera seulement de la rareté des modèles de ce type d'assiette qui ont pu être importés en Méditerranée orientale. La sigillée grise du Sud de la Gaule (DS.P.), tout comme sa contrepartie macédonienne, est une renaissance, au Ve s. ap. J.-C., de pratiques artisanales éteintes depuis l'époque archaïque (Hayes 1972, 405, note 1 ). Comme l'a très bien montré J. Rigoir (1968, fig. 1), elle descend des sigillées gauloises tout en subissant l'influence des sigillées africaines, principalement sur le plan des décors imprimés (Rigoir 1997 ; Rivet 2001, 513-515).

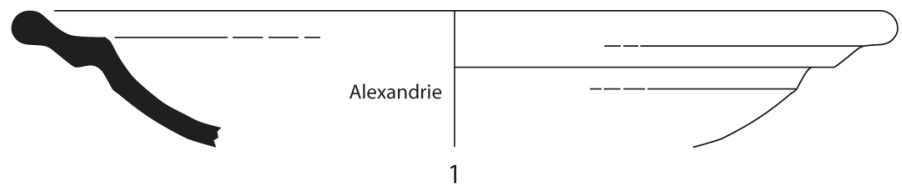

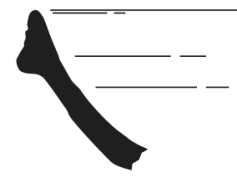
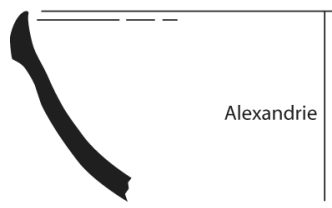

3

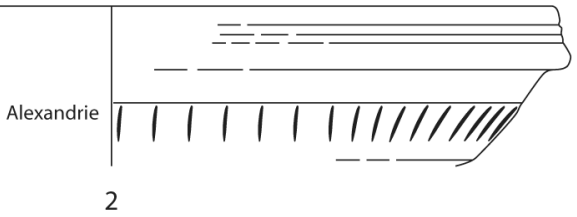

2

Fig. 258. Imitations de sigillées africaines en sigillées égyptiennes A (1-3) et B (4).

\section{- Céramiques cherchant à copier la sigillée africaine}

D'autres productions, visant une imitation plus servile des sigillées africaines, sont signalées en plusieurs points $\mathrm{du}$ bassin méditerranéen: péninsule Ibérique (Conimbriga IV, P1. LXXXIV), Italie (Fontana 1998), Grèce (Hayes 1972, 407 : Athenian ware), Jordanie (Uscatescu 2003, fig. 3). Le cas de l'Egypte est plus complexe; c'est un lieu commun que de rappeler l'ancienneté de la double tradition artisanale de la céramique, d'une part en pâte nilotique, tout au long de la vallée du Nil et jusqu'au delta, d'autre part en pâte kaolinitique dans la région d'Assouan (Ballet, Picon 1987, 29-44). Chacune des deux catégories de céramiques produit des vaisselles fines à engobe rouge tout au long de l'époque romaine mais, à la fin du IVes., elles trouvent un second souffle en puisant leur inspiration dans le répertoire africain. Le groupe nilotique (Egyptian $B=$ groupe $\mathrm{K}$ de Rodziewicz), tout en conservant certaines formes plus proprement égyptiennes (ex. : Rodziewicz 1976, forme K36) ou inspirées des sigillées assouanaises (ex.: Bonifay 1998c, fig. 1, $\mathrm{n}^{\circ} 14$; cf. Gempeler 1992, forme T608), s'ingénie à copier, souvent assez maladroitement en raison de la grossièreté de la pâte, le répertoire des productions africaines (4 : exemple de bol Hayes 99). Les sigillées d'Assouan (Egyptian $A=$ groupe $\mathrm{O}$ de Rodziewicz), dont une partie du répertoire reste de tradition nubienne (ex. : Bonifay 1998c, fig. 1, $\mathrm{n}^{\circ} 8$ : forme Gempeler T608), parviennent à imiter de manière très convaincante un large éventail de formes africaines : on citera comme exemples des plats Hayes 67, 84, 99 (Gempeler 1992, types T211, T218, T324) (13).

Exemples (fig. 258) :

*1 Alexandrie, chantier du théâtre Diana (Inv DI3282.7). Sigillée égyptienne A, imitation de plat Hayes 67.

*2 Idem (Inv. DI3576.5). Sigillée égyptienne A, imitation de plat Hayes 84 .

*3 Idem (Inv. DI3091.2). Sigillée égyptienne A, imitation de bol Hayes 99.

*4 Idem (Bonifay 1998c, fig. 1, $\mathrm{n}^{\circ} 13$ ). Sigillée égyptienne B, imitation de bol Hayes 99 .

La diversité des formes africaines copiées par les ateliers d'Assouan paraît même plus grande que celle des modèles originaux retrouvés en Egypte. Il est intéressant de constater que les sigillées orientales n'ont en général pas inspiré les potiers égyptiens, la copie en Egyptian B d'une forme 9 de sigillée chypriote tardive (Bonifay 
1998c, fig. $1, \mathrm{n}^{\circ} 12$ ) constituant cependant une exception notable.

\section{- Le problème des céramiques dites « Egyptian $C$ » ou « Imitation Late B »}

La sigillée «Egyptian C » de Hayes (1972, 399-401) reste une catégorie «even more shadowy» (Hayes 1980a, 530). On a récemment proposé de localiser sa production à Abu Mina (Ballet 1997, 55, note 10) ${ }^{296}$ mais «La quantité réduite de céramique de ce type » à Alexandrie fait douter de son origine locale (Rodziewicz 1984, 236). M. Rodziewicz (Ibid., note 215) soupçonne à juste titre que certains objets classés par Waagé en «Imitation Late B ware » sont en fait des productions africaines tardives (notre type D4, à pâte marron et engobe rouge carmin ; supra, p. 207). De fait, on peut se demander si une partie au moins du groupe appelé «Egyptian $\mathrm{C}$ » ne pourrait pas correspondre aux exemplaires les plus tardifs de la production africaine importés en Méditerranée orientale. Cette hypothèse est confortée par les récentes découvertes de Crète (Lippolis 2001, fig. XIX : vernis rouge carmin et décor lustré du GROUPE 2).

\section{Imitation des autres vaisselles africaines}

Les sigillées ne sont pas les seules vaisselles africaines ayant fait l'objet d'imitations. Toujours plus nombreuses sont les copies de céramiques culinaires africaines recensées en Occident, notamment en Grande-Bretagne (Swan 1992: uniquement des formes de culinaire B, Hayes 181-182, associées à des vases à décor plastique inspirés également des productions de Byzacène, à l'exclusion de toute forme septentrionale telle que Hayes 196 ou 197), dans le Midi de la France (région de Béziers : Dodinet, Leblanc 1988, Pellecuer, Pomaredes 1991 et Mauné 1996 : formes de Tunisie septentrionale Hayes 23B, 196, 197), en Espagne (Aguarod 1991, 245, et Bernal Casasola 1998: formes de Tunisie septentrionale). Je me demande si des céramiques communes africaines ne peuvent pas avoir également influencé les productions locales. Il pourrait en être ainsi de deux formes-phares de la vaisselle africaine: les mortiers à inclusions de basalte et les bassins. Ces deux formes, importées en quantités non négligeables en Provence et en Languedoc, ont pu, à mon sens, inspirer les formes Rigoir 29 et Rigoir 25 de la production de sigillée grise du sud de la Gaule (DS.P.) mais également la production de bon nombre d'ateliers locaux de céramiques communes. On pourrait se poser la même question à propos de bassins à pâte nilotique trouvés à Alexandrie et dont la forme est assez inhabituelle en Egypte (Bonifay, Leffy 2002, 42 et fig. 2, n 7-9).

\footnotetext{
${ }^{296}$ Cite ENGEMANN (J.) - A propos des amphores d'Abou Mina. Cahiers de la Céramique Egyptienne, 3, 1992, p. 156.
}

\section{Imitation des lampes africaines}

Les lampes en sigillée africaine des Ve-VIIe s. sont les objets qui ont été le plus facilement imités, par la technique du surmoulage. Mais dans ce cas, seule la forme est copiée, plus ou moins adroitement, l'aspect de la pâte permettant dans la plupart des cas de faire la différence avec les lampes originales. La liste des sites où ont été mises en évidence des imitations de lampes africaines serait très longue. A titre d'exemples, et sans aucune prétention à l'exhaustivité, on peut citer: Trèves (Goethert 1997, fig. 113-114, moules), Graviscae (Hanoune 1970, Pl. 10), Rome (Bailey 1980, types R et S), Naples (Garcea 1999, fig. 1, Pl. 3-4), Sassari (Galli 2000, 72), Crecchio (Odoardi 1993, fig. 2, $\mathrm{n}^{\circ}$ 13-14), Ordona (Mertens 1979, fig. 11, $\mathrm{n}^{\circ} 1$, Pl. XX, a : moule de lampe du groupe C2), région de Rimini (Maioli 1993), Classe (Berti 1983, 147-148 et 153), Invillino (Mackensen 1987, fig. 40, $n^{\circ} 8-13$ ), Corinthe (Slane 1990 ; Lindros Wohl 1993), Delphes (Petridis 1997, 690 et fig. 13, fig. 6 : moule), Demetrias (Eiwanger 1981, P1. 74-85), Constanta (Roumanie) (Bucovala 1998), Halmyris (Roumanie) (Topoleanu 2000, Pl. VII), Beyrouth (Aubert 1996, fig. 10), Cyrénaïque (Catani 1989), Toulouse (Catalo, Foy, Llech 1998, fig. 6), Générac (Raynaud 1982) et Marseille (Bonifay et al. 1998, 366). Je retiendrai, dans le Midi de la Gaule, ces deux derniers exemples :

\section{- Atelier de Générac}

L'atelier de Générac, près de Nîmes, mérite une attention particulière. Cet atelier a produit à la fois des sigillées tardives apparentées aux DS.P. et des lampes de type africain dont cinq moules en céramique ont été retrouvés. Exemples (fig. 259) :

*1 Atelier de Générac (Raynaud 1982, fig. 5, n³24). Moule en céramique pour imitation de lampe en sigillée africaine Atlante VIIIC1d (supra, LAMPE TYPE 48), face supérieure.

*2 Idem (Ibid., fig. 5, $\mathrm{n}^{\circ} 325$ ). Moule en céramique pour imitation de lampe Atlante VIII, face inférieure.

Ces lampes relèvent des variantes les plus tardives du type Atlante VIII C et D (supra, LAMPES TYPES 48-50). Il convient donc peut-être de réviser la datation qui a été proposée pour cet ensemble: décennies centrales du IVe s. sur la foi de trouvailles monétaires (Raynaud 1982, 348). A Carthage, ces lampes sont caractéristiques des contextes du milieu ou de la seconde moitié du Ves. (supra, p. 368).

\section{- Atelier de Marseille}

La production de lampes de type africain à Marseille est prouvée par la découverte, sur le chantier de La Bourse, d'un fragment de moule en céramique (valve inférieure) pour une lampe de type Atlante X. Les lampes provenant des mêmes contextes qui peuvent être rattachées à cette production locale sont en pâte chamois micacée. Toutes 
appartiennent au type Atlante VIII (Bonifay 1983, fig. 31, $\mathrm{n}^{\circ} 198$ : type VIII C1e ; Cour-Mezzoud 1998, fig. 106, $\mathrm{n}^{\circ} 50$ : type VIII A1a; Treglia 1998, fig. 149, $\mathrm{n}^{\circ} 30$ ).

Exemples (fig. 259) :

*1 Marseille, chantier de La Bourse (Inv. MB2701.21).

Moule en céramique pour imitation de lampe en
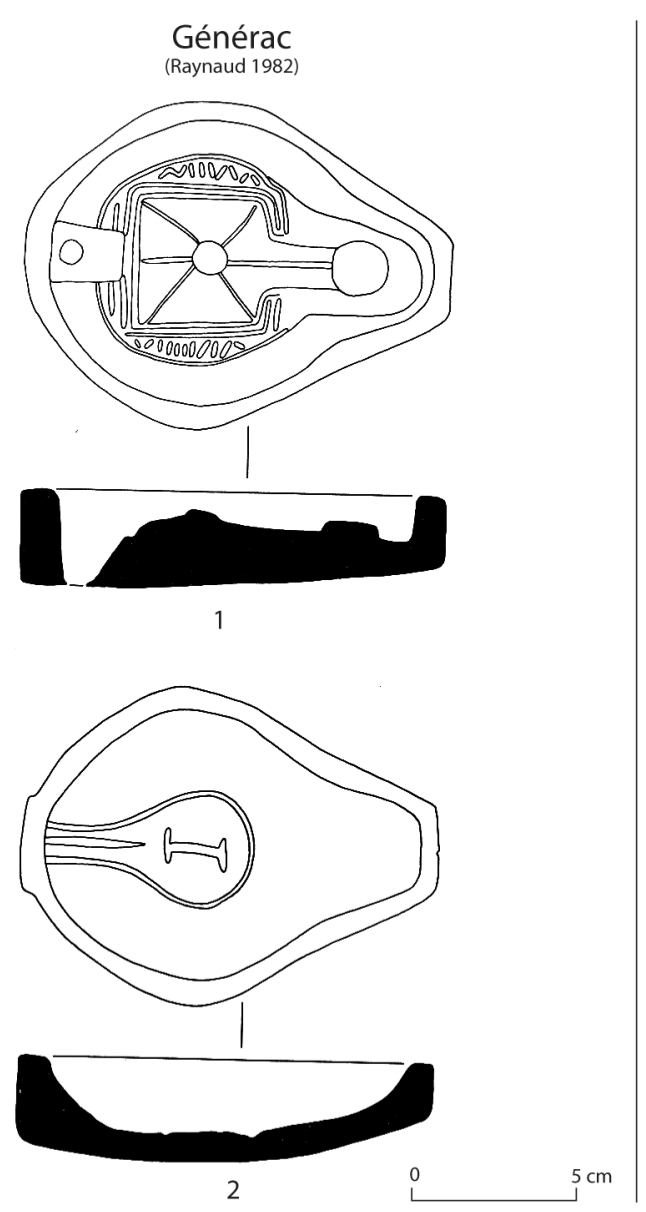

2

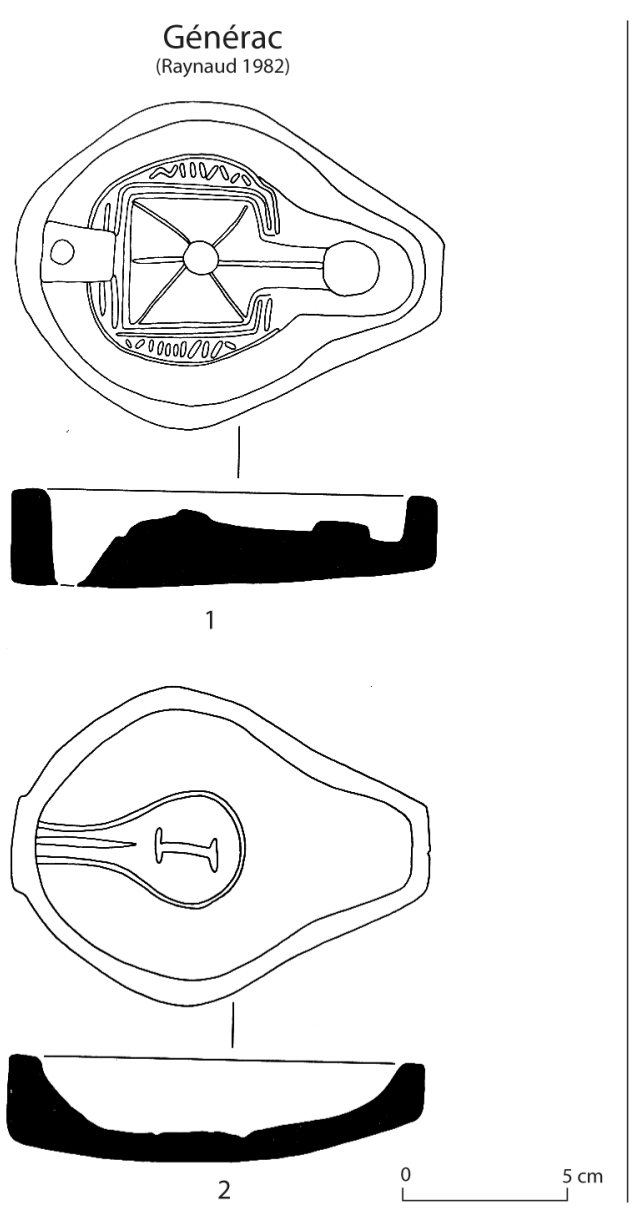

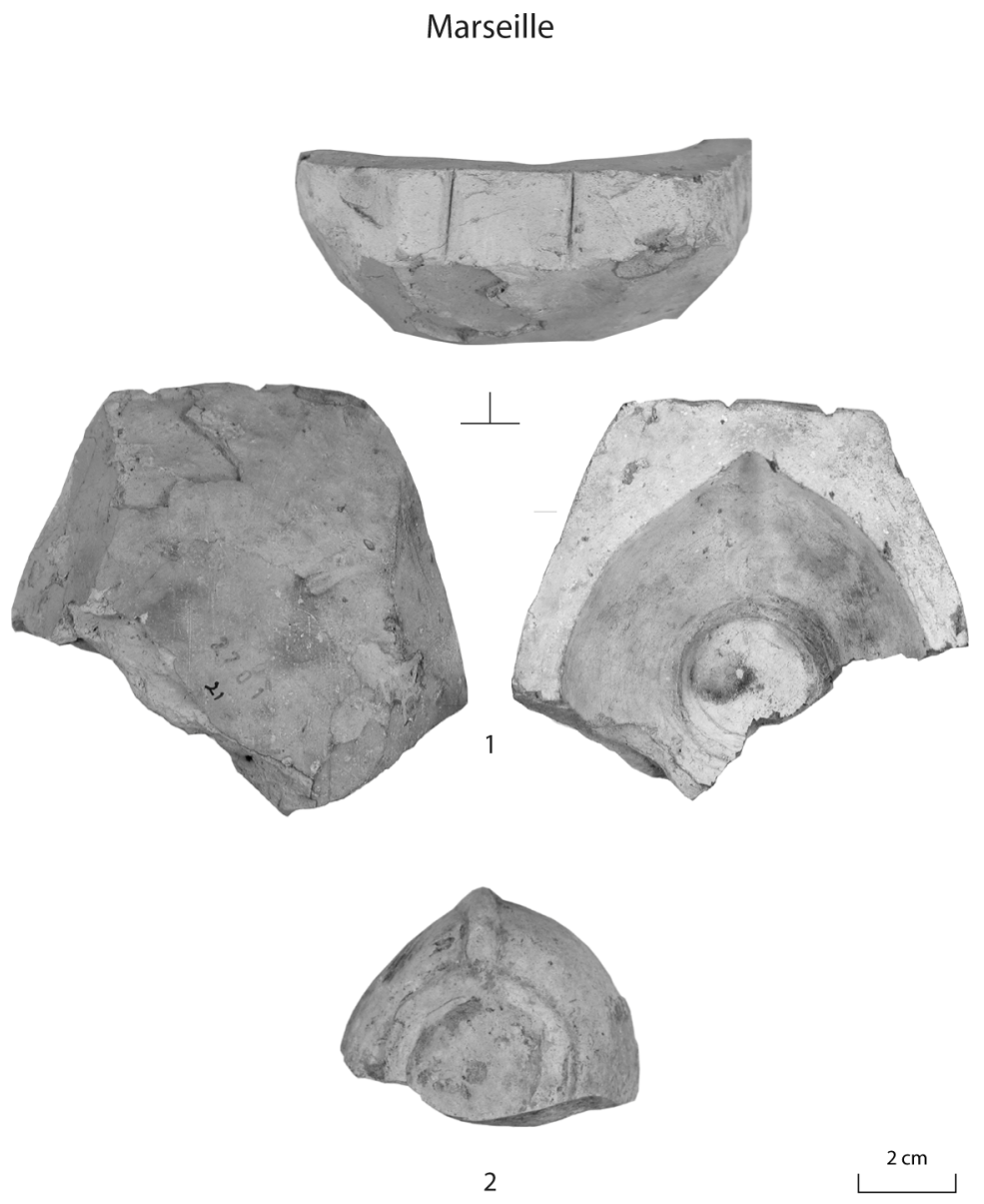

sigillée africaine Atlante X, face inférieure

*2 Idem (Inv. MB1152.sn). Lampe en céramique commune locale imitant les lampes en sigillée africaine Atlante X.

Datation proposée : Ve s.

Fig. 259. Imitations de lampes africaines.

Exemples en Gaule du Sud. 


\section{CÉRAMIQUE AFRICAINE ET PRODUCTION VIVRIÈRE}

L'explication de la large diffusion des céramiques africaines a longtemps reposé sur deux postulats : - les vaisselles africaines sont diffusées en accompagnement des amphores, selon le fameux «diptyque » unissant les vases-conteneurs et la vaisselle (Morel 1983, 71);

- les amphores transportent une denrée de première nécessité, l'huile, massivement produite en Afrique et donc appelée à une large commercialisation.

On a vu que la première hypothèse subissait un certain nombre d'exceptions, notamment en Méditerranée orientale (Sodini 2000, 191) où, à l'afflux de vaisselles sigillées africaines ne correspond pas un afflux d'amphores de même origine. Il faut donc imaginer que les vaisselles étaient alors commercialisées pour leur valeur propre, ou bien qu'elles voyageaient parfois en accompagnement d'autres marchandises, périssables et non conditionnées en amphores.

Qu'en est-il du second postulat? Peut-on se contenter, pour la diffusion des amphores africaines, d'une explication fondée sur un «olive-boom» (selon l'expression de Mattingly 1988b) en Afrique du Nord?

\section{Etat de la question}

Le contenu des amphores africaines est une question qui a fait couler beaucoup d'encre (Ben Lazreg et al. 1995, 119-121). La mise en évidence d'amphores en provenance de Byzacène (Zevi, Tchernia 1969) avait permis tout à la fois de donner un nom à une catégorie de conteneurs qui envahit les marchés de Méditerranée occidentale à partir de la fin du IIe s. ou du début du IIIe s., et de mettre en concordance des témoins archéologiques «objectifs » avec les textes concernant le développement de l'arboriculture africaine sous les Antonins (Carandini 1970a). Il paraissait clair que les amphores africaines étaient majoritairement destinées au transport de l'huile. Cette opinion était toutefois nuancée par F. Zevi : l'existence de deux types distincts « africano piccolo » et « africano grande », produits dans les mêmes ateliers comme le prouvaient les timbres parfois identiques, semblait indiquer deux contenus différents. Or, comme le premier type (Africaine I) avait été trouvé en abondance aux abords d'une des deux seules usines de salaison fouillées en Tunisie (celle de Salakta), il devait être destiné de préférence au transport des salaisons de poisson, et le second, de plus grandes dimensions (Africaine II), au transport de l'huile.

Cette opinion fut reprise durant les années 1970 par Cl. Panella et D. Manacorda dans leur typologie des amphores africaines basée sur le matériel des thermes du
Nageur à Ostie (Panella 1973 ; Manacorda 1977). Cette hypothèse se trouvait confortée par un titulus pictus sur une amphore Africaine II D provenant du même site ${ }^{297}$, dont le premier mot était lu OLEI. Par ailleurs, dans la stratigraphie, l'augmentation du nombre des amphores africaines coïncidait avec une diminution de la proportion des Dressel 20, et démontrait, selon ces auteurs, le remplacement des importations d'huile de Bétique par les importations d'huile africaine au IIIe siècle.

Pourtant, depuis les travaux de R. Lequément (1975, 1976, 1980), le doute s'était installé. Ce chercheur avait démontré tout d'abord qu'un certain nombre d'amphores africaines, comme celles récupérées au large d'Annaba (Lequément 1975) ou sur l'épave de Pampelonne (Lequément 1976), étaient poissées. Or, R. Lequément attirait l'attention sur le fait que la poix est incompatible avec l'huile (Lequément 1975, 678). De plus, les amphores d'Annaba portaient des étiquettes de plomb faisant référence à des « officines" que cet auteur interprétait comme des fabriques de salaison de poisson; pour les amphores de Pampelonne, R. Lequément n'excluait pas une autre possibilité de contenu : le vin (Lequément 1980, 191, note 3).

Cette remise en question du contenu des amphores africaines et l'attention nouvellement portée au poissage de ces conteneurs a poussé A. Tchernia à organiser un programme d'analyses sur des tessons d'amphores de types I et II (rapport non publié, cf. Panella 1982, 171186 ; Gibbins, Parker 1986, 267-304). Sur les quatorze échantillons de type I analysés par Fr. Formenti, dix présentaient des traces de contenu oléagineux, tandis que ce n'était le cas d'aucun des neuf échantillons de type II ; en outre, deux de ces tessons portaient des traces de poix. L'hypothèse initiale de F. Zevi se trouvait donc inversée : les amphores Africaines I auraient transporté principalement de l'huile et les amphores Africaines II une denrée différente, peut-être des salaisons de poisson.

Sur la base de ces différentes réflexions, on a assisté au cours des années 1980 à la constitution de véritables « écoles », les archéologues anglo-saxons restant le plus souvent fidèles à l'huile comme contenu de la majorité des amphores africaines (Keay 1984, Peacock, Williams 1986 ; voir cependant les observations de Gibbins, Parker 1986, 290, à propos des amphores de l'épave Plemmirio B), les archéologues français préférant une nette distinction entre les deux types d'amphores africaines associés à deux contenus différents (Leguilloux 1988b ; Sciallano, Sibella 1991) et les archéologues italiens

\footnotetext{
${ }^{297}$ A ma connaissance non publiée.
} 
prônant une possible interchangeabilité des contenus (Panella 1982 ; voir également Laubenheimer 1990).

J'ai été amené, au début des années 1990, à reprendre ce dossier, à l'occasion de la publication des prospections du littoral tunisien et de la fouille des fabriques de salaisons de Nabeul (Ben Lazreg et al. 1995, 121-132; Slim, Bonifay, Trousset 1999, 172-173 ; Bonifay et al. 20022003). Les observations sur la présence ou l'absence de poix dans les amphores ont constitué le fil directeur de cette enquête.

\begin{tabular}{|c|c|c|c|c|c|c|c|c|c|c|c|c|c|c|}
\hline & $\begin{array}{c}\text { TYPE } \\
1 \\
\end{array}$ & $\begin{array}{c}\text { TYPE } \\
2 \mathrm{~A} \\
\end{array}$ & $\begin{array}{c}\text { TYPE } \\
2 \mathrm{~B}\end{array}$ & $\begin{array}{c}\text { TYPE } \\
2 \mathrm{C}\end{array}$ & $\begin{array}{c}\text { TYPE } \\
\text { 2D }\end{array}$ & $\begin{array}{c}\text { KEAY } \\
25.1 \\
\end{array}$ & $\begin{array}{c}\text { KEAY } \\
25.3 \\
\end{array}$ & $\begin{array}{c}\text { KEAY } \\
25.2 \\
\end{array}$ & Spatheia & $\begin{array}{c}\text { KEAY } \\
35 \mathrm{~A} \\
\end{array}$ & $\begin{array}{l}\text { KEAY } \\
35 \text { B }\end{array}$ & $\begin{array}{c}\text { KEAY } \\
62 \\
\end{array}$ & $\begin{array}{l}\text { KEAY } \\
61 / 8 \mathrm{~A} \\
\end{array}$ & $\begin{array}{l}\text { Datation } \\
\text { proposée : }\end{array}$ \\
\hline CAMARINA A (I) & $\square$ & & & & & & & & & & & & & $175-200$ \\
\hline PROCCHIO (I) & $\square \mathrm{F}$ & & & & & & & & & & & & & $160-200$ \\
\hline PLEMMIRIO B (I) & $\square 0$ & 口 & & & & & & & & & & & & C. 200 \\
\hline $\operatorname{MONACOA}(\mathrm{F})$ & & 口 & & & & & & & & & & & & $200-250+$ \\
\hline GIGLIO PORTO (I) & & $\overline{\mathrm{DC}}$ & & & & & & & & & & & & $200-225$ \\
\hline GIANNUTRI (I) & $\square$ & & & & & & & & & & & & & C. 250 \\
\hline CABRERA A (E) & & & & E & & & & & & & & & & $250-300$ \\
\hline CABRERAC (E) & & & & $\square 0 \mathrm{P}$ & & & & & & & & & & C. 250 \\
\hline CAP BLANC (E) & & & & $\square \mathrm{P}$ & & & & & & & & & & $290-325$ \\
\hline CAP DE GARDE (ALG) & & & & & & & & & & & & & & $290-365$ \\
\hline PLANIER 7 (F) & & & & 口 & & & & & & & & & & $300-350 ?$ \\
\hline LAZZARETTO (I) & & & & & $\square \mathrm{P}$ & & & & & & & & & C. 320 \\
\hline FEMMINA MORTA (I) & & & & & & 口 & & & & & & & & $290-325$ \\
\hline PAMPELONNE (F) & & & & $\mathbf{D C}$ & & $\mathrm{DC}$ & & & & & & & & $300-350$ \\
\hline HELIOPOLIS 1 (F) & & & & & & Dv? & & & & & & & & $300-350$ \\
\hline LA LUQUE B (F) & & & & & & & $\overline{\mathrm{C}}$ & & & & & & & $300-325$ \\
\hline LES CATALANS $(\mathrm{F})$ & & & & & & & 口? & & & & & & & C. 350 \\
\hline PORT MIOU (F) & & & & & & & 口? & & & & & & & $400-425$ \\
\hline DRAMONT F (F) & & & & & & & & 图 & & & & & & $400-425$ \\
\hline DRAMONT E (F) & & & & & & & & & 0 & $\square$ & 口 & & & $425-450$ \\
\hline FILICUDI PORTO (I) & & & & & & & & & & & & $\square$ & & C. 550 \\
\hline SAINT-GERVAIS $(\mathrm{F})$ & & & & & & & & & & & & & 国 & $580-650 ?$ \\
\hline
\end{tabular}

$\begin{array}{ll}\square \text { non poissé } & \mathrm{F}: \text { pépins de figues } \\ \square \text { poissé } & 0: \text { noyaux d'olives } \\ \mathbb{Q} \text { rempli de résine } & \mathrm{P}: \text { restes de poissons }\end{array}$

C : coquillages ou crustacés

$\mathrm{V}:$ vin?

Fig. 260. Attestations d'amphores africaines poissées sur les épaves de Méditerranée (d'après Parker 1992).

\section{Les mentions d'amphores poissées dans la bibliographie}

L'examen des données rassemblées par A. J. Parker (1992) dans son inventaire des épaves de Méditerranée a permis de dresser le tableau de la fig. 260 (Ben Lazreg et al. 1995, fig. 8). L'échantillonnage est faible : 22 épaves seulement livrent des informations sur le contenu des amphores africaines.

a) Absence de poix : si les fouilleurs signalent parfois qu'une amphore est poissée, ils restent le plus souvent silencieux lorsque cette observation est négative. Toutefois, des amphores Africaines I sont formellement décrites comme non poissées dans quatre chargements.

b) Présence de poix : parmi les amphores poissées, le groupe le plus important est celui des amphores de type II, soit douze épaves datées du IIIe s. au début du IVe siècle. Des traces d'arêtes et d'écailles de poissons ont été retrouvées dans trois de ces chargements (Cabrera III, Cap Blanc, Lazaretto); dans un cas, on signale également des noyaux d'olives (Cabrera III). Malheureusement, la publication de l'épave de Cabrera III ne précise pas la typologie des Africaines II qui contenaient l'un ou l'autre type de résidus. En ce qui concerne les amphores cylindriques de moyennes dimensions du IVes. (sept épaves), aucun résidu de poisson n'est signalé. Enfin, les épaves sont plus rares à partir du Ve siècle. La seule information importante est fournie par l'épave du Dramont E dont le chargement était composé de trois types d'amphores: le type Keay 35A non poissé, le type Keay 35B poissé et le type Keay 25.2 et/ou «spatheion », poissé et contenant des noyaux d'olives. Les amphores Keay 62 de l'épave de Filicudi Porto étaient également poissées. Les coquillages et crustacés recueillis dans les amphores sur trois chargements différents posent un problème non résolu : appartiennent-ils au contenu de l'amphore ou bien se sont-ils introduits après le naufrage? En revanche, il 
convient de ne pas tenir compte des amphores entièrement remplies de résine présentes sur trois épaves : il s'agit vraisemblablement, dans la plupart des cas, d'une réserve de poix pour le calfatage du navire et, dans le cas de l'épave du Dramont F, d'un commerce local de résine réemployant des amphores africaines ;

Il importe en effet de se méfier des réutilisations d'amphores, même si ce procédé n'a pas la fréquence qu'on lui attribue parfois. L'épave de Grado (Auriemma 2000, 81 et note 5) en est un bon exemple avec le remploi d'amphores italiques, orientales et africaines, y compris des amphores à huile Africaines I et Tripolitaines I, non poissées, pour le transport de salaisons de poissons produites dans le Frioul.

En examinant le matériel recueilli dans le port de Carthage, A. Opait (1998a) souligne la présence de poix dans les amphores Keay 62 et les «spatheia»; en revanche, le type Keay $8 \mathrm{~B}$ ne paraît pas poissé. Enfin, il faut rappeler qu'un certain nombre de cruches africaines sont poissées et ont pu servir de conteneur de transport (supra, fig. 162, COMMUNE TYPE 62).

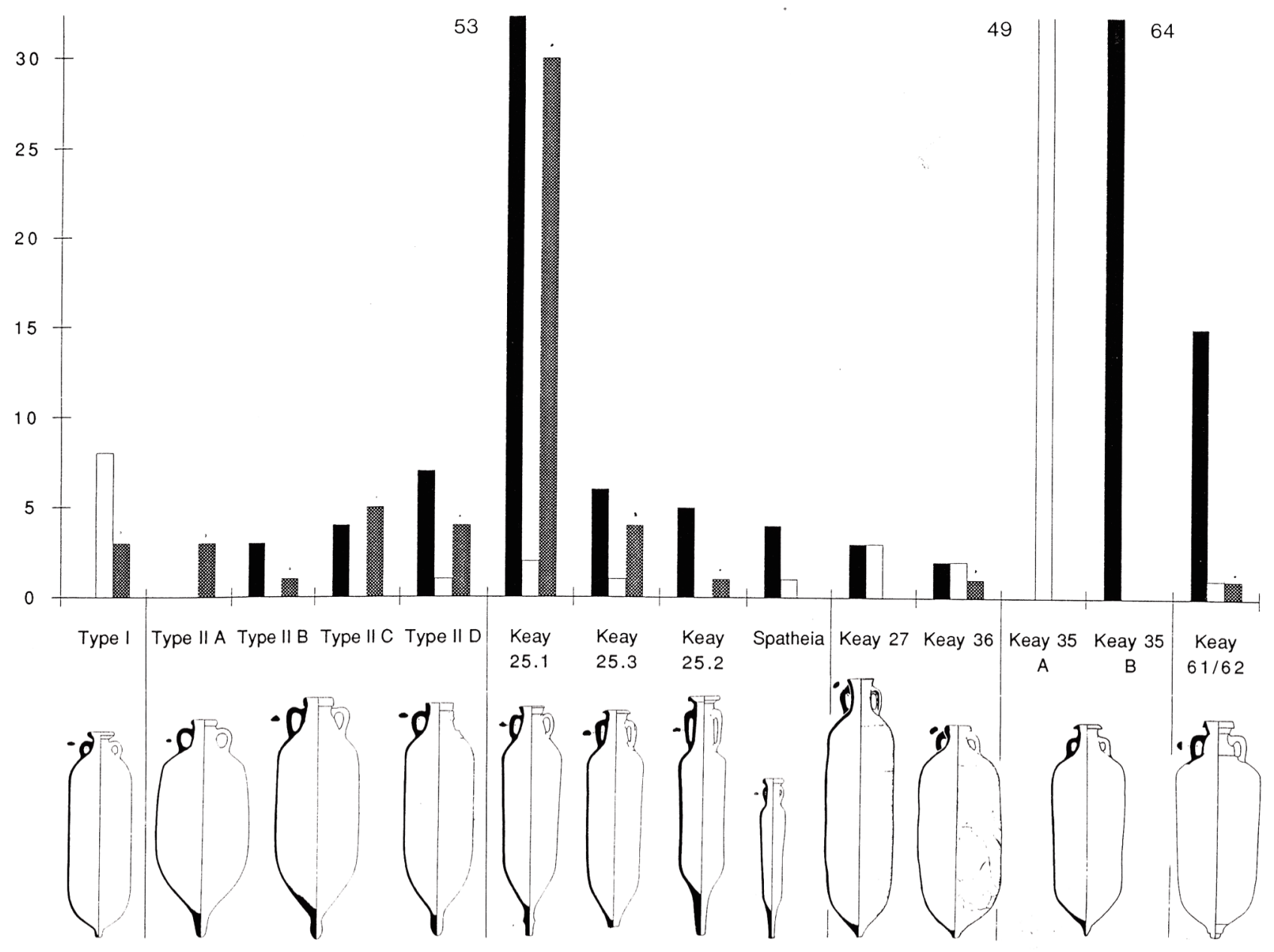

Fig. 261. Examen des traces de poix sur les amphores africaines du littoral français.

En noir : traces de poix. En blanc : sans trace de poix. Tramé : incertain.

\section{Enquête dans les dépôts de fouille}

J'ai examiné en 1993 la paroi intérieure de plus de 200 amphores complètes ou fragmentaires issues de fouilles sous-marines ou terrestres en milieu humide et, lorsque cela était possible, des prélèvements de poix ont été effectués. La plupart des amphores proviennent du littoral français (Ben Lazreg et al. 1995, fig. 9 et Annexe I) et ont été observées dans les dépôts du Département des
Recherches Archéologiques Subaquatiques et SousMarines; quelques tessons ont également été examinés à Salakta et à Carthage. L'examen de ces amphores permet de préciser les données type par type (fig. 261) :

- Aucune amphore de type I ne conserve de traces de poix, sauf peut-être un fragment à Arles, douteux.

- Les amphores Africaines II sont peu nombreuses, dans les dépôts français d'archéologie sous-marine, par rapport à ce que montre le recensement de Parker 

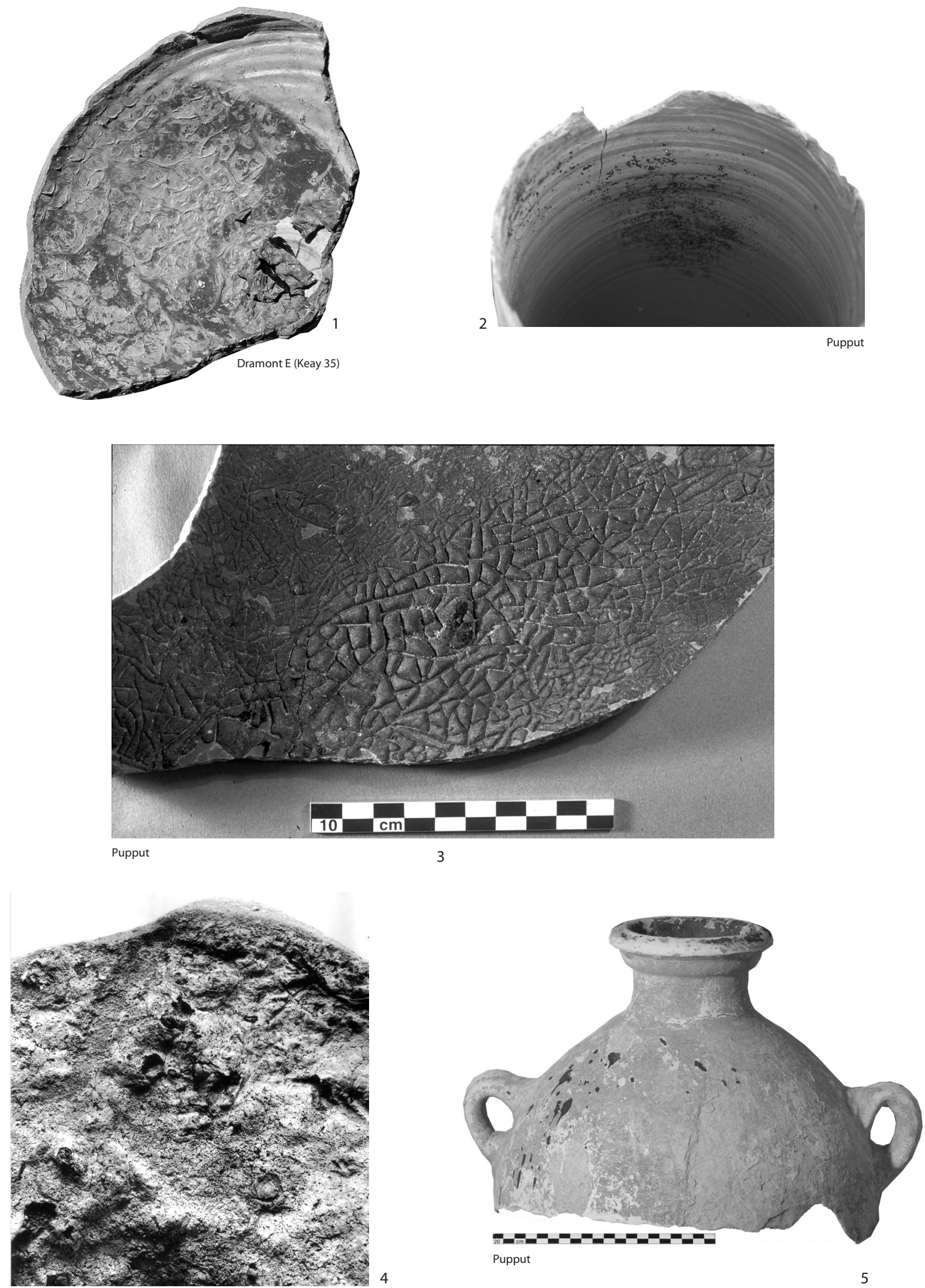

Pointe de la Luque

Fig. 262. Amphores africaines poissées. 
sur l'ensemble de la Méditerranée. Les quatre soustypes sont cependant représentés et beaucoup sont poissés.

- Les amphores cylindriques de moyennes dimension sont les conteneurs africains les mieux représentés dans les dépôts français. On note une très forte proportion d'amphores poissées.

- Deux types ressortent parmi les amphores cylindriques de grandes dimensions : le type Keay 35B avec au moins treize exemplaires poissés répartis sur cinq sites, et le type Keay 62 avec une quinzaine d'exemplaires poissés.

Les observations de traces de poix dans les amphores africaines ne sont pas toujours faciles. La poix des amphores africaine n'est pas très adhérente et a tendance à ne laisser parfois qu'une vague trace jaunâtre ${ }^{298}$ (F. Mayet in Bost et al. 1992, 143).

Des données plus récentes ont été obtenues sur le chantier de Pupput. Plus d'une quinzaine d'exemplaires d'amphores Africaines II portent des traces de poix, parfois très évidentes (fig. 262, $n^{\circ} 3$ ), alors que ce n'est jamais le cas des amphores Africaines I (Bonifay 2004a, 30). Par ailleurs, le type originaire de Maurétanie Césarienne (type «station 48 de la place des corporations "; supra, AMPHORE TYPE 30) récemment identifié sur cette nécropole est également poissé (Ben Abed, Bonifay, Griesheimer 1999, 172).

Exemples (fig. 262) :

*1 Epave Dramont E (sans $\mathrm{n}^{\circ} \mathrm{d}$ 'inv.). Fond d'amphore Keay 35B.

*2 Pupput, tombe 1301 (Inv. PP2992.1). AMPHORE TYPE 16.

*3 Pupput (Bonifay à paraître, c, fig. 10). Amphore Africaine II A.

*4 Epave pointe de la Luque B (Inv. PL1960). Amphore Africaine II D. Poix et pépins de raisin.

*5 Pupput (Inv. PP6606.1). Amphore Tripolitaine II, enduite de poix ou de bitume (?).

\section{Renseignements apportés par le mode d'ouverture des amphores}

Nous avons vu que les amphores remployées dans l'architecture des tombes de la nécropole de Pupput apportaient beaucoup de renseignements sur l'origine des productions, l'épigraphie, le contenu (poissage éventuel). Un dernier aspect n'a pas encore été abordé : la façon dont ces amphores ont été ouvertes.

On sait qu'il existait essentiellement deux façons de boucher ces amphores pour le transport. La première consistait à placer dans le col un opercule (supra, fig. 56, $\mathrm{n}^{\circ} 5$ ) ou un tesson d'amphore grossièrement retaillé de

\footnotetext{
${ }^{298}$ Il conviendrait toutefois de vérifier par des analyses qu'il s'agit bien toujours de poix et non d'une substance de type gomme, compatible avec l'huile.
}

façon circulaire, face bombée vers le bas, et à colmater l'embouchure avec du plâtre. On rencontre ce système de bouchage principalement sur le type Africaine I (1) et également sur certains types tardifs (2). Les bouchons du deuxième type sont en liège. Ils paraissent associés de préférence $^{299}$ à des amphores africaines II (Ex. : épave de Giglio Porto, Parker 1992, 193 ; épave du Cap Blanc, Ibid., 99) et Keay 25 (Ex. : épave Héliopolis 1, Ibid., 99); Les données sont parfois contradictoires, par exemple celles concernant les «spatheia» miniatures du VIIe s. (supra, AMPHORE TYPE 33) : un exemplaire est bouché avec un tesson d'amphore (Villedieu 1994, fig. 80, $\mathrm{n}^{\circ}$ 9), un autre, provenant d'Egypte, devait être fermé avec un bouchon en liège puisque l'amphore a pu être vidée en perçant simplement deux trous dans l'opercule de plâtre (Hayes 1976b, Pl. 27, $\mathrm{n}^{\circ}$ 362). Comme sur ce dernier exemple, les opercules de pâtre portaient parfois des estampilles.

Exemples (fig. 263) :

*1 Alexandrie, chantier du Majestic (Inv MA92.1.149.1). Amphore Africaine I B. Traces de bouchage en place.

*2 Epave de la Palud (Long, Volpe 1998, fig. 297, $\mathrm{n}^{\circ} 80$ ). AMPHORE TYPE 45 (?). Bouchon en place sans le plâtre.

*3 El Jem, maison d'Africa (fouilles H. Slim, Inv. EJMA7503). Bouchon d'amphore enduit de plâtre sur une face.

Or, l'ouverture de ces conteneurs ne se faisait pas toujours par l'embouchure, comme le suggèrent les amphores de la nécropole de Pupput et quelques exemplaires d'El Jem. Les trous plus ou moins grands, que ces amphores portent sur leur paroi ${ }^{300}$, montrent qu'elles étaient tantôt mises en perce comme des tonneaux, tantôt ouvertes comme des boîtes de conserve. On peut distinguer quatre types de perforations :

A : Des trous de petite taille (entre 1 et $2 \mathrm{~cm}$ de diamètre), la plupart du temps forés (1-3) (un foret cassé est encore en place dans l'un des trous), d'autres obtenus par percussion, situés généralement dans le tiers inférieur de la panse. Ces perforations concernent principalement des amphores de tradition punique du golfe d'Hammamet, des amphores Africaines II A con gradino et quelques exemplaires de type Keay 25.3. Certes, ces trous pourraient avoir facilité, par appel d'air, la sortie d'un contenu semisolide par l'encolure (salaisons de poisson), mais ils peuvent également indiquer que l'amphore était stockée debout pour être " mise en perce », la petite taille des trous paraît quant à elle mieux convenir à

\footnotetext{
${ }^{299}$ On ne sait pas si ceux de l'épave Monaco A doivent être associés aux amphores Africaines II A ou bien aux amphores Dressel 30 (Mouchot 1970, 171).

${ }^{300} \mathrm{Qu}$ 'il est facile de distinguer des grandes ouvertures pratiquées sur les amphores ayant servi de sarcophages. Ex. : fig. 53, AMPHORE TYPE $16, \mathrm{n}^{\circ} 2$.
} 

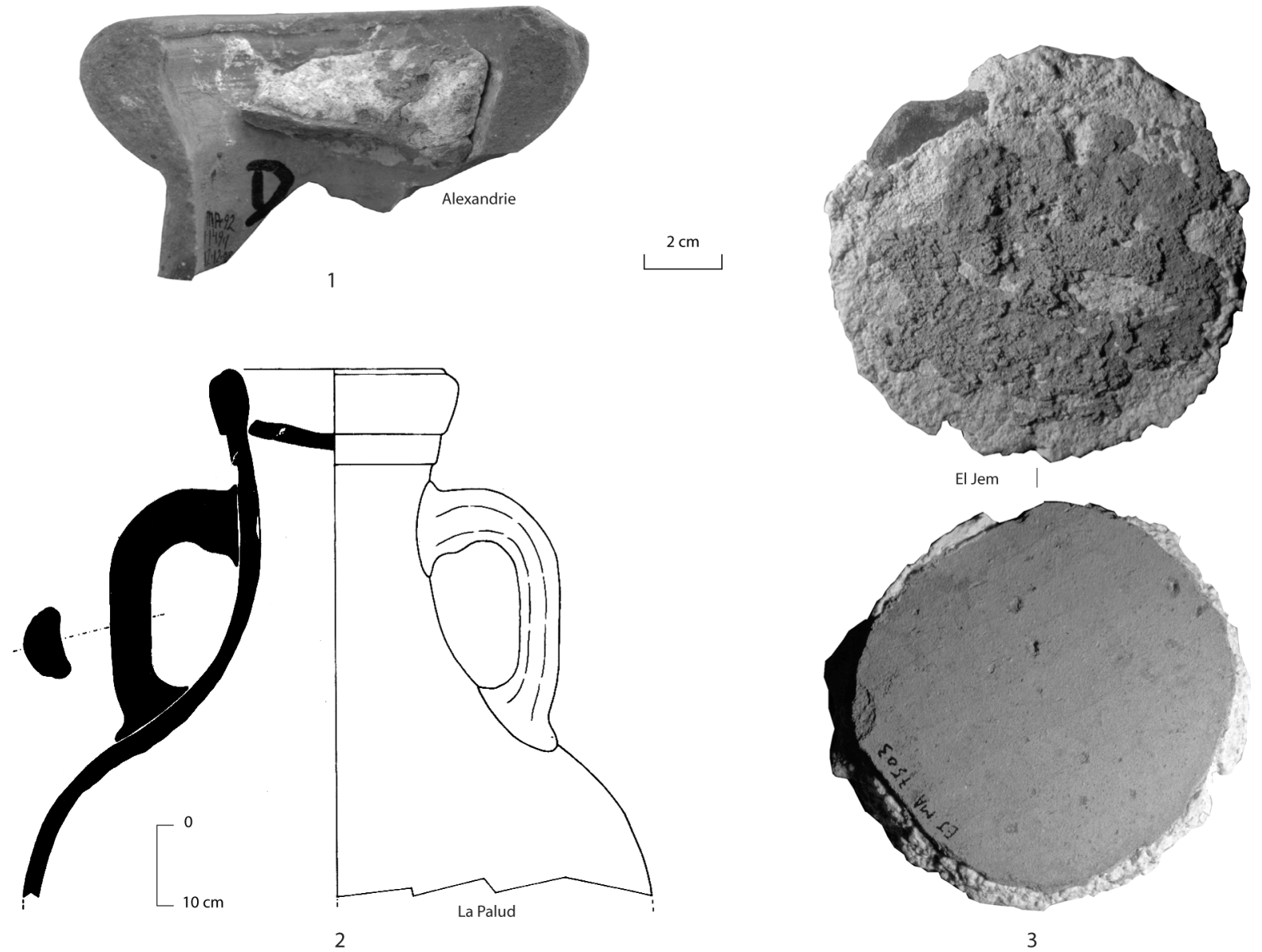

Fig. 263. Modes de bouchage des amphores africaines.

un contenu aqueux (vin, garum) qu'à un liquide dense comme l'huile (?); une seule amphore Africaine I (sur 32 complètes) porte une perforation de ce type. On remarque que ces trous de petite taille sont parfois percés à des emplacements précédemment affaiblis, comme les éclats de surface réparés au plâtre des amphores de Salakta (2).

B: Des trous de taille moyenne (env. $10 \mathrm{~cm} \mathrm{de}$ diamètre), découpés sur l'épaulement (4-6). Ces trous se rencontrent sur des amphores Africaines II A con gradino et sur les amphores Africaines I. L'une d'elle conserve un opercule inséré dans le col, ce qui confirme que l'amphore n'a pas été ouverte autrement que par une découpe sur l'épaulement. Une autre conservait à l'intérieur le tesson de panse découpé pour l'ouverture, ce qui pourrait indiquer que le contenu (un semi-solide ou un liquide dense, comme l'huile) a été vidé en une seule fois.

$\mathrm{C}$ : Des trous de grande taille $(15-20 \mathrm{~cm})$, également découpés sur l'épaulement (8). Ces grandes perforations concernent trois exemplaires d'amphores Africaines II A con gradino, dont une est poissée. De tels trous ne se comprennent qu'avec un contenu semi-solide, comme par exemple des poissons salés.
D : Enfin, un certain nombre d'amphores de type Hammamet 1 sont ouvertes à l'extrémité de leur fond tronconique creux, ce dernier ayant été alors simplement décalotté ou scié. Dans ce cas, on peut imaginer que les amphores étaient posées horizontalement, peut-être sur des étagères murales $^{301}$, durant le temps nécessaire au tirage de leur contenu liquide par la pointe.

Exemples (fig. 264) :

Mode A

*1 Pupput (Bonifay 2004b, fig. 17, n 41). Amphore Hammamet 1.

*2 Idem, tombe 1007 (Inv. PP1685.3). Amphore Africaine II A.

*3 Idem, tombe 1058 (Inv. PP2306.6). Amphore Keay 25.1 .

Mode B

*4 Idem, tombe 425 (Inv. PP2342.4). Amphore Africaine I.

*5 Idem (Inv. PP2342.7). Amphore Africaine I. Ebauche de trou.

*6 Idem (Inv. PP2342.5). Amphore Africaine I. Trou, tesson découpé et traces de repentir.

${ }^{301}$ A l'image de celles retrouvées à Herculanum : Mols 1999 : 62 et fig. 149-153: « amphora track ». 
Diffusion - Céramique africaine et production vivrière

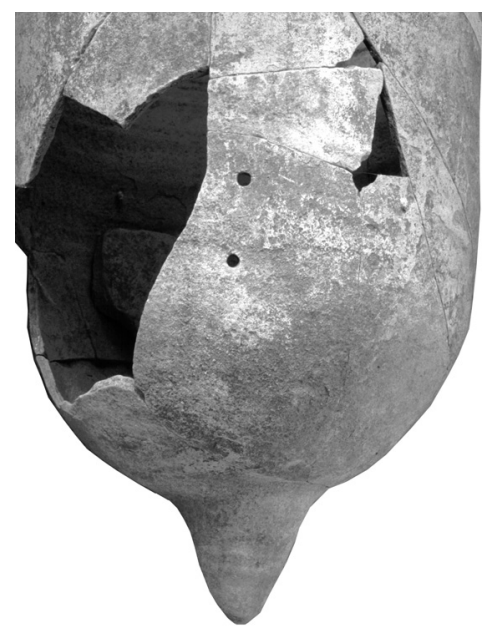

A

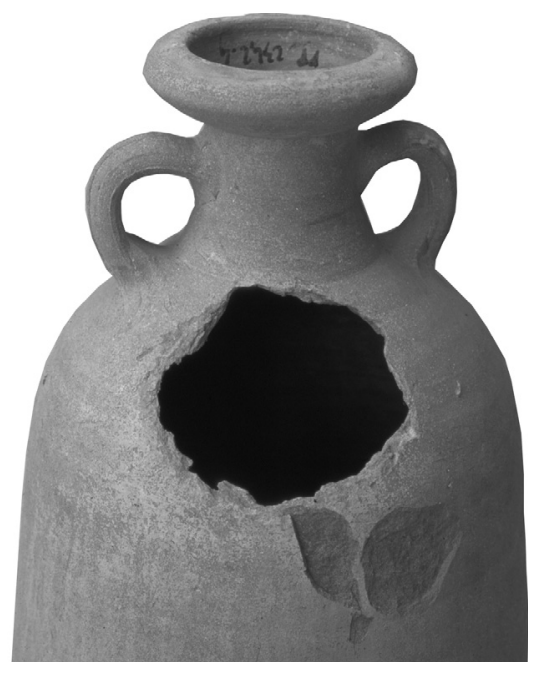

4

B

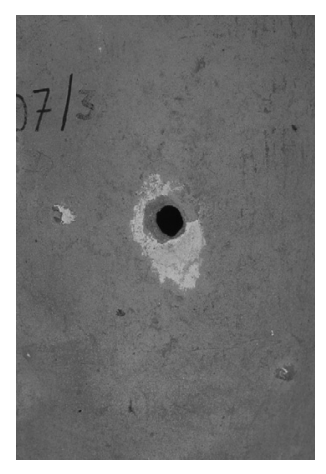

2

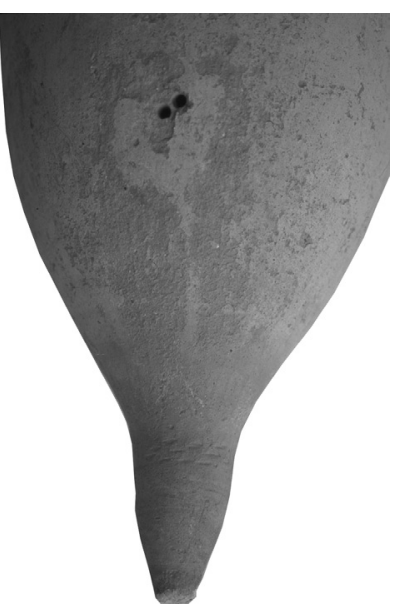

3

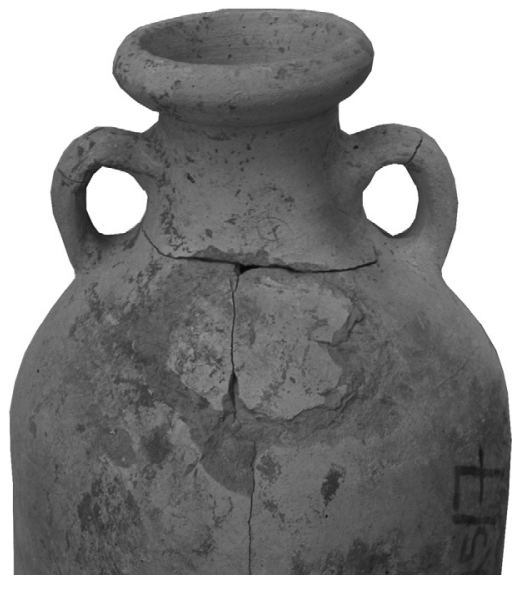

5

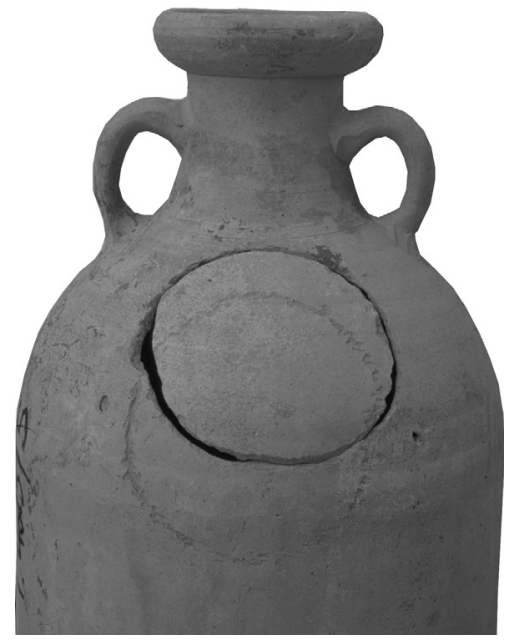

6

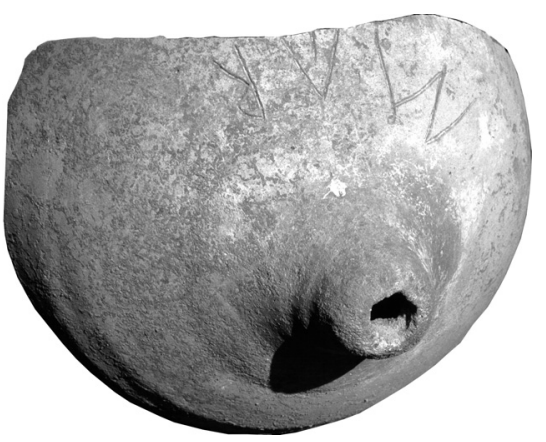

8

Fig. 264. Modes d'ouverture des amphores : l'exemple de Pupput. 
*7 Idem, tombe 1043 (Inv. PP1824.4). Amphore Africaine II A.

Mode C

*8 Idem (Bonifay 2004b, fig. 17, n 39). Amphore Hammamet 1.

\section{Renseignements apportés par la localisation des ateliers}

La localisation des ateliers pourrait-elle aider à définir les types d'amphores destinés aux salaisons de poisson ? Sur la carte de la fig. 2 (supra, p. 8), on observe que les grands ateliers littoraux ont produit les types principaux des IIIe et IVe s., non seulement les types Africaines II et III souvent poissés, mais également le type Africaine I qui n'est généralement pas poissé. Les ateliers qui ont produit les amphores des Ve-VIIes. le plus souvent exportées outre-mer ne sont pas très éloignés des côtes, que ce soient ceux de l'arrière pays de Salakta (Henchir ech-Chekaf) ou ceux de la région de Nabeul (Sidi Zahruni). En revanche, les types attestés sur les ateliers de l'intérieur (région entre Mactar, Sbeitla et El Jem) sont moins facilement identifiables (Peacock, Bejaoui, Ben Lazreg 1990,83$)^{302}$ : le plus fréquent semble assimilable au type Africaine II B «variante pseudo-tripolitaine » (supra, AMPHORE TYPE 24). Le type Keay 25.2 ou "spatheion" 1 est présent sur un atelier situé à $20 \mathrm{~km}$ des côtes (Peacock, Bejaoui, Ben Lazreg 1990, fig. 2, $\mathrm{n}^{\circ} 12$ et 18). La difficulté de la question est bien illustrée par l'atelier d'Oued el-Akarit, situé en bordure de mer, à proximité de cuves de salaison : cet atelier semble avoir produit en majorité des amphores Africaines II D ou Keay 25.1, des amphores Africaines I et des amphores Keay 25.2 ou « spatheion » 1 .

\section{Le cas des amphores tripolitaines}

Dans ce panorama, la région de Tripolitaine a été laissée à l'écart. Les types Tripolitaines I et III sont généralement considérés comme des conteneurs à huile. De fait, aucun exemplaire poissé ne paraît avoir été signalé. En revanche, le contenu du type II est plus douteux; des exemplaires poissés sont signalés dans les ports de Toulon (Leguilloux 1988b, 157-158) et de Fos (observations personnelles); un exemplaire de Pupput pourrait même être enduit de bitume (fig. 262, $\mathrm{n}^{\circ} 5$ ).

\section{Le cas des amphores de tradition punique du golfe d'Hammamet}

On dispose d'indices variés pour tenter de déterminer le contenu et la fonction de ces amphores. Quelques-unes d'entre elles, tout d'abord, aussi bien à Pupput (Bonifay 2004b, 224) qu'à Oued R'mel, sont poissées, ce qui exclut un contenu oléagineux. Ensuite, un modèle réduit du type 2 a été déposé en offrande dans le mausolée 1 de

302 «Anomalous forms which are difficult to parallel elsewhere ». la nécropole de Pupput: on pensera que cet objet symbolisait plus vraisemblablement un apport de vin que d'huile. Enfin, ces amphores sont souvent associées, dans des contextes de celliers, à Sidi Jdidi (Bonifay, Reynaud 2004, 259) et à Oued R'mel (Bonifay 2004b, 223), à des couvercles fabriqués dans la même pâte et généralement percés de trous.

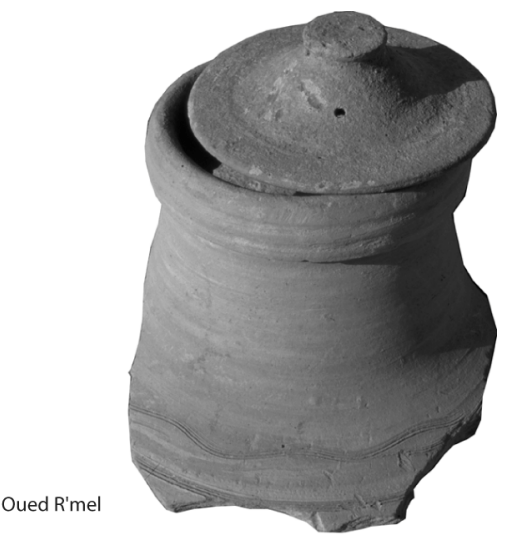

a

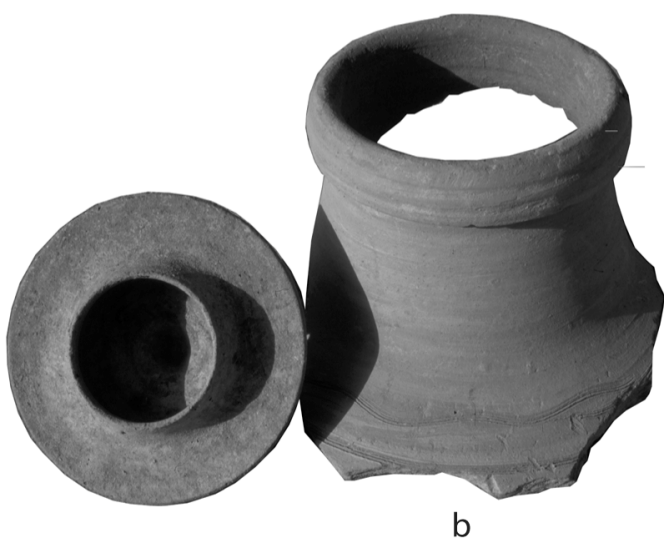

Fig. 265. Amphores de tradition punique du golfe d'Hammamet et leurs couvercles.

Un tel système de bouchage non hermétique (fig. 265) ne peut guère se concevoir qu'avec un type de contenu, le vin. En effet, les fûts, les dolia ou les amphores d'un cellier $^{303}$ ne doivent jamais être fermés hermétiquement, car, en cas de fermentation secondaire, l'accumulation des gaz peut entraîner l'éjection brutale du bouchon. C'est pour cette raison que l'on trouve parfois un petit trou percé sur le col de certaines amphores. En outre, certains viticulteurs de l'époque romaine ont pu rechercher volontairement un « goût de jaune », c'est-àdire une saveur madérisée proche de celle du Xérès, qui s'obtient notamment par le vieillissement du vin dans un récipient non hermétiquement fermé (Tchernia 1998, 503-509; Tchernia, Brun 1999, 122-125). Selon ce

\footnotetext{
${ }^{303}$ Des couvercles de forme similaire, ainsi qu'un entonnoir, sont associés aux amphores africaines du cellier attenant à la basilique de Fornells à Minorque (Palol $1982 ;$ Id. 1987).
} 
raisonnement $^{304}$, les grandes amphores du golfe d'Hammamet devraient être considérées tout aussi bien comme des jarres $^{305}$, du moins pour ce qui concerne la phase la plus tardive de la production (augmentation de la taille des conteneurs). Mais, dans ce cas, il n'est pas prouvé que la denrée stockée était toujours du vin. Dans l'établissement rural d'Oued R'mel, beaucoup de ces amphores proviennent de la partie oléicole de la ferme et on observe parallèlement qu'un certain nombre de couvercles ne portent pas de trous ou des trous incomplets (Bonifay, Reynaud 2004, $\mathrm{n}^{\circ} 23.3$ ) ; la même observation vaut pour des couvercles de la ferme d'Aïn Wassel à Dougga ${ }^{306}$. Enfin, un fragment de bord de type Hammamet $1 \mathrm{E}$ a été mis au jour dans le dépotoir d'amphores à huile du Monte Testaccio (Revilla 2003, fig. $\left.66, \mathrm{n}^{\circ} 15\right)$.

\section{Les analyses}

Les analyses en chromatographie en phase gazeuse ont été utilisées avec succès pour déterminer le contenu des amphores. Elles ont notamment permis de mettre en évidence des traces d'acides phénoliques et d'acide tartrique, caractéristiques du vin, sur des amphores Dressel 1B et Lamboglia 2 de l'épave de la Madrague de Giens (Condamin et al. 1976; Formenti, Hesnard, Tchernia 1978) et des traces de lipides, caractéristiques de l'huile, sur des tessons d'amphores Africaines I (Fr. Formenti et A. Tchernia, rapport dactylographié). Il est probable qu'un programme d'analyse de ce type apporterait beaucoup d'informations sur le contenu des amphores africaines.

De ce point de vue, puisque les amphores non poissées sont vraisemblablement destinées au transport de l'huile, la problématique actuelle consisterait à analyser des amphores africaines poissées pour tenter de distinguer le vin des salsamenta. Or, le problème qui se pose ici est d'ordre technique : «il faut envisager des extractions sélectives pour séparer les substances recherchées à l'état de trace dans une matrice complexe telle que la poix » (Formenti in Ben Lazreg et al. 1995, 137). La tentative qui a été faite sur une amphore Keay 25.1 de l'épave Héliopolis 1 est cependant encourageante. Fr. Formenti a cherché à identifier les traces d'acide tartrique pour mettre en évidence l'éventuelle présence de vin dans cette amphore. Le spectre obtenu par spectrométrie FT.IR est très comparable au spectre du tartrate de sodium et à celui obtenu sur l'amphore Lamboglia 2 de l'épave de Giens. Cette première approche archéométrique ne suffit pas à prouver clairement la présence de vin (Formenti, in Ben Lazreg et al. 1995, 139) mais fournit cependant des présomptions sérieuses.

\footnotetext{
${ }^{304}$ Je remercie A. Tchernia et J.-P. Brun pour leurs suggestions.

${ }^{305}$ Cette utilisation est attestée pour une amphore Tripolitaine II dans une ferme de l'arrière-pays de Lepcis Magna: Barker et al. 1996, 279-280 et fig. 9.11.

${ }^{306}$ Renseignement B. Maurina.
}

Des analyses effectuées sur des amphores africaines de la Schola Praeconum à Rome ont révélé des traces d'huile végétale mais les types d'amphore d'où sont issus les échantillons ne sont pas précisés (Passi, Whitehouse 1985).

\section{Conclusions provisoires}

Peut-on conclure, au moins provisoirement, sur le contenu des amphores africaines?

\section{- L'huile}

De cet examen, il ressort tout d'abord que les types africains non poissés sont peu nombreux. Est-ce que la poix est réellement incompatible avec l'huile ? C'est bien ce que tendent à démontrer les textes antiques et les études en laboratoire ${ }^{307}$. Dans ces conditions, les conteneurs africains destinés au transport de l'huile deviennent minoritaires, au moins dans l'échantillonnage considéré $^{308}$. Ces observations incitent à remettre en question les hypothèses émises il y a trente ans sur la principale denrée transportée par les amphores africaines. Il $\mathrm{y}$ a là un problème historique, déjà soulevé par A. Tchernia dans son rapport de 1980, qu'il faudra résoudre.

Quels sont les types d'amphores vraisemblablement destinés au transport de l'huile?

a) Les amphores Africaines I semblent décidément constituer le conteneur à huile par excellence, comme le prouve l'absence quasi systématique de poissage. Ce sont également les conteneurs présents sur le Testaccio à Rome, aux côtés des amphores à huile de Bétique Dressel 20, et en l'absence d'amphores Africaines II (Revilla 1999).

b) Les amphores Tripolitaines I et III n'ont fourni aucun argument permettant de remettre en cause leur contenu oléagineux. Elles sont également présentes sur le Monte Testaccio (Ibid.).

c) L'amphore Africaine II B « pseudo-tripolitaine » est la seule variante de sa catégorie qui a pu transporter de l'huile, en raison de l'absence de poix et de la situation des ateliers.

d) Le type Keay $35 \mathrm{~A}$ pourrait constituer la contrepartie non poissée du type Keay 35B et être destiné au transport de l'huile de la région de Nabeul, au Ve siècle.

e) Les types Keay 59 et $8 \mathrm{~B}$, qui ne sont jamais poissés, sont de bons candidats, dans la tradition des amphores

\footnotetext{
${ }^{307}$ CHARLIN (G.), GASSEND (J.-M.), LEQUÉMENT (R.) L'épave antique de la baie de Cavalière (Le Lavandou, Var). Archaeonautica, 2, 1978, pp. 21-22.

${ }^{308}$ Plus de la moitié des 235 amphores examinées, présentant des traces de poix, n'ont pu transporter de l'huile.
} 
tripolitaines, pour le transport de l'huile de Byzacène méridionale, au Ve siècle.

f) Le type Keay 34 porte des inscriptions peintes qui donnent des indications contradictoires (supra, p. 143); l'une, cependant, mentionne l'huile.

g) Parmi les types les plus tardifs, seule la forme Keay $61 \mathrm{C}$ n'a pas, jusqu'à présent, révélé de traces de poix.

h) Certains types du Ve s., probablement originaires des régions situées à l'ouest de Carthage, paraissent ne pas être systématiquement poissés : Keay 3 similis, Keay 27 et 36, mais ils ne sont pas représentés en nombre suffisant pour que cette observation soit réellement significative.

\section{- Les salsamenta}

En l'absence de résidus, il est difficile d'argumenter en faveur des salaisons de poisson. En effet, manquent sur les amphores africaines les tituli picti qui ont permis, sur les amphores hispaniques, d'identifier les conteneurs à garum et autres salsamenta: que saurions-nous sur le contenu des amphores de Bétique sans ces inscriptions? Un M peint en rouge se rencontre sur le col d'amphores originaires de Nabeul (fig. 266), qu'il serait bien hardi de développer en (M)uria (cf. Martin-Kilcher 1999, fig. 10 : inscription peinte $M V R$ sur amphore Dressel 18).

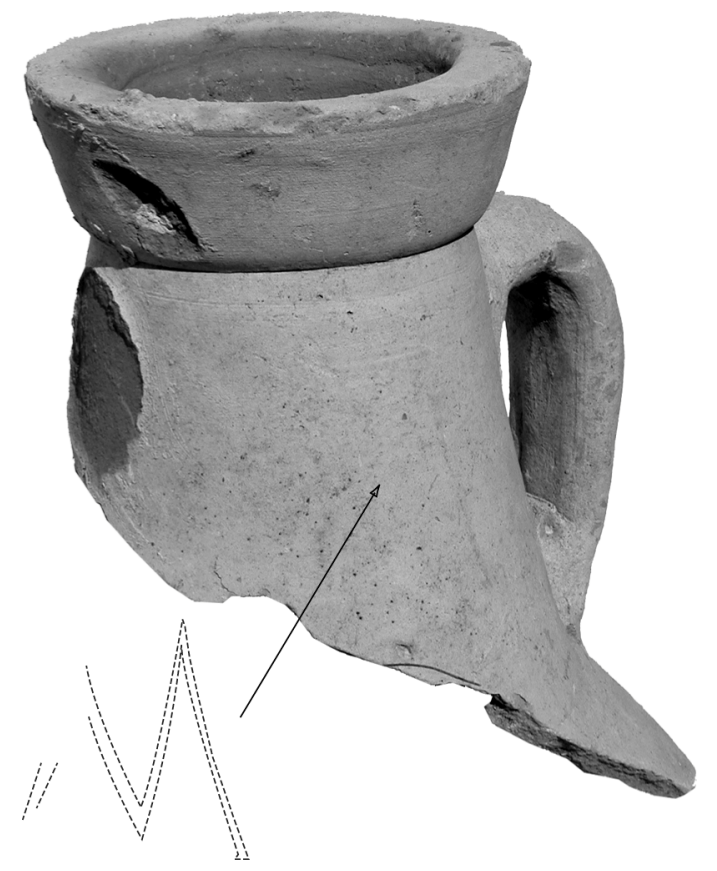

Fig. 266. Titulus pictus

sur amphore Africaine Keay 25.1 de Nabeul.

Les résidus de poissons attestés dans trois épaves (fig. 260 : Cabrera C, Cap Blanc et Lazarretto), sont des arguments forts dans la mesure où il s'agit, dans les trois cas, du même type d'amphore (Africaine II). En revanche, il ne faut peut-être pas accorder trop d'importance à la présence de coquillages ou de crustacés au fond de certaines amphores, ces animaux ayant pu s'introduire dans les conteneurs postérieurement au naufrage (Ben Lazreg et al. 1995, 128, note 116 ; contra : Dovis-Vicente 2001, 91).

Quels sont les types d'amphores susceptibles d'avoir été voués au transport des salsamenta?

a) L'hypothèse émise par A. Opait (2000) que son type Leptiminus I, également produit à Salakta (supra, p. 33), était destiné au transport des salsamenta, se trouve confirmée par la découverte, à El Jem-Thysdrus, dans la maison d'Africa, d'une pointe appartenant à ce type d'amphore qui contenait encore des restes de poissons (Bonifay et al. 2002-2003, fig. 20, $\mathrm{n}^{\circ} 289$ ).

b) La logique voudrait qu'une partie au moins des amphores africaines II A con gradino ait transporté des salaisons de poissons. L'alternative pour le contenu des amphores Africaines I et II, énoncée par F. Zevi, était claire : salsamenta ou huile (Zevi, Tchernia 1969, 185). A. Tchernia a démontré par la suite qu'il fallait inverser les hypothèses initiales et admettre que les amphores Africaines II A contenaient autre chose que de l'huile, peut-être des salaisons de poissons (Fr. Formenti, A. Tchernia, rapport dactylographié). Le poissage systématique de ces conteneurs, leur mode d'ouverture par un grand trou sur le sommet de la panse sont des arguments en faveur de cette hypothèse.

c) Les amphores Africaines II C sont l'objet de plusieurs évidences: étiquettes de plomb d'Annaba, résidus de poissons du Cap Blanc et peut-être de Cabrera III, présence dans les fabriques de salaison de Nabeul. A mon sens, cette amphore dérive des variantes tardives du type précédent (Africaine II A con gradino) produites à Nabeul. Je ne sais s'il faut attribuer le même contenu aux lointains descendants de cette amphore, les types Keay 57-56-55.

d) Le type Keay 35B a été produit, au moins en partie, sur l'atelier de Sidi Zahruni, à 6 kilomètres au nord de Nabeul et largement exporté. Tous les exemplaires retrouvés en milieu humide, notamment sur le rivage septentrional de la Méditerranée, sont poissés. Une amphore d'Aguilas (Espagne), probablement du même type (le bord manque), contenait des restes de maquereaux et de thons (Pareja 1972, 107-108). Enfin, ce type est particulièrement fréquent sur les sites qui bordent la lagune de Korba et qu'il y a tout lieu d'identifier comme des installations de salaison de poissons.

e) Je ne sais pas comment interpréter les restes de poissons trouvés dans un «spatheion" de type 1 à Tarragone (Morales Muñiz 1989) dans la mesure où ceux de l'épave du Dramont E contenaient des noyaux d'olives (Santamaria 1995, 55). 


\section{- Le vin}

Il y a longtemps eu des réticences pour attribuer des amphores africaines au transport du vin. S. MartinKilcher (1998) penche pour un transport du vin en outres, à échelle strictement locale. Quelles pourraient être les amphores africaines destinées au transport du vin?

a) Il n'est guère contestable que du vin ait été commercialisé dans des imitations africaines d'amphores à vin de type non africain : les diverses variations du type Dressel 2/4 en Tripolitaine occidentale (supra, AMPHORES TYPES 56-58), le type Dressel 30, imitation des amphores gauloises produites en plusieurs points des territoires africains (supra, AMPHORE TYPE 60), les éventuelles copies d'amphores orientales $L R A 1$.

b) On ne peut exclure qu'une partie au moins des amphores Africaines II A con gradino aient servi au transport du vin, cette hypothèse ne s'opposant pas forcément à celle des salsamenta, énoncée plus haut.

c) Il me paraît très probable que le vin ait été le contenu habituel des amphores cylindriques de moyennes dimensions ainsi que des «spatheia». En effet, les noyaux d'olives retrouvés dans certains «spatheia» du Dramont E font pencher plutôt pour une production agricole que pour le garum, hypothèse qui a pourtant été évoquée (Reynolds 1993, 113), et comme les olives étaient souvent conservées dans du vin cuit, on pourrait en déduire que les grands «spatheia» de type 1 sont des amphores vinaires. Cette hypothèse a été avancée par Martine Leguilloux $(1988,38)$ qui cite Caton $(A g r ., 7,4)$ et les exemples de conserves d'olives dans des amphores à vin Dressel $1 \mathrm{~A}$ et $1 \mathrm{C}$ (épave de Cavalière) et Haltern 70 (épave de Port-Vendres II). On remarque que les amphores Keay 25 sont parmi les mieux diffusées du répertoire africain, y compris dans des régions où les amphores africaines sont peu nombreuses, par exemple à Beyrouth ou dans des régions grandes productrices d'huile, comme à Lepcis Magna (fouilles A. Laronde, observations personnelles). A Alexandrie, on ne sait pas si on se trouve face à des importations plus nombreuses qu'à l'ordinaire d'amphores africaines ou bien s'il s'agit d'une production locale (?) imitant le type Keay 25 (Bonifay, Leffy 2002, fig. 4 et 5 ; supra). L'ample diffusion des «spatheia» miniatures de type 3 en Méditerranée orientale, notamment le long du Danube (Bjelajac 1996, 88 : carte) et souvent sur des sites militaires byzantins (Arthur 1998, 175), pourrait également être un argument pour le vin.

\section{- Autres denrées}

D'autres contenus sont signalés sporadiquement: conserves d'olives (voir l'inscription peinte $O L I$ sur une amphore Keay 25 d'Augst: Martin-Kilcher 1994, Pl.
$248)^{309}$, dont on vient de voir qu'elles sont probablement liées aux amphores à vin, et conserves de viande de porc (Santamaria 1995, 47). Des pépins de figues ont été retrouvés dans les amphores Africaines I de l'épave de Procchio (Parker 1992, 343) et il a été suggéré que les dattes aient pu parfois être conditionnées dans des amphores africaines apparentées au type Dressel 2/4 (Carrazé 1976, 68).

On rappellera enfin que certaines amphores africaines ne sont pas seulement des conteneurs pour le transport mais également des vases de stockage, car les établissements agricoles d'Afrique proconsulaire paraissent avoir été généralement dépourvus de dolia (Brun 2003).

\footnotetext{
${ }^{309}$ OLI pour OLIVAE. Cf. l'inscription peinte OLIVA NIGRA EX DEFR sur amphore Haltern 70: Laubenheimer 1990, 117. Merci à M. Bats pour ses suggestions.
} 


\begin{tabular}{|c|c|c|c|c|c|}
\hline Type & Index & poix & contenu & origine & datation \\
\hline Van der Werff 1 & TYPE 1 & $\bullet$ & salsamenta? & Nord Tunisie & IIe-Ier av. J.-C. \\
\hline Van der Werff 2 & TYPE $2 \mathrm{~A}$ & $\bullet$ & vin? & Sahel & IIe-Ier av. J.-C. \\
\hline Schöne-Mau XL & TYPE 2B & & vin? & Sahel & Ier s. \\
\hline Van der Werff 3 & TYPE 3 & $\bullet$ & vin? & Sahel, Tripolitaine & IIe-Ier av. J.-C. \\
\hline Tripolitaine 2 & & $\bullet / 0$ & $\begin{array}{l}\text { salsamenta? } \\
\text { huile? }\end{array}$ & Tripolitaine & fin Ier - milieu IIIe s. \\
\hline Leptiminus II & TYPE 5 & $\bullet$ & salsamenta? & Sahel & fin Ier- milieu IIIe s. (?) \\
\hline Hammamet 1 & TYPE 8 & $\bullet / 0$ & $\begin{array}{l}\text { vin? Variante E : } \\
\text { huile? }\end{array}$ & golfe d'Hammamet & fin Ier (?) - IIe s. \\
\hline Hammamet 2 & TYPE 9 & $\bullet / 0$ & vin? & $I d$. & IIIe-Ve s. \\
\hline Hammamet 3 & TYPE 10 & $\bullet / 0$ & vin? & $I d$. & Ve-VIIe s. \\
\hline Carthage $E A$ IV & TYPE 11 & $?$ & $?$ & Carthage & Ier s. \\
\hline Leptiminus I & TYPE 12 & $?$ & salsamenta? & Sahel & fin Ier- IIIe s. (?) \\
\hline Dressel 26 & TYPE 13 & 0 & huile & Tripolitaine & fin IIe - Ier s. av. J.-C. \\
\hline Ostia XXIII & TYPE 14 & $?$ & huile? & $?$ & fin Ier - milieu IIe s. \\
\hline Ostia LIX & TYPE 15 & $?$ & huile? & $?$ & fin Ier - milieu IIe s. \\
\hline & TYPE 16 & $\bullet / 0$ & $?$ & Sahel? & IIe s. \\
\hline & TYPE 17 & $?$ & $?$ & Sahel? & IIe s. \\
\hline Uzita Pl. 52, 10 & TYPE 18 & $\bullet / 0$ & salsamenta? & Sahel & IIe s. ? \\
\hline Tripolitaine I & TYPE 19 & 0 & huile & Tripolitaine & Ier s. - milieu IIe s. \\
\hline Tripolitaine III & TYPE 20 & 0 & huile & Tripolitaine & milieu IIe - IVe s. (?) \\
\hline Africaine I & TYPE 21 & 0 & huile & Afrique proconsulaire & milieu IIe - IVe s. (?) \\
\hline Africaine II A & TYPE 22 & $\bullet$ & salsamenta, vin? & Afrique proconsulaire & milieu IIe- IIIe s. \\
\hline Africaine II B & TYPE 23 & $?$ & $?$ & Afrique proconsulaire & IIIe s. \\
\hline $\begin{array}{l}\text { Africaine II B } \\
\text { «pseudo-tripolitaine » }\end{array}$ & TYPE 24 & o & huile? & $\begin{array}{l}\text { Afrique proconsulaire } \\
\text { (intérieur) }\end{array}$ & IIIe s. (?) \\
\hline Africaine II C & TYPE 25 & $\bullet$ & salsamenta? & Nabeul & milieu IIIe - IVe s. \\
\hline Africaine II D & TYPE 26 & $\bullet$ & salsamenta? & Sahel? & milieu IIIe - IVe s. \\
\hline $\begin{array}{l}\text { « station } 48 \text { place } \\
\text { des corporations » }\end{array}$ & TYPE 30 & $\bullet$ & salsamenta, vin? & $\begin{array}{l}\text { Maurétanie } \\
\text { Césarienne? }\end{array}$ & IIe - milieu IIIe s. \\
\hline Keay 25.1 & TYPE 27 & $\bullet$ & vin? & Zeugitane, Byzacène & IVe s. \\
\hline Keay 25.3 & TYPE 28 & $\bullet$ & vin? & Zeugitane, Byzacène & IVe s. \\
\hline Keay 25.2 & TYPE 29 & $\bullet$ & $\begin{array}{l}\text { conserves d'olives, } \\
\text { vin? }\end{array}$ & Zeugitane, Byzacène & fin IVe s. - milieu Ve s. \\
\hline «spatheion » 1 & TYPE 31 & $\bullet$ & $\begin{array}{l}\text { conserves d'olives, } \\
\text { vin? salsamenta? }\end{array}$ & Zeugitane, Byzacène & fin IVe s. - milieu Ve s. \\
\hline «spatheion » 2 & TYPE 32 & $?$ & $?$ & Zeugitane, Byzacène & milieu Ve - milieu VIe s. \\
\hline «spatheion » 3 & TYPE 33 & $\bullet$ & vin? & Zeugitane, Byzacène & fin VIe - VIIe s. \\
\hline $\begin{array}{l}\text { Keay 3B « similis » } \\
\text { /Keay } 39\end{array}$ & TYPE 34 & $\circ$ & huile? & $\begin{array}{l}\text { Ouest Carthage, } \\
\text { Algérie? }\end{array}$ & Ve s. \\
\hline Keay 27 & TYPE 35 & $\bullet / 0$ & $?$ & Ouest Carthage? & fin IVe - Ve s. \\
\hline Keay 36 & TYPE 36 & $\bullet / 0$ & $?$ & Ouest Carthage? & fin IVe - Ve s. \\
\hline Keay 59 & TYPE 37 & $\circ$ & huile? & Sud Byzacène & fin IVe - milieu Ve s. \\
\hline Keay 8B & TYPE 38 & $\circ$ & huile? & Sud Byzacène & milieu Ve - milieu VIe s. \\
\hline Keay 35A & TYPE 40 & o & huile? & Nabeul & Ve s. \\
\hline Keay 35B & TYPE 41 & $\bullet$ & salsamenta? & Nabeul & Ve s. \\
\hline Keay 57 & TYPE 42 & $\bullet / 0$ & $?$ & Nabeul & seconde moitié Ve s. \\
\hline Keay 56 & TYPE 43 & $\bullet / 0$ & $?$ & Nabeul & fin Ve - VIe s. \\
\hline Keay 55 & TYPE 44 & $\bullet / 0$ & $?$ & Nabeul & fin Ve - VIe s. \\
\hline Keay 62Q-R & TYPE 45 & $?$ & $?$ & $?$ & fin Ve - VIe s. \\
\hline Keay 62 & TYPE 46 & $\bullet / 0$ & $?$ & Sahel, Nabeul & VIe s. \\
\hline Keay 62 var. & TYPE 47 & $\bullet$ & salsamenta, vin? & Sahel & fin VIe - milieu VIIe s. \\
\hline Keay 61C & TYPE 48 & $\circ$ & huile? & Sahel & fin VIe - milieu VIIe s. \\
\hline Keay 61 & TYPE 49 & $?$ & $?$ & Sahel, Nabeul & VIIe s. \\
\hline
\end{tabular}




\begin{tabular}{|c|c|c|c|c|c|}
\hline Type & Index & poix & contenu & origine & datation \\
\hline Keay 8A & TYPE 50 & $\bullet$ & salsamenta, vin? & $\begin{array}{l}\text { Sahel? } \\
\text { Nord Tunisie? }\end{array}$ & seconde moitié VIIe s. \\
\hline Keay 50 & TYPE 51 & $?$ & $?$ & Nord Tunisie? & seconde moitié VIIe s. \\
\hline « orlo a fascia » & TYPE 52 & $?$ & $?$ & Nord Tunisie & seconde moitié VIIe $\mathrm{s}$. \\
\hline Keay 34 & TYPE 53 & $?$ & huile? & Sud Byzacène & fin VIe -VIIe s. \\
\hline Sidi Jdidi 1 & TYPE 54 & $?$ & $?$ & Nabeul? & VIIe s. \\
\hline Sidi Jdidi 2 & TYPE 55 & $?$ & $?$ & Nord Tunisie? & VIIe s. \\
\hline $\begin{array}{l}\text { Dressel 2/4 et pseudo } \\
\text { Dressel 2/4 }\end{array}$ & TYPES 56-57 & $\bullet$ & vin, dattes? & Tripolitaine & Ier-milieu IIe s. \\
\hline Schöne-Mau XXXV & TYPE 58 & $\bullet$ & vin & Tripolitaine & Ier-milieu IIe s. \\
\hline Dressel 30 & TYPE 60 & $\bullet$ & vin & $\begin{array}{l}\text { Afrique proconsulaire, } \\
\text { Maurétanie } \\
\text { Césarienne }\end{array}$ & IIIe-IVe s. \\
\hline globulaires 1-4 & TYPES 63-66 & $?$ & vin? & Afrique/Ifriqiyya & VIIe s. + \\
\hline
\end{tabular}

Tableau IV. Amphores africaines : résumé des hypothèses de contenu.

$(\bullet:$ traces de poix ; $\circ:$ pas de trace de poix) 


\section{CÉRAMIQUE AFRICAINE ET DÉVELOPPEMENT ÉCONOMIQUE}

Finalement, à lire des synthèses récemment publiées sur l'Afrique romaine et son économie, on constate que c'est la documentation céramique qui est, le plus souvent, parfois même exclusivement, mise à contribution pour reconstruire les phases du développement économique de la province (Carandini 1970 et 1983 ; Fulford 1983; Panella 1993). L'Afrique est encore privée des fouilles récentes d'installations agricoles qui, dans d'autres provinces moins actives sur le plan des productions céramiques, nous éclairent de manière plus fiable sur les rythmes de la production (Brun 2003). Les données des prospections de surface qui sont, en revanche, nombreuses en Libye, en Tunisie (Segermes $I$ ) et en Algérie, restent, à mon sens, très fragiles. La complexité des problèmes chronologiques, techniques et commerciaux soulevés par l'étude de la fabrique de salaisons de poissons à Nabeul (Slim, Bonifay, Trousset 1999) montre bien que les fouilles restent indispensables et qu'en dépit des discours actuels, il est urgent de les multiplier.

Une autre question à laquelle il est difficile, en l'absence de fouilles archéologiques, d'apporter actuellement des éléments de réponse, concerne la façon dont les ateliers de céramique étaient intégrés aux structures productives (domaines agricoles) ou administratives (cités). Alors qu'ils sont nombreux à avoir été repérés, aucun atelier important lié à une installation agricole n'a été à ma connaissance dégagé. Un seul atelier d'amphores périurbain, celui de Leptiminus (Stone, Stirling, Ben Lazreg 1998 ; Stirling Ben Lazreg 2001), nous est connu par des fouilles. Un seul four de sigillée, tardif et urbain, a été complètement mis au jour, isolé de son contexte, à Oudhna (Barraud et al. 1998). Déjà A. Carandini (1970a, 115) déplorait l'indigence de la documentation permettant d'aborder le statut des ateliers; il faut reconnaître que la situation n'a pas beaucoup évolué depuis trente ans.

Condamnés à gérer cette pénurie de documentation, les archéologues et les historiens se rabattent, pour étudier l'économie de l'Afrique, sur la céramique des sites de consommation africains et non-africains et surexploitent les données typologiques. L'utilisation de ces données, fragiles et sujettes à de constants réajustements morphologiques et chronologiques, est délicate. Il est rare que les changements dans les faciès céramiques correspondent exactement aux césures historiques (Bonifay à paraître, c). Ainsi, on ne sait pas si l'on doit attribuer certains contextes du deuxième quart du Ve s. à l'époque romaine tardive ou à l'époque vandale : c'est l'exemple de l'épave du Dramont E (Santamaria 1995) ou celui des niveaux de construction de la basilique sud de Sidi Jdidi (Bonifay, Reynaud 2004, 273). La même question se pose pour les contextes du deuxième quart du VIe s. : l'épave de la Palud est-elle d'époque vandale tardive ou bien d'époque byzantine?

Malgré ces réserves, je souhaiterais à mon tour livrer à ce dossier quelques réflexions quelque peu disparates, classées, par commodité, selon un ordre chronologique ${ }^{310}$.

\subsection{LA CÉRAMIQUE, TÉMOIN DU « DÉCOLlaGE »DE L'ÉCONOMIE AFRICAINE ? (fig. 269, 1)}

La céramique africaine est modestement représentée dans les contextes du Ier s. en Méditerranée occidentale. Seules, les importations d'huile tripolitaine, attestées dès les IIe-Ier av. J.-C. par le type Dressel 26 (Py, Adroher Auroux, Sanchez 2001, 253-257 ; Pascual, Ribera 2002), se maintiennent en bonne place à Pompéi, avec le type Tripolitaine I (Panella 1977) ; à Rome, ce sont plutôt les arrivages de vin qui sont mis en évidence par les types Schöne-Mau XXXV (Panella 1992, 190, 192, 195, 196 ; Rizzo 2003, graph. 15 et 16) et pseudo-Dressel 2/4 (Ibid., 154). Ces denrées atteignent également la Méditerranée orientale (Paphos: Hayes 1991, fig. XXXIX, $\mathrm{n}^{\circ} 14-15$ ). Les amphores puniques romanisées de la région de Carthage sont plus rares : on relève quelques fragments du type $E A$ IV à Arles (inédit) ainsi qu'un exemplaire sur l'épave de Saint-Gervais 3 à Fos-sur-Mer (Martin-Kilcher 1999, fig. 7, A10). Quelques amphores de tradition punique du golfe d'Hammamet atteignent Luni (Luni I, P1. 79, $\mathrm{n}^{\circ} 16$; Luni II, P1. 281, $\mathrm{n}^{\circ}$ 17) et peut-être Rome si l'on accepte d'assimiler le type 18 de Dressel à cette production (Bonifay 2004b, 227). On ne sait pas exactement d'où proviennent les amphores africaines précoces de types Ostia XXIII et LIX (supra, AMPHORES TYPES 14-15), ni ce qu'elles contenaient : probablement de l'huile ${ }^{311}$ ? Elles sont modérément attestées dans le midi de la Gaule (Ex. à Fréjus: Béraud, Gébara, Pasqualini 1992) et à Rome (Rizzo 2003, 154 et graph. 16). La date d'apparition des premières sigillées africaines sur les marchés de Méditerranée occidentale reste encore controversée; les attestations ne sont pas sûres à Rome avant l'époque flavienne (Ibid., 107) et restent encore fragiles à Pompéi (Carandini 1977, 23 : seulement quelques formes fermées). En revanche, la céramique culinaire africaine n'est pas rare à Pompéi (ex. : De Caro 1994, fig. 146, $n^{\circ} 151$ ), de même que sur beaucoup de sites contemporains de Méditerranée occidentale, notamment à Ostie et en Catalogne (Aquilué 1985).

\footnotetext{
${ }^{310}$ Une première version de ce texte a été publiée dans la revue Antiquité Tardive, 11, 2003 : Bonifay 2003.

${ }^{311}$ Inscription peinte $O L E V M$ sur un exemplaire de Pompéi : Stefani 2003, 222.
} 
La présence de la céramique africaine va rapidement augmenter durant la première moitié du IIe s. et, vers 160-180, la sigillée africaine, pour la première fois, surpasse en quantité les autres catégories de céramique fine à Ostie (Panella 1993, 620) et à Rome (Rizzo 2003, Tabl. 31). C'est également à la fin du Ier s. et au début du IIe s. que se produisent les changements en Afrique. Les importations de sigillées italiques cessent vers la fin du Ier s. à Carthage (Panella 1983, 56). Sur la nécropole de Pupput, dès la première moitié du IIe s., l'essentiel de la céramique est d'origine africaine (Bonifay 2004a, 57). La ville n'est plus dépendante des productions italiques ni pour la vaisselle fine, ni même pour les lampes, qui sont très tôt majoritairement africaines. Les amphores sont en quasi-totalité africaines en accord avec les tendances enregistrées à Carthage à la même époque : « a partire dal II secolo la città appare chiusa alle importazioni dall'esterno » (Panella 1983, 56 ; voir également MartinKilcher 1998, 513-514 : phase III).

\subsection{LA CÉRAMIQUE, INDICE DE L'HÉGÉMONIE ÉCONOMIQUE DE L'AFRIQUE}

Cette formule empruntée à Cl. Panella $(1993,624)$ traduit la prééminence des productions africaines dans la plupart des statistiques de céramiques en Méditerranée occidentale, à partir des décennies centrales du IIe siècle. Ces comptages nous renseignent sur le dynamisme des productions vivrières africaines qui supplantent, au cours du IIe s., celles de la plupart des autres provinces, à commencer par l'Italie elle-même. Comme le résume J.M. Lassère $(1977,290)$ : « au début du principat, trois provinces se détachaient de l'ensemble de l'Occident, par leur prospérité et leur dynamisme: la Narbonnaise, la Tarraconnaise et la Bétique. Il est incontestable que dans le courant du IIe s. l'Afrique rejoint le peloton de tête (...) : c'est désormais une province sinon opulente, du moins productive $»$.

Or le moteur de ce développement économique a été recherché depuis plus de cinquante ans dans le développement de l'oléiculture (voir déjà Haywood 1938, 47-50, mais surtout Camps-Fabrer 1953) qui aurait pris le pas, dans le courant du IIe s., sur la céréaliculture implantée de longue date en Afrique (Carandini 1970 et 1983 ; Lassère 1977, 300 ; Mattingly 1988a) : « l'agricoltura africana deve all'olio e non al grano il suo sviluppo » (Panella 1993, 629). Je me demande s'il ne faut pas, à la lumière des récentes études sur la céramique africaine, nuancer un peu ces observations.

\section{L'apparition de la sigillée C et l'émergence économique de la Byzacène (fig. 269, 2)}

On a constaté que la fin de l'époque antonine et le début de l'époque sévérienne coïncidaient avec un déplacement des forces productives africaines de la région de Carthage vers la région d'Hadrumetum, soit du Nord vers le Sud, reproduisant en miniature un phénomène de « méridionalisation des forces productives » (Panella 1989, 133) observé à l'échelle méditerranéenne à la même époque (Carandini 1983, 149). Il a également été soutenu que le développement des ateliers de sigillée $\mathrm{C}$ en Byzacène était lié au développement de l'oléiculture africaine (Carandini 1970a ; Panella 1993, 629) avec, pour preuve, l'afflux apparemment jumelé des amphores africaines et de la sigillée $C$ sur les marchés de Méditerranée occidentale.

Or, il apparaît aujourd'hui que la vaisselle sigillée et les amphores de Byzacène que l'on retrouve à Ostie ou en Gaule du Sud n'ont vraisemblablement pas la même origine (Peña 1998, 212-213). Les amphores africaines en Méditerranée occidentale, sauf quelques exceptions (par exemple, une amphore de type Africaine II B «pseudotripolitaine » découverte à Tarragone : supra, AMPHORE TYPE 24, $n^{\circ} 3$ ), proviennent principalement des grandes cités portuaires du Sahel: Hadrumetum, Leptiminus, Sullecthum, ou parfois même de cités qui n'appartiennent pas à la Byzacène, comme Nabeul. En revanche, nous savons maintenant que la majeure partie de la sigillée $\mathrm{C}$ provient d'ateliers situés à plus de $100 \mathrm{~km}$ des côtes, celui de Sidi Marzouk Tounsi, à l'ouest de Kairouan, étant sans doute l'un des plus importants (Mackensen, Schneider 2002, 131). De même, les amphores entières du dépôt de fouille d'El Jem ne comptent aucun conteneur à huile de type Africaine I (observations personnelles; cf. désormais : Nacef 2002). Dans cette ville comme sur les ateliers prospectés par D. P. S. Peacock, F. Bejaoui et N. Ben Lazreg, les amphores Africaines I sont rares (sauf à Sidi Saad : Peacock, Bejaoui, Ben Lazreg 1990, fig. 2, $\left.\mathrm{n}^{\circ} 4\right)$ tandis que d'autres formes peu diffusées en Méditerranée (« anomalous forms »: Ibid., 83) dominent. D. P. S. Peacock avait bien éprouvé cette difficulté et en avait conclu, contre toute vraisemblance, que le groupement des ateliers d'amphores Africaines I sur le littoral pouvait signifier que ces amphores étaient destinées au transport des produits de la mer (Ibid., 82). Il paraît dès lors difficile de lier, aussi étroitement qu'on ne l'a fait, production oléicole et production de vaisselle sigillée dans le centre de la Tunisie. Cet exercice est encore plus difficile pour le IVe s., lorsqu'on suppose (Panella 1993, 629) que les grandes plantations d'oliviers gagnent la région de Sufetula-Cillium-Thélepte, dont les ateliers de sigillée, appartenant au groupe continental (fig. 23), ont peu diffusé en Méditerranée.

Un tel décalage géographique entre les lieux de productions des sigillées $\mathrm{C}$ et les lieux de production des amphores les plus fréquemment exportées outre-mer pourrait, certes, se comprendre si l'huile avait été transportée dans d'autres récipients (outres ?) depuis les domaines agricoles jusqu'aux villes du littoral où elles auraient été mises en amphores ${ }^{312}$. C'est le modèle qui

\footnotetext{
${ }^{312}$ Haywood 1938, 45, suggère également que les olives aient pu être transportées non pressurées.
} 
paraît attesté à Carthage dans la seconde moitié du IVe s. et qu'il est tentant de transposer à la Byzacène de la première moitié du IIIe s. (Peña 1998, 213).

Cette explication n'est cependant pas entièrement satisfaisante. On sait désormais qu'une partie des amphores africaines retrouvées sur les sites consommateurs de Méditerranée occidentale n'a pas transporté de l'huile mais des salaisons de poissons et peut-être aussi du vin (supra, Tabl. IV). La réinterprétation des statistiques d'Ostie $(\mathrm{Cl}$. Panella in Anselmino et al. 1986, 79 et Tabl. 3) montre que les amphores à huile (Africaines I) ne représentent finalement, au milieu du IIIe s., que la moitié du total des amphores africaines, soit $15 \%$ du total des amphores toutes origines confondues ; ce pourcentage est même légèrement inférieur à celui des amphores africaines à l'époque antonine. Face à la rareté des traces d'huilerie dans le Sahel tunisien, mis à part les traces fossiles de plantations observables sur les photographies aériennes, mais de datation incertaine (Mattingly 1988a, 45), les fabriques de salaison de poissons, par définition localisées sur la côte, ont laissé des traces archéologiques évidentes, souvent révélées par l'érosion du littoral (Ben Lazreg et al. 1995). En revanche, il est plus difficile d'apporter les preuves matérielles de la production du vin, les sites de pressoir étant le plus souvent mais peutêtre un peu hâtivement interprétés, en prospection de surface, comme des huileries (Brun 2003). Les réticences des historiens face à la production massive de vin en Afrique ont été sans doute fondées en partie sur le silence des textes (Février 1990, 95), mais je me demande pour ma part si le peu d'encouragement à la culture de la vigne apporté par les mesures fiscales de Trajan et Hadrien (Julien 1951, 151 ; contra : Lassère 1977, 203) ne signifie pas qu'elle était, de fait, abondante en Afrique.

La troisième composante, après l'huile et le vin, de la trilogie traditionnelle des productions agricoles méditerranéennes (Février 1990, 94) est encore plus difficile à saisir : qu'en est-il du blé ? On est bien renseigné à ce titre sur le caractère vital des arrivages de blé africain à Rome et dans les provinces (Rickman 1980, 231-235; Tengström 1974 ; Sirks 1991, 147), un peu moins par l'épigraphie et l'archéologie africaines (Février 1990, 95-97). Les zones de production céréalières ne peuvent guère être déduites sur le terrain que de la cartographie géologique et hydrométrique (Carandini 1970, 98 et Pl. A et B ; Segermes I, 39-49). De fait, la zone où est produite la sigillée $\mathrm{C}$, qui est aujourd'hui complantée d'oliviers $^{313}$, n'est pourtant pas des plus propices à l'oléiculture (Ibid., Pl. B) : on conçoit tout aussi bien, dans le bassin d'El Ala inclus entre les chaînons de la dorsale tunisienne, des cultures céréalières, peut-être des «cultures inondées » (Despois 1955, 242-

\footnotetext{
${ }^{313}$ D'après la carte au $1 / 200000$.
}

$249)^{314}$, que fruitières. Le port le plus proche pour la commercialisation méditerranéenne de la sigillée $\mathrm{C}$ est sans doute celui d'Hadrumetum, voisin de celui d'Horrea Caelia (Hergla) où ont été mis au jour des entrepôts très probablement destinés au stockage des céréales (Février $1990,97)^{315}$.

L'Afrique antique est un pays de culture mixte et, comme le rappelle P.-A. Février (1990, 95), «sans doute cultivait-on le blé entre les oliviers et les figuiers ». Mais si le développement de la sigillée $\mathrm{C}$ doit être lié, au moins sur le plan des débouchés commerciaux, à une production agricole maîtresse, on peut se demander si ce n'est pas plus vraisemblablement à la céréaliculture qu'à l'oléiculture. Cette hypothèse n'est pas nouvelle mais elle a surtout jusqu'à présent servi à expliquer les débuts de la commercialisation des sigillées (Mattingly 1988a, 53-54). Or il semble qu'elle puisse également aider à comprendre son développement.

\section{L'apparition de la sigillée $D$ et le nouveau dynamisme de la région de Carthage (fig. 269, 3)}

En effet, peut-être faut-il interpréter de la même manière l'émergence (Mackensen 1993; Pavolini, Tortorella 1997), plutôt que le renouveau (?) (Carandini 1983, 150), des ateliers de sigillée africaine dans la vallée de la Mejerda, notamment le grand centre d'El-Mahrine, qui semble avoir produit l'essentiel des sigillées africaines D1 exportées en Méditerranée du deuxième quart du IVe s. jusqu'au milieu du Ve siècle. Les terres irriguées par les fleuves Mejerda et Miliane sont, plus clairement encore, propices à la culture du blé (Rickman 1980, 110). On peut également remarquer (Panella 1999, 187) que la date de la création des ateliers de la vallée de la Mejerda coïncide avec celle de l'accroissement probable de la dépendance des provinces de Méditerranée nordoccidentale vis-à-vis de l'Afrique pour leur approvisionnement en blé. Il est vraisemblable, en effet (Panella 1993, 635 et note 84), que dès avant 330, le blé d'Egypte a été détourné de Rome pour alimenter la future ville de Constantinople ${ }^{316}$. M. Mackensen supposait que les ateliers de sigillée D de Thuburbo Minus aient pu bénéficier de la migration d'artisans venus de Byzacène avec leur savoir-faire et peut-être même leurs outils; l'augmentation de l'une des principales productions agricoles de la vallée de la Mejerda, peut-être stimulée par de nouvelles conditions commerciales ou fiscales, pourrait effectivement expliquer ces déplacements

\footnotetext{
314 Procédé attesté à l'époque romaine : Frontin, éd. Lachmann, p. 46-47, ainsi qu'à l'époque vandale : Corippe, Just., 4, p. 215223.

315 BONIFAY (M.), TROUSSET (P.) - sv Hergla, in Encyclopédie Berbère, XXII, Aix-en-Provence, 2000, p. 3444.

${ }^{316}$ Cependant cette thèse ne fait pas l'unanimité : cf. Vera $1997-$ 98, 45 et note 50. D. Vera pense que la Sicile et l'Italie du Sud ont pris le relais de l'Egypte dans l'approvisionnement de Rome en céréales (Ibid., 50).
} 
d'artisans. La liaison entre la commercialisation des céréales et celle des vaisselles sigillées $\mathrm{C}$ et $\mathrm{D}$ a parfois été invoquée pour expliquer le contraste entre la faible proportion d'amphores et la quantité importante de vaisselles sigillées africaines en Méditerranée orientale (Panella 1993, 639). Pourquoi donc cette remarque ne serait-elle valable que pour l'Orient et pas pour l'Occident?

Le maintien d'une route du blé en direction de Constantinople $^{317}$ pourrait effectivement expliquer (Panella 1993, 638) le pourcentage élevé des sigillées africaines sur les côtes méridionales du Péloponnèse (Abadie-Reynal 1989, 144-145). On suggérera également que si le Code Théodosien ${ }^{318}$ interdit aux navires de l'annone de faire escale en Méditerranée orientale pour vendre des marchandises (Tomber 1993, 147), c'est précisément qu'ils le font. Par ailleurs, mis à part le cas particulier d'Alexandrie qui reçoit d'assez nombreuses amphores à huile Tripolitaines III et Africaines I (observations personnelles), les amphores africaines présentes en Méditerranée orientale paraissent plutôt dévolues au transport des salsamenta et du vin : amphores Africaines II A con gradino de Salakta (?), l'une avec un timbre $P A S$ à Beyrouth (Reynolds 1997-98, fig. 203), l'autre avec un timbre $S M$ (cf. supra, fig. 4, $\mathrm{n}^{\circ} 8$ ) à Knossos (Hayes 1983, fig. 24, n 72), amphores Africaines II C de Nabeul (?) à Caesarea de Palestine (Riley 1975, 38, n 52 ; Peleg, Reich 1992, fig. 15, $\mathrm{n}^{\circ} 16$ ) et à Athènes (Grace 1961, fig. 37: variante C2), amphores Africaines II D à Athènes (Robinson 1959, K116 et peutêtre K117, avec un timbre de Sullecthum), amphores Keay 25 à Caesarea (Peleg, Reich 1992, fig. 15, n $17-$ 18) et à Beyrouth (Bonifay à paraître, e, n 34-36). En tout état de cause, ces amphores, témoins peut-être d'un commerce «normal» (Sodini 2000, 196), «ne constituent qu'une part minime de l'ensemble du matériel » (Abadie-Reynal 1989, 147).

A Ostie, les pourcentages d'amphores africaines sont évidemment plus forts mais on s'aperçoit que celles qui ont certainement transporté de l'huile ne représentent, au IVe s., qu'un quart du total des importations de Zeugitane et/ou de Byzacène et seulement $10 \%$ du total des conteneurs, toutes provenances confondues $(\mathrm{Cl}$. Panella, in Anselmino et al. 1986, Tabl. 3). Il est aujourd'hui possible de tempérer un peu l'impression d'effondrement du vin sur les marchés d'Ostie au IVe s. (Tchernia 1986, 294). Si l'on admet que les amphores cylindriques de moyenne dimension de type Keay 25 (supra, p. 473) ont pu transporter non seulement des salaisons de poisson mais également du vin, on pourrait peut-être proposer de redresser un peu les courbes «en ciseaux» des

\footnotetext{
${ }^{317}$ Mais peut-être seulement en période de crise alimentaire : Durliat 1990, $42-48$ et 226.

${ }^{318}$ C. Th. 13.5.33 (409) : PHARR (C.) - Theodosian Code and Novels and the Simondian Constitution. Princeton, Princeton University Press, 1952, p. 396.
}

importations de vin et des arrivages de salsamenta à cette époque (Ibid., graphique de la p. 293). Il paraît tout au moins difficile de considérer que l'oléiculture, au IVe s., constitue le moteur de l'exportation des sigillées africaines.

De fait, il n'existe pas, à ma connaissance, d'épaves contenant un chargement conjoint d'amphores Africaines I ou II et de sigillée africaine $\mathrm{C}^{319}$, ou bien associant des amphores cylindriques de moyennes dimensions (Keay $25)$ et des sigillées $D 1^{320}$. Vraisemblablement, la cargaison principale avec laquelle, habituellement, voyageaient ces vaisselles pourrait ne pas avoir été conditionnée en amphores (cf. également Fulford 1987, 60-61). En revanche, les deux seules cargaisons évidentes de sigillée africaine sur des épaves de Méditerranée, celle du Dramont E et de Port-Miou, appartiennent au groupe D2. Elles semblent toutes deux originaires (supra, p. 452453) de la région de Nabeul, manifestement peu propice à la culture du blé. Dans ce cas précis, l'huile, le garum et peut-être le vin sont les contenus probables des amphores qui constituaient le chargement principal de l'épave du Dramont E, exhaustivement fouillée.

\subsection{LES EFFETS DE L'INVASION VANDALE ET DE LA RECONQUÊTE BYZANTINE SUR LA PRODUCTION ET LA COMMERCIALISATION DES CÉRAMIQUES AFRICAINES}

La question, âprement discutée, des effets éventuels de l'occupation vandale puis de la reconquête byzantine sur l'économie africaine a suscité une volumineuse littérature qu'il est hors de mon propos de commenter ici en détail. Il serait pour cela nécessaire de réviser entièrement la documentation, y compris en retournant aux tessons euxmêmes, pour homogénéiser les critères d'identification typologique, les méthodes de comptages et les systèmes de datation.

\section{La « première époque vandale » (fig. 269, 4)}

En effet, les révisions opérées depuis quinze ans sur la typologie et la chronologie des amphores africaines tardives ont généré des modèles historiques successifs et contradictoires. Cl. Panella (1993) distinguait deux périodes vandales, la première encore empreinte du dynamisme agricole et commercial de l'Afrique romaine, la seconde, à partir de la fin du Ve s., témoignant du

319 En revanche, l'épave de Trincere (Tarquinia) montre l'association d'un chargement de céramiques culinaires (Hayes 23B, 196, 197) et d'amphores Africaines II A (salsamenta ?) et Dressel 30 (vin) : Pontacolone, Incitti 1991.

320 L'épave de Femina Morte (Parker 1976-77, P1. CXXXIIICXXXVII, et 1992, 177) contenant des amphores Africaines II $C$ et II D tardives et un petit chargement de sigillée D (C ?) pourrait constituer une exception. Mais cette épave, comportant également une cargaison complémentaire d'amphores hispaniques, n'est peut-être pas un bon exemple d'épave homogène. 
déclin de la production et des exportations ; la reconquête byzantine aurait ralenti cette tendance sans cependant pouvoir l'inverser (en dernier lieu, Saguì, Panella 2001, 788). S. J. Keay $(1998,150-151)$ a remis en cause ce schéma en démontrant que les types autrefois attribués à la première époque vandale apparaissaient en fait beaucoup plus tard, " peut-être sous les Byzantins » et que les exportations africaines en Méditerranée occidentale se poursuivaient loin dans le VIIe siècle. En fait, si l'on considère le plus objectivement possible les données archéologiques, on doit constater que les changements typologiques ne correspondent pas exactement aux changements politiques (Bonifay à paraître, c ; même observations pour la céramique commune chez Fulford 1984b, 231). Tout d'abord, il paraît acquis que les premières amphores cylindriques de grandes dimensions apparaissent avant la conquête vandale (types Keay 3 similis, Keay 59, Keay 36 et probablement Keay 35). Ensuite, il semble difficile de repousser après 533 l'apparition de la seconde génération de ces amphores (notamment type Keay 62) : comme pour la sigillée africaine, les changements typologiques se font plus vraisemblablement à l'extrême fin du Ve s. et au début du VIe siècle.

En effet, à partir des décennies centrales du Ve s., les ateliers de la vallée de la Mejerda perdent leur hégémonie sur les marchés méditerranéens ; cette remarque se déduit aisément des cartes de diffusion de l'atelier d'El-Mahrine (Mackensen 1993, comparer les cartes des fig. 128 et 129). L'observation du répertoire de formes des ateliers septentrionaux laisse entrevoir une certaine stagnation morphologique et décorative tandis que les ateliers du centre de la Tunisie connaissent un renouveau spectaculaire: s'il y a une sigillée africaine d'époque vandale, c'est bien la sigillée $\mathrm{C}^{321}$. Il semble ainsi que les forces productives se soient à nouveau, dans la seconde moitié du Ves., déplacées vers la Tunisie centrale. Ce nouveau coup de balancier en faveur de la Byzacène, après celui du IIIe s., n'est peut-être pas, cette fois, étranger aux conditions politiques (?) : en effet, la présence vandale, les persécutions religieuses et les transferts de propriété au profit des nouveaux maîtres sont peut-être moins sensibles hors de Zeugitane (cf. Courtois 1955, 218, note 8, carte p. 219 et surtout Modéran 2002, 107-110).

Des changements se produisent également, dans la seconde moitié du Ves., sur le plan de la commercialisation des sigillées africaines. $\mathrm{Si}$ ces dernières restent présentes en Méditerranée occidentale, c'est le moment où néanmoins leur proportion est la plus faible. L'exemple de Marseille est particulièrement net (Bonifay 1998b, 204-205). On ignore cependant si cette faiblesse trouve une explication dans la concurrence que leur ferait subir le développement concomitant des

\footnotetext{
${ }^{321}$ Cette observation se déduit aisément des tableaux publiés par A. Bourgeois (2002, Tabl. 2 et 3 ).
}

Dérivées de Sigillées Paléochrétiennes Provençales ou bien si le vide créé par la diminution des importations africaines a dû être comblé par une production locale de moindre qualité. La même question a été posée en Méditerranée orientale à propos de l'inversion des proportions entre les sigillées africaines et les deux grandes catégories de sigillées orientales tardives. Le déclin des importations de sigillées africaines, mis en évidence de manière indiscutable à Athènes et à Antioche (Hayes 1972, 417 et 419), est-il dû à la concurrence des sigillées phocéennes (Abadie-Reynal 1989, 150) et chypriotes ou bien procède-t-il de conditions économiques plus générales?

Certes, tout contact entre l'Afrique vandale et le bassin oriental de la Méditerranée ne semble pas rompu. Des amphores africaines arrivent encore en Orient durant la seconde moitié du Ve siècle. Ces arrivages traduisent surtout le dynamisme des régions les plus méridionales de la Byzacène. Par exemple, le type Keay 8B (supra, AMPHORE TYPES 38-39), bien attesté sur les sites ruraux de la région de Kasserine (Neuru 1990b), est exporté en assez grande quantité à la fois à Carthage (Peacock 1984b ; observations personnelles) et à Constantinople (Hayes 1992 fig. 22, $\mathrm{n}^{\circ}$ 1). Si les amphores africaines ne semblent ni plus, ni moins nombreuses en Orient que par le passé, ne doit-on pas expliquer la diminution très sensible des importations de vaisselle sigillée en Orient par l'arrêt des livraisons de blé africain à la suite de l'occupation vandale (Wickham 1988, 193)? En Méditerranée occidentale, la diversification des ateliers fournisseurs de sigillée D pourrait indiquer que cette vaisselle voyage avec des marchandises plus variées (y compris avec des chargements d'huile: cf. l'épave du Dramont E) que par le passé : la région de Carthage paraît moins bien représentée, tandis qu'émergent les produits de Byzacène et du nord du golfe d'Hammamet (atelier de Sidi Khalifa). Enfin, l'exception que constituent les nombreuses sigillées C5 découvertes en Egypte peut s'expliquer, au moins en partie, par le fait qu'elles n'arrivent pas toutes par voie maritime (supra, p. 456) mais peut-être également par le fait qu'Alexandrie reste, comme par le passé, un cas isolé parmi les marchés orientaux, avec des besoins en huile et peu de besoins en blé.

Il reste que le milieu du Ves. voit des changements importants dans l'organisation et la commercialisation de la production africaine. Il ne me semble pas que ces changements puissent être interprétés en termes réellement positifs, surtout pour la région de Carthage. Je me rangerais plutôt à l'opinion de Fulford $(1983,11)$ et de Reynolds $(1995,112)$ qui considèrent que les années 440-475 sont une période de relative stagnation dans l'économie de cette région. 
« Deuxième époque vandale » et reconquête byzantine (fig. 269, 5)

En revanche, la fin du Ves. et le début du VIe s. pourraient marquer, d'une certaine façon, un retour à la situation antérieure. Les ateliers septentrionaux redeviennent plus dynamiques mais il semble qu'il y ait un transfert de position dominante entre les centres de la vallée de la Mejerda (El-Mahrine) et ceux de l'Oued Miliane (Oudhna). Il paraît clair, à l'examen des contextes de Carthage, que l'atelier septentrional le mieux diffusé dans cette ville avant 450 est celui d'ElMahrine, tandis que l'atelier d'Oudhna est particulièrement bien attesté au VIe siècle ${ }^{322}$. Ce nouveau dynamisme du centre d'Uthina est peut-être favorisé par les contacts directs - outils, artisans (?) - qu'il entretient, vers la fin du Ve s., avec ceux de Byzacène. De nouvelles formes, notamment le bol Hayes 99, et de nouveaux modes décoratifs, le style E(i), adaptent ou copient directement (poinçon Hayes 289b) les modèles fournis par la sigillée C5. La diffusion de la sigillée D2 d'Oudhna en Méditerranée, y compris dans les franges septentrionales (Bretagne: Thomas 1981; Germanie : Fremersdorf 1958, fig. 10 : Hayes 97) et dans la partie orientale, malgré, dans ce dernier cas, la concurrence toujours active des sigillées phocéennes et chypriotes, traduit incontestablement une reprise $\mathrm{e}^{323}$. La situation de la seconde moitié du Ves. donne d'autant mieux l'impression d'une parenthèse, au cours de laquelle les produits de Tunisie centrale étaient très inégalement répartis et les ateliers septentrionaux (Sidi Khalifa) autres que ceux de la Mejerda n'atteignaient pas la diffusion qu'avaient eu ces derniers par le passé. Cette reprise va s'amplifier à l'époque byzantine avec le développement de l'« atelier X » (Mackensen, Schneider 2002 : « large D2 pottery »), caractérisé par le style décoratif E(ii), dont la production connaît également une large diffusion. Cette phase est bien représentée dans le Midi de la Gaule par les ensembles de Sainte-Propice (Boixadera et al. 1987), de Saint-Blaise (Cavaillès, Vallauri 1994, fig. 61) et de l'épave de la Palud (Long, Volpe 1998), en Orient par ceux de Roumanie (Opait 1996, 329, n 8-12), de Thasos (Abadie-Reynal, Sodini 1992, 31-32), d'Antioche (Waagé 1947, fig. 31) ou encore de Gortyne (Dello Preite 1997, fig. 11 et 12).

Ces nouvelles tendances dans la production et la commercialisation des sigillées africaines précèdent de quelques décennies la date de la reconquête byzantine. On peut les mettre en relation avec l'augmentation des importations constatée à la même époque par M. G. Fulford (1980, 71, et 1983, 11) à Carthage. Certes, $\mathrm{Cl}$. Panella souligne à juste titre que Carthage n'est

\footnotetext{
${ }^{322}$ Comparer les contextes de Tomber 1988 et de Riley 1981.

${ }^{323}$ A Corinthe, cependant, K. W. Slane (2000, graphique fig. 10) ne détecte aucune reprise, au VIe s., des importations de sigillées africaines, particulièrement abondantes dans cette ville du IIIe s. au début du Ve siècle.
}

jamais autant prospère que lorsqu'elle dépend peu de l'extérieur pour son approvisionnement : aux IIIe-IVe s., les importations de céramiques sont au plus bas (Panella 1983, 56). Cependant, même si les céramiques émettent des signaux économiques contradictoires, il reste plausible, si l'on suit M. G. Fulford (Fulford, Peacock 1984,114 et 260 ) et avec P. Reynolds (1995, 115), que l'augmentation conjointe des exportations et des importations de la région de Carthage durant la «deuxième époque vandale » constitue un signe du décollage économique de cette région préalablement à la reconquête byzantine.

La reconquête byzantine ne signe pas, toutefois, l'arrêt définitif des ateliers de Tunisie centrale, ni probablement de ceux du sud et du sud-ouest de la Byzacène (Neuru 1987). Les premiers continuent à produire après 550 les grands plats Hayes 90B1 puis, probablement, une partie des plats Hayes 105, ainsi que des lampes jusqu'au VIIe s. (supra, LAMPES TYPES 56-57, groupes C4 et C5). La fin du VIe et la première moitié du VIIe s. semblent même constituer une période de relatif dynamisme économique pour cette région. De fait, les productions céramiques des derniers temps de la Byzacène byzantine sont parfaitement identifiables au sein du matériel de Marseille (Bonifay et al. 1998, faciès D) avec notamment les amphores Keay 62 tardives et Keay 62Q de l'atelier d'Henchir ech-Chekaf à Ksour Essaf. Ces formes tardives atteignent également la Méditerranée orientale (amphore Keay 61D à Samos : Hautumm 1981, fig. 301-302) et les côtes atlantiques (amphore Keay 61B à Banassa, Maroc : Hassini 2002).

\section{La mobilité des ateliers aux époques vandale et byzantine}

Il convient également de réexaminer le modèle selon lequel on assisterait, à partir de l'époque vandale, à une migration des ateliers d'amphores vers l'intérieur des terres, modèle construit principalement à partir des prospections réalisées dans la région de Salakta. En effet, D. P. S. Peacock (1989, 199-201) distinguait deux sortes d'ateliers, urbains et ruraux, les premiers ayant fonctionné jusqu'au début du Ve s., les seconds ayant pris le relais à partir du deuxième quart du Ves., ce changement paraissant coïncider avec l'invasion vandale (Ibid., fig. 2). Cette constatation objective, qui a vite pris valeur de dogme dans la littérature archéologique, mérite cependant, à la lueur des nouvelles données sur les ateliers (supra), d'être un peu tempérée (fig. 267, a). Tout d'abord, la période du déplacement des ateliers n'est pas clairement établie : certains types (notamment Keay 62) qui étaient datés du milieu du Ve s. en 1989 (Keay 1984) sont maintenant - je l'ai signalé à plusieurs reprisesramenés au VIe s. (Keay 1998). Ensuite, l'ampleur du déplacement n'est pas considérable : 5 ou $6 \mathrm{~km}$ séparent les ateliers de la périphérie de Sullecthum de ceux de Ksour Essaf. Enfin, les fouilles menées dans la cité 


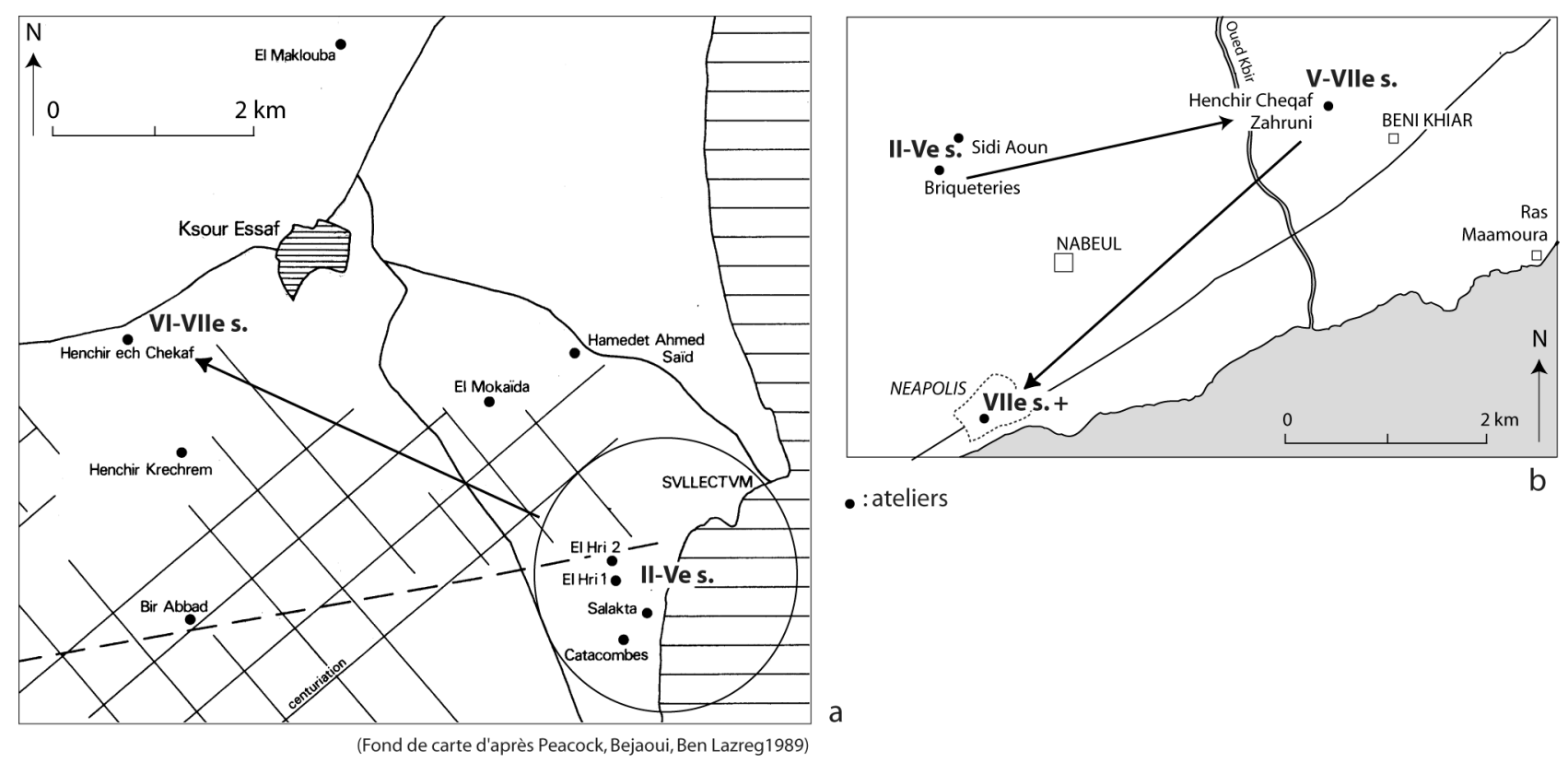

Fig. 267. Déplacements des ateliers d'amphores : exemples de Salakta (a) et de Nabeul (b).

voisine de Leptiminus montrent qu'il existe également, aux VIe-VIIe s., des ateliers à l'intérieur de la ville (Stirling 2001) ${ }^{324}$. Ces remarques trouvent un parallèle dans les recherches faites à Nabeul (fig. 267, b). Les ateliers de l'époque romaine sont déjà assez éloignés de la cité car ils sont implantés sur les bancs d'argile adossés au relief, à environ $2-3 \mathrm{~km}$ au nord du périmètre urbain. Comme à Sullecthum, il y a bien un déplacement des ateliers, vraisemblablement au cours du Ve s., dans une zone plus rurale du territoire de Neapolis (atelier de Sidi Zahruni), à 5-6 km au nord-est de la cité antique mais à égale distance de la côte (Ghalia, Bonifay, Capelli 2004). La notion de migration des ateliers vers l'intérieur est donc toute relative. Enfin, comme à Leptiminus, des ateliers sont installés dans la ville de Neapolis au VIIe s. et fonctionnent peut-être encore au début du VIIIe siècle. C'est donc une situation plus complexe, du point de vue des centres producteurs, que laissent entrevoir les recherches récentes, aussi bien dans le Sahel que dans le Cap Bon, mais qui ne semble pas réellement affecter les exportations outre-mer, ces deux régions restant bien représentées, du Ve au VIIe s., parmi les arrivages d'amphores africaines en Méditerranée occidentale.

On pourrait, plus globalement, envisager une évolution selon le modèle suivant (fig. 267, b) :

- Phase 1: Dès le IIe s. et jusqu'aux décennies centrales du Ve s., il semble qu'il y ait coexistence de deux sortes d'ateliers d'amphores en Afrique, certains liés à des établissements ruraux, d'autres regroupés à la périphérie des villes.

- 1A : Les ateliers du premier type, qui ne sont peut-être pas les plus importants du point de vue de la commercialisation outre-mer, se rencon-

\footnotetext{
${ }^{324}$ Pour la datation, voir Dore 2001, 76-77.
}

trent surtout dans les régions de l'intérieur (Peacock, Bejaoui, Ben Lazreg 1989 et 1990); ils ne sont toutefois pas absents du littoral (Oued el-Akarit : supra, p. 31).

- 1B : Ceux du second type, dont une partie de la production porte des timbres au nom de la cité, ont été mis en évidence sur le littoral de Byzacène (Leptiminus, Salakta) ou en Tripolitaine (Zitha). Dans certains cas, le relatif éloignement par rapport à la ville s'explique par des impératifs techniques (Nabeul). Peut-être faut-il encore ranger dans cette deuxième catégorie les fours de l'Ariana, à proximité de Carthage (Panella 2001, 209).

- Phase 2 : Aux Ve -VIe s., et peut-être pendant une partie du VIIes., des concentrations d'ateliers en milieu rural semblent prendre le relais des ateliers péri-urbains et peut-être, dans certains cas, la succession de plus petits ateliers ruraux. On rangera dans cette catégorie le site d'Henchir ech-Chekaf à Ksour Essaf, celui de Moknine et surtout le grand centre potier de Sidi Zahruni à Beni Khiar.

- Phase 3: Dès le VIe s. mais surtout au VIIe et jusqu'à une date très tardive, des ateliers s'installent à l'intérieur même des villes, réutilisant des maisons (Nabeul) ou des édifices thermaux (Leptiminus).

Comment expliquer ces déplacements d'ateliers ? Comme l'a suggéré Th. Peña (1998, 213), le déplacement des ateliers péri-urbains de Salakta vers des zones rurales dans le courant du Ves., peut signer la fin du système annonaire de collecte centralisée de l'huile, qui impliquait que le produit soit mis en amphores dans les ports exportateurs. Mais l'exemple de Nabeul pourrait également suggérer que le transfert des ateliers a été dicté par la «délocalisation» des installations, agricoles ou 
autres, qui utilisent des amphores pour commercialiser leurs produits. En effet, il semble bien que les usines de salaisons auxquelles, notamment, l'atelier de Sidi Zahruni fournissait au Ves. des conteneurs (type Keay 35B) soient situés non plus, comme aux IIe -IVe s., dans ou près de la ville (Slim, Bonifay, Trousset 1999), mais plutôt le long de la côte, entre Maamoura et Clipea (Ben Lazreg et al. 1995, 111 et fig. 4). Cette implantation nouvelle pourrait avoir été favorisée par la présence de lagunes en arrière du cordon littoral servant à la fois de viviers à poissons (Ibid., 112) et de gisements de sel. Je me demande même s'il ne faut pas envisager un déplacement des activités portuaires de Neapolis vers Maamoura, site portuaire plus proche des unités de production et plus favorable du point de vue naturel $^{325}$.

On serait ainsi dans le même cas de figure que celui des ateliers de sigillée, dont on a vu qu'ils pouvaient se déplacer au gré des fluctuations économiques régionales. Cependant, si le développement des ateliers de sigillée $\mathrm{C}$ en Tunisie centrale et la création des ateliers de sigillée D1 en Tunisie septentrionale peuvent trouver des parallèles, même imparfaits ou controversés, dans l'accroissement de la production agricole des régions concernées au IIIe puis au IVe s., le renouveau (?) de l'atelier d'Oudhna à la fin du Ve s. ou au début du VIe s. est plus difficile à expliquer. Le fait le plus troublant concerne les rapports très étroits que semble entretenir cet atelier avec ceux du centre de la Tunisie, en particulier celui de Sidi Marzouk Tounsi. Oudhna est sans doute le plus centro-méridional de tous les ateliers de Tunisie septentrionale comme le montrent l'emprunt direct de certains motifs décoratifs (poinçon Hayes 289), les probables surmoulages de lampes du groupe $\mathrm{C} 2$ ou encore les parallèles dans le décor des lampes Atlante XII (fig. 268).

Ces correspondances sont plus nettes encore que celles établies par M. Mackensen (1993, 469) sur le plan des décors et de certaines formes entre la sigillée et les premières productions d'El-Mahrine. La deuxième particularité est qu'il s'agit d'un centre de production lié non pas à un domaine agricole mais à une cité (supra, p. 53). Dans l'état actuel de la documentation, car on ne connaît pas les structures de production de la sigillée africaine du Haut-Empire (catégorie A) (Pavolini, Tortorella 1997, 267), les ateliers de sigillée liés à des cités semblent plutôt constituer un phénomène tardif. Sidi Khalifa en est un autre exemple (supra, p. 55) ; ce dernier atelier connaît également un développement important à la fin du Ve s. avec un répertoire de formes et une qualité de pâte qui se rapprochent des productions de Tunisie centrale (supra, p. 49). Ce renouveau des ateliers de Tunisie septentrionale dans un cadre préférentiellement urbain, alors même qu'elle préfigure une situation plus

\footnotetext{
${ }^{325}$ Comme le montre l'implantation de l'actuel port de l'Office National des Pêches.
}

répandue encore à l'époque byzantine, précède manifestement de quelques décennies la reconquête.
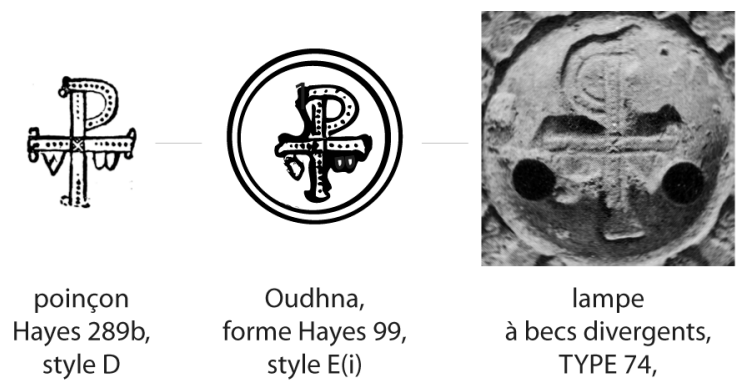

lampe

à becs divergents, TYPE 74, groupe D2

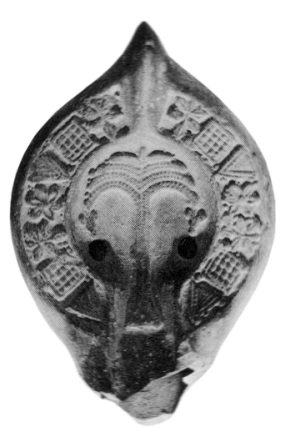

lampe TYPE 46 groupe C2

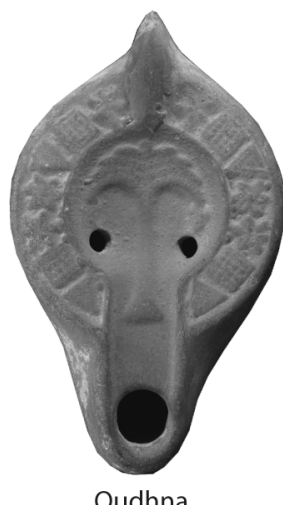

ampe TYPE 65, groupe D2

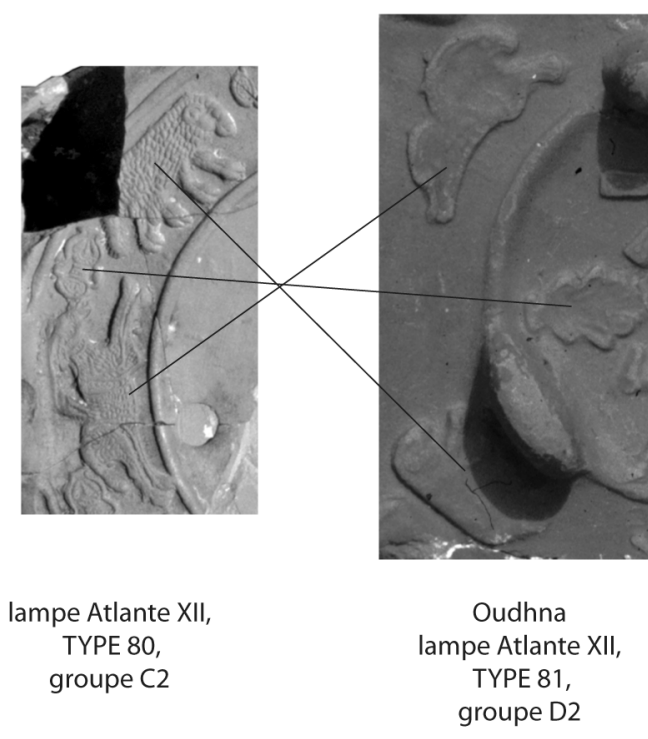

Fig. 268. Exemples de connexions décoratives entre les ateliers de Tunisie centrale et l'atelier d'Oudhna.

\subsection{LA CÉRAMIQUE AFRICAINE DES DERNIERS TEMPS DE L'ÉPOQUE BYZANTINE (fig. 269, 6)}

Les fouilles tuniso-françaises menées depuis une dizaine d'années dans les trois villes antiques limitrophes de Neapolis/Nabeul, Pupput/Hammamet et Aradi/Sidi Jdidi 
ont buté sur les difficultés persistantes de datation par la céramique des niveaux d'occupation les plus tardifs des villes antiques de Tunisie (Bonifay 2002). L'une des raisons de cette situation consiste dans le caractère essentiellement local du mobilier céramique. Cette documentation suggère donc une relative autarcie économique qui, elle-même, doit avoir pour corollaire le maintien d'une production agricole importante, notamment celle du vin - d'où, peut-être, la rareté des importations d'amphores orientales.

La comparaison avec Carthage reste cependant pertinente pour une partie de la sigillée africaine, à vernis rouge carmin et à décors lustrés (supra, p. 210), qui se trouve associée dans la métropole comme dans la petite bourgade d'Aradi à des monnaies de la fin du VIIe siècle. Cette catégorie dégénérée de sigillée africaine témoigne de la persistance des modèles économiques des siècles passés puisqu'elle connaît une certaine diffusion en Méditerranée occidentale (Rome: Saguì 1998, fig. 3, $\mathrm{n}^{\circ}$ 9) et même orientale (Alexandrie : Rodziewicz 1984, fig. 14, $\mathrm{n}^{\circ} 116$; Constantinople: Hayes 1992 fig. 164, $\left.\mathrm{n}^{\circ} 30.109\right)$. Il est probable également qu'une partie des sigillées D de la Crypta Balbi puisse provenir d'Oudhna : c'est le cas, à mon sens, des bols Hayes 80B/99 ou 99D (supra, SIGILLÉE TYPE $55 \mathrm{D}$ ) et des cruches qui leur sont associées (Saguì 1998, fig. 3, n 3, et fig. 4, n $1-3$ ) ; les mortiers en céramique commune de type Carthage Class 2c (supra, COMMUNE TYPE 11 C) sont vraisemblablement de même origine (Ibid., fig. 4, $\mathrm{n}^{\circ} 4-5$ ). Les lampes en sigillée, pourtant tout aussi dégradées en qualité, voyagent de la même façon (Pavolini 1998). Comme par le passé, enfin, ces vaisselles et ces lampes côtoient des amphores: conteneurs cylindriques de grandes dimensions, «spatheia » miniatures et amphores globulaires se retrouvent également sur les marchés méditerranéens. Le phénomène le plus spectaculaire est sans doute la très large diffusion des «spatheia» de type 3. Ces objets sont trouvés dans les territoires sous contrôle byzantin (Arthur1998, 175; Constantinople : Hayes 1992, fig. 49, $\mathrm{n}^{\circ} 30.187$ : Gortyne : Rendini 1997, fig. 143-144, Pl. CXLII, e-f), et spécialement sur le limes danubien (Bjelajac 1996, 88 et Pl. 90), mais également dans des régions qui n'appartiennent pas à l'Empire, par exemple à Marseille (Bien 2004, fig. 2, $\mathrm{n}^{\circ}$ 10, fig. 7 , $\left.\mathrm{n}^{\circ} 1\right)$.

L'ample diffusion des produits de l'Afrique byzantine tardive en Méditerranée orientale est un phénomène marquant, souligné à plusieurs reprises (voir notamment le contexte de Saraçhane, troisième quart du VIIe s. : Hayes 1992). Peut-être ces transports de céramiques sontils favorisés par la reprise de livraisons à Constantinople de denrées de première nécessité, peut-être de blé, comme par le passé. Mais une seule épave de Méditerranée, à ma connaissance ${ }^{326}$, a livré un

326 On pourrait également y ajouter l'épave des Laurons II,
trouvée certes vide de tout chargement (bateau en réparation : chargement de blé : l'épave de Saint-Gervais 2 à Fos-surMer (Jézégou 1998). Or, il est très significatif que sa cargaison complémentaire de céramique (amphores et vaisselle de bord) soit en grande partie africaine, mais il est paradoxal qu'elle soit très tardive (VIIe s.) et qu'elle ait été découverte sur les côtes de l'ancien royaume franc (à Fos-sur-Mer). De fait, les contacts entre l'Afrique et le royaume franc semblent se prolonger jusqu'à une date avancée du VIIes. et peut-être même se poursuivre durant les premières décennies du VIIIe s., comme le montrent les contextes les plus tardifs de Marseille (Bonifay et al. 1998, faciès E). Des indications identiques proviennent de Catalogne (Macias, Remolà 2000), de Ligurie (Murialdo 2001) et, bien sûr, de Rome (Saguì 1998 ; Panella, Saguì 2001). De même, la découverte, dans l'incendie de la maison forte de Sant-Peyre, au Bouquet, Gard (Pellecuer, Pène 1992), d'amphores africaines Keay 61 et 50 associées à un sceau en caractères coufiques, montre que des liens commerciaux existaient encore entre le Midi de la France et des régions d'Afrique déjà sous contrôle omeyyade dans le premier quart du VIIIe s. (Bonifay 2000a, 39).

S'il paraît désormais certain que les modèles économiques tels que nous les percevons au travers de la céramique n'ont pas fondamentalement changé à l'extrême fin du VIIe s., on peut se demander si ce n'est pas faire un contresens historique que de se cantonner, pour ces ultimes niveaux d'occupation, dans les datations préislamiques traditionnellement admises. L'exemple de la Syrie, conquise par les Arabes plus d'un demi-siècle avant l'Afrique, devrait nous inciter à la prudence : ici comme là, sans doute, la céramique des premiers temps de la domination arabe était-elle fort peu différente de celle des derniers temps de la période byzantine.

Ximénès, Moerman 1991, note 3) mais dans laquelle ont été recueillis, sur le fond de la cale, des grains de blé (Ibid., 209 et fig. 3) ainsi qu'un objet en bois interprété comme une pelle à grains (Ibid., fig. 4). 


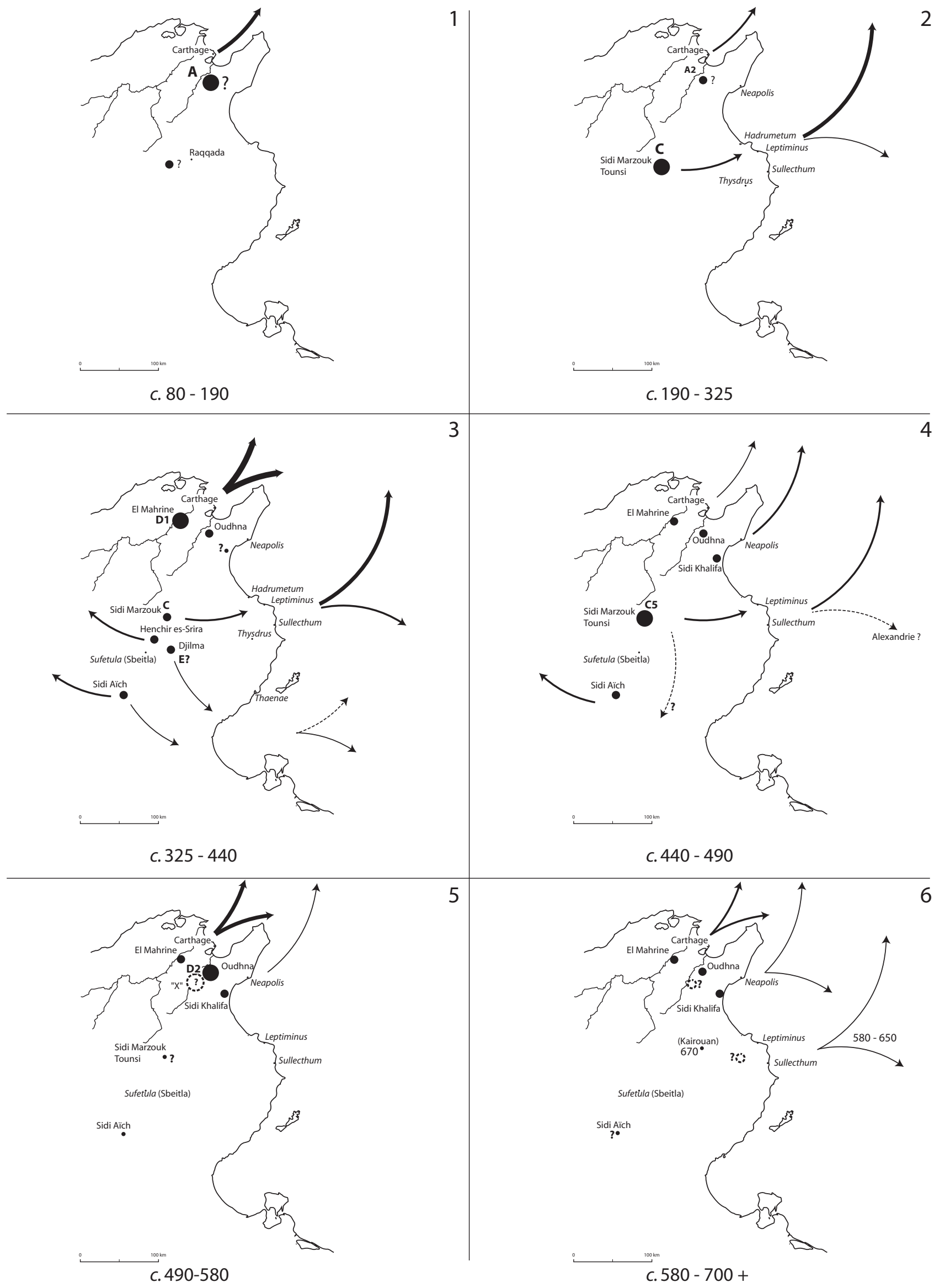

Fig. 269. Hypothèses de déplacements des principaux ateliers de sigillée africaine. 


\section{CONCLUSION}

La céramique africaine, entendue au sens large, présente à la fois une homogénéité très affirmée et de forts particularismes régionaux. J'ai essayé de montrer qu'il était possible de commencer à caractériser ces différents faciès, même avec une documentation très lacunaire et en se servant d'un éventail de critères très simples. Parmi ces derniers, certains, comme les timbres, sont utilisés de longue date mais peuvent apporter encore beaucoup d'informations, surtout en développant conjointement l'étude typologique des amphores ou des lampes sur lesquelles ils sont apposés. La typologie elle-même et l'étude des décors peuvent permettre des avancées importantes sur l'origine des productions en exploitant simplement la documentation disponible dans les publications. L'exemple des lampes en sigillée de type Atlante $\mathrm{X}$, au sein desquelles je propose de reconnaître plusieurs groupes caractéristiques, à mon sens, d'ateliers ou de régions productrices bien déterminés, me paraît particulièrement significatif. L'accès au terrain est en revanche nécessaire pour apprécier concrètement la diffusion des types de céramiques, diffusion qui, en Afrique, est souvent révélatrice de la proximité des zones de production. Cette remarque est particulièrement valable pour la vaisselle (sigillée, culinaire, commune) qui ne paraît pas, en Afrique, voyager autant que les amphores, comme le montrent, par exemple, les différences de faciès entre les deux grandes villes littorales limitrophes que sont Nabeul et Pupput. Enfin, des méthodes archéométriques simples, tout au moins peu coûteuses, comme la pétrographie, apportent des résultats encourageants pour peu que les échantillons soient, de préférence, reliés à un atelier.

En effet, les progrès décisifs ne peuvent venir que des prospections d'ateliers. L'état extrêmement clairsemé des cartographies d'ateliers d'amphores ou de sigillées (fig. 2 et 22), pour ne pas parler de nos ignorances en matière de céramiques culinaires ou communes (fig. 33 et 36 ), sont bien révélateurs des carences actuelles de la recherche en ce domaine. Un tel sujet mériterait un programme de travail ambitieux, alors qu'il ne se nourrit actuellement que de recherches ponctuelles. La mise en évidence de la production des amphores Keay 35 à Nabeul (Ghalia, Bonifay, Capelli 2004) ou des amphores Keay 8B en Byzacène méridionale (Bonifay et al. 2002-2003) est ainsi un acquis non négligeable pour tous les archéologues qui, du Portugal à la mer Noire, rencontrent ces types d'objets. Mais, pour une production dont l'origine est enfin découverte, combien restent encore inaccessibles à la communauté scientifique par manque de communication entre les acteurs de la recherche archéologique en Afrique?
Pourtant, un grand nombre de structures d'ateliers ont été repérées au cours des prospections menées dans le cadre de la carte archéologique de Tunisie; il suffirait de s'y rendre à nouveau, d'effectuer les ramassages nécessaires et de dessiner soigneusement les formes représentatives. L'étude pourrait être assez facilement complétée par une caractérisation pétrographique des argiles. Une telle entreprise, qui peut se concevoir de manière collective, rendrait d'inestimables services à l'ensemble des céramologues du bassin méditerranéen.

La typologie et la chronologie des céramiques africaines, productions susceptibles d'être mises au jour dans plus d'une trentaine de nos pays actuels, sont devenues, avec l'affluence et la dispersion des publications, un maquis véritablement inextricable. Sur la base d'une documentation de première main qu'il s'agissait de mettre en perspective par rapport aux classifications existantes, j'ai souhaité réunir dans un même ouvrage toutes les catégories de céramiques africaines que j'avais rencontrées; seules celles pour lesquelles je ne disposais pas de nouvelle documentation se sont trouvées exclues (par exemple, les plats rectangulaires à décor moulé). Je suis conscient que ce travail reste superficiel et qu'il ne rendra réellement des services que dans les régions d'où la documentation est issue. Ainsi, il ne remplacera pas un ouvrage consacré entièrement à l'atelier d'Oudhna, dont je ne fais qu'effleurer la production, et il ne sera guère utile dans les régions continentales de l'Afrique romaine, que je n'ai pas fréquentées.

Il sera sans doute nécessaire un jour de réunir l'ensemble des typologies de la céramique africaine ainsi que les hypothèses de chronologie, justifiées par des listes de contextes datés, même de manière contradictoire, car une telle entreprise ne peut s'entendre, ici encore, que de manière collective. Nul doute que les moyens modernes de communication en ligne constitueraient un bon support pour la mise à disposition de cet outil au profit du plus grand nombre.

Les interprétations économiques que l'on peut tirer de la céramique africaine et de son ample diffusion offrent un vaste champ de recherche. En réaction aux surinterprétations dont cette documentation a fait l'objet durant ces dernières années, j'ai souhaité, en tant que praticien de la céramique africaine, mettre en garde les historiens sur la fragilité des identifications et des datations proposées par les archéologues. Les cartes de diffusions, les statistiques, les modèles de développement économique basés sur la céramique sont à utiliser avec la plus grande prudence, comme le montrent les exemples que j'ai fournis. Mais peut-être les révisions les plus radicales concernent-elles les denrées de première 
nécessité qui sont supposées avoir été le moteur du développement économique de l'Afrique romaine et dont la céramique pourrait se faire le témoin.

A ce titre, il semble que l'on ait peut-être accordé, depuis trente ans, une trop grande importance à l'huile ${ }^{327}$. Certes, l'huile est bien attestée dans la documentation céramique (amphores Africaine I) mais les amphores les plus nombreuses pourraient avoir transporté d'autres denrées. Une partie était certainement dévolue au transport des salsamenta, car il faut bien concevoir que les productions des nombreuses fabriques de salaison du littoral aient fait l'objet d'une commercialisation. Une autre partie est probablement la trace archéologique d'un commerce du vin: peut-être faut-il voir dans la série d'amphores cylindriques de moyennes dimension (Keay 25) de la fin du IIIe s. et du IVe s. un effet des distributions de vin de qualité courante décidées en marge de l'annone à partir d'Aurélien $(?)^{328}$. Compte tenu de ces révisions, ne convient-il pas de revenir à des hypothèses plus traditionnelles et de considérer que la sigillée a pu voyager en accompagnement des exportations les plus volumineuses de l'Afrique romaine, celles du ble ${ }^{329}$ ?

Pas plus que les deux précédents, ce dossier n'est clos. Un espoir réel de mieux savoir ce que l'Afrique exportait dans ses amphores est lié au développement des analyses de contenu. Les questions de production sont indissociables également des recherches sur le terrain africain et on doit souhaiter que les fouilles d'installations agricoles et de fabriques de salaisons se multiplient en Libye, Tunisie et Algérie. Enfin, il n'est peut-être pas vain de suggérer qu'un dialogue plus étroit s'instaure entre les céramologues et les historiens, pour aider les premiers à dépasser un travail purement technique et pour éviter que les modèles conçus par les seconds, en utilisant de manière non critique les travaux des premiers, ne soient par trop fragiles.

Faute, selon une expression désormais célèbre de Chr. Goudineau, de pouvoir «faire l'Histoire par la céramique », peut-être est-il plus sage d'en rester à «l'histoire de la céramique». Sur ce plan, on peut aisément discerner les trois influences qui paraissent régir

\footnotetext{
${ }^{327}$ Voir également sur l'oléiculture en Tunisie les remarques de $\mathrm{Ph}$. Leveau $(2003,305)$ : « La surévaluation de son importance à l'époque romaine résulte d'une construction idéologique de la colonisation qui justifie son action par une restauration de la prospérité d'un passé valorisé. Il convient donc de relativiser l'importance traditionnellement attribuée au verger d'olivier en Tunisie à cette époque $»$.

${ }^{328}$ B. Sirks (1991, 392 et note 24) n'exclut pas que l'Afrique ait contribué au canon uinarius. En revanche, selon D. Vera (communication personnelle), seules les provinces italiennes y étaient soumises, les expéditions se faisant en tonneaux.

${ }^{329}$ Selon Fr. De Romanis (2003), les arrivages de blé africain à Rome augmentent de manière significative à partir du règne d'Hadrien.
}

le développement de la céramique africaine du IIe au VIIe siècle.

D'une part, il est assez remarquable que la céramique africaine reste durant toute cette période soumise à certains caractères libyco-puniques que l'on aurait pu croire totalement disparus au début du IIe s., après 250 ans de romanisation. Ainsi, jusqu'au VIIe s., survit en Tunisie une famille d'amphore de type phénico-punique, c'est-à-dire avec les anses placées sur l'épaulement et non sur le col comme la plupart des autres amphores du monde romain. En cela, la situation africaine est proche de celle du Levant, autre région à peuplement phénicien, qui garde ce type d'amphores ( $L R A 4$ et 5-6) jusqu'à la conquête arabe (et après encore). Il a été souligné à plusieurs reprises que les céramiques culinaires tournées qui ont contribué, jusqu'au Ve s., à la renommée des productions africaines, puisent leur origine dans la céramique d'époque punique. Lorsqu'elles disparaissent vers la fin du Ve s. ou la première moitié du VIe s., c'est pour laisser la place à des céramiques modelées dont l'origine remonte à l'époque libyque et qui n'ont jamais réellement cessé d'être fabriquées durant la période romaine. La céramique modelée fournit également une partie des braseros à trois ergots qui font la particularité des cuisines africaines, alors que dans d'autres provinces de l'Empire (en Gaule du Nord par exemple), ce sont les vases à cuire eux-mêmes qui sont munis de trépieds, pour pouvoir être disposés sur une plaque-foyer. D'un autre côté, les inscriptions néo-puniques ne semblent jamais totalement disparaître des céramiques africaines, et constituent une partie, faible au demeurant, des marques sur amphores et sur lampes. Enfin, il est assez émouvant de retrouver dans des tombes des IIe et IIIe s. de petites cruches anthropomorphes, évoquant les figurines de la déesse Astarté, communes à l'époque punique. De la même façon, une continuité assez troublante se décèle entre les figurines de Tanit, les figurines de déessesmères des IIe et IIIe $\mathrm{s}$. et les figurines à la Vierge du VIe s.; une représentation similaire se retrouve encore sur des carreaux de décor de basilique dont on a souligné que les dimensions reprenaient une métrique punique.

D'autre part, même si ces exemples de persistance des traditions libyco-puniques dans la céramique peuvent être multipliés, il reste que la partie la plus importante des productions des IIe-VIIe s. s'insère sans équivoque dans la tradition romaine. Très vite, les amphores puniques vont se doter des attributs gréco-romains: la nette distinction entre le col et la panse, le fond terminé en pointe effilée et surtout les anses placées sur le col et non plus sur l'épaulement. Les premières à adopter cette mutation sont, dès l'époque de la conquête, les amphores de Tripolitaine (type Dressel 26), suivies, seulement au Ier s. ap. J.-C., par les amphores de la région de Carthage (type $E A$ IV). L'établissement d'un répertoire de formes d'amphores véritablement romano-africain n'intervient pas, cependant, avant le milieu du IIe s. (amphores Africaines I et II). Les sigillées africaines, apparues vers 
la fin du Ier s., ont emprunté une partie de leur répertoire de formes à celui des sigillées italiques et gauloises. Ce n'est qu'au cours du IIe s. que se mettent en place des formes plus originales, mais néanmoins tout à fait romaines, qui vont faire le succès de cette production. Enfin, l'Afrique, qui est restée tributaire des importations de lampes italiques jusqu'au début du IIe s., se met à cette date, à en produire des imitations qui vont rapidement satisfaire l'ensemble des besoins locaux. Les lampes proprement romano-africaines ne vont apparaître qu'à la fin du IIe siècle. Ces trois exemples montrent bien que c'est seulement dans le courant du IIe s. que l'Afrique, du point de vue de la documentation matérielle, va réellement rejoindre le monde romain, en intégrant dans ses propres productions (et en les «africanisant») les modèles gréco-italiques qu'elle va d'ailleurs, par la suite, supplanter sur leur propre terrain.

Enfin, la céramique africaine subit, à partir du VIe s., l'influence de la céramique byzantine. Peu à peu, l'amphore globulaire inspirée, au moins en partie, de modèles orientaux (types $L R A 1$ et 2 ), tend à s'imposer aux côtés des types africains plus traditionnels. Les seules vaisselles culinaires tournées imitent des formes orientales. Les lampes tournées dites autrefois « de type vandale » sont plus vraisemblablement issues de modèles orientaux (Orssaud, Sodini 1997, 63-64 ; Bussière 2000, 127 : en Afrique, " on ne lui connaît pas de modèles antérieurs »). Ainsi, à la veille de la conquête arabe, la céramique africaine a perdu beaucoup de son originalité. Elle tend à se fondre dans le « moule byzantin » commun à de nombreuses productions du sud de l'Espagne, du sud de l'Italie, de mer Egée et que l'Orient déjà sous domination islamique conserve encore largement et contribue à diffuser. On a cru également pouvoir discerner dans ce mouvement les prémices d'une influence islamique, avec notamment le développement de grandes jarres décorées d'ondes sur plusieurs registres superposés qui trouvent des comparaisons en SyrieJordanie au début de l'époque omeyyade (Sodini, Villeneuve 1992, 212 et fig. 1) et la prépondérance de formes de céramiques culinaires modelées que l'on retrouvera presque inchangées dans l'Espagne islamique du VIIIe s. (Rossello Bordoy 1993, 25 et fig. 3). Même s'il est difficile de faire la part des différentes influences culturelles qui ne vont réellement s'affirmer qu'au cours $\mathrm{du}$ VIIIe s., les phénomènes de continuité sont à souligner, que ce soit dans la production de variantes dégénérées de sigillées africaines et de lampes moulées ou encore dans le recyclage des formes d'amphores globulaires byzantines par la civilisation islamique.

Pour terminer, je ferai trois remarques ${ }^{330}$.

Tout d'abord, l'étude des céramiques africaines a été trop longtemps menée hors d'Afrique. Le mouvement classique depuis près de quarante ans est celui d'archéologues occidentaux qui ont appris à connaître la céramique africaine sur les sites de consommation non africains et qui, dans un second temps, sont allés à la rencontre de cette documentation sur les lieux de production. C'est la démarche suivie par Paul-Albert Février au début des années soixante puis, dix ans plus tard, par J. W. Hayes, venu travailler à Carthage au lendemain de la publication de son manuel qui fait une si grande place aux sigillées africaines. Nous sommes nombreux, avec des fortunes diverses, à avoir emprunté cette voie, alors même que la céramologie demeurait un sujet peu couru localement. Nous avons connu le même phénomène en France dans la première moitié du siècle dernier: comme le relevait Paul-Albert Février: «ce n'est pas non plus un hasard, si ce sont des archéologues anglais qui sont venus s'intéresser aux potiers de la Gaule centrale (...) ils l'ont fait préoccupés qu'ils étaient par les fouilles de Grande-Bretagne et par les exportations dont ils pouvaient dresser la carte [sur leur propre sol]» (Février 1980, 186).

Or, il est clair que la seule façon de progresser dans les connaissances est maintenant d'entreprendre un inventaire exhaustif des collections africaines, notamment tunisiennes, et l'étude du plus grand nombre possible d'ateliers. On doit donc se féliciter qu'une nouvelle génération d'étudiants tunisiens soit dirigée sur ce matériau si abondant sur les sites tunisiens et si largement exporté dans tout le monde méditerranéen. C'est la juste ré-appropriation par les africains d'une problématique trop longtemps abandonnée aux habitants actuels des anciens sites consommateurs de l'Antiquité.

Une deuxième remarque : la céramique africaine produite en Tunisie et, dans une moindre mesure, celle produite dans la partie libyenne de la Tripolitaine sont de mieux en mieux connues et il devient évident qu'un certain nombre d'objets que nous trouvons en Méditerranée occidentale ne proviennent pas de ces régions. Une question vient alors à l'esprit : et l'Algérie ? La céramologie africaine moderne est née en Algérie il y a quarante ans, mais finalement, on s'aperçoit que l'on sait encore peu de choses, aujourd'hui, sur la localisation et la production d'ateliers qui furent certainement très nombreux et dynamiques. Il reste à espérer que nos collègues algériens, dont le travail n'a certainement pas été facile durant ces quinze dernières années, retrouvent bien vite la sérénité que réclame l'avancement de leur recherches.

Enfin, il apparaît que les problèmes d'origine, de chronologie et de diffusion des céramiques africaines sont étroitement liés et que, pour réellement progresser, une coopération est plus que jamais nécessaire non seulement entre les chercheurs des différents pays du Maghreb comme le souhaitait P.-A. Février (1964, 136), mais, d'une manière plus générale et dans l'ensemble du bassin méditerranéen, entre des spécialistes de bonne volonté.

\footnotetext{
${ }^{330} \mathrm{Cf}$. Bonifay à paraître, c.
} 


\section{BIBLIOGRAPHIE}

Nota : les abréviations sont celles de l'Année Philologique.

Abadie-Reynal 1989 : ABADIE-REYNAL (C.) - Céramique et commerce dans le bassin égéen du IVe au VIIe siècle. In : Hommes et richesses dans l'Empire byzantin, I. Paris, Lethielleux, 1989, pp.143-159 (Réalités byzantines).

Abadie-Reynal 1999: ABADIE-REYNAL (C.) - Les amphores romaines en mer Noire. In : GARLAN (Y.) dir. Production et commerce des amphores anciennes en Mer Noire. Actes du colloque international (Istanbul, 25-28 mai 1994). Aixen-Provence, Université de Provence, 1999, pp. 255-264.

Abadie-Reynal, Sodini 1992 : ABADIE-REYNAL (C.), SODINI (J.-P.) - La céramique paléochrétienne de Thasos (Aliki, Delkos, fouilles anciennes). Athènes, EFA, 1992 (Etudes Thasiennes, XIII).

Albore Livadie 1984 : ALBORE LIVADIE (C.) - Relitto Porto A di età tardo-imperiale. In : Archeologia Subacquea 2, Rome 1984, pp. 95-97 (Boll. d'Arte, Suppl. al N²9).

Aguarod 1991 : AGUAROD OTAL (C.) - Cerámica romana importada de cocina en la Tarraconense. Saragosse, Institución Fernando el Católico, 1991.

Amar, Liou 1984 : AMAR (G.), LIOU (B. ) - Les estampilles sur amphores du golfe de Fos. Archaeonautica, 4, 1984, pp. 145-211.

Amiel, Berthault 1996 : AMIEL (C.), BERTHAULT (F.) - Les amphores du Bas-Empire et de l'Antiquité tardive dans le SudOuest de la France. Apport à l'étude du commerce à grande distance pendant l'Antiquité. Aquitania, XIV, 1996, pp. 255263.

Anselmino 1982 : ANSELMINO (L.) - Le lucerne rinvenute nelli scavi della missione archeologica italiana a Cartagine : problemi tipologici e cronologici. In : Actes du colloque sur la céramique antique (Carthage, 23-24 juin 1980). Carthage, Tunis 1982, pp. 157-170 (CEDAC, Dossier 1).

Anselmino et al. 1986 : ANSELMINO (L.), COLETTI (C. M.), FERRANTINI (M. L.), PANELLA (C.) - Ostia. Terme del Nuotatore. In : GIARDINA (A.) dir. - Società romana e impero tardoantico. III. Le merci, gli insediamenti. Rome, Laterza, 1986, pp. 45-81.

Aounallah 2001 : AOUNALLAH (S.) - Le Cap Bon, jardin de Carthage, Recherches d'épigraphie et d'histoire romanoafricaines (146 a. C. - 235 p. C.). Bordeaux, Ausonius, 2001 (Scripta Antiqua).

Aoyagi 1994 : AOYAGI (M.) - Le site romain de Cazzanello (Tarquinia). Recherches archéologiques. Rapport provisoire, 2. Tokyo, Université de Tokyo, 1994 (Annual Report of the Institute for the Study of Cultural Exchange, $\mathrm{N}^{\circ} 10$ ). (en japonais)

Aquilué 1985: AQUILUÉ ABADIAS (X.) - Algunas consideraciones sobre el comercio africano. Tres facies características de la cerámica común africana de época altoimperial. Empúries, 47, 1985, pp. 210-222.

Aquilué 1986-1989 : AQUILUÉ ABADIAS (X.) - Cerámicas decoradas africanas procedentes de la Torre de la Audiencia (Tarragona). Empúries, 48-50, I, 1986-1989, pp. 26-35.

Aquilué 1989 : AQUILUÉ ABADIAS (X.) - Terra sigillata africana. In : Ted'a - Un abocador del segle $V D$. C. en el fórum provincial de Tàrraco. Tarragone, 1989, pp. 123-155 (Memòries d'Excavació, 2).

Aquilué 1992 : AQUILUÉ (X.) - Sobre algunas cerámicas de producción africana con decoración espatulada. Revista d'Arqueologia de Ponent, 2, 1992, pp. 177-198.

Aquilué 1993 : AQUILUÉ (X.) - Las cerámicas finas de los liveles tardo-romanos. In : DUPRÉ I RAVENTOS (X.), CARRETÉ I NADAL (J. M.) dir. - La «Antiga Audiència ». Un acceso al foro provincial de Tarraco. Madrid, 1993, pp. 117-150 (Excavaciones arqueologicas en España, 163).

Aquilué 1994 : AQUILUÉ (X.) - La ceràmica común africana. In : AQUILUÉ (X.), ROCA (M.) dir. - Ceràmica comuna romana d'època alto-imperial a la península ibèrica. Estat de la qüestió. Empúries, Conjunt Monumental d'Empúries, 1994, pp. 61-74 (Monografies emporitanes VIII).

Arcelin, Truffreau-Libre 1998: ARCELIN (P.), TRUFFREAU-LIBRE (M.) dir. - La quantification des céramiques. Conditions et protocole. Actes de la table ronde (Glux-en-Glennes, 7-9 avril 1998). Glux-en-Glennes, Centre Archéologique Européen du Mont Beuvray, 1998 (Bibracte 1).

Arthur 1982 : ARTHUR (P.) - Amphora Production in the Tripolitanian Gebel. Libyan Studies, 13, 1982, pp. 61-72.

Arthur 1998 : ARTHUR (P.) - Eastern Mediterranean amphorae between 500 and $700:$ a view from Italy. In : Saguì dir. 1998, pp. 157-183.

Arthur, Oren 1998 : ARTHUR (P.), OREN (E. D.) - The North Sinai survey and the evidence of transport amphorae for Roman and Byzantine trading patterns. JRA, 11, 1998, pp. 193212 .

Atlante I : CARANDINI (A.) dir., ANSELMINO (L.), PAVOLINI (C.), SAGUÌ (L.), TORTORELLA (S.), TORTORICI (E.) - Atlante delle forme ceramiche, I. Ceramica fine romana nel Bacino mediterraneo (medio e tardo impero). Enciclopedia dell'arte antica. Rome, Enciclopedia Italiana, 1981.

Aubert 1996: AUBERT (C.) - Bey 002, Rapport préliminaire. Bulletin d'Archéologie et d'Architecture du Liban, 1, 1996, pp. 60-96. 
Aupert 1980 : AUPERT (P.) - Objets de la vie quotidienne à Argos en 585 ap. J.-C. In : Etudes Argiennes. Athènes, EFA, 1980, pp. 395-457 (BCH, Suppl. VI).

Auriemma 2000 : AURIEMMA (R.) - Le anfore del relitto di Grado e il loro contenuto. MEFRA, 112, 2000-1, pp. 27-51.

Ayala 1998 : AYALA (G.) - Lyon Saint-Jean : évolution d'un mobilier céramique au cours de l'Antiquité tardive. RAE, 49, 1998 [2000], pp. 207-247.

Baccheli, Pasqualucci 1998 : BACCHELI (B.), PASQUALUCCI (R.) - Lucerne dal contesto di VII secolo della Crypta Balbi. In : Saguì dir. 1998, pp. 343-350.

Bailey 1980 : BAILEY (D. M.) - A Catalogue of the Lamps in the British Museum. II. Roman Lamps made in Italy. Londres, British Museum Publications, 1980.

Bailey 1988 : BAILEY (D. M.) - A Catalogue of the Lamps in the British Museum, III, Roman Provincial Lamps. Londres, British Museum Publications, 1988.

Bailey 1996 : BAILEY (D. M.) - A Catalogue of the Lamps in the British Museum, IV. Lamps of metal and stone, and lampsstands. Londres, British Museum Publications, 1996.

Bailey 1998 : BAILEY (D. M.) - Excavations at El-Ashmunein, $V$. Pottery, Lamps and Glass of the Late Roman and Early Arab Periods. Londres, The Trustees of the British Museum, 1998.

Baldassare 1967 : BALDASSARE (I.) - La ceramica delle necropoli longobarde di Nocera Umbra e Castel Trosino. Alto Medioevo, I, 1967, pp. 141-177.

Ballet 1997 : BALLET (P.) - De l'Empire romain à la conquête arabe. Les productions céramiques égyptiennes. In : $L a$ céramique médiévale en Méditerranée. Actes du VIe Congrès de l'AICM2 (Aix-en-Provence, 13-18 novembre 1995). Aix-enProvence, Narration, 1997, pp. 53-61.

Ballet 2000 : BALLET (P.) - La céramique. In : VALBELLE (D.), CARREZ-MARATRAY (J.-Y.) dir. - Le camp romain $d u$ Bas-Empire à Tell el-Herr. Paris, Errance, 2000, pp. 208-227.

Ballet et al. 1991 : BALLET (P.), MAHMOUD (F.), VICHY (M.), PICON (M.) - Artisanat de la céramique dans l'Egypte romaine tardive et byzantine. Prospections d'ateliers de potiers de Minia à Assouan. Cahiers de la Céramique Egyptienne, 2, 1991, pp. 129-144.

Ballet, Picon 1987 : BALLET (P.), PICON (M.) - Recherches préliminaires sur les origines de la céramique des Kellia (Egypte). Importations et productions égyptiennes. Cahiers de la Céramique Egyptienne, 1, 1987, pp. 17-48.

Barat, Morize 1999 : BARAT (Y.), MORIZE (D.) - Les pots d'horticulture dans le monde antique et le jardin de la villa gallo-romaine de Richebourg (Yvelines). In : SFECAG, Actes du congrès de Fribourg (13-16 mai 1999). Marseille, 1999, pp. 213-236.

Barat, Morize, Van Ossel 1993 : BARAT (Y.), MORIZE (D.), VAN OSSEL (P.) - Variété et provenance des approvisionnements en céramique de la villa gallo-romaine de
Limetz-Villez (Yvelines). In : SFECAG. Actes du congrès de Versailles (20-23 mai 1993). Marseille, 1993, pp. 183-190.

Baratte, Bejaoui, Ben Abdallah 1999: BARATTE (F.), BEJAOUI (F.), BEN ABDALLAH (Z.) - Recherches archéologiques à Haïdra. Miscellanea, 2. Rome, EFR, 1999 (Coll. de l'Ecole française de Rome, $\mathrm{n}^{\circ}$ 17/2).

Barbera, Petriaggi 1993 : BARBERA (M. R.), PETRIAGGI (R.) - Le lucerne tardo-antiche di produzione africana. Rome, Museo Nazionale Romano, 1993.

Barker et al. 1996 : BARKER (G.), GILBERTSON (D.), JONES (B.), MATTINGLY (D.) - Farming the Desert. The UNESCO Libyan Valleys Archaeological Survey, 1. Synthesis. Londres, UNESCO/Soc. Lib. Stud., 1996.

Barraud et al. 1998: BARRAUD (D.), BONIFAY (M.), DRIDI (F.), PICHONNEAU (J.-F.) - L'industrie céramique de l'Antiquité tardive. In : BEN HASSEN (H.), MAURIN (L.) dir. - Uthina (Oudhna), La redécouverte d'une ville antique de Tunisie. Bordeaux-Paris-Tunis, Ausonius-Publications, 1998, pp. 139-167 (Mémoires 2).

Basile 1996 : BASILE (B.) - Giarranauti : un insediamento tardo-antico in territorio di Sortino. In : Atti delle Giornate di Studio sugli Insediamenti Rurali nella Sicilia Antica (Caltagirone, 29-30 juin 1992). Catane, 1996, pp. 141-150 (AITNA, Quaderni di Topografia Antica, 2).

Bass, Van Doorninck 1971 : BASS (G. F.), VAN DOORNINCK (F. H.) - A Fourth-Century Shipwreck at Yassi Ada. $A J A, 75-1,1971$, pp. 27-37.

Bass,Van Doornick 1982 : BASS (G.), VAN DOORNICK (F.) - Yassi Ada, I : a seventh century shipwreck. Texas, A \& M University Press, 1982.

Batigne, Desbat 1996 : BATIGNE (C.), DESBAT (A.) - Un type particulier de "cruche »: les bouilloires en céramique d'époque romaine (Ier - IIIe s.). In : SFECAG. Actes du congrès de Dijon (16-19 mai 1996). Marseille, 1996, pp. 297-312.

Bats 1996 : BATS (M.) - Remarques finales. In : BATS (M.) dir. - Les céramiques communes de Campanie et de Narbonnaise (Ier s. av. J.-C. - IIe s. ap. J.-C.). La vaisselle de cuisine et de table. Actes des journées d'étude (Naples, 27-28 mai 1994). Naples, Centre Jean Bérard, 1996, pp. 481-484.

Becatti 1961 : BECATTI (G.) - Scavi di Ostia. IV, I Mosaici. Rome, Istituto Poligrafico dello Stato, 1961.

Bejaoui 1997 : BEJAOUI (F.) - Céramique et religion chrétienne. Les thèmes bibliques sur la Sigillée Africaine. Tunis, INP, 1997.

Bémont 2002 : BÉMONT (C.) - Les lampes de Glanum. Montpellier, Association de la RAN, 2002 (RAN, Suppl. 34).

Bémont, Bonnet 1984 : BÉMONT (C.), BONNET (J.) Lampes et fabricants de lampes. In : Studien zur römischen Keramik. Vorträge des 13. Internationalen Kongresses der $R C R F$ in München. Munich, Prähistorische Staatssammlung München, 1984, pp. 135-154. 
Bémont, Jacob 1986 : BÉMONT (C.), JACOB (J.-P.) - La sigillée gallo-romaine. Lieux de production du Haut Empire : implantations, produits, relations. Paris, MSH, 1986 (Documents d'Archéologie Française, 6).

Ben Abed, Bonifay 1998 : BEN ABED BEN KHADER (A.), BONIFAY (M.) - La céramique de l'édifice des Asclépeia à Thuburbo Majus. In : Hommages à Georges Souville, 2. Antiquités Africaines, 35, 1998 [2000], pp. 231-250.

Ben Abed, Bonifay, Fixot 1997 : BEN ABED (A.), BONIFAY (M.), FIXOT (M.) - Note préliminaire sur la céramique de la basilique orientale de Sidi Jdidi (Tunisie) (Ve-VIIe s.). In : La céramique médiévale en Méditerranée. Actes du VIe Congrès de l'AICM2 (Aix-en-Provence, 13-18 novembre 1995). Aix-enProvence, Narration, 1997, pp. 13-25.

Ben Abed, Bonifay, Griesheimer 1999: BEN ABED BEN KHADER (A.), BONIFAY (M.), GRIESHEIMER (M.) L'amphore maurétanienne de la station 48 de la Place des Corporations, identifiée à Pupput (Hammamet, Tunisie). AntAfr, 34, 1999 [2001], p 169-180.

Ben Abed, Griesheimer 2001: BEN ABED (A.), GRIESHEIMER (M.) - Fouilles de la nécropole romaine de Pupput (Tunisie). CRAI, janv.-mars 2001, pp. 553-592.

Ben Abed, Griesheimer 2004 : BEN ABED BEN KHADER (A.), GRIESHEIMER (M.) dir. - La nécropole romaine de Pupput. Rome, EFR, 2004 (Coll. de l'Ecole française de Rome, $323)$.

Ben Abed et al. 2000 : BEN ABED BEN KHADER (A.), BONIFAY (M.), FILANTROPI (G.), GIOMBLANCO (F.), GRIESHEIMER (M.), LARCHER (M.), TREGLIA (J.-C.) Une sépulture romaine tardive en milieu rural (jebel Harboun, région d'Hammamet, Tunisie). AntAfr, 36, 2000 [2002], pp. 135-144.

Ben Abed 2003 : BEN ABED (F.) - Uthina. Découverte d'un quartier d'habitat. Tunis, Centre de Publication Universitaire, 2003.

Ben Baaziz 1998 : BEN BAAZIZ (S.) - Les établissements ruraux du sahel antique : aspects sociaux-économiques. In : MRABET (A.) dir. - Du Byzacium au Sahel. Itinéraire d'une région tunisienne. Actes du colloque (Sousse, décembre 1996). Tunis, L'Or du Temps, 1998, pp. 31-50.

Ben Lazreg 1991 : BEN LAZREG (N.) - Une production du pays d'El-Jem : les carreaux de terre cuite chrétiens d'époque byzantine. In : L'Africa Romana, VIII. Sassari, Gallizzi, 1991, pp. 523-541.

Ben Lazreg 1994 : BEN LAZREG (N.) - La céramique romaine et byzantine. In : Couleurs de Tunisie, 25 siècles de céramique. Catalogue de l'exposition (Paris-Toulouse, 19941995). Paris, IMA, 1994, pp. $47-81$.

Ben Lazreg 2000 : BEN LAZREG (N.) - Archäologische und ethnographische Gegenstände und Utensilien im Zusammenhang mit dem Olivenöl. In : Der Ölbaum in der Ausstellung für Kulturerbe und Bildende Künste. Catalogue de l'exposition. Hannovre, 2000.
Ben Lazreg et al. 1995 : BEN LAZREG (N.), BONIFAY (M.), DRINE (A.), TROUSSET (P.) - Production et commercialisation des salsamenta de l'Afrique ancienne. In : L'Afrique du Nord antique et médiévale. Production et exportations africaines. Actualités archéologiques. Actes du VIe colloque d'Histoire et d'Archéologie de l'Afrique (Pau, 2529 octobre 1993). Paris, CTHS, 1995, pp. 103-142.

Ben Moussa 2000 : BEN MOUSSA (M.) - Production et circulation des sigillée africaines de la Tunisie septentrionale. Mésogeios-Méditerranée, 7, 2000, pp. 44-78.

Ben Moussa 2001 : BEN MOUSSA (M.) - Les ateliers de sigillées africaines dans la Tunisie septentrionale. Thèse de doctorat. Aix-en-Provence, Université de Provence, 2001. (dactylographiée)

Ben Younès 1988: BEN YOUNÈS (H.) - La nécropole punique d'El Hkayma. Seconde campagne, septembre 1985. Reppal, IV, 1988, pp. 49-160.

Benoit 1962 : BENOIT (F.) - Relations commerciales entre le monde ibéro-punique et le Midi de la Gaule de l'époque archaïque à l'époque romaine. REA, 63, 1961, pp. 321-330.

Béraud, Gébara, Pasqualini 1992 : BÉRAUD (I.), GÉBARA (C.), PASQUALINI (M.) - Découverte d'un vide sanitaire à la Plate-Forme de Fréjus. Provence Historique, XLII, fasc. 167168, 1992, pp. 65-82.

Bernal Casasola 1997a: BERNAL CASASOLA (D.) Economía i comercio de la Bética mediterránea y el circulo del estrecho en la Antigüedad Tardía a través del registro anfórico. Thèse de doctorat, Madrid, universidad Autónoma de Madrid. (microfiches)

Bernal Casasola 1997b : BERNAL CASASOLA (D.) - Las ánforas romanas bajoimperiales y tardoantiguas del Museo Municipal de Ceuta. In : Ánforas del Museo de Ceuta. Ceuta, Museo de Ceuta, 1997, pp. 61-129.

Bernal Casasola 1998 : BERNAL CASASOLA (D.) dir. - Los Matagallares (Salobreña, Granada). Un centro romano de producción alfarera en el siglo III d. C. Salobrena, Ayuntamiento de Salobreña, 1998.

Bernard, Bonifay 2003 : BERNARD (H.), BONIFAY (M.) Les amphores de l'épave des Embiez. In : FOY (D.) dir. - Cour de verre. Production et diffusion du verre antique. Lyon, Pôle Archéologique du Département du Rhône, 2003, pp. 166-169.

Berthault 1999 : BERTHAULT (F.) - Les amphores de la place Camille-Jullian à Bordeaux. Aquitania, XVI, 1999, pp. 251-293.

Berthier 2000: BERHIER (A.) - Tiddis, cité antique de Numidie. Paris, De Boccard, 2000 (Mémoires de l'Ac. des Inscr. et Belles Lettres, n. s., 20).

Berti 1983: BERTI (F.) - Lucerne. In: BERMOND MONTANARI (G.) - Ravenna e il porto di Classe, Venti anni di ricerche archeologiche tra Ravenna e Classe. Bologne, University Press, 1983, pp. 147-154. 
Biagini-Piera, Torre 1998 : BIAGINI-PIERA (M.), TORRE (E.) - La ceramica comune in Liguria nel VI-VII secolo : Genova. In : Saguì dir. 1998, pp. 577-584.

Bien 1998 : BIEN (S.) - Contextes de l'Antiquité tardive sur le chantier du Parc des Phocéens (îlot 24 N). In : Bonifay, Carre, Rigoir dir. 1998, pp. 275-283.

Bien 2001 : BIEN (S.) - La céramique de l'Antiquité tardive. In : BOUIRON (M.) dir. - 26 siècles d'occupation suburbaine à Marseille (B.-du-Rh.) : Document Final de Synthèse. Marseille, Ville de Marseille, 2001.

Bien 2003 : BIEN (S.) - Contextes céramiques du VIIe siècle aux abords du pavillon Bargemon à Marseille. RAN, 36, 2003, pp. 305-318.

Bien 2004 : BIEN (S.) - Des niveaux du VIIe s. sous le MusicHall de l'Alcazar à Marseille. In : 1st Conference on Late Roman Coarse Wares, Cooking Wares and Amphorae in the Mediterranean : Archaeology and Archaeometry (Barcelone, 14-16 mars 2002). Oxford, Archaeopress, 2004, sous presse (BAR IS).

Biffino et al. 1998 : BIFFINO (A.), DE FELICE (G.), FIORELLO (C. S.), LAPADULLA (E.), PIETROPAOLO (L.) - I materiali ceramici e metallici. In : VOLPE (G.) dir. - San Giusto. La villa, le ecclesiae. Primi risultati dagli scavi nel sito rurale di San Giusto (Lucera) : 1995-1997. Bari, Edipuglia, 1998, pp. 263-276.

Bjelajac 1996 : BJELAJAC (L.) - Amfore gornjomezijskog Podunavlja (Amphorae of the Danubian Basin in upper Moesia). Belgrade, Arheoloski Institut Beograd, 1996 (Posebna Izdanja 30).

Boardman 1989 : BOARDMAN (J.) - The finds. In : BALLANCE (M.), BOARDMAN (J.), CORBETT (S.), HOOD (S.) - Excavations in Chios 1952-1955. Byzantine Emporio. Oxford, The British School of Archaeology at Athens, 1989.

Boixadera et al. 1987 : BOIXADERA (M.), BONIFAY (M.), PELLETIER (J.-P.), RIGOIR (J. et Y.), RIVET (L.) - L'habitat de hauteur de Sainte-Propice (Velaux, B.-d.-Rh.). L'occupation de l'Antiquité tardive. Documents d'Archéologie Méridionale 10, 1987, pp. 91-113.

Bonifay 1983 : BONIFAY (M.) avec la collab. de PELLETIER (J.-P.) - Eléments d'évolution des céramiques de l'Antiquité tardive à Marseille d'après les fouilles de la Bourse. RAN, XVI, 1983, pp. 285-346.

Bonifay 1986 : BONIFAY (M.) - Observations sur les amphores tardives de Marseille d'après les fouilles de la Bourse (1980-1984). RAN, XIX, 1986, pp. 269-305.

Bonifay 1990 : BONIFAY (M.) - Notes céramologiques. In : BONIFAY (M.), OUESLATI (A.), PASKOFF (R.), SLIM (H.), TROUSSET (P.) - Programme tuniso-français d'étude du littoral de la Tunisie (bilan des travaux 1987-1990). Bulletin des Travaux de l'Institut National du Patrimoine, 5, janvier-juin 1990, pp. 108-112.

Bonifay 1996: BONIFAY (M.) - Annexe 1, Bey 002, Les sigillées tardives. In : Aubert 1996, pp. 85-89.
Bonifay 1998a : BONIFAY (M.) - Sur quelques problèmes de datation des sigillées africaines à Marseille. In : Saguì dir. 1998, pp. 71-82.

Bonifay 1998b : BONIFAY (M.) - Le puits de la rue du BonJésus (îlot 39N). Les vaisselles méditerranéennes importées. In : Bonifay, Carre, Rigoir dir. 1998, pp. 200-205.

Bonifay 1998c : BONIFAY (M.) - Alexandrie. Chantier du théâtre Diana. Note préliminaire sur les sigillées tardives (IVeVIIe s.). In : EMPEREUR (J.-Y.) dir. - Alexandrina 1. Le Caire, IFAO, 1998, pp. 141-148 (Etudes Alexandrines 1).

Bonifay 1998d : BONIFAY (M.) - La céramique indicateur des courants commerciaux vers la Gaule du Sud (Ve-VIIe s.). In : Comerç $i$ vies de comunicació (1000 aC - 700 dC). XI Col.loqui internacional d'arqueologia de Puigcerdà (Puigcerdà, 31 octobre-1 novembre 1997). Puigcerdà, Institut d'Estudis Ceretans, 1998, pp. 327-344.

Bonifay 2000a : BONIFAY (M.) - La fin du grand commerce méditerranéen en royaume franc ? Le témoignage de la céramique. In: Les échanges au Moyen-Age. Justinien, Mahomet et Charlemagne. Trois empires dans l'économie médiévale. Les Dossiers d'Archéologie, $\mathrm{n}^{\circ} 255$, juillet-août 2000, pp. 36-39.

Bonifay 2000b: BONIFAY (M.) - Les sigillées tardives d'Afrique du Nord. In : Coptos. L'Egypte antique aux portes $d u$ désert. Catalogue de l'exposition. Lyon, Musée des Beaux-Arts, 2000, p. 218.

Bonifay 2000c : BONIFAY (M.) - Compte-rendu de : Lucia Saguì (a cura di), Ceramica in Italia : VI-VII secolo. Atti del Convegno in onore di John W. Hayes, Roma, 11-13 maggio 1995 (biblioteca di Archeologia Medievale 14). AnTard, 8, 2000, pp. 365-368.

Bonifay 2002: BONIFAY (M.) - Les ultimes niveaux d'occupation de Sidi Jdidi, Pupput et Neapolis : difficultés de datation par la céramique. In : L'Afrique vandale et byzantine, I. Actes du colloque international (Tunis, 5-8 octobre 2000). AntTard, 10, 2002, pp. 182-190.

Bonifay 2003 : BONIFAY (M.) - La céramique africaine, un indice du développement économique ? AnTard, 11, 2003, pp. 113-128.

Bonifay 2004a : BONIFAY (M.), avec la collab. de MUKAI (T.), PIERI (D.), TREGLIA (J.-C.) - Observations préliminaires sur la céramique de la nécropole de Pupput. In : Ben Abed, Griesheimer 2004, pp. 21-58.

Bonifay 2004b : BONIFAY (M.) - Amphores de tradition punique du golfe d'Hammamet. In : Ben Abed, Griesheimer 2004, pp. 197-238.

Bonifay 2004c: BONIFAY (M.) - Observations sur la typologie des amphores africaines de l'Antiquité tardive. In : $1 s t$ Conference on Late Roman Coarse Wares, Cooking Wares and Amphorae in the Mediterranean : Archaeology and Archaeometry (Barcelone, 14-16 mars 2002). Oxford, Archaeopress, 2004, sous presse (BAR IS). 
Bonifay à paraître, a : BONIFAY (M.) - La céramique de la fosse $\mathrm{B} 846$ : un contexte du deuxième quart du Ve $\mathrm{s}$. ? In : MOREL (J.-P.) dir. - Byrsa IV. Rome, EFR, à paraître.

Bonifay à paraître, b : BONIFAY (M.) - Les céramiques sigillées africaines et phocéennes de la place Camille-Jullian à Bordeaux. Aquitania, à paraître.

Bonifay à paraître, c : BONIFAY (M.) - A la suite des remarques de Paul-Albert Février sur la céramique romaine d'Afrique du Nord. In : La Méditerranée de Paul-Albert Février (Dix ans après). Actes du colloque de Fréjus (7-8 avril 2001). Aix-en-Provence, Université de Provence, à paraître.

Bonifay à paraître, d : BONIFAY (M.) - Amphores africaines de l'oasis de Bahariya. Cahiers de la Céramique Egyptienne, 8, à paraître.

Bonifay à paraître, e : BONIFAY (M.) - Un contexte du IVe $\mathrm{s}$. sur le chantier 027 de la place des Martyrs à Beyrouth. Bulletin d'Archéologie et d'Architecture du Liban, à paraître.

Bonifay, Capelli, Long 2002 : BONIFAY (M.), CAPELLI (C.), LONG (L.) - Recherches sur l'origine des cargaisons africaines de quelques épaves du littoral français. In : RIVET (L.), SCIALLANO (M.) éd. - Vivre, produire et échanger : reflets méditerranéens. Mélanges offerts à Bernard Liou. Montagnac, EMM, 2002, pp. 195-200.

Bonifay, Carre, Rigoir dir. 1998 : BONIFAY (M.), CARRE (M.-B.), RIGOIR (Y.) dir. - Fouilles à Marseille. Les mobiliers (Ier-VIIe s.). Paris, Errance,1998 (Etudes Massaliètes 5).

Bonifay, Cerova 2002 : BONIFAY (M.), CEROVA (Y.) - Le matériel céramique. In : BEAUDRY (N.) et al. - Byllis (Albanie). In : Etudes, rapports et chroniques. BCH, 126, 2002, pp. 679-682.

Bonifay, Congès, Leguilloux 1989 : BONIFAY (M.), CONGÈS (G.), LEGUILLOUX (M.) - Amphores tardives (VVIIème siècle) à Arles et à Marseille. In : Amphores romaines et histoire économique. Dix ans de recherche. Actes du colloque de Sienne (22-24 mai 1986). Rome, EFR, 1989, pp. 660-663 (Coll. de l'Ecole française de Rome, 114).

Bonifay, Dridi, Jacquest à paraître : BONIFAY (M.), DRIDI (F.), JACQUEST (H.) - Un ensemble de céramiques du IVe s. dans une citerne du capitole d'Uthina. In : BEN HASSEN (H.), MAURIN (L.) dir. - Uthina II. Bordeaux-Paris-Tunis, Ausonius-Publications, à paraître.

Bonifay, Leffy 2002 : BONIFAY (M.), LEFFY (R.), avec la collab. de CAPELLI (C.) et PIERI (D.) - Les céramiques du remplissage de la citerne du Sérapéum à Alexandrie. In : EMPEREUR (J.-Y.) dir. - Alexandrina 2. Le Caire, IFAO, 2002, pp. 39-84 (Etudes Alexandrines 6).

Bonifay, Pieri 1995 : BONIFAY (M.), PIERI (D.) - Amphores $\mathrm{du} \mathrm{Ve}$ au VIIe s. à Marseille : nouvelles données sur la typologie et le contenu. JRA, 8, 1995, pp. 94-120.

Bonifay, Reynaud 2004 : BONIFAY (M.), REYNAUD (P.) La céramique. In : BEN ABED (A.), FIXOT (M.), BONIFAY (M.), ROUCOLE (S.) - Sidi Jdidi I. La basilique sud. Rome, EFR, 2004, sous presse (Coll. de l'Ecole française de Rome).
Bonifay, Vallauri 2003 : BONIFAY (M.), VALLAURI (L.) France méridionale. In: BONIFAY (M.) éd. - Table-ronde «De Rome à Byzance; de Fostat à Cordoue : évolution des faciès céramiques en Méditerranée ( $\mathrm{Ve}$ - IXe s.) ». In : BAKIRTZIS (C.) éd. - VIIe Congrès International sur la Céramique Médiévale en Méditerranée (Thessalonique, 11-16 octobre 1999). Athènes, Ministère de la Culture, 2003, pp. 585590 .

Bonifay, Villedieu 1989 : BONIFAY (M.), VILLEDIEU (F.) Importations d'amphores orientales en Gaule ( $\mathrm{V}^{\circ}-\mathrm{VII}^{\circ}$ siècles $)$. In : DÉROCHE (V.), SPIESER (J.-M.) dir. - Recherches sur la céramique byzantine. Athènes, EFA, 1989, pp. 17-46 (BCH, Suppl. XVIII).

Bonifay et al. 1998 : BONIFAY (M.), BRENOT (C.), FOY (D.), PELlETIER (J.-P.), PIERI (D.), RIGOIR (Y.) - Le mobilier de l'Antiquité tardive. In : Bonifay, Carre, Rigoir dir. 1998, pp. 355- 375 .

Bonifay et al. 2002-2003 : BONIFAY (M.), CAPELLI (C.), MARTIN (T.), PICON (M.), VALLAURI (L.) - Le littoral de la Tunisie, étude géoarchéologique et historique (1987-1993) : la céramique. AntAfr, 38-39, 2002-2003, sous presse.

Boninu 1971-1972 : BONINU (A.) - Catalogo della ceramica « sigillata chiara africana » del Museo di Cagliari. Studi Sardi, XXII, 1971-1972, pp. 293-352.

Borgard 1984 : BORGARD (P.) - Le Village de la Colline du Château à Fontaine de Vaucluse (Vaucluse). Un site de l'Antiquité Tardive (V-VIe siecle). Bulletin Archéologique de Provence, 13, 1994, pp. 1-14.

Bost et al. 1992 : BOST (J.-P.), CAMPO (M.), COLLS (D.), GUERRERO (V.), MAYET (F.) - L'épave Cabrera III (Majorque). Echanges commerciaux et circuits monétaires au milieu du IIIe siècle ap. J.-C. Paris, De Boccard, 1992 (Publications du Centre Pierre Paris, 23).

Bouchenaki 1975: BOUCHENAKI (M.) - Fouilles de la nécropole occidentale de Tipasa (Matarès) (1968-1970). Alger, SNED, 1975 (Bibliothèque Nationale, Histoire et Civilisations, 1).

Bouet 1999 : BOUET (A.) - Les matériaux de construction en terre cuite dans les thermes de Gaule Narbonnaise. Bordeaux, Ausonius, 1999 (Scripta Antiqua).

Bourgeois 1977 : BOURGEOIS (A.) - La céramique. In : PICARD (G. C.), PICARD (C.), BOURGEOIS (A.), BOURGEOIS (C.) - Recherches archéologiques francotunisiennes à Mactar, I. La maison de Vénus, 1. Stratigraphie et étude des pavements. Rome, EFR, 1977, pp. 87-186 (Coll. de l'Ecole française de Rome, 34).

Bourgeois 1977-78 : BOURGEOIS (A.) - Les lampes en céramique de Mactar. Karthago, XIX, 1977-78 [1980], pp. 3386.

Bourgeois 1982 : BOURGEOIS (A.) - La céramique du Sanctuaire d'Hoter Miskar à Mactar. Karthago, XX, 1982, pp. 17-69. 
Bourgeois 1985 : BOURGEOIS (A.) - Le matériel du puits de la maison de Vénus. AntAfr, 21, 1985, pp. 193-205.

Bourgeois 1986 : BOURGEOIS (A.) - La céramique sigillée de la Graufesenque en Afrique Proconsulaire. In : Melanges offerts à M. Michel Labrousse. Pallas Hors Série, 1986, pp. 323-334.

Bourgeois 2002 : BOURGEOIS (A.) - Remarques sur la sigillée claire d'époque vandale. In : L'Afrique vandale et byzantine, I. Actes du colloque international (Tunis, 5-8 octobre 2000). AntTard, 10, 2002, pp. 191-195.

Bourgeois, Gautier 1975-76 : BOURGEOIS (A.), GAUTIER (J.) - Etude au laboratoire de céramiques locales de Mactar. Karthago, XVIII, 1975-76 [1978], pp. 117-126.

Bourgeois, Mayet 1991 : BOURGEOIS (A.), MAYET (F.) Belo VI. Les sigillées. Madrid, Casa de Velásquez, 1991 (Coll. de la Casa de Velásquez, XIV).

Brun 2001 : BRUN (C.) - Etude pétrographique et analyse chimique de céramiques sigillées africaines de type D (Site de l'Alcazar, Marseille, VIIe et début VIIIe siècle ap. J.-C.). DESS, Dijon, Université de Bourgogne, 2001. (dactylographié)

Brun 1994 : BRUN (J.-P.) - Le facies céramique d'Al-Zarqa. Observations préliminaires. BIFAO, 94, 1994, pp. 7-26.

Brun 2003 : BRUN (J.-P.) - Les pressoirs à vin d'Afrique et de Maurétanie à l'époque romaine. Africa, n. s., Scéances Scientifiques, 1, 2003, pp. 7-30.

Bruno 2002 : BRUNO (B.) - Importazione e consumo di derrate nel tempio : l'evidenza delle anfore. In : ROSSI (F.) dir. - Nuove ricerche sul Capitolium di Brescia. Scavi, studi e restauri. Actes du congrès (Brescia, 3 avril 2001). Milan, ET, 2002, pp. 277-307.

Bucovala 1998 : BUCOVALA (M.) - Raport preliminar privind certetarile arheologice cu caracter de salvare din Constanta, strada Sulmona nr. 7. Pontica, XXXI, 1998, pp. 171200.

Bulla Regia I: BESCHAOUCH (A.), HANOUNE (R.), KHANOUSSI (M.), OLIVIER (A.), THÉBERT (Y.), ANTIT (A.), BONTE (J.), BROISE (H.), STORZ (S.) - Recherches archéologiques franco-tunisiennes à Bulla Regia, I. Miscellanea, 1. Rome, EFR, 1983 (Coll. de l'Ecole française de Rome, 28/I).

Bulla Regia II : BROISE (H.), THÉBERT (Y.) dir. Recherches archéologiques franco-tunisiennes à Bulla Regia, II. Les architectures, 1. Les thermes memmiens. Histoire architecturale et histoire urbaine. Rome, EFR, 1993 (Coll. de l'Ecole française de Rome, 28/II).

Bussière 2000 : BUSSIÈRE (J.) - Lampes antiques d'Algérie. Montagnac, EMM, 2000, (Monographies Instrumentum, 16).

Byrsa II : LANCEL (S.) dir. - Byrsa II, rapports préliminaires des fouilles (1977-1978) : niveaux et vestiges puniques. Rome, EFR, 1982 (Coll. de l'Ecole française de Rome, 41).

Camps 1955 : CAMPS (G.) - La nécropole de Draria-ElAchour. Libyca, III, 1955, pp. 225-264.
Camps-Fabrer 1953 : CAMPS-FABRER (H.) - L'olivier et l'huile dans l'Afrique romaine. Alger, Imprimerie Officielle, 1953.

Capelli 1998 : CAPELLI (C.) - Analisi minero-petrografiche preliminari su ceramiche di Thuburbo Majus. AntAfr, 34, 1998, pp. 251-253.

Capelli 2001 : CAPELLI (C.) - Ricerche archeometriche sulle ceramiche di S. Antonino. In : Mannoni, Murialdo 2001, pp. 727-735.

Capelli 2002-2003 : CAPELLI (C.) - Ricerche petrografiche preliminari sulle ceramiche « eoliche ». In : Bonifay et al. 20022003, sous presse.

Capelli, Ben Lazreg, Bonifay à paraître : CAPELLI (C.), BEN LAZREG (N.), BONIFAY (M.) - Nuove prospettive nelle ricerche archeometriche sulle ceramiche nordafricane : l'esempio dell'atelier di Sullecthum-Salakta (Tunisia centrale). In : Mélanges en l'honneur de T. Mannoni, à paraître.

Capelli et al. 2001 : CAPELLI (C.), BEN LAZREG (N.), BONIFAY (M.), DRINE (A.), GHALIA (T.), JEDDI (N.) - Il contributo delle analisi minero-petrografiche agli studi di provenienza sulle ceramiche antiche nordafricane. In : Geoitalia 2001, $3^{\circ}$ Forum ialiano di Scienze della Terra (Chieti). Riassunti, pp. 835-836.

Caprino 1999 : CAPRINO (C.) - Rivenimenti a Villa Adriana (Tivoli). Rome, Bretschneider, 1999 (Ac. Naz. Dei Lincei, Monumenti Antichi, S. Misc., vol. VI-1).

Carandini 1969 : CARANDINI (A.) - Una nuova forma di terra sigillata chiara. ArchClass, XXI-2, 1969, pp. 284-286.

Carandini 1970a : CARANDINI (A.) - Produzione agricola e produzione ceramica nell'Africa de età imperiale. In : Omaggio a R. Bianchi Bandinelli. Rome, De Luca, 1970, pp. 97-119 (Studi Miscellanei, 15).

Carandini 1970b : CARANDINI (A.) - Ampullae oleariae, appunti sulla produzione e il commercio della ceramica africana in età imperiale. MEFRA, 82, 1970, pp. 753-785.

Carandini 1976 : CARANDINI (A.) - Studio di una forma ceramica africana, un esempio di selezione artigianale. In: Scritti in memoria di G. Becatti. Rome, 1976, pp. 45-56 (Studi Miscellanei, 22).

Carandini 1977 : CARANDINI (A.) - La sigillata africana, la ceramica a patina cenerognola e ad orlo annerito. In : L'instrumentum domesticum di Ercolano e Pompei nella prima età imperiale. Roma, L'Erma di Bretschneider, 1977, pp. 23-24.

Carandini 1983 : CARANDINI (A.) - Pottery and the African Economy. In : GARNSEY (P. D. A.), HOPKINS (K.), WHITTAKER (C. R.) dir. - Trade in Ancient Economy. Londres, Chatto Windus, 1983, pp. 45-62.

Cardaillac 1890 : CARDAILLAC (F. de) - Histoire de la lampe antique en Afrique. Bulletin de la Société de Géographie et d'Archéologie de la Province d'Oran, 10, 1890, pp. 241-324. 
Carrazé 1976 : CARRAZÉ (F.) - De l'importance des objets isolés dans la recherche archéologique sous-marine. Cahiers d'Archéologie Subaquatique, V, 1976, pp. 65-74.

Carton 1900 : CARTON (L.) - Statuettes en terre cuite de la nécropole d'Hadrumète (Tunisie). Mémoires de la Société Nationale des Antiquaires de France, 61, 190, pp. 23-242.

Carton 1909 : CARTON (L.) - Les nécropoles de Gurza. Bulletin de la Société Archéologique de Sousse, 13, 1909, pp. 20-43.

Carton 1915 : CARTON (L.) - Les lampes d'art indigène trouvées à Thuburnic et à Simittu (suite et fin). Revue Tunisienne, 110, mai 1915, pp. 138-156.

Carton 1916 : CARTON (L.) - Les fabriques de lampes dans l'Afrique ancienne. Bulletin de la Société de Géographie et d'Archéologie de la Province d'Oran, XXXVI, 1916, pp. 61103 .

Casas et al. 1990 : CASAS (J.), CASTANYER (P.), NOLLA (J. M.), TREMOLEDO (J.) - Ceràmiques comunes $i$ de produccio local d'epoca romana. I. Materials augustals $i$ altoimperials a les comarques orientals de Girona. Gérone, Centre d'Investigaciones Arqueologices de Girona, 1990 (Serie Monogràfica, 12).

Casas, Nolla 1986-89 : CASAS (J.), NOLLA (J. M.) - Un conjunt tancat amb ceràmica africana a la vil.la romana dels Tolegassos (Viladamat, Alt Empordà). Empúries, 48-50, I, 1986-89, pp. 202-213.

Cassaigne 1914 : CASSAIGNE (Cap.) - Tombeaux et sépultures antiques des environs de Bir-Bou-Rekba (Siagu) et de Souk-el-Abiod (Puppu). Cahiers d'Archéologie Tunisienne, n. s., 2, 1914, pp. 19-66.

Castanyer, Tremoleda, Roure 1990: CASTANYER I MASOLIVER (P.), TREMOLEDA I TRILLA (J.), ROURE I BONAVENTURA (A.) - Un conjunt ceràmic de finals del segle III d. C. a Vilauba (Camós, Pla de l'Estany). Cypsela, VIII, 1990, pp. 157-191.

Castanyer, Tremoleda 1999 : CASTANYER I MASOLIVER (P.), TREMOLEDA I TRILLA (J.) - La vil.la romana de Vilauba. Un exemple de l'ocupació $i$ explotació romana del territori a la comarca del pla de l'Estany. Gérone, 1999.

Catalo, Foy, Llech 1998 : CATALO (J.), FOY (D.), LLECH (L.) - Mobilier de la fin de l'Antiquité et du haut Moyen-Age, à Toulouse sur le site du "Donjon du Capitole ». Céramiquesverres-creusets de verrier. Archéologie Médiévale, XXVIII, 1998, pp. 1-31.

Catani 1989: CATANI (E.) - Lucerne fittili dalla fattoria bizantina di Siret el Giamel in Cirenaica : tipologia ed inquadramento cronologico. In : L'Africa Romana, VI. Sassari, Gallizzi, 1989, pp. 459-474.

C.A.T.H.M.A. 1986 : Association C.A.T.H.M.A. (G. Démians d'Archimbaud, M. Bonifay, J.-P. Pelletier, M. Picon, Cl. Raynaud, Y. et J. Rigoir, L. Rivet, L. Vallauri) - La céramique du Haut Moyen-Age en France méridionale : Eléments comparatifs et essai d'interprétation. In : La Ceramica
Medievale nel Mediterraneo Occidentale. Actes du colloque (Sienne-Faenza, 8-12 octobre 1984). Florence, All'Insegna del Giglio, 1986, pp. 27-50.

C.A.T.H.M.A. 1990 : Association C.A.T.H.M.A. Quantification et chronologie: quelques applications sur des contextes de l'Antiquité tardive et du haut Moyen-Age dans le Midi de la Gaule; méthodes, intérêts et limites. In : SFECAG, Actes du congrès de Mandeure-Mathay (24-27 mai 1990). Marseille, 1990, pp. 149-160.

C.A.T.H.M.A. 1991 : association C.A.T.H.M.A. (M. Bonifay, Cl. Raynaud, J. et Y. Rigoir, L. Rivet, L. Vallauri) Importations de céramiques communes méditerranéennes dans le Midi de la Gaule (Ve-VIIe s.). In : A cerâmica medieval no Mediterrâneo Ocidental, IV Congresso Internacional (Lisbonne, 16-22 novembre 1987). Mértola, 1991, pp. 27-48.

Cavaillès-Llopis 1986 : CAVAILLÈS-LLOPIS (M.-T.) Céramiques de l'Antiquité tardive à Marseille (corne du port antique, sondages DII11 et DII15). Documents d'Archéologie Méridionale 9, 1986, pp. 167-195.

Cavaillès-Llopis, Vallauri 1994 : CAVAILLÈS-LLOPIS (M.), VALLAURI (L.) - Les céramiques fines importées. In: Démians d'Archimbaud (G.) dir. - L'oppidum de Saint-Blaise du Ve au VIIe s. (Bouches-du-Rhône).Paris, MSH, 1994, pp. 86115 (Documents d'Archéologie Française, 45).

Ceci 2001 : CECI (M.) - La production des lampes à huile : l'exemple de l'atelier d'Annius Serapiodorus. In : DESCOEUDRES (J.-P.) - Ostia, port et porte de Rome. Genève, Musées d'Art et d'Histoire, 2001, pp. 192-195.

Ceci 2003 : CECI (M.) - L'officina di Annius Serapiodorus ad Ostia. RCRF Acta, 38, 2003, pp. 73-76.

Celuzza, Rendini 1991 : CELUZZA (M.), RENDINI (P.) dir. Relitti di storia. Archeologia subacquea in Maremma. Catalogue de l'exposition. Sienne, Nuova Immagine, 1991.

Chapman, Davies, Peacock 1984 : CHAPMAN (S. V.), DAVIES (S. M.), PEACOCK (D. P. S.) - The Lamps. In : Fulford, Peacock 1984, pp. 232-241.

Chergui, Ichkhakh, Limane 2000 : CHERGUI (A.), ICHKHAKH (A.), LIMANE (H.) - Note sur un moule en terre cuite. In : L'Africa Romana, XIII. Rome, Carocci, 2000, pp. 1261-1625.

Chrzanovski et al. 1998-1999: CHRZANOVSKI (L.) , SANDOZ (C.), PICCAMIGLIO (A.), REMY (B.) - Catalogue de la collection Dr A. Devant, Musée de Viuz Faverges. Lampes et monnaies romaines de Carthage. Bulletin d'Histoire et d'Archéologie Les Amis de Viuz-Faverges, 38-39, 1998-1999, pp. 1-72.

Cintas 1950 : CINTAS ( P.) - Céramique punique. Paris, Klincksieck, 1950 (Publications de l'Institut des Hautes Etudes de Tunis, III).

Cintas, Duval 1958 : CINTAS (P.), DUVAL (N.) - L'église du prêtre Félix (région de Kelibia). Karthago, IX, 1958, pp. 156269. 
Ciotola 2000 : CIOTOLA (A.) - Le ceramiche da mensa, da cucina, le lucerne : un'analisi preliminare. In : De Vos 2000, pp. 38-49.

Cipriano, Carre 1987 : CIPRIANO (M. T.), CARRE (M.-B.) Note sulle anfore conservate nel museo di Aquileia. Antichità Altoadriatiche, XXIX, II, 1987, pp. 479-494.

Clariana, Jarrega 1994 : CLARIANA I ROIG (J.-F.), JARREGA I DOMINGUEZ (R.) - Estudi de la fase baix imperial de la vil.la romana de Torre Llauder (Mataro, El Maresme). Les ceràmiques. Laietana, 9, 1994, pp. 253-289.

$\boldsymbol{C M A}$ : Feu DU COUDRAY LA BLANCHERE, GAUCKLER (P.) - Catalogue des Musées et Collections Archéologiques de l'Algérie et de la Tunisie. Musée Alaoui. Paris, E. Leroux, 1897.

CMA Suppl. : HAUTECEUR (L.), MERLIN (A.), POINSSOT (L.) - Catalogue du Musée Alaoui. Supplément. Paris, E. Leroux, 1909.

CMA Suppl. 2 : MERLIN (A.), LANTIER (R.) - Catalogue du Musée Alaoui. 2eme Supplément. Paris, E. Leroux, 1922.

Cœur-Mezzoud 1998 : CEEUR-MEZZOUD (F.) - Les fouilles de la Bourse (1967-1984). La vaisselle du sondage 10. In : Bonifay, Carre, Rigoir dir. 1998, pp. 137-161.

Combès, Louis 1967 : COMBÈS (J.-L.), LOUIS (A.) - Les potiers de Djerba. Tunis, 1967 (Publication du Centre des Arts et Traditions Populaires, 1).

Condamin et al. 1976 : CONDAMIN (J.), FORMENTI (F.), METAIS (M. O.), MICHEL (M.), BLOND (P.) - The application of gas chromatography to the tracing of oil in ancient amphorae. Archaeometry, 18, 1976, pp. 195-201.

Conimbriga IV : DELGADO (M.), MAYET (F.), MOUTINHO DE ALARCÃO (A.) - Fouilles de Conimbriga, IV. Les sigillées. Paris, De Boccard, 1975.

Congès, Leguilloux 1991 : CONGÈS (G.), LEGUILLOUX (M.) - Un dépotoir de l'Antiquité Tardive dans le quartier de l'Esplanade à Arles. RAN, 24, 1991, pp. 201-234.

Congès et al. 1983 : CONGÈS (G.), BONIFAY (M.), BRUN (J.-P.), PASQUALINI (M.) - Un dépotoir de la fin de l'Antiquité dans la grotte de La Fourbine, St. Martin-de-Crau. $R A N$, XVI, 1983, pp. 347-364.

Conrad 1999: CONRAD (S.) - $\mathrm{Zu}$ Typologie und Funktionsbestimmung der Amphoren aus dem Kastell Iatrus. In: Der Limes an der unteren Donau von Diokletian bis Heraclios. Actes du congrès international (Sofia, 1-5 septembre 1978). Sofia, 1999, pp. 175-188.

Courtois 1955 : COURTOIS (C.) - Les Vandales et l'Afrique. Paris, A.M.G., 1955.

Cristofani, Zevi 1966 : CRISTOFANI (M.), ZEVI (F.) - Su alcuni tipi di anfore ostiensi. Archeologia (problemi-ricerchescoperte), IV, 31, pp. 9-15.
Crypta Balbi : ARENA (M. S.) et al. - Roma dall'antichità al Medioevo : archeologia e storia nel Museo Nazionale romano Crypta Balbi. Milan, Electa, 2001.

Cunja 1991 : CUNJA (R.), Katalog/Catalogo. In : GUŠTIN (M.) dir. - Koper, zwischen Rom und Venedig/Capodistria, tra Roma e Venezia. Koper, 1991, pp. 40-88.

D'Alembert, Diderot 1751-1765 : D'ALEMBERT (J. LE ROND), DIDEROT (D.) - Encyclopédie ou dictionnaire raisonné des arts et métiers. Paris, 1751-1765.

D'Oriano 1989 : D'ORIANO (R.) - Matrici tipo Uzita-Ostia dalla Sardegna. In : L'Africa Romana, VI. Sassari, Gallizzi, 1989, pp. 503-512.

Darmon 1964 : DARMON (J.-P.) - Note sur le tarif de Zaraï. Les Cahiers de Tunisie, XII, 1964, pp. 7-23.

De Caro 1994 : DE CARO (S.) - La villa rustica in località Villa Regina a Boscoreale. Rome, Bretschneider, 1994.

Delattre 1889 : DELATTRE (R. P.) - Catalogue du Musée Lavigerie de Carthage. Paris, 1889.

Delattre 1907 : DELATTRE (R. P.) - Le culte de la Sainte Vierge en Afrique d'après les monuments archéologiques. Paris, Saint-Augustin, 1907.

Delattre 1913 : DELATTRE (R. P.) - Lampes romaines trouvées à Bordj Djedid. Revue Tunisienne, 20, pp. 185-189, 299-306, 439-446.

Dello Preite 1997 : DELLO PREITE (A.) - Sigillata africana. In : DI VITA (A.), MARTIN (A.) - Gortina II. Pretorio. Il materiale degli scavi Colini 1970-1977. Padoue, Aldo Ausilio, 1997, pp. 132-154 (Monografie della Scuola Archeologica di Atene e delle missioni italiane in Oriente, VII).

Del Vais 1998a : DEL VAIS (C.) - La céramique culinaire africaine (Fouilles de la Bourse, secteur de l'épave). In : Bonifay, Carre, Rigoir dir. 1998, pp. 78-81.

Del Vais 1998b : DEL VAIS (C.) - Les lampes (Fouilles de la Bourse, secteur de l'épave). In : Bonifay, Carre, Rigoir dir. 1998, pp. 75-77.

Deneauve 1964-65 : DENEAUVE (J.) - Terres cuites de l'Afrique romaine. In : Mélanges de Carthage offerts à Ch. Saumagne, L. Poinssot et M. Pinard. Paris, 1964-65, pp. 123134 (Cahiers de Byrsa, $\mathrm{N}^{\circ}$ spécial).

Deneauve 1969 : DENEAUVE (J.) - Lampes de Carthage. Paris, CNRS, 1969 (Etudes d'Antiquités Africaines).

Deneauve 1972 : DENEAUVE (J.) - Céramique et lampes africaines sur la côte de Provence. AntAfr, 6, 1972, pp. 219-240.

Deneauve 1974 : DENEAUVE (J.) - Un dépotoir paléochrétien sur la colline de Byrsa à Carthage. AntAfr, 8, 1974, pp. 133-156.

Deneauve 1986a : DENEAUVE (J.) - Note sur quelques lampes africaines du IIIe siecle. AntAfr, 22, 1986, pp. 141-161. 
Deneauve 1986b : DENEAUVE (J.) - Un groupe de moules africains en terre cuite et les éléments similaires découverts en Gaule. In : SFECAG, Actes du congrès de Toulouse (9-11 mai 1986). Marseille, 1986, pp. 139-143.

Deneauve 1987 : DENEAUVE (J.) - Figurines et lampes africaines. AntAfr, 23, 1987, pp. 197-251.

De Romanis 2003 : DE ROMANIS (F.) - Per una storia del tributo granario africano all'anona della Roma imperiale. In : MARIN (B.), VIRLOUVET (C.) éd. - Nourrir les cités de Méditerranée, Antiquité-Temps Modernes. Paris, L'atelier méditerranéen, 2003, pp. 691-738.

Despois 1955 : Despois (J.) - La Tunisie orientale, Sahel et Basses Steppes. Etude géographique. Paris, P.U.F., 1955 (Publication de l'Institut des Hautes Etudes de Tunis - Section des Lettres - Vol. I).

De Vos 2000 : DE VOS (M.) - Rus Africum. Terra acqua olio nell'Africa settentrionale. Scavo e ricognizione nei dintorni di Dougga (alto tell tunisino). Catalogue de l'exposition. Trento, Università degli Studi di Trento, 2000 (Labirinti, 50).

De Vos, Polla, Gliozzo 2004 : DE VOS (M.), POLLA (S.), GLIOZZO (E.) - Pottery from rural settlements around Dougga (Northern Tunisia). In : 1st Conference on Late Roman Coarse Wares, Cooking Wares and Amphorae in the Mediterranean : Archaeology and Archaeometry (Barcelone, 14-16 mars 2002). Oxford, Archaeopress, 2004, sous presse (BAR IS).

Dietz, Trolle 1979 : DIETZ (S.), TROLLE (S.) dir. - Premier rapport préliminaire sur les Fouilles Danoises à Carthage. Les campagnes de 1975 et 1977. Copenhague, Museum National, 1979 (Working Papers, The National Museum of Denmark, 10).

Di Vita-Evrard 1985 : DI VITA-EVRARD (G.) - Note sur quelques timbres d'amphores de Tripolitaine. $B C T H$, nouv. ser., fasc. $19 \mathrm{~B}, 1985$, pp. 147-159.

Dodinet, Leblanc 1988 : DODINET (M.) et LEBLANC (J.) La production de céramique gallo-romaine à « bords noircis » et à « patine cendrée » dans le Biterrois. Documents d'Archéologie Méridionale, 11, 1988, pp. 135-143.

Dore 1989 : DORE (J.) - The coarse pottery. In : DORE (J.), KEAY (N.) dir. - Excavations at Sabratha 1948-1951. Vol. II. The finds. Tripoli, Society for Libyan Studies, 1989, pp. 87-248.

Dore 1992 : DORE (J. N.), avec la collab. de SCHINKE (R.) First report on the pottery. In : Leptiminus I, pp. 115-156.

Dore 1996 : DORE (J.) - The UNESCO Libyan Valleys Archaeological Survey Pottery. In : BARKER (G.), GILBERTSON (D.), JONES (B.), MATTINGLY (D.) Farming the Desert. The UNESCO Libyan Valleys Archaeological Survey, 2. Gazetter and Pottery. Londres, UNESCO/Soc. Lib. Stud., 1996, pp. 318-389.

Dore 2001 : DORE (J.) - The major pottery deposits following the disuse of the East Baths. In : Leptiminus II, pp. 75-98.

Dovis-Vicente 2001 : DOVIS-VICENTE (C.) - Etude du commerce maritime au IVe siècle : cas de l'épave de la
Luque B. Villeneuve d'Ascq, Presses Universitaires du Septentrion, 2001.

Drine 1999 : DRINE (A.) - Restes de pressoirs à huile et à vin à Gigthi et à Zarzis. Africa, XVII, 1999, pp. 47-68.

Durliat 1990 : DURLIAT (J.) - De la ville antique à la ville byzantine : le problème des subsistances. Rome, EFR, 1990 (Coll. de l'Ecole française de Rome, 136).

Duval 1971: DUVAL (N.) - Recherches archéologiques à Sbeitla, I. Les basiliques de Sbeitla à deux sanctuaires opposés (Basiliques I, II et IV). Paris, de Boccard, 1971 (Bibl. BEFAR, 218).

Duval 1994 : DUVAL (N.) - L'histoire de l'Afrique du nord chrétienne et le rôle de saint Augustin. In : Carthage, l'histoire, la trace et son écho. Catalogue de l'exposition (Paris, 1995). Paris, Ed. des musées de la ville de Paris, 1994, pp. 276-291.

Dvoržak Schrunk 1989 : DVORŽAK SCHRUNK (I.) - The Red Slip wares. In : MC NALLY (S.), MARASOVIC (J.), MARASOVIC (T.) dir. - Diocletian's Palace, AmericanYugoslav Joint Excavations, vol. V. Minneapolis, University of Minesota, 1989, pp. 47-208.

Egloff 1977 : EGLOFF (M.) - Kellia, La poterie copte, Quatre siècles d'artisanat et d'échanges en Basse-Egypte. Genève, 1977 (Recherches Suisses d'Archéologie Copte, vol. III).

Eiwanger 1981 : EIWANGER (J.) - Demetrias $I V$. Keramik und Kleinfunde aus der Damokratia-Basilika in Demetrias. Bonn, Rudolf Habelt, 1981 (Die deutschen archäologischen Forschungen in Thessalien). 2 vol.

Emery, Kirwan 1938 : EMERY (W. B.), KIRWAN (L. P.) The Royal Tombs of Ballana and Qustul. Le Caire, 1938 (Mission Archéologique de Nubie 1929-1934). 2 vol.

Ennabli 1970-73 : ENNABLI (A.) - Lampes en terre cuite. In : ENNABLI (A.), MAHJOUBI (A.), SALOMONSON (J.-W.) La nécropole romaine de Raqqada. Tunis, 1970-73, pp. 83-143. ( Coll. Notes et Documents, VIII, 1-2).

Ennabli 1976 : ENNABLI (A.) - Lampes chrétiennes de Tunisie (Musée du Bardo et de Carthage). Paris, CNRS, 1976 (Etudes d'Antiquités Africaines).

Ennabli, Mahjoubi, Salomonson 1973: ENNABLI (A.), MAHJOUBI (A.), SALOMONSON (J.-W.) - La nécropole romaine de Raqqada. Tunis, 1973 (Coll. Notes et Documents, VIII, 2).

Ennabli 2000 : ENNABLI (L.) - La basilique de Carthagenna et le locus des sept moines de Gafsa. Nouveaux édifices chrétiens de Carthage. Paris, CNRS, 2000 (Etudes d'Antiquités Africaines).

Ennaïfer 1976 : ENNAÏFER (M.) - La cité d'Althiburos et l'édifice des Asclepieia. Tunis, INAA, 1976 (Bibliothèque Archéologique, I).

Fallico 1967 : FALLICO (A.-M.) - Ragusa, Esplorazione di necropoli tarde. NSA, 1967, pp. 407-418. 
Fantar 1984 : FANTAR (M.) - Kerkouane, cité punique du Cap Bon (Tunisie), I. Tunis, INAA, 1984.

Faraj Shakshuki, Shebani 1998 : FARAJ SHAKSHUKI (M.), SHEBANI (R.) - The roman kilns of Hai al-Andalus, Tripoli. Libya Antiqua, n. s. 4, 1998, pp. 279-282.

Fayolle 1992 : FAYOLLE (V.) - La poterie modelée du Maghreb oriental de ses origines au XXes. Technologie, morphologie, fonction. Paris, CNRS, 1992.

Felici, Pentiricci 2002 : FELICI (F.), PENTIRICCI (M.) - Per una definizione delle dinamiche economiche e commerciali del territorio di Leptis Magna. In : Lo spazio marittimo del Mediterraneo occidentale : geografia storica ed economia. L'Africa Romana, XIV. Roma, Carocci, 2002, pp. 1875-1900.

Fendri 1961 : FENDRI (M.) - Basiliques chrétiennes de la Skhira. Paris, P.U.F., 1961.

Fentress 2001 : FENTRESS (L.) - Villas, wine and kilns : the landscape of Jerba in the late Hellenistic period. JRA, 14, 2001, pp. 249-268.

Fentress, Perkins 1988 : FENTRESS (E.), PERKINS ( P.) Counting African Red Slip Ware. In : L'Africa Romana, V. Sassari,Università di Sassari, 1988, pp. 205-221.

Fentress et al. 2004: FENTRESS (L.), FONTANA (S.), HITCHNER (B.), PERKINS (P.) - Accounting for ARS : Fineware and Sites in Sicily and Africa. In : ALCOCK (S. E.), CHERRY (J. F.) éd. - Side-by-Side Survey: Comparative Regional Studies in the Mediterranean World. Oxford, Oxbow, 2004, pp. 147-162.

Féraud 1987 : FÉRAUD (J.-B.) - Découvertes de spatheia à Saint-Jean-de-Garguier «Locus Gargarius ». Archéologie du Midi Médiéval, 5, 1987, pp. 181-182.

Ferron, Aubet 1974 : FERRON (J.), AUBET (M. E.) - Orants de Carthage. Paris, 1974 (Coll. Cahiers de Byrsa, Série Monographique, I). 2 vol.

Ferjaoui 1993 : FERJAOUI (A.) - Recherches sur les relations entre l'Orient phénicien et Carthage. Fribourg, Editions Universitaires, 1993 (Orbis Biblicus et Orientalis, 124).

Février 1963 : FÉVRIER (P.-A.) - Remarques préliminaires sur la céramique romaine d'Afrique du Nord (à propos des fouilles de Sétif). RELig, XXIX, 1963, pp. 125-136.

Février 1964 : FÉVRIER (P.-A.) - Remarques sur la céramique d'Afrique du Nord. Cahiers de Tunisie, 12, 1964, pp. 129-137.

Février 1965 : FEVRIER (P.-A.) - Fouilles de Sétif. Les basiliques chrétiennes du quartier nord-ouest. Paris, CNRS, 1965.

Février 1976 : FÉVRIER (P.-A.) - De Sétif à Conimbriga, en passant par l'Orient (à propos de la céramique de la fin de l'Antiquité). Conimbriga, XV, 1976, pp. 63-72.

Février 1980 : FÉVRIER (P.-A.) - A propos de la céramique de Méditerranée occidentale (Ier-VIe siècle après J.-C.). In : Céramiques hellénistiques et romaines. Paris, Annales
Littéraires de l'Université de Besançon, 1980, pp. 159-200 (Centre de Recherches d'Histoire Ancienne, vol. 36).

Février 1982 : FÉVRIER (P.-A.) - A quoi sert la céramique? Provence Historique, 32, 1982, pp. 235-240.

Février 1989 : FÉVRIER (P.-A.) - Approches du Maghreb romain. Pouvoirs, différences et conflits, I. Aix-en-Provence, Edisud, 1989.

Février 1990 : FÉVRIER (P.-A.) - Approches du Maghreb romain. Pouvoirs, différences et conflits, II. Aix-en-Provence, Edisud, 1990

Février 1992 : FÉVRIER (P.-A.) - Quelques observations sur la céramique des IVe-VIIe siècles. In : III Reunio d'Arqueologia Cristiana Hispànica (Maó, 1988). Barcelone, 1992, pp. 245255 .

Février, Leyge 1986 : FÉVRIER (P.-A.), LEYGE (F.) dir. Premiers temps chrétiens en Gaule méridionale : Antiquité tardive et haut Moyen-Age, IIIe-VIIIe siècle. Catalogue de l'exposition. Lyon, 1986.

Fingerlin et al. 1968 : FINGERLIN (G.), GARBSCH (J.), WERNER (J.) - Die Ausgrabungen in longobardische Kastell Ibligo-Invillino (Friaul). Aquileia Nostra, 39, 1968, pp. 57-135.

Fixot 1990 : FIXOT (M.) dir. - Le site de Notre-Dame d'Avinionet à Mandelieu. Paris, CNRS, 1990 (Monographie du CRA n $\left.{ }^{\circ} 3\right)$.

Floriani Squarciapino 1954 : FLORIANI SQUARCIAPINO (M.) - Forme Ostiensi. ArchClass, VI, fasc. 1, 1954, pp. 83-99.

Fontana 1998 : FONTANA (S.) - Le «imitazioni» della sigillata africana e le ceramiche da mensa italiche tardo-antiche. In : Saguì dir. 1998, pp. 83-100.

Fontana 2000 : FONTANA (S.) - Un « immondezzaio » di VI secolo da Meninx : la fine della produzione di porpora e la cultura materiale a Gerba nella prima età bizantina. In : L'Africa romana, XIII. Roma, Carocci, 2000, pp. 95-114.

Formenti, Hesnard, Tchernia 1978: FORMENTI (F.), HESNARD (A.), TCHERNIA (A.) - Une amphore "Lamboglia 2" contenant du vin dans la Madrague de Giens. Archaeonautica, 2, 1978, pp. 95-100.

Foy 1998 : FOY (D.) - Méprise sur l'iconographie d'un four de verrier antique. In : Hommages à Georges Souville, 2. AntAfr, 35, 1998 [2000], pp. 227-230.

Foy, Nenna 2001 : FOY (D.), NENNA (M.-D.) - Tout feu, tout sable. Mille ans de verre antique dans le Midi de la France. Aix-en-Provence, Musées de Marseille/Edisud, 2001.

Freed 1983 : FREED (J.) - Pottery from the late middens at San Giovanni. In : GUALTIERI (M.), SALVATORE (M.), SMALL (A. M.) éd. - Lo Scavo di San Giovanni di Ruoti ed il periodo tardo antico in Basilicata. Bari, 1983, pp. 91-106.

Freed 1990 : FREED (J.) - Tunisian amphoras of the fourth century A. D. built into the roman theater at Carthage. $C E D A C$, 11, juin 1990, pp. 19-22. 
Freed 1993 : FREED (J.) - Pottery from sondage 1. In : STEVENS (S.) dir. - Bir El Knissia at Carthage : A rediscovered cemetery church, Report no. 1. Ann Arbor, 1993, pp. 73-92 (JRA, Suppl. Ser. 7).

Freed 1994 : FREED (J.) - The Pottery from the Late-Roman Shipwreck. In : Mc CANN (A. M.), FREED (J.) - Deep Water Archaeology : a Late Roman Ship from Carthage and an ancient Trade Route near Skerki Bank of Northwest Sicily. Ann Arbor, 1994, pp. 21-48 (JRA, Suppl. Ser. 13).

Freed 1995 : FREED (J.) - The late series of Tunisian cylindrical amphoras at Carthage. JRA, 8, 1995, pp. 155-191.

Freed 2000 : FREED (J.) - Adoption of the form of the Koan amphora to the production of « Dressel 2-4 » amphoras in Italy and northeastern Spain. RCRF Acta, 36, 2000, pp. 459-466.

Freed, Hurst 1991 : FREED (J.), HURST (H.) - Pottery from dredging of the circular harbour, May 1990. CEDAC, 12, juin 1991, pp. 24-28.

Freed, Wilson 1999 : FREED (J.), WILSON (R. J. A.) Sicilian Naxian Wine Amphoras : A New Look at Wine in North Africa. AJA, 103, 1999, pp. 268.

Fremersdorf 1958 : FREMERSDORF (F.) - Nordafrikanische Terra Sigillata aus Köln. Kölner Jahrbuch für Vor- und Frühgeschichte, 3, 1958, pp. 11-19.

Fulford 1980 : FULFORD (M. G.) - Overseas Trade and the Political Economy, c AD 400-700. Reading Medieval Studies, vol. 6,1980, pp. 68-80.

Fulford 1983 : FULFORD (M. G.) - Pottery and the Economy of Carthage and its Hinterland. Opus, II, 1983, pp. 5-14.

Fulford 1984a : FULFORD (M. G.) - The Red-slipped Wares. In : Fulford, Peacock 1984, pp. 48-115.

Fulford 1984b : FULFORD (M. G.) - The Coarse (kitchen and domestic) and Painted Wares. In : Fulford, Peacock 1984, pp. 155-231.

Fulford 1987 : FULFORD (M. G.) - Economic interdependance among urban communities of the Roman Mediterranean. World Archaeology, 19-1, 1987, pp. 58-75.

Fulford 1989 : FULFORD (M. G.) - Byzantium and Britain : a Mediterranean perspective on Post-Roman Mediterranean Imports in Western Britain and Ireland. Medieval Archaeology, XXXIII, 1989, pp. 1-6.

Fulford 1994 : FULFORD (M. G.) - The Cooking and Domestic wares. In : Fulford, Peacock 1994, pp. 53-75.

Fulford, Peacock 1984 : FULFORD (M. G.), PEACOCK (D. P. S.) - Excavations at Carthage : The British Mission, Vol. I, 2, The avenue du Président Habib Bourguiba, Salambo : The Pottery and other Ceramic Objects from the site. Sheffield, University of Sheffield, 1984.

Fulford, Peacock 1994 : FULFORD (M. G.), PEACOCK (D. P. S.) dir. - Excavations at Carthage, II, 2, The circular
Harbour, North side, The pottery. Oxford, The British Academy, 1994.

Fulford, Timby 1994 : FULFORD (M. G.) ET TIMBY (J.) The fine wares. In : Fulford, Peacock 1994, pp. 1-22.

Fulford, Tomber 1994 : FULFORD (M. G.), TOMBER (R.) Excavations at Sabratha 1948-1951, II. The Finds, 2. The Finewares and Lamps. Londres, The Society for Libyan Studies, 1994 (Monograph No. 3).

Gagnière 1965 : GAGNIÈRE (S.) - Les sépultures à inhumation du IIIe au XIIIe $s$. de notre ère dans la Basse Vallée $\mathrm{du}$ Rhône. Essai de chronologie typologique. Cahiers Rhodaniens, XII, 1965, pp. 53-110.

Galli 2000 : GALLI (F.) - Le Lucerne del Museo «G. A. Sanna» di Sassari. Piedimonte Matese, Soprintendenza Archeologica di Sassari e Nuoro/Imago Media, 2000.

Galliou 1990 : GALLIOU (P.) - Afrique et Armorique. A propos d'une amphore d'Afrique du Nord mise au jour à Rennes. AntAfr, 26, 1990, pp. 223-229.

Gandolfi 1981 : GANDOLFI (D.) - Terra sigillata chiara D di Albintimilium. RELig, XLVII, 1-4, 1981, pp. 53-149.

Garcea 1999 : GARCEA (F.) - Le produzioni di lucerne fittili nel golfo di Napoli fra tardoantico ed altomedioevo (IV-VIII secolo). Archeologia Medievale, XXVI, 1999, pp. 447-461.

García, Rosselló 1992 : GARCÍA VILLANUEVA (I.), ROSSELLÓ MESQUIDA (M.) - Las ánforas tardorromanas de Punta de l'Illa de Cullera. In : Estudios de Arqueología Ibérica y Romana, Homenaje a Enrique Pla Ballester. Valence, Servicio de Investigación Prehistórica,1992, p 639-661 (Serie de Trabajos Varios, 89).

Gauckler 1895 : GAUCKLER (P.) - Musée de Cherchel. Paris, E. Leroux, 1895 (Musées et collections archéologiques de l'Algérie et de la Tunisie).

Gauckler 1896 : GAUCKLER (P.) - Le domaine des Laberii à Uthina. Paris, 1896, pp. 177-229 (Monuments Piot, III).

Gauckler 1897 : GAUCKLER (P.) - Rapport épigraphique sur les découvertes en Tunisie par le Service des Antiquités. BCTH, 1897, pp. 454-458.

Gempeler 1992 : GEMPELER (R. D.) - Elephantine X, Die Keramik römischer bis früharabischer Zeit. Mayence, Philipp von Zabern, 1992 (Archäologische Veröffentlichungen, 43).

Ghalia, Bonifay, Capelli 2004: GHALIA (T.), BONIFAY (M.), CAPELLI (C.) - L'atelier de Sidi-Zahruni : mise en évidence d'une production d'amphores de l'Antiquité tardive sur le territoire de la cité de Neapolis (Nabeul, Tunisie). In : 1st Conference on Late Roman Coarse Wares, Cooking Wares and Amphorae in the Mediterranean : Archaeology and Archaeometry (Barcelone, 14-16 mars 2002). Oxford, Archaeopress, 2004, sous presse (BAR IS).

Gibbins 2001 : GIBBINS (D. J. L.) - A Roman shipwreck at Plemmirio, Sicily ; evidence for north African amphora 
production during the Severan period. World Archaeology, 32 (3), 2001, pp. 311-334

Gibbins, Parker 1986 : GIBBINS (D. J. L.), PARKER A. J.) The roman Wreck of c. AD 200 at Plemmirio, near Syracusa (Sicily) : interim report. IJNA, 15, 1986, pp. 267-304.

Gilkes, King, French 1999 : GILKES (O. J.), KING (A.), FRENCH (A.) - From villa to village : ceramics and Late Antique settlement in the Sabina Tiberina. Archeologia Medievale, XXVI, 1999, pp. 269-277.

Ginouvez 1996-97 - GINOUVEZ (O.) dir., AMANDRY (M.), BELBENOIT (V.), DURAND (G.), FEUGËRE (M.), FOY (D.), GADEISEN (A.), MANNIEZ (Y.), PRADIÈS (C.), RICHIER (A.) - Les fouilles de l'Hôtel-Dieu de Narbonne. Bulletin de la Commission Archéologique et Littéraire de Narbonne, 47-48, 1996-97, pp. 115-186.

Girard, Raynaud 1982 : GIRARD (A.), RAYNAUD (C.) Une nécropole du IVe siècle de notre ère à Lansargues (Hérault). Documents d'Archéologie Méridionale, 5, 1982, pp. 159-167.

Goethert 1997: GOETHERT (K.) - Römische Lampen und Leuchter. Auswahlkatalog des Rheinischen Landesmuseums Trier. Trèves, Rheinisches Landesmuseum, 1997 (Schriftenreihe des rheinischen Landesmuseums Trier, 14).

Gonzalez Villaescusa 1990 : GONZALEZ VILLAESCUSA (R.) - El vertedero de la Avda. de España, 3 y el siglo III d. de C. en Ebusus. Ibiza, 1990 (Trabajos del Museo Arqueológico de Ibiza, $\left.\mathrm{n}^{\circ} 22\right)$.

Gonzalez Villaescusa 1993 : GONZALEZ VILLAESCUSA (R.) - Origine et diffusion d'une forme peu courante de céramique africaine. nouvelle contribution à la connaissance du commerce de Byzacène au IIIe s. après J.-C. AntAfr, 29, 1993, pp. 151-161.

Goodchild 1951 : GOODCHILD (R. G.) - Roman sites on the Tarhuna plateau of Tripolitania. PBSR, 19, 1951, pp. 43-77.

Gourvest 1998 : †GOURVEST (J.) - Introduction à l'étude des Terres Sigillées Claires, Orangées et Luisantes. Essai de classification du matériel des fouilles de Marseille. In : Bonifay, Carre, Rigoir dir. 1998, pp. 19-52.

Grace 1961 : GRACE (V. R.) - Amphoras and the ancient Wine Trade. Princeton, American School of Classical Studies at Athens, 1961.

Graziani Abbiani 1969 : GRAZIANI ABBIANI (M.) Lucerne fittili paleocristiane nell'italia settentrionale. Bologne, 1969 (Studi di antichità cristiana, 6).

Gridel 1926 : GRIDEL (H.) - Note sur un temple à Sidi El Hani. Bulletin de la Société Archéologique de Sousse, 17, 1926, pp. $74-80$.

Guerrini 1974 : GUERRINI (L.) - Materiali ceramici. In : Missione Archeologica in Egitto dell'Università di Roma Antinoe (1965-1968). Rome, Istituto di Studi del Vicino Oriente, 1974.
Guéry 1968 : GUÉRY (R.) - Notes de céramique. I, Un vase décoré de la nécropole de Sétif. II, Un poinçon-matrice pour estampiller la terre sigillée « $\mathrm{D}$ » à Tiddis. III, Une empreinte sur un fragment de terre sigillée « $\mathrm{D}$ » de Rusguniae. $B A A$, III, 1968, pp. 271-282.

Guéry 1970a : GUÉRY (R.) - Notes de céramique (deuxième série). IV, Deux nouveaux vases décorés de la nécropole de Sétif. V, Une reproduction monétaire de Théodose II sur des lampes tardives. VI, La terre sigillée « $\mathrm{D} »$ de Rusguniae (Tamedfoust). BAA, IV, 1970, pp. 267-296.

Guéry 1970b : GUÉRY (R.) - Stratigraphie. In : FÉVRIER (P.A.), GASPARY (A.) - Fouilles de Sétif (1959-1966). Le quartier nord-ouest de Sétif. Rapport préliminaire sur les fouilles effectuées de 1959 à 1964. Alger, 1970, pp. 114-142 (BAA, Suppl. 1).

Guéry 1982 : GUÉRY (R.) - L'importation de la Terra Sigillata gauloise en Afrique. RCRF Acta, XXI/XXII, 1982, pp. 63-70.

Guéry 1984 : GUÉRY (R.) - L'occupation de Rougga $(B A R A R V S)$ d'après la stratigraphie du forum. BCTH, n. s., fasc.17 B, 1984, pp. 7-99.

Guéry 1985a : GUÉRY (R.) - La nécropole orientale de Sitifis (Sétif, Algérie). Fouilles de 1966-1967. Paris, 1985, (Etudes d'Antiquités Africaines).

Guéry 1985b : GUÉRY (R.) - Survivance de la vie sédentaire pendant les invasions arabes en Tunisie centrale : l'exemple de Rougga. In : IIe Colloque International sur l'Histoire et l'Archéologie de l'Afrique du Nord (Grenoble, 5-9 avril 1983). $B C T H$, n. s., fasc. 19B, Paris, 1985, pp. 399-410.

Guéry 1986 : GUÉRY (R.) - Chronologie de quelques établissements de la frontière romaine du sud tunisien à partir de la céramique collectée sur les sites. In : Studien zu den Militärgrenzen Roms III. 13. Internationaler Limeskongress (Aalen, 1983). Stuttgart, 1986, pp. 600-604.

Guéry 1987 : GUÉRY (R.) - Les marques de potiers sur terra sigillata découvertes en Algérie, II. Sigillée tardo-italique. AntAfr, 23, 1987, pp. 149-191.

Guéry 1992 : GUÉRY (R.) - Les marques de potiers sur terra sigillata découvertes en Algérie, IV/1. Sigillée italique (A( ) à C. M( ) R( )). AntAfr, 28, 1992, pp. 15-131.

Guéry 1994 : GUÉRY (R.) - Les marques de potiers sur terra sigillata découvertes en Algérie, IV/2. Sigillée italique (ME( ) à C. VOLVSENVS (NESTOR ?). AntAfr, 30, 1994, pp. 89-187.

Guéry, Bonifay à paraître : †GUÉRY (R.), BONIFAY (M.) La céramique antique. In : EUZENNAT (M.), SLIM (H.) dir.Rougga, I. Le forum et ses abords. Rome, EFR, à paraître.

Guéry, Morrisson, Slim 1982 : GUÉRY (R.), MORRISSON (C.), SLIM (H.) - Recherches archéologiques francotunisiennes à Rougga, III. Le trésor de monnaies d'or byzantines. Rome, EFR, 1982 (Coll. de l'Ecole française de Rome, 60).

Guéry, Slim 1998 : †GUÉRY (R.), SLIM (L.) - Trois matrices de plats rectangulaires à décor moulé du Bas-Empire. In : 
Hommages à Georges Souville, 2. AntAfr, 34, 1998, pp. 199212.

Guild, Guyon, Rivet 1980 : GUILD (R.), GUYON (J.), RIVET (L.) - Recherches archéologiques dans le cloître Saint-Sauveur d'Aix-en-Provence. Bilan de quatre campagnes de fouilles (1976-1979). RAN, XIII, 1980, pp. 115-164.

Gutiérrez Lloret 1998 : GUTIÉRREZ LLORET (S.) - Il confronto con la Hispania orientale : la ceramica nei secoli VIVII. In : Saguì dir. 1998, pp. 549-567.

Hanoune 1970 : HANOUNE (R.) - Lampes de Graviscae. MEFRA, 82, 1970, pp. 237-262.

Hanoune 1996 : HANOUNE (R.) - Antiquités africaines dans les collections du Nord. V, Sigillée claire et céramique commune africaines dans le Nord de la Gaule. VI, Un tube à voûte de Beauvais ? In: Archéologie de la Picardie et du nord de la France. Revue du Nord, LXXVIII, 1996, n 318, pp. 225228.

Hassini 2002 : HASSINI (H.) - Amphores africaines tardives à Banasa. BAM, XIX, 2002, pp. 423-427.

Hautumm 1981 : HAUTUMM (W.) - Studien zu Amphoren der spätrömischen und frühbyzantinischen Zeit. Fulda, 1981.

Hawthorne 2000 : HAWTHORNE (J.) - Vessel volume as a factor in ceramic quantification : the case of African Red Slip Ware. In : LOCKYEAR (K.), SLY (T. J. T.), MIHÀILESCUBÎRLIBA (V.) dir. - CAA 96. Computer Applications and Quantitative Methods in Archaeology. Oxford, Archaeopress, 2000 (BAR, IS. 845).

Haxhimihali 1998 : HAXHIMIHALI (M.) - Les fouilles de la Bourse (1967-1984). Les amphores du sondage 10. In : Bonifay, Carre, Rigoir dir. 1998, pp. 161-165.

Hayes 1972 : HAYES (J. W.) - Late Roman Pottery. Londres, British School at Rome, 1972.

Hayes 1976a : HAYES (J. W.) - Pottery : Stratified Groups and Typology. In : HUMPHREY (J. H.) dir. - Excavations at Carthage 1975 conducted by the University of Michigan, I. Tunis, Cérès, 1976, pp. 47-123.

Hayes 1976b : HAYES (J. W.) - Roman Pottery in the Royal Ontario Museum. A catalogue. Toronto, Royal Ontario Museum, 1976.

Hayes 1977 : HAYES (J. W.) - North African Flanged Bowls : a problem in fifth century chronology. In : DORE (J.), GREENE (K.) éd. - Roman Pottery Studies in Britain and Beyond. Papers presented to John Gillam, July 1977. Oxford,1977, pp. 273-287 (British Archeological Reports, suppl. Series 30).

Hayes 1978a : HAYES (J. W.) - Selected deposits (continued). In : HUMPHREY (J. H.) dir. - Excavations at Carthage conducted by the University of Michigan, II. Ann Arbor, Kelsey Museum, 1978, pp. 113-118.

Hayes 1978b : HAYES (J. W.) - Pottery report-1976. In : HUMPHREY (J. H.) dir. - Excavations at Carthage, 1976, conducted by the University of Michigan, IV. Ann Arbor, Kelsey Museum, 1978, pp. 23-98.

Hayes 1980a : HAYES (J. W.) - Supplement to Late Roman Pottery. London, British School at Rome, 1980.

Hayes 1980b : HAYES (J. W.) - Ancient lamps in the Royal Ontario Museum, I. Greek and roman lamps. Toronto, Royal Ontario Museum, 1980.

Hayes 1983 : HAYES (J. W.) - The villa Dionysos Excavations, Knossos, The pottery. ABSA, 78, 1983, p 98-169.

Hayes 1991 : HAYES (J. W.) - Paphos, Vol. III. The Hellenistic and Roman Pottery. Nicosie, Department of Antiquities, 1991.

Hayes 1992 : HAYES (J. W.) - Excavations at Saraçhane, II, The Pottery. Princeton, Princeton University Press, 1992.

Hayes 1997 : HAYES (J. W.) - Handbook of Mediterranean Roman Pottery. Londres, British Museum Press, 1997.

Hayes 2001 : HAYES (J. W.) - Selected finds, Site 10, 1991. In : Leptiminus II, pp. 201-205.

Hayes 2003 : HAYES (J. W.) - Remarques préliminaires. In : BONIFAY (M.) éd. - Table-ronde « De Rome à Byzance ; de Fostat à Cordoue : évolution des faciès céramiques en Méditerranée (Ve - IXe s.) ». In : BAKIRTZIS (C.) éd. - VIIe Congrès International sur la Céramique Médiévale en Méditerranée (Thessalonique, 11-16 octobre 1999). Athènes, Ministère de la Culture, 2003, pp. 527-529.

Haywood 1938 : HAYWOOD (R. M.) - Roman Africa. In : FRANK (T.) - An Economic Survey of Ancient Rome. Paterson, Pageant Book, 1938 [2ème édition 1959], pp. 1-120.

Hermann, Van der Hoek 2002: HERMANN (J. J.), VAN DEN HOEK (A.) - Light from the Age of Augustine. Late Antique Ceramics From North Africa (Tunisia). Austin, The University of Texas, 2003 (2nd edition).

Hesnard 1980 : HESNARD (A.) - Un dépôt augustéen d'amphores à La Longarina, Ostie. In : D'ARMS (J.H.), KOPFF (E.C.) dir. - The Seaborne Commerce of Ancient Rome, Studies in Archaeology and History. Rome, American Academy, 1980, pp. 141-156.

Hitchner 1993 : HITCHNER (R. B.) - Olive Production and the Roman Economy : the case for intensive growth in the Roman Empire. In : AMOURETTI (M. C.), BRUN (J. P.) dir. La production du vin et de l'huile en Méditerranée. Paris, EFA, 1993, pp. 499-508 (BCH, Suppl. XXVI).

Hoff 1986 : HOFF (V.) - Lampes romaines tardives et chrétiennes. In : METZGER (C.) dir. - Catalogue des lampes en terre cuite grecques et chrétiennes, Musée du Louvre. Paris, Réunion des Musées Nationaux, 1986.

Hoxha 1992 : HOXHA (G.) - Amfora antike te vona nga qyteti i shkodres (Shek. V-fillimi i shek. VII). Iliria, 1-2, 1992, pp. 209-243. 
Ikäheimo 2001 : IKÄHEIMO (J. P.) - High-Quality Space Filler ? African Cookware and the Late Roman Trade. In : The102 Annual Meeting of the AIA. AJA, 105-2, 2001, p. 271.

Ikäheimo 2003 : IKÄHEIMO (J. P.) - Late Roman African Cookware of the Palatine East Excavations, Rome. A holistic approach. Oxford, Archaeopress, 2003 (BAR IS 1143).

Jacquest 1998 : JACQUEST (H.) - Recherches sur la céramique d'Ammaedara, actuellement Haïdra, Tunisie. Mémoire de Maîtrise, Université de Paris-Sorbonne (Paris IV), 1998. (dactylographié)

Janon 1978 : JANON (M.) - Note sur un moule bivalve en terre cuite découvert à Fréjus. RAN, XI, 1978, pp. 251-256.

Janon 1984 : JANON (M.) - Compléments carthaginois à un moule de Fréjus. RAN, XVII, 1984, pp. 349-352.

Jarrega Dominguez 1991 : JARREGA DOMINGUEZ (R.) Cerámicas finas tardorromanas y del Mediterráneo Oriental en España. Estado de la cuestion. Madrid, CSIC, 1991 (Anejos de Archivo Español de Arqueologia, XI).

Jézégou 1998 : JÉZÉGOU (M.-P.) - Le mobilier de l'épave Saint-Gervais 2 (VIIe siècle) à Fos-sur-Mer (Bouches-duRhône). In : Bonifay, Carre, Rigoir dir. 1998, pp. 343-352.

Jodin, Ponsich 1960 : JODIN (A.), PONSICH (M.) - La céramique estampée du Maroc romain. BAM, IV, 1960, pp. 287318.

Johnson 1988 : JOHNSON (B. L.) - The Pottery. In : WEINBERG (G. D.) dir. - Excavations at Jalame. Site of a Glass Factory in Late Roman Palestine. Columbia, University of Missouri Press, 1988, pp. 137-226.

Joly 1974 : JOLY (E.) - Lucerne del Museo di Sabratha. Rome, L'Erma di Bretschneider, 1974 (Monografie di Archeologia Libica, XI).

Joly 1992 : JOLY (E.) - Produzione ceramica e matrici di terracotta a Sabratha. $Q A L, 15,1992$, pp. 283-306.

Joncheray 1975a : JONCHERAY (J.P.) - L'épave E du cap Dramont, sigillée claire D et amphores rescapées du pillage. Cahiers d'Archéologie Subaquatique, IV, 1975, pp. 141-146.

Joncheray 1975b : JONCHERAY (J.-P.) - Une épave du BasEmpire : Dramont F. Cahiers d'Archéologie Subaquatique, IV, 1975, pp. 92-132.

Joncheray 1997 : JONCHERAY (J.-P.) - Deux épaves du BasEmpire romain, Deuxième partie : l'épave Héliopolis 1. Cahiers d'Archéologie Subaquatique, XIII, 1997, pp. 137-164.

Kalinovski 1993 : KALINOVSKI (A.) - Pottery from unit 4000. In : STEVENS (S.) dir. - Bir El Knissia at Carthage : A rediscovered cemetery church, Report no. 1. Ann Arbor, 1993, pp. 155-177 (JRA, Suppl. Ser. 7).

Keay 1989 : KEAY (N.) - The amphorae. In : DORE (J.), KEAY (N.) dir. - Excavations at Sabratha 1948-1951. Vol. II. The finds. Tripoli, The Society for Libyan Studies, 1989, pp. 567 et 80-83 (Monograph No 1).
Keay 1984 : KEAY (S. J.) - Late roman amphorae in the Western Mediterranean, A typology and economic study : the Catalan evidence. Oxford, 1984 (BAR IS, 196).

Keay 1998 : KEAY (S. J.) - African amphorae. In : Saguì dir. 1998, pp. 141-155.

Kenrick 1985 : KENRICK (P. M.) - Excavations at Sidi Khrabish, Benghazi (Berenice), III, 1, The Fine Pottery. Tripoli, 1985 (Libya Antiqua, Suppl. V).

Kirwan 1939 : KIRWAN (L. P.) - The Oxford University Excavation at Firka. Oxford, University Press, 1939.

Knific 1979 : KNIFIC (T.) - Vranje pri Sevnici. Drobne najde z Ajdovskega gradca (leto 1974). Arheološki Vestnik, XXX, 1979, pp. 732-763.

Knowles 1994 : KNOWLES (K.) - The lamps. In : Fulford, Peacock 1994, pp. 23-41.

Ladstätter 1998 : LADSTÄTTER (S.) - Afrikanische Sigillaten und Lampen aus Ovilava/Wels. Carnuntum Jahrbuch, 1998, pp. 51-63.

Ladstätter 2000 : LADSTÄTTER (S.) - Die materielle Kultur der Spätantike in den Ostalpen. Eine Fallstudie am Beispiel der Westlichen Doppelkirchenanlage auf dem Hemmaberg. Vienne, Österreichischen Akademie der Wissenschaften, 2000, (Mitteilungen der Prähistorischen Kommission, 35). 2 vol.

Ladstätter 2003 : LADSTÄTTER (S.) - Zur Charakterisierung des spätantiken Kermikspektrums in Ostalpenraum. In : SENNHÄUSER (H. R.) éd. - Frühe Kirchen im östlichen Alpengebiet. Von der Spätantike bis in ottonische Zeit. Munich, C. H. Beck, 2003, pp. 831-857 (Bayerische Akademie der Wissenschaften, Philosophisch-historische Klasse, Abhandlungen, neue Folge, 123).

Lamboglia 1950 : LAMBOGLIA (N.) - Gli scavi di Albintimilium e la cronologia della ceramica romana. Bordighera, Instituto Internazionale di Studi Liguri, 1950.

Lamboglia 1958 : LAMBOGLIA (N.) - Nuove osservazioni sulla «terra sigillata chiara», I. Tipi A e B. RELig, XXIV, 1958, pp. 257-330.

Lamboglia 1963 : LAMBOGLIA (N.) - Nuove osservazioni sulla « terra sigillata chiara », II. Tipi C, Lucente e D. RELig, XXIX, 1963, pp. 145-212.

Lamboglia 1974 : LAMBOGLIA (N.) - I problemi attuali della terra sigillata chiara : Italia o Africa? In : Aquileia e l'Africa. Atti della Sttimana di Studi Aquileiesi (28-4 mai 1973). Udine, 1974, pp. 119-131 (Antichità Altoadriatiche, 5).

Lancel 1962-65 : LANCEL (S.) - Tipasitana I : fouilles dans la nécropole occidentale de Tipasa. BAA, I, 1962-65, pp. 41-74.

Lancel 1970 : LANCEL (S.) - Tipasitana, IV : la nécropole romaine occidentale de la porte de Césarée. Rapport préliminaire. $B A A$, IV, 1970, pp. 149-266.

Lancel 1987 : LANCEL (S.) - La céramique punique d'époque hellénistique. In : Céramiques hellénistiques et romaines, II. 
Paris, Annales Littéraires de l'Université de Besançon, 1987, pp. 99-138 (Centre de Recherches d'Histoire Ancienne, 70).

Landes, Ben Hassen dir. 2001 : LANDES (C.), BEN HASSEN (H.) dir. - Tunisie : du christianisme à l'islam. IVe-XIVe siecle. Catalogue de l'exposition. Lattes, Musée archéologique Henri Prades, 2001

Lang 1998 : LANG (S.) - La sigillée africaine A (Fouilles de la Bourse, secteur de l'épave). In : Bonifay, Carre, Rigoir dir. 1998, pp. 73-75.

Laporte 1976-1978 : LAPORTE (J.-P.) - Les amphores de Maurétanie et l'huile de Tubusuctu. $B C T H$, n. s., fasc. 12-14B, 1976-1978, pp. 131-157.

Lassère 1977 : LASSÈRE (J.-M.) - Vbique populus. Peuplement et mouvements de population dans l'Afrique romaine de la chute de Carthage à la fin de la dynastie des Sévères (146 a. C. - 235 p. C.). Paris, CNRS, 1977 (Etudes d'Antiquités Africaines).

Laubenheimer 1990 : LAUBENHEIMER (F.) - Le temps des amphores en Gaule. Paris, Errance, 1990.

Lavagna 1996 : LAVAGNA (R.) - Materiali di età tardoantica. In : VARALDO (C.) et al. - Lo scavo della contrada di S. Domenico al Priamàr (Savona). Relazioni preliminari sulle campagne di scavo 1989-1995. Archeologia Medievale XXIII, 1996 , p 347 et fig. 32-33.

Lavagna 1998 : LAVAGNA (R.) - Savona, Complesso monumentale del Priamàr. La ceramica comune. In : Saguì dir. 1998, pp. 585-590.

Lavoie 1989 : LAVOIE (C.) - Les traces d'ateliers de poterie à Sullecthum. In : Sullecthum, I. CEA, XXII, 1989, pp. 91-109.

Leciejewicz, Tabaczyńska, Tabaczyński 1977 : LECIEJEWICZ (L.), TABACZYŃSKA (E.), TABACZYŃSKI (S.) - Torcello. Scavi 1961-62. Rome, Instituto Nazionale di Archeologia e Storia dell'Arte, 1977.

Leguilloux 1988a : LEGUILLOUX (M.) - Les amphores romaines, guide typologique, II. Les amphores à vin tardives. Annales de la Société des Sciences Naturelles et d'Archéologie de Toulon et du Var, t. 40, fasc. 1, $1^{\circ}$ trimestre 1988, pp. 31-40.

Leguilloux 1988b : LEGUILLOUX (M.) - Les amphores romaines, guide typologique, III. Les amphores à garum et conserve de poisson. Annales de la Société des Sciences Naturelles et d'Archéologie de Toulon et du Var, t. 40, fasc. 3, $3^{\circ}$ trimestre 1988, pp. 143-159.

Lepelley 1981 : LEPELLEY (C.) - Les cités de l'Afrique romaine au Bas-Empire, II. Notices d'histoire municipale. Paris, Etudes Augustiniennes, 1981.

Leptiminus I : BEN LAZREG (N.), MATTINGLY (D. J.) dir. Leptiminus (Lamta) : a Roman port city in Tunisia. Report $N^{\circ} 1$. Ann Arbor, 1992 (JRA, Suppl. Ser. 4).

Leptiminus II : STIRLING (L.), MATTINGLY (D. J.), BEN LAZREG (N.) dir. - Leptiminus (Lamta). Report $N^{\circ} 2$. Portsmouth, 2001 (JRA, Suppl. Ser. 41).
Lequément 1968 : LEQUÉMENT (R.) - Fouilles à l'amphithéâtre de Tebessa (1965-1968). Alger, 1968 (BAA, Suppl. 2).

Lequément 1975 : LEQUÉMENT (R.) - Etiquettes de plomb sur des amphores d'Afrique. MEFRA, 87, 1975, pp. 667-680.

Lequément 1976 : LEQUÉMENT (R) - Une épave du BasEmpire dans la Baie de Pampelonne (presqu'île de Saint Tropez). RAN, IX, 1976, pp. 177-188.

Lequément 1980 : LEQUÉMENT (R.) - Le vin africain à l'époque impériale. AntAfr, 16, 1980, pp. 185-193.

Leveau 1983 : LEVEAU (P.) - Recherches sur les nécropoles occidentales de Cherchel (Caesarea Mauretaniae) 1880-1961. AntAfr, 19, 1983, pp. 85-173.

Leveau 1984 : LEVEAU (P.) - Caesarea de Maurétanie. Une ville romaine et ses campagnes. Rome, EFR, 1984 (Coll. de l'Ecole française de Rome, 70).

Leveau 1999 : LEVEAU (P.) dir. - Fouilles sur la nécropole de la gare routière de Cherchell, Algérie (1992-1993). AntAfr, 35, 1999 [2001], pp. 77-133.

Leveau 2003 : LEVEAU (P.) - L'oléiculture en Gaule Narbonnaise : données archéologiques et paléoenvironnementales, présentation-interprétation. RAPic, 2003, n 1-2, pp. 299308.

L'Hour et al. 1985 : L'HOUR (M.), POMEY (P.), LONG (L.), RICHEZ (F.) - Archéologie sous-marine sur les côtes de France. Vingt ans de recherches. Catalogue de l'exposition. Nantes, 1985.

Lindros Wohl 1993 : LINDROS WOHL (B.) - Lamps from the excavations at Isthmia by UCLA. In : GREGORY (T. E.) dir. Tha Corinthia in the roman period. Ann Arbor, 1993, pp. 130138 (JRA, Suppl. Ser. 8).

Liou 1973 : LIOU (B.) - Informations archéologiques. Recherches archéologiques sous-marines. Gallia, 31-2, 1973, pp. 571-608.

Liou 1975 : LIOU (B.) - Informations archéologiques. Recherches archéologiques sous-marines. Gallia, 33-2, 1975, pp. 571-606.

Liou, Gassend 1990 : LIOU (B.), GASSEND (J.-M.) - L'épave Saint-Gervais 3 à Fos-sur-Mer (milieu du IIe s. ap. J.-C.). Inscriptions peintes sur amphores de Bétique. Vestiges de la coque. Archaeonautica, 10, 1990, pp. 157-264.

Liou, Pomey 1985 : LIOU (B.), POMEY (P.) - Informations archéologiques. Direction des recherches archéologiques sousmarines. Gallia, 43-2, 1985, pp. 547-576.

Lippolis 2001 : LIPPOLIS (E.) - Terra sigillata tarda affine all'Africana e Egiziana C. In : DI VITA (A.) dir. - Gortina, V, 3. Lo scavo del Pretorio (1989-1995). I materiali. Padoue, Bottega d'Erasmo, 2001, pp. 69-71 (Monografie della Scuola Archeologica Italiana di Atene e delle Missioni Italiane in Oriente, XII). 
Lisse, Louis 1956 : LISSE (P.), LOUIS (A.) - Les potiers de Nabeul. Etude de sociologie tunisienne. Tunis, 1956 (Publications de l'Institut des Belles Lettres Arabes - Tunis, 23).

Long 1994 : LONG (L.) - Prospections et sondages archéologiques dans le Rhône, à Arles et ses environs. In : Histoire du Rhône en Pays d'Arles (Actes du colloque (7 novembre 1992). Arles, Groupe Archéologique Arlésien, 1994, pp. 45-71.

Long 2002 : LONG (L.) - Carte archéologique. Au large de la Camargue. In : Bilan scientifique du DRASSM, 2000. Paris, MCC, 2002, pp. 57-61.

Long, Volpe 1998 : LONG (L.), VOLPE (G.) - Le chargement de l'épave de la Palud (VIe s.) à Port-Cros (Var). Note préliminaire. In : Bonifay, Carre, Rigoir dir. 1998, pp. 317-342.

Lund 1995 : LUND (J.) - Hellenistic, Roman and Late Roman Fine Wares from the Segermes Valley. Forms and Chronology. In : DIETZ (S.), LADJIMI SEBAÏ (L.), BEN HASSEN (H.) Africa Proconsularis. Regional Studies in the Segermes Valley of Northern Tunesia, II. Copenhague, The National Museum of Denmark, 1995, pp. 449-629.

Luni I: FROVA (A.) dir. - Scavi di Luni. Relazione preliminare delle campagne di scavo 1970-1971. Rome, Bretschneider, 1973. 2 vol.

Luni II : FROVA (A.) dir. - Scavi di Luni, II. Relazione delle campagne di scavo 1972-1973-1974. Rome, Bretschneider, 1977. 3 vol.

Macias 1999 : MACIAS SOLÉ (J. M.) - La ceràmica comuna tardoantiga a Tàrraco. Anàlisi tipològica i històrica (segles $V$ VII). Tarragone, Museu Arqueologic de Tarragona, 1999 (TULCIS. Monografies Tarraconenses, 1).

Macias, Remolà 2000 : MACIAS I SOLÉ (J.), REMOLÀ I VALLVERDU (J. A.) - Tarraco visigoda : caracterisación del material cerámico del siglo VII dC. In : V Reunió d'Arqueologia Cristiana Hispánica (Cartagene, 16-19 avril 1998), Barcelone, 2000, pp. 485-497 (Monografies de la Seccio Historico Arqueologica, VII).

Mackensen 1980 : MACKENSEN (M.) - Spätantike nordafrikanische Lampelmodel und Lampen. Zur Herstellung der reliefverzierten Lampen Typ Pohl 1a/Hayes IIA. Bayerische Vorgeschichtsblätter, 45, 1980, pp. 51-224.

Mackensen 1985 : MACKENSEN (M.) - Prospektion einer spätantiken Sigillatatöpferei in El Mahrine/Nordtunesien. CEDAC, 6, mars 1985, pp. 29-39.

Mackensen 1987 : MACKENSEN (M.) - Mediterrane Sigillata, Lampen und Amphoren. In : BIERBRAUER (V.) dir. - Invillino-Ibligo in Friaul I. Munich, 1987, C. H. Bec'sche, pp. 229-265 (Münchner Beiträge zur Vor- und Frühgeschichte, 33).

Mackensen 1991 : MACKENSEN (M.) - Keramikinventare. In : RAKOB (F.) dir. - Karthago I. Die deutsche Ausgrabungen in Karthago. Mayence, Philipp von Zabern, 1991, pp. 72-74, 85-87, 198-200.
Mackensen 1992 : MACKENSEN (M.) - Amphoren und spatheia von Golemanovo Kale. In: UENZE (S.) - Die spätantiken Befestigungen von Sadovec (Bulgarien). Herausgegeben von Joachim Werner. Munich, C. H. Beck'sche, 1992, pp. 239-254 (Münchner Beiträge zur Vor- und Frühgeschichte, 43).

Mackensen 1993 : MACKENSEN (M.) - Die spätantiken sigillata- und Lampentöpfereien von El Mahrine (Nordtunesien). Munich, C. H. Beck'sche, 1993 (Münchner Beiträge zur Vor- und Frühgeschichte, 50).

Mackensen 1998a : MACKENSEN (M.) - Centres of African red slip ware production in Tunisia from the late 5 th to the 7 th century. In : Saguì dir. 1998, pp. 23-40.

Mackensen 1998b : MACKENSEN (M.) - New evidence for Central Tunisian red slip ware with stamped decoration (ARS style D). JRA, 11, 1998, pp. 355-370.

Mackensen 1998c : MACKENSEN (M.) - Arbeitsgeräte aus dem spätantiken Töpfereizentrum von El Mahrine (Nordtunesien). $\operatorname{MDAI}(R), 105,1998$, pp. 431-439.

Mackensen 1998d : MACKENSEN (M.) - Spätantike nordafrikanische Feinkeramik und Lampen. In : WAMSER (L.), ZAHLHAAS (G.) éd. - Rom und Byzanz. Archäologische Kostbarkeiten aus Bayern. Munich, Hirmer, 1998, pp. 120-138.

Mackensen 1999a : MACKENSEN (M.) - Spätantike Keramikensembles und Baumassnahmen in der Südlichen Raumzeile der Insula E 218. In : RAKOB (F.) dir. - Karthago III. Die deutschen Ausgrabungen in Karthago. Mayence, Philipp von Zabern, 1999, pp. 545-565.

Mackensen 1999b : MACKENSEN (M.) - Ein Keramikensemble der Mitte des 7. Jahrhunderts N. Chr. aus Raum R M in Insula E 118. In : RAKOB (F.) dir. - Karthago III. Die deutschen Ausgrabungen in Karthago. Mayence, Philipp von Zabern, 1999, pp. 566-570.

Mackensen 2001 : MACKENSEN (M.) - Lampen, Leuchten, Licht. In : Byzanz. Das Licht aus dem Osten. Kult und Alltag im Byzantinischen Reich vom 4. bis 15 Jahrhundert. Catalogue de l'exposition (Paderborn, 2001). Mayence, Philipp von Zabern, 2001, pp. 221-225.

Mackensen 2002a : MACKENSEN (M.) - A late mid-Roman Afrian red slip ware lamp from Sabratha and lamp production at Djilma (central Tunisia). Libyan Studies, 33, 2002, pp. 57-69.

Mackensen 2002b : MACKENSEN (M.) - Späntantike Zweischneuzige Lampen mit christlichen Symbolen aus Nordafrika. In : Zwischen Rom und Barbaricum. Festschrift für T. Kolnik zum 70. Gebustag. Nitra, Archäologisches Institut der Slowakischen Akademie der Wissenschaften, 2002, pp. 167180 .

Mackensen, Schneider 2002 : MACKENSEN (M.), SCHNEIDER (G.) - Production centres of African red slip ware (3rd-7th c.) in northern and central Tunisia : archeological provenance et reference groups based on chemical analysis. $J R A, 15,2002$, pp. 121-158. 
Mactar I : PICARD (G.-C.), PICARD (C.), BOURGEOIS (A.), BOURGEOIS (C.) - Recherches archéologiques francotunisiennes à Mactar, I. La maison de Vénus, 1. Stratigraphie et étude des pavements. Rome, EFR, 1977 (Coll. de l'Ecole française de Rome, 34).

Maioli 1983 : MAIOLI (M. G.) - La ceramica fine da mensa (terra sigillata). In : BERMOND MONTANARI (G.) - Ravenna e il porto di Classe, Venti anni di ricerche archeologiche tra Ravenna e Classe. Bologne, University Press, 1983, pp. 87-112.

Maioli 1989 : MAIOLI (M. G.) - Ravenna, loc. Classe. La fornace per ceramica nel podere Chiavichetta. In : Amphores romaines et histoire économique. Dix ans de recherche. Actes du Colloque de Sienne (22-24 mai 1986). Rome, EFR, 1989, pp. 568-569 (Coll. de l'Ecole française de Rome, 114).

Maioli 1993 : MAIOLI (M. G.) - Le lucerne. In : STOPPIONI (M. L.) dir. - Con la terra e con il fuoco. Fornaci romani del Riminese. Rimini, Guaraldi, 1993, pp. 161-170.

Maioli, Stoppioni 1989a : MAIOLI (M. G.), STOPPIONI (M.) - Classe, Podere Chiavichetta : anfore di produzione locale. In : Amphores romaines et histoire économique. Dix ans de recherche. Actes du colloque de Sienne (22-24 mai 1986). Rome, EFR, 1989, pp. 570-571 (Coll. de l'Ecole française de Rome, 114).

Maioli, Stoppioni 1989b : MAIOLI (M. G.), STOPPIONI (M.) - Classe, Podere Chiavichetta : anfore di importazione. In : Amphores romaines et histoire économique. Dix ans de recherche. Actes du colloque de Sienne (22-24 mai 1986). Rome, EFR, 1989, pp. 572-573 (Coll. de l'Ecole française de Rome, 114).

Manacorda 1976-77 : MANACORDA (D.) - Testimonianze sulla produzione e il consumo dell'olio tripolitano nel III secolo. DArch, IX-X, 1976-77, pp. 542-601.

Manacorda 1977 : MANACORDA ( D.) - Le anfore. In : Ostia IV, pp. 117-285.

Manacorda 1983 : MANACORDA (D.) - Prosopografia e anfore tripolitane : nuove osservazioni. In : Producción y comercio del aceite en la Antigüedad. Segundo congresso internacional (Seville, 24-28 février 1982). Madrid, Universidad Complutense, 1983, pp. 483-500.

Manacorda 1989 : MANACORDA (D.) - I materiali. In : ANSELMINO (L.), BOUCHENAKI (M.), CARANDINI (A.), LEVEAU (P.), MANACORDA (D.), PAVOLINI (C.), PUCCI (G.), SALAMA (P.) - Il castellum del Nador, Storia di una fattoria tra Tipasa e Caesarea (I-VI sec d. C.).Rome, L'Erma di Bretschneider, 1989, pp. 127-216 (Monografie di Archeologia Libyca, XXIII).

Manacorda, Panella 1993 : MANACORDA (D.), PANELLA (C.) - Anfore. In : HARRIS (W. V.) - The Inscribed Economy. Production and distribution in the Roman empire in the light of instrumentum domesticum. Actes du colloque (Rome, 10-11 janv. 1992). Ann Arbor, 1993, pp. 55-64 (JRA, Suppl. Ser. 6).

Mandruzzato 1992 : MANDRUZZATO (A.) - Ceramiche e terracotte. In : JOLY (E.), GARRAFFO (S.),
MANDRUZZATO (A.) - Materiali minori dallo scavo del teatro di Leptis Magna. $Q A L, 15,1992$, pp. 135-195.

Manniez 1993 : MANNIEZ (Y.) - Les niveaux romains tardifs. In : MONTEIL (M.) dir. - Les fouilles de la Z.A.C. des Halles à Nîmes (Gard). Nîmes, Musée Archéologique, 1993, pp. 167185 (Bulletin de l'Ecole Antique de Nîmes, Suppl. 1).

Mannoni 1972 : MANNONI (T.) - Analisi mineralogiche e tecnologiche delle ceramiche medievali. Nota II. Albisola, 1972, pp. 107-128.

Mannoni, Murialdo 2001 : MANNONI (T.), MURIALDO (G.) dir. - S. Antonino : un insediamento fortificato nella Liguria bizantina. Bordighera, Istituto Internazionale di Studi Liguri, 2001 (Coll. di Monografie Preistoriche ed archeologiche, XII). 2 vol.

Marchand 2000 : MARCHAND (S.) - Le survey de Dendara (1996-1997). Cahiers de la Céramique Egyptienne, 6, 2000, pp. 261-299.

Marchand à paraître: MARCHAND (S.) - La céramique d'époque romaine tardive du fort de Qaret et-Tub. In : COLIN (F.) et al. - A Jupiter, à Hercule et à la Victoire. Premier rapport sur les sondages de Qaret et-Tub. Le Caire, IFAO, à paraître.

Marchesi 2000 : MARCHESI (H.) - L'habitat rural de Musoleu: contribution à la connaissance des céramiques antiques en Corse (Ier - Ve s.). MEFRA, 112-2, 2000, pp. 959997.

Márquez, Molina 2001 : MÁRQUEZ VILLORA (J. C.), MOLINA VIDAL (J.) - El comercio en el territorio de Ilici. Epigrafia, importación de alimentos y relación con los mercados mediterráneos. Alicante, Universidad de Alicante, 2001.

Martin 1999 : MARTIN (A.) - Amphorae. In : SOREN (D. et S.) dir. - A Roman Villa and a Late Roman Infant Cemetery. Excavation at Poggio Gramignano, Lugnano in Teverina. Rome, L'Erma di Bretschneider, 1999, pp. 329-362.

Martin 1977 : MARTIN (T.) - Quelques formes inédites de sigillée claire D. Figlina, 2, 1977, pp. 97-106.

Martin 1996 : MARTIN (T.) - Céramiques sigillées et potiers gallo-romains de Montans. Toulouse, CDEFAM, 1996.

Martin-Kilcher 1994 : MARTIN-KILCHER (S.) - Die römischen Amphoren aus Augst und Kaiseraugst, 2 et 3. Die Amphoren für Wein, Fischsauce, Südfrüchte (Gruppen 2-24). Augst, Römer Museum Augst, 1994 (Forschungen in Augst, 7). 2 vol.

Martin-Kilcher 1998 : MARTIN-KILCHER (S.) - Le vin dans la Colonia Iulia Karthago. In : El vi a l'Antiguitat. Economia, producció i commerç al Mediterrani occidental. Actes del II col.loqui international d'arqueologia romana (Badalone, 6-9 mai 1998). Badalone, Museu de Badalona, pp. 511-529 (Monografies Badalonines, 14).

Martin-Kilcher 1999 : MARTIN-KILCHER (S.) - Karthago 1993. Die Füllung eines frühkaiserzeitlichen Pozzo. In : 
RAKOB (F.) dir. - Karthago III. Die deutschen Ausgrabungen in Karthago. Mayence, Philipp von Zabern, 1999, pp. 403-434.

Marty 2002 : MARTY (F.) - Aperçu sur les céramiques à pâte claire du golfe de Fos. In : RIVET (L.), SCIALLANO (M.) éd. - Vivre, produire et échanger : reflets méditerranéens. Mélanges offerts à Bernard Liou. Montagnac, EMM, 2002, pp. 201-220.

Mattingly 1988a : MATTINGLY (D. J.) - Oil for export ? A comparison of Libyan, Spanish and Tunisian olive oil production in the Roman empire. JRA, 1, 1988, pp. 33-56.

Mattingly 1988b : MATTINGLY (D. J.) - The olive boom. Oil surpluses, Wealth and Power in Roman Tripolitania. Libyan Studies, 19, 1988, pp. 21-41.

Mattingly et al. 2000 : MATTINGLY (D. J.), STONE (D.), STIRLING (L.), BEN LAZREG (N.) - Leptiminus (Tunisia). A «producer » city ? In : MATTINGLY (D. J.), SALMON (J.) éd. - Economies beyond agriculture in the Classical World. New York, Routledge, 2000, pp. 66-89 (Leicester-Nottingham Studies in Ancient History).

Mauné 1996 : MAUNÉ (S.) - Nouvelles données sur la céramique «Brune Orangée Biterroise » (B.O.B.). L'atelier des Demoiselles-ouest à Tourbes (Hérault). In : SFECAG. Actes du congrès de Dijon (16-19 mai 1996). Marseille, 1996, pp. 395407.

Mauné, Feugère 1999 : MAUNÉ (S.), FEUGÈRE (M.) - La villa gallo-romaine de Lieussac (Montagnac, Hérault, France) au VIe s. de notre ère. Archäologisches Korrespondenzblatt, 29, 1999, pp. 377-394.

Maurières, Chambon 2002 : MAURIÈRES (A.), CHAMBON (P.) - Nabeul, en vert et jaune. Aix-en-Provence, Edisud, 2002.

Maurina 2000 : MAURINA (B.) - I contenitori da trasporto e da conserva. In : De Vos 2000, pp. 50-57.

Megaw 1972 : MEGAW (A. H. S.) - Supplementary Excavations on a Castle Site at Paphos, Cyprus, 1970-1971. DOP, 26, 1972, pp. 322-344.

Merlin 1910 : MERLIN (A.) - Le sanctuaire de Baal et de Tanit pres de Siagu. Paris, E. Leroux, 1910 (Direction des Antiquités et Arts de Tunisie, Notes et Documents, IV).

Mertens 1979 : MERTENS (J.) dir. - Ordona VI. Rapports et études. Bruxelles-Rome, Institut Historique Belge de Rome, 1979.

Modéran 2002 : MODÉRAN (Y.) - L'établissement territorial des Vandales en Afrique. In : L'Afrique vandale et byzantine, I. Actes du colloque international (Tunis, 5-8 octobre 2000). AntTard, 10, pp. 87-122.

Moliner 1998 : MOLINER (M.) - Le puits de la rue de la cathédrale (îlot 55). In : Bonifay, Carre, Rigoir dir. 1998, pp. 264-275.

Mols 1999 : MOLS (S. T. A. M.) - Wooden furniture in Herculanum. Form, technique and function. Amsterdam, J. C. Gieben, 1999.
Morales Muñiz 1989 : MORALES MUÑIZ (A.) - Annex 2. Informe sobre la fauna ictiologica recuperade en una amfora tardo-romana del typus Keay XXVI (spatheion). In : Ted'a - Un abocador del segle V D. C. en el fórum provincial de Tàrraco. Tarragone 1989, pp. 324-328 (Memòries d'Excavació, 2).

Morel 1962-65: MOREL (J.-P.) - Céramiques d'Hippone. $B A A, 1,1962-1965$, pp. 107-139.

Morel 1982 : MOREL (J. P.) - La céramique à vernis noir de Carthage-Byrsa : nouvelles données et éléments de comparaison. In : Actes du colloque sur la céramique antique (Carthage, 23-24 juin 1980). Carthage, 1982, pp. 43-76 (CEDAC, Dossiers 1).

Morel 1983 : MOREL (J.-P.) - La céramique comme indice du commerce antique, réalités et interprétations. In : GARNSEY (P.), WHITTAKER (C. R.) dir. - Trade and famine in classical Antiquity. Cambridge, Philological Society, 1983, pp. 66-74 (Cambridge Philological Society, Suppl. Vol. 8).

Morel 1998 : MOREL (J.-P.) - Sur quelques particularités céramiques du Sahel tunisien à l'époque pré-impériale. $B C T H$, Afrique du Nord, 25, 1996-98, pp. 129-131.

Mouchot 1970 : MOUCHOT (D.) - Epave romaine « $\mathrm{A} » \mathrm{du}$ Port de Monaco. Bulletin du Musée d'Anthropologie Préhistorique de Monaco, 15, 1970, pp. 159-201.

Murialdo 1988 : MURIALDO (G.) - Necropoli e sepolture tardo-antiche del Finale. RELig, LIV, 1988, pp. 221-242.

Murialdo 1994 : MURIALDO (G.) - Anfore tardoantiche nel Finale (VI-VII secolo). In : Hommage à Paul-Albert Février, RELig, LIX-LX, 1993-1994, pp. 213-246.

Murialdo 1995 : MURIALDO (G.) - Alcune considerazioni sulle anfore africane di VII secolo dal castrum di S. Antonino nel Finale. Archeologia Medievale, XXII, 1995, pp. 433-453.

Murialdo 2001 : MURIALDO (G.) - Le anfore da trasporto. In : Mannoni, Murialdo 2001, pp. 255-296.

Nacef 2001 : NACEF (J.) - Etude de la collection d'amphores de la réserve du Musée d'El Jem. Diplôme d'Etudes Approfondies en Patrimoine et Archéologie, spécialité Archéologie, sous la direction de M. Khanoussi. Tunis, Université de Tunis I, 2001. (dactylographié)

Nasr 1992 : NASR (M.) - Recherches sur la céramique rouge orange dans la région de Gafsa à l'époque romaine : l'atelier de Sidi Aïch. Certificat d'Aptitude à la Recherche, Université de Tunis, 1992. (dactylographié)

Nasr 1995 : NASR (M.) - Recherches sur la sigillée claire africaine de la Byzacène du Sud-ouest : les dépotoirs de Thélepte. Diplôme d'Etudes Approfondies, Université de Provence, 1995. (dactylographié)

Navarro Sáez 1982 : NAVARRO SÁEZ (R.) - Las cerámicas finas de la basílica de Fornells, Menorca. In : Palol 1982, pp. 431-454.

Nenna, Seif el-Din 2000 : NENNA (M.-D.), SEIF EL-DIN (M.) - La vaisselle en faïence d'époque gréco-romaine. 
Catalogue du Musée gréco-romain d'Alexandrie. Le Caire, IFAO, 2000 (Etudes Alexandrines, 4).

Neuru 1980 : NEURU (L.) - Late Roman Pottery : a fifth century deposit from Carthage. AntAfr, 16, 1980, pp. 195-211.

Neuru 1986 : NEURU (L.) - Cooking wares of the byzantine epoch at Carthage : some observations. In : Carthage VIII. CEA, XVIII,1986, pp. 69-79.

Neuru 1987 : NEURU (L.) - Red slipped wares of southwestern central Tunisia : new evidence. RCRF Acta, XXV/XXVI, 1987, pp. 175-188.

Neuru 1990a : NEURU (L.) - Pottery from occupation levels of Byzantine Carthage. CEDAC, 11, juin 1990, pp. 29-39.

Neuru 1990b : NEURU (L.) - Appendix 2 : The Pottery of the Kasserine Survey. In : HITCHNER (B.) dir. - The Kasserine Archeological Survey, 1987. AntAfr, 26, 1990, pp. 231-260.

Nicholson, Patterson 1992 : NICHOLSON (T.), PATTERSON (H. L.) - The Ballas Pottery Project : Ethnoarchaeology in Upper Egypt. In : BEY (G. J. III), POOL (C. A.) dir. - Ceramic Production and Distribution. An Integrated Approach. Boulder/San Francisco/Oxford, Westview Press, 1992, pp. 2548.

Nieto Prieto 1993 : NIETO PRIETO (J.) - El edificio « $A$ » de la ciudadela de Roses (la terra sigillata africana). Gérone, Centre d'Investigacions Arqueológiques de Girona, 1993 (Serie Monogràfica, 14).

Nobile 1992 : NOBILE (I.) - Necropoli tardoromana nel territorio Lariano. Côme, 1992 (Archeologia dell'Italia Settentrionale, 6).

Nolla, Casas 1997 : NOLLA (J. M.), CASAS (J.) - Material ceràmic del Puig de les Muralles Puig Rom, Roses). In : Contextos ceràmics d'època romana tardana i de l'alta edat mitjana (segles $I V-X$ ). Actes de la table-ronde (Badalona, 6-8 novembre 1996). Barcelone, Universitat de Barcelona, 1997, pp. 7-19 (Arqueo Mediterrània, 2).

Odoardi 1993 : ODOARDI (R.) - Lucerne tardo-antiche dal sito «bizantino » di Casino Vezzani-Vassarella di Crecchio (Abruzzo, Chieti). Archeologia Medievale, XX, 1993, pp. 611615 .

Olivier, Storz 1983 : OLIVIER (A.), STORZ (S.) - Analyse et restitution d'un procédé de construction antique: réalisation d'une voûte d'arête sur coffrage perdu en tubes de terre cuite. In : Bulla Regia I, pp. 111-127.

Opait 1996 : OPAIT (A.) - Aspecte ale vietii economice din provincia Scythia (secolele IV-VI p. Ch.). Productia ceramicii locale si de import. Bucarest, Institutul Român de Tracologie, 1996 (Bibliotheca Tracologica, XVI).

Opait 1997-98 : OPAIT (A.) - North african and Spanish Amphorae in Scythia Minor. In : Il Mar Nero. Annali di archeologia e storia, III, 1997/98, pp. 47-95.

Opait 1998a : OPAIT (A.) - New pottery from the Circular Harbour of Carthage. CEDAC, 18, juin 1998, pp. 21-35.
Opait 1998b : OPAIT (A.) - The north african Dressel 1. In : El vi a l'Antiguitat. Economia, producció $i$ commerç al Mediterrani occidental. Actes del II col.loqui international d'arqueologia romana (Badalone, 6-9 mai 1998). Badalone, Museu de Badalona, pp. 427-429 (Monografies Badalonines, 14).

Opait 2000 : OPAIT (A.) - Early Roman Amphorae from Leptiminus. RCRF Acta, 36, 2000, pp. 439-442.

Orfila 1989 : ORFILA (M.) - Cerámicas de la primera metad del siglo V d.C. procedentes de la cisterna de Sa Mesquida (Santa Ponca, Mallorca). In : L'africa Romana, VI. Sassari, Gillizzi, 1989, pp. 513-533.

Orssaud, Sodini 1997 : ORSSAUD (D.), SODINI (J.-P.) - Les lampes tournées de Qal'at Sem'an et leurs parallèles dans le bassin méditerranéen. In : La céramique médiévale en Méditerranée. Actes du VIe Congres de l'AICM2 (Aix-enProvence, 13-18 novembre 1995). Aix-en-Provence, Narration, 1997, pp. 63-72.

Ortisi 1999 : ORTISI (S.) - Ein frühkaiserzeitlicher Keramikkomplex aus einem Schöpfbrunnen in Insula E 117 West in Karthago. MDAI(R), 106, 1999, pp. 439-493.

Ostia I: CARANDINI (A.) dir. - Ostia I. Le terme del Nuotatore. Scavo dell'ambiente IV. Rome, De Luca, 1968 (Studi Miscellanei, 13).

Ostia II : CARANDINI (A.) dir. - Ostia II. Le terme del Nuotatore. Scavo dell'ambiente I. Rome, De Luca, 1970 (Studi Miscellanei, 16).

Ostia III : CARANDINI (A.), PANELLA (C.) dir. - Ostia III. Le terme del Nuotatore. Scavo dell'ambiente $V$ e di un saggio nell'area SO. Rome, De Luca, 1973 (Studi Miscellanei, 21).

Ostia IV : CARANDINI (A.), PANELLA (C.) dir. - Ostia IV. Le Terme del Nuotatore. Scavo dell'ambiente XVI e dell'area $X X V$. Rome, De Luca, 1977 (Studi Miscellanei, 23).

Pallarès 1987 : PALLARÈS (F.) - Alcune considerazione sulle anfore del Battistero di Albenga, RELig, LIII, 1-4, 1987, pp. 269-306.

Palol 1982 : PALOL (P. de) dir.- La basílica des Cap des Port, de Fornells, Menorca. In : II Reunió d'Arqueologia Paleocristiana Hispánica (Montserrat, 2-5 novembre 1978). Barcelone, Institut d'Arqueologia i Prehistòria, 1982, pp. 353404.

Palol 1987 : PALOL (P. de) - Els dipòsits d'àmfores de vi i d'oli en els àmbits basilicals cristians. In : El vi a l' Antiguitat, Economia, producció $i$ comerç al Mediterrani Occidental. Actes del I col.loqui international d'arqueologia romana (Badalone, 6-9 mai 1998). Badalona, Museu de Badalona, 1987, pp. 419-436 (Monografies Badalonines, 9).

Panella 1972 : PANELLA (C.) - Annotazioni in margine alle stratigrafie delle terme ostiensi del Nuotatore. In : Recherches sur les amphores romaines. Rome, EFR, 1972, pp. 69-106 (Coll. de l'Ecole française de Rome, 10). 
Panella 1973 : PANELLA (C.) - Le anfore. In : Ostia III, pp. 463-633.

Panella 1976 : PANELLA (C.) - Per uno studio delle anfore di Pompei. In : Scritti in memoria di G. Becatti. Rome, De Luca, 1976, pp.151-165 (Studi Miscellanei, 22).

Panella 1977 : PANELLA (C.) - Anfore tripolitane a Pompei. In : L'intrumentum domesticum di Ercolano e Pompei nella prima età imperiale. Roma, L'Erma di Bretschneider, 1977, pp.135-149.

Panella 1982 : PANELLA (C.) - Le anfore africane della prima, media e tarda età imperiale, tipologia e problemi. In : Actes $d u$ colloque sur la céramique antique (Carthage, 23-24 juin 1980). Carthage, 1982, pp. 171-186 (CEDAC, Dossiers 1).

Panella 1983a : PANELLA (C.) - I contenitori oleari presenti ad Ostia in età antonina : analisi tipologica, epigrafica, quantitativa. In : Producción y comercio del aceite en la Antigüedad. Segundo congresso internacional (Seville, 24-28 février 1982). Madrid, Universidad Complutense, 1983, pp. 225-262.

Panella 1983b : PANELLA (C.) - Le anfore di Cartagine : Nuovi elementi per la ricostruzione dei flussi commerciali del Mediterraneo in età imperiale romano. Opus, 2, pp. 53-73.

Panella 1986 : PANELLA (C.) - Le anfore tardoantiche : centri di produzione e mercati preferenziali. In : GIARDINA (A.) dir. - Società romana e impero tardoantico. III. Le merci, gli insediamenti. Rome, Laterza, 1986. pp. 251-272.

Panella 1989 : PANELLA (C.) - Gli scambi nel Mediterraneo occidentale dal IV al VII secolo, dal punto di visto di alcune merci. In : Hommes et richesses dans l'Empire byzantin, I. Paris, Lethielleux, 1989, pp. 129-141 (Réalités byzantines).

Panella 1991 : PANELLA (C.) - Un contesto di età antonina dalle Terme del Nuotatore di Ostia. In : Giornate di studio in onore di A. Adriani (Rome 26-27 novembre 1984). Rome, L'Erma di Bretschneider, 1991, pp. 283-297 (Studi Miscellanei, 28).

Panella 1992 : PANELLA (C.) - Mercato di Roma e anfore galliche nella prima età imperiale. In : LAUBENHEIMER $(\mathrm{F}$.) éd. - Les amphores en Gaule. Paris, Annales Littéraires de l'Université de Besançon, 1992, pp. 185-206 (Centre de Recherches d'Histoire Ancienne, 116).

Panella 1993 : PANELlA (C.) - Merci e scambi nel Mediterraneo tardoantico. In : Storia di Roma, III, 2. Turin, Giulio Einaudi, 1993, pp. 613-697.

Panella 1999 : PANELLA (C.) - Rifornimenti urbani e cultura materiale tra Aureliano e Alarico. In : HARRIS (W. V.) éd. The transformations of Vrbs Roma in Late Antiquity. Portsmouth, 1999, pp. 183-215 (JRA, Suppl. Ser. 33).

Panella 2001 : PANELLA (C.) - Le anfore di età imperiale nel Mediterraneo occidentale. In : Céramiques hellénistiques et romaines, III. Paris, Presses Universitaires Franc-Comtoises, 2001, pp. 177-275.
Panella, Saguì 2001 : PANELLA (C.), SAGUÌ (L.) - Consumo e produzione a Roma tra tardoantico e altomedioevo : le merci, i contesti. In : Roma nell'alto medioevo. Settimane di studio del Centro Italliano di Studi sull'Alto Medioevo, XLVIII. Spolete, 2001, pp. 757-820.

Pareja 1972 : PAREJA (F.) - Marques sur une amphore de l'île de Fraile (Aguilas). Cahiers d'Archéologie Subaquatique, I, 1972, pp. 107-108.

Parker 1976: PARKER (A. J.) - Il relitto romano delle colonne a Camarina. Sicilia Archeologica, 30, 1976, pp. 25-29.

Parker 1976-77 : PARKER (A. J.) - Sicilia e Malta nel commercio marittimo dell'antichità. Kokalos, XXII-XXIII, 1976-77, tome II, 1, pp. 622-631.

Parker 1992 : PARKER (A. J.) - Ancient Shipwrecks of the Mediterranean and the Roman Provinces. Oxford, Tempus Reparatum, 1992 (BAR IS 580).

Pascual, Ribera 2002: PASCUAL BERLANGA (G.), RIBERA Y LACOMBA (A.) - Las ánforas tripolitanas antiguas en el contexto del Occidente Mediterráneo : un contenidor poco conocido de la época republicana. In : RIVET (L.), SCIALLANO (M.) éd. - Vivre, produire, échanger : reflets méditerranéens. Mélanges offerts à Bernard Liou. Montagnac, EMM, 2002, pp. 303-318 (Archéologie et histoire romaine, 8).

Pasqualini 2002 : PASQUALINI (M.) - Le pot de chambre, une forme particulière du vaisselier céramique dans la maison romaine entre les Ier et IIIe siècles de notre ère. In : RIVET (L.), SCIALLANO (M.) éd. - Vivre, produire et échanger : reflets méditerranéens. Mélanges offerts à Bernard Liou. Montagnac, EMM, 2002, pp. 267-274.

Pasqui 1906 : PASQUI (A.) - Matrici fittili per formare pani da distribuire in pubblici spettacoli, scoperte presso il casone. NSA, 1906, p. 182.

Passi et al. 1981 : PASSI (S.), ROTHSCHILD-BOROS (M.C.), FASELLA (P.), NAZZARO-PORRO (M.), WHITEHOUSE (D.) - An application of high performance liquid chromatography to analysis of lipids in archaeological samples. Journal of Lipid Research, 22, 1981, pp. 778-784.

Passi, Whitehouse 1985 : PASSI (S.), WHITEHOUSE (D.) The contents of amphorae from Byzacena and Gaza. In : WHITEHOUSE (D.) et al. - The Schola Praeconum II. PBSR, LIII, 1985, pp. 200-206.

Pavolini 1998 : PAVOLINI (C.) - Le lucerne in Italia nel VIVII secolo d. C. : alcuni contesti significativi. In : Saguì dir. 1998, pp. 123-140.

Pavolini 2000 : PAVOLINI (C.) - Scavi di Ostia, XIII. La ceramica comune. Le forme in argilla depurata dell'antiquarium. Rome, Istituto Poligrafico e zecca dello Stato, 2000.

Pavolini, Tortorella 1997 : PAVOLINI (C.), TORTORELLA (S.) - Le officine di El Mahrine, il libro di M. Mackensen e lo stato attuale della ricerca sui centri di produzione della ceramica africana. In : Le province dell'Impero. Miscellanea in Onore di 
Maria Floriani Squarciapino. Archeologia Classica, XLIX, 1997, pp. 247-274.

Peacock 1984a : PEACOCK (D. P. S.) - Petrology and Origins. In : Fulford, Peacock 1984, pp. 6-20.

Peacock 1984b : PEACOCK (D. P. S.) - The Amphorae : Typology and Chronology. In : Fulford, Peacock 1984, pp. 116140.

Peacock 1984c : PEACOCK (D. P. S.) - Seawater, Salt and Ceramics. In : Fulford, Peacock 1984, pp. 263-264.

Peacock 1994 : PEACOCK (D. P. S.) - The Amphorae : Typology, Fabric and Chronology. In : Fulford, Peacock 1994, pp. $42-52$.

Peacock, Bejaoui, Ben Lazreg 1989 : PEACOCK (D. P. S.), BEJAOUI (F.), BEN LAZREG (N.) - Roman amphora production in the Sahel region of Tunisia. In : Amphores romaines et histoire économique. Dix ans de recherche. Actes du colloque de Sienne (22-24 mai 1986). Rome, EFR, 1989, pp. 179-222 (Coll. de l'Ecole française de Rome, 114).

Peacock, Bejaoui, Ben Lazreg 1990 : PEACOCK (D. P. S.), BEJAOUI (F. ), BEN LAZREG (N.) - Roman pottery production in central Tunisia. JRA, 3, 1990, pp. 59-84.

Peacock, Tomber 1991 : PEACOCK (D. P. S.), TOMBER (R.) - Roman amphoras kilns in the Sahel of Tunisia : petrographic investigation of kiln material from sedimentary environment. In : MIDDLETON (A.), FREESTONE (I.) dir. - Recent developments in ceramic petrology. Londres, British Museum, 1991, pp. 289-304 (British Museum Occasional Papers, 81).

Peacock, Williams 1986 : PEACOCK (D. P. S.), WILLIAMS (D. F.) - Amphorae and the roman economy. An introductory guide. London/ New-York, Longman, 1986.

Peleg, Reich 1992 : PELEG (M.), REICH (R.) - Excavations of a Segment of the Byzantine City Wall of Caesarea Maritima. Atiqot, XXI, 1992, pp. 137-155.

Pellecuer, Pène 1996 : PELLECUER (C.), PÈNE (J.-M.) - Les importations d'origine méditerranéenne en Languedoc aux VIIe et VIIIe s. : l'exemple de San Peyre (Le Bouquet, Gard, France). In : CITTER (C.), PAROLI (L.), PELLECUER (C.), PÈNE (J.-M.) - Commerci nel Mediterraneo nell'Alto Medioevo. In : BROGIOLO (G. P.) dir. - Early Medieval Towns in the Western Mediterranean. Actes du colloque (Ravello, 22-24 septembre 1994). Ravello, Società Archeologica Padana, 1996, pp. 126-132 (Documenti di Archeologia, 10).

Pellecuer, Pomaredes 1991 : PELLECUER (C.), POMAREDES (H.) - La céramique commune « Brune Orangée Biterroise » (B.O.B.) : une production languedocienne des IIe IIIe s. ap. J.-C. In : SFECAG. Actes du congrès de Cognac (8-11 mai 1991). Marseille, 1991, pp. 365-384.

Pelletier, Poguet 1989 : PELLETIER (J.-P.), POGUET (M.) A propos des découvertes anciennes de canalisations en amphores de type spatheion à Eyguières (Bouches-du-Rhône). Documents d'Archéologie Méridionale, 12, 1989, pp. 252-257.
Pelletier, Poguet 1993 : PELLETIER (J.-P.), POGUET (M.) Des prospections à la fouille : recherches à Eyguières (B.-d.-R.). $R A N, 26,1993$, pp. 181-246.

Pelletier, Poguet 2000 : PELLETIER (J.-P.), POGUET (M.) et al. - Eyguières : l'occupation du site Saint-Pierre 1, de l'âge du Fer au Xe siècle et premières études des céramiques. In : Milieu et société dans la vallée des Baux. RAN, 33, 2000, pp. 275-328.

Peña 1998 : PEÑA (J. T.) - The mobilization of state olive oil in roman Africa : the evidence of late 4th-c. ostraca from Carthage. In : Carthage Papers : the Early Colony's Economy, Water Supply, a Public Bath, and the Mobilization of State Olive Oil. Portsmouth, 1998, pp. 117-238 (JRA, Suppl. Ser. 28).

Pensabene 1981 : PENSABENE (P.) - Anfore tarde con iscrizioni cristiane dal Palatino. In: Hommage à Nino Lamboglia, V. RELig, XLVII, 1981, pp.189-213.

Pentiricci et al. 1998 : PENTIRICCI (M.), CHRZANOVSKI (L.), CIRELLI (E.), FELICI (F.), FONTANA (S.) - La villa suburbana di uadi er-Rsaf (Leptis Magna) : il contesto ceramico di età antonina (150-180 d.C.). Libya Antiqua, n. s. 4, 1998, pp. 41-98.

Petridis 1997 : PETRIDIS (P.) - Delphes dans l'Antiquité tardive : première approche topographique et céramologique. $B C H, 121,1997$, pp. 681-695.

Picard 1943-45 : PICARD (G.-C.) - Activité du Service des Antiquités et Arts de la Tunisie en 1943 et 1944. BCTH (séance du 12 février 1945), pp. 354-368.

Picon 1973 : PICON (M.) - Introduction à l'étude technique des céramiques sigillées de Lezoux. Dijon, Centre de recherche sur les techniques gallo-romaines, 1973.

Picon 1998 : PICON (M.) - Pour une histoire des céramiques communes et particulièrement culinaires. RdA, XXII, 1998, pp. 145-151.

Pieri 1998a : PIERI (D.) - Les fouilles de la Bourse (19671984). Les amphores des sondages 6 et 7. In : Bonifay, Carre, Rigoir dir. 1998, pp. 108-126.

Pieri 1998b : PIERI (D.) - Le puits de la rue du Bon-Jésus (îlot $39 \mathrm{~N}$ ). Les amphores. In : Bonifay, Carre, Rigoir dir. 1998, pp. 231-241.

Pieri 1998c : PIERI (D.) - Le puits du Cap Titol. Les amphores. In : Bonifay, Carre, Rigoir dir. 1998, pp. 260-264.

Pietropaolo 1998 : PIETROPAOLO (L.) - Les céramiques communes importées (Fouilles de la Bourse, secteur de l'épave). In : Bonifay, Carre, Rigoir dir. 1998, pp. 80-87.

Pillet 1982 : PILLET (M.) - Potiers et poteries populaires en France. Paris, Dessain et Tobra, 1982.

Pinard 1952 : PINARD (M.) - Poteries et fragments chrétiens à décor incisé provenant de Carthage. Cahiers de Byrsa, II, 1952, pp. 121-131.

Piton 1998: PITON (J.) - Contexte amphorique du début du Ve s. à Arles (Bouches-du-Rhône). In : SFECAG, Actes du 
Congrès d'Istres (21-24 mai 1998). Marseille, 1998, pp. 107115 .

Pohl 1962 : POHL (G.) - Die frühchristliche Lampe vom Lorenzberg bei Epfach, Landkreis Schongau. In : Aus Bayern Frühzeit. Friedrich Wagner zum 75. Geburstag. Munich, 1962, pp. 219-228 (Schriftenreihe zur Bayerischen Landesgeschichte, 62).

Pons Pujol 2000 : PONS PUJOL (L.) - La economía de la Mauretania Tingitana y su relación con la Bética en el Alto Imperio. In : L'Africa romana, XIII. Roma, Carocci, 2000, pp. 1251-1289.

Pomey et al. 1987-88 : POMEY (P.), LONG (L.), L'HOUR (M.), RICHEZ (F.), BERNARD (H.) - Recherches sousmarines. Gallia Informations, 1, 1987-88, pp. 1-78.

Ponsich 1960 : PONSICH (M.) - Lampes romaines de Carthage (collection Georges Louis). RA, 2, 1960, pp. 155-172.

Ponsich 1961 : PONSICH (M.) - Les lampes romaines en terre cuite de la Maurétanie Tingitane. Rabat, 1961 (PSAM, 15).

Ponsich 1969-70 : PONSICH (M.) - Note préliminaire sur l'industrie de la céramique en Tingitane (Kouass, région d'Arcila). Karthago, 15, 1969-70, pp. 77-97.

Pontacolone, Incitti 1991 : PONTACOLONE (L.), INCITTI (M.) - Un relitto con carico di merci africane di età imperiale alle Trincere (Tarquinia). In : L'Africa Romana, VIII. Sassari, Gallizzi, 1991, pp. 543-570.

Portale, Romeo 2001 : PORTALE (E. C.), ROMEO (I.) Contenitori da trasporto. In : DI VITA (A.) dir. - Gortina, $V, 3$. Lo scavo del Pretorio (1989-1995). I materiali. Padoue, Bottega d'Erasmo, 2001, pp. 260-410 (Monografie della Scuola Archeologica Italiana di Atene e delle Missioni Italiane in Oriente, XII)

Poulsen 1986 : POULSEN (E.) - Tombs of the IVth-Vth centuries A.D. in the Danish sector at Carthage (Falbe, site $\mathrm{n}^{\circ}$ 90). In : Carthage VIII. CEA, XVIII, 1986, pp. 141-154.

Poulsen 2000 : POULSEN (E.) - Trade and Communication : The Pottery Aspect. In : ØRSTED (P.) dir. - Africa Proconsularis. Regional Studies in the Segermes Valley of Northern Tunisia, III. Aarhus, Aarhus University Press, 2000, pp. 225-291.

Pouyé et al. 1994: POUYÉ (B.), ALLOUIS (M.-F.), BONIFAY (M.), BOUVILLE (C.), CALVET (A.), LOPEZ (A. et C.) - Une nécropole de l'Antiquité tardive à Cadarache (Saint-Paul-lès-Durance, Bouches-du-Rhône). Archéologie Médiévale, XXIV, 1994, pp. 51-136.

Preece 2000 : PREECE (C.) - Marsa-el-Brega : a fatal port of call. Evidence for shipwreck, anchorage and trade in antiquity in the Gulf of Sirte. Libyan Studies, 31, 2000, pp. 29-57.

Pröttel 1996 : PRÖTTEL (P. M.) - Mediterrane Feinkeramikimporte des 2. bis 7. Jahrhunderts N. Chr. im Oberen Adriaraum und in Slovenien. Cologne, Marie Leidorf, 1996 (Kölner Studien zur Archäologie der Römischen Provinzen, 2).
Provost et al. 1999: PROVOST (A.) et al. - Carte Archéologique de la Gaule. Le Gard, 30/2. Paris, MSH, 1999.

Pucci 1974-75 : PUCCI (G.) - La ceramica. In : DI VITA (A.), PROCACCINI (P.), PUCCI (G.) - Lo scavo a Nord del mausoleo punico-ellenistico A di Sabratha. Libya Antiqua, XIXII, 1974-75, pp. 57-111.

Puglisi, Sardella 1998 : PUGLISI (M.), SARDELLA (A.) Ceramica locale in Sicilia tra il VI e il VII secolo d. C. Situazione attuale e prospettive future della ricerca. In : Saguì dir. 1998, pp. 777-785.

Py, Adroher Auroux, Sanchez 2001 - PY (M.), ADROHER AUROUX (A.), SANCHEZ (C.) - Dicocer 2. Corpus des céramiques de l'Age du Fer de Lattes (fouilles 1963-1999). Lattes, ADALR, 2001 (Lattara, 14).

Py, Raynaud 1982 : PY (M.), RAYNAUD (C.) - Stratigraphie du Marduel (Saint-Bonnet-du-Gard), I. Les sondages préliminaires (zones 01, 03-09, 05 et 08). Documents d'Archéologie Méridionale, 5, 1982, pp. 5-32.

Radič 1993 : RADIČ (I.) - Adriatic in Mediterranean communications and trade in roman times according to underwater finds. In : Actes du XIIe Congrès International des Sciences Préhistoriques et Protohistoriques (Bratislava, 1-7 septembre 1991). Bratislava, UISPP, 1993, pp. 337-344.

Ramallo, Ruiz, Berrocal 1996 : RAMALLO ASENSIO (S. F.), RUIZ VALDERAS (E.), BERROCAL CAPARROS (M. D. C.) - Contextos cerámicos de los siglos V-VII en Cartagena. AEA, 69, 1996, pp. 135-190.

Ramon 1986 : RAMON (J.) - El Baix Imperi i l'época Bisantina a les Illes Pitiuses. Ibiza, 1986.

Ramon, Cau 1997 : RAMON (J.), CAU (M. A.) - Niveles de época vandala de Es Catell (Eivissa). In : Contextos ceràmics d'època romana tardana $i$ de l'alta edat mitjana (segles IV-X). Actes de la table-ronde (Badalona, 6-8 novembre 1996). Barcelone, Universitat de Barcelona, 1997, pp. 269-311 (Arqueo Mediterrània, 2).

Raynaud 1982 : RAYNAUD (C.) - Un atelier de potier du IVe s. ap. J.-C. à Générac, Gard. RAN, XV, 1982, pp. 325-350.

Raynaud 1984 : RAYNAUD (C.) - Le quartier sud de l'agglomération antique de Lunel-Viel (Hérault). Documents d'Archéologie Méridionale, 7, 1984, pp. 121-147.

Raynaud 1987 : RAYNAUD (C.) - Typologie des sépultures et problèmes de datation. L'apport des fouilles de Lunel-Viel (Hérault). In : Nécropoles languedociennes de l'Antiquité tardive et du haut Moyen-Age. Archéologie en Languedoc, 12, 1987-4, pp. 121-132.

Raynaud 1991 : RAYNAUD (C.) - Les céramiques communes. In : SOLIER (Y.) dir. - La basilique paléochrétienne du Clos de la Lombarde, à Narbonne. Cadre archéologique, vestiges et mobiliers. Paris, CNRS, 1991, p 215234 (RAN, Suppl. 23).

Raynaud, Bonifay 1993 : RAYNAUD (C.), BONIFAY (M.) Amphores africaines. In : PY (M.), ADROHER AUROUX 
(M.), RAYNAUD (C.) dir. - DICOCER. Dictionnaire des céramiques antiques (VIIes. av. n.è. - VIIes. de n.è.) en Méditerranée nord-occidentale (Provence, Languedoc, Ampurdan). Lattes, A.R.A.L.O., 1993, pp. 15-22 (Lattara 6).

Rebourg 1987 : REBOURG (A.) - Du pain ? Des jeux ? Note sur deux moules découverts à Autun (Saône et Loire). In : Mélanges Lutz. RAE, XXXVIII, 1987, pp. 219-222.

Rebuffat 1987 : REBUFFAT (R.) - Lampes romaines à Gholaia (Bu Njem, Libye). In : OZIOL (T.), REBUFFAT (R.) Les lampes de terre cuite en Méditerranée. Des origines à Justinien. Actes de la Table ronde du CNRS (Lyon, 7-11 déc. 1981), Lyon, Maison de l'Orient, 1987, pp. 83-90.

Rebuffat 1997 : REBUFFAT (R.) - Les marques d'amphores de $\mathrm{Bu}$ Njem (Notes et Documents XII). Libya Antiqua, n. s. 3, 1997, pp. 163-174.

Rebuffat $\boldsymbol{e}$ al. 1966-67 : REBUFFAT (R.), DENEAUVE (J.), GASSEND (J.-M.), HALLIER (G.) - Bu Njem 1967. Libya Antiqua, III/IV, 1966-67, pp. 49-137.

Rebuffat et al. 1969-70 : REBUFFAT (R.), GASSEND (J.-M.), GUÉRY (R.), HALLIER (G.) - Bu Njem 1968. Libya Antiqua, VI-VII, 1969-70, pp. 9-106.

Remolà 1993 : REMOLÀ I VALLVERDÙ (J. A.) - Las ánforas de los niveles tardo-romanos. In : DUPRÉ I RAVENTOS (X.), CARRET I NADAL (J. M.) dir. - $L a$ "Antiga Audiència». Un accesso al foro provincial de Tarraco. Madrid, 1993, 173 p. (Excavaciones arqueologicas en España, 163).

Remolà 2000 : REMOLÀ I VALLVERDÙ (J. A.) - Las ànforas tardo-antiguas en Tarraco (Hispania tarraconensis). Siglos IV-VII d. C. Barcelone, Universitat de Barcelona, 2000 (Instrumenta, 7).

Remolà, Abello 1989 : REMOLÀ I VALLVERDÙ (J. A.), ABELLO I RILEY (A.) - Les àmfores. In : Ted'a - Un abocador del segle V D. C. en el forum provincial de Tàrraco. Tarragone, 1989, pp. 249-320 (Memories d'Excavacio, 2).

Renault 1908 : RENAULT (S.) - Le Kef. Cahiers d'Archéologie Tunisienne, I, 1908, p. 43-45.

Renault 1910 : RENAULT (S.) - Moule en terre cuite. Cahiers d'Archéologie Tunisienne, III, 1910, pp. 60-61.

Renault 1913 : RENAULT (S.) - Les bassins du Trik DarSamiat. Fouilles exécutées par l'auteur à Carthage. Cahiers d'Archéologie Tunisienne, n.s. 1, 1913, pp. 1-112.

Rendini 1988 : RENDINI (P.) - Anfore. In : DI VITA (A.) dir. - Gortina, I. Rome, L'Erma di Bretschneider, 1988, pp. 263278 (Monografie della Scuola Archeologica di Atene e delle Missioni Italiane in Oriente, III).

Rendini 1997 : RENDINI (P.) - Anfore. In : DI VITA (A.), MARTIN (A.) - Gortina II. Pretorio. Il materiale degli scavi Colini 1970-1977. Padoue, Aldo Ausilio, 1997, pp. 371-389 (Monografie della Scuola Archeologica di Atene e delle missioni italiane in Oriente, VII).
Revilla 1999 : REVILLA (V.) - Las ánforas africanas. In : BLÁZQUEZ MARTÍNEZ (J. M.), REMESAL RODRÍGUEZ (J.) dir. - Estudios sobre el Monte Testaccio (Roma), I. Barcelone, Universitat de Barcelona, 1999, pp. 75-90 (Instrumenta, 6).

Revilla 2001 : REVILLA CALVO (V.) - Las ánforas tunecinas y tripolitanas de los siglos II y III d. C. : tipología y circulación. In : BLÁZQUEZ MARTÍNEZ (J. M.), REMESAL RODRÍGUEZ (J.) dir. - Estudios sobre el Monte Testaccio (Roma), II. Barcelone, Universitat de Barcelona, 2001, pp. 367378 (Instrumenta, 10).

Revilla 2003 : REVILLA CALVO (V.) - Las ánforas africanas del siglo II d. C. In : BLÁZQUEZ MARTÍNEZ (J. M.), REMESAL RODRÍGUEZ (J.) dir. - Estudios sobre el Monte Testaccio (Roma), III. Barcelone, Universitat de Barcelona, 2003, pp. 399-411 (Instrumenta, 14).

Reynaud 1998 : REYNAUD (P.) - Le puits du Cap Titol. La vaisselle. In : Bonifay, Carre, Rigoir dir. 1998, pp. 254-260.

Reynolds 1987 : REYNOLDS (P.) - El yacimiento tardorromano de Lucentum (Benalua-Alicante) : las cerámicas finas. Alicante, Museo Arqueológico Provincial, 1987 (Catálogo de fondos del Museo Arqueológico, II).

Reynolds 1993 : REYNOLDS (P.) - Settlement and Pottery in the Vinalopo valley (Alicante, Spain) A.D. 400-700. Oxford, Tempus Reparatum, 1993 (BAR, IS 588).

Reynolds 1995 : REYNOLDS (P.) - Trade in the Western Mediterranean AD 400-700 : The Ceramic Evidence. Oxford, Tempus Reparatum, 1995 (BAR IS 604).

Reynolds 1997 : REYNOLDS (P.) - A First Century AD Pottery Assemblage from Lepcis Magna. In : WALDA (H.) et al. - The 1996 Excavations at Lepcis Magna. Libyan Studies, 28, 1997, pp. 49-63.

Reynolds 1997-98 : REYNOLDS (P.) - Pottery production and economic exchange in second century Berytus : some preliminary observations of ceramic trends from quantified ceramic deposits from the AUB-Leverhulme excavations in Beirut. Berytus, XLIII, 1997-98, pp. 35-110.

Rickman 1980 : RICKMAN (G.) - The Corn Supply of Ancient Rome. Oxford, Clarendon Press, 1980.

Rigoir 1968 : RIGOIR ( J.) - Les sigillées paléochrétiennes grises et orangées. Gallia, XXVI-1, 1968, pp. 177-244.

Rigoir 1997 : RIGOIR (Y.) - Héritages et innovations dans le décor des Dérivées-des-Sigillées Paléochrétiennes. In : $L a$ céramique médiévale en Méditerranée. Actes du VIe Congres de l'AICM2 (Aix-en-Provence, 13-18 novembre 1995). Aix-enProvence, Narration, 1997, pp. 27-33.

Riley 1975 : RILEY (J. A.) - The pottery from the first session of excavation in the Cesarea Hippodrome, Bulletin of the American School of Oriental Research, 218, 1975, pp. 25-63.

Riley 1979 : RILEY (J. A.) - The Coarse Pottery from Berenice. In : LLOYD (J. A.) dir. - Excavations at Sidi 
Khrebish-Benghazi (Berenice), II. Tripoli, 1979, pp.91-467 (Libya Antiqua, Suppl. II).

Riley 1981 : RILEY (J. A.) - The pottery from the cistern 1977.1, 1977.2 and 1977.3. In : HUMPHREY (J. H.) dir. Excavations at Carthage conducted by the University of Michigan, VI. Ann Arbor, Kelsey Museum, 1981, pp. 86-124.

Rivet 2001 : RIVET (L.) - Les sigillées tardives issues des fouilles 1946-1970 de Saint-Blaise (Bouches-du-Rhône). Quantification et mise en évidence des décors. In : SFECAG, Actes du Congrès de Lille-Bavay (24-27mai 2001). Marseille, 2001, pp. 489-516.

Rivet 2003 : RIVET (L.) - Lampes antiques du golfe de Fos. Collections du Musée d'Istres et du Service du Patrimoine de Fos-sur-Mer. Production et consommation. Aix-en-Provence, Musée d'Istres-Edisud, 2003.

Rizzo 2003 : RIZZO (G.) - Instrumenta Vrbis. 1, Ceramiche fine da mensa, lucerne ed anfore a Roma nei primi due secoli dell'impero. Rome, EFR, 2003 (Coll. de l'Ecole française de Rome, 307).

Robin Petitot 2000 : ROBIN PETITOT (B.) - Catalogue des lampes grecques et romaines. Arles, 2000 (Les Collections du musée de l'Arles antique).

Robinson 1959 : ROBINSON (H. S.) - The Athenian Agora $V$. Pottery of the Roman Period. Chronology. Princeton, American School of Classical Studies at Athens, 1959.

Rodziewicz 1976 : RODZIEWIECZ (M.) - Alexandrie I. La céramique romaine tardive d'Alexandrie. Varsovie, PWN, 1976.

Rodziewicz 1984 : RODZIEWIECZ (M.) - Alexandrie III. Les habitations romaines tardives d'Alexandrie à la lumière des fouilles polonaises à Kôm el-Dikka. Varsovie, PWN,1984.

Rolland 1951 : ROLLAND (H.) - Fouilles de Saint-Blaise (Bouches-du-Rhône). Paris, 1951 (Gallia, suppl. III).

Romancuk, Sazanov 1991 : ROMANCUK (A. I.), SAZANOV (A.) - Krasnolakovaja keramika rannevizantiskogo Chersona, Srednevekovyj Cherson, Istorija, Stratigrafija, Nachodki. Sverdlovsk, 1991. (en russe)

Rosen 1995 : ROSEN (J.) - La faïence en France du XIVe au XIXe s. Histoire et techniques. Paris, Errance, 1995.

Rosselló Bordoy 1993 : ROSSELLÓ BORDOY (M.) - Las cerámicas de primera época : algunas observaciones metodologicas. In : La cerámica altomedieval en el sur de AlAndalus. Grenade, Universidad de Granada, 1993, pp. 13-36.

Rossiter 1988 : ROSSITER (J. J.) - Lamps from the late-4th to early-5th century deposit. In : HUMPHREY (J. H.) dir. - The Circus and a Byzantine Cemetery at Carthage. Vol. I. Ann Arbor, The University of Michigan Press, 1988, pp. 529-548.

Rossiter 1993 : ROSSITER (J. J.) - Lamps from unit 4000. In : STEVENS (S.) dir. - Bir El Knissia at Carthage : A rediscovered cemetery church, Report no. 1. Ann Arbor, 1993, pp. 178-180 (JRA, Suppl. Ser. 7).
Rouquet, Loridan 2000 : ROUQUET (N.), LORIDANT (F.) Note sur les biberons en Gaule romaine. In : SFECAG, actes $d u$ congrès de Libourne (1er-4 juin 2000). Marseille, 2000, pp. $425-440$.

Rouquet, Loridan 2003 : ROUQUET (N.), LORIDANT (F.) Archéologie expérimentale : le tire-lait à l'épreuve. In : SFECAG, actes du congrès de Saint-Romain-en-Gal (29 mailer juin 2003). Marseille, 2003, pp. 665-666.

Rovina 1990 : ROVINA (D.) - Un tipo ceramico da corredi funerari : la forma «Boninu 1971-72». In : Le sepolture in Sardegna dal IV al VII secolo. IV Convegno sull'archeologia tardoromana e medievale (Cuglieri, 27-28 juin 1987). Mediterraneo Tardoantico e Medievale, Scavi e ricerche, 8, 1990, pp. 83-89.

RTAR I: CARRE (M.-B.), GAGGADIS-ROBIN (V.), HESNARD (A.), TCHERNIA (A.) - Recueil des timbres sur amphores romaines (1987-88). Aix-en-Provence, Université de Provence, 1995.

$\boldsymbol{R T A R} \boldsymbol{I I}$ : BLANC-BIJON (V.), CARRE (M.-B.), HESNARD (A.), TCHERNIA (A.) - Recueil des timbres sur amphores romaines, II. Aix-en-Provence, Université de Provence, 1998.

Rütti 1991 : RÜTTI (B.) - Die römischen Gläser aus Augst und Kaiseraugst. Augst, Römer Museum Augst, 1991 (Forschungen in Augst, 13).

Sabrié 1991 : SABRIÉ (R.) et (M.) - Les céramiques importées. In : SOLIER (Y.) dir. - La basilique paléochrétienne du Clos de la Lombarde, à Narbonne. Cadre archéologique, vestiges et mobiliers. Paris, CNRS, 1991, pp. 87-122 (RAN, Suppl. 23).

Saguì 1979 : SAGUÌ (L.) - Ceramica africana al Museo Archeologico Nazionale di Sperlonga. ArchClass, XXXI, 1979, pp. 255-272.

Saguì 1980 : SAGUÌ (L.) - Ceramica africana dalla « villa di Tiberio » a Sperlonga. MEFRA, 92, 1980, pp. 471- 544.

Saguì 1995 : SAGUÌ (L.) - L'esedra della Crypta Balbi e il monastero di S. Lorenzo in Pallacinis. Quaderni di Archeologia Etrusco-italica, 23, 1995, pp. 121-129 (Archeologia Laziale, XII, 1).

Saguì 1998 : SAGUİ (L.) - Il deposito della Crypta Balbi : una testimonianza imprevidibile sulla Roma del VII secolo ? In : Saguì dir. 1998, pp. 305-330.

Saguì dir. 1998 : SAGUÌ (L.) dir. - Ceramica in Italia : VI-VII secolo. Atti del Convegno in onore di John W. Hayes (Rome, 11-13 mai 1995). Florence, All'Insegna del Giglio, 1998 (Biblioteca di Archeologia Medievale, 11). 2 vol.

Saguì, Coletti 2004 : SAGUİ (L.), COLETTI (C. M.) Contesti tardoantichi dall'area a S-E della Crypta Balbi. In : PAROLI (L.), VENDITELLI (L.) dir. - Roma dall'antichità all medioevo, II. Contesti tardoantichi e altomedievali. Milan, 2004, pp. 242-277.

Saguì et al. 1997 : SAGUÌ (L.), RICCI (M.), ROMEI (D.) Nuovi dati ceramologici per la storia economica di Roma tra 
VII et VIII secolo. In : La céramique médiévale en Méditerranée. Actes du VIe Congres de l'AICM2 (Aix-enProvence, 13-18 novembre 1995). Aix-en-Provence, Narration, 1997, pp. 35-48.

Salomonson 1962 : SALOMONSON (J. W.) - Late-Roman Earthenware with Relief Decoration found in Northern-Africa and Egypt. OMRL, XLIII, 1962, pp. 53-95.

Salomonson 1968 : SALOMONSON (J. W.) - Etude sur la céramique romaine d'Afrique sigillée claire et céramique commune de Henchir el Ouiba (Raqqada) en Tunisie centrale. BABesch, XLIII, 1968, pp. 80-145.

Salomonson 1969 : SALOMONSON (J. W) - Spätrömische rote Tonware mit Reliefverzierung aus Nordafrikanischen Werkstätten. Entwicklungsgeschitliche Untersuchungen zur reliefgeschmückten Terra Sigillata Chiara « $\mathrm{C} »$. BABesch, XLIV, 1969, pp. 4-109.

Salomonson 1970 : SALOMONSON (J. W.) - La céramique. In : MAHJOUBI (A.), SALOMONSON (J.-W.), ENNABLI (A.) - La nécropole romaine de Raqqada. Tunis, 1970, pp. 2381. ( Coll. Notes et Documents, VIII, 1).

Salomonson 1971 : SALOMONSON (J. W.) - Roman pottery. A source of information for historians and archaeologists. BABesch, XLVI, 1971, pp. 173-192.

Salomonson 1972 : SALOMONSON (J. W.) - Römische Tonformen mit Inschriften, ein Beitrag zum Problem der sogenannten «Kuchenformen» aus Ostia. BABesch, XLVII, 1972, pp. 88-113.

Salomonson 1982 : SALOMONSON (J. W.) - «Litterae Africanae ». Ein Tonfragment mit kursiven lateinischer Inschrift in der archäologischen Sammlung der Utrechter Universität. In : Actus. Studies in Honour of H. L. W. Nelson. Utrecht, 1982, pp. 343-364.

Sant'Antonino 1988 : BONORA (E.), FALCETTI (C.), FOSSATI (A.), , IMPERIALE (G.), MANNONI (T.), MURIALDO (G.), VICINO (G.) - Il « castrum » tardo antico di S. Antonino di Perti, Finale Ligure (Savona) : fasi stratigrafiche e reperti dell'area D. Seconde notizie premiminari sulle campagne di scavo 1982-1987. Archeologia Medievale, XV, 1988, pp. 335-396.

Sant'Antonino 1992 : CASTIGLIONI (E.), CUPELLI (G.), FALCETTI (C.), FERRETTI (F.), FOSSATI (A.), GIOVINAZZO (R.), MURIALDO (G.), MANNONI (T.), PALAZZI (P.), PANIZZA (M.), PARODI (L.), RICCI (R.), VICINO (G.) - Il « castrum » tardoantico di S. Antonino di Perti, Finale Ligure (Savona) : terze notizie preliminari sulle campagne di scavo 1982-1991. Archeologia Medievale, XIX, pp. 302-314.

Santamaria 1995 : SANTAMARIA (C.) - L'épave Dramont E à Saint-Raphaël (Ves. ap.J.-C.). Paris, CNRS, 1995 (Archaeonautica, 13).

Sazanov 1991 : SAZANOV (A.) - Amforniï kompleks pervoï tchetverti VII v. n. e. iz severo-vostotchnogo raïona khersonesa (Les amphores de l'ensemble du premier quart du VIIe s. du quartier nord-est de Chersonese). In : Materiali po arkheologii, istorii, i etnografii tavrii. Bilousk II. Simferopol, Traviia, 1991, pp. 60-72. (en russe)

Schindler 2001 : SCHINDLER (R.) - Painted Terracotta mask from the cemetery (site 200). In : Leptiminus II, pp. 415-419.

Schuring 1984 : SCHURING (J. M.) - Studies on Roman Amphorae I-II. BABesch, 59, 1984, pp. 137-195.

Schuring 1988 : SCHURING (J. M.) - Terra Sigillata Africana from the San Sisto Vecchio in Rome. BABesch, 63, 1988, pp. 168.

Sciallano, Sibella 1991 : SCIALLANO (M.) ET SIBELLA (P.) - Amphores, Comment les identifier? Aix-en-Provence, Edisud, 1991.

Segermes I : DIETZ (S.), LADJIMI SEBAÏ (L.) BEN HASSEN (H.) - Africa Proconsularis, Regional Studies in the Segermes Valley of Northern Tunesia, I. Copenhague, The National Museum of Denmark, 1995.

Sherriff, McCammon, Stirling 2002 : SHERRIFF (B. L.), MCCAMMON (C.), STIRLING (L.) - A Mössbauer Study of the Color of Roman Pottery from the Leptiminus Archaeological Site, Tunisia. Geoarcheology, 17-8, 2002, pp. 863-874.

Simitthus II : KHANOUSSI (M.), $†$ KRAUS (Th.), RAKOB (F.), VEGAS (M.) - Simitthus II. Der Tempelberg und das römische Lager. Mayence, Philipp von Zabern, 1994.

Sirks 1991 : SIRKS (B.) - Food for Rome. Amsterdam, J. C. Gieben, 1991.

Slane 1990 : SLANE (K. W.) - Corinth XVIII, 2. The Sanctuary of Demeter and Kore. The roman Pottery and Lamps. Princeton, The American School of Classical Studies at Athens, 1990.

Slane 2000 : SLANE (K. W.) - East-West trade in fine wares and commodities : the view from Corinth. RCRF Acta 36, 2000, pp. 299-312.

Slim 1969-70 : SLIM (L.) - Découverte d'une nécropole romaine à El-Mahrine. Africa, III-IV, 1969-70, pp. 247-248.

Slim 1985 : SLIM (H.) - Nouveaux témoignages sur la vie économique à Thysdrus. $B C T H$, n. s., fasc. $19 \mathrm{~B}, 1985$, pp. 6385 .

Slim, Bonifay, Piton 2002 : SLIM (L.), BONIFAY (M.), PITON (J.) - Etat des données archéologiques sur Neapolis (Nabeul) à la fin de l'Antiquité. In : L'Afrique vandale et byzantine, I. Actes du colloque international (Tunis, 5-8 octobre 2000). AntTard, 10, 2002, pp. 178-182.

Slim, Bonifay, Trousset 1999 : SLIM (L.), BONIFAY (M.), TROUSSET (P.), avec BLANC-BIJON (V.), FOY (D.), GASSEND (J.-M.), HALLIER (G.), PASKOFF (R.), PASQUALINI (M.), PITON (J.), STERNBERG (M.) - L'usine de salaison de Neapolis (Nabeul). Premiers résultats des fouilles 1995-1998. Africa, XVI, 1999, pp. 153-197.

Small, Buck 1994 : SMALL (A. M.), BUCK (R. J.) dir. - The excavations of San Giovanni di Ruoti. Vol. I. The villas and 
their Environment. Toronto/Buffalo/Londres, University of Toronto Press, 1994.

Sodini 2000 : SODINI (J.-P.) - Productions et échanges dans le monde protobyzantin (IVe-VIIe s.) : le cas de la céramique. In : BELKE (K.), HILD (F.), KODER (J.), SOUSTAL (P.) éd. Byzanz als Raum. Zu Methoden und Inhalten der historischen Geographie des Östlichen Mittelmeeraumes. Vienne, Österreichische Akademie der Wissenschaften, 2000, pp. 181196 (Tabula Imperii Byzantini, 7).

Sodini, Villeneuve 1992 : SODINI (J.-P.), VILLENEUVE (E.) - Le passage de la céramique byzantine à la céramique omeyyade en Syrie du Nord, en Palestine et en Transjordanie. In : CANIVET (P.), REY-COQUAIS (J. P.) dir. - La Syrie de Byzance à l'Islam (VIIe-VIIIe s.). Actes du Colloque international (Lyon-Paris, septembre 1990). Paris/Damas, 1992, pp. 195-212.

Soren 1978 : SOREN (D.) - The roman pottery from Utica (Tunisia). CEA, VIII, 1978, p 109-141.

Soricelli 1987 : SORICELLI (G.) - « Tripolitanian Sigillata » : North African or Campanian ? Libyan Studies, 18, 1987, pp. 7387.

Soricelli 1994 : SORICELLI (G.) - «Terra Sigillata » della prima, media e tarda età imperiale. In : ARTHUR (P.) dir. - Il complesso Archeologio di Carminiello ai Mannesi, Napoli (Scavi 1983-1984). Naples, Congedo, 1994, pp. 109-168.

Staffa 1991 : STAFFA (A.) - Scavi nel centro storico di Pescara, 1 : primi elementi per una ricostruzione dell'assetto antico ed altomedievale dell'abitato di «Ostia AterniAternum ». Archeologia Medievale, XVIII, 1991, pp. 201-367.

Staffa 1998 : STAFFA (A. R.) - Le produzioni ceramiche in Abruzzo tra fine V e VII secolo. In : Saguì dir. 1998, pp. 437480 .

Staffa, Pellegrini 1993 : STAFFA (A. R.), PELLEGRINI (W.) dir. - Dall' Egitto copto all'Abruzzo bizantino. I Bizantini in Abruzzo (secc. VI-VII). Crecchio, Soc. Coop. Polis, 1993.

Stefani 2003 : STEFANI (G.) - Menander. La casa del Menandro di Pompei. Catalogue de l'exposition (Antiquarium de Boscoreale, 2003). Milan, Electa, 2003.

Stern 1968 : STERN (E. M.) - Note analytique sur des tessons de sigillée claire ramassés à Henchir es Srira et Sidi Aïch. BABesch, 43, 1968, pp. 146-154.

Stevens, Kalinovski, Van der Leest 1998 : STEVENS (S. T.), KALINOWSKI (A. V.), VAN DER LEEST (H.) - The Early Christian pilgrimage complex at Bir Ftouha, Carthage : interim report. JRA, 11, 1998, pp. 371-383.

Stirling 2001 : STIRLING (L.) - The East Baths and their industrial re-use in late antiquity : 1992 excavations. In : Leptiminus II, pp. 29-74.

Stirling, Ben Lazreg 1999 : STIRLING (L.), BEN LAZREG (N.) - Roman kilns and pottery production at Leptiminus, Tunisia : results of excavation in 1995-1998. In : DOLTER (R. F.), MOORMAN (E. M.) éd. - Proceedings of the XVth
International Congress of Classical Archaeology (Amsterdam, 12-17 juillet 1998). Amsterdam, Allard Pierson Series, 1999, pp. 402-403.

Stirling, Ben Lazreg 2001 : STIRLING (L.), BEN LAZREG (N.) - A Roman kiln complex (Site 290) : preliminary results of excavations, 1995-98. In : Leptiminus II, pp. 221-235.

Stone, Stirling, Ben Lazrreg 1998 : STONE (D. L.), STIRLING (L. M.), BEN LAZREG (N.) - Suburban land-use and ceramic production around Leptiminus (Tunisia) : interim report. JRA, 11, 1998, pp. 304-317.

Swan 1992 : SWAN (V. G.) - Legio VI and its Men : African Legionaries in Britain. Journal of Roman Pottery Studies, 5, 1992, pp. 1-34.

Taylor, Robinson, Gibbins 1997 : TAYLOR (R. J.), ROBINSON (V. J.), GIBBINS (D. J. L.) - An investigation of the provenance of the Roman amphora cargo from the Plemmirio B shipwreck. Archaeometry, 39-1, février 1997, pp. 9-22.

Tengström 1974 : TENGSTRÖM (E.) - Bread for the people : studies of the corn supply of Rome during the late Empire. Stockholm, Paul Aströms, 1974.

Tchernia 1986 : TCHERNIA (A.) - Le vin de l'Italie romaine. Essai d'histoire économique d'après les amphores. Rome, EFR, 1986 (BEFAR, 261).

Tchernia 1998 : TCHERNIA (A.) - Archéologie expérimentale et goût du vin romain. In : El vi a l'Antiguitat. Economia, producció $i$ commerç al Mediterrani occidental. Actes du II col.loqui internacional d'arqueologia romana (Badalona, 6-9 mai 1998). Badalona, Museu de Badalona, 1998, pp. 503-509 (Monografies Badalonines, 14).

Tchernia, Brun 1999 : TCHERNIA (A.), BRUN (J.-P.) - Le vin romain antique. Grenoble, Glénat, 1999.

Thébert 2000 : THÉBERT (Y.) - Transport à grande distance et magasinage de briques dans l'empire romain. Quelques remarques sur les relations entre production et consommation. In : BOUCHERON (P.), BROISE (H.), THÉBERT (Y.) éd. La brique antique et médiévale. Production et commercialisation d'un matériau. Actes du colloque international (Saint-Cloud, 16-18 novembre 1995). Rome, EFR, 2000, pp. 341-356 (Coll. de l'Ecole française de Rome, 272).

Thomas 1981 : THOMAS (C.) - A provisional list of imported pottery in post-roman western Britain and Ireland. The Institute of Cornish Studies, 1981 (ICS Special Report N7).

Tomber 1986 : TOMBER (R.) - Pottery from the south side of the circular harbour. $C E D A C, 7$, mars 1986, pp. 34-58.

Tomber 1987 : TOMBER (R.) - Evidence for long-distance commerce : imported bricks and tiles at Carthage. RCRF Acta, XXV/XXVI, 1987, pp. 161-174.

Tomber 1988 : TOMBER (R. S.) - Pottery from the 1982-83 excavations. In : HUMPHREY (J. H.) dir. - The Circus and a Byzantine Cemetery at Carthage. Vol. I. Ann Arbor, The University of Michigan Press, 1988, pp. 437-528. 
Tomber 1990 : TOMBER (R.) - Pottery from occupation levels of byzantine Carthage. CEDAC, 11, juin 1990, pp. 29-39.

Tomber 1993 : TOMBER (R.) - Quantitative approaches to the investigation of long-distance exchange. JRA, 6, 1993, pp. 142166.

Tomber 1996 : TOMBER (R.) - Provisioning the desert : pottery supply to Mons Claudianus. In :Archeological Research in Roman Egypt. Ann Arbor, 1996, pp. 39-49 (JRA Suppl. Ser. 19).

Tomber 1998 : TOMBER (R.) - The Pottery. In : SIDEBOTHAM (S. E.), WENDRICH (W. Z.) - Berenike 1996. Report of the 1996 Excavations at Berenike (Egyptian Red Sea Coast) and the Survey of the Eastern desert. Leiden, CNWS, 1998, pp. 163-180.

Tomber 1999 : TOMBER (R.) - Pottery from the sediments of the Inner Harbour (area I 14). In : HOLUM (K. G.), RABAN (A.), PATRICH (J.) éd. - Caesarea Paper 2. Herod's Temple, the Provincial Governor's praetorium and granaries, the Later Harbor, a Gold Coin Hoard, and others studies. Portsmouth, 1999, pp. 293-322 (JRA, Suppl. Ser. 35).

Topoleanu 2000 : TOPOLEANU (F.) - Roman and romanbyzantin pottery from Halmyris. North-africa importation and local imitation. In : Istro-Pontica. Muzeul tulcean la a 50-a aniversare. Tulcea, 2000, pp. 257-294.

Torrecilla Aznar 1999 : TORRECILLA AZNAR (A.) Materiales de construcción en las termas de la Hispania Romana, a propósito de los materiales hallados en la villa de el Saucedo (Talavera la Nueva, Toledo). In: Actas del XXIV Congreso Nacional de Arqueología (Cartagena, 1997). Murcia, Instituto de Patrimonio Histórico, 1999, pp. 397-416.

Tortorella 1981 : TORTORELLA (S.) - Ceramica di produzione africana e rinvenimenti archeologici sottomarini della media e tarda età imperiale. MEFRA, 93, 1981, pp. 355415.

Tortorella 1982 : TORTORELLA (S.) - La sigillata africana a Cartagine fra il 400 D.C. e la conquista vandala : i dati dello scavo della missione archeologica italiana. In : Actes du colloque sur la céramique antique (Carthage, 23-24 juin 1980). Carthage, 1982, pp. 125-139 (CEDAC, Dossiers 1).

Tortorella 1986 : TORTORELLA (S.) - La ceramica fine da mensa africana dal IV al VII secolo D. C. In : GIARDINA (A.) dir. - Società romana e impero tardoantico, III, Le merci, gli insediamenti. Rome, Laterza, 1986, pp. 211-225.

Tortorella 1987 : TORTORELLA (S.) - La ceramica africana : un riesame della problematica. In : Céramiques hellénistiques et romaines, II. Paris, Annales Littéraires de l'Université de Besançon, 1987, pp. 279-327 (Centre de Recherches d'Histoire Ancienne, 70).

Tortorella 1995 : TORTORELLA (S.) - La ceramica africana. Un bilancio dell'ultimo decennio di ricerche. In : L'Afrique $d u$ Nord antique et médiévale. Production et exportations africaines. Actualités archéologiques. Actes du VIe Colloque International sur l'Histoire et l'Archéologie de l'Afrique du Nord (Pau, octobre 1993). Paris, CTHS, 1995, pp. 79-101.
Tortorella 1998 : TORTORELLA (S.) - La sigillata africana in Italia nel VI e nel VII secolo d. C. : problemi di cronologia e distribuzione. In : Saguì dir. 1998, pp. 41-69.

Treglia 1998 : TREGLIA (J.-C.) - Les fouilles de la Bourse (1967-1984). La vaisselle des sondages 11 et 12. In : Bonifay, Carre, Rigoir dir. 1998, pp. 175-189.

Treglia 2002 : TREGLIA (J.-C.) - Flanged bowl Hayes 91 : simple bol décoré, mortier ou râpe ? In : RIVET (L.), SCIALLANO (M.) éd. - Vivre, produire et échanger : reflets méditerranéens. Mélanges offerts à Bernard Liou. Montagnac, EMM, 2002, pp. 287-290.

Trost, Hellmann 1996 : TROST (C.), HELLMANN (M.-C.) Lampes antiques du département des Monnaies, Médailles et Antiques. III. Fonds général : Lampes chrétiennes. Paris, BNF,1996.

Trousset 1974 : TROUSSET (P.) - Recherches sur le limes tripolitanus, du chott el-Djerid à la frontière tuniso-libyenne. Paris, CNRS, 1974 (Etudes d'Antiquités Africaines).

Uscatescu 2003 : USCATESCU (A.) - Report on the Levant Pottery (5th-9th century AD). In : BONIFAY (M.) éd. - Tableronde «De Rome à Byzance ; de Fostat à Cordoue : évolution des faciès céramiques en Méditerranée (Ve - IXe s.) ». In : BAKIRTZIS (C.) éd. - VIIe Congrès International sur la Céramique Médiévale en Méditerranée (Thessalonique, 11-16 octobre 1999). Athènes, Ministère de la Culture, 2003, pp. 546568 .

Vallauri 1994 : VALLAURI (L.) - Les céramiques communes importées. In: DÉMIANS D'ARCHIMBAUD (G.) dir. L'oppidum de Saint-Blaise du Ve au VIIes. (Bouches-duRhône). Paris, MSH, 1994, pp. 116-132 (Documents d'Archéologie Française, 45).

Van der Werff 1977-78 : VAN DER WERFF (J. H.) Amphores de tradition punique à Uzita. BABesch, 52-53, 197778, pp. 171-198.

Van der Werff 1982a : VAN DER WERFF (J. H.) - Uzita. Matériel de fouilles d'une cité antique en Tunisie centrale. Utrecht, 1982. 2 vol. (en néerlandais)

Van der Werff 1982b : VAN DER WERFF (J. H.) - Amphores de tradition punique mise en cause de la datation. In : Actes $d u$ colloque sur la céramique antique (Carthage, 23-24 juin 1980). Carthage, 1982, pp. 213-218 (CEDAC, Dossiers 1).

Van der Werff 1984 : VAN DER WERFF (J. H.) - Céramique modelée d'Uzita. BABesch, 59, 1984, pp. 125-135.

Vegas 1973 : VEGAS (M.) - Cerámica común romana del Mediterráneo occidental. Barcelone, Universidad de Barcelona, 1973 (Publicaciones Eventuales, N. 22).

Vegas 1994a : VEGAS (M.) - La céramique du « camp » à Simitthus. In : Simitthus II, pp. 141-244.

Vegas 1994b : VEGAS (M.) - Ein frühkaiserzeitlicher Fundkomplex aus Karthago. MDAI(R), 101, 1994, pp. 339-364. 
Vera 1997-98 : VERA (D.) - Fra Egitto ed Africa, fra Roma e Constantinopoli, fra annona e commercio: la Sicilia nel Mediterraneo tardoantico. In : Atti del IX congresso internazionale di studi sulla Sicilia antica. Kokalos, XLIIIXLIV, I-1, 1997-1998, pp. 33-73.

Vernhet 1981 : VERNHET (A.) - Un four de la Graufesenque (Aveyron) : la cuisson des vases sigillés. Gallia, XXXIX, 1981, pp. 25-43.

Vertet 1983 : VERTET (H.) - Recherches sur les techniques de fabrication des lampes en terre cuite du centre de la Gaule. Avignon, 1983 (Revue archéologique Sites, Hors-série n²0).

Vidrih Perko 1995 : VIDRIH PERKO (V.) - Spätantike Keramische Neufunde aus Piran. RCRF Acta, 34, 1995, pp. 241248.

Villa 1998 : VILLA (L.) - Alcuni aspetti della circolazione di prodotti di importazione in Friuli tra VI e VII secolo. In : Saguì dir. 1998, pp. 275-288.

Villedieu 1984 : VILLEDIEU (F.) - Turris Libisonis. Fouille d'un site romain tardif à Porto Torres, Sardaigne. Oxford, 1984 (BAR IS, 224).

Villedieu 1994 : VILLEDIEU (F.), Les amphores : observations préliminaires. In : DÉMIANS D'ARCHIMBAUD (G.) dir. L'oppidum de Saint-Blaise du Ve au VIIe s. (Bouches-du-Rhône) Paris, MSH, 1994, pp. 133-135 (Documents d'Archéologie Française, 45).

Waagé 1933 : WAAGÉ ( F. O.) - The American Excavations in the Athenian Agora. First Report : The Roman and Byzantine Pottery. Hesperia, II, 1933, pp. 279-328.

Waagé 1948 : WAAGÉ (F. O.) - Hellenistic and Roman Tableware of North Syria. In : Antioch-on-the-Orontes IV, 1 . Ceramics and Islamic Coins. Princeton, Princeton University Press, 1948, pp. 1-60.

Wells et al. 1988 : WELLS (C.), FREED (J.), GALLAGHER (J.) - Houses of the Theodosian Period at Carthage. Echos $d u$ Monde Classique/Classical Views, XXXII, n. s. 7, 1988, pp. 195-210.

Whitehouse et al. 1982 : WHITEHOUSE (D.), BARKER (G.), REECE (R.), REESE (D.) - The Schola Praeconum I. The coins, pottery, lamps, and fauna. PBSR, L, 1982, pp. 53-101.

Wickham 1988 : WICKHAM (C.) - Marx, Sherlock Holmes, and Late Roman Commerce. JRS, LXXVIII, 1988, pp. 183-193.

Wilson 1990 : WILSON (R. J. A.) - Sicily under the Roman Empire. The archaeology of a Roman province (36 BC - AD 535). Warminster, Aris and Philipp, 1990.

Wilson 1992 : WILSON (R. J. A.) - Terracotta vaulting tubes (tubi fittili) : on their origin and distribution. JRA, 4, 1992, pp. 97-129.

Wilson 1999 : WILSON (R. J. A.) - Iscrizioni su manufatti siciliani in età ellenistico-romana. In : GULLETTA (M. I.) éd. Sicilia Epigrafica. Atti del convegno di studi (Erice, 15-18 octobre 1998). Pise, Nenci, 1999, pp. 531-556 (Annali della
Scuola Normale Superiore di Pisa, Serie IV, Quaderni 1999, 12).

Wilson 2000 : WILSON (R. J. A.) - Rural settlement in hellenistic and roman Sicily : excavations at Campanaio (AG), 1994-8. PBSR, LXVIII, 2000, pp. 337-369.

Winlock, Crum 1926 : WINLOCK (H. E.), CRUM (W. E.) The Monastery of Epiphanius at Thebes. Part I. New York, 1926 (The MMA Egyptian Expedition, III).

Wooding 1996 : WOODING (J. M.) - Communication and Commerce along the Western Sealanes $A D$ 400-800. Oxford, Tempus Reparatum, 1996 (BAR IS 654).

Ximénès, Moerman 1991 : XIMÉNÈS (S.), MOERMAN (M.) - Le matériel archéologique de l'épave Laurons II (Martigues, Bouches-du-Rhône). Cahiers d'Archéologie Subaquatique, X, 1991, pp. 209-222.

Yacoub 1996: YACOUB (M.) - Le Musée du Bardo (Départements antiques). Tunis, ANEP, 1996.

Younes 1999 : YOUNES (A.) - Estampille sur col d'amphore africaine. ZPE, 125, 1999, pp. 259-260.

Zanini 1996 : ZANINI (E.) - Ricontando la terra sigillata africana. Archeologia Medievale, XXIII, 1996, pp. 677-688.

Zanini 1998 : ZANINI (E.) - Le Italie Bizantine. Territorio, insediamenti ed economia nella provincia bizantina d'Italia (VIVIII secolo). Bari, Edipuglia, 1998 (Studi Storici sulla Tarda Antichità, 10).

Zevi, Tchernia 1969 : ZEVI (F.), TCHERNIA (A.) Amphores de Byzacène au Bas-Empire. AntAfr, 3, 1969, pp. 173-214.

Zucca 1987 : ZUCCA (R.) - L'opus doliare urbano in Africa ed in Sardinia. In : L'Africa Romana, IV. Sassari, Università di Sassari, 1987, pp. 659-676. 


\section{INDEX TYPOLOGIQUE}

\begin{tabular}{|c|c|c|c|}
\hline \multicolumn{4}{|c|}{ AMPHORES } \\
\hline Type & INDEX & pages & figures \\
\hline Africaine $\mathrm{I}=$ Keay 3 & AMPHORE TYPE 21 & 107 & 56 \\
\hline Africaine II A = Keay 4 & AMPHORE TYPE 22 & 111 & $57-58$ \\
\hline Africaine II B = Keay 5 & AMPHORE TYPE 23 & 111 & 59 \\
\hline $\begin{array}{l}\text { Africaine II B « pseudo- } \\
\text { tripolitaine } »=\text { Keay 5bis }\end{array}$ & AMPHORE TYPE 24 & 114 & 59 \\
\hline Africaine II C = Keay 6 & AMPHORE TYPE 25 & 114 & $60-61$ \\
\hline Africaine II D = Keay 7 & AMPHORE TYPE 26 & 115 & $62 a-b$ \\
\hline Africaine III A = Keay 25.1 & AMPHORE TYPE 27 & 119 & 63 \\
\hline Africaine III B = Keay 25.3 & AMPHORE TYPE 28 & 119 & 64 \\
\hline Africaine III C = Keay 25.2 & AMPHORE TYPE 29 & 119 & 65 \\
\hline $\begin{array}{l}\text { Agora M254 } \\
=\text { Ostia } \mathrm{I}, 453-454\end{array}$ & - & 148 & 80 \\
\hline $\begin{array}{l}\text { Albenga } 11-12=\text { Keay } 62 \mathrm{Q} \\
=\text { Keay } 62 \mathrm{R}\end{array}$ & AMPHORE TYPE 45 & 137 & 74 \\
\hline Bonifay 1986 , fig. 12.55 & AMPHORE TYPE 47 & 140 & 75 \\
\hline $\begin{array}{l}\text { Carthage } E A \text { IV } \\
=\text { Martin-Kilcher A9 }\end{array}$ & AMPHORE TYPE 11 & 99 & 52 \\
\hline Carthage $L R A 1$ & - & 151 & - \\
\hline Dressel 1 (pseudo-) & AMPHORE TYPE 59 & 146 & 79 \\
\hline Dressel 2/4 & AMPHORE TYPE 56 & 146 & 79 \\
\hline Dressel 2/4 (pseudo-) & AMPHORE TYPE 57 & 146 & 79 \\
\hline Dressel 26 & AMPHORE TYPE 13 & 101 & 52 \\
\hline Dressel $30=$ Keay 1 & AMPHORE TYPE 60 & 148 & $81-82$ \\
\hline $\begin{array}{l}\text { Globulaire } 1 \\
=\text { type Aïn Wassel }\end{array}$ & AMPHORE TYPE 63 & 153 & 83 \\
\hline $\begin{array}{l}\text { Globulaire } 2 \\
=\text { type Carthage F11-12 }\end{array}$ & AMPHORE TYPE 64 & 153 & 83 \\
\hline $\begin{array}{l}\text { Globulaire } 3 \\
=\text { type Castrum Perti }\end{array}$ & AMPHORE TYPE 65 & 153 & 83 \\
\hline $\begin{array}{l}\text { Globulaire } 4 \\
=\text { type Benghazi } L R A 13\end{array}$ & AMPHORE TYPE 66 & 153 & 83 \\
\hline Guéry 1985, Pl. LXI, 80 & AMPHORE TYPE 6 & 92 & 48 \\
\hline Hammamet 1 & AMPHORE TYPE 8 & 93 & 49 \\
\hline Hammamet 2 & AMPHORE TYPE 9 & 93 & 50 \\
\hline Hammamet 3 & AMPHORE TYPE 10 & 97 & 51 \\
\hline Keay 8A & AMPHORE TYPE 50 & 141 & 76 \\
\hline Keay 8B & AMPHORE TYPE 38 & 132 & 71 \\
\hline Keay 27 & AMPHORE TYPE 35 & 129 & 70 \\
\hline Keay 34 & AMPHORE TYPE 53 & 143 & 77 \\
\hline Keay 35A & AMPHORE TYPE 40 & 134 & $72 \mathrm{a}$ \\
\hline Keay 35B & AMPHORE TYPE 41 & 134 & $72 a-b$ \\
\hline Keay 36 & AMPHORE TYPE 36 & 129 & 70 \\
\hline Keay 39 & AMPHORE TYPE 34 & 129 & 70 \\
\hline Keay 3B « similis » & AMPHORE TYPE 34 & 129 & 70 \\
\hline Keay 50 & AMPHORE TYPE 51 & 141 & 76 \\
\hline Keay 55 & AMPHORE TYPE 44 & 135 & 73 \\
\hline Keay 56 & AMPHORE TYPE 43 & 135 & 73 \\
\hline Keay 57 & AMPHORE TYPE 42 & 135 & 73 \\
\hline Keay 59 & AMPHORE TYPE 37 & 132 & 71 \\
\hline Keay 61A-D & AMPHORE TYPE 49 & 140 & 75 \\
\hline Keay $61 \mathrm{C}$ & AMPHORE TYPE 48 & 140 & 75 \\
\hline Keay 62A-D-E & AMPHORE TYPE 46 & 137 & 74 \\
\hline Leptiminus I & AMPHORE TYPE 12 & 99 & 52 \\
\hline Leptiminus II & AMPHORE TYPE 5 & 92 & 48 \\
\hline Ostia XXIII & AMPHORE TYPE 14 & 101 & 53 \\
\hline Ostia LIX & AMPHORE TYPE 15 & 101 & 53 \\
\hline Ostia IV, 172 & AMPHORE TYPE 61 & 151 & 82 \\
\hline Ostia IV, 263 & AMPHORE TYPE 62 & 151 & 82 \\
\hline Pupput T700.4 & AMPHORE TYPE 16 & 103 & 53 \\
\hline Pupput T700.5 & AMPHORE TYPE 17 & 103 & 53 \\
\hline Schöne-Mau XXXV & AMPHORE TYPE 58 & 146 & 79 \\
\hline Sidi Jdidi 1 & AMPHORE TYPE 54 & 143 & 78 \\
\hline Sidi Jdidi 2 & AMPHORE TYPE 55 & 146 & 78 \\
\hline «spatheion $» 1=$ Keay 26 & AMPHORE TYPE 31 & 125 & 67 \\
\hline «spatheion $» 2=$ Keay 26 & AMPHORE TYPE 32 & 127 & 68 \\
\hline «spatheion $» 3=$ Keay 26 & AMPHORE TYPE 33 & 127 & 69 \\
\hline Tripolitaine I & AMPHORE TYPE 19 & 105 & $55 \mathrm{a}$ \\
\hline
\end{tabular}

\begin{tabular}{|l|r|r|r|}
\hline Type & INDEX & pages & figures \\
\hline Tripolitaine II & AMPHORE TYPE 4 & 89 & $47-48$ \\
\hline Tripolitaine II & AMPHORE TYPE 20 & 105 & $55 \mathrm{a}-\mathrm{b}$ \\
\hline Type « con orlo a fascia » & AMPHORE TYPE 52 & 141 & 76 \\
\hline $\begin{array}{l}\text { Type «Station 48 de la place } \\
\text { des Corporations» }\end{array}$ & AMPHORE TYPE 30 & 122 & 66 \\
\hline Uzita Pl. 52, 10 & AMPHORE TYPE 18 & 103 & 54 \\
\hline Van der Werff 1 & AMPHORE TYPE 1 & 89 & 47 \\
\hline Van der Werff 2 & AMPHORE TYPE 2 & 89 & 47 \\
\hline Van der Werff 3 & AMPHORE TYPE 3 & 89 & 47 \\
\hline $\begin{array}{l}\text { Vegas 1994, fig. 179, } \mathrm{n}^{\circ} \\
\text { 397-398 }\end{array}$ & AMPHORE TYPE 7 & 92 & 48 \\
\hline
\end{tabular}

\begin{tabular}{|c|c|c|c|}
\hline \multicolumn{4}{|c|}{ SIGILLÉES } \\
\hline Type & INDEX & pages & figures \\
\hline $\begin{array}{l}\text { Atlante XVII, } 17 \\
=\text { Atlante LXXII, } 2\end{array}$ & SIGILLÉE TYPE 14 & 159 & 86 \\
\hline Atlante XLI, 3-4 & SIGILLÉE TYPE 85 & 207 & 110 \\
\hline Atlante XLI, 3-4, var. tard. & SIGILLÉE TYPE 89 & 210 & 110 \\
\hline $\begin{array}{l}\text { Atlante LXXIII, } 2 \\
=\text { Salomonson XXVIII }\end{array}$ & SIGILLÉE TYPE 18 & 159 & 86 \\
\hline Fulford 27 & SIGILLÉE TYPE 75 & 201 & 107 \\
\hline Fulford 39-40 & SIGILLÉE TYPE 76 & 203 & 107 \\
\hline Fulford Closed form 1 & SIGILLÉE TYPE 61 & 189 & 100 \\
\hline Fulford Closed form 2 & SIGILLÉE TYPE 62 & 189 & 100 \\
\hline Gourvest E3 & SIGILLÉE TYPE 31 & 166 & 89 \\
\hline Hayes $2=$ Lamboglia A4/35 & SIGILLÉE TYPE 1 & 156 & 84 \\
\hline Hayes $3 \mathrm{~A}=$ Salomonson $\mathrm{A} 1$ & SIGILLÉE TYPE 1 & 156 & 84 \\
\hline $\begin{array}{l}\text { Hayes 3B-C } \\
=\text { Lamboglia A4/36A-B }\end{array}$ & SIGILLÉE TYPE 2 & 156 & 84 \\
\hline Hayes 8 = Lamboglia A1 & SIGILLÉE TYPE 3 & 156 & 84 \\
\hline Hayes $10=$ Lamboglia A21 & SIGILLÉE TYPE 4 & 156 & 84 \\
\hline Hayes $12 / 110$ & SIGILLÉE TYPE 30 & 165 & 89 \\
\hline $\begin{array}{l}\text { Hayes 14A } \\
=\text { Lamboglia A3a }\end{array}$ & SIGILLÉE TYPE 5 & 157 & 85 \\
\hline $\begin{array}{l}\text { Hayes 14B } \\
=\text { Lamboglia A3a }\end{array}$ & SIGILLÉE TYPE 7 & 157 & 85 \\
\hline $\begin{array}{l}\text { Hayes } 14 \mathrm{C} \\
=\text { Lamboglia A3b2 }\end{array}$ & SIGILLÉE TYPE 9 & 157 & 85 \\
\hline Hayes 15= Lamboglia A3b1 & SIGILLÉE TYPE 8 & 157 & 85 \\
\hline Hayes $16=$ Lamboglia A3c & SIGILLÉE TYPE 6 & 157 & 85 \\
\hline Hayes $17=$ Lamboglia A8 & SIGILLÉE TYPE 10 & 157 & 85 \\
\hline $\begin{array}{l}\text { Hayes } 24 \\
=\text { Salomonson XXVIIIb }\end{array}$ & SIGILLÉE TYPE 19 & 162 & 87 \\
\hline Hayes 26 & SIGILLÉE TYPE 12 & 159 & 85 \\
\hline Hayes 27 & SIGILLÉE TYPE 13 & 159 & 85 \\
\hline Hayes 31 & SIGILLÉE TYPE 11 & 157 & 85 \\
\hline Hayes 32 & SIGILLÉE TYPE 25 & 162 & 88 \\
\hline Hayes 35 & SIGILLÉE TYPE 21 & 162 & 87 \\
\hline $\begin{array}{l}\text { Hayes } 36 \\
=\text { Salomonson XXIV }\end{array}$ & SIGILLÉE TYPE 22 & 162 & 87 \\
\hline Hayes 38 & SIGILLÉE TYPE 20 & 162 & 87 \\
\hline $\begin{array}{l}\text { Hayes } 50 \mathrm{~B}, \mathrm{n}^{\circ} 61 \text { Late } \\
\text { variant }\end{array}$ & SIGILLÉE TYPE 65 & 197 & 105 \\
\hline $\begin{array}{l}\text { Hayes 53B, var. Sperlonga } \\
33\end{array}$ & SIGILLÉE TYPE 66 & 197 & 105 \\
\hline $\begin{array}{l}\text { Hayes } 58 \text { variante } \\
=\text { Lamboglia } \mathrm{D} 52 \mathrm{~B}\end{array}$ & SIGILLÉE TYPE 35 & 166 & 92 \\
\hline $\begin{array}{l}\text { Hayes 59C } \\
=\text { Jodin, Ponsich 1960, fig. } 6\end{array}$ & SIGILLÉE TYPE 36 & 167 & 92 \\
\hline Hayes $60, n^{\circ} 3$ & SIGILLÉE TYPE 70 & 199 & 106 \\
\hline Hayes 61A/B & SIGILLÉE TYPE 37 & 167 & 90 \\
\hline Hayes 61B & SIGILLÉE TYPE 38 & 167 & $90-91$ \\
\hline Hayes $61 \mathrm{C}$ & SIGILLÉE TYPE 39 & 170 & 91 \\
\hline $\begin{array}{l}\text { Hayes } 61 \text { variante Sidi } \\
\text { Zahruni }\end{array}$ & SIGILLÉE TYPE 67 & 199 & 26 \\
\hline $\begin{array}{l}\text { Hayes } 61 \text { sitifienne (?) } \\
=\text { Février 1963, fig. } 8\end{array}$ & - & 199 & 105 \\
\hline
\end{tabular}




\begin{tabular}{|c|c|c|c|}
\hline Type & INDEX & pages & figures \\
\hline $\begin{array}{l}\text { Hayes } 61 \text { tripolitaine }= \\
\text { Tripolitanian } R S W \text {, Hayes } 3\end{array}$ & - & 199 & 105 \\
\hline Hayes $62 / 64=$ Fulford 6 & SIGILLÉE TYPE 40 & 171 & 92 \\
\hline Hayes $67=$ Lamboglia D42 & SIGILLÉE TYPE 41 & 171 & 92 \\
\hline Hayes 68 & - & 51,199 & 23 \\
\hline Hayes 74 & SIGILLÉE TYPE 29 & 165 & 89 \\
\hline Hayes $79=$ Lamboglia D59 & SIGILLÉE TYPE 42 & 173 & 92 \\
\hline Hayes 80 & SIGILLÉE TYPE 43 & 173 & 92 \\
\hline Hayes 81 & SIGILLÉE TYPE 44 & 173 & 92 \\
\hline Hayes 82 & - & 165 & 89 \\
\hline $\begin{array}{l}\text { Hayes } 82 / 87, \text { dérivés }=\text { Dore } \\
2001 \text {, fig. } 1.64, n^{\circ} 22\end{array}$ & SIGILLÉE TYPE 77 & 203 & 107 \\
\hline Hayes 83 & SIGILLÉE TYPE 28 & 165 & 89 \\
\hline Hayes 84 & - & 165 & 89 \\
\hline Hayes 85 & - & 165 & 89 \\
\hline Hayes $86, n^{\circ} 1$ & SIGILLÉE TYPE 73 & 201 & 107 \\
\hline Hayes $86, n^{\circ} 2$ & SIGILLÉE TYPE 74 & 201 & 107 \\
\hline Hayes 87A & SIGILLÉE TYPE 45 & 173 & 93 \\
\hline Hayes 88 & SIGILLÉE TYPE 46 & 175 & 93 \\
\hline Hayes 90A & SIGILLÉE TYPE 33 & 166 & 89 \\
\hline Hayes 90B & SIGILLÉE TYPE 47 & 177 & 94 \\
\hline $\begin{array}{l}\text { Hayes } 91 \text { précoce } \\
=\text { Atlante XLVIII, } 11\end{array}$ & SIGILLÉE TYPE 48 & 179 & 95 \\
\hline Hayes 91A & SIGILLÉE TYPE 49 & 179 & 95 \\
\hline Hayes 91B & SIGILLÉE TYPE 50 & 179 & 95 \\
\hline Hayes 91B tardive & SIGILLÉE TYPE 51 & 179 & 95 \\
\hline Hayes 91C & SIGILLÉE TYPE 52 & 179 & 95 \\
\hline Hayes 91D & SIGILLÉE TYPE 54 & 179 & 95 \\
\hline $\begin{array}{l}\text { Hayes } 91 \text { variante Sperlonga } \\
64=\text { Atlante XLIX, } 10\end{array}$ & SIGILLÉE TYPE 53 & 179 & 95 \\
\hline $\begin{array}{l}\text { Hayes 91, variante Sidi Aïch } \\
=\text { Stern XXXV }\end{array}$ & - & 203 & 108 \\
\hline $\begin{array}{l}\text { Hayes 91, variante Sidi } \\
\text { Khalifa }\end{array}$ & SIGILLÉE TYPE 78 & 203 & 108 \\
\hline $\begin{array}{l}\text { Hayes } 91 \text { sitifienne (?) } \\
=\text { Février 1963, fig. } 5\end{array}$ & - & 203 & 108 \\
\hline Hayes 91, dérivés & SIGILLÉE TYPE 94 & 210 & 111 \\
\hline Hayes 92 & - & 203 & 108 \\
\hline Hayes 98 & SIGILLÉE TYPE 58 & 185 & 99 \\
\hline Hayes 99 & SIGILLÉE TYPE 55 & 181 & 96 \\
\hline Hayes 99 , variantes tardives & SIGILLÉE TYPE 86 & 207 & 110 \\
\hline Hayes 101 , variante tardive & SIGILLÉE TYPE 87 & 210 & 110 \\
\hline Hayes 103 , variante Rougga & SIGILLÉE TYPE 84 & 205 & 109 \\
\hline $\begin{array}{l}\text { Hayes 103, variante Sidi } \\
\text { Khalifa }\end{array}$ & SIGILLÉE TYPE 79 & 203 & 108 \\
\hline Hayes 104 & SIGILLÉE TYPE 56 & 181 & 97 \\
\hline $\begin{array}{l}\text { Hayes 104, variante Sidi } \\
\text { Khalifa }\end{array}$ & SIGILLÉE TYPE 80 & 205 & 108 \\
\hline Hayes 105 & SIGILLÉE TYPE 57 & 183 & 98 \\
\hline $\begin{array}{l}\text { Hayes } 105 \text {, variantes } \\
\text { tardives }\end{array}$ & SIGILLÉE TYPE 88 & 210 & 110 \\
\hline Hayes 105 , dérivés & SIGILLÉE TYPE 95 & 210 & 111 \\
\hline Hayes 106 , variante tardive & SIGILLÉE TYPE 91 & 210 & 110 \\
\hline $\begin{array}{l}\text { Hayes } 107, \text { variantes } \\
\text { tardives }\end{array}$ & SIGILLÉE TYPE 92 & 210 & 110 \\
\hline Hayes 108 & SIGILLÉE TYPE 59 & 185 & 99 \\
\hline Hayes 109 & SIGILLÉE TYPE 60 & 187 & 99 \\
\hline $\begin{array}{l}\text { Hayes } 109 \text {, variantes } \\
\text { tardives }\end{array}$ & SIGILLÉE TYPE 93 & 210 & 110 \\
\hline Ostia III, 156 & SIGILLÉE TYPE 23 & 162 & 87 \\
\hline $\begin{array}{l}\text { Peacock et al. } 1990 \text {, fig. } \\
7.12\end{array}$ & SIGILLÉE TYPE 32 & 166 & 89 \\
\hline $\begin{array}{l}\text { Peacock et al. } 1990 \text {, fig. } \\
13.19\end{array}$ & SIGILLÉE TYPE 34 & 166 & 89 \\
\hline Salomonson A17 & SIGILLÉE TYPE 16 & 159 & 86 \\
\hline Salomonson A3 & SIGILLÉE TYPE 17 & 159 & 86 \\
\hline Salomonson C9 (dérivés) & $\begin{array}{r}\text { SIGILLÉE TYPES 26- } \\
27\end{array}$ & 163 & 88 \\
\hline Sidi Jdidi 1 & SIGILLÉE TYPE 69 & 199 & 106 \\
\hline Sidi Jdidi 2 & SIGILLÉE TYPE 72 & 201 & 106 \\
\hline Sidi Jdidi 3 & SIGILLÉE TYPE 71 & 199 & 106 \\
\hline
\end{tabular}

\begin{tabular}{|l|r|r|r|}
\hline Type & INDEX & pages & figures \\
\hline Sidi Jdidi 4 Hayes 88/109 & SIGILLÉE TYPE 81 & 205 & 108 \\
\hline Sidi Jdidi 7 & SIGILLÉE TYPE 82 & 205 & 109 \\
\hline Sidi Jdidi 8 & SIGILLÉE TYPE 83 & 205 & 109 \\
\hline Sidi Jdidi 8, variante tardive & SIGILLÉE TYPE 90 & 210 & 110 \\
\hline Sperlonga 39 & SIGILLÉE TYPE 24 & 162 & 88 \\
\hline Décor imprimé style A(iii) & - & 192 & $101-102$ \\
\hline Décor imprimé style E(i) & - & 192 & 102 \\
\hline Décor imprimé style E(ii) & - & 193 & 102 \\
\hline Décor imprimé style « F » & - & 193 & 102 \\
\hline Décors lustrés & - & 193 & $103-104$ \\
\hline
\end{tabular}

\begin{tabular}{|c|c|c|c|}
\hline \multicolumn{4}{|c|}{ CULINAIRE } \\
\hline Type & INDEX & pages & figures \\
\hline Bouilloires Uzita Pl. 48, 1 & CULINAIRE TYPE 18 & 229 & 123 \\
\hline $\begin{array}{l}\text { Bouilloires tardives Poulsen } \\
\text { 1986, fig. } 6\end{array}$ & CULINAIRE TYPE 33 & 242 & 130 \\
\hline $\begin{array}{l}\text { Bouilloires tardives Fulford } \\
\text { Closed form } 27\end{array}$ & CULINAIRE TYPE 34 & 242 & 130 \\
\hline $\begin{array}{l}\text { Casseroles Hayes } 1978 \text { b, } \\
\text { fig. } 9.17=\text { Sidi Jdidi } 9\end{array}$ & CULINAIRE TYPE 35 & 242 & 131 \\
\hline $\begin{array}{l}\text { Couvercle Pupput } 1= \\
\text { Hayes } 185, \mathrm{n}^{\circ} 3=\text { Uzita } 13\end{array}$ & CULINAIRE TYPE 22 & 234 & 124 \\
\hline Couvercle Sidi Jdidi 1 & CULINAIRE TYPE 30 & 237 & 127 \\
\hline $\begin{array}{l}\text { Fulford Casserole } 19= \\
L R C W 1, \mathrm{C} 24=\mathrm{CATHMA} \\
\text { A3 }\end{array}$ & CULINAIRE TYPE 32 & 239 & 129 \\
\hline $\begin{array}{l}\text { Fulford Dish } 1=\text { Tomber } \\
\text { LR Cooking Pot } 2\end{array}$ & CULINAIRE TYPE 19 & 231 & 123 \\
\hline Fulford Lid 3 & CULINAIRE TYPE 36 & 242 & 131 \\
\hline Hayes 23 = Lamboglia 10 & CULINAIRE TYPE 1 & 211 & 112 \\
\hline Hayes $181, \mathrm{n}^{\circ} 1$ & CULINAIRE TYPE 4 & 213 & 114 \\
\hline $\begin{array}{l}\text { Hayes } 181 \text {, production A } \\
=\text { Atlante } \mathrm{CVI}, 4\end{array}$ & CULINAIRE TYPE 3 & 211 & 112 \\
\hline $\begin{array}{l}\text { Hayes } 181 \text {, production B } \\
=\text { Ostia I, } 15\end{array}$ & CULINAIRE TYPE 5 & 213 & 114 \\
\hline Hayes $182=$ Ostia I, 17 & CULINAIRE TYPE 6 & 217 & 115 \\
\hline Hayes 183 & CULINAIRE TYPE 15 & 227 & $122 \mathrm{a}$ \\
\hline $\begin{array}{l}\text { Hayes } 183 \text {, variante } \\
\text { tripolitaine }\end{array}$ & CULINAIRE TYPE 17 & 229 & $122 \mathrm{a}$ \\
\hline $\begin{array}{l}\text { Hayes } 183 \text {, variante tardive } \\
\text { tripolitaine }\end{array}$ & - & 229 & $122 b$ \\
\hline Hayes 184 & CULINAIRE TYPE 7 & 217 & $116-117$ \\
\hline Hayes 184 , dérivés & CULINAIRE TYPE 8 & 219 & $117 \mathrm{a}$ \\
\hline $\begin{array}{l}\text { Hayes } 184 \text {, variante } \\
\text { tripolitaine }\end{array}$ & - & 219 & $117 \mathrm{~b}$ \\
\hline Hayes 185 & CULINAIRE TYPE 9 & 221 & 118 \\
\hline Hayes 185 , variante & CULINAIRE TYPE 16 & 229 & $122 \mathrm{a}$ \\
\hline Hayes $193=$ Ostia I, 273 & CULINAIRE TYPE 2 & 211 & 112 \\
\hline Hayes $195=$ Ostia I, 264 & CULINAIRE TYPE 12 & 227 & 121 \\
\hline $\begin{array}{l}\text { Hayes } 196=\text { Ostia } \mathrm{I}, 261= \\
\text { Ostia III, } 332\end{array}$ & CULINAIRE TYPE 11 & 225 & 121 \\
\hline Hayes $197=$ Ostia III, 267 & CULINAIRE TYPE 10 & 225 & 120 \\
\hline $\begin{array}{l}\text { Marmite Pupput } 1 \\
=\text { Uzita } \mathrm{Pl} .51,5\end{array}$ & CULINAIRE TYPE 20 & 231 & 124 \\
\hline Marmite Pupput 2 & CULINAIRE TYPE 21 & 231 & 124 \\
\hline Marmite Sidi Jdidi 1 & CULINAIRE TYPE 23 & 234 & 125 \\
\hline $\begin{array}{l}\text { Marmite Sidi Jdidi } 2= \\
\text { Hayes } 197\end{array}$ & CULINAIRE TYPE 24 & 234 & 125 \\
\hline $\begin{array}{l}\text { Marmite Sidi Jdidi } 3 \\
=\text { Ostia I, } 267\end{array}$ & CULINAIRE TYPE 25 & 234 & 125 \\
\hline Marmite Sidi Jdidi 4 & CULINAIRE TYPE 31 & 239 & 128 \\
\hline Marmite Sidi Jdidi 5 & CULINAIRE TYPE 26 & 234 & 126 \\
\hline Marmite Sidi Jdidi 6 & CULINAIRE TYPE 27 & 237 & 126 \\
\hline Marmite Sidi Jdidi 7 & CULINAIRE TYPE 28 & 237 & 127 \\
\hline Marmite Sidi Jdidi 8 & CULINAIRE TYPE 29 & 237 & 127 \\
\hline $\begin{array}{l}\text { Plats à cuire, Byzacène } \\
\text { méridionale }\end{array}$ & CULINAIRE TYPE 38 & 244 & 131 \\
\hline $\begin{array}{l}\text { Plats à cuire, golfe } \\
\text { d'Hammamet }\end{array}$ & CULINAIRE TYPE 37 & 244 & 131 \\
\hline Tomber Black Top Lid D & CULINAIRE TYPE 13 & 227 & 121 \\
\hline Tomber LR Cooking Pot 1 & CULINAIRE TYPE 14 & 227 & 121 \\
\hline
\end{tabular}




\begin{tabular}{|c|c|c|c|}
\hline \multicolumn{4}{|c|}{ COMMUNE } \\
\hline Type & INDEX & pages & figures \\
\hline Barattes & COMMUNE TYPE 68 & 298 & 167 \\
\hline $\begin{array}{l}\text { Bassin Carthage } L R \text { Basin } 1 \\
=\text { Fulford Jar } 2\end{array}$ & COMMUNE TYPE 29 & 268 & 147 \\
\hline $\begin{array}{l}\text { Bassin Carthage LR Basin } 2 \\
=\text { Fulford Handled Bowl 2- } \\
3 / 5-6\end{array}$ & COMMUNE TYPE 30 & 268 & 147 \\
\hline $\begin{array}{l}\text { Bassin Carthage LR Basin } 4 \\
=\text { bassin Sidi Jdidi } 2\end{array}$ & COMMUNE TYPE 31 & 268 & 148 \\
\hline $\begin{array}{l}\text { Bassin Carthage } L R \text { Basin } 5 \\
=\text { Fulford Bowl } 3\end{array}$ & COMMUNE TYPE 33 & 272 & 149 \\
\hline $\begin{array}{l}\text { Bassin Carthage } L R \text { Basin } 6 \\
=\text { bassin Sidi Jdidi } 3\end{array}$ & COMMUNE TYPE 32 & 272 & 148 \\
\hline Bassin Uzita 1 & COMMUNE TYPE 20 & 263 & 142 \\
\hline Bassin Uzita 1, dérivés & COMMUNE TYPE 23 & 265 & 145 \\
\hline Bassin Uzita 2 & COMMUNE TYPE 21 & 263 & 142 \\
\hline Bassin Uzita 2, dérivés & $\begin{array}{r}\text { COMMUNE TYPES } \\
24-28 \\
\end{array}$ & 265 & 146 \\
\hline Bassin Uzita Pl. 45, $\mathrm{n}^{\circ} 3$ & COMMUNE TYPE 22 & 263 & 144 \\
\hline Bassins de tradition punique & COMMUNE TYPE 19 & 260 & 142 \\
\hline $\begin{array}{l}\text { Bassins tardifs à bord } \\
\text { déversé }\end{array}$ & COMMUNE TYPE 37 & 275 & 151 \\
\hline $\begin{array}{l}\text { Bassins tardifs à bord en } \\
\text { amande }\end{array}$ & COMMUNE TYPE 34 & 272 & 150 \\
\hline $\begin{array}{l}\text { Bassins tardifs à bord en } \\
\text { bourrelet épaissi }\end{array}$ & COMMUNE TYPE 36 & 272 & 151 \\
\hline $\begin{array}{l}\text { Bassins tardifs à bord } \\
\text { triangulaire }\end{array}$ & COMMUNE TYPE 35 & 272 & 150 \\
\hline $\begin{array}{l}\text { Bassins tardifs de Byzacène } \\
\text { centrale }\end{array}$ & COMMUNE TYPE 38 & 275 & 152 \\
\hline $\begin{array}{l}\text { Biberons (voir également } \\
\text { cruches à filtre) }\end{array}$ & COMMUNE TYPE 69 & 298 & 167 \\
\hline Bol à marli courbe 1 & COMMUNE TYPE 6 & 249 & 134 \\
\hline $\begin{array}{l}\text { Bol à marli courbe } 2 \\
=\text { Uzita } 5\end{array}$ & COMMUNE TYPE 7 & 249 & 134 \\
\hline Bol Uzita 1 & COMMUNE TYPE 1 & 245 & 132 \\
\hline Bol Uzita 2 & COMMUNE TYPE 2 & 245 & 132 \\
\hline Bols à listel : voir mortiers & COMMUNE TYPE 8 & 249 & 135 \\
\hline Braseros à ergots & COMMUNE TYPE 66 & 295 & $\begin{array}{l}165- \\
166 a\end{array}$ \\
\hline Braseros quadrangulaires & COMMUNE TYPE 67 & 298 & $166 \mathrm{a}$ \\
\hline Brûle-parfums & COMMUNE TYPE 70 & 301 & 167 \\
\hline Céramique à décor excisé & - & 301 & 168 \\
\hline Céramique à décor peint & - & 301 & 169 \\
\hline Couvercles « saucer type » & COMMUNE TYPE 44 & 278 & 153 \\
\hline $\begin{array}{l}\text { Couvercles à bord } \\
\text { chanfreiné }\end{array}$ & COMMUNE TYPE 40 & 275 & 152 \\
\hline $\begin{array}{l}\text { Couvercles à bord en } \\
\text { amande = Sabratha } 104\end{array}$ & COMMUNE TYPE 39 & 275 & 152 \\
\hline Couvercles d'amphores & COMMUNE TYPE 43 & 278 & 153 \\
\hline $\begin{array}{l}\text { Couvercles-opercules = } \\
\text { Uzita } 1-3\end{array}$ & COMMUNE TYPE 41 & 275 & 152 \\
\hline Couvercles-patères & COMMUNE TYPE 42 & 278 & 152 \\
\hline Cruche Carthage LR Jug 1 & COMMUNE TYPE 60 & 290 & 161 \\
\hline $\begin{array}{l}\text { Cruche CATHMA A2 = } \\
\text { Fulford Closed forms } 4,18\end{array}$ & COMMUNE TYPE 62 & 293 & 162 \\
\hline $\begin{array}{l}\text { Cruche CATHMA A6 = } \\
\text { Fulford Closed Form } 6\end{array}$ & COMMUNE TYPE 61 & 290 & 161 \\
\hline Cruche CATHMA A24 & COMMUNE TYPE 64 & 293 & 163 \\
\hline $\begin{array}{l}\text { Cruche type « Trésor de } \\
\text { Rougga »= Guéry 1982, } \\
\text { fig. } 6\end{array}$ & COMMUNE TYPE 63 & 293 & 163 \\
\hline Cruches à filtre & COMMUNE TYPE 53 & 287 & $159 \mathrm{a}$ \\
\hline $\begin{array}{l}\text { Cruches bi-ansées à col } \\
\text { tubulaire }\end{array}$ & $\begin{array}{r}\text { COMMUNE TYPES } \\
48-49\end{array}$ & & \\
\hline $\begin{array}{l}\text { Cruches biconiques à bord } \\
\text { en bandeau }\end{array}$ & COMMUNE TYPE 51 & 285 & 158 \\
\hline $\begin{array}{l}\text { Cruches piriformes à bord } \\
\text { arrondi }\end{array}$ & COMMUNE TYPE 52 & 287 & $159 \mathrm{a}$ \\
\hline $\begin{array}{l}\text { Cruches piriformes à col } \\
\text { tubulaire }\end{array}$ & COMMUNE TYPE 55 & 287 & $159 \mathrm{c}$ \\
\hline
\end{tabular}

\begin{tabular}{|c|c|c|c|}
\hline Type & INDEX & pages & figures \\
\hline $\begin{array}{l}\text { Cruches piriformes à col } \\
\text { tronconique = Vegas } 43.3\end{array}$ & COMMUNE TYPE 50 & 285 & 158 \\
\hline Cruches Pupput 1 & COMMUNE TYPE 47 & 282 & $155-156$ \\
\hline $\begin{array}{l}\text { Cruches Pupput } 2=\text { Cintas } \\
337-338=\text { Uzita fig. } 9, n^{\circ} \\
2 \mathrm{a}-\mathrm{c}\end{array}$ & COMMUNE TYPE 45 & 282 & 154 \\
\hline $\begin{array}{l}\text { Cruches trapues à col } \\
\text { tubulaire }\end{array}$ & COMMUNE TYPE 54 & 287 & $159 \mathrm{~b}$ \\
\hline $\begin{array}{l}\text { Cruches/amphores mono- } \\
\text { ansées }\end{array}$ & COMMUNE TYPE 46 & 282 & 154 \\
\hline $\begin{array}{l}\text { Cruches/amphorettes à } \\
\text { profil lancéolé }\end{array}$ & COMMUNE TYPE 57 & 288 & 160 \\
\hline $\begin{array}{l}\text { Cruches/gobelets } \\
\text { tronconiques = Uzita fig. } 5 \text {, } \\
n^{\circ} 3\end{array}$ & COMMUNE TYPE 56 & 288 & 160 \\
\hline Ecopes (?) & COMMUNE TYPE 71 & 301 & 167 \\
\hline Encriers & COMMUNE TYPE 72 & 301 & 167 \\
\hline Flacons anthropomorphes & COMMUNE TYPE 59 & 288 & 160 \\
\hline Flacons tubulaires & COMMUNE TYPE 58 & 288 & 160 \\
\hline Jarres & COMMUNE TYPE 65 & 293 & 164 \\
\hline Jattes à anses en panier & COMMUNE TYPE 5 & 249 & 133 \\
\hline $\begin{array}{l}\text { Jattes à bord trifide } \\
=\text { Uzita } \mathrm{Pl} .50, \mathrm{n}^{\circ} 7\end{array}$ & COMMUNE TYPE 3 & 245 & 133 \\
\hline Jattes hémisphériques & COMMUNE TYPE 4 & 245 & 133 \\
\hline $\begin{array}{l}\text { Bols à listel / mortiers } \\
=\text { Uzita } 4\end{array}$ & COMMUNE TYPE 8 & 249 & 135 \\
\hline $\begin{array}{l}\text { Mortiers, variante de } \\
\text { Byzacène }\end{array}$ & COMMUNE TYPE 9 & 252 & 136 \\
\hline $\begin{array}{l}\text { Mortiers tardifs à décor } \\
\text { imprimé }\end{array}$ & COMMUNE TYPE 16 & 258 & 141 \\
\hline $\begin{array}{l}\text { Mortiers tardifs à décor } \\
\text { peint }\end{array}$ & COMMUNE TYPE 17 & 259 & 141 \\
\hline $\begin{array}{l}\text { Mortiers tardifs Carthage } \\
\text { Class } 1 \text { = Fulford Flanged } \\
\text { Bowl } 1-3\end{array}$ & COMMUNE TYPE 11 & 252 & 138 \\
\hline $\begin{array}{l}\text { Mortiers tardifs Carthage } \\
\text { Class } 2=\text { Fulford Flanged } \\
\text { Bowl 14-15 }\end{array}$ & COMMUNE TYPE 12 & 252 & 138 \\
\hline Mortiers tardifs Sidi Jdidi 1 & COMMUNE TYPE 14 & 258 & 140 \\
\hline Mortiers tardifs Sidi Jdidi 2 & COMMUNE TYPE 15 & 258 & 140 \\
\hline $\begin{array}{l}\text { Mortiers tardifs, variante } \\
\text { Nabeul = Fulford Bowl 22- } \\
23\end{array}$ & COMMUNE TYPE 13 & 255 & 139 \\
\hline $\begin{array}{l}\text { Mortiers tardifs à listel } \\
\text { cannelé }\end{array}$ & COMMUNE TYPE 10 & 252 & 137 \\
\hline Mortiers tardifs, divers & COMMUNE TYPE 18 & 260 & 141 \\
\hline Tirelires & COMMUNE TYPE 73 & 301 & 168 \\
\hline Vases miniatures & COMMUNE TYPE 74 & 301 & 168 \\
\hline \multicolumn{4}{|c|}{ MODELÉE } \\
\hline Type & INDEX & pages & figures \\
\hline Céramique modelée A-B & - & 303 & 170 \\
\hline $\begin{array}{l}\text { Céramique modelée } \mathrm{C}= \\
\text { «Calcitic ware » }\end{array}$ & $\begin{array}{r}\text { MODELÉE C TYPES } \\
1-6\end{array}$ & 305 & $171-174$ \\
\hline
\end{tabular}

\begin{tabular}{|c|c|c|c|}
\hline \multicolumn{4}{|c|}{ LAMPES } \\
\hline Type & INDEX & pages & figures \\
\hline Atlante I & LAMPE TYPE 37 & 353 & 199 \\
\hline Atlante IV & LAMPE TYPE 38 & 353 & 199 \\
\hline Atlante V & LAMPE TYPE 39 & 353 & 199 \\
\hline Atlante VI & LAMPE TYPE 40 & 357 & 200 \\
\hline Atlante VI, variante & LAMPE TYPE 41 & 357 & 200 \\
\hline Atlante VII & LAMPE TYPE 42 & 357 & 201 \\
\hline Atlante VIII A1a-b / A2a & LAMPE TYPE 45 & 359 & 203 \\
\hline Atlante VIII A1c / A2b & LAMPE TYPE 44 & 359 & 203 \\
\hline Atlante VIII B & LAMPE TYPE 43 & 358 & 201 \\
\hline Atlante VIII B / IX & LAMPE TYPE 51 & 370 & 207 \\
\hline Atlante VIII C1 / X & LAMPE TYPE 61 & 391 & 218 \\
\hline Atlante VIII C1a-b & LAMPE TYPE 46 & 364 & 204 \\
\hline Atlante VIII C1c-d-e & LAMPE TYPE 48 & 366 & 205 \\
\hline Atlante VIII C2a-b & LAMPE TYPE 47 & 364 & 204 \\
\hline
\end{tabular}




\begin{tabular}{|c|c|c|c|}
\hline Type & INDEX & pages & figures \\
\hline Atlante VIII C2c-d & LAMPE TYPE 49 & 366 & 207 \\
\hline Atlante VIII D & LAMPE TYPE 50 & 368 & 206 \\
\hline Atlante VIII D / X & LAMPE TYPE 62 & 391 & 218 \\
\hline Atlante VIII-IX-X, dérivés & LAMPE TYPE 71 & 417 & 233 \\
\hline Atlante IX B-C & LAMPE TYPE 52 & 370 & 207 \\
\hline Atlante X A, groupe C1 & LAMPE TYPE 53 & 371 & 208 \\
\hline Atlante X A, groupe C2 & LAMPE TYPE 54 & 373 & $208-213$ \\
\hline Atlante X A, groupe C3 & LAMPE TYPE 55 & 382 & 214 \\
\hline Atlante X A, groupe C4 & LAMPE TYPE 56 & 386 & 215 \\
\hline Atlante X A, groupe C5 & LAMPE TYPE 57 & 388 & 216 \\
\hline Atlante X B & LAMPE TYPE 58 & 390 & 217 \\
\hline Atlante X D & LAMPE TYPE 59 & 390 & 217 \\
\hline Atlante X D2 & LAMPE TYPE 72 & 417 & 234 \\
\hline Atlante X précoce & LAMPE TYPE 63 & 391 & 218 \\
\hline Atlante X, groupe D1 & LAMPE TYPE 64 & 391 & $219-220$ \\
\hline Atlante $\mathrm{X}$, groupe D2 & LAMPE TYPE 65 & 395 & $221-223$ \\
\hline Atlante $\mathrm{X}$, groupe D3 & LAMPE TYPE 66 & 401 & $224-22$ \\
\hline Atlante $\mathrm{X}$, groupe $\mathrm{D} 4$ & LAMPE TYPE 67 & 408 & 228 \\
\hline $\begin{array}{l}\text { Atlante } \mathrm{X} \text { tardif à décors } \\
\text { estompés }\end{array}$ & LAMPE TYPE 69 & 410 & 230 \\
\hline $\begin{array}{l}\text { Atlante X tardif à décors } \\
\text { linéaires }\end{array}$ & LAMPE TYPE 70 & 413 & $231-232$ \\
\hline $\begin{array}{l}\text { Atlante X tardif à décors } \\
\text { saillants }\end{array}$ & LAMPE TYPE 68 & 410 & 229 \\
\hline Atlante XI & LAMPE TYPE 60 & 390 & 217 \\
\hline $\begin{array}{l}\text { Atlante XI A1b / X A1d / XI } \\
\text { B1b/ }\end{array}$ & LAMPE TYPE 77 & 420 & 236 \\
\hline Atlante XI B1 & LAMPE TYPE 73 & 420 & 235 \\
\hline Atlante XI B1 & LAMPE TYPE 74 & 420 & 235 \\
\hline Atlante XI B1 & LAMPE TYPE 76 & 420 & 236 \\
\hline Atlante XII, groupe $\mathrm{C} 2$ & LAMPE TYPE 80 & 427 & 238 \\
\hline Atlante XII, groupe D2 & LAMPE TYPE 81 & 427 & 239 \\
\hline Bussière C V 2 = Bailey K & LAMPE TYPE 2 & 313 & 176 \\
\hline $\begin{array}{l}\text { Bussière C V } 3 \text { / C VI = } \\
\text { Ennabli } 9\end{array}$ & LAMPE TYPE 3 & 313 & 176 \\
\hline Bussière E IV & LAMPE TYPE 34 & 351 & 198 \\
\hline Bussière E V & LAMPE TYPE 35 & 351 & 198 \\
\hline Deneauve V G & LAMPE TYPE 1 & 313 & 176 \\
\hline $\begin{array}{l}\text { Deneauve VII, sous-type } 1 \\
=\text { Salomonson } \mathrm{f} 1-2= \\
\text { Ennabli } 11,\left(1^{\circ}-2^{\circ}\right)= \\
\text { Bussière D II } 1=\text { Pupput } 1\end{array}$ & LAMPE TYPE 4 & 317 & $177-179$ \\
\hline $\begin{array}{l}\text { Deneauve VII, sous-type 1, } \\
\text { dérivés tardifs }\end{array}$ & LAMPE TYPE 25 & 343 & 193 \\
\hline $\begin{array}{l}\text { Deneauve VII, sous-type } 2 \\
=\text { Salomonson f } 3=\text { Ennabli } \\
11\left(3^{\circ}\right)=\text { Bussière D II } 1= \\
\text { Pupput } 2\end{array}$ & LAMPE TYPE 5 & 322 & $180-181$ \\
\hline $\begin{array}{l}\text { Deneauve VII, sous-type } 2 \text {, } \\
\text { dérivés tardifs }\end{array}$ & LAMPE TYPE 26 & 343 & 193 \\
\hline Deneauve VII, sous-type 3 & LAMPE TYPE 6 & 322 & 181 \\
\hline $\begin{array}{l}\text { Deneauve VII, sous-type } 3 \text {, } \\
\text { dérivés tardifs }\end{array}$ & LAMPE TYPE 27 & 347 & 193 \\
\hline $\begin{array}{l}\text { Deneauve VII, sous-type } 4 \\
=\text { Bussière D VI = Pupput } 4\end{array}$ & LAMPE TYPE 7 & 322 & 181 \\
\hline $\begin{array}{l}\text { Deneauve VII, sous-type } 4 \text {, } \\
\text { Tripolitaine }\end{array}$ & LAMPE TYPE 19 & 339 & 191 \\
\hline $\begin{array}{l}\text { Deneauve VII, sous-type } 5 \\
=\text { Deneauve VII C = } \\
\text { Bussière D III / D V / D X } 1 \\
=\text { Pupput } 5\end{array}$ & LAMPE TYPE 8 & 325 & $182-183$ \\
\hline $\begin{array}{l}\text { Deneauve VII, sous-type } 6 \\
=\text { Bussière D X } 2\end{array}$ & LAMPE TYPE 9 & 329 & 183 \\
\hline $\begin{array}{l}\text { Deneauve VIII à déc. De } \\
\text { festons, dérivés tardifs }\end{array}$ & LAMPE TYPE 28 & 347 & 194 \\
\hline $\begin{array}{l}\text { Deneauve VIII, sous-type } 1 \\
=\text { Salomonson } \mathrm{g} 1=\text { Ennabli } \\
12\left(1^{\circ}-2^{\circ}\right)=\text { Bussière D X } \\
4 \mathrm{a}=\text { Pupput } 6 \mathrm{~A}\end{array}$ & LAMPE TYPE 10 & 329 & 184 \\
\hline $\begin{array}{l}\text { Deneauve VIII, sous-type } 1 \\
\text { dérivés tardif }\end{array}$ & LAMPE TYPE 29 & 347 & 194 \\
\hline
\end{tabular}

\begin{tabular}{|c|c|c|c|}
\hline Type & INDEX & pages & figures \\
\hline $\begin{array}{l}\text { Deneauve VIII, sous-type } 2 \\
=\text { Salomonson g } 2=\text { Ennabli } \\
12\left(3^{\circ}\right)=\text { Bussière D X } 4 \mathrm{~b}= \\
\text { Pupput } 6 \mathrm{~B}\end{array}$ & LAMPE TYPE 11 & 331 & 185 \\
\hline $\begin{array}{l}\text { Deneauve VIII, sous-type } 2 \text {, } \\
\text { dérivés tardifs }\end{array}$ & LAMPE TYPE 30 & 347 & 195 \\
\hline $\begin{array}{l}\text { Deneauve VIII, sous-type } 3 \\
=\text { Bussière D X } 5=\text { Pupput } \\
6 \mathrm{C}\end{array}$ & LAMPE TYPE 12 & 331 & 186 \\
\hline $\begin{array}{l}\text { Deneauve VIII, sous-type } 3 \text {, } \\
\text { dérivés tardifs }\end{array}$ & LAMPE TYPE 31 & 349 & 195 \\
\hline $\begin{array}{l}\text { Deneauve VIII, sous-type } 4 \\
=\text { Ennabli } 12\left(4^{\circ}\right)=\text { Bussière } \\
\text { D X } 6=\text { Pupput } 6 \mathrm{D}\end{array}$ & LAMPE TYPE 13 & 334 & 187 \\
\hline $\begin{array}{l}\text { Deneauve VIII, sous-type } 4 \text {, } \\
\text { dérivés tardifs }\end{array}$ & LAMPE TYPE 32 & 349 & 196 \\
\hline $\begin{array}{l}\text { Deneauve } \mathrm{X} \text {, sous-type } 1= \\
\text { Deneauve X B = Bussière E } \\
\text { I } 3\end{array}$ & LAMPE TYPE 14 & 334 & 188 \\
\hline $\begin{array}{l}\text { Deneauve } \mathrm{X} \text {, sous-type } 2= \\
\text { Deneauve } \mathrm{X} A=\text { Bussière } \mathrm{E} \\
\text { I } 1\end{array}$ & LAMPE TYPE 15 & 335 & 189 \\
\hline $\begin{array}{l}\text { Deneauve } \mathrm{X} \text {, sous-type } 3= \\
\text { Deneauve } \mathrm{X} A=\text { Bussière } \mathrm{E} \\
\text { I } 2\end{array}$ & LAMPE TYPE 16 & 337 & 190 \\
\hline Ennabli 13 & LAMPE TYPE 20 & 341 & 191 \\
\hline Ennabli 14 & LAMPE TYPE 21 & 341 & 191 \\
\hline Ennabli 15 & LAMPE TYPE 22 & 341 & 191 \\
\hline Ennabli 16 & LAMPE TYPE 23 & 341 & 191 \\
\hline Hayes $1980 \mathrm{~b}, \mathrm{n}^{\circ} 280$ & LAMPE TYPE 24 & 341 & 192 \\
\hline $\begin{array}{l}\text { Lampes à becs multiples } \\
\text { (céramique commune) }\end{array}$ & LAMPE TYPE 36 & 351 & 198 \\
\hline $\begin{array}{l}\text { Lampes à becs multiples } \\
\text { (céramique sigillée) }\end{array}$ & LAMPE TYPE 79 & 422 & 237 \\
\hline $\begin{array}{l}\text { Lampes à côtes de melon = } \\
\text { Bussière E III } 1\end{array}$ & LAMPE TYPE 17 & 339 & 190 \\
\hline $\begin{array}{l}\text { Lampes à côtes de melon } \\
\text { tardives = Deneauve XI B }\end{array}$ & LAMPE TYPE 33 & 349 & 197 \\
\hline $\begin{array}{l}\text { "Lampes-sabots » de Sétif } \\
=\text { Guéry type local A = } \\
\text { Bussière C VIII }\end{array}$ & LAMPE TYPE 18 & 339 & 191 \\
\hline $\begin{array}{l}\text { Lampes tournées Bussière E } \\
\text { VI 3-4 }\end{array}$ & LAMPE TYPE 85 & 429 & 241 \\
\hline $\begin{array}{l}\text { Lampes tournées dites } \\
\text { «vandales » }\end{array}$ & $\begin{array}{r}\text { LAMPES TYPE S 83- } \\
84\end{array}$ & 429 & 241 \\
\hline Lampes tripolitaines & LAMPE TYPE 82 & 427 & 240 \\
\hline
\end{tabular}

\section{AUTRES CÉRAMIQUES}

\begin{tabular}{|l|r|r|r|}
\hline Type & INDEX & pages & figures \\
\hline $\begin{array}{l}\text { Ampullae oleariae }= \\
\text { Carandini 1970b, fig. 12 }\end{array}$ & DÉCOR PLASTIQUE 1 & 431 & 242 \\
\hline $\begin{array}{l}\text { Vases en forme de grenade } \\
\text { = Carandini 1969, fig. 1 }\end{array}$ & DÉCOR PLASTIQUE 2 & 431 & 242 \\
\hline Céramique dite de Navigius & DÉCOR PLASTIQUE 3 & 431 & 242 \\
\hline Figurines & FIGURINES TYPES & 433 & 243 \\
\hline Masques & MASQUES TYPES 1-2 & 435 & 244 \\
\hline Moules & MOULES TYPES 1-3 & 435 & 245 \\
\hline
\end{tabular}

CÉRAMIQUES ARCHITECTURALES
\begin{tabular}{|l|r|r|r|}
\hline Type & INDEX & pages & figures \\
\hline Carreaux & - & 439 & 247 \\
\hline Tuiles & - & 439 & 248 \\
\hline Tubes de voûte & - & 442 & 249 \\
\hline Tuyaux & - & 442 & 249 \\
\hline
\end{tabular}




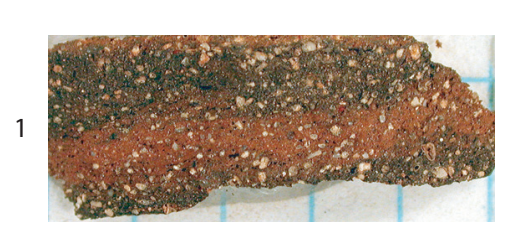

Origine : région de Leptis Magna Amphore Tripolitaine III

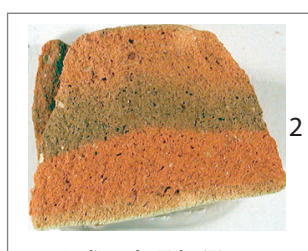

Ateliers de Zitha/Ziane Amphore Tripolitaine III
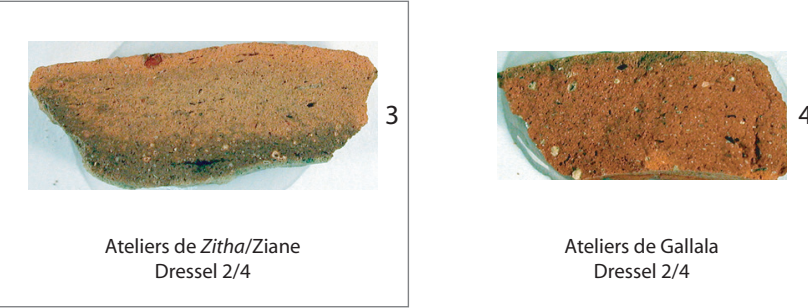

Ateliers de Gallala Dressel 2/4

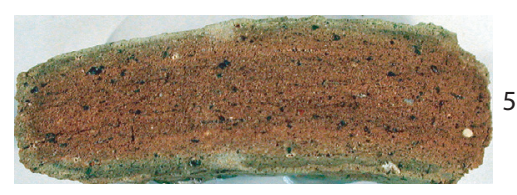

Atelier de Oued el-Akarit Keay 25.1

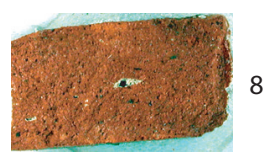

Origine : région de Rougga Keay 34

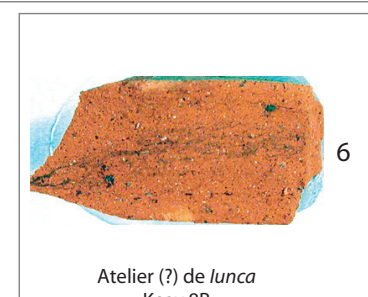

Keay 8B
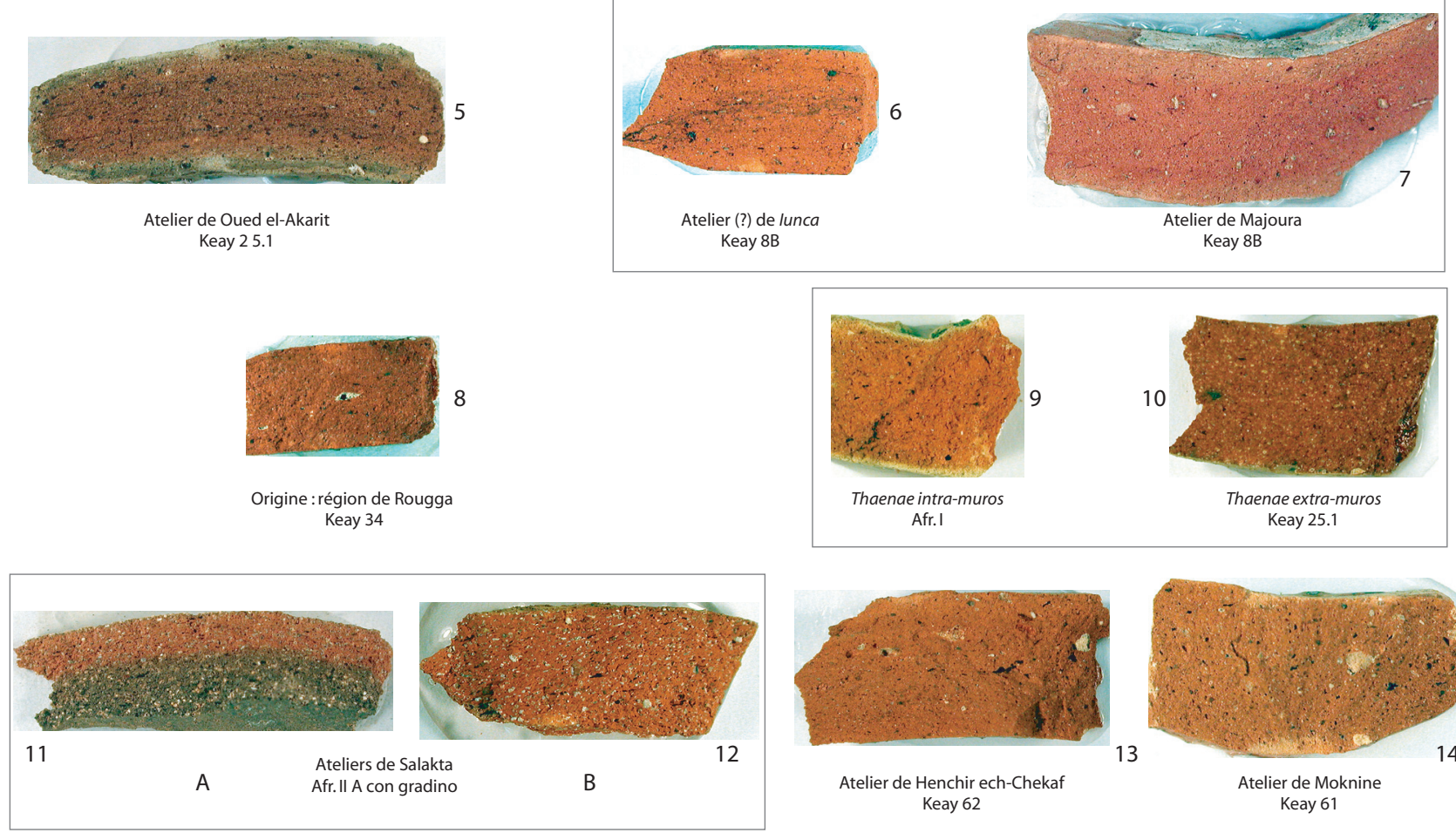

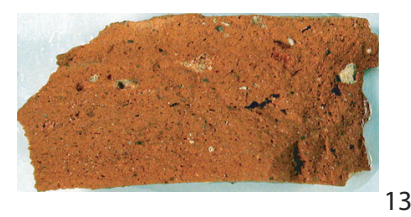

Atelier de Henchir ech-Chekaf Keay 62

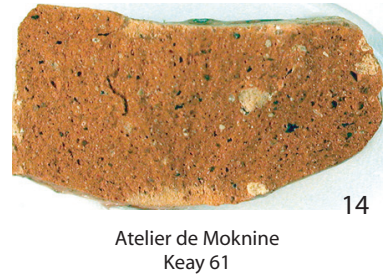

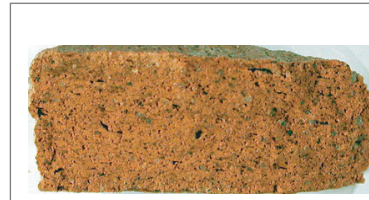

15 Type précoce

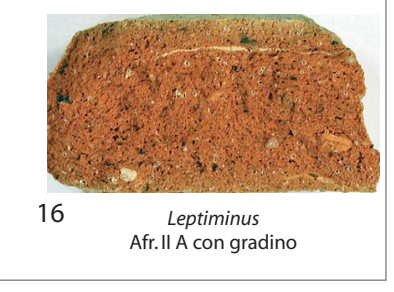

17

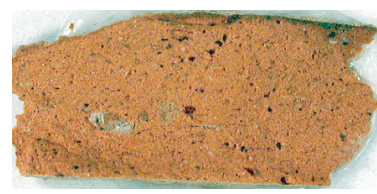

Origine : Hadrumetum/Sousse (?) Pupput, Afr. II B timbre FAFO

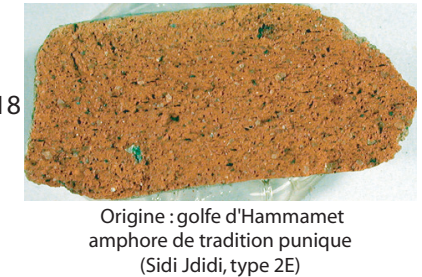

(Sidi Jdidi, type 2E)

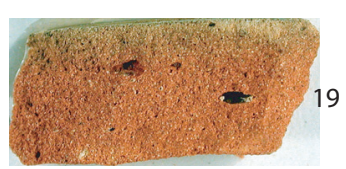

Atelier de Sidi Aoun Afr.II C

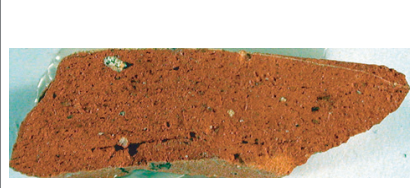

20

Atelier de Sidi Zahruni Keay $35 \mathrm{~B}$
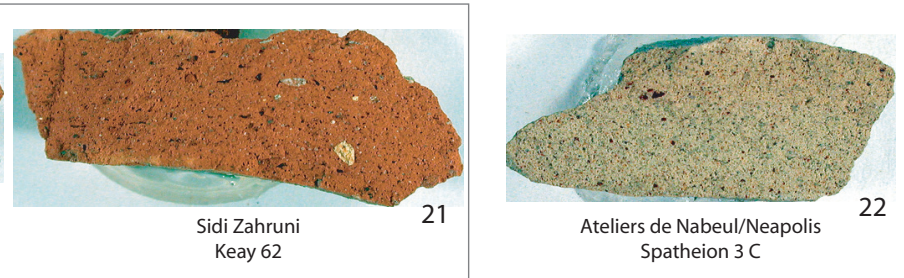
Spatheion $3 \mathrm{C}$

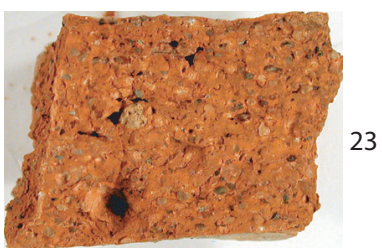

Origine : basse vallée de la Méjerda (?) El Mahrine, type Keay 36

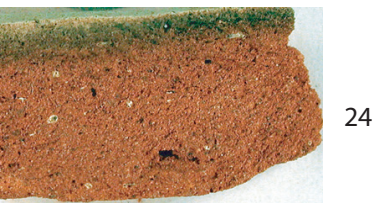

Origine : Maurétanie Césarienne (?), Cherchell (?) Golfe de Fos

Type "station 48 de la place des Corporations"

Planche I. Amphores. Macro-photographies des pâtes (Ech. 2/1). 


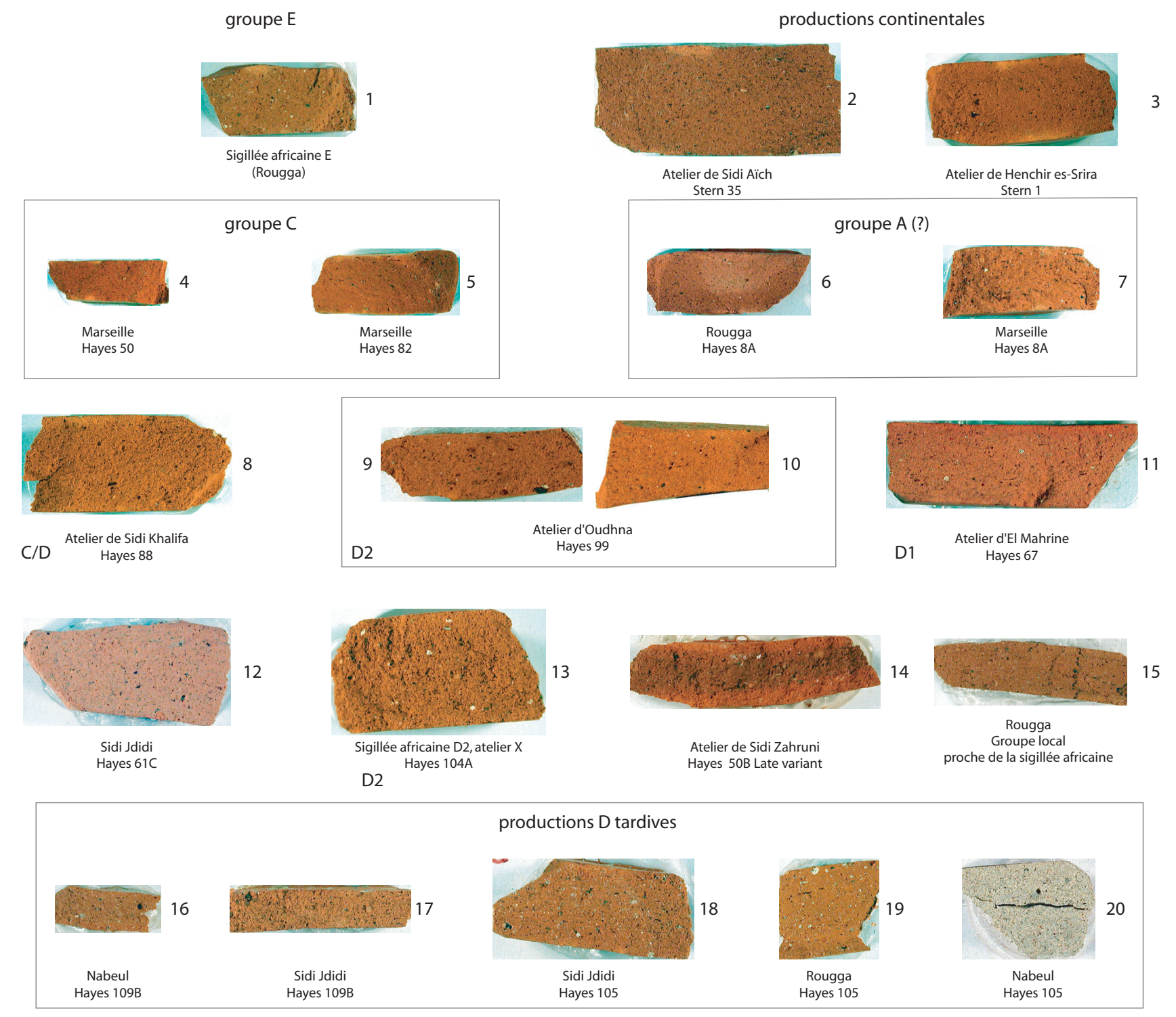

Planche II. Sigillées africaines. Macro-photographies des pâtes (Ech. 2/1). 
Céramique culinaire

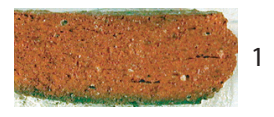

Rougga

Plat à cuire

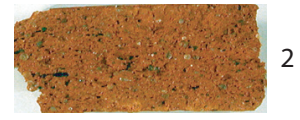

Ateliers de Leptiminus Hayes 182

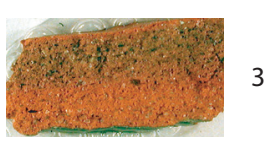

Sidi Jdidi

Sidi Jdidi
Casserole type 7

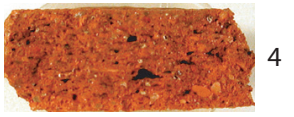

Cap Bon (?)

Nabeul, Marmite Sidi Jdidi 4

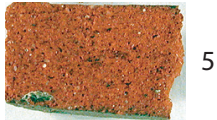

Byrsa

\section{Céramique commune}

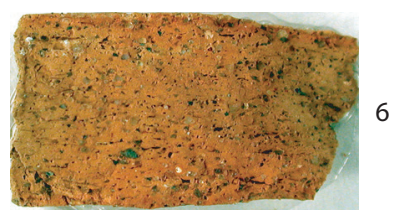

Byrsa

LR Basin 2

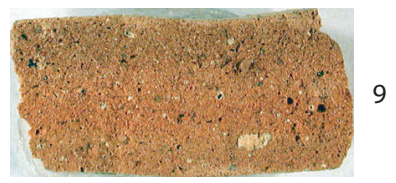

Thuburbo Majus Bassin

(Document 2.11, fig. 2, 22)

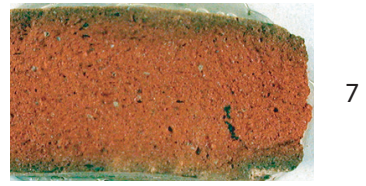

Atelier de Sidi Aoun

bassin

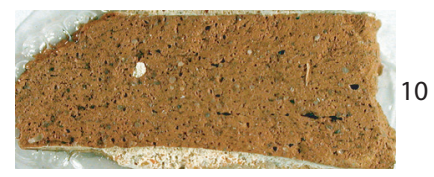

Sidi Jdidi Bassin type 1

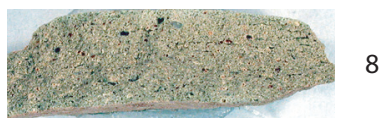

Atelier de Nabeul/Neapolis

Cruche

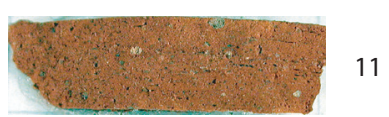

Rougga

Bassin à ressaut interne
Céramique peinte

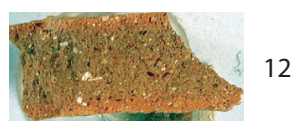

Carthage Céramique peinte

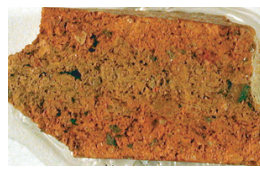

Sidi Jdidi Modelée A
Céramique modelée

13

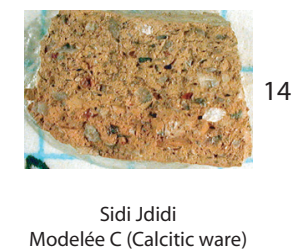

Modelée C (Calcitic ware)

Planche III. Céramiques culinaires, communes et modelées. Macro-photographies des pâtes (Ech. 2/1). 